DOE/EIA-0487(94)

Distribution Category UC-950

Petroleum Marketing Annuna】 994

\title{
August 1995
}

\author{
Energy Information Administration \\ Office of Oil and Gas \\ U.S. Department of Energy \\ Washington, DC 20585
}

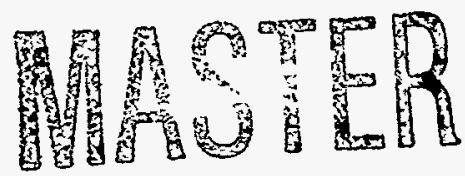

This report was prepared by the Energy Information Administration, the independent statistical and analytical agency within the Department of Energy. The information contained herein should not be construed as advocating or reflecting any policy position of the Department of Energy or of any other organization. 


\section{Contacts}

The Petroleum Marketing Annual (PMA) is prepared in the Energy Information Administration (EIA) under the general direction of Charles P. Shirkey (202) 586-6567, Petroleum Marketing Division, Office of Oil and Gas, EIA.

Detailed technical questions for specific areas of the PMA may be directed to the EIA staff listed below.

For primary program responsibility:

- Charles W. Riner (202) 586-6610 Internet E-Mail: criner@eia.doe.gov

For tables referencing the EIA-782A, the EIA-782B, and the EIA-782C:
- Charles W. Riner (202) 586-6610

Internet E-Mail: criner@eia.doe.gov

- Kenneth Platto (202) 586-6364

Internet E-Mail: kplatto@eia.doe.gov

For tables referencing the EIA-14 and EIA-856:

- Lamar Gowland (202) 586-6608 Internet E-Mail: lgowland@eia.doe.gov

- Elizabeth Scott (202) 586-1258 Internet E-Mail: escott@eia.doe.gov

For tables referencing the EIA-182:

- Alan Griffith (202) 586-7225 Internet E-Mail: agriffit@eia.doe.gov 


\section{DISCLAIMER}

Portions of this document may be illegible in electronic image products. Images are produced from the best available original document. 


\section{DISCLAIMER}

This report was prepared as an account of work sponsored by an agency of the United States Government. Neither the United States Government nor any agency thereof, nor any of their employees, make any warranty, express or implied, or assumes any legal liability or responsibility for the accuracy, completeness, or usefulness of any information, apparatus, product, or process disclosed, or represents that its use would not infringe privately owned rights. Reference herein to any specific commercial product, process, or service by trade name, trademark, manufacturer, or otherwise does not necessarily constitute or imply its endorsement, recommendation, or favoring by the United States Government or any agency thereof. The views and opinions of authors expressed herein do not necessarily state or reflect those of the United States Government or any agency thereof. 


\section{Preface}

The Petroleum Marketing Annual (PMA) provides information and statistical data on a variety of crude oils and refined petroleum products. The publication presents statistics on crude oil costs and refined petroleum products sales for use by industry, government, private sector analysts, educational institutions, and consumers. Data on crude oil include the domestic first purchase price, the f.o.b. and landed cost of imported crude oil, and the refiners' acquisition cost of crude oil. Refined petroleum product sales data include motor gasoline, distillates, residuals, aviation fuels, kerosene, and propane. The Petroleum Marketing Division, Office of Oil and Gas, Energy Information Administration ensures the accuracy, quality, and confidentiality of the published data in the Petroleum Marketing Annual.

For this publication, all estimates have been recalculated since their earlier publication in the Petroleum Marketing Montbly (PMM). These calculations made use of additional data anad corrections that were received after the PMM publication date.

\section{Scope of Data}

The data within the Petroleum Marketing Annual are compiled from six Energy Information Administration (EIA) survey forms. The crude oil statistics are calculated from data collected on the following three survey forms: Form EIA-182, "Domestic Crude Oil First Purchase Report"; Form EIA-856, "Monthly Foreign Crude Oil Acquisition Report"; and Form EIA-14, "Refiners' Monthly Cost Report."

The statistics on petroleum product sales prices and volumes are derived from Form EIA-782A, "Refiners'/Gas Plant Operators' Monthly Petroleum Product Sales Report" and Form EIA-782B, "Resellers'/Retailers' Monthly Petroleum Product Sales Report."
The data presented in Tables 48 to 50 are derived from aggregations of data from Form EIA-782C, "Monthly Report of Prime Supplier Sales of Petroleum Products Sold for Local Consumption."

\section{Sections}

Monthly statistics on purchases of crude oil and sales of petroleum products are presented in the Petroleum Marketing Annual in five sections:

- Summary Statistics

- Crude Oil Prices

- Prices of Petroleum Products

- Volumes of Petroleum Products

- Prime Supplier Sales Volumes of Petroleum Products for Local Consumption.

The publication highlights salient statistics for the United States in the Summary Statistics section. More detailed geographic coverage occurs in the other four sections. Geographic coverage for crude oil includes country of origin for foreign crude and Petroleum Administration for Defense (PAD) Districts and individual States for domestic crude oil. Geographic coverage of the petroleum products includes PAD Districts and individual States.

Detailed statistics for crude oil, including the price of imported crude oil by country of origin, by gravity, and by crude stream, can be found in the Crude Oil Prices section.

PAD District and/or State-level statistics for petroleum products are presented in the Prices, Volumes, and Prime Supplier Sales of Petroleum Products sections. All tables show 12 months of data for 1994. 


\section{Notes on the Tables}

- For the crude oil statistics referencing Form EIA182, United States includes the 50 States, the outer continental shelf, and the District of Columbia. For crude oil statistics referencing either Form EIA14 or Form EIA-856, United States includes the 50 States, the District of Columbia, Puerto Rico, the Virgin Islands, and all American territories and possessions. For the petroleum products data, United States includes the 50 States and the District of Columbia.

- Values showsn are final. Refer to the Explanatory Notes for a discussion of proceassing late submissions and resubmissions.

- Prices exclude taxes. Refer to the Explanatory Notes for a tax table on motor fuels.

- Some of the tables use State abbreviations. Refer to the Explanatory Notes for a table of U.S. Postal State abbreviations.

- Sales of leaded gasoline are reported in the Conventional gasoline category by appropriate grade in the Prime Supplier Sales Volumes section, but are ex- cluded from gasoline sales prices and volumes in all other sections of the publication. Leaded gasoline is a component of averages and totals prior to October 1993.

- References to "Refiners" include gas plant operators (see the Glossary for definition of "Gas Plant Operators"). All tables whose titles do not specifically reference "Refiners" contain data from all sellers. "All Sellers" includes refiners, gas plant operators, resellers, and retailers.

- "Prime Supplier" refers to a firm that produces, imports, or transports any of the selected petroleum products across State boundaries and local marketing areas and sells the product to local distributors, local retailers, or end users.

- The category "Retail Outlet" refers to any company-operated outlet selling gasoline, on-highway low-sulfur diesel fuel, or propane for on-highway vehicle use (see Glossary).

- No. 2 distillate volumes and prices are classified in accordance with what the product was sold as, regardless of the actual specifications of that product (see definitions of No. 2 distillate in the Glossary). 


\section{Contents}

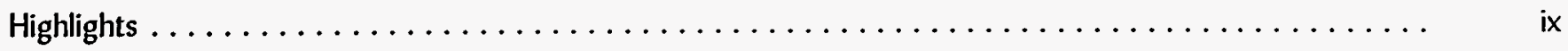

Summary Statistics $\ldots \ldots \ldots \ldots \ldots \ldots \ldots \ldots \ldots \ldots \ldots \ldots \ldots \ldots \ldots \ldots \ldots \ldots \ldots \ldots \ldots \ldots \ldots$

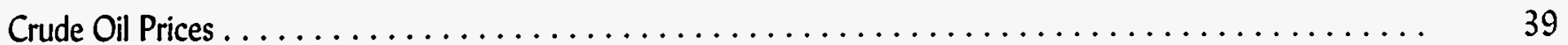

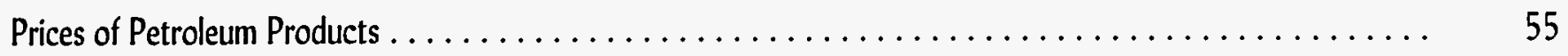

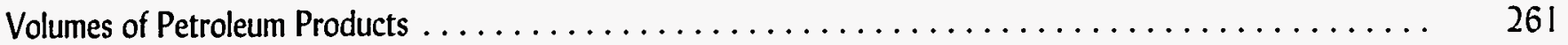

Prime Supplier Sales Volumes of Petroleum Products for Local Consumption . . . . . . . . . . . . . 355

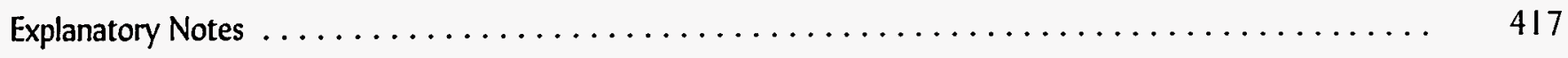

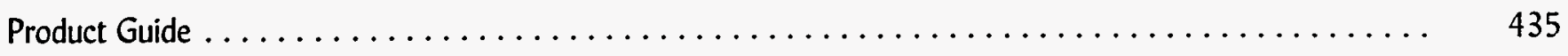

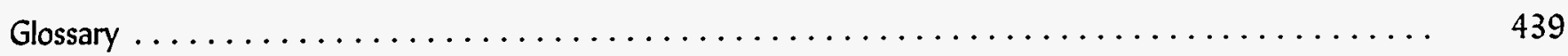

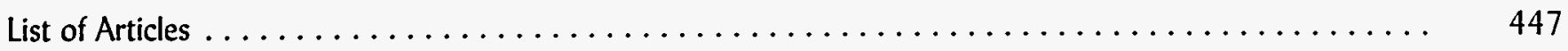

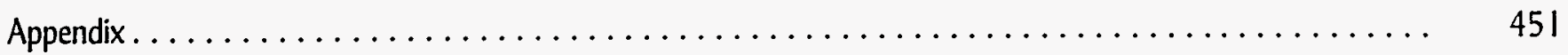




\section{Tables}

\section{Summary Statistics}

I. Crude Oil Prices............................................. 2

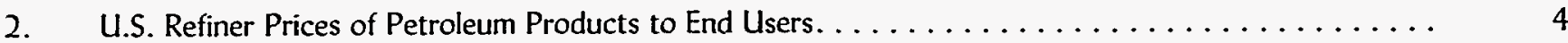

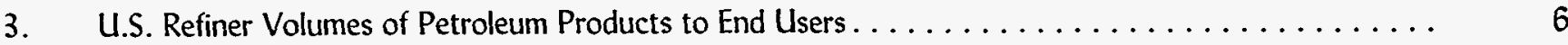

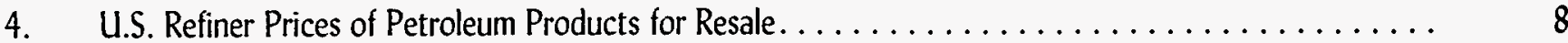

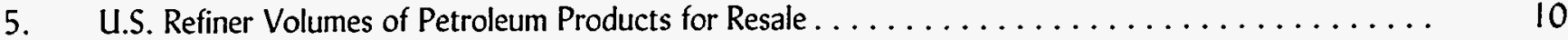

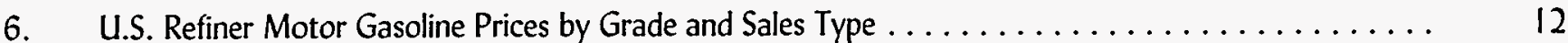

7. U.S. Refiner Motor Gasoline Volumes by Grade and Sales Type ................ 14

8. U.S. Refiner Conventional Motor Gasoline Prices by Grade and Sales Type. . . . . . . . . 16

9. U.S. Refiner Conventional Motor Gasoline Volumes by Grade and Sales Type............ 18

10. U.S. Refiner Oxygenated Motor Gasoline Prices by Grade and Sales Type . . . . . . . . . . . . 20

11. U.S. Refiner Oxygenated Motor Gasoline Volumes by Grade and Sales Type . . . . . . . . . . 22

12. U.S. Refiner Reformulated Motor Gasoline Prices by Grade and Sales Type . . . . . . . . . . 24

13. U.S. Refiner Reformulated Motor Gasoline Volumes by Grade and Sales Type. . . . . . . . . . . . . 26

14. U.S. Propane (Consumer Grade) Prices by Sales Type $\ldots \ldots \ldots \ldots \ldots \ldots \ldots \ldots \ldots \ldots \ldots \ldots$

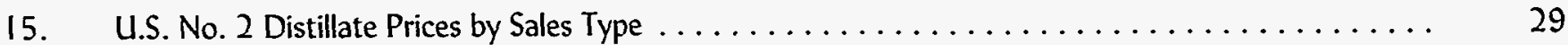

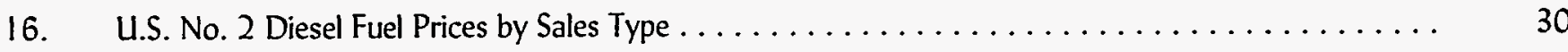

17. U.S. No. 2 Diesel Fuel Prices by Sulfur Content and Sales Type $\ldots \ldots \ldots \ldots \ldots \ldots \ldots \ldots \ldots$

18. Prices of No. 2 Distillate to Residences by PAD District and Selected States . . . . . . . . . 32

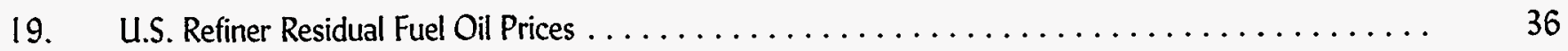

20. U.S. Refiner Residual Fuel Oil Volumes $\ldots \ldots \ldots \ldots \ldots \ldots \ldots \ldots \ldots \ldots \ldots \ldots \ldots \ldots \ldots$ 


\section{Crude Oil Prices}

21. Domestic Crude Oil First Purchase Prices $\ldots \ldots \ldots \ldots \ldots \ldots \ldots \ldots \ldots \ldots \ldots \ldots \ldots \ldots, 4$. 4

22. Domestic Crude Oil First Purchase Prices for Selected Crude Streams .................. 44

23. Domestic Crude Oil First Purchase Prices by API Gravity..................... 45

24. F.O.B. Costs of Imported Crude Oil, by Selected Country ..................... 46

25. Landed Costs of Imported Crude Oil, by Selected Country.................... 47

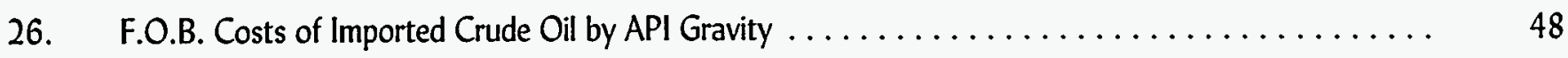

27. Landed Costs of Imported Crude Oil by API Gravity ....................... 49

28. Percentages of Total Imported Crude Oil by API Gravity $\ldots \ldots \ldots \ldots \ldots \ldots \ldots \ldots \ldots \ldots \ldots \ldots \ldots \ldots$

29. F.O.B. Costs of Imported Crude Oil for Selected Crude Streams................... 5 I

30. Landed Costs of Imported Crude Oil for Selected Crude Streams ................... 53

\section{Prices of Petroleum Products}

31. Motor Gasoline Prices by Grade, Sales Type, PAD District, and State $\ldots \ldots \ldots \ldots \ldots \ldots \ldots \ldots$

32. Conventional Motor Gasoline Prices by Grade, Sales Type, PAD District, and State $\ldots \ldots \ldots \ldots \ldots \quad 86$

33. Oxygenated Motor Gasoline Prices by Grade, Sales Type, PAD District, and State .......... 116

34. Reformulated Motor Gasoline Prices by Grade, Sales Type, PAD District, and State . . . . . . . . 146

35. Refiner Motor Gasoline Prices by Grade, Sales Type, PAD District and State ............. 176

36. Refiner Prices of Aviation Fuels and Kerosene by PAD District and State ............... 191

37. Refiner Prices of Distillate Fuels by PAD District and State $\ldots \ldots \ldots \ldots \ldots \ldots \ldots \ldots \ldots \ldots \ldots$

38. Propane (Consumer Grade) Prices by Sales Type and PAD District ................. 221

39. No. 2 Distillate Prices by Sales Type, PAD District, and Selected States ............... 224

40. No. 2 Diesel Fuel Prices by Sales Type, PAD District, and Selected States .............. 233

41. No. 2 Diesel Fuel Prices by Sulfur Content, Sales Type, and PAD District .............. 242

42. Residual Fuel Oil Prices by PAD District and State $\ldots \ldots \ldots \ldots \ldots \ldots \ldots \ldots \ldots \ldots \ldots \ldots \ldots \ldots \ldots$ 


\section{Volumes of Petroleum Products}

43. Refiner Motor Gasoline Volumes by Grade, Sales Type, PAD District, and State . . . . . . . . 262

44. Refiner Motor Gasoline Volumes by Formulation, Sales Type, PAD District, and State. . . . . . . 292

45. Refiner Volumes of Aviation Fuels, Kerosene, No. I Distillate, and Propane by PAD District and State . . . . . . . . . . . . 322

46. Refiner No. 2 Distillate, Diesel Fuel, and Fuel Oil Volumes by PAD District and State . . . . . . 337

47. Refiner Residual Fuel Oil and No. 4 Fuel Volumes by PAD District $\ldots \ldots \ldots \ldots \ldots \ldots \ldots \ldots \ldots$

\section{Prime Supplier Sales Volumes of Petroleum}

Products for Local Consumption

48. Prime Supplier Sales Volumes of Motor Gasoline by Grade, Formulation,

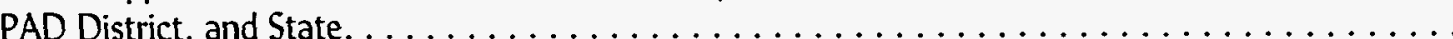

49. Prime Supplier Sales Volumes of Aviation Fuels, Propane, and Residual Fuel Oil by PAD District and State . . . . . . . . . . . . . . . . . . . . . . . .

50. Prime Supplier Sales Volumes of Distillate Fuel Oils and Kerosene by PAD District and State

\section{Appendix}

A1. Refiner/Reseller Motor Gasoline Prices by Grade, PAD District, and State, 1984-Present . . . . . . .

A2. Refiner/Reseller Prices of Aviation Fuels, Propane, and Kerosene, by PAD District, I983-Present. . . .

A3. Refiner/Reseller Prices of Distillate and Residual Fuel Oils, by PAD District, 1983-Present.

\section{Figures}

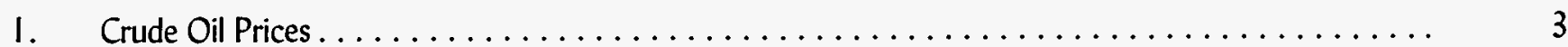

2. U.S. Refiner Retail Petroleum Product Prices $\ldots \ldots \ldots \ldots \ldots \ldots \ldots \ldots \ldots \ldots \ldots \ldots \ldots$

3. U.S. Refiner Retail Petroleum Product Volumes $\ldots \ldots \ldots \ldots \ldots \ldots \ldots \ldots \ldots \ldots \ldots \ldots$

4. U.S. Refiner Wholesale Petroleum Product Prices . . . . . . . . . . . . . . . . . . . . 9

5. U.S. Refiner Wholesale Petroleum Product Volumes $\ldots \ldots \ldots \ldots \ldots \ldots \ldots \ldots \ldots \ldots \ldots \ldots$

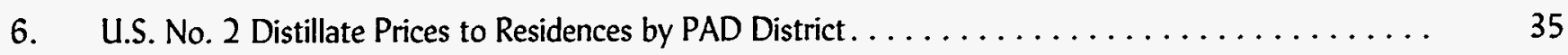

7. U.S. Refiner Residual Fuel Oil Prices and Volumes. . . . . . . . . . . . . . . . . . 37 
Highlights 



\section{Highlights \\ I 994 Year in Review}

rude oil prices on world markets recovered strongly during portions of 1994, offsetting most of the decline experienced the previous year. After languishing at relatively low levels through March despite declining global inventories, prices surged in the second quarter, in response to a variety of influences. Production discipline by the Organization of Petroleum Exporting Countries (OPEC), combined with a Nigerian oil workers' strike, civil war in Yemen, and other international events, pushed prices upward through July. Markets softened in August, as the Nigerian government regained control of oil facili- ties, and prices remained within a relatively narrow range for the balance of the year.

As has been the case for two decades, OPEC action or inaction regarding world crude oil supply remained the most significant oil market influence in 1994. When the cartel announced the continuation of its existing output ceiling after its March 1994 meeting, initial market reaction was negative, expecting a resumption of excess world oil supplies. However, OPEC's stable monthly production through July 1994 allowed prices to recover to early-1993 levels, despite

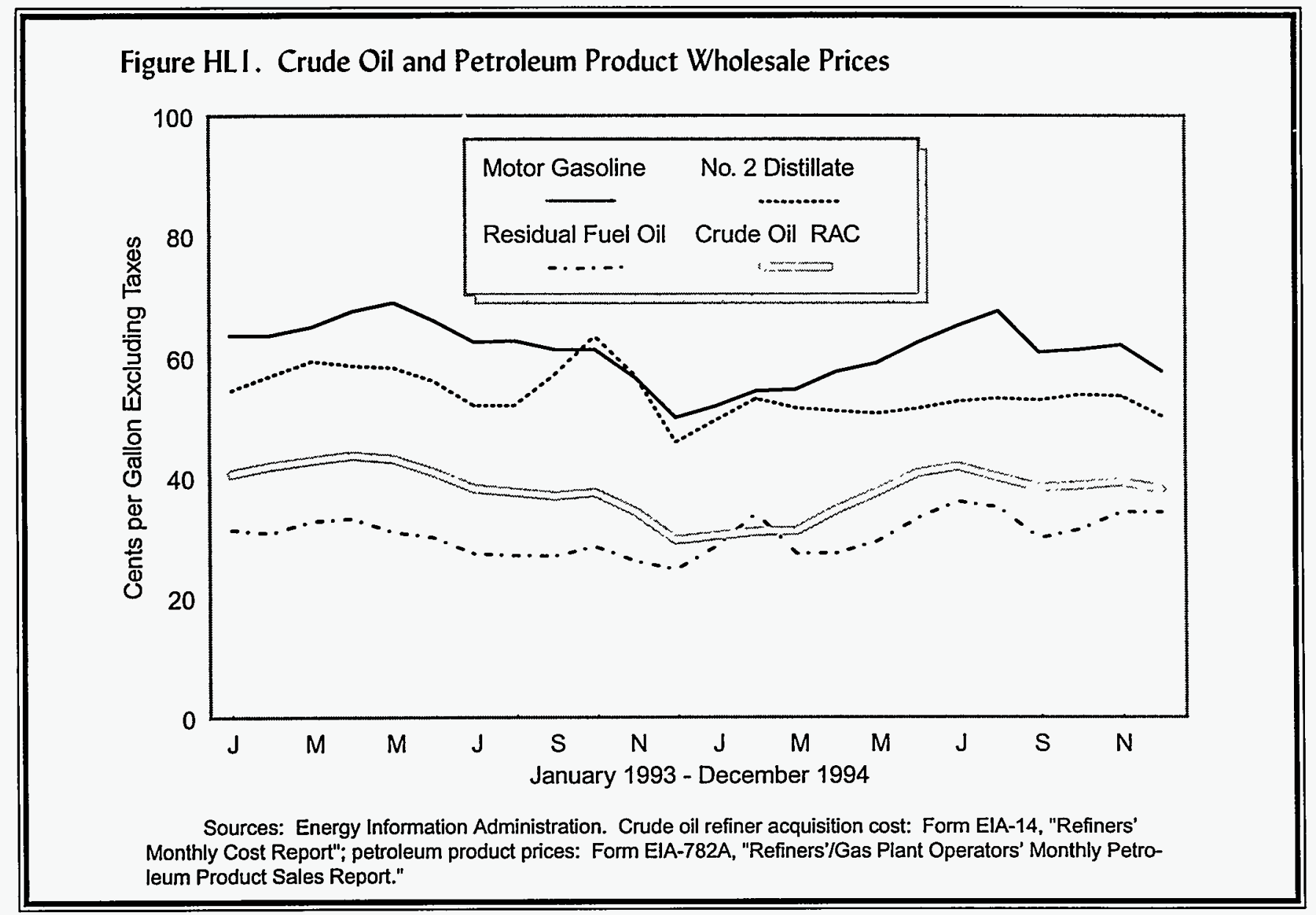


Figure HL2. U.S. Spot Prices of Crude Oil and Petroleum Products

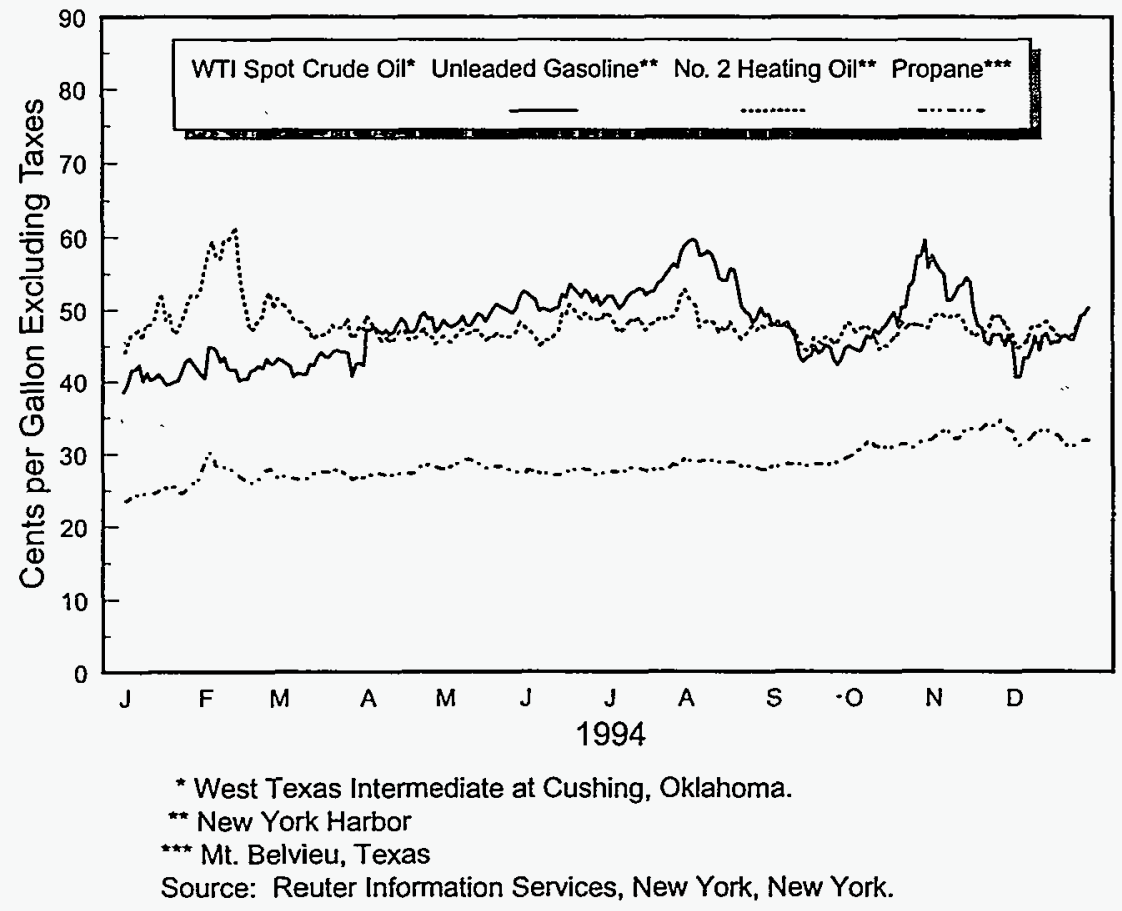

Production and distribution of RFG to meet program startup deadlines, expected to present challenges for the industry, were further complicated by last-minute changes in fuel requirements for some areas. "Opt-ins" to the RFG program for areas in serious or moderate ozone nonattainment status, initially assumed to be permanent, were reconsidered by several Northeastern States in December 1994. The Environmental Protection Agency eventually approved "opt-outs" for 39 counties in Pennsylvania, New York, and Maine, even as suppliers were struggling to build sufficient RFG inventories in those and other areas. Concerns over RFG supply adequacy pushed prices for the new fuel to higher-thananticipated premiums over conventional gasoline, as 1994 rising outpur from non-OPEC sources, most notably the North Sea.. World demand growth strengthened in 1994, aided by a cold U.S. winter and surging economic growth, particularly in Asia. Iraq's continued absence from world markets afforded other exporters the opportunity to raise production with less impact on revenues.

In the United States, crude oil prices followed world market trends in 1994, while preparation for the beginning of the reformulated gasoline (RFG) program dominated the downstream sector of the petroleum industry. The benchmark West Texas Intermediate (WTI) crude oil price received an additional boost over other world crude streams in the second quarter, as seasonally higher mid-continent demand outstripped deliverability due to logistical bottlenecks. Heating fuel prices were supported by extreme cold weather in the Northeast and Midwest in January and February, but quickly returned to seasonal levels. Strong summer demand, along with concerns about the Nigerian strike, sent conventional gasoline prices soaring through July, but they dropped even more sharply in August and September as emphasis shifted to RFG. October floods in Texas caused the rupture of the Colonial Pipeline and others, briefly spiking prices and delaying early RFG shipments. ended on the eve of the official beginning of retail RFG sales. Other environmental programs also influenced the U.S. oil industry in 1994, including the low-sulfur diesel requirements instituted in late 1993, and the requirement for Certificates of Financial Responsibility from oil tanker operators under the Oil Pollution Act.

Market and sales activity for crude oil and the major petroleum products is summarized in the following sections.

\section{Crude Oil}

The WTI crude oil daily spot price at Cushing, Oklahoma, generally followed international crude oil price trends in 1994. The WTI spot price showed early strength and recovered slightly from a slide that persisted through the last three quarters of 1993. Early gains, however, quickly gave way to a sharp mid-winter drop that posted a 5-year low of $\$ 13.89$ per barrel on February 16. Strong winter heating demand and supply concerns were instrumental to the market's recovery. For the remainder of the winter, the WTI 
spot price wavered before falling to just above the \$14-per-barrel mark at the end of March. The onset of warm weather, speculation on changes in self-imposed OPEC production levels, and tight supplies all helped U.S. crude oil prices gradually climb to the year's high, $\$ 20.72$ per barrel, on June 16. The WTI spot price fluctuated through the summer, rebounded near the year's high in early August and then tumbled to slightly under $\$ 17$ per barrel in response to supply surpluses as the summer driving season ended. Brief rises throughout the remainder of the year were shortlived and prices never regained the strength seen during the summer high nor threatened the first quarter lows. WTI ended the year at $\$ 17.77$ per barrel, $\$ 3.88$ above the 5-year record low observed in February.

- The average domestic crude oil first purchase price declined $\$ 1.06$ per barrel (7.4 percent) from 1993 , to $\$ 13.19$ per barrel.

- The average free-on-board (f.o.b.) cost of imported crude oil fell 53 cents per barrel (3.6 percent) from 1993 , to $\$ 14.18$ per barrel. The average landed cost of foreign crude oil was $\$ 15.18$ per barrel, down 54 cents (3.4 percent) from 1993.

- The average refiner acquisition cost of domestic crude oil dropped an even dollar from the previous year, to $\$ 15.67$ per barrel (6.0 percent). The average cost of imported crude oil to L.S. refiners fell 63 cents ( 3.9 percent) to $\$ 15.51$ per barrel. The composite refiner acquisition cost of crude in the United States in 1994 declined as a result to $\$ 15.59$ per barrel, down 82 cents (5.0 percent) from 1993.

\section{Petroleum Products}

\section{Motor Gasoline}

The New York Harbor daily spot price for unleaded regular gasoline had difficulty sustaining consistent direction for most of 1994. Unleaded regular gasoline spot prices at New York Harbor opened at 39.9 cents per gallon on January 3, the low point for the year, and then vacillated between the low- to mid-40 cents per gallon mark until late March. Anticipation of the summer driving season and rising crude oil prices spurred the New York Harbor spot price upward at the start of the second quarter until it peaked at the year's high, 61.0 cents per gallon, on August 3. The price then dropped dramatically throughout August and September, as refiners prepared for the oxygenated gasoline season and the startup of the RFG program by selling off conventional summer grades. Gasoline prices soared in late October, when flooding near Houston disrupted pipeline distribution to the Northeast amid the changeover to oxygenated gasoline and RFG. Prices eased late in the year when market activity was dominated by flood damaged pipeline repairs and the RFG switch over. The New York Harbor daily spot price for unleaded regular ended the year at 51.5 cents per gallon, up 11.7 cents per gallon from where it began.

- Average motor gasoline prices were down at most levels in 1994. The annual average refiner retail price declined 2.1 cents below the 1993 level, to 73.8 cents per gallon. Average refiner wholesale prices fell 2.7 cents to 59.9 cents per gallon. Including data reported by the sample of motor gasoline marketers, national average prices at company-operated retail outlets fell 2.2 cents to 73.6 cents per gallon. The average differential between regular unleaded and premium gasoline was 16.9 cents per gallon at company-operated retail outlets and 12.5 cents per gallon for wholesale. National average wholesale prices fell 2.6 cents from 1993, to 60.2 cents per gallon.

- Refiner sales of finished motor gasoline increased to 331.7 million gallons per day in 1994, a rise of 7.6 million gallons per day (2.3 percent) from 1993. Total retail sales by refiners fell 2.2 million gallons per day and wholesale sales increased by 9.8 million gallons per day. Sales for consumption by grade remained virtually unchanged from levels observed in 1993 levels. Regular unleaded dominated the market with 67.7 percent of the total and midgrade and premium remained steady at 12.0 percent and 20.3 percent, respectively.

\section{No. 2 Distillate}

The daily spot price for No. 2 heating oil at New York Harbor peaked early in 1994 and then steadied around the 50-cent-per-gallon mark for the remainder of the year. Like gasoline, No. 2 heating oil posted its low on January 3 , at 45.2 cents per gallon. Severe January temperatures in the Eastern and North Central United States heightened space heating demand and quickly pushed No. 2 heating oil prices to the year's high, 62.8 cents per gallon, on February 11. Prices fell as abruptly as they rose just 1 month later when stocks 
stabilized and warmer weather arrived. No. 2 heating oil prices were calm for the last three quarters of the year, even in the final quarter despite seasonal demand. The New York Harbor daily spot price closed the year at 51.4 cents per gallon.

- Average No. 2 distillate prices fell in all categories in 1994. The annual average refiner retail price fell to 55.6 cents per gallon, a 4.6-cent decline from 1993, while the refiner wholesale price dropped 3.7 cents to 52.2 cents per gallon. Including data reported by the sample of distillate fuel marketers, the national average price for No. 2 distillate sales to residences decreased 2.7 cents to 88.4 cents per gallon and the average wholesale price dropped 3.7 cents per gallon from 1993 to 52.9 cents from 1993.

- Total refiner sales of No. 2 distillate rose to 130.0 million gallons per day, an increase of 4.5 million gallons per day (3.5 percent) from 1993. Sales of No. 2 fuel oil by refiners declined 10.2 million gallons per day, down 21.9 percent, while No. 2 diesel fuel sales grew 14.9 million gallons per day, up 18.9 percent from 1993. Implementation of the Clean Air Act Amendments of 1990 was largely responsible for the sellers' switch from No. 2 fuel oil to No. 2 diesel in 1994 . Total retail sales of low-sulfur No. 2 diesel in 1994 were 12.9 million gallons per day and 57.6 million gallons per day at the wholesale level. No. 2 high-sulfur diesel sales were 8.4 and 14.8 million gallons per day at the retail and wholesale levels, respectively. Total No. 2 fuel oil sales were 3.4 million gallons per day for end users, and 32.9 million gallons per day for resale. Overall 1994 No. 2 distillate sales to end users were 24.6 million gallons per day, a 3.8 percent increase from last year. Wholesale sales rose to 105.3 million gallons per day, a 3.6 percent increase from 1993.

\section{Residual Fuel Oil}

- Residual fuel oil prices for 1994 rose from 1993 levels. Refiner retail and wholesale prices increased slightly for low-sulfur residual fuel oil by 0.4 cent per gallon and 0.8 cent per gallon, respectively.
High-sulfur residual fuel oil prices by refiners showed more strength than in the previous year. Refiner retail high-sulfur residual fuel oil prices rose 2.7 cents, to 33.0 cents per gallon and wholesale prices were up 3.1 cents, to 28.7 cents per gallon. Including data from the sample of residual fuel marketers, average retail prices for low-sulfur moved up only 1.0 cent above the 1993 level and low-sulfur residual wholesale increased 0.9 cent per gallon. The high-sulfur retail price increased by 1.5 cents per gallon, while the wholesale price rose by 2.6 cents.

- Total refiner sales of residual fuel oil declined again in 1994. Sales fell to 26.3 million gallons per day, an 11.7 percent drop from the 1993 level of 29.8 million gallons per day. Low-sulfur residual fuel sales decreased 1.1 million gallons per day (9.2 percent) and high-sulfur sales fell 2.5 million gallons per day (13.9 percent). Residual fuel oil sales to end users fell 3.7 million gallons per day (21.5 percent), while resale sales decreased 200,000 gallons per day (1.6 percent).

\section{Other Products}

- Market activity for other petroleum products was mixed. Average refiner propane prices to end users fell 14.3 cents per gallon and wholesale prices declined 2.7 cents per gallon. Refiner retail prices for kerosene-type jet fuel fell 4.6 cents per gallon; wholesale prices declined 4.3 cents per gallon. Both refiner retail and wholesale average prices were down for aviation gasoline and No. 1 distillate. Kerosene retail prices fell and wholesale prices rose, while No. 4 retail remained unchanged from last year and wholesale declined.

- Total refiner sales volumes of kerosene-type jet fuel, aviation gasoline, kerosene, and No. 4 all rose. Propane and No. 1 distillate sales volumes, on the other hand, fell from 1993 levels. Total propane sales by refiners declined 800,000 gallons per day and kerosene-type jet fuel sales increased 4.3 million gallons per day (8.6 percent). 
Summary

Statistics 
Table 1. Crude Oil Prices

(Dollars per Barrel)

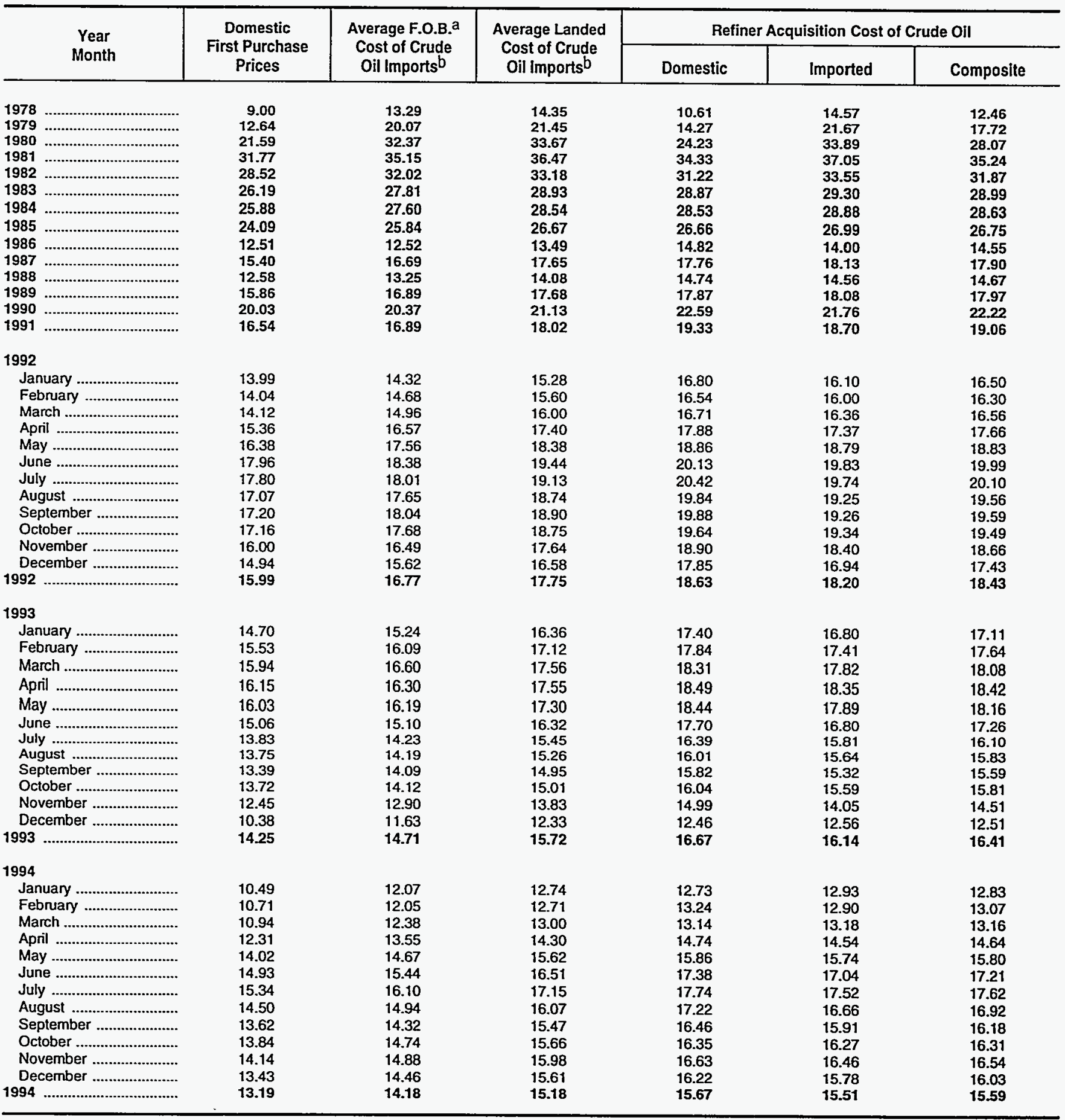

a Free on Board. See Glossary.

b Values through 1980 reflect the month of reporting; values since then reflect the month of acquisition, which can be the month of loading, the month of landing, or sometime between those events. Prices for crude oil can be determined at a time other than the acquisition date. See the Explanatory Notes section for additional detail.

Sources: Domestic first purchase prices - See "Sources" from Table 21. Crude oil imports costs - See "Sources" from Table 24. Refiner acquisition costs Energy Information Administration, Form FEA-P110-M-1, "Refiners' Monthly Cost Allocation Report," January 1978 through June 1978; Form ERA-49, "Domestic Crude Oil Entitlements Program Refiners' Monthly Report," July 1978 through December 1980; Form ElA-14, "Refiners' Monthly Cost Report," January 1981 to present. 
Figure 1. Crude Oil Prices

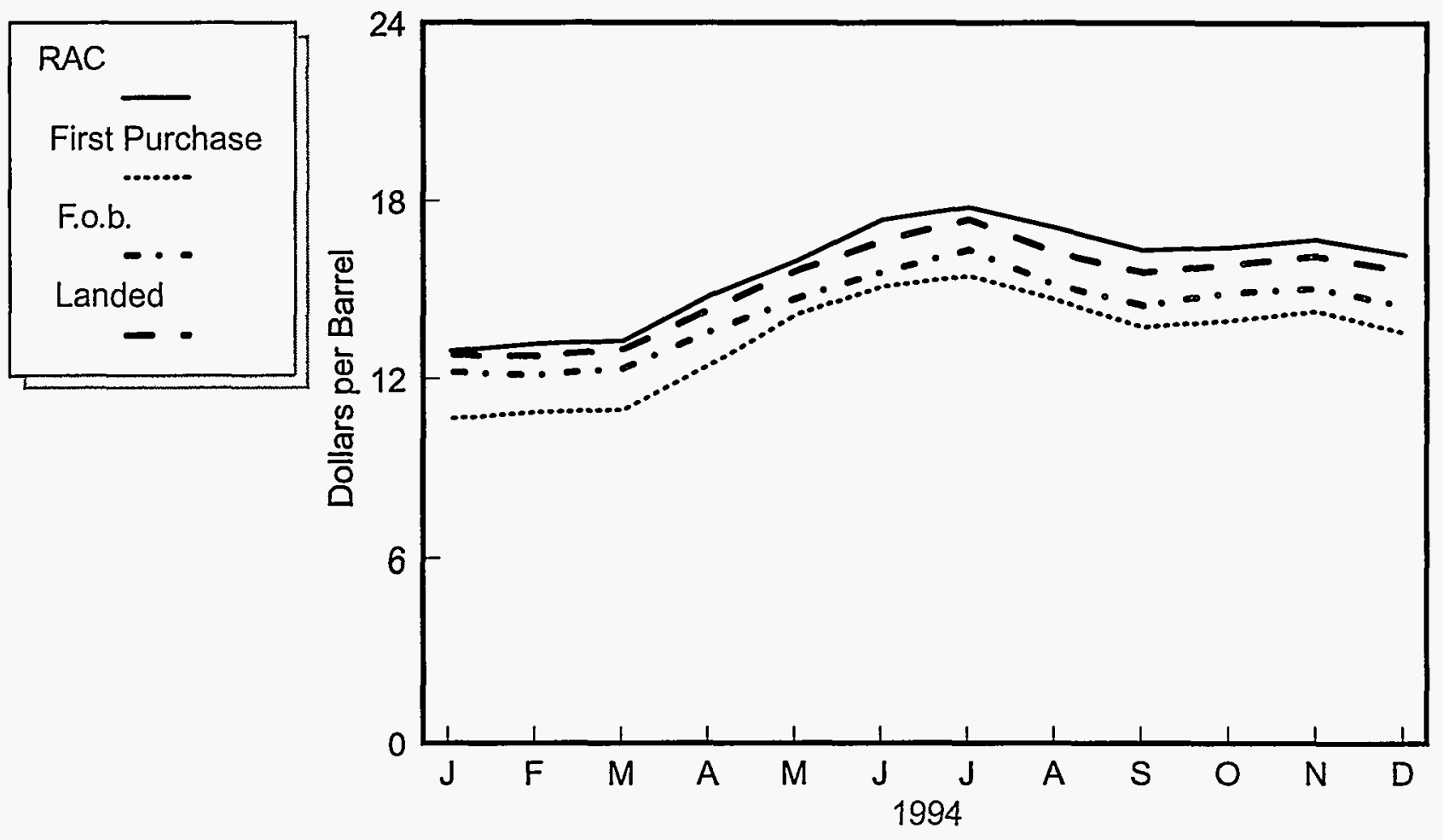

Sources: Energy Information Administration, Form EIA-182, "Domestic Crude Oil First Purchase Report"; Form ElA-856, "Monthly Foreign Crude Oll Acquisition Report"; and Form EIA-14, "Refiners' Monthly Cost Report." 
Table 2. U.S. Refiner Prices of Petroleum Products to End Users (Cents per Gallon Excluding Taxes)

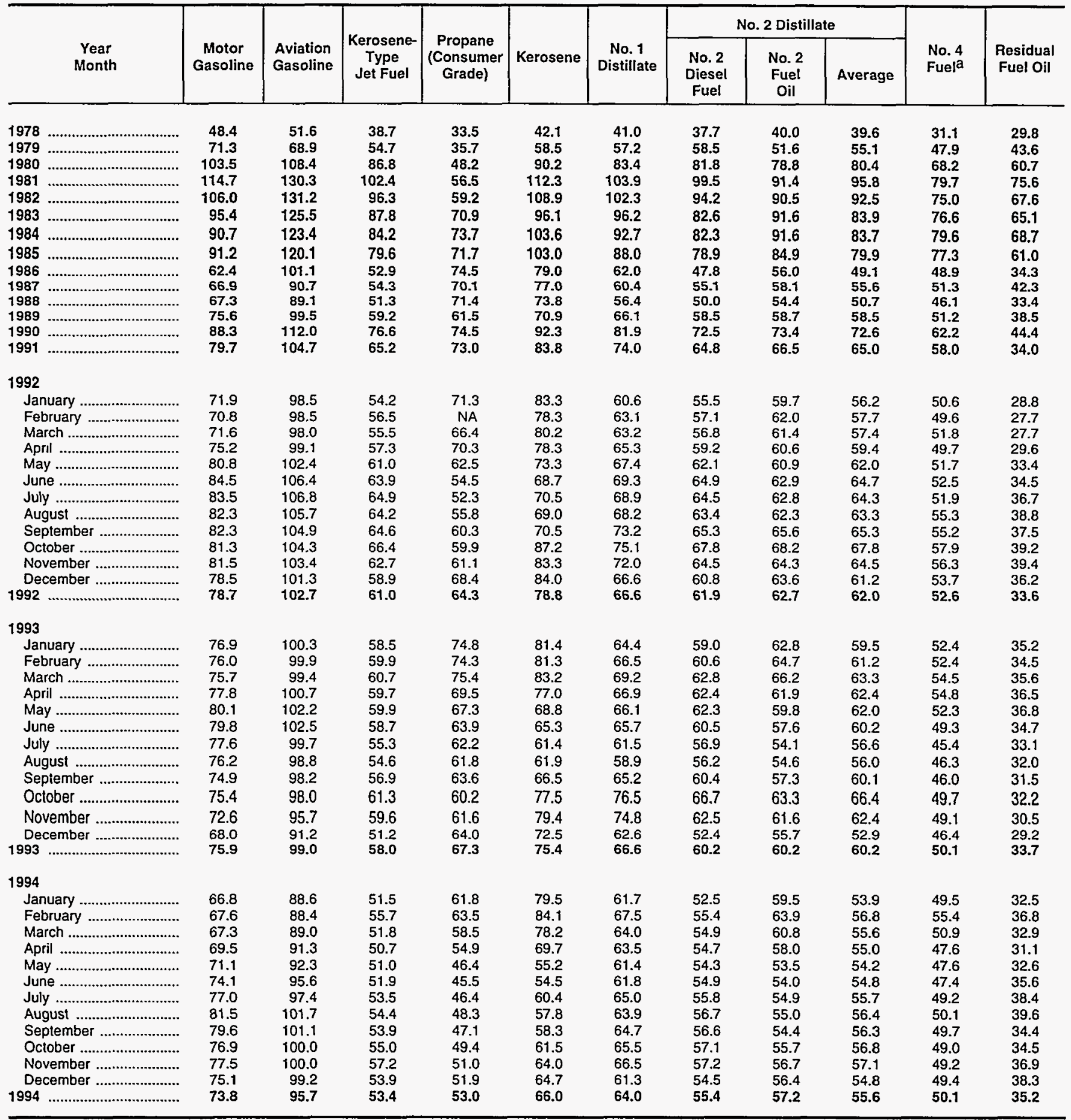

NA $=$ Not available.

a Includes No. 4 fuel oil and No. 4 diesel fuel.

Note: Motor gasoline averages and totals prior to October 1993 include leaded gasoline.

Sources: Energy Information Administration Form ElA-782A, "Refiners'/Gas Plant Operators' Monthly Petroleum Product Sales Report," January 1983 forward; Form EIA-460, "Petroleum Industry Monthly Report for Product Prices," source for backcast estimates prior to January 1983. 
Figure 2. U.S. Refiner Retail Petroleum Product Prices
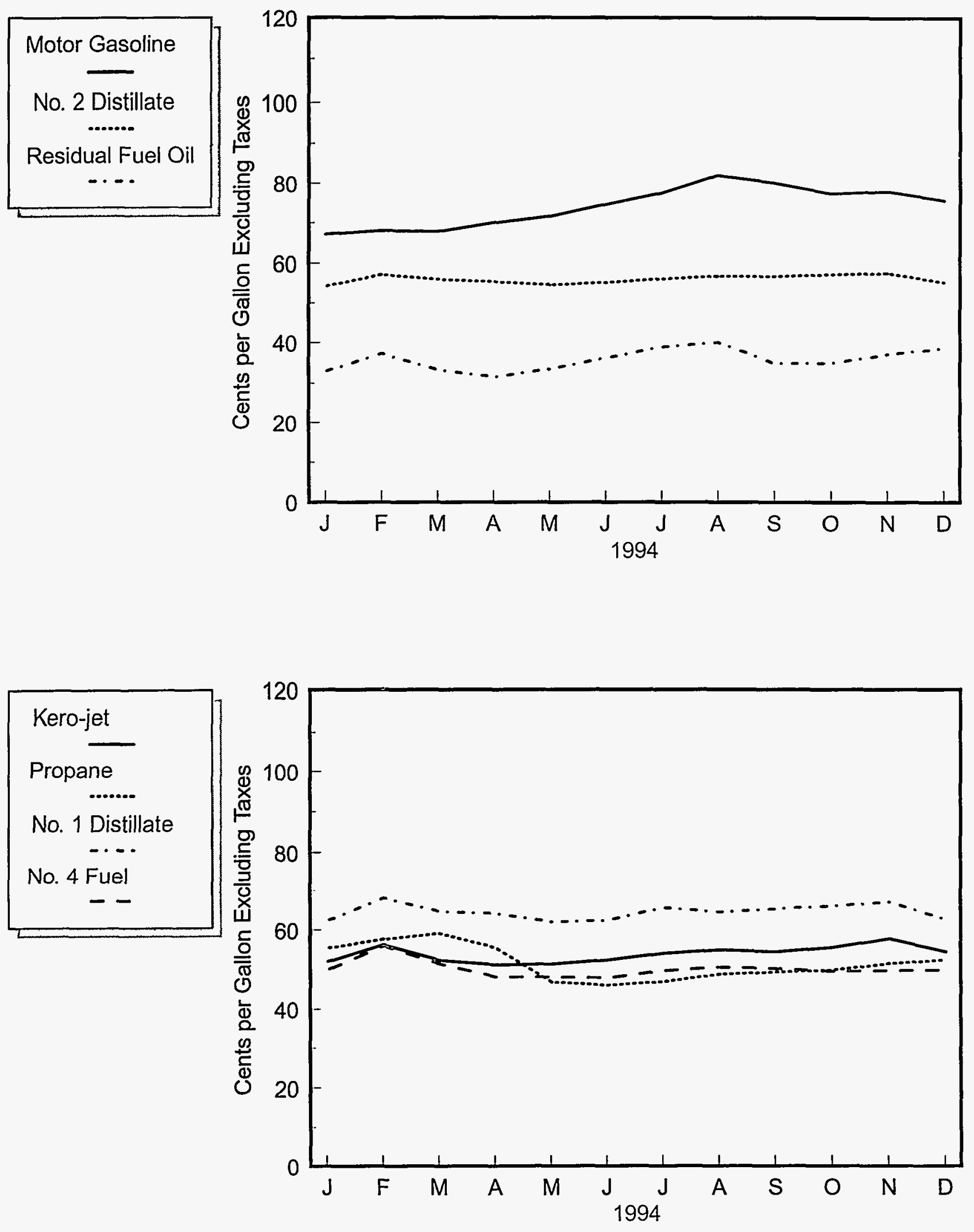

Source: Energy Information Administration, Form ElA-782A, "Refiners'/Gas Plant Operators' Monthly Petroleum Product Sales Report." 
Table 3. U.S. Refiner Volumes of Petroleum Products to End Users (Million Gallons per Day)

\begin{tabular}{|c|c|c|c|c|c|c|c|c|c|c|c|}
\hline \multirow[b]{2}{*}{$\begin{array}{c}\text { Year } \\
\text { Month }\end{array}$} & \multirow[b]{2}{*}{$\begin{array}{l}\text { Motor } \\
\text { Gasoline }\end{array}$} & \multirow[b]{2}{*}{$\begin{array}{l}\text { Aviation } \\
\text { Gasoline }\end{array}$} & \multirow[b]{2}{*}{$\begin{array}{c}\text { Kerosene- } \\
\text { Type } \\
\text { Jet Fuel }\end{array}$} & \multirow[b]{2}{*}{$\begin{array}{c}\text { Propane } \\
\text { (Consumer } \\
\text { Grade) }\end{array}$} & \multirow[b]{2}{*}{ Kerosene } & \multirow[b]{2}{*}{$\begin{array}{c}\text { No. } 1 \\
\text { Distillate }\end{array}$} & \multicolumn{3}{|c|}{ No. 2 Distillate } & \multirow[b]{2}{*}{$\begin{array}{l}\text { No. } 4 \\
\text { Fuela }\end{array}$} & \multirow[b]{2}{*}{$\begin{array}{l}\text { Residual } \\
\text { Fuel Oil }\end{array}$} \\
\hline & & & & & & & $\begin{array}{l}\text { No. } 2 \\
\text { Diesel } \\
\text { Fuel }\end{array}$ & $\begin{array}{c}\text { No. } 2 \\
\text { Fuel } \\
\text { Oil }\end{array}$ & Total & & \\
\hline 1983 & 51.1 & 0.4 & 30.8 & 3.1 & 0.2 & 0.5 & 23.3 & 3.7 & 27.0 & 0.7 & 28.3 \\
\hline 1984 & 57.6 & 0.3 & 32.9 & 3.3 & 0.3 & 0.5 & 26.3 & 4.9 & 31.2 & 0.7 & 32.9 \\
\hline 1985 & 57.5 & 0.3 & 34.6 & 3.7 & 0.3 & 0.5 & 25.0 & 5.0 & 29.9 & 0.5 & 25.2 \\
\hline 1986 & 61.2 & 0.3 & 35.1 & 3.4 & 0.3 & 0.4 & 24.4 & 4.4 & 28.8 & 0.7 & 31.6 \\
\hline 1987 & 61.0 & 0.2 & 36.8 & 3.8 & 0.3 & 0.4 & 24.1 & 4.5 & 28.5 & 0.8 & 29.0 \\
\hline 1988 & 61.0 & 0.2 & 38.2 & 4.3 & 0.3 & 0.4 & 24.5 & 4.6 & 29.1 & 1.1 & 30.2 \\
\hline 1989 & 61.2 & 0.2 & 40.1 & 2.8 & 0.3 & 0.5 & 24.3 & 4.5 & 28.8 & 0.9 & 30.4 \\
\hline 1990 & 60.3 & 0.2 & 39.9 & 2.7 & 0.2 & 0.5 & 22.2 & 3.6 & 25.9 & 0.8 & 25.9 \\
\hline 1991 & 61.2 & 0.2 & 38.5 & 3.1 & 0.2 & 0.5 & 21.1 & 3.2 & 24.4 & 0.7 & 24.0 \\
\hline \multicolumn{12}{|l|}{1992} \\
\hline 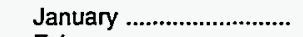 & 56.4 & 0.2 & 36.8 & 4.7 & 0.3 & 0.9 & 20.7 & 4.1 & 24.8 & 1.0 & 28.4 \\
\hline 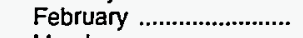 & 58.3 & 0.2 & 37.9 & 4.5 & 0.3 & 0.7 & 20.6 & 3.4 & 23.9 & 0.8 & 27.9 \\
\hline March ................................. & 59.6 & 0.2 & 38.5 & 3.8 & 0.2 & 0.5 & 21.9 & 3.3 & 25.2 & 0.8 & 26.2 \\
\hline April & 60.0 & 0.2 & 39.3 & 2.7 & 0.1 & 0.3 & 22.4 & 3.2 & 25.6 & 0.5 & 22.8 \\
\hline 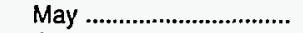 & 59.6 & 0.2 & 39.1 & 2.1 & 0.1 & 0.2 & 21.3 & 2.8 & 24.1 & 0.4 & 19.5 \\
\hline 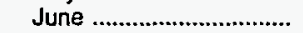 & 60.4 & 0.2 & 41.3 & 2.7 & 0.1 & 0.2 & 22.1 & 2.9 & 25.0 & 0.2 & 21.5 \\
\hline 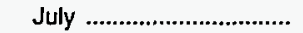 & 60.4 & 0.2 & 42.0 & 3.2 & 0.1 & 0.3 & 22.0 & 2.8 & 24.8 & 0.5 & 21.0 \\
\hline 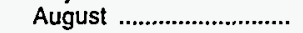 & 59.1 & 0.2 & 42.1 & 3.1 & 0.1 & 0.2 & 21.6 & 2.6 & 24.2 & 0.3 & 18.9 \\
\hline 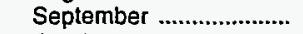 & 58.6 & 0.2 & 41.3 & 3.4 & 0.2 & 0.3 & 22.4 & 2.7 & 25.1 & 0.4 & 20.0 \\
\hline October & 59.0 & 0.2 & 40.3 & 4.3 & 0.2 & 0.4 & 22.0 & 3.0 & 25.1 & 0.5 & 19.7 \\
\hline November .......................... & 56.9 & 0.2 & 40.1 & 5.4 & 0.2 & 0.6 & 20.6 & 2.8 & 23.3 & 0.5 & 20.7 \\
\hline 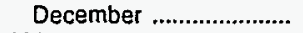 & 59.3 & 0.2 & 38.9 & 5.9 & 0.3 & 0.9 & 20.7 & 3.6 & 24.3 & 0.9 & 22.2 \\
\hline 1992 & 59.0 & 0.2 & 39.8 & 3.8 & 0.2 & 0.5 & 21.5 & 3.1 & 24.6 & 0.6 & 22.4 \\
\hline \multicolumn{12}{|l|}{1993} \\
\hline 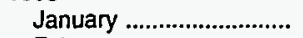 & 53.8 & 0.1 & 39.3 & 4.9 & 0.3 & 0.8 & 19.8 & 3.4 & 23.2 & 0.8 & 20.8 \\
\hline 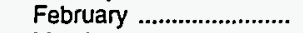 & 57.3 & 0.2 & 39.2 & 5.2 & 0.3 & 0.9 & 20.5 & 3.7 & 24.2 & 0.9 & 21.4 \\
\hline March .................................. & 57.6 & 0.2 & 40.6 & 4.4 & 0.2 & 0.6 & 21.1 & 3.4 & 24.5 & 0.8 & 19.4 \\
\hline April & 58.1 & 0.2 & 40.4 & 3.1 & 0.1 & 0.3 & 21.3 & 3.0 & 24.3 & 0.5 & 19.9 \\
\hline 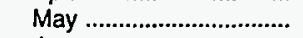 & 57.5 & 0.2 & 41.4 & 2.0 & 0.1 & 0.2 & 19.9 & 2.4 & 22.3 & 0.4 & 15.2 \\
\hline June & 60.4 & 0.2 & 41.8 & 2.3 & 0.1 & 0.3 & 21.1 & 2.7 & 23.9 & 0.4 & 17.1 \\
\hline 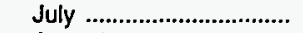 & 58.8 & 0.2 & 43.0 & 2.1 & 0.1 & 0.3 & 20.6 & 2.6 & 23.1 & 0.5 & 16.1 \\
\hline 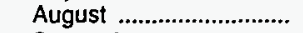 & 58.5 & 0.2 & 42.4 & 2.3 & 0.1 & 0.2 & 20.8 & 2.6 & 23.4 & 0.4 & 17.3 \\
\hline September ........................... & 57.5 & 0.2 & 42.5 & 2.9 & 0.2 & 0.3 & 20.7 & 2.8 & 23.5 & 0.5 & 17.2 \\
\hline 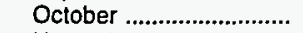 & 55.4 & 0.2 & 42.4 & 3.7 & 0.2 & 0.3 & 21.7 & 2.4 & 24.1 & 0.6 & 13.6 \\
\hline November .......................... & 55.7 & 0.2 & 43.4 & 4.8 & 0.2 & 0.4 & 21.1 & 2.8 & 23.9 & 0.7 & 13.0 \\
\hline December ....................... & 56.1 & 0.2 & 43.5 & 4.9 & 0.4 & 0.6 & 21.3 & 3.4 & 24.7 & 0.9 & 16.1 \\
\hline 1993 & 57.2 & 0.2 & 41.7 & 3.5 & 0.2 & 0.4 & 20.8 & 2.9 & 23.8 & 0.6 & 17.2 \\
\hline \multicolumn{12}{|l|}{1994} \\
\hline 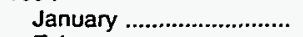 & 51.5 & 0.2 & 40.5 & 3.3 & 0.6 & 0.8 & 19.8 & 4.7 & 24.6 & 1.4 & 17.5 \\
\hline February .............................. & 54.3 & 0.2 & 41.2 & 2.9 & 0.6 & 0.8 & 21.6 & 4.1 & 25.7 & 1.4 & 15.5 \\
\hline 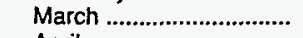 & 55.4 & 0.2 & 43.3 & 2.2 & 0.3 & 0.5 & 22.5 & 3.1 & 25.6 & 1.1 & 15.2 \\
\hline 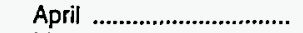 & 55.0 & 0.2 & 45.6 & 1.7 & 0.2 & 0.2 & 22.1 & 2.3 & 24.4 & 0.6 & 12.6 \\
\hline 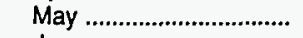 & 55.5 & 0.2 & 45.2 & 1.9 & 0.4 & 0.2 & 22.6 & 2.3 & 24.9 & 0.5 & 12.2 \\
\hline 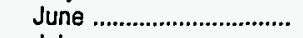 & 57.2 & 0.3 & 46.5 & 1.8 & 0.4 & 0.3 & 22.9 & 2.3 & 25.2 & 0.6 & 14.0 \\
\hline 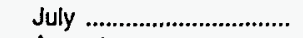 & 55.8 & 0.2 & 46.8 & 1.7 & 0.2 & 0.2 & 21.0 & 2.1 & 23.0 & 0.4 & $\$ 1.5$ \\
\hline 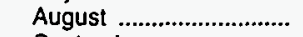 & 56.4 & 0.3 & 48.1 & 2.0 & 0.6 & 0.2 & 21.5 & 3.7 & 25.1 & 0.6 & 11.6 \\
\hline September ......................... & 55.0 & 0.2 & 47.3 & 1.9 & 0.4 & 0.3 & 21.2 & 3.7 & 24.9 & 0.4 & 12.5 \\
\hline 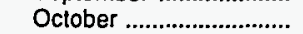 & 54.2 & 0.2 & 46.1 & 2.3 & 0.5 & 0.3 & 20.4 & 3.9 & 24.2 & 0.6 & 13.1 \\
\hline November ........................ & 54.5 & 0.2 & 45.6 & 2.2 & 0.6 & 0.4 & 20.2 & 4.0 & 24.2 & 0.8 & 12.9 \\
\hline 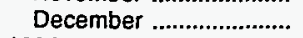 & 55.6 & 0.2 & 46.6 & 2.7 & 0.7 & 0.5 & 19.8 & 4.3 & 24.1 & 1.1 & 14.0 \\
\hline 1994 & 55.0 & 0.2 & 45.2 & 2.2 & 0.4 & 0.4 & 21.3 & 3.4 & 24.6 & 0.8 & 13.5 \\
\hline
\end{tabular}

a Includes No. 4 fuel oil and No. 4 diesel fuel.

Note: Motor gasoline averages and totals prior to October 1993 include leaded gasoline.

Note: Totals may not equal the sum of the components due to rounding.

Source: Energy Information Administration Form ElA-782A, "Refiners'/Gas Plant Operators' Monthly Petroleum Product Sales Report." 
Figure 3. U.S. Refiner Retail Petroleum Product Volumes

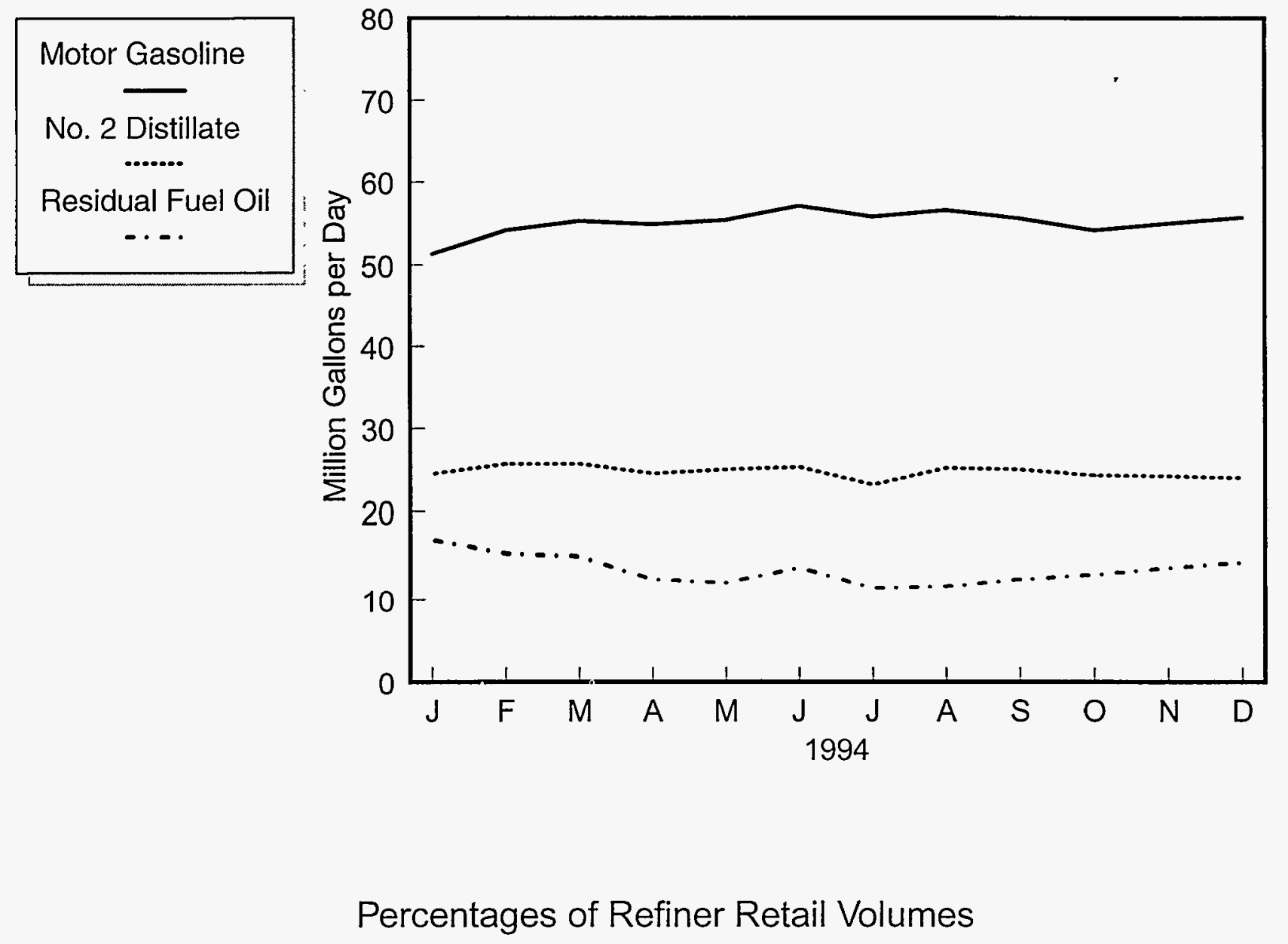

No. 2 Distillate

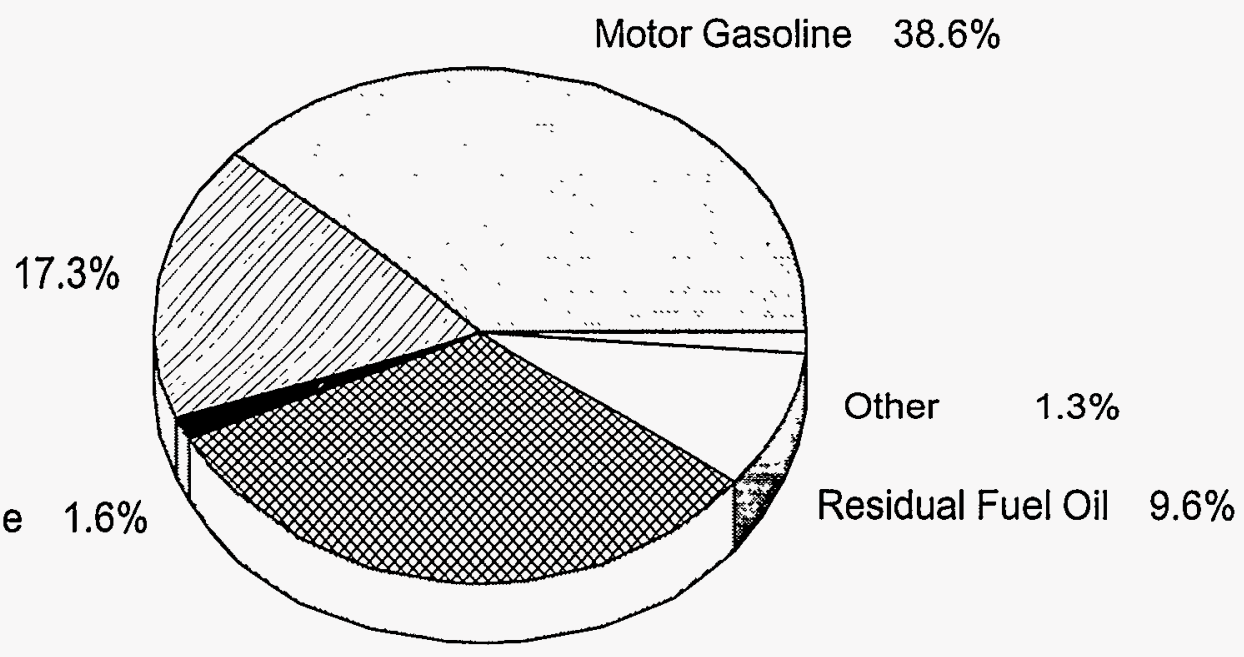

Kero-jet $\quad 31.7 \%$

Source: Energy Information Administration, Form EIA-782A, "Refiners'/Gas Plant Operators' Monthly Petroleum Product Sales Report." 
Table 4. U.S. Refiner Prices of Petroleum Products for Resale (Cents per Gallon Excluding Taxes)

\begin{tabular}{|c|c|c|c|c|c|c|c|c|c|c|c|}
\hline \multirow[b]{2}{*}{$\begin{array}{c}\text { Year } \\
\text { Month }\end{array}$} & \multirow[b]{2}{*}{$\begin{array}{c}\text { Motor } \\
\text { Gasoline }\end{array}$} & \multirow[b]{2}{*}{$\begin{array}{l}\text { Aviation } \\
\text { Gasoline }\end{array}$} & \multirow[b]{2}{*}{$\begin{array}{c}\text { Kerosene- } \\
\text { Type } \\
\text { Jet Fuel }\end{array}$} & \multirow[b]{2}{*}{$\begin{array}{c}\text { Propane } \\
\text { (Consumer } \\
\text { Grade) }\end{array}$} & \multirow[b]{2}{*}{ Kerosene } & \multirow[b]{2}{*}{$\begin{array}{c}\text { No. } 1 \\
\text { Distillate }\end{array}$} & \multicolumn{3}{|c|}{ No. 2 Distillate } & \multirow[b]{2}{*}{$\begin{array}{l}\text { No. } 4 \\
\text { Fuela }\end{array}$} & \multirow[b]{2}{*}{$\begin{array}{l}\text { Residual } \\
\text { Fuel Oil }\end{array}$} \\
\hline & & & & & & & $\begin{array}{c}\text { No. } 2 \\
\text { Diesel } \\
\text { Fuel }\end{array}$ & $\begin{array}{c}\text { No. } 2 \\
\text { Fuel } \\
\text { Oil }\end{array}$ & Average & & \\
\hline 1978 & 43.4 & 53.7 & 38.6 & 23.7 & 40.4 & 40.6 & 36.5 & 36.9 & 36.7 & 30.5 & 26.3 \\
\hline 1979 & 63.7 & 72.1 & 66.0 & 29.1 & 62.4 & 58.3 & 57.4 & 56.9 & 57.1 & 47.0 & 39.9 \\
\hline 1980 & 94.1 & 112.8 & 86.8 & 41.5 & 86.4 & 88.0 & 80.1 & 80.3 & 80.2 & 67.0 & 52.8 \\
\hline 1981 & 106.4 & 125.0 & 101.2 & 46.6 & 106.6 & 107.1 & 97.2 & 97.6 & 97.4 & 78.3 & 66.3 \\
\hline 1982 & 97.3 & 122.8 & 95.3 & 42.7 & 101.8 & 103.8 & 91.4 & 91.4 & 91.4 & 73.7 & 61.2 \\
\hline 1983 & 88.2 & 117.8 & 85.4 & 48.4 & 89.2 & 89.6 & 80.8 & 81.5 & 81.2 & 72.6 & 60.9 \\
\hline 1984 & 83.2 & 116.5 & 83.0 & 45.0 & 91.6 & 89.2 & 80.3 & 82.1 & 81.3 & 70.7 & 65.4 \\
\hline 1985 & 83.5 & 113.0 & 79.4 & 39.8 & 87.4 & 86.3 & 77.2 & 77.6 & 77.4 & 67.2 & $\mathbf{5 7 . 7}$ \\
\hline 1986 & 53.1 & 91.2 & 49.5 & 29.0 & 60.6 & 57.9 & 45.2 & 48.6 & 47.0 & 40.9 & 30.5 \\
\hline 1987 & 58.9 & 85.9 & 53.8 & 25.2 & 59.2 & 59.9 & 53.4 & $\mathbf{5 2 . 7}$ & 53.1 & 46.2 & 38.5 \\
\hline 1988 & 57.7 & 85.0 & 49.5 & 24.0 & 54.9 & 54.9 & 47.3 & 47.3 & 47.3 & 42.5 & 30.0 \\
\hline 1989 & 65.4 & 95.0 & 58.3 & 24.7 & 66.9 & 66.8 & 56.7 & 56.5 & 56.6 & 48.0 & 36.0 \\
\hline 1990 & 78.6 & 106.3 & 77.3 & 38.6 & 83.9 & 83.8 & 69.4 & 69.7 & 69.5 & 59.0 & 41.3 \\
\hline 1991 & 69.9 & 100.1 & 65.0 & 34.9 & 72.3 & 73.0 & 61.5 & 62.2 & 61.8 & 55.6 & 31.4 \\
\hline \multicolumn{12}{|l|}{1992} \\
\hline January ............................... & 60.0 & 94.9 & 53.9 & 30.9 & 59.9 & 58.4 & 51.4 & 51.9 & 51.7 & 49.5 & 24.4 \\
\hline February ............................ & 61.7 & 93.1 & 55.2 & 30.2 & 62.0 & 62.1 & 54.1 & 54.0 & 54.0 & 48.2 & 25.6 \\
\hline 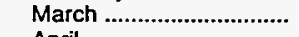 & 62.7 & 92.5 & 54.6 & 29.5 & 59.1 & 62.3 & 54.0 & 53.7 & 53.9 & 46.5 & 24.6 \\
\hline 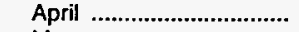 & 66.6 & 96.4 & 56.9 & 29.0 & 61.6 & 64.3 & 57.0 & 56.5 & 56.8 & 46.5 & 27.4 \\
\hline May .................................. & 71.5 & 100.5 & 60.8 & 29.4 & 62.1 & 66.6 & 60.1 & 58.8 & 59.5 & 48.4 & 30.2 \\
\hline 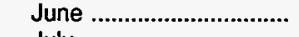 & 74.2 & 101.5 & 63.3 & 31.6 & 63.7 & 69.3 & 62.7 & 61.7 & 62.2 & 49.5 & 32.5 \\
\hline 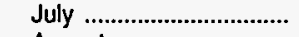 & 71.0 & 102.0 & 64.8 & 31.5 & 65.7 & 68.8 & 61.8 & 61.3 & 61.6 & 49.5 & 34.7 \\
\hline 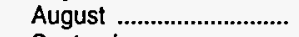 & 70.6 & 102.6 & 63.9 & 32.9 & 64.2 & 68.0 & 60.4 & 60.1 & 60.3 & 49.1 & 34.7 \\
\hline September ........................ & 71.0 & 102.3 & 64.3 & 35.4 & 68.8 & 71.4 & 63.3 & 62.7 & 63.0 & 50.1 & 34.8 \\
\hline 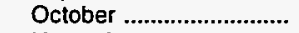 & 70.4 & 100.5 & 66.0 & 36.6 & 70.1 & 73.6 & 65.5 & 64.6 & 65.1 & 52.7 & 37.4 \\
\hline November ........................ & 68.1 & 99.7 & 61.5 & 36.2 & 64.5 & 68.7 & 60.4 & 58.8 & 59.6 & 52.2 & 35.9 \\
\hline December ............................ & 63.8 & 97.6 & 58.9 & 36.3 & 62.8 & 63.7 & 56.4 & 55.7 & 56.0 & 51.6 & 30.6 \\
\hline 1992 & 67.7 & 99.1 & 60.5 & 32.8 & 63.2 & 65.2 & 59.1 & 57.9 & 58.5 & 49.5 & 30.8 \\
\hline \multicolumn{12}{|l|}{1993} \\
\hline January ............................... & 63.8 & 96.9 & 57.7 & 40.2 & 61.4 & 63.2 & 54.9 & 54.4 & 54.6 & 50.3 & 31.5 \\
\hline February ............................. & 63.8 & 96.5 & 60.4 & 36.7 & 63.7 & 65.7 & 57.4 & 56.9 & 57.1 & 49.9 & 30.9 \\
\hline 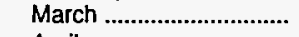 & 65.2 & 97.4 & 60.3 & 38.2 & 65.4 & 67.4 & 60.0 & 59.0 & 59.5 & 53.8 & 32.9 \\
\hline April & 67.7 & 97.7 & 59.8 & 36.2 & 60.8 & 65.4 & 59.8 & 57.5 & 58.7 & 52.4 & 33.3 \\
\hline 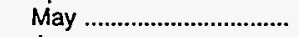 & 69.1 & 99.4 & 60.1 & 34.0 & 58.3 & 66.4 & 59.6 & 56.9 & 58.4 & 51.3 & 31.1 \\
\hline 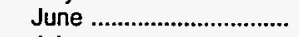 & 66.2 & 99.1 & 58.5 & 33.8 & 56.9 & 63.2 & 57.2 & 55.0 & 56.2 & 46.9 & 30.2 \\
\hline July …................................ & 62.7 & 97.9 & 55.1 & 33.3 & 53.6 & 59.0 & 53.2 & 51.0 & 52.2 & 45.4 & 27.5 \\
\hline 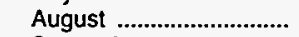 & 62.9 & 96.9 & 55.1 & 33.3 & 55.6 & 57.9 & 53.2 & 51.0 & 52.2 & 46.7 & 27.2 \\
\hline September ....................... & 61.5 & 96.3 & 56.6 & 34.1 & 58.7 & 66.1 & 58.9 & 54.8 & 57.3 & 47.5 & 27.1 \\
\hline October & 61.7 & 95.0 & 60.5 & 34.7 & 65.5 & 75.7 & 65.8 & 58.1 & 63.6 & 45.2 & 28.7 \\
\hline November ........................ & 57.0 & 92.7 & 58.7 & 33.6 & 62.4 & 69.8 & 58.9 & 53.1 & 57.1 & 45.2 & 26.2 \\
\hline 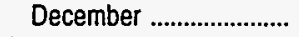 & 50.3 & 87.4 & 51.0 & 30.9 & 53.6 & 56.7 & 46.8 & 45.1 & 46.1 & 43.4 & 24.8 \\
\hline 1993 & 62.6 & 96.5 & 57.7 & 35.1 & 60.4 & 64.6 & $\mathbf{5 7 . 0}$ & 54.4 & 55.9 & 48.8 & 29.3 \\
\hline \multicolumn{12}{|l|}{1994} \\
\hline 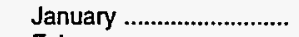 & 52.2 & 87.1 & 52.9 & 32.3 & 65.7 & 59.3 & 49.1 & 50.7 & 49.8 & 46.9 & 28.3 \\
\hline February .............................. & 54.6 & 87.8 & 56.0 & 34.0 & 73.5 & 63.6 & 52.8 & 54.2 & 53.4 & 52.9 & 33.8 \\
\hline 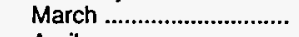 & 54.9 & 87.4 & 52.5 & 31.8 & 59.9 & 61.3 & 52.9 & 49.7 & 51.8 & 48.7 & 27.4 \\
\hline April & 57.9 & 89.5 & 50.9 & 30.4 & 55.1 & 57.8 & 52.3 & 48.9 & 51.3 & 39.4 & 27.5 \\
\hline 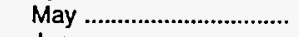 & 59.2 & 91.2 & 50.6 & 30.4 & 53.2 & 57.0 & 51.7 & 49.0 & 51.0 & 42.6 & 29.5 \\
\hline 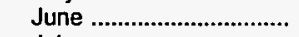 & 62.6 & 93.2 & 51.5 & 29.9 & 53.9 & 57.6 & 52.3 & 49.8 & 51.6 & 41.0 & 33.5 \\
\hline 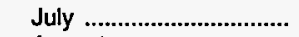 & 65.4 & 96.1 & 53.8 & 29.8 & 55.1 & 60.3 & 53.7 & 50.9 & 52.9 & 43.9 & 36.2 \\
\hline 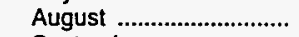 & 67.8 & 98.5 & 54.4 & 31.0 & 55.1 & 61.1 & 54.1 & 51.4 & 53.4 & 44.9 & 35.2 \\
\hline September ...................... & 61.0 & 97.3 & 54.0 & 31.7 & 55.3 & 61.9 & 54.2 & 50.1 & 53.1 & 39.6 & 30.1 \\
\hline 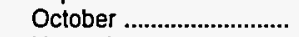 & 61.4 & 95.4 & 54.4 & 33.5 & 59.1 & 64.1 & 55.2 & 50.8 & 54.0 & 43.1 & 31.6 \\
\hline November ....................... & 62.2 & 95.2 & 56.3 & 35.0 & 60.7 & 64.6 & 55.1 & 51.0 & 53.8 & 44.2 & 34.2 \\
\hline 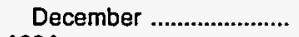 & 58.0 & 94.2 & 53.1 & 35.7 & 57.4 & 60.7 & 51.0 & 49.5 & 50.5 & 44.5 & 34.1 \\
\hline 1994 & 59.9 & 93.3 & 53.4 & 32.4 & 61.8 & 61.5 & 52.9 & 50.6 & 52.2 & 46.2 & 31.7 \\
\hline
\end{tabular}

a Includes No. 4 fuel oil and No. 4 diesel fuel.

Note: Motor gasoline averages and totals prior to October 1993 include leaded gasoline.

Sources: Energy Information Administration Form ElA-782A, "Refiners'/Gas Plant Operators' Monthly Petroleum Product Sales Report," January 1983 torward; Form EIA-460, "Petroleum Industry Monthly Report for Product Prices," source for backcast estimates prior to January 1983. 
Figure 4. U.S. Refiner Wholesale Petroleum Product Prices
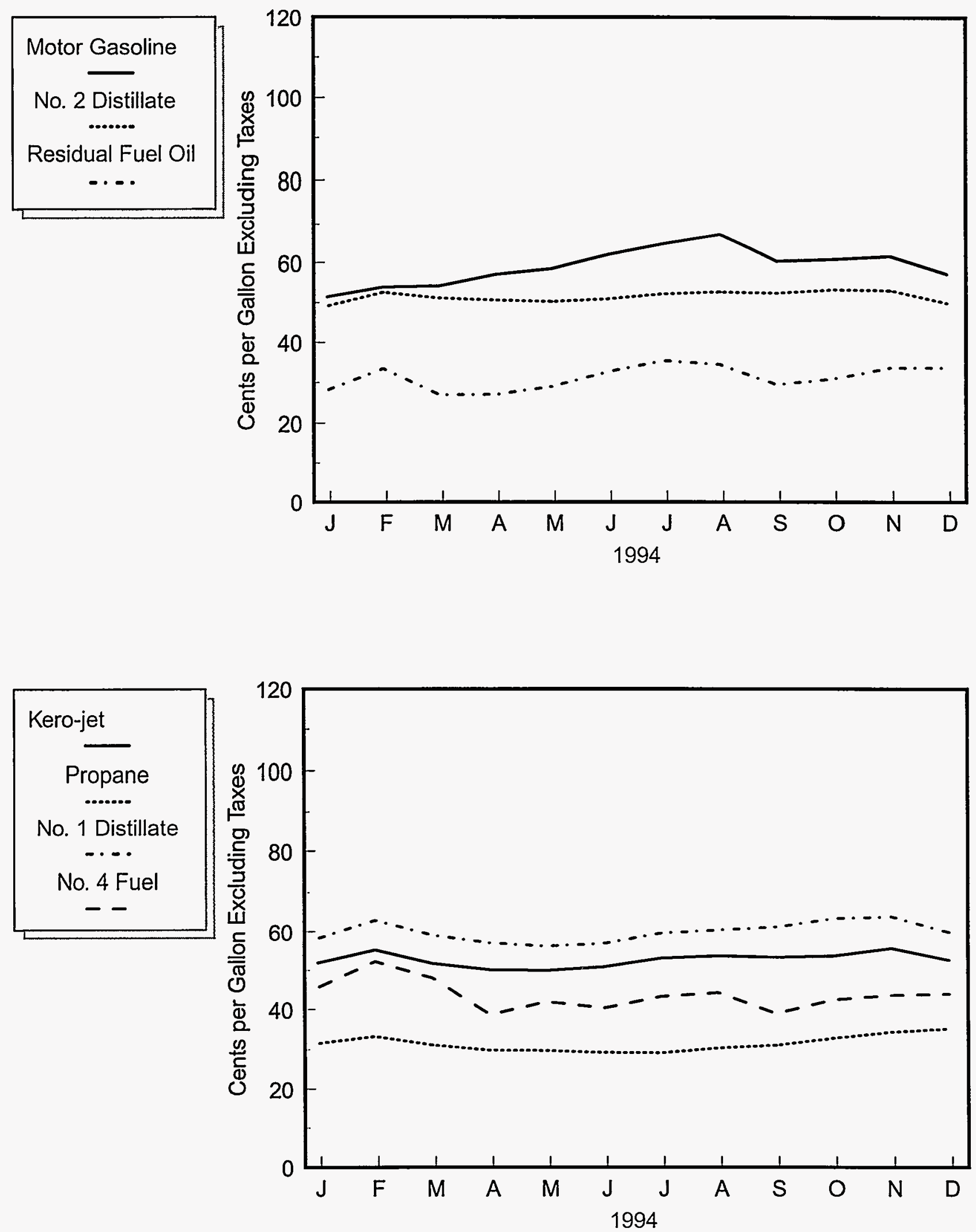

Source: Energy Information Administration, Form EIA-782A, "Refiners'/Gas Plant Operators' Monthly Petroleum Product Sales Report." 
Table 5. U.S. Refiner Volumes of Petroleum Products for Resale (Million Gallons per Day)

\begin{tabular}{|c|c|c|c|c|c|c|c|c|c|c|c|}
\hline \multirow[b]{2}{*}{$\begin{array}{l}\text { Year } \\
\text { Month }\end{array}$} & \multirow[b]{2}{*}{$\begin{array}{l}\text { Motor } \\
\text { Gasoline }\end{array}$} & \multirow[b]{2}{*}{$\begin{array}{l}\text { Aviation } \\
\text { Gasoline }\end{array}$} & \multirow[b]{2}{*}{$\begin{array}{c}\text { Kerosene- } \\
\text { Type } \\
\text { Jet Fuel }\end{array}$} & \multirow[b]{2}{*}{$\begin{array}{c}\text { Propane } \\
\text { (Consumer } \\
\text { Grade) }\end{array}$} & \multirow[b]{2}{*}{ Kerosene } & \multirow[b]{2}{*}{$\begin{array}{c}\text { No. } 1 \\
\text { Distillate }\end{array}$} & \multicolumn{3}{|c|}{ No. 2 Distillate } & \multirow[b]{2}{*}{$\begin{array}{l}\text { No. } 4 \\
\text { Fueja }\end{array}$} & \multirow[b]{2}{*}{$\begin{array}{l}\text { Residual } \\
\text { Fuel Oil }\end{array}$} \\
\hline & & & & & & & $\begin{array}{c}\text { No. } 2 \\
\text { Diesel } \\
\text { Fuel }\end{array}$ & $\begin{array}{c}\text { No. } 2 \\
\text { Fuel } \\
\text { Oil }\end{array}$ & Total & & \\
\hline 1983 & 242.5 & 0.7 & 5.4 & 26.0 & 2.5 & 2.4 & 38.1 & 47.3 & 85.5 & 0.9 & 20.2 \\
\hline 1984 & 246.3 & 0.8 & 6.6 & 26.7 & 2.2 & 2.6 & 42.8 & 51.4 & 94.2 & 1.7 & 21.3 \\
\hline 1985 & 256.9 & 0.7 & 7.6 & 29.2 & 2.4 & 2.7 & 43.3 & 53.9 & 97.3 & 1.2 & 19.9 \\
\hline 1986 & 257.2 & 0.7 & 9.2 & 26.3 & 2.4 & 2.5 & 46.4 & 53.8 & 100.3 & 1.2 & 18.6 \\
\hline $1987 \ldots \ldots \ldots \ldots \ldots \ldots \ldots \ldots \ldots$ & 257.2 & 0.8 & 10.1 & 27.0 & 2.3 & 2.0 & 44.3 & 49.3 & 93.6 & 1.5 & 16.9 \\
\hline 1988 & 263.7 & 0.7 & 10.0 & 27.7 & 2.7 & 2.6 & 47.8 & 50.1 & 97.9 & 1.2 & 18.9 \\
\hline 1989 & 260.7 & 0.7 & 8.6 & 25.9 & 2.7 & 2.7 & 50.7 & 46.7 & 97.5 & 1.2 & 21.0 \\
\hline 1990 & 264.8 & 0.7 & 8.8 & 25.5 & 2.2 & 2.4 & 51.9 & 45.9 & 97.8 & 0.8 & 17.9 \\
\hline 1991 & 261.3 & 0.7 & 8.7 & 25.4 & 2.1 & 2.4 & 51.5 & 46.9 & 98.3 & 0.4 & 17.8 \\
\hline \multicolumn{12}{|l|}{1992} \\
\hline 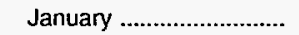 & 249.5 & 0.5 & 7.4 & 33.9 & 4.6 & 4.6 & 47.9 & 61.7 & 109.6 & 0.8 & 16.8 \\
\hline February ................. & 252.8 & 0.5 & 8.7 & 28.4 & 3.4 & 3.0 & 45.7 & 56.4 & 102.1 & 0.7 & 13.6 \\
\hline 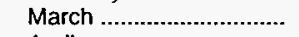 & 259.5 & 0.7 & 7.6 & 24.1 & 2.4 & 1.7 & 49.4 & 50.4 & 99.8 & 0.7 & 16.7 \\
\hline April & 271.5 & 0.6 & 7.7 & 21.6 & 1.2 & 0.9 & 53.4 & 47.4 & 100.9 & 0.4 & 17.9 \\
\hline 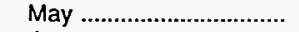 & 269.5 & 0.8 & 7.2 & 19.6 & 0.8 & 0.6 & 50.8 & 39.5 & 90.3 & 0.3 & 17.1 \\
\hline June & 271.7 & 0.8 & 8.5 & 20.7 & 0.9 & 0.6 & 50.4 & 41.9 & 92.4 & 0.1 & 16.2 \\
\hline 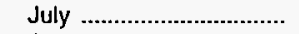 & 272.8 & 0.9 & 7.9 & 22.9 & 0.6 & 0.7 & 52.7 & 37.6 & 90.3 & 0.2 & 15.6 \\
\hline 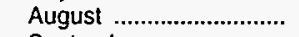 & 265.8 & 0.8 & 7.7 & 24.2 & 1.1 & 1.1 & 50.8 & 39.2 & 90.0 & 0.2 & 12.6 \\
\hline September ..................... & 268.3 & 0.7 & 7.9 & 25.6 & 1.8 & 1.9 & 52.6 & 52.8 & 105.4 & 0.2 & 14.3 \\
\hline 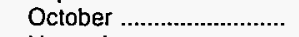 & 266.6 & 0.6 & 9.1 & 27.4 & 2.6 & 2.4 & 55.8 & 45.5 & 101.3 & 0.5 & 13.1 \\
\hline 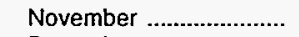 & 260.9 & 0.5 & 8.7 & 33.4 & 2.9 & 4.0 & 48.9 & 50.8 & 99.6 & 0.5 & 14.3 \\
\hline December ......................... & 275.8 & 0.4 & 8.2 & 37.9 & 4.2 & 6.0 & 50.8 & 63.6 & 114.4 & 0.8 & 14.0 \\
\hline 1992 & 265.4 & 0.7 & 8.0 & 26.7 & 2.2 & 2.3 & 50.8 & 48.9 & 99.7 & 0.4 & 15.2 \\
\hline \multicolumn{12}{|l|}{1993} \\
\hline 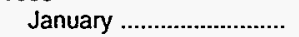 & 245.1 & 0.4 & 9.4 & 34.5 & 3.8 & 5.3 & 47.3 & 53.9 & 101.3 & 0.6 & 10.3 \\
\hline February ........................... & 260.1 & 0.5 & 7.7 & 35.2 & 4.3 & 4.5 & 49.0 & 56.0 & 105.1 & 0.7 & 14.4 \\
\hline 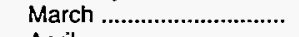 & 262.5 & 0.6 & 8.7 & 30.4 & 3.3 & 2.5 & 50.9 & 55.8 & 106.7 & 0.8 & 13.2 \\
\hline April & 267.7 & 0.6 & 7.6 & 21.9 & 1.3 & 0.9 & 51.7 & 46.2 & 97.9 & 0.4 & 12.4 \\
\hline 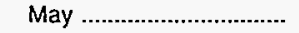 & 264.1 & 0.7 & 7.3 & 19.1 & 0.9 & 0.6 & 50.6 & 39.8 & 90.4 & 0.2 & 13.8 \\
\hline 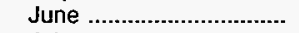 & 277.1 & 0.8 & 7.5 & 23.3 & 0.8 & 0.6 & 52.8 & 42.5 & 95.3 & 0.2 & 11.3 \\
\hline 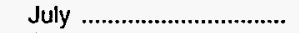 & 276.5 & 0.8 & 7.9 & 21.7 & 0.8 & 0.6 & 53.1 & 39.2 & 92.3 & 0.1 & 10.9 \\
\hline 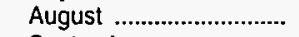 & 274.3 & 0.8 & 8.2 & 24.8 & 1.1 & 1.0 & 56.0 & 43.1 & 99.1 & 0.1 & 11.7 \\
\hline September ..................... & 267.3 & 0.7 & 8.3 & 27.3 & 1.9 & 1.4 & 61.9 & 39.5 & 101.4 & 0.1 & 13.8 \\
\hline 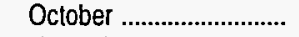 & 263.3 & 0.6 & 8.0 & 29.8 & 2.2 & 1.7 & 72.5 & 29.9 & 102.4 & 0.4 & 15.3 \\
\hline November ..................... & 268.3 & 0.5 & 9.6 & 32.3 & 3.2 & 3.9 & 71.6 & 32.8 & 104.4 & 0.4 & 13.1 \\
\hline 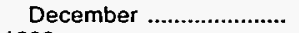 & 276.7 & 0.5 & 9.7 & 34.5 & 4.7 & 4.5 & 78.1 & 45.8 & 123.9 & 0.6 & 11.4 \\
\hline 1993 & 266.9 & 0.6 & 8.3 & 27.9 & 2.3 & 2.3 & 58.0 & 43.6 & 101.7 & 0.4 & 12.6 \\
\hline \multicolumn{12}{|l|}{1994} \\
\hline January ............................. & 254.5 & 0.4 & 8.2 & 40.0 & 7.0 & 5.1 & 63.4 & 46.5 & 109.9 & 0.9 & 14.0 \\
\hline February ............................ & 261.2 & 0.5 & 8.0 & 33.7 & 4.9 & 3.7 & 65.3 & 47.2 & 112.5 & 0.9 & 16.0 \\
\hline 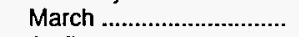 & 269.0 & 0.6 & 7.1 & 26.1 & 2.7 & 1.2 & 71.8 & 38.6 & 110.4 & 0.6 & 16.0 \\
\hline 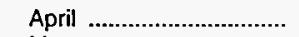 & 276.2 & 0.6 & 7.5 & 21.0 & 1.1 & 0.7 & 74.3 & 29.8 & 104.1 & 0.3 & 12.8 \\
\hline May & 279.4 & 0.8 & 9.1 & 19.4 & 0.9 & 0.6 & 74.9 & 26.6 & 101.5 & 0.1 & 13.4 \\
\hline June & 287.7 & 0.9 & 9.2 & 22.6 & 0.7 & 0.6 & 79.6 & 29.3 & 108.9 & 0.2 & 12.7 \\
\hline 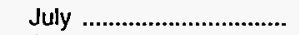 & 279.2 & 0.9 & 10.0 & 24.0 & 0.7 & 0.5 & 69.9 & 25.0 & 94.9 & 0.2 & 11.6 \\
\hline 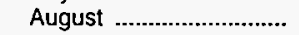 & 288.4 & 0.9 & 11.0 & 26.3 & 1.7 & 0.7 & 77.2 & 26.4 & 103.5 & 0.2 & 13.8 \\
\hline September ....................... & 282.0 & 0.8 & 9.7 & 27.2 & 2.0 & 1.3 & 78.6 & 28.6 & 107.2 & 0.2 & 10.5 \\
\hline 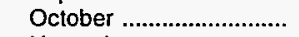 & 276.1 & 0.6 & 9.6 & 32.6 & 2.2 & 1.7 & 75.7 & 28.2 & 103.9 & 0.2 & 9.6 \\
\hline 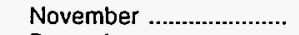 & 275.9 & 0.5 & 9.8 & 31.1 & 2.5 & 3.4 & 69.0 & 31.0 & 100.0 & 0.3 & 11.6 \\
\hline December ............................. & 290.0 & 0.4 & 10.4 & 36.8 & 3.9 & 3.9 & 68.9 & 38.7 & 107.5 & 0.6 & 11.7 \\
\hline 1994 & 276.7 & 0.7 & 9.1 & 28.4 & 2.5 & 1.9 & 72.4 & 32.9 & 105.3 & 0.4 & 12.8 \\
\hline
\end{tabular}

a Includes No. 4 fuel oil and No. 4 diesel fuel.

Note: Motor gasoline averages and totals prior to October 1993 include leaded gasoline.

Note: Totals may not equal the sum of the components due to rounding.

Source: Energy Information Administration Form ElA-782A, "Refiners'/Gas Plant Operators' Monthly Petroleum Product Sales Report." 
Figure 5. U.S. Refiner Wholesale Petroleum Product Volumes

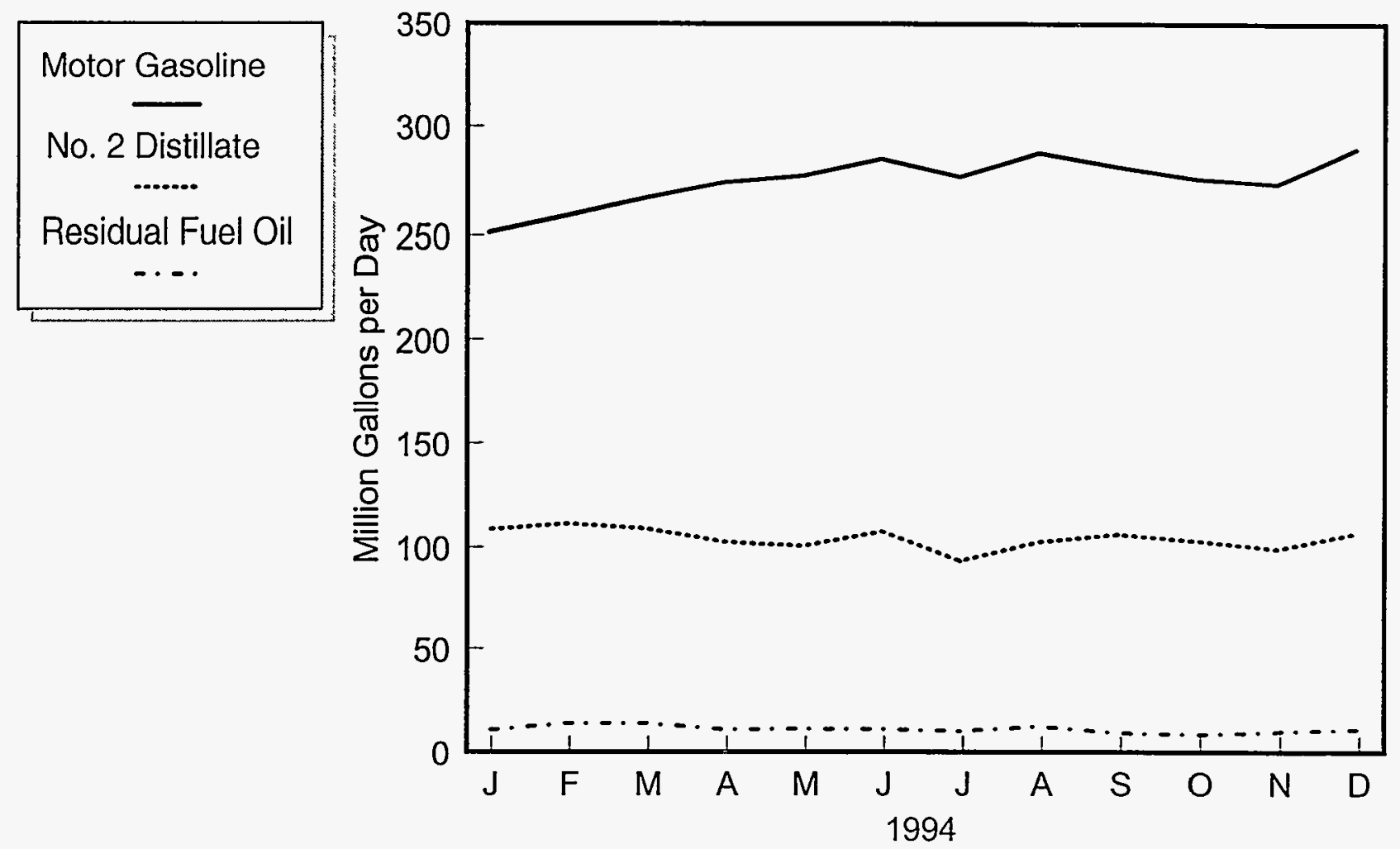

\section{Percentages of Refiner Wholesale Volumes}

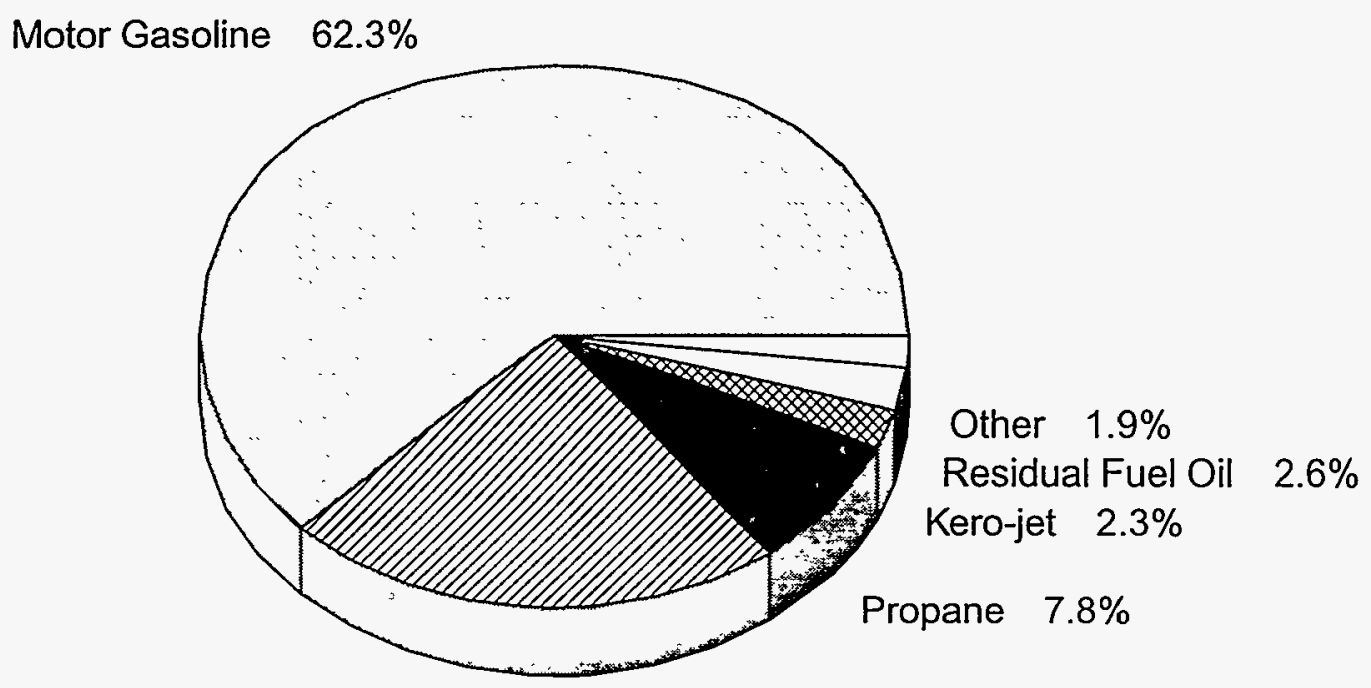

No. 2 Distillate $23.1 \%$ 
Table 6. U.S. Refiner Motor Gasoline Prices by Grade and Sales Type (Cents per Gallon Excluding Taxes)

\begin{tabular}{|c|c|c|c|c|c|c|c|c|c|c|c|c|}
\hline \multirow{3}{*}{$\begin{array}{l}\text { Year } \\
\text { Month }\end{array}$} & \multicolumn{6}{|c|}{ Regular } & \multicolumn{6}{|c|}{ Midgrade } \\
\hline & \multicolumn{2}{|c|}{ Sales to End Users } & \multicolumn{4}{|c|}{ Sales for Resale } & \multicolumn{2}{|c|}{ Sales to End Users } & \multicolumn{4}{|c|}{ Sales for Resale } \\
\hline & $\begin{array}{c}\text { Through } \\
\text { Retail } \\
\text { Outlets }\end{array}$ & Average $\mathrm{a}^{\mathrm{a}}$ & DTW & Rack & Bulk & Average & $\begin{array}{c}\text { Through } \\
\text { Retail } \\
\text { Outlets }\end{array}$ & Average $^{a}$ & DTW & Rack & Bulk & Average \\
\hline 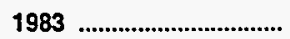 & 98.0 & 97.0 & - & - & - & 89.5 & - & - & - & - & - & - \\
\hline 1984 & 92.2 & 91.4 & - & - & - & 84.2 & - & - & - & - & - & - \\
\hline 1985 & 92.5 & 91.7 & - & - & - & 84.3 & - & - & - & - & - & - \\
\hline 1986 & 62.4 & 61.6 & - & - & - & 52.2 & - & - & - & - & - & - \\
\hline 1987 & 65.9 & 65.0 & - & - & - & 56.9 & - & - & - & - & - & - \\
\hline 1988 & 64.9 & 64.1 & - & - & - & 54.8 & - & - & - & - & - & - \\
\hline 1989 & 72.0 & 71.4 & - & - & - & 61.8 & 79.6 & 79.3 & - & - & - & 68.6 \\
\hline 1990 & 85.3 & 84.9 & - & - & - & 75.8 & 92.3 & 92.1 & - & - & - & 81.4 \\
\hline 1991 & 76.4 & 76.1 & - & - & - & 67.2 & 84.7 & 84.3 & - & - & - & 73.3 \\
\hline \multicolumn{13}{|l|}{1992} \\
\hline 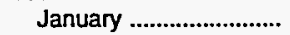 & 67.6 & 67.1 & - & - & - & 56.5 & 76.8 & 76.2 & - & - & - & 63.7 \\
\hline 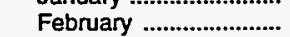 & 66.4 & 66.1 & - & - & - & 58.5 & 75.4 & 74.8 & - & - & - & 65.0 \\
\hline March & 67.2 & 66.9 & - & - & - & 59.7 & 76.1 & 75.6 & - & - & - & 65.2 \\
\hline April & 70.9 & 70.6 & - & - & - & 63.7 & 79.6 & 79.2 & - & - & - & 68.8 \\
\hline 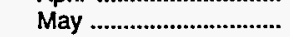 & 76.7 & 76.4 & - & - & - & 68.5 & 85.0 & 84.7 & - & - & - & 73.8 \\
\hline June & 80.7 & 80.3 & - & - & - & 71.2 & 88.7 & 88.3 & - & - & - & 76.7 \\
\hline 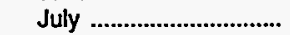 & 79.4 & 79.0 & - & - & - & 67.7 & 87.7 & 87.3 & - & - & - & 73.7 \\
\hline August & 78.2 & $\pi .8$ & - & - & - & 67.3 & 86.6 & 86.2 & - & - & - & 73.3 \\
\hline 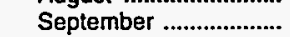 & 78.3 & 78.0 & - & - & - & 67.8 & 86.8 & 86.4 & - & - & - & 74.0 \\
\hline 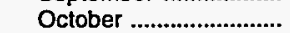 & 77.3 & 76.9 & - & - & - & 67.1 & 85.5 & 85.1 & - & - & - & 73.4 \\
\hline November ..................... & 77.4 & 76.9 & - & - & - & 64.4 & 85.7 & 85.3 & - & - & - & 72.2 \\
\hline 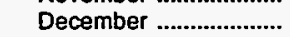 & 74.3 & 73.8 & - & - & - & 60.0 & 82.9 & 82.4 & - & - & - & 68.2 \\
\hline 1992 & 74.6 & 74.3 & - & - & - & 64.5 & 83.1 & 82.7 & - & - & - & 70.8 \\
\hline \multicolumn{13}{|l|}{1993} \\
\hline January ........................... & 72.6 & 72.1 & - & - & - & 60.3 & 81.7 & 81.3 & - & - & - & 68.0 \\
\hline 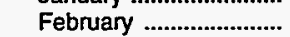 & 71.9 & 71.4 & - & - & - & 60.5 & 80.9 & 80.4 & - & - & - & 67.5 \\
\hline 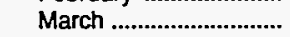 & 71.5 & 71.1 & - & - & - & 62.0 & 80.9 & 80.4 & - & - & - & 68.6 \\
\hline April & 73.5 & 73.1 & - & - & - & 64.6 & 83.2 & 82.8 & - & - & - & 70.8 \\
\hline May ................................. & 75.8 & 75.4 & - & - & - & 66.1 & 85.3 & 84.9 & - & - & - & 72.3 \\
\hline 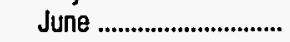 & 75.5 & 75.1 & - & - & - & 62.9 & 85.0 & 84.6 & - & - & - & 69.7 \\
\hline 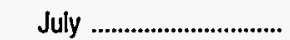 & 73.1 & 72.7 & - & - & - & 59.3 & 82.6 & 82.2 & - & - & - & 66.1 \\
\hline 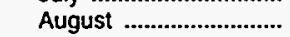 & 71.7 & 71.3 & - & - & - & 59.6 & 81.4 & 80.9 & - & - & - & 66.1 \\
\hline September ....................... & 70.4 & 69.9 & - & - & - & 58.1 & 80.1 & 79.5 & - & - & - & 64.3 \\
\hline 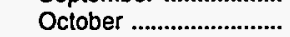 & 71.2 & 70.6 & 66.3 & 56.5 & 52.3 & 58.6 & 80.4 & 79.7 & 71.0 & 58.8 & NA & 64.5 \\
\hline 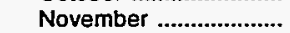 & 68.3 & 67.7 & 63.2 & 50.8 & 46.5 & 53.6 & $\pi 7.4$ & 76.7 & 68.5 & 54.0 & NA & 60.6 \\
\hline 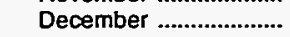 & 63.6 & 63.0 & 58.4 & 43.0 & 40.4 & 46.6 & 73.0 & 72.3 & 63.9 & 46.9 & NA & 54.6 \\
\hline 1993 & 71.6 & 71.2 & - & $\rightarrow$ & $\rightarrow$ & 59.3 & 81.0 & 80.5 & - & - & - & 66.0 \\
\hline \multicolumn{13}{|l|}{1994} \\
\hline 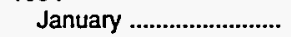 & 62.2 & 61.6 & 57.3 & 46.6 & 42.1 & 48.7 & 71.6 & 71.0 & 62.8 & 50.5 & NA & 56.2 \\
\hline 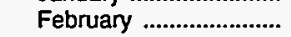 & 63.3 & 62.8 & 58.4 & 49.5 & 45.2 & 51.3 & 72.6 & 72.0 & 64.0 & 53.6 & NA & 58.3 \\
\hline 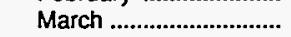 & 62.9 & 62.4 & 58.0 & 50.0 & 46.2 & 51.7 & 72.5 & 71.9 & 63.5 & 54.0 & NA & 58.3 \\
\hline April & 65.0 & 64.5 & 60.2 & 53.5 & 49.3 & 54.6 & 74.8 & 74.3 & 66.1 & 57.6 & NA & 61.4 \\
\hline 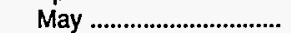 & 66.7 & 66.2 & 62.0 & 54.7 & 50.3 & 56.0 & 76.4 & 75.9 & 67.7 & 58.4 & NA & 62.5 \\
\hline 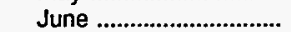 & 69.7 & 69.3 & 65.3 & 58.2 & 53.1 & 59.4 & 79.5 & 79.0 & 71.2 & 61.8 & NA & 65.9 \\
\hline July ................................. & 72.6 & 72.2 & 68.0 & 61.1 & 56.0 & 62.2 & 82.3 & 81.8 & 73.8 & 63.9 & NA & 68.3 \\
\hline August & 77.4 & 76.9 & 71.1 & 63.7 & 57.9 & 64.8 & 86.9 & 86.3 & 77.0 & 66.4 & NA & 71.0 \\
\hline September .................... & 75.7 & 75.0 & 68.9 & 54.7 & 51.7 & 57.7 & 85.3 & 84.4 & 74.8 & 57.2 & NA & 64.9 \\
\hline 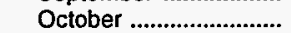 & 72.7 & 72.0 & 68.4 & 55.2 & 50.7 & 57.9 & 82.5 & 81.7 & 74.0 & 59.2 & NA & 65.8 \\
\hline 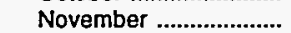 & 73.2 & 72.7 & 69.2 & 55.8 & 51.8 & 58.6 & 83.0 & 82.4 & 75.0 & 60.7 & NA & 67.1 \\
\hline December ...................... & 70.8 & 70.1 & 67.4 & 50.7 & 47.8 & 54.2 & 80.7 & 80.0 & 73.1 & 55.4 & NA & 63.4 \\
\hline 1994 & 69.5 & 68.9 & 64.6 & 54.7 & 50.2 & 56.6 & 79.1 & 78.5 & 70.4 & 58.4 & NA & 63.8 \\
\hline
\end{tabular}

See footnotes at end of table. 
Table 6. U.S. Refiner Motor Gasoline Prices by Grade and Sales Type (Cents per Gallon Excluding Taxes) — Continued

\begin{tabular}{|c|c|c|c|c|c|c|c|c|c|c|c|c|}
\hline \multirow{3}{*}{$\begin{array}{l}\text { Year } \\
\text { Month }\end{array}$} & \multicolumn{6}{|c|}{ Premium } & \multicolumn{6}{|c|}{ All Grades } \\
\hline & \multicolumn{2}{|c|}{ Sales to End Users } & \multicolumn{4}{|c|}{ Sales for Resale } & \multicolumn{2}{|c|}{ Sales to End Users } & \multicolumn{4}{|c|}{ Sales for Resale } \\
\hline & $\begin{array}{c}\text { Through } \\
\text { Retail } \\
\text { Outlets }\end{array}$ & Average $^{\mathrm{a}}$ & DTW & Rack & Bulk & Average & $\begin{array}{c}\text { Through } \\
\text { Retail } \\
\text { Outlets }\end{array}$ & Average $\mathrm{a}^{\mathrm{a}}$ & DTW & Rack & Bulk & Average \\
\hline $\begin{array}{l}1983 \\
1984 \\
1985 \\
1986 \\
1987 \\
1988 \ldots \ldots \ldots \ldots \\
1989 \\
1990\end{array}$ & $\begin{array}{r}108.0 \\
102.1 \\
103.0 \\
74.8 \\
79.0 \\
79.4 \\
87.4 \\
99.0 \\
91.2\end{array}$ & $\begin{array}{r}105.7 \\
101.5 \\
102.3 \\
73.7 \\
78.4 \\
78.8 \\
86.8 \\
98.5 \\
90.7\end{array}$ & $\begin{array}{l}- \\
- \\
- \\
- \\
- \\
- \\
-\end{array}$ & $\begin{array}{l}- \\
- \\
- \\
- \\
- \\
-\end{array}$ & $\begin{array}{l}- \\
- \\
- \\
- \\
- \\
- \\
-\end{array}$ & $\begin{array}{l}96.4 \\
91.6 \\
92.2 \\
61.0 \\
67.1 \\
67.2 \\
74.9 \\
87.4 \\
79.2\end{array}$ & $\begin{array}{l}96.4 \\
91.4 \\
92.1 \\
63.2 \\
67.8 \\
68.1 \\
76.3 \\
88.8 \\
80.0\end{array}$ & $\begin{array}{l}95.4 \\
90.7 \\
91.2 \\
62.4 \\
66.9 \\
67.3 \\
75.6 \\
88.3 \\
79.7\end{array}$ & $\begin{array}{l}- \\
- \\
- \\
- \\
- \\
- \\
-\end{array}$ & $\begin{array}{l}- \\
- \\
- \\
- \\
- \\
-\end{array}$ & $\begin{array}{l}- \\
- \\
- \\
- \\
- \\
- \\
- \\
-\end{array}$ & $\begin{array}{l}88.2 \\
83.2 \\
83.5 \\
53.1 \\
58.9 \\
57.7 \\
65.4 \\
78.6 \\
69.9\end{array}$ \\
\hline 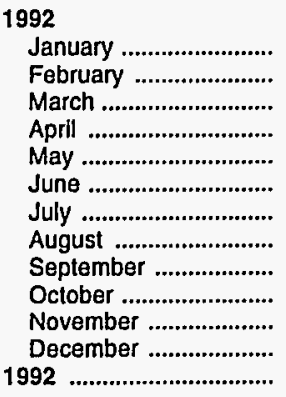 & $\begin{array}{l}85.5 \\
84.5 \\
85.0 \\
88.3 \\
93.7 \\
97.5 \\
96.8 \\
95.9 \\
95.8 \\
94.7 \\
95.2 \\
92.5 \\
92.0\end{array}$ & $\begin{array}{l}84.8 \\
83.9 \\
84.5 \\
87.8 \\
93.2 \\
96.9 \\
96.1 \\
95.3 \\
95.2 \\
94.1 \\
94.5 \\
91.8 \\
91.4\end{array}$ & $\begin{array}{l}- \\
- \\
- \\
- \\
- \\
- \\
- \\
- \\
- \\
-\end{array}$ & $\begin{array}{l}- \\
- \\
- \\
- \\
- \\
- \\
- \\
- \\
- \\
-\end{array}$ & $\begin{array}{l}- \\
- \\
- \\
- \\
- \\
- \\
- \\
- \\
- \\
-\end{array}$ & $\begin{array}{l}70.2 \\
71.6 \\
71.9 \\
75.4 \\
80.6 \\
83.3 \\
80.6 \\
80.3 \\
80.9 \\
80.2 \\
78.9 \\
74.4 \\
77.4\end{array}$ & $\begin{array}{l}72.5 \\
71.3 \\
72.0 \\
75.6 \\
81.2 \\
85.0 \\
84.0 \\
82.8 \\
82.8 \\
81.8 \\
82.0 \\
79.0 \\
79.2\end{array}$ & $\begin{array}{l}71.9 \\
70.8 \\
71.6 \\
75.2 \\
80.8 \\
84.5 \\
83.5 \\
82.3 \\
82.3 \\
81.3 \\
81.5 \\
78.5 \\
78.7\end{array}$ & $\begin{array}{l}- \\
- \\
- \\
- \\
- \\
- \\
- \\
- \\
-\end{array}$ & $\begin{array}{l}- \\
- \\
- \\
- \\
- \\
- \\
- \\
- \\
- \\
-\end{array}$ & $\begin{array}{l}- \\
- \\
- \\
- \\
- \\
- \\
- \\
- \\
- \\
-\end{array}$ & $\begin{array}{l}60.0 \\
61.7 \\
62.7 \\
66.6 \\
71.5 \\
74.2 \\
71.0 \\
70.6 \\
71.0 \\
70.4 \\
68.1 \\
63.8 \\
67.7\end{array}$ \\
\hline 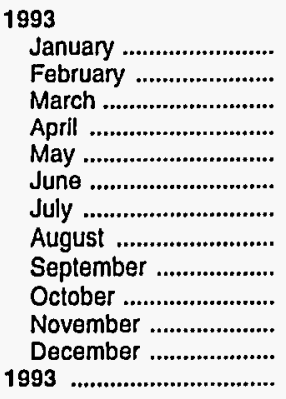 & $\begin{array}{l}90.5 \\
88.4 \\
88.3 \\
91.7 \\
93.6 \\
93.4 \\
91.2 \\
90.2 \\
89.2 \\
89.6 \\
86.4 \\
82.3 \\
89.6\end{array}$ & $\begin{array}{l}89.9 \\
87.9 \\
87.7 \\
91.0 \\
93.1 \\
92.8 \\
90.5 \\
89.5 \\
88.4 \\
88.8 \\
85.6 \\
81.4 \\
88.9\end{array}$ & $\begin{array}{c}- \\
- \\
- \\
- \\
- \\
- \\
- \\
- \\
- \\
80.5 \\
77.7 \\
73.2 \\
-\end{array}$ & $\begin{array}{c}- \\
- \\
- \\
- \\
- \\
- \\
- \\
- \\
- \\
64.9 \\
59.7 \\
52.3 \\
-\end{array}$ & $\begin{array}{c}- \\
- \\
- \\
- \\
- \\
- \\
- \\
- \\
- \\
56.7 \\
50.2 \\
44.1 \\
-\end{array}$ & $\begin{array}{l}74.6 \\
73.6 \\
74.8 \\
76.7 \\
78.4 \\
76.0 \\
72.5 \\
72.4 \\
70.9 \\
71.1 \\
66.7 \\
60.2 \\
72.2\end{array}$ & $\begin{array}{l}77.4 \\
76.5 \\
76.1 \\
78.3 \\
80.5 \\
80.2 \\
78.1 \\
76.8 \\
75.5 \\
76.1 \\
73.2 \\
68.8 \\
76.5\end{array}$ & $\begin{array}{l}76.9 \\
76.0 \\
75.7 \\
77.8 \\
80.1 \\
79.8 \\
77.6 \\
76.2 \\
74.9 \\
75.4 \\
72.6 \\
68.0 \\
75.9\end{array}$ & $\begin{array}{c}- \\
- \\
- \\
- \\
- \\
- \\
- \\
- \\
- \\
70.8 \\
68.0 \\
63.4 \\
-\end{array}$ & $\begin{array}{c}- \\
- \\
- \\
- \\
- \\
- \\
- \\
- \\
- \\
58.1 \\
52.6 \\
45.0 \\
-\end{array}$ & $\begin{array}{c}- \\
- \\
- \\
- \\
- \\
- \\
- \\
- \\
- \\
52.9 \\
47.3 \\
41.1 \\
-\end{array}$ & $\begin{array}{l}63.8 \\
63.8 \\
65.2 \\
67.7 \\
69.1 \\
66.2 \\
62.7 \\
62.9 \\
61.5 \\
61.7 \\
57.0 \\
50.3 \\
62.6\end{array}$ \\
\hline 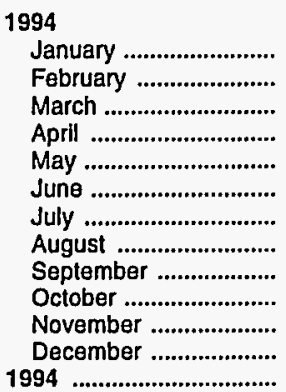 & $\begin{array}{l}80.8 \\
79.5 \\
81.5 \\
83.4 \\
84.9 \\
87.6 \\
90.4 \\
95.1 \\
93.7 \\
91.0 \\
91.7 \\
89.6 \\
87.3\end{array}$ & $\begin{array}{l}80.0 \\
78.8 \\
80.7 \\
82.7 \\
84.2 \\
86.9 \\
89.7 \\
94.3 \\
92.6 \\
90.1 \\
90.8 \\
88.6 \\
86.5\end{array}$ & $\begin{array}{l}71.4 \\
72.3 \\
71.9 \\
74.2 \\
75.7 \\
79.3 \\
82.0 \\
85.0 \\
83.4 \\
82.9 \\
83.7 \\
82.3 \\
78.7\end{array}$ & $\begin{array}{l}55.8 \\
58.7 \\
59.3 \\
62.8 \\
64.0 \\
67.6 \\
70.2 \\
72.9 \\
63.6 \\
65.1 \\
65.8 \\
60.7 \\
64.0\end{array}$ & $\begin{array}{l}47.4 \\
49.9 \\
50.7 \\
55.5 \\
56.9 \\
59.8 \\
62.8 \\
64.2 \\
55.9 \\
55.5 \\
57.1 \\
52.2 \\
55.6\end{array}$ & $\begin{array}{l}61.7 \\
63.7 \\
64.2 \\
67.2 \\
68.3 \\
71.8 \\
74.5 \\
77.1 \\
71.1 \\
71.9 \\
72.6 \\
68.6 \\
69.5\end{array}$ & $\begin{array}{l}67.5 \\
68.3 \\
68.0 \\
70.1 \\
71.7 \\
74.7 \\
77.5 \\
82.1 \\
80.4 \\
77.7 \\
78.2 \\
75.9 \\
74.4\end{array}$ & $\begin{array}{l}66.8 \\
67.6 \\
67.3 \\
69.5 \\
71.1 \\
74.1 \\
77.0 \\
81.5 \\
79.6 \\
76.9 \\
77.5 \\
75.1 \\
73.8\end{array}$ & $\begin{array}{l}62.1 \\
63.0 \\
62.7 \\
65.0 \\
66.7 \\
70.0 \\
72.7 \\
75.7 \\
73.7 \\
73.1 \\
74.0 \\
72.3 \\
69.3\end{array}$ & $\begin{array}{l}48.6 \\
51.6 \\
52.1 \\
55.6 \\
56.8 \\
60.3 \\
63.0 \\
65.5 \\
56.5 \\
57.3 \\
58.0 \\
53.0 \\
56.7\end{array}$ & $\begin{array}{l}42.9 \\
45.9 \\
46.8 \\
49.9 \\
51.2 \\
54.1 \\
56.9 \\
58.7 \\
52.2 \\
51.2 \\
52.4 \\
48.3 \\
50.9\end{array}$ & $\begin{array}{l}52.2 \\
54.6 \\
54.9 \\
57.9 \\
59.2 \\
62.6 \\
65.4 \\
67.8 \\
61.0 \\
61.4 \\
62.2 \\
58.0 \\
59.9\end{array}$ \\
\hline
\end{tabular}

Dash $(-)=$ No data reported.

NA $=$ Not avallable.

a Includes sales through retail outlets as well as all direct sales to end users that were not made through company-operated retail outlets, e.g., sales to agricultural customers, commercial sales, and industrial sales.

Notes: Data for the 4th quarter of 1993 were derived from two separate survey systems. The DTW, Rack, and Bulk components were derived from the revised EIA-782 survey system, while the End-Use and Average Resale categories were derived from the predecessor ElA-782 survey system. Therefore, the DTW, Rack, and Bulk components are not consistent with the Average Resale category. Beginning January 1994, all data are from the revised ElA-782 survey system and are consistent.

Note: Motor gasoline averages and totals prior to October 1993 include leaded gasoline.

Source: Energy Information Administration Form ElA-782A, "Refiners'/Gas Plant Operators' Monthly Petroleum Product Sales Report." 
Table 7. U.S. Refiner Motor Gasoline Volumes by Grade and Sales Type (Million Gallons per Day)

\begin{tabular}{|c|c|c|c|c|c|c|c|c|c|c|c|c|}
\hline \multirow{3}{*}{$\begin{array}{c}\text { Year } \\
\text { Month }\end{array}$} & \multicolumn{6}{|c|}{ Regular } & \multicolumn{6}{|c|}{ Midgrade } \\
\hline & \multicolumn{2}{|c|}{ Sales to End Users } & \multicolumn{4}{|c|}{ Sales for Resale } & \multicolumn{2}{|c|}{ Sales to End Users } & \multicolumn{4}{|c|}{ Sales for Resale } \\
\hline & $\begin{array}{l}\text { Through } \\
\text { Retail } \\
\text { Outtets }\end{array}$ & Totala & DTW & Rack & Bulk & Total & $\begin{array}{c}\text { Through } \\
\text { Retail } \\
\text { Outlets } \\
\end{array}$ & Total ${ }^{a}$ & DTW & Rack & Bulk & Total \\
\hline $\begin{array}{l}1983 \\
1984 \\
1985 \\
1986 \\
1987 \\
1988 \\
1989\end{array}$ & $\begin{array}{l}20.0 \\
24.3 \\
26.2 \\
30.9 \\
32.7 \\
34.2 \\
34.3 \\
36.7 \\
38.4\end{array}$ & $\begin{array}{l}23.5 \\
27.8 \\
29.9 \\
34.7 \\
36.1 \\
37.3 \\
36.8 \\
38.8 \\
40.4\end{array}$ & $\begin{array}{l}- \\
- \\
- \\
- \\
- \\
-\end{array}$ & $\begin{array}{l}- \\
- \\
- \\
- \\
- \\
- \\
-\end{array}$ & $\begin{array}{l}- \\
\overline{-} \\
\bar{z} \\
\bar{z} \\
\bar{z}\end{array}$ & $\begin{array}{r}98.3 \\
106.8 \\
119.7 \\
127.0 \\
141.9 \\
153.6 \\
155.7 \\
174.5 \\
180.9\end{array}$ & $\begin{array}{l}- \\
\overline{-} \\
\overline{-} \\
\overline{-} \\
\overline{4.9} \\
7.4 \\
7.9\end{array}$ & $\begin{array}{l}- \\
\overline{-} \\
\overline{-} \\
\overline{-} \\
\overline{5.1} \\
7.6 \\
8.2\end{array}$ & $\begin{array}{l}- \\
- \\
- \\
- \\
- \\
-\end{array}$ & $\begin{array}{l}- \\
- \\
\overline{-} \\
\overline{-} \\
\overline{-}\end{array}$ & $\begin{array}{l}- \\
\overline{-} \\
- \\
\overline{-} \\
\overline{-} \\
\overline{-}\end{array}$ & $\begin{array}{c}\overline{-} \\
\overline{-} \\
\overline{-} \\
\overline{-} \\
\overline{16.4} \\
23.1 \\
23.7\end{array}$ \\
\hline 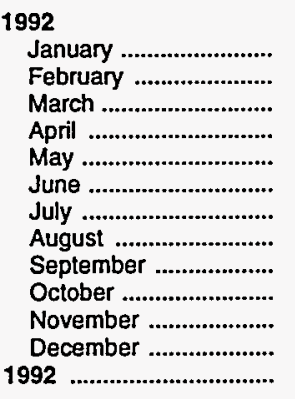 & $\begin{array}{l}34.4 \\
35.5 \\
36.3 \\
36.7 \\
36.8 \\
37.8 \\
37.5 \\
37.1 \\
37.0 \\
37.0 \\
35.6 \\
36.9 \\
36.5\end{array}$ & $\begin{array}{l}36.2 \\
37.4 \\
38.3 \\
38.7 \\
38.7 \\
39.6 \\
39.4 \\
38.8 \\
38.7 \\
38.7 \\
37.2 \\
38.5 \\
38.4\end{array}$ & $\begin{array}{l}- \\
- \\
- \\
- \\
- \\
- \\
- \\
- \\
- \\
-\end{array}$ & $\begin{array}{l}- \\
- \\
- \\
- \\
- \\
- \\
- \\
- \\
-\end{array}$ & $\begin{array}{l}- \\
- \\
- \\
- \\
- \\
- \\
- \\
- \\
- \\
-\end{array}$ & $\begin{array}{l}170.2 \\
172.8 \\
177.8 \\
185.6 \\
184.9 \\
186.6 \\
186.8 \\
182.1 \\
187.2 \\
182.8 \\
179.9 \\
189.5 \\
182.2\end{array}$ & $\begin{array}{l}8.4 \\
8.7 \\
8.9 \\
9.0 \\
8.9 \\
9.0 \\
9.1 \\
8.9 \\
8.7 \\
8.9 \\
8.6 \\
9.1 \\
8.9\end{array}$ & $\begin{array}{l}8.7 \\
9.1 \\
9.3 \\
9.3 \\
9.2 \\
9.2 \\
9.4 \\
9.2 \\
9.0 \\
9.2 \\
8.9 \\
9.3 \\
9.2\end{array}$ & $\begin{array}{l}- \\
- \\
- \\
- \\
- \\
- \\
- \\
- \\
- \\
- \\
-\end{array}$ & $\begin{array}{l}- \\
- \\
- \\
- \\
- \\
- \\
- \\
- \\
- \\
- \\
-\end{array}$ & $\begin{array}{l}- \\
- \\
- \\
- \\
- \\
- \\
- \\
- \\
- \\
- \\
-\end{array}$ & $\begin{array}{l}25.9 \\
26.3 \\
26.8 \\
27.7 \\
27.4 \\
28.1 \\
28.8 \\
28.0 \\
27.4 \\
28.0 \\
27.0 \\
28.7 \\
27.5\end{array}$ \\
\hline 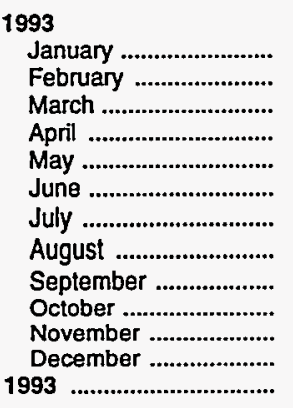 & $\begin{array}{l}33.5 \\
35.3 \\
35.6 \\
36.5 \\
36.1 \\
38.0 \\
36.5 \\
36.1 \\
35.5 \\
34.5 \\
34.7 \\
34.6 \\
35.6\end{array}$ & $\begin{array}{l}35.0 \\
37.0 \\
37.4 \\
38.3 \\
37.7 \\
39.7 \\
38.0 \\
37.7 \\
37.1 \\
36.2 \\
36.2 \\
36.3 \\
37.2\end{array}$ & $\begin{array}{c}- \\
- \\
- \\
- \\
- \\
- \\
- \\
- \\
- \\
47.9 \\
47.7 \\
47.9 \\
-\end{array}$ & $\begin{array}{c}- \\
- \\
- \\
- \\
- \\
- \\
- \\
- \\
- \\
116.5 \\
121.0 \\
122.0 \\
-\end{array}$ & $\begin{array}{c}- \\
- \\
- \\
- \\
- \\
- \\
- \\
- \\
- \\
18.2 \\
16.9 \\
20.7 \\
-\end{array}$ & $\begin{array}{l}170.6 \\
179.9 \\
182.3 \\
184.4 \\
182.2 \\
191.9 \\
189.3 \\
187.0 \\
181.9 \\
182.6 \\
185.6 \\
190.5 \\
184.0\end{array}$ & $\begin{array}{l}8.2 \\
8.6 \\
8.5 \\
8.6 \\
8.6 \\
8.9 \\
9.0 \\
9.0 \\
8.6 \\
8.7 \\
8.6 \\
8.6 \\
8.7\end{array}$ & $\begin{array}{l}8.4 \\
8.8 \\
8.8 \\
8.9 \\
8.9 \\
9.2 \\
9.3 \\
9.2 \\
8.9 \\
9.0 \\
8.9 \\
8.9 \\
8.9\end{array}$ & $\begin{array}{l}- \\
- \\
- \\
- \\
- \\
- \\
- \\
- \\
- \\
13.1 \\
12.8 \\
13.1 \\
-\end{array}$ & $\begin{array}{c}- \\
- \\
- \\
- \\
- \\
- \\
- \\
- \\
- \\
14.9 \\
15.0 \\
15.6 \\
-\end{array}$ & $\begin{array}{l}\overline{-} \\
\overline{-} \\
- \\
\overline{-} \\
- \\
- \\
\overline{0} \\
0.5 \\
0.0 \\
-\end{array}$ & $\begin{array}{l}25.2 \\
27.0 \\
26.8 \\
27.6 \\
27.1 \\
28.2 \\
28.9 \\
28.4 \\
27.9 \\
28.1 \\
28.4 \\
28.6 \\
27.7\end{array}$ \\
\hline 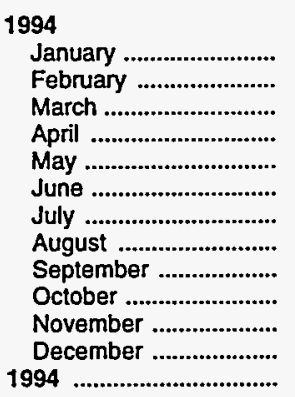 & $\begin{array}{l}31.4 \\
32.5 \\
34.4 \\
34.2 \\
34.6 \\
35.8 \\
35.1 \\
36.0 \\
35.1 \\
33.9 \\
34.3 \\
34.8 \\
34.3\end{array}$ & $\begin{array}{l}32.9 \\
34.2 \\
36.2 \\
35.8 \\
36.3 \\
37.5 \\
36.6 \\
37.6 \\
36.6 \\
35.5 \\
35.8 \\
36.3 \\
35.9\end{array}$ & $\begin{array}{l}44.3 \\
46.7 \\
48.0 \\
48.0 \\
48.2 \\
49.2 \\
48.4 \\
49.0 \\
47.5 \\
47.5 \\
47.5 \\
47.7 \\
47.7\end{array}$ & $\begin{array}{l}108.4 \\
112.6 \\
116.1 \\
119.8 \\
120.2 \\
124.7 \\
123.3 \\
128.1 \\
124.8 \\
121.0 \\
122.3 \\
121.9 \\
120.3\end{array}$ & $\begin{array}{l}22.6 \\
21.0 \\
21.1 \\
24.1 \\
24.3 \\
24.5 \\
21.3 \\
25.0 \\
26.0 \\
24.9 \\
23.5 \\
33.1 \\
24.3\end{array}$ & $\begin{array}{l}175.3 \\
180.2 \\
185.3 \\
191.9 \\
192.7 \\
198.4 \\
193.0 \\
202.0 \\
198.3 \\
193.4 \\
193.2 \\
202.8 \\
192.3\end{array}$ & $\begin{array}{l}8.1 \\
8.3 \\
8.4 \\
8.4 \\
8.5 \\
8.6 \\
8.6 \\
8.6 \\
8.3 \\
8.3 \\
8.6 \\
8.7 \\
8.5\end{array}$ & $\begin{array}{l}8.4 \\
8.6 \\
8.7 \\
8.7 \\
8.8 \\
8.9 \\
8.8 \\
8.9 \\
8.6 \\
8.6 \\
8.9 \\
9.0 \\
8.7\end{array}$ & $\begin{array}{l}12.1 \\
12.2 \\
12.8 \\
12.9 \\
12.9 \\
13.3 \\
13.0 \\
13.0 \\
12.7 \\
12.8 \\
12.8 \\
13.6 \\
12.8\end{array}$ & $\begin{array}{l}13.6 \\
14.4 \\
15.4 \\
15.5 \\
15.9 \\
16.5 \\
16.2 \\
16.7 \\
16.0 \\
15.5 \\
15.6 \\
16.2 \\
15.7\end{array}$ & $\begin{array}{l}0.2 \\
0.1 \\
0.2 \\
0.1 \\
0.1 \\
0.3 \\
0.2 \\
0.2 \\
0.2 \\
0.2 \\
0.2 \\
0.2 \\
0.2\end{array}$ & $\begin{array}{l}25.9 \\
26.7 \\
28.4 \\
28.6 \\
29.0 \\
30.1 \\
29.5 \\
30.0 \\
28.9 \\
28.5 \\
28.6 \\
30.0 \\
28.7\end{array}$ \\
\hline
\end{tabular}

See footnotes at end of table. 
Table 7. U.S. Refiner Motor Gasoline Volumes by Grade and Sales Type (Million Gallons per Day) - Continued

\begin{tabular}{|c|c|c|c|c|c|c|c|c|c|c|c|c|}
\hline \multirow{3}{*}{$\begin{array}{c}\text { Year } \\
\text { Month }\end{array}$} & \multicolumn{6}{|c|}{ Premium } & \multicolumn{6}{|c|}{ All Grades } \\
\hline & \multicolumn{2}{|c|}{ Sales to End Users } & \multicolumn{4}{|c|}{ Sales for Resale } & \multicolumn{2}{|c|}{ Sales to End Users } & \multicolumn{4}{|c|}{ Sales for Resale } \\
\hline & $\begin{array}{c}\text { Through } \\
\text { Retall } \\
\text { Outlots }\end{array}$ & Totala & DTW & Rack & Bulk & Total & $\begin{array}{c}\text { Through } \\
\text { Retail } \\
\text { Outlets }\end{array}$ & Totala & DTW & Rack & Bulk & Tota \\
\hline $\begin{array}{l}1983 \\
1984 \\
1985 \\
1986\end{array}$ & $\begin{array}{r}5.0 \\
8.5 \\
9.2 \\
9.0 \\
11.2 \\
13.8 \\
13.5 \\
11.2 \\
10.5\end{array}$ & $\begin{array}{r}6.2 \\
9.2 \\
10.0 \\
9.8 \\
11.6 \\
14.5 \\
14.2 \\
11.7 \\
10.9\end{array}$ & $\begin{array}{l}\overline{-} \\
\overline{-} \\
\bar{z} \\
\overline{-} \\
\overline{-}\end{array}$ & $\begin{array}{l}- \\
\overline{-} \\
- \\
- \\
- \\
- \\
-\end{array}$ & $\begin{array}{l}\overline{-} \\
\overline{-} \\
- \\
\bar{z} \\
\overline{-}\end{array}$ & $\begin{array}{l}28.7 \\
33.7 \\
38.0 \\
45.1 \\
53.0 \\
62.4 \\
60.8 \\
53.7 \\
48.3\end{array}$ & $\begin{array}{l}\mathbf{4 2 . 3} \\
\mathbf{5 0 . 3} \\
\mathbf{5 0 . 5} \\
\mathbf{5 4 . 2} \\
\mathbf{5 5 . 7} \\
\mathbf{5 6 . 7} \\
\mathbf{5 7 . 5} \\
\mathbf{5 7 . 4} \\
\mathbf{5 8 . 4}\end{array}$ & $\begin{array}{l}51.1 \\
57.6 \\
57.5 \\
61.2 \\
61.0 \\
61.0 \\
61.2 \\
60.3 \\
61.2\end{array}$ & $\begin{array}{l}- \\
\overline{-} \\
- \\
- \\
- \\
- \\
-\end{array}$ & $\begin{array}{l}- \\
- \\
\overline{-} \\
\overline{-} \\
\overline{-} \\
-\end{array}$ & $\begin{array}{l}- \\
- \\
- \\
- \\
- \\
- \\
-\end{array}$ & $\begin{array}{l}242.5 \\
246.3 \\
256.9 \\
257.2 \\
257.2 \\
263.7 \\
260.7 \\
264.8 \\
261.3\end{array}$ \\
\hline 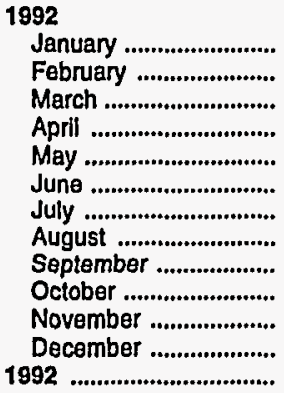 & $\begin{array}{r}10.3 \\
10.7 \\
10.8 \\
10.8 \\
10.5 \\
10.2 \\
10.5 \\
10.0 \\
9.8 \\
10.1 \\
9.8 \\
10.4 \\
10.3\end{array}$ & $\begin{array}{l}10.7 \\
11.1 \\
11.2 \\
11.2 \\
10.9 \\
10.7 \\
10.9 \\
10.4 \\
10.2 \\
10.5 \\
10.2 \\
10.8 \\
10.7\end{array}$ & $\begin{array}{l}- \\
- \\
\overline{-} \\
\overline{-} \\
\overline{-} \\
- \\
\overline{-} \\
- \\
- \\
-\end{array}$ & $\begin{array}{l}- \\
- \\
- \\
- \\
- \\
- \\
- \\
- \\
- \\
- \\
-\end{array}$ & $\begin{array}{l}- \\
- \\
- \\
- \\
- \\
- \\
- \\
- \\
- \\
- \\
-\end{array}$ & $\begin{array}{l}49.7 \\
49.9 \\
50.9 \\
53.8 \\
52.9 \\
52.4 \\
52.8 \\
51.3 \\
49.6 \\
51.9 \\
50.6 \\
54.5 \\
51.7\end{array}$ & $\begin{array}{l}\mathbf{5 3 . 8} \\
\mathbf{5 5 . 6} \\
\mathbf{5 6 . 8} \\
\mathbf{5 7 . 2} \\
\mathbf{5 7 . 0} \\
\mathbf{5 7 . 7} \\
\mathbf{5 7 . 9} \\
\mathbf{5 6 . 7} \\
\mathbf{5 6 . 2} \\
\mathbf{5 6 . 6} \\
\mathbf{5 4 . 6} \\
\mathbf{5 7 . 1} \\
\mathbf{5 6 . 4}\end{array}$ & $\begin{array}{l}56.4 \\
58.3 \\
59.6 \\
60.0 \\
59.6 \\
60.4 \\
60.4 \\
59.1 \\
58.6 \\
59.0 \\
56.9 \\
59.3 \\
59.0\end{array}$ & $\begin{array}{l}- \\
- \\
- \\
- \\
- \\
- \\
- \\
- \\
- \\
- \\
- \\
-\end{array}$ & $\begin{array}{l}- \\
- \\
- \\
- \\
- \\
- \\
- \\
- \\
- \\
- \\
-\end{array}$ & $\begin{array}{l}- \\
- \\
- \\
- \\
- \\
- \\
- \\
- \\
- \\
- \\
-\end{array}$ & $\begin{array}{l}249.5 \\
252.8 \\
259.5 \\
271.5 \\
269.5 \\
271.7 \\
272.8 \\
265.8 \\
268.3 \\
266.6 \\
260.9 \\
275.8 \\
265.4\end{array}$ \\
\hline 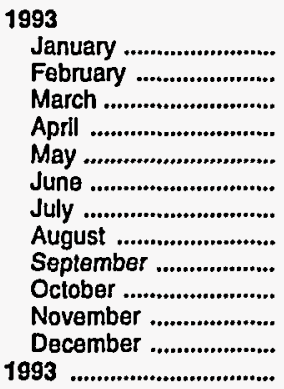 & $\begin{array}{r}9.6 \\
10.6 \\
10.5 \\
10.0 \\
9.9 \\
10.5 \\
10.7 \\
10.6 \\
10.4 \\
9.8 \\
10.2 \\
10.5 \\
10.3\end{array}$ & $\begin{array}{r}9.9 \\
10.9 \\
10.9 \\
10.4 \\
10.3 \\
10.9 \\
11.0 \\
11.0 \\
10.8 \\
10.2 \\
10.6 \\
10.9 \\
10.6\end{array}$ & $\begin{array}{c}\overline{-} \\
- \\
- \\
- \\
\overline{-} \\
\overline{-} \\
\overline{-} \\
22.4 \\
22.7 \\
23.6 \\
-\end{array}$ & $\begin{array}{c}\overline{-} \\
- \\
- \\
- \\
- \\
- \\
- \\
\overline{-} \\
27.1 \\
28.4 \\
29.9 \\
-\end{array}$ & $\begin{array}{l}- \\
- \\
- \\
- \\
- \\
- \\
- \\
- \\
- \\
3.1 \\
4.0 \\
4.4 \\
-\end{array}$ & $\begin{array}{l}46.5 \\
50.3 \\
50.3 \\
52.4 \\
51.5 \\
53.6 \\
55.0 \\
55.4 \\
54.3 \\
52.5 \\
54.3 \\
57.6 \\
52.8\end{array}$ & $\begin{array}{l}\mathbf{5 1 . 7} \\
\mathbf{5 5 . 0} \\
\mathbf{5 5 . 2} \\
\mathbf{5 5 . 7} \\
\mathbf{5 5 . 2} \\
\mathbf{5 8 . 1} \\
\mathbf{5 6 . 7} \\
\mathbf{5 6 . 2} \\
\mathbf{5 5 . 1} \\
\mathbf{5 3 . 0} \\
\mathbf{5 3 . 5} \\
\mathbf{5 3 . 7} \\
\mathbf{5 4 . 9}\end{array}$ & $\begin{array}{l}\mathbf{5 3 . 8} \\
\mathbf{5 7 . 3} \\
\mathbf{5 7 . 6} \\
\mathbf{5 8 . 1} \\
\mathbf{5 7 . 5} \\
\mathbf{6 0 . 4} \\
\mathbf{5 8 . 8} \\
\mathbf{5 8 . 5} \\
\mathbf{5 7 . 5} \\
\mathbf{5 5 . 4} \\
\mathbf{5 5 . 7} \\
\mathbf{5 6 . 1} \\
\mathbf{5 7 . 2}\end{array}$ & $\begin{array}{c}\overline{-} \\
\overline{-} \\
- \\
- \\
- \\
- \\
- \\
\overline{-} \\
83.4 \\
83.2 \\
84.6 \\
-\end{array}$ & $\begin{array}{r}- \\
- \\
- \\
- \\
- \\
- \\
- \\
- \\
- \\
158.5 \\
164.5 \\
167.5 \\
-\end{array}$ & $\begin{array}{c}- \\
- \\
- \\
- \\
- \\
- \\
- \\
- \\
- \\
21.5 \\
21.5 \\
25.1 \\
-\end{array}$ & $\begin{array}{l}245.1 \\
260.1 \\
262.5 \\
267.7 \\
264.1 \\
277.1 \\
276.5 \\
274.3 \\
267.3 \\
263.3 \\
268.3 \\
276.7 \\
266.9\end{array}$ \\
\hline 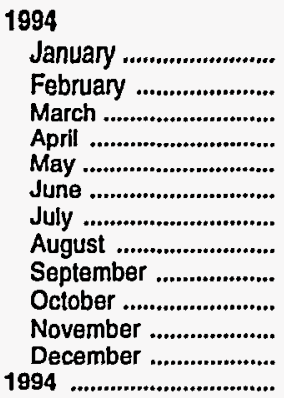 & $\begin{array}{r}9.9 \\
11.1 \\
10.1 \\
10.1 \\
10.1 \\
10.4 \\
10.1 \\
9.5 \\
9.4 \\
9.7 \\
9.4 \\
9.9 \\
10.0\end{array}$ & $\begin{array}{r}10.2 \\
11.5 \\
10.5 \\
10.5 \\
10.5 \\
10.8 \\
10.4 \\
9.9 \\
9.8 \\
10.1 \\
9.8 \\
10.3 \\
10.3\end{array}$ & $\begin{array}{l}22.1 \\
22.2 \\
23.2 \\
23.3 \\
23.4 \\
23.6 \\
22.8 \\
22.3 \\
22.0 \\
22.2 \\
21.8 \\
22.4 \\
22.6\end{array}$ & $\begin{array}{l}27.5 \\
28.4 \\
29.4 \\
29.8 \\
31.0 \\
31.8 \\
30.9 \\
30.6 \\
29.8 \\
29.4 \\
29.7 \\
30.8 \\
29.9\end{array}$ & $\begin{array}{l}3.7 \\
3.6 \\
2.6 \\
2.6 \\
3.4 \\
3.8 \\
3.0 \\
3.5 \\
3.0 \\
2.7 \\
2.6 \\
4.0 \\
3.2\end{array}$ & $\begin{array}{l}53.3 \\
54.2 \\
55.3 \\
55.7 \\
57.7 \\
59.2 \\
56.7 \\
56.4 \\
54.8 \\
54.2 \\
54.1 \\
57.2 \\
55.7\end{array}$ & $\begin{array}{l}49.4 \\
51.9 \\
52.9 \\
52.7 \\
53.2 \\
54.8 \\
53.7 \\
54.1 \\
52.8 \\
52.0 \\
52.2 \\
53.4 \\
52.8\end{array}$ & $\begin{array}{l}\mathbf{5 1 . 5} \\
\mathbf{5 4 . 3} \\
\mathbf{5 5 . 4} \\
\mathbf{5 5 . 0} \\
\mathbf{5 5 . 5} \\
\mathbf{5 7 . 2} \\
\mathbf{5 5 . 8} \\
\mathbf{5 6 . 4} \\
\mathbf{5 5 . 0} \\
\mathbf{5 4 . 2} \\
\mathbf{5 4 . 5} \\
\mathbf{5 5 . 6} \\
\mathbf{5 5 . 0}\end{array}$ & $\begin{array}{l}78.4 \\
81.0 \\
84.1 \\
84.2 \\
84.5 \\
86.0 \\
84.2 \\
84.3 \\
82.2 \\
82.5 \\
82.2 \\
83.7 \\
83.1\end{array}$ & $\begin{array}{l}149.5 \\
155.5 \\
160.9 \\
165.1 \\
167.1 \\
173.0 \\
170.4 \\
175.4 \\
170.6 \\
165.9 \\
167.5 \\
168.9 \\
165.9\end{array}$ & $\begin{array}{l}26.5 \\
24.7 \\
24.0 \\
26.8 \\
27.8 \\
28.7 \\
24.5 \\
28.7 \\
29.2 \\
27.7 \\
26.2 \\
37.4 \\
27.7\end{array}$ & $\begin{array}{l}254.5 \\
261.2 \\
269.0 \\
276.2 \\
279.4 \\
287.7 \\
279.2 \\
288.4 \\
282.0 \\
276.1 \\
275.9 \\
290.0 \\
276.7\end{array}$ \\
\hline
\end{tabular}

Dash $(-)=$ No data reported.

a Includes sales through retail outlets as well as all direct sales to end users that were not made through company-operated retail outlets, e.g., sales to agricultural customers, commerclal sales, and industrial sales.

Notes: Data for the 4th quarter of 1993 were derived from two separate survey systems. The DTW, Rack, and Bulk components were derived from the revised EIA-782 survey system, while the End-Use and Average Resale categories were derived trom the predecessor ElA-782 survey system. Therefore, the DTW, Rack, and Bulk components are not consistent with the Average Resale category. Beginning January 1994, all data are from the revised ElA-782 survey system and are consistent.

Note: Motor gasoline averages and totals prior to October 1993 include leaded gasoline.

Note: Totals may not equal the sum of the components due to rounding.

Source: Energy Information Administration Form ElA-782A, "Refiners'/Gas Plant Operators' Monthly Petroleum Product Sales Report." 
Table 8. U.S. Refiner Conventional Motor Gasoline Prices by Grade and Sales Type (Cents per Gallon Excluding Taxes)

\begin{tabular}{|c|c|c|c|c|c|c|c|c|c|c|c|c|}
\hline \multirow{3}{*}{$\begin{array}{l}\text { Year } \\
\text { Month }\end{array}$} & \multicolumn{6}{|c|}{ Regular } & \multicolumn{6}{|c|}{ Midgrade } \\
\hline & \multicolumn{2}{|c|}{ Sales to End Users } & \multicolumn{4}{|c|}{ Sales for Resale } & \multicolumn{2}{|c|}{ Sales to End Users } & \multicolumn{4}{|c|}{ Sales for Resale } \\
\hline & $\begin{array}{c}\text { Through } \\
\text { Rotall } \\
\text { Outlots }\end{array}$ & Average $\mathrm{a}$ & DTW & Rack & Bulk & Average & $\begin{array}{c}\text { Through } \\
\text { Retall } \\
\text { Outlots }\end{array}$ & Average $a$ & DTW & Rack & Bulk & Averago \\
\hline \multicolumn{13}{|l|}{1993} \\
\hline 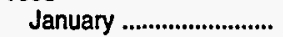 & - & - & - & - & - & - & - & - & - & - & - & - \\
\hline 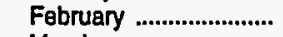 & - & - & - & - & - & - & - & - & - & - & - & - \\
\hline 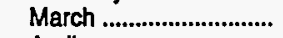 & - & - & - & - & - & - & - & - & - & - & - & - \\
\hline April & - & - & - & - & - & - & - & - & - & - & - & - \\
\hline 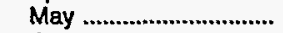 & - & - & - & - & - & - & - & - & - & - & - & - \\
\hline 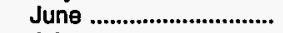 & - & - & - & - & - & - & - & - & - & - & - & - \\
\hline 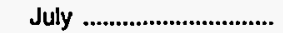 & - & - & - & - & - & - & - & - & - & - & - & - \\
\hline 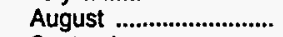 & - & - & - & - & - & - & - & - & - & - & - & - \\
\hline September ........................ & - & - & - & - & - & - & - & - & - & - & - & - \\
\hline 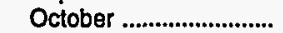 & 69.2 & 68.7 & 62.8 & 56.0 & 52.1 & 56.8 & 79.4 & 78.8 & 68.4 & 58.1 & NA & 62.0 \\
\hline 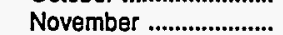 & 65.4 & 64.9 & 59.1 & 50.2 & 46.4 & 51.2 & 75.2 & 74.6 & 65.3 & 53.2 & NA & 57.3 \\
\hline December ...................... & 60.4 & 59.8 & 54.0 & 42.3 & 40.1 & 43.8 & 70.8 & 70.1 & 60.2 & 46.0 & NA & 50.9 \\
\hline 1993 & - & - & - & - & - & - & - & - & - & - & - & - \\
\hline \multicolumn{13}{|l|}{1994} \\
\hline 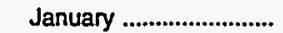 & 59.4 & 58.8 & 54.2 & 46.0 & 41.8 & 46.6 & 69.8 & 69.2 & 60.4 & 49.8 & NA & 53.6 \\
\hline 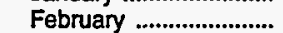 & 61.7 & 61.1 & 57.0 & 49.2 & 45.0 & 50.0 & 71.5 & 70.9 & 62.9 & 53.3 & NA & 56.9 \\
\hline 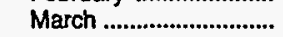 & 62.2 & 61.7 & 57.4 & 49.9 & 46.2 & 51.3 & 72.0 & 71.4 & 63.3 & 54.0 & NA & 58.0 \\
\hline 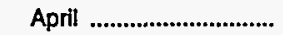 & 64.9 & 64.5 & 60.1 & 53.5 & 49.3 & 54.5 & 74.6 & 74.1 & 66.0 & 57.6 & NA & 61.2 \\
\hline 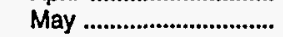 & 66.6 & 66.2 & 62.0 & 54.7 & 50.3 & 56.0 & 76.4 & 75.9 & 67.7 & 58.4 & NA & 62.6 \\
\hline 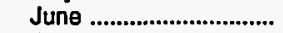 & 69.7 & 69.2 & 65.3 & 58.2 & 53.1 & 59.3 & 79.5 & 78.9 & 71.2 & 61.8. & NA & 65.9 \\
\hline 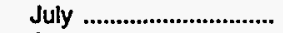 & 72.6 & 72.2 & 68.0 & 61.0 & 56.0 & 62.2 & 82.3 & 81.8 & 73.8 & 63.9 & NA & 68.3 \\
\hline 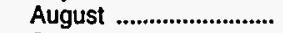 & 77.4 & 76.9 & 71.2 & 63.6 & 57.9 & 64.7 & 86.9 & 86.3 & 77.0 & 66.4 & NA & 71.0 \\
\hline September ...................... & 75.5 & 74.8 & 68.6 & 54.6 & 51.6 & 57.4 & 85.2 & 84.4 & 74.7 & 57.1 & NA & 64.6 \\
\hline 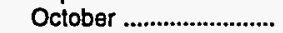 & 71.1 & 70.3 & 64.6 & 54.4 & 50.1 & 55.5 & 81.4 & 80.6 & 70.4 & 58.2 & $w$ & 62.6 \\
\hline November ...................... & 70.6 & 70.0 & 64.2 & 54.7 & 50.5 & 55.5 & 80.6 & 79.9 & 70.7 & 59.3 & $w$ & 63.0 \\
\hline 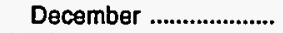 & 66.6 & 65.8 & 58.3 & 48.8 & 46.4 & 49.4 & 76.6 & 75.8 & 65.7 & 52.9 & NA & 56.3 \\
\hline 1994 & 68.7 & 68.1 & 63.6 & 54.5 & 50.0 & 55.8 & 78.4 & 77.8 & 69.4 & NA & NA & 62.7 \\
\hline
\end{tabular}

See footnotes at end of table. 
Table 8. U.S. Refiner Conventional Motor Gasoline Prices by Grade and Sales Type (Cents per Gallon Excluding Taxes) - Continued

\begin{tabular}{|c|c|c|c|c|c|c|c|c|c|c|c|c|}
\hline \multirow{3}{*}{$\begin{array}{l}\text { Yoar } \\
\text { Month }\end{array}$} & \multicolumn{6}{|c|}{ Premlum } & \multicolumn{6}{|c|}{ All Grades } \\
\hline & \multicolumn{2}{|c|}{ Sales to End Users } & \multicolumn{4}{|c|}{ Sales tor Resale } & \multicolumn{2}{|c|}{ Sales to End Users } & \multicolumn{4}{|c|}{ Sales for Resale } \\
\hline & $\begin{array}{l}\text { Through } \\
\text { Retall } \\
\text { Outlets }\end{array}$ & Average $^{a}$ & DTW & Rack & Bulk & Average & $\begin{array}{c}\text { Through } \\
\text { Retail } \\
\text { Outtets }\end{array}$ & Averagea & DTW & Rack & Bulk & Average \\
\hline \multicolumn{13}{|l|}{1993} \\
\hline 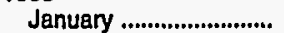 & - & - & - & - & - & - & - & - & - & - & - & - \\
\hline 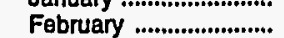 & - & - & - & - & - & - & - & - & - & - & - & - \\
\hline March .............................. & - & - & - & - & - & - & - & - & - & - & - & - \\
\hline Aprll ................................ & - & - & - & - & - & - & - & - & - & - & - & - \\
\hline May ................................. & - & - & - & - & - & - & - & - & - & - & - & - \\
\hline June ............................... & - & - & - & - & - & - & - & - & - & - & - & - \\
\hline July ................................. & - & - & - & - & - & - & - & - & - & - & - & - \\
\hline 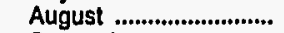 & - & - & - & - & - & - & - & - & - & - & - & - \\
\hline September .................... & - & - & - & - & - & - & - & - & - & - & - & - \\
\hline October ............................. & 87.7 & 86.9 & 76.7 & 64.4 & 56.5 & 67.7 & 74.4 & 73.7 & 67.4 & 57.6 & 52.8 & 59.4 \\
\hline Novamber ................... & 83.5 & 82.7 & 73.6 & 58.9 & 49.7 & 62.0 & 70.5 & 69.9 & 63.9 & 51.9 & 47.1 & 53.8 \\
\hline December ........................ & 79.3 & 78.4 & 68.9 & 51.5 & 43.7 & 55.4 & 65.9 & 65.2 & 59.0 & 44.3 & 40.7 & 46.7 \\
\hline 1993 & - & - & - & - & - & - & - & - & - & - & - & - \\
\hline \multicolumn{13}{|l|}{1994} \\
\hline January ........................ & 78.1 & 77.3 & 68.5 & 55.2 & 46.9 & 58.1 & 65.0 & 64.3 & 59.3 & 48.0 & 42.5 & 49.5 \\
\hline February ....................... & 77.3 & 76.7 & 70.8 & 58.4 & 49.3 & 61.3 & 66.8 & 66.2 & 61.7 & 51.2 & 45.6 & 52.9 \\
\hline March ............................ & 80.4 & 79.6 & 71.4 & 59.2 & 50.6 & 63.3 & 67.1 & 66.5 & 61.9 & 52.0 & 46.7 & 54.3 \\
\hline April ................................ & 83.1 & 82.3 & 74.1 & 62.8 & 55.5 & 66.7 & 69.9 & 69.3 & 64.6 & 55.5 & 49.9 & 57.5 \\
\hline May ............................... & 84,9 & 84.1 & 75.8 & 64.0 & 56.9 & 68.3 & 71.6 & 71.1 & 66.6 & 56.8 & 51.2 & 59.2 \\
\hline June ............................. & 87.5 & 86.8 & 79.4 & 67.6 & 59.8 & 71.7 & 74.6 & 74.0 & 70.0 & 60.3 & 54.1 & 62.6 \\
\hline 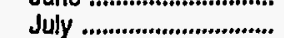 & 90.4 & 89.7 & 82.1 & 70.2 & 62.8 & 74.5 & 77.5 & 76.9 & 72.7 & 63.0 & 56.9 & 65.3 \\
\hline August ........................... & 95.1 & 94.3 & 85.1 & 72.9 & 64.2 & 77.1 & 82.0 & 81.4 & 75.7 & 65.5 & 58.7 & 67.8 \\
\hline September .................... & 93.5 & 92.4 & 83.1 & 63.5 & 55.5 & 70.6 & 80.2 & 79.4 & 73.3 & 56.4 & 52.0 & 60.7 \\
\hline October ........................... & 89.3 & 88.3 & 79.0 & 64.2 & 54.0 & 68.0 & 76.3 & 75.4 & 69.2 & 56.5 & 50.5 & 58.5 \\
\hline November ...................... & 88.6 & 87.6 & 78.8 & 64.6 & 54.7 & 67.7 & 75.5 & 74.8 & 69.0 & 56.8 & 50.9 & 58.4 \\
\hline December ...................... & 84.5 & 83.4 & 74.0 & 58.4 & 49.8 & 61.1 & 71.6 & 70.7 & 63.6 & 50.9 & 46.7 & 52.0 \\
\hline 1994 & 86.3 & 85.5 & 77.8 & 63.8 & 55.5 & 68.2 & 73.6 & 72.9 & 68.3 & 56.5 & 50.7 & 58.9 \\
\hline
\end{tabular}

Dash $(-)=$ No data reported.

NA $=$ Not available.

$W=$ Witheld to avold disclosure of individual company data.

a Includes sales through retall outlets as well as all direct sales to end users that were not made through company-operated retail outlets, e.g., sales to agricultural customers, commerclal sales, and industrial sales.

Notes: The 4th quarter of 1993 was a transitional period between the predecessor ElA-782 survey system and the revised ElA-782 survey sytem. The revised survey system contains additional product and sales categories, which may not be consistent with categories derived from the predecessor survey system. Beginning January 1994 all data are from the revised survey system and are consistent.

Source: Energy Information Administration Form EIA-782A, "Refiners'/Gas Plant Operators' Monthly Petroleum Product Sales Report." 
Table 9. U.S. Refiner Conventional Motor Gasoline Volumes by Grade and Sales Type (Million Gallons per Day)

\begin{tabular}{|c|c|c|c|c|c|c|c|c|c|c|c|c|}
\hline \multirow{3}{*}{$\begin{array}{l}\text { Year } \\
\text { Month }\end{array}$} & \multicolumn{6}{|c|}{ Regular } & \multicolumn{6}{|c|}{ Midgrade } \\
\hline & \multicolumn{2}{|c|}{ Sales to End Users } & \multicolumn{4}{|c|}{ Sales for Resale } & \multicolumn{2}{|c|}{ Sales to End Users } & \multicolumn{4}{|c|}{ Sales for Resale } \\
\hline & $\begin{array}{c}\text { Through } \\
\text { Retail } \\
\text { Outlets }\end{array}$ & Totala & DTW & Rack & Bulk & Total & $\begin{array}{c}\text { Through } \\
\text { Retail } \\
\text { Outlets }\end{array}$ & Totala & DTW & Rack & Bulk & Total \\
\hline \multicolumn{13}{|l|}{1993} \\
\hline 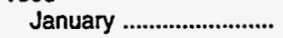 & - & - & - & - & - & - & - & - & - & - & - & - \\
\hline 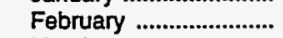 & - & - & - & - & - & - & - & - & - & - & - & - \\
\hline March .............................. & - & - & - & - & - & - & - & - & - & - & - & - \\
\hline April & - & - & - & - & - & - & - & - & - & - & - & - \\
\hline May ................................ & - & - & - & - & - & - & - & - & - & - & - & - \\
\hline June ................................ & - & - & - & - & - & - & - & - & - & - & - & - \\
\hline 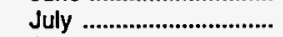 & - & - & - & - & - & - & - & - & - & - & - & - \\
\hline 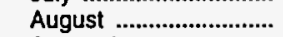 & - & - & - & - & - & - & - & - & - & - & - & - \\
\hline September ....................... & - & - & - & - & - & - & - & - & - & - & - & - \\
\hline 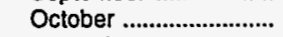 & 27.2 & 28.7 & 26.9 & 105.7 & 16.1 & 148.6 & 7.3 & 7.5 & 8.0 & $w$ & $W$ & 21.2 \\
\hline 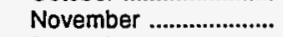 & 25.0 & 26.3 & 22.1 & 105.9 & 14.6 & 142.6 & 6.7 & 7.0 & 6.7 & $W$ & W & 20.0 \\
\hline December ....................... & 24.6 & 25.9 & 22.2 & 107.5 & 18.0 & 147.6 & 6.6 & 6.9 & 7.0 & W & $W$ & 20.4 \\
\hline 1993 & - & - & - & - & - & - & - & - & - & - & - & - \\
\hline \multicolumn{13}{|l|}{1994} \\
\hline 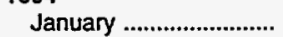 & 22.2 & 23.4 & 20.4 & 96.1 & 20.6 & 137.2 & 6.3 & 6.5 & 6.5 & 11.7 & 0.1 & 18.3 \\
\hline 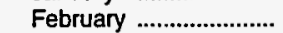 & 24.6 & 26.0 & 25.6 & 104.0 & 19.9 & 149.6 & 6.9 & 7.1 & 7.9 & $w$ & $w$ & 21.2 \\
\hline 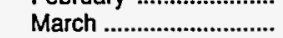 & 31.6 & 33.2 & 42.2 & 113.4 & 20.6 & 176.2 & 7.9 & 8.2 & 11.6 & W & W & 26.8 \\
\hline 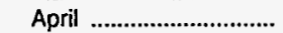 & 32.9 & 34.5 & 43.5 & 117.7 & 23.8 & 185.0 & 8.1 & 8.4 & 11.7 & $W$ & $W$ & 27.0 \\
\hline 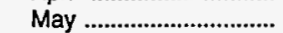 & 34.2 & 35.8 & 47.6 & 119.7 & 24.3 & 191.6 & 8.5 & 8.8 & $W$ & $W$ & 0.1 & 28.9 \\
\hline 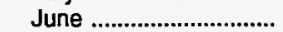 & 35.3 & 37.1 & $W$ & $W$ & 24.5 & 197.4 & W & $\mathbf{W}$ & $\mathbf{W}$ & W & 0.3 & $w$ \\
\hline 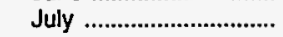 & 34.7 & 36.2 & $W$ & 122.7 & $W$ & 191.9 & $W$ & W & W & $w$ & 0.2 & W \\
\hline 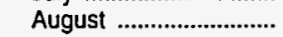 & 35.6 & 37.2 & 48.6 & W & W & 200.6 & $w$ & 8.9 & 13.0 & 16.6 & 0.2 & 29.8 \\
\hline 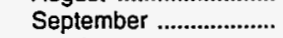 & 34.1 & 35.6 & 44.7 & 123.2 & 25.0 & 193.0 & 8.2 & 8.5 & 12.0 & $W$ & W & 27.8 \\
\hline 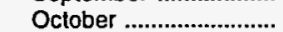 & 26.7 & 28.1 & 27.4 & 110.9 & 22.9 & 161.2 & 7.2 & 7.5 & 8.0 & $W$ & $w$ & 22.1 \\
\hline November ..................... & 24.0 & 25.3 & 21.7 & 107.3 & 20.1 & 149.1 & 6.5 & 6.7 & 6.6 & W & W & 20.0 \\
\hline 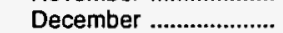 & 20.5 & 21.6 & 14.7 & 94.7 & 25.9 & 135.2 & 5.5 & 5.7 & 4.3 & 11.9 & 0.1 & 16.3 \\
\hline 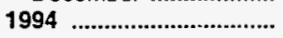 & 29.7 & 31.2 & 36.1 & 113.5 & 22.8 & 172.4 & 7.6 & 7.8 & 10.1 & 14.6 & 0.1 & $\mathbf{2 4 . 8}$ \\
\hline
\end{tabular}

See footnotes at end of table. 
Table 9. U.S. Refiner Conventional Motor Gasoline Volumes by Grade and Sales Type (Million Gallons per Day) - Continued

\begin{tabular}{|c|c|c|c|c|c|c|c|c|c|c|c|c|}
\hline \multirow{3}{*}{$\begin{array}{l}\text { Year } \\
\text { Month }\end{array}$} & \multicolumn{6}{|c|}{ Premium } & \multicolumn{6}{|c|}{ All Grades } \\
\hline & \multicolumn{2}{|c|}{ Sales to End Users } & \multicolumn{4}{|c|}{ Sales for Resale } & \multicolumn{2}{|c|}{ Sales to End Users } & \multicolumn{4}{|c|}{ Sales for Resale } \\
\hline & $\begin{array}{c}\text { Through } \\
\text { Retail } \\
\text { Outlets }\end{array}$ & Totala & DTW & Rack & Bulk & Total & $\begin{array}{c}\text { Through } \\
\text { Retail } \\
\text { Outlets }\end{array}$ & Total $\left.\right|^{a}$ & DTW & Rack & Bulk & Total \\
\hline \multicolumn{13}{|l|}{1993} \\
\hline January .......................... & - & - & - & - & - & - & - & - & - & - & - & - \\
\hline February ........................ & - & - & - & - & - & - & - & - & - & - & - & - \\
\hline March .............................. & - & - & - & - & - & - & - & - & - & - & - & - \\
\hline Aprll & - & - & - & - & - & - & - & - & - & - & - & - \\
\hline 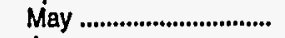 & - & - & - & - & - & - & - & - & - & - & - & - \\
\hline June .............................. & - & - & - & - & - & $\rightarrow$ & - & - & - & - & - & - \\
\hline 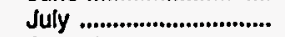 & - & - & - & - & - & - & - & - & - & - & - & - \\
\hline August .......................... & - & - & - & - & - & - & - & - & - & - & - & - \\
\hline September .................... & - & - & - & - & - & - & - & - & - & - & - & - \\
\hline 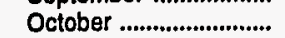 & 7.9 & 8.2 & 12.2 & $W$ & $w$ & 39.1 & 42.3 & 44.3 & 47.1 & 143.0 & 18.8 & 208.9 \\
\hline November ..................... & 7.5 & 7.8 & 10.0 & $w$ & $\ddot{w}$ & 37.7 & 39.2 & 41.1 & 38.9 & 143.1 & 18.3 & 200.3 \\
\hline December ..................... & 7.7 & 8.0 & 10.5 & W & $w$ & 40.2 & 39.0 & 40.8 & 39.7 & 146.9 & 21.5 & 208.2 \\
\hline 1993 & - & - & - & - & - & - & - & - & 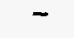 & - & - & - \\
\hline \multicolumn{13}{|l|}{1994} \\
\hline January ......................... & 7.3 & 7.6 & 10.3 & 24.1 & 3.2 & 37.7 & 35.8 & 37.5 & 37.3 & 132.0 & 23.9 & 193.2 \\
\hline February ....................... & 8.9 & 9.2 & 12.0 & $w$ & W & 40.9 & 40.3 & 42.2 & 45.6 & 142.9 & 23.1 & 211.6 \\
\hline March ............................. & 8.9 & 9.2 & 18.4 & w & $W$ & 49.2 & 48.4 & 50.7 & 72.1 & 156.9 & 23.2 & 252.2 \\
\hline April & 9.3 & 9.7 & 18.8 & $\ddot{w}$ & $w$ & 49.9 & 50.4 & 52.6 & 73.9 & 161.6 & 26.3 & 261.9 \\
\hline 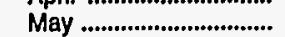 & 9.8 & 10.2 & $w$ & $w$ & 3.4 & 56.9 & 52.6 & 54.8 & 83.2 & 166.4 & 27.8 & 277.4 \\
\hline 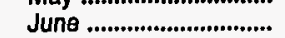 & $w$ & $w$ & $W$ & 31.7 & 3.8 & $w$ & 54.0 & 56.4 & $W$ & W & 28.7 & 285.8 \\
\hline 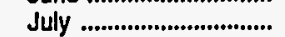 & $w$ & $w$ & $W$ & $w$ & 3.0 & $W$ & 53.1 & 55.2 & W & 169.5 & $w$ & 277.3 \\
\hline 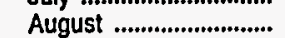 & W & 9.7 & $w$ & $w$ & 3.5 & 55.6 & 53.5 & 55.7 & $w$ & 174.4 & $W$ & 286.1 \\
\hline September ..................... & 9.0 & 9.4 & 19.9 & $w$ & $W$ & 52.0 & 51.3 & 53.5 & 76.6 & 168.2 & 27.9 & 272.7 \\
\hline 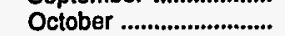 & 7.7 & 8.0 & 12.2 & $\ddot{w}$ & $\dddot{w}$ & 41.1 & 41.6 & 43.6 & 47.6 & 151.6 & 25.3 & 224.5 \\
\hline November ....................... & 6.6 & 6.9 & 9.5 & w & w & 37.1 & 37.1 & 38.9 & 37.7 & 146.5 & 21.9 & 206.2 \\
\hline December ..................... & 5.8 & 6.0 & 6.6 & 23.1 & 2.0 & 31.7 & 31.7 & 33.3 & 25.6 & 129.7 & 27.9 & 183.2 \\
\hline 1994 & 8.5 & 8.9 & 16.5 & 28.0 & 2.8 & 47.2 & 45.8 & 47.9 & 62.7 & 156.0 & 25.8 & 244.5 \\
\hline
\end{tabular}

Dash (-) $=$ No data reported.

$W=$ Withheld to avoid disclosure of individual company data.

a Includes sales through retail outlets as well as all direct sales to end users that were not made through company-operated retail outlets, e.g., sales to agricultural customers, commerclal sales, and industrial sales.

Notes: The 4th quarter of 1993 was a transitional period between the predecessor ElA-782 survey system and the revised ElA-782 survey sytem. The revised survey system contalns additional product and sales categories, which may not be consistent with categories derived from the predecessor survey system. Beginning January 1994 all data are from the revised survey system and are consistent.

Note: Totals may not equal the sum of the components due to rounding.

Source: Energy Information Administration Form EIA-782A, "Refiners'/Gas Plant Operators' Monthly Petroleum Product Sales Report." 
Table 10. U.S. Refiner Oxygenated Motor Gasoline Prices by Grade and Sales Type (Cents per Gallon Excluding Taxes)

\begin{tabular}{|c|c|c|c|c|c|c|c|c|c|c|c|c|}
\hline \multirow{3}{*}{$\begin{array}{l}\text { Year } \\
\text { Month }\end{array}$} & \multicolumn{6}{|c|}{ Regular } & \multicolumn{6}{|c|}{ Midgrade } \\
\hline & \multicolumn{2}{|c|}{ Sales to End Users } & \multicolumn{4}{|c|}{ Sales for Resale } & \multicolumn{2}{|c|}{ Sales to End Users } & \multicolumn{4}{|c|}{ Sales for Resale } \\
\hline & $\begin{array}{c}\text { Through } \\
\text { Retall } \\
\text { Outlets }\end{array}$ & Averagea & DTW & Rack & Bulk & Average & $\begin{array}{c}\text { Through } \\
\text { Retail } \\
\text { Outlets }\end{array}$ & Average ${ }^{a}$ & DTW & Rack & Bulk & Average \\
\hline \multicolumn{13}{|l|}{1993} \\
\hline 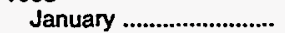 & - & - & - & - & - & - & - & - & - & - & - & - \\
\hline 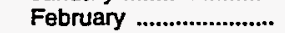 & - & - & - & - & - & - & - & - & - & - & - & - \\
\hline 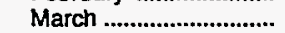 & - & - & - & - & - & - & - & - & - & - & - & - \\
\hline 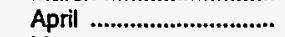 & - & - & - & - & - & - & - & - & - & - & - & - \\
\hline May ................................. & - & - & - & - & - & - & - & - & - & - & - & - \\
\hline 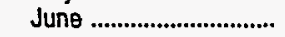 & - & - & - & - & - & - & - & - & - & - & - & - \\
\hline July & - & - & - & - & - & - & - & - & - & - & - & - \\
\hline 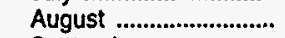 & - & - & - & - & - & - & - & - & - & - & - & - \\
\hline September ..................... & - & - & - & - & - & - & - & - & - & - & - & - \\
\hline 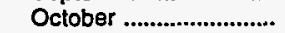 & 78.0 & 77.4 & 70.6 & 61.2 & 53.1 & 66.5 & 84.5 & 83.7 & 75.1 & 63.7 & $w$ & 71.9 \\
\hline November ....................... & 75.9 & 75.3 & 66.8 & 55.2 & 47.0 & 61.6 & 85.0 & 84.2 & 72.1 & 58.4 & $w$ & 68.3 \\
\hline December ...................... & 71.5 & 70.9 & 62.2 & 48.2 & 42.7 & 56.2 & 80.7 & 79.9 & 68.1 & 52.5 & $\ddot{w}$ & 63.9 \\
\hline 1993 & - & - & - & - & - & - & - & - & - & - & - & - \\
\hline \multicolumn{13}{|l|}{1994} \\
\hline January ............................. & 69.0 & 68.4 & 60.0 & 51.0 & 45.4 & 56.3 & 78.0 & 77.3 & 65.7 & 54.8 & $w$ & 62.7 \\
\hline 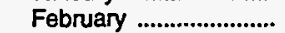 & 68.3 & 67.8 & 60.1 & 53.2 & 48.7 & 57.8 & 78.1 & 77.4 & 65.9 & 56.8 & $w$ & 63.7 \\
\hline 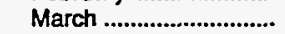 & 71.0 & 70.2 & 62.6 & 54.1 & 46.9 & 59.1 & 80.4 & 79.5 & 65.7 & 57.1 & $w$ & 63.8 \\
\hline 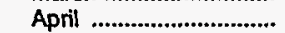 & 66.5 & 66.0 & 60.8 & 54.4 & 49.6 & 58.3 & 80.1 & 79.6 & 66.5 & 57.9 & $w$ & 64.7 \\
\hline 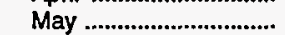 & 70.6 & 70.5 & 61.9 & 61.1 & - & 61.6 & 82.5 & 82.5 & $W$ & $W$ & - & 58.8 \\
\hline June & 71.9 & 71.9 & $w$ & 64.9 & - & 63.8 & $w$ & $W$ & $w$ & $w$ & - & $w$ \\
\hline July & 75.1 & 75.1 & $w$ & 70.0 & $w$ & 67.4 & $\ddot{w}$ & $w$ & $\ddot{w}$ & $\dddot{w}$ & - & W \\
\hline 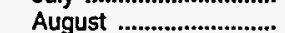 & 81.9 & 81.8 & 67.6 & 75.7 & $w$ & 70.0 & $\mathbf{W}$ & 98.1 & - & 69.4 & - & 69.4 \\
\hline September ..................... & 80.9 & 80.5 & 74.1 & 65.4 & 54.6 & 67.8 & 94.1 & 93.5 & 77.1 & 62.1 & $w$ & 71.6 \\
\hline 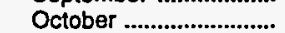 & 78.7 & 78.3 & 73.5 & 63.7 & 57.8 & 69.5 & 89.5 & 89.2 & 79.9 & 68.4 & $w$ & 77.0 \\
\hline November ...................... & 79.6 & 79.2 & 73.4 & 63.8 & 59.4 & 69.4 & 90.4 & 90.1 & 79.7 & 69.2 & $W$ & 76.6 \\
\hline December ...................... & 77.1 & 76.9 & 70.1 & 58.5 & $W$ & 63.7 & 87.2 & 86.9 & 75.0 & 62.2 & $W$ & 69.3 \\
\hline 1994 & 74.3 & 73.9 & 66.7 & 58.6 & 52.7 & 63.2 & 84.3 & 83.8 & 72.7 & 62.2 & $W$ & 69.6 \\
\hline
\end{tabular}

See footnotes at end of table. 
Table 10. U.S. Refiner Oxygenated Motor Gasoline Prices by Grade and Sales Type (Cents per Gallon Excluding Taxes) - Continued

\begin{tabular}{|c|c|c|c|c|c|c|c|c|c|c|c|c|}
\hline \multirow{3}{*}{$\begin{array}{l}\text { Year } \\
\text { Month }\end{array}$} & \multicolumn{6}{|c|}{ Premlum } & \multicolumn{6}{|c|}{ All Grades } \\
\hline & \multicolumn{2}{|c|}{ Sales to End Users } & \multicolumn{4}{|c|}{ Sales for Resale } & \multicolumn{2}{|c|}{ Sales to End Users } & \multicolumn{4}{|c|}{ Sales for Resale } \\
\hline & $\begin{array}{c}\text { Through } \\
\text { Rotall } \\
\text { Outlets }\end{array}$ & Averagea & DTW & Rack & Bulk & Average & $\begin{array}{c}\text { Through } \\
\text { Retail } \\
\text { Outlets }\end{array}$ & Average ${ }^{a}$ & DTW & Rack & Bulk & Average \\
\hline \multicolumn{13}{|l|}{1993} \\
\hline 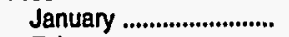 & - & - & - & - & - & - & - & - & - & - & - & - \\
\hline February .......................... & - & - & - & - & - & - & - & - & - & - & - & - \\
\hline March ............................... & - & - & - & - & - & - & - & - & - & - & - & - \\
\hline 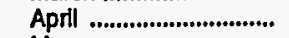 & - & - & - & - & - & - & $\rightarrow$ & - & - & - & - & - \\
\hline 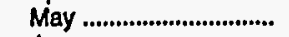 & - & - & - & - & - & - & - & - & - & - & - & - \\
\hline 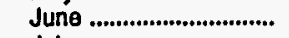 & - & - & - & - & - & - & - & - & - & $\rightarrow$ & - & - \\
\hline July & - & - & - & - & - & - & - & - & - & - & - & - \\
\hline 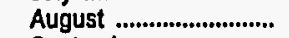 & - & - & - & - & - & - & - & - & - & - & - & - \\
\hline September .................... & - & - & - & - & - & - & - & - & - & - & - & - \\
\hline 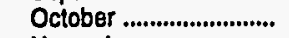 & 97.2 & 96.1 & 84.9 & 69.2 & 57.7 & 80.6 & 82.3 & 81.6 & 75.3 & 63.0 & 54.0 & 70.7 \\
\hline November ....................... & 94.7 & 93.9 & 80.9 & 64.5 & 52.1 & 75.9 & 80.6 & 80.0 & 71.6 & 57.3 & 48.1 & 66.1 \\
\hline December ...................... & 90.6 & 89.8 & 76.6 & 57.5 & 45.6 & 71.0 & 76.4 & 75.7 & 67.2 & 50.4 & 43.4 & 61.0 \\
\hline $1993 \ldots \ldots . . . . . . . . . . . . . . . . . . .$. & - & - & - & - & - & - & - & - & - & - & - & - \\
\hline \multicolumn{13}{|l|}{1994} \\
\hline 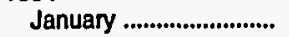 & 88.4 & 87.8 & 74.0 & 60.1 & 50.6 & 70.2 & 74.0 & 73.3 & 64.7 & 53.1 & 46.4 & 60.7 \\
\hline February ......................... & 88.0 & 87.2 & 74.0 & 62.0 & 53.1 & 70.8 & 73.3 & 72.7 & 64.8 & 55.4 & 50.1 & 61.9 \\
\hline March ............................ & 89.1 & 88.4 & 74.0 & 61.6 & 52.2 & 71.0 & 76.9 & 76.1 & 67.5 & 56.2 & 48.6 & 63.9 \\
\hline 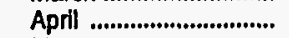 & 87.4 & 87.2 & 74.6 & 62.2 & 55.9 & 71.7 & 74.9 & 74.4 & 67.6 & 57.0 & 52.1 & 64.5 \\
\hline May ................................ & 87.9 & 87.6 & 72.9 & 63.7 & - & 71.1 & 77.0 & 76.9 & 67.8 & 61.2 & - & 65.4 \\
\hline 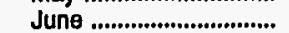 & 88.8 & 88.8 & $W$ & 68.2 & - & 73.2 & 78.8 & 78.8 & $W$ & 65.4 & - & 67.6 \\
\hline 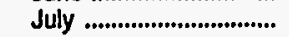 & 90.9 & 90.9 & $W$ & 72.0 & - & 75.7 & 81.4 & 81.4 & $w$ & 70.0 & $w$ & 70.6 \\
\hline 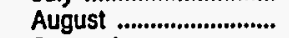 & 93.9 & 93.9 & $W$ & 76.1 & - & 78.7 & 86.4 & 86.3 & $W$ & 75.0 & $w$ & 72.9 \\
\hline September .................... & 97.1 & 96.8 & 85.7 & 73.0 & 60.0 & 81.3 & 86.4 & 86.0 & 78.9 & 66.3 & 55.8 & 72.3 \\
\hline 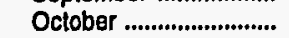 & 97.3 & 97.0 & 87.7 & 73.8 & 64.0 & 84.1 & 83.6 & 83.2 & 78.5 & 66.1 & 58.9 & 74.1 \\
\hline November ..................... & 99.2 & 98.7 & 87.8 & 74.9 & 66.1 & 84.4 & 84.5 & 84.1 & 78.2 & 66.3 & 60.0 & 73.8 \\
\hline December ...................... & 96.8 & 96.5 & 83.7 & 68.8 & $w$ & 77.8 & 81.5 & 81.2 & 73.5 & 60.4 & W & 66.8 \\
\hline 1994 & 92.9 & 92.4 & 79.9 & 67.5 & 56.7 & 76.5 & 79.3 & 78.8 & 71.5 & 60.7 & 53.5 & 67.5 \\
\hline
\end{tabular}

Dash $(-)=$ No data reported.

$W=$ Withheld to avold disclosure of individual company data.

a Includes sales through retall outlets as well as all direct sales to end users that were not made through company-operated retail outlets, e.g., sales to agricultural customers, commerclal sales, and industrial sales.

Notes: The 4th quarter of 1993 was a transitional period between the predecessor EIA-782 survey system and the revised EIA-782 survey sytem. The revised survey system contains additional product and sales categories, which may not be consistent with categories derived from the predecessor survey system. Beginning January 1994 all data are from the revised survey system and are consistent.

Source: Energy Information Administration Form ElA-782A, "Refiners'/Gas Plant Operators' Monthly Petroleum Product Sales Report." 
Table 11. U.S. Refiner Oxygenated Motor Gasoline Volumes by Grade and Sales Type (Million Gallons per Day)

\begin{tabular}{|c|c|c|c|c|c|c|c|c|c|c|c|c|}
\hline \multirow{3}{*}{$\begin{array}{c}\text { Year } \\
\text { Month }\end{array}$} & \multicolumn{6}{|c|}{ Regular } & \multicolumn{6}{|c|}{ Midgrado } \\
\hline & \multicolumn{2}{|c|}{ Sales to End Users } & \multicolumn{4}{|c|}{ Sales for Resale } & \multicolumn{2}{|c|}{ Sales to End Users } & \multicolumn{4}{|c|}{ Sales for Resale } \\
\hline & $\begin{array}{c}\text { Through } \\
\text { Retail } \\
\text { Outlets }\end{array}$ & Totala & DTW & Rack & Bulk & Total & $\begin{array}{c}\text { Through } \\
\text { Retail } \\
\text { Outlets }\end{array}$ & Totala & DTW & Rack & Bulk & Total \\
\hline
\end{tabular}

1993

January

February

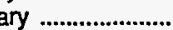

March

April

May ......................................

July .......

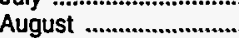

September

Novembe

December ......................

1993

1994

January .........................

February

March

April

May

June

July

(n)

August .

September ....................

October

November

December

........................

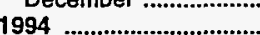

$\begin{array}{rr}- & - \\ - & - \\ - & \\ - & - \\ - & - \\ - & - \\ - & - \\ 7.5 & 7.8 \\ 9.7 & 10.0 \\ 10.0 & 10.3 \\ - & -\end{array}$

$\begin{array}{ll}- & - \\ - & - \\ - & - \\ - & - \\ - & - \\ - & \\ 7.8 & 21.1 \\ 10.0 & 25.3 \\ 10.3 & 25.8\end{array}$

$\begin{array}{ll}- & \\ - & \\ - & \\ - & \\ - & \\ - & \\ - & \\ - & \\ 21.1 & 10.8 \\ 25.5 & 15.1 \\ 25.8 & 14.6 \\ - & \end{array}$

$\begin{array}{ll}- & - \\ - & - \\ - & - \\ - & - \\ - & - \\ - & - \\ 10.8 & 2.1 \\ 15.1 & 2.3 \\ 14.6 & 2.7 \\ - & \end{array}$

$\begin{array}{lll}- & - & - \\ - & - & - \\ - & - & - \\ - & - & - \\ - & - & - \\ - & - & - \\ - & - & - \\ - & - & 1.5 \\ - & - & 1 . \\ 2.1 & 34.0 & \\ 2.3 & 43.0 & \\ 2.7 & 43.1 & \\ - & - & \end{array}$

$\begin{array}{ll}- & \\ - & \\ - & \\ - & \\ - & \\ - & \\ - & \end{array}$

$\begin{array}{lll}- & - & - \\ - & - & - \\ - & - & - \\ - & - & - \\ - & - & - \\ - & - & - \\ - & - & - \\ - & - & W \\ - & - & W \\ 1.5 & 5.1 & W \\ 2.0 & 6.1 & - \\ 2.0 & 6.0 & -\end{array}$

$\begin{array}{lll}- & - & - \\ - & - & - \\ - & - & - \\ - & - & - \\ - & - & - \\ - & - & - \\ - & - & - \\ - & - & - \\ \bar{W} & - & - \\ W & w & 7.0 \\ W & w & 8.4 \\ - & w & 8.3\end{array}$

See footnotes at end of table.

\begin{tabular}{rrrrrrrrrrr}
9.5 & 23.9 & 12.3 & 2.0 & 38.2 & 1.8 & 1.9 & 5.5 & 1.9 & $W$ & 7.5 \\
8.2 & 21.0 & 8.6 & 1.1 & 30.7 & 1.4 & 1.5 & 4.2 & $W$ & $W$ & 5.6 \\
2.9 & 5.9 & 2.7 & 0.5 & 9.1 & 0.4 & 0.5 & 1.2 & $W$ & $W$ & 1.6 \\
1.3 & 4.5 & 2.1 & 0.3 & 6.9 & 0.3 & 0.3 & 1.2 & $W$ & $W$ & 1.6 \\
0.4 & 0.6 & 0.5 & - & 1.1 & 0.0 & 0.0 & $W$ & $W$ & - & 0.1 \\
0.4 & $W$ & $W$ & - & 1.0 & $W$ & $W$ & $W$ & $W$ & - & $W$ \\
0.4 & $W$ & 0.6 & $W$ & 1.0 & $W$ & $W$ & $W$ & $W$ & - & $W$ \\
0.4 & 0.4 & $W$ & $W$ & 1.4 & $W$ & 0.0 & - & 0.1 & - & 0.1 \\
1.0 & 2.7 & 1.6 & 1.0 & 5.3 & 0.1 & 0.1 & 0.7 & $W$ & $W$ & 1.1 \\
7.4 & 20.1 & 10.1 & 1.9 & 32.2 & 1.2 & 1.2 & 4.8 & $W$ & $W$ & 6.3 \\
10.2 & 24.1 & 14.2 & 2.0 & 40.2 & 1.9 & 2.0 & 5.8 & $W$ & $W$ & 8.0 \\
7.7 & 10.0 & $W$ & $W$ & 20.2 & 1.3 & 1.3 & 1.8 & $W$ & $W$ & 3.1 \\
4.1 & 9.4 & 5.2 & 0.9 & 15.5 & 0.7 & 0.7 & 2.1 & 0.8 & $W$ & 2.9 \\
\hline
\end{tabular}


Table 11. U.S. Refiner Oxygenated Motor Gasoline Volumes by Grade and Sales Type (Million Gallons per Day) - Continued

\begin{tabular}{|c|c|c|c|c|c|c|c|c|c|c|c|c|}
\hline \multirow{3}{*}{$\begin{array}{l}\text { Yoar } \\
\text { Month }\end{array}$} & \multicolumn{6}{|c|}{ Promium } & \multicolumn{6}{|c|}{ All Grades } \\
\hline & \multicolumn{2}{|c|}{ Sales to End Users } & \multicolumn{4}{|c|}{ Sales for Resale } & \multicolumn{2}{|c|}{ Sales to End Users } & \multicolumn{4}{|c|}{ Sales for Resale } \\
\hline & $\begin{array}{c}\text { Through } \\
\text { Retall } \\
\text { Outlets }\end{array}$ & Totala & DTW & Rack & Bulk & Total & $\begin{array}{c}\text { Through } \\
\text { Retail } \\
\text { Outlets }\end{array}$ & Totala & DTW & Rack & Bulk & Total \\
\hline \multicolumn{13}{|l|}{1893} \\
\hline January .......................... & - & - & - & - & - & - & - & - & - & - & - & - \\
\hline February .......................... & - & - & - & - & - & - & - & - & - & - & - & - \\
\hline March ............................... & - & - & - & - & - & - & - & - & - & $\rightarrow$ & - & - \\
\hline 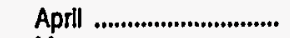 & - & - & - & - & - & - & - & - & - & - & - & - \\
\hline 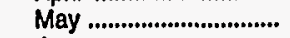 & - & - & - & - & - & - & - & - & - & - & - & - \\
\hline June ................................... & - & - & - & - & - & - & - & - & - & - & - & - \\
\hline 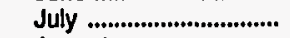 & - & - & - & - & - & - & - & - & - & - & - & - \\
\hline 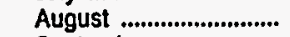 & - & - & - & - & - & - & - & $\rightarrow$ & - & - & - & - \\
\hline September .................... & - & - & - & - & - & - & - & - & - & - & - & - \\
\hline October ......................... & 1.9 & 2.0 & 10.2 & $W$ & $W$ & 13.6 & 10.9 & 11.4 & 36.4 & 15.5 & 2.7 & 54.5 \\
\hline November .................... & 2.7 & 2.8 & 12.7 & $W$ & $W$ & 17.5 & 14.2 & 14.7 & 44.4 & 21.4 & 3.2 & 68.9 \\
\hline December ...................... & 2.8 & 2.9 & 13.0 & $W$ & $W$ & 17.7 & 14.8 & 15.2 & 44.8 & 20.6 & 3.5 & 69.0 \\
\hline 1993 & - & - & - & - & - & - & - & - & - & - & - & - \\
\hline \multicolumn{13}{|l|}{1994} \\
\hline January ......................... & 2.6 & 2.7 & 11.7 & 3.3 & 0.5 & 15.6 & 13.6 & 14.0 & 41.2 & 17.6 & 2.6 & 61.3 \\
\hline 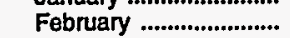 & 2.3 & 2.3 & 10.2 & $w$ & $w$ & 13.3 & 11.6 & 12.0 & 35.4 & 12.5 & 1.6 & 49.6 \\
\hline 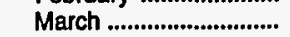 & 1.2 & 1.3 & 4.9 & $\ddot{w}$ & $\ddot{w}$ & 6.1 & 4.5 & 4.7 & 12.0 & 4.1 & 0.8 & 16.8 \\
\hline 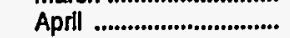 & 0.7 & 0.8 & 4.6 & W & w & 5.8 & 2.3 & 2.3 & 10.3 & 3.5 & 0.5 & 14.3 \\
\hline 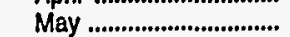 & 0.2 & 0.2 & 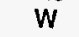 & $w$ & - & 0.8 & 0.7 & 0.7 & 1.3 & 0.7 & - & 2.0 \\
\hline 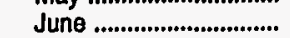 & $w$ & $w$ & W & 0.2 & - & $W$ & 0.7 & 0.7 & $\ddot{w}$ & $\ddot{w}$ & - & 1.9 \\
\hline 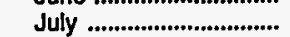 & $w$ & $w$ & w & $w$ & - & W & 0.6 & 0.6 & $w$ & 0.9 & $w$ & 1.9 \\
\hline 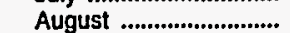 & $w$ & 0.2 & $w$ & $w$ & - & 0.8 & 0.7 & 0.7 & $w$ & 1.0 & w & 2.3 \\
\hline September ................... & 0.5 & 0.5 & 2.1 & $w$ & $w$ & 2.8 & 1.5 & 1.5 & 5.6 & 2.4 & 1.3 & 9.3 \\
\hline 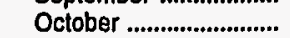 & 2.1 & 2.1 & 10.0 & $\ddot{W}$ & $w$ & 13.1 & 10.4 & 10.6 & 34.8 & 14.3 & 2.4 & 51.6 \\
\hline November ......................... & 2.5 & 2.6 & 11.0 & $\ddot{W}$ & $\ddot{w}$ & 14.8 & 14.4 & 14.8 & 40.9 & 19.7 & 2.4 & 63.0 \\
\hline 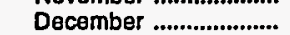 & 1.7 & 1.7 & 3.1 & $\ddot{w}$ & $\ddot{w}$ & 5.0 & 10.6 & 10.8 & 14.9 & $w$ & $w$ & 28.2 \\
\hline 1994 & 1.2 & 1.2 & 5.0 & 1.4 & 0.2 & 6.6 & 5.9 & 6.1 & 16.5 & 7.4 & 1.1 & 25.0 \\
\hline
\end{tabular}

Dash $(-)=$ No data reported.

$W=$ Witheild to avold disclosure of individual company data.

a Includes sales through retall outlets as well as all direct sales to end users that were not made through company-operated retail outlets, e.g., sales to agricultural customers, commercial sales, and industrial sales.

Notes: The 4th quarter of 1993 was a transitional period between the predecessor ElA-782 survey system and the revised ElA-782 survey sytem. The revised survey system contains additional product and sales categories, which may not be consistent with categories derived from the predecessor survey system. Beginning January 1994 all data are from the revised survey system and are consistent.

Note: Totals may not equal the sum of the components due to rounding.

Source: Energy information Administration Form ElA-782A, "Refiners'/Gas Plant Operators' Monthly Petroleum Product Sales Report." 
Table 12. U.S. Refiner Reformulated Motor Gasoline Prices by Grade and Sales Type (Cents per Gallon Excluding Taxes)

\begin{tabular}{|c|c|c|c|c|c|c|c|c|c|c|c|c|}
\hline \multirow{3}{*}{$\begin{array}{l}\text { Year } \\
\text { Month }\end{array}$} & \multicolumn{6}{|c|}{ Regular } & \multicolumn{6}{|c|}{ Midgrado } \\
\hline & \multicolumn{2}{|c|}{ Sales to End Users } & \multicolumn{4}{|c|}{ Sales for Resale } & \multicolumn{2}{|c|}{ Sales to End Users } & \multicolumn{4}{|c|}{ Sales for Resalo } \\
\hline & $\begin{array}{c}\text { Through } \\
\text { Retail } \\
\text { Outlets }\end{array}$ & Averagea & DTW & Rack & Bulk & Average & $\begin{array}{c}\text { Through } \\
\text { Retail } \\
\text { Outlets }\end{array}$ & Average $a$ & DTW & Rack & Bulk & Average \\
\hline
\end{tabular}

1993

January

February

March

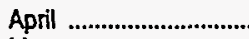

May

July ...

August

西

September

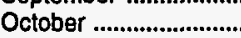

November

December .......................

1993

1994

January

February

March

April

May

June

July

August

September .....................

October

November .....................

December .....................

1994

$\begin{array}{lll}- & - & - \\ - & - & - \\ - & - & - \\ - & - & - \\ - & - & - \\ - & - & - \\ - & - & - \\ - & - & - \\ - & - & \end{array}$

-
-
-
-
-
-
-
-
-

$\begin{array}{llll}- & - & - & - \\ - & - & - & - \\ - & - & - & - \\ - & - & - & - \\ - & - & - & - \\ - & - & - & - \\ - & - & - & - \\ - & - & - & - \\ - & - & - & - \\ 77.9 & 77.7 & 72.6 & 60.3 \\ 76.4 & 75.7 & 72.0 & 56.7\end{array}$

$\begin{array}{lll}- & - & - \\ - & - & - \\ - & - & - \\ - & - & - \\ - & - & - \\ - & - & - \\ - & - & - \\ - & - & - \\ - & - & - \\ - & - & - \\ - & - & - \\ - & - & -\end{array}$

-
$\bar{z}$
$\overline{-}$
$\overline{-}$
$\overline{-}$
$\overline{-}$
-

-
$\overline{-}$
$\overline{-}$
$\overline{-}$
$\overline{-}$
-

-
-
$\overline{-}$
$\overline{-}$
$\overline{-}$
$\overline{-}$
58.7

$\begin{array}{llll}- & - & - & - \\ - & - & - & - \\ - & - & - & - \\ - & - & - & - \\ - & - & - & - \\ - & - & - & - \\ - & - & - & - \\ - & - & - & - \\ - & - & - & - \\ - & - & - & - \\ - & - & - & - \\ - & - & - & - \\ - & - & - & - \\ & & & \\ - & - & - & - \\ - & - & - & - \\ - & - & - & - \\ - & - & - & - \\ - & - & - & - \\ - & - & - & - \\ - & - & - & - \\ - & - & - & - \\ - & - & - & - \\ - & - & - & - \\ 77.9 & 69.0 & - & 75.4 \\ 77.0 & 62.5 & w & 72.6 \\ 77.0 & 62.8 & w & 72.8 \\ & & & \end{array}$

See footnotes at end of table. 
Table 12. U.S. Refiner Reformulated Motor Gasoline Prices by Grade and Sales Type (Cents per Gallon Excluding Taxes) - Continued

\begin{tabular}{|c|c|c|c|c|c|c|c|c|c|c|c|c|}
\hline \multirow{3}{*}{$\begin{array}{l}\text { Yoar } \\
\text { Month }\end{array}$} & \multicolumn{6}{|c|}{ Premium } & \multicolumn{6}{|c|}{ All Grades } \\
\hline & \multicolumn{2}{|c|}{ Sales to End Users } & \multicolumn{4}{|c|}{ Sales for Resale } & \multicolumn{2}{|c|}{ Sales to End Users } & \multicolumn{4}{|c|}{ Sales for Resale } \\
\hline & $\begin{array}{c}\text { Through } \\
\text { Retall } \\
\text { Outlets }\end{array}$ & Averagea & DTW & Rack & Bulk & Average & $\begin{array}{l}\text { Through } \\
\text { Retail } \\
\text { Outlets }\end{array}$ & Averagea & DTW & Rack & Bulk & Average \\
\hline \multicolumn{13}{|l|}{1993} \\
\hline January ,......................... & - & - & - & - & - & - & - & - & - & - & - & - \\
\hline February ....................... & - & - & - & - & - & - & - & - & - & - & - & - \\
\hline 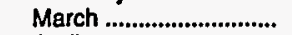 & - & - & - & - & - & - & - & - & - & - & - & - \\
\hline 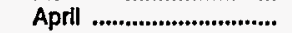 & - & - & - & - & - & - & - & - & - & $\rightarrow$ & - & - \\
\hline 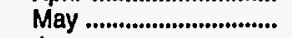 & - & - & - & - & - & - & - & - & - & - & - & - \\
\hline 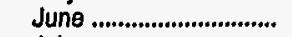 & - & - & - & - & - & - & - & - & - & - & - & - \\
\hline July ................................. & - & - & - & - & - & - & - & - & - & - & - & - \\
\hline August & - & - & - & - & - & - & - & - & - & - & $\sim$ & - \\
\hline September .................... & - & - & - & - & - & - & - & - & - & - & - & - \\
\hline 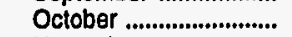 & - & - & - & - & - & - & - & - & - & - & - & - \\
\hline November ...................... & - & - & - & - & - & - & - & - & - & - & - & - \\
\hline December ...................... & - & - & - & - & - & - & - & - & - & - & - & - \\
\hline 1993 & - & - & - & - & - & - & - & - & - & - & - & - \\
\hline \multicolumn{13}{|l|}{1994} \\
\hline January ......................... & - & - & - & - & - & - & - & - & - & - & - & - \\
\hline 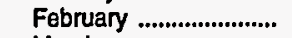 & - & - & - & - & - & - & - & - & - & - & - & - \\
\hline 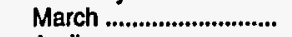 & - & - & - & - & - & - & - & - & - & - & - & - \\
\hline 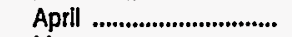 & - & - & - & - & - & - & - & - & - & - & - & - \\
\hline May .................................. & - & - & - & - & - & - & - & - & - & - & - & - \\
\hline 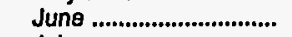 & - & - & - & - & - & - & - & - & - & - & - & - \\
\hline 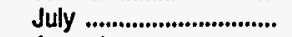 & - & - & - & - & - & - & - & - & - & - & - & - \\
\hline 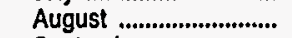 & - & - & - & - & - & - & - & - & - & - & - & - \\
\hline September ..................... & - & - & - & - & - & - & - & - & - & - & - & - \\
\hline 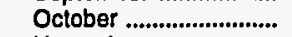 & - & - & - & - & - & - & - & - & - & - & - & - \\
\hline November ...................... & 97.2 & $\begin{array}{l}97.0 \\
95.7\end{array}$ & $\begin{array}{l}84.6 \\
86.3\end{array}$ & $\begin{array}{l}69.5 \\
67.5\end{array}$ & $\begin{array}{l}61.2 \\
54.5\end{array}$ & $\begin{array}{l}76.8 \\
77.8\end{array}$ & 87.4 & 87.2 & $\begin{array}{l}77.8 \\
77.0\end{array}$ & 64.1 & 59.4 & 70.0 \\
\hline 1994 & 96.6 & 95.8 & 86.1 & 67.7 & 55.8 & 77.7 & 83.1 & 82.4 & 77.1 & 59.9 & 54.7 & 68.7 \\
\hline
\end{tabular}

Dash $(-)=$ No data reported.

$W=$ Witheld to avold disclosure of individual company data.

a Includes sales through retail outlets as well as all direct sales to end users that were not made through company-operated retail outlets, e.g., sales to agricultural customers, commercial sales, and industrial sales.

Source: Energy Information Administration Form ElA-782A, "Refiners'/Gas Plant Operators' Monthly Petroleum Product Sales Report." 
Table 13. U.S. Refiner Reformulated Motor Gasoline Volumes by Grade and Sales Type (Million Gallons per Day)

\begin{tabular}{|c|c|c|c|c|c|c|c|c|c|c|c|c|}
\hline \multirow{3}{*}{$\begin{array}{c}\text { Year } \\
\text { Month }\end{array}$} & \multicolumn{6}{|c|}{ Regular } & \multicolumn{6}{|c|}{ Midgrade } \\
\hline & \multicolumn{2}{|c|}{ Sales to End Users } & \multicolumn{4}{|c|}{ Sales for Resale } & \multicolumn{2}{|c|}{ Sales to End Users } & \multicolumn{4}{|c|}{ Salos for Resale } \\
\hline & $\begin{array}{c}\text { Through } \\
\text { Retail } \\
\text { Outlets }\end{array}$ & Totafa & DTW & Rack & Bulk & Total & $\begin{array}{c}\text { Through } \\
\text { Retall } \\
\text { Outlets }\end{array}$ & Totafa & DTW & Rack & Bulk & Total \\
\hline \multicolumn{13}{|l|}{1993} \\
\hline 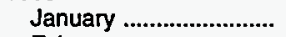 & - & - & - & - & - & - & - & - & - & - & - & - \\
\hline 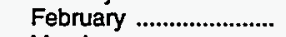 & - & - & - & - & - & - & - & - & - & - & - & - \\
\hline 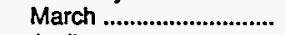 & - & - & - & - & - & - & - & - & - & - & - & - \\
\hline 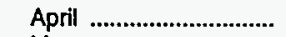 & - & - & - & - & - & - & - & - & - & - & - & - \\
\hline 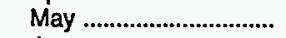 & - & - & - & - & - & - & - & - & - & - & - & - \\
\hline 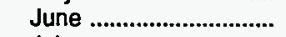 & - & - & - & - & - & - & - & - & - & - & - & - \\
\hline July & - & - & - & - & - & - & - & - & - & - & - & - \\
\hline August & - & - & - & - & - & - & - & - & - & - & - & - \\
\hline September ......................... & - & - & - & - & - & - & - & - & - & - & - & - \\
\hline October & - & - & - & - & - & - & - & - & - & - & - & - \\
\hline November ......................... & - & - & - & - & - & - & - & - & - & - & - & - \\
\hline 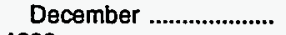 & - & - & - & - & - & - & - & - & - & - & - & - \\
\hline 1993 & - & - & - & - & - & - & - & - & - & - & - & - \\
\hline \multicolumn{13}{|l|}{1994} \\
\hline 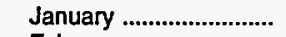 & - & - & - & - & - & - & - & - & - & - & - & - \\
\hline February .......................... & - & - & - & - & - & - & - & - & - & - & - & - \\
\hline 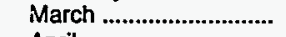 & - & - & - & - & - & - & - & - & - & - & - & - \\
\hline April & - & - & - & - & - & - & - & - & - & - & - & - \\
\hline 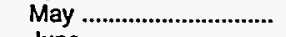 & - & - & - & - & - & - & - & - & - & - & - & - \\
\hline 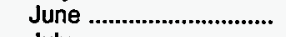 & - & - & - & - & - & - & - & - & - & - & - & - \\
\hline 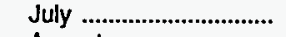 & - & - & - & - & - & - & - & - & - & - & - & - \\
\hline 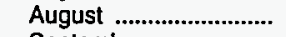 & - & - & - & - & - & - & - & - & - & - & - & - \\
\hline September ....................... & - & - & - & - & - & - & - & - & - & - & - & - \\
\hline 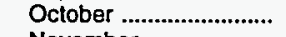 & - & - & - & - & - & - & - & - & - & - & - & - \\
\hline November ...................... & 0.3 & 0.3 & 1.7 & 0.8 & 1.4 & 3.9 & 0.2 & 0.2 & 0.4 & 0.2 & - & 0.6 \\
\hline December ....................... & 6.7 & 7.0 & 23.0 & $W$ & $W$ & 47.3 & 2.0 & 2.0 & 7.5 & $w$ & $w$ & 10.7 \\
\hline 1994 & 0.6 & 0.6 & 2.1 & 1.6 & 0.6 & 4.3 & 0.2 & 0.2 & 0.7 & 0.3 & w & 1.0 \\
\hline
\end{tabular}

See footnotes at end of table. 
Table 13. U.S. Refiner Reformulated Motor Gasoline Volumes by Grade and Sales Type (Million Gallons per Day) - Continued

\begin{tabular}{|c|c|c|c|c|c|c|c|c|c|c|c|c|}
\hline \multirow{3}{*}{$\begin{array}{l}\text { Year } \\
\text { Month }\end{array}$} & \multicolumn{6}{|c|}{ Premlum } & \multicolumn{6}{|c|}{ All Grades } \\
\hline & \multicolumn{2}{|c|}{ Sales to End Users } & \multicolumn{4}{|c|}{ Sales for Resale } & \multicolumn{2}{|c|}{ Sales to End Users } & \multicolumn{4}{|c|}{ Sales for Resale } \\
\hline & $\begin{array}{c}\text { Through } \\
\text { Retail } \\
\text { Outlots }\end{array}$ & Totala & DTW & Rack & Bulk & Total & $\begin{array}{c}\text { Through } \\
\text { Retail } \\
\text { Outlets }\end{array}$ & Totala & DTW & Rack & Bulk & Total \\
\hline \multicolumn{13}{|l|}{1993} \\
\hline 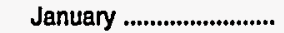 & - & - & - & - & - & - & - & - & - & - & - & - \\
\hline February ......................... & - & - & - & - & - & - & - & - & - & - & - & - \\
\hline 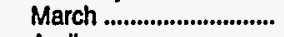 & - & - & - & - & - & - & - & - & - & - & - & - \\
\hline April & - & - & - & - & - & - & - & - & - & - & - & - \\
\hline May ................................. & - & - & - & - & - & - & - & - & - & - & - & - \\
\hline June .................................... & - & - & - & - & - & - & - & - & - & - & - & - \\
\hline July .................................. & - & - & - & - & - & - & - & - & - & - & - & - \\
\hline August ........................... & - & - & - & - & - & - & - & - & - & - & - & - \\
\hline September .................... & - & - & - & - & - & - & - & - & - & - & - & - \\
\hline 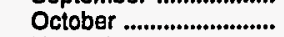 & - & - & - & - & - & - & - & - & - & - & - & - \\
\hline November ..................... & - & - & - & - & - & - & - & - & - & - & - & - \\
\hline December ....................... & - & - & - & - & - & - & - & - & - & - & - & - \\
\hline $1993 \ldots$ & - & - & - & - & - & - & - & - & - & - & - & - \\
\hline \multicolumn{13}{|l|}{1894} \\
\hline January ......................... & - & - & - & - & - & - & - & - & - & - & - & - \\
\hline February ......................... & - & - & - & - & - & - & - & - & - & - & - & - \\
\hline March ............................. & - & - & - & - & - & - & - & - & - & - & - & - \\
\hline April ................................ & - & - & - & - & - & - & - & - & - & - & - & - \\
\hline May ................................ & - & - & - & - & - & - & - & - & - & - & - & - \\
\hline June ............................... & - & - & - & - & - & - & - & - & - & - & - & - \\
\hline 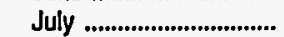 & - & - & - & - & - & - & - & - & - & - & - & - \\
\hline 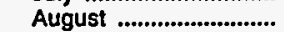 & - & - & - & - & - & - & - & - & - & - & - & - \\
\hline September .................. & - & - & - & - & - & - & - & - & - & - & - & - \\
\hline October .......................... & - & - & - & - & - & - & - & - & - & - & - & - \\
\hline Novembet ...................... & 0.3 & 0.3 & 1.4 & 0.4 & 0.5 & 2.2 & 0.7 & 0.7 & 3.5 & 1.3 & 1.9 & 6.8 \\
\hline December .................... & 2.5 & 2.5 & 12.6 & $w$ & $w$ & 20.5 & 11.1 & 11.5 & 43.1 & $W$ & $W$ & 78.5 \\
\hline 1994 & 0.2 & 0.2 & 1.2 & 0.5 & 0.2 & 1.9 & 1.0 & 1.0 & 4.0 & 2.4 & 0.8 & 7.2 \\
\hline
\end{tabular}

Dash $(-)=$ No data reported.

$W=$ Withheld to avoid disclosure of individual company data.

a Inciudes seles through retail outlets as well as all direct sales to end users that were not made through company-operated retail outlets, e.g., sales to agricultural customers, commercial sales, and industrial sales.

Note: Totals may not equal the sum of the components due to rounding.

Source: Energy Information Administration Form ElA-782A, "Refiners'/Gas Plant Operators' Monthly Petroleum Product Sales Report." 
Table 14. U.S. Propane (Consumer Grade) Prices by Sales Type (Cents per Gallon Excluding Taxes)

\begin{tabular}{|c|c|c|c|c|c|c|c|c|}
\hline \multirow[b]{2}{*}{$\begin{array}{c}\text { Year } \\
\text { Month }\end{array}$} & \multicolumn{7}{|c|}{ Sales to End Users } & \multirow[b]{2}{*}{$\begin{array}{c}\text { Sales } \\
\text { for } \\
\text { Resale }\end{array}$} \\
\hline & $\begin{array}{l}\text { Residential } \\
\text { Consumers }\end{array}$ & $\begin{array}{c}\text { Commercial } \\
\text { Institutional } \\
\text { Consumers }\end{array}$ & $\begin{array}{l}\text { Industrtal } \\
\text { Consumers }\end{array}$ & $\begin{array}{l}\text { Through } \\
\text { Retail } \\
\text { Outlets }\end{array}$ & $\begin{array}{c}\text { Petro- } \\
\text { Chemical }\end{array}$ & $\begin{array}{c}\text { Other } \\
\text { End Users }\end{array}$ & Averago & \\
\hline \multicolumn{9}{|l|}{1993} \\
\hline 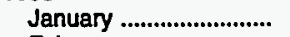 & - & - & - & - & - & - & - & - \\
\hline 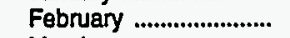 & - & - & - & - & - & - & - & - \\
\hline 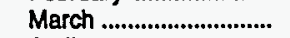 & - & - & - & - & - & - & - & - \\
\hline April & - & - & - & - & - & - & - & - \\
\hline 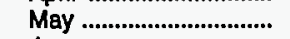 & - & - & - & - & - & - & - & - \\
\hline 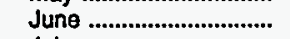 & - & - & - & - & - & - & - & - \\
\hline 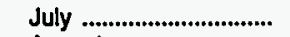 & - & - & - & - & - & - & - & - \\
\hline 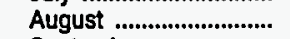 & - & - & - & - & - & - & - & - \\
\hline September .................... & - & - & - & - & - & - & - & - \\
\hline 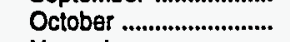 & 83.5 & 69.0 & 64.0 & 73.3 & 31.2 & 58.3 & 71.2 & 35.4 \\
\hline November ...................... & 84.3 & 53.1 & 45.4 & $W$ & 27.9 & 57.8 & 62.3 & 33.8 \\
\hline December .................... & 86.7 & 52.9 & 39.7 & $W$ & 25.9 & 61.1 & 63.8 & 30.9 \\
\hline 1993 & - & - & - & - & - & - & - & - \\
\hline \multirow{2}{*}{\multicolumn{9}{|c|}{1994}} \\
\hline 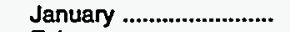 & 88.4 & 75.9 & 64.4 & 71.4 & 27.3 & 65.1 & & 33.2 \\
\hline 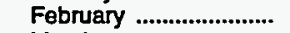 & 89.8 & 77.0 & 67.5 & 72.7 & 29.4 & 68.1 & 82.1 & 35.3 \\
\hline March .............................. & 92.0 & 77.4 & 67.2 & 72.6 & 29.1 & 67.2 & 82.1 & 33.2 \\
\hline 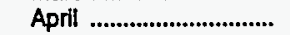 & 92.3 & 76.8 & 69.0 & 73.8 & 29.6 & 69.2 & 80.9 & 31.9 \\
\hline 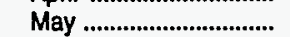 & 94.1 & 76.3 & 69.0 & 74.8 & 30.1 & 72.1 & 77.6 & 32.0 \\
\hline June ................................. & 93.2 & 77.6 & 68.8 & 75.2 & 29.5 & 70.0 & 76.9 & 31.4 \\
\hline 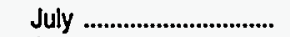 & 87.6 & 76.3 & 67.9 & 75.0 & 29.6 & 67.5 & 73.9 & 31.0 \\
\hline 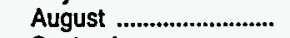 & NA & 75.2 & 63.6 & 74.6 & 31.4 & 63.8 & 71.0 & 32.0 \\
\hline September ...................... & 82.5 & 75.2 & 63.0 & 73.6 & 31.4 & 62.1 & 73.0 & 32.8 \\
\hline 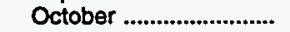 & 83.9 & 76.4 & 62.6 & 74.4 & 33.3 & 55.9 & 71.1 & 34.2 \\
\hline November ..................... & 85.1 & $\pi .2$ & 65.0 & 74.5 & 34.7 & 60.1 & 75.7 & 36.0 \\
\hline December ....................... & 86.2 & 77.7 & 64.7 & 74.8 & 34.4 & 65.0 & 79.3 & 36.8 \\
\hline 1994 & 87.2 & 76.5 & 65.2 & 73.6 & 31.1 & 63.4 & $\pi 7.6$ & 33.6 \\
\hline
\end{tabular}

Dash $(-)=$ No data reported.

NA $=$ Not available.

$W=$ Withheld to avold disclosure of individual company data.

Notes: The 4th quarter of 1993 was a transitional period between the predecessor EIA-782 survey system and the revised ElA-782 survey sytem. The revised survey system contains additional product and sales categories, which may not be consistent with categories derived from the predecessor survey system. Beginning January 1994 all data are from the revised survey system and are consistent.

Sources: Energy Information Administration Forms EIA-782A, "Reliners'/Gas Plant Operators' Monthly Petroleum Product Sales Report," and ElA-782B, "Resellers'/Retailers' Monthly Petroleum Product Sales Report." 
Table 15. U.S. No. 2 Distillate ${ }^{a}$ Prices by Sales Type (Cents per Gallon Excluding Taxes)

\begin{tabular}{|c|c|c|c|c|c|c|c|}
\hline \multirow[b]{2}{*}{$\begin{array}{l}\text { Year } \\
\text { Month }\end{array}$} & \multicolumn{6}{|c|}{ Sales to End Users } & \multirow[b]{2}{*}{$\begin{array}{c}\text { Sales } \\
\text { for } \\
\text { Resale }\end{array}$} \\
\hline & $\begin{array}{l}\text { Resldential } \\
\text { Consumers }\end{array}$ & $\begin{array}{l}\text { Commerclal } \\
\text { Instltutlonal } \\
\text { Consumers }\end{array}$ & $\begin{array}{l}\text { Industrial } \\
\text { Consumers }\end{array}$ & $\begin{array}{c}\text { Through } \\
\text { Retail } \\
\text { Outlets b }\end{array}$ & $\begin{array}{c}\text { Other } \\
\text { End Usersc }\end{array}$ & Average & \\
\hline 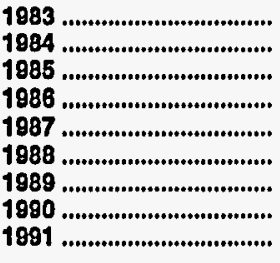 & $\begin{array}{r}107.8 \\
109.1 \\
105.3 \\
83.6 \\
80.3 \\
81.3 \\
90.0 \\
106.3 \\
101.9\end{array}$ & $\begin{array}{l}86.3 \\
85.7 \\
82.1 \\
51.4 \\
56.6 \\
51.9 \\
60.8 \\
75.1 \\
67.5\end{array}$ & $\begin{array}{l}88.3 \\
87.0 \\
83.4 \\
53.7 \\
59.7 \\
54.2 \\
63.8 \\
78.0 \\
69.7\end{array}$ & $\begin{array}{l}94.3 \\
92.0 \\
88.6 \\
59.8 \\
64.4 \\
61.6 \\
68.5 \\
85.2 \\
74.5\end{array}$ & $\begin{array}{l}89.7 \\
89.2 \\
85.3 \\
56.8 \\
63.1 \\
58.7 \\
66.7 \\
82.8 \\
73.8\end{array}$ & $\begin{array}{l}93.3 \\
92.6 \\
89.0 \\
61.4 \\
64.3 \\
61.2 \\
69.5 \\
84.1 \\
76.0\end{array}$ & $\begin{array}{l}81.8 \\
81.9 \\
78.1 \\
48.0 \\
53.5 \\
48.2 \\
57.2 \\
70.6 \\
62.7\end{array}$ \\
\hline 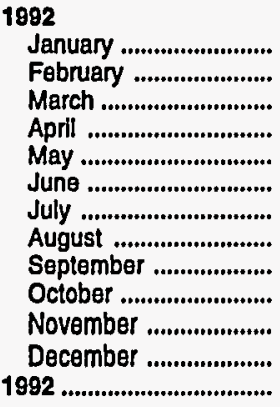 & $\begin{array}{l}94.2 \\
94.2 \\
93.2 \\
92.5 \\
92.3 \\
92.0 \\
90.4 \\
88.6 \\
90.1 \\
93.7 \\
94.8 \\
94.5 \\
93.4\end{array}$ & $\begin{array}{l}58.9 \\
60.7 \\
59.8 \\
61.5 \\
63.8 \\
66.0 \\
65.4 \\
64.4 \\
66.9 \\
68.8 \\
65.3 \\
63.0 \\
63.7\end{array}$ & $\begin{array}{l}60.9 \\
62.7 \\
62.5 \\
65.5 \\
67.9 \\
70.4 \\
69.9 \\
68.8 \\
70.9 \\
72.7 \\
69.0 \\
66.0 \\
67.5\end{array}$ & $\begin{array}{l}67.9 \\
67.3 \\
67.4 \\
69.5 \\
72.0 \\
74.2 \\
74.6 \\
73.8 \\
74.3 \\
76.2 \\
74.9 \\
72.1 \\
72.1\end{array}$ & $\begin{array}{l}65.3 \\
66.5 \\
67.5 \\
69.9 \\
73.3 \\
74.4 \\
73.5 \\
73.1 \\
75.5 \\
77.5 \\
73.9 \\
69.9 \\
72.1\end{array}$ & $\begin{array}{l}72.7 \\
73.0 \\
71.1 \\
70.3 \\
70.9 \\
72.0 \\
71.3 \\
70.5 \\
73.1 \\
76.1 \\
75.1 \\
74.9 \\
72.6\end{array}$ & $\begin{array}{l}52.8 \\
54.9 \\
54.6 \\
57.5 \\
60.1 \\
62.7 \\
62.1 \\
60.9 \\
63.5 \\
65.5 \\
60.3 \\
57.0 \\
59.1\end{array}$ \\
\hline 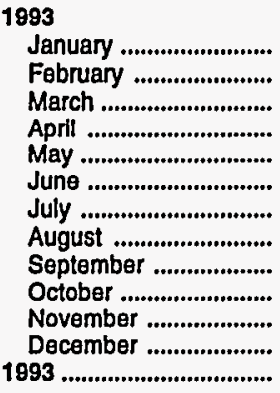 & $\begin{array}{l}94.3 \\
94.6 \\
95.4 \\
92.6 \\
91.1 \\
88.9 \\
85.6 \\
84.1 \\
85.5 \\
88.7 \\
88.5 \\
86.6 \\
91.1\end{array}$ & $\begin{array}{l}61.6 \\
63.5 \\
65.3 \\
63.9 \\
63.1 \\
61.3 \\
58.0 \\
57.8 \\
62.0 \\
67.5 \\
63.7 \\
55.5 \\
62.0\end{array}$ & $\begin{array}{l}64.3 \\
65.7 \\
67.8 \\
68.8 \\
68.8 \\
67.0 \\
63.9 \\
63.8 \\
68.3 \\
73.1 \\
68.2 \\
60.3 \\
66.7\end{array}$ & $\begin{array}{l}70.2 \\
70.2 \\
72.2 \\
71.8 \\
71.4 \\
70.7 \\
68.7 \\
67.4 \\
70.7 \\
78.1 \\
75.1 \\
65.8 \\
71.1\end{array}$ & $\begin{array}{l}68.4 \\
69.9 \\
71.8 \\
72.3 \\
72.7 \\
69.9 \\
67.1 \\
67.1 \\
71.7 \\
77.7 \\
72.6 \\
62.8 \\
70.5\end{array}$ & $\begin{array}{l}74.2 \\
75.7 \\
76.1 \\
72.2 \\
69.9 \\
67.9 \\
64.8 \\
64.6 \\
69.2 \\
75.2 \\
72.9 \\
67.4 \\
71.0\end{array}$ & $\begin{array}{l}\mathbf{5 5 . 8} \\
58.1 \\
60.1 \\
\mathbf{5 9 . 3} \\
\mathbf{5 8 . 9} \\
\mathbf{5 6 . 7} \\
\mathbf{5 3 . 0} \\
\mathbf{5 3 . 0} \\
\mathbf{5 7 . 7} \\
63.4 \\
\mathbf{5 7 . 5} \\
\mathbf{4 7 . 4} \\
\mathbf{5 6 . 6}\end{array}$ \\
\hline 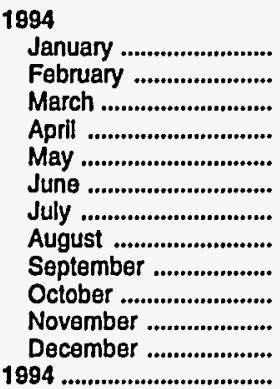 & $\begin{array}{l}89.6 \\
92.9 \\
91.4 \\
88.2 \\
86.1 \\
85.2 \\
82.7 \\
82.1 \\
83.2 \\
84.7 \\
85.7 \\
86.8 \\
88.4\end{array}$ & $\begin{array}{l}58.2 \\
60.9 \\
58.9 \\
57.7 \\
57.1 \\
57.3 \\
58.3 \\
59.2 \\
59.3 \\
59.8 \\
60.0 \\
58.0 \\
58.7\end{array}$ & $\begin{array}{l}61.6 \\
64.8 \\
63.3 \\
62.9 \\
62.4 \\
63.1 \\
64.2 \\
65.0 \\
65.0 \\
66.0 \\
65.9 \\
63.3 \\
64.1\end{array}$ & $\begin{array}{l}64.2 \\
67.5 \\
67.3 \\
67.0 \\
66.2 \\
66.6 \\
67.5 \\
68.5 \\
68.1 \\
68.2 \\
68.8 \\
66.9 \\
67.3\end{array}$ & $\begin{array}{l}61.1 \\
64.7 \\
64.7 \\
65.7 \\
64.5 \\
64.4 \\
65.4 \\
67.4 \\
67.9 \\
69.1 \\
68.1 \\
65.2 \\
65.5\end{array}$ & $\begin{array}{l}70.5 \\
72.7 \\
69.7 \\
65.8 \\
63.7 \\
63.2 \\
63.8 \\
65.3 \\
66.0 \\
67.6 \\
68.5 \\
68.9 \\
67.5\end{array}$ & $\begin{array}{l}\mathbf{5 1 . 1} \\
54.7 \\
52.6 \\
52.1 \\
51.8 \\
52.4 \\
53.8 \\
53.9 \\
53.6 \\
54.3 \\
54.1 \\
51.2 \\
52.9\end{array}$ \\
\hline
\end{tabular}

\footnotetext{
a Inciudes sales of No. 2 fuel oil and high- and low-sulfur diesel fuels.

b Includes low-sulfur diesel fuel only.

c All end-user sales not included in the other end-user categories shown, e.g., sales to agricultural customers or utilities.

Sources: Energy Information Administration Forms EIA-782A, "Refiners'/Gas Plant Operators' Monthly Petroleum Product Sales Report," and EIA-7828, "Resellers'/Retallers' Monthly Petroleum Product Sales Report."
} 
Table 16. U.S. No. 2 Diesel Fuel Prices by Sales Type

(Cents per Gallon Excluding Taxes)

\begin{tabular}{|c|c|c|c|c|c|c|}
\hline \multirow[b]{2}{*}{$\begin{array}{c}\text { Year } \\
\text { Month }\end{array}$} & \multicolumn{5}{|c|}{ Salos to End Users } & \multirow[b]{2}{*}{$\begin{array}{c}\text { Sales } \\
\text { for } \\
\text { Resale }\end{array}$} \\
\hline & $\begin{array}{l}\text { Commercial } \\
\text { Institutlonal } \\
\text { Consumers }\end{array}$ & $\begin{array}{l}\text { Industrial } \\
\text { Consumers }\end{array}$ & $\begin{array}{c}\text { Through } \\
\text { Retail } \\
\text { Outletsa }\end{array}$ & $\begin{array}{l}\text { Other } \\
\text { End Users b }\end{array}$ & Average & \\
\hline \multicolumn{7}{|l|}{1993} \\
\hline 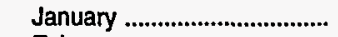 & - & - & - & - & - & - \\
\hline 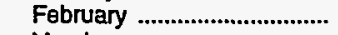 & - & - & - & - & - & - \\
\hline 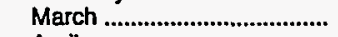 & - & - & - & - & - & - \\
\hline April & - & - & - & - & - & - \\
\hline 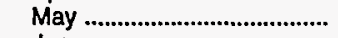 & - & - & - & - & - & - \\
\hline 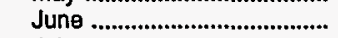 & - & - & - & - & - & - \\
\hline 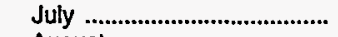 & - & - & - & - & - & - \\
\hline 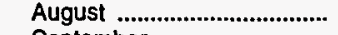 & - & - & - & - & - & - \\
\hline 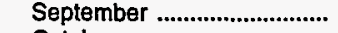 & - & - & - & - & - & - \\
\hline 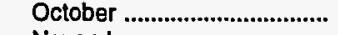 & 67.4 & 73.7 & 78.3 & 78.1 & 73.3 & 65.8 \\
\hline November ................................ & 60.3 & 63.9 & 73.6 & 67.4 & 64.4 & 59.0 \\
\hline December ................................ & 49.9 & 52.5 & 64.9 & 56.0 & 53.2 & 46.6 \\
\hline 1993 & - & - & - & - & - & - \\
\hline \multicolumn{7}{|l|}{1994} \\
\hline 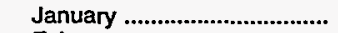 & 55.0 & 61.3 & 64.2 & 62.3 & 59.9 & 50.2 \\
\hline 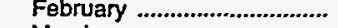 & 57.9 & 64.5 & 67.5 & 64.9 & 62.6 & 53.9 \\
\hline March & 56.9 & 63.4 & 67.3 & 65.1 & 62.2 & 53.8 \\
\hline April & 56.8 & 63.2 & 67.0 & 66.1 & 62.2 & 53.4 \\
\hline 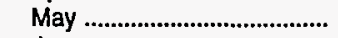 & 56.6 & 62.7 & 66.2 & 64.9 & 61.6 & 52.7 \\
\hline 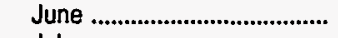 & 57.0 & 63.5 & 66.6 & 64.8 & 61.9 & 53.2 \\
\hline 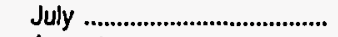 & 58.1 & 64.6 & 67.5 & 65.9 & 62.9 & 54.7 \\
\hline 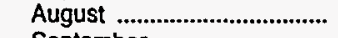 & 59.2 & 65.5 & 68.5 & 67.7 & 64.2 & 54.8 \\
\hline 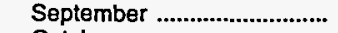 & 59.4 & 65.7 & 68.1 & 68.3 & 64.4 & 54.9 \\
\hline 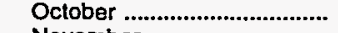 & 59.8 & 66.7 & 68.2 & 69.6 & 65.1 & 55.8 \\
\hline 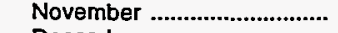 & 59.6 & 66.5 & 68.8 & 68.5 & 64.9 & 55.6 \\
\hline 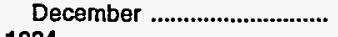 & 56.7 & 63.6 & 66.9 & 65.8 & 62.2 & 52.0 \\
\hline 1994 & 57.7 & 64.5 & 67.3 & 66.1 & 62.8 & 53.8 \\
\hline
\end{tabular}

Dash $(-)=$ No data reported.

a Includes low-sulfur diesel fuel only.

b All end-user sales not included in the other end-user categories shown, e.g., sales to agricultural customers or utilities.

Notes: The 4th quarter of 1993 was a transitional period between the predecessor EIA-782 survey system and the revised ElA-782 survey sytem. The revised survey system contains additional product and sales categories, which may not be consistent with categories derived from the predecessor survey system. Beginning January 1994 all data are from the revised survey system and are consistent.

Sources: Energy Information Administration Forms EIA-782A, "Refiners'/Gas Plant Operators' Monthly Petroleum Product Sales Report," and EIA-782B,

"Resellers'/Retailers' Monthly Petroleum Product Sales Report." 
Table 17. U.S. No. 2 Diesel Fuel Prices by Sulfur Content and Sales Type (Cents per Gallon Excluding Taxes)

\begin{tabular}{|c|c|c|c|c|c|c|c|c|c|c|c|}
\hline \multirow{3}{*}{$\begin{array}{l}\text { Year } \\
\text { Month }\end{array}$} & \multicolumn{6}{|c|}{ Low-Sulfur Diesel Fuel } & \multicolumn{5}{|c|}{ High-Sulfur Diesel Fuel } \\
\hline & \multicolumn{5}{|c|}{ Sales to End Users } & \multirow{2}{*}{$\begin{array}{c}\text { Sales } \\
\text { for } \\
\text { Resale }\end{array}$} & \multicolumn{4}{|c|}{ Sales to End Users } & \multirow[b]{2}{*}{$\begin{array}{c}\text { Sales } \\
\text { for } \\
\text { Resale }\end{array}$} \\
\hline & $\begin{array}{l}\text { Commercial } \\
\text { Institutional } \\
\text { Consumers }\end{array}$ & $\begin{array}{c}\text { Industrial } \\
\text { Consumers }\end{array}$ & $\begin{array}{c}\text { Through } \\
\text { Retail } \\
\text { Outlets }\end{array}$ & $\begin{array}{l}\text { Other } \\
\text { End } \\
\text { Users }^{a}\end{array}$ & Average & & $\begin{array}{l}\text { Commercial/ } \\
\text { Institutional } \\
\text { Consumers }\end{array}$ & $\begin{array}{c}\text { Industrial } \\
\text { Consumers }\end{array}$ & $\begin{array}{l}\text { Other } \\
\text { End } \\
\text { Users }\end{array}$ & Average & \\
\hline \multicolumn{12}{|l|}{1993} \\
\hline 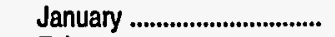 & - & - & - & - & - & - & - & - & - & - & - \\
\hline 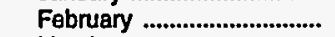 & - & - & - & - & - & - & - & - & - & - & - \\
\hline 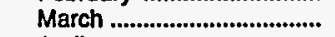 & - & - & - & - & - & - & - & - & - & - & - \\
\hline 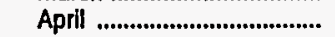 & - & - & - & - & - & - & - & - & - & - & - \\
\hline 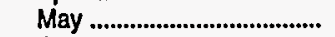 & - & - & - & - & - & - & - & - & - & - & - \\
\hline 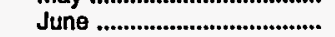 & - & - & - & - & - & - & - & - & - & - & - \\
\hline 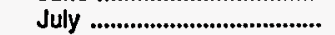 & - & - & - & - & - & - & - & - & - & - & - \\
\hline August & - & - & - & - & - & - & - & - & - & - & - \\
\hline 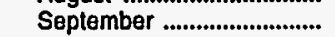 & - & - & - & - & - & - & - & - & - & - & - \\
\hline 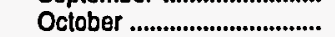 & 69.9 & 76.6 & 78.3 & 80.3 & 75.5 & 66.9 & 63.5 & 70.3 & 74.5 & 68.0 & 61.9 \\
\hline 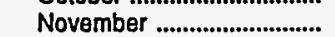 & 61.2 & 66.1 & 73.6 & 69.2 & 66.7 & 59.9 & 59.2 & 62.0 & 66.3 & 60.8 & 56.1 \\
\hline 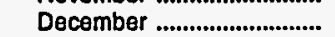 & 49.0 & 52.7 & 64.9 & 54.5 & 54.2 & 46.7 & 50.9 & 52.4 & 57.6 & 51.9 & 46.3 \\
\hline 1993 & - & - & - & - & - & - & - & - & - & - & - \\
\hline \multicolumn{12}{|l|}{1994} \\
\hline 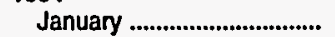 & 56.1 & 62.5 & 64.2 & 63.3 & 60.9 & 50.7 & 53.3 & 59.8 & 60.9 & 57.4 & 48.6 \\
\hline 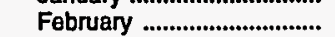 & 59.5 & 66.2 & 67.5 & 66.2 & 64.1 & 54.4 & 55.2 & 62.6 & 62.9 & 59.2 & 51.9 \\
\hline 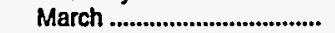 & 59.1 & 65.3 & 67.3 & 66.3 & 64.0 & 54.6 & 53.6 & 61.3 & 63.6 & 58.1 & 50.5 \\
\hline April & 58.5 & 64.9 & 67.0 & 66.5 & 63.7 & 54.0 & 54.3 & 61.5 & 65.5 & 59.0 & 50.9 \\
\hline 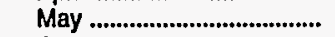 & 57.8 & 64.4 & 66.2 & 66.5 & 62.9 & 53.1 & 54.7 & 60.9 & 63.0 & 58.7 & 51.2 \\
\hline June ..................................... & 58.0 & 64.7 & 66.6 & 66.8 & 63.3 & 53.6 & 55.4 & 62.2 & 62.5 & 58.9 & 51.5 \\
\hline 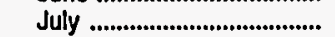 & 59.3 & 66.0 & 67.5 & 67.6 & 64.3 & 55.0 & 56.0 & 63.0 & 63.7 & 59.7 & 52.8 \\
\hline August & 60.1 & 66.8 & 68.5 & 68.6 & 65.2 & 55.1 & 57.7 & 64.4 & 66.6 & 61.8 & 53.7 \\
\hline September ........................... & 60.4 & 67.8 & 68.1 & 69.3 & 65.4 & 55.2 & 57.7 & 63.7 & 66.9 & 61.9 & 53.5 \\
\hline 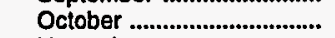 & 60.9 & 68.8 & 68.2 & 70.2 & 66.0 & 56.1 & 57.7 & 64.6 & 68.8 & 63.0 & 54.2 \\
\hline 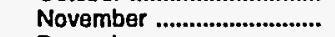 & 60.8 & 68.4 & 68.8 & 69.2 & 65.9 & 56.0 & 57.4 & 64.7 & 67.6 & 62.3 & 54.2 \\
\hline 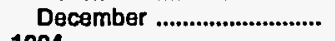 & 58.1 & 65.2 & 66.9 & 66.0 & 63.4 & 52.2 & 54.5 & 62.1 & 65.5 & 59.4 & 51.0 \\
\hline 1994 & 59.1 & 66.0 & 67.3 & 67.4 & 64.2 & 54.2 & 55.3 & 62.9 & 64.6 & 59.8 & 51.9 \\
\hline
\end{tabular}

Dash $(-)=$ No data reported.

a All end-user sales not included in the other end-user categories shown, e.g., sales to agricultural customers or utilities.

Notes: The 4th quarter of 1993 was a transitional period between the predecessor EIA-782 survey system and the revised EIA-782 survey sytem. The revised survey system contains additional product and sales categories, which may not be consistent with categories derived from the predecessor survey system. Beginning January 1994 all data are from the revised survey system and are consistent.

Sources: Energy Information Administration Forms ElA-782A, "Refiners'/Gas Plant Operators' Monthly Petroleum Product Sales Report," and ElA-782B,

'Resellers'/Retallers' Monthly Petroleum Product Sales Report." 
Table 18. Prices of No. 2 Distillate to Residences by PAD District and Selected States

(Cents per Gallon Excluding Taxes)

\begin{tabular}{|c|c|c|c|c|c|c|c|c|c|c|}
\hline \multirow{2}{*}{$\begin{array}{l}\text { Year } \\
\text { Month }\end{array}$} & \multirow{2}{*}{$\begin{array}{c}\text { U.S. } \\
\text { Average }\end{array}$} & \multicolumn{9}{|c|}{ PAD District I } \\
\hline & & Average & $\mathrm{CT}$ & $M E$ & MA & NH & RI & VT & $\mathrm{DE}$ & DC \\
\hline 1978 & 49.0 & - & 50.1 & 48.6 & 48.8 & 50.3 & 50.7 & 50.8 & 47.8 & 50.7 \\
\hline 1979 & 70.4 & - & 72.0 & 68.8 & 70.9 & 72.5 & 72.8 & 72.5 & 68.2 & 74.2 \\
\hline 1980 & 97.4 & - & 98.3 & 96.3 & 97.8 & 100.4 & 101.1 & 101.5 & 95.4 & 102.6 \\
\hline 1981 & 119.4 & - & 121.7 & 120.4 & 121.3 & 123.7 & 123.8 & 125.4 & 117.3 & 127.4 \\
\hline 1982 & 116.0 & - & 118.3 & 115.5 & 117.6 & 117.4 & 120.1 & 120.1 & 111.3 & 124.5 \\
\hline 1983 & 107.8 & 109.0 & 109.1 & 102.8 & 109.1 & 104.1 & 110.5 & 112.9 & 106.0 & 117.0 \\
\hline 1984 & 109.1 & 111.3 & 112.1 & 103.9 & 111.6 & 108.4 & 111.4 & 111.9 & 109.6 & 118.7 \\
\hline 1985 & 105.3 & 106.8 & 108.0 & 99.7 & 107.0 & 102.4 & 106.7 & 107.7 & 104.6 & 114.3 \\
\hline 1986 & 83.6 & 86.2 & 89.0 & 74.4 & 82.1 & 75.9 & 82.8 & 86.6 & 85.0 & 93.1 \\
\hline 1987 & 80.3 & 81.4 & 83.4 & 74.7 & 80.6 & 76.5 & 82.5 & 81.1 & 79.3 & 91.8 \\
\hline 1988 & 81.3 & 82.7 & 85.3 & 77.7 & 82.1 & 78.2 & 83.6 & 82.6 & 80.1 & 91.6 \\
\hline 1989 & 90.0 & 91.7 & 92.9 & 89.4 & 92.6 & 89.3 & 93.9 & 90.5 & 88.2 & 98.6 \\
\hline 1990 & 106.3 & 108.1 & 109.8 & 98.9 & 108.4 & 102.8 & 108.6 & 107.0 & 105.8 & 107.8 \\
\hline 1991 & 101.9 & 104.1 & 106.2 & 96.0 & 103.0 & 91.6 & 99.9 & 101.9 & 99.7 & 112.2 \\
\hline \multicolumn{11}{|l|}{1992} \\
\hline January ............................. & 94.2 & 96.1 & 96.4 & 87.7 & 93.2 & 88.1 & 90.7 & 92.4 & 94.4 & 107.3 \\
\hline 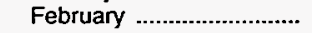 & 94.2 & 96.0 & 95.5 & 88.2 & 92.5 & 86.5 & 91.7 & 92.8 & 92.7 & 107.3 \\
\hline 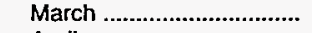 & 93.2 & 94.6 & 94.0 & 86.4 & 91.5 & 83.3 & 90.9 & 92.2 & 92.4 & 105.3 \\
\hline April & 92.5 & 93.9 & 93.3 & 85.5 & 91.4 & 81.8 & 90.4 & 91.7 & 91.5 & 104.8 \\
\hline May & 92.3 & 93.4 & 93.1 & 85.5 & 91.0 & 81.7 & 90.9 & 91.5 & 90.2 & 102.3 \\
\hline 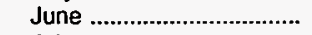 & 92.0 & 93.2 & 91.8 & 87.1 & 91.3 & 82.9 & 89.7 & 90.7 & 91.4 & 102.7 \\
\hline 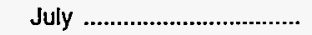 & 90.4 & 91.6 & 93.1 & 87.7 & 90.4 & 82.3 & 89.9 & 89.1 & 90.6 & 102.0 \\
\hline 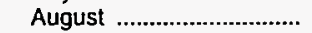 & 88.6 & 89.8 & 90.5 & 87.8 & 89.6 & 81.8 & 89.4 & 89.4 & 89.5 & 101.9 \\
\hline 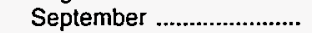 & 90.1 & 91.2 & 91.8 & 86.8 & 90.7 & 83.0 & 89.8 & 91.6 & 90.3 & 101.2 \\
\hline 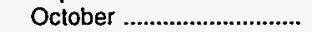 & 93.7 & 94.9 & 94.9 & 89.3 & 93.5 & 87.6 & 92.7 & 92.0 & 93.7 & 104.0 \\
\hline 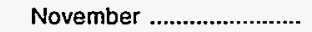 & 94.8 & 96.3 & 95.8 & 88.3 & 93.8 & 87.6 & 92.5 & 92.6 & 92.8 & 105.7 \\
\hline 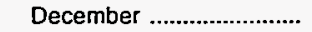 & 94.5 & 95.9 & 95.2 & 85.7 & 93.5 & 87.7 & 91.5 & 92.9 & 90.9 & 105.4 \\
\hline 1992 & 93.4 & 94.9 & 94.7 & 87.1 & 92.5 & 85.6 & 91.2 & 92.1 & 92.3 & 105.7 \\
\hline \multicolumn{11}{|l|}{1993} \\
\hline 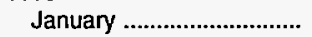 & 94.3 & 95.7 & 94.9 & 85.2 & 94.0 & 87.1 & 91.7 & 93.4 & 91.2 & 105.2 \\
\hline 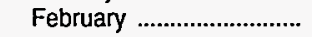 & 94.6 & 95.9 & 96.2 & 85.4 & 94.4 & 86.9 & 91.8 & 93.3 & 90.8 & 106.8 \\
\hline 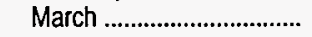 & 95.4 & 96.5 & 96.7 & 86.4 & 94.8 & 86.6 & 92.4 & 93.7 & 92.4 & 108.5 \\
\hline 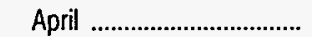 & 92.6 & 93.4 & 93.6 & 83.0 & 91.5 & 84.5 & 90.4 & 91.2 & 91.6 & 106.7 \\
\hline May & 91.1 & 91.7 & 91.6 & 81.7 & 91.1 & 83.9 & 90.7 & 91.3 & 89.4 & 104.3 \\
\hline 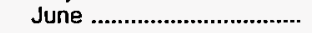 & 88.9 & 89.4 & 88.6 & 81.1 & 88.6 & 82.4 & 87.6 & 89.7 & 90.6 & 100.4 \\
\hline 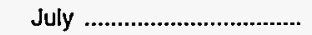 & 85.6 & 85.9 & 86.5 & 78.5 & 83.9 & 78.3 & 85.2 & 85.5 & 86.4 & 100.2 \\
\hline 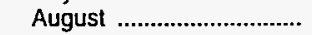 & 84.1 & 84.6 & 84.0 & 77.4 & 83.4 & 76.0 & 82.7 & 85.6 & 83.5 & 96.1 \\
\hline September ............................ & 85.5 & 85.8 & 84.2 & 78.3 & 83.8 & 74.9 & 84.8 & 86.6 & 84.6 & 95.5 \\
\hline 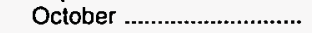 & 88.7 & 88.6 & 88.6 & 82.9 & 86.1 & 77.0 & 86.0 & 87.6 & 87.4 & 102.1 \\
\hline 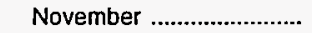 & 88.5 & 88.7 & 88.8 & 80.8 & 85.7 & 76.9 & 87.8 & 86.6 & 88.3 & 100.9 \\
\hline 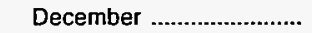 & 86.6 & 87.6 & 88.2 & 79.6 & 83.9 & 77.5 & 85.9 & 86.9 & 88.6 & 100.5 \\
\hline 1993 & 91.1 & 92.1 & 91.9 & 82.6 & 89.7 & 82.8 & 89.3 & 90.4 & 89.9 & 104.5 \\
\hline \multicolumn{11}{|l|}{1994} \\
\hline 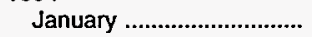 & 89.6 & 91.0 & 90.2 & 83.8 & 88.4 & 80.4 & 87.3 & 88.8 & 92.1 & 102.5 \\
\hline 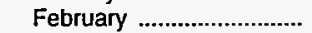 & 92.9 & 94.6 & 93.8 & 90.4 & 91.3 & 86.6 & 91.4 & 92.3 & 91.5 & 105.5 \\
\hline 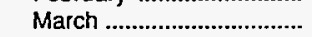 & 91.4 & 92.5 & 92.1 & 85.9 & 88.3 & 83.6 & 89.4 & 91.0 & 91.2 & 102.0 \\
\hline April & 88.2 & 89.0 & 89.4 & 80.8 & 86.0 & 78.2 & 85.1 & 88.3 & 89.2 & 93.7 \\
\hline 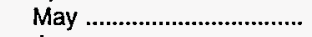 & 86.1 & 86.6 & 85.4 & 76.8 & 85.1 & 75.4 & 83.3 & 86.7 & 84.4 & 83.1 \\
\hline June & 85.2 & 85.6 & 86.1 & 75.6 & 83.7 & 73.1 & 82.3 & 84.6 & 82.0 & $w$ \\
\hline 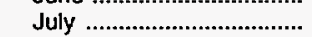 & 82.7 & 83.1 & 84.2 & 75.6 & 82.1 & 71.8 & 81.6 & 83.0 & 80.5 & $\ddot{w}$ \\
\hline August & 82.1 & 82.4 & 79.7 & 78.0 & 78.7 & 72.8 & 84.0 & 83.8 & 82.3 & 81.9 \\
\hline 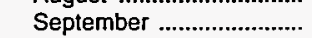 & 83.2 & 83.7 & 80.5 & 78.5 & 81.1 & 72.9 & 84.7 & 83.3 & 83.1 & 86.2 \\
\hline 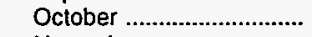 & 84.7 & 85.2 & 83.7 & 77.5 & 83.0 & 74.0 & 84.4 & 83.9 & 84.9 & 95.5 \\
\hline 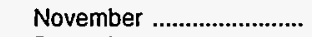 & 85.7 & 86.1 & 84.0 & 77.7 & 83.6 & 73.7 & 85.8 & 84.3 & 86.0 & 97.7 \\
\hline December .......................... & 86.8 & 87.3 & 86.1 & 77.5 & 84.2 & 77.3 & 87.2 & 85.3 & 86.1 & 101.3 \\
\hline 1994 & 88.4 & 89.4 & 89.0 & 81.8 & 87.0 & 79.2 & 88.5 & 87.6 & 89.4 & 100.0 \\
\hline
\end{tabular}

See footnotes at end of table. 
Table 18. Prices of No. 2 Distillate to Residences by PAD District and Selected States

(Cents per Gallon Excluding Taxes) - Continued

\begin{tabular}{|c|c|c|c|c|c|c|c|c|c|c|}
\hline \multirow{2}{*}{$\begin{array}{l}\text { Year } \\
\text { Month }\end{array}$} & \multicolumn{6}{|c|}{ PAD District I (Continued) } & \multicolumn{4}{|c|}{ PAD District II } \\
\hline & MD & NJ & NY & PA & VA & wv & Average & IL & IN & MI \\
\hline 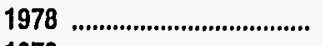 & 49.2 & 49.6 & 50.1 & 48.8 & 49.1 & 46.2 & - & 46.5 & 48.5 & 47.9 \\
\hline 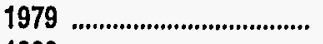 & 70.1 & 71.0 & 71.2 & 69.8 & 70.4 & 65.1 & - & 68.8 & 72.7 & 70.9 \\
\hline 1980 & 97.9 & 97.9 & 98.2 & 96.4 & 98.5 & 92.2 & - & 95.8 & 99.6 & 97.8 \\
\hline 1981 & 121.4 & 121.5 & 123.2 & 118.1 & 120.5 & 115.0 & - & 114.9 & 118.5 & 118.3 \\
\hline $1982 \ldots \ldots \ldots \ldots \ldots \ldots$ & 117.1 & 117.4 & 120.5 & 113.7 & 117.7 & 109.3 & - & 110.9 & 114.3 & 113.9 \\
\hline 1983 & 110.3 & 107.9 & 112.1 & 105.8 & 108.7 & 101.0 & 102.0 & 100.4 & 100.7 & 106.4 \\
\hline 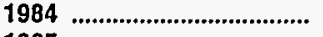 & 113.5 & 111.0 & 115.5 & 107.9 & 110.5 & 102.1 & 101.7 & 100.1 & 103.1 & 105.0 \\
\hline 1985 & 108.8 & 105.9 & 111.3 & 102.3 & 106.3 & 98.0 & 99.4 & 97.5 & 99.1 & 102.1 \\
\hline 1986 & 91.4 & 90.2 & 91.1 & 81.4 & 86.6 & 74.6 & 72.7 & NA & 74.8 & 81.0 \\
\hline 1987 & 86.6 & 84.3 & 85.2 & 76.9 & 79.5 & 76.4 & 74.8 & 79.8 & 75.4 & 77.5 \\
\hline $1988 \ldots \ldots \ldots \ldots \ldots \ldots \ldots \ldots \ldots \ldots \ldots$ & 87.0 & 84.8 & 86.3 & 77.8 & 80.5 & 74.2 & 74.3 & 77.6 & 75.4 & 77.5 \\
\hline 1989 & 93.8 & 91.8 & 95.8 & 85.1 & 87.0 & 83.0 & 81.9 & 80.9 & 83.2 & 85.3 \\
\hline 1990 & 111.9 & 108.8 & 112.5 & 102.6 & 110.6 & 99.1 & 97.8 & 96.1 & 99.3 & 100.9 \\
\hline 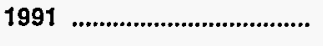 & 108.4 & 104.0 & 111.3 & 99.7 & 101.1 & 93.4 & 90.8 & 92.7 & 91.8 & 94.2 \\
\hline \multicolumn{11}{|l|}{1992} \\
\hline 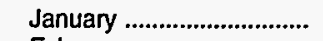 & 101.6 & 95.6 & 103.4 & 91.4 & 94.3 & 85.5 & 80.6 & 85.2 & 77.8 & 86.6 \\
\hline February ............................... & 100.9 & 95.1 & 103.8 & 91.5 & 93.7 & 86.9 & 81.1 & 85.6 & 78.7 & 86.5 \\
\hline 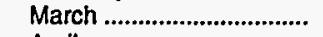 & 100.3 & 93.5 & 102.1 & 90.1 & 93.7 & 86.6 & 81.2 & 88.1 & 79.5 & 86.6 \\
\hline April & 99.0 & 92.9 & 101.1 & 89.4 & 92.6 & 85.6 & 82.1 & 88.4 & 80.2 & 86.7 \\
\hline 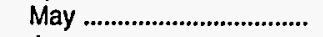 & 97.2 & 89.2 & 101.1 & 88.6 & 91.7 & 84.2 & 82.7 & 89.0 & 81.2 & 86.4 \\
\hline 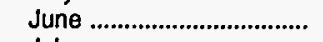 & 97.6 & 90.4 & 101.7 & 86.5 & 89.6 & 86.5 & 83.0 & 90.8 & 79.6 & 86.1 \\
\hline 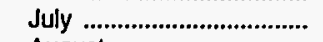 & 95.7 & 90.3 & 100.7 & 83.0 & 90.2 & 82.3 & 82.7 & 87.9 & 82.4 & 85.0 \\
\hline August & 95.2 & 88.1 & 99.0 & 81.7 & 88.4 & 81.4 & 82.6 & 86.4 & 83.1 & 85.7 \\
\hline September ......................... & 95.7 & 90.8 & 99.7 & 84.4 & 89.4 & 85.4 & 85.0 & 88.9 & 84.8 & 88.2 \\
\hline 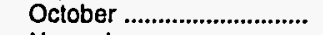 & 98.8 & 94.0 & 102.7 & 87.5 & 91.9 & 88.3 & 86.4 & 90.8 & 85.8 & 90.0 \\
\hline November ........................... & 100.4 & 94.6 & 104.7 & 89.6 & 92.1 & 88.0 & 85.1 & 90.4 & 82.7 & 88.2 \\
\hline 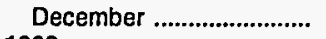 & 100.4 & 95.4 & 104.3 & 89.3 & 93.3 & 89.0 & 84.0 & 88.2 & 81.8 & 87.9 \\
\hline 1992 & 100.0 & 93.9 & 102.8 & 89.0 & 92.8 & 86.4 & 82.9 & 87.7 & 81.2 & 87.2 \\
\hline \multicolumn{11}{|l|}{1993} \\
\hline 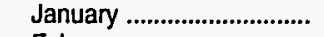 & 100.5 & 96.2 & 104.4 & 88.6 & 92.4 & 88.5 & 83.5 & 87.3 & 81.8 & 88.1 \\
\hline 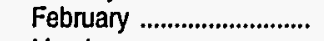 & 101.4 & 96.4 & 104.2 & 89.1 & 93.5 & 88.8 & 84.0 & 88.2 & 82.3 & 87.5 \\
\hline 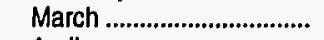 & 101.7 & 96.2 & 104.3 & 89.8 & 94.2 & 90.1 & 85.4 & 90.0 & 83.1 & 89.9 \\
\hline April & 99.2 & 95.0 & 100.4 & 89.0 & 90.3 & 87.6 & 85.7 & 86.5 & 84.9 & 90.5 \\
\hline 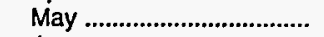 & 96.2 & 91.6 & 99.5 & 86.7 & 88.4 & 87.0 & 85.4 & 84.8 & 83.6 & 89.2 \\
\hline June & 94.7 & 87.1 & 97.8 & 83.9 & 85.7 & 87.0 & 83.9 & 81.3 & 82.0 & 87.2 \\
\hline 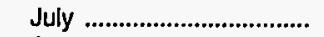 & 92.3 & 87.4 & 95.1 & 78.8 & 84.5 & 81.0 & 81.1 & 79.4 & 79.1 & 83.2 \\
\hline 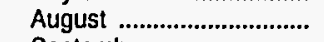 & 91.3 & 85.3 & 92.7 & 77.1 & 84.0 & 80.1 & 78.9 & 77.4 & 76.7 & 82.1 \\
\hline September ............................. & 92.4 & 85.9 & 93.6 & 80.4 & 84.9 & 80.5 & 82.1 & 81.2 & 79.3 & 85.5 \\
\hline 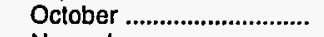 & 94.1 & 89.7 & 96.3 & 83.2 & 85.1 & 84.3 & 85.6 & 87.2 & 82.7 & 89.9 \\
\hline November .......................... & 95.8 & 89.4 & 95.9 & 84.7 & 84.2 & 84.3 & 83.9 & 82.4 & 80.2 & 86.6 \\
\hline December ........................... & 94.6 & 87.2 & 93.9 & 84.2 & 85.5 & 84.8 & 79.4 & 78.6 & 77.1 & 82.0 \\
\hline 1993 & 98.1 & 92.4 & 100.1 & 86.3 & 89.3 & 85.6 & 83.3 & 84.4 & 81.0 & 87.2 \\
\hline \multicolumn{11}{|l|}{1994} \\
\hline 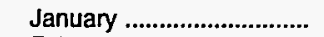 & 98.8 & 91.7 & 97.2 & 87.7 & 88.6 & 86.3 & 80.4 & 78.8 & 79.1 & 85.6 \\
\hline February ........................... & 99.5 & 94.8 & 101.7 & 92.5 & 88.6 & 86.3 & 82.1 & 82.2 & 82.0 & 88.0 \\
\hline 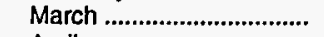 & 96.3 & 93.9 & 100.3 & 90.4 & 86.6 & 85.0 & 82.0 & 78.7 & 81.0 & 87.7 \\
\hline 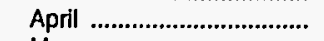 & 92.4 & 90.7 & 96.4 & 86.2 & 83.0 & 77.8 & 81.4 & 76.1 & 81.2 & 87.7 \\
\hline 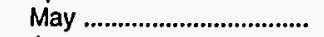 & 86.8 & 85.4 & 96.3 & 83.7 & 82.2 & 73.5 & 80.6 & 73.3 & 79.9 & 87.3 \\
\hline 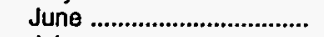 & 87.7 & 83.5 & 96.8 & 80.1 & 79.7 & 72.4 & 80.5 & 75.5 & 81.5 & 86.9 \\
\hline July ..................................... & 87.8 & 82.9 & 93.9 & 75.7 & 79.6 & 72.9 & 80.2 & 75.3 & 80.0 & 87.7 \\
\hline August & 86.0 & 85.9 & 89.1 & 77.9 & 80.5 & 74.8 & 79.8 & 77.2 & 81.6 & 84.3 \\
\hline September ......................... & 87.8 & 85.4 & 90.8 & 79.1 & 80.4 & 76.2 & 80.0 & 76.6 & 82.6 & 84.2 \\
\hline 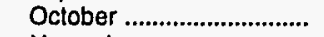 & 90.0 & 86.8 & 92.9 & 80.2 & 82.3 & 79.3 & 80.1 & 77.6 & 81.7 & 85.2 \\
\hline November .......................... & 92.4 & 88.6 & 93.3 & 81.4 & 84.1 & 81.4 & 80.9 & 80.8 & 81.2 & 85.9 \\
\hline December ............................ & 94.3 & 89.6 & 94.6 & 82.0 & 84.8 & 81.3 & 81.1 & 80.4 & 82.4 & 86.1 \\
\hline 1994 & 95.0 & 89.5 & 96.6 & 85.7 & 85.3 & 80.9 & 80.8 & 78.4 & 81.2 & 86.3 \\
\hline
\end{tabular}

See footnotes at end of table. 
Table 18. Prices of No. 2 Distillate to Residences by PAD District and Selected States

(Cents per Gallon Excluding Taxes) - Continued

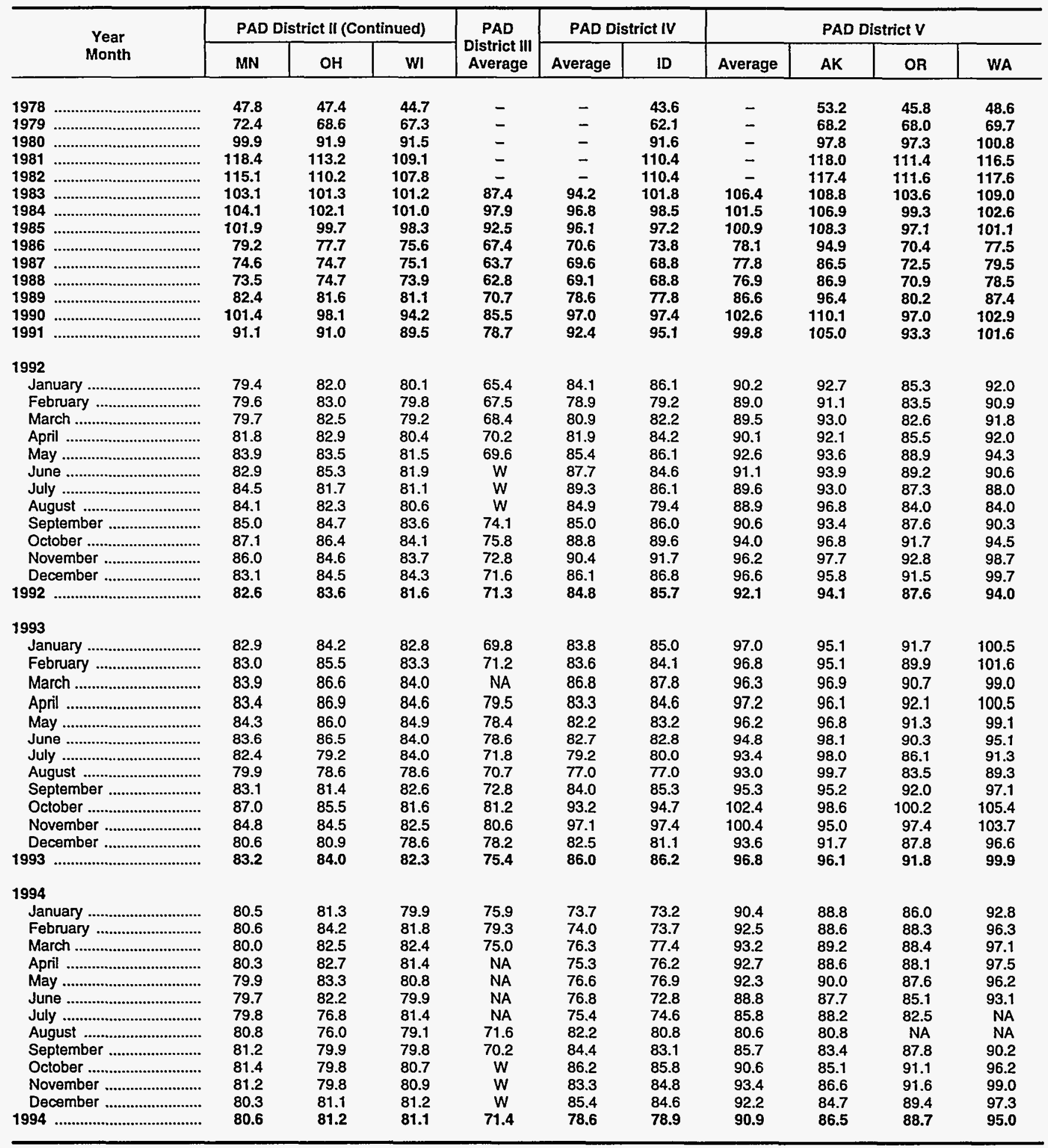

Dash $(-)=$ No data reported.

NA $=$ Not available.

$W=$ Withheld to avoid disclosure of individual company data.

Sources: Energy Information Administration Forms ElA-782A, "Refiners'/Gas Plant Operators' Monthly Petroleum Product Sales Report, and EIA-782B, "Resellers'/Retailers' Monthly Petroleum Product Sales Report," January 1983 forward; Form ElA-9A, "No. 2 Distillate Price Monitoring Report," source for backcast estimates prior to January 1983. 
Figure 6. U.S. No. 2 Distillate Prices to Residences by PAD District

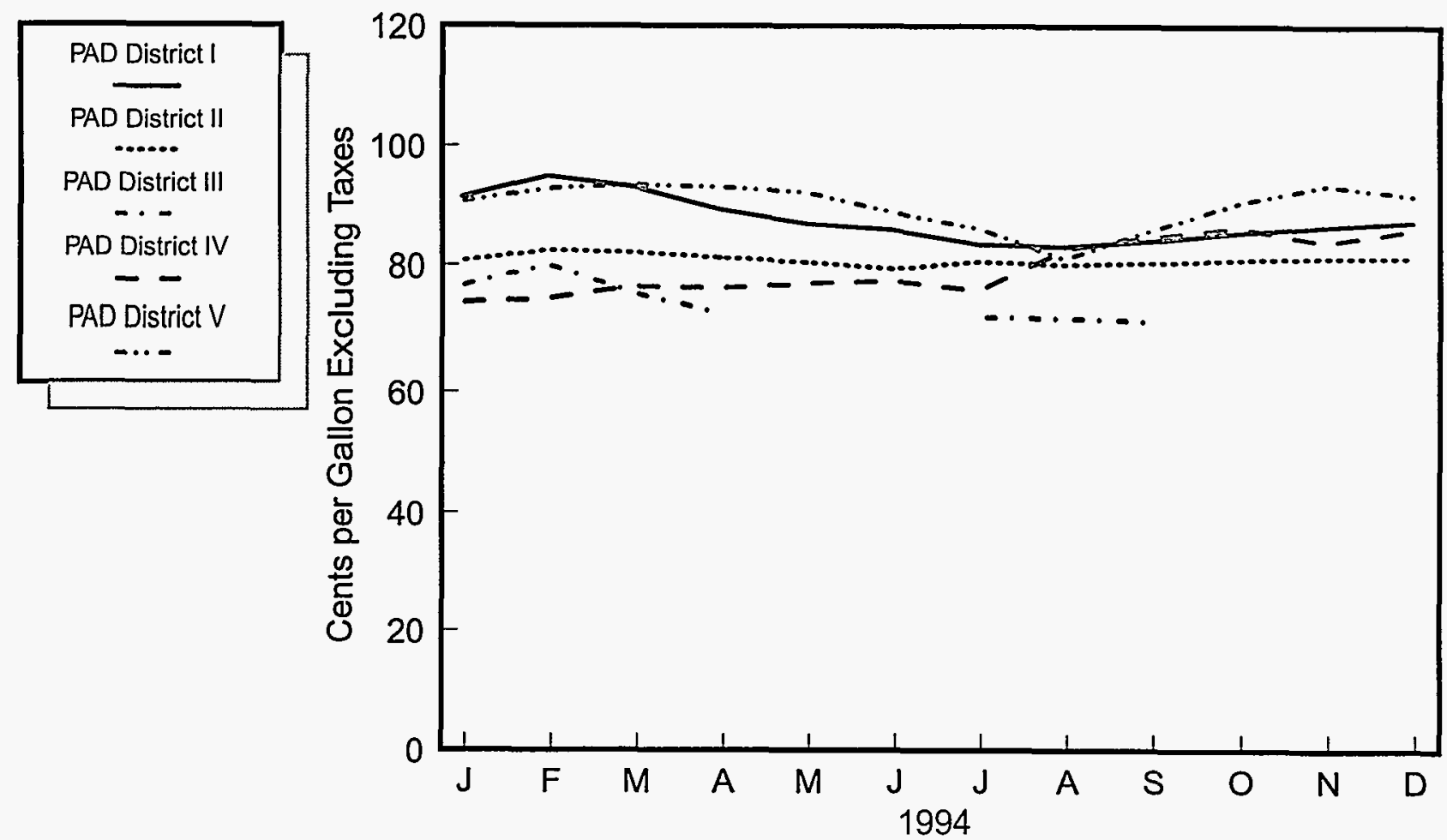


Table 19. U.S. Refiner Residual Fuel Oil Prices (Cents per Gallon Excluding Taxes)

\begin{tabular}{|c|c|c|c|c|c|c|}
\hline \multirow{2}{*}{$\begin{array}{l}\text { Year } \\
\text { Month }\end{array}$} & \multicolumn{2}{|c|}{$\begin{array}{l}\text { Sulfur Less Than } \\
\text { or Equal to } 1 \text { Percent }\end{array}$} & \multicolumn{2}{|c|}{$\begin{array}{c}\text { Sulfur Greater Than } \\
1 \text { Percent }\end{array}$} & \multicolumn{2}{|c|}{ Average } \\
\hline & $\begin{array}{l}\text { Sales to } \\
\text { End Users }\end{array}$ & $\begin{array}{l}\text { Sales for } \\
\text { Resale }\end{array}$ & $\begin{array}{l}\text { Sales to } \\
\text { End Users }\end{array}$ & $\begin{array}{l}\text { Sales for } \\
\text { Resale }\end{array}$ & $\begin{array}{l}\text { Sales to } \\
\text { End Users }\end{array}$ & $\begin{array}{c}\text { Sales for } \\
\text { Resale }\end{array}$ \\
\hline $\begin{array}{l}1978 \\
1979 \\
1980 \\
1981 \\
1982 \\
1983 \\
1984\end{array}$ & $\begin{array}{l}31.4 \\
46.8 \\
67.5 \\
82.9 \\
74.7 \\
69.5 \\
72.0 \\
64.4 \\
37.2 \\
44.7 \\
37.2 \\
43.6 \\
50.5 \\
40.2\end{array}$ & $\begin{array}{l}29.3 \\
45.0 \\
60.8 \\
74.8 \\
69.5 \\
64.3 \\
68.5 \\
61.0 \\
32.8 \\
41.2 \\
33.3 \\
40.7 \\
47.2 \\
36.4\end{array}$ & $\begin{array}{l}27.5 \\
38.9 \\
52.3 \\
67.3 \\
61.1 \\
61.1 \\
65.9 \\
58.2 \\
31.7 \\
39.6 \\
30.0 \\
34.4 \\
40.0 \\
30.6\end{array}$ & $\begin{array}{l}24.5 \\
36.6 \\
47.9 \\
62.2 \\
57.2 \\
59.1 \\
63.9 \\
56.0 \\
28.9 \\
36.2 \\
27.1 \\
33.1 \\
37.2 \\
29.2\end{array}$ & $\begin{array}{l}29.8 \\
43.6 \\
60.7 \\
75.6 \\
67.6 \\
65.1 \\
68.7 \\
61.0 \\
34.3 \\
42.3 \\
33.4 \\
38.5 \\
44.4 \\
34.0\end{array}$ & $\begin{array}{l}26.3 \\
39.9 \\
52.8 \\
66.3 \\
61.2 \\
60.9 \\
65.4 \\
57.7 \\
30.5 \\
38.5 \\
30.0 \\
36.0 \\
41.3 \\
31.4\end{array}$ \\
\hline 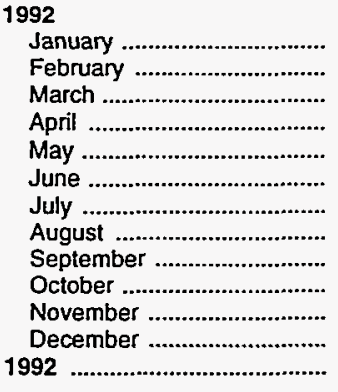 & $\begin{array}{l}35.7 \\
36.2 \\
34.8 \\
35.3 \\
37.2 \\
38.8 \\
41.4 \\
42.1 \\
42.0 \\
44.7 \\
42.8 \\
40.2 \\
38.9\end{array}$ & $\begin{array}{l}30.3 \\
32.7 \\
30.8 \\
31.6 \\
33.1 \\
35.9 \\
38.0 \\
37.7 \\
37.9 \\
41.4 \\
39.2 \\
35.9 \\
35.1\end{array}$ & $\begin{array}{l}24.7 \\
23.6 \\
24.4 \\
27.5 \\
32.0 \\
33.1 \\
34.9 \\
37.0 \\
35.3 \\
37.3 \\
37.6 \\
33.4 \\
31.2\end{array}$ & $\begin{array}{l}21.1 \\
20.9 \\
21.1 \\
25.2 \\
29.1 \\
30.7 \\
33.3 \\
33.2 \\
32.9 \\
35.5 \\
33.8 \\
28.1 \\
28.6\end{array}$ & $\begin{array}{l}28.8 \\
27.7 \\
27.7 \\
29.6 \\
33.4 \\
34.5 \\
36.7 \\
38.8 \\
37.5 \\
39.2 \\
39.4 \\
36.2 \\
33.6\end{array}$ & $\begin{array}{l}24.4 \\
25.6 \\
24.6 \\
27.4 \\
30.2 \\
32.5 \\
34.7 \\
34.7 \\
34.8 \\
37.4 \\
35.9 \\
30.6 \\
30.8\end{array}$ \\
\hline 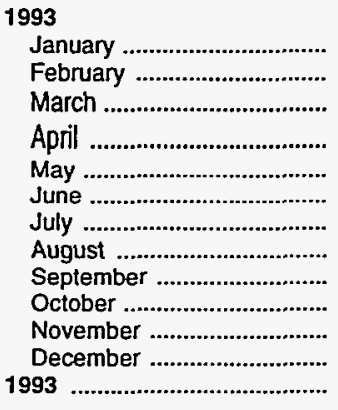 & $\begin{array}{l}40.7 \\
40.8 \\
42.6 \\
43.6 \\
41.9 \\
40.6 \\
40.2 \\
36.4 \\
37.0 \\
38.3 \\
38.1 \\
35.1 \\
39.7\end{array}$ & $\begin{array}{l}36.8 \\
35.5 \\
39.1 \\
38.4 \\
34.8 \\
33.7 \\
32.7 \\
31.6 \\
31.9 \\
32.1 \\
30.7 \\
27.5 \\
33.7\end{array}$ & $\begin{array}{l}32.3 \\
31.0 \\
31.6 \\
32.4 \\
34.1 \\
31.5 \\
28.5 \\
28.7 \\
28.6 \\
29.6 \\
27.5 \\
25.8 \\
30.3\end{array}$ & $\begin{array}{l}27.3 \\
26.7 \\
27.5 \\
29.0 \\
27.8 \\
26.7 \\
24.6 \\
23.7 \\
24.1 \\
25.7 \\
22.5 \\
21.8 \\
25.6\end{array}$ & $\begin{array}{l}35.2 \\
34.5 \\
35.6 \\
36.5 \\
36.8 \\
34.7 \\
33.1 \\
32.0 \\
31.5 \\
32.2 \\
30.5 \\
29.2 \\
33.7\end{array}$ & $\begin{array}{l}31.5 \\
30.9 \\
32.9 \\
33.3 \\
31.1 \\
30.2 \\
27.5 \\
27.2 \\
27.1 \\
28.7 \\
26.2 \\
24.8 \\
29.3\end{array}$ \\
\hline 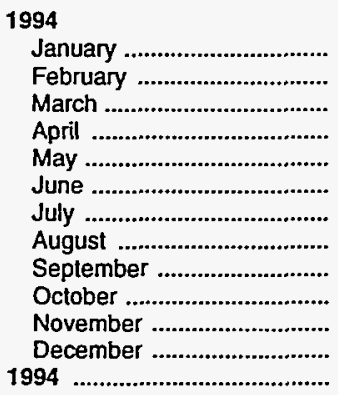 & $\begin{array}{l}39.1 \\
44.8 \\
39.9 \\
35.2 \\
35.9 \\
38.6 \\
41.2 \\
43.0 \\
41.1 \\
38.7 \\
40.0 \\
42.2 \\
40.1\end{array}$ & $\begin{array}{l}33.6 \\
39.3 \\
30.0 \\
29.4 \\
31.7 \\
35.8 \\
37.8 \\
37.1 \\
32.6 \\
32.6 \\
35.6 \\
36.9 \\
34.5\end{array}$ & $\begin{array}{l}27.8 \\
31.3 \\
29.5 \\
29.5 \\
31.1 \\
34.2 \\
37.2 \\
38.2 \\
32.2 \\
33.0 \\
35.7 \\
36.9 \\
33.0\end{array}$ & $\begin{array}{l}22.8 \\
25.7 \\
24.3 \\
25.8 \\
27.5 \\
31.1 \\
34.5 \\
32.7 \\
27.8 \\
30.6 \\
32.9 \\
32.0 \\
28.7\end{array}$ & $\begin{array}{l}32.5 \\
36.8 \\
32.9 \\
31.1 \\
32.6 \\
35.6 \\
38.4 \\
39.6 \\
34.4 \\
34.5 \\
36.9 \\
38.3 \\
35.2\end{array}$ & $\begin{array}{l}28.3 \\
33.8 \\
27.4 \\
27.5 \\
29.5 \\
33.5 \\
36.2 \\
35.2 \\
30.1 \\
31.6 \\
34.2 \\
34.1 \\
31.7\end{array}$ \\
\hline
\end{tabular}

Sources: Energy Information Administration Form ElA-782A, "Refiners'/Gas Plant Operators' Monthly Petroleum Product Sales Report," January 1983 forward; Form ElA-460, "Petroleum industry Monthly Report for Product Prices," source for backcast estimates prior to January 1983. 
Prices

\begin{tabular}{|c|}
\hline Retail $<$ or $=1 \%$ \\
Wholesale $<$ or $=1 \%$ \\
$\ldots . .$. \\
Retail $>1 \%$ \\
$-\cdots$ \\
Wholesale $>1 \%$ \\
--
\end{tabular}

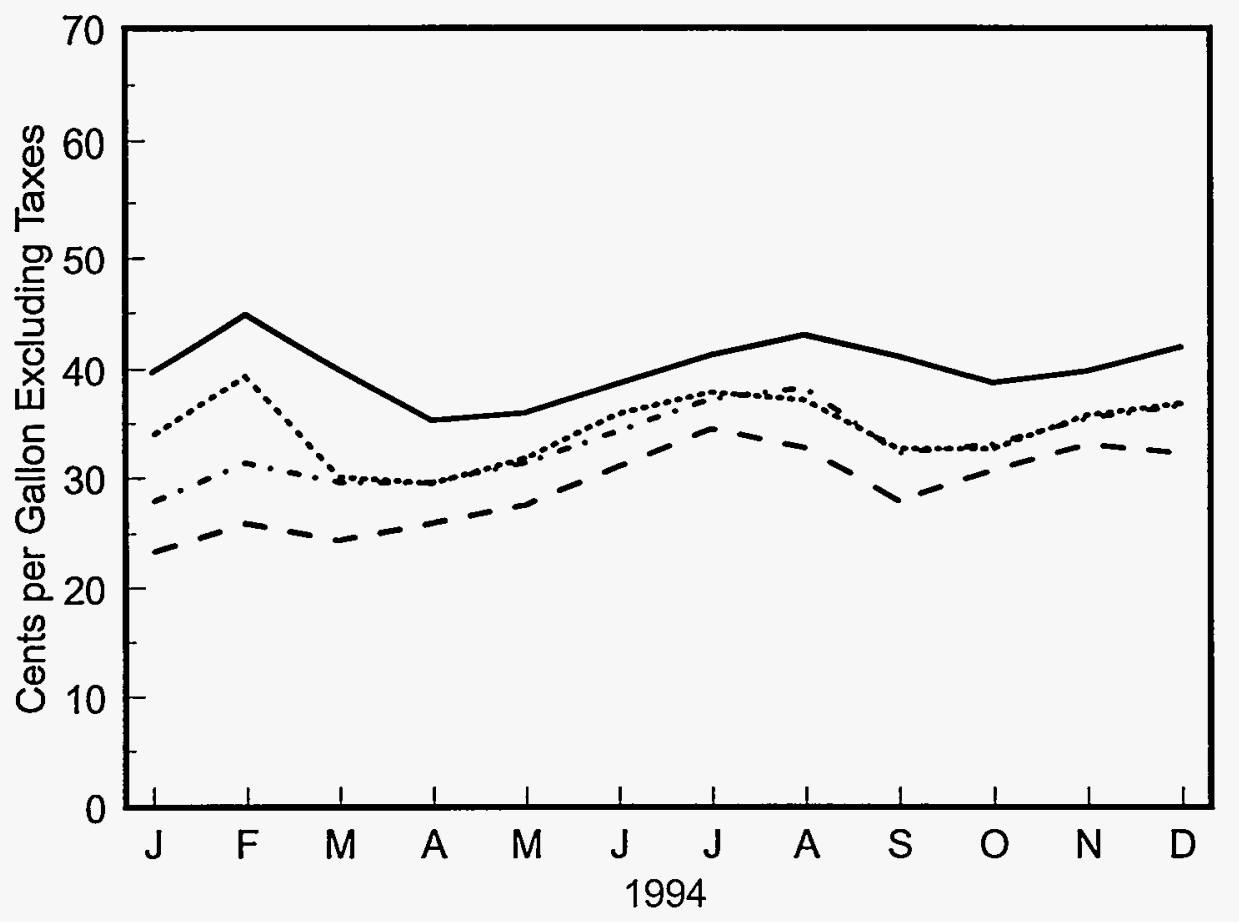

Volumes

Total Resid. $<$ or $=1 \%$
Total Resid. $>1 \%$
.......

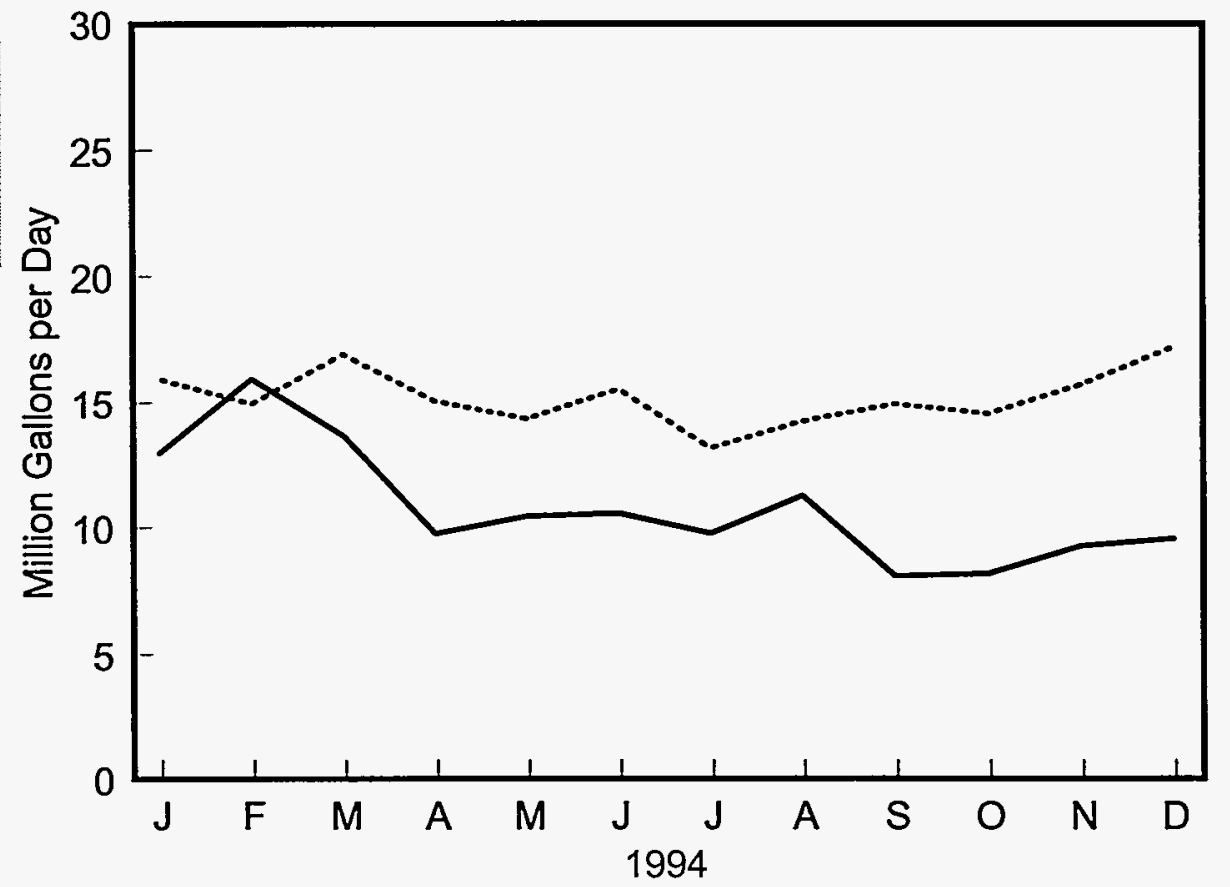


Table 20. U.S. Refiner Residual Fuel Oil Volumes

(Million Gallons per Day)

\begin{tabular}{|c|c|c|c|c|c|c|}
\hline \multirow{2}{*}{$\begin{array}{l}\text { Year } \\
\text { Month }\end{array}$} & \multicolumn{2}{|c|}{$\begin{array}{l}\text { Sulfur Less Than } \\
\text { or Equal to } 1 \text { Percent }\end{array}$} & \multicolumn{2}{|c|}{$\begin{array}{c}\text { Sulfur Greater Than } \\
1 \text { Percent }\end{array}$} & \multicolumn{2}{|c|}{ Total } \\
\hline & $\begin{array}{l}\text { Sales to } \\
\text { End Users }\end{array}$ & $\begin{array}{l}\text { Sales for } \\
\text { Resale }\end{array}$ & $\begin{array}{l}\text { Sales to } \\
\text { End Users }\end{array}$ & $\begin{array}{l}\text { Sales for } \\
\text { Resale }\end{array}$ & $\begin{array}{l}\text { Sales to } \\
\text { End Users }\end{array}$ & $\begin{array}{c}\text { Sales for } \\
\text { Resale }\end{array}$ \\
\hline $\begin{array}{l}1983 \\
1984 \\
1985 \\
1986 \\
1987 \\
1988 \\
1989 \\
1990 \\
1991\end{array}$ & $\begin{array}{r}13.4 \\
15.1 \\
11.4 \\
15.2 \\
15.1 \\
14.2 \\
13.4 \\
11.1 \\
8.6\end{array}$ & $\begin{array}{l}7.2 \\
6.7 \\
7.0 \\
7.9 \\
7.8 \\
8.7 \\
7.9 \\
7.4 \\
5.6\end{array}$ & $\begin{array}{l}14.9 \\
17.8 \\
13.8 \\
16.4 \\
13.9 \\
15.9 \\
17.0 \\
14.9 \\
15.5\end{array}$ & $\begin{array}{r}12.9 \\
14.6 \\
12.9 \\
10.7 \\
9.1 \\
10.3 \\
13.1 \\
10.5 \\
12.2\end{array}$ & $\begin{array}{l}28.3 \\
32.9 \\
25.2 \\
31.6 \\
29.0 \\
30.2 \\
30.4 \\
25.9 \\
24.0\end{array}$ & $\begin{array}{l}20.2 \\
21.3 \\
19.9 \\
18.6 \\
16.9 \\
18.9 \\
21.0 \\
17.9 \\
17.8\end{array}$ \\
\hline 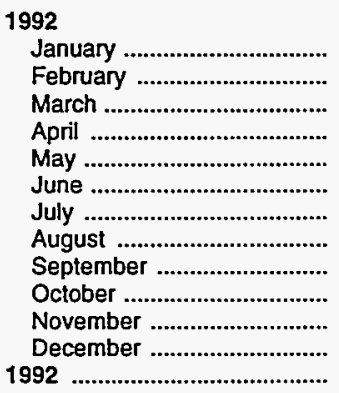 & $\begin{array}{r}10.5 \\
9.1 \\
8.4 \\
6.0 \\
5.3 \\
5.2 \\
5.9 \\
6.5 \\
6.6 \\
5.1 \\
7.1 \\
9.0 \\
7.1\end{array}$ & $\begin{array}{l}6.0 \\
5.5 \\
5.9 \\
6.3 \\
4.9 \\
5.8 \\
4.5 \\
4.0 \\
5.4 \\
4.2 \\
5.7 \\
4.5 \\
5.2\end{array}$ & $\begin{array}{l}17.9 \\
18.8 \\
17.9 \\
16.8 \\
14.1 \\
16.3 \\
15.1 \\
12.4 \\
13.5 \\
14.6 \\
13.6 \\
13.3 \\
15.3\end{array}$ & $\begin{array}{r}10.8 \\
8.2 \\
10.7 \\
11.7 \\
12.1 \\
10.5 \\
11.2 \\
8.6 \\
8.9 \\
8.9 \\
8.6 \\
9.5 \\
10.0\end{array}$ & $\begin{array}{l}28.4 \\
27.9 \\
26.2 \\
22.8 \\
19.5 \\
21.5 \\
21.0 \\
18.9 \\
20.0 \\
19.7 \\
20.7 \\
22.2 \\
22.4\end{array}$ & $\begin{array}{l}16.8 \\
13.6 \\
16.7 \\
17.9 \\
17.1 \\
16.2 \\
15.6 \\
12.6 \\
14.3 \\
13.1 \\
14.3 \\
14.0 \\
15.2\end{array}$ \\
\hline 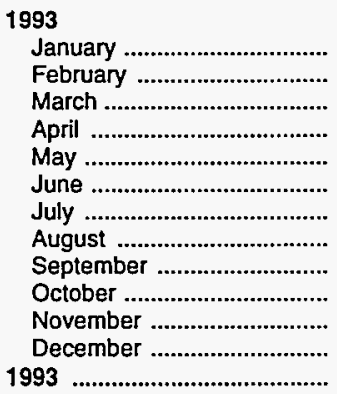 & $\begin{array}{l}7.2 \\
7.7 \\
7.0 \\
7.2 \\
5.3 \\
6.1 \\
6.3 \\
7.4 \\
6.1 \\
4.1 \\
3.7 \\
5.9 \\
6.2\end{array}$ & $\begin{array}{l}4.5 \\
6.8 \\
6.2 \\
5.7 \\
6.5 \\
5.6 \\
4.0 \\
5.3 \\
5.4 \\
7.0 \\
5.8 \\
6.0 \\
5.7\end{array}$ & $\begin{array}{r}13.7 \\
13.7 \\
12.4 \\
12.7 \\
9.9 \\
11.0 \\
9.8 \\
9.9 \\
11.2 \\
9.5 \\
9.2 \\
10.2 \\
11.1\end{array}$ & $\begin{array}{l}5.8 \\
7.7 \\
7.0 \\
6.7 \\
7.4 \\
5.7 \\
7.0 \\
6.5 \\
8.4 \\
8.3 \\
7.2 \\
5.4 \\
6.9\end{array}$ & $\begin{array}{l}20.8 \\
21.4 \\
19.4 \\
19.9 \\
15.2 \\
17.1 \\
16.1 \\
17.3 \\
17.2 \\
13.6 \\
13.0 \\
16.1 \\
17.2\end{array}$ & $\begin{array}{l}10.3 \\
14.4 \\
13.2 \\
12.4 \\
13.8 \\
11.3 \\
10.9 \\
11.7 \\
13.8 \\
15.3 \\
13.1 \\
11.4 \\
12.6\end{array}$ \\
\hline $\begin{array}{l}1994 \\
\text { January } \\
\text { February } \\
\text { March } \\
\text { April } \\
\text { May } \\
\text { June } \\
\text { July } \\
\text { August } \\
\text { September } \\
\text { October } \\
\text { November } \\
\text { December } \\
1994\end{array}$ & $\begin{array}{l}7.2 \\
6.3 \\
5.0 \\
3.6 \\
3.9 \\
4.4 \\
3.4 \\
3.3 \\
3.1 \\
3.4 \\
3.5 \\
3.8 \\
4.2\end{array}$ & $\begin{array}{l}7.1 \\
9.6 \\
8.6 \\
6.1 \\
6.5 \\
6.4 \\
6.3 \\
7.9 \\
4.9 \\
4.7 \\
5.6 \\
5.1 \\
6.6\end{array}$ & $\begin{array}{r}10.3 \\
9.2 \\
10.2 \\
9.0 \\
8.3 \\
9.6 \\
8.1 \\
8.3 \\
9.3 \\
9.7 \\
9.3 \\
10.2 \\
9.3\end{array}$ & $\begin{array}{l}6.8 \\
6.4 \\
7.4 \\
6.7 \\
6.9 \\
6.3 \\
5.3 \\
5.9 \\
5.6 \\
4.8 \\
6.0 \\
6.6 \\
6.2\end{array}$ & $\begin{array}{l}17.5 \\
15.5 \\
15.2 \\
12.6 \\
12.2 \\
14.0 \\
11.5 \\
11.6 \\
12.5 \\
13.1 \\
12.9 \\
14.0 \\
13.5\end{array}$ & $\begin{array}{r}14.0 \\
16.0 \\
16.0 \\
12.8 \\
13.4 \\
12.7 \\
11.6 \\
13.8 \\
10.5 \\
9.6 \\
11.6 \\
11.7 \\
12.8\end{array}$ \\
\hline
\end{tabular}

Note: Totals may not equal the sum of the components due to rounding.

Source: Energy Information Administration Form EIA-782A, "Refiners'/Gas Plant Operators' Monthly Petroleum Product Sales Report." 
Crude Oil Prices 

Table 21. Domestic Crude Oil First Purchase Prices (Dollars per Barrel)

\begin{tabular}{|c|c|c|c|c|c|c|c|c|c|c|c|c|c|}
\hline \multirow[b]{2}{*}{$\begin{array}{l}\text { Year } \\
\text { Month }\end{array}$} & \multicolumn{2}{|c|}{ U.S. Average } & \multicolumn{4}{|c|}{ PAD District I } & \multicolumn{7}{|c|}{ PAD District II } \\
\hline & $\begin{array}{c}\text { U.S. } \\
\text { Average }\end{array}$ & $\begin{array}{c}\text { Less } \\
\text { AK } \\
\text { North } \\
\text { Slope }\end{array}$ & Average & NY & PA & WV & Average & IL & IN & KS & $\mathrm{KY}$ & $\mathrm{MI}$ & NE \\
\hline $\begin{array}{l}1978 \\
1979 \\
1980 \\
1981 \\
1982 \\
1983\end{array}$ & $\begin{array}{r}9.00 \\
12.64 \\
21.59 \\
31.77 \\
28.52 \\
26.19 \\
25.88 \\
24.09 \\
12.51 \\
15.40 \\
12.58 \\
15.86 \\
20.03 \\
16.54\end{array}$ & $\begin{array}{r}9.56 \\
13.01 \\
22.65 \\
33.71 \\
30.43 \\
28.00 \\
27.59 \\
25.74 \\
14.13 \\
16.83 \\
13.97 \\
17.13 \\
21.57 \\
18.16\end{array}$ & $\begin{array}{l}12.25 \\
14.30 \\
22.66 \\
35.22 \\
31.77 \\
28.32 \\
27.76 \\
25.88 \\
14.76 \\
16.52 \\
14.21 \\
17.16 \\
22.06 \\
19.01\end{array}$ & $\begin{array}{c}W \\
W \\
w \\
w \\
30.91 \\
28.19 \\
27.70 \\
25.19 \\
16.03 \\
17.40 \\
W \\
W \\
23.32 \\
19.67\end{array}$ & $\begin{array}{l}14.72 \\
24.13 \\
37.46 \\
36.03 \\
30.77 \\
28.28 \\
27.71 \\
25.05 \\
15.77 \\
17.43 \\
15.26 \\
18.15 \\
23.00 \\
19.48\end{array}$ & $\begin{array}{l}14.48 \\
23.35 \\
36.92 \\
35.63 \\
29.98 \\
27.27 \\
26.90 \\
24.35 \\
14.68 \\
16.56 \\
14.35 \\
17.18 \\
22.16 \\
W\end{array}$ & $\begin{array}{l}11.91 \\
18.33 \\
30.12 \\
35.63 \\
31.65 \\
29.17 \\
28.62 \\
25.94 \\
14.30 \\
17.42 \\
14.65 \\
18.04 \\
22.88 \\
19.58\end{array}$ & $\begin{array}{l}13.81 \\
23.49 \\
35.78 \\
36.03 \\
31.69 \\
29.12 \\
28.76 \\
26.90 \\
14.70 \\
17.53 \\
14.79 \\
18.36 \\
23.36 \\
20.19\end{array}$ & $\begin{array}{l}13.70 \\
23.28 \\
35.91 \\
36.07 \\
31.66 \\
29.06 \\
28.72 \\
26.82 \\
14.55 \\
17.49 \\
14.78 \\
18.37 \\
23.46 \\
20.20\end{array}$ & $\begin{array}{l}13.20 \\
21.57 \\
34.20 \\
35.80 \\
30.79 \\
28.45 \\
27.99 \\
25.33 \\
14.02 \\
17.37 \\
14.55 \\
18.18 \\
23.21 \\
19.84\end{array}$ & $\begin{array}{l}13.73 \\
22.55 \\
34.98 \\
35.90 \\
31.19 \\
28.60 \\
28.24 \\
26.20 \\
14.20 \\
17.19 \\
14.58 \\
18.36 \\
23.20 \\
19.84\end{array}$ & $\begin{array}{l}11.86 \\
14.47 \\
23.54 \\
35.74 \\
31.80 \\
28.93 \\
28.54 \\
26.16 \\
14.61 \\
17.63 \\
14.92 \\
18.06 \\
22.92 \\
19.88\end{array}$ & $\begin{array}{l}11.40 \\
18.13 \\
30.60 \\
35.32 \\
30.98 \\
28.58 \\
27.83 \\
25.42 \\
13.70 \\
17.08 \\
14.08 \\
17.36 \\
21.94 \\
18.78\end{array}$ \\
\hline 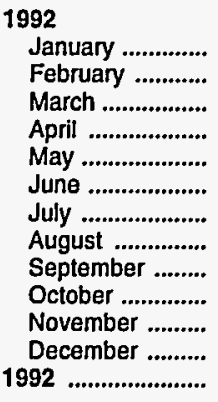 & $\begin{array}{l}13.99 \\
14.04 \\
14.12 \\
15.36 \\
16.38 \\
17.96 \\
17.80 \\
17.07 \\
17.20 \\
17.16 \\
16.00 \\
14.94 \\
15.99\end{array}$ & $\begin{array}{l}15.55 \\
15.61 \\
15.55 \\
16.83 \\
17.79 \\
19.44 \\
18.98 \\
18.31 \\
18.64 \\
18.52 \\
17.22 \\
16.26 \\
17.38\end{array}$ & $\begin{array}{l}16.51 \\
16.73 \\
16.54 \\
17.95 \\
18.85 \\
20.53 \\
19.49 \\
19.33 \\
19.93 \\
19.85 \\
18.74 \\
17.68 \\
18.52\end{array}$ & $\begin{array}{l}16.88 \\
W \\
W \\
W \\
W \\
W \\
W \\
19.03 \\
20.09 \\
20.51 \\
19.60 \\
18.94 \\
19.05\end{array}$ & $\begin{array}{l}17.10 \\
17.32 \\
17.13 \\
18.16 \\
19.24 \\
20.67 \\
19.86 \\
19.35 \\
19.86 \\
20.09 \\
20.09 \\
18.73 \\
19.01\end{array}$ & $\begin{array}{l}16.22 \\
16.27 \\
16.09 \\
17.43 \\
18.28 \\
19.87 \\
18.77 \\
18.66 \\
19.17 \\
19.68 \\
19.22 \\
18.10 \\
18.09\end{array}$ & $\begin{array}{l}16.95 \\
17.06 \\
16.99 \\
18.31 \\
19.08 \\
20.48 \\
19.81 \\
19.39 \\
19.95 \\
19.72 \\
18.46 \\
17.56 \\
18.63\end{array}$ & $\begin{array}{l}17.65 \\
17.66 \\
17.62 \\
18.93 \\
19.75 \\
21.07 \\
20.43 \\
20.01 \\
20.56 \\
20.32 \\
18.98 \\
18.09 \\
19.26\end{array}$ & $\begin{array}{l}17.62 \\
17.74 \\
17.68 \\
19.02 \\
19.77 \\
21.11 \\
20.54 \\
19.93 \\
20.47 \\
20.20 \\
18.91 \\
18.22 \\
19.27\end{array}$ & $\begin{array}{l}16.94 \\
16.99 \\
16.91 \\
18.16 \\
18.95 \\
20.28 \\
19.60 \\
19.25 \\
19.83 \\
19.61 \\
18.28 \\
17.41 \\
18.50\end{array}$ & $\begin{array}{l}17.17 \\
17.32 \\
17.30 \\
18.52 \\
19.39 \\
20.78 \\
19.97 \\
19.23 \\
19.85 \\
19.56 \\
18.40 \\
17.40 \\
18.75\end{array}$ & $\begin{array}{l}17.28 \\
17.48 \\
17.36 \\
18.60 \\
19.40 \\
20.79 \\
20.20 \\
19.76 \\
20.38 \\
20.13 \\
18.79 \\
17.81 \\
18.99\end{array}$ & $\begin{array}{l}16.18 \\
16.19 \\
16.08 \\
17.19 \\
17.92 \\
19.22 \\
18.56 \\
18.18 \\
18.79 \\
18.63 \\
17.26 \\
16.31 \\
17.51\end{array}$ \\
\hline 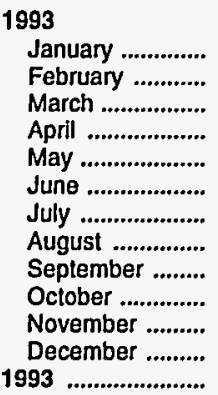 & $\begin{array}{l}14.70 \\
15.53 \\
15.94 \\
16.15 \\
16.03 \\
15.06 \\
13.83 \\
13.75 \\
13.39 \\
13.72 \\
12.45 \\
10.38 \\
14.25\end{array}$ & $\begin{array}{l}15.98 \\
16.79 \\
17.13 \\
17.17 \\
16.98 \\
16.04 \\
14.68 \\
14.74 \\
14.21 \\
14.91 \\
13.50 \\
11.51 \\
15.31\end{array}$ & $\begin{array}{l}17.16 \\
17.87 \\
18.70 \\
19.19 \\
18.68 \\
18.11 \\
16.99 \\
16.98 \\
16.55 \\
17.32 \\
15.89 \\
13.99 \\
17.28\end{array}$ & $\begin{array}{c}W \\
17.78 \\
18.62 \\
18.71 \\
18.72 \\
17.85 \\
W \\
16.47 \\
15.96 \\
17.26 \\
15.52 \\
14.31 \\
17.20\end{array}$ & $\begin{array}{l}18.20 \\
18.21 \\
18.97 \\
19.25 \\
18.85 \\
17.98 \\
17.07 \\
16.88 \\
16.85 \\
17.24 \\
16.02 \\
14.59 \\
17.53\end{array}$ & $\begin{array}{l}17.44 \\
17.45 \\
18.02 \\
18.20 \\
17.86 \\
17.57 \\
16.41 \\
16.22 \\
15.91 \\
16.88 \\
15.27 \\
13.63 \\
16.76\end{array}$ & $\begin{array}{l}17.14 \\
18.09 \\
18.29 \\
18.20 \\
17.78 \\
16.74 \\
15.51 \\
15.63 \\
15.12 \\
15.77 \\
14.39 \\
12.21 \\
16.27\end{array}$ & $\begin{array}{l}17.81 \\
18.75 \\
18.92 \\
18.86 \\
18.47 \\
17.47 \\
16.25 \\
16.46 \\
15.96 \\
16.70 \\
15.02 \\
12.85 \\
16.97\end{array}$ & $\begin{array}{l}17.77 \\
18.81 \\
18.93 \\
18.83 \\
18.38 \\
17.42 \\
16.25 \\
16.50 \\
16.03 \\
16.47 \\
15.04 \\
12.83 \\
16.97\end{array}$ & $\begin{array}{l}17.10 \\
18.04 \\
18.15 \\
18.06 \\
17.49 \\
16.34 \\
15.09 \\
15.22 \\
14.70 \\
15.22 \\
14.01 \\
11.80 \\
15.95\end{array}$ & $\begin{array}{l}17.21 \\
18.08 \\
18.22 \\
18.12 \\
17.84 \\
16.83 \\
15.78 \\
16.03 \\
15.47 \\
16.12 \\
14.61 \\
12.37 \\
16.51\end{array}$ & $\begin{array}{l}17.52 \\
18.57 \\
18.75 \\
18.70 \\
18.34 \\
17.29 \\
16.00 \\
16.18 \\
15.74 \\
16.31 \\
14.87 \\
12.81 \\
16.79\end{array}$ & $\begin{array}{l}15.93 \\
16.88 \\
16.95 \\
16.91 \\
16.28 \\
15.40 \\
14.10 \\
14.18 \\
13.58 \\
14.26 \\
12.87 \\
10.77 \\
14.90\end{array}$ \\
\hline $\begin{array}{l}1994 \\
\text { January .............. } \\
\text { February .......... } \\
\text { March .................. } \\
\text { April ................. } \\
\text { May ..................... } \\
\text { June ................. } \\
\text { July ................... } \\
\text { August .............. } \\
\text { September ......... } \\
\text { October .............. } \\
\text { November ......... } \\
\text { December ........... } \\
1994 \text {....................... }\end{array}$ & $\begin{array}{l}10.49 \\
10.71 \\
10.94 \\
12.31 \\
14.02 \\
14.93 \\
15.34 \\
14.50 \\
13.62 \\
13.84 \\
14.14 \\
13.43 \\
13.19\end{array}$ & $\begin{array}{l}11.78 \\
11.79 \\
11.91 \\
13.40 \\
15.12 \\
16.13 \\
16.50 \\
15.47 \\
14.66 \\
14.92 \\
15.24 \\
14.43 \\
14.30\end{array}$ & $\begin{array}{l}14.13 \\
14.04 \\
13.93 \\
15.07 \\
16.58 \\
17.95 \\
18.76 \\
17.59 \\
16.45 \\
16.45 \\
16.88 \\
16.23 \\
16.23\end{array}$ & $\begin{array}{l}13.87 \\
14.13 \\
13.88 \\
14.20 \\
15.58 \\
17.34 \\
18.35 \\
17.61 \\
16.24 \\
15.90 \\
16.37 \\
16.03 \\
15.94\end{array}$ & $\begin{array}{l}14.32 \\
14.51 \\
14.31 \\
14.69 \\
16.00 \\
17.59 \\
18.50 \\
17.68 \\
16.42 \\
16.09 \\
16.52 \\
16.21 \\
16.13\end{array}$ & $\begin{array}{l}13.56 \\
13.75 \\
13.56 \\
14.31 \\
15.56 \\
17.09 \\
18.06 \\
17.16 \\
16.10 \\
15.81 \\
16.21 \\
15.90 \\
15.68\end{array}$ & $\begin{array}{l}12.75 \\
12.50 \\
12.41 \\
14.12 \\
15.93 \\
17.17 \\
17.67 \\
16.18 \\
15.33 \\
15.58 \\
15.91 \\
15.03 \\
15.05\end{array}$ & $\begin{array}{l}13.39 \\
13.11 \\
13.07 \\
14.87 \\
16.70 \\
17.95 \\
18.39 \\
16.86 \\
15.99 \\
16.28 \\
16.54 \\
15.67 \\
15.76\end{array}$ & $\begin{array}{l}13.35 \\
13.02 \\
13.04 \\
14.78 \\
16.57 \\
17.79 \\
18.24 \\
16.75 \\
15.84 \\
16.12 \\
16.40 \\
15.54 \\
15.66\end{array}$ & $\begin{array}{l}12.33 \\
12.10 \\
12.01 \\
13.83 \\
15.57 \\
16.83 \\
17.33 \\
15.85 \\
14.97 \\
15.27 \\
15.61 \\
14.73 \\
14.71\end{array}$ & $\begin{array}{l}13.05 \\
12.67 \\
12.77 \\
14.49 \\
16.17 \\
17.45 \\
17.84 \\
16.23 \\
15.42 \\
15.65 \\
15.96 \\
15.10 \\
15.33\end{array}$ & $\begin{array}{l}13.21 \\
12.88 \\
12.85 \\
14.57 \\
16.37 \\
17.61 \\
18.10 \\
16.53 \\
15.71 \\
15.95 \\
16.29 \\
15.35 \\
15.43\end{array}$ & $\begin{array}{l}11.19 \\
10.92 \\
10.88 \\
12.67 \\
14.52 \\
15.76 \\
16.32 \\
14.81 \\
13.91 \\
14.22 \\
14.55 \\
13.65 \\
13.60\end{array}$ \\
\hline
\end{tabular}

See footnotes at end of table. 
Table 21. Domestic Crude Oil First Purchase Prices

(Dollars per Barrel) - Continued

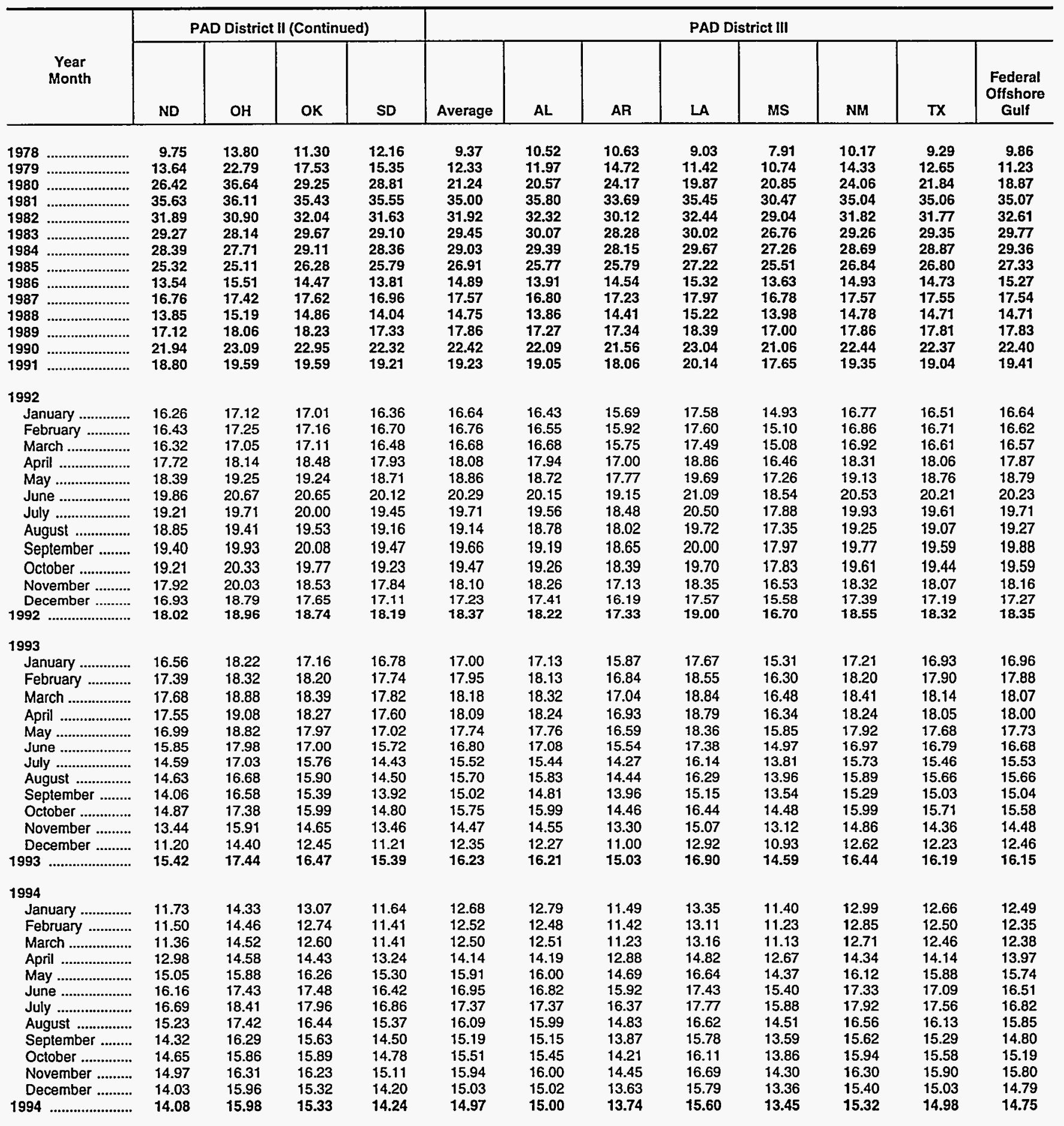

See footnotes at end of table. 
Table 21. Domestic Crude Oil First Purchase Prices

(Dollars per Barrel) - Continued

\begin{tabular}{|c|c|c|c|c|c|c|c|c|c|c|}
\hline \multirow{2}{*}{$\begin{array}{c}\text { Year } \\
\text { Month }\end{array}$} & \multicolumn{5}{|c|}{ PAD District IV } & \multicolumn{5}{|c|}{ PAD District V } \\
\hline & Average & $\mathrm{CO}$ & MT & UT & Wr & Average & $\begin{array}{c}\text { AK } \\
\text { North } \\
\text { Slope }\end{array}$ & $\begin{array}{c}\text { AK } \\
\text { Other }\end{array}$ & CA & $\begin{array}{l}\text { Federal } \\
\text { Offshore } \\
\text { California }\end{array}$ \\
\hline $\begin{array}{l}1978 \\
1979 \\
1980 \\
1981 \\
1982 \\
1983 \\
1984 \\
1984 \\
1985\end{array}$ & $\begin{array}{r}9.50 \\
11.98 \\
21.29 \\
33.38 \\
30.14 \\
27.81 \\
27.18 \\
24.78 \\
13.24 \\
16.77 \\
13.85 \\
17.37 \\
21.68 \\
18.21\end{array}$ & $\begin{array}{l}10.84 \\
13.28 \\
22.91 \\
35.69 \\
31.56 \\
28.92 \\
28.09 \\
25.64 \\
13.98 \\
17.71 \\
14.83 \\
18.86 \\
23.16 \\
19.95\end{array}$ & \begin{tabular}{r|}
9.04 \\
12.03 \\
20.53 \\
34.69 \\
31.25 \\
28.80 \\
28.07 \\
25.29 \\
13.58 \\
16.57 \\
13.84 \\
17.03 \\
21.61 \\
18.17
\end{tabular} & $\begin{array}{r}9.98 \\
11.41 \\
19.79 \\
34.14 \\
30.50 \\
28.12 \\
27.21 \\
23.98 \\
13.33 \\
17.22 \\
14.24 \\
18.63 \\
22.61 \\
19.99\end{array}$ & $\begin{array}{r}9.16 \\
11.73 \\
21.34 \\
32.30 \\
29.37 \\
27.19 \\
26.73 \\
24.67 \\
12.94 \\
16.45 \\
13.47 \\
16.73 \\
21.04 \\
17.33\end{array}$ & $\begin{array}{r}6.60 \\
11.17 \\
19.09 \\
24.79 \\
21.84 \\
19.66 \\
19.52 \\
19.11 \\
8.53 \\
11.89 \\
9.28 \\
12.71 \\
16.15 \\
12.30\end{array}$ & \begin{tabular}{r|}
5.21 \\
10.57 \\
16.87 \\
23.23 \\
19.92 \\
17.69 \\
17.91 \\
16.98 \\
6.45 \\
10.83 \\
8.43 \\
12.00 \\
15.23 \\
11.57
\end{tabular} & \begin{tabular}{r|}
5.45 \\
6.22 \\
10.25 \\
30.15 \\
27.74 \\
23.59 \\
24.37 \\
22.46 \\
13.13 \\
15.48 \\
12.92 \\
16.17 \\
21.16 \\
15.36
\end{tabular} & $\begin{array}{r}8.58 \\
12.78 \\
23.87 \\
26.80 \\
24.58 \\
22.61 \\
22.09 \\
22.14 \\
11.90 \\
13.92 \\
10.97 \\
14.06 \\
17.81 \\
13.72\end{array}$ & $\begin{array}{r}6.10 \\
8.06 \\
16.28 \\
24.56 \\
23.37 \\
20.54 \\
20.41 \\
20.08 \\
9.48 \\
11.82 \\
9.41 \\
12.64 \\
16.21 \\
11.33\end{array}$ \\
\hline $\begin{array}{l}1992 \\
\text { January ............... } \\
\text { February ........... } \\
\text { March ................ } \\
\text { April .................... } \\
\text { May .................. } \\
\text { June ................... } \\
\text { July ................... } \\
\text { August .............. } \\
\text { September ........ } \\
\text { October .............. } \\
\text { November ......... } \\
\text { December ........... } \\
1992 \text {..................... }\end{array}$ & $\begin{array}{l}15.47 \\
15.67 \\
15.58 \\
16.95 \\
17.69 \\
19.14 \\
18.53 \\
18.10 \\
18.61 \\
18.39 \\
17.06 \\
16.18 \\
17.27\end{array}$ & $\begin{array}{l}17.33 \\
17.46 \\
17.46 \\
18.80 \\
19.49 \\
20.87 \\
20.19 \\
19.71 \\
20.31 \\
20.11 \\
18.82 \\
17.83 \\
19.04\end{array}$ & $\begin{array}{l}15.43 \\
15.51 \\
15.44 \\
16.76 \\
17.49 \\
18.78 \\
18.26 \\
17.84 \\
18.36 \\
18.19 \\
16.86 \\
16.18 \\
17.08\end{array}$ & $\begin{array}{l}17.41 \\
17.63 \\
17.63 \\
19.22 \\
19.74 \\
21.38 \\
20.74 \\
20.19 \\
20.84 \\
20.62 \\
19.22 \\
18.32 \\
19.39\end{array}$ & $\begin{array}{l}14.57 \\
14.78 \\
14.66 \\
15.99 \\
16.77 \\
18.23 \\
17.66 \\
17.28 \\
17.73 \\
17.51 \\
16.21 \\
15.28 \\
16.38\end{array}$ & $\begin{array}{r}9.87 \\
9.89 \\
10.19 \\
11.16 \\
12.58 \\
14.35 \\
14.87 \\
13.90 \\
13.48 \\
13.65 \\
12.81 \\
11.42 \\
12.32\end{array}$ & $\begin{array}{r}9.29 \\
9.40 \\
9.84 \\
10.82 \\
12.03 \\
13.40 \\
14.06 \\
13.23 \\
12.90 \\
13.03 \\
12.29 \\
10.93 \\
11.73\end{array}$ & $\begin{array}{l}11.56 \\
12.52 \\
13.20 \\
14.75 \\
16.21 \\
18.53 \\
18.47 \\
17.16 \\
16.61 \\
17.12 \\
16.25 \\
14.68 \\
15.56\end{array}$ & $\begin{array}{l}11.18 \\
11.03 \\
10.97 \\
11.91 \\
13.70 \\
16.19 \\
16.52 \\
15.19 \\
14.70 \\
14.93 \\
13.89 \\
12.52 \\
13.55\end{array}$ & $\begin{array}{r}8.52 \\
8.09 \\
8.27 \\
9.07 \\
10.90 \\
13.63 \\
13.44 \\
12.82 \\
12.03 \\
11.87 \\
11.01 \\
9.62 \\
10.78\end{array}$ \\
\hline 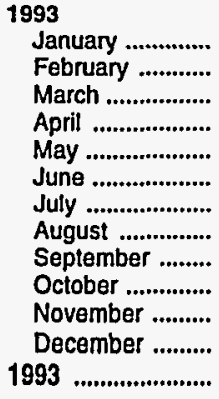 & $\begin{array}{l}15.95 \\
16.83 \\
17.20 \\
17.15 \\
16.78 \\
15.87 \\
14.57 \\
14.74 \\
14.22 \\
14.93 \\
13.58 \\
11.39 \\
15.30\end{array}$ & $\begin{array}{l}17.46 \\
18.36 \\
18.51 \\
18.48 \\
17.94 \\
17.30 \\
15.82 \\
15.98 \\
15.51 \\
16.15 \\
14.86 \\
12.75 \\
16.59\end{array}$ & $\begin{array}{l}15.78 \\
16.68 \\
16.82 \\
16.63 \\
16.23 \\
15.17 \\
13.88 \\
14.04 \\
13.50 \\
14.22 \\
12.78 \\
10.63 \\
14.70\end{array}$ & $\begin{array}{l}18.24 \\
18.98 \\
19.24 \\
19.23 \\
18.87 \\
18.02 \\
16.76 \\
16.91 \\
16.25 \\
16.82 \\
15.81 \\
13.76 \\
17.48\end{array}$ & $\begin{array}{l}15.08 \\
16.00 \\
16.47 \\
16.41 \\
16.11 \\
15.11 \\
13.91 \\
14.08 \\
13.57 \\
14.32 \\
12.92 \\
10.66 \\
14.59\end{array}$ & $\begin{array}{r}11.24 \\
11.82 \\
12.53 \\
13.12 \\
13.40 \\
12.36 \\
11.10 \\
10.77 \\
10.77 \\
10.62 \\
9.75 \\
7.62 \\
11.23\end{array}$ & $\begin{array}{r}10.83 \\
11.58 \\
12.28 \\
12.91 \\
12.96 \\
11.79 \\
10.81 \\
10.46 \\
10.55 \\
10.05 \\
9.06 \\
7.00 \\
10.84\end{array}$ & $\begin{array}{r}14.16 \\
14.57 \\
16.06 \\
16.84 \\
17.40 \\
15.60 \\
13.20 \\
13.00 \\
12.75 \\
13.65 \\
12.36 \\
9.34 \\
14.11\end{array}$ & $\begin{array}{r}12.16 \\
12.49 \\
13.15 \\
13.69 \\
14.37 \\
13.56 \\
11.80 \\
11.58 \\
11.40 \\
11.89 \\
10.89 \\
8.93 \\
12.11\end{array}$ & $\begin{array}{r}9.16 \\
9.52 \\
10.00 \\
10.59 \\
11.25 \\
10.44 \\
9.18 \\
8.58 \\
8.46 \\
9.11 \\
8.13 \\
6.30 \\
9.20\end{array}$ \\
\hline 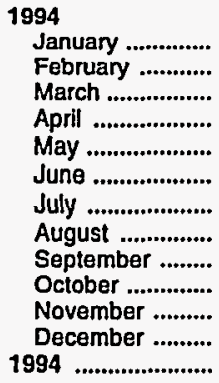 & $\begin{array}{l}11.82 \\
11.62 \\
11.61 \\
13.21 \\
15.11 \\
16.32 \\
16.89 \\
15.47 \\
14.66 \\
15.01 \\
15.27 \\
14.31 \\
14.27\end{array}$ & $\begin{array}{l}13.12 \\
12.87 \\
12.78 \\
14.44 \\
16.23 \\
17.48 \\
18.02 \\
16.66 \\
15.77 \\
16.10 \\
16.47 \\
15.49 \\
15.44\end{array}$ & $\begin{array}{l}11.04 \\
10.80 \\
10.75 \\
12.38 \\
14.24 \\
15.49 \\
16.03 \\
14.62 \\
13.77 \\
14.07 \\
14.42 \\
13.50 \\
13.43\end{array}$ & $\begin{array}{l}14.13 \\
13.89 \\
13.73 \\
15.39 \\
17.13 \\
18.43 \\
18.95 \\
17.57 \\
16.69 \\
17.00 \\
17.29 \\
16.37 \\
16.38\end{array}$ & $\begin{array}{l}11.12 \\
10.93 \\
11.04 \\
12.59 \\
14.54 \\
15.72 \\
16.31 \\
14.89 \\
14.10 \\
14.48 \\
14.68 \\
13.71 \\
13.67\end{array}$ & $\begin{array}{r}7.31 \\
8.15 \\
8.65 \\
9.56 \\
11.26 \\
11.90 \\
12.27 \\
12.11 \\
11.26 \\
11.48 \\
11.54 \\
11.23 \\
10.53\end{array}$ & $\begin{array}{r}6.67 \\
7.38 \\
8.01 \\
8.83 \\
10.70 \\
11.19 \\
11.72 \\
11.40 \\
10.32 \\
10.63 \\
10.67 \\
10.47 \\
9.77\end{array}$ & $\begin{array}{r}9.37 \\
11.17 \\
11.66 \\
13.35 \\
15.29 \\
15.76 \\
15.15 \\
15.36 \\
14.99 \\
14.76 \\
14.76 \\
14.13 \\
13.87\end{array}$ & $\begin{array}{r}8.67 \\
9.58 \\
9.99 \\
10.88 \\
12.47 \\
13.30 \\
13.49 \\
13.61 \\
13.14 \\
13.27 \\
13.37 \\
12.95 \\
12.12\end{array}$ & $\begin{array}{r}6.43 \\
7.25 \\
7.69 \\
8.41 \\
9.58 \\
10.30 \\
10.47 \\
10.49 \\
9.82 \\
10.10 \\
9.93 \\
9.57 \\
9.32\end{array}$ \\
\hline
\end{tabular}

$W=$ Witheid to avoid disclosure of individual company data.

Notes: The actual domestic average price represents the average price at the lease (or wellhead) at which domestic crude oil is purchased.

Sources: Energy Information Administration, Form ERA-182, "Domestic Crude Oil First Purchaser's Report," January 1978 through December 1982; Form ElA-182, -Domestic Crude Oil First Purchase Report," January 1983 to present. 
Table 22. Domestic Crude Oil First Purchase Prices for Selected Crude Streams (Dollars per Barrel)

\begin{tabular}{|c|c|c|c|c|c|c|c|c|c|}
\hline $\begin{array}{c}\text { Year } \\
\text { Month }\end{array}$ & $\begin{array}{l}\text { Alaska } \\
\text { North } \\
\text { Slope }\end{array}$ & $\begin{array}{l}\text { California } \\
\text { Midway- } \\
\text { Sunset }\end{array}$ & $\begin{array}{c}\text { California } \\
\text { Kern } \\
\text { River }\end{array}$ & $\begin{array}{c}\text { California } \\
\text { Wilmington }\end{array}$ & $\begin{array}{l}\text { Louisiana } \\
\text { South } \\
\text { Mix }\end{array}$ & $\begin{array}{l}\text { North } \\
\text { Dakota } \\
\text { Sweet }\end{array}$ & $\begin{array}{c}\text { West } \\
\text { Texas } \\
\text { Intermediate }\end{array}$ & $\begin{array}{l}\text { West } \\
\text { Texas } \\
\text { Sour }\end{array}$ & $\begin{array}{c}\text { Wyoming } \\
\text { Sour }\end{array}$ \\
\hline \multicolumn{10}{|l|}{1993} \\
\hline 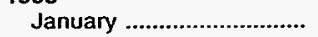 & - & - & - & - & - & - & - & - & - \\
\hline 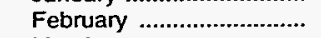 & - & - & - & - & - & - & - & - & - \\
\hline 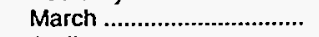 & - & - & - & - & - & - & - & - & - \\
\hline April & - & - & - & - & - & - & - & - & - \\
\hline 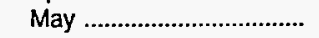 & - & - & - & - & - & - & - & - & - \\
\hline 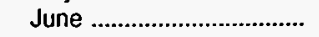 & - & - & - & - & - & - & - & - & - \\
\hline 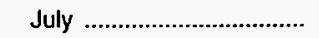 & - & - & - & - & - & - & - & - & - \\
\hline 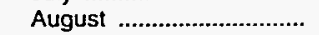 & - & - & - & - & - & - & - & - & - \\
\hline 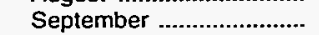 & - & - & - & - & - & - & - & - & - \\
\hline 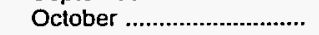 & 10.05 & 11.23 & 11.29 & 12.54 & 16.70 & 15.33 & 16.31 & 14.87 & 12.71 \\
\hline November .............................. & 9.06 & 9.94 & 10.12 & W & 15.14 & 13.95 & 15.22 & 13.29 & 11.01 \\
\hline 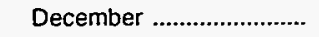 & 7.00 & 8.17 & 8.26 & 10.09 & 13.13 & 11.68 & 12.99 & 11.28 & 8.84 \\
\hline 1993 & - & - & - & - & - & - & - & - & - \\
\hline \multicolumn{10}{|l|}{1994} \\
\hline 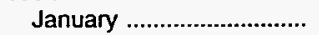 & 6.67 & 8.20 & 8.27 & 9.10 & 13.56 & 12.21 & 13.40 & 11.77 & 9.29 \\
\hline 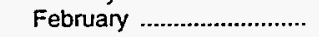 & 7.38 & 8.90 & 9.00 & 10.08 & 13.32 & 11.92 & 13.17 & 11.65 & 9.07 \\
\hline 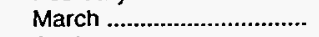 & 8.01 & 9.29 & 9.43 & 10.38 & 13.29 & 11.82 & 13.04 & 11.61 & 9.16 \\
\hline 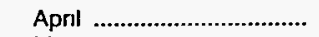 & 8.83 & 10.22 & 10.31 & 11.40 & 14.91 & 13.38 & 14.76 & 13.24 & 10.87 \\
\hline 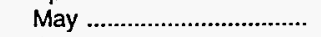 & 10.70 & 11.50 & 11.72 & 12.82 & 16.69 & 15.52 & 16.49 & 15.01 & 12.73 \\
\hline 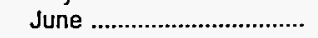 & 11.19 & 12.49 & 12.72 & 13.66 & 17.41 & 16.62 & 17.74 & 16.18 & 13.97 \\
\hline July & 11.72 & 12.92 & 13.09 & 13.86 & 17.78 & 17.16 & 18.27 & 16.66 & 14.54 \\
\hline 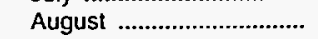 & 11.40 & 13.11 & 13.25 & 14.03 & 16.72 & 15.74 & 16.85 & 15.26 & 12.99 \\
\hline 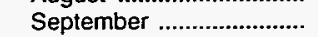 & 10.32 & 12.79 & 12.91 & 13.61 & 15.88 & 14.81 & 15.99 & 14.39 & 12.29 \\
\hline 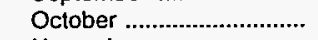 & 10.63 & 12.82 & 12.61 & 13.67 & 16.21 & 15.11 & 16.27 & 14.71 & 12.61 \\
\hline November ......................... & 10.67 & 12.79 & 12.94 & 13.63 & 16.76 & 15.46 & 16.62 & 15.08 & 12.92 \\
\hline 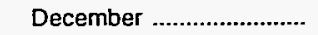 & 10.47 & 12.33 & 12.47 & 13.55 & 15.88 & 14.59 & 15.71 & 14.17 & 11.96 \\
\hline 1994 & 9.77 & 11.79 & 11.65 & 12.47 & 15.71 & 14.54 & 15.65 & 14.16 & 11.87 \\
\hline
\end{tabular}

Dash $(-)=$ No data reported.

$\mathrm{W}=$ Withheld to avoid disclosure of individual company data.

Source: Energy Information Administration, Form EIA-182, "Domestic Crude Oil First Purchase Report." 
Table 23. Domestic Crude Oil First Purchase Prices by API Gravity (Dollars per Barrel)

\begin{tabular}{|c|c|c|c|c|c|c|}
\hline $\begin{array}{c}\text { Year } \\
\text { Month }\end{array}$ & $\begin{array}{c}20.0 \\
\text { or } \\
\text { Less }\end{array}$ & $\begin{array}{c}20.1 \\
\text { to } \\
25.0\end{array}$ & $\begin{array}{c}25.1 \\
\text { to } \\
30.0\end{array}$ & $\begin{array}{c}30.1 \\
\text { to } \\
35.0\end{array}$ & $\begin{array}{c}35.1 \\
\text { to } \\
40.0\end{array}$ & $\begin{array}{c}40.1 \\
\text { or } \\
\text { Greater }\end{array}$ \\
\hline \multicolumn{7}{|l|}{1993} \\
\hline 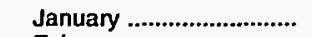 & - & - & - & - & - & - \\
\hline 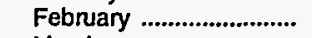 & - & - & - & - & - & - \\
\hline March ................................. & - & - & - & - & - & - \\
\hline 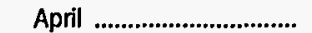 & - & - & - & - & - & - \\
\hline 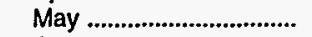 & - & - & - & - & - & - \\
\hline 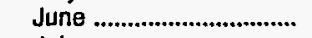 & - & - & - & - & - & - \\
\hline 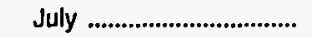 & - & - & - & - & - & - \\
\hline 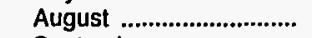 & - & - & - & - & - & - \\
\hline September ....................... & - & - & - & - & - & - \\
\hline 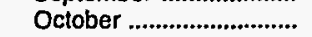 & 11.41 & 13.52 & 10.08 & 15.49 & 15.49 & 16.27 \\
\hline November ........................ & 10.69 & 11.99 & 9.09 & 14.13 & 14.33 & 15.21 \\
\hline December ......................... & 8.49 & 9.84 & 7.03 & 12.00 & 12.01 & 12.95 \\
\hline 1993 & - & - & - & - & - & - \\
\hline \multicolumn{7}{|l|}{1994} \\
\hline 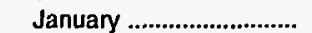 & 8.51 & 10.22 & 6.70 & 12.25 & 12.25 & 13.35 \\
\hline 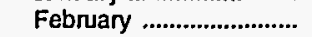 & 9.39 & 10.13 & 7.40 & 12.13 & 12.15 & 13.14 \\
\hline 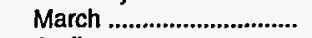 & 9.79 & 10.16 & 8.03 & 12.24 & 12.23 & 13.01 \\
\hline 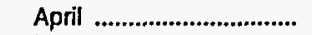 & 10.77 & 11.73 & 8.85 & 13.86 & 13.75 & 14.72 \\
\hline 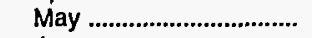 & 11.97 & 13.53 & 10.72 & 15.64 & 15.70 & 16.47 \\
\hline June ................................. & 12.91 & 14.70 & 11.22 & 16.54 & 16.83 & 17.69 \\
\hline 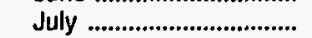 & 13.02 & 15.23 & 11.75 & 16.87 & 17.26 & 18.20 \\
\hline 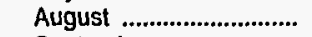 & 13.08 & 14.01 & 11.42 & 15.85 & 16.05 & 16.79 \\
\hline September ..................... & 12.64 & 13.25 & 10.34 & 14.91 & 15.19 & 15.91 \\
\hline 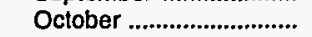 & 12.63 & 13.59 & 10.64 & 15.27 & 15.52 & 16.22 \\
\hline November ......................... & 12.68 & 13.86 & 10.69 & 15.74 & 15.69 & 16.59 \\
\hline December ............................ & 12.26 & 12.91 & 10.48 & 14.82 & 14.89 & 15.68 \\
\hline 1994 & 11.83 & 12.83 & 9.79 & 14.72 & 14.79 & 15.62 \\
\hline
\end{tabular}

Dash $(-)=$ No data reported.

Source: Energy Information Administration, Form ElA-182, "Domestic Crude Oil First Purchase Report." 
Table 24. F.O.B. ${ }^{\text {a }}$ Costs of Imported Crude Oil by Selected Country (Dollars per Barrel)

\begin{tabular}{|c|c|c|c|c|c|c|c|c|c|c|}
\hline \multirow{2}{*}{$\begin{array}{c}\text { Year } \\
\text { Month }\end{array}$} & \multicolumn{8}{|c|}{ Selected Countries } & \multicolumn{2}{|c|}{ OPEC } \\
\hline & Algeria & Indonesia & Mexico & Nigeria & $\begin{array}{c}\text { Saudi } \\
\text { Arabia }\end{array}$ & $\begin{array}{c}\text { United } \\
\text { Kingdom }\end{array}$ & Venezuela & $\begin{array}{l}\text { Other } \\
\text { Countries }\end{array}$ & $\begin{array}{c}\text { Arab } \\
\text { OPECb }\end{array}$ & $\begin{array}{c}\text { Total } \\
\text { OPECC }\end{array}$ \\
\hline $\begin{array}{l}1978 \\
1979 \\
1980 \\
1981 \\
1982 \\
1983 \\
1984 \\
1985\end{array}$ & $\begin{array}{l}14.12 \\
20.53 \\
36.67 \\
39.08 \\
34.20 \\
30.09 \\
28.34 \\
26.89 \\
13.62 \\
16.79 \\
W \\
W \\
W \\
W\end{array}$ & $\begin{array}{l}13.61 \\
19.03 \\
32.17 \\
35.62 \\
35.11 \\
29.92 \\
29.13 \\
27.12 \\
13.19 \\
17.40 \\
13.81 \\
17.01 \\
21.29 \\
18.69\end{array}$ & $\begin{array}{l}13.24 \\
20.27 \\
31.06 \\
33.01 \\
28.08 \\
25.20 \\
26.39 \\
25.33 \\
11.84 \\
16.36 \\
12.18 \\
15.96 \\
19.26 \\
15.37\end{array}$ & $\begin{array}{l}14.05 \\
21.69 \\
35.93 \\
38.31 \\
35.13 \\
29.81 \\
29.51 \\
28.04 \\
14.35 \\
18.47 \\
15.16 \\
18.31 \\
22.46 \\
20.29\end{array}$ & $\begin{array}{l}12.70 \\
17.28 \\
28.17 \\
32.60 \\
33.73 \\
27.53 \\
27.67 \\
22.04 \\
11.35 \\
15.12 \\
12.16 \\
16.29 \\
20.36 \\
14.62\end{array}$ & $\begin{array}{l}13.82 \\
21.70 \\
34.36 \\
36.06 \\
33.42 \\
29.91 \\
28.87 \\
27.64 \\
13.84 \\
18.28 \\
14.80 \\
17.89 \\
23.43 \\
20.81\end{array}$ & $\begin{array}{l}12.38 \\
16.90 \\
24.81 \\
28.95 \\
23.74 \\
21.48 \\
24.23 \\
23.64 \\
10.92 \\
15.08 \\
12.96 \\
16.09 \\
19.55 \\
14.91\end{array}$ & $\begin{array}{l}13.35 \\
21.10 \\
34.34 \\
36.69 \\
31.96 \\
27.96 \\
27.79 \\
26.12 \\
13.32 \\
17.11 \\
13.45 \\
17.12 \\
19.88 \\
17.79\end{array}$ & $\begin{array}{l}13.28 \\
19.27 \\
31.57 \\
34.79 \\
33.84 \\
28.28 \\
27.79 \\
24.34 \\
11.59 \\
15.80 \\
12.57 \\
16.72 \\
18.84 \\
15.59\end{array}$ & $\begin{array}{l}13.31 \\
19.88 \\
32.21 \\
35.17 \\
33.48 \\
28.46 \\
27.79 \\
25.67 \\
12.21 \\
16.43 \\
13.43 \\
17.06 \\
20.40 \\
16.99\end{array}$ \\
\hline 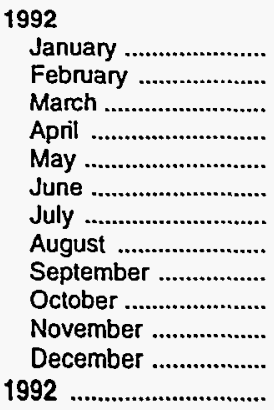 & $\begin{array}{l}W \\
W \\
- \\
W \\
W \\
W \\
W \\
W \\
- \\
- \\
- \\
W \\
W\end{array}$ & $\begin{array}{c}W \\
W \\
W \\
16.23 \\
W \\
W \\
W \\
W \\
W \\
W \\
W \\
W \\
17.06\end{array}$ & $\begin{array}{l}12.45 \\
12.40 \\
12.68 \\
14.11 \\
16.05 \\
17.09 \\
16.88 \\
16.36 \\
16.88 \\
16.90 \\
15.78 \\
14.79 \\
15.26\end{array}$ & $\begin{array}{l}18.58 \\
18.28 \\
18.10 \\
19.59 \\
20.47 \\
21.42 \\
20.83 \\
20.33 \\
20.84 \\
20.76 \\
20.00 \\
18.42 \\
19.98\end{array}$ & $\begin{array}{c}W \\
14.61 \\
14.87 \\
W \\
17.61 \\
W \\
17.60 \\
W \\
16.69 \\
W \\
14.62 \\
15.62 \\
15.85\end{array}$ & $\begin{array}{c}- \\
W \\
W \\
W \\
W \\
20.14 \\
W \\
20.00 \\
20.20 \\
W \\
19.82 \\
W \\
19.61\end{array}$ & $\begin{array}{l}12.32 \\
12.53 \\
12.45 \\
14.38 \\
15.03 \\
15.33 \\
15.10 \\
15.38 \\
16.21 \\
15.40 \\
13.82 \\
13.38 \\
14.39\end{array}$ & $\begin{array}{l}15.44 \\
16.04 \\
16.01 \\
17.10 \\
18.35 \\
19.20 \\
18.74 \\
18.43 \\
18.65 \\
18.70 \\
17.57 \\
16.13 \\
17.65\end{array}$ & $\begin{array}{l}14.07 \\
15.35 \\
15.20 \\
17.26 \\
18.13 \\
17.95 \\
18.20 \\
17.99 \\
17.11 \\
15.89 \\
15.12 \\
15.91 \\
16.50\end{array}$ & $\begin{array}{l}14.50 \\
15.04 \\
15.28 \\
17.25 \\
17.83 \\
18.44 \\
18.09 \\
17.69 \\
18.01 \\
17.42 \\
15.97 \\
15.60 \\
16.87\end{array}$ \\
\hline 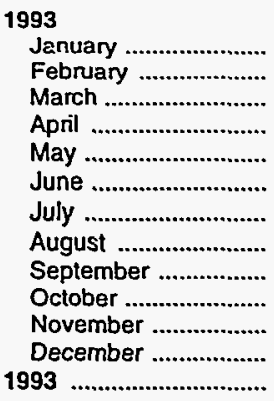 & $\begin{array}{l}- \\
\bar{w} \\
- \\
- \\
\bar{w} \\
\bar{w} \\
w \\
W \\
W \\
w\end{array}$ & $\begin{array}{c}W \\
W \\
W \\
W \\
19.14 \\
W \\
16.48 \\
17.74 \\
W \\
W \\
W \\
W \\
17.13\end{array}$ & $\begin{array}{l}14.14 \\
14.64 \\
15.16 \\
15.04 \\
15.15 \\
14.04 \\
13.09 \\
13.20 \\
13.50 \\
13.74 \\
12.27 \\
11.19 \\
13.74\end{array}$ & $\begin{array}{l}17.95 \\
19.06 \\
19.33 \\
19.21 \\
18.90 \\
18.00 \\
17.46 \\
17.42 \\
16.73 \\
17.02 \\
15.80 \\
14.21 \\
17.79\end{array}$ & $\begin{array}{c}15.55 \\
16.13 \\
16.34 \\
15.23 \\
13.62 \\
W \\
W \\
W \\
W \\
11.16 \\
11.15 \\
W \\
13.77\end{array}$ & $\begin{array}{l}18.29 \\
18.13 \\
18.51 \\
18.36 \\
18.29 \\
17.03 \\
16.07 \\
16.73 \\
16.06 \\
16.31 \\
15.29 \\
14.19 \\
16.64\end{array}$ & $\begin{array}{r}12.99 \\
13.68 \\
14.22 \\
14.52 \\
13.89 \\
12.44 \\
11.96 \\
12.56 \\
12.72 \\
11.87 \\
9.97 \\
9.34 \\
12.46\end{array}$ & $\begin{array}{l}15.19 \\
16.51 \\
16.84 \\
16.76 \\
16.63 \\
15.86 \\
14.97 \\
14.68 \\
14.23 \\
14.88 \\
13.85 \\
11.86 \\
15.17\end{array}$ & $\begin{array}{l}15.63 \\
16.36 \\
16.73 \\
15.46 \\
14.09 \\
14.20 \\
13.67 \\
14.13 \\
12.72 \\
12.94 \\
12.19 \\
11.47 \\
14.25\end{array}$ & $\begin{array}{l}15.63 \\
16.49 \\
16.91 \\
16.41 \\
16.16 \\
14.95 \\
14.19 \\
14.18 \\
14.13 \\
13.75 \\
12.45 \\
11.44 \\
14.78\end{array}$ \\
\hline 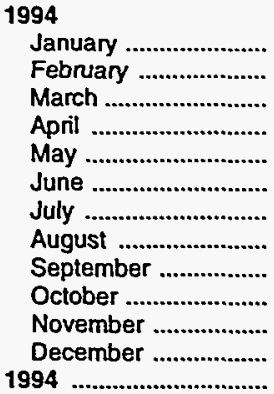 & $\begin{array}{l}w \\
\bar{w} \\
w \\
\bar{w} \\
w \\
w \\
- \\
- \\
\bar{w} \\
w\end{array}$ & $\begin{array}{c}W \\
14.46 \\
W \\
13.52 \\
15.26 \\
15.91 \\
17.56 \\
W \\
W \\
W \\
W \\
W \\
15.57\end{array}$ & $\begin{array}{l}11.26 \\
11.44 \\
11.68 \\
12.88 \\
13.67 \\
15.02 \\
15.70 \\
14.57 \\
13.51 \\
14.42 \\
15.19 \\
14.74 \\
13.68\end{array}$ & $\begin{array}{l}15.02 \\
14.00 \\
14.27 \\
15.65 \\
16.77 \\
17.32 \\
18.02 \\
16.69 \\
16.35 \\
17.01 \\
17.13 \\
16.18 \\
16.32\end{array}$ & $\begin{array}{c}10.29 \\
12.81 \\
14.19 \\
14.91 \\
15.59 \\
14.83 \\
W \\
14.14 \\
14.80 \\
14.22 \\
W \\
W \\
14.12\end{array}$ & $\begin{array}{c}W \\
W \\
13.68 \\
W \\
15.77 \\
16.53 \\
17.29 \\
16.70 \\
15.41 \\
16.42 \\
17.01 \\
15.75 \\
15.66\end{array}$ & $\begin{array}{l}10.93 \\
10.35 \\
11.09 \\
11.81 \\
12.80 \\
13.21 \\
14.28 \\
12.31 \\
12.09 \\
12.90 \\
11.93 \\
12.38 \\
12.21\end{array}$ & $\begin{array}{l}12.16 \\
12.16 \\
12.36 \\
13.73 \\
15.23 \\
16.11 \\
16.71 \\
15.95 \\
15.44 \\
15.29 \\
15.82 \\
15.14 \\
14.68\end{array}$ & $\begin{array}{c}10.73 \\
12.19 \\
13.70 \\
14.53 \\
15.72 \\
15.21 \\
14.76 \\
14.09 \\
14.82 \\
14.20 \\
W \\
14.65 \\
14.05\end{array}$ & $\begin{array}{l}12.35 \\
11.96 \\
12.58 \\
13.75 \\
14.73 \\
15.24 \\
15.76 \\
14.29 \\
13.91 \\
14.48 \\
14.30 \\
13.94 \\
14.00\end{array}$ \\
\hline
\end{tabular}

Dash $(-)=$ No data reported.

$W=$ Withheld to avoid disclosure of individual company data.

a Free on Board. See Glossary.

b Includes Algeria, Libya, Saudi Arabia, United Arab Emirates, Iraq, Kuwait, and Qatar.

C Includes Algeria, Gabon, Indonesia, Iran, Iraq, Kuwait, Libya, Nigeria, Qatar, Saudi Arabia, United Arab Emirates and Venezuela. Prior to January 1, 1993, data included Ecuador, which was then a member of OPEC.

Notes: Values through 1980 reflect the month of reporting; values since then reflect the month of acquisition, which can be the month of loading, the month of landing, or sometime between those events. Prices for crude oil can be determined at a time other than the acquisition date. See the Explanatory Notes section for additional detail.

Sources: Energy Information Administration, Form FEA-F701-M-0, "Transfer Pricing Report," January 1978 through December 1978 ; Form ERA-51, "Transier Pricing Report," January 1979 through September 1982; Form EP-51, "Monthly Foreign Crude Oil Transaction Report," October 1982 through June 1984; Form EIA-856, "Monthly Foreign Crude Oil Acquisition Report," July 1984 to present. 
Table 25. Landed Costs of Imported Crude Oil by Selected Country

(Dollars per Barrel)

\begin{tabular}{|c|c|c|c|c|c|c|c|c|c|c|c|}
\hline \multirow{2}{*}{$\begin{array}{l}\text { Yoar } \\
\text { Month }\end{array}$} & \multicolumn{9}{|c|}{ Selected Countrles } & \multicolumn{2}{|c|}{ OPEC } \\
\hline & Algeria & Canada & Indonesla & Mexico & Nigeria & $\begin{array}{l}\text { Saudi } \\
\text { Arabla }\end{array}$ & $\begin{array}{c}\text { United } \\
\text { KIngdom }\end{array}$ & Venezuela & $\begin{array}{c}\text { Other } \\
\text { Countrles }\end{array}$ & $\begin{array}{c}\text { Arab } \\
\text { OPECa }\end{array}$ & $\begin{array}{c}\text { Total } \\
\text { OPEC }\end{array}$ \\
\hline $\begin{array}{l}1978 \ldots \ldots \\
1979 \\
1980 \\
1981 \\
1982\end{array}$ & $\begin{array}{l}14.93 \\
21.88 \\
37.92 \\
40.46 \\
35.35 \\
31.26 \\
29.06 \\
27.51 \\
14.82 \\
17.87 \\
W \\
19.13 \\
W \\
W\end{array}$ & $\begin{array}{l}14.41 \\
20.22 \\
30.11 \\
32.32 \\
27.15 \\
25.63 \\
26.56 \\
25.71 \\
13.43 \\
17.04 \\
13.50 \\
16.81 \\
20.48 \\
17.16\end{array}$ & $\begin{array}{l}14.65 \\
20.63 \\
33.92 \\
37.31 \\
36.70 \\
31.57 \\
30.87 \\
28.67 \\
14.63 \\
18.49 \\
15.15 \\
18.35 \\
22.50 \\
20.20\end{array}$ & $\begin{array}{l}13.56 \\
20.77 \\
31.77 \\
33.70 \\
28.63 \\
25.78 \\
26.85 \\
25.63 \\
12.17 \\
16.69 \\
12.58 \\
16.35 \\
19.64 \\
15.89\end{array}$ & $\begin{array}{l}14.88 \\
22.97 \\
37.15 \\
39.66 \\
36.16 \\
30.85 \\
30.36 \\
28.96 \\
15.29 \\
19.32 \\
15.88 \\
19.19 \\
23.33 \\
21.39\end{array}$ & $\begin{array}{l}13.94 \\
18.95 \\
29.80 \\
34.20 \\
34.99 \\
29.27 \\
29.20 \\
24.72 \\
12.84 \\
16.81 \\
13.37 \\
17.34 \\
21.82 \\
17.22\end{array}$ & $\begin{array}{l}14.53 \\
22.97 \\
35.68 \\
37.29 \\
34.25 \\
30.87 \\
29.45 \\
28.36 \\
14.63 \\
18.78 \\
15.82 \\
18.74 \\
22.65 \\
21.37\end{array}$ & $\begin{array}{l}12.84 \\
17.65 \\
25.92 \\
29.91 \\
24.93 \\
22.94 \\
25.19 \\
24.43 \\
11.52 \\
15.76 \\
13.66 \\
16.78 \\
20.31 \\
15.92\end{array}$ & $\begin{array}{l}14.58 \\
22.86 \\
36.15 \\
38.54 \\
34.03 \\
29.68 \\
29.21 \\
27.33 \\
14.25 \\
18.30 \\
14.45 \\
18.08 \\
20.52 \\
19.73\end{array}$ & $\begin{array}{l}14.36 \\
20.79 \\
32.97 \\
36.22 \\
35.15 \\
29.87 \\
29.10 \\
25.90 \\
13.14 \\
17.32 \\
13.60 \\
17.41 \\
20.64 \\
17.45\end{array}$ & $\begin{array}{l}14.34 \\
21.29 \\
33.56 \\
36.60 \\
34.81 \\
29.84 \\
29.06 \\
26.86 \\
13.46 \\
17.64 \\
14.18 \\
17.78 \\
21.23 \\
18.08\end{array}$ \\
\hline 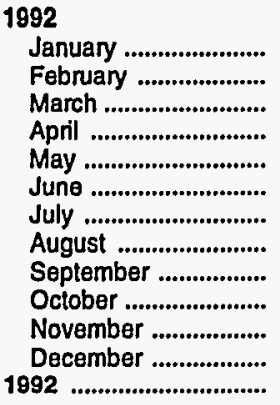 & $\begin{array}{l}W \\
w \\
\bar{w} \\
w \\
w \\
w \\
w \\
\bar{w} \\
\bar{w} \\
w\end{array}$ & $\begin{array}{l}14.83 \\
15.57 \\
15.68 \\
16.42 \\
17.35 \\
18.40 \\
18.50 \\
18.28 \\
18.35 \\
18.35 \\
17.26 \\
15.85 \\
17.04\end{array}$ & $\begin{array}{l}W \\
W \\
W \\
17.76 \\
17.66 \\
19.60 \\
21.06 \\
21.26 \\
W \\
W \\
W \\
W \\
18.76\end{array}$ & $\begin{array}{l}13.02 \\
12.78 \\
13.06 \\
14.40 \\
16.39 \\
17.41 \\
17.20 \\
16.74 \\
17.34 \\
17.26 \\
16.18 \\
15.12 \\
15.60\end{array}$ & $\begin{array}{l}19.34 \\
19.10 \\
19.05 \\
20.32 \\
21.25 \\
22.11 \\
21.49 \\
21.05 \\
21.57 \\
21.60 \\
20.79 \\
19.32 \\
20.78\end{array}$ & $\begin{array}{l}14.81 \\
15.61 \\
16.05 \\
18.01 \\
18.62 \\
19.49 \\
19.00 \\
18.45 \\
18.45 \\
17.96 \\
17.02 \\
16.64 \\
17.48\end{array}$ & $\begin{array}{c}W \\
W \\
18.83 \\
18.97 \\
19.99 \\
20.85 \\
21.45 \\
21.37 \\
20.72 \\
21.17 \\
21.00 \\
19.46 \\
20.63\end{array}$ & $\begin{array}{l}13.20 \\
13.47 \\
13.41 \\
15.06 \\
15.73 \\
16.01 \\
15.78 \\
16.10 \\
16.89 \\
16.14 \\
14.51 \\
14.07 \\
15.13\end{array}$ & $\begin{array}{l}17.46 \\
17.64 \\
17.44 \\
18.10 \\
19.58 \\
20.93 \\
20.49 \\
20.10 \\
20.12 \\
20.09 \\
19.25 \\
17.80 \\
19.25\end{array}$ & $\begin{array}{l}15.16 \\
15.85 \\
16.14 \\
18.11 \\
18.80 \\
19.60 \\
19.15 \\
18.79 \\
18.51 \\
18.08 \\
17.05 \\
16.69 \\
17.63\end{array}$ & $\begin{array}{l}15.38 \\
15.87 \\
16.29 \\
18.07 \\
18.65 \\
19.57 \\
19.06 \\
18.70 \\
18.83 \\
18.56 \\
17.28 \\
16.62 \\
17.81\end{array}$ \\
\hline 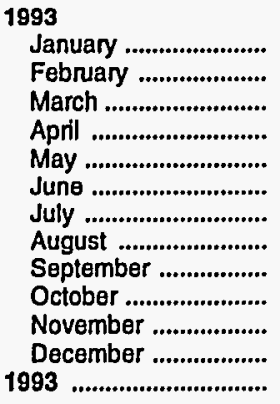 & $\begin{array}{c}- \\
\bar{w} \\
W \\
W \\
\bar{W} \\
\bar{w} \\
W \\
W \\
W \\
17.34\end{array}$ & $\begin{array}{l}15.28 \\
15.84 \\
16.48 \\
16.79 \\
16.82 \\
16.25 \\
15.30 \\
14.94 \\
14.56 \\
15.14 \\
14.28 \\
12.44 \\
15.27\end{array}$ & $\begin{array}{c}W \\
W \\
W \\
20.01 \\
20.67 \\
W \\
17.86 \\
19.28 \\
W \\
W \\
W \\
15.72 \\
18.55\end{array}$ & $\begin{array}{l}14.50 \\
14.98 \\
15.50 \\
15.56 \\
15.57 \\
14.49 \\
13.44 \\
13.66 \\
13.83 \\
14.11 \\
12.63 \\
11.39 \\
14.11\end{array}$ & $\begin{array}{l}18.94 \\
19.92 \\
20.25 \\
20.18 \\
19.83 \\
18.94 \\
18.31 \\
18.10 \\
17.65 \\
17.98 \\
16.72 \\
15.09 \\
18.73\end{array}$ & $\begin{array}{l}16.46 \\
17.30 \\
17.56 \\
17.46 \\
16.45 \\
15.83 \\
14.95 \\
15.04 \\
14.31 \\
14.13 \\
13.03 \\
11.74 \\
15.40\end{array}$ & $\begin{array}{l}19.12 \\
19.28 \\
19.43 \\
19.32 \\
19.33 \\
18.67 \\
17.51 \\
17.56 \\
16.95 \\
16.67 \\
16.57 \\
15.14 \\
17.92\end{array}$ & $\begin{array}{l}14.07 \\
14.60 \\
15.14 \\
15.55 \\
14.91 \\
13.49 \\
12.92 \\
13.32 \\
13.46 \\
12.70 \\
10.81 \\
10.14 \\
13.39\end{array}$ & $\begin{array}{l}17.22 \\
18.17 \\
18.44 \\
18.41 \\
18.33 \\
17.42 \\
16.45 \\
16.04 \\
15.53 \\
15.68 \\
14.74 \\
12.82 \\
16.44\end{array}$ & $\begin{array}{l}16.49 \\
17.30 \\
17.62 \\
17.45 \\
16.56 \\
15.92 \\
14.98 \\
15.09 \\
14.34 \\
14.34 \\
13.15 \\
11.67 \\
15.28\end{array}$ & $\begin{array}{l}16.67 \\
17.44 \\
17.84 \\
17.71 \\
17.22 \\
16.06 \\
15.32 \\
15.23 \\
14.85 \\
14.70 \\
13.34 \\
12.05 \\
15.68\end{array}$ \\
\hline 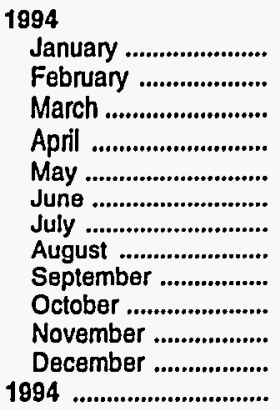 & $\begin{array}{l}W \\
\bar{W} \\
W \\
\bar{w} \\
W \\
W \\
W \\
W \\
W \\
W \\
W \\
W\end{array}$ & $\begin{array}{l}12.13 \\
12.05 \\
11.92 \\
13.43 \\
15.25 \\
16.45 \\
17.53 \\
16.51 \\
15.50 \\
15.54 \\
16.06 \\
15.41 \\
14.83\end{array}$ & $\begin{array}{c}W \\
16.17 \\
W \\
15.08 \\
16.42 \\
17.00 \\
18.41 \\
19.96 \\
W \\
W \\
W \\
16.99 \\
16.91\end{array}$ & $\begin{array}{l}11.61 \\
11.73 \\
11.97 \\
13.23 \\
14.10 \\
15.44 \\
16.17 \\
14.97 \\
14.04 \\
14.82 \\
15.61 \\
15.56 \\
14.09\end{array}$ & $\begin{array}{l}15.76 \\
14.68 \\
15.13 \\
16.46 \\
17.36 \\
18.21 \\
18.74 \\
17.78 \\
17.39 \\
17.85 \\
18.04 \\
17.24 \\
17.21\end{array}$ & $\begin{array}{l}11.66 \\
12.32 \\
13.31 \\
14.30 \\
15.81 \\
16.60 \\
16.81 \\
15.68 \\
15.62 \\
15.41 \\
15.85 \\
15.56 \\
15.11\end{array}$ & $\begin{array}{l}14.98 \\
15.40 \\
14.67 \\
15.31 \\
16.33 \\
17.40 \\
17.96 \\
17.41 \\
16.62 \\
17.06 \\
17.19 \\
16.84 \\
16.64\end{array}$ & $\begin{array}{l}11.78 \\
11.12 \\
11.87 \\
12.72 \\
13.53 \\
14.15 \\
15.02 \\
13.24 \\
13.04 \\
13.85 \\
13.03 \\
13.50 \\
13.12\end{array}$ & $\begin{array}{l}13.52 \\
13.60 \\
13.33 \\
15.09 \\
16.48 \\
17.18 \\
17.73 \\
16.92 \\
16.38 \\
16.28 \\
16.97 \\
16.45 \\
15.95\end{array}$ & $\begin{array}{l}11.86 \\
12.24 \\
12.85 \\
14.21 \\
15.72 \\
16.58 \\
16.86 \\
15.72 \\
15.46 \\
15.34 \\
15.84 \\
15.56 \\
15.02\end{array}$ & $\begin{array}{l}12.94 \\
12.59 \\
13.05 \\
14.47 \\
15.62 \\
16.48 \\
16.88 \\
15.69 \\
15.25 \\
15.51 \\
15.63 \\
15.34 \\
15.08\end{array}$ \\
\hline
\end{tabular}

Dash $(-)=$ No data reported.

$W=$ Withheld to avoid disclosure of individual company data.

a Includes Algeria, Libya, Saudi Arabia, United Arab Emirates, Iraq, Kuwait, and Qatar.

b Includes Algeria, Gabon, Indonesia, Iran, Iraq, Kuwait, Libya, Nigeria, Qatar, Saudi Arabia, United Arab Emirates and Venezuela. Prior to January 1, 1993, data included Ecuador, which was then a member of OPEC.

Notes: Values through 1980 reflect the month of reporting; values since then reflect the month of acquisition, which can be the month of loading, the month of landing, or sometime between those events. Prices for crude oil can be determined at a time other than the acquisition date. See the Explanatory Notes section for additional detail.

Sources: Energy Information Administration, Form FEA-F701-M-0. "Transter Pricing Report," January 1978 through December 1978 ; Form ERA-51, "Transfer Pricing Report," January 1979 through September 1982; Form EP-51, "Monthly Foreign Crude Oil Transaction Report," October 1982 through June 1984; Form EIA-856, "Monthly Foreign Crude Oil Acquisition Report," July 1984 to present. 
Table 26. F.O.B. ${ }^{\text {a }}$ Costs of Imported Crude Oil by API Gravity

(Dollars per Barrel)

\begin{tabular}{|c|c|c|c|c|c|c|c|}
\hline $\begin{array}{l}\text { Year } \\
\text { Month }\end{array}$ & $\begin{array}{l}20.0 \\
\text { or } \\
\text { Less }\end{array}$ & $\begin{array}{c}20.1 \\
t 0 \\
25.0\end{array}$ & $\begin{array}{c}25.1 \\
\text { to } \\
30.0\end{array}$ & $\begin{array}{c}30.1 \\
\text { to } \\
35.0\end{array}$ & $\begin{array}{c}35.1 \\
\text { to } \\
40.0\end{array}$ & $\begin{array}{c}40.1 \\
\text { to } \\
45.0\end{array}$ & $\begin{array}{c}\mathbf{4 5 . 1} \\
\text { or } \\
\text { Greater }\end{array}$ \\
\hline $\begin{array}{l}1978 \\
1979 \\
1980 \\
1981 \\
1982 \\
1983 \\
1984 \\
1985 \\
1986 \\
1987 \\
1988\end{array}$ & $\begin{array}{l}11.98 \\
14.43 \\
23.09 \\
26.70 \\
23.08 \\
21.77 \\
24.10 \\
23.45 \\
10.51 \\
15.21 \\
11.92 \\
14.00 \\
15.98 \\
11.91\end{array}$ & $\begin{array}{l}11.74 \\
18.54 \\
28.76 \\
31.20 \\
25.82 \\
24.27 \\
25.31 \\
24.27 \\
10.96 \\
15.37 \\
11.65 \\
14.89 \\
18.00 \\
13.72\end{array}$ & $\begin{array}{l}12.51 \\
19.91 \\
30.72 \\
33.61 \\
31.48 \\
27.38 \\
27.22 \\
24.86 \\
12.25 \\
15.76 \\
12.48 \\
16.95 \\
20.54 \\
16.33\end{array}$ & $\begin{array}{l}13.06 \\
19.54 \\
30.31 \\
34.38 \\
33.56 \\
29.04 \\
28.55 \\
26.46 \\
12.83 \\
17.24 \\
13.82 \\
17.50 \\
20.77 \\
17.67\end{array}$ & $\begin{array}{l}13.62 \\
21.24 \\
34.33 \\
36.85 \\
34.29 \\
29.74 \\
29.18 \\
27.43 \\
13.83 \\
17.99 \\
14.38 \\
18.09 \\
22.19 \\
20.15\end{array}$ & $\begin{array}{l}14.00 \\
21.65 \\
35.39 \\
38.42 \\
34.82 \\
30.10 \\
29.40 \\
27.79 \\
14.19 \\
18.03 \\
14.89 \\
18.23 \\
22.78 \\
19.69\end{array}$ & $\begin{array}{l}14.01 \\
19.77 \\
36.13 \\
38.59 \\
34.48 \\
30.12 \\
28.02 \\
26.90 \\
13.76 \\
17.37 \\
15.25 \\
18.05 \\
22.28 \\
20.85\end{array}$ \\
\hline 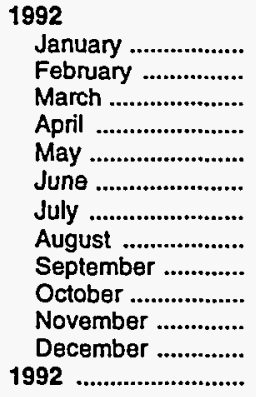 & $\begin{array}{r}9.20 \\
9.35 \\
9.51 \\
10.21 \\
11.30 \\
13.09 \\
12.13 \\
12.95 \\
13.53 \\
13.46 \\
12.51 \\
12.58 \\
11.83\end{array}$ & $\begin{array}{l}11.12 \\
11.10 \\
11.70 \\
13.26 \\
14.73 \\
15.69 \\
15.49 \\
15.28 \\
15.55 \\
15.46 \\
13.74 \\
12.87 \\
13.96\end{array}$ & $\begin{array}{l}14.14 \\
14.02 \\
15.02 \\
16.74 \\
17.91 \\
18.58 \\
18.34 \\
17.94 \\
18.05 \\
17.75 \\
15.84 \\
15.24 \\
16.74\end{array}$ & $\begin{array}{l}16.15 \\
16.26 \\
16.69 \\
18.34 \\
19.12 \\
19.71 \\
19.32 \\
18.58 \\
18.56 \\
18.74 \\
17.41 \\
16.76 \\
18.02\end{array}$ & $\begin{array}{l}17.83 \\
18.05 \\
17.79 \\
19.04 \\
19.85 \\
20.97 \\
20.42 \\
20.00 \\
20.46 \\
20.46 \\
19.28 \\
18.28 \\
19.50\end{array}$ & $\begin{array}{l}18.11 \\
17.82 \\
17.85 \\
19.22 \\
20.32 \\
21.76 \\
20.83 \\
20.02 \\
20.61 \\
20.30 \\
19.82 \\
18.46 \\
19.58\end{array}$ & $\begin{array}{c}W \\
W \\
W \\
19.43 \\
20.23 \\
W \\
20.93 \\
21.46 \\
W \\
W \\
20.41 \\
18.99 \\
20.05\end{array}$ \\
\hline 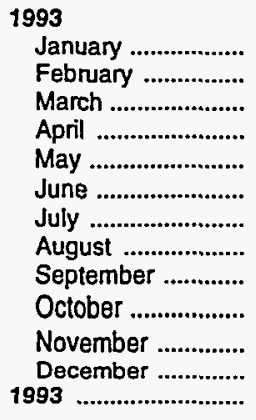 & $\begin{array}{r}11.69 \\
12.19 \\
12.81 \\
12.60 \\
12.22 \\
11.16 \\
10.58 \\
11.48 \\
11.81 \\
11.17 \\
9.61 \\
8.93 \\
11.33\end{array}$ & $\begin{array}{r}12.53 \\
13.21 \\
13.71 \\
13.90 \\
13.65 \\
12.43 \\
11.85 \\
12.09 \\
12.01 \\
11.89 \\
10.21 \\
9.31 \\
12.22\end{array}$ & $\begin{array}{l}15.50 \\
16.75 \\
17.11 \\
16.70 \\
16.60 \\
16.00 \\
14.62 \\
14.17 \\
14.23 \\
14.13 \\
13.27 \\
11.02 \\
15.14\end{array}$ & $\begin{array}{l}16.21 \\
16.98 \\
17.39 \\
16.93 \\
16.49 \\
16.03 \\
15.31 \\
15.03 \\
14.49 \\
14.93 \\
13.92 \\
12.03 \\
15.44\end{array}$ & $\begin{array}{l}17.71 \\
18.68 \\
18.77 \\
18.84 \\
18.43 \\
17.57 \\
16.71 \\
16.64 \\
16.21 \\
16.46 \\
15.35 \\
13.68 \\
17.04\end{array}$ & $\begin{array}{c}17.57 \\
18.67 \\
19.71 \\
18.92 \\
18.95 \\
W \\
18.97 \\
W \\
16.48 \\
16.71 \\
16.21 \\
14.54 \\
17.53\end{array}$ & $\begin{array}{c}W \\
18.63 \\
20.50 \\
W \\
19.50 \\
W \\
17.50 \\
18.55 \\
17.04 \\
16.61 \\
W \\
13.55 \\
17.61\end{array}$ \\
\hline 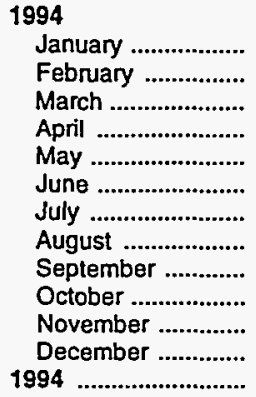 & $\begin{array}{r}10.54 \\
9.32 \\
9.60 \\
10.68 \\
11.45 \\
11.91 \\
13.01 \\
10.66 \\
11.55 \\
11.66 \\
11.93 \\
12.46 \\
11.43\end{array}$ & $\begin{array}{r}10.05 \\
9.84 \\
10.17 \\
11.51 \\
12.42 \\
13.58 \\
14.49 \\
13.12 \\
12.22 \\
13.14 \\
13.08 \\
12.67 \\
12.19\end{array}$ & $\begin{array}{l}12.65 \\
12.05 \\
12.46 \\
14.36 \\
14.99 \\
15.99 \\
16.88 \\
14.83 \\
14.73 \\
14.93 \\
14.83 \\
14.50 \\
14.45\end{array}$ & $\begin{array}{l}12.19 \\
12.95 \\
13.55 \\
14.43 \\
15.80 \\
16.09 \\
16.64 \\
15.57 \\
15.30 \\
15.12 \\
15.41 \\
14.94 \\
14.93\end{array}$ & $\begin{array}{l}14.05 \\
13.79 \\
13.82 \\
15.22 \\
16.25 \\
17.08 \\
17.75 \\
16.94 \\
15.93 \\
16.57 \\
17.02 \\
16.03 \\
15.91\end{array}$ & $\begin{array}{c}14.85 \\
14.15 \\
14.04 \\
W \\
15.69 \\
W \\
16.96 \\
W \\
16.09 \\
W \\
17.03 \\
15.87 \\
15.70\end{array}$ & $\begin{array}{c}14.24 \\
14.30 \\
13.70 \\
15.21 \\
W \\
17.47 \\
17.61 \\
17.40 \\
16.00 \\
16.10 \\
16.73 \\
16.78 \\
16.11\end{array}$ \\
\hline
\end{tabular}

$W=$ Withheld to avoid disclosure of individual company data.

a Free on Board. See Glossary.

Notes: Values through 1980 reflect the month of reporting; values since then reflect the month of acquisition, which can be the month of loading, the month of landing, or sometime between those events. Prices for crude oil can be determined at a time other than the acquisition date. See the Explanatory Notes section for additional detail.

Sources: Energy Information Administration, Form FEA-F701-M-0, "Transfer Pricing Report," January 1978 through December 1978; Form ERA-51, "Transfer Pricing Report," January 1979 through September 1982; Form EP-51, "Monthly Foreign Crude Oil Transaction Report;" October 1982 through June 1984; Form EIA-856, "Monthly Foreign Crude Oil Acquisition Report," July 1984 to present. 
Table 27. Landed Costs of Imported Crude Oil by API Gravity (Dollars per Barrel)

\begin{tabular}{|c|c|c|c|c|c|c|c|}
\hline $\begin{array}{l}\text { Yoar } \\
\text { Month }\end{array}$ & $\begin{array}{c}20.0 \\
\text { or } \\
\text { Lo88 }\end{array}$ & $\begin{array}{c}20.1 \\
t 0 \\
25.0\end{array}$ & $\begin{array}{c}25.1 \\
\text { to } \\
30.0\end{array}$ & $\begin{array}{c}30.1 \\
\text { to } \\
35.0\end{array}$ & $\begin{array}{c}35.1 \\
\text { to } \\
40.0\end{array}$ & $\begin{array}{c}40.1 \\
\text { to } \\
45.0\end{array}$ & $\begin{array}{c}45.1 \\
\text { or } \\
\text { Greater }\end{array}$ \\
\hline 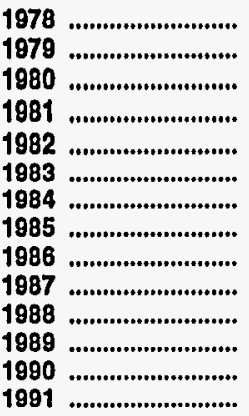 & $\begin{array}{l}12.75 \\
15.57 \\
24.54 \\
27.94 \\
24.17 \\
23.17 \\
25.08 \\
24.33 \\
11.30 \\
16.14 \\
12.75 \\
14.90 \\
16.82 \\
13.06\end{array}$ & $\begin{array}{l}13.11 \\
20.05 \\
29.65 \\
32.00 \\
26.46 \\
24.95 \\
25.97 \\
24.65 \\
11.49 \\
15.87 \\
12.11 \\
15.42 \\
18.54 \\
14.41\end{array}$ & $\begin{array}{l}13.76 \\
20.88 \\
31.83 \\
34.86 \\
32.62 \\
28.62 \\
28.38 \\
26.17 \\
13.28 \\
17.21 \\
13.54 \\
17.59 \\
21.59 \\
17.17\end{array}$ & $\begin{array}{l}14.10 \\
21.01 \\
31.73 \\
35.71 \\
34.76 \\
30.25 \\
29.58 \\
27.10 \\
13.59 \\
18.16 \\
14.35 \\
17.87 \\
21.18 \\
18.65\end{array}$ & $\begin{array}{l}14.69 \\
22.61 \\
35.81 \\
38.36 \\
35.43 \\
30.96 \\
30.16 \\
28.29 \\
14.99 \\
18.72 \\
15.21 \\
18.74 \\
22.47 \\
20.86\end{array}$ & $\begin{array}{l}14.87 \\
23.06 \\
36.85 \\
39.78 \\
35.78 \\
31.28 \\
30.16 \\
28.39 \\
14.80 \\
18.89 \\
15.74 \\
19.05 \\
23.47 \\
20.88\end{array}$ & $\begin{array}{l}15.16 \\
21.23 \\
37.57 \\
39.97 \\
35.81 \\
31.27 \\
29.05 \\
27.73 \\
15.37 \\
18.57 \\
16.24 \\
19.13 \\
23.41 \\
22.15\end{array}$ \\
\hline 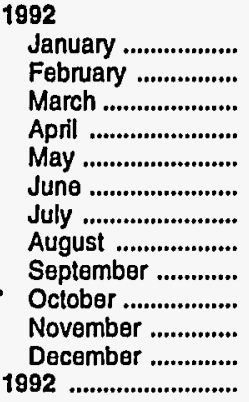 & $\begin{array}{l}10.13 \\
10.41 \\
10.63 \\
11.27 \\
12.38 \\
13.94 \\
13.46 \\
13.95 \\
14.43 \\
14.63 \\
13.45 \\
13.48 \\
12.89\end{array}$ & $\begin{array}{l}11.75 \\
11.89 \\
12.54 \\
13.81 \\
15.31 \\
16.31 \\
16.18 \\
15.92 \\
16.13 \\
16.11 \\
14.32 \\
13.47 \\
14.58\end{array}$ & $\begin{array}{l}14.82 \\
14.72 \\
15.64 \\
17.40 \\
18.21 \\
19.33 \\
19.00 \\
18.49 \\
18.66 \\
18.65 \\
16.86 \\
16.06 \\
17.39\end{array}$ & $\begin{array}{l}16.34 \\
16.66 \\
17.03 \\
18.45 \\
19.26 \\
20.28 \\
19.81 \\
19.37 \\
19.40 \\
19.31 \\
18.03 \\
17.50 \\
18.50\end{array}$ & $\begin{array}{l}18.19 \\
18.38 \\
18.41 \\
19.26 \\
20.33 \\
21.46 \\
21.19 \\
20.82 \\
21.12 \\
21.10 \\
20.16 \\
18.74 \\
20.11\end{array}$ & $\begin{array}{l}18.94 \\
18.55 \\
18.98 \\
20.28 \\
20.90 \\
22.43 \\
21.87 \\
21.33 \\
21.34 \\
21.10 \\
20.41 \\
19.41 \\
20.55\end{array}$ & $\begin{array}{l}20.61 \\
20.03 \\
19.56 \\
20.31 \\
21.17 \\
22.19 \\
21.93 \\
21.71 \\
22.66 \\
21.94 \\
20.56 \\
19.57 \\
20.95\end{array}$ \\
\hline 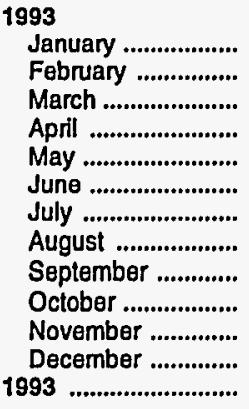 & $\begin{array}{r}13.07 \\
13.25 \\
13.94 \\
13.87 \\
13.43 \\
12.37 \\
11.74 \\
12.40 \\
12.63 \\
12.07 \\
10.55 \\
9.72 \\
12.44\end{array}$ & $\begin{array}{r}13.09 \\
13.79 \\
14.49 \\
14.73 \\
14.53 \\
13.19 \\
12.66 \\
12.86 \\
12.67 \\
12.67 \\
10.98 \\
9.91 \\
12.96\end{array}$ & $\begin{array}{l}16.23 \\
17.04 \\
17.56 \\
17.49 \\
17.33 \\
16.62 \\
15.48 \\
14.97 \\
14.82 \\
14.82 \\
13.73 \\
11.60 \\
15.72\end{array}$ & $\begin{array}{l}17.15 \\
17.94 \\
18.17 \\
18.13 \\
17.45 \\
16.81 \\
16.06 \\
15.77 \\
15.08 \\
15.23 \\
14.19 \\
12.43 \\
16.06\end{array}$ & $\begin{array}{l}18.48 \\
19.22 \\
19.51 \\
19.55 \\
19.31 \\
18.54 \\
17.61 \\
17.37 \\
16.97 \\
17.12 \\
16.27 \\
14.37 \\
17.88\end{array}$ & $\begin{array}{l}18.48 \\
19.49 \\
20.41 \\
20.22 \\
20.18 \\
18.94 \\
18.77 \\
18.78 \\
17.41 \\
17.64 \\
17.09 \\
15.33 \\
18.38\end{array}$ & $\begin{array}{l}19.00 \\
19.64 \\
21.29 \\
20.05 \\
20.64 \\
19.43 \\
18.46 \\
18.35 \\
17.38 \\
17.62 \\
14.92 \\
14.41 \\
18.22\end{array}$ \\
\hline 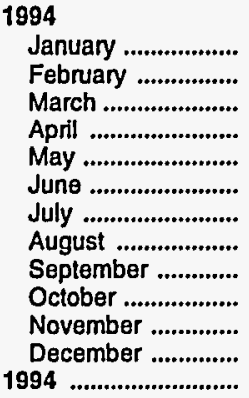 & $\begin{array}{l}11.39 \\
10.24 \\
10.61 \\
11.53 \\
12.36 \\
12.93 \\
13.87 \\
11.71 \\
12.44 \\
12.76 \\
13.22 \\
13.54 \\
12.42\end{array}$ & $\begin{array}{l}10.70 \\
10.43 \\
10.82 \\
12.24 \\
13.12 \\
14.36 \\
15.23 \\
13.83 \\
13.06 \\
13.84 \\
13.85 \\
13.83 \\
12.93\end{array}$ & $\begin{array}{l}12.93 \\
12.38 \\
12.88 \\
14.59 \\
15.56 \\
16.84 \\
17.35 \\
15.68 \\
15.36 \\
15.59 \\
15.78 \\
15.30 \\
15.10\end{array}$ & $\begin{array}{l}12.85 \\
13.21 \\
13.33 \\
14.80 \\
16.30 \\
16.99 \\
17.40 \\
16.49 \\
16.03 \\
15.84 \\
16.34 \\
15.92 \\
15.61\end{array}$ & $\begin{array}{l}14.55 \\
14.37 \\
14.59 \\
15.72 \\
16.87 \\
17.78 \\
18.32 \\
17.53 \\
16.81 \\
17.08 \\
17.41 \\
16.79 \\
16.65\end{array}$ & $\begin{array}{l}15.21 \\
14.43 \\
14.33 \\
15.73 \\
16.55 \\
17.82 \\
18.50 \\
18.06 \\
17.01 \\
17.24 \\
17.51 \\
17.28 \\
16.64\end{array}$ & $\begin{array}{l}14.63 \\
14.63 \\
14.43 \\
15.47 \\
16.50 \\
17.80 \\
18.81 \\
18.77 \\
16.65 \\
16.90 \\
17.44 \\
17.22 \\
16.91\end{array}$ \\
\hline
\end{tabular}

Notes: Values through 1980 reflect the month of reporting; values since then reflect the month of acquisition, which can be the month of loading, the month of landing, or sometime between those events. Prices for crude oil can be determined at a time other than the acquisition date. See the Explanatory Notes section for additional detail.

Sources: Energy Information Administration, Form FEA-F701-M-0, "Transfer Pricing Report," January 1978 through December 1978; Form ERA-51, "Transfer Pricing Report," January 1979 through September 1982; Form EP-51, "Monthly Foreign Crude Oil Transaction Report," October 1982 through June 1984; Form EIA-856, "Monthly Foreign Crude Oil Acquisition Report," July 1984 to present. 
Table 28. Percentages of Total Imported Crude Oil by API Gravity (Percent by Interval)

\begin{tabular}{|c|c|c|c|c|c|c|c|}
\hline $\begin{array}{l}\text { Year } \\
\text { Month }\end{array}$ & $\begin{array}{c}20.0 \\
\text { or } \\
\text { Less }\end{array}$ & $\begin{array}{c}20.1 \\
\text { to } \\
25.0\end{array}$ & $\begin{array}{c}25.1 \\
\text { to } \\
30.0\end{array}$ & $\begin{array}{c}30.1 \\
\text { to } \\
35.0\end{array}$ & $\begin{array}{c}35.1 \\
\text { to } \\
40.0\end{array}$ & $\begin{array}{c}40.1 \\
\text { to } \\
45.0\end{array}$ & $\begin{array}{c}45.1 \\
\text { or } \\
\text { Greater }\end{array}$ \\
\hline $\begin{array}{l}1978 \\
1979 \\
1980 \\
1981 \\
1982 \\
1983\end{array}$ & $\begin{array}{l}1.26 \\
1.65 \\
1.70 \\
2.19 \\
3.39 \\
3.91 \\
6.48 \\
7.62 \\
5.54 \\
4.04 \\
3.52 \\
2.55 \\
3.64 \\
3.76\end{array}$ & $\begin{array}{r}3.57 \\
3.96 \\
6.18 \\
8.88 \\
14.90 \\
20.40 \\
20.52 \\
20.46 \\
19.36 \\
19.68 \\
18.27 \\
14.39 \\
14.96 \\
16.02\end{array}$ & $\begin{array}{r}7.93 \\
8.45 \\
9.25 \\
9.46 \\
11.72 \\
15.14 \\
11.59 \\
11.19 \\
14.12 \\
16.88 \\
15.99 \\
16.80 \\
18.13 \\
20.79\end{array}$ & $\begin{array}{l}38.79 \\
38.98 \\
38.43 \\
37.37 \\
35.58 \\
24.95 \\
21.05 \\
27.14 \\
27.49 \\
26.91 \\
30.72 \\
36.27 \\
34.44 \\
34.84\end{array}$ & $\begin{array}{l}31.66 \\
30.64 \\
27.02 \\
26.60 \\
23.76 \\
23.63 \\
25.75 \\
24.93 \\
25.74 \\
24.79 \\
24.45 \\
23.79 \\
23.21 \\
20.94\end{array}$ & $\begin{array}{r}13.48 \\
13.36 \\
13.56 \\
12.53 \\
8.44 \\
7.74 \\
8.12 \\
4.02 \\
3.65 \\
3.87 \\
4.04 \\
3.55 \\
2.94 \\
2.11\end{array}$ & $\begin{array}{l}3.31 \\
2.96 \\
3.85 \\
2.98 \\
2.20 \\
4.23 \\
6.48 \\
4.65 \\
4.11 \\
3.85 \\
3.02 \\
2.64 \\
2.67 \\
1.55\end{array}$ \\
\hline 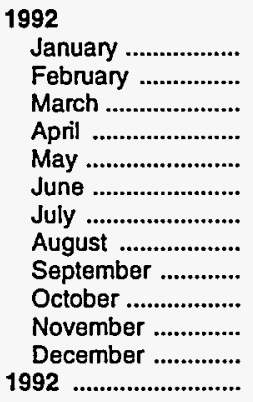 & $\begin{array}{l}3.58 \\
3.04 \\
4.64 \\
2.90 \\
4.24 \\
4.91 \\
4.25 \\
4.09 \\
3.81 \\
4.83 \\
3.85 \\
4.12 \\
4.05\end{array}$ & $\begin{array}{l}18.58 \\
18.66 \\
17.43 \\
18.47 \\
17.87 \\
17.09 \\
17.81 \\
18.15 \\
17.54 \\
17.46 \\
15.65 \\
17.08 \\
17.64\end{array}$ & $\begin{array}{l}26.18 \\
20.73 \\
24.55 \\
21.30 \\
19.27 \\
22.36 \\
21.24 \\
21.36 \\
25.29 \\
23.20 \\
20.05 \\
23.71 \\
22.41\end{array}$ & $\begin{array}{l}32.19 \\
35.10 \\
27.87 \\
33.55 \\
32.27 \\
28.15 \\
29.43 \\
30.46 \\
27.81 \\
33.36 \\
32.64 \\
34.71 \\
31.38\end{array}$ & $\begin{array}{l}15.42 \\
18.44 \\
20.14 \\
19.48 \\
20.83 \\
23.37 \\
22.85 \\
21.68 \\
22.36 \\
18.60 \\
24.33 \\
17.13 \\
20.49\end{array}$ & $\begin{array}{l}2.69 \\
2.38 \\
4.50 \\
3.27 \\
4.46 \\
3.14 \\
3.03 \\
3.24 \\
2.43 \\
2.18 \\
2.49 \\
2.03 \\
3.00\end{array}$ & $\begin{array}{l}1.36 \\
1.66 \\
0.87 \\
1.02 \\
1.07 \\
0.98 \\
1.39 \\
1.02 \\
0.76 \\
0.37 \\
1.00 \\
1.22 \\
1.04\end{array}$ \\
\hline 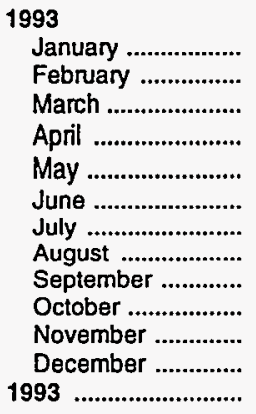 & $\begin{array}{l}4.52 \\
4.19 \\
4.98 \\
3.87 \\
4.08 \\
5.15 \\
4.29 \\
5.99 \\
4.67 \\
4.78 \\
4.39 \\
3.46 \\
4.52\end{array}$ & $\begin{array}{l}18.16 \\
18.11 \\
18.66 \\
19.19 \\
17.79 \\
18.63 \\
20.18 \\
21.29 \\
19.54 \\
18.66 \\
18.81 \\
16.62 \\
18.79\end{array}$ & $\begin{array}{l}22.93 \\
19.48 \\
20.35 \\
18.99 \\
20.20 \\
18.93 \\
22.37 \\
18.91 \\
18.63 \\
16.53 \\
19.45 \\
14.68 \\
19.24\end{array}$ & $\begin{array}{l}28.47 \\
35.50 \\
28.62 \\
34.21 \\
30.71 \\
32.48 \\
29.86 \\
27.30 \\
31.51 \\
36.43 \\
34.22 \\
39.78 \\
32.49\end{array}$ & $\begin{array}{l}23.99 \\
17.92 \\
23.43 \\
20.14 \\
22.34 \\
22.10 \\
20.49 \\
23.42 \\
21.74 \\
17.94 \\
18.98 \\
19.54 \\
20.99\end{array}$ & $\begin{array}{l}1.48 \\
3.57 \\
2.50 \\
2.46 \\
3.43 \\
1.55 \\
1.55 \\
1.69 \\
1.89 \\
3.57 \\
3.15 \\
4.06 \\
2.59\end{array}$ & $\begin{array}{l}0.45 \\
1.22 \\
1.46 \\
1.14 \\
1.45 \\
1.17 \\
1.26 \\
1.40 \\
2.02 \\
2.10 \\
1.00 \\
1.87 \\
1.39\end{array}$ \\
\hline 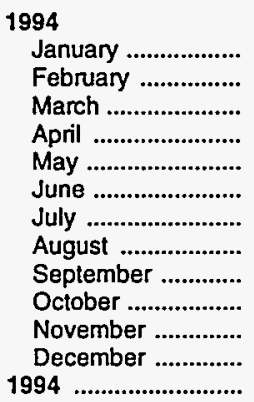 & $\begin{array}{l}4.11 \\
2.31 \\
2.84 \\
3.83 \\
3.29 \\
3.74 \\
4.61 \\
3.66 \\
3.75 \\
4.31 \\
4.03 \\
5.04 \\
3.80\end{array}$ & $\begin{array}{l}23.91 \\
22.26 \\
19.63 \\
20.65 \\
18.38 \\
19.70 \\
16.73 \\
17.89 \\
18.25 \\
16.62 \\
18.13 \\
17.60 \\
18.98\end{array}$ & $\begin{array}{l}21.31 \\
18.45 \\
19.11 \\
20.98 \\
17.25 \\
17.26 \\
20.40 \\
16.13 \\
16.21 \\
19.92 \\
17.87 \\
17.59 \\
18.46\end{array}$ & $\begin{array}{l}25.95 \\
28.61 \\
31.67 \\
31.93 \\
30.44 \\
31.58 \\
29.89 \\
31.55 \\
33.46 \\
31.89 \\
30.78 \\
30.05 \\
30.77\end{array}$ & $\begin{array}{l}19.61 \\
22.18 \\
23.06 \\
19.27 \\
27.38 \\
25.64 \\
22.48 \\
26.68 \\
22.93 \\
21.57 \\
23.73 \\
23.92 \\
23.37\end{array}$ & $\begin{array}{l}3.91 \\
4.36 \\
2.25 \\
1.51 \\
2.24 \\
0.80 \\
2.99 \\
2.21 \\
3.03 \\
3.21 \\
3.74 \\
3.50 \\
2.75\end{array}$ & $\begin{array}{l}1.19 \\
1.83 \\
1.44 \\
1.82 \\
1.03 \\
1.28 \\
2.91 \\
1.89 \\
2.36 \\
2.48 \\
1.72 \\
2.31 \\
1.87\end{array}$ \\
\hline
\end{tabular}

Notes: Values through 1980 reflect the month of reporting; values since then reflect the month of acquisition, which can be the month of loading, the month of landing, or sometime between those events. Prices for crude oil can be determined at a time other than the acquisition date. See the Explanatory Notes section for additional detail.

Sources: Energy Information Administration, Form FEA-F701-M-0, "Transfer Pricing Report," January 1978 through December 1978; Form ERA-51, "Transfer Pricing Report," January 1979 through September 1982; Form EP-51, "Monthly Foreign Crude Oil Transaction Report," October 1982 through June 1984; Form EIA-856, "Monthly Foreign Crude Oil Acquisition Report," July 1984 to present. 
Table 29. F.O.B.a Costs of Imported Crude Oil for Selected Crude Streams (Dollars per Barrel)

\begin{tabular}{|c|c|c|c|c|c|c|c|}
\hline $\begin{array}{c}\text { Year } \\
\text { Quarter } \\
\text { Month }\end{array}$ & $\begin{array}{c}\text { Algerlan } \\
\text { Condensate } \\
\end{array}$ & $\begin{array}{l}\text { Angolan } \\
\text { Cabinda } \\
\end{array}$ & $\begin{array}{c}\text { Canadian } \\
\text { Lloydminster }\end{array}$ & $\begin{array}{c}\text { Cameroon } \\
\text { Kole Marine }\end{array}$ & $\begin{array}{c}\text { Ecuadorian } \\
\text { Orlente }\end{array}$ & $\begin{array}{l}\text { Mexican } \\
\text { Isthmus } \\
\end{array}$ & $\begin{array}{c}\text { Mexlcan } \\
\text { Mayan }\end{array}$ \\
\hline 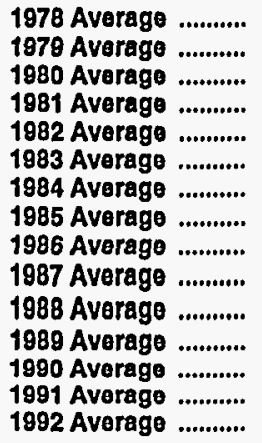 & $\begin{array}{l}W \\
W \\
35.81 \\
38.38 \\
32.58 \\
29.86 \\
27.77 \\
26.57 \\
13.25 \\
16.66 \\
W \\
W \\
W \\
W \\
W\end{array}$ & $\begin{array}{l}13.32 \\
20.35 \\
33.24 \\
35.55 \\
31.86 \\
28.14 \\
27.58 \\
26.30 \\
13.39 \\
17.31 \\
14.52 \\
17.15 \\
w \\
w \\
18.46\end{array}$ & $\begin{array}{c}- \\
\bar{w} \\
W \\
w \\
24.54 \\
24.70 \\
23.79 \\
12.77 \\
15.12 \\
11.28 \\
W \\
18.50 \\
13.51 \\
W\end{array}$ & $\begin{array}{c}W \\
W \\
35.92 \\
37.51 \\
33.73 \\
29.03 \\
28.56 \\
26.86 \\
13.64 \\
W \\
14.28 \\
17.46 \\
W \\
W \\
W\end{array}$ & $\begin{array}{l}12.87 \\
27.59 \\
34.51 \\
32.66 \\
32.36 \\
28.22 \\
28.16 \\
26.12 \\
13.32 \\
16.53 \\
12.96 \\
16.26 \\
W \\
16.04 \\
17.60\end{array}$ & $\begin{array}{l}13.24 \\
20.29 \\
32.78 \\
36.23 \\
32.50 \\
29.41 \\
29.00 \\
27.25 \\
13.88 \\
17.94 \\
14.23 \\
W \\
W \\
23.39 \\
18.55 \\
17.92\end{array}$ & $\begin{array}{l}- \\
21.50 \\
28.73 \\
30.82 \\
25.29 \\
23.99 \\
25.35 \\
24.23 \\
10.93 \\
15.72 \\
11.26 \\
14.71 \\
17.29 \\
13.02 \\
13.42\end{array}$ \\
\hline 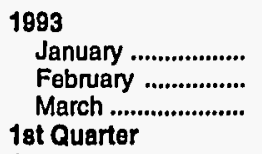 & $\bar{w}$ & $\begin{array}{l}17.03 \\
W \\
W\end{array}$ & $\begin{array}{l}W \\
w \\
w\end{array}$ & $\bar{z}$ & $\begin{array}{l}W \\
W \\
W\end{array}$ & $\begin{array}{l}16.27 \\
17.64 \\
17.82\end{array}$ & $\begin{array}{l}12.31 \\
12.95 \\
13.32\end{array}$ \\
\hline 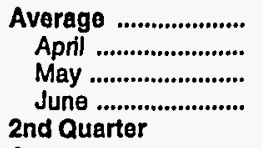 & $\begin{array}{l}W \\
- \\
-\end{array}$ & $\begin{array}{l}17.12 \\
W \\
17.72 \\
16.70\end{array}$ & $\begin{array}{c}W \\
W \\
W \\
13.39\end{array}$ & $\begin{array}{l}\overline{-} \\
\bar{w} \\
w\end{array}$ & $\begin{array}{l}W \\
W \\
W \\
W\end{array}$ & $\begin{array}{l}17.18 \\
17.85 \\
17.88 \\
16.97\end{array}$ & $\begin{array}{l}12.87 \\
13.59 \\
13.19 \\
11.91\end{array}$ \\
\hline 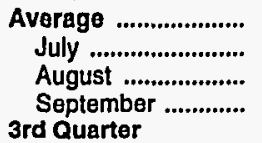 & $\begin{array}{l}\bar{w} \\
\bar{w}\end{array}$ & $\begin{array}{l}17.18 \\
15.71 \\
15.62 \\
14.84\end{array}$ & $\begin{array}{l}W \\
W \\
W \\
W\end{array}$ & $\begin{array}{l}W \\
- \\
- \\
-\end{array}$ & $\begin{array}{c}W \\
14.06 \\
W \\
W\end{array}$ & $\begin{array}{c}17.56 \\
15.47 \\
15.21 \\
W\end{array}$ & $\begin{array}{l}12.90 \\
11.50 \\
11.72 \\
11.83\end{array}$ \\
\hline 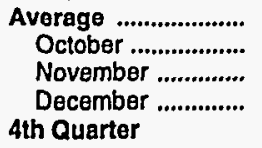 & $\begin{array}{l}w \\
W \\
W \\
W\end{array}$ & $\begin{array}{l}15.44 \\
15.52 \\
13.85 \\
12.02\end{array}$ & $\begin{array}{c}W \\
W \\
11.82 \\
9.81\end{array}$ & $\begin{array}{l}- \\
- \\
-\end{array}$ & $\begin{array}{c}13.61 \\
w \\
w \\
w\end{array}$ & $\begin{array}{l}15.30 \\
15.54 \\
13.97 \\
12.15\end{array}$ & $\begin{array}{r}11.68 \\
11.90 \\
10.33 \\
9.13\end{array}$ \\
\hline 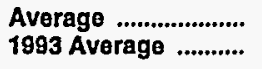 & $\begin{array}{l}w \\
w\end{array}$ & $\begin{array}{l}13.80 \\
15.65\end{array}$ & $\stackrel{11.35}{W}$ & $\bar{w}$ & $\begin{array}{c}W \\
14.57\end{array}$ & $\begin{array}{l}13.86 \\
15.95\end{array}$ & $\begin{array}{l}10.58 \\
12.03\end{array}$ \\
\hline 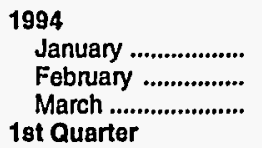 & $\begin{array}{l}\mathbf{W} \\
\bar{w}\end{array}$ & $\begin{array}{c}W \\
13.40 \\
13.65\end{array}$ & $\begin{array}{l}W \\
w \\
w\end{array}$ & $\begin{array}{l}- \\
-\end{array}$ & $\begin{array}{l}W \\
W \\
W\end{array}$ & $\begin{array}{l}12.98 \\
12.71 \\
12.89\end{array}$ & $\begin{array}{r}9.90 \\
9.87 \\
10.01\end{array}$ \\
\hline 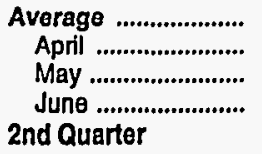 & $\begin{array}{l}W \\
w \\
\bar{w}\end{array}$ & $\begin{array}{c}13.33 \\
14.40 \\
W \\
16.02\end{array}$ & $\begin{array}{l}W \\
W \\
W \\
W\end{array}$ & $\overline{-}$ & $\begin{array}{l}12.33 \\
W \\
W\end{array}$ & $\begin{array}{c}12.88 \\
14.52 \\
15.80 \\
W\end{array}$ & $\begin{array}{r}9.92 \\
11.41 \\
12.32 \\
13.70\end{array}$ \\
\hline 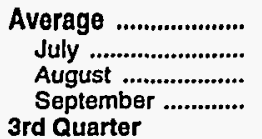 & $\begin{array}{l}W \\
W \\
W \\
-\end{array}$ & $\begin{array}{l}15.20 \\
16.67 \\
15.54 \\
15.33\end{array}$ & $\begin{array}{l}w \\
w \\
w \\
w\end{array}$ & $\begin{array}{l}W \\
- \\
-\end{array}$ & $\begin{array}{c}15.20 \\
W \\
- \\
-\end{array}$ & $\begin{array}{l}15.56 \\
W \\
W \\
W\end{array}$ & $\begin{array}{l}12.48 \\
14.46 \\
13.32 \\
12.22\end{array}$ \\
\hline 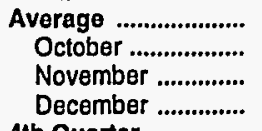 & $\begin{array}{l}w \\
\bar{w}\end{array}$ & $\begin{array}{c}15.89 \\
15.95 \\
W \\
W\end{array}$ & $\begin{array}{l}w \\
w \\
w \\
w\end{array}$ & $\begin{array}{l}\bar{z} \\
\overline{-}\end{array}$ & $\begin{array}{l}w \\
\bar{w}\end{array}$ & $\begin{array}{l}w \\
w \\
w \\
w\end{array}$ & $\begin{array}{l}13.33 \\
13.42 \\
14.04 \\
13.53\end{array}$ \\
\hline 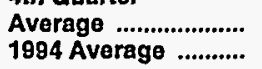 & $\begin{array}{l}w \\
w\end{array}$ & $\begin{array}{l}15.89 \\
15.15\end{array}$ & $\underset{w}{w}$ & $\bar{w}$ & $\begin{array}{c}W \\
13.70\end{array}$ & $\begin{array}{c}W \\
14.79\end{array}$ & $\begin{array}{l}13.67 \\
12.39\end{array}$ \\
\hline
\end{tabular}

See footnotes at end of table. 
Table 29. F.O.B. a Costs of Imported Crude Oil for Selected Crude Streams (Dollars per Barrel) - Continued

\begin{tabular}{|c|c|c|c|c|c|c|c|}
\hline $\begin{array}{l}\text { Year } \\
\text { Quarter } \\
\text { Month }\end{array}$ & $\begin{array}{c}\text { Nigerian } \\
\text { Brass River }\end{array}$ & $\begin{array}{c}\text { Nigerian } \\
\text { Bonny Light }\end{array}$ & $\begin{array}{l}\text { Norweglan } \\
\text { Ekoflsk }\end{array}$ & $\begin{array}{c}\text { Saudl Arabian } \\
\text { Light }\end{array}$ & $\begin{array}{c}\text { Saudi Arabian } \\
\text { Heavy }\end{array}$ & $\begin{array}{c}\text { United KIngdom } \\
\text { Brent }\end{array}$ & $\begin{array}{c}\text { Venezuelan } \\
\text { Boscan }\end{array}$ \\
\hline 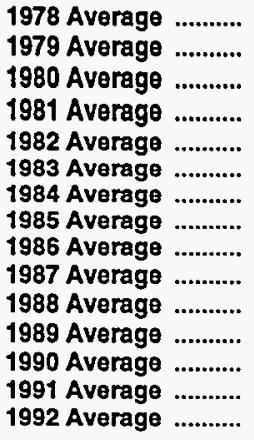 & $\begin{array}{l}14.17 \\
21.89 \\
35.57 \\
38.64 \\
35.18 \\
30.31 \\
29.82 \\
28.23 \\
14.07 \\
18.32 \\
15.39 \\
18.42 \\
23.47 \\
21.10 \\
20.26\end{array}$ & $\begin{array}{l}14.11 \\
25.68 \\
37.71 \\
38.19 \\
35.58 \\
30.07 \\
29.67 \\
W \\
14.02 \\
18.45 \\
15.33 \\
18.58 \\
22.67 \\
20.46 \\
20.10\end{array}$ & $\begin{array}{l}13.91 \\
21.36 \\
35.86 \\
37.72 \\
34.04 \\
29.73 \\
29.17 \\
W \\
16.23 \\
18.25 \\
14.58 \\
17.80 \\
W \\
20.39 \\
19.62\end{array}$ & $\begin{array}{l}12.74 \\
17.33 \\
27.79 \\
32.62 \\
34.08 \\
29.22 \\
29.11 \\
23.70 \\
11.79 \\
14.46 \\
12.98 \\
18.28 \\
21.72 \\
16.83 \\
17.34\end{array}$ & $\begin{array}{l}12.07 \\
15.83 \\
26.14 \\
31.42 \\
31.10 \\
26.30 \\
26.52 \\
W \\
11.00 \\
14.85 \\
11.68 \\
W \\
19.13 \\
13.25 \\
14.76\end{array}$ & $\begin{array}{l}-\overline{21.92} \\
33.13 \\
36.22 \\
33.55 \\
30.30 \\
29.25 \\
27.88 \\
14.07 \\
18.37 \\
14.40 \\
18.38 \\
29.33 \\
22.17 \\
19.74\end{array}$ & 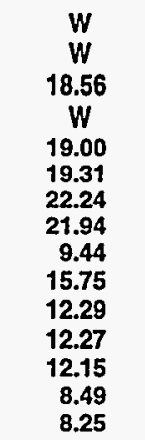 \\
\hline $\begin{array}{l}1993 \\
\text { January ................... } \\
\text { February ................ } \\
\text { March ..................... } \\
\text { 1st Quarter }\end{array}$ & $\begin{array}{c}17.65 \\
W \\
W\end{array}$ & $\begin{array}{l}17.92 \\
19.14 \\
19.42\end{array}$ & $\begin{array}{l}\bar{w} \\
w\end{array}$ & $\begin{array}{l}W \\
W \\
W\end{array}$ & $\begin{array}{l}W \\
W \\
W\end{array}$ & $\begin{array}{c}W \\
18.13 \\
18.51\end{array}$ & $\begin{array}{l}W \\
W \\
-\end{array}$ \\
\hline $\begin{array}{l}\text { Average ................... } \\
\text { April ........................ } \\
\text { May ...................... } \\
\text { June ....................... } \\
\text { 2nd Quarter }\end{array}$ & $\begin{array}{c}19.14 \\
19.34 \\
W \\
W\end{array}$ & $\begin{array}{l}18.64 \\
19.27 \\
18.88 \\
18.09\end{array}$ & $\begin{array}{c}19.22 \\
- \\
W \\
-\end{array}$ & $\begin{array}{l}W \\
W \\
W \\
-\end{array}$ & $\begin{array}{c}15.01 \\
W \\
13.32 \\
W\end{array}$ & $\begin{array}{c}18.40 \\
W \\
W \\
W\end{array}$ & $\begin{array}{l}W \\
\bar{W} \\
8.96\end{array}$ \\
\hline 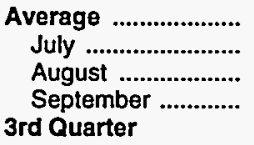 & $\begin{array}{c}19.15 \\
- \\
\bar{w}\end{array}$ & $\begin{array}{c}18.89 \\
17.59 \\
W \\
W\end{array}$ & $\begin{array}{l}W \\
- \\
- \\
-\end{array}$ & $\begin{array}{c}15.90 \\
- \\
- \\
-\end{array}$ & $\begin{array}{c}13.54 \\
W \\
W \\
W\end{array}$ & $\begin{array}{c}18.45 \\
W \\
W \\
W\end{array}$ & $\begin{array}{l}9.50 \\
W \\
W \\
W\end{array}$ \\
\hline $\begin{array}{l}\text { Average ................... } \\
\text { October ................... } \\
\text { November .............. } \\
\text { December .............. } \\
\text { 4th Quarter }\end{array}$ & $\begin{array}{l}W \\
W \\
W \\
W\end{array}$ & $\begin{array}{c}17.39 \\
W \\
16.26 \\
W\end{array}$ & $\begin{array}{l}- \\
- \\
-\end{array}$ & $\begin{array}{l}- \\
W \\
W \\
W\end{array}$ & $\begin{array}{c}W \\
12.38 \\
W \\
W\end{array}$ & $\begin{array}{c}W \\
W \\
W \\
13.99\end{array}$ & $\begin{array}{c}9.61 \\
\bar{W} \\
-\end{array}$ \\
\hline $\begin{array}{l}\text { Average .............. } \\
1993 \text { Average ......... }\end{array}$ & $\begin{array}{l}15.09 \\
17.63\end{array}$ & $\begin{array}{l}15.58 \\
17.89\end{array}$ & $19 . \overline{03}$ & $\begin{array}{l}13.09 \\
15.61\end{array}$ & $\begin{array}{l}10.74 \\
12.70\end{array}$ & $\begin{array}{l}15.09 \\
16.77\end{array}$ & $\begin{array}{l}W \\
9.17\end{array}$ \\
\hline $\begin{array}{l}1994 \\
\text { January ................... } \\
\text { February ................ } \\
\text { March ...................... } \\
\text { 1st Quarter }\end{array}$ & $\begin{array}{c}W \\
14.20 \\
W\end{array}$ & $\begin{array}{c}W \\
14.22 \\
W\end{array}$ & $\begin{array}{l}- \\
-\end{array}$ & $\begin{array}{l}W \\
W \\
W\end{array}$ & $\begin{array}{l}w \\
\bar{w}\end{array}$ & $\begin{array}{l}W \\
W \\
W\end{array}$ & $\overline{-}$ \\
\hline 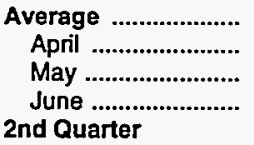 & $\begin{array}{c}14.45 \\
- \\
- \\
w\end{array}$ & $\begin{array}{c}14.50 \\
W \\
W \\
W\end{array}$ & $\begin{array}{l}- \\
- \\
-\end{array}$ & $\begin{array}{c}13.57 \\
W \\
W \\
W\end{array}$ & $\begin{array}{l}W \\
W \\
W \\
W\end{array}$ & $\begin{array}{l}W \\
W \\
W \\
W\end{array}$ & $\begin{array}{l}W \\
W \\
W \\
W\end{array}$ \\
\hline $\begin{array}{l}\text { Average .................. } \\
\text { July ....................... } \\
\text { August .................. } \\
\text { September ............. } \\
\text { 3rd Quarter }\end{array}$ & $\begin{array}{l}W \\
- \\
w \\
W\end{array}$ & $\begin{array}{c}16.55 \\
W \\
W \\
W\end{array}$ & $\begin{array}{l}- \\
- \\
-\end{array}$ & $\begin{array}{c}W \\
W \\
W \\
15.44\end{array}$ & $\begin{array}{c}14.85 \\
W \\
W \\
-\end{array}$ & $\begin{array}{l}W \\
W \\
W \\
W\end{array}$ & $\begin{array}{l}W \\
W \\
W \\
-\end{array}$ \\
\hline $\begin{array}{l}\text { Average .................. } \\
\text { October ................. } \\
\text { November .............. } \\
\text { December .............. } \\
\text { 4th Quarter }\end{array}$ & $\begin{array}{l}W \\
\bar{w} \\
w\end{array}$ & $\begin{array}{l}W \\
W \\
W \\
W\end{array}$ & $\begin{array}{l}- \\
- \\
-\end{array}$ & $\begin{array}{c}14.86 \\
W \\
W \\
W\end{array}$ & $\begin{array}{l}W \\
W \\
- \\
-\end{array}$ & $\begin{array}{l}W \\
W \\
W \\
W\end{array}$ & $\begin{array}{l}8.78 \\
W \\
\bar{W}\end{array}$ \\
\hline $\begin{array}{l}\text { Average ................... } \\
1994 \text { Average ........... }\end{array}$ & $\begin{array}{l}16.94 \\
15.56\end{array}$ & $\begin{array}{c}W \\
16.06\end{array}$ & $\overline{-}$ & $\begin{array}{c}W \\
14.83\end{array}$ & $\begin{array}{c}W \\
13.54\end{array}$ & $\begin{array}{l}W \\
W\end{array}$ & $\begin{array}{l}W \\
8.56\end{array}$ \\
\hline
\end{tabular}

Dash $(-)=$ No data reported.

$W=$ Withheld to avoid disclosure of individual company data.

a Free on Board. See Glossary.

Notes: Values through 1980 reflect the month of reporting; values since then reflect the month of acquisition, which can be the month of loading, the month of landing, or sometime between those events. Prices for crude oil can be determined at a time other than the acquisition date. See the Explanatory Notes section for additional detail.

Sources: Energy Information Administration, Form FEA-F701-M-0, "Transfer Pricing Report," January 1978 through December 1978; Form ERA-51, "Transfer Pricing Report," January 1979 through September 1982; Form EP-51, "Monthly Foreign Crude Oil Transaction Report," October 1982 through June 1984; Form EIA-856, "Monthly Foreign Crude Oil Acquisition Report," July 1984 to present. 
Table 30. Landed Costs of Imported Crude Oil for Selected Crude Streams (Dollars per Barrel)

\begin{tabular}{|c|c|c|c|c|c|c|c|}
\hline $\begin{array}{l}\text { Year } \\
\text { Quarter } \\
\text { Month }\end{array}$ & $\begin{array}{c}\text { Algerian } \\
\text { Condensate }\end{array}$ & $\begin{array}{l}\text { Angolan } \\
\text { Cabinda }\end{array}$ & $\begin{array}{c}\text { Canadian } \\
\text { Lloydminster }\end{array}$ & $\begin{array}{c}\text { Cameroon } \\
\text { Kole Marlne }\end{array}$ & $\begin{array}{c}\text { Ecuadorian } \\
\text { Oriente }\end{array}$ & $\begin{array}{l}\text { Mexican } \\
\text { Isthmus }\end{array}$ & $\begin{array}{c}\text { Mexican } \\
\text { Mayan }\end{array}$ \\
\hline 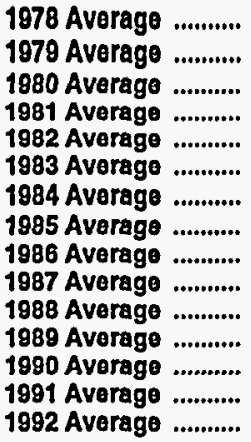 & $\begin{array}{l}W \\
W \\
37.73 \\
40.03 \\
33.71 \\
30.79 \\
28.59 \\
27.21 \\
14.54 \\
17.72 \\
W \\
W \\
W \\
W \\
W\end{array}$ & $\begin{array}{l}14.07 \\
21.51 \\
34.68 \\
36.84 \\
33.08 \\
29.31 \\
28.63 \\
27.48 \\
14.27 \\
18.43 \\
14.96 \\
18.15 \\
20.01 \\
18.31 \\
19.59\end{array}$ & $\begin{array}{c}- \\
- \\
W \\
w \\
W \\
25.27 \\
25.35 \\
24.38 \\
13.52 \\
15.98 \\
12.21 \\
15.36 \\
19.55 \\
14.63 \\
W\end{array}$ & $\begin{array}{c}W \\
25.40 \\
37.89 \\
38.95 \\
34.95 \\
30.28 \\
29.51 \\
27.94 \\
13.71 \\
18.63 \\
15.21 \\
18.71 \\
19.76 \\
W \\
W\end{array}$ & $\begin{array}{l}13.85 \\
29.17 \\
34.61 \\
33.56 \\
32.97 \\
28.90 \\
28.79 \\
26.97 \\
14.39 \\
17.60 \\
13.77 \\
17.69 \\
21.63 \\
17.52 \\
18.52\end{array}$ & $\begin{array}{l}13.54 \\
20.78 \\
33.42 \\
36.87 \\
33.11 \\
30.00 \\
29.46 \\
27.60 \\
14.28 \\
18.32 \\
14.69 \\
W \\
23.79 \\
19.16 \\
18.40\end{array}$ & $\begin{array}{l}- \\
22.23 \\
29.49 \\
31.52 \\
25.86 \\
24.56 \\
25.84 \\
24.57 \\
11.24 \\
16.03 \\
11.65 \\
15.14 \\
17.75 \\
13.62 \\
13.80\end{array}$ \\
\hline $\begin{array}{l}1993 \\
\text { January ................... } \\
\text { February ................ } \\
\text { March ..................... } \\
\text { 18t Quarter }\end{array}$ & $\bar{w}$ & $\begin{array}{l}17.69 \\
17.73 \\
18.80\end{array}$ & $\begin{array}{l}W \\
W \\
W\end{array}$ & $\begin{array}{l}- \\
- \\
-\end{array}$ & $\begin{array}{c}16.72 \\
17.70 \\
W\end{array}$ & $\begin{array}{l}16.83 \\
18.14 \\
18.30\end{array}$ & $\begin{array}{l}12.71 \\
13.35 \\
13.75\end{array}$ \\
\hline $\begin{array}{l}\text { Average .................... } \\
\text { April ......................... } \\
\text { May ....................... } \\
\text { June ......................... } \\
\text { 2nd Quarter }\end{array}$ & $\begin{array}{l}\text { W } \\
- \\
-\end{array}$ & $\begin{array}{l}18.02 \\
18.71 \\
18.84 \\
17.79\end{array}$ & $\begin{array}{c}W \\
W \\
W \\
14.54\end{array}$ & $\begin{array}{l}- \\
\bar{W} \\
W\end{array}$ & $\begin{array}{c}17.23 \\
W \\
18.27 \\
16.45\end{array}$ & $\begin{array}{l}17.69 \\
18.48 \\
18.53 \\
17.55\end{array}$ & $\begin{array}{l}13.28 \\
14.08 \\
13.69 \\
12.45\end{array}$ \\
\hline $\begin{array}{l}\text { Average ..................... } \\
\text { July .......................... } \\
\text { August .................. } \\
\text { September ............. } \\
\text { 3rd Quarter }\end{array}$ & $\begin{array}{l}\vec{w} \\
\bar{w}\end{array}$ & $\begin{array}{l}18.42 \\
17.17 \\
16.72 \\
16.01\end{array}$ & $\begin{array}{c}W \\
13.41 \\
13.35 \\
12.97\end{array}$ & $\begin{array}{l}W \\
- \\
- \\
-\end{array}$ & $\begin{array}{l}17.50 \\
15.83 \\
15.06 \\
14.57\end{array}$ & $\begin{array}{c}18.18 \\
16.06 \\
15.76 \\
W\end{array}$ & $\begin{array}{l}13.40 \\
11.94 \\
12.23 \\
12.22\end{array}$ \\
\hline $\begin{array}{l}\text { Avorage .................... } \\
\text { October ................. } \\
\text { November .............. } \\
\text { December .............. } \\
\text { 4th Quarter }\end{array}$ & $\begin{array}{l}W \\
W \\
W \\
W\end{array}$ & $\begin{array}{l}16.70 \\
16.47 \\
15.15 \\
13.39\end{array}$ & $\begin{array}{l}13.23 \\
13.77 \\
12.91 \\
10.92\end{array}$ & $\begin{array}{l}- \\
- \\
-\end{array}$ & $\begin{array}{l}15.28 \\
15.54 \\
14.32 \\
12.92\end{array}$ & $\begin{array}{l}15.84 \\
16.06 \\
14.49 \\
12.62\end{array}$ & $\begin{array}{r}12.13 \\
12.30 \\
10.74 \\
9.50\end{array}$ \\
\hline $\begin{array}{l}\text { Average ..................... } \\
1993 \text { Average ........... }\end{array}$ & $\begin{array}{l}W \\
W\end{array}$ & $\begin{array}{l}15.00 \\
16.95\end{array}$ & $\begin{array}{l}12.47 \\
13.65\end{array}$ & $\bar{w}$ & $\begin{array}{l}14.28 \\
15.79\end{array}$ & $\begin{array}{l}14.36 \\
16.50\end{array}$ & $\begin{array}{l}10.92 \\
12.45\end{array}$ \\
\hline $\begin{array}{l}1994 \\
\text { January .................. } \\
\text { Febnuary ................ } \\
\text { March ....................... } \\
\text { 1st Quarter }\end{array}$ & $\begin{array}{l}w \\
\bar{w}\end{array}$ & $\begin{array}{l}13.73 \\
14.35 \\
14.28\end{array}$ & $\begin{array}{c}W \\
10.52 \\
10.58\end{array}$ & $\begin{array}{l}- \\
-\end{array}$ & $\begin{array}{l}12.64 \\
13.80 \\
13.20\end{array}$ & $\begin{array}{l}13.52 \\
13.29 \\
13.44\end{array}$ & $\begin{array}{l}10.32 \\
10.31 \\
10.43\end{array}$ \\
\hline 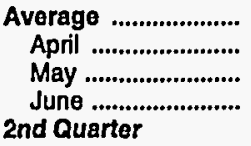 & $\begin{array}{l}W \\
w \\
\bar{w}\end{array}$ & $\begin{array}{l}14.13 \\
15.43 \\
16.45 \\
17.25\end{array}$ & $\begin{array}{l}10.60 \\
12.40 \\
14.21 \\
15.79\end{array}$ & $\begin{array}{l}- \\
\bar{w}\end{array}$ & $\begin{array}{l}13.08 \\
14.72 \\
16.20 \\
16.87\end{array}$ & $\begin{array}{c}13.43 \\
15.10 \\
16.11 \\
W\end{array}$ & $\begin{array}{l}10.35 \\
11.83 \\
12.74 \\
14.15\end{array}$ \\
\hline $\begin{array}{l}\text { Average .................... } \\
\text { July ......................... } \\
\text { August ................... } \\
\text { September ............. } \\
\text { 3rd Quarter }\end{array}$ & $\begin{array}{l}W \\
W \\
W \\
W\end{array}$ & $\begin{array}{l}16.35 \\
17.53 \\
16.59 \\
16.52\end{array}$ & $\begin{array}{c}13.90 \\
16.34 \\
15.69 \\
W\end{array}$ & $\begin{array}{l}W \\
- \\
-\end{array}$ & $\begin{array}{l}15.92 \\
16.62 \\
16.35 \\
15.52\end{array}$ & $\begin{array}{c}16.09 \\
W \\
W \\
W\end{array}$ & $\begin{array}{l}12.89 \\
14.87 \\
13.78 \\
12.64\end{array}$ \\
\hline $\begin{array}{l}\text { Average .................... } \\
\text { October ................... } \\
\text { November ............. } \\
\text { December .............. } \\
\text { 4th Quarter }\end{array}$ & $\begin{array}{l}W \\
W \\
W \\
W\end{array}$ & $\begin{array}{l}16.94 \\
16.59 \\
16.94 \\
16.54\end{array}$ & $\begin{array}{c}15.52 \\
W \\
W \\
W\end{array}$ & $\begin{array}{l}- \\
- \\
-\end{array}$ & $\begin{array}{c}16.29 \\
15.65 \\
W \\
15.75\end{array}$ & $\begin{array}{l}W \\
W \\
W \\
W\end{array}$ & $\begin{array}{l}13.76 \\
13.80 \\
14.42 \\
14.58\end{array}$ \\
\hline 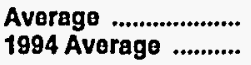 & $\begin{array}{l}W \\
W\end{array}$ & $\begin{array}{l}16.68 \\
16.07\end{array}$ & $\begin{array}{c}W \\
13.58\end{array}$ & $\bar{w}$ & $\begin{array}{l}15.82 \\
15.24\end{array}$ & $\begin{array}{c}W \\
15.36\end{array}$ & $\begin{array}{l}14.24 \\
12.79\end{array}$ \\
\hline
\end{tabular}

See footnotes at end of table. 
Table 30. Landed Costs of Imported Crude Oil for Selected Crude Streams (Dollars per Barrel) - Continued

\begin{tabular}{|c|c|c|c|c|c|c|c|}
\hline $\begin{array}{l}\text { Year } \\
\text { Quarter } \\
\text { Month }\end{array}$ & $\begin{array}{c}\text { Nigerian } \\
\text { Brass River }\end{array}$ & $\begin{array}{c}\text { Nigerian } \\
\text { Bonny Llght }\end{array}$ & $\begin{array}{c}\text { Norweglan } \\
\text { Ekoflslk }\end{array}$ & $\begin{array}{c}\text { Saudi Arablan } \\
\text { Light }\end{array}$ & $\begin{array}{c}\text { Saudl Arabian } \\
\text { Heavy }\end{array}$ & $\begin{array}{c}\text { United Kingdom } \\
\text { Brent }\end{array}$ & $\begin{array}{c}\text { Venezuelan } \\
\text { Boscan }\end{array}$ \\
\hline 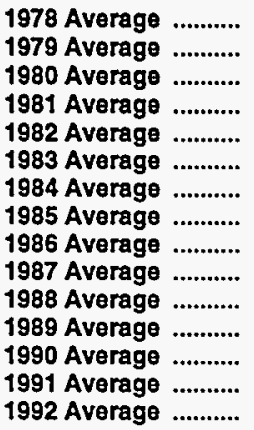 & $\begin{array}{l}14.97 \\
23.19 \\
37.02 \\
40.01 \\
36.26 \\
31.44 \\
30.71 \\
29.14 \\
14.89 \\
19.39 \\
16.06 \\
19.34 \\
24.29 \\
22.27 \\
21.25\end{array}$ & $\begin{array}{l}15.04 \\
27.11 \\
38.58 \\
39.25 \\
36.45 \\
31.06 \\
30.46 \\
28.98 \\
15.00 \\
19.26 \\
16.02 \\
19.38 \\
23.21 \\
21.57 \\
20.85\end{array}$ & $\begin{array}{l}14.68 \\
22.64 \\
36.91 \\
38.70 \\
34.70 \\
30.79 \\
29.99 \\
28.16 \\
15.07 \\
18.96 \\
15.45 \\
18.67 \\
21.53 \\
21.66 \\
20.96\end{array}$ & $\begin{array}{l}14.04 \\
19.18 \\
29.57 \\
34.32 \\
35.65 \\
30.95 \\
30.61 \\
25.35 \\
13.06 \\
17.88 \\
14.04 \\
17.96 \\
22.49 \\
18.49 \\
18.54\end{array}$ & $\begin{array}{l}13.32 \\
17.68 \\
28.16 \\
33.02 \\
32.64 \\
28.12 \\
28.10 \\
23.69 \\
12.17 \\
16.20 \\
12.80 \\
16.56 \\
21.46 \\
15.28 \\
16.10\end{array}$ & $\begin{array}{l}23.26 \\
34.57 \\
37.58 \\
34.53 \\
31.26 \\
29.89 \\
28.49 \\
14.64 \\
18.71 \\
15.84 \\
18.83 \\
24.40 \\
21.65 \\
20.68\end{array}$ & $\begin{array}{c}W \\
W \\
20.34 \\
W \\
20.32 \\
20.69 \\
23.20 \\
22.85 \\
10.42 \\
16.65 \\
13.23 \\
13.16 \\
13.43 \\
10.17 \\
9.65\end{array}$ \\
\hline \multicolumn{8}{|l|}{1993} \\
\hline $\begin{array}{l}\text { January ................... } \\
\text { February .................. } \\
\text { March .................... } \\
\text { 1st Quarter }\end{array}$ & $\begin{array}{l}19.09 \\
19.98 \\
20.61\end{array}$ & $\begin{array}{l}18.79 \\
20.07 \\
20.18\end{array}$ & $\begin{array}{c}\bar{w} \\
20.02\end{array}$ & $\begin{array}{l}17.86 \\
18.27 \\
18.42\end{array}$ & $\begin{array}{l}15.37 \\
15.77 \\
16.34\end{array}$ & $\begin{array}{l}19.05 \\
19.28 \\
19.43\end{array}$ & $\begin{array}{l}W \\
W \\
-\end{array}$ \\
\hline 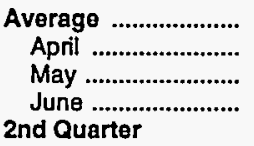 & $\begin{array}{c}19.91 \\
20.73 \\
W \\
W\end{array}$ & $\begin{array}{l}19.52 \\
20.26 \\
19.65 \\
18.91\end{array}$ & $\begin{array}{c}19.95 \\
w \\
W\end{array}$ & $\begin{array}{l}18.20 \\
17.93 \\
17.42 \\
16.82\end{array}$ & $\begin{array}{l}15.78 \\
16.12 \\
15.27 \\
14.56\end{array}$ & $\begin{array}{l}19.31 \\
19.60 \\
19.46 \\
18.98\end{array}$ & $\begin{array}{c}W \\
\bar{w} \\
11.20\end{array}$ \\
\hline $\begin{array}{l}\text { Average .................. } \\
\text { July .......................... } \\
\text { August ................. } \\
\text { September ............ } \\
\text { 3rd Quarter }\end{array}$ & $\begin{array}{l}20.37 \\
W \\
W \\
W\end{array}$ & $\begin{array}{c}19.82 \\
18.26 \\
W \\
W\end{array}$ & $\begin{array}{c}19.31 \\
- \\
- \\
-\end{array}$ & $\begin{array}{l}17.46 \\
16.10 \\
16.30 \\
15.53\end{array}$ & $\begin{array}{l}15.28 \\
13.56 \\
13.91 \\
13.28\end{array}$ & $\begin{array}{l}19.35 \\
17.67 \\
17.65 \\
17.01\end{array}$ & $\begin{array}{l}11.54 \\
W \\
W \\
W\end{array}$ \\
\hline $\begin{array}{l}\text { Average ................... } \\
\text { October ................. } \\
\text { November .............. } \\
\text { December ............... } \\
\text { 4th Quarter }\end{array}$ & $\begin{array}{l}W \\
W \\
W \\
W\end{array}$ & $\begin{array}{c}17.95 \\
17.71 \\
17.24 \\
W\end{array}$ & $\begin{array}{l}- \\
- \\
-\end{array}$ & $\begin{array}{l}15.99 \\
15.25 \\
13.89 \\
12.78\end{array}$ & $\begin{array}{l}13.57 \\
13.56 \\
12.14 \\
10.79\end{array}$ & $\begin{array}{l}17.41 \\
16.95 \\
16.51 \\
15.03\end{array}$ & $\begin{array}{c}11.42 \\
\bar{w} \\
-\end{array}$ \\
\hline $\begin{array}{l}\text { Average .................. } \\
1993 \text { Average .......... }\end{array}$ & $\begin{array}{l}16.25 \\
18.66\end{array}$ & $\begin{array}{l}16.50 \\
18.75\end{array}$ & $19 . \overline{72}$ & $\begin{array}{l}13.93 \\
16.62\end{array}$ & $\begin{array}{l}11.89 \\
14.19\end{array}$ & $\begin{array}{l}16.18 \\
18.02\end{array}$ & $\underset{11.32}{W}$ \\
\hline \multicolumn{8}{|l|}{1994} \\
\hline $\begin{array}{l}\text { January ................... } \\
\text { February ................ } \\
\text { March ..................... } \\
\text { 1st Quarter }\end{array}$ & $\begin{array}{c}W \\
14.73 \\
W\end{array}$ & $\begin{array}{c}W \\
14.87 \\
W\end{array}$ & $\begin{array}{l}- \\
- \\
-\end{array}$ & $\begin{array}{l}12.81 \\
13.42 \\
13.88\end{array}$ & $\begin{array}{l}10.64 \\
10.85 \\
11.74\end{array}$ & $\begin{array}{c}14.98 \\
W \\
14.82\end{array}$ & $\bar{w}$ \\
\hline 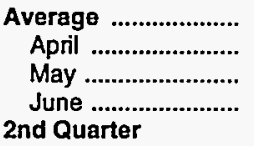 & $\begin{array}{c}15.03 \\
W \\
W \\
17.90\end{array}$ & $\begin{array}{c}15.10 \\
16.42 \\
W \\
W\end{array}$ & $\begin{array}{l}- \\
- \\
-\end{array}$ & $\begin{array}{l}13.46 \\
15.32 \\
16.85 \\
17.38\end{array}$ & $\begin{array}{l}11.15 \\
13.19 \\
14.79 \\
16.00\end{array}$ & $\begin{array}{l}15.14 \\
15.01 \\
16.41 \\
17.63\end{array}$ & $\begin{array}{l}W \\
W \\
W \\
W\end{array}$ \\
\hline 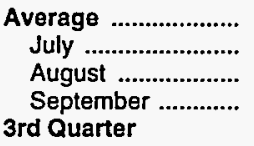 & $\begin{array}{l}16.56 \\
- \\
18.43 \\
17.61\end{array}$ & $\begin{array}{l}17.27 \\
18.72 \\
17.91 \\
17.42\end{array}$ & $\begin{array}{l}- \\
- \\
-\end{array}$ & $\begin{array}{l}16.46 \\
17.01 \\
16.34 \\
16.36\end{array}$ & $\begin{array}{l}14.67 \\
16.57 \\
14.85 \\
14.71\end{array}$ & $\begin{array}{l}16.61 \\
17.95 \\
17.59 \\
17.04\end{array}$ & $\begin{array}{l}W \\
W \\
W \\
W\end{array}$ \\
\hline $\begin{array}{l}\text { Average ................ } \\
\text { October ................ } \\
\text { November ............. } \\
\text { December ............... } \\
\text { 4th Quarter }\end{array}$ & $\begin{array}{c}17.96 \\
W \\
W\end{array}$ & $\begin{array}{c}18.03 \\
17.60 \\
W \\
18.33\end{array}$ & $\begin{array}{l}- \\
- \\
-\end{array}$ & $\begin{array}{l}16.56 \\
15.87 \\
16.60 \\
16.15\end{array}$ & $\begin{array}{l}15.43 \\
14.69 \\
15.52 \\
14.64\end{array}$ & $\begin{array}{l}17.56 \\
17.25 \\
17.19 \\
17.59\end{array}$ & $\begin{array}{c}10.86 \\
W \\
\bar{W}\end{array}$ \\
\hline $\begin{array}{l}\text { Average .................... } \\
1994 \text { Average .......... }\end{array}$ & $\begin{array}{l}17.82 \\
16.30\end{array}$ & $\begin{array}{l}18.02 \\
17.23\end{array}$ & - & $\begin{array}{l}16.16 \\
15.83\end{array}$ & $\begin{array}{l}14.94 \\
14.27\end{array}$ & $\begin{array}{l}17.29 \\
16.65\end{array}$ & $\begin{array}{c}W \\
10.81\end{array}$ \\
\hline
\end{tabular}

Dash $(-)=$ No data reported.

$W=$ Withheld to avoid disclosure of individual company data.

Notes: Values through 1980 reflect the month of reporting; values since then reflect the month of acquisition, which can be the month of loading, the month of landing, or sometime between those events. Prices for crude oil can be determined at a time other than the acquisition date. See the Explanatory Notes section for additional detail.

Sources: Energy Inlormation Administration, Form FEA-F701-M-0, "Transfer Pricing Report," January 1978 through December 1978; Form ERA-51, "Transfer Pricing Report," January 1979 through September 1982; Form EP-51, "Monthly Foreign Crude Oil Transaction Report," October 1982 through June 1984; Form ElA-856, "Monthly Foreign Crude Oil Acquisition Report," July 1984 to present. 
Prices of

Petroleum

Products 
Table 31. Motor Gasoline Prices by Grade, Sales Type, PAD District, and State (Cents per Gallon Excluding Taxes)

\begin{tabular}{|c|c|c|c|c|c|c|c|c|c|c|c|c|}
\hline \multirow{3}{*}{$\begin{array}{c}\text { Geographic Area } \\
\text { Month }\end{array}$} & \multicolumn{6}{|c|}{ Regular } & \multicolumn{6}{|c|}{ Midgrade } \\
\hline & \multicolumn{2}{|c|}{ Sales to End Users } & \multicolumn{4}{|c|}{ Sales for Resale } & \multicolumn{2}{|c|}{ Sales to End Users } & \multicolumn{4}{|c|}{ Sales for Resale } \\
\hline & $\begin{array}{c}\text { Through } \\
\text { Retail } \\
\text { Outlets } \\
\end{array}$ & Averagea & DTW & Rack & Bulk & Average & $\begin{array}{c}\text { Through } \\
\text { Retail } \\
\text { Outlets }\end{array}$ & Averagea & DTW & Rack & Bulk & Averago \\
\hline United States & & & & & & & & & & & & \\
\hline 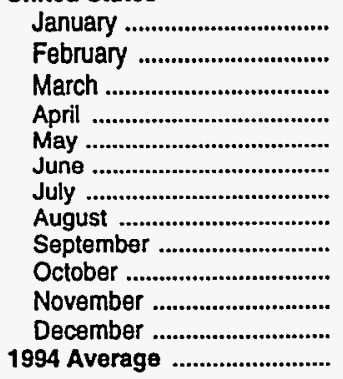 & $\begin{array}{l}62.3 \\
63.3 \\
63.0 \\
65.0 \\
66.7 \\
69.6 \\
72.7 \\
76.7 \\
75.1 \\
72.8 \\
73.0 \\
70.4 \\
69.4\end{array}$ & $\begin{array}{l}61.9 \\
62.9 \\
62.7 \\
64.8 \\
66.4 \\
69.3 \\
72.5 \\
76.3 \\
74.4 \\
72.2 \\
72.5 \\
69.8 \\
69.0\end{array}$ & $\begin{array}{l}55.9 \\
57.3 \\
57.3 \\
59.8 \\
61.3 \\
64.4 \\
67.3 \\
69.5 \\
66.1 \\
65.9 \\
66.5 \\
63.8 \\
62.8\end{array}$ & $\begin{array}{l}46.9 \\
49.8 \\
50.3 \\
53.6 \\
54.9 \\
58.4 \\
61.2 \\
63.7 \\
54.9 \\
55.4 \\
56.1 \\
51.1 \\
54.9\end{array}$ & $\begin{array}{l}41.7 \\
44.7 \\
45.9 \\
49.1 \\
50.2 \\
52.9 \\
55.5 \\
57.6 \\
51.4 \\
50.2 \\
51.7 \\
47.6 \\
49.9\end{array}$ & $\begin{array}{l}49.2 \\
51.7 \\
52.2 \\
55.2 \\
56.6 \\
59.8 \\
62.7 \\
65.0 \\
58.2 \\
58.3 \\
59.0 \\
54.7 \\
57.1\end{array}$ & $\begin{array}{l}70.5 \\
71.6 \\
71.4 \\
73.5 \\
75.1 \\
77.8 \\
80.9 \\
84.8 \\
83.4 \\
81.3 \\
81.7 \\
79.1 \\
77.7\end{array}$ & $\begin{array}{l}69.9 \\
70.9 \\
70.8 \\
72.9 \\
74.5 \\
77.2 \\
80.4 \\
84.1 \\
82.3 \\
80.4 \\
80.9 \\
78.3 \\
77.0\end{array}$ & $\begin{array}{l}61.4 \\
62.8 \\
62.7 \\
65.4 \\
66.8 \\
69.9 \\
72.7 \\
74.9 \\
71.4 \\
71.2 \\
72.1 \\
69.6 \\
68.4\end{array}$ & $\begin{array}{l}51.0 \\
54.0 \\
54.3 \\
57.8 \\
58.8 \\
62.1 \\
64.3 \\
66.7 \\
57.6 \\
59.5 \\
60.9 \\
55.9 \\
58.8\end{array}$ & $\begin{array}{l}\text { NA } \\
\text { NA } \\
\text { NA } \\
\text { NA } \\
\text { NA } \\
\text { NA } \\
\text { NA } \\
\text { NA } \\
\text { NA } \\
\text { NA } \\
\text { NA } \\
\text { NA } \\
\text { NA }\end{array}$ & $\begin{array}{l}56.8 \\
58.8 \\
58.9 \\
61.9 \\
63.1 \\
66.2 \\
68.8 \\
71.1 \\
65.1 \\
65.9 \\
67.1 \\
63.5 \\
64.1\end{array}$ \\
\hline 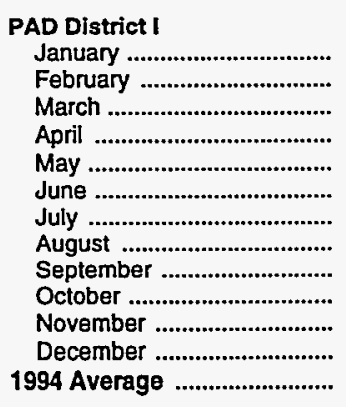 & $\begin{array}{l}60.2 \\
61.3 \\
61.2 \\
62.4 \\
63.7 \\
66.4 \\
69.3 \\
73.3 \\
72.9 \\
71.8 \\
72.8 \\
71.2 \\
67.3\end{array}$ & $\begin{array}{l}59.7 \\
60.9 \\
60.8 \\
62.1 \\
63.4 \\
66.0 \\
69.0 \\
72.7 \\
71.7 \\
70.8 \\
72.1 \\
70.3 \\
66.8\end{array}$ & $\begin{array}{l}55.4 \\
56.8 \\
56.6 \\
58.3 \\
59.8 \\
63.0 \\
65.4 \\
67.9 \\
64.3 \\
64.6 \\
66.5 \\
64.7 \\
62.1\end{array}$ & $\begin{array}{l}46.1 \\
49.1 \\
49.4 \\
52.4 \\
53.5 \\
56.5 \\
58.1 \\
60.2 \\
51.6 \\
54.6 \\
57.0 \\
52.2 \\
53.6\end{array}$ & $\begin{array}{l}43.0 \\
45.1 \\
45.5 \\
48.9 \\
50.7 \\
53.3 \\
55.5 \\
56.8 \\
50.3 \\
50.3 \\
55.8 \\
51.4 \\
50.8\end{array}$ & $\begin{array}{l}49.4 \\
51.7 \\
51.6 \\
54.4 \\
55.6 \\
58.5 \\
60.6 \\
62.8 \\
56.1 \\
57.9 \\
60.5 \\
56.8 \\
56.6\end{array}$ & $\begin{array}{l}71.0 \\
71.8 \\
71.7 \\
72.8 \\
74.2 \\
76.7 \\
79.5 \\
83.2 \\
83.0 \\
81.9 \\
82.9 \\
81.2 \\
77.6\end{array}$ & $\begin{array}{l}70.2 \\
71.0 \\
70.9 \\
72.1 \\
73.5 \\
76.0 \\
78.9 \\
82.3 \\
81.5 \\
80.7 \\
81.9 \\
80.1 \\
76.8\end{array}$ & $\begin{array}{l}62.0 \\
63.1 \\
62.7 \\
64.6 \\
65.9 \\
69.0 \\
71.4 \\
74.0 \\
70.8 \\
70.9 \\
73.0 \\
71.3 \\
68.3\end{array}$ & $\begin{array}{l}50.6 \\
53.7 \\
53.9 \\
57.0 \\
58.0 \\
61.1 \\
62.6 \\
65.2 \\
56.5 \\
59.1 \\
62.1 \\
56.9 \\
58.3\end{array}$ & $\begin{array}{l}N A \\
N A \\
W \\
N A \\
W \\
N A \\
W \\
W \\
W \\
W \\
W \\
W \\
N A\end{array}$ & $\begin{array}{l}56.7 \\
58.8 \\
58.6 \\
61.1 \\
62.2 \\
65.3 \\
67.2 \\
69.8 \\
63.9 \\
65.3 \\
67.9 \\
64.5 \\
63.6\end{array}$ \\
\hline 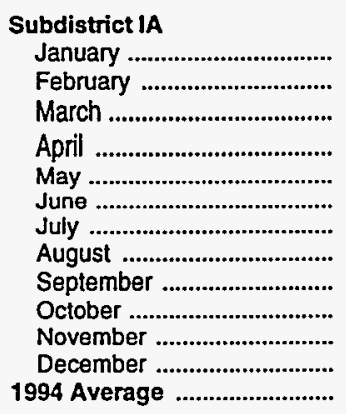 & $\begin{array}{l}64.7 \\
65.6 \\
65.3 \\
66.0 \\
67.9 \\
71.0 \\
73.8 \\
78.2 \\
77.7 \\
76.6 \\
77.4 \\
75.5 \\
71.9\end{array}$ & $\begin{array}{l}63.9 \\
64.6 \\
64.4 \\
65.3 \\
67.2 \\
70.2 \\
73.1 \\
77.4 \\
76.1 \\
75.7 \\
76.5 \\
74.8 \\
71.0\end{array}$ & $\begin{array}{l}56.8 \\
58.8 \\
58.6 \\
59.1 \\
61.0 \\
64.4 \\
67.0 \\
70.4 \\
67.6 \\
66.7 \\
68.5 \\
69.5 \\
64.3\end{array}$ & $\begin{array}{l}46.9 \\
49.9 \\
49.8 \\
52.2 \\
54.6 \\
57.4 \\
58.6 \\
61.2 \\
53.8 \\
55.1 \\
58.7 \\
57.6 \\
55.0\end{array}$ & $\begin{array}{l}42.4 \\
44.4 \\
44.9 \\
48.7 \\
49.2 \\
53.4 \\
53.9 \\
55.8 \\
48.4 \\
48.4 \\
54.4 \\
52.6 \\
49.8\end{array}$ & $\begin{array}{l}50.4 \\
52.3 \\
52.2 \\
54.6 \\
55.7 \\
59.4 \\
60.9 \\
63.9 \\
57.5 \\
57.6 \\
62.0 \\
61.4 \\
57.6\end{array}$ & $\begin{array}{l}75.7 \\
76.3 \\
76.2 \\
77.0 \\
79.0 \\
81.6 \\
84.4 \\
88.6 \\
88.3 \\
87.5 \\
87.6 \\
85.4 \\
82.5\end{array}$ & $\begin{array}{l}73.9 \\
74.6 \\
74.5 \\
75.5 \\
77.5 \\
79.9 \\
82.6 \\
87.0 \\
85.7 \\
85.8 \\
85.8 \\
83.8 \\
80.8\end{array}$ & $\begin{array}{l}63.5 \\
65.2 \\
65.0 \\
65.6 \\
67.1 \\
70.5 \\
73.3 \\
76.6 \\
74.4 \\
73.4 \\
75.5 \\
76.5 \\
70.8\end{array}$ & $\begin{array}{l}50.8 \\
53.9 \\
53.7 \\
56.0 \\
58.8 \\
61.4 \\
62.8 \\
65.7 \\
57.9 \\
59.3 \\
62.8 \\
61.3 \\
59.1\end{array}$ & $\begin{array}{l}\text { W } \\
- \\
- \\
- \\
- \\
\bar{W} \\
- \\
\bar{W} \\
\bar{W} \\
\text { NA }\end{array}$ & $\begin{array}{l}57.7 \\
60.4 \\
60.0 \\
61.4 \\
63.4 \\
66.5 \\
68.6 \\
71.4 \\
66.5 \\
66.7 \\
69.9 \\
69.7 \\
65.5\end{array}$ \\
\hline 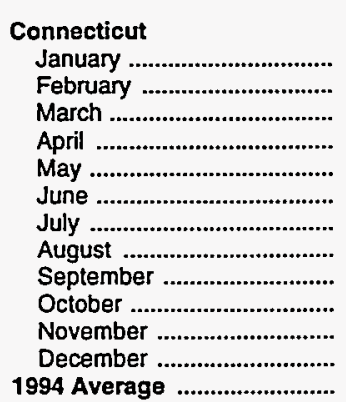 & $\begin{array}{l}65.7 \\
66.1 \\
65.3 \\
65.7 \\
67.0 \\
69.7 \\
72.3 \\
75.7 \\
75.3 \\
75.4 \\
76.3 \\
74.7 \\
71.1\end{array}$ & $\begin{array}{l}64.5 \\
65.0 \\
64.4 \\
65.0 \\
66.4 \\
69.1 \\
71.7 \\
74.9 \\
74.0 \\
74.5 \\
75.5 \\
73.8 \\
70.2\end{array}$ & $\begin{array}{l}58.9 \\
60.7 \\
60.6 \\
61.3 \\
61.6 \\
64.8 \\
67.5 \\
70.9 \\
68.4 \\
68.1 \\
69.8 \\
70.5 \\
65.3\end{array}$ & $\begin{array}{l}47.3 \\
50.4 \\
50.7 \\
52.9 \\
54.6 \\
57.4 \\
58.5 \\
61.0 \\
54.1 \\
56.5 \\
60.0 \\
58.9 \\
55.6\end{array}$ & $\begin{array}{c}W \\
W \\
W \\
W \\
W \\
W \\
54.5 \\
W \\
W \\
W \\
W \\
W \\
50.1\end{array}$ & $\begin{array}{l}52.4 \\
52.8 \\
54.3 \\
55.7 \\
55.9 \\
60.7 \\
60.5 \\
65.7 \\
59.3 \\
59.8 \\
64.3 \\
62.9 \\
58.9\end{array}$ & $\begin{array}{l}77.7 \\
77.9 \\
77.4 \\
78.1 \\
79.4 \\
81.3 \\
83.5 \\
87.0 \\
86.7 \\
87.0 \\
87.9 \\
85.1 \\
82.6\end{array}$ & $\begin{array}{l}74.7 \\
74.9 \\
74.5 \\
75.8 \\
77.1 \\
78.9 \\
81.4 \\
84.5 \\
83.3 \\
84.7 \\
84.7 \\
82.5 \\
80.1\end{array}$ & $\begin{array}{l}65.6 \\
67.2 \\
66.7 \\
67.2 \\
67.0 \\
70.4 \\
73.1 \\
76.5 \\
74.5 \\
74.3 \\
75.7 \\
76.6 \\
71.2\end{array}$ & $\begin{array}{l}51.0 \\
54.5 \\
54.3 \\
56.5 \\
58.6 \\
61.2 \\
62.4 \\
65.3 \\
58.3 \\
60.4 \\
63.8 \\
62.7 \\
59.3\end{array}$ & $\begin{array}{l}\text { W } \\
- \\
- \\
- \\
- \\
- \\
- \\
- \\
- \\
- \\
- \\
\bar{w}\end{array}$ & $\begin{array}{l}58.5 \\
61.6 \\
61.0 \\
62.4 \\
63.3 \\
66.3 \\
68.3 \\
71.2 \\
66.7 \\
67.5 \\
70.2 \\
70.7 \\
65.8\end{array}$ \\
\hline
\end{tabular}

See footnotes at end of table. 
Table 31. Motor Gasoline Prices by Grade, Sales Type, PAD District, and State (Cents per Gallon Excluding Taxes) - Continued

\begin{tabular}{|c|c|c|c|c|c|c|c|c|c|c|c|c|}
\hline \multirow{3}{*}{$\begin{array}{l}\text { Geographic Area } \\
\text { Month }\end{array}$} & \multicolumn{6}{|c|}{ Premium } & \multicolumn{6}{|c|}{ All Grades } \\
\hline & \multicolumn{2}{|c|}{ Sales to End Users } & \multicolumn{4}{|c|}{ Sales for Resale } & \multicolumn{2}{|c|}{ Sales to End Users } & \multicolumn{4}{|c|}{ Sales for Resale } \\
\hline & $\begin{array}{c}\text { Through } \\
\text { Retail } \\
\text { Outlets }\end{array}$ & Average ${ }^{a}$ & DTW & Rack & Bulk & Average & $\begin{array}{c}\text { Through } \\
\text { Retail } \\
\text { Outlets }\end{array}$ & Average ${ }^{a}$ & DTW & Rack & Bulk & Average \\
\hline United States & & & & & & & & & & & & \\
\hline 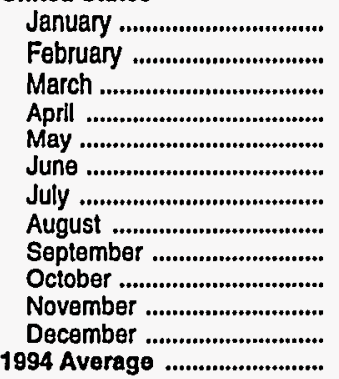 & $\begin{array}{l}79.5 \\
79.5 \\
80.4 \\
82.3 \\
84.0 \\
86.5 \\
89.4 \\
93.3 \\
92.0 \\
90.0 \\
90.5 \\
88.1 \\
86.3\end{array}$ & $\begin{array}{l}78.5 \\
78.6 \\
79.4 \\
81.4 \\
83.1 \\
85.6 \\
88.6 \\
92.1 \\
90.6 \\
88.8 \\
89.4 \\
86.9 \\
85.2\end{array}$ & $\begin{array}{l}69.5 \\
70.7 \\
70.7 \\
73.0 \\
74.5 \\
77.8 \\
80.5 \\
82.9 \\
80.1 \\
80.0 \\
80.6 \\
78.4 \\
76.4\end{array}$ & $\begin{array}{l}56.0 \\
58.8 \\
59.3 \\
62.8 \\
64.1 \\
67.7 \\
70.3 \\
73.0 \\
63.7 \\
65.3 \\
66.1 \\
61.0 \\
64.2\end{array}$ & $\begin{array}{l}47.2 \\
49.3 \\
50.5 \\
55.1 \\
57.2 \\
59.9 \\
62.7 \\
64.8 \\
55.7 \\
55.7 \\
57.6 \\
52.2 \\
55.6\end{array}$ & $\begin{array}{l}61.9 \\
63.8 \\
64.4 \\
67.5 \\
68.6 \\
72.0 \\
74.9 \\
77.2 \\
71.1 \\
71.9 \\
72.6 \\
68.6 \\
69.6\end{array}$ & $\begin{array}{l}66.6 \\
67.5 \\
67.3 \\
69.3 \\
70.9 \\
73.7 \\
76.8 \\
80.7 \\
79.2 \\
77.0 \\
77.2 \\
74.8 \\
73.6\end{array}$ & $\begin{array}{l}66.1 \\
67.0 \\
66.8 \\
68.8 \\
70.5 \\
73.3 \\
76.4 \\
80.0 \\
78.2 \\
76.2 \\
76.5 \\
74.1 \\
72.9\end{array}$ & $\begin{array}{l}60.1 \\
61.3 \\
61.3 \\
63.8 \\
65.3 \\
68.3 \\
71.2 \\
73.2 \\
70.0 \\
69.9 \\
70.6 \\
68.1 \\
66.8\end{array}$ & $\begin{array}{l}49.0 \\
51.8 \\
52.3 \\
55.7 \\
57.0 \\
60.5 \\
63.2 \\
65.6 \\
56.6 \\
57.5 \\
58.3 \\
53.4 \\
56.9\end{array}$ & $\begin{array}{l}42.4 \\
45.3 \\
46.3 \\
49.6 \\
51.1 \\
53.9 \\
56.3 \\
58.4 \\
51.8 \\
50.7 \\
52.2 \\
48.0 \\
50.5\end{array}$ & $\begin{array}{l}52.5 \\
54.8 \\
55.3 \\
58.3 \\
59.7 \\
62.9 \\
65.7 \\
67.9 \\
61.4 \\
61.7 \\
62.4 \\
58.3 \\
60.2\end{array}$ \\
\hline 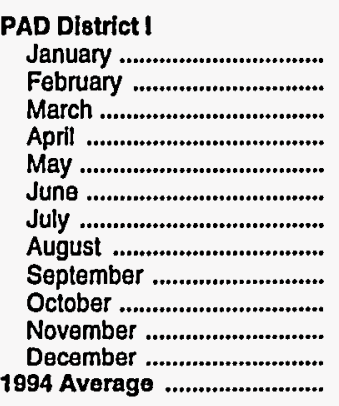 & $\begin{array}{l}80.5 \\
81.1 \\
81.0 \\
82.2 \\
83.4 \\
85.5 \\
88.2 \\
92.6 \\
92.3 \\
91.3 \\
92.2 \\
90.6 \\
86.7\end{array}$ & $\begin{array}{l}79.4 \\
80.0 \\
79.9 \\
81.1 \\
82.5 \\
84.7 \\
87.4 \\
91.3 \\
90.6 \\
89.8 \\
91.0 \\
89.2 \\
85.6\end{array}$ & $\begin{array}{l}70.4 \\
71.4 \\
70.9 \\
72.5 \\
74.0 \\
77.5 \\
80.0 \\
82.8 \\
80.2 \\
80.3 \\
81.9 \\
80.5 \\
76.8\end{array}$ & $\begin{array}{l}56.3 \\
59.1 \\
59.4 \\
62.6 \\
64.1 \\
67.1 \\
69.0 \\
71.6 \\
62.6 \\
65.8 \\
68.0 \\
62.7 \\
64.2\end{array}$ & $\begin{array}{l}50.5 \\
51.3 \\
51.0 \\
56.2 \\
61.0 \\
61.4 \\
66.5 \\
68.8 \\
54.8 \\
59.3 \\
61.1 \\
53.9 \\
57.7\end{array}$ & $\begin{array}{l}63.2 \\
64.9 \\
64.9 \\
67.5 \\
68.9 \\
71.9 \\
74.6 \\
77.0 \\
71.0 \\
72.9 \\
74.7 \\
70.7 \\
70.3\end{array}$ & $\begin{array}{l}66.5 \\
67.4 \\
67.3 \\
68.5 \\
69.8 \\
72.3 \\
75.1 \\
78.9 \\
78.6 \\
77.5 \\
78.5 \\
77.0 \\
73.2\end{array}$ & $\begin{array}{l}65.8 \\
66.7 \\
66.6 \\
67.9 \\
69.3 \\
71.8 \\
74.7 \\
78.1 \\
77.2 \\
76.4 \\
77.7 \\
76.0 \\
72.5\end{array}$ & $\begin{array}{l}61.0 \\
62.2 \\
61.8 \\
63.6 \\
65.1 \\
68.3 \\
70.7 \\
73.1 \\
69.8 \\
70.0 \\
71.8 \\
70.2 \\
67.3\end{array}$ & $\begin{array}{l}49.0 \\
52.0 \\
52.3 \\
55.3 \\
56.6 \\
59.5 \\
61.2 \\
63.4 \\
54.7 \\
57.7 \\
60.0 \\
55.1 \\
56.6\end{array}$ & $\begin{array}{l}44.7 \\
46.3 \\
46.3 \\
50.1 \\
52.6 \\
54.8 \\
56.8 \\
58.7 \\
50.7 \\
51.2 \\
56.5 \\
51.9 \\
51.9\end{array}$ & $\begin{array}{l}54.0 \\
56.0 \\
55.9 \\
58.6 \\
59.9 \\
62.8 \\
65.0 \\
67.1 \\
60.7 \\
62.4 \\
64.8 \\
61.2 \\
60.9\end{array}$ \\
\hline 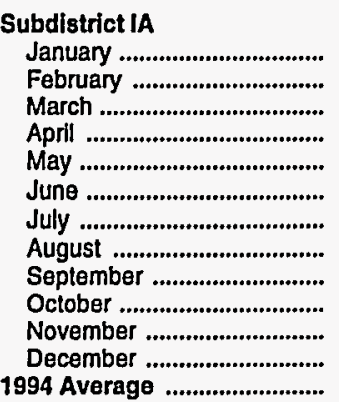 & $\begin{array}{l}84.4 \\
85.0 \\
84.8 \\
85.7 \\
87.8 \\
90.0 \\
92.7 \\
96.7 \\
96.7 \\
95.9 \\
96.5 \\
94.8 \\
90.8\end{array}$ & $\begin{array}{l}82.8 \\
83.1 \\
82.6 \\
84.0 \\
86.3 \\
88.4 \\
91.1 \\
95.4 \\
94.4 \\
94.4 \\
94.9 \\
93.2 \\
89.1\end{array}$ & $\begin{array}{l}70.5 \\
72.6 \\
72.2 \\
72.9 \\
75.0 \\
78.4 \\
81.4 \\
85.1 \\
82.4 \\
81.4 \\
82.8 \\
83.7 \\
78.2\end{array}$ & $\begin{array}{l}57.0 \\
60.1 \\
59.6 \\
62.1 \\
65.8 \\
68.1 \\
70.1 \\
73.6 \\
65.1 \\
66.9 \\
69.7 \\
68.1 \\
65.7\end{array}$ & $\begin{array}{l}49.1 \\
W \\
W \\
W \\
W \\
62.7 \\
66.1 \\
69.5 \\
56.8 \\
W \\
W \\
W \\
58.0\end{array}$ & $\begin{array}{l}63.4 \\
65.2 \\
66.0 \\
67.7 \\
70.4 \\
72.6 \\
75.7 \\
79.1 \\
73.0 \\
73.6 \\
76.1 \\
75.1 \\
71.6\end{array}$ & $\begin{array}{l}70.9 \\
71.5 \\
71.2 \\
71.9 \\
73.8 \\
76.5 \\
79.4 \\
83.5 \\
83.1 \\
82.2 \\
82.8 \\
80.9 \\
77.5\end{array}$ & $\begin{array}{l}69.8 \\
70.3 \\
70.0 \\
70.9 \\
72.8 \\
75.5 \\
78.4 \\
82.5 \\
81.3 \\
81.1 \\
81.7 \\
79.9 \\
76.3\end{array}$ & $\begin{array}{l}61.6 \\
63.5 \\
63.1 \\
63.7 \\
65.6 \\
69.0 \\
71.7 \\
75.0 \\
72.3 \\
71.3 \\
73.1 \\
74.0 \\
68.8\end{array}$ & $\begin{array}{l}49.9 \\
52.9 \\
52.7 \\
54.9 \\
57.7 \\
60.4 \\
61.8 \\
64.5 \\
56.8 \\
58.2 \\
61.5 \\
60.4 \\
58.0\end{array}$ & $\begin{array}{l}43.2 \\
45.6 \\
45.1 \\
48.9 \\
49.7 \\
54.6 \\
54.3 \\
56.4 \\
49.0 \\
48.9 \\
54.5 \\
52.8 \\
50.3\end{array}$ & $\begin{array}{l}54.5 \\
56.4 \\
56.2 \\
58.4 \\
59.7 \\
63.3 \\
65.1 \\
68.1 \\
61.7 \\
61.9 \\
66.0 \\
65.3 \\
61.6\end{array}$ \\
\hline 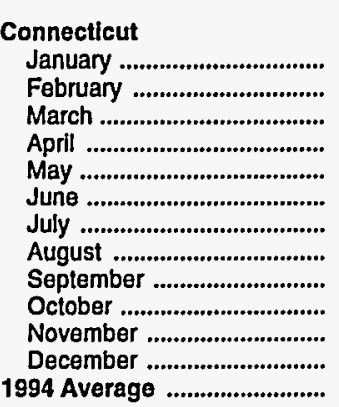 & $\begin{array}{l}87.3 \\
87.8 \\
87.2 \\
88.1 \\
89.3 \\
90.8 \\
93.5 \\
96.8 \\
96.6 \\
97.2 \\
97.8 \\
96.0 \\
92.3\end{array}$ & $\begin{array}{l}85.5 \\
86.1 \\
85.4 \\
86.7 \\
88.0 \\
89.2 \\
92.0 \\
95.1 \\
94.5 \\
95.8 \\
96.1 \\
93.8 \\
90.7\end{array}$ & $\begin{array}{l}72.4 \\
74.9 \\
74.7 \\
75.4 \\
75.5 \\
78.8 \\
81.7 \\
84.9 \\
82.8 \\
82.4 \\
83.7 \\
84.5 \\
79.0\end{array}$ & $\begin{array}{l}57.6 \\
61.6 \\
61.3 \\
63.7 \\
66.1 \\
68.5 \\
70.2 \\
73.4 \\
66.2 \\
68.9 \\
72.3 \\
72.5 \\
67.1\end{array}$ & $\begin{array}{l}W \\
- \\
- \\
- \\
\bar{W} \\
- \\
\bar{w} \\
W \\
\bar{w} \\
\overline{54.1}\end{array}$ & $\begin{array}{l}64.1 \\
68.4 \\
68.2 \\
69.8 \\
70.9 \\
73.4 \\
76.0 \\
79.2 \\
74.0 \\
74.5 \\
77.9 \\
78.3 \\
72.9\end{array}$ & $\begin{array}{l}72.9 \\
73.1 \\
72.3 \\
72.9 \\
74.3 \\
76.5 \\
78.9 \\
82.0 \\
81.7 \\
82.0 \\
82.7 \\
80.7 \\
77.7\end{array}$ & $\begin{array}{l}71.2 \\
71.6 \\
70.9 \\
71.8 \\
73.3 \\
75.4 \\
77.9 \\
80.8 \\
80.0 \\
80.8 \\
81.4 \\
79.4 \\
76.5\end{array}$ & $\begin{array}{l}63.9 \\
65.8 \\
65.4 \\
66.1 \\
66.3 \\
69.7 \\
72.3 \\
75.3 \\
73.0 \\
72.7 \\
74.2 \\
74.8 \\
69.9\end{array}$ & $\begin{array}{l}50.6 \\
53.8 \\
54.0 \\
56.1 \\
58.1 \\
60.8 \\
61.9 \\
64.6 \\
57.5 \\
59.9 \\
63.4 \\
62.5 \\
59.0\end{array}$ & $\begin{array}{c}45.8 \\
W \\
W \\
W \\
W \\
W \\
54.5 \\
W \\
W \\
52.3 \\
W \\
W \\
\mathbf{5 0 . 3}\end{array}$ & $\begin{array}{l}56.7 \\
57.6 \\
58.7 \\
59.9 \\
60.2 \\
64.9 \\
64.8 \\
69.8 \\
63.7 \\
64.0 \\
68.4 \\
67.3 \\
63.2\end{array}$ \\
\hline
\end{tabular}

See footnotes at end of table. 
Table 31. Motor Gasoline Prices by Grade, Sales Type, PAD District, and State (Cents per Gallon Excluding Taxes) - Continued

\begin{tabular}{|c|c|c|c|c|c|c|c|c|c|c|c|c|}
\hline \multirow{3}{*}{$\begin{array}{l}\text { Geographlc Area } \\
\text { Month }\end{array}$} & \multicolumn{6}{|c|}{ Regular } & \multicolumn{6}{|c|}{ Midgrade } \\
\hline & \multicolumn{2}{|c|}{ Sales to End Users } & \multicolumn{4}{|c|}{ Sales for Resale } & \multicolumn{2}{|c|}{ Sales to End Users } & \multicolumn{4}{|c|}{ Sales for Resale } \\
\hline & $\begin{array}{c}\text { Through } \\
\text { Retail } \\
\text { Outlots }\end{array}$ & Averagea & DTW & Rack & Bulk & Average & $\begin{array}{c}\text { Through } \\
\text { Retail } \\
\text { Outlets }\end{array}$ & Averagea & DTW & Rack & Bulk & Average \\
\hline Maine & & & & & & & & & & & & \\
\hline 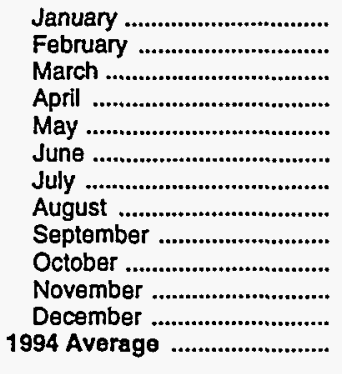 & $\begin{array}{l}67.7 \\
69.2 \\
69.3 \\
70.4 \\
73.9 \\
76.3 \\
76.8 \\
80.7 \\
79.5 \\
77.5 \\
80.2 \\
77.2 \\
75.1\end{array}$ & $\begin{array}{l}66.9 \\
68.4 \\
68.7 \\
69.9 \\
73.3 \\
75.8 \\
76.4 \\
80.7 \\
79.0 \\
76.9 \\
79.5 \\
76.5 \\
74.5\end{array}$ & $\begin{array}{l}55.7 \\
57.7 \\
57.9 \\
59.4 \\
61.1 \\
64.2 \\
65.3 \\
70.1 \\
66.2 \\
64.7 \\
67.5 \\
65.0 \\
62.9\end{array}$ & $\begin{array}{l}48.2 \\
51.6 \\
51.5 \\
53.9 \\
56.5 \\
59.4 \\
60.5 \\
62.7 \\
55.2 \\
55.0 \\
59.4 \\
56.6 \\
56.2\end{array}$ & $\begin{array}{c}W \\
47.9 \\
48.0 \\
50.0 \\
W \\
57.2 \\
W \\
60.8 \\
50.3 \\
48.2 \\
W \\
52.0 \\
51.7\end{array}$ & $\begin{array}{l}49.0 \\
52.6 \\
52.6 \\
54.6 \\
57.7 \\
60.4 \\
61.8 \\
64.1 \\
57.1 \\
55.6 \\
61.1 \\
57.2 \\
57.1\end{array}$ & $\begin{array}{l}76.3 \\
78.2 \\
78.3 \\
80.5 \\
83.8 \\
85.7 \\
86.4 \\
90.3 \\
89.3 \\
87.3 \\
89.3 \\
86.8 \\
84.6\end{array}$ & $\begin{array}{l}75.2 \\
77.0 \\
76.9 \\
79.4 \\
82.6 \\
84.4 \\
85.4 \\
89.3 \\
87.6 \\
86.2 \\
88.1 \\
85.6 \\
83.3\end{array}$ & $\begin{array}{l}60.4 \\
62.2 \\
63.4 \\
64.2 \\
65.8 \\
69.4 \\
70.6 \\
75.2 \\
71.0 \\
76.8 \\
80.1 \\
77.7 \\
70.4\end{array}$ & $\begin{array}{l}51.9 \\
55.3 \\
55.4 \\
57.6 \\
60.5 \\
63.5 \\
64.6 \\
67.0 \\
59.5 \\
58.5 \\
63.2 \\
60.8 \\
60.2\end{array}$ & $\begin{array}{l}- \\
- \\
- \\
- \\
- \\
- \\
- \\
\overline{-} \\
\bar{w} \\
- \\
\bar{w}\end{array}$ & $\begin{array}{l}54.3 \\
57.3 \\
57.7 \\
59.6 \\
61.9 \\
65.2 \\
66.1 \\
68.9 \\
62.3 \\
62.5 \\
68.8 \\
66.4 \\
62.9\end{array}$ \\
\hline 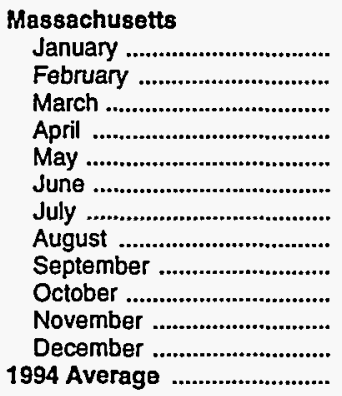 & $\begin{array}{l}61.9 \\
62.6 \\
62.6 \\
63.3 \\
65.1 \\
68.0 \\
71.5 \\
77.1 \\
76.7 \\
75.4 \\
75.9 \\
75.3 \\
69.8\end{array}$ & $\begin{array}{l}61.1 \\
61.6 \\
61.6 \\
62.7 \\
64.3 \\
67.0 \\
70.5 \\
75.9 \\
74.5 \\
74.3 \\
75.0 \\
74.6 \\
68.6\end{array}$ & $\begin{array}{l}55.7 \\
57.7 \\
57.4 \\
57.6 \\
60.2 \\
63.7 \\
66.8 \\
69.9 \\
67.5 \\
66.8 \\
68.1 \\
70.4 \\
63.8\end{array}$ & $\begin{array}{l}46.2 \\
49.0 \\
48.7 \\
51.3 \\
53.9 \\
56.6 \\
57.9 \\
60.7 \\
53.0 \\
54.4 \\
57.8 \\
57.7 \\
54.3\end{array}$ & $\begin{array}{l}41.5 \\
44.2 \\
44.1 \\
47.1 \\
48.8 \\
52.6 \\
54.2 \\
54.8 \\
48.2 \\
46.0 \\
54.5 \\
53.4 \\
49.3\end{array}$ & $\begin{array}{l}49.0 \\
51.1 \\
50.6 \\
53.7 \\
54.7 \\
58.2 \\
61.2 \\
62.2 \\
55.7 \\
57.4 \\
60.8 \\
61.6 \\
56.7\end{array}$ & $\begin{array}{l}73.9 \\
74.5 \\
74.4 \\
74.9 \\
77.0 \\
79.5 \\
82.9 \\
88.2 \\
87.9 \\
87.1 \\
86.7 \\
85.2 \\
81.2\end{array}$ & $\begin{array}{l}72.1 \\
72.8 \\
72.7 \\
73.6 \\
75.5 \\
77.9 \\
81.0 \\
86.8 \\
85.1 \\
85.6 \\
85.0 \\
83.9 \\
79.4\end{array}$ & $\begin{array}{l}62.8 \\
64.4 \\
64.5 \\
65.1 \\
67.2 \\
70.8 \\
73.8 \\
76.8 \\
75.0 \\
73.0 \\
75.5 \\
77.3 \\
70.9\end{array}$ & $\begin{array}{l}50.3 \\
52.8 \\
52.6 \\
55.0 \\
58.2 \\
60.8 \\
62.2 \\
65.3 \\
56.9 \\
58.8 \\
61.9 \\
60.9 \\
58.5\end{array}$ & $\begin{array}{l}w \\
- \\
\overline{-} \\
\overline{-} \\
\bar{w} \\
- \\
\overline{-} \\
\overline{-} \\
\bar{w} \\
w\end{array}$ & $\begin{array}{l}58.0 \\
60.2 \\
59.9 \\
61.0 \\
63.6 \\
66.7 \\
69.2 \\
71.9 \\
67.1 \\
67.1 \\
70.0 \\
70.3 \\
65.9\end{array}$ \\
\hline 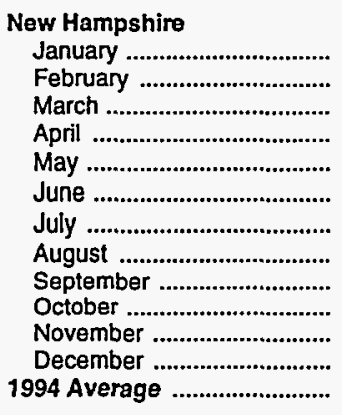 & $\begin{array}{l}66.7 \\
67.8 \\
67.3 \\
68.2 \\
69.1 \\
72.7 \\
75.3 \\
79.6 \\
79.5 \\
78.1 \\
78.4 \\
76.4 \\
73.3\end{array}$ & $\begin{array}{l}66.2 \\
67.3 \\
67.1 \\
68.1 \\
68.9 \\
72.5 \\
75.1 \\
79.1 \\
77.6 \\
77.5 \\
77.8 \\
76.0 \\
72.7\end{array}$ & $\begin{array}{l}56.7 \\
58.6 \\
58.4 \\
59.3 \\
61.4 \\
64.5 \\
66.9 \\
70.3 \\
66.6 \\
65.3 \\
67.9 \\
67.3 \\
63.8\end{array}$ & $\begin{array}{l}47.6 \\
49.8 \\
49.3 \\
51.7 \\
53.9 \\
56.6 \\
58.0 \\
61.4 \\
55.0 \\
55.9 \\
59.3 \\
59.5 \\
55.3\end{array}$ & $\begin{array}{l}w \\
- \\
- \\
- \\
- \\
- \\
- \\
- \\
- \\
- \\
- \\
\bar{w}\end{array}$ & $\begin{array}{l}54.4 \\
56.1 \\
55.6 \\
57.0 \\
59.1 \\
62.1 \\
64.4 \\
67.4 \\
62.9 \\
62.3 \\
65.2 \\
64.9 \\
61.2\end{array}$ & $\begin{array}{l}77.8 \\
78.1 \\
78.1 \\
79.1 \\
80.6 \\
83.4 \\
86.0 \\
89.6 \\
89.7 \\
88.4 \\
88.9 \\
86.6 \\
83.9\end{array}$ & $\begin{array}{l}77.1 \\
77.6 \\
77.6 \\
78.5 \\
79.9 \\
82.5 \\
84.8 \\
88.1 \\
88.4 \\
87.2 \\
88.1 \\
85.6 \\
83.1\end{array}$ & $\begin{array}{l}62.9 \\
64.9 \\
64.7 \\
64.7 \\
66.8 \\
70.3 \\
73.0 \\
76.6 \\
73.3 \\
72.3 \\
74.2 \\
74.3 \\
69.9\end{array}$ & $\begin{array}{l}49.1 \\
51.2 \\
52.0 \\
53.8 \\
57.0 \\
59.9 \\
61.5 \\
64.9 \\
58.5 \\
58.0 \\
61.4 \\
62.8 \\
58.3\end{array}$ & $\begin{array}{l}- \\
- \\
- \\
- \\
- \\
- \\
- \\
- \\
- \\
- \\
- \\
-\end{array}$ & $\begin{array}{l}60.3 \\
62.5 \\
62.0 \\
62.5 \\
64.8 \\
68.3 \\
70.6 \\
73.5 \\
69.7 \\
69.1 \\
71.7 \\
70.8 \\
67.4\end{array}$ \\
\hline 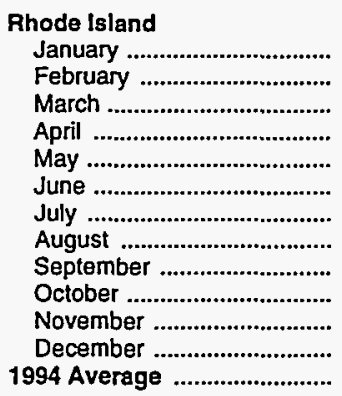 & $\begin{array}{l}65.2 \\
66.0 \\
65.1 \\
65.8 \\
68.0 \\
72.9 \\
77.0 \\
80.7 \\
79.9 \\
77.5 \\
76.6 \\
71.8 \\
72.3\end{array}$ & $\begin{array}{l}64.2 \\
65.0 \\
64.2 \\
64.9 \\
67.2 \\
71.7 \\
75.8 \\
79.6 \\
78.5 \\
76.3 \\
76.1 \\
71.2 \\
71.3\end{array}$ & $\begin{array}{l}54.0 \\
56.0 \\
55.5 \\
56.3 \\
59.2 \\
62.9 \\
65.3 \\
69.1 \\
66.0 \\
63.5 \\
64.7 \\
67.4 \\
61.9\end{array}$ & $\begin{array}{l}46.0 \\
48.6 \\
48.6 \\
51.7 \\
53.7 \\
56.7 \\
57.8 \\
60.2 \\
52.7 \\
54.0 \\
57.8 \\
56.0 \\
53.9\end{array}$ & $\begin{array}{c}W \\
W \\
45.9 \\
W \\
W \\
W \\
W \\
- \\
- \\
48.9 \\
W \\
W \\
49.7\end{array}$ & $\begin{array}{l}48.8 \\
50.2 \\
50.0 \\
51.9 \\
53.2 \\
57.1 \\
56.7 \\
63.4 \\
57.7 \\
53.1 \\
59.3 \\
59.1 \\
55.1\end{array}$ & $\begin{array}{l}74.1 \\
74.5 \\
74.7 \\
75.3 \\
77.7 \\
82.5 \\
86.4 \\
90.1 \\
89.3 \\
86.7 \\
85.4 \\
81.5 \\
81.5\end{array}$ & $\begin{array}{l}73.6 \\
74.0 \\
74.0 \\
74.7 \\
77.0 \\
81.3 \\
84.8 \\
88.5 \\
87.6 \\
85.5 \\
84.4 \\
80.7 \\
80.5\end{array}$ & $\begin{array}{l}60.5 \\
62.4 \\
61.4 \\
62.5 \\
65.3 \\
68.8 \\
71.1 \\
74.8 \\
72.4 \\
69.5 \\
71.1 \\
73.1 \\
67.9\end{array}$ & $\begin{array}{l}49.5 \\
52.8 \\
52.4 \\
55.5 \\
58.4 \\
60.8 \\
62.1 \\
65.1 \\
56.7 \\
58.8 \\
61.9 \\
59.8 \\
57.9\end{array}$ & $\begin{array}{l}- \\
- \\
- \\
- \\
\bar{w} \\
- \\
- \\
- \\
- \\
\bar{w}\end{array}$ & $\begin{array}{l}54.2 \\
57.4 \\
56.7 \\
58.9 \\
61.9 \\
64.5 \\
66.2 \\
69.6 \\
64.4 \\
64.1 \\
66.6 \\
66.4 \\
62.7\end{array}$ \\
\hline
\end{tabular}

See footnotes at end of table. 
Table 31. Motor Gasoline Prices by Grade, Sales Type, PAD District, and State (Cents per Gallon Excluding Taxes) - Continued

\begin{tabular}{|c|c|c|c|c|c|c|c|c|c|c|c|c|}
\hline \multirow{3}{*}{$\begin{array}{c}\text { Goographic Area } \\
\text { Month }\end{array}$} & \multicolumn{6}{|c|}{ Premium } & \multicolumn{6}{|c|}{ All Grades } \\
\hline & \multicolumn{2}{|c|}{ Sales to End Users } & \multicolumn{4}{|c|}{ Sales for Resale } & \multicolumn{2}{|c|}{ Sales to End Users } & \multicolumn{4}{|c|}{ Sales for Resale } \\
\hline & $\begin{array}{c}\text { Through } \\
\text { Retall } \\
\text { Outlots }\end{array}$ & Averagea & DTW & Rack & Bulk & Average & $\begin{array}{l}\text { Through } \\
\text { Retail } \\
\text { Outlets }\end{array}$ & Averagea & DTW & Rack & Bulk & Average \\
\hline \multicolumn{13}{|l|}{ Maine } \\
\hline 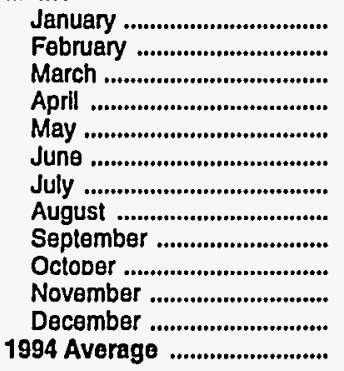 & $\begin{array}{l}83.5 \\
85.1 \\
85.5 \\
87.4 \\
91.3 \\
93.2 \\
94.0 \\
97.6 \\
97.0 \\
94.7 \\
97.9 \\
95.1 \\
91.7\end{array}$ & $\begin{array}{l}82.2 \\
84.0 \\
83.8 \\
86.3 \\
90.0 \\
92.0 \\
92.6 \\
96.3 \\
95.5 \\
93.5 \\
96.7 \\
93.9 \\
90.4\end{array}$ & $\begin{array}{l}67.1 \\
69.8 \\
69.7 \\
70.8 \\
73.4 \\
77.0 \\
78.2 \\
83.9 \\
79.6 \\
77.5 \\
79.9 \\
78.3 \\
75.3\end{array}$ & $\begin{array}{l}58.5 \\
61.7 \\
61.4 \\
63.8 \\
67.5 \\
70.0 \\
71.7 \\
74.6 \\
66.5 \\
66.5 \\
70.4 \\
67.2 \\
66.9\end{array}$ & $\begin{array}{l}W \\
W \\
W \\
W \\
W \\
W \\
W \\
W \\
W \\
W \\
W \\
W \\
W\end{array}$ & $\begin{array}{l}60.7 \\
63.7 \\
62.7 \\
65.8 \\
69.2 \\
72.0 \\
73.4 \\
76.7 \\
68.8 \\
68.6 \\
72.0 \\
69.4 \\
68.8\end{array}$ & $\begin{array}{l}71.9 \\
73.3 \\
73.3 \\
74.6 \\
78.1 \\
80.3 \\
81.1 \\
84.9 \\
83.7 \\
81.7 \\
84.2 \\
81.4 \\
79.2\end{array}$ & $\begin{array}{l}71.0 \\
72.5 \\
72.5 \\
73.9 \\
77.3 \\
79.7 \\
80.6 \\
84.6 \\
82.9 \\
81.0 \\
83.4 \\
80.7 \\
78.5\end{array}$ & $\begin{array}{l}58.4 \\
60.7 \\
60.7 \\
61.9 \\
64.0 \\
67.2 \\
68.4 \\
73.2 \\
69.1 \\
68.6 \\
71.6 \\
69.5 \\
66.1\end{array}$ & $\begin{array}{l}50.8 \\
54.2 \\
53.9 \\
56.2 \\
59.1 \\
62.0 \\
63.3 \\
65.6 \\
57.8 \\
57.5 \\
61.7 \\
59.0 \\
58.7\end{array}$ & $\begin{array}{c}W \\
49.3 \\
49.1 \\
50.8 \\
W \\
58.3 \\
W \\
61.3 \\
52.5 \\
49.4 \\
W \\
52.5 \\
52.8\end{array}$ & $\begin{array}{l}51.6 \\
55.3 \\
55.1 \\
57.0 \\
60.4 \\
63.0 \\
64.6 \\
66.9 \\
59.8 \\
58.5 \\
63.9 \\
60.2 \\
59.8\end{array}$ \\
\hline \multicolumn{13}{|l|}{ Massachusetts } \\
\hline 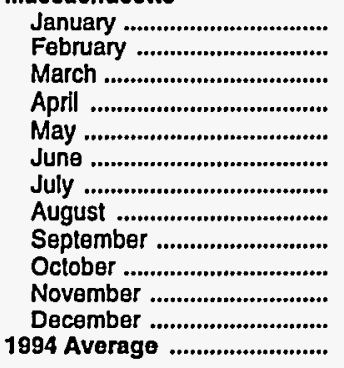 & $\begin{array}{l}82.8 \\
83.3 \\
83.2 \\
84.0 \\
86.0 \\
88.4 \\
91.2 \\
96.3 \\
96.2 \\
95.4 \\
95.6 \\
94.8 \\
89.6\end{array}$ & $\begin{array}{l}80.9 \\
80.7 \\
80.3 \\
81.7 \\
84.2 \\
86.4 \\
89.5 \\
94.8 \\
93.6 \\
93.1 \\
93.4 \\
92.8 \\
87.4\end{array}$ & $\begin{array}{l}69.7 \\
71.6 \\
71.3 \\
71.9 \\
74.6 \\
78.1 \\
81.6 \\
85.4 \\
82.9 \\
81.8 \\
83.2 \\
84.8 \\
78.2\end{array}$ & $\begin{array}{l}56.1 \\
58.9 \\
58.4 \\
60.8 \\
65.3 \\
67.4 \\
69.6 \\
73.2 \\
64.1 \\
65.9 \\
68.1 \\
66.1 \\
64.7\end{array}$ & $\begin{array}{l}W \\
W \\
- \\
\bar{W} \\
W \\
W \\
W \\
W \\
W \\
\bar{W} \\
57.0\end{array}$ & $\begin{array}{l}63.0 \\
63.3 \\
65.4 \\
66.8 \\
70.0 \\
71.8 \\
75.8 \\
79.2 \\
72.8 \\
74.0 \\
75.9 \\
74.6 \\
71.2\end{array}$ & $\begin{array}{l}68.8 \\
69.3 \\
69.1 \\
69.8 \\
71.6 \\
74.3 \\
77.7 \\
82.9 \\
82.6 \\
81.6 \\
81.9 \\
81.0 \\
76.0\end{array}$ & $\begin{array}{l}67.6 \\
67.9 \\
67.7 \\
68.7 \\
70.5 \\
73.0 \\
76.4 \\
81.7 \\
80.2 \\
80.2 \\
80.7 \\
80.1 \\
74.5\end{array}$ & $\begin{array}{l}60.8 \\
62.7 \\
62.3 \\
62.7 \\
65.3 \\
68.8 \\
71.9 \\
75.0 \\
72.7 \\
71.7 \\
73.2 \\
75.2 \\
68.8\end{array}$ & $\begin{array}{l}49.1 \\
51.9 \\
51.6 \\
53.9 \\
57.1 \\
59.7 \\
61.1 \\
64.1 \\
55.9 \\
57.4 \\
60.4 \\
60.0 \\
57.2\end{array}$ & $\begin{array}{l}41.8 \\
46.0 \\
44.1 \\
47.1 \\
49.4 \\
54.1 \\
54.7 \\
55.5 \\
48.5 \\
46.6 \\
54.5 \\
53.5 \\
49.8\end{array}$ & $\begin{array}{l}53.5 \\
55.3 \\
54.8 \\
57.8 \\
59.0 \\
62.4 \\
65.7 \\
66.7 \\
60.2 \\
62.1 \\
64.9 \\
65.4 \\
60.9\end{array}$ \\
\hline \multicolumn{13}{|l|}{ New Hampshire } \\
\hline 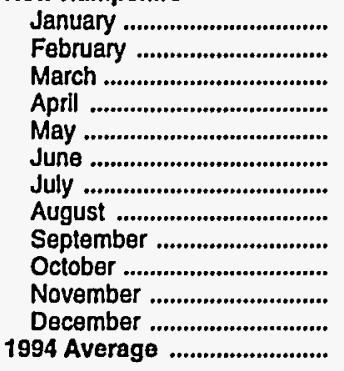 & $\begin{array}{l}86.0 \\
86.6 \\
85.7 \\
87.1 \\
88.2 \\
90.9 \\
93.3 \\
96.4 \\
97.0 \\
95.9 \\
96.1 \\
94.5 \\
91.3\end{array}$ & $\begin{array}{l}85.6 \\
86.3 \\
85.1 \\
86.5 \\
87.9 \\
90.0 \\
92.3 \\
95.6 \\
94.0 \\
95.3 \\
95.5 \\
94.1 \\
90.6\end{array}$ & $\begin{array}{l}70.9 \\
73.1 \\
71.3 \\
72.8 \\
75.6 \\
78.9 \\
81.3 \\
85.3 \\
81.1 \\
79.5 \\
82.1 \\
80.7 \\
77.7\end{array}$ & $\begin{array}{l}57.2 \\
59.1 \\
58.6 \\
61.2 \\
65.2 \\
66.9 \\
69.2 \\
73.8 \\
65.9 \\
67.2 \\
70.0 \\
68.8 \\
65.7\end{array}$ & $\begin{array}{l}- \\
- \\
- \\
- \\
- \\
- \\
- \\
- \\
- \\
-\end{array}$ & $\begin{array}{l}67.9 \\
69.5 \\
68.1 \\
69.8 \\
72.8 \\
75.7 \\
78.3 \\
81.9 \\
76.8 \\
75.9 \\
78.7 \\
77.1 \\
74.5\end{array}$ & $\begin{array}{l}72.1 \\
72.8 \\
72.5 \\
73.0 \\
73.9 \\
77.5 \\
80.1 \\
84.1 \\
84.1 \\
82.8 \\
83.1 \\
81.2 \\
78.1\end{array}$ & $\begin{array}{l}71.6 \\
72.3 \\
72.0 \\
72.8 \\
73.7 \\
77.2 \\
79.7 \\
83.5 \\
82.1 \\
82.1 \\
82.5 \\
80.7 \\
77.5\end{array}$ & $\begin{array}{l}61.0 \\
62.9 \\
62.3 \\
63.2 \\
65.3 \\
68.6 \\
71.0 \\
74.4 \\
70.6 \\
69.3 \\
71.7 \\
71.1 \\
67.8\end{array}$ & $\begin{array}{l}49.8 \\
51.9 \\
51.5 \\
53.7 \\
56.5 \\
59.1 \\
60.6 \\
64.3 \\
57.5 \\
58.5 \\
61.6 \\
61.8 \\
57.7\end{array}$ & $\begin{array}{l}W \\
- \\
- \\
- \\
- \\
- \\
- \\
- \\
- \\
- \\
- \\
\bar{W}\end{array}$ & $\begin{array}{l}58.3 \\
59.9 \\
59.3 \\
60.5 \\
62.8 \\
65.9 \\
68.2 \\
71.2 \\
66.7 \\
66.1 \\
68.8 \\
68.2 \\
64.9\end{array}$ \\
\hline 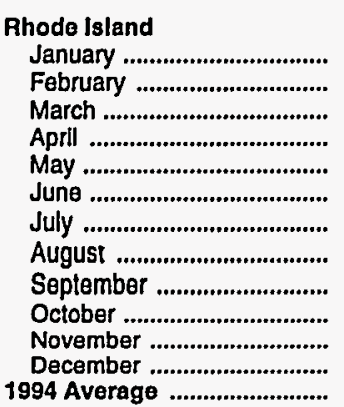 & $\begin{array}{l}82.7 \\
82.9 \\
82.5 \\
83.1 \\
85.4 \\
89.2 \\
92.9 \\
96.8 \\
95.9 \\
92.3 \\
92.3 \\
89.8 \\
88.5\end{array}$ & $\begin{array}{l}81.9 \\
82.2 \\
81.9 \\
82.5 \\
84.6 \\
88.2 \\
91.9 \\
96.0 \\
94.9 \\
91.8 \\
91.6 \\
89.4 \\
87.7\end{array}$ & $\begin{array}{l}67.6 \\
69.5 \\
68.9 \\
69.8 \\
73.0 \\
76.8 \\
79.5 \\
83.7 \\
80.3 \\
78.1 \\
79.0 \\
81.0 \\
75.7\end{array}$ & $\begin{array}{l}56.4 \\
58.7 \\
58.0 \\
61.3 \\
65.4 \\
67.8 \\
69.7 \\
73.1 \\
64.1 \\
65.8 \\
68.4 \\
65.5 \\
64.6\end{array}$ & $\begin{array}{l}- \\
- \\
- \\
- \\
- \\
- \\
- \\
- \\
- \\
- \\
-\end{array}$ & $\begin{array}{l}60.8 \\
63.2 \\
62.5 \\
65.0 \\
68.7 \\
71.5 \\
73.7 \\
77.4 \\
71.3 \\
71.0 \\
73.2 \\
72.0 \\
69.2\end{array}$ & $\begin{array}{l}71.5 \\
72.0 \\
71.1 \\
71.9 \\
74.1 \\
78.4 \\
82.3 \\
85.9 \\
85.2 \\
82.6 \\
81.8 \\
77.6 \\
77.8\end{array}$ & $\begin{array}{l}70.7 \\
71.1 \\
70.2 \\
71.0 \\
73.2 \\
77.2 \\
81.1 \\
84.8 \\
83.7 \\
81.5 \\
81.2 \\
76.9 \\
76.8\end{array}$ & $\begin{array}{l}58.9 \\
60.8 \\
60.1 \\
61.0 \\
64.0 \\
67.7 \\
70.1 \\
73.9 \\
70.8 \\
68.2 \\
69.5 \\
71.8 \\
66.6\end{array}$ & $\begin{array}{l}49.3 \\
51.7 \\
51.5 \\
54.6 \\
57.1 \\
60.0 \\
61.2 \\
63.9 \\
55.8 \\
57.3 \\
60.7 \\
58.5 \\
57.0\end{array}$ & $\begin{array}{c}W \\
W \\
45.9 \\
W \\
W \\
W \\
W \\
- \\
- \\
48.9 \\
W \\
W \\
49.7\end{array}$ & $\begin{array}{l}52.8 \\
54.3 \\
53.6 \\
55.5 \\
57.3 \\
60.6 \\
60.6 \\
67.7 \\
61.9 \\
56.5 \\
63.3 \\
62.7 \\
58.9\end{array}$ \\
\hline
\end{tabular}

See lootnotes at end of table. 
Table 31. Motor Gasoline Prices by Grade, Sales Type, PAD District, and State (Cents per Gallon Excluding Taxes) - Continued

\begin{tabular}{|c|c|c|c|c|c|c|c|c|c|c|c|c|}
\hline \multirow{3}{*}{$\begin{array}{c}\text { Geographic Area } \\
\text { Month }\end{array}$} & \multicolumn{6}{|c|}{ Regular } & \multicolumn{6}{|c|}{ Midgrade } \\
\hline & \multicolumn{2}{|c|}{ Sales to End Users } & \multicolumn{4}{|c|}{ Sales for Resale } & \multicolumn{2}{|c|}{ Sales to End Users } & \multicolumn{4}{|c|}{ Sales for Resale } \\
\hline & $\begin{array}{c}\text { Through } \\
\text { Rotail } \\
\text { Outlets }\end{array}$ & Average ${ }^{a}$ & DTW & Rack & Bulk & Average & $\begin{array}{c}\text { Through } \\
\text { Retail } \\
\text { Outlets }\end{array}$ & Averagea & DTW & Rack & Bulk & Average \\
\hline \multicolumn{13}{|l|}{ Vermont } \\
\hline 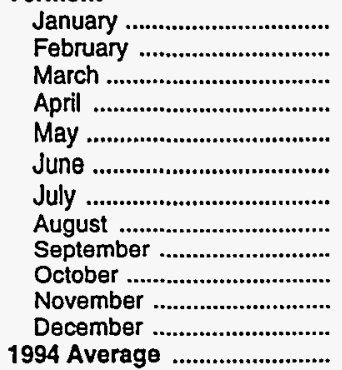 & $\begin{array}{l}70.9 \\
71.5 \\
71.6 \\
71.7 \\
73.5 \\
76.1 \\
80.5 \\
82.4 \\
82.6 \\
82.4 \\
82.3 \\
77.2 \\
77.2\end{array}$ & $\begin{array}{l}69.3 \\
70.0 \\
70.4 \\
70.7 \\
72.6 \\
74.9 \\
79.3 \\
81.5 \\
81.3 \\
81.1 \\
81.1 \\
76.3 \\
76.0\end{array}$ & $\begin{array}{l}61.3 \\
63.5 \\
63.3 \\
63.9 \\
65.3 \\
68.6 \\
70.7 \\
73.3 \\
70.3 \\
68.6 \\
71.7 \\
68.6 \\
67.7\end{array}$ & $\begin{array}{l}48.6 \\
52.2 \\
51.4 \\
53.6 \\
56.5 \\
59.2 \\
61.3 \\
64.1 \\
56.2 \\
56.0 \\
60.1 \\
55.6 \\
56.6\end{array}$ & $\begin{array}{l}- \\
- \\
- \\
- \\
- \\
- \\
- \\
- \\
-\end{array}$ & $\begin{array}{l}57.7 \\
60.6 \\
60.0 \\
61.5 \\
63.3 \\
66.1 \\
67.9 \\
70.6 \\
66.7 \\
65.2 \\
68.6 \\
65.2 \\
64.7\end{array}$ & $\begin{array}{l}80.7 \\
81.3 \\
81.3 \\
81.1 \\
82.7 \\
85.5 \\
89.7 \\
91.2 \\
92.0 \\
91.4 \\
91.0 \\
87.5 \\
86.8\end{array}$ & $\begin{array}{l}77.4 \\
78.7 \\
78.4 \\
78.8 \\
79.9 \\
82.5 \\
86.8 \\
89.0 \\
89.7 \\
89.0 \\
89.0 \\
85.4 \\
84.4\end{array}$ & $\begin{array}{l}67.5 \\
68.1 \\
69.0 \\
69.9 \\
71.4 \\
73.6 \\
76.9 \\
78.6 \\
76.3 \\
74.8 \\
77.0 \\
75.0 \\
73.5\end{array}$ & $\begin{array}{l}53.2 \\
56.7 \\
56.1 \\
57.6 \\
60.6 \\
63.6 \\
66.0 \\
69.1 \\
61.6 \\
60.3 \\
65.0 \\
60.0 \\
61.2\end{array}$ & $\begin{array}{l}- \\
- \\
- \\
- \\
- \\
- \\
- \\
- \\
- \\
- \\
- \\
-\end{array}$ & $\begin{array}{l}63.6 \\
65.0 \\
65.7 \\
67.4 \\
69.2 \\
71.1 \\
73.5 \\
76.3 \\
72.9 \\
71.4 \\
74.2 \\
71.3 \\
70.5\end{array}$ \\
\hline \multicolumn{13}{|l|}{ Subdistrict IB } \\
\hline 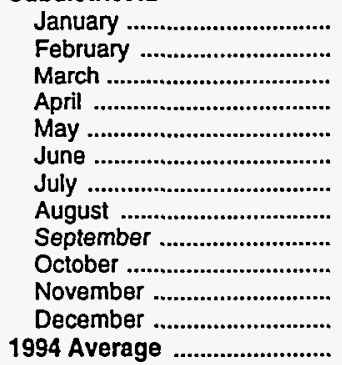 & $\begin{array}{l}62.9 \\
63.0 \\
62.2 \\
62.5 \\
64.2 \\
67.1 \\
70.4 \\
74.5 \\
74.6 \\
74.0 \\
75.3 \\
74.2 \\
69.0\end{array}$ & $\begin{array}{l}62.0 \\
62.4 \\
61.6 \\
61.9 \\
63.7 \\
66.6 \\
69.9 \\
73.8 \\
73.3 \\
72.9 \\
74.7 \\
73.3 \\
68.3\end{array}$ & $\begin{array}{l}56.6 \\
57.3 \\
56.5 \\
57.6 \\
59.6 \\
62.9 \\
65.4 \\
68.5 \\
66.4 \\
66.5 \\
69.2 \\
68.3 \\
62.9\end{array}$ & $\begin{array}{l}46.6 \\
49.1 \\
48.8 \\
51.4 \\
53.6 \\
56.2 \\
57.9 \\
60.8 \\
53.9 \\
56.4 \\
60.3 \\
56.6 \\
54.7\end{array}$ & $\begin{array}{l}43.3 \\
45.0 \\
45.3 \\
48.2 \\
51.1 \\
52.9 \\
55.9 \\
56.7 \\
51.4 \\
51.1 \\
57.0 \\
52.8 \\
51.3\end{array}$ & $\begin{array}{l}50.7 \\
52.2 \\
51.4 \\
53.7 \\
55.7 \\
58.3 \\
60.9 \\
63.3 \\
58.5 \\
59.9 \\
63.5 \\
61.0 \\
57.8\end{array}$ & $\begin{array}{l}72.8 \\
73.1 \\
72.1 \\
72.3 \\
74.2 \\
77.2 \\
80.1 \\
84.2 \\
84.4 \\
83.8 \\
85.2 \\
84.3 \\
79.0\end{array}$ & $\begin{array}{l}71.5 \\
71.9 \\
70.8 \\
71.2 \\
73.2 \\
76.0 \\
79.4 \\
83.0 \\
82.7 \\
82.3 \\
84.2 \\
83.2 \\
77.8\end{array}$ & $\begin{array}{l}63.7 \\
63.9 \\
62.7 \\
63.8 \\
65.6 \\
68.9 \\
71.1 \\
74.3 \\
73.0 \\
73.1 \\
76.4 \\
75.8 \\
69.4\end{array}$ & $\begin{array}{l}51.4 \\
54.1 \\
53.4 \\
55.5 \\
57.9 \\
60.7 \\
62.4 \\
66.0 \\
59.5 \\
61.4 \\
66.7 \\
63.4 \\
59.8\end{array}$ & $\begin{array}{l}\text { NA } \\
W \\
N A \\
N A \\
W \\
W \\
W \\
W \\
W \\
- \\
- \\
W \\
\text { NA }\end{array}$ & $\begin{array}{l}59.7 \\
60.7 \\
59.6 \\
61.0 \\
62.9 \\
66.0 \\
68.0 \\
71.3 \\
67.8 \\
68.9 \\
72.8 \\
71.2 \\
66.1\end{array}$ \\
\hline \multicolumn{13}{|l|}{ Delaware } \\
\hline 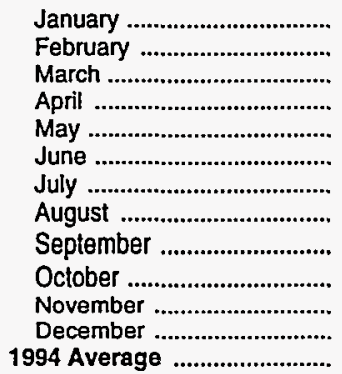 & $\begin{array}{l}57.5 \\
59.5 \\
58.6 \\
59.1 \\
62.1 \\
65.1 \\
67.4 \\
71.4 \\
71.1 \\
70.9 \\
73.2 \\
72.8 \\
66.5\end{array}$ & $\begin{array}{l}56.7 \\
58.8 \\
58.2 \\
59.0 \\
61.8 \\
64.5 \\
67.0 \\
70.7 \\
69.9 \\
69.8 \\
72.2 \\
72.3 \\
65.7\end{array}$ & $\begin{array}{l}55.6 \\
55.5 \\
54.8 \\
56.2 \\
58.0 \\
60.5 \\
62.8 \\
66.4 \\
64.4 \\
63.9 \\
66.4 \\
67.1 \\
61.3\end{array}$ & $\begin{array}{l}44.6 \\
47.3 \\
48.2 \\
49.7 \\
52.7 \\
55.1 \\
56.6 \\
59.4 \\
52.0 \\
54.5 \\
58.8 \\
58.0 \\
53.4\end{array}$ & $\begin{array}{l}-\bar{w} \\
W \\
W \\
W \\
W \\
W \\
W \\
W \\
W \\
W \\
W \\
W\end{array}$ & $\begin{array}{l}49.8 \\
50.6 \\
51.3 \\
52.2 \\
55.1 \\
57.8 \\
59.1 \\
62.7 \\
57.3 \\
58.3 \\
62.3 \\
62.0 \\
56.9\end{array}$ & $\begin{array}{l}70.1 \\
69.8 \\
69.3 \\
65.8 \\
73.2 \\
75.9 \\
78.2 \\
82.4 \\
82.4 \\
82.3 \\
84.7 \\
84.2 \\
77.2\end{array}$ & $\begin{array}{l}68.7 \\
68.8 \\
68.1 \\
65.6 \\
72.4 \\
75.3 \\
77.5 \\
81.5 \\
80.5 \\
81.1 \\
83.7 \\
83.7 \\
76.1\end{array}$ & $\begin{array}{l}62.0 \\
61.8 \\
61.1 \\
62.7 \\
64.4 \\
66.5 \\
68.6 \\
71.9 \\
70.5 \\
69.9 \\
72.7 \\
73.5 \\
67.2\end{array}$ & $\begin{array}{l}48.1 \\
51.0 \\
52.3 \\
53.5 \\
56.9 \\
59.4 \\
60.7 \\
64.1 \\
57.0 \\
58.9 \\
63.1 \\
63.1 \\
57.8\end{array}$ & $\begin{array}{l}- \\
- \\
- \\
- \\
- \\
- \\
- \\
- \\
- \\
- \\
- \\
-\end{array}$ & $\begin{array}{l}55.3 \\
56.5 \\
56.8 \\
57.9 \\
60.4 \\
62.9 \\
64.7 \\
67.8 \\
62.6 \\
63.5 \\
67.7 \\
67.4 \\
62.2\end{array}$ \\
\hline \multicolumn{13}{|l|}{ District of Columbia } \\
\hline 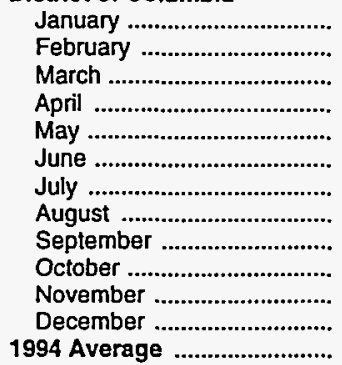 & $\begin{array}{l}W \\
W \\
W \\
W \\
W \\
W \\
W \\
W \\
W \\
W \\
W \\
W \\
W\end{array}$ & $\begin{array}{l}54.2 \\
56.1 \\
53.5 \\
55.8 \\
58.3 \\
61.8 \\
64.6 \\
61.6 \\
59.4 \\
62.0 \\
71.0 \\
67.2 \\
60.1\end{array}$ & $\begin{array}{l}62.7 \\
62.1 \\
60.2 \\
61.1 \\
62.3 \\
64.4 \\
66.0 \\
68.4 \\
67.1 \\
66.8 \\
74.7 \\
74.6 \\
66.0\end{array}$ & $\begin{array}{l}W \\
W \\
W \\
W \\
W \\
W \\
W \\
W \\
W \\
W \\
W \\
W \\
W\end{array}$ & $\begin{array}{l}- \\
- \\
- \\
- \\
- \\
- \\
- \\
- \\
-\end{array}$ & $\begin{array}{l}62.5 \\
61.8 \\
60.1 \\
61.0 \\
62.2 \\
64.3 \\
66.0 \\
68.3 \\
66.8 \\
66.6 \\
74.6 \\
74.3 \\
65.8\end{array}$ & $\begin{array}{l}W \\
W \\
W \\
W \\
W \\
W \\
W \\
W \\
W \\
W \\
W \\
W \\
W\end{array}$ & $\begin{array}{r}61.9 \\
64.4 \\
57.6 \\
61.0 \\
66.1 \\
71.3 \\
72.5 \\
\text { NA } \\
\text { NA } \\
\text { NA } \\
78.3 \\
75.7 \\
65.0\end{array}$ & $\begin{array}{l}68.2 \\
67.7 \\
65.0 \\
65.9 \\
67.9 \\
69.9 \\
70.8 \\
72.3 \\
70.7 \\
70.4 \\
80.4 \\
79.9 \\
70.6\end{array}$ & $\begin{array}{l}W \\
\bar{W} \\
- \\
- \\
- \\
- \\
- \\
- \\
- \\
- \\
\bar{w}\end{array}$ & $\begin{array}{l}- \\
- \\
- \\
- \\
- \\
- \\
- \\
- \\
- \\
- \\
- \\
-\end{array}$ & $\begin{array}{l}68.2 \\
67.7 \\
65.0 \\
65.9 \\
67.9 \\
69.9 \\
70.8 \\
72.3 \\
70.7 \\
70.4 \\
80.4 \\
79.9 \\
70.6\end{array}$ \\
\hline
\end{tabular}

See footnotes at end of table. 
Table 31. Motor Gasoline Prices by Grade, Sales Type, PAD District, and State (Cents per Gallon Excluding Taxes) - Continued

\begin{tabular}{|c|c|c|c|c|c|c|c|c|c|c|c|c|}
\hline \multirow{3}{*}{$\begin{array}{c}\text { Goographle Area } \\
\text { Month }\end{array}$} & \multicolumn{6}{|c|}{ Promium } & \multicolumn{6}{|c|}{ All Grades } \\
\hline & \multicolumn{2}{|c|}{ Sales to End Users } & \multicolumn{4}{|c|}{ Sales for Resale } & \multicolumn{2}{|c|}{ Sales to End Users } & \multicolumn{4}{|c|}{ Sales for Resale } \\
\hline & $\begin{array}{c}\text { Through } \\
\text { Retall } \\
\text { Outlets }\end{array}$ & Average ${ }^{a}$ & DTW & Rack & Bulk & Average & $\begin{array}{c}\text { Through } \\
\text { Retail } \\
\text { Outlets }\end{array}$ & Averagea & DTW & Rack & Bulk & Average \\
\hline 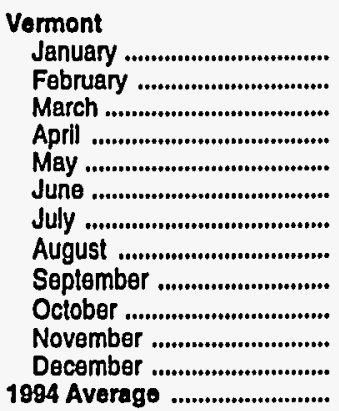 & $\begin{array}{r}87.9 \\
89.0 \\
89.2 \\
89.4 \\
90.9 \\
93.7 \\
97.7 \\
98.9 \\
100.1 \\
101.4 \\
101.3 \\
96.2 \\
94.7\end{array}$ & $\begin{array}{l}86.0 \\
86.5 \\
87.4 \\
87.8 \\
89.4 \\
91.8 \\
95.4 \\
97.7 \\
98.5 \\
99.6 \\
99.9 \\
94.5 \\
92.9\end{array}$ & $\begin{array}{l}74.4 \\
76.3 \\
77.0 \\
77.4 \\
79.6 \\
81.8 \\
84.3 \\
86.2 \\
84.3 \\
82.9 \\
84.7 \\
81.3 \\
80.9\end{array}$ & $\begin{array}{l}58.6 \\
62.1 \\
60.6 \\
62.6 \\
66.0 \\
68.7 \\
71.6 \\
75.0 \\
66.7 \\
67.0 \\
69.6 \\
65.0 \\
66.4\end{array}$ & $\begin{array}{l}- \\
- \\
- \\
- \\
- \\
- \\
- \\
- \\
- \\
- \\
-\end{array}$ & $\begin{array}{l}70.3 \\
72.6 \\
72.7 \\
74.1 \\
76.4 \\
78.0 \\
80.5 \\
83.3 \\
79.9 \\
78.8 \\
80.7 \\
77.3 \\
77.2\end{array}$ & $\begin{array}{l}76.1 \\
76.4 \\
76.2 \\
76.2 \\
77.8 \\
80.3 \\
84.8 \\
86.8 \\
87.2 \\
87.2 \\
87.1 \\
82.2 \\
81.9\end{array}$ & $\begin{array}{l}74.1 \\
74.6 \\
74.7 \\
75.0 \\
76.6 \\
78.9 \\
83.2 \\
85.6 \\
85.7 \\
85.6 \\
85.8 \\
81.1 \\
80.4\end{array}$ & $\begin{array}{l}65.4 \\
67.2 \\
67.0 \\
67.5 \\
69.1 \\
72.1 \\
74.6 \\
77.2 \\
73.9 \\
72.3 \\
75.0 \\
72.0 \\
71.3\end{array}$ & $\begin{array}{l}\mathbf{5 1 . 5} \\
55.1 \\
53.9 \\
56.0 \\
59.0 \\
61.9 \\
64.2 \\
67.1 \\
59.0 \\
58.7 \\
62.5 \\
57.9 \\
59.2\end{array}$ & $\begin{array}{l}- \\
- \\
- \\
- \\
- \\
- \\
- \\
- \\
- \\
- \\
- \\
-\end{array}$ & $\begin{array}{l}61.5 \\
64.0 \\
63.5 \\
64.9 \\
66.8 \\
69.3 \\
71.5 \\
74.4 \\
70.2 \\
68.8 \\
71.7 \\
68.4 \\
68.2\end{array}$ \\
\hline 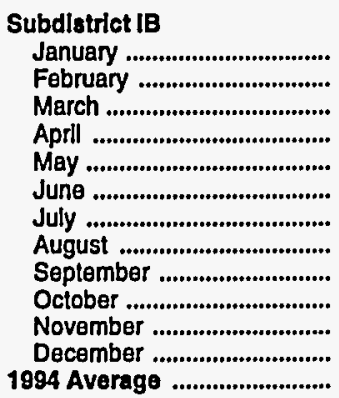 & $\begin{array}{l}82.6 \\
82.5 \\
81.8 \\
82.0 \\
83.3 \\
85.3 \\
87.5 \\
93.2 \\
93.5 \\
93.2 \\
94.3 \\
93.4 \\
87.8\end{array}$ & $\begin{array}{l}80.9 \\
80.9 \\
80.2 \\
80.5 \\
82.2 \\
84.3 \\
86.6 \\
91.7 \\
91.5 \\
91.2 \\
93.0 \\
91.9 \\
86.4\end{array}$ & $\begin{array}{l}72.1 \\
72.4 \\
71.3 \\
72.3 \\
74.0 \\
78.0 \\
80.3 \\
83.4 \\
82.2 \\
82.8 \\
85.1 \\
84.7 \\
78.1\end{array}$ & $\begin{array}{l}56.8 \\
58.9 \\
58.8 \\
61.5 \\
64.7 \\
67.0 \\
69.2 \\
72.8 \\
65.0 \\
68.0 \\
71.9 \\
67.0 \\
65.4\end{array}$ & $\begin{array}{l}51.2 \\
50.3 \\
49.7 \\
55.7 \\
61.1 \\
61.2 \\
66.5 \\
68.8 \\
54.8 \\
60.1 \\
62.0 \\
54.1 \\
57.7\end{array}$ & $\begin{array}{l}65.1 \\
66.1 \\
65.4 \\
67.6 \\
69.6 \\
72.7 \\
75.9 \\
78.4 \\
74.3 \\
76.3 \\
78.9 \\
75.0 \\
72.2\end{array}$ & $\begin{array}{l}69.0 \\
69.0 \\
68.1 \\
68.3 \\
69.9 \\
72.7 \\
75.8 \\
79.9 \\
80.1 \\
79.6 \\
80.8 \\
79.8 \\
74.7\end{array}$ & $\begin{array}{l}67.8 \\
68.0 \\
67.1 \\
67.4 \\
69.2 \\
71.9 \\
75.2 \\
78.9 \\
78.5 \\
78.3 \\
79.9 \\
78.8 \\
73.7\end{array}$ & $\begin{array}{l}62.8 \\
63.2 \\
62.2 \\
63.3 \\
65.2 \\
68.7 \\
71.1 \\
73.9 \\
72.2 \\
72.4 \\
75.0 \\
74.3 \\
68.6\end{array}$ & $\begin{array}{l}49.6 \\
52.0 \\
51.7 \\
54.2 \\
56.8 \\
59.2 \\
61.1 \\
64.1 \\
57.0 \\
59.6 \\
63.5 \\
59.7 \\
57.7\end{array}$ & $\begin{array}{l}45.6 \\
46.1 \\
46.1 \\
49.7 \\
53.5 \\
54.6 \\
57.3 \\
59.1 \\
51.8 \\
52.2 \\
57.8 \\
53.2 \\
52.5\end{array}$ & $\begin{array}{l}55.9 \\
57.0 \\
56.1 \\
58.4 \\
60.5 \\
63.1 \\
65.8 \\
68.2 \\
63.5 \\
65.1 \\
68.4 \\
65.8 \\
62.6\end{array}$ \\
\hline 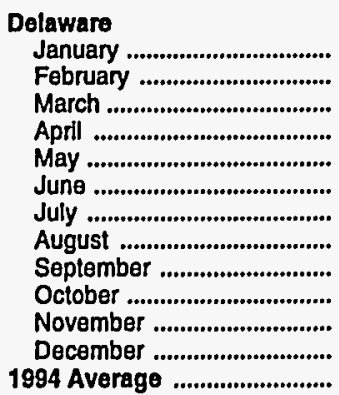 & $\begin{array}{l}74.0 \\
78.8 \\
77.3 \\
78.6 \\
83.0 \\
85.8 \\
88.1 \\
91.6 \\
91.6 \\
91.3 \\
92.9 \\
93.5 \\
86.0\end{array}$ & $\begin{array}{l}73.4 \\
78.2 \\
76.5 \\
78.1 \\
82.4 \\
85.1 \\
87.3 \\
90.9 \\
90.2 \\
90.2 \\
91.8 \\
92.4 \\
85.2\end{array}$ & $\begin{array}{l}69.2 \\
69.7 \\
68.8 \\
70.1 \\
72.3 \\
74.5 \\
77.0 \\
80.7 \\
79.2 \\
78.5 \\
80.6 \\
81.7 \\
75.3\end{array}$ & $\begin{array}{l}54.8 \\
57.5 \\
57.6 \\
60.1 \\
63.9 \\
66.5 \\
68.3 \\
72.0 \\
63.8 \\
66.4 \\
70.5 \\
70.1 \\
64.7\end{array}$ & $\begin{array}{l}- \\
\overline{-} \\
\overline{-} \\
\bar{w} \\
- \\
\bar{w} \\
- \\
\bar{w} \\
w\end{array}$ & $\begin{array}{l}62.3 \\
63.5 \\
63.2 \\
64.7 \\
67.8 \\
67.2 \\
72.8 \\
76.0 \\
70.4 \\
71.5 \\
75.3 \\
67.6 \\
68.7\end{array}$ & $\begin{array}{l}63.5 \\
65.4 \\
64.4 \\
64.2 \\
68.4 \\
71.4 \\
73.7 \\
77.4 \\
77.2 \\
76.9 \\
78.9 \\
78.7 \\
72.3\end{array}$ & $\begin{array}{l}62.5 \\
64.4 \\
63.6 \\
64.0 \\
67.9 \\
70.6 \\
73.2 \\
76.6 \\
75.8 \\
75.7 \\
77.8 \\
78.0 \\
71.5\end{array}$ & $\begin{array}{l}60.0 \\
59.9 \\
59.0 \\
60.5 \\
62.2 \\
64.7 \\
67.0 \\
70.4 \\
68.6 \\
68.1 \\
70.5 \\
71.2 \\
65.4\end{array}$ & $\begin{array}{l}47.3 \\
50.1 \\
51.0 \\
52.8 \\
55.9 \\
58.4 \\
59.9 \\
63.0 \\
55.4 \\
57.9 \\
61.8 \\
61.7 \\
56.7\end{array}$ & $\begin{array}{l}- \\
W \\
W \\
W \\
W \\
W \\
W \\
W \\
W \\
W \\
W \\
W \\
W\end{array}$ & $\begin{array}{l}53.5 \\
54.3 \\
54.8 \\
55.7 \\
58.7 \\
61.3 \\
62.9 \\
66.3 \\
60.9 \\
62.0 \\
65.8 \\
64.6 \\
60.4\end{array}$ \\
\hline 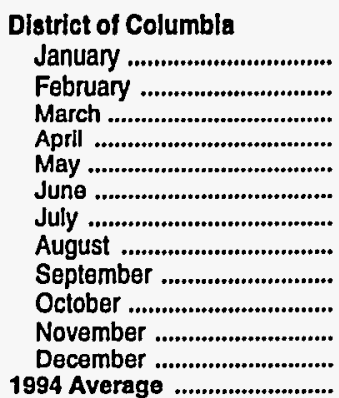 & $\begin{array}{l}W \\
W \\
W \\
W \\
W \\
W \\
W \\
W \\
W \\
W \\
W \\
W \\
W\end{array}$ & $\begin{array}{l}66.1 \\
67.5 \\
64.5 \\
67.8 \\
70.9 \\
75.9 \\
77.6 \\
72.7 \\
71.4 \\
74.6 \\
84.6 \\
82.8 \\
72.1\end{array}$ & $\begin{array}{l}75.6 \\
75.1 \\
73.5 \\
74.6 \\
75.8 \\
77.9 \\
79.4 \\
81.7 \\
80.5 \\
80.4 \\
88.0 \\
88.0 \\
78.8\end{array}$ & $\begin{array}{l}W \\
W \\
W \\
W \\
W \\
W \\
- \\
- \\
- \\
- \\
- \\
\bar{W}\end{array}$ & $\begin{array}{l}- \\
- \\
- \\
- \\
- \\
- \\
- \\
- \\
- \\
-\end{array}$ & $\begin{array}{l}75.6 \\
75.1 \\
73.5 \\
74.5 \\
75.8 \\
77.9 \\
79.4 \\
81.7 \\
80.5 \\
80.4 \\
88.0 \\
88.0 \\
78.8\end{array}$ & $\begin{array}{l}W \\
W \\
W \\
W \\
W \\
W \\
W \\
W \\
W \\
W \\
W \\
W \\
W\end{array}$ & $\begin{array}{l}59.1 \\
60.9 \\
57.5 \\
60.3 \\
63.7 \\
67.7 \\
70.5 \\
65.4 \\
63.4 \\
66.0 \\
76.2 \\
72.9 \\
64.6\end{array}$ & $\begin{array}{l}70.2 \\
69.7 \\
67.8 \\
68.9 \\
70.4 \\
72.4 \\
73.6 \\
75.5 \\
74.3 \\
74.1 \\
81.2 \\
81.9 \\
73.2\end{array}$ & $\begin{array}{l}W \\
W \\
W \\
54.7 \\
W \\
W \\
W \\
W \\
W \\
W \\
W \\
W \\
W\end{array}$ & $\begin{array}{l}- \\
- \\
- \\
- \\
- \\
- \\
- \\
- \\
- \\
- \\
- \\
-\end{array}$ & $\begin{array}{l}70.1 \\
69.6 \\
67.8 \\
68.9 \\
70.3 \\
72.3 \\
73.6 \\
75.4 \\
74.2 \\
74.0 \\
81.1 \\
81.8 \\
73.1\end{array}$ \\
\hline
\end{tabular}

See footnotes at end of table. 
Table 31. Motor Gasoline Prices by Grade, Sales Type, PAD District, and State (Cents per Gallon Excluding Taxes) - Continued

\begin{tabular}{|c|c|c|c|c|c|c|c|c|c|c|c|c|}
\hline \multirow{3}{*}{$\begin{array}{c}\text { Geographic Area } \\
\text { Month }\end{array}$} & \multicolumn{6}{|c|}{ Regular } & \multicolumn{6}{|c|}{ Midgrado } \\
\hline & \multicolumn{2}{|c|}{ Sales to End Users } & \multicolumn{4}{|c|}{ Sales for Resale } & \multicolumn{2}{|c|}{ Sales to End Users } & \multicolumn{4}{|c|}{ Sales for Resale } \\
\hline & $\begin{array}{c}\text { Through } \\
\text { Retail } \\
\text { Oullets }\end{array}$ & Average ${ }^{a}$ & DTW & Rack & Bulk & Average & $\begin{array}{c}\text { Through } \\
\text { Retail } \\
\text { Outlets }\end{array}$ & Averago $a$ & DTW & Rack & Bulk & Average \\
\hline 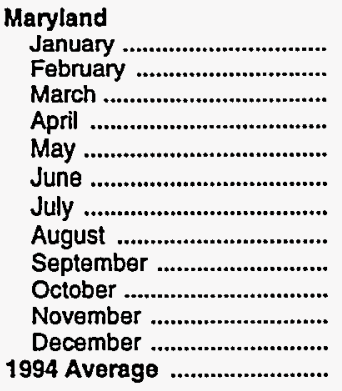 & $\begin{array}{l}61.5 \\
62.3 \\
60.6 \\
61.4 \\
63.4 \\
66.0 \\
69.2 \\
73.4 \\
73.6 \\
73.1 \\
78.0 \\
75.0 \\
68.2\end{array}$ & $\begin{array}{l}59.1 \\
60.9 \\
58.2 \\
58.8 \\
61.5 \\
63.8 \\
66.9 \\
70.7 \\
69.4 \\
69.3 \\
75.3 \\
72.2 \\
65.6\end{array}$ & $\begin{array}{l}58.3 \\
58.6 \\
56.7 \\
57.7 \\
59.4 \\
62.3 \\
64.1 \\
67.7 \\
65.6 \\
64.9 \\
71.6 \\
70.0 \\
63.3\end{array}$ & $\begin{array}{l}47.2 \\
49.9 \\
48.5 \\
51.1 \\
53.2 \\
56.0 \\
57.1 \\
60.1 \\
51.3 \\
54.6 \\
63.1 \\
58.6 \\
\mathbf{5 4 . 5}\end{array}$ & $\begin{array}{l}\bar{W} \\
W \\
W \\
W \\
W \\
W \\
W \\
W \\
W \\
58.9 \\
54.7 \\
56.2\end{array}$ & $\begin{array}{l}54.7 \\
55.9 \\
54.0 \\
55.6 \\
57.2 \\
60.0 \\
61.7 \\
64.8 \\
60.6 \\
61.3 \\
68.2 \\
66.1 \\
60.3\end{array}$ & $\begin{array}{l}70.3 \\
71.6 \\
70.9 \\
71.5 \\
73.6 \\
76.3 \\
79.0 \\
83.5 \\
83.6 \\
83.2 \\
87.8 \\
84.8 \\
78.1\end{array}$ & $\begin{array}{l}68.5 \\
70.0 \\
68.7 \\
69.1 \\
71.6 \\
74.1 \\
77.0 \\
80.4 \\
79.0 \\
79.3 \\
84.1 \\
81.7 \\
75.5\end{array}$ & $\begin{array}{l}64.9 \\
64.8 \\
62.8 \\
64.0 \\
65.8 \\
68.4 \\
70.1 \\
73.7 \\
72.0 \\
71.3 \\
78.1 \\
76.7 \\
69.5\end{array}$ & $\begin{array}{l}53.3 \\
56.3 \\
52.9 \\
55.0 \\
57.4 \\
60.4 \\
61.5 \\
64.6 \\
56.5 \\
60.0 \\
69.0 \\
65.1 \\
59.8\end{array}$ & $\begin{array}{l}\overline{-} \\
\bar{w} \\
w \\
\bar{w} \\
W \\
w \\
w \\
- \\
\bar{w} \\
w\end{array}$ & $\begin{array}{l}62.2 \\
63.0 \\
60.3 \\
61.8 \\
63.3 \\
66.1 \\
67.5 \\
71.0 \\
67.5 \\
68.2 \\
75.6 \\
73.6 \\
66.9\end{array}$ \\
\hline 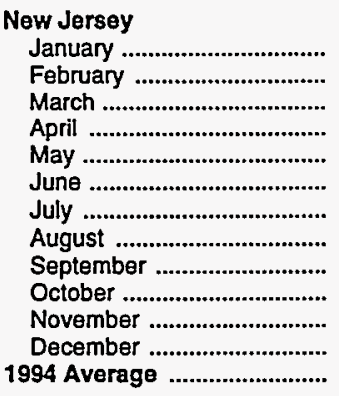 & $\begin{array}{l}66.9 \\
66.3 \\
66.0 \\
64.8 \\
65.4 \\
69.2 \\
71.0 \\
74.7 \\
75.6 \\
77.0 \\
78.3 \\
77.0 \\
71.4\end{array}$ & $\begin{array}{l}65.6 \\
65.2 \\
65.0 \\
64.0 \\
64.7 \\
68.4 \\
70.3 \\
73.9 \\
74.4 \\
75.5 \\
77.7 \\
76.1 \\
70.5\end{array}$ & $\begin{array}{l}59.1 \\
60.3 \\
59.1 \\
58.7 \\
60.9 \\
65.4 \\
67.3 \\
70.1 \\
69.8 \\
71.0 \\
72.4 \\
72.3 \\
65.6\end{array}$ & $\begin{array}{l}48.4 \\
50.4 \\
49.5 \\
51.8 \\
53.0 \\
55.2 \\
56.1 \\
58.6 \\
52.6 \\
59.7 \\
61.3 \\
58.9 \\
55.4\end{array}$ & $\begin{array}{l}43.4 \\
44.7 \\
45.2 \\
47.6 \\
51.0 \\
52.5 \\
55.6 \\
56.6 \\
51.9 \\
50.1 \\
56.6 \\
53.2 \\
51.3\end{array}$ & $\begin{array}{l}50.9 \\
51.9 \\
51.0 \\
53.3 \\
55.1 \\
57.4 \\
60.5 \\
61.2 \\
57.1 \\
59.7 \\
62.7 \\
60.1 \\
57.2\end{array}$ & $\begin{array}{l}81.8 \\
81.3 \\
80.5 \\
79.1 \\
79.2 \\
83.5 \\
84.9 \\
88.4 \\
89.6 \\
90.1 \\
90.2 \\
89.7 \\
85.3\end{array}$ & $\begin{array}{l}80.0 \\
79.3 \\
78.6 \\
77.7 \\
77.9 \\
81.9 \\
83.7 \\
87.1 \\
88.0 \\
88.7 \\
89.5 \\
88.8 \\
84.0\end{array}$ & $\begin{array}{l}66.2 \\
66.9 \\
65.3 \\
65.2 \\
67.2 \\
71.6 \\
73.1 \\
76.0 \\
75.6 \\
76.9 \\
78.2 \\
77.8 \\
71.8\end{array}$ & $\begin{array}{l}54.3 \\
56.2 \\
55.2 \\
56.5 \\
58.3 \\
60.7 \\
61.7 \\
65.2 \\
60.4 \\
65.2 \\
70.2 \\
66.2 \\
61.5\end{array}$ & $\begin{array}{l}W \\
W \\
W \\
W \\
W \\
W \\
W \\
W \\
- \\
- \\
- \\
- \\
\text { NA }\end{array}$ & $\begin{array}{l}63.1 \\
64.0 \\
62.7 \\
62.7 \\
65.0 \\
68.9 \\
70.0 \\
72.9 \\
71.3 \\
73.3 \\
75.7 \\
73.9 \\
68.9\end{array}$ \\
\hline 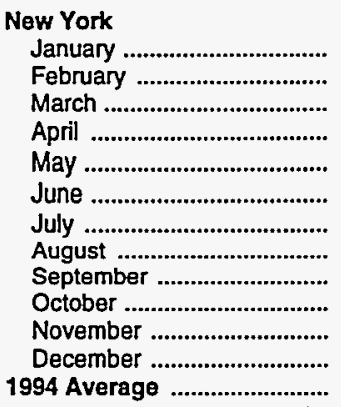 & $\begin{array}{l}64.7 \\
64.5 \\
63.6 \\
63.6 \\
65.2 \\
67.8 \\
71.7 \\
75.6 \\
75.6 \\
75.4 \\
75.5 \\
73.9 \\
69.8\end{array}$ & $\begin{array}{l}63.7 \\
63.6 \\
62.9 \\
63.0 \\
64.7 \\
67.2 \\
71.4 \\
75.2 \\
74.6 \\
74.6 \\
75.1 \\
73.2 \\
69.2\end{array}$ & $\begin{array}{l}56.5 \\
56.9 \\
56.2 \\
57.7 \\
59.6 \\
62.5 \\
65.5 \\
68.4 \\
65.8 \\
66.9 \\
67.8 \\
66.0 \\
62.4\end{array}$ & $\begin{array}{l}47.5 \\
50.1 \\
50.0 \\
52.3 \\
54.3 \\
57.0 \\
58.8 \\
62.1 \\
55.4 \\
57.6 \\
60.5 \\
55.9 \\
55.4\end{array}$ & $\begin{array}{c}W \\
45.7 \\
45.5 \\
46.8 \\
50.8 \\
53.5 \\
56.1 \\
58.6 \\
49.8 \\
56.7 \\
58.1 \\
52.9 \\
50.6\end{array}$ & $\begin{array}{l}51.4 \\
52.9 \\
52.1 \\
54.5 \\
56.4 \\
59.4 \\
61.7 \\
65.1 \\
60.3 \\
62.2 \\
64.1 \\
61.0 \\
58.7\end{array}$ & $\begin{array}{l}74.7 \\
74.6 \\
73.2 \\
73.7 \\
74.8 \\
77.2 \\
80.7 \\
84.5 \\
85.1 \\
85.7 \\
85.5 \\
83.5 \\
79.6\end{array}$ & $\begin{array}{l}72.5 \\
72.5 \\
71.2 \\
71.8 \\
73.2 \\
75.4 \\
80.0 \\
83.6 \\
83.5 \\
84.1 \\
84.3 \\
82.1 \\
78.0\end{array}$ & $\begin{array}{l}64.0 \\
63.6 \\
62.6 \\
64.2 \\
65.5 \\
68.8 \\
71.6 \\
74.6 \\
74.0 \\
75.6 \\
76.1 \\
75.8 \\
69.6\end{array}$ & $\begin{array}{l}53.0 \\
56.0 \\
55.7 \\
57.5 \\
58.6 \\
61.5 \\
63.4 \\
67.5 \\
61.5 \\
63.4 \\
66.3 \\
62.2 \\
61.1\end{array}$ & $\begin{array}{l}W \\
W \\
W \\
W \\
- \\
W \\
W \\
- \\
- \\
- \\
- \\
\bar{w}\end{array}$ & $\begin{array}{l}60.5 \\
61.3 \\
60.6 \\
62.3 \\
63.3 \\
66.5 \\
68.9 \\
72.2 \\
69.9 \\
71.7 \\
72.9 \\
71.3 \\
67.0\end{array}$ \\
\hline 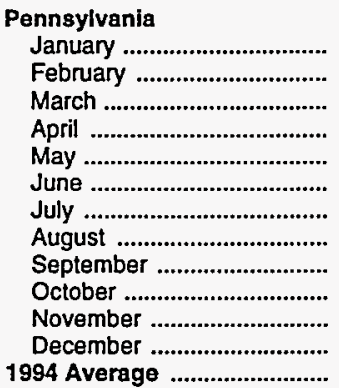 & $\begin{array}{l}59.8 \\
60.8 \\
60.2 \\
61.2 \\
62.9 \\
66.1 \\
69.2 \\
73.8 \\
73.5 \\
71.8 \\
73.8 \\
73.3 \\
67.7\end{array}$ & $\begin{array}{l}59.7 \\
60.8 \\
60.2 \\
61.1 \\
62.9 \\
66.0 \\
69.2 \\
73.3 \\
72.6 \\
71.3 \\
73.2 \\
72.7 \\
67.3\end{array}$ & $\begin{array}{l}53.4 \\
54.9 \\
54.9 \\
56.5 \\
58.7 \\
62.0 \\
64.8 \\
68.1 \\
65.2 \\
63.9 \\
67.2 \\
67.5 \\
61.5\end{array}$ & $\begin{array}{l}44.9 \\
47.7 \\
47.7 \\
50.7 \\
53.4 \\
55.9 \\
58.0 \\
60.7 \\
53.8 \\
54.5 \\
59.1 \\
55.7 \\
53.9\end{array}$ & $\begin{array}{c}W \\
44.8 \\
45.0 \\
49.3 \\
51.3 \\
53.4 \\
56.0 \\
56.1 \\
48.4 \\
51.2 \\
57.6 \\
50.4 \\
50.9\end{array}$ & $\begin{array}{l}48.0 \\
50.4 \\
50.2 \\
52.7 \\
55.0 \\
57.6 \\
60.2 \\
63.0 \\
57.3 \\
57.4 \\
61.9 \\
59.5 \\
56.4\end{array}$ & $\begin{array}{l}69.5 \\
70.5 \\
69.7 \\
70.4 \\
72.9 \\
75.7 \\
78.7 \\
82.9 \\
82.7 \\
81.0 \\
83.2 \\
83.0 \\
77.1\end{array}$ & $\begin{array}{l}69.1 \\
70.0 \\
69.3 \\
70.0 \\
72.6 \\
75.2 \\
78.6 \\
82.3 \\
82.0 \\
80.4 \\
82.7 \\
82.4 \\
76.6\end{array}$ & $\begin{array}{l}60.0 \\
60.8 \\
60.5 \\
62.0 \\
64.3 \\
67.4 \\
70.2 \\
73.6 \\
71.0 \\
69.6 \\
73.3 \\
72.9 \\
67.2\end{array}$ & $\begin{array}{l}49.3 \\
52.0 \\
52.0 \\
54.6 \\
57.7 \\
60.4 \\
62.6 \\
66.3 \\
59.6 \\
59.8 \\
65.1 \\
62.1 \\
58.9\end{array}$ & $\begin{array}{l}W \\
- \\
- \\
- \\
w \\
w \\
w \\
w \\
w \\
- \\
- \\
\bar{w}\end{array}$ & $\begin{array}{l}55.2 \\
57.0 \\
56.7 \\
58.7 \\
61.2 \\
64.0 \\
66.5 \\
69.9 \\
64.9 \\
64.8 \\
69.1 \\
67.7 \\
63.3\end{array}$ \\
\hline
\end{tabular}

See footnotes at end of table. 
Table 31. Motor Gasoline Prices by Grade, Sales Type, PAD District, and State (Cents per Gallon Excluding Taxes) - Continued

\begin{tabular}{|c|c|c|c|c|c|c|c|c|c|c|c|c|}
\hline \multirow{3}{*}{$\begin{array}{l}\text { Geographlc Area } \\
\text { Month }\end{array}$} & \multicolumn{6}{|c|}{ Premium } & \multicolumn{6}{|c|}{ All Grades } \\
\hline & \multicolumn{2}{|c|}{ Sales to End Users } & \multicolumn{4}{|c|}{ Sales for Resale } & \multicolumn{2}{|c|}{ Sales to End Users } & \multicolumn{4}{|c|}{ Sales for Resale } \\
\hline & $\begin{array}{c}\text { Through } \\
\text { Retail } \\
\text { Outlets }\end{array}$ & Averagoa & DTW & Rack & Bulk & Average & $\begin{array}{c}\text { Through } \\
\text { Retail } \\
\text { Outlots }\end{array}$ & Averagea & DTW & Rack & Bulk & Average \\
\hline 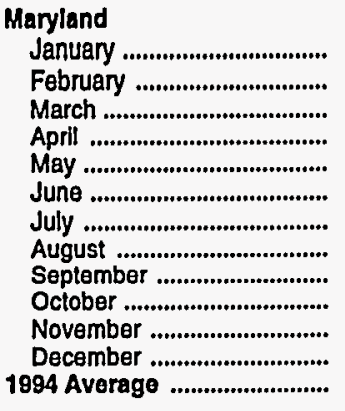 & $\begin{array}{l}76.8 \\
78.0 \\
77.2 \\
77.8 \\
80.8 \\
83.6 \\
86.7 \\
90.9 \\
90.8 \\
90.6 \\
95.0 \\
92.0 \\
84.7\end{array}$ & $\begin{array}{l}75.1 \\
75.6 \\
74.1 \\
73.6 \\
78.0 \\
81.0 \\
84.0 \\
86.5 \\
85.2 \\
86.6 \\
90.5 \\
88.1 \\
81.4\end{array}$ & $\begin{array}{l}71.4 \\
71.6 \\
69.6 \\
70.8 \\
73.2 \\
76.0 \\
77.8 \\
81.4 \\
79.4 \\
78.6 \\
85.9 \\
84.1 \\
76.6\end{array}$ & $\begin{array}{l}58.4 \\
60.7 \\
58.0 \\
60.6 \\
63.4 \\
66.2 \\
67.9 \\
70.7 \\
62.6 \\
65.8 \\
74.5 \\
70.9 \\
65.3\end{array}$ & $\begin{array}{c}- \\
W \\
W \\
W \\
W \\
N A \\
W \\
W \\
W \\
W \\
- \\
W \\
64.8\end{array}$ & $\begin{array}{l}68.4 \\
69.2 \\
66.8 \\
68.4 \\
70.3 \\
73.0 \\
75.0 \\
78.1 \\
74.6 \\
75.0 \\
82.9 \\
80.8 \\
73.6\end{array}$ & $\begin{array}{l}66.7 \\
67.6 \\
66.0 \\
67.0 \\
69.0 \\
71.7 \\
74.9 \\
78.9 \\
79.0 \\
78.7 \\
83.1 \\
80.2 \\
73.6\end{array}$ & $\begin{array}{l}64.2 \\
65.8 \\
63.2 \\
63.9 \\
66.8 \\
69.1 \\
72.4 \\
75.8 \\
74.5 \\
74.7 \\
80.1 \\
77.0 \\
70.7\end{array}$ & $\begin{array}{l}63.5 \\
63.7 \\
61.7 \\
62.8 \\
64.8 \\
67.6 \\
69.3 \\
72.8 \\
70.8 \\
70.0 \\
76.7 \\
75.1 \\
68.3\end{array}$ & $\begin{array}{l}50.7 \\
53.4 \\
51.5 \\
54.0 \\
56.6 \\
59.3 \\
60.6 \\
63.5 \\
55.0 \\
58.2 \\
66.6 \\
62.4 \\
58.0\end{array}$ & $\begin{array}{c}- \\
W \\
W \\
W \\
W \\
59.8 \\
W \\
61.3 \\
55.7 \\
55.3 \\
58.9 \\
58.8 \\
57.8\end{array}$ & $\begin{array}{l}59.9 \\
60.9 \\
58.7 \\
60.3 \\
62.1 \\
64.8 \\
66.5 \\
69.5 \\
65.7 \\
66.2 \\
73.1 \\
71.2 \\
65.1\end{array}$ \\
\hline 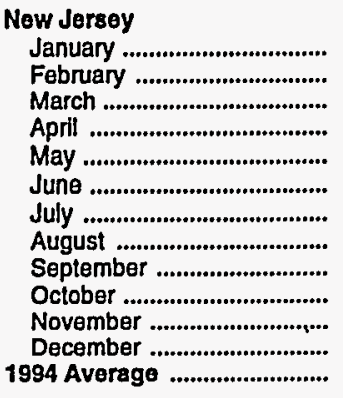 & $\begin{array}{l}90.0 \\
89.4 \\
88.6 \\
87.2 \\
87.9 \\
91.7 \\
93.3 \\
96.5 \\
97.4 \\
98.7 \\
99.6 \\
98.4 \\
93.5\end{array}$ & $\begin{array}{l}87.6 \\
86.7 \\
86.1 \\
85.5 \\
86.1 \\
89.9 \\
91.7 \\
94.8 \\
95.3 \\
96.3 \\
98.3 \\
96.8 \\
91.7\end{array}$ & $\begin{array}{l}74.1 \\
75.1 \\
73.7 \\
73.3 \\
76.0 \\
80.2 \\
82.1 \\
85.1 \\
84.6 \\
85.5 \\
86.9 \\
86.6 \\
80.2\end{array}$ & $\begin{array}{l}58.5 \\
60.3 \\
60.0 \\
62.0 \\
64.8 \\
66.7 \\
68.1 \\
71.9 \\
64.1 \\
70.6 \\
73.4 \\
67.5 \\
66.1\end{array}$ & $\begin{array}{l}52.2 \\
49.7 \\
49.3 \\
55.6 \\
61.7 \\
61.4 \\
66.3 \\
69.2 \\
54.5 \\
59.5 \\
61.2 \\
53.8 \\
\mathbf{5 7 . 6}\end{array}$ & $\begin{array}{l}65.7 \\
67.3 \\
65.4 \\
68.5 \\
70.2 \\
73.6 \\
77.2 \\
78.3 \\
74.0 \\
77.6 \\
79.0 \\
71.8 \\
72.4\end{array}$ & $\begin{array}{l}76.0 \\
75.3 \\
74.8 \\
73.7 \\
73.9 \\
77.8 \\
79.6 \\
83.0 \\
84.0 \\
85.0 \\
86.0 \\
85.0 \\
79.9\end{array}$ & $\begin{array}{l}74.3 \\
73.6 \\
73.3 \\
72.4 \\
72.8 \\
76.6 \\
78.6 \\
81.9 \\
82.5 \\
83.3 \\
85.2 \\
83.9 \\
78.6\end{array}$ & $\begin{array}{l}66.0 \\
66.9 \\
65.4 \\
65.2 \\
67.7 \\
71.9 \\
73.8 \\
76.5 \\
76.2 \\
77.2 \\
78.6 \\
78.4 \\
72.0\end{array}$ & $\begin{array}{l}51.9 \\
54.1 \\
53.4 \\
55.5 \\
57.3 \\
59.3 \\
60.4 \\
63.2 \\
56.8 \\
63.5 \\
65.0 \\
62.2 \\
59.2\end{array}$ & $\begin{array}{l}46.0 \\
45.7 \\
46.0 \\
48.9 \\
53.7 \\
54.0 \\
56.9 \\
58.9 \\
52.2 \\
51.4 \\
57.2 \\
53.4 \\
52.5\end{array}$ & $\begin{array}{l}57.1 \\
57.8 \\
56.3 \\
58.9 \\
60.9 \\
63.0 \\
66.5 \\
67.0 \\
62.5 \\
66.1 \\
68.0 \\
64.8 \\
62.7\end{array}$ \\
\hline 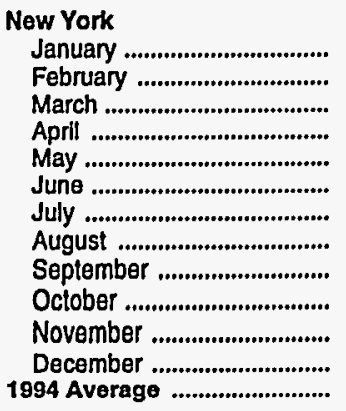 & $\begin{array}{l}84.3 \\
83.9 \\
82.8 \\
82.9 \\
83.8 \\
84.3 \\
87.5 \\
93.4 \\
93.7 \\
94.7 \\
93.8 \\
92.2 \\
88.1\end{array}$ & $\begin{array}{l}81.8 \\
81.8 \\
80.8 \\
81.4 \\
82.5 \\
83.1 \\
86.7 \\
92.5 \\
92.3 \\
92.3 \\
92.9 \\
91.0 \\
86.5\end{array}$ & $\begin{array}{l}73.3 \\
72.4 \\
71.4 \\
73.0 \\
73.3 \\
78.1 \\
80.8 \\
83.5 \\
82.8 \\
85.1 \\
84.8 \\
84.5 \\
78.3\end{array}$ & $\begin{array}{l}57.8 \\
59.9 \\
59.7 \\
62.5 \\
64.6 \\
67.5 \\
70.0 \\
73.8 \\
66.7 \\
70.1 \\
72.4 \\
67.2 \\
66.2\end{array}$ & $\begin{array}{c}W \\
W \\
W \\
W \\
61.7 \\
W \\
W \\
W \\
W \\
W \\
W \\
W \\
57.1\end{array}$ & $\begin{array}{l}67.2 \\
67.4 \\
67.2 \\
69.4 \\
70.3 \\
74.3 \\
76.8 \\
80.1 \\
77.0 \\
79.8 \\
80.7 \\
78.4 \\
74.1\end{array}$ & $\begin{array}{l}70.2 \\
69.8 \\
68.7 \\
68.8 \\
70.3 \\
72.6 \\
76.3 \\
80.2 \\
80.4 \\
80.6 \\
80.3 \\
78.8 \\
74.8\end{array}$ & $\begin{array}{l}68.8 \\
68.6 \\
67.6 \\
67.9 \\
69.4 \\
71.7 \\
75.9 \\
79.6 \\
79.2 \\
79.4 \\
79.6 \\
77.9 \\
73.9\end{array}$ & $\begin{array}{l}63.5 \\
63.2 \\
62.4 \\
64.0 \\
65.3 \\
68.9 \\
71.6 \\
74.0 \\
72.2 \\
73.7 \\
74.1 \\
72.9 \\
68.4\end{array}$ & $\begin{array}{l}50.2 \\
52.7 \\
52.5 \\
54.9 \\
56.9 \\
59.6 \\
61.7 \\
65.0 \\
58.2 \\
60.7 \\
63.5 \\
58.7 \\
58.2\end{array}$ & $\begin{array}{l}46.5 \\
47.1 \\
45.9 \\
47.7 \\
52.1 \\
55.6 \\
57.8 \\
59.7 \\
50.8 \\
58.2 \\
58.8 \\
53.5 \\
51.7\end{array}$ & $\begin{array}{l}57.0 \\
58.0 \\
57.1 \\
59.6 \\
61.2 \\
64.5 \\
66.8 \\
69.9 \\
65.7 \\
67.8 \\
69.4 \\
66.6 \\
63.7\end{array}$ \\
\hline 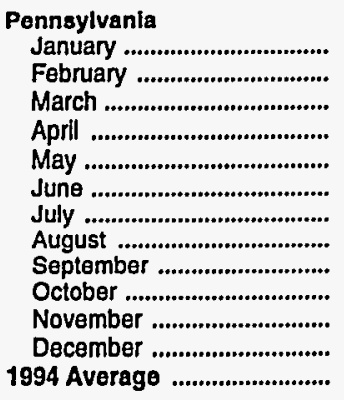 & $\begin{array}{l}78.6 \\
78.8 \\
78.4 \\
79.1 \\
81.0 \\
83.4 \\
84.5 \\
91.4 \\
91.5 \\
89.2 \\
91.7 \\
91.8 \\
85.1\end{array}$ & $\begin{array}{l}78.1 \\
78.3 \\
78.0 \\
78.9 \\
80.8 \\
83.2 \\
84.5 \\
90.6 \\
90.3 \\
88.4 \\
90.8 \\
90.7 \\
84.5\end{array}$ & $\begin{array}{l}67.3 \\
68.7 \\
68.6 \\
70.4 \\
72.8 \\
76.3 \\
79.3 \\
82.9 \\
80.4 \\
78.7 \\
82.3 \\
82.4 \\
75.8\end{array}$ & $\begin{array}{l}54.8 \\
57.0 \\
57.7 \\
60.7 \\
65.1 \\
67.0 \\
69.5 \\
73.0 \\
64.8 \\
65.4 \\
70.0 \\
65.2 \\
64.4\end{array}$ & $\begin{array}{l}W \\
W \\
W \\
W \\
W \\
60.9 \\
66.5 \\
67.8 \\
53.8 \\
59.0 \\
63.0 \\
53.7 \\
57.8\end{array}$ & $\begin{array}{l}59.6 \\
61.4 \\
62.2 \\
64.1 \\
67.6 \\
70.0 \\
73.6 \\
76.7 \\
70.9 \\
71.0 \\
74.3 \\
72.3 \\
68.8\end{array}$ & $\begin{array}{l}65.8 \\
66.4 \\
65.7 \\
66.5 \\
68.4 \\
71.4 \\
74.3 \\
78.8 \\
78.6 \\
77.0 \\
78.9 \\
78.7 \\
73.0\end{array}$ & $\begin{array}{l}65.4 \\
66.1 \\
65.4 \\
66.2 \\
68.3 \\
71.1 \\
74.2 \\
78.2 \\
77.7 \\
76.3 \\
78.3 \\
77.9 \\
72.5\end{array}$ & $\begin{array}{l}58.1 \\
59.1 \\
59.1 \\
60.7 \\
63.1 \\
66.3 \\
69.1 \\
72.4 \\
69.7 \\
68.2 \\
71.5 \\
71.8 \\
65.8\end{array}$ & $\begin{array}{l}47.8 \\
50.3 \\
50.4 \\
53.4 \\
56.5 \\
58.9 \\
61.0 \\
63.9 \\
56.8 \\
57.5 \\
62.0 \\
58.4 \\
56.8\end{array}$ & $\begin{array}{l}44.2 \\
46.2 \\
45.9 \\
50.8 \\
53.4 \\
55.0 \\
57.7 \\
58.9 \\
49.1 \\
51.7 \\
58.8 \\
50.8 \\
52.3\end{array}$ & $\begin{array}{l}51.9 \\
53.8 \\
53.7 \\
56.0 \\
58.7 \\
61.2 \\
63.9 \\
66.9 \\
61.2 \\
61.1 \\
65.4 \\
63.2 \\
60.0\end{array}$ \\
\hline
\end{tabular}

See footnotes at end of table. 
Table 31. Motor Gasoline Prices by Grade, Sales Type, PAD District, and State (Cents per Gallon Excluding Taxes) - Continued

\begin{tabular}{|c|c|c|c|c|c|c|c|c|c|c|c|c|}
\hline \multirow{3}{*}{$\begin{array}{c}\text { Geographic Area } \\
\text { Month }\end{array}$} & \multicolumn{6}{|c|}{ Regular } & \multicolumn{6}{|c|}{ Midgrade } \\
\hline & \multicolumn{2}{|c|}{ Sales to End Users } & \multicolumn{4}{|c|}{ Sales for Resale } & \multicolumn{2}{|c|}{ Sales to End Users } & \multicolumn{4}{|c|}{ Sales for Resale } \\
\hline & $\begin{array}{c}\text { Through } \\
\text { Retail } \\
\text { Outlets }\end{array}$ & Average ${ }^{a}$ & DTW & Rack & Bulk & Average & $\begin{array}{c}\text { Through } \\
\text { Retail } \\
\text { Outlets }\end{array}$ & Average ${ }^{a}$ & DTW & Rack & Bulk & Average \\
\hline Subdistrict IC & & & & & & & & & & & & \\
\hline 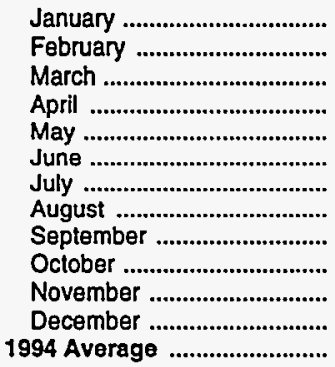 & $\begin{array}{l}58.0 \\
59.6 \\
59.9 \\
61.6 \\
62.6 \\
65.0 \\
67.8 \\
71.5 \\
71.0 \\
69.5 \\
70.4 \\
68.7 \\
65.5\end{array}$ & $\begin{array}{l}57.7 \\
59.4 \\
59.7 \\
61.5 \\
62.5 \\
64.9 \\
67.6 \\
71.0 \\
69.9 \\
68.7 \\
69.8 \\
67.8 \\
65.1\end{array}$ & $\begin{array}{l}53.7 \\
55.6 \\
56.0 \\
58.9 \\
59.7 \\
62.6 \\
64.7 \\
66.3 \\
60.7 \\
61.5 \\
62.8 \\
58.9 \\
60.3\end{array}$ & $\begin{array}{l}45.8 \\
48.9 \\
49.6 \\
52.9 \\
53.2 \\
56.4 \\
58.0 \\
59.6 \\
49.8 \\
53.5 \\
54.7 \\
48.4 \\
52.7\end{array}$ & $\begin{array}{l}42.5 \\
47.3 \\
47.4 \\
52.7 \\
53.2 \\
55.5 \\
58.0 \\
59.0 \\
48.1 \\
51.3 \\
52.6 \\
46.1 \\
50.7\end{array}$ & $\begin{array}{l}48.3 \\
51.1 \\
51.7 \\
54.9 \\
55.4 \\
58.4 \\
60.3 \\
61.9 \\
53.4 \\
56.1 \\
57.4 \\
51.7 \\
55.2\end{array}$ & $\begin{array}{l}69.4 \\
70.5 \\
70.8 \\
72.3 \\
73.3 \\
75.6 \\
78.3 \\
81.7 \\
81.4 \\
80.0 \\
81.1 \\
79.1 \\
76.2\end{array}$ & $\begin{array}{l}68.9 \\
70.0 \\
70.3 \\
71.9 \\
73.0 \\
75.3 \\
78.0 \\
81.1 \\
80.2 \\
79.0 \\
80.1 \\
78.0 \\
75.6\end{array}$ & $\begin{array}{l}60.2 \\
61.9 \\
62.1 \\
65.0 \\
65.8 \\
68.7 \\
71.1 \\
73.0 \\
67.8 \\
68.2 \\
69.4 \\
66.1 \\
66.7\end{array}$ & $\begin{array}{l}50.2 \\
53.5 \\
54.1 \\
57.7 \\
57.9 \\
61.2 \\
62.7 \\
64.8 \\
54.9 \\
58.1 \\
60.0 \\
53.4 \\
57.5\end{array}$ & $\begin{array}{l}W \\
W \\
W \\
W \\
W \\
W \\
W \\
W \\
W \\
W \\
W \\
W \\
\text { NA }\end{array}$ & $\begin{array}{l}54.8 \\
57.3 \\
57.7 \\
61.0 \\
61.4 \\
64.6 \\
66.5 \\
68.5 \\
60.7 \\
62.7 \\
64.3 \\
59.2 \\
61.7\end{array}$ \\
\hline 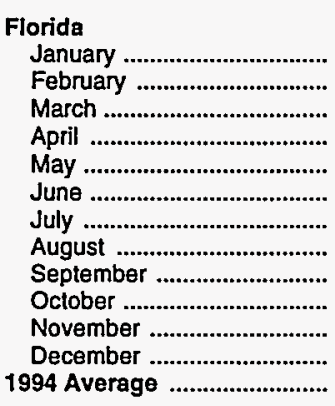 & $\begin{array}{l}58.8 \\
60.6 \\
61.6 \\
63.4 \\
64.8 \\
66.6 \\
69.4 \\
74.0 \\
73.9 \\
72.4 \\
71.4 \\
69.9 \\
66.9\end{array}$ & $\begin{array}{l}58.6 \\
60.5 \\
61.4 \\
63.3 \\
64.6 \\
66.5 \\
69.2 \\
73.4 \\
72.6 \\
71.2 \\
70.8 \\
68.9 \\
66.5\end{array}$ & $\begin{array}{l}54.7 \\
56.2 \\
56.6 \\
59.7 \\
60.3 \\
63.4 \\
66.5 \\
68.5 \\
64.5 \\
63.7 \\
63.2 \\
59.7 \\
61.4\end{array}$ & $\begin{array}{l}46.1 \\
49.5 \\
49.9 \\
53.0 \\
53.2 \\
56.4 \\
58.0 \\
59.8 \\
50.1 \\
53.8 \\
53.9 \\
47.9 \\
52.6\end{array}$ & $\begin{array}{c}W \\
W \\
46.6 \\
W \\
51.0 \\
52.4 \\
W \\
57.6 \\
46.2 \\
50.0 \\
50.9 \\
44.8 \\
48.2\end{array}$ & $\begin{array}{l}49.1 \\
52.0 \\
52.3 \\
55.5 \\
55.9 \\
59.0 \\
61.2 \\
63.1 \\
55.5 \\
57.5 \\
57.4 \\
52.0 \\
55.9\end{array}$ & $\begin{array}{l}71.4 \\
72.7 \\
73.5 \\
74.9 \\
76.4 \\
78.0 \\
80.7 \\
84.6 \\
85.0 \\
83.6 \\
82.9 \\
81.0 \\
78.5\end{array}$ & $\begin{array}{l}70.7 \\
72.0 \\
72.8 \\
74.3 \\
75.7 \\
77.4 \\
80.1 \\
83.8 \\
83.0 \\
81.9 \\
81.3 \\
79.4 \\
77.4\end{array}$ & $\begin{array}{l}61.8 \\
62.9 \\
63.2 \\
66.4 \\
66.8 \\
70.2 \\
73.4 \\
76.1 \\
72.4 \\
71.2 \\
70.3 \\
67.6 \\
68.5\end{array}$ & $\begin{array}{l}50.2 \\
53.5 \\
54.2 \\
57.6 \\
57.8 \\
61.1 \\
62.8 \\
64.9 \\
55.2 \\
58.3 \\
59.0 \\
52.7 \\
57.2\end{array}$ & $\begin{array}{l}\bar{w} \\
w \\
- \\
- \\
- \\
- \\
- \\
- \\
- \\
- \\
\bar{w}\end{array}$ & $\begin{array}{l}56.5 \\
58.6 \\
59.0 \\
62.4 \\
62.7 \\
66.1 \\
68.6 \\
71.1 \\
64.7 \\
65.2 \\
65.2 \\
60.6 \\
63.4\end{array}$ \\
\hline 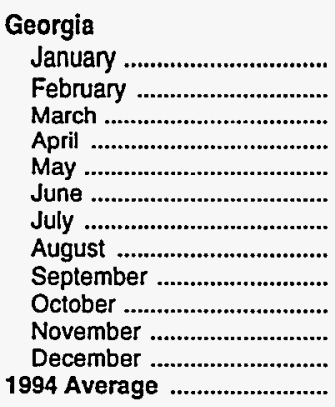 & $\begin{array}{l}56.2 \\
57.6 \\
57.3 \\
58.9 \\
59.9 \\
62.4 \\
64.9 \\
69.5 \\
69.0 \\
67.5 \\
67.9 \\
66.1 \\
63.1\end{array}$ & $\begin{array}{l}56.0 \\
57.6 \\
57.3 \\
59.0 \\
60.1 \\
62.4 \\
64.9 \\
69.1 \\
68.4 \\
67.0 \\
67.7 \\
65.6 \\
63.0\end{array}$ & $\begin{array}{l}50.3 \\
53.1 \\
53.7 \\
57.0 \\
57.8 \\
60.8 \\
62.7 \\
64.0 \\
56.5 \\
57.5 \\
59.5 \\
53.8 \\
57.6\end{array}$ & $\begin{array}{l}45.5 \\
48.3 \\
49.4 \\
52.8 \\
53.0 \\
56.2 \\
57.9 \\
59.1 \\
49.1 \\
53.2 \\
53.2 \\
47.2 \\
52.2\end{array}$ & $\begin{array}{c}W \\
W \\
W \\
52.3 \\
54.1 \\
55.1 \\
W \\
57.1 \\
47.0 \\
W \\
51.6 \\
46.4 \\
51.2\end{array}$ & $\begin{array}{l}46.9 \\
49.8 \\
50.7 \\
54.1 \\
54.6 \\
57.6 \\
59.3 \\
60.7 \\
51.6 \\
54.5 \\
55.3 \\
49.4 \\
54.0\end{array}$ & $\begin{array}{l}66.7 \\
68.0 \\
67.7 \\
69.3 \\
70.2 \\
72.7 \\
75.0 \\
80.0 \\
79.7 \\
78.0 \\
77.8 \\
75.8 \\
73.3\end{array}$ & $\begin{array}{l}66.4 \\
67.6 \\
67.3 \\
69.1 \\
70.1 \\
72.5 \\
74.9 \\
79.5 \\
78.8 \\
77.5 \\
77.4 \\
75.2 \\
73.0\end{array}$ & $\begin{array}{l}55.5 \\
58.2 \\
58.9 \\
62.3 \\
63.3 \\
66.4 \\
68.3 \\
70.0 \\
61.6 \\
62.6 \\
64.6 \\
58.9 \\
62.8\end{array}$ & $\begin{array}{l}50.1 \\
53.3 \\
54.1 \\
57.9 \\
58.2 \\
61.4 \\
62.8 \\
64.7 \\
54.4 \\
58.1 \\
58.8 \\
52.5 \\
57.2\end{array}$ & $\begin{array}{l}- \\
- \\
\bar{w} \\
\bar{w} \\
w \\
w \\
\bar{w} \\
w \\
w \\
w\end{array}$ & $\begin{array}{l}52.4 \\
55.5 \\
56.2 \\
59.8 \\
60.4 \\
63.5 \\
65.2 \\
67.1 \\
57.6 \\
60.2 \\
61.5 \\
55.5 \\
59.8\end{array}$ \\
\hline 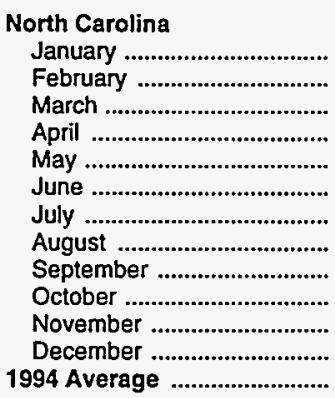 & $\begin{array}{l}55.7 \\
58.0 \\
58.4 \\
60.4 \\
60.8 \\
64.1 \\
66.0 \\
69.7 \\
68.8 \\
67.1 \\
69.3 \\
67.1 \\
64.5\end{array}$ & $\begin{array}{l}55.4 \\
57.6 \\
58.0 \\
60.1 \\
60.5 \\
63.8 \\
65.7 \\
69.0 \\
67.3 \\
65.9 \\
68.3 \\
65.6 \\
63.7\end{array}$ & $\begin{array}{l}53.8 \\
55.6 \\
56.3 \\
59.1 \\
60.0 \\
62.6 \\
64.5 \\
64.5 \\
58.7 \\
60.8 \\
61.5 \\
57.2 \\
59.8\end{array}$ & $\begin{array}{l}46.2 \\
49.2 \\
49.5 \\
53.1 \\
53.2 \\
56.5 \\
58.0 \\
59.7 \\
49.7 \\
53.5 \\
55.2 \\
48.0 \\
52.8\end{array}$ & $\begin{array}{l}W \\
W \\
W \\
W \\
53.7 \\
W \\
W \\
W \\
W \\
W \\
53.3 \\
W \\
53.4\end{array}$ & $\begin{array}{l}48.4 \\
51.1 \\
51.6 \\
54.9 \\
55.3 \\
58.4 \\
60.0 \\
61.0 \\
52.1 \\
55.5 \\
56.7 \\
50.4 \\
54.7\end{array}$ & $\begin{array}{l}65.4 \\
67.4 \\
67.5 \\
69.7 \\
70.2 \\
73.5 \\
75.6 \\
79.1 \\
78.0 \\
76.5 \\
79.3 \\
76.9 \\
74.1\end{array}$ & $\begin{array}{l}65.1 \\
66.9 \\
67.2 \\
69.4 \\
70.0 \\
73.2 \\
75.3 \\
78.6 \\
77.1 \\
75.8 \\
78.4 \\
75.8 \\
73.6\end{array}$ & $\begin{array}{l}60.3 \\
62.0 \\
62.1 \\
65.0 \\
66.1 \\
68.7 \\
71.1 \\
70.6 \\
65.3 \\
67.2 \\
68.6 \\
64.6 \\
66.0\end{array}$ & $\begin{array}{l}50.7 \\
53.8 \\
54.1 \\
57.8 \\
57.8 \\
61.3 \\
62.7 \\
64.6 \\
54.5 \\
57.9 \\
60.4 \\
53.0 \\
57.6\end{array}$ & $\begin{array}{l}- \\
- \\
w \\
w \\
w \\
w \\
w \\
w \\
w \\
w \\
w \\
w \\
w\end{array}$ & $\begin{array}{l}54.2 \\
56.8 \\
57.0 \\
60.4 \\
60.7 \\
63.9 \\
65.7 \\
66.5 \\
57.9 \\
60.8 \\
62.9 \\
56.5 \\
60.4\end{array}$ \\
\hline
\end{tabular}

See footnotes at end of table. 
Table 31. Motor Gasoline Prices by Grade, Sales Type, PAD District, and State (Cents per Gallon Excluding Taxes) - Continued

\begin{tabular}{|c|c|c|c|c|c|c|c|c|c|c|c|c|}
\hline \multirow{3}{*}{$\begin{array}{c}\text { Geographic Area } \\
\text { Month }\end{array}$} & \multicolumn{6}{|c|}{ Promium } & \multicolumn{6}{|c|}{ All Grades } \\
\hline & \multicolumn{2}{|c|}{ Sales to End Users } & \multicolumn{4}{|c|}{ Sales for Resale } & \multicolumn{2}{|c|}{ Sales to End Users } & \multicolumn{4}{|c|}{ Sales for Resale } \\
\hline & $\begin{array}{c}\text { Through } \\
\text { Retail } \\
\text { Outlets }\end{array}$ & Average ${ }^{a}$ & DTW & Rack & Bulk & Average & $\begin{array}{c}\text { Through } \\
\text { Retali } \\
\text { Outlets }\end{array}$ & Average ${ }^{a}$ & DTW & Rack & Bulk & Average \\
\hline Subdlstrict IC & & & & & & & & & & & & \\
\hline 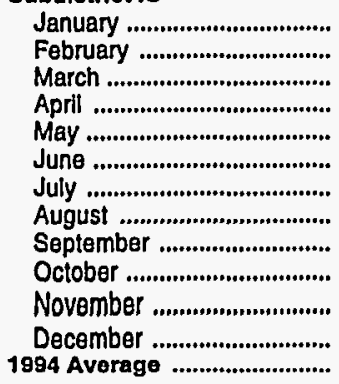 & $\begin{array}{l}78.7 \\
79.7 \\
79.9 \\
81.6 \\
82.7 \\
84.8 \\
87.7 \\
91.4 \\
90.8 \\
89.3 \\
90.3 \\
88.3 \\
85.4\end{array}$ & $\begin{array}{l}77.8 \\
79.0 \\
79.2 \\
80.9 \\
82.0 \\
84.2 \\
87.1 \\
90.3 \\
89.3 \\
88.0 \\
89.1 \\
87.0 \\
84.4\end{array}$ & $\begin{array}{l}68.4 \\
69.9 \\
70.1 \\
72.7 \\
73.6 \\
76.6 \\
79.2 \\
81.2 \\
76.7 \\
76.6 \\
77.6 \\
74.3 \\
74.8\end{array}$ & $\begin{array}{l}55.9 \\
59.0 \\
59.6 \\
63.2 \\
63.5 \\
66.9 \\
68.7 \\
70.4 \\
60.6 \\
64.1 \\
65.4 \\
59.1 \\
63.1\end{array}$ & $\begin{array}{c}46.6 \\
55.9 \\
W \\
59.8 \\
56.6 \\
61.2 \\
W \\
W \\
W \\
56.2 \\
W \\
W \\
57.4\end{array}$ & $\begin{array}{l}61.3 \\
63.8 \\
64.2 \\
67.3 \\
67.8 \\
70.9 \\
73.1 \\
75.0 \\
67.3 \\
69.3 \\
70.5 \\
65.4 \\
68.1\end{array}$ & $\begin{array}{l}64.5 \\
65.9 \\
66.2 \\
67.9 \\
68.9 \\
71.2 \\
73.9 \\
77.4 \\
76.9 \\
75.5 \\
76.4 \\
74.8 \\
71.6\end{array}$ & $\begin{array}{l}64.0 \\
65.4 \\
65.8 \\
67.5 \\
68.6 \\
70.9 \\
73.6 \\
76.7 \\
75.7 \\
74.5 \\
75.6 \\
73.7 \\
71.1\end{array}$ & $\begin{array}{l}59.0 \\
60.8 \\
61.0 \\
63.9 \\
64.8 \\
67.6 \\
69.9 \\
71.4 \\
66.2 \\
66.8 \\
68.0 \\
64.4 \\
65.4\end{array}$ & $\begin{array}{l}48.6 \\
51.8 \\
52.5 \\
55.9 \\
56.2 \\
59.5 \\
61.1 \\
62.7 \\
52.9 \\
56.4 \\
57.8 \\
51.4 \\
55.7\end{array}$ & $\begin{array}{l}43.2 \\
48.5 \\
49.0 \\
53.7 \\
53.7 \\
56.8 \\
59.4 \\
60.4 \\
48.5 \\
52.2 \\
53.1 \\
46.8 \\
51.7\end{array}$ & $\begin{array}{l}52.4 \\
55.2 \\
55.6 \\
58.9 \\
59.4 \\
62.5 \\
64.3 \\
65.9 \\
57.7 \\
60.2 \\
61.5 \\
56.1 \\
59.3\end{array}$ \\
\hline 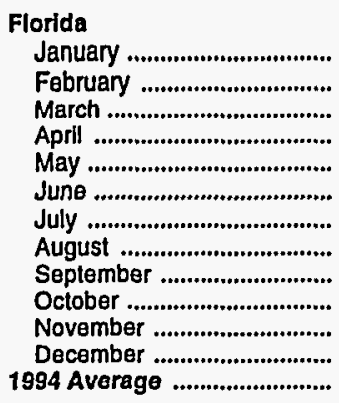 & $\begin{array}{l}80.1 \\
81.3 \\
82.0 \\
83.6 \\
85.0 \\
86.7 \\
89.7 \\
93.9 \\
93.8 \\
92.3 \\
91.3 \\
89.2 \\
87.0\end{array}$ & $\begin{array}{l}79.4 \\
80.5 \\
81.3 \\
83.0 \\
84.1 \\
86.0 \\
89.0 \\
92.7 \\
92.3 \\
90.8 \\
89.9 \\
87.7 \\
86.0\end{array}$ & $\begin{array}{l}71.0 \\
72.3 \\
71.9 \\
74.9 \\
75.4 \\
79.0 \\
82.3 \\
85.0 \\
82.2 \\
80.2 \\
79.4 \\
76.4 \\
77.4\end{array}$ & $\begin{array}{l}56.7 \\
59.7 \\
60.4 \\
63.6 \\
64.0 \\
67.3 \\
69.2 \\
70.7 \\
61.4 \\
64.7 \\
65.0 \\
59.0 \\
63.5\end{array}$ & $\begin{array}{l}W \\
W \\
W \\
W \\
W \\
W \\
- \\
- \\
W \\
W \\
W \\
W \\
53.7\end{array}$ & $\begin{array}{l}65.1 \\
67.1 \\
67.1 \\
70.2 \\
70.6 \\
73.9 \\
76.7 \\
78.9 \\
73.2 \\
73.5 \\
72.9 \\
68.4 \\
71.4\end{array}$ & $\begin{array}{l}65.6 \\
67.2 \\
68.2 \\
70.0 \\
71.4 \\
73.2 \\
75.8 \\
80.1 \\
80.1 \\
78.6 \\
77.7 \\
76.1 \\
73.4\end{array}$ & $\begin{array}{l}65.2 \\
66.8 \\
67.8 \\
69.6 \\
71.0 \\
72.8 \\
75.4 \\
79.4 \\
78.5 \\
77.1 \\
76.7 \\
74.8 \\
72.7\end{array}$ & $\begin{array}{l}61.7 \\
63.0 \\
63.1 \\
66.3 \\
66.9 \\
70.1 \\
73.3 \\
75.3 \\
71.8 \\
70.5 \\
69.8 \\
66.7 \\
68.1\end{array}$ & $\begin{array}{l}48.9 \\
52.3 \\
52.9 \\
56.0 \\
56.4 \\
59.6 \\
61.2 \\
62.8 \\
53.2 \\
56.7 \\
57.0 \\
51.0 \\
55.7\end{array}$ & $\begin{array}{c}43.1 \\
W \\
48.3 \\
W \\
52.0 \\
53.7 \\
W \\
57.6 \\
46.8 \\
50.1 \\
51.4 \\
45.1 \\
48.9\end{array}$ & $\begin{array}{l}54.6 \\
57.2 \\
57.4 \\
60.7 \\
61.3 \\
64.4 \\
66.8 \\
68.5 \\
61.6 \\
63.0 \\
62.7 \\
57.6 \\
61.3\end{array}$ \\
\hline 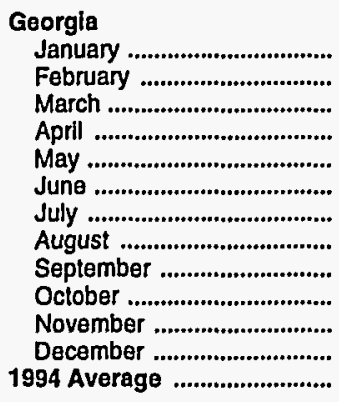 & $\begin{array}{l}76.5 \\
77.5 \\
77.2 \\
79.1 \\
80.1 \\
82.7 \\
85.5 \\
90.0 \\
89.0 \\
87.7 \\
88.0 \\
85.8 \\
82.8\end{array}$ & $\begin{array}{l}75.4 \\
76.9 \\
76.6 \\
78.6 \\
79.6 \\
82.2 \\
85.0 \\
89.0 \\
87.6 \\
86.7 \\
87.0 \\
84.7 \\
82.1\end{array}$ & $\begin{array}{l}63.0 \\
65.4 \\
66.3 \\
69.4 \\
70.5 \\
73.7 \\
75.8 \\
77.4 \\
69.8 \\
70.3 \\
72.0 \\
67.0 \\
70.2\end{array}$ & $\begin{array}{l}55.6 \\
58.3 \\
59.3 \\
62.9 \\
63.1 \\
66.7 \\
68.4 \\
69.7 \\
59.8 \\
63.6 \\
63.6 \\
57.6 \\
62.4\end{array}$ & $\begin{array}{c}W \\
\bar{W} \\
W \\
- \\
60.9 \\
W \\
W \\
W \\
W \\
\bar{W} \\
60.4\end{array}$ & $\begin{array}{l}58.2 \\
61.1 \\
61.8 \\
65.2 \\
65.8 \\
68.9 \\
70.9 \\
72.5 \\
63.3 \\
66.0 \\
66.8 \\
61.3 \\
65.4\end{array}$ & $\begin{array}{l}62.6 \\
64.0 \\
63.7 \\
65.3 \\
66.3 \\
68.7 \\
71.1 \\
75.2 \\
74.8 \\
73.3 \\
73.6 \\
71.9 \\
69.1\end{array}$ & $\begin{array}{l}62.2 \\
63.7 \\
63.5 \\
65.2 \\
66.3 \\
68.6 \\
71.0 \\
74.8 \\
74.1 \\
72.8 \\
73.2 \\
71.3 \\
68.8\end{array}$ & $\begin{array}{l}54.4 \\
57.3 \\
57.9 \\
61.0 \\
62.0 \\
65.1 \\
66.9 \\
68.1 \\
60.3 \\
61.4 \\
63.3 \\
57.9 \\
61.6\end{array}$ & $\begin{array}{l}48.3 \\
51.3 \\
52.3 \\
55.8 \\
56.1 \\
59.3 \\
60.8 \\
62.1 \\
52.1 \\
56.1 \\
56.2 \\
50.2 \\
55.1\end{array}$ & $\begin{array}{c}W \\
W \\
W \\
54.2 \\
54.1 \\
56.8 \\
W \\
59.8 \\
47.9 \\
W \\
52.0 \\
47.3 \\
53.1\end{array}$ & $\begin{array}{l}50.3 \\
53.4 \\
54.2 \\
57.5 \\
58.1 \\
61.1 \\
62.9 \\
64.2 \\
55.0 \\
57.9 \\
58.7 \\
52.9 \\
57.5\end{array}$ \\
\hline 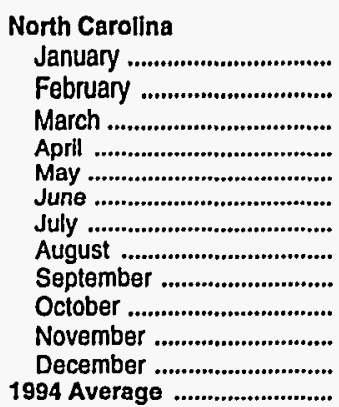 & $\begin{array}{l}75.1 \\
77.4 \\
77.4 \\
79.6 \\
80.1 \\
83.5 \\
85.4 \\
88.5 \\
87.7 \\
86.3 \\
89.0 \\
87.0 \\
83.9\end{array}$ & $\begin{array}{l}74.5 \\
76.7 \\
76.7 \\
78.7 \\
79.5 \\
82.9 \\
84.6 \\
87.3 \\
86.0 \\
85.0 \\
87.7 \\
85.3 \\
82.7\end{array}$ & $\begin{array}{l}66.3 \\
68.4 \\
69.3 \\
70.8 \\
72.9 \\
75.0 \\
77.4 \\
76.8 \\
70.9 \\
73.3 \\
74.7 \\
70.3 \\
72.4\end{array}$ & $\begin{array}{l}56.2 \\
59.2 \\
59.5 \\
63.4 \\
63.6 \\
67.0 \\
68.6 \\
70.6 \\
60.5 \\
64.1 \\
65.9 \\
58.7 \\
63.3\end{array}$ & $\begin{array}{l}- \\
\text { NA } \\
W \\
W \\
W \\
W \\
- \\
- \\
- \\
\bar{W} \\
\overline{57.2}\end{array}$ & $\begin{array}{l}59.2 \\
62.0 \\
62.5 \\
65.8 \\
66.3 \\
69.5 \\
71.4 \\
72.2 \\
63.4 \\
66.6 \\
68.2 \\
61.8 \\
65.8\end{array}$ & $\begin{array}{l}61.3 \\
63.7 \\
63.9 \\
66.1 \\
66.4 \\
69.8 \\
71.7 \\
75.3 \\
74.4 \\
72.9 \\
75.3 \\
73.2 \\
70.3\end{array}$ & $\begin{array}{l}60.8 \\
63.1 \\
63.3 \\
65.6 \\
66.0 \\
69.3 \\
71.2 \\
74.5 \\
72.9 \\
71.6 \\
74.1 \\
71.7 \\
69.4\end{array}$ & $\begin{array}{l}57.6 \\
59.4 \\
60.1 \\
62.9 \\
63.9 \\
66.4 \\
68.5 \\
68.2 \\
62.4 \\
64.6 \\
65.6 \\
61.4 \\
63.7\end{array}$ & $\begin{array}{l}49.0 \\
52.1 \\
52.5 \\
56.1 \\
56.3 \\
59.6 \\
61.1 \\
62.8 \\
52.7 \\
56.5 \\
58.3 \\
51.2 \\
55.9\end{array}$ & $\begin{array}{c}W \\
W \\
W \\
W \\
54.3 \\
W \\
W \\
W \\
W \\
W \\
54.2 \\
W \\
53.9\end{array}$ & $\begin{array}{l}51.6 \\
54.3 \\
54.8 \\
58.2 \\
58.6 \\
61.7 \\
63.4 \\
64.2 \\
55.3 \\
58.7 \\
60.0 \\
53.8 \\
58.0\end{array}$ \\
\hline
\end{tabular}

See footnotes at end of table. 
Table 31. Motor Gasoline Prices by Grade, Sales Type, PAD District, and State (Cents per Gallon Excluding Taxes) — Continued

\begin{tabular}{|c|c|c|c|c|c|c|c|c|c|c|c|c|}
\hline \multirow{3}{*}{$\begin{array}{c}\text { Geographic Area } \\
\text { Month }\end{array}$} & \multicolumn{6}{|c|}{ Regular } & \multicolumn{6}{|c|}{ Midgrado } \\
\hline & \multicolumn{2}{|c|}{ Sales to End Users } & \multicolumn{4}{|c|}{ Sales for Resale } & \multicolumn{2}{|c|}{ Sales to End Users } & \multicolumn{4}{|c|}{ Sales for Resale } \\
\hline & $\begin{array}{c}\text { Through } \\
\text { Retail } \\
\text { Outlets }\end{array}$ & Average ${ }^{a}$ & DTW & Rack & Bulk & Average & $\begin{array}{c}\text { Through } \\
\text { Retail } \\
\text { Outlets }\end{array}$ & Averagea & DTW & Rack & Bulk & Average \\
\hline
\end{tabular}

South Carolina

\begin{tabular}{|c|c|c|c|c|c|c|c|c|c|c|c|c|}
\hline & & & & & & & & & & & & \\
\hline 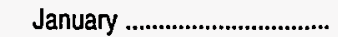 & 54.1 & 54.1 & 50.8 & 45.2 & $W$ & 46.3 & 65.8 & 65.6 & 55.8 & 49.8 & $W$ & 51.3 \\
\hline 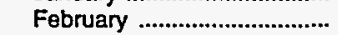 & 56.6 & 56.6 & 54.1 & 48.4 & w & 49.6 & 68.0 & 67.8 & 59.2 & 53.0 & $w$ & 54.5 \\
\hline March & 57.5 & 57.6 & 54.8 & 49.5 & w & 50.5 & 68.4 & 68.3 & 59.6 & 54.1 & - & 55.9 \\
\hline April & 59.8 & 59.9 & 58.2 & 52.9 & w & 54.2 & 71.0 & 70.7 & 63.4 & 57.7 & - & 59.5 \\
\hline May & 60.2 & 60.3 & 58.8 & 53.1 & $w$ & 54.5 & 71.5 & 71.7 & 63.9 & 57.9 & - & 59.9 \\
\hline 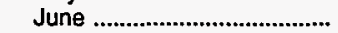 & 63.4 & 63.5 & 62.3 & 56.1 & W & 57.7 & 74.2 & 74.9 & 66.9 & 61.1 & - & 62.9 \\
\hline July & 65.3 & 65.3 & 63.3 & 57.7 & W & 59.0 & 76.7 & 77.2 & 68.3 & 62.4 & - & 64.2 \\
\hline 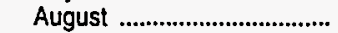 & 69.7 & 69.4 & 66.2 & 59.5 & W & 61.3 & 80.6 & 80.1 & 71.7 & 64.3 & - & 66.6 \\
\hline 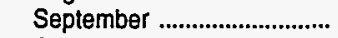 & 68.8 & 68.0 & 59.7 & 49.8 & $W$ & 52.1 & 79.8 & 78.9 & 65.1 & 54.3 & - & 57.4 \\
\hline 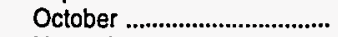 & 66.9 & 66.3 & 60.9 & 53.8 & W & 55.4 & 77.8 & 77.0 & 66.3 & 58.0 & - & 60.4 \\
\hline 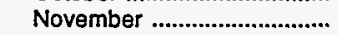 & 68.7 & 68.1 & 62.4 & 54.4 & W & 56.1 & 80.3 & 79.5 & 66.9 & 59.0 & - & 61.2 \\
\hline 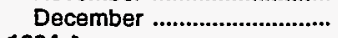 & 65.5 & 65.0 & 57.1 & 47.7 & $w$ & 49.5 & 76.6 & 75.7 & 63.4 & 52.2 & - & 55.4 \\
\hline 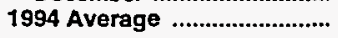 & 62.8 & 62.7 & 59.4 & 52.4 & 48.7 & 53.9 & 73.9 & $\mathbf{7 3 . 8}$ & 64.6 & 57.1 & $w$ & 59.3 \\
\hline Virginia & & & & & & & & & & & & \\
\hline 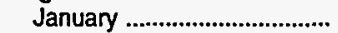 & 61.5 & 60.9 & 56.6 & 45.4 & $W$ & 49.6 & 72.5 & 71.9 & 63.2 & 49.8 & - & 56.9 \\
\hline 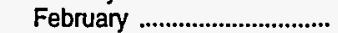 & 61.6 & 61.1 & 57.6 & 49.0 & 46.8 & 52.0 & 71.8 & 71.4 & 64.1 & 53.6 & - & 58.9 \\
\hline March & 61.1 & 60.7 & 56.7 & 49.4 & $W$ & 52.3 & 72.3 & 71.9 & 63.4 & 53.9 & $w$ & 58.7 \\
\hline April & 62.4 & 62.0 & 59.1 & 52.8 & W & 55.3 & 73.1 & 72.7 & 65.7 & 57.3 & $w$ & 61.5 \\
\hline 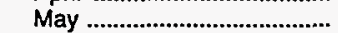 & 63.3 & 63.1 & 60.5 & 53.2 & $w$ & 56.0 & 73.7 & 73.4 & 66.6 & 57.6 & - & 61.9 \\
\hline 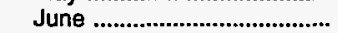 & 65.9 & 65.7 & 62.6 & 56.5 & W & 58.9 & 76.2 & 75.8 & 69.0 & 61.1 & $w$ & 65.0 \\
\hline 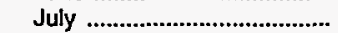 & 70.4 & 70.0 & 64.5 & 58.0 & $w$ & 60.5 & 80.3 & 79.8 & 70.6 & 62.4 & W & 66.3 \\
\hline 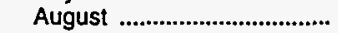 & 71.5 & 71.1 & 66.7 & 59.8 & W & 62.4 & 81.7 & 81.0 & 72.6 & 64.9 & W & 68.8 \\
\hline 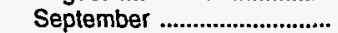 & 71.0 & 70.4 & 61.9 & 50.2 & W & 54.6 & 81.5 & 80.7 & 69.0 & 55.5 & - & 62.2 \\
\hline 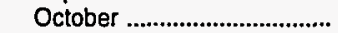 & 70.1 & 69.6 & 63.4 & 53.3 & $W$ & 57.2 & 80.8 & 79.9 & 70.0 & 57.9 & $W$ & 64.2 \\
\hline 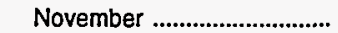 & 72.8 & 72.4 & 66.9 & 57.3 & $W$ & 61.1 & 83.0 & 82.4 & 73.5 & 62.8 & - & 68.5 \\
\hline 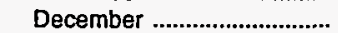 & 72.2 & 71.6 & 65.3 & 51.4 & $w$ & 57.0 & 82.6 & 82.0 & 72.9 & 56.9 & $w$ & 65.4 \\
\hline 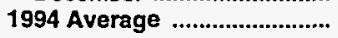 & 67.2 & 66.8 & 62.2 & 53.2 & 54.4 & 56.7 & 77.6 & 77.1 & 68.7 & 58.1 & $w$ & 63.5 \\
\hline West Virginia & & & & & & & & & & & & \\
\hline 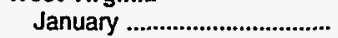 & 69.0 & 67.8 & 57.9 & 46.8 & $w$ & 52.4 & 79.6 & 78.4 & 64.4 & 50.7 & - & 58.7 \\
\hline 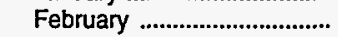 & 68.6 & 67.7 & 59.7 & 50.2 & w & 55.0 & 78.6 & 77.4 & 65.6 & 54.5 & - & 61.2 \\
\hline 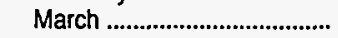 & 67.5 & 66.7 & 59.8 & 50.0 & $W$ & 54.6 & 77.5 & 76.3 & 66.0 & 54.3 & - & 61.3 \\
\hline April & 68.0 & 67.4 & 62.0 & 53.5 & $W$ & 57.8 & 78.4 & 77.4 & 67.4 & 57.5 & - & 63.2 \\
\hline 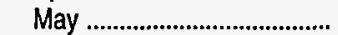 & 69.1 & 68.4 & 63.0 & 54.0 & $W$ & 58.4 & 79.3 & 78.2 & 68.8 & 58.4 & - & 64.5 \\
\hline 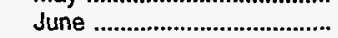 & 69.7 & 69.2 & 65.6 & 58.1 & $w$ & 61.8 & 79.7 & 78.8 & 71.2 & 62.0 & - & 67.5 \\
\hline July ............................................. & 72.1 & 71.7 & 68.1 & 60.2 & - & 64.3 & 82.1 & 81.5 & 73.7 & 64.9 & - & 70.1 \\
\hline 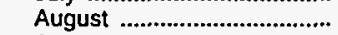 & 76.6 & 76.1 & 70.3 & 62.9 & - & 67.0 & 86.4 & 85.4 & 75.5 & 67.5 & - & 72.5 \\
\hline 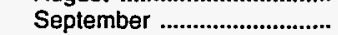 & 76.4 & 75.4 & 64.3 & 53.9 & $W$ & 59.5 & 86.2 & 84.6 & 69.8 & 58.8 & - & 65.6 \\
\hline 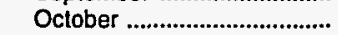 & 74.6 & 73.8 & 64.9 & 53.9 & $W$ & 59.6 & 84.0 & 83.1 & 70.8 & 58.8 & $w$ & 66.1 \\
\hline 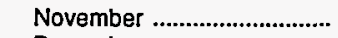 & 76.2 & 75.6 & 67.0 & 58.0 & - & 62.8 & 86.1 & 85.3 & 72.9 & 62.8 & - & 69.0 \\
\hline 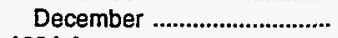 & 74.4 & 73.4 & 62.9 & 51.7 & $W$ & 57.1 & 84.2 & 83.2 & 68.8 & 56.3 & - & 63.9 \\
\hline 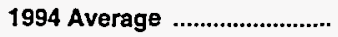 & 72.1 & 71.4 & 64.1 & 54.6 & W & 59.3 & 82.2 & 81.2 & 69.7 & 59.2 & $\mathbf{W}$ & 65.4 \\
\hline PAD District II & & & & & & & & & & & & \\
\hline 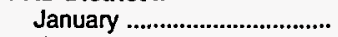 & 60.5 & 60.3 & 53.3 & 47.2 & 42.0 & 48.7 & 68.8 & 68.4 & 59.4 & 52.4 & - & 56.4 \\
\hline 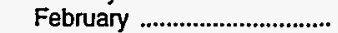 & 62.4 & 62.2 & 55.5 & 50.1 & 46.2 & 51.2 & 70.2 & 69.9 & 61.7 & 55.0 & - & 58.7 \\
\hline 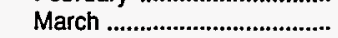 & 61.7 & 61.6 & 55.1 & 50.1 & 47.0 & 51.4 & 69.5 & 69.2 & 60.8 & 55.0 & - & 58.2 \\
\hline April & 64.7 & 64.6 & 58.6 & 54.2 & 50.4 & 55.2 & 72.6 & 72.4 & 64.5 & 58.8 & $W$ & 61.9 \\
\hline 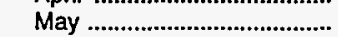 & 66.5 & 66.4 & 60.5 & 55.7 & 52.1 & 56.9 & 74.3 & 74.0 & 66.2 & 60.4 & - & 63.5 \\
\hline 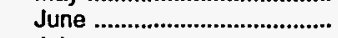 & 69.9 & 69.8 & 64.1 & 59.6 & 55.4 & 60.7 & 77.7 & 77.3 & 70.0 & 64.1 & $w$ & 67.3 \\
\hline July & 73.5 & 73.4 & 67.7 & 63.2 & 58.5 & 64.2 & 81.0 & 80.7 & 73.3 & 66.8 & W & 70.3 \\
\hline August & 78.3 & 78.0 & 70.9 & 66.2 & 62.3 & 67.3 & 85.9 & 85.4 & 76.5 & 69.0 & - & 73.1 \\
\hline 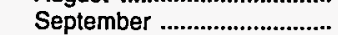 & 74.6 & 74.2 & 63.3 & 55.0 & 54.9 & 57.4 & 82.2 & 81.6 & 69.9 & 58.2 & $W$ & 64.8 \\
\hline 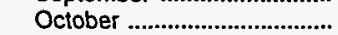 & 70.5 & 70.3 & 61.3 & 54.2 & 51.1 & 55.9 & 78.2 & 77.8 & 67.5 & 59.0 & - & 63.9 \\
\hline 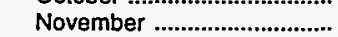 & 70.1 & 69.9 & 61.2 & 54.1 & 50.2 & 55.8 & 78.0 & 77.6 & 68.0 & 59.7 & $w$ & 64.5 \\
\hline 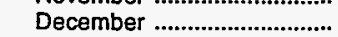 & 65.9 & 65.8 & 57.2 & 49.0 & 47.2 & 51.2 & 73.6 & 73.4 & 64.4 & 54.2 & W & 59.7 \\
\hline 1994 Average & 68.5 & 68.4 & 61.0 & $\mathbf{5 5 . 2}$ & $\mathbf{5 1 . 7}$ & 56.6 & 76.2 & 75.8 & 66.9 & 59.6 & $w$ & 63.7 \\
\hline
\end{tabular}

See footnotes at end of table. 
Table 31. Motor Gasoline Prices by Grade, Sales Type, PAD District, and State (Cents per Gallon Excluding Taxes) - Continued

\begin{tabular}{|c|c|c|c|c|c|c|c|c|c|c|c|c|}
\hline \multirow{3}{*}{$\begin{array}{c}\text { Geographic Area } \\
\text { Month }\end{array}$} & \multicolumn{6}{|c|}{ Premium } & \multicolumn{6}{|c|}{ All Grades } \\
\hline & \multicolumn{2}{|c|}{ Sales to End Users } & \multicolumn{4}{|c|}{ Sales for Resale } & \multicolumn{2}{|c|}{ Sales to End Users } & \multicolumn{4}{|c|}{ Sales for Resale } \\
\hline & $\begin{array}{c}\text { Through } \\
\text { Retail } \\
\text { Outlets }\end{array}$ & Averagea & DTW & Rack & Bulk & Average & $\begin{array}{c}\text { Through } \\
\text { Retail } \\
\text { Outlets }\end{array}$ & Averagea & DTW & Rack & Bulk & Average \\
\hline South Carolina & & & & & & & & & & & & \\
\hline 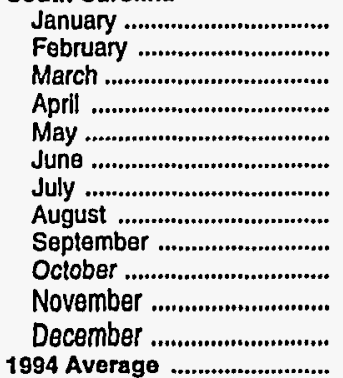 & $\begin{array}{l}75.9 \\
78.3 \\
78.3 \\
81.2 \\
81.8 \\
82.9 \\
85.8 \\
91.3 \\
90.5 \\
87.3 \\
90.7 \\
87.1 \\
84.0\end{array}$ & $\begin{array}{l}75.4 \\
77.7 \\
78.1 \\
81.2 \\
82.0 \\
83.0 \\
85.5 \\
90.8 \\
89.8 \\
86.7 \\
89.9 \\
86.2 \\
83.8\end{array}$ & $\begin{array}{l}62.4 \\
66.0 \\
66.8 \\
70.0 \\
69.9 \\
73.0 \\
74.8 \\
78.5 \\
72.9 \\
73.1 \\
75.3 \\
70.7 \\
71.3\end{array}$ & $\begin{array}{l}55.7 \\
58.6 \\
59.8 \\
63.0 \\
63.5 \\
66.6 \\
68.2 \\
70.4 \\
60.6 \\
64.6 \\
65.1 \\
58.6 \\
63.0\end{array}$ & $\begin{array}{l}W \\
w \\
\bar{w} \\
- \\
- \\
\overline{-} \\
\overline{-} \\
- \\
- \\
\bar{w}\end{array}$ & $\begin{array}{l}56.9 \\
59.9 \\
61.7 \\
64.6 \\
65.2 \\
68.2 \\
69.8 \\
72.8 \\
63.7 \\
66.4 \\
67.5 \\
61.5 \\
64.9\end{array}$ & $\begin{array}{l}60.1 \\
62.6 \\
63.3 \\
65.8 \\
66.2 \\
69.0 \\
71.1 \\
75.4 \\
74.6 \\
72.5 \\
74.6 \\
71.4 \\
68.7\end{array}$ & $\begin{array}{l}60.0 \\
62.5 \\
63.3 \\
65.8 \\
66.5 \\
69.3 \\
71.3 \\
75.2 \\
73.8 \\
71.9 \\
74.0 \\
70.9 \\
68.6\end{array}$ & $\begin{array}{l}54.2 \\
57.5 \\
58.3 \\
61.6 \\
62.2 \\
65.3 \\
66.5 \\
69.6 \\
63.4 \\
64.0 \\
65.8 \\
61.0 \\
62.8\end{array}$ & $\begin{array}{l}47.9 \\
51.1 \\
52.3 \\
55.7 \\
55.9 \\
59.0 \\
60.5 \\
62.3 \\
52.6 \\
56.5 \\
57.2 \\
50.6 \\
55.2\end{array}$ & $\begin{array}{l}W \\
W \\
W \\
W \\
W \\
W \\
W \\
W \\
W \\
W \\
W \\
W \\
48.6\end{array}$ & $\begin{array}{l}49.1 \\
52.5 \\
53.6 \\
57.2 \\
57.6 \\
60.6 \\
62.0 \\
64.3 \\
55.1 \\
58.2 \\
59.0 \\
52.7 \\
56.9\end{array}$ \\
\hline 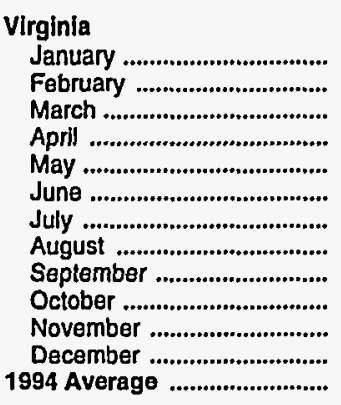 & $\begin{array}{l}81.7 \\
81.5 \\
81.4 \\
82.1 \\
82.9 \\
85.4 \\
89.3 \\
91.2 \\
90.4 \\
89.6 \\
91.4 \\
91.3 \\
86.6\end{array}$ & $\begin{array}{l}80.5 \\
80.4 \\
80.3 \\
81.2 \\
82.3 \\
84.6 \\
88.5 \\
90.0 \\
89.1 \\
88.5 \\
90.7 \\
90.4 \\
85.7\end{array}$ & $\begin{array}{l}70.2 \\
70.9 \\
70.2 \\
72.9 \\
74.0 \\
76.3 \\
78.1 \\
80.7 \\
77.0 \\
77.8 \\
81.2 \\
80.6 \\
76.2\end{array}$ & $\begin{array}{l}54.8 \\
58.5 \\
59.1 \\
62.9 \\
63.2 \\
66.6 \\
68.4 \\
70.5 \\
60.6 \\
63.6 \\
67.6 \\
61.9 \\
63.4\end{array}$ & $\begin{array}{l}\vec{W} \\
W \\
W \\
W \\
W \\
W \\
W \\
- \\
W \\
W \\
W \\
67.1\end{array}$ & $\begin{array}{l}62.2 \\
64.3 \\
64.4 \\
67.6 \\
68.1 \\
70.9 \\
72.8 \\
75.0 \\
67.9 \\
70.2 \\
73.8 \\
70.7 \\
69.3\end{array}$ & $\begin{array}{l}68.3 \\
68.0 \\
67.8 \\
68.9 \\
69.8 \\
72.2 \\
76.5 \\
77.7 \\
77.3 \\
76.4 \\
78.9 \\
78.4 \\
73.5\end{array}$ & $\begin{array}{l}67.5 \\
67.3 \\
67.2 \\
68.3 \\
69.4 \\
71.8 \\
76.0 \\
77.1 \\
76.5 \\
75.8 \\
78.3 \\
77.7 \\
72.9\end{array}$ & $\begin{array}{l}61.8 \\
62.6 \\
61.9 \\
64.3 \\
65.5 \\
67.7 \\
69.4 \\
71.6 \\
67.4 \\
68.7 \\
72.0 \\
70.8 \\
67.3\end{array}$ & $\begin{array}{l}48.2 \\
52.0 \\
52.5 \\
55.8 \\
56.3 \\
59.7 \\
61.2 \\
63.0 \\
53.4 \\
56.4 \\
60.5 \\
54.6 \\
56.4\end{array}$ & $\begin{array}{c}W \\
47.9 \\
W \\
W \\
W \\
W \\
W \\
W \\
W \\
W \\
W \\
W \\
56.7\end{array}$ & $\begin{array}{l}53.9 \\
56.2 \\
56.5 \\
59.4 \\
60.1 \\
63.0 \\
64.7 \\
66.6 \\
59.2 \\
61.6 \\
65.5 \\
61.7 \\
61.0\end{array}$ \\
\hline 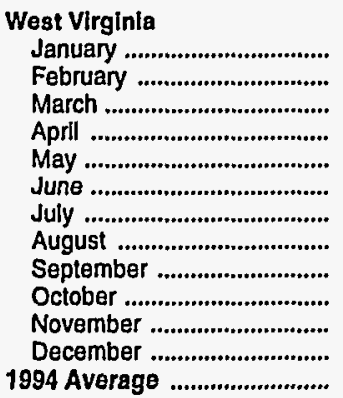 & $\begin{array}{l}85.6 \\
84.1 \\
83.8 \\
84.4 \\
85.9 \\
86.5 \\
89.4 \\
93.7 \\
93.2 \\
90.8 \\
93.6 \\
91.5 \\
88.8\end{array}$ & $\begin{array}{l}83.7 \\
82.6 \\
82.4 \\
83.2 \\
84.5 \\
85.5 \\
88.6 \\
92.5 \\
91.1 \\
89.5 \\
92.1 \\
89.4 \\
87.2\end{array}$ & $\begin{array}{l}71.2 \\
73.0 \\
73.5 \\
74.7 \\
76.4 \\
78.7 \\
81.6 \\
83.1 \\
77.7 \\
77.9 \\
79.8 \\
75.6 \\
76.9\end{array}$ & $\begin{array}{l}57.5 \\
61.1 \\
58.8 \\
64.6 \\
64.9 \\
68.9 \\
71.7 \\
74.1 \\
64.9 \\
65.0 \\
69.1 \\
61.9 \\
65.2\end{array}$ & $\begin{array}{l}- \\
- \\
\overline{-} \\
\overline{-} \\
\overline{-} \\
\overline{-} \\
-\end{array}$ & $\begin{array}{l}65.3 \\
67.9 \\
66.1 \\
70.4 \\
71.2 \\
74.3 \\
77.4 \\
79.4 \\
72.3 \\
72.3 \\
75.2 \\
69.6 \\
71.7\end{array}$ & $\begin{array}{l}74.0 \\
73.1 \\
72.1 \\
72.8 \\
73.9 \\
74.5 \\
76.9 \\
81.2 \\
81.1 \\
79.2 \\
81.1 \\
79.2 \\
76.9\end{array}$ & $\begin{array}{l}72.7 \\
72.1 \\
71.2 \\
72.0 \\
73.0 \\
73.9 \\
76.4 \\
80.6 \\
79.8 \\
78.4 \\
80.4 \\
78.1 \\
76.0\end{array}$ & $\begin{array}{l}61.9 \\
63.6 \\
63.7 \\
65.5 \\
66.9 \\
69.4 \\
71.9 \\
73.8 \\
67.9 \\
68.6 \\
70.7 \\
66.7 \\
67.7\end{array}$ & $\begin{array}{l}49.4 \\
52.9 \\
52.5 \\
56.0 \\
56.7 \\
60.8 \\
62.9 \\
65.7 \\
56.7 \\
56.8 \\
60.8 \\
54.5 \\
57.3\end{array}$ & $\begin{array}{l}w \\
w \\
w \\
w \\
w \\
w \\
- \\
- \\
w \\
w \\
- \\
w \\
w\end{array}$ & $\begin{array}{l}56.0 \\
58.6 \\
58.0 \\
61.1 \\
61.9 \\
65.2 \\
67.8 \\
70.3 \\
63.0 \\
63.2 \\
66.3 \\
60.7 \\
62.8\end{array}$ \\
\hline 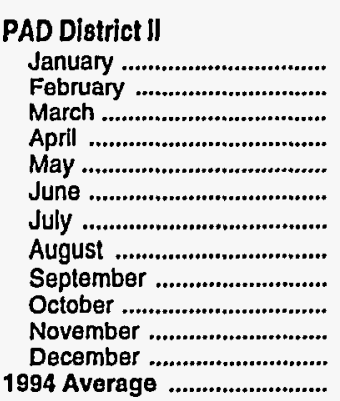 & $\begin{array}{l}75.2 \\
74.5 \\
76.5 \\
79.5 \\
81.5 \\
84.6 \\
88.0 \\
92.8 \\
88.8 \\
84.8 \\
85.2 \\
81.0 \\
82.5\end{array}$ & $\begin{array}{l}74.6 \\
74.1 \\
75.9 \\
78.9 \\
80.9 \\
84.0 \\
87.5 \\
91.9 \\
88.0 \\
84.1 \\
84.5 \\
80.4 \\
81.9\end{array}$ & $\begin{array}{l}65.3 \\
67.5 \\
66.8 \\
70.5 \\
72.3 \\
76.3 \\
79.4 \\
82.4 \\
75.6 \\
73.6 \\
73.5 \\
69.6 \\
72.7\end{array}$ & $\begin{array}{l}55.4 \\
58.0 \\
58.2 \\
62.3 \\
63.9 \\
67.9 \\
71.1 \\
74.3 \\
62.6 \\
62.9 \\
62.8 \\
57.8 \\
63.2\end{array}$ & $\begin{array}{l}46.1 \\
50.8 \\
51.8 \\
54.9 \\
57.7 \\
59.1 \\
67.1 \\
67.3 \\
57.1 \\
54.0 \\
53.0 \\
51.7 \\
55.2\end{array}$ & $\begin{array}{l}59.3 \\
61.6 \\
61.5 \\
65.4 \\
67.2 \\
71.0 \\
74.4 \\
77.4 \\
67.7 \\
66.9 \\
66.9 \\
62.3 \\
66.8\end{array}$ & $\begin{array}{l}64.0 \\
65.6 \\
64.9 \\
67.9 \\
69.7 \\
73.0 \\
76.5 \\
81.2 \\
77.6 \\
73.6 \\
73.3 \\
69.3 \\
71.6\end{array}$ & $\begin{array}{l}63.7 \\
65.3 \\
64.7 \\
67.6 \\
69.5 \\
72.8 \\
76.3 \\
80.8 \\
77.0 \\
73.2 \\
73.0 \\
69.0 \\
71.3\end{array}$ & $\begin{array}{l}56.7 \\
58.7 \\
58.1 \\
61.7 \\
63.5 \\
67.2 \\
70.6 \\
73.6 \\
66.3 \\
64.4 \\
64.3 \\
60.5 \\
63.9\end{array}$ & $\begin{array}{l}48.8 \\
51.6 \\
51.7 \\
55.7 \\
57.2 \\
61.1 \\
64.5 \\
67.5 \\
56.2 \\
55.7 \\
55.6 \\
50.6 \\
56.6\end{array}$ & $\begin{array}{l}42.2 \\
46.4 \\
47.2 \\
50.6 \\
52.2 \\
55.5 \\
58.6 \\
62.5 \\
55.1 \\
51.3 \\
50.3 \\
47.3 \\
51.9\end{array}$ & $\begin{array}{l}51.2 \\
53.5 \\
53.5 \\
57.3 \\
59.0 \\
62.8 \\
66.2 \\
69.2 \\
59.4 \\
58.2 \\
58.2 \\
53.6 \\
58.8\end{array}$ \\
\hline
\end{tabular}

See footnotes at end of table. 
Table 31. Motor Gasoline Prices by Grade, Sales Type, PAD District, and State (Cents per Gallon Excluding Taxes) - Continued

\begin{tabular}{|c|c|c|c|c|c|c|c|c|c|c|c|c|}
\hline \multirow{3}{*}{$\begin{array}{c}\text { Geographic Area } \\
\text { Month }\end{array}$} & \multicolumn{6}{|c|}{ Regular } & \multicolumn{6}{|c|}{ Midgrade } \\
\hline & \multicolumn{2}{|c|}{ Sales to End Users } & \multicolumn{4}{|c|}{ Sales for Resale } & \multicolumn{2}{|c|}{ Sales to End Users } & \multicolumn{4}{|c|}{ Sales for Resale } \\
\hline & $\begin{array}{c}\text { Through } \\
\text { Retail } \\
\text { Outlets }\end{array}$ & Average ${ }^{a}$ & DTW & Rack & Bulk & Average & $\begin{array}{c}\text { Through } \\
\text { Retail } \\
\text { Outlets }\end{array}$ & Averagea & DTW & Rack & Bulk & Average \\
\hline
\end{tabular}

lllinois

\begin{tabular}{|c|c|c|c|c|c|c|c|c|c|c|c|c|}
\hline $\begin{array}{l}\text { Inots } \\
\text { January ...................................... }\end{array}$ & 616 & 612 & 539 & 473 & 401 & & 68.5 & $68 ?$ & & & & \\
\hline February & 62.6 & 62.5 & 56.3 & 49.5 & 47.4 & $\begin{array}{l}49.3 \\
51.3\end{array}$ & 69.3 & $\begin{array}{l}68.2 \\
69.1\end{array}$ & $\begin{array}{l}60.6 \\
63.3\end{array}$ & $\begin{array}{l}54.1 \\
55.5\end{array}$ & $\bar{z}$ & $\begin{array}{l}59.0 \\
61.5\end{array}$ \\
\hline 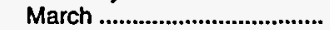 & 61.1 & 61.1 & 55.3 & 48.6 & 46.0 & 50.5 & 68.2 & 68.0 & 62.4 & 54.2 & - & 60.2 \\
\hline April & 64.4 & 64.4 & 59.5 & 53.1 & 50.9 & 54.9 & 71.6 & 71.6 & 66.5 & 58.4 & - & 64.3 \\
\hline 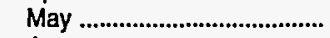 & 65.6 & 65.7 & 61.5 & 55.0 & 51.0 & 56.9 & 72.3 & 72.3 & 68.5 & 62.5 & - & 66.8 \\
\hline June & 70.0 & 69.9 & 66.4 & 59.2 & 56.0 & 61.6 & 77.3 & 77.0 & 73.6 & 64.8 & - & 71.2 \\
\hline 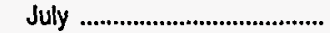 & 73.6 & 73.6 & 69.5 & 62.4 & 56.6 & 64.0 & 80.7 & 80.5 & 76.6 & 68.0 & - & 74.3 \\
\hline August & 80.0 & 79.7 & 72.8 & 64.9 & 62.9 & 67.0 & 85.9 & 85.6 & 80.1 & 71.1 & - & 78.2 \\
\hline 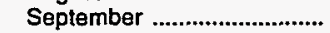 & 77.5 & 76.9 & 68.5 & 53.5 & 56.0 & 58.5 & 85.1 & 84.4 & 76.4 & 59.1 & - & 72.4 \\
\hline October & 73.5 & 73.0 & 65.8 & 53.2 & 51.6 & 56.8 & 80.3 & 79.9 & 73.1 & 59.1 & - & 70.1 \\
\hline 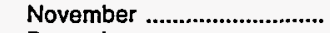 & 72.0 & 71.8 & 64.7 & 53.1 & 50.5 & 56.4 & 77.7 & 77.6 & 72.0 & 58.4 & - & 69.2 \\
\hline 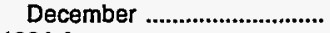 & 68.5 & 68.3 & 64.9 & 48.6 & 47.6 & 53.7 & 73.8 & 73.8 & 71.3 & 54.8 & - & 67.6 \\
\hline 1994 Average & 69.4 & 69.2 & 63.4 & 54.1 & 52.5 & 56.9 & 76.4 & 76.3 & 70.4 & 60.1 & - & 67.8 \\
\hline \multicolumn{13}{|l|}{ Indiana } \\
\hline January & 59.8 & 59.7 & 52.6 & 45.7 & 39.4 & 48.1 & 67.6 & 67.4 & 58.1 & 51.0 & - & 55.6 \\
\hline 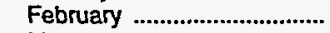 & 62.0 & 61.7 & 55.4 & 48.4 & 46.0 & 50.6 & 69.8 & 68.9 & 61.3 & 53.8 & - & 58.6 \\
\hline March & 61.4 & 61.3 & 54.4 & 48.0 & 46.2 & 49.8 & 69.2 & 68.5 & 60.1 & 53.5 & - & 57.5 \\
\hline April & 65.2 & 65.0 & 58.6 & 53.1 & 48.4 & 54.4 & 72.8 & 72.2 & 64.6 & 58.1 & - & 62.1 \\
\hline 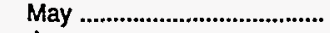 & 66.4 & 66.4 & 60.3 & 54.2 & 51.4 & 56.0 & 74.6 & 73.9 & 66.2 & 59.7 & - & 63.5 \\
\hline June & 68.9 & 68.9 & 63.9 & 58.3 & 54.2 & 60.1 & 76.1 & 75.6 & 69.4 & 63.8 & - & 67.1 \\
\hline July & 72.7 & 72.7 & 67.1 & 60.8 & 57.4 & 62.6 & 80.1 & 79.7 & 73.2 & 66.3 & - & 70.4 \\
\hline August & 76.5 & 76.0 & 69.8 & 63.6 & 61.6 & 65.4 & 84.1 & 83.8 & 75.7 & 68.7 & - & 72.8 \\
\hline 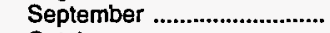 & 70.1 & 70.1 & 62.0 & 52.3 & 57.5 & 56.2 & 77.6 & 77.4 & 68.0 & 57.6 & $w$ & 64.0 \\
\hline October & 66.7 & 66.9 & 59.6 & 53.0 & 51.4 & 55.2 & 74.3 & 74.4 & 64.9 & 57.5 & - & 61.8 \\
\hline 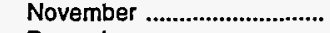 & 68.2 & 68.2 & 59.7 & 53.3 & 51.6 & 55.4 & 76.0 & 75.8 & 65.3 & 58.5 & $W$ & 62.3 \\
\hline 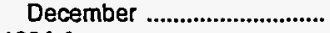 & 63.9 & 64.0 & 55.0 & 47.5 & 47.2 & 49.9 & 71.5 & 71.5 & 61.2 & 52.4 & $W$ & 57.2 \\
\hline 1994 Average .......................... & 67.3 & 67.2 & 60.3 & 53.5 & 51.9 & 55.7 & 74.8 & 74.4 & 65.8 & 58.7 & $W$ & 63.0 \\
\hline \multicolumn{13}{|l|}{ lowa } \\
\hline 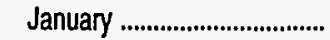 & 58.0 & 58.5 & 53.7 & 48.3 & $W$ & 48.9 & 63.8 & 64.1 & 56.9 & 58.1 & - & 57.2 \\
\hline 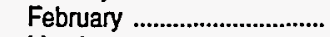 & 60.4 & 60.6 & 57.0 & 51.7 & - & 52.3 & 66.7 & 66.9 & 60.1 & 60.6 & - & 60.2 \\
\hline 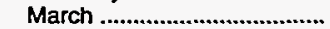 & 61.1 & 61.6 & 58.1 & 52.3 & - & 53.0 & 67.0 & 67.4 & 60.3 & 60.5 & - & 60.4 \\
\hline 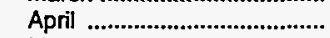 & 64.2 & 64.5 & 60.3 & 55.4 & - & 56.0 & 68.9 & 69.2 & 63.5 & 63.3 & - & 63.4 \\
\hline May & 65.1 & 65.7 & 62.0 & 56.7 & - & 57.4 & 69.8 & 70.1 & 64.8 & 65.2 & - & 65.0 \\
\hline 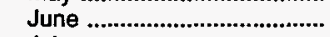 & 69.7 & 69.9 & 65.6 & 60.4 & - & 61.0 & 75.1 & 74.8 & 67.3 & 69.4 & - & 68.0 \\
\hline July & 73.3 & 73.6 & 69.9 & 64.8 & - & 65.5 & 79.3 & 78.7 & 72.0 & 72.3 & - & 72.1 \\
\hline August & 78.4 & 78.6 & 72.4 & 68.4 & - & 69.0 & 83.9 & 83.8 & 73.9 & 74.2 & - & 74.0 \\
\hline 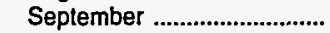 & 77.9 & 77.7 & 67.0 & 57.9 & - & 59.0 & 82.4 & 81.9 & 69.0 & 66.7 & - & 68.7 \\
\hline 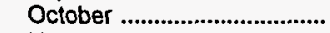 & 76.1 & 75.9 & 63.7 & 54.7 & - & 55.7 & 80.3 & 79.1 & 65.7 & 61.3 & - & 65.0 \\
\hline 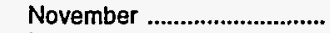 & 73.8 & 73.9 & 62.9 & 54.1 & $w$ & 55.1 & 78.4 & 78.3 & 67.1 & 63.7 & - & 66.4 \\
\hline 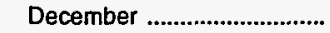 & 69.0 & 69.3 & 59.4 & 50.0 & - & 51.2 & 72.8 & 73.5 & 64.1 & 56.9 & - & 62.3 \\
\hline 1994 Average & 69.3 & 69.6 & 62.9 & 56.6 & $\mathbf{w}$ & 57.4 & 75.0 & $\mathbf{7 4 . 8}$ & 65.2 & 64.2 & - & 65.0 \\
\hline \multicolumn{13}{|l|}{ Kansas } \\
\hline 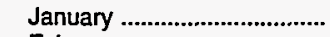 & 58.1 & 58.2 & 49.9 & 46.6 & 43.9 & 46.7 & 65.9 & 66.0 & 55.9 & 52.9 & - & 65.0 \\
\hline 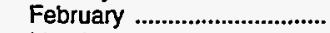 & 60.4 & 60.5 & 53.4 & 50.0 & 46.6 & 49.9 & 67.9 & 68.0 & 59.4 & 56.2 & - & 58.3 \\
\hline March & 60.9 & 60.9 & 54.1 & 50.9 & 47.9 & 51.0 & 68.3 & 68.4 & 59.1 & 57.1 & - & 58.4 \\
\hline April & 63.8 & 63.8 & 57.7 & 54.3 & 50.8 & 54.4 & 71.3 & 71.2 & 63.0 & 60.1 & - & 62.0 \\
\hline 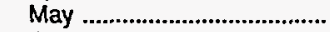 & 64.5 & 64.6 & 58.8 & 55.6 & 52.3 & 55.7 & 72.0 & 71.9 & 64.3 & 61.3 & - & 63.3 \\
\hline June & 68.9 & 69.0 & 59.2 & 59.3 & 55.8 & 58.9 & 75.7 & 75.6 & 67.5 & 64.8 & - & 66.4 \\
\hline July & 73.8 & 73.8 & 67.5 & 64.0 & $w$ & 64.4 & 80.5 & 80.4 & 72.9 & 69.3 & - & 71.5 \\
\hline August & 78.4 & 78.5 & 71.0 & 67.5 & 63.7 & 67.4 & 87.4 & 87.2 & 77.8 & 73.5 & - & 75.7 \\
\hline 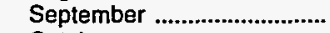 & 73.8 & 73.6 & 63.6 & 57.4 & W & 57.2 & 80.7 & 80.6 & 69.9 & 64.5 & - & 67.5 \\
\hline 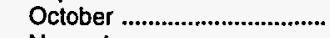 & 68.3 & 68.2 & 58.1 & 53.5 & 50.8 & 53.9 & 75.2 & 75.1 & 62.4 & 59.4 & - & 61.2 \\
\hline 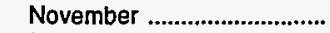 & 66.1 & 66.2 & 57.5 & 52.5 & W & 52.9 & 73.2 & 73.0 & 62.3 & 58.6 & - & 60.9 \\
\hline 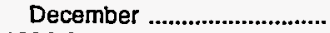 & 61.6 & 61.7 & 52.6 & 48.7 & W & 48.7 & 66.9 & 66.9 & 55.4 & 55.0 & - & 55.2 \\
\hline 1994 Average & 66.8 & 66.9 & 58.5 & $\mathbf{5 5 . 3}$ & 51.5 & 55.3 & 73.8 & 73.7 & 63.9 & 61.6 & - & 63.0 \\
\hline
\end{tabular}

See footnotes at end of table. 
Table 31. Motor Gasoline Prices by Grade, Sales Type, PAD District, and State (Cents per Gallon Excluding Taxes) - Continued

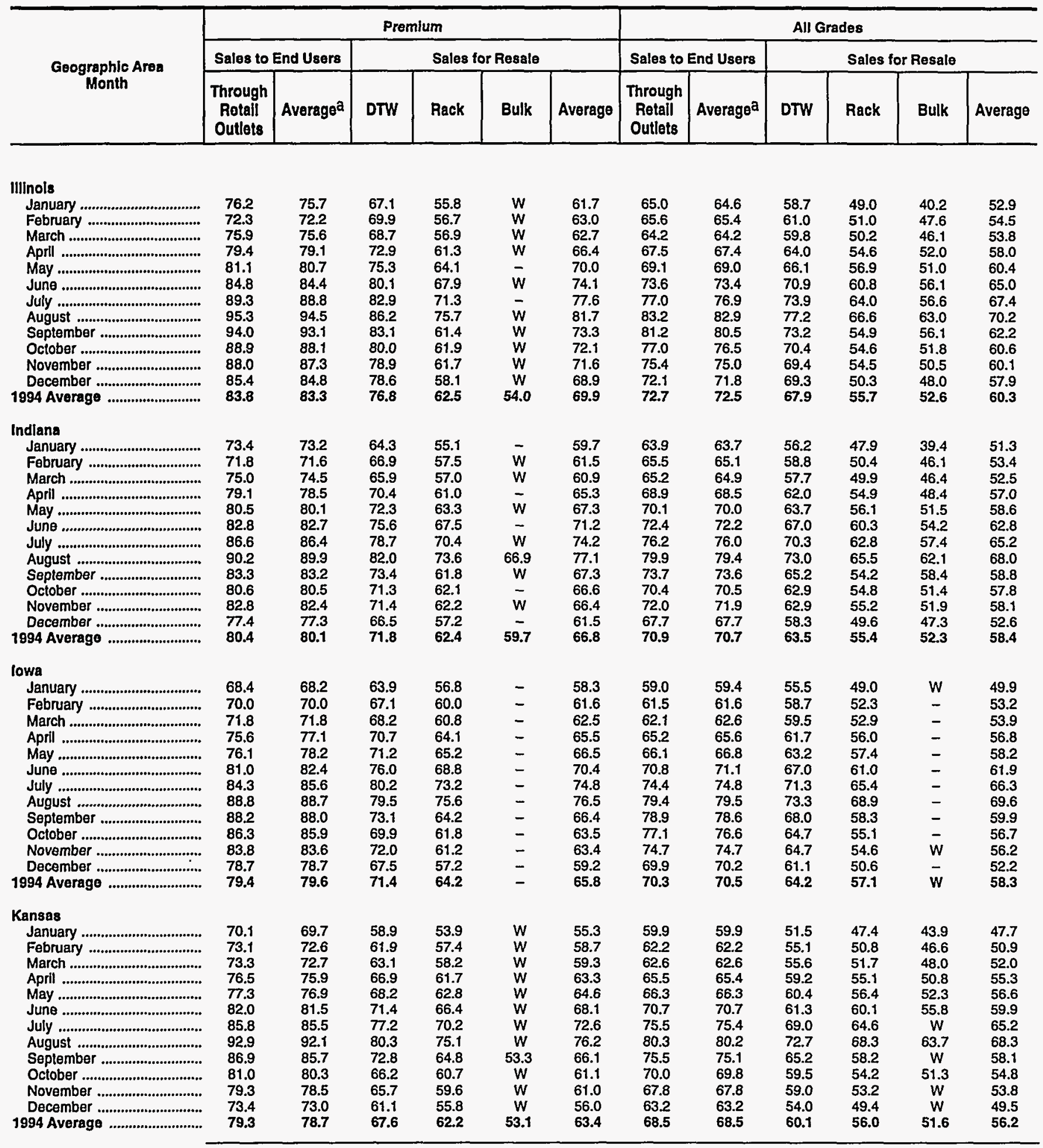

See footnotes at end of table. 
Table 31. Motor Gasoline Prices by Grade, Sales Type, PAD District, and State (Cents per Gallon Excluding Taxes) - Continued

\begin{tabular}{|c|c|c|c|c|c|c|c|c|c|c|c|c|}
\hline \multirow{3}{*}{$\begin{array}{c}\text { Geographic Area } \\
\text { Month }\end{array}$} & \multicolumn{6}{|c|}{ Regular } & \multicolumn{6}{|c|}{ Midgrade } \\
\hline & \multicolumn{2}{|c|}{ Sales to End Users } & \multicolumn{4}{|c|}{ Sales for Resale } & \multicolumn{2}{|c|}{ Sales to End Users } & \multicolumn{4}{|c|}{ Sales for Resale } \\
\hline & $\begin{array}{c}\text { Through } \\
\text { Retail } \\
\text { Outlets }\end{array}$ & Averagea & DTW & Rack & Bulk & Average & $\begin{array}{c}\text { Through } \\
\text { Retail } \\
\text { Outlets }\end{array}$ & Averagea & DTW & Rack & Bulk & Average \\
\hline
\end{tabular}

Kentucky

January

February

................................. 62.

May

June

July ........

August .

September

October ....

November

December ...

1994 Average

Michigan

January

February

62.0

May .............................................. $66 .$.

June ..................................... 70.5

July ...................................... 74.1

August

September ................................ 72.8

October...

November

December
1994 Average

Minnesota

January

February

March

70.4

June ............................................... 75.8

July .....

August

September

October .................................... 76.9

November

December

1994 Average ................................

Missouri

January ....

February ..................................... 58.7

March ................................ 58.2

April .................................. 60.7

May ....................................... 63.1

June ................................................ 66.8

July .

August

September ...............................

September ............................

November

December

1994 Average
$0.4 \quad 59.6$

$\begin{array}{ll}6.7 & 65.2 \\ 6.7 & 67.8\end{array}$

67.6

69.5

71.3

73.8

69.5

66.9

68.5

67.1
67.0

58.6

58.6
61.6

59.7

64.3

66.2

70.2

74.0

77.6
72.6

72.6
68.7

69.3

63.9

67.7

70.7

71.1
69.9

69.9
71.4

71.4
73.3

75.8

79.3

84.1

81.8

76.1

75.2

71.4

75.4

\section{6}

58.6

58.4

60.7

63.0

66.8
70.9

70.9

74.0

68.4

68.4
67.0
61.4

61.4

65.3

$\begin{array}{ll}\mathbf{5 4 . 0} & 46.7 \\ \mathbf{5 5 . 8} & 49.8 \\ \mathbf{5 7 . 7} & \mathbf{5 0 . 4} \\ \mathbf{5 9 . 9} & \mathbf{5 4 . 0} \\ 61.0 & \mathbf{5 4 . 7} \\ 64.7 & \mathbf{5 8 . 4} \\ 67.3 & 60.9 \\ 67.7 & 62.2 \\ 60.2 & \mathbf{5 1 . 6} \\ 60.0 & \mathbf{5 3 . 8} \\ 61.8 & \mathbf{5 4 . 7} \\ \mathbf{5 7 . 1} & \mathbf{5 0 . 2} \\ \mathbf{6 0 . 8} & \mathbf{5 4 . 2}\end{array}$

$\begin{array}{lll}\text { W } & 48.8 & 68.8 \\ \text { W } & 51.7 & 71.2 \\ - & 52.8 & 73.0 \\ - & 55.9 & 74.8 \\ - & 56.7 & 78.0 \\ - & 60.5 & 79.9 \\ - & 63.0 & 81.5 \\ - & 64.0 & 86.3 \\ \text { W } & 54.3 & 81.1 \\ - & 55.8 & 79.0 \\ - & 57.1 & 80.4 \\ - & \mathbf{5 2 . 3} & 78.4 \\ \mathbf{W} & \mathbf{5 6 . 3} & \mathbf{7 7 . 7}\end{array}$

67.8
70.3
72.0
73.8
76.6
78.8
80.7
85.0
79.5
77.7
79.0
77.2
76.5

60.0
61.5
61.9
65.3
66.5
70.2
73.0
74.0
66.9
66.1
68.0
63.8
66.6

$\begin{array}{lll}\mathbf{5 1 . 4} & - & \mathbf{5 5 . 2} \\ \mathbf{5 4 . 2} & - & 56.9 \\ 54.9 & - & 57.6 \\ \mathbf{5 8 . 6} & - & 61.3 \\ \mathbf{5 9 . 3} & - & 62.3 \\ 63.5 & - & 66.3 \\ 66.4 & - & 69.2 \\ 68.0 & - & 70.2 \\ 56.9 & - & 61.0 \\ 58.6 & - & 62.0 \\ 61.4 & - & 64.7 \\ 55.9 & - & 59.3 \\ 59.3 & - & 62.4\end{array}$

$\begin{array}{lll}52.6 & 46.8 & -49.4\end{array}$

$\begin{array}{ll}52.6 & 46.8 \\ 54.8 & 50.1\end{array}$

$53.5 \quad 48.5$

$57.0 \quad 53.7$

$58.9 \quad 56.3$

$63.4 \quad 60.7$

$66.3 \quad 64.1$

$70.8 \quad 66.8$

$62.0 \quad 54.1$

$59.4 \quad 54.4$

54.9

$\begin{array}{ll}54.7 & 47.8 \\ 55.7 & 55.3\end{array}$

$\begin{array}{lll}- & 49.4 & 67.3 \\ - & 522 & 69.9\end{array}$

- 50.8

50.8

55.2
57.4

57.4
61.9

65.1

68.5

68.5
57.6

57.6
56.6

57.3

50.7
$\mathbf{5 7 . 3}$

67.8

67.3

69.7
67.8

67.8
72.0

73.8

77.9

73.8
77.8

81.4
85.6

80.8
76.5

77.5

72.1
75.5

$59.0 \quad 51.1$

$59.3 \quad 54.3$

$59.6 \quad 54.9$

$62.3 \quad 57.9$

$63.9 \quad 59.1$

$66.7 \quad 62.5$

$71.6 \quad 67.2$

$74.9 \quad 71.4$

$66.2 \quad 61.0$

$64.6 \quad 57.4$

$63.1 \quad 57.1$

$59.8 \quad 53.9$

$64.8 \quad 59.5$

$W$
$W$
$W$
$W$
$W$
$W$
$W$
$W$
$W$
$W$
$W$
$W$
$W$

$52.7 \quad 77.4$

$\begin{array}{ll}55.1 & 76.6 \\ 55.7 & 75.3\end{array}$

$58.5 \quad 76.5$

$59.9 \quad 78.1$

$63.2 \quad 80.5$

67.9

71.9

61.8

58.7

58.2

60.4

84.3

89.6
83.4

77.9

$52.1 \quad 46.5$

$\begin{array}{ll}54.7 & 49.6\end{array}$

$54.1 \quad 50.0$

$57.7 \quad 53.6$

$\begin{array}{ll}59.8 & 55.3 \\ 63.3 & 59.2\end{array}$

$67.7 \quad 63.0$

$70.3 \quad 66.2$

$63.2 \quad 55.6$

$59.5 \quad 53.4$

$58.8 \quad 52.7$

$53.9 \quad 47.9$

$\begin{array}{cc}W & 47 \\ W & 50.7 \\ W & 51.0 \\ W & 54 \\ \mathbf{5 1 . 2} & 56.3 \\ \mathbf{5 4 . 6} & 60 \\ \mathbf{W} & 64 \\ \mathbf{W} & 67 \\ \mathbf{5 0 . 2} & 57.3 \\ \mathbf{W} & 54.9 \\ \mathbf{W} & 54.5 \\ \mathbf{W} & 49.7 \\ \mathbf{4 8 . 5} & \mathbf{5 6}\end{array}$

$47.8 \quad 64.1$

$\begin{array}{lll}64.1 & 64.2 & 58.0\end{array}$

$\begin{array}{lll}68.2 & 68.2 & 61.2 \\ 67.3 & 67.2 & 59.9\end{array}$

$69.8 \quad 69.7$

69.7
72.4

76.4

76.1

79.7

85.5

86.0

82.9

82.3
77.0

77.0
75.9

69.7

$\begin{array}{llll}57.4 & 51.7 & - & 55.6 \\ 59.8 & 54.7 & - & 58.2 \\ 58.0 & 53.1 & - & 56.4 \\ 62.2 & 58.0 & - & 60.8 \\ 64.1 & 61.2 & - & 63.1 \\ 68.5 & 66.2 & - & 67.7 \\ 71.6 & 69.2 & - & 70.9 \\ 76.4 & 71.1 & - & 74.8 \\ 68.3 & 58.8 & - & 65.6 \\ 64.5 & 59.8 & - & 63.3 \\ 66.0 & 59.3 & - & 64.2 \\ 60.2 & 53.2 & - & 58.4 \\ 64.9 & 59.9 & - & 63.4\end{array}$

See footnotes at end of table. 
Table 31. Motor Gasoline Prices by Grade, Sales Type, PAD District, and State (Cents per Gallon Excluding Taxes) - Continued

\begin{tabular}{|c|c|c|c|c|c|c|c|c|c|c|c|c|}
\hline \multirow{3}{*}{$\begin{array}{l}\text { Geographic Area } \\
\text { Month }\end{array}$} & \multicolumn{6}{|c|}{ Premlum } & \multicolumn{6}{|c|}{ All Grades } \\
\hline & \multicolumn{2}{|c|}{ Sales to End Users } & \multicolumn{4}{|c|}{ Sales for Resale } & \multicolumn{2}{|c|}{ Sales to End Users } & \multicolumn{4}{|c|}{ Sales for Resale } \\
\hline & $\begin{array}{c}\text { Through } \\
\text { Retall } \\
\text { Outlots }\end{array}$ & Averagea & DTW & Rack & Bulk & Average & $\begin{array}{c}\text { Through } \\
\text { Retail } \\
\text { Outlets }\end{array}$ & Averagea & DTW & Rack & Bulk & Average \\
\hline 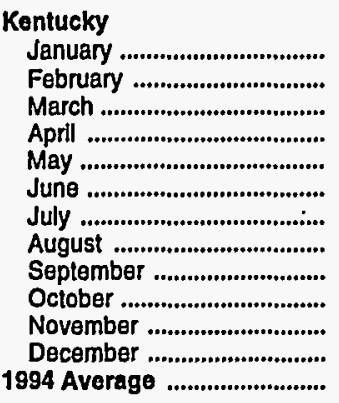 & $\begin{array}{l}76.9 \\
79.8 \\
81.4 \\
82.7 \\
86.3 \\
87.5 \\
89.0 \\
91.5 \\
87.4 \\
84.5 \\
86.4 \\
85.0 \\
84.4\end{array}$ & $\begin{array}{l}75.8 \\
78.8 \\
80.3 \\
81.8 \\
85.0 \\
86.5 \\
88.3 \\
90.4 \\
85.9 \\
83.4 \\
85.2 \\
83.7 \\
83.3\end{array}$ & $\begin{array}{l}66.7 \\
68.5 \\
70.2 \\
72.1 \\
72.9 \\
76.5 \\
80.1 \\
80.0 \\
72.2 \\
71.7 \\
74.0 \\
69.1 \\
72.9\end{array}$ & $\begin{array}{l}56.0 \\
58.8 \\
59.7 \\
63.3 \\
63.9 \\
68.2 \\
70.9 \\
72.8 \\
61.6 \\
63.9 \\
65.3 \\
60.7 \\
63.8\end{array}$ & $\begin{array}{l}\bar{w} \\
\bar{w} \\
\overline{-} \\
\overline{-} \\
\overline{-} \\
\overline{-} \\
\overline{-} \\
\bar{w}\end{array}$ & $\begin{array}{l}60.1 \\
62.4 \\
63.0 \\
66.5 \\
67.2 \\
71.1 \\
74.4 \\
75.3 \\
65.1 \\
66.4 \\
68.3 \\
63.2 \\
66.9\end{array}$ & $\begin{array}{l}65.4 \\
67.8 \\
68.9 \\
70.6 \\
73.6 \\
75.0 \\
76.6 \\
79.1 \\
75.2 \\
72.6 \\
74.0 \\
72.8 \\
72.4\end{array}$ & $\begin{array}{l}64.6 \\
67.0 \\
68.1 \\
69.9 \\
72.6 \\
74.3 \\
76.2 \\
78.4 \\
74.1 \\
71.7 \\
73.2 \\
71.8 \\
71.6\end{array}$ & $\begin{array}{l}58.1 \\
59.7 \\
61.3 \\
63.5 \\
64.5 \\
68.1 \\
71.2 \\
71.1 \\
63.6 \\
63.3 \\
65.1 \\
60.7 \\
64.3\end{array}$ & $\begin{array}{l}49.3 \\
52.2 \\
52.9 \\
56.4 \\
57.1 \\
61.0 \\
63.6 \\
64.9 \\
54.2 \\
56.4 \\
57.6 \\
53.2 \\
56.8\end{array}$ & $\begin{array}{c}W \\
W \\
W \\
- \\
- \\
- \\
- \\
- \\
W \\
- \\
- \\
- \\
46.6\end{array}$ & $\begin{array}{l}52.1 \\
54.7 \\
55.8 \\
58.9 \\
59.7 \\
63.5 \\
66.2 \\
67.0 \\
57.3 \\
58.7 \\
60.3 \\
55.6 \\
59.3\end{array}$ \\
\hline 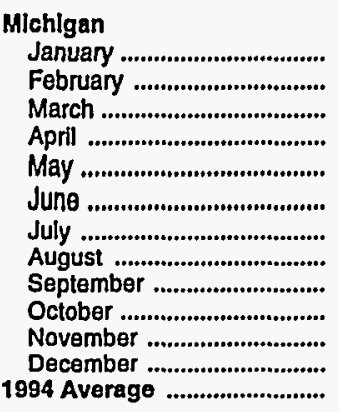 & $\begin{array}{l}73.6 \\
71.9 \\
74.6 \\
77.8 \\
80.4 \\
84.1 \\
87.6 \\
91.6 \\
87.1 \\
83.2 \\
83.8 \\
78.4 \\
81.1\end{array}$ & $\begin{array}{l}72.9 \\
71.5 \\
73.9 \\
77.1 \\
79.6 \\
83.3 \\
87.2 \\
90.9 \\
86.5 \\
82.6 \\
83.3 \\
78.1 \\
80.6\end{array}$ & $\begin{array}{l}63.2 \\
65.4 \\
63.8 \\
68.0 \\
69.8 \\
74.0 \\
77.3 \\
82.2 \\
74.0 \\
70.6 \\
71.1 \\
65.1 \\
70.3\end{array}$ & $\begin{array}{l}55.8 \\
58.5 \\
56.9 \\
62.3 \\
64.9 \\
69.6 \\
73.1 \\
76.2 \\
63.6 \\
63.8 \\
64.1 \\
57.0 \\
64.0\end{array}$ & $\begin{array}{l}- \\
- \\
- \\
- \\
- \\
\bar{w} \\
- \\
- \\
- \\
\bar{w}\end{array}$ & $\begin{array}{l}59.7 \\
62.3 \\
60.7 \\
65.5 \\
67.5 \\
71.9 \\
75.3 \\
79.2 \\
69.2 \\
67.5 \\
67.9 \\
61.4 \\
67.4\end{array}$ & $\begin{array}{l}62.5 \\
65.2 \\
63.2 \\
67.5 \\
69.3 \\
73.3 \\
76.9 \\
80.6 \\
75.7 \\
71.8 \\
72.5 \\
67.1 \\
70.9\end{array}$ & $\begin{array}{l}62.2 \\
64.7 \\
62.9 \\
67.2 \\
69.1 \\
73.0 \\
76.8 \\
80.3 \\
75.5 \\
71.6 \\
72.3 \\
67.0 \\
70.6\end{array}$ & $\begin{array}{l}55.4 \\
57.5 \\
56.0 \\
59.7 \\
61.5 \\
66.0 \\
69.0 \\
73.5 \\
65.0 \\
62.1 \\
63.0 \\
57.0 \\
62.3\end{array}$ & $\begin{array}{l}48.7 \\
51.7 \\
50.1 \\
55.2 \\
57.8 \\
62.4 \\
65.7 \\
68.3 \\
55.6 \\
56.0 \\
56.5 \\
49.5 \\
56.8\end{array}$ & $\begin{array}{c}- \\
- \\
- \\
- \\
- \\
- \\
\bar{w} \\
W \\
- \\
- \\
- \\
55.7\end{array}$ & $\begin{array}{l}52.0 \\
54.6 \\
53.0 \\
57.4 \\
59.6 \\
64.1 \\
67.3 \\
70.8 \\
60.1 \\
59.0 \\
59.7 \\
53.2 \\
59.5\end{array}$ \\
\hline 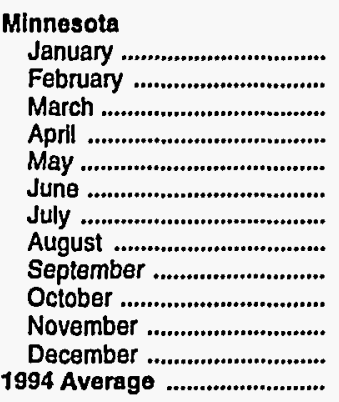 & $\begin{array}{l}85.3 \\
85.6 \\
84.5 \\
84.7 \\
87.1 \\
89.0 \\
92.6 \\
99.4 \\
96.4 \\
89.9 \\
89.8 \\
85.2 \\
89.1\end{array}$ & $\begin{array}{l}85.0 \\
85.2 \\
84.2 \\
84.5 \\
86.6 \\
88.2 \\
92.2 \\
99.0 \\
95.9 \\
89.5 \\
89.5 \\
85.0 \\
88.8\end{array}$ & $\begin{array}{l}71.0 \\
70.8 \\
70.4 \\
72.1 \\
74.7 \\
77.2 \\
80.6 \\
84.6 \\
77.5 \\
75.4 \\
74.1 \\
71.7 \\
75.2\end{array}$ & $\begin{array}{l}58.1 \\
61.4 \\
62.3 \\
65.5 \\
66.8 \\
70.2 \\
75.0 \\
79.3 \\
69.7 \\
65.1 \\
64.3 \\
61.6 \\
66.5\end{array}$ & $\begin{array}{l}W \\
W \\
W \\
W \\
W \\
W \\
W \\
W \\
W \\
W \\
W \\
W \\
W\end{array}$ & $\begin{array}{l}60.7 \\
63.2 \\
64.1 \\
67.0 \\
68.6 \\
71.8 \\
76.1 \\
80.6 \\
71.3 \\
67.5 \\
66.6 \\
64.0 \\
68.5\end{array}$ & $\begin{array}{l}73.7 \\
73.8 \\
72.3 \\
73.5 \\
75.6 \\
77.7 \\
81.4 \\
86.8 \\
84.6 \\
78.6 \\
77.7 \\
73.6 \\
77.7\end{array}$ & $\begin{array}{l}73.2 \\
73.1 \\
71.8 \\
73.2 \\
75.0 \\
77.5 \\
81.1 \\
86.0 \\
83.5 \\
77.7 \\
76.9 \\
73.1 \\
77.1\end{array}$ & $\begin{array}{l}61.2 \\
61.2 \\
61.4 \\
63.6 \\
65.0 \\
67.7 \\
72.3 \\
75.7 \\
67.4 \\
66.0 \\
65.0 \\
62.0 \\
66.1\end{array}$ & $\begin{array}{l}52.5 \\
55.4 \\
56.0 \\
58.8 \\
60.1 \\
63.4 \\
68.1 \\
72.1 \\
61.9 \\
58.4 \\
58.1 \\
55.0 \\
60.4\end{array}$ & $\begin{array}{l}W \\
W \\
W \\
W \\
W \\
W \\
W \\
W \\
W \\
W \\
W \\
W \\
W\end{array}$ & $\begin{array}{l}54.5 \\
56.6 \\
57.0 \\
59.6 \\
61.0 \\
64.2 \\
68.9 \\
72.8 \\
62.9 \\
59.9 \\
59.5 \\
56.4 \\
61.6\end{array}$ \\
\hline 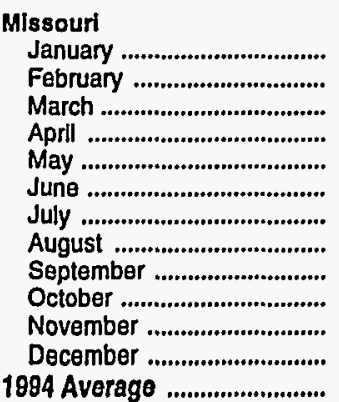 & $\begin{array}{l}71.1 \\
73.6 \\
75.1 \\
77.4 \\
80.0 \\
84.0 \\
87.7 \\
93.9 \\
90.5 \\
85.1 \\
84.0 \\
77.4 \\
81.3\end{array}$ & $\begin{array}{l}70.6 \\
72.9 \\
74.3 \\
76.9 \\
79.3 \\
83.1 \\
86.9 \\
93.2 \\
89.8 \\
84.5 \\
83.4 \\
77.0 \\
80.7\end{array}$ & $\begin{array}{l}63.2 \\
66.5 \\
65.0 \\
68.7 \\
70.4 \\
74.1 \\
78.3 \\
81.3 \\
74.6 \\
71.4 \\
70.4 \\
65.2 \\
70.9\end{array}$ & $\begin{array}{l}54.1 \\
57.4 \\
57.8 \\
61.5 \\
63.0 \\
67.2 \\
70.6 \\
74.2 \\
63.3 \\
61.1 \\
60.5 \\
55.7 \\
62.4\end{array}$ & $\begin{array}{l}\text { W } \\
- \\
- \\
- \\
- \\
- \\
- \\
- \\
- \\
\bar{W}\end{array}$ & $\begin{array}{l}57.2 \\
60.5 \\
60.3 \\
63.9 \\
65.5 \\
69.6 \\
73.3 \\
76.7 \\
67.4 \\
64.6 \\
63.9 \\
59.1 \\
65.4\end{array}$ & $\begin{array}{l}58.8 \\
62.1 \\
61.5 \\
63.8 \\
66.2 \\
69.9 \\
74.0 \\
80.0 \\
77.1 \\
71.3 \\
69.9 \\
64.3 \\
68.4\end{array}$ & $\begin{array}{l}58.8 \\
61.8 \\
61.4 \\
63.6 \\
66.0 \\
69.7 \\
73.7 \\
79.7 \\
76.7 \\
71.2 \\
69.9 \\
64.4 \\
68.2\end{array}$ & $\begin{array}{l}54.9 \\
57.4 \\
56.5 \\
60.2 \\
62.1 \\
65.9 \\
70.1 \\
72.8 \\
65.9 \\
62.2 \\
61.5 \\
56.5 \\
62.4\end{array}$ & $\begin{array}{l}48.0 \\
51.0 \\
51.3 \\
55.0 \\
56.7 \\
60.6 \\
64.3 \\
67.5 \\
56.8 \\
54.7 \\
54.0 \\
49.3 \\
56.0\end{array}$ & $\begin{array}{c}W \\
W \\
W \\
W \\
51.2 \\
54.6 \\
W \\
W \\
50.2 \\
W \\
W \\
W \\
48.5\end{array}$ & $\begin{array}{l}49.9 \\
52.7 \\
52.9 \\
56.3 \\
58.1 \\
62.2 \\
66.1 \\
69.1 \\
59.7 \\
56.8 \\
56.4 \\
51.7 \\
57.9\end{array}$ \\
\hline
\end{tabular}

See footnotes at end of table. 
Table 31. Motor Gasoline Prices by Grade, Sales Type, PAD District, and State (Cents per Gallon Excluding Taxes) - Continued

\begin{tabular}{|c|c|c|c|c|c|c|c|c|c|c|c|c|}
\hline \multirow{3}{*}{$\begin{array}{l}\text { Geographic Area } \\
\text { Month }\end{array}$} & \multicolumn{6}{|c|}{ Regular } & \multicolumn{6}{|c|}{ Midgrado } \\
\hline & \multicolumn{2}{|c|}{ Sales to End Users } & \multicolumn{4}{|c|}{ Sales for Resale } & \multicolumn{2}{|c|}{ Sales to End Users } & \multicolumn{4}{|c|}{ Sales for Resale } \\
\hline & $\begin{array}{c}\text { Through } \\
\text { Retail } \\
\text { Outlets }\end{array}$ & Averagea & DTW & Rack & Bulk & Average & $\begin{array}{c}\text { Through } \\
\text { Retail } \\
\text { Outlets }\end{array}$ & Averagea & DTW & Rack & Bulk & Average \\
\hline \multicolumn{13}{|l|}{ Nebraska } \\
\hline 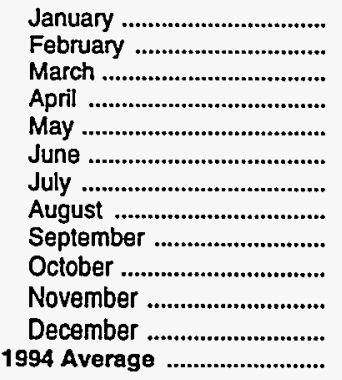 & $\begin{array}{l}63.4 \\
66.9 \\
67.6 \\
68.9 \\
69.2 \\
72.1 \\
76.9 \\
81.4 \\
78.2 \\
73.2 \\
71.6 \\
68.1 \\
71.6\end{array}$ & $\begin{array}{l}63.0 \\
66.5 \\
67.1 \\
68.7 \\
69.1 \\
71.7 \\
76.6 \\
81.2 \\
78.0 \\
73.1 \\
71.5 \\
68.0 \\
71.4\end{array}$ & $\begin{array}{l}54.4 \\
57.7 \\
58.4 \\
61.2 \\
62.0 \\
65.7 \\
70.0 \\
73.2 \\
68.1 \\
64.9 \\
61.1 \\
58.3 \\
63.2\end{array}$ & $\begin{array}{l}47.5 \\
51.1 \\
52.1 \\
55.3 \\
56.6 \\
60.1 \\
64.6 \\
68.6 \\
58.2 \\
55.1 \\
53.6 \\
49.8 \\
56.5\end{array}$ & $\begin{array}{l}- \\
\overline{-} \\
- \\
\bar{w} \\
w \\
- \\
- \\
- \\
\bar{w}\end{array}$ & $\begin{array}{l}48.8 \\
52.3 \\
53.3 \\
56.4 \\
57.6 \\
61.1 \\
65.7 \\
69.4 \\
60.1 \\
57.0 \\
55.1 \\
51.5 \\
57.8\end{array}$ & $\begin{array}{l}68.6 \\
73.7 \\
74.4 \\
76.7 \\
75.3 \\
78.9 \\
82.1 \\
88.9 \\
85.4 \\
80.3 \\
77.1 \\
74.1 \\
77.3\end{array}$ & $\begin{array}{l}68.2 \\
73.2 \\
74.0 \\
76.5 \\
75.1 \\
78.4 \\
82.0 \\
88.6 \\
85.1 \\
79.9 \\
76.7 \\
73.5 \\
76.9\end{array}$ & $\begin{array}{l}60.8 \\
66.7 \\
64.6 \\
66.7 \\
67.8 \\
71.0 \\
75.3 \\
78.1 \\
68.9 \\
64.3 \\
63.6 \\
60.5 \\
67.2\end{array}$ & $\begin{array}{l}55.3 \\
61.1 \\
60.5 \\
64.1 \\
64.8 \\
68.4 \\
72.9 \\
76.0 \\
65.5 \\
63.6 \\
62.6 \\
60.0 \\
64.4\end{array}$ & $\begin{array}{l}- \\
- \\
- \\
- \\
- \\
- \\
- \\
- \\
- \\
- \\
- \\
-\end{array}$ & $\begin{array}{l}56.6 \\
63.3 \\
61.4 \\
64.7 \\
65.4 \\
69.0 \\
73.5 \\
76.9 \\
66.9 \\
63.8 \\
63.0 \\
60.2 \\
65.3\end{array}$ \\
\hline \multicolumn{13}{|l|}{ North Dakota } \\
\hline 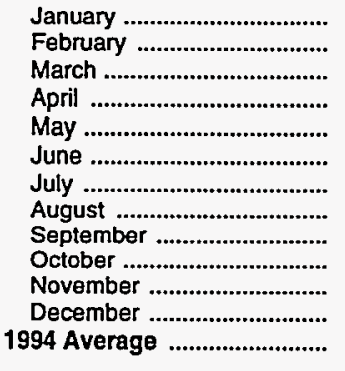 & $\begin{array}{l}75.1 \\
74.8 \\
73.7 \\
77.2 \\
79.4 \\
80.4 \\
83.5 \\
88.0 \\
87.2 \\
84.0 \\
81.0 \\
78.2 \\
80.7\end{array}$ & $\begin{array}{l}74.4 \\
73.9 \\
72.9 \\
75.8 \\
78.3 \\
79.4 \\
82.5 \\
87.3 \\
86.1 \\
82.7 \\
79.8 \\
77.0 \\
79.6\end{array}$ & $\begin{array}{l}60.2 \\
60.3 \\
60.4 \\
63.2 \\
65.7 \\
67.9 \\
71.4 \\
75.6 \\
69.4 \\
66.0 \\
63.6 \\
62.5 \\
66.3\end{array}$ & $\begin{array}{l}51.0 \\
53.2 \\
54.0 \\
57.2 \\
58.9 \\
62.3 \\
66.4 \\
72.0 \\
60.7 \\
56.5 \\
55.8 \\
52.2 \\
58.9\end{array}$ & $\begin{array}{l}w \\
w \\
\bar{w} \\
- \\
\bar{w} \\
w \\
w \\
\bar{w} \\
w \\
w\end{array}$ & $\begin{array}{l}52.0 \\
54.1 \\
54.8 \\
57.9 \\
59.7 \\
62.9 \\
67.1 \\
72.9 \\
62.7 \\
58.4 \\
57.3 \\
54.3 \\
60.2\end{array}$ & $\begin{array}{l}82.3 \\
82.2 \\
80.2 \\
83.7 \\
84.6 \\
85.4 \\
89.1 \\
93.2 \\
92.9 \\
88.6 \\
87.1 \\
84.6 \\
86.6\end{array}$ & $\begin{array}{l}77.4 \\
77.2 \\
76.4 \\
78.6 \\
79.1 \\
84.0 \\
87.0 \\
89.8 \\
90.3 \\
84.7 \\
84.8 \\
79.8 \\
81.7\end{array}$ & $\begin{array}{c}W \\
69.0 \\
W \\
W \\
W \\
75.5 \\
78.0 \\
W \\
77.4 \\
71.9 \\
72.7 \\
W \\
73.3\end{array}$ & $\begin{array}{c}60.7 \\
62.2 \\
63.1 \\
59.4 \\
62.7 \\
65.9 \\
\text { NA } \\
78.4 \\
67.8 \\
63.7 \\
63.5 \\
59.9 \\
64.5\end{array}$ & $\begin{array}{l}- \\
- \\
- \\
- \\
- \\
- \\
- \\
- \\
- \\
- \\
-\end{array}$ & $\begin{array}{c}63.0 \\
63.9 \\
64.7 \\
62.2 \\
66.9 \\
67.4 \\
\text { NA } \\
80.5 \\
72.7 \\
68.5 \\
68.4 \\
65.0 \\
67.3\end{array}$ \\
\hline \multicolumn{13}{|l|}{ Ohio } \\
\hline 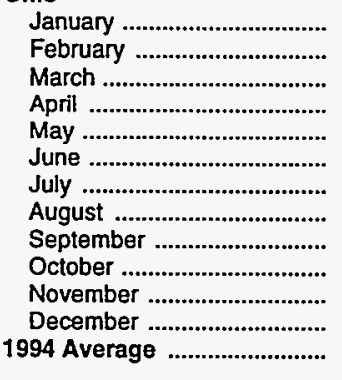 & $\begin{array}{l}62.4 \\
62.3 \\
62.3 \\
65.0 \\
67.7 \\
71.4 \\
74.0 \\
78.3 \\
72.5 \\
68.8 \\
70.1 \\
64.0 \\
68.5\end{array}$ & $\begin{array}{l}61.8 \\
62.0 \\
61.9 \\
64.7 \\
67.4 \\
71.0 \\
73.6 \\
77.8 \\
72.0 \\
68.4 \\
69.8 \\
63.7 \\
68.1\end{array}$ & $\begin{array}{l}53.6 \\
55.0 \\
54.5 \\
58.5 \\
60.5 \\
64.4 \\
66.9 \\
69.8 \\
61.7 \\
60.6 \\
61.6 \\
55.1 \\
60.4\end{array}$ & $\begin{array}{l}47.0 \\
49.1 \\
48.8 \\
53.5 \\
55.3 \\
59.2 \\
61.9 \\
64.1 \\
52.5 \\
53.8 \\
55.0 \\
47.8 \\
54.2\end{array}$ & $\begin{array}{l}W \\
W \\
W \\
51.5 \\
W \\
W \\
W \\
W \\
W \\
W \\
W \\
46.7 \\
W\end{array}$ & $\begin{array}{l}49.9 \\
51.7 \\
51.4 \\
55.7 \\
57.6 \\
61.5 \\
64.2 \\
66.5 \\
56.7 \\
56.8 \\
57.7 \\
50.9 \\
56.9\end{array}$ & $\begin{array}{l}70.7 \\
70.7 \\
70.6 \\
73.7 \\
76.9 \\
80.6 \\
83.1 \\
87.6 \\
81.3 \\
77.9 \\
78.4 \\
72.6 \\
77.0\end{array}$ & $\begin{array}{l}69.8 \\
70.2 \\
69.9 \\
73.1 \\
76.2 \\
79.7 \\
82.4 \\
86.7 \\
80.4 \\
77.2 \\
77.7 \\
72.1 \\
76.3\end{array}$ & $\begin{array}{l}60.5 \\
61.8 \\
61.0 \\
65.1 \\
67.2 \\
71.4 \\
73.9 \\
77.0 \\
69.4 \\
67.5 \\
68.2 \\
62.0 \\
67.1\end{array}$ & $\begin{array}{l}51.3 \\
54.1 \\
53.7 \\
58.0 \\
60.5 \\
64.1 \\
66.0 \\
68.3 \\
58.3 \\
58.5 \\
60.7 \\
53.3 \\
59.6\end{array}$ & $\begin{array}{l}- \\
- \\
\bar{w} \\
\bar{w} \\
- \\
- \\
- \\
- \\
- \\
\bar{w}\end{array}$ & $\begin{array}{l}57.6 \\
59.4 \\
58.7 \\
62.7 \\
65.0 \\
68.5 \\
71.0 \\
73.2 \\
65.6 \\
64.4 \\
65.7 \\
58.4 \\
64.5\end{array}$ \\
\hline \multicolumn{13}{|l|}{ Oklahoma } \\
\hline 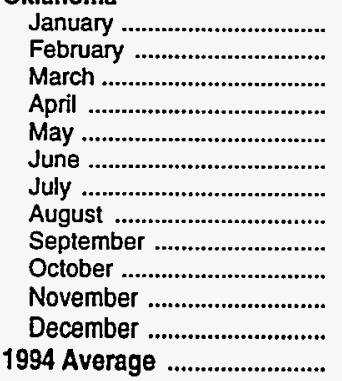 & $\begin{array}{l}52.8 \\
55.9 \\
57.4 \\
60.2 \\
62.3 \\
65.6 \\
71.2 \\
75.0 \\
70.8 \\
63.5 \\
63.8 \\
59.4 \\
63.5\end{array}$ & $\begin{array}{l}52.6 \\
56.1 \\
57.5 \\
60.3 \\
62.2 \\
65.5 \\
71.1 \\
74.7 \\
70.5 \\
63.4 \\
63.5 \\
59.2 \\
63.3\end{array}$ & $\begin{array}{l}52.2 \\
55.4 \\
55.0 \\
57.9 \\
59.1 \\
62.0 \\
66.3 \\
68.6 \\
63.2 \\
60.7 \\
59.9 \\
57.9 \\
59.7\end{array}$ & $\begin{array}{l}44.9 \\
48.2 \\
49.5 \\
52.7 \\
54.2 \\
57.8 \\
62.6 \\
66.8 \\
56.3 \\
52.6 \\
51.3 \\
47.6 \\
53.7\end{array}$ & $\begin{array}{l}41.6 \\
45.4 \\
47.0 \\
50.0 \\
52.0 \\
54.9 \\
58.8 \\
62.4 \\
55.1 \\
50.7 \\
49.5 \\
47.1 \\
51.4\end{array}$ & $\begin{array}{l}44.9 \\
48.0 \\
49.7 \\
52.6 \\
54.3 \\
57.4 \\
61.8 \\
65.3 \\
56.6 \\
52.7 \\
51.6 \\
48.6 \\
53.6\end{array}$ & $\begin{array}{l}60.3 \\
63.7 \\
64.5 \\
68.2 \\
70.3 \\
73.1 \\
78.9 \\
83.0 \\
78.5 \\
70.4 \\
71.2 \\
66.4 \\
70.8\end{array}$ & $\begin{array}{l}61.0 \\
63.8 \\
64.6 \\
68.2 \\
70.2 \\
73.0 \\
78.7 \\
82.9 \\
78.3 \\
70.3 \\
71.1 \\
66.4 \\
70.8\end{array}$ & $\begin{array}{l}59.9 \\
60.7 \\
59.9 \\
62.6 \\
64.2 \\
67.1 \\
71.2 \\
72.7 \\
66.7 \\
64.7 \\
64.3 \\
62.1 \\
64.1\end{array}$ & $\begin{array}{l}47.9 \\
51.7 \\
52.9 \\
56.3 \\
57.4 \\
61.1 \\
65.6 \\
69.7 \\
59.6 \\
55.7 \\
54.3 \\
51.1 \\
57.0\end{array}$ & $\begin{array}{l}- \\
-\cdot \\
- \\
- \\
- \\
- \\
- \\
- \\
- \\
- \\
- \\
-\end{array}$ & $\begin{array}{l}56.4 \\
57.2 \\
57.6 \\
60.4 \\
61.6 \\
65.0 \\
69.0 \\
71.6 \\
64.1 \\
61.0 \\
60.1 \\
57.3 \\
61.2\end{array}$ \\
\hline
\end{tabular}

See footnotes at end of table. 
Table 31. Motor Gasoline Prices by Grade, Sales Type, PAD District, and State (Cents per Gallon Excluding Taxes) - Continued

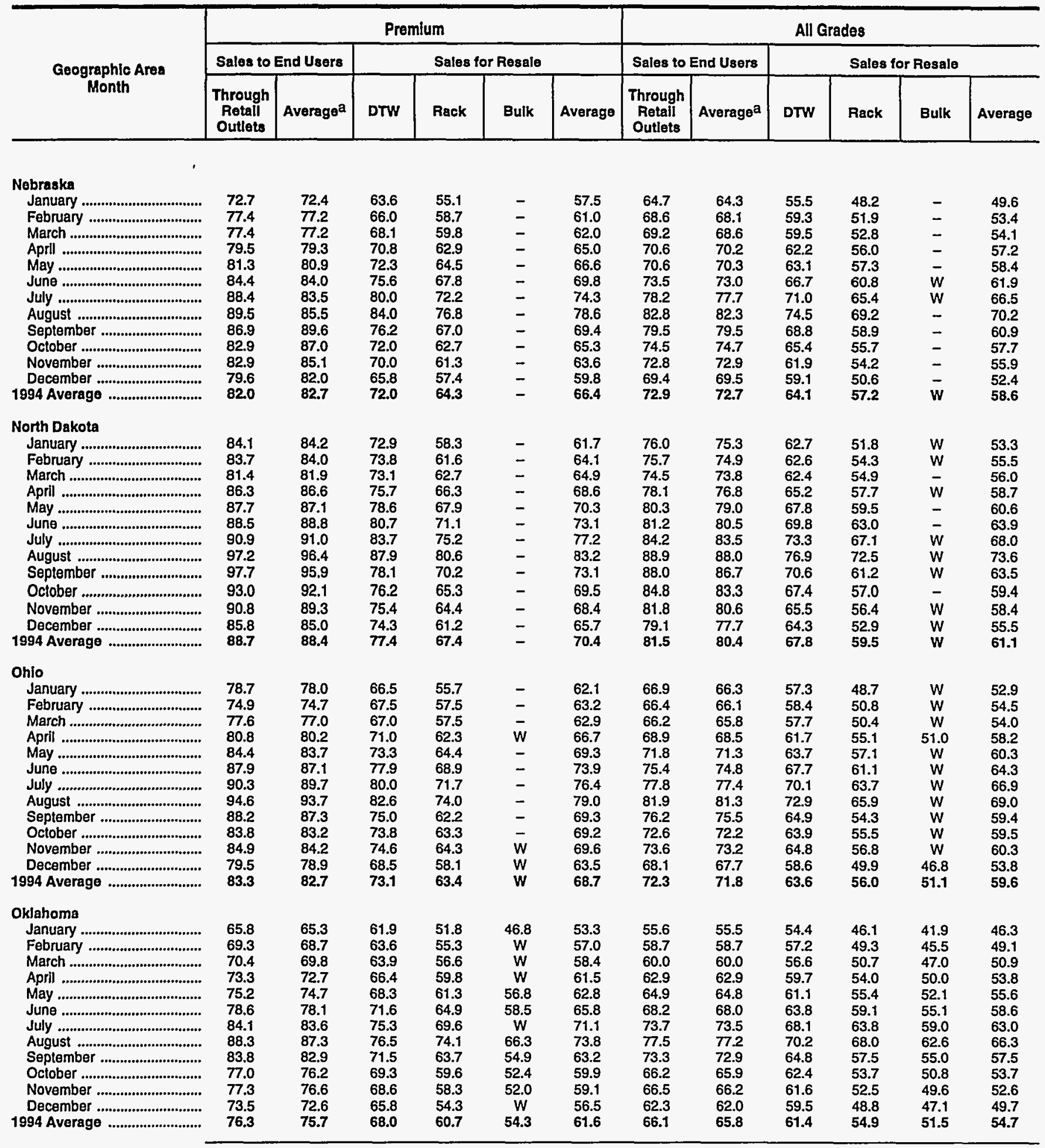

See footnotes at end of table. 
Table 31. Motor Gasoline Prices by Grade, Sales Type, PAD District, and State (Cents per Gallon Excluding Taxes) - Continued

\begin{tabular}{|c|c|c|c|c|c|c|c|c|c|c|c|c|}
\hline \multirow{3}{*}{$\begin{array}{c}\text { Geographic Area } \\
\text { Month }\end{array}$} & \multicolumn{6}{|c|}{ Regular } & \multicolumn{6}{|c|}{ Midgrade } \\
\hline & \multicolumn{2}{|c|}{ Sales to End Users } & \multicolumn{4}{|c|}{ Sales for Resale } & \multicolumn{2}{|c|}{ Sales to End Users } & \multicolumn{4}{|c|}{ Sales for Resale } \\
\hline & $\begin{array}{c}\text { Through } \\
\text { Rotail } \\
\text { Outlets }\end{array}$ & Average ${ }^{a}$ & DTW & Rack & Bulk & Average & $\begin{array}{c}\text { Through } \\
\text { Retail } \\
\text { Outlets }\end{array}$ & Average ${ }^{a}$ & DTW & Rack & Bulk & Average \\
\hline \multicolumn{13}{|l|}{ South Dakota } \\
\hline 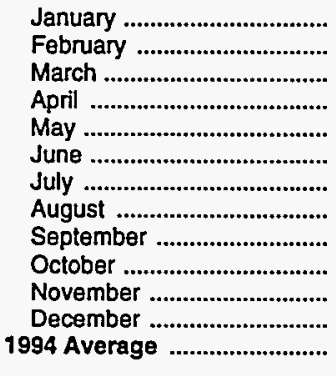 & $\begin{array}{l}69.3 \\
68.3 \\
68.7 \\
71.4 \\
73.1 \\
76.3 \\
79.8 \\
84.9 \\
83.1 \\
78.0 \\
75.1 \\
71.9 \\
75.4\end{array}$ & $\begin{array}{l}68.6 \\
68.0 \\
68.4 \\
71.2 \\
72.8 \\
76.0 \\
79.6 \\
82.9 \\
82.1 \\
77.3 \\
74.2 \\
71.1 \\
74.9\end{array}$ & $\begin{array}{l}56.3 \\
56.9 \\
62.2 \\
61.6 \\
65.7 \\
68.7 \\
73.4 \\
77.0 \\
68.7 \\
65.0 \\
63.8 \\
60.8 \\
65.8\end{array}$ & $\begin{array}{l}48.7 \\
51.8 \\
52.8 \\
56.3 \\
58.6 \\
62.0 \\
66.4 \\
70.9 \\
60.7 \\
56.7 \\
55.7 \\
51.4 \\
58.3\end{array}$ & $\begin{array}{l}-\bar{W} \\
W \\
W \\
W \\
W \\
W \\
W \\
W \\
W \\
W \\
W \\
W\end{array}$ & $\begin{array}{l}50.5 \\
52.8 \\
54.8 \\
57.5 \\
60.1 \\
63.6 \\
68.1 \\
72.5 \\
62.8 \\
58.7 \\
57.7 \\
53.7 \\
60.2\end{array}$ & $\begin{array}{l}75.9 \\
76.1 \\
74.3 \\
77.9 \\
77.6 \\
80.0 \\
85.5 \\
92.7 \\
91.4 \\
88.4 \\
88.2 \\
84.2 \\
81.3\end{array}$ & $\begin{array}{l}75.0 \\
76.1 \\
74.0 \\
78.3 \\
77.9 \\
80.3 \\
85.3 \\
91.6 \\
89.5 \\
87.1 \\
86.9 \\
83.5 \\
81.2\end{array}$ & $\begin{array}{l}62.1 \\
65.1 \\
66.8 \\
67.4 \\
69.6 \\
71.8 \\
76.3 \\
80.9 \\
71.2 \\
70.5 \\
69.2 \\
65.8 \\
70.4\end{array}$ & $\begin{array}{c}W \\
W \\
W \\
61.1 \\
W \\
67.4 \\
N A \\
71.5 \\
W \\
W \\
W \\
W \\
W\end{array}$ & $\begin{array}{l}- \\
- \\
- \\
- \\
- \\
\bar{w} \\
- \\
- \\
- \\
- \\
\bar{w}\end{array}$ & $\begin{array}{c}59.1 \\
60.0 \\
60.9 \\
62.7 \\
66.1 \\
68.4 \\
\text { NA } \\
74.7 \\
63.9 \\
65.9 \\
62.0 \\
61.9 \\
65.6\end{array}$ \\
\hline \multicolumn{13}{|l|}{ Tennessee } \\
\hline 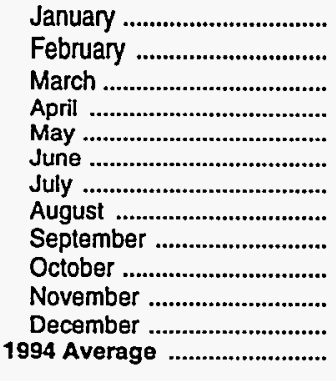 & $\begin{array}{l}56.1 \\
58.1 \\
58.1 \\
61.0 \\
61.6 \\
63.9 \\
66.2 \\
71.3 \\
70.4 \\
68.3 \\
68.9 \\
66.4 \\
64.6\end{array}$ & $\begin{array}{l}55.7 \\
57.7 \\
57.8 \\
60.8 \\
61.4 \\
63.7 \\
66.0 \\
70.8 \\
69.5 \\
67.7 \\
68.4 \\
65.8 \\
64.1\end{array}$ & $\begin{array}{l}52.9 \\
54.8 \\
55.7 \\
58.3 \\
59.6 \\
62.1 \\
64.6 \\
65.7 \\
60.7 \\
63.0 \\
62.2 \\
59.6 \\
59.9\end{array}$ & $\begin{array}{l}45.1 \\
48.0 \\
49.4 \\
53.2 \\
53.1 \\
56.5 \\
58.2 \\
59.5 \\
49.5 \\
53.2 \\
53.5 \\
47.5 \\
52.5\end{array}$ & $\begin{array}{l}- \\
W \\
W \\
W \\
W \\
W \\
W \\
W \\
W \\
W \\
W \\
W \\
W\end{array}$ & $\begin{array}{l}46.7 \\
49.3 \\
50.7 \\
54.3 \\
54.4 \\
57.6 \\
59.5 \\
60.7 \\
51.5 \\
54.9 \\
55.0 \\
49.7 \\
53.9\end{array}$ & $\begin{array}{l}67.3 \\
68.3 \\
68.1 \\
71.1 \\
71.8 \\
74.5 \\
77.0 \\
81.5 \\
80.8 \\
79.0 \\
79.7 \\
77.3 \\
75.1\end{array}$ & $\begin{array}{l}66.7 \\
67.8 \\
67.5 \\
70.8 \\
71.4 \\
74.1 \\
76.6 \\
80.9 \\
80.1 \\
78.4 \\
79.2 \\
76.8 \\
74.6\end{array}$ & $\begin{array}{l}59.2 \\
60.7 \\
61.3 \\
64.1 \\
65.3 \\
67.7 \\
70.7 \\
71.5 \\
66.8 \\
69.6 \\
68.9 \\
66.2 \\
65.9\end{array}$ & $\begin{array}{l}49.8 \\
52.9 \\
54.3 \\
58.2 \\
58.1 \\
61.7 \\
63.1 \\
65.3 \\
54.8 \\
58.3 \\
58.9 \\
52.7 \\
57.5\end{array}$ & $\begin{array}{l}- \\
- \\
- \\
- \\
- \\
- \\
- \\
- \\
- \\
- \\
- \\
-\end{array}$ & $\begin{array}{l}52.6 \\
55.2 \\
56.4 \\
59.9 \\
60.2 \\
63.5 \\
65.4 \\
67.0 \\
58.1 \\
61.2 \\
61.6 \\
56.1 \\
59.8\end{array}$ \\
\hline \multicolumn{13}{|l|}{ Wisconsin } \\
\hline 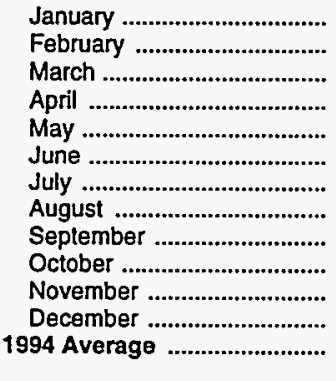 & $\begin{array}{l}60.6 \\
64.3 \\
62.0 \\
65.7 \\
68.3 \\
71.1 \\
74.5 \\
79.9 \\
76.0 \\
72.8 \\
71.7 \\
69.8 \\
70.0\end{array}$ & $\begin{array}{l}60.4 \\
63.7 \\
61.8 \\
65.5 \\
68.1 \\
70.8 \\
74.4 \\
79.2 \\
75.0 \\
72.0 \\
70.9 \\
69.5 \\
69.5\end{array}$ & $\begin{array}{l}52.9 \\
54.6 \\
53.6 \\
58.5 \\
60.9 \\
63.8 \\
67.7 \\
72.2 \\
60.6 \\
59.6 \\
59.1 \\
57.3 \\
60.4\end{array}$ & $\begin{array}{l}48.2 \\
50.7 \\
49.5 \\
54.6 \\
56.7 \\
60.6 \\
64.2 \\
68.5 \\
54.8 \\
54.6 \\
54.6 \\
49.1 \\
55.9\end{array}$ & $\begin{array}{c}W \\
W \\
49.8 \\
W \\
W \\
W \\
\bar{W} \\
- \\
\bar{W} \\
\overline{4} \\
49.2\end{array}$ & $\begin{array}{l}49.4 \\
51.7 \\
50.6 \\
55.6 \\
57.8 \\
61.4 \\
65.1 \\
69.7 \\
56.8 \\
56.2 \\
56.1 \\
51.8 \\
57.3\end{array}$ & $\begin{array}{l}68.1 \\
72.2 \\
70.5 \\
73.8 \\
76.4 \\
78.9 \\
82.2 \\
88.3 \\
84.2 \\
80.8 \\
79.8 \\
77.9 \\
77.8\end{array}$ & $\begin{array}{l}67.9 \\
71.9 \\
70.4 \\
73.7 \\
76.3 \\
78.6 \\
82.4 \\
87.5 \\
83.7 \\
79.9 \\
79.4 \\
77.6 \\
77.5\end{array}$ & $\begin{array}{l}57.0 \\
60.5 \\
59.3 \\
62.5 \\
65.1 \\
68.1 \\
72.9 \\
77.6 \\
67.2 \\
64.1 \\
64.9 \\
64.4 \\
65.4\end{array}$ & $\begin{array}{l}53.6 \\
56.4 \\
54.8 \\
60.0 \\
61.9 \\
66.2 \\
69.5 \\
73.8 \\
60.3 \\
60.4 \\
60.6 \\
55.3 \\
61.2\end{array}$ & $\begin{array}{l}- \\
- \\
- \\
- \\
- \\
- \\
- \\
- \\
- \\
- \\
- \\
-\end{array}$ & $\begin{array}{l}55.2 \\
58.1 \\
56.6 \\
61.1 \\
63.2 \\
67.0 \\
70.9 \\
75.7 \\
63.6 \\
62.3 \\
62.8 \\
59.3 \\
63.1\end{array}$ \\
\hline \multicolumn{13}{|l|}{ PAD District III } \\
\hline 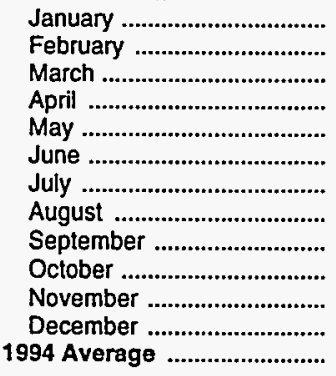 & $\begin{array}{l}60.0 \\
61.0 \\
61.1 \\
63.9 \\
65.6 \\
67.8 \\
70.8 \\
74.3 \\
73.4 \\
71.6 \\
71.8 \\
70.1 \\
67.6\end{array}$ & $\begin{array}{l}59.4 \\
60.4 \\
60.6 \\
63.5 \\
65.1 \\
67.4 \\
70.4 \\
73.4 \\
71.9 \\
70.4 \\
70.6 \\
68.8 \\
66.8\end{array}$ & $\begin{array}{l}52.7 \\
54.1 \\
55.4 \\
58.2 \\
58.9 \\
61.4 \\
64.3 \\
66.5 \\
64.2 \\
62.8 \\
62.8 \\
61.1 \\
59.5\end{array}$ & $\begin{array}{l}44.7 \\
48.0 \\
49.6 \\
52.6 \\
53.2 \\
56.7 \\
59.1 \\
61.7 \\
52.3 \\
53.3 \\
53.0 \\
48.7 \\
52.9\end{array}$ & $\begin{array}{l}40.9 \\
43.2 \\
44.8 \\
47.9 \\
49.0 \\
51.3 \\
53.3 \\
56.0 \\
48.6 \\
47.7 \\
47.7 \\
45.2 \\
47.6\end{array}$ & $\begin{array}{l}44.8 \\
48.0 \\
49.7 \\
52.6 \\
53.4 \\
56.4 \\
58.9 \\
61.6 \\
53.8 \\
53.5 \\
53.4 \\
49.4 \\
53.0\end{array}$ & $\begin{array}{l}69.5 \\
70.5 \\
70.6 \\
73.3 \\
74.8 \\
76.9 \\
80.0 \\
83.2 \\
82.5 \\
80.6 \\
81.2 \\
80.1 \\
77.0\end{array}$ & $\begin{array}{l}68.6 \\
69.6 \\
69.8 \\
72.6 \\
74.1 \\
76.2 \\
79.4 \\
82.3 \\
81.1 \\
79.4 \\
80.1 \\
78.7 \\
75.9\end{array}$ & $\begin{array}{l}57.8 \\
59.4 \\
60.2 \\
63.3 \\
64.0 \\
66.2 \\
69.0 \\
71.2 \\
67.6 \\
66.5 \\
66.5 \\
65.3 \\
64.2\end{array}$ & $\begin{array}{l}49.1 \\
52.5 \\
53.5 \\
57.5 \\
57.7 \\
61.1 \\
63.4 \\
66.1 \\
56.1 \\
57.5 \\
57.3 \\
52.9 \\
57.3\end{array}$ & $\begin{array}{c}W \\
W \\
N A \\
W \\
N A \\
N A \\
N A \\
W \\
N A \\
W \\
N A \\
N A \\
N A\end{array}$ & $\begin{array}{l}52.7 \\
55.3 \\
56.1 \\
59.8 \\
60.2 \\
63.1 \\
65.6 \\
68.2 \\
60.9 \\
61.2 \\
61.2 \\
58.0 \\
60.2\end{array}$ \\
\hline
\end{tabular}

See footnotes at end of table. 
Table 31. Motor Gasoline Prices by Grade, Sales Type, PAD District, and State (Cents per Gallon Excluding Taxes) - Continued

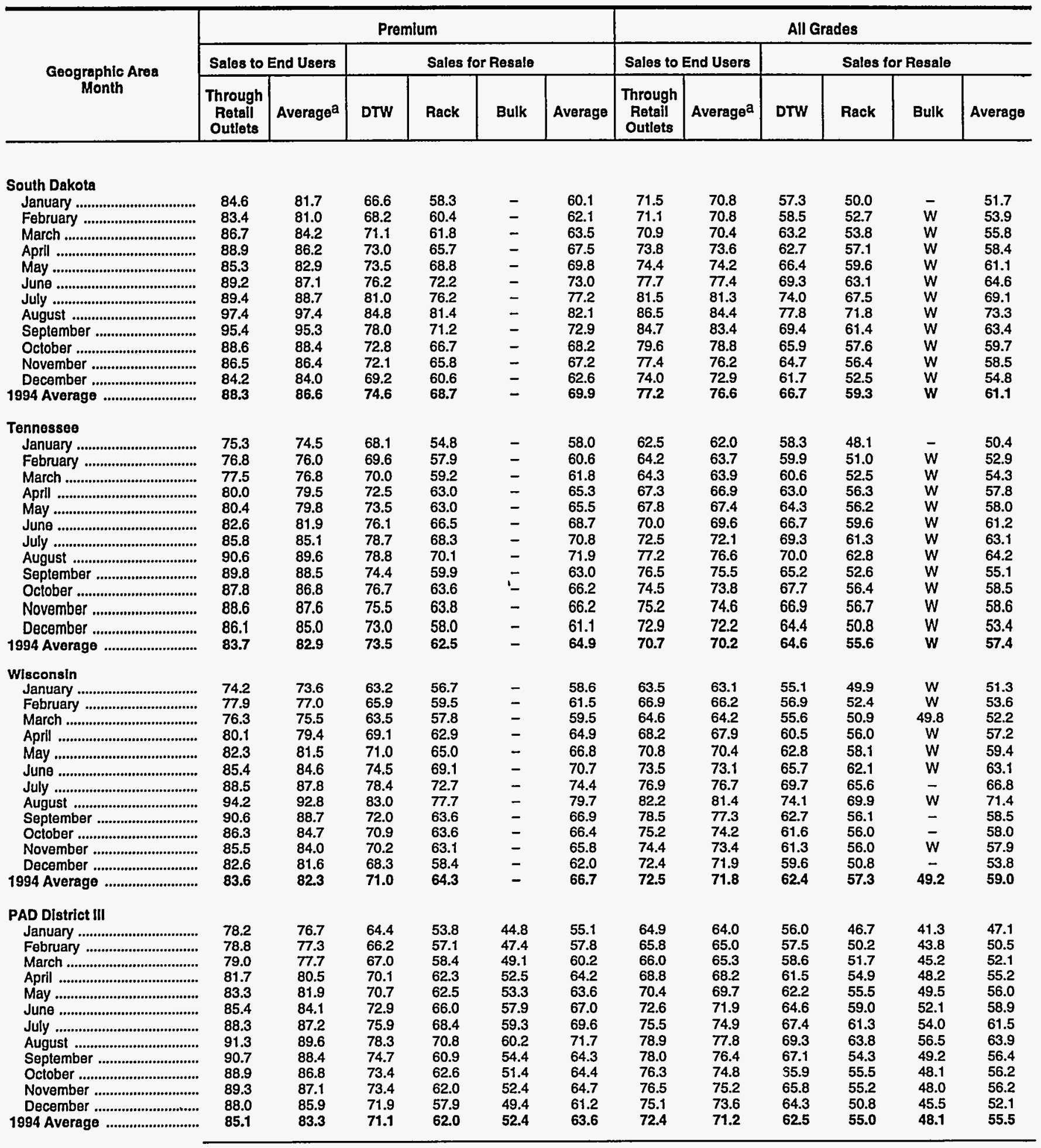

See footnotes at end of table. 
Table 31. Motor Gasoline Prices by Grade, Sales Type, PAD District, and State (Cents per Gallon Excluding Taxes) - Continued

\begin{tabular}{|c|c|c|c|c|c|c|c|c|c|c|c|c|}
\hline \multirow{3}{*}{$\begin{array}{l}\text { Geographic Area } \\
\text { Month }\end{array}$} & \multicolumn{6}{|c|}{ Regular } & \multicolumn{6}{|c|}{ Midgrado } \\
\hline & \multicolumn{2}{|c|}{ Sales to End Users } & \multicolumn{4}{|c|}{ Sales for Resale } & \multicolumn{2}{|c|}{ Sales to End Users } & \multicolumn{4}{|c|}{ Sales for Resale } \\
\hline & $\begin{array}{l}\text { Through } \\
\text { Retail } \\
\text { Outlets }\end{array}$ & Averagea & DTW & Rack & Bulk & Average & $\begin{array}{l}\text { Through } \\
\text { Retail } \\
\text { Outlets }\end{array}$ & Averagea & DTW & Rack & Bulk & Average \\
\hline
\end{tabular}

\begin{tabular}{|c|c|c|c|c|c|c|c|c|c|c|c|c|}
\hline \multicolumn{13}{|l|}{ Alabama } \\
\hline 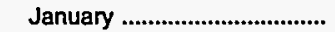 & 60.2 & 59.9 & 57.0 & 45.1 & - & 48.0 & 68.9 & 68.4 & 62.3 & 49.9 & - & 53.8 \\
\hline 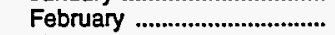 & 62.4 & 61.9 & 58.9 & 48.2 & $w$ & 50.8 & 70.7 & 70.2 & 64.6 & 53.0 & - & 56.6 \\
\hline March ...................................... & 62.8 & 62.3 & 59.6 & 49.1 & $w$ & 51.7 & 71.4 & 70.9 & 64.8 & 54.1 & $W$ & 57.3 \\
\hline April & 64.3 & 64.1 & 61.3 & 53.0 & W & 54.9 & 73.1 & 72.7 & 66.9 & 58.1 & - & 60.6 \\
\hline 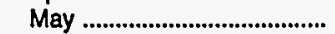 & 66.0 & 65.5 & 62.2 & 53.0 & $w$ & 55.1 & 74.7 & 74.1 & 67.9 & 58.0 & $W$ & 60.9 \\
\hline 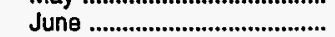 & 68.4 & 67.9 & 64.1 & 56.2 & W & 58.0 & 77.5 & 77.0 & 69.7 & 61.6 & - & 63.9 \\
\hline July & 71.4 & 70.8 & 66.1 & 57.8 & W & 59.7 & 80.9 & 80.4 & 72.4 & 63.1 & - & 65.7 \\
\hline 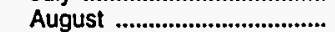 & 72.4 & 71.7 & 68.4 & 59.5 & $W$ & 61.5 & 81.1 & 80.4 & 74.0 & 65.2 & - & 67.8 \\
\hline 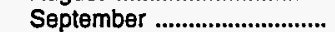 & 71.8 & 70.6 & 65.5 & 49.4 & W & 52.8 & 80.8 & 79.6 & 70.9 & 54.6 & - & 59.5 \\
\hline 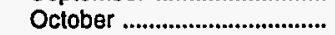 & 71.2 & 70.3 & 66.1 & 52.8 & W & 55.7 & 80.1 & 79.2 & 71.9 & 57.8 & - & 61.8 \\
\hline November ............................... & 70.9 & 70.0 & 65.0 & 53.3 & W & 55.8 & 79.9 & 79.1 & 70.4 & 58.9 & - & 62.3 \\
\hline 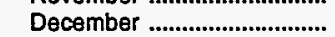 & 69.2 & 68.2 & 62.3 & 47.2 & W & 50.5 & 78.4 & 77.5 & 67.7 & 52.3 & - & 56.5 \\
\hline 1994 Average & 67.4 & 66.7 & 63.2 & 52.1 & $\mathbf{W}$ & 54.6 & 76.3 & 75.6 & 68.8 & 57.4 & $\mathbf{w}$ & 60.6 \\
\hline \multicolumn{13}{|l|}{ Arkansas } \\
\hline 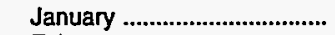 & 58.0 & 57.5 & 48.9 & 44.8 & $W$ & 46.0 & 68.4 & 67.5 & 52.2 & 49.6 & - & 50.9 \\
\hline 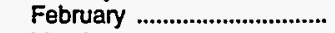 & 59.7 & 58.9 & 52.0 & 48.1 & - & 49.3 & 69.7 & 68.8 & 55.2 & 52.5 & - & 53.8 \\
\hline March & 60.0 & 59.5 & 52.8 & 49.4 & $W$ & 50.5 & 69.7 & 68.9 & 55.7 & 53.8 & - & 54.6 \\
\hline April & 63.5 & 62.9 & 55.9 & 52.8 & $W$ & 53.8 & 72.7 & 71.9 & 59.9 & 57.4 & - & 58.6 \\
\hline May & 64.0 & 63.5 & 56.9 & 53.4 & W & 54.5 & 72.9 & 72.2 & 60.0 & 57.9 & - & 58.9 \\
\hline 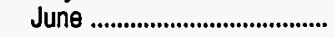 & 66.8 & 66.1 & 60.1 & 56.9 & $W$ & 57.9 & 75.9 & 75.0 & 63.7 & 61.5 & - & 62.5 \\
\hline 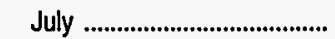 & 69.8 & 69.2 & 63.9 & 59.6 & W & 60.8 & 79.1 & 78.4 & 66.8 & 63.7 & - & 65.0 \\
\hline August & 74.3 & 72.4 & 66.5 & 61.7 & - & 62.5 & 82.9 & 81.6 & 72.3 & 65.6 & - & 67.3 \\
\hline 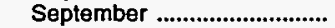 & 72.9 & 70.6 & 60.6 & 51.3 & $\mathbf{w}$ & 52.8 & 82.3 & 80.9 & 67.8 & 55.1 & - & 58.2 \\
\hline 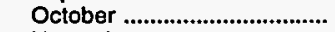 & 70.9 & 69.4 & 59.8 & 52.3 & 49.4 & 53.5 & 80.8 & 79.4 & 66.2 & $\mathbf{5 7 . 4}$ & - & 59.5 \\
\hline 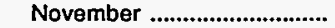 & 69.9 & 68.4 & 58.3 & 51.9 & W & 52.9 & 79.5 & 77.9 & 64.9 & 56.9 & - & 58.8 \\
\hline 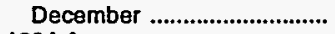 & 66.6 & 65.7 & 57.4 & 47.5 & $w$ & 49.1 & 76.7 & 75.3 & 62.7 & 52.1 & - & 54.7 \\
\hline 1994 Average ................................ & 66.3 & 65.5 & 57.0 & 52.6 & 50.4 & 53.6 & 76.0 & 74.9 & 60.7 & 57.2 & - & 58.4 \\
\hline \multicolumn{13}{|l|}{ Louisiana } \\
\hline 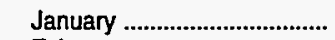 & 61.4 & 61.0 & 58.6 & 44.1 & 41.1 & 44.6 & 73.1 & 72.1 & 62.8 & 49.6 & W & 54.6 \\
\hline 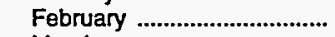 & 61.3 & 60.8 & 58.4 & 47.4 & 43.1 & 48.0 & 72.4 & 71.5 & 64.0 & 52.7 & - & 56.8 \\
\hline March & 61.4 & 61.0 & 59.7 & 49.0 & 44.4 & 49.4 & 72.6 & 71.8 & 65.2 & 53.8 & W & 57.5 \\
\hline Aprit & 63.1 & 62.8 & 61.7 & 52.7 & 47.4 & 53.1 & 74.2 & 73.4 & 67.3 & 57.7 & - & 61.1 \\
\hline 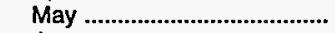 & 64.4 & 63.8 & 61.9 & 52.7 & 48.2 & 53.0 & 75.8 & 75.0 & 67.5 & 57.7 & - & 61.1 \\
\hline June & 65.9 & 65.6 & 64.8 & 55.6 & 50.0 & 55.2 & 76.9 & 76.2 & 70.0 & 60.9 & - & 64.0 \\
\hline July & 68.5 & 68.0 & 66.8 & 57.8 & 53.0 & 57.7 & 79.5 & 78.8 & 72.2 & 62.8 & - & 65.9 \\
\hline August & 72.2 & 71.6 & 66.6 & 59.8 & 55.8 & 59.7 & 82.4 & 81.6 & 72.2 & 65.1 & - & 67.6 \\
\hline 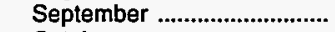 & 71.9 & 71.2 & 61.9 & 49.8 & 47.7 & 51.2 & 82.4 & 81.2 & 67.8 & 54.9 & - & 59.6 \\
\hline 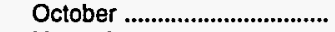 & 70.2 & 69.6 & 63.4 & 52.2 & 48.6 & 52.9 & 81.1 & 80.2 & 69.3 & 56.9 & - & 61.2 \\
\hline 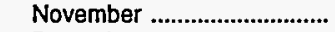 & 70.7 & 70.1 & 61.8 & 52.6 & 47.9 & 53.3 & 81.4 & 80.5 & 68.3 & 57.6 & - & 61.5 \\
\hline 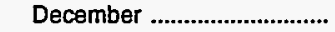 & 68.8 & 68.3 & 59.6 & 46.8 & 47.1 & 48.9 & 79.8 & 78.8 & 66.1 & 51.8 & - & 56.7 \\
\hline 1994 Average .......................... & 66.3 & 65.8 & 62.3 & 51.6 & 47.6 & 52.1 & 77.3 & 76.5 & 67.8 & 56.8 & $\mathbf{W}$ & 60.6 \\
\hline \multicolumn{13}{|l|}{ Mississippi } \\
\hline 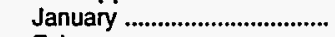 & 59.6 & 58.8 & 53.1 & 45.7 & 39.5 & 44.9 & 68.7 & 67.9 & 58.8 & 49.2 & - & 51.5 \\
\hline 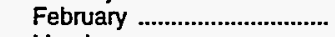 & 60.9 & 60.3 & 54.8 & 47.7 & 43.8 & 48.7 & 69.9 & 69.2 & 60.4 & 52.5 & - & 54.4 \\
\hline March & 61.5 & 60.9 & 56.1 & 49.0 & $W$ & 50.6 & 70.5 & 69.4 & 61.7 & 53.7 & - & 55.4 \\
\hline April & 63.5 & 63.2 & 58.2 & 53.0 & 49.0 & 53.0 & 72.6 & 71.8 & 63.9 & 57.6 & - & 59.0 \\
\hline 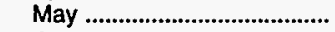 & 64.1 & 63.7 & 58.8 & 52.8 & 48.4 & 51.9 & 72.7 & 72.0 & 64.8 & 57.7 & - & 59.3 \\
\hline June & 66.1 & 65.7 & 61.1 & 56.1 & 49.8 & 55.3 & 74.6 & 74.2 & 66.9 & 60.9 & - & 62.3 \\
\hline July & 68.7 & 68.3 & 63.1 & 57.1 & 52.8 & 57.2 & 77.5 & 77.0 & 68.6 & 62.4 & - & 63.7 \\
\hline August & 73.0 & 72.4 & 64.5 & 59.0 & 55.1 & 59.5 & 82.3 & 81.7 & 71.0 & 64.4 & - & 65.8 \\
\hline 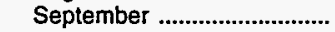 & 72.4 & 71.6 & 61.3 & 49.1 & 50.8 & 51.1 & 81.7 & 80.9 & 66.7 & 54.2 & - & 57.3 \\
\hline October & 72.3 & 71.6 & 61.9 & 52.4 & 47.0 & 52.7 & 81.2 & 80.5 & 67.4 & 57.5 & - & 59.8 \\
\hline 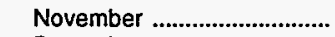 & 72.4 & 71.7 & 61.9 & 52.7 & 49.9 & 53.5 & 81.5 & 80.9 & 67.8 & 58.2 & - & 60.6 \\
\hline 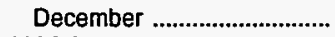 & 70.8 & 70.1 & 60.4 & 47.1 & 44.1 & 48.3 & 80.1 & 79.4 & 66.1 & 51.9 & - & 55.3 \\
\hline 1994 Average & 66.9 & 66.3 & 59.5 & 51.9 & 47.7 & 52.2 & 75.8 & 75.1 & 65.6 & 57.0 & - & 58.9 \\
\hline
\end{tabular}

See footnotes at end of table. 
Table 31. Motor Gasoline Prices by Grade, Sales Type, PAD Distrlct, and State (Cents per Gallon Excluding Taxes) - Continued

\begin{tabular}{|c|c|c|c|c|c|c|c|c|c|c|c|c|}
\hline \multirow{3}{*}{$\begin{array}{c}\text { Ceographle Area } \\
\text { Month }\end{array}$} & \multicolumn{6}{|c|}{ Premlum } & \multicolumn{6}{|c|}{ All Grades } \\
\hline & \multicolumn{2}{|c|}{ Sales to End Users } & \multicolumn{4}{|c|}{ Sales for Resale } & \multicolumn{2}{|c|}{ Sales to End Users } & \multicolumn{4}{|c|}{ Sales for Resale } \\
\hline & $\begin{array}{c}\text { Through } \\
\text { Rotail } \\
\text { Outlets }\end{array}$ & Averagea & DTW & Rack & Bulk & Average & $\begin{array}{c}\text { Through } \\
\text { Retail } \\
\text { Outlets }\end{array}$ & Average ${ }^{a}$ & DTW & Rack & Bulk & Average \\
\hline 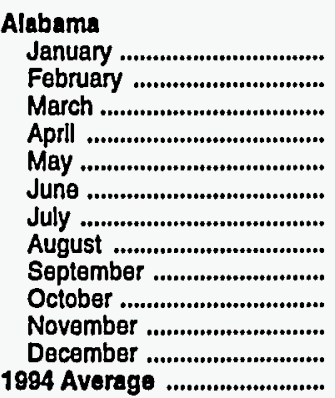 & $\begin{array}{l}78.3 \\
80.1 \\
80.6 \\
82.7 \\
84.5 \\
87.2 \\
90.6 \\
89.8 \\
89.9 \\
89.4 \\
89.3 \\
87.4 \\
85.3\end{array}$ & $\begin{array}{l}77.0 \\
78.8 \\
79.4 \\
81.6 \\
83.1 \\
85.9 \\
89.1 \\
88.0 \\
87.0 \\
87.6 \\
87.5 \\
85.4 \\
83.4\end{array}$ & $\begin{array}{l}69.3 \\
71.0 \\
71.7 \\
73.7 \\
74.8 \\
76.7 \\
80.0 \\
81.5 \\
78.3 \\
79.4 \\
78.2 \\
74.4 \\
75.6\end{array}$ & $\begin{array}{l}55.4 \\
58.5 \\
59.5 \\
63.2 \\
63.5 \\
66.9 \\
68.8 \\
70.8 \\
60.4 \\
63.8 \\
64.3 \\
58.1 \\
62.9\end{array}$ & $\begin{array}{l}- \\
- \\
- \\
- \\
- \\
- \\
- \\
-\end{array}$ & $\begin{array}{l}59.5 \\
62.2 \\
63.0 \\
66.0 \\
66.6 \\
69.6 \\
71.8 \\
73.4 \\
64.7 \\
67.4 \\
67.6 \\
61.6 \\
66.1\end{array}$ & $\begin{array}{l}65.7 \\
67.8 \\
68.3 \\
70.0 \\
71.6 \\
74.1 \\
77.2 \\
77.6 \\
77.1 \\
76.5 \\
76.3 \\
74.7 \\
72.7\end{array}$ & $\begin{array}{l}65.1 \\
67.1 \\
67.5 \\
69.5 \\
70.9 \\
73.4 \\
76.5 \\
76.8 \\
75.6 \\
75.5 \\
75.2 \\
73.6 \\
71.7\end{array}$ & $\begin{array}{l}61.0 \\
63.0 \\
63.7 \\
65.4 \\
66.5 \\
68.4 \\
70.9 \\
72.4 \\
69.5 \\
70.2 \\
69.0 \\
65.9 \\
67.3\end{array}$ & $\begin{array}{l}48.0 \\
51.2 \\
52.2 \\
56.1 \\
56.1 \\
59.5 \\
61.1 \\
62.8 \\
52.5 \\
56.0 \\
56.6 \\
50.5 \\
\mathbf{5 5 . 3}\end{array}$ & $\begin{array}{c}-\bar{W} \\
W \\
W \\
50.7 \\
W \\
W \\
W \\
W \\
W \\
W \\
W \\
W\end{array}$ & $\begin{array}{l}51.5 \\
54.3 \\
55.2 \\
58.3 \\
58.7 \\
61.6 \\
63.4 \\
65.1 \\
56.4 \\
59.2 \\
59.4 \\
53.9 \\
58.1\end{array}$ \\
\hline 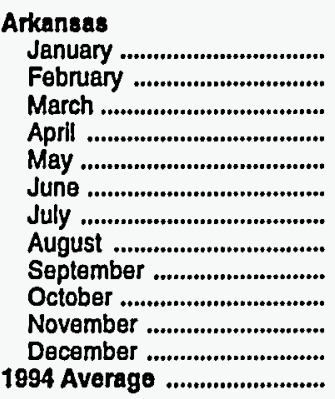 & $\begin{array}{l}76.4 \\
77.6 \\
76.1 \\
80.2 \\
80.5 \\
83.4 \\
86.8 \\
90.0 \\
88.9 \\
87.2 \\
86.3 \\
83.3 \\
83.1\end{array}$ & $\begin{array}{l}75.0 \\
75.8 \\
74.7 \\
78.8 \\
79.0 \\
81.8 \\
85.1 \\
86.7 \\
85.2 \\
84.3 \\
83.3 \\
81.0 \\
81.1\end{array}$ & $\begin{array}{l}59.1 \\
61.0 \\
61.9 \\
66.5 \\
66.5 \\
69.4 \\
73.8 \\
75.0 \\
69.3 \\
68.9 \\
68.0 \\
67.3 \\
65.8\end{array}$ & $\begin{array}{l}53.0 \\
56.0 \\
58.0 \\
61.7 \\
61.8 \\
65.7 \\
68.5 \\
70.8 \\
60.5 \\
61.9 \\
60.9 \\
56.7 \\
61.4\end{array}$ & $\begin{array}{l}\bar{w} \\
\bar{w} \\
\overline{-} \\
\overline{-} \\
\overline{-} \\
\overline{-} \\
\bar{w}\end{array}$ & $\begin{array}{l}55.0 \\
57.7 \\
59.4 \\
63.5 \\
63.5 \\
67.0 \\
70.4 \\
71.5 \\
62.1 \\
63.2 \\
62.2 \\
58.7 \\
62.6\end{array}$ & $\begin{array}{l}62.0 \\
63.7 \\
63.6 \\
67.3 \\
67.7 \\
70.5 \\
73.7 \\
77.9 \\
76.9 \\
74.9 \\
73.8 \\
70.7 \\
70.2\end{array}$ & $\begin{array}{l}61.3 \\
62.7 \\
62.9 \\
66.5 \\
67.0 \\
69.6 \\
72.9 \\
75.8 \\
74.4 \\
73.2 \\
72.1 \\
69.6 \\
69.2\end{array}$ & $\begin{array}{l}51.6 \\
54.4 \\
55.2 \\
58.7 \\
59.5 \\
62.6 \\
66.4 \\
68.8 \\
63.1 \\
62.3 \\
61.0 \\
59.9 \\
59.3\end{array}$ & $\begin{array}{l}46.7 \\
50.1 \\
51.4 \\
54.8 \\
55.5 \\
59.0 \\
61.6 \\
63.7 \\
53.2 \\
54.5 \\
54.1 \\
49.5 \\
54.7\end{array}$ & $\begin{array}{c}W \\
- \\
W \\
W \\
W \\
W \\
W \\
- \\
W \\
49.4 \\
W \\
W \\
50.3\end{array}$ & $\begin{array}{l}48.2 \\
51.5 \\
52.7 \\
56.2 \\
56.8 \\
60.2 \\
63.1 \\
64.6 \\
55.0 \\
55.8 \\
55.2 \\
51.3 \\
55.8\end{array}$ \\
\hline 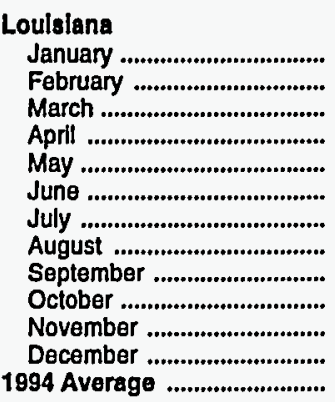 & $\begin{array}{l}81.7 \\
80.2 \\
81.5 \\
82.7 \\
84.5 \\
85.6 \\
88.1 \\
90.8 \\
90.4 \\
88.6 \\
89.2 \\
87.6 \\
85.5\end{array}$ & $\begin{array}{l}79.9 \\
78.8 \\
80.0 \\
81.5 \\
82.8 \\
84.2 \\
86.7 \\
88.7 \\
88.3 \\
86.8 \\
87.3 \\
85.8 \\
84.0\end{array}$ & $\begin{array}{l}71.7 \\
71.5 \\
72.1 \\
74.8 \\
74.9 \\
77.1 \\
79.2 \\
79.8 \\
75.9 \\
76.7 \\
75.7 \\
73.7 \\
75.5\end{array}$ & $\begin{array}{l}53.7 \\
56.5 \\
58.2 \\
62.2 \\
62.3 \\
65.6 \\
67.6 \\
69.9 \\
59.6 \\
61.8 \\
62.4 \\
56.7 \\
61.4\end{array}$ & $\begin{array}{l}41.8 \\
47.1 \\
47.7 \\
48.8 \\
53.4 \\
58.2 \\
59.7 \\
62.8 \\
W \\
50.2 \\
W \\
W \\
52.5\end{array}$ & $\begin{array}{l}53.1 \\
59.2 \\
61.1 \\
65.5 \\
63.7 \\
67.7 \\
68.8 \\
70.3 \\
63.1 \\
64.1 \\
66.6 \\
62.3 \\
63.7\end{array}$ & $\begin{array}{l}67.8 \\
67.3 \\
67.6 \\
69.3 \\
70.8 \\
72.1 \\
74.7 \\
78.0 \\
77.7 \\
76.2 \\
76.6 \\
74.9 \\
72.3\end{array}$ & $\begin{array}{l}67.1 \\
66.6 \\
67.0 \\
68.8 \\
70.0 \\
71.6 \\
74.1 \\
77.2 \\
76.7 \\
75.4 \\
75.8 \\
74.1 \\
71.7\end{array}$ & $\begin{array}{l}63.3 \\
63.2 \\
64.4 \\
66.5 \\
66.9 \\
69.4 \\
71.3 \\
71.5 \\
67.1 \\
68.4 \\
67.1 \\
65.1 \\
67.2\end{array}$ & $\begin{array}{l}46.7 \\
50.1 \\
51.7 \\
55.5 \\
55.6 \\
58.5 \\
60.6 \\
62.7 \\
52.8 \\
55.1 \\
55.6 \\
49.7 \\
54.5\end{array}$ & $\begin{array}{l}41.3 \\
43.7 \\
44.9 \\
47.5 \\
49.4 \\
51.0 \\
54.3 \\
57.6 \\
49.0 \\
48.8 \\
48.4 \\
47.1 \\
48.3\end{array}$ & $\begin{array}{l}47.4 \\
51.4 \\
52.8 \\
56.7 \\
56.5 \\
58.7 \\
61.1 \\
63.2 \\
54.9 \\
56.3 \\
57.2 \\
52.3 \\
55.6\end{array}$ \\
\hline 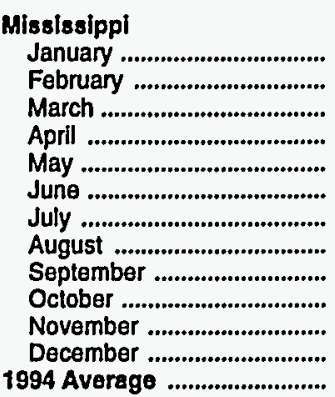 & $\begin{array}{l}77.8 \\
79.2 \\
79.2 \\
81.3 \\
81.1 \\
83.6 \\
86.4 \\
90.8 \\
89.4 \\
89.3 \\
89.5 \\
88.5 \\
83.9\end{array}$ & $\begin{array}{l}76.1 \\
77.8 \\
77.6 \\
80.2 \\
80.1 \\
82.7 \\
85.5 \\
90.1 \\
88.5 \\
88.4 \\
88.7 \\
87.6 \\
82.7\end{array}$ & $\begin{array}{l}64.3 \\
66.3 \\
67.6 \\
69.6 \\
70.4 \\
72.4 \\
74.9 \\
78.2 \\
73.7 \\
73.9 \\
73.9 \\
72.5 \\
71.4\end{array}$ & $\begin{array}{l}54.7 \\
57.7 \\
58.9 \\
62.7 \\
62.7 \\
66.1 \\
68.0 \\
69.9 \\
59.8 \\
63.0 \\
63.3 \\
57.4 \\
62.1\end{array}$ & $\begin{array}{c}46.2 \\
48.8 \\
- \\
W \\
W \\
W \\
W \\
57.1 \\
53.4 \\
51.5 \\
50.9 \\
51.8 \\
52.2\end{array}$ & $\begin{array}{l}54.0 \\
55.9 \\
60.9 \\
63.9 \\
63.1 \\
67.2 \\
67.7 \\
67.5 \\
59.3 \\
60.4 \\
62.8 \\
58.5 \\
61.6\end{array}$ & $\begin{array}{l}64.7 \\
66.0 \\
66.6 \\
68.9 \\
68.9 \\
71.2 \\
73.6 \\
78.2 \\
77.2 \\
77.1 \\
77.1 \\
75.9 \\
71.7\end{array}$ & $\begin{array}{l}63.8 \\
65.3 \\
65.8 \\
68.3 \\
68.4 \\
70.7 \\
73.1 \\
77.6 \\
76.3 \\
76.3 \\
76.4 \\
75.1 \\
71.0\end{array}$ & $\begin{array}{l}56.2 \\
57.9 \\
59.3 \\
61.4 \\
62.1 \\
64.2 \\
66.3 \\
68.5 \\
65.1 \\
65.6 \\
65.6 \\
64.1 \\
62.9\end{array}$ & $\begin{array}{l}47.9 \\
50.2 \\
51.7 \\
55.6 \\
55.5 \\
58.9 \\
59.9 \\
61.9 \\
51.9 \\
55.3 \\
55.6 \\
49.8 \\
54.6\end{array}$ & $\begin{array}{c}40.9 \\
46.8 \\
W \\
49.1 \\
49.0 \\
50.0 \\
53.6 \\
56.2 \\
51.8 \\
48.9 \\
50.1 \\
46.1 \\
48.8\end{array}$ & $\begin{array}{l}47.3 \\
51.1 \\
53.4 \\
55.7 \\
54.5 \\
58.2 \\
59.9 \\
62.3 \\
53.8 \\
55.5 \\
56.3 \\
51.3 \\
54.9\end{array}$ \\
\hline
\end{tabular}

See footnotes at end of table. 
Table 31. Motor Gasoline Prices by Grade, Sales Type, PAD District, and State

(Cents per Gallon Excluding Taxes) - Continued

\begin{tabular}{|c|c|c|c|c|c|c|c|c|c|c|c|c|}
\hline \multirow{3}{*}{$\begin{array}{l}\text { Geographic Area } \\
\text { Month }\end{array}$} & \multicolumn{6}{|c|}{ Regular } & \multicolumn{6}{|c|}{ Midgrade } \\
\hline & \multicolumn{2}{|c|}{ Sales to End Users } & \multicolumn{4}{|c|}{ Sales for Resale } & \multicolumn{2}{|c|}{ Sales to End Users } & \multicolumn{4}{|c|}{ Sales for Resale } \\
\hline & $\begin{array}{c}\text { Through } \\
\text { Retail } \\
\text { Outlets }\end{array}$ & Average $^{a}$ & DTW & Rack & Bulk & Average & $\begin{array}{c}\text { Through } \\
\text { Retail } \\
\text { Outlets }\end{array}$ & Averagea & DTW & Rack & Bulk & Average \\
\hline New Moxico & & & & & & & & & & & & \\
\hline 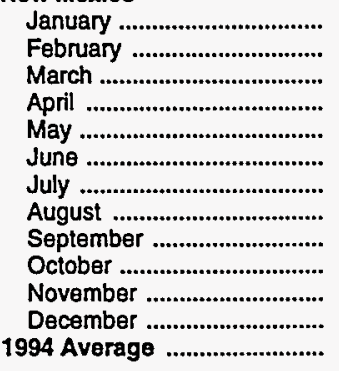 & $\begin{array}{l}70.3 \\
67.4 \\
67.3 \\
69.1 \\
72.8 \\
75.4 \\
78.2 \\
84.1 \\
82.7 \\
80.7 \\
80.7 \\
75.3 \\
75.4\end{array}$ & $\begin{array}{l}69.5 \\
67.2 \\
67.1 \\
69.0 \\
72.4 \\
74.9 \\
77.8 \\
83.5 \\
81.8 \\
79.8 \\
79.9 \\
74.7 \\
74.8\end{array}$ & $\begin{array}{l}57.8 \\
58.6 \\
58.9 \\
62.6 \\
65.0 \\
67.6 \\
70.8 \\
75.6 \\
69.4 \\
66.0 \\
65.9 \\
61.9 \\
65.2\end{array}$ & $\begin{array}{l}50.1 \\
54.1 \\
54.7 \\
58.3 \\
61.0 \\
63.1 \\
67.1 \\
73.6 \\
66.8 \\
60.6 \\
60.5 \\
54.2 \\
60.6\end{array}$ & $\begin{array}{l}- \\
- \\
- \\
- \\
- \\
\overline{-} \\
\bar{w} \\
\bar{w}\end{array}$ & $\begin{array}{l}52.1 \\
55.3 \\
55.7 \\
59.5 \\
62.1 \\
64.3 \\
68.1 \\
74.1 \\
67.5 \\
61.7 \\
61.9 \\
56.0 \\
61.7\end{array}$ & $\begin{array}{l}75.3 \\
74.3 \\
72.7 \\
74.4 \\
78.0 \\
80.6 \\
84.2 \\
90.9 \\
88.4 \\
85.7 \\
86.9 \\
81.8 \\
81.5\end{array}$ & $\begin{array}{l}74.1 \\
73.8 \\
72.5 \\
74.2 \\
77.8 \\
80.3 \\
83.8 \\
89.3 \\
86.5 \\
84.2 \\
86.8 \\
81.8 \\
80.9\end{array}$ & $\begin{array}{l}64.4 \\
64.3 \\
63.3 \\
66.4 \\
69.5 \\
72.9 \\
76.4 \\
81.1 \\
79.6 \\
75.6 \\
77.9 \\
71.5 \\
71.5\end{array}$ & $\begin{array}{l}55.9 \\
59.5 \\
58.9 \\
63.3 \\
64.9 \\
67.4 \\
72.2 \\
79.5 \\
72.6 \\
66.9 \\
69.6 \\
62.8 \\
66.4\end{array}$ & $\begin{array}{l}- \\
- \\
- \\
- \\
- \\
- \\
- \\
- \\
- \\
- \\
- \\
-\end{array}$ & $\begin{array}{l}60.2 \\
61.3 \\
60.5 \\
64.4 \\
66.9 \\
69.4 \\
73.9 \\
80.0 \\
74.5 \\
69.7 \\
72.2 \\
65.5 \\
67.9\end{array}$ \\
\hline 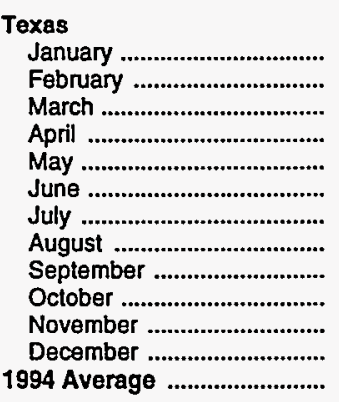 & $\begin{array}{l}58.7 \\
60.0 \\
60.1 \\
63.5 \\
65.4 \\
67.5 \\
70.7 \\
74.0 \\
73.0 \\
70.8 \\
71.3 \\
70.3 \\
67.3\end{array}$ & $\begin{array}{l}58.0 \\
59.4 \\
59.6 \\
63.0 \\
64.8 \\
67.2 \\
70.2 \\
73.2 \\
71.4 \\
69.4 \\
70.0 \\
68.7 \\
66.2\end{array}$ & $\begin{array}{l}51.6 \\
53.0 \\
54.4 \\
57.6 \\
58.1 \\
60.5 \\
63.5 \\
65.9 \\
64.6 \\
62.3 \\
63.0 \\
61.5 \\
58.8\end{array}$ & $\begin{array}{l}44.0 \\
47.6 \\
49.5 \\
52.0 \\
52.7 \\
56.5 \\
59.1 \\
61.8 \\
52.8 \\
53.0 \\
52.4 \\
49.3 \\
52.7\end{array}$ & $\begin{array}{l}40.9 \\
43.1 \\
44.8 \\
47.8 \\
49.2 \\
51.5 \\
53.3 \\
56.1 \\
48.6 \\
47.5 \\
47.5 \\
45.1 \\
47.6\end{array}$ & $\begin{array}{l}44.0 \\
47.0 \\
48.9 \\
51.7 \\
52.9 \\
55.8 \\
58.4 \\
61.2 \\
54.0 \\
52.8 \\
52.6 \\
49.2 \\
52.5\end{array}$ & $\begin{array}{l}68.9 \\
70.0 \\
70.0 \\
73.2 \\
75.0 \\
77.0 \\
80.2 \\
83.7 \\
82.9 \\
80.4 \\
81.4 \\
80.8 \\
77.2\end{array}$ & $\begin{array}{l}67.8 \\
69.0 \\
69.1 \\
72.4 \\
74.2 \\
76.2 \\
79.5 \\
82.7 \\
81.2 \\
79.0 \\
80.1 \\
79.1 \\
75.9\end{array}$ & $\begin{array}{l}56.9 \\
58.3 \\
59.2 \\
62.7 \\
63.4 \\
65.3 \\
68.2 \\
70.5 \\
67.0 \\
65.2 \\
65.7 \\
64.9 \\
63.4\end{array}$ & $\begin{array}{l}48.5 \\
52.2 \\
53.1 \\
57.0 \\
57.4 \\
60.8 \\
63.5 \\
66.7 \\
56.9 \\
57.4 \\
56.4 \\
53.5 \\
57.1\end{array}$ & $\begin{array}{l}W \\
W \\
W \\
W \\
W \\
N A \\
N A \\
W \\
N A \\
W \\
\text { NA } \\
\text { NA } \\
\text { NA }\end{array}$ & $\begin{array}{l}52.3 \\
55.0 \\
55.8 \\
59.6 \\
60.1 \\
62.8 \\
65.6 \\
68.6 \\
62.0 \\
61.3 \\
61.1 \\
59.2 \\
60.3\end{array}$ \\
\hline 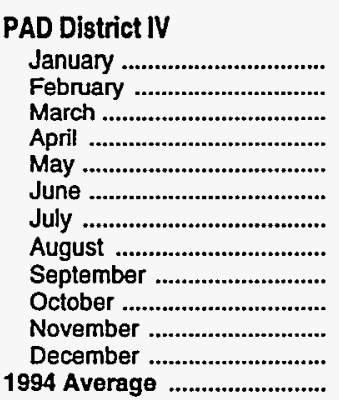 & $\begin{array}{l}69.1 \\
68.9 \\
67.7 \\
67.4 \\
70.8 \\
76.2 \\
79.6 \\
84.9 \\
85.7 \\
81.6 \\
79.9 \\
77.4 \\
76.1\end{array}$ & $\begin{array}{l}68.6 \\
68.5 \\
67.5 \\
67.5 \\
70.9 \\
76.2 \\
79.8 \\
85.2 \\
85.8 \\
81.2 \\
79.6 \\
77.0 \\
76.0\end{array}$ & $\begin{array}{l}56.9 \\
57.9 \\
57.9 \\
60.0 \\
63.5 \\
68.8 \\
72.6 \\
76.6 \\
75.6 \\
68.7 \\
67.7 \\
63.0 \\
66.6\end{array}$ & $\begin{array}{l}50.9 \\
53.4 \\
54.2 \\
55.8 \\
60.2 \\
66.1 \\
69.4 \\
74.4 \\
71.8 \\
63.7 \\
62.5 \\
57.0 \\
62.1\end{array}$ & $\begin{array}{l}W \\
W \\
W \\
W \\
W \\
W \\
W \\
W \\
W \\
W \\
W \\
W \\
59.3\end{array}$ & $\begin{array}{l}52.4 \\
54.5 \\
55.1 \\
56.8 \\
61.0 \\
66.8 \\
70.2 \\
74.9 \\
72.9 \\
65.2 \\
64.0 \\
58.8 \\
63.2\end{array}$ & $\begin{array}{l}76.8 \\
78.0 \\
77.2 \\
77.2 \\
80.0 \\
85.6 \\
88.5 \\
95.7 \\
95.8 \\
90.7 \\
90.1 \\
86.8 \\
85.8\end{array}$ & $\begin{array}{l}75.8 \\
77.3 \\
76.4 \\
76.5 \\
79.3 \\
84.7 \\
87.8 \\
94.9 \\
95.2 \\
89.9 \\
89.4 \\
85.9 \\
85.2\end{array}$ & $\begin{array}{l}60.5 \\
62.2 \\
61.5 \\
62.9 \\
66.3 \\
71.5 \\
75.8 \\
81.8 \\
79.0 \\
72.9 \\
71.6 \\
67.0 \\
70.3\end{array}$ & $\begin{array}{l}53.8 \\
57.2 \\
58.1 \\
59.1 \\
63.6 \\
68.8 \\
72.7 \\
78.5 \\
76.0 \\
68.6 \\
66.9 \\
62.0 \\
65.4\end{array}$ & $\begin{array}{l}- \\
- \\
- \\
- \\
- \\
- \\
- \\
- \\
- \\
-\end{array}$ & $\begin{array}{l}57.2 \\
59.7 \\
59.8 \\
61.0 \\
64.9 \\
70.2 \\
74.3 \\
80.4 \\
77.8 \\
71.1 \\
69.6 \\
64.7 \\
68.0\end{array}$ \\
\hline 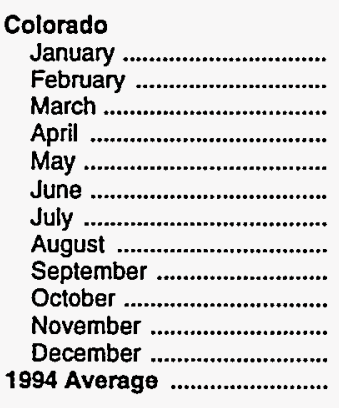 & $\begin{array}{l}72.6 \\
73.6 \\
71.2 \\
70.3 \\
70.9 \\
74.9 \\
79.3 \\
87.4 \\
87.7 \\
81.9 \\
81.4 \\
78.8 \\
77.8\end{array}$ & $\begin{array}{l}72.0 \\
73.0 \\
70.7 \\
70.0 \\
70.8 \\
74.6 \\
79.1 \\
87.2 \\
87.4 \\
81.2 \\
80.8 \\
78.1 \\
77.4\end{array}$ & $\begin{array}{l}58.2 \\
60.6 \\
59.0 \\
60.5 \\
62.0 \\
65.0 \\
71.3 \\
77.3 \\
75.2 \\
65.5 \\
65.3 \\
59.9 \\
65.8\end{array}$ & $\begin{array}{l}51.2 \\
55.0 \\
54.5 \\
55.9 \\
57.5 \\
61.6 \\
67.0 \\
75.2 \\
67.2 \\
58.5 \\
57.8 \\
51.6 \\
59.6\end{array}$ & $\begin{array}{l}W \\
- \\
- \\
- \\
- \\
\bar{w} \\
- \\
- \\
- \\
\bar{w}\end{array}$ & $\begin{array}{l}53.1 \\
56.4 \\
55.6 \\
57.0 \\
58.7 \\
62.5 \\
68.1 \\
75.6 \\
69.7 \\
60.9 \\
60.4 \\
54.5 \\
61.3\end{array}$ & $\begin{array}{l}81.6 \\
83.2 \\
82.0 \\
81.5 \\
82.1 \\
86.8 \\
90.6 \\
99.0 \\
98.7 \\
92.7 \\
93.2 \\
90.0 \\
89.0\end{array}$ & $\begin{array}{l}80.1 \\
82.2 \\
80.9 \\
80.6 \\
81.2 \\
85.8 \\
89.8 \\
97.8 \\
97.9 \\
91.5 \\
92.2 \\
88.9 \\
88.2\end{array}$ & $\begin{array}{l}62.7 \\
65.2 \\
63.6 \\
65.2 \\
66.5 \\
70.5 \\
75.7 \\
83.9 \\
79.2 \\
72.1 \\
72.2 \\
66.6 \\
71.0\end{array}$ & $\begin{array}{l}54.8 \\
58.2 \\
57.5 \\
59.5 \\
61.9 \\
65.5 \\
71.0 \\
79.4 \\
74.0 \\
64.4 \\
64.2 \\
57.3 \\
64.3\end{array}$ & $\begin{array}{l}- \\
- \\
- \\
- \\
- \\
- \\
- \\
- \\
- \\
- \\
- \\
-\end{array}$ & $\begin{array}{l}59.2 \\
62.4 \\
60.9 \\
62.6 \\
64.3 \\
68.3 \\
73.5 \\
82.1 \\
77.2 \\
69.2 \\
69.2 \\
63.0 \\
68.2\end{array}$ \\
\hline
\end{tabular}

See footnotes at end of table. 
Table 31. Motor Gasoline Prices by Grade, Sales Type, PAD District, and State (Cents per Gallon Excluding Taxes) - Continued

\begin{tabular}{|c|c|c|c|c|c|c|c|c|c|c|c|c|}
\hline \multirow{3}{*}{$\begin{array}{l}\text { Geographlc Area } \\
\text { Month }\end{array}$} & \multicolumn{6}{|c|}{ Premium } & \multicolumn{6}{|c|}{ All Grades } \\
\hline & \multicolumn{2}{|c|}{ Sales to End Users } & \multicolumn{4}{|c|}{ Sales for Rasalo } & \multicolumn{2}{|c|}{ Sales to End Users } & \multicolumn{4}{|c|}{ Sales for Resale } \\
\hline & $\begin{array}{c}\text { Through } \\
\text { Retall } \\
\text { Outlots }\end{array}$ & Average ${ }^{a}$ & DTW & Rack & Bulk & Average & $\begin{array}{c}\text { Through } \\
\text { Retall } \\
\text { Outlets }\end{array}$ & Average ${ }^{a}$ & DTW & Rack & Bulk & Average \\
\hline \multicolumn{13}{|l|}{ New Moxico } \\
\hline 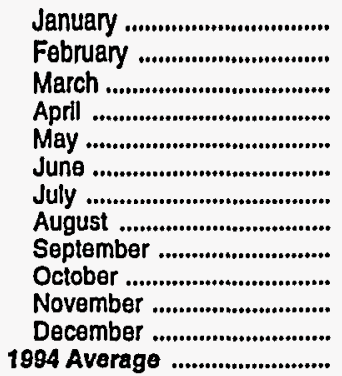 & $\begin{array}{l}83.8 \\
81.1 \\
80.4 \\
81.9 \\
86.6 \\
88.8 \\
92.5 \\
98.2 \\
96.6 \\
94.8 \\
95.3 \\
89.6 \\
89.4\end{array}$ & $\begin{array}{l}83.0 \\
80.7 \\
80.2 \\
81.6 \\
86.1 \\
88.2 \\
91.8 \\
97.6 \\
95.8 \\
94.0 \\
94.7 \\
89.1 \\
88.8\end{array}$ & $\begin{array}{l}69.1 \\
69.5 \\
69.2 \\
71.5 \\
75.1 \\
77.9 \\
80.8 \\
86.6 \\
80.9 \\
77.8 \\
78.9 \\
73.4 \\
76.3\end{array}$ & $\begin{array}{l}58.6 \\
62.2 \\
63.6 \\
67.3 \\
70.3 \\
72.5 \\
76.0 \\
82.4 \\
76.1 \\
69.2 \\
68.7 \\
62.5 \\
69.3\end{array}$ & $\begin{array}{l}- \\
- \\
- \\
- \\
- \\
- \\
- \\
- \\
-\end{array}$ & $\begin{array}{l}61.4 \\
64.1 \\
64.9 \\
68.5 \\
71.7 \\
73.7 \\
77.2 \\
83.6 \\
77.4 \\
71.3 \\
71.2 \\
65.0 \\
71.0\end{array}$ & $\begin{array}{l}72.0 \\
69.3 \\
69.1 \\
71.0 \\
74.7 \\
77.5 \\
80.4 \\
86.3 \\
84.6 \\
82.7 \\
82.8 \\
77.5 \\
77.4\end{array}$ & $\begin{array}{l}71.2 \\
69.0 \\
68.9 \\
70.9 \\
74.2 \\
76.9 \\
79.9 \\
85.6 \\
83.7 \\
81.8 \\
82.0 \\
76.9 \\
76.8\end{array}$ & $\begin{array}{l}59.5 \\
60.2 \\
60.2 \\
63.8 \\
66.5 \\
69.0 \\
72.3 \\
77.3 \\
71.1 \\
67.8 \\
67.8 \\
63.6 \\
66.8\end{array}$ & $\begin{array}{l}51.2 \\
55.2 \\
55.8 \\
59.5 \\
62.2 \\
64.4 \\
68.4 \\
74.8 \\
68.0 \\
61.7 \\
61.7 \\
55.4 \\
61.8\end{array}$ & $\begin{array}{l}- \\
- \\
- \\
- \\
- \\
- \\
- \\
\bar{w} \\
- \\
\bar{w}\end{array}$ & $\begin{array}{l}53.4 \\
56.5 \\
56.8 \\
60.7 \\
63.4 \\
65.6 \\
69.5 \\
75.4 \\
68.8 \\
63.0 \\
63.3 \\
57.3 \\
63.0\end{array}$ \\
\hline \multicolumn{13}{|l|}{ Texas } \\
\hline 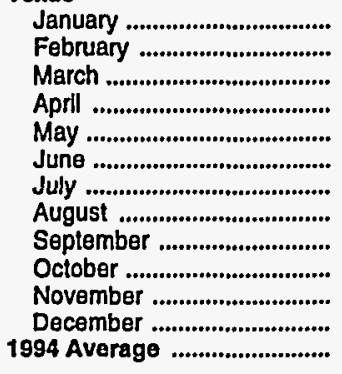 & $\begin{array}{l}77.1 \\
77.9 \\
78.1 \\
81.3 \\
83.0 \\
85.2 \\
87.9 \\
91.4 \\
91.0 \\
88.6 \\
89.1 \\
88.5 \\
85.0\end{array}$ & $\begin{array}{l}75.6 \\
76.4 \\
76.9 \\
80.2 \\
81.8 \\
83.7 \\
86.9 \\
89.8 \\
88.6 \\
86.2 \\
86.7 \\
86.1 \\
83.1\end{array}$ & $\begin{array}{l}62.7 \\
64.9 \\
65.7 \\
69.1 \\
69.8 \\
71.9 \\
74.8 \\
77.5 \\
74.1 \\
71.9 \\
72.4 \\
71.5 \\
70.0\end{array}$ & $\begin{array}{l}53.1 \\
56.6 \\
57.7 \\
61.8 \\
61.9 \\
65.4 \\
68.0 \\
70.6 \\
60.9 \\
62.1 \\
60.8 \\
58.4 \\
61.6\end{array}$ & $\begin{array}{l}46.3 \\
47.1 \\
49.4 \\
52.8 \\
53.0 \\
57.8 \\
59.5 \\
59.6 \\
55.1 \\
52.0 \\
52.4 \\
49.0 \\
52.4\end{array}$ & $\begin{array}{l}54.8 \\
56.7 \\
59.1 \\
63.3 \\
62.7 \\
65.8 \\
69.0 \\
72.1 \\
65.5 \\
64.4 \\
64.1 \\
61.4 \\
63.3\end{array}$ & $\begin{array}{l}63.7 \\
64.9 \\
65.0 \\
68.4 \\
70.2 \\
72.3 \\
75.4 \\
78.8 \\
77.9 \\
75.7 \\
76.2 \\
75.4 \\
72.2\end{array}$ & $\begin{array}{l}62.7 \\
64.0 \\
64.2 \\
67.6 \\
69.4 \\
71.6 \\
74.7 \\
77.7 \\
76.1 \\
74.0 \\
74.6 \\
73.5 \\
70.9\end{array}$ & $\begin{array}{l}54.7 \\
56.1 \\
57.4 \\
60.7 \\
61.2 \\
63.5 \\
66.4 \\
68.4 \\
67.1 \\
65.0 \\
65.5 \\
64.4 \\
61.6\end{array}$ & $\begin{array}{l}45.8 \\
49.5 \\
51.2 \\
54.0 \\
54.8 \\
58.5 \\
61.0 \\
63.7 \\
54.6 \\
55.0 \\
54.3 \\
51.3 \\
54.6\end{array}$ & $\begin{array}{l}41.3 \\
43.6 \\
45.2 \\
48.1 \\
49.6 \\
52.4 \\
53.9 \\
56.3 \\
49.0 \\
47.8 \\
47.8 \\
45.3 \\
48.0\end{array}$ & $\begin{array}{l}46.1 \\
49.2 \\
51.1 \\
54.0 \\
55.2 \\
58.1 \\
60.7 \\
63.4 \\
56.6 \\
55.4 \\
55.3 \\
51.7 \\
54.8\end{array}$ \\
\hline \multicolumn{13}{|l|}{ PAD Dlstrict IV } \\
\hline 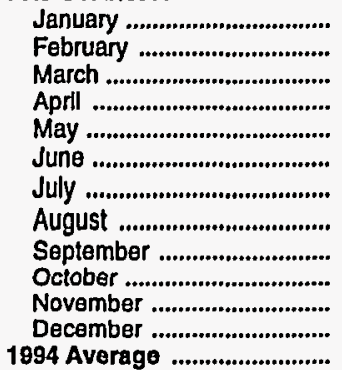 & $\begin{array}{r}82.4 \\
82.8 \\
82.6 \\
82.7 \\
86.7 \\
92.3 \\
95.3 \\
100.2 \\
100.8 \\
96.8 \\
95.2 \\
92.1 \\
91.3\end{array}$ & $\begin{array}{l}81.3 \\
81.7 \\
81.4 \\
81.9 \\
86.0 \\
91.5 \\
94.6 \\
99.4 \\
99.8 \\
95.7 \\
94.1 \\
91.0 \\
90.4\end{array}$ & $\begin{array}{l}65.3 \\
66.3 \\
66.6 \\
67.9 \\
72.4 \\
78.1 \\
82.0 \\
86.3 \\
84.2 \\
78.9 \\
77.5 \\
72.7 \\
75.7\end{array}$ & $\begin{array}{l}58.7 \\
61.6 \\
61.6 \\
63.7 \\
68.9 \\
75.3 \\
78.4 \\
83.1 \\
81.5 \\
73.5 \\
72.2 \\
66.7 \\
70.9\end{array}$ & $\begin{array}{l}\bar{w} \\
\bar{w} \\
\overline{-} \\
\overline{-} \\
\bar{w} \\
\overline{-} \\
\overline{-} \\
\bar{w}\end{array}$ & $\begin{array}{l}60.9 \\
63.0 \\
63.0 \\
64.9 \\
69.9 \\
76.1 \\
79.5 \\
84.1 \\
82.4 \\
75.4 \\
73.9 \\
68.7 \\
72.3\end{array}$ & $\begin{array}{l}71.9 \\
72.0 \\
71.0 \\
71.0 \\
74.4 \\
79.8 \\
83.1 \\
88.6 \\
89.2 \\
85.1 \\
83.6 \\
81.0 \\
79.6\end{array}$ & $\begin{array}{l}71.3 \\
71.4 \\
70.5 \\
70.7 \\
74.1 \\
79.4 \\
82.9 \\
88.5 \\
89.0 \\
84.5 \\
83.1 \\
80.4 \\
79.3\end{array}$ & $\begin{array}{l}59.0 \\
60.0 \\
60.0 \\
61.7 \\
65.4 \\
70.7 \\
74.7 \\
79.0 \\
77.6 \\
71.1 \\
69.9 \\
65.3 \\
68.7\end{array}$ & $\begin{array}{l}\mathbf{5 2 . 3} \\
\mathbf{5 5 . 0} \\
\mathbf{5 5 . 7} \\
\mathbf{5 7 . 2} \\
61.8 \\
67.8 \\
71.0 \\
76.1 \\
73.5 \\
65.5 \\
64.3 \\
58.9 \\
\mathbf{6 3 . 7}\end{array}$ & $\begin{array}{l}W \\
W \\
W \\
W \\
W \\
W \\
W \\
W \\
W \\
W \\
W \\
W \\
59.4\end{array}$ & $\begin{array}{l}54.2 \\
56.3 \\
56.9 \\
58.4 \\
62.8 \\
68.6 \\
72.1 \\
76.9 \\
74.8 \\
67.3 \\
66.1 \\
61.0 \\
65.1\end{array}$ \\
\hline \multicolumn{13}{|l|}{ Colorado } \\
\hline 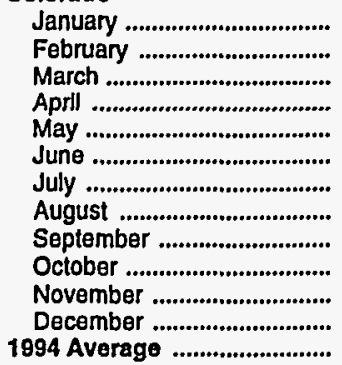 & $\begin{array}{r}91.0 \\
92.2 \\
90.7 \\
90.4 \\
90.6 \\
94.3 \\
99.6 \\
106.9 \\
107.0 \\
101.6 \\
101.9 \\
98.7 \\
97.4\end{array}$ & $\begin{array}{r}89.7 \\
91.0 \\
89.4 \\
89.5 \\
89.8 \\
93.3 \\
98.6 \\
106.2 \\
106.0 \\
100.3 \\
100.6 \\
97.6 \\
96.4\end{array}$ & $\begin{array}{l}67.9 \\
70.4 \\
69.5 \\
70.8 \\
72.5 \\
75.9 \\
81.5 \\
88.7 \\
84.0 \\
76.9 \\
76.7 \\
71.1 \\
76.3\end{array}$ & $\begin{array}{l}58.8 \\
63.1 \\
61.6 \\
64.0 \\
66.2 \\
70.6 \\
75.7 \\
83.7 \\
76.3 \\
67.3 \\
67.0 \\
60.5 \\
68.0\end{array}$ & $\begin{array}{l}- \\
- \\
- \\
- \\
- \\
- \\
- \\
- \\
-\end{array}$ & $\begin{array}{l}62.1 \\
65.3 \\
63.5 \\
66.1 \\
68.0 \\
72.3 \\
77.5 \\
85.6 \\
79.3 \\
71.0 \\
70.9 \\
64.6 \\
70.7\end{array}$ & $\begin{array}{l}76.3 \\
77.4 \\
75.4 \\
74.9 \\
75.5 \\
79.6 \\
84.0 \\
91.9 \\
92.0 \\
86.3 \\
86.2 \\
83.5 \\
82.2\end{array}$ & $\begin{array}{l}75.5 \\
76.7 \\
74.7 \\
74.3 \\
75.0 \\
79.0 \\
83.5 \\
91.5 \\
91.4 \\
85.4 \\
85.5 \\
82.7 \\
81.7\end{array}$ & $\begin{array}{l}60.6 \\
63.0 \\
61.6 \\
63.0 \\
64.4 \\
67.9 \\
73.7 \\
80.2 \\
77.2 \\
68.3 \\
68.2 \\
62.8 \\
68.5\end{array}$ & $\begin{array}{l}52.5 \\
56.4 \\
56.0 \\
57.2 \\
59.1 \\
63.2 \\
68.5 \\
76.7 \\
68.8 \\
60.1 \\
59.5 \\
53.3 \\
61.1\end{array}$ & $\begin{array}{l}W \\
- \\
- \\
- \\
- \\
- \\
\bar{w} \\
- \\
- \\
- \\
\bar{w}\end{array}$ & $\begin{array}{l}54.9 \\
58.3 \\
57.4 \\
58.9 \\
60.6 \\
64.6 \\
70.1 \\
77.8 \\
71.8 \\
63.2 \\
62.9 \\
56.9 \\
63.4\end{array}$ \\
\hline
\end{tabular}

See tootnotes at end of table. 
Table 31. Motor Gasoline Prices by Grade, Sales Type, PAD District, and State (Cents per Gallon Excluding Taxes) — Continued

\begin{tabular}{|c|c|c|c|c|c|c|c|c|c|c|c|c|}
\hline \multirow{3}{*}{$\begin{array}{l}\text { Geographic Area } \\
\text { Month }\end{array}$} & \multicolumn{6}{|c|}{ Regular } & \multicolumn{6}{|c|}{ Midgrade } \\
\hline & \multicolumn{2}{|c|}{ Sales to End Users } & \multicolumn{4}{|c|}{ Sales for Resale } & \multicolumn{2}{|c|}{ Sales to End Users } & \multicolumn{4}{|c|}{ Sales for Resale } \\
\hline & $\begin{array}{c}\text { Through } \\
\text { Retail } \\
\text { Outlets }\end{array}$ & Average $^{a}$ & DTW & Rack & Bulk & Average & $\begin{array}{c}\text { Through } \\
\text { Retail } \\
\text { Outlets }\end{array}$ & Averagea & DTW & Rack & Bulk & Average \\
\hline
\end{tabular}

Idaho

\begin{tabular}{|c|c|c|c|c|c|c|c|c|c|c|c|c|}
\hline 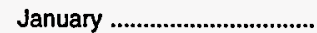 & 67.4 & 66.7 & 57.5 & 50.1 & - & 52.6 & 78.3 & 69.0 & 59.2 & $w$ & - & 52.1 \\
\hline 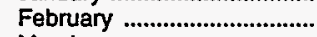 & 64.4 & 63.9 & 56.1 & 51.6 & - & 53.2 & 75.9 & 68.9 & 57.3 & $w$ & - & 52.4 \\
\hline March & 63.2 & 63.4 & 56.4 & 53.0 & - & 54.2 & NA & 65.3 & 57.5 & $w$ & - & 54.7 \\
\hline April & 63.9 & 64.3 & 59.4 & 53.7 & - & 55.6 & 71.3 & 70.1 & 63.7 & 55.2 & - & 57.2 \\
\hline 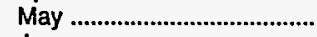 & 67.6 & 68.3 & 63.3 & 60.4 & - & 61.4 & 75.4 & 74.1 & 70.6 & 61.9 & - & 65.5 \\
\hline June & 74.6 & 75.2 & 71.3 & 68.5 & - & 69.5 & 81.3 & 78.2 & NA & 69.5 & - & 71.7 \\
\hline July & 78.2 & 78.6 & 73.7 & 71.8 & - & 72.5 & NA & NA & 74.9 & 71.4 & - & 73.0 \\
\hline 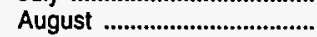 & 82.5 & 82.5 & 76.5 & 74.2 & - & 75.0 & 90.0 & 88.6 & 80.4 & 74.6 & - & 76.3 \\
\hline 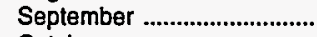 & 83.0 & 83.0 & 77.2 & 76.3 & - & 76.6 & 89.3 & 90.4 & 81.7 & 77.6 & - & 78.6 \\
\hline October & 81.7 & 81.1 & 72.5 & 70.0 & - & 70.9 & 88.9 & 89.6 & 76.2 & 73.7 & - & 74.5 \\
\hline 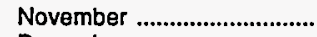 & 79.0 & 79.1 & 71.5 & 67.6 & - & 68.9 & 86.8 & 87.1 & 75.3 & 69.5 & - & 70.7 \\
\hline 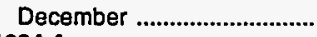 & 76.9 & 76.7 & 67.9 & 63.0 & - & 64.7 & 84.3 & 82.0 & 72.4 & 65.8 & - & 67.9 \\
\hline 1994 Average & 74.1 & $\mathbf{7 4 . 1}$ & 67.4 & 64.0 & - & 65.2 & 80.5 & 78.4 & 71.9 & 65.2 & - & 67.2 \\
\hline \multicolumn{13}{|l|}{ Montana } \\
\hline 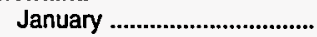 & 72.6 & 72.3 & 66.9 & 55.7 & $W$ & 57.1 & W & $w$ & - & $w$ & - & $w$ \\
\hline 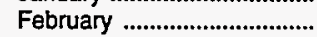 & 70.8 & 71.0 & 67.6 & 56.0 & W & 57.5 & $w$ & 77.9 & - & $W$ & - & $w$ \\
\hline 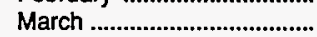 & 70.4 & 70.8 & 68.6 & $\mathbf{5 7 . 4}$ & W & 58.9 & 64.3 & NA & - & $w$ & - & $w$ \\
\hline 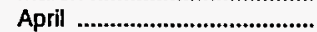 & 71.9 & 72.5 & 72.2 & 60.8 & W & 62.4 & 63.6 & 70.4 & - & $w$ & - & w \\
\hline 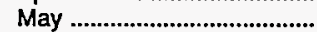 & 80.4 & 79.9 & 76.4 & 65.2 & - & 66.8 & $W$ & NA & - & $w$ & - & $w$ \\
\hline 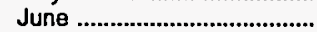 & 84.5 & 84.0 & 80.0 & 71.7 & - & 72.9 & 91.3 & 86.5 & - & $w$ & - & $w$ \\
\hline 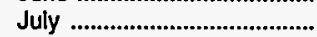 & 85.9 & 85.7 & 79.8 & 72.6 & $W$ & 73.5 & 94.8 & 92.8 & $w$ & $w$ & - & $w$ \\
\hline 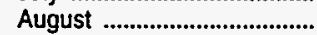 & 86.2 & 87.4 & 80.5 & 75.4 & W & 76.3 & 93.7 & 93.1 & $\dddot{w}$ & $w$ & - & $w$ \\
\hline 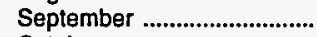 & 87.1 & 88.0 & 78.4 & 74.0 & $\ddot{W}$ & 74.8 & $w$ & 90.5 & $w$ & $w$ & - & $w$ \\
\hline October & 85.3 & 85.3 & 72.4 & 64.9 & $\ddot{W}$ & 66.3 & w & 88.7 & w & $w$ & - & $w$ \\
\hline November ............................... & 82.7 & 82.9 & 73.9 & 65.4 & $W$ & 67.2 & 90.5 & 88.6 & w & $w$ & - & W \\
\hline 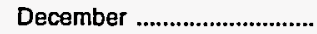 & 80.3 & 80.5 & 70.4 & 60.4 & $W$ & 62.4 & 85.8 & 84.5 & W & $w$ & - & 66.0 \\
\hline 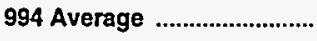 & 81.0 & 80.8 & 74.4 & 65.8 & W & 67.1 & 80.1 & 82.6 & 86.5 & $\mathbf{W}$ & - & $w$ \\
\hline \multicolumn{13}{|l|}{ Utah } \\
\hline 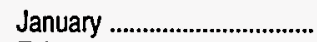 & 59.1 & 59.2 & 52.1 & 47.6 & $W$ & 48.9 & 64.5 & 64.5 & 56.3 & 50.6 & - & 54.1 \\
\hline 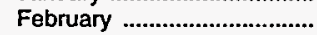 & 58.5 & 58.6 & 52.1 & 49.4 & w & 50.2 & 64.3 & 64.3 & 56.8 & 56.5 & - & 56.7 \\
\hline March & 59.6 & 59.7 & 54.3 & 51.0 & w & 52.0 & 65.5 & 65.5 & 57.9 & 58.6 & - & 58.2 \\
\hline April & 60.0 & 60.0 & 55.4 & 52.1 & $W$ & 53.0 & 65.4 & 65.4 & 58.8 & 55.2 & - & 57.4 \\
\hline May & 67.2 & 67.1 & 60.9 & 59.2 & W & 59.7 & 73.6 & 73.6 & 65.5 & 61.6 & - & 63.9 \\
\hline 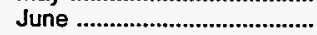 & 75.4 & 75.2 & 67.5 & 65.9 & $\ddot{W}$ & 66.5 & 82.2 & 82.2 & 73.3 & 70.5 & - & 72.2 \\
\hline 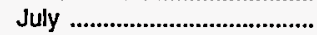 & 76.2 & 77.1 & 70.7 & 68.0 & $W$ & 68.9 & 82.6 & 82.6 & 76.1 & 73.4 & - & 75.0 \\
\hline August & 77.8 & 79.6 & 72.9 & 71.2 & $W$ & 71.7 & 85.1 & 85.1 & 78.6 & 77.5 & - & 78.1 \\
\hline 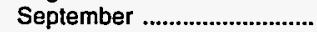 & 79.9 & 81.5 & 74.1 & 73.4 & $W$ & 73.6 & 87.6 & 87.5 & 79.0 & 79.0 & - & 79.0 \\
\hline October & 77.0 & 77.4 & 70.0 & 68.0 & $W$ & 68.6 & 84.6 & 84.6 & 74.8 & 73.2 & - & 74.0 \\
\hline 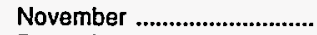 & 73.9 & 73.7 & 66.3 & 64.7 & W & 65.1 & 81.2 & 81.2 & 70.5 & 69.9 & - & 70.2 \\
\hline December ............................... & 72.0 & 71.7 & 62.3 & 60.9 & - & 61.3 & 78.2 & 78.1 & 66.9 & 66.5 & - & 66.6 \\
\hline 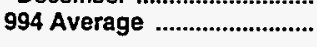 & 70.0 & 70.3 & 63.7 & 61.2 & $\mathbf{W}$ & 61.9 & 76.8 & 76.8 & 68.7 & 67.0 & - & 68.0 \\
\hline \multicolumn{13}{|l|}{ Wyoming } \\
\hline 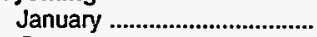 & 73.0 & 71.9 & 54.5 & 49.8 & - & 50.6 & 76.1 & 76.0 & NA & $w$ & - & 64.3 \\
\hline February & 72.1 & 71.3 & 58.0 & 53.6 & - & 54.7 & 77.8 & 77.8 & $w$ & $w$ & - & 62.8 \\
\hline 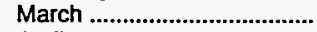 & 70.8 & 70.4 & 59.6 & 55.6 & - & 56.3 & 77.2 & 77.2 & 62.0 & $W$ & - & 69.0 \\
\hline April & 71.6 & 71.4 & 61.8 & 58.4 & - & 59.0 & 78.9 & 79.0 & 64.5 & $W$ & - & 72.0 \\
\hline 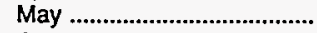 & 75.8 & 75.5 & 65.9 & 62.1 & - & 62.8 & 83.6 & 83.7 & 69.7 & $W$ & - & 78.4 \\
\hline June & 80.2 & 79.8 & 71.1 & 67.7 & - & 68.4 & 88.8 & 88.8 & 74.5 & W & - & 79.8 \\
\hline 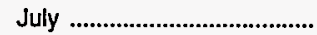 & 84.8 & 84.5 & 74.5 & 70.9 & W & 71.7 & 93.8 & 93.7 & 78.4 & W & - & 81.3 \\
\hline 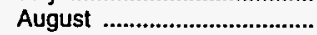 & 87.7 & 87.8 & 76.5 & 76.9 & w & 76.8 & 96.3 & 96.3 & 72.2 & $w$ & - & 77.1 \\
\hline 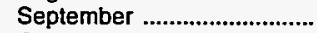 & 89.6 & 89.0 & 73.4 & 72.7 & $W$ & 72.9 & 99.2 & 99.0 & 68.2 & $w$ & - & 70.7 \\
\hline 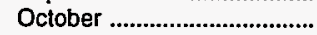 & 87.2 & 85.9 & 68.5 & 62.3 & $\ddot{W}$ & 63.5 & 94.3 & 94.3 & 68.1 & $W$ & - & 71.2 \\
\hline 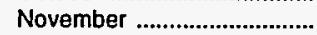 & 84.9 & 83.6 & 65.0 & 60.8 & $W$ & 61.7 & 90.7 & 90.2 & 63.4 & $w$ & - & 66.9 \\
\hline 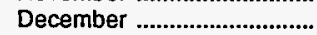 & 80.8 & 79.5 & 61.2 & 53.7 & $W$ & 55.1 & 85.2 & 85.0 & 60.9 & 69.2 & - & 63.1 \\
\hline 1994 Average & 80.7 & 80.0 & 67.5 & 62.8 & $w$ & 63.7 & 88.3 & 88.2 & 67.3 & 78.0 & - & 71.7 \\
\hline
\end{tabular}

See footnotes at end of table. 
Table 31. Motor Gasoline Prices by Grade, Sales Type, PAD District, and State (Cents per Gallon Excluding Taxes) - Continued

\begin{tabular}{|c|c|c|c|c|c|c|c|c|c|c|c|c|}
\hline \multirow{3}{*}{$\begin{array}{c}\text { Geographlc Area } \\
\text { Month }\end{array}$} & \multicolumn{6}{|c|}{ Premium } & \multicolumn{6}{|c|}{ All Grades } \\
\hline & \multicolumn{2}{|c|}{ Sales to End Users } & \multicolumn{4}{|c|}{ Sales for Resale } & \multicolumn{2}{|c|}{ Sales to End Users } & \multicolumn{4}{|c|}{ Sales for Resale } \\
\hline & $\begin{array}{c}\text { Through } \\
\text { Retaif } \\
\text { Outlets }\end{array}$ & Averagea & DTW & Rack & Bulk & Averago & $\begin{array}{l}\text { Through } \\
\text { Retall } \\
\text { Outlots }\end{array}$ & Average $^{a}$ & DTW & Rack & Bulk & Average \\
\hline
\end{tabular}

\begin{tabular}{|c|c|c|c|c|c|c|c|c|c|c|c|c|}
\hline \multicolumn{13}{|l|}{ Idaho } \\
\hline 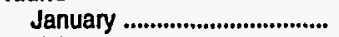 & 75.7 & 75.6 & 65.8 & 58.2 & - & 61.1 & 68.4 & 67.8 & 58.9 & 51.2 & - & 53.9 \\
\hline 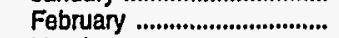 & 73.6 & 73.3 & 64.7 & 59.9 & - & 61.8 & 65.5 & 65.1 & 57.6 & 52.8 & - & 54.6 \\
\hline 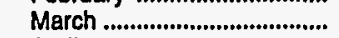 & 74.0 & 74.0 & 65.0 & 61.1 & - & 62.6 & 64.5 & 64.6 & 57.9 & 54.1 & - & 55.5 \\
\hline 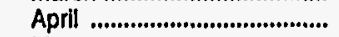 & 75.9 & 75.9 & 66.2 & 61.5 & - & 63.2 & 65.4 & 65.7 & 60.5 & 54.8 & - & 56.7 \\
\hline 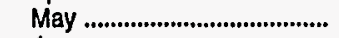 & 79.6 & 79.5 & 71.4 & 69.2 & - & 70.0 & 69.3 & 69.7 & 64.8 & 61.7 & - & 62.8 \\
\hline 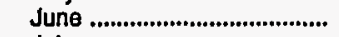 & 87.0 & 86.5 & 79.5 & 77.7 & - & 78.4 & 76.3 & 76.5 & 72.7 & 69.9 & - & 70.9 \\
\hline July & 90.1 & 90.0 & 84.3 & 80.9 & - & 82.3 & 79.8 & 80.0 & 75.9 & 73.2 & - & 74.2 \\
\hline 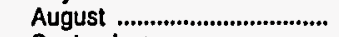 & 94.8 & 94.6 & 87.2 & 83.4 & - & 85.0 & 84.4 & 84.3 & 78.7 & 75.7 & - & 76.7 \\
\hline 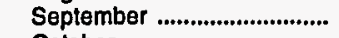 & 94.7 & 94.2 & 86.1 & 85.6 & - & 85.8 & 84.8 & 84.6 & 79.0 & 77.7 & - & 78.2 \\
\hline 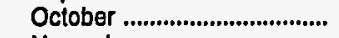 & 92.6 & 92.2 & 83.0 & 78.7 & - & 80.5 & 83.4 & 82.7 & 74.6 & 71.4 & - & 72.5 \\
\hline November .............................. & 89.8 & 89.8 & 81.0 & 76.3 & - & 78.1 & 80.7 & 80.7 & 73.3 & 69.0 & - & 70.5 \\
\hline December ............................... & 87.8 & 87.5 & 77.4 & 72.2 & - & 74.4 & 78.7 & 78.5 & 70.0 & 64.6 & - & 66.5 \\
\hline 1994 Average ............................ & 86.1 & 85.7 & 77.2 & 73.1 & - & 74.7 & 75.8 & 75.7 & 69.3 & 65.4 & - & 66.8 \\
\hline \multicolumn{13}{|l|}{ Montana } \\
\hline 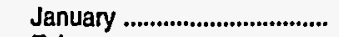 & 82.8 & 82.0 & 76.1 & 64.2 & - & 65.6 & 74.1 & 73.7 & 68.3 & 57.1 & $w$ & 58.4 \\
\hline 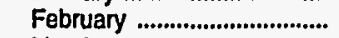 & 80.2 & 79.7 & 77.6 & 64.7 & - & 66.2 & 72.2 & 72.1 & 69.2 & 57.5 & $w$ & 58.9 \\
\hline 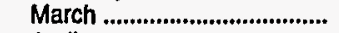 & 79.5 & 79.3 & 78.2 & 65.9 & - & 67.4 & 71.8 & 72.0 & 70.1 & 58.9 & $w$ & 60.3 \\
\hline April & 83.4 & 83.0 & 81.8 & 69.4 & - & 70.9 & 73.7 & 73.9 & 73.6 & 62.3 & $w$ & 63.8 \\
\hline 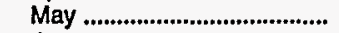 & 90.4 & 89.5 & 84.8 & 74.4 & - & 75.6 & 82.0 & 81.2 & 77.7 & 67.0 & - & 68.4 \\
\hline 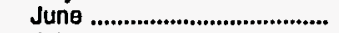 & 94.8 & 92.7 & 87.4 & 81.0 & - & 81.6 & 86.1 & 85.3 & 81.0 & 73.4 & - & 74.4 \\
\hline 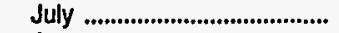 & 96.2 & 94.3 & 87.7 & 82.6 & - & 83.1 & 87.6 & 87.0 & 80.8 & 74.4 & $w$ & 75.2 \\
\hline 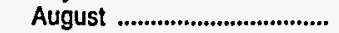 & 95.3 & 95.5 & 88.8 & 84.7 & - & 85.3 & 87.8 & 88.7 & 81.8 & 77.0 & $w$ & 77.8 \\
\hline 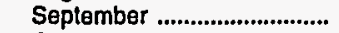 & 96.7 & 96.7 & 86.8 & 84.0 & - & 84.5 & 88.7 & 89.4 & 79.6 & 75.6 & $w$ & 76.3 \\
\hline 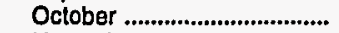 & 94.8 & 94.5 & 79.8 & 74.6 & - & 75.5 & 86.9 & 86.7 & 73.6 & 66.5 & $w$ & 67.7 \\
\hline November ................................ & 92.4 & 92.5 & 82.6 & 74.9 & - & 76.4 & 84.3 & 84.4 & 75.1 & 67.0 & $w$ & 68.7 \\
\hline 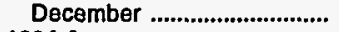 & 90.0 & 90.1 & 77.6 & 69.9 & - & 71.3 & 81.9 & 82.0 & 71.6 & 62.0 & $w$ & 63.9 \\
\hline 1994 Average ........................... & 90.9 & 90.1 & 82.7 & 75.0 & - & 76.0 & 82.6 & 82.2 & 75.7 & 67.3 & $\mathbf{w}$ & 68.5 \\
\hline \multicolumn{13}{|l|}{ Utah } \\
\hline January ..................................... & 71.2 & 71.1 & 61.7 & 55.5 & - & 57.8 & 62.3 & 62.3 & 55.1 & 49.4 & W & 51.3 \\
\hline 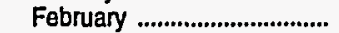 & 71.5 & 71.4 & 61.7 & 58.5 & - & 59.6 & 61.9 & 62.0 & 55.2 & 51.8 & $w$ & 52.8 \\
\hline March ......................................... & 73.0 & 72.7 & 63.1 & 59.1 & $w$ & 60.4 & 63.1 & 63.2 & 56.7 & 53.3 & $w$ & 54.4 \\
\hline April & 73.1 & 73.0 & 63.6 & 60.2 & - & 61.3 & 63.4 & 63.5 & 57.7 & 54.0 & $w$ & 55.1 \\
\hline 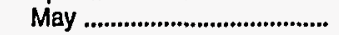 & 81.1 & 80.7 & 70.2 & 67.7 & $\rightarrow$ & 68.5 & 70.8 & 70.6 & 63.4 & 61.2 & w & 61.9 \\
\hline 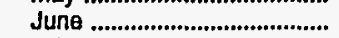 & 89.8 & 89.3 & 77.6 & 75.2 & - & 76.0 & 79.0 & 78.7 & 70.0 & 68.1 & $\ddot{w}$ & 68.8 \\
\hline July & 90.0 & 89.9 & 79.8 & 77.1 & - & 78.0 & 79.9 & 80.3 & 73.1 & 70.2 & $w$ & 71.3 \\
\hline 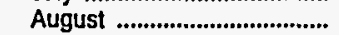 & 92.4 & 91.7 & 82.3 & 80.5 & $w$ & 81.1 & 81.7 & 82.8 & 76.1 & 73.6 & $w$ & 74.4 \\
\hline 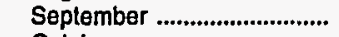 & 94.2 & 93.3 & 83.1 & 82.9 & - & 83.0 & 83.9 & 84.7 & 77.1 & 75.7 & $w$ & 76.2 \\
\hline October ................................... & 90.8 & 89.8 & 78.9 & 77.7 & - & 78.2 & 81.0 & 81.0 & 73.3 & 70.5 & $w$ & 71.4 \\
\hline November ................................ & 87.2 & 86.2 & 75.5 & 73.9 & - & 74.4 & 77.7 & 77.4 & 69.2 & 67.2 & $w$ & 67.8 \\
\hline December ................................ & 84.2 & 83.2 & 71.6 & 69.9 & - & 70.5 & 75.5 & 75.2 & 65.3 & 63.4 & - & 64.0 \\
\hline 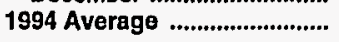 & 83.5 & 82.9 & 72.8 & 70.1 & $w$ & 70.9 & 73.6 & 73.8 & 66.5 & 63.5 & $w$ & 64.4 \\
\hline \multicolumn{13}{|l|}{ Wyoming } \\
\hline 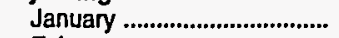 & 83.0 & 81.2 & 62.6 & 58.9 & - & 59.7 & 74.7 & 73.4 & 56.2 & 51.3 & - & 52.2 \\
\hline 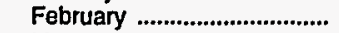 & 83.4 & 81.8 & 66.1 & 62.0 & - & 63.2 & 74.0 & 73.0 & 59.5 & 55.0 & - & 56.2 \\
\hline 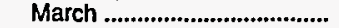 & 82.7 & 81.5 & 66.8 & 63.6 & - & 64.3 & 72.8 & 72.2 & 61.0 & 56.9 & - & 57.7 \\
\hline April & 84.2 & 83.1 & 69.7 & 66.7 & - & 67.4 & 73.8 & 73.3 & 63.5 & 59.8 & - & 60.5 \\
\hline 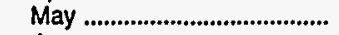 & 88.2 & 87.5 & 74.7 & 71.0 & - & 71.9 & 77.9 & 77.3 & 67.8 & 63.7 & - & 64.6 \\
\hline 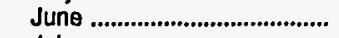 & 92.9 & 91.9 & 79.5 & 76.6 & - & 77.3 & 82.3 & 81.7 & 72.9 & 69.3 & - & 70.1 \\
\hline 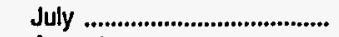 & 97.5 & 96.7 & 83.2 & 79.5 & - & 80.5 & 87.0 & 86.5 & 76.5 & 72.5 & $w$ & 73.4 \\
\hline 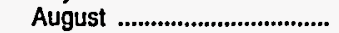 & 99.3 & 99.1 & 87.5 & 85.6 & - & 86.0 & 90.0 & 89.9 & 78.5 & 78.6 & w & 78.5 \\
\hline 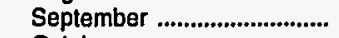 & 100.6 & 99.6 & 82.4 & 82.2 & - & 82.2 & 91.8 & 91.0 & 74.8 & 74.3 & $w$ & 74.4 \\
\hline 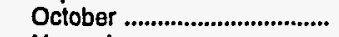 & 98.6 & 97.7 & 77.2 & 72.1 & - & 73.2 & 89.4 & 88.0 & 70.0 & 64.0 & W & 65.2 \\
\hline 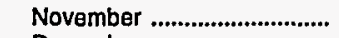 & 95.0 & 94.0 & 73.4 & 70.5 & - & 71.1 & 86.8 & 85.5 & 66.2 & 62.5 & W & 63.3 \\
\hline 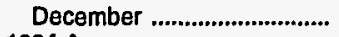 & 92.1 & 89.7 & 68.4 & 62.9 & - & 63.9 & 82.9 & 81.5 & 62.3 & 55.2 & W & 56.6 \\
\hline 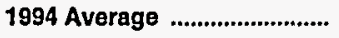 & 92.6 & 91.4 & 76.5 & 72.1 & - & 73.1 & 82.8 & 82.0 & 69.2 & 64.4 & $w$ & 65.3 \\
\hline
\end{tabular}

See footnotes at end of table. 
Table 31. Motor Gasoline Prices by Grade, Sales Type, PAD District, and State (Cents per Gallon Excluding Taxes) - Continued

\begin{tabular}{|c|c|c|c|c|c|c|c|c|c|c|c|c|}
\hline \multirow{3}{*}{$\begin{array}{l}\text { Geographic Area } \\
\text { Month }\end{array}$} & \multicolumn{6}{|c|}{ Regular } & \multicolumn{6}{|c|}{ Midgrade } \\
\hline & \multicolumn{2}{|c|}{ Sales to End Users } & \multicolumn{4}{|c|}{ Sales for Resale } & \multicolumn{2}{|c|}{ Sales to End Users } & \multicolumn{4}{|c|}{ Sales for Resale } \\
\hline & $\begin{array}{c}\text { Through } \\
\text { Retail } \\
\text { Outlets }\end{array}$ & Average ${ }^{a}$ & DTW & Rack & Bulk & Average & $\begin{array}{c}\text { Through } \\
\text { Retail } \\
\text { Outlets }\end{array}$ & Averagea & DTW & Rack & Bulk & Average \\
\hline \multicolumn{13}{|l|}{ PAD District V } \\
\hline $\begin{array}{l}\text { January } \\
\text { February } \\
\text { April ................ } \\
\text { May } \\
\text { June } \\
\text { July } \\
\text { August } \\
\text { September } \\
\text { October } \\
\text { November } \\
\text { December } \\
1994 \text { Average }\end{array}$ & $\begin{array}{l}72.3 \\
71.1 \\
71.2 \\
72.2 \\
73.6 \\
75.5 \\
77.9 \\
79.8 \\
79.9 \\
80.4 \\
80.8 \\
79.3 \\
76.1\end{array}$ & $\begin{array}{l}71.7 \\
70.6 \\
70.6 \\
71.7 \\
73.1 \\
75.0 \\
77.4 \\
79.3 \\
79.4 \\
79.9 \\
80.4 \\
78.6 \\
75.6\end{array}$ & $\begin{array}{l}60.3 \\
61.0 \\
61.2 \\
63.5 \\
65.0 \\
67.4 \\
70.3 \\
71.0 \\
70.7 \\
72.9 \\
73.3 \\
70.4 \\
67.0\end{array}$ & $\begin{array}{l}51.3 \\
52.5 \\
52.8 \\
56.2 \\
57.1 \\
59.4 \\
63.6 \\
63.9 \\
62.0 \\
62.8 \\
62.9 \\
58.6 \\
58.9\end{array}$ & $\begin{array}{l}43.7 \\
47.5 \\
48.5 \\
51.7 \\
50.9 \\
54.9 \\
57.8 \\
57.1 \\
56.1 \\
55.4 \\
58.3 \\
51.8 \\
53.2\end{array}$ & $\begin{array}{l}55.8 \\
56.9 \\
57.3 \\
59.9 \\
60.8 \\
63.5 \\
66.8 \\
67.1 \\
66.4 \\
67.4 \\
67.8 \\
64.3 \\
62.9\end{array}$ & $\begin{array}{l}77.0 \\
77.0 \\
78.7 \\
80.3 \\
81.9 \\
83.8 \\
87.0 \\
87.7 \\
88.1 \\
89.9 \\
90.6 \\
88.5 \\
84.4\end{array}$ & $\begin{array}{l}76.2 \\
76.1 \\
77.6 \\
79.5 \\
80.9 \\
82.8 \\
86.3 \\
86.9 \\
87.2 \\
89.1 \\
89.9 \\
87.8 \\
83.5\end{array}$ & $\begin{array}{l}65.6 \\
66.9 \\
67.3 \\
70.4 \\
72.2 \\
74.4 \\
77.3 \\
76.7 \\
76.0 \\
79.1 \\
78.7 \\
74.4 \\
73.0\end{array}$ & $\begin{array}{l}56.3 \\
57.4 \\
57.6 \\
61.0 \\
61.1 \\
63.3 \\
67.8 \\
67.7 \\
65.4 \\
69.2 \\
70.0 \\
64.1 \\
63.8\end{array}$ & $\begin{array}{l}W \\
W \\
W \\
W \\
W \\
W \\
W \\
W \\
W \\
W \\
W \\
W \\
W\end{array}$ & $\begin{array}{l}63.2 \\
64.4 \\
65.1 \\
68.3 \\
69.5 \\
71.7 \\
74.9 \\
74.7 \\
73.7 \\
76.8 \\
76.5 \\
72.2 \\
70.9\end{array}$ \\
\hline \multicolumn{13}{|l|}{ Alaska } \\
\hline 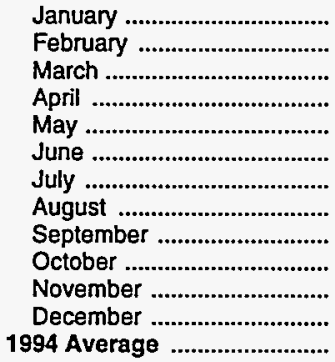 & $\begin{array}{l}108.0 \\
106.5 \\
106.9 \\
107.0 \\
106.6 \\
110.2 \\
110.0 \\
113.3 \\
112.9 \\
112.4 \\
113.0 \\
111.8 \\
109.1\end{array}$ & $\begin{array}{l}102.8 \\
101.3 \\
102.0 \\
101.9 \\
102.0 \\
105.4 \\
103.4 \\
109.0 \\
110.6 \\
110.1 \\
110.2 \\
109.6 \\
104.8\end{array}$ & $\begin{array}{l}76.3 \\
75.1 \\
74.7 \\
76.8 \\
78.0 \\
81.7 \\
83.1 \\
87.6 \\
87.9 \\
85.9 \\
85.0 \\
85.5 \\
82.2\end{array}$ & $\begin{array}{l}69.3 \\
67.6 \\
67.9 \\
67.8 \\
69.3 \\
70.3 \\
70.8 \\
72.2 \\
73.0 \\
74.1 \\
72.0 \\
71.6 \\
70.7\end{array}$ & $\begin{array}{l}W \\
W \\
W \\
64.5 \\
62.3 \\
70.6 \\
72.6 \\
W \\
W \\
W \\
- \\
W \\
69.1\end{array}$ & $\begin{array}{l}73.3 \\
71.1 \\
72.0 \\
72.6 \\
73.0 \\
75.4 \\
76.6 \\
79.4 \\
79.9 \\
80.3 \\
78.6 \\
79.1 \\
76.4\end{array}$ & $\begin{array}{c}W \\
W \\
W \\
N A \\
W \\
N A \\
N A \\
- \\
W \\
W \\
W \\
W \\
N A\end{array}$ & $\begin{array}{l}\text { NA } \\
\text { NA } \\
\text { NA } \\
\text { NA } \\
\text { NA } \\
\text { NA } \\
\text { NA } \\
\text { W } \\
\text { NA } \\
\text { NA } \\
\text { NA } \\
\text { NA } \\
\text { NA }\end{array}$ & $\begin{array}{c}W \\
W \\
79.7 \\
80.2 \\
81.4 \\
84.5 \\
86.0 \\
87.7 \\
88.1 \\
87.7 \\
86.2 \\
88.6 \\
85.3\end{array}$ & $\begin{array}{l}- \\
- \\
\overline{-} \\
\overline{-} \\
\overline{-} \\
- \\
\bar{W} \\
W \\
W \\
W \\
W \\
W\end{array}$ & $\begin{array}{l}\overline{-} \\
\overline{-} \\
- \\
\bar{W} \\
W \\
\bar{W} \\
W \\
W \\
W \\
W \\
W\end{array}$ & $\begin{array}{c}W \\
W \\
79.7 \\
80.2 \\
81.4 \\
84.1 \\
86.0 \\
87.7 \\
88.4 \\
90.7 \\
86.8 \\
89.1 \\
86.2\end{array}$ \\
\hline \multicolumn{13}{|l|}{ Arizona } \\
\hline 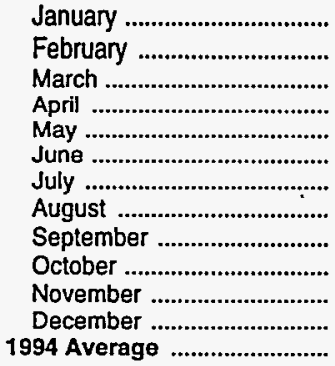 & $\begin{array}{l}81.2 \\
79.0 \\
78.1 \\
77.8 \\
78.0 \\
78.6 \\
79.2 \\
81.2 \\
81.7 \\
81.5 \\
80.7 \\
79.4 \\
79.6\end{array}$ & $\begin{array}{l}80.2 \\
78.1 \\
77.3 \\
77.2 \\
77.6 \\
78.1 \\
78.9 \\
81.1 \\
81.5 \\
81.2 \\
80.4 \\
79.0 \\
79.1\end{array}$ & $\begin{array}{l}69.4 \\
69.2 \\
69.0 \\
67.6 \\
68.8 \\
70.4 \\
71.8 \\
72.1 \\
72.8 \\
73.0 \\
72.8 \\
70.6 \\
70.5\end{array}$ & $\begin{array}{l}54.6 \\
56.2 \\
58.0 \\
59.4 \\
61.7 \\
63.1 \\
65.5 \\
65.7 \\
63.9 \\
63.2 \\
65.9 \\
59.9 \\
61.4\end{array}$ & $\begin{array}{c}45.3 \\
W \\
W \\
52.9 \\
55.3 \\
W \\
W \\
W \\
59.2 \\
W \\
59.5 \\
54.5 \\
54.5\end{array}$ & $\begin{array}{l}62.8 \\
63.6 \\
64.7 \\
63.8 \\
65.7 \\
67.3 \\
69.2 \\
69.0 \\
68.8 \\
68.3 \\
69.4 \\
65.4 \\
66.4\end{array}$ & $\begin{array}{r}88.8 \\
88.7 \\
87.4 \\
88.4 \\
88.8 \\
89.0 \\
92.0 \\
91.7 \\
92.3 \\
\text { NA } \\
93.3 \\
86.4 \\
89.7\end{array}$ & $\begin{array}{r}88.6 \\
88.2 \\
86.8 \\
87.9 \\
88.1 \\
88.3 \\
91.5 \\
91.2 \\
91.5 \\
\text { NA } \\
92.9 \\
86.2 \\
89.1\end{array}$ & $\begin{array}{r}63.6 \\
64.9 \\
66.5 \\
\text { NA } \\
73.8 \\
76.4 \\
79.8 \\
76.3 \\
76.1 \\
73.2 \\
74.3 \\
71.2 \\
70.8\end{array}$ & $\begin{array}{c}W \\
W \\
W \\
W \\
W \\
W \\
W \\
W \\
W \\
69.4 \\
W \\
W \\
70.2\end{array}$ & $\begin{array}{l}- \\
- \\
- \\
- \\
- \\
- \\
\bar{w} \\
- \\
\bar{w} \\
\bar{w}\end{array}$ & $\begin{array}{r}63.6 \\
64.9 \\
66.5 \\
\text { NA } \\
73.7 \\
76.3 \\
79.7 \\
77.0 \\
77.1 \\
72.8 \\
73.4 \\
70.6 \\
70.7\end{array}$ \\
\hline \multicolumn{13}{|l|}{ California } \\
\hline 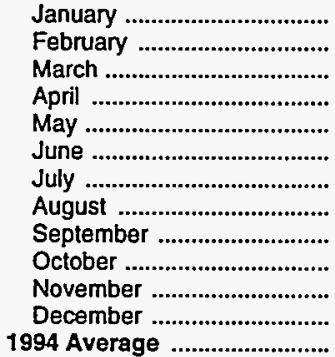 & $\begin{array}{l}65.9 \\
64.9 \\
65.6 \\
67.2 \\
68.8 \\
71.0 \\
73.6 \\
75.4 \\
75.7 \\
77.2 \\
77.7 \\
76.1 \\
71.8\end{array}$ & $\begin{array}{l}65.8 \\
65.1 \\
65.7 \\
67.2 \\
68.6 \\
70.7 \\
73.3 \\
75.1 \\
75.1 \\
76.9 \\
77.6 \\
75.6 \\
71.5\end{array}$ & $\begin{array}{l}58.1 \\
59.1 \\
59.8 \\
62.7 \\
64.1 \\
66.7 \\
69.7 \\
69.9 \\
69.3 \\
72.5 \\
73.1 \\
70.0 \\
66.0\end{array}$ & $\begin{array}{l}50.0 \\
51.2 \\
51.3 \\
54.3 \\
54.5 \\
56.3 \\
61.2 \\
60.7 \\
58.2 \\
61.1 \\
61.5 \\
57.0 \\
56.8\end{array}$ & $\begin{array}{l}45.6 \\
48.3 \\
48.2 \\
51.5 \\
50.3 \\
54.3 \\
57.9 \\
55.7 \\
55.4 \\
55.1 \\
58.4 \\
51.7 \\
53.2\end{array}$ & $\begin{array}{l}54.7 \\
55.7 \\
56.0 \\
58.9 \\
59.3 \\
62.2 \\
65.7 \\
65.7 \\
64.6 \\
66.6 \\
67.1 \\
63.6 \\
61.8\end{array}$ & $\begin{array}{l}74.7 \\
74.8 \\
76.8 \\
78.7 \\
80.5 \\
82.8 \\
85.6 \\
86.8 \\
87.0 \\
89.5 \\
89.9 \\
88.0 \\
83.0\end{array}$ & $\begin{array}{l}74.3 \\
74.3 \\
76.0 \\
78.3 \\
79.9 \\
81.8 \\
85.1 \\
86.0 \\
85.9 \\
88.8 \\
89.2 \\
87.2 \\
82.3\end{array}$ & $\begin{array}{l}65.0 \\
66.3 \\
66.7 \\
69.9 \\
71.6 \\
73.9 \\
76.9 \\
76.3 \\
75.4 \\
78.8 \\
78.6 \\
74.0 \\
72.5\end{array}$ & $\begin{array}{l}56.0 \\
57.2 \\
57.4 \\
60.8 \\
60.7 \\
62.9 \\
67.4 \\
67.2 \\
64.9 \\
68.9 \\
69.7 \\
63.4 \\
63.4\end{array}$ & $\begin{array}{l}w \\
W \\
w \\
W \\
W \\
W \\
W \\
W \\
W \\
W \\
W \\
W \\
W\end{array}$ & $\begin{array}{l}62.7 \\
63.9 \\
64.7 \\
67.9 \\
69.1 \\
71.3 \\
74.6 \\
74.3 \\
73.1 \\
76.5 \\
76.3 \\
71.8 \\
70.5\end{array}$ \\
\hline
\end{tabular}

See footnotes at end of table. 
Table 31. Motor Gasoline Prices by Grade, Sales Type, PAD District, and State (Cents per Gallon Excluding Taxes) - Continued

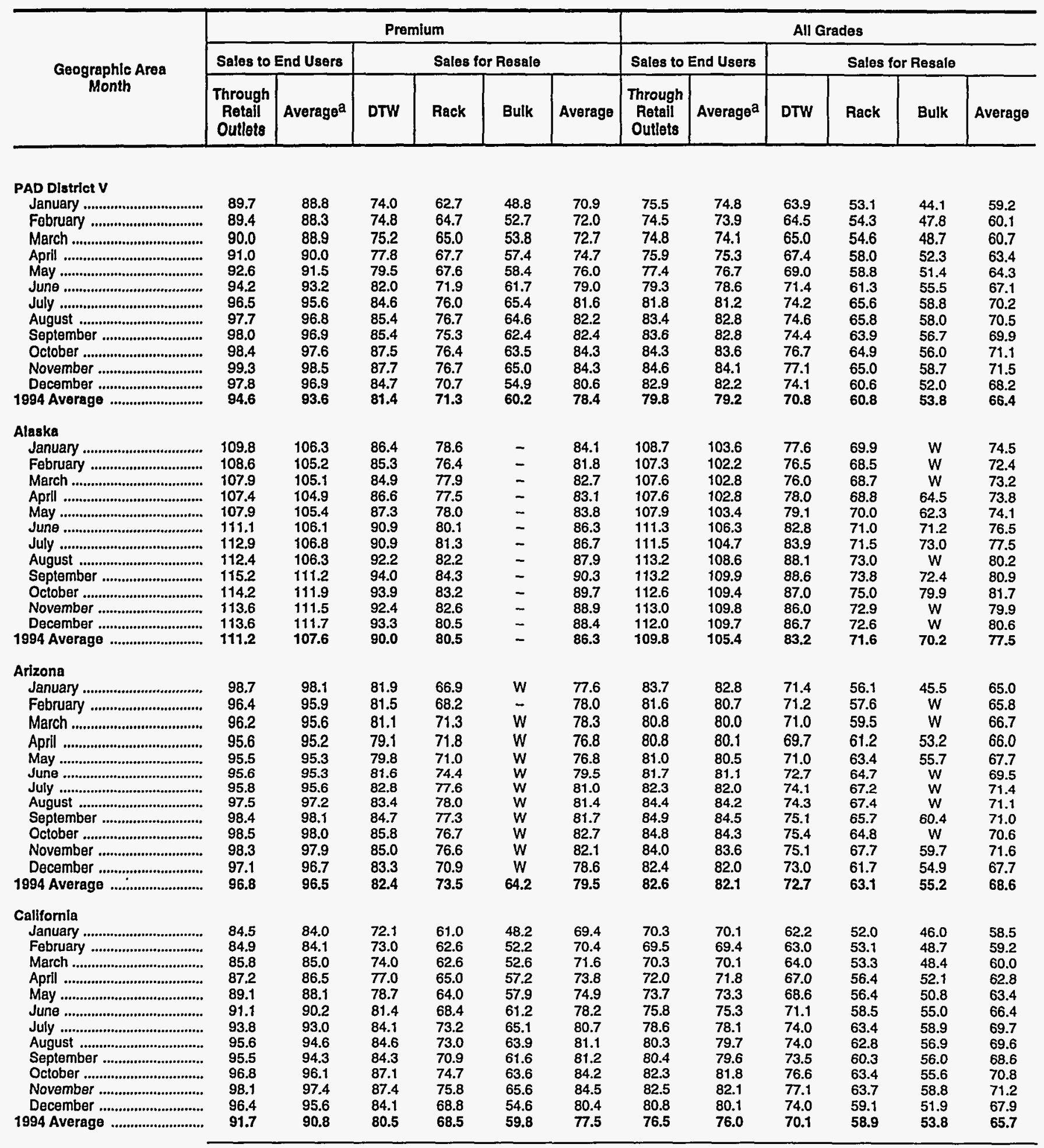

See footnotes at end of table. 
Table 31. Motor Gasoline Prices by Grade, Sales Type, PAD District, and State (Cents per Gallon Excluding Taxes) - Continued

\begin{tabular}{|c|c|c|c|c|c|c|c|c|c|c|c|c|}
\hline \multirow{3}{*}{$\begin{array}{c}\text { Geographic Area } \\
\text { Month }\end{array}$} & \multicolumn{6}{|c|}{ Regular } & \multicolumn{6}{|c|}{ Midgrade } \\
\hline & \multicolumn{2}{|c|}{ Sales to End Users } & \multicolumn{4}{|c|}{ Sales for Resale } & \multicolumn{2}{|c|}{ Sales to End Users } & \multicolumn{4}{|c|}{ Sales for Resalo } \\
\hline & $\begin{array}{c}\text { Through } \\
\text { Retail } \\
\text { Outlets }\end{array}$ & Averago $a$ & DTW & Rack & Bulk & Average & $\begin{array}{c}\text { Through } \\
\text { Retail } \\
\text { Outlets }\end{array}$ & Average ${ }^{a}$ & DTW & Rack & Bulk & Average \\
\hline Hawaii & & & & & & & & & & & & \\
\hline 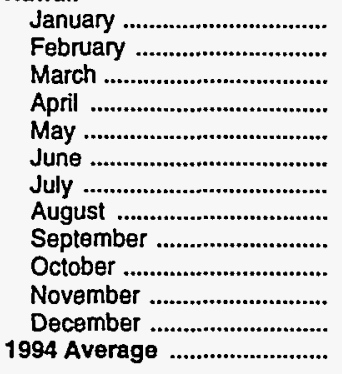 & $\begin{array}{r}105.3 \\
104.3 \\
105.0 \\
105.5 \\
104.1 \\
104.1 \\
104.0 \\
98.7 \\
99.1 \\
99.7 \\
100.4 \\
100.0 \\
102.9\end{array}$ & $\begin{array}{l}96.3 \\
95.3 \\
96.0 \\
98.0 \\
96.3 \\
96.5 \\
97.1 \\
93.0 \\
92.8 \\
93.2 \\
95.1 \\
92.8 \\
95.5\end{array}$ & $\begin{array}{l}85.6 \\
84.0 \\
84.3 \\
86.2 \\
86.4 \\
87.6 \\
89.7 \\
91.2 \\
92.2 \\
92.9 \\
92.8 \\
91.5 \\
88.8\end{array}$ & $\begin{array}{l}76.2 \\
74.9 \\
75.3 \\
76.8 \\
77.9 \\
79.0 \\
79.6 \\
80.2 \\
80.5 \\
80.1 \\
81.6 \\
78.0 \\
78.3\end{array}$ & $\begin{array}{l}\overline{-} \\
\bar{w} \\
\overline{-} \\
\overline{-} \\
\overline{-} \\
\overline{-} \\
\overline{-} \\
\bar{w}\end{array}$ & $\begin{array}{l}83.8 \\
82.5 \\
68.8 \\
84.5 \\
84.9 \\
86.2 \\
87.9 \\
89.4 \\
90.4 \\
90.8 \\
90.9 \\
89.5 \\
84.9\end{array}$ & $\begin{array}{l}107.5 \\
106.9 \\
107.0 \\
107.2 \\
105.7 \\
105.8 \\
113.0 \\
105.6 \\
105.6 \\
106.1 \\
106.4 \\
106.6 \\
107.2\end{array}$ & $\begin{array}{r}97.3 \\
97.1 \\
97.1 \\
97.2 \\
96.2 \\
96.5 \\
105.7 \\
98.1 \\
97.6 \\
98.5 \\
99.9 \\
98.4 \\
98.5\end{array}$ & $\begin{array}{l}90.2 \\
89.3 \\
89.7 \\
91.5 \\
92.2 \\
93.4 \\
95.9 \\
97.4 \\
98.4 \\
99.3 \\
99.2 \\
98.1 \\
94.7\end{array}$ & $\begin{array}{c}87.1 \\
85.9 \\
84.6 \\
86.8 \\
88.9 \\
87.5 \\
89.6 \\
W \\
W \\
W \\
W \\
W \\
88.6\end{array}$ & $\begin{array}{l}- \\
- \\
- \\
- \\
- \\
- \\
- \\
- \\
- \\
- \\
- \\
-\end{array}$ & $\begin{array}{l}90.1 \\
89.1 \\
89.5 \\
91.3 \\
92.1 \\
93.1 \\
95.6 \\
97.1 \\
98.1 \\
98.9 \\
98.9 \\
97.9 \\
94.4\end{array}$ \\
\hline 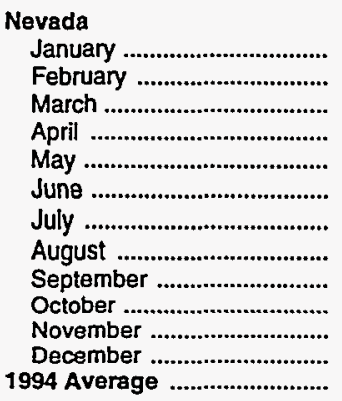 & $\begin{array}{l}76.8 \\
76.4 \\
76.6 \\
76.7 \\
77.8 \\
78.9 \\
80.5 \\
83.0 \\
84.8 \\
83.4 \\
86.6 \\
89.1 \\
80.8\end{array}$ & $\begin{array}{l}75.3 \\
74.7 \\
74.9 \\
75.5 \\
76.4 \\
78.0 \\
79.5 \\
82.1 \\
84.0 \\
82.5 \\
85.2 \\
87.1 \\
79.6\end{array}$ & $\begin{array}{l}60.2 \\
61.0 \\
60.4 \\
61.9 \\
63.2 \\
65.0 \\
67.6 \\
69.0 \\
70.3 \\
71.1 \\
70.6 \\
67.5 \\
65.7\end{array}$ & $\begin{array}{l}53.2 \\
54.1 \\
54.0 \\
58.1 \\
58.0 \\
61.2 \\
65.2 \\
65.3 \\
63.1 \\
65.6 \\
64.5 \\
58.8 \\
60.8\end{array}$ & $\begin{array}{l}W \\
W \\
W \\
W \\
W \\
W \\
W \\
W \\
W \\
W \\
W \\
W \\
W\end{array}$ & $\begin{array}{l}57.0 \\
57.6 \\
57.3 \\
60.0 \\
60.8 \\
63.1 \\
66.4 \\
67.1 \\
66.6 \\
68.3 \\
67.7 \\
63.2 \\
63.2\end{array}$ & $\begin{array}{l}83.6 \\
83.6 \\
84.3 \\
83.9 \\
85.1 \\
86.0 \\
87.5 \\
89.3 \\
90.2 \\
90.0 \\
91.1 \\
93.6 \\
87.5\end{array}$ & $\begin{array}{l}83.1 \\
83.0 \\
83.3 \\
83.5 \\
84.7 \\
85.6 \\
87.1 \\
88.8 \\
89.7 \\
89.6 \\
90.6 \\
93.1 \\
87.0\end{array}$ & $\begin{array}{l}65.5 \\
66.3 \\
67.9 \\
69.8 \\
71.4 \\
72.7 \\
75.0 \\
76.4 \\
77.0 \\
77.6 \\
76.2 \\
73.5 \\
72.4\end{array}$ & $\begin{array}{l}57.6 \\
58.7 \\
59.4 \\
63.6 \\
64.6 \\
66.8 \\
71.2 \\
72.5 \\
70.9 \\
72.5 \\
72.3 \\
69.4 \\
67.1\end{array}$ & $\begin{array}{l}- \\
- \\
- \\
- \\
- \\
- \\
- \\
- \\
- \\
- \\
-\end{array}$ & $\begin{array}{l}62.8 \\
63.6 \\
64.6 \\
67.6 \\
68.8 \\
70.2 \\
73.4 \\
74.9 \\
74.6 \\
76.0 \\
74.9 \\
72.4 \\
70.5\end{array}$ \\
\hline 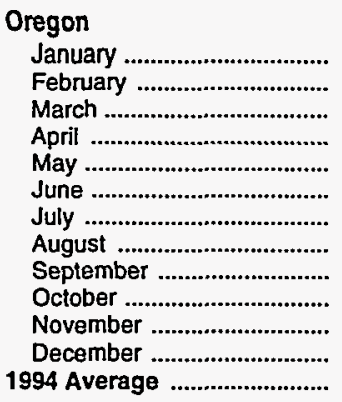 & $\begin{array}{l}75.8 \\
75.5 \\
73.7 \\
74.5 \\
76.8 \\
78.4 \\
81.4 \\
83.7 \\
82.9 \\
81.2 \\
81.2 \\
79.0 \\
78.8\end{array}$ & $\begin{array}{l}74.6 \\
74.4 \\
73.2 \\
73.8 \\
76.1 \\
77.7 \\
80.6 \\
83.0 \\
82.3 \\
80.3 \\
80.4 \\
77.9 \\
78.0\end{array}$ & $\begin{array}{l}63.5 \\
63.0 \\
60.8 \\
62.8 \\
65.3 \\
67.0 \\
70.0 \\
71.9 \\
71.9 \\
70.5 \\
70.8 \\
66.9 \\
67.3\end{array}$ & $\begin{array}{l}49.7 \\
52.8 \\
51.9 \\
58.1 \\
59.9 \\
61.6 \\
65.5 \\
67.8 \\
67.1 \\
63.7 \\
63.5 \\
59.8 \\
60.2\end{array}$ & $\begin{array}{c}45.5 \\
W \\
W \\
W \\
53.0 \\
W \\
58.0 \\
60.0 \\
57.8 \\
55.9 \\
54.9 \\
50.3 \\
55.3\end{array}$ & $\begin{array}{l}55.0 \\
56.8 \\
56.0 \\
59.6 \\
62.4 \\
63.9 \\
67.3 \\
67.4 \\
67.8 \\
65.3 \\
65.6 \\
61.4 \\
62.7\end{array}$ & $\begin{array}{l}75.8 \\
75.7 \\
75.2 \\
76.4 \\
76.6 \\
77.5 \\
81.1 \\
82.9 \\
82.7 \\
82.9 \\
84.8 \\
82.3 \\
80.0\end{array}$ & $\begin{array}{l}74.8 \\
75.2 \\
74.8 \\
75.8 \\
76.0 \\
76.9 \\
80.4 \\
85.5 \\
84.8 \\
84.4 \\
85.8 \\
83.6 \\
80.8\end{array}$ & $\begin{array}{l}\text { W } \\
60.1 \\
64.8 \\
68.1 \\
70.5 \\
72.3 \\
\text { NA } \\
\text { NA } \\
\text { NA } \\
73.1 \\
73.6 \\
73.2 \\
71.0\end{array}$ & $\begin{array}{c}W \\
W \\
W \\
57.4 \\
68.3 \\
65.5 \\
W \\
69.1 \\
67.2 \\
68.8 \\
69.2 \\
65.8 \\
67.1\end{array}$ & $\begin{array}{l}\bar{z} \\
\overline{-} \\
\bar{z} \\
\bar{z} \\
\bar{z} \\
\overline{-} \\
\bar{z} \\
-\end{array}$ & $\begin{array}{c}W \\
58.5 \\
63.4 \\
65.8 \\
69.7 \\
70.3 \\
72.9 \\
\text { NA } \\
\text { NA } \\
71.5 \\
72.1 \\
70.1 \\
69.9\end{array}$ \\
\hline 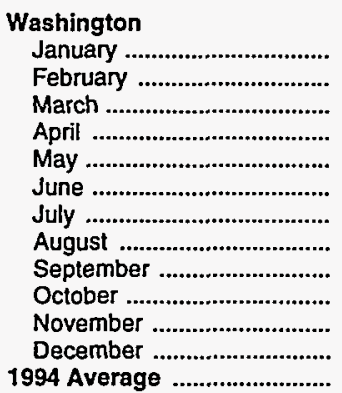 & $\begin{array}{l}69.4 \\
68.8 \\
68.6 \\
69.7 \\
72.8 \\
75.8 \\
79.4 \\
82.8 \\
83.6 \\
82.7 \\
83.6 \\
81.5 \\
76.8\end{array}$ & $\begin{array}{l}69.0 \\
68.5 \\
68.4 \\
69.6 \\
72.6 \\
75.4 \\
79.0 \\
82.4 \\
82.9 \\
82.3 \\
83.1 \\
81.0 \\
76.5\end{array}$ & $\begin{array}{l}61.6 \\
61.5 \\
60.2 \\
62.0 \\
64.1 \\
66.7 \\
70.2 \\
72.7 \\
73.5 \\
73.2 \\
73.7 \\
71.2 \\
67.6\end{array}$ & $\begin{array}{l}52.6 \\
52.8 \\
53.7 \\
57.5 \\
59.8 \\
63.3 \\
66.9 \\
69.2 \\
69.4 \\
66.2 \\
65.4 \\
61.2 \\
61.9\end{array}$ & $\begin{array}{c}W \\
W \\
-\bar{W} \\
W \\
W \\
54.2 \\
W \\
W \\
54.2 \\
W \\
50.9 \\
45.7\end{array}$ & $\begin{array}{l}53.5 \\
56.0 \\
57.3 \\
59.8 \\
61.7 \\
64.9 \\
67.6 \\
70.8 \\
71.1 \\
69.5 \\
69.6 \\
66.5 \\
64.1\end{array}$ & $\begin{array}{c}73.2 \\
70.6 \\
69.3 \\
70.1 \\
\text { NA } \\
\text { NA } \\
77.2 \\
86.8 \\
90.6 \\
87.2 \\
91.9 \\
88.4 \\
81.3\end{array}$ & $\begin{array}{r}70.5 \\
69.5 \\
70.3 \\
70.9 \\
70.4 \\
76.0 \\
\text { NA } \\
84.9 \\
91.4 \\
86.9 \\
90.8 \\
87.7 \\
80.1\end{array}$ & $\begin{array}{c}60.5 \\
60.4 \\
62.0 \\
66.2 \\
68.8 \\
69.9 \\
71.2 \\
W \\
W \\
78.4 \\
75.7 \\
73.0 \\
75.1\end{array}$ & $\begin{array}{c}W \\
61.0 \\
W \\
W \\
N A \\
N A \\
N A \\
W \\
W \\
73.5 \\
73.1 \\
69.6 \\
66.4\end{array}$ & $\begin{array}{l}- \\
- \\
- \\
- \\
- \\
- \\
- \\
- \\
- \\
-\end{array}$ & $\begin{array}{c}61.5 \\
60.7 \\
56.3 \\
61.3 \\
\text { NA } \\
\text { NA } \\
\text { NA } \\
73.6 \\
W \\
77.3 \\
75.1 \\
72.3 \\
72.7\end{array}$ \\
\hline
\end{tabular}

See footnotes at end of table. 
Table 31. Motor Gasoline Prices by Grade, Sales Type, PAD District, and State (Cents per Gallon Excluding Taxes) - Continued

\begin{tabular}{|c|c|c|c|c|c|c|c|c|c|c|c|c|}
\hline \multirow{3}{*}{$\begin{array}{l}\text { Geographic Area } \\
\text { Month }\end{array}$} & \multicolumn{6}{|c|}{ Premium } & \multicolumn{6}{|c|}{ All Grades } \\
\hline & \multicolumn{2}{|c|}{ Sales to End Users } & \multicolumn{4}{|c|}{ Sales for Resale } & \multicolumn{2}{|c|}{ Sales to End Users } & \multicolumn{4}{|c|}{ Sales for Resale } \\
\hline & $\begin{array}{c}\text { Through } \\
\text { Retail } \\
\text { Outlets }\end{array}$ & Averagoa & DTW & Rack & Bulk & Average & $\begin{array}{c}\text { Through } \\
\text { Retail } \\
\text { Outlets }\end{array}$ & Average ${ }^{a}$ & DTW & Rack & Bulk & Average \\
\hline Hawall & & & & & & & & & & & & \\
\hline 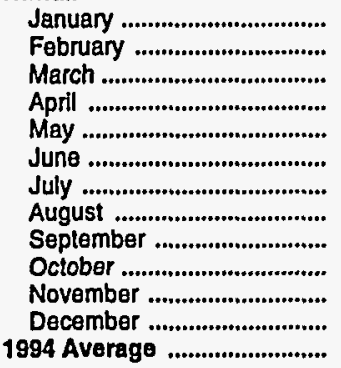 & $\begin{array}{l}123.0 \\
121.9 \\
123.1 \\
123.7 \\
121.9 \\
122.1 \\
123.5 \\
117.6 \\
117.3 \\
117.4 \\
117.9 \\
117.8 \\
121.1\end{array}$ & $\begin{array}{l}111.1 \\
110.4 \\
111.6 \\
113.0 \\
111.5 \\
111.8 \\
113.6 \\
109.3 \\
108.5 \\
109.0 \\
109.5 \\
108.2 \\
110.9\end{array}$ & $\begin{array}{r}98.3 \\
96.9 \\
97.3 \\
99.1 \\
99.6 \\
100.4 \\
102.8 \\
104.3 \\
105.4 \\
104.9 \\
106.1 \\
104.8 \\
101.8\end{array}$ & $\begin{array}{l}89.4 \\
88.3 \\
87.9 \\
89.3 \\
89.5 \\
91.1 \\
93.0 \\
94.2 \\
94.2 \\
93.8 \\
95.3 \\
92.5 \\
91.4\end{array}$ & $\begin{array}{l}- \\
- \\
- \\
- \\
- \\
- \\
- \\
- \\
-\end{array}$ & $\begin{array}{r}97.2 \\
95.9 \\
96.0 \\
97.7 \\
98.2 \\
99.3 \\
101.5 \\
103.0 \\
104.2 \\
103.6 \\
104.8 \\
103.4 \\
100.5\end{array}$ & $\begin{array}{l}110.0 \\
109.1 \\
109.8 \\
110.4 \\
108.8 \\
108.9 \\
110.1 \\
104.2 \\
104.3 \\
104.8 \\
105.4 \\
105.3 \\
108.0\end{array}$ & $\begin{array}{r}100.3 \\
99.4 \\
100.2 \\
101.9 \\
100.3 \\
100.5 \\
102.5 \\
97.7 \\
97.3 \\
97.8 \\
99.3 \\
97.4 \\
99.8\end{array}$ & $\begin{array}{l}90.6 \\
89.1 \\
89.4 \\
91.3 \\
91.7 \\
92.7 \\
95.0 \\
96.4 \\
97.5 \\
97.9 \\
98.1 \\
96.9 \\
94.0\end{array}$ & $\begin{array}{l}80.4 \\
79.3 \\
79.5 \\
81.0 \\
81.8 \\
83.1 \\
83.8 \\
84.9 \\
85.0 \\
84.5 \\
85.8 \\
82.9 \\
82.6\end{array}$ & $\begin{array}{l}\overline{-} \\
\bar{w} \\
- \\
- \\
\overline{-} \\
\overline{-} \\
\overline{-} \\
\overline{-} \\
\bar{w}\end{array}$ & $\begin{array}{l}89.0 \\
87.8 \\
77.3 \\
89.7 \\
90.3 \\
91.4 \\
93.3 \\
94.8 \\
96.0 \\
96.1 \\
96.4 \\
95.2 \\
91.1\end{array}$ \\
\hline 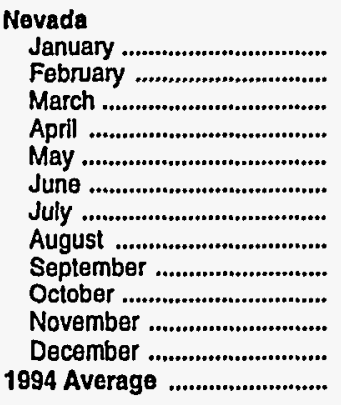 & $\begin{array}{r}95.0 \\
94.9 \\
96.3 \\
96.1 \\
97.1 \\
98.1 \\
99.3 \\
101.8 \\
101.5 \\
101.4 \\
102.6 \\
102.9 \\
98.9\end{array}$ & $\begin{array}{r}94.6 \\
94.2 \\
95.5 \\
95.5 \\
96.3 \\
97.5 \\
98.6 \\
101.1 \\
100.8 \\
100.6 \\
101.9 \\
102.0 \\
98.2\end{array}$ & $\begin{array}{l}75.2 \\
75.5 \\
75.4 \\
77.0 \\
78.3 \\
79.5 \\
81.9 \\
83.3 \\
83.7 \\
85.1 \\
84.4 \\
81.5 \\
80.2\end{array}$ & $\begin{array}{l}65.7 \\
66.2 \\
66.5 \\
70.9 \\
72.1 \\
74.8 \\
77.3 \\
79.1 \\
76.3 \\
77.2 \\
76.9 \\
69.5 \\
73.8\end{array}$ & $\begin{array}{l}W \\
W \\
W \\
W \\
W \\
W \\
W \\
W \\
W \\
W \\
W \\
W \\
W\end{array}$ & $\begin{array}{l}71.9 \\
72.1 \\
71.9 \\
74.9 \\
75.8 \\
77.3 \\
79.9 \\
81.3 \\
80.3 \\
82.1 \\
81.5 \\
76.7 \\
77.6\end{array}$ & $\begin{array}{l}80.3 \\
80.0 \\
80.2 \\
80.6 \\
81.7 \\
82.9 \\
84.4 \\
86.8 \\
88.2 \\
87.1 \\
89.7 \\
91.8 \\
84.4\end{array}$ & $\begin{array}{l}78.8 \\
78.4 \\
78.4 \\
79.3 \\
80.3 \\
81.7 \\
83.2 \\
85.7 \\
87.2 \\
86.1 \\
88.3 \\
90.0 \\
83.2\end{array}$ & $\begin{array}{l}63.3 \\
63.9 \\
63.6 \\
65.3 \\
66.6 \\
68.3 \\
70.9 \\
72.3 \\
73.4 \\
74.2 \\
73.5 \\
70.6 \\
68.9\end{array}$ & $\begin{array}{l}55.0 \\
55.8 \\
56.0 \\
60.0 \\
60.3 \\
63.5 \\
67.4 \\
67.9 \\
65.5 \\
67.5 \\
66.5 \\
61.0 \\
63.0\end{array}$ & $\begin{array}{l}W \\
W \\
W \\
W \\
W \\
W \\
W \\
W \\
W \\
W \\
W \\
W \\
W\end{array}$ & $\begin{array}{l}59.6 \\
60.2 \\
59.9 \\
62.8 \\
63.7 \\
65.9 \\
69.2 \\
70.2 \\
69.6 \\
71.0 \\
70.4 \\
66.2 \\
66.1\end{array}$ \\
\hline 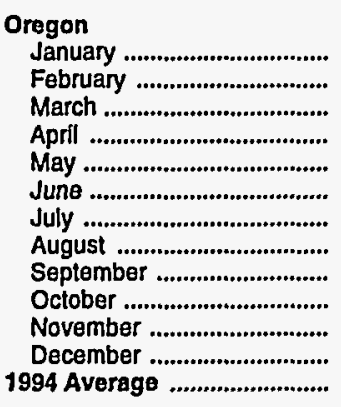 & $\begin{array}{l}93.0 \\
91.9 \\
91.5 \\
92.3 \\
94.4 \\
95.6 \\
98.1 \\
97.6 \\
99.5 \\
97.1 \\
96.8 \\
94.9 \\
95.4\end{array}$ & $\begin{array}{l}91.7 \\
90.9 \\
90.9 \\
91.3 \\
93.6 \\
94.8 \\
97.2 \\
97.2 \\
98.7 \\
96.5 \\
96.0 \\
94.1 \\
94.6\end{array}$ & $\begin{array}{l}74.4 \\
76.9 \\
76.3 \\
78.3 \\
80.2 \\
81.8 \\
84.8 \\
86.8 \\
87.0 \\
85.3 \\
84.8 \\
81.8 \\
82.1\end{array}$ & $\begin{array}{l}61.2 \\
67.0 \\
67.8 \\
71.8 \\
74.9 \\
76.2 \\
80.0 \\
80.8 \\
81.9 \\
78.0 \\
77.2 \\
73.6 \\
74.6\end{array}$ & $\begin{array}{l}\bar{w} \\
w \\
\bar{w} \\
- \\
\bar{w} \\
W \\
W \\
W \\
W \\
60.6\end{array}$ & $\begin{array}{l}68.2 \\
72.7 \\
72.4 \\
75.2 \\
77.6 \\
79.2 \\
82.5 \\
83.2 \\
84.6 \\
79.4 \\
78.0 \\
75.0 \\
77.7\end{array}$ & $\begin{array}{l}77.9 \\
77.6 \\
75.9 \\
76.8 \\
79.1 \\
80.7 \\
83.7 \\
85.6 \\
85.1 \\
83.4 \\
83.5 \\
81.1 \\
81.0\end{array}$ & $\begin{array}{l}76.6 \\
76.5 \\
75.4 \\
76.0 \\
78.2 \\
79.9 \\
82.8 \\
85.0 \\
84.4 \\
82.5 \\
82.6 \\
80.1 \\
80.2\end{array}$ & $\begin{array}{l}65.6 \\
65.4 \\
63.1 \\
65.1 \\
67.5 \\
69.2 \\
72.3 \\
74.4 \\
74.4 \\
73.0 \\
73.2 \\
69.3 \\
69.7\end{array}$ & $\begin{array}{l}51.2 \\
54.4 \\
53.5 \\
59.7 \\
61.7 \\
63.3 \\
67.4 \\
69.8 \\
69.0 \\
65.6 \\
65.4 \\
61.6 \\
62.0\end{array}$ & $\begin{array}{c}45.5 \\
W \\
W \\
W \\
53.7 \\
W \\
58.0 \\
60.3 \\
57.9 \\
56.7 \\
56.5 \\
50.8 \\
55.7\end{array}$ & $\begin{array}{l}57.0 \\
58.9 \\
58.0 \\
61.6 \\
64.5 \\
65.9 \\
69.4 \\
69.5 \\
70.0 \\
67.5 \\
67.6 \\
63.5 \\
64.8\end{array}$ \\
\hline 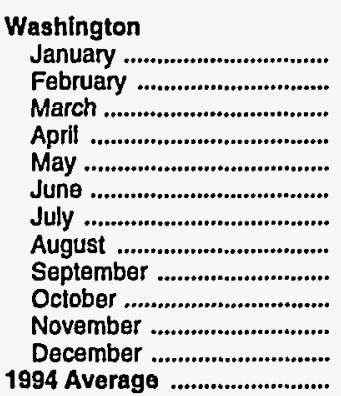 & $\begin{array}{r}87.4 \\
86.0 \\
85.8 \\
87.2 \\
91.1 \\
93.9 \\
97.2 \\
100.1 \\
101.6 \\
100.2 \\
100.5 \\
98.7 \\
94.2\end{array}$ & $\begin{array}{r}86.8 \\
85.5 \\
85.3 \\
86.8 \\
90.6 \\
93.5 \\
96.7 \\
99.4 \\
100.5 \\
99.1 \\
99.4 \\
97.7 \\
93.4\end{array}$ & $\begin{array}{l}75.9 \\
75.5 \\
74.3 \\
76.2 \\
78.7 \\
81.7 \\
85.2 \\
87.8 \\
88.9 \\
87.5 \\
87.6 \\
85.0 \\
82.0\end{array}$ & $\begin{array}{l}63.9 \\
65.9 \\
66.4 \\
69.9 \\
73.0 \\
76.1 \\
79.4 \\
81.6 \\
81.6 \\
78.9 \\
77.6 \\
73.7 \\
74.5\end{array}$ & $\begin{array}{c}W \\
W \\
W \\
- \\
- \\
- \\
- \\
- \\
- \\
- \\
- \\
\overline{49.3}\end{array}$ & $\begin{array}{l}71.4 \\
72.4 \\
71.5 \\
73.9 \\
76.6 \\
79.5 \\
82.9 \\
85.3 \\
85.9 \\
84.3 \\
83.8 \\
81.1 \\
79.2\end{array}$ & $\begin{array}{l}72.3 \\
71.6 \\
71.4 \\
72.6 \\
75.7 \\
78.5 \\
82.2 \\
85.5 \\
86.3 \\
85.5 \\
86.5 \\
84.3 \\
79.6\end{array}$ & $\begin{array}{l}71.8 \\
71.3 \\
71.1 \\
72.4 \\
75.3 \\
78.2 \\
81.7 \\
85.0 \\
85.6 \\
84.9 \\
85.9 \\
83.7 \\
79.2\end{array}$ & $\begin{array}{l}64.9 \\
64.7 \\
63.1 \\
64.8 \\
66.9 \\
69.5 \\
73.1 \\
75.7 \\
76.7 \\
76.2 \\
76.5 \\
74.1 \\
70.6\end{array}$ & $\begin{array}{l}54.4 \\
54.7 \\
55.5 \\
59.2 \\
61.5 \\
65.1 \\
68.8 \\
71.0 \\
71.3 \\
68.1 \\
67.3 \\
63.1 \\
63.8\end{array}$ & $\begin{array}{c}W \\
40.3 \\
W \\
W \\
W \\
W \\
54.2 \\
W \\
W \\
54.2 \\
W \\
50.9 \\
45.7\end{array}$ & $\begin{array}{l}56.6 \\
58.9 \\
59.8 \\
62.3 \\
64.1 \\
67.3 \\
70.1 \\
73.3 \\
73.7 \\
72.2 \\
72.2 \\
69.3 \\
66.8\end{array}$ \\
\hline
\end{tabular}

Dash $(-)=$ No data reported.

$N A=$ Not avallable.

$W=$ Withneld to avold disclosure of individual company data.

a Includes sales through retail outlets as well as all direct sales to end users that were not made through company-operated retail outlets, $\theta . g$., sales to agricultural customers, commercial sales, and industrial sales.

Sources: Energy Information Administration Forms ElA-782A, "Refiners'/Gas Plant Operators' Monthly Petroleum Product Sales Report," and ElA-782B,

"Resellers'/Retailers' Monthly Petroleum Product Sales Report." 
Table 32. Conventional Motor Gasoline Prices by Grade, Sales Type, PAD District, and State

(Cents per Gallon Excluding Taxes)

\begin{tabular}{|c|c|c|c|c|c|c|c|c|c|c|c|c|}
\hline \multirow{3}{*}{$\begin{array}{c}\text { Geographic Area } \\
\text { Month }\end{array}$} & \multicolumn{6}{|c|}{ Regular } & \multicolumn{6}{|c|}{ Midgrade } \\
\hline & \multicolumn{2}{|c|}{ Sales to End Users } & \multicolumn{4}{|c|}{ Sales for Resale } & \multicolumn{2}{|c|}{ Sales to End Users } & \multicolumn{4}{|c|}{ Sales for Resale } \\
\hline & $\begin{array}{c}\text { Through } \\
\text { Retall } \\
\text { Outlets }\end{array}$ & Averagea & DTW & Rack & Bulk & Average & $\begin{array}{c}\text { Through } \\
\text { Retall } \\
\text { Outlots }\end{array}$ & Average $a$ & DTW & Rack & Bulk & Average \\
\hline Inited States & & & & & & & & & & & & \\
\hline 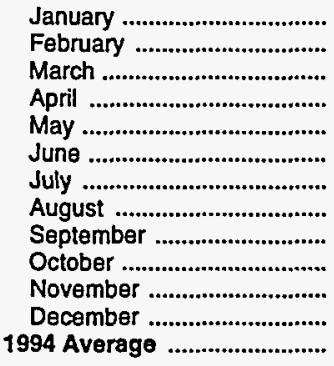 & $\begin{array}{l}60.6 \\
62.2 \\
62.5 \\
65.0 \\
66.6 \\
69.5 \\
72.7 \\
76.7 \\
75.0 \\
72.0 \\
71.6 \\
68.3 \\
68.9\end{array}$ & $\begin{array}{l}60.3 \\
61.9 \\
62.3 \\
64.8 \\
66.4 \\
69.3 \\
72.5 \\
76.3 \\
74.3 \\
71.4 \\
71.1 \\
67.8 \\
68.5\end{array}$ & $\begin{array}{l}53.9 \\
56.2 \\
56.9 \\
59.7 \\
61.3 \\
64.4 \\
67.3 \\
69.5 \\
65.9 \\
63.3 \\
63.1 \\
58.4 \\
62.1\end{array}$ & $\begin{array}{l}46.3 \\
49.4 \\
50.1 \\
53.6 \\
54.9 \\
58.4 \\
61.2 \\
63.6 \\
54.7 \\
54.6 \\
54.9 \\
49.1 \\
54.7\end{array}$ & $\begin{array}{l}41.4 \\
44.6 \\
45.9 \\
49.1 \\
50.2 \\
52.9 \\
55.5 \\
57.6 \\
51.3 \\
49.8 \\
50.9 \\
46.3 \\
49.7\end{array}$ & $\begin{array}{l}47.5 \\
50.6 \\
51.9 \\
55.1 \\
56.5 \\
59.8 \\
62.7 \\
64.9 \\
58.0 \\
56.4 \\
56.6 \\
50.9 \\
56.5\end{array}$ & $\begin{array}{l}69.4 \\
70.9 \\
71.1 \\
73.4 \\
75.0 \\
77.8 \\
80.9 \\
84.8 \\
83.3 \\
80.5 \\
80.3 \\
76.7 \\
77.3\end{array}$ & $\begin{array}{l}68.8 \\
70.2 \\
70.5 \\
72.8 \\
74.5 \\
77.2 \\
80.4 \\
84.1 \\
82.2 \\
79.7 \\
79.6 \\
76.0 \\
76.6\end{array}$ & $\begin{array}{l}59.4 \\
61.9 \\
62.5 \\
65.4 \\
66.8 \\
69.9 \\
72.7 \\
74.9 \\
71.4 \\
68.5 \\
68.7 \\
64.3 \\
67.6\end{array}$ & $\begin{array}{l}\mathbf{5 0 . 2} \\
\mathbf{5 3 . 6} \\
\mathbf{5 4 . 2} \\
57.8 \\
\mathbf{5 8 . 8} \\
62.1 \\
64.3 \\
66.6 \\
\mathbf{5 7 . 4} \\
\mathbf{5 8 . 5} \\
\mathbf{5 9 . 5} \\
\mathbf{5 3 . 2} \\
\mathbf{5 8 . 5}\end{array}$ & $\begin{array}{l}\text { NA } \\
N A \\
N A \\
N A \\
N A \\
N A \\
N A \\
N A \\
N A \\
N A \\
N A \\
N A \\
N A\end{array}$ & $\begin{array}{l}54.7 \\
57.7 \\
58.6 \\
61.8 \\
63.1 \\
66.3 \\
68.8 \\
71.1 \\
65.0 \\
63.5 \\
64.0 \\
58.3 \\
63.3\end{array}$ \\
\hline 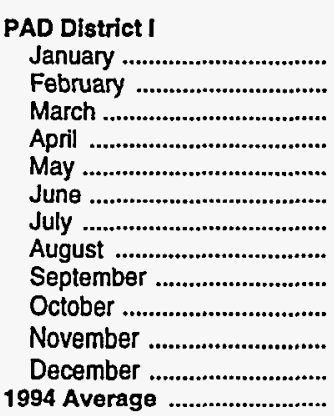 & $\begin{array}{l}59.5 \\
60.9 \\
61.0 \\
62.3 \\
63.7 \\
66.4 \\
69.3 \\
73.3 \\
72.9 \\
71.4 \\
72.1 \\
69.8 \\
67.1\end{array}$ & $\begin{array}{l}59.2 \\
60.5 \\
60.6 \\
62.0 \\
63.4 \\
66.0 \\
69.0 \\
72.7 \\
71.7 \\
70.5 \\
71.5 \\
69.0 \\
66.5\end{array}$ & $\begin{array}{l}53.6 \\
55.5 \\
56.1 \\
58.1 \\
59.8 \\
63.0 \\
65.4 \\
67.9 \\
63.9 \\
63.0 \\
63.8 \\
58.5 \\
61.3\end{array}$ & $\begin{array}{l}45.5 \\
48.6 \\
49.2 \\
52.3 \\
53.5 \\
56.5 \\
58.1 \\
60.2 \\
51.6 \\
53.8 \\
55.9 \\
48.7 \\
53.3\end{array}$ & $\begin{array}{l}42.7 \\
44.7 \\
45.5 \\
48.9 \\
50.7 \\
53.3 \\
55.6 \\
56.8 \\
50.3 \\
49.8 \\
54.7 \\
48.8 \\
50.6\end{array}$ & $\begin{array}{l}48.0 \\
50.5 \\
51.2 \\
54.1 \\
55.6 \\
58.5 \\
60.6 \\
62.7 \\
55.9 \\
56.5 \\
58.4 \\
51.9 \\
55.9\end{array}$ & $\begin{array}{l}70.1 \\
71.1 \\
71.3 \\
72.5 \\
74.2 \\
76.7 \\
79.5 \\
83.2 \\
82.9 \\
81.4 \\
82.0 \\
79.4 \\
77.2\end{array}$ & $\begin{array}{l}69.4 \\
70.4 \\
70.6 \\
71.9 \\
73.5 \\
76.0 \\
78.9 \\
82.3 \\
81.5 \\
80.2 \\
81.0 \\
78.3 \\
76.4\end{array}$ & $\begin{array}{l}59.9 \\
61.6 \\
62.2 \\
64.3 \\
65.9 \\
69.0 \\
71.4 \\
74.0 \\
70.4 \\
69.1 \\
70.0 \\
65.2 \\
67.5\end{array}$ & $\begin{array}{l}49.8 \\
53.1 \\
53.7 \\
56.9 \\
58.0 \\
61.1 \\
62.6 \\
65.2 \\
56.3 \\
58.3 \\
60.6 \\
53.2 \\
\mathbf{5 7 . 9}\end{array}$ & $\begin{array}{l}N A \\
N A \\
W \\
W \\
W \\
N A \\
W \\
W \\
W \\
W \\
W \\
W \\
\text { NA }\end{array}$ & $\begin{array}{l}54.5 \\
57.1 \\
57.9 \\
60.6 \\
62.2 \\
65.3 \\
67.2 \\
69.8 \\
63.5 \\
63.6 \\
64.9 \\
58.5 \\
62.8\end{array}$ \\
\hline 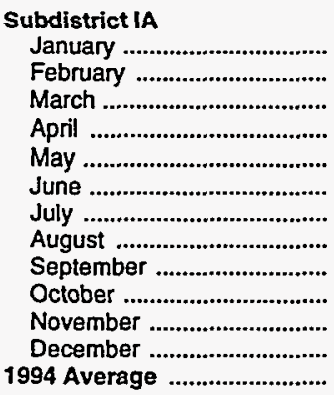 & $\begin{array}{l}64.4 \\
65.3 \\
65.1 \\
65.8 \\
67.9 \\
71.0 \\
73.8 \\
78.2 \\
77.6 \\
76.5 \\
77.2 \\
75.9 \\
71.6\end{array}$ & $\begin{array}{l}63.6 \\
64.3 \\
64.3 \\
65.2 \\
67.2 \\
70.2 \\
73.1 \\
77.4 \\
76.0 \\
75.5 \\
76.4 \\
75.3 \\
70.7\end{array}$ & $\begin{array}{l}56.3 \\
58.3 \\
58.1 \\
58.6 \\
61.0 \\
64.4 \\
67.0 \\
70.4 \\
67.5 \\
66.1 \\
67.9 \\
66.2 \\
63.6\end{array}$ & $\begin{array}{l}46.6 \\
49.5 \\
49.5 \\
51.9 \\
54.6 \\
57.4 \\
58.6 \\
61.2 \\
53.8 \\
54.6 \\
58.2 \\
54.8 \\
54.6\end{array}$ & $\begin{array}{l}42.4 \\
44.4 \\
44.9 \\
48.7 \\
49.2 \\
53.4 \\
53.9 \\
55.8 \\
48.4 \\
48.4 \\
54.4 \\
53.3 \\
49.6\end{array}$ & $\begin{array}{l}49.8 \\
51.8 \\
51.8 \\
54.1 \\
55.7 \\
59.4 \\
60.9 \\
63.9 \\
57.3 \\
56.9 \\
61.3 \\
58.8 \\
57.0\end{array}$ & $\begin{array}{l}75.1 \\
75.8 \\
75.8 \\
76.5 \\
79.0 \\
81.6 \\
84.4 \\
88.6 \\
88.2 \\
87.2 \\
87.4 \\
85.1 \\
82.2\end{array}$ & $\begin{array}{l}73.6 \\
74.2 \\
74.1 \\
75.1 \\
77.5 \\
79.9 \\
82.6 \\
87.0 \\
85.7 \\
85.5 \\
85.8 \\
83.7 \\
80.5\end{array}$ & $\begin{array}{l}62.9 \\
64.6 \\
64.5 \\
65.1 \\
67.1 \\
70.5 \\
73.3 \\
76.6 \\
74.2 \\
72.8 \\
75.0 \\
73.3 \\
70.1\end{array}$ & $\begin{array}{l}50.4 \\
53.5 \\
53.4 \\
55.7 \\
58.8 \\
61.4 \\
62.8 \\
65.7 \\
57.8 \\
58.8 \\
62.2 \\
58.9 \\
58.7\end{array}$ & $\begin{array}{l}w \\
\overline{-} \\
\overline{-} \\
\overline{-} \\
\bar{w} \\
\overline{-} \\
\bar{w} \\
\bar{w} \\
\bar{w}\end{array}$ & $\begin{array}{l}56.9 \\
59.6 \\
59.3 \\
60.8 \\
63.4 \\
66.5 \\
68.6 \\
71.4 \\
66.3 \\
65.8 \\
69.0 \\
66.9 \\
64.8\end{array}$ \\
\hline 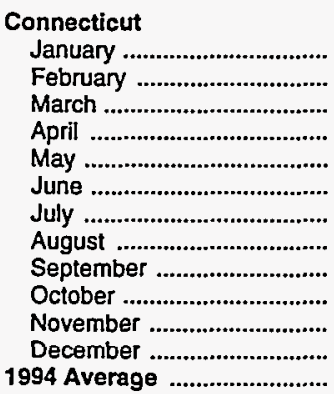 & $\begin{array}{l}63.6 \\
64.2 \\
64.2 \\
64.7 \\
67.0 \\
69.7 \\
72.3 \\
75.7 \\
75.1 \\
74.5 \\
74.9 \\
72.0 \\
70.4\end{array}$ & $\begin{array}{l}62.5 \\
63.1 \\
63.3 \\
64.1 \\
66.4 \\
69.1 \\
71.7 \\
74.9 \\
73.8 \\
73.5 \\
74.4 \\
71.7 \\
69.6\end{array}$ & $\begin{array}{c}56.8 \\
58.9 \\
58.7 \\
59.5 \\
61.6 \\
64.8 \\
67.5 \\
70.9 \\
67.7 \\
65.4 \\
67.4 \\
W \\
64.1\end{array}$ & $\begin{array}{r}45.5 \\
48.8 \\
49.2 \\
51.5 \\
54.6 \\
57.4 \\
58.5 \\
61.0 \\
54.0 \\
54.8 \\
58.0 \\
\text { NA } \\
54.6\end{array}$ & $\begin{array}{c}W \\
W \\
W \\
W \\
W \\
W \\
54.5 \\
W \\
W \\
W \\
W \\
- \\
50.2\end{array}$ & $\begin{array}{r}49.9 \\
50.5 \\
52.6 \\
53.8 \\
55.9 \\
60.7 \\
60.5 \\
65.7 \\
58.5 \\
57.0 \\
61.3 \\
\text { NA } \\
57.6\end{array}$ & $\begin{array}{l}75.1 \\
75.5 \\
75.4 \\
75.9 \\
79.4 \\
81.3 \\
83.5 \\
87.0 \\
86.4 \\
85.4 \\
86.0 \\
80.6 \\
81.6\end{array}$ & $\begin{array}{l}72.2 \\
72.5 \\
72.6 \\
73.6 \\
77.1 \\
78.9 \\
81.4 \\
84.5 \\
83.0 \\
83.1 \\
84.0 \\
79.0 \\
79.2\end{array}$ & $\begin{array}{c}63.5 \\
65.8 \\
64.9 \\
65.4 \\
66.9 \\
70.4 \\
73.1 \\
76.5 \\
73.9 \\
71.8 \\
73.3 \\
W \\
70.1\end{array}$ & $\begin{array}{c}49.6 \\
53.2 \\
53.1 \\
55.4 \\
58.6 \\
61.2 \\
62.4 \\
65.3 \\
58.0 \\
59.0 \\
62.2 \\
\text { NA } \\
58.5\end{array}$ & $\begin{array}{l}\text { w } \\
- \\
\overline{-} \\
\overline{-} \\
\overline{-} \\
- \\
\overline{-} \\
\overline{-} \\
\overline{-} \\
\overline{-} \\
\bar{w}\end{array}$ & $\begin{array}{r}55.6 \\
59.0 \\
58.5 \\
60.1 \\
63.3 \\
66.3 \\
68.3 \\
71.2 \\
65.8 \\
64.2 \\
67.1 \\
\text { NA } \\
64.3\end{array}$ \\
\hline
\end{tabular}

See footnotes at end of table. 
Table 32. Conventional Motor Gasoline Prices by Grade, Sales Type, PAD District, and State

(Cents per Gallon Excluding Taxes) - Continued

\begin{tabular}{|c|c|c|c|c|c|c|c|c|c|c|c|c|}
\hline \multirow{3}{*}{$\begin{array}{l}\text { Geographlc Area } \\
\text { Month }\end{array}$} & \multicolumn{6}{|c|}{ Premium } & \multicolumn{6}{|c|}{ All Grades } \\
\hline & \multicolumn{2}{|c|}{ Sales to End Users } & \multicolumn{4}{|c|}{ Sales for Resale } & \multicolumn{2}{|c|}{ Sales to End Users } & \multicolumn{4}{|c|}{ Sales for Resale } \\
\hline & $\begin{array}{c}\text { Through } \\
\text { Retall } \\
\text { Outlots }\end{array}$ & Averagea & DTW & Rack & Bulk & Average & $\begin{array}{c}\text { Through } \\
\text { Retall } \\
\text { Outlets }\end{array}$ & Avoragea & DTW & Rack & Bulk & Averago \\
\hline United States & & & & & & & & & & & & \\
\hline 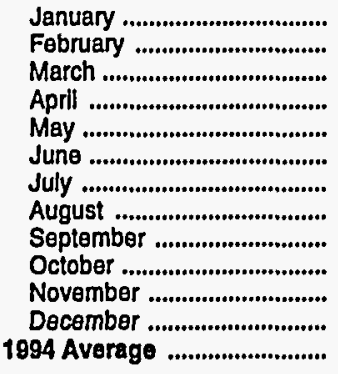 & $\begin{array}{l}77.7 \\
78.1 \\
79.7 \\
82.1 \\
83.9 \\
86.5 \\
89.3 \\
93.3 \\
91.9 \\
89.0 \\
88.7 \\
85.2 \\
85.6\end{array}$ & $\begin{array}{l}76.8 \\
77.3 \\
78.8 \\
81.3 \\
83.1 \\
85.6 \\
88.6 \\
92.1 \\
90.4 \\
87.7 \\
87.5 \\
84.1 \\
84.6\end{array}$ & $\begin{array}{l}66.8 \\
69.2 \\
70.1 \\
72.8 \\
74.5 \\
77.8 \\
80.6 \\
83.0 \\
79.8 \\
76.6 \\
76.1 \\
71.4 \\
75.5\end{array}$ & $\begin{array}{l}55.4 \\
58.4 \\
59.2 \\
62.8 \\
64.1 \\
67.7 \\
70.3 \\
72.9 \\
63.6 \\
64.3 \\
64.7 \\
58.5 \\
63.9\end{array}$ & $\begin{array}{l}46.8 \\
48.8 \\
50.4 \\
55.0 \\
57.2 \\
59.9 \\
62.7 \\
64.8 \\
55.4 \\
54.4 \\
55.7 \\
50.0 \\
55.5\end{array}$ & $\begin{array}{l}59.0 \\
61.9 \\
63.8 \\
67.1 \\
68.6 \\
72.0 \\
74.8 \\
77.2 \\
70.7 \\
68.8 \\
68.7 \\
62.8 \\
68.6\end{array}$ & $\begin{array}{l}65.0 \\
66.5 \\
66.8 \\
69.2 \\
70.9 \\
73.7 \\
76.8 \\
80.6 \\
79.0 \\
76.2 \\
75.8 \\
72.5 \\
73.0\end{array}$ & $\begin{array}{l}64.5 \\
66.0 \\
66.3 \\
68.7 \\
70.5 \\
73.3 \\
76.4 \\
80.0 \\
78.1 \\
75.4 \\
75.1 \\
71.8 \\
72.4\end{array}$ & $\begin{array}{l}57.7 \\
60.0 \\
60.7 \\
63.5 \\
65.3 \\
68.3 \\
71.2 \\
73.2 \\
69.8 \\
67.0 \\
66.7 \\
62.1 \\
65.9\end{array}$ & $\begin{array}{l}48.3 \\
51.4 \\
52.1 \\
55.6 \\
56.9 \\
60.4 \\
63.1 \\
65.5 \\
56.5 \\
56.7 \\
57.0 \\
51.1 \\
56.7\end{array}$ & $\begin{array}{l}42.0 \\
45.1 \\
46.3 \\
49.6 \\
51.1 \\
53.9 \\
56.3 \\
58.4 \\
51.7 \\
50.2 \\
51.2 \\
46.5 \\
50.3\end{array}$ & $\begin{array}{l}50.4 \\
53.4 \\
54.8 \\
58.0 \\
59.6 \\
62.9 \\
65.7 \\
67.9 \\
61.0 \\
59.3 \\
59.4 \\
53.6 \\
59.4\end{array}$ \\
\hline 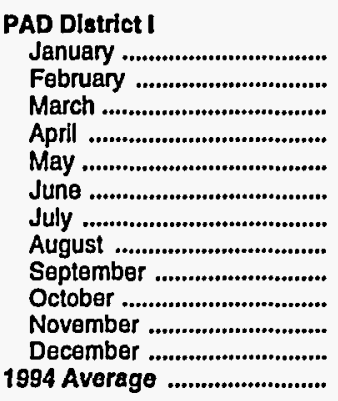 & $\begin{array}{l}79.3 \\
80.2 \\
80.4 \\
81.8 \\
83.4 \\
85.5 \\
88.2 \\
92.6 \\
92.1 \\
90.4 \\
91.1 \\
88.6 \\
86.2\end{array}$ & $\begin{array}{l}78.3 \\
79.3 \\
79.4 \\
80.8 \\
82.5 \\
84.7 \\
87.4 \\
91.3 \\
90.4 \\
88.9 \\
89.9 \\
87.3 \\
85.1\end{array}$ & $\begin{array}{l}67.7 \\
69.5 \\
69.9 \\
71.8 \\
74.0 \\
77.5 \\
80.0 \\
82.8 \\
79.5 \\
77.6 \\
78.0 \\
73.1 \\
75.9\end{array}$ & $\begin{array}{l}55.6 \\
58.5 \\
59.2 \\
62.4 \\
64.1 \\
67.1 \\
69.0 \\
71.6 \\
62.4 \\
64.6 \\
66.5 \\
58.9 \\
63.8\end{array}$ & $\begin{array}{l}50.4 \\
50.5 \\
50.7 \\
56.3 \\
61.0 \\
61.4 \\
66.5 \\
68.8 \\
54.5 \\
58.1 \\
60.3 \\
50.4 \\
58.4\end{array}$ & $\begin{array}{l}60.4 \\
62.7 \\
63.7 \\
66.7 \\
68.9 \\
71.9 \\
74.6 \\
77.0 \\
70.4 \\
70.2 \\
71.1 \\
64.5 \\
69.3\end{array}$ & $\begin{array}{l}65.5 \\
66.6 \\
66.8 \\
68.1 \\
69.8 \\
72.3 \\
75.1 \\
78.9 \\
78.5 \\
76.9 \\
77.5 \\
75.3 \\
72.8\end{array}$ & $\begin{array}{l}64.9 \\
66.1 \\
66.2 \\
67.6 \\
69.3 \\
71.8 \\
74.7 \\
78.1 \\
77.2 \\
75.8 \\
76.7 \\
74.3 \\
72.1\end{array}$ & $\begin{array}{l}58.4 \\
60.2 \\
60.8 \\
62.9 \\
65.1 \\
68.3 \\
70.7 \\
73.1 \\
69.3 \\
67.7 \\
68.3 \\
63.2 \\
66.3\end{array}$ & $\begin{array}{l}\mathbf{4 8 . 3} \\
\mathbf{5 1 . 4} \\
52.1 \\
\mathbf{5 5 . 2} \\
\mathbf{5 6 . 6} \\
\mathbf{5 9 . 5} \\
61.2 \\
63.4 \\
\mathbf{5 4 . 6} \\
\mathbf{5 6 . 7} \\
\mathbf{5 8 . 7} \\
\mathbf{5 1 . 4} \\
\mathbf{5 6 . 2}\end{array}$ & $\begin{array}{l}44.3 \\
45.6 \\
46.2 \\
49.9 \\
52.6 \\
54.8 \\
56.8 \\
58.7 \\
50.7 \\
50.6 \\
55.2 \\
49.0 \\
51.7\end{array}$ & $\begin{array}{l}51.8 \\
54.2 \\
55.1 \\
58.0 \\
59.9 \\
62.8 \\
65.0 \\
67.1 \\
60.2 \\
60.5 \\
61.9 \\
55.6 \\
60.0\end{array}$ \\
\hline 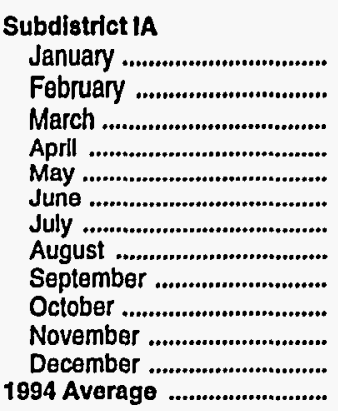 & $\begin{array}{l}83.7 \\
84.3 \\
84.2 \\
85.1 \\
\mathbf{8 7 . 8} \\
\mathbf{9 0 . 0} \\
\mathbf{9 2 . 7} \\
96.7 \\
\mathbf{9 6 . 6} \\
\mathbf{9 5 . 5} \\
\mathbf{9 6 . 0} \\
\mathbf{9 4 . 7} \\
\mathbf{9 0 . 3}\end{array}$ & $\begin{array}{l}82.1 \\
82.4 \\
82.1 \\
83.4 \\
86.3 \\
88.4 \\
91.1 \\
95.4 \\
94.3 \\
93.9 \\
94.5 \\
93.3 \\
88.7\end{array}$ & $\begin{array}{l}70.0 \\
72.0 \\
71.5 \\
72.3 \\
75.0 \\
78.4 \\
81.4 \\
85.1 \\
82.3 \\
80.8 \\
82.2 \\
79.1 \\
77.5\end{array}$ & $\begin{array}{l}56.5 \\
59.6 \\
59.1 \\
61.6 \\
65.8 \\
68.1 \\
70.1 \\
73.6 \\
65.1 \\
66.3 \\
68.8 \\
65.6 \\
65.3\end{array}$ & $\begin{array}{c}49.1 \\
W \\
W \\
W \\
W \\
62.7 \\
66.1 \\
69.5 \\
56.8 \\
59.4 \\
W \\
W \\
58.3\end{array}$ & $\begin{array}{l}62.7 \\
64.5 \\
65.2 \\
67.0 \\
70.4 \\
72.6 \\
75.7 \\
79.1 \\
72.8 \\
72.9 \\
75.2 \\
72.6 \\
71.0\end{array}$ & $\begin{array}{l}70.4 \\
71.1 \\
70.9 \\
71.5 \\
73.8 \\
76.5 \\
79.4 \\
83.5 \\
83.1 \\
82.0 \\
82.4 \\
81.1 \\
77.2\end{array}$ & $\begin{array}{l}69.4 \\
69.8 \\
69.7 \\
70.6 \\
72.8 \\
75.5 \\
78.4 \\
82.5 \\
81.2 \\
80.9 \\
81.4 \\
80.2 \\
76.0\end{array}$ & $\begin{array}{l}60.9 \\
62.9 \\
62.5 \\
63.1 \\
65.6 \\
69.0 \\
71.7 \\
75.0 \\
72.2 \\
70.7 \\
72.4 \\
69.6 \\
68.1\end{array}$ & $\begin{array}{l}49.5 \\
52.5 \\
52.3 \\
54.6 \\
57.7 \\
60.4 \\
61.8 \\
64.5 \\
56.7 \\
57.6 \\
60.9 \\
57.3 \\
57.6\end{array}$ & $\begin{array}{l}43.2 \\
45.6 \\
45.1 \\
48.9 \\
49.7 \\
54.6 \\
54.3 \\
56.4 \\
49.0 \\
48.8 \\
54.5 \\
53.6 \\
50.1\end{array}$ & $\begin{array}{l}53.8 \\
55.7 \\
55.6 \\
57.8 \\
59.7 \\
63.3 \\
65.1 \\
68.1 \\
61.5 \\
61.1 \\
65.1 \\
61.8 \\
61.0\end{array}$ \\
\hline 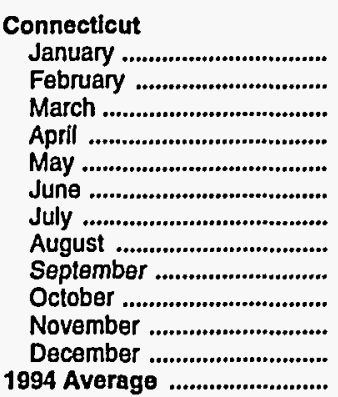 & $\begin{array}{l}84.0 \\
84.5 \\
84.6 \\
85.5 \\
89.3 \\
90.8 \\
93.5 \\
96.8 \\
96.2 \\
95.4 \\
95.5 \\
92.2 \\
91.1\end{array}$ & $\begin{array}{l}82.3 \\
82.9 \\
83.0 \\
84.2 \\
88.0 \\
89.2 \\
92.0 \\
95.1 \\
94.1 \\
94.1 \\
94.8 \\
91.3 \\
89.6\end{array}$ & $\begin{array}{l}70.7 \\
72.8 \\
72.4 \\
73.2 \\
75.5 \\
78.8 \\
81.7 \\
84.9 \\
82.3 \\
79.7 \\
80.9 \\
W \\
77.9\end{array}$ & $\begin{array}{c}55.5 \\
59.8 \\
59.6 \\
62.1 \\
66.1 \\
68.5 \\
70.2 \\
73.4 \\
66.0 \\
66.8 \\
69.7 \\
W \\
\mathbf{6 5 . 9}\end{array}$ & $\begin{array}{c}w \\
- \\
\overline{-} \\
\overline{-} \\
\bar{w} \\
\overline{-} \\
\bar{w} \\
w \\
\bar{w} \\
\overline{-} \\
53.0\end{array}$ & $\begin{array}{l}61.1 \\
65.7 \\
65.4 \\
67.2 \\
70.9 \\
73.4 \\
76.0 \\
79.2 \\
73.3 \\
71.6 \\
74.4 \\
\text { NA } \\
71.4\end{array}$ & $\begin{array}{l}70.3 \\
70.7 \\
70.7 \\
71.3 \\
74.3 \\
76.5 \\
78.9 \\
82.0 \\
81.5 \\
80.7 \\
80.8 \\
77.5 \\
76.8\end{array}$ & $\begin{array}{l}68.8 \\
69.1 \\
69.3 \\
70.2 \\
73.3 \\
75.4 \\
77.9 \\
80.8 \\
79.7 \\
79.6 \\
80.0 \\
76.9 \\
75.6\end{array}$ & $\begin{array}{c}61.7 \\
63.7 \\
63.2 \\
64.0 \\
66.3 \\
69.7 \\
72.3 \\
75.3 \\
72.5 \\
70.0 \\
71.7 \\
W \\
68.7\end{array}$ & $\begin{array}{r}48.8 \\
52.2 \\
52.4 \\
54.6 \\
58.1 \\
60.8 \\
61.9 \\
64.6 \\
57.4 \\
58.1 \\
61.3 \\
\text { NA } \\
\mathbf{5 8 . 0}\end{array}$ & $\begin{array}{c}45.8 \\
W \\
W \\
W \\
W \\
W \\
54.5 \\
W \\
W \\
52.0 \\
W \\
- \\
50.3\end{array}$ & $\begin{array}{c}53.9 \\
54.8 \\
56.5 \\
57.5 \\
60.2 \\
64.9 \\
64.8 \\
69.8 \\
62.9 \\
60.8 \\
65.2 \\
\text { NA } \\
61.7\end{array}$ \\
\hline
\end{tabular}

See footnotes at end of table. 
Table 32. Conventional Motor Gasoline Prices by Grade, Sales Type,

PAD District, and State

(Cents per Gallon Excluding Taxes) - Continued

\begin{tabular}{|c|c|c|c|c|c|c|c|c|c|c|c|c|}
\hline \multirow{3}{*}{$\begin{array}{l}\text { Geographic Area } \\
\text { Month }\end{array}$} & \multicolumn{6}{|c|}{ Regular } & \multicolumn{6}{|c|}{ Mildgrado } \\
\hline & \multicolumn{2}{|c|}{ Sales to End Users } & \multicolumn{4}{|c|}{ Sales for Resale } & \multicolumn{2}{|c|}{ Sales to End Users } & \multicolumn{4}{|c|}{ Sales for Resale } \\
\hline & $\begin{array}{c}\text { Through } \\
\text { Rotail } \\
\text { Outlets }\end{array}$ & Averagea & DTW & Rack & Bulk & Average & $\begin{array}{c}\text { Through } \\
\text { Retall } \\
\text { Outlets }\end{array}$ & Averagea & DTW & Rack & Bulk & Averago \\
\hline \multicolumn{13}{|l|}{ Maine } \\
\hline 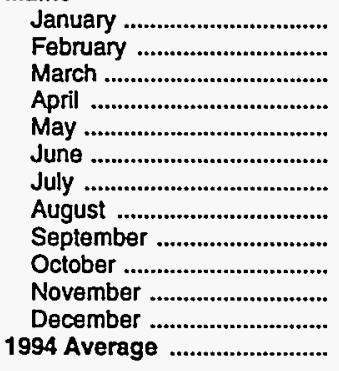 & $\begin{array}{l}67.7 \\
69.2 \\
69.3 \\
70.4 \\
73.9 \\
76.3 \\
76.8 \\
80.7 \\
79.5 \\
77.5 \\
80.2 \\
78.8 \\
75.1\end{array}$ & $\begin{array}{l}66.9 \\
68.4 \\
68.7 \\
69.9 \\
73.3 \\
75.8 \\
76.4 \\
80.7 \\
79.0 \\
76.9 \\
79.5 \\
78.3 \\
74.6\end{array}$ & $\begin{array}{l}55.7 \\
57.7 \\
57.9 \\
59.4 \\
61.1 \\
64.2 \\
65.3 \\
70.1 \\
66.2 \\
64.7 \\
67.6 \\
64.1 \\
62.8\end{array}$ & $\begin{array}{l}48.2 \\
51.6 \\
51.5 \\
53.9 \\
56.5 \\
59.4 \\
60.5 \\
62.7 \\
55.2 \\
55.0 \\
59.4 \\
54.7 \\
56.1\end{array}$ & $\begin{array}{c}W \\
47.9 \\
48.0 \\
50.0 \\
W \\
57.2 \\
W \\
60.8 \\
50.3 \\
48.2 \\
W \\
W \\
51.5\end{array}$ & $\begin{array}{l}49.0 \\
52.6 \\
52.6 \\
54.6 \\
57.7 \\
60.4 \\
61.8 \\
64.1 \\
57.1 \\
55.6 \\
61.1 \\
55.6 \\
57.0\end{array}$ & $\begin{array}{l}76.3 \\
78.2 \\
78.3 \\
80.5 \\
83.8 \\
85.7 \\
86.4 \\
90.3 \\
89.3 \\
87.3 \\
89.3 \\
88.3 \\
84.6\end{array}$ & $\begin{array}{l}75.2 \\
77.0 \\
76.9 \\
79.4 \\
82.6 \\
84.4 \\
85.4 \\
89.3 \\
87.6 \\
86.2 \\
88.1 \\
87.0 \\
83.3\end{array}$ & $\begin{array}{l}60.4 \\
62.2 \\
63.4 \\
64.2 \\
65.8 \\
69.4 \\
70.6 \\
75.2 \\
71.0 \\
76.8 \\
80.2 \\
73.9 \\
69.8\end{array}$ & $\begin{array}{l}51.9 \\
55.3 \\
55.4 \\
57.6 \\
60.5 \\
63.5 \\
64.6 \\
67.0 \\
59.5 \\
58.5 \\
63.2 \\
59.4 \\
60.1\end{array}$ & $\begin{array}{l}- \\
- \\
- \\
- \\
- \\
- \\
- \\
\bar{w} \\
- \\
\bar{w}\end{array}$ & $\begin{array}{l}54.3 \\
57.3 \\
57.7 \\
59.6 \\
61.9 \\
65.2 \\
66.1 \\
68.9 \\
62.3 \\
62.5 \\
68.9 \\
64.7 \\
62.7\end{array}$ \\
\hline \multicolumn{13}{|l|}{ Massachusetts } \\
\hline 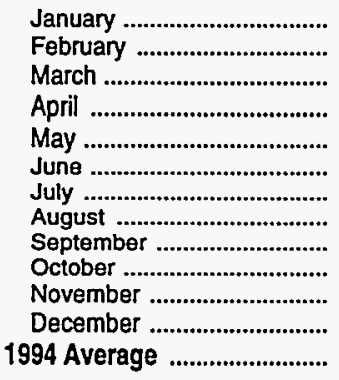 & $\begin{array}{l}61.9 \\
62.6 \\
62.6 \\
63.3 \\
65.1 \\
68.0 \\
71.5 \\
77.1 \\
76.7 \\
75.4 \\
75.9 \\
74.4 \\
69.3\end{array}$ & $\begin{array}{l}61.2 \\
61.6 \\
61.6 \\
62.7 \\
64.3 \\
67.0 \\
70.5 \\
75.9 \\
74.5 \\
74.3 \\
75.0 \\
73.7 \\
68.2\end{array}$ & $\begin{array}{l}55.7 \\
57.7 \\
57.4 \\
57.6 \\
60.2 \\
63.7 \\
66.8 \\
69.9 \\
67.5 \\
66.8 \\
68.1 \\
63.7 \\
63.2\end{array}$ & $\begin{array}{l}46.2 \\
49.0 \\
48.7 \\
51.2 \\
53.9 \\
56.6 \\
57.9 \\
60.7 \\
53.0 \\
54.4 \\
57.8 \\
60.3 \\
54.0\end{array}$ & $\begin{array}{l}41.5 \\
44.2 \\
44.1 \\
47.1 \\
48.8 \\
52.6 \\
54.2 \\
54.8 \\
48.2 \\
N A \\
54.5 \\
W \\
49.1\end{array}$ & $\begin{array}{l}49.0 \\
51.1 \\
50.6 \\
53.6 \\
54.7 \\
58.2 \\
61.2 \\
62.2 \\
55.7 \\
57.4 \\
60.7 \\
56.5 \\
56.2\end{array}$ & $\begin{array}{l}73.9 \\
74.5 \\
74.4 \\
74.9 \\
77.0 \\
79.5 \\
82.9 \\
88.2 \\
87.9 \\
87.1 \\
86.8 \\
83.8 \\
80.8\end{array}$ & $\begin{array}{l}72.5 \\
72.8 \\
72.7 \\
73.6 \\
75.5 \\
77.9 \\
81.0 \\
86.8 \\
85.1 \\
85.6 \\
85.0 \\
83.1 \\
79.1\end{array}$ & $\begin{array}{l}62.8 \\
64.4 \\
64.5 \\
65.1 \\
67.2 \\
70.8 \\
73.8 \\
76.8 \\
75.0 \\
73.0 \\
75.4 \\
71.4 \\
70.2\end{array}$ & $\begin{array}{l}50.3 \\
52.8 \\
52.6 \\
55.0 \\
58.2 \\
60.8 \\
62.2 \\
65.3 \\
56.9 \\
58.8 \\
61.6 \\
62.4 \\
58.2\end{array}$ & $\begin{array}{l}W \\
- \\
- \\
- \\
- \\
\bar{w} \\
- \\
- \\
- \\
- \\
- \\
w\end{array}$ & $\begin{array}{l}58.0 \\
60.2 \\
59.9 \\
61.1 \\
63.6 \\
66.7 \\
69.2 \\
71.9 \\
67.1 \\
67.1 \\
69.8 \\
69.9 \\
65.4\end{array}$ \\
\hline \multicolumn{13}{|l|}{ New Hampshire } \\
\hline 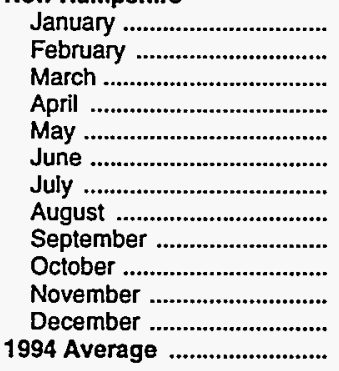 & $\begin{array}{l}66.7 \\
67.8 \\
67.3 \\
68.2 \\
69.1 \\
72.7 \\
75.3 \\
79.6 \\
79.5 \\
78.1 \\
78.4 \\
76.9 \\
73.1\end{array}$ & $\begin{array}{l}66.2 \\
67.3 \\
67.1 \\
68.1 \\
68.9 \\
72.5 \\
75.1 \\
79.1 \\
77.6 \\
77.5 \\
77.8 \\
76.4 \\
72.6\end{array}$ & $\begin{array}{l}56.7 \\
58.6 \\
58.4 \\
59.3 \\
61.4 \\
64.5 \\
66.9 \\
70.3 \\
66.6 \\
65.3 \\
67.9 \\
64.5 \\
63.6\end{array}$ & $\begin{array}{l}47.6 \\
49.8 \\
49.3 \\
51.7 \\
53.9 \\
56.6 \\
58.0 \\
61.4 \\
55.0 \\
55.9 \\
59.2 \\
57.0 \\
54.9\end{array}$ & $\begin{array}{l}\text { W } \\
- \\
- \\
- \\
- \\
- \\
- \\
- \\
- \\
\bar{w}\end{array}$ & $\begin{array}{l}54.4 \\
56.1 \\
55.6 \\
57.0 \\
59.1 \\
62.1 \\
64.4 \\
67.4 \\
62.9 \\
62.3 \\
65.2 \\
62.7 \\
60.9\end{array}$ & $\begin{array}{l}77.8 \\
78.1 \\
78.1 \\
79.1 \\
80.6 \\
83.4 \\
86.0 \\
89.6 \\
89.7 \\
88.4 \\
88.9 \\
86.3 \\
83.8\end{array}$ & $\begin{array}{l}77.1 \\
77.6 \\
77.6 \\
78.5 \\
79.9 \\
82.5 \\
84.8 \\
88.1 \\
88.4 \\
87.2 \\
88.1 \\
84.7 \\
82.9\end{array}$ & $\begin{array}{l}62.9 \\
64.9 \\
64.7 \\
64.7 \\
66.8 \\
70.3 \\
73.0 \\
76.6 \\
73.3 \\
72.3 \\
74.2 \\
69.4 \\
69.5\end{array}$ & $\begin{array}{l}49.1 \\
51.2 \\
52.0 \\
53.8 \\
57.0 \\
59.9 \\
61.5 \\
64.9 \\
58.5 \\
58.0 \\
61.0 \\
59.1 \\
57.7\end{array}$ & $\begin{array}{l}- \\
- \\
- \\
- \\
- \\
- \\
- \\
- \\
- \\
- \\
- \\
-\end{array}$ & $\begin{array}{l}60.3 \\
62.5 \\
62.0 \\
62.5 \\
64.8 \\
68.3 \\
70.6 \\
73.5 \\
69.7 \\
69.1 \\
71.7 \\
67.1 \\
67.0\end{array}$ \\
\hline \multicolumn{13}{|l|}{ Rhode Island } \\
\hline 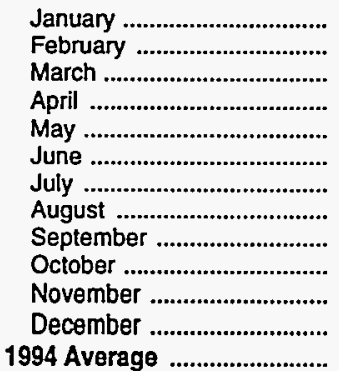 & $\begin{array}{r}65.2 \\
66.0 \\
65.1 \\
65.8 \\
68.0 \\
72.9 \\
77.0 \\
80.7 \\
79.9 \\
77.5 \\
76.7 \\
\text { NA } \\
72.4\end{array}$ & $\begin{array}{r}64.2 \\
65.0 \\
64.2 \\
64.9 \\
67.2 \\
71.7 \\
75.8 \\
79.6 \\
78.5 \\
76.3 \\
76.1 \\
\text { NA } \\
71.3\end{array}$ & $\begin{array}{l}54.0 \\
56.0 \\
55.5 \\
56.3 \\
59.2 \\
62.9 \\
65.3 \\
69.1 \\
66.0 \\
63.5 \\
64.7 \\
W \\
61.4\end{array}$ & $\begin{array}{c}46.0 \\
48.6 \\
48.6 \\
51.7 \\
53.7 \\
56.7 \\
57.8 \\
60.2 \\
52.7 \\
54.0 \\
57.7 \\
W \\
53.7\end{array}$ & $\begin{array}{l}W \\
W \\
45.9 \\
W \\
W \\
W \\
W \\
- \\
- \\
48.9 \\
W \\
- \\
49.5\end{array}$ & $\begin{array}{l}48.8 \\
50.2 \\
50.0 \\
51.9 \\
53.2 \\
57.1 \\
56.7 \\
63.4 \\
57.7 \\
53.1 \\
59.2 \\
58.0 \\
54.7\end{array}$ & $\begin{array}{r}74.1 \\
74.5 \\
74.7 \\
75.3 \\
77.7 \\
82.5 \\
86.4 \\
90.1 \\
89.3 \\
86.7 \\
85.5 \\
\text { NA } \\
81.4\end{array}$ & $\begin{array}{r}73.6 \\
74.0 \\
74.0 \\
74.7 \\
77.0 \\
81.3 \\
84.8 \\
88.5 \\
87.6 \\
85.5 \\
84.5 \\
\text { NA } \\
80.4\end{array}$ & $\begin{array}{c}60.5 \\
62.4 \\
61.4 \\
62.5 \\
65.3 \\
68.8 \\
71.1 \\
74.8 \\
72.4 \\
69.5 \\
71.0 \\
- \\
67.4\end{array}$ & $\begin{array}{c}49.5 \\
52.8 \\
52.4 \\
55.5 \\
58.4 \\
60.8 \\
62.1 \\
65.1 \\
56.7 \\
58.8 \\
61.6 \\
W \\
57.7\end{array}$ & $\begin{array}{l}\overline{-} \\
\overline{-} \\
\overline{-} \\
\bar{w} \\
\overline{-} \\
\overline{-} \\
\overline{-} \\
\bar{w}\end{array}$ & $\begin{array}{c}54.2 \\
57.4 \\
56.7 \\
58.9 \\
61.9 \\
64.5 \\
66.2 \\
69.6 \\
64.4 \\
64.1 \\
66.5 \\
W \\
62.3\end{array}$ \\
\hline
\end{tabular}

See footnotes at end of table. 
Table 32. Conventional Motor Gasoline Prices by Grade, Sales Type,

PAD District, and State

(Cents per Gallon Excluding Taxes) - Continued

\begin{tabular}{|c|c|c|c|c|c|c|c|c|c|c|c|c|}
\hline \multirow{3}{*}{$\begin{array}{l}\text { Geographic Area } \\
\text { Month }\end{array}$} & \multicolumn{6}{|c|}{ Premium } & \multicolumn{6}{|c|}{ All Grades } \\
\hline & \multicolumn{2}{|c|}{ Sales to End Users } & \multicolumn{4}{|c|}{ Sales for Resale } & \multicolumn{2}{|c|}{ Sales to End Users } & \multicolumn{4}{|c|}{ Sales for Resale } \\
\hline & $\begin{array}{c}\text { Through } \\
\text { Retall } \\
\text { Outlets }\end{array}$ & Averagea & DTW & Rack & Bulk & Average & $\begin{array}{c}\text { Through } \\
\text { Retail } \\
\text { Outlets }\end{array}$ & Averagea & DTW & Rack & Bulk & Average \\
\hline \multicolumn{13}{|l|}{ Maine } \\
\hline 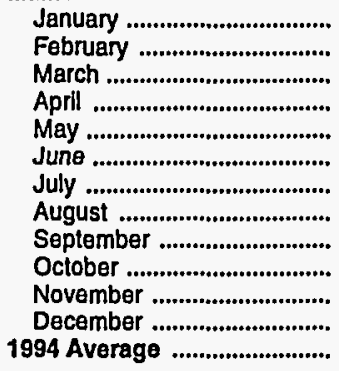 & $\begin{array}{l}83.5 \\
85.1 \\
85.5 \\
87.4 \\
91.3 \\
93.2 \\
94.0 \\
97.6 \\
97.0 \\
94.7 \\
97.9 \\
97.1 \\
91.7\end{array}$ & $\begin{array}{l}82.2 \\
84.0 \\
83.8 \\
86.3 \\
90.0 \\
92.0 \\
92.6 \\
96.3 \\
95.5 \\
93.5 \\
96.7 \\
95.7 \\
90.4\end{array}$ & $\begin{array}{l}67.1 \\
69.8 \\
69.7 \\
70.8 \\
73.4 \\
77.0 \\
78.2 \\
83.9 \\
79.6 \\
77.5 \\
80.0 \\
77.2 \\
75.1\end{array}$ & $\begin{array}{l}58.5 \\
61.7 \\
61.4 \\
63.8 \\
67.5 \\
70.0 \\
71.7 \\
74.6 \\
66.5 \\
66.5 \\
70.5 \\
65.9 \\
66.9\end{array}$ & $\begin{array}{l}W \\
W \\
W \\
W \\
W \\
W \\
W \\
W \\
W \\
W \\
W \\
W \\
W\end{array}$ & $\begin{array}{l}60.7 \\
63.7 \\
62.7 \\
65.8 \\
69.2 \\
72.0 \\
73.4 \\
76.7 \\
68.8 \\
68.6 \\
72.1 \\
68.3 \\
68.7\end{array}$ & $\begin{array}{l}71.9 \\
73.3 \\
73.3 \\
74.6 \\
78.1 \\
80.3 \\
81.1 \\
84.9 \\
83.7 \\
81.7 \\
84.2 \\
83.1 \\
79.2\end{array}$ & $\begin{array}{l}71.0 \\
72.5 \\
72.5 \\
73.9 \\
77.3 \\
79.7 \\
80.6 \\
84.6 \\
82.9 \\
81.0 \\
83.4 \\
82.5 \\
78.5\end{array}$ & $\begin{array}{l}58.4 \\
60.7 \\
60.7 \\
61.9 \\
64.0 \\
67.2 \\
68.4 \\
73.2 \\
69.1 \\
68.6 \\
71.6 \\
67.7 \\
65.9\end{array}$ & $\begin{array}{l}50.8 \\
54.2 \\
53.9 \\
56.2 \\
59.1 \\
62.0 \\
63.3 \\
65.6 \\
57.8 \\
57.5 \\
61.8 \\
57.1 \\
58.6\end{array}$ & $\begin{array}{c}W \\
49.3 \\
49.1 \\
50.8 \\
W \\
58.3 \\
W \\
61.3 \\
52.5 \\
49.4 \\
W \\
W \\
52.7\end{array}$ & $\begin{array}{l}51.6 \\
55.3 \\
55.1 \\
57.0 \\
60.4 \\
63.0 \\
64.6 \\
66.9 \\
59.8 \\
58.5 \\
63.9 \\
58.5 \\
59.7\end{array}$ \\
\hline \multicolumn{13}{|l|}{ Massachusetts } \\
\hline 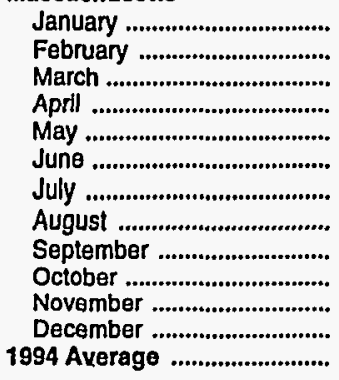 & $\begin{array}{l}82.8 \\
83.3 \\
83.2 \\
84.0 \\
86.0 \\
88.4 \\
91.2 \\
96.3 \\
96.2 \\
95.4 \\
95.6 \\
94.2 \\
89.2\end{array}$ & $\begin{array}{l}80.9 \\
80.7 \\
80.3 \\
81.7 \\
84.2 \\
86.4 \\
89.5 \\
94.8 \\
93.6 \\
93.1 \\
93.3 \\
92.6 \\
87.1\end{array}$ & $\begin{array}{l}69.7 \\
71.6 \\
71.3 \\
71.9 \\
74.6 \\
78.1 \\
81.6 \\
85.4 \\
82.9 \\
81.8 \\
83.1 \\
\text { NA } \\
77.5\end{array}$ & $\begin{array}{l}56.1 \\
58.9 \\
58.4 \\
60.8 \\
65.3 \\
67.4 \\
69.6 \\
73.2 \\
64.1 \\
65.9 \\
67.9 \\
74.0 \\
64.6\end{array}$ & $\begin{array}{l}W \\
W \\
- \\
\bar{w} \\
W \\
W \\
W \\
W \\
W \\
\overline{-} \\
\overline{57.4}\end{array}$ & $\begin{array}{c}63.0 \\
63.3 \\
65.4 \\
66.9 \\
70.0 \\
71.8 \\
75.8 \\
79.2 \\
72.8 \\
74.0 \\
75.7 \\
N A \\
70.8\end{array}$ & $\begin{array}{l}68.8 \\
69.3 \\
69.1 \\
69.8 \\
71.6 \\
74.3 \\
77.7 \\
82.9 \\
82.6 \\
81.6 \\
81.8 \\
80.9 \\
75.6\end{array}$ & $\begin{array}{l}67.8 \\
67.9 \\
67.7 \\
68.7 \\
70.5 \\
73.0 \\
76.4 \\
81.7 \\
80.2 \\
80.2 \\
80.5 \\
80.1 \\
74.2\end{array}$ & $\begin{array}{l}60.8 \\
62.7 \\
62.3 \\
62.7 \\
65.3 \\
68.8 \\
71.9 \\
75.0 \\
72.7 \\
71.7 \\
73.1 \\
67.3 \\
68.2\end{array}$ & $\begin{array}{l}49.1 \\
51.9 \\
51.6 \\
53.9 \\
57.1 \\
59.7 \\
61.1 \\
64.1 \\
55.9 \\
57.4 \\
60.3 \\
63.0 \\
57.0\end{array}$ & $\begin{array}{c}41.8 \\
46.0 \\
44.1 \\
47.1 \\
49.4 \\
54.1 \\
54.7 \\
55.5 \\
48.5 \\
46.6 \\
54.5 \\
W \\
49.7\end{array}$ & $\begin{array}{l}53.5 \\
55.3 \\
54.8 \\
57.8 \\
59.0 \\
62.4 \\
65.7 \\
66.7 \\
60.2 \\
62.1 \\
64.8 \\
57.8 \\
60.5\end{array}$ \\
\hline \multicolumn{13}{|l|}{ New Hampshire } \\
\hline 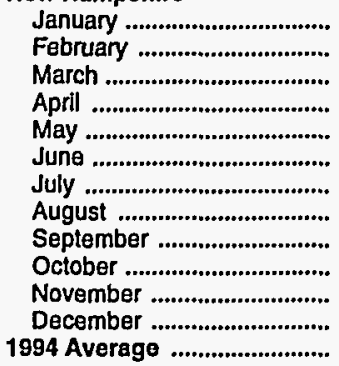 & $\begin{array}{l}86.0 \\
86.6 \\
85.7 \\
87.1 \\
88.2 \\
90.9 \\
93.3 \\
96.4 \\
97.0 \\
95.9 \\
96.1 \\
94.4 \\
91.1\end{array}$ & $\begin{array}{l}85.6 \\
86.3 \\
85.1 \\
86.5 \\
87.9 \\
90.0 \\
92.3 \\
95.6 \\
94.0 \\
95.3 \\
95.5 \\
94.0 \\
90.5\end{array}$ & $\begin{array}{l}70.9 \\
73.1 \\
71.3 \\
72.8 \\
75.6 \\
78.9 \\
81.3 \\
85.3 \\
81.1 \\
79.5 \\
82.1 \\
77.6 \\
77.5\end{array}$ & $\begin{array}{l}57.2 \\
59.1 \\
58.6 \\
61.2 \\
65.2 \\
66.9 \\
69.2 \\
73.8 \\
65.9 \\
67.2 \\
69.9 \\
68.5 \\
65.5\end{array}$ & $\begin{array}{l}- \\
\overline{-} \\
- \\
- \\
- \\
- \\
- \\
- \\
- \\
-\end{array}$ & $\begin{array}{l}67.9 \\
69.5 \\
68.1 \\
69.8 \\
72.8 \\
75.7 \\
78.3 \\
81.9 \\
76.8 \\
75.9 \\
78.7 \\
75.2 \\
74.3\end{array}$ & $\begin{array}{l}72.1 \\
72.8 \\
72.5 \\
73.0 \\
73.9 \\
77.5 \\
80.1 \\
84.1 \\
84.1 \\
82.8 \\
83.1 \\
81.4 \\
78.0\end{array}$ & $\begin{array}{l}71.6 \\
72.3 \\
72.0 \\
72.8 \\
73.7 \\
77.2 \\
79.7 \\
83.5 \\
82.1 \\
82.1 \\
82.5 \\
80.8 \\
77.4\end{array}$ & $\begin{array}{l}61.0 \\
62.9 \\
62.3 \\
63.2 \\
65.3 \\
68.6 \\
71.0 \\
74.4 \\
70.6 \\
69.3 \\
71.7 \\
67.5 \\
67.5\end{array}$ & $\begin{array}{l}49.8 \\
51.9 \\
51.5 \\
53.7 \\
56.5 \\
59.1 \\
60.6 \\
64.3 \\
57.5 \\
58.5 \\
61.5 \\
59.7 \\
57.3\end{array}$ & $\begin{array}{l}\text { w } \\
- \\
- \\
- \\
- \\
- \\
- \\
- \\
- \\
- \\
- \\
\bar{w}\end{array}$ & $\begin{array}{l}58.3 \\
59.9 \\
59.3 \\
60.5 \\
62.8 \\
65.9 \\
68.2 \\
71.2 \\
66.7 \\
66.1 \\
68.8 \\
65.6 \\
64.6\end{array}$ \\
\hline \multicolumn{13}{|l|}{ Rhode Island } \\
\hline 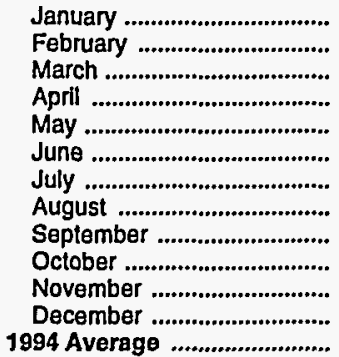 & $\begin{array}{l}82.7 \\
82.9 \\
82.5 \\
83.1 \\
85.4 \\
89.2 \\
92.9 \\
96.8 \\
95.9 \\
92.3 \\
92.4 \\
91.2 \\
88.3\end{array}$ & $\begin{array}{l}81.9 \\
82.2 \\
81.9 \\
82.5 \\
84.6 \\
88.2 \\
91.9 \\
96.0 \\
94.9 \\
91.8 \\
91.6 \\
86.0 \\
87.5\end{array}$ & $\begin{array}{l}67.6 \\
69.5 \\
68.9 \\
69.8 \\
73.0 \\
76.8 \\
79.5 \\
83.7 \\
80.3 \\
78.1 \\
79.0 \\
- \\
75.2\end{array}$ & $\begin{array}{l}56.4 \\
58.7 \\
58.0 \\
61.3 \\
65.4 \\
67.8 \\
69.7 \\
73.1 \\
64.1 \\
65.8 \\
68.3 \\
W \\
64.5\end{array}$ & $\begin{array}{l}- \\
\overline{-} \\
- \\
- \\
- \\
- \\
- \\
- \\
-\end{array}$ & $\begin{array}{l}60.8 \\
63.2 \\
62.5 \\
65.0 \\
68.7 \\
71.5 \\
73.7 \\
77.4 \\
71.3 \\
71.0 \\
73.1 \\
W \\
69.0\end{array}$ & $\begin{array}{l}71.5 \\
72.0 \\
71.1 \\
71.9 \\
74.1 \\
78.4 \\
82.3 \\
85.9 \\
85.2 \\
82.6 \\
81.8 \\
76.4 \\
77.8\end{array}$ & $\begin{array}{l}70.7 \\
71.1 \\
70.2 \\
71.0 \\
73.2 \\
77.2 \\
81.1 \\
84.8 \\
83.7 \\
81.5 \\
81.0 \\
72.7 \\
76.8\end{array}$ & $\begin{array}{c}58.9 \\
60.8 \\
60.1 \\
61.0 \\
64.0 \\
67.7 \\
70.1 \\
73.9 \\
70.8 \\
68.2 \\
69.5 \\
W \\
66.1\end{array}$ & $\begin{array}{l}49.3 \\
51.7 \\
51.5 \\
54.6 \\
57.1 \\
60.0 \\
61.2 \\
63.9 \\
55.8 \\
57.3 \\
60.6 \\
60.4 \\
56.8\end{array}$ & $\begin{array}{c}W \\
W \\
45.9 \\
W \\
W \\
W \\
W \\
- \\
- \\
48.9 \\
W \\
- \\
4 \overline{9} .5\end{array}$ & $\begin{array}{l}52.8 \\
54.3 \\
53.6 \\
55.5 \\
57.3 \\
60.6 \\
60.6 \\
67.7 \\
61.9 \\
56.5 \\
63.2 \\
60.5 \\
58.6\end{array}$ \\
\hline
\end{tabular}

See footnotes at end of table. 
Table 32. Conventional Motor Gasoline Prices by Grade, Sales Type, PAD District, and State

(Cents per Gallon Excluding Taxes) - Continued

\begin{tabular}{|c|c|c|c|c|c|c|c|c|c|c|c|c|}
\hline \multirow{3}{*}{$\begin{array}{c}\text { Goographic Area } \\
\text { Month }\end{array}$} & \multicolumn{6}{|c|}{ Regular } & \multicolumn{6}{|c|}{ Midgrade } \\
\hline & \multicolumn{2}{|c|}{ Sales to End Users } & \multicolumn{4}{|c|}{ Sales for Resale } & \multicolumn{2}{|c|}{ Sales to End Users } & \multicolumn{4}{|c|}{ Sales for Resale } \\
\hline & $\begin{array}{c}\text { Through } \\
\text { Retail } \\
\text { Outlets }\end{array}$ & Averagea & DTW & Rack & Bulk & Average & $\begin{array}{c}\text { Through } \\
\text { Retail } \\
\text { Outlets }\end{array}$ & Average ${ }^{a}$ & DTW & Rack & Bulk & Average \\
\hline
\end{tabular}

Vermont
January

January ............................... 70.9

February ............................. 71.5

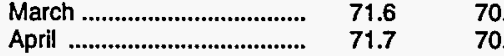

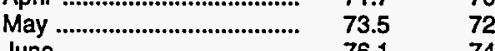

June ................................... $76.1 \quad 74.9$

July .................................... 80.5

August .................................. 82.4

September .............................. 82.6

October ................................ 82.4

November ............................ 82.3

December ........................... $\quad 77.2$

79.3

81.5

81.3

$81.1 \quad 68.0$

56.0

$\begin{array}{lllll}81.1 & 71.7 & 60.1 & - & 68.6\end{array}$

$\begin{array}{lllll}76.3 & 68.6 & 55.6 & - & 65.2\end{array}$

76.0

$67.7 \quad 56.6$

Subdistrict IB

January

61.8

March .....

April ................................... 62.3

May ............................................

June ...................................... 67.1

July .................................... $\quad 70.4$

August ................................. 74.5

September .......................... 74.5

October .................................. 73.3

November ............................. 74.3

December ........................... 73.1

61.2

$52.6 \quad 44.9$

$\begin{array}{lll}62.1 & 54.5 & 47.8 \\ 61.2 & 55.4 & 48.1\end{array}$

61.7

63.7

66.6
69.9

69.9
73.8

73.2

72.2

73.8

72.4
68.0

$56.7 \quad 48.1$

$56.7-50.8$

$\begin{array}{ll}59.6 & 53.6 \\ 62.9 & 56.2\end{array}$

$\begin{array}{ll}65.4 & 57.9\end{array}$

$68.5 \quad 60.8$

$65.8 \quad 53.8$

$\begin{array}{ll}63.6 & 54.3 \\ 64.5 & 58.4\end{array}$

$64.5 \quad 58.4$

$\begin{array}{ll}60.0 & 52.0 \\ 61.8 & 54.1\end{array}$

43.0
44.3
45.2
48.1
51.1
52.9
55.9
56.7
51.4
50.4
55.8
51.4
51.1

47.1
49.2
50.3
52.7
55.7
58.3
60.9
63.3
58.1
57.0
59.7
54.8
56.7

$\begin{array}{ll}80.7 & 77.4 \\ 81.3 & 78.7 \\ 81.3 & 78.4 \\ 81.1 & 78.8 \\ 82.7 & 79.9 \\ 85.5 & 82.5 \\ 89.7 & 86.8 \\ 91.2 & 89.0 \\ 92.0 & 89.7 \\ 91.4 & 89.0 \\ 91.0 & 89.0 \\ 87.5 & 85.4 \\ 86.8 & 84.4\end{array}$

67.5

68.1

69.0

1994 Average ....................... 68.7

Delaware

January ................................ $\quad 57.5$

56.8

February ........................... $59.5 \quad 58.8$

March ..................................... 58.6

April ....................................... 59.1

May ................................... 62.1

June ..................................... 65.1

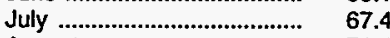

August ................................ 71.4

September ................... 71.1

October ................................. 70.8

November .................................. 73.2

December ......... 69.9

1994 Average .......................... 65.8

58.2

59.0

61.8

64.5
67.0

67.0
70.7

69.9

69.7

72.3

70.1

$55.1 \quad 43.8$

$\begin{array}{ll}54.8 & 46.6 \\ 54.8 & 48.2\end{array}$

$56.2 \quad 49.7$

$58.0 \quad 52.7$

$\begin{array}{ll}60.5 & 55.1 \\ 62.8 & 56.6\end{array}$

$66.4 \quad 59.4$

$64.4 \quad 52.0$

$63.6 \quad 53.9$

$66.1 \quad 57.5$

61.1

60.6

$-\bar{W}$
$W$
$W$
$W$
$W$
$W$
$W$
$W$
$W$
$W$
-
$W$

$\begin{array}{rrr}49.1 & 70.3 & 68.9 \\ 49.9 & 70.0 & 69.1 \\ 51.3 & 69.3 & 68.3 \\ 52.2 & \text { NA } & \text { NA } \\ 55.1 & 73.2 & 72.4 \\ 57.8 & 75.9 & 75.3 \\ 59.1 & 78.2 & 77.5 \\ 62.7 & 82.4 & 81.5 \\ 57.3 & 82.4 & 80.5 \\ 57.8 & 82.0 & 80.9 \\ 61.6 & 84.7 & 83.8 \\ 59.8 & 84.2 & 85.1 \\ \mathbf{5 6 . 2} & \mathbf{7 6 . 5} & \mathbf{7 5 . 6}\end{array}$

$\begin{array}{ll}70.4 & 69.2 \\ 71.1 & 70.1 \\ 71.0 & 69.8 \\ 71.3 & 70.3 \\ 74.2 & 73.2 \\ 77.2 & 76.0 \\ 80.1 & 79.4 \\ 84.2 & 83.0 \\ 84.2 & 82.5 \\ 82.3 & 80.8 \\ 83.2 & 82.5 \\ 81.4 & 80.3 \\ 78.1 & 77.0\end{array}$

71.4

73.6

73.6
76.9

76.9
78.6

76.3

74.8

74.8
77.0

75.0

$\begin{array}{lll}53.2 & - & 63.6 \\ 56.7 & - & 65.0 \\ 56.1 & - & 65.7 \\ 57.6 & - & 67.4 \\ 60.6 & - & 69.2 \\ 63.6 & - & 71.1 \\ 66.0 & - & 73.5 \\ 69.1 & - & 76.3 \\ 61.6 & - & 72.9 \\ 60.3 & - & 71.4 \\ 65.0 & - & 74.2 \\ 60.0 & - & 71.3 \\ 61.2 & - & 70.5\end{array}$

District of Columbia

January

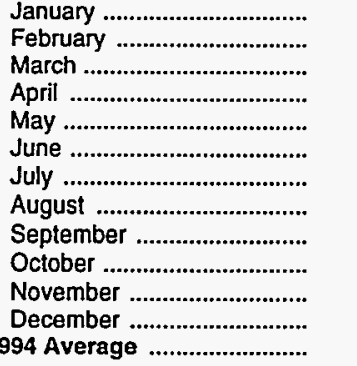

$\begin{array}{ccccc}- & - & - & W & - \\ - & - & - & W & - \\ W & 53.8 & 60.2 & W & - \\ W & 55.8 & 61.1 & W & - \\ W & 58.3 & 62.3 & W & - \\ W & 61.8 & 64.4 & W & - \\ W & 64.6 & 66.0 & W & - \\ W & 61.6 & 68.4 & W & - \\ W & 59.4 & 67.1 & W & - \\ W & 62.4 & 65.7 & W & - \\ - & - & - & - & - \\ - & - & - & - & - \\ \text { W } & 59.1 & 64.3 & W & -\end{array}$

$\begin{array}{lc}- & W \\ - & W \\ - & 60.1 \\ - & 61.0 \\ - & 62.2 \\ - & 64.3 \\ - & 66.0 \\ - & 68.3 \\ - & 66.8 \\ - & 65.6 \\ - & - \\ - & - \\ - & 64.2\end{array}$

$\begin{array}{cccc}- & - & - & W \\ - & - & - & - \\ W & 57.6 & 65.0 & W \\ W & 61.0 & 65.9 & - \\ W & 66.1 & 67.9 & - \\ W & 71.3 & 69.9 & - \\ W & 72.5 & 70.8 & - \\ W & \text { NA } & 72.3 & - \\ W & \text { NA } & 70.7 & - \\ W & \text { NA } & 69.0 & - \\ - & - & - & - \\ - & - & - & - \\ \text { W } & 63.3 & 68.7 & \text { W }\end{array}$

$\begin{array}{lll}48.8 & \text { W } & 53.9 \\ 51.8 & \text { W } & 56.1 \\ 52.2 & \text { W } & 58.0 \\ 54.5 & \text { NA } & 59.6 \\ 57.9 & \text { W } & 62.9 \\ 60.7 & \text { W } & 66.0 \\ 62.4 & \text { W } & 68.0 \\ 66.0 & \text { W } & 71.3 \\ 59.1 & \text { W } & 67.0 \\ 58.9 & - & 64.8 \\ 63.7 & - & 66.6 \\ 56.8 & - & 61.8 \\ 58.8 & \text { NA } & 64.5\end{array}$

See footnotes at end of table. 
Table 32. Conventional Motor Gasoline Prices by Grade, Sales Type, PAD District, and State

(Cents per Gallon Excluding Taxes) - Continued

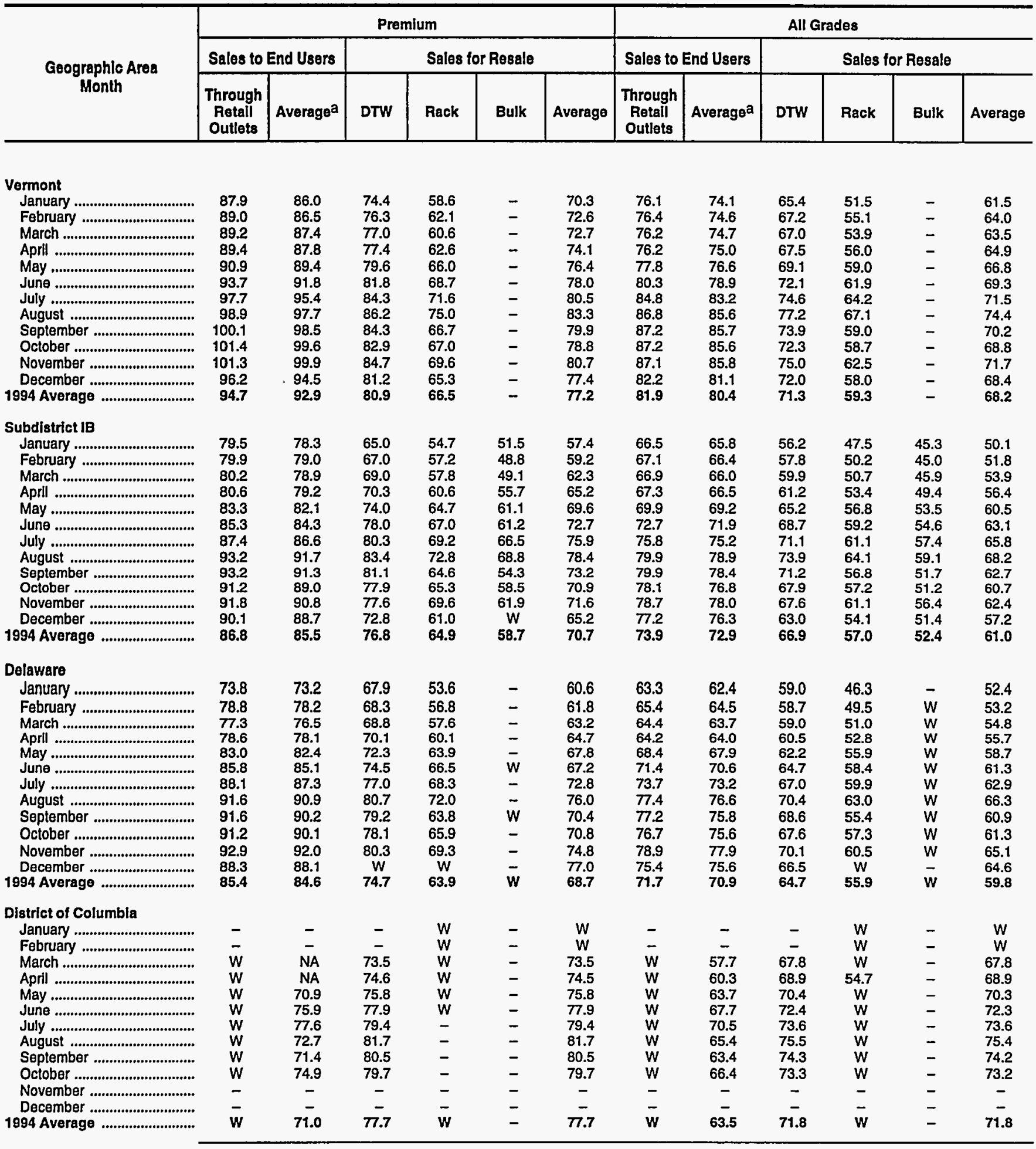

See footnotes at end of table. 
Table 32. Conventional Motor Gasoline Prices by Grade, Sales Type, PAD District, and State

(Cents per Gallon Excluding Taxes) - Continued

\begin{tabular}{|c|c|c|c|c|c|c|c|c|c|c|c|c|}
\hline \multirow{3}{*}{$\begin{array}{l}\text { Geographic Area } \\
\text { Month }\end{array}$} & \multicolumn{6}{|c|}{ Regular } & \multicolumn{6}{|c|}{ Midgrade } \\
\hline & \multicolumn{2}{|c|}{ Sales to End Users } & \multicolumn{4}{|c|}{ Sales for Resale } & \multicolumn{2}{|c|}{ Sales to End Users } & \multicolumn{4}{|c|}{ Sales for Resale } \\
\hline & $\begin{array}{c}\text { Through } \\
\text { Retail } \\
\text { Outlets }\end{array}$ & Averagea & DTW & Rack & Bulk & Average & $\begin{array}{c}\text { Through } \\
\text { Retali } \\
\text { Outlets }\end{array}$ & Averagea & DTW & Rack & Bulk & Average \\
\hline
\end{tabular}

Maryland

\begin{tabular}{|c|c|c|c|c|c|c|c|c|c|c|c|c|}
\hline January & 59.9 & 59.3 & 51.3 & 43.4 & - & 46.5 & 66.8 & 665 & 579 & 509 & - & 504 \\
\hline February & 61.2 & 60.8 & 53.5 & 45.9 & $w$ & 48.9 & 68.7 & 68.0 & $\begin{array}{l}57.9 \\
59.6\end{array}$ & $\begin{array}{l}50.9 \\
54.4\end{array}$ & $\overline{-}$ & $\begin{array}{l}54.4 \\
57.0\end{array}$ \\
\hline March & 60.6 & 58.1 & 56.7 & 48.4 & $w$ & 53.9 & 71.2 & 68.8 & 62.8 & 52.8 & $w$ & 60.3 \\
\hline April & 61.4 & 58.9 & 57.7 & 51.0 & $w$ & 55.6 & 71.5 & 69.1 & 64.0 & 55.0 & $W$ & 61.8 \\
\hline May & 63.4 & 61.5 & 59.4 & 53.2 & $w$ & 57.2 & 73.6 & 71.6 & 65.8 & 57.4 & - & 63.3 \\
\hline June & 66.0 & 63.8 & 62.3 & 56.0 & $\ddot{w}$ & 60.0 & 76.3 & 74.1 & 68.4 & 60.4 & $w$ & 66.1 \\
\hline July & 69.2 & 66.9 & 64.1 & 57.1 & $\ddot{w}$ & 61.7 & 79.0 & 77.0 & 70.1 & 61.5 & $\ddot{W}$ & 67.5 \\
\hline August & 73.4 & 70.7 & 67.7 & 60.1 & W & 64.8 & 83.5 & 80.4 & 73.7 & 64.6 & $w$ & 71.0 \\
\hline September ............................. & 73.6 & 69.4 & 65.6 & 51.3 & $w$ & 60.6 & 83.6 & 79.0 & 72.0 & 56.3 & $\ddot{W}$ & 67.7 \\
\hline 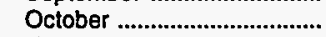 & 72.8 & 68.9 & 64.2 & 52.1 & $w$ & 59.8 & 82.7 & 78.9 & 70.4 & 57.2 & - & 66.7 \\
\hline 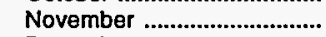 & 77.5 & 75.5 & 66.3 & 57.4 & w & 60.5 & 86.7 & 83.1 & 71.0 & 63.9 & - & 66.8 \\
\hline 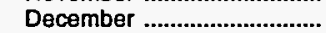 & 75.0 & 71.8 & 62.4 & 52.1 & $\ddot{w}$ & 57.1 & 82.4 & 78.9 & 67.5 & 56.7 & - & 62.6 \\
\hline 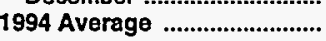 & 67.8 & 65.2 & 62.1 & 53.5 & 55.4 & $\mathbf{5 9 . 0}$ & 77.7 & 75.1 & 68.4 & 58.6 & $w$ & 65.6 \\
\hline \multicolumn{13}{|l|}{ New Jersey } \\
\hline 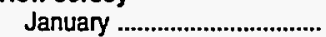 & - & - & - & 44.9 & 43.1 & 43.1 & - & - & - & 54.6 & - & 54.6 \\
\hline 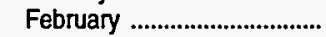 & - & - & - & 46.0 & 44.3 & 44.4 & - & - & - & 50.6 & - & 50.6 \\
\hline 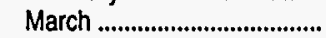 & 64.8 & 64.3 & 55.9 & 47.2 & 44.9 & 46.8 & 77.3 & 76.7 & 61.2 & 51.7 & - & 57.8 \\
\hline 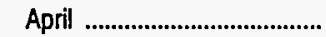 & 64.2 & 63.8 & 56.0 & 49.8 & 47.3 & 49.5 & 76.6 & 75.5 & 61.2 & 53.6 & $W$ & 57.9 \\
\hline 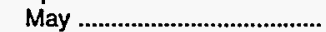 & 65.4 & 64.7 & 60.9 & 53.0 & 51.0 & 55.1 & 79.3 & 77.9 & 67.2 & 58.3 & $w$ & 65.0 \\
\hline June & 69.2 & 68.4 & 65.4 & 55.2 & 52.5 & 57.4 & 83.4 & 81.9 & 71.6 & 60.7 & $w$ & 68.9 \\
\hline 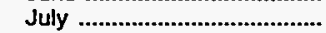 & 71.0 & 70.3 & 67.3 & 56.1 & 55.8 & 60.6 & 84.9 & 83.7 & 73.1 & 61.7 & $\ddot{w}$ & 70.0 \\
\hline August & 74.7 & 73.9 & 70.1 & 58.6 & 56.6 & 61.2 & 88.4 & 87.1 & 76.0 & 65.2 & $\dddot{w}$ & 72.9 \\
\hline September .............................. & 75.3 & 74.1 & 68.7 & 51.9 & 51.9 & 56.2 & 88.9 & 87.3 & 74.1 & 58.7 & - & 69.3 \\
\hline 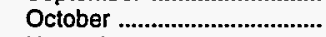 & 76.9 & 74.2 & 63.7 & 55.5 & 49.2 & 52.0 & 88.4 & 86.1 & 67.5 & 59.8 & - & 63.7 \\
\hline November .............................. & - & - & - & $W$ & 55.7 & 55.7 & - & - & - & 60.1 & - & 60.1 \\
\hline December ............................... & - & - & - & - & 53.3 & 53.3 & - & - & - & - & - & - \\
\hline 1994 Average & 71.1 & 70.1 & 65.5 & 54.3 & 51.1 & 55.3 & 84.5 & 83.2 & 71.3 & 60.1 & NA & 68.0 \\
\hline \multicolumn{13}{|l|}{ New York } \\
\hline 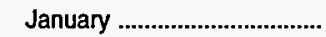 & 64.7 & 63.7 & 53.1 & 46.0 & $w$ & 48.6 & 74.6 & 72.2 & 59.4 & 50.1 & $w$ & 54.7 \\
\hline 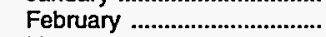 & 65.0 & 64.1 & 54.9 & 49.0 & 45.2 & 51.0 & 75.4 & 73.1 & 60.9 & 53.4 & $w$ & 57.2 \\
\hline March & 64.3 & 63.5 & 54.5 & 49.1 & 46.3 & 50.9 & 73.9 & 71.7 & 60.1 & 53.3 & w & 56.7 \\
\hline April & 64.0 & 63.3 & 55.9 & 51.5 & 46.2 & 52.8 & 74.1 & 71.9 & 61.5 & 55.7 & w & 58.6 \\
\hline 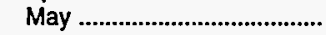 & 65.2 & 64.7 & 59.6 & 54.3 & 50.8 & 56.4 & 74.8 & 73.1 & 65.5 & 58.6 & - & 63.3 \\
\hline June & 67.8 & 67.2 & 62.5 & 57.0 & 53.5 & 59.4 & $\pi 7.2$ & 75.4 & 68.8 & 61.5 & $W$ & 66.5 \\
\hline July & 71.7 & 71.4 & 65.5 & 58.8 & 56.1 & 61.7 & 80.7 & 80.0 & 71.6 & 63.4 & $W$ & 68.9 \\
\hline August & 75.6 & 75.2 & 68.4 & 62.1 & 58.6 & 65.1 & 84.5 & 83.6 & 74.6 & 67.5 & - & 72.2 \\
\hline 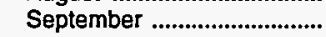 & 75.7 & 74.7 & 64.9 & 55.3 & 49.5 & 59.7 & 85.0 & 83.4 & 72.5 & 61.1 & - & 68.2 \\
\hline October & 75.1 & 74.3 & 63.3 & 55.4 & 54.3 & 58.8 & 84.8 & 82.7 & 68.9 & 60.4 & - & 64.4 \\
\hline 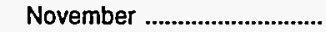 & 75.2 & 74.8 & 64.0 & 58.9 & 57.7 & 60.8 & 84.6 & 83.2 & 69.9 & 64.0 & - & 66.7 \\
\hline 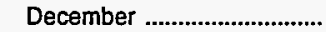 & 73.8 & 73.2 & 59.1 & 52.8 & 49.1 & $\mathbf{5 5 . 5}$ & 82.7 & 80.9 & 65.7 & 57.8 & - & 61.3 \\
\hline 1994 Average & 69.9 & 69.3 & 61.3 & 55.0 & 51.1 & 57.8 & 79.6 & 77.9 & 68.3 & 60.1 & W & 65.1 \\
\hline \multicolumn{13}{|l|}{ Pennsylvania } \\
\hline 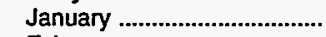 & 59.3 & 59.2 & 52.2 & 44.3 & $w$ & 46.9 & 68.5 & 67.9 & 58.7 & 48.1 & - & 53.4 \\
\hline 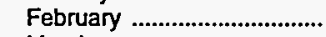 & 60.5 & 60.5 & 54.3 & 47.2 & 43.6 & 49.4 & 69.4 & 69.0 & 60.1 & 51.1 & - & 55.7 \\
\hline 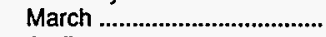 & 60.1 & 60.0 & 54.9 & 47.5 & 45.0 & 50.2 & 69.3 & 68.9 & 60.5 & 51.6 & - & 56.7 \\
\hline 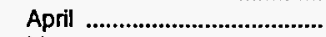 & 61.1 & 61.1 & 56.5 & 50.5 & 49.3 & 52.6 & 70.2 & 69.8 & 62.0 & 54.2 & - & 58.7 \\
\hline 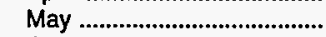 & 62.9 & 62.9 & 58.7 & 53.4 & 51.3 & 55.0 & 72.9 & 72.6 & 64.3 & 57.7 & $w$ & 61.2 \\
\hline 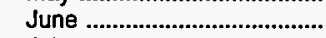 & 66.1 & 66.0 & 62.0 & 55.9 & 53.4 & 57.6 & 75.7 & 75.2 & 67.4 & 60.4 & $w$ & 64.0 \\
\hline 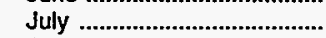 & 69.2 & 69.2 & 64.8 & 58.0 & 56.0 & 60.2 & 78.7 & 78.6 & 70.2 & 62.6 & $w$ & 66.5 \\
\hline 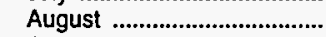 & 73.8 & 73.3 & 68.1 & 60.7 & 56.1 & 63.0 & 82.9 & 82.3 & 73.6 & 66.3 & 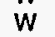 & 69.9 \\
\hline 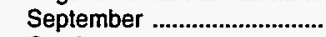 & 73.5 & 72.6 & 65.2 & 53.8 & 48.4 & 57.3 & 82.7 & 82.0 & 71.0 & 59.6 & $W$ & 64.9 \\
\hline 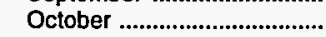 & 71.8 & 71.2 & 63.5 & 53.9 & 51.2 & 56.9 & 80.8 & 80.2 & 69.0 & 58.8 & - & 64.0 \\
\hline November & 73.3 & 72.8 & 64.5 & 58.2 & 55.0 & 59.9 & 82.2 & 81.9 & 70.2 & 63.9 & - & 66.5 \\
\hline 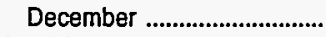 & 72.4 & 71.7 & 60.8 & 51.0 & 47.3 & 54.0 & 80.8 & 80.2 & 67.3 & 55.6 & - & 61.9 \\
\hline 1994 Average & 67.4 & 67.1 & 60.8 & 53.5 & 50.7 & 55.9 & 76.6 & 76.1 & 66.5 & 58.3 & $W$ & 62.6 \\
\hline
\end{tabular}

See footnotes at end of table. 
Table 32. Conventional Motor Gasoline Prices by Grade, Sales Type, PAD District, and State

(Cents per Gallon Excluding Taxes) - Continued

\begin{tabular}{|c|c|c|c|c|c|c|c|c|c|c|c|c|}
\hline \multirow{3}{*}{$\begin{array}{c}\text { Coographlo Ares } \\
\text { Month }\end{array}$} & \multicolumn{6}{|c|}{ Premium } & \multicolumn{6}{|c|}{ All Grades } \\
\hline & \multicolumn{2}{|c|}{ Sales to End Users } & \multicolumn{4}{|c|}{ Sales for Resale } & \multicolumn{2}{|c|}{ Sales to End Users } & \multicolumn{4}{|c|}{ Sales for Resale } \\
\hline & $\begin{array}{c}\text { Through } \\
\text { Retail } \\
\text { Outlets }\end{array}$ & Average $a$ & DTW & Rack & Bulk & Average & $\begin{array}{c}\text { Through } \\
\text { Retail } \\
\text { Outlets }\end{array}$ & Averagea & DTW & Rack & Bulk & Average \\
\hline 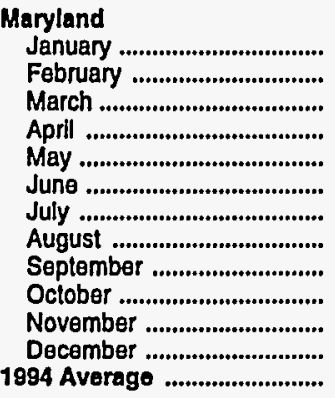 & $\begin{array}{l}73.6 \\
75.8 \\
77.6 \\
77.8 \\
80.8 \\
83.6 \\
86.7 \\
90.9 \\
90.8 \\
89.9 \\
93.9 \\
89.0 \\
84.5\end{array}$ & $\begin{array}{l}73.3 \\
75.2 \\
74.2 \\
73.6 \\
78.0 \\
81.0 \\
84.0 \\
86.5 \\
85.2 \\
85.6 \\
89.2 \\
83.9 \\
80.9\end{array}$ & $\begin{array}{l}62.5 \\
64.7 \\
69.6 \\
70.8 \\
73.2 \\
76.0 \\
77.8 \\
81.4 \\
79.4 \\
78.0 \\
79.4 \\
74.8 \\
75.6\end{array}$ & $\begin{array}{l}55.7 \\
57.9 \\
58.0 \\
60.5 \\
63.4 \\
66.2 \\
67.9 \\
70.7 \\
62.6 \\
63.1 \\
66.8 \\
61.5 \\
64.1\end{array}$ & $\begin{array}{l}- \\
\bar{W} \\
W \\
W \\
N A \\
W \\
W \\
W \\
W \\
- \\
\overrightarrow{63.9}\end{array}$ & $\begin{array}{l}58.9 \\
61.2 \\
66.7 \\
68.4 \\
70.3 \\
73.0 \\
75.0 \\
78.1 \\
74.6 \\
73.7 \\
72.3 \\
69.1 \\
72.3\end{array}$ & $\begin{array}{l}64.2 \\
65.8 \\
66.1 \\
67.0 \\
69.0 \\
71.7 \\
74.9 \\
78.9 \\
79.0 \\
78.2 \\
82.7 \\
79.1 \\
73.2\end{array}$ & $\begin{array}{l}63.6 \\
65.2 \\
63.2 \\
63.9 \\
66.8 \\
69.1 \\
72.4 \\
75.8 \\
74.5 \\
74.1 \\
79.9 \\
75.7 \\
70.3\end{array}$ & $\begin{array}{l}54.7 \\
57.2 \\
61.7 \\
62.8 \\
64.8 \\
67.6 \\
69.3 \\
72.8 \\
70.8 \\
69.4 \\
69.6 \\
65.8 \\
67.2\end{array}$ & $\begin{array}{l}46.3 \\
49.1 \\
51.5 \\
54.0 \\
56.6 \\
59.3 \\
60.6 \\
63.5 \\
54.9 \\
55.5 \\
60.3 \\
54.7 \\
56.9\end{array}$ & $\begin{array}{c}-\bar{W} \\
W \\
W \\
W \\
59.8 \\
W \\
61.3 \\
55.7 \\
55.3 \\
W \\
W \\
57.0\end{array}$ & $\begin{array}{l}49.8 \\
52.5 \\
58.7 \\
60.3 \\
62.1 \\
64.8 \\
66.5 \\
69.5 \\
65.7 \\
64.7 \\
63.6 \\
60.3 \\
63.8\end{array}$ \\
\hline 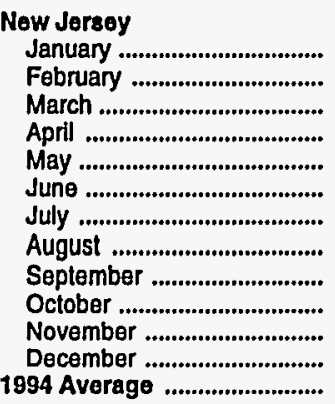 & $\begin{array}{l}- \\
- \\
85.6 \\
85.4 \\
87.8 \\
91.7 \\
93.3 \\
96.5 \\
96.7 \\
98.2 \\
- \\
\overline{9} .9\end{array}$ & $\begin{array}{c}\bar{W} \\
84.8 \\
83.6 \\
86.1 \\
89.9 \\
91.7 \\
94.9 \\
94.6 \\
93.5 \\
- \\
\overline{91.1}\end{array}$ & $\begin{array}{c}- \\
- \\
69.5 \\
69.2 \\
75.9 \\
80.2 \\
82.1 \\
84.9 \\
83.3 \\
76.5 \\
- \\
80.2\end{array}$ & $\begin{array}{l}W \\
52.5 \\
55.6 \\
58.6 \\
64.8 \\
66.7 \\
68.1 \\
71.9 \\
62.5 \\
66.4 \\
W \\
- \\
65.8\end{array}$ & $\begin{array}{l}53.0 \\
47.8 \\
48.5 \\
55.2 \\
61.7 \\
61.4 \\
66.3 \\
69.2 \\
54.0 \\
58.4 \\
61.7 \\
- \\
58.9\end{array}$ & $\begin{array}{c}53.1 \\
48.5 \\
56.0 \\
62.5 \\
70.1 \\
73.6 \\
77.2 \\
78.2 \\
72.1 \\
65.9 \\
62.2 \\
- \\
71.2\end{array}$ & $\begin{array}{c}- \\
- \\
73.3 \\
72.9 \\
73.8 \\
77.8 \\
79.6 \\
83.0 \\
83.5 \\
84.5 \\
- \\
- \\
79.4\end{array}$ & $\begin{array}{c}- \\
W \\
72.7 \\
71.8 \\
72.7 \\
76.6 \\
78.5 \\
81.8 \\
81.9 \\
81.3 \\
- \\
- \\
78.1\end{array}$ & $\begin{array}{c}- \\
- \\
61.1 \\
61.1 \\
67.6 \\
71.9 \\
73.8 \\
76.4 \\
74.7 \\
68.1 \\
- \\
- \\
71.8\end{array}$ & $\begin{array}{c}48.1 \\
48.4 \\
50.2 \\
52.7 \\
57.3 \\
59.3 \\
60.4 \\
63.2 \\
55.6 \\
59.2 \\
62.4 \\
- \\
58.4\end{array}$ & $\begin{array}{l}45.8 \\
44.8 \\
45.6 \\
48.4 \\
53.7 \\
54.0 \\
57.0 \\
58.9 \\
52.2 \\
50.4 \\
56.2 \\
53.3 \\
52.3\end{array}$ & $\begin{array}{l}45.9 \\
45.0 \\
49.4 \\
52.8 \\
60.9 \\
63.0 \\
66.5 \\
67.0 \\
60.9 \\
55.2 \\
56.3 \\
53.3 \\
60.4\end{array}$ \\
\hline 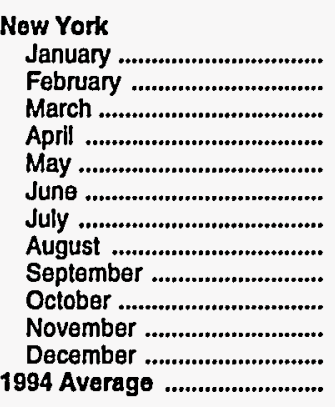 & $\begin{array}{l}83.8 \\
84.1 \\
83.8 \\
83.5 \\
83.8 \\
84.3 \\
87.5 \\
93.4 \\
93.6 \\
93.6 \\
92.5 \\
90.9 \\
87.9\end{array}$ & $\begin{array}{l}81.5 \\
82.2 \\
81.9 \\
81.8 \\
82.4 \\
83.1 \\
86.7 \\
92.5 \\
92.2 \\
90.3 \\
91.8 \\
89.7 \\
86.4\end{array}$ & $\begin{array}{l}65.5 \\
67.2 \\
66.2 \\
67.6 \\
73.3 \\
78.1 \\
80.8 \\
83.5 \\
81.1 \\
77.6 \\
76.4 \\
70.5 \\
77.0\end{array}$ & $\begin{array}{l}56.3 \\
59.4 \\
59.4 \\
61.9 \\
64.6 \\
67.5 \\
70.0 \\
73.8 \\
66.6 \\
67.0 \\
70.5 \\
63.7 \\
66.3\end{array}$ & $\begin{array}{c}W \\
W \\
W \\
W \\
61.7 \\
W \\
W \\
W \\
W \\
- \\
W \\
- \\
58.3\end{array}$ & $\begin{array}{l}59.8 \\
62.0 \\
61.9 \\
64.4 \\
70.3 \\
74.3 \\
76.8 \\
80.1 \\
75.4 \\
71.9 \\
72.8 \\
66.4 \\
72.6\end{array}$ & $\begin{array}{l}69.1 \\
69.2 \\
68.6 \\
68.1 \\
70.3 \\
72.6 \\
76.3 \\
80.2 \\
80.3 \\
78.9 \\
78.8 \\
77.3 \\
74.4\end{array}$ & $\begin{array}{l}67.7 \\
68.0 \\
67.4 \\
67.2 \\
69.4 \\
71.8 \\
75.9 \\
79.6 \\
79.1 \\
77.8 \\
78.3 \\
76.5 \\
73.5\end{array}$ & $\begin{array}{l}56.2 \\
57.8 \\
57.2 \\
58.6 \\
65.3 \\
68.9 \\
71.6 \\
74.0 \\
70.5 \\
66.2 \\
66.6 \\
61.3 \\
66.3\end{array}$ & $\begin{array}{l}48.2 \\
51.2 \\
51.2 \\
53.6 \\
56.9 \\
59.6 \\
61.7 \\
65.0 \\
58.1 \\
57.8 \\
61.3 \\
55.0 \\
57.6\end{array}$ & $\begin{array}{l}45.5 \\
46.0 \\
46.5 \\
46.3 \\
52.1 \\
55.6 \\
57.8 \\
59.7 \\
50.0 \\
54.3 \\
57.9 \\
49.1 \\
52.0\end{array}$ & $\begin{array}{l}51.2 \\
53.5 \\
53.2 \\
55.2 \\
61.2 \\
64.5 \\
66.8 \\
69.9 \\
64.4 \\
61.4 \\
63.3 \\
57.6 \\
61.9\end{array}$ \\
\hline 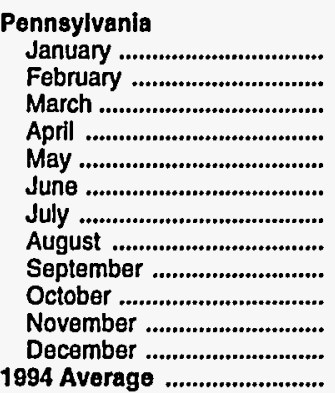 & $\begin{array}{l}77.2 \\
77.6 \\
78.0 \\
78.9 \\
81.0 \\
83.4 \\
84.5 \\
91.4 \\
91.5 \\
88.9 \\
90.9 \\
89.6 \\
84.5\end{array}$ & $\begin{array}{l}76.7 \\
77.2 \\
77.6 \\
78.6 \\
80.8 \\
83.2 \\
84.5 \\
90.6 \\
90.3 \\
88.2 \\
90.2 \\
88.6 \\
84.0\end{array}$ & $\begin{array}{l}64.6 \\
67.0 \\
68.6 \\
70.4 \\
72.8 \\
76.3 \\
79.3 \\
82.9 \\
80.4 \\
78.1 \\
78.0 \\
74.5 \\
74.9\end{array}$ & $\begin{array}{l}53.9 \\
56.2 \\
57.3 \\
60.4 \\
65.1 \\
67.0 \\
69.5 \\
73.0 \\
64.8 \\
64.7 \\
69.4 \\
58.4 \\
64.0\end{array}$ & $\begin{array}{l}W \\
W \\
W \\
W \\
W \\
60.9 \\
66.5 \\
67.8 \\
53.8 \\
59.0 \\
62.0 \\
W \\
57.8\end{array}$ & $\begin{array}{l}57.1 \\
59.3 \\
62.1 \\
64.0 \\
67.6 \\
70.0 \\
73.6 \\
76.7 \\
70.9 \\
70.2 \\
71.7 \\
63.2 \\
67.9\end{array}$ & $\begin{array}{l}64.7 \\
65.5 \\
65.4 \\
66.3 \\
68.4 \\
71.4 \\
74.3 \\
78.8 \\
78.6 \\
76.9 \\
78.1 \\
77.0 \\
72.5\end{array}$ & $\begin{array}{l}64.4 \\
65.3 \\
65.1 \\
66.1 \\
68.3 \\
71.1 \\
74.2 \\
78.2 \\
77.7 \\
76.2 \\
77.7 \\
76.3 \\
72.1\end{array}$ & $\begin{array}{l}56.1 \\
57.8 \\
59.1 \\
60.7 \\
63.1 \\
66.3 \\
69.1 \\
72.4 \\
69.7 \\
67.7 \\
67.9 \\
64.3 \\
65.0\end{array}$ & $\begin{array}{l}47.1 \\
49.8 \\
50.2 \\
53.2 \\
56.5 \\
58.9 \\
61.0 \\
63.9 \\
56.8 \\
56.8 \\
61.0 \\
53.0 \\
56.3\end{array}$ & $\begin{array}{l}43.9 \\
45.1 \\
45.9 \\
50.8 \\
53.4 \\
55.0 \\
57.7 \\
58.9 \\
49.1 \\
51.7 \\
56.3 \\
48.0 \\
52.2\end{array}$ & $\begin{array}{l}50.2 \\
52.3 \\
53.7 \\
56.0 \\
58.7 \\
61.2 \\
63.9 \\
66.9 \\
61.2 \\
60.5 \\
62.9 \\
56.6 \\
59.4\end{array}$ \\
\hline
\end{tabular}

See footnotes at end of table. 
Table 32. Conventional Motor Gasoline Prices by Grade, Sales Type, PAD District, and State

(Cents per Gallon Excluding Taxes) - Continued

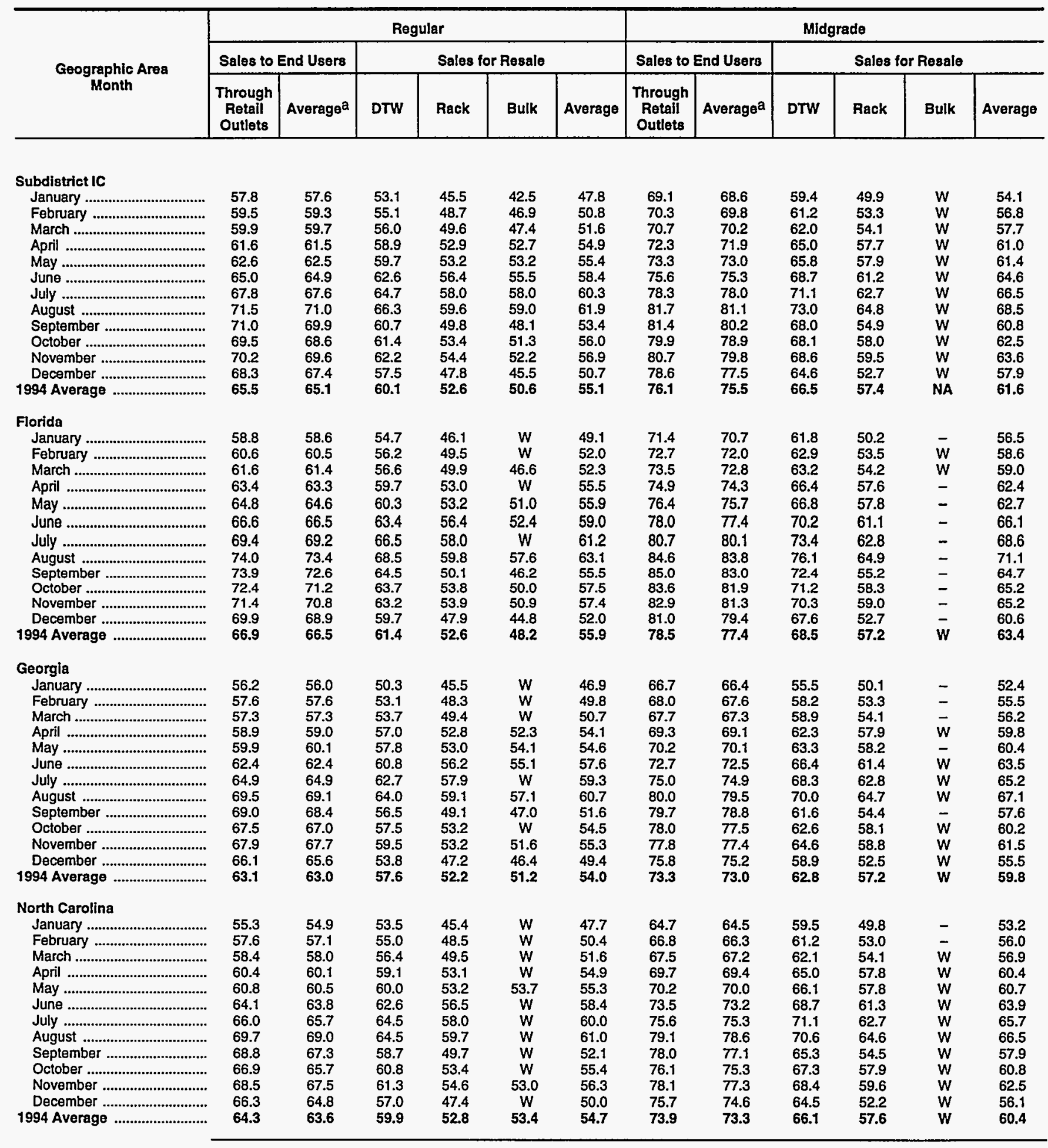

See footnotes at end of table. 
Table 32. Conventional Motor Gasoline Prices by Grade, Sales Type, PAD District, and State

(Cents per Gallon Excluding Taxes) - Continued

\begin{tabular}{|c|c|c|c|c|c|c|c|c|c|c|c|c|}
\hline \multirow{3}{*}{$\begin{array}{c}\text { Geographlo Area } \\
\text { Month }\end{array}$} & \multicolumn{6}{|c|}{ Premium } & \multicolumn{6}{|c|}{ All Grades } \\
\hline & \multicolumn{2}{|c|}{ Sales to End Users } & \multicolumn{4}{|c|}{ Sales for Resale } & \multicolumn{2}{|c|}{ Sales to End Users } & \multicolumn{4}{|c|}{ Sales for Resale } \\
\hline & $\begin{array}{c}\text { Through } \\
\text { Retall } \\
\text { Outlets }\end{array}$ & Average ${ }^{\mathrm{a}}$ & DTW & Rack & Bulk & Average & $\begin{array}{c}\text { Through } \\
\text { Retail } \\
\text { Outlets } \\
\end{array}$ & Averagea & DTW & Rack & Bulk & Average \\
\hline \multicolumn{13}{|l|}{ Subdlstrict IC } \\
\hline 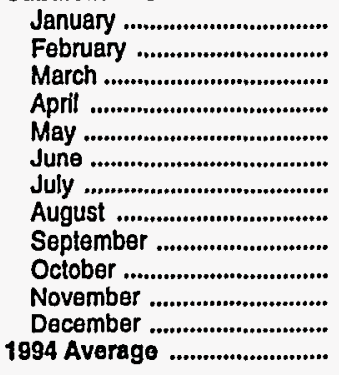 & $\begin{array}{l}78.4 \\
79.5 \\
79.8 \\
81.6 \\
82.7 \\
84.8 \\
87.7 \\
91.4 \\
90.8 \\
89.2 \\
89.9 \\
87.8 \\
85.2\end{array}$ & $\begin{array}{l}77.5 \\
78.8 \\
79.1 \\
80.9 \\
82.0 \\
84.2 \\
87.1 \\
90.3 \\
89.3 \\
87.9 \\
88.8 \\
86.5 \\
84.3\end{array}$ & $\begin{array}{l}67.8 \\
69.4 \\
70.1 \\
72.7 \\
73.6 \\
76.6 \\
79.2 \\
81.2 \\
76.7 \\
76.5 \\
76.9 \\
72.9 \\
74.6\end{array}$ & $\begin{array}{l}55.6 \\
58.7 \\
59.6 \\
63.2 \\
63.5 \\
66.9 \\
68.7 \\
70.4 \\
60.6 \\
64.0 \\
65.0 \\
58.4 \\
63.1\end{array}$ & $\begin{array}{c}46.6 \\
W \\
W \\
59.8 \\
56.6 \\
61.2 \\
W \\
W \\
W \\
56.2 \\
W \\
W \\
57.2\end{array}$ & $\begin{array}{l}60.8 \\
63.3 \\
64.1 \\
67.3 \\
67.8 \\
70.9 \\
73.1 \\
75.0 \\
67.3 \\
69.2 \\
69.9 \\
64.2 \\
68.0\end{array}$ & $\begin{array}{l}64.2 \\
65.7 \\
66.1 \\
67.9 \\
68.9 \\
71.2 \\
73.9 \\
77.4 \\
76.9 \\
75.4 \\
76.1 \\
74.3 \\
71.5\end{array}$ & $\begin{array}{l}63.8 \\
65.3 \\
65.7 \\
67.5 \\
68.6 \\
70.9 \\
73.6 \\
76.7 \\
75.7 \\
74.4 \\
75.3 \\
73.3 \\
71.0\end{array}$ & $\begin{array}{l}58.4 \\
60.3 \\
61.0 \\
63.9 \\
64.8 \\
67.6 \\
69.9 \\
71.4 \\
66.2 \\
66.6 \\
67.2 \\
62.9 \\
65.3\end{array}$ & $\begin{array}{l}48.3 \\
51.6 \\
52.5 \\
55.9 \\
56.2 \\
59.5 \\
61.1 \\
62.7 \\
52.9 \\
56.3 \\
57.4 \\
50.8 \\
55.6\end{array}$ & $\begin{array}{l}43.2 \\
47.9 \\
49.0 \\
53.7 \\
53.7 \\
56.8 \\
59.4 \\
60.4 \\
48.5 \\
52.2 \\
52.8 \\
45.9 \\
51.6\end{array}$ & $\begin{array}{l}51.9 \\
54.7 \\
55.6 \\
58.9 \\
59.4 \\
62.5 \\
64.3 \\
65.9 \\
57.8 \\
60.1 \\
60.9 \\
54.9 \\
59.2\end{array}$ \\
\hline \multicolumn{13}{|l|}{ Florida } \\
\hline 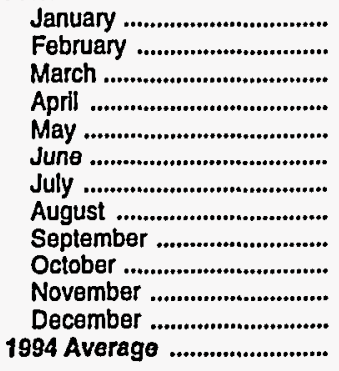 & $\begin{array}{l}80.1 \\
81.3 \\
82.0 \\
83.6 \\
85.0 \\
86.7 \\
89.7 \\
93.9 \\
93.8 \\
92.3 \\
91.3 \\
89.2 \\
87.0\end{array}$ & $\begin{array}{l}79.4 \\
80.5 \\
81.3 \\
83.0 \\
84.1 \\
86.0 \\
89.0 \\
92.7 \\
92.3 \\
90.8 \\
89.9 \\
87.7 \\
86.0\end{array}$ & $\begin{array}{l}71.0 \\
72.3 \\
71.9 \\
74.9 \\
75.4 \\
79.0 \\
82.3 \\
85.0 \\
82.2 \\
80.2 \\
79.4 \\
76.4 \\
77.4\end{array}$ & $\begin{array}{l}56.7 \\
59.7 \\
60.4 \\
63.6 \\
64.0 \\
67.3 \\
69.2 \\
70.7 \\
61.4 \\
64.7 \\
65.0 \\
59.0 \\
63.5\end{array}$ & $\begin{array}{l}W \\
W \\
W \\
W \\
W \\
W \\
- \\
- \\
W \\
W \\
W \\
W \\
53.7\end{array}$ & $\begin{array}{l}65.1 \\
67.1 \\
67.1 \\
70.2 \\
70.6 \\
73.9 \\
76.7 \\
78.9 \\
73.2 \\
73.5 \\
72.9 \\
68.4 \\
71.4\end{array}$ & $\begin{array}{l}65.6 \\
67.2 \\
68.2 \\
70.0 \\
71.4 \\
73.2 \\
75.8 \\
80.1 \\
80.1 \\
78.6 \\
77.7 \\
76.1 \\
73.4\end{array}$ & $\begin{array}{l}65.2 \\
66.8 \\
67.8 \\
69.6 \\
71.0 \\
72.8 \\
75.4 \\
79.4 \\
78.5 \\
77.1 \\
76.7 \\
74.8 \\
72.7\end{array}$ & $\begin{array}{l}61.7 \\
63.0 \\
63.1 \\
66.3 \\
66.9 \\
70.1 \\
73.3 \\
75.3 \\
71.8 \\
70.5 \\
69.8 \\
66.7 \\
68.1\end{array}$ & $\begin{array}{l}48.9 \\
52.3 \\
52.9 \\
56.0 \\
56.4 \\
59.6 \\
61.2 \\
62.8 \\
53.2 \\
56.7 \\
57.0 \\
51.0 \\
55.7\end{array}$ & $\begin{array}{c}43.1 \\
W \\
48.3 \\
W \\
52.0 \\
53.7 \\
W \\
57.6 \\
46.8 \\
50.1 \\
51.4 \\
45.1 \\
48.9\end{array}$ & $\begin{array}{l}54.6 \\
57.2 \\
57.4 \\
60.7 \\
61.3 \\
64.4 \\
66.8 \\
68.5 \\
61.6 \\
63.0 \\
62.7 \\
57.6 \\
61.3\end{array}$ \\
\hline \multicolumn{13}{|l|}{ Georgla } \\
\hline 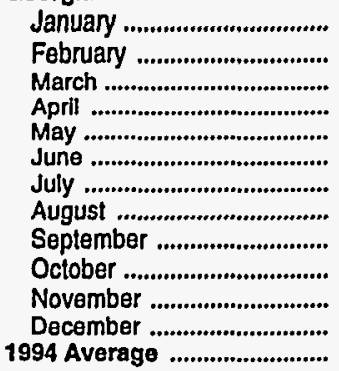 & $\begin{array}{l}76.5 \\
77.5 \\
77.2 \\
79.1 \\
80.1 \\
82.7 \\
85.5 \\
90.0 \\
89.0 \\
87.7 \\
88.0 \\
85.8 \\
82.8\end{array}$ & $\begin{array}{l}75.4 \\
76.9 \\
76.6 \\
78.6 \\
79.6 \\
82.2 \\
85.0 \\
89.0 \\
87.6 \\
86.7 \\
87.0 \\
84.7 \\
82.1\end{array}$ & $\begin{array}{l}63.0 \\
65.4 \\
66.3 \\
69.4 \\
70.5 \\
73.7 \\
75.8 \\
77.4 \\
69.8 \\
70.3 \\
72.0 \\
67.0 \\
70.2\end{array}$ & $\begin{array}{l}55.6 \\
58.3 \\
59.3 \\
62.9 \\
63.1 \\
66.7 \\
68.4 \\
69.7 \\
59.8 \\
63.6 \\
63.6 \\
57.6 \\
62.4\end{array}$ & $\begin{array}{c}W \\
- \\
W \\
W \\
- \\
60.9 \\
W \\
W \\
W \\
W \\
- \\
w \\
60.4\end{array}$ & $\begin{array}{l}58.2 \\
61.1 \\
61.8 \\
65.2 \\
65.8 \\
68.9 \\
70.9 \\
72.5 \\
63.3 \\
66.0 \\
66.8 \\
61.3 \\
65.4\end{array}$ & $\begin{array}{l}62.6 \\
64.0 \\
63.7 \\
65.3 \\
66.3 \\
68.7 \\
71.1 \\
75.2 \\
74.8 \\
73.3 \\
73.6 \\
71.9 \\
69.1\end{array}$ & $\begin{array}{l}62.2 \\
63.7 \\
63.5 \\
65.2 \\
66.3 \\
68.6 \\
71.0 \\
74.8 \\
74.1 \\
72.8 \\
73.2 \\
71.3 \\
68.8\end{array}$ & $\begin{array}{l}54.4 \\
57.3 \\
57.9 \\
61.0 \\
62.0 \\
65.1 \\
66.9 \\
68.1 \\
60.3 \\
61.4 \\
63.3 \\
57.9 \\
61.6\end{array}$ & $\begin{array}{l}48.3 \\
51.3 \\
52.3 \\
55.8 \\
56.1 \\
59.3 \\
60.8 \\
62.1 \\
52.1 \\
56.1 \\
56.2 \\
50.2 \\
55.1\end{array}$ & $\begin{array}{c}W \\
W \\
W \\
54.2 \\
54.1 \\
56.8 \\
W \\
59.8 \\
47.9 \\
W \\
52.0 \\
47.3 \\
53.1\end{array}$ & $\begin{array}{l}50.3 \\
53.4 \\
54.2 \\
57.5 \\
58.1 \\
61.1 \\
62.9 \\
64.2 \\
55.0 \\
57.9 \\
58.7 \\
52.9 \\
57.5\end{array}$ \\
\hline \multicolumn{13}{|l|}{ North Carolina } \\
\hline 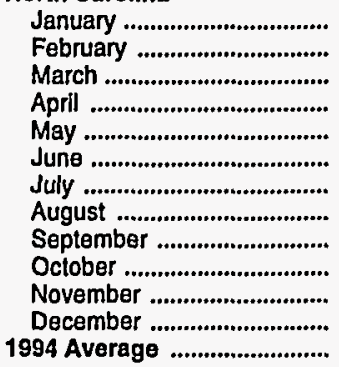 & $\begin{array}{l}74.2 \\
76.9 \\
77.4 \\
79.6 \\
80.1 \\
83.5 \\
85.4 \\
88.5 \\
87.7 \\
85.8 \\
87.7 \\
85.7 \\
83.6\end{array}$ & $\begin{array}{l}73.5 \\
76.1 \\
76.7 \\
78.7 \\
79.5 \\
82.9 \\
84.6 \\
87.3 \\
86.0 \\
84.5 \\
86.4 \\
84.1 \\
82.4\end{array}$ & $\begin{array}{l}65.2 \\
67.3 \\
69.4 \\
70.8 \\
72.9 \\
75.0 \\
77.4 \\
76.8 \\
70.9 \\
73.3 \\
74.4 \\
70.3 \\
72.4\end{array}$ & $\begin{array}{l}55.2 \\
58.4 \\
59.5 \\
63.4 \\
63.6 \\
67.0 \\
68.6 \\
70.6 \\
60.5 \\
64.0 \\
65.2 \\
57.9 \\
63.2\end{array}$ & $\begin{array}{l}- \\
\bar{w} \\
w \\
w \\
w \\
- \\
- \\
- \\
\bar{w} \\
\overline{57.9}\end{array}$ & $\begin{array}{l}58.1 \\
61.0 \\
62.4 \\
65.8 \\
66.3 \\
69.5 \\
71.4 \\
72.2 \\
63.4 \\
66.5 \\
67.7 \\
61.3 \\
65.8\end{array}$ & $\begin{array}{l}60.7 \\
63.2 \\
63.9 \\
66.1 \\
66.4 \\
69.8 \\
71.7 \\
75.3 \\
74.4 \\
72.5 \\
74.2 \\
72.2 \\
70.1\end{array}$ & $\begin{array}{l}60.1 \\
62.5 \\
63.3 \\
65.6 \\
66.0 \\
69.3 \\
71.2 \\
74.5 \\
72.9 \\
71.2 \\
73.0 \\
70.6 \\
69.2\end{array}$ & $\begin{array}{l}56.9 \\
58.5 \\
60.1 \\
62.9 \\
63.9 \\
66.4 \\
68.5 \\
68.2 \\
62.4 \\
64.6 \\
65.3 \\
61.2 \\
63.7\end{array}$ & $\begin{array}{l}48.1 \\
51.3 \\
52.5 \\
56.1 \\
56.3 \\
59.6 \\
61.1 \\
62.8 \\
52.7 \\
56.4 \\
57.6 \\
50.5 \\
55.8\end{array}$ & $\begin{array}{c}W \\
W \\
W \\
W \\
54.3 \\
W \\
W \\
W \\
W \\
W \\
54.0 \\
W \\
54.0\end{array}$ & $\begin{array}{l}50.7 \\
53.4 \\
54.8 \\
58.2 \\
58.6 \\
61.7 \\
63.4 \\
64.2 \\
55.3 \\
58.6 \\
59.6 \\
53.3 \\
58.0\end{array}$ \\
\hline
\end{tabular}

See footnotes at end of table. 
Table 32. Conventional Motor Gasoline Prices by Grade, Sales Type, PAD District, and State

(Cents per Gallon Excluding Taxes) - Continued

\begin{tabular}{|c|c|c|c|c|c|c|c|c|c|c|c|c|}
\hline \multirow{3}{*}{$\begin{array}{l}\text { Geographic Area } \\
\text { Month }\end{array}$} & \multicolumn{6}{|c|}{ Regular } & \multicolumn{6}{|c|}{ Midgrade } \\
\hline & \multicolumn{2}{|c|}{ Sales to End Users } & \multicolumn{4}{|c|}{ Sales for Resale } & \multicolumn{2}{|c|}{ Sales to End Users } & \multicolumn{4}{|c|}{ Sales for Resale } \\
\hline & $\begin{array}{l}\text { Through } \\
\text { Retail } \\
\text { Outlets }\end{array}$ & Averagea & DTW & Rack & Bulk & Average & $\begin{array}{c}\text { Through } \\
\text { Retall } \\
\text { Outlets }\end{array}$ & Averagea & DTW & Rack & Bulk & Average \\
\hline
\end{tabular}

South Carolina

\begin{tabular}{|c|c|c|c|c|c|c|c|c|c|c|c|c|}
\hline \multicolumn{13}{|l|}{ South Carolina } \\
\hline 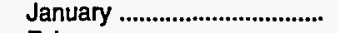 & 54.1 & 54.1 & 50.8 & 45.2 & W & 46.3 & 65.8 & 65.6 & 55.8 & 49.8 & $W$ & 51.3 \\
\hline 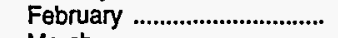 & 56.6 & 56.6 & 54.1 & 48.4 & $W$ & 49.6 & 68.0 & 67.8 & 59.2 & 53.0 & $w$ & 54.5 \\
\hline 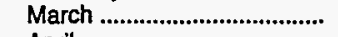 & 57.5 & 57.6 & 54.8 & 49.5 & $W$ & 50.5 & 68.4 & 68.3 & 59.6 & 54.1 & - & 55.9 \\
\hline April & 59.8 & 59.9 & 58.2 & 52.9 & $W$ & 54.2 & 71.0 & 70.7 & 63.4 & 57.7 & - & 59.5 \\
\hline May & 60.2 & 60.3 & 58.8 & 53.1 & $W$ & 54.5 & 71.5 & 71.7 & 63.9 & 57.9 & - & 59.9 \\
\hline 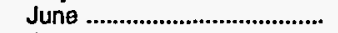 & 63.4 & 63.5 & 62.3 & 56.1 & $W$ & 57.7 & 74.2 & 74.9 & 66.9 & 61.1 & - & 62.9 \\
\hline July & 65.3 & 65.3 & 63.3 & 57.7 & $W$ & 59.0 & 76.7 & 77.2 & 68.3 & 62.4 & - & 64.2 \\
\hline 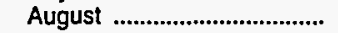 & 69.7 & 69.4 & 66.2 & 59.5 & W & 61.3 & 80.6 & 80.1 & 71.7 & 64.3 & - & 66.6 \\
\hline 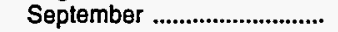 & 68.8 & 68.0 & 59.7 & 49.8 & W & 52.1 & 79.8 & 78.9 & 65.1 & 54.3 & - & 57.4 \\
\hline 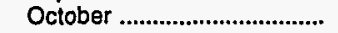 & 66.9 & 66.3 & 60.9 & 53.8 & W & 55.4 & 77.8 & 77.0 & 66.3 & 58.0 & - & 60.4 \\
\hline 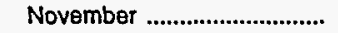 & 68.7 & 68.1 & 62.4 & 54.4 & W & 56.1 & 80.3 & 79.5 & 66.9 & 59.0 & - & 61.2 \\
\hline 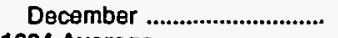 & 65.5 & 65.0 & 57.1 & 47.7 & $w$ & 49.5 & 76.6 & 75.7 & 63.4 & 52.2 & - & 55.4 \\
\hline 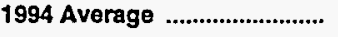 & 62.8 & 62.7 & 59.4 & 52.4 & 48.7 & 53.9 & 73.9 & 73.8 & 64.6 & 57.1 & $\mathbf{W}$ & 59.3 \\
\hline \multicolumn{13}{|l|}{ Virginia } \\
\hline 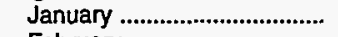 & 60.6 & 60.2 & 53.7 & 44.7 & $w$ & 47.6 & 71.0 & 70.5 & 59.8 & 48.7 & - & 53.9 \\
\hline 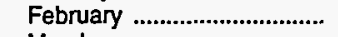 & 60.8 & 60.5 & 54.9 & 48.6 & 45.8 & 50.4 & 70.6 & 70.3 & 61.1 & 53.0 & - & 56.4 \\
\hline March & 60.8 & 60.5 & 56.7 & 49.4 & $W$ & 52.2 & 71.9 & 71.5 & 63.4 & 53.9 & $W$ & 58.6 \\
\hline April & 62.4 & 62.0 & 59.1 & 52.8 & $W$ & 55.3 & 73.1 & 72.7 & 65.7 & 57.3 & $W$ & 61.5 \\
\hline 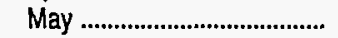 & 63.3 & 63.1 & 60.5 & 53.2 & W & 56.0 & 73.7 & 73.4 & 66.6 & 57.6 & - & 61.9 \\
\hline June & 65.9 & 65.7 & 62.6 & 56.5 & $W$ & 58.9 & 76.2 & 75.8 & 69.0 & 61.1 & $w$ & 65.0 \\
\hline July & 70.4 & 70.0 & 64.5 & 58.0 & $w$ & 60.5 & 80.3 & 79.8 & 70.6 & 62.4 & $w$ & 66.3 \\
\hline August & 71.5 & 71.1 & 66.7 & 59.8 & $w$ & 62.4 & 81.7 & 81.0 & 72.6 & 64.9 & $w$ & 68.8 \\
\hline 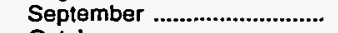 & 71.0 & 70.4 & 61.9 & 50.2 & $w$ & 54.6 & 81.5 & 80.7 & 69.8 & 55.4 & $\overline{-}$ & 62.5 \\
\hline October & 69.8 & 69.4 & 62.8 & 52.9 & W & 56.6 & 80.3 & 79.5 & 69.4 & 57.3 & $w$ & 63.5 \\
\hline 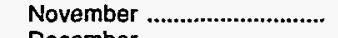 & 72.3 & 72.0 & 64.1 & 56.4 & $w$ & 59.0 & 82.3 & 81.7 & 70.2 & 61.5 & - & 65.6 \\
\hline 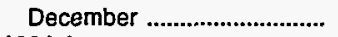 & 71.4 & 71.0 & 59.1 & 48.6 & $W$ & 51.6 & 81.1 & 80.8 & 66.8 & 54.0 & - & 58.8 \\
\hline 1994 Average & 66.9 & 66.5 & 61.2 & 53.0 & 53.9 & 56.0 & 77.2 & 76.7 & 67.7 & 57.8 & $W$ & 62.6 \\
\hline \multicolumn{13}{|l|}{ West Virginia } \\
\hline 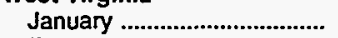 & 69.2 & 67.9 & 57.9 & 46.8 & w & 52.3 & 79.8 & 78.5 & 64.3 & 50.7 & - & 58.7 \\
\hline 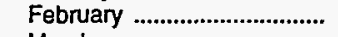 & 68.7 & 67.7 & 59.7 & 50.2 & $w$ & 55.0 & 78.6 & 77.4 & 65.6 & 54.5 & - & 61.2 \\
\hline 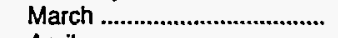 & 67.5 & 66.7 & 59.8 & 50.0 & $W$ & 54.6 & $\pi .5$ & 76.3 & 66.0 & 54.3 & - & 61.3 \\
\hline April & 68.0 & 67.4 & 62.0 & 53.5 & $w$ & 57.8 & 78.4 & 77.4 & 67.4 & 57.5 & - & 63.2 \\
\hline May & 69.1 & 68.4 & 63.0 & 54.0 & $w$ & 58.4 & 79.3 & 78.2 & 68.8 & 58.4 & - & 64.5 \\
\hline 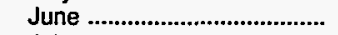 & 69.7 & 69.2 & 65.6 & 58.1 & $W$ & 61.8 & 79.7 & 78.8 & 71.2 & 62.0 & - & 67.5 \\
\hline July & 72.1 & 71.7 & 68.1 & 60.2 & - & 64.3 & 82.1 & 81.5 & 73.7 & 64.9 & - & 70.1 \\
\hline August & 76.6 & 76.1 & 70.3 & 62.9 & - & 67.0 & 86.4 & 85.4 & 75.5 & 67.5 & - & 72.5 \\
\hline 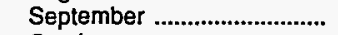 & 76.4 & 75.4 & 64.3 & 53.9 & $w$ & 59.5 & 86.2 & 84.6 & 69.8 & 58.8 & - & 65.6 \\
\hline 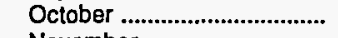 & 74.6 & 73.9 & 64.9 & 53.9 & W & 59.6 & 84.0 & 83.2 & 70.8 & 58.8 & - & 66.1 \\
\hline 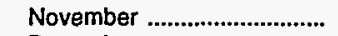 & 76.2 & 75.6 & 67.0 & 58.0 & - & 62.8 & 86.1 & 85.3 & 72.9 & 62.8 & - & 69.0 \\
\hline 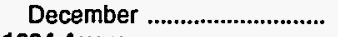 & 74.4 & 73.4 & 62.9 & 51.7 & W & 57.1 & 84.2 & 83.2 & 68.8 & 56.3 & - & 63.9 \\
\hline 1994 Average & 72.1 & 71.4 & 64.1 & 54.6 & $\mathbf{W}$ & 59.3 & 82.2 & 81.2 & 69.7 & 59.2 & - & 65.4 \\
\hline \multicolumn{13}{|l|}{ PAD District II } \\
\hline 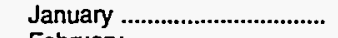 & 59.8 & 59.7 & 53.1 & 47.0 & 41.9 & 48.5 & 68.2 & 67.8 & 59.1 & 51.9 & - & 56.1 \\
\hline 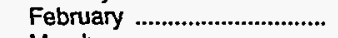 & 62.2 & 62.0 & 55.4 & 50.0 & 46.2 & 51.2 & 70.1 & 69.7 & 61.7 & 54.8 & - & 58.7 \\
\hline 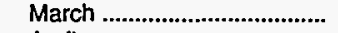 & 61.6 & 61.5 & 55.0 & 50.0 & 47.0 & 51.3 & 69.5 & 69.2 & 60.8 & 54.9 & - & 58.2 \\
\hline April & 64.6 & 64.5 & 58.6 & 54.1 & 50.4 & 55.1 & 72.6 & 72.4 & 64.5 & 58.8 & $W$ & 61.9 \\
\hline 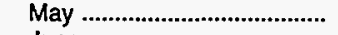 & 66.4 & 66.4 & 60.4 & 55.7 & 52.1 & 56.8 & 74.3 & 74.0 & 66.2 & 60.4 & - & 63.5 \\
\hline June & 69.8 & 69.7 & 64.1 & 59.5 & 55.4 & 60.6 & 77.7 & 77.3 & 70.0 & 64.1 & $W$ & 67.3 \\
\hline 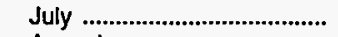 & 73.4 & 73.3 & 67.6 & 63.1 & 58.5 & 64.1 & 81.0 & 80.7 & 73.3 & 66.7 & $W$ & 70.3 \\
\hline August & 78.3 & 78.0 & 70.9 & 66.1 & 62.3 & 67.2 & 85.9 & 85.4 & 76.5 & 68.9 & - & 73.0 \\
\hline 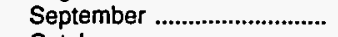 & 74.5 & 74.1 & 63.3 & 54.9 & 54.9 & 57.3 & 82.1 & 81.5 & 69.9 & 58.0 & $W$ & 64.7 \\
\hline 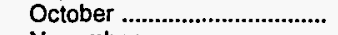 & 70.2 & 70.1 & 61.2 & 54.0 & 51.1 & 55.8 & 78.0 & 77.6 & 67.4 & 58.9 & - & 63.8 \\
\hline 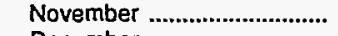 & 69.8 & 69.7 & 61.0 & 53.9 & 50.2 & 55.7 & 77.8 & 77.5 & 67.9 & 59.6 & $W$ & 64.4 \\
\hline 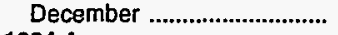 & 65.2 & 65.1 & 55.6 & 48.4 & 47.1 & 50.2 & 72.9 & 72.7 & 62.6 & 53.5 & $W$ & 58.3 \\
\hline 1994 Average ............................ & 68.4 & 68.2 & 60.9 & 55.1 & 51.7 & 56.5 & 76.0 & 75.7 & 66.8 & 59.6 & $w$ & 63.6 \\
\hline
\end{tabular}

See footnotes at end of table. 
Table 32. Conventional Motor Gasoline Prices by Grade, Sales Type, PAD District, and State

(Cents per Gallon Excluding Taxes) - Continued

\begin{tabular}{|c|c|c|c|c|c|c|c|c|c|c|c|c|}
\hline \multirow{3}{*}{$\begin{array}{c}\text { Geographic Area } \\
\text { Month }\end{array}$} & \multicolumn{6}{|c|}{ Premium } & \multicolumn{6}{|c|}{ All Grades } \\
\hline & \multicolumn{2}{|c|}{ Sales to End Users } & \multicolumn{4}{|c|}{ Sales for Resale } & \multicolumn{2}{|c|}{ Sales to End Users } & \multicolumn{4}{|c|}{ Sales for Resale } \\
\hline & $\begin{array}{c}\text { Through } \\
\text { Retall } \\
\text { Outlets }\end{array}$ & Averagea & DTW & Rack & Bulk & Average & $\begin{array}{c}\text { Through } \\
\text { Retail } \\
\text { Outlets }\end{array}$ & Averagea & DTW & Rack & Bulk & Average \\
\hline South Carolina & & & & & & & & & & & & \\
\hline 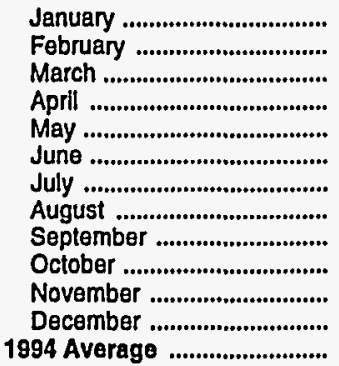 & $\begin{array}{l}75.9 \\
78.3 \\
78.3 \\
81.2 \\
81.8 \\
82.9 \\
85.8 \\
91.3 \\
90.5 \\
87.3 \\
90.7 \\
87.1 \\
84.0\end{array}$ & $\begin{array}{l}75.4 \\
77.7 \\
78.1 \\
81.2 \\
82.0 \\
83.0 \\
85.5 \\
90.8 \\
89.8 \\
86.7 \\
89.9 \\
86.2 \\
83.8\end{array}$ & $\begin{array}{l}62.4 \\
66.0 \\
66.8 \\
70.0 \\
69.9 \\
73.0 \\
74.8 \\
78.5 \\
72.9 \\
73.1 \\
75.3 \\
70.7 \\
71.3\end{array}$ & $\begin{array}{l}55.7 \\
58.6 \\
59.8 \\
63.0 \\
63.5 \\
66.6 \\
68.2 \\
70.4 \\
60.6 \\
64.6 \\
65.1 \\
58.6 \\
63.0\end{array}$ & $\begin{array}{l}W \\
W \\
\bar{W} \\
- \\
\overline{-} \\
\overline{-} \\
\overline{-} \\
\overline{-} \\
\bar{W}\end{array}$ & $\begin{array}{l}56.9 \\
59.9 \\
61.7 \\
64.6 \\
65.2 \\
68.2 \\
69.8 \\
72.8 \\
63.7 \\
66.4 \\
67.5 \\
61.5 \\
64.9\end{array}$ & $\begin{array}{l}60.1 \\
62.6 \\
63.3 \\
65.8 \\
66.2 \\
69.0 \\
71.1 \\
75.4 \\
74.6 \\
72.5 \\
74.6 \\
71.4 \\
68.7\end{array}$ & $\begin{array}{l}60.0 \\
62.5 \\
63.3 \\
65.8 \\
66.5 \\
69.3 \\
71.3 \\
75.2 \\
73.8 \\
71.9 \\
74.0 \\
70.9 \\
68.6\end{array}$ & $\begin{array}{l}54.2 \\
57.5 \\
58.3 \\
61.6 \\
62.2 \\
65.3 \\
66.5 \\
69.6 \\
63.4 \\
64.0 \\
65.8 \\
61.0 \\
62.8\end{array}$ & $\begin{array}{l}47.9 \\
51.1 \\
52.3 \\
55.7 \\
55.9 \\
59.0 \\
60.5 \\
62.3 \\
52.6 \\
56.5 \\
57.2 \\
50.6 \\
55.2\end{array}$ & $\begin{array}{l}W \\
W \\
W \\
W \\
W \\
W \\
W \\
W \\
W \\
W \\
W \\
W \\
48.6\end{array}$ & $\begin{array}{l}49.1 \\
52.5 \\
53.6 \\
57.2 \\
57.6 \\
60.6 \\
62.0 \\
64.3 \\
55.1 \\
58.2 \\
59.0 \\
52.7 \\
56.9\end{array}$ \\
\hline Virginla & & & & & & & & & & & & \\
\hline 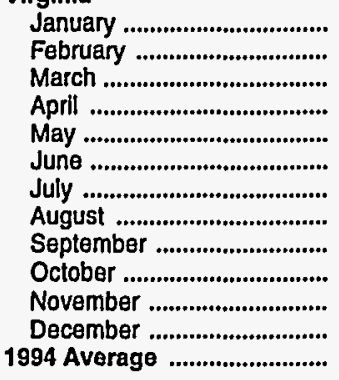 & $\begin{array}{l}80.1 \\
80.3 \\
80.8 \\
82.1 \\
82.9 \\
85.4 \\
89.3 \\
91.2 \\
90.4 \\
89.1 \\
90.6 \\
90.0 \\
86.2\end{array}$ & $\begin{array}{l}79.3 \\
79.5 \\
79.7 \\
81.2 \\
82.3 \\
84.6 \\
88.5 \\
90.0 \\
89.1 \\
88.0 \\
90.0 \\
89.3 \\
85.3\end{array}$ & $\begin{array}{l}67.0 \\
67.9 \\
70.2 \\
72.9 \\
74.0 \\
76.3 \\
78.1 \\
80.7 \\
77.0 \\
77.2 \\
78.3 \\
73.9 \\
75.1\end{array}$ & $\begin{array}{l}53.8 \\
58.0 \\
59.1 \\
62.9 \\
63.2 \\
66.6 \\
68.4 \\
70.5 \\
60.6 \\
63.1 \\
66.5 \\
58.7 \\
63.1\end{array}$ & $\begin{array}{l}- \\
\bar{W} \\
W \\
W \\
W \\
W \\
W \\
- \\
W \\
W \\
- \\
66.5\end{array}$ & $\begin{array}{l}59.4 \\
62.0 \\
64.3 \\
67.6 \\
68.1 \\
70.9 \\
72.8 \\
75.0 \\
67.9 \\
69.4 \\
71.1 \\
63.3 \\
68.4\end{array}$ & $\begin{array}{l}66.9 \\
66.9 \\
67.4 \\
68.9 \\
69.8 \\
72.2 \\
76.5 \\
77.7 \\
77.3 \\
76.0 \\
78.2 \\
77.4 \\
73.1\end{array}$ & $\begin{array}{l}66.3 \\
66.5 \\
66.8 \\
68.3 \\
69.4 \\
71.8 \\
76.0 \\
77.1 \\
76.5 \\
75.4 \\
77.7 \\
76.9 \\
72.6\end{array}$ & $\begin{array}{l}58.6 \\
59.7 \\
61.9 \\
64.3 \\
65.5 \\
67.7 \\
69.4 \\
71.6 \\
67.5 \\
68.0 \\
69.0 \\
64.0 \\
66.3\end{array}$ & $\begin{array}{l}47.3 \\
51.5 \\
52.4 \\
55.8 \\
56.3 \\
59.7 \\
61.2 \\
63.0 \\
53.4 \\
55.9 \\
59.5 \\
51.7 \\
56.1\end{array}$ & $\begin{array}{c}W \\
45.8 \\
W \\
W \\
W \\
W \\
W \\
W \\
W \\
W \\
W \\
W \\
56.0\end{array}$ & $\begin{array}{l}51.5 \\
54.2 \\
56.4 \\
59.4 \\
60.1 \\
63.0 \\
64.7 \\
66.6 \\
59.2 \\
60.9 \\
63.0 \\
55.4 \\
60.2\end{array}$ \\
\hline 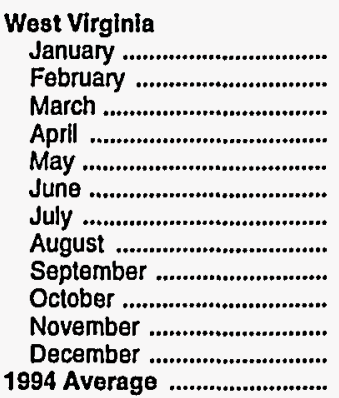 & $\begin{array}{l}85.8 \\
84.1 \\
83.8 \\
84.4 \\
85.9 \\
86.5 \\
89.4 \\
93.7 \\
93.2 \\
90.8 \\
93.6 \\
91.5 \\
88.8\end{array}$ & $\begin{array}{l}83.8 \\
82.6 \\
82.4 \\
83.2 \\
84.5 \\
85.5 \\
88.6 \\
92.5 \\
91.1 \\
89.5 \\
92.1 \\
89.4 \\
87.3\end{array}$ & $\begin{array}{l}71.1 \\
73.0 \\
73.5 \\
74.7 \\
76.4 \\
78.7 \\
81.6 \\
83.1 \\
77.7 \\
77.9 \\
79.8 \\
75.7 \\
76.9\end{array}$ & $\begin{array}{l}57.5 \\
61.1 \\
58.8 \\
64.6 \\
64.9 \\
68.9 \\
71.7 \\
74.1 \\
64.9 \\
65.0 \\
69.1 \\
61.9 \\
65.2\end{array}$ & $\begin{array}{l}- \\
- \\
- \\
- \\
- \\
- \\
- \\
- \\
- \\
-\end{array}$ & $\begin{array}{l}65.2 \\
67.9 \\
66.1 \\
70.4 \\
71.2 \\
74.3 \\
77.4 \\
79.4 \\
72.3 \\
72.3 \\
75.2 \\
69.6 \\
71.7\end{array}$ & $\begin{array}{l}74.1 \\
73.1 \\
72.1 \\
72.8 \\
73.9 \\
74.5 \\
76.9 \\
81.2 \\
81.1 \\
79.2 \\
81.1 \\
79.2 \\
76.9\end{array}$ & $\begin{array}{l}72.8 \\
72.1 \\
71.2 \\
72.0 \\
73.0 \\
73.9 \\
76.4 \\
80.6 \\
79.8 \\
78.4 \\
80.4 \\
78.1 \\
76.0\end{array}$ & $\begin{array}{l}61.9 \\
63.6 \\
63.7 \\
65.5 \\
66.9 \\
69.4 \\
71.9 \\
73.8 \\
67.9 \\
68.6 \\
70.7 \\
66.7 \\
67.7\end{array}$ & $\begin{array}{l}49.4 \\
52.9 \\
52.5 \\
56.0 \\
56.7 \\
60.8 \\
62.9 \\
65.7 \\
56.7 \\
56.8 \\
60.8 \\
54.5 \\
57.3\end{array}$ & $\begin{array}{l}w \\
W \\
W \\
W \\
w \\
w \\
- \\
\bar{w} \\
w \\
\vec{w} \\
w\end{array}$ & $\begin{array}{l}56.0 \\
58.6 \\
58.0 \\
61.1 \\
61.9 \\
65.2 \\
67.8 \\
70.3 \\
63.0 \\
63.2 \\
66.3 \\
60.7 \\
62.8\end{array}$ \\
\hline 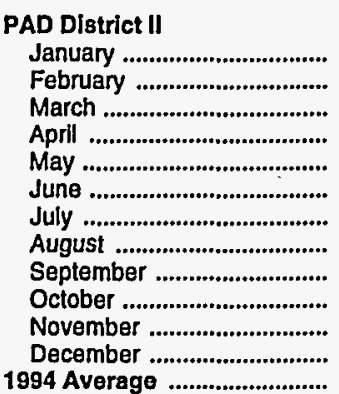 & $\begin{array}{l}74.7 \\
74.4 \\
76.4 \\
79.4 \\
81.5 \\
84.6 \\
88.0 \\
92.7 \\
88.8 \\
84.6 \\
85.0 \\
80.1 \\
82.4\end{array}$ & $\begin{array}{l}74.1 \\
74.0 \\
75.8 \\
78.9 \\
80.9 \\
84.0 \\
87.5 \\
91.9 \\
87.9 \\
83.9 \\
84.3 \\
79.6 \\
81.8\end{array}$ & $\begin{array}{l}65.2 \\
67.5 \\
66.8 \\
70.5 \\
72.3 \\
76.3 \\
79.4 \\
82.4 \\
75.6 \\
73.5 \\
73.4 \\
67.6 \\
72.5\end{array}$ & $\begin{array}{l}55.3 \\
58.0 \\
58.2 \\
62.3 \\
63.9 \\
67.8 \\
71.1 \\
74.2 \\
62.5 \\
62.8 \\
62.8 \\
57.1 \\
63.1\end{array}$ & $\begin{array}{l}46.1 \\
50.8 \\
51.8 \\
54.9 \\
57.7 \\
59.1 \\
67.1 \\
67.3 \\
57.1 \\
54.0 \\
52.7 \\
51.7 \\
55.2\end{array}$ & $\begin{array}{l}59.2 \\
61.6 \\
61.5 \\
65.4 \\
67.2 \\
71.0 \\
74.4 \\
77.4 \\
67.6 \\
66.9 \\
66.9 \\
60.9 \\
66.8\end{array}$ & $\begin{array}{l}63.5 \\
65.4 \\
64.9 \\
67.8 \\
69.7 \\
73.0 \\
76.5 \\
81.2 \\
77.5 \\
73.3 \\
73.1 \\
68.6 \\
71.5\end{array}$ & $\begin{array}{l}63.1 \\
65.1 \\
64.6 \\
67.6 \\
69.4 \\
72.7 \\
76.3 \\
80.7 \\
76.9 \\
73.0 \\
72.8 \\
68.4 \\
71.2\end{array}$ & $\begin{array}{l}56.5 \\
58.7 \\
58.1 \\
61.7 \\
63.5 \\
67.1 \\
70.6 \\
73.6 \\
66.3 \\
64.3 \\
64.2 \\
58.8 \\
63.8\end{array}$ & $\begin{array}{l}48.6 \\
51.5 \\
51.6 \\
55.6 \\
57.1 \\
61.0 \\
64.4 \\
67.3 \\
56.1 \\
55.5 \\
55.5 \\
50.0 \\
56.5\end{array}$ & $\begin{array}{l}42.1 \\
46.3 \\
47.2 \\
50.6 \\
52.2 \\
55.5 \\
58.6 \\
62.5 \\
55.1 \\
51.3 \\
50.3 \\
47.2 \\
51.9\end{array}$ & $\begin{array}{l}51.0 \\
53.5 \\
53.5 \\
57.3 \\
59.0 \\
62.8 \\
66.1 \\
69.1 \\
59.3 \\
58.1 \\
58.0 \\
52.5 \\
58.7\end{array}$ \\
\hline
\end{tabular}

See footnotes at end of table. 
Table 32. Conventional Motor Gasoline Prices by Grade, Sales Type, PAD District, and State

(Cents per Gallon Excluding Taxes) - Continued

\begin{tabular}{|c|c|c|c|c|c|c|c|c|c|c|c|c|}
\hline \multirow{3}{*}{$\begin{array}{c}\text { Geographic Area } \\
\text { Month }\end{array}$} & \multicolumn{6}{|c|}{ Regular } & \multicolumn{6}{|c|}{ Midgrade } \\
\hline & \multicolumn{2}{|c|}{ Sales to End Users } & \multicolumn{4}{|c|}{ Sales for Resale } & \multicolumn{2}{|c|}{ Sales to End Users } & \multicolumn{4}{|c|}{ Sales for Resale } \\
\hline & $\begin{array}{l}\text { Through } \\
\text { Retail } \\
\text { Outlets }\end{array}$ & Average ${ }^{a}$ & DTW & Rack & Bulk & Average & $\begin{array}{c}\text { Through } \\
\text { Retail } \\
\text { Outlots }\end{array}$ & Average ${ }^{a}$ & DTW & Rack & Bulk & Average \\
\hline
\end{tabular}

Illinois

January

Fobruan

March

64.4

May

June ...................................... 70.0

July.

August .

October ....................................... $\quad 73.5$

November

December

1994 Average .......................... 69.3

$\begin{array}{llll}61.6 & 61.2 & 53.9 & 47.3 \\ 62.6 & 62.5 & 56.3 & 49.5 \\ 61.1 & 61.1 & 55.3 & 48.6 \\ 64.4 & 64.4 & 59.5 & 53.1 \\ 65.6 & 65.7 & 61.5 & 55.0 \\ 70.0 & 69.9 & 66.4 & 59.2 \\ 73.6 & 73.6 & 69.5 & 62.4 \\ 80.0 & 79.7 & 72.8 & 64.9 \\ 77.5 & 76.9 & 68.5 & 53.5 \\ 73.5 & 73.0 & 65.8 & 53.2 \\ 72.0 & 71.8 & 64.7 & 53.1 \\ 67.0 & 67.0 & 56.5 & 46.9 \\ 69.3 & 69.1 & 63.0 & 54.1\end{array}$

40.1
47.4
46.0
50.9
51.0
56.0
56.6
62.9
56.0
51.6
50.5
47.6
52.5

$49.3 \quad 68$

51.3
50.5
54.9

56.9

61.6

64.0

67.0

58.5

56.8

56.4

56.7

Indiana

January ...

59.8

March ...

April

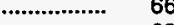

July ........................................ $\quad 72.7$

August ........................................ 76.5

September ........................... 70.1

October ............................. 66.7

November .............................. 68.2

December

1994 Average

lowa

January

$\quad 58.0$

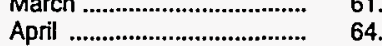

May ............... 65.

June ...................... 69.7

July

August .................................

September 77.9

October ..................................... 76.

November ................................. 73.8

December

1994 Average

ge .............................. 69

Kansas

January ................................. 58.1

February .......................... 60.4

March ..................................... 60.9

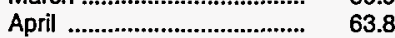

May .................................... 64.5

June ................................... 68.9

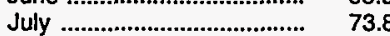

August ..................................... $\quad 78.4$

September ......................... 73.8

October .................................. 68.3

November ................................... 66.1

December

1994 Average

\section{7}

61.7

61.3

65.0

66.4

68.9

72.7

76.0

70.1

66.9

68.2

63.9
67.2

\section{5}

60.6

61.6

64.5

65.7

69.9

73.6

78.6

77.7

75.9

73.9

69.3

69.6

\section{2}

60.5

60.9

63.8

64.6

69.0

73.8

78.5

73.6

68.2

66.2

61.7

66.9

\section{$52.6 \quad 45.7 \quad 39.4$}

$55.4 \quad 48.4$

$54.4 \quad 48.0$

$58.6 \quad 53.1$

$60.3 \quad 54.2$

$63.9 \quad 58.3$

$67.1 \quad 60.8$

$69.8 \quad 63.6$

$62.0 \quad 52.3$

$59.6 \quad 53.0$

$\begin{array}{ll}59.7 & 53.3 \\ 54.5 & 46.8\end{array}$

$\begin{array}{ll}54.5 & 46.8 \\ 60.3 & 53.5\end{array}$

$\begin{array}{ll}53.7 & 48.3 \\ 57.0 & 51.7\end{array}$

$58.1 \quad 52.3$

$62.0 \quad 56.7$

$65.6 \quad 60.4$

$69.9 \quad 64.8$

$72.4 \quad 68.4$

$\begin{array}{ll}67.0 & 57.9 \\ 63.7 & 54.7\end{array}$

$\begin{array}{ll}63.7 & 54.7 \\ 62.9 & 54.1\end{array}$

$\begin{array}{ll}62.9 & 54.1 \\ 59.4 & 50.0\end{array}$

$62.9 \quad 56.6$

$53.4 \quad 50.0$

$54.1 \quad 50.9$

$57.7 \quad 54.3$

$58.8 \quad 55.6$

59.2

NA 64.0

$71.0 \quad 67.5$

$\begin{array}{ll}58.1 & 53.5 \\ 57.5 & 52.5\end{array}$

$\begin{array}{ll}57.5 & 52.5 \\ 52.6 & 48.7\end{array}$

58.5

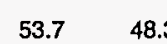

$60.3 \quad 55.4$

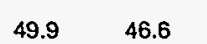

$53.6 \quad 57.4$

$\begin{array}{lll}39.4 & 48.1 & 67 . \\ 46.0 & 50.6 & 69.8 \\ 46.2 & 49.8 & 69 . \\ 48.4 & 54.4 & 72.8 \\ 51.4 & 56.0 & 74 . \\ 54.2 & 60.1 & 76.1 \\ 57.4 & 62.6 & 80.1 \\ 61.6 & 65.4 & 84.1 \\ \mathbf{5 7 . 5} & 56.2 & 77.6 \\ \mathbf{5 1 . 4} & 55.2 & 74.3 \\ \mathbf{5 1 . 6} & 55.4 & 76.0 \\ 46.3 & 49.3 & 71.3 \\ \mathbf{5 1 . 8} & \mathbf{5 5 . 7} & 74.8\end{array}$

W 48.9

\begin{tabular}{l}
$W$ \\
$-\quad 52.9$ \\
\hline
\end{tabular}

- $\quad 53.0$

-56.0
$-\quad 56.4$

-57.4
$-\quad 61.0$

- 65.5

- 69.0

- $\quad 59.0$

$\bar{w}$

$\bar{w}$

55.7
55.1

51.2

57.4

$43.9 \quad 46.7$

47.9

50.8

52.3

$55.8 \quad 58.9$

$\begin{array}{ccc}W & 64.4 & 80.5 \\ 63.7 & 67.4\end{array}$

$\begin{array}{lll}63.7 & 67.4 & 87.4\end{array}$

$50.8 \quad 53.9$

Wo.8 53.9

$\begin{array}{ll}W & 52.9 \\ W & 48.7\end{array}$

$\begin{array}{cr}W & 48.7 \\ 51.5 & 55.3\end{array}$

09.8

75.1

79.3

83.9

82.4

80.3
78.4

72.8
- 61.0

$\begin{array}{ll}68.5 & 68.2 \\ 69.3 & 69.1 \\ 68.2 & 68.0 \\ 71.6 & 71.6 \\ 72.3 & 72.3 \\ 77.3 & 77.0 \\ 80.7 & 80.5 \\ 85.9 & 85.6 \\ 85.1 & 84.4 \\ 80.3 & 79.9 \\ 77.7 & 77.6 \\ 71.9 & 71.9 \\ 76.3 & 76.2\end{array}$

$60.6 \quad 54.1$

$\begin{array}{ll}63.3 & 55.5 \\ 62.4 & 54.2\end{array}$

$66.5 \quad 58.4$

$68.5 \quad 62.5$

73.6

76.6

80.1

76.4

73.1
72.0

66.9

70.1

$67.6 \quad 67.4$

$69.2 \quad 68.5$

$72.8 \quad 72.2$

$\begin{array}{ll}73.6 & 73.9\end{array}$

$76.1 \quad 75.6$

$80.1 \quad 79.7$

$\begin{array}{ll}84.1 & 83.8\end{array}$

74.3

$76.0 \quad 75.8$

$\begin{array}{ll}71.3 & 71.5 \\ 74.8 & 74.4\end{array}$

74.4

$\begin{array}{lll}63.8 & 64.1 & 56.9\end{array}$

$66.7 \quad 66.9 \quad 60.1$

67.0

$68.9 \quad 69.2$

$69.8 \quad 70.1$

70.1
74.8

78.7

83.8

81.9

79.1
78.3

73.5

74.8

\section{1}

61.3

60.1
64.6

66.2

69.4
73.2

73.2
75.7

68.0

64.9

65.3

61.0

62.5
64.8

68.0

71.1

59.1

59.1

58.4

52.8

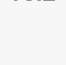

51.0

53.8

53.5

58.1

59.7

63.8

66.3

68.7

57.6

57.5

58.5

52.3

58.7

59.0
$-\quad 61.5$

\begin{tabular}{l}
-61.5 \\
$-\quad 60.2$ \\
\hline
\end{tabular}

- 64.3

- 66.8

$\begin{array}{ll}- & 71.2 \\ - & 74.3\end{array}$

78.2
$-\quad 78.4$

- $\quad 72.4$

$\begin{array}{ll}- & 70.1 \\ \text { - } & 69.2\end{array}$

- $\quad 62.6$

See footnotes at end of table. 
Table 32. Conventional Motor Gasoline Prices by Grade, Sales Type, PAD District, and State

(Cents per Gallon Excluding Taxes) - Continued



See footnotes at end of table. 
Table 32. Conventional Motor Gasoline Prices by Grade, Sales Type, PAD District, and State

(Cents per Gallon Excluding Taxes) - Continued

\begin{tabular}{|c|c|c|c|c|c|c|c|c|c|c|c|c|}
\hline \multirow{3}{*}{$\begin{array}{l}\text { Geographic Area } \\
\text { Month }\end{array}$} & \multicolumn{6}{|c|}{ Regular } & \multicolumn{6}{|c|}{ Midgrade } \\
\hline & \multicolumn{2}{|c|}{ Sales to End Users } & \multicolumn{4}{|c|}{ Sales for Resale } & \multicolumn{2}{|c|}{ Sales to End Users } & \multicolumn{4}{|c|}{ Sales for Resale } \\
\hline & $\begin{array}{l}\text { Through } \\
\text { Retail } \\
\text { Outlets }\end{array}$ & Averagea & DTW & Rack & Bulk & Average & $\begin{array}{c}\text { Through } \\
\text { Retail } \\
\text { Outlets }\end{array}$ & Averagea & DTW & Rack & Bulk & Average \\
\hline
\end{tabular}

\begin{tabular}{|c|c|c|c|c|c|c|c|c|c|c|c|c|}
\hline \multicolumn{13}{|l|}{ Kentucky } \\
\hline 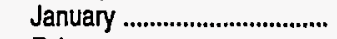 & 60.4 & 59.6 & 54.0 & 46.7 & $W$ & 48.8 & 68.8 & 67.8 & 60.0 & 51.4 & - & 55.2 \\
\hline 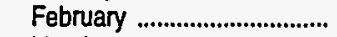 & 62.9 & 62.3 & 55.8 & 49.8 & $W$ & 51.7 & 71.2 & 70.3 & 61.5 & 54.2 & - & 56.9 \\
\hline 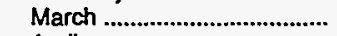 & 63.8 & 63.2 & 57.7 & 50.4 & - & 52.8 & 73.0 & 72.0 & 61.9 & 54.9 & - & 57.6 \\
\hline April & 65.7 & 65.2 & 59.9 & 54.0 & - & 55.9 & 74.8 & 73.8 & 65.3 & 58.6 & - & 61.3 \\
\hline 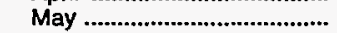 & 68.6 & 67.8 & 61.0 & 54.7 & - & 56.7 & 78.0 & 76.6 & 66.5 & 59.3 & - & 62.3 \\
\hline 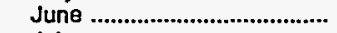 & 70.0 & 69.5 & 64.7 & 58.4 & - & 60.5 & 79.9 & 78.8 & 70.2 & 63.5 & - & 66.3 \\
\hline July & 71.7 & 71.3 & 67.3 & 60.9 & - & 63.0 & 81.5 & 80.7 & 73.0 & 66.4 & - & 69.2 \\
\hline 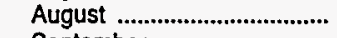 & 74.4 & 73.8 & 67.7 & 62.2 & - & 64.0 & 86.3 & 85.0 & 74.0 & 68.0 & - & 70.2 \\
\hline 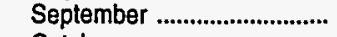 & 70.4 & 69.5 & 60.2 & 51.6 & W & 54.3 & 81.1 & 79.5 & 66.9 & 56.9 & - & 61.0 \\
\hline October & 67.6 & 66.9 & 60.0 & 53.8 & - & 55.8 & 79.0 & 77.7 & 66.1 & 58.6 & - & 62.0 \\
\hline 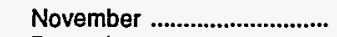 & 69.1 & 68.5 & 61.8 & 54.7 & - & 57.1 & 80.4 & 79.0 & 68.0 & 61.4 & - & 64.7 \\
\hline 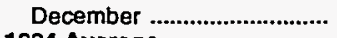 & 67.7 & 66.9 & 56.7 & 48.2 & $\overline{-}$ & 51.1 & 78.2 & 76.9 & 63.4 & 53.7 & - & 58.3 \\
\hline 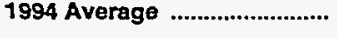 & 67.6 & 67.0 & 60.8 & 54.1 & $\mathbf{w}$ & 56.2 & 77.7 & 76.4 & 66.6 & 59.3 & - & 62.4 \\
\hline \multicolumn{13}{|l|}{ Michigan } \\
\hline 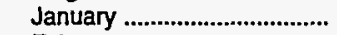 & 58.9 & 58.6 & 52.6 & 46.8 & - & 49.4 & 67.3 & 67.3 & 57.4 & 51.7 & - & 55.6 \\
\hline 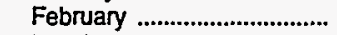 & 62.0 & 61.6 & 54.8 & 50.1 & - & 52.2 & 69.9 & 69.7 & 59.8 & 54.7 & - & 58.2 \\
\hline 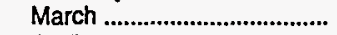 & 59.9 & 59.7 & 53.5 & 48.5 & - & 50.8 & 67.8 & 67.8 & 58.0 & 53.1 & - & 56.4 \\
\hline April & 64.5 & 64.3 & 57.0 & 53.7 & - & 55.2 & 72.0 & 72.0 & 62.2 & 58.0 & - & 60.8 \\
\hline May & 66.4 & 66.2 & 58.9 & 56.3 & - & 57.4 & 73.8 & 73.8 & 64.1 & 61.2 & - & 63.1 \\
\hline June & 70.5 & 70.2 & 63.4 & 60.7 & - & 61.9 & 77.9 & 77.8 & 68.5 & 66.2 & - & 67.7 \\
\hline July & 74.1 & 74.0 & 66.3 & 64.1 & - & 65.1 & 81.4 & 81.3 & 71.6 & 69.2 & - & 70.9 \\
\hline August & 77.8 & 77.6 & 70.8 & 66.8 & - & 68.5 & 85.6 & 85.4 & 76.4 & 71.1 & - & 74.8 \\
\hline 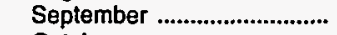 & 72.8 & 72.6 & 62.0 & 54.1 & $w$ & 57.6 & 80.8 & 80.6 & 68.3 & 58.8 & - & 65.6 \\
\hline October & 68.8 & 68.7 & 59.4 & 54.4 & - & 56.6 & 76.5 & 76.4 & 64.5 & 59.8 & - & 63.3 \\
\hline 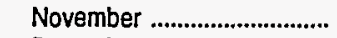 & 69.3 & 69.3 & 60.2 & 54.9 & - & 57.3 & 77.5 & 77.3 & 66.0 & 59.3 & - & 64.2 \\
\hline 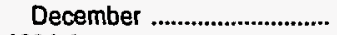 & 63.8 & 63.9 & 54.1 & 47.8 & - & 50.7 & 72.1 & 72.1 & 60.2 & 53.2 & - & 58.4 \\
\hline 1994 Average ............................ & 68.0 & 67.7 & 59.7 & 55.3 & $\mathbf{W}$ & 57.3 & 75.5 & 75.4 & 64.9 & 59.9 & - & 63.4 \\
\hline \multicolumn{13}{|l|}{ Minnesota } \\
\hline 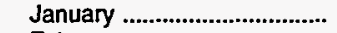 & 67.5 & 67.4 & 57.3 & 49.8 & $w$ & 51.0 & 74.2 & 73.5 & 59.4 & 57.3 & - & 58.5 \\
\hline 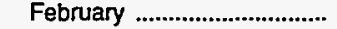 & 71.3 & 70.8 & 59.2 & 53.6 & $\mathbf{w}$ & 54.5 & 75.7 & 75.2 & 64.9 & 60.2 & - & 62.9 \\
\hline March & 70.2 & 69.7 & 59.3 & 54.1 & $w$ & 55.0 & 75.1 & 74.8 & 63.3 & 60.1 & - & 61.8 \\
\hline April & 71.3 & 71.1 & 62.1 & 57.3 & $w$ & 57.9 & 76.2 & 76.1 & 64.1 & 60.9 & - & 62.5 \\
\hline 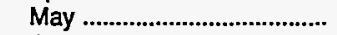 & 73.5 & 73.1 & 63.6 & 58.6 & $w$ & 59.4 & 77.8 & 77.5 & 64.3 & 62.3 & - & 63.3 \\
\hline June & 75.7 & 75.6 & 66.4 & 61.9 & W & 62.6 & 80.2 & 80.1 & 66.2 & 64.6 & - & 65.4 \\
\hline July & 79.6 & 79.3 & 71.4 & 66.5 & $w$ & 67.4 & 84.1 & 83.8 & 70.7 & 69.4 & - & 70.1 \\
\hline 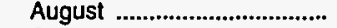 & 85.0 & 84.1 & 74.4 & 70.5 & $\mathbf{w}$ & 71.2 & 92.3 & 91.3 & 74.0 & 72.5 & - & 73.2 \\
\hline 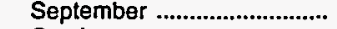 & 82.5 & 81.3 & 65.8 & 60.0 & W & 61.0 & 88.5 & 87.3 & 67.6 & 63.7 & - & 65.7 \\
\hline October & 76.9 & 75.7 & 63.5 & 55.6 & $w$ & 56.9 & 81.2 & 79.9 & NA & NA & - & NA \\
\hline 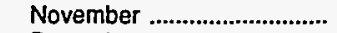 & 74.6 & 73.8 & 60.9 & 55.2 & $w$ & 56.1 & 79.9 & 78.5 & 68.0 & 64.3 & - & 66.2 \\
\hline 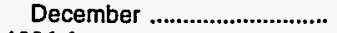 & 71.9 & 71.4 & 58.0 & 51.6 & $w$ & 52.7 & 76.6 & 75.7 & 65.8 & 60.4 & - & 63.2 \\
\hline 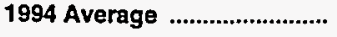 & 76.0 & 75.4 & 64.6 & 58.8 & $\mathbf{W}$ & 59.8 & 80.4 & 79.9 & 67.3 & 64.6 & - & 66.0 \\
\hline \multicolumn{13}{|l|}{ Missouri } \\
\hline 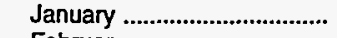 & 55.4 & 55.6 & 52.1 & 46.5 & $W$ & 47.8 & 64.1 & 64.2 & 58.0 & 51.2 & - & 55.4 \\
\hline 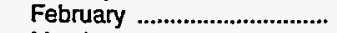 & 58.7 & 58.6 & 54.7 & 49.6 & $W$ & 50.7 & 68.2 & 68.2 & 61.2 & 54.4 & - & 58.6 \\
\hline 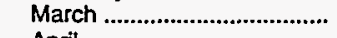 & 58.2 & 58.4 & 54.1 & 50.0 & $W$ & 51.0 & 67.3 & 67.2 & 59.9 & 54.3 & - & 57.9 \\
\hline April & 60.7 & 60.7 & 57.7 & 53.6 & $W$ & 54.5 & 69.8 & 69.7 & 63.4 & 58.5 & - & 61.7 \\
\hline 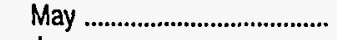 & 63.1 & 63.0 & 59.8 & 55.3 & 51.2 & 56.3 & 72.5 & 72.4 & 65.1 & 60.2 & - & 63.5 \\
\hline June & 66.8 & 66.8 & 63.3 & 59.2 & 54.6 & 60.2 & 76.4 & 76.1 & 69.6 & 64.4 & - & 67.8 \\
\hline 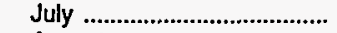 & 71.1 & 70.9 & 67.7 & 63.0 & $w$ & 64.2 & 80.0 & 79.7 & 73.1 & 67.3 & - & 71.1 \\
\hline August & 77.1 & 77.0 & 70.3 & 66.2 & $\mathbf{w}$ & 67.3 & 86.0 & 85.5 & 77.1 & 70.5 & - & 74.9 \\
\hline 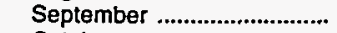 & 74.2 & 74.0 & 63.2 & 55.6 & 50.2 & 57.8 & 82.9 & 82.3 & 70.9 & 59.6 & - & 67.3 \\
\hline 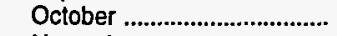 & 68.3 & 68.4 & 59.5 & 53.4 & $W$ & 54.9 & 77.1 & 77.0 & 66.6 & 57.9 & - & 63.5 \\
\hline 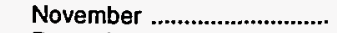 & 66.8 & 67.0 & 58.8 & 52.7 & $W$ & 54.5 & 75.9 & 75.9 & 65.9 & 58.6 & - & 63.4 \\
\hline 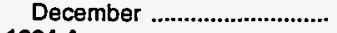 & 61.2 & 61.4 & 53.9 & 47.9 & $W$ & 49.7 & 69.6 & 69.7 & 60.2 & 51.9 & - & 57.4 \\
\hline 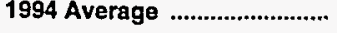 & 65.4 & 65.3 & 59.8 & 54.7 & 48.5 & 56.1 & 74.2 & 74.1 & 66.0 & 59.0 & - & 63.7 \\
\hline
\end{tabular}

See footnotes at end of table. 
Table 32. Conventional Motor Gasoline Prices by Grade, Sales Type, PAD District, and State

(Cents per Gallon Excluding Taxes) - Continued

\begin{tabular}{|c|c|c|c|c|c|c|c|c|c|c|c|c|}
\hline \multirow{3}{*}{$\begin{array}{c}\text { Geographlc Area } \\
\text { Month }\end{array}$} & \multicolumn{6}{|c|}{ Premium } & \multicolumn{6}{|c|}{ All Grades } \\
\hline & \multicolumn{2}{|c|}{ Sales to End Users } & \multicolumn{4}{|c|}{ Sales for Resale } & \multicolumn{2}{|c|}{ Sales to End Users } & \multicolumn{4}{|c|}{ Sales for Resale } \\
\hline & $\begin{array}{c}\text { Through } \\
\text { Retail } \\
\text { Outlets }\end{array}$ & Average $a$ & DTW & Rack & Bulk & Average & $\begin{array}{c}\text { Through } \\
\text { Retail } \\
\text { Outlets }\end{array}$ & Average ${ }^{a}$ & DTW & Rack & Bulk & Average \\
\hline
\end{tabular}

Kentucky

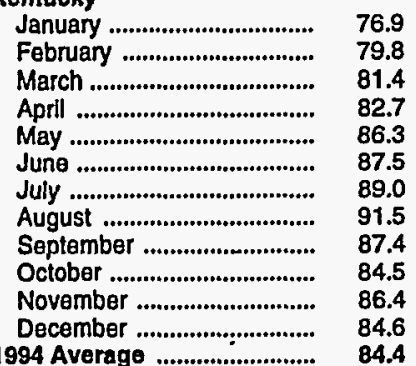

1994 Average ........................ 84.4

Michigan

February .............................. 71.9

March ............................. 74.6

April $\quad 77.8$

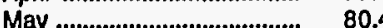

June ....................................... 84.1

July

August

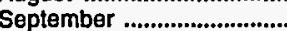

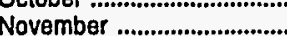

December

MInnesota

January

80.2

February

March

April .

May

June

July ....

August .

October

December ...............................

Missouri

January ............................... 71.

February

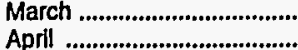

May.

Juns

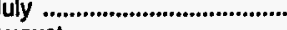

Oclober .

November

December

1994 Average
January ............................. $\quad 73.6$

1994 Average ...........................

1994 Average

August ..................................

$\begin{array}{lll}75.8 & 66.7 & 56.0 \\ 78.8 & 68.5 & 58.8 \\ 80.3 & 70.2 & 59.7 \\ 81.8 & 72.1 & 63.3 \\ 85.0 & 72.9 & 63.9 \\ 86.5 & 76.5 & 68.2 \\ 88.3 & 80.1 & 70.9 \\ 90.4 & 80.0 & 72.8 \\ 85.9 & 72.2 & 61 . \\ 83.4 & 71.7 & 63.9 \\ 85.2 & 74.0 & 65.3 \\ 83.3 & 68.4 & 58.4 \\ 83.2 & \mathbf{7 2 . 9} & 63.7\end{array}$

56.0
58.8
59.7
63.3
63.9
68.2
70.9
72.8
61.6
63.9
65.3
58.4
63.7

$\overline{-}$
$\bar{w}$
$\overline{-}$
$\overline{-}$
$\overline{-}$
$\overline{-}$
$\bar{w}$

$\begin{array}{ll}60.1 & 65.4 \\ 62.4 & 67.8 \\ 63.0 & 68.9 \\ 66.5 & 70.6 \\ 67.2 & 73.6 \\ 71.1 & 75.0 \\ 74.4 & 76.6 \\ 75.3 & 79.1 \\ 65.1 & 75.2 \\ 66.4 & 72.6 \\ 68.3 & 74.0 \\ 61.7 & 72.6 \\ 66.9 & 72.4\end{array}$

$$
\begin{aligned}
& 64.6 \\
& 67.0 \\
& 68.1 \\
& 69.9 \\
& 72.6 \\
& 74.3 \\
& 76.2 \\
& 78.4 \\
& 74.1 \\
& 71.7 \\
& 73.2 \\
& 71.6 \\
& 71.5
\end{aligned}
$$

\section{9}

71.5

73.9

77.1

79.6

83.3

87.2

90.9

86.5

82.6

83.3

78.1

63.2
65.4
63.8
68.0
69.8
74.0
77.3
82.2
74.0
70.6
71.1
65.1
70.3

55.8
58.5
56.9
62.3
64.9
69.6
73.1
76.2
63.6
63.8
64.1
57.0
64.0

$\begin{array}{lll}79.8 & 68.5 & 58.0\end{array}$

$85.4 \quad 72.5 \quad 62.0$

$84.3 \quad 71.1 \quad 62.3$

$84.2 \quad 72.4 \quad 65.6$

$86.4 \quad 75.2 \quad 67.0$

$87.9 \quad 77.4 \quad 70.5$

$92.2 \quad 80.7 \quad 75.1$

$\begin{array}{lll}98.8 & 84.6 & 79.2\end{array}$

$87.2 \quad 72.7 \quad 64.1$

$87.1 \quad 70.5 \quad 63.3$

$84.3 \quad 70.1 \quad 60.0$

$88.7 \quad 75.5$

67.1

$\begin{array}{cc}- & 59.7 \\ - & 62.3 \\ - & 60.7 \\ - & 65.5 \\ - & 67.5 \\ - & 71.9 \\ \bar{w} & 75.3 \\ \text { W } & 79.2 \\ - & 69.2 \\ - & 67.5 \\ \overline{\text { W }} & 67.9 \\ & 61.4 \\ & 67.4\end{array}$

62.5

65.2

63.2

67.5

69.3

73.3

76.9

80.6

75.7

71.8
72.5

67.1

70.9

62.2
64.7
62.9
67.2
69.1
73.0
76.8
80.3
75.5
71.6
72.3
67.0
70.6

\section{W $\quad 59.6$}

$59.6 \quad 69$

$69.9 \quad 69.6$

73.3

72.2
73.2

73.2
75.4

77.6

81.4

86.9

84.2

77.9

75.8
73.2
77.7

72.7
71.7
72.9
74.8
77.3
81.0
85.9
82.9
76.8
75.0
72.6
77.0

$70.6 \quad 63$

72.9

74.3

76.9

6.96 .7

$79.3 \quad 70.4$

$83.1 \quad 74.1$

$86.9 \quad 78.3$

93.

$\begin{array}{ll}93.2 & 81.3 \\ 89.8 & 74.6\end{array}$

$84.5 \quad 71.4$

$83.4 \quad 70.4$

77.0

80.7

63.2
66.5
65.0
68.7
70.4
74.1
78.3
81.3
74.6
71.4
70.4
65.2
70.9

54.1

$\begin{array}{lll}57.4 & W & 57.2\end{array}$

57.8

63.0

67.2

74.2

74.2
63.3
61.1

61.1
60.5

55.7

70.9

62.4 $\begin{array}{lll}95.6 & 77.7 & 69.4\end{array}$
$58.8 \quad 58.8$

62.1

61.5

63.8

66.2
69.9

69.9
74.0

80.0

77.1

71.3

69.9

64.3
61.8
61.4
61.4
63.6
66.0
69.7
73.7
79.7
76.7
71.2
69.9
64.4
68.2
$58.1 \quad 49.3$

59.7

61.3

63.5

64.5

68.1
71.2

71.2

63.6

63.3

65.1

60.0

64.3

$55.4 \quad 48.7$

$57.5 \quad 51.7$

$56.0 \quad 50.1$

59.7

61.5

66.0

69.0

73.5

65.0

62.1

63.0

62.3

$58.4 \quad 50.7$

$61.4 \quad 54.6$

$61.3 \quad 55.2$

$63.4 \quad 58.2$

$64.8 \quad 59.5$

$67.4 \quad 62.7$

$72.0 \quad 67.4$

$75.2 \quad 71.2$

$67.1 \quad 60.8$

$64.2 \quad 56.3$

$62.4 \quad 56.0$

$60.1 \quad 52.6$

$\begin{array}{ll}65.9 & 59.7\end{array}$

$54.9 \quad 48.0$

$\begin{array}{ll}57.4 & 51.0 \\ 56.5 & 51.3\end{array}$

$60.2 \quad 55.0$

62.1

65.9

70.1

72.8

65.9

62.2
61.5

56.5

62.4
$\begin{array}{cc}W & 52.1 \\ W & 54.7 \\ W & 55.8 \\ - & 58.9 \\ - & 59.7 \\ - & 63.5 \\ - & 66.2 \\ - & 67.0 \\ \text { W } & 57.3 \\ - & 58.7 \\ - & 60.3 \\ - & 54.1 \\ 46.6 & 59.3\end{array}$

$-\quad 52.0$

- $\quad 54.6$

-53.0
$-\quad 57.4$

- $\quad 57.4$

- $\quad 59.6$

\begin{tabular}{l}
64.1 \\
$-\quad 67.3$ \\
\hline
\end{tabular}

W $\quad 70.8$

W $\quad 60.1$

- $\quad 59.0$

$-\quad 59.7$
$-\quad 53.2$

$55.7 \quad 59.5$

Seo footnotes at end of table. 
Table 32. Conventional Motor Gasoline Prices by Grade, Sales Type, PAD District, and State (Cents per Gallon Excluding Taxes) - Continued

\begin{tabular}{|c|c|c|c|c|c|c|c|c|c|c|c|c|}
\hline \multirow{3}{*}{$\begin{array}{l}\text { Goographic Area } \\
\text { Month }\end{array}$} & \multicolumn{6}{|c|}{ Regular } & \multicolumn{6}{|c|}{ Midgrade } \\
\hline & \multicolumn{2}{|c|}{ Sales to End Users } & \multicolumn{4}{|c|}{ Sales for Resale } & \multicolumn{2}{|c|}{ Sales to End Users } & \multicolumn{4}{|c|}{ Sales for Resale } \\
\hline & $\begin{array}{c}\text { Through } \\
\text { Retail } \\
\text { Outlets }\end{array}$ & Averagea & DTW & Rack & Bulk & Average & \begin{tabular}{c|} 
Through \\
Retail \\
Outlets
\end{tabular} & Averagea & DTW & Rack & Bulk & Average \\
\hline \multicolumn{13}{|l|}{ Nebraska } \\
\hline 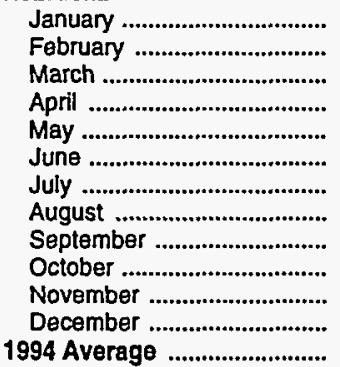 & $\begin{array}{l}63.4 \\
66.9 \\
67.6 \\
68.9 \\
69.2 \\
72.1 \\
76.9 \\
81.4 \\
78.2 \\
73.2 \\
71.6 \\
68.1 \\
71.6\end{array}$ & $\begin{array}{l}63.0 \\
66.5 \\
67.1 \\
68.7 \\
69.1 \\
71.7 \\
76.6 \\
81.2 \\
78.0 \\
73.1 \\
71.5 \\
68.0 \\
71.4\end{array}$ & $\begin{array}{l}54.4 \\
57.7 \\
58.4 \\
61.2 \\
62.0 \\
65.7 \\
70.0 \\
73.2 \\
68.1 \\
64.9 \\
61.1 \\
58.3 \\
63.2\end{array}$ & $\begin{array}{l}47.5 \\
51.1 \\
52.1 \\
55.3 \\
56.6 \\
60.1 \\
64.6 \\
68.6 \\
58.2 \\
55.1 \\
53.6 \\
49.8 \\
56.5\end{array}$ & $\begin{array}{l}\overline{-} \\
\overline{-} \\
\overline{-} \\
\bar{w} \\
\bar{W} \\
\overline{-} \\
\overline{-} \\
\bar{w}\end{array}$ & $\begin{array}{l}48.8 \\
52.3 \\
53.3 \\
56.4 \\
57.6 \\
61.1 \\
65.7 \\
69.4 \\
60.1 \\
57.0 \\
55.1 \\
51.5 \\
57.8\end{array}$ & $\begin{array}{l}68.6 \\
73.7 \\
74.4 \\
76.7 \\
75.3 \\
78.9 \\
82.1 \\
88.9 \\
85.4 \\
80.3 \\
77.1 \\
74.1 \\
77.3\end{array}$ & $\begin{array}{l}68.2 \\
73.2 \\
74.0 \\
76.5 \\
75.1 \\
78.4 \\
82.0 \\
88.6 \\
85.1 \\
79.9 \\
76.7 \\
73.5 \\
76.9\end{array}$ & $\begin{array}{l}60.8 \\
66.7 \\
64.6 \\
66.7 \\
67.8 \\
71.0 \\
75.3 \\
78.1 \\
68.9 \\
64.3 \\
63.6 \\
60.5 \\
67.2\end{array}$ & $\begin{array}{l}55.3 \\
61.1 \\
60.5 \\
64.1 \\
64.8 \\
68.4 \\
72.9 \\
76.0 \\
65.5 \\
63.6 \\
62.6 \\
60.0 \\
64.4\end{array}$ & $\begin{array}{l}- \\
- \\
- \\
- \\
- \\
- \\
- \\
- \\
- \\
- \\
- \\
-\end{array}$ & $\begin{array}{l}56.6 \\
63.3 \\
61.4 \\
64.7 \\
65.4 \\
69.0 \\
73.5 \\
76.9 \\
66.9 \\
63.8 \\
63.0 \\
60.2 \\
65.3\end{array}$ \\
\hline \multicolumn{13}{|l|}{ North Dakota } \\
\hline 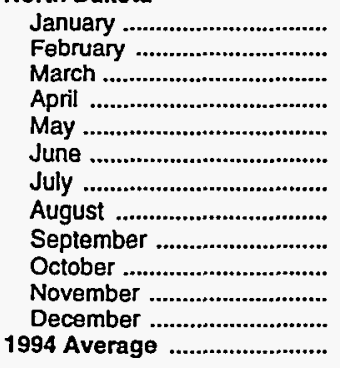 & $\begin{array}{l}75.1 \\
74.8 \\
73.7 \\
77.2 \\
79.4 \\
80.4 \\
83.5 \\
88.0 \\
87.2 \\
84.0 \\
81.0 \\
78.2 \\
80.7\end{array}$ & $\begin{array}{l}74.4 \\
73.9 \\
72.9 \\
75.8 \\
78.3 \\
79.4 \\
82.5 \\
87.3 \\
86.1 \\
82.7 \\
79.8 \\
77.0 \\
79.6\end{array}$ & $\begin{array}{l}60.2 \\
60.3 \\
60.4 \\
63.2 \\
65.7 \\
67.9 \\
71.4 \\
75.6 \\
69.4 \\
66.0 \\
63.6 \\
62.5 \\
66.3\end{array}$ & $\begin{array}{l}\mathbf{5 1 . 0} \\
\mathbf{5 3 . 2} \\
\mathbf{5 4 . 0} \\
\mathbf{5 7 . 2} \\
\mathbf{5 8 . 9} \\
62.3 \\
\mathbf{6 6 . 4} \\
\mathbf{7 2 . 0} \\
60.7 \\
\mathbf{5 6 . 5} \\
\mathbf{5 5 . 8} \\
\mathbf{5 2 . 2} \\
\mathbf{5 8 . 9}\end{array}$ & $\begin{array}{l}W \\
w \\
\bar{w} \\
\overline{-} \\
\bar{w} \\
W \\
W \\
\bar{w} \\
W \\
w\end{array}$ & $\begin{array}{l}52.0 \\
54.1 \\
54.8 \\
57.9 \\
59.7 \\
62.9 \\
67.1 \\
72.9 \\
62.7 \\
58.4 \\
57.3 \\
54.3 \\
60.2\end{array}$ & $\begin{array}{l}82.3 \\
82.2 \\
80.2 \\
83.7 \\
84.6 \\
85.4 \\
89.1 \\
93.2 \\
92.9 \\
88.6 \\
87.1 \\
84.6 \\
86.6\end{array}$ & $\begin{array}{l}77.4 \\
77.2 \\
76.4 \\
78.6 \\
79.1 \\
84.0 \\
87.0 \\
89.8 \\
90.3 \\
84.7 \\
84.8 \\
79.8 \\
81.7\end{array}$ & $\begin{array}{c}W \\
69.0 \\
W \\
W \\
W \\
75.5 \\
78.0 \\
W \\
77.4 \\
71.9 \\
72.7 \\
W \\
73.3\end{array}$ & $\begin{array}{r}60.7 \\
62.2 \\
63.1 \\
\mathrm{NA} \\
62.7 \\
65.9 \\
\mathrm{NA} \\
78.4 \\
67.8 \\
63.7 \\
63.5 \\
59.9 \\
64.5\end{array}$ & $\begin{array}{l}\overline{-} \\
\overline{-} \\
- \\
- \\
- \\
- \\
- \\
- \\
- \\
- \\
-\end{array}$ & $\begin{array}{c}63.0 \\
63.9 \\
64.7 \\
62.2 \\
66.9 \\
67.4 \\
N A \\
80.5 \\
72.7 \\
68.5 \\
68.4 \\
65.0 \\
67.3\end{array}$ \\
\hline \multicolumn{13}{|l|}{ Ohio } \\
\hline 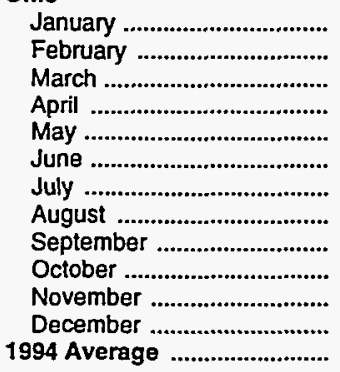 & $\begin{array}{l}62.4 \\
62.3 \\
62.3 \\
65.0 \\
67.7 \\
71.4 \\
74.0 \\
78.3 \\
72.5 \\
68.8 \\
70.1 \\
64.0 \\
68.5\end{array}$ & $\begin{array}{l}61.8 \\
62.0 \\
61.9 \\
64.7 \\
67.4 \\
71.0 \\
73.6 \\
77.8 \\
72.0 \\
68.4 \\
69.8 \\
63.7 \\
68.1\end{array}$ & $\begin{array}{l}53.6 \\
55.0 \\
54.5 \\
58.5 \\
60.5 \\
64.4 \\
66.9 \\
69.8 \\
61.7 \\
60.6 \\
61.6 \\
55.1 \\
60.4\end{array}$ & $\begin{array}{l}47.0 \\
49.1 \\
48.8 \\
53.5 \\
55.3 \\
59.2 \\
61.9 \\
64.1 \\
52.5 \\
53.8 \\
55.0 \\
47.8 \\
54.2\end{array}$ & $\begin{array}{l}W \\
W \\
W \\
51.5 \\
W \\
W \\
W \\
W \\
W \\
W \\
W \\
46.7 \\
W\end{array}$ & $\begin{array}{l}49.9 \\
51.7 \\
51.4 \\
55.7 \\
57.6 \\
61.5 \\
64.2 \\
66.5 \\
56.7 \\
56.8 \\
57.7 \\
50.9 \\
56.9\end{array}$ & $\begin{array}{l}70.7 \\
70.7 \\
70.6 \\
73.7 \\
76.9 \\
80.6 \\
83.1 \\
87.6 \\
81.3 \\
77.9 \\
78.4 \\
72.6 \\
77.0\end{array}$ & $\begin{array}{l}69.8 \\
70.2 \\
69.9 \\
73.1 \\
76.2 \\
79.7 \\
82.4 \\
86.7 \\
80.4 \\
77.2 \\
77.7 \\
72.1 \\
76.3\end{array}$ & $\begin{array}{l}60.5 \\
61.8 \\
61.0 \\
65.1 \\
67.2 \\
71.4 \\
73.9 \\
77.0 \\
69.4 \\
67.5 \\
68.2 \\
62.0 \\
67.1\end{array}$ & $\begin{array}{l}51.3 \\
54.1 \\
53.7 \\
58.0 \\
60.5 \\
64.1 \\
66.0 \\
68.3 \\
58.3 \\
58.5 \\
60.7 \\
53.2 \\
59.6\end{array}$ & $\begin{array}{l}- \\
- \\
\bar{w} \\
\bar{w} \\
- \\
- \\
- \\
- \\
- \\
\bar{w}\end{array}$ & $\begin{array}{l}57.6 \\
59.4 \\
58.7 \\
62.7 \\
65.0 \\
68.5 \\
71.0 \\
73.2 \\
65.6 \\
64.4 \\
65.7 \\
58.4 \\
64.5\end{array}$ \\
\hline \multicolumn{13}{|l|}{ Oklahoma } \\
\hline 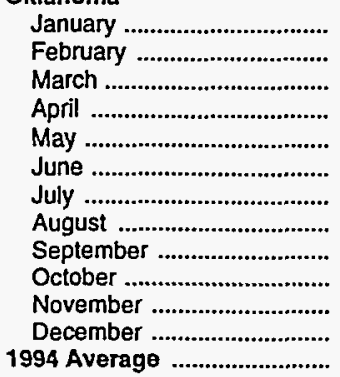 & $\begin{array}{l}52.8 \\
55.9 \\
57.4 \\
60.2 \\
62.3 \\
65.6 \\
71.2 \\
75.0 \\
70.8 \\
63.5 \\
63.8 \\
59.4 \\
63.5\end{array}$ & $\begin{array}{l}52.6 \\
56.1 \\
57.5 \\
60.3 \\
62.2 \\
65.5 \\
71.1 \\
74.7 \\
70.5 \\
63.4 \\
63.5 \\
59.2 \\
63.3\end{array}$ & $\begin{array}{l}52.2 \\
55.4 \\
55.0 \\
57.9 \\
59.1 \\
62.0 \\
66.3 \\
68.6 \\
63.2 \\
60.7 \\
59.9 \\
57.9 \\
59.7\end{array}$ & $\begin{array}{l}44.9 \\
48.2 \\
49.5 \\
52.7 \\
54.2 \\
57.8 \\
62.6 \\
66.8 \\
56.3 \\
52.6 \\
51.3 \\
47.6 \\
53.7\end{array}$ & $\begin{array}{l}41.6 \\
45.4 \\
47.0 \\
50.0 \\
52.0 \\
54.9 \\
58.8 \\
62.4 \\
55.1 \\
50.7 \\
49.5 \\
47.1 \\
51.4\end{array}$ & $\begin{array}{l}44.9 \\
48.0 \\
49.7 \\
52.6 \\
54.3 \\
57.4 \\
61.8 \\
65.3 \\
56.6 \\
52.7 \\
51.6 \\
48.6 \\
53.6\end{array}$ & $\begin{array}{l}60.3 \\
63.7 \\
64.5 \\
68.2 \\
70.3 \\
73.1 \\
78.9 \\
83.0 \\
78.5 \\
70.4 \\
71.2 \\
66.4 \\
70.8\end{array}$ & $\begin{array}{l}61.0 \\
63.8 \\
64.6 \\
68.2 \\
70.2 \\
73.0 \\
78.7 \\
82.9 \\
78.3 \\
70.3 \\
71.1 \\
66.4 \\
70.8\end{array}$ & $\begin{array}{l}59.9 \\
60.7 \\
59.9 \\
62.6 \\
64.2 \\
67.1 \\
71.2 \\
72.7 \\
66.7 \\
64.7 \\
64.3 \\
62.1 \\
64.1\end{array}$ & $\begin{array}{l}47.9 \\
51.7 \\
52.9 \\
56.3 \\
57.4 \\
61.1 \\
65.6 \\
69.7 \\
59.6 \\
55.7 \\
54.3 \\
51.1 \\
57.0\end{array}$ & $\begin{array}{l}- \\
- \\
- \\
- \\
- \\
- \\
- \\
- \\
- \\
- \\
- \\
-\end{array}$ & $\begin{array}{l}56.4 \\
57.2 \\
57.6 \\
60.4 \\
61.6 \\
65.0 \\
69.0 \\
71.6 \\
64.1 \\
61.0 \\
60.1 \\
57.3 \\
61.2\end{array}$ \\
\hline
\end{tabular}

See footnotes at end of table. 
Table 32. Conventional Motor Gasoline Prices by Grade, Sales Type, PAD District, and State

(Cents per Gallon Excluding Taxes) — Continued

\begin{tabular}{|c|c|c|c|c|c|c|c|c|c|c|c|c|}
\hline \multirow{3}{*}{$\begin{array}{l}\text { Geographlc Area } \\
\text { Month }\end{array}$} & \multicolumn{6}{|c|}{ Premium } & \multicolumn{6}{|c|}{ All Grades } \\
\hline & \multicolumn{2}{|c|}{ Sales to End Users } & \multicolumn{4}{|c|}{ Sales for Resale } & \multicolumn{2}{|c|}{ Sales to End Users } & \multicolumn{4}{|c|}{ Sales for Resale } \\
\hline & $\begin{array}{l}\text { Through } \\
\text { Retail } \\
\text { Outlote }\end{array}$ & Averagea & DTW & Rack & Bulk & Average & $\begin{array}{c}\text { Through } \\
\text { Retail } \\
\text { Outlets }\end{array}$ & Averagea & DTW & Rack & Bulk & Average \\
\hline 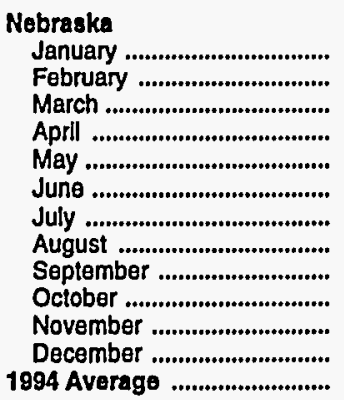 & $\begin{array}{l}72.7 \\
77.4 \\
77.4 \\
79.5 \\
81.3 \\
84.4 \\
88.4 \\
89.5 \\
86.9 \\
82.9 \\
82.9 \\
79.6 \\
82.0\end{array}$ & $\begin{array}{l}72.4 \\
77.2 \\
77.2 \\
79.3 \\
80.9 \\
84.0 \\
83.5 \\
85.5 \\
89.6 \\
87.0 \\
85.1 \\
82.0 \\
82.7\end{array}$ & $\begin{array}{l}63.6 \\
66.0 \\
68.1 \\
70.8 \\
72.3 \\
75.6 \\
80.0 \\
84.0 \\
76.2 \\
72.0 \\
70.0 \\
65.8 \\
72.0\end{array}$ & $\begin{array}{l}55.1 \\
58.7 \\
59.8 \\
62.9 \\
64.5 \\
67.8 \\
72.2 \\
76.8 \\
67.0 \\
62.7 \\
61.3 \\
57.4 \\
64.3\end{array}$ & $\begin{array}{l}- \\
- \\
- \\
- \\
- \\
- \\
- \\
- \\
-\end{array}$ & $\begin{array}{l}57.5 \\
61.0 \\
62.0 \\
65.0 \\
66.6 \\
69.8 \\
74.3 \\
78.6 \\
69.4 \\
65.3 \\
63.6 \\
59.8 \\
66.4\end{array}$ & $\begin{array}{l}64.7 \\
68.6 \\
69.2 \\
70.6 \\
70.6 \\
73.5 \\
78.2 \\
82.8 \\
79.5 \\
74.5 \\
72.8 \\
69.4 \\
72.9\end{array}$ & $\begin{array}{l}64.3 \\
68.1 \\
68.6 \\
70.2 \\
70.3 \\
73.0 \\
77.7 \\
82.3 \\
79.5 \\
74.7 \\
72.9 \\
69.5 \\
72.7\end{array}$ & $\begin{array}{l}55.5 \\
59.3 \\
59.5 \\
62.2 \\
63.1 \\
66.7 \\
71.0 \\
74.5 \\
68.8 \\
65.4 \\
61.9 \\
59.1 \\
64.1\end{array}$ & $\begin{array}{l}48.2 \\
51.9 \\
52.8 \\
56.0 \\
57.3 \\
60.8 \\
65.4 \\
69.2 \\
58.9 \\
55.7 \\
54.2 \\
50.6 \\
57.2\end{array}$ & $\begin{array}{l}- \\
- \\
- \\
\bar{w} \\
w \\
- \\
- \\
- \\
- \\
\bar{w}\end{array}$ & $\begin{array}{l}49.6 \\
53.4 \\
54.1 \\
57.2 \\
58.4 \\
61.9 \\
66.5 \\
70.2 \\
60.9 \\
57.7 \\
55.9 \\
52.4 \\
\mathbf{5 8 . 6}\end{array}$ \\
\hline 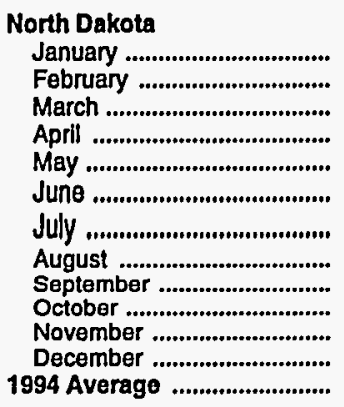 & $\begin{array}{l}84.1 \\
83.7 \\
81.4 \\
86.3 \\
87.7 \\
88.5 \\
90.9 \\
97.2 \\
97.7 \\
93.0 \\
90.8 \\
85.8 \\
88.7\end{array}$ & $\begin{array}{l}84.2 \\
84.0 \\
81.9 \\
86.6 \\
87.1 \\
88.8 \\
91.0 \\
96.4 \\
95.9 \\
92.1 \\
89.3 \\
85.0 \\
88.4\end{array}$ & $\begin{array}{l}72.9 \\
73.8 \\
73.1 \\
75.7 \\
78.6 \\
80.7 \\
83.7 \\
87.9 \\
78.1 \\
76.2 \\
75.4 \\
74.3 \\
77.4\end{array}$ & $\begin{array}{l}58.3 \\
61.6 \\
62.7 \\
66.3 \\
67.9 \\
71.1 \\
75.2 \\
80.6 \\
70.2 \\
65.3 \\
64.4 \\
61.2 \\
67.4\end{array}$ & $\begin{array}{l}- \\
- \\
- \\
- \\
- \\
- \\
- \\
- \\
- \\
-\end{array}$ & $\begin{array}{l}61.7 \\
64.1 \\
64.9 \\
68.6 \\
70.3 \\
73.1 \\
77.2 \\
83.2 \\
73.1 \\
69.5 \\
68.4 \\
65.7 \\
70.4\end{array}$ & $\begin{array}{l}76.0 \\
75.7 \\
74.5 \\
78.1 \\
80.3 \\
81.2 \\
84.2 \\
88.9 \\
88.0 \\
84.8 \\
81.8 \\
79.1 \\
81.5\end{array}$ & $\begin{array}{l}75.3 \\
74.9 \\
73.8 \\
76.8 \\
79.0 \\
80.5 \\
83.5 \\
88.0 \\
86.7 \\
83.3 \\
80.6 \\
77.7 \\
80.4\end{array}$ & $\begin{array}{l}62.7 \\
62.6 \\
62.4 \\
65.2 \\
67.8 \\
69.8 \\
73.3 \\
76.9 \\
70.6 \\
67.4 \\
65.5 \\
64.3 \\
67.8\end{array}$ & $\begin{array}{l}51.8 \\
54.3 \\
54.9 \\
57.7 \\
59.5 \\
63.0 \\
67.1 \\
72.5 \\
61.2 \\
57.0 \\
56.4 \\
52.9 \\
59.5\end{array}$ & $\begin{array}{l}W \\
W \\
\bar{w} \\
- \\
- \\
W \\
W \\
w \\
\bar{w} \\
W \\
w\end{array}$ & $\begin{array}{l}53.3 \\
55.5 \\
56.0 \\
58.7 \\
60.6 \\
63.9 \\
68.0 \\
73.6 \\
63.5 \\
59.4 \\
58.4 \\
55.5 \\
61.1\end{array}$ \\
\hline 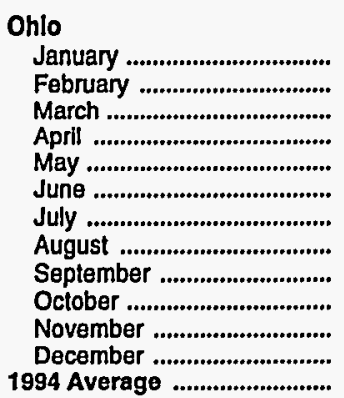 & $\begin{array}{l}78.7 \\
74.9 \\
77.6 \\
80.8 \\
84.4 \\
87.9 \\
90.3 \\
94.6 \\
88.2 \\
83.8 \\
84.9 \\
79.5 \\
83.3\end{array}$ & $\begin{array}{l}78.0 \\
74.7 \\
77.0 \\
80.2 \\
83.7 \\
87.1 \\
89.7 \\
93.7 \\
87.3 \\
83.2 \\
84.2 \\
78.9 \\
82.7\end{array}$ & $\begin{array}{l}66.5 \\
67.5 \\
67.0 \\
71.0 \\
73.3 \\
77.9 \\
80.0 \\
82.6 \\
75.0 \\
73.8 \\
74.6 \\
68.5 \\
73.1\end{array}$ & $\begin{array}{l}55.7 \\
57.5 \\
57.5 \\
62.3 \\
64.4 \\
68.9 \\
71.7 \\
74.0 \\
62.2 \\
63.3 \\
64.3 \\
58.1 \\
63.4\end{array}$ & $\begin{array}{l}- \\
\bar{w} \\
\bar{w} \\
\overline{-} \\
- \\
\overline{-} \\
\bar{w} \\
w \\
w\end{array}$ & $\begin{array}{l}62.1 \\
63.2 \\
62.9 \\
66.7 \\
69.3 \\
73.9 \\
76.4 \\
79.0 \\
69.3 \\
69.2 \\
69.6 \\
63.5 \\
68.7\end{array}$ & $\begin{array}{l}66.9 \\
66.4 \\
66.2 \\
68.9 \\
71.8 \\
75.4 \\
77.8 \\
81.9 \\
76.2 \\
72.6 \\
73.6 \\
68.1 \\
72.3\end{array}$ & $\begin{array}{l}66.3 \\
66.1 \\
65.8 \\
68.5 \\
71.3 \\
74.8 \\
77.4 \\
81.3 \\
75.5 \\
72.2 \\
73.2 \\
67.7 \\
71.8\end{array}$ & $\begin{array}{l}57.3 \\
58.4 \\
57.7 \\
61.7 \\
63.7 \\
67.7 \\
70.1 \\
72.9 \\
64.9 \\
63.9 \\
64.8 \\
58.6 \\
63.6\end{array}$ & $\begin{array}{l}48.7 \\
50.8 \\
50.4 \\
55.1 \\
57.1 \\
61.1 \\
63.7 \\
65.9 \\
54.3 \\
55.5 \\
56.8 \\
49.9 \\
56.0\end{array}$ & $\begin{array}{c}W \\
W \\
W \\
51.0 \\
W \\
W \\
W \\
W \\
W \\
W \\
W \\
46.8 \\
51.1\end{array}$ & $\begin{array}{l}52.9 \\
54.5 \\
54.0 \\
58.2 \\
60.3 \\
64.3 \\
66.9 \\
69.0 \\
59.4 \\
59.5 \\
60.3 \\
53.8 \\
59.6\end{array}$ \\
\hline 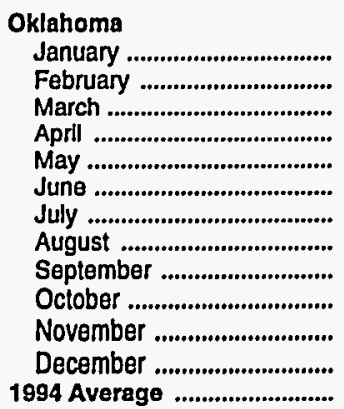 & $\begin{array}{l}65.8 \\
69.3 \\
70.4 \\
73.3 \\
75.2 \\
78.6 \\
84.1 \\
88.3 \\
83.8 \\
77.0 \\
77.3 \\
73.5 \\
76.3\end{array}$ & $\begin{array}{l}65.3 \\
68.7 \\
69.8 \\
72.7 \\
74.7 \\
78.1 \\
83.6 \\
87.3 \\
82.9 \\
76.2 \\
76.6 \\
72.6 \\
75.7\end{array}$ & $\begin{array}{l}61.9 \\
63.6 \\
63.9 \\
66.4 \\
68.3 \\
71.6 \\
75.3 \\
76.5 \\
71.5 \\
69.3 \\
68.6 \\
65.8 \\
68.0\end{array}$ & $\begin{array}{l}51.8 \\
55.3 \\
56.6 \\
59.8 \\
61.3 \\
64.9 \\
69.6 \\
74.1 \\
63.7 \\
59.6 \\
58.3 \\
54.3 \\
60.7\end{array}$ & $\begin{array}{c}46.8 \\
W \\
W \\
W \\
56.8 \\
58.5 \\
W \\
66.3 \\
54.9 \\
52.4 \\
52.0 \\
W \\
54.3\end{array}$ & $\begin{array}{l}53.3 \\
57.0 \\
58.4 \\
61.5 \\
62.8 \\
65.8 \\
71.1 \\
73.8 \\
63.2 \\
59.9 \\
59.1 \\
56.5 \\
61.6\end{array}$ & $\begin{array}{l}55.6 \\
58.7 \\
60.0 \\
62.9 \\
64.9 \\
68.2 \\
73.7 \\
77.5 \\
73.3 \\
66.2 \\
66.5 \\
62.3 \\
66.1\end{array}$ & $\begin{array}{l}55.5 \\
58.7 \\
60.0 \\
62.9 \\
64.8 \\
68.0 \\
73.5 \\
77.2 \\
72.9 \\
65.9 \\
66.2 \\
62.0 \\
65.8\end{array}$ & $\begin{array}{l}54.4 \\
57.2 \\
56.6 \\
59.7 \\
61.1 \\
63.8 \\
68.1 \\
70.2 \\
64.8 \\
62.4 \\
61.6 \\
59.5 \\
61.4\end{array}$ & $\begin{array}{l}46.1 \\
49.3 \\
50.7 \\
54.0 \\
55.4 \\
59.1 \\
63.8 \\
68.0 \\
57.5 \\
53.7 \\
52.5 \\
48.8 \\
54.9\end{array}$ & $\begin{array}{l}41.9 \\
45.5 \\
47.0 \\
50.0 \\
52.1 \\
55.1 \\
59.0 \\
62.6 \\
55.0 \\
50.8 \\
49.6 \\
47.1 \\
51.5\end{array}$ & $\begin{array}{l}46.3 \\
49.1 \\
50.9 \\
53.8 \\
55.6 \\
58.6 \\
63.0 \\
66.3 \\
57.5 \\
53.7 \\
52.6 \\
49.7 \\
54.7\end{array}$ \\
\hline
\end{tabular}

See footnotes at end of table. 
Table 32. Conventional Motor Gasoline Prices by Grade, Sales Type, PAD District, and State

(Cents per Gallon Excluding Taxes) - Continued

\begin{tabular}{|c|c|c|c|c|c|c|c|c|c|c|c|c|}
\hline \multirow{3}{*}{$\begin{array}{l}\text { Geographic Area } \\
\text { Month }\end{array}$} & \multicolumn{6}{|c|}{ Regular } & \multicolumn{6}{|c|}{ Midgrade } \\
\hline & \multicolumn{2}{|c|}{ Sales to End Users } & \multicolumn{4}{|c|}{ Sales for Rosale } & \multicolumn{2}{|c|}{ Sales to End Users } & \multicolumn{4}{|c|}{ Sales for Resale } \\
\hline & $\begin{array}{c}\text { Through } \\
\text { Retail } \\
\text { Outlots }\end{array}$ & Average $a$ & DTW & Rack & Bulk & Average & $\begin{array}{c}\text { Through } \\
\text { Retail } \\
\text { Outlets }\end{array}$ & Average $\mathrm{a}^{\mathrm{a}}$ & DTW & Rack & Bulk & Average \\
\hline
\end{tabular}

\begin{tabular}{|c|c|c|c|c|c|c|c|c|c|c|c|c|}
\hline \multicolumn{13}{|l|}{ South Dakota } \\
\hline 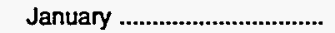 & 69.3 & 68.6 & 56.3 & 48.7 & - & 50.5 & 75.9 & 75.0 & 62.1 & $w$ & - & 59.1 \\
\hline 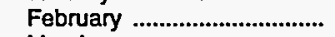 & 68.3 & 68.0 & 56.9 & 51.8 & $w$ & 52.8 & 76.1 & 76.1 & 65.1 & W & - & 60.0 \\
\hline 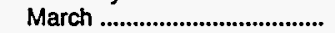 & 68.7 & 68.4 & 62.2 & 52.8 & W & 54.8 & 74.3 & 74.0 & 66.8 & $w$ & - & 60.9 \\
\hline 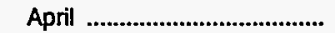 & 71.4 & 71.2 & 61.6 & 56.3 & $w$ & 57.5 & 77.9 & 78.3 & 67.4 & 61.1 & - & 62.7 \\
\hline 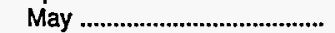 & 73.1 & 72.8 & 65.7 & 58.6 & W & 60.1 & 77.6 & 77.9 & 69.6 & $W$ & - & 66.1 \\
\hline June & 76.3 & 76.0 & 68.7 & 62.0 & $W$ & 63.6 & 80.0 & 80.3 & 71.8 & 67.4 & - & 68.4 \\
\hline July .......................................... & 79.8 & 79.6 & 73.4 & 66.4 & W & 68.1 & 85.5 & 85.3 & 76.3 & NA & W & NA \\
\hline 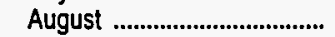 & 84.9 & 82.9 & 77.0 & 70.9 & W & 72.5 & 92.7 & 91.6 & 80.9 & 71.5 & - & 74.7 \\
\hline September ........................... & 83.1 & 82.1 & 68.7 & 60.7 & $W$ & 62.8 & 91.4 & 89.5 & 71.2 & $W$ & - & 63.9 \\
\hline 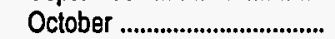 & 78.0 & 77.3 & 65.0 & 56.7 & $W$ & 58.7 & 88.4 & 87.1 & 70.5 & W & - & 65.9 \\
\hline 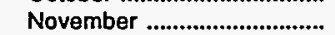 & 75.1 & 74.2 & 63.8 & 55.7 & $w$ & 57.7 & 88.2 & 86.9 & 69.2 & W & - & 62.0 \\
\hline 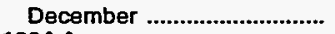 & 71.9 & 71.1 & 60.8 & 51.4 & $W$ & 53.7 & 84.2 & 83.5 & 65.8 & $w$ & - & 61.9 \\
\hline 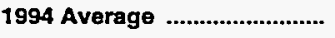 & 75.4 & 74.9 & 65.8 & 58.3 & $\mathbf{w}$ & 60.2 & 81.3 & 81.2 & 70.4 & $w$ & $\mathbf{w}$ & 65.6 \\
\hline \multicolumn{13}{|l|}{ Tennessee } \\
\hline 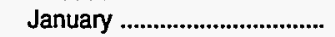 & 56.1 & 55.7 & 52.9 & 45.1 & - & 46.7 & 67.3 & 66.7 & 59.2 & 49.8 & - & 52.6 \\
\hline 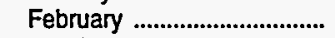 & 58.1 & 57.7 & 54.8 & 48.0 & $W$ & 49.3 & 68.3 & 67.8 & 60.7 & 52.9 & - & 55.2 \\
\hline 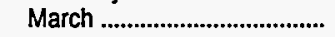 & 58.1 & 57.8 & 55.7 & 49.4 & $W$ & 50.7 & 68.1 & 67.5 & 61.3 & 54.3 & - & 56.4 \\
\hline April & 61.0 & 60.8 & 58.3 & 53.2 & $\ddot{W}$ & 54.3 & 71.1 & 70.8 & 64.1 & 58.2 & - & 59.9 \\
\hline 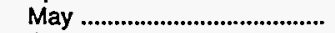 & 61.6 & 61.4 & 59.6 & 53.1 & $w$ & 54.4 & 71.8 & 71.4 & 65.3 & 58.1 & - & 60.2 \\
\hline 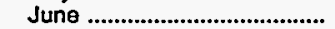 & 63.9 & 63.7 & 62.1 & 56.5 & w & 57.6 & 74.5 & 74.1 & 67.7 & 61.7 & - & 63.5 \\
\hline July & 66.2 & 66.0 & 64.6 & 58.2 & $w$ & 59.5 & 77.0 & 76.6 & 70.7 & 63.1 & - & 65.4 \\
\hline 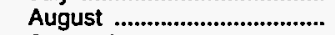 & 71.3 & 70.8 & 65.7 & 59.5 & W & 60.7 & 81.5 & 80.9 & 71.5 & 65.3 & - & 67.0 \\
\hline 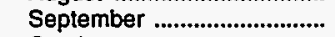 & 70.4 & 69.5 & 60.7 & 49.5 & $W$ & 51.5 & 80.8 & 80.1 & 66.8 & 54.8 & - & 58.1 \\
\hline 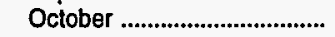 & 68.3 & 67.7 & 63.0 & 53.2 & $W$ & 54.9 & 79.0 & 78.4 & 69.6 & 58.3 & - & 61.2 \\
\hline November ................................. & 68.9 & 68.4 & 62.2 & 53.5 & W & 55.0 & 79.7 & 79.2 & 68.9 & 58.9 & - & 61.6 \\
\hline 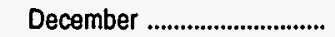 & 66.4 & 65.8 & 59.6 & 47.5 & $W$ & 49.7 & 77.3 & 76.8 & 66.2 & 52.7 & - & 56.1 \\
\hline 1994 Average ............................ & 64.6 & 64.1 & 59.9 & 52.5 & $\mathbf{W}$ & 53.9 & 75.1 & 74.6 & 65.9 & 57.5 & - & 59.8 \\
\hline \multicolumn{13}{|l|}{ Wisconsin } \\
\hline 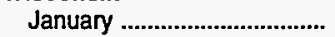 & 60.6 & 60.4 & 52.9 & 48.2 & W & 49.4 & 68.1 & 67.9 & 57.0 & 53.6 & - & 55.2 \\
\hline 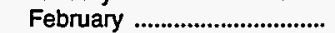 & 64.3 & 63.7 & 54.6 & 50.7 & W & 51.7 & 72.2 & 71.9 & 60.5 & 56.4 & - & 58.1 \\
\hline March & 62.0 & 61.8 & 53.6 & 49.5 & 49.8 & 50.6 & 70.5 & 70.4 & 59.3 & 54.8 & - & 56.6 \\
\hline April & 65.7 & 65.5 & 58.5 & 54.6 & $w$ & 55.6 & 73.8 & 73.7 & 62.5 & 60.0 & - & 61.1 \\
\hline 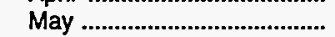 & 68.3 & 68.1 & 60.9 & 56.7 & $w$ & 57.8 & 76.4 & 76.3 & 65.1 & 61.9 & - & 63.2 \\
\hline 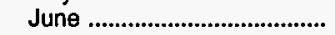 & 71.1 & 70.8 & 63.8 & 60.6 & $w$ & 61.4 & 78.9 & 78.6 & 68.1 & 66.2 & - & 67.0 \\
\hline July & 74.5 & 74.4 & 67.7 & 64.2 & - & 65.1 & 82.2 & 82.4 & 72.9 & 69.5 & - & 70.9 \\
\hline 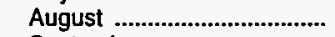 & 79.9 & 79.2 & 72.2 & 68.5 & $w$ & 69.7 & 88.3 & 87.5 & 77.6 & 73.8 & - & 75.7 \\
\hline 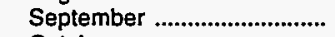 & 76.0 & 75.0 & 60.6 & 54.8 & - & 56.8 & 84.2 & 83.7 & 67.2 & 60.3 & - & 63.6 \\
\hline 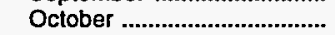 & 72.8 & 72.0 & 59.6 & 54.6 & - & 56.2 & 80.8 & 79.9 & 64.1 & 60.4 & - & 62.3 \\
\hline 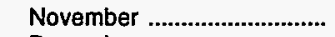 & 71.7 & 70.9 & 59.1 & 54.6 & $w$ & 56.1 & 79.8 & 79.4 & 64.9 & 60.6 & - & 62.8 \\
\hline 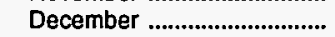 & 68.1 & 67.8 & 54.4 & 48.2 & - & 50.0 & 76.0 & 75.8 & 62.2 & 55.1 & - & 57.7 \\
\hline 1994 Average ......................... & 69.9 & 69.4 & 60.3 & 56.0 & 49.2 & 57.3 & 77.7 & 77.4 & 65.3 & 61.2 & - & 63.1 \\
\hline \multicolumn{13}{|l|}{ PAD District III } \\
\hline 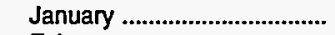 & 59.3 & 58.8 & 52.5 & 44.4 & 40.8 & 44.6 & 69.3 & 68.4 & 57.7 & 49.1 & $W$ & 52.6 \\
\hline 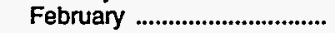 & 60.6 & 60.0 & 54.0 & 47.8 & 43.2 & 47.8 & 70.3 & 69.5 & 59.3 & 52.5 & $\mathbf{W}$ & 55.3 \\
\hline March & 60.9 & 60.5 & 55.3 & 49.4 & 44.8 & 49.6 & 70.6 & 69.8 & 60.1 & 53.5 & NA & 56.1 \\
\hline April & 63.9 & 63.5 & 58.2 & 52.6 & 47.9 & 52.6 & 73.3 & 72.6 & 63.3 & 57.5 & $W$ & 59.9 \\
\hline May & 65.5 & 65.0 & 58.9 & 53.2 & 49.0 & 53.4 & 74.8 & 74.1 & 64.0 & 57.7 & NA & 60.3 \\
\hline 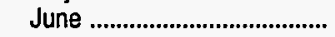 & 67.7 & 67.3 & 61.4 & 56.7 & 51.3 & 56.4 & 76.9 & 76.2 & 66.2 & 61.1 & NA & 63.1 \\
\hline July & 70.7 & 70.3 & 64.2 & 59.1 & 53.3 & 58.9 & 80.0 & 79.4 & 69.0 & 63.4 & NA & 65.6 \\
\hline August & 74.2 & 73.4 & 66.5 & 61.7 & 56.0 & 61.6 & 83.2 & 82.3 & 71.2 & 66.2 & $W$ & 68.3 \\
\hline September & 73.3 & 71.8 & 64.2 & 52.2 & 48.6 & 53.7 & 82.5 & 81.1 & 67.6 & 56.1 & NA & 61.0 \\
\hline 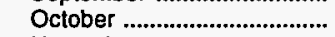 & 71.2 & 70.0 & 62.7 & 53.0 & 47.7 & 53.3 & 80.5 & 79.3 & 66.4 & 57.5 & $w$ & 61.1 \\
\hline 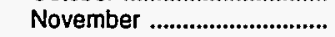 & 71.3 & 70.1 & 62.6 & 52.6 & 47.6 & 53.1 & 80.8 & 79.6 & 66.3 & 57.2 & NA & 61.0 \\
\hline 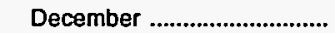 & 69.2 & 67.9 & 60.1 & 47.8 & 45.0 & 48.5 & 78.6 & 77.1 & 63.5 & 52.0 & NA & 56.4 \\
\hline 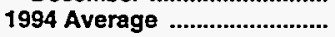 & 67.3 & 66.5 & 59.3 & 52.8 & 47.6 & 52.9 & 76.7 & 75.6 & 64.1 & 57.2 & NA & 60.2 \\
\hline
\end{tabular}

See footnotes at end of table. 
Table 32. Conventional Motor Gasoline Prices by Grade, Sales Type, PAD District, and State

(Cents per Gallon Excluding Taxes) - Continued

\begin{tabular}{|c|c|c|c|c|c|c|c|c|c|c|c|c|}
\hline \multirow{3}{*}{$\begin{array}{l}\text { Geographlc Area } \\
\text { Month }\end{array}$} & \multicolumn{6}{|c|}{ Premlum } & \multicolumn{6}{|c|}{ All Grades } \\
\hline & \multicolumn{2}{|c|}{ Sales to End Users } & \multicolumn{4}{|c|}{ Sales for Resale } & \multicolumn{2}{|c|}{ Sales to End Users } & \multicolumn{4}{|c|}{ Sales for Resale } \\
\hline & $\begin{array}{c}\text { Through } \\
\text { Retail } \\
\text { Outlets }\end{array}$ & Average a & DTW & Rack & Bulk & Average & $\begin{array}{c}\text { Through } \\
\text { Retall } \\
\text { Outlets }\end{array}$ & Average ${ }^{a}$ & DTW & Rack & Bulk & Average \\
\hline \multicolumn{13}{|l|}{ South Dakota } \\
\hline 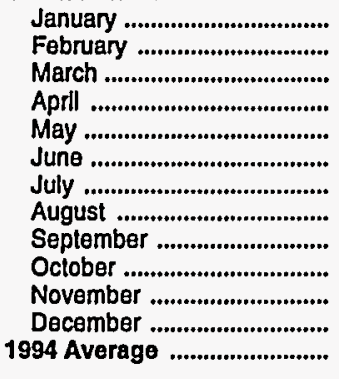 & $\begin{array}{l}84.6 \\
83.4 \\
86.7 \\
88.9 \\
85.3 \\
89.2 \\
89.4 \\
97.4 \\
95.4 \\
88.6 \\
86.5 \\
84.2 \\
88.3\end{array}$ & $\begin{array}{l}81.7 \\
81.0 \\
84.2 \\
86.2 \\
82.9 \\
87.1 \\
88.7 \\
97.4 \\
95.3 \\
88.4 \\
86.4 \\
84.0 \\
86.6\end{array}$ & $\begin{array}{l}66.6 \\
68.2 \\
71.1 \\
73.0 \\
73.5 \\
76.2 \\
81.0 \\
84.8 \\
78.0 \\
72.8 \\
72.1 \\
69.2 \\
74.6\end{array}$ & $\begin{array}{l}58.3 \\
60.4 \\
61.8 \\
65.7 \\
68.8 \\
72.2 \\
76.2 \\
81.4 \\
71.2 \\
66.7 \\
65.8 \\
60.6 \\
68.7\end{array}$ & $\begin{array}{l}- \\
- \\
- \\
- \\
- \\
- \\
- \\
- \\
- \\
-\end{array}$ & $\begin{array}{l}60.1 \\
62.1 \\
63.5 \\
67.5 \\
69.8 \\
73.0 \\
77.2 \\
82.1 \\
72.9 \\
68.2 \\
67.2 \\
62.6 \\
69.9\end{array}$ & $\begin{array}{l}71.5 \\
71.1 \\
70.9 \\
73.8 \\
74.4 \\
77.7 \\
81.5 \\
86.5 \\
84.7 \\
79.6 \\
77.4 \\
74.0 \\
77.2\end{array}$ & $\begin{array}{l}70.8 \\
70.8 \\
70.4 \\
73.6 \\
74.2 \\
77.4 \\
81.3 \\
84.4 \\
83.4 \\
78.8 \\
76.2 \\
72.9 \\
76.6\end{array}$ & $\begin{array}{l}57.3 \\
58.5 \\
63.2 \\
62.7 \\
66.4 \\
69.3 \\
74.0 \\
77.8 \\
69.4 \\
65.9 \\
64.7 \\
61.7 \\
66.7\end{array}$ & $\begin{array}{l}50.0 \\
52.7 \\
53.8 \\
57.1 \\
59.6 \\
63.1 \\
67.5 \\
71.8 \\
61.4 \\
57.6 \\
56.4 \\
52.5 \\
59.3\end{array}$ & $\begin{array}{l}-\bar{w} \\
w \\
w \\
w \\
w \\
w \\
w \\
w \\
w \\
W \\
W \\
w\end{array}$ & $\begin{array}{l}51.7 \\
53.9 \\
55.8 \\
58.4 \\
61.1 \\
64.6 \\
69.1 \\
73.3 \\
63.4 \\
59.7 \\
58.5 \\
54.8 \\
61.1\end{array}$ \\
\hline \multicolumn{13}{|l|}{ Tennesseo } \\
\hline 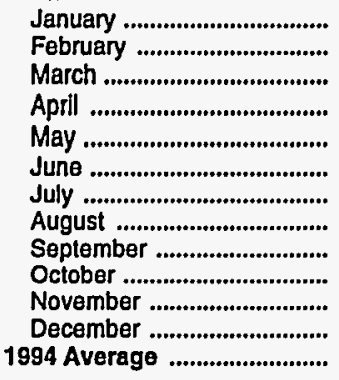 & $\begin{array}{l}75.3 \\
76.8 \\
77.5 \\
80.0 \\
80.4 \\
82.6 \\
85.8 \\
90.6 \\
89.8 \\
87.8 \\
88.6 \\
86.1 \\
83.7\end{array}$ & $\begin{array}{l}74.5 \\
76.0 \\
76.8 \\
79.5 \\
79.8 \\
81.9 \\
85.1 \\
89.6 \\
88.5 \\
86.8 \\
87.6 \\
85.0 \\
82.9\end{array}$ & $\begin{array}{l}68.1 \\
69.6 \\
70.0 \\
72.5 \\
73.5 \\
76.1 \\
78.7 \\
78.8 \\
74.4 \\
76.7 \\
75.5 \\
73.0 \\
73.5\end{array}$ & $\begin{array}{l}54.8 \\
57.9 \\
59.2 \\
63.0 \\
63.0 \\
66.5 \\
68.3 \\
70.1 \\
59.9 \\
63.6 \\
63.8 \\
58.0 \\
62.5\end{array}$ & $\begin{array}{l}- \\
- \\
- \\
- \\
- \\
- \\
- \\
- \\
-\end{array}$ & $\begin{array}{l}58.0 \\
60.6 \\
61.8 \\
65.3 \\
65.5 \\
68.7 \\
70.8 \\
71.9 \\
63.0 \\
66.2 \\
66.2 \\
61.1 \\
64.9\end{array}$ & $\begin{array}{l}62.5 \\
64.2 \\
64.3 \\
67.3 \\
67.8 \\
70.0 \\
72.5 \\
77.2 \\
76.5 \\
74.5 \\
75.2 \\
72.9 \\
70.7\end{array}$ & $\begin{array}{l}62.0 \\
63.7 \\
63.9 \\
66.9 \\
67.4 \\
69.6 \\
72.1 \\
76.6 \\
75.5 \\
73.8 \\
74.6 \\
72.2 \\
70.2\end{array}$ & $\begin{array}{l}58.3 \\
59.9 \\
60.6 \\
63.0 \\
64.3 \\
66.7 \\
69.3 \\
70.0 \\
65.2 \\
67.7 \\
66.9 \\
64.4 \\
64.6\end{array}$ & $\begin{array}{l}48.1 \\
51.0 \\
52.5 \\
56.3 \\
56.2 \\
59.6 \\
61.3 \\
62.8 \\
52.6 \\
56.4 \\
56.7 \\
50.8 \\
55.6\end{array}$ & $\begin{array}{l}\bar{W} \\
W \\
W \\
W \\
W \\
W \\
W \\
W \\
W \\
W \\
W \\
W\end{array}$ & $\begin{array}{l}50.4 \\
52.9 \\
54.3 \\
57.8 \\
58.0 \\
61.2 \\
63.1 \\
64.2 \\
55.1 \\
58.5 \\
58.6 \\
53.4 \\
57.4\end{array}$ \\
\hline \multicolumn{13}{|l|}{ Wisconsin } \\
\hline 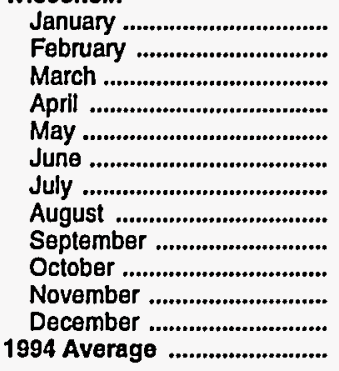 & $\begin{array}{l}74.2 \\
77.9 \\
76.3 \\
80.1 \\
82.3 \\
85.4 \\
88.5 \\
94.2 \\
90.6 \\
86.3 \\
85.5 \\
80.6 \\
83.4\end{array}$ & $\begin{array}{l}73.6 \\
77.0 \\
75.5 \\
79.4 \\
81.5 \\
84.6 \\
87.8 \\
92.8 \\
88.7 \\
84.7 \\
84.0 \\
79.9 \\
82.2\end{array}$ & $\begin{array}{l}63.2 \\
65.9 \\
63.5 \\
69.1 \\
71.0 \\
74.5 \\
78.4 \\
83.0 \\
72.0 \\
70.9 \\
70.2 \\
65.7 \\
70.9\end{array}$ & $\begin{array}{l}56.7 \\
59.5 \\
57.8 \\
62.9 \\
65.0 \\
69.1 \\
72.7 \\
77.7 \\
63.6 \\
63.6 \\
63.1 \\
57.6 \\
64.3\end{array}$ & $\begin{array}{l}- \\
- \\
- \\
- \\
- \\
- \\
- \\
- \\
- \\
-\end{array}$ & $\begin{array}{l}58.6 \\
61.5 \\
59.5 \\
64.9 \\
66.8 \\
70.7 \\
74.4 \\
79.7 \\
66.9 \\
66.4 \\
65.8 \\
60.2 \\
66.6\end{array}$ & $\begin{array}{l}63.5 \\
66.9 \\
64.6 \\
68.2 \\
70.8 \\
73.5 \\
76.9 \\
82.2 \\
78.5 \\
75.2 \\
74.4 \\
70.7 \\
72.4\end{array}$ & $\begin{array}{l}63.1 \\
66.2 \\
64.2 \\
67.9 \\
70.4 \\
73.1 \\
76.7 \\
81.4 \\
77.3 \\
74.2 \\
73.4 \\
70.3 \\
71.7\end{array}$ & $\begin{array}{l}55.1 \\
56.9 \\
55.6 \\
60.5 \\
62.8 \\
65.7 \\
69.7 \\
74.1 \\
62.7 \\
61.6 \\
61.3 \\
56.8 \\
62.3\end{array}$ & $\begin{array}{l}49.9 \\
52.4 \\
50.9 \\
56.0 \\
58.1 \\
62.1 \\
65.6 \\
69.9 \\
56.1 \\
56.0 \\
56.0 \\
49.9 \\
57.4\end{array}$ & $\begin{array}{c}W \\
W \\
49.8 \\
W \\
W \\
W \\
- \\
W \\
- \\
- \\
W \\
- \\
49.2\end{array}$ & $\begin{array}{l}51.3 \\
53.6 \\
52.2 \\
57.2 \\
59.4 \\
63.1 \\
66.8 \\
71.4 \\
58.5 \\
58.0 \\
57.9 \\
52.0 \\
59.0\end{array}$ \\
\hline \multicolumn{13}{|l|}{ PAD District III } \\
\hline 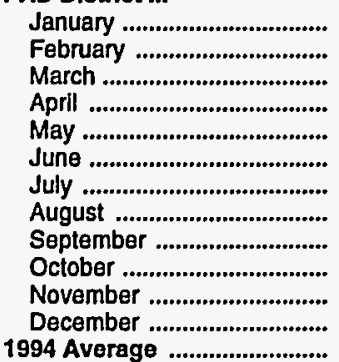 & $\begin{array}{l}77.8 \\
78.5 \\
78.9 \\
81.6 \\
83.2 \\
85.4 \\
88.3 \\
91.2 \\
90.6 \\
88.6 \\
88.9 \\
86.6 \\
84.8\end{array}$ & $\begin{array}{l}76.4 \\
77.1 \\
77.7 \\
80.5 \\
81.9 \\
84.0 \\
87.1 \\
89.5 \\
88.3 \\
86.5 \\
86.6 \\
84.2 \\
83.0\end{array}$ & $\begin{array}{l}64.3 \\
66.1 \\
67.0 \\
70.1 \\
70.7 \\
72.9 \\
75.9 \\
78.3 \\
74.6 \\
73.3 \\
73.1 \\
70.0 \\
70.9\end{array}$ & $\begin{array}{l}53.8 \\
57.0 \\
58.4 \\
62.4 \\
62.5 \\
66.0 \\
68.4 \\
70.9 \\
60.8 \\
62.5 \\
61.9 \\
57.1 \\
62.0\end{array}$ & $\begin{array}{l}44.8 \\
47.4 \\
49.1 \\
52.5 \\
53.3 \\
57.9 \\
59.3 \\
60.2 \\
54.4 \\
51.4 \\
52.4 \\
49.2 \\
52.4\end{array}$ & $\begin{array}{l}55.0 \\
57.7 \\
60.2 \\
64.2 \\
63.6 \\
67.0 \\
69.6 \\
71.7 \\
64.3 \\
64.3 \\
64.5 \\
59.6 \\
63.5\end{array}$ & $\begin{array}{l}64.4 \\
65.5 \\
65.9 \\
68.8 \\
70.4 \\
72.5 \\
75.5 \\
78.8 \\
77.9 \\
76.0 \\
76.0 \\
73.9 \\
72.1\end{array}$ & $\begin{array}{l}63.6 \\
64.7 \\
65.2 \\
68.1 \\
69.6 \\
71.8 \\
74.8 \\
77.7 \\
76.3 \\
74.6 \\
74.6 \\
72.3 \\
71.0\end{array}$ & $\begin{array}{l}55.9 \\
57.4 \\
58.6 \\
61.5 \\
62.2 \\
64.6 \\
67.4 \\
69.2 \\
67.1 \\
65.8 \\
65.6 \\
62.8 \\
62.4\end{array}$ & $\begin{array}{l}46.5 \\
50.0 \\
51.6 \\
54.9 \\
55.5 \\
59.0 \\
61.2 \\
63.8 \\
54.2 \\
55.3 \\
54.9 \\
50.0 \\
55.0\end{array}$ & $\begin{array}{l}41.3 \\
43.8 \\
45.2 \\
48.2 \\
49.5 \\
52.1 \\
54.0 \\
56.5 \\
49.2 \\
48.1 \\
47.9 \\
45.3 \\
48.1\end{array}$ & $\begin{array}{l}47.0 \\
50.3 \\
52.1 \\
55.2 \\
56.0 \\
58.9 \\
61.5 \\
63.9 \\
56.4 \\
56.1 \\
55.9 \\
50.9 \\
55.4\end{array}$ \\
\hline
\end{tabular}

See footnoles at end of table. 
Table 32. Conventional Motor Gasoline Prices by Grade, Sales Type, PAD District, and State

(Cents per Gallon Excluding Taxes) - Continued

\begin{tabular}{|c|c|c|c|c|c|c|c|c|c|c|c|c|}
\hline \multirow{3}{*}{$\begin{array}{c}\text { Geographic Area } \\
\text { Month }\end{array}$} & \multicolumn{6}{|c|}{ Regular } & \multicolumn{6}{|c|}{ Midgrade } \\
\hline & \multicolumn{2}{|c|}{ Sales to End Users } & \multicolumn{4}{|c|}{ Sales for Resale } & \multicolumn{2}{|c|}{ Sales to End Users } & \multicolumn{4}{|c|}{ Sales for Resale } \\
\hline & $\begin{array}{c}\text { Through } \\
\text { Retail } \\
\text { Outlets }\end{array}$ & Averagea & DTW & Rack & Bulk & Average & $\begin{array}{c}\text { Through } \\
\text { Retail } \\
\text { Outlets }\end{array}$ & Averagea & DTW & Rack & Bulk & Average \\
\hline
\end{tabular}

Alabama

Alabama
January ................................. 60.2

March ...

April .................................... 64.3

May .................................. 66.0

June $\quad 68.4$

July .

72.4

September 71.8

October ............. 71.

November ............................... 70.9

December .

1994 Average

Arkansas

January .................................

February

March

April ........................................

May ..........................................

June

July ...

August

September

October ...

November

December .
1994 Average

1994 Aver

January

February

March

April .............................. 61.4

June ................................................. 65.9

July ..................................... 68.5

August ............................. 72.2

September .......................... 71.9

October ...

November

70.7

1994 Average

Mississippi

January 59.6

February .................................... 60.9

March ................................. 61.5

April .................................... 63.5

May ...................................... 64.1

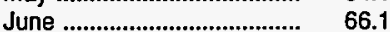

July $\quad 68.7$

August .................................. $\quad 73.0$

September .............................. 72.4

October ................................. 72.3

November

December

1994 Average

$\begin{array}{lll}59.9 & 57.0 & 45.1 \\ 61.9 & 58.9 & 48.2 \\ 62.3 & 59.6 & 49.1 \\ 64.1 & 61.3 & 53.0 \\ 65.5 & 62.2 & 53.0 \\ 67.9 & 64.1 & 56.2 \\ 70.8 & 66.1 & 57.8 \\ 71.7 & 68.4 & 59.5 \\ 70.6 & 65.5 & 49.4 \\ 70.3 & 66.1 & 52.8 \\ 70.0 & 65.0 & 53.3 \\ 68.2 & 62.3 & 47.2 \\ 66.7 & 63.2 & 52.1\end{array}$

$\begin{array}{ll}- & 48.0 \\ W & 50.8 \\ W & 51.7 \\ W & 54.9 \\ W & 55.1 \\ W & 58.0 \\ W & 59.7 \\ W & 61.5 \\ W & 52.8 \\ W & 55.7 \\ W & 55.8 \\ W & 50.5 \\ W & 54.6\end{array}$

68.9
70.7
71.4
73.1
74.7
77.5
80.9
81.1
80.8
80.1
79.9
78.4
76.3

68.4
70.2
70.9
72.7
74.1
77.0
80.4
80.4
79.6
79.2
79.1
77.5
75.6

62.3
64.6
64.8
66.9
67.9
69.7
72.4
74.0
70.9
71.9
70.4
67.7
68.8

49.9
53.0
54.1
58.1
58.0
61.6
63.1
65.2
54.6
57.8
58.9
52.3
57.4

- $\quad 53.8$

$-56.6$

N $\quad 57.3$

- $\quad 60.6$

$-\quad 63.9$

- $\quad 65.7$

- $\quad 67.8$

- $\quad 59.5$

- $\quad 61.8$

\begin{tabular}{l}
- \\
$-\quad 61.8$ \\
\hline
\end{tabular}

$\begin{array}{llllll}76.3 & 77.5 & 67.7 & 52.3 & - & 56.5 \\ & 75.6 & 68.8 & 57.4 & w & 60.6\end{array}$

\section{$57.5 \quad 48.9 \quad 44.8$}

$58.9 \quad 52.0 \quad 48.1$

$59.5 \quad 52.8$

$62.9 \quad 55.9$

52.8

$\begin{array}{lll}63.5 & 56.9 & 53.4\end{array}$

$66.1 \quad 60.1$

$69.2 \quad 63.9$

$\begin{array}{ll}72.4 & 66.5 \\ 70.6 & 60.6\end{array}$

$\begin{array}{ll}70.6 & 60.6 \\ 69.4 & 59.8\end{array}$

$68.4 \quad 58.3$

$65.7 \quad 57.4$

65.5

57.0

$61.0 \quad 58.6$

$60.8 \quad 58.4$

$61.0 \quad 59.7$

$62.8 \quad 61.7$

$\begin{array}{ll}63.8 & 61.9 \\ 65.6 & 64.8\end{array}$

$\begin{array}{ll}65.6 & 64.8 \\ 68.0 & 66.8\end{array}$

$71.6 \quad 66.6$

$\begin{array}{ll}71.2 & 61.9 \\ 69.6 & 63.4\end{array}$

$\begin{array}{ll}69.6 & 63.4 \\ 70.1 & 61.8\end{array}$

$68.3 \quad 59.6$

$65.8 \quad 62.3$

W 46.0

w $\quad 49.3$

W $\quad 53.8$

54.5

56.9

59.6

61.7

51.3

52.3

51.9

47.5
52.6

68.4

69.7
69.7

72.7

72.9
75.9

75.9
79.1

82.9

82.3

80.8

79.5

76.7

68.8

68.9

72.2

75.0

78.4

81.6

80.9
79.4

79.4

75.3

74.9

52.2

$\begin{array}{ll}55.2 & 52.5 \\ 55.7 & 53.8\end{array}$

59.9

60.0

63.7
66.8

72.3

67.8

66.2

64.9

62.7

60.7

$\begin{array}{lll}44.1 & 41.1 \quad 44.6\end{array}$

44.1
47.4

49.0

52.7

52.7
55.6

55.6
57.8

59.8

49.8
52.2

52.2

46.8

41.1
43.1

44.4
47.4

48.2

50.0

53.0

55.8

$48.6 \quad 52.9$

$47.9 \quad 53.3$

47.0

48.9

51.6

47.6

52.1

73.1

72.1

71.5
71.8

71.8
73.4

75.0

75.0
76.2
78.8

78.8

81.6

81.2
80.2

80.2
80.5

78.8

62.8
64.0
65.
67.
67.5
70.
72.
72.
67.
69.
68.
66.
67.

$62.8 \quad 49.6$

$65.2 \quad 53.8$

67.3
67.5

$67.5 \quad 57.7$

$\begin{array}{ll}72.2 & 60.9 \\ 72.8\end{array}$

$72.2 \quad 65.1$

$67.8 \quad 54.9$

$69.3 \quad 56.9$

$68.3 \quad 57.6$

$66.1 \quad 51.8$

56.8

\begin{tabular}{|c|c|c|c|c|c|c|c|c|c|c|}
\hline 58.8 & 53.1 & 45.7 & 39.5 & 44.9 & 68.7 & 67.9 & 58.8 & 49.2 & - & 51.5 \\
\hline 60.3 & 54.8 & 47.7 & 43.8 & 48.7 & 69.9 & 69.2 & 60.4 & 52.5 & - & 54.4 \\
\hline 60.9 & 56.1 & 49.0 & $w$ & 50.6 & 70.5 & 69.4 & 61.7 & 53.7 & - & 55.4 \\
\hline 63.2 & 58.2 & 53.0 & 49.0 & 53.0 & 72.6 & 71.8 & 63.9 & 57.6 & - & 59.0 \\
\hline 63.7 & 58.8 & 52.8 & 48.4 & 51.9 & 72.7 & 72.0 & 64.8 & 57.7 & - & 59.3 \\
\hline 65.7 & 61.1 & 56.1 & 49.8 & 55.3 & 74.6 & 74.2 & 66.9 & 60.9 & - & 62.3 \\
\hline 68.3 & 63.1 & 57.1 & 52.8 & 57.2 & 77.5 & 77.0 & 68.6 & 62.4 & - & 63.7 \\
\hline 72.4 & 64.5 & 59.0 & 55.1 & 59.5 & 82.3 & 81.7 & 71.0 & 64.4 & - & 65.8 \\
\hline 71.6 & 61.3 & 49.1 & 50.8 & 51.1 & 81.7 & 80.9 & 66.7 & 54.2 & - & 57.3 \\
\hline 71.6 & 61.9 & 52.4 & 47.0 & 52.7 & 81.2 & 80.5 & 67.4 & 57.5 & - & 59.8 \\
\hline 71.7 & 61.9 & 52.7 & 49.1 & 53.6 & 81.5 & 80.9 & 67.8 & 58.2 & - & 60.6 \\
\hline 70.1 & 60.4 & 47.1 & 44.1 & 48.3 & 80.1 & 79.4 & 66.1 & 51.9 & - & 55.3 \\
\hline 66.3 & 59.5 & 51.9 & 47.6 & 52.2 & 75.8 & 75.1 & 65.6 & 57.0 & - & 58.9 \\
\hline
\end{tabular}

See footnotes at end of table. 
Table 32. Conventional Motor Gasoline Prices by Grade, Sales Type, PAD District, and State

(Cents per Gallon Excluding Taxes) - Continued

\begin{tabular}{|c|c|c|c|c|c|c|c|c|c|c|c|c|}
\hline \multirow{3}{*}{$\begin{array}{c}\text { Geographlc Area } \\
\text { Month }\end{array}$} & \multicolumn{6}{|c|}{ Premium } & \multicolumn{6}{|c|}{ All Grades } \\
\hline & \multicolumn{2}{|c|}{ Sales to End Users } & \multicolumn{4}{|c|}{ Sales for Resale } & \multicolumn{2}{|c|}{ Sales to End Users } & \multicolumn{4}{|c|}{ Sales for Resale } \\
\hline & $\begin{array}{c}\text { Through } \\
\text { Retail } \\
\text { Outlets }\end{array}$ & Averagea & DTW & Rack & Bulk & Average & $\begin{array}{c}\text { Through } \\
\text { Retail } \\
\text { Outlets }\end{array}$ & Averagea $^{a}$ & DTW & Rack & Bulk & Average \\
\hline Alabama & & & & & & & & & & & & \\
\hline 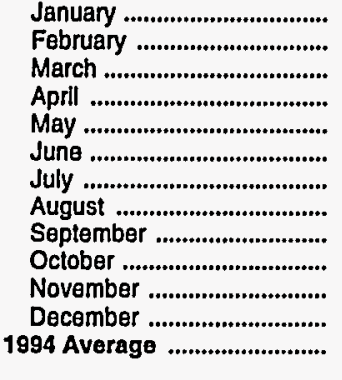 & $\begin{array}{l}78.3 \\
80.1 \\
80.6 \\
82.7 \\
84.5 \\
87.2 \\
90.6 \\
89.8 \\
89.9 \\
89.4 \\
89.3 \\
87.4 \\
85.3\end{array}$ & $\begin{array}{l}77.0 \\
78.8 \\
79.4 \\
81.6 \\
83.1 \\
85.9 \\
89.1 \\
88.0 \\
87.0 \\
87.6 \\
87.5 \\
85.4 \\
83.4\end{array}$ & $\begin{array}{l}69.3 \\
71.0 \\
71.7 \\
73.7 \\
74.8 \\
76.7 \\
80.0 \\
81.5 \\
78.3 \\
79.4 \\
78.2 \\
74.4 \\
75.6\end{array}$ & $\begin{array}{l}55.4 \\
58.5 \\
59.5 \\
63.2 \\
63.5 \\
66.9 \\
68.8 \\
70.8 \\
60.4 \\
63.8 \\
64.3 \\
58.1 \\
62.9\end{array}$ & $\begin{array}{l}- \\
- \\
- \\
- \\
- \\
- \\
- \\
- \\
-\end{array}$ & $\begin{array}{l}59.5 \\
62.2 \\
63.0 \\
66.0 \\
66.6 \\
69.6 \\
71.8 \\
73.4 \\
64.7 \\
67.4 \\
67.6 \\
61.6 \\
66.1\end{array}$ & $\begin{array}{l}65.7 \\
67.8 \\
68.3 \\
70.0 \\
71.6 \\
74.1 \\
77.2 \\
77.6 \\
77.1 \\
76.5 \\
76.3 \\
74.7 \\
72.7\end{array}$ & $\begin{array}{l}65.1 \\
67.1 \\
67.5 \\
69.5 \\
70.9 \\
73.4 \\
76.5 \\
76.8 \\
75.6 \\
75.5 \\
75.2 \\
73.6 \\
71.7\end{array}$ & $\begin{array}{l}61.0 \\
63.0 \\
63.7 \\
65.4 \\
66.5 \\
68.4 \\
70.9 \\
72.4 \\
69.5 \\
70.2 \\
69.0 \\
65.9 \\
67.3\end{array}$ & $\begin{array}{l}48.0 \\
51.2 \\
52.2 \\
56.1 \\
56.1 \\
59.5 \\
61.1 \\
62.8 \\
52.5 \\
56.0 \\
56.6 \\
50.5 \\
55.3\end{array}$ & $\begin{array}{c}- \\
W \\
W \\
W \\
50.7 \\
W \\
W \\
W \\
W \\
W \\
W \\
W \\
W\end{array}$ & $\begin{array}{l}51.5 \\
54.3 \\
55.2 \\
58.3 \\
58.7 \\
61.6 \\
63.4 \\
65.1 \\
56.4 \\
59.2 \\
59.4 \\
53.9 \\
58.1\end{array}$ \\
\hline 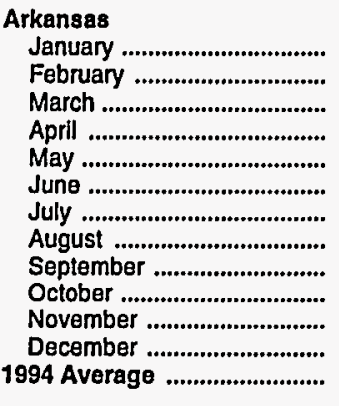 & $\begin{array}{l}76.4 \\
77.6 \\
76.1 \\
80.2 \\
80.5 \\
83.4 \\
86.8 \\
90.0 \\
88.9 \\
87.2 \\
86.3 \\
83.3 \\
83.1\end{array}$ & $\begin{array}{l}75.0 \\
75.8 \\
74.7 \\
78.8 \\
79.0 \\
81.8 \\
85.1 \\
86.7 \\
85.2 \\
84.3 \\
83.3 \\
81.0 \\
81.1\end{array}$ & $\begin{array}{l}59.1 \\
61.0 \\
61.9 \\
66.5 \\
66.5 \\
69.4 \\
73.8 \\
75.0 \\
69.3 \\
68.9 \\
68.0 \\
67.3 \\
65.8\end{array}$ & $\begin{array}{l}53.0 \\
56.0 \\
58.0 \\
61.7 \\
61.8 \\
65.7 \\
68.5 \\
70.8 \\
60.5 \\
61.9 \\
60.9 \\
56.7 \\
61.4\end{array}$ & $\begin{array}{l}- \\
\vec{w} \\
- \\
- \\
- \\
- \\
- \\
- \\
- \\
- \\
\bar{w}\end{array}$ & $\begin{array}{l}55.0 \\
57.7 \\
59.4 \\
63.5 \\
63.5 \\
67.0 \\
70.4 \\
71.5 \\
62.1 \\
63.2 \\
62.2 \\
58.7 \\
62.6\end{array}$ & $\begin{array}{l}62.0 \\
63.7 \\
63.6 \\
67.3 \\
67.7 \\
70.5 \\
73.7 \\
77.9 \\
76.9 \\
74.9 \\
73.8 \\
70.7 \\
70.2\end{array}$ & $\begin{array}{l}61.3 \\
62.7 \\
62.9 \\
66.5 \\
67.0 \\
69.6 \\
72.9 \\
75.8 \\
74.4 \\
73.2 \\
72.1 \\
69.6 \\
69.2\end{array}$ & $\begin{array}{l}51.6 \\
54.4 \\
55.2 \\
58.7 \\
59.5 \\
62.6 \\
66.4 \\
68.8 \\
63.1 \\
62.3 \\
61.0 \\
59.9 \\
59.3\end{array}$ & $\begin{array}{l}46.7 \\
50.1 \\
51.4 \\
54.8 \\
55.5 \\
59.0 \\
61.6 \\
63.7 \\
53.2 \\
54.5 \\
54.1 \\
49.5 \\
54.7\end{array}$ & $\begin{array}{c}W \\
- \\
W \\
W \\
W \\
W \\
W \\
- \\
W \\
49.4 \\
W \\
W \\
50.3\end{array}$ & $\begin{array}{l}48.2 \\
51.5 \\
52.7 \\
56.2 \\
56.8 \\
60.2 \\
63.1 \\
64.6 \\
55.0 \\
55.8 \\
55.2 \\
51.3 \\
55.8\end{array}$ \\
\hline 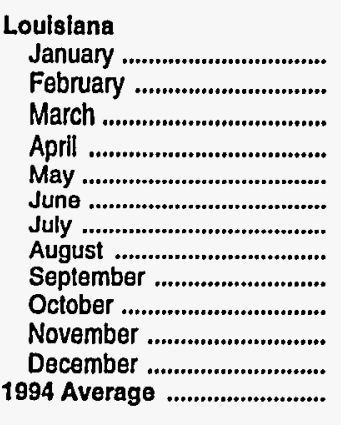 & $\begin{array}{l}81.7 \\
80.2 \\
81.5 \\
82.7 \\
84.5 \\
85.6 \\
88.1 \\
90.8 \\
90.4 \\
88.6 \\
89.2 \\
87.6 \\
85.5\end{array}$ & $\begin{array}{l}79.9 \\
78.8 \\
80.0 \\
81.5 \\
82.8 \\
84.2 \\
86.7 \\
88.7 \\
88.3 \\
86.8 \\
87.3 \\
85.8 \\
84.0\end{array}$ & $\begin{array}{l}71.7 \\
71.5 \\
72.1 \\
74.8 \\
74.9 \\
77.1 \\
79.2 \\
79.8 \\
75.9 \\
76.7 \\
75.7 \\
73.7 \\
75.5\end{array}$ & $\begin{array}{l}53.7 \\
56.5 \\
58.2 \\
62.2 \\
62.3 \\
65.6 \\
67.6 \\
69.9 \\
59.6 \\
61.8 \\
62.4 \\
56.7 \\
61.4\end{array}$ & $\begin{array}{c}41.8 \\
47.1 \\
47.7 \\
48.8 \\
53.4 \\
58.2 \\
59.7 \\
62.8 \\
W \\
50.2 \\
W \\
W \\
52.5\end{array}$ & $\begin{array}{l}53.1 \\
59.2 \\
61.1 \\
65.5 \\
63.7 \\
67.7 \\
68.8 \\
70.3 \\
63.1 \\
64.1 \\
66.6 \\
62.3 \\
63.7\end{array}$ & $\begin{array}{l}67.8 \\
67.3 \\
67.6 \\
69.3 \\
70.8 \\
72.1 \\
74.7 \\
78.0 \\
77.7 \\
76.2 \\
76.6 \\
74.9 \\
72.3\end{array}$ & $\begin{array}{l}67.1 \\
66.6 \\
67.0 \\
68.8 \\
70.0 \\
71.6 \\
74.1 \\
77.2 \\
76.7 \\
75.4 \\
75.8 \\
74.1 \\
71.7\end{array}$ & $\begin{array}{l}63.3 \\
63.2 \\
64.4 \\
66.5 \\
66.9 \\
69.4 \\
71.3 \\
71.5 \\
67.1 \\
68.4 \\
67.1 \\
65.1 \\
67.2\end{array}$ & $\begin{array}{l}46.7 \\
50.1 \\
51.7 \\
55.5 \\
55.6 \\
58.5 \\
60.6 \\
62.7 \\
52.8 \\
55.1 \\
55.6 \\
49.7 \\
54.5\end{array}$ & $\begin{array}{l}41.3 \\
43.7 \\
44.9 \\
47.5 \\
49.4 \\
51.0 \\
54.3 \\
57.6 \\
49.0 \\
48.8 \\
48.4 \\
47.0 \\
48.3\end{array}$ & $\begin{array}{l}47.4 \\
51.4 \\
52.8 \\
56.7 \\
56.5 \\
58.7 \\
61.1 \\
63.2 \\
54.9 \\
56.3 \\
57.2 \\
52.3 \\
55.6\end{array}$ \\
\hline 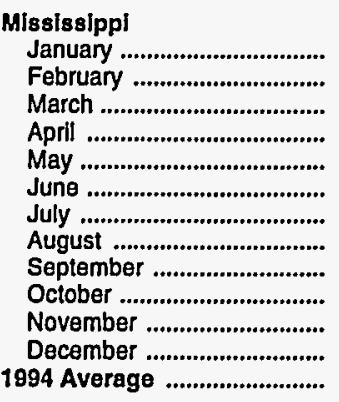 & $\begin{array}{l}77.8 \\
79.2 \\
79.2 \\
81.3 \\
81.1 \\
83.6 \\
86.4 \\
90.8 \\
89.4 \\
89.3 \\
89.5 \\
88.5 \\
83.9\end{array}$ & $\begin{array}{l}76.1 \\
77.8 \\
77.6 \\
80.2 \\
80.1 \\
82.7 \\
85.5 \\
90.1 \\
88.5 \\
88.4 \\
88.7 \\
87.6 \\
82.7\end{array}$ & $\begin{array}{l}64.3 \\
66.3 \\
67.6 \\
69.6 \\
70.4 \\
72.4 \\
74.9 \\
78.2 \\
73.7 \\
73.9 \\
73.9 \\
72.5 \\
71.4\end{array}$ & $\begin{array}{l}54.7 \\
57.7 \\
58.9 \\
62.7 \\
62.7 \\
66.1 \\
68.0 \\
69.9 \\
59.8 \\
63.0 \\
63.3 \\
57.4 \\
62.1\end{array}$ & $\begin{array}{c}46.2 \\
48.8 \\
- \\
W \\
W \\
W \\
W \\
57.1 \\
53.4 \\
51.5 \\
50.9 \\
51.8 \\
52.2\end{array}$ & $\begin{array}{l}54.0 \\
55.9 \\
60.9 \\
63.9 \\
63.1 \\
67.2 \\
67.7 \\
67.5 \\
59.3 \\
60.4 \\
62.8 \\
58.5 \\
61.6\end{array}$ & $\begin{array}{l}64.7 \\
66.0 \\
66.6 \\
68.9 \\
68.9 \\
71.2 \\
73.6 \\
78.2 \\
77.2 \\
77.1 \\
77.1 \\
75.9 \\
71.7\end{array}$ & $\begin{array}{l}63.8 \\
65.3 \\
65.8 \\
68.3 \\
68.4 \\
70.7 \\
73.1 \\
77.6 \\
76.3 \\
76.3 \\
76.4 \\
75.1 \\
71.0\end{array}$ & $\begin{array}{l}56.2 \\
57.9 \\
59.3 \\
61.4 \\
62.1 \\
64.2 \\
66.3 \\
68.5 \\
65.1 \\
65.6 \\
65.6 \\
64.1 \\
62.9\end{array}$ & $\begin{array}{l}47.9 \\
50.2 \\
51.7 \\
55.6 \\
55.5 \\
58.9 \\
59.9 \\
61.9 \\
51.9 \\
55.3 \\
55.6 \\
49.8 \\
54.6\end{array}$ & $\begin{array}{c}40.9 \\
46.8 \\
W \\
49.1 \\
49.0 \\
50.0 \\
53.6 \\
56.2 \\
51.8 \\
48.9 \\
49.6 \\
46.1 \\
48.7\end{array}$ & $\begin{array}{l}47.3 \\
51.1 \\
53.4 \\
55.7 \\
54.5 \\
58.2 \\
59.9 \\
62.3 \\
53.8 \\
55.5 \\
56.4 \\
51.3 \\
54.9\end{array}$ \\
\hline
\end{tabular}

See footnotes at end of table. 
Table 32. Conventional Motor Gasoline Prices by Grade, Sales Type, PAD District, and State

(Cents per Gallon Excluding Taxes) - Continued

\begin{tabular}{|c|c|c|c|c|c|c|c|c|c|c|c|c|}
\hline \multirow{3}{*}{$\begin{array}{l}\text { Goographic Aroa } \\
\text { Month }\end{array}$} & \multicolumn{6}{|c|}{ Regular } & \multicolumn{6}{|c|}{ Midgrade } \\
\hline & \multicolumn{2}{|c|}{ Sales to End Usors } & \multicolumn{4}{|c|}{ Sales for Resale } & \multicolumn{2}{|c|}{ Sales to End Users } & \multicolumn{4}{|c|}{ Sales for Resale } \\
\hline & $\begin{array}{c}\text { Through } \\
\text { Retail } \\
\text { Outlets }\end{array}$ & Averagea & DTW & Rack & Bulk & Average & $\begin{array}{c}\text { Through } \\
\text { Retail } \\
\text { Outlets }\end{array}$ & Averagea & DTW & Rack & Bulk & Average \\
\hline
\end{tabular}

Now Mexico

January

February

68.2

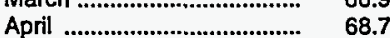

May ................................... 72.2

June ............................ 74.8

July ....................................... 77.8

August ................................... 83.6

September ............................ 82.1

October

November ........................... 79.1

December .

1994 Average

Texas

January ......

............................. 59.7

March ................................. 59.9

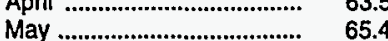

June .................................... 67.5

July ......................................... 70.7

August ................................. $\quad 74.0$

September ............................ 73.0

October ................................. 70.4

November .................................. 70.8

December .

1994 Average

\section{...........}

PAD District IV

January...

February

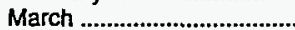

May

70.8

June ...................................... 76.2

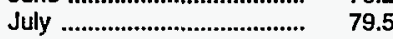

August .......................................... 84.9

September ........................... 85.7

October ............................... 81.8

November ................... 79.0

December

1994 Average

Colorado

January ................................ $73.2 \quad 73.0$

February ............................. $74.1 \quad 73.5$

March

Aptil

June ............................... $\quad 74.9$

July ..................... 79.3

August .................................. 87.4

September ......................... 87.7

October ................................ 82.4

November ....................... 81.1

December

1994 Average

67.6
66.4
66.7
68.6
71.8
74.3
77.5
83.1
81.2
79.5
78.5
74.6
74.3

\section{6}

$58.5 \quad 52.9$

62.8

65.2

67.8

71.0

75.7

69.3

65.6

$\begin{array}{ll}61.3 & 59.6 \\ 63.3\end{array}$

$\begin{array}{ll}65.3 & 60.7\end{array}$

57.5

59.1
59.4

63.0

64.8

67.2

70.2

73.2

71.4

69.0
69.5

67.0

65.9

\section{8}

66.1

67.5
67.5

70.9

76.2

79.8

85.2
85.8

81.5

78.9

76.3

$51.5 \quad 43.7$

$52.9 \quad 47.3$

$54.3 \quad 49.1$

$\begin{array}{ll}57.6 & 52.0 \\ 58.1 & 52.7\end{array}$

$60.5 \quad 56.5$

$\begin{array}{ll}63.5 & 59.1\end{array}$

$65.9 \quad 61.8$

$64.5 \quad 52.6$

$62.2 \quad 52.7$

$\begin{array}{ll}62.8 & 52.0 \\ 60.0 & 47.8\end{array}$

$\begin{array}{ll}58.0 & 47.8 \\ & 52.6\end{array}$

\section{$56.4 \quad 50.6$}

$57.4 \quad 52.9$

$57.9 \quad 53.8$

$60.0 \quad 55.6$

$63.5 \quad 60.1$

$68.8 \quad 66.1$

$\begin{array}{ll}72.6 & 69.3 \\ 76.6 & 74.3\end{array}$

$\begin{array}{ll}75.6 & 74.3 \\ 7 & 71.8\end{array}$

$69.5 \quad 63.9$

$68.8 \quad 62.7$

$64.3 \quad 57.3$

$66.9 \quad 62.3$

$\begin{array}{lll}57.6 & 50.5 & \text { W } \\ 60.7 & 54.5 & - \\ 59.0 & 53.6 & - \\ 60.5 & 55.3 & - \\ 62.0 & 57.2 & - \\ 65.0 & 61.3 & - \\ 71.3 & 66.6 & - \\ 77.3 & 74.8 & \text { W } \\ 75.3 & 66.9 & - \\ 66.3 & 57.6 & - \\ 65.8 & 56.5 & - \\ 60.7 & 50.1 & - \\ 66.6 & 59.9 & \text { W }\end{array}$

$\begin{array}{lll}- & 51.1 & 71.7 \\ - & 54.2 & 71.6 \\ - & 55.6 & 72.7 \\ - & 59.5 & 74.4 \\ - & 62.1 & 78.0 \\ - & 64.3 & 80.6 \\ - & 68.1 & 84.2 \\ - & 74.1 & 90.9 \\ \text { - } & 67.5 & 88.4 \\ \text { W } & 61.3 & 86.1 \\ \text { - } & 60.7 & 84.9 \\ \text { W } & 55.0 & 81.4 \\ \text { 61.7 } & 81.4\end{array}$

$70.4 \quad 63.4$

$\begin{array}{lll}71.0 & 64.3 & 52.8\end{array}$

$72.5 \quad 63.3$

$74.2 \quad 66.4$

77.8

80.3

83.8

89.3

86.5

86.0

84.9
81.4

80.9

$\begin{array}{lll}40.9 & 43.8 & 68.5\end{array}$

43.1

44.8
47.8

47.8
49.2

51.5

53.3

56.0

48.6

47.5
47.5

44.9

$$
\begin{aligned}
& 46.9 \\
& 48.7 \\
& 51.7 \\
& 52.9 \\
& 55.8 \\
& 58.4 \\
& 61.2 \\
& 53.9 \\
& 52.6 \\
& 52.4 \\
& 47.9 \\
& 52.3
\end{aligned}
$$

\section{W 5}

521

54.0
54.9

56.7

$$
61.0
$$

66.9

$$
\begin{aligned}
& 70.2 \\
& 74.9
\end{aligned}
$$

$$
72.9
$$

$$
65.4
$$

64.3

59.2
63.5

68.9

77.1
77.2

80.0

85.6
88.5

88.5
95.7

95.8

90.7
85.0

85.0
82.8

85.3

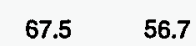

$68.8 \quad 58.1$

$69.0 \quad 59.1$

$72.4 \quad 62.7$

74.2

76.2

79.5

82.7

81.2

78.7

79.4
76.1

75.5

63.4

65.3

68.2

70.5

65.1

65.5

62.0

63.1

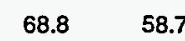

68.8

76.5

79.3

$84.7 \quad 71.5$

$87.8 \quad 75.8$

$94.9 \quad 81.8$

$90.2 \quad 74.5$

$\begin{array}{ll}90.2 & 74.5 \\ 84.8 & 71.7\end{array}$

$82.4 \quad 67.5$

70.8

\section{$52.5 \quad 81$}$$
56.1
$$

55.0

56.7

$$
58.5
$$

67.9
75.4

69.2

60.2

58.7
52.6

61.6

$\begin{array}{lllll}79.7 & 61.7 & 54.4 & - & 57.3 \\ 79.1 & 63.5 & 57.4 & - & 60.5 \\ 80.9 & 63.6 & 57.5 & - & 60.9 \\ 80.6 & 65.2 & 59.4 & - & 62.6 \\ 81.2 & 66.5 & 61.9 & - & 64.3 \\ 85.8 & 70.5 & 65.5 & - & 68.3 \\ 89.8 & 75.7 & 71.0 & - & 73.5 \\ 97.8 & 83.9 & 79.4 & - & 82.1 \\ 97.9 & 79.6 & 74.0 & - & 77.2 \\ 92.3 & 74.5 & 63.3 & - & 69.6 \\ 89.0 & 74.8 & 62.5 & - & 67.9 \\ 88.2 & 67.9 & 55.7 & - & 60.7 \\ 88.6 & 72.1 & 64.7 & - & 68.7\end{array}$

See footnotes at end of table. 
Table 32. Conventional Motor Gasoline Prices by Grade, Sales Type,

PAD District, and State

(Cents per Gallon Excluding Taxes) - Continued

\begin{tabular}{|c|c|c|c|c|c|c|c|c|c|c|c|c|}
\hline \multirow{3}{*}{$\begin{array}{c}\text { Coographlc Area } \\
\text { Month }\end{array}$} & \multicolumn{6}{|c|}{ Premium } & \multicolumn{6}{|c|}{ All Grades } \\
\hline & \multicolumn{2}{|c|}{ Sales to End Users } & \multicolumn{4}{|c|}{ Sales for Resale } & \multicolumn{2}{|c|}{ Sales to End Users } & \multicolumn{4}{|c|}{ Sales for Resale } \\
\hline & $\begin{array}{c}\text { Through } \\
\text { Retail } \\
\text { Outlets }\end{array}$ & Average $\mathrm{a}$ & DTW & Rack & Bulk & Average & $\begin{array}{c}\text { Through } \\
\text { Retail } \\
\text { Outlets }\end{array}$ & Average ${ }^{a}$ & DTW & Rack & Bulk & Average \\
\hline 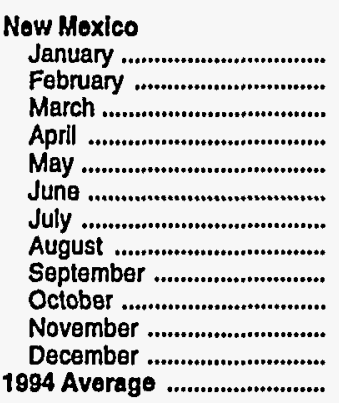 & $\begin{array}{l}77.9 \\
76.1 \\
79.3 \\
80.8 \\
85.2 \\
87.5 \\
91.7 \\
96.9 \\
95.2 \\
93.0 \\
91.3 \\
87.0 \\
87.5\end{array}$ & $\begin{array}{l}77.2 \\
75.9 \\
79.1 \\
80.5 \\
84.7 \\
87.0 \\
91.0 \\
96.3 \\
94.4 \\
92.2 \\
90.8 \\
86.5 \\
86.9\end{array}$ & $\begin{array}{l}68.6 \\
69.3 \\
69.2 \\
71.6 \\
75.2 \\
78.1 \\
81.0 \\
86.7 \\
80.9 \\
77.0 \\
76.8 \\
71.7 \\
76.3\end{array}$ & $\begin{array}{l}57.7 \\
61.8 \\
63.6 \\
67.3 \\
70.3 \\
72.5 \\
76.0 \\
82.4 \\
76.1 \\
68.8 \\
67.5 \\
61.5 \\
69.4\end{array}$ & $\begin{array}{l}- \\
- \\
- \\
- \\
- \\
- \\
- \\
- \\
-\end{array}$ & $\begin{array}{l}60.4 \\
63.7 \\
64.9 \\
68.5 \\
71.7 \\
73.7 \\
77.3 \\
83.6 \\
77.4 \\
70.6 \\
69.5 \\
63.4 \\
71.1\end{array}$ & $\begin{array}{l}69.4 \\
67.8 \\
68.6 \\
70.6 \\
74.0 \\
76.8 \\
80.0 \\
85.7 \\
84.0 \\
82.1 \\
80.8 \\
77.0 \\
76.8\end{array}$ & $\begin{array}{l}68.8 \\
67.6 \\
68.4 \\
70.4 \\
73.6 \\
76.2 \\
79.5 \\
85.0 \\
83.0 \\
81.4 \\
80.1 \\
76.4 \\
76.2\end{array}$ & $\begin{array}{l}59.2 \\
60.1 \\
60.3 \\
64.0 \\
66.6 \\
69.2 \\
72.6 \\
77.3 \\
71.1 \\
67.2 \\
66.1 \\
62.6 \\
66.9\end{array}$ & $\begin{array}{l}50.0 \\
54.0 \\
55.8 \\
59.5 \\
62.2 \\
64.4 \\
68.4 \\
74.8 \\
68.0 \\
61.4 \\
60.7 \\
54.4 \\
61.9\end{array}$ & $\begin{array}{l}- \\
- \\
- \\
- \\
- \\
- \\
- \\
\bar{w} \\
- \\
\bar{w}\end{array}$ & $\begin{array}{l}52.4 \\
55.5 \\
56.8 \\
60.7 \\
63.4 \\
65.6 \\
69.5 \\
75.4 \\
68.8 \\
62.5 \\
62.0 \\
56.2 \\
63.0\end{array}$ \\
\hline 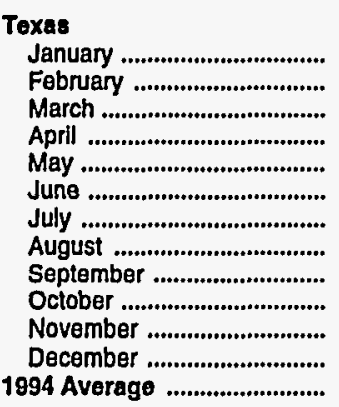 & $\begin{array}{l}76.8 \\
77.7 \\
78.0 \\
81.3 \\
83.0 \\
85.2 \\
87.9 \\
91.4 \\
91.0 \\
88.3 \\
88.7 \\
85.9 \\
84.6\end{array}$ & $\begin{array}{l}75.3 \\
76.2 \\
76.8 \\
80.2 \\
81.8 \\
83.7 \\
86.9 \\
89.8 \\
88.6 \\
86.0 \\
86.2 \\
83.0 \\
82.8\end{array}$ & $\begin{array}{l}62.5 \\
64.7 \\
65.6 \\
69.1 \\
69.8 \\
71.9 \\
74.8 \\
77.5 \\
74.1 \\
71.8 \\
72.1 \\
67.9 \\
69.6\end{array}$ & $\begin{array}{l}53.1 \\
56.6 \\
57.7 \\
61.9 \\
62.0 \\
65.4 \\
68.0 \\
70.7 \\
60.9 \\
61.9 \\
60.5 \\
56.3 \\
61.6\end{array}$ & $\begin{array}{l}46.3 \\
47.1 \\
49.4 \\
52.8 \\
53.0 \\
57.8 \\
59.5 \\
59.6 \\
55.1 \\
52.0 \\
52.4 \\
48.8 \\
52.4\end{array}$ & $\begin{array}{l}54.7 \\
56.6 \\
59.0 \\
63.4 \\
62.8 \\
65.9 \\
69.0 \\
72.2 \\
65.5 \\
64.3 \\
63.7 \\
58.4 \\
63.1\end{array}$ & $\begin{array}{l}63.3 \\
64.6 \\
64.9 \\
68.4 \\
70.2 \\
72.3 \\
75.4 \\
78.8 \\
77.9 \\
75.4 \\
75.7 \\
73.3 \\
71.8\end{array}$ & $\begin{array}{l}62.3 \\
63.7 \\
64.1 \\
67.6 \\
69.4 \\
71.6 \\
74.7 \\
77.7 \\
76.1 \\
73.7 \\
74.0 \\
71.2 \\
70.5\end{array}$ & $\begin{array}{l}54.5 \\
56.0 \\
57.3 \\
60.7 \\
61.2 \\
63.5 \\
66.4 \\
68.4 \\
67.0 \\
64.9 \\
65.3 \\
62.0 \\
61.4\end{array}$ & $\begin{array}{l}45.6 \\
49.3 \\
51.0 \\
54.0 \\
54.8 \\
58.5 \\
61.0 \\
63.7 \\
54.4 \\
54.7 \\
54.0 \\
49.6 \\
54.5\end{array}$ & $\begin{array}{l}41.3 \\
43.6 \\
45.2 \\
48.1 \\
49.6 \\
52.4 \\
53.9 \\
56.2 \\
49.0 \\
47.8 \\
47.8 \\
45.1 \\
47.9\end{array}$ & $\begin{array}{l}46.0 \\
49.1 \\
50.9 \\
54.0 \\
55.2 \\
58.1 \\
60.7 \\
63.4 \\
56.5 \\
55.3 \\
55.0 \\
49.8 \\
54.7\end{array}$ \\
\hline 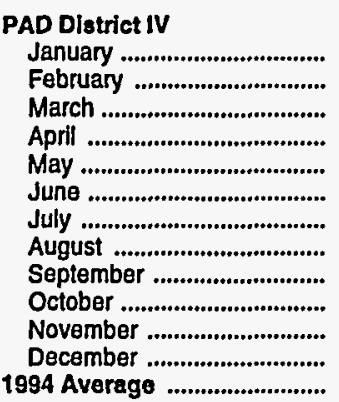 & $\begin{array}{r}76.4 \\
76.2 \\
82.5 \\
82.7 \\
86.7 \\
92.3 \\
95.3 \\
100.2 \\
100.8 \\
96.6 \\
90.6 \\
88.1 \\
90.6\end{array}$ & $\begin{array}{l}76.0 \\
75.7 \\
81.4 \\
81.9 \\
86.0 \\
91.5 \\
94.6 \\
99.4 \\
99.8 \\
95.6 \\
89.8 \\
87.2 \\
89.7\end{array}$ & $\begin{array}{l}64.4 \\
65.3 \\
66.6 \\
67.9 \\
72.4 \\
78.1 \\
82.0 \\
86.3 \\
84.5 \\
79.9 \\
78.0 \\
73.4 \\
76.0\end{array}$ & $\begin{array}{l}58.5 \\
61.3 \\
61.5 \\
63.6 \\
68.9 \\
75.3 \\
78.4 \\
83.1 \\
81.6 \\
73.7 \\
72.3 \\
66.9 \\
71.1\end{array}$ & $\begin{array}{l}\overline{-} \\
\bar{w} \\
- \\
\overline{-} \\
\bar{w} \\
\overline{-} \\
\overline{-} \\
\bar{w}\end{array}$ & $\begin{array}{l}60.3 \\
62.5 \\
62.9 \\
64.8 \\
69.9 \\
76.1 \\
79.5 \\
84.1 \\
82.5 \\
75.7 \\
73.9 \\
68.9 \\
72.5\end{array}$ & $\begin{array}{l}68.5 \\
67.8 \\
71.0 \\
71.0 \\
74.4 \\
79.8 \\
83.1 \\
88.6 \\
89.2 \\
85.2 \\
81.5 \\
79.2 \\
79.4\end{array}$ & $\begin{array}{l}68.4 \\
67.7 \\
70.5 \\
70.7 \\
74.1 \\
79.4 \\
82.9 \\
88.5 \\
89.0 \\
84.7 \\
81.2 \\
78.9 \\
79.1\end{array}$ & $\begin{array}{l}58.1 \\
59.2 \\
60.0 \\
61.7 \\
65.4 \\
70.7 \\
74.7 \\
79.0 \\
77.7 \\
72.0 \\
70.7 \\
66.4 \\
69.0\end{array}$ & $\begin{array}{l}52.0 \\
54.5 \\
55.5 \\
57.1 \\
61.7 \\
67.8 \\
71.0 \\
76.0 \\
73.6 \\
65.7 \\
64.5 \\
59.3 \\
64.0\end{array}$ & $\begin{array}{l}W \\
W \\
W \\
W \\
W \\
W \\
W \\
W \\
W \\
W \\
W \\
W \\
59.4\end{array}$ & $\begin{array}{l}53.7 \\
55.8 \\
56.7 \\
58.4 \\
62.8 \\
68.7 \\
72.1 \\
76.9 \\
74.8 \\
67.6 \\
66.2 \\
61.2 \\
65.4\end{array}$ \\
\hline 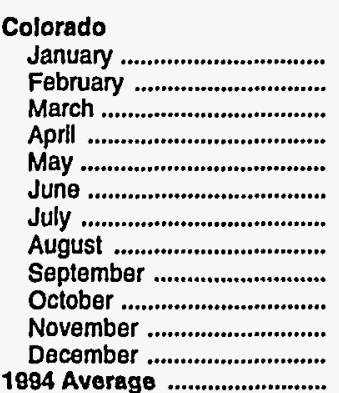 & $\begin{array}{r}89.4 \\
88.6 \\
90.6 \\
90.5 \\
90.6 \\
94.3 \\
99.6 \\
106.9 \\
107.0 \\
101.9 \\
97.0 \\
95.8 \\
97.5\end{array}$ & $\begin{array}{r}88.2 \\
87.5 \\
89.3 \\
89.6 \\
89.8 \\
93.3 \\
98.6 \\
106.2 \\
106.0 \\
100.8 \\
95.4 \\
94.7 \\
96.6\end{array}$ & $\begin{array}{l}66.6 \\
68.7 \\
69.4 \\
70.8 \\
72.5 \\
75.9 \\
81.5 \\
88.7 \\
84.6 \\
80.0 \\
78.5 \\
72.3 \\
77.3\end{array}$ & $\begin{array}{l}58.4 \\
63.0 \\
61.4 \\
63.8 \\
66.1 \\
70.5 \\
75.6 \\
83.5 \\
76.2 \\
66.4 \\
65.7 \\
58.8 \\
68.3\end{array}$ & $\begin{array}{l}- \\
- \\
- \\
- \\
- \\
- \\
- \\
- \\
- \\
-\end{array}$ & $\begin{array}{l}61.0 \\
64.6 \\
63.4 \\
66.1 \\
68.0 \\
72.3 \\
77.5 \\
85.5 \\
79.2 \\
70.8 \\
68.9 \\
61.9 \\
71.0\end{array}$ & $\begin{array}{l}75.4 \\
76.1 \\
75.4 \\
74.9 \\
75.4 \\
79.6 \\
84.0 \\
91.9 \\
92.0 \\
86.8 \\
84.3 \\
83.1 \\
82.5\end{array}$ & $\begin{array}{l}74.9 \\
75.3 \\
74.7 \\
74.3 \\
75.0 \\
79.0 \\
83.5 \\
91.5 \\
91.4 \\
86.0 \\
83.8 \\
82.3 \\
82.0\end{array}$ & $\begin{array}{l}59.4 \\
62.5 \\
61.6 \\
63.0 \\
64.4 \\
67.9 \\
73.7 \\
80.2 \\
77.7 \\
69.5 \\
68.7 \\
63.2 \\
69.3\end{array}$ & $\begin{array}{l}\mathbf{5 1 . 9} \\
\mathbf{5 6 . 2} \\
\mathbf{5 5 . 4} \\
\mathbf{5 6 . 8} \\
58.8 \\
63.0 \\
68.3 \\
76.4 \\
68.7 \\
59.2 \\
\mathbf{5 8 . 1} \\
\mathbf{5 1 . 7} \\
\mathbf{6 1 . 5}\end{array}$ & $\begin{array}{l}w \\
- \\
- \\
- \\
\overline{-} \\
\bar{w} \\
\overline{-} \\
\overline{-} \\
\bar{w}\end{array}$ & $\begin{array}{l}54.1 \\
57.9 \\
57.2 \\
58.7 \\
60.5 \\
64.5 \\
70.0 \\
77.6 \\
71.5 \\
62.6 \\
60.8 \\
54.6 \\
63.8\end{array}$ \\
\hline
\end{tabular}

See footnotes at end of table. 
Table 32. Conventional Motor Gasoline Prices by Grade, Sales Type, PAD District, and State

(Cents per Gallon Excluding Taxes) - Continued

\begin{tabular}{|c|c|c|c|c|c|c|c|c|c|c|c|c|}
\hline \multirow{3}{*}{$\begin{array}{c}\text { Goographic Area } \\
\text { Month }\end{array}$} & \multicolumn{6}{|c|}{ Regular } & \multicolumn{6}{|c|}{ Midgrade } \\
\hline & \multicolumn{2}{|c|}{ Sales to End Users } & \multicolumn{4}{|c|}{ Sales for Resale } & \multicolumn{2}{|c|}{ Sales to End Users } & \multicolumn{4}{|c|}{ Sales for Resale } \\
\hline & $\begin{array}{c}\text { Through } \\
\text { Retail } \\
\text { Outlets }\end{array}$ & Averagea & DTW & Rack & Bulk & Average & $\begin{array}{c}\text { Through } \\
\text { Retail } \\
\text { Outlets }\end{array}$ & Averagea & DTW & Rack & Bulk & Average \\
\hline
\end{tabular}

Idaho

\begin{tabular}{|c|c|c|c|c|c|c|c|c|c|c|c|c|}
\hline 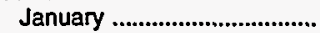 & 67.4 & 66.7 & 57.5 & 50.1 & - & 52.6 & 78.3 & 69.0 & 59.2 & $w$ & - & 52.1 \\
\hline 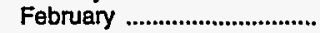 & 64.4 & 63.9 & 56.1 & 51.6 & - & 53.2 & 75.9 & 68.9 & 57.3 & $\ddot{w}$ & - & 52.4 \\
\hline March & 63.2 & 63.4 & 56.4 & 53.0 & - & 54.2 & NA & NA & 57.5 & $w$ & - & 54.7 \\
\hline 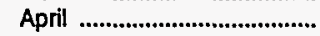 & 63.9 & 64.3 & 59.4 & 53.7 & - & 55.6 & 71.3 & 70.1 & 63.7 & 55.2 & - & 57.2 \\
\hline 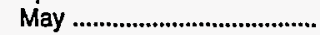 & 67.6 & 68.3 & 63.3 & 60.4 & - & 61.4 & 75.4 & 74.1 & 70.6 & 61.9 & - & 65.5 \\
\hline 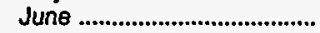 & 74.6 & 75.2 & 71.3 & 68.5 & - & 69.5 & 81.3 & 78.2 & NA & 69.5 & - & 71.7 \\
\hline July & 78.2 & 78.6 & 73.7 & 71.8 & - & 72.5 & NA & NA & 74.9 & 71.4 & - & 73.0 \\
\hline August & 82.5 & 82.5 & 76.5 & 74.2 & - & 75.0 & NA & NA & 80.8 & 74.6 & - & 76.3 \\
\hline September ............................... & 83.0 & 83.0 & $\pi .2$ & 76.3 & - & 76.6 & 89.3 & 90.4 & 82.5 & 77.6 & - & 78.7 \\
\hline 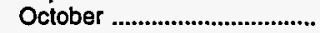 & 81.7 & 81.1 & 72.5 & 70.0 & - & 70.9 & 88.9 & 89.6 & 78.5 & 73.7 & - & 74.8 \\
\hline 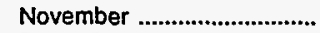 & 79.0 & 79.1 & 71.5 & 67.6 & - & 68.9 & 86.8 & 87.1 & 75.2 & 69.5 & - & 70.6 \\
\hline 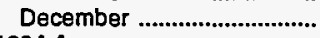 & 76.9 & 76.7 & 67.2 & 63.0 & - & 64.4 & 84.3 & 82.0 & 72.0 & 65.8 & - & 67.7 \\
\hline 1994 Average ............................ & 74.1 & 74.1 & 67.3 & 64.0 & - & 65.2 & 80.5 & 78.4 & 71.7 & 65.2 & - & 67.0 \\
\hline \multicolumn{13}{|l|}{ Montana } \\
\hline 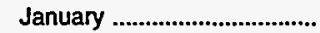 & 72.3 & 72.2 & 67.9 & 55.5 & $w$ & 56.8 & $w$ & $w$ & - & $w$ & - & $w$ \\
\hline 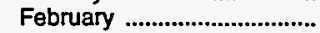 & 70.7 & 70.9 & 68.3 & 55.8 & W & 57.2 & $w$ & 77.9 & - & $w$ & - & $\ddot{w}$ \\
\hline March & 70.4 & 70.8 & 68.6 & 57.4 & $w$ & 58.9 & NA & NA & - & $w$ & - & $w$ \\
\hline Aprit & 71.9 & 72.5 & 72.2 & 60.8 & $w$ & 62.4 & NA & 70.4 & - & $w$ & - & w \\
\hline 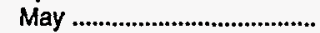 & 80.4 & 79.9 & 76.4 & 65.2 & - & 66.8 & $w$ & NA & - & W & - & $w$ \\
\hline June & 84.5 & 84.0 & 80.0 & 71.7 & - & 72.9 & 91.3 & 86.5 & - & $w$ & - & W \\
\hline July & 85.9 & 85.7 & 79.8 & 72.6 & $w$ & 73.5 & 94.8 & 92.8 & $w$ & $w$ & - & W \\
\hline August & 86.2 & 87.4 & 80.5 & 75.4 & $W$ & 76.3 & 93.7 & 93.1 & w & w & - & $w$ \\
\hline 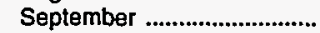 & 87.1 & 88.0 & 78.4 & 74.0 & $w$ & 74.8 & $w$ & 90.5 & w & $w$ & - & W \\
\hline 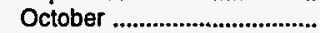 & 85.3 & 85.3 & 72.4 & 64.8 & W & 66.2 & $w$ & 88.7 & $w$ & $w$ & - & $w$ \\
\hline 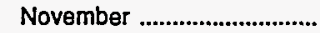 & 82.4 & 82.7 & 73.9 & 64.8 & W & 66.8 & 90.5 & 88.6 & $w$ & W & - & $w$ \\
\hline 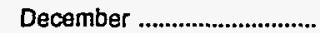 & 80.0 & 80.3 & 70.5 & 59.8 & $w$ & 62.0 & 85.8 & 84.5 & $W$ & $W$ & - & 63.7 \\
\hline 1994 Average & 80.9 & 80.7 & 74.6 & 65.7 & $\mathbf{W}$ & 67.1 & 80.1 & 82.6 & 86.5 & $\mathbf{w}$ & - & W \\
\hline \multicolumn{13}{|l|}{ Utah } \\
\hline 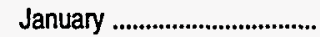 & 58.5 & 58.6 & 51.8 & 47.1 & $W$ & 48.5 & 64.2 & 64.2 & 55.9 & 50.0 & - & 53.8 \\
\hline 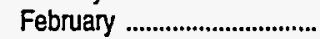 & 58.4 & 58.4 & 52.0 & 48.8 & $W$ & 49.7 & 64.2 & 64.2 & 56.8 & 56.5 & - & 56.7 \\
\hline March & 59.6 & 59.7 & 54.3 & 51.0 & $W$ & 52.0 & 65.5 & 65.5 & 57.9 & 58.6 & - & 58.2 \\
\hline April & 60.0 & 60.0 & 55.4 & 52.1 & $w$ & 53.0 & 65.4 & 65.4 & 58.8 & 55.2 & - & 57.4 \\
\hline 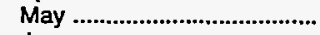 & 67.2 & 67.1 & 60.9 & 59.2 & $w$ & 59.7 & 73.6 & 73.6 & 65.5 & 61.6 & - & 63.9 \\
\hline June & 75.4 & 75.2 & 67.5 & 65.9 & $w$ & 66.5 & 82.2 & 82.2 & 73.3 & 70.5 & - & 72.2 \\
\hline July & 76.2 & 77.1 & 70.7 & 68.0 & $w$ & 68.9 & 82.6 & 82.6 & 76.1 & 73.4 & - & 75.0 \\
\hline August & 77.8 & 79.6 & 72.9 & 71.2 & $W$ & 71.7 & 85.1 & 85.1 & 78.6 & 77.5 & - & 78.1 \\
\hline 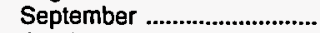 & 79.9 & 81.5 & 74.1 & 73.4 & W & 73.6 & 87.6 & 87.5 & 79.0 & 79.0 & - & 79.0 \\
\hline October & 77.0 & 77.4 & 69.9 & 68.0 & $w$ & 68.6 & 84.6 & 84.6 & 74.7 & 73.2 & - & 74.0 \\
\hline 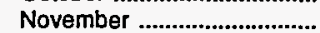 & 73.8 & 73.6 & 66.1 & 64.3 & W & 64.8 & 81.1 & 81.0 & 70.1 & 69.4 & - & 69.8 \\
\hline 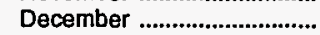 & 71.7 & 71.5 & 62.0 & 60.4 & - & 60.9 & 78.2 & 78.1 & 66.4 & 65.9 & - & 66.2 \\
\hline 1994 Average & 70.0 & 70.4 & 63.7 & 61.2 & $\mathbf{w}$ & 61.9 & 76.9 & 76.9 & 68.7 & 67.1 & - & 68.0 \\
\hline \multicolumn{13}{|l|}{ Wyoming } \\
\hline 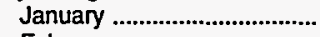 & 73.0 & 71.9 & 54.5 & 49.8 & - & 50.6 & 76.1 & 76.0 & NA & $w$ & - & 64.3 \\
\hline 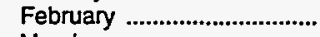 & 72.1 & 71.3 & 58.0 & 53.6 & - & 54.7 & 77.8 & 77.8 & $w$ & w & - & 62.8 \\
\hline March & 70.8 & 70.4 & 59.6 & 55.6 & - & 56.3 & 77.2 & 77.2 & 62.0 & $\ddot{w}$ & - & 69.0 \\
\hline April & 71.6 & 71.4 & 61.8 & 58.4 & - & 59.0 & 78.9 & 79.0 & 64.5 & W & - & 72.0 \\
\hline May & 75.8 & 75.5 & 65.9 & 62.1 & - & 62.8 & 83.6 & 83.7 & 69.7 & $\ddot{w}$ & - & 78.4 \\
\hline June & 80.2 & 79.8 & 71.1 & 67.7 & - & 68.4 & 88.8 & 88.8 & 74.5 & $w$ & - & 79.8 \\
\hline July & 84.8 & 84.5 & 74.5 & 70.9 & $w$ & 71.7 & 93.8 & 93.7 & 78.4 & w & - & 81.3 \\
\hline August & 87.7 & 87.8 & 76.5 & 76.9 & $w$ & 76.8 & 96.3 & 96.3 & 72.2 & $w$ & - & 77.1 \\
\hline September .............................. & 89.6 & 89.0 & 73.4 & 72.7 & $\mathbf{w}$ & 72.9 & 99.2 & 99.0 & 68.2 & $w$ & - & 70.7 \\
\hline October & 87.2 & 85.9 & 68.5 & 62.3 & $w$ & 63.5 & 94.3 & 94.3 & 68.1 & $\ddot{w}$ & - & 71.2 \\
\hline 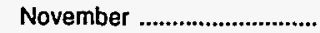 & 84.9 & 83.6 & 65.0 & 60.8 & W & 61.7 & 90.7 & 90.2 & 63.4 & $w$ & - & 66.9 \\
\hline 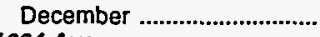 & 80.8 & 79.5 & 61.2 & 53.7 & w & 55.1 & 85.2 & 85.0 & 60.9 & 69.2 & - & 63.1 \\
\hline 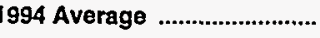 & 80.7 & 80.0 & 67.5 & 62.8 & $\mathbf{w}$ & 63.7 & 88.3 & 88.2 & 67.3 & 78.0 & - & 71.7 \\
\hline
\end{tabular}

See footnotes at end of table. 
Table 32. Conventional Motor Gasoline Prices by Grade, Sales Type, PAD District, and State

(Cents per Gallon Excluding Taxes) - Continued

\begin{tabular}{|c|c|c|c|c|c|c|c|c|c|c|c|c|}
\hline \multirow{3}{*}{$\begin{array}{c}\text { Geographlc Area } \\
\text { Month }\end{array}$} & \multicolumn{6}{|c|}{ Premium } & \multicolumn{6}{|c|}{ All Grades } \\
\hline & \multicolumn{2}{|c|}{ Sales to End Users } & \multicolumn{4}{|c|}{ Sales for Resale } & \multicolumn{2}{|c|}{ Sales to End Users } & \multicolumn{4}{|c|}{ Sales for Resale } \\
\hline & $\begin{array}{c}\text { Through } \\
\text { Retail } \\
\text { Outlets }\end{array}$ & Averagea & DTW & Rack & Bulk & Average & $\begin{array}{c}\text { Through } \\
\text { Retail } \\
\text { Outlets }\end{array}$ & Average ${ }^{a}$ & DTW & Rack & Bulk & Average \\
\hline \multicolumn{13}{|l|}{ Idaho } \\
\hline 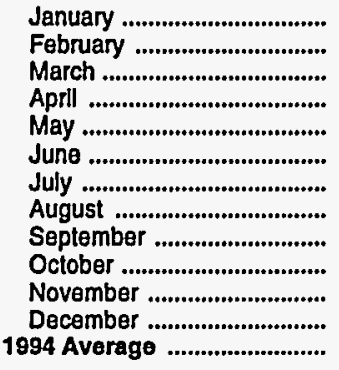 & $\begin{array}{l}75.7 \\
73.6 \\
74.0 \\
75.9 \\
79.6 \\
87.0 \\
90.1 \\
94.8 \\
95.1 \\
92.6 \\
89.8 \\
87.8 \\
86.1\end{array}$ & $\begin{array}{l}75.6 \\
73.3 \\
74.0 \\
75.9 \\
79.5 \\
86.5 \\
90.0 \\
94.6 \\
94.5 \\
92.2 \\
89.8 \\
87.5 \\
85.8\end{array}$ & $\begin{array}{l}65.8 \\
64.7 \\
65.0 \\
66.2 \\
71.4 \\
79.5 \\
84.3 \\
87.2 \\
86.1 \\
83.0 \\
81.0 \\
77.1 \\
77.1\end{array}$ & $\begin{array}{l}58.2 \\
59.9 \\
61.1 \\
61.5 \\
69.2 \\
77.7 \\
80.9 \\
83.4 \\
85.6 \\
78.7 \\
76.3 \\
72.2 \\
73.1\end{array}$ & $\begin{array}{l}- \\
- \\
- \\
- \\
- \\
- \\
- \\
- \\
- \\
-\end{array}$ & $\begin{array}{l}61.1 \\
61.8 \\
62.6 \\
63.2 \\
70.0 \\
78.4 \\
82.3 \\
85.0 \\
85.9 \\
80.5 \\
78.1 \\
74.2 \\
74.7\end{array}$ & $\begin{array}{l}68.4 \\
65.5 \\
64.5 \\
65.4 \\
69.3 \\
76.3 \\
79.8 \\
84.4 \\
84.8 \\
83.4 \\
80.7 \\
78.7 \\
75.8\end{array}$ & $\begin{array}{l}67.8 \\
65.1 \\
64.6 \\
65.7 \\
69.7 \\
76.5 \\
80.0 \\
84.3 \\
84.7 \\
82.7 \\
80.7 \\
78.5 \\
75.7\end{array}$ & $\begin{array}{l}58.9 \\
57.6 \\
57.9 \\
60.5 \\
64.8 \\
72.7 \\
75.9 \\
78.8 \\
79.0 \\
74.7 \\
73.3 \\
69.4 \\
69.2\end{array}$ & $\begin{array}{l}51.2 \\
52.8 \\
54.1 \\
54.8 \\
61.7 \\
69.9 \\
73.2 \\
75.7 \\
77.7 \\
71.4 \\
69.0 \\
64.6 \\
65.4\end{array}$ & $\begin{array}{l}- \\
- \\
- \\
- \\
- \\
- \\
- \\
- \\
- \\
- \\
- \\
-\end{array}$ & $\begin{array}{l}53.9 \\
54.6 \\
55.5 \\
56.7 \\
62.8 \\
70.9 \\
74.2 \\
76.7 \\
78.2 \\
72.5 \\
70.5 \\
66.3 \\
66.7\end{array}$ \\
\hline \multicolumn{13}{|l|}{ Montana } \\
\hline 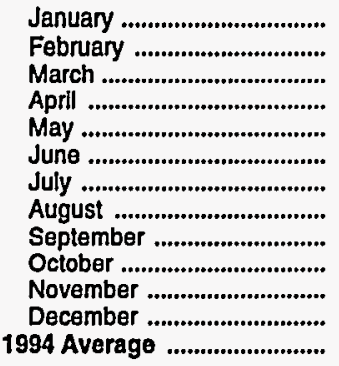 & $\begin{array}{l}82.3 \\
80.0 \\
79.5 \\
83.4 \\
90.4 \\
94.8 \\
96.2 \\
95.3 \\
96.7 \\
94.8 \\
92.0 \\
89.5 \\
90.8\end{array}$ & $\begin{array}{l}81.6 \\
79.6 \\
79.3 \\
83.0 \\
89.5 \\
92.7 \\
94.3 \\
95.5 \\
96.7 \\
94.5 \\
92.1 \\
89.7 \\
90.0\end{array}$ & $\begin{array}{l}77.6 \\
79.2 \\
78.2 \\
81.8 \\
84.8 \\
87.4 \\
87.7 \\
88.8 \\
86.8 \\
79.8 \\
82.6 \\
77.6 \\
83.0\end{array}$ & $\begin{array}{l}64.0 \\
64.4 \\
65.9 \\
69.4 \\
74.4 \\
81.0 \\
82.6 \\
84.7 \\
83.9 \\
74.3 \\
74.1 \\
69.1 \\
74.9\end{array}$ & $\begin{array}{l}- \\
- \\
- \\
- \\
- \\
- \\
- \\
- \\
-\end{array}$ & $\begin{array}{l}65.3 \\
65.9 \\
67.4 \\
71.0 \\
75.6 \\
81.6 \\
83.1 \\
85.3 \\
84.5 \\
75.3 \\
75.8 \\
70.7 \\
76.0\end{array}$ & $\begin{array}{l}73.8 \\
72.1 \\
71.8 \\
73.7 \\
82.0 \\
86.1 \\
87.6 \\
87.8 \\
88.7 \\
86.9 \\
83.9 \\
81.6 \\
82.5\end{array}$ & $\begin{array}{l}73.4 \\
72.0 \\
72.0 \\
73.9 \\
81.2 \\
85.3 \\
87.0 \\
88.7 \\
89.4 \\
86.8 \\
84.1 \\
81.8 \\
82.1\end{array}$ & $\begin{array}{l}69.4 \\
70.0 \\
70.1 \\
73.6 \\
77.7 \\
81.0 \\
80.8 \\
81.8 \\
79.6 \\
73.5 \\
75.1 \\
71.6 \\
75.9\end{array}$ & $\begin{array}{l}56.8 \\
57.2 \\
58.9 \\
62.3 \\
67.0 \\
73.4 \\
74.3 \\
77.0 \\
75.5 \\
66.3 \\
66.3 \\
61.4 \\
67.2\end{array}$ & $\begin{array}{l}W \\
W \\
W \\
w \\
- \\
-\bar{w} \\
W \\
W \\
W \\
W \\
W \\
W\end{array}$ & $\begin{array}{l}58.1 \\
58.6 \\
60.3 \\
63.8 \\
68.4 \\
74.4 \\
75.2 \\
77.8 \\
76.3 \\
67.6 \\
68.2 \\
63.4 \\
68.5\end{array}$ \\
\hline \multicolumn{13}{|l|}{ Utah } \\
\hline 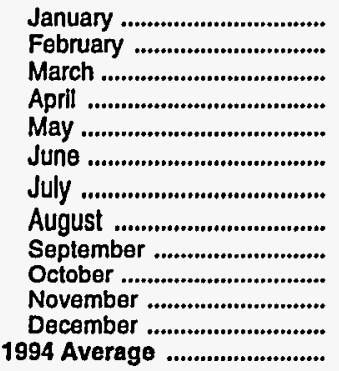 & $\begin{array}{l}70.9 \\
71.5 \\
72.9 \\
73.1 \\
81.1 \\
89.8 \\
90.0 \\
92.4 \\
94.2 \\
90.8 \\
87.1 \\
84.0 \\
83.6\end{array}$ & $\begin{array}{l}70.8 \\
71.4 \\
72.7 \\
73.0 \\
80.7 \\
89.3 \\
89.9 \\
91.7 \\
93.3 \\
89.8 \\
86.0 \\
83.1 \\
83.0\end{array}$ & $\begin{array}{l}61.5 \\
61.7 \\
63.1 \\
63.6 \\
70.2 \\
77.6 \\
79.8 \\
82.3 \\
83.3 \\
78.9 \\
75.2 \\
71.3 \\
72.8\end{array}$ & $\begin{array}{l}54.9 \\
58.0 \\
59.0 \\
60.2 \\
67.7 \\
75.2 \\
77.1 \\
80.5 \\
82.9 \\
77.7 \\
73.5 \\
69.4 \\
70.1\end{array}$ & $\begin{array}{l}\overline{-} \\
\bar{w} \\
\overline{-} \\
\overline{-} \\
\bar{w} \\
\overline{-} \\
\overline{-} \\
\bar{w}\end{array}$ & $\begin{array}{l}57.5 \\
59.3 \\
60.3 \\
61.3 \\
68.5 \\
76.0 \\
78.0 \\
81.1 \\
83.0 \\
78.2 \\
74.1 \\
70.1 \\
71.0\end{array}$ & $\begin{array}{l}61.8 \\
61.8 \\
63.1 \\
63.4 \\
70.8 \\
79.0 \\
79.9 \\
81.7 \\
83.9 \\
81.0 \\
77.6 \\
75.4 \\
73.7\end{array}$ & $\begin{array}{l}61.9 \\
61.9 \\
63.2 \\
63.5 \\
70.6 \\
78.7 \\
80.3 \\
82.8 \\
84.7 \\
81.0 \\
77.3 \\
75.1 \\
73.8\end{array}$ & $\begin{array}{l}54.8 \\
55.1 \\
56.7 \\
57.7 \\
63.4 \\
70.0 \\
73.1 \\
76.1 \\
77.0 \\
73.2 \\
69.0 \\
65.0 \\
66.5\end{array}$ & $\begin{array}{l}48.8 \\
51.2 \\
53.3 \\
54.0 \\
61.2 \\
68.1 \\
70.2 \\
73.6 \\
75.7 \\
70.5 \\
66.8 \\
62.9 \\
63.5\end{array}$ & $\begin{array}{l}W \\
W \\
W \\
W \\
W \\
W \\
W \\
W \\
W \\
W \\
W \\
\bar{W}\end{array}$ & $\begin{array}{l}50.9 \\
52.5 \\
54.4 \\
55.1 \\
61.9 \\
68.8 \\
71.3 \\
74.4 \\
76.1 \\
71.4 \\
67.5 \\
63.6 \\
64.4\end{array}$ \\
\hline \multicolumn{13}{|l|}{ Wyoming } \\
\hline 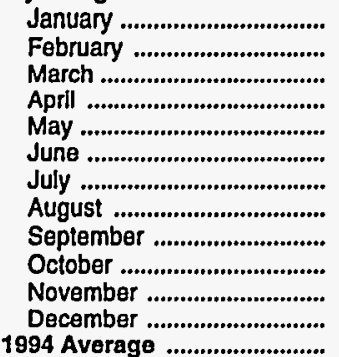 & $\begin{array}{r}83.0 \\
83.4 \\
82.7 \\
84.2 \\
88.2 \\
92.9 \\
97.5 \\
99.3 \\
100.6 \\
98.6 \\
95.0 \\
92.1 \\
92.6\end{array}$ & $\begin{array}{l}81.2 \\
81.8 \\
81.5 \\
83.1 \\
87.5 \\
91.9 \\
96.7 \\
99.1 \\
99.6 \\
97.7 \\
94.0 \\
89.7 \\
91.4\end{array}$ & $\begin{array}{l}62.6 \\
66.1 \\
66.8 \\
69.7 \\
74.7 \\
79.5 \\
83.2 \\
87.5 \\
82.4 \\
77.2 \\
73.4 \\
68.4 \\
76.5\end{array}$ & $\begin{array}{l}58.9 \\
62.0 \\
63.6 \\
66.7 \\
71.0 \\
76.6 \\
79.5 \\
85.6 \\
82.2 \\
72.1 \\
70.5 \\
62.9 \\
72.1\end{array}$ & $\begin{array}{l}- \\
\overline{-} \\
- \\
- \\
- \\
- \\
- \\
-\end{array}$ & $\begin{array}{l}59.7 \\
63.2 \\
64.3 \\
67.4 \\
71.9 \\
77.3 \\
80.5 \\
86.0 \\
82.2 \\
73.2 \\
71.1 \\
63.9 \\
73.1\end{array}$ & $\begin{array}{l}74.7 \\
74.0 \\
72.8 \\
73.8 \\
77.9 \\
82.3 \\
87.0 \\
90.0 \\
91.8 \\
89.4 \\
86.8 \\
82.9 \\
82.8\end{array}$ & $\begin{array}{l}73.4 \\
73.0 \\
72.2 \\
73.3 \\
77.3 \\
81.7 \\
86.5 \\
89.9 \\
91.0 \\
88.0 \\
85.5 \\
81.5 \\
82.0\end{array}$ & $\begin{array}{l}56.2 \\
59.5 \\
61.0 \\
63.5 \\
67.8 \\
72.9 \\
76.5 \\
78.5 \\
74.8 \\
70.0 \\
66.2 \\
62.3 \\
69.2\end{array}$ & $\begin{array}{l}51.3 \\
55.0 \\
56.9 \\
59.8 \\
63.7 \\
69.3 \\
72.5 \\
78.6 \\
74.3 \\
64.0 \\
62.5 \\
55.2 \\
64.4\end{array}$ & $\begin{array}{l}- \\
- \\
- \\
- \\
- \\
\bar{W} \\
W \\
W \\
W \\
W \\
W \\
W\end{array}$ & $\begin{array}{l}52.2 \\
56.2 \\
57.7 \\
60.5 \\
64.6 \\
70.1 \\
73.4 \\
78.5 \\
74.4 \\
65.2 \\
63.3 \\
56.6 \\
65.3\end{array}$ \\
\hline
\end{tabular}

See footnotes at end of table. 
Table 32. Conventional Motor Gasoline Prices by Grade, Sales Type, PAD District, and State

(Cents per Gallon Excluding Taxes) - Continued

\begin{tabular}{|c|c|c|c|c|c|c|c|c|c|c|c|c|}
\hline \multirow{3}{*}{$\begin{array}{c}\text { Geographic Area } \\
\text { Month }\end{array}$} & \multicolumn{6}{|c|}{ Regular } & \multicolumn{6}{|c|}{ Midgrade } \\
\hline & \multicolumn{2}{|c|}{ Sales to End Users } & \multicolumn{4}{|c|}{ Sales for Resale } & \multicolumn{2}{|c|}{ Sales to End Users } & \multicolumn{4}{|c|}{ Sales for Resale } \\
\hline & $\begin{array}{l}\text { Through } \\
\text { Retail } \\
\text { Outlets }\end{array}$ & Averagea & DTW & Rack & Bulk & Average & $\begin{array}{c}\text { Through } \\
\text { Retail } \\
\text { Outlets }\end{array}$ & Average ${ }^{a}$ & DTW & Rack & Bulk & Avorage \\
\hline
\end{tabular}

\begin{tabular}{|c|c|c|c|c|c|c|c|c|c|c|c|c|}
\hline \multicolumn{13}{|l|}{ PAD District V } \\
\hline 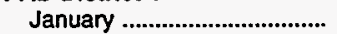 & 80.9 & 78.8 & 65.5 & 50.5 & 42.3 & 51.7 & 90.6 & 86.5 & 74.9 & 60.4 & - & 71.3 \\
\hline 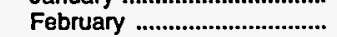 & 74.2 & 72.9 & 63.7 & 52.0 & 47.4 & 55.1 & 80.7 & 79.2 & 69.5 & 56.9 & $w$ & 64.7 \\
\hline March & 69.9 & 69.5 & 60.7 & 52.7 & 48.5 & 56.7 & 78.2 & 77.1 & 67.3 & 57.6 & $\ddot{W}$ & 65.2 \\
\hline April & 72.4 & 71.9 & 63.6 & 56.2 & 51.7 & 59.8 & 80.3 & 79.6 & 70.5 & 61.0 & $w$ & 68.4 \\
\hline May & 73.8 & 73.3 & 65.2 & 57.1 & 50.9 & 60.8 & 81.9 & 81.0 & 72.2 & 61.1 & $W$ & 69.5 \\
\hline 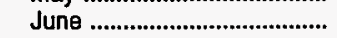 & 75.7 & 75.2 & 67.6 & 59.4 & 54.9 & 63.6 & 83.8 & 82.8 & 74.5 & 63.3 & $\ddot{W}$ & 71.7 \\
\hline 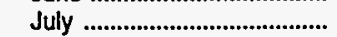 & 78.1 & 77.6 & 70.4 & 63.6 & 57.8 & 66.8 & 87.0 & 86.2 & 77.3 & 67.8 & W & 75.0 \\
\hline 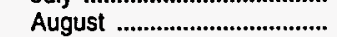 & 79.9 & 79.4 & 71.0 & 63.9 & 57.1 & 67.1 & 87.7 & 86.9 & 76.7 & 67.7 & $\ddot{w}$ & 74.7 \\
\hline 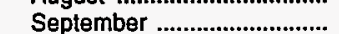 & 79.9 & 79.3 & 71.5 & 61.8 & 56.3 & 66.6 & 88.0 & 87.1 & 78.1 & 65.4 & NA & 75.2 \\
\hline 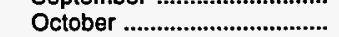 & 82.2 & 81.6 & 72.1 & 61.4 & 54.6 & 63.4 & 90.3 & 90.0 & 80.2 & 68.1 & $w$ & 77.6 \\
\hline 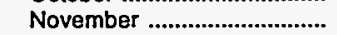 & 87.4 & 85.5 & 73.1 & 61.3 & 57.9 & 62.7 & 93.6 & 92.7 & 79.5 & 71.8 & $w$ & 77.4 \\
\hline 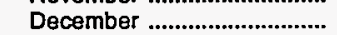 & 85.4 & 83.2 & 71.0 & 59.0 & 51.7 & 60.1 & 88.8 & 88.6 & 80.6 & 67.4 & $\ddot{w}$ & 77.2 \\
\hline 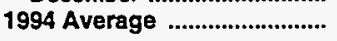 & 76.5 & 76.0 & 67.1 & 58.8 & $\mathbf{5 3 . 0}$ & 62.3 & 84.5 & 83.7 & 73.2 & 63.4 & $\mathbf{w}$ & 71.0 \\
\hline \multicolumn{13}{|l|}{ Alaska } \\
\hline 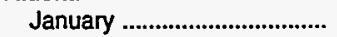 & 108.0 & 102.8 & 76.3 & 69.3 & $w$ & 73.3 & $w$ & NA & $W$ & - & - & $w$ \\
\hline 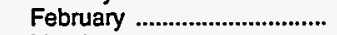 & 106.5 & 101.3 & 75.1 & 67.6 & w & 71.1 & $\mathbf{w}$ & NA & $w$ & - & - & $w$ \\
\hline March & 106.9 & 102.0 & 74.7 & 67.9 & $w$ & 72.0 & $W$ & NA & 79.7 & - & - & 79.7 \\
\hline April & 107.0 & 101.9 & 76.8 & 67.8 & 64.5 & 72.6 & NA & NA & 80.2 & - & - & 80.2 \\
\hline 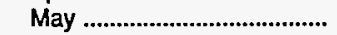 & 106.6 & 102.0 & 78.0 & 69.3 & 62.3 & 73.0 & $W$ & NA & 81.4 & - & - & 81.4 \\
\hline 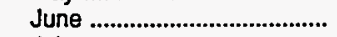 & 110.2 & 105.4 & 81.7 & 70.3 & 70.6 & 75.4 & NA & NA & 84.5 & - & $W$ & 84.1 \\
\hline 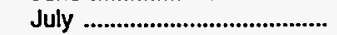 & 110.0 & NA & 83.1 & 70.8 & 72.6 & 76.6 & $W$ & NA & 86.0 & - & - & 86.0 \\
\hline 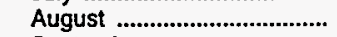 & 113.3 & 109.0 & 87.6 & 72.2 & $W$ & 79.4 & - & $W$ & 87.7 & - & - & 87.7 \\
\hline 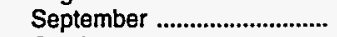 & 112.9 & 110.6 & 87.9 & 73.0 & $W$ & 79.9 & $W$ & NA & 88.1 & $W$ & $W$ & 88.4 \\
\hline 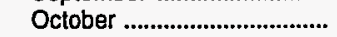 & 112.4 & 110.1 & 85.9 & 74.1 & W & 80.3 & $W$ & NA & 87.7 & W & $W$ & 90.7 \\
\hline 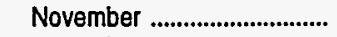 & 113.0 & 110.2 & 85.0 & 72.0 & - & 78.6 & W & NA & 86.2 & W & $W$ & 86.8 \\
\hline December .............................. & 111.8 & 109.6 & 85.1 & 71.6 & W & 78.7 & $W$ & NA & 86.8 & W & $W$ & 87.5 \\
\hline 1994 Average & 109.1 & 104.8 & 82.2 & 70.7 & 69.1 & 76.3 & NA & NA & 85.0 & $W$ & $W$ & 86.0 \\
\hline \multicolumn{13}{|l|}{ Arizona } \\
\hline 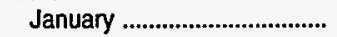 & 81.6 & 79.1 & 63.2 & 53.9 & 45.3 & 56.5 & 88.7 & 88.7 & 63.5 & $W$ & - & 63.6 \\
\hline 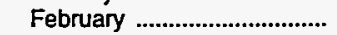 & 78.2 & 75.7 & 64.7 & 55.3 & $W$ & 58.5 & 88.5 & 88.1 & 64.9 & $W$ & - & 64.9 \\
\hline 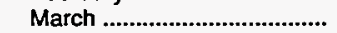 & 77.7 & 76.0 & 65.3 & 57.3 & $W$ & 60.6 & 87.8 & 87.3 & 66.5 & w & - & 66.5 \\
\hline April & 77.8 & 77.2 & 67.6 & 59.4 & 52.9 & 63.8 & 88.4 & 87.9 & NA & $w$ & - & NA \\
\hline May & 78.0 & 77.6 & 68.8 & 61.7 & 55.3 & 65.7 & 88.8 & 88.1 & 73.8 & W & - & 73.7 \\
\hline June & 78.6 & 78.1 & 70.4 & 63.1 & $W$ & 67.3 & 89.0 & 88.3 & 76.4 & $w$ & - & 76.3 \\
\hline July & 79.2 & 78.9 & 71.8 & 65.5 & $w$ & 69.2 & 92.0 & 91.5 & 79.8 & w & - & 79.7 \\
\hline 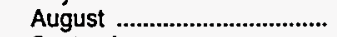 & 81.3 & 81.2 & 72.1 & 65.7 & $W$ & 69.0 & 91.7 & 91.2 & 76.3 & W & - & 77.0 \\
\hline 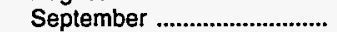 & 81.6 & 81.3 & 71.7 & 63.7 & 59.2 & 67.3 & 92.2 & 91.3 & 75.9 & $\mathbf{W}$ & $W$ & 77.0 \\
\hline 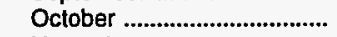 & 85.3 & 83.7 & 71.1 & 62.6 & W & 64.9 & NA & NA & 73.7 & 70.0 & - & 73.5 \\
\hline 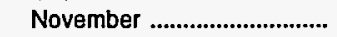 & 84.9 & 83.1 & 70.7 & 63.1 & 59.5 & 65.5 & 94.1 & 94.1 & 75.5 & $W$ & - & 72.8 \\
\hline December ................................ & 82.3 & 80.5 & 65.7 & 56.8 & 54.5 & 59.6 & 84.7 & 84.7 & 72.7 & $W$ & - & 70.3 \\
\hline 1994 Average & 79.5 & 78.9 & 69.2 & 60.9 & 54.5 & 64.6 & 89.6 & 89.2 & 70.1 & 69.9 & $\mathbf{w}$ & 70.2 \\
\hline \multicolumn{13}{|l|}{ California } \\
\hline 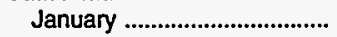 & - & w & NA & 45.4 & 44.1 & 44.7 & - & - & - & 60.3 & - & 60.3 \\
\hline 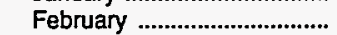 & 66.3 & 66.0 & 62.9 & 50.8 & 48.3 & 54.4 & 77.3 & 76.2 & 68.6 & 56.6 & W & 63.8 \\
\hline 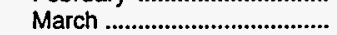 & 65.6 & 65.7 & 60.0 & 51.3 & 48.2 & 56.0 & 76.4 & 75.6 & 66.8 & 57.4 & W & 64.7 \\
\hline April & 67.5 & 67.4 & 62.9 & 54.3 & 51.5 & 58.9 & 78.7 & 78.3 & 70.0 & 60.8 & $W$ & 68.0 \\
\hline May & 69.0 & 68.8 & 64.3 & 54.5 & 50.3 & 59.3 & 80.5 & 79.9 & 71.7 & 60.7 & W & 69.1 \\
\hline 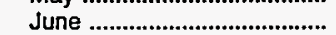 & 71.2 & 70.9 & 66.9 & 56.3 & 54.3 & 62.2 & 82.7 & 81.9 & 74.0 & 62.9 & $\ddot{w}$ & 71.3 \\
\hline July & 73.7 & 73.5 & 69.8 & 61.2 & 57.9 & 65.7 & 85.6 & 85.1 & 76.9 & 67.4 & $W$ & 74.6 \\
\hline 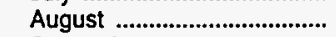 & 75.6 & 75.2 & 70.0 & 60.7 & 55.7 & 65.6 & 86.8 & 86.0 & 76.3 & 67.2 & $w$ & 74.3 \\
\hline 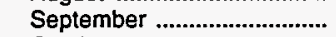 & 75.8 & 75.2 & 70.5 & 58.1 & 55.4 & 65.0 & 86.9 & 85.8 & 77.6 & 64.8 & $\mathbf{w}$ & 74.6 \\
\hline 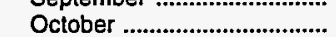 & 77.1 & 77.1 & 68.3 & 55.8 & 53.9 & 57.7 & 89.6 & 89.6 & 76.5 & 65.2 & - & 73.5 \\
\hline 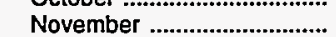 & - & NA & $W$ & 56.9 & 58.0 & 57.6 & - & NA & W & 73.3 & - & NA \\
\hline 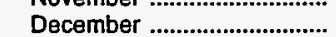 & - & $w$ & - & 52.3 & 51.4 & 51.5 & - & - & - & $W$ & - & $w$ \\
\hline 1994 Average & 71.4 & 71.1 & 65.9 & 56.1 & 53.0 & 60.9 & 82.8 & 82.1 & 72.5 & 62.8 & $w$ & 70.3 \\
\hline
\end{tabular}

See footnotes at end of table. 
Table 32. Conventional Motor Gasoline Prices by Grade, Sales Type, PAD District, and State

(Cents per Gallon Excluding Taxes) - Continued

\begin{tabular}{|c|c|c|c|c|c|c|c|c|c|c|c|c|}
\hline \multirow{3}{*}{$\begin{array}{c}\text { Geographlc Area } \\
\text { Month }\end{array}$} & \multicolumn{6}{|c|}{ Premium } & \multicolumn{6}{|c|}{ All Grades } \\
\hline & \multicolumn{2}{|c|}{ Sales to End Users } & \multicolumn{4}{|c|}{ Sales for Resale } & \multicolumn{2}{|c|}{ Sales to End Users } & \multicolumn{4}{|c|}{ Sales for Resale } \\
\hline & $\begin{array}{c}\text { Through } \\
\text { Retail } \\
\text { Outlets }\end{array}$ & Averagea & DTW & Rack & Bulk & Average & $\begin{array}{c}\text { Through } \\
\text { Retail } \\
\text { Outlets }\end{array}$ & Averagea & DTW & Rack & Bulk & Average \\
\hline \multicolumn{13}{|l|}{ PAD Dlatrict V } \\
\hline 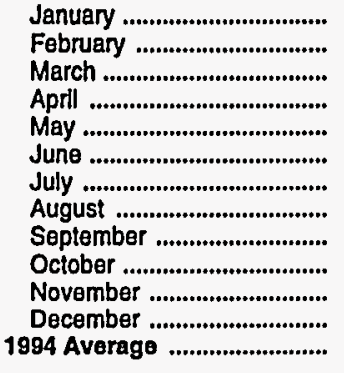 & $\begin{array}{r}99.5 \\
93.9 \\
89.6 \\
91.6 \\
93.1 \\
94.9 \\
97.0 \\
98.2 \\
98.4 \\
100.6 \\
103.7 \\
102.0 \\
95.5\end{array}$ & $\begin{array}{r}96.7 \\
91.8 \\
88.2 \\
90.6 \\
91.9 \\
93.8 \\
96.0 \\
97.1 \\
97.2 \\
99.5 \\
101.1 \\
99.4 \\
94.3\end{array}$ & $\begin{array}{l}80.9 \\
77.7 \\
75.6 \\
78.4 \\
80.1 \\
82.6 \\
85.3 \\
85.9 \\
86.9 \\
88.9 \\
91.6 \\
89.9 \\
82.1\end{array}$ & $\begin{array}{l}63.6 \\
65.4 \\
64.9 \\
67.7 \\
67.6 \\
71.9 \\
76.0 \\
76.7 \\
75.0 \\
76.7 \\
76.5 \\
71.7 \\
71.4\end{array}$ & $\begin{array}{r}48.4 \\
52.5 \\
53.8 \\
57.4 \\
58.4 \\
61.7 \\
65.4 \\
64.6 \\
62.5 \\
62.9 \\
64.8 \\
\text { NA } \\
60.3\end{array}$ & $\begin{array}{l}69.0 \\
72.3 \\
72.7 \\
75.0 \\
76.2 \\
79.3 \\
81.8 \\
82.4 \\
83.3 \\
82.2 \\
81.7 \\
78.6 \\
78.3\end{array}$ & $\begin{array}{l}84.2 \\
77.9 \\
73.5 \\
76.0 \\
77.5 \\
79.4 \\
81.9 \\
83.5 \\
83.4 \\
85.9 \\
90.3 \\
88.1 \\
80.1\end{array}$ & $\begin{array}{l}81.8 \\
76.4 \\
72.9 \\
75.4 \\
76.8 \\
78.7 \\
81.2 \\
82.8 \\
82.7 \\
85.2 \\
88.2 \\
85.9 \\
79.4\end{array}$ & $\begin{array}{l}69.6 \\
67.6 \\
64.6 \\
67.5 \\
69.1 \\
71.5 \\
74.3 \\
74.7 \\
75.5 \\
75.7 \\
77.0 \\
75.4 \\
70.8\end{array}$ & $\begin{array}{l}52.1 \\
53.7 \\
54.5 \\
58.0 \\
58.8 \\
61.2 \\
65.6 \\
65.8 \\
63.7 \\
63.2 \\
62.9 \\
60.9 \\
60.6\end{array}$ & $\begin{array}{l}42.8 \\
47.7 \\
48.7 \\
52.3 \\
51.4 \\
55.5 \\
58.8 \\
58.0 \\
56.7 \\
55.0 \\
58.2 \\
51.8 \\
53.6\end{array}$ & $\begin{array}{l}54.5 \\
58.4 \\
60.2 \\
63.2 \\
64.2 \\
67.1 \\
70.2 \\
70.4 \\
70.2 \\
66.2 \\
65.1 \\
63.1 \\
65.7\end{array}$ \\
\hline \multicolumn{13}{|l|}{ Alaska } \\
\hline 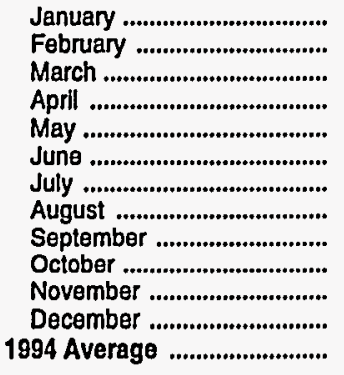 & $\begin{array}{l}109.8 \\
108.6 \\
107.9 \\
107.4 \\
107.9 \\
111.1 \\
112.3 \\
112.4 \\
115.2 \\
114.2 \\
113.6 \\
113.5 \\
111.1\end{array}$ & $\begin{array}{r}106.3 \\
105.2 \\
105.1 \\
104.9 \\
105.4 \\
106.1 \\
106.2 \\
106.3 \\
\text { NA } \\
111.9 \\
111.5 \\
111.7 \\
107.5\end{array}$ & $\begin{array}{l}86.4 \\
85.3 \\
84.9 \\
86.6 \\
87.3 \\
90.9 \\
90.9 \\
92.2 \\
94.0 \\
93.9 \\
92.4 \\
92.7 \\
89.9\end{array}$ & $\begin{array}{l}78.6 \\
76.4 \\
77.9 \\
77.5 \\
78.0 \\
80.1 \\
81.3 \\
82.2 \\
84.3 \\
83.2 \\
82.6 \\
80.5 \\
80.5\end{array}$ & $\begin{array}{l}- \\
- \\
- \\
\overline{-} \\
\overline{-} \\
\overline{-} \\
\overline{-} \\
- \\
-\end{array}$ & $\begin{array}{l}84.1 \\
81.8 \\
82.7 \\
83.1 \\
83.8 \\
86.3 \\
86.7 \\
87.9 \\
90.3 \\
89.7 \\
88.9 \\
87.9 \\
86.3\end{array}$ & $\begin{array}{l}108.7 \\
107.3 \\
107.6 \\
107.6 \\
107.9 \\
111.3 \\
111.3 \\
113.2 \\
113.2 \\
112.6 \\
113.0 \\
112.0 \\
109.8\end{array}$ & $\begin{array}{l}103.6 \\
102.2 \\
102.8 \\
102.8 \\
103.4 \\
106.3 \\
104.5 \\
108.6 \\
109.9 \\
109.4 \\
109.8 \\
109.7 \\
105.4\end{array}$ & $\begin{array}{l}77.6 \\
76.5 \\
76.0 \\
78.0 \\
79.1 \\
82.8 \\
83.9 \\
88.1 \\
88.6 \\
87.0 \\
86.0 \\
86.2 \\
83.1\end{array}$ & $\begin{array}{l}69.9 \\
68.5 \\
68.7 \\
68.8 \\
70.0 \\
71.0 \\
71.5 \\
73.0 \\
73.8 \\
75.0 \\
72.9 \\
72.6 \\
71.6\end{array}$ & $\begin{array}{c}W \\
W \\
W \\
64.5 \\
62.3 \\
71.2 \\
72.6 \\
W \\
72.4 \\
79.9 \\
W \\
W \\
70.2\end{array}$ & $\begin{array}{l}74.5 \\
72.4 \\
73.2 \\
73.8 \\
74.1 \\
76.5 \\
77.5 \\
80.2 \\
80.9 \\
81.7 \\
79.9 \\
80.1 \\
77.5\end{array}$ \\
\hline \multicolumn{13}{|l|}{ Arizona } \\
\hline 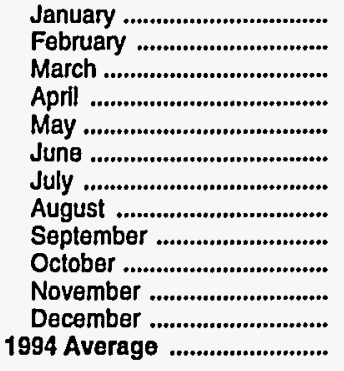 & $\begin{array}{r}99.4 \\
98.5 \\
97.5 \\
95.6 \\
95.5 \\
95.6 \\
95.8 \\
97.5 \\
98.0 \\
103.6 \\
104.5 \\
100.6 \\
96.7\end{array}$ & $\begin{array}{r}96.9 \\
95.7 \\
94.8 \\
95.2 \\
95.2 \\
95.3 \\
95.6 \\
97.2 \\
97.5 \\
101.5 \\
102.3 \\
98.8 \\
96.1\end{array}$ & $\begin{array}{l}76.9 \\
77.8 \\
78.4 \\
79.1 \\
79.8 \\
81.6 \\
82.8 \\
83.4 \\
83.7 \\
86.7 \\
84.8 \\
78.8 \\
81.3\end{array}$ & $\begin{array}{l}66.5 \\
67.5 \\
70.6 \\
71.8 \\
71.0 \\
74.4 \\
77.6 \\
78.0 \\
77.1 \\
75.9 \\
72.9 \\
67.1 \\
72.8\end{array}$ & $\begin{array}{l}W \\
- \\
W \\
W \\
W \\
W \\
W \\
W \\
W \\
W \\
W \\
W \\
64.2\end{array}$ & $\begin{array}{l}71.1 \\
72.6 \\
74.4 \\
76.8 \\
76.8 \\
79.5 \\
81.0 \\
81.4 \\
80.1 \\
79.6 \\
77.0 \\
70.4 \\
77.7\end{array}$ & $\begin{array}{l}84.4 \\
81.5 \\
81.0 \\
80.8 \\
81.0 \\
81.7 \\
82.3 \\
84.4 \\
84.7 \\
89.1 \\
89.4 \\
85.1 \\
82.7\end{array}$ & $\begin{array}{l}82.0 \\
79.0 \\
79.2 \\
80.2 \\
80.5 \\
81.1 \\
82.0 \\
84.2 \\
84.3 \\
87.5 \\
87.6 \\
83.4 \\
82.0\end{array}$ & $\begin{array}{l}65.1 \\
66.4 \\
67.2 \\
69.7 \\
71.0 \\
72.7 \\
74.1 \\
74.3 \\
73.9 \\
73.2 \\
72.4 \\
67.4 \\
71.3\end{array}$ & $\begin{array}{l}55.5 \\
56.8 \\
58.8 \\
61.1 \\
63.4 \\
64.7 \\
67.2 \\
67.4 \\
65.5 \\
64.0 \\
64.8 \\
58.6 \\
62.5\end{array}$ & $\begin{array}{c}45.5 \\
W \\
W \\
53.2 \\
55.7 \\
W \\
W \\
W \\
60.4 \\
W \\
59.7 \\
54.9 \\
55.2\end{array}$ & $\begin{array}{l}58.4 \\
60.3 \\
62.5 \\
66.0 \\
67.7 \\
69.5 \\
71.4 \\
71.1 \\
69.4 \\
66.7 \\
67.1 \\
61.2 \\
66.7\end{array}$ \\
\hline \multicolumn{13}{|l|}{ California } \\
\hline 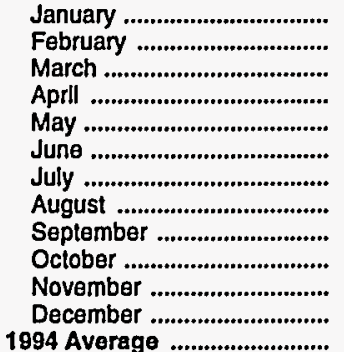 & $\begin{array}{l}8 \overline{8} .1 \\
85.7 \\
87.7 \\
89.5 \\
91.8 \\
94.4 \\
96.2 \\
95.7 \\
98.2 \\
- \\
\overline{91.9}\end{array}$ & $\begin{array}{r}\text { NA } \\
86.9 \\
84.8 \\
86.9 \\
88.4 \\
90.7 \\
93.4 \\
95.0 \\
94.5 \\
97.9 \\
\text { NA } \\
- \\
90.9\end{array}$ & $\begin{array}{c}\text { NA } \\
75.7 \\
74.8 \\
77.8 \\
79.5 \\
82.2 \\
84.9 \\
85.1 \\
86.0 \\
84.0 \\
\text { W } \\
- \\
80.9\end{array}$ & $\begin{array}{l}66.3 \\
63.8 \\
62.5 \\
64.9 \\
63.9 \\
68.4 \\
73.2 \\
72.9 \\
70.6 \\
70.4 \\
\text { NA } \\
\text { W } \\
67.9\end{array}$ & $\begin{array}{l}47.6 \\
51.8 \\
52.6 \\
57.2 \\
57.9 \\
61.2 \\
65.1 \\
63.9 \\
61.3 \\
W \\
W \\
W \\
59.7\end{array}$ & $\begin{array}{r}\text { NA } \\
70.8 \\
72.0 \\
74.1 \\
75.2 \\
78.6 \\
81.1 \\
81.3 \\
82.3 \\
77.3 \\
\text { NA } \\
\text { NA } \\
\text { T7.2 }\end{array}$ & $\begin{array}{c}- \\
71.5 \\
69.8 \\
72.0 \\
73.7 \\
75.8 \\
78.5 \\
80.3 \\
80.2 \\
82.6 \\
- \\
- \\
75.9\end{array}$ & $\begin{array}{c}W \\
70.9 \\
69.6 \\
71.8 \\
73.3 \\
75.3 \\
78.1 \\
79.6 \\
79.4 \\
82.5 \\
W \\
W \\
75.5\end{array}$ & $\begin{array}{c}\text { NA } \\
66.8 \\
64.2 \\
67.2 \\
68.7 \\
71.2 \\
74.1 \\
74.0 \\
74.8 \\
72.0 \\
W \\
- \\
70.0\end{array}$ & $\begin{array}{l}46.1 \\
52.7 \\
53.2 \\
56.3 \\
56.4 \\
58.5 \\
63.4 \\
62.8 \\
60.2 \\
57.0 \\
57.3 \\
53.2 \\
58.1\end{array}$ & $\begin{array}{l}44.6 \\
48.5 \\
48.4 \\
52.1 \\
50.8 \\
55.0 \\
58.9 \\
56.9 \\
55.8 \\
54.1 \\
58.1 \\
51.5 \\
53.6\end{array}$ & $\begin{array}{l}45.3 \\
57.9 \\
59.9 \\
62.7 \\
63.3 \\
66.3 \\
69.6 \\
69.5 \\
69.2 \\
59.9 \\
58.0 \\
51.6 \\
64.8\end{array}$ \\
\hline
\end{tabular}

See footnotes at end of table. 
Table 32. Conventional Motor Gasoline Prices by Grade, Sales Type, PAD District, and State

(Cents per Gallon Excluding Taxes) - Continued

\begin{tabular}{|c|c|c|c|c|c|c|c|c|c|c|c|c|}
\hline \multirow{3}{*}{$\begin{array}{c}\text { Geographic Area } \\
\text { Month }\end{array}$} & \multicolumn{6}{|c|}{ Regular } & \multicolumn{6}{|c|}{ Midgrade } \\
\hline & \multicolumn{2}{|c|}{ Sales to End Users } & \multicolumn{4}{|c|}{ Sales for Resale } & \multicolumn{2}{|c|}{ Sales to End Users } & \multicolumn{4}{|c|}{ Sales for Resale } \\
\hline & $\begin{array}{c}\text { Through } \\
\text { Retail } \\
\text { Outlets }\end{array}$ & Averagea & DTW & Rack & Bulk & Average & $\begin{array}{c}\text { Through } \\
\text { Retail } \\
\text { Outlets }\end{array}$ & Average $^{a}$ & DTW & Rack & Bulk & Average \\
\hline Hawaii & & & & & & & & & & & & \\
\hline 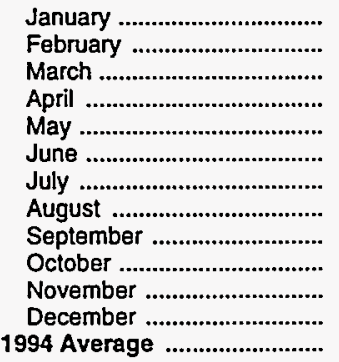 & $\begin{array}{r}105.3 \\
104.3 \\
105.0 \\
105.5 \\
104.1 \\
104.1 \\
104.0 \\
\mathrm{NA} \\
99.1 \\
99.7 \\
100.4 \\
100.0 \\
102.9\end{array}$ & $\begin{array}{r}96.3 \\
95.3 \\
96.0 \\
98.0 \\
96.3 \\
96.5 \\
97.1 \\
\text { NA } \\
92.8 \\
93.2 \\
95.1 \\
92.8 \\
95.5\end{array}$ & $\begin{array}{l}85.6 \\
84.0 \\
84.3 \\
86.2 \\
86.4 \\
87.6 \\
89.7 \\
91.2 \\
92.2 \\
92.9 \\
92.8 \\
91.5 \\
88.8\end{array}$ & $\begin{array}{l}76.2 \\
74.9 \\
75.3 \\
76.8 \\
77.9 \\
79.0 \\
79.6 \\
80.2 \\
80.5 \\
80.1 \\
81.6 \\
78.0 \\
78.3\end{array}$ & $\begin{array}{l}- \\
\bar{W} \\
- \\
- \\
- \\
- \\
- \\
- \\
- \\
- \\
\bar{w}\end{array}$ & $\begin{array}{l}83.8 \\
82.5 \\
68.8 \\
84.5 \\
84.9 \\
86.2 \\
87.9 \\
89.4 \\
90.4 \\
90.8 \\
90.9 \\
89.5 \\
84.9\end{array}$ & $\begin{array}{r}107.5 \\
106.9 \\
107.0 \\
107.2 \\
105.7 \\
105.8 \\
113.0 \\
\text { NA } \\
105.6 \\
106.1 \\
106.4 \\
106.6 \\
107.2\end{array}$ & $\begin{array}{r}97.3 \\
97.1 \\
97.1 \\
97.2 \\
96.2 \\
96.5 \\
105.7 \\
\text { NA } \\
97.6 \\
98.5 \\
99.9 \\
98.4 \\
98.5\end{array}$ & $\begin{array}{l}90.2 \\
89.3 \\
89.7 \\
91.5 \\
92.2 \\
93.4 \\
95.9 \\
97.4 \\
98.4 \\
99.3- \\
99.2 \\
98.1 \\
94.7\end{array}$ & $\begin{array}{c}87.1 \\
85.9 \\
84.6 \\
86.8 \\
88.9 \\
87.5 \\
89.6 \\
W \\
W \\
W \\
W \\
W \\
88.6\end{array}$ & $\begin{array}{l}- \\
- \\
- \\
- \\
- \\
- \\
- \\
- \\
- \\
- \\
- \\
-\end{array}$ & $\begin{array}{l}90.1 \\
89.1 \\
89.5 \\
91.3 \\
92.1 \\
93.1 \\
95.6 \\
97.1 \\
98.1 \\
98.9 \\
98.9 \\
97.9 \\
94.4\end{array}$ \\
\hline 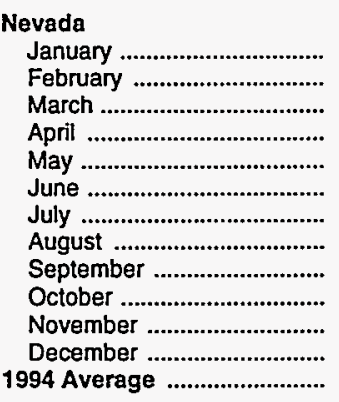 & $\begin{array}{r}66.3 \\
65.7 \\
70.8 \\
\text { NA } \\
78.2 \\
79.3 \\
80.8 \\
83.2 \\
86.0 \\
76.6 \\
77.6 \\
76.7 \\
78.2\end{array}$ & $\begin{array}{r}66.1 \\
64.9 \\
69.4 \\
\text { NA } \\
76.7 \\
78.3 \\
79.7 \\
82.3 \\
84.9 \\
77.0 \\
77.1 \\
75.5 \\
77.3\end{array}$ & $\begin{array}{l}59.5 \\
57.9 \\
60.4 \\
61.9 \\
63.2 \\
65.1 \\
67.7 \\
69.0 \\
69.3 \\
69.3 \\
68.4 \\
64.4 \\
64.7\end{array}$ & $\begin{array}{l}52.0 \\
53.7 \\
54.0 \\
58.1 \\
58.0 \\
61.2 \\
65.2 \\
65.3 \\
63.0 \\
64.2 \\
62.9 \\
57.1 \\
60.5\end{array}$ & $\begin{array}{l}W \\
W \\
W \\
W \\
W \\
W \\
W \\
W \\
W \\
W \\
W \\
W \\
W\end{array}$ & $\begin{array}{l}54.0 \\
54.6 \\
57.2 \\
60.0 \\
60.7 \\
63.1 \\
66.4 \\
67.1 \\
65.2 \\
64.6 \\
63.8 \\
57.5 \\
62.1\end{array}$ & $\begin{array}{l}77.5 \\
76.0 \\
81.0 \\
83.9 \\
85.1 \\
86.0 \\
87.5 \\
89.3 \\
90.6 \\
89.1 \\
87.4 \\
85.6 \\
86.2\end{array}$ & $\begin{array}{l}77.1 \\
76.0 \\
79.7 \\
83.5 \\
84.7 \\
85.6 \\
87.1 \\
88.8 \\
90.1 \\
88.9 \\
86.8 \\
85.0 \\
85.7\end{array}$ & $\begin{array}{l}62.9 \\
63.0 \\
67.8 \\
69.8 \\
71.3 \\
72.7 \\
75.0 \\
76.4 \\
77.5 \\
75.6 \\
73.9 \\
68.1 \\
71.7\end{array}$ & $\begin{array}{l}57.0 \\
58.6 \\
59.4 \\
63.6 \\
64.6 \\
66.8 \\
71.2 \\
72.5 \\
70.8 \\
73.1 \\
72.0 \\
68.8 \\
66.8\end{array}$ & $\begin{array}{l}- \\
- \\
- \\
- \\
- \\
- \\
- \\
- \\
- \\
- \\
-\end{array}$ & $\begin{array}{l}60.1 \\
60.8 \\
64.6 \\
67.6 \\
68.8 \\
70.2 \\
73.4 \\
74.9 \\
74.3 \\
74.5 \\
72.8 \\
68.5 \\
69.7\end{array}$ \\
\hline 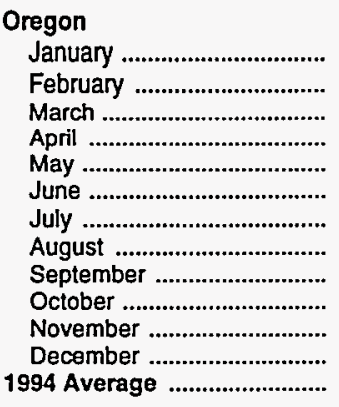 & $\begin{array}{l}75.4 \\
75.3 \\
74.1 \\
74.8 \\
77.1 \\
78.7 \\
82.0 \\
83.7 \\
83.0 \\
80.9 \\
80.0 \\
77.8 \\
79.0\end{array}$ & $\begin{array}{l}73.8 \\
73.9 \\
73.6 \\
74.1 \\
76.3 \\
77.9 \\
81.1 \\
83.0 \\
82.3 \\
80.1 \\
79.1 \\
76.4 \\
78.1\end{array}$ & $\begin{array}{l}61.1 \\
60.9 \\
60.8 \\
62.8 \\
65.3 \\
67.0 \\
70.0 \\
71.9 \\
71.9 \\
69.6 \\
68.9 \\
64.7 \\
67.0\end{array}$ & $\begin{array}{l}48.3 \\
51.6 \\
51.9 \\
58.1 \\
59.9 \\
61.6 \\
65.5 \\
67.8 \\
67.1 \\
63.2 \\
61.9 \\
58.0 \\
59.9\end{array}$ & $\begin{array}{c}45.5 \\
W \\
W \\
W \\
53.0 \\
W \\
58.0 \\
60.0 \\
57.8 \\
55.9 \\
54.9 \\
50.3 \\
\mathbf{5 5 . 3}\end{array}$ & $\begin{array}{l}51.1 \\
53.6 \\
56.0 \\
59.6 \\
62.4 \\
63.9 \\
67.3 \\
67.4 \\
67.8 \\
64.2 \\
62.6 \\
58.2 \\
62.1\end{array}$ & $\begin{array}{l}75.2 \\
75.1 \\
75.1 \\
76.4 \\
76.6 \\
77.5 \\
81.1 \\
82.9 \\
82.7 \\
82.8 \\
84.5 \\
83.1 \\
79.6\end{array}$ & $\begin{array}{l}74.3 \\
74.7 \\
74.7 \\
75.8 \\
76.0 \\
76.9 \\
80.4 \\
85.5 \\
84.8 \\
84.3 \\
86.2 \\
84.6 \\
80.5\end{array}$ & $\begin{array}{c}\text { W } \\
60.1 \\
64.8 \\
68.1 \\
70.5 \\
72.3 \\
\text { NA } \\
\text { NA } \\
\text { NA } \\
\text { NA } \\
\text { NA } \\
71.5 \\
\text { NA }\end{array}$ & $\begin{array}{c}W \\
W \\
W \\
57.4 \\
68.3 \\
65.5 \\
W \\
69.1 \\
67.2 \\
68.1 \\
W \\
W \\
66.0\end{array}$ & $\begin{array}{l}- \\
- \\
- \\
- \\
- \\
- \\
- \\
- \\
- \\
- \\
-\end{array}$ & $\begin{array}{c}W \\
58.5 \\
63.4 \\
65.8 \\
69.7 \\
70.3 \\
72.9 \\
\text { NA } \\
\text { NA } \\
70.0 \\
69.8 \\
67.9 \\
68.8\end{array}$ \\
\hline 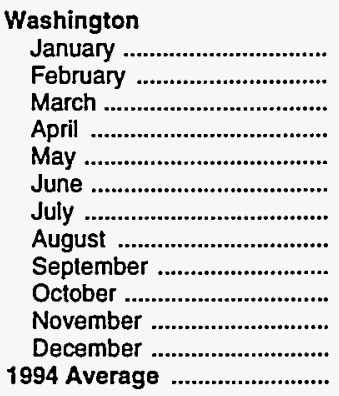 & $\begin{array}{l}70.2 \\
70.5 \\
67.9 \\
69.3 \\
72.7 \\
75.8 \\
79.4 \\
82.6 \\
83.0 \\
82.3 \\
84.5 \\
82.3 \\
76.6\end{array}$ & $\begin{array}{l}69.6 \\
69.8 \\
67.7 \\
69.2 \\
72.5 \\
75.4 \\
79.0 \\
82.3 \\
82.4 \\
81.9 \\
83.7 \\
81.6 \\
76.3\end{array}$ & $\begin{array}{l}57.5 \\
57.6 \\
57.8 \\
60.8 \\
63.8 \\
66.7 \\
70.2 \\
72.7 \\
73.3 \\
71.5 \\
69.3 \\
66.2 \\
66.9\end{array}$ & $\begin{array}{l}50.6 \\
50.7 \\
53.7 \\
57.4 \\
59.8 \\
63.3 \\
66.9 \\
69.1 \\
68.7 \\
65.4 \\
63.7 \\
59.5 \\
61.5\end{array}$ & $\begin{array}{l}W \\
W \\
- \\
W \\
W \\
W \\
54.2 \\
W \\
W \\
54.2 \\
W \\
50.9 \\
45.7\end{array}$ & $\begin{array}{l}47.4 \\
50.4 \\
55.6 \\
59.0 \\
61.5 \\
64.9 \\
67.6 \\
70.7 \\
70.7 \\
67.6 \\
65.0 \\
61.3 \\
63.0\end{array}$ & $\begin{array}{r}74.8 \\
71.5 \\
69.3 \\
70.1 \\
\text { NA } \\
\text { NA } \\
77.2 \\
86.8 \\
\text { NA } \\
87.2 \\
88.1 \\
86.2 \\
79.9\end{array}$ & $\begin{array}{c}73.3 \\
71.9 \\
70.3 \\
70.9 \\
70.4 \\
76.0 \\
\text { NA } \\
84.9 \\
\text { NA } \\
86.9 \\
87.4 \\
85.6 \\
79.3\end{array}$ & $\begin{array}{c}W \\
W \\
62.0 \\
66.2 \\
68.8 \\
69.9 \\
71.2 \\
W \\
W \\
77.2 \\
W \\
68.7 \\
73.9\end{array}$ & $\begin{array}{c}W \\
- \\
W \\
W \\
N A \\
N A \\
N A \\
W \\
- \\
W \\
W \\
W \\
64.5\end{array}$ & $\begin{array}{l}- \\
- \\
- \\
- \\
- \\
- \\
- \\
- \\
- \\
- \\
- \\
-\end{array}$ & $\begin{array}{c}N A \\
W \\
56.6 \\
61.8 \\
N A \\
N A \\
N A \\
73.6 \\
W \\
76.4 \\
72.7 \\
68.4 \\
71.8\end{array}$ \\
\hline
\end{tabular}

See footnotes at end of table. 
Table 32. Conventional Motor Gasoline Prices by Grade, Sales Type, PAD District, and State

(Cents per Gallon Excluding Taxes) - Continued

\begin{tabular}{|c|c|c|c|c|c|c|c|c|c|c|c|c|}
\hline \multirow{3}{*}{$\begin{array}{l}\text { Goographlc Area } \\
\text { Month }\end{array}$} & \multicolumn{6}{|c|}{ Premium } & \multicolumn{6}{|c|}{ All Grades } \\
\hline & \multicolumn{2}{|c|}{ Sales to End Users } & \multicolumn{4}{|c|}{ Sales for Resale } & \multicolumn{2}{|c|}{ Sales to End Users } & \multicolumn{4}{|c|}{ Sales for Resale } \\
\hline & $\begin{array}{c}\text { Through } \\
\text { Retall } \\
\text { Outlets }\end{array}$ & Average $a$ & DTW & Rack & Bulk & Average & $\begin{array}{c}\text { Through } \\
\text { Retall } \\
\text { Outlets }\end{array}$ & Averagea & DTW & Rack & Bulk & Average \\
\hline Hawali & & & & & & & & & & & & \\
\hline 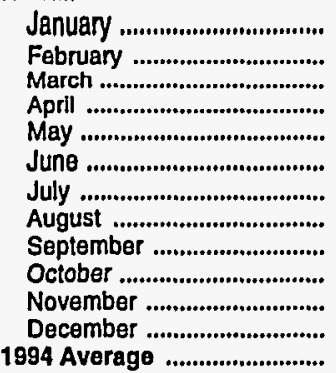 & $\begin{array}{r}123.0 \\
121.9 \\
123.1 \\
123.7 \\
121.9 \\
122.1 \\
123.5 \\
\text { NA } \\
117.3 \\
117.4 \\
117.9 \\
117.8 \\
121.1\end{array}$ & $\begin{array}{r}111.1 \\
110.4 \\
111.6 \\
113.0 \\
111.5 \\
111.8 \\
113.6 \\
\text { NA } \\
108.5 \\
109.0 \\
109.5 \\
108.2 \\
110.9\end{array}$ & $\begin{array}{r}98.3 \\
96.9 \\
97.3 \\
99.1 \\
99.6 \\
100.4 \\
102.8 \\
104.3 \\
105.4 \\
104.9 \\
106.1 \\
104.8 \\
101.8\end{array}$ & $\begin{array}{l}89.4 \\
88.3 \\
87.9 \\
89.3 \\
89.5 \\
91.1 \\
93.0 \\
94.2 \\
94.2 \\
93.8 \\
95.3 \\
92.5 \\
91.4\end{array}$ & $\begin{array}{l}- \\
- \\
\overline{-} \\
- \\
- \\
- \\
- \\
- \\
-\end{array}$ & $\begin{array}{r}97.2 \\
95.9 \\
96.0 \\
97.7 \\
98.2 \\
99.3 \\
101.5 \\
103.0 \\
104.2 \\
103.6 \\
104.8 \\
103.4 \\
100.5\end{array}$ & $\begin{array}{r}110.0 \\
109.1 \\
109.8 \\
110.4 \\
108.8 \\
108.9 \\
110.1 \\
\text { NA } \\
104.3 \\
104.8 \\
105.4 \\
105.3 \\
108.0\end{array}$ & $\begin{array}{r}100.3 \\
99.4 \\
100.2 \\
101.9 \\
100.3 \\
100.5 \\
102.5 \\
N A \\
97.3 \\
97.8 \\
99.3 \\
97.4 \\
99.8\end{array}$ & $\begin{array}{l}90.6 \\
89.1 \\
89.4 \\
91.3 \\
91.7 \\
92.7 \\
95.0 \\
96.4 \\
97.5 \\
97.9 \\
98.1 \\
96.9 \\
94.0\end{array}$ & $\begin{array}{l}80.4 \\
79.3 \\
79.5 \\
81.0 \\
81.8 \\
83.1 \\
83.8 \\
84.9 \\
85.0 \\
84.5 \\
85.8 \\
82.9 \\
\mathbf{8 2 . 6}\end{array}$ & $\begin{array}{l}- \\
- \\
- \\
- \\
- \\
- \\
- \\
- \\
- \\
- \\
w\end{array}$ & $\begin{array}{l}89.0 \\
87.8 \\
77.3 \\
89.7 \\
90.3 \\
91.4 \\
93.3 \\
94.8 \\
96.0 \\
96.1 \\
96.4 \\
95.2 \\
91.1\end{array}$ \\
\hline 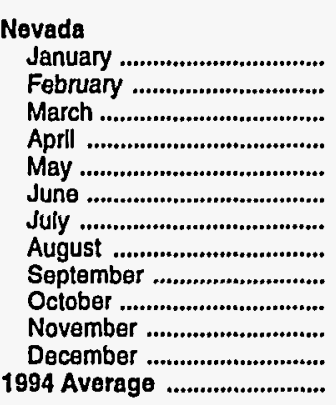 & $\begin{array}{r}83.8 \\
81.6 \\
90.1 \\
\text { NA } \\
97.1 \\
98.1 \\
99.3 \\
101.8 \\
102.2 \\
96.1 \\
91.6 \\
90.8 \\
97.4\end{array}$ & $\begin{array}{r}83.7 \\
81.0 \\
89.2 \\
N A \\
96.3 \\
97.5 \\
98.6 \\
101.1 \\
101.4 \\
95.2 \\
90.7 \\
89.8 \\
96.6\end{array}$ & $\begin{array}{l}69.3 \\
69.8 \\
75.4 \\
77.0 \\
78.3 \\
79.5 \\
81.9 \\
83.3 \\
83.7 \\
83.8 \\
82.2 \\
76.7 \\
79.3\end{array}$ & $\begin{array}{l}64.6 \\
65.7 \\
66.5 \\
70.9 \\
72.1 \\
74.8 \\
77.3 \\
79.1 \\
76.2 \\
76.0 \\
74.8 \\
67.3 \\
73.5\end{array}$ & $\begin{array}{l}w \\
w \\
w \\
w \\
w \\
w \\
w \\
w \\
w \\
w \\
w \\
w \\
w\end{array}$ & $\begin{array}{l}65.2 \\
66.6 \\
71.9 \\
74.9 \\
75.8 \\
77.3 \\
79.9 \\
81.3 \\
79.2 \\
77.3 \\
76.2 \\
68.2 \\
76.3\end{array}$ & $\begin{array}{r}68.6 \\
67.9 \\
74.3 \\
N A \\
82.1 \\
83.2 \\
84.7 \\
87.0 \\
89.3 \\
81.1 \\
79.9 \\
79.3 \\
82.1\end{array}$ & $\begin{array}{r}68.0 \\
66.9 \\
72.6 \\
\text { NA } \\
80.5 \\
82.0 \\
83.4 \\
85.9 \\
88.1 \\
80.8 \\
79.0 \\
77.6 \\
80.9\end{array}$ & $\begin{array}{l}61.5 \\
60.4 \\
63.7 \\
65.4 \\
66.7 \\
68.4 \\
71.0 \\
72.4 \\
72.9 \\
72.5 \\
71.4 \\
66.9 \\
68.1\end{array}$ & $\begin{array}{l}53.8 \\
55.4 \\
56.0 \\
60.0 \\
60.3 \\
63.5 \\
67.4 \\
67.9 \\
65.3 \\
65.8 \\
64.9 \\
59.1 \\
62.7\end{array}$ & $\begin{array}{l}W \\
W \\
W \\
W \\
W \\
W \\
W \\
W \\
W \\
W \\
W \\
W \\
W\end{array}$ & $\begin{array}{l}55.8 \\
56.6 \\
59.9 \\
62.8 \\
63.8 \\
66.0 \\
69.2 \\
70.2 \\
68.2 \\
66.7 \\
66.0 \\
59.7 \\
64.9\end{array}$ \\
\hline 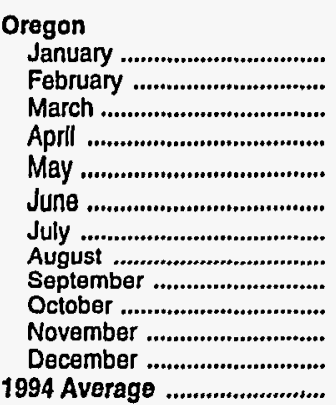 & $\begin{array}{l}92.2 \\
91.4 \\
91.6 \\
92.6 \\
94.7 \\
96.0 \\
98.3 \\
97.6 \\
99.5 \\
96.8 \\
94.2 \\
92.2 \\
95.3\end{array}$ & $\begin{array}{l}90.6 \\
90.0 \\
91.0 \\
91.5 \\
93.8 \\
95.1 \\
97.5 \\
97.2 \\
98.7 \\
96.3 \\
93.3 \\
91.2 \\
94.5\end{array}$ & $\begin{array}{l}71.1 \\
77.1 \\
76.3 \\
78.3 \\
80.2 \\
81.8 \\
84.8 \\
86.8 \\
87.0 \\
84.7 \\
83.9 \\
80.4 \\
82.2\end{array}$ & $\begin{array}{l}58.5 \\
65.9 \\
67.8 \\
71.8 \\
74.9 \\
76.2 \\
80.0 \\
80.8 \\
81.9 \\
77.8 \\
76.4 \\
72.3 \\
74.6\end{array}$ & $\begin{array}{c}- \\
W \\
W \\
\vec{w} \\
- \\
\vec{w} \\
W \\
W \\
W \\
W \\
60.6\end{array}$ & $\begin{array}{l}63.9 \\
71.0 \\
72.4 \\
75.2 \\
77.6 \\
79.2 \\
82.5 \\
83.2 \\
84.6 \\
78.2 \\
74.4 \\
70.7 \\
77.4\end{array}$ & $\begin{array}{l}77.4 \\
77.4 \\
76.4 \\
77.1 \\
79.4 \\
81.0 \\
84.2 \\
85.6 \\
85.2 \\
83.1 \\
81.9 \\
79.7 \\
81.1\end{array}$ & $\begin{array}{l}75.8 \\
75.9 \\
75.7 \\
76.2 \\
78.5 \\
80.1 \\
83.2 \\
85.0 \\
84.5 \\
82.2 \\
81.0 \\
78.5 \\
80.2\end{array}$ & $\begin{array}{l}63.4 \\
63.8 \\
63.1 \\
65.1 \\
67.5 \\
69.2 \\
72.3 \\
74.4 \\
74.4 \\
72.0 \\
71.3 \\
67.1 \\
69.4\end{array}$ & $\begin{array}{l}49.5 \\
53.0 \\
53.5 \\
59.7 \\
61.7 \\
63.3 \\
67.4 \\
69.8 \\
69.0 \\
65.0 \\
63.7 \\
59.7 \\
61.7\end{array}$ & $\begin{array}{c}45.5 \\
W \\
W \\
W \\
53.7 \\
W \\
58.0 \\
60.3 \\
57.9 \\
56.7 \\
56.5 \\
50.8 \\
55.7\end{array}$ & $\begin{array}{l}52.9 \\
55.6 \\
58.0 \\
61.6 \\
64.5 \\
65.9 \\
69.4 \\
69.5 \\
70.0 \\
66.2 \\
64.5 \\
60.0 \\
64.2\end{array}$ \\
\hline 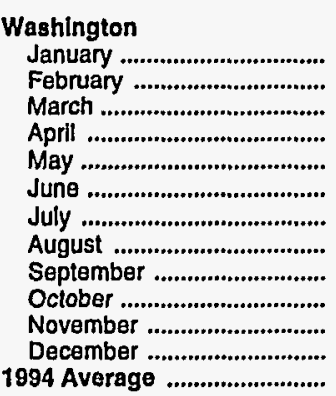 & $\begin{array}{r}\mathbf{8 7 . 5} \\
87.4 \\
85.2 \\
87.1 \\
91.1 \\
93.9 \\
97.2 \\
100.1 \\
101.6 \\
101.2 \\
100.8 \\
99.2 \\
94.5\end{array}$ & $\begin{array}{r}86.9 \\
86.5 \\
84.5 \\
86.7 \\
90.6 \\
93.5 \\
96.7 \\
99.4 \\
100.6 \\
99.7 \\
99.1 \\
97.6 \\
93.6\end{array}$ & $\begin{array}{l}74.2 \\
73.9 \\
72.2 \\
75.2 \\
78.8 \\
81.7 \\
85.2 \\
87.8 \\
89.1 \\
86.8 \\
84.7 \\
81.5 \\
82.0\end{array}$ & $\begin{array}{l}61.9 \\
64.3 \\
66.2 \\
69.9 \\
73.0 \\
76.1 \\
79.4 \\
81.6 \\
81.3 \\
78.3 \\
76.0 \\
72.3 \\
74.2\end{array}$ & $\begin{array}{c}W \\
w \\
w \\
= \\
= \\
= \\
= \\
- \\
= \\
\overline{4} \\
4.3\end{array}$ & $\begin{array}{l}66.7 \\
68.6 \\
69.3 \\
72.9 \\
76.5 \\
79.5 \\
82.9 \\
85.3 \\
85.9 \\
82.8 \\
79.2 \\
76.3 \\
78.4\end{array}$ & $\begin{array}{l}73.4 \\
73.6 \\
70.5 \\
72.1 \\
75.6 \\
78.5 \\
82.2 \\
85.5 \\
86.0 \\
85.6 \\
87.0 \\
85.2 \\
79.5\end{array}$ & $\begin{array}{l}72.6 \\
72.8 \\
70.2 \\
71.9 \\
75.2 \\
78.2 \\
81.7 \\
85.0 \\
85.3 \\
84.8 \\
86.0 \\
84.2 \\
79.1\end{array}$ & $\begin{array}{l}62.5 \\
62.3 \\
60.2 \\
63.4 \\
66.7 \\
69.5 \\
73.1 \\
75.7 \\
76.6 \\
74.5 \\
72.6 \\
69.7 \\
70.0\end{array}$ & $\begin{array}{l}52.3 \\
52.6 \\
55.5 \\
59.2 \\
61.5 \\
65.1 \\
68.8 \\
71.0 \\
70.6 \\
67.3 \\
65.6 \\
61.4 \\
63.3\end{array}$ & $\begin{array}{c}W \\
40.3 \\
W \\
W \\
W \\
W \\
54.2 \\
W \\
W \\
54.2 \\
W \\
50.9 \\
45.7\end{array}$ & $\begin{array}{l}50.2 \\
53.4 \\
57.7 \\
61.2 \\
63.9 \\
67.3 \\
70.1 \\
73.2 \\
73.5 \\
70.2 \\
67.6 \\
64.0 \\
65.6\end{array}$ \\
\hline
\end{tabular}

Dash $(-)=$ No data reported.

NA $=$ Not avallable.

$W=$ Withneld to avoid disclosure of individual company data.

a Includes sales through retail outlets as well as all direct sales to end users that were not made through company-operated retail outlets, e.g., sales to agricultural customers, commerclal sales, and industrial sales.

Sources: Energy Information Administration Forms EIA-782A, "Refiners'/Gas Plant Operators' Monthly Petroleum Product Sales Report," and ElA-782B,

"Resellers'/Retailers' Monthly Petroleum Product Sales Report." 
Table 33. Oxygenated Motor Gasoline Prices by Grade, Sales Type, PAD District, and State

(Cents per Gallon Excluding Taxes)

\begin{tabular}{|c|c|c|c|c|c|c|c|c|c|c|c|c|}
\hline \multirow{3}{*}{$\begin{array}{l}\text { Geographic Area } \\
\text { Month }\end{array}$} & \multicolumn{6}{|c|}{ Regular } & \multicolumn{6}{|c|}{ Midgrade } \\
\hline & \multicolumn{2}{|c|}{ Sales to End Users } & \multicolumn{4}{|c|}{ Sales for Pesale } & \multicolumn{2}{|c|}{ Sales to End Users } & \multicolumn{4}{|c|}{ Sales for Resale } \\
\hline & $\begin{array}{c}\text { Through } \\
\text { Retall } \\
\text { Outlets }\end{array}$ & Averagea & DTW & Rack & Bulk & Average & $\begin{array}{c}\text { Through } \\
\text { Retail } \\
\text { Outlots }\end{array}$ & Averagea & DTW & Rack & Bulk & Averago \\
\hline \multicolumn{13}{|l|}{ United States } \\
\hline 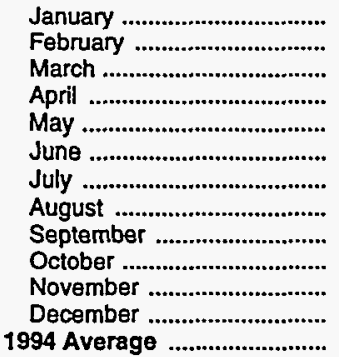 & $\begin{array}{l}69.8 \\
69.0 \\
71.1 \\
65.7 \\
71.6 \\
73.0 \\
75.5 \\
81.6 \\
81.9 \\
78.4 \\
79.2 \\
77.2 \\
74.3\end{array}$ & $\begin{array}{l}68.9 \\
68.4 \\
70.3 \\
65.2 \\
71.5 \\
72.8 \\
75.5 \\
81.7 \\
81.5 \\
77.9 \\
78.7 \\
76.6 \\
73.7\end{array}$ & $\begin{array}{l}59.6 \\
59.8 \\
61.7 \\
60.5 \\
62.2 \\
63.3 \\
66.7 \\
71.1 \\
68.5 \\
72.5 \\
72.8 \\
68.2 \\
65.7\end{array}$ & $\begin{array}{l}51.3 \\
53.4 \\
54.5 \\
55.4 \\
62.2 \\
65.6 \\
70.7 \\
75.9 \\
65.5 \\
63.6 \\
63.6 \\
58.5 \\
58.7\end{array}$ & $\begin{array}{c}45.6 \\
48.4 \\
45.7 \\
49.4 \\
- \\
- \\
W \\
W \\
54.6 \\
57.8 \\
59.4 \\
W \\
52.1\end{array}$ & $\begin{array}{l}56.2 \\
57.6 \\
57.7 \\
58.2 \\
62.2 \\
64.5 \\
68.6 \\
71.8 \\
66.2 \\
68.9 \\
68.9 \\
63.5 \\
62.7\end{array}$ & $\begin{array}{l}77.0 \\
76.9 \\
78.4 \\
77.6 \\
81.6 \\
85.8 \\
88.4 \\
98.0 \\
92.9 \\
88.4 \\
89.2 \\
86.5 \\
83.2\end{array}$ & $\begin{array}{l}76.0 \\
75.8 \\
76.7 \\
76.1 \\
79.1 \\
81.5 \\
87.6 \\
97.7 \\
92.3 \\
87.4 \\
88.3 \\
85.7 \\
82.1\end{array}$ & $\begin{array}{c}65.4 \\
65.4 \\
65.3 \\
66.2 \\
66.3 \\
68.6 \\
72.3 \\
W \\
70.8 \\
78.3 \\
78.3 \\
71.4 \\
71.2\end{array}$ & $\begin{array}{l}55.6 \\
57.8 \\
58.6 \\
59.7 \\
59.4 \\
64.4 \\
67.3 \\
70.8 \\
62.9 \\
68.7 \\
69.4 \\
62.5 \\
62.7\end{array}$ & $\begin{array}{l}N A \\
W \\
W \\
W \\
- \\
\bar{W} \\
\bar{W} \\
W \\
W \\
W \\
W\end{array}$ & $\begin{array}{l}62.6 \\
63.6 \\
63.5 \\
64.4 \\
61.7 \\
65.7 \\
68.9 \\
71.8 \\
68.9 \\
75.9 \\
75.9 \\
68.5 \\
68.9\end{array}$ \\
\hline \multicolumn{13}{|l|}{ PAD District I } \\
\hline 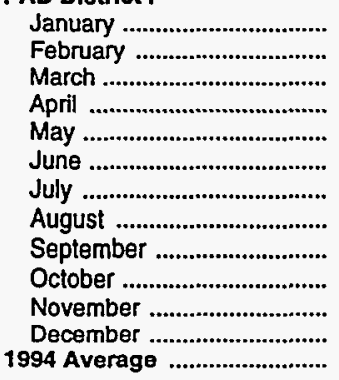 & $\begin{array}{l}64.5 \\
64.3 \\
64.3 \\
64.0 \\
W \\
W \\
W \\
W \\
77.4 \\
75.9 \\
77.4 \\
74.3 \\
69.4\end{array}$ & $\begin{array}{l}63.0 \\
63.3 \\
63.6 \\
63.5 \\
67.6 \\
70.5 \\
W \\
W \\
75.8 \\
75.1 \\
76.4 \\
73.7 \\
68.4\end{array}$ & $\begin{array}{l}59.2 \\
59.6 \\
59.4 \\
60.0 \\
62.9 \\
W \\
W \\
W \\
74.6 \\
71.5 \\
72.3 \\
67.9 \\
64.2\end{array}$ & $\begin{array}{c}49.6 \\
51.9 \\
51.8 \\
53.8 \\
\text { NA } \\
57.6 \\
\text { W } \\
- \\
57.6 \\
62.6 \\
63.6 \\
57.2 \\
55.9\end{array}$ & $\begin{array}{c}44.2 \\
48.1 \\
45.6 \\
49.4 \\
- \\
- \\
W \\
- \\
51.2 \\
59.8 \\
61.3 \\
50.0 \\
49.7\end{array}$ & $\begin{array}{c}54.7 \\
56.2 \\
55.0 \\
57.2 \\
60.2 \\
57.5 \\
W \\
W \\
67.6 \\
67.6 \\
68.5 \\
61.3 \\
60.3\end{array}$ & $\begin{array}{c}76.4 \\
76.5 \\
77.5 \\
77.4 \\
W \\
W \\
W \\
W \\
92.3 \\
87.6 \\
88.0 \\
85.0 \\
81.6\end{array}$ & $\begin{array}{c}74.7 \\
74.9 \\
75.5 \\
76.0 \\
W \\
W \\
W \\
W \\
91.2 \\
86.7 \\
86.9 \\
84.1 \\
80.2\end{array}$ & $\begin{array}{c}65.8 \\
65.8 \\
65.5 \\
66.3 \\
67.2 \\
W \\
W \\
- \\
77.7 \\
77.8 \\
78.5 \\
74.2 \\
70.6\end{array}$ & $\begin{array}{c}54.9 \\
57.3 \\
58.9 \\
60.1 \\
59.8 \\
W \\
- \\
W \\
62.7 \\
69.5 \\
70.2 \\
60.9 \\
61.8\end{array}$ & $\begin{array}{l}W \\
W \\
W \\
W \\
- \\
- \\
- \\
- \\
- \\
W \\
- \\
\bar{w}\end{array}$ & $\begin{array}{c}62.8 \\
63.6 \\
64.0 \\
64.9 \\
65.1 \\
N A \\
W \\
W \\
73.9 \\
75.8 \\
76.2 \\
68.3 \\
68.3\end{array}$ \\
\hline \multicolumn{13}{|l|}{ Subdistrict IA } \\
\hline 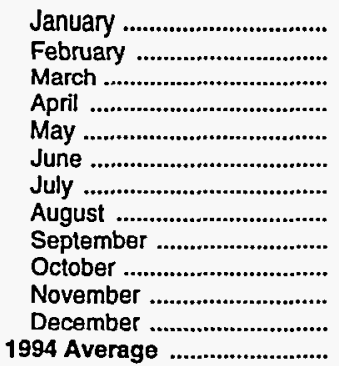 & $\begin{array}{c}71.4 \\
70.9 \\
68.1 \\
68.3 \\
- \\
- \\
- \\
\text { NA } \\
\text { W } \\
78.5 \\
80.7 \\
76.4 \\
73.2\end{array}$ & $\begin{array}{c}68.6 \\
70.1 \\
67.4 \\
67.6 \\
- \\
- \\
- \\
\text { NA } \\
\text { W } \\
77.8 \\
78.5 \\
74.4 \\
71.9\end{array}$ & $\begin{array}{c}62.8 \\
64.1 \\
64.0 \\
64.5 \\
W \\
- \\
- \\
- \\
72.6 \\
72.1 \\
73.2 \\
73.4 \\
67.5\end{array}$ & $\begin{array}{c}53.3 \\
56.2 \\
56.0 \\
57.8 \\
W \\
W \\
- \\
- \\
N A \\
64.6 \\
69.7 \\
W \\
59.7\end{array}$ & $\begin{array}{l}- \\
\bar{w} \\
- \\
- \\
- \\
- \\
- \\
- \\
- \\
\bar{w}\end{array}$ & $\begin{array}{c}58.9 \\
60.9 \\
58.2 \\
61.7 \\
64.3 \\
W \\
- \\
- \\
70.8 \\
69.4 \\
72.0 \\
73.3 \\
64.1\end{array}$ & $\begin{array}{c}84.9 \\
84.2 \\
83.3 \\
84.8 \\
- \\
- \\
- \\
- \\
W \\
93.7 \\
90.4 \\
\text { NA } \\
87.1\end{array}$ & $\begin{array}{c}78.0 \\
81.8 \\
80.5 \\
82.9 \\
- \\
- \\
- \\
- \\
W \\
90.7 \\
86.5 \\
\text { NA } \\
83.4\end{array}$ & $\begin{array}{c}68.9 \\
69.0 \\
69.4 \\
69.9 \\
W \\
- \\
- \\
- \\
79.1 \\
77.7 \\
78.8 \\
W \\
72.7\end{array}$ & $\begin{array}{c}58.1 \\
60.8 \\
60.6 \\
62.2 \\
W \\
- \\
- \\
- \\
69.8 \\
70.9 \\
75.6 \\
W \\
64.7\end{array}$ & $\begin{array}{l}- \\
- \\
- \\
- \\
- \\
- \\
- \\
- \\
- \\
- \\
-\end{array}$ & $\begin{array}{c}65.9 \\
67.1 \\
67.2 \\
67.9 \\
W \\
- \\
- \\
- \\
77.7 \\
76.3 \\
78.0 \\
\text { NA } \\
70.8\end{array}$ \\
\hline \multicolumn{13}{|l|}{ Connecticut } \\
\hline 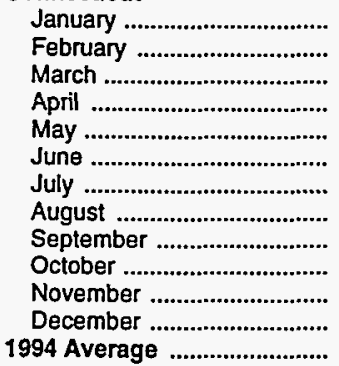 & $\begin{array}{c}71.4 \\
70.9 \\
68.1 \\
68.3 \\
- \\
- \\
- \\
\text { NA } \\
\text { W } \\
78.5 \\
81.7 \\
76.4 \\
73.1\end{array}$ & $\begin{array}{c}70.1 \\
70.1 \\
67.4 \\
67.6 \\
- \\
- \\
- \\
\text { NA } \\
\text { W } \\
77.8 \\
79.0 \\
74.4 \\
72.1\end{array}$ & $\begin{array}{c}62.8 \\
64.1 \\
64.0 \\
64.5 \\
W \\
- \\
- \\
- \\
72.6 \\
72.1 \\
73.2 \\
73.4 \\
67.5\end{array}$ & $\begin{array}{c}53.3 \\
56.2 \\
56.0 \\
57.9 \\
W \\
W \\
- \\
- \\
59.5 \\
64.6 \\
69.6 \\
W \\
59.7\end{array}$ & $\begin{array}{l}\overline{-} \\
\bar{w} \\
- \\
- \\
- \\
- \\
- \\
- \\
- \\
\bar{w}\end{array}$ & $\begin{array}{c}59.0 \\
60.9 \\
58.2 \\
61.8 \\
64.3 \\
W \\
- \\
- \\
70.8 \\
69.4 \\
72.0 \\
73.3 \\
64.1\end{array}$ & $\begin{array}{c}84.9 \\
84.2 \\
83.3 \\
84.8 \\
- \\
- \\
- \\
- \\
W \\
93.7 \\
93.7 \\
\text { NA } \\
87.3\end{array}$ & $\begin{array}{c}82.2 \\
81.8 \\
80.5 \\
82.9 \\
- \\
- \\
- \\
- \\
W \\
90.7 \\
87.1 \\
N A \\
84.1\end{array}$ & $\begin{array}{c}68.9 \\
69.0 \\
69.4 \\
69.9 \\
W \\
- \\
- \\
- \\
79.1 \\
77.7 \\
78.8 \\
W \\
72.7\end{array}$ & $\begin{array}{c}58.2 \\
60.8 \\
60.6 \\
62.9 \\
W \\
- \\
- \\
- \\
69.8 \\
70.9 \\
74.8 \\
W \\
64.6\end{array}$ & $\begin{array}{l}- \\
- \\
- \\
- \\
- \\
- \\
- \\
- \\
- \\
- \\
- \\
-\end{array}$ & $\begin{array}{c}66.0 \\
67.1 \\
67.2 \\
68.3 \\
\text { W } \\
- \\
- \\
- \\
77.7 \\
76.3 \\
77.9 \\
\text { NA } \\
70.8\end{array}$ \\
\hline
\end{tabular}

See footnotes at end of table. 
Table 33. Oxygenated Motor Gasoline Prices by Grade, Sales Type, PAD District, and State

(Cents per Gallon Excluding Taxes) - Continued

\begin{tabular}{|c|c|c|c|c|c|c|c|c|c|c|c|c|}
\hline \multirow{3}{*}{$\begin{array}{l}\text { Geographic Area } \\
\text { Month }\end{array}$} & \multicolumn{6}{|c|}{ Premium } & \multicolumn{6}{|c|}{ All Grades } \\
\hline & \multicolumn{2}{|c|}{ Sales to End Users } & \multicolumn{4}{|c|}{ Sales for Resale } & \multicolumn{2}{|c|}{ Sales to End Users } & \multicolumn{4}{|c|}{ Sales for Resale } \\
\hline & $\begin{array}{c}\text { Through } \\
\text { Retail } \\
\text { Outlots }\end{array}$ & Averagea & DTW & Rack & Bulk & Average & $\begin{array}{c}\text { Through } \\
\text { Retail } \\
\text { Outlets }\end{array}$ & Average $\mathrm{a}$ & DTW & Rack & Bulk & Average \\
\hline \multicolumn{13}{|l|}{ United States } \\
\hline 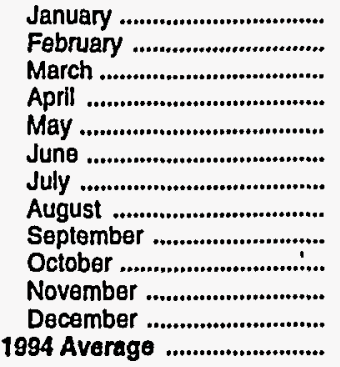 & $\begin{array}{l}87.4 \\
86.9 \\
88.0 \\
85.6 \\
87.8 \\
88.7 \\
91.1 \\
94.3 \\
97.3 \\
96.8 \\
98.1 \\
95.7 \\
91.9\end{array}$ & $\begin{array}{l}86.0 \\
85.4 \\
86.5 \\
84.4 \\
87.3 \\
88.4 \\
90.9 \\
93.8 \\
96.4 \\
95.9 \\
97.1 \\
95.0 \\
90.8\end{array}$ & $\begin{array}{l}73.5 \\
73.6 \\
73.6 \\
74.1 \\
73.2 \\
W \\
W \\
W \\
83.2 \\
86.7 \\
87.1 \\
81.4 \\
79.0\end{array}$ & $\begin{array}{l}60.2 \\
61.9 \\
62.0 \\
63.6 \\
64.6 \\
68.9 \\
72.8 \\
76.9 \\
72.5 \\
73.9 \\
74.9 \\
68.7 \\
67.4\end{array}$ & $\begin{array}{l}50.7 \\
53.0 \\
52.2 \\
55.9 \\
- \\
- \\
- \\
- \\
60.0 \\
64.0 \\
66.1 \\
W \\
56.6\end{array}$ & $\begin{array}{l}69.7 \\
70.3 \\
70.3 \\
71.1 \\
71.4 \\
73.2 \\
76.1 \\
79.4 \\
79.7 \\
83.2 \\
83.6 \\
77.1 \\
75.7\end{array}$ & $\begin{array}{l}73.9 \\
73.3 \\
75.8 \\
73.0 \\
76.5 \\
78.1 \\
80.5 \\
85.4 \\
86.2 \\
83.1 \\
83.8 \\
81.2 \\
78.7\end{array}$ & $\begin{array}{l}73.0 \\
72.5 \\
74.8 \\
72.2 \\
76.2 \\
77.8 \\
80.5 \\
85.3 \\
85.6 \\
82.4 \\
83.1 \\
80.6 \\
77.9\end{array}$ & $\begin{array}{l}64.1 \\
64.2 \\
66.6 \\
66.7 \\
66.9 \\
68.3 \\
71.5 \\
75.8 \\
72.6 \\
77.1 \\
77.2 \\
71.3 \\
70.1\end{array}$ & $\begin{array}{l}53.5 \\
55.7 \\
56.6 \\
58.0 \\
62.3 \\
66.0 \\
70.7 \\
75.4 \\
66.4 \\
66.1 \\
66.2 \\
60.4 \\
60.8\end{array}$ & $\begin{array}{c}46.6 \\
49.9 \\
46.8 \\
51.9 \\
- \\
- \\
W \\
W \\
55.8 \\
58.9 \\
60.0 \\
W \\
53.0\end{array}$ & $\begin{array}{l}60.3 \\
61.5 \\
62.4 \\
63.6 \\
65.2 \\
67.3 \\
70.9 \\
74.0 \\
69.8 \\
73.2 \\
73.1 \\
66.5 \\
66.6\end{array}$ \\
\hline 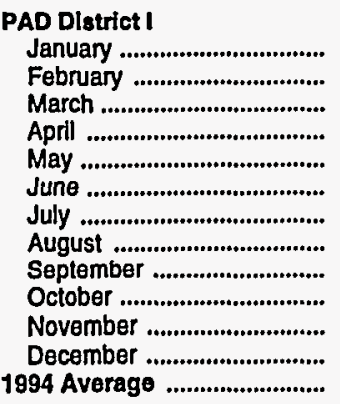 & $\begin{array}{c}86.1 \\
85.6 \\
85.9 \\
85.7 \\
W \\
W \\
W \\
W \\
101.1 \\
96.8 \\
97.4 \\
94.1 \\
90.3\end{array}$ & $\begin{array}{l}83.9 \\
83.3 \\
83.7 \\
84.3 \\
86.5 \\
N A \\
W \\
W \\
99.0 \\
95.8 \\
95.9 \\
93.3 \\
88.5\end{array}$ & $\begin{array}{c}73.9 \\
73.9 \\
73.7 \\
74.5 \\
N A \\
W \\
W \\
W \\
89.2 \\
86.5 \\
86.9 \\
82.2 \\
78.5\end{array}$ & $\begin{array}{l}59.6 \\
61.6 \\
61.5 \\
63.6 \\
64.4 \\
N A \\
W \\
W \\
71.8 \\
73.7 \\
75.3 \\
67.3 \\
66.2\end{array}$ & $\begin{array}{c}50.6 \\
53.0 \\
52.2 \\
55.9 \\
- \\
- \\
- \\
- \\
57.9 \\
63.8 \\
67.8 \\
- \\
55.1\end{array}$ & $\begin{array}{c}69.1 \\
69.8 \\
70.0 \\
71.1 \\
\mathrm{NA} \\
74.6 \\
W \\
W \\
83.5 \\
82.4 \\
83.5 \\
75.9 \\
74.5\end{array}$ & $\begin{array}{c}72.6 \\
72.4 \\
72.7 \\
72.6 \\
W \\
W \\
W \\
W \\
87.0 \\
83.8 \\
84.6 \\
81.5 \\
77.3\end{array}$ & $\begin{array}{c}70.8 \\
70.8 \\
71.3 \\
71.6 \\
\text { NA } \\
76.9 \\
\text { W } \\
\text { NA } \\
85.2 \\
82.8 \\
83.4 \\
80.7 \\
75.9\end{array}$ & $\begin{array}{c}65.7 \\
65.8 \\
66.2 \\
66.9 \\
N A \\
W \\
W \\
W \\
81.1 \\
78.1 \\
78.3 \\
73.2 \\
70.5\end{array}$ & $\begin{array}{c}53.0 \\
55.2 \\
55.3 \\
57.3 \\
56.7 \\
59.1 \\
W \\
W \\
62.6 \\
66.4 \\
67.3 \\
59.9 \\
59.4\end{array}$ & $\begin{array}{c}46.2 \\
49.8 \\
46.8 \\
51.9 \\
- \\
- \\
W \\
- \\
54.0 \\
61.2 \\
62.2 \\
50.0 \\
51.2\end{array}$ & $\begin{array}{c}60.6 \\
61.8 \\
61.4 \\
63.4 \\
N A \\
59.2 \\
W \\
W \\
74.7 \\
73.8 \\
74.2 \\
66.0 \\
66.2\end{array}$ \\
\hline \multicolumn{13}{|l|}{ Subdistrict IA } \\
\hline 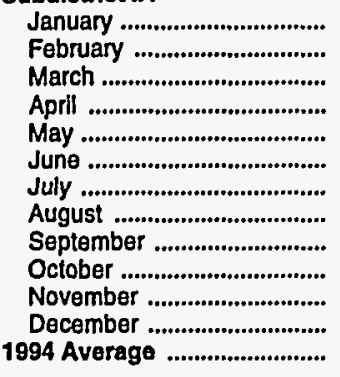 & $\begin{array}{r}95.3 \\
95.1 \\
93.3 \\
94.5 \\
- \\
- \\
- \\
\bar{W} \\
102.5 \\
101.2 \\
\text { NA } \\
97.1\end{array}$ & $\begin{array}{c}93.3 \\
93.5 \\
91.1 \\
92.7 \\
- \\
- \\
- \\
\bar{W} \\
101.2 \\
98.2 \\
\text { NA } \\
95.0\end{array}$ & $\begin{array}{l}75.0 \\
78.1 \\
77.9 \\
78.4 \\
W \\
- \\
- \\
- \\
87.1 \\
86.2 \\
87.3 \\
88.5 \\
80.6\end{array}$ & $\begin{array}{c}64.4 \\
67.2 \\
66.5 \\
68.2 \\
W \\
W \\
- \\
- \\
72.6 \\
77.2 \\
82.5 \\
W \\
71.1\end{array}$ & $\begin{array}{l}- \\
- \\
- \\
- \\
- \\
- \\
\bar{w} \\
- \\
\bar{w}\end{array}$ & $\begin{array}{c}71.1 \\
74.1 \\
73.7 \\
74.6 \\
W \\
W \\
- \\
- \\
83.9 \\
80.7 \\
85.6 \\
88.4 \\
76.9\end{array}$ & $\begin{array}{c}79.7 \\
79.1 \\
76.6 \\
77.2 \\
- \\
- \\
\overrightarrow{N A} \\
W \\
86.1 \\
88.3 \\
N A \\
81.4\end{array}$ & $\begin{array}{c}76.1 \\
77.9 \\
75.4 \\
76.2 \\
- \\
- \\
- \\
N A \\
W \\
85.1 \\
85.5 \\
N A \\
79.5\end{array}$ & $\begin{array}{c}67.6 \\
69.2 \\
69.1 \\
69.6 \\
W \\
- \\
- \\
- \\
76.5 \\
76.6 \\
77.6 \\
78.1 \\
72.0\end{array}$ & $\begin{array}{c}57.0 \\
59.9 \\
59.5 \\
61.2 \\
W \\
W \\
- \\
- \\
64.9 \\
68.7 \\
74.1 \\
W \\
63.5\end{array}$ & $\begin{array}{l}\overline{-} \\
\bar{w} \\
- \\
- \\
- \\
- \\
\overline{-} \\
\bar{w} \\
\overline{-} \\
\bar{w}\end{array}$ & $\begin{array}{c}63.7 \\
65.8 \\
63.5 \\
66.4 \\
69.3 \\
W \\
- \\
- \\
74.7 \\
73.6 \\
76.4 \\
78.0 \\
68.7\end{array}$ \\
\hline 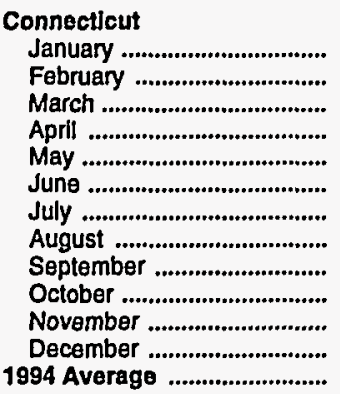 & $\begin{array}{c}95.3 \\
95.1 \\
93.3 \\
94.5 \\
- \\
- \\
- \\
\bar{W} \\
102.5 \\
104.3 \\
\text { NA } \\
97.3\end{array}$ & $\begin{array}{c}93.3 \\
93.5 \\
91.1 \\
92.7 \\
- \\
- \\
- \\
\bar{W} \\
101.2 \\
99.6 \\
\text { NA } \\
95.0\end{array}$ & $\begin{array}{c}75.0 \\
78.1 \\
77.9 \\
78.4 \\
W \\
- \\
- \\
- \\
87.1 \\
86.2 \\
87.3 \\
88.5 \\
80.6\end{array}$ & $\begin{array}{c}64.4 \\
67.3 \\
66.5 \\
68.6 \\
W \\
W \\
- \\
- \\
72.6 \\
77.2 \\
82.0 \\
W \\
71.0\end{array}$ & $\begin{array}{l}\overline{-} \\
\overline{-} \\
\bar{z} \\
\overline{-} \\
\overline{-} \\
\bar{w} \\
\bar{w} \\
\bar{w}\end{array}$ & $\begin{array}{c}71.2 \\
74.1 \\
73.7 \\
74.9 \\
W \\
W \\
- \\
- \\
83.9 \\
80.7 \\
85.5 \\
\text { NA } \\
76.9\end{array}$ & $\begin{array}{c}79.7 \\
79.1 \\
76.6 \\
77.2 \\
- \\
- \\
- \\
N A \\
W \\
86.1 \\
89.3 \\
81.9 \\
81.2\end{array}$ & $\begin{array}{c}78.1 \\
77.9 \\
75.4 \\
76.2 \\
- \\
- \\
- \\
\text { NA } \\
\text { W } \\
85.1 \\
85.6 \\
78.9 \\
79.6\end{array}$ & $\begin{array}{c}67.6 \\
69.2 \\
69.1 \\
69.6 \\
w \\
- \\
- \\
- \\
76.5 \\
76.6 \\
77.6 \\
78.1 \\
72.0\end{array}$ & $\begin{array}{c}57.1 \\
59.9 \\
59.5 \\
61.5 \\
W \\
W \\
- \\
- \\
64.9 \\
68.7 \\
73.7 \\
W \\
63.4\end{array}$ & $\begin{array}{l}\bar{z} \\
\bar{w} \\
\bar{z} \\
\bar{z} \\
\bar{z} \\
\bar{w} \\
\bar{w} \\
\bar{w}\end{array}$ & $\begin{array}{c}63.7 \\
65.8 \\
63.5 \\
66.6 \\
69.3 \\
W \\
- \\
- \\
74.7 \\
73.6 \\
76.3 \\
78.0 \\
68.7\end{array}$ \\
\hline
\end{tabular}

See footnotes at end of table. 
Table 33. Oxygenated Motor Gasoline Prices by Grade, Sales Type, PAD District, and State

(Cents per Gallon Excluding Taxes) - Continued

\begin{tabular}{|c|c|c|c|c|c|c|c|c|c|c|c|c|}
\hline \multirow{3}{*}{$\begin{array}{l}\text { Geographic Area } \\
\text { Month }\end{array}$} & \multicolumn{6}{|c|}{ Regular } & \multicolumn{6}{|c|}{ Midgrade } \\
\hline & \multicolumn{2}{|c|}{ Sales to End Users } & \multicolumn{4}{|c|}{ Sales for Resale } & \multicolumn{2}{|c|}{ Sales to End Users } & \multicolumn{4}{|c|}{ Sales for Resale } \\
\hline & $\begin{array}{c}\text { Through } \\
\text { Retail } \\
\text { Outlots }\end{array}$ & Averagea & DTW & Rack & Bulk & Average & $\begin{array}{l}\text { Through } \\
\text { Retail } \\
\text { Outlets }\end{array}$ & Average a & DTW & Rack & Bulk & Average \\
\hline
\end{tabular}

Maine

January .

March .

April

May

June

July ....

August

September

October

November

December ............................

1994 Average

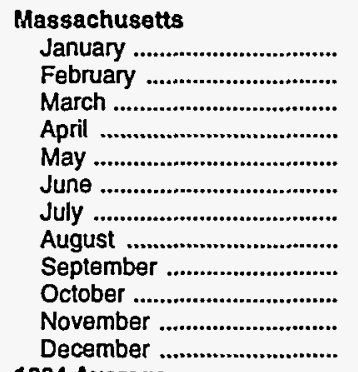

994 Average

New Hampshire

January ..

February

March

April

May

June

July ...

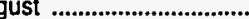

September

October

November

December

1994 Average

Rhode Island

January .

February

March

April

May

June

July ....

September

October .

November

December

1994 Average

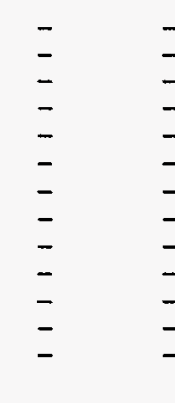

$\begin{array}{lll}- & w & - \\ - & - & - \\ - & - & - \\ - & - & - \\ - & - & - \\ - & - & - \\ - & - & - \\ - & - & - \\ - & - & - \\ \bar{w} & \bar{w} & - \\ \bar{w} & \bar{w} & - \\ & - & -\end{array}$

$\begin{array}{lll}- & - & - \\ - & - & - \\ - & - & - \\ - & - & - \\ - & - & - \\ - & - & - \\ - & - & - \\ - & - & - \\ - & - & - \\ - & - & - \\ - & - & - \\ - & - & -\end{array}$

$\begin{array}{lllll}- & - & - & - & - \\ - & - & - & - & - \\ - & - & - & - & - \\ - & - & - & - & - \\ - & - & - & - & - \\ - & - & - & - & - \\ - & - & - & - & - \\ - & - & - & - & - \\ - & - & - & - & - \\ - & - & - & - & - \\ - & - & - & - & - \\ - & - & - & - & - \\ - & - & - & - & -\end{array}$

See footnotes at end of table. 
Table 33. Oxygenated Motor Gasoline Prices by Grade, Sales Type, PAD District, and State

(Cents per Gallon Excluding Taxes) - Continued

\begin{tabular}{|c|c|c|c|c|c|c|c|c|c|c|c|c|}
\hline \multirow{3}{*}{$\begin{array}{l}\text { Geographic Area } \\
\text { Month }\end{array}$} & \multicolumn{6}{|c|}{ Premium } & \multicolumn{6}{|c|}{ All Grades } \\
\hline & \multicolumn{2}{|c|}{ Sales to End Users } & \multicolumn{4}{|c|}{ Sales for Resale } & \multicolumn{2}{|c|}{ Sales to End Users } & \multicolumn{4}{|c|}{ Sales for Resalo } \\
\hline & $\begin{array}{c}\text { Through } \\
\text { Rotall } \\
\text { Outlots }\end{array}$ & Average $\mathrm{a}$ & DTW & Rack & Bulk & Average & $\begin{array}{l}\text { Through } \\
\text { Retall } \\
\text { Outlets }\end{array}$ & Averagea & DTW & Rack & Bulk & Average \\
\hline
\end{tabular}

Maine

January .

February

March

Aprll

May

June

July ..........

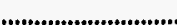

September .............................

October

November

December

1994 Average

Massachusetts

January ...................................

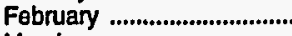

March ...

April

May

June

July ....

September

October

November ..................................

December

1994 Average

Now Hampshiro

January

February

March

April

May

June.

July ...

August

(n)

November

December

Rhode lsland

January...

February

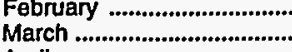

April

May

July ...

August

September

October ...

November

December ...

1994 Averago

$\begin{array}{llll}- & - & - & - \\ - & - & - & - \\ - & - & - & - \\ - & - & - & - \\ - & - & - & - \\ - & - & - & - \\ - & - & - & - \\ - & - & - & - \\ - & - & - & -\end{array}$

$\begin{array}{lll}- & - & \\ - & - & - \\ - & - & - \\ - & - & - \\ - & - & - \\ - & - & - \\ - & - & - \\ - & - & -\end{array}$

$\begin{array}{lll}- & - & - \\ - & - & - \\ - & - & - \\ - & - & - \\ - & - & - \\ - & - & - \\ - & - & - \\ - & - & -\end{array}$

$\begin{array}{llll}- & w & - & w \\ \overline{-} & - & - & w \\ \overline{-} & - & - & \bar{w} \\ - & - & - & - \\ - & - & - & - \\ - & - & - & - \\ \bar{w} & \bar{w} & - & \bar{w} \\ \bar{w} & \bar{w} & - & \bar{w}\end{array}$

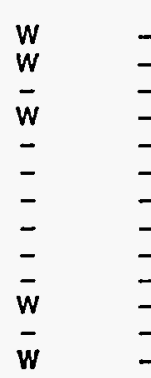

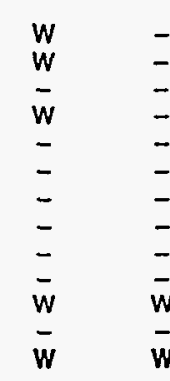

$\begin{array}{lll}- & w & - \\ - & - & - \\ - & - & - \\ - & - & - \\ - & - & - \\ - & - & - \\ - & - & - \\ \bar{w} & \bar{w} & - \\ \bar{w} & \bar{w} & \end{array}$

$\begin{array}{llll}- & w & - & w \\ - & w & - & w \\ - & \bar{w} & - & \bar{w} \\ - & - & - & - \\ - & - & - & - \\ - & - & - & - \\ - & - & - & - \\ - & - & - & - \\ - & \bar{w} & - & \bar{w} \\ - & \bar{w} & - & - \\ - & \bar{w} & - & \end{array}$

See footnotes at end of table. 
Table 33. Oxygenated Motor Gasoline Prices by Grade, Sales Type, PAD District, and State

(Cents per Gallon Excluding Taxes) - Continued

\begin{tabular}{|c|c|c|c|c|c|c|c|c|c|c|c|c|}
\hline \multirow{3}{*}{$\begin{array}{l}\text { Geographic Area } \\
\text { Month }\end{array}$} & \multicolumn{6}{|c|}{ Regular } & \multicolumn{6}{|c|}{ Midgrade } \\
\hline & \multicolumn{2}{|c|}{ Sales to End Users } & \multicolumn{4}{|c|}{ Sales for Resale } & \multicolumn{2}{|c|}{ Sales to End Users } & \multicolumn{4}{|c|}{ Sales for Resale } \\
\hline & $\begin{array}{c}\text { Through } \\
\text { Retail } \\
\text { Outlets }\end{array}$ & Average ${ }^{a}$ & DTW & Rack & Bulk & Average & $\begin{array}{c}\text { Through } \\
\text { Retail } \\
\text { Outlets }\end{array}$ & Averagea & DTW & Rack & Bulk & Average \\
\hline
\end{tabular}

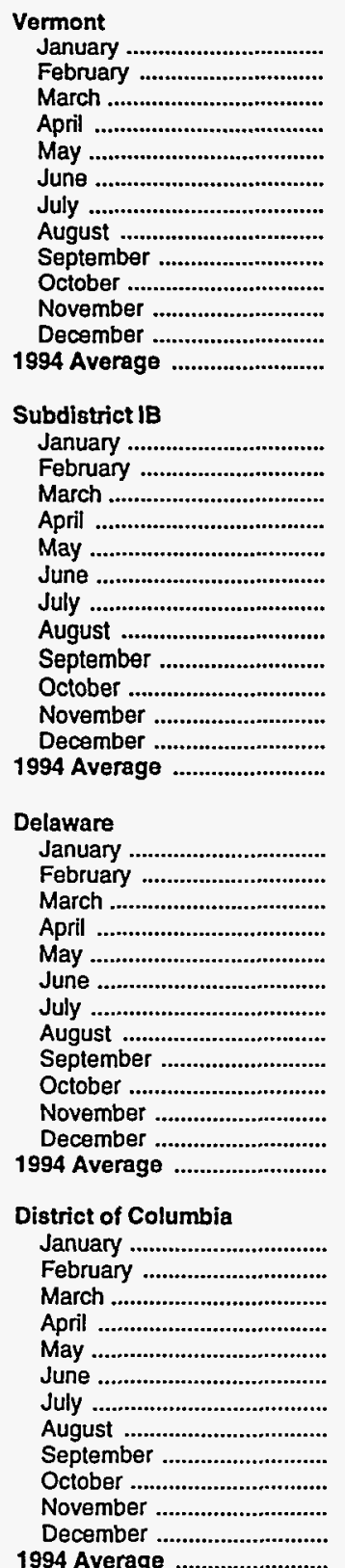

$\begin{array}{ll}- & \\ - & \end{array}$

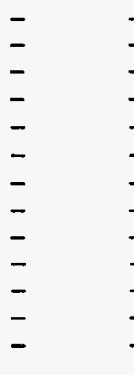

$\begin{array}{cccc}65.1 & 63.4 & 59.0 & 49.4 \\ 64.3 & 63.2 & 59.2 & 51.5 \\ 63.6 & 63.0 & 59.1 & 51.3 \\ 63.6 & 63.1 & 59.6 & 53.4 \\ W & 67.6 & 62.7 & 52.8 \\ W & 70.5 & W & W \\ W & W & W & W \\ W & W & W & - \\ 77.0 & 75.4 & 74.9 & 57.5 \\ 76.6 & 75.6 & 71.6 & 62.4 \\ 77.7 & 76.6 & 72.3 & 63.4 \\ 74.9 & 74.3 & 69.4 & 59.6 \\ 69.4 & 68.3 & 64.0 & 56.0\end{array}$

$\begin{array}{ccc}44.2 & 54.6 & 76.8 \\ 47.8 & 56.0 & 76.6 \\ 45.7 & 54.7 & 76.5 \\ 49.4 & 56.8 & 76.5 \\ - & 60.5 & W \\ - & 60.0 & W \\ W & W & W \\ - & W & W \\ 51.2 & 67.2 & 91.7 \\ 59.8 & 67.5 & 88.9 \\ 61.3 & 68.4 & 88.7 \\ W & 63.9 & 85.8 \\ 49.6 & 60.2 & 81.6\end{array}$

$\begin{array}{ccc}76.8 & 75.1 & 65.5 \\ 76.6 & 74.8 & 65.3 \\ 76.5 & 74.6 & 65.1 \\ 76.5 & 75.2 & 65.9 \\ W & W & 66.9 \\ W & W & W \\ W & W & W \\ W & W & - \\ 91.7 & 90.5 & 79.9 \\ 88.9 & 87.9 & 77.9 \\ 88.7 & 87.5 & 78.4 \\ 85.8 & 84.8 & 75.2 \\ 81.6 & 80.1 & 70.4\end{array}$

$\begin{array}{cccc}65.5 & 55.0 & W & 63.1 \\ 65.3 & 57.4 & W & 63.6 \\ 65.1 & 58.7 & W & 63.7 \\ 65.9 & 59.8 & W & 64.6 \\ 66.9 & 59.9 & - & 64.8 \\ W & W & - & 66.6 \\ W & - & - & W \\ - & W & - & W \\ 79.9 & 66.4 & - & 77.3 \\ 77.9 & 69.6 & - & 76.0 \\ 78.4 & 70.8 & - & 76.6 \\ 75.2 & \text { NA } & - & 74.5 \\ 70.4 & 62.5 & \text { W } & 68.6\end{array}$

Delaware

January

February

May

July

tember

October

994 Averag

\begin{tabular}{|c|c|c|c|c|}
\hline- & NA & $w$ & 49.2 & - \\
\hline - & NA & $w$ & 50.9 & - \\
\hline- & $w$ & - & 51.8 & - \\
\hline- & - & - & $W$ & - \\
\hline- & - & - & $w$ & - \\
\hline- & - & - & - & - \\
\hline- & - & - & - & - \\
\hline- & - & - & - & - \\
\hline- & - & - & - & - \\
\hline$w$ & $w$ & $w$ & 65.5 & - \\
\hline- & - & $w$ & 65.6 & - \\
\hline- & - & - & $w$ & - \\
\hline$w$ & 65.1 & $w$ & 57.1 & - \\
\hline
\end{tabular}

$\begin{array}{ccccccc}53.4 & \text { W } & 63.3 & \text { W } & 53.6 & - & 59.3 \\ 54.5 & W & W & W & 56.1 & - & 60.9 \\ 51.8 & - & W & - & 56.3 & - & 56.3 \\ W & - & - & - & - & - & - \\ W & - & - & - & W & - & \text { W } \\ - & - & - & - & - & - & - \\ - & - & - & - & - & - & - \\ - & - & - & - & - & - & - \\ - & - & - & - & - & - & - \\ 66.8 & \text { W } & \text { NA } & \text { W } & 69.7 & - & 71.8 \\ 66.9 & \text { W } & 77.5 & \text { W } & 70.7 & - & 72.5 \\ W & \text { W } & W & - & W & - & \text { W } \\ 59.3 & \text { W } & 68.1 & W & 62.1 & - & 65.0\end{array}$

istrict of Columbia

January

$\begin{array}{lll}W & 54.2 & 62.7\end{array}$

$\begin{array}{cc}62.7 & W \\ 62.1 & W \\ W & \\ - & - \\ - & - \\ - & - \\ - & - \\ - & - \\ 70.6 & - \\ 74.6 & W \\ W & W \\ 67.1 & W\end{array}$

$\begin{array}{lr}W & 61.9 \\ W & 64.4 \\ - & - \\ - & - \\ - & - \\ - & - \\ - & - \\ - & - \\ \bar{W} & - \\ W & 78.3 \\ W & 75.9 \\ & 71.2\end{array}$

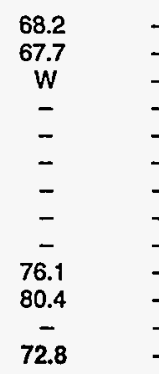

$\begin{array}{ccc}- & - & 68.2 \\ - & - & 67.7 \\ - & - & w \\ - & - & - \\ - & - & - \\ - & - & - \\ - & - & - \\ - & - & - \\ - & - & - \\ - & - & 76.1 \\ - & - & 80.4 \\ - & - & - \\ - & - & 72.8\end{array}$

See footnotes at end of table. 
Table 33. Oxygenated Motor Gasoline Prices by Grade, Sales Type, PAD District, and State

(Cents per Gallon Excluding Taxes) - Continued

\begin{tabular}{|c|c|c|c|c|c|c|c|c|c|c|c|c|}
\hline \multirow{3}{*}{$\begin{array}{l}\text { Geographic Area } \\
\text { Month }\end{array}$} & \multicolumn{6}{|c|}{ Promium } & \multicolumn{6}{|c|}{ All Grades } \\
\hline & \multicolumn{2}{|c|}{ Sales to End Users } & \multicolumn{4}{|c|}{ Sales for Resale } & \multicolumn{2}{|c|}{ Sales to End Users } & \multicolumn{4}{|c|}{ Sales for Resale } \\
\hline & $\begin{array}{c}\text { Through } \\
\text { Retail } \\
\text { Outlets }\end{array}$ & Averagea & DTW & Rack & Bulk & Average & $\begin{array}{l}\text { Through } \\
\text { Retall } \\
\text { Outlets }\end{array}$ & Averagea & DTW & Rack & Bulk & Average \\
\hline
\end{tabular}

Vermont

$$
\text { February }
$$

March ......

April

May

June

July .........

August

October

November

December

1994 Average

Subdlstrict IB

January .................................

February .................................

April

May ......................................

June

July ...

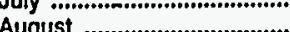

September ..............................

October ...................................

November

December .............................

1994 Average

Dolaware

January

March

April

May .........................................

June

July ...

August

September ..............................

Oclober .

November ...............................

December ...............................

1994 Average ...........................

District of Columbia

January ...................................

February

March

April

June

July

August

September ...............................

October

November

December

1994 Average

-
-
-
-
-
-
-
-
-

$86.2 \quad 83.8$

$85.5 \quad 83.0 \quad 73.9$

85.2

85.0

83.6

$W$

W

100.6

97.2

97.4

94.1

90.0

$\begin{array}{lll}- & - & - \\ - & - & - \\ - & - & - \\ - & - & - \\ - & - & - \\ - & - & - \\ - & - & - \\ - & - & - \\ - & - & - \\ - & - & - \\ - & - & - \\ - & - & - \\ - & - & -\end{array}$

73.7

61.1

52.5

$73.6 \quad 61.0 \quad 52.2$

$74.3 \quad 63.2$

80.5

NA

$W$
98.4

98.4
96.0

95.9

93.5

88.2

64.4

$W$
$W$
$W$

$W$
71.7

71.7
73.5
75.2

75.2
73.4

73.4
66.0

$\begin{array}{ll}- & - \\ - & - \\ - & - \\ - & - \\ - & - \\ - & - \\ - & - \\ - & - \\ - & - \\ - & - \\ - & - \\ - & -\end{array}$

$\begin{array}{ll}- & - \\ - & - \\ - & - \\ - & - \\ - & - \\ - & - \\ - & - \\ - & - \\ - & - \\ - & - \\ - & - \\ - & -\end{array}$

$\begin{array}{ll}- & - \\ - & - \\ - & - \\ - & - \\ - & - \\ - & - \\ - & - \\ - & - \\ - & - \\ - & -\end{array}$

$\begin{array}{ll}- & - \\ - & - \\ - & - \\ - & - \\ - & - \\ - & - \\ - & - \\ - & - \\ - & - \\ - & - \\ - & -\end{array}$

78.4

$\begin{array}{cccc}W & 72.5 & 59.9 & - \\ W & W & 62.2 & - \\ W & - & W & - \\ - & - & W & - \\ - & - & - & - \\ - & - & - & - \\ - & - & - & - \\ - & - & - & - \\ - & - & - & - \\ W & W & 77.3 & - \\ W & W & 76.8 & - \\ W & - & N A & - \\ W & 75.2 & 68.7 & -\end{array}$

$\begin{array}{lr}- & 67.9 \\ - & 69.6 \\ - & W \\ - & W \\ - & - \\ - & - \\ - & - \\ - & - \\ - & - \\ - & 80.2 \\ - & 79.0 \\ - & \text { NA } \\ - & \mathbf{7 2 . 5}\end{array}$

$\begin{array}{cccc}69.3 & 73.4 & 71.3 & 65.7 \\ 69.8 & 72.5 & 70.8 & 65.6 \\ 69.8 & 72.0 & 70.7 & 66.0 \\ 71.0 & 72.1 & 71.1 & 66.7 \\ 78.4 & W & 77.8 & N A \\ 75.7 & W & 76.9 & W \\ W & W & W & W \\ W & W & 81.6 & W \\ 83.5 & 86.6 & 84.7 & 82.1 \\ 82.6 & 84.6 & 83.5 & 78.4 \\ 83.7 & 84.9 & 83.6 & 78.4 \\ 81.9 & 82.3 & 81.5 & 75.1 \\ 74.6 & 77.4 & 76.0 & 70.6\end{array}$

$\begin{array}{ccc}52.8 & 46.2 & 60.9 \\ 54.9 & 49.4 & 61.9 \\ 54.8 & 46.9 & 61.2 \\ 56.9 & 51.9 & 63.2 \\ 57.1 & - & 68.1 \\ \text { NA } & - & 65.8 \\ W & W & W \\ W & - & W \\ 63.0 & 54.0 & 75.3 \\ 66.2 & 61.3 & 73.9 \\ 67.1 & 62.2 & 74.3 \\ 62.2 & W & 70.0 \\ 59.4 & 51.1 & 66.3\end{array}$

See footnotes at end of table. 
Table 33. Oxygenated Motor Gasoline Prices by Grade, Sales Type, PAD District, and State

(Cents per Gallon Excluding Taxes) - Continued

\begin{tabular}{|c|c|c|c|c|c|c|c|c|c|c|c|c|}
\hline \multirow{3}{*}{$\begin{array}{c}\text { Geographic Area } \\
\text { Month }\end{array}$} & \multicolumn{6}{|c|}{ Regular } & \multicolumn{6}{|c|}{ Midgrade } \\
\hline & \multicolumn{2}{|c|}{ Sales to End Users } & \multicolumn{4}{|c|}{ Sales for Resale } & \multicolumn{2}{|c|}{ Sales to End Users } & \multicolumn{4}{|c|}{ Sales for Resale } \\
\hline & $\begin{array}{c}\text { Through } \\
\text { Retail } \\
\text { Outlets }\end{array}$ & Average ${ }^{a}$ & DTW & Rack & Bulk & Average & $\begin{array}{c}\text { Through } \\
\text { Retail } \\
\text { Outlets }\end{array}$ & Averagea & DTW & Reck & Bulk & Average \\
\hline \multicolumn{13}{|l|}{ Maryland } \\
\hline 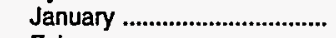 & 62.5 & 59.0 & 59.1 & 48.9 & - & 56.3 & 72.5 & 69.7 & 65.4 & 53.9 & - & 63.0 \\
\hline 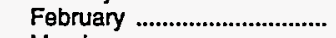 & 62.9 & 60.9 & 59.1 & 51.8 & $W$ & 57.3 & 73.1 & 71.0 & 65.2 & 56.9 & - & 63.7 \\
\hline 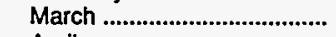 & 60.7 & 59.7 & 59.8 & 51.5 & - & 56.5 & 66.1 & 66.1 & 65.0 & 54.1 & - & 61.8 \\
\hline April & - & W & - & W & - & W & - & - & - & W & - & W \\
\hline May ......................................... & $\rightarrow$ & - & - & W & - & W & - & - & W & - & - & $W$ \\
\hline June & - & W & - & - & - & - & - & - & - & - & - & - \\
\hline July .......................................... & - & - & - & - & - & - & - & - & - & - & - & - \\
\hline 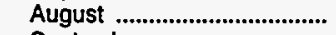 & - & - & - & - & - & - & - & - & - & - & - & - \\
\hline 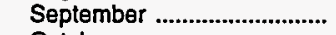 & - & - & - & - & - & - & - & - & $W$ & $w$ & - & $w$ \\
\hline October & 76.1 & 72.9 & 67.4 & 66.2 & - & 67.0 & 88.0 & 83.0 & 73.9 & 71.2 & - & 73.3 \\
\hline November .............................. & 78.5 & 75.1 & 72.3 & 66.1 & W & 70.7 & 89.0 & 85.1 & 78.7 & 71.2 & - & 77.1 \\
\hline 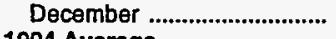 & 76.8 & 73.5 & 70.1 & 60.2 & $W$ & 68.9 & 87.4 & 83.3 & 76.1 & W & - & 75.8 \\
\hline 1994 Average & 68.9 & 66.1 & 64.1 & 56.7 & $\mathbf{W}$ & 62.1 & 79.0 & 76.3 & 70.2 & 62.2 & - & 68.5 \\
\hline \multicolumn{13}{|l|}{ New Jersey } \\
\hline 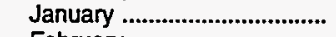 & 66.9 & 65.6 & 59.1 & 48.6 & 44.5 & 53.8 & 81.8 & 80.0 & 66.2 & 54.3 & W & 63.1 \\
\hline 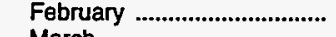 & 66.3 & 65.2 & 60.3 & 50.8 & 46.5 & 55.7 & 81.3 & 79.3 & 66.9 & 56.4 & $W$ & 64.1 \\
\hline March .................................... & 66.4 & 65.3 & 60.0 & 50.6 & 46.9 & 55.9 & 82.2 & 79.6 & 66.5 & 57.3 & $W$ & 64.5 \\
\hline 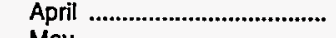 & 65.0 & 64.0 & 59.7 & 52.7 & 49.2 & 56.8 & 80.5 & 79.1 & 66.5 & 58.3 & $W$ & 64.7 \\
\hline 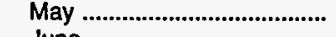 & W & $W$ & NA & 53.1 & - & 61.4 & W & W & 67.5 & 61.7 & - & 65.6 \\
\hline 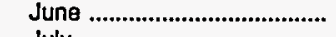 & $W$ & NA & $W$ & W & - & 58.7 & W & $W$ & $W$ & $w$ & - & $W$ \\
\hline July & $W$ & $W$ & $W$ & $W$ & $\mathbf{w}$ & W & $W$ & $W$ & $W$ & - & - & $w$ \\
\hline 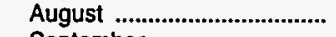 & $W$ & $W$ & $W$ & - & - & $W$ & $W$ & $W$ & - & - & - & - \\
\hline 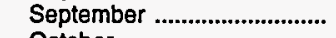 & 79.2 & 78.1 & 75.1 & 57.4 & $W$ & 65.9 & 98.1 & 97.1 & 80.2 & 69.7 & - & 78.2 \\
\hline October & 77.0 & 76.2 & 72.7 & 61.4 & 59.0 & 67.5 & 91.0 & 90.2 & 78.8 & 68.4 & - & 76.2 \\
\hline 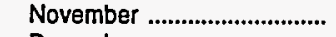 & 78.3 & 77.7 & 72.2 & 61.2 & 60.5 & 66.1 & 90.2 & 89.5 & 78.1 & 70.2 & - & 75.5 \\
\hline 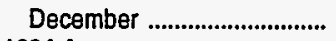 & 76.5 & 76.3 & 71.6 & $W$ & W & 58.6 & 89.8 & 89.5 & 78.7 & NA & - & 67.3 \\
\hline 1994 Average ........................... & 71.0 & 70.0 & 64.4 & 55.6 & 50.3 & 59.9 & 85.4 & 84.1 & 71.1 & 61.8 & W & 68.7 \\
\hline \multicolumn{13}{|l|}{ New York } \\
\hline 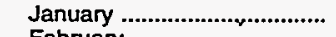 & 64.7 & 63.7 & 60.0 & 50.9 & $w$ & 55.8 & 74.8 & 73.0 & 66.0 & 59.7 & - & 65.0 \\
\hline February ................................. & 62.5 & 62.1 & 59.1 & 52.7 & $w$ & 56.2 & 73.1 & 71.4 & 64.8 & 62.6 & - & 64.5 \\
\hline 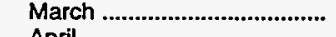 & 61.0 & 60.8 & 58.0 & 52.0 & 44.8 & 53.8 & 72.0 & 70.4 & 63.7 & 61.6 & - & 63.4 \\
\hline 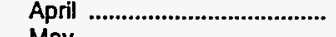 & 62.2 & 62.2 & 59.5 & 54.0 & W & 57.2 & 72.9 & 71.6 & 65.4 & 62.3 & - & 64.9 \\
\hline May ............................................. & W & NA & 59.7 & $W$ & - & 58.0 & W & $W$ & NA & W & - & 62.9 \\
\hline June ...................................... & - & - & - & $W$ & - & W & - & $W$ & - & W & - & W \\
\hline July & - & - & - & - & - & - & - & - & - & - & - & - \\
\hline 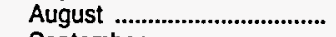 & - & $W$ & $W$ & - & - & $W$ & - & $W$ & - & $W$ & - & $W$ \\
\hline 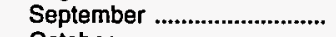 & 74.8 & 72.9 & 74.7 & 57.5 & $W$ & 68.9 & 86.4 & 85.3 & 79.9 & 73.0 & - & 79.4 \\
\hline 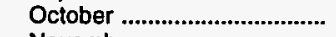 & 76.6 & 75.7 & 71.9 & 63.6 & $W$ & 68.5 & 87.2 & 86.6 & 78.9 & 73.4 & - & 78.1 \\
\hline November ............................... & 76.9 & 76.4 & 72.4 & 66.4 & $W$ & 70.4 & 87.0 & 86.7 & 78.9 & 73.6 & - & 78.2 \\
\hline 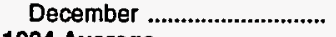 & NA & NA & 70.3 & 60.4 & - & 68.8 & NA & NA & 80.1 & NA & - & NA \\
\hline 1994 Average .......................... & 67.7 & 67.1 & 63.7 & 56.3 & 48.3 & 60.3 & 78.6 & 77.2 & 70.3 & 65.6 & - & 69.6 \\
\hline \multicolumn{13}{|l|}{ Pennsylvania } \\
\hline 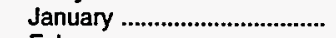 & 63.4 & 62.5 & 56.3 & 49.0 & $W$ & 51.9 & 74.3 & 74.3 & 62.5 & 53.9 & w & 59.8 \\
\hline 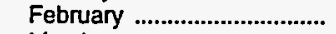 & 63.2 & 62.8 & 56.5 & 50.7 & W & 54.1 & 75.9 & 75.4 & 62.0 & 56.0 & - & 60.3 \\
\hline 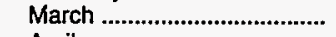 & 62.9 & 62.9 & NA & $W$ & - & W & 77.5 & 77.5 & NA & $W$ & - & $w$ \\
\hline April & $w$ & 62.6 & NA & $W$ & - & $W$ & W & 77.7 & $w$ & $W$ & - & $w$ \\
\hline 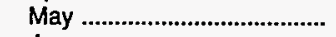 & - & $W$ & - & - & - & - & - & - & - & - & - & - \\
\hline June & - & - & - & - & - & - & - & - & - & - & - & - \\
\hline 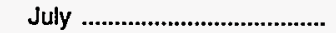 & - & W & - & - & - & - & - & $w$ & - & - & - & - \\
\hline 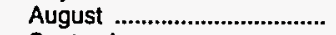 & - & $w$ & - & - & - & - & - & - & - & - & - & - \\
\hline September .............................. & - & - & - & - & - & - & - & - & - & $w$ & - & $w$ \\
\hline 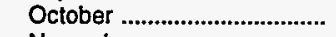 & 73.2 & 72.8 & 68.3 & 60.9 & - & 63.6 & 87.4 & 86.6 & 75.1 & 67.3 & - & 70.8 \\
\hline 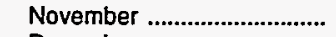 & 77.0 & 75.8 & 71.7 & 64.8 & $w$ & 68.9 & 88.1 & 86.7 & 77.0 & 70.1 & - & 74.8 \\
\hline 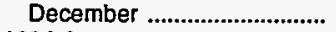 & NA & NA & 66.5 & $W$ & - & 62.6 & 85.7 & 85.6 & 70.3 & NA & - & 70.5 \\
\hline 1994 Average ................................ & 68.5 & 68.0 & 62.4 & $\mathbf{5 5 . 8}$ & $\mathbf{W}$ & 58.4 & 80.6 & 80.1 & 67.7 & 61.1 & W & 65.2 \\
\hline
\end{tabular}

See footnotes at end of table. 
Table 33. Oxygenated Motor Gasoline Prices by Grade, Sales Type, PAD District, and State

(Cents per Gallon Excluding Taxes) - Continued

\begin{tabular}{|c|c|c|c|c|c|c|c|c|c|c|c|c|}
\hline \multirow{3}{*}{$\begin{array}{c}\text { Geographic Area } \\
\text { Month }\end{array}$} & \multicolumn{6}{|c|}{ Premium } & \multicolumn{6}{|c|}{ All Grades } \\
\hline & \multicolumn{2}{|c|}{ Sales to End Users } & \multicolumn{4}{|c|}{ Sales for Resale } & \multicolumn{2}{|c|}{ Sales to End Users } & \multicolumn{4}{|c|}{ Sales for Resale } \\
\hline & $\begin{array}{c}\text { Through } \\
\text { Retail } \\
\text { Outlets }\end{array}$ & Averagea & DTW & Rack & Bulk & Average & $\begin{array}{c}\text { Through } \\
\text { Retail } \\
\text { Outlets }\end{array}$ & Averagea & DTW & Rack & Bulk & Average \\
\hline
\end{tabular}

\section{Maryland}

January

January ......................................

April

June

July ......

August

September

clober ................................

November

December .

1994 Average

New Jersey

January

March

April

May .

July ...............

September

October ...

November

December .

Now York

January

February

April ........................................

May

June

July

August .................................

October

November ......................... 95.5

December

1994 Average

Pennsylvania

February

March ..................................... 84.3

May

June

July ....

September.

October .

November

December

1994 Average
1994 Average

............................ 83.6

81.6

January ................................ 84.3

$\begin{array}{ccc}75.9 & 71.9 & 59.0 \\ 75.8 & 72.0 & 61.6 \\ 71.3 & 73.0 & W \\ - & - & W \\ - & - & - \\ - & - & - \\ - & - & - \\ - & - & - \\ - & - & - \\ 93.8 & 80.7 & 77.8 \\ 91.8 & 86.3 & 77.2 \\ 90.5 & W & W \\ 82.1 & 77.1 & 67.3\end{array}$

$\bar{w}$
-
-
-
-
-
-
-
$\bar{w}$

69.2
70.0
70.3
$W$
-
-
-
-
-
80.0
84.4
84.0
75.1

$\begin{array}{cc}68.1 & 64.4 \\ 68.5 & 66.1 \\ 64.6 & 63.9 \\ - & W \\ - & - \\ - & W \\ - & - \\ - & - \\ - & - \\ 83.2 & 79.4 \\ 83.6 & 80.2 \\ 82.0 & 78.5 \\ 74.2 & 71.3\end{array}$

$\begin{array}{cc}64.4 & 64.2 \\ 66.1 & 64.2 \\ 63.9 & 63.8 \\ W & - \\ - & W \\ W & - \\ - & - \\ - & - \\ - & W \\ 79.4 & 72.4 \\ 80.2 & 77.5 \\ 78.5 & 76.5 \\ 71.3 & 69.1\end{array}$

64.2
64.2
63.8
$-\bar{W}$
-
-
$\bar{W}$
72.4
77.5
76.5
69.1

52.2
55.1
53.7
$W$
$W$
-
-
-
$W$
69.9
NA
NA
60.2

$\begin{array}{cc}- & 61.3 \\ W & 62.2 \\ - & 60.2 \\ - & W \\ - & W \\ - & - \\ - & - \\ - & - \\ - & W \\ - & 71.7 \\ W & 75.5 \\ W & 76.0 \\ W & 67.0\end{array}$

$\begin{array}{ccc}87.6 & 74.1 & 58.8 \\ 86.7 & 75.1 & 61.0 \\ 86.6 & 74.7 & 61.7 \\ 86.4 & 74.2 & 63.0 \\ 86.4 & N A & N A \\ W & W & W \\ W & W & W \\ W & W & - \\ 102.5 & 89.3 & 72.8 \\ 97.8 & 86.9 & 72.3 \\ 98.4 & 86.8 & 73.7 \\ 96.7 & 85.7 & W \\ 91.6 & 79.0 & 66.1\end{array}$

$\begin{array}{cc}50.3 & 68.4 \\ 52.3 & 69.9 \\ 52.3 & 70.2 \\ 56.5 & 70.7 \\ - & \text { NA } \\ - & 74.2 \\ - & W \\ - & W \\ W & 82.0 \\ 64.1 & 81.9 \\ 68.5 & 82.2 \\ - & 74.8 \\ 54.5 & 74.2\end{array}$

$\begin{array}{cc}76.0 & 74.3 \\ 75.3 & 73.6 \\ 75.4 & 73.5 \\ 74.0 & 72.7 \\ W & \text { NA } \\ W & \text { NA } \\ W & W \\ W & W \\ 90.1 & 88.7 \\ 85.3 & 84.4 \\ 86.0 & 85.2 \\ 85.1 & 84.9 \\ 79.6 & 78.4\end{array}$

66.0

$66.9 \quad 52.1$

66.6

66.4

$\begin{array}{ll}\text { NA } & 58.4\end{array}$

$\begin{array}{ll}W & W \\ W & W\end{array}$

$W$
81.8

81.8
79.0

78.4

77.4

71.0

$82.2 \quad 75.3$

$\begin{array}{lll}81.3 & 73.7 & 60.5\end{array}$

$\begin{array}{lll}79.5 & 72.6 & 60.0\end{array}$

$\begin{array}{ccc}80.9 & 74.3 & 63.0 \\ W & N A & W\end{array}$

W

$\bar{W}$

94.0

94.8

94.7

NA
85.8

-

w

$W$
89.2

87.5

$$
\begin{aligned}
& 87.1 \\
& 89.3
\end{aligned}
$$

78.5

$\begin{array}{ccc}83.9 & 71.3 & 60.0 \\ 83.3 & 71.0 & 62.2 \\ 84.1 & \text { NA } & \text { W } \\ 85.4 & \text { W } & \text { W } \\ - & - & - \\ - & - & - \\ - & - & - \\ - & - & - \\ - & - & - \\ 93.1 & 83.1 & 74.8 \\ 93.4 & 86.9 & 76.4 \\ 94.6 & \text { NA } & \text { NA } \\ 87.6 & 76.8 & 67.7\end{array}$

See footnotes at end of table. 
Table 33. Oxygenated Motor Gasoline Prices by Grade, Sales Type, PAD District, and State

(Cents per Gallon Excluding Taxes) - Continued

\begin{tabular}{|c|c|c|c|c|c|c|c|c|c|c|c|c|}
\hline \multirow{3}{*}{$\begin{array}{l}\text { Geographic Area } \\
\text { Month }\end{array}$} & \multicolumn{6}{|c|}{ Regular } & \multicolumn{6}{|c|}{ Midgrade } \\
\hline & \multicolumn{2}{|c|}{ Sales to End Users } & \multicolumn{4}{|c|}{ Sales for Resale } & \multicolumn{2}{|c|}{ Sales to End Users } & \multicolumn{4}{|c|}{ Sales for Resale } \\
\hline & $\begin{array}{c}\text { Through } \\
\text { Retail } \\
\text { Outlets }\end{array}$ & Averagea & DTW & Rack & Bulk & Average & $\begin{array}{c}\text { Through } \\
\text { Retall } \\
\text { Outlets }\end{array}$ & Averagea & DTW & Rack & Bulk & Average \\
\hline \multicolumn{13}{|l|}{ Subdistrict IC } \\
\hline 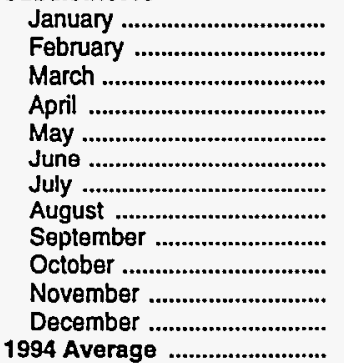 & $\begin{array}{c}61.3 \\
63.0 \\
\text { NA } \\
- \\
- \\
- \\
- \\
- \\
- \\
71.4 \\
75.3 \\
73.1 \\
68.1\end{array}$ & $\begin{array}{c}60.6 \\
62.2 \\
\text { NA } \\
- \\
- \\
- \\
- \\
- \\
- \\
71.0 \\
74.8 \\
72.5 \\
67.4\end{array}$ & $\begin{array}{c}59.2 \\
60.8 \\
\text { NA } \\
\text { W } \\
- \\
- \\
- \\
- \\
- \\
68.8 \\
72.3 \\
65.3 \\
64.2\end{array}$ & $\begin{array}{l}49.7 \\
52.4 \\
53.3 \\
W \\
W \\
W \\
W \\
- \\
- \\
62.2 \\
63.1 \\
55.8 \\
54.4\end{array}$ & $\begin{array}{l}\bar{W} \\
- \\
- \\
- \\
- \\
- \\
\bar{W} \\
W \\
W \\
W\end{array}$ & $\begin{array}{c}53.9 \\
56.2 \\
55.2 \\
W \\
W \\
W \\
W \\
- \\
- \\
65.9 \\
67.4 \\
58.6 \\
58.7\end{array}$ & $\begin{array}{c}73.6 \\
74.4 \\
\text { NA } \\
- \\
- \\
- \\
- \\
- \\
- \\
82.2 \\
85.8 \\
83.9 \\
80.2\end{array}$ & $\begin{array}{c}72.8 \\
73.7 \\
\text { NA } \\
- \\
- \\
- \\
- \\
- \\
- \\
81.8 \\
85.4 \\
83.3 \\
79.6\end{array}$ & $\begin{array}{c}66.8 \\
67.8 \\
N A \\
W \\
- \\
- \\
- \\
- \\
W \\
75.2 \\
78.8 \\
71.6 \\
70.6\end{array}$ & $\begin{array}{c}54.2 \\
56.8 \\
59.2 \\
- \\
W \\
- \\
- \\
W \\
W \\
67.2 \\
67.4 \\
59.1 \\
59.0\end{array}$ & $\begin{array}{l}- \\
- \\
- \\
- \\
- \\
- \\
- \\
- \\
\bar{w} \\
- \\
\bar{w}\end{array}$ & $\begin{array}{c}61.0 \\
62.9 \\
63.6 \\
W \\
W \\
- \\
\bar{W} \\
W \\
72.2 \\
73.8 \\
63.3 \\
65.0\end{array}$ \\
\hline \multicolumn{13}{|l|}{ Florida } \\
\hline 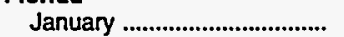 & - & - & - & - & - & - & - & - & - & - & - & - \\
\hline February ................................. & - & - & - & - & - & - & - & - & - & - & - & - \\
\hline 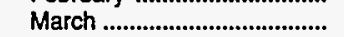 & - & - & - & - & - & - & - & - & - & - & - & - \\
\hline April & - & - & - & - & - & - & - & - & - & - & - & - \\
\hline 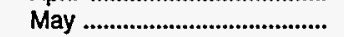 & - & - & - & - & - & - & - & - & - & - & - & - \\
\hline 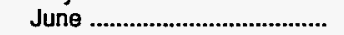 & - & - & - & - & - & - & - & - & - & - & - & - \\
\hline 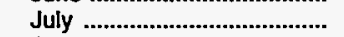 & - & - & - & - & - & - & - & - & - & - & - & - \\
\hline 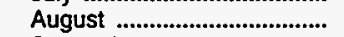 & - & - & - & - & - & - & - & - & - & - & - & - \\
\hline 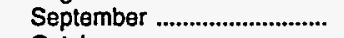 & - & - & - & - & - & - & - & - & - & - & - & - \\
\hline October ..................................... & - & - & - & - & - & - & - & - & - & - & - & - \\
\hline 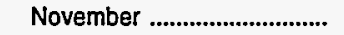 & - & - & - & - & - & - & - & - & - & - & - & - \\
\hline December ............................... & - & - & - & - & - & - & - & - & - & - & - & - \\
\hline 1994 Average .......................... & - & - & - & - & - & - & - & - & - & - & - & - \\
\hline \multicolumn{13}{|l|}{ Georgia } \\
\hline 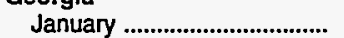 & - & - & - & - & - & - & - & - & - & - & - & - \\
\hline 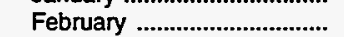 & - & - & - & - & - & - & - & - & - & - & - & - \\
\hline 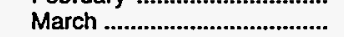 & - & - & - & - & - & - & - & - & - & - & - & - \\
\hline April & - & - & - & - & - & - & - & - & - & - & - & - \\
\hline 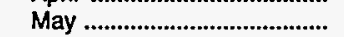 & - & - & - & - & - & - & - & - & - & - & - & - \\
\hline 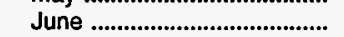 & - & - & - & - & - & - & - & - & - & - & - & - \\
\hline July & - & - & - & - & - & - & - & - & - & - & - & - \\
\hline August & - & - & - & - & - & - & - & - & - & - & - & - \\
\hline September .............................. & - & - & - & - & - & - & - & - & - & - & - & - \\
\hline 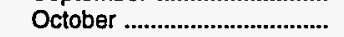 & - & - & - & - & - & - & - & - & - & - & - & - \\
\hline November .............................. & - & - & - & - & - & - & - & - & - & - & - & - \\
\hline December .............................. & - & - & - & - & - & - & - & - & - & - & - & - \\
\hline 1994 Average & - & - & - & - & - & - & - & - & - & - & - & - \\
\hline \multicolumn{13}{|l|}{ North Carolina } \\
\hline 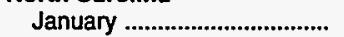 & 57.5 & 57.3 & 54.7 & 49.5 & - & 51.2 & 68.0 & 67.5 & 62.5 & 53.9 & - & 57.2 \\
\hline 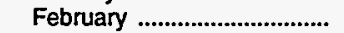 & 60.0 & 59.7 & 57.7 & 52.2 & $W$ & 54.1 & 69.9 & 69.5 & 64.6 & 56.5 & - & 59.6 \\
\hline 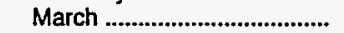 & $w$ & NA & W & 52.7 & - & 54.9 & $w$ & NA & $w$ & 54.9 & - & $w$ \\
\hline April & - & - & - & $W$ & - & $w$ & - & - & - & - & - & - \\
\hline 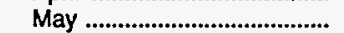 & - & - & - & W & - & $w$ & - & - & - & - & - & - \\
\hline 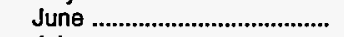 & - & - & - & W & - & W & - & - & - & - & - & - \\
\hline 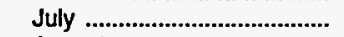 & - & - & - & W & - & W & - & - & - & - & - & - \\
\hline 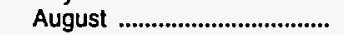 & - & - & - & - & - & - & - & - & - & - & - & - \\
\hline September ............................ & - & - & - & - & - & - & - & - & w & $W$ & - & $\mathbf{W}$ \\
\hline 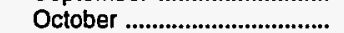 & $W$ & W & $w$ & 63.2 & - & 62.0 & $W$ & $W$ & w & 66.8 & - & 66.4 \\
\hline November .............................. & 74.6 & 74.5 & 67.6 & 62.4 & $w$ & 62.7 & 85.0 & 84.8 & 72.9 & 66.1 & - & 67.1 \\
\hline December .............................. & 72.3 & 72.2 & 59.7 & 55.6 & $w$ & 56.0 & 83.3 & 83.1 & NA & 59.1 & $\rightarrow$ & 60.6 \\
\hline 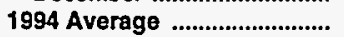 & 66.1 & 65.7 & 57.7 & 53.4 & $\mathbf{W}$ & 54.5 & 77.8 & 77.4 & 64.8 & 58.0 & - & 60.0 \\
\hline
\end{tabular}

See footnotes at end of table. 
Table 33. Oxygenated Motor Gasoline Prices by Grade, Sales Type, PAD District, and State

(Cents per Gallon Excluding Taxes) - Continued

\begin{tabular}{|c|c|c|c|c|c|c|c|c|c|c|c|c|}
\hline \multirow{3}{*}{$\begin{array}{l}\text { Geographic Area } \\
\text { Month }\end{array}$} & \multicolumn{6}{|c|}{ Premium } & \multicolumn{6}{|c|}{ All Grades } \\
\hline & \multicolumn{2}{|c|}{ Sales to End Users } & \multicolumn{4}{|c|}{ Sales for Resale } & \multicolumn{2}{|c|}{ Sales to End Users } & \multicolumn{4}{|c|}{ Sales for Resale } \\
\hline & $\begin{array}{c}\text { Through } \\
\text { Rotall } \\
\text { Outlots }\end{array}$ & Average ${ }^{a}$ & DTW & Rack & Bulk & Average & $\begin{array}{c}\text { Through } \\
\text { Retail } \\
\text { Outlets }\end{array}$ & Average a & DTW & Rack & Bulk & Average \\
\hline
\end{tabular}

Subdistrict IC

Januany

February

March

May

June

July ...

August

October .

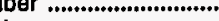

December .

1994 Average

Florida

January

Mabruary

$$
\text { April . }
$$

May ............................................

June ..........................................

July .

August

September

October ...

November

December ...

1994 Averago ...........................

Georgia

January

February

March

April .......................................

May.

June

July

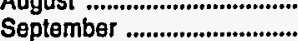

October.

November

December ................................
1994 Average

North Carolina

January .

February

March

April

May .

June

July .......

August ....................................

September ..............................

October ...

November ............................

December

1994 Average

See footnotes at end of table.

\begin{tabular}{|c|c|c|c|c|c|c|c|c|c|c|c|}
\hline $\begin{array}{c}83.6 \\
83.7 \\
\text { NA }\end{array}$ & $\begin{array}{r}82.2 \\
82.3 \\
\text { NA }\end{array}$ & $\begin{array}{c}74.3 \\
75.2 \\
\text { NA }\end{array}$ & $\begin{array}{c}60.0 \\
62.5 \\
\text { NA }\end{array}$ & $\begin{array}{l}\bar{w} \\
-\end{array}$ & $\begin{array}{r}67.0 \\
68.8 \\
\text { NA }\end{array}$ & $\begin{array}{r}68.8 \\
70.1 \\
\text { NA }\end{array}$ & $\begin{array}{r}67.8 \\
69.0 \\
\text { NA }\end{array}$ & $\begin{array}{c}64.7 \\
66.0 \\
\text { NA }\end{array}$ & $\begin{array}{l}52.9 \\
55.5 \\
57.4\end{array}$ & $\bar{w}$ & $\begin{array}{l}58.4 \\
60.5 \\
60.2\end{array}$ \\
\hline- & - & $w$ & $w$ & - & $w$ & - & - & $w$ & 59.4 & - & 59.9 \\
\hline - & - & - & - & - & - & - & - & - & $W$ & - & $w$ \\
\hline- & - & - & - & - & - & - & - & - & $w$ & - & $w$ \\
\hline - & - & - & - & - & - & - & - & - & $w$ & - & $w$ \\
\hline - & - & - & $w$ & - & $w$ & - & - & - & $w$ & - & $w$ \\
\hline- & - & - & - & - & - & - & - & $w$ & $w$ & - & $w$ \\
\hline 92.6 & 92.2 & 83.4 & 73.0 & - & 78.7 & 79.1 & 78.6 & 74.2 & 66.3 & $w$ & 70.9 \\
\hline 95.9 & 95.2 & 86.5 & 73.5 & - & 80.4 & 82.4 & 81.8 & $\pi .4$ & 66.5 & $w$ & 71.9 \\
\hline 94.1 & 93.0 & 78.4 & 66.1 & - & 69.8 & 80.1 & 79.3 & 69.4 & 58.9 & $w$ & 62.0 \\
\hline 89.6 & 88.4 & 78.5 & 65.0 & $\mathbf{W}$ & 71.5 & 75.6 & 74.7 & 69.3 & 57.7 & $\mathbf{w}$ & 63.1 \\
\hline
\end{tabular}

\begin{tabular}{|c|c|c|c|c|c|c|c|c|c|c|c|}
\hline - & - & - & - & - & - & - & - & - & - & - & - \\
\hline- & - & - & - & - & - & - & - & - & - & - & - \\
\hline- & - & - & - & - & - & - & - & - & - & - & - \\
\hline- & - & - & - & - & - & - & - & - & - & - & - \\
\hline- & - & - & - & - & - & - & - & - & - & - & - \\
\hline- & - & - & - & - & - & - & - & - & - & - & - \\
\hline- & - & - & - & - & - & - & - & - & - & - & - \\
\hline- & - & - & - & - & - & - & - & - & $\rightarrow$ & - & - \\
\hline- & - & - & - & - & - & - & - & - & - & - & - \\
\hline- & - & - & - & - & - & - & - & - & - & - & - \\
\hline- & - & - & - & - & - & - & - & - & - & - & - \\
\hline- & - & - & - & - & - & - & - & - & - & - & - \\
\hline- & - & - & - & - & - & - & - & - & - & - & - \\
\hline- & - & - & $w$ & - & $w$ & - & - & - & $w$ & - & $w$ \\
\hline- & - & - & - & - & - & - & - & - & - & - & - \\
\hline- & - & - & - & - & - & - & - & - & - & - & - \\
\hline- & - & - & - & - & - & - & - & - & - & - & - \\
\hline- & - & - & - & - & $\rightarrow$ & - & - & - & - & - & - \\
\hline- & - & - & - & - & - & - & - & - & - & - & - \\
\hline- & - & - & - & - & - & - & - & - & - & - & - \\
\hline- & - & - & - & - & - & - & - & - & - & - & - \\
\hline- & - & - & - & - & - & - & - & - & - & - & - \\
\hline- & - & - & - & - & - & - & - & - & - & - & - \\
\hline- & - & - & - & - & - & - & - & - & - & - & - \\
\hline- & - & - & - & - & - & - & - & - & - & - & - \\
\hline- & - & - & 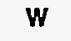 & - & $w$ & - & - & - & $w$ & - & $w$ \\
\hline 78.5 & 78.0 & 69.3 & 59.8 & - & 63.0 & 63.5 & 63.1 & 59.5 & 52.5 & - & 54.9 \\
\hline 79.4 & 79.0 & 71.7 & 62.5 & NA & 65.3 & 66.3 & 65.8 & 62.2 & 55.3 & $w$ & 57.6 \\
\hline$w$ & $w$ & $w$ & 62.5 & - & 66.7 & W & 59.4 & W & 55.2 & - & 59.4 \\
\hline- & - & - & $w$ & - & $w$ & - & - & - & 59.4 & - & 59.4 \\
\hline- & - & - & - & - & - & - & - & - & $w$ & - & $w$ \\
\hline- & - & - & - & - & - & - & - & - & $w$ & - & $w$ \\
\hline- & - & - & - & - & - & - & - & - & $w$ & - & $w$ \\
\hline- & - & - & - & - & - & - & - & - & - & - & $\overline{-}$ \\
\hline- & - & - & - & - & - & - & - & $w$ & $w$ & - & $w$ \\
\hline$w$ & W & $W$ & 71.9 & - & 72.2 & W & W & $W$ & 67.5 & - & 66.4 \\
\hline 96.2 & 96.0 & 80.7 & 72.7 & - & 73.9 & 81.7 & 81.6 & 72.1 & 65.6 & $W$ & 66.2 \\
\hline 93.9 & 93.7 & NA & 66.1 & - & 67.1 & 79.6 & 79.4 & NA & 58.9 & W & 59.6 \\
\hline 87.7 & 87.2 & 71.5 & 64.1 & NA & 66.0 & 73.2 & 72.7 & 62.4 & 56.8 & 52.6 & 58.2 \\
\hline
\end{tabular}


Table 33. Oxygenated Motor Gasoline Prices by Grade, Sales Type, PAD District, and State

(Cents per Gallon Excluding Taxes) - Continued

\begin{tabular}{|c|c|c|c|c|c|c|c|c|c|c|c|c|}
\hline \multirow{3}{*}{$\begin{array}{l}\text { Geographic Area } \\
\text { Month }\end{array}$} & \multicolumn{6}{|c|}{ Regular } & \multicolumn{6}{|c|}{ Midgrade } \\
\hline & \multicolumn{2}{|c|}{ Sales to End Users } & \multicolumn{4}{|c|}{ Sales for Resale } & \multicolumn{2}{|c|}{ Sales to End Users } & \multicolumn{4}{|c|}{ Sales for Resale } \\
\hline & $\begin{array}{c}\text { Through } \\
\text { Rotail } \\
\text { Outlets }\end{array}$ & Average ${ }^{a}$ & DTW & Rack & Bulk & Average & $\begin{array}{c}\text { Through } \\
\text { Retail } \\
\text { Outlets }\end{array}$ & Averagea & DTW & Rack & Bulk & Average \\
\hline \multicolumn{13}{|l|}{ South Carolina } \\
\hline 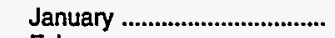 & - & - & - & - & - & - & - & - & - & - & - & - \\
\hline 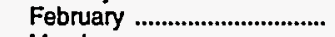 & - & - & - & - & - & - & - & - & - & - & - & - \\
\hline 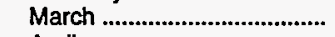 & - & - & - & - & - & - & - & - & - & - & - & - \\
\hline April & - & - & - & - & - & - & - & - & - & - & - & - \\
\hline May & - & - & - & - & - & - & - & - & - & - & - & - \\
\hline June & - & - & - & - & - & - & - & - & - & - & - & - \\
\hline July & - & - & - & - & - & - & - & - & - & - & - & - \\
\hline August & - & - & - & - & - & - & - & - & - & - & - & - \\
\hline 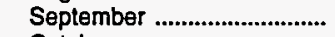 & - & - & - & - & - & - & - & - & - & - & - & - \\
\hline October & - & - & - & - & - & - & - & - & - & - & - & - \\
\hline November ................................. & - & - & - & - & - & - & - & - & - & - & - & - \\
\hline 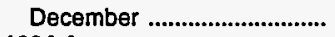 & - & - & - & - & - & - & - & - & - & - & - & - \\
\hline 1994 Average ........................... & - & - & - & - & - & - & - & - & - & - & - & - \\
\hline \multicolumn{13}{|l|}{ Virginia } \\
\hline 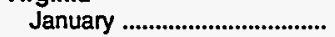 & 67.9 & 65.8 & 63.1 & 50.3 & - & 58.0 & 81.2 & 79.7 & 69.4 & 55.0 & - & 65.0 \\
\hline February ................................. & 67.5 & 65.4 & 63.4 & 52.8 & w & 59.5 & 80.5 & 79.1 & 69.6 & 57.6 & - & 66.3 \\
\hline March ....................................... & $W$ & $w$ & 58.6 & 54.3 & - & 56.6 & $W$ & $w$ & 66.4 & 61.4 & - & 64.2 \\
\hline April & - & - & $w$ & - & - & $w$ & - & - & $w$ & - & - & $w$ \\
\hline 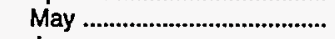 & - & - & - & $w$ & - & W & - & - & - & $w$ & - & W \\
\hline June & - & - & - & - & - & - & - & - & - & - & - & - \\
\hline July & - & - & - & - & - & - & - & - & - & - & - & - \\
\hline 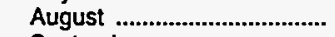 & - & - & - & - & - & - & - & - & - & $w$ & - & $w$ \\
\hline 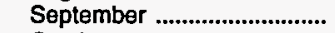 & - & - & - & - & - & - & - & - & $W$ & $W$ & - & $w$ \\
\hline October & 75.3 & 74.0 & 69.8 & 62.0 & - & 66.5 & 88.2 & 86.7 & 76.0 & 67.3 & - & 72.9 \\
\hline 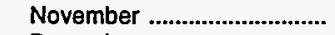 & 76.2 & 75.2 & 72.7 & 64.1 & W & 69.8 & 86.9 & 86.1 & 79.3 & 69.5 & - & 76.9 \\
\hline 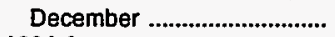 & 75.6 & 73.4 & 70.0 & $W$ & - & 68.2 & 86.1 & 83.7 & 78.6 & 62.0 & - & 78.4 \\
\hline 1994 Average ................................ & 71.8 & 70.2 & 67.2 & 56.5 & $\mathbf{w}$ & 63.4 & 84.1 & 82.8 & $\mathbf{7 2 . 7}$ & 61.1 & - & 69.4 \\
\hline \multicolumn{13}{|l|}{ West Virginia } \\
\hline January .................................. & $W$ & W & $W$ & - & - & $W$ & $W$ & $W$ & W & - & - & $W$ \\
\hline 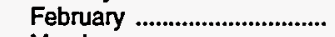 & $w$ & W & - & - & - & - & W & $w$ & - & - & - & - \\
\hline 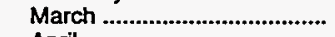 & - & - & - & - & - & - & - & - & - & - & - & - \\
\hline 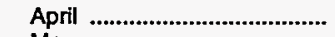 & - & - & - & - & - & - & - & - & - & $\dot{-}$ & - & - \\
\hline 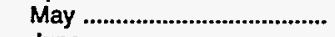 & - & - & - & - & - & - & - & - & - & - & - & - \\
\hline June & - & - & - & - & - & - & - & $w$ & - & - & - & - \\
\hline July & - & - & - & - & - & - & - & - & - & - & - & - \\
\hline August & - & - & - & - & - & - & - & - & - & - & - & - \\
\hline September .............................. & - & - & - & - & - & - & - & - & - & - & - & - \\
\hline 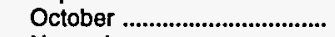 & - & W & - & - & W & W & - & $w$ & - & - & W & W \\
\hline November ................................. & - & - & - & - & - & - & - & - & - & - & - & - \\
\hline 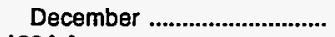 & - & - & - & - & - & - & - & - & - & - & - & - \\
\hline 1994 Average ........................... & $w$ & 62.4 & $\mathbf{W}$ & - & $w$ & $\mathbf{w}$ & $w$ & 67.7 & $w$ & - & $w$ & $w$ \\
\hline \multicolumn{13}{|l|}{ PAD District II } \\
\hline 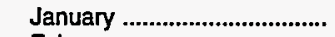 & 73.6 & 73.1 & 60.9 & 53.9 & $w$ & 55.8 & 79.7 & 79.5 & 65.4 & 58.3 & - & 61.5 \\
\hline February ................................... & 73.0 & 72.2 & 59.6 & 57.7 & W & 57.8 & 78.4 & 77.3 & 61.5 & 59.2 & - & 60.2 \\
\hline 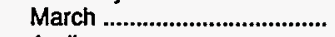 & 71.8 & 71.0 & 61.3 & 58.9 & $w$ & 59.2 & 77.6 & 76.1 & $W$ & 59.5 & - & 60.3 \\
\hline April & 73.8 & 73.7 & 63.9 & 61.4 & - & 62.0 & 81.7 & 81.7 & w & 62.1 & - & 62.8 \\
\hline 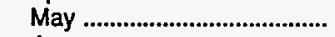 & 76.0 & 76.0 & 65.6 & 62.6 & - & 63.3 & 82.7 & 82.7 & $W$ & 63.1 & - & 64.1 \\
\hline June & 77.1 & 77.1 & 68.9 & 65.7 & - & 66.3 & 85.1 & 85.1 & $w$ & 66.1 & - & 67.1 \\
\hline 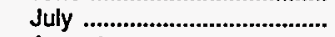 & 79.6 & 79.6 & 73.2 & 70.7 & - & 71.2 & 86.6 & 86.6 & $w$ & 71.1 & - & 71.9 \\
\hline 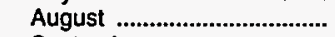 & 84.7 & 84.8 & 78.1 & 75.4 & - & 75.9 & 98.3 & 98.3 & $W$ & 76.0 & - & 76.8 \\
\hline September ............................... & 85.0 & 84.8 & 67.8 & 65.9 & - & 66.3 & 94.0 & 94.0 & 71.6 & 66.6 & - & 67.4 \\
\hline 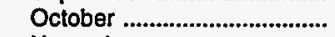 & 77.0 & 76.7 & 66.3 & 61.2 & - & 62.5 & 84.8 & 84.1 & 73.2 & 63.3 & - & 67.2 \\
\hline November ................................ & 77.2 & 76.7 & 66.2 & 60.4 & - & 61.9 & 84.2 & 83.5 & 71.7 & 62.2 & - & 66.3 \\
\hline 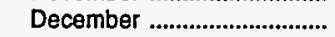 & 71.8 & 71.4 & 62.0 & 57.2 & - & 58.5 & 78.5 & 77.8 & 68.5 & 58.6 & - & 61.9 \\
\hline 1994 Average ........................... & 75.7 & 75.3 & 65.4 & 61.8 & $\mathbf{w}$ & 62.6 & 82.2 & 81.6 & 68.8 & 62.7 & - & 64.7 \\
\hline
\end{tabular}

See footnotes at end of table. 
Table 33. Oxygenated Motor Gasoline Prices by Grade, Sales Type, PAD District, and State

(Cents per Gallon Excluding Taxes) - Continued

\begin{tabular}{|c|c|c|c|c|c|c|c|c|c|c|c|c|}
\hline \multirow{3}{*}{$\begin{array}{c}\text { Geographlc Area } \\
\text { Month }\end{array}$} & \multicolumn{6}{|c|}{ Premium } & \multicolumn{6}{|c|}{ All Grades } \\
\hline & \multicolumn{2}{|c|}{ Sales to End Users } & \multicolumn{4}{|c|}{ Sales for Resale } & \multicolumn{2}{|c|}{ Sales to End Users } & \multicolumn{4}{|c|}{ Sales for Resale } \\
\hline & $\begin{array}{c}\text { Through } \\
\text { Retail } \\
\text { Outlots }\end{array}$ & Average $a$ & DTW & Rack & Bulk & Average & $\begin{array}{c}\text { Through } \\
\text { Retail } \\
\text { Outlets }\end{array}$ & Average ${ }^{a}$ & DTW & Rack & Bulk & Average \\
\hline
\end{tabular}

South Carolina

January

Fobruary

March

Aprll

May .

June

July .........

August

September

November

December

1994 Averago

Virginia

January ...........

February

March

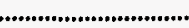

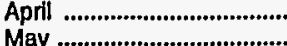

May

June

July

August

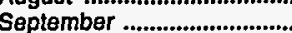

October.

ovember .

December

1994 Average ..............................

West Virginib

January .

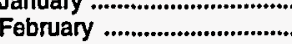

March .

April

June

July .

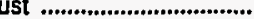

September ............................

October.

November

1994 Average .......................

PAD District II

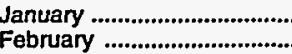

March .

Aprill

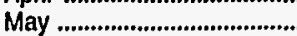

June ..........................................

July ...........................................

August

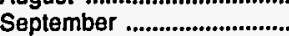

October .

November

Necember

1994 Average

$\overline{-}$
$\overline{-}$
$\overline{-}$
$\bar{z}$
$\overline{-}$
$\bar{z}$
$\bar{z}$

-
-
-
-
-
-
-
-
-

$\begin{array}{lll}- & - & - \\ - & - & - \\ - & - & - \\ - & - & - \\ - & - & - \\ - & - & - \\ - & - & - \\ - & - & - \\ - & - & - \\ - & - & - \\ - & - & -\end{array}$

$\begin{array}{ll}- & - \\ - & - \\ - & - \\ - & - \\ - & - \\ - & - \\ - & - \\ - & - \\ - & - \\ - & -\end{array}$

-
-
-
-
-
-
-
-
-

$\begin{array}{ll}- & - \\ - & - \\ - & - \\ - & - \\ - & - \\ - & - \\ - & - \\ - & - \\ - & - \\ - & -\end{array}$

$\begin{array}{lll}- & - & - \\ - & - & - \\ - & - & - \\ - & - & - \\ - & - & - \\ - & - & - \\ - & - & - \\ - & - & - \\ - & - & - \\ - & - & - \\ - & - & - \\ - & - & - \\ - & - & -\end{array}$

$\begin{array}{rccccccccccc}88.8 & 86.1 & 77.3 & 60.7 & - & 71.7 & 76.5 & 74.1 & 68.5 & 53.8 & - & 63.2 \\ 89.6 & 86.1 & 77.2 & 62.6 & W & 72.9 & 75.4 & 73.0 & 68.7 & 56.0 & W & 64.5 \\ W & W & 73.3 & \text { NA } & - & 72.0 & W & W & 65.3 & 60.0 & - & 63.1 \\ - & - & W & - & - & W & - & - & W & - & - & W \\ - & - & - & - & - & - & - & - & - & W & - & W \\ - & - & - & - & - & - & - & - & - & - & - & - \\ - & - & - & - & - & - & - & - & - & - & - & - \\ - & - & - & W & - & W & - & - & - & W & - & W \\ - & - & - & - & - & - & - & - & W & W & - & W \\ 97.6 & 96.2 & 84.2 & 73.5 & - & 80.2 & 83.6 & 82.2 & 75.2 & 66.0 & - & 71.6 \\ 95.5 & 94.4 & 87.1 & 74.6 & - & 83.4 & 83.3 & 82.1 & 77.9 & 67.6 & W & 74.6 \\ 95.1 & 91.1 & 86.9 & 63.4 & - & 86.7 & 81.8 & 79.1 & 74.8 & W & - & 73.0 \\ 92.4 & 90.0 & 81.2 & 66.9 & W & 76.8 & 79.6 & 77.7 & 72.2 & 59.9 & W & 68.1\end{array}$

See footnotes at end of table.

\begin{tabular}{|c|c|c|c|c|c|c|c|c|c|c|c|}
\hline$w$ & $w$ & $w$ & - & - & $w$ & $w$ & $w$ & $w$ & - & - & $w$ \\
\hline$w$ & $w$ & $w$ & - & - & $w$ & $w$ & $w$ & $w$ & - & - & $w$ \\
\hline- & - & - & - & - & - & - & - & - & - & - & - \\
\hline- & - & - & - & - & - & - & - & - & - & - & - \\
\hline- & - & - & - & - & - & - & - & - & - & - & - \\
\hline- & - & - & - & - & - & - & - & - & - & - & - \\
\hline- & - & - & - & - & - & - & - & - & - & - & - \\
\hline- & - & - & - & - & - & - & - & - & - & - & - \\
\hline- & - & - & - & - & - & - & - & - & - & - & - \\
\hline- & $w$ & - & - & - & - & - & $w$ & - & - & $w$ & $w$ \\
\hline- & - & - & - & - & - & - & - & - & - & - & - \\
\hline- & - & - & - & - & - & - & - & - & - & - & - \\
\hline$W$ & $W$ & $w$ & - & - & $\mathbf{W}$ & $\mathbf{W}$ & 68.7 & $W$ & - & $W$ & $W$ \\
\hline
\end{tabular}

88.3

$88.0 \quad 72.4$

84.7
83.7

87.3

88.8

91.5

92.8

102.4

98.8

91.6

91.2

85.5

89.1
72.4
65.6
67.2
$W$
$W$
$W$
$W$
$W$
$W$
78.0
77.4
73.3
74.5

58.0
60.1
62.4
65.2
66.1
69.6
74.5
79.4
70.4
65.8
65.0
62.6
65.6

$\begin{array}{lll}- & 61.5 & 76.3 \\ - & 61.1 & 75.0 \\ - & 63.2 & 73.1 \\ - & 66.0 & 75.4 \\ - & 67.2 & 77.5 \\ - & 70.5 & 78.8 \\ - & 75.2 & 81.5 \\ - & 80.2 & 86.5 \\ - & 71.2 & 86.9 \\ - & 68.5 & 79.3 \\ - & 67.8 & 79.5 \\ - & 65.1 & 74.0 \\ - & 67.4 & 77.8\end{array}$

$\begin{array}{ll}75.8 & 63.6 \\ 74.2 & 60.8 \\ 72.3 & 62.1 \\ 75.3 & 64.7 \\ 77.5 & 66.5 \\ 78.8 & 69.9 \\ 81.5 & 74.1 \\ 86.6 & 78.9 \\ 86.7 & 68.8 \\ 79.0 & 68.6 \\ 79.0 & 68.3 \\ 73.5 & 64.1 \\ 77.3 & 66.8\end{array}$

55.3

58.4
59.4

62.0

63.1

66.3

71.3

76.0

66.5

62.0

61.2

58.1

\begin{tabular}{ll} 
W & 57.7 \\
$W$ & 58.8 \\
$W$ & 59.8 \\
- & 62.6 \\
- & 63.8 \\
- & 67.0 \\
- & 71.8 \\
- & 76.5 \\
- & 67.0 \\
- & 63.8 \\
- & 63.2 \\
\hline W & 59.7 \\
\hline
\end{tabular}


Table 33. Oxygenated Motor Gasoline Prices by Grade, Sales Type, PAD District, and State

(Cents per Gallon Excluding Taxes) - Continued

\begin{tabular}{|c|c|c|c|c|c|c|c|c|c|c|c|c|}
\hline \multirow{3}{*}{$\begin{array}{l}\text { Geographic Area } \\
\text { Month }\end{array}$} & \multicolumn{6}{|c|}{ Regular } & \multicolumn{6}{|c|}{ Mldgrade } \\
\hline & \multicolumn{2}{|c|}{ Sales to End Users } & \multicolumn{4}{|c|}{ Sales for Resale } & \multicolumn{2}{|c|}{ Sales to End Users } & \multicolumn{4}{|c|}{ Sales for Resale } \\
\hline & $\begin{array}{l}\text { Through } \\
\text { Retail } \\
\text { Outlots }\end{array}$ & Average $\mathrm{a}$ & DTW & Rack & Bulk & Average & $\begin{array}{l}\text { Through } \\
\text { Retail } \\
\text { Outlets }\end{array}$ & Averagea & DTW & Rack & Bulk & Average \\
\hline
\end{tabular}

minols

January .

February

March

April
May

June...

July ....

August .

September

October .

November

December

Indiana

January

February

March

April

May

June

July ....

August ....

October ...

November

December ..

1994 Average

lowa

January

February

March

April

May

June

July ....

September

October .

November

December .

Kansas

January

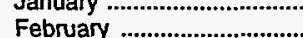

March .

April

May

June.

July ....

August

September

November

December

1994 Average

...

-

$\begin{array}{lllllllllll}- & - & - & - & - & - & - & - & - & - & - \\ - & - & - & - & - & - & - & - & - & - & - \\ - & - & - & - & - & - & - & - & - & - & - \\ - & - & - & - & - & - & - & - & - & - \\ - & - & - & - & - & - & - & - & - & - & - \\ - & - & - & - & - & - & - & - & - & - & - \\ - & - & - & - & - & - & - & - & - & - & - \\ - & - & - & - & - & - & - & - & - & - & - \\ - & - & - & - & - & - & - & - & - & - & - \\ - & - & - & - & - & - & - & - & - & - & - \\ - & - & - & - & - & - & - & - & - & - & - \\ - & - & - & - & - & - & - & - & - & - & - \\ - & - & - & - & - & - & - & - & - & - & -\end{array}$

See footnotes at end of table. 
Table 33. Oxygenated Motor Gasoline Prices by Grade, Sales Type, PAD Dlstrict, and State

(Cents per Gallon Excluding Taxes) - Continued

\begin{tabular}{|c|c|c|c|c|c|c|c|c|c|c|c|c|}
\hline \multirow{3}{*}{$\begin{array}{l}\text { Geographic Area } \\
\text { Month }\end{array}$} & \multicolumn{6}{|c|}{ Premium } & \multicolumn{6}{|c|}{ All Grades } \\
\hline & \multicolumn{2}{|c|}{ Sales to End Users } & \multicolumn{4}{|c|}{ Sales for Resale } & \multicolumn{2}{|c|}{ Sales to End Users } & \multicolumn{4}{|c|}{ Sales for Resalo } \\
\hline & $\begin{array}{l}\text { Through } \\
\text { Retell } \\
\text { Outlots }\end{array}$ & Average ${ }^{a}$ & DTW & Rack & Bulk & Average & $\begin{array}{l}\text { Through } \\
\text { Retall } \\
\text { Outlets }\end{array}$ & Averagea & DTW & Rack & Bulk & Averago \\
\hline
\end{tabular}

Illinals

January

February

March

Aprll .

May .

June

July ...

August

September.

October ...

December

1994 Average

\section{Indiana}

January .

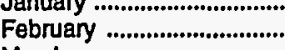

March .

April

May.

June.

July ..

August

Septemb

October

November

December .

lowa

January

February

March

April

May.

June.

July ...

August

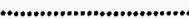

September .............................

October ...

November

December

1994 Average

Kansas

January

February

March

June .

July .....

September

October.

November

December

1994 Average

\begin{tabular}{|c|c|c|c|c|c|c|c|c|c|c|c|}
\hline- & - & - & - & - & - & - & - & - & - & - & - \\
\hline- & - & - & - & - & - & - & - & - & - & - & - \\
\hline- & - & - & - & - & - & - & - & - & - & - & - \\
\hline - & - & - & - & - & - & - & - & - & - & - & - \\
\hline- & - & - & - & - & - & - & - & - & - & - & - \\
\hline - & - & - & - & - & - & - & - & - & - & - & - \\
\hline- & - & - & - & - & - & - & - & - & - & - & - \\
\hline- & - & - & - & - & - & - & - & - & - & - & - \\
\hline- & - & - & - & - & - & - & - & - & - & - & - \\
\hline- & - & - & - & - & - & - & - & - & - & - & - \\
\hline- & - & - & - & - & - & - & - & - & - & - & - \\
\hline- & - & - & - & - & - & - & - & - & - & - & - \\
\hline- & - & - & - & - & - & - & - & - & - & - & - \\
\hline- & - & - & - & - & - & - & - & - & - & - & - \\
\hline- & - & - & - & - & - & - & - & - & - & - & - \\
\hline- & - & - & - & - & - & - & - & - & - & - & - \\
\hline- & - & - & - & - & - & - & - & - & - & - & - \\
\hline- & - & - & - & - & - & - & - & - & - & - & - \\
\hline- & - & - & - & - & - & - & - & - & - & - & - \\
\hline- & - & - & - & - & - & - & - & - & - & - & - \\
\hline- & - & - & - & - & - & - & - & - & - & - & - \\
\hline- & - & - & - & - & - & - & - & - & - & - & - \\
\hline - & - & - & - & - & - & - & - & - & - & - & - \\
\hline- & - & - & - & - & - & - & - & - & - & - & - \\
\hline- & - & - & - & - & - & - & - & - & - & - & - \\
\hline - & - & - & - & - & - & - & - & - & - & - & - \\
\hline
\end{tabular}

See footnotes at end of table. 
Table 33. Oxygenated Motor Gasoline Prices by Grade, Sales Type, PAD District, and State

(Cents per Gallon Excluding Taxes) - Continued

\begin{tabular}{|c|c|c|c|c|c|c|c|c|c|c|c|c|}
\hline \multirow{3}{*}{$\begin{array}{l}\text { Geographic Area } \\
\text { Month }\end{array}$} & \multicolumn{6}{|c|}{ Regular } & \multicolumn{6}{|c|}{ Midgrade } \\
\hline & \multicolumn{2}{|c|}{ Sales to End Users } & \multicolumn{4}{|c|}{ Sales for Resale } & \multicolumn{2}{|c|}{ Sales to End Users } & \multicolumn{4}{|c|}{ Sales for Resale } \\
\hline & $\begin{array}{c}\text { Through } \\
\text { Retail } \\
\text { Outlets }\end{array}$ & Averagea & DTW & Rack & Bulk & Average & $\begin{array}{l}\text { Through } \\
\text { Retall } \\
\text { Outlets }\end{array}$ & Average ${ }^{a}$ & DTW & Rack & Bulk & Average \\
\hline
\end{tabular}

Kentucky

January

February

March

April

May

June

July ...

August .

September

October ...

November

December .

Michigan

January

February

March

April

May .

June

July ...

August

September

October

November

December .

1994 Average

Minnesota

January

February .................................

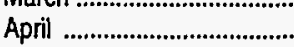

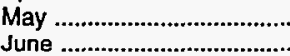

July ....

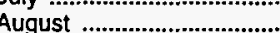

September .............................

October

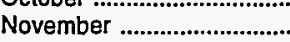

December

1994 Average

$73.0 \quad 72.2$

$71.8 \quad 71.0$

$73.8 \quad 73.7$

$76.0 \quad 76.0$

77.1

79.6

$84.7 \quad 84.8$

85.0

$77.0 \quad 76.7$

77.2

$\begin{array}{ll}76.7 & 66.2 \\ 71.4 & 62.0\end{array}$

$60.9 \quad 53.9$

$59.6 \quad 57.7$

$61.3 \quad 58.9$

$63.9 \quad 61.4$

$\begin{array}{ll}65.6 & 62.6 \\ 68.9 & 65.7\end{array}$

$\begin{array}{ll}68.9 & 65.7 \\ 73.2 & 70.7\end{array}$

$78.1 \quad 75.4$

$68.5 \quad 65.9$

65.9
61.2

61.2
60.4

57.2

-
-
-
-
-
-
-
-
-
-

$\begin{array}{lllll}- & - & - & - & - \\ - & - & - & - & - \\ - & - & - & - & - \\ - & - & - & - & - \\ - & - & - & - & - \\ - & - & - & - & - \\ - & - & - & - & - \\ - & - & - & - & - \\ - & - & - & - & - \\ - & - & - & - & - \\ - & - & - & - & - \\ - & - & - & - & - \\ - & - & - & - & -\end{array}$

Missouri

January

February

March

April

May

June

July ...

August ...

October ...

November

December

1994 Average

$\begin{array}{llll}75.7 & 75.3 & 65.4 & 61.8\end{array}$

$\begin{array}{ll}\text { W } & 55.8 \\ \text { W } & 57.8 \\ \text { W } & 59.2 \\ - & 62.0 \\ - & 63.3 \\ - & 66.3 \\ - & 71.2 \\ - & 75.9 \\ - & 66.4 \\ - & 62.5 \\ - & 61.9 \\ \overline{\text { W }} & 58.5 \\ & 62.6\end{array}$

$\begin{array}{llc}79.7 & 79.5 & 65.4 \\ 78.4 & 77.3 & 61.5 \\ 77.6 & 76.1 & W \\ 81.7 & 81.7 & W \\ 82.7 & 82.7 & W \\ 85.1 & 85.1 & W \\ 86.6 & 86.6 & W \\ 98.3 & 98.3 & W \\ 94.0 & 94.0 & W \\ 84.8 & 84.1 & 73.2 \\ 84.2 & 83.5 & 71.7 \\ 78.5 & 77.8 & 68.5 \\ 82.2 & 81.6 & 68.8\end{array}$

$\begin{array}{lll}58.3 & - & 61.5 \\ 59.2 & - & 60.2 \\ 59.5 & - & 60.3 \\ 62.1 & - & 62.8 \\ 63.1 & - & 64.1 \\ 66.1 & - & 67.1 \\ 71.1 & - & 71.9 \\ 76.0 & - & 76.8 \\ 66.6 & - & 67.5 \\ 63.3 & - & 67.2 \\ 62.2 & - & 66.3 \\ 58.6 & - & 61.9 \\ 62.7 & - & 64.7\end{array}$

See footnotes at end of table. 
Table 33. Oxygenated Motor Gasoline Prices by Grade, Sales Type, PAD District, and State

(Cents per Gallon Excluding Taxes) - Continued

\begin{tabular}{|c|c|c|c|c|c|c|c|c|c|c|c|c|}
\hline \multirow{3}{*}{$\begin{array}{c}\text { Goographlc Area } \\
\text { Month }\end{array}$} & \multicolumn{6}{|c|}{ Premium } & \multicolumn{6}{|c|}{ All Grades } \\
\hline & \multicolumn{2}{|c|}{ Sales to End Users } & \multicolumn{4}{|c|}{ Sales for Resale } & \multicolumn{2}{|c|}{ Sales to End Users } & \multicolumn{4}{|c|}{ Sales for Resale } \\
\hline & $\begin{array}{c}\text { Through } \\
\text { Retall } \\
\text { Outlets }\end{array}$ & Average ${ }^{a}$ & DTW & Rack & Bulk & Average & $\begin{array}{l}\text { Through } \\
\text { Retail } \\
\text { Outlets }\end{array}$ & Average a & DTW & Rack & Bulk & Average \\
\hline
\end{tabular}

Kentucky

January

February

March

April

May

June

July ........

August ....

October

November

December

1994 Average

Michlgan

January

February ..................................

March.

April

May

June

July ...

August

September

November ...............................

December

1994 Average

Minnesota

January ...................................

Februan

March ......................................

April

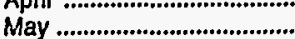

June

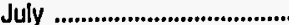

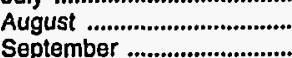

Septembe

October .

November

December .

1994 Average

Missouri

January ..

February

March

April

May .........................................

June

July .

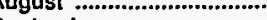

September

October.

November

December

1994 Average

See footnotes at end of table.

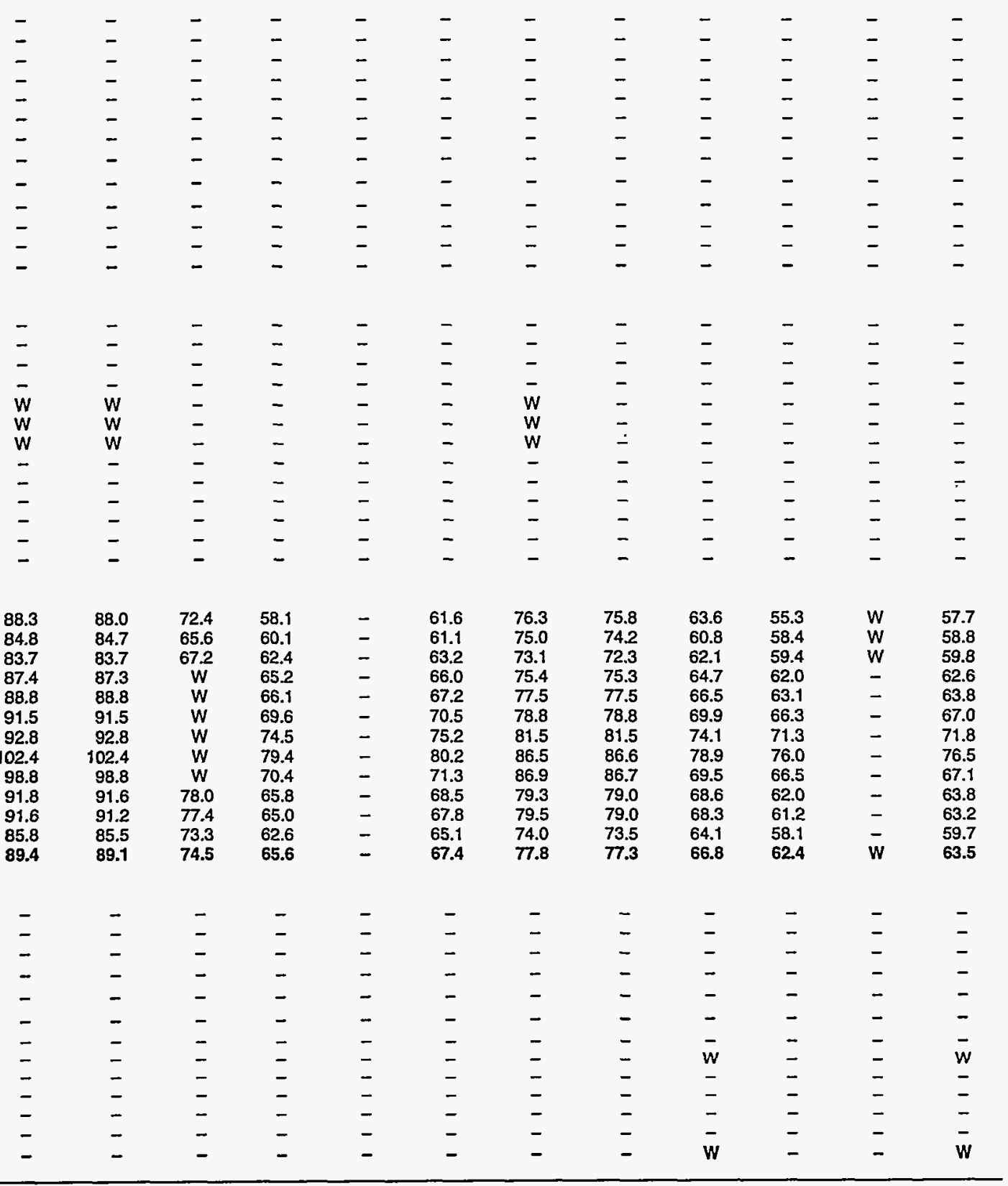


Table 33. Oxygenated Motor Gasoline Prices by Grade, Sales Type, PAD District, and State

(Cents per Gallon Excluding Taxes) - Continued

\begin{tabular}{|c|c|c|c|c|c|c|c|c|c|c|c|c|c|}
\hline \multirow{3}{*}{$\begin{array}{c}\text { Geographlc Area } \\
\text { Month }\end{array}$} & & \multicolumn{6}{|c|}{ Regular } & \multicolumn{6}{|c|}{ Midgrade } \\
\hline & & \multicolumn{2}{|c|}{ Sales to End Users } & \multicolumn{4}{|c|}{ Sales for Resale } & \multicolumn{2}{|c|}{ Sales to End Users } & \multicolumn{4}{|c|}{ Sales for Resale } \\
\hline & & $\begin{array}{c}\text { Through } \\
\text { Retail } \\
\text { Outlets }\end{array}$ & Averagea & DTW & Rack & Bulk & Average & $\begin{array}{c}\text { Through } \\
\text { Retail } \\
\text { Outlets }\end{array}$ & Averagea & DTW & Rack & Bulk & Average \\
\hline
\end{tabular}

Nobraska

January

February

March

April

May

June .

July ......

September

October .

November

December

1994 Average

North Dakota

January

February

March

April

May.

June.

July ...

August ......

September

October.

November

December

1994 Average

Ohio

January

February

March

April

May

June

July ....

August

September

October ...

November ................................

December

1994 Average

Oklahoma

January

February

March

April

May

June

July ..

Aligust .

September

October.

November

December

1994 Average

See footnotes at end of table. 
Table 33. Oxygenated Motor Gasoline Prices by Grade, Sales Type,

PAD District, and State

(Cents per Gallon Excluding Taxes) - Continued

\begin{tabular}{|c|c|c|c|c|c|c|c|c|c|c|c|c|}
\hline \multirow{3}{*}{$\begin{array}{l}\text { Geographic Area } \\
\text { Month }\end{array}$} & \multicolumn{6}{|c|}{ Premium } & \multicolumn{6}{|c|}{ All Grades } \\
\hline & \multicolumn{2}{|c|}{ Sales to End Users } & \multicolumn{4}{|c|}{ Sales for Resale } & \multicolumn{2}{|c|}{ Sales to End Users } & \multicolumn{4}{|c|}{ Sales for Resale } \\
\hline & $\begin{array}{c}\text { Through } \\
\text { Retail } \\
\text { Outlots }\end{array}$ & Average & DTW & Rack & Bulk & Average & $\begin{array}{l}\text { Through } \\
\text { Retail } \\
\text { Outlets }\end{array}$ & Average ${ }^{2}$ & DTW & Rack & Bulk & Average \\
\hline
\end{tabular}

\section{Nobraska}

January .

February

April

May .........................................

June

July ...

August

October

November

December

1994 Average ............................

North Dakota

January .

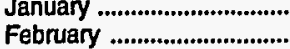

March .

April

May..

June

July .

August

Soptember

October .

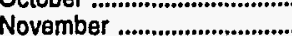

December .

1994 Average .............................

Onlo

January .

February

March

April

May

June ........................................

July .

August

tember

October....

December

1994 Average

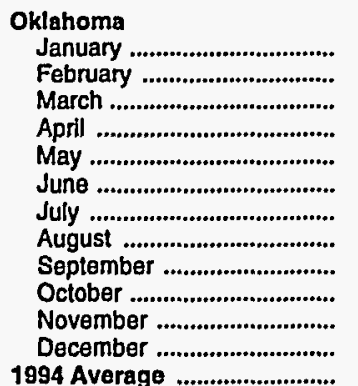

$\begin{array}{lllll}- & - & - & - & - \\ - & - & - & - & - \\ - & - & - & - & - \\ - & - & - & - & - \\ - & - & - & - & - \\ - & - & - & - & - \\ - & - & - & - & - \\ - & - & - & - & - \\ - & - & - & - & - \\ - & - & - & - & -\end{array}$

$\begin{array}{ll}- & - \\ - & - \\ - & - \\ - & - \\ - & - \\ - & - \\ - & - \\ - & - \\ - & - \\ - & -\end{array}$

-
-
-
-
-
-
-
-
-
-

-
-
-
-
-
-
-
-
-

-
-
-
-
-
-
-
-
-

$\begin{array}{ll}- & - \\ - & - \\ - & - \\ - & - \\ - & - \\ - & - \\ - & - \\ \bar{w} & - \\ - & - \\ - & - \\ \bar{w} & -\end{array}$

-
-
-
-
-
$\bar{w}$
-
$\bar{w}$

See footnotes at end of table. 
Table 33. Oxygenated Motor Gasoline Prices by Grade, Sales Type, PAD District, and State

(Cents per Gallon Excluding Taxes) - Continued

\begin{tabular}{|c|c|c|c|c|c|c|c|c|c|c|c|c|}
\hline \multirow{3}{*}{$\begin{array}{l}\text { Geographic Area } \\
\text { Month }\end{array}$} & \multicolumn{6}{|c|}{ Regular } & \multicolumn{6}{|c|}{ Midgrade } \\
\hline & \multicolumn{2}{|c|}{ Sales to End Users } & \multicolumn{4}{|c|}{ Sales for Resale } & \multicolumn{2}{|c|}{ Sales to End Users } & \multicolumn{4}{|c|}{ Sales for Resale } \\
\hline & $\begin{array}{c}\text { Through } \\
\text { Retail } \\
\text { Outlets }\end{array}$ & Averagea & DTW & Rack & Bulk & Average & $\begin{array}{c}\text { Through } \\
\text { Retail } \\
\text { Outlets }\end{array}$ & Averagea & DTW & Rack & Bulk & Average \\
\hline
\end{tabular}

South Dakota

January

February

March

April

May

June

July ....

(n)

September

October

November

December

1994 Average

Tennessee

January

February

March

May

May

July ....

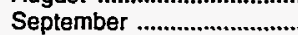

October

November

December

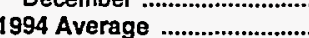

Wisconsin

January

February

March

April

May

June

August

September

October.

November

December

1994 Average

PAD District III

January

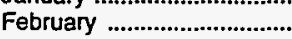

March

April

May

June

July ....

August .

er ..............................

October

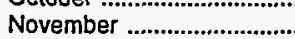

December

1994 Average

$\begin{array}{ll}- & - \\ - & - \\ - & - \\ - & - \\ - & - \\ - & - \\ - & - \\ - & - \\ - & - \\ - & - \\ - & \end{array}$

$\begin{array}{ll}- & \\ - & \\ - & - \\ - & - \\ - & - \\ - & - \\ - & - \\ - & \\ - & \end{array}$

$\begin{array}{ll}- & - \\ - & - \\ - & - \\ - & - \\ - & - \\ - & - \\ - & - \\ - & - \\ - & - \\ - & - \\ - & -\end{array}$

$\begin{array}{ll}- & - \\ - & - \\ - & - \\ - & - \\ - & - \\ - & - \\ - & - \\ - & - \\ - & - \\ - & - \\ - & -\end{array}$

$\begin{array}{lllll}- & - & - & - & - \\ - & - & - & - & - \\ - & - & - & - & - \\ - & - & - & - & - \\ - & - & - & - & - \\ - & - & - & - & - \\ - & - & - & - & - \\ - & - & - & - & - \\ - & - & - & - & - \\ - & - & - & - & - \\ - & - & - & - & - \\ - & - & - & - & - \\ - & - & - & - & -\end{array}$

See footnotes at end of table. 
Table 33. Oxygenated Motor Gasoline Prices by Grade, Sales Type, PAD District, and State

(Cents per Gallon Excluding Taxes) - Continued

\begin{tabular}{|c|c|c|c|c|c|c|c|c|c|c|c|c|}
\hline \multirow{3}{*}{$\begin{array}{l}\text { Geographic Area } \\
\text { Month }\end{array}$} & \multicolumn{6}{|c|}{ Premium } & \multicolumn{6}{|c|}{ All Grades } \\
\hline & \multicolumn{2}{|c|}{ Sales to End Users } & \multicolumn{4}{|c|}{ Sales for Resale } & \multicolumn{2}{|c|}{ Sales to End Users } & \multicolumn{4}{|c|}{ Sales for Resale } \\
\hline & $\begin{array}{l}\text { Through } \\
\text { Retall } \\
\text { Outlots }\end{array}$ & Average ${ }^{a}$ & DTW & Rack & Bulk & Average & $\begin{array}{l}\text { Through } \\
\text { Retail } \\
\text { Outlets }\end{array}$ & Average $a$ & DTW & Rack & Bulk & Average \\
\hline
\end{tabular}

South Dakota

January ...

February

March

April

May

June

July ....

August

October .

November

December ...

1994 Averago

Tennessee

January

March

April

May

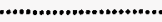

July ...

August ...

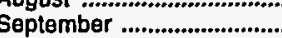

October

November

December ..............................

1994 Average

Wlsconsin

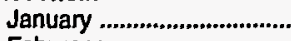

February

March

April

May

June

July ....

August

September

Oclober .

November

December

AD District III

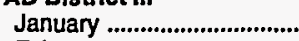
February

March .......................................

April

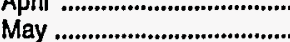

June

July ...

August

August

September ..............................

October

November

December ................................

1994 Average

-
-
-
-
-
-
-
-

$\overline{-}$
$\overline{-}$
$\overline{-}$
$\overline{-}$
$\bar{z}$
$\overline{-}$
-

-
-
$\overline{-}$
-
-
$\overline{-}$
-
-
-

$\begin{array}{ll}- & \\ - & \\ - & \\ - & \\ - & - \\ - & - \\ - & - \\ - & - \\ - & - \\ - & \end{array}$

$\begin{array}{ll}- & - \\ - & - \\ - & - \\ - & - \\ - & - \\ - & - \\ - & - \\ - & - \\ - & - \\ - & - \\ - & - \\ - & -\end{array}$

$\begin{array}{ll}- & - \\ - & - \\ - & - \\ - & - \\ - & - \\ - & - \\ - & - \\ - & - \\ - & - \\ - & - \\ - & - \\ - & \end{array}$

$\begin{array}{ll}- & - \\ - & - \\ - & - \\ - & - \\ - & - \\ - & - \\ - & - \\ - & - \\ - & - \\ - & - \\ - & -\end{array}$

$\begin{array}{llll}- & - & - & - \\ - & - & - & - \\ - & - & - & - \\ - & - & - & - \\ - & - & - & - \\ - & - & - & - \\ - & - & - & - \\ - & - & - & - \\ - & - & - & - \\ - & - & - & - \\ - & - & - & - \\ - & - & - & - \\ - & - & - & -\end{array}$

-
-
-
-
-
-

-
$=$
$\bar{z}$
$\bar{z}$
$\bar{z}$
$\bar{z}$

$\begin{array}{ll}- & - \\ - & - \\ - & - \\ - & - \\ - & - \\ - & - \\ - & - \\ - & - \\ - & - \\ - & -\end{array}$

$\begin{array}{ll}- & \\ - & \\ - & \\ - & \end{array}$

$\begin{array}{ll}- & - \\ - & - \\ - & - \\ - & - \\ - & - \\ - & - \\ - & - \\ - & - \\ - & - \\ - & - \\ - & -\end{array}$

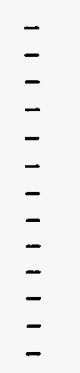

$$
\begin{aligned}
& - \\
& - \\
& - \\
& - \\
& - \\
& - \\
& - \\
& - \\
& - \\
& -
\end{aligned}
$$

$\begin{array}{llll}- & - & - & - \\ - & - & - & - \\ - & - & - & - \\ - & - & - & - \\ - & - & - & - \\ - & - & - & - \\ - & - & - & - \\ - & - & - & - \\ - & - & - & - \\ - & - & - & - \\ - & - & - & - \\ - & - & - & - \\ - & - & - & -\end{array}$

$\begin{array}{ll}- & \\ - & \\ - & \\ - & \\ - & \\ - & \\ - & \\ - & \end{array}$

\begin{tabular}{|c|c|c|c|}
\hline $\begin{array}{l}93.4 \\
87.7\end{array}$ & $\begin{array}{l}91.6 \\
86.4\end{array}$ & $\begin{array}{l}72.6 \\
71.9\end{array}$ & $\begin{array}{l}56.2 \\
59.6\end{array}$ \\
\hline 85.7 & 84.3 & 70.9 & 61.2 \\
\hline$W$ & $W$ & $w$ & $w$ \\
\hline$W$ & $W$ & $w$ & $w$ \\
\hline$w$ & $w$ & $w$ & W \\
\hline$w$ & $w$ & $w$ & w \\
\hline$w$ & $w$ & $w$ & W \\
\hline$w$ & 101.3 & 85.9 & 63.8 \\
\hline 99.9 & 98.5 & 86.1 & 69.9 \\
\hline 96.7 & 96.2 & 87.1 & 75.7 \\
\hline 97.7 & 96.6 & 82.0 & 69.9 \\
\hline 95.3 & 94.3 & 78.0 & 63.1 \\
\hline
\end{tabular}

See footnotes at end of table. 
Table 33. Oxygenated Motor Gasoline Prices by Grade, Sales Type, PAD District, and State

(Cents per Gallon Excluding Taxes) - Continued

\begin{tabular}{|c|c|c|c|c|c|c|c|c|c|c|c|c|}
\hline \multirow{3}{*}{$\begin{array}{c}\text { Geographic Area } \\
\text { Month }\end{array}$} & \multicolumn{6}{|c|}{ Regular } & \multicolumn{6}{|c|}{ Midgrade } \\
\hline & \multicolumn{2}{|c|}{ Sales to End Users } & \multicolumn{4}{|c|}{ Sales for Resale } & \multicolumn{2}{|c|}{ Sales to End Users } & \multicolumn{4}{|c|}{ Sales for Resale } \\
\hline & $\begin{array}{c}\text { Through } \\
\text { Ratail } \\
\text { Outlots }\end{array}$ & Averagea & DTW & Rack & Bulk & Average & $\begin{array}{c}\text { Through } \\
\text { Retail } \\
\text { Outlets }\end{array}$ & Average ${ }^{a}$ & DTW & Rack & Bulk & Average \\
\hline
\end{tabular}

Alabama

January

February

March

April

May

June

July .....

September

October ...

November

December

1994 Average

Arkansas

January

February

March

April

May

June

August .

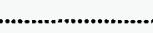

September

October .

November

Decomber

1994 Average

Louisiana

January

February

March

April

May

June

July ....

September

October ...

November

December

1994 Average

Mississippi

January

February

March

April

May .

June

July ...

September

October.

November

December .

1994 Average

See footnotes at end of table. 
Table 33. Oxygenated Motor Gasoline Prices by Grade, Sales Type, PAD District, and State

(Cents per Gallon Excluding Taxes) - Continued

\begin{tabular}{|c|c|c|c|c|c|c|c|c|c|c|c|c|}
\hline \multirow{3}{*}{$\underbrace{\text { Geographlc Area }}_{\text {Month }}$} & \multicolumn{6}{|c|}{ Premlum } & \multicolumn{6}{|c|}{ All Grades } \\
\hline & \multicolumn{2}{|c|}{ Sales to End Users } & \multicolumn{4}{|c|}{ Sales for Resale } & \multicolumn{2}{|c|}{ Sales to End Users } & \multicolumn{4}{|c|}{ Sales for Resale } \\
\hline & $\begin{array}{c}\text { Through } \\
\text { Retail } \\
\text { Outlets }\end{array}$ & Average $e^{a}$ & DTW & Rack & Bulk & Average & $\begin{array}{c}\text { Through } \\
\text { Retail } \\
\text { Outlets }\end{array}$ & Average ${ }^{a}$ & DTW & Rack & Bulk & Average \\
\hline
\end{tabular}

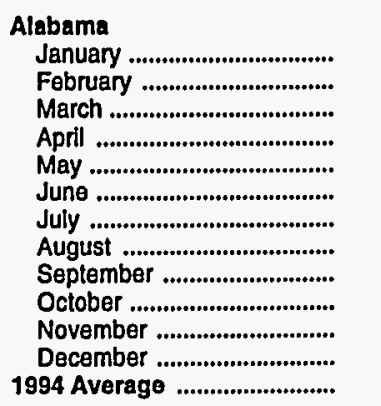

Arkansas
January .............................
February
March

Louislana

January

March .

April

May

June

July ....

August .....

October .......

November

December

1994 Average

\section{Mississippl}

January.

February

March

April

May

June

July .....

Septembe

October ....

November

December

\begin{tabular}{|c|c|c|c|c|c|c|c|c|c|c|c|}
\hline- & - & - & - & - & - & - & - & - & - & - & - \\
\hline- & - & - & - & - & - & - & - & - & - & - & - \\
\hline- & - & - & - & - & - & - & - & - & - & - & - \\
\hline - & - & - & - & - & - & - & - & - & - & - & - \\
\hline- & - & - & - & - & - & - & - & - & - & - & - \\
\hline- & - & - & - & - & - & - & - & - & - & - & - \\
\hline- & - & - & - & - & - & - & - & - & - & - & - \\
\hline- & - & - & - & - & - & - & - & - & - & - & - \\
\hline- & - & - & - & - & - & - & - & - & - & - & - \\
\hline- & - & - & - & - & - & - & - & - & - & - & - \\
\hline- & - & - & - & - & - & - & - & - & - & - & - \\
\hline- & - & - & - & - & - & - & - & - & - & - & - \\
\hline- & - & - & - & - & - & - & - & - & - & - & - \\
\hline- & - & - & - & - & - & - & - & - & - & - & - \\
\hline- & - & - & $w$ & - & $w$ & - & - & - & $w$ & - & $w$ \\
\hline- & - & - & - & - & - & - & - & - & - & - & - \\
\hline- & - & - & - & - & - & - & - & - & - & - & - \\
\hline- & - & - & - & - & - & - & - & - & - & - & - \\
\hline- & - & - & - & - & - & - & - & - & - & - & - \\
\hline - & - & - & - & - & - & - & - & - & - & - & - \\
\hline- & - & - & - & - & $\rightarrow$ & - & - & - & - & - & - \\
\hline- & - & - & - & - & - & - & - & - & - & - & - \\
\hline- & - & - & - & - & - & - & - & - & - & - & $\rightarrow$ \\
\hline- & - & - & - & - & - & - & - & - & - & - & - \\
\hline- & - & - & - & - & - & - & - & - & - & - & - \\
\hline- & - & - & $W$ & - & $w$ & - & - & - & $W$ & - & $w$ \\
\hline- & - & - & - & - & - & - & - & - & - & - & - \\
\hline- & - & - & - & - & - & - & - & - & - & - & - \\
\hline- & - & - & - & - & - & - & - & - & - & - & - \\
\hline - & - & - & - & - & - & - & - & - & - & - & - \\
\hline- & - & - & - & - & - & $\rightarrow$ & - & - & $\rightarrow$ & - & - \\
\hline- & - & - & - & - & - & - & - & - & - & - & - \\
\hline- & - & - & - & - & - & - & - & - & - & - & - \\
\hline- & - & - & - & - & - & - & - & - & - & - & - \\
\hline- & - & - & - & - & - & - & - & - & - & - & - \\
\hline- & - & - & - & - & - & - & - & - & - & - & - \\
\hline- & - & - & - & - & - & - & - & - & - & - & - \\
\hline- & - & - & - & - & - & - & - & - & - & - & - \\
\hline- & - & - & - & - & - & - & - & - & - & - & - \\
\hline- & - & - & - & - & - & - & - & - & - & - & - \\
\hline- & - & - & - & - & - & - & - & - & - & - & - \\
\hline- & - & - & - & - & - & - & - & - & - & - & - \\
\hline- & - & - & - & - & - & - & - & - & - & - & - \\
\hline- & - & - & - & - & - & - & - & - & - & - & - \\
\hline- & - & - & - & - & - & - & - & - & - & - & - \\
\hline- & - & - & - & - & - & - & - & - & - & - & - \\
\hline- & - & - & - & - & - & - & - & - & - & - & - \\
\hline- & - & - & - & - & - & - & - & - & - & - & - \\
\hline- & - & - & - & - & - & - & - & - & - & - & - \\
\hline- & - & - & - & - & - & - & - & - & - & - & - \\
\hline- & - & - & - & - & - & - & - & - & - & - & - \\
\hline- & - & - & - & - & - & - & - & - & - & - & - \\
\hline
\end{tabular}

See footnotes at end of table. 
Table 33. Oxygenated Motor Gasoline Prices by Grade, Sales Type, PAD District, and State (Cents per Gallon Excluding Taxes) - Continued

\begin{tabular}{|c|c|c|c|c|c|c|c|c|c|c|c|c|}
\hline \multirow{3}{*}{$\begin{array}{c}\text { Geographic Area } \\
\text { Month }\end{array}$} & \multicolumn{6}{|c|}{ Regular } & \multicolumn{6}{|c|}{ Midgrade } \\
\hline & \multicolumn{2}{|c|}{ Sales to End Users } & \multicolumn{4}{|c|}{ Sales for Resale } & \multicolumn{2}{|c|}{ Sales to End Users } & \multicolumn{4}{|c|}{ Sales for Resale } \\
\hline & $\begin{array}{c}\text { Through } \\
\text { Retail } \\
\text { Outlets }\end{array}$ & Averagea & DTW & Rack & Bulk & Average & $\begin{array}{l}\text { Through } \\
\text { Retail } \\
\text { Outlets }\end{array}$ & Averagea & DTW & Rack & Bulk & Average \\
\hline
\end{tabular}

New Mexico

January .

February

March

April

May

July

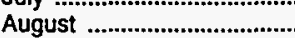

September ...............................

October

November

December

1994 Average

Texas

January

February

March

April

May ..

July .

August

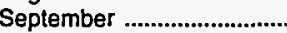

October

November ......

Decemb

1994 Average

PAD District IV

January

February

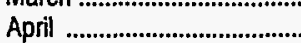

May

June

July ....

September ................................

October

November ..........................

December

Colorado

January

February

March

April

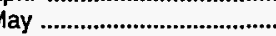

June .

July ...

August

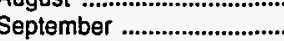

October...

November

December .................................

1994 Average

$\begin{array}{cc}73.5 & 72.7 \\ 68.7 & 68 . \\ W & W \\ W & W \\ W & W \\ W & W \\ W & W \\ W & W \\ W & W \\ 81.9 & 80 . \\ 83.8 & 82 . \\ 75.6 & 75 . \\ 77.3 & 76 .\end{array}$

72.7
68.6
$W$
$W$
$W$
$W$
$W$
$W$
$W$
80.9
82.9
75.1
76.8

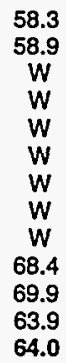

$$
\begin{gathered}
54.1 \\
58.6 \\
60.4 \\
W \\
- \\
- \\
- \\
- \\
- \\
66.6 \\
65.3 \\
58.4 \\
59.4
\end{gathered}
$$

-
-
-
-
-
-
-
-
-

55.3
58.7
$W$
$W$
$W$
$W$
$W$
$W$
$W$
67.6
66.9
60.1
61.2

79.7
76.7
-
-
-
-
-
-
-
NA
91.7
NA
82.1

79.2
76.6
-
-
-
-
-
-
-
NA
91.3
82.6
81.1

$W$
$W$
-
-
-
-
-
-
76.
79.3
71
71.8

$\begin{array}{ccc}60.1 & - & 62.9 \\ 63.5 & - & 63.8 \\ - & - & - \\ w & - & w \\ - & - & - \\ - & - & - \\ - & - & - \\ - & - & - \\ - & - & - \\ 71.5 & - & 73.9 \\ 70.8 & - & 74.4 \\ 64.4 & - & 67.3 \\ 65.8 & - & 68.4\end{array}$

77.7

$74.5 \quad 73.2$

71.0

69.9

W

$\begin{array}{cc}W & 50.8 \\ W & 54.6 \\ W & 57.5 \\ - & W \\ - & W \\ - & - \\ - & - \\ - & \text { W } \\ \text { W } & \text { NA } \\ \text { W } & \text { NA } \\ \text { NA } & \text { NA } \\ \text { W } & 64.5 \\ \mathbf{6 5 . 4} & \mathbf{5 9 . 9}\end{array}$

$w$
-
-
$\overline{-}$
-
$\bar{w}$
$\bar{w}$
$\bar{w}$
$w$

49.9
55.6
57.5
$W$
$W$
-
-
$W$
NA
NA
NA
66.5

$86.4 \quad 85.3$

$80.1 \quad 79.6$

76.7

75.9

-

$-$

$\bar{w}$

93.8

NA

87.7

54.0

$\begin{array}{lll}71.4 & 59.3 & 52.4\end{array}$

72.4

60.3

55.8

70.8

W

W

W 60.9

W
$-\quad 62.1$

- 66.0

$\bar{w}$

W

64.3

62.3

$\begin{array}{ll}65.2 & 61.7 \\ 60.5 & 55.6\end{array}$

63.7

59.3

-

$81.3 \quad 80.0$

$83.2 \quad 82.3$

80.0
$W$

60.9$$
62.1
$$

66.0

NA

$$
\text { NA }
$$

63.1

63.1
57.6

60.5

-
-
-
$\bar{W}$
93.
90.
87.7

\section{$53.9 \quad 81$}

$\begin{array}{ccc}59.4 & 52.2 & - \\ 60.3 & 55.8 & - \\ \text { W } & 59.1 & - \\ - & 60.9 & - \\ - & 61.9 & - \\ - & 65.5 & - \\ - & \text { NA } & - \\ - & \text { NA } & - \\ \text { W } & \text { NA } & - \\ 64.1 & 61.5 & - \\ 65.0 & 59.6 & - \\ 59.6 & 53.3 & - \\ 63.5 & 58.6 & -\end{array}$

56.8
59.1
60.9
61.9
65.5
NA
NA
NA
62.7
62.0
56.
60.1
81.
83.
80.9
$W$
-
-
-
-
$W$
94.
90
88

\begin{tabular}{c}
$W$ \\
$W$ \\
$W$ \\
\hline \\
- \\
- \\
$W$ \\
$W$ \\
$W$ \\
$W$ \\
68.7 \\
63. \\
66.5 \\
$W$ \\
- \\
\hline \\
\hline \\
$W$ \\
$W$ \\
68.9 \\
71.6 \\
66.6 \\
68.1
\end{tabular}

49.8

53.7

55.5

W

W

W

58.3

NA

NA
57.3

- $\quad 55.4$

57.7
$-\quad 58.8$

$-\quad 58.8$

-$$
\text { - }
$$$$
\text { - }
$$$$
\text { - }
$$$$
\text { - }
$$$$
\text { - }
$$$$
\begin{array}{rr}
-\quad & \text { NA } \\
-\quad 59.9
\end{array}
$$

See footnotes at end of table. 
Table 33. Oxygenated Motor Gasoline Prices by Grade, Sales Type, PAD District, and State

(Cents per Gallon Excluding Taxes) - Continued

\begin{tabular}{|c|c|c|c|c|c|c|c|c|c|c|c|c|}
\hline \multirow{3}{*}{$\begin{array}{l}\text { Goographic Area } \\
\text { Month }\end{array}$} & \multicolumn{6}{|c|}{ Premlum } & \multicolumn{6}{|c|}{ All Grades } \\
\hline & \multicolumn{2}{|c|}{ Sales to End Users } & \multicolumn{4}{|c|}{ Sales for Resale } & \multicolumn{2}{|c|}{ Sales to End Users } & \multicolumn{4}{|c|}{ Sales for Resale } \\
\hline & $\begin{array}{c}\text { Through } \\
\text { Retail } \\
\text { Outlets }\end{array}$ & Averagea & DTW & Rack & Bulk & Average & $\begin{array}{c}\text { Through } \\
\text { Retail } \\
\text { Outlets }\end{array}$ & Averagea & DTW & Rack & Bulk & Average \\
\hline
\end{tabular}

Now Mexico

$$
\text { January ... }
$$

February

March

April .......................................

May ..............................................

June

July ...

August ................................

September ..............................

October...

November

1894 Average

Texas

January

February

94.1

March .

April , ........................................

May .........................................

June

July ...

August

September

October ...................................

November ...............................

December

1994 Average ..... $\quad 94.6$

PAD District IV

January

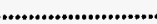

May

June

July

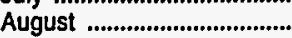

September ..............................

October

November ...............................

December

1994 Average ............................... 96.2

Colorado

January

91.3

March

April

May .

July ....

August

October

November

December .

1994 Average

92.8
87.7
$W$
$W$
$W$
$W$
$W$
$W$
$W$
99.5
101.9
94.1
96.1

92.3
87.8
$W$
$W$
$W$
$W$
$W$
$W$
$W$
99.0
101.4
93.8
95.8

$\begin{array}{cc}70.7 & 63.0 \\ 70.0 & 63.4 \\ W & W \\ W & W \\ W & - \\ W & - \\ W & - \\ W & - \\ W & - \\ 81.4 & 75.5 \\ 83.5 & 75.0 \\ 77.0 & 68.2 \\ 76.4 & 67.3\end{array}$

-
-
-
-
-
-
-
-
-

65.7
65.2
$W$
$W$
$W$
$W$
$W$
$W$
$W$
78.4
78.3
71.6
70.8

$\begin{array}{cc}76.0 & 75.2 \\ 71.4 & 71.2 \\ W & W \\ W & W \\ W & W \\ W & W \\ W & W \\ W & W \\ W & W \\ 84.4 & 83.0 \\ 86.7 & 85.7 \\ 78.7 & 78.1 \\ 80.0 & 79.5\end{array}$

60.2
60.5
$W$
$W$
$W$
$W$
$W$
$W$
$W$
70.9
72.4
66.2
65.9

\section{1}

59.5
61.1

w

-

-

68.3

66.7

59.7

60.6

$\begin{array}{ll}- & 56.7 \\ - & 59.8 \\ - & W \\ - & W \\ - & W \\ - & W \\ - & W \\ - & W \\ - & W \\ - & 69.6 \\ - & 68.7 \\ - & 61.9 \\ - & 62.7\end{array}$

$\begin{array}{ccccccccccc}90.8 & 73.5 & 54.2 & - & 59.1 & 83.1 & 80.9 & W & 51.2 & W & 51.4 \\ 84.7 & W & 58.5 & - & 61.7 & 77.5 & 76.1 & W & 55.0 & - & 56.7 \\ 82.4 & W & 61.2 & - & 64.1 & 73.9 & 72.8 & W & 57.7 & - & 58.5 \\ W & - & W & - & W & - & W & - & W & - & W \\ - & - & W & - & W & - & - & - & W & - & W \\ - & - & W & - & W & - & - & - & W & - & W \\ - & - & W & - & W & - & - & - & W & - & W \\ - & - & W & - & W & - & - & - & W & W & W \\ W & W & 63.8 & - & 67.3 & W & 87.3 & W & N A & - & 67.4 \\ 98.2 & W & 68.9 & - & 72.5 & 90.3 & 89.3 & W & N A & W & 70.5 \\ \text { NA } & \text { W } & \text { NA } & - & \text { NA } & 85.5 & 85.1 & W & 70.0 & - & 72.1 \\ 99.5 & W & \text { NA } & - & \text { NA } & 91.6 & 90.4 & W & 65.6 & W & 68.6 \\ 92.8 & 79.0 & 62.4 & - & 65.2 & 84.4 & 83.3 & 68.5 & 59.9 & W & 60.5\end{array}$

See footnotes at end of table. 
Table 33. Oxygenated Motor Gasoline Prices by Grade, Sales Type, PAD District, and State

(Cents per Gallon Excluding Taxes) - Continued

\begin{tabular}{|c|c|c|c|c|c|c|c|c|c|c|c|c|}
\hline \multirow{3}{*}{$\begin{array}{l}\text { Geographlc Area } \\
\text { Month }\end{array}$} & \multicolumn{6}{|c|}{ Regular } & \multicolumn{6}{|c|}{ Midgrade } \\
\hline & \multicolumn{2}{|c|}{ Sales to End Users } & \multicolumn{4}{|c|}{ Sales for Resale } & \multicolumn{2}{|c|}{ Sales to End Users } & \multicolumn{4}{|c|}{ Sales for Resale } \\
\hline & $\begin{array}{l}\text { Through } \\
\text { Retail } \\
\text { Outlets }\end{array}$ & Averagea & DTW & Rack & Bulk & Average & $\begin{array}{c}\text { Through } \\
\text { Retail } \\
\text { Outlets }\end{array}$ & Averagea & DTW & Rack & Bulk & Average \\
\hline
\end{tabular}

Idaho

January.

February

March

April

May

June

July ...

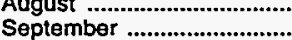

October

November

December .............

1994 Average

\section{Montana}

January .

February

March

April

May

June

July ....

.

September ................................

October .

November

December

1994 Average

Utah

January .

February

March

April

May

June

July ...

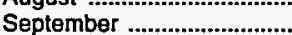

October

November

December ..............................

1994 Average

Wyoming

January

February

March

April

May

June

July .

August .

September

October

Novembe

December

1994 Average

-
-
-
-
-
-
-
-

-
-
-
-
-
-

-
-
-
-
-
-
$W$
$W$
$W$
$W$
$W$

$\begin{array}{lll}- & - & - \\ - & - & - \\ - & - & - \\ - & - & - \\ - & - & - \\ - & - & W \\ - & - & W \\ - & - & W \\ - & - & W \\ - & - & W\end{array}$

$\begin{array}{ll}- & - \\ - & - \\ - & - \\ - & - \\ - & - \\ - & - \\ W & - \\ W & - \\ W & \\ W & - \\ W & - \\ W & \end{array}$

$\begin{array}{ll}- & - \\ - & - \\ - & - \\ - & - \\ - & - \\ - & \\ - & \end{array}$

$\begin{array}{lllll}- & - & - & - & - \\ - & - & - & - & - \\ - & - & - & - & - \\ - & - & - & - & - \\ - & - & - & - & - \\ - & - & - & - & - \\ - & - & - & - & - \\ - & w & - & - & W \\ - & w & - & - & w \\ - & w & - & - & w \\ - & W & - & - & W \\ - & W & - & - & W \\ - & W & - & - & W\end{array}$

$\begin{array}{lr}W & 80.4 \\ W & 75.6 \\ - & - \\ - & - \\ - & - \\ - & - \\ - & - \\ - & - \\ W & - \\ 89.4 & 76.3 \\ 86.2 & 85.5 \\ 86.0 & 84.3\end{array}$

80.4
75.6
-
-
-
-
-
-
76.3
88.5
85.4
84.3

$\begin{array}{lll}W & W & - \\ W & W & - \\ - & - & - \\ - & - & - \\ - & W & - \\ - & W & - \\ - & W & - \\ - & W & - \\ - & W & - \\ W & 72.5 & - \\ W & 74.1 & - \\ W & 69.2 & - \\ W & 69.7 & -\end{array}$

62.2
63.0
-
-
$W$
$W$
$W$
$W$
$W$
72.4
74.1
69.2
68.9

-
-
-
-
-
-
-
-
-

$\begin{array}{llll}- & W & - & W \\ - & W & - & W \\ - & W & - & W \\ - & W & - & W \\ - & W & - & W \\ - & - & - & - \\ - & - & - & - \\ - & - & - & - \\ - & - & - & - \\ - & - & - & - \\ - & - & - & - \\ - & W & - & W \\ - & W & - & W\end{array}$

See footnotes at end of table. 
Table 33. Oxygenated Motor Gasoline Prices by Grade, Sales Type, PAD District, and State

(Cents per Gallon Excluding Taxes) - Continued

\begin{tabular}{|c|c|c|c|c|c|c|c|c|c|c|c|c|}
\hline \multirow{3}{*}{$\begin{array}{l}\text { Goographlo Area } \\
\text { Month }\end{array}$} & \multicolumn{6}{|c|}{ Premlum } & \multicolumn{6}{|c|}{ All Grades } \\
\hline & \multicolumn{2}{|c|}{ Salos to End Users } & \multicolumn{4}{|c|}{ Sales for Resale } & \multicolumn{2}{|c|}{ Sales to End Users } & \multicolumn{4}{|c|}{ Sales for Resale } \\
\hline & $\begin{array}{c}\text { Through } \\
\text { Retall } \\
\text { Outlets }\end{array}$ & Averagea & DTW & Rack & Bulk & Average & $\begin{array}{c}\text { Through } \\
\text { Retail } \\
\text { Outlets }\end{array}$ & Average $\mathrm{a}^{\mathrm{a}}$ & DTW & Rack & Bulk & Average \\
\hline
\end{tabular}

Idaho

January ......

February

March

April

June

August

September .............................

October

November

December ................................

1994 Average

Montana

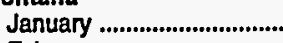

February

March

May

June

July ...

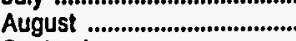

September ..............................

October ..

November

December .

1994 Average

Utah

January

February

March

April

June

July ...

August

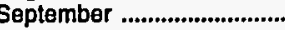

October

November

December

1994 Average

Wyoming

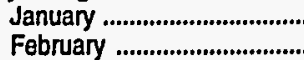

March

April ......................................

May

July

August

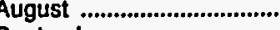

September .............................

October .

November

December

1994 Average

$\begin{array}{ll}- & - \\ \overline{-} & - \\ \bar{z} & \overline{-} \\ \overline{-} & \overline{-} \\ \overline{-} & - \\ \bar{w} & \bar{w} \\ \overline{-} & - \\ \bar{w} & \bar{w}\end{array}$

$\overline{-}$
$\overline{-}$
$\overline{-}$
$\overline{-}$
$W$
$W$
$W$
$W$
$W$
$W$

$\begin{array}{ccc}W & W & W \\ W & W & W \\ - & - & - \\ - & - & - \\ - & - & - \\ - & - & - \\ - & - & - \\ - & - & - \\ - & - & - \\ W & W & W \\ 99.6 & 99.6 & W \\ 96.9 & 95.8 & W \\ 96.2 & 95.0 & W\end{array}$

$W$
70.7
$W$
$W$
$W$
$W$
$W$
$W$
$W$
81.6
83.0
78.1
77.8

$\begin{array}{cc}74.8 & 74.7 \\ 71.6 & 71.3 \\ W & W \\ - & - \\ - & - \\ - & - \\ - & - \\ - & - \\ - & - \\ - & W \\ 90.5 & 90.6 \\ 87.0 & 86.7 \\ 78.9 & 78.2\end{array}$

$\begin{array}{ll}- & - \\ - & - \\ - & - \\ - & - \\ - & - \\ - & - \\ - & - \\ - & - \\ - & - \\ - & -\end{array}$

$\begin{array}{ll}- & - \\ - & - \\ - & - \\ - & - \\ - & - \\ - & - \\ - & - \\ W & - \\ W & W \\ W & - \\ W & - \\ W & - \\ W & \text { W }\end{array}$

-
-
-
-
-
$\bar{w}$
-
$\overline{-}$
$\bar{w}$

-
-
-
-
-
-
$w$
$W$
$w$
$W$
$W$
$W$

$\begin{array}{lll}- & - & - \\ - & - & - \\ - & - & - \\ - & - & - \\ - & - & - \\ - & - & - \\ - & - & - \\ - & - & W \\ - & - & W \\ - & - & W \\ - & - & W \\ - & - & W \\ - & - & W\end{array}$

See footnotes at end of table. 
Table 33. Oxygenated Motor Gasoline Prices by Grade, Sales Type, PAD District, and State (Cents per Gallon Excluding Taxes) - Continued

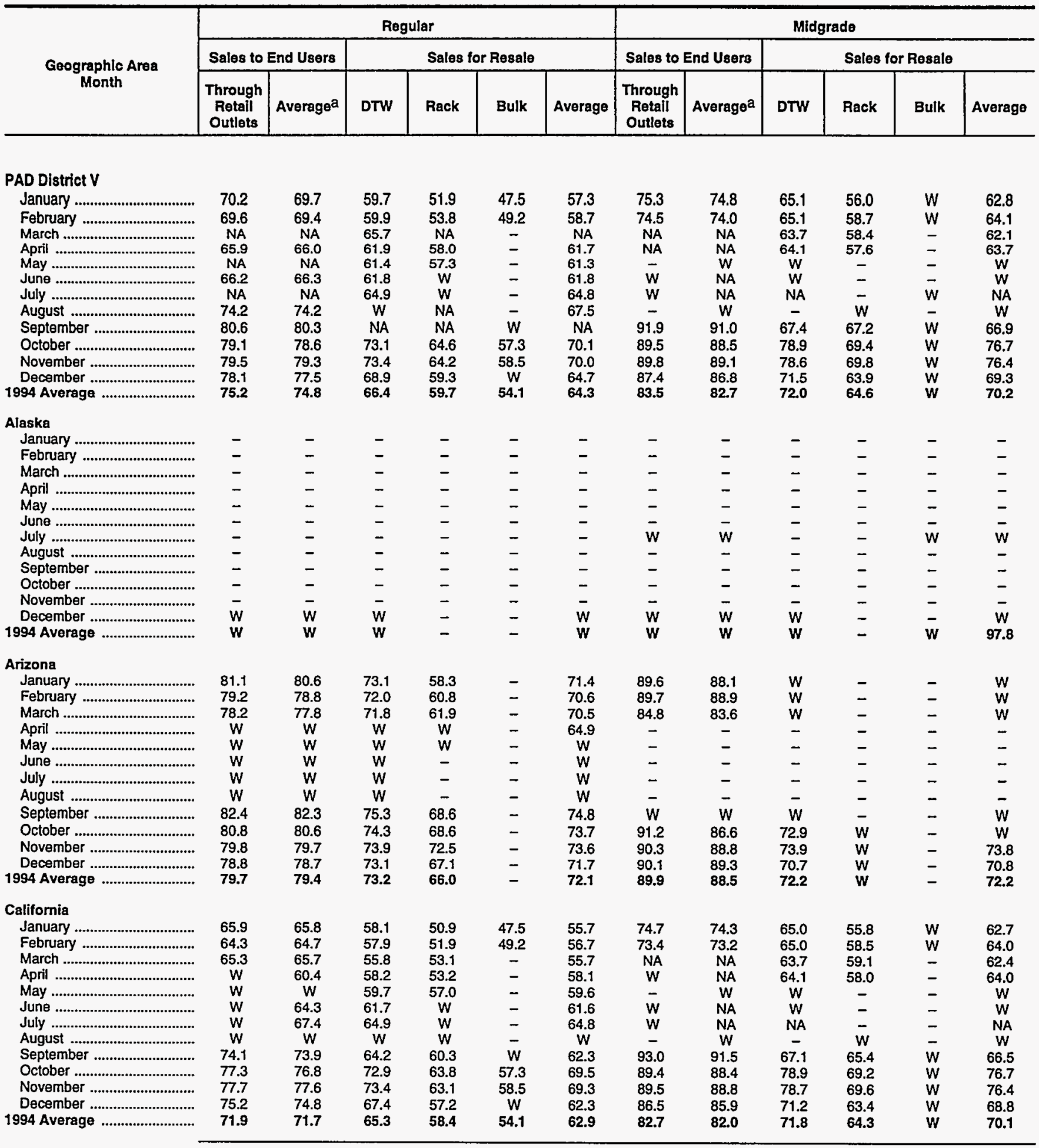

See footnotes at end of table. 
Table 33. Oxygenated Motor Gasoline Prices by Grade, Sales Type, PAD District, and State

(Cents per Gallon Excluding Taxes) - Continued

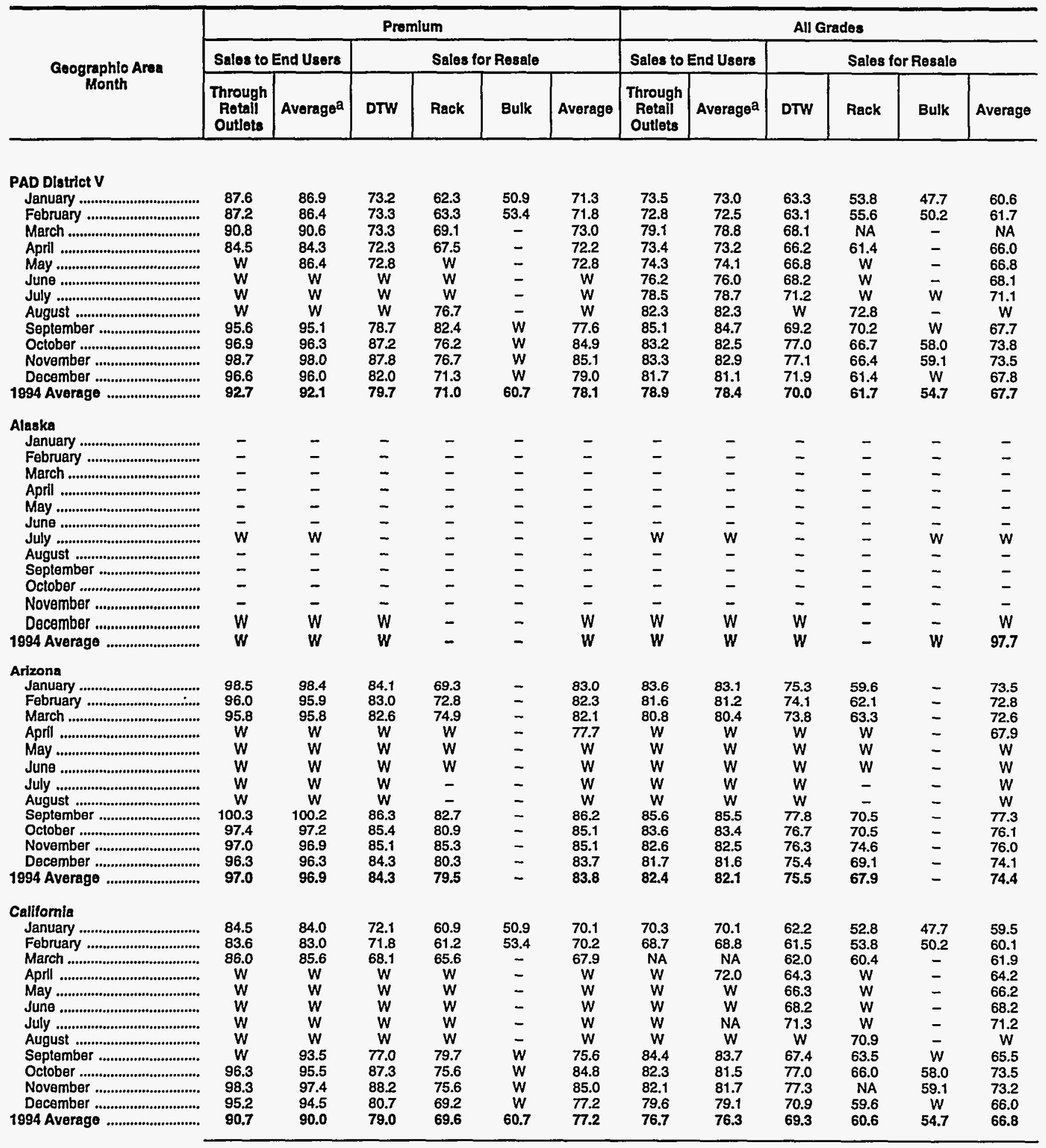

See footnotes at end of table. 
Table 33. Oxygenated Motor Gasoline Prices by Grade, Sales Type, PAD District, and State

(Cents per Gallon Excluding Taxes) - Continued

\begin{tabular}{|c|c|c|c|c|c|c|c|c|c|c|c|c|}
\hline \multirow{3}{*}{$\begin{array}{c}\text { Geographic Area } \\
\text { Month }\end{array}$} & \multicolumn{6}{|c|}{ Regular } & \multicolumn{6}{|c|}{ Mldgrado } \\
\hline & \multicolumn{2}{|c|}{ Sales to End Users } & \multicolumn{4}{|c|}{ Sales for Resale } & \multicolumn{2}{|c|}{ Sales to End Users } & \multicolumn{4}{|c|}{ Sales for Resale } \\
\hline & $\begin{array}{c}\text { Through } \\
\text { Retail } \\
\text { Outlets }\end{array}$ & Averagea & DTW & Rack & Bulk & Average & $\begin{array}{c}\text { Through } \\
\text { Rotail } \\
\text { Outlets }\end{array}$ & Average $a$ & DTW & Rack & Bulk & Averago \\
\hline
\end{tabular}

Hawail

January ...

February

March

April

May

June ..

July ....

September

October ...

December

1994 Average

Nevada

January

February

March

April

May

July ...

August

(n)

October

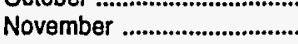

December

1994 Average

.

Oregon

January

February

March

April

May

June.

August

September

October

December

1994 Average

Washington

January

February

March ........................................

April

May

June

July ...

August

September

October...

December

1994 Average

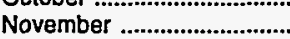

November

80.0
80.9
$W$
$W$
$W$
$W$
$W$
$W$
$N A$
89.1
89.1
91.3
85.7

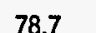

60.4

W

$W$

$W$
$W$
$W$

NA

87.9

88.3

90.2

84.8

62.5
$W$
$W$
$W$
$W$
$W$
$W$
71.7
71.3
70.9
67.9

57.8

-

$\bar{w}$

$W$

69.2

68.5

67.6

62.2

63.5

76.3
75.7
$W$
$W$
$W$
$W$
$W$
$W$
$W$
84.6
83.2
80.7
78.0

$\begin{array}{ccc}75.8 & 64.9 & 56.6 \\ 75.1 & 64.4 & 58.6 \\ W & W & W \\ W & - & W \\ W & - & - \\ W & - & - \\ W & - & - \\ W & - & - \\ W & - & - \\ 83.8 & 73.4 & 69.7 \\ 82.6 & 72.2 & 67.4 \\ 80.3 & 68.6 & 63.9 \\ 77.7 & 68.3 & 63.2\end{array}$

$68.8 \quad 68.6$

$67.9 \quad 67.9$

71.9

W

$W$

NA

W

90.2

83.6

83.3

81.2

77.2 $\begin{array}{lll}62.8 & 62.7 & 60.9\end{array}$

$\begin{array}{lll}71.8 & 66.2 & 56.3\end{array}$

$W$

W

89.3

83.4

82.8

76.9
$\begin{array}{ccr}W & 67.4 & 60 . \\ W & W & -\end{array}$

$\begin{array}{ll}- & - \\ - & - \\ - & - \\ - & - \\ - & - \\ - & - \\ - & - \\ - & - \\ - & - \\ - & -\end{array}$

$\begin{array}{ll}- & - \\ - & - \\ - & - \\ - & - \\ - & - \\ - & - \\ - & - \\ - & - \\ - & - \\ - & -\end{array}$

$\begin{array}{lll}- & - & - \\ - & - & - \\ - & - & - \\ - & - & - \\ - & - & - \\ - & - & - \\ - & - & - \\ - & - & - \\ - & - & - \\ - & - & - \\ - & - & -\end{array}$

-
$\overline{-}$
$\overline{-}$
$\overline{-}$
$\overline{-}$
$\overline{-}$
-

See footnotes at end of table. 
Table 33. Oxygenated Motor Gasoline Prices by Grade, Sales Type,

PAD District, and State

(Cents per Gallon Excluding Taxes) - Continued

\begin{tabular}{|c|c|c|c|c|c|c|c|c|c|c|c|c|}
\hline \multirow{3}{*}{$\begin{array}{l}\text { Geographlc Area } \\
\text { Month }\end{array}$} & \multicolumn{6}{|c|}{ Promium } & \multicolumn{6}{|c|}{ All Grades } \\
\hline & \multicolumn{2}{|c|}{ Sales to End Users } & \multicolumn{4}{|c|}{ Sales for Resale } & \multicolumn{2}{|c|}{ Sales to End Users } & \multicolumn{4}{|c|}{ Sales for Resale } \\
\hline & $\begin{array}{l}\text { Through } \\
\text { Rotall } \\
\text { Outlets }\end{array}$ & Average ${ }^{\mathrm{a}}$ & DTW & Rack & Bulk & Average & $\begin{array}{l}\text { Through } \\
\text { Retail } \\
\text { Outlets }\end{array}$ & Average ${ }^{a}$ & DTW & Rack & Bulk & Average \\
\hline
\end{tabular}

Hawall

January

February

March

May .

May .......

July ....

August .

September

October

November

December

1994 Average

\section{Nevada}

January

March

April

May.

June

August

September ................................

October .

November

December

1994 Average

Oregon

January .................................. 94.3

February ................................... 92.5

March

April

May

June

July ....

August ..................................

September ..........................

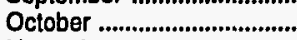

November

December

1994 Average

Washington

January

February

March

Aprll

May

June

July ......

September

October

November

December

1994 Average

-
-
-
-
-
-
-
-
-

$\begin{array}{cc}96.4 & 96.0 \\ 97.2 & 96.7 \\ W & W \\ W & W \\ - & - \\ - & - \\ - & - \\ - & - \\ N A & N A \\ 105.2 & 104.6 \\ 104.0 & 103.6 \\ 104.3 & 103.7 \\ 101.8 & 101.4\end{array}$

$\begin{array}{cc}76.6 & 67.2 \\ 77.9 & 68.8 \\ W & W \\ - & - \\ - & - \\ - & W \\ - & W \\ - & - \\ 83.7 & 81.1 \\ 85.3 & 78.6 \\ 84.7 & 80.5 \\ 82.0 & 74.1 \\ 81.9 & 75.5\end{array}$

$\begin{array}{ccc}- & 75.1 & 83.3 \\ - & 77.2 & 84.4 \\ - & W & W \\ - & - & W \\ - & - & W \\ - & W & W \\ - & W & W \\ - & - & W \\ - & 83.6 & \text { NA } \\ \bar{W} & 84.0 & 92.2 \\ - & 84.1 & 92.0 \\ \mathbf{W} & 80.7 & 93.8 \\ & 81.0 & 88.8\end{array}$

82.0
83.5
$W$
$W$
$W$
$W$
$W$
$W$
$N A$
91.0
91.3
92.9
88.0

$\begin{array}{cccc}63.8 & 56.9 & - & 62.3 \\ 65.8 & 59.7 & - & 65.3 \\ W & W & - & N A \\ W & - & - & W \\ W & - & - & W \\ W & W & - & W \\ W & W & - & W \\ W & W & - & W \\ 74.2 & 72.2 & - & 74.1 \\ 74.4 & 70.4 & - & 73.5 \\ 73.9 & 69.7 & W & 73.1 \\ 71.0 & 64.4 & - & 69.7 \\ 70.4 & 65.6 & W & 69.6\end{array}$

$\begin{array}{cccccc}93.4 & 77.6 & 69.3 & - & 75.1 & 78.5 \\ 92.2 & 76.8 & 69.5 & - & 74.9 & 77.9 \\ 89.1 & W & - & - & W & N A \\ W & - & W & - & W & W \\ W & - & - & - & - & W \\ W & - & - & - & - & W \\ W & - & - & - & - & W \\ W & - & - & - & - & W \\ W & - & - & - & - & W \\ 98.9 & 86.8 & 79.9 & - & 85.0 & 87.3 \\ 99.8 & 85.3 & 78.5 & - & 83.0 & 85.8 \\ 97.9 & 82.6 & 75.7 & - & 80.3 & 83.2 \\ 95.6 & 81.6 & 74.7 & - & 79.4 & 80.4\end{array}$

$\begin{array}{ccccc}77.9 & 67.0 & 58.8 & - & 64.7 \\ 77.3 & 66.5 & 60.6 & - & 65.0 \\ \text { NA } & W & W & - & 66.8 \\ W & - & W & - & W \\ W & - & - & - & - \\ W & - & - & - & - \\ W & - & - & - & - \\ W & - & - & - & - \\ W & - & - & - & - \\ 86.5 & 76.0 & 72.0 & - & 75.0 \\ 85.2 & 74.6 & 69.2 & - & 72.6 \\ 82.8 & 71.0 & 65.8 & - & 69.2 \\ 80.1 & 70.7 & 65.2 & - & 69.0\end{array}$

86.7
84.9
87.6
$W$
$W$
$W$
$N A$
$W$
98.5
96.7
99.5
97.7
92.8

$\begin{array}{ccccccc}76.0 & 71.4 & 71.1 & 65.7 & 61.9 & - & 65.0 \\ 75.8 & 70.6 & 70.5 & 65.5 & 62.4 & - & 65.0 \\ 77.1 & 75.6 & 75.5 & 69.2 & 58.5 & - & 68.5 \\ 78.6 & W & W & 70.6 & 62.1 & - & 70.2 \\ W & W & W & W & - & - & W \\ W & W & W & - & W & - & W \\ W & N A & W & - & W & - & W \\ 87.9 & W & W & W & 78.0 & - & 79.2 \\ 85.3 & 90.6 & 89.6 & 79.8 & 78.1 & - & 78.6 \\ 87.6 & 85.2 & 84.9 & 79.2 & 74.3 & - & 78.2 \\ 87.4 & 86.3 & 85.8 & 78.0 & 72.2 & - & 76.7 \\ 84.9 & 84.0 & 83.5 & 75.7 & 67.6 & - & 74.0 \\ 81.4 & 79.8 & 79.5 & 72.1 & 68.3 & - & 71.3\end{array}$

Dash $(-)=$ No data reported.

NA $=$ Not avallable.

$W=$ Withheld to avold disclosure of individual company data.

a Includes sales through retail outlets as well as all direct sales to end users that were not made through company-operated retail outlets, e.g., sales to agricultural customers, commerclal sales, and industrial sales.

Sources: Energy Information Administration Forms ElA-782A, "Refiners'/Gas Plant Operators' Monthly Petroleum Product Sales Report," and ElA-782B,

'Resellers'/Retallers' Monthly Petroleum Product Sales Report." 
Table 34. Reformulated Motor Gasoline Prices by Grade, Sales Type, PAD District, and State

(Cents per Gallon Excluding Taxes)

\begin{tabular}{|c|c|c|c|c|c|c|c|c|c|c|c|c|}
\hline \multirow{3}{*}{$\begin{array}{l}\text { Goographic Area } \\
\text { Month }\end{array}$} & \multicolumn{6}{|c|}{ Regular } & \multicolumn{6}{|c|}{ Midgrade } \\
\hline & \multicolumn{2}{|c|}{ Sales to End Users } & \multicolumn{4}{|c|}{ Sales for Rosalo } & \multicolumn{2}{|c|}{ Sales to End Users } & \multicolumn{4}{|c|}{ Sales for Resalo } \\
\hline & $\begin{array}{l}\text { Through } \\
\text { Retall } \\
\text { Outlets }\end{array}$ & Average ${ }^{a}$ & DTW & Rack & Bulk & Average & $\begin{array}{l}\text { Through } \\
\text { Retail } \\
\text { Outlots }\end{array}$ & Averagea & DTW & Rack & Bulk & Average \\
\hline
\end{tabular}

United States

January

February

March

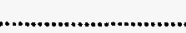

May

June

July .

August .

September

October

November ....

December

1994 Average

PAD District I

January

February

March

April

May

June

July ....

Septemb

October ...

vember

December

1994 Average

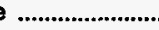

Subdistrict IA

January

February

March

April

May

June

July ..

August .

r............................

October

November ..................................

December

1994 Average

Connecticut

January

February

March

April

May

June

July .

September

October...

November

1994 Average

$\begin{array}{cccc}- & - & - & - \\ - & - & - & - \\ - & - & - & - \\ - & - & - & - \\ - & - & - & - \\ - & - & - & - \\ - & - & - & - \\ - & - & - & - \\ - & - & - & - \\ 77.8 & 77.2 & 71.4 & 60.3 \\ 75.0 & 74.2 & 70.6 & 57.1 \\ 75.1 & 74.3 & 70.7 & 57.2\end{array}$

$\begin{array}{ll}- & \\ - & \\ - & \\ - & \\ - & \\ - & \\ - & \\ - & \\ 60.3 & 59.1 \\ 57.1 & 53.1 \\ 57.2 & 54.0\end{array}$

$\begin{array}{ll}- & - \\ - & - \\ - & - \\ \overline{-} & - \\ - & - \\ - & - \\ - & - \\ - & - \\ 59.1 & 65.7 \\ 53.1 & 63.0 \\ 54.0 & 63.2\end{array}$

$\begin{array}{lr}- & - \\ - & - \\ - & - \\ - & - \\ - & - \\ - & - \\ - & - \\ - & - \\ - & - \\ - & - \\ \text { NA } & \text { NA } \\ 86.0 & 84.9 \\ 86.1 & 85.1\end{array}$

$\begin{array}{ccc}- & - & - \\ - & - & - \\ - & - & - \\ - & - & - \\ - & - & - \\ - & - & - \\ - & - & - \\ - & - & - \\ - & - & - \\ - & - & - \\ \text { NA } & 77.8 & 69.0 \\ 84.9 & 76.3 & 62.8 \\ 85.1 & 76.4 & 63.1\end{array}$

$\begin{array}{ll}- & - \\ - & - \\ - & - \\ - & - \\ - & - \\ - & - \\ - & - \\ - & - \\ - & - \\ - & 75.6 \\ w & 72.1 \\ w & 72.2\end{array}$

\begin{tabular}{|c|c|c|c|c|c|c|c|c|c|c|c|}
\hline - & - & - & - & - & - & - & - & - & - & - & - \\
\hline- & - & - & - & - & - & - & - & - & - & - & - \\
\hline- & - & - & - & - & - & - & - & - & - & - & - \\
\hline - & - & - & - & - & - & - & - & - & - & - & - \\
\hline- & - & - & - & - & - & - & - & - & - & - & - \\
\hline- & - & - & - & - & - & - & - & - & - & - & - \\
\hline- & - & - & - & - & - & - & - & - & - & - & - \\
\hline- & - & - & - & - & - & - & - & - & - & - & - \\
\hline - & - & - & - & - & - & - & - & - & - & - & - \\
\hline- & - & - & - & - & - & - & - & - & - & - & - \\
\hline 75.2 & 71.6 & 712 & 61.4 & 59.2 & 65.0 & 90.6 & 78.8 & 78.8 & 70.2 & - & 76.4 \\
\hline 75.1 & 74.2 & 70.7 & 58.5 & 53.2 & 63.0 & 86.1 & 84.9 & 77.1 & 63.9 & w & 72.2 \\
\hline 75.1 & 74.1 & 70.8 & 58.7 & 54.2 & 63.2 & 86.2 & 84.8 & 77.2 & 64.2 & $w$ & 72.4 \\
\hline
\end{tabular}

See footnotes at end of table. 
Table 34. Reformulated Motor Gasoline Prices by Grade, Sales Type, PAD District, and State

(Cents per Gallon Excluding Taxes) - Continued

\begin{tabular}{|c|c|c|c|c|c|c|c|c|c|c|c|c|}
\hline \multirow{3}{*}{$\begin{array}{l}\text { Geographlc Area } \\
\text { Month }\end{array}$} & \multicolumn{6}{|c|}{ Premlum } & \multicolumn{6}{|c|}{ All Grades } \\
\hline & \multicolumn{2}{|c|}{ Sales to End Users } & \multicolumn{4}{|c|}{ Sales for Resale } & \multicolumn{2}{|c|}{ Sales to End Users } & \multicolumn{4}{|c|}{ Sales for Resale } \\
\hline & $\begin{array}{c}\text { Through } \\
\text { Retall } \\
\text { Outlets }\end{array}$ & Averagea & DTW & Rack & Bulk & Average & $\begin{array}{c}\text { Through } \\
\text { Retail } \\
\text { Outlets }\end{array}$ & Averagoa & DTW & Rack & Bulk & Average \\
\hline \multicolumn{13}{|l|}{ United States } \\
\hline 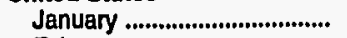 & - & - & - & - & - & - & - & - & - & - & - & - \\
\hline February ................................ & - & - & - & - & - & - & - & - & - & - & - & - \\
\hline March ...................................... & - & - & - & - & - & - & - & - & - & $\rightarrow$ & - & - \\
\hline April & - & - & - & - & - & - & - & - & - & - & - & - \\
\hline May ........................................... & - & - & - & - & - & - & - & - & - & - & - & - \\
\hline June ......................................... & - & - & - & - & - & - & - & - & - & - & - & - \\
\hline July .......................................... & - & - & - & - & - & - & - & - & - & - & - & - \\
\hline 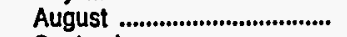 & - & - & - & - & - & - & - & - & - & - & - & - \\
\hline September ........................... & - & - & - & - & - & - & - & - & - & - & - & - \\
\hline October ..................................... & - & - & - & - & - & - & - & - & - & - & - & - \\
\hline Novamber ............................... & $\begin{array}{l}97.2 \\
94.9\end{array}$ & $\begin{array}{l}96.4 \\
93.6 \\
93.7\end{array}$ & $\begin{array}{l}84.5 \\
85.1 \\
85.0\end{array}$ & $\begin{array}{l}69.4 \\
67.6 \\
67.7\end{array}$ & $\begin{array}{l}61.2 \\
54.3 \\
55.5\end{array}$ & $\begin{array}{l}77.4 \\
76.8 \\
76.9\end{array}$ & $\begin{array}{l}87.5 \\
80.9 \\
81.1\end{array}$ & $\begin{array}{l}86.5 \\
79.9 \\
80.2\end{array}$ & $\begin{array}{l}76.7 \\
75.6 \\
75.7\end{array}$ & $\begin{array}{l}64.1 \\
60.0 \\
60.2\end{array}$ & $\begin{array}{l}59.6 \\
53.4\end{array}$ & $\begin{array}{l}70.2 \\
67.7\end{array}$ \\
\hline 1994 Average ............................. & & & & & & & & & & & & \\
\hline \multicolumn{13}{|l|}{ PAD Dlatrict I } \\
\hline 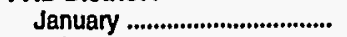 & - & - & - & - & - & - & - & - & - & - & - & - \\
\hline February ................................ & - & - & - & - & - & - & - & - & - & - & - & - \\
\hline 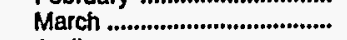 & - & - & - & - & - & - & - & - & - & - & - & - \\
\hline 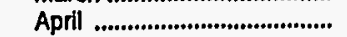 & - & - & - & - & - & - & - & - & - & - & - & - \\
\hline May ......................................... & - & - & - & - & - & - & - & - & - & - & - & - \\
\hline June ........................................ & - & - & - & - & - & - & - & - & - & - & - & - \\
\hline 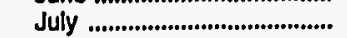 & - & - & - & - & - & - & - & - & - & - & - & - \\
\hline August $\ldots . . . . . . . . . . . . . . . . . . . . . . . . . . .$. & - & - & - & - & - & - & - & - & - & - & - & - \\
\hline September .......................... & - & - & - & - & - & - & - & - & - & - & - & - \\
\hline October .................................. & - & - & - & - & - & - & - & - & - & - & - & - \\
\hline 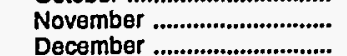 & $\begin{array}{l}97.3 \\
95.4\end{array}$ & $\begin{array}{r}\text { NA } \\
93.7\end{array}$ & $\begin{array}{l}86.6 \\
85.7\end{array}$ & $\begin{array}{l}69.2 \\
68.9\end{array}$ & $\begin{array}{l}60.7 \\
54.5\end{array}$ & $\begin{array}{l}74.5 \\
76.5\end{array}$ & $\begin{array}{l}85.9 \\
81.5\end{array}$ & $\begin{array}{l}77.4 \\
80.2\end{array}$ & $\begin{array}{l}76.5 \\
76.4\end{array}$ & $\begin{array}{l}64.9 \\
61.6\end{array}$ & $\begin{array}{l}59.7 \\
53.6\end{array}$ & $\begin{array}{l}68.9 \\
67.9\end{array}$ \\
\hline 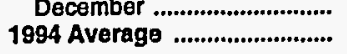 & $\begin{array}{l}95.4 \\
95.4\end{array}$ & 93.6 & 85.7 & 68.9 & 55.6 & 76.4 & 81.5 & 80.2 & 76.4 & 61.8 & 54.6 & 67.9 \\
\hline \multicolumn{13}{|l|}{ Subdistrict IA } \\
\hline January .................................. & - & - & - & - & - & - & - & - & - & - & - & - \\
\hline 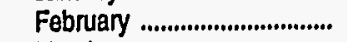 & - & - & - & - & - & - & - & - & - & - & - & - \\
\hline March ...................................... & - & - & - & - & - & - & - & - & - & - & - & - \\
\hline 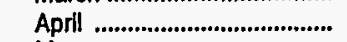 & - & - & - & - & - & - & - & - & - & - & - & - \\
\hline 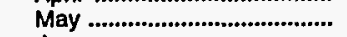 & - & - & - & - & - & - & - & - & - & - & - & - \\
\hline 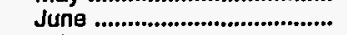 & - & - & - & - & - & - & - & - & - & - & - & - \\
\hline 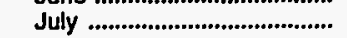 & - & - & - & - & - & - & - & - & - & - & - & - \\
\hline 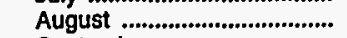 & - & - & - & - & - & - & - & - & - & - & - & - \\
\hline September ............................. & - & - & - & - & - & - & - & - & - & - & - & - \\
\hline 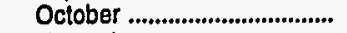 & - & - & - & - & - & - & - & - & - & - & - & - \\
\hline November ............................. & $w$ & NA & 85.9 & 70.2 & - & 81.3 & $W$ & 77.7 & 76.8 & 61.7 & - & 72.1 \\
\hline December ............................. & 95.0 & 93.2 & 84.2 & 68.3 & W & 75.3 & 80.8 & 79.8 & 74.7 & 60.7 & 52.5 & 65.8 \\
\hline 1994 Average ............................. & 95.0 & 93.2 & 84.3 & 68.3 & $w$ & 75.4 & 80.8 & 79.8 & 74.7 & 60.7 & 52.5 & 65.9 \\
\hline \multicolumn{13}{|l|}{ Connecticut } \\
\hline 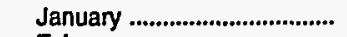 & - & - & - & - & - & - & - & - & - & - & - & - \\
\hline 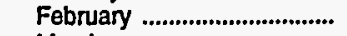 & - & - & - & - & - & - & - & - & - & - & - & - \\
\hline 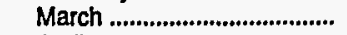 & - & - & - & - & - & - & - & - & - & - & - & - \\
\hline Aptil ..................................... & - & - & - & - & - & - & - & - & - & - & - & - \\
\hline May ......................................... & - & $\rightarrow$ & - & - & - & - & - & - & - & - & - & - \\
\hline June ....................................... & - & - & - & - & - & - & - & - & - & - & - & - \\
\hline 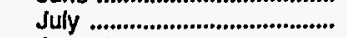 & - & - & - & - & - & - & - & - & - & - & - & - \\
\hline 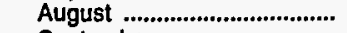 & - & - & - & - & - & - & - & 一 & - & - & - & - \\
\hline September ............................. & - & - & - & - & - & - & - & - & - & - & - & - \\
\hline 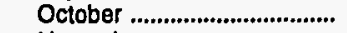 & - & - & - & - & - & - & - & - & - & - & - & $\overline{-}$ \\
\hline November ............................. & - & NA & W & 73.2 & - & 84.4 & - & W & $W$ & 64.5 & - & 75.2 \\
\hline 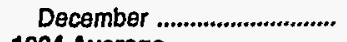 & 97.5 & 95.2 & 84.5 & 72.8 & - & 78.4 & 82.0 & 80.5 & 74.8 & 62.8 & $W$ & 67.4 \\
\hline 1994 Average & 97.5 & 95.0 & 84.6 & 72.8 & - & 78.5 & 82.0 & 80.4 & 74.9 & 62.8 & $w$ & 67.5 \\
\hline
\end{tabular}

See footnotes at end of table. 
Table 34. Reformulated Motor Gasoline Prices by Grade, Sales Type, PAD District, and State

(Cents per Gallon Excluding Taxes) - Continued

\begin{tabular}{|c|c|c|c|c|c|c|c|c|c|c|c|c|}
\hline \multirow{3}{*}{$\begin{array}{l}\text { Geographic Area } \\
\text { Month }\end{array}$} & \multicolumn{6}{|c|}{ Regular } & \multicolumn{6}{|c|}{ Midgrado } \\
\hline & \multicolumn{2}{|c|}{ Sales to End Users } & \multicolumn{4}{|c|}{ Sales for Resale } & \multicolumn{2}{|c|}{ Sales to End Users } & \multicolumn{4}{|c|}{ Sales for Resale } \\
\hline & $\begin{array}{c}\text { Through } \\
\text { Retail } \\
\text { Outlots }\end{array}$ & Average ${ }^{a}$ & DTw & Rack & Bulk & Average & $\begin{array}{l}\text { Through } \\
\text { Rotail } \\
\text { Outlets }\end{array}$ & Average $\mathrm{a}$ & DTW & Rack & Bulk & Averago \\
\hline
\end{tabular}

Maine

January

February

March

April

May .

July

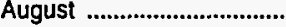

September

October ....

November ..........................

December ...............................

1994 Averag

Massachusetts

January

February

March

April

May

June

July ....

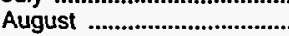

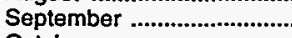

October

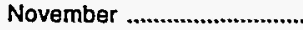

December

1994 Average

New Hampshire

January .

February

March

April

May

June

August

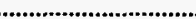

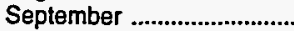

October

November

December

1994 Average

Rhode lsland

January

February

March ...

April

May

June

July ....

September

October

November

December .

1994 Average

$\begin{array}{cccc}- & - & - & - \\ - & - & - & - \\ - & - & - & - \\ - & - & - & - \\ - & - & - & - \\ - & - & - & - \\ - & - & - & - \\ - & - & - & - \\ - & - & - & - \\ - & - & - & - \\ - & - & w & 55.9 \\ 73.8 & 73.0 & 66.3 & 58.0 \\ 73.8 & 73.0 & 66.2 & 57.9\end{array}$

-
-
-
-
-
-
-
-
$\bar{w}$
$w$

$\begin{array}{ll}- & - \\ - & - \\ - & - \\ - & - \\ - & - \\ - & - \\ - & - \\ - & - \\ - & - \\ - & - \\ - & - \\ 83.3 & 82.3 \\ 83.3 & 82.3\end{array}$

-
-
$\overline{-}$
$\overline{-}$
-
-
$\overline{-}$
$\overline{N A}$
81.5
81.4

$\begin{array}{ccc}- & - & - \\ - & - & - \\ - & - & - \\ - & - & - \\ - & - & - \\ - & - & - \\ - & - & - \\ - & - & - \\ - & - & - \\ - & - & - \\ 59.7 & - & \text { NA } \\ 61.9 & - & 67.7 \\ 61.8 & - & 67.6\end{array}$

\begin{tabular}{|c|c|c|c|c|c|c|c|c|c|c|}
\hline - & - & - & - & - & - & - & - & - & - & - \\
\hline - & - & - & - & - & - & - & - & - & - & - \\
\hline- & - & - & - & - & - & - & - & - & - & - \\
\hline- & - & - & - & - & - & - & - & - & - & - \\
\hline- & - & - & - & - & - & - & - & - & - & - \\
\hline - & - & - & - & - & - & - & - & - & - & - \\
\hline - & - & - & - & - & - & - & - & - & - & - \\
\hline- & - & - & - & - & - & - & - & - & - & - \\
\hline- & - & - & - & - & - & - & - & - & - & - \\
\hline- & - & - & - & - & - & - & - & - & - & - \\
\hline$w$ & 70.8 & 56.9 & - & 68.3 & - & $w$ & 76.7 & 64.1 & - & 75.7 \\
\hline 74.9 & 70.6 & 57.7 & 52.5 & 62.0 & 85.8 & 84.2 & 77.5 & 60.9 & $w$ & 70.3 \\
\hline 74.9 & 70.6 & 57.7 & 52.5 & 62.0 & 85.8 & 84.2 & 77.4 & 60.9 & $w$ & 70.4 \\
\hline
\end{tabular}

See footnotes at end of table. 
Table 34. Reformulated Motor Gasoline Prices by Grade, Sales Type, PAD Dlstrict, and State

(Cents per Gallon Excluding Taxes) - Continued

\begin{tabular}{|c|c|c|c|c|c|c|c|c|c|c|c|c|}
\hline \multirow{3}{*}{$\begin{array}{l}\text { Geographic Area } \\
\text { Month }\end{array}$} & \multicolumn{6}{|c|}{ Premium } & \multicolumn{6}{|c|}{ All Grades } \\
\hline & \multicolumn{2}{|c|}{ Sales to End Users } & \multicolumn{4}{|c|}{ Sales for Resale } & \multicolumn{2}{|c|}{ Sales to End Users } & \multicolumn{4}{|c|}{ Sales for Resale } \\
\hline & $\begin{array}{l}\text { Through } \\
\text { Retail } \\
\text { Outlete }\end{array}$ & Averagea & DTW & Rack & Bulk & Average & $\begin{array}{l}\text { Through } \\
\text { Rotail } \\
\text { Outlets }\end{array}$ & Averagea & DTW & Rack & Bulk & Average \\
\hline
\end{tabular}

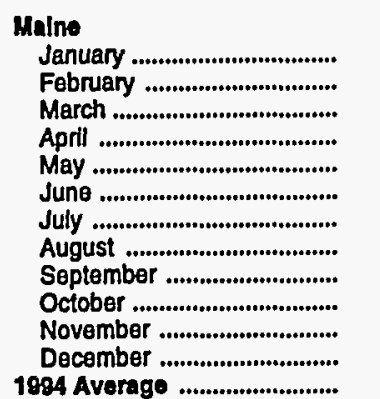

\begin{tabular}{|c|c|c|}
\hline - & - & - \\
\hline - & - & - \\
\hline - & - & - \\
\hline- & - & - \\
\hline $\bar{z}$ & $\bar{z}$ & $\overline{-}$ \\
\hline - & - & - \\
\hline & . & - \\
\hline- & - & - \\
\hline - & $\overline{-}$ & $\vec{w}$ \\
\hline 91.0 & 90.2 & 79.6 \\
\hline 91.0 & 90.2 & 79.5 \\
\hline
\end{tabular}

-
$=$
$=$
$=$
$=$
$=$
65.8
68.1

$\begin{array}{ll}= & - \\ = & - \\ = & - \\ = & = \\ = & = \\ = & - \\ = & - \\ = & 65.8 \\ - & 70.4\end{array}$

\begin{tabular}{|c|c|c|}
\hline- & - & - \\
\hline - & - & - \\
\hline- & - & - \\
\hline - & - & - \\
\hline- & 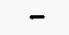 & - \\
\hline & - & - \\
\hline - & $\overline{-}$ & $\overline{-}$ \\
\hline - & - & - \\
\hline & - & - \\
\hline$\overline{\pi 9}$ & - & NA \\
\hline $\begin{array}{l}77.9 \\
77.9\end{array}$ & 77.0 & 71.9 \\
\hline 77.9 & 77.0 & 71.7 \\
\hline
\end{tabular}

\begin{tabular}{|c|c|c|}
\hline - & - & - \\
\hline - & - & - \\
\hline - & - & I \\
\hline$\overline{-}$ & - & $\overline{-}$ \\
\hline$\overline{-}$ & - & - \\
\hline _- & - & - \\
\hline- & - & \\
\hline$=$ & - & - \\
\hline 58.2 & $\overline{-}$ & $\overline{58.4}$ \\
\hline 60.3 & W & 61.7 \\
\hline 60.3 & W & 61.6 \\
\hline
\end{tabular}

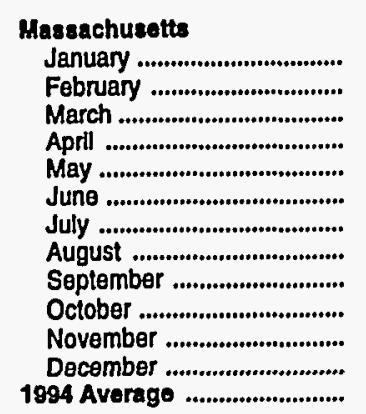

\begin{tabular}{|c|c|c|c|}
\hline- & - & - & - \\
\hline & - & - & - \\
\hline$\overline{-}$ & $\bar{z}$ & $\bar{z}$ & 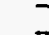 \\
\hline - & $\overline{-}$ & $\overline{-}$ & - \\
\hline - & - & - & - \\
\hline - & - & - & - \\
\hline & - & - & - \\
\hline 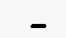 & - & - & - \\
\hline - & $w$ & 84.6 & 69 \\
\hline $\begin{array}{l}95.1 \\
95.1\end{array}$ & $\begin{array}{l}92.9 \\
92.9\end{array}$ & $\begin{array}{l}85.1 \\
85.1\end{array}$ & $\begin{array}{l}66 \\
66\end{array}$ \\
\hline
\end{tabular}

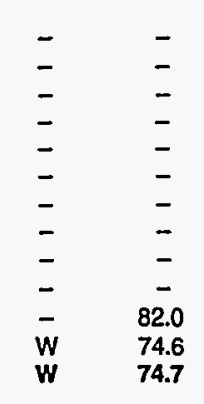

\begin{tabular}{|c|c|c|c|c|c|}
\hline- & - & - & - & - & - \\
\hline - & - & - & - & - & - \\
\hline - & - & - & - & - & - \\
\hline - & - & - & - & - & - \\
\hline - & - & - & - & - & - \\
\hline- & - & - & - & - & - \\
\hline- & - & - & - & - & - \\
\hline- & - & - & - & - & - \\
\hline - & $=$ & $\overline{-}$ & $\overline{-}$ & $\overline{-}$ & $\overline{-}$ \\
\hline - & $w$ & 75.6 & 61.0 & - & 73.3 \\
\hline 81.1 & 80.1 & 75.4 & 60.0 & 52.7 & 65.9 \\
\hline 81.1 & 80.1 & 75.4 & 60.0 & 52.7 & 66.0 \\
\hline
\end{tabular}

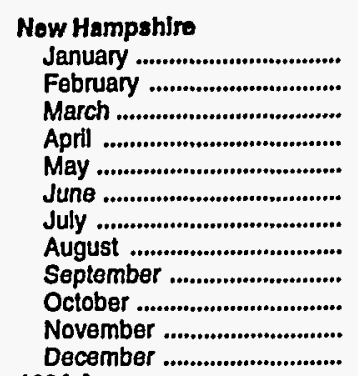
1994 Average

\begin{tabular}{|c|c|c|c|c|}
\hline - & - & - & - & - \\
\hline - & - & - & - & - \\
\hline - & - & - & - & - \\
\hline - & - & - & - & - \\
\hline- & - & - & - & - \\
\hline - & - & - & - & - \\
\hline - & - & - & - & - \\
\hline & - & - & - & - \\
\hline- & - & - & - & - \\
\hline - & $\overline{-}$ & $\bar{w}$ & $\bar{w}$ & $=$ \\
\hline 94.6 & 94.1 & 82.3 & 68.9 & - \\
\hline
\end{tabular}

$\begin{array}{llllll}- & - & - & - & - & - \\ \overline{-} & - & - & - & - & - \\ \overline{-} & - & - & - & - & - \\ \overline{-} & - & - & - & - & - \\ - & - & - & - & - & - \\ - & - & - & - & - & - \\ - & - & - & - & - & - \\ - & - & - & - & - & - \\ - & - & \bar{w} & \bar{w} & - & \bar{w} \\ 81.1 & 80.6 & 73.2 & 62.6 & - & 69.6 \\ 81.1 & 80.6 & 73.2 & 62.7 & - & 69.6\end{array}$

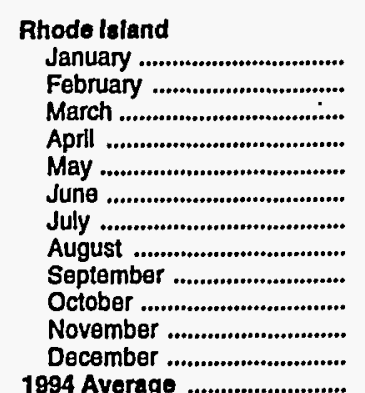

\begin{tabular}{|c|c|c|c|}
\hline - & - & - & - \\
\hline- & - & - & - \\
\hline - & - & - & - \\
\hline - & - & - & - \\
\hline - & - & - & - \\
\hline- & 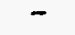 & - & - \\
\hline- & - & - & - \\
\hline - & - & - & - \\
\hline- & - & - & - \\
\hline$w$ & $\bar{w}$ & $\bar{w}$ & $\bar{z}$ \\
\hline 89.8 & 89.7 & 81.0 & 65.5 \\
\hline 89.9 & 89.9 & 81.0 & 65.5 \\
\hline
\end{tabular}

$\begin{array}{ll}= & = \\ = & = \\ = & = \\ = & = \\ = & = \\ - & 721\end{array}$

\begin{tabular}{|c|c|}
\hline - & - \\
\hline - & - \\
\hline- & - \\
\hline - & - \\
\hline- & - \\
\hline - & - \\
\hline - & - \\
\hline- & - \\
\hline$\overline{-}$ & $\bar{z}$ \\
\hline $\bar{w}$ & $\bar{w}$ \\
\hline 77.6 & $\pi 7.4$ \\
\hline 77.8 & 77.5 \\
\hline
\end{tabular}

See footnotes at end of table. 
Table 34. Reformulated Motor Gasoline Prices by Grade, Sales Type, PAD District, and State

(Cents per Gallon Excluding Taxes) - Continued

\begin{tabular}{|c|c|c|c|c|c|c|c|c|c|c|c|c|}
\hline \multirow{3}{*}{$\begin{array}{l}\text { Geographic Area } \\
\text { Month }\end{array}$} & \multicolumn{6}{|c|}{ Regular } & \multicolumn{6}{|c|}{ Midgrade } \\
\hline & \multicolumn{2}{|c|}{ Sales to End Users } & \multicolumn{4}{|c|}{ Sales for Resale } & \multicolumn{2}{|c|}{ Sales to End Users } & \multicolumn{4}{|c|}{ Sales for Resale } \\
\hline & $\begin{array}{l}\text { Through } \\
\text { Rotall } \\
\text { Outlets }\end{array}$ & Average ${ }^{a}$ & DTW & Rack & Bulk & Average & $\begin{array}{c}\text { Through } \\
\text { Retail } \\
\text { Outlets }\end{array}$ & Average ${ }^{a}$ & DTW & Rack & Bulk & Average \\
\hline
\end{tabular}

Vermont

January

February

March .

April

May

June

July .....

August ...

October ...

November

December

Subdistriot

January .

February

March

April

May

June

July ........

August

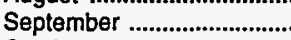

October

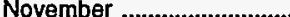

December

1994 Average

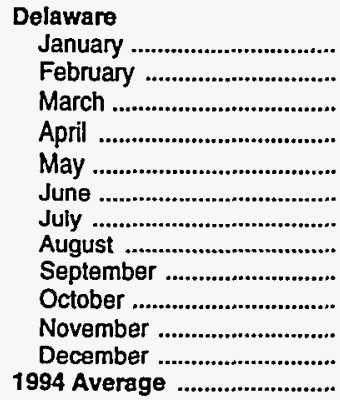

1994 Average

\section{District of Columbia}

January

February

March

April

May

June

July ....

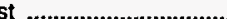

September ................................

October

November

December

1994 Average

-
$=$
$=$
-
$=$
-
-
-
-

$\begin{array}{ll}- & - \\ - & - \\ - & - \\ - & - \\ - & - \\ - & - \\ - & - \\ - & - \\ - & - \\ \bar{W} & 70.5 \\ W & 70.5\end{array}$

$\begin{array}{ll}- & - \\ - & - \\ - & - \\ - & - \\ - & - \\ - & - \\ - & - \\ - & - \\ - & - \\ \bar{w} & - \\ W & -\end{array}$

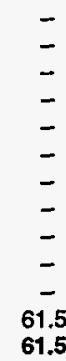

-
-
-
-
-
-
-
$\overline{-}$
$\overline{-}$
$\mathbf{w}$
$\mathbf{W}$

-
-
-
-
-
-
-
$\bar{w}$
$w$

$\begin{array}{ll}- & - \\ - & - \\ - & - \\ - & - \\ - & - \\ - & - \\ - & - \\ - & \\ W & \end{array}$

-
-
-
$\overline{-}$
-
$\overline{-}$
$\overline{-}$
$\overline{72.0}$
72.0

$\begin{array}{ccc}- & - & - \\ - & - & - \\ - & - & - \\ - & - & - \\ - & - & - \\ - & - & - \\ - & - & - \\ - & - & - \\ - & - & - \\ - & - & - \\ 75.3 & 72.2 & 70.9 \\ 75.2 & 74.2 & 71.2 \\ 75.2 & 74.1 & 71.2\end{array}$

$\begin{array}{ll}- & - \\ - & - \\ - & - \\ - & - \\ - & - \\ - & - \\ - & - \\ - & - \\ - & - \\ 61.4 & 59.2 \\ 59.1 & 53.4 \\ 59.2 & 54.5\end{array}$

\section{-
-
$\overline{-}$
-
-
$\overline{-}$
$\overline{-}$
90.3
86.4
86.4}

$\begin{array}{ll}- & - \\ - & - \\ - & - \\ - & - \\ - & - \\ - & - \\ - & - \\ - & - \\ - & - \\ 81.5 & 78.9 \\ 85.3 & 77.3 \\ 85.3 & 77.5\end{array}$

$\begin{array}{ccc}- & - & - \\ - & - & - \\ - & - & - \\ - & - & - \\ - & - & - \\ - & - & - \\ - & - & - \\ - & - & - \\ - & - & - \\ - & - & - \\ 70.3 & - & 76.5 \\ 65.4 & w & 73.2 \\ 65.8 & w & 73.5\end{array}$

See footnotes at end of table. 
Table 34. Reformulated Motor Gasoline Prices by Grade, Sales Type,

PAD District, and State

(Cents per Gallon Excluding Taxes) - Continued

\begin{tabular}{|c|c|c|c|c|c|c|c|c|c|c|c|c|}
\hline \multirow{3}{*}{$\begin{array}{l}\text { Geographic Area } \\
\text { Month }\end{array}$} & \multicolumn{6}{|c|}{ Promlum } & \multicolumn{6}{|c|}{ All Grades } \\
\hline & \multicolumn{2}{|c|}{ Sales to End Users } & \multicolumn{4}{|c|}{ Sales for Resale } & \multicolumn{2}{|c|}{ Sales to End Users } & \multicolumn{4}{|c|}{ Sales for Resale } \\
\hline & $\begin{array}{c}\text { Through } \\
\text { Rotall } \\
\text { Outlots }\end{array}$ & Average ${ }^{a}$ & DTW & Rack & Bulk & Average & $\begin{array}{c}\text { Through } \\
\text { Retall } \\
\text { Outlots }\end{array}$ & Averagea & DTW & Rack & Bulk & Average \\
\hline
\end{tabular}

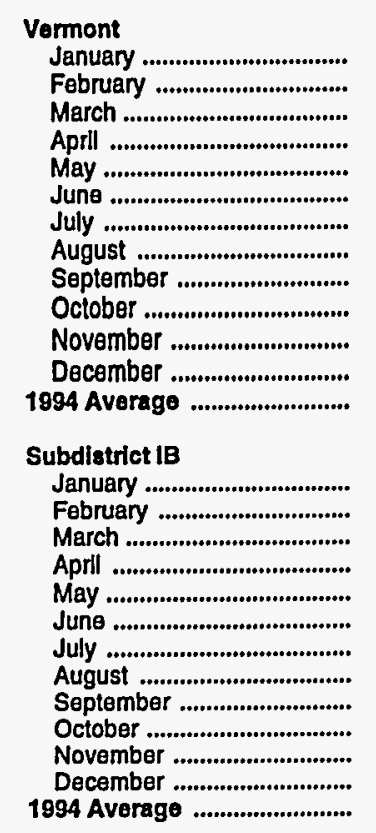

-
-
-

$\begin{array}{lc}- & - \\ - & - \\ - & - \\ \bar{z} & - \\ \overline{-} & - \\ - & - \\ - & - \\ \overline{-} & - \\ \bar{W} & - \\ w & 86.0\end{array}$

$\begin{array}{llll}- & - & - & - \\ - & - & - & - \\ - & - & - & - \\ - & - & - & - \\ - & - & - & - \\ - & - & - & - \\ - & - & - & - \\ - & - & - & - \\ - & - & - & - \\ - & - & - & - \\ - & - & - & - \\ W & - & 71.3 & - \\ W & - & 71.3 & -\end{array}$

$\begin{array}{lllll}- & - & - & - & - \\ - & - & - & - & - \\ - & - & - & - & - \\ - & - & - & - & - \\ - & - & - & - & - \\ - & - & - & - & - \\ - & - & - & - & - \\ - & - & - & - & - \\ - & - & - & - & - \\ - & - & - & - & - \\ - & - & - & - & - \\ w & 75.2 & w & - & 64.5 \\ w & 75.2 & w & - & 64.5\end{array}$

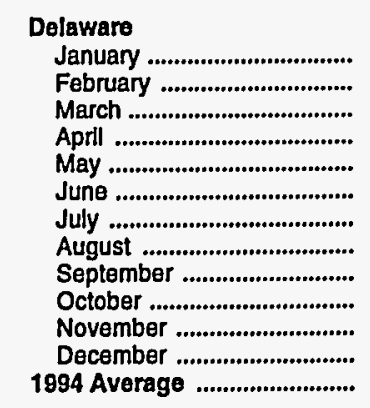

-
$\overline{-}$
$\overline{-}$
$\overline{-}$
$\overline{-}$
$\overline{-}$
97.2
95.7

$\begin{array}{ccc}- & - & - \\ - & - & - \\ - & - & - \\ - & - & - \\ - & - & - \\ - & - & - \\ - & - & - \\ - & - & - \\ - & - & - \\ \overline{N A} & 86.6 & 68.2 \\ 93.9 & 86.2 & 69.2 \\ 93.8 & 86.3 & 69.1\end{array}$

$\begin{array}{ccc}- & - & - \\ - & = & - \\ - & - & - \\ \overline{-} & - & - \\ = & - & - \\ - & - & - \\ - & - & - \\ - & - & - \\ 60.7 & 73.7 & 85.3 \\ 54.3 & 76.7 & 82.0 \\ 55.5 & 76.4 & 82.0\end{array}$

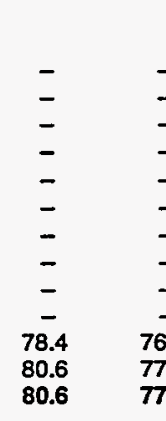

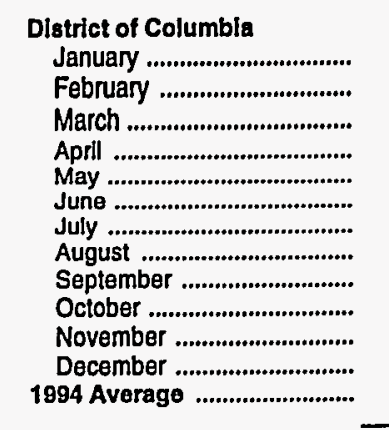

\begin{tabular}{|c|c|c|c|c|c|c|c|c|c|c|c|}
\hline - & - & - & - & - & - & - & - & - & - & - & - \\
\hline- & - & - & - & - & - & - & - & - & - & - & - \\
\hline- & - & - & - & - & - & - & - & - & - & - & - \\
\hline$\overline{-}$ & $=$ & $\overline{-}$ & $=$ & $\overline{-}$ & - & $\bar{z}$ & - & $\overline{-}$ & $\bar{z}$ & $\overline{-}$ & $\bar{z}$ \\
\hline - & - & - & - & - & - & - & - & - & - & - & - \\
\hline - & - & - & - & - & - & - & - & - & - & - & - \\
\hline $\bar{z}$ & - & - & - & - & - & - & - & - & - & - & - \\
\hline$\overline{-}$ & $\bar{z}$ & $=$ & $\bar{z}$ & $\overline{-}$ & - & - & $=$ & $\overline{-}$ & - & $\bar{z}$ & - \\
\hline - & $w$ & $\bar{w}$ & $\overline{-}$ & $\overline{-}$ & $\bar{w}$ & - & $\bar{w}$ & $\bar{w}$ & $\overline{-}$ & $\overline{-}$ & $\bar{w}$ \\
\hline $\begin{array}{l}94.0 \\
94.0\end{array}$ & $\begin{array}{l}92.8 \\
92.7\end{array}$ & $\begin{array}{l}81.6 \\
81.7\end{array}$ & $\begin{array}{l}70.0 \\
70.0\end{array}$ & $\begin{array}{l}W \\
W\end{array}$ & $\begin{array}{l}67.3 \\
67.3\end{array}$ & $\begin{array}{l}79.0 \\
79.0\end{array}$ & $\begin{array}{l}78.3 \\
78.2\end{array}$ & $\begin{array}{l}71.7 \\
71.7\end{array}$ & $\begin{array}{l}61.9 \\
61.9\end{array}$ & $\begin{array}{l}w \\
w\end{array}$ & $\begin{array}{l}64.6 \\
64.6\end{array}$ \\
\hline - & - & - & - & - & - & - & - & - & - & - & - \\
\hline - & - & - & - & - & - & - & - & - & - & - & - \\
\hline- & - & - & - & - & - & - & - & - & - & - & - \\
\hline $\bar{z}$ & - & - & - & - & - & - & - & - & - & - & - \\
\hline $\bar{z}$ & $\bar{z}$ & $\overline{-}$ & $\bar{z}$ & $\bar{z}$ & $=$ & z & $\bar{z}$ & $\bar{z}$ & $\bar{z}$ & $\overline{-}$ & I \\
\hline - & - & - & - & - & - & - & - & - & - & - & $\overline{-}$ \\
\hline - & - & - & - & - & - & - & - & - & - & - & - \\
\hline- & - & - & - & - & - & - & - & - & - & - & - \\
\hline - & $\bar{z}$ & $\bar{w}$ & $\overline{-}$ & $\overline{-}$ & $\bar{w}$ & $\bar{z}$ & $\bar{w}$ & $\bar{w}$ & - & $\overline{-}$ & $\bar{w}$ \\
\hline- & $\bar{w}$ & 88.0 & $=$ & $\overrightarrow{-}$ & 88.0 & - & 61.3 & 81.9 & $\bar{w}$ & - & 81.9 \\
\hline - & $w$ & 88.0 & - & - & 88.0 & - & 61.3 & 81.9 & $\mathbf{w}$ & - & 81.9 \\
\hline
\end{tabular}

See footnotes at end of table. 
Table 34. Reformulated Motor Gasoline Prices by Grade, Sales Type,

PAD District, and State

(Cents per Gallon Excluding Taxes) - Continued

\begin{tabular}{|c|c|c|c|c|c|c|c|c|c|c|c|c|}
\hline \multirow{3}{*}{$\begin{array}{l}\text { Geographlc Area } \\
\text { Month }\end{array}$} & \multicolumn{6}{|c|}{ Regular } & \multicolumn{6}{|c|}{ Midgrade } \\
\hline & \multicolumn{2}{|c|}{ Sales to End Users } & \multicolumn{4}{|c|}{ Sales for Resale } & \multicolumn{2}{|c|}{ Sales to End Users } & \multicolumn{4}{|c|}{ Sales for Resale } \\
\hline & $\begin{array}{l}\text { Through } \\
\text { Retail } \\
\text { Outlets }\end{array}$ & Averagea & DTW & Rack & Bulk & Average & $\begin{array}{c}\text { Through } \\
\text { Retail } \\
\text { Outlets }\end{array}$ & Averagea & DTW & Rack & Bulk & Average \\
\hline
\end{tabular}

Maryland

January

Fabruary

$$
\text { April }
$$

May .

June .

July ....

September

October ...

November

December

1994 Average

New Jersey

January

February

March

April

May

June

July ......

September

October ...

November

December

1994 Average

New York

January

February

$$
\text { March }
$$$$
\text { April }
$$

May

July ..

August

September

October...

November

December ...............................

1994 Average

Pennsylvania

January .

February

March

April

May

June

August

September

October

November

December

1994 Average

$\begin{array}{rrr}- & - & - \\ - & - & - \\ - & - & - \\ - & - & - \\ - & - & - \\ - & - & - \\ - & - & - \\ - & - & - \\ - & - & - \\ - & - & - \\ - & w & 74.6 \\ 73.2 & 71.5 & 71.3 \\ 73.2 & 71.5 & 71.5\end{array}$

-
-
$\overline{-}$
-
-
-
-
-
$\overline{N A}$
60.7
61.4

-
-
$\overline{-}$
-
-
-
-
$\bar{w}$
$w$
$w$

-
-
-
-
-
-
-
-
-
68.7
68.0
68.1

-
-
$\overline{-}$
-
-
-
-
-
8
84.5

-
-
-
-
-
-
-
-
$\bar{w}$
83.0
83.0

-
-
-
-
-
-
-
-
-
80.4
77.9
78.1

-
-
-
-
-
-
-
-
NA
67.1
68.0

$\begin{array}{ll}- & - \\ - & - \\ - & - \\ - & - \\ - & - \\ - & - \\ - & - \\ - & - \\ - & - \\ \bar{w} & 79.4 \\ w & 75.1 \\ & 75.5\end{array}$

$\begin{array}{llllll}- & - & - & - & - & - \\ - & - & - & - & - & - \\ - & - & - & - & - & - \\ - & - & - & - & - & - \\ - & - & - & - & - & - \\ - & - & - & - & - & - \\ - & - & - & - & - & - \\ - & - & - & - & - & - \\ - & - & - & - & - & - \\ - & - & - & - & - & - \\ - & W & 80.0 & W & - & 79.3 \\ 89.6 & 88.5 & 77.8 & 66.3 & - & 74.0 \\ 89.6 & 88.5 & 78.0 & 66.6 & - & 74.3\end{array}$

See footnotes at end of table. 
Table 34. Reformulated Motor Gasoline Prices by Grade, Sales Type, PAD District, and State

(Cents per Gallon Excluding Taxes) - Continued

\begin{tabular}{|c|c|c|c|c|c|c|c|c|c|c|c|c|}
\hline \multirow{3}{*}{$\begin{array}{l}\text { Geographle Area } \\
\text { Month }\end{array}$} & \multicolumn{6}{|c|}{ Promium } & \multicolumn{6}{|c|}{ All Grades } \\
\hline & \multicolumn{2}{|c|}{ Sales to End Users } & \multicolumn{4}{|c|}{ Sales for Resalo } & \multicolumn{2}{|c|}{ Sales to End Users } & \multicolumn{4}{|c|}{ Sales for Resale } \\
\hline & $\begin{array}{c}\text { Through } \\
\text { Rotail } \\
\text { Outlots }\end{array}$ & Average $e^{a}$ & DTW & Rack & Bulk & Average & $\begin{array}{c}\text { Through } \\
\text { Retall } \\
\text { Outlots }\end{array}$ & Averagea & DTW & Rack & Bulk & Average \\
\hline
\end{tabular}

Maryland

January

February

March

April

May

June.

August

- len

September

October ...

November

Anber

1994 Averago ...........................

Now Jersey

January

February

March

April

June

August

August ...................................

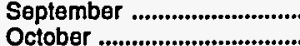

November.

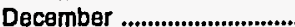

1994 Average

Now York

January

February ..................................

March

April

May

July ...

August

September

November

December ................................

1994 Average

Pennsylvania

January

February

March

April

June

July .

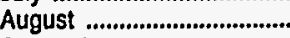

September

October...

November

Decomber

1994 Average

See footnotes at end of table.

$\begin{array}{cccc}- & - & - & - \\ - & - & - & - \\ - & - & - & - \\ - & - & - & - \\ - & - & - & - \\ - & - & - & - \\ - & - & - & - \\ - & - & - & - \\ - & - & - & - \\ - & - & - & - \\ - & \text { W } & 87.9 & \text { NA } \\ 92.9 & 90.9 & 85.1 & 73.0 \\ 92.9 & 90.9 & 85.3 & 73.9\end{array}$

$\begin{array}{ll}- & - \\ - & - \\ - & - \\ - & - \\ - & - \\ - & - \\ - & - \\ - & - \\ - & - \\ - & - \\ \bar{w} & 87.0 \\ w & 82.2\end{array}$

$\begin{array}{ccc}- & - & - \\ - & - & - \\ - & - & - \\ - & - & - \\ - & - & - \\ - & - & - \\ - & - & - \\ - & - & - \\ - & - & - \\ - & - & - \\ - & w & 79.4 \\ 79.3 & 76.9 & 76.3 \\ 79.3 & 76.9 & 76.5\end{array}$

$\begin{array}{ccc}- & - & - \\ - & - & - \\ - & - & - \\ - & - & - \\ - & - & - \\ - & - & - \\ - & - & - \\ - & - & - \\ - & - & - \\ - & - & - \\ 75.2 & W & 74.3 \\ 64.5 & W & 73.0 \\ 65.3 & w & 73.1\end{array}$

$\begin{array}{cccc}- & - & - & - \\ - & - & - & - \\ - & - & - & - \\ \overline{-} & - & - & - \\ - & - & - & - \\ - & - & - & - \\ - & - & - & - \\ - & - & - & - \\ - & - & - & - \\ - & \overline{1} & 88.5 & 70.6 \\ 99.1 & 96.8 & 86.6 & 67.6 \\ 99.1 & 96.8 & 86.7 & 67.7\end{array}$

$\begin{array}{cc}- & - \\ - & - \\ - & - \\ - & - \\ - & - \\ - & - \\ - & - \\ - & - \\ - & - \\ - & - \\ 59.5 & 68.7 \\ 53.8 & 71.8 \\ 54.7 & 71.5\end{array}$

$\begin{array}{ccc}- & - & - \\ - & - & - \\ - & - & - \\ - & - & - \\ - & - & - \\ - & - & - \\ - & - & - \\ - & - & - \\ - & - & - \\ - & - & - \\ - & 79.0 & 80.8 \\ 84.9 & 83.6 & 78.4 \\ 84.9 & 83.6 & 78.6\end{array}$

$\begin{array}{lll}- & - & - \\ - & - & - \\ - & - & - \\ - & - & - \\ - & - & - \\ - & - & - \\ - & - & - \\ - & - & - \\ - & - & - \\ - & - & - \\ 66.5 & 58.1 & 64.7 \\ 62.3 & 53.4 & 65.6 \\ 62.4 & 54.1 & 65.5\end{array}$


Table 34. Reformulated Motor Gasoline Prices by Grade, Sales Type, PAD District, and State

(Cents per Gallon Excluding Taxes) - Continued

\begin{tabular}{|c|c|c|c|c|c|c|c|c|c|c|c|c|}
\hline \multirow{3}{*}{$\begin{array}{l}\text { Geographic Area } \\
\text { Month }\end{array}$} & \multicolumn{6}{|c|}{ Regular } & \multicolumn{6}{|c|}{ Midgrade } \\
\hline & \multicolumn{2}{|c|}{ Sales to End Users } & \multicolumn{4}{|c|}{ Sales for Resale } & \multicolumn{2}{|c|}{ Sales to End Users } & \multicolumn{4}{|c|}{ Sales for Resale } \\
\hline & $\begin{array}{c}\text { Through } \\
\text { Retail } \\
\text { Outlets }\end{array}$ & Averagea & DTW & Rack & Bulk & Average & $\begin{array}{c}\text { Through } \\
\text { Retall } \\
\text { Outlets }\end{array}$ & Averagea & DTW & Rack & Bulk & Average \\
\hline \multicolumn{13}{|l|}{ Subdistrict IC } \\
\hline 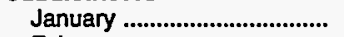 & - & - & - & - & - & - & - & - & - & - & - & - \\
\hline 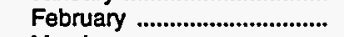 & - & - & - & - & - & - & - & - & - & - & - & - \\
\hline 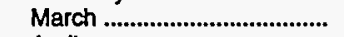 & - & $\rightarrow$ & - & - & - & - & - & - & - & - & - & - \\
\hline 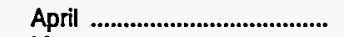 & - & - & - & - & - & - & - & - & - & - & - & - \\
\hline 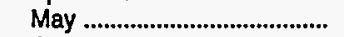 & - & - & - & - & - & - & - & - & - & - & - & - \\
\hline June ....................................... & - & - & - & - & - & - & - & - & - & - & - & - \\
\hline July ............................................ & - & - & - & - & - & - & - & - & - & - & - & - \\
\hline August ..................................... & - & - & - & - & - & - & - & - & - & - & - & - \\
\hline September .............................. & - & - & - & - & - & - & - & - & - & - & - & - \\
\hline 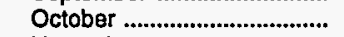 & - & - & - & - & - & - & - & - & - & - & - & - \\
\hline November ................................ & - & W & 73.4 & 63.3 & - & 68.7 & - & $w$ & 79.0 & 71.7 & - & 76.2 \\
\hline 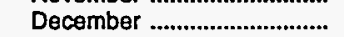 & 74.0 & 73.0 & 69.1 & 56.9 & $w$ & 63.5 & 86.3 & 85.1 & 75.9 & 62.3 & $w$ & 71.1 \\
\hline 1994 Average & 74.0 & 73.0 & 69.4 & 57.3 & $\mathbf{W}$ & 63.8 & 86.3 & 84.9 & 76.1 & 63.0 & $\mathbf{w}$ & 71.5 \\
\hline \multicolumn{13}{|l|}{ Florida } \\
\hline 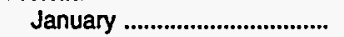 & - & - & - & - & - & - & - & - & - & - & - & - \\
\hline February ................................ & - & - & - & - & - & - & - & - & - & - & - & - \\
\hline 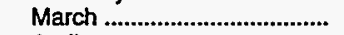 & - & - & - & - & - & - & - & - & - & - & - & - \\
\hline 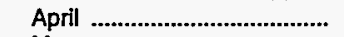 & - & - & - & - & - & - & - & - & - & - & - & - \\
\hline 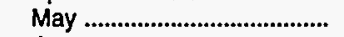 & - & - & - & - & - & - & - & $\rightarrow$ & - & - & - & - \\
\hline June ........................................ & - & - & - & - & - & - & - & - & - & - & - & - \\
\hline 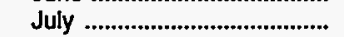 & - & - & - & - & - & - & - & - & - & - & - & - \\
\hline 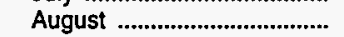 & - & - & - & - & - & - & - & - & - & - & - & - \\
\hline 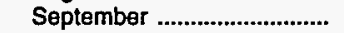 & - & - & - & - & - & - & - & - & - & - & - & - \\
\hline October & - & - & - & - & - & - & - & - & - & - & - & - \\
\hline November ............................. & - & - & - & - & - & - & - & - & - & - & - & - \\
\hline 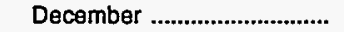 & - & - & - & - & - & - & - & - & - & - & - & - \\
\hline 1994 Average & - & - & - & - & - & - & - & - & - & - & - & - \\
\hline \multicolumn{13}{|l|}{ Georgia } \\
\hline 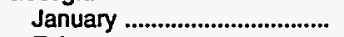 & - & - & - & - & - & - & - & - & - & - & - & - \\
\hline 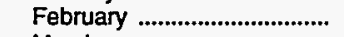 & - & - & - & - & - & - & - & - & - & - & - & - \\
\hline 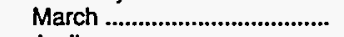 & - & - & - & - & - & - & - & - & - & - & - & - \\
\hline April & - & - & - & - & - & - & - & - & - & - & - & - \\
\hline May ........................................... & - & - & - & - & - & - & - & - & - & - & - & - \\
\hline 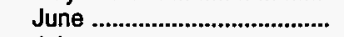 & - & - & - & - & - & - & - & - & - & - & - & - \\
\hline July ........................................... & - & - & - & - & - & - & - & - & - & - & - & - \\
\hline 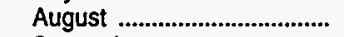 & - & - & - & - & - & - & - & - & - & - & - & - \\
\hline 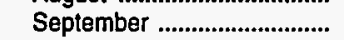 & - & - & - & - & - & - & $\rightarrow$ & - & - & - & - & - \\
\hline 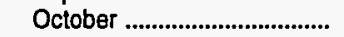 & - & - & - & - & - & - & - & - & - & - & - & - \\
\hline 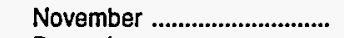 & - & - & - & - & - & - & - & - & - & - & - & - \\
\hline December .................................... & - & - & - & - & - & - & - & - & - & - & - & - \\
\hline 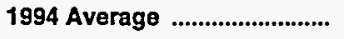 & - & - & - & - & - & - & - & - & - & - & - & - \\
\hline \multicolumn{13}{|l|}{ North Carolina } \\
\hline 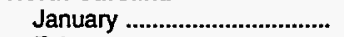 & - & - & - & - & - & - & - & - & - & - & - & - \\
\hline February ................................ & - & - & - & - & - & - & - & - & - & - & - & - \\
\hline 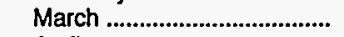 & - & - & - & - & - & - & - & - & - & - & - & - \\
\hline April .......................................... & - & - & - & - & - & - & - & - & - & - & - & - \\
\hline 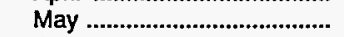 & - & - & - & - & - & - & - & - & - & - & - & - \\
\hline 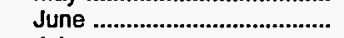 & - & - & - & - & - & - & - & - & - & - & - & - \\
\hline 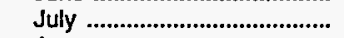 & - & - & - & - & - & - & - & - & - & - & - & - \\
\hline 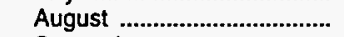 & - & - & - & - & - & - & - & - & - & - & - & - \\
\hline September ............................. & - & - & - & - & - & - & - & - & - & - & - & - \\
\hline 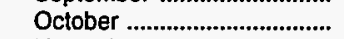 & - & - & - & - & - & - & - & - & - & - & - & - \\
\hline 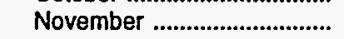 & - & - & - & - & - & - & - & - & - & - & - & - \\
\hline December ................................ & - & - & - & $W$ & - & $W$ & - & - & - & - & - & - \\
\hline 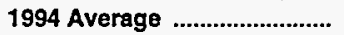 & - & - & - & $w$ & - & $\mathbf{W}$ & - & - & - & - & - & - \\
\hline
\end{tabular}

See footnotes at end of table. 
Table 34. Reformulated Motor Gasoline Prices by Grade, Sales Type,

PAD District, and State

(Cents per Gallon Excluding Taxes) - Continued

\begin{tabular}{|c|c|c|c|c|c|c|c|c|c|c|c|c|}
\hline \multirow{3}{*}{$\begin{array}{l}\text { Geographle Area } \\
\text { Month }\end{array}$} & \multicolumn{6}{|c|}{ Premlum } & \multicolumn{6}{|c|}{ All Grades } \\
\hline & \multicolumn{2}{|c|}{ Sales to End Users } & \multicolumn{4}{|c|}{ Sales for Resale } & \multicolumn{2}{|c|}{ Sales to End Users } & \multicolumn{4}{|c|}{ Sales for Resale } \\
\hline & $\begin{array}{l}\text { Through } \\
\text { Retall } \\
\text { Outlots }\end{array}$ & Avoragea & DTW & Rack & Bulk & Average & $\begin{array}{c}\text { Through } \\
\text { Retall } \\
\text { Outlets }\end{array}$ & Averagea & DTW & Rack & Bulk & Average \\
\hline
\end{tabular}

Subdistrict IC

January ...

February

March

Aprll

May

July ....

September

November

December ..............................

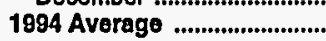

Florida

January .................................. February

March

April

May

June

July ....

August ...

October...

November

December .

1994 Averago

\section{Georgla}

January

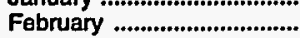

March .

April

May

June

July ....

August

September

October ...

November

Decomber

1994 Average

North Carolina

January

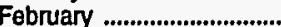

March

April

May

June

July ....

August ...

September

October ...

November

December

1994 Average

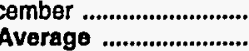

See footnotes at end of table.

$\begin{array}{cccc}- & - & - & - \\ - & - & - & - \\ - & - & - & - \\ - & - & - & - \\ - & - & - & - \\ - & - & - & - \\ - & - & - & - \\ - & - & - & - \\ - & - & - & - \\ - & - & - & - \\ - & w & 86.8 & 77.5 \\ 94.5 & 93.4 & 83.7 & 68.3 \\ 94.5 & 93.3 & 83.9 & 68.8\end{array}$

$\begin{array}{ccc}- & - & - \\ - & - & - \\ - & - & - \\ - & - & - \\ - & - & - \\ - & - & - \\ - & - & - \\ - & - & - \\ - & - & - \\ - & - & - \\ - & w & 78.4 \\ 80.8 & 79.7 & 74.7 \\ 80.8 & 79.6 & 74.9\end{array}$

$\begin{array}{ccc}- & - & - \\ - & - & - \\ - & - & - \\ - & - & - \\ - & - & - \\ - & - & - \\ - & - & - \\ - & - & - \\ - & - & - \\ - & - & - \\ 68.4 & - & 74.1 \\ 60.4 & W & 68.7 \\ 60.9 & w & 69.0\end{array}$


Table 34. Reformulated Motor Gasoline Prices by Grade, Sales Type,

PAD District, and State

(Cents per Gallon Excluding Taxes) - Continued

\begin{tabular}{|c|c|c|c|c|c|c|c|c|c|c|c|c|}
\hline \multirow{3}{*}{$\begin{array}{l}\text { Geographic Area } \\
\text { Month }\end{array}$} & \multicolumn{6}{|c|}{ Regular } & \multicolumn{6}{|c|}{ Midgrado } \\
\hline & \multicolumn{2}{|c|}{ Sales to End Users } & \multicolumn{4}{|c|}{ Sales for Resale } & \multicolumn{2}{|c|}{ Sales to End Users } & \multicolumn{4}{|c|}{ Sales for Resale } \\
\hline & $\begin{array}{c}\text { Through } \\
\text { Retail } \\
\text { Outlets }\end{array}$ & Averagea & DTW & Rack & Bulk & Average & $\begin{array}{l}\text { Through } \\
\text { Retail } \\
\text { Outlets }\end{array}$ & Average ${ }^{a}$ & DTW & Rack & Bulk & Average \\
\hline
\end{tabular}

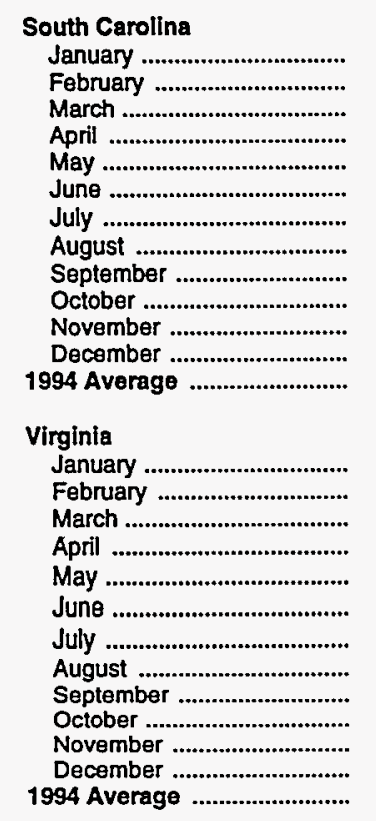

$\bar{z}$
$\bar{z}$
$\bar{z}$
$\bar{z}$
$=$
$=$
$=$
$=$

West Virginia
January ....

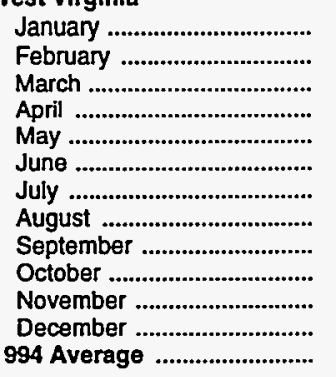

$=$
$=$
$=$
$=$
$=$
$=$
$=$
$\mathbf{7 4 . 0}$
$\mathbf{7 4 . 0}$

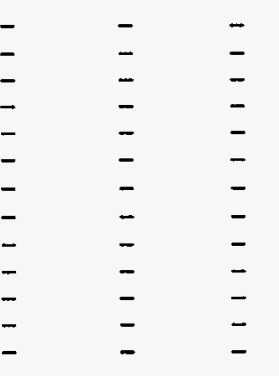

$\begin{array}{ll}- & - \\ = & - \\ = & - \\ = & - \\ = & - \\ = & - \\ = & - \\ = & - \\ - & -\end{array}$

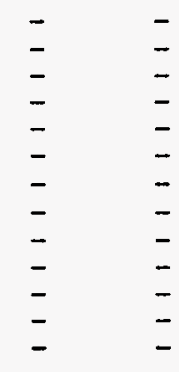

$\begin{array}{llll}- & - & - & - \\ - & - & - & = \\ - & - & - & = \\ - & - & - & = \\ - & - & - & = \\ - & - & - & = \\ - & - & - & = \\ - & - & - & = \\ - & - & - & -\end{array}$

PAD District II

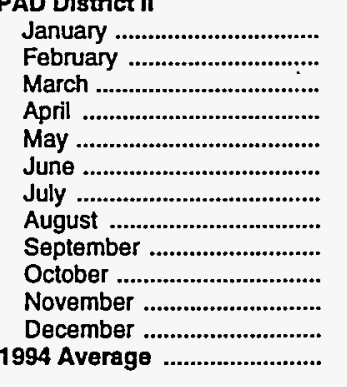

\begin{tabular}{|c|c|c|c|c|c|c|c|c|c|c|c|}
\hline - & - & - & - & - & - & - & - & - & - & - & - \\
\hline- & $\bar{z}$ & $\bar{z}$ & $\overline{-}$ & $\bar{z}$ & $\bar{z}$ & $\bar{z}$ & $\bar{z}$ & $\overline{-}$ & $\overline{-}$ & - & $\bar{z}$ \\
\hline- & - & - & $\overline{-}$ & $\overline{-}$ & - & - & - & - & - & - & - \\
\hline - & $\overline{-}$ & $\bar{z}$ & $\overline{-}$ & $\bar{z}$ & $\overline{-}$ & $\bar{z}$ & $\bar{z}$ & $\overline{-}$ & $\bar{z}$ & $\bar{z}$ & $\overline{-}$ \\
\hline- & - & - & - & - & - & - & - & - & - & - & - \\
\hline- & $\overline{-}$ & $\bar{z}$ & $\overline{-}$ & $\overline{-}$ & $\overline{-}$ & $\overline{-}$ & - & $\overline{-}$ & - & $\bar{z}$ & $\bar{z}$ \\
\hline$\overline{-}$ & - & - & - & - & - & - & - & - & - & - & - \\
\hline- & $\overline{-}$ & $\bar{z}$ & $\bar{w}$ & $\overline{-}$ & $\bar{w}$ & $\overline{-}$ & - & $\bar{w}$ & $\bar{w}$ & - & $\bar{w}$ \\
\hline - & - & - & w & - & $w$ & - & - & w & $w$ & - & $w$ \\
\hline - & - & - & - & - & - & - & - & - & - & - & - \\
\hline$\overline{-}$ & $=$ & $=$ & $\overline{-}$ & $\overline{-}$ & $\bar{z}$ & $\overline{-}$ & $\bar{z}$ & $\bar{z}$ & $\overline{-}$ & $\overline{-}$ & $\bar{z}$ \\
\hline - & - & - & - & - & - & - & - & - & - & - & - \\
\hline$\overline{-}$ & $\overline{-}$ & $=$ & $\overline{-}$ & $\overline{-}$ & $\overline{-}$ & $\overline{-}$ & $\overline{-}$ & $\overline{-}$ & $\bar{z}$ & $\overline{-}$ & $\bar{z}$ \\
\hline- & - & - & - & - & - & - & - & - & - & - & - \\
\hline$\overline{-}$ & - & $\overline{-}$ & $\overline{-}$ & $\overline{-}$ & $\overline{-}$ & $\bar{z}$ & $\bar{z}$ & $\overline{-}$ & $\bar{z}$ & $\overline{-}$ & $\bar{z}$ \\
\hline - & - & $\bar{\omega}$ & $\bar{w}$ & - & $\bar{w}$ & - & - & $\bar{w}$ & $\bar{w}$ & - & $\bar{s}$ \\
\hline 73.8 & $\overline{73.0}$ & & $\begin{array}{c}w \\
54.3\end{array}$ & $\bar{w}$ & $\begin{array}{c}w \\
60.9\end{array}$ & & & & & $\overline{-}$ & $\begin{array}{c}w \\
69.6\end{array}$ \\
\hline & 73.0 & 67.8 & 54.3 & $\ddot{w}$ & 60.9 & 82.1 & 81.7 & 73.1 & 59.4 & - & 69.6 \\
\hline
\end{tabular}

See footnotes at end of table. 
Table 34. Reformulated Motor Gasoline Prices by Grade, Sales Type, PAD District, and State

(Cents per Gallon Excluding Taxes) - Continued

\begin{tabular}{|c|c|c|c|c|c|c|c|c|c|c|c|c|}
\hline \multirow{3}{*}{$\underset{\text { Month }}{\text { Goographlc Area }}$} & \multicolumn{6}{|c|}{ Premium } & \multicolumn{6}{|c|}{ All Grades } \\
\hline & \multicolumn{2}{|c|}{ Sales to End Users } & \multicolumn{4}{|c|}{ Sales for Resale } & \multicolumn{2}{|c|}{ Sales to End Users } & \multicolumn{4}{|c|}{ Sales for Resale } \\
\hline & $\begin{array}{l}\text { Through } \\
\text { Retall } \\
\text { Outlote }\end{array}$ & Averago $a$ & DTW & Rack & Bulk & Average & $\begin{array}{c}\text { Through } \\
\text { Retail } \\
\text { Outlets }\end{array}$ & Averagea & DTW & Rack & Bulk & Average \\
\hline
\end{tabular}

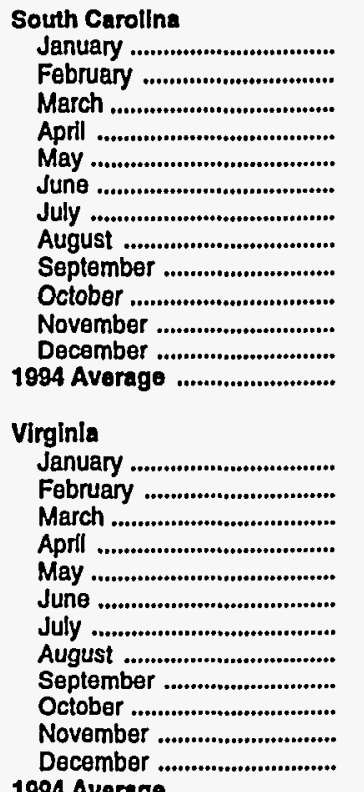

\begin{tabular}{|c|c|c|c|c|c|c|c|c|c|c|c|}
\hline- & - & - & - & - & - & - & - & - & - & - & - \\
\hline- & - & - & - & - & - & - & - & - & - & - & - \\
\hline- & - & - & - & - & - & - & - & - & - & - & - \\
\hline- & - & - & - & - & - & - & - & - & - & - & - \\
\hline- & - & - & - & - & - & - & - & - & - & - & - \\
\hline- & - & - & - & - & - & - & - & - & - & - & - \\
\hline- & - & - & - & - & - & - & - & - & - & - & - \\
\hline- & - & - & - & - & - & - & - & - & - & - & - \\
\hline- & - & - & - & - & - & - & - & - & - & - & - \\
\hline- & - & - & - & - & - & - & - & - & - & - & - \\
\hline- & - & - & - & - & - & - & - & - & - & - & - \\
\hline - & - & - & - & - & - & - & - & - & - & - & - \\
\hline- & - & - & - & - & - & - & - & - & - & - & - \\
\hline- & - & - & - & - & - & - & - & - & - & - & - \\
\hline- & - & - & - & - & - & - & - & - & - & - & - \\
\hline - & - & - & - & - & - & - & - & - & - & - & - \\
\hline- & - & - & $\rightarrow$ & - & - & - & - & - & - & - & - \\
\hline- & - & - & - & - & - & - & - & - & - & - & - \\
\hline- & - & - & - & - & - & - & - & $\rightarrow$ & - & - & - \\
\hline- & - & - & - & - & - & - & - & - & - & - & - \\
\hline- & - & - & - & - & - & - & - & - & - & - & - \\
\hline- & - & - & - & - & - & - & - & - & - & - & - \\
\hline - & - & - & - & - & - & - & - & - & - & - & - \\
\hline- & $w$ & 86.8 & 77.5 & - & 83.0 & - & $w$ & 78.4 & 68.4 & - & 74.1 \\
\hline 94.5 & 93.4 & 83.7 & 68.3 & $W$ & 77.9 & 80.8 & 79.7 & 74.7 & 60.4 & $w$ & 68.7 \\
\hline
\end{tabular}

West Virginia

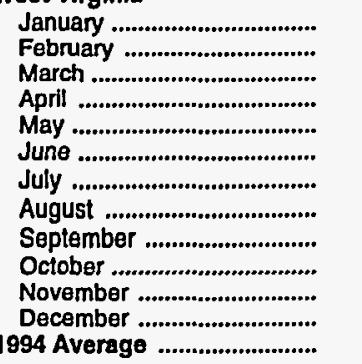

\begin{tabular}{|c|c|c|c|c|c|c|c|c|c|c|c|}
\hline - & - & - & - & - & - & - & - & - & - & - & - \\
\hline - & - & - & - & - & - & - & - & - & - & - & - \\
\hline- & $\overline{-}$ & $\bar{z}$ & $\overline{-}$ & $\bar{z}$ & $\overline{-}$ & $\overline{-}$ & $\bar{z}$ & $\bar{z}$ & $\overline{-}$ & $\overline{-}$ & $\overline{-}$ \\
\hline- & - & - & - & - & - & - & - & - & - & - & - \\
\hline- & - & - & - & - & - & - & - & - & - & - & - \\
\hline- & - & - & - & - & - & - & - & - & - & - & - \\
\hline 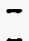 & - & $\overline{-}$ & $\overline{-}$ & $\bar{z}$ & $\bar{z}$ & $\bar{z}$ & $\bar{z}$ & $\overline{-}$ & $\bar{I}$ & $\bar{z}$ & $\bar{z}$ \\
\hline & - & - & - & - & - & - & - & - & - & - & - \\
\hline & - & - & - & - & - & - & - & - & - & - & - \\
\hline & - & $w$ & $w$ & - & w & - & - & $w$ & $w$ & - & $w$ \\
\hline & - & $\mathbf{W}$ & $w$ & - & $\mathbf{w}$ & - & - & w & $\mathbf{w}$ & - & $w$ \\
\hline
\end{tabular}

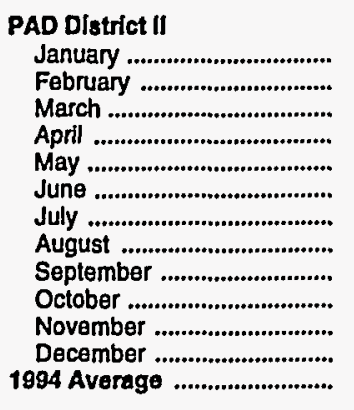

\begin{tabular}{|c|c|c|c|c|c|c|c|c|c|c|c|}
\hline- & - & - & - & - & - & - & - & - & - & - & - \\
\hline - & - & - & - & - & - & - & - & - & - & - & - \\
\hline - & $\rightarrow$ & - & - & - & - & - & - & - & - & - & - \\
\hline - & - & - & - & - & - & - & - & - & - & - & - \\
\hline - & - & - & - & - & - & - & - & - & - & - & - \\
\hline - & - & - & - & - & - & - & - & - & - & - & - \\
\hline- & - & - & - & - & - & - & - & - & - & - & - \\
\hline- & - & - & - & - & - & - & - & - & - & - & - \\
\hline- & - & - & - & - & - & - & - & - & - & - & - \\
\hline - & - & - & - & - & - & - & - & - & - & - & - \\
\hline- & - & W & $W$ & $w$ & $W$ & - & - & $w$ & $w$ & $w$ & $w$ \\
\hline 92.0 & 90.4 & 80.0 & 63.4 & - & 72.4 & 78.1 & 77.1 & 71.3 & 56.5 & $W$ & 64.4 \\
\hline 92.0 & 90.4 & 80.0 & 63.4 & $\mathbf{w}$ & 72.4 & 78.1 & 77.1 & 71.3 & 56.5 & 64.0 & 64.4 \\
\hline
\end{tabular}

See footnotes at end of table. 
Table 34. Reformulated Motor Gasoline Prices by Grade, Sales Type, PAD District, and State (Cents per Gallon Excluding Taxes) - Continued

\begin{tabular}{|c|c|c|c|c|c|c|c|c|c|c|c|c|}
\hline \multirow{3}{*}{$\begin{array}{l}\text { Goographic Area } \\
\text { Month }\end{array}$} & \multicolumn{6}{|c|}{ Regular } & \multicolumn{6}{|c|}{ Midgrado } \\
\hline & \multicolumn{2}{|c|}{ Sales to End Users } & \multicolumn{4}{|c|}{ Sales for Resale } & \multicolumn{2}{|c|}{ Sales to End Users } & \multicolumn{4}{|c|}{ Sales for Resale } \\
\hline & $\begin{array}{c}\text { Through } \\
\text { Rotall } \\
\text { Outlots }\end{array}$ & Averagea & DTW & Rack & Bulk & Average & $\begin{array}{l}\text { Through } \\
\text { Retail } \\
\text { Outlots }\end{array}$ & Averagoa & DTw & Rack & Bulk & Average \\
\hline
\end{tabular}

Illinols

January

February

April

May

June

July ....

August ...

September

October.

November

December .....

1994 Average

Indiana

January.

February

March

April

May

June .

July .....

August ......................................

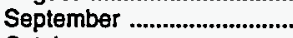

October .

November

December .................................

1994 Average

lowa

January .

February

March

April

May

June

July .......

August ....

October .

November

December

1994 Average

Kansas

January

February

March

April

May .

June

July ...

August .

September

October .

November

December .

1994 Average

$\begin{array}{ccc}- & - & - \\ - & - & - \\ - & - & - \\ - & - & - \\ - & - & - \\ - & - & - \\ - & - & - \\ - & - & - \\ - & - & - \\ - & - & - \\ - & - & W \\ 73.9 & 73.0 & 70.5 \\ 73.9 & 73.0 & 70.5\end{array}$

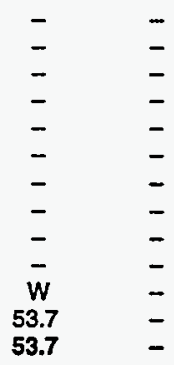

-
-
$\bar{z}$
-
-
-
-
-
82.4
82.4

$\begin{array}{rr}- & - \\ - & - \\ - & - \\ - & - \\ - & - \\ - & - \\ - & - \\ - & - \\ - & - \\ - & w \\ 82.1 & 74.6 \\ 82.1 & 74.6\end{array}$

-
$\overline{-}$
$\overline{-}$
-
$\overline{-}$
$\overline{-}$
$\mathbf{W}$
58.5
58.5

-
-
-
-
-
-
-
-
$\bar{W}$
72.3
72.3

67

$\begin{array}{lll}- & - & - \\ - & - & - \\ - & - & - \\ - & - & - \\ - & - & - \\ - & - & - \\ - & - & - \\ - & - & - \\ - & - & - \\ - & - & 54.1 \\ 67.0 & 62.2 & 54.1 \\ 67.0 & 62.2 & 54.1\end{array}$

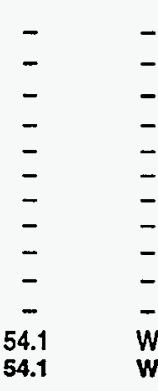

$\begin{array}{ll}- & \\ - & \\ - & \\ - & \\ - & \\ - & \\ - & \\ - & \\ - & \\ 57.4 & 76.4 \\ 57.4 & 76.4\end{array}$

$\begin{array}{ll}- & - \\ - & - \\ - & - \\ - & - \\ - & - \\ - & - \\ - & - \\ - & - \\ - & - \\ - & - \\ 76.4 & 73.8 \\ 76.4 & 73.8\end{array}$

$\begin{array}{ll}- & - \\ - & \\ - & \\ - & - \\ - & - \\ - & - \\ - & - \\ - & - \\ - & \\ 73.8 & 64.7 \\ 73.8 & 64.7\end{array}$

$\begin{array}{cccc}- & - & - & - \\ - & - & - & - \\ - & - & - & - \\ - & - & - & - \\ - & - & - & - \\ - & - & - & - \\ - & - & - & - \\ - & - & - & - \\ - & - & - & - \\ - & - & - & - \\ - & - & - & - \\ 64.7 & 58.2 & - & 63.1 \\ 64.7 & 58.2 & - & 63.1\end{array}$

See footnotes at end of table. 
Table 34. Reformulated Motor Gasoline Prices by Grade, Sales Type, PAD District, and State

(Cents per Gallon Excluding Taxes) - Continued

\begin{tabular}{|c|c|c|c|c|c|c|c|c|c|c|c|c|}
\hline \multirow{3}{*}{$\begin{array}{l}\text { Geographic Area } \\
\text { Month }\end{array}$} & \multicolumn{6}{|c|}{ Premilum } & \multicolumn{6}{|c|}{ All Grades } \\
\hline & \multicolumn{2}{|c|}{ Sales to End Users } & \multicolumn{4}{|c|}{ Sales for Resale } & \multicolumn{2}{|c|}{ Sales to End Users } & \multicolumn{4}{|c|}{ Sales for Resale } \\
\hline & $\begin{array}{c}\text { Through } \\
\text { Retail } \\
\text { Outlets }\end{array}$ & Average ${ }^{a}$ & DTW & Rack & Bulk & Average & $\begin{array}{c}\text { Through } \\
\text { Retail } \\
\text { Outlets }\end{array}$ & Averagea & DTW & Rack & Bulk & Average \\
\hline
\end{tabular}

IIIInofs

January .

March

April

May

June .........................................

July

August ....................................

September ..............................

October ...

November ..............................

December

1994 Avore

Indiana

January

March

April

May ..........................................

June

July ....

September ..............................

October .

November

December

1994 Avorage

lowa

January

February

March

April

May

June

August

October

November

December

1994 Average

Kansas

January .

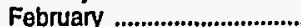

March

April

May

June

July

August .......

October.

November

December
1994 Average

$\begin{array}{cccc}- & - & - & - \\ - & - & - & - \\ - & - & - & - \\ - & - & - & - \\ \overline{-} & - & - & - \\ - & - & - & - \\ - & - & - & - \\ - & - & - & - \\ - & - & - & - \\ - & - & - & - \\ 93.5 & 92.4 & 82.1 & 62.0 \\ 93.5 & 92.4 & 82.1 & 62.0\end{array}$

$\begin{array}{ll}- & - \\ - & - \\ - & - \\ - & - \\ - & - \\ - & - \\ - & - \\ - & - \\ - & - \\ - & \text { w } \\ - & 75.7\end{array}$

$\begin{array}{ll}- & - \\ - & - \\ - & - \\ - & - \\ - & - \\ - & - \\ - & - \\ - & - \\ - & - \\ 78.0 & 74.1 \\ 78.0 & 74.1\end{array}$

$\begin{array}{ll}- & - \\ - & - \\ - & - \\ - & - \\ - & - \\ - & - \\ - & - \\ - & - \\ \text { W } & - \\ 55.7 & - \\ 55.7 & \end{array}$

$$
\begin{gathered}
- \\
- \\
- \\
- \\
- \\
- \\
- \\
- \\
- \\
\bar{w} \\
67.5 \\
67.5
\end{gathered}
$$

\begin{tabular}{|c|c|c|c|c|c|c|c|c|c|c|c|}
\hline- & - & - & - & - & - & - & - & - & - & - & - \\
\hline- & - & - & - & - & - & - & - & - & - & - & - \\
\hline- & - & - & - & - & - & - & - & - & - & - & - \\
\hline- & - & - & - & - & - & - & - & - & - & - & - \\
\hline- & - & - & - & - & - & - & - & - & - & - & - \\
\hline- & - & - & - & - & - & - & - & - & - & - & - \\
\hline- & - & - & - & - & - & - & - & - & - & - & - \\
\hline- & - & - & - & - & - & - & - & - & - & - & - \\
\hline- & - & - & - & - & - & - & - & - & - & - & - \\
\hline - & - & - & - & - & - & - & - & - & - & - & - \\
\hline- & - & - & - & $w$ & $w$ & - & - & - & - & $w$ & $w$ \\
\hline $\begin{array}{l}84.2 \\
84.2\end{array}$ & $\begin{array}{l}82.4 \\
82.4\end{array}$ & $\begin{array}{l}71.8 \\
71.8\end{array}$ & $\begin{array}{l}62.0 \\
62.0\end{array}$ & $\bar{w}$ & $\begin{array}{l}64.4 \\
63.6\end{array}$ & $\begin{array}{l}72.4 \\
72.4\end{array}$ & $\begin{array}{l}71.0 \\
71.0\end{array}$ & $\begin{array}{l}63.9 \\
63.9\end{array}$ & $\begin{array}{l}55.9 \\
55.9\end{array}$ & $\begin{array}{c}W \\
64.0\end{array}$ & $\begin{array}{l}59.1 \\
59.0\end{array}$ \\
\hline
\end{tabular}

See footnotes at end of table. 
Table 34. Reformulated Motor Gasoline Prices by Grade, Sales Type, PAD District, and State

(Cents per Gallon Excluding Taxes) - Continued

\begin{tabular}{|c|c|c|c|c|c|c|c|c|c|c|c|c|}
\hline \multirow{3}{*}{$\begin{array}{l}\text { Geographic Area } \\
\text { Month }\end{array}$} & \multicolumn{6}{|c|}{ Regular } & \multicolumn{6}{|c|}{ Midgrade } \\
\hline & \multicolumn{2}{|c|}{ Sales to End Users } & \multicolumn{4}{|c|}{ Sales for Resale } & \multicolumn{2}{|c|}{ Sales to End Usors } & \multicolumn{4}{|c|}{ Sales for Resale } \\
\hline & $\begin{array}{c}\text { Through } \\
\text { Retail } \\
\text { Outlets }\end{array}$ & Averagea & DTW & Rack & Bulk & Average & $\begin{array}{l}\text { Through } \\
\text { Retail } \\
\text { Outlets }\end{array}$ & Averagea & DTW & Rack & Bulk & Average \\
\hline
\end{tabular}

Kentucky

January

February

March

April

May

June

July ...

August

September

October .

November

December

994 Average

Michigan

January

February

March

April

May

June

July ..

September

October ...

November

December ...

1994 Average

Minnesota

January

February

March

April

May

June .

July ...

August ..

October ...

November

December

Missour

January

February

March

April

May

June

July ........

August

September

October .

November

December

1994 Average

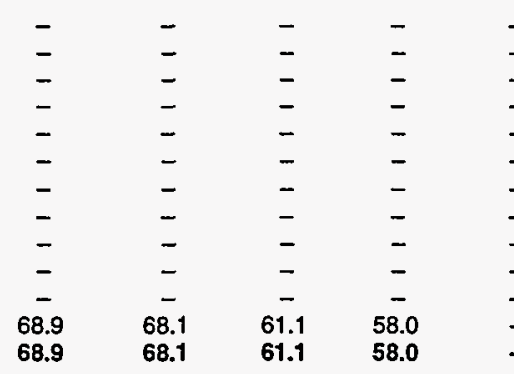

-
-
-
-
-
-
-
-
-
-
-
-

-
$=$
$=$
$=$
$=$
$=$
$=$
$=$
58.6
58.6

$\begin{array}{cc}- & = \\ = & = \\ = & = \\ = & = \\ = & = \\ = & = \\ = & = \\ 79.5 & 79.3 \\ 79.5 & 79.3\end{array}$

$\begin{array}{ll}- & - \\ = & = \\ = & = \\ = & = \\ = & - \\ = & - \\ - & - \\ - & - \\ 66.1 & 60.9 \\ 66.1 & 60.9\end{array}$

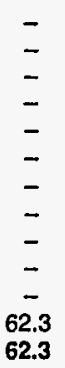

See footnotes at end of table. 
Table 34. Reformulated Motor Gasoline Prices by Grade, Sales Type,

PAD District, and State

(Cents per Gallon Excluding Taxes) - Continued

\begin{tabular}{|c|c|c|c|c|c|c|c|c|c|c|c|c|}
\hline \multirow{3}{*}{$\begin{array}{l}\text { Geographlc Area } \\
\text { Month }\end{array}$} & \multicolumn{6}{|c|}{ Premium } & \multicolumn{6}{|c|}{ All Grades } \\
\hline & \multicolumn{2}{|c|}{ Sales to End Users } & \multicolumn{4}{|c|}{ Sales for Resale } & \multicolumn{2}{|c|}{ Sales to End Users } & \multicolumn{4}{|c|}{ Sales for Resalo } \\
\hline & $\begin{array}{c}\text { Through } \\
\text { Retail } \\
\text { Outlets }\end{array}$ & Average ${ }^{a}$ & DTW & Rack & Bulk & Average & $\begin{array}{l}\text { Through } \\
\text { Retail } \\
\text { Outlets }\end{array}$ & Averagea & DTW & Rack & Bulk & Average \\
\hline
\end{tabular}

Kontucky

January.

March

April

May

July

Septembe

(..........................

October

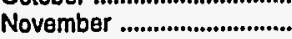

December

1994 Average

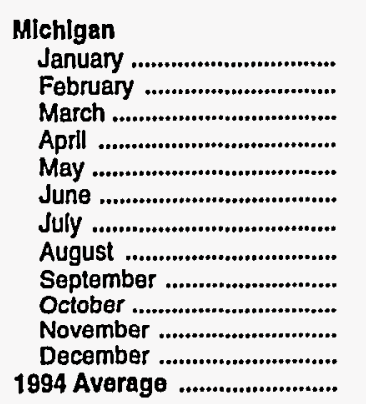

$\begin{array}{lll}- & - & - \\ - & - & - \\ - & - & - \\ - & - & - \\ - & - & - \\ - & - & - \\ - & - & - \\ - & - & - \\ - & - & - \\ - & - & - \\ - & - & - \\ 87.8 & 87.3 & 72.4\end{array}$

$\begin{array}{lll}- & - & - \\ - & - & - \\ - & - & - \\ - & - & - \\ - & - & - \\ - & - & - \\ - & - & - \\ - & - & - \\ - & - & - \\ - & - & - \\ - & - & - \\ 72.4 & 67.0 & - \\ 72.4 & 67.0 & -\end{array}$

$\begin{array}{lllll}- & - & - & - & - \\ - & - & - & - & - \\ - & - & - & - & - \\ - & - & - & - & - \\ - & - & - & - & - \\ - & - & - & - & - \\ - & - & - & - & - \\ - & - & - & - & - \\ - & - & - & - & - \\ - & - & - & - & - \\ 73.5 & 65.1 & 60.9 & - & - \\ 73.5 & 65.1 & 60.9 & - & 61.7\end{array}$

\section{Minnesola}

January

February

April

May

July

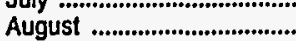

September

October .

November

1994 Average

Missouri

January ...

February

March

Aprll

May

July ....

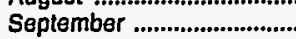

October

November

December

1994 Average

\begin{tabular}{|c|c|c|c|c|c|c|c|c|c|c|c|}
\hline- & - & - & - & - & - & - & - & - & - & - & - \\
\hline- & - & - & - & - & - & - & - & - & - & - & - \\
\hline- & - & - & - & - & - & - & - & - & - & - & - \\
\hline- & - & - & - & $\rightarrow$ & - & - & - & - & - & - & - \\
\hline- & - & - & - & - & - & - & - & - & - & - & - \\
\hline- & - & - & - & - & - & - & - & - & - & - & - \\
\hline- & - & - & - & - & - & - & - & - & - & - & - \\
\hline- & - & - & - & - & - & - & - & - & - & - & - \\
\hline- & - & - & - & - & - & - & - & - & - & - & - \\
\hline- & - & - & - & - & - & - & - & - & - & - & - \\
\hline- & - & - & - & - & - & - & - & - & - & - & - \\
\hline- & - & - & - & - & - & - & - & - & - & - & - \\
\hline- & - & - & - & - & - & - & - & - & - & - & - \\
\hline
\end{tabular}

See footnotes at end of table. 
Table 34. Reformulated Motor Gasoline Prices by Grade, Sales Type, PAD District, and State

(Cents per Gallon Excluding Taxes) - Continued

\begin{tabular}{|c|c|c|c|c|c|c|c|c|c|c|c|c|}
\hline \multirow{3}{*}{$\begin{array}{l}\text { Geographic Area } \\
\text { Month }\end{array}$} & \multicolumn{6}{|c|}{ Regular } & \multicolumn{6}{|c|}{ Midgrade } \\
\hline & \multicolumn{2}{|c|}{ Sales to End Users } & \multicolumn{4}{|c|}{ Sales for Resale } & \multicolumn{2}{|c|}{ Sales to End Users } & \multicolumn{4}{|c|}{ Sales for Resale } \\
\hline & $\begin{array}{c}\text { Through } \\
\text { Retall } \\
\text { Outlets }\end{array}$ & Average $\mathrm{a}$ & DTW & Rack & Bulk & Average & $\begin{array}{l}\text { Through } \\
\text { Retail } \\
\text { Outlets }\end{array}$ & Averagea & DTW & Rack & Bulk & Average \\
\hline
\end{tabular}

\begin{tabular}{|c|c|c|c|c|c|c|c|c|c|c|c|c|}
\hline \multicolumn{13}{|l|}{ Nebraska } \\
\hline 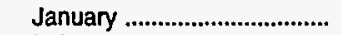 & - & - & - & - & - & - & - & - & - & - & - & - \\
\hline 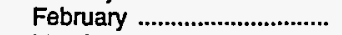 & - & - & - & - & - & - & - & - & - & - & - & - \\
\hline 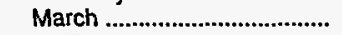 & - & - & - & - & - & - & - & - & - & - & - & - \\
\hline April .................................... & - & - & - & - & - & - & - & - & - & - & - & - \\
\hline 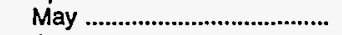 & - & - & - & - & - & - & - & - & - & - & - & - \\
\hline 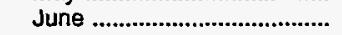 & - & - & - & - & - & - & - & - & - & - & - & - \\
\hline 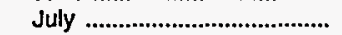 & - & - & - & - & - & - & - & - & - & - & - & - \\
\hline 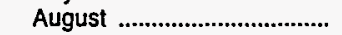 & - & - & - & - & - & - & - & - & - & - & - & - \\
\hline 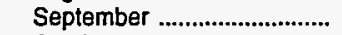 & - & - & - & - & - & - & - & - & - & - & - & - \\
\hline 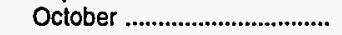 & - & - & - & - & - & - & - & - & - & - & - & - \\
\hline 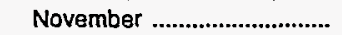 & - & - & - & - & - & - & - & - & - & - & - & - \\
\hline December .................................. & - & - & - & - & - & - & - & - & - & - & - & - \\
\hline 1994 Average ............................... & - & - & - & - & - & - & - & - & - & - & - & - \\
\hline \multicolumn{13}{|l|}{ North Dakota } \\
\hline 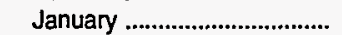 & - & - & - & - & - & - & - & - & - & - & - & - \\
\hline 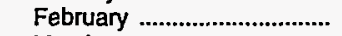 & - & - & - & - & - & - & - & - & - & - & - & - \\
\hline 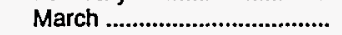 & - & - & - & - & - & - & - & - & - & - & - & - \\
\hline April & - & - & - & - & - & - & - & - & - & - & - & - \\
\hline 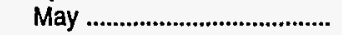 & - & - & - & - & - & - & - & - & - & - & - & - \\
\hline 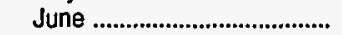 & - & - & - & - & - & - & - & - & - & - & - & - \\
\hline July & - & - & - & - & - & - & - & - & - & - & - & - \\
\hline 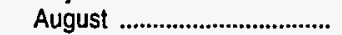 & - & - & - & - & - & - & - & - & - & - & - & - \\
\hline 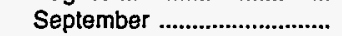 & - & - & - & - & - & - & - & - & - & - & - & - \\
\hline 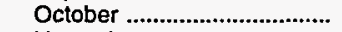 & - & - & - & - & - & - & - & - & - & - & - & - \\
\hline 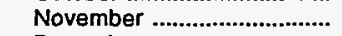 & - & - & - & - & - & - & - & - & - & - & - & - \\
\hline 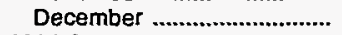 & - & - & - & - & - & - & - & - & - & - & - & - \\
\hline 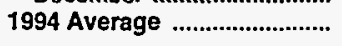 & - & - & - & - & - & - & - & - & - & - & - & - \\
\hline \multicolumn{13}{|l|}{ Ohio } \\
\hline 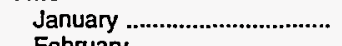 & - & - & - & - & - & - & - & - & - & - & - & - \\
\hline 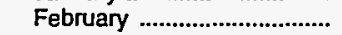 & - & - & - & - & - & - & - & - & - & - & - & - \\
\hline 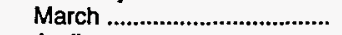 & - & - & - & - & - & - & - & - & - & - & - & - \\
\hline 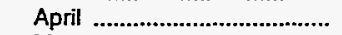 & - & - & - & - & - & - & - & - & - & - & - & - \\
\hline May & - & - & - & - & - & - & - & - & - & - & - & - \\
\hline 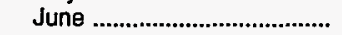 & - & - & - & - & - & - & - & - & - & - & - & - \\
\hline July ......................................... & - & - & - & - & - & - & - & - & - & - & - & - \\
\hline 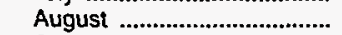 & - & - & - & - & - & - & - & - & - & - & - & - \\
\hline 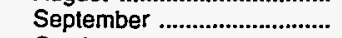 & - & - & - & - & - & - & - & - & - & - & - & - \\
\hline October & - & - & - & - & - & - & - & - & - & - & - & - \\
\hline November ................................ & - & - & - & - & - & - & - & - & - & - & - & _- \\
\hline 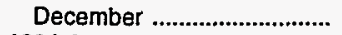 & - & w & w & w & - & w & - & w & w & w & - & $w$ \\
\hline 1994 Average ............................. & - & w & $w$ & w & - & $w$ & - & $w$ & $w$ & w & - & $\ddot{w}$ \\
\hline \multicolumn{13}{|l|}{ Oklahoma } \\
\hline 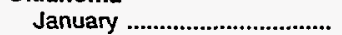 & - & - & _- & - & - & _- & - & _ & - & - & - & _- \\
\hline 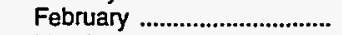 & - & - & - & - & - & - & - & - & - & - & - & - \\
\hline 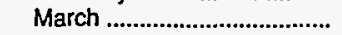 & - & - & - & - & - & - & - & - & - & - & - & - \\
\hline April & - & - & - & - & - & - & _ & - & - & - & - & - \\
\hline 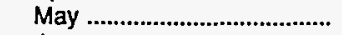 & - & - & - & - & - & - & - & - & - & - & - & - \\
\hline June ............................................. & - & - & - & - & - & - & - & - & - & - & - & - \\
\hline 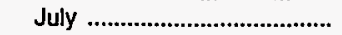 & - & - & - & - & - & - & - & - & - & - & - & - \\
\hline 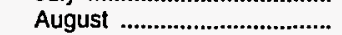 & - & - & - & - & - & - & - & - & - & - & - & _ \\
\hline September ....................................... & - & - & - & - & - & - & - & - & - & - & - & - \\
\hline 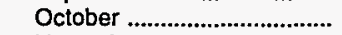 & - & - & - & - & - & - & - & - & - & - & - & - \\
\hline 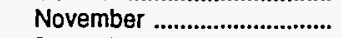 & - & - & - & - & - & - & - & - & - & - & - & - \\
\hline 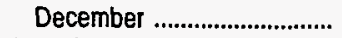 & - & - & - & - & - & - & - & - & - & - & - & - \\
\hline 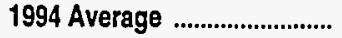 & - & - & - & - & - & - & - & - & - & - & - & - \\
\hline
\end{tabular}

See footnotes at end of table. 
Table 34. Reformulated Motor Gasoline Prices by Grade, Sales Type, PAD District, and State

(Cents per Gallon Excluding Taxes) - Continued

\begin{tabular}{|c|c|c|c|c|c|c|c|c|c|c|c|c|}
\hline \multirow{3}{*}{$\begin{array}{l}\text { Geographic Area } \\
\text { Month }\end{array}$} & \multicolumn{6}{|c|}{ Premium } & \multicolumn{6}{|c|}{ All Grades } \\
\hline & \multicolumn{2}{|c|}{ Sales to End Users } & \multicolumn{4}{|c|}{ Sales for Resale } & \multicolumn{2}{|c|}{ Sales to End Users } & \multicolumn{4}{|c|}{ Sales for Resale } \\
\hline & $\begin{array}{c}\text { Through } \\
\text { Retail } \\
\text { Outlots }\end{array}$ & Average ${ }^{a}$ & DTW & Rack & Bulk & Average & $\begin{array}{c}\text { Through } \\
\text { Retail } \\
\text { Outlots }\end{array}$ & Average $\mathrm{a}$ & DTW & Rack & Bulk & Average \\
\hline
\end{tabular}

Nobraske

January

February

March

April

Maye

June

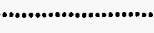

August

September

Oclober

1994 Average

North Dakota

January ....

February

March

April

May

June

July ...

September

October ...

November

December .

Ohio

January

February

March

April

(n)

May

June .

July ....

gist

September

October

November

December

1994 Average

Oklahoma

January

February

March

April

May

June

July ...

August

September

October.

November

December .

1994 Average

\begin{tabular}{|c|c|c|c|c|c|c|c|c|c|c|c|}
\hline- & - & - & - & - & - & - & - & - & - & - & - \\
\hline $\bar{z}$ & - & - & - & - & - & - & - & - & - & - & - \\
\hline$\overline{-}$ & $\bar{z}$ & $\overline{-}$ & $\overline{-}$ & $\bar{z}$ & I & $\bar{z}$ & $\bar{z}$ & $z$ & $\bar{z}$ & $\bar{z}$ & $\overline{-}$ \\
\hline- & - & - & - & - & - & - & - & - & - & - & 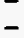 \\
\hline$\overline{-}$ & - & - & - & - & - & - & - & - & - & - & - \\
\hline$\overline{-}$ & - & - & - & - & - & - & - & - & - & - & - \\
\hline- & $\overline{-}$ & $\overline{-}$ & $\bar{z}$ & $\bar{z}$ & $=$ & - & I & $\overline{-}$ & $\bar{z}$ & $\bar{z}$ & $\overline{-}$ \\
\hline- & - & - & - & - & - & - & - & - & - & - & - \\
\hline$\overline{-}$ & - & - & - & - & - & - & - & - & - & - & - \\
\hline $\bar{z}$ & - & - & - & - & - & - & - & - & - & - & - \\
\hline 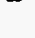 & - & - & - & - & - & - & - & - & - & - & - \\
\hline$\overline{-}$ & - & - & - & - & - & - & - & - & - & - & - \\
\hline- & $\overline{-}$ & $\bar{z}$ & $\overline{-}$ & - & - & - & - & - & - & - & - \\
\hline- & - & - & - & - & $\overline{-}$ & $\overline{-}$ & $\bar{z}$ & $=$ & $\bar{z}$ & $\bar{z}$ & - \\
\hline- & - & - & - & - & - & - & - & - & - & - & - \\
\hline $\bar{z}$ & - & - & - & - & - & - & - & - & - & - & - \\
\hline$\overline{-}$ & - & - & - & - & - & - & - & - & - & - & - \\
\hline$\overline{-}$ & - & - & - & - & - & - & - & - & - & - & - \\
\hline- & $\overline{-}$ & $\bar{z}$ & $\bar{z}$ & - & $\overline{-}$ & - & - & $=$ & $\bar{z}$ & - & - \\
\hline - & - & - & - & - & $\overline{-}$ & $\bar{z}$ & $\vec{z}$ & $=$ & $\overline{-}$ & $\overline{-}$ & $\bar{z}$ \\
\hline $\bar{z}$ & - & - & - & - & - & - & - & - & - & - & - \\
\hline - & - & - & - & - & - & - & - & - & - & - & - \\
\hline - & - & - & - & - & - & - & - & - & - & - & - \\
\hline $\bar{z}$ & - & - & - & - & - & - & - & - & - & - & - \\
\hline$\overline{-}$ & $\overline{-}$ & $\bar{z}$ & $\bar{z}$ & $\bar{I}$ & $\bar{z}$ & $\overline{-}$ & $\bar{z}$ & $\bar{z}$ & $\vec{z}$ & - & I- \\
\hline - & - & - & - & - & - & - & - & - & - & - & - \\
\hline- & - & - & - & - & - & - & - & - & - & - & - \\
\hline$\overline{-}$ & - & - & - & - & - & - & - & - & - & - & - \\
\hline$\vec{z}$ & $\overline{-}$ & $\overline{-}$ & I & $\bar{z}$ & $\overline{-}$ & $\overline{-}$ & $\bar{z}$ & $\overline{-}$ & $\bar{z}$ & $\overline{-}$ & $\bar{z}$ \\
\hline- & - & - & - & - & $\overline{-}$ & - & - & - & - & - & $I$ \\
\hline - & - & - & - & - & - & - & - & - & - & - & - \\
\hline- & - & $w$ & $w$ & - & $w$ & - & W & w & w & - & $w$ \\
\hline- & - & $\mathbf{W}$ & $\mathbf{w}$ & - & $w$ & - & w & $\mathbf{w}$ & $w$ & - & $w$ \\
\hline$\overline{-}$ & - & - & - & - & - & - & - & - & - & - & - \\
\hline $\bar{z}$ & - & - & - & - & - & - & - & - & - & - & - \\
\hline$\overline{-}$ & $\bar{z}$ & $\overline{-}$ & $\bar{z}$ & $\bar{z}$ & $\bar{z}$ & $\vec{z}$ & $\overline{-}$ & $\overline{-}$ & $\underline{-}$ & I & - \\
\hline - & - & - & - & - & - & - & - & - & - & - & - \\
\hline- & - & - & - & - & - & - & - & - & - & - & - \\
\hline- & - & - & - & - & - & - & - & - & - & - & - \\
\hline- & $\bar{z}$ & - & $\overline{-}$ & $=$ & - & $\overline{-}$ & - & - & - & - & - \\
\hline $\bar{z}$ & $\bar{z}$ & $\overrightarrow{-}$ & $\overline{-}$ & $\overline{-}$ & $\bar{z}$ & $\overline{-}$ & $\overline{-}$ & $\overline{-}$ & $\bar{z}$ & $\bar{z}$ & - \\
\hline- & - & - & - & - & - & - & - & - & - & - & - \\
\hline- & - & - & - & - & - & - & - & - & - & - & - \\
\hline - & - & - & - & - & - & - & - & - & - & - & - \\
\hline
\end{tabular}

See footnotes at end of table. 
Table 34. Reformulated Motor Gasoline Prices by Grade, Sales Type, PAD District, and State (Cents per Gallon Excluding Taxes) - Continued

\begin{tabular}{|c|c|c|c|c|c|c|c|c|c|c|c|c|}
\hline \multirow{3}{*}{$\begin{array}{l}\text { Geographic Area } \\
\text { Month }\end{array}$} & \multicolumn{6}{|c|}{ Regular } & \multicolumn{6}{|c|}{ Midgrade } \\
\hline & \multicolumn{2}{|c|}{ Sales to End Users } & \multicolumn{4}{|c|}{ Sales for Resale } & \multicolumn{2}{|c|}{ Sales to End Users } & \multicolumn{4}{|c|}{ Sales for Resale } \\
\hline & $\begin{array}{l}\text { Through } \\
\text { Retail } \\
\text { Outlets }\end{array}$ & Averagea & DTW & Rack & Bulk & Average & $\begin{array}{l}\text { Through } \\
\text { Retail } \\
\text { Outlets }\end{array}$ & Averagea & DTW & Rack & Bulk & Average \\
\hline
\end{tabular}

South Dakota

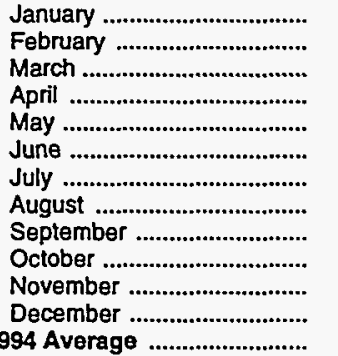

Tennessee

January.

February

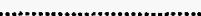

April

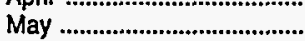

June ......................................

July .

August

September

October .

November

December ..

1994 Average

Wisconsin

January .

February ................................

March ...

April

May

Auly .....

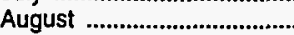

September ...............................

October .

November

December

1994 Average

PAD District III

January

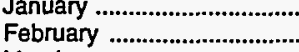

March

April

May .

June

July .

August ..

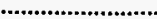

October

November

December

1994 Average

-
-
-
-
-
-
-
-
-
-

-
-
-
-
-
-
-
-

$\begin{array}{llllll}- & - & - & - & - & - \\ - & - & - & - & - & - \\ - & - & - & - & - & - \\ - & - & - & - & - & - \\ - & - & - & - & - & - \\ - & - & - & - & - & - \\ - & - & - & - & - & - \\ - & - & - & - & - & - \\ - & - & - & - & - & - \\ - & - & - & - & - & - \\ - & - & - & - & - & - \\ - & - & - & - & - & -\end{array}$

$\begin{array}{lllll}- & - & - & - & - \\ - & - & - & - & - \\ - & - & - & - & - \\ - & - & - & - & - \\ - & - & - & - & - \\ - & - & - & - & - \\ - & - & - & - & - \\ - & - & - & - & - \\ - & - & - & - & - \\ - & - & - & - & - \\ - & - & - & - & - \\ - & - & - & - & - \\ - & - & - & - & -\end{array}$

$\begin{array}{ll}- & - \\ - & - \\ - & - \\ - & - \\ - & - \\ - & - \\ - & - \\ - & - \\ 76.3 & - \\ 76.3 & 75.4\end{array}$

-
-
-
-
-
-
-
-

$\begin{array}{ll}- & - \\ - & - \\ - & - \\ - & - \\ - & - \\ - & - \\ - & - \\ - & - \\ - & - \\ - & - \\ - & -\end{array}$

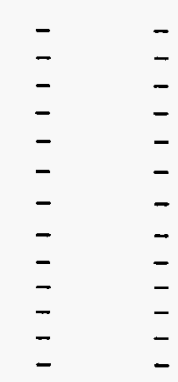

$\begin{array}{lllll}- & - & - & - & - \\ - & - & - & - & - \\ - & - & - & - & - \\ - & - & - & - & - \\ - & - & - & - & - \\ - & - & - & - & - \\ - & - & - & - & - \\ - & - & - & - & - \\ - & - & - & - & - \\ - & - & - & - & - \\ - & - & - & - & - \\ - & - & - & - & -\end{array}$

See footnotes at end of table. 
Table 34. Reformulated Motor Gasoline Prices by Grade, Sales Type, PAD District, and State

(Cents per Gallon Excluding Taxes) - Continued

\begin{tabular}{|c|c|c|c|c|c|c|c|c|c|c|c|c|}
\hline \multirow{3}{*}{$\begin{array}{l}\text { Geographic Area } \\
\text { Month }\end{array}$} & \multicolumn{6}{|c|}{ Premium } & \multicolumn{6}{|c|}{ All Grades } \\
\hline & \multicolumn{2}{|c|}{ Sales to End Users } & \multicolumn{4}{|c|}{ Sales for Resale } & \multicolumn{2}{|c|}{ Sales to End Users } & \multicolumn{4}{|c|}{ Sales for Resale } \\
\hline & $\begin{array}{c}\text { Through } \\
\text { Retall } \\
\text { Outlets }\end{array}$ & Averagea & DTW & Rack & Bulk & Average & $\begin{array}{c}\text { Through } \\
\text { Retail } \\
\text { Outlets }\end{array}$ & Averagea & DTW & Rack & Bulk & Average \\
\hline
\end{tabular}

South Dakota

January ...

February

March

April

June

July ....

August

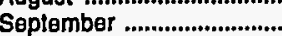

October .

November

December

1994 Averago

Tennesseo

January ..................................

Fobruary

March ....................................

April .

May

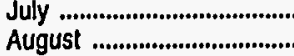

September

October ....

November

Nocembe

1994 Average

Wisconsin

January

February

March

April

May

June

July .

August ...

.

October

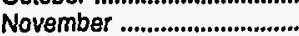

December .

1994 Average

PAD Diatrict III

January

Februany

March

April .

May .

ne

July .

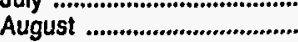

September

October .

November .............................

December .

1994 Average

ne.........................

-
$=$
-

-
-
-
-
-
-
-

-
$\overline{-}$
$\overline{-}$
$\overline{-}$
$\overline{-}$
-
-

$\begin{array}{ll}- & - \\ - & - \\ - & - \\ - & - \\ - & - \\ - & - \\ - & - \\ - & - \\ - & - \\ - & - \\ - & -\end{array}$

$\begin{array}{ll}- & - \\ - & - \\ - & - \\ - & - \\ - & - \\ - & - \\ - & - \\ - & - \\ - & - \\ - & - \\ - & -\end{array}$

$\begin{array}{lll}- & - & - \\ - & - & - \\ - & - & - \\ - & - & - \\ - & - & - \\ - & - & - \\ - & - & - \\ - & - & - \\ - & - & - \\ - & - & - \\ - & - & -\end{array}$

See footnotes at end of table. 
Table 34. Reformulated Motor Gasoline Prices by Grade, Sales Type,

PAD District, and State

(Cents per Gallon Excluding Taxes) - Continued

\begin{tabular}{|c|c|c|c|c|c|c|c|c|c|c|c|c|}
\hline \multirow{3}{*}{$\begin{array}{l}\text { Geographic Area } \\
\text { Month }\end{array}$} & \multicolumn{6}{|c|}{ Regular } & \multicolumn{6}{|c|}{ Midgrade } \\
\hline & \multicolumn{2}{|c|}{ Sales to End Users } & \multicolumn{4}{|c|}{ Sales for Resale } & \multicolumn{2}{|c|}{ Sales to End Users } & \multicolumn{4}{|c|}{ Sales for Resale } \\
\hline & $\begin{array}{c}\text { Through } \\
\text { Retail } \\
\text { Outlets }\end{array}$ & Average ${ }^{a}$ & DTW & Rack & Bulk & Average & $\begin{array}{c}\text { Through } \\
\text { Retail } \\
\text { Outlets }\end{array}$ & Averagea & DTW & Rack & Bulk & Average \\
\hline
\end{tabular}

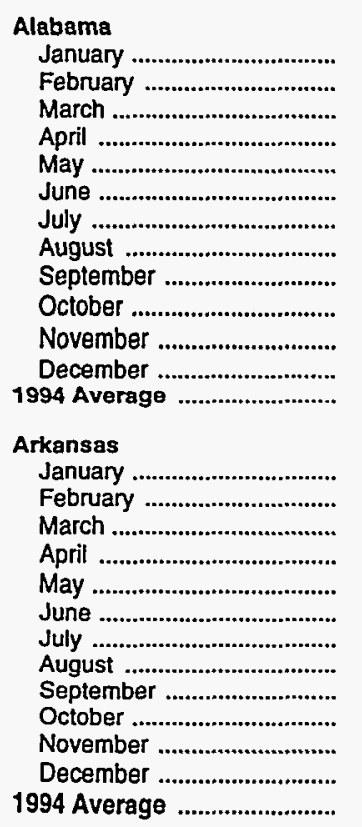

\begin{tabular}{|c|c|c|c|c|c|c|c|c|c|c|c|}
\hline- & - & - & - & - & - & - & - & - & - & - & - \\
\hline- & - & - & - & - & - & - & - & - & - & - & - \\
\hline- & - & - & - & - & - & - & - & - & - & - & - \\
\hline- & - & - & - & - & - & - & - & - & - & - & - \\
\hline- & - & - & - & - & - & - & - & - & - & - & - \\
\hline- & - & - & - & - & - & - & - & - & - & - & - \\
\hline- & - & - & - & - & - & - & - & - & - & - & - \\
\hline- & - & - & - & - & - & - & - & - & - & - & - \\
\hline- & - & - & - & - & - & - & - & - & - & - & - \\
\hline- & - & - & - & - & - & - & - & - & - & - & - \\
\hline- & - & - & - & - & - & - & - & - & - & - & - \\
\hline- & - & - & - & - & - & - & - & - & - & - & - \\
\hline - & - & - & $\rightarrow$ & - & - & - & - & - & - & - & - \\
\hline
\end{tabular}

\footnotetext{
Louisiana

January

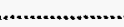

March

March

May

July .

Auly

September

October

November

December
}

Mississipi

Mississippi

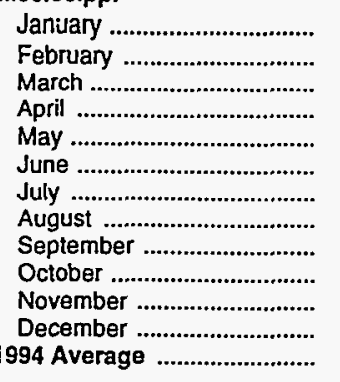

-
-
-
-
-
-
-
-
-
-

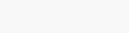

$\begin{array}{lllllll}- & - & - & - & - & - & - \\ - & - & - & - & - & - & - \\ - & - & - & - & - & - & - \\ - & - & - & - & - & - & - \\ - & - & - & - & - & - & - \\ - & - & - & - & - & - & - \\ - & - & - & - & - & - & - \\ - & - & - & - & - & - & - \\ - & - & - & - & - & - & - \\ - & - & - & - & - & - & - \\ - & - & - & - & - & - & - \\ - & - & - & - & - & - & - \\ - & - & - & - & - & - & -\end{array}$

See footnotes at end of table. 
Table 34. Reformulated Motor Gasoline Prices by Grade, Sales Type, PAD District, and State

(Cents per Gallon Excluding Taxes) - Continued

\begin{tabular}{|c|c|c|c|c|c|c|c|c|c|c|c|c|}
\hline \multirow{3}{*}{$\begin{array}{l}\text { Geographic Area } \\
\text { Month }\end{array}$} & \multicolumn{6}{|c|}{ Premlum } & \multicolumn{6}{|c|}{ All Grades } \\
\hline & \multicolumn{2}{|c|}{ Sales to End Users } & \multicolumn{4}{|c|}{ Sales for Resale } & \multicolumn{2}{|c|}{ Sales to End Users } & \multicolumn{4}{|c|}{ Sales for Resale } \\
\hline & $\begin{array}{c}\text { Through } \\
\text { Retail } \\
\text { Outlets }\end{array}$ & Average ${ }^{\mathrm{a}}$ & DTW & Rack & Bulk & Average & $\begin{array}{l}\text { Through } \\
\text { Retail } \\
\text { Outlets }\end{array}$ & Averagea & DTW & Rack & Bulk & Average \\
\hline
\end{tabular}

\begin{tabular}{|c|c|c|c|c|c|c|c|c|c|c|c|c|}
\hline \multicolumn{13}{|l|}{ Alabama } \\
\hline 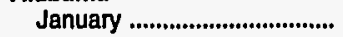 & - & - & - & - & - & - & - & - & - & - & - & - \\
\hline 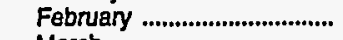 & - & - & - & - & - & - & - & - & - & - & - & - \\
\hline 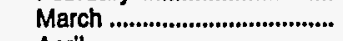 & - & - & - & - & - & - & - & - & - & - & - & - \\
\hline 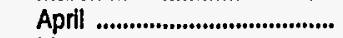 & - & - & - & - & - & - & - & - & - & - & - & - \\
\hline 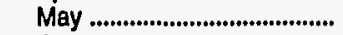 & - & - & - & - & - & - & - & - & - & - & - & - \\
\hline 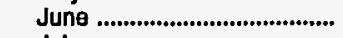 & - & - & - & - & - & - & - & - & - & - & - & - \\
\hline July ........................................... & - & - & - & - & - & - & - & - & - & - & - & - \\
\hline 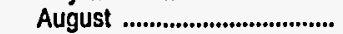 & - & - & - & - & - & - & - & - & - & - & - & - \\
\hline 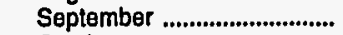 & - & - & - & - & - & - & - & - & - & - & - & - \\
\hline October & - & - & - & - & - & - & - & - & - & - & - & - \\
\hline November ................................. & - & - & - & - & - & - & - & - & - & - & - & - \\
\hline December ................................. & - & - & - & - & - & - & - & - & - & - & - & - \\
\hline 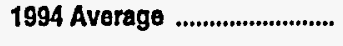 & - & - & - & - & - & - & - & - & - & - & - & - \\
\hline \multicolumn{13}{|l|}{ Arkansas } \\
\hline 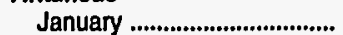 & - & - & - & - & - & - & - & - & - & - & - & - \\
\hline February ................................ & - & - & - & - & - & - & - & - & - & - & - & - \\
\hline 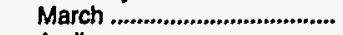 & - & - & - & - & - & - & - & - & - & - & - & - \\
\hline 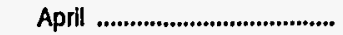 & - & - & - & - & - & - & - & - & - & - & - & - \\
\hline 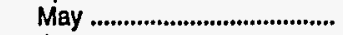 & - & - & - & - & - & - & - & - & - & - & - & - \\
\hline June ................................................ & - & - & - & - & - & - & - & - & - & - & - & - \\
\hline 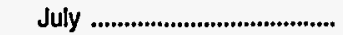 & - & - & - & - & - & - & - & - & - & - & - & - \\
\hline 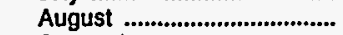 & - & - & - & - & - & - & - & - & - & - & - & - \\
\hline September ............................ & - & - & - & - & - & - & - & - & - & - & - & - \\
\hline 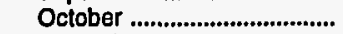 & - & - & - & - & - & - & - & - & - & - & - & - \\
\hline November ................................ & - & - & - & - & - & - & - & - & - & - & - & - \\
\hline December .................................... & - & - & - & - & - & - & - & - & - & - & - & - \\
\hline 1994 Average ................................. & - & - & - & - & - & - & - & - & - & - & - & - \\
\hline \multicolumn{13}{|l|}{ Loulslana } \\
\hline 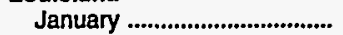 & - & - & - & - & - & - & - & - & - & - & - & - \\
\hline 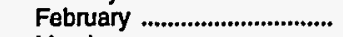 & - & - & - & - & - & - & - & - & - & - & - & - \\
\hline 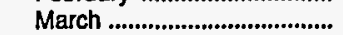 & - & - & - & - & - & - & - & - & - & - & - & - \\
\hline April .............................................. & - & - & - & - & - & - & - & - & - & - & - & - \\
\hline May ......................................... & - & - & - & - & - & - & - & - & - & - & - & - \\
\hline 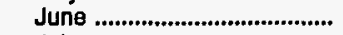 & - & - & - & - & - & - & - & - & - & - & - & - \\
\hline 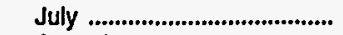 & - & - & - & - & - & - & - & - & - & - & - & - \\
\hline 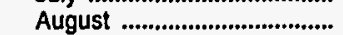 & - & - & - & - & - & - & - & - & - & - & - & - \\
\hline 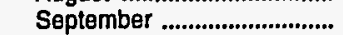 & - & - & - & - & - & - & - & - & - & - & - & - \\
\hline 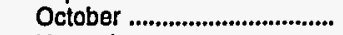 & - & - & - & - & - & - & - & - & - & - & - & - \\
\hline 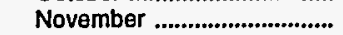 & - & - & - & - & - & - & - & - & - & - & - & - \\
\hline 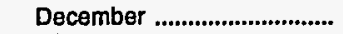 & - & - & - & - & - & - & - & - & - & - & $w$ & w \\
\hline 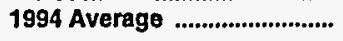 & - & - & - & - & - & - & - & - & - & - & $w$ & $\mathbf{w}$ \\
\hline \multicolumn{13}{|l|}{ Mississippi } \\
\hline 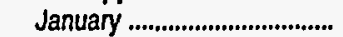 & - & - & - & - & - & - & - & - & - & - & - & - \\
\hline February ..................................... & - & - & - & - & - & - & - & - & - & - & - & - \\
\hline 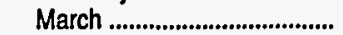 & - & - & - & - & - & - & - & - & - & - & - & - \\
\hline 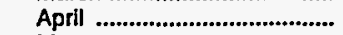 & - & - & - & - & - & - & - & - & - & - & - & - \\
\hline 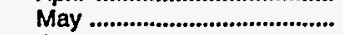 & - & - & - & - & - & - & - & - & - & - & - & - \\
\hline 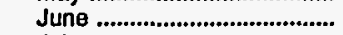 & - & - & - & - & - & - & - & - & - & - & - & - \\
\hline July & - & - & - & - & - & - & - & - & - & - & - & - \\
\hline 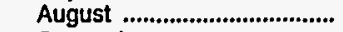 & - & - & - & - & - & - & - & - & - & - & - & - \\
\hline 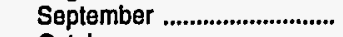 & - & - & - & - & - & - & - & - & $\overline{-}$ & - & - & - \\
\hline 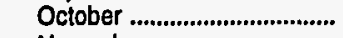 & - & - & $\overline{-}$ & $\overline{-}$ & $\overline{-}$ & - & - & - & $\overline{-}$ & - & $\bar{w}$ & $\bar{w}$ \\
\hline 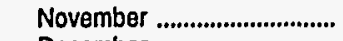 & - & - & - & $\overline{-}$ & $\overline{-}$ & $\overline{-}$ & $\overline{-}$ & - & - & - & w & W \\
\hline 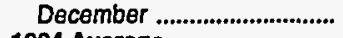 & $\overline{-}$ & $\overline{-}$ & $\overline{-}$ & $\overline{-}$ & $\overline{-}$ & $\overline{-}$ & $\bar{z}$ & $\overline{-}$ & $\overline{-}$ & $\overline{-}$ & $\bar{w}$ & $\bar{w}$ \\
\hline 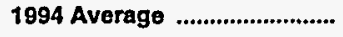 & & & & & & & & & & & & $\mathbf{W}$ \\
\hline
\end{tabular}

See footnotes at end of table. 
Table 34. Reformulated Motor Gasoline Prices by Grade, Sales Type, PAD District, and State

(Cents per Gallon Excluding Taxes) - Continued

\begin{tabular}{|c|c|c|c|c|c|c|c|c|c|c|c|c|}
\hline \multirow{3}{*}{$\begin{array}{l}\text { Geographic Area } \\
\text { Month }\end{array}$} & \multicolumn{6}{|c|}{ Regular } & \multicolumn{6}{|c|}{ Midgrado } \\
\hline & \multicolumn{2}{|c|}{ Sales to End Users } & \multicolumn{4}{|c|}{ Sales for Resale } & \multicolumn{2}{|c|}{ Sales to End Users } & \multicolumn{4}{|c|}{ Sales for Resale } \\
\hline & $\begin{array}{l}\text { Through } \\
\text { Retall } \\
\text { Outlets }\end{array}$ & Averagea & DTW & Rack & Bulk & Average & $\begin{array}{c}\text { Through } \\
\text { Retail } \\
\text { Outlets }\end{array}$ & Average $\mathrm{a}$ & DTW & Rack & Bulk & Average \\
\hline
\end{tabular}

Now Mexico

January ...

February

March

April

May .

June.

July .........

September

October...

November

December

1994 Average

Texas

January .

February

March

April

May ............................................

June

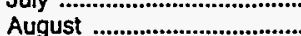

September

October.

November

December ......

1994 Average

PAD District IV

January .

February

March

April

May

June

July ..

August

September

October .

November

December

Colorado

January .

February

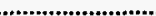

March

April

May

June

July ........

Sugust ....

October .

November

December

1994 Average

\begin{tabular}{|c|c|c|}
\hline- & - & - \\
\hline- & - & - \\
\hline - & - & $=$ \\
\hline $\bar{I}$ & $\overline{-}$ & $\overline{-}$ \\
\hline - & - & - \\
\hline - & - & - \\
\hline 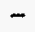 & - & - \\
\hline - & - & - \\
\hline - & - & - \\
\hline - & - & - \\
\hline$=$ & - & - \\
\hline
\end{tabular}

$\begin{array}{cccccc}- & - & - & - & - & - \\ = & - & - & - & - & - \\ - & - & - & - & - & - \\ = & - & - & - & - & - \\ = & - & - & - & - & - \\ = & - & - & - & - & - \\ - & - & - & - & - & - \\ - & - & - & - & - & - \\ 72.6 & 72.2 & 65.4 & 51.7 & \bar{w} & 58.5 \\ 72.6 & 72.2 & 65.4 & 53.1 & 51.0 & 56.8 \\ & & & & 51.3 & 56.9\end{array}$

$\begin{array}{ll}= & - \\ = & = \\ = & = \\ = & = \\ = & = \\ = & = \\ = & =\end{array}$

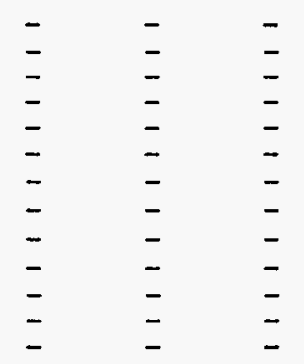

See footnotes at end of table. 
Table 34. Reformulated Motor Gasoline Prices by Grade, Sales Type,

PAD District, and State

(Cents per Gallon Excluding Taxes) - Continued

\begin{tabular}{|c|c|c|c|c|c|c|c|c|c|c|c|c|}
\hline \multirow{3}{*}{$\begin{array}{l}\text { Geographlc Area } \\
\text { Month }\end{array}$} & \multicolumn{6}{|c|}{ Premium } & \multicolumn{6}{|c|}{ All Grades } \\
\hline & \multicolumn{2}{|c|}{ Sales to End Users } & \multicolumn{4}{|c|}{ Sales for Resale } & \multicolumn{2}{|c|}{ Sales to End Users } & \multicolumn{4}{|c|}{ Sales for Resale } \\
\hline & $\begin{array}{c}\text { Through } \\
\text { Retall } \\
\text { Outlots }\end{array}$ & Averagea & DTW & Rack & Bulk & Average & $\begin{array}{l}\text { Through } \\
\text { Retail } \\
\text { Outlets }\end{array}$ & Averagea & DTW & Rack & Bulk & Average \\
\hline
\end{tabular}

New Mexico

January

February

March

Aprll

May

June

July .....

August

September ...........................

October ...

November

December .

1994 Averago

Texas

January

February

March .

Aprll

May

June

July ....

(2)

September

October .................................

November

December ...............................

1994 Averago

PAD District IV

January.

February

March

Aprll

May

June

July .....

September

.............................

October

November ................................

December

1994 Average

Colorado

January

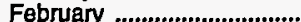

March

April

May

July .

September

October

November

December .

1994 Average

$\begin{array}{ll}- & \\ = & \\ = & \\ - & \end{array}$

-
-
-
-
-
-
-

-
-
$\overline{-}$
-
-
-
-
-

$\begin{array}{ccc}- & - & - \\ - & - & - \\ - & - & - \\ - & - & - \\ - & - & - \\ - & - & - \\ - & - & - \\ - & - & - \\ - & - & - \\ - & - & - \\ - & - & 78.4 \\ 93.0 & 92.2 & 78.2 \\ 93.0 & 92.2 & 78.2\end{array}$

$\begin{array}{ll}- & - \\ - & - \\ - & - \\ - & - \\ - & - \\ - & - \\ - & - \\ - & - \\ - & - \\ - & -\end{array}$

$\begin{array}{ll}- & - \\ - & - \\ - & - \\ - & - \\ - & - \\ - & - \\ - & - \\ - & - \\ - & -\end{array}$

$\begin{array}{llll}- & - & - & - \\ - & - & - & - \\ - & - & - & - \\ - & - & - & - \\ - & - & - & - \\ - & - & - & - \\ - & - & - & - \\ - & - & - & - \\ - & - & - & - \\ - & - & - & - \\ - & - & - & - \\ - & - & - & - \\ - & - & - & -\end{array}$

$\begin{array}{lll}- & - & - \\ - & - & - \\ - & - & - \\ - & - & - \\ - & - & - \\ - & - & - \\ - & - & - \\ - & - & - \\ - & - & - \\ - & - & - \\ 63.3 & - & 73.8 \\ 63.2 & w & 69.2 \\ 63.2 & w & 69.5\end{array}$

$\begin{array}{cccc}- & - & - & - \\ - & - & - & - \\ - & - & - & - \\ - & - & - & - \\ - & - & - & - \\ - & - & - & - \\ - & - & - & - \\ - & - & - & - \\ - & - & - & - \\ - & - & - & - \\ 70.7 & 55.5 & w & 63.8 \\ 70.0 & 55.8 & 51.0 & 60.7 \\ 70.1 & 55.7 & 51.3 & 60.9\end{array}$

See footnotes at end of table. 
Table 34. Reformulated Motor Gasoline Prices by Grade, Sales Type,

PAD District, and State

(Cents per Gallon Excluding Taxes) - Continued

\begin{tabular}{|c|c|c|c|c|c|c|c|c|c|c|c|c|}
\hline \multirow{3}{*}{$\begin{array}{l}\text { Geographic Area } \\
\text { Month }\end{array}$} & \multicolumn{6}{|c|}{ Regular } & \multicolumn{6}{|c|}{ Midgrade } \\
\hline & \multicolumn{2}{|c|}{ Sales to End Users } & \multicolumn{4}{|c|}{ Sales for Resale } & \multicolumn{2}{|c|}{ Sales to End Users } & \multicolumn{4}{|c|}{ Sales for Resale } \\
\hline & $\begin{array}{c}\text { Through } \\
\text { Retail } \\
\text { Outlets }\end{array}$ & Average ${ }^{a}$ & DTW & Rack & Bulk & Average & $\begin{array}{l}\text { Through } \\
\text { Retail } \\
\text { Outlots }\end{array}$ & Averagea & DTW & Rack & Bulk & Average \\
\hline
\end{tabular}

Idaho

January .

February

March.

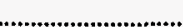

April

May

June

July ....

September .............................

October .

November

December

Montana

January

February

March .

April

May

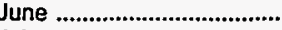

July

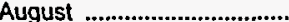

September

October .

November

December

1994 Average

Utah

January .

February

March .

April

May

August

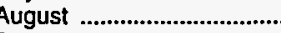

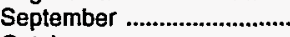

October

November

December .................................

1994 Average

Wyoming

January

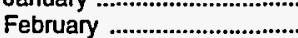

March

April

May

June

August

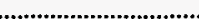

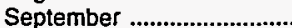

October

November

December

1994 Average

\begin{tabular}{|c|c|c|c|c|c|c|c|c|c|c|c|}
\hline - & - & - & - & - & - & - & - & - & - & - & _ \\
\hline- & - & - & - & - & - & - & - & - & - & - & - \\
\hline- & - & - & - & - & - & - & - & - & - & - & - \\
\hline- & - & - & - & - & - & - & - & - & - & - & - \\
\hline- & - & - & - & - & - & - & - & - & - & - & - \\
\hline - & - & - & - & - & - & - & - & - & - & - & - \\
\hline- & - & - & - & - & - & - & - & - & - & - & - \\
\hline- & - & - & - & - & $=$ & - & $=$ & $=$ & $I$ & $\bar{I}$ & $=$ \\
\hline - & - & - & - & - & - & - & - & - & - & - & _ \\
\hline - & - & - & - & - & - & - & - & - & - & - & - \\
\hline- & - & - & - & - & - & - & - & - & - & - & - \\
\hline - & - & - & - & - & - & - & - & - & - & - & - \\
\hline - & - & - & - & - & - & - & - & - & - & - & - \\
\hline- & - & - & - & - & - & - & - & - & - & - & - \\
\hline - & - & - & - & - & - & - & - & - & - & - & - \\
\hline- & - & - & - & - & - & - & - & - & - & - & - \\
\hline - & - & - & - & - & - & - & - & - & - & - & - \\
\hline- & - & - & - & - & - & - & - & - & - & - & - \\
\hline- & - & - & - & - & - & $=$ & - & - & - & 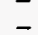 & 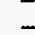 \\
\hline - & - & - & - & - & - & - & - & - & - & - & _ \\
\hline- & - & - & - & - & - & - & - & - & - & - & - \\
\hline- & - & - & - & - & - & - & - & - & - & - & - \\
\hline- & - & - & - & - & - & - & - & - & - & - & - \\
\hline . & - & - & - & - & - & - & - & - & - & - & _ \\
\hline
\end{tabular}

See footnotes at end of table. 
Table 34. Reformulated Motor Gasoline Prices by Grade, Sales Type, PAD District, and State

(Cents per Gallon Excluding Taxes) - Continued

\begin{tabular}{|c|c|c|c|c|c|c|c|c|c|c|c|c|}
\hline \multirow{3}{*}{$\begin{array}{l}\text { Geographic Area } \\
\text { Month }\end{array}$} & \multicolumn{6}{|c|}{ Premium } & \multicolumn{6}{|c|}{ All Grades } \\
\hline & \multicolumn{2}{|c|}{ Sales to End Users } & \multicolumn{4}{|c|}{ Sales for Resale } & \multicolumn{2}{|c|}{ Sales to End Users } & \multicolumn{4}{|c|}{ Sales for Resale } \\
\hline & $\begin{array}{l}\text { Through } \\
\text { Retall } \\
\text { Outlots }\end{array}$ & Average ${ }^{a}$ & DTW & Rack & Bulk & Average & $\begin{array}{l}\text { Through } \\
\text { Retail } \\
\text { Outlots }\end{array}$ & Averagea & DTW & Rack & Bulk & Averago \\
\hline
\end{tabular}

Idaho

January .

March .

April

May .

July .....

August ........................................ September

October ...

November

December ................................

1994 Average

Montana

January.

April

May

June

July

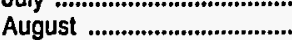

September

October .

November ...............................

December

1994 Average

Utah

January

February

March .

April

May .

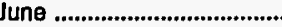

July

August

September

October .

November

December

1994 Average

Wyoming

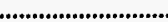

February

March

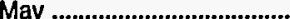

June

July

ger

October

November

December

1994 Average

See footnotes at end of table.

\begin{tabular}{|c|c|c|c|c|c|c|c|c|c|c|c|}
\hline- & - & - & - & - & - & - & - & - & - & - & - \\
\hline- & - & - & - & - & - & - & - & - & - & - & - \\
\hline- & - & - & - & - & - & - & - & - & - & - & - \\
\hline- & - & - & - & - & - & - & - & - & - & - & - \\
\hline- & - & - & - & - & - & - & - & - & - & - & - \\
\hline- & - & - & - & - & - & - & - & - & - & - & - \\
\hline- & - & - & - & - & - & - & - & - & - & - & - \\
\hline- & - & - & - & - & - & - & - & - & - & - & - \\
\hline- & - & - & - & - & - & - & - & - & - & - & - \\
\hline- & - & - & - & - & - & $\rightarrow$ & - & - & - & - & - \\
\hline- & - & - & - & - & - & - & - & - & - & - & - \\
\hline- & - & - & - & - & - & - & - & - & - & - & - \\
\hline- & - & - & - & - & - & - & - & - & - & - & - \\
\hline
\end{tabular}

\begin{tabular}{|c|c|c|c|c|c|c|c|c|c|c|c|}
\hline - & - & - & - & - & - & - & - & - & - & - & - \\
\hline - & - & - & - & - & - & - & - & - & - & - & - \\
\hline - & - & - & - & - & - & - & - & - & - & - & - \\
\hline - & - & - & - & - & - & - & - & - & - & - & - \\
\hline - & - & - & - & - & - & - & - & - & - & - & - \\
\hline - & - & - & - & - & - & - & - & - & - & - & - \\
\hline - & - & - & - & - & - & - & - & - & - & - & - \\
\hline- & - & - & - & - & - & - & - & - & - & - & - \\
\hline - & - & - & - & - & - & - & - & - & - & - & - \\
\hline - & - & - & - & - & - & - & - & - & - & - & - \\
\hline - & - & - & - & - & - & - & - & - & - & - & - \\
\hline- & - & - & - & - & - & - & - & - & - & - & - \\
\hline- & - & - & - & - & - & - & - & - & - & - & - \\
\hline
\end{tabular}

\begin{tabular}{|c|c|c|c|c|c|c|c|c|c|c|c|}
\hline - & - & - & - & - & - & - & - & - & - & - & - \\
\hline- & - & - & - & - & - & - & - & - & - & - & - \\
\hline - & - & - & - & - & - & - & - & - & - & - & - \\
\hline- & - & - & - & - & - & - & - & - & - & - & - \\
\hline- & - & - & - & - & - & - & - & - & - & - & - \\
\hline- & - & - & - & - & - & - & - & - & - & - & - \\
\hline- & - & - & - & - & - & - & - & - & - & - & - \\
\hline- & - & - & - & - & - & - & - & - & - & - & - \\
\hline- & - & - & - & - & - & - & - & - & - & - & - \\
\hline- & - & - & - & - & - & - & - & - & - & - & - \\
\hline- & - & - & - & - & - & - & - & - & - & - & - \\
\hline- & - & - & - & - & - & - & - & - & - & - & - \\
\hline - & - & - & - & - & - & - & - & - & - & - & - \\
\hline- & - & - & - & - & - & - & - & - & - & - & - \\
\hline- & - & - & - & - & - & - & - & - & - & - & - \\
\hline- & - & - & - & - & - & - & - & - & - & - & - \\
\hline- & - & - & - & - & - & - & - & - & - & - & - \\
\hline- & - & - & - & - & - & - & - & - & - & - & - \\
\hline- & - & - & - & - & - & - & - & - & - & - & - \\
\hline- & - & - & - & - & - & - & - & - & - & - & - \\
\hline- & - & - & - & - & - & - & - & - & - & - & - \\
\hline- & - & - & - & - & - & - & - & - & - & - & - \\
\hline- & - & - & - & - & - & - & - & - & - & - & - \\
\hline- & - & - & - & - & - & - & - & - & - & - & - \\
\hline- & - & - & - & - & - & - & - & $\rightarrow$ & - & - & - \\
\hline- & - & - & - & - & - & - & - & - & - & - & - \\
\hline
\end{tabular}


Table 34. Reformulated Motor Gasoline Prices by Grade, Sales Type, PAD District, and State

(Cents per Gallon Excluding Taxes) - Continued

\begin{tabular}{|c|c|c|c|c|c|c|c|c|c|c|c|c|}
\hline \multirow{3}{*}{$\begin{array}{l}\text { Geographic Area } \\
\text { Month }\end{array}$} & \multicolumn{6}{|c|}{ Regular } & \multicolumn{6}{|c|}{ Midgrado } \\
\hline & \multicolumn{2}{|c|}{ Sales to End Users } & \multicolumn{4}{|c|}{ Sales for Resale } & \multicolumn{2}{|c|}{ Sales to End Users } & \multicolumn{4}{|c|}{ Sales for Resale } \\
\hline & $\begin{array}{c}\text { Through } \\
\text { Retail } \\
\text { Outlets }\end{array}$ & Averagea & DTW & Rack & Bulk & Average & $\begin{array}{l}\text { Through } \\
\text { Retail } \\
\text { Outlets }\end{array}$ & Averagea & DTW & Rack & Bulk & Average \\
\hline
\end{tabular}

\section{PAD Dlstrict V}

January

February

March

June

July .

August

September

October

November

December .

1994 Average

Alaska

January .

February

March

April

May

July

August

September

October

November

December .

1994 Average

\section{Arizona}

January .

February

March

April

May ....

June

July ....

September

October .

November

December

1994 Average

California

January

February

April

May

June .

July .........

September

October .

November

1994 Average

$\begin{array}{ccccc}- & - & - & - & - \\ - & - & - & - & - \\ - & - & - & - & - \\ - & - & - & - & - \\ - & - & - & - & - \\ - & - & - & - & - \\ - & - & - & - & - \\ - & - & - & - & - \\ - & - & - & - & - \\ - & - & - & - & - \\ 77.9 & 78.0 & 72.8 & \text { NA } & 63.2 \\ 78.0 & 77.6 & 72.4 & 56.8 & 53.5 \\ 78.0 & 77.6 & 72.5 & 57.0 & 55.2\end{array}$

$\begin{array}{ll}- & - \\ - & - \\ - & - \\ - & - \\ - & - \\ - & - \\ - & - \\ - & - \\ - & - \\ 63.2 & 70.4 \\ 53.5 & 66.8 \\ 55.2 & 67.1\end{array}$

$\begin{array}{rr}- & - \\ - & - \\ - & - \\ - & - \\ - & - \\ - & - \\ - & - \\ - & - \\ - & - \\ W & - \\ 92.8 & 91.1 \\ 93.3 & 91.9\end{array}$

$\begin{array}{cccc}- & - & - & - \\ - & - & - & - \\ - & - & - & - \\ - & - & - & - \\ - & - & - & - \\ - & - & - & - \\ - & - & - & - \\ - & - & - & - \\ - & - & - & - \\ - & - & - & - \\ 78.6 & \text { NA } & - & 78.4 \\ 77.0 & 63.6 & - & 75.7 \\ 77.0 & 63.7 & - & 75.8\end{array}$

See footnotes at end of table. 
Table 34. Reformulated Motor Gasoline Prices by Grade, Sales Type, PAD District, and State

(Cents per Gallon Excluding Taxes) - Continued

\begin{tabular}{|c|c|c|c|c|c|c|c|c|c|c|c|c|}
\hline \multirow{3}{*}{$\begin{array}{l}\text { Geographic Area } \\
\text { Month }\end{array}$} & \multicolumn{6}{|c|}{ Premium } & \multicolumn{6}{|c|}{ All Grades } \\
\hline & \multicolumn{2}{|c|}{ Sales to End Users } & \multicolumn{4}{|c|}{ Sales for Resale } & \multicolumn{2}{|c|}{ Sales to End Users } & \multicolumn{4}{|c|}{ Sales for Resale } \\
\hline & $\begin{array}{c}\text { Through } \\
\text { Retail } \\
\text { Outlets }\end{array}$ & Averagea & DTW & Rack & Bulk & Average & $\begin{array}{c}\text { Through } \\
\text { Retail } \\
\text { Outlets }\end{array}$ & Averagea & DTW & Rack & Bulk & Average \\
\hline
\end{tabular}

\section{PAD District $V$}

January.

Fobruary

March

April

May .

June

July ....

August ........................................

September

October

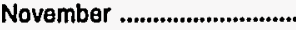

December .

1994 Avorago

Alaska

January...

Fobruary .............................

March

April

May

Juno

July ...

September

October ..

November

December

Arizona

January

February

March

April

May

June

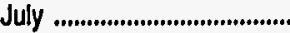

August

September .............................. October .

November

December

1994 Average

Califomla

January

February ..................................... March .

April

May .

June

August

September

October

November

December

1994 Average

$\begin{array}{ll}- & - \\ - & - \\ - & - \\ - & - \\ - & - \\ - & - \\ - & - \\ - & - \\ 97.2 & - \\ 98.3 & 97 . \\ 97.9 & 97.5\end{array}$

$\begin{array}{ccc}- & - & - \\ - & - & - \\ - & - & - \\ - & - & - \\ - & - & - \\ - & - & - \\ - & - & - \\ - & - & - \\ - & - & - \\ - & - & - \\ 97.2 & 83.6 & \text { NA } \\ 97.6 & 86.5 & 68.2 \\ 97.5 & 86.0 & 68.8\end{array}$

$\begin{array}{llllll}- & - & - & - & - & - \\ - & - & - & - & - & - \\ - & - & - & - & - & - \\ - & - & - & - & - & - \\ - & - & - & - & - & - \\ - & - & - & - & - & - \\ - & - & - & - & - & - \\ - & - & - & - & - & - \\ - & - & - & - & - & - \\ - & - & - & - & - & - \\ 87.9 & 87.8 & 78.0 & 69.1 & 63.6 & 75.6 \\ 83.1 & 82.6 & 76.7 & 58.7 & 53.6 & 71.5 \\ 83.9 & 83.4 & 76.9 & 58.9 & 55.5 & 72.0\end{array}$

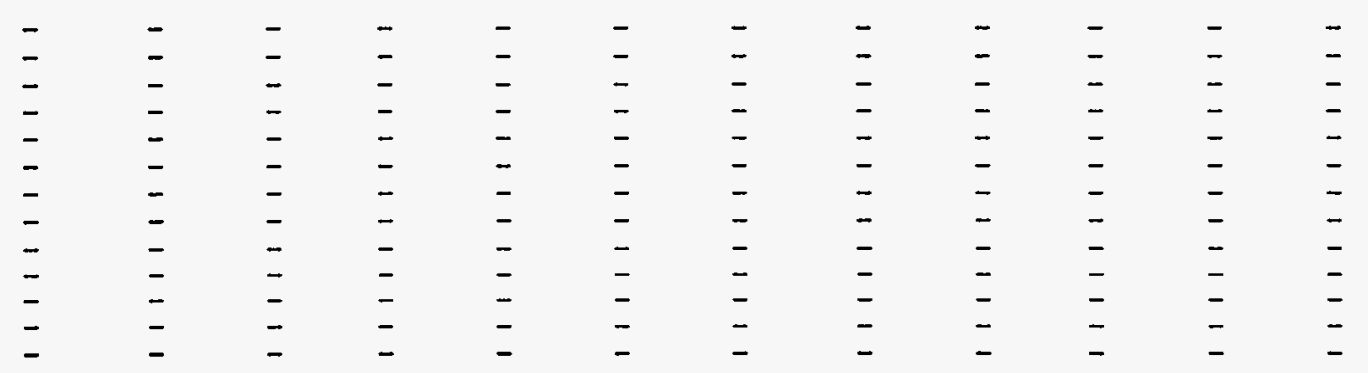

See footnotes at end of table. 
Table 34. Reformulated Motor Gasoline Prices by Grade, Sales Type, PAD District, and State

(Cents per Gallon Excluding Taxes) - Continued

\begin{tabular}{|c|c|c|c|c|c|c|c|c|c|c|c|c|}
\hline \multirow{3}{*}{$\begin{array}{l}\text { Goographle Area } \\
\text { Month }\end{array}$} & \multicolumn{6}{|c|}{ Regular } & \multicolumn{6}{|c|}{ Midgrado } \\
\hline & \multicolumn{2}{|c|}{ Sales to End Users } & \multicolumn{4}{|c|}{ Sales for Resale } & \multicolumn{2}{|c|}{ Sales to End Users } & \multicolumn{4}{|c|}{ Sales for Resale } \\
\hline & $\begin{array}{c}\text { Through } \\
\text { Rotali } \\
\text { Outlots }\end{array}$ & Average ${ }^{a}$ & DTW & Rack & Bulk & Average & $\begin{array}{l}\text { Through } \\
\text { Retail } \\
\text { Outlots }\end{array}$ & Averagea & DTW & Rack & Bulk & Average \\
\hline
\end{tabular}

\begin{tabular}{|c|c|c|c|c|c|c|c|c|c|c|c|c|}
\hline Hawali & & & & & & & & & & & & \\
\hline 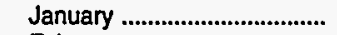 & - & - & - & - & - & - & - & - & - & - & - & - \\
\hline 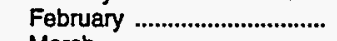 & - & - & - & - & - & - & - & - & - & - & - & - \\
\hline 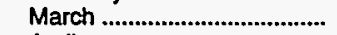 & - & - & - & - & - & - & - & - & - & - & - & - \\
\hline April ....................................... & - & - & - & - & - & - & - & - & - & - & - & - \\
\hline 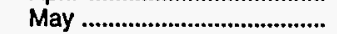 & - & - & - & - & - & - & - & - & - & - & - & - \\
\hline 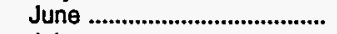 & - & - & - & - & - & - & - & - & - & - & - & - \\
\hline 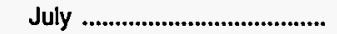 & - & - & - & - & - & - & - & - & - & - & - & - \\
\hline 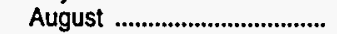 & - & - & - & - & - & - & - & - & - & - & - & - \\
\hline 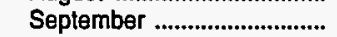 & - & - & - & - & - & - & - & - & - & - & - & - \\
\hline 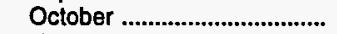 & - & - & - & - & - & - & - & - & - & - & - & - \\
\hline 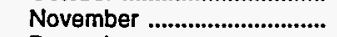 & - & - & - & - & - & - & - & - & - & - & - & - \\
\hline 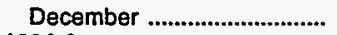 & - & - & - & - & - & - & - & - & - & - & - & - \\
\hline 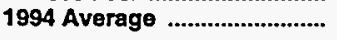 & - & - & - & - & - & - & - & - & - & - & - & - \\
\hline Nevada & & & & & & & & & & & & \\
\hline 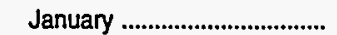 & - & - & - & - & - & - & - & - & - & - & - & _ \\
\hline 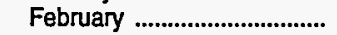 & - & - & - & - & - & - & - & - & - & - & - & - \\
\hline 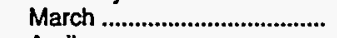 & - & - & - & - & - & - & - & - & - & - & - & - \\
\hline 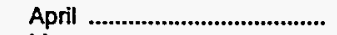 & - & - & - & - & - & - & - & - & - & - & - & - \\
\hline 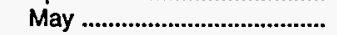 & - & - & - & - & - & - & - & - & - & - & - & - \\
\hline 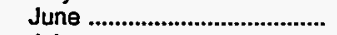 & - & - & - & - & - & - & - & - & - & - & - & - \\
\hline 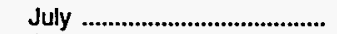 & - & - & - & - & - & - & - & - & - & - & - & - \\
\hline August .............................. & - & - & - & - & - & - & - & - & - & - & - & - \\
\hline 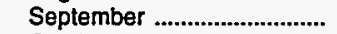 & - & - & - & - & - & - & - & - & - & - & - & - \\
\hline October & - & - & - & - & - & - & - & - & - & - & - & - \\
\hline 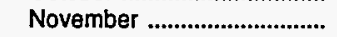 & - & - & - & - & - & - & - & - & - & - & - & - \\
\hline 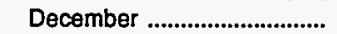 & - & - & - & - & - & - & - & - & - & - & - & - \\
\hline 1994 Average ................................... & - & - & - & - & - & - & - & - & - & - & - & - \\
\hline Oregon & & & & & & & & & & & & \\
\hline 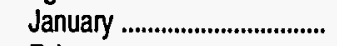 & - & - & - & - & - & - & - & - & - & - & - & - \\
\hline 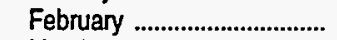 & - & - & - & - & - & - & - & - & - & - & - & - \\
\hline March & - & - & - & - & - & - & - & - & - & - & - & - \\
\hline April & - & - & - & - & - & - & - & - & - & - & - & - \\
\hline 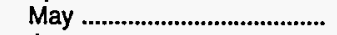 & - & - & - & - & - & - & - & - & - & - & - & - \\
\hline 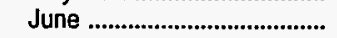 & - & - & - & - & - & - & - & - & - & - & - & - \\
\hline July .............................................. & - & - & - & - & _- & _- & - & - & _- & - & - & - \\
\hline 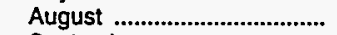 & - & - & - & - & - & - & - & - & - & - & - & _ \\
\hline 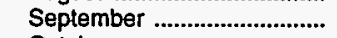 & - & - & - & - & - & - & - & - & - & - & - & - \\
\hline 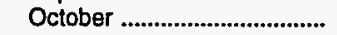 & - & - & - & - & - & - & - & - & - & - & _ & - \\
\hline 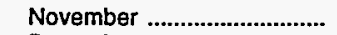 & - & - & - & - & - & - & - & - & - & - & - & - \\
\hline 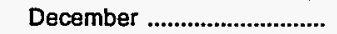 & - & - & - & - & - & - & - & - & - & - & - & _ \\
\hline 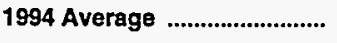 & - & - & - & - & - & - & - & - & - & - & - & - \\
\hline Washington & & & & & & & & & & & & \\
\hline 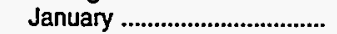 & - & - & - & - & - & - & - & - & - & _- & - & - \\
\hline 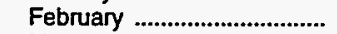 & - & - & - & - & - & - & - & - & - & - & - & - \\
\hline 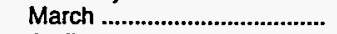 & - & - & - & - & - & - & - & - & - & - & - & - \\
\hline 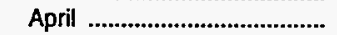 & - & - & - & - & - & - & - & - & - & - & _- & - \\
\hline 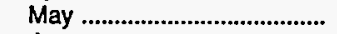 & - & - & - & - & - & - & - & - & - & - & - & - \\
\hline 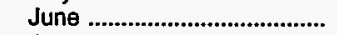 & - & - & - & - & - & - & - & - & - & - & - & _ \\
\hline 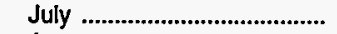 & - & - & - & - & - & - & - & - & - & - & - & - \\
\hline 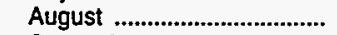 & - & - & - & - & - & - & - & - & - & - & _- & _ \\
\hline 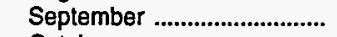 & - & - & - & - & - & - & - & - & - & - & - & - \\
\hline 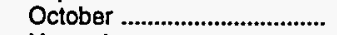 & - & - & - & - & - & - & - & - & - & - & _- & - \\
\hline 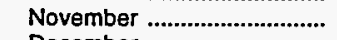 & - & - & - & - & - & - & - & - & - & - & - & - \\
\hline 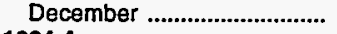 & - & - & - & - & - & - & - & - & - & - & - & - \\
\hline 1994 Average .............................. & - & - & - & - & - & - & - & - & - & - & - & - \\
\hline
\end{tabular}

See footnotes at end of table. 
Table 34. Reformulated Motor Gasoline Prices by Grade, Sales Type, PAD District, and State

(Cents per Gallon Excluding Taxes) - Continued

\begin{tabular}{|c|c|c|c|c|c|c|c|c|c|c|c|c|}
\hline \multirow{3}{*}{$\begin{array}{l}\text { Geographlc Area } \\
\text { Month }\end{array}$} & \multicolumn{6}{|c|}{ Premium } & \multicolumn{6}{|c|}{ All Grades } \\
\hline & \multicolumn{2}{|c|}{ Sales to End Users } & \multicolumn{4}{|c|}{ Sales for Resale } & \multicolumn{2}{|c|}{ Sales to End Users } & \multicolumn{4}{|c|}{ Sales for Resale } \\
\hline & $\begin{array}{c}\text { Through } \\
\text { Retall } \\
\text { Outlets }\end{array}$ & Average ${ }^{\mathrm{a}}$ & DTW & Rack & Bulk & Averago & $\begin{array}{c}\text { Through } \\
\text { Retail } \\
\text { Outlets }\end{array}$ & Average ${ }^{a}$ & DTW & Rack & Bulk & Average \\
\hline
\end{tabular}

Hawall

January.

February

March

April

June

July ....

August ...

September

October .

November

December

1994 Average

Nevada

January .

March

April

May

June

July ...........

August ....

October ...

November

December

1994 Average

Oregon

January

March ...

April

May .

June

July .....

August ....

October

November

December

1994 Average

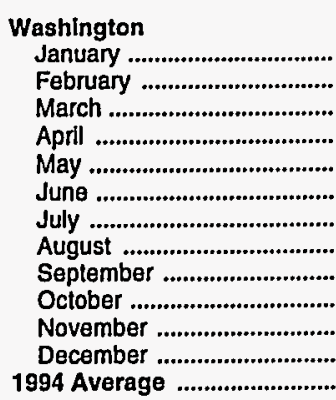

-
-
-
-
-
-
-
-
-

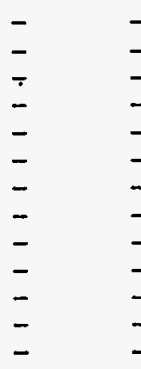

-
-
-
-

$\begin{array}{lll}- & - & - \\ - & - & - \\ - & - & - \\ - & - & - \\ - & - & - \\ - & - & - \\ - & - & - \\ - & - & - \\ - & - & - \\ - & - & - \\ - & - & - \\ - & - & - \\ - & - & -\end{array}$

$\begin{array}{ll}- & - \\ - & - \\ - & - \\ - & - \\ - & - \\ - & - \\ - & - \\ - & - \\ - & - \\ - & - \\ - & -\end{array}$

$\begin{array}{llll}- & - & - & - \\ - & - & - & - \\ - & - & - & - \\ - & - & - & - \\ - & - & - & - \\ - & - & - & - \\ - & - & - & - \\ - & - & - & - \\ - & - & - & - \\ - & - & - & - \\ - & - & - & - \\ - & - & - & - \\ - & - & - & -\end{array}$

$\begin{array}{lll}- & - & - \\ - & - & - \\ - & - & - \\ - & - & - \\ - & - & - \\ - & - & - \\ - & - & - \\ - & - & - \\ - & - & - \\ - & - & - \\ - & - & - \\ - & - & -\end{array}$

$\begin{array}{ll}- & - \\ - & - \\ - & - \\ - & - \\ - & - \\ - & - \\ - & - \\ - & - \\ - & - \\ - & - \\ - & -\end{array}$

$\begin{array}{ll}- & - \\ - & - \\ - & - \\ - & - \\ - & - \\ - & - \\ - & - \\ - & - \\ - & - \\ - & - \\ - & -\end{array}$

$\begin{array}{llll}- & - & - & - \\ - & - & - & - \\ - & - & - & - \\ - & - & - & - \\ - & - & - & - \\ - & - & - & - \\ - & - & - & - \\ - & - & - & - \\ - & - & - & - \\ - & - & - & - \\ - & - & - & - \\ - & - & - & - \\ - & - & - & -\end{array}$

Dash $(-)=$ No data reported.

NA $=$ Not avallable.

$W=$ Withheld to avoid disclosure of individual company data.

a Includes sales through retail outlets as well as all direct sales to end users that were not made through company-operated retail outlets, e.g., sales to agricultural customers, commercial sales, and industrial sales.

Sources: Energy Information Administration Forms ElA-782A, "Reliners'/Gas Plant Operators' Monthly Petroleum Product Sales Report," and ElA-782B,

"Resellers'/Retallers' Monthly Petroleum Product Sales Report." 
Table 35. Refiner Motor Gasoline Prices by Grade, Sales Type, PAD District, and State (Cents per Gallon Excluding Taxes)

\begin{tabular}{|c|c|c|c|c|c|c|c|c|c|c|c|c|}
\hline \multirow{3}{*}{$\begin{array}{l}\text { Goographlc Area } \\
\text { Month }\end{array}$} & \multicolumn{3}{|c|}{ Regular } & \multicolumn{3}{|c|}{ Midgrade } & \multicolumn{3}{|c|}{ Premium } & \multicolumn{3}{|c|}{ All Grades } \\
\hline & \multicolumn{2}{|c|}{ Sales to End Users } & \multirow{2}{*}{$\begin{array}{c}\text { Sales } \\
\text { for } \\
\text { Resale }\end{array}$} & \multicolumn{2}{|c|}{ Sales to End Users } & \multirow{2}{*}{$\begin{array}{c}\text { Sales } \\
\text { for } \\
\text { Regale }\end{array}$} & \multicolumn{2}{|c|}{ Sales to End Users } & \multirow[b]{2}{*}{$\begin{array}{c}\text { Sales } \\
\text { for } \\
\text { Resale }\end{array}$} & \multicolumn{2}{|c|}{ Sales to End Users } & \multirow[b]{2}{*}{$\begin{array}{c}\text { Sales } \\
\text { for } \\
\text { Resale }\end{array}$} \\
\hline & $\begin{array}{c}\text { Through } \\
\text { Retail } \\
\text { Outlets }\end{array}$ & $\begin{array}{l}\text { Other } \\
\text { End } \\
\text { Usersa }\end{array}$ & & $\begin{array}{c}\text { Through } \\
\text { Retail } \\
\text { Outlets }\end{array}$ & $\begin{array}{c}\text { Other } \\
\text { End } \\
\text { Usersa }\end{array}$ & & $\begin{array}{c}\text { Through } \\
\text { Retail } \\
\text { Outlets }\end{array}$ & $\begin{array}{c}\text { Other } \\
\text { End } \\
\text { Users }^{\mathrm{a}}\end{array}$ & & $\begin{array}{c}\text { Through } \\
\text { Retall } \\
\text { Outlets }\end{array}$ & $\begin{array}{l}\text { Other } \\
\text { End } \\
\text { Usersa }\end{array}$ & \\
\hline \multicolumn{13}{|l|}{ United States } \\
\hline 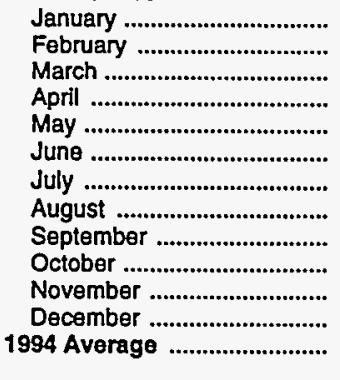 & $\begin{array}{l}62.2 \\
63.3 \\
62.9 \\
65.0 \\
66.7 \\
69.7 \\
72.6 \\
77.4 \\
75.7 \\
72.7 \\
73.2 \\
70.8 \\
69.5\end{array}$ & $\begin{array}{l}48.6 \\
51.8 \\
51.9 \\
55.0 \\
56.5 \\
59.2 \\
61.7 \\
65.2 \\
58.3 \\
56.5 \\
60.5 \\
54.1 \\
56.6\end{array}$ & $\begin{array}{l}48.7 \\
51.3 \\
51.7 \\
54.6 \\
56.0 \\
59.4 \\
62.2 \\
64.8 \\
57.7 \\
57.9 \\
58.6 \\
54.2 \\
56.6\end{array}$ & $\begin{array}{l}71.6 \\
72.6 \\
72.5 \\
74.8 \\
76.4 \\
79.5 \\
82.3 \\
86.9 \\
85.3 \\
82.5 \\
83.0 \\
80.7 \\
79.1\end{array}$ & $\begin{array}{l}52.1 \\
55.3 \\
55.3 \\
58.8 \\
60.0 \\
62.9 \\
64.6 \\
68.1 \\
60.0 \\
59.4 \\
63.6 \\
56.5 \\
59.7\end{array}$ & $\begin{array}{l}56.2 \\
58.3 \\
58.3 \\
61.4 \\
62.5 \\
65.9 \\
68.3 \\
71.0 \\
64.9 \\
65.8 \\
67.1 \\
63.4 \\
63.8\end{array}$ & $\begin{array}{l}80.8 \\
79.5 \\
81.5 \\
83.4 \\
84.9 \\
87.6 \\
90.4 \\
95.1 \\
93.7 \\
91.0 \\
91.7 \\
89.6 \\
87.3\end{array}$ & $\begin{array}{l}57.6 \\
60.8 \\
60.9 \\
63.9 \\
65.4 \\
69.0 \\
71.3 \\
74.9 \\
67.5 \\
66.1 \\
68.5 \\
62.7 \\
65.8\end{array}$ & $\begin{array}{l}61.7 \\
63.7 \\
64.2 \\
67.2 \\
68.3 \\
71.8 \\
74.5 \\
77.1 \\
71.1 \\
71.9 \\
72.6 \\
68.6 \\
69.5\end{array}$ & $\begin{array}{l}67.5 \\
68.3 \\
68.0 \\
70.1 \\
71.7 \\
74.7 \\
77.5 \\
82.1 \\
80.4 \\
77.7 \\
78.2 \\
75.9 \\
74.4\end{array}$ & $\begin{array}{l}50.6 \\
53.7 \\
53.8 \\
56.9 \\
58.4 \\
61.2 \\
63.6 \\
67.3 \\
60.1 \\
58.4 \\
62.3 \\
55.8 \\
58.5\end{array}$ & $\begin{array}{l}52.2 \\
54.6 \\
54.9 \\
57.9 \\
59.2 \\
62.6 \\
65.4 \\
67.8 \\
61.0 \\
61.4 \\
62.2 \\
58.0 \\
59.9\end{array}$ \\
\hline \multicolumn{13}{|l|}{ PAD District I } \\
\hline 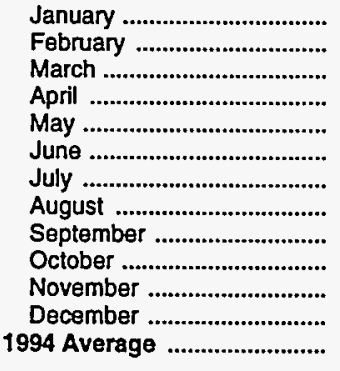 & $\begin{array}{l}59.7 \\
60.5 \\
60.3 \\
61.5 \\
62.5 \\
65.2 \\
68.3 \\
72.7 \\
72.6 \\
70.8 \\
71.6 \\
70.7 \\
66.5\end{array}$ & $\begin{array}{l}46.9 \\
50.1 \\
50.1 \\
52.9 \\
54.1 \\
57.1 \\
58.0 \\
61.7 \\
53.5 \\
53.3 \\
60.1 \\
53.3 \\
54.3\end{array}$ & $\begin{array}{l}49.0 \\
51.2 \\
51.2 \\
53.8 \\
55.0 \\
58.1 \\
60.1 \\
62.5 \\
55.8 \\
57.7 \\
60.2 \\
56.4 \\
56.1\end{array}$ & $\begin{array}{l}72.0 \\
72.7 \\
72.5 \\
73.7 \\
74.5 \\
77.1 \\
80.0 \\
84.1 \\
84.2 \\
82.4 \\
82.8 \\
82.2 \\
78.3\end{array}$ & $\begin{array}{l}50.0 \\
53.7 \\
53.4 \\
56.6 \\
57.5 \\
60.8 \\
61.6 \\
65.2 \\
55.9 \\
56.2 \\
62.4 \\
55.2 \\
57.4\end{array}$ & $\begin{array}{l}56.4 \\
58.3 \\
58.0 \\
60.5 \\
61.5 \\
64.8 \\
66.7 \\
69.6 \\
63.9 \\
65.2 \\
67.9 \\
64.6 \\
63.3\end{array}$ & $\begin{array}{l}81.5 \\
81.9 \\
81.6 \\
82.7 \\
83.2 \\
85.1 \\
88.0 \\
93.4 \\
93.2 \\
91.4 \\
92.1 \\
91.3 \\
87.0\end{array}$ & $\begin{array}{l}55.6 \\
59.2 \\
58.7 \\
61.6 \\
62.8 \\
66.6 \\
67.8 \\
71.5 \\
61.8 \\
62.9 \\
68.7 \\
61.1 \\
63.3\end{array}$ & $\begin{array}{l}63.1 \\
64.8 \\
64.8 \\
67.3 \\
68.7 \\
71.8 \\
74.5 \\
77.0 \\
71.4 \\
73.2 \\
75.0 \\
71.1 \\
70.3\end{array}$ & $\begin{array}{l}67.3 \\
67.9 \\
67.6 \\
68.8 \\
69.7 \\
72.2 \\
75.2 \\
79.4 \\
79.4 \\
77.6 \\
78.3 \\
77.6 \\
73.4\end{array}$ & $\begin{array}{l}49.0 \\
52.3 \\
52.1 \\
55.0 \\
56.3 \\
59.2 \\
60.3 \\
64.1 \\
55.4 \\
55.4 \\
62.0 \\
55.0 \\
56.4\end{array}$ & $\begin{array}{l}53.9 \\
55.9 \\
55.8 \\
58.4 \\
59.7 \\
62.7 \\
64.8 \\
67.2 \\
60.8 \\
62.6 \\
65.0 \\
61.3 \\
60.8\end{array}$ \\
\hline \multicolumn{13}{|l|}{ Subdistrict IA } \\
\hline 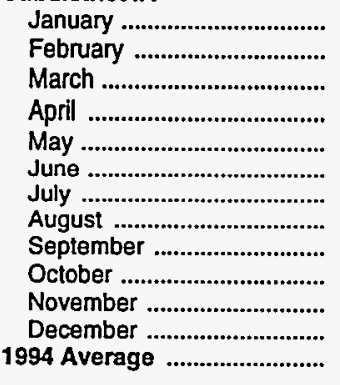 & $\begin{array}{l}65.9 \\
66.5 \\
65.9 \\
65.5 \\
65.4 \\
69.1 \\
72.8 \\
77.9 \\
78.7 \\
76.8 \\
76.9 \\
80.6 \\
72.0\end{array}$ & $\begin{array}{l}48.7 \\
48.4 \\
49.4 \\
51.0 \\
53.5 \\
56.5 \\
57.7 \\
61.6 \\
54.1 \\
52.8 \\
60.1 \\
57.9 \\
54.2\end{array}$ & $\begin{array}{l}50.6 \\
52.5 \\
53.2 \\
54.6 \\
56.0 \\
59.8 \\
60.9 \\
64.6 \\
58.4 \\
59.2 \\
61.6 \\
61.0 \\
58.0\end{array}$ & $\begin{array}{l}78.3 \\
79.0 \\
78.9 \\
78.7 \\
78.9 \\
82.1 \\
85.1 \\
89.3 \\
90.1 \\
88.9 \\
87.6 \\
90.4 \\
84.3\end{array}$ & $\begin{array}{l}50.2 \\
52.7 \\
53.0 \\
55.6 \\
58.5 \\
61.6 \\
62.8 \\
65.9 \\
56.5 \\
56.7 \\
62.4 \\
61.5 \\
57.9\end{array}$ & $\begin{array}{l}57.5 \\
60.2 \\
59.9 \\
61.2 \\
63.1 \\
66.3 \\
68.5 \\
71.6 \\
67.4 \\
67.2 \\
70.0 \\
70.2 \\
65.5\end{array}$ & $\begin{array}{r}89.8 \\
90.4 \\
89.4 \\
89.3 \\
89.1 \\
91.0 \\
93.9 \\
99.1 \\
100.2 \\
99.1 \\
99.1 \\
102.3 \\
94.3\end{array}$ & $\begin{array}{l}56.1 \\
58.3 \\
56.6 \\
60.5 \\
65.7 \\
67.4 \\
69.2 \\
73.4 \\
61.1 \\
64.0 \\
66.7 \\
63.1 \\
63.4\end{array}$ & $\begin{array}{l}63.1 \\
64.9 \\
66.1 \\
67.8 \\
70.3 \\
73.2 \\
75.8 \\
79.3 \\
73.6 \\
73.7 \\
76.5 \\
76.2 \\
71.7\end{array}$ & $\begin{array}{l}75.0 \\
75.4 \\
74.7 \\
74.4 \\
74.2 \\
77.6 \\
80.8 \\
85.4 \\
86.3 \\
84.8 \\
84.8 \\
88.2 \\
80.3\end{array}$ & $\begin{array}{l}50.3 \\
50.9 \\
51.2 \\
53.5 \\
56.4 \\
59.3 \\
60.6 \\
64.1 \\
55.6 \\
55.5 \\
62.0 \\
59.4 \\
56.4\end{array}$ & $\begin{array}{l}54.9 \\
56.8 \\
57.4 \\
58.8 \\
60.3 \\
64.0 \\
65.3 \\
69.0 \\
63.0 \\
63.5 \\
66.0 \\
65.4 \\
62.3\end{array}$ \\
\hline \multicolumn{13}{|l|}{ Connecticut } \\
\hline 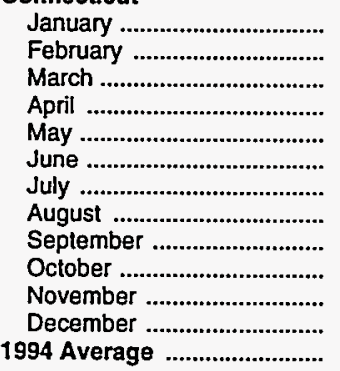 & $\begin{array}{l}W \\
W \\
W \\
W \\
W \\
W \\
W \\
W \\
W \\
W \\
W \\
W \\
W\end{array}$ & $\begin{array}{l}46.9 \\
50.1 \\
W \\
51.7 \\
54.0 \\
55.8 \\
W \\
W \\
W \\
W \\
W \\
W \\
W\end{array}$ & $\begin{array}{l}52.2 \\
53.9 \\
54.7 \\
56.2 \\
56.2 \\
60.2 \\
59.6 \\
65.3 \\
60.8 \\
60.8 \\
63.9 \\
62.3 \\
59.1\end{array}$ & $\begin{array}{l}W \\
W \\
W \\
W \\
W \\
W \\
W \\
W \\
W \\
W \\
W \\
W \\
W\end{array}$ & $\begin{array}{l}57.0 \\
56.8 \\
58.2 \\
60.6 \\
60.9 \\
63.6 \\
64.6 \\
67.0 \\
W \\
57.3 \\
65.0 \\
W \\
61.0\end{array}$ & $\begin{array}{l}58.1 \\
61.1 \\
60.7 \\
62.1 \\
62.9 \\
66.0 \\
68.1 \\
71.3 \\
67.6 \\
67.5 \\
70.5 \\
71.0 \\
65.7\end{array}$ & $\begin{array}{l}W \\
W \\
W \\
W \\
W \\
W \\
W \\
W \\
W \\
W \\
W \\
W \\
W\end{array}$ & $\begin{array}{c}61.5 \\
62.1 \\
W \\
63.0 \\
66.9 \\
68.3 \\
67.2 \\
70.7 \\
62.3 \\
65.6 \\
70.3 \\
W \\
65.7\end{array}$ & $\begin{array}{l}63.9 \\
68.0 \\
67.8 \\
69.4 \\
70.3 \\
72.9 \\
75.6 \\
79.2 \\
74.4 \\
74.0 \\
78.0 \\
79.0 \\
72.7\end{array}$ & $\begin{array}{l}w \\
W \\
W \\
W \\
W \\
W \\
W \\
W \\
W \\
W \\
W \\
W \\
W\end{array}$ & $\begin{array}{c}52.2 \\
53.4 \\
53.2 \\
55.8 \\
57.9 \\
59.6 \\
60.8 \\
63.0 \\
W \\
54.0 \\
61.7 \\
W \\
57.2\end{array}$ & $\begin{array}{l}56.5 \\
58.6 \\
59.1 \\
60.6 \\
60.5 \\
64.5 \\
64.2 \\
69.8 \\
65.4 \\
65.1 \\
68.4 \\
67.3 \\
63.5\end{array}$ \\
\hline
\end{tabular}

See footnotes at end of table. 
Table 35. Refiner Motor Gasoline Prices by Grade, Sales Type, PAD District, and State (Cents per Gallon Excluding Taxes) - Continued

\begin{tabular}{|c|c|c|c|c|c|c|c|c|c|c|c|c|}
\hline \multirow{3}{*}{$\begin{array}{l}\text { Geographle Area } \\
\text { Month }\end{array}$} & \multicolumn{3}{|c|}{ Regular } & \multicolumn{3}{|c|}{ MIdgrado } & \multicolumn{3}{|c|}{ Premium } & \multicolumn{3}{|c|}{ All Grados } \\
\hline & \multicolumn{2}{|c|}{ Sales to End Users } & \multirow{2}{*}{$\begin{array}{c}\text { Sales } \\
\text { for } \\
\text { Resale }\end{array}$} & \multicolumn{2}{|c|}{ Sales to End Users } & \multirow{2}{*}{$\begin{array}{c}\text { Sales } \\
\text { for } \\
\text { Resale }\end{array}$} & \multicolumn{2}{|c|}{ Sales to End Users } & \multirow{2}{*}{$\begin{array}{c}\text { Sales } \\
\text { for } \\
\text { Resale }\end{array}$} & \multicolumn{2}{|c|}{ Sales to End Users } & \multirow{2}{*}{$\begin{array}{l}\text { Sales } \\
\text { for } \\
\text { Resale }\end{array}$} \\
\hline & $\begin{array}{c}\text { Through } \\
\text { Retail } \\
\text { Outlets }\end{array}$ & $\begin{array}{c}\text { Other } \\
\text { End } \\
\text { Usersa }\end{array}$ & & $\begin{array}{c}\text { Through } \\
\text { Rotall } \\
\text { Outlets }\end{array}$ & $\begin{array}{c}\text { Other } \\
\text { End } \\
\text { Usersa }\end{array}$ & & $\begin{array}{l}\text { Through } \\
\text { Retail } \\
\text { Outlets }\end{array}$ & $\begin{array}{l}\text { Other } \\
\text { End } \\
\text { Usersa }\end{array}$ & & $\begin{array}{c}\text { Through } \\
\text { Retail } \\
\text { Outlets }\end{array}$ & $\begin{array}{c}\text { Other } \\
\text { End } \\
\text { Users }\end{array}$ & \\
\hline
\end{tabular}

Maine

January

March .......................................

April .

July

August

September

November

1994 Average

\section{Massachusetts}

January

March ......................................

April

May ............................................

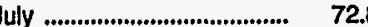

August

Aeptember

Oclober

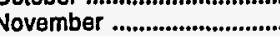

December

Now Hampshire

January ...

February

March

June

uly

August

Septemb

October

November

ar

1994 Average

Rhode Island

January ...

64.7

March .................................. 61.7

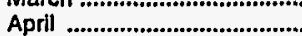

May

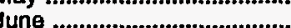

July .....................................

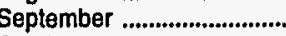

October ....

November

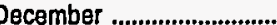

1994 Average

$\begin{array}{ll}- & W \\ - & W \\ - & W \\ - & W \\ - & W \\ - & W \\ - & W \\ - & W \\ - & W \\ - & W \\ - & W \\ - & W\end{array}$

$W$
$W$
$W$
$W$
$W$
$W$
$W$
$W$
$W$
$W$
$W$
$W$
$W$

$$
\begin{aligned}
& 48.1 \\
& 51.7 \\
& 50.7 \\
& 53.9 \\
& 56.5 \\
& 58.9 \\
& 60.5 \\
& 62.4 \\
& 54.9 \\
& 54.8 \\
& 59.1 \\
& 55.0 \\
& 55.8
\end{aligned}
$$

\section{6}

46.7

48.6

50.3

52.8

56.2

57.2

61.4

53.4

52.6

59.8

58.2

$\mathbf{5 3 . 8}$

\section{$50.5 \quad 77.2$}

$\begin{array}{ll}50.5 & 77.2 \\ 52.1 & 78.2\end{array}$

$53.3 \quad 78.2$

$\begin{array}{ll}54.1 & 78.2 \\ 5 & 78.1\end{array}$

$55.5 \quad 77.7$

$59.7 \quad 81.1$

$62.4 \quad 84.3$

$\begin{array}{ll}64.5 & 88.9\end{array}$

57.6

59.4

61.3

62.3
58.0

89.8

88.7

87.0
89.4

83.6

W

$\begin{array}{lll}W & 53.9 & 78.7\end{array}$

53.3

55.2

55.0

55.7

57.5
60.9

60.9

66.7

66.7
63.4

63.4
62.6

64.8

66.7

66.7
60.6

78.7
79.7
78.7
79.3
79.4
83.0
85.8
88.3
$W$
$W$
$W$
$W$
$W$

\section{$\begin{array}{ll}48.6 & 72.3\end{array}$}

$50.5 \quad 72.7$

$51.6 \quad 73.1$

$\begin{array}{ll}52.8 & 72.9\end{array}$

$56.4 \quad 73.9$

$59.6 \quad 78.9$

58.3

65.0

59.7

58.0

59.4

59.4

$\mathbf{5 6 . 8}$

83.7

81.7

$W$
$W$
$W$
$W$
$W$
$W$
$W$
$W$
$W$
$W$
$W$
$W$
$w$
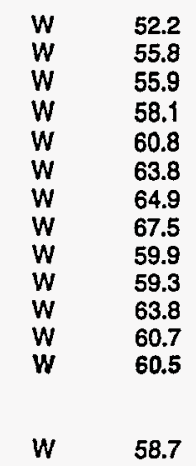

52.2
51.7

51.7
54.7

58.0

61.5

62.6

W
56.0

57.0

62.0

62.2
57.3

$58.7 \quad 88.1$

60.7

61.5

63.8

67.1

69.9
72.9

68.9

68.7

71.5
72.3

66.7

$\begin{array}{ll}W & 59.9 \\ W & 61.5 \\ W & 61.0 \\ W & 61.6 \\ W & 63.2 \\ W & 66.4 \\ W & 68.7 \\ W & 72.2 \\ W & 69.9 \\ W & 69.3 \\ \bar{W} & 71.3 \\ W & 71.2 \\ W & 66.7\end{array}$

59.9
61.5
61.0
61.6
63.2
66.4
68.7
72.2
69.9
69.3
71.3
71.2
66.7

$\begin{array}{lll}W & 54.4 & 85.4\end{array}$

$\begin{array}{lll}W & 58.2 & 85.7\end{array}$

$\begin{array}{lll}W & 57.4 & 81.7\end{array}$

$\begin{array}{ll}W & 57.4 \\ W & 59.4\end{array}$

$62.5 \quad 81.8$

$65.4 \quad 85.8$

$\begin{array}{ll}67.3 & 89.7\end{array}$

70.8

66.6

$\begin{array}{ll}65.1 & 95.5 \\ 67.7 & 90.5\end{array}$

$67.7 \quad 90.5$

86.8
79.8

$\begin{array}{ll}- & W \\ - & W \\ - & W \\ - & W \\ - & W \\ - & W \\ - & W \\ - & W \\ - & W \\ - & W \\ - & W \\ - & W\end{array}$

58.9
62.4
60.9
64.5
67.9
70.3
71.9
75.0
65.8
66.6
70.3
67.0
67.0

$\begin{array}{ll}- & W \\ - & W \\ - & W \\ - & W \\ - & W \\ - & W \\ - & W \\ - & W \\ - & W \\ - & W \\ - & W \\ - & W\end{array}$

$\begin{array}{ll}W & 50.9\end{array}$

53.2

56.3

59.2

61.5

63.3

65.2

57.7

57.5

61.7
57.4

58.4

See footnotes at end of table. 
Table 35. Refiner Motor Gasoline Prices by Grade, Sales Type, PAD District, and State (Cents per Gallon Excluding Taxes) - Continued

\begin{tabular}{|c|c|c|c|c|c|c|c|c|c|c|c|c|}
\hline \multirow{3}{*}{$\begin{array}{c}\text { Geographic Area } \\
\text { Month }\end{array}$} & \multicolumn{3}{|c|}{ Regular } & \multicolumn{3}{|c|}{ Midgrade } & \multicolumn{3}{|c|}{ Premium } & \multicolumn{3}{|c|}{ All Grades } \\
\hline & \multicolumn{2}{|c|}{ Sales to End Users } & \multirow{2}{*}{$\begin{array}{c}\text { Sales } \\
\text { for } \\
\text { Resale }\end{array}$} & \multicolumn{2}{|c|}{ Sales to End Users } & \multirow{2}{*}{$\begin{array}{c}\text { Sales } \\
\text { for } \\
\text { Resale }\end{array}$} & \multicolumn{2}{|c|}{ Sales to End Users } & \multirow{2}{*}{$\begin{array}{c}\text { Sales } \\
\text { for } \\
\text { Resale }\end{array}$} & \multicolumn{2}{|c|}{ Sales to End Users } & \multirow[b]{2}{*}{$\begin{array}{c}\text { Sales } \\
\text { for } \\
\text { Resale }\end{array}$} \\
\hline & $\begin{array}{c}\text { Through } \\
\text { Retail } \\
\text { Outlets }\end{array}$ & $\begin{array}{c}\text { Other } \\
\text { End } \\
\text { Usersa }\end{array}$ & & $\begin{array}{c}\text { Through } \\
\text { Retail } \\
\text { Outlets }\end{array}$ & $\begin{array}{c}\text { Other } \\
\text { End } \\
\text { Usersa }\end{array}$ & & $\begin{array}{c}\text { Through } \\
\text { Retail } \\
\text { Outlets }\end{array}$ & $\begin{array}{l}\text { Other } \\
\text { End } \\
\text { Usersa }\end{array}$ & & $\begin{array}{c}\text { Through } \\
\text { Retail } \\
\text { Outlets }\end{array}$ & $\begin{array}{c}\text { Other } \\
\text { End } \\
\text { Usersa }\end{array}$ & \\
\hline
\end{tabular}

Vermont

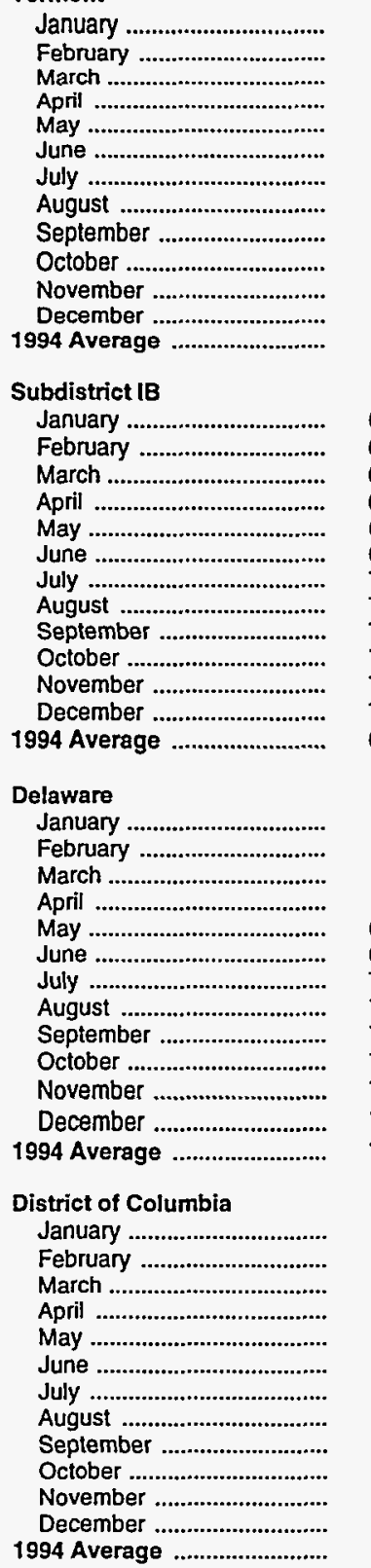

$-W$

I

62.9

63.0

62.1

62.2
63.4

66.7

70.0

74.3

74.6

73.3

74.4
74.3

68.6

$\begin{array}{cc}W & W \\ W & W \\ W & W \\ W & W \\ 67.2 & W \\ 69.1 & W \\ 71.1 & W \\ 74.9 & W \\ 78.5 & W \\ 77.5 & W \\ 76.8 & W \\ 78.7 & W \\ 70.7 & W\end{array}$

56.8

56.1

58.1

62.5

64.3

68.1

62.0

64.1

47.8

50.4

49.8

52.1

54.5

57.9
61.9

55.5

55.8

63.9

58.3

$\mathbf{5 5 . 4}$

58.2

58.2
59.5

61.1

64.1
60.1
60.8

\section{6}

$520 \quad 75.1$

51.4

53.3

55.5

60.7
63.5

58.8

60.1

64.0

61.5

57.8

48.5

49.9

51.0

51.9

54.8

57.4

58.6

62.4

57.0

62.5

62.6

56.4

W

75.6
74.5

85.9

$\begin{array}{ll}- & - \\ - & - \\ - & - \\ - & - \\ - & - \\ - & - \\ - & - \\ - & - \\ - & - \\ - & - \\ - & -\end{array}$

59.1

62.2

62.3

64.3

65.3

73.6

68.8

67.2

70.6

66.7

66.7

74.6

$78.9 \quad 61.7$

$81.9 \quad 62.5$

$85.6 \quad 65.2$

$86.1 \quad 59.1$

$85.0 \quad 59.0$

86.5
80.6

67.9

61.5
59.6

$\begin{array}{cc}W & W \\ W & W \\ W & W \\ W & W \\ 80.8 & W \\ 82.7 & W \\ 85.8 & W \\ 89.4 & - \\ 92.0 & W \\ 91.8 & W \\ 86.3 & W \\ 88.0 & - \\ 81.8 & W\end{array}$

$\begin{array}{rr}54.2 & W \\ 55.8 & W \\ 56.7 & W \\ 57.5 & W \\ 60.0 & 93.0 \\ 62.4 & 93.9 \\ 64.2 & 97.1 \\ 67.4 & 99.5 \\ 62.3 & 102.6 \\ 63.3 & 99.3 \\ 68.0 & 100.8 \\ 67.8 & 102.4 \\ 61.8 & 92.7\end{array}$

59.3

60.8

60.8
62.5
65.7

67.7

71.1
68.1

69.2

73.3

71.9

66.0

85.1

84.0
84.1

84.3

85.5

88.4
94.8

94.8
95.3

94.7

96.0
96.5

$\begin{array}{ll}- & 64.2 \\ - & 67.7 \\ - & 67.4 \\ - & 69.2 \\ - & 70.4 \\ - & 73.5 \\ - & 75.4 \\ - & 79.8 \\ - & 74.2 \\ - & 73.2 \\ - & 75.3 \\ - & 71.4 \\ - & 71.9\end{array}$

-
$\overline{-}$
$\overline{-}$
-
-
-
-
-
-

$\begin{array}{ll}\text { W } & 56.8 \\ W & 60.4 \\ W & 59.5 \\ W & 61.5 \\ W & 62.7 \\ W & 65.8 \\ W & 67.6 \\ W & 71.5 \\ W & 65.6 \\ W & 64.5 \\ - & 67.3 \\ \bar{W} & 63.4 \\ \text { W } & 64.1\end{array}$

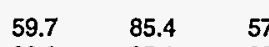

$\begin{array}{ll}57.5 & 65.4\end{array}$

96.5
89.4

$$
\begin{aligned}
& 57.5 \\
& 60.7 \\
& 59.4 \\
& 61.5 \\
& 65.7 \\
& 68.9 \\
& 69.9 \\
& 72.7 \\
& 65.2 \\
& 67.2 \\
& 74.4 \\
& 67.9 \\
& 66.0
\end{aligned}
$$

66.3

65.7
67.7

67.7
69.8

72.9

76.0

78.8

75.3

77.3

79.6

76.0

72.6

$\begin{array}{ll}\text { W } & 61.5 \\ \text { W } & 63.0 \\ \text { W } & 63.1 \\ \text { W } & 64.5 \\ \text { W } & 67.6 \\ \text { W } & 66.5 \\ \text { W } & 72.4 \\ \text { W } & 76.0 \\ \text { W } & 70.7 \\ \text { W } & 71.7 \\ \text { W } & 76.2 \\ \text { W } & 67.1 \\ \text { W } & 68.3\end{array}$

61.5
63.0
63.1
64.5
67.6
66.5
72.4
76.0
70.7
71.7
76.2
67.1
68.3

$\begin{array}{ccc}W & W & 52.4 \\ W & W & 53.6 \\ W & W & 54.7 \\ W & 52.8 & 55.4 \\ 76.4 & W & 58.5 \\ 77.9 & W & 60.9 \\ 80.7 & W & 62.4 \\ 83.7 & 62.9 & 66.2 \\ 87.2 & W & 60.8 \\ 85.9 & W & 61.9 \\ 83.8 & W & 66.2 \\ 86.1 & 60.0 & 64.9 \\ 78.4 & W & 60.1\end{array}$

$$
\begin{aligned}
& 62.9 \\
& 62.2 \\
& 60.5 \\
& 61.4 \\
& 62.3 \\
& 64.4 \\
& 66.1 \\
& 69.0 \\
& 67.9 \\
& 67.5 \\
& 74.9 \\
& 74.7 \\
& 66.3
\end{aligned}
$$

$\begin{array}{ccccc}W & 68.5 & - & W & 76.0 \\ W & 67.9 & - & W & 75.3 \\ W & 66.2 & - & W & 73.7 \\ W & 67.0 & - & W & 74.7 \\ W & 67.9 & - & W & 75.8 \\ W & 70.0 & - & 65.5 & 77.9 \\ W & 70.9 & - & 67.1 & 79.5 \\ W & 74.4 & - & W & 82.1 \\ W & 73.1 & - & 64.5 & 80.9 \\ W & 72.6 & - & 62.6 & 80.8 \\ 69.5 & 80.5 & - & 75.4 & 88.2 \\ W & 80.1 & - & 66.6 & 88.1 \\ \mathbf{5 7 . 6} & 71.7 & - & 64.0 & 79.0\end{array}$

$\begin{array}{lll}\mathbf{7 0 . 6} & \mathbf{4 9 . 8} & \mathbf{5 6 . 4} \\ \mathbf{7 0 . 4} & \mathbf{5 2 . 6} & \mathbf{5 7 . 3} \\ \mathbf{6 9 . 4} & \mathbf{5 1 . 8} & \mathbf{5 6 . 6} \\ \mathbf{6 9 . 4} & \mathbf{5 4 . 0} & \mathbf{5 8 . 4} \\ \mathbf{7 0 . 4} & \mathbf{5 6 . 7} & 60.6 \\ \mathbf{7 3 . 5} & \mathbf{5 9 . 5} & 63.4 \\ \mathbf{7 6 . 7} & \mathbf{6 0 . 4} & 65.9 \\ \mathbf{8 0 . 9} & \mathbf{6 4 . 3} & 68.8 \\ \mathbf{8 1 . 3} & \mathbf{5 7 . 5} & \mathbf{6 4 . 4} \\ 80.2 & 57.8 & \mathbf{6 5 . 9} \\ \mathbf{8 1 . 1} & \mathbf{6 5 . 9} & 69.4 \\ \mathbf{8 1 . 4} & 60.1 & 66.9 \\ \mathbf{7 5 . 5} & \mathbf{5 7 . 5} & \mathbf{6 3 . 1}\end{array}$

See footnotes at end of table. 
Table 35. Refiner Motor Gasoline Prices by Grade, Sales Type, PAD District, and State (Cents per Gallon Excluding Taxes) - Continued

\begin{tabular}{|c|c|c|c|c|c|c|c|c|c|c|c|c|}
\hline \multirow{3}{*}{$\begin{array}{c}\text { Geographic Area } \\
\text { Month }\end{array}$} & \multicolumn{3}{|c|}{ Regular } & \multicolumn{3}{|c|}{ Midgrade } & \multicolumn{3}{|c|}{ Premium } & \multicolumn{3}{|c|}{ All Grades } \\
\hline & \multicolumn{2}{|c|}{ Sales to End Users } & \multirow{2}{*}{$\begin{array}{c}\text { Sales } \\
\text { for } \\
\text { Resale }\end{array}$} & \multicolumn{2}{|c|}{ Sales to End Users } & \multirow{2}{*}{$\begin{array}{c}\text { Sales } \\
\text { for } \\
\text { Resalo }\end{array}$} & \multicolumn{2}{|c|}{ Sales to End Users } & \multirow{2}{*}{$\begin{array}{c}\text { Sales } \\
\text { for } \\
\text { Resale }\end{array}$} & \multicolumn{2}{|c|}{ Sales to End Users } & \multirow{2}{*}{$\begin{array}{c}\text { Sales } \\
\text { for } \\
\text { Resale }\end{array}$} \\
\hline & $\begin{array}{c}\text { Through } \\
\text { Retail } \\
\text { Outlets }\end{array}$ & $\begin{array}{c}\text { Other } \\
\text { End } \\
\text { Usersa }\end{array}$ & & $\begin{array}{c}\text { Through } \\
\text { Retail } \\
\text { Outlets }\end{array}$ & $\begin{array}{l}\text { Other } \\
\text { End } \\
\text { Usersa }\end{array}$ & & $\begin{array}{c}\text { Through } \\
\text { Retall } \\
\text { Outlets }\end{array}$ & $\begin{array}{c}\text { Other } \\
\text { End } \\
\text { Usersa }\end{array}$ & & $\begin{array}{c}\text { Through } \\
\text { Retail } \\
\text { Outlets }\end{array}$ & $\begin{array}{l}\text { Other } \\
\text { End } \\
\text { Users a }\end{array}$ & \\
\hline Maryland & & & & & & & & & & & & \\
\hline 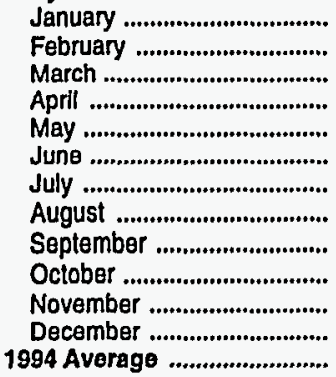 & $\begin{array}{l}W \\
W \\
W \\
W \\
W \\
W \\
W \\
- \\
- \\
- \\
- \\
\bar{W}\end{array}$ & $\begin{array}{l}46.1 \\
50.2 \\
47.8 \\
51.3 \\
52.6 \\
55.5 \\
56.5 \\
59.9 \\
52.8 \\
50.7 \\
65.1 \\
58.5 \\
\mathbf{5 4 . 0}\end{array}$ & $\begin{array}{l}55.5 \\
56.2 \\
54.3 \\
55.6 \\
57.3 \\
60.1 \\
61.8 \\
65.3 \\
61.0 \\
61.6 \\
68.8 \\
67.5 \\
60.7\end{array}$ & $\begin{array}{l}W \\
W \\
W \\
W \\
- \\
- \\
- \\
- \\
- \\
- \\
- \\
\bar{w}\end{array}$ & $\begin{array}{l}50.7 \\
55.3 \\
W \\
W \\
W \\
W \\
61.3 \\
63.0 \\
57.5 \\
54.8 \\
68.6 \\
62.3 \\
58.1\end{array}$ & $\begin{array}{l}62.9 \\
63.5 \\
60.6 \\
61.9 \\
63.5 \\
66.2 \\
67.6 \\
71.5 \\
67.6 \\
68.5 \\
76.3 \\
74.9 \\
67.3\end{array}$ & $\begin{array}{l}W \\
W \\
W \\
W \\
W \\
W \\
W \\
- \\
- \\
- \\
- \\
- \\
W\end{array}$ & $\begin{array}{c}55.2 \\
60.7 \\
58.2 \\
60.6 \\
W \\
65.8 \\
67.7 \\
68.5 \\
61.5 \\
60.6 \\
73.1 \\
70.2 \\
63.9\end{array}$ & $\begin{array}{l}69.4 \\
70.1 \\
67.3 \\
68.7 \\
70.7 \\
73.3 \\
75.4 \\
78.6 \\
75.3 \\
75.8 \\
83.7 \\
82.4 \\
74.2\end{array}$ & $\begin{array}{l}W \\
W \\
W \\
W \\
W \\
W \\
W \\
- \\
- \\
- \\
- \\
- \\
\bar{w}\end{array}$ & $\begin{array}{l}47.9 \\
52.1 \\
49.9 \\
53.2 \\
54.3 \\
57.2 \\
58.3 \\
62.3 \\
55.0 \\
52.2 \\
66.6 \\
60.2 \\
56.0\end{array}$ & $\begin{array}{l}60.9 \\
61.5 \\
59.3 \\
60.6 \\
62.4 \\
65.1 \\
66.8 \\
70.2 \\
66.3 \\
66.8 \\
74.0 \\
72.9 \\
65.7\end{array}$ \\
\hline 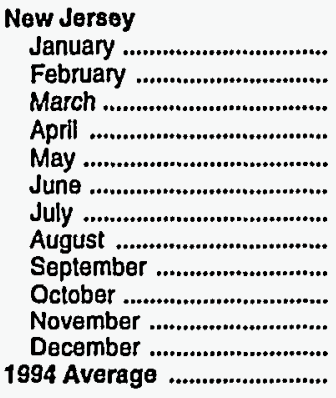 & $\begin{array}{l}67.9 \\
67.5 \\
66.4 \\
65.4 \\
66.9 \\
70.6 \\
72.0 \\
76.3 \\
77.5 \\
77.3 \\
79.0 \\
78.6 \\
72.3\end{array}$ & $\begin{array}{l}49.1 \\
50.5 \\
49.7 \\
51.0 \\
53.3 \\
55.6 \\
56.0 \\
60.2 \\
53.9 \\
57.3 \\
65.5 \\
58.2 \\
54.8\end{array}$ & $\begin{array}{l}52.2 \\
53.1 \\
52.2 \\
53.6 \\
55.9 \\
58.6 \\
60.8 \\
62.9 \\
58.8 \\
62.0 \\
64.4 \\
61.6 \\
58.4\end{array}$ & $\begin{array}{l}83.8 \\
83.1 \\
81.4 \\
80.2 \\
80.4 \\
84.8 \\
86.0 \\
90.0 \\
91.9 \\
91.2 \\
91.6 \\
91.6 \\
86.6\end{array}$ & $\begin{array}{l}52.4 \\
55.2 \\
54.0 \\
55.5 \\
57.3 \\
60.3 \\
60.7 \\
65.2 \\
58.1 \\
61.0 \\
69.6 \\
61.2 \\
59.4\end{array}$ & $\begin{array}{l}63.2 \\
64.2 \\
62.7 \\
63.0 \\
65.0 \\
68.9 \\
70.0 \\
73.3 \\
72.1 \\
73.8 \\
76.0 \\
74.5 \\
69.1\end{array}$ & $\begin{array}{r}92.1 \\
91.4 \\
89.9 \\
88.7 \\
89.4 \\
93.3 \\
94.6 \\
98.3 \\
99.6 \\
100.2 \\
101.3 \\
101.5 \\
95.1\end{array}$ & $\begin{array}{l}57.6 \\
60.0 \\
59.2 \\
60.9 \\
66.1 \\
69.1 \\
68.9 \\
74.5 \\
64.4 \\
69.5 \\
75.4 \\
66.1 \\
66.1\end{array}$ & $\begin{array}{l}65.6 \\
67.2 \\
65.9 \\
68.8 \\
71.2 \\
74.3 \\
77.3 \\
79.3 \\
76.2 \\
80.1 \\
79.9 \\
72.9 \\
73.1\end{array}$ & $\begin{array}{l}77.8 \\
77.1 \\
75.8 \\
74.8 \\
75.6 \\
79.8 \\
81.2 \\
85.1 \\
86.5 \\
86.3 \\
87.4 \\
87.4 \\
81.4\end{array}$ & $\begin{array}{l}51.4 \\
53.6 \\
52.5 \\
53.8 \\
57.2 \\
59.8 \\
60.4 \\
65.1 \\
57.3 \\
61.0 \\
68.5 \\
60.7 \\
58.3\end{array}$ & $\begin{array}{l}58.3 \\
59.2 \\
58.1 \\
59.7 \\
62.2 \\
64.8 \\
67.2 \\
69.4 \\
64.7 \\
68.7 \\
70.2 \\
66.5 \\
64.3\end{array}$ \\
\hline 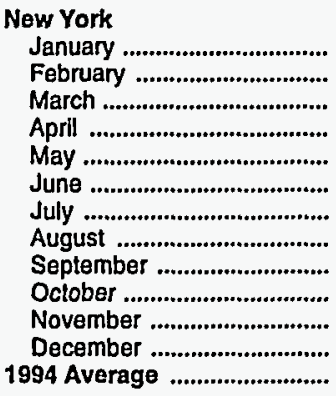 & $\begin{array}{l}61.6 \\
61.4 \\
60.4 \\
60.4 \\
61.9 \\
64.5 \\
68.6 \\
72.8 \\
73.0 \\
72.3 \\
72.1 \\
71.6 \\
66.8\end{array}$ & $\begin{array}{l}49.8 \\
52.0 \\
51.9 \\
53.9 \\
56.4 \\
59.5 \\
58.9 \\
63.9 \\
57.6 \\
59.3 \\
64.7 \\
58.9 \\
57.3\end{array}$ & $\begin{array}{l}51.2 \\
52.6 \\
52.4 \\
54.3 \\
56.3 \\
59.3 \\
61.7 \\
64.9 \\
60.7 \\
62.4 \\
64.5 \\
61.2 \\
58.6\end{array}$ & $\begin{array}{l}73.2 \\
72.9 \\
72.0 \\
72.3 \\
73.3 \\
76.2 \\
79.5 \\
83.3 \\
84.0 \\
84.1 \\
83.9 \\
83.5 \\
78.5\end{array}$ & $\begin{array}{l}57.5 \\
57.9 \\
57.3 \\
59.5 \\
60.1 \\
63.5 \\
63.3 \\
66.3 \\
59.8 \\
61.8 \\
68.5 \\
62.3 \\
61.7\end{array}$ & $\begin{array}{l}60.7 \\
61.2 \\
60.3 \\
62.2 \\
63.0 \\
66.4 \\
68.8 \\
72.1 \\
70.7 \\
72.7 \\
73.7 \\
72.2 \\
67.3\end{array}$ & $\begin{array}{l}83.5 \\
83.0 \\
81.8 \\
82.0 \\
81.8 \\
80.9 \\
84.0 \\
92.5 \\
92.9 \\
94.1 \\
93.6 \\
93.4 \\
86.7\end{array}$ & $\begin{array}{l}59.9 \\
61.9 \\
60.4 \\
62.3 \\
67.1 \\
70.0 \\
71.3 \\
76.0 \\
68.0 \\
67.3 \\
73.2 \\
67.8 \\
66.8\end{array}$ & $\begin{array}{l}68.3 \\
68.3 \\
68.0 \\
70.0 \\
70.7 \\
74.9 \\
77.4 \\
80.5 \\
78.3 \\
81.2 \\
82.2 \\
80.5 \\
75.0\end{array}$ & $\begin{array}{l}68.2 \\
67.8 \\
66.7 \\
66.8 \\
67.9 \\
70.3 \\
74.1 \\
78.6 \\
78.9 \\
78.8 \\
78.3 \\
78.0 \\
73.0\end{array}$ & $\begin{array}{l}51.9 \\
54.0 \\
53.7 \\
55.5 \\
58.2 \\
61.2 \\
61.1 \\
65.5 \\
58.9 \\
60.4 \\
66.0 \\
60.4 \\
58.9\end{array}$ & $\begin{array}{l}57.7 \\
58.5 \\
58.1 \\
60.0 \\
61.5 \\
65.0 \\
67.3 \\
70.3 \\
67.1 \\
69.1 \\
70.9 \\
68.2 \\
64.6\end{array}$ \\
\hline 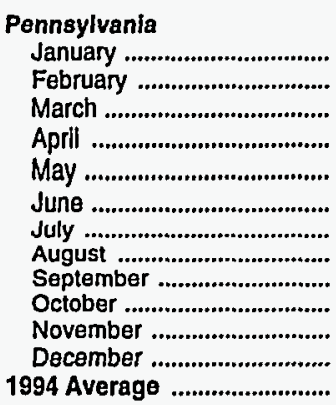 & $\begin{array}{l}61.7 \\
62.4 \\
61.5 \\
62.3 \\
63.2 \\
66.8 \\
70.4 \\
74.7 \\
74.5 \\
72.2 \\
74.2 \\
74.7 \\
68.4\end{array}$ & $\begin{array}{l}46.3 \\
49.2 \\
49.4 \\
52.1 \\
55.1 \\
57.6 \\
59.3 \\
63.0 \\
56.9 \\
55.7 \\
61.5 \\
57.8 \\
55.1\end{array}$ & $\begin{array}{l}46.6 \\
48.7 \\
48.7 \\
51.4 \\
53.8 \\
56.5 \\
59.3 \\
62.1 \\
56.5 \\
56.2 \\
61.2 \\
58.9 \\
55.3\end{array}$ & $\begin{array}{l}72.6 \\
73.9 \\
72.9 \\
73.6 \\
75.0 \\
77.8 \\
81.2 \\
85.0 \\
84.6 \\
82.6 \\
84.5 \\
85.8 \\
79.2\end{array}$ & $\begin{array}{l}50.3 \\
56.0 \\
54.8 \\
56.5 \\
62.0 \\
64.3 \\
65.7 \\
69.7 \\
62.3 \\
58.2 \\
64.1 \\
60.0 \\
60.2\end{array}$ & $\begin{array}{l}53.6 \\
55.2 \\
54.8 \\
57.1 \\
59.6 \\
62.6 \\
65.2 \\
68.8 \\
63.9 \\
63.7 \\
68.4 \\
67.2 \\
61.9\end{array}$ & $\begin{array}{l}82.4 \\
82.5 \\
81.7 \\
82.4 \\
82.8 \\
84.7 \\
88.2 \\
93.9 \\
93.8 \\
90.5 \\
93.9 \\
95.2 \\
87.4\end{array}$ & $\begin{array}{l}57.5 \\
61.2 \\
61.2 \\
64.1 \\
68.6 \\
72.1 \\
74.1 \\
78.8 \\
70.9 \\
69.5 \\
74.9 \\
71.1 \\
68.2\end{array}$ & $\begin{array}{l}58.9 \\
60.5 \\
61.2 \\
63.1 \\
66.6 \\
69.1 \\
73.0 \\
76.0 \\
70.3 \\
70.2 \\
73.8 \\
71.9 \\
68.0\end{array}$ & $\begin{array}{l}68.9 \\
69.2 \\
68.2 \\
68.8 \\
69.8 \\
72.9 \\
76.4 \\
80.4 \\
80.3 \\
78.0 \\
80.1 \\
81.0 \\
74.5\end{array}$ & $\begin{array}{l}48.0 \\
50.7 \\
50.9 \\
53.5 \\
57.1 \\
59.4 \\
61.3 \\
65.1 \\
58.7 \\
57.2 \\
62.9 \\
59.1 \\
56.8\end{array}$ & $\begin{array}{l}50.7 \\
52.5 \\
52.4 \\
54.9 \\
57.7 \\
60.2 \\
63.1 \\
66.1 \\
60.5 \\
60.1 \\
65.0 \\
62.8 \\
59.1\end{array}$ \\
\hline
\end{tabular}

See footnotes at end of table. 
Table 35. Refiner Motor Gasoline Prices by Grade, Sales Type, PAD District, and State (Cents per Gallon Excluding Taxes) - Continued

\begin{tabular}{|c|c|c|c|c|c|c|c|c|c|c|c|c|}
\hline \multirow{3}{*}{$\begin{array}{l}\text { Geographic Area } \\
\text { Month }\end{array}$} & \multicolumn{3}{|c|}{ Regular } & \multicolumn{3}{|c|}{ Midgrade } & \multicolumn{3}{|c|}{ Premlum } & \multicolumn{3}{|c|}{ All Grades } \\
\hline & \multicolumn{2}{|c|}{ Sales to End Users } & \multirow{2}{*}{$\begin{array}{c}\text { Sales } \\
\text { for } \\
\text { Resale }\end{array}$} & \multicolumn{2}{|c|}{ Sales to End Users } & \multirow{2}{*}{$\begin{array}{c}\text { Sales } \\
\text { for } \\
\text { Resale }\end{array}$} & \multicolumn{2}{|c|}{ Sales to End Users } & \multirow{2}{*}{$\begin{array}{c}\text { Sales } \\
\text { for } \\
\text { Resale }\end{array}$} & \multicolumn{2}{|c|}{ Sales to End Users } & \multirow{2}{*}{$\begin{array}{c}\text { Sales } \\
\text { for } \\
\text { Resale }\end{array}$} \\
\hline & \begin{tabular}{|c|} 
Through \\
Retail \\
Outlets
\end{tabular} & $\begin{array}{c}\text { Other } \\
\text { End } \\
\text { Usersa }\end{array}$ & & $\begin{array}{c}\text { Through } \\
\text { Retail } \\
\text { Outlots }\end{array}$ & $\begin{array}{l}\text { Other } \\
\text { End } \\
\text { Usersa }\end{array}$ & & $\begin{array}{c}\text { Through } \\
\text { Retall } \\
\text { Outlets }\end{array}$ & $\begin{array}{c}\text { Other } \\
\text { End } \\
\text { Usersa }\end{array}$ & & $\begin{array}{c}\text { Through } \\
\text { Retall } \\
\text { Outlets }\end{array}$ & $\begin{array}{c}\text { Other } \\
\text { End } \\
\text { Usersa }\end{array}$ & \\
\hline Subdlatrict IC & & & & & & & & & & & & \\
\hline 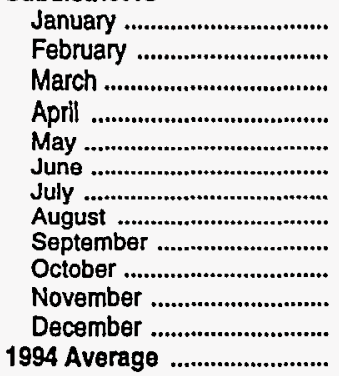 & $\begin{array}{l}57.3 \\
58.6 \\
58.9 \\
60.8 \\
61.7 \\
63.8 \\
66.7 \\
71.1 \\
70.9 \\
68.7 \\
69.2 \\
67.5 \\
64.6\end{array}$ & $\begin{array}{l}45.9 \\
50.3 \\
50.5 \\
53.8 \\
53.9 \\
57.0 \\
58.2 \\
61.6 \\
52.1 \\
52.0 \\
57.6 \\
49.6 \\
53.6\end{array}$ & $\begin{array}{l}47.3 \\
50.2 \\
50.7 \\
54.1 \\
54.4 \\
57.5 \\
59.3 \\
61.1 \\
52.3 \\
55.1 \\
56.6 \\
50.6 \\
54.2\end{array}$ & $\begin{array}{l}69.9 \\
70.8 \\
71.0 \\
72.8 \\
73.5 \\
75.8 \\
78.6 \\
82.7 \\
82.6 \\
80.4 \\
80.7 \\
79.0 \\
76.5\end{array}$ & $\begin{array}{l}49.1 \\
53.1 \\
53.2 \\
56.9 \\
57.1 \\
60.2 \\
61.1 \\
65.1 \\
54.8 \\
55.3 \\
60.5 \\
52.6 \\
56.6\end{array}$ & $\begin{array}{l}53.9 \\
56.5 \\
56.8 \\
60.2 \\
60.5 \\
63.8 \\
65.6 \\
68.0 \\
60.0 \\
61.8 \\
63.7 \\
58.2 \\
60.8\end{array}$ & $\begin{array}{l}78.3 \\
79.3 \\
79.5 \\
81.3 \\
81.9 \\
84.3 \\
87.1 \\
91.7 \\
91.0 \\
88.5 \\
89.0 \\
87.2 \\
84.7\end{array}$ & $\begin{array}{l}54.4 \\
58.6 \\
58.5 \\
61.8 \\
61.0 \\
65.3 \\
66.5 \\
70.6 \\
60.3 \\
61.0 \\
66.5 \\
58.0 \\
62.0\end{array}$ & $\begin{array}{l}60.7 \\
63.2 \\
63.5 \\
66.8 \\
67.2 \\
70.3 \\
72.5 \\
74.6 \\
66.8 \\
68.8 \\
70.0 \\
64.7 \\
67.5\end{array}$ & $\begin{array}{l}64.8 \\
65.8 \\
66.1 \\
68.0 \\
68.8 \\
71.0 \\
73.7 \\
77.8 \\
77.6 \\
75.4 \\
75.9 \\
74.3 \\
71.6\end{array}$ & $\begin{array}{l}48.1 \\
52.4 \\
52.5 \\
55.9 \\
56.0 \\
59.1 \\
60.3 \\
64.0 \\
54.2 \\
54.2 \\
59.8 \\
51.7 \\
55.7\end{array}$ & $\begin{array}{l}51.6 \\
54.5 \\
54.9 \\
58.3 \\
58.6 \\
61.7 \\
63.6 \\
65.4 \\
57.0 \\
59.5 \\
60.9 \\
55.2 \\
58.5\end{array}$ \\
\hline 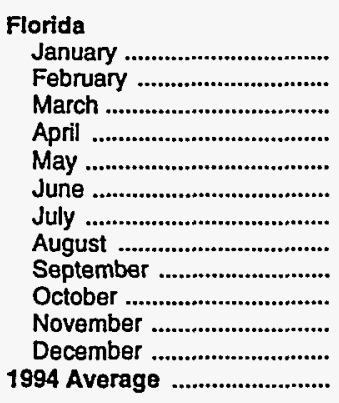 & $\begin{array}{l}56.4 \\
58.1 \\
58.9 \\
61.3 \\
62.6 \\
64.5 \\
68.0 \\
72.8 \\
72.6 \\
70.4 \\
69.2 \\
66.9 \\
65.0\end{array}$ & $\begin{array}{l}45.6 \\
49.9 \\
50.5 \\
53.4 \\
53.1 \\
56.4 \\
57.6 \\
60.9 \\
50.4 \\
51.9 \\
55.6 \\
47.9 \\
52.6\end{array}$ & $\begin{array}{l}48.6 \\
51.6 \\
51.9 \\
55.3 \\
55.5 \\
58.6 \\
61.0 \\
63.1 \\
55.3 \\
57.4 \\
57.4 \\
51.7 \\
55.5\end{array}$ & $\begin{array}{l}70.2 \\
71.2 \\
71.9 \\
74.7 \\
75.6 \\
77.5 \\
80.9 \\
85.2 \\
85.2 \\
83.0 \\
81.7 \\
79.7 \\
77.9\end{array}$ & $\begin{array}{l}49.1 \\
52.5 \\
53.6 \\
56.4 \\
56.2 \\
59.4 \\
60.6 \\
64.1 \\
53.7 \\
54.9 \\
59.0 \\
51.0 \\
55.6\end{array}$ & $\begin{array}{l}56.2 \\
58.3 \\
58.7 \\
62.1 \\
62.4 \\
65.9 \\
68.4 \\
71.2 \\
65.0 \\
65.3 \\
65.6 \\
60.5 \\
63.3\end{array}$ & $\begin{array}{l}78.8 \\
79.5 \\
80.2 \\
82.7 \\
83.6 \\
85.9 \\
89.3 \\
93.5 \\
93.5 \\
91.0 \\
89.7 \\
87.7 \\
85.9\end{array}$ & $\begin{array}{l}54.0 \\
57.8 \\
58.1 \\
60.6 \\
59.3 \\
63.7 \\
65.4 \\
69.7 \\
58.9 \\
60.3 \\
64.7 \\
56.2 \\
60.6\end{array}$ & $\begin{array}{l}65.0 \\
66.8 \\
67.2 \\
70.3 \\
70.5 \\
74.0 \\
77.0 \\
79.5 \\
73.9 \\
74.2 \\
73.2 \\
68.6 \\
71.5\end{array}$ & $\begin{array}{l}65.4 \\
66.6 \\
67.3 \\
69.9 \\
71.2 \\
73.1 \\
76.4 \\
80.6 \\
80.5 \\
78.3 \\
77.0 \\
75.0 \\
73.2\end{array}$ & $\begin{array}{l}48.0 \\
51.9 \\
52.6 \\
55.4 \\
55.2 \\
58.4 \\
59.7 \\
63.2 \\
52.7 \\
53.8 \\
58.1 \\
50.1 \\
54.7\end{array}$ & $\begin{array}{l}54.3 \\
57.0 \\
57.3 \\
60.7 \\
61.1 \\
64.3 \\
66.8 \\
68.8 \\
61.8 \\
63.2 \\
63.0 \\
57.7 \\
61.2\end{array}$ \\
\hline 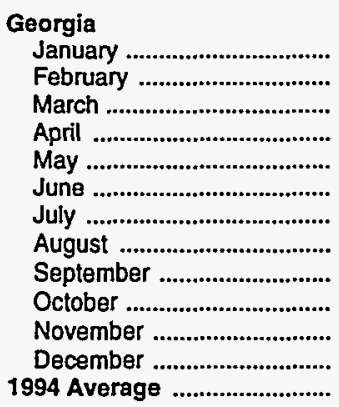 & $\begin{array}{l}54.8 \\
56.4 \\
56.3 \\
58.0 \\
59.2 \\
61.5 \\
64.0 \\
68.7 \\
68.6 \\
66.4 \\
66.8 \\
64.2 \\
62.2\end{array}$ & $\begin{array}{l}45.1 \\
49.9 \\
50.4 \\
53.4 \\
54.4 \\
57.2 \\
58.1 \\
61.6 \\
52.9 \\
51.1 \\
57.5 \\
49.2 \\
53.8\end{array}$ & $\begin{array}{l}45.8 \\
48.8 \\
49.7 \\
53.1 \\
53.5 \\
56.6 \\
58.3 \\
59.8 \\
50.3 \\
53.5 \\
53.9 \\
48.1 \\
52.8\end{array}$ & $\begin{array}{l}66.6 \\
68.2 \\
68.0 \\
68.7 \\
70.0 \\
72.4 \\
74.9 \\
79.5 \\
79.2 \\
77.2 \\
77.5 \\
74.2 \\
73.1\end{array}$ & $\begin{array}{l}48.0 \\
52.6 \\
51.9 \\
56.6 \\
57.4 \\
60.4 \\
60.8 \\
65.3 \\
54.7 \\
55.0 \\
60.9 \\
52.2 \\
56.6\end{array}$ & $\begin{array}{l}51.7 \\
54.6 \\
55.3 \\
58.9 \\
59.4 \\
62.7 \\
64.4 \\
66.5 \\
57.1 \\
59.6 \\
60.6 \\
54.7 \\
58.9\end{array}$ & $\begin{array}{l}75.7 \\
77.0 \\
76.7 \\
77.9 \\
78.9 \\
81.8 \\
84.3 \\
89.0 \\
88.0 \\
85.6 \\
86.5 \\
83.2 \\
81.9\end{array}$ & $\begin{array}{l}52.6 \\
56.9 \\
57.2 \\
61.3 \\
61.3 \\
64.4 \\
65.7 \\
69.5 \\
58.9 \\
59.1 \\
64.7 \\
55.8 \\
60.9\end{array}$ & $\begin{array}{l}57.0 \\
59.9 \\
60.7 \\
64.2 \\
64.8 \\
67.7 \\
69.8 \\
71.4 \\
62.0 \\
64.8 \\
65.4 \\
59.9 \\
64.1\end{array}$ & $\begin{array}{l}61.7 \\
63.2 \\
63.1 \\
64.5 \\
65.6 \\
67.9 \\
70.4 \\
74.8 \\
74.6 \\
72.4 \\
73.0 \\
70.2 \\
68.5\end{array}$ & $\begin{array}{l}47.4 \\
51.9 \\
52.1 \\
55.8 \\
56.4 \\
59.2 \\
60.1 \\
63.9 \\
54.4 \\
53.3 \\
59.6 \\
51.1 \\
55.8\end{array}$ & $\begin{array}{l}49.3 \\
52.3 \\
53.2 \\
56.6 \\
57.1 \\
60.1 \\
61.8 \\
63.4 \\
53.9 \\
56.9 \\
57.3 \\
51.6 \\
56.3\end{array}$ \\
\hline 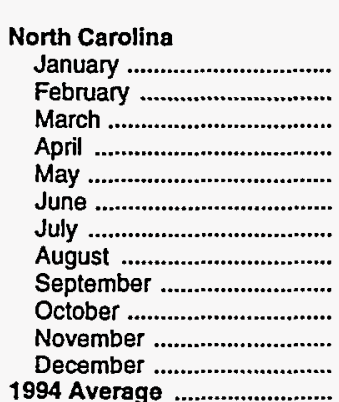 & $\begin{array}{l}\mathbf{5 5 . 9} \\
\mathbf{5 8 . 0} \\
\mathbf{5 7 . 2} \\
\mathbf{5 8 . 9} \\
\mathbf{5 9 . 8} \\
63.0 \\
65.8 \\
69.4 \\
68.5 \\
66.4 \\
69.3 \\
66.7 \\
63.1\end{array}$ & $\begin{array}{l}44.8 \\
49.2 \\
48.8 \\
52.8 \\
52.8 \\
55.8 \\
56.7 \\
60.7 \\
50.1 \\
50.6 \\
57.6 \\
48.4 \\
52.4\end{array}$ & $\begin{array}{l}46.4 \\
49.4 \\
49.6 \\
53.3 \\
53.4 \\
56.7 \\
58.3 \\
59.8 \\
49.9 \\
53.6 \\
55.5 \\
48.3 \\
53.0\end{array}$ & $\begin{array}{l}65.6 \\
67.5 \\
66.7 \\
68.5 \\
69.2 \\
72.8 \\
75.6 \\
79.2 \\
78.6 \\
76.4 \\
79.7 \\
77.2 \\
73.0\end{array}$ & $\begin{array}{c}49.1 \\
53.0 \\
52.4 \\
56.2 \\
56.0 \\
59.5 \\
W \\
64.7 \\
53.4 \\
54.1 \\
59.8 \\
51.4 \\
55.7\end{array}$ & $\begin{array}{l}51.3 \\
54.3 \\
54.5 \\
58.2 \\
58.2 \\
61.7 \\
63.1 \\
64.9 \\
55.1 \\
58.3 \\
60.9 \\
53.5 \\
58.0\end{array}$ & $\begin{array}{l}73.3 \\
75.8 \\
75.0 \\
76.8 \\
76.8 \\
81.7 \\
84.0 \\
87.8 \\
87.0 \\
84.8 \\
87.6 \\
85.0 \\
81.0\end{array}$ & $\begin{array}{c}52.4 \\
56.8 \\
W \\
60.9 \\
60.8 \\
64.5 \\
66.7 \\
70.6 \\
59.8 \\
59.3 \\
67.3 \\
57.5 \\
61.0\end{array}$ & $\begin{array}{l}56.8 \\
59.9 \\
60.0 \\
63.8 \\
64.1 \\
67.4 \\
69.2 \\
71.0 \\
61.0 \\
64.5 \\
66.5 \\
59.3 \\
63.8\end{array}$ & $\begin{array}{l}61.0 \\
63.1 \\
62.4 \\
64.1 \\
64.9 \\
68.4 \\
71.0 \\
74.5 \\
73.8 \\
71.6 \\
74.5 \\
72.2 \\
68.4\end{array}$ & $\begin{array}{l}46.8 \\
51.0 \\
50.3 \\
54.6 \\
54.6 \\
57.3 \\
58.8 \\
63.0 \\
52.2 \\
52.6 \\
59.2 \\
50.2 \\
54.2\end{array}$ & $\begin{array}{l}49.4 \\
52.5 \\
52.7 \\
56.4 \\
56.5 \\
59.9 \\
61.5 \\
63.0 \\
53.1 \\
56.7 \\
58.7 \\
51.5 \\
56.1\end{array}$ \\
\hline
\end{tabular}

See iootnotes at end of table. 
Table 35. Refiner Motor Gasoline Prices by Grade, Sales Type, PAD District, and State (Cents per Gallon Excluding Taxes) - Continued

\begin{tabular}{|c|c|c|c|c|c|c|c|c|c|c|c|c|}
\hline \multirow{3}{*}{$\begin{array}{c}\text { Geographle Area } \\
\text { Month }\end{array}$} & \multicolumn{3}{|c|}{ Regular } & \multicolumn{3}{|c|}{ Midgrado } & \multicolumn{3}{|c|}{ Premlum } & \multicolumn{3}{|c|}{ All Grades } \\
\hline & \multicolumn{2}{|c|}{ Sates to End Users } & \multirow{2}{*}{$\begin{array}{c}\text { Sales } \\
\text { tor } \\
\text { Resale }\end{array}$} & \multicolumn{2}{|c|}{ Sales to End Users } & \multirow{2}{*}{$\begin{array}{c}\text { Sales } \\
\text { for } \\
\text { Resale }\end{array}$} & \multicolumn{2}{|c|}{ Sales to End Users } & \multirow{2}{*}{$\begin{array}{c}\text { Sales } \\
\text { for } \\
\text { Resale }\end{array}$} & \multicolumn{2}{|c|}{ Sales to End Users } & \multirow{2}{*}{$\begin{array}{c}\text { Sales } \\
\text { for } \\
\text { Resale }\end{array}$} \\
\hline & $\begin{array}{c}\text { Through } \\
\text { Retall } \\
\text { Outlots }\end{array}$ & $\begin{array}{l}\text { Other } \\
\text { End } \\
\text { Useraa }\end{array}$ & & $\begin{array}{c}\text { Through } \\
\text { Rotall } \\
\text { Outlets }\end{array}$ & $\begin{array}{c}\text { Other } \\
\text { End } \\
\text { Usersa }\end{array}$ & & $\begin{array}{c}\text { Through } \\
\text { Retall } \\
\text { Outlets }\end{array}$ & $\begin{array}{c}\text { Other } \\
\text { End } \\
\text { Usersa }\end{array}$ & & $\begin{array}{c}\text { Through } \\
\text { Retall } \\
\text { Outlets }\end{array}$ & $\begin{array}{l}\text { Other } \\
\text { End } \\
\text { Usersa }\end{array}$ & \\
\hline
\end{tabular}

South Carolina

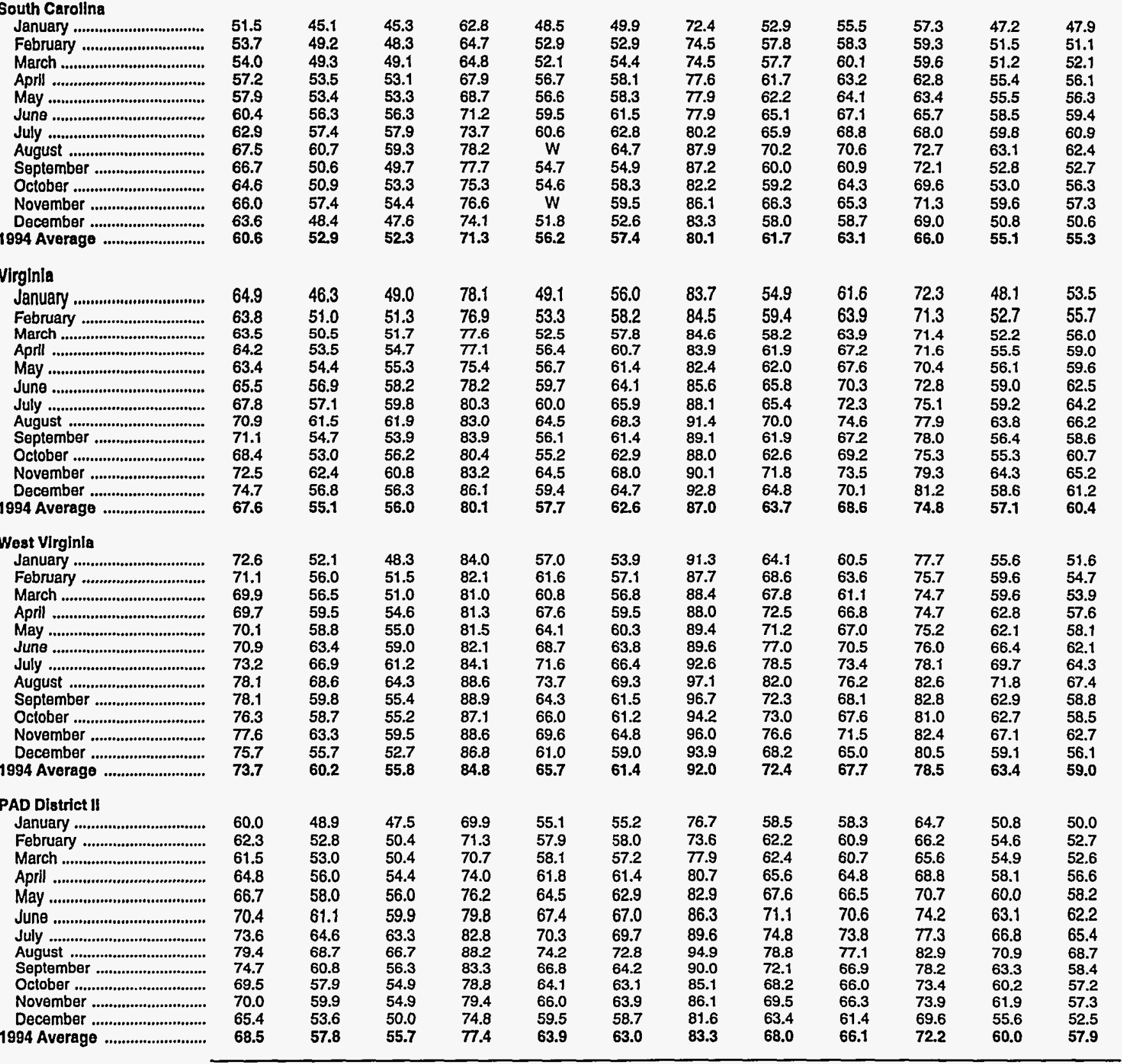

See footnotes at end of table. 
Table 35. Refiner Motor Gasoline Prices by Grade, Sales Type, PAD District, and State (Cents per Gallon Excluding Taxes) - Continued

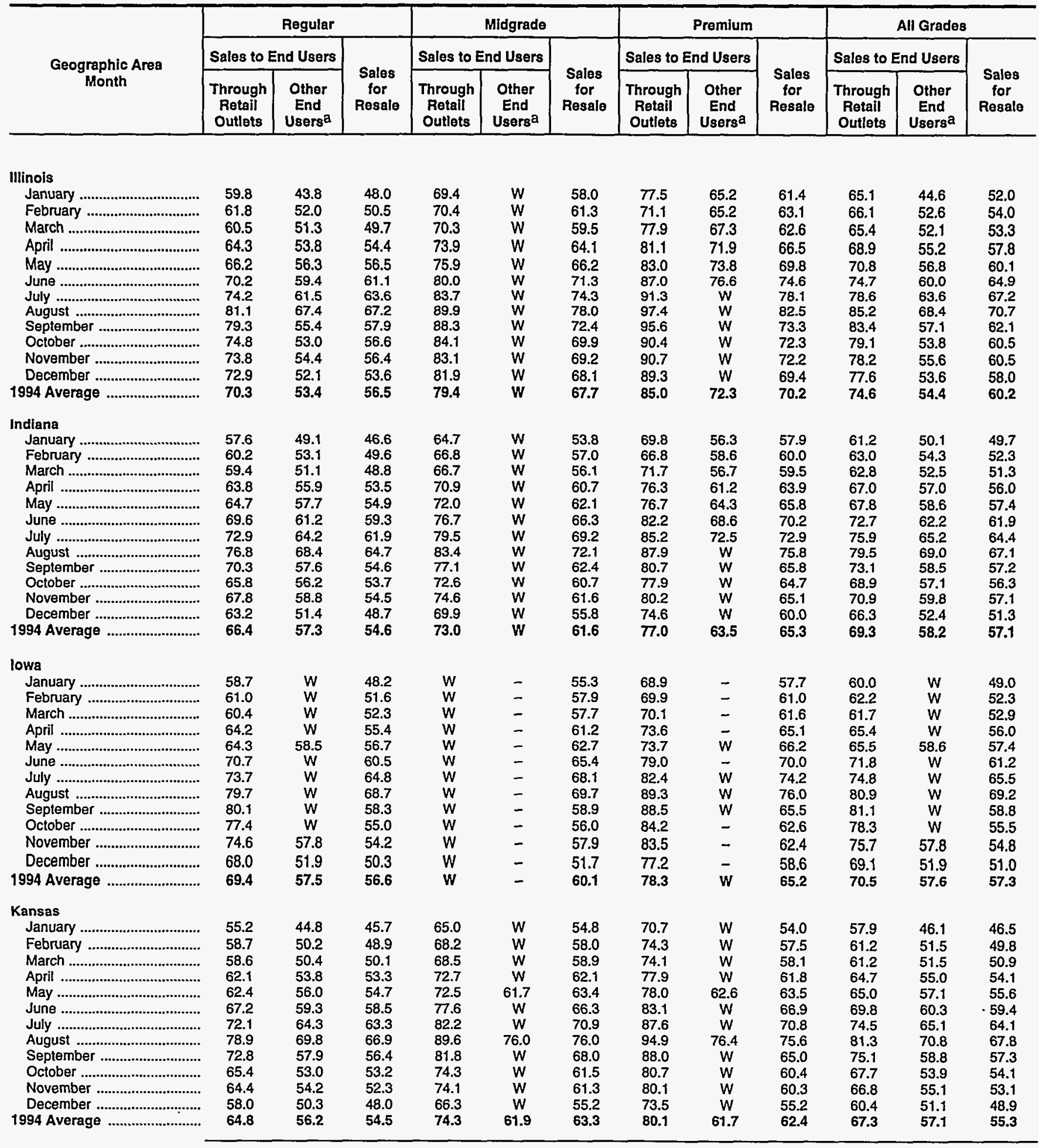

See footnotes at end of table. 
Table 35. Refiner Motor Gasoline Prices by Grade, Sales Type, PAD District, and State (Cents per Gallon Excluding Taxes) - Continued

\begin{tabular}{|c|c|c|c|c|c|c|c|c|c|c|c|c|}
\hline \multirow{3}{*}{$\begin{array}{c}\text { Geographlc Area } \\
\text { Month }\end{array}$} & \multicolumn{3}{|c|}{ Regular } & \multicolumn{3}{|c|}{ Midgrade } & \multicolumn{3}{|c|}{ Premium } & \multicolumn{3}{|c|}{ All Grades } \\
\hline & \multicolumn{2}{|c|}{ Sales to End Users } & \multirow[b]{2}{*}{$\begin{array}{c}\text { Sales } \\
\text { for } \\
\text { Resale }\end{array}$} & \multicolumn{2}{|c|}{ Sales to End Users } & \multirow[b]{2}{*}{$\begin{array}{c}\text { Sales } \\
\text { for } \\
\text { Regale }\end{array}$} & \multicolumn{2}{|c|}{ Sales to End Users } & \multirow[b]{2}{*}{$\begin{array}{c}\text { Sales } \\
\text { for } \\
\text { Resale }\end{array}$} & \multicolumn{2}{|c|}{ Sales to End Users } & \multirow[b]{2}{*}{$\begin{array}{c}\text { Sales } \\
\text { for } \\
\text { Resale }\end{array}$} \\
\hline & $\begin{array}{c}\text { Through } \\
\text { Retall } \\
\text { Outlets }\end{array}$ & $\begin{array}{c}\text { Other } \\
\text { End } \\
\text { Usersa }\end{array}$ & & $\begin{array}{c}\text { Through } \\
\text { Retail } \\
\text { Outlets }\end{array}$ & $\begin{array}{l}\text { Other } \\
\text { End } \\
\text { Usersa }\end{array}$ & & $\begin{array}{c}\text { Through } \\
\text { Retall } \\
\text { Outlets }\end{array}$ & $\begin{array}{l}\text { Other } \\
\text { End } \\
\text { Usersa }\end{array}$ & & $\begin{array}{c}\text { Through } \\
\text { Retail } \\
\text { Outlets }\end{array}$ & $\begin{array}{c}\text { Other } \\
\text { End } \\
\text { Usersa }\end{array}$ & \\
\hline \multicolumn{13}{|l|}{ Kentucky } \\
\hline 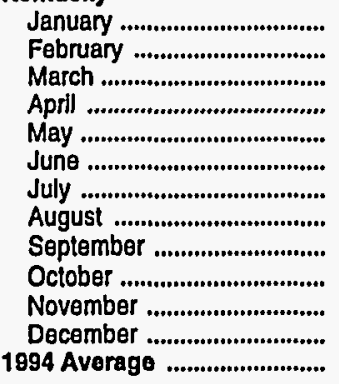 & $\begin{array}{l}59.3 \\
63.2 \\
64.3 \\
66.7 \\
69.8 \\
71.4 \\
72.1 \\
77.2 \\
72.4 \\
69.8 \\
71.9 \\
70.9 \\
69.4\end{array}$ & $\begin{array}{l}49.4 \\
52.2 \\
53.4 \\
57.0 \\
58.9 \\
61.6 \\
62.9 \\
67.2 \\
60.1 \\
58.4 \\
62.3 \\
55.2 \\
58.3\end{array}$ & $\begin{array}{l}47.4 \\
50.4 \\
51.1 \\
54.6 \\
55.4 \\
59.2 \\
61.7 \\
63.3 \\
52.8 \\
54.6 \\
55.8 \\
51.1 \\
\mathbf{5 5 . 0}\end{array}$ & $\begin{array}{l}70.3 \\
74.7 \\
75.9 \\
78.6 \\
81.5 \\
83.2 \\
83.4 \\
88.7 \\
83.8 \\
81.2 \\
83.7 \\
82.8 \\
80.9\end{array}$ & $\begin{array}{l}61.0 \\
W \\
W \\
W \\
W \\
W \\
W \\
78.2 \\
70.4 \\
W \\
W \\
W \\
69.7\end{array}$ & $\begin{array}{l}52.5 \\
55.2 \\
55.9 \\
59.6 \\
60.5 \\
64.8 \\
67.5 \\
69.2 \\
58.6 \\
60.0 \\
63.0 \\
57.7 \\
60.6\end{array}$ & $\begin{array}{l}77.5 \\
82.2 \\
83.5 \\
86.1 \\
88.6 \\
90.3 \\
90.4 \\
95.9 \\
89.7 \\
87.2 \\
90.2 \\
89.0 \\
87.6\end{array}$ & $\begin{array}{l}60.0 \\
64.2 \\
64.7 \\
69.1 \\
69.9 \\
74.2 \\
74.1 \\
79.8 \\
71.1 \\
70.2 \\
75.2 \\
66.1 \\
69.6\end{array}$ & $\begin{array}{l}57.4 \\
60.2 \\
60.4 \\
64.5 \\
65.2 \\
69.6 \\
72.2 \\
74.3 \\
63.5 \\
65.2 \\
66.9 \\
62.1 \\
65.2\end{array}$ & $\begin{array}{l}65.2 \\
69.0 \\
70.0 \\
72.3 \\
75.3 \\
77.0 \\
77.4 \\
82.3 \\
77.6 \\
75.1 \\
77.3 \\
76.3 \\
74.8\end{array}$ & $\begin{array}{l}52.4 \\
55.5 \\
56.6 \\
60.2 \\
61.9 \\
64.8 \\
66.2 \\
70.4 \\
63.0 \\
61.2 \\
65.6 \\
58.2 \\
61.4\end{array}$ & $\begin{array}{l}50.3 \\
53.2 \\
53.9 \\
57.4 \\
58.1 \\
62.1 \\
64.6 \\
66.3 \\
55.7 \\
57.6 \\
59.0 \\
54.4 \\
57.9\end{array}$ \\
\hline \multicolumn{13}{|l|}{ Michigan } \\
\hline 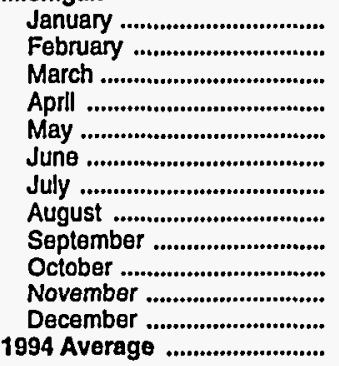 & $\begin{array}{l}58.3 \\
62.0 \\
59.8 \\
64.2 \\
65.9 \\
69.6 \\
73.5 \\
78.9 \\
72.9 \\
67.0 \\
68.6 \\
62.2 \\
67.3\end{array}$ & $\begin{array}{l}48.9 \\
51.8 \\
\mathbf{5 1 . 9} \\
54.4 \\
57.2 \\
60.7 \\
64.6 \\
68.8 \\
63.1 \\
58.3 \\
61.1 \\
\mathbf{5 5 . 6} \\
\mathbf{5 7 . 6}\end{array}$ & $\begin{array}{l}48.2 \\
51.2 \\
49.4 \\
54.8 \\
56.9 \\
61.2 \\
64.4 \\
68.1 \\
56.7 \\
55.0 \\
56.4 \\
49.2 \\
56.3\end{array}$ & $\begin{array}{l}67.8 \\
70.8 \\
68.2 \\
72.4 \\
74.1 \\
78.2 \\
82.0 \\
87.6 \\
81.5 \\
75.5 \\
77.4 \\
71.0 \\
75.5\end{array}$ & $\begin{array}{c}W \\
56.0 \\
54.1 \\
W \\
W \\
66.6 \\
68.7 \\
W \\
W \\
57.2 \\
62.4 \\
W \\
61.3\end{array}$ & $\begin{array}{l}54.9 \\
58.0 \\
55.6 \\
61.0 \\
63.1 \\
67.4 \\
70.5 \\
74.8 \\
65.3 \\
61.8 \\
63.7 \\
57.5 \\
62.8\end{array}$ & $\begin{array}{l}74.6 \\
70.5 \\
75.4 \\
77.6 \\
80.6 \\
83.4 \\
87.1 \\
92.4 \\
86.5 \\
81.4 \\
82.9 \\
77.0 \\
80.2\end{array}$ & $\begin{array}{l}58.2 \\
59.4 \\
61.7 \\
64.3 \\
66.6 \\
70.6 \\
75.4 \\
78.5 \\
75.7 \\
69.4 \\
69.2 \\
68.3 \\
68.4\end{array}$ & $\begin{array}{l}59.0 \\
61.9 \\
60.2 \\
65.6 \\
67.6 \\
72.0 \\
75.4 \\
79.2 \\
68.7 \\
66.4 \\
67.7 \\
60.7 \\
67.1\end{array}$ & $\begin{array}{l}62.3 \\
65.3 \\
63.3 \\
67.4 \\
69.0 \\
72.6 \\
76.5 \\
81.7 \\
75.8 \\
70.1 \\
71.8 \\
65.6 \\
70.3\end{array}$ & $\begin{array}{l}50.8 \\
53.2 \\
54.0 \\
56.9 \\
59.4 \\
62.9 \\
67.4 \\
71.5 \\
66.8 \\
61.0 \\
62.7 \\
57.7 \\
60.0\end{array}$ & $\begin{array}{l}50.9 \\
53.8 \\
51.9 \\
57.2 \\
59.3 \\
63.6 \\
66.8 \\
70.4 \\
59.4 \\
57.5 \\
58.9 \\
51.9 \\
\mathbf{5 8 . 7}\end{array}$ \\
\hline \multicolumn{13}{|l|}{ Minnesota } \\
\hline 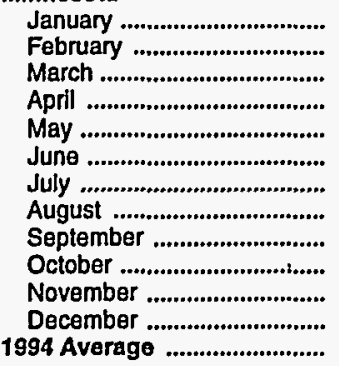 & $\begin{array}{l}72.8 \\
73.1 \\
71.9 \\
73.3 \\
75.4 \\
77.0 \\
79.6 \\
88.6 \\
84.8 \\
77.7 \\
76.1 \\
70.8 \\
76.9\end{array}$ & $\begin{array}{l}\mathbf{5 4 . 6} \\
\mathbf{5 3 . 2} \\
\mathbf{5 3 . 2} \\
\mathbf{5 6 . 4} \\
\mathbf{5 7 . 6} \\
61.3 \\
64.7 \\
69.9 \\
60.5 \\
\mathbf{5 9 . 6} \\
\mathbf{5 9 . 4} \\
\mathbf{5 7 . 4} \\
\mathbf{5 8 . 8}\end{array}$ & $\begin{array}{l}51.5 \\
54.0 \\
54.6 \\
57.4 \\
58.9 \\
62.3 \\
67.0 \\
71.2 \\
60.7 \\
57.5 \\
57.0 \\
53.8 \\
59.2\end{array}$ & $\begin{array}{l}80.9 \\
80.7 \\
79.4 \\
80.7 \\
82.6 \\
84.5 \\
87.4 \\
96.6 \\
92.4 \\
84.4 \\
84.9 \\
78.4 \\
84.1\end{array}$ & $\begin{array}{l}W \\
W \\
W \\
W \\
W \\
W \\
W \\
W \\
W \\
W \\
W \\
W \\
66.7\end{array}$ & $\begin{array}{l}63.4 \\
64.1 \\
62.9 \\
65.2 \\
66.0 \\
69.0 \\
73.0 \\
77.4 \\
69.2 \\
67.7 \\
67.1 \\
62.1 \\
67.5\end{array}$ & $\begin{array}{r}87.9 \\
89.3 \\
88.6 \\
88.5 \\
90.7 \\
91.7 \\
94.4 \\
103.3 \\
99.7 \\
93.1 \\
92.9 \\
86.9 \\
92.1\end{array}$ & $\begin{array}{c}W \\
W \\
W \\
W \\
W \\
W \\
W \\
W \\
W \\
65.4 \\
W \\
W \\
74.8\end{array}$ & $\begin{array}{l}60.2 \\
62.5 \\
63.4 \\
66.7 \\
68.0 \\
71.3 \\
75.5 \\
80.2 \\
70.4 \\
66.6 \\
65.7 \\
63.0 \\
67.8\end{array}$ & $\begin{array}{l}76.1 \\
75.8 \\
74.5 \\
75.8 \\
77.9 \\
79.5 \\
82.1 \\
90.8 \\
87.0 \\
79.9 \\
78.8 \\
73.3 \\
79.4\end{array}$ & $\begin{array}{l}55.0 \\
53.6 \\
53.6 \\
56.7 \\
58.3 \\
61.8 \\
65.1 \\
70.0 \\
61.1 \\
60.1 \\
59.8 \\
57.8 \\
59.2\end{array}$ & $\begin{array}{l}53.2 \\
55.4 \\
55.8 \\
58.6 \\
60.1 \\
63.5 \\
68.1 \\
72.3 \\
61.8 \\
58.8 \\
58.3 \\
55.2 \\
60.4\end{array}$ \\
\hline \multicolumn{13}{|l|}{ Missouri } \\
\hline 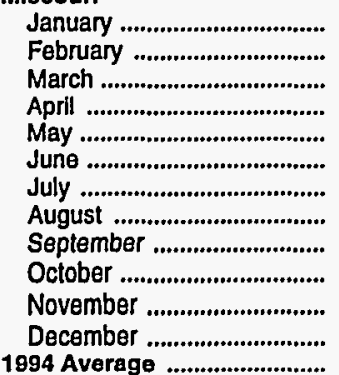 & $\begin{array}{l}54.8 \\
58.6 \\
58.7 \\
61.8 \\
63.4 \\
67.5 \\
72.0 \\
79.2 \\
73.8 \\
65.8 \\
65.5 \\
58.2 \\
65.0\end{array}$ & $\begin{array}{l}48.0 \\
51.6 \\
54.8 \\
53.7 \\
55.7 \\
W \\
63.4 \\
69.5 \\
59.6 \\
53.3 \\
54.6 \\
48.7 \\
54.8\end{array}$ & $\begin{array}{l}46.4 \\
49.7 \\
50.1 \\
53.6 \\
55.3 \\
59.4 \\
63.3 \\
66.9 \\
56.8 \\
53.8 \\
53.5 \\
48.6 \\
55.0\end{array}$ & $\begin{array}{l}67.0 \\
71.5 \\
70.6 \\
73.2 \\
74.7 \\
79.0 \\
83.5 \\
90.3 \\
85.2 \\
77.0 \\
77.0 \\
69.0 \\
76.2\end{array}$ & $\begin{array}{l}W \\
W \\
W \\
W \\
W \\
W \\
W \\
W \\
W \\
W \\
W \\
W \\
W\end{array}$ & $\begin{array}{l}54.9 \\
58.5 \\
57.4 \\
61.5 \\
62.9 \\
67.5 \\
71.2 \\
75.5 \\
67.6 \\
63.0 \\
63.0 \\
56.5 \\
63.3\end{array}$ & $\begin{array}{l}75.0 \\
72.9 \\
79.6 \\
81.2 \\
83.0 \\
87.6 \\
92.2 \\
99.0 \\
93.9 \\
85.7 \\
85.3 \\
75.0 \\
83.1\end{array}$ & $\begin{array}{c}51.6 \\
58.2 \\
57.5 \\
60.9 \\
62.6 \\
66.8 \\
W \\
W \\
W \\
W \\
W \\
56.8 \\
62.1\end{array}$ & $\begin{array}{l}56.4 \\
59.9 \\
59.8 \\
63.4 \\
64.9 \\
69.1 \\
72.9 \\
76.8 \\
67.0 \\
63.8 \\
63.2 \\
58.1 \\
64.7\end{array}$ & $\begin{array}{l}59.8 \\
63.2 \\
63.3 \\
66.0 \\
67.6 \\
71.7 \\
76.1 \\
83.0 \\
77.7 \\
69.8 \\
69.6 \\
62.5 \\
69.1\end{array}$ & $\begin{array}{l}48.4 \\
52.3 \\
55.1 \\
54.6 \\
56.5 \\
60.0 \\
65.1 \\
71.2 \\
61.4 \\
55.1 \\
56.6 \\
50.7 \\
56.0\end{array}$ & $\begin{array}{l}48.6 \\
51.8 \\
52.1 \\
55.5 \\
57.2 \\
61.4 \\
65.3 \\
68.8 \\
58.8 \\
55.8 \\
55.5 \\
50.6 \\
57.0\end{array}$ \\
\hline
\end{tabular}

See footnotes at end of table. 
Table 35. Refiner Motor Gasoline Prices by Grade, Sales Type, PAD District, and State (Cents per Gallon Excluding Taxes) - Continued

\begin{tabular}{|c|c|c|c|c|c|c|c|c|c|c|c|c|}
\hline \multirow{3}{*}{$\begin{array}{l}\text { Geographic Area } \\
\text { Month }\end{array}$} & \multicolumn{3}{|c|}{ Regular } & \multicolumn{3}{|c|}{ MIdgrade } & \multicolumn{3}{|c|}{ Premium } & \multicolumn{3}{|c|}{ All Grades } \\
\hline & \multicolumn{2}{|c|}{ Salos to End Users } & \multirow{2}{*}{$\begin{array}{c}\text { Sales } \\
\text { for } \\
\text { Resale }\end{array}$} & \multicolumn{2}{|c|}{ Sales to End Users } & \multirow{2}{*}{$\begin{array}{c}\text { Sales } \\
\text { tor } \\
\text { Resale }\end{array}$} & \multicolumn{2}{|c|}{ Sales to End Usero } & \multirow{2}{*}{$\begin{array}{c}\text { Sales } \\
\text { for } \\
\text { Resale }\end{array}$} & \multicolumn{2}{|c|}{ Sales to End Users } & \multirow{2}{*}{$\begin{array}{c}\text { Sales } \\
\text { for } \\
\text { Resalo }\end{array}$} \\
\hline & $\begin{array}{c}\text { Through } \\
\text { Rotall } \\
\text { Outlets }\end{array}$ & $\begin{array}{c}\text { Other } \\
\text { End } \\
\text { Usersa }\end{array}$ & & $\begin{array}{c}\text { Through } \\
\text { Retail } \\
\text { Outlots }\end{array}$ & $\begin{array}{c}\text { Other } \\
\text { End } \\
\text { Usersa }\end{array}$ & & $\begin{array}{c}\text { Through } \\
\text { Retail } \\
\text { Outlets }\end{array}$ & $\begin{array}{c}\text { Other } \\
\text { End } \\
\text { Usersa }\end{array}$ & & $\begin{array}{c}\text { Through } \\
\text { Rotail } \\
\text { Outlets }\end{array}$ & $\begin{array}{c}\text { Other } \\
\text { End } \\
\text { Usersa }\end{array}$ & \\
\hline Nebraska & & & & & & & & & & & & \\
\hline 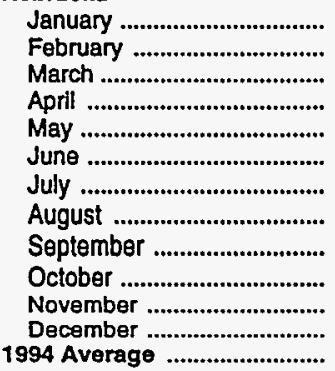 & $\begin{array}{l}60.5 \\
66.3 \\
64.5 \\
66.0 \\
67.3 \\
72.4 \\
75.8 \\
81.3 \\
76.5 \\
69.2 \\
69.0 \\
64.6 \\
69.5\end{array}$ & $\begin{array}{l}45.6 \\
51.1 \\
51.1 \\
53.5 \\
56.0 \\
59.2 \\
63.7 \\
71.5 \\
62.8 \\
53.7 \\
55.2 \\
49.4 \\
54.6\end{array}$ & $\begin{array}{l}47.8 \\
51.4 \\
52.5 \\
55.6 \\
56.9 \\
60.5 \\
64.9 \\
69.1 \\
58.7 \\
55.4 \\
53.9 \\
50.2 \\
56.8\end{array}$ & $\begin{array}{l}65.7 \\
70.4 \\
68.7 \\
71.9 \\
72.7 \\
78.6 \\
82.2 \\
W \\
W \\
W \\
W \\
W \\
75.3\end{array}$ & $\begin{array}{l}- \\
- \\
- \\
- \\
- \\
- \\
- \\
- \\
-\end{array}$ & $\begin{array}{c}W \\
W \\
W \\
W \\
-\bar{W} \\
W \\
W \\
W \\
W \\
W \\
W \\
67.3\end{array}$ & $\begin{array}{l}74.5 \\
79.8 \\
77.8 \\
80.0 \\
81.0 \\
86.3 \\
90.0 \\
95.6 \\
90.5 \\
83.2 \\
84.0 \\
79.0 \\
83.3\end{array}$ & $\begin{array}{l}W \\
W \\
W \\
W \\
W \\
W \\
W \\
- \\
W \\
- \\
- \\
\bar{w}\end{array}$ & $\begin{array}{l}57.6 \\
61.2 \\
62.2 \\
65.1 \\
66.5 \\
69.6 \\
74.0 \\
78.6 \\
68.8 \\
64.4 \\
63.2 \\
59.2 \\
66.3\end{array}$ & $\begin{array}{l}62.2 \\
67.8 \\
66.0 \\
67.7 \\
69.0 \\
74.1 \\
77.5 \\
82.9 \\
78.2 \\
70.9 \\
70.8 \\
66.5 \\
71.2\end{array}$ & $\begin{array}{l}45.9 \\
51.4 \\
51.4 \\
53.9 \\
56.6 \\
59.7 \\
63.9 \\
71.5 \\
63.5 \\
53.7 \\
55.2 \\
49.4 \\
54.9\end{array}$ & $\begin{array}{l}48.4 \\
52.3 \\
53.0 \\
56.2 \\
57.5 \\
61.1 \\
65.5 \\
69.7 \\
59.3 \\
55.9 \\
54.5 \\
50.8 \\
57.4\end{array}$ \\
\hline 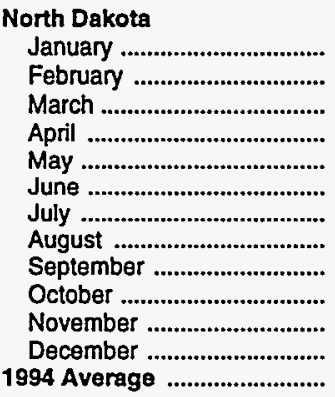 & $\begin{array}{l}73.0 \\
71.2 \\
68.9 \\
72.4 \\
75.3 \\
76.8 \\
78.2 \\
87.1 \\
82.7 \\
77.8 \\
72.2 \\
70.4 \\
75.5\end{array}$ & $\begin{array}{l}52.7 \\
W \\
W \\
59.8 \\
W \\
W \\
W \\
W \\
W \\
W \\
W \\
W \\
59.4\end{array}$ & $\begin{array}{l}50.3 \\
53.4 \\
54.2 \\
57.5 \\
59.2 \\
62.4 \\
66.4 \\
72.2 \\
61.1 \\
57.1 \\
56.2 \\
52.7 \\
59.1\end{array}$ & $\begin{array}{l}W \\
W \\
W \\
78.1 \\
78.9 \\
79.6 \\
W \\
W \\
W \\
W \\
W \\
W \\
83.1\end{array}$ & $\begin{array}{l}- \\
- \\
- \\
- \\
- \\
- \\
- \\
- \\
- \\
-\end{array}$ & $\begin{array}{l}W \\
W \\
W \\
W \\
W \\
W \\
W \\
W \\
W \\
W \\
W \\
W \\
W\end{array}$ & $\begin{array}{r}87.6 \\
85.5 \\
85.4 \\
88.0 \\
92.1 \\
93.7 \\
92.2 \\
97.7 \\
100.9 \\
93.5 \\
88.8 \\
87.4 \\
90.9\end{array}$ & $\begin{array}{l}- \\
- \\
- \\
- \\
- \\
- \\
- \\
- \\
- \\
- \\
- \\
-\end{array}$ & $\begin{array}{l}62.2 \\
64.3 \\
65.1 \\
68.8 \\
70.7 \\
73.7 \\
77.5 \\
82.3 \\
73.0 \\
68.1 \\
67.6 \\
63.9 \\
70.0\end{array}$ & $\begin{array}{l}75.5 \\
73.5 \\
71.2 \\
74.5 \\
77.1 \\
78.4 \\
80.3 \\
88.7 \\
85.2 \\
80.1 \\
74.6 \\
73.1 \\
77.7\end{array}$ & $\begin{array}{c}52.7 \\
W \\
W \\
59.8 \\
W \\
W \\
W \\
W \\
W \\
W \\
W \\
W \\
\mathbf{5 9 . 4}\end{array}$ & $\begin{array}{l}51.6 \\
54.7 \\
55.2 \\
58.4 \\
60.2 \\
63.4 \\
67.5 \\
73.1 \\
62.1 \\
58.0 \\
57.3 \\
53.9 \\
60.1\end{array}$ \\
\hline 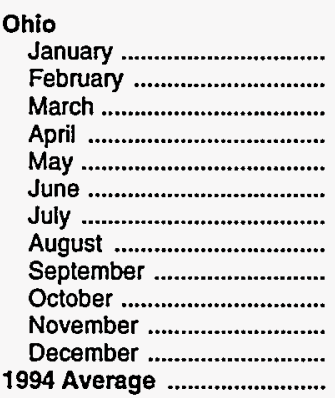 & $\begin{array}{l}62.6 \\
62.7 \\
62.8 \\
65.7 \\
68.4 \\
72.2 \\
74.5 \\
79.0 \\
73.0 \\
69.1 \\
70.4 \\
64.4 \\
69.1\end{array}$ & $\begin{array}{l}51.7 \\
56.2 \\
55.3 \\
59.0 \\
60.8 \\
W \\
66.9 \\
71.0 \\
63.5 \\
60.8 \\
63.3 \\
54.8 \\
60.8\end{array}$ & $\begin{array}{l}49.2 \\
51.3 \\
51.0 \\
55.4 \\
57.4 \\
61.5 \\
63.9 \\
66.5 \\
56.4 \\
56.3 \\
57.2 \\
50.1 \\
56.5\end{array}$ & $\begin{array}{l}71.3 \\
71.9 \\
72.0 \\
75.1 \\
78.3 \\
82.0 \\
84.4 \\
88.6 \\
81.9 \\
78.7 \\
79.2 \\
73.3 \\
78.1\end{array}$ & $\begin{array}{l}W \\
W \\
W \\
W \\
W \\
W \\
W \\
W \\
W \\
W \\
W \\
W \\
W\end{array}$ & $\begin{array}{l}57.7 \\
59.6 \\
58.9 \\
63.4 \\
65.6 \\
69.2 \\
71.4 \\
73.7 \\
66.1 \\
64.6 \\
66.0 \\
58.2 \\
64.9\end{array}$ & $\begin{array}{l}79.8 \\
75.6 \\
79.6 \\
82.4 \\
85.9 \\
89.6 \\
91.9 \\
96.4 \\
89.8 \\
84.8 \\
86.1 \\
80.5 \\
84.7\end{array}$ & $\begin{array}{l}63.6 \\
68.3 \\
66.6 \\
69.4 \\
72.3 \\
74.7 \\
78.8 \\
82.8 \\
74.8 \\
72.6 \\
73.5 \\
66.7 \\
72.1\end{array}$ & $\begin{array}{l}62.0 \\
63.2 \\
62.9 \\
67.2 \\
69.4 \\
74.2 \\
76.5 \\
79.5 \\
69.5 \\
68.9 \\
69.3 \\
62.8 \\
68.8\end{array}$ & $\begin{array}{l}67.6 \\
67.2 \\
67.2 \\
70.0 \\
72.8 \\
76.5 \\
78.7 \\
83.0 \\
76.9 \\
73.3 \\
74.4 \\
68.7 \\
73.2\end{array}$ & $\begin{array}{c}54.0 \\
58.1 \\
57.3 \\
60.8 \\
62.9 \\
W \\
69.0 \\
73.2 \\
65.7 \\
63.0 \\
65.3 \\
57.3 \\
62.9\end{array}$ & $\begin{array}{l}52.5 \\
54.3 \\
53.8 \\
58.1 \\
60.2 \\
64.5 \\
66.9 \\
69.3 \\
59.4 \\
59.2 \\
60.0 \\
53.1 \\
59.5\end{array}$ \\
\hline 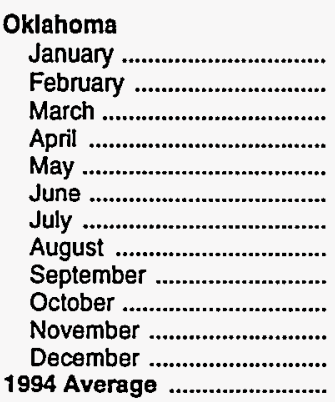 & $\begin{array}{l}51.6 \\
55.6 \\
56.7 \\
59.7 \\
62.1 \\
65.9 \\
70.3 \\
77.7 \\
72.6 \\
62.7 \\
62.6 \\
56.3 \\
63.0\end{array}$ & $\begin{array}{l}44.4 \\
48.9 \\
49.6 \\
52.7 \\
54.3 \\
57.5 \\
61.7 \\
66.8 \\
58.4 \\
51.9 \\
53.6 \\
49.1 \\
54.3\end{array}$ & $\begin{array}{l}43.7 \\
47.0 \\
48.5 \\
51.5 \\
53.4 \\
56.6 \\
61.1 \\
64.8 \\
55.6 \\
51.5 \\
50.4 \\
47.4 \\
52.8\end{array}$ & $\begin{array}{l}60.4 \\
64.2 \\
65.5 \\
68.3 \\
70.8 \\
74.6 \\
78.9 \\
86.3 \\
81.4 \\
71.0 \\
70.9 \\
64.5 \\
71.3\end{array}$ & $\begin{array}{c}W \\
W \\
53.2 \\
55.7 \\
57.1 \\
W \\
W \\
70.9 \\
57.1 \\
57.0 \\
52.0 \\
49.9 \\
55.5\end{array}$ & $\begin{array}{l}48.2 \\
51.9 \\
53.1 \\
56.6 \\
57.7 \\
61.4 \\
65.9 \\
70.1 \\
60.1 \\
56.0 \\
54.6 \\
51.1 \\
57.2\end{array}$ & $\begin{array}{l}67.7 \\
71.9 \\
73.3 \\
76.0 \\
78.6 \\
82.5 \\
86.6 \\
94.3 \\
89.1 \\
79.3 \\
79.1 \\
72.8 \\
79.0\end{array}$ & $\begin{array}{l}50.5 \\
55.6 \\
56.0 \\
59.3 \\
60.9 \\
64.0 \\
68.7 \\
74.2 \\
65.6 \\
58.7 \\
59.5 \\
55.0 \\
60.7\end{array}$ & $\begin{array}{l}51.0 \\
55.0 \\
56.6 \\
59.7 \\
60.9 \\
64.5 \\
69.6 \\
73.0 \\
61.2 \\
57.7 \\
56.9 \\
54.0 \\
59.8\end{array}$ & $\begin{array}{l}55.6 \\
59.5 \\
60.7 \\
63.6 \\
66.0 \\
69.8 \\
74.0 \\
81.2 \\
76.2 \\
66.4 \\
66.3 \\
60.2 \\
66.7\end{array}$ & $\begin{array}{l}45.7 \\
50.3 \\
51.0 \\
54.1 \\
55.6 \\
58.8 \\
63.1 \\
68.2 \\
59.7 \\
53.4 \\
54.6 \\
50.2 \\
55.6\end{array}$ & $\begin{array}{l}44.7 \\
47.9 \\
49.5 \\
52.5 \\
54.3 \\
57.5 \\
62.1 \\
65.7 \\
56.3 \\
52.3 \\
51.2 \\
48.2 \\
53.6\end{array}$ \\
\hline
\end{tabular}

See footnotes at end of table. 
Table 35. Refiner Motor Gasoline Prices by Grade, Sales Type, PAD District, and State (Cents per Gallon Excluding Taxes) - Continued

\begin{tabular}{|c|c|c|c|c|c|c|c|c|c|c|c|c|}
\hline \multirow{3}{*}{$\begin{array}{l}\text { Geographlc Area } \\
\text { Month }\end{array}$} & \multicolumn{3}{|c|}{ Regular } & \multicolumn{3}{|c|}{ Mldgrade } & \multicolumn{3}{|c|}{ Premlum } & \multicolumn{3}{|c|}{ All Grades } \\
\hline & \multicolumn{2}{|c|}{ Sales to End Users } & \multirow[b]{2}{*}{$\begin{array}{c}\text { Sales } \\
\text { for } \\
\text { Resale }\end{array}$} & \multicolumn{2}{|c|}{ Sales to End Users } & \multirow{2}{*}{$\begin{array}{c}\text { Sales } \\
\text { for } \\
\text { Resale }\end{array}$} & \multicolumn{2}{|c|}{ Sales to End Users } & \multirow[b]{2}{*}{$\begin{array}{c}\text { Sales } \\
\text { for } \\
\text { Resale }\end{array}$} & \multicolumn{2}{|c|}{ Sales to End Users } & \multirow[b]{2}{*}{$\begin{array}{c}\text { Sales } \\
\text { for } \\
\text { Resale }\end{array}$} \\
\hline & $\begin{array}{c}\text { Through } \\
\text { Rotall } \\
\text { Outlots }\end{array}$ & $\begin{array}{l}\text { Other } \\
\text { End } \\
\text { Usersa }\end{array}$ & & $\begin{array}{c}\text { Through } \\
\text { Rotail } \\
\text { Outlets }\end{array}$ & $\begin{array}{c}\text { Other } \\
\text { End } \\
\text { Usersa }\end{array}$ & & $\begin{array}{c}\text { Through } \\
\text { Retall } \\
\text { Outlets }\end{array}$ & $\begin{array}{c}\text { Other } \\
\text { End } \\
\text { Usersa }\end{array}$ & & $\begin{array}{c}\text { Through } \\
\text { Retaij } \\
\text { Outlets }\end{array}$ & $\begin{array}{l}\text { Other } \\
\text { End } \\
\text { Usersa }\end{array}$ & \\
\hline outh Dakota & & & & & & & & & & & & \\
\hline 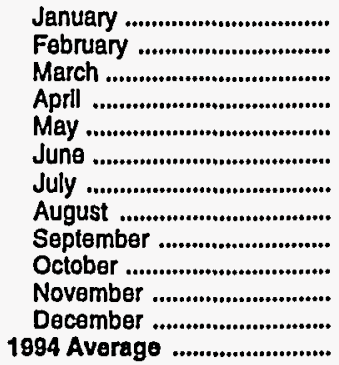 & $\begin{array}{l}64.1 \\
66.9 \\
66.0 \\
69.1 \\
W \\
W \\
W \\
W \\
W \\
79.7 \\
W \\
W \\
73.7\end{array}$ & $\begin{array}{l}47.3 \\
50.9 \\
W \\
W \\
W \\
W \\
W \\
W \\
- \\
W \\
W \\
W \\
55.2\end{array}$ & $\begin{array}{l}48.9 \\
52.3 \\
53.1 \\
56.7 \\
58.8 \\
62.3 \\
66.8 \\
71.6 \\
61.3 \\
57.0 \\
56.0 \\
51.7 \\
58.7\end{array}$ & $\begin{array}{l}W \\
W \\
W \\
W \\
W \\
W \\
W \\
W \\
W \\
W \\
W \\
W \\
W\end{array}$ & $\begin{array}{l}- \\
- \\
- \\
- \\
- \\
- \\
- \\
- \\
-\end{array}$ & $\begin{array}{l}W \\
W \\
W \\
W \\
W \\
W \\
W \\
W \\
W \\
W \\
W \\
W \\
W\end{array}$ & $\begin{array}{l}81.3 \\
81.9 \\
79.2 \\
82.4 \\
84.3 \\
85.3 \\
89.7 \\
97.1 \\
97.9 \\
92.8 \\
86.4 \\
82.5 \\
86.4\end{array}$ & $\begin{array}{l}W \\
W \\
W \\
w \\
W \\
W \\
W \\
- \\
- \\
- \\
- \\
\bar{w}\end{array}$ & $\begin{array}{l}58.6 \\
61.4 \\
62.5 \\
66.6 \\
69.4 \\
73.0 \\
76.7 \\
82.3 \\
72.1 \\
67.2 \\
66.3 \\
61.2 \\
69.3\end{array}$ & $\begin{array}{l}65.1 \\
67.7 \\
66.6 \\
69.8 \\
71.8 \\
73.2 \\
77.1 \\
85.5 \\
85.1 \\
80.3 \\
76.3 \\
70.8 \\
74.3\end{array}$ & $\begin{array}{c}48.8 \\
52.1 \\
W \\
W \\
W \\
W \\
W \\
W \\
- \\
W \\
W \\
W \\
56.6\end{array}$ & $\begin{array}{l}49.7 \\
53.0 \\
54.0 \\
57.4 \\
59.7 \\
63.3 \\
67.8 \\
72.5 \\
62.1 \\
57.7 \\
56.8 \\
52.4 \\
59.5\end{array}$ \\
\hline 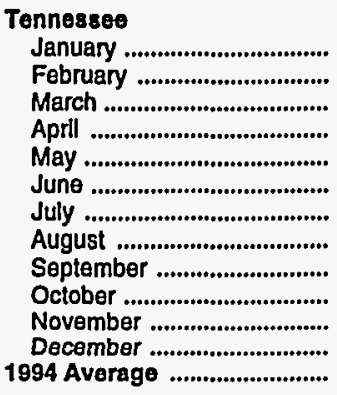 & $\begin{array}{l}56.3 \\
59.4 \\
58.9 \\
61.7 \\
62.6 \\
65.1 \\
66.9 \\
73.0 \\
71.7 \\
69.1 \\
69.6 \\
66.9 \\
65.2\end{array}$ & $\begin{array}{l}50.0 \\
49.9 \\
52.3 \\
55.0 \\
54.0 \\
55.9 \\
59.3 \\
59.6 \\
50.9 \\
54.1 \\
54.7 \\
48.4 \\
53.7\end{array}$ & $\begin{array}{l}45.6 \\
48.5 \\
49.9 \\
53.5 \\
53.4 \\
56.8 \\
58.4 \\
60.0 \\
50.2 \\
53.7 \\
54.0 \\
48.1 \\
52.9\end{array}$ & $\begin{array}{l}69.6 \\
70.8 \\
70.1 \\
72.6 \\
73.6 \\
75.9 \\
79.0 \\
84.4 \\
83.1 \\
81.0 \\
81.5 \\
79.2 \\
76.8\end{array}$ & $\begin{array}{l}48.8 \\
52.0 \\
53.0 \\
56.8 \\
56.5 \\
60.6 \\
63.2 \\
65.1 \\
52.7 \\
54.8 \\
56.7 \\
50.7 \\
56.3\end{array}$ & $\begin{array}{l}\mathbf{5 1 . 3} \\
\mathbf{5 4 . 1} \\
55.3 \\
58.9 \\
58.9 \\
62.4 \\
64.0 \\
66.3 \\
\mathbf{5 6 . 6} \\
59.6 \\
60.2 \\
\mathbf{5 4 . 2} \\
\mathbf{5 8 . 7}\end{array}$ & $\begin{array}{l}77.7 \\
78.9 \\
78.7 \\
81.2 \\
81.4 \\
83.3 \\
87.0 \\
92.3 \\
91.1 \\
89.1 \\
89.9 \\
87.3 \\
84.7\end{array}$ & $\begin{array}{l}52.0 \\
56.4 \\
57.4 \\
61.8 \\
61.9 \\
65.2 \\
66.7 \\
70.6 \\
60.9 \\
60.2 \\
63.2 \\
55.5 \\
61.3\end{array}$ & $\begin{array}{l}56.3 \\
59.1 \\
60.3 \\
63.9 \\
64.0 \\
67.3 \\
69.1 \\
71.1 \\
61.6 \\
64.8 \\
65.0 \\
59.4 \\
63.6\end{array}$ & $\begin{array}{l}63.8 \\
66.4 \\
65.9 \\
68.5 \\
69.3 \\
71.4 \\
73.8 \\
79.4 \\
78.3 \\
76.0 \\
76.5 \\
74.1 \\
72.0\end{array}$ & $\begin{array}{l}50.1 \\
51.0 \\
53.3 \\
56.3 \\
55.8 \\
58.0 \\
61.2 \\
62.1 \\
52.9 \\
55.5 \\
56.5 \\
50.2 \\
55.4\end{array}$ & $\begin{array}{l}49.2 \\
51.8 \\
53.2 \\
56.8 \\
56.8 \\
60.2 \\
61.8 \\
63.5 \\
53.8 \\
57.2 \\
57.5 \\
51.8 \\
56.3\end{array}$ \\
\hline 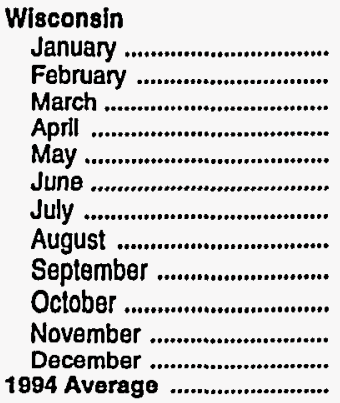 & $\begin{array}{l}57.6 \\
61.6 \\
59.8 \\
64.1 \\
67.0 \\
69.2 \\
72.3 \\
79.0 \\
76.3 \\
71.3 \\
70.3 \\
71.9 \\
68.6\end{array}$ & $\begin{array}{l}47.7 \\
51.7 \\
49.5 \\
54.6 \\
56.7 \\
60.3 \\
63.5 \\
69.0 \\
57.7 \\
54.6 \\
55.8 \\
51.9 \\
56.3\end{array}$ & $\begin{array}{l}48.1 \\
51.0 \\
49.4 \\
54.6 \\
56.5 \\
60.2 \\
63.8 \\
68.8 \\
55.4 \\
54.9 \\
54.5 \\
50.0 \\
56.0\end{array}$ & $\begin{array}{l}69.3 \\
73.1 \\
71.2 \\
75.7 \\
78.3 \\
80.4 \\
83.0 \\
89.9 \\
86.5 \\
81.0 \\
80.5 \\
79.9 \\
79.0\end{array}$ & $\begin{array}{l}W \\
\bar{W} \\
- \\
- \\
- \\
- \\
W \\
W \\
W \\
W \\
W \\
W\end{array}$ & $\begin{array}{l}54.6 \\
57.9 \\
56.0 \\
61.0 \\
62.8 \\
66.5 \\
69.9 \\
75.0 \\
63.6 \\
62.2 \\
62.7 \\
58.5 \\
62.7\end{array}$ & $\begin{array}{l}74.6 \\
78.9 \\
77.3 \\
81.4 \\
84.2 \\
86.4 \\
88.9 \\
95.9 \\
92.6 \\
85.3 \\
86.4 \\
85.4 \\
84.5\end{array}$ & $\begin{array}{c}59.9 \\
59.4 \\
60.7 \\
67.0 \\
69.7 \\
69.3 \\
77.3 \\
W \\
W \\
66.2 \\
W \\
56.5 \\
65.4\end{array}$ & $\begin{array}{l}57.4 \\
60.8 \\
58.9 \\
63.8 \\
65.9 \\
69.6 \\
73.1 \\
78.6 \\
65.5 \\
64.9 \\
64.5 \\
60.3 \\
65.4\end{array}$ & $\begin{array}{l}61.7 \\
65.3 \\
63.4 \\
67.6 \\
70.4 \\
72.6 \\
75.5 \\
82.0 \\
79.3 \\
74.3 \\
73.5 \\
74.8 \\
71.8\end{array}$ & $\begin{array}{l}48.8 \\
52.2 \\
50.7 \\
55.7 \\
57.7 \\
61.1 \\
65.1 \\
69.9 \\
58.7 \\
56.2 \\
56.7 \\
54.2 \\
57.3\end{array}$ & $\begin{array}{l}50.2 \\
53.0 \\
51.2 \\
56.2 \\
58.2 \\
62.0 \\
65.5 \\
70.5 \\
57.2 \\
56.6 \\
56.3 \\
52.1 \\
57.7\end{array}$ \\
\hline 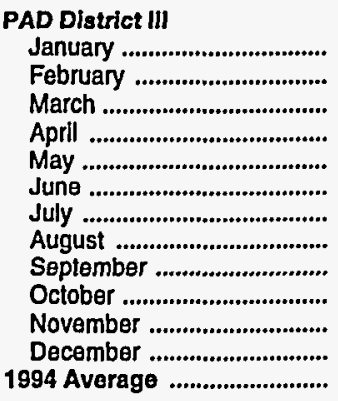 & $\begin{array}{l}59.3 \\
59.8 \\
59.5 \\
63.0 \\
64.8 \\
67.1 \\
69.5 \\
74.5 \\
74.2 \\
71.6 \\
72.0 \\
71.4 \\
67.3\end{array}$ & $\begin{array}{l}44.1 \\
47.8 \\
48.5 \\
52.6 \\
53.0 \\
\mathbf{5 5 . 8} \\
\mathbf{5 8 . 2} \\
63.2 \\
\mathbf{5 5 . 0} \\
\mathbf{5 2 . 4} \\
\mathbf{5 4 . 5} \\
\mathbf{4 8 . 3} \\
\mathbf{5 2 . 7}\end{array}$ & $\begin{array}{l}44.0 \\
47.4 \\
48.8 \\
51.6 \\
52.4 \\
55.5 \\
58.2 \\
60.7 \\
52.2 \\
52.3 \\
52.3 \\
48.2 \\
51.9\end{array}$ & $\begin{array}{l}70.5 \\
71.2 \\
70.8 \\
74.3 \\
75.8 \\
77.9 \\
80.5 \\
85.0 \\
85.4 \\
82.6 \\
82.9 \\
83.1 \\
78.4\end{array}$ & $\begin{array}{l}46.6 \\
50.3 \\
51.0 \\
55.1 \\
55.3 \\
58.0 \\
60.1 \\
64.6 \\
54.9 \\
53.4 \\
56.5 \\
49.2 \\
54.5\end{array}$ & $\begin{array}{l}51.0 \\
53.8 \\
54.6 \\
58.4 \\
58.8 \\
62.0 \\
64.3 \\
67.4 \\
58.5 \\
59.4 \\
59.2 \\
55.8 \\
58.8\end{array}$ & $\begin{array}{l}79.2 \\
79.4 \\
79.1 \\
82.5 \\
84.1 \\
86.3 \\
88.6 \\
93.1 \\
93.3 \\
90.3 \\
90.9 \\
91.4 \\
86.5\end{array}$ & $\begin{array}{l}51.5 \\
55.5 \\
56.8 \\
60.1 \\
61.1 \\
64.1 \\
66.7 \\
71.0 \\
63.3 \\
60.8 \\
60.8 \\
57.3 \\
60.6\end{array}$ & $\begin{array}{l}53.6 \\
56.9 \\
58.6 \\
62.6 \\
62.0 \\
65.6 \\
67.9 \\
70.5 \\
62.2 \\
62.7 \\
62.8 \\
59.0 \\
62.1\end{array}$ & $\begin{array}{l}65.8 \\
66.2 \\
65.9 \\
69.4 \\
71.1 \\
73.4 \\
75.7 \\
80.3 \\
80.3 \\
77.7 \\
78.0 \\
77.9 \\
73.5\end{array}$ & $\begin{array}{l}45.7 \\
49.4 \\
50.2 \\
54.2 \\
54.8 \\
57.4 \\
59.9 \\
64.8 \\
56.5 \\
54.0 \\
56.2 \\
50.1 \\
54.3\end{array}$ & $\begin{array}{l}46.2 \\
49.7 \\
51.1 \\
54.0 \\
54.7 \\
58.0 \\
60.6 \\
63.1 \\
54.6 \\
54.8 \\
54.8 \\
50.6 \\
54.4\end{array}$ \\
\hline
\end{tabular}

See footnotes at end of table. 
Table 35. Refiner Motor Gasoline Prices by Grade, Sales Type, PAD District, and State (Cents per Gallon Excluding Taxes) - Continued

\begin{tabular}{|c|c|c|c|c|c|c|c|c|c|c|c|c|}
\hline \multirow{3}{*}{$\begin{array}{l}\text { Geographic Area } \\
\text { Month }\end{array}$} & \multicolumn{3}{|c|}{ Regular } & \multicolumn{3}{|c|}{ Midgrade } & \multicolumn{3}{|c|}{ Premium } & \multicolumn{3}{|c|}{ All Grades } \\
\hline & \multicolumn{2}{|c|}{ Sales to End Users } & \multirow{2}{*}{$\begin{array}{c}\text { Sales } \\
\text { for } \\
\text { Resale }\end{array}$} & \multicolumn{2}{|c|}{ Sales to End Users } & \multirow{2}{*}{$\begin{array}{c}\text { Sales } \\
\text { for } \\
\text { Resale }\end{array}$} & \multicolumn{2}{|c|}{ Sales to End Users } & \multirow[b]{2}{*}{$\begin{array}{c}\text { Sales } \\
\text { for } \\
\text { Resale }\end{array}$} & \multicolumn{2}{|c|}{ Sales to End Users } & \multirow[b]{2}{*}{$\begin{array}{c}\text { Sales } \\
\text { for } \\
\text { Resale }\end{array}$} \\
\hline & $\begin{array}{c}\text { Through } \\
\text { Retail } \\
\text { Outlots }\end{array}$ & $\begin{array}{c}\text { Other } \\
\text { End } \\
\text { Usersa }\end{array}$ & & $\begin{array}{l}\text { Through } \\
\text { Retail } \\
\text { Outlets }\end{array}$ & $\begin{array}{l}\text { Other } \\
\text { End } \\
\text { Usersa }\end{array}$ & & $\begin{array}{l}\text { Through } \\
\text { Petail } \\
\text { Outlets }\end{array}$ & $\begin{array}{l}\text { Other } \\
\text { End } \\
\text { Usersa }\end{array}$ & & $\begin{array}{c}\text { Through } \\
\text { Retail } \\
\text { Outlets }\end{array}$ & $\begin{array}{l}\text { Other } \\
\text { End } \\
\text { Usersa }\end{array}$ & \\
\hline \multicolumn{13}{|l|}{ Alabama } \\
\hline 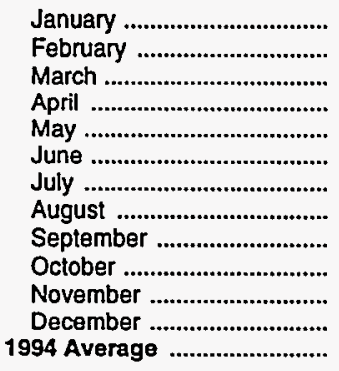 & $\begin{array}{l}56.3 \\
58.0 \\
58.4 \\
61.0 \\
62.2 \\
64.8 \\
67.1 \\
71.7 \\
70.6 \\
68.9 \\
68.8 \\
66.6 \\
64.6\end{array}$ & $\begin{array}{l}44.0 \\
48.4 \\
48.3 \\
52.8 \\
52.3 \\
55.9 \\
57.3 \\
60.9 \\
50.0 \\
49.7 \\
55.0 \\
47.2 \\
52.1\end{array}$ & $\begin{array}{l}45.4 \\
48.5 \\
49.4 \\
53.2 \\
53.1 \\
56.4 \\
58.1 \\
59.8 \\
49.7 \\
53.2 \\
53.7 \\
47.6 \\
52.5\end{array}$ & $\begin{array}{l}66.1 \\
68.0 \\
68.6 \\
71.0 \\
72.5 \\
75.4 \\
77.7 \\
82.0 \\
80.9 \\
79.3 \\
78.8 \\
76.7 \\
74.8\end{array}$ & $\begin{array}{l}47.1 \\
51.0 \\
51.3 \\
55.9 \\
55.7 \\
58.9 \\
60.4 \\
64.7 \\
52.9 \\
53.5 \\
58.9 \\
50.2 \\
55.0\end{array}$ & $\begin{array}{l}50.8 \\
53.9 \\
54.8 \\
58.7 \\
58.6 \\
62.0 \\
63.6 \\
65.7 \\
55.6 \\
58.5 \\
59.6 \\
53.3 \\
58.1\end{array}$ & $\begin{array}{l}74.1 \\
75.7 \\
75.7 \\
78.6 \\
81.1 \\
84.0 \\
86.2 \\
89.1 \\
88.5 \\
87.4 \\
87.3 \\
84.3 \\
82.5\end{array}$ & $\begin{array}{l}51.8 \\
56.0 \\
56.6 \\
60.6 \\
60.9 \\
65.8 \\
66.0 \\
68.6 \\
58.9 \\
59.6 \\
64.1 \\
56.5 \\
60.5\end{array}$ & $\begin{array}{l}56.1 \\
59.2 \\
60.0 \\
63.8 \\
63.9 \\
67.3 \\
69.2 \\
71.3 \\
61.2 \\
64.4 \\
65.0 \\
58.9 \\
63.5\end{array}$ & $\begin{array}{l}62.3 \\
64.0 \\
64.5 \\
67.1 \\
68.5 \\
71.1 \\
73.4 \\
77.8 \\
76.5 \\
74.9 \\
74.7 \\
72.6 \\
70.6\end{array}$ & $\begin{array}{l}46.4 \\
50.7 \\
50.6 \\
55.3 \\
54.7 \\
58.2 \\
59.8 \\
63.4 \\
52.5 \\
53.1 \\
57.9 \\
50.2 \\
54.6\end{array}$ & $\begin{array}{l}48.6 \\
51.7 \\
52.6 \\
56.4 \\
56.4 \\
59.7 \\
61.4 \\
63.2 \\
53.1 \\
56.5 \\
57.0 \\
51.0 \\
55.7\end{array}$ \\
\hline 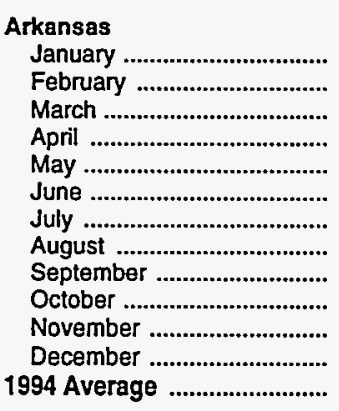 & $\begin{array}{l}56.3 \\
58.0 \\
57.9 \\
62.7 \\
62.2 \\
65.6 \\
68.3 \\
73.7 \\
72.7 \\
70.4 \\
68.6 \\
65.7 \\
65.3\end{array}$ & $\begin{array}{c}W \\
W \\
W \\
W \\
W \\
W \\
W \\
64.4 \\
54.0 \\
51.8 \\
53.7 \\
48.6 \\
54.2\end{array}$ & $\begin{array}{l}44.8 \\
47.9 \\
49.3 \\
52.8 \\
53.3 \\
56.8 \\
59.5 \\
61.9 \\
51.3 \\
52.2 \\
51.7 \\
47.4 \\
52.5\end{array}$ & $\begin{array}{l}68.8 \\
70.3 \\
69.9 \\
74.4 \\
74.2 \\
77.1 \\
80.1 \\
84.5 \\
84.5 \\
82.0 \\
79.8 \\
75.8 \\
76.9\end{array}$ & $\begin{array}{l}- \\
- \\
W \\
W \\
w \\
- \\
- \\
- \\
\bar{w} \\
- \\
- \\
W\end{array}$ & $\begin{array}{l}49.8 \\
52.5 \\
53.8 \\
57.6 \\
57.8 \\
61.5 \\
63.7 \\
66.2 \\
55.5 \\
57.5 \\
57.1 \\
52.2 \\
57.3\end{array}$ & $\begin{array}{l}77.2 \\
78.2 \\
77.8 \\
82.3 \\
82.2 \\
85.5 \\
88.2 \\
93.8 \\
92.9 \\
90.5 \\
88.2 \\
84.5 \\
85.1\end{array}$ & $\begin{array}{c}- \\
W \\
W \\
W \\
- \\
W \\
W \\
69.2 \\
W \\
W \\
W \\
W \\
60.8\end{array}$ & $\begin{array}{l}53.1 \\
56.0 \\
58.1 \\
61.8 \\
61.9 \\
65.8 \\
68.6 \\
71.2 \\
60.8 \\
62.1 \\
61.2 \\
56.9 \\
61.6\end{array}$ & $\begin{array}{l}61.3 \\
63.0 \\
63.0 \\
67.6 \\
67.3 \\
70.5 \\
73.2 \\
78.2 \\
77.5 \\
75.3 \\
73.4 \\
70.2 \\
70.2\end{array}$ & $\begin{array}{c}W \\
50.8 \\
51.1 \\
53.7 \\
54.9 \\
W \\
61.3 \\
65.1 \\
54.5 \\
52.5 \\
55.0 \\
49.3 \\
54.8\end{array}$ & $\begin{array}{l}46.8 \\
50.0 \\
51.4 \\
54.9 \\
55.5 \\
59.0 \\
61.6 \\
64.0 \\
53.4 \\
54.5 \\
54.0 \\
49.5 \\
54.7\end{array}$ \\
\hline 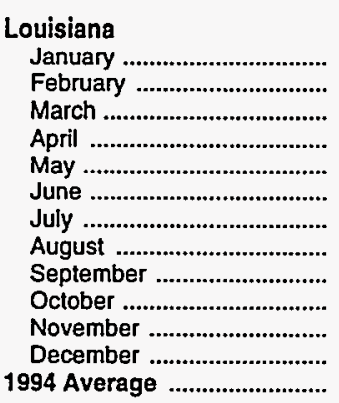 & $\begin{array}{l}62.6 \\
62.3 \\
61.0 \\
63.3 \\
64.1 \\
65.4 \\
68.0 \\
72.7 \\
73.3 \\
71.2 \\
71.7 \\
70.0 \\
67.2\end{array}$ & $\begin{array}{l}43.1 \\
48.0 \\
48.0 \\
52.4 \\
52.7 \\
55.4 \\
57.2 \\
60.8 \\
51.0 \\
50.0 \\
54.2 \\
47.4 \\
51.5\end{array}$ & $\begin{array}{l}43.9 \\
47.4 \\
48.6 \\
52.2 \\
52.1 \\
54.2 \\
56.8 \\
59.2 \\
50.3 \\
51.8 \\
52.5 \\
48.1 \\
51.3\end{array}$ & $\begin{array}{l}75.9 \\
75.6 \\
74.4 \\
76.3 \\
76.7 \\
77.7 \\
79.8 \\
84.0 \\
85.1 \\
83.1 \\
83.2 \\
81.8 \\
79.6\end{array}$ & $\begin{array}{l}W \\
W \\
W \\
W \\
W \\
W \\
W \\
W \\
W \\
W \\
W \\
W \\
W\end{array}$ & $\begin{array}{l}53.2 \\
55.6 \\
56.4 \\
60.0 \\
59.9 \\
62.6 \\
64.5 \\
67.1 \\
58.6 \\
59.9 \\
60.6 \\
55.3 \\
59.5\end{array}$ & $\begin{array}{l}84.7 \\
84.2 \\
83.0 \\
84.9 \\
85.2 \\
85.7 \\
87.4 \\
91.9 \\
92.8 \\
90.1 \\
90.5 \\
89.2 \\
87.5\end{array}$ & $\begin{array}{c}W \\
W \\
55.1 \\
W \\
59.9 \\
63.2 \\
65.5 \\
W \\
60.1 \\
58.1 \\
62.6 \\
53.8 \\
58.8\end{array}$ & $\begin{array}{l}51.9 \\
57.8 \\
59.6 \\
64.3 \\
62.3 \\
66.3 \\
67.4 \\
69.4 \\
61.8 \\
62.6 \\
65.7 \\
60.9 \\
62.4\end{array}$ & $\begin{array}{l}70.8 \\
70.4 \\
69.0 \\
71.3 \\
71.9 \\
73.0 \\
75.3 \\
79.6 \\
80.4 \\
78.4 \\
78.7 \\
77.3 \\
74.7\end{array}$ & $\begin{array}{l}45.4 \\
50.2 \\
50.3 \\
54.6 \\
54.8 \\
57.7 \\
59.7 \\
62.7 \\
53.5 \\
52.1 \\
56.8 \\
49.0 \\
53.7\end{array}$ & $\begin{array}{l}46.4 \\
50.7 \\
51.9 \\
55.7 \\
55.3 \\
57.5 \\
60.0 \\
62.4 \\
53.8 \\
55.0 \\
56.3 \\
51.1 \\
54.6\end{array}$ \\
\hline 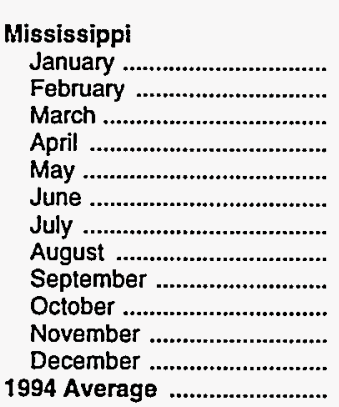 & $\begin{array}{l}59.0 \\
60.8 \\
60.9 \\
63.7 \\
64.0 \\
66.5 \\
68.6 \\
72.5 \\
72.5 \\
71.4 \\
71.9 \\
67.9 \\
66.8\end{array}$ & $\begin{array}{l}43.3 \\
48.3 \\
48.2 \\
52.6 \\
52.3 \\
54.9 \\
56.1 \\
60.0 \\
50.0 \\
50.0 \\
54.3 \\
47.0 \\
51.6\end{array}$ & $\begin{array}{l}44.3 \\
47.5 \\
49.0 \\
52.1 \\
50.9 \\
54.3 \\
56.6 \\
58.7 \\
49.8 \\
51.4 \\
52.4 \\
46.4 \\
51.1\end{array}$ & $\begin{array}{l}68.1 \\
70.1 \\
69.8 \\
72.6 \\
72.8 \\
75.4 \\
78.4 \\
83.0 \\
82.9 \\
81.7 \\
81.9 \\
78.1 \\
76.3\end{array}$ & $\begin{array}{c}45.9 \\
W \\
52.0 \\
55.5 \\
55.2 \\
57.5 \\
58.8 \\
62.4 \\
53.4 \\
52.8 \\
57.9 \\
49.2 \\
54.4\end{array}$ & $\begin{array}{l}49.5 \\
52.8 \\
53.9 \\
57.7 \\
57.8 \\
61.0 \\
62.5 \\
64.6 \\
54.4 \\
57.6 \\
58.5 \\
52.1 \\
57.1\end{array}$ & $\begin{array}{l}75.5 \\
78.0 \\
78.0 \\
80.5 \\
80.8 \\
83.9 \\
86.7 \\
91.6 \\
91.5 \\
90.1 \\
90.8 \\
87.1 \\
84.1\end{array}$ & $\begin{array}{l}51.2 \\
56.9 \\
56.2 \\
59.9 \\
61.1 \\
62.3 \\
64.5 \\
68.4 \\
58.2 \\
58.5 \\
62.9 \\
55.1 \\
59.5\end{array}$ & $\begin{array}{l}52.0 \\
56.4 \\
59.0 \\
62.4 \\
61.3 \\
65.8 \\
66.1 \\
65.8 \\
57.2 \\
58.4 \\
60.7 \\
56.1 \\
60.0\end{array}$ & $\begin{array}{l}63.9 \\
65.9 \\
65.9 \\
68.6 \\
68.9 \\
71.4 \\
73.8 \\
77.5 \\
77.6 \\
76.5 \\
76.8 \\
73.0 \\
71.7\end{array}$ & $\begin{array}{l}45.6 \\
50.7 \\
50.3 \\
54.5 \\
54.5 \\
56.5 \\
58.2 \\
62.0 \\
51.9 \\
52.0 \\
56.2 \\
48.8 \\
53.5\end{array}$ & $\begin{array}{l}46.5 \\
50.2 \\
51.8 \\
54.6 \\
53.2 \\
57.0 \\
59.3 \\
61.3 \\
52.2 \\
53.9 \\
54.8 \\
49.2 \\
53.7\end{array}$ \\
\hline
\end{tabular}

See footnotes at end of table. 
Table 35. Refiner Motor Gasoline Prices by Grade, Sales Type, PAD District, and State (Cents per Gallon Excluding Taxes) - Continued

\begin{tabular}{|c|c|c|c|c|c|c|c|c|c|c|c|c|}
\hline \multirow{3}{*}{$\begin{array}{c}\text { Goographic Area } \\
\text { Month }\end{array}$} & \multicolumn{3}{|c|}{ Regular } & \multicolumn{3}{|c|}{ Midgrade } & \multicolumn{3}{|c|}{ Premium } & \multicolumn{3}{|c|}{ All Grades } \\
\hline & \multicolumn{2}{|c|}{ Sales to End Users } & \multirow{2}{*}{$\begin{array}{c}\text { Sales } \\
\text { for } \\
\text { Resale }\end{array}$} & \multicolumn{2}{|c|}{ Sales to End Users } & \multirow[b]{2}{*}{$\begin{array}{c}\text { Sales } \\
\text { for } \\
\text { Resale }\end{array}$} & \multicolumn{2}{|c|}{ Sales to End Users } & \multirow{2}{*}{$\begin{array}{c}\text { Sales } \\
\text { for } \\
\text { Resale }\end{array}$} & \multicolumn{2}{|c|}{ Sales to End Users } & \multirow[b]{2}{*}{$\begin{array}{c}\text { Sales } \\
\text { for } \\
\text { Resale }\end{array}$} \\
\hline & $\begin{array}{c}\text { Through } \\
\text { Retall } \\
\text { Outlets }\end{array}$ & $\begin{array}{l}\text { Other } \\
\text { End } \\
\text { Usersa }\end{array}$ & & $\begin{array}{c}\text { Through } \\
\text { Retall } \\
\text { Outlets }\end{array}$ & $\begin{array}{c}\text { Other } \\
\text { End } \\
\text { Usersa }^{\text {and }}\end{array}$ & & $\begin{array}{c}\text { Through } \\
\text { Retail } \\
\text { Outlets }\end{array}$ & $\begin{array}{c}\text { Other } \\
\text { End } \\
\text { Usersa }\end{array}$ & & $\begin{array}{c}\text { Through } \\
\text { Retail } \\
\text { Outlets }\end{array}$ & $\begin{array}{l}\text { Other } \\
\text { End } \\
\text { Usersa }^{\text {a }}\end{array}$ & \\
\hline \multicolumn{13}{|l|}{ New Mexico } \\
\hline 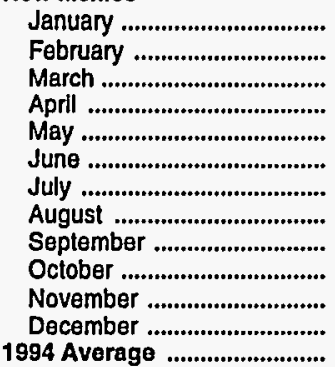 & $\begin{array}{l}74.1 \\
68.2 \\
68.6 \\
70.4 \\
75.6 \\
77.9 \\
78.7 \\
86.1 \\
86.2 \\
82.5 \\
84.6 \\
76.7 \\
77.5\end{array}$ & $\begin{array}{l}53.7 \\
57.1 \\
56.8 \\
59.5 \\
62.0 \\
63.9 \\
66.7 \\
73.3 \\
70.6 \\
64.5 \\
65.1 \\
60.1 \\
63.8\end{array}$ & $\begin{array}{l}50.6 \\
54.0 \\
54.4 \\
58.0 \\
61.0 \\
63.1 \\
66.9 \\
72.9 \\
66.2 \\
59.9 \\
60.4 \\
54.2 \\
60.2\end{array}$ & $\begin{array}{l}W \\
W \\
W \\
W \\
W \\
W \\
W \\
W \\
W \\
89.3 \\
95.8 \\
84.7 \\
W\end{array}$ & $\begin{array}{l}- \\
- \\
- \\
- \\
- \\
- \\
- \\
- \\
-\end{array}$ & $\begin{array}{l}59.2 \\
61.3 \\
59.0 \\
62.5 \\
65.9 \\
68.1 \\
72.3 \\
78.7 \\
72.8 \\
67.7 \\
70.6 \\
64.1 \\
67.5\end{array}$ & $\begin{array}{r}91.7 \\
85.1 \\
86.2 \\
88.3 \\
93.5 \\
95.8 \\
96.9 \\
104.2 \\
104.3 \\
100.5 \\
102.9 \\
94.2 \\
95.7\end{array}$ & $\begin{array}{c}- \\
- \\
w \\
\bar{W} \\
W \\
W \\
W \\
W \\
73.9 \\
W \\
W \\
75.7\end{array}$ & $\begin{array}{l}60.0 \\
62.9 \\
63.8 \\
67.3 \\
70.7 \\
72.9 \\
76.3 \\
82.6 \\
76.7 \\
70.3 \\
70.2 \\
63.9 \\
70.1\end{array}$ & $\begin{array}{l}76.3 \\
70.4 \\
70.8 \\
72.9 \\
78.1 \\
80.6 \\
81.5 \\
88.9 \\
88.8 \\
85.1 \\
87.4 \\
79.6 \\
80.2\end{array}$ & $\begin{array}{l}53.7 \\
57.1 \\
57.1 \\
59.5 \\
62.5 \\
64.1 \\
67.9 \\
74.7 \\
71.9 \\
66.2 \\
66.3 \\
61.0 \\
65.0\end{array}$ & $\begin{array}{l}51.9 \\
55.2 \\
55.6 \\
59.2 \\
62.3 \\
64.4 \\
68.3 \\
74.3 \\
67.6 \\
61.4 \\
61.9 \\
55.7 \\
61.6\end{array}$ \\
\hline 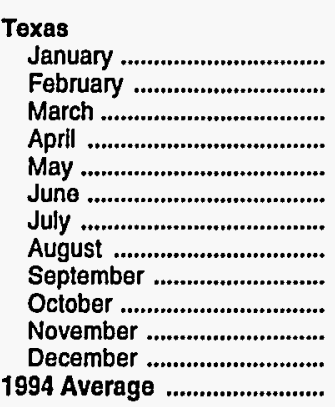 & $\begin{array}{l}58.0 \\
59.1 \\
58.7 \\
62.5 \\
64.4 \\
66.7 \\
69.2 \\
74.0 \\
73.6 \\
71.0 \\
71.4 \\
71.9 \\
66.8\end{array}$ & $\begin{array}{l}43.9 \\
47.2 \\
48.2 \\
52.3 \\
52.8 \\
55.5 \\
57.9 \\
63.4 \\
55.9 \\
52.4 \\
53.7 \\
47.9 \\
52.3\end{array}$ & $\begin{array}{l}43.4 \\
46.7 \\
48.3 \\
50.8 \\
51.9 \\
55.1 \\
57.8 \\
60.4 \\
52.4 \\
51.8 \\
51.5 \\
48.3 \\
51.5\end{array}$ & $\begin{array}{l}70.1 \\
70.8 \\
70.5 \\
74.3 \\
75.9 \\
78.1 \\
80.7 \\
85.3 \\
85.7 \\
82.7 \\
83.2 \\
84.1 \\
78.6\end{array}$ & $\begin{array}{l}46.7 \\
49.7 \\
50.8 \\
54.9 \\
55.0 \\
57.8 \\
60.2 \\
65.1 \\
56.4 \\
53.7 \\
55.4 \\
48.9 \\
54.5\end{array}$ & $\begin{array}{l}50.7 \\
53.5 \\
54.2 \\
58.0 \\
58.7 \\
61.9 \\
64.6 \\
68.2 \\
60.0 \\
59.8 \\
59.0 \\
57.6 \\
59.0\end{array}$ & $\begin{array}{l}78.6 \\
78.9 \\
78.7 \\
82.4 \\
84.0 \\
86.3 \\
88.7 \\
93.1 \\
93.3 \\
90.2 \\
90.8 \\
92.5 \\
86.4\end{array}$ & $\begin{array}{l}51.7 \\
55.4 \\
57.3 \\
60.1 \\
61.3 \\
64.2 \\
67.0 \\
71.9 \\
65.0 \\
60.9 \\
59.6 \\
57.9 \\
60.8\end{array}$ & $\begin{array}{l}53.9 \\
56.1 \\
57.7 \\
61.8 \\
61.3 \\
64.7 \\
67.5 \\
71.0 \\
63.5 \\
63.0 \\
61.8 \\
59.2 \\
61.9\end{array}$ & $\begin{array}{l}65.0 \\
65.8 \\
65.4 \\
69.3 \\
71.0 \\
73.3 \\
75.8 \\
80.1 \\
80.2 \\
77.5 \\
77.9 \\
78.7 \\
73.4\end{array}$ & $\begin{array}{l}45.4 \\
48.7 \\
49.9 \\
53.8 \\
54.5 \\
57.1 \\
59.6 \\
65.0 \\
57.5 \\
53.8 \\
55.4 \\
49.7 \\
54.0\end{array}$ & $\begin{array}{l}45.5 \\
48.8 \\
50.3 \\
52.9 \\
54.1 \\
57.4 \\
60.1 \\
62.7 \\
54.7 \\
54.2 \\
53.8 \\
50.5 \\
\mathbf{5 3 . 7}\end{array}$ \\
\hline 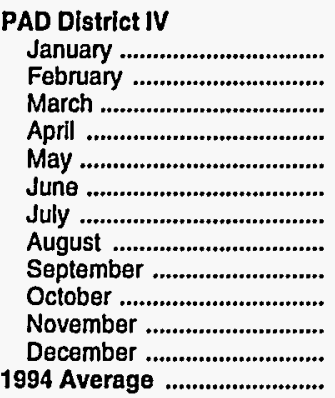 & $\begin{array}{l}69.3 \\
71.2 \\
68.7 \\
67.6 \\
69.9 \\
74.9 \\
78.6 \\
86.5 \\
86.6 \\
79.8 \\
80.6 \\
76.9 \\
76.0\end{array}$ & $\begin{array}{l}51.4 \\
53.0 \\
53.8 \\
54.1 \\
60.6 \\
66.4 \\
69.5 \\
73.5 \\
74.7 \\
66.6 \\
63.9 \\
60.5 \\
62.2\end{array}$ & $\begin{array}{l}50.6 \\
53.1 \\
53.7 \\
55.3 \\
59.7 \\
65.7 \\
69.1 \\
74.1 \\
71.9 \\
63.9 \\
62.7 \\
57.1 \\
62.0\end{array}$ & $\begin{array}{l}78.4 \\
80.3 \\
79.3 \\
78.6 \\
81.4 \\
86.6 \\
89.6 \\
97.3 \\
97.2 \\
90.8 \\
91.7 \\
88.1 \\
86.8\end{array}$ & $\begin{array}{c}W \\
W \\
- \\
\bar{W} \\
\bar{W} \\
\bar{W} \\
W \\
W \\
64.7 \\
W \\
63.1\end{array}$ & $\begin{array}{l}56.4 \\
59.0 \\
58.5 \\
59.6 \\
63.3 \\
68.7 \\
73.1 \\
79.5 \\
77.7 \\
69.8 \\
68.5 \\
63.5 \\
66.9\end{array}$ & $\begin{array}{r}85.0 \\
87.1 \\
86.6 \\
86.2 \\
90.0 \\
95.8 \\
98.9 \\
105.9 \\
106.0 \\
99.6 \\
99.4 \\
95.9 \\
94.6\end{array}$ & $\begin{array}{l}55.4 \\
57.4 \\
58.8 \\
61.4 \\
67.6 \\
74.7 \\
77.4 \\
80.5 \\
83.4 \\
76.9 \\
72.2 \\
68.2 \\
69.7\end{array}$ & $\begin{array}{l}59.3 \\
61.6 \\
62.0 \\
63.5 \\
68.7 \\
75.1 \\
78.5 \\
83.1 \\
81.9 \\
74.1 \\
72.7 \\
67.4 \\
71.3\end{array}$ & $\begin{array}{l}73.7 \\
75.5 \\
73.6 \\
72.8 \\
75.4 \\
80.6 \\
84.1 \\
91.5 \\
91.6 \\
85.1 \\
85.8 \\
82.3 \\
81.1\end{array}$ & $\begin{array}{l}52.2 \\
54.0 \\
54.7 \\
55.4 \\
62.1 \\
68.3 \\
71.1 \\
74.9 \\
76.8 \\
68.8 \\
65.4 \\
62.1 \\
63.8\end{array}$ & $\begin{array}{l}52.4 \\
54.9 \\
55.4 \\
57.0 \\
61.5 \\
67.5 \\
71.0 \\
75.9 \\
73.9 \\
65.9 \\
64.7 \\
59.4 \\
63.9\end{array}$ \\
\hline 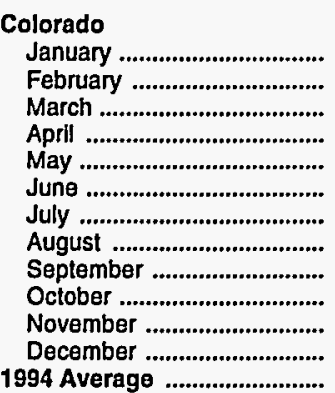 & $\begin{array}{l}71.9 \\
73.7 \\
70.7 \\
69.4 \\
70.3 \\
74.7 \\
79.0 \\
88.0 \\
87.7 \\
80.0 \\
82.1 \\
78.3 \\
77.2\end{array}$ & $\begin{array}{l}W \\
W \\
W \\
W \\
W \\
W \\
65.5 \\
W \\
W \\
W \\
W \\
W \\
W\end{array}$ & $\begin{array}{l}51.2 \\
54.7 \\
53.9 \\
55.9 \\
57.3 \\
61.2 \\
66.8 \\
75.1 \\
68.4 \\
59.2 \\
58.9 \\
52.7 \\
60.1\end{array}$ & $\begin{array}{l}81.8 \\
83.7 \\
82.4 \\
81.7 \\
82.8 \\
87.2 \\
90.9 \\
99.9 \\
99.5 \\
92.0 \\
94.3 \\
90.6 \\
89.1\end{array}$ & $\begin{array}{l}\bar{w} \\
\overline{-} \\
\overline{-} \\
\overline{-} \\
\bar{w} \\
\overline{-} \\
\overline{-} \\
\bar{w} \\
w \\
w\end{array}$ & $\begin{array}{l}58.5 \\
61.9 \\
60.4 \\
62.1 \\
63.5 \\
67.1 \\
72.5 \\
81.5 \\
77.2 \\
67.2 \\
68.0 \\
61.4 \\
67.0\end{array}$ & $\begin{array}{r}91.9 \\
93.6 \\
92.3 \\
91.6 \\
92.7 \\
97.4 \\
101.6 \\
110.6 \\
110.1 \\
102.2 \\
104.2 \\
100.2 \\
98.9\end{array}$ & $\begin{array}{c}58.9 \\
W \\
W \\
65.2 \\
W \\
70.3 \\
76.0 \\
83.7 \\
W \\
W \\
68.8 \\
W \\
70.3\end{array}$ & $\begin{array}{l}60.8 \\
64.2 \\
63.3 \\
65.2 \\
66.7 \\
70.6 \\
76.2 \\
84.9 \\
78.4 \\
69.0 \\
69.1 \\
62.7 \\
69.7\end{array}$ & $\begin{array}{l}76.7 \\
78.5 \\
76.0 \\
75.1 \\
76.0 \\
80.5 \\
84.7 \\
93.4 \\
92.9 \\
85.5 \\
87.7 \\
84.0 \\
82.6\end{array}$ & $\begin{array}{c}W \\
59.7 \\
W \\
W \\
W \\
61.2 \\
66.4 \\
75.8 \\
75.6 \\
W \\
65.1 \\
W \\
W\end{array}$ & $\begin{array}{l}53.3 \\
56.8 \\
56.0 \\
57.9 \\
59.3 \\
63.2 \\
68.8 \\
77.1 \\
70.6 \\
61.3 \\
61.2 \\
55.0 \\
62.2\end{array}$ \\
\hline
\end{tabular}

See footnotes at end of table. 
Table 35. Refiner Motor Gasoline Prices by Grade, Sales Type, PAD District, and State (Cents per Gallon Excluding Taxes) - Continued

\begin{tabular}{|c|c|c|c|c|c|c|c|c|c|c|c|c|}
\hline \multirow{3}{*}{$\begin{array}{c}\text { Geographic Area } \\
\text { Month }\end{array}$} & \multicolumn{3}{|c|}{ Regular } & \multicolumn{3}{|c|}{ MIdgrade } & \multicolumn{3}{|c|}{ Premium } & \multicolumn{3}{|c|}{ All Grades } \\
\hline & \multicolumn{2}{|c|}{ Sales to End Users } & \multirow{2}{*}{$\begin{array}{c}\text { Sales } \\
\text { for } \\
\text { Resale }\end{array}$} & \multicolumn{2}{|c|}{ Sales to End Users } & \multirow{2}{*}{$\begin{array}{c}\text { Sales } \\
\text { for } \\
\text { Resale }\end{array}$} & \multicolumn{2}{|c|}{ Sales to End Users } & \multirow{2}{*}{$\begin{array}{c}\text { Sales } \\
\text { for } \\
\text { Resale }\end{array}$} & \multicolumn{2}{|c|}{ Sales to End Users } & \multirow{2}{*}{$\begin{array}{c}\text { Sales } \\
\text { for } \\
\text { Resale }\end{array}$} \\
\hline & $\begin{array}{c}\text { Through } \\
\text { Rotail } \\
\text { Outlets }\end{array}$ & $\begin{array}{c}\text { Other } \\
\text { End } \\
\text { Usersa }\end{array}$ & & $\begin{array}{c}\text { Through } \\
\text { Retail } \\
\text { Outlets }\end{array}$ & $\begin{array}{c}\text { Other } \\
\text { End } \\
\text { Usersa }\end{array}$ & & $\begin{array}{c}\text { Through } \\
\text { Retail } \\
\text { Outlets }\end{array}$ & $\begin{array}{c}\text { Othor } \\
\text { End } \\
\text { Usersa }\end{array}$ & & $\begin{array}{c}\text { Through } \\
\text { Retall } \\
\text { Outlets }\end{array}$ & $\begin{array}{l}\text { Other } \\
\text { End } \\
\text { Usersa }\end{array}$ & \\
\hline
\end{tabular}

Idaho

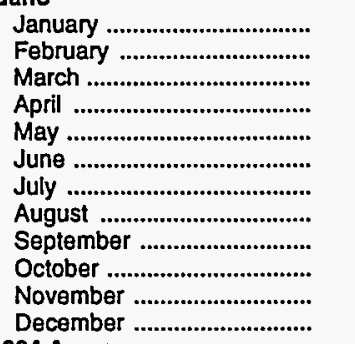

December

1994 Average

Montana

January

February

March .

April

May .

June

July ..............

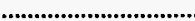

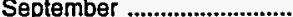

October .

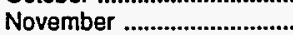

December

1994 Average ..........................

Utah

January

February ................................

March

April .......

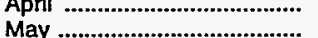

May

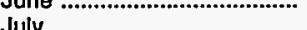

August

September .............................

October .

November

December

1994 Average

Wyoming

January ..................................

March ...

April

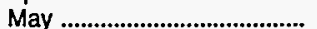

June

July .

August

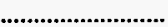

(a)

October

November

994 Averag

$\begin{array}{lcc}W & W & 50.5 \\ W & 53.7 & 51.8 \\ W & 54.7 & 53.1 \\ W & 55.6 & 53.6 \\ W & 62.1 & 60.4 \\ W & 69.4 & 68.5 \\ W & 72.9 & 71.7 \\ W & 75.2 & 74.2 \\ W & 78.2 & 76.4 \\ W & 73.5 & 70.2 \\ W & 68.1 & 67.8 \\ W & 66.1 & 63.4 \\ W & 65.9 & 64.1\end{array}$

$\begin{array}{ccc}- & W & W \\ - & W & W \\ - & - & W \\ - & - & 54.5 \\ - & - & 62.0 \\ - & - & 69.7 \\ - & - & 71.7 \\ \bar{W} & - & 74.6 \\ W & W & 77.4 \\ W & W & 73.3 \\ W & - & 68.9 \\ W & \bar{W} & 66.7 \\ & & 65.3\end{array}$

$w$
$w$
$w$
$w$
$w$
$w$
$w$
$W$
$W$
$W$
$W$
$w$
$w$

$\begin{array}{ll}W & 59.8 \\ W & 60.6 \\ W & 61.6 \\ W & 61.7 \\ W & 69.2 \\ W & 77.8 \\ W & 81.4 \\ W & 83.8 \\ W & 86.4 \\ W & 79.6 \\ W & 77.1 \\ W & 73.3 \\ W & 73.5\end{array}$

$\begin{array}{lcc}\text { W } & \text { W } & 52.0 \\ \text { W } & 54.3 & 53.2 \\ \text { W } & 55.0 & 54.4 \\ \text { W } & 55.8 & 54.9 \\ \text { W } & 62.2 & 61.8 \\ \text { W } & 69.6 & 70.0 \\ W & 73.1 & 73.4 \\ W & 75.3 & 75.8 \\ \text { W } & 78.1 & 78.0 \\ \text { W } & 73.8 & 71.8 \\ \text { W } & 68.3 & 69.4 \\ \text { W } & 66.4 & 65.2 \\ \text { W } & 65.2 & 65.6\end{array}$

$\begin{array}{lcl}W & 53.8 & 55.1 \\ W & 55.1 & 55.8 \\ W & 56.5 & 57.1 \\ W & 60.0 & 60.7 \\ W & W & 65.1 \\ W & W & 71.6 \\ W & W & 72.3 \\ W & W & 75.2 \\ W & W & 73.8 \\ W & W & 64.7 \\ W & 63.3 & 65.3 \\ W & W & 60.2 \\ W & 65.4 & 65.6\end{array}$

$\begin{array}{lll}- & - & - \\ - & - & - \\ - & - & - \\ \bar{W} & - & - \\ W & - & - \\ W & - & - \\ W & - & - \\ W & - & - \\ W & - & - \\ W & - & - \\ W & - & - \\ W & - & W\end{array}$

$W$
$W$
$W$
$W$
$W$
$W$
$W$
$W$
$W$
$W$
$W$
$W$
$W$

$\begin{array}{ll}W & 63.7 \\ W & 64.5 \\ W & 65.5 \\ W & 69.2 \\ W & 74.0 \\ W & 80.7 \\ W & 82.3 \\ W & 84.5 \\ W & 83.8 \\ W & 74.4 \\ W & 74.7 \\ W & 69.7 \\ W & 74.8\end{array}$

$\begin{array}{lcl}W & 55.3 & 56.5 \\ W & 56.4 & 57.3 \\ W & 57.9 & 58.5 \\ W & 61.6 & 62.1 \\ W & W & 66.6 \\ W & W & 73.2 \\ W & 75.6 & 74.0 \\ W & W & 76.8 \\ W & W & 75.4 \\ W & W & 66.3 \\ W & 64.5 & 66.8 \\ W & W & 61.9 \\ W & 67.0 & 67.2\end{array}$

57.7

58.0

57.6
66.6

66.6
75.3

74.8

77.2

79.7
76.8

76.8
71.9

68.3
68.5

$\begin{array}{lll}48.1 & 47.8 & 64.2 \\ 48.9 & 49.9 & 65.6 \\ 51.5 & 50.9 & 65.8 \\ 52.2 & 51.7 & 65.7 \\ 59.1 & 58.7 & 74.7 \\ 66.0 & 65.9 & 83.9 \\ 68.8 & 67.9 & 83.5 \\ 71.4 & 70.5 & 85.9 \\ 73.3 & 72.6 & 88.3 \\ 68.6 & 67.7 & 85.5 \\ 64.4 & 64.3 & 80.9 \\ 60.4 & 60.3 & 77.4 \\ 61.0 & 60.9 & 77.2\end{array}$

$\begin{array}{ll}- & 52.9 \\ - & 54.1 \\ - & 54.9 \\ \bar{W} & 55.3 \\ - & 63.0 \\ - & 72.3 \\ - & 74.7 \\ - & 76.8 \\ W & 78.6 \\ W & 73.5 \\ W & 69.5 \\ W & 65.5 \\ & 67.0\end{array}$

70.4
72.6
73.6
73.7
82.9
91.9
91.8
94.2
96.5
92.9
88.0
84.9
84.1

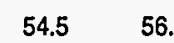

$\begin{array}{cc}54.5 & 58.4 \\ 57.9 & 59.2\end{array}$

$58.8 \quad 60.1$

$66.7 \quad 67.7$

$\begin{array}{ll}74.2 & 75.5 \\ 76.5 & 77.3\end{array}$

$79.2 \quad 79.9$

$81.4 \quad 82.3$

$\begin{array}{ll}76.6 & 77.7\end{array}$

$\begin{array}{ll}71.8 & 73.7\end{array}$

$68.0 \quad 69.8$

$68.6 \quad 70.1$

$\begin{array}{lll}61.5 & 50.0 & 50.0 \\ 63.3 & 50.8 & 52.0 \\ 63.7 & 53.0 & 53.1 \\ 63.5 & 53.3 & 53.8 \\ 72.4 & 61.6 & 61.1 \\ 81.1 & 68.3 & 68.4 \\ 80.9 & 71.0 & 70.4 \\ 83.2 & 73.4 & 73.0 \\ 85.6 & 75.3 & 75.2 \\ 82.6 & 70.8 & 70.4 \\ 77.9 & 66.0 & 67.0 \\ 74.7 & 62.7 & 63.1 \\ 74.3 & 63.0 & 63.4\end{array}$

$\begin{array}{lll}68.9 & 52.9 & 48.6 \\ 68.2 & 57.3 & 52.9 \\ 65.1 & 60.0 & 55.0 \\ 66.6 & 59.7 & 57.5 \\ 73.1 & 66.3 & 61.2 \\ 76.8 & 71.9 & 66.8 \\ 83.2 & 70.6 & 70.1 \\ 87.9 & 79.9 & 76.4 \\ 89.9 & 79.0 & 72.9 \\ 85.0 & 61.6 & 62.0 \\ 81.7 & 59.1 & 60.5 \\ 76.8 & 60.5 & 53.0 \\ 77.5 & 63.5 & 62.3\end{array}$

$\begin{array}{ll}- & W \\ - & W \\ - & W \\ - & W \\ - & W \\ - & W \\ \bar{w} & W \\ \bar{W} & 67.1\end{array}$

$\begin{array}{lr}W & 80 \\ W & 81 \\ W & 81 \\ W & 83 . \\ W & 89.5 \\ W & 94 \\ W & 101 \\ W & 104 \\ W & 105 \\ W & 99 \\ W & 97 \\ 62.8 & 93 \\ 67.1 & 92\end{array}$

$\begin{array}{rcrlll}80.5 & W & 57.2 & 71.5 & 53.8 & 49.9 \\ 81.8 & W & 61.3 & 71.2 & 58.5 & 54.2 \\ 81.5 & W & 63.1 & 68.7 & 60.2 & 56.3 \\ 83.8 & W & 66.0 & 70.4 & 62.2 & 58.9 \\ 89.5 & W & 70.2 & 76.7 & 66.9 & 62.7 \\ 94.5 & W & 75.8 & 80.6 & 73.3 & 68.4 \\ 101.1 & W & 79.3 & 86.8 & 73.5 & 71.8 \\ 104.7 & W & 85.0 & 91.4 & 81.2 & 78.1 \\ 105.2 & 88.0 & 82.5 & 92.9 & 84.2 & 74.4 \\ 99.9 & 80.9 & 71.6 & 87.9 & 65.4 & 63.5 \\ 97.5 & 75.0 & 70.0 & 84.8 & 62.7 & 62.1 \\ 93.9 & W & 62.4 & 80.2 & 62.6 & 54.6 \\ 92.9 & 74.4 & 71.8 & 80.8 & 66.6 & 63.9\end{array}$

See footnotes at end of table. 
Table 35. Refiner Motor Gasoline Prices by Grade, Sales Type, PAD District, and State (Cents per Gallon Excluding Taxes) - Continued

\begin{tabular}{|c|c|c|c|c|c|c|c|c|c|c|c|c|}
\hline \multirow{3}{*}{$\begin{array}{l}\text { Geographlo Area } \\
\text { Month }\end{array}$} & \multicolumn{3}{|c|}{ Regular } & \multicolumn{3}{|c|}{ Midgrade } & \multicolumn{3}{|c|}{ Premium } & \multicolumn{3}{|c|}{ All Grades } \\
\hline & \multicolumn{2}{|c|}{ Sales to End Users } & \multirow{2}{*}{$\begin{array}{c}\text { Sales } \\
\text { for } \\
\text { Resale }\end{array}$} & \multicolumn{2}{|c|}{ Sales to End Users } & \multirow{2}{*}{$\begin{array}{c}\text { Sales } \\
\text { for } \\
\text { Resale }\end{array}$} & \multicolumn{2}{|c|}{ Sales to End Users } & \multirow{2}{*}{$\begin{array}{c}\text { Sales } \\
\text { for } \\
\text { Resale }\end{array}$} & \multicolumn{2}{|c|}{ Sales to End Users } & \multirow{2}{*}{$\begin{array}{c}\text { Sales } \\
\text { for } \\
\text { Resale }\end{array}$} \\
\hline & $\begin{array}{c}\text { Through } \\
\text { Retall } \\
\text { Outlots }\end{array}$ & $\begin{array}{l}\text { Other } \\
\text { End } \\
\text { Usersa }\end{array}$ & & $\begin{array}{c}\text { Through } \\
\text { Retail } \\
\text { Outlets }\end{array}$ & $\begin{array}{l}\text { Other } \\
\text { End } \\
\text { Usersa }\end{array}$ & & $\begin{array}{c}\text { Through } \\
\text { Retail } \\
\text { Outlets }\end{array}$ & $\begin{array}{c}\text { Other } \\
\text { End } \\
\text { Usersa }\end{array}$ & & $\begin{array}{c}\text { Through } \\
\text { Retail } \\
\text { Outlets }\end{array}$ & $\begin{array}{l}\text { Other } \\
\text { End } \\
\text { Usersa }\end{array}$ & \\
\hline 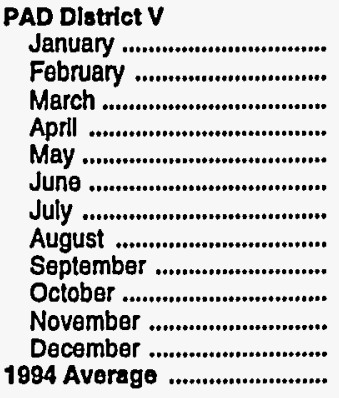 & $\begin{array}{l}69.5 \\
69.1 \\
69.1 \\
70.2 \\
72.0 \\
74.1 \\
76.7 \\
79.1 \\
79.5 \\
80.3 \\
80.6 \\
78.8 \\
75.0\end{array}$ & $\begin{array}{l}57.7 \\
59.0 \\
58.2 \\
60.4 \\
61.6 \\
62.8 \\
66.3 \\
67.7 \\
68.0 \\
67.6 \\
70.3 \\
64.5 \\
63.6\end{array}$ & $\begin{array}{l}55.8 \\
57.1 \\
57.2 \\
59.7 \\
60.8 \\
63.7 \\
66.8 \\
67.5 \\
67.1 \\
68.3 \\
68.5 \\
65.1 \\
63.2\end{array}$ & $\begin{array}{l}75.3 \\
75.9 \\
78.5 \\
80.3 \\
82.5 \\
84.5 \\
87.3 \\
89.1 \\
89.2 \\
91.4 \\
91.4 \\
88.9 \\
84.7\end{array}$ & $\begin{array}{l}62.1 \\
63.0 \\
63.7 \\
66.6 \\
66.9 \\
68.9 \\
73.3 \\
73.7 \\
73.1 \\
75.1 \\
77.8 \\
70.8 \\
69.0\end{array}$ & $\begin{array}{l}63.0 \\
64.3 \\
65.4 \\
68.1 \\
69.7 \\
72.2 \\
75.3 \\
76.1 \\
75.5 \\
78.2 \\
77.7 \\
73.9 \\
71.9\end{array}$ & $\begin{array}{r}88.3 \\
88.4 \\
88.8 \\
89.8 \\
91.9 \\
93.7 \\
96.2 \\
98.2 \\
98.3 \\
98.9 \\
100.0 \\
98.3 \\
94.3\end{array}$ & $\begin{array}{l}70.2 \\
70.5 \\
70.5 \\
72.9 \\
74.0 \\
75.5 \\
80.8 \\
81.8 \\
80.5 \\
81.4 \\
83.7 \\
77.4 \\
76.1\end{array}$ & $\begin{array}{l}71.4 \\
72.2 \\
73.1 \\
74.8 \\
76.2 \\
79.1 \\
81.7 \\
82.9 \\
83.2 \\
85.0 \\
84.9 \\
81.5 \\
79.0\end{array}$ & $\begin{array}{l}73.4 \\
73.1 \\
73.4 \\
74.6 \\
76.5 \\
78.5 \\
81.2 \\
83.5 \\
83.7 \\
84.9 \\
85.0 \\
83.0 \\
79.4\end{array}$ & $\begin{array}{l}60.4 \\
61.6 \\
60.8 \\
63.1 \\
64.1 \\
65.6 \\
68.6 \\
70.8 \\
70.4 \\
70.4 \\
72.9 \\
67.0 \\
66.1\end{array}$ & $\begin{array}{l}59.4 \\
60.4 \\
60.9 \\
63.4 \\
64.6 \\
67.5 \\
70.5 \\
71.2 \\
70.9 \\
72.3 \\
72.4 \\
69.1 \\
67.0\end{array}$ \\
\hline 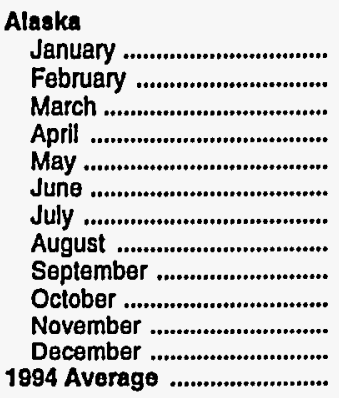 & $\begin{array}{r}100.3 \\
99.8 \\
99.9 \\
100.1 \\
100.4 \\
103.5 \\
104.0 \\
105.7 \\
107.3 \\
106.9 \\
107.2 \\
105.8 \\
103.5\end{array}$ & $\begin{array}{l}W \\
W \\
W \\
W \\
W \\
W \\
W \\
W \\
W \\
W \\
W \\
W \\
W\end{array}$ & $\begin{array}{l}70.9 \\
68.6 \\
70.1 \\
69.7 \\
69.1 \\
71.5 \\
72.3 \\
73.9 \\
74.9 \\
76.2 \\
74.2 \\
74.7 \\
72.3\end{array}$ & $\begin{array}{l}- \\
- \\
- \\
- \\
- \\
- \\
\bar{W} \\
W \\
W \\
W \\
W\end{array}$ & $\begin{array}{l}- \\
- \\
- \\
- \\
- \\
- \\
- \\
- \\
-\end{array}$ & $\begin{array}{l}- \\
-\bar{w} \\
w \\
w \\
w \\
w \\
w \\
w \\
w \\
W \\
W \\
w\end{array}$ & $\begin{array}{l}107.4 \\
106.4 \\
105.4 \\
105.6 \\
105.4 \\
108.9 \\
109.6 \\
111.3 \\
113.2 \\
113.4 \\
112.4 \\
113.2 \\
109.5\end{array}$ & $\begin{array}{l}w \\
W \\
W \\
W \\
W \\
w \\
W \\
W \\
W \\
W \\
W \\
W \\
W\end{array}$ & $\begin{array}{l}82.0 \\
80.1 \\
81.3 \\
80.7 \\
81.4 \\
83.3 \\
83.9 \\
85.1 \\
87.9 \\
87.5 \\
86.4 \\
85.7 \\
83.9\end{array}$ & $\begin{array}{l}101.3 \\
100.8 \\
100.7 \\
100.9 \\
101.2 \\
104.3 \\
104.9 \\
106.5 \\
108.2 \\
107.9 \\
108.0 \\
106.9 \\
104.4\end{array}$ & $\begin{array}{l}W \\
W \\
W \\
W \\
W \\
W \\
W \\
W \\
W \\
W \\
W \\
W \\
W\end{array}$ & $\begin{array}{l}72.2 \\
70.2 \\
71.5 \\
71.1 \\
70.5 \\
72.7 \\
73.5 \\
75.1 \\
76.3 \\
77.8 \\
75.9 \\
76.6 \\
73.7\end{array}$ \\
\hline 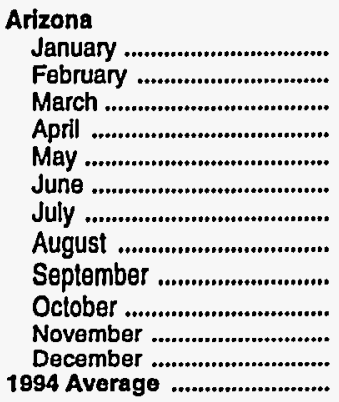 & $\begin{array}{l}82.5 \\
80.0 \\
78.3 \\
77.2 \\
76.6 \\
77.3 \\
77.5 \\
79.7 \\
81.1 \\
82.3 \\
81.3 \\
79.9 \\
79.5\end{array}$ & $\begin{array}{l}55.8 \\
57.5 \\
57.3 \\
60.1 \\
63.3 \\
65.5 \\
67.9 \\
69.8 \\
70.4 \\
67.5 \\
70.6 \\
66.0 \\
63.6\end{array}$ & $\begin{array}{l}63.2 \\
63.8 \\
64.8 \\
63.4 \\
64.5 \\
66.0 \\
67.7 \\
68.1 \\
68.1 \\
68.0 \\
69.6 \\
65.5 \\
66.0\end{array}$ & $\begin{array}{l}W \\
W \\
W \\
W \\
W \\
W \\
W \\
91.1 \\
93.1 \\
90.8 \\
89.2 \\
88.6 \\
89.1\end{array}$ & $\begin{array}{l}- \\
- \\
- \\
- \\
- \\
- \\
- \\
- \\
- \\
-\end{array}$ & $\begin{array}{c}63.3 \\
64.1 \\
65.6 \\
\text { NA } \\
74.3 \\
74.6 \\
77.8 \\
80.5 \\
80.4 \\
\text { W } \\
73.2 \\
70.3 \\
69.7\end{array}$ & $\begin{array}{l}99.8 \\
97.2 \\
96.0 \\
94.8 \\
94.4 \\
94.4 \\
94.8 \\
96.2 \\
97.7 \\
99.0 \\
98.6 \\
97.9 \\
96.7\end{array}$ & $\begin{array}{c}W \\
72.4 \\
W \\
72.5 \\
W \\
W \\
W \\
W \\
W \\
W \\
W \\
W \\
79.7\end{array}$ & $\begin{array}{l}78.3 \\
78.3 \\
78.5 \\
76.1 \\
75.8 \\
78.3 \\
79.6 \\
80.6 \\
81.1 \\
82.3 \\
82.0 \\
78.8 \\
79.2\end{array}$ & $\begin{array}{l}85.6 \\
83.1 \\
81.4 \\
80.6 \\
80.3 \\
80.9 \\
81.3 \\
83.2 \\
84.5 \\
85.9 \\
84.8 \\
83.4 \\
82.9\end{array}$ & $\begin{array}{l}56.7 \\
58.2 \\
58.2 \\
60.5 \\
64.4 \\
66.5 \\
68.7 \\
70.8 \\
71.3 \\
68.9 \\
71.5 \\
67.7 \\
64.6\end{array}$ & $\begin{array}{l}65.5 \\
66.0 \\
66.9 \\
65.6 \\
66.7 \\
68.3 \\
70.0 \\
70.4 \\
70.5 \\
70.4 \\
72.0 \\
68.0 \\
68.3\end{array}$ \\
\hline 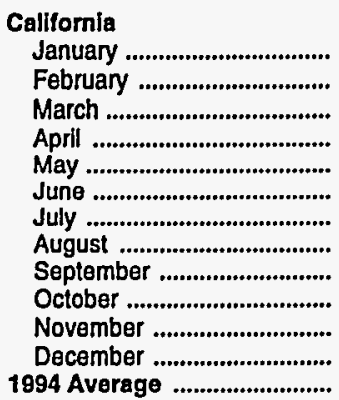 & $\begin{array}{l}64.3 \\
64.4 \\
65.3 \\
66.8 \\
68.6 \\
70.8 \\
73.6 \\
76.1 \\
76.4 \\
77.6 \\
78.1 \\
76.4 \\
71.7\end{array}$ & $\begin{array}{l}55.1 \\
57.3 \\
56.4 \\
58.9 \\
59.4 \\
60.2 \\
63.8 \\
64.8 \\
64.7 \\
66.0 \\
68.2 \\
62.6 \\
61.4\end{array}$ & $\begin{array}{l}55.0 \\
56.0 \\
56.1 \\
58.8 \\
59.7 \\
62.8 \\
66.2 \\
66.3 \\
65.5 \\
67.9 \\
68.1 \\
64.8 \\
62.4\end{array}$ & $\begin{array}{l}74.5 \\
75.1 \\
77.8 \\
79.6 \\
81.9 \\
84.0 \\
86.9 \\
88.6 \\
88.7 \\
91.0 \\
90.9 \\
88.4 \\
84.1\end{array}$ & $\begin{array}{c}W \\
W \\
63.5 \\
66.8 \\
66.9 \\
68.7 \\
73.8 \\
73.9 \\
73.8 \\
77.9 \\
79.5 \\
W \\
69.3\end{array}$ & $\begin{array}{l}62.4 \\
63.7 \\
64.8 \\
67.6 \\
69.1 \\
71.7 \\
74.9 \\
75.7 \\
75.0 \\
77.9 \\
77.4 \\
73.5 \\
71.4\end{array}$ & $\begin{array}{l}84.4 \\
85.3 \\
86.2 \\
87.6 \\
89.7 \\
91.8 \\
94.6 \\
96.6 \\
96.5 \\
97.4 \\
98.8 \\
97.0 \\
92.3\end{array}$ & $\begin{array}{l}69.9 \\
70.8 \\
70.6 \\
73.4 \\
74.8 \\
74.9 \\
80.8 \\
80.4 \\
80.2 \\
84.3 \\
85.7 \\
80.7 \\
75.8\end{array}$ & $\begin{array}{l}70.0 \\
70.6 \\
72.1 \\
74.0 \\
75.3 \\
78.6 \\
81.1 \\
82.2 \\
82.3 \\
85.1 \\
85.3 \\
81.6 \\
78.3\end{array}$ & $\begin{array}{l}69.4 \\
69.5 \\
70.5 \\
72.2 \\
74.1 \\
76.2 \\
79.1 \\
81.4 \\
81.5 \\
83.2 \\
83.2 \\
81.4 \\
77.0\end{array}$ & $\begin{array}{l}58.8 \\
60.8 \\
59.6 \\
62.1 \\
62.6 \\
63.2 \\
65.9 \\
68.1 \\
67.8 \\
69.7 \\
71.8 \\
66.2 \\
64.4\end{array}$ & $\begin{array}{l}59.0 \\
59.6 \\
60.3 \\
63.0 \\
64.0 \\
67.2 \\
70.4 \\
70.6 \\
70.1 \\
72.5 \\
72.4 \\
69.3 \\
66.7\end{array}$ \\
\hline
\end{tabular}

See footnotes at end of table. 
Table 35. Refiner Motor Gasoline Prices by Grade, Sales Type, PAD District, and State (Cents per Gallon Excluding Taxes) - Continued

\begin{tabular}{|c|c|c|c|c|c|c|c|c|c|c|c|c|}
\hline \multirow{3}{*}{$\begin{array}{c}\text { Geographic Area } \\
\text { Month }\end{array}$} & \multicolumn{3}{|c|}{ Regular } & \multicolumn{3}{|c|}{ Midgrade } & \multicolumn{3}{|c|}{ Premlum } & \multicolumn{3}{|c|}{ All Grades } \\
\hline & \multicolumn{2}{|c|}{ Sales to End Users } & \multirow[b]{2}{*}{$\begin{array}{c}\text { Sales } \\
\text { for } \\
\text { Resale }\end{array}$} & \multicolumn{2}{|c|}{ Sales to End Users } & \multirow[b]{2}{*}{$\begin{array}{c}\text { Sales } \\
\text { for } \\
\text { Resale }\end{array}$} & \multicolumn{2}{|c|}{ Sales to End Users } & \multirow{2}{*}{$\begin{array}{c}\text { Sales } \\
\text { for } \\
\text { Resale }\end{array}$} & \multicolumn{2}{|c|}{ Sales to End Users } & \multirow[b]{2}{*}{$\begin{array}{c}\text { Sales } \\
\text { for } \\
\text { Resalo }\end{array}$} \\
\hline & $\begin{array}{c}\text { Through } \\
\text { Retail } \\
\text { Outlets }\end{array}$ & $\begin{array}{l}\text { Other } \\
\text { End } \\
\text { Usersa }\end{array}$ & & $\begin{array}{c}\text { Through } \\
\text { Retail } \\
\text { Outlets }\end{array}$ & $\begin{array}{c}\text { Other } \\
\text { End } \\
\text { Usersa }\end{array}$ & & $\begin{array}{c}\text { Through } \\
\text { Retali } \\
\text { Outlets }\end{array}$ & $\begin{array}{l}\text { Other } \\
\text { End } \\
\text { Usersa }\end{array}$ & & $\begin{array}{l}\text { Through } \\
\text { Retail } \\
\text { Outlots }\end{array}$ & $\begin{array}{l}\text { Other } \\
\text { End } \\
\text { Usersa }\end{array}$ & \\
\hline
\end{tabular}

Hawail

\begin{tabular}{|c|c|}
\hline January ... & 101.2 \\
\hline February .............. & 100.5 \\
\hline March & 100.2 \\
\hline 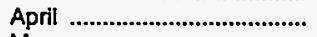 & 100.1 \\
\hline May & 100.1 \\
\hline June & 100.1 \\
\hline 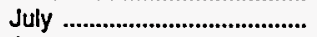 & 101.6 \\
\hline 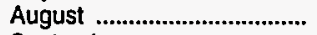 & 102.1 \\
\hline 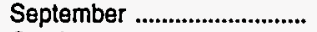 & 103.0 \\
\hline 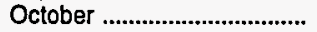 & 103.7 \\
\hline ember ................................. & 103.9 \\
\hline ber & \\
\hline
\end{tabular}

$\begin{array}{ccc}59.5 & 83.3 & 105.2 \\ 60.3 & 82.4 & 104.1 \\ 61.0 & 68.4 & 104.3 \\ 62.4 & 84.4 & 104.1 \\ W & 85.0 & 104.1 \\ 64.2 & 86.1 & 104.1 \\ 69.1 & 87.8 & 105.7 \\ W & 89.1 & 107.1 \\ 69.4 & 90.3 & 106.9 \\ W & 90.6 & 107.6 \\ W & 90.9 & 107.6 \\ W & 89.6 & 107.6 \\ 65.5 & 84.7 & 105.7\end{array}$

$\begin{array}{lll}W & 90.0 & 117.6 \\ W & 89.0 & 116.3 \\ W & 89.5 & 116.3 \\ W & 91.3 & 116.2 \\ W & 92.1 & 116.1 \\ W & 93.1 & 116.3 \\ W & 95.6 & 118.8 \\ W & 97.1 & 118.9 \\ W & 98.0 & 118.4 \\ W & 98.9 & 118.8 \\ W & 98.9 & 119.0 \\ W & 97.9 & 119.0 \\ W & 94.4 & 117.7\end{array}$

$\begin{array}{lrr}W & 96.7 & 106.2 \\ W & 95.8 & 105.3 \\ W & 95.9 & 105.1 \\ W & 97.6 & 105.0 \\ W & 98.4 & 105.0 \\ W & 99.4 & 105.1 \\ W & 101.5 & 106.8 \\ W & 102.8 & 107.2 \\ W & 104.0 & 107.7 \\ W & 103.4 & 108.3 \\ W & 104.7 & 108.5 \\ W & 103.5 & 108.3 \\ W & 100.3 & 106.6\end{array}$

$\begin{array}{cc}63.0 & 88.6 \\ 63.3 & 87.7 \\ W & 77.1 \\ 65.7 & 89.7 \\ W & 90.4 \\ W & 91.4 \\ 72.1 & 93.3 \\ W & 94.6 \\ W & 95.9 \\ W & 96.0 \\ W & 96.5 \\ W & 95.4 \\ W & 90.9\end{array}$

Nevada

January

February ................................ $\quad 71.0$

March ........................................ $\quad 70.1$

April ................................... 70.3

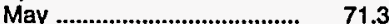

June ..................................... 72.8

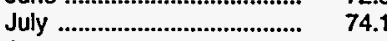

August ................................ 76.4

September .......................... $\quad 78.0$

October ...................................... $\quad 77.7$

November .............................. 76.5

$59.9 \quad 57.4$

$59.4 \quad 57.8$

$57.5 \quad 57.6$

$62.7 \quad 60.2$

$62.3 \quad 61.5$

$\begin{array}{ll}64.3 & 63.3 \\ 68.9 & 66.8\end{array}$

$68.9 \quad 66.8$

$\begin{array}{ll}69.4 & 67.5 \\ 68.9 & 67.4\end{array}$

$\begin{array}{ll}68.9 & 67.4 \\ 72.7 & 68.5\end{array}$

$73.4 \quad 67.9$

$W$
80.1
79.5
80.6
81.8
82.8
84.4
86.4
87.1
89.6
89.8
77.7
82.7

$\begin{array}{lll}W & 63.5 & 86.7 \\ W & 64.1 & 86.4 \\ W & 65.4 & 88.2 \\ W & 68.2 & 87.6 \\ W & 69.6 & 88.6 \\ W & 70.8 & 90.1 \\ W & 73.8 & 91.4 \\ W & 75.5 & 93.4 \\ W & 75.7 & 94.7 \\ W & 76.6 & 95.2 \\ W & 75.2 & 93.5 \\ W & 72.6 & 91.9 \\ W & 71.0 & 90.7\end{array}$

\begin{tabular}{cc}
$W$ & 72.3 \\
- & 72.5 \\
$W$ & 72.2 \\
$\bar{W}$ & 75.1 \\
$W$ & 76.0 \\
- & 77.4 \\
$W$ & 80.0 \\
$W$ & 81.5 \\
$W$ & 80.6 \\
$W$ & 82.3 \\
$W$ & 81.7 \\
$W$ & 76.8 \\
\hline & 77.7
\end{tabular}

73.4

60.1

$\begin{array}{ll}71.0 & 59.7 \\ 73.1 & 57.7\end{array}$

$73.3 \quad 62.8$

$74.4 \quad 62.5$

75.9

77.5

79.7

81.1

81.1
79.7

79.7

76.5

$62.5 \quad 64.5$

$64.5 \quad 66.3$

$69.0 \quad 69.7$

$69.6 \quad 70.6$

$69.2 \quad 70.3$

$72.9 \quad 71.3$

$73.5 \quad 70.7$

1994 Average ....................... 73.4

$65.3 \quad 63.4$

Oregon

January .............................. $75.8 \quad 54.6 \quad 54.5$

February ............................. $75.5 \quad 56.5 \quad 56.3$

April ............................................ $74.6 \quad 56.2 \quad 59.1$

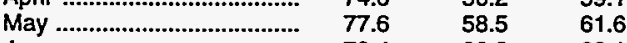

June ....................................... $79.4 \quad 60.8$

July ..................................... $82.3 \quad 64.3 \quad 66.5$

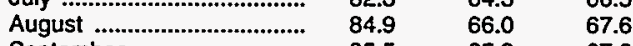

September .............................. $85.5 \quad 65.3 \quad 67.6$

October ................................ $83.9 \quad 61.4 \quad 65.2$

November ............................. $84.7 \quad 64.2 \quad 65.5$

December ................................. $81.6 \quad 61.6 \quad 61.3$

1994 Average ......................... $80.0 \quad 60.1 \quad 62.2$

$\begin{array}{ll}\mathbf{W} & - \\ \mathbf{W} & - \\ \mathbf{W} & - \\ \mathbf{W} & \mathbf{W} \\ \mathbf{W} & - \\ \mathbf{W} & - \\ \mathbf{W} & - \\ \mathbf{W} & - \\ \mathbf{W} & - \\ \mathbf{W} & - \\ \mathbf{W} & \mathbf{W}\end{array}$

$\begin{array}{llr}- & - & 95.8 \\ - & - & 94.3 \\ - & - & 93.4 \\ \bar{W} & W & 94.3 \\ - & W & 96.7 \\ - & W & 98.2 \\ - & W & 100.5 \\ - & W & 103.0 \\ - & W & 103.2 \\ - & W & 101.8 \\ - & W & 101.3 \\ W & \text { W } & 99.2\end{array}$

$\begin{array}{ccccc}\text { W } & 68.7 & 78.7 & 54.7 & 56.6 \\ \mathbf{6 7 . 8} & 72.4 & 78.5 & 56.9 & 58.5 \\ \text { W } & 71.9 & 76.3 & 53.0 & 57.4 \\ \text { W } & 74.8 & 77.7 & 56.5 & 61.1 \\ \text { W } & 77.0 & 80.8 & 58.8 & 63.7 \\ \text { W } & 78.6 & 82.5 & 61.2 & 65.2 \\ \text { W } & 82.0 & 85.4 & 64.4 & 68.7 \\ \text { W } & 82.4 & 88.0 & 66.3 & 69.7 \\ \text { W } & 84.6 & 88.4 & 65.7 & 69.8 \\ \text { W } & 78.9 & 87.0 & 62.3 & 67.3 \\ \text { W } & 77.1 & 87.6 & 64.7 & 67.4 \\ \text { W } & 74.3 & 84.7 & 61.6 & 63.3 \\ 70.6 & 77.0 & 83.1 & 60.4 & 64.3\end{array}$

Washington

January .............................. $68.5 \quad 54.3 \quad 52.9$

February ............................ $68.4 \quad 57.9 \quad 55.5$

March ............................... $68.0 \quad 55.3 \quad 56.9$

April .............................................. $69.0 \quad 59.4$

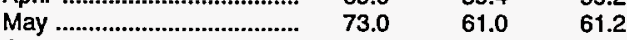

June ................................. $75.8 \quad 61.1 \quad 64.4$

July .................................. $79.5 \quad 64.6 \quad 67.1$

August ......................................... $82.5 \quad 73.0 \quad 70.5$

September ............................. $83.3 \quad 65.9 \quad 70.9$

October ................................ $82.5 \quad 64.8 \quad 69.3$

November ........................... $83.6 \quad 66.2 \quad 69.7$

December ............................... $81.0 \quad 60.9 \quad 66.7$

1994 Average ........................... $\quad 76.3 \quad 60.7 \quad 63.8$

$\begin{array}{ll}W & - \\ W & - \\ W & - \\ W & - \\ W & - \\ W & - \\ W & - \\ W & - \\ 93.2 & - \\ 97.0 & - \\ W & - \\ 94.5 & -\end{array}$

$\begin{array}{lcr}- & 61.0 & 87.5 \\ - & 59.7 & 86.6 \\ - & W & 85.9 \\ - & W & 87.0 \\ - & W & 92.0 \\ - & W & 94.6 \\ - & W & 97.8 \\ - & W & 100.8 \\ - & 74.2 & 101.8 \\ - & W & 100.3 \\ - & 77.3 & 100.8 \\ - & W & 98.7 \\ - & 75.1 & 94.4\end{array}$

$\begin{array}{lllll}W & 71.3 & 71.6 & 54.7 & 56.0 \\ W & 72.5 & 71.6 & 59.1 & 58.5 \\ W & 71.4 & 71.1 & 56.3 & 59.6 \\ W & 73.5 & 72.1 & 60.5 & 61.8 \\ W & 76.2 & 76.1 & 61.2 & 63.6 \\ W & 79.1 & 78.8 & 62.6 & 66.9 \\ W & 82.5 & 82.6 & 65.0 & 69.6 \\ W & 85.0 & 85.5 & 76.3 & 72.9 \\ W & 85.6 & 86.0 & 66.5 & 73.3 \\ W & 84.4 & 85.5 & 66.7 & 72.0 \\ W & 83.9 & 86.8 & 66.6 & 72.3 \\ W & 81.3 & 84.0 & 62.5 & 69.4 \\ W & 78.9 & 79.4 & 61.8 & 66.4\end{array}$

Dash $(-)=$ No data reported.

NA $=$ Not available.

$W=$ Withheld to avoid disclosure of individual company data.

a Sales to "other end users" are all end-user sales that were not made through company-operated retail outlets, e.g., sales to agricultural customers or utilities.

Source: Energy Information Administration Form ElA-782A, "Refiners'/Gas Plant Operators' Monthly Petroleum Product Sales Report." 
Table 36. Refiner Prices of Aviation Fuels and Kerosene by PAD District and State (Cents per Gallon Excluding Taxes)

\begin{tabular}{|c|c|c|c|c|c|c|}
\hline \multirow{2}{*}{$\begin{array}{c}\text { Goographic Area } \\
\text { Month }\end{array}$} & \multicolumn{2}{|c|}{ Aviation Gasollne } & \multicolumn{2}{|c|}{ Kerosene-Type Jet Fuel } & \multicolumn{2}{|c|}{ Kerosene } \\
\hline & $\begin{array}{l}\text { Sales to } \\
\text { End Users }\end{array}$ & $\begin{array}{c}\text { Sales for } \\
\text { Resale }\end{array}$ & $\begin{array}{l}\text { Sales to } \\
\text { End Users }\end{array}$ & $\begin{array}{l}\text { Sales for } \\
\text { Resale }\end{array}$ & $\begin{array}{l}\text { Sales to } \\
\text { End Users }\end{array}$ & $\begin{array}{c}\text { Sales for } \\
\text { Resale }\end{array}$ \\
\hline \multicolumn{7}{|l|}{ Unltod States } \\
\hline 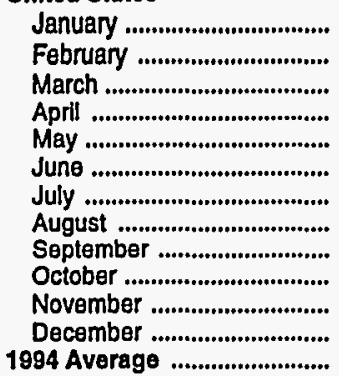 & $\begin{array}{r}88.6 \\
88.4 \\
89.0 \\
91.3 \\
92.3 \\
95.6 \\
97.4 \\
101.7 \\
101.1 \\
100.0 \\
100.0 \\
99.2 \\
95.7\end{array}$ & $\begin{array}{l}87.1 \\
87.8 \\
87.4 \\
89.5 \\
91.2 \\
93.2 \\
96.1 \\
98.5 \\
97.3 \\
95.4 \\
95.2 \\
94.2 \\
93.3\end{array}$ & $\begin{array}{l}51.5 \\
55.7 \\
51.8 \\
50.7 \\
51.0 \\
51.9 \\
53.5 \\
54.4 \\
53.9 \\
55.0 \\
57.2 \\
53.9 \\
53.4\end{array}$ & $\begin{array}{l}52.9 \\
56.0 \\
52.5 \\
50.9 \\
50.6 \\
51.5 \\
53.8 \\
54.4 \\
54.0 \\
54.4 \\
56.3 \\
53.1 \\
53.4\end{array}$ & $\begin{array}{l}79.5 \\
84.1 \\
78.2 \\
69.7 \\
55.2 \\
54.5 \\
60.4 \\
57.8 \\
58.3 \\
61.5 \\
64.0 \\
64.7 \\
66.0\end{array}$ & $\begin{array}{l}65.7 \\
73.5 \\
59.9 \\
55.1 \\
53.2 \\
53.9 \\
55.1 \\
55.1 \\
55.3 \\
59.1 \\
60.7 \\
57.4 \\
61.8\end{array}$ \\
\hline \multicolumn{7}{|l|}{ PAD Dlstrict I } \\
\hline 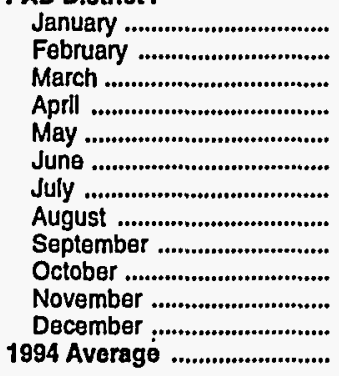 & $\begin{array}{r}85.9 \\
86.1 \\
86.6 \\
89.1 \\
91.4 \\
94.2 \\
96.7 \\
100.8 \\
101.0 \\
101.1 \\
102.4 \\
101.0 \\
94.9\end{array}$ & $\begin{array}{l}86.7 \\
88.6 \\
88.7 \\
89.0 \\
90.5 \\
92.7 \\
95.7 \\
97.6 \\
94.6 \\
93.2 \\
94.2 \\
93.8 \\
92.5\end{array}$ & $\begin{array}{l}52.9 \\
57.9 \\
49.7 \\
49.9 \\
50.5 \\
51.7 \\
53.7 \\
54.0 \\
52.3 \\
53.4 \\
55.2 \\
52.7 \\
52.8\end{array}$ & $\begin{array}{l}58.0 \\
61.8 \\
52.5 \\
52.1 \\
52.4 \\
53.3 \\
55.5 \\
55.8 \\
54.0 \\
54.5 \\
55.4 \\
53.6 \\
54.9\end{array}$ & $\begin{array}{l}77.4 \\
83.3 \\
76.2 \\
66.9 \\
54.4 \\
56.5 \\
59.3 \\
60.1 \\
64.5 \\
65.4 \\
65.6 \\
69.7 \\
69.7\end{array}$ & $\begin{array}{l}67.2 \\
75.1 \\
61.0 \\
55.7 \\
54.9 \\
55.0 \\
56.7 \\
55.3 \\
55.1 \\
58.0 \\
59.5 \\
56.8 \\
62.8\end{array}$ \\
\hline \multicolumn{7}{|l|}{ Subdistrict IA } \\
\hline 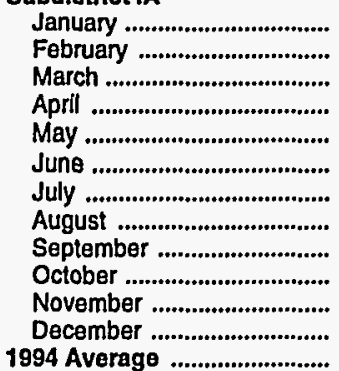 & $\begin{array}{l}W \\
W \\
W \\
W \\
W \\
W \\
W \\
W \\
W \\
W \\
W \\
W \\
W\end{array}$ & $\begin{array}{c}85.5 \\
88.9 \\
W \\
90.7 \\
W \\
W \\
96.5 \\
W \\
W \\
W \\
W \\
W \\
W\end{array}$ & $\begin{array}{l}56.7 \\
61.8 \\
53.0 \\
53.4 \\
53.7 \\
54.1 \\
57.0 \\
57.2 \\
55.5 \\
56.3 \\
58.1 \\
56.0 \\
56.1\end{array}$ & $\begin{array}{l}63.2 \\
71.9 \\
55.5 \\
54.7 \\
55.3 \\
56.5 \\
59.3 \\
59.3 \\
58.3 \\
59.2 \\
59.9 \\
58.4 \\
59.8\end{array}$ & $\begin{array}{l}65.0 \\
83.8 \\
68.6 \\
63.8 \\
58.8 \\
58.6 \\
61.2 \\
59.2 \\
62.3 \\
65.4 \\
63.9 \\
61.9 \\
68.9\end{array}$ & $\begin{array}{l}65.8 \\
73.5 \\
61.9 \\
56.7 \\
54.7 \\
57.0 \\
60.8 \\
58.0 \\
57.4 \\
58.0 \\
59.4 \\
57.4 \\
62.6\end{array}$ \\
\hline \multicolumn{7}{|l|}{ Connecticut } \\
\hline 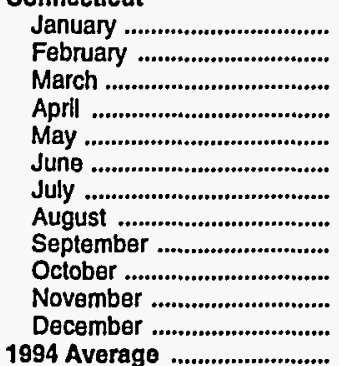 & $\begin{array}{l}W \\
W \\
W \\
W \\
W \\
W \\
W \\
W \\
W \\
W \\
W \\
W \\
W\end{array}$ & $\begin{array}{l}86.3 \\
91.2 \\
90.8 \\
88.7 \\
W \\
W \\
W \\
W \\
W \\
W \\
W \\
W \\
95.7\end{array}$ & $\begin{array}{c}57.5 \\
62.9 \\
53.1 \\
54.5 \\
53.7 \\
50.6 \\
56.4 \\
56.9 \\
55.6 \\
W \\
58.0 \\
55.9 \\
56.0\end{array}$ & $\begin{array}{c}56.8 \\
W \\
W \\
W \\
W \\
W \\
W \\
W \\
W \\
56.8 \\
W \\
57.8 \\
56.7\end{array}$ & $\begin{array}{l}72.8 \\
W \\
W \\
W \\
W \\
W \\
W \\
W \\
W \\
W \\
W \\
W \\
W\end{array}$ & $\begin{array}{c}W \\
W \\
W \\
W \\
W \\
W \\
57.9 \\
W \\
W \\
60.1 \\
60.6 \\
58.9 \\
64.9\end{array}$ \\
\hline
\end{tabular}

See footnotes at end of table. 
Table 36. Refiner Prices of Aviation Fuels and Kerosene by PAD District and State (Cents per Gallon Excluding Taxes) - Continued

\begin{tabular}{|c|c|c|c|c|c|c|}
\hline \multirow{2}{*}{$\begin{array}{l}\text { Geographic Area } \\
\text { Month }\end{array}$} & \multicolumn{2}{|c|}{ Avlation Gasoline } & \multicolumn{2}{|c|}{ Kerosene-Type Jet Fuel } & \multicolumn{2}{|c|}{ Keroseno } \\
\hline & $\begin{array}{l}\text { Sales to } \\
\text { End Users }\end{array}$ & $\begin{array}{l}\text { Sales for } \\
\text { Resale }\end{array}$ & $\begin{array}{l}\text { Sales to } \\
\text { End Users }\end{array}$ & $\begin{array}{c}\text { Sales for } \\
\text { Resale }\end{array}$ & $\begin{array}{l}\text { Sales to } \\
\text { End Users }\end{array}$ & $\begin{array}{c}\text { Sales for } \\
\text { Resale }\end{array}$ \\
\hline \multicolumn{7}{|l|}{ Maine } \\
\hline 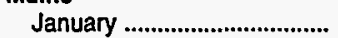 & $w$ & - & 63.9 & $w$ & $w$ & 63.8 \\
\hline 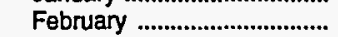 & $\ddot{W}$ & $w$ & $W$ & $\ddot{W}$ & $w$ & NA \\
\hline March & $w$ & - & $w$ & $w$ & $w$ & 61.5 \\
\hline 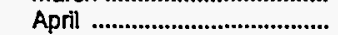 & W & $w$ & $W$ & $w$ & - & 57.6 \\
\hline 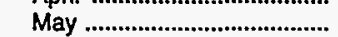 & $w$ & - & $w$ & $w$ & $w$ & 56.2 \\
\hline 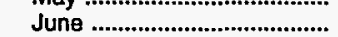 & $w$ & $w$ & $w$ & 60.8 & $w$ & 56.4 \\
\hline July & $\dddot{w}$ & - & W & $W$ & $w$ & 61.3 \\
\hline 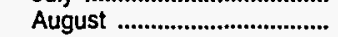 & $w$ & $w$ & W & 65.4 & $w$ & 56.9 \\
\hline September .............................. & $W$ & - & $\ddot{W}$ & 67.3 & $w$ & 56.6 \\
\hline 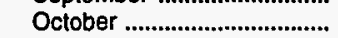 & $W$ & - & W & 64.3 & $w$ & 58.6 \\
\hline 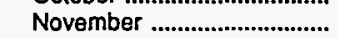 & $w$ & - & $W$ & 63.3 & $w$ & 59.1 \\
\hline 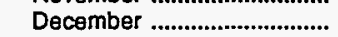 & $w$ & $w$ & w & $W$ & $w$ & 57.1 \\
\hline 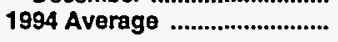 & $\mathbf{W}$ & $w$ & $w$ & 69.1 & $w$ & 62.1 \\
\hline \multicolumn{7}{|l|}{ Massachusetts } \\
\hline 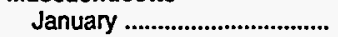 & W & 90.8 & 55.5 & 56.7 & 61.1 & 67.7 \\
\hline 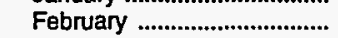 & W & $W$ & 60.0 & 64.8 & 78.9 & 73.9 \\
\hline 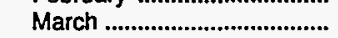 & $\mathbf{w}$ & $\ddot{w}$ & 52.0 & 53.6 & W & 58.8 \\
\hline 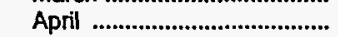 & $w$ & 91.4 & 52.4 & 53.5 & $w$ & 54.7 \\
\hline 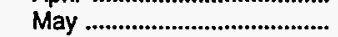 & $\mathbf{w}$ & 93.9 & 52.9 & 54.4 & w & 53.3 \\
\hline 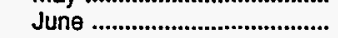 & $\ddot{w}$ & 95.8 & 54.1 & 56.0 & $w$ & 56.1 \\
\hline 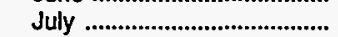 & $\ddot{w}$ & 95.7 & 56.1 & 58.6 & 61.9 & w \\
\hline 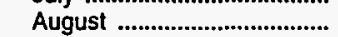 & $\ddot{w}$ & 101.4 & 56.2 & 58.3 & $w$ & 57.8 \\
\hline 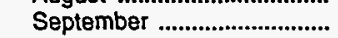 & 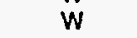 & 98.4 & 54.6 & 56.0 & $w$ & $w$ \\
\hline 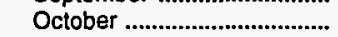 & W & W & 55.6 & 57.0 & 60.1 & 55.6 \\
\hline 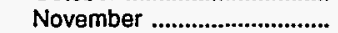 & $\mathbf{w}$ & $w$ & 57.2 & 58.1 & 62.1 & 57.1 \\
\hline 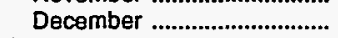 & $w$ & $\ddot{w}$ & 55.4 & 56.1 & 60.6 & 55.2 \\
\hline 1994 Average ........................... & $\mathbf{W}$ & 95.6 & 55.1 & 56.7 & 64.9 & 61.4 \\
\hline \multicolumn{7}{|l|}{ New Hampshire } \\
\hline 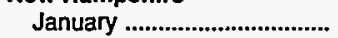 & W & - & 59.5 & $w$ & $w$ & $w$ \\
\hline 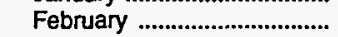 & W & $w$ & 67.0 & w & $\ddot{w}$ & $w$ \\
\hline March & W & $w$ & 55.4 & $\dddot{w}$ & W & $w$ \\
\hline April & $w$ & $w$ & 53.6 & $\ddot{w}$ & $W$ & $w$ \\
\hline 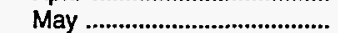 & $W$ & $W$ & 55.7 & $w$ & W & $w$ \\
\hline June & $w$ & $w$ & 54.6 & $w$ & $W$ & $w$ \\
\hline July & $w$ & $w$ & 58.4 & $w$ & W & $w$ \\
\hline 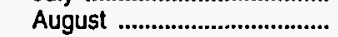 & W & $w$ & 58.2 & w & w & 61.4 \\
\hline 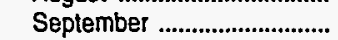 & W & W & 56.5 & w & W & W \\
\hline 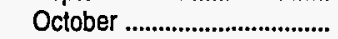 & $W$ & W & $W$ & $W$ & W & 59.7 \\
\hline 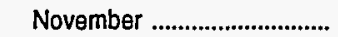 & $W$ & W & W & $w$ & $w$ & $W$ \\
\hline 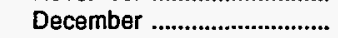 & $w$ & W & W & $w$ & $W$ & $w$ \\
\hline 1994 Average & $\mathbf{w}$ & $\mathbf{w}$ & 57.9 & 65.2 & $\dot{W}$ & 62.6 \\
\hline \multicolumn{7}{|l|}{ Rhode Island } \\
\hline 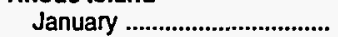 & $w$ & $W$ & 58.2 & $w$ & $w$ & $w$ \\
\hline 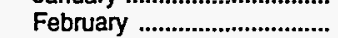 & $W$ & $w$ & 64.3 & 64.9 & $W$ & - \\
\hline 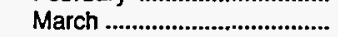 & W & W & 53.4 & $w$ & $w$ & W \\
\hline April & $w$ & W & 53.5 & $w$ & - & $w$ \\
\hline 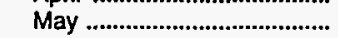 & $w$ & w & 53.7 & W & - & 54.9 \\
\hline 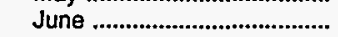 & W & W & 54.8 & $\ddot{w}$ & - & $w$ \\
\hline 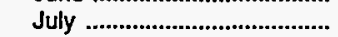 & w & W & 57.1 & $\ddot{w}$ & - & $w$ \\
\hline August & w & $w$ & 57.1 & $\ddot{w}$ & - & $W$ \\
\hline 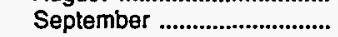 & $\ddot{w}$ & W & 56.0 & W & - & $w$ \\
\hline 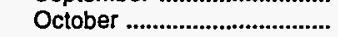 & $\ddot{w}$ & $\mathbf{w}$ & 57.2 & 61.4 & - & $w$ \\
\hline 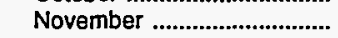 & $\ddot{W}$ & $\ddot{w}$ & 59.1 & 59.8 & $w$ & 60.2 \\
\hline 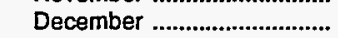 & w & w & 56.4 & 58.3 & $w$ & W \\
\hline 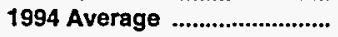 & $W$ & W & 56.7 & 61.9 & $\mathbf{w}$ & 58.8 \\
\hline
\end{tabular}

See footnotes at end of table. 
Table 36. Refiner Prices of Aviation Fuels and Kerosene by PAD District and State (Cents per Gallon Excluding Taxes) - Continued

\begin{tabular}{|c|c|c|c|c|c|c|}
\hline \multirow{2}{*}{$\begin{array}{c}\text { Geographic Area } \\
\text { Month }\end{array}$} & \multicolumn{2}{|c|}{ Aviation Gasoline } & \multicolumn{2}{|c|}{ Kerosene-Type Jet Fuel } & \multicolumn{2}{|c|}{ Kerosene } \\
\hline & $\begin{array}{l}\text { Sales to } \\
\text { End Users }\end{array}$ & $\begin{array}{c}\text { Sales for } \\
\text { Resale }\end{array}$ & $\begin{array}{l}\text { Sales to } \\
\text { End Users }\end{array}$ & $\begin{array}{c}\text { Sales for } \\
\text { Resale }\end{array}$ & $\begin{array}{l}\text { Sales to } \\
\text { End Users }\end{array}$ & $\begin{array}{c}\text { Sales for } \\
\text { Resale }\end{array}$ \\
\hline \multicolumn{7}{|l|}{ Vormont } \\
\hline 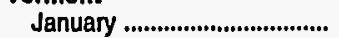 & $w$ & $W$ & 64.8 & $w$ & $w$ & $w$ \\
\hline 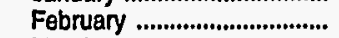 & $\ddot{W}$ & $\ddot{W}$ & 73.1 & $w$ & $\ddot{W}$ & 68.0 \\
\hline March .......................................... & W & $\ddot{W}$ & 64.0 & 60.7 & - & 60.8 \\
\hline Aprll ........................................ & $W$ & W & 63.0 & 60.9 & - & $w$ \\
\hline 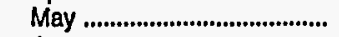 & $W$ & $W$ & 62.9 & 67.1 & - & $w$ \\
\hline 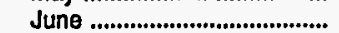 & W & $w$ & 62.7 & 61.9 & - & 58.4 \\
\hline 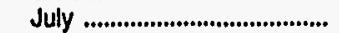 & $W$ & $W$ & 64.1 & 66.1 & - & $w$ \\
\hline 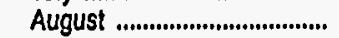 & $W$ & $W$ & 65.2 & 67.9 & - & w \\
\hline September ........................... & W & W & 63.1 & 70.6 & - & $W$ \\
\hline 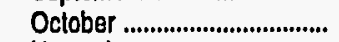 & W & $W$ & 63.4 & 67.9 & - & 60.8 \\
\hline 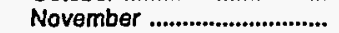 & $\mathbf{w}$ & W & 63.0 & $w$ & - & $w$ \\
\hline 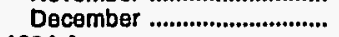 & $w$ & $\dddot{w}$ & 63.0 & $\dddot{w}$ & - & $w$ \\
\hline 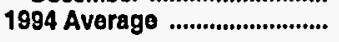 & $w$ & $\mathbf{w}$ & 64.2 & 63.8 & $w$ & 62.9 \\
\hline \multicolumn{7}{|l|}{ Subdistrict IB } \\
\hline 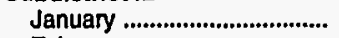 & $w$ & 85.4 & 52.7 & 57.5 & 74.9 & 70.3 \\
\hline February ................................... & 90.3 & 89.3 & 59.7 & 61.7 & 81.8 & 79.8 \\
\hline March ........................................ & $w$ & 88.8 & 49.8 & 51.6 & 75.5 & 63.1 \\
\hline 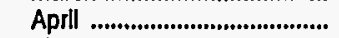 & 94.3 & 87.9 & 49.7 & 50.6 & 66.7 & 56.3 \\
\hline 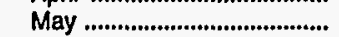 & 95.0 & 90.5 & 50.3 & 51.1 & NA & 56.2 \\
\hline June ......................................... & $w$ & 93.0 & 51.2 & 52.0 & $w$ & 54.9 \\
\hline 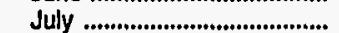 & 99.4 & 98.3 & 53.1 & 54.3 & $w$ & 56.8 \\
\hline 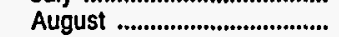 & 103.2 & 96.7 & 53.6 & 54.4 & $w$ & 54.9 \\
\hline 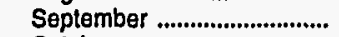 & W & 93.8 & 51.8 & 52.5 & 64.7 & 54.3 \\
\hline October & 103.9 & 92.3 & 52.7 & 53.8 & 63.2 & 57.7 \\
\hline November .............................. & W & 96.1 & 54.6 & 54.5 & 62.9 & 59.3 \\
\hline 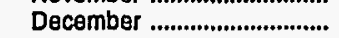 & $\ddot{W}$ & 95.1 & 52.4 & 52.8 & 65.3 & 57.4 \\
\hline 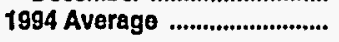 & 99.1 & 93.0 & 52.6 & 54.0 & 67.4 & 64.4 \\
\hline \multicolumn{7}{|l|}{ Delaware } \\
\hline January ................................ & $w$ & - & 60.8 & - & $w$ & 83.2 \\
\hline 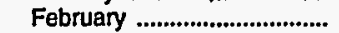 & - & $w$ & 65.1 & - & $w$ & $w$ \\
\hline March ...................................... & $W$ & W & 62.5 & - & $w$ & $\ddot{w}$ \\
\hline 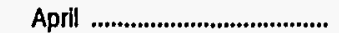 & W & $w$ & 61.1 & $w$ & - & - \\
\hline 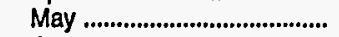 & $W$ & W & 60.8 & - & - & - \\
\hline 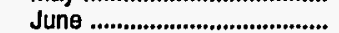 & $w$ & w & 60.8 & - & - & - \\
\hline 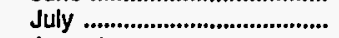 & - & $w$ & 64.3 & $w$ & - & $w$ \\
\hline 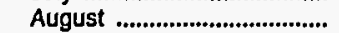 & $w$ & $w$ & $w$ & $\ddot{w}$ & - & - \\
\hline 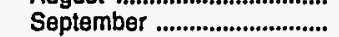 & $\dddot{w}$ & $w$ & 63.8 & $w$ & - & - \\
\hline 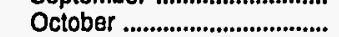 & w & $w$ & 65.2 & $w$ & $\bar{w}$ & $\bar{w}$ \\
\hline November ................................ & $w$ & $W$ & 65.9 & $w$ & $w$ & - \\
\hline December ............................... & $\ddot{w}$ & W & 66.8 & $\ddot{w}$ & $w$ & $w$ \\
\hline 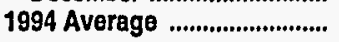 & W & w & 63.7 & $\dddot{w}$ & W & 83.2 \\
\hline \multicolumn{7}{|l|}{ District of Columbla } \\
\hline 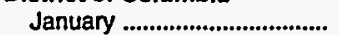 & - & - & - & - & - & $w$ \\
\hline 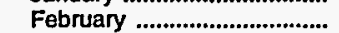 & $w$ & - & - & - & - & $w$ \\
\hline March & - & - & - & - & - & $w$ \\
\hline 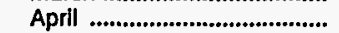 & - & - & - & - & - & - \\
\hline 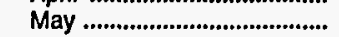 & $w$ & - & - & - & - & - \\
\hline 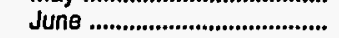 & $\ddot{w}$ & - & - & - & - & - \\
\hline 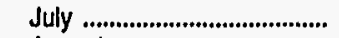 & - & - & - & - & - & - \\
\hline 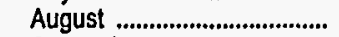 & W & - & - & - & - & - \\
\hline September .............................. & $w$ & - & - & - & - & - \\
\hline 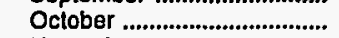 & - & - & - & - & - & - \\
\hline 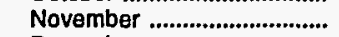 & w & - & - & - & - & - \\
\hline December ................................ & - & - & - & - & - & - \\
\hline 1994 Average .......................... & $w$ & - & - & - & - & $w$ \\
\hline
\end{tabular}

See footnotes at end of table. 
Table 36. Refiner Prices of Aviation Fuels and Kerosene by PAD District and State (Cents per Gallon Excluding Taxes) - Continued

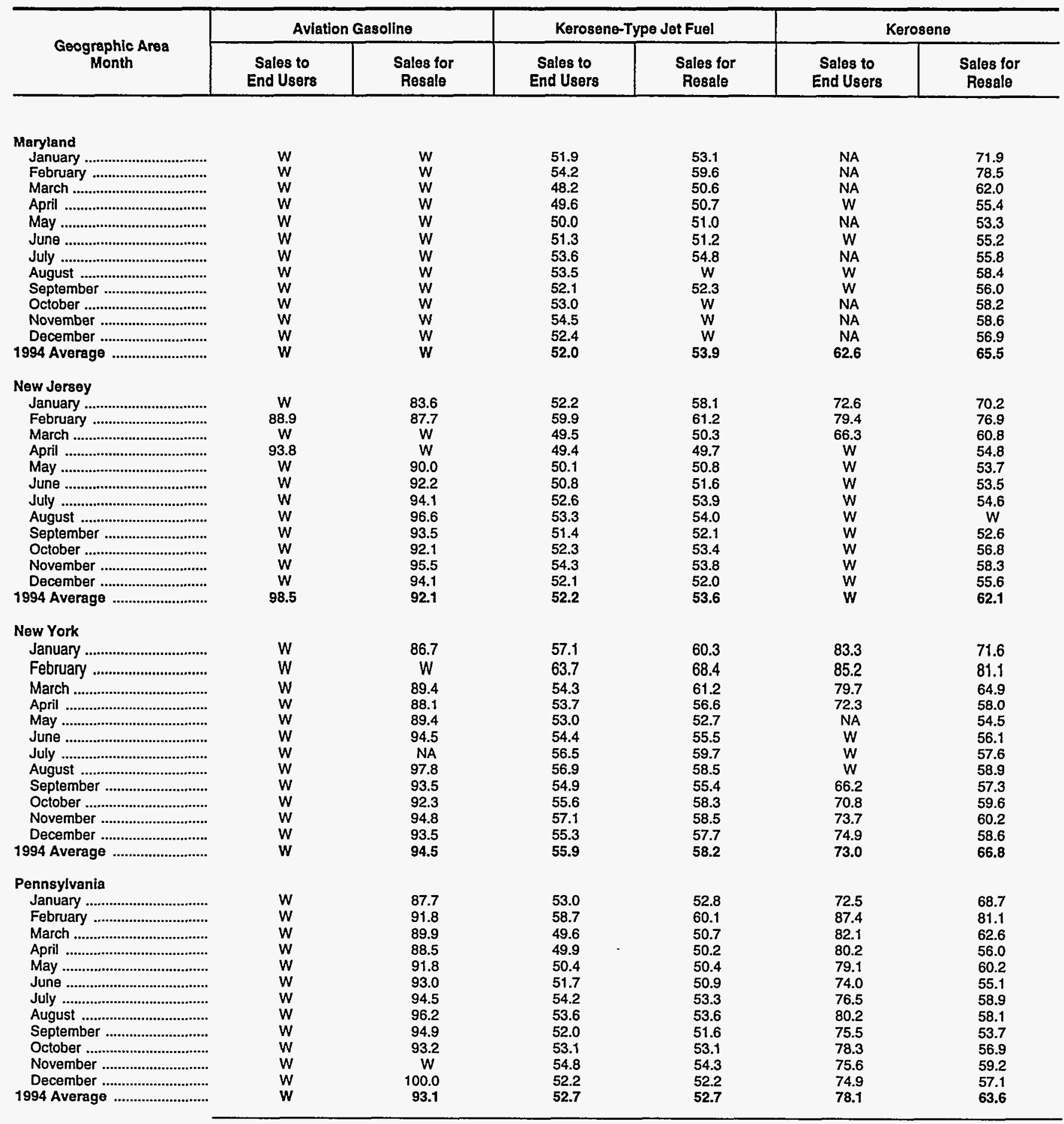

See footnotes at end of table. 
Table 36. Refiner Prices of Aviation Fuels and Kerosene by PAD District and State (Cents per Gallon Excluding Taxes) - Continued

\begin{tabular}{|c|c|c|c|c|c|c|}
\hline \multirow{2}{*}{$\begin{array}{l}\text { Geographic Area } \\
\text { Month }\end{array}$} & \multicolumn{2}{|c|}{ Aviation Gasoline } & \multicolumn{2}{|c|}{ Kerosene-Type Jet Fuel } & \multicolumn{2}{|c|}{ Kerosene } \\
\hline & $\begin{array}{l}\text { Sales to } \\
\text { End Users }\end{array}$ & $\begin{array}{l}\text { Sales for } \\
\text { Resale }\end{array}$ & $\begin{array}{l}\text { Sales to } \\
\text { End Users }\end{array}$ & $\begin{array}{l}\text { Sales for } \\
\text { Resale }\end{array}$ & $\begin{array}{l}\text { Sales to } \\
\text { End Users }\end{array}$ & $\begin{array}{c}\text { Sales for } \\
\text { Resale }\end{array}$ \\
\hline \multicolumn{7}{|l|}{ Subdiatrict IC } \\
\hline 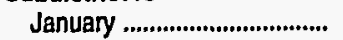 & 85.3 & 87.1 & 52.6 & 57.0 & 89.8 & 64.8 \\
\hline 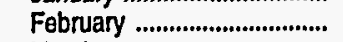 & 83.9 & 88.3 & 55.7 & 59.3 & 91.2 & 70.0 \\
\hline March ..................................... & 84.3 & 88.6 & 49.1 & 53.8 & 82.6 & 57.9 \\
\hline 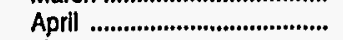 & 86.4 & 89.1 & 49.4 & 54.5 & 69.2 & 54.4 \\
\hline May ......................................... & 88.9 & 90.1 & 50.1 & 54.9 & 63.0 & 52.5 \\
\hline 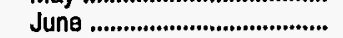 & 91.0 & 92.3 & 51.8 & 56.2 & 60.1 & 54.2 \\
\hline July ......................................... & 93.9 & 94.0 & 53.7 & 58.4 & 61.6 & 55.0 \\
\hline 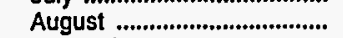 & 97.9 & 97.4 & 53.8 & 58.2 & 62.4 & 56.0 \\
\hline September ............................ & 97.8 & 94.3 & 52.2 & 56.9 & 64.3 & 55.7 \\
\hline 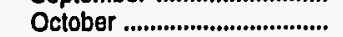 & 98.3 & 93.2 & 53.4 & 54.8 & 79.3 & 58.3 \\
\hline November ............................... & 99.4 & 92.8 & 55.1 & 55.8 & 83.0 & 59.6 \\
\hline 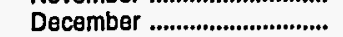 & 98.2 & 93.1 & 52.3 & 53.9 & 85.8 & 56.3 \\
\hline 1994 Average ............................. & 91.9 & 91.9 & 52.4 & 55.9 & 82.8 & 61.2 \\
\hline \multicolumn{7}{|l|}{ Florida } \\
\hline 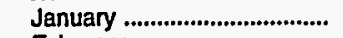 & 84.3 & 85.2 & 53.3 & 57.3 & NA & 64.8 \\
\hline 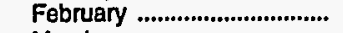 & 81.6 & 85.9 & 56.7 & 60.4 & NA & 69.6 \\
\hline March ....................................... & 81.1 & 85.9 & 49.6 & 53.8 & NA & 56.4 \\
\hline April & 83.5 & 86.4 & 50.0 & 53.9 & $w$ & 53.3 \\
\hline 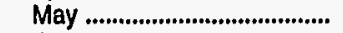 & 85.0 & 86.0 & 50.8 & 54.8 & $W$ & 52.4 \\
\hline June ........................................ & 87.0 & 88.3 & 52.2 & 56.0 & W & 54.2 \\
\hline 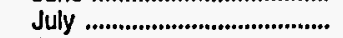 & 90.5 & 90.2 & 54.2 & 58.3 & $\ddot{w}$ & 54.8 \\
\hline 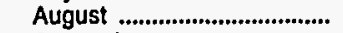 & 94.4 & 93.3 & 54.2 & 57.9 & W & 57.0 \\
\hline September ............................. & 95.2 & 91.6 & 52.9 & 56.4 & $\ddot{w}$ & 55.7 \\
\hline 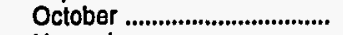 & 94.8 & 91.4 & 53.8 & 57.5 & $w$ & 57.9 \\
\hline 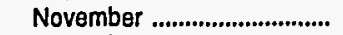 & 96.5 & 91.2 & 55.9 & 58.2 & NA & 59.3 \\
\hline 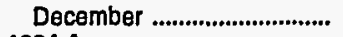 & 95.6 & 91.4 & 52.6 & 56.1 & NA & 56.9 \\
\hline 1994 Average .............................. & 88.6 & 88.9 & 53.0 & 56.6 & NA & 60.1 \\
\hline \multicolumn{7}{|l|}{ Georgia } \\
\hline 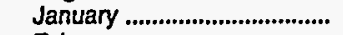 & 89.0 & w & 51.6 & 55.7 & NA & 65.4 \\
\hline 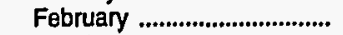 & 88.7 & $w$ & 54.2 & 55.9 & NA & 70.8 \\
\hline 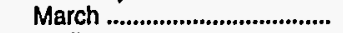 & 91.4 & W & 47.9 & 52.4 & NA & 55.1 \\
\hline April & 90.4 & 91.3 & 47.9 & 54.3 & NA & 52.3 \\
\hline 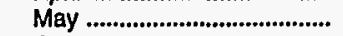 & 92.9 & 92.3 & 48.3 & 53.5 & NA & 52.2 \\
\hline June & 96.4 & w & 50.8 & 54.9 & $w$ & 54.6 \\
\hline 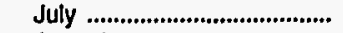 & 96.6 & 95.9 & 52.7 & 57.4 & $W$ & 55.3 \\
\hline 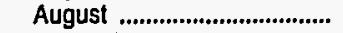 & 100.4 & 99.3 & 52.9 & 57.6 & $W$ & 55.3 \\
\hline September .............................. & 98.6 & 95.3 & 51.2 & 55.9 & $\mathrm{NA}$ & 54.9 \\
\hline 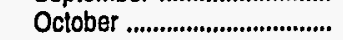 & 99.0 & 93.3 & 52.8 & 51.7 & NA & 58.3 \\
\hline November .............................. & 98.7 & $W$ & 53.9 & 53.6 & NA & 59.9 \\
\hline 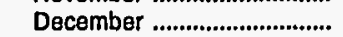 & 98.5 & 93.4 & 51.4 & 51.3 & NA & 55.8 \\
\hline 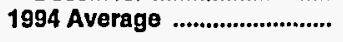 & 95.2 & 94.0 & 51.3 & $\mathbf{5 3 . 5}$ & NA & 60.9 \\
\hline \multicolumn{7}{|l|}{ North Carolina } \\
\hline 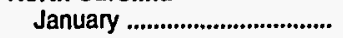 & $w$ & $w$ & 52.2 & 57.5 & NA & 64.4 \\
\hline February .................................. & 94.3 & W & 54.6 & 59.1 & NA & 68.2 \\
\hline March ....................................... & $W$ & W & 49.9 & 54.9 & NA & 56.0 \\
\hline 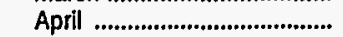 & W & $\ddot{w}$ & 49.5 & 56.0 & $w$ & 51.5 \\
\hline May ............................................ & 94.4 & $\dddot{w}$ & 50.4 & 56.2 & $w$ & 50.5 \\
\hline 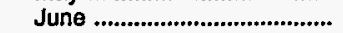 & $w$ & w & 52.0 & 57.2 & $w$ & 53.3 \\
\hline 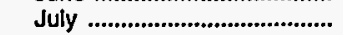 & 102.3 & $\ddot{w}$ & 53.7 & 59.1 & $\ddot{w}$ & 54.5 \\
\hline 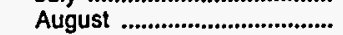 & 103.2 & W & 54.0 & 58.5 & $\ddot{w}$ & 55.2 \\
\hline 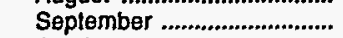 & 102.8 & w & 52.4 & 58.1 & $\ddot{w}$ & 55.3 \\
\hline 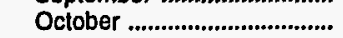 & 103.3 & w & 53.4 & 58.0 & NA & 57.9 \\
\hline November ............................... & $W$ & W & 54.4 & 59.3 & NA & 58.9 \\
\hline December ............................... & W & w & 52.3 & 56.4 & NA & 55.6 \\
\hline 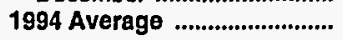 & $w$ & $w$ & 52.3 & 57.6 & NA & 60.4 \\
\hline
\end{tabular}

See footnotes at end of table. 
Table 36. Refiner Prices of Aviation Fuels and Kerosene by PAD District and State (Cents per Gallon Excluding Taxes) - Continued

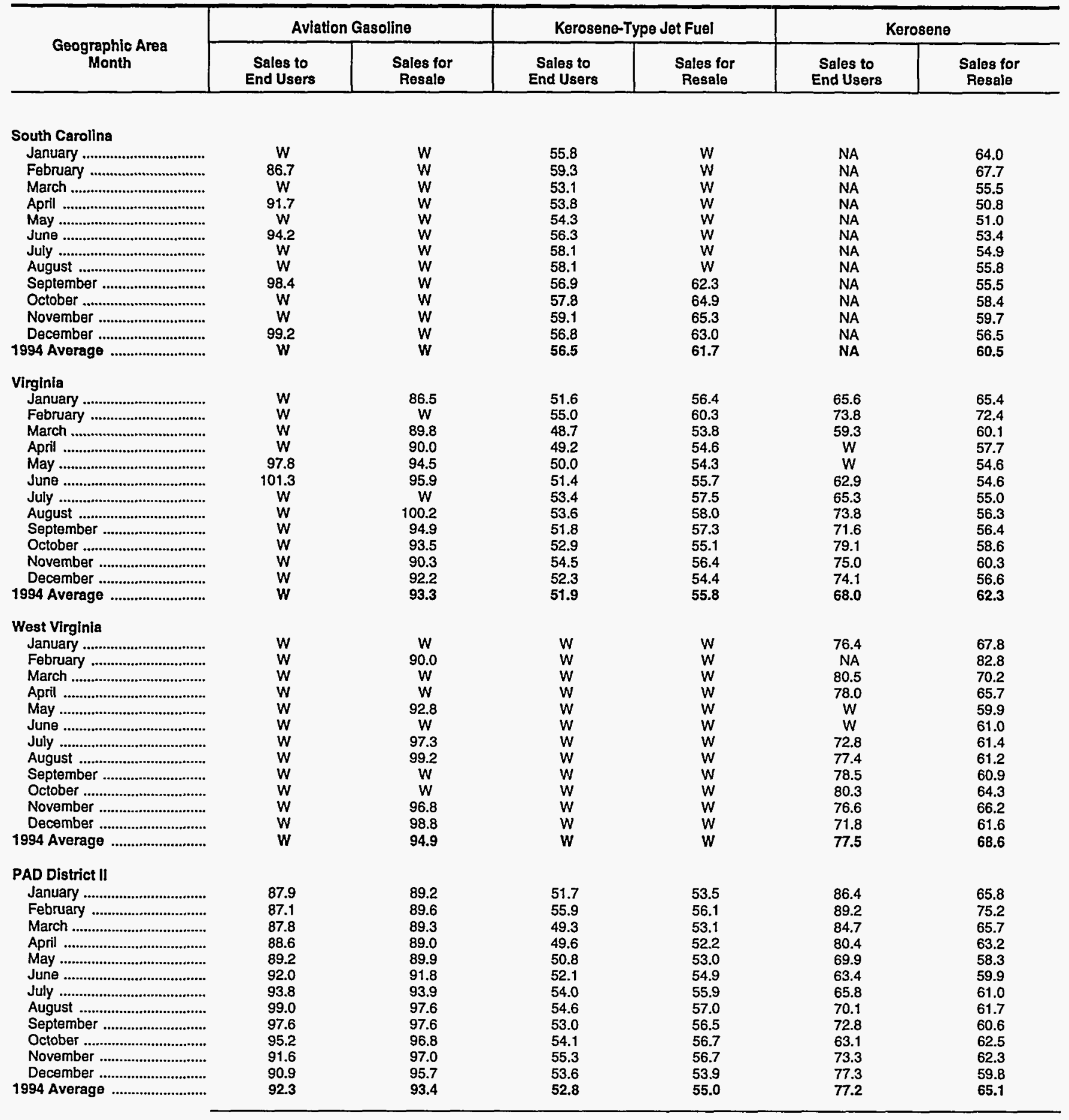

See footnotes at end of table. 
Table 36. Refiner Prices of Aviation Fuels and Kerosene by PAD District and State (Cents per Gallon Excluding Taxes) - Continued

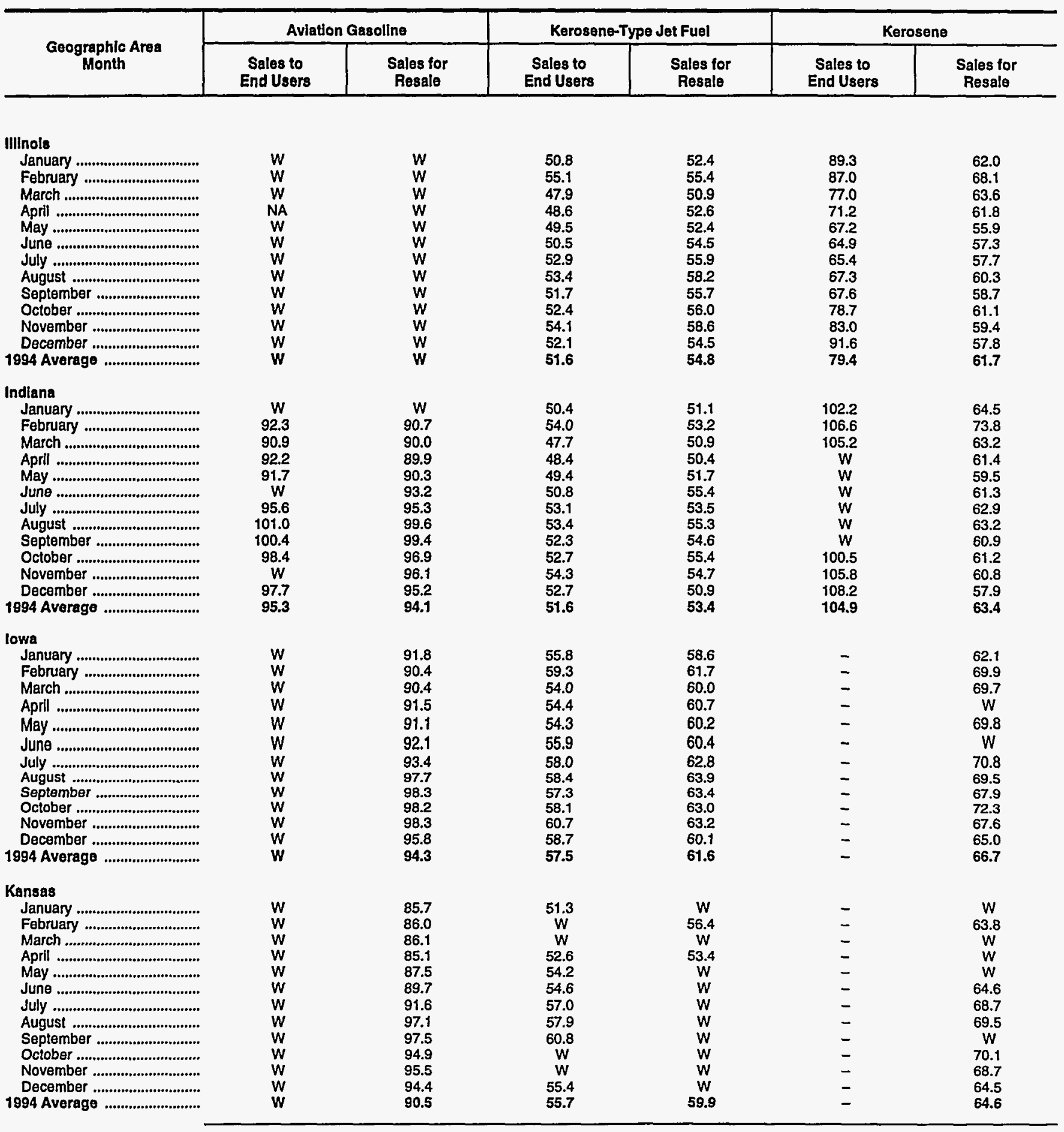

See foolnotes at end of table. 
Table 36. Refiner Prices of Aviation Fuels and Kerosene by PAD District and State (Cents per Gallon Excluding Taxes) - Continued

\begin{tabular}{|c|c|c|c|c|c|c|}
\hline \multirow{2}{*}{$\begin{array}{l}\text { Geographic Area } \\
\text { Month }\end{array}$} & \multicolumn{2}{|c|}{ Aviation Gasoline } & \multicolumn{2}{|c|}{ Kerosene-Type Jet Fuel } & \multicolumn{2}{|c|}{ Keroseno } \\
\hline & $\begin{array}{l}\text { Sales to } \\
\text { End Users }\end{array}$ & $\begin{array}{l}\text { Sales for } \\
\text { Resale }\end{array}$ & $\begin{array}{l}\text { Sales to } \\
\text { End Users }\end{array}$ & $\begin{array}{l}\text { Sales for } \\
\text { Resale }\end{array}$ & $\begin{array}{l}\text { Sales to } \\
\text { End Users }\end{array}$ & $\begin{array}{c}\text { Sales for } \\
\text { Resale }\end{array}$ \\
\hline \multicolumn{7}{|l|}{ Kentucky } \\
\hline 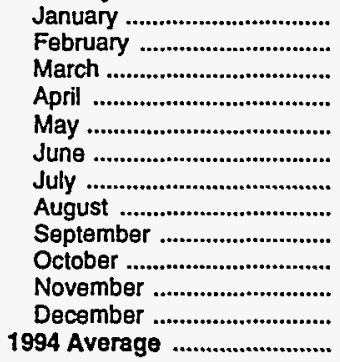 & $\begin{array}{r}W \\
W \\
92.8 \\
91.9 \\
92.4 \\
97.1 \\
96.1 \\
101.5 \\
101.5 \\
100.1 \\
W \\
101.2 \\
96.3\end{array}$ & $\begin{array}{l}85.1 \\
W \\
W \\
W \\
89.6 \\
90.1 \\
92.0 \\
W \\
92.3 \\
W \\
W \\
W \\
91.2\end{array}$ & $\begin{array}{l}54.7 \\
\mathbf{5 8 . 5} \\
\mathbf{5 1 . 7} \\
52.3 \\
53.4 \\
53.8 \\
\mathbf{5 7 . 7} \\
56.5 \\
\mathbf{5 6 . 5} \\
\mathbf{5 7 . 5} \\
\mathbf{5 7 . 3} \\
\mathbf{5 4 . 5} \\
\mathbf{5 5 . 2}\end{array}$ & $\begin{array}{l}52.5 \\
56.9 \\
55.9 \\
50.7 \\
53.3 \\
54.8 \\
54.9 \\
57.1 \\
54.4 \\
54.3 \\
53.5 \\
51.4 \\
53.4\end{array}$ & $\begin{array}{l}79.9 \\
81.6 \\
78.6 \\
84.5 \\
87.4 \\
W \\
W \\
90.7 \\
W \\
W \\
N A \\
78.1 \\
81.0\end{array}$ & $\begin{array}{l}67.3 \\
79.3 \\
69.5 \\
65.4 \\
59.3 \\
59.8 \\
60.8 \\
61.4 \\
61.1 \\
63.6 \\
66.1 \\
60.9 \\
67.4\end{array}$ \\
\hline \multicolumn{7}{|l|}{ Michigan } \\
\hline 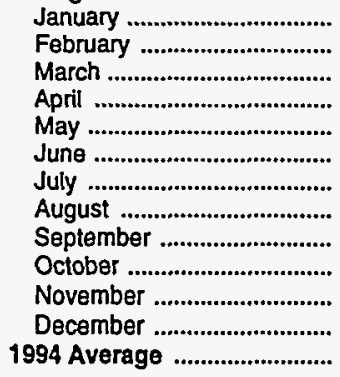 & $\begin{array}{l}W \\
W \\
W \\
W \\
W \\
W \\
W \\
W \\
W \\
W \\
W \\
W \\
W\end{array}$ & $\begin{array}{l}W \\
W \\
W \\
W \\
W \\
W \\
W \\
W \\
W \\
W \\
W \\
W \\
W\end{array}$ & $\begin{array}{l}51.7 \\
56.5 \\
49.0 \\
49.6 \\
50.7 \\
52.0 \\
54.3 \\
55.1 \\
53.2 \\
54.1 \\
55.0 \\
53.6 \\
52.8\end{array}$ & $\begin{array}{l}54.5 \\
57.2 \\
50.9 \\
51.7 \\
52.4 \\
54.5 \\
56.5 \\
56.3 \\
54.7 \\
55.4 \\
56.4 \\
54.6 \\
54.4\end{array}$ & $\begin{array}{r}109.8 \\
116.9 \\
121.4 \\
117.5 \\
118.7 \\
\text { NA } \\
\text { NA } \\
\text { NA } \\
\text { NA } \\
\text { NA } \\
118.6 \\
117.6 \\
114.4\end{array}$ & $\begin{array}{l}68.0 \\
78.4 \\
69.2 \\
65.8 \\
61.9 \\
60.7 \\
61.6 \\
62.6 \\
63.1 \\
63.5 \\
60.1 \\
61.2 \\
66.3\end{array}$ \\
\hline \multicolumn{7}{|l|}{ Minnesota } \\
\hline 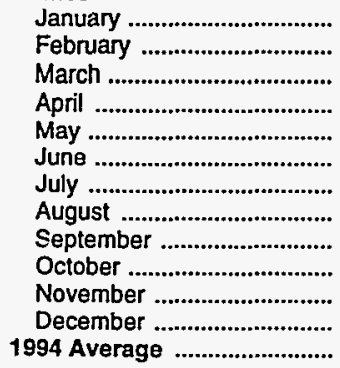 & $\begin{array}{l}w \\
W \\
W \\
W \\
W \\
W \\
W \\
W \\
W \\
W \\
W \\
W \\
w\end{array}$ & $\begin{array}{c}W \\
89.8 \\
89.4 \\
88.9 \\
88.8 \\
90.3 \\
92.9 \\
96.7 \\
98.0 \\
97.6 \\
97.9 \\
96.8 \\
93.1\end{array}$ & $\begin{array}{l}51.2 \\
56.1 \\
49.5 \\
48.1 \\
51.5 \\
53.1 \\
54.7 \\
56.1 \\
54.2 \\
56.3 \\
55.4 \\
54.2 \\
53.4\end{array}$ & $\begin{array}{l}56.0 \\
56.8 \\
51.5 \\
52.2 \\
53.9 \\
55.4 \\
56.1 \\
57.5 \\
55.4 \\
56.8 \\
57.4 \\
53.4 \\
54.9\end{array}$ & $\begin{array}{l}W \\
W \\
W \\
W \\
W \\
W \\
W \\
W \\
W \\
W \\
W \\
W \\
W\end{array}$ & $\begin{array}{l}60.9 \\
66.2 \\
65.1 \\
65.1 \\
64.0 \\
68.1 \\
68.7 \\
69.5 \\
67.2 \\
65.4 \\
67.8 \\
64.0 \\
64.6\end{array}$ \\
\hline \multicolumn{7}{|l|}{ Missouri } \\
\hline 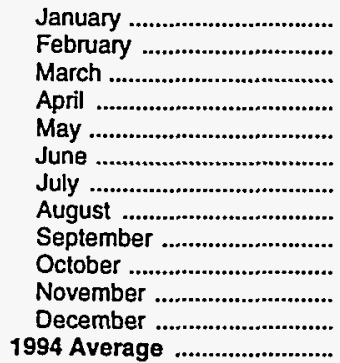 & $\begin{array}{l}W \\
W \\
W \\
W \\
W \\
W \\
W \\
W \\
W \\
W \\
W \\
W \\
W\end{array}$ & $\begin{array}{l}89.8 \\
89.6 \\
90.1 \\
88.6 \\
91.1 \\
92.2 \\
92.9 \\
97.3 \\
97.6 \\
97.2 \\
96.4 \\
95.4 \\
93.5\end{array}$ & $\begin{array}{l}51.5 \\
55.5 \\
49.3 \\
50.4 \\
50.9 \\
52.9 \\
54.4 \\
54.8 \\
53.2 \\
54.2 \\
55.9 \\
53.7 \\
53.2\end{array}$ & $\begin{array}{l}55.0 \\
57.7 \\
55.0 \\
54.7 \\
55.9 \\
57.6 \\
61.0 \\
61.5 \\
60.4 \\
61.2 \\
62.8 \\
60.0 \\
58.2\end{array}$ & $\begin{array}{l}58.1 \\
W \\
W \\
- \\
- \\
- \\
\bar{w} \\
\bar{w} \\
W \\
W \\
W\end{array}$ & $\begin{array}{l}61.5 \\
65.6 \\
65.0 \\
62.2 \\
60.7 \\
58.3 \\
64.0 \\
63.6 \\
61.9 \\
63.2 \\
62.3 \\
59.0 \\
62.2\end{array}$ \\
\hline
\end{tabular}

See footnotes at end of table. 
Table 36. Refiner Prices of Aviation Fuels and Kerosene by PAD District and State (Cents per Gallon Excluding Taxes) - Continued

\begin{tabular}{|c|c|c|c|c|c|c|}
\hline \multirow{2}{*}{$\begin{array}{l}\text { Geographic Area } \\
\text { Month }\end{array}$} & \multicolumn{2}{|c|}{ Avlation Gasoline } & \multicolumn{2}{|c|}{ Kerosene-Type Jet Fuel } & \multicolumn{2}{|c|}{ Kerosene } \\
\hline & $\begin{array}{l}\text { Sales to } \\
\text { End Users }\end{array}$ & $\begin{array}{c}\text { Sales for } \\
\text { Resale }\end{array}$ & $\begin{array}{l}\text { Sales to } \\
\text { End Users }\end{array}$ & $\begin{array}{c}\text { Sales for } \\
\text { Resale }\end{array}$ & $\begin{array}{l}\text { Sales to } \\
\text { End Users }\end{array}$ & $\begin{array}{c}\text { Sales for } \\
\text { Resale }\end{array}$ \\
\hline \multicolumn{7}{|l|}{ Nebraska } \\
\hline January ................................. & $W$ & 88.5 & 53.8 & 58.9 & - & 60.9 \\
\hline February ............................. & W & $W$ & 56.6 & 60.9 & - & 64.4 \\
\hline March ...................................... & W & 89.4 & 50.5 & 57.3 & - & $w$ \\
\hline 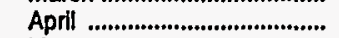 & W & $w$ & 51.4 & 58.8 & - & $w$ \\
\hline May ....................................... & $W$ & 90.4 & 52.0 & 59.0 & - & $w$ \\
\hline 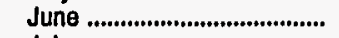 & $W$ & $w$ & 53.5 & 58.7 & - & - \\
\hline July ......................................... & $W$ & 94.9 & 54.5 & 64.2 & - & $w$ \\
\hline 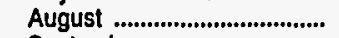 & W & 97.8 & 55.5 & 65.8 & - & 72.9 \\
\hline September ............................ & W & $w$ & 53.7 & 65.5 & - & $W$ \\
\hline 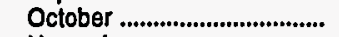 & W & $W$ & 54.8 & 64.4 & - & 72.1 \\
\hline November .............................. & W & $W$ & 56.1 & 63.2 & - & $w$ \\
\hline December .............................. & W & 94.1 & 53.6 & 60.9 & - & 67.2 \\
\hline 1994 Average ............................. & w & 94.1 & 53.9 & 61.3 & - & 66.5 \\
\hline \multicolumn{7}{|l|}{ North Dakota } \\
\hline January ................................... & W & $w$ & 61.2 & 68.1 & $w$ & $w$ \\
\hline 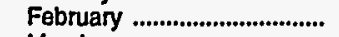 & $W$ & $w$ & 63.5 & 70.3 & NA & 70.8 \\
\hline March ....................................... & 91.5 & $w$ & 58.9 & 67.3 & - & $w$ \\
\hline 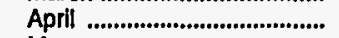 & 82.8 & 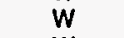 & 60.7 & 64.9 & - & $w$ \\
\hline May ........................................ & 85.7 & $w$ & 60.9 & 65.2 & $W$ & - \\
\hline June ........................................ & 87.6 & $w$ & 61.1 & 69.1 & - & $w$ \\
\hline July ........................................ & 86.6 & $w$ & 62.8 & 68.2 & $\rightarrow$ & $w$ \\
\hline August ................................ & NA & W & 62.9 & 69.0 & $w$ & $\ddot{w}$ \\
\hline 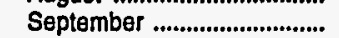 & 85.3 & w & 62.4 & 68.7 & - & $w$ \\
\hline October & $W$ & $w$ & 62.2 & 67.0 & $w$ & $W$ \\
\hline November ............................. & $\ddot{W}$ & $w$ & 63.8 & 67.9 & $w$ & 69.7 \\
\hline December ................................ & $w$ & w & 59.1 & 68.7 & - & $w$ \\
\hline 1994 Average ............................ & 87.9 & $\mathbf{w}$ & 61.7 & 68.0 & $\mathbf{w}$ & 68.7 \\
\hline \multicolumn{7}{|l|}{ Ohio } \\
\hline 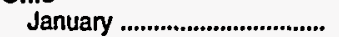 & $w$ & 90.9 & 53.5 & 55.8 & 84.3 & 67.7 \\
\hline 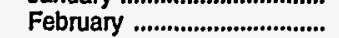 & $\ddot{w}$ & 91.7 & 56.3 & 56.7 & 87.2 & 79.5 \\
\hline March ...................................... & $w$ & 89.5 & 50.3 & NA & 83.0 & 67.3 \\
\hline 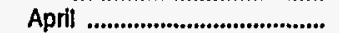 & $w$ & 90.6 & 51.2 & 52.5 & 75.4 & 64.5 \\
\hline May ......................................... & $w$ & 91.6 & 52.4 & 54.5 & 65.7 & 59.8 \\
\hline June ........................................ & w & 93.7 & 54.7 & 55.0 & 61.0 & 60.4 \\
\hline 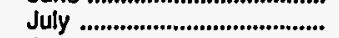 & $\ddot{w}$ & 94.8 & 55.6 & 55.7 & 63.4 & 61.4 \\
\hline 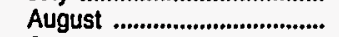 & w & 95.7 & 55.7 & 55.8 & 68.9 & 62.2 \\
\hline September ............................. & W & 95.9 & 54.6 & 56.6 & 70.8 & 60.4 \\
\hline October & $\ddot{W}$ & 96.0 & 55.4 & 57.6 & 80.0 & 63.3 \\
\hline November ............................ & 102.3 & 97.0 & 57.0 & 58.7 & 84.3 & 63.4 \\
\hline December ......................... & W & 99.8 & 54.9 & 56.9 & 87.3 & 61.4 \\
\hline 1994 Average .......................... & $\mathbf{W}$ & 94.4 & 54.3 & 55.6 & 79.6 & 67.0 \\
\hline \multicolumn{7}{|l|}{ Oklahoma } \\
\hline 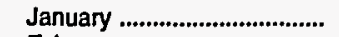 & $w$ & 85.4 & 50.4 & 50.4 & $w$ & $w$ \\
\hline February .............................. & $W$ & 84.0 & 54.6 & 55.2 & w & 59.2 \\
\hline March ..................................... & W & 84.6 & 47.8 & 53.8 & - & $W$ \\
\hline 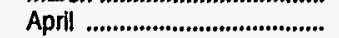 & $\ddot{w}$ & 84.6 & 48.5 & 50.1 & $w$ & $w$ \\
\hline May ....................................... & $w$ & 85.7 & 49.1 & 49.3 & W & - \\
\hline June & $w$ & 87.1 & 50.7 & 51.5 & $w$ & $\bar{W}$ \\
\hline 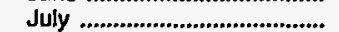 & $W$ & 89.5 & 52.6 & 54.8 & $w$ & $w$ \\
\hline 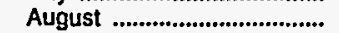 & $W$ & 93.7 & 53.6 & 55.9 & $\ddot{w}$ & $w$ \\
\hline 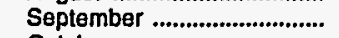 & $w$ & 93.5 & 51.7 & 60.2 & w & $w$ \\
\hline 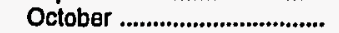 & W & 93.9 & 53.8 & 55.4 & $w$ & 63.9 \\
\hline November ............................ & W & 93.3 & 55.5 & 54.8 & - & 63.7 \\
\hline December .............................. & $W$ & 89.9 & 54.2 & 56.1 & W & $w$ \\
\hline 1994 Average ......................... & $\mathbf{w}$ & 88.7 & 51.9 & 53.3 & $w$ & 61.1 \\
\hline
\end{tabular}

See footnotes at end of table. 
Table 36. Refiner Prices of Aviation Fuels and Kerosene by PAD District and State (Cents per Gallon Excluding Taxes) - Continued

\begin{tabular}{|c|c|c|c|c|c|c|}
\hline \multirow{2}{*}{$\begin{array}{c}\text { Geographic Area } \\
\text { Month }\end{array}$} & \multicolumn{2}{|c|}{ Avlation Gasoline } & \multicolumn{2}{|c|}{ Kerosene-Type Jet Fuel } & \multicolumn{2}{|c|}{ Kerosene } \\
\hline & $\begin{array}{l}\text { Sales to } \\
\text { End Users }\end{array}$ & $\begin{array}{c}\text { Sales for } \\
\text { Resale }\end{array}$ & $\begin{array}{l}\text { Sales to } \\
\text { End Users }\end{array}$ & $\begin{array}{c}\text { Sales for } \\
\text { Resale }\end{array}$ & $\begin{array}{l}\text { Sales to } \\
\text { End Users }\end{array}$ & $\begin{array}{c}\text { Sales for } \\
\text { Resale }\end{array}$ \\
\hline \multicolumn{7}{|l|}{ South Dakota } \\
\hline January ................................... & $w$ & $W$ & 60.1 & $w$ & - & 62.0 \\
\hline 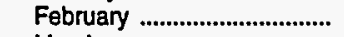 & $W$ & $W$ & 63.7 & $W$ & - & 66.9 \\
\hline 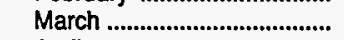 & $\ddot{w}$ & $\ddot{W}$ & 60.2 & $w$ & - & $W$ \\
\hline April & $W$ & $W$ & 60.9 & $\ddot{W}$ & - & $w$ \\
\hline 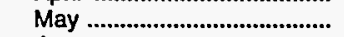 & $\ddot{w}$ & W & 60.2 & $w$ & - & $w$ \\
\hline 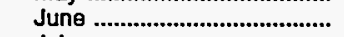 & $\ddot{w}$ & $\ddot{w}$ & 60.1 & $w$ & - & - \\
\hline July & $W$ & $W$ & 62.5 & $w$ & - & $\bar{W}$ \\
\hline 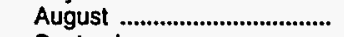 & W & $W$ & 64.6 & w & - & $w$ \\
\hline September ............................. & $W$ & $W$ & 62.4 & $w$ & - & 68.4 \\
\hline 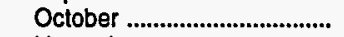 & $W$ & $W$ & 63.1 & $w$ & - & 74.6 \\
\hline November ............................... & $W$ & $W$ & 61.7 & W & - & 73.2 \\
\hline 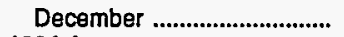 & $W$ & $W$ & 61.4 & $\ddot{W}$ & - & 66.2 \\
\hline 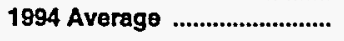 & $\mathbf{w}$ & $\mathbf{w}$ & 61.8 & $w$ & - & 67.4 \\
\hline \multicolumn{7}{|l|}{ Tennessee } \\
\hline 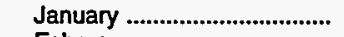 & 87.0 & 89.5 & 52.9 & 57.6 & 80.5 & 64.5 \\
\hline 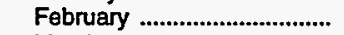 & 88.4 & 90.8 & 58.0 & 60.2 & 82.6 & 70.2 \\
\hline 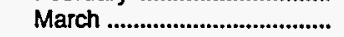 & 89.1 & 90.3 & 52.7 & 55.3 & 81.5 & 58.8 \\
\hline 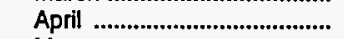 & 91.0 & 88.7 & 51.1 & 53.2 & 73.0 & 56.4 \\
\hline 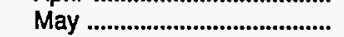 & 91.3 & 89.6 & 51.6 & 56.0 & $W$ & 56.6 \\
\hline June ........................................ & 94.3 & 92.0 & 51.3 & $\mathbf{5 7 . 8}$ & $\ddot{W}$ & 55.9 \\
\hline July & 96.2 & 92.7 & 53.1 & 58.7 & $\ddot{w}$ & 56.7 \\
\hline 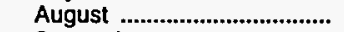 & 99.8 & 95.4 & 53.2 & 59.9 & W & 57.2 \\
\hline September .............................. & 98.9 & 95.5 & 51.9 & 58.2 & $W$ & 55.2 \\
\hline October & 98.9 & 94.6 & 52.9 & 58.6 & 73.4 & 60.1 \\
\hline 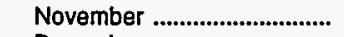 & W & 95.5 & 53.8 & 60.5 & 81.5 & 61.3 \\
\hline 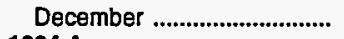 & 98.6 & 95.0 & 52.9 & 57.9 & 85.6 & 56.7 \\
\hline 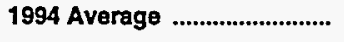 & 94.5 & 92.6 & 52.9 & 57.5 & 77.8 & 62.0 \\
\hline \multicolumn{7}{|l|}{ Wisconsin } \\
\hline 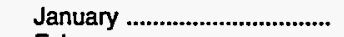 & $w$ & $w$ & 52.1 & 53.8 & W & 62.7 \\
\hline February ................................... & $W$ & 90.0 & 56.5 & 59.2 & $W$ & 68.8 \\
\hline 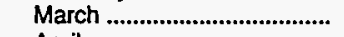 & $W$ & 90.4 & 49.6 & 53.6 & $W$ & 65.1 \\
\hline April & $W$ & 90.1 & 51.9 & 51.5 & W & 66.3 \\
\hline May & - & 90.5 & 51.4 & 52.3 & W & $w$ \\
\hline 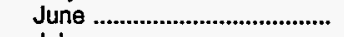 & - & 92.8 & 53.6 & 54.0 & $W$ & 64.9 \\
\hline July & $W$ & 95.8 & 55.8 & 56.4 & w & 67.3 \\
\hline 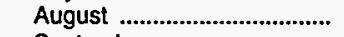 & $W$ & 100.2 & 55.5 & NA & $W$ & 69.7 \\
\hline 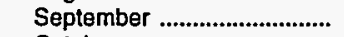 & - & 99.6 & 54.6 & 57.6 & W & 66.4 \\
\hline 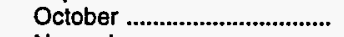 & $w$ & 99.5 & 55.5 & 56.2 & W & 67.5 \\
\hline 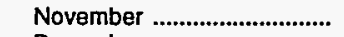 & - & 99.4 & 57.0 & 58.1 & W & 65.4 \\
\hline 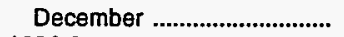 & - & 97.4 & 54.5 & 55.1 & $\ddot{W}$ & 61.4 \\
\hline 1994 Average & $\mathbf{w}$ & 95.3 & 53.8 & 55.2 & $W$ & 61.3 \\
\hline \multicolumn{7}{|l|}{ PAD District III } \\
\hline 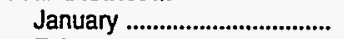 & 80.8 & 74.9 & 50.0 & 51.4 & 78.3 & 55.9 \\
\hline 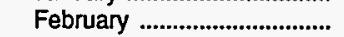 & 82.7 & 76.6 & 52.9 & 54.5 & 82.2 & 57.0 \\
\hline 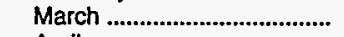 & 84.3 & 76.1 & 47.6 & 47.6 & 75.9 & 48.4 \\
\hline April & 87.3 & 80.4 & 47.6 & 48.8 & 66.0 & 48.7 \\
\hline 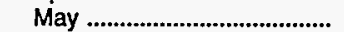 & 87.7 & 82.1 & 48.2 & 48.8 & W & 48.5 \\
\hline June & 90.5 & 83.5 & 49.9 & 49.7 & w & 49.7 \\
\hline July & 91.8 & 86.2 & 51.2 & 52.4 & 67.3 & 51.3 \\
\hline 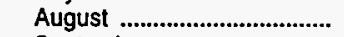 & 96.6 & 90.3 & 52.2 & 52.1 & $w$ & 51.3 \\
\hline 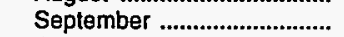 & 96.0 & 88.2 & 51.6 & 50.9 & W & 50.1 \\
\hline 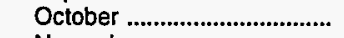 & 95.7 & 86.1 & 51.3 & 51.5 & W & 53.8 \\
\hline 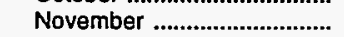 & 97.8 & 86.5 & 53.6 & 53.6 & $\ddot{w}$ & 54.6 \\
\hline 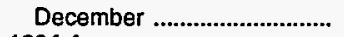 & 96.5 & 85.3 & 51.1 & 51.1 & $\ddot{W}$ & 52.5 \\
\hline 1994 Average .............................. & 90.9 & 83.3 & 50.6 & 51.1 & $\ddot{w}$ & 51.9 \\
\hline
\end{tabular}

See footnotes at end of table. 
Table 36. Refiner Prices of Aviation Fuels and Kerosene by PAD District and State (Cents per Gallon Excluding Taxes) - Continued

\begin{tabular}{|c|c|c|c|c|c|c|}
\hline \multirow{2}{*}{$\begin{array}{c}\text { Goographic Area } \\
\text { Month }\end{array}$} & \multicolumn{2}{|c|}{ Aviation Gasoline } & \multicolumn{2}{|c|}{ Kerosene-Type Jet Fuel } & \multicolumn{2}{|c|}{ Kerosene } \\
\hline & $\begin{array}{c}\text { Sales to } \\
\text { End Users }\end{array}$ & $\begin{array}{c}\text { Sales tor } \\
\text { Resale }\end{array}$ & $\begin{array}{l}\text { Sales to } \\
\text { End Users }\end{array}$ & $\begin{array}{l}\text { Sales for } \\
\text { Resale }\end{array}$ & $\begin{array}{l}\text { Sales to } \\
\text { End Users }\end{array}$ & $\begin{array}{c}\text { Sales for } \\
\text { Resale }\end{array}$ \\
\hline \multicolumn{7}{|l|}{ Alabama } \\
\hline 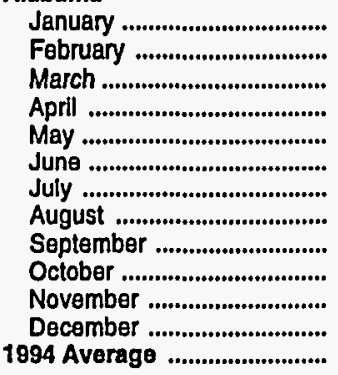 & $\begin{array}{c}83.3 \\
85.0 \\
88.6 \\
W \\
89.8 \\
93.1 \\
95.9 \\
99.1 \\
96.9 \\
97.2 \\
98.2 \\
98.2 \\
93.4\end{array}$ & $\begin{array}{l}90.6 \\
90.0 \\
89.3 \\
89.6 \\
90.3 \\
92.6 \\
92.2 \\
97.1 \\
94.8 \\
92.9 \\
93.9 \\
94.2 \\
92.2\end{array}$ & $\begin{array}{l}\mathbf{5 6 . 0} \\
\mathbf{5 8 . 9} \\
\mathbf{5 3 . 0} \\
\mathbf{5 3 . 4} \\
\mathbf{5 3 . 9} \\
\mathbf{5 5 . 4} \\
\mathbf{5 6 . 5} \\
\mathbf{5 6 . 7} \\
\mathbf{5 4 . 7} \\
\mathbf{5 5 . 5} \\
\mathbf{5 7 . 2} \\
\mathbf{5 4 . 8} \\
\mathbf{5 5 . 5}\end{array}$ & $\begin{array}{l}57.1 \\
61.0 \\
53.8 \\
53.3 \\
54.0 \\
53.5 \\
57.8 \\
59.1 \\
57.5 \\
59.1 \\
60.1 \\
57.1 \\
55.9\end{array}$ & $\begin{array}{l}\text { NA } \\
\text { NA } \\
\text { NA } \\
W \\
W \\
W \\
W \\
W \\
W \\
W \\
W \\
\text { NA } \\
\text { NA }\end{array}$ & $\begin{array}{l}69.5 \\
68.3 \\
58.3 \\
55.2 \\
54.8 \\
57.5 \\
60.9 \\
58.6 \\
59.2 \\
61.3 \\
60.3 \\
55.9 \\
62.9\end{array}$ \\
\hline \multicolumn{7}{|l|}{ Arkansas } \\
\hline 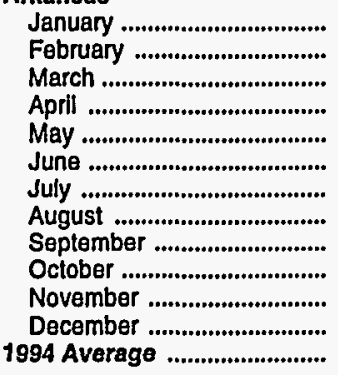 & $\begin{array}{l}W \\
W \\
W \\
W \\
W \\
W \\
W \\
W \\
W \\
W \\
W \\
W \\
W\end{array}$ & $\begin{array}{l}82.9 \\
W \\
W \\
W \\
W \\
W \\
W \\
W \\
92.8 \\
W \\
94.3 \\
W \\
W\end{array}$ & $\begin{array}{l}56.7 \\
58.7 \\
53.3 \\
53.9 \\
53.5 \\
55.8 \\
57.4 \\
58.7 \\
58.3 \\
57.4 \\
60.4 \\
59.4 \\
58.1\end{array}$ & $\begin{array}{l}57.1 \\
60.0 \\
55.7 \\
56.4 \\
54.7 \\
57.2 \\
58.6 \\
58.8 \\
55.6 \\
59.8 \\
60.8 \\
55.4 \\
57.0\end{array}$ & $\begin{array}{l}W \\
W \\
W \\
- \\
- \\
- \\
- \\
- \\
\bar{w} \\
\bar{w}\end{array}$ & $\begin{array}{c}58.3 \\
W \\
59.2 \\
W \\
51.8 \\
51.9 \\
53.2 \\
52.9 \\
51.5 \\
47.7 \\
49.5 \\
51.6 \\
52.1\end{array}$ \\
\hline \multicolumn{7}{|l|}{ Louigiana } \\
\hline 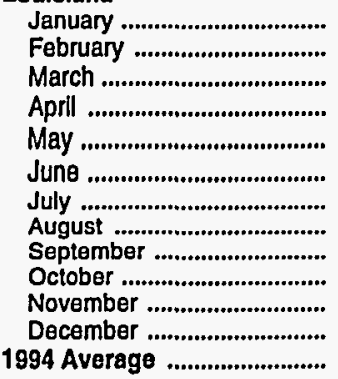 & $\begin{array}{l}W \\
W \\
W \\
W \\
W \\
W \\
W \\
W \\
W \\
W \\
97.1 \\
96.1 \\
W\end{array}$ & $\begin{array}{l}78.9 \\
81.8 \\
82.2 \\
86.4 \\
83.4 \\
85.0 \\
91.2 \\
92.4 \\
91.9 \\
93.2 \\
94.2 \\
93.2 \\
88.2\end{array}$ & $\begin{array}{l}49.7 \\
53.6 \\
49.0 \\
46.7 \\
49.1 \\
50.6 \\
50.5 \\
52.7 \\
52.0 \\
50.8 \\
54.8 \\
52.4 \\
50.9\end{array}$ & $\begin{array}{l}50.9 \\
55.1 \\
47.5 \\
49.7 \\
49.5 \\
50.0 \\
52.1 \\
52.5 \\
51.8 \\
50.9 \\
54.6 \\
52.5 \\
51.4\end{array}$ & $\begin{array}{l}W \\
W \\
W \\
W \\
W \\
W \\
W \\
W \\
W \\
W \\
W \\
W \\
W\end{array}$ & $\begin{array}{c}53.4 \\
48.7 \\
47.4 \\
47.6 \\
W \\
W \\
W \\
49.9 \\
W \\
51.6 \\
57.7 \\
49.8 \\
49.7\end{array}$ \\
\hline \multicolumn{7}{|l|}{ Mississippl } \\
\hline 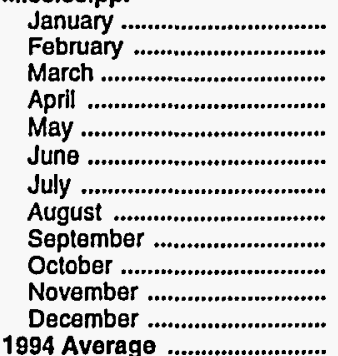 & $\begin{array}{l}W \\
W \\
W \\
W \\
W \\
W \\
W \\
W \\
W \\
W \\
W \\
W \\
W\end{array}$ & $\begin{array}{l}86.2 \\
87.9 \\
86.9 \\
86.8 \\
88.0 \\
89.8 \\
91.9 \\
95.6 \\
94.5 \\
87.0 \\
W \\
92.7 \\
90.6\end{array}$ & $\begin{array}{l}47.7 \\
53.4 \\
46.4 \\
47.7 \\
47.6 \\
49.2 \\
50.6 \\
51.2 \\
50.7 \\
50.7 \\
53.0 \\
50.4 \\
50.0\end{array}$ & $\begin{array}{c}W \\
56.9 \\
56.7 \\
W \\
W \\
48.8 \\
51.4 \\
51.7 \\
48.7 \\
W \\
52.1 \\
49.9 \\
50.9\end{array}$ & $\begin{array}{l}W \\
W \\
W \\
W \\
W \\
W \\
W \\
W \\
W \\
W \\
W \\
W \\
W\end{array}$ & $\begin{array}{l}W \\
W \\
W \\
64.0 \\
W \\
W \\
W \\
W \\
48.1 \\
W \\
63.1 \\
W \\
W\end{array}$ \\
\hline
\end{tabular}

See footnotes at end of table. 
Table 36. Refiner Prices of Aviation Fuels and Kerosene by PAD District and State (Cents per Gallon Excluding Taxes) - Continued

\begin{tabular}{|c|c|c|c|c|c|c|}
\hline \multirow{2}{*}{$\begin{array}{l}\text { Geographic Area } \\
\text { Month }\end{array}$} & \multicolumn{2}{|c|}{ Aviation Gasoline } & \multicolumn{2}{|c|}{ Kerosene-Type Jet Fuel } & \multicolumn{2}{|c|}{ Kerosene } \\
\hline & $\begin{array}{l}\text { Sales to } \\
\text { End Users }\end{array}$ & $\begin{array}{l}\text { Sales for } \\
\text { Resale }\end{array}$ & $\begin{array}{l}\text { Sales to } \\
\text { End Users }\end{array}$ & $\begin{array}{l}\text { Sales for } \\
\text { Resale }\end{array}$ & $\begin{array}{l}\text { Sales to } \\
\text { End Users }\end{array}$ & $\begin{array}{c}\text { Sales for } \\
\text { Resale }\end{array}$ \\
\hline \multicolumn{7}{|l|}{ Now Mexico } \\
\hline 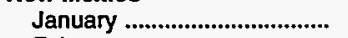 & w & w & 53.2 & 53.4 & w & w \\
\hline 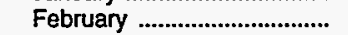 & $w$ & 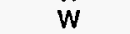 & 53.1 & 56.1 & - & 75.2 \\
\hline March …………....................... & $w$ & $w$ & 46.7 & 51.4 & - & $w$ \\
\hline April .................................. & $\ddot{w}$ & $w$ & 56.6 & 52.8 & - & 78.3 \\
\hline 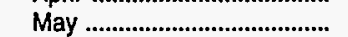 & w & w & 54.4 & 53.3 & w & $w$ \\
\hline 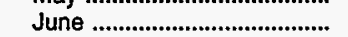 & $w$ & $\ddot{w}$ & 54.5 & 55.3 & - & $w$ \\
\hline July …………………………........ & $\ddot{w}$ & $w$ & 53.5 & 57.2 & - & 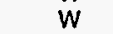 \\
\hline 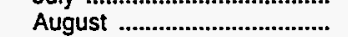 & $\underline{w}$ & w & 54.5 & 57.3 & - & $w$ \\
\hline 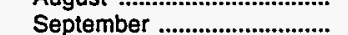 & $w$ & $\dddot{w}$ & 56.2 & 55.5 & - & 84.2 \\
\hline 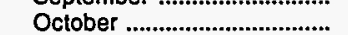 & $\dddot{w}$ & $w$ & 56.2 & 56.3 & - & $w$ \\
\hline November ............................. & $w$ & $\ddot{w}$ & 60.1 & 57.4 & - & $\ddot{w}$ \\
\hline 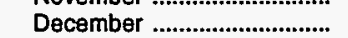 & $w$ & $w$ & 57.3 & 53.0 & - & $w$ \\
\hline 1994 Average & $w$ & $w$ & 54.5 & $\mathbf{5 5 . 0}$ & $\bar{w}$ & $\mathbf{w}$ \\
\hline \multicolumn{7}{|l|}{ Texas } \\
\hline 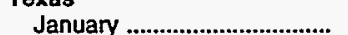 & 78.3 & 71.2 & 50.0 & 51.4 & $w$ & 57.1 \\
\hline 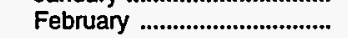 & 81.4 & 72.5 & 52.5 & 53.6 & $w$ & 61.3 \\
\hline March & 83.0 & 73.1 & 47.1 & 47.4 & $w$ & 56.8 \\
\hline 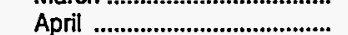 & 86.8 & 77.5 & 47.5 & 48.2 & $w$ & 54.5 \\
\hline May & $w$ & 78.6 & 47.5 & 48.4 & $w$ & 54.4 \\
\hline 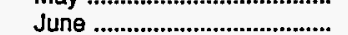 & 90.3 & 79.4 & 49.2 & 49.4 & $\ddot{w}$ & 54.3 \\
\hline 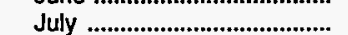 & 91.7 & 83.0 & 51.5 & 52.5 & $w$ & 57.2 \\
\hline 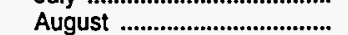 & 96.0 & 87.4 & 51.8 & 51.9 & w & 58.2 \\
\hline September ........................... & 96.5 & 85.1 & 51.1 & 50.6 & $w$ & 56.7 \\
\hline 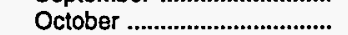 & 95.8 & 83.7 & 51.3 & 51.6 & $w$ & 58.8 \\
\hline 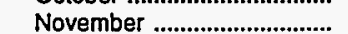 & $w$ & 84.1 & 52.9 & 53.3 & $w$ & 53.1 \\
\hline December ................................ & 96.5 & 82.4 & 50.3 & 50.6 & $w$ & 53.2 \\
\hline 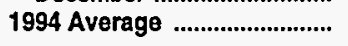 & 90.6 & 80.0 & 50.3 & 50.9 & $w$ & 55.1 \\
\hline \multicolumn{7}{|l|}{ PAD District IV } \\
\hline 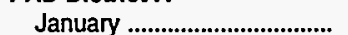 & 93.6 & 94.6 & 55.8 & 59.8 & $w$ & 62.0 \\
\hline February ................................. & 92.9 & 93.3 & 57.7 & 62.1 & $w$ & 59.6 \\
\hline 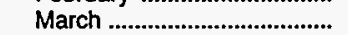 & 93.8 & 93.8 & 56.0 & 60.3 & $w$ & 62.2 \\
\hline 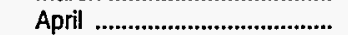 & 93.1 & 93.8 & 54.6 & 58.4 & w & 65.8 \\
\hline May ........................................ & 94.0 & 94.9 & 54.6 & 59.0 & - & 64.4 \\
\hline June ……………………. & 99.5 & 96.4 & 55.3 & 59.3 & - & 66.6 \\
\hline 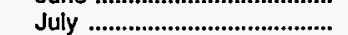 & 102.9 & 98.0 & 57.2 & 62.0 & - & 68.9 \\
\hline August .................................. & 106.4 & 100.6 & 59.5 & 64.4 & - & 71.7 \\
\hline September ......................... & 106.8 & 100.6 & 60.9 & 64.7 & - & 76.0 \\
\hline October & 106.9 & 99.5 & 61.4 & 64.9 & $w$ & 74.4 \\
\hline 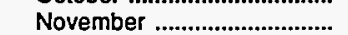 & 104.8 & 99.8 & 63.2 & 66.7 & $w$ & 74.3 \\
\hline December .............................. & 104.1 & 98.3 & 58.3 & 62.1 & $w$ & 68.3 \\
\hline 1994 Average & 101.1 & 97.2 & 57.7 & 62.0 & $w$ & 66.1 \\
\hline \multicolumn{7}{|l|}{ Colorado } \\
\hline January ........................................ & $w$ & 92.3 & 52.6 & 56.7 & - & w \\
\hline February ..................................... & $w$ & 92.3 & 55.3 & 59.8 & - & 57.8 \\
\hline March & $w$ & 92.3 & 50.8 & 55.3 & - & 59.7 \\
\hline 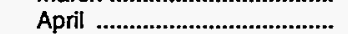 & $\ddot{w}$ & 92.9 & 52.6 & 55.7 & - & $w$ \\
\hline May .............................. & w & 93.7 & 52.3 & 55.4 & - & $w$ \\
\hline 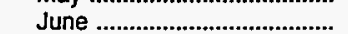 & w & 95.3 & 53.3 & 56.9 & - & 64.2 \\
\hline 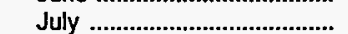 & 98.1 & 96.5 & 55.2 & 59.7 & - & $w$ \\
\hline August ................................ & 99.0 & 100.3 & 56.3 & 61.3 & - & 71.5 \\
\hline September .......................... & $w$ & 100.9 & 55.5 & 59.2 & - & 73.6 \\
\hline October & 99.7 & 100.2 & 54.8 & 58.8 & - & 72.3 \\
\hline November .................................... & 100.3 & 100.5 & 56.2 & 59.9 & - & 67.7 \\
\hline 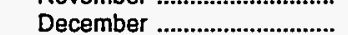 & 98.9 & 97.6 & 52.6 & 57.4 & _ & 61.2 \\
\hline 1994 Average & 95.8 & 96.4 & 53.8 & 58.1 & _- & 62.9 \\
\hline
\end{tabular}

See footnotes at end of table. 
Table 36. Refiner Prices of Aviation Fuels and Kerosene by PAD District and State (Cents per Gallon Excluding Taxes) - Continued

\begin{tabular}{|c|c|c|c|c|c|c|}
\hline \multirow{2}{*}{$\begin{array}{l}\text { Goographic Area } \\
\text { Month }\end{array}$} & \multicolumn{2}{|c|}{ Aviation Gasoline } & \multicolumn{2}{|c|}{ Kerosene-Type Jet Fuel } & \multicolumn{2}{|c|}{ Kerosene } \\
\hline & $\begin{array}{l}\text { Sales to } \\
\text { End Users }\end{array}$ & $\begin{array}{l}\text { Sales for } \\
\text { Resale }\end{array}$ & $\begin{array}{l}\text { Sales to } \\
\text { End Users }\end{array}$ & $\begin{array}{c}\text { Sales for } \\
\text { Resale }\end{array}$ & $\begin{array}{l}\text { Sales to } \\
\text { End Users }\end{array}$ & $\begin{array}{c}\text { Sales for } \\
\text { Resale }\end{array}$ \\
\hline \multicolumn{7}{|l|}{ Idaho } \\
\hline 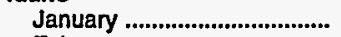 & $w$ & w & 68.8 & 71.4 & - & $w$ \\
\hline February .............................. & W & W & 66.7 & 69.4 & - & - \\
\hline March ....................................... & $w$ & $\ddot{W}$ & 67.1 & 70.3 & - & - \\
\hline April & - & W & 61.6 & 66.7 & - & $\bar{w}$ \\
\hline May .......................................... & $W$ & W & 61.6 & 66.7 & - & $W$ \\
\hline 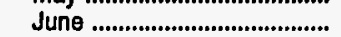 & $w$ & $\ddot{w}$ & 61.2 & 66.8 & - & $w$ \\
\hline July .......................................... & $W$ & W & 63.2 & 69.2 & - & $W$ \\
\hline August .................................... & $\ddot{w}$ & 107.7 & 66.0 & 70.2 & - & $w$ \\
\hline September ............................ & $\mathbf{w}$ & $w$ & 72.2 & 66.4 & - & $w$ \\
\hline 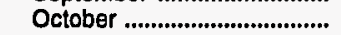 & $\ddot{W}$ & $\ddot{w}$ & 74.8 & 79.7 & - & $w$ \\
\hline November .............................. & W & $w$ & 77.0 & 82.1 & - & 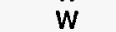 \\
\hline December ............................... & - & $w$ & 70.4 & 75.0 & - & $w$ \\
\hline 1994 Average .............................. & $\mathbf{W}$ & $\ddot{w}$ & 67.6 & 69.9 & - & $w$ \\
\hline \multicolumn{7}{|l|}{ Montana } \\
\hline January ................................... & $W$ & $W$ & 62.4 & $w$ & - & $w$ \\
\hline 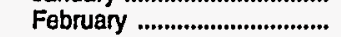 & W & $\ddot{w}$ & 63.6 & $\ddot{w}$ & - & 60.3 \\
\hline 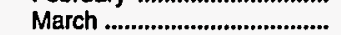 & $w$ & $\ddot{w}$ & 65.3 & $w$ & - & 62.1 \\
\hline 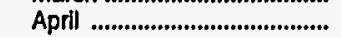 & $\ddot{W}$ & w & 65.3 & $w$ & - & $W$ \\
\hline May ...................................... & W & $\dddot{w}$ & $w$ & $\mathbf{w}$ & - & $W$ \\
\hline 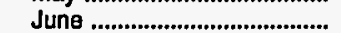 & $W$ & w & 65.0 & $w$ & - & $w$ \\
\hline July & $w$ & $w$ & 67.2 & $w$ & - & $W$ \\
\hline August & $W$ & $W$ & 68.8 & $w$ & - & $w$ \\
\hline 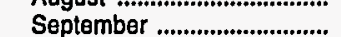 & $W$ & $W$ & 70.0 & $w$ & - & 76.5 \\
\hline 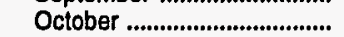 & W & W & 71.9 & $w$ & - & 76.6 \\
\hline 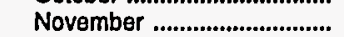 & W & $w$ & 74.5 & $w$ & - & 78.0 \\
\hline 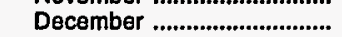 & W & W & 72.2 & $w$ & - & 69.9 \\
\hline 1994 Average .............................. & $\mathbf{W}$ & $\mathbf{W}$ & 67.8 & $w$ & - & 65.0 \\
\hline \multicolumn{7}{|l|}{ Utah } \\
\hline 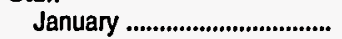 & W & 95.2 & 61.1 & 62.4 & - & $w$ \\
\hline February ................................ & 99.1 & 91.5 & 60.1 & 62.8 & - & W \\
\hline March ..................................... & 96.5 & 92.8 & 61.3 & 63.8 & - & $W$ \\
\hline 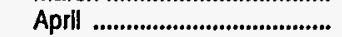 & $W$ & 92.7 & 56.2 & 58.9 & - & $W$ \\
\hline May & $\ddot{w}$ & 94.4 & 56.4 & 60.8 & - & $\ddot{w}$ \\
\hline 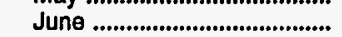 & $\ddot{w}$ & 95.1 & 56.4 & 59.6 & - & $w$ \\
\hline 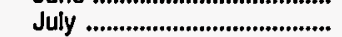 & 96.8 & 98.1 & 57.7 & 61.6 & - & $w$ \\
\hline August & 103.1 & 100.0 & 60.9 & 64.0 & - & W \\
\hline September ............................. & $w$ & 98.7 & 66.1 & 69.6 & - & $W$ \\
\hline 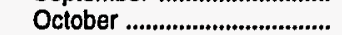 & $\mathbf{W}$ & 97.0 & 69.5 & 74.9 & - & $W$ \\
\hline November ................................. & $W$ & 95.0 & 72.0 & 77.5 & - & $w$ \\
\hline December ............................. & W & 96.4 & 65.6 & 70.3 & - & $W$ \\
\hline 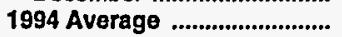 & 99.7 & 96.3 & 61.5 & 64.4 & - & $w$ \\
\hline \multicolumn{7}{|l|}{ Wyoming } \\
\hline 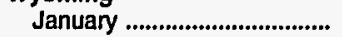 & W & $W$ & 71.7 & $w$ & $w$ & $w$ \\
\hline 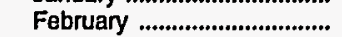 & 95.5 & W & 71.2 & w & $w$ & $W$ \\
\hline March ................................. & $w$ & W & 74.0 & $w$ & $W$ & - \\
\hline April & $w$ & $W$ & 67.9 & $w$ & $W$ & - \\
\hline May & $w$ & W & 67.2 & $w$ & - & - \\
\hline 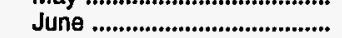 & $w$ & $W$ & 68.5 & $w$ & - & $\vec{w}$ \\
\hline July & $w$ & $w$ & 68.9 & $w$ & - & $w$ \\
\hline 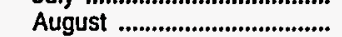 & $w$ & W & 70.5 & $w$ & - & - \\
\hline September ........................... & w & W & 72.8 & $w$ & - & $\bar{w}$ \\
\hline October ............................... & $w$ & $W$ & 75.8 & $w$ & $\bar{w}$ & 75.7 \\
\hline November ........................... & $\ddot{w}$ & $w$ & 77.9 & $\ddot{w}$ & $w$ & w \\
\hline 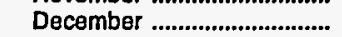 & $\ddot{w}$ & $w$ & 72.7 & $w$ & $w$ & $w$ \\
\hline 1994 Average & $w$ & $\mathbf{W}$ & 71.4 & $\mathbf{w}$ & $w$ & $w$ \\
\hline
\end{tabular}

See footnotes at end of table. 
Table 36. Refiner Prices of Aviation Fuels and Kerosene by PAD District and State (Cents per Gallon Excluding Taxes) - Continued

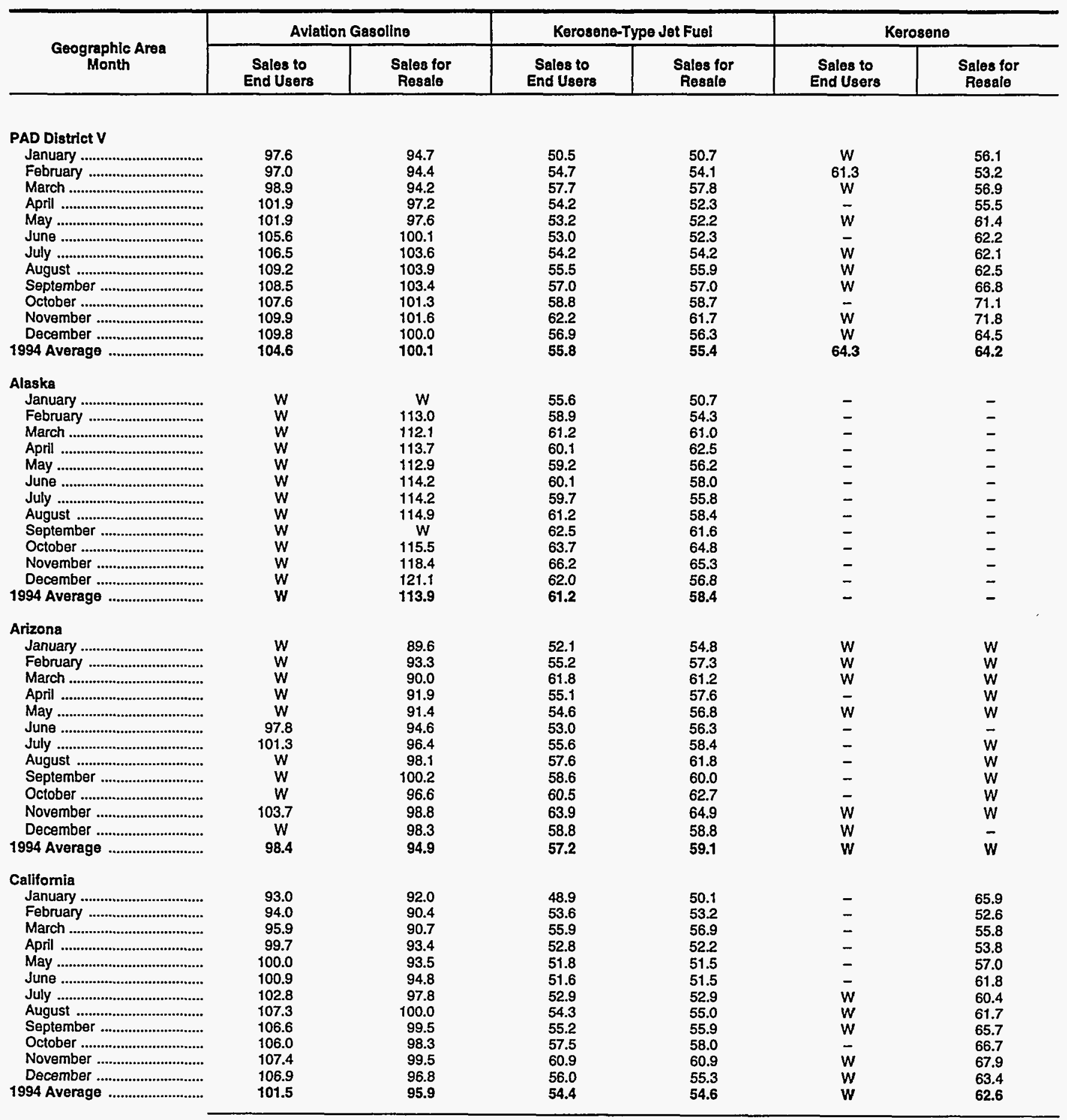

See footnotes at end of table. 
Table 36. Refiner Prices of Aviation Fuels and Kerosene by PAD District and State (Cents per Gallon Excluding Taxes) - Continued

\begin{tabular}{|c|c|c|c|c|c|c|}
\hline \multirow{2}{*}{$\begin{array}{l}\text { Geographlc Aros } \\
\text { Month }\end{array}$} & \multicolumn{2}{|c|}{ Aviation Gasoline } & \multicolumn{2}{|c|}{ Kerosene-Type Jet Fuel } & \multicolumn{2}{|c|}{ Kerosene } \\
\hline & $\begin{array}{c}\text { Sales to } \\
\text { End Users }\end{array}$ & $\begin{array}{c}\text { Sales for } \\
\text { Resale }\end{array}$ & $\begin{array}{c}\text { Sales to } \\
\text { End Users }\end{array}$ & $\begin{array}{c}\text { Sales for } \\
\text { Resale }\end{array}$ & $\begin{array}{c}\text { Sales to } \\
\text { End Users }\end{array}$ & $\begin{array}{c}\text { Sales for } \\
\text { Resale }\end{array}$ \\
\hline \multicolumn{7}{|l|}{ Hawail } \\
\hline 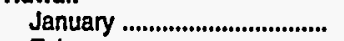 & $w$ & $w$ & 54.2 & $w$ & - & - \\
\hline Fobruary ........................................... & $w$ & $w$ & 58.1 & $w$ & - & - \\
\hline 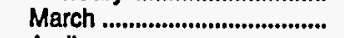 & $w$ & $w$ & 60.7 & $w$ & - & - \\
\hline 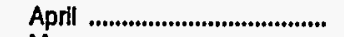 & W & $w$ & 56.1 & $\ddot{w}$ & - & - \\
\hline 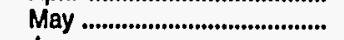 & w & $w$ & 55.8 & $w$ & - & - \\
\hline 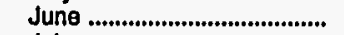 & w & $w$ & 55.4 & w & - & - \\
\hline 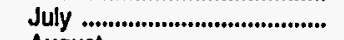 & $w$ & $w$ & 57.5 & $w$ & - & - \\
\hline 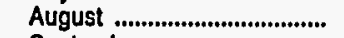 & w & $w$ & 58.5 & $w$ & - & - \\
\hline 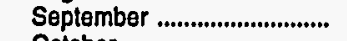 & w & $w$ & 59.5 & w & - & - \\
\hline October .............................................. & $w$ & w & 61.0 & $w$ & _- & - \\
\hline 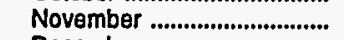 & $w$ & $w$ & 64.0 & w & - & - \\
\hline 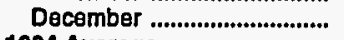 & $w$ & $\mathbf{w}$ & 58.3 & $w$ & - & - \\
\hline 1994 Average .................................... & $w$ & $\ddot{w}$ & 58.2 & $w$ & - & - \\
\hline \multicolumn{7}{|l|}{ Nevada } \\
\hline 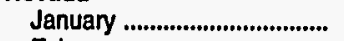 & $w$ & 93.8 & 52.3 & 54.1 & - & - \\
\hline 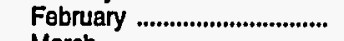 & $\ddot{w}$ & 93.0 & 56.4 & 56.6 & - & - \\
\hline March & w & $w$ & 61.9 & 62.6 & - & - \\
\hline 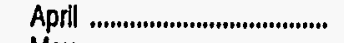 & W & $W$ & 55.5 & 57.1 & - & - \\
\hline 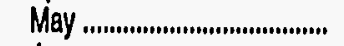 & $W$ & W & 53.8 & 54.7 & - & - \\
\hline 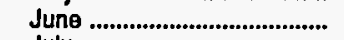 & $w$ & $w$ & 53.7 & 54.9 & - & - \\
\hline & $w$ & $w$ & 55.5 & 57.7 & - & - \\
\hline $\begin{array}{l}\text { August } \\
\text { September }\end{array}$ & $w$ & 101.7 & 57.4 & 58.0 & - & - \\
\hline & $w$ & 100.9 & 58.5 & 60.0 & - & w \\
\hline 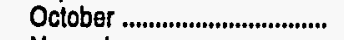 & $w$ & 102.1 & 60.4 & 61.6 & - & - \\
\hline November ................................... & w & 101.7 & 63.7 & 64.6 & - & w \\
\hline 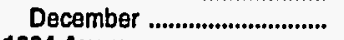 & w & w & 56.1 & 59.3 & - & $w$ \\
\hline 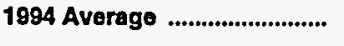 & $\mathbf{w}$ & 88.9 & 57.1 & 58.6 & - & w \\
\hline \multicolumn{7}{|l|}{ Oregon } \\
\hline 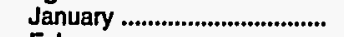 & - & 95.5 & 51.1 & 50.9 & NA & w \\
\hline 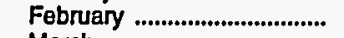 & $w$ & 93.6 & 54.8 & 57.5 & w & w \\
\hline 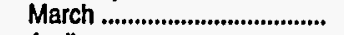 & $\mathbf{w}$ & 92.8 & 59.5 & 58.8 & w & $w$ \\
\hline April & $w$ & 93.8 & 53.7 & 62.3 & - & W \\
\hline 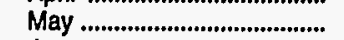 & $w$ & 93.9 & 53.1 & 61.3 & - & $w$ \\
\hline 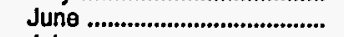 & $w$ & 95.6 & 52.4 & 63.6 & - & $w$ \\
\hline 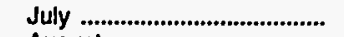 & $\mathbf{w}$ & 98.4 & 54.2 & 62.4 & - & w \\
\hline 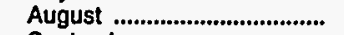 & $\mathbf{w}$ & 99.6 & 56.5 & 65.5 & - & 63.5 \\
\hline Seplember ................................ & $w$ & 99.8 & 57.6 & 64.4 & - & 66.3 \\
\hline 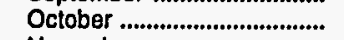 & $w$ & 96.8 & 59.7 & 66.6 & - & 75.8 \\
\hline 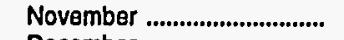 & $w$ & 95.6 & 62.9 & 71.8 & - & 73.4 \\
\hline 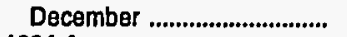 & w & 94.2 & 56.8 & 67.8 & - & 63.9 \\
\hline 1994 Average ................................. & $w$ & 96.5 & 56.2 & 59.3 & $w$ & 62.8 \\
\hline \multicolumn{7}{|l|}{ Washington } \\
\hline 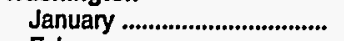 & $w$ & $w$ & 51.5 & 51.1 & - & w \\
\hline 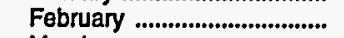 & $w$ & $\ddot{w}$ & 53.5 & 55.4 & $w$ & $\ddot{w}$ \\
\hline 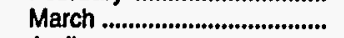 & w & $\ddot{w}$ & 57.5 & 59.6 & $w$ & 64.3 \\
\hline 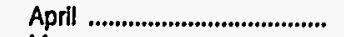 & $w$ & $w$ & 53.7 & 50.0 & - & NA \\
\hline 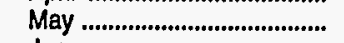 & $\ddot{w}$ & $\ddot{w}$ & 53.0 & 50.3 & - & 63.0 \\
\hline 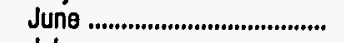 & $W$ & $w$ & 51.9 & 49.7 & - & 61.7 \\
\hline 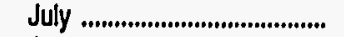 & $W$ & $W$ & 53.6 & 55.4 & - & 61.6 \\
\hline 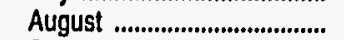 & $w$ & $\ddot{w}$ & 53.7 & 55.3 & - & 62.2 \\
\hline 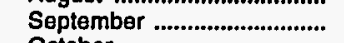 & $\ddot{w}$ & $\ddot{w}$ & 57.0 & 56.8 & - & 66.8 \\
\hline 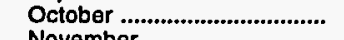 & $\mathbf{w}$ & w & 57.4 & 57.4 & - & 72.9 \\
\hline 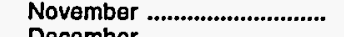 & $\mathbf{w}$ & w & 62.8 & 65.1 & - & 75.7 \\
\hline 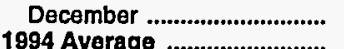 & $\mathbf{w}$ & $w$ & 55.6 & 55.4 & - & 67.4 \\
\hline 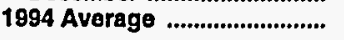 & $\ddot{w}$ & $\ddot{w}$ & 55.2 & 54.1 & $w$ & 67.2 \\
\hline
\end{tabular}

Dash $(-)=$ No data reported.

$N A=$ Not available.

$W=$ Withheld to avoid disclosure of individual company data

Notes: PAD Dlstrict and U.S. averages represent data for all States. In certain PAD Districts, however, prices are not shown for every State.

Source: Energy Information Administration Form ElA-782A, "Refiners'/Gas Plant Operators' Monthly Petroleum Product Sales Report." 
Table 37. Refiner Prices of Distillate Fuels by PAD District and State (Cents per Gallon Excluding Taxes)

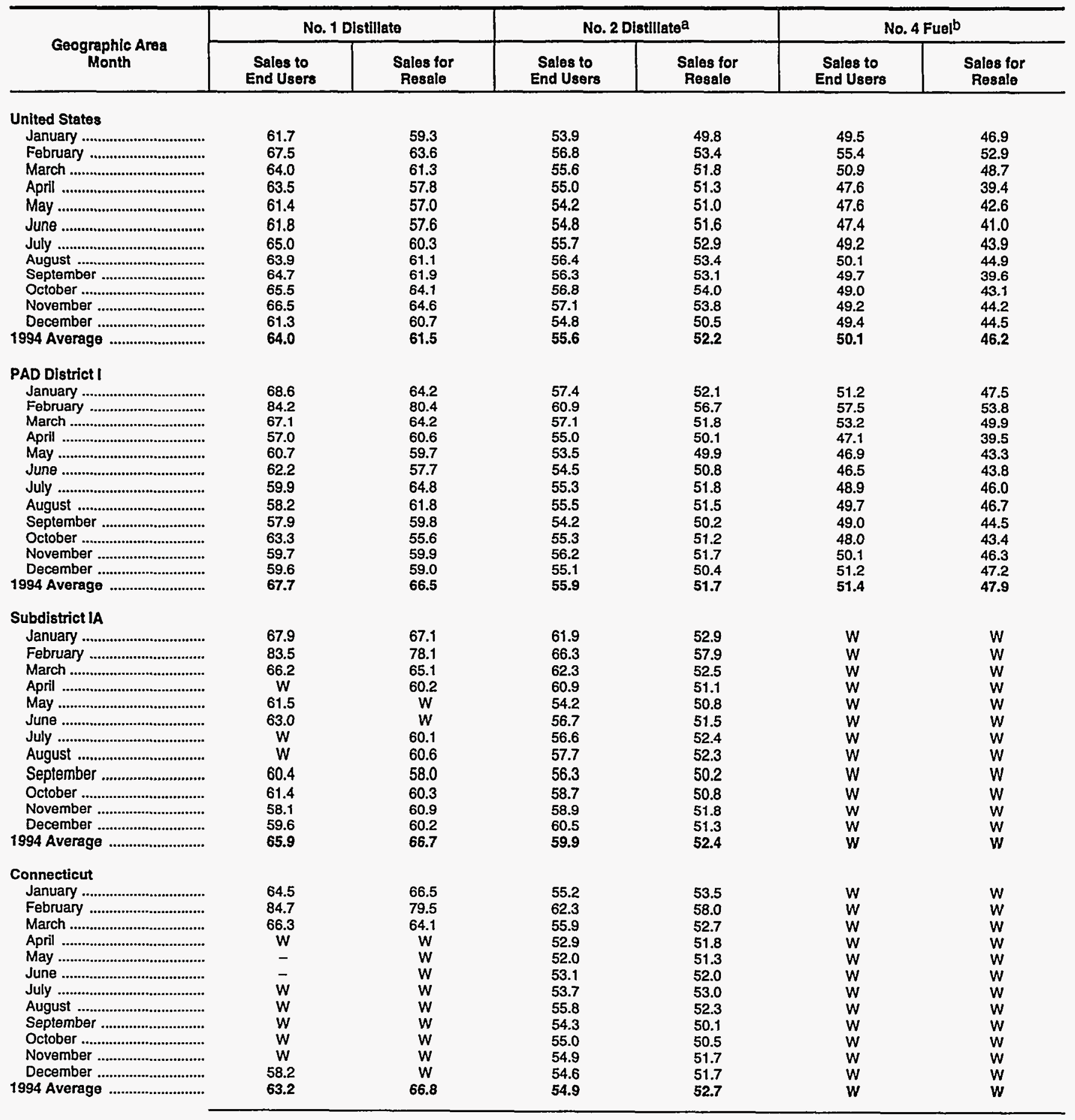

See footnotes at end of table. 
Table 37. Refiner Prices of Distillate Fuels by PAD District and State

(Cents per Gallon Excluding Taxes) - Continued

\begin{tabular}{|c|c|c|c|c|c|c|}
\hline \multirow{2}{*}{$\begin{array}{c}\text { Goographlc Area } \\
\text { Month }\end{array}$} & \multicolumn{2}{|c|}{ No. 1 Distillate } & \multicolumn{2}{|c|}{ No. 2 Distillatea } & \multicolumn{2}{|c|}{ No. 4 Fuejb } \\
\hline & $\begin{array}{c}\text { Sales to } \\
\text { End Users }\end{array}$ & $\begin{array}{c}\text { Sales for } \\
\text { Resale }\end{array}$ & $\begin{array}{c}\text { Sales to } \\
\text { End Users }\end{array}$ & $\begin{array}{c}\text { Sales for } \\
\text { Resale }\end{array}$ & $\begin{array}{l}\text { Sales to } \\
\text { End Users }\end{array}$ & $\begin{array}{c}\text { Sales for } \\
\text { Resale }\end{array}$ \\
\hline \multicolumn{7}{|l|}{ Maine } \\
\hline 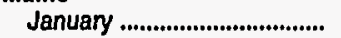 & w & 68.0 & 55.2 & 54.2 & $w$ & $w$ \\
\hline 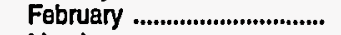 & w & 75.3 & 63.1 & 57.7 & w & $w$ \\
\hline March ............................................. & W & 65.9 & 56.9 & 51.9 & $\ddot{w}$ & $w$ \\
\hline 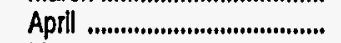 & - & 62.0 & 53.1 & 50.2 & W & - \\
\hline May ............................................ & $w$ & $W$ & 52.7 & 50.4 & - & $w$ \\
\hline 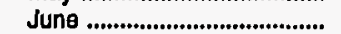 & - & $w$ & 54.6 & 52.1 & - & - \\
\hline 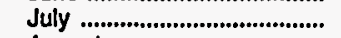 & - & - & 54.0 & 52.0 & - & - \\
\hline 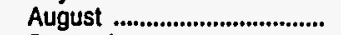 & - & w & $w$ & 52.4 & - & - \\
\hline 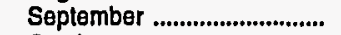 & w & 59.8 & 52.3 & 49.9 & - & - \\
\hline 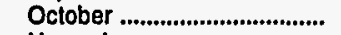 & - & 59.8 & 53.8 & 51.6 & w & - \\
\hline 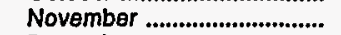 & - & $w$ & 54.4 & 51.7 & - & - \\
\hline December ............................... & w & 59.7 & 54.9 & 50.2 & - & - \\
\hline 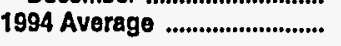 & $\ddot{w}$ & 67.1 & 55.3 & 52.4 & $\mathbf{w}$ & $w$ \\
\hline \multicolumn{7}{|l|}{ Massachusetts } \\
\hline 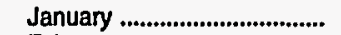 & w & w & 63.7 & 52.6 & w & w \\
\hline 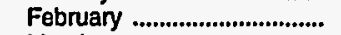 & $w$ & w & 66.3 & 58.2 & $w$ & - \\
\hline 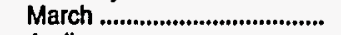 & w & w & 63.5 & 53.1 & w & w \\
\hline 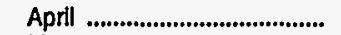 & - & - & 64.4 & 51.2 & $w$ & $w$ \\
\hline 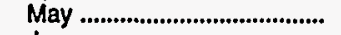 & w & $w$ & 54.6 & 50.3 & $w$ & $w$ \\
\hline 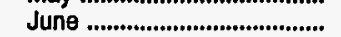 & $\ddot{w}$ & $\ddot{w}$ & 58.0 & 50.5 & $\ddot{w}$ & $w$ \\
\hline 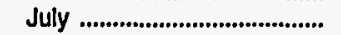 & - & - & 57.8 & 51.9 & $\ddot{w}$ & $w$ \\
\hline 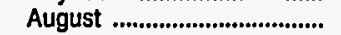 & - & - & 59.0 & 52.0 & $\ddot{w}$ & $w$ \\
\hline 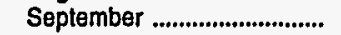 & - & - & 57.5 & 50.2 & $w$ & $w$ \\
\hline 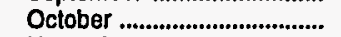 & NA & w & 60.8 & 51.1 & $w$ & $w$ \\
\hline November .................................... & - & w & 60.9 & 52.3 & $w$ & $\ddot{w}$ \\
\hline December ................................... & $w$ & $w$ & 62.2 & 51.4 & $w$ & $w$ \\
\hline 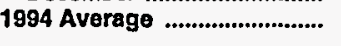 & $w$ & w & 61.5 & 52.4 & $\ddot{w}$ & $w$ \\
\hline \multicolumn{7}{|l|}{ New Hampshire } \\
\hline 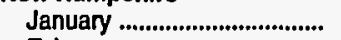 & $w$ & 65.3 & 62.9 & 53.8 & $w$ & $w$ \\
\hline 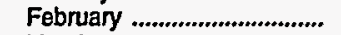 & w & 86.0 & 69.4 & 60.6 & $w$ & $\ddot{w}$ \\
\hline 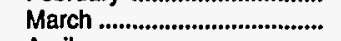 & $w$ & $w$ & 66.7 & 54.1 & $\ddot{w}$ & $w$ \\
\hline 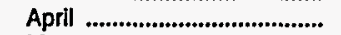 & w & - & 61.4 & 51.0 & $w$ & $w$ \\
\hline May ......................................... & $\ddot{w}$ & - & 59.1 & 52.1 & $\ddot{w}$ & - \\
\hline 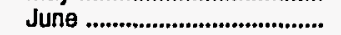 & $w$ & - & 60.0 & 54.0 & $\ddot{w}$ & - \\
\hline July ................................................. & w & w & 60.9 & 54.4 & $w$ & - \\
\hline 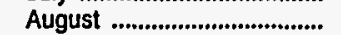 & $w$ & $\mathrm{NA}$ & 60.3 & 53.2 & $\ddot{w}$ & - \\
\hline 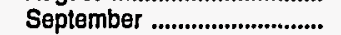 & w & - & 59.2 & 51.8 & $w$ & _- \\
\hline 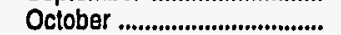 & w & - & 59.0 & 52.5 & $w$ & - \\
\hline November .............................. & $w$ & w & 61.8 & 53.3 & $\ddot{w}$ & - \\
\hline December ................................. & w & w & $w$ & 52.7 & w & _- \\
\hline 1994 Averago .............................. & $\ddot{w}$ & 65.8 & 63.2 & 53.6 & $w$ & $\mathbf{w}$ \\
\hline \multicolumn{7}{|l|}{ Rhode Island } \\
\hline 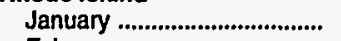 & $w$ & $w$ & 64.3 & 51.3 & $w$ & - \\
\hline February ....................................... & $w$ & - & 72.2 & 56.5 & $w$ & - \\
\hline March .......................................... & $w$ & $w$ & 65.3 & 50.8 & $w$ & - \\
\hline 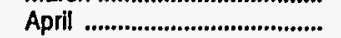 & - & $w$ & 61.3 & 50.2 & - & - \\
\hline May ............................................. & - & $w$ & 55.4 & 50.6 & - & - \\
\hline June & $w$ & $w$ & 56.0 & 51.8 & - & - \\
\hline 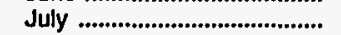 & $w$ & $w$ & 55.7 & 52.6 & - & - \\
\hline August ....................................... & $w$ & $w$ & 56.6 & 52.4 & - & - \\
\hline 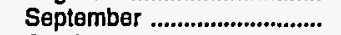 & - & - & 56.4 & 49.6 & $w$ & - \\
\hline 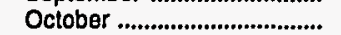 & - & w & 64.7 & 49.4 & w & $=$ \\
\hline 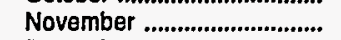 & $w$ & w & 59.2 & 51.1 & $\ddot{w}$ & - \\
\hline 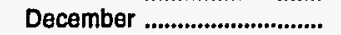 & $w$ & $w$ & 62.1 & 50.9 & $w$ & - \\
\hline 1994 Average .............................. & $w$ & $w$ & 61.1 & 51.5 & $w$ & - \\
\hline
\end{tabular}

See footnotes at end of table. 
Table 37. Refiner Prices of Distillate Fuels by PAD District and State (Cents per Gallon Excluding Taxes) - Continued

\begin{tabular}{|c|c|c|c|c|c|c|}
\hline \multirow{2}{*}{$\begin{array}{l}\text { Goographic Area } \\
\text { Month }\end{array}$} & \multicolumn{2}{|c|}{ No. 1 Dlstillate } & \multicolumn{2}{|c|}{ No. 2 Distillatea } & \multicolumn{2}{|c|}{ No. 4 Fuelb } \\
\hline & $\begin{array}{c}\text { Sales to } \\
\text { End Users }\end{array}$ & $\begin{array}{c}\text { Salos for } \\
\text { Resale }\end{array}$ & $\begin{array}{c}\text { Sales to } \\
\text { End Users }\end{array}$ & $\begin{array}{c}\text { Sales for } \\
\text { Resale }\end{array}$ & $\begin{array}{c}\text { Sales to } \\
\text { End Users }\end{array}$ & $\begin{array}{c}\text { Sales for } \\
\text { Resalo }\end{array}$ \\
\hline \multicolumn{7}{|l|}{ Vermont } \\
\hline 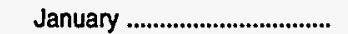 & W & w & 59.9 & $w$ & w & - \\
\hline 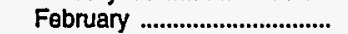 & W & w & 70.2 & 61.5 & $w$ & - \\
\hline 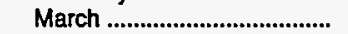 & W & 69.8 & 60.7 & 56.3 & w & - \\
\hline 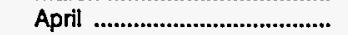 & - & w & 56.9 & 54.2 & w & - \\
\hline 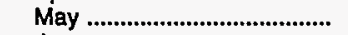 & - & $\mathbf{w}$ & 55.4 & 54.0 & $w$ & - \\
\hline 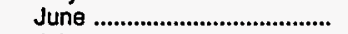 & - & $w$ & 56.6 & 55.4 & $w$ & - \\
\hline July .......................................... & - & $w$ & $w$ & 56.1 & $w$ & - \\
\hline 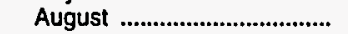 & - & w & w & 55.0 & $w$ & - \\
\hline 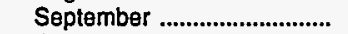 & - & w & 55.6 & 53.8 & $\ddot{w}$ & - \\
\hline 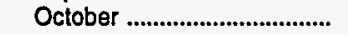 & - & w & 57.4 & 53.2 & W & - \\
\hline 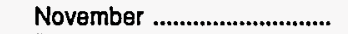 & W & w & 57.3 & 53.9 & w & - \\
\hline 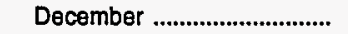 & w & w & 57.3 & 53.3 & W & - \\
\hline 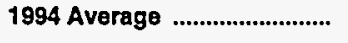 & $w$ & $\mathbf{w}$ & 58.6 & 55.5 & $\ddot{w}$ & - \\
\hline \multicolumn{7}{|l|}{ Subdistrict IB } \\
\hline 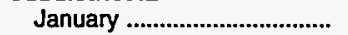 & 71.7 & 63.8 & 61.2 & 52.5 & $w$ & 48.8 \\
\hline 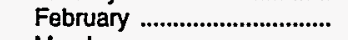 & 87.0 & 81.6 & 65.5 & 57.9 & $w$ & 54.8 \\
\hline 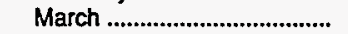 & 67.2 & 64.8 & 60.9 & 52.2 & $w$ & 50.2 \\
\hline 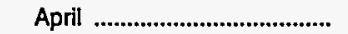 & $w$ & 60.9 & 57.6 & 50.3 & 47.3 & 39.1 \\
\hline 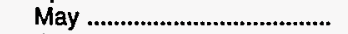 & $w$ & 59.5 & 55.0 & 50.0 & 46.8 & 43.4 \\
\hline 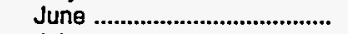 & w & 58.7 & 55.3 & 50.7 & $w$ & 43.8 \\
\hline 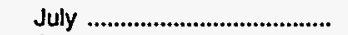 & 61.7 & $w$ & 56.2 & 51.6 & w & 45.9 \\
\hline 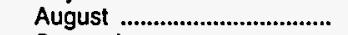 & $w$ & 62.1 & 56.5 & 51.3 & w & 46.7 \\
\hline 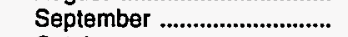 & $w$ & 60.6 & 55.0 & 50.0 & 49.2 & 44.7 \\
\hline 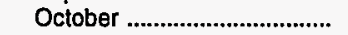 & 63.7 & $w$ & 56.5 & 50.8 & 48.1 & 44.2 \\
\hline 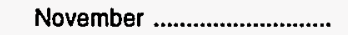 & 61.3 & 59.4 & 57.4 & 51.3 & 50.3 & 46.3 \\
\hline 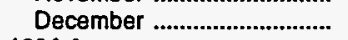 & 59.4 & 58.6 & 57.6 & 50.5 & 51.3 & 47.3 \\
\hline 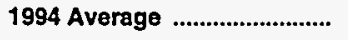 & 69.0 & 67.0 & 58.3 & 51.9 & 51.5 & 48.4 \\
\hline \multicolumn{7}{|l|}{ Delaware } \\
\hline January ............................................. & - & - & 53.2 & 49.8 & w & - \\
\hline 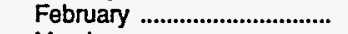 & - & - & 61.9 & 57.5 & w & - \\
\hline 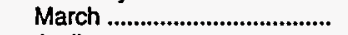 & - & - & 55.8 & $w$ & $w$ & - \\
\hline 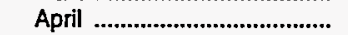 & - & - & 53.6 & 49.9 & $w$ & - \\
\hline 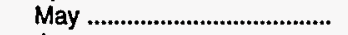 & - & - & 53.0 & 50.0 & $w$ & - \\
\hline 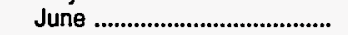 & - & - & 54.6 & 51.1 & $w$ & - \\
\hline July ....................................................... & - & - & 54.5 & 52.6 & $w$ & - \\
\hline August & - & - & 55.1 & 50.7 & w & - \\
\hline 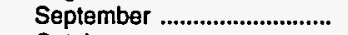 & - & - & 53.9 & $w$ & w & - \\
\hline 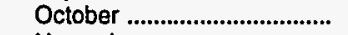 & - & - & 55.6 & w & w & - \\
\hline November .................................... & - & - & 55.8 & 51.2 & w & - \\
\hline December ....................................... & w & - & 54.5 & 49.7 & W & - \\
\hline 1994 Average & $w$ & - & 55.7 & 51.2 & w & - \\
\hline \multicolumn{7}{|l|}{ District of Columbia } \\
\hline 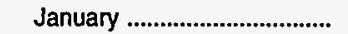 & - & - & 53.2 & 52.2 & w & - \\
\hline 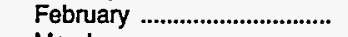 & - & - & 57.5 & 51.0 & $w$ & - \\
\hline 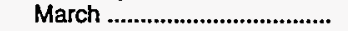 & - & - & w & 50.8 & $w$ & - \\
\hline 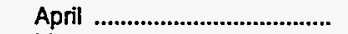 & - & - & w & 53.2 & $w$ & - \\
\hline 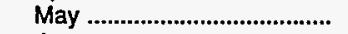 & - & - & $w$ & 55.7 & W & - \\
\hline June & - & - & $\mathbf{w}$ & 55.5 & w & - \\
\hline 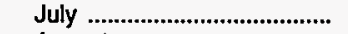 & - & - & w & 54.3 & w & - \\
\hline 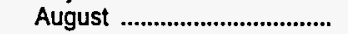 & - & - & w & 55.5 & $w$ & - \\
\hline 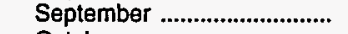 & - & - & 50.4 & 51.7 & $w$ & - \\
\hline 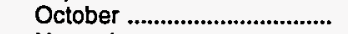 & - & - & $w$ & 51.3 & $w$ & - \\
\hline 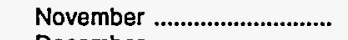 & - & - & 54.3 & 54.5 & $w$ & - \\
\hline 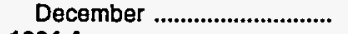 & - & - & 52.2 & 51.9 & w & - \\
\hline 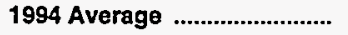 & - & - & $\mathbf{w}$ & 52.2 & $\mathbf{w}$ & - \\
\hline
\end{tabular}

See footnotes at end of table. 
Table 37. Refiner Prices of Distillate Fuels by PAD District and State (Cents per Gallon Excluding Taxes) - Continued

\begin{tabular}{|c|c|c|c|c|c|c|}
\hline \multirow{2}{*}{$\begin{array}{c}\text { Geographlo Area } \\
\text { Month }\end{array}$} & \multicolumn{2}{|c|}{ No. 1 Distlllate } & \multicolumn{2}{|c|}{ No. 2 Distillatea } & \multicolumn{2}{|c|}{ No. 4 Fuelb } \\
\hline & $\begin{array}{l}\text { Sales to } \\
\text { End Users }\end{array}$ & $\begin{array}{c}\text { Sales for } \\
\text { Resale }\end{array}$ & $\begin{array}{l}\text { Sales to } \\
\text { End Users }\end{array}$ & $\begin{array}{l}\text { Sales tor } \\
\text { Resale }\end{array}$ & $\begin{array}{l}\text { Sales to } \\
\text { End Users }\end{array}$ & $\begin{array}{c}\text { Sales for } \\
\text { Resale }\end{array}$ \\
\hline \multicolumn{7}{|l|}{ Maryland } \\
\hline January .................................. & 63.6 & $w$ & $\mathbf{5 1 . 7}$ & 53.0 & $w$ & $w$ \\
\hline February ............................. & 80.7 & 85.0 & 56.5 & 57.9 & $w$ & $w$ \\
\hline March .................................... & 64.6 & $W$ & 52.4 & 52.1 & $w$ & $w$ \\
\hline 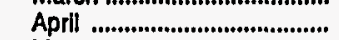 & - & $\dddot{w}$ & 49.7 & 50.6 & $w$ & $w$ \\
\hline 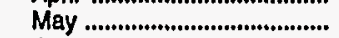 & - & - & 50.5 & 50.9 & $\ddot{w}$ & $w$ \\
\hline June .......................................... & - & $W$ & 51.5 & 52.2 & $w$ & $w$ \\
\hline 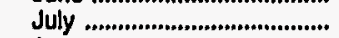 & $w$ & NA & 53.0 & 52.9 & $w$ & $w$ \\
\hline 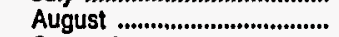 & $w$ & - & 52.9 & 52.3 & $w$ & $w$ \\
\hline September ............................. & $\ddot{w}$ & - & 51.2 & 50.6 & w & $\ddot{w}$ \\
\hline Oclober ..................................... & $w$ & $W$ & 51.5 & 51.8 & $w$ & $w$ \\
\hline November .............................. & $\ddot{w}$ & $\ddot{W}$ & 52.5 & 52.6 & $w$ & $w$ \\
\hline December ............................. & $w$ & $\ddot{W}$ & 50.9 & 50.3 & $w$ & $w$ \\
\hline 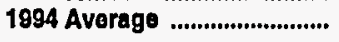 & 68.5 & 65.1 & 52.2 & 52.4 & w & $w$ \\
\hline \multicolumn{7}{|l|}{ New Jersey } \\
\hline 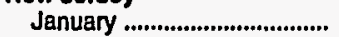 & $w$ & $W$ & 56.9 & 51.6 & 54.2 & 49.8 \\
\hline February .............................. & $\ddot{w}$ & W & 62.6 & 56.9 & 60.6 & 55.8 \\
\hline 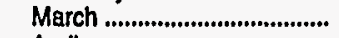 & $W$ & $W$ & 57.0 & 51.1 & 55.5 & 50.9 \\
\hline April & W & - & 54.2 & 49.1 & 47.7 & 43.3 \\
\hline 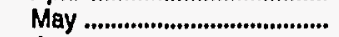 & - & - & 53.4 & 49.1 & 48.6 & 42.2 \\
\hline June .......................................... & - & - & 54.2 & 49.9 & $w$ & 43.1 \\
\hline July ......................................... & - & - & 54.9 & 50.4 & 51.1 & 46.4 \\
\hline 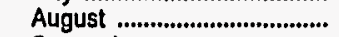 & - & - & 54.6 & 50.4 & 51.3 & 48.3 \\
\hline September ......................... & - & - & 52.4 & 48.9 & 47.8 & 45.6 \\
\hline 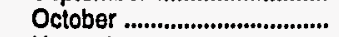 & - & $w$ & 53.9 & 49.8 & 47.8 & 45.0 \\
\hline November ............................. & $w$ & - & 54.8 & 50.4 & 50.1 & 47.1 \\
\hline December .............................. & $\ddot{w}$ & $w$ & 53.4 & 49.7 & 51.0 & 48.3 \\
\hline 1994 Average ......................... & $\mathbf{W}$ & $\mathbf{W}$ & 55.3 & 50.8 & 53.8 & 49.9 \\
\hline \multicolumn{7}{|l|}{ Now York } \\
\hline January .................................. & $w$ & 60.7 & 64.1 & 54.2 & $w$ & $w$ \\
\hline Fabruary ............................... & $w$ & $w$ & 69.4 & 60.4 & $w$ & $w$ \\
\hline March ....................................... & $\ddot{w}$ & $\ddot{w}$ & 65.1 & 54.0 & $\ddot{w}$ & $w$ \\
\hline 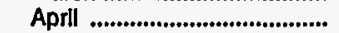 & $\ddot{w}$ & $W$ & 61.9 & 51.2 & 47.3 & $\ddot{w}$ \\
\hline May ...................................... & $w$ & $w$ & 58.1 & 50.6 & 46.5 & W \\
\hline June ...................................... & $W$ & W & 58.1 & 50.8 & $w$ & W \\
\hline July ........................................ & $W$ & $w$ & 58.9 & 52.1 & $w$ & $w$ \\
\hline 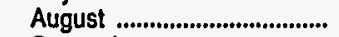 & $W$ & W & 58.4 & 51.6 & w & W \\
\hline September ............................. & $w$ & 58.2 & 57.5 & 51.6 & $\dddot{w}$ & W \\
\hline October ..................................... & $\ddot{w}$ & $w$ & 58.6 & 51.7 & $w$ & $\mathbf{W}$ \\
\hline November ............................. & $w$ & 59.5 & 60.0 & 52.1 & $w$ & $W$ \\
\hline 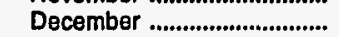 & $\ddot{w}$ & 59.4 & 61.1 & 51.7 & $w$ & $W$ \\
\hline 1994 Average .......................... & $\mathbf{W}$ & 62.2 & 61.9 & 53.1 & $\mathbf{w}$ & $\mathbf{w}$ \\
\hline \multicolumn{7}{|l|}{ Pennoyivanla } \\
\hline 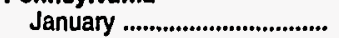 & 78.0 & 68.8 & 65.0 & 52.4 & $w$ & $w$ \\
\hline February ............................... & 93.4 & 82.2 & 68.7 & 57.6 & $w$ & $W$ \\
\hline March ..................................... & 69.3 & 64.4 & 64.6 & 52.4 & $w$ & - \\
\hline 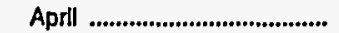 & $W$ & 61.5 & 60.8 & 51.2 & w & $w$ \\
\hline 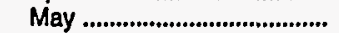 & $w$ & 59.8 & 55.7 & 50.5 & w & - \\
\hline 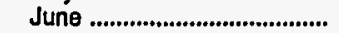 & $w$ & $w$ & 56.4 & 51.2 & w & - \\
\hline July ......................................... & $w$ & NA & 56.7 & 52.4 & $w$ & - \\
\hline 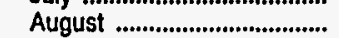 & w & 62.4 & 58.4 & 52.1 & $w$ & - \\
\hline September .......................... & $w$ & $w$ & 56.9 & 50.6 & $w$ & - \\
\hline October .................................. & $\ddot{w}$ & 61.0 & 59.0 & 51.4 & $w$ & - \\
\hline 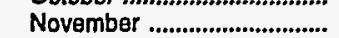 & $w$ & 59.2 & 59.8 & 51.9 & $w$ & - \\
\hline December .............................. & 60.6 & 58.1 & 60.9 & 50.6 & $\ddot{w}$ & - \\
\hline 1994 Average ........................... & 80.3 & 72.4 & 60.5 & 52.2 & $\mathbf{w}$ & $\mathbf{w}$ \\
\hline
\end{tabular}

See footnotes at end of table. 
Table 37. Refiner Prices of Distillate Fuels by PAD District and State

(Cents per Gallon Excluding Taxes) - Continued

\begin{tabular}{|c|c|c|c|c|c|c|}
\hline \multirow{2}{*}{$\begin{array}{l}\text { Geographic Area } \\
\text { Month }\end{array}$} & \multicolumn{2}{|c|}{ No. 1 Distillate } & \multicolumn{2}{|c|}{ No. 2 Distillatea } & \multicolumn{2}{|c|}{ No. 4 Fuelb } \\
\hline & $\begin{array}{l}\text { Sales to } \\
\text { End Users }\end{array}$ & $\begin{array}{c}\text { Sales for } \\
\text { Resale }\end{array}$ & $\begin{array}{l}\text { Sales to } \\
\text { End Users }\end{array}$ & $\begin{array}{l}\text { Sales for } \\
\text { Resale }\end{array}$ & $\begin{array}{c}\text { Sales to } \\
\text { End Users }\end{array}$ & $\begin{array}{c}\text { Sales for } \\
\text { Resale }\end{array}$ \\
\hline \multicolumn{7}{|l|}{ Subdistrict IC } \\
\hline 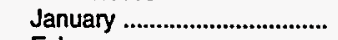 & 62.0 & 62.3 & 52.9 & 50.8 & 49.5 & $w$ \\
\hline 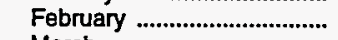 & 76.5 & 75.8 & 56.1 & 53.8 & 55.2 & $w$ \\
\hline 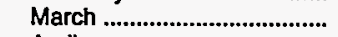 & 68.6 & 61.9 & 53.6 & 50.8 & 51.1 & $w$ \\
\hline April & $w$ & 59.9 & 52.6 & 49.6 & 44.2 & $\ddot{w}$ \\
\hline 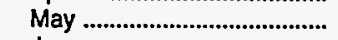 & $\mathbf{w}$ & 59.9 & 52.5 & 49.7 & 47.2 & $w$ \\
\hline 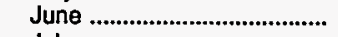 & $w$ & W & 53.8 & 50.9 & 48.6 & $w$ \\
\hline 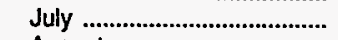 & w & 66.3 & 54.7 & 52.1 & $w$ & $\ddot{w}$ \\
\hline 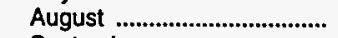 & w & $w$ & 54.6 & 51.5 & $w$ & $\ddot{w}$ \\
\hline 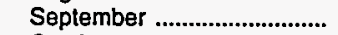 & $w$ & 60.2 & 53.5 & 50.5 & $\ddot{w}$ & $w$ \\
\hline 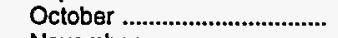 & 71.7 & 58.5 & 54.4 & 51.9 & w & $\dddot{w}$ \\
\hline 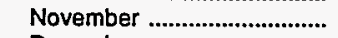 & $w$ & 60.2 & 55.1 & 52.3 & $w$ & $w$ \\
\hline 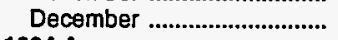 & 61.0 & 57.5 & 52.8 & 49.9 & $w$ & $w$ \\
\hline 1994 Average & 67.3 & 64.3 & 53.9 & 51.1 & 49.8 & $w$ \\
\hline \multicolumn{7}{|l|}{ Florida } \\
\hline 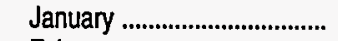 & - & $w$ & 53.1 & 50.9 & $w$ & - \\
\hline 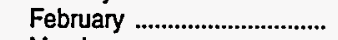 & - & - & 57.0 & 54.7 & W & - \\
\hline 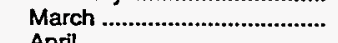 & - & w & 55.1 & 52.0 & $w$ & - \\
\hline April & - & - & 53.2 & 50.0 & $\ddot{w}$ & - \\
\hline 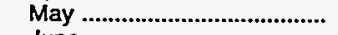 & - & - & 52.7 & 50.3 & $\underline{w}$ & - \\
\hline 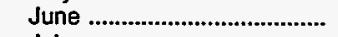 & - & - & 54.0 & 51.5 & $w$ & - \\
\hline 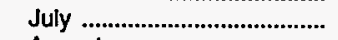 & - & - & 55.0 & 52.6 & W & - \\
\hline August & - & - & 55.1 & 52.2 & $w$ & - \\
\hline 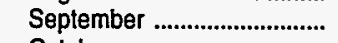 & - & - & 53.7 & 51.1 & $\dddot{w}$ & - \\
\hline October & - & - & 54.9 & 52.2 & $\ddot{w}$ & - \\
\hline 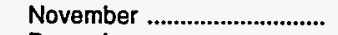 & - & - & 55.8 & 52.4 & $\ddot{w}$ & - \\
\hline 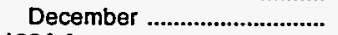 & - & - & 53.4 & 50.3 & $w$ & - \\
\hline 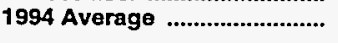 & - & $w$ & 54.4 & 51.7 & $\dddot{w}$ & - \\
\hline \multicolumn{7}{|l|}{ Georgia } \\
\hline 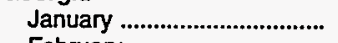 & - & $w$ & 52.2 & 49.6 & $w$ & - \\
\hline 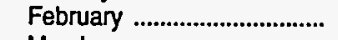 & W & $W$ & 55.4 & 52.2 & $\ddot{w}$ & - \\
\hline 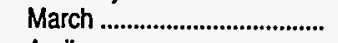 & - & - & 53.0 & 50.0 & $\ddot{w}$ & - \\
\hline 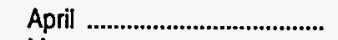 & - & - & 52.4 & 48.9 & - & - \\
\hline 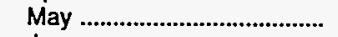 & - & - & 52.5 & 49.2 & - & - \\
\hline 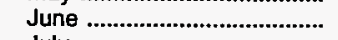 & - & - & 53.8 & 50.2 & - & - \\
\hline 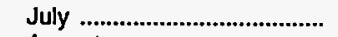 & - & - & 54.5 & 51.5 & - & - \\
\hline 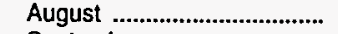 & - & - & 54.7 & 50.8 & - & - \\
\hline 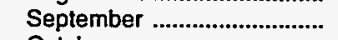 & - & w & 53.8 & 50.2 & w & _- \\
\hline 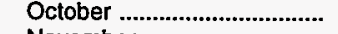 & - & - & 54.3 & 51.5 & - & - \\
\hline 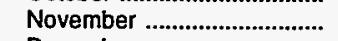 & - & - & 55.4 & 51.8 & - & - \\
\hline 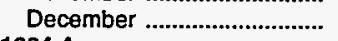 & - & - & 52.8 & 49.5 & - & - \\
\hline 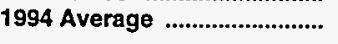 & $w$ & $w$ & 53.7 & 50.5 & $w$ & - \\
\hline \multicolumn{7}{|l|}{ North Carolina } \\
\hline 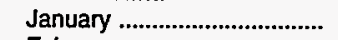 & 61.2 & 62.4 & 52.3 & 51.1 & w & - \\
\hline 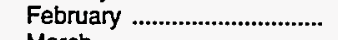 & 63.8 & NA & 54.4 & 53.4 & $w$ & - \\
\hline 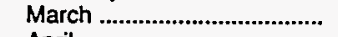 & w & 57.6 & 50.9 & 49.6 & $\ddot{w}$ & - \\
\hline 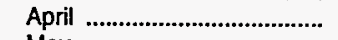 & - & - & 50.3 & 48.9 & $w$ & $z$ \\
\hline 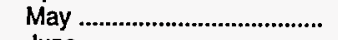 & - & $w$ & 50.9 & 49.0 & W & - \\
\hline 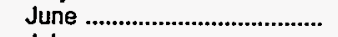 & - & - & 52.0 & 50.7 & $w$ & - \\
\hline 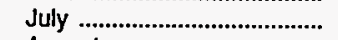 & - & - & 53.0 & 51.7 & $\ddot{w}$ & - \\
\hline August & - & - & 52.7 & 51.2 & $w$ & - \\
\hline 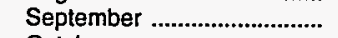 & - & - & 51.8 & 50.2 & w & - \\
\hline 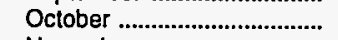 & - & - & 53.0 & 51.7 & $w$ & - \\
\hline 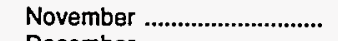 & - & $w$ & 53.3 & 52.2 & $w$ & - \\
\hline 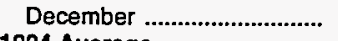 & $w$ & $w$ & 51.2 & 49.7 & $w$ & - \\
\hline 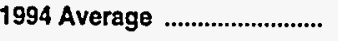 & 62.2 & 63.5 & 52.1 & 50.8 & $\ddot{w}$ & - \\
\hline
\end{tabular}

See footnotes at end of table. 
Table 37. Refiner Prices of Distillate Fuels by PAD District and State (Cents per Gallon Excluding Taxes) - Continued

\begin{tabular}{|c|c|c|c|c|c|c|}
\hline \multirow{2}{*}{$\begin{array}{l}\text { Geographlc Area } \\
\text { Month }\end{array}$} & \multicolumn{2}{|c|}{ No. 1 Distlllate } & \multicolumn{2}{|c|}{ No. 2 Distillatea } & \multicolumn{2}{|c|}{ No. 4 Fuelb } \\
\hline & $\begin{array}{l}\text { Sales to } \\
\text { End Users }\end{array}$ & $\begin{array}{l}\text { Sales for } \\
\text { Resale }\end{array}$ & $\begin{array}{l}\text { Sales to } \\
\text { End Users }\end{array}$ & $\begin{array}{c}\text { Sales for } \\
\text { Resale }\end{array}$ & $\begin{array}{l}\text { Sales to } \\
\text { End Users }\end{array}$ & $\begin{array}{c}\text { Sales for } \\
\text { Resale }\end{array}$ \\
\hline \multicolumn{7}{|l|}{ South Carollna } \\
\hline 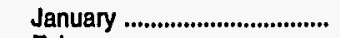 & $W$ & $W$ & 54.6 & 51.0 & $w$ & - \\
\hline February ..................................... & - & $w$ & 57.0 & 54.0 & w & - \\
\hline 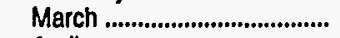 & $W$ & NA & 53.8 & 50.1 & $w$ & - \\
\hline April & - & - & 52.8 & 49.4 & $\ddot{W}$ & - \\
\hline 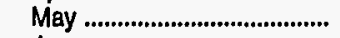 & - & - & 53.0 & 49.6 & $\mathbf{w}$ & - \\
\hline 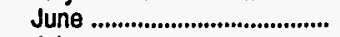 & - & - & 54.6 & 50.6 & $w$ & - \\
\hline 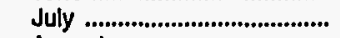 & - & - & 55.4 & 52.0 & $w$ & - \\
\hline 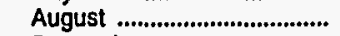 & - & - & 55.4 & 51.2 & $w$ & - \\
\hline 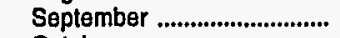 & - & - & 54.3 & 50.5 & $w$ & - \\
\hline 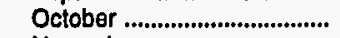 & - & - & 55.1 & 51.9 & $w$ & - \\
\hline 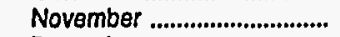 & - & - & 55.8 & 52.2 & $w$ & - \\
\hline December ................................ & - & - & 53.5 & 49.7 & $w$ & - \\
\hline 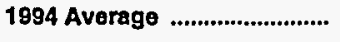 & $\mathbf{w}$ & $\mathbf{w}$ & 54.6 & 51.0 & $w$ & - \\
\hline \multicolumn{7}{|l|}{ Virginia } \\
\hline 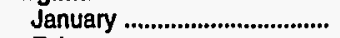 & 62.8 & 63.4 & 51.6 & 50.9 & $w$ & $w$ \\
\hline February .................................... & 70.1 & 74.2 & 54.2 & 54.0 & $w$ & $w$ \\
\hline March ...................................... & 59.2 & 61.8 & 50.5 & 50.6 & W & w \\
\hline April & W & 58.3 & 49.5 & 49.4 & $W$ & $w$ \\
\hline 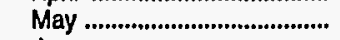 & $w$ & $w$ & 49.9 & 49.5 & $w$ & w \\
\hline 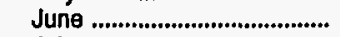 & W & w & 51.5 & 50.7 & $W$ & $w$ \\
\hline 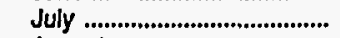 & $w$ & $w$ & 52.6 & 51.8 & W & w \\
\hline August .................................... & W & W & 52.1 & 51.1 & $\ddot{w}$ & w \\
\hline September ............................. & $w$ & w & 51.0 & 50.2 & $\ddot{w}$ & w \\
\hline 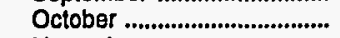 & $w$ & $w$ & 52.1 & 51.6 & W & $\ddot{w}$ \\
\hline November ................................. & $W$ & $w$ & 52.5 & 52.3 & $\ddot{W}$ & $w$ \\
\hline December ............................... & $W$ & W & 51.0 & 49.8 & $W$ & $W$ \\
\hline 1994 Average ........................... & 62.3 & 64.2 & 51.6 & 51.0 & $W$ & $\mathbf{W}$ \\
\hline \multicolumn{7}{|l|}{ West Virglnla } \\
\hline 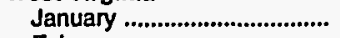 & $w$ & 60.8 & 55.9 & 51.7 & - & - \\
\hline 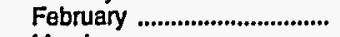 & $W$ & 77.3 & 60.2 & 56.8 & - & - \\
\hline March & $W$ & 70.7 & 59.6 & 55.7 & $w$ & - \\
\hline April & W & $W$ & 59.8 & 55.9 & $W$ & - \\
\hline 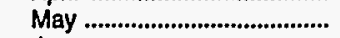 & - & - & 57.4 & 52.9 & $w$ & - \\
\hline 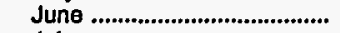 & - & $w$ & 58.5 & 53.5 & $w$ & - \\
\hline July & $W$ & $w$ & 58.9 & 54.6 & $w$ & - \\
\hline 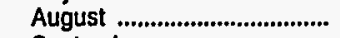 & - & $w$ & 59.0 & 54.6 & $w$ & - \\
\hline September ................................ & W & $w$ & 56.8 & 52.1 & - & $w$ \\
\hline 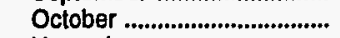 & $W$ & $w$ & 57.0 & 53.6 & $w$ & - \\
\hline 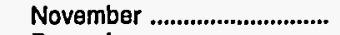 & $\mathbf{W}$ & W & 59.1 & 55.1 & $W$ & - \\
\hline December .................................. & W & $w$ & 55.5 & 51.1 & $w$ & - \\
\hline 1994 Average & $\mathbf{W}$ & 67.0 & 58.1 & 53.9 & $\mathbf{W}$ & $w$ \\
\hline \multicolumn{7}{|l|}{ PAD District If } \\
\hline 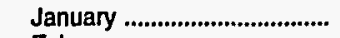 & 58.5 & 58.3 & 51.4 & 48.5 & 43.8 & $w$ \\
\hline February ................................... & 65.6 & 62.5 & 54.3 & 51.6 & 49.3 & w \\
\hline 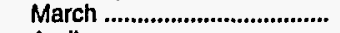 & 62.4 & 59.1 & 54.2 & 52.7 & $w$ & - \\
\hline 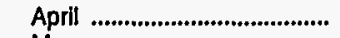 & 59.7 & 56.4 & 54.8 & 53.2 & W & - \\
\hline May ............................................. & 57.7 & 55.9 & 53.9 & 52.5 & $W$ & - \\
\hline June .......................................... & 58.4 & 56.9 & 54.7 & 53.5 & $W$ & $w$ \\
\hline July ......................................... & 59.8 & 59.1 & 55.8 & 55.0 & $\ddot{w}$ & - \\
\hline 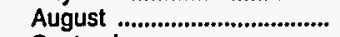 & 60.7 & 59.8 & 56.4 & 55.5 & $w$ & - \\
\hline September ............................... & 60.0 & 59.0 & 55.3 & 53.8 & $\ddot{w}$ & - \\
\hline 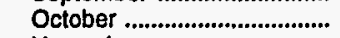 & 60.3 & 61.4 & 55.4 & 54.6 & $w$ & - \\
\hline 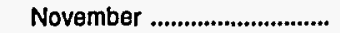 & 61.3 & 61.4 & 55.8 & 53.9 & $w$ & $w$ \\
\hline December .............................. & 58.5 & 58.7 & 53.2 & 50.5 & w & - \\
\hline 1994 Average ........................... & 60.6 & 59.7 & 54.6 & 53.0 & W & $\mathbf{w}$ \\
\hline
\end{tabular}

See footnotes at end of table. 
Table 37. Refiner Prices of Distillate Fuels by PAD District and State (Cents per Gallon Excluding Taxes) - Continued

\begin{tabular}{|c|c|c|c|c|c|c|}
\hline \multirow{2}{*}{$\begin{array}{l}\text { Geographlc Area } \\
\text { Month }\end{array}$} & \multicolumn{2}{|c|}{ No. 1 Dlstillate } & \multicolumn{2}{|c|}{ No. 2 Distillatea } & \multicolumn{2}{|c|}{ No. 4 Fuejb } \\
\hline & $\begin{array}{l}\text { Sales to } \\
\text { End Users }\end{array}$ & $\begin{array}{c}\text { Sales for } \\
\text { Resale }\end{array}$ & $\begin{array}{l}\text { Sales to } \\
\text { End Users }\end{array}$ & $\begin{array}{c}\text { Sales for } \\
\text { Resale }\end{array}$ & $\begin{array}{l}\text { Sales to } \\
\text { End Users }\end{array}$ & $\begin{array}{c}\text { Sales for } \\
\text { Resale }\end{array}$ \\
\hline \multicolumn{7}{|l|}{ Illinols } \\
\hline 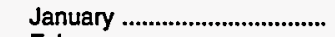 & 56.1 & 59.6 & 48.6 & 46.8 & $w$ & - \\
\hline 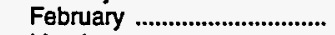 & 66.1 & 66.4 & 51.6 & 50.2 & $\ddot{w}$ & - \\
\hline March ........................................ & $w$ & 61.8 & 52.7 & 51.6 & $w$ & - \\
\hline April & W & 57.3 & 53.2 & 51.4 & $\ddot{w}$ & - \\
\hline May & $W$ & 54.3 & 52.5 & 50.9 & W & - \\
\hline June & W & 55.8 & 53.4 & 52.0 & $w$ & - \\
\hline 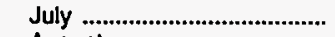 & $W$ & 57.2 & 54.4 & 52.9 & w & - \\
\hline 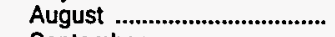 & W & 57.7 & 55.5 & 53.3 & $\ddot{w}$ & - \\
\hline 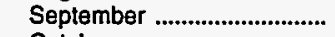 & 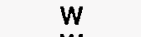 & 57.5 & 54.4 & 52.0 & $\ddot{w}$ & - \\
\hline October ..................................... & $W$ & 57.2 & 53.8 & 52.6 & $\ddot{w}$ & - \\
\hline 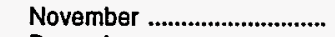 & W & 57.9 & 54.3 & 51.4 & $w$ & - \\
\hline 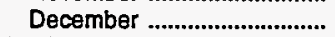 & w & 56.3 & 52.1 & 49.1 & W & - \\
\hline 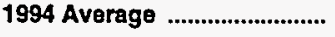 & $\mathbf{W}$ & 59.5 & 53.1 & 51.3 & $w$ & - \\
\hline \multicolumn{7}{|l|}{ Indiana } \\
\hline 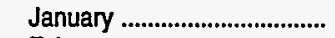 & 59.8 & 59.6 & 50.3 & 47.3 & $W$ & - \\
\hline 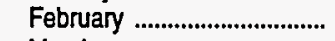 & 68.5 & 59.9 & 53.3 & 50.5 & W & - \\
\hline 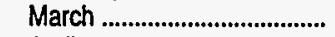 & 61.0 & 56.3 & 53.5 & 53.0 & W & - \\
\hline April & $W$ & 58.8 & 54.2 & 53.3 & W & - \\
\hline 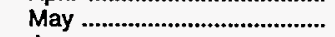 & $w$ & 56.5 & 53.2 & 51.8 & $w$ & - \\
\hline 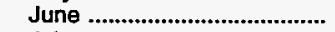 & w & 59.6 & 54.4 & 52.5 & $\ddot{w}$ & - \\
\hline 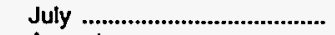 & w & 58.6 & 54.9 & 53.6 & W & - \\
\hline 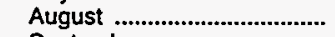 & 61.9 & 59.9 & 55.5 & 54.0 & $w$ & - \\
\hline September ............................... & $w$ & 56.4 & 54.4 & 52.4 & W & - \\
\hline 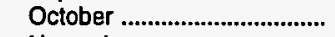 & W & 58.8 & 54.6 & 53.5 & W & - \\
\hline November .............................. & 60.6 & 59.5 & 55.1 & 52.6 & W & $w$ \\
\hline December ................................ & 58.8 & 57.7 & 52.5 & 50.1 & W & - \\
\hline 1994 Average & 61.4 & 58.9 & 53.9 & 52.1 & $w$ & $w$ \\
\hline \multicolumn{7}{|l|}{ lowa } \\
\hline 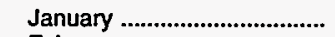 & 57.7 & 57.2 & 51.4 & 49.4 & - & - \\
\hline February ................................... & 59.9 & 59.8 & 53.2 & 51.4 & - & - \\
\hline March ................................. & 62.4 & 60.1 & 54.4 & 54.1 & - & - \\
\hline 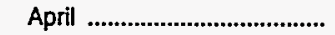 & $W$ & 58.8 & 55.4 & 55.1 & - & - \\
\hline May & w & 58.3 & 53.6 & 53.9 & - & - \\
\hline June & 62.8 & 59.9 & 54.7 & 55.3 & - & - \\
\hline July & $W$ & 63.4 & 56.6 & 57.5 & - & - \\
\hline 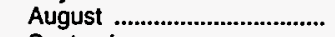 & W & 63.6 & 58.2 & 58.4 & - & - \\
\hline September ................................ & $w$ & 61.1 & 56.8 & 56.2 & - & - \\
\hline October & $w$ & 63.6 & 56.8 & 57.3 & - & - \\
\hline November ............................... & 62.0 & 62.4 & 57.0 & 56.2 & - & - \\
\hline 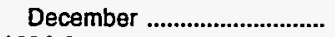 & $W$ & 59.2 & 53.6 & 51.6 & - & - \\
\hline 1994 Average & 59.6 & 59.6 & 55.2 & 55.0 & - & - \\
\hline \multicolumn{7}{|l|}{ Kansas } \\
\hline 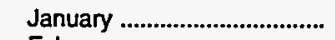 & 55.9 & 53.4 & 49.3 & 47.2 & - & - \\
\hline 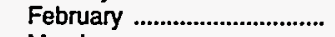 & 58.5 & 56.1 & 52.3 & 48.7 & - & - \\
\hline March & 60.5 & 56.1 & 50.8 & 51.6 & - & - \\
\hline April & - & 54.0 & 53.7 & 52.3 & - & - \\
\hline 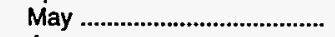 & W & 55.3 & 53.6 & 52.2 & - & - \\
\hline 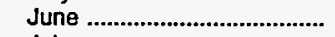 & W & 56.3 & 55.1 & 54.1 & - & - \\
\hline 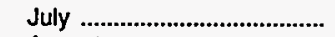 & W & 59.7 & 56.4 & 56.2 & - & - \\
\hline 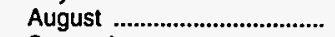 & W & 59.7 & 57.6 & 57.4 & - & - \\
\hline September ............................ & $w$ & 57.7 & 56.9 & 55.2 & - & - \\
\hline 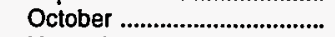 & 60.5 & 61.3 & 55.7 & 55.8 & - & - \\
\hline November ................................ & $W$ & 59.7 & 54.7 & 54.2 & - & - \\
\hline 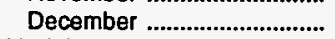 & 57.9 & 56.8 & 51.3 & 49.8 & - & - \\
\hline 1994 Average & 57.9 & 57.0 & 53.8 & 53.4 & - & - \\
\hline
\end{tabular}

See footnotes at end of table. 
Table 37. Refiner Prices of Distillate Fuels by PAD District and State (Cents per Gallon Excluding Taxes) - Continued

\begin{tabular}{|c|c|c|c|c|c|c|}
\hline \multirow{2}{*}{$\begin{array}{l}\text { Ceographlo Area } \\
\text { Month }\end{array}$} & \multicolumn{2}{|c|}{ No. 1 Distllate } & \multicolumn{2}{|c|}{ No. 2 Distillatea } & \multicolumn{2}{|c|}{ No. 4 Fuelb } \\
\hline & $\begin{array}{l}\text { Sales to } \\
\text { End Usere }\end{array}$ & $\begin{array}{l}\text { Sales for } \\
\text { Resale }\end{array}$ & $\begin{array}{l}\text { Sales to } \\
\text { End Users }\end{array}$ & $\begin{array}{c}\text { Sales for } \\
\text { Resale }\end{array}$ & $\begin{array}{l}\text { Sales to } \\
\text { End Users }\end{array}$ & $\begin{array}{l}\text { Sales for } \\
\text { Resalo }\end{array}$ \\
\hline \multicolumn{7}{|l|}{ Kenlucky } \\
\hline 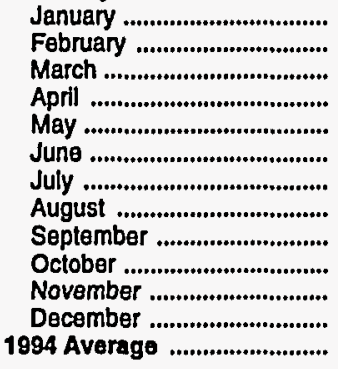 & $\begin{array}{l}78.4 \\
83.1 \\
66.2 \\
W \\
W \\
W \\
W \\
W \\
W \\
W \\
82.3 \\
68.9 \\
78.3\end{array}$ & $\begin{array}{l}63.1 \\
71.1 \\
66.2 \\
58.9 \\
53.8 \\
W \\
W \\
W \\
W \\
58.7 \\
61.0 \\
56.4 \\
63.3\end{array}$ & $\begin{array}{l}\mathbf{5 3 . 4} \\
\mathbf{5 6 . 7} \\
\mathbf{5 5 . 5} \\
\mathbf{5 6 . 4} \\
\mathbf{5 4 . 9} \\
\mathbf{5 6 . 0} \\
\mathbf{5 6 . 4} \\
\mathbf{5 6 . 4} \\
\mathbf{5 4 . 9} \\
\mathbf{5 6 . 3} \\
\mathbf{5 6 . 5} \\
\mathbf{5 3 . 7} \\
\mathbf{5 5 . 6}\end{array}$ & $\begin{array}{l}\mathbf{5 0 . 6} \\
\mathbf{5 3 . 9} \\
\mathbf{5 4 . 1} \\
\mathbf{5 3 . 9} \\
\mathbf{5 2 . 1} \\
\mathbf{5 2 . 9} \\
\mathbf{5 3 . 9} \\
\mathbf{5 3 . 6} \\
\mathbf{5 2 . 2} \\
\mathbf{5 3 . 1} \\
\mathbf{5 4 . 0} \\
\mathbf{5 0 . 9} \\
\mathbf{5 2 . 9}\end{array}$ & $\begin{array}{l}W \\
W \\
W \\
W \\
W \\
- \\
W \\
W \\
W \\
W \\
W \\
W \\
W\end{array}$ & $\begin{array}{l}\text { W } \\
- \\
- \\
- \\
- \\
- \\
- \\
- \\
- \\
\bar{w}\end{array}$ \\
\hline \multicolumn{7}{|l|}{ Michigan } \\
\hline 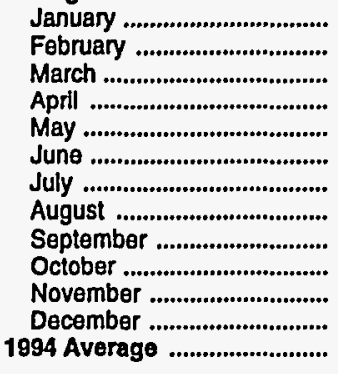 & $\begin{array}{c}58.1 \\
66.8 \\
64.8 \\
W \\
W \\
W \\
W \\
W \\
W \\
W \\
58.9 \\
57.1 \\
61.1\end{array}$ & $\begin{array}{l}58.5 \\
64.6 \\
60.1 \\
57.5 \\
W \\
W \\
W \\
59.1 \\
56.8 \\
57.8 \\
57.5 \\
57.9 \\
58.6\end{array}$ & $\begin{array}{l}49.8 \\
53.7 \\
55.0 \\
54.4 \\
53.4 \\
54.2 \\
55.3 \\
56.0 \\
54.8 \\
54.9 \\
54.7 \\
52.8 \\
54.2\end{array}$ & $\begin{array}{l}48.0 \\
51.9 \\
52.8 \\
52.9 \\
52.5 \\
53.5 \\
54.8 \\
54.8 \\
53.4 \\
54.0 \\
53.0 \\
50.8 \\
52.7\end{array}$ & $\begin{array}{l}- \\
\overline{-} \\
- \\
\overline{-} \\
\bar{w} \\
\bar{w} \\
w \\
W \\
W\end{array}$ & $\begin{array}{l}- \\
- \\
- \\
- \\
- \\
- \\
- \\
- \\
- \\
-\end{array}$ \\
\hline \multicolumn{7}{|l|}{ Minnesota } \\
\hline 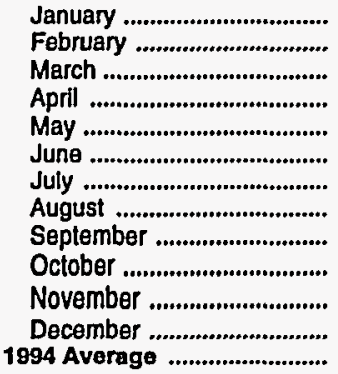 & $\begin{array}{l}60.0 \\
62.9 \\
62.1 \\
W \\
W \\
59.3 \\
W \\
W \\
W \\
W \\
62.1 \\
58.3 \\
60.3\end{array}$ & $\begin{array}{l}59.4 \\
63.1 \\
60.3 \\
59.4 \\
60.6 \\
62.3 \\
63.8 \\
65.4 \\
63.1 \\
64.6 \\
63.8 \\
61.0 \\
61.8\end{array}$ & $\begin{array}{l}51.6 \\
53.7 \\
52.4 \\
53.2 \\
53.4 \\
53.1 \\
55.7 \\
57.4 \\
55.6 \\
55.5 \\
55.9 \\
53.9 \\
54.3\end{array}$ & $\begin{array}{l}51.2 \\
52.7 \\
54.1 \\
55.8 \\
55.5 \\
56.2 \\
58.6 \\
59.8 \\
57.4 \\
58.5 \\
57.5 \\
52.8 \\
\mathbf{5 6 . 1}\end{array}$ & $\begin{array}{l}W \\
W \\
\bar{w} \\
- \\
\bar{w} \\
- \\
\bar{w} \\
W \\
W \\
w\end{array}$ & $\begin{array}{l}- \\
- \\
- \\
- \\
- \\
- \\
- \\
- \\
- \\
-\end{array}$ \\
\hline \multicolumn{7}{|l|}{ Missouri } \\
\hline 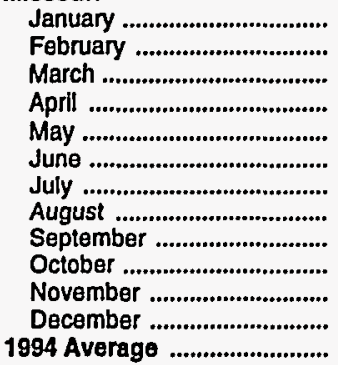 & $\begin{array}{l}W \\
W \\
W \\
W \\
W \\
W \\
W \\
W \\
W \\
W \\
W \\
W \\
W\end{array}$ & $\begin{array}{c}56.1 \\
58.8 \\
60.7 \\
58.2 \\
65.0 \\
W \\
63.7 \\
64.0 \\
59.0 \\
63.1 \\
62.3 \\
58.6 \\
59.1\end{array}$ & $\begin{array}{l}48.8 \\
52.1 \\
54.2 \\
54.9 \\
53.6 \\
54.3 \\
56.2 \\
56.9 \\
56.0 \\
55.8 \\
55.5 \\
52.7 \\
54.2\end{array}$ & $\begin{array}{l}48.7 \\
51.1 \\
53.1 \\
53.6 \\
52.3 \\
53.4 \\
55.5 \\
56.1 \\
53.9 \\
54.8 \\
53.8 \\
50.5 \\
53.1\end{array}$ & $\begin{array}{l}- \\
- \\
- \\
- \\
- \\
- \\
- \\
- \\
- \\
- \\
- \\
- \\
-\end{array}$ & $\begin{array}{l}- \\
- \\
- \\
- \\
- \\
- \\
- \\
- \\
- \\
- \\
- \\
- \\
-\end{array}$ \\
\hline
\end{tabular}

See footnotes at end of table. 
Table 37. Refiner Prices of Distillate Fuels by PAD District and State (Cents per Gallon Excluding Taxes) - Continued

\begin{tabular}{|c|c|c|c|c|c|c|}
\hline \multirow{2}{*}{$\begin{array}{l}\text { Geographic Area } \\
\text { Month }\end{array}$} & \multicolumn{2}{|c|}{ No. 1 Distillate } & \multicolumn{2}{|c|}{ No. 2 Distillatea } & \multicolumn{2}{|c|}{ No. 4 Fuelb } \\
\hline & $\begin{array}{c}\text { Sales to } \\
\text { End Users } \\
\end{array}$ & $\begin{array}{c}\text { Sales for } \\
\text { Resale }\end{array}$ & $\begin{array}{l}\text { Sales to } \\
\text { End Users }\end{array}$ & $\begin{array}{c}\text { Sales for } \\
\text { Resale }\end{array}$ & $\begin{array}{l}\text { Sales to } \\
\text { End Users }\end{array}$ & $\begin{array}{c}\text { Sales for } \\
\text { Resale }\end{array}$ \\
\hline \multicolumn{7}{|l|}{ Nebraska } \\
\hline January ..................................... & $W$ & 57.1 & 50.5 & 49.7 & - & - \\
\hline 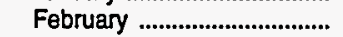 & W & 59.5 & 50.7 & 51.4 & - & - \\
\hline 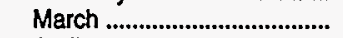 & W & 60.4 & 56.5 & 53.6 & - & - \\
\hline 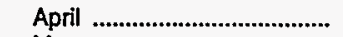 & $W$ & 60.2 & 54.2 & 55.2 & - & - \\
\hline May & - & 58.4 & 53.5 & 54.5 & - & - \\
\hline 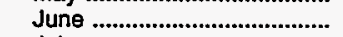 & - & 57.4 & 54.9 & 56.0 & - & - \\
\hline July & - & 64.7 & 56.3 & 58.1 & - & - \\
\hline 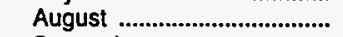 & - & 63.4 & 56.9 & 59.2 & - & - \\
\hline September ............................... & $W$ & 61.5 & 57.5 & 56.9 & - & - \\
\hline 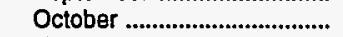 & W & 64.0 & 57.2 & 57.7 & - & - \\
\hline November ............................... & 62.6 & 62.4 & 57.1 & 56.5 & - & - \\
\hline 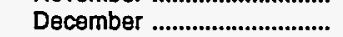 & 58.7 & 59.4 & 53.8 & 52.1 & - & - \\
\hline 1994 Average & 58.9 & 60.1 & 54.5 & 55.7 & - & - \\
\hline \multicolumn{7}{|l|}{ North Dakota } \\
\hline 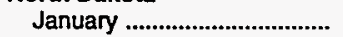 & 59.6 & 60.9 & $w$ & 52.4 & - & - \\
\hline 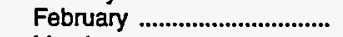 & 64.1 & 64.0 & $w$ & 53.4 & - & - \\
\hline 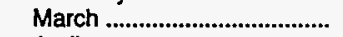 & $w$ & 61.7 & 49.9 & 55.4 & - & - \\
\hline April & W & 63.3 & $w$ & 57.5 & - & - \\
\hline May ........................................... & - & 62.1 & $\ddot{w}$ & 57.6 & - & - \\
\hline 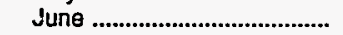 & - & 63.1 & W & 58.3 & - & - \\
\hline July & - & 66.3 & W & 60.3 & - & - \\
\hline 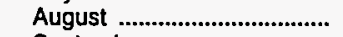 & W & 66.9 & W & 62.1 & - & - \\
\hline September ............................... & W & 65.1 & W & 59.6 & - & - \\
\hline 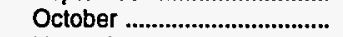 & W & 66.5 & $\ddot{w}$ & 59.6 & - & - \\
\hline November .............................. & $W$ & 66.2 & $W$ & 59.6 & - & - \\
\hline 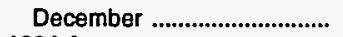 & $W$ & 64.1 & 51.8 & 55.1 & - & - \\
\hline 1994 Average & W & 64.0 & $w$ & 58.3 & - & - \\
\hline \multicolumn{7}{|l|}{ Ohio } \\
\hline January ................................. & 62.1 & 66.5 & 55.1 & 50.8 & $W$ & - \\
\hline February ................................. & 75.2 & 72.1 & 58.6 & 55.3 & W & - \\
\hline March .................................... & 66.2 & 64.7 & 59.0 & 55.6 & $W$ & - \\
\hline 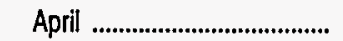 & W & 57.6 & 59.0 & 56.0 & W & - \\
\hline 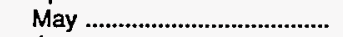 & 62.2 & $w$ & 57.6 & 53.7 & $w$ & - \\
\hline June ........................................ & $w$ & 57.7 & 57.4 & 54.5 & - & - \\
\hline 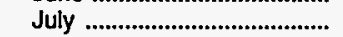 & 80.1 & w & 58.3 & 54.8 & $w$ & - \\
\hline 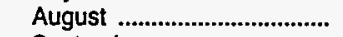 & W & 58.0 & 58.9 & 55.2 & W & - \\
\hline 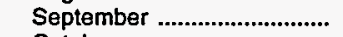 & W & $w$ & 57.6 & 53.7 & - & - \\
\hline 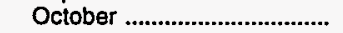 & $W$ & 60.3 & 58.3 & 55.1 & W & - \\
\hline November ............................... & 75.0 & 61.7 & 58.3 & 54.6 & W & - \\
\hline 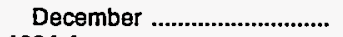 & 63.0 & 58.4 & 56.2 & 52.0 & W & - \\
\hline 1994 Average & 68.0 & 63.7 & $\mathbf{5 7 . 9}$ & 54.2 & $\mathbf{W}$ & - \\
\hline \multicolumn{7}{|l|}{ Oklahoma } \\
\hline 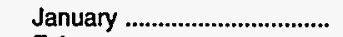 & 59.2 & 49.7 & 47.3 & 45.7 & - & - \\
\hline February ................................ & 61.3 & 51.8 & 48.2 & 48.3 & - & - \\
\hline 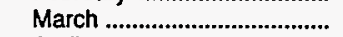 & W & 51.9 & 47.8 & 49.7 & - & - \\
\hline 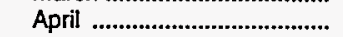 & W & 51.5 & 50.1 & 50.6 & - & - \\
\hline 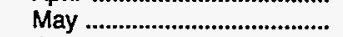 & W & 52.6 & 50.8 & 50.9 & - & - \\
\hline 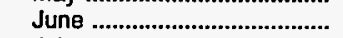 & $\ddot{W}$ & 53.6 & 51.5 & 52.4 & - & - \\
\hline 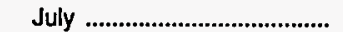 & $W$ & $w$ & 53.4 & 54.6 & - & - \\
\hline 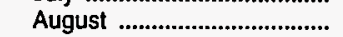 & W & 57.7 & 55.1 & 55.8 & - & - \\
\hline 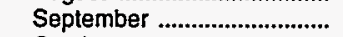 & W & 56.6 & 54.4 & 53.4 & - & - \\
\hline 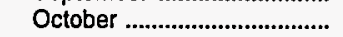 & W & 56.6 & 52.2 & 53.4 & - & - \\
\hline November ............................... & W & 55.7 & 53.1 & 53.4 & - & - \\
\hline 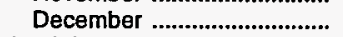 & 61.1 & 53.4 & 50.2 & 48.9 & - & - \\
\hline 1994 Average ............................... & 61.3 & 53.8 & 51.2 & 51.4 & - & - \\
\hline
\end{tabular}

See footnotes at end of table. 
Table 37. Refiner Prices of Distillate Fuels by PAD District and State

(Cents per Gallon Excluding Taxes) - Continued



See footnotes at end of table. 
Table 37. Refiner Prices of Distillate Fuels by PAD District and State

(Cents per Gallon Excluding Taxes) - Continued

\begin{tabular}{|c|c|c|c|c|c|c|}
\hline \multirow{2}{*}{$\begin{array}{l}\text { Goographic Area } \\
\text { Month }\end{array}$} & \multicolumn{2}{|c|}{ No. 1 Distillate } & \multicolumn{2}{|c|}{ No. 2 Distillatea } & \multicolumn{2}{|c|}{ No. 4 Fuelb } \\
\hline & $\begin{array}{l}\text { Sales to } \\
\text { End Users }\end{array}$ & $\begin{array}{c}\text { Sales for } \\
\text { Rosale }\end{array}$ & $\begin{array}{l}\text { Sales to } \\
\text { End Users }\end{array}$ & $\begin{array}{c}\text { Sales for } \\
\text { Resale }\end{array}$ & $\begin{array}{l}\text { Sales to } \\
\text { End Users }\end{array}$ & $\begin{array}{c}\text { Sales for } \\
\text { Rosalo } \\
\end{array}$ \\
\hline \multicolumn{7}{|l|}{ Alabama } \\
\hline 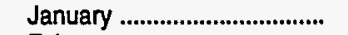 & - & w & 51.3 & 49.0 & - & w \\
\hline 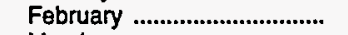 & - & w & 53.1 & 51.7 & - & - \\
\hline 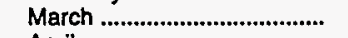 & - & w & 50.9 & 48.7 & - & - \\
\hline 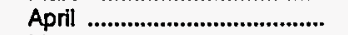 & - & - & 50.1 & 48.4 & - & - \\
\hline 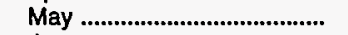 & - & w & 50.8 & 49.1 & - & - \\
\hline 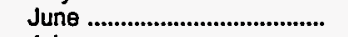 & - & - & 51.7 & 50.4 & - & - \\
\hline 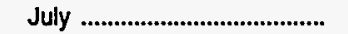 & - & w & 53.0 & 51.1 & - & - \\
\hline August & - & - & 52.3 & 50.9 & - & - \\
\hline September .............................. & - & w & 51.2 & 50.1 & - & - \\
\hline October …………………….......... & - & w & 53.2 & 51.5 & - & - \\
\hline 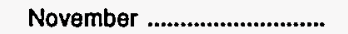 & - & w & 52.2 & 51.7 & - & - \\
\hline 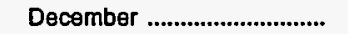 & - & w & 51.0 & 49.2 & - & - \\
\hline 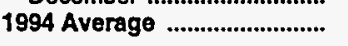 & - & $\ddot{w}$ & 51.7 & 50.1 & - & $w$ \\
\hline \multicolumn{7}{|l|}{ Arkansas } \\
\hline 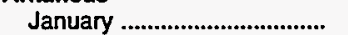 & - & w & 51.7 & 47.2 & - & _- \\
\hline 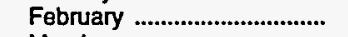 & - & 58.9 & 54.7 & 50.4 & - & - \\
\hline 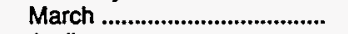 & - & $w$ & 53.9 & 50.0 & - & - \\
\hline 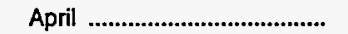 & - & $w$ & 54.1 & 50.3 & - & - \\
\hline 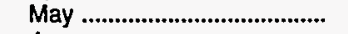 & - & - & 52.1 & 49.9 & - & - \\
\hline June .................................................... & - & - & 54.5 & 51.2 & - & - \\
\hline 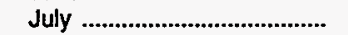 & - & w & 56.1 & 52.5 & - & - \\
\hline August ............................. & - & w & 56.5 & 52.5 & - & - \\
\hline September ................................ & - & $w$ & 54.7 & 51.0 & - & - \\
\hline 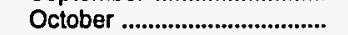 & - & $w$ & 54.3 & 51.7 & - & - \\
\hline 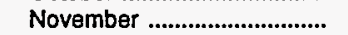 & - & w & 55.2 & 51.8 & - & - \\
\hline 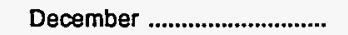 & - & $w$ & 54.3 & 49.1 & - & - \\
\hline 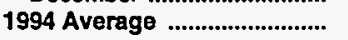 & - & 54.1 & 54.3 & 50.7 & - & - \\
\hline \multicolumn{7}{|l|}{ Louisiana } \\
\hline 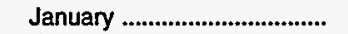 & - & 54.7 & 48.5 & 46.3 & - & - \\
\hline 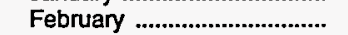 & - & $w$ & 51.1 & 48.8 & - & - \\
\hline 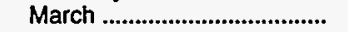 & - & - & 48.8 & 45.7 & - & - \\
\hline 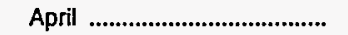 & w & w & 46.6 & 45.6 & - & - \\
\hline 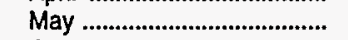 & - & $w$ & 49.7 & 46.9 & - & - \\
\hline 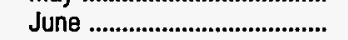 & - & - & 51.6 & 47.6 & - & - \\
\hline 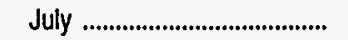 & - & - & 52.6 & 48.9 & - & - \\
\hline 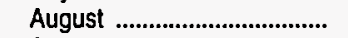 & - & - & 53.2 & 49.2 & - & - \\
\hline 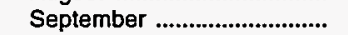 & - & - & 52.0 & 47.8 & - & - \\
\hline October ……………….......... & - & $w$ & 50.4 & 48.5 & - & - \\
\hline November ....................................... & - & $\mathbf{w}$ & 51.7 & 49.0 & - & - \\
\hline 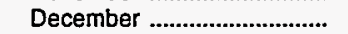 & - & $w$ & 50.2 & 47.4 & - & - \\
\hline 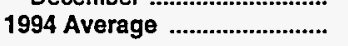 & $\mathbf{w}$ & 55.5 & 50.3 & 47.6 & - & - \\
\hline \multicolumn{7}{|l|}{ Mississippi } \\
\hline 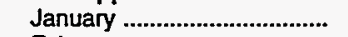 & - & - & 50.7 & 48.8 & w & w \\
\hline 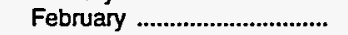 & - & - & 53.5 & 49.8 & $w$ & w \\
\hline March .......................................... & - & - & 49.9 & 47.5 & w & W \\
\hline April ............................................ & - & - & 50.5 & 46.1 & w & $w$ \\
\hline 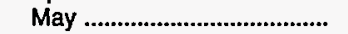 & - & - & 50.4 & 47.0 & $\mathbf{w}$ & w \\
\hline 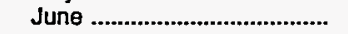 & - & - & 52.1 & 48.8 & $w$ & $\ddot{w}$ \\
\hline July ...................................... & - & - & 52.8 & 49.5 & $w$ & w \\
\hline 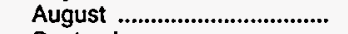 & - & - & 52.6 & 49.6 & $\ddot{w}$ & $\ddot{w}$ \\
\hline 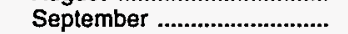 & - & - & 51.9 & 49.0 & $w$ & $w$ \\
\hline October ……………………...... & - & - & 52.8 & 49.9 & $w$ & $w$ \\
\hline 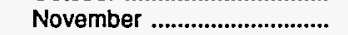 & - & w & 53.6 & 50.2 & w & W \\
\hline 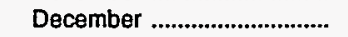 & - & - & 51.0 & 47.9 & $w$ & w \\
\hline 1994 Average ........................... & - & w & 51.8 & 48.5 & $\mathbf{w}$ & $\mathbf{w}$ \\
\hline
\end{tabular}

See footnotes at end of table. 
Table 37. Refiner Prices of Distillate Fuels by PAD District and State (Cents per Gallon Excluding Taxes) - Continued

\begin{tabular}{|c|c|c|c|c|c|c|}
\hline \multirow{2}{*}{$\begin{array}{c}\text { Goographic Area } \\
\text { Month }\end{array}$} & \multicolumn{2}{|c|}{ No. 1 Distlllate } & \multicolumn{2}{|c|}{ No. 2 Distillatea } & \multicolumn{2}{|c|}{ No. 4 Fuel $^{\mathrm{b}}$} \\
\hline & $\begin{array}{l}\text { Sales to } \\
\text { End Users }\end{array}$ & $\begin{array}{c}\text { Sales for } \\
\text { Resale }\end{array}$ & $\begin{array}{l}\text { Sales to } \\
\text { End Users }\end{array}$ & $\begin{array}{c}\text { Sales for } \\
\text { Resale }\end{array}$ & $\begin{array}{l}\text { Sales to } \\
\text { End Users }\end{array}$ & $\begin{array}{c}\text { Sales for } \\
\text { Resale }\end{array}$ \\
\hline \multicolumn{7}{|l|}{ New Mexico } \\
\hline 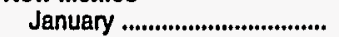 & $w$ & 64.2 & 62.5 & 49.3 & - & - \\
\hline February .............................. & W & 68.3 & 63.5 & 54.4 & - & - \\
\hline 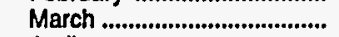 & W & 70.0 & 63.4 & 57.4 & - & - \\
\hline 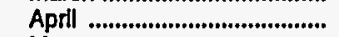 & $w$ & 69.1 & 61.8 & 58.2 & - & - \\
\hline May ........................................ & W & $w$ & 61.4 & 57.8 & - & - \\
\hline June ........................................ & $W$ & $W$ & 61.1 & 57.9 & - & - \\
\hline July ...................................... & W & W & 63.7 & 60.0 & - & - \\
\hline 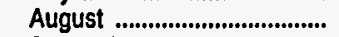 & W & W & 68.3 & 61.6 & - & - \\
\hline September .......................... & $W$ & 71.6 & 64.9 & 60.2 & - & - \\
\hline October ................................ & W & 70.9 & 67.2 & 60.7 & - & - \\
\hline November ............................. & $W$ & 76.7 & 67.5 & 60.9 & - & - \\
\hline 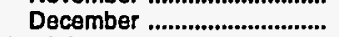 & $w$ & 71.0 & 62.4 & 55.5 & - & - \\
\hline 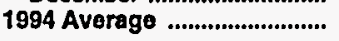 & $w$ & 69.6 & 63.9 & 58.0 & - & - \\
\hline \multicolumn{7}{|l|}{ Texas } \\
\hline 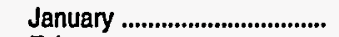 & $W$ & 53.0 & 50.5 & 46.3 & - & - \\
\hline February ............................... & $W$ & 57.1 & 52.4 & 48.6 & - & - \\
\hline 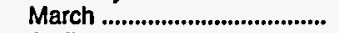 & $W$ & 62.1 & 51.5 & 46.8 & - & - \\
\hline April & W & 57.4 & 51.8 & 47.1 & - & - \\
\hline May & - & 52.8 & 51.7 & 47.7 & - & - \\
\hline June ....................................... & $W$ & 61.5 & 53.0 & 49.1 & - & - \\
\hline July ........................................... & W & 59.4 & 54.1 & 50.3 & - & - \\
\hline 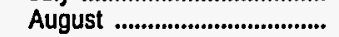 & $w$ & 60.0 & 55.5 & 50.9 & - & - \\
\hline September .............................. & W & 60.7 & 54.6 & 50.0 & - & - \\
\hline 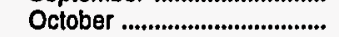 & $w$ & 57.4 & 54.7 & 49.4 & - & - \\
\hline November .............................. & w & 59.9 & 54.6 & 50.5 & - & - \\
\hline 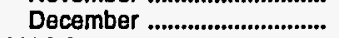 & $\ddot{w}$ & 56.6 & 53.2 & 47.9 & - & $w$ \\
\hline 1994 Average & 59.3 & 57.6 & 53.1 & 48.7 & - & $w$ \\
\hline \multicolumn{7}{|l|}{ PAD District IV } \\
\hline 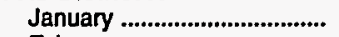 & 67.9 & 61.2 & 50.0 & 49.7 & - & - \\
\hline February ................................. & 68.1 & 62.4 & 52.9 & 53.2 & - & - \\
\hline March ..................................... & 70.2 & 62.0 & 54.1 & 54.7 & - & - \\
\hline April .......................................... & $w$ & 64.3 & 55.3 & 57.9 & - & - \\
\hline May ....................................... & W & 66.0 & 57.9 & 58.6 & - & - \\
\hline 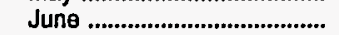 & W & 66.5 & 57.8 & 58.7 & - & - \\
\hline 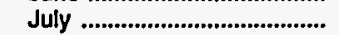 & W & 66.6 & 58.9 & 59.3 & - & - \\
\hline 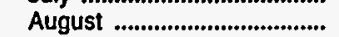 & $w$ & 69.7 & 61.0 & 62.6 & - & - \\
\hline 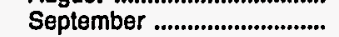 & 81.1 & 73.2 & 65.8 & 67.6 & - & - \\
\hline 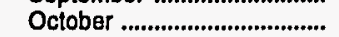 & 78.0 & 74.7 & 66.3 & 66.5 & - & - \\
\hline 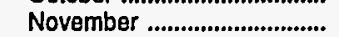 & 78.5 & 76.3 & 64.9 & 65.9 & - & - \\
\hline 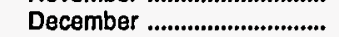 & 71.7 & 68.4 & 60.6 & 57.9 & - & - \\
\hline 1994 Average & 74.0 & 67.9 & $\mathbf{5 9 . 0}$ & 59.7 & - & - \\
\hline \multicolumn{7}{|l|}{ Colorado } \\
\hline January ................................... & $w$ & 57.4 & 52.2 & 49.9 & - & - \\
\hline February ............................... & 72.2 & 57.0 & 53.2 & 50.2 & - & - \\
\hline March ..................................... & $W$ & 58.4 & 52.3 & 51.6 & - & - \\
\hline 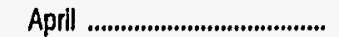 & W & 62.6 & 52.4 & 55.9 & - & - \\
\hline May ......................................... & W & 61.4 & 56.1 & 55.3 & - & - \\
\hline 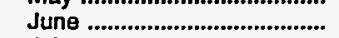 & $w$ & 62.2 & 56.4 & 56.5 & - & - \\
\hline July .......................................... & w & 65.1 & 58.2 & 59.3 & - & - \\
\hline 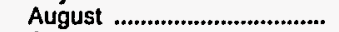 & $W$ & 68.2 & 60.0 & 62.6 & - & - \\
\hline September ........................... & $w$ & 71.2 & 61.8 & 64.2 & - & - \\
\hline October ................................. & $W$ & 70.6 & 62.9 & 62.7 & - & - \\
\hline November ............................... & 77.0 & 68.2 & 60.2 & 59.7 & - & - \\
\hline 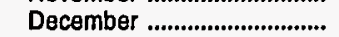 & $w$ & 59.3 & 58.3 & 52.3 & - & - \\
\hline 1994 Average & $\mathbf{W}$ & 62.5 & 57.1 & 57.1 & - & - \\
\hline
\end{tabular}

See footnotes at end of table. 
Table 37. Refiner Prices of Distillate Fuels by PAD District and State (Cents per Gallon Excluding Taxes) - Continued

\begin{tabular}{|c|c|c|c|c|c|c|}
\hline \multirow{2}{*}{$\begin{array}{l}\text { Geographic Area } \\
\text { Month }\end{array}$} & \multicolumn{2}{|c|}{ No. 1 Distillate } & \multicolumn{2}{|c|}{ No. 2 Distillatea } & \multicolumn{2}{|c|}{ No. 4 Fuelb } \\
\hline & $\begin{array}{l}\text { Sales to } \\
\text { End Users }\end{array}$ & $\begin{array}{l}\text { Sales for } \\
\text { Resale }\end{array}$ & $\begin{array}{l}\text { Sales to } \\
\text { End Users }\end{array}$ & $\begin{array}{c}\text { Sales for } \\
\text { Resale }\end{array}$ & $\begin{array}{l}\text { Sales to } \\
\text { End Users }\end{array}$ & $\begin{array}{c}\text { Sales for } \\
\text { Resalo }\end{array}$ \\
\hline \multicolumn{7}{|l|}{ Idaho } \\
\hline 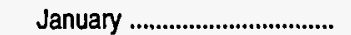 & W & 64.3 & W & 49.6 & - & - \\
\hline 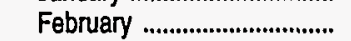 & 69.6 & 68.8 & W & 57.5 & - & - \\
\hline 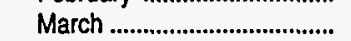 & $w$ & 68.7 & W & 59.3 & - & - \\
\hline April ……………………... & - & 69.6 & $\ddot{w}$ & 60.6 & - & - \\
\hline May ................................................. & - & $w$ & $\dddot{w}$ & 61.7 & - & - \\
\hline 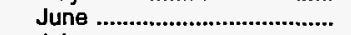 & - & 66.5 & $w$ & 58.7 & - & - \\
\hline July ................................................ & - & 67.0 & w & 58.6 & - & - \\
\hline 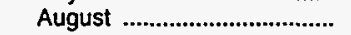 & - & 70.6 & w & 62.4 & - & - \\
\hline 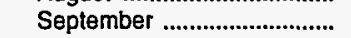 & - & $w$ & w & 70.8 & - & - \\
\hline 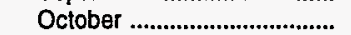 & W & 78.7 & w & 70.1 & - & - \\
\hline 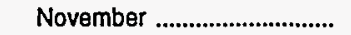 & 81.3 & 79.8 & $w$ & 70.0 & - & - \\
\hline 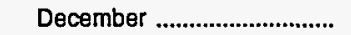 & w & 74.5 & $w$ & 64.5 & - & - \\
\hline 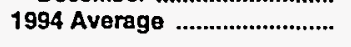 & 74.4 & 72.5 & $w$ & 61.9 & - & - \\
\hline \multicolumn{7}{|l|}{ Montana } \\
\hline 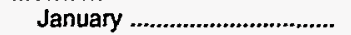 & 61.9 & 61.5 & 50.0 & 49.4 & - & - \\
\hline 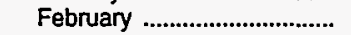 & 60.0 & 60.8 & 49.3 & 50.1 & - & - \\
\hline 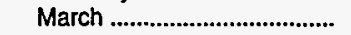 & 63.6 & 60.0 & 51.3 & 52.9 & - & - \\
\hline 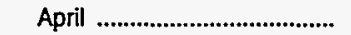 & - & 65.7 & 53.4 & 56.8 & - & - \\
\hline 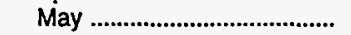 & w & 67.0 & 55.9 & 58.8 & - & - \\
\hline June ................................................... & - & 70.9 & 57.8 & 62.3 & - & - \\
\hline 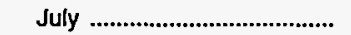 & w & 67.1 & 59.3 & 61.3 & - & - \\
\hline August ……................................... & - & 67.2 & 58.4 & 61.1 & - & - \\
\hline 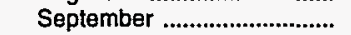 & w & 70.9 & 57.8 & 65.9 & - & - \\
\hline 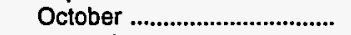 & w & 74.7 & 61.3 & 64.1 & - & - \\
\hline November ................................. & 76.7 & 77.9 & 60.3 & 67.0 & - & - \\
\hline 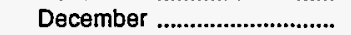 & 69.8 & 70.9 & 58.0 & 59.7 & - & - \\
\hline 1994 Average ............................... & 70.1 & 68.7 & 55.7 & 59.9 & - & - \\
\hline \multicolumn{7}{|l|}{ Utah } \\
\hline 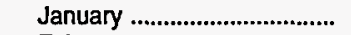 & 64.3 & 62.5 & 48.3 & 49.1 & - & - \\
\hline 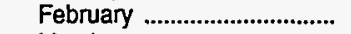 & 69.2 & 67.7 & 54.8 & 56.3 & - & - \\
\hline 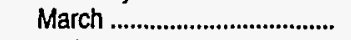 & 66.6 & 68.6 & 57.0 & 57.8 & - & - \\
\hline April & W & 69.5 & 58.2 & 59.2 & - & - \\
\hline 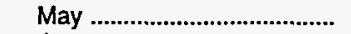 & - & 70.4 & 60.1 & 61.2 & - & - \\
\hline June & w & 67.1 & 57.5 & 58.0 & - & - \\
\hline July & - & 67.0 & 57.0 & 57.6 & - & - \\
\hline 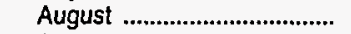 & $w$ & $w$ & 61.2 & 62.3 & - & - \\
\hline September ................................. & w & 83.1 & 73.0 & 73.1 & - & - \\
\hline 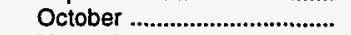 & 82.9 & 82.0 & 71.5 & 72.4 & - & - \\
\hline 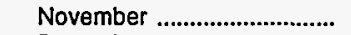 & 83.3 & 82.2 & 71.3 & 71.7 & - & - \\
\hline December ................................... & 74.7 & 73.3 & 64.3 & 62.6 & - & - \\
\hline 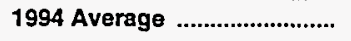 & 71.7 & 72.2 & 61.6 & 61.6 & - & - \\
\hline \multicolumn{7}{|l|}{ Wyoming } \\
\hline 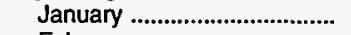 & 64.2 & 61.8 & 49.8 & 50.5 & - & - \\
\hline 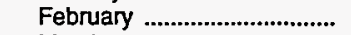 & 62.1 & 62.9 & 54.1 & 52.5 & - & - \\
\hline 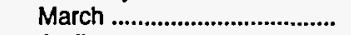 & 63.6 & 63.5 & 54.6 & 54.1 & - & - \\
\hline April & 63.4 & 61.9 & 56.9 & 57.9 & - & - \\
\hline 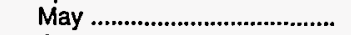 & 67.2 & 67.4 & 58.6 & 58.6 & - & - \\
\hline 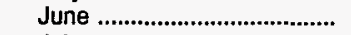 & 70.9 & 70.1 & 60.0 & 59.5 & - & - \\
\hline July & w & 69.0 & 61.2 & 60.4 & - & - \\
\hline 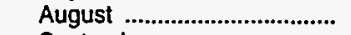 & 73.2 & 71.5 & 63.1 & 64.6 & - & - \\
\hline September ..................................... & 76.0 & 76.2 & 66.3 & 66.2 & - & - \\
\hline 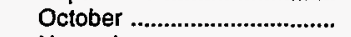 & 74.3 & 75.7 & 65.6 & 65.7 & - & - \\
\hline 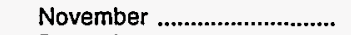 & 76.9 & 77.5 & 65.6 & 63.8 & - & - \\
\hline 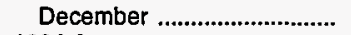 & 71.9 & 67.4 & 61.5 & 55.4 & - & - \\
\hline 1994 Average .................................. & 68.3 & 67.5 & 60.0 & 59.6 & - & - \\
\hline
\end{tabular}

See footnotes at end of table. 
Table 37. Refiner Prices of Distillate Fuels by PAD District and State (Cents per Gallon Excluding Taxes) - Continued

\begin{tabular}{|c|c|c|c|c|c|c|}
\hline \multirow{2}{*}{$\begin{array}{c}\text { Geographic Area } \\
\text { Month }\end{array}$} & \multicolumn{2}{|c|}{ No. 1 Distillate } & \multicolumn{2}{|c|}{ No. 2 Distillatea } & \multicolumn{2}{|c|}{ No. 4 Fuelb } \\
\hline & $\begin{array}{l}\text { Sales to } \\
\text { End Users }\end{array}$ & $\begin{array}{c}\text { Sales for } \\
\text { Resale }\end{array}$ & $\begin{array}{l}\text { Sales to } \\
\text { End Users }\end{array}$ & $\begin{array}{l}\text { Sales for } \\
\text { Resale }\end{array}$ & $\begin{array}{l}\text { Sales to } \\
\text { End Users }\end{array}$ & $\begin{array}{c}\text { Sales for } \\
\text { Resale }\end{array}$ \\
\hline \multicolumn{7}{|l|}{ PAD Dlstrict V } \\
\hline January ................................... & 71.0 & 62.8 & 55.7 & 49.4 & $W$ & 31.0 \\
\hline 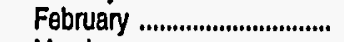 & 71.0 & 66.7 & 58.5 & 54.1 & $W$ & 38.6 \\
\hline 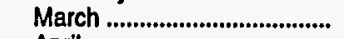 & 66.5 & 67.6 & 62.1 & 58.2 & W & 39.6 \\
\hline April & 82.6 & 61.6 & 61.6 & 56.4 & $\ddot{W}$ & 40.9 \\
\hline 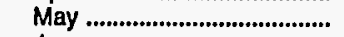 & 84.8 & 65.4 & 59.2 & 53.9 & W & 38.8 \\
\hline 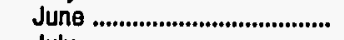 & 82.4 & NA & 57.2 & 52.8 & $W$ & W \\
\hline July & NA & 62.0 & 57.1 & 54.4 & - & $w$ \\
\hline August & NA & 63.0 & 58.4 & 54.9 & - & $W$ \\
\hline September ............................. & NA & 64.5 & 62.2 & 60.3 & $w$ & $w$ \\
\hline 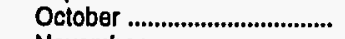 & 76.8 & 71.1 & 64.9 & 62.4 & - & W \\
\hline November ............................... & 76.0 & 70.8 & 65.8 & 61.5 & W & $w$ \\
\hline 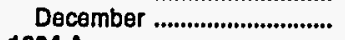 & 73.8 & 65.4 & 59.5 & 53.5 & $\ddot{W}$ & $\ddot{w}$ \\
\hline 1994 Average ............................ & 73.3 & 65.5 & 60.1 & 56.0 & $\mathbb{W}$ & 39.7 \\
\hline \multicolumn{7}{|l|}{ Alaska } \\
\hline 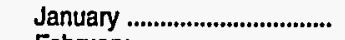 & 70.2 & 66.8 & 79.7 & 53.3 & $W$ & W \\
\hline February ................................ & 70.8 & 70.3 & 78.4 & 48.7 & $w$ & W \\
\hline 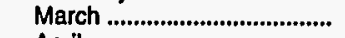 & 65.7 & 67.7 & 78.3 & 57.1 & $W$ & $W$ \\
\hline 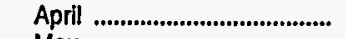 & 81.7 & 61.6 & NA & 57.7 & $W$ & NA \\
\hline 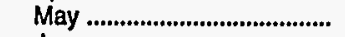 & 83.7 & 65.5 & 73.2 & 54.3 & - & $w$ \\
\hline June ......................................... & 81.7 & NA & 69.0 & 52.8 & - & $\ddot{W}$ \\
\hline 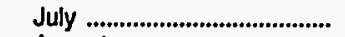 & NA & 61.6 & 70.7 & 53.6 & - & $\mathbf{w}$ \\
\hline 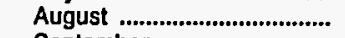 & NA & 62.5 & 72.9 & 54.7 & - & W \\
\hline 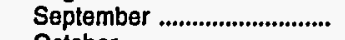 & NA & 64.0 & 76.7 & 57.8 & $W$ & W \\
\hline October & 76.1 & 70.0 & 80.8 & 59.5 & - & W \\
\hline November .............................. & 74.9 & 67.5 & 78.3 & 52.2 & $W$ & $W$ \\
\hline December ................................. & 71.1 & 64.8 & 77.2 & 49.9 & $W$ & W \\
\hline 1994 Average & 72.7 & 65.2 & $\mathbf{7 4 . 8}$ & 54.2 & $\mathbf{w}$ & $w$ \\
\hline \multicolumn{7}{|l|}{ Arizona } \\
\hline 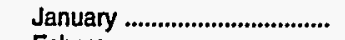 & - & 59.2 & 54.4 & 46.8 & - & - \\
\hline February ............................... & $W$ & 65.2 & 57.9 & 52.7 & - & - \\
\hline 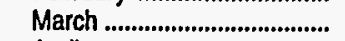 & $W$ & 72.5 & 63.3 & 57.7 & - & - \\
\hline 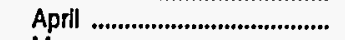 & - & $W$ & 61.5 & 56.8 & - & - \\
\hline 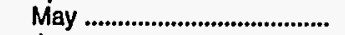 & - & - & 59.8 & 54.7 & - & - \\
\hline June ...................................... & - & $w$ & 57.2 & 49.8 & - & - \\
\hline July ....................................... & - & $w$ & 58.3 & 54.1 & - & - \\
\hline August .................................. & - & W & 59.8 & 54.3 & - & - \\
\hline September ........................... & - & $w$ & 62.6 & 58.4 & - & - \\
\hline 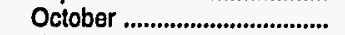 & - & 74.5 & 65.7 & 63.1 & - & - \\
\hline November .............................. & - & 75.1 & 68.2 & 63.9 & - & - \\
\hline December .............................. & - & 63.6 & 58.1 & 52.8 & - & - \\
\hline 1994 Average & $\mathbf{W}$ & 67.6 & 60.6 & 55.3 & - & - \\
\hline \multicolumn{7}{|l|}{ Callfornla } \\
\hline January ................................ & $w$ & $w$ & 54.7 & 49.6 & - & $w$ \\
\hline February ................................. & $w$ & 64.4 & 59.1 & 55.5 & - & W \\
\hline 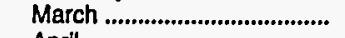 & $W$ & $w$ & 64.6 & 60.4 & - & $w$ \\
\hline April & W & $W$ & 63.2 & 57.8 & - & W \\
\hline May & - & $w$ & 59.0 & 54.4 & - & $W$ \\
\hline 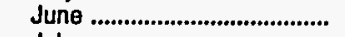 & - & W & 58.2 & 53.4 & - & $\ddot{W}$ \\
\hline July ......................................... & - & w & 60.0 & 55.5 & - & w \\
\hline 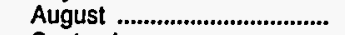 & - & $w$ & 60.4 & 55.6 & - & W \\
\hline 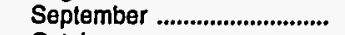 & - & W & 65.1 & 61.7 & - & $\ddot{W}$ \\
\hline October ................................... & - & $w$ & 66.2 & 62.7 & - & $w$ \\
\hline November ............................... & - & $w$ & 65.7 & 62.9 & - & W \\
\hline December ................................. & - & $w$ & 58.8 & 55.1 & - & $\ddot{W}$ \\
\hline 1994 Average & $w$ & 63.4 & 61.2 & 57.1 & - & $\mathbf{W}$ \\
\hline
\end{tabular}

See footnotes at end of table. 
Table 37. Refiner Prices of Distillate Fuels by PAD District and State (Cents per Gallon Excluding Taxes) - Continued

\begin{tabular}{|c|c|c|c|c|c|c|}
\hline \multirow{2}{*}{$\begin{array}{l}\text { Goographle Area } \\
\text { Month }\end{array}$} & \multicolumn{2}{|c|}{ No. 1 Distillato } & \multicolumn{2}{|c|}{ No. 2 Distillatea } & \multicolumn{2}{|c|}{ No. 4 Fualb } \\
\hline & $\begin{array}{l}\text { Sales to } \\
\text { End Usera }\end{array}$ & $\begin{array}{c}\text { Sales for } \\
\text { Resale }\end{array}$ & $\begin{array}{l}\text { Sales to } \\
\text { End Users }\end{array}$ & $\begin{array}{l}\text { Sales for } \\
\text { Resale }\end{array}$ & $\begin{array}{l}\text { Sales to } \\
\text { End Users }\end{array}$ & $\begin{array}{c}\text { Sales for } \\
\text { Resale }\end{array}$ \\
\hline \multicolumn{7}{|l|}{ Hawall } \\
\hline 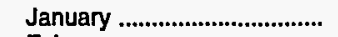 & $w$ & - & $W$ & 76.8 & - & - \\
\hline 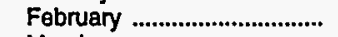 & - & - & $w$ & 76.1 & - & - \\
\hline March & - & - & $W$ & 76.4 & - & - \\
\hline April & - & - & $W$ & 75.5 & - & - \\
\hline May & - & - & $W$ & 75.4 & - & - \\
\hline June ......................................... & - & - & W & 74.7 & - & - \\
\hline 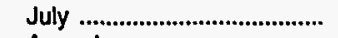 & - & - & $W$ & 74.3 & - & - \\
\hline August & - & W & W & 74.0 & - & - \\
\hline 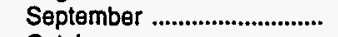 & - & - & W & 74.2 & - & - \\
\hline 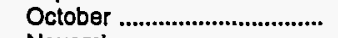 & - & - & $W$ & 74.4 & - & - \\
\hline November .............................. & - & - & W & 74.4 & - & - \\
\hline December ................................ & - & $W$ & $W$ & 63.8 & - & - \\
\hline 1994 Average ............................ & $\mathbf{W}$ & $\mathbf{W}$ & $\mathbf{W}$ & 73.7 & - & - \\
\hline \multicolumn{7}{|l|}{ Nevada } \\
\hline 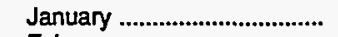 & $\mathbf{W}$ & 60.7 & 51.2 & 49.3 & - & - \\
\hline 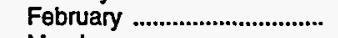 & W & 64.4 & 54.0 & 55.6 & - & $w$ \\
\hline March & W & W & 59.8 & 58.3 & $w$ & W \\
\hline April & - & $W$ & 58.4 & 57.5 & - & W \\
\hline 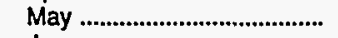 & - & $W$ & 56.1 & 56.3 & - & W \\
\hline 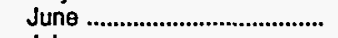 & - & $W$ & 55.5 & 54.7 & - & - \\
\hline July & - & W & 55.9 & 55.3 & - & - \\
\hline 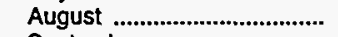 & W & $W$ & 56.4 & 56.0 & - & - \\
\hline 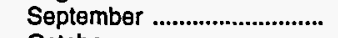 & - & $W$ & 63.4 & 62.1 & - & - \\
\hline October & $W$ & 78.9 & 68.3 & 65.1 & - & - \\
\hline November ............................... & $W$ & 80.4 & 64.5 & 64.8 & - & - \\
\hline 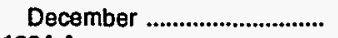 & $W$ & 77.0 & 59.4 & 53.7 & - & - \\
\hline 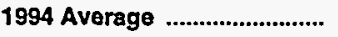 & $\mathbf{W}$ & 71.1 & 58.8 & 57.4 & $w$ & $\mathbf{w}$ \\
\hline \multicolumn{7}{|l|}{ Oregon } \\
\hline 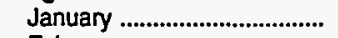 & 74.7 & 61.4 & 53.0 & 48.7 & - & - \\
\hline February ............................... & 79.5 & 62.9 & 57.7 & 55.1 & - & - \\
\hline March ...................................... & W & 68.3 & 56.5 & 55.9 & - & - \\
\hline 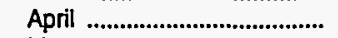 & W & 66.6 & 56.9 & 55.1 & - & - \\
\hline May ....................................... & $W$ & 64.7 & 54.8 & 52.9 & - & - \\
\hline June ......................................... & W & 64.3 & 52.2 & 51.6 & - & - \\
\hline 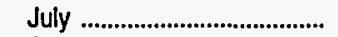 & W & $W$ & 52.6 & 51.3 & - & - \\
\hline 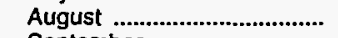 & $w$ & 66.0 & 53.8 & 53.2 & - & - \\
\hline 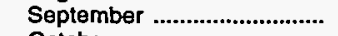 & $w$ & 72.1 & 58.2 & 58.5 & - & - \\
\hline 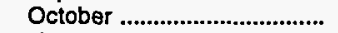 & $w$ & 75.3 & 61.4 & 61.6 & - & - \\
\hline 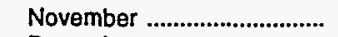 & W & 75.7 & 62.9 & 61.4 & - & - \\
\hline 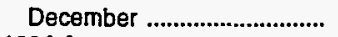 & 82.3 & 65.3 & 54.8 & 50.6 & - & - \\
\hline 1994 Averago ............................ & 84.8 & 66.6 & 56.3 & 54.7 & - & - \\
\hline \multicolumn{7}{|l|}{ Washington } \\
\hline 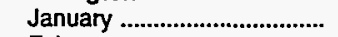 & 72.1 & 59.5 & 56.0 & 48.0 & - & - \\
\hline 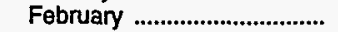 & 77.5 & 61.9 & 56.1 & 50.7 & - & $w$ \\
\hline 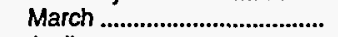 & 80.6 & 64.8 & 58.8 & 53.0 & - & W \\
\hline April & W & 59.3 & 59.9 & 52.1 & - & - \\
\hline 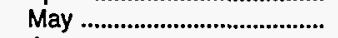 & W & 64.2 & 58.6 & 51.1 & $w$ & - \\
\hline June & $W$ & 64.1 & 53.5 & 51.2 & W & - \\
\hline 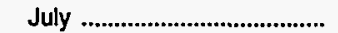 & W & 63.4 & 51.5 & 51.9 & - & $\rightarrow$ \\
\hline 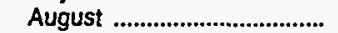 & $w$ & 64.8 & 53.2 & 53.0 & - & - \\
\hline 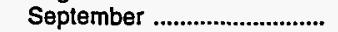 & $W$ & 69.5 & 58.0 & 57.3 & - & - \\
\hline 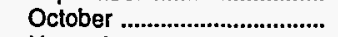 & 86.2 & 74.8 & 62.0 & 60.8 & - & - \\
\hline 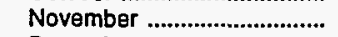 & 89.4 & 76.0 & 65.0 & 58.2 & - & - \\
\hline 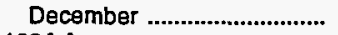 & 96.3 & 66.6 & 58.0 & 50.6 & - & - \\
\hline 1994 Average ............................. & 83.2 & 65.8 & 56.9 & 53.0 & $\mathbf{W}$ & $\mathbf{w}$ \\
\hline
\end{tabular}

Dash $(-)=$ No data reported.

NA = Not avallable.

$W=$ Withheld to avoid disclosure of individual company data.

a Includes sales of No. 2 fuel oil and high- and low-sulfur diesel fuels.

b Includes No. 4 fuel oil and No. 4 diesel fuel.

Notes: PAD District and U.S. averages represent data for all States. In certain PAD Districts, however, prices are not shown for every State.

Source; Energy Information Administration Form EIA-782A, "Refiners'/Gas Plant Operators' Monthly Petroleum Product Sales Report." 
Table 38. Propane (Consumer Grade) Prices by Sales Type and PAD District (Cents per Gallon Excluding Taxes)

\begin{tabular}{|c|c|c|c|c|c|c|c|c|}
\hline \multirow[b]{2}{*}{$\begin{array}{l}\text { Geographlo Araa } \\
\text { Month }\end{array}$} & \multicolumn{7}{|c|}{ Sales to End Users } & \multirow[b]{2}{*}{$\begin{array}{c}\text { Sales } \\
\text { for } \\
\text { Resale }\end{array}$} \\
\hline & $\begin{array}{l}\text { Resldential } \\
\text { Consumers }\end{array}$ & $\begin{array}{l}\text { Commercial } \\
\text { Institutlonal } \\
\text { Consumers }\end{array}$ & $\begin{array}{l}\text { Industrial } \\
\text { Consumers }\end{array}$ & $\begin{array}{c}\text { Through } \\
\text { Rotall } \\
\text { Outlets }\end{array}$ & $\begin{array}{l}\text { Potro- } \\
\text { Chemleal }\end{array}$ & $\begin{array}{l}\text { Other } \\
\text { End Ueers }\end{array}$ & Average & \\
\hline \multicolumn{9}{|l|}{ United States } \\
\hline 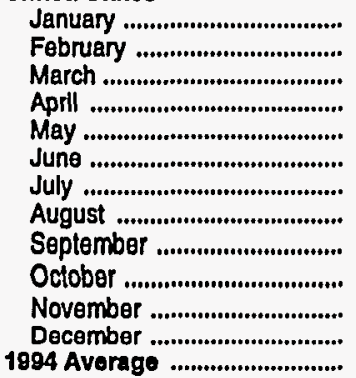 & $\begin{array}{l}88.4 \\
89.8 \\
92.0 \\
92.3 \\
94.1 \\
93.2 \\
87.6 \\
N A \\
82.5 \\
83.9 \\
85.1 \\
86.2 \\
87.2\end{array}$ & $\begin{array}{l}75.9 \\
77.0 \\
77.4 \\
76.8 \\
76.3 \\
77.6 \\
76.3 \\
75.2 \\
75.2 \\
76.4 \\
77.2 \\
77.7 \\
76.5\end{array}$ & $\begin{array}{l}64.4 \\
67.5 \\
67.2 \\
69.0 \\
69.0 \\
68.8 \\
67.9 \\
63.6 \\
63.0 \\
62.6 \\
65.0 \\
64.7 \\
65.2\end{array}$ & $\begin{array}{l}71.4 \\
72.7 \\
72.6 \\
73.8 \\
74.8 \\
75.2 \\
75.0 \\
74.6 \\
73.6 \\
74.4 \\
74.5 \\
74.8 \\
73.6\end{array}$ & $\begin{array}{l}27.3 \\
29.4 \\
29.1 \\
29.6 \\
30.1 \\
29.5 \\
29.6 \\
31.4 \\
31.4 \\
33.3 \\
34.7 \\
34.4 \\
31.1\end{array}$ & $\begin{array}{l}65.1 \\
68.1 \\
67.2 \\
69.2 \\
72.1 \\
70.0 \\
67.5 \\
63.8 \\
62.1 \\
55.9 \\
60.1 \\
65.0 \\
63.4\end{array}$ & $\begin{array}{l}80.9 \\
82.1 \\
82.1 \\
80.9 \\
77.6 \\
76.9 \\
73.9 \\
71.0 \\
73.0 \\
71.1 \\
75.7 \\
79.3 \\
77.6\end{array}$ & $\begin{array}{l}33.2 \\
35.3 \\
33.2 \\
31.9 \\
32.0 \\
31.4 \\
31.0 \\
32.0 \\
32.8 \\
34.2 \\
36.0 \\
36.8 \\
33.6\end{array}$ \\
\hline \multicolumn{9}{|l|}{ PAD Dlatrict I } \\
\hline 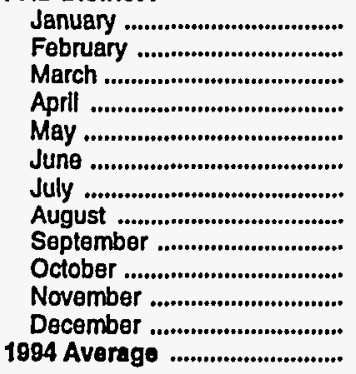 & $\begin{array}{l}107.5 \\
111.0 \\
112.0 \\
114.3 \\
116.2 \\
116.2 \\
115.6 \\
108.8 \\
106.5 \\
106.1 \\
108.0 \\
107.2 \\
109.2\end{array}$ & $\begin{array}{l}81.9 \\
82.4 \\
82.6 \\
82.5 \\
81.1 \\
82.9 \\
80.1 \\
79.6 \\
79.6 \\
82.0 \\
83.4 \\
84.2 \\
82.0\end{array}$ & $\begin{array}{l}68.4 \\
72.2 \\
71.6 \\
73.2 \\
70.0 \\
68.9 \\
67.9 \\
60.6 \\
61.1 \\
62.4 \\
64.2 \\
66.2 \\
66.9\end{array}$ & $\begin{array}{l}64.9 \\
69.1 \\
69.4 \\
72.4 \\
72.2 \\
71.8 \\
71.9 \\
71.1 \\
70.3 \\
72.4 \\
70.0 \\
71.0 \\
70.3\end{array}$ & $\begin{array}{l}W \\
W \\
W \\
W \\
W \\
W \\
W \\
W \\
W \\
W \\
W \\
W \\
W\end{array}$ & $\begin{array}{l}66.1 \\
72.1 \\
69.2 \\
74.6 \\
72.0 \\
70.5 \\
67.0 \\
69.1 \\
67.7 \\
68.5 \\
72.7 \\
72.6 \\
69.5\end{array}$ & $\begin{array}{l}96.2 \\
98.5 \\
98.9 \\
99.2 \\
97.7 \\
96.9 \\
92.5 \\
85.5 \\
87.3 \\
91.1 \\
94.1 \\
96.5 \\
\mathbf{9 4 . 9}\end{array}$ & $\begin{array}{l}39.0 \\
44.7 \\
40.8 \\
39.6 \\
39.5 \\
38.5 \\
36.9 \\
36.7 \\
37.4 \\
39.7 \\
42.1 \\
42.5 \\
40.1\end{array}$ \\
\hline \multicolumn{9}{|l|}{ Subdlatrict IA } \\
\hline 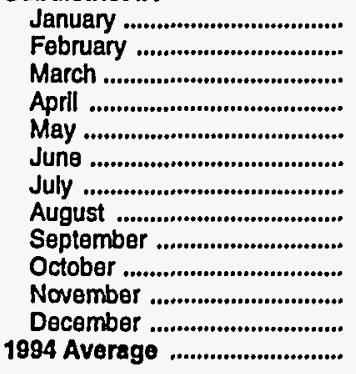 & $\begin{array}{l}111.7 \\
113.9 \\
114.8 \\
117.2 \\
120.3 \\
122.8 \\
122.5 \\
118.7 \\
117.4 \\
116.2 \\
114.9 \\
112.6 \\
115.6\end{array}$ & $\begin{array}{l}83.8 \\
84.2 \\
83.7 \\
84.8 \\
85.2 \\
86.2 \\
85.3 \\
85.6 \\
84.8 \\
86.0 \\
87.2 \\
86.3 \\
85.1\end{array}$ & $\begin{array}{l}77.9 \\
80.7 \\
82.1 \\
94.0 \\
89.3 \\
92.4 \\
92.5 \\
\text { NA } \\
\text { NA } \\
\text { NA } \\
\text { NA } \\
\text { NA } \\
\text { NA }\end{array}$ & $\begin{array}{l}W \\
W \\
69.3 \\
70.2 \\
W \\
W \\
W \\
W \\
W \\
71.6 \\
71.2 \\
67.7 \\
W\end{array}$ & $\begin{array}{l}- \\
- \\
- \\
- \\
- \\
- \\
-\end{array}$ & $\begin{array}{r}92.4 \\
\text { NA } \\
86.5 \\
\text { NA } \\
\text { NA } \\
\text { NA } \\
\text { NA } \\
98.0 \\
101.3 \\
\text { NA } \\
101.6 \\
102.7 \\
94.7\end{array}$ & $\begin{array}{r}103.0 \\
104.5 \\
105.7 \\
108.0 \\
109.0 \\
109.3 \\
108.3 \\
98.6 \\
\text { NA } \\
\text { NA } \\
\text { NA } \\
100.2 \\
102.4\end{array}$ & $\begin{array}{l}40.2 \\
48.9 \\
48.2 \\
47.5 \\
51.1 \\
50.7 \\
45.2 \\
43.8 \\
44.4 \\
43.9 \\
46.1 \\
48.1 \\
46.7\end{array}$ \\
\hline \multicolumn{9}{|l|}{ Subdistrict IB } \\
\hline 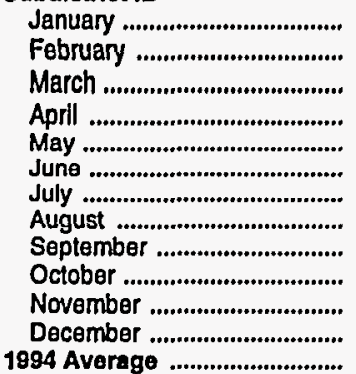 & $\begin{array}{l}113.4 \\
119.0 \\
118.4 \\
120.8 \\
122.7 \\
124.2 \\
125.0 \\
120.1 \\
118.2 \\
116.4 \\
117.5 \\
114.8 \\
118.2\end{array}$ & $\begin{array}{l}86.9 \\
93.4 \\
90.5 \\
88.1 \\
87.4 \\
89.5 \\
89.8 \\
89.1 \\
87.2 \\
87.8 \\
88.5 \\
89.5 \\
90.5\end{array}$ & $\begin{array}{l}71.0 \\
71.6 \\
74.6 \\
75.3 \\
74.1 \\
71.7 \\
70.4 \\
58.7 \\
57.4 \\
60.4 \\
61.1 \\
62.4 \\
66.7\end{array}$ & $\begin{array}{l}66.8 \\
76.9 \\
71.4 \\
75.1 \\
75.8 \\
74.9 \\
74.9 \\
76.5 \\
73.5 \\
77.1 \\
70.0 \\
73.9 \\
73.7\end{array}$ & $\begin{array}{l}- \\
- \\
- \\
\overline{-} \\
\overline{-} \\
\overline{-} \\
\bar{w} \\
\bar{w}\end{array}$ & $\begin{array}{r}68.9 \\
75.2 \\
73.8 \\
73.9 \\
74.1 \\
85.0 \\
76.8 \\
\text { NA } \\
86.4 \\
73.0 \\
79.1 \\
86.1 \\
78.7\end{array}$ & $\begin{array}{r}101.7 \\
106.6 \\
106.2 \\
105.9 \\
106.1 \\
107.3 \\
106.2 \\
100.6 \\
99.8 \\
97.5 \\
99.6 \\
103.1 \\
104.4\end{array}$ & $\begin{array}{l}38.5 \\
45.4 \\
41.8 \\
39.7 \\
39.3 \\
38.3 \\
37.7 \\
34.0 \\
35.5 \\
39.2 \\
42.7 \\
42.9 \\
39.7\end{array}$ \\
\hline
\end{tabular}

See footnotes at end of table. 
Table 38. Propane (Consumer Grade) Prices by Sales Type and PAD District

(Cents per Gallon Excluding Taxes) - Continued

\begin{tabular}{|c|c|c|c|c|c|c|c|c|}
\hline \multirow[b]{2}{*}{$\begin{array}{c}\text { Geographic Area } \\
\text { Month }\end{array}$} & \multicolumn{7}{|c|}{ Sales to End Users } & \multirow[b]{2}{*}{$\begin{array}{c}\text { Sales } \\
\text { for } \\
\text { Resale }\end{array}$} \\
\hline & $\begin{array}{l}\text { Residential } \\
\text { Consumers }\end{array}$ & $\begin{array}{c}\text { Commercial } \\
\text { Institutlonal } \\
\text { Consumers }\end{array}$ & $\begin{array}{l}\text { Industrial } \\
\text { Consumers }\end{array}$ & $\begin{array}{c}\text { Through } \\
\text { Retail } \\
\text { Outlets }\end{array}$ & $\begin{array}{l}\text { Petro- } \\
\text { Chemical }\end{array}$ & $\begin{array}{c}\text { Other } \\
\text { End Users }\end{array}$ & Average & \\
\hline \multicolumn{9}{|l|}{ Subdistrict IC } \\
\hline 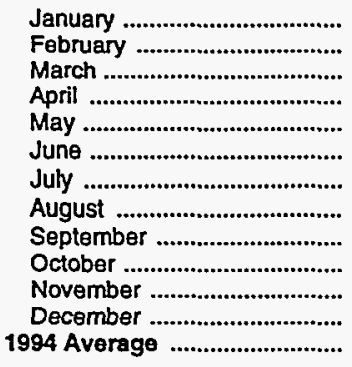 & $\begin{array}{r}103.2 \\
104.8 \\
105.1 \\
105.8 \\
105.6 \\
103.6 \\
102.8 \\
96.1 \\
95.2 \\
97.3 \\
100.0 \\
101.0 \\
101.5\end{array}$ & $\begin{array}{l}78.3 \\
75.5 \\
76.9 \\
78.2 \\
76.3 \\
78.4 \\
74.6 \\
73.6 \\
74.4 \\
77.3 \\
78.4 \\
79.5 \\
76.8\end{array}$ & $\begin{array}{l}66.4 \\
71.8 \\
68.3 \\
68.3 \\
64.6 \\
64.0 \\
63.9 \\
63.8 \\
67.0 \\
67.7 \\
70.9 \\
72.7 \\
68.1\end{array}$ & $\begin{array}{l}63.8 \\
65.3 \\
67.4 \\
70.2 \\
70.0 \\
70.2 \\
69.1 \\
66.8 \\
68.4 \\
69.1 \\
69.6 \\
69.8 \\
68.1\end{array}$ & $\begin{array}{l}W \\
W \\
W \\
W \\
W \\
W \\
W \\
W \\
W \\
W \\
W \\
W \\
W\end{array}$ & $\begin{array}{l}62.9 \\
69.8 \\
65.8 \\
65.4 \\
64.3 \\
66.4 \\
64.8 \\
66.1 \\
65.1 \\
65.6 \\
67.8 \\
67.0 \\
65.8\end{array}$ & $\begin{array}{l}91.8 \\
91.9 \\
91.0 \\
89.9 \\
85.9 \\
84.8 \\
80.4 \\
76.0 \\
78.7 \\
85.2 \\
88.9 \\
91.6 \\
87.5\end{array}$ & $\begin{array}{l}39.1 \\
43.5 \\
38.9 \\
37.8 \\
37.7 \\
37.0 \\
35.7 \\
37.6 \\
37.7 \\
39.6 \\
41.1 \\
41.5 \\
39.4\end{array}$ \\
\hline 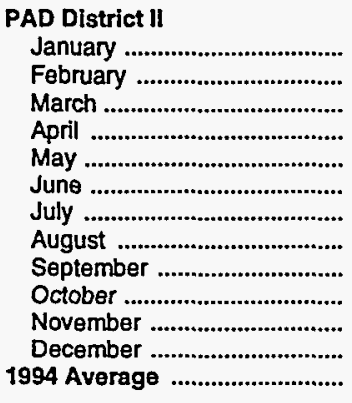 & $\begin{array}{l}74.8 \\
75.4 \\
76.1 \\
75.2 \\
75.4 \\
73.0 \\
68.9 \\
66.9 \\
67.9 \\
69.0 \\
70.0 \\
72.1 \\
72.7\end{array}$ & $\begin{array}{l}69.0 \\
69.4 \\
69.2 \\
66.6 \\
65.5 \\
65.9 \\
65.5 \\
63.9 \\
63.1 \\
63.8 \\
64.9 \\
66.8 \\
67.1\end{array}$ & $\begin{array}{l}60.0 \\
63.8 \\
65.4 \\
70.4 \\
74.4 \\
75.1 \\
74.7 \\
74.6 \\
71.9 \\
69.8 \\
71.6 \\
71.3 \\
69.0\end{array}$ & $\begin{array}{l}72.6 \\
73.5 \\
73.9 \\
74.0 \\
76.3 \\
76.5 \\
76.6 \\
77.4 \\
77.2 \\
77.6 \\
79.0 \\
77.5 \\
75.1\end{array}$ & $\begin{array}{c}W \\
W \\
W \\
29.9 \\
W \\
28.1 \\
W \\
W \\
W \\
W \\
W \\
W \\
29.4\end{array}$ & $\begin{array}{l}60.1 \\
60.9 \\
60.4 \\
61.4 \\
61.1 \\
58.9 \\
57.5 \\
54.4 \\
54.7 \\
52.4 \\
55.0 \\
57.1 \\
56.2\end{array}$ & $\begin{array}{l}71.6 \\
72.5 \\
72.8 \\
71.6 \\
70.3 \\
68.5 \\
66.8 \\
64.7 \\
64.8 \\
61.2 \\
65.5 \\
69.7 \\
68.8\end{array}$ & $\begin{array}{l}32.5 \\
34.0 \\
31.9 \\
30.8 \\
30.8 \\
30.1 \\
30.4 \\
32.2 \\
33.3 \\
33.6 \\
34.2 \\
34.7 \\
32.8\end{array}$ \\
\hline 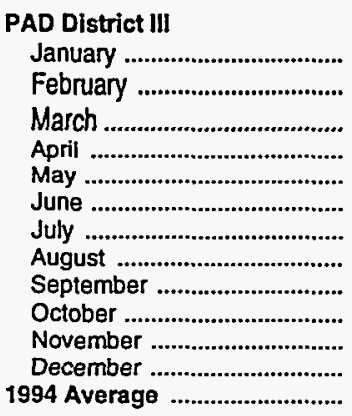 & $\begin{array}{l}87.1 \\
86.8 \\
86.6 \\
86.2 \\
84.1 \\
82.1 \\
82.3 \\
81.6 \\
82.1 \\
83.2 \\
84.8 \\
86.1 \\
84.6\end{array}$ & $\begin{array}{l}63.2 \\
67.1 \\
70.6 \\
70.2 \\
71.3 \\
72.2 \\
71.4 \\
74.0 \\
73.6 \\
73.5 \\
74.6 \\
73.9 \\
71.5\end{array}$ & $\begin{array}{l}53.5 \\
54.0 \\
52.0 \\
50.9 \\
50.9 \\
50.4 \\
50.5 \\
54.8 \\
55.6 \\
52.1 \\
54.4 \\
51.1 \\
52.6\end{array}$ & $\begin{array}{l}68.3 \\
68.5 \\
69.9 \\
70.1 \\
69.9 \\
70.9 \\
71.3 \\
70.6 \\
68.0 \\
68.4 \\
69.9 \\
71.0 \\
69.6\end{array}$ & $\begin{array}{l}26.6 \\
28.7 \\
28.6 \\
29.4 \\
30.1 \\
29.7 \\
29.6 \\
31.4 \\
31.2 \\
33.1 \\
34.2 \\
34.4 \\
30.9\end{array}$ & $\begin{array}{l}58.2 \\
60.6 \\
57.2 \\
53.4 \\
61.8 \\
60.2 \\
59.2 \\
64.9 \\
63.9 \\
63.0 \\
64.2 \\
65.2 \\
61.1\end{array}$ & $\begin{array}{l}68.6 \\
67.0 \\
62.1 \\
59.9 \\
51.9 \\
52.2 \\
51.3 \\
58.2 \\
63.4 \\
65.5 \\
68.3 \\
69.7 \\
63.5\end{array}$ & $\begin{array}{l}29.0 \\
30.9 \\
29.8 \\
29.2 \\
29.9 \\
29.4 \\
29.6 \\
30.3 \\
30.5 \\
32.4 \\
34.3 \\
34.8 \\
30.9\end{array}$ \\
\hline 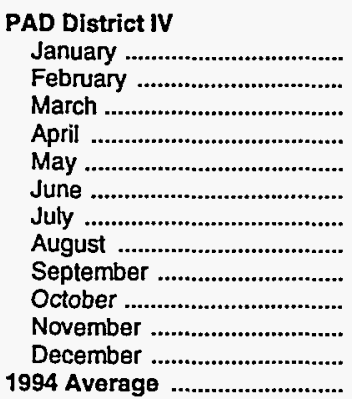 & $\begin{array}{l}80.5 \\
80.2 \\
79.6 \\
78.6 \\
77.5 \\
74.2 \\
72.7 \\
67.5 \\
69.3 \\
74.7 \\
75.3 \\
76.0 \\
76.3\end{array}$ & $\begin{array}{l}73.9 \\
75.5 \\
69.9 \\
72.1 \\
66.3 \\
68.4 \\
68.0 \\
67.3 \\
69.9 \\
70.7 \\
72.3 \\
70.9 \\
71.6\end{array}$ & $\begin{array}{l}71.5 \\
67.3 \\
64.9 \\
56.5 \\
51.8 \\
51.7 \\
50.6 \\
44.8 \\
44.9 \\
49.5 \\
59.1 \\
55.1 \\
54.6\end{array}$ & $\begin{array}{l}68.2 \\
66.2 \\
64.9 \\
66.5 \\
64.2 \\
63.6 \\
63.9 \\
67.0 \\
67.0 \\
67.0 \\
63.1 \\
65.6 \\
65.4\end{array}$ & $\begin{array}{l}- \\
- \\
- \\
- \\
- \\
- \\
- \\
- \\
- \\
- \\
-\end{array}$ & $\begin{array}{l}72.0 \\
71.6 \\
70.0 \\
68.6 \\
68.7 \\
64.6 \\
67.0 \\
69.8 \\
65.3 \\
66.3 \\
65.6 \\
64.8 \\
67.7\end{array}$ & $\begin{array}{l}77.8 \\
77.3 \\
75.5 \\
73.7 \\
71.5 \\
68.7 \\
67.7 \\
64.4 \\
65.0 \\
69.9 \\
72.1 \\
72.1 \\
72.1\end{array}$ & $\begin{array}{l}35.3 \\
34.5 \\
31.7 \\
29.4 \\
28.3 \\
27.5 \\
27.4 \\
28.9 \\
30.1 \\
31.7 \\
34.0 \\
36.5 \\
31.6\end{array}$ \\
\hline
\end{tabular}

See footnotes at end of table. 
Table 38. Propane (Consumer Grade) Prices by Sales Type and PAD District (Cents per Gallon Excluding Taxes) - Continued

\begin{tabular}{|c|c|c|c|c|c|c|c|c|}
\hline \multirow[b]{2}{*}{$\begin{array}{c}\text { Coographic Area } \\
\text { Month }\end{array}$} & \multicolumn{7}{|c|}{ Sales to End Users } & \multirow[b]{2}{*}{$\begin{array}{c}\text { Sales } \\
\text { for } \\
\text { Resale }\end{array}$} \\
\hline & $\begin{array}{l}\text { Resldentlal } \\
\text { Consumers }\end{array}$ & $\begin{array}{c}\text { Commercial/ } \\
\text { Institutlonal } \\
\text { Consumers }\end{array}$ & $\begin{array}{l}\text { Industrial } \\
\text { Consumers }\end{array}$ & $\begin{array}{c}\text { Through } \\
\text { Retail } \\
\text { Outlets }\end{array}$ & $\begin{array}{l}\text { Petro- } \\
\text { Chemical }\end{array}$ & $\begin{array}{l}\text { Other } \\
\text { End Users }\end{array}$ & Average & \\
\hline 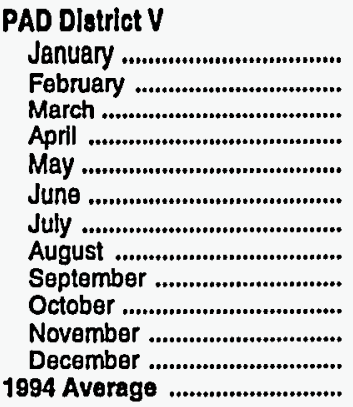 & $\begin{array}{r}113.3 \\
111.0 \\
108.4 \\
105.6 \\
103.1 \\
99.8 \\
98.0 \\
94.8 \\
93.3 \\
96.1 \\
101.4 \\
104.0 \\
103.9\end{array}$ & $\begin{array}{l}92.2 \\
89.3 \\
85.7 \\
85.0 \\
86.6 \\
85.4 \\
87.1 \\
86.1 \\
88.7 \\
87.2 \\
88.1 \\
89.3 \\
87.4\end{array}$ & $\begin{array}{l}88.8 \\
86.6 \\
81.5 \\
83.4 \\
83.7 \\
82.5 \\
82.0 \\
65.8 \\
66.9 \\
66.8 \\
69.6 \\
70.2 \\
74.5\end{array}$ & $\begin{array}{l}80.7 \\
79.9 \\
78.3 \\
79.9 \\
80.5 \\
83.0 \\
81.3 \\
79.5 \\
77.4 \\
77.9 \\
82.4 \\
83.1 \\
80.3\end{array}$ & $\begin{array}{l}- \\
- \\
- \\
- \\
- \\
- \\
- \\
- \\
- \\
- \\
-\end{array}$ & $\begin{array}{r}100.8 \\
103.4 \\
100.6 \\
100.8 \\
101.8 \\
100.9 \\
100.4 \\
94.1 \\
94.2 \\
96.0 \\
\mathrm{NA} \\
94.1 \\
98.2\end{array}$ & $\begin{array}{r}104.7 \\
102.3 \\
99.1 \\
97.0 \\
96.0 \\
93.8 \\
92.9 \\
86.7 \\
87.6 \\
88.8 \\
92.4 \\
95.8 \\
96.0\end{array}$ & $\begin{array}{l}46.2 \\
41.8 \\
40.6 \\
39.3 \\
37.1 \\
35.1 \\
33.4 \\
32.7 \\
33.8 \\
39.0 \\
42.6 \\
45.8 \\
39.5\end{array}$ \\
\hline
\end{tabular}

Dash $(-)=$ No data reported.

$N A=$ Not avallable.

$W=$ Withheld to avold disclosure of individual company data.

Sources: Energy Information Administration Forms EIA-782A, "Refiners'/Gas Plant Operators' Monthly Petroleum Product Sales Report," and EIA-782B, "Resellers'/Retallers' Monthly Petroleum Product Sales Report." 
Table 39. No. 2 Distillate ${ }^{a}$ Prices by Sales Type, PAD District, and Selected States ${ }^{b}$ (Cents per Gallon Excluding Taxes)

\begin{tabular}{|c|c|c|c|c|c|c|c|}
\hline \multirow[b]{2}{*}{$\begin{array}{c}\text { Goographic Area } \\
\text { Month }\end{array}$} & \multicolumn{6}{|c|}{ Sales to End Users } & \multirow{2}{*}{$\begin{array}{c}\text { Sales } \\
\text { for } \\
\text { Resale }\end{array}$} \\
\hline & $\begin{array}{l}\text { Residential } \\
\text { Consumers }\end{array}$ & $\begin{array}{c}\text { Commercial/ } \\
\text { Institutional } \\
\text { Consumers }\end{array}$ & $\begin{array}{l}\text { Industrial } \\
\text { Consumers }\end{array}$ & $\begin{array}{c}\text { Through } \\
\text { Retail } \\
\text { Outletec }\end{array}$ & $\begin{array}{l}\text { Other } \\
\text { End Users d }\end{array}$ & Average & \\
\hline \multicolumn{8}{|l|}{ United States } \\
\hline 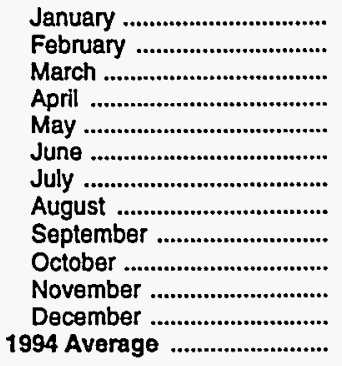 & $\begin{array}{l}89.6 \\
92.9 \\
91.4 \\
88.2 \\
86.1 \\
85.2 \\
82.7 \\
82.1 \\
83.2 \\
84.7 \\
85.7 \\
86.8 \\
88.4\end{array}$ & $\begin{array}{l}58.2 \\
60.9 \\
58.9 \\
57.7 \\
57.1 \\
57.3 \\
58.3 \\
59.2 \\
59.3 \\
59.8 \\
60.0 \\
58.0 \\
\mathbf{5 8 . 7}\end{array}$ & $\begin{array}{l}61.6 \\
64.8 \\
63.3 \\
62.9 \\
62.4 \\
63.1 \\
64.2 \\
65.0 \\
65.0 \\
66.0 \\
65.9 \\
63.3 \\
64.1\end{array}$ & $\begin{array}{l}64.2 \\
67.5 \\
67.3 \\
67.0 \\
66.2 \\
66.6 \\
67.5 \\
68.5 \\
68.1 \\
68.2 \\
68.8 \\
66.9 \\
67.3\end{array}$ & $\begin{array}{l}61.1 \\
64.7 \\
64.7 \\
65.7 \\
64.5 \\
64.4 \\
65.4 \\
67.4 \\
67.9 \\
69.1 \\
68.1 \\
65.2 \\
65.5\end{array}$ & $\begin{array}{l}70.5 \\
72.7 \\
69.7 \\
65.8 \\
63.7 \\
63.2 \\
63.8 \\
65.3 \\
66.0 \\
67.6 \\
68.5 \\
68.9 \\
67.5\end{array}$ & $\begin{array}{l}\mathbf{5 1 . 1} \\
\mathbf{5 4 . 7} \\
\mathbf{5 2 . 6} \\
\mathbf{5 2 . 1} \\
\mathbf{5 1 . 8} \\
\mathbf{5 2 . 4} \\
\mathbf{5 3 . 8} \\
\mathbf{5 3 . 9} \\
\mathbf{5 3 . 6} \\
\mathbf{5 4 . 3} \\
\mathbf{5 4 . 1} \\
\mathbf{5 1 . 2} \\
\mathbf{5 2 . 9}\end{array}$ \\
\hline 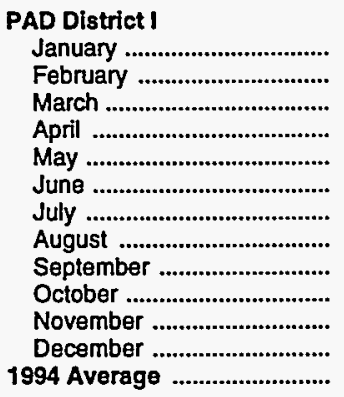 & $\begin{array}{l}91.0 \\
94.6 \\
92.5 \\
89.0 \\
86.6 \\
85.6 \\
83.1 \\
82.4 \\
83.7 \\
85.2 \\
86.1 \\
87.3 \\
89.4\end{array}$ & $\begin{array}{l}64.2 \\
67.5 \\
63.3 \\
60.2 \\
58.6 \\
59.0 \\
59.5 \\
59.7 \\
58.8 \\
59.9 \\
60.8 \\
60.8 \\
61.5\end{array}$ & $\begin{array}{l}64.5 \\
68.2 \\
64.1 \\
62.9 \\
62.0 \\
63.3 \\
63.9 \\
63.7 \\
62.5 \\
63.6 \\
64.2 \\
62.8 \\
64.0\end{array}$ & $\begin{array}{l}66.6 \\
70.5 \\
68.8 \\
67.3 \\
66.7 \\
66.9 \\
67.7 \\
68.6 \\
67.6 \\
67.6 \\
68.4 \\
67.3 \\
67.9\end{array}$ & $\begin{array}{l}60.5 \\
65.2 \\
63.0 \\
62.3 \\
61.2 \\
61.9 \\
62.4 \\
63.2 \\
62.0 \\
63.7 \\
64.3 \\
62.9 \\
63.0\end{array}$ & $\begin{array}{l}78.6 \\
81.5 \\
77.5 \\
71.0 \\
67.0 \\
65.7 \\
65.6 \\
67.1 \\
67.4 \\
70.2 \\
72.3 \\
74.8 \\
73.4\end{array}$ & $\begin{array}{l}\mathbf{5 3 . 2} \\
\mathbf{5 7 . 8} \\
\mathbf{5 2 . 7} \\
\mathbf{5 1 . 1} \\
\mathbf{5 1 . 0} \\
\mathbf{5 1 . 8} \\
\mathbf{5 2 . 8} \\
\mathbf{5 2 . 3} \\
\mathbf{5 1 . 0} \\
\mathbf{5 1 . 9} \\
\mathbf{5 2 . 4} \\
\mathbf{5 1 . 4} \\
\mathbf{5 2 . 7}\end{array}$ \\
\hline 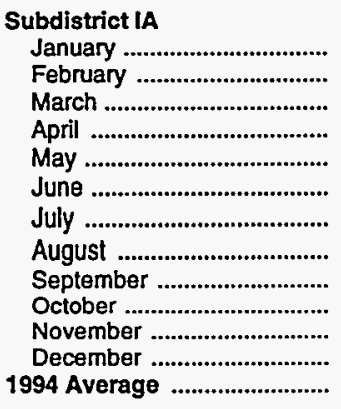 & $\begin{array}{l}87.7 \\
91.6 \\
88.9 \\
85.6 \\
83.1 \\
82.4 \\
81.2 \\
79.0 \\
80.1 \\
81.8 \\
81.8 \\
83.5 \\
86.4\end{array}$ & $\begin{array}{l}70.4 \\
75.3 \\
70.3 \\
66.5 \\
65.0 \\
65.1 \\
65.4 \\
64.8 \\
63.9 \\
65.5 \\
65.7 \\
66.1 \\
68.1\end{array}$ & $\begin{array}{l}70.0 \\
74.4 \\
69.5 \\
66.5 \\
65.9 \\
67.0 \\
66.8 \\
68.0 \\
66.4 \\
67.3 \\
67.3 \\
66.4 \\
67.8\end{array}$ & $\begin{array}{l}76.0 \\
81.8 \\
80.0 \\
76.3 \\
75.1 \\
73.3 \\
73.7 \\
73.2 \\
72.6 \\
72.5 \\
73.7 \\
72.3 \\
74.4\end{array}$ & $\begin{array}{l}62.4 \\
66.6 \\
64.6 \\
63.2 \\
59.7 \\
63.2 \\
63.2 \\
65.6 \\
64.8 \\
64.7 \\
65.9 \\
64.9 \\
64.1\end{array}$ & $\begin{array}{l}83.0 \\
86.9 \\
83.4 \\
78.8 \\
74.9 \\
72.8 \\
72.0 \\
71.8 \\
72.5 \\
74.9 \\
76.0 \\
77.8 \\
79.7\end{array}$ & $\begin{array}{l}54.3 \\
59.2 \\
53.1 \\
51.6 \\
51.7 \\
52.5 \\
53.1 \\
53.0 \\
51.1 \\
51.5 \\
52.7 \\
52.3 \\
53.6\end{array}$ \\
\hline 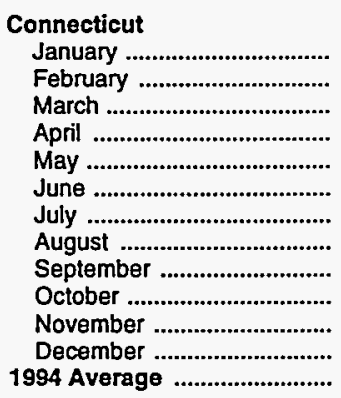 & $\begin{array}{l}90.2 \\
93.8 \\
92.1 \\
89.4 \\
85.4 \\
86.1 \\
84.2 \\
79.7 \\
80.5 \\
83.7 \\
84.0 \\
86.1 \\
89.0\end{array}$ & $\begin{array}{l}68.0 \\
73.8 \\
70.1 \\
66.3 \\
64.2 \\
63.6 \\
64.0 \\
63.1 \\
62.6 \\
64.7 \\
63.9 \\
65.6 \\
65.6\end{array}$ & $\begin{array}{l}69.0 \\
75.8 \\
71.2 \\
63.8 \\
60.0 \\
61.3 \\
59.8 \\
60.6 \\
59.5 \\
60.3 \\
61.4 \\
60.1 \\
62.5\end{array}$ & $\begin{array}{l}77.9 \\
81.0 \\
79.4 \\
77.8 \\
77.5 \\
77.0 \\
77.3 \\
77.4 \\
77.5 \\
77.7 \\
79.2 \\
78.7 \\
78.2\end{array}$ & $\begin{array}{l}60.5 \\
65.4 \\
70.1 \\
70.8 \\
69.4 \\
67.4 \\
69.2 \\
68.1 \\
67.2 \\
70.3 \\
72.9 \\
70.9 \\
68.5\end{array}$ & $\begin{array}{l}85.4 \\
89.1 \\
86.5 \\
81.9 \\
77.3 \\
75.3 \\
74.4 \\
71.7 \\
72.4 \\
76.3 \\
76.8 \\
79.8 \\
81.5\end{array}$ & $\begin{array}{l}54.3 \\
58.9 \\
52.3 \\
52.0 \\
52.3 \\
52.6 \\
53.6 \\
52.9 \\
50.8 \\
50.7 \\
52.1 \\
52.1 \\
53.3\end{array}$ \\
\hline
\end{tabular}

See footnotes at end of table. 
Table 39. No. 2 Distillate ${ }^{a}$ Prices by Sales Type, PAD District, and Selected States ${ }^{b}$

(Cents per Gallon Excluding Taxes) - Continued

\begin{tabular}{|c|c|c|c|c|c|c|c|}
\hline \multirow[b]{2}{*}{$\begin{array}{c}\text { Geographlo Area } \\
\text { Month }\end{array}$} & \multicolumn{6}{|c|}{ Sales to End Users } & \multirow[b]{2}{*}{$\begin{array}{c}\text { Sales } \\
\text { for } \\
\text { Resala }\end{array}$} \\
\hline & $\begin{array}{l}\text { Residential } \\
\text { Consumers }\end{array}$ & $\begin{array}{c}\text { Commerclal/ } \\
\text { Institutional } \\
\text { Consumers }\end{array}$ & $\begin{array}{l}\text { Industrial } \\
\text { Consumers }\end{array}$ & $\begin{array}{c}\text { Through } \\
\text { Retail } \\
\text { Outletsc }\end{array}$ & $\begin{array}{l}\text { Other } \\
\text { End Users d }\end{array}$ & Average & \\
\hline \multicolumn{8}{|l|}{ Malne } \\
\hline 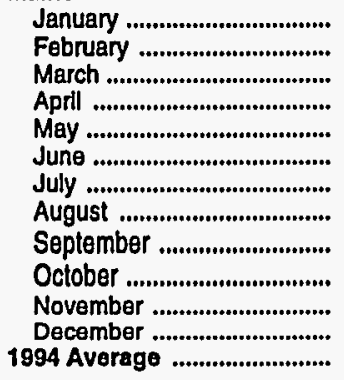 & $\begin{array}{l}83.8 \\
90.4 \\
85.9 \\
80.8 \\
76.8 \\
75.6 \\
75.6 \\
78.0 \\
78.5 \\
77.5 \\
77.7 \\
77.5 \\
81.8\end{array}$ & $\begin{array}{l}69.7 \\
75.5 \\
69.1 \\
64.5 \\
63.3 \\
65.9 \\
66.0 \\
69.4 \\
67.7 \\
67.0 \\
66.8 \\
66.2 \\
68.2\end{array}$ & $\begin{array}{l}69.4 \\
74.6 \\
68.6 \\
64.8 \\
63.5 \\
64.7 \\
65.4 \\
67.9 \\
65.8 \\
65.4 \\
66.5 \\
66.6 \\
67.0\end{array}$ & $\begin{array}{l}77.6 \\
85.4 \\
84.9 \\
77.3 \\
75.4 \\
73.2 \\
73.1 \\
72.5 \\
71.6 \\
71.2 \\
71.5 \\
71.9 \\
75.9\end{array}$ & $\begin{array}{l}68.9 \\
75.3 \\
68.3 \\
64.2 \\
64.8 \\
66.2 \\
67.0 \\
67.3 \\
64.8 \\
64.8 \\
65.7 \\
65.9 \\
67.1\end{array}$ & $\begin{array}{l}79.2 \\
85.4 \\
80.1 \\
74.2 \\
71.1 \\
70.1 \\
69.9 \\
72.3 \\
72.1 \\
71.9 \\
72.8 \\
73.3 \\
75.9\end{array}$ & $\begin{array}{l}55.0 \\
60.3 \\
54.5 \\
52.1 \\
51.6 \\
53.3 \\
53.8 \\
53.9 \\
51.7 \\
53.4 \\
53.4 \\
53.1 \\
54.3\end{array}$ \\
\hline \multicolumn{8}{|l|}{ Massachusetts } \\
\hline 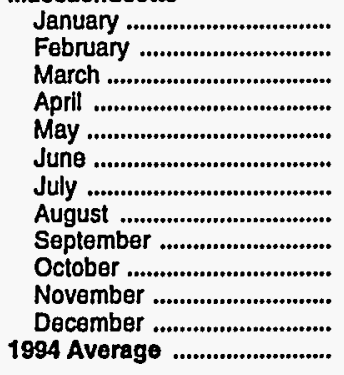 & $\begin{array}{l}88.4 \\
91.3 \\
88.3 \\
86.0 \\
85.1 \\
83.7 \\
82.1 \\
78.7 \\
81.1 \\
83.0 \\
83.6 \\
84.2 \\
87.0\end{array}$ & $\begin{array}{l}71.3 \\
75.3 \\
69.5 \\
66.1 \\
65.0 \\
64.3 \\
64.5 \\
62.3 \\
61.6 \\
63.6 \\
65.1 \\
65.5 \\
68.7\end{array}$ & $\begin{array}{l}70.8 \\
72.8 \\
69.6 \\
70.0 \\
70.9 \\
73.4 \\
71.8 \\
75.1 \\
72.1 \\
74.0 \\
73.9 \\
72.5 \\
71.7\end{array}$ & $\begin{array}{l}74.2 \\
78.7 \\
76.4 \\
74.5 \\
74.5 \\
74.7 \\
75.3 \\
72.4 \\
71.5 \\
71.6 \\
73.4 \\
71.5 \\
72.2\end{array}$ & $\begin{array}{r}59.7 \\
62.4 \\
60.3 \\
60.4 \\
\text { NA } \\
58.7 \\
58.4 \\
61.0 \\
59.6 \\
57.8 \\
58.7 \\
57.9 \\
59.3\end{array}$ & $\begin{array}{l}83.2 \\
86.0 \\
82.3 \\
79.0 \\
75.2 \\
72.5 \\
71.3 \\
70.5 \\
71.8 \\
74.6 \\
76.7 \\
77.8 \\
80.1\end{array}$ & $\begin{array}{l}54.2 \\
59.6 \\
53.2 \\
51.5 \\
51.1 \\
51.7 \\
52.7 \\
52.5 \\
51.0 \\
51.5 \\
53.0 \\
51.9 \\
53.5\end{array}$ \\
\hline 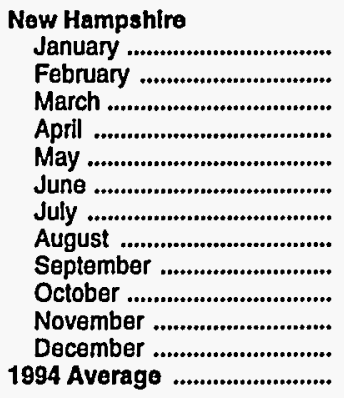 & $\begin{array}{l}80.4 \\
86.6 \\
83.6 \\
78.2 \\
75.4 \\
73.1 \\
71.8 \\
72.8 \\
72.9 \\
74.0 \\
73.7 \\
77.3 \\
79.2\end{array}$ & $\begin{array}{l}69.4 \\
75.4 \\
72.2 \\
68.3 \\
66.9 \\
68.8 \\
68.8 \\
67.3 \\
64.6 \\
66.3 \\
64.9 \\
65.2 \\
68.0\end{array}$ & $\begin{array}{r}68.6 \\
74.0 \\
69.4 \\
63.1 \\
61.9 \\
\text { NA } \\
\text { NA } \\
64.0 \\
66.1 \\
64.4 \\
63.2 \\
\text { NA } \\
64.4\end{array}$ & $\begin{array}{r}75.2 \\
79.5 \\
77.6 \\
\text { NA } \\
75.0 \\
70.1 \\
71.2 \\
72.8 \\
72.5 \\
72.2 \\
73.5 \\
71.1 \\
73.7\end{array}$ & $\begin{array}{l}65.9 \\
72.6 \\
69.9 \\
66.3 \\
65.2 \\
65.7 \\
67.5 \\
68.6 \\
65.2 \\
65.5 \\
67.2 \\
67.1 \\
67.5\end{array}$ & $\begin{array}{l}77.9 \\
83.8 \\
80.5 \\
75.3 \\
72.1 \\
70.2 \\
70.1 \\
70.9 \\
70.5 \\
71.3 \\
72.0 \\
73.6 \\
75.3\end{array}$ & $\begin{array}{l}54.8 \\
57.8 \\
53.9 \\
51.5 \\
52.1 \\
53.5 \\
53.9 \\
52.8 \\
51.2 \\
52.1 \\
52.3 \\
52.7 \\
53.8\end{array}$ \\
\hline 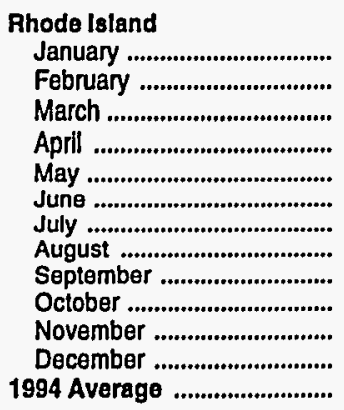 & $\begin{array}{l}87.3 \\
91.4 \\
89.4 \\
85.1 \\
83.3 \\
82.3 \\
81.6 \\
84.0 \\
84.7 \\
84.4 \\
85.8 \\
87.2 \\
88.5\end{array}$ & $\begin{array}{l}75.6 \\
81.4 \\
75.2 \\
69.1 \\
66.2 \\
66.7 \\
68.0 \\
69.6 \\
69.4 \\
73.3 \\
73.2 \\
72.3 \\
72.5\end{array}$ & $\begin{array}{l}68.3 \\
72.0 \\
66.3 \\
63.8 \\
62.9 \\
63.7 \\
61.8 \\
64.7 \\
61.6 \\
64.4 \\
62.9 \\
66.1 \\
66.4\end{array}$ & $\begin{array}{r}74.2 \\
78.9 \\
\text { NA } \\
69.2 \\
68.8 \\
71.7 \\
71.8 \\
70.7 \\
68.0 \\
69.2 \\
72.3 \\
69.5 \\
69.8\end{array}$ & $\begin{array}{r}55.2 \\
60.3 \\
57.1 \\
55.2 \\
55.9 \\
54.4 \\
\text { NA } \\
62.7 \\
70.8 \\
71.0 \\
72.8 \\
75.9 \\
64.3\end{array}$ & $\begin{array}{l}84.7 \\
89.2 \\
85.9 \\
80.0 \\
76.1 \\
74.1 \\
73.1 \\
75.6 \\
77.1 \\
79.5 \\
80.4 \\
83.1 \\
83.3\end{array}$ & $\begin{array}{l}53.1 \\
58.6 \\
51.8 \\
50.0 \\
51.1 \\
52.4 \\
52.0 \\
52.6 \\
49.8 \\
50.6 \\
52.0 \\
51.9 \\
52.7\end{array}$ \\
\hline
\end{tabular}

See footnotes at end of table. 
Table 39. No. 2 Distillate ${ }^{a}$ Prices by Sales Type, PAD District, and Selected States ${ }^{b}$ (Cents per Gallon Excluding Taxes) - Continued

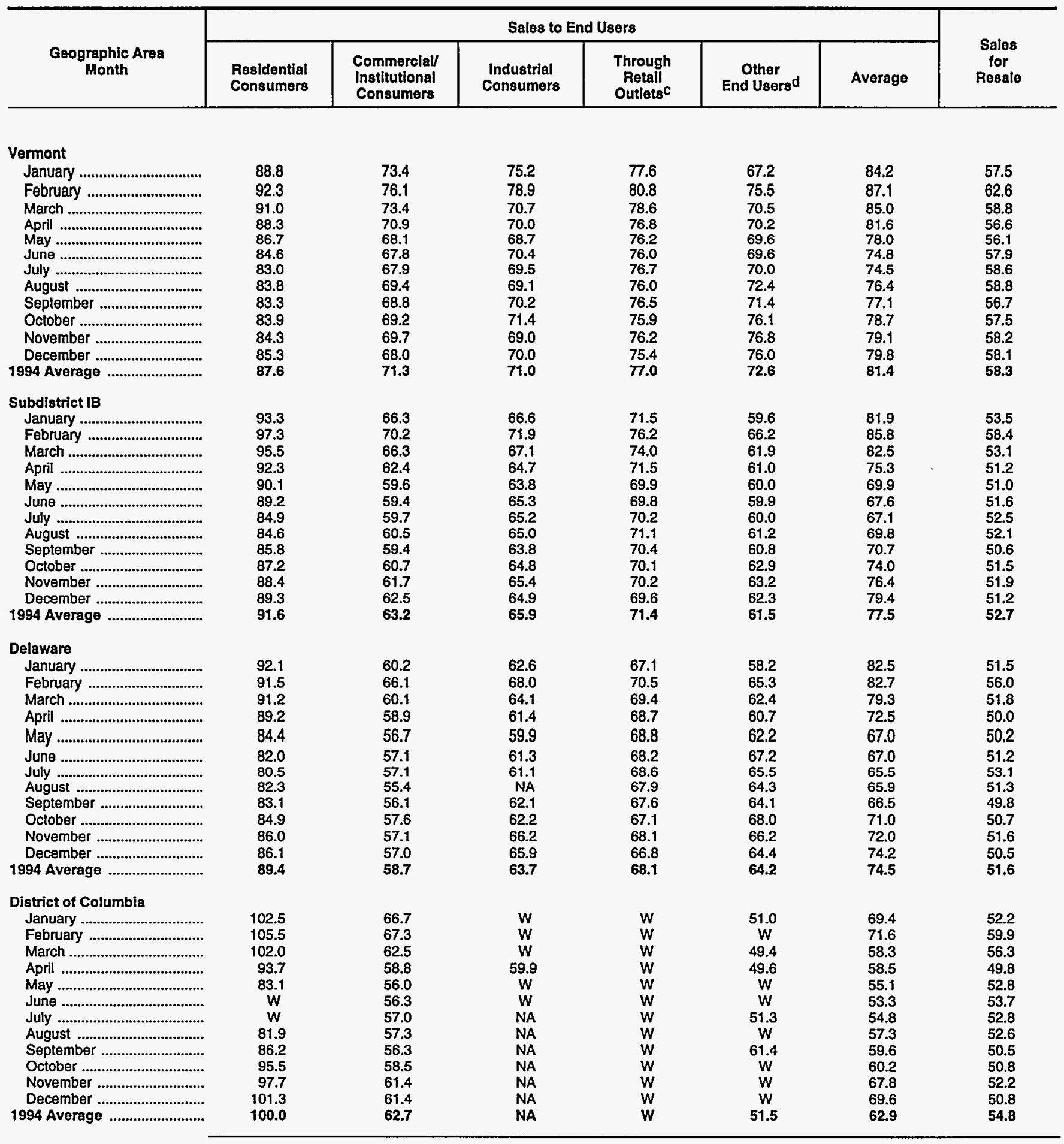

See footnotes at end of table. 
Table 39. No. 2 Distillate ${ }^{a}$ Prices by Sales Type, PAD District, and Selected States ${ }^{b}$ (Cents per Gallon Excluding Taxes) — Continued

\begin{tabular}{|c|c|c|c|c|c|c|c|}
\hline \multirow[b]{2}{*}{$\begin{array}{c}\text { Geographlc Area } \\
\text { Month }\end{array}$} & \multicolumn{6}{|c|}{ Sales to End Usera } & \multirow[b]{2}{*}{$\begin{array}{c}\text { Sales } \\
\text { for } \\
\text { Resale }\end{array}$} \\
\hline & $\begin{array}{l}\text { Residentlal } \\
\text { Consumers }\end{array}$ & $\begin{array}{l}\text { Commerclay } \\
\text { Institutlonal } \\
\text { Consumers }\end{array}$ & $\begin{array}{l}\text { Industrial } \\
\text { Consumers }\end{array}$ & $\begin{array}{c}\text { Through } \\
\text { Retall } \\
\text { Outletsc }\end{array}$ & $\begin{array}{l}\text { Other } \\
\text { End Users d }\end{array}$ & Average & \\
\hline \multicolumn{8}{|l|}{ Maryland } \\
\hline 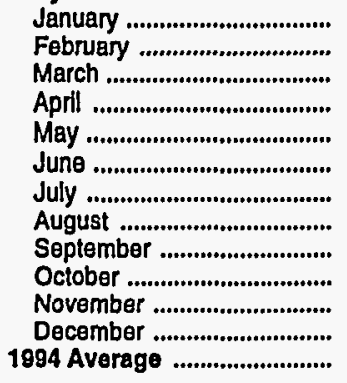 & $\begin{array}{l}98.8 \\
99.5 \\
96.3 \\
92.4 \\
86.8 \\
87.7 \\
87.8 \\
86.0 \\
87.8 \\
90.0 \\
92.4 \\
94.3 \\
95.0\end{array}$ & $\begin{array}{l}60.9 \\
64.2 \\
59.4 \\
56.3 \\
55.6 \\
55.9 \\
57.6 \\
56.5 \\
55.4 \\
57.0 \\
57.7 \\
56.8 \\
58.1\end{array}$ & $\begin{array}{l}64.7 \\
68.2 \\
63.2 \\
60.6 \\
60.2 \\
60.6 \\
60.7 \\
58.5 \\
58.0 \\
59.2 \\
60.0 \\
\text { NA } \\
61.6\end{array}$ & $\begin{array}{l}71.3 \\
75.5 \\
72.4 \\
70.8 \\
69.6 \\
69.7 \\
69.4 \\
70.2 \\
69.3 \\
68.7 \\
68.8 \\
64.9 \\
70.0\end{array}$ & $\begin{array}{l}54.6 \\
61.4 \\
58.7 \\
57.3 \\
58.8 \\
58.5 \\
58.7 \\
58.3 \\
58.5 \\
61.3 \\
61.7 \\
59.6 \\
57.2\end{array}$ & $\begin{array}{l}73.2 \\
79.8 \\
74.9 \\
66.5 \\
63.7 \\
61.9 \\
62.7 \\
62.1 \\
62.3 \\
67.4 \\
69.3 \\
72.0 \\
69.6\end{array}$ & $\begin{array}{l}\mathbf{5 3 . 4} \\
\mathbf{5 8 . 5} \\
\mathbf{5 2 . 5} \\
\mathbf{5 1 . 8} \\
\mathbf{5 2 . 3} \\
\mathbf{5 3 . 3} \\
\mathbf{5 4 . 0} \\
\mathbf{5 3 . 0} \\
\mathbf{5 1 . 7} \\
\mathbf{5 3 . 0} \\
\mathbf{5 3 . 4} \\
\mathbf{5 1 . 4} \\
\mathbf{5 3 . 3}\end{array}$ \\
\hline \multicolumn{8}{|l|}{ New Jersey } \\
\hline 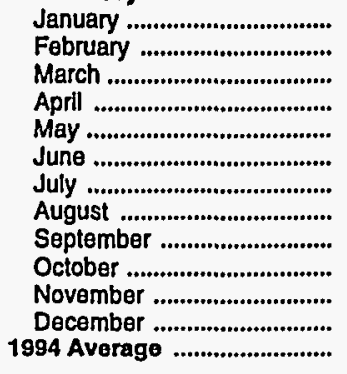 & $\begin{array}{l}91.7 \\
94.8 \\
93.9 \\
90.7 \\
85.4 \\
83.5 \\
82.9 \\
85.9 \\
85.4 \\
86.8 \\
88.6 \\
89.6 \\
89.5\end{array}$ & $\begin{array}{l}63.4 \\
68.8 \\
62.8 \\
60.5 \\
57.4 \\
58.2 \\
57.8 \\
58.0 \\
56.7 \\
58.2 \\
58.1 \\
58.7 \\
\mathbf{5 9 . 7}\end{array}$ & $\begin{array}{l}66.1 \\
75.5 \\
64.4 \\
62.2 \\
64.9 \\
66.1 \\
66.7 \\
65.3 \\
63.4 \\
67.3 \\
67.7 \\
67.3 \\
66.4\end{array}$ & $\begin{array}{l}70.6 \\
72.7 \\
73.2 \\
70.7 \\
70.5 \\
71.4 \\
71.0 \\
70.0 \\
70.1 \\
71.0 \\
69.8 \\
69.3 \\
70.7\end{array}$ & $\begin{array}{l}59.1 \\
63.3 \\
60.8 \\
60.6 \\
60.8 \\
60.0 \\
60.6 \\
56.3 \\
N A \\
55.5 \\
60.3 \\
58.4 \\
59.1\end{array}$ & $\begin{array}{l}81.3 \\
85.1 \\
82.1 \\
73.0 \\
66.6 \\
65.1 \\
65.4 \\
72.3 \\
73.4 \\
77.4 \\
79.5 \\
82.9 \\
77.9\end{array}$ & $\begin{array}{l}51.3 \\
56.3 \\
51.2 \\
49.3 \\
49.5 \\
50.2 \\
50.6 \\
50.7 \\
49.2 \\
50.1 \\
50.5 \\
49.8 \\
51.0\end{array}$ \\
\hline \multicolumn{8}{|l|}{ Now York } \\
\hline 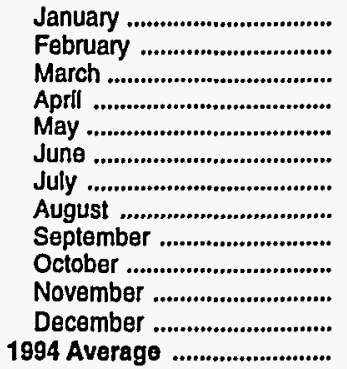 & $\begin{array}{r}97.2 \\
101.7 \\
100.3 \\
96.4 \\
96.3 \\
96.8 \\
93.9 \\
89.1 \\
90.8 \\
92.9 \\
93.3 \\
94.6 \\
96.6\end{array}$ & $\begin{array}{l}71.0 \\
75.9 \\
71.6 \\
65.7 \\
64.1 \\
64.0 \\
64.0 \\
64.2 \\
64.1 \\
65.3 \\
67.3 \\
68.6 \\
68.7\end{array}$ & $\begin{array}{l}69.8 \\
73.6 \\
71.6 \\
68.3 \\
65.6 \\
67.5 \\
66.7 \\
64.5 \\
63.7 \\
64.6 \\
65.0 \\
64.8 \\
67.6\end{array}$ & $\begin{array}{l}78.7 \\
82.3 \\
81.5 \\
78.2 \\
76.7 \\
76.9 \\
76.7 \\
79.2 \\
78.3 \\
79.0 \\
79.3 \\
79.0 \\
79.3\end{array}$ & $\begin{array}{l}60.3 \\
66.3 \\
63.2 \\
60.0 \\
59.7 \\
60.2 \\
61.4 \\
62.3 \\
63.7 \\
63.0 \\
65.8 \\
65.1 \\
62.8\end{array}$ & $\begin{array}{l}87.7 \\
91.7 \\
88.7 \\
82.0 \\
77.4 \\
75.0 \\
73.5 \\
74.6 \\
77.2 \\
79.7 \\
82.6 \\
85.2 \\
84.5\end{array}$ & $\begin{array}{l}55.8 \\
60.3 \\
54.9 \\
52.4 \\
51.6 \\
51.6 \\
52.8 \\
52.5 \\
52.0 \\
52.3 \\
52.6 \\
52.5 \\
54.2\end{array}$ \\
\hline \multicolumn{8}{|l|}{ Pennsylvania } \\
\hline 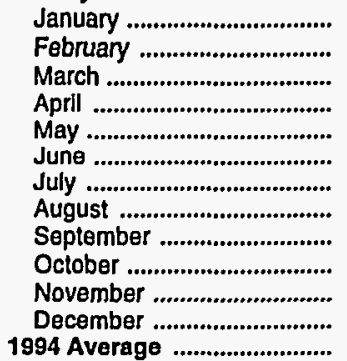 & $\begin{array}{l}87.7 \\
92.5 \\
90.4 \\
86.2 \\
83.7 \\
80.1 \\
75.7 \\
77.9 \\
79.1 \\
80.2 \\
81.4 \\
82.0 \\
85.7\end{array}$ & $\begin{array}{l}64.5 \\
67.9 \\
65.5 \\
62.9 \\
58.6 \\
57.9 \\
58.4 \\
60.8 \\
59.5 \\
60.3 \\
61.4 \\
61.1 \\
62.1\end{array}$ & $\begin{array}{l}64.4 \\
70.6 \\
66.7 \\
66.0 \\
63.9 \\
65.6 \\
65.6 \\
66.3 \\
65.2 \\
64.7 \\
65.4 \\
64.7 \\
65.9\end{array}$ & $\begin{array}{l}68.5 \\
75.1 \\
71.6 \\
69.4 \\
67.2 \\
66.5 \\
67.1 \\
68.6 \\
67.7 \\
66.8 \\
67.4 \\
66.8 \\
68.5\end{array}$ & $\begin{array}{l}67.0 \\
68.9 \\
66.2 \\
63.9 \\
60.9 \\
61.0 \\
59.8 \\
63.5 \\
62.0 \\
66.0 \\
62.4 \\
61.9 \\
63.7\end{array}$ & $\begin{array}{l}79.0 \\
81.8 \\
79.3 \\
72.1 \\
66.8 \\
64.4 \\
64.4 \\
67.0 \\
66.4 \\
68.7 \\
70.6 \\
72.9 \\
72.8\end{array}$ & $\begin{array}{l}53.8 \\
59.2 \\
54.0 \\
52.6 \\
52.0 \\
52.7 \\
54.2 \\
53.2 \\
51.6 \\
52.5 \\
52.8 \\
51.8 \\
53.5\end{array}$ \\
\hline
\end{tabular}

See footnotes at end of table. 
Table 39. No. 2 Distillate ${ }^{a}$ Prices by Sales Type, PAD District, and Selected States ${ }^{b}$ (Cents per Gallon Excluding Taxes) - Continued

\begin{tabular}{|c|c|c|c|c|c|c|c|}
\hline \multirow[b]{2}{*}{$\begin{array}{l}\text { Geographic Area } \\
\text { Month }\end{array}$} & \multicolumn{6}{|c|}{ Sales to End Users } & \multirow[b]{2}{*}{$\begin{array}{c}\text { Sales } \\
\text { for } \\
\text { Resalo }\end{array}$} \\
\hline & $\begin{array}{l}\text { Residential } \\
\text { Consumers }\end{array}$ & $\begin{array}{c}\text { Commercial/ } \\
\text { Institutional } \\
\text { Consumers }\end{array}$ & $\begin{array}{l}\text { Industrial } \\
\text { Consumers }\end{array}$ & $\begin{array}{c}\text { Through } \\
\text { Retail } \\
\text { Outlets }\end{array}$ & $\begin{array}{l}\text { Other } \\
\text { End Users d }\end{array}$ & Average & \\
\hline \multicolumn{8}{|l|}{ Subdistrict IC } \\
\hline 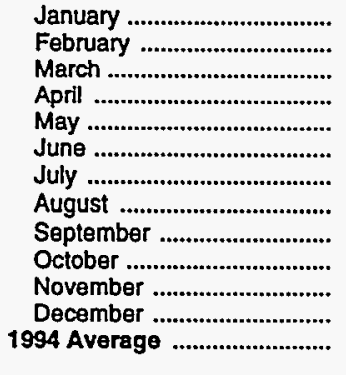 & $\begin{array}{l}90.4 \\
89.9 \\
87.9 \\
84.4 \\
84.7 \\
81.8 \\
80.8 \\
78.8 \\
81.0 \\
82.3 \\
84.9 \\
85.9 \\
86.6\end{array}$ & $\begin{array}{l}\mathbf{5 7 . 5} \\
\mathbf{5 9 . 2} \\
\mathbf{5 6 . 3} \\
\mathbf{5 5 . 6} \\
\mathbf{5 5 . 8} \\
\mathbf{5 6 . 9} \\
\mathbf{5 7 . 6} \\
\mathbf{5 7 . 5} \\
\mathbf{5 6 . 5} \\
\mathbf{5 7 . 1} \\
\mathbf{5 7 . 7} \\
\mathbf{5 5 . 7} \\
\mathbf{5 7 . 0}\end{array}$ & $\begin{array}{l}61.8 \\
64.1 \\
61.0 \\
61.2 \\
60.2 \\
61.1 \\
62.4 \\
62.1 \\
60.7 \\
61.9 \\
62.6 \\
60.3 \\
61.9\end{array}$ & $\begin{array}{l}63.4 \\
66.9 \\
65.5 \\
64.6 \\
64.4 \\
64.9 \\
65.9 \\
66.7 \\
65.5 \\
65.7 \\
66.8 \\
65.4 \\
65.4\end{array}$ & $\begin{array}{l}61.3 \\
63.9 \\
63.6 \\
63.0 \\
62.3 \\
63.0 \\
63.9 \\
63.9 \\
62.1 \\
63.9 \\
64.6 \\
62.8 \\
63.7\end{array}$ & $\begin{array}{l}66.3 \\
67.1 \\
63.6 \\
61.4 \\
60.9 \\
61.7 \\
62.4 \\
62.8 \\
61.9 \\
63.3 \\
64.2 \\
63.6 \\
63.5\end{array}$ & $\begin{array}{l}51.1 \\
54.8 \\
51.7 \\
50.6 \\
50.7 \\
51.9 \\
53.0 \\
52.3 \\
51.4 \\
52.7 \\
53.2 \\
50.8 \\
52.0\end{array}$ \\
\hline \multicolumn{8}{|l|}{ Virginia } \\
\hline 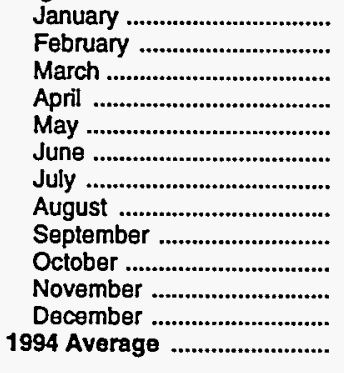 & $\begin{array}{l}88.6 \\
88.6 \\
86.6 \\
83.0 \\
82.2 \\
79.7 \\
79.6 \\
80.5 \\
80.4 \\
82.3 \\
84.1 \\
84.8 \\
85.3\end{array}$ & $\begin{array}{l}58.9 \\
61.4 \\
57.7 \\
56.1 \\
56.4 \\
57.7 \\
58.5 \\
58.9 \\
58.1 \\
59.1 \\
59.2 \\
59.1 \\
58.2\end{array}$ & $\begin{array}{l}62.6 \\
63.0 \\
58.6 \\
59.1 \\
59.4 \\
60.4 \\
60.4 \\
62.4 \\
62.2 \\
62.9 \\
64.3 \\
62.6 \\
62.0\end{array}$ & $\begin{array}{l}63.4 \\
68.6 \\
67.4 \\
65.2 \\
66.3 \\
66.8 \\
68.8 \\
67.0 \\
66.8 \\
65.5 \\
66.9 \\
66.9 \\
66.7\end{array}$ & $\begin{array}{r}58.2 \\
62.2 \\
65.0 \\
63.5 \\
67.1 \\
67.9 \\
N A \\
65.6 \\
65.2 \\
65.4 \\
66.6 \\
63.9 \\
64.3\end{array}$ & $\begin{array}{l}70.9 \\
71.6 \\
67.3 \\
62.6 \\
62.6 \\
63.4 \\
63.4 \\
64.5 \\
64.4 \\
66.2 \\
67.0 \\
68.4 \\
66.6\end{array}$ & $\begin{array}{l}\mathbf{5 1 . 1} \\
55.0 \\
51.2 \\
50.2 \\
50.1 \\
51.7 \\
52.8 \\
52.0 \\
51.1 \\
52.4 \\
53.2 \\
51.1 \\
51.8\end{array}$ \\
\hline \multicolumn{8}{|l|}{ West Virginia } \\
\hline 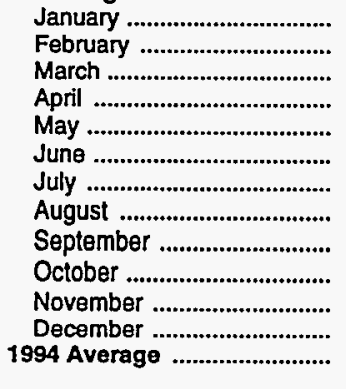 & $\begin{array}{l}86.3 \\
86.3 \\
85.0 \\
77.8 \\
73.5 \\
72.4 \\
72.9 \\
74.8 \\
76.2 \\
79.3 \\
81.4 \\
81.3 \\
80.9\end{array}$ & $\begin{array}{l}57.7 \\
61.0 \\
59.7 \\
59.7 \\
57.0 \\
59.1 \\
59.4 \\
59.7 \\
57.2 \\
58.9 \\
60.3 \\
56.2 \\
58.6\end{array}$ & $\begin{array}{l}61.0 \\
64.6 \\
62.6 \\
62.6 \\
61.0 \\
61.7 \\
63.1 \\
63.0 \\
60.7 \\
63.0 \\
64.6 \\
60.4 \\
62.3\end{array}$ & $\begin{array}{l}67.7 \\
70.0 \\
70.3 \\
69.6 \\
69.3 \\
70.2 \\
69.9 \\
71.4 \\
71.3 \\
71.6 \\
72.0 \\
71.0 \\
70.6\end{array}$ & $\begin{array}{l}58.4 \\
63.2 \\
61.9 \\
63.1 \\
59.4 \\
59.3 \\
60.2 \\
65.2 \\
63.1 \\
58.6 \\
62.9 \\
62.6 \\
60.8\end{array}$ & $\begin{array}{l}64.3 \\
66.3 \\
64.2 \\
63.0 \\
60.7 \\
61.7 \\
62.6 \\
63.5 \\
61.6 \\
63.1 \\
65.0 \\
62.1 \\
62.9\end{array}$ & $\begin{array}{l}53.0 \\
57.6 \\
56.3 \\
56.7 \\
54.4 \\
54.8 \\
56.0 \\
55.8 \\
53.5 \\
54.9 \\
56.2 \\
52.5 \\
\mathbf{5 5 . 1}\end{array}$ \\
\hline \multicolumn{8}{|l|}{ PAD District II } \\
\hline 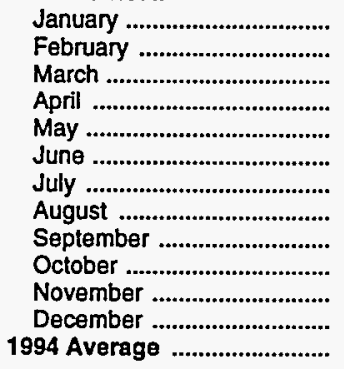 & $\begin{array}{l}80.4 \\
82.1 \\
82.0 \\
81.4 \\
80.6 \\
80.5 \\
80.2 \\
79.8 \\
80.0 \\
80.1 \\
80.9 \\
81.1 \\
80.8\end{array}$ & $\begin{array}{l}53.3 \\
55.5 \\
55.2 \\
56.0 \\
56.2 \\
56.5 \\
57.9 \\
58.5 \\
57.8 \\
57.9 \\
57.9 \\
55.5 \\
56.6\end{array}$ & $\begin{array}{l}59.8 \\
63.3 \\
62.6 \\
63.3 \\
62.7 \\
63.6 \\
64.7 \\
65.8 \\
65.1 \\
65.8 \\
65.0 \\
62.6 \\
64.2\end{array}$ & $\begin{array}{l}62.2 \\
65.5 \\
65.6 \\
66.0 \\
64.6 \\
65.2 \\
66.2 \\
67.2 \\
66.3 \\
65.8 \\
66.3 \\
64.8 \\
65.6\end{array}$ & $\begin{array}{l}64.3 \\
66.7 \\
68.4 \\
69.7 \\
70.1 \\
69.4 \\
71.9 \\
71.5 \\
72.2 \\
73.0 \\
72.0 \\
68.3 \\
70.0\end{array}$ & $\begin{array}{l}62.4 \\
64.2 \\
63.3 \\
63.5 \\
62.8 \\
62.7 \\
63.8 \\
65.0 \\
64.9 \\
65.6 \\
65.1 \\
63.5 \\
63.9\end{array}$ & $\begin{array}{l}49.7 \\
52.7 \\
53.5 \\
54.3 \\
53.4 \\
54.3 \\
55.9 \\
56.1 \\
54.4 \\
55.2 \\
54.5 \\
51.5 \\
53.8\end{array}$ \\
\hline
\end{tabular}

See footnotes at end of table. 
Table 39. No. 2 Distillate ${ }^{a}$ Prices by Sales Type, PAD District, and Selected States ${ }^{b}$ (Cents per Gallon Excluding Taxes) - Continued

\begin{tabular}{|c|c|c|c|c|c|c|c|}
\hline \multirow[b]{2}{*}{$\begin{array}{l}\text { Geographic Area } \\
\text { Month }\end{array}$} & \multicolumn{6}{|c|}{ Sales to End Users } & \multirow[b]{2}{*}{$\begin{array}{c}\text { Sales } \\
\text { for } \\
\text { Resale }\end{array}$} \\
\hline & $\begin{array}{l}\text { Residential } \\
\text { Consumers }\end{array}$ & $\begin{array}{l}\text { Commercial } \\
\text { Institutional } \\
\text { Consumers }\end{array}$ & $\begin{array}{l}\text { Industrial } \\
\text { Consumere }\end{array}$ & $\begin{array}{c}\text { Through } \\
\text { Retail } \\
\text { Outletsc }\end{array}$ & $\begin{array}{l}\text { Other } \\
\text { End Users d }\end{array}$ & Average & \\
\hline \multicolumn{8}{|l|}{ Illinole } \\
\hline 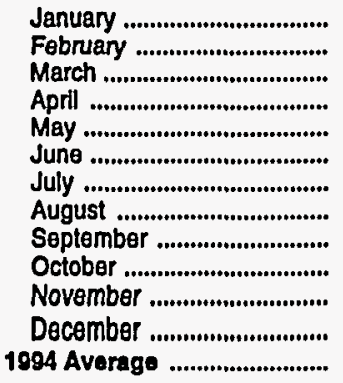 & $\begin{array}{l}78.8 \\
82.2 \\
78.7 \\
76.1 \\
73.3 \\
75.5 \\
75.3 \\
77.2 \\
76.6 \\
77.6 \\
80.8 \\
80.4 \\
78.4\end{array}$ & $\begin{array}{l}53.5 \\
57.0 \\
57.4 \\
58.8 \\
57.8 \\
58.1 \\
59.4 \\
60.3 \\
59.0 \\
58.2 \\
58.8 \\
57.5 \\
58.6\end{array}$ & $\begin{array}{l}62.9 \\
65.6 \\
67.2 \\
68.7 \\
67.0 \\
69.7 \\
70.3 \\
70.7 \\
70.5 \\
70.7 \\
70.7 \\
66.9 \\
70.3\end{array}$ & $\begin{array}{l}64.4 \\
67.7 \\
66.7 \\
67.6 \\
67.4 \\
66.9 \\
67.6 \\
68.2 \\
67.5 \\
67.8 \\
67.8 \\
67.3 \\
67.3\end{array}$ & $\begin{array}{l}63.8 \\
66.2 \\
68.2 \\
69.9 \\
69.6 \\
68.8 \\
71.6 \\
73.6 \\
75.1 \\
76.3 \\
75.0 \\
72.7 \\
71.6\end{array}$ & $\begin{array}{l}60.5 \\
63.5 \\
63.4 \\
64.6 \\
64.0 \\
63.8 \\
64.8 \\
66.3 \\
66.6 \\
67.7 \\
66.4 \\
64.2 \\
65.5\end{array}$ & $\begin{array}{l}48.2 \\
51.4 \\
52.9 \\
53.0 \\
52.4 \\
53.0 \\
53.9 \\
54.3 \\
53.1 \\
53.7 \\
52.4 \\
50.2 \\
52.5\end{array}$ \\
\hline 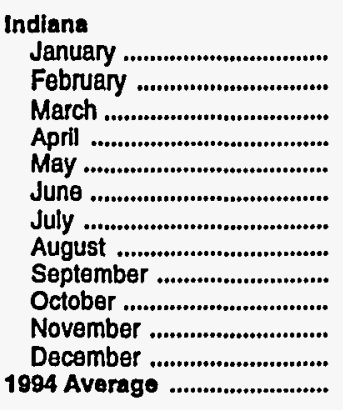 & $\begin{array}{l}79.1 \\
82.0 \\
81.0 \\
81.2 \\
79.9 \\
81.5 \\
80.0 \\
81.6 \\
82.6 \\
81.7 \\
81.2 \\
82.4 \\
81.2\end{array}$ & $\begin{array}{l}53.0 \\
54.4 \\
55.9 \\
55.4 \\
54.1 \\
55.7 \\
57.2 \\
57.4 \\
56.2 \\
57.3 \\
57.3 \\
55.1 \\
55.6\end{array}$ & $\begin{array}{l}56.6 \\
60.3 \\
60.9 \\
60.9 \\
59.8 \\
61.0 \\
62.1 \\
62.9 \\
61.3 \\
64.0 \\
62.2 \\
60.1 \\
61.5\end{array}$ & $\begin{array}{l}60.2 \\
66.1 \\
65.0 \\
65.6 \\
63.7 \\
63.7 \\
64.5 \\
65.5 \\
64.4 \\
63.9 \\
65.2 \\
62.8 \\
64.2\end{array}$ & $\begin{array}{l}65.5 \\
72.9 \\
73.2 \\
74.5 \\
75.9 \\
73.9 \\
76.6 \\
74.5 \\
75.2 \\
78.9 \\
76.8 \\
72.7 \\
75.1\end{array}$ & $\begin{array}{l}60.9 \\
64.4 \\
63.8 \\
63.9 \\
62.9 \\
62.5 \\
63.2 \\
63.3 \\
63.3 \\
65.2 \\
64.2 \\
62.1 \\
63.3\end{array}$ & $\begin{array}{l}47.4 \\
51.0 \\
53.4 \\
53.8 \\
52.4 \\
53.0 \\
54.0 \\
54.2 \\
52.5 \\
53.3 \\
52.9 \\
50.9 \\
52.4\end{array}$ \\
\hline 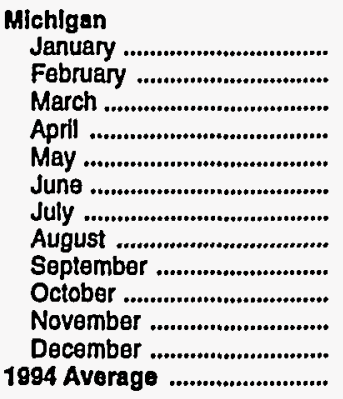 & $\begin{array}{l}85.6 \\
88.0 \\
87.7 \\
87.7 \\
87.3 \\
86.9 \\
87.7 \\
84.3 \\
84.2 \\
85.2 \\
85.9 \\
86.1 \\
86.3\end{array}$ & $\begin{array}{l}56.8 \\
60.5 \\
60.7 \\
60.9 \\
59.9 \\
60.4 \\
61.8 \\
58.5 \\
58.9 \\
58.4 \\
59.3 \\
55.6 \\
59.2\end{array}$ & $\begin{array}{l}62.6 \\
63.0 \\
62.9 \\
62.2 \\
63.8 \\
63.6 \\
64.4 \\
64.3 \\
63.7 \\
66.4 \\
64.2 \\
63.0 \\
63.6\end{array}$ & $\begin{array}{l}65.9 \\
69.8 \\
69.9 \\
69.7 \\
69.3 \\
69.7 \\
69.3 \\
69.8 \\
68.9 \\
68.0 \\
67.9 \\
66.4 \\
68.7\end{array}$ & $\begin{array}{l}64.4 \\
66.9 \\
69.8 \\
68.5 \\
71.0 \\
68.8 \\
70.5 \\
68.5 \\
69.1 \\
72.1 \\
70.4 \\
67.9 \\
68.4\end{array}$ & $\begin{array}{l}68.5 \\
70.6 \\
69.3 \\
67.3 \\
66.0 \\
64.9 \\
66.3 \\
65.1 \\
65.9 \\
67.3 \\
67.4 \\
67.3 \\
66.9\end{array}$ & $\begin{array}{l}50.1 \\
53.6 \\
54.4 \\
56.7 \\
54.1 \\
55.2 \\
57.4 \\
56.4 \\
55.0 \\
55.7 \\
55.1 \\
52.9 \\
54.7\end{array}$ \\
\hline 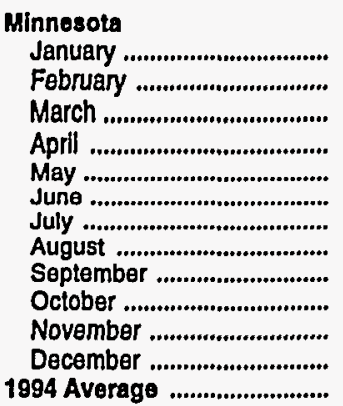 & $\begin{array}{l}80.5 \\
80.6 \\
80.0 \\
80.3 \\
79.9 \\
79.7 \\
79.8 \\
80.8 \\
81.2 \\
81.4 \\
81.2 \\
80.3 \\
80.6\end{array}$ & $\begin{array}{l}57.4 \\
59.7 \\
56.6 \\
56.9 \\
56.9 \\
56.5 \\
59.0 \\
59.9 \\
58.4 \\
58.1 \\
58.3 \\
56.5 \\
57.6\end{array}$ & $\begin{array}{l}63.5 \\
66.1 \\
65.5 \\
65.1 \\
65.1 \\
67.5 \\
68.6 \\
68.4 \\
66.2 \\
69.1 \\
69.5 \\
69.3 \\
67.8\end{array}$ & $\begin{array}{l}70.2 \\
70.8 \\
69.7 \\
69.5 \\
69.3 \\
68.6 \\
70.4 \\
73.4 \\
72.1 \\
72.0 \\
71.9 \\
71.3 \\
71.0\end{array}$ & $\begin{array}{l}63.9 \\
66.0 \\
69.8 \\
73.0 \\
72.5 \\
72.5 \\
73.5 \\
78.1 \\
77.1 \\
76.0 \\
76.2 \\
71.6 \\
73.7\end{array}$ & $\begin{array}{l}69.0 \\
69.7 \\
67.0 \\
67.2 \\
65.9 \\
64.7 \\
66.5 \\
70.0 \\
69.8 \\
70.2 \\
70.0 \\
69.4 \\
68.6\end{array}$ & $\begin{array}{l}53.9 \\
55.5 \\
56.2 \\
57.2 \\
56.9 \\
57.7 \\
59.8 \\
60.5 \\
58.1 \\
59.0 \\
58.1 \\
53.9 \\
57.1\end{array}$ \\
\hline
\end{tabular}

See footnotes at end of table. 
Table 39. No. 2 Distillate ${ }^{a}$ Prices by Sales Type, PAD District, and Selected States ${ }^{b}$

(Cents per Gallon Excluding Taxes) - Continued

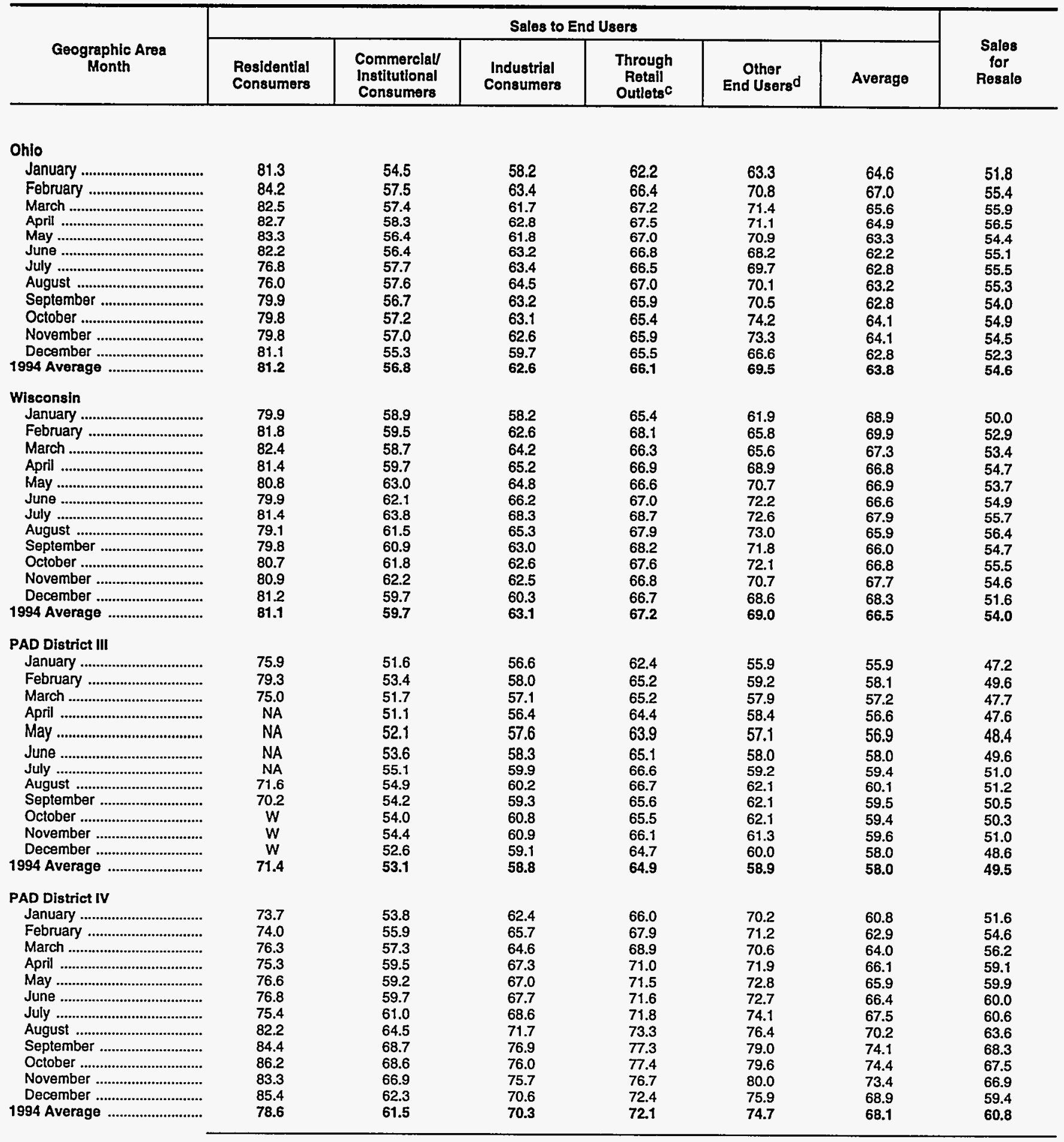

See footnotes at end of table. 
Table 39. No. 2 Distillate ${ }^{a}$ Prices by Sales Type, PAD District, and Selected States ${ }^{b}$ (Cents per Gallon Excluding Taxes) - Continued

\begin{tabular}{|c|c|c|c|c|c|c|c|}
\hline \multirow[b]{2}{*}{$\begin{array}{l}\text { Ceographlc Area } \\
\text { Month }\end{array}$} & \multicolumn{6}{|c|}{ Sales to End Users } & \multirow[b]{2}{*}{$\begin{array}{c}\text { Sales } \\
\text { for } \\
\text { Resale }\end{array}$} \\
\hline & $\begin{array}{l}\text { Resldential } \\
\text { Consumers }\end{array}$ & $\begin{array}{l}\text { Commerclay } \\
\text { Instltutlonal } \\
\text { Consumers }\end{array}$ & $\begin{array}{l}\text { Industrial } \\
\text { Consumers }\end{array}$ & $\begin{array}{c}\text { Through } \\
\text { Retail } \\
\text { Outletec }\end{array}$ & $\begin{array}{l}\text { Other } \\
\text { End Users d }\end{array}$ & Average & \\
\hline \multicolumn{8}{|l|}{ Idaho } \\
\hline 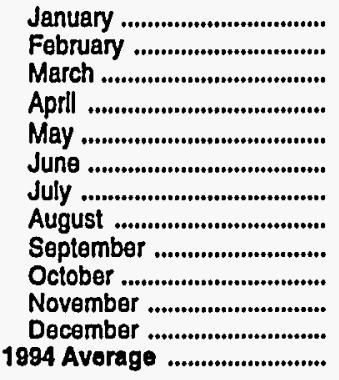 & $\begin{array}{l}73.2 \\
73.7 \\
77.4 \\
76.2 \\
76.9 \\
72.8 \\
74.6 \\
80.8 \\
83.1 \\
85.8 \\
84.8 \\
84.6 \\
78.9\end{array}$ & $\begin{array}{l}55.6 \\
58.4 \\
61.9 \\
62.7 \\
63.3 \\
63.0 \\
63.7 \\
66.3 \\
74.5 \\
73.7 \\
72.7 \\
66.6 \\
64.8\end{array}$ & $\begin{array}{l}58.8 \\
66.9 \\
66.4 \\
68.1 \\
68.0 \\
66.1 \\
67.7 \\
73.2 \\
78.3 \\
78.8 \\
78.9 \\
76.7 \\
71.9\end{array}$ & $\begin{array}{l}64.7 \\
72.3 \\
75.1 \\
76.2 \\
75.9 \\
75.7 \\
75.0 \\
75.6 \\
81.3 \\
82.0 \\
81.8 \\
79.8 \\
76.3\end{array}$ & $\begin{array}{l}69.4 \\
71.0 \\
71.6 \\
73.7 \\
74.5 \\
73.4 \\
74.5 \\
76.9 \\
80.8 \\
82.8 \\
83.2 \\
80.5 \\
75.9\end{array}$ & $\begin{array}{l}63.7 \\
67.7 \\
69.8 \\
71.1 \\
71.0 \\
69.9 \\
71.1 \\
73.5 \\
79.0 \\
79.8 \\
79.6 \\
76.1 \\
72.7\end{array}$ & $\begin{array}{l}50.8 \\
58.5 \\
59.7 \\
60.7 \\
61.8 \\
59.3 \\
59.5 \\
63.4 \\
71.3 \\
70.8 \\
70.7 \\
65.7 \\
62.5\end{array}$ \\
\hline 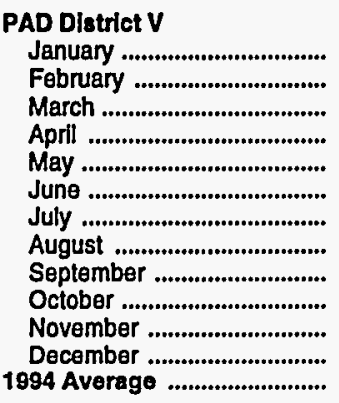 & $\begin{array}{l}90.4 \\
92.5 \\
93.2 \\
92.7 \\
92.3 \\
88.8 \\
85.8 \\
80.6 \\
85.7 \\
90.6 \\
93.4 \\
92.2 \\
90.9\end{array}$ & $\begin{array}{l}57.9 \\
61.4 \\
64.7 \\
64.3 \\
61.1 \\
59.2 \\
59.4 \\
62.6 \\
66.5 \\
68.5 \\
68.6 \\
61.1 \\
62.9\end{array}$ & $\begin{array}{l}63.7 \\
69.1 \\
70.7 \\
68.7 \\
67.3 \\
66.5 \\
67.5 \\
68.5 \\
72.8 \\
73.9 \\
73.7 \\
67.8 \\
69.2\end{array}$ & $\begin{array}{l}68.5 \\
71.7 \\
74.0 \\
74.3 \\
73.3 \\
71.8 \\
72.2 \\
73.2 \\
76.1 \\
78.6 \\
79.5 \\
75.7 \\
74.8\end{array}$ & $\begin{array}{l}63.9 \\
66.6 \\
69.7 \\
70.1 \\
67.5 \\
66.8 \\
66.6 \\
68.5 \\
71.4 \\
72.4 \\
72.5 \\
68.2 \\
68.9\end{array}$ & $\begin{array}{l}64.4 \\
67.9 \\
70.0 \\
69.1 \\
66.3 \\
64.6 \\
64.9 \\
66.9 \\
70.6 \\
72.8 \\
73.9 \\
68.3 \\
68.4\end{array}$ & $\begin{array}{l}\mathbf{5 0 . 3} \\
\mathbf{5 4 . 9} \\
\mathbf{5 8 . 7} \\
\mathbf{5 7 . 1} \\
\mathbf{5 4 . 7} \\
\mathbf{5 3 . 6} \\
\mathbf{5 5 . 2} \\
\mathbf{5 5 . 5} \\
\mathbf{6 0 . 7} \\
\mathbf{6 2 . 8} \\
\mathbf{6 1 . 8} \\
\mathbf{5 4 . 0} \\
\mathbf{5 6 . 6}\end{array}$ \\
\hline 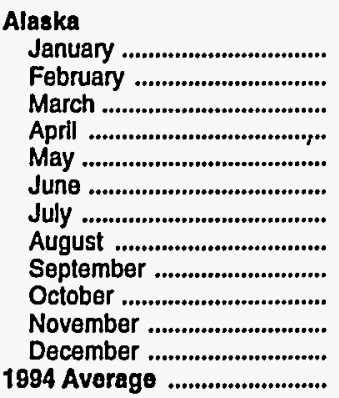 & $\begin{array}{l}88.8 \\
88.6 \\
89.2 \\
88.6 \\
90.0 \\
87.7 \\
88.2 \\
80.8 \\
83.4 \\
85.1 \\
86.6 \\
84.7 \\
86.5\end{array}$ & $\begin{array}{c}80.2 \\
\text { NA } \\
79.6 \\
\text { NA } \\
80.1 \\
77.2 \\
77.2 \\
76.9 \\
79.2 \\
80.8 \\
78.1 \\
78.2 \\
78.3\end{array}$ & $\begin{array}{l}76.7 \\
80.6 \\
82.9 \\
81.7 \\
78.7 \\
75.5 \\
81.9 \\
80.0 \\
81.6 \\
82.3 \\
84.4 \\
83.5 \\
79.9\end{array}$ & $\begin{array}{l}79.7 \\
84.4 \\
83.6 \\
80.7 \\
79.8 \\
81.2 \\
82.2 \\
80.4 \\
81.8 \\
83.2 \\
85.3 \\
85.8 \\
81.7\end{array}$ & $\begin{array}{l}75.4 \\
77.7 \\
77.1 \\
74.9 \\
76.4 \\
83.1 \\
83.7 \\
85.8 \\
86.5 \\
85.2 \\
79.8 \\
77.4 \\
83.4\end{array}$ & $\begin{array}{l}83.1 \\
83.6 \\
83.0 \\
79.0 \\
81.8 \\
79.7 \\
80.9 \\
78.5 \\
81.0 \\
82.6 \\
82.0 \\
81.5 \\
81.1\end{array}$ & $\begin{array}{l}55.3 \\
50.8 \\
59.3 \\
59.9 \\
55.9 \\
54.7 \\
56.3 \\
57.4 \\
61.7 \\
62.6 \\
55.7 \\
54.6 \\
57.0\end{array}$ \\
\hline 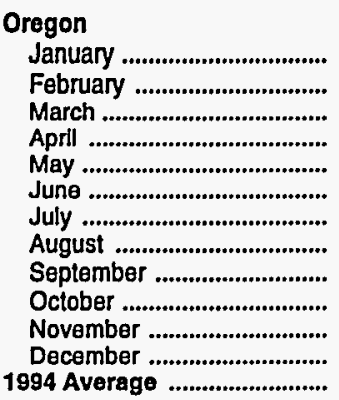 & $\begin{array}{r}86.0 \\
88.3 \\
88.4 \\
88.1 \\
87.6 \\
85.1 \\
82.5 \\
\text { NA } \\
87.8 \\
91.1 \\
91.6 \\
89.4 \\
88.7\end{array}$ & $\begin{array}{l}56.6 \\
60.8 \\
61.2 \\
61.1 \\
59.4 \\
56.9 \\
57.1 \\
59.2 \\
62.6 \\
64.9 \\
66.0 \\
57.8 \\
60.3\end{array}$ & $\begin{array}{l}63.0 \\
64.3 \\
65.5 \\
63.8 \\
64.6 \\
60.6 \\
63.9 \\
64.1 \\
67.5 \\
70.3 \\
70.7 \\
65.0 \\
65.2\end{array}$ & $\begin{array}{l}64.2 \\
69.6 \\
69.7 \\
71.3 \\
70.2 \\
69.5 \\
69.3 \\
71.5 \\
74.2 \\
77.3 \\
77.5 \\
73.8 \\
72.9\end{array}$ & $\begin{array}{l}65.3 \\
69.4 \\
68.8 \\
68.5 \\
65.4 \\
64.4 \\
63.9 \\
63.7 \\
69.4 \\
70.5 \\
69.4 \\
63.5 \\
66.6\end{array}$ & $\begin{array}{l}63.7 \\
68.1 \\
67.5 \\
66.8 \\
64.9 \\
63.1 \\
63.0 \\
64.2 \\
67.8 \\
70.8 \\
72.3 \\
66.2 \\
66.6\end{array}$ & $\begin{array}{l}49.5 \\
55.9 \\
56.4 \\
55.7 \\
53.5 \\
52.2 \\
51.9 \\
53.5 \\
58.4 \\
61.8 \\
61.5 \\
50.9 \\
55.2\end{array}$ \\
\hline
\end{tabular}

See footnotes at end of table. 
Table 39. No. 2 Distillate ${ }^{a}$ Prices by Sales Type, PAD District, and Selected States ${ }^{b}$ (Cents per Gallon Excluding Taxes) - Continued

\begin{tabular}{|c|c|c|c|c|c|c|c|}
\hline \multirow[b]{2}{*}{$\begin{array}{c}\text { Goographic Ares } \\
\text { Month }\end{array}$} & \multicolumn{6}{|c|}{ Salos to End Users } & \multirow{2}{*}{$\begin{array}{c}\text { Sales } \\
\text { for } \\
\text { Resale }\end{array}$} \\
\hline & $\begin{array}{l}\text { Residential } \\
\text { Consumers }\end{array}$ & $\begin{array}{l}\text { Commorclay } \\
\text { Instltutlonal } \\
\text { Consumars }\end{array}$ & $\begin{array}{l}\text { Industrial } \\
\text { Consumare }\end{array}$ & $\begin{array}{c}\text { Through } \\
\text { Retail } \\
\text { Outlotsc }\end{array}$ & $\begin{array}{l}\text { Other } \\
\text { End Usersd }\end{array}$ & Average & \\
\hline \multicolumn{8}{|l|}{ Washington } \\
\hline 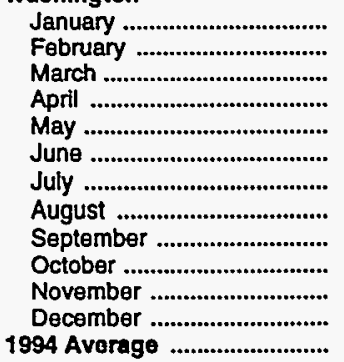 & $\begin{array}{r}92.8 \\
96.3 \\
97.1 \\
97.5 \\
96.2 \\
93.1 \\
N A \\
\text { NA } \\
90.2 \\
96.2 \\
99.0 \\
97.3 \\
95.0\end{array}$ & $\begin{array}{l}\mathbf{5 6 . 0} \\
\mathbf{5 8 . 2} \\
\mathbf{5 9 . 7} \\
61.1 \\
\mathbf{5 8 . 2} \\
\mathbf{5 5 . 3} \\
\mathbf{5 3 . 5} \\
\mathbf{5 8 . 4} \\
61.6 \\
\mathbf{6 5 . 1} \\
\mathbf{6 6 . 7} \\
\mathbf{5 8 . 8} \\
\mathbf{5 8 . 6}\end{array}$ & $\begin{array}{r}56.2 \\
65.9 \\
63.9 \\
64.1 \\
62.4 \\
63.9 \\
\text { NA } \\
67.2 \\
71.0 \\
71.2 \\
73.5 \\
66.8 \\
65.5\end{array}$ & $\begin{array}{l}70.7 \\
71.1 \\
72.6 \\
73.1 \\
72.9 \\
72.3 \\
72.6 \\
73.8 \\
75.0 \\
78.0 \\
77.8 \\
76.4 \\
74.5\end{array}$ & $\begin{array}{l}63.1 \\
67.4 \\
67.4 \\
68.2 \\
63.2 \\
64.8 \\
64.8 \\
66.7 \\
69.4 \\
71.6 \\
71.9 \\
64.9 \\
65.9\end{array}$ & $\begin{array}{l}65.8 \\
70.2 \\
67.9 \\
67.0 \\
63.1 \\
60.2 \\
58.3 \\
62.9 \\
66.4 \\
70.9 \\
75.3 \\
69.2 \\
65.7\end{array}$ & $\begin{array}{l}48.4 \\
51.3 \\
53.5 \\
52.7 \\
51.5 \\
51.6 \\
52.2 \\
53.3 \\
57.7 \\
61.2 \\
59.2 \\
51.3 \\
53.5\end{array}$ \\
\hline
\end{tabular}

NA $=$ Not avallable.

$W=$ Withheld to avold disclosure of individual company data.

a Includes sales of No. 2 fuel oll and high- and low-sulfur diesel fuels.

b Some State data are not sufficlent for publication individually, but are used in calculating the PAD District average.

c Includes low-sulfur diesel fuel only with the exception of Alaska, which currently is exempt from the Clean Air Act's diesel fuel sulfur content requirement.

d All end-user sales not included in the other end-user categories shown, e.g.. sales to agricultural customers or utilities.

Sources: Energy Information Administration Forms EIA-782A, "Refiners'/Gas Plant Operators' Monthly Petroleum Product Sales Report," and EIA-782B, "Resellers'/Retallers' Monthly Petroleum Product Sales Report." 
Table 40. No. 2 Diesel Fuel Prices by Sales Type, PAD District, and Selected States (Cents per Gallon Excluding Taxes)

\begin{tabular}{|c|c|c|c|c|c|c|}
\hline \multirow[b]{2}{*}{$\begin{array}{c}\text { Goographic Area } \\
\text { Month }\end{array}$} & \multicolumn{5}{|c|}{ Sales to End Users } & \multirow[b]{2}{*}{$\begin{array}{c}\text { Sales } \\
\text { for } \\
\text { Resale }\end{array}$} \\
\hline & $\begin{array}{c}\text { Commerciay } \\
\text { Institutlonal } \\
\text { Consumers }\end{array}$ & $\begin{array}{l}\text { Industrial } \\
\text { Consumers }\end{array}$ & $\begin{array}{l}\text { Through } \\
\text { Retall } \\
\text { Outlotsa }\end{array}$ & $\begin{array}{l}\text { Other } \\
\text { End Users b }\end{array}$ & Average & \\
\hline \multicolumn{7}{|l|}{ United States } \\
\hline 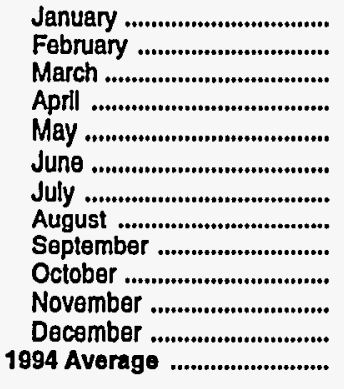 & $\begin{array}{l}55.0 \\
57.9 \\
56.9 \\
56.8 \\
56.6 \\
57.0 \\
58.1 \\
59.2 \\
59.4 \\
59.8 \\
59.6 \\
56.7 \\
57.7\end{array}$ & $\begin{array}{l}61.3 \\
64.5 \\
63.4 \\
63.2 \\
62.7 \\
63.5 \\
64.6 \\
65.5 \\
65.7 \\
66.7 \\
66.5 \\
63.6 \\
64.5\end{array}$ & $\begin{array}{l}64.2 \\
67.5 \\
67.3 \\
67.0 \\
66.2 \\
66.6 \\
67.5 \\
68.5 \\
68.1 \\
68.2 \\
68.8 \\
66.9 \\
67.3\end{array}$ & $\begin{array}{l}62.3 \\
64.9 \\
65.1 \\
66.1 \\
64.9 \\
64.8 \\
65.9 \\
67.7 \\
68.3 \\
69.6 \\
68.5 \\
65.8 \\
66.1\end{array}$ & $\begin{array}{l}59.9 \\
62.6 \\
62.2 \\
62.2 \\
61.6 \\
61.9 \\
62.9 \\
64.2 \\
64.4 \\
65.1 \\
64.9 \\
62.2 \\
62.8\end{array}$ & $\begin{array}{l}50.2 \\
53.9 \\
53.8 \\
53.4 \\
52.7 \\
53.2 \\
54.7 \\
54.8 \\
54.9 \\
55.8 \\
55.6 \\
52.0 \\
53.8\end{array}$ \\
\hline 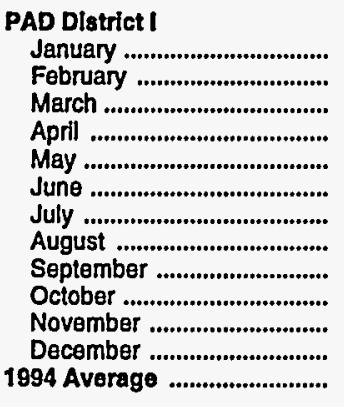 & $\begin{array}{l}58.4 \\
62.5 \\
58.8 \\
57.7 \\
57.1 \\
58.2 \\
58.8 \\
59.2 \\
58.1 \\
58.7 \\
58.9 \\
57.4 \\
58.7\end{array}$ & $\begin{array}{l}64.5 \\
68.6 \\
65.0 \\
64.0 \\
62.9 \\
64.2 \\
65.0 \\
64.4 \\
63.2 \\
64.3 \\
65.0 \\
63.3 \\
64.7\end{array}$ & $\begin{array}{l}66.6 \\
70.5 \\
68.8 \\
67.3 \\
66.7 \\
66.9 \\
67.7 \\
68.6 \\
67.6 \\
67.6 \\
68.4 \\
67.3 \\
67.9\end{array}$ & $\begin{array}{l}63.9 \\
66.6 \\
64.4 \\
63.1 \\
62.5 \\
63.1 \\
63.9 \\
63.7 \\
62.4 \\
64.6 \\
65.1 \\
63.7 \\
64.3\end{array}$ & $\begin{array}{l}62.6 \\
66.1 \\
63.3 \\
62.1 \\
61.2 \\
62.0 \\
62.8 \\
63.2 \\
62.1 \\
62.9 \\
63.5 \\
62.1 \\
63.0\end{array}$ & $\begin{array}{l}52.3 \\
57.2 \\
53.6 \\
52.1 \\
52.0 \\
52.8 \\
53.9 \\
53.1 \\
52.0 \\
53.3 \\
53.8 \\
51.9 \\
53.1\end{array}$ \\
\hline 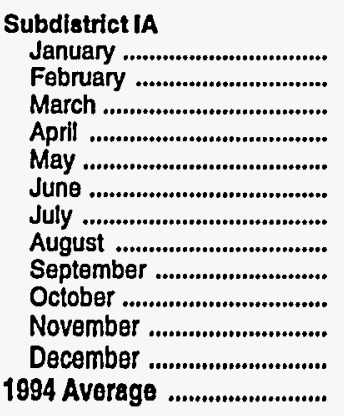 & $\begin{array}{l}65.2 \\
71.2 \\
65.8 \\
63.4 \\
63.3 \\
64.3 \\
64.9 \\
63.6 \\
62.9 \\
63.8 \\
63.5 \\
63.1 \\
64.8\end{array}$ & $\begin{array}{l}72.3 \\
77.8 \\
72.1 \\
69.5 \\
69.1 \\
70.0 \\
70.4 \\
72.2 \\
69.9 \\
72.2 \\
72.8 \\
67.9 \\
70.9\end{array}$ & $\begin{array}{l}76.0 \\
81.8 \\
80.0 \\
76.3 \\
75.1 \\
73.3 \\
73.7 \\
73.2 \\
72.6 \\
72.5 \\
73.7 \\
72.3 \\
74.4\end{array}$ & $\begin{array}{l}65.3 \\
69.6 \\
66.4 \\
64.8 \\
61.6 \\
64.9 \\
65.5 \\
67.3 \\
65.0 \\
65.8 \\
66.2 \\
66.0 \\
65.6\end{array}$ & $\begin{array}{l}68.4 \\
73.7 \\
69.5 \\
66.9 \\
65.9 \\
66.7 \\
67.3 \\
67.2 \\
66.3 \\
67.0 \\
67.2 \\
66.4 \\
67.7\end{array}$ & $\begin{array}{l}55.0 \\
62.4 \\
56.5 \\
54.5 \\
53.4 \\
53.8 \\
54.4 \\
54.4 \\
52.3 \\
53.7 \\
55.5 \\
55.0 \\
55.1\end{array}$ \\
\hline 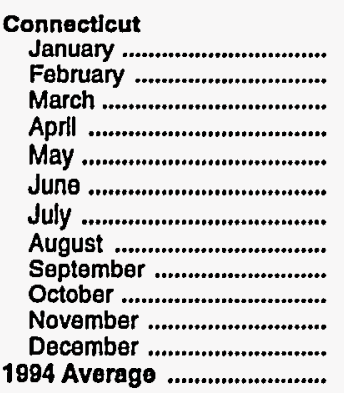 & $\begin{array}{l}62.8 \\
69.2 \\
63.6 \\
62.8 \\
62.3 \\
62.5 \\
63.4 \\
62.5 \\
62.1 \\
63.0 \\
62.9 \\
63.1 \\
62.2\end{array}$ & $\begin{array}{l}65.7 \\
71.3 \\
61.7 \\
59.6 \\
56.9 \\
61.1 \\
59.4 \\
61.9 \\
60.0 \\
60.5 \\
61.3 \\
56.5 \\
60.3\end{array}$ & $\begin{array}{l}77.9 \\
81.0 \\
79.4 \\
77.8 \\
77.5 \\
77.0 \\
77.3 \\
77.4 \\
77.5 \\
77.7 \\
79.2 \\
78.7 \\
78.2\end{array}$ & $\begin{array}{l}64.2 \\
68.4 \\
68.8 \\
71.5 \\
69.6 \\
68.6 \\
68.9 \\
68.7 \\
68.2 \\
70.6 \\
72.0 \\
68.5 \\
68.8\end{array}$ & $\begin{array}{l}64.2 \\
70.3 \\
65.2 \\
64.4 \\
63.9 \\
64.1 \\
64.9 \\
64.3 \\
63.9 \\
64.7 \\
64.9 \\
64.1 \\
64.0\end{array}$ & $\begin{array}{l}56.2 \\
62.5 \\
55.5 \\
53.7 \\
53.8 \\
53.5 \\
55.0 \\
54.3 \\
51.3 \\
53.5 \\
54.0 \\
54.2 \\
54.4\end{array}$ \\
\hline
\end{tabular}

See lootnotes at end of table. 
Table 40. No. 2 Diesel Fuel Prices by Sales Type, PAD District, and Selected States (Cents per Gallon Excluding Taxes) - Continued

\begin{tabular}{|c|c|c|c|c|c|c|}
\hline \multirow[b]{2}{*}{$\begin{array}{c}\text { Geographic Area } \\
\text { Month }\end{array}$} & \multicolumn{5}{|c|}{ Sales to End Users } & \multirow[b]{2}{*}{$\begin{array}{c}\text { Sales } \\
\text { for } \\
\text { Resale }\end{array}$} \\
\hline & $\begin{array}{l}\text { Commercial } \\
\text { Institutional } \\
\text { Consumers }\end{array}$ & $\begin{array}{l}\text { Industrial } \\
\text { Consumers }\end{array}$ & $\begin{array}{c}\text { Through } \\
\text { Retail } \\
\text { Outletsa }\end{array}$ & $\begin{array}{l}\text { Other } \\
\text { End Users } b\end{array}$ & Average & \\
\hline \multicolumn{7}{|l|}{ Maine } \\
\hline 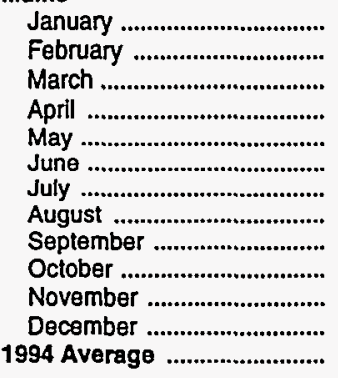 & $\begin{array}{r}67.3 \\
74.7 \\
68.4 \\
62.5 \\
62.4 \\
66.9 \\
66.5 \\
\text { NA } \\
71.2 \\
70.5 \\
69.4 \\
71.3 \\
68.8\end{array}$ & $\begin{array}{l}76.1 \\
83.6 \\
78.7 \\
76.1 \\
73.7 \\
75.7 \\
73.8 \\
74.4 \\
70.7 \\
71.3 \\
76.0 \\
73.8 \\
74.7\end{array}$ & $\begin{array}{l}77.6 \\
85.4 \\
84.9 \\
77.3 \\
75.4 \\
73.2 \\
73.1 \\
72.5 \\
71.6 \\
71.2 \\
71.5 \\
71.9 \\
75.9\end{array}$ & $\begin{array}{l}69.8 \\
76.8 \\
69.5 \\
65.2 \\
65.5 \\
66.7 \\
67.0 \\
67.4 \\
64.7 \\
64.7 \\
65.6 \\
66.0 \\
67.5\end{array}$ & $\begin{array}{l}72.7 \\
80.2 \\
75.5 \\
70.0 \\
69.1 \\
69.4 \\
69.5 \\
71.1 \\
69.4 \\
69.2 \\
69.2 \\
69.9 \\
71.5\end{array}$ & $\begin{array}{l}58.4 \\
66.1 \\
58.2 \\
54.4 \\
54.0 \\
55.3 \\
55.9 \\
55.2 \\
54.3 \\
54.4 \\
\mathbf{5 5 . 7} \\
\mathbf{5 5 . 5} \\
\mathbf{5 6 . 0}\end{array}$ \\
\hline \multicolumn{7}{|l|}{ Massachusetts } \\
\hline 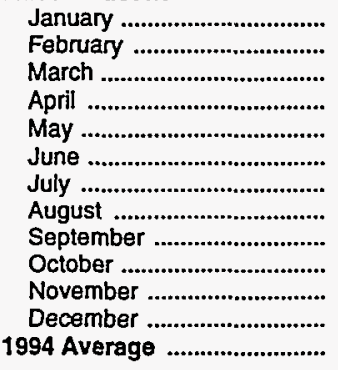 & $\begin{array}{l}65.1 \\
70.8 \\
64.2 \\
61.5 \\
62.4 \\
63.4 \\
64.1 \\
61.0 \\
60.6 \\
61.9 \\
62.2 \\
61.1 \\
65.0\end{array}$ & $\begin{array}{l}76.8 \\
81.1 \\
76.6 \\
74.2 \\
74.9 \\
76.4 \\
76.7 \\
82.9 \\
78.6 \\
83.6 \\
83.5 \\
82.2 \\
78.9\end{array}$ & $\begin{array}{l}74.2 \\
78.7 \\
76.4 \\
74.5 \\
74.5 \\
74.7 \\
75.3 \\
72.4 \\
71.5 \\
71.6 \\
73.4 \\
71.5 \\
72.2\end{array}$ & $\begin{array}{r}61.1 \\
61.7 \\
61.6 \\
62.0 \\
N A \\
60.3 \\
61.3 \\
64.6 \\
61.0 \\
60.7 \\
61.2 \\
61.0 \\
60.6\end{array}$ & $\begin{array}{l}67.1 \\
71.3 \\
67.1 \\
65.0 \\
64.1 \\
65.9 \\
66.6 \\
65.8 \\
64.9 \\
66.0 \\
66.3 \\
65.5 \\
67.1\end{array}$ & $\begin{array}{l}53.0 \\
59.2 \\
55.2 \\
54.6 \\
52.2 \\
52.3 \\
53.3 \\
53.4 \\
51.3 \\
52.8 \\
55.7 \\
54.2 \\
54.3\end{array}$ \\
\hline \multicolumn{7}{|l|}{ New Hampshire } \\
\hline 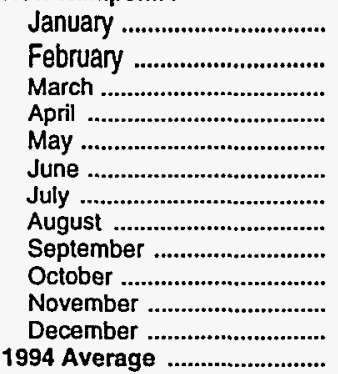 & $\begin{array}{l}66.2 \\
72.6 \\
70.8 \\
69.3 \\
67.8 \\
70.2 \\
70.6 \\
67.0 \\
64.3 \\
65.5 \\
65.3 \\
64.9 \\
67.0\end{array}$ & $\begin{array}{r}62.7 \\
74.0 \\
62.9 \\
60.1 \\
60.5 \\
58.5 \\
59.3 \\
\text { NA } \\
69.8 \\
67.0 \\
65.8 \\
\text { NA } \\
66.5\end{array}$ & $\begin{array}{r}75.2 \\
79.5 \\
77.6 \\
\text { NA } \\
75.0 \\
70.1 \\
71.2 \\
72.8 \\
72.5 \\
72.2 \\
73.5 \\
71.1 \\
73.7\end{array}$ & $\begin{array}{l}68.1 \\
74.2 \\
68.6 \\
66.8 \\
65.8 \\
66.0 \\
67.8 \\
69.6 \\
66.2 \\
66.9 \\
68.1 \\
68.1 \\
67.9\end{array}$ & $\begin{array}{l}71.7 \\
76.2 \\
73.5 \\
72.2 \\
70.2 \\
69.4 \\
70.6 \\
70.2 \\
69.6 \\
69.5 \\
70.4 \\
69.1 \\
70.8\end{array}$ & $\begin{array}{l}57.8 \\
67.8 \\
60.4 \\
55.2 \\
54.9 \\
55.7 \\
55.8 \\
54.8 \\
53.8 \\
54.1 \\
56.6 \\
56.6 \\
56.7\end{array}$ \\
\hline \multicolumn{7}{|l|}{ Rhode Island } \\
\hline 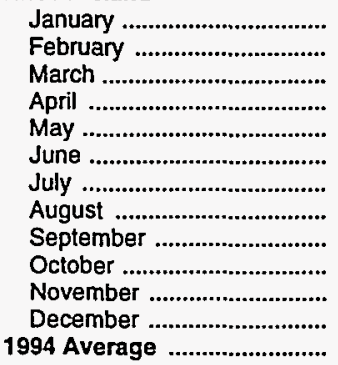 & $\begin{array}{l}66.1 \\
73.4 \\
69.1 \\
65.2 \\
64.1 \\
65.6 \\
66.0 \\
66.4 \\
64.7 \\
67.1 \\
63.8 \\
63.8 \\
65.4\end{array}$ & $\begin{array}{l}62.6 \\
68.7 \\
63.8 \\
62.4 \\
61.3 \\
61.4 \\
60.9 \\
61.3 \\
59.7 \\
60.2 \\
61.1 \\
60.8 \\
61.8\end{array}$ & $\begin{array}{c}74.2 \\
78.9 \\
\text { NA } \\
69.2 \\
68.8 \\
71.7 \\
71.8 \\
70.7 \\
68.0 \\
69.2 \\
72.3 \\
69.5 \\
69.8\end{array}$ & $\begin{array}{l}55.4 \\
60.6 \\
56.1 \\
55.4 \\
56.5 \\
56.3 \\
55.5 \\
59.2 \\
57.7 \\
58.6 \\
58.9 \\
57.5 \\
57.5\end{array}$ & $\begin{array}{l}65.3 \\
72.2 \\
68.4 \\
64.7 \\
63.7 \\
65.0 \\
65.3 \\
65.6 \\
63.8 \\
65.4 \\
63.9 \\
63.4 \\
64.7\end{array}$ & $\begin{array}{l}55.1 \\
64.0 \\
56.1 \\
53.6 \\
53.2 \\
54.1 \\
53.7 \\
54.1 \\
52.5 \\
53.8 \\
54.8 \\
52.7 \\
54.5\end{array}$ \\
\hline
\end{tabular}

See footnotes at end of table. 
Table 40. No. 2 Dlesel Fuel Prices by Sales Type, PAD District, and Selected States (Cents per Gallon Excluding Taxes) - Continued

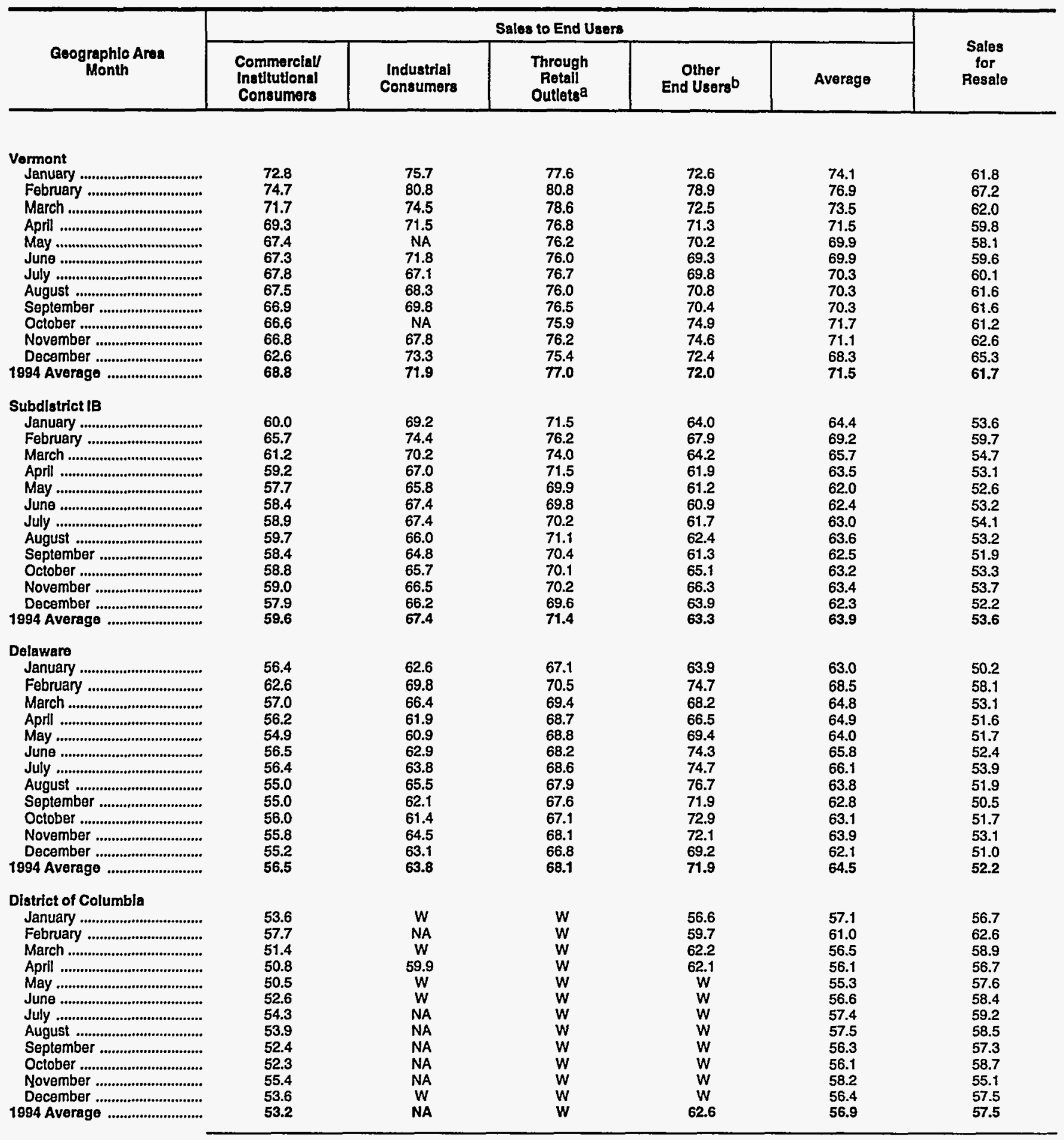

See footnotes at end of table. 
Table 40. No. 2 Diesel Fuel Prices by Sales Type, PAD District, and Selected States (Cents per Gallon Excluding Taxes) - Continued

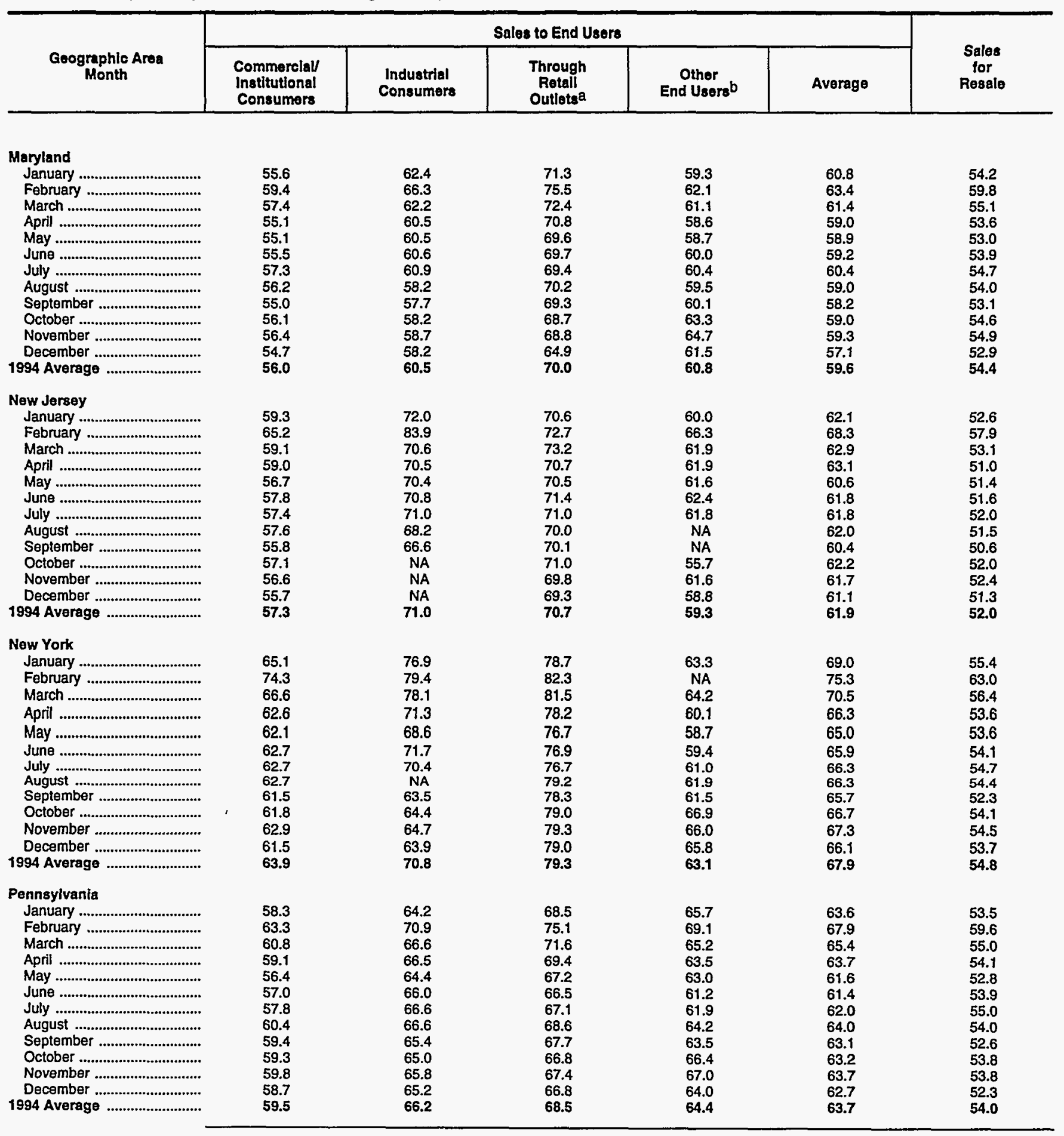

See footnotes at end of table. 
Table 40. No. 2 Dlesel Fuel Prices by Sales Type, PAD District, and Selected States (Cents per Gallon Excluding Taxes) - Continued

\begin{tabular}{|c|c|c|c|c|c|c|}
\hline \multirow[b]{2}{*}{$\begin{array}{l}\text { Coographlo Area } \\
\text { Month }\end{array}$} & \multicolumn{5}{|c|}{ Sales to End Usere } & \multirow{2}{*}{$\begin{array}{c}\text { Sales } \\
\text { for } \\
\text { Resale }\end{array}$} \\
\hline & $\begin{array}{l}\text { Commerciny } \\
\text { Institutional } \\
\text { Consumars }\end{array}$ & $\begin{array}{l}\text { Industrial } \\
\text { Consumers }\end{array}$ & $\begin{array}{c}\text { Through } \\
\text { Retall } \\
\text { Outletsa }\end{array}$ & $\begin{array}{l}\text { Other } \\
\text { End Users } b\end{array}$ & Average & \\
\hline 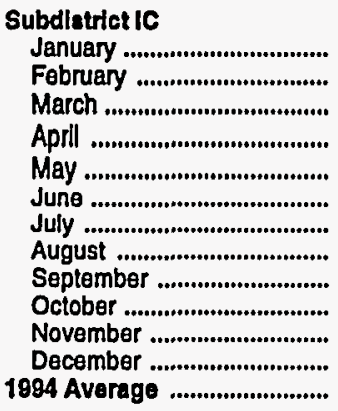 & $\begin{array}{l}55.7 \\
58.0 \\
55.7 \\
55.3 \\
55.3 \\
56.5 \\
57.2 \\
57.7 \\
56.7 \\
57.3 \\
57.8 \\
55.6 \\
56.6\end{array}$ & $\begin{array}{l}61.7 \\
65.0 \\
61.8 \\
61.9 \\
60.6 \\
61.5 \\
62.9 \\
62.5 \\
61.2 \\
62.3 \\
63.2 \\
60.9 \\
62.5\end{array}$ & $\begin{array}{l}63.4 \\
66.9 \\
65.5 \\
64.6 \\
64.4 \\
64.9 \\
65.9 \\
66.7 \\
65.5 \\
65.7 \\
66.8 \\
65.4 \\
65.4\end{array}$ & $\begin{array}{l}63.6 \\
65.3 \\
64.2 \\
63.6 \\
63.3 \\
64.2 \\
65.0 \\
63.9 \\
62.5 \\
64.3 \\
64.7 \\
63.4 \\
64.6\end{array}$ & $\begin{array}{l}60.4 \\
62.9 \\
61.0 \\
60.5 \\
60.1 \\
61.0 \\
61.9 \\
62.2 \\
61.1 \\
62.1 \\
62.9 \\
61.2 \\
61.6\end{array}$ & $\begin{array}{l}51.0 \\
54.7 \\
52.4 \\
51.1 \\
51.2 \\
52.2 \\
53.6 \\
52.6 \\
51.9 \\
53.2 \\
53.6 \\
51.1 \\
52.4\end{array}$ \\
\hline 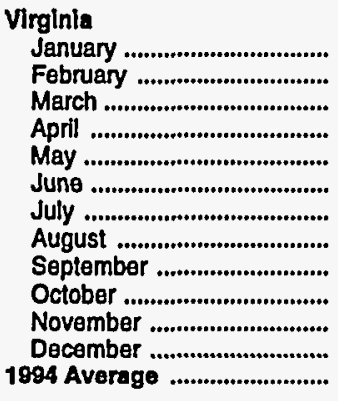 & $\begin{array}{l}\mathbf{5 7 . 1} \\
\mathbf{5 9 . 6} \\
\mathbf{5 6 . 9} \\
\mathbf{5 5 . 9} \\
\mathbf{5 6 . 2} \\
\mathbf{5 7 . 6} \\
\mathbf{5 8 . 5} \\
\mathbf{5 9 . 3} \\
\mathbf{5 8 . 3} \\
\mathbf{5 9 . 3} \\
\mathbf{5 9 . 3} \\
\mathbf{5 8 . 6} \\
\mathbf{5 7 . 7}\end{array}$ & $\begin{array}{l}60.9 \\
64.4 \\
59.0 \\
59.0 \\
59.2 \\
59.8 \\
60.6 \\
62.5 \\
62.6 \\
62.4 \\
64.0 \\
63.0 \\
62.1\end{array}$ & $\begin{array}{l}63.4 \\
68.6 \\
67.4 \\
65.2 \\
66.3 \\
66.8 \\
68.8 \\
67.0 \\
66.8 \\
65.5 \\
66.9 \\
66.9 \\
66.7\end{array}$ & $\begin{array}{l}63.4 \\
66.9 \\
66.8 \\
66.1 \\
67.1 \\
68.4 \\
66.8 \\
67.1 \\
66.7 \\
67.7 \\
67.5 \\
66.7 \\
67.3\end{array}$ & $\begin{array}{l}60.7 \\
64.1 \\
61.4 \\
60.1 \\
60.4 \\
61.4 \\
62.5 \\
63.1 \\
62.7 \\
63.4 \\
64.1 \\
63.6 \\
62.4\end{array}$ & $\begin{array}{l}52.0 \\
55.3 \\
52.8 \\
51.3 \\
51.2 \\
52.2 \\
53.3 \\
52.6 \\
51.7 \\
53.4 \\
54.1 \\
51.6 \\
52.7\end{array}$ \\
\hline 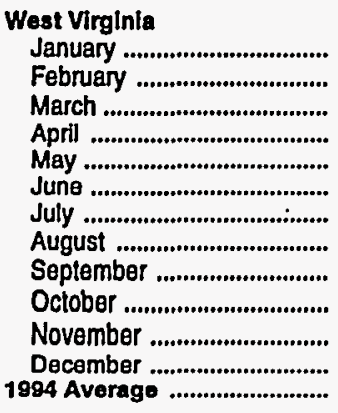 & $\begin{array}{l}57.2 \\
60.8 \\
59.9 \\
60.1 \\
57.3 \\
59.2 \\
59.4 \\
59.8 \\
57.3 \\
58.9 \\
60.4 \\
56.1 \\
58.6\end{array}$ & $\begin{array}{l}61.8 \\
65.3 \\
63.2 \\
63.1 \\
61.7 \\
62.4 \\
63.8 \\
63.9 \\
61.6 \\
64.2 \\
65.4 \\
61.3 \\
63.1\end{array}$ & $\begin{array}{l}67.7 \\
70.0 \\
70.3 \\
69.6 \\
69.3 \\
70.2 \\
69.9 \\
71.4 \\
71.3 \\
71.6 \\
72.0 \\
71.0 \\
70.6\end{array}$ & $\begin{array}{l}59.7 \\
62.1 \\
62.0 \\
63.4 \\
63.2 \\
62.9 \\
62.6 \\
65.7 \\
65.4 \\
64.9 \\
67.0 \\
62.9 \\
63.3\end{array}$ & $\begin{array}{l}60.9 \\
63.9 \\
62.8 \\
62.8 \\
61.1 \\
62.3 \\
62.8 \\
63.4 \\
61.4 \\
63.3 \\
64.5 \\
60.5 \\
62.4\end{array}$ & $\begin{array}{l}\mathbf{5 3 . 1} \\
57.8 \\
\mathbf{5 7 . 3} \\
\mathbf{5 7 . 6} \\
\mathbf{5 4 . 8} \\
\mathbf{5 5 . 0} \\
\mathbf{5 6 . 7} \\
\mathbf{5 6 . 9} \\
\mathbf{5 4 . 4} \\
\mathbf{5 5 . 4} \\
\mathbf{5 6 . 9} \\
\mathbf{5 3 . 0} \\
\mathbf{5 5 . 7}\end{array}$ \\
\hline 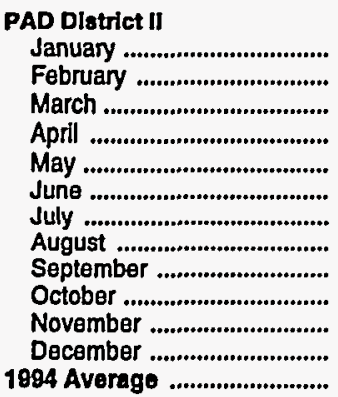 & $\begin{array}{l}\mathbf{5 3 . 0} \\
\mathbf{5 5 . 3} \\
\mathbf{5 5 . 1} \\
\mathbf{5 5 . 9} \\
\mathbf{5 6 . 3} \\
\mathbf{5 6 . 6} \\
\mathbf{5 8 . 1} \\
\mathbf{5 9 . 2} \\
\mathbf{5 8 . 3} \\
\mathbf{5 8 . 7} \\
\mathbf{5 8 . 5} \\
\mathbf{5 5 . 9} \\
\mathbf{5 6 . 7}\end{array}$ & $\begin{array}{l}60.3 \\
63.6 \\
62.7 \\
63.6 \\
63.1 \\
64.0 \\
65.2 \\
66.9 \\
66.4 \\
66.9 \\
66.1 \\
63.3 \\
64.9\end{array}$ & $\begin{array}{l}62.2 \\
65.5 \\
65.6 \\
66.0 \\
64.6 \\
65.2 \\
66.2 \\
67.2 \\
66.3 \\
65.8 \\
66.3 \\
64.8 \\
65.6\end{array}$ & $\begin{array}{l}65.6 \\
66.8 \\
68.5 \\
70.1 \\
70.5 \\
70.0 \\
72.5 \\
71.9 \\
72.7 \\
73.2 \\
72.2 \\
69.0 \\
70.5\end{array}$ & $\begin{array}{l}59.0 \\
61.4 \\
61.6 \\
62.8 \\
62.5 \\
62.7 \\
63.8 \\
65.4 \\
65.0 \\
65.6 \\
64.7 \\
62.1 \\
63.1\end{array}$ & $\begin{array}{l}50.2 \\
52.9 \\
54.2 \\
55.0 \\
53.8 \\
54.7 \\
56.4 \\
56.6 \\
54.9 \\
55.7 \\
54.8 \\
51.8 \\
\mathbf{5 4 . 3}\end{array}$ \\
\hline
\end{tabular}

See footnotes at end of table. 
Table 40. No. 2 Diesel Fuel Prices by Sales Type, PAD District, and Selected States (Cents per Gallon Excluding Taxes) - Continued

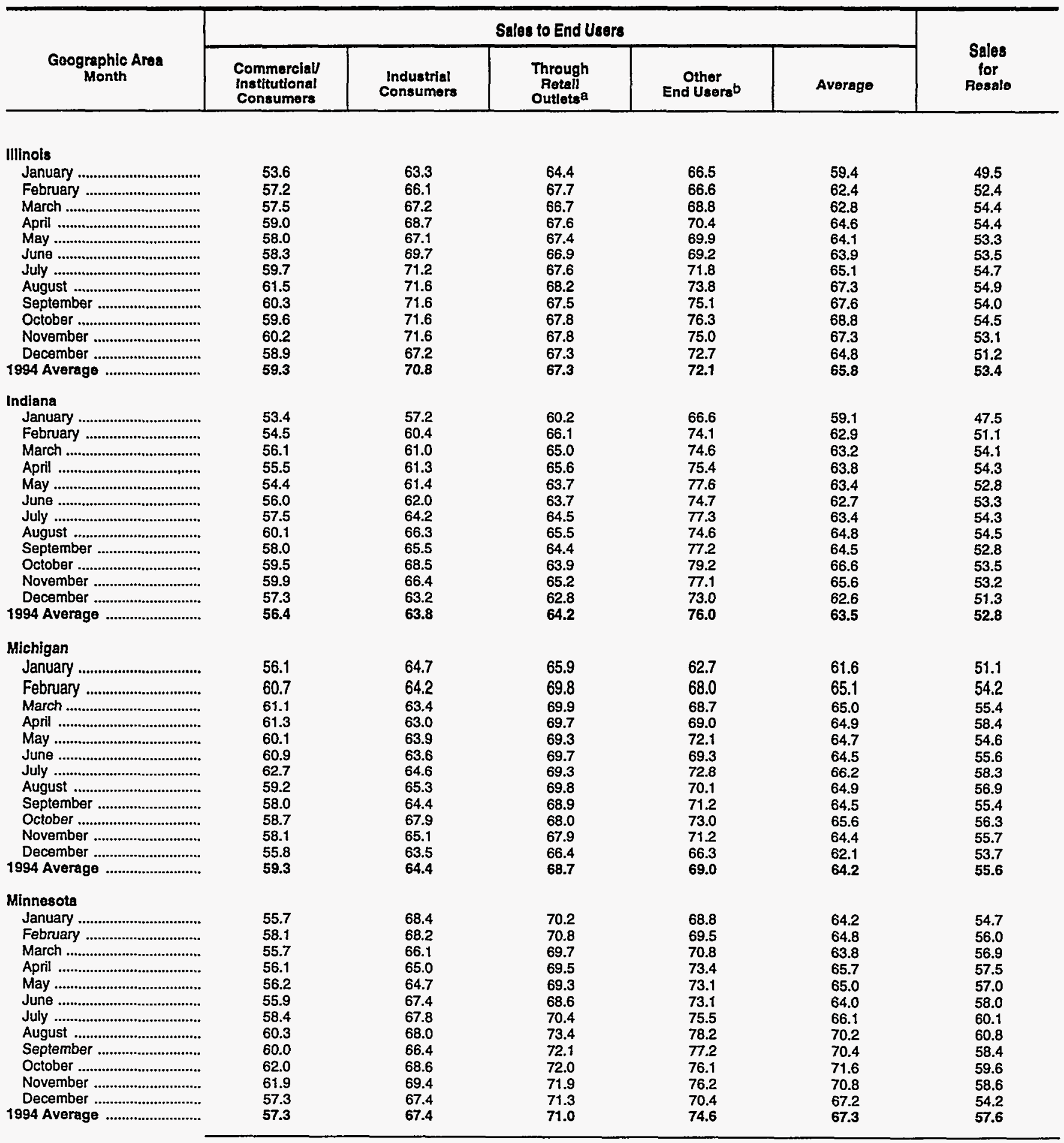

See footnotes at end of table. 
Table 40. No. 2 Diesel Fuel Prices by Sales Type, PAD District, and Selected States (Cents per Gallon Excluding Taxes) - Continued

\begin{tabular}{|c|c|c|c|c|c|c|}
\hline \multirow[b]{2}{*}{$\begin{array}{l}\text { Geographlc Area } \\
\text { Month }\end{array}$} & \multicolumn{5}{|c|}{ Seles to End Users } & \multirow[b]{2}{*}{$\begin{array}{c}\text { Sales } \\
\text { for } \\
\text { Resale }\end{array}$} \\
\hline & $\begin{array}{l}\text { Commercial } \\
\text { Institutlonal } \\
\text { Consumers }\end{array}$ & $\begin{array}{l}\text { Industrial } \\
\text { Consumers }\end{array}$ & $\begin{array}{c}\text { Through } \\
\text { Retail } \\
\text { Outlets }\end{array}$ & $\begin{array}{l}\text { Other } \\
\text { End Users } b\end{array}$ & Average & \\
\hline 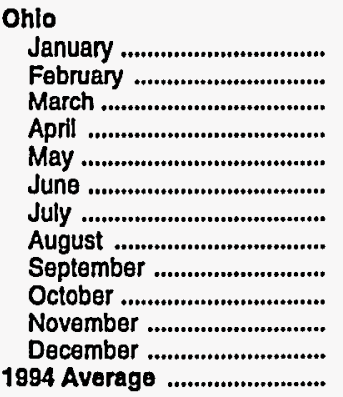 & $\begin{array}{l}54.9 \\
57.6 \\
57.9 \\
58.7 \\
57.0 \\
56.9 \\
58.2 \\
58.1 \\
57.1 \\
57.7 \\
57.4 \\
55.5 \\
\mathbf{5 7 . 2}\end{array}$ & $\begin{array}{l}58.0 \\
63.2 \\
61.6 \\
63.1 \\
62.6 \\
64.0 \\
64.1 \\
65.0 \\
63.5 \\
63.1 \\
62.4 \\
59.7 \\
62.9\end{array}$ & $\begin{array}{l}62.2 \\
66.4 \\
67.2 \\
67.5 \\
67.0 \\
66.8 \\
66.5 \\
67.0 \\
65.9 \\
65.4 \\
65.9 \\
65.5 \\
66.1\end{array}$ & $\begin{array}{l}68.0 \\
73.4 \\
72.6 \\
74.3 \\
72.9 \\
72.3 \\
71.6 \\
74.2 \\
73.8 \\
75.5 \\
75.2 \\
72.4 \\
72.9\end{array}$ & $\begin{array}{l}59.5 \\
63.1 \\
63.1 \\
64.4 \\
63.3 \\
62.7 \\
63.1 \\
63.6 \\
62.5 \\
63.3 \\
62.7 \\
60.6 \\
62.5\end{array}$ & $\begin{array}{l}52.8 \\
55.7 \\
57.1 \\
57.8 \\
55.2 \\
55.6 \\
56.0 \\
55.7 \\
54.4 \\
55.1 \\
54.8 \\
52.9 \\
\mathbf{5 5 . 2}\end{array}$ \\
\hline 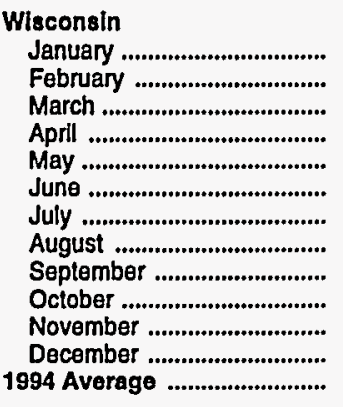 & $\begin{array}{l}58.1 \\
58.9 \\
58.4 \\
59.3 \\
63.3 \\
62.4 \\
63.9 \\
61.7 \\
61.0 \\
62.0 \\
62.3 \\
59.5 \\
59.7\end{array}$ & $\begin{array}{l}57.8 \\
62.4 \\
63.9 \\
65.6 \\
65.4 \\
66.8 \\
68.9 \\
66.2 \\
63.6 \\
63.1 \\
63.1 \\
60.3 \\
63.4\end{array}$ & $\begin{array}{l}65.4 \\
68.1 \\
66.3 \\
66.9 \\
66.6 \\
67.0 \\
68.7 \\
67.9 \\
68.2 \\
67.6 \\
66.8 \\
66.7 \\
67.2\end{array}$ & $\begin{array}{l}61.8 \\
61.9 \\
64.8 \\
69.1 \\
69.8 \\
72.0 \\
73.6 \\
73.0 \\
71.8 \\
72.1 \\
70.8 \\
68.0 \\
69.4\end{array}$ & $\begin{array}{l}61.7 \\
63.6 \\
62.8 \\
64.6 \\
65.9 \\
66.2 \\
67.6 \\
65.6 \\
65.2 \\
65.6 \\
65.4 \\
63.6 \\
63.8\end{array}$ & $\begin{array}{l}50.9 \\
53.4 \\
54.2 \\
55.3 \\
54.1 \\
55.3 \\
56.1 \\
56.6 \\
55.0 \\
55.8 \\
54.8 \\
51.8 \\
54.6\end{array}$ \\
\hline 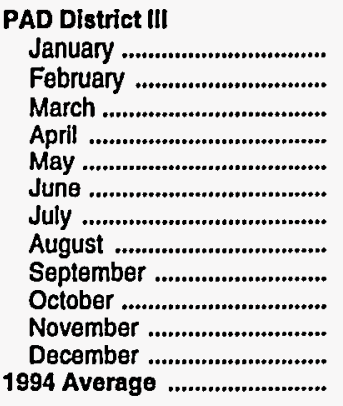 & $\begin{array}{l}51.6 \\
53.3 \\
51.7 \\
51.0 \\
52.1 \\
53.6 \\
55.1 \\
55.0 \\
54.3 \\
54.1 \\
54.5 \\
52.7 \\
53.1\end{array}$ & $\begin{array}{l}56.5 \\
57.9 \\
56.5 \\
56.3 \\
56.9 \\
58.2 \\
59.8 \\
60.3 \\
59.3 \\
60.9 \\
61.0 \\
59.2 \\
58.7\end{array}$ & $\begin{array}{l}62.4 \\
65.2 \\
65.2 \\
64.4 \\
63.9 \\
65.1 \\
66.6 \\
66.7 \\
65.6 \\
65.5 \\
66.1 \\
64.7 \\
64.9\end{array}$ & $\begin{array}{l}56.0 \\
59.2 \\
57.9 \\
58.4 \\
57.1 \\
58.0 \\
59.1 \\
62.1 \\
62.1 \\
62.1 \\
61.3 \\
59.9 \\
58.9\end{array}$ & $\begin{array}{l}56.0 \\
58.1 \\
57.2 \\
56.6 \\
56.9 \\
58.0 \\
59.4 \\
60.2 \\
59.6 \\
59.5 \\
59.6 \\
58.0 \\
58.0\end{array}$ & $\begin{array}{l}47.8 \\
50.7 \\
49.5 \\
48.8 \\
49.4 \\
50.5 \\
51.8 \\
52.2 \\
51.4 \\
51.2 \\
52.2 \\
49.7 \\
50.5\end{array}$ \\
\hline 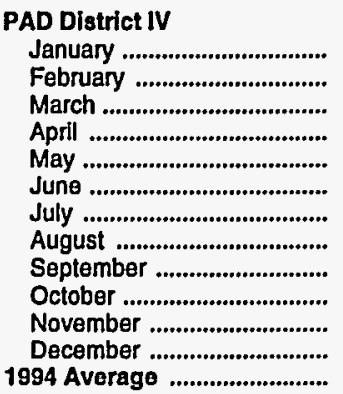 & $\begin{array}{l}53.4 \\
55.7 \\
57.1 \\
59.3 \\
59.2 \\
59.5 \\
60.8 \\
64.8 \\
68.5 \\
68.4 \\
66.6 \\
62.0 \\
61.3\end{array}$ & $\begin{array}{l}62.4 \\
65.8 \\
64.7 \\
67.4 \\
67.2 \\
67.9 \\
68.8 \\
71.9 \\
77.0 \\
76.1 \\
75.8 \\
70.8 \\
70.5\end{array}$ & $\begin{array}{l}66.0 \\
67.9 \\
68.9 \\
71.0 \\
71.5 \\
71.6 \\
71.8 \\
73.3 \\
77.3 \\
77.4 \\
76.7 \\
72.4 \\
72.1\end{array}$ & $\begin{array}{l}70.2 \\
71.1 \\
70.6 \\
71.9 \\
72.8 \\
72.7 \\
74.1 \\
76.2 \\
78.9 \\
79.2 \\
79.8 \\
75.9 \\
74.5\end{array}$ & $\begin{array}{l}60.3 \\
62.5 \\
63.7 \\
65.9 \\
65.8 \\
66.3 \\
67.5 \\
70.3 \\
74.1 \\
74.3 \\
73.2 \\
68.7 \\
68.0\end{array}$ & $\begin{array}{l}51.7 \\
54.6 \\
56.2 \\
59.1 \\
60.0 \\
60.1 \\
60.6 \\
63.7 \\
68.3 \\
67.5 \\
66.9 \\
59.4 \\
60.8\end{array}$ \\
\hline
\end{tabular}

See footnotes at end of table. 
Table 40. No. 2 Diesel Fuel Prices by Sales Type, PAD District, and Selected States (Cents per Gallon Excluding Taxes) - Continued

\begin{tabular}{|c|c|c|c|c|c|c|}
\hline \multirow[b]{2}{*}{$\begin{array}{l}\text { Geographic Area } \\
\text { Month }\end{array}$} & \multicolumn{5}{|c|}{ Sales to End Users } & \multirow{2}{*}{$\begin{array}{c}\text { Sales } \\
\text { for } \\
\text { Resale }\end{array}$} \\
\hline & $\begin{array}{l}\text { Commercial } \\
\text { Institutional } \\
\text { Consumers }\end{array}$ & $\begin{array}{l}\text { Industrial } \\
\text { Consumers }\end{array}$ & $\begin{array}{c}\text { Through } \\
\text { Retall } \\
\text { Outlots }\end{array}$ & $\begin{array}{l}\text { Other } \\
\text { End Usersb }\end{array}$ & Average & \\
\hline \multicolumn{7}{|l|}{ Idaho } \\
\hline 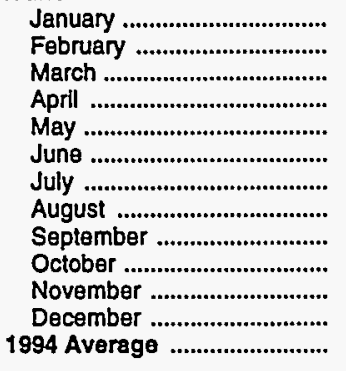 & $\begin{array}{l}54.7 \\
58.1 \\
61.8 \\
62.8 \\
63.2 \\
63.1 \\
63.6 \\
66.3 \\
74.6 \\
73.8 \\
72.9 \\
68.4 \\
64.8\end{array}$ & $\begin{array}{l}58.8 \\
66.9 \\
66.4 \\
68.1 \\
68.0 \\
66.1 \\
67.7 \\
73.2 \\
78.4 \\
78.9 \\
79.0 \\
76.8 \\
71.9\end{array}$ & $\begin{array}{l}64.7 \\
72.3 \\
75.1 \\
76.2 \\
75.9 \\
75.7 \\
75.0 \\
75.6 \\
81.3 \\
82.0 \\
81.8 \\
79.8 \\
76.3\end{array}$ & $\begin{array}{l}69.4 \\
70.7 \\
71.5 \\
73.7 \\
74.5 \\
73.4 \\
74.5 \\
76.9 \\
80.8 \\
82.8 \\
83.2 \\
80.5 \\
75.9\end{array}$ & $\begin{array}{l}62.2 \\
66.9 \\
69.3 \\
71.0 \\
70.9 \\
69.9 \\
71.1 \\
73.5 \\
79.0 \\
79.7 \\
79.4 \\
76.8 \\
72.5\end{array}$ & $\begin{array}{l}50.7 \\
58.5 \\
59.7 \\
60.7 \\
61.8 \\
59.3 \\
59.5 \\
63.4 \\
71.3 \\
70.8 \\
70.6 \\
65.6 \\
62.5\end{array}$ \\
\hline \multicolumn{7}{|l|}{ PAD District V } \\
\hline 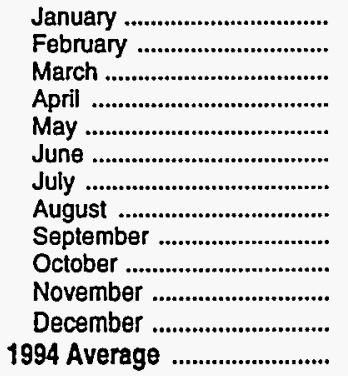 & $\begin{array}{l}57.4 \\
60.9 \\
64.4 \\
64.1 \\
61.0 \\
59.1 \\
59.5 \\
62.7 \\
66.7 \\
68.7 \\
68.4 \\
60.8 \\
62.8\end{array}$ & $\begin{array}{l}63.5 \\
69.0 \\
70.7 \\
68.6 \\
67.2 \\
66.8 \\
67.3 \\
68.4 \\
72.7 \\
73.8 \\
73.5 \\
67.6 \\
69.2\end{array}$ & $\begin{array}{l}68.5 \\
71.7 \\
74.0 \\
74.3 \\
73.3 \\
71.8 \\
72.2 \\
73.2 \\
76.1 \\
78.6 \\
79.5 \\
75.7 \\
74.8\end{array}$ & $\begin{array}{l}63.8 \\
66.6 \\
69.8 \\
70.1 \\
67.4 \\
66.7 \\
66.5 \\
68.4 \\
71.3 \\
72.3 \\
72.5 \\
68.1 \\
68.8\end{array}$ & $\begin{array}{l}62.1 \\
65.6 \\
68.5 \\
68.1 \\
65.6 \\
64.2 \\
64.6 \\
66.8 \\
70.4 \\
72.4 \\
72.8 \\
66.6 \\
67.5\end{array}$ & $\begin{array}{l}50.1 \\
55.1 \\
58.7 \\
57.1 \\
54.6 \\
53.5 \\
55.2 \\
55.5 \\
60.7 \\
62.9 \\
62.0 \\
54.1 \\
56.7\end{array}$ \\
\hline \multicolumn{7}{|l|}{ Alaska } \\
\hline 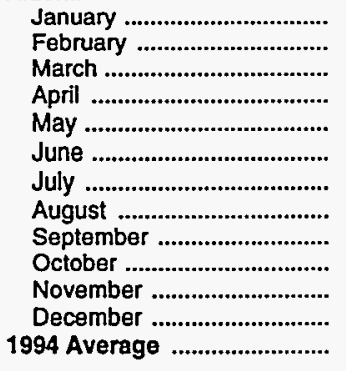 & $\begin{array}{r}\text { NA } \\
\text { NA } \\
78.7 \\
75.4 \\
\text { NA } \\
78.2 \\
78.1 \\
77.5 \\
\text { NA } \\
81.7 \\
77.6 \\
77.9 \\
78.5\end{array}$ & $\begin{array}{l}69.5 \\
79.5 \\
82.1 \\
81.4 \\
79.4 \\
77.1 \\
79.3 \\
81.4 \\
81.6 \\
81.4 \\
82.7 \\
81.0 \\
79.9\end{array}$ & $\begin{array}{l}79.7 \\
84.4 \\
83.6 \\
80.7 \\
79.8 \\
81.2 \\
82.2 \\
80.4 \\
81.8 \\
83.2 \\
85.3 \\
85.8 \\
81.7\end{array}$ & $\begin{array}{r}79.3 \\
82.5 \\
82.0 \\
79.6 \\
77.7 \\
\text { NA } \\
84.1 \\
86.2 \\
86.8 \\
86.2 \\
83.8 \\
82.6 \\
85.7\end{array}$ & $\begin{array}{l}79.5 \\
81.3 \\
80.2 \\
76.8 \\
80.5 \\
78.8 \\
79.5 \\
78.9 \\
81.0 \\
82.6 \\
80.5 \\
80.6 \\
80.2\end{array}$ & $\begin{array}{l}54.1 \\
58.3 \\
56.9 \\
60.2 \\
55.2 \\
54.5 \\
56.1 \\
57.9 \\
62.6 \\
62.8 \\
64.9 \\
58.2 \\
58.3\end{array}$ \\
\hline \multicolumn{7}{|l|}{ Oregon } \\
\hline 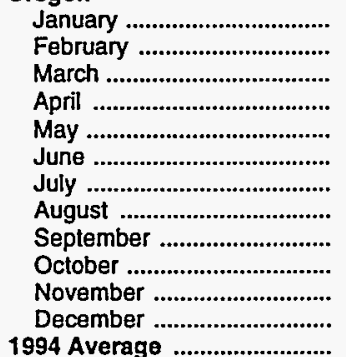 & $\begin{array}{l}56.4 \\
60.6 \\
61.0 \\
61.0 \\
59.3 \\
56.9 \\
57.5 \\
59.2 \\
63.3 \\
65.7 \\
65.7 \\
57.3 \\
60.3\end{array}$ & $\begin{array}{l}62.9 \\
64.3 \\
65.5 \\
63.8 \\
64.6 \\
64.4 \\
63.9 \\
64.1 \\
67.5 \\
70.3 \\
70.7 \\
65.0 \\
65.6\end{array}$ & $\begin{array}{l}64.2 \\
69.6 \\
69.7 \\
71.3 \\
70.2 \\
69.5 \\
69.3 \\
71.5 \\
74.2 \\
77.3 \\
77.5 \\
73.8 \\
72.9\end{array}$ & $\begin{array}{l}65.3 \\
69.4 \\
68.8 \\
68.5 \\
65.4 \\
64.4 \\
63.9 \\
63.7 \\
69.4 \\
70.3 \\
69.2 \\
63.2 \\
66.5\end{array}$ & $\begin{array}{l}61.5 \\
65.5 \\
66.0 \\
65.9 \\
64.4 \\
63.1 \\
63.2 \\
64.1 \\
67.9 \\
70.5 \\
70.8 \\
63.9 \\
65.6\end{array}$ & $\begin{array}{l}49.5 \\
55.9 \\
56.4 \\
55.7 \\
53.5 \\
52.2 \\
51.9 \\
53.5 \\
58.4 \\
61.7 \\
61.5 \\
50.8 \\
55.2\end{array}$ \\
\hline
\end{tabular}

See footnotes at end of table. 
Table 40. No. 2 Diesel Fuel Prices by Sales Type, PAD District, and Selected States (Cents per Gallon Excluding Taxes) - Continued

\begin{tabular}{|c|c|c|c|c|c|c|}
\hline \multirow[b]{2}{*}{$\begin{array}{c}\text { Geographlo Aroa } \\
\text { Month }\end{array}$} & \multicolumn{5}{|c|}{ Sales to End Users } & \multirow[b]{2}{*}{$\begin{array}{c}\text { Sales } \\
\text { for } \\
\text { Resale }\end{array}$} \\
\hline & $\begin{array}{l}\text { Commerclay } \\
\text { Institutional } \\
\text { Consumers }\end{array}$ & $\begin{array}{l}\text { Industrial } \\
\text { Consumars }\end{array}$ & $\begin{array}{c}\text { Through } \\
\text { Retail } \\
\text { Outletsa }\end{array}$ & $\begin{array}{l}\text { Other } \\
\text { End Usersb }\end{array}$ & Average & \\
\hline \multicolumn{7}{|l|}{ Washington } \\
\hline 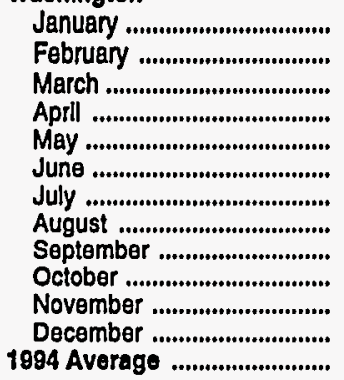 & $\begin{array}{l}55.6 \\
57.7 \\
59.4 \\
60.9 \\
58.2 \\
55.2 \\
53.5 \\
58.6 \\
61.7 \\
65.6 \\
66.7 \\
58.9 \\
58.6\end{array}$ & $\begin{array}{r}56.0 \\
65.8 \\
63.7 \\
64.0 \\
62.5 \\
64.1 \\
N A \\
67.5 \\
70.8 \\
71.1 \\
73.4 \\
66.5 \\
65.4\end{array}$ & $\begin{array}{l}70.7 \\
71.1 \\
72.6 \\
73.1 \\
72.9 \\
72.3 \\
72.6 \\
73.8 \\
75.0 \\
78.0 \\
77.8 \\
76.4 \\
74.5\end{array}$ & $\begin{array}{l}63.1 \\
67.6 \\
67.6 \\
68.1 \\
63.2 \\
64.2 \\
64.4 \\
66.5 \\
69.2 \\
71.5 \\
72.0 \\
64.8 \\
65.8\end{array}$ & $\begin{array}{l}60.0 \\
63.3 \\
63.2 \\
64.0 \\
61.2 \\
59.1 \\
57.7 \\
62.7 \\
65.9 \\
69.9 \\
72.2 \\
64.7 \\
63.2\end{array}$ & $\begin{array}{l}48.3 \\
51.1 \\
53.3 \\
52.6 \\
51.4 \\
51.5 \\
52.2 \\
53.3 \\
57.6 \\
61.0 \\
58.8 \\
50.9 \\
53.3\end{array}$ \\
\hline
\end{tabular}

$N A=$ Not avallable.

$W=$ Withheld to avoid disclosure of individual company data.

a includes low-sulfur diesel fual only with the exceptlon of Alaska, which currently is exempt from the Clean Air Act's dlesel fuel sulfur content requirement.

b All end-user sales not included in the other end-user categories shown, e.g., sales to agricultural customers or utilities.

Sources: Energy Information Administration Forms EIA-782A, "Refiners'/Gas Plant Operators' Monthly Petroleum Product Sales Report," and ElA-782B,

'Resellers'/Retallers' Monthly Petroleum Product Sales Report." 
Table 41. No. 2 Diesel Fuel Prices by Sulfur Content, Sales Type, and PAD District (Cents per Gallon Excluding Taxes)

\begin{tabular}{|c|c|c|c|c|c|c|c|c|c|c|c|}
\hline \multirow{3}{*}{$\begin{array}{c}\text { Geographic Area } \\
\text { Month }\end{array}$} & \multicolumn{6}{|c|}{ Low-Sulfur Diesel Fuel } & \multicolumn{5}{|c|}{ High-Sulfur Diesel Fuel } \\
\hline & \multicolumn{5}{|c|}{ Sales to End Users } & \multirow{2}{*}{$\begin{array}{c}\text { Sales } \\
\text { for } \\
\text { Resale }\end{array}$} & \multicolumn{4}{|c|}{ Sales to End Users } & \multirow{2}{*}{$\begin{array}{c}\text { Sales } \\
\text { for } \\
\text { Resale }\end{array}$} \\
\hline & $\begin{array}{c}\text { Commercial/ } \\
\text { Institutional } \\
\text { Consumers }\end{array}$ & $\begin{array}{c}\text { Industrial } \\
\text { Consumers }\end{array}$ & $\begin{array}{c}\text { Through } \\
\text { Retail } \\
\text { Outletsa }\end{array}$ & $\begin{array}{l}\text { Other } \\
\text { End } \\
\text { Users b }\end{array}$ & Avarage & & $\begin{array}{c}\text { Commercial/ } \\
\text { Institutional } \\
\text { Consumers }\end{array}$ & $\begin{array}{c}\text { Industrial } \\
\text { Consumers }\end{array}$ & $\begin{array}{c}\text { Other } \\
\text { End } \\
\text { Users } b\end{array}$ & Average & \\
\hline \multicolumn{12}{|l|}{ United States } \\
\hline 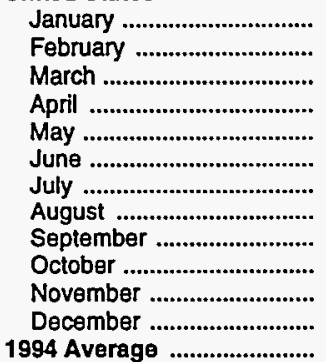 & $\begin{array}{l}56.1 \\
59.5 \\
59.1 \\
58.5 \\
57.8 \\
58.0 \\
59.3 \\
60.1 \\
60.4 \\
60.9 \\
60.8 \\
58.1 \\
59.1\end{array}$ & $\begin{array}{l}62.5 \\
66.2 \\
65.3 \\
64.9 \\
64.4 \\
64.7 \\
66.0 \\
66.8 \\
67.8 \\
68.8 \\
68.4 \\
65.2 \\
66.0\end{array}$ & $\begin{array}{l}64.2 \\
67.5 \\
67.3 \\
67.0 \\
66.2 \\
66.6 \\
67.5 \\
68.5 \\
68.1 \\
68.2 \\
68.8 \\
66.9 \\
67.3\end{array}$ & $\begin{array}{l}63.3 \\
66.2 \\
66.3 \\
66.5 \\
66.5 \\
66.8 \\
67.6 \\
68.6 \\
69.3 \\
70.2 \\
69.2 \\
66.0 \\
67.4\end{array}$ & $\begin{array}{l}60.9 \\
64.1 \\
64.0 \\
63.7 \\
62.9 \\
63.3 \\
64.3 \\
65.2 \\
65.4 \\
66.0 \\
65.9 \\
63.4 \\
64.2\end{array}$ & $\begin{array}{l}50.7 \\
54.4 \\
54.6 \\
54.0 \\
53.1 \\
53.6 \\
55.0 \\
55.1 \\
55.2 \\
56.1 \\
56.0 \\
52.2 \\
54.2\end{array}$ & $\begin{array}{l}53.3 \\
55.2 \\
53.6 \\
54.3 \\
54.7 \\
55.4 \\
56.0 \\
57.7 \\
57.7 \\
57.7 \\
57.4 \\
54.5 \\
\mathbf{5 5 . 3}\end{array}$ & $\begin{array}{l}59.8 \\
62.6 \\
61.3 \\
61.5 \\
60.9 \\
62.2 \\
63.0 \\
64.4 \\
63.7 \\
64.6 \\
64.7 \\
62.1 \\
62.9\end{array}$ & $\begin{array}{l}60.9 \\
62.9 \\
63.6 \\
65.5 \\
63.0 \\
62.5 \\
63.7 \\
66.6 \\
66.9 \\
68.8 \\
67.6 \\
65.5 \\
64.6\end{array}$ & $\begin{array}{l}57.4 \\
59.2 \\
58.1 \\
59.0 \\
58.7 \\
58.9 \\
59.7 \\
61.8 \\
61.9 \\
63.0 \\
62.3 \\
59.4 \\
59.8\end{array}$ & $\begin{array}{l}48.6 \\
51.9 \\
50.5 \\
50.9 \\
51.2 \\
51.5 \\
52.8 \\
53.7 \\
53.5 \\
54.2 \\
54.2 \\
51.0 \\
51.9\end{array}$ \\
\hline \multicolumn{12}{|l|}{ PAD District I } \\
\hline 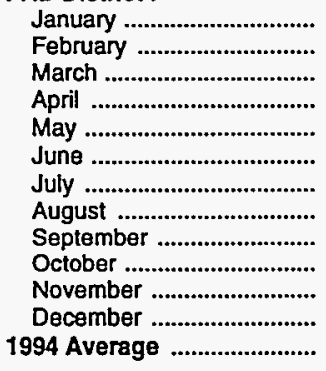 & $\begin{array}{l}58.6 \\
63.3 \\
59.9 \\
58.2 \\
57.2 \\
58.0 \\
59.1 \\
58.7 \\
57.8 \\
58.7 \\
59.0 \\
57.7 \\
58.9\end{array}$ & $\begin{array}{l}64.7 \\
69.3 \\
64.8 \\
63.3 \\
63.1 \\
64.1 \\
65.3 \\
65.0 \\
63.8 \\
65.2 \\
66.0 \\
64.3 \\
64.9\end{array}$ & $\begin{array}{l}66.6 \\
70.5 \\
68.8 \\
67.3 \\
66.7 \\
66.9 \\
67.7 \\
68.6 \\
67.6 \\
67.6 \\
68.4 \\
67.3 \\
67.9\end{array}$ & $\begin{array}{l}62.0 \\
66.0 \\
63.4 \\
62.0 \\
62.4 \\
63.0 \\
63.4 \\
63.2 \\
62.2 \\
64.4 \\
65.2 \\
63.2 \\
63.7\end{array}$ & $\begin{array}{l}62.5 \\
66.6 \\
64.0 \\
62.5 \\
61.7 \\
62.3 \\
63.3 \\
63.3 \\
62.4 \\
63.2 \\
63.8 \\
62.4 \\
63.3\end{array}$ & $\begin{array}{l}53.0 \\
57.7 \\
54.2 \\
52.4 \\
52.1 \\
52.9 \\
54.0 \\
53.1 \\
52.2 \\
53.5 \\
54.0 \\
52.1 \\
53.4\end{array}$ & $\begin{array}{l}58.0 \\
60.4 \\
56.1 \\
56.3 \\
56.9 \\
58.7 \\
58.2 \\
60.6 \\
58.9 \\
58.7 \\
58.8 \\
56.6 \\
58.1\end{array}$ & $\begin{array}{l}64.3 \\
68.0 \\
65.2 \\
64.9 \\
62.7 \\
64.3 \\
64.7 \\
63.7 \\
62.7 \\
63.5 \\
64.2 \\
62.4 \\
64.6\end{array}$ & $\begin{array}{l}66.7 \\
67.4 \\
65.5 \\
64.5 \\
62.6 \\
63.2 \\
64.6 \\
64.4 \\
62.6 \\
64.8 \\
65.1 \\
64.3 \\
65.0\end{array}$ & $\begin{array}{l}62.8 \\
64.5 \\
61.2 \\
60.8 \\
59.9 \\
61.2 \\
61.3 \\
62.6 \\
61.3 \\
62.2 \\
62.7 \\
61.1 \\
62.1\end{array}$ & $\begin{array}{l}49.2 \\
53.7 \\
49.4 \\
49.3 \\
50.3 \\
51.8 \\
52.6 \\
52.5 \\
50.1 \\
51.5 \\
51.8 \\
50.4 \\
50.8\end{array}$ \\
\hline \multicolumn{12}{|l|}{ Subdistrict IA } \\
\hline 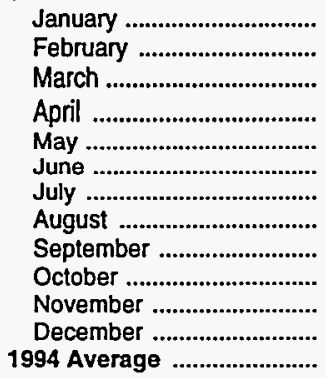 & $\begin{array}{l}65.2 \\
71.5 \\
65.5 \\
63.5 \\
63.6 \\
64.6 \\
65.2 \\
63.2 \\
62.6 \\
63.5 \\
63.1 \\
62.8 \\
64.8\end{array}$ & $\begin{array}{l}73.0 \\
78.7 \\
72.7 \\
69.9 \\
69.4 \\
70.3 \\
72.6 \\
73.0 \\
70.0 \\
72.5 \\
73.7 \\
67.5 \\
71.5\end{array}$ & $\begin{array}{l}76.0 \\
81.8 \\
80.0 \\
76.3 \\
75.1 \\
73.3 \\
73.7 \\
73.2 \\
72.6 \\
72.5 \\
73.7 \\
72.3 \\
74.4\end{array}$ & $\begin{array}{l}65.5 \\
69.5 \\
66.5 \\
64.8 \\
63.9 \\
64.9 \\
65.1 \\
66.9 \\
64.3 \\
64.7 \\
65.7 \\
65.4 \\
65.6\end{array}$ & $\begin{array}{l}68.7 \\
74.2 \\
69.8 \\
67.3 \\
66.9 \\
67.1 \\
67.9 \\
67.2 \\
66.2 \\
66.9 \\
67.2 \\
66.4 \\
68.0\end{array}$ & $\begin{array}{l}56.2 \\
64.9 \\
57.5 \\
54.5 \\
53.3 \\
53.7 \\
54.4 \\
54.4 \\
52.6 \\
53.7 \\
55.6 \\
55.0 \\
\mathbf{5 5 . 3}\end{array}$ & $\begin{array}{l}65.5 \\
70.2 \\
67.3 \\
62.7 \\
62.1 \\
63.1 \\
63.5 \\
65.5 \\
64.5 \\
66.0 \\
65.9 \\
64.7 \\
64.9\end{array}$ & $\begin{array}{l}67.5 \\
72.0 \\
69.0 \\
67.4 \\
67.2 \\
68.0 \\
62.7 \\
69.0 \\
69.2 \\
70.8 \\
68.1 \\
70.7 \\
67.8\end{array}$ & $\begin{array}{l}64.7 \\
69.8 \\
65.3 \\
64.1 \\
53.2 \\
65.2 \\
68.2 \\
69.8 \\
68.8 \\
73.7 \\
70.2 \\
70.0 \\
66.0\end{array}$ & $\begin{array}{l}65.8 \\
70.4 \\
67.4 \\
63.6 \\
60.7 \\
63.9 \\
64.1 \\
66.7 \\
67.0 \\
67.7 \\
67.1 \\
66.5 \\
65.8\end{array}$ & $\begin{array}{c}W \\
W \\
W \\
56.0 \\
57.6 \\
57.9 \\
58.4 \\
58.1 \\
W \\
56.8 \\
53.2 \\
56.3 \\
50.7\end{array}$ \\
\hline \multicolumn{12}{|l|}{ Subdistrict IB } \\
\hline 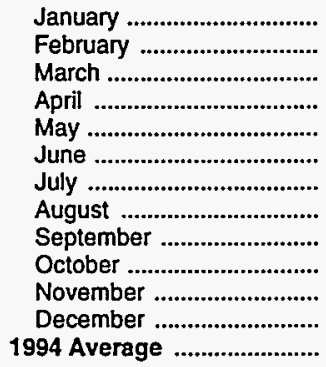 & $\begin{array}{l}59.9 \\
66.4 \\
61.9 \\
59.4 \\
57.7 \\
58.0 \\
58.7 \\
59.2 \\
57.9 \\
58.6 \\
59.1 \\
58.2 \\
59.7\end{array}$ & $\begin{array}{l}67.1 \\
74.2 \\
68.8 \\
65.2 \\
64.2 \\
65.8 \\
65.9 \\
67.0 \\
65.5 \\
67.6 \\
68.7 \\
68.1 \\
67.4\end{array}$ & $\begin{array}{l}71.5 \\
76.2 \\
74.0 \\
71.5 \\
69.9 \\
69.8 \\
70.2 \\
71.1 \\
70.4 \\
70.1 \\
70.2 \\
69.6 \\
71.4\end{array}$ & $\begin{array}{l}61.4 \\
66.9 \\
63.8 \\
61.2 \\
60.4 \\
60.4 \\
61.5 \\
61.7 \\
60.2 \\
62.4 \\
65.0 \\
62.3 \\
62.3\end{array}$ & $\begin{array}{l}64.0 \\
69.7 \\
66.3 \\
63.7 \\
62.2 \\
62.5 \\
63.3 \\
63.7 \\
62.6 \\
63.3 \\
63.9 \\
62.8 \\
64.2\end{array}$ & $\begin{array}{l}53.9 \\
59.9 \\
55.3 \\
53.1 \\
52.6 \\
53.2 \\
54.1 \\
53.2 \\
52.1 \\
53.5 \\
53.9 \\
52.5 \\
53.7\end{array}$ & $\begin{array}{l}60.1 \\
63.2 \\
59.2 \\
58.6 \\
57.9 \\
59.5 \\
59.3 \\
61.3 \\
59.9 \\
59.1 \\
58.7 \\
57.2 \\
59.1\end{array}$ & $\begin{array}{l}73.8 \\
75.0 \\
72.6 \\
71.3 \\
69.3 \\
70.8 \\
71.4 \\
65.0 \\
64.3 \\
64.2 \\
64.7 \\
64.4 \\
67.5\end{array}$ & $\begin{array}{l}69.9 \\
71.6 \\
66.0 \\
63.9 \\
63.1 \\
61.8 \\
62.4 \\
63.8 \\
63.7 \\
70.0 \\
68.8 \\
68.1 \\
65.7\end{array}$ & $\begin{array}{l}65.5 \\
67.2 \\
63.4 \\
62.7 \\
61.1 \\
62.1 \\
61.9 \\
63.0 \\
62.1 \\
62.8 \\
62.0 \\
60.7 \\
62.7\end{array}$ & $\begin{array}{l}51.4 \\
57.8 \\
50.0 \\
51.4 \\
51.6 \\
52.5 \\
53.0 \\
53.3 \\
49.7 \\
51.0 \\
51.4 \\
50.5 \\
51.6\end{array}$ \\
\hline
\end{tabular}

See footnotes at end of table. 
Table 41. No. 2 Diesel Fuel Prices by Sulfur Content, Sales Type, and PAD District (Cents per Gallon Excluding Taxes) - Continued

\begin{tabular}{|c|c|c|c|c|c|c|c|c|c|c|c|}
\hline \multirow{3}{*}{$\begin{array}{c}\text { Geographlc Area } \\
\text { Month }\end{array}$} & \multicolumn{6}{|c|}{ Low-Sulfur Diesel Fuel } & \multicolumn{5}{|c|}{ High-Sulfur Dlesel Fuel } \\
\hline & \multicolumn{5}{|c|}{ Sales to End Users } & \multirow{2}{*}{$\begin{array}{c}\text { Sales } \\
\text { for } \\
\text { Resale }\end{array}$} & \multicolumn{4}{|c|}{ Sales to End Users } & \multirow{2}{*}{$\begin{array}{c}\text { Sales } \\
\text { for } \\
\text { Resale }\end{array}$} \\
\hline & $\begin{array}{c}\text { Commercial/ } \\
\text { Institutional } \\
\text { Consumers }\end{array}$ & $\begin{array}{c}\text { Industrial } \\
\text { Consumers }\end{array}$ & $\begin{array}{c}\text { Through } \\
\text { Retail } \\
\text { Outletsa }\end{array}$ & $\begin{array}{l}\text { Other } \\
\text { End } \\
\text { Usersb }\end{array}$ & Averago & & $\begin{array}{l}\text { Commercial/ } \\
\text { Institutional } \\
\text { Consumers }\end{array}$ & $\begin{array}{c}\text { Industrial } \\
\text { Consumers }\end{array}$ & $\begin{array}{c}\text { Other } \\
\text { End } \\
\text { Usersb }\end{array}$ & Average & \\
\hline
\end{tabular}

Subdistrict IC

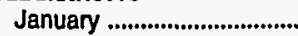

Fobruary

April

(n)

July

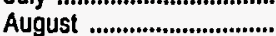

September ............................

October

November ...............................

December

1994 Average

PAD District II

January .

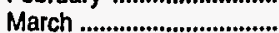

May

June

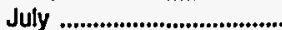

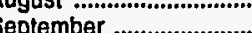

October

November ..............................

December ..........................

1994 Average

PAD District III

January ...

(n)

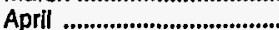

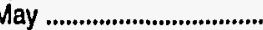

June ....................................

July .

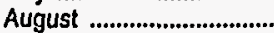

September ..............................

October ...............................

November ..........................

December .

1994 Average

PAD District IV

January .

March ...

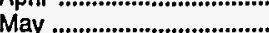

June

July ......................................

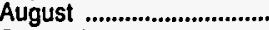

September ..........................

October ...

November ..........

December ..........................

1994 Average

\begin{tabular}{|l|}
55.5 \\
58.3 \\
56.8 \\
55.7 \\
55.2 \\
55.9 \\
57.5 \\
57.0 \\
56.4 \\
57.3 \\
57.7 \\
55.8 \\
56.5
\end{tabular}

53.7

56.4

56.9

57.3

57.5

57.6

59.0
60.0

59.0

59.4

59.2

56.9

57.9

54.1

56.2

55.2

54.5
54.7

55.8

57.3

57.3

56.6

56.7

57.0
55.0

56.0

\section{3}

55.2
58.7

61.4

60.8

61.3

62.9

67.2

71.1

71.6

69.4

63.3
63.8
61.4

$63.4 \quad 63.4$

60.3

60.4

60.5

60.5

63.0

62.2

61.1

61.8

62.3

60.6

61.5

$63.4 \quad 61.7$

$66.9 \quad 64.0$

$65.5 \quad 62.0$

$\begin{array}{ll}64.6 & 62.1 \\ 64.4 & 63.7\end{array}$

$64.9 \quad 64.9$

$65.9 \quad 64.9$

$65.5 \quad 63.1$

$65.7 \quad 65.5$

$65.4 \quad 63.2$

64.3

\section{9}

62.8

63.0
63.6

63.4

63.6

65.0

64.7

64.6

65.5

64.3

61.7

63.8

62.2

65.5

65.6

66.0

64.6

66.2

67.2

66.3

65.8

66.3
64.8

65.6

65.5
67.8
68.6
69.4
70.1
70.3
72.4
72.8
72.
72.
71.7
68.4
70.4

59.5

60.6

59.3

60.1

61.5

63.7

66.6

64.9

66.1

65.6

62.7

63.0

62.4

$\begin{array}{ll}62.4 & 57.9 \\ 65.2 & 60.8\end{array}$

$65.2 \quad 59.8$

$64.4 \quad 60.2$

$63.9 \quad 60.0$

$65.1 \quad 62.1$

$66.7 \quad 62.1$

$65.6 \quad 62.9$

$65.5 \quad 63.2$

$\begin{array}{ll}64.7 & 62.0 \\ 60.3\end{array}$

$64.9 \quad 61.3$

\section{$\begin{array}{lll}63.2 & 66.0 & 71.1\end{array}$}

64.9

63.4

66.4

66.7
67.5

67.5

68.7

71.1

75.2

75.6

70.3

70.0

$67.9 \quad 70.9$

$\begin{array}{ll}71.0 & 71.4\end{array}$

$\begin{array}{ll}71.5 & 72.8 \\ 71.6 & 72.6\end{array}$

$\begin{array}{ll}73.3 & 74.3 \\ 77.3 & 78.7\end{array}$

$77.3 \quad 78.7$

$77.4 \quad 79.4$

$\begin{array}{ll}76.7 & 80.1\end{array}$

$\begin{array}{ll}72.4 & 76.2 \\ \mathbf{7 2 . 1} & \mathbf{7 4 . 6}\end{array}$
$66.7 \quad 63.4$

$66.8 \quad 65.1$

$66.6 \quad 62.3$

$\begin{array}{ll}60.1 & 51.7 \\ 63.0 & 55.1 \\ 61.4 & 53.0 \\ 60.8 & 51.4 \\ 60.4 & 51.4 \\ 61.2 & 52.3 \\ 62.4 & 53.8 \\ 62.2 & 52.7 \\ 61.4 & 52.1 \\ 62.4 & 53.4 \\ 63.0 & 53.8 \\ 61.2 & 51.2 \\ 61.6 & 52.6\end{array}$

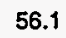

57.5

53.3

54.6

55.6

56.8

59.4

57.4

57.3

58.1

55.1

56.6

\section{4 \\ $50.2 \quad 51.8$}

59.4
62.1
62.7

63.3

62.9

63.2

64.2

65.6

64.9

65.2

64.6

62.4

63.5

$58.9 \quad 48.5$

61.3

60.9

60.4

60.1

61.5

62.8

62.9

62.4

62.4

62.5

61.0

61.4

$68.9-70.6$

$71.8 \quad 74.3$

\begin{abstract}
$62.2 \quad 53.1$
\end{abstract}
63.3

65.2

$67.4 \quad 60.2$

$67.9 \quad 60.5$

$69.0 \quad 61.0$

71.5

75.4

75.8

75.0

70.1
69.8

$52.9 \quad 53.2$

$54.6 \quad 51.8$

$55.1 \quad 53.4$

$53.7 \quad 54.0$

54.7

56.6

54.8
55.8

54.9
51.8

54.4

51.4
51.0

50.0
50.0

51.1

52.5
52.8

52.4

52.0

53.0
50.3

51.4

64.0

68.0

67.3

59.0

61.1

See tootnotes at end of table.

$\begin{array}{llll}61.9 & 65.3 & 61.3 & 48.5 \\ 66.1 & 66.4 & 62.9 & 53.0 \\ 62.8 & 65.4 & 60.0 & 48.9 \\ 62.9 & 64.7 & 59.9 & 48.6 \\ 60.6 & 63.0 & 59.3 & 49.6 \\ 62.0 & 63.6 & 60.6 & 51.5 \\ 62.9 & 65.2 & 60.8 & 52.3 \\ 62.8 & 64.3 & 62.2 & 52.1 \\ 61.3 & 62.1 & 60.5 & 50.5 \\ 62.6 & 63.3 & 61.5 & 51.6 \\ 63.8 & 64.3 & 62.9 & 51.9 \\ 61.1 & 63.6 & 61.0 & 50.2 \\ 63.1 & 64.8 & 61.6 & 50.5\end{array}$

$\begin{array}{llll}60.7 & 65.6 & 57.8 & 49.8 \\ 64.3 & 64.7 & 59.1 & 52.9 \\ 62.5 & 68.4 & 58.7 & 51.7 \\ 63.6 & 71.1 & 61.3 & 54.4 \\ 62.8 & 71.0 & 61.6 & 54.2 \\ 64.3 & 69.5 & 61.3 & 54.5 \\ 65.4 & 72.6 & 62.6 & 55.9 \\ 68.5 & 70.7 & 64.8 & 56.3 \\ 67.8 & 72.9 & 65.3 & 54.9 \\ 68.2 & 74.1 & 66.9 & 55.1 \\ 67.6 & 72.9 & 64.9 & 54.7 \\ 64.8 & 69.9 & 61.4 & 51.7 \\ \mathbf{6 5 . 9} & 70.8 & 62.1 & \mathbf{5 3 . 8}\end{array}$

$\begin{array}{lllll}49.6 & 55.0 & 54.8 & 52.3 & 46.3 \\ \mathbf{5 1 . 4} & \mathbf{5 6 . 5} & 57.9 & \mathbf{5 4 . 1} & 48.8 \\ \mathbf{4 9 . 3} & \mathbf{5 5 . 0} & \mathbf{5 6 . 6} & \mathbf{5 2 . 4} & 46.0 \\ \mathbf{4 8 . 8} & \mathbf{5 4 . 4} & \mathbf{5 7 . 2} & \mathbf{5 2 . 1} & 46.4 \\ \mathbf{5 0 . 0} & \mathbf{5 5 . 4} & 55.6 & 53.2 & 48.0 \\ \mathbf{5 1 . 9} & \mathbf{5 6 . 2} & \mathbf{5 5 . 9} & \mathbf{5 4 . 2} & 48.9 \\ \mathbf{5 3 . 4} & 57.7 & 57.2 & 55.6 & 50.0 \\ \mathbf{5 3 . 1} & \mathbf{5 7 . 4} & 62.2 & 56.4 & 50.5 \\ \mathbf{5 2 . 4} & \mathbf{5 6 . 4} & 61.3 & \mathbf{5 5 . 6} & 49.0 \\ \mathbf{5 2 . 0} & \mathbf{5 8 . 2} & 61.1 & 55.4 & 48.9 \\ \mathbf{5 2 . 4} & \mathbf{5 8 . 5} & 60.6 & \mathbf{5 5 . 4} & 49.9 \\ \mathbf{5 1 . 1} & \mathbf{5 7 . 5} & 59.5 & \mathbf{5 4 . 0} & 48.1 \\ \mathbf{5 1 . 0} & \mathbf{5 6 . 4} & \mathbf{5 7 . 4} & \mathbf{5 4 . 0} & \mathbf{4 8 . 4}\end{array}$

$\begin{array}{lllll}\mathbf{5 2 . 4} & 60.1 & 68.4 & 56.0 & 46.1 \\ 56.3 & 68.7 & 71.7 & 60.1 & 52.7 \\ 55.0 & 68.0 & 70.5 & 59.9 & 54.2 \\ 56.7 & 69.8 & 72.9 & 62.0 & 57.0 \\ 56.9 & 68.6 & 72.6 & 61.5 & 58.8 \\ 57.1 & 68.9 & 72.9 & 62.3 & 57.1 \\ 58.2 & 69.1 & 73.6 & 63.9 & 57.8 \\ 61.4 & 73.4 & 75.8 & 67.5 & 62.2 \\ 65.3 & 79.3 & 79.3 & 70.8 & 70.1 \\ 65.2 & 79.2 & 78.9 & 70.4 & 68.9 \\ 63.5 & 76.9 & 79.0 & 68.0 & 68.6 \\ 60.4 & 73.6 & 75.0 & 64.6 & 62.6 \\ 58.4 & 71.7 & 74.3 & 63.5 & 59.0\end{array}$


Table 41. No. 2 Diesel Fuel Prices by Sulfur Content, Sales Type, and PAD District (Cents per Gallon Excluding Taxes) - Continued

\begin{tabular}{|c|c|c|c|c|c|c|c|c|c|c|c|}
\hline \multirow{3}{*}{$\begin{array}{c}\text { Goographic Area } \\
\text { Month }\end{array}$} & \multicolumn{6}{|c|}{ Low-Sulfur Dlesel Fuol } & \multicolumn{5}{|c|}{ Hlgh-Sulfur Diesel Fuel } \\
\hline & \multicolumn{5}{|c|}{ Sales to End Users } & \multirow{2}{*}{$\begin{array}{c}\text { Sales } \\
\text { for } \\
\text { Resale }\end{array}$} & \multicolumn{4}{|c|}{ Sales to End Users } & \multirow{2}{*}{$\begin{array}{c}\text { Salos } \\
\text { for } \\
\text { Resale }\end{array}$} \\
\hline & $\begin{array}{c}\text { Commerciav } \\
\text { Institutional } \\
\text { Consumers }\end{array}$ & $\begin{array}{c}\text { Industrial } \\
\text { Consumers }\end{array}$ & $\begin{array}{c}\text { Through } \\
\text { Rotail } \\
\text { Outlets a }\end{array}$ & $\begin{array}{l}\text { Other } \\
\text { End } \\
\text { Usersb }\end{array}$ & Average & & $\begin{array}{c}\text { Commerclal/ } \\
\text { Institutional } \\
\text { Consumers }\end{array}$ & $\begin{array}{c}\text { Industrial } \\
\text { Consumers }\end{array}$ & $\begin{array}{l}\text { Other } \\
\text { End } \\
\text { Usersb }\end{array}$ & Average & \\
\hline \multicolumn{12}{|l|}{ PAD District V } \\
\hline 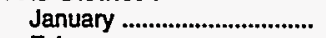 & 58.1 & 64.1 & 68.5 & 64.9 & 63.2 & 50.1 & 56.2 & 60.5 & 61.4 & 59.3 & 50.4 \\
\hline 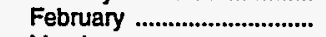 & 62.3 & 70.3 & 71.7 & 68.7 & 67.1 & 55.7 & 58.8 & 63.3 & 63.2 & 61.9 & 53.9 \\
\hline 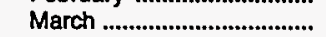 & 67.2 & 71.5 & 74.0 & 71.2 & 70.6 & 59.4 & 60.8 & 67.2 & 67.0 & 63.6 & 56.5 \\
\hline 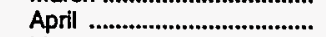 & 65.6 & 70.2 & 74.3 & 70.6 & 69.7 & 58.0 & 62.4 & 64.3 & 69.0 & 64.6 & 54.8 \\
\hline 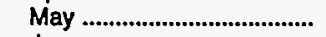 & 61.6 & 68.4 & 73.3 & 69.0 & 67.2 & 55.3 & 59.9 & 63.6 & 63.6 & 61.5 & 52.6 \\
\hline 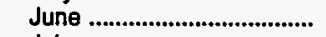 & 60.0 & 67.3 & 71.8 & 67.4 & 65.8 & 54.1 & 57.7 & 65.0 & 64.9 & 60.2 & 52.0 \\
\hline 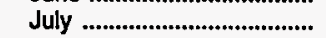 & 61.3 & 68.1 & 72.2 & 68.1 & 66.7 & 55.5 & 56.9 & 64.7 & 62.6 & 59.2 & 54.1 \\
\hline August & 63.7 & 69.0 & 73.2 & 69.9 & 68.4 & 55.7 & 61.4 & 67.0 & 65.5 & 63.1 & 54.9 \\
\hline 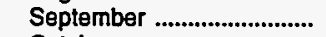 & 68.7 & 74.0 & 76.1 & 74.1 & 72.5 & 60.8 & 63.5 & 69.2 & 66.0 & 65.1 & 60.2 \\
\hline October & 70.1 & 74.9 & 78.6 & 73.9 & 74.0 & 63.2 & 66.1 & 70.5 & 68.9 & 68.0 & 61.7 \\
\hline November ............................ & 69.6 & 74.1 & 79.5 & 73.9 & 73.9 & 62.6 & 65.6 & 72.1 & 69.9 & 69.3 & 60.2 \\
\hline December .............................. & 62.6 & 68.4 & 75.7 & 68.7 & 68.3 & 54.1 & 57.8 & 65.4 & 67.0 & 62.3 & 54.0 \\
\hline 1994 Average ........................ & 64.3 & 70.0 & 74.8 & 69.8 & 69.2 & 57.1 & 60.6 & 66.5 & 66.8 & 63.4 & 55.3 \\
\hline
\end{tabular}

$W=$ Withheld to avoid disclosure of individual company data.

a Includes low-sulfur diesel fuel only with the exception of Alaska, which currently is exempt from the Clean Air Act's diesel fuel sulfur content requirement.

b All end-user sales not included in the other end-user categories shown, e.g., sales to agricultural customers or utilities.

Notes: Some State data are not sufficient for publication individually, but are used in calculating the PAD District average.

Sources: Energy Information Administration Forms ElA-782A, "Refiners'/Gas Plant Operators' Monthly Petroleum Product Sales Report," and ElA-782B,

'Resellers'/Retallers' Monthly Petroleum Product Sales Report." 
Table 42. Residual Fuel Oll Prices by PAD District and State (Cents per Gallon Excluding Taxes)

\begin{tabular}{|c|c|c|c|c|c|c|}
\hline \multirow{2}{*}{$\begin{array}{l}\text { Geographlc Ares } \\
\text { Month }\end{array}$} & \multicolumn{2}{|c|}{$\begin{array}{l}\text { Sulfur Less Than } \\
\text { or Equal to } 1 \text { Percent }\end{array}$} & \multicolumn{2}{|c|}{$\begin{array}{c}\text { Sulfur Greater Than } \\
1 \text { Percent }\end{array}$} & \multicolumn{2}{|c|}{ Average } \\
\hline & $\begin{array}{l}\text { Sales to } \\
\text { End Users }\end{array}$ & $\begin{array}{c}\text { Sales tor } \\
\text { Resale }\end{array}$ & $\begin{array}{l}\text { Sales to } \\
\text { End Usars }\end{array}$ & $\begin{array}{l}\text { Sales for } \\
\text { Resale }\end{array}$ & $\begin{array}{l}\text { Sales to } \\
\text { End Users }\end{array}$ & $\begin{array}{c}\text { Sales for } \\
\text { Resale }\end{array}$ \\
\hline Unitad States & & & & & & \\
\hline 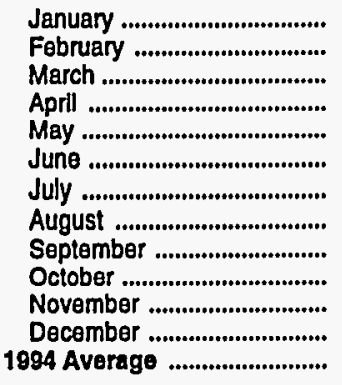 & $\begin{array}{l}39.1 \\
42.8 \\
39.6 \\
34.7 \\
35.9 \\
37.5 \\
40.1 \\
41.3 \\
38.5 \\
38.1 \\
40.8 \\
43.3 \\
40.3\end{array}$ & $\begin{array}{l}33.5 \\
37.9 \\
32.1 \\
30.0 \\
32.0 \\
36.3 \\
38.0 \\
38.0 \\
33.4 \\
32.5 \\
36.0 \\
37.8 \\
35.0\end{array}$ & $\begin{array}{l}28.7 \\
31.6 \\
29.7 \\
29.5 \\
30.9 \\
33.3 \\
36.4 \\
36.6 \\
32.9 \\
33.1 \\
35.3 \\
36.4 \\
32.7\end{array}$ & $\begin{array}{l}24.4 \\
27.5 \\
26.1 \\
25.9 \\
29.3 \\
32.3 \\
36.0 \\
33.2 \\
28.1 \\
30.7 \\
32.6 \\
32.4 \\
29.8\end{array}$ & $\begin{array}{l}33.4 \\
37.3 \\
33.9 \\
31.3 \\
32.4 \\
34.8 \\
37.8 \\
38.3 \\
34.8 \\
34.8 \\
37.2 \\
38.9 \\
35.8\end{array}$ & $\begin{array}{l}29.4 \\
33.3 \\
29.0 \\
27.7 \\
30.3 \\
34.1 \\
37.0 \\
35.9 \\
30.6 \\
31.4 \\
34.0 \\
34.4 \\
32.2\end{array}$ \\
\hline 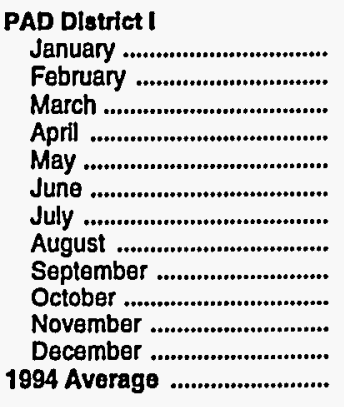 & $\begin{array}{l}40.3 \\
44.5 \\
40.9 \\
35.3 \\
36.2 \\
37.7 \\
40.1 \\
41.0 \\
37.7 \\
38.8 \\
41.5 \\
44.8 \\
41.3\end{array}$ & $\begin{array}{l}37.5 \\
43.3 \\
38.2 \\
33.5 \\
34.7 \\
37.8 \\
39.4 \\
39.6 \\
33.8 \\
34.7 \\
37.3 \\
39.9 \\
38.1\end{array}$ & $\begin{array}{l}30.8 \\
34.0 \\
31.7 \\
30.2 \\
30.9 \\
32.8 \\
35.5 \\
36.4 \\
33.0 \\
33.2 \\
36.3 \\
37.9 \\
33.3\end{array}$ & $\begin{array}{c}28.3 \\
32.7 \\
29.2 \\
25.3 \\
30.7 \\
\text { NA } \\
\text { NA } \\
33.0 \\
27.5 \\
30.0 \\
\text { NA } \\
\text { NA } \\
31.2\end{array}$ & $\begin{array}{l}36.0 \\
40.3 \\
36.5 \\
32.4 \\
32.9 \\
34.9 \\
37.7 \\
38.3 \\
35.1 \\
35.4 \\
38.6 \\
41.1 \\
37.3\end{array}$ & $\begin{array}{l}34.6 \\
40.2 \\
33.8 \\
29.6 \\
32.4 \\
35.6 \\
38.3 \\
37.1 \\
31.7 \\
32.0 \\
34.8 \\
36.5 \\
35.1\end{array}$ \\
\hline 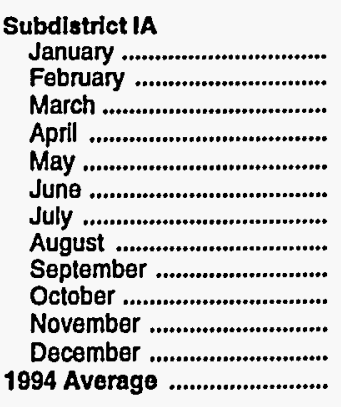 & $\begin{array}{l}37.2 \\
43.0 \\
41.8 \\
34.9 \\
35.7 \\
37.4 \\
38.2 \\
41.9 \\
38.7 \\
36.6 \\
37.2 \\
41.8 \\
39.2\end{array}$ & $\begin{array}{l}38.1 \\
40.8 \\
35.2 \\
32.6 \\
33.9 \\
38.4 \\
38.4 \\
37.4 \\
30.6 \\
33.6 \\
37.7 \\
39.7 \\
37.1\end{array}$ & $\begin{array}{l}28.9 \\
33.1 \\
30.6 \\
30.3 \\
29.1 \\
31.5 \\
33.3 \\
33.3 \\
33.4 \\
33.0 \\
35.3 \\
35.7 \\
32.0\end{array}$ & $\begin{array}{c}26.4 \\
34.3 \\
27.9 \\
W \\
29.1 \\
34.8 \\
W \\
W \\
30.0 \\
32.0 \\
W \\
37.1 \\
31.3\end{array}$ & $\begin{array}{l}34.3 \\
39.2 \\
36.4 \\
32.8 \\
31.8 \\
33.8 \\
35.9 \\
37.4 \\
36.0 \\
35.2 \\
36.5 \\
39.2 \\
36.0\end{array}$ & $\begin{array}{l}34.9 \\
38.4 \\
31.8 \\
30.6 \\
32.3 \\
38.3 \\
38.0 \\
36.1 \\
30.5 \\
32.7 \\
37.6 \\
39.2 \\
35.3\end{array}$ \\
\hline 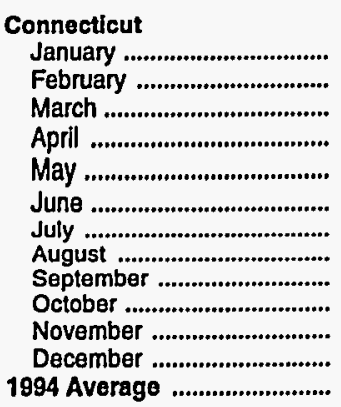 & $\begin{array}{l}42.4 \\
50.9 \\
46.2 \\
39.0 \\
39.4 \\
40.2 \\
42.9 \\
47.4 \\
42.4 \\
41.5 \\
46.1 \\
46.5 \\
44.6\end{array}$ & $\begin{array}{c}36.3 \\
42.9 \\
38.1 \\
33.1 \\
W \\
W \\
W \\
37.6 \\
W \\
W \\
W \\
40.2 \\
37.7\end{array}$ & $\begin{array}{c}W \\
W \\
W \\
W \\
W \\
W \\
W \\
W \\
N A \\
\bar{W} \\
W \\
42.5\end{array}$ & $\begin{array}{l}- \\
- \\
- \\
- \\
- \\
- \\
- \\
\bar{w} \\
- \\
\bar{w}\end{array}$ & $\begin{array}{l}42.4 \\
50.9 \\
46.1 \\
39.0 \\
39.3 \\
40.2 \\
42.9 \\
47.4 \\
42.4 \\
41.5 \\
46.0 \\
46.5 \\
44.6\end{array}$ & $\begin{array}{c}36.3 \\
42.9 \\
38.1 \\
33.1 \\
W \\
W \\
W \\
37.6 \\
W \\
W \\
W \\
40.2 \\
37.7\end{array}$ \\
\hline
\end{tabular}

See tootnotes at end of table. 
Table 42. Residual Fuel Oil Prices by PAD District and State

(Cents per Gallon Excluding Taxes) - Continued



See footnotes at end of table. 
Table 42. Residual Fuel Oil Prices by PAD District and State

(Cents per Gallon Excluding Taxes) - Continued

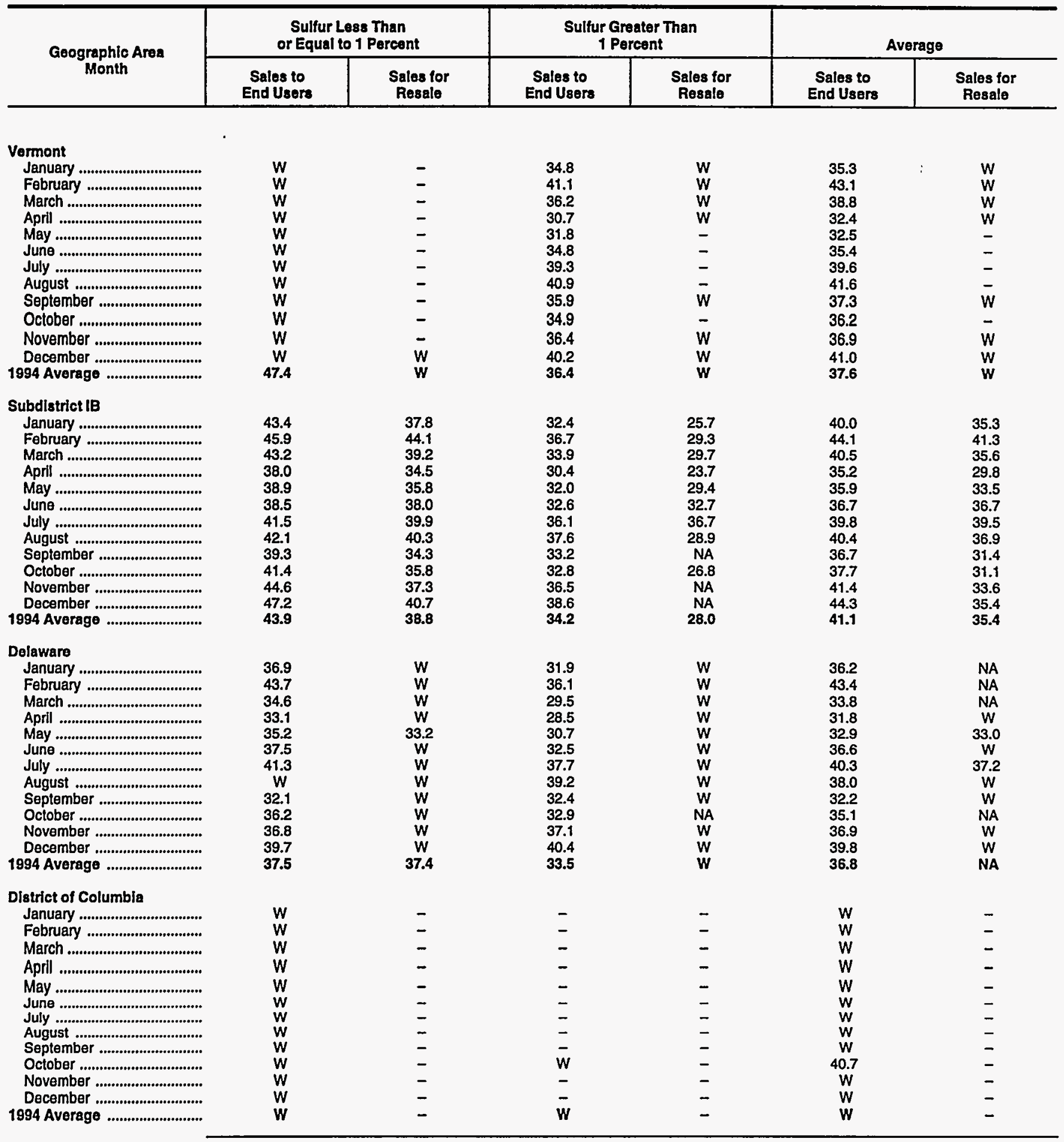

See footnotes at end of table. 
Table 42. Residual Fuel OIl Prices by PAD District and State (Cents per Gallon Excluding Taxes) - Continued

\begin{tabular}{|c|c|c|c|c|c|c|}
\hline \multirow{2}{*}{$\begin{array}{c}\text { Geographic Area } \\
\text { Month }\end{array}$} & \multicolumn{2}{|c|}{$\begin{array}{l}\text { Sulfur Less Than } \\
\text { or Equal to } 1 \text { Percent }\end{array}$} & \multicolumn{2}{|c|}{$\begin{array}{c}\text { Sulfur Greater Than } \\
1 \text { Percent }\end{array}$} & \multicolumn{2}{|c|}{ Average } \\
\hline & $\begin{array}{l}\text { Sales to } \\
\text { End Users }\end{array}$ & $\begin{array}{c}\text { Sales for } \\
\text { Resale }\end{array}$ & $\begin{array}{l}\text { Sales to } \\
\text { End Users }\end{array}$ & $\begin{array}{c}\text { Sales for } \\
\text { Resalo }\end{array}$ & $\begin{array}{c}\text { Sales to } \\
\text { End Users }\end{array}$ & $\begin{array}{c}\text { Sales for } \\
\text { Resalo }\end{array}$ \\
\hline \multicolumn{7}{|l|}{ Maryland } \\
\hline January ................................... & 39.6 & $W$ & 28.5 & $W$ & 33.0 & 30.7 \\
\hline February .............................. & 43.9 & $W$ & 34.1 & $W$ & 37.3 & W \\
\hline 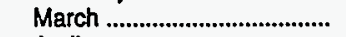 & 37.4 & $W$ & 30.3 & $W$ & 32.7 & 33.0 \\
\hline 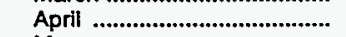 & $w$ & $w$ & 28.0 & $\dot{W}$ & 29.0 & $w$ \\
\hline May ........................................... & $w$ & $w$ & 31.1 & W & 32.6 & w \\
\hline June ............................................ & 37.0 & $w$ & NA & $W$ & 34.8 & $w$ \\
\hline July & 40.4 & W & NA & $W$ & 37.9 & 40.4 \\
\hline 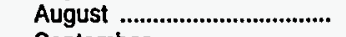 & W & $W$ & NA & $W$ & NA & $w$ \\
\hline September ............................. & $W$ & $W$ & 35.7 & $W$ & 35.5 & 30.3 \\
\hline 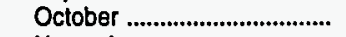 & $W$ & $W$ & NA & $W$ & NA & W \\
\hline November .............................. & $w$ & $W$ & NA & $W$ & NA & 41.9 \\
\hline December ................................. & 40.2 & W & NA & W & 37.2 & W \\
\hline 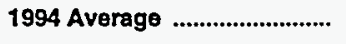 & 38.3 & 35.8 & 31.6 & 32.5 & 34.3 & 34.1 \\
\hline \multicolumn{7}{|l|}{ New Jersey } \\
\hline 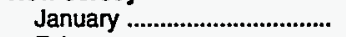 & 43.2 & 37.1 & 29.3 & 27.0 & 40.9 & 33.0 \\
\hline 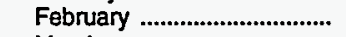 & 47.8 & 44.7 & 31.0 & 30.1 & 46.0 & 42.2 \\
\hline March & 44.5 & 41.1 & 30.3 & NA & 41.7 & 36.1 \\
\hline April & 39.2 & 37.6 & 27.5 & 24.3 & 33.9 & 28.8 \\
\hline May & 38.2 & 37.2 & 32.2 & 28.9 & 36.3 & 32.8 \\
\hline 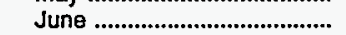 & 41.4 & 38.7 & 32.2 & 32.3 & 38.2 & 37.7 \\
\hline 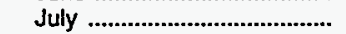 & 41.4 & 41.2 & 36.0 & 37.9 & 39.5 & 40.5 \\
\hline 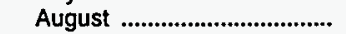 & 41.3 & 41.4 & 37.2 & NA & 40.4 & 35.5 \\
\hline 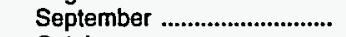 & 37.2 & 33.2 & 31.1 & NA & 35.3 & 30.4 \\
\hline 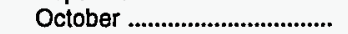 & W & 38.2 & 32.6 & NA & 37.5 & 32.4 \\
\hline November .............................. & 42.6 & 35.8 & 35.7 & 31.6 & 39.2 & 34.5 \\
\hline 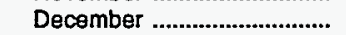 & 44.2 & 41.4 & 37.7 & 32.3 & 40.8 & 35.7 \\
\hline 1994 Average & 43.1 & 39.3 & 33.1 & 29.3 & 40.3 & 35.4 \\
\hline \multicolumn{7}{|l|}{ New York } \\
\hline 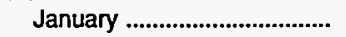 & 46.2 & 38.5 & 35.6 & 33.5 & 43.8 & 38.5 \\
\hline 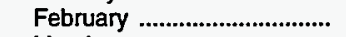 & 47.5 & 44.8 & 42.4 & 42.4 & 46.8 & 44.8 \\
\hline March & 44.4 & 40.0 & 37.3 & 35.9 & 42.8 & 39.2 \\
\hline 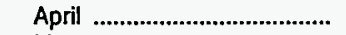 & 40.1 & 35.4 & 34.5 & 32.5 & 38.8 & 35.1 \\
\hline 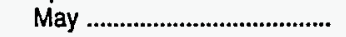 & 40.0 & 35.5 & 33.5 & 30.8 & 37.9 & 34.4 \\
\hline June & 38.5 & 38.2 & 33.7 & $W$ & 37.5 & 37.0 \\
\hline 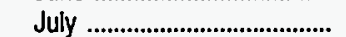 & 47.7 & 40.5 & 37.1 & 39.2 & 43.9 & 40.5 \\
\hline 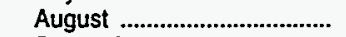 & 46.0 & 39.0 & 40.0 & 41.2 & 43.9 & 39.1 \\
\hline 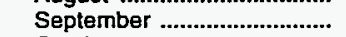 & 41.9 & 35.2 & 34.1 & 34.9 & 38.9 & 35.2 \\
\hline 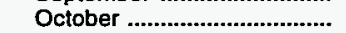 & 42.5 & 36.0 & 33.4 & $w$ & 39.7 & 34.8 \\
\hline November ............................... & 47.4 & 39.0 & 37.4 & 37.1 & 44.6 & 39.0 \\
\hline December ..................................... & 49.4 & 40.7 & 40.5 & W & 47.6 & 39.9 \\
\hline 1994 Average & 46.3 & 39.4 & 36.6 & 35.2 & 44.4 & 38.9 \\
\hline \multicolumn{7}{|l|}{ Pennsylvania } \\
\hline 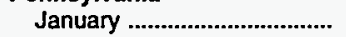 & 39.1 & 36.2 & 35.8 & w & 37.8 & 35.7 \\
\hline 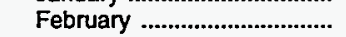 & 40.3 & 41.4 & 33.5 & 30.6 & 39.2 & 39.8 \\
\hline 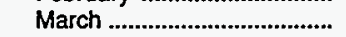 & 44.7 & 34.9 & 32.8 & 29.6 & 37.6 & 32.6 \\
\hline 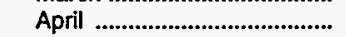 & 38.1 & 32.3 & 30.2 & 26.9 & 33.4 & 29.2 \\
\hline 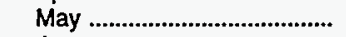 & 39.5 & 34.3 & 30.6 & $w$ & 33.5 & 32.8 \\
\hline June & 37.9 & 37.6 & 33.0 & 32.9 & 34.6 & 36.1 \\
\hline 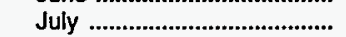 & 37.6 & 39.1 & 37.4 & 36.3 & 37.6 & 38.5 \\
\hline 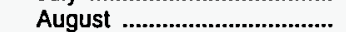 & 39.0 & 43.8 & 38.4 & 36.2 & 38.7 & 41.8 \\
\hline September .............................. & 39.6 & 33.3 & 32.1 & 29.7 & 33.3 & 32.2 \\
\hline October & 41.1 & 34.4 & 32.1 & 31.4 & 34.1 & 33.6 \\
\hline 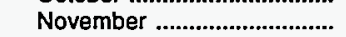 & 41.2 & 36.7 & 37.7 & $w$ & 38.7 & 36.4 \\
\hline December & 42.9 & 40.0 & 38.8 & $w$ & 40.2 & 39.3 \\
\hline 1994 Average & 39.7 & 37.8 & 34.3 & 31.9 & 37.2 & 36.1 \\
\hline
\end{tabular}

See footnotes at end of table. 
Table 42. Residual Fuel OIl Prices by PAD District and State (Cents per Gallon Excluding Taxes) - Continued

\begin{tabular}{|c|c|c|c|c|c|c|}
\hline \multirow{2}{*}{$\begin{array}{l}\text { Goographle Area } \\
\text { Month }\end{array}$} & \multicolumn{2}{|c|}{$\begin{array}{l}\text { Sulfur Less Than } \\
\text { or Equal to } 1 \text { Percent }\end{array}$} & \multicolumn{2}{|c|}{$\begin{array}{c}\text { Sulfur Greater Than } \\
1 \text { Percent }\end{array}$} & \multicolumn{2}{|c|}{ Average } \\
\hline & $\begin{array}{l}\text { Sales to } \\
\text { End Usors }\end{array}$ & $\begin{array}{c}\text { Sales for } \\
\text { Resalo }\end{array}$ & $\begin{array}{l}\text { Sales to } \\
\text { End Users }\end{array}$ & $\begin{array}{l}\text { Sales for } \\
\text { Resalo }\end{array}$ & $\begin{array}{l}\text { Sales to } \\
\text { End Users }\end{array}$ & $\begin{array}{l}\text { Sales for } \\
\text { Resale }\end{array}$ \\
\hline \multicolumn{7}{|l|}{ Subdlstrict IC } \\
\hline 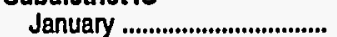 & 31.0 & w & 30.4 & 31.7 & 30.6 & 31.1 \\
\hline 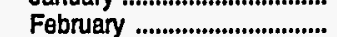 & 35.9 & $\ddot{w}$ & 32.9 & 36.7 & 33.5 & 37.1 \\
\hline 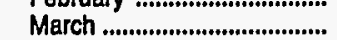 & 30.5 & 39.1 & 30.9 & 29.3 & 30.8 & 30.6 \\
\hline 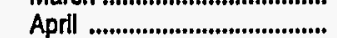 & 31.9 & $w$ & 30.2 & 27.0 & 30.7 & 28.2 \\
\hline May ...................................... & 33.3 & 31.6 & 31.0 & 31.4 & 31.6 & 31.4 \\
\hline June ........................................... & 36.0 & $w$ & 33.2 & NA & 33.8 & NA \\
\hline 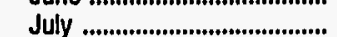 & 39.4 & $w$ & 36.0 & NA & 37.0 & NA \\
\hline August ............................ & 37.9 & 39.8 & 37.0 & NA & 37.2 & 38.2 \\
\hline Soptember .......................... & 34.8 & $w$ & 32.8 & 32.3 & 33.5 & 33.3 \\
\hline October & 34.4 & 32.1 & 33.4 & NA & 33.6 & 33.5 \\
\hline November ............................... & 38.5 & $\ddot{w}$ & 36.4 & 36.4 & 36.8 & 36.5 \\
\hline 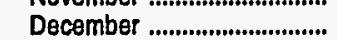 & 38.2 & 36.7 & 38.1 & NA & 38.1 & NA \\
\hline 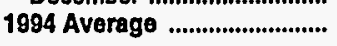 & 34.6 & 35.3 & 33.2 & 34.0 & 33.6 & 34.3 \\
\hline \multicolumn{7}{|l|}{ Florida } \\
\hline 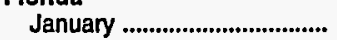 & 30.0 & $w$ & 28.9 & 28.6 & 29.3 & 27.9 \\
\hline February ............................... & 34.0 & $\underline{-}$ & 30.7 & $w$ & 31.2 & $w$ \\
\hline 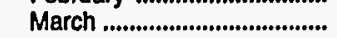 & 29.8 & - & 29.5 & $w$ & 29.6 & $w$ \\
\hline 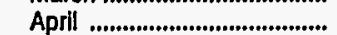 & 31.6 & w & 30.1 & 30.5 & 30.6 & 30.8 \\
\hline 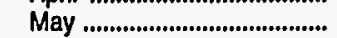 & 32.9 & $w$ & 30.8 & $w$ & 31.4 & 32.0 \\
\hline June ........................................ & 35.5 & $w$ & 33.3 & $w$ & 33.8 & NA \\
\hline July ................................ & 39.0 & $\ddot{w}$ & 35.8 & NA & 36.9 & NA \\
\hline August & 37.1 & $w$ & 36.5 & NA & 36.7 & 38.1 \\
\hline September ........................... & 34.2 & $\ddot{w}$ & 32.3 & 32.0 & 33.1 & 33.3 \\
\hline October & 35.8 & $\ddot{w}$ & 33.7 & NA & 33.9 & 33.4 \\
\hline November ............................... & 37.7 & $\ddot{w}$ & 36.0 & NA & 36.3 & 36.4 \\
\hline December ............................ & 36.6 & $w$ & 37.2 & $w$ & 37.0 & $\mathrm{NA}$ \\
\hline 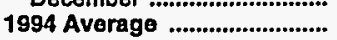 & 33.9 & 34.7 & 32.6 & NA & 33.0 & 34.7 \\
\hline \multicolumn{7}{|l|}{ Georgla } \\
\hline 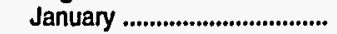 & w & - & 35.0 & w & 35.0 & w \\
\hline Fobruary .................................. & W & - & 38.1 & W & 38.1 & $w$ \\
\hline 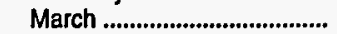 & - & - & 38.8 & w & 38.8 & $w$ \\
\hline April & - & - & 34.1 & $w$ & 34.1 & $w$ \\
\hline 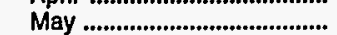 & - & - & 33.6 & $\dddot{w}$ & 33.6 & $w$ \\
\hline June & - & - & 33.8 & $w$ & 33.8 & $w$ \\
\hline July & - & - & 36.4 & $\ddot{w}$ & 36.4 & $w$ \\
\hline August & - & - & 39.3 & $w$ & 39.3 & $w$ \\
\hline September ............................. & - & - & 36.6 & $W$ & 36.6 & w \\
\hline October (................................... & - & - & 35.2 & $\ddot{w}$ & 35.2 & 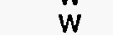 \\
\hline 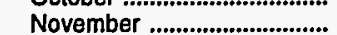 & - & - & 38.5 & $w$ & 38.5 & $w$ \\
\hline 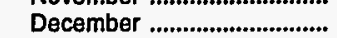 & _- & - & 40.6 & $\ddot{w}$ & 40.6 & 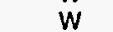 \\
\hline 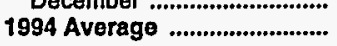 & $\bar{w}$ & - & 36.5 & 31.4 & 36.5 & 31.4 \\
\hline \multicolumn{7}{|l|}{ North Carolina } \\
\hline 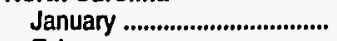 & $w$ & - & 32.8 & 32.7 & 33.8 & 32.7 \\
\hline February ................................ & $w$ & - & 37.8 & w & 38.5 & $w$ \\
\hline March ......................................... & $\dddot{W}$ & - & W & 30.0 & 34.5 & 30.0 \\
\hline April .................................. & w & - & 29.5 & $W$ & 30.2 & W \\
\hline May & $w$ & w & 31.5 & 30.5 & 32.2 & 30.5 \\
\hline June ………………………….... & $w$ & - & 33.1 & $w$ & 33.8 & $w$ \\
\hline 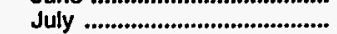 & $w$ & - & $w$ & w & 38.5 & w \\
\hline August & $\ddot{w}$ & w & 38.2 & $w$ & 38.8 & 38.0 \\
\hline 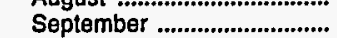 & 52.4 & - & 33.1 & 33.9 & 34.1 & 33.9 \\
\hline October & 51.6 & - & 33.3 & 35.3 & 34.3 & 35.3 \\
\hline November & 52.2 & - & 37.5 & 36.3 & 38.2 & 36.3 \\
\hline December ............................. & 52.9 & - & w & W & w & $w$ \\
\hline 1994 Average & $w$ & $\mathbf{w}$ & 34.9 & 34.4 & 35.6 & 34.7 \\
\hline
\end{tabular}

See footnotes at end of table. 
Table 42. Residual Fuel Oil Prices by PAD District and State (Cents per Gallon Excluding Taxes) - Continued

\begin{tabular}{|c|c|c|c|c|c|c|}
\hline \multirow{2}{*}{$\begin{array}{l}\text { Geographic Area } \\
\text { Month }\end{array}$} & \multicolumn{2}{|c|}{$\begin{array}{l}\text { Sulfur Less Than } \\
\text { or Equal to } 1 \text { Percent }\end{array}$} & \multicolumn{2}{|c|}{$\begin{array}{c}\text { Sulfur Greater Than } \\
1 \text { Percent }\end{array}$} & \multicolumn{2}{|c|}{ Average } \\
\hline & $\begin{array}{l}\text { Sales to } \\
\text { End Users }\end{array}$ & $\begin{array}{c}\text { Sales for } \\
\text { Resale }\end{array}$ & $\begin{array}{c}\text { Sales to } \\
\text { End Users }\end{array}$ & $\begin{array}{c}\text { Sales for } \\
\text { Resale }\end{array}$ & $\begin{array}{c}\text { Sales to } \\
\text { End Users }\end{array}$ & $\begin{array}{c}\text { Sales for } \\
\text { Resale }\end{array}$ \\
\hline \multicolumn{7}{|l|}{ South Carolina } \\
\hline 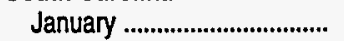 & $W$ & - & $W$ & $W$ & $W$ & $W$ \\
\hline February ............................... & $W$ & - & $W$ & $W$ & $W$ & W \\
\hline 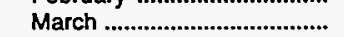 & $w$ & - & $w$ & $\ddot{w}$ & $w$ & $w$ \\
\hline April & w & - & $w$ & $w$ & w & $w$ \\
\hline May & W & - & w & $w$ & $w$ & $\dddot{w}$ \\
\hline 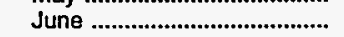 & W & - & w & W & W & $w$ \\
\hline 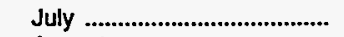 & $w$ & - & W & $W$ & W & w \\
\hline 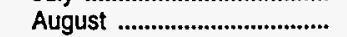 & W & - & W & W & $W$ & W \\
\hline 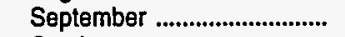 & W & - & W & $W$ & $W$ & $W$ \\
\hline 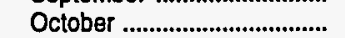 & $w$ & - & W & W & $W$ & W \\
\hline 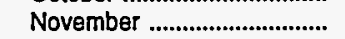 & W & - & $w$ & W & W & W \\
\hline 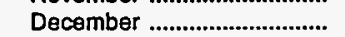 & $\ddot{w}$ & - & w & W & $w$ & $w$ \\
\hline 1994 Average & $\mathbf{W}$ & - & $w$ & $w$ & $w$ & $w$ \\
\hline \multicolumn{7}{|l|}{ Virginia } \\
\hline 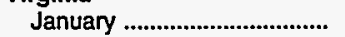 & 40.6 & W & 31.1 & $w$ & 31.8 & $W$ \\
\hline 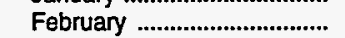 & W & W & 35.1 & 35.2 & 36.1 & 36.2 \\
\hline 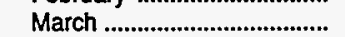 & 41.5 & W & 32.7 & $W$ & 33.5 & 35.5 \\
\hline April & 39.3 & $W$ & 30.0 & 25.9 & 30.7 & 26.1 \\
\hline 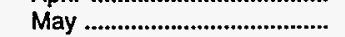 & 38.0 & $W$ & 30.8 & $w$ & 31.2 & $W$ \\
\hline June & 40.3 & w & 32.0 & $w$ & 32.7 & W \\
\hline July & 42.1 & $\dddot{w}$ & 35.7 & 35.9 & 36.3 & 36.6 \\
\hline August & 41.4 & 44.2 & 37.9 & 37.9 & 38.9 & 39.6 \\
\hline September ............................. & 40.5 & $w$ & 33.1 & 32.5 & 34.0 & 33.4 \\
\hline October .................................... & 31.6 & $w$ & 31.7 & 32.9 & 31.6 & 33.8 \\
\hline 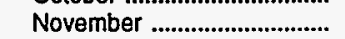 & 42.6 & $W$ & 37.4 & $w$ & 38.1 & $W$ \\
\hline 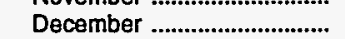 & 45.4 & $w$ & 39.2 & $w$ & 40.0 & $w$ \\
\hline 1994 Average & 36.8 & $\mathbf{w}$ & 33.4 & 31.7 & 34.2 & 33.2 \\
\hline \multicolumn{7}{|l|}{ West Virginia } \\
\hline 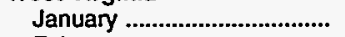 & W & - & $w$ & W & $w$ & $w$ \\
\hline 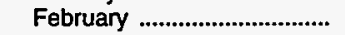 & W & $w$ & 32.2 & - & 32.8 & w \\
\hline 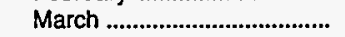 & W & $w$ & 35.2 & - & 35.5 & $w$ \\
\hline 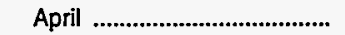 & $w$ & $w$ & $w$ & - & $W$ & $w$ \\
\hline 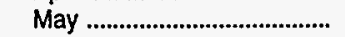 & W & - & W & - & $W$ & - \\
\hline June & $W$ & - & $W$ & - & W & - \\
\hline 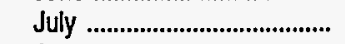 & - & - & $W$ & - & $W$ & - \\
\hline August .................................... & $w$ & - & $W$ & - & W & - \\
\hline 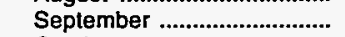 & $w$ & - & $w$ & - & 34.8 & - \\
\hline 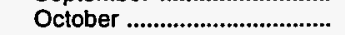 & $w$ & - & $w$ & - & $w$ & - \\
\hline 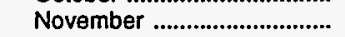 & $w$ & - & 36.3 & $w$ & 36.4 & $w$ \\
\hline 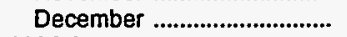 & $w$ & - & $W$ & - & $W$ & - \\
\hline 1994 Average & $\mathbf{W}$ & $\mathbf{W}$ & 34.3 & $\mathbf{W}$ & 34.5 & 33.9 \\
\hline \multicolumn{7}{|l|}{ PAD District II } \\
\hline 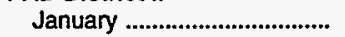 & 41.4 & 39.5 & 31.8 & 24.7 & 34.4 & 28.3 \\
\hline 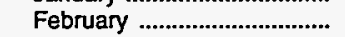 & 41.7 & 42.1 & 32.0 & 27.3 & 35.0 & 30.8 \\
\hline 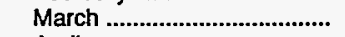 & 37.8 & 42.6 & 30.1 & 25.1 & 32.6 & 28.7 \\
\hline April & 38.4 & 45.2 & 29.8 & 25.9 & 30.9 & 29.8 \\
\hline May ........................................ & 38.3 & 41.5 & 31.3 & 26.3 & 32.7 & 28.5 \\
\hline 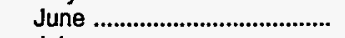 & 40.1 & 36.7 & 31.9 & 28.7 & 34.8 & 30.3 \\
\hline July ........................................ & 41.9 & 31.3 & 34.0 & 32.1 & 38.1 & 31.9 \\
\hline August & 40.2 & 33.9 & 32.9 & 31.1 & 34.5 & 32.1 \\
\hline 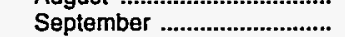 & 40.8 & 34.3 & 31.1 & 29.1 & 33.6 & 30.1 \\
\hline 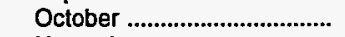 & 31.8 & 33.8 & 31.9 & 28.8 & 31.9 & 30.7 \\
\hline 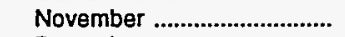 & 40.7 & 34.1 & 31.5 & 28.7 & 32.9 & 29.9 \\
\hline 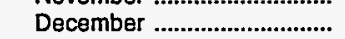 & 41.1 & 39.5 & 32.7 & 27.1 & 34.2 & 28.3 \\
\hline 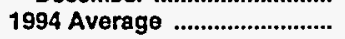 & 38.5 & 36.8 & 31.7 & 27.8 & 33.7 & 30.0 \\
\hline
\end{tabular}

See footnotes at end of table. 
Table 42. Residual Fuel Oil Prices by PAD District and State (Cents per Gallon Excluding Taxes) - Continued

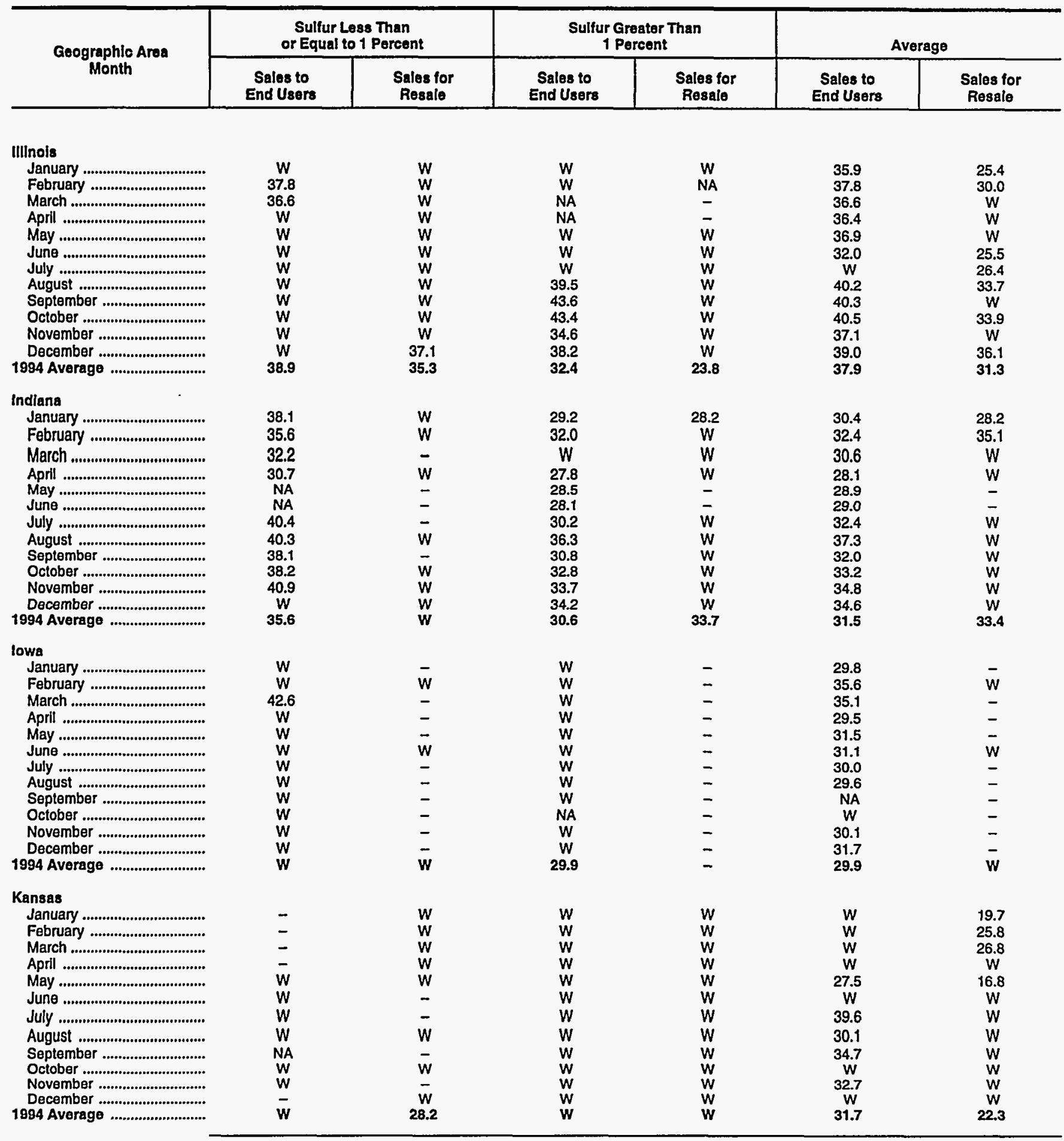

See footnotes at end of table. 
Table 42. Residual Fuel OII Prices by PAD District and State (Cents per Gallon Excluding Taxes) - Continued

\begin{tabular}{|c|c|c|c|c|c|c|}
\hline \multirow{2}{*}{$\begin{array}{l}\text { Geographle Area } \\
\text { Month }\end{array}$} & \multicolumn{2}{|c|}{$\begin{array}{l}\text { Sulfur Lese Than } \\
\text { or Equal to } 1 \text { Percent }\end{array}$} & \multicolumn{2}{|c|}{$\begin{array}{c}\text { Sulfur Greater Than } \\
1 \text { Porcent }\end{array}$} & \multicolumn{2}{|c|}{ Average } \\
\hline & $\begin{array}{l}\text { Sales to } \\
\text { End Users }\end{array}$ & $\begin{array}{l}\text { Sales for } \\
\text { Resale }\end{array}$ & $\begin{array}{l}\text { Sales to } \\
\text { End Users }\end{array}$ & $\begin{array}{l}\text { Sales for } \\
\text { Resale }\end{array}$ & $\begin{array}{l}\text { Sales to } \\
\text { End Users }\end{array}$ & $\begin{array}{l}\text { Sales for } \\
\text { Resalo }\end{array}$ \\
\hline \multicolumn{7}{|l|}{ Kentucky } \\
\hline January .................................... & $w$ & - & $w$ & - & 43.5 & - \\
\hline 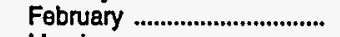 & $W$ & $w$ & W & - & 32.8 & $w$ \\
\hline March ........................................ & $W$ & - & $W$ & - & 33.5 & - \\
\hline 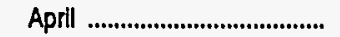 & $W$ & W & W & - & 31.9 & $w$ \\
\hline May ........................................... & $W$ & - & $\ddot{W}$ & - & 32.3 & - \\
\hline June ....................................... & W & - & $w$ & - & 32.7 & - \\
\hline 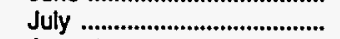 & W & - & $W$ & - & 36.2 & - \\
\hline August & $w$ & $w$ & $w$ & $w$ & 43.1 & $w$ \\
\hline September ............................. & $w$ & - & $w$ & - & 40.7 & - \\
\hline 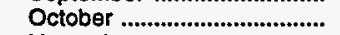 & 47.5 & - & $w$ & - & 38.5 & - \\
\hline November ............................... & $W$ & - & $\ddot{w}$ & - & 39.9 & - \\
\hline 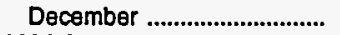 & $W$ & $w$ & w & $w$ & 41.6 & W \\
\hline 1994 Average & 47.5 & 38.9 & $W$ & $W$ & 36.1 & 38.7 \\
\hline \multicolumn{7}{|l|}{ Michigan } \\
\hline 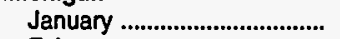 & 43.4 & $w$ & 33.7 & 29.4 & 39.1 & 39.0 \\
\hline 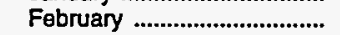 & 43.1 & $\ddot{w}$ & 34.5 & 35.8 & 40.8 & 43.8 \\
\hline 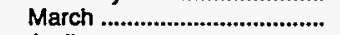 & 44.8 & w & NA & $\mathbf{3 4 . 0}$ & 38.0 & 39.1 \\
\hline April & 42.6 & $w$ & NA & 28.7 & 36.2 & 35.4 \\
\hline 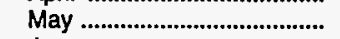 & 44.1 & $\ddot{w}$ & 41.6 & 26.6 & 42.8 & 29.8 \\
\hline 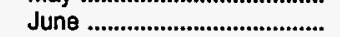 & 44.1 & W & 40.4 & 36.4 & 43.0 & 40.2 \\
\hline July .......................................... & 43.4 & $w$ & 40.2 & $W$ & 42.6 & $W$ \\
\hline 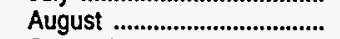 & NA & $\dddot{W}$ & NA & 35.8 & 38.8 & 40.1 \\
\hline 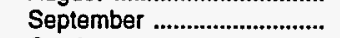 & 41.9 & W & NA & $w$ & 38.7 & $w$ \\
\hline October ..................................... & 42.7 & $w$ & NA & w & 39.0 & $\dddot{w}$ \\
\hline November ............................. & 45.4 & $w$ & NA & $\ddot{w}$ & 38.1 & 37.6 \\
\hline December ................................ & 42.8 & $w$ & 37.2 & $\dddot{w}$ & 38.8 & 43.6 \\
\hline 1994 Average .......................... & 43.5 & 44.6 & 35.6 & 31.9 & 39.9 & 37.6 \\
\hline \multicolumn{7}{|l|}{ Minnesota } \\
\hline January .................................. & $W$ & $W$ & 31.9 & W & 32.0 & $w$ \\
\hline February ................................. & $W$ & $W$ & 32.7 & $w$ & 32.8 & W \\
\hline 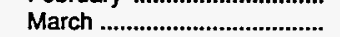 & $w$ & W & 29.8 & $w$ & 30.0 & $w$ \\
\hline 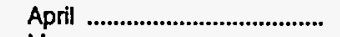 & NA & - & 29.7 & w & 29.8 & $w$ \\
\hline 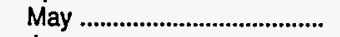 & - & $W$ & $W$ & w & $W$ & $w$ \\
\hline 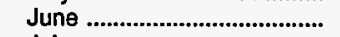 & - & W & 25.8 & $\ddot{w}$ & 25.8 & $w$ \\
\hline July & - & $W$ & $W$ & $\ddot{w}$ & $W$ & $w$ \\
\hline 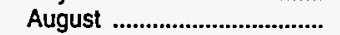 & NA & $W$ & NA & $w$ & NA & $w$ \\
\hline 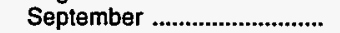 & NA & - & $w$ & $w$ & $w$ & $w$ \\
\hline 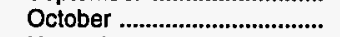 & NA & W & NA & $w$ & NA & $w$ \\
\hline 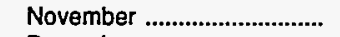 & NA & $W$ & NA & $\ddot{w}$ & NA & $w$ \\
\hline 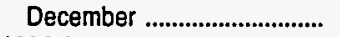 & NA & - & NA & W & NA & w \\
\hline 1994 Average .......................... & $W$ & $\mathbf{W}$ & 30.6 & $w$ & 30.7 & W \\
\hline \multicolumn{7}{|l|}{ Missouri } \\
\hline 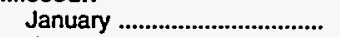 & $w$ & $w$ & $w$ & - & 37.9 & $w$ \\
\hline 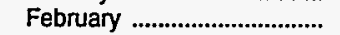 & NA & W & W & - & 23.2 & $w$ \\
\hline 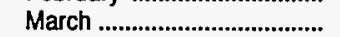 & NA & $W$ & W & NA & NA & NA \\
\hline 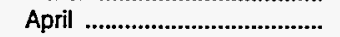 & - & 40.4 & W & NA & $w$ & NA \\
\hline 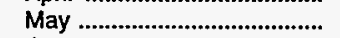 & - & $W$ & $w$ & - & $w$ & $W$ \\
\hline 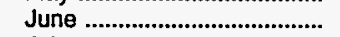 & - & W & $W$ & - & $w$ & $w$ \\
\hline 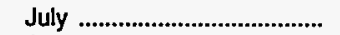 & - & $W$ & $\dddot{w}$ & - & $\dddot{w}$ & $\dddot{w}$ \\
\hline August & $w$ & $w$ & NA & NA & NA & 34.8 \\
\hline September ............................ & W & 29.5 & 21.7 & NA & 22.6 & 27.0 \\
\hline 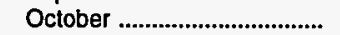 & $W$ & $W$ & 19.8 & $w$ & 20.1 & 24.1 \\
\hline 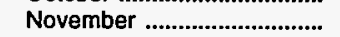 & $w$ & $w$ & NA & $w$ & NA & $\begin{array}{l}<4.1 \\
23.7\end{array}$ \\
\hline 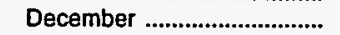 & $w$ & W & NA & 22.3 & NA & 23.0 \\
\hline 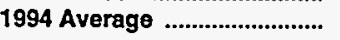 & 48.9 & 35.2 & 22.6 & 21.7 & 23.3 & 30.3 \\
\hline
\end{tabular}

See footnotes at end of table. 
Table 42. Residual Fuel OIl Prices by PAD District and State (Cents per Gallon Excluding Taxes) - Continued

\begin{tabular}{|c|c|c|c|c|c|c|}
\hline \multirow{2}{*}{$\begin{array}{l}\text { Geographio Area } \\
\text { Month }\end{array}$} & \multicolumn{2}{|c|}{$\begin{array}{l}\text { Sulfur Lose Than } \\
\text { or Equal to } 1 \text { Porcent }\end{array}$} & \multicolumn{2}{|c|}{$\begin{array}{c}\text { Sulfur Greater Than } \\
1 \text { Percent }\end{array}$} & \multicolumn{2}{|c|}{ Average } \\
\hline & $\begin{array}{l}\text { Sales to } \\
\text { End Users }\end{array}$ & $\begin{array}{l}\text { Sales for } \\
\text { Resale }\end{array}$ & $\begin{array}{l}\text { Sales to } \\
\text { End Users }\end{array}$ & $\begin{array}{l}\text { Sales tor } \\
\text { Resale }\end{array}$ & $\begin{array}{l}\text { Sales to } \\
\text { End Usara }\end{array}$ & $\begin{array}{c}\text { Sales for } \\
\text { Resale }\end{array}$ \\
\hline \multicolumn{7}{|l|}{ Nebraaka } \\
\hline January .................................. & $w$ & $w$ & W & - & $W$ & $w$ \\
\hline February ................................ & $W$ & $W$ & W & - & W & $w$ \\
\hline March ....................................... & $W$ & $W$ & NA & - & $w$ & $\ddot{w}$ \\
\hline 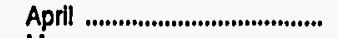 & $W$ & - & NA & - & $w$ & - \\
\hline May ........................................ & $W$ & $W$ & - & - & W & $w$ \\
\hline June ....................................... & $W$ & W & - & - & $\dddot{W}$ & W \\
\hline July ........................................... & $W$ & - & - & - & W & - \\
\hline August ................................... & $W$ & - & NA & $W$ & W & $W$ \\
\hline September ............................. & $w$ & - & NA & - & $\ddot{w}$ & - \\
\hline October ................................... & $\mathbf{W}$ & - & NA & - & $\ddot{w}$ & - \\
\hline November ............................. & W & - & NA & - & w & - \\
\hline December ............................... & $w$ & - & NA & $w$ & $\ddot{W}$ & $w$ \\
\hline 1984 Avarage ............................ & $\mathbf{w}$ & $\mathbf{w}$ & $w$ & $w$ & 29.6 & 33.3 \\
\hline \multicolumn{7}{|l|}{ North Dakota } \\
\hline 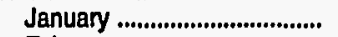 & $w$ & - & $w$ & W & 30.6 & $w$ \\
\hline 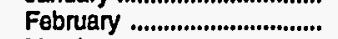 & $w$ & - & $w$ & w & $W$ & $w$ \\
\hline 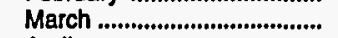 & w & - & $W$ & $W$ & $W$ & w \\
\hline April & - & $w$ & $w$ & - & $\ddot{w}$ & $\dddot{w}$ \\
\hline May & - & W & $w$ & NA & $\dddot{w}$ & W \\
\hline June ...................................... & - & $\ddot{w}$ & $\ddot{w}$ & NA & w & $\mathbf{w}$ \\
\hline July ........................................ & - & $W$ & w & $w$ & $\dddot{w}$ & NA \\
\hline 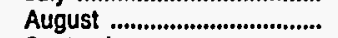 & - & $w$ & $\ddot{w}$ & - & $\ddot{w}$ & $w$ \\
\hline September ............................ & - & $w$ & $\ddot{w}$ & - & w & $w$ \\
\hline 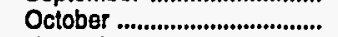 & - & w & $\ddot{w}$ & - & w & $w$ \\
\hline November ................................ & - & - & $w$ & $w$ & $w$ & $w$ \\
\hline December .............................. & - & - & $w$ & $\mathbf{W}$ & $w$ & $w$ \\
\hline 1994 Average ................................. & $\mathbf{w}$ & $\mathbf{W}$ & 31.4 & 37.5 & 35.8 & 40.8 \\
\hline \multicolumn{7}{|l|}{ Ohlo } \\
\hline 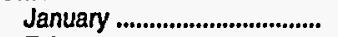 & 39.5 & $w$ & 35.5 & $w$ & 38.3 & 22.0 \\
\hline February ................................ & 43.0 & $w$ & 37.9 & 26.3 & 39.5 & 26.8 \\
\hline March ...................................... & 41.5 & $\mathbf{w}$ & 36.6 & $W$ & 37.5 & 27.1 \\
\hline 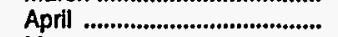 & 39.7 & $\ddot{w}$ & 39.3 & w & 39.3 & 25.1 \\
\hline May ......................................... & $w$ & $w$ & 35.5 & w & 36.8 & 26.2 \\
\hline 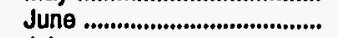 & $w$ & $w$ & 33.6 & w & 34.3 & 30.2 \\
\hline 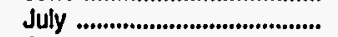 & 38.3 & $\ddot{w}$ & 37.1 & $\ddot{w}$ & 37.4 & 32.8 \\
\hline 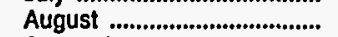 & $w$ & - & 38.6 & w & 39.0 & $w$ \\
\hline September ............................. & $\ddot{w}$ & - & 36.2 & $w$ & 37.1 & $w$ \\
\hline 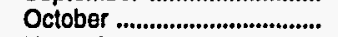 & $w$ & - & 36.7 & $w$ & 37.5 & W \\
\hline November .............................. & $w$ & - & 33.2 & $w$ & 33.8 & $w$ \\
\hline December ............................ & $w$ & - & 35.0 & $\ddot{W}$ & 35.3 & $w$ \\
\hline 1894 Average ........................... & 40.7 & $\mathbf{w}$ & 36.5 & w & 37.6 & 28.3 \\
\hline \multicolumn{7}{|l|}{ Oklahoma } \\
\hline 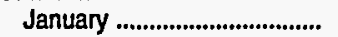 & - & $W$ & $w$ & $w$ & $w$ & $w$ \\
\hline February ................................. & - & $w$ & $w$ & $w$ & W & W \\
\hline March ..................................... & NA & $\rightarrow$ & $w$ & - & $w$ & - \\
\hline 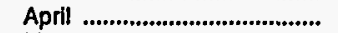 & NA & - & $w$ & - & $\mathbf{w}$ & - \\
\hline 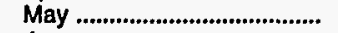 & - & $w$ & $w$ & - & $w$ & $w$ \\
\hline 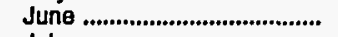 & $w$ & $\mathbf{w}$ & $\mathbf{w}$ & - & $w$ & $\ddot{w}$ \\
\hline July ........................................ & - & $w$ & $w$ & - & $\ddot{w}$ & $w$ \\
\hline 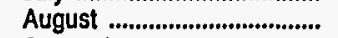 & $W$ & $w$ & $w$ & - & 32.3 & $\ddot{w}$ \\
\hline September ........................... & NA & $w$ & $w$ & - & $W$ & $w$ \\
\hline October .................................... & NA & W & $w$ & - & W & w \\
\hline November .............................. & NA & $\ddot{w}$ & $w$ & $w$ & $w$ & $\ddot{w}$ \\
\hline 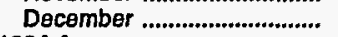 & NA & $w$ & $w$ & $w$ & $w$ & $w$ \\
\hline 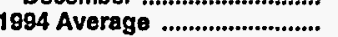 & $\mathbf{W}$ & 28.7 & w & $\mathbf{w}$ & $\mathbf{w}$ & 28.3 \\
\hline
\end{tabular}

See footnotes at end of table. 
Table 42. Residual Fuel Oil Prices by PAD District and State

(Cents per Gallon Excluding Taxes) - Continued

\begin{tabular}{|c|c|c|c|c|c|c|}
\hline \multirow{2}{*}{$\begin{array}{l}\text { Goographic Area } \\
\text { Month }\end{array}$} & \multicolumn{2}{|c|}{$\begin{array}{l}\text { Sulfur Less Than } \\
\text { or Equal to } 1 \text { Percent }\end{array}$} & \multicolumn{2}{|c|}{$\begin{array}{c}\text { Sulfur Greater Than } \\
1 \text { Percent }\end{array}$} & \multicolumn{2}{|c|}{ Average } \\
\hline & $\begin{array}{l}\text { Sales to } \\
\text { End Users }\end{array}$ & $\begin{array}{l}\text { Sales for } \\
\text { Resalo }\end{array}$ & $\begin{array}{l}\text { Sales to } \\
\text { End Users }\end{array}$ & $\begin{array}{c}\text { Sales for } \\
\text { Resale }\end{array}$ & $\begin{array}{l}\text { Sales to } \\
\text { End Users }\end{array}$ & $\begin{array}{l}\text { Sales for } \\
\text { Resale }\end{array}$ \\
\hline \multicolumn{7}{|l|}{ South Dakota } \\
\hline 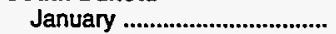 & - & w & w & w & $w$ & $w$ \\
\hline February .............................. & - & $w$ & - & $w$ & - & 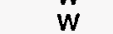 \\
\hline 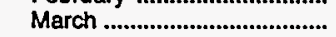 & - & $w$ & NA & $w$ & NA & $\ddot{w}$ \\
\hline April & - & $w$ & NA & $\ddot{w}$ & NA & $\dddot{w}$ \\
\hline 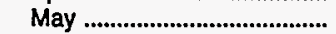 & - & W & $w$ & w & $w$ & $w$ \\
\hline 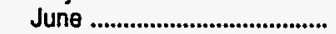 & - & w & - & w & - & $w$ \\
\hline 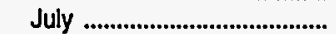 & - & W & - & - & - & $w$ \\
\hline 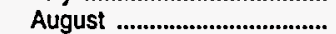 & - & $w$ & NA & - & NA & $w$ \\
\hline September ............................... & - & $w$ & NA & - & NA & $w$ \\
\hline 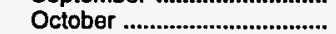 & - & $\ddot{w}$ & NA & - & NA & $w$ \\
\hline November .............................. & - & - & NA & - & NA & - \\
\hline December ................................. & - & - & NA & - & NA & - \\
\hline 1994 Average & - & $\bar{w}$ & $w$ & $\bar{w}$ & w & $\bar{w}$ \\
\hline \multicolumn{7}{|l|}{ Tennessee } \\
\hline 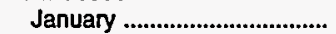 & w & w & $w$ & w & 40.7 & 29.8 \\
\hline 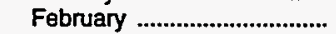 & W & - & 37.3 & 32.0 & 39.6 & 32.0 \\
\hline March & $\ddot{w}$ & w & $w$ & $w$ & 39.2 & 34.1 \\
\hline April & $w$ & $w$ & $w$ & $w$ & 41.3 & 30.3 \\
\hline 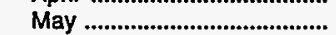 & W & - & $w$ & $w$ & $w$ & $w$ \\
\hline June ………………………........ & $w$ & w & $w$ & $w$ & $w$ & 30.9 \\
\hline 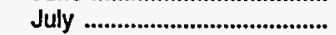 & $w$ & $w$ & w & w & 41.3 & 34.9 \\
\hline 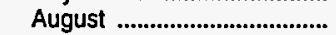 & w & $w$ & $w$ & $\ddot{w}$ & $w$ & 34.9 \\
\hline 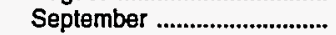 & w & w & w & w & w & $w$ \\
\hline October & $\mathbf{w}$ & w & $w$ & $w$ & $w$ & 32.5 \\
\hline 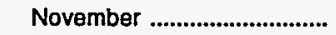 & w & $w$ & w & $\mathbf{w}$ & $w$ & $w$ \\
\hline 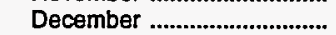 & $\ddot{w}$ & $\ddot{w}$ & $\ddot{w}$ & w & $w$ & $\ddot{w}$ \\
\hline 1994 Average & w & $w$ & 37.9 & 30.2 & 40.5 & 30.7 \\
\hline \multicolumn{7}{|l|}{ Wisconsin } \\
\hline 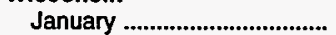 & 33.8 & $w$ & 34.1 & $w$ & 34.1 & $w$ \\
\hline 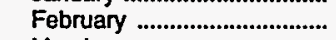 & $w$ & $\ddot{w}$ & $w$ & $\dddot{w}$ & $w$ & $w$ \\
\hline 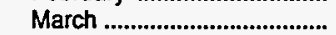 & NA & $w$ & $w$ & w & $w$ & $\ddot{w}$ \\
\hline 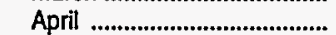 & $w$ & $w$ & NA & 24.4 & NA & 24.4 \\
\hline 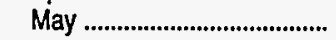 & NA & $w$ & 36.0 & 27.5 & 35.9 & 27.5 \\
\hline 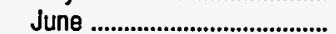 & NA & - & 34.5 & 26.0 & 34.5 & 26.0 \\
\hline 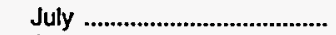 & $w$ & - & 35.3 & w & 35.3 & $w$ \\
\hline August & $w$ & - & NA & 29.3 & NA & 29.3 \\
\hline September ............................ & $\ddot{w}$ & - & NA & $w$ & NA & $w$ \\
\hline 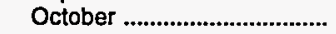 & w & - & NA & $w$ & NA & $w$ \\
\hline 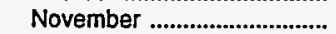 & $w$ & - & NA & $\ddot{w}$ & NA & $w$ \\
\hline 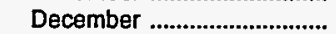 & NA & - & $w$ & $w$ & $w$ & $\ddot{w}$ \\
\hline 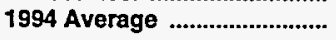 & 42.5 & $w$ & NA & 24.6 & NA & 24.6 \\
\hline \multicolumn{7}{|l|}{ PAD District III } \\
\hline 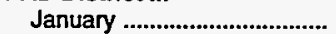 & $w$ & 25.5 & 24.5 & 21.8 & 24.7 & 23.4 \\
\hline February ...................................... & $w$ & 25.2 & 26.0 & 23.8 & 26.2 & 24.4 \\
\hline 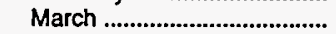 & $w$ & 27.0 & 24.9 & 22.7 & 25.0 & 24.8 \\
\hline 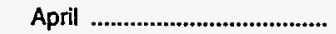 & $w$ & 26.6 & 26.9 & 25.6 & 27.0 & 26.0 \\
\hline May & $w$ & 29.2 & 29.1 & 27.9 & 29.1 & 28.5 \\
\hline 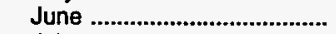 & 33.8 & 35.4 & 32.4 & 30.5 & 32.6 & 32.6 \\
\hline 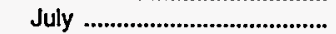 & $w$ & 37.2 & NA & NA & 37.1 & 36.3 \\
\hline 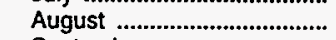 & w & 37.0 & 33.7 & 30.6 & 33.8 & 34.4 \\
\hline 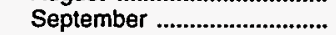 & $w$ & 32.3 & 28.2 & 25.3 & 28.4 & 27.5 \\
\hline October & w & 29.4 & 31.0 & 30.9 & 31.5 & 30.4 \\
\hline 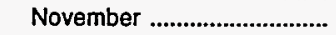 & $w$ & 34.2 & 33.4 & 33.3 & 33.9 & 33.6 \\
\hline 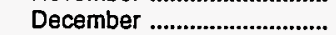 & $w$ & 31.8 & 33.6 & 31.4 & 33.9 & 31.4 \\
\hline 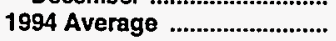 & $w$ & 31.0 & 29.8 & 28.1 & 30.1 & 29.4 \\
\hline
\end{tabular}

See footnotes at end of table. 
Table 42. Residual Fuel Oil Prices by PAD District and State

(Cents per Gallon Excluding Taxes) - Continued

\begin{tabular}{|c|c|c|c|c|c|c|}
\hline \multirow{2}{*}{$\begin{array}{l}\text { Geographlc Area } \\
\text { Month }\end{array}$} & \multicolumn{2}{|c|}{$\begin{array}{l}\text { Sulfur Less Than } \\
\text { or Equal to } 1 \text { Percent }\end{array}$} & \multicolumn{2}{|c|}{$\begin{array}{c}\text { Sulfur Greater Than } \\
1 \text { Percent } \\
\end{array}$} & \multicolumn{2}{|c|}{ Average } \\
\hline & $\begin{array}{c}\text { Sales to } \\
\text { End Users }\end{array}$ & $\begin{array}{l}\text { Sales for } \\
\text { Resale }\end{array}$ & $\begin{array}{c}\text { Sales to } \\
\text { End Users }\end{array}$ & $\begin{array}{c}\text { Sales for } \\
\text { Resale }\end{array}$ & $\begin{array}{l}\text { Sales to } \\
\text { End Users }\end{array}$ & $\begin{array}{c}\text { Sales for } \\
\text { Resale }\end{array}$ \\
\hline \multicolumn{7}{|l|}{ Alabama } \\
\hline 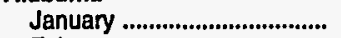 & $w$ & $w$ & 27.2 & - & 27.4 & $w$ \\
\hline 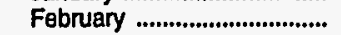 & - & w & 31.3 & w & 31.3 & $\ddot{w}$ \\
\hline March ……............................... & - & W & 27.5 & $w$ & 27.5 & w \\
\hline April ........................................... & - & $w$ & 26.8 & $w$ & 26.8 & 30.9 \\
\hline May .................................... & - & $\ddot{w}$ & 32.5 & $w$ & 32.5 & 39.2 \\
\hline 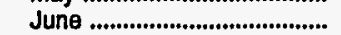 & - & $w$ & 34.2 & W & 34.2 & 33.2 \\
\hline 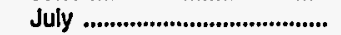 & w & w & 37.4 & 33.3 & 37.4 & 33.6 \\
\hline 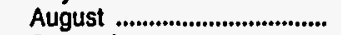 & w & w & 39.7 & $w$ & 39.7 & NA \\
\hline 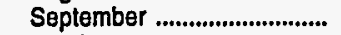 & $\mathbf{w}$ & w & 32.9 & w & 33.0 & 39.6 \\
\hline October .......................................... & W & w & 33.6 & 32.0 & 33.7 & 35.0 \\
\hline November ............................... & W & $W$ & 35.5 & $W$ & 35.6 & 45.1 \\
\hline December ................................. & w & W & 38.5 & W & 38.5 & $W$ \\
\hline 1994 Average & 44.4 & $w$ & 32.2 & 33.5 & 32.3 & 34.8 \\
\hline \multicolumn{7}{|l|}{ Arkansas } \\
\hline 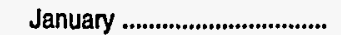 & - & - & w & - & w & - \\
\hline 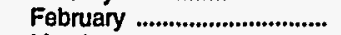 & - & - & w & - & w & - \\
\hline 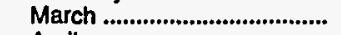 & - & - & $w$ & - & w & - \\
\hline 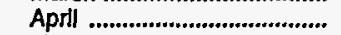 & w & - & $\mathbf{3 7 . 3}$ & - & 37.2 & - \\
\hline 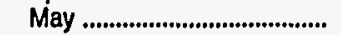 & - & - & $w$ & - & $w$ & - \\
\hline June ............................................. & - & - & $\ddot{w}$ & - & $\ddot{w}$ & - \\
\hline 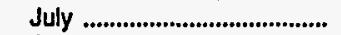 & w & - & $w$ & - & 34.5 & - \\
\hline 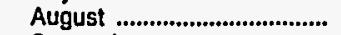 & - & - & $w$ & - & $w$ & - \\
\hline September ............................. & - & - & W & - & $w$ & - \\
\hline 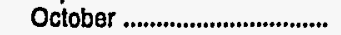 & - & - & w & - & $w$ & - \\
\hline November .......................... & - & - & $w$ & - & w & - \\
\hline December ........................... & - & - & 30.0 & - & 30.0 & - \\
\hline 1994 Average ................................. & $\mathbf{w}$ & - & 32.2 & - & 33.1 & - \\
\hline \multicolumn{7}{|l|}{ Loulsiana } \\
\hline January ....................................... & w & 27.9 & 22.5 & 21.8 & 23.5 & 23.3 \\
\hline February ....................................... & $w$ & NA & 24.7 & 24.3 & 25.5 & 24.8 \\
\hline 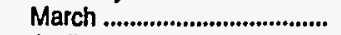 & w & 29.1 & 25.1 & 22.2 & 25.2 & 24.3 \\
\hline April .............................................. & $w$ & w & 25.9 & 25.5 & 26.6 & 25.6 \\
\hline 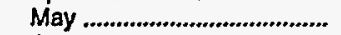 & $w$ & 32.4 & 27.4 & 28.6 & 27.4 & 28.7 \\
\hline 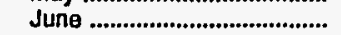 & $w$ & 38.8 & 30.8 & 30.9 & 31.9 & 33.9 \\
\hline 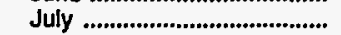 & $w$ & $w$ & 34.7 & 35.6 & 35.2 & 37.5 \\
\hline 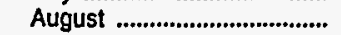 & w & 40.3 & 32.0 & 31.0 & 32.9 & 36.1 \\
\hline 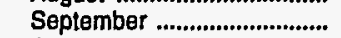 & w & 38.2 & 27.8 & 26.2 & 28.2 & 28.8 \\
\hline 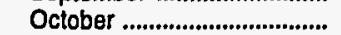 & W & $w$ & 30.3 & 31.6 & 31.5 & 31.6 \\
\hline November ..................................... & $w$ & w & 33.6 & 32.8 & 34.4 & 33.7 \\
\hline 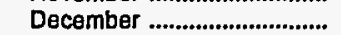 & $w$ & 32.8 & 33.1 & 31.2 & 33.7 & 31.2 \\
\hline 1994 Average & $\mathbf{w}$ & 36.0 & 29.0 & 28.5 & 29.8 & 30.2 \\
\hline \multicolumn{7}{|l|}{ Misslssippi } \\
\hline 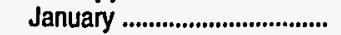 & - & - & 26.0 & NA & 26.0 & NA \\
\hline 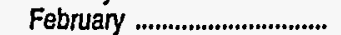 & w & NA & 31.1 & NA & 31.1 & NA \\
\hline 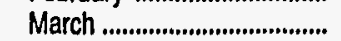 & W & W & 27.4 & NA & 27.5 & $\mathrm{~W}$ \\
\hline 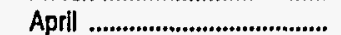 & w & W & 28.2 & W & 28.5 & 25.2 \\
\hline 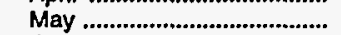 & $w$ & $w$ & 28.3 & - & 28.6 & $w$ \\
\hline 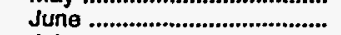 & $w$ & - & 28.4 & $w$ & 28.9 & $w$ \\
\hline 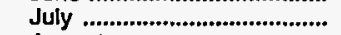 & $\mathbf{w}$ & - & 29.3 & $w$ & 29.9 & $w$ \\
\hline 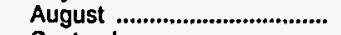 & w & - & 37.3 & $w$ & 37.5 & w \\
\hline 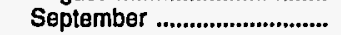 & w & - & 30.3 & w & 30.5 & w \\
\hline 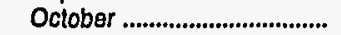 & w & - & 36.4 & NA & 36.5 & NA \\
\hline 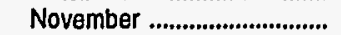 & - & - & 37.1 & NA & 37.1 & NA \\
\hline December ...................................... & - & - & 37.4 & w & 37.4 & $w$ \\
\hline 1994 Average ................................ & $\mathbf{w}$ & w & 32.3 & W & 32.5 & NA \\
\hline
\end{tabular}

See footnotes at end of table. 
Table 42. Residual Fuel Oil Prices by PAD District and State (Cents per Gallon Excluding Taxes) - Continued

\begin{tabular}{|c|c|c|c|c|c|c|}
\hline \multirow{2}{*}{$\begin{array}{l}\text { Geographic Area } \\
\text { Month }\end{array}$} & \multicolumn{2}{|c|}{$\begin{array}{l}\text { Sulfur Less Than } \\
\text { or Equal to } 1 \text { Porcent }\end{array}$} & \multicolumn{2}{|c|}{$\begin{array}{c}\text { Sulfur Greater Than } \\
1 \text { Percent }\end{array}$} & \multicolumn{2}{|c|}{ Average } \\
\hline & $\begin{array}{l}\text { Sales to } \\
\text { End Users }\end{array}$ & $\begin{array}{l}\text { Sales for } \\
\text { Resale }\end{array}$ & $\begin{array}{l}\text { Sales to } \\
\text { End Users }\end{array}$ & $\begin{array}{l}\text { Sales for } \\
\text { Resale }\end{array}$ & $\begin{array}{c}\text { Sales to } \\
\text { End Users }\end{array}$ & $\begin{array}{c}\text { Sales for } \\
\text { Resale }\end{array}$ \\
\hline \multicolumn{7}{|l|}{ New Mexico } \\
\hline 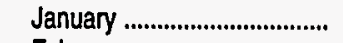 & - & $W$ & - & - & - & $W$ \\
\hline 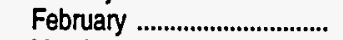 & - & $W$ & - & - & - & $\ddot{w}$ \\
\hline 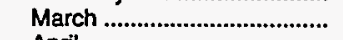 & - & w & - & $w$ & - & $w$ \\
\hline 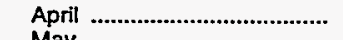 & - & $w$ & - & - & - & $w$ \\
\hline & - & $w$ & - & - & - & $w$ \\
\hline 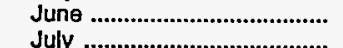 & - & $\mathbf{w}$ & - & w & - & $\ddot{w}$ \\
\hline & - & w & - & $w$ & - & 18.8 \\
\hline August ................................... & - & $w$ & - & $w$ & - & $w$ \\
\hline 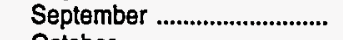 & - & w & - & - & - & w \\
\hline 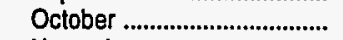 & - & W & - & - & - & $\dddot{w}$ \\
\hline 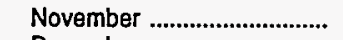 & - & w & - & - & - & $w$ \\
\hline 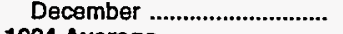 & - & w & - & - & - & $w$ \\
\hline 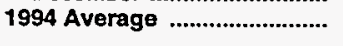 & - & $w$ & - & $w$ & - & 19.1 \\
\hline \multicolumn{7}{|l|}{ Texas } \\
\hline 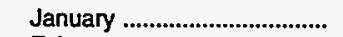 & - & 24.8 & 25.3 & 21.7 & 25.3 & 23.5 \\
\hline 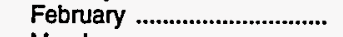 & - & 25.5 & 25.1 & 22.9 & 25.1 & 24.4 \\
\hline 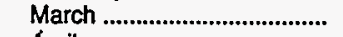 & w & 26.4 & 24.1 & 23.1 & 24.1 & 25.4 \\
\hline 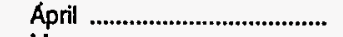 & - & 26.8 & 27.2 & 25.5 & 27.2 & 26.3 \\
\hline 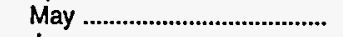 & - & 29.1 & 29.0 & 26.7 & 29.0 & 28.4 \\
\hline 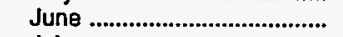 & w & 32.5 & 33.1 & 29.8 & 33.1 & 31.2 \\
\hline July ................................................... & NA & 35.3 & NA & NA & 38.9 & 35.0 \\
\hline August ..................................... & w & 34.9 & 33.8 & 30.1 & 33.8 & 33.2 \\
\hline September ................................... & w & 29.8 & 28.1 & 24.1 & 28.1 & 26.5 \\
\hline 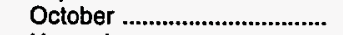 & w & 29.2 & 31.0 & 29.9 & 30.9 & 29.6 \\
\hline 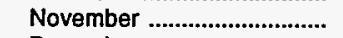 & W & 32.8 & 32.5 & 33.9 & 32.5 & 33.4 \\
\hline 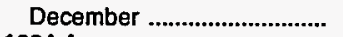 & - & 31.7 & 33.4 & 31.3 & 33.4 & 31.5 \\
\hline 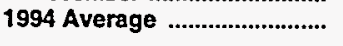 & 31.2 & 29.7 & 29.9 & 27.5 & 29.9 & 28.8 \\
\hline \multicolumn{7}{|l|}{ PAD District IV } \\
\hline 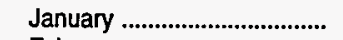 & $w$ & 30.8 & 30.9 & $w$ & 28.7 & 29.5 \\
\hline 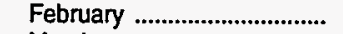 & w & 29.8 & 27.4 & W & $w$ & 21.5 \\
\hline 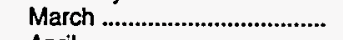 & $w$ & $w$ & 27.7 & W & 30.3 & $w$ \\
\hline April & w & w & 29.3 & w & $w$ & 29.7 \\
\hline 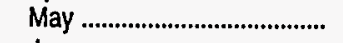 & W & W & 29.2 & $w$ & $w$ & 17.3 \\
\hline 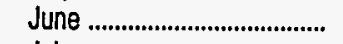 & NA & $W$ & $W$ & W & $W$ & 31.9 \\
\hline 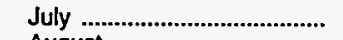 & $w$ & $w$ & 31.8 & w & 32.3 & 23.4 \\
\hline 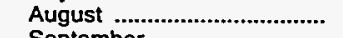 & w & w & 32.1 & w & $w$ & 30.5 \\
\hline September & W & w & 26.5 & w & 26.7 & 23.7 \\
\hline 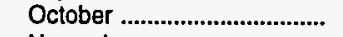 & 35.6 & w & 26.0 & w & 26.8 & 32.9 \\
\hline 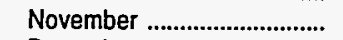 & 35.4 & w & 28.3 & w & 29.4 & 23.2 \\
\hline December ....................................... & 33.3 & 32.7 & 34.2 & $\ddot{w}$ & 34.0 & 22.8 \\
\hline 1994 Average & $w$ & 29.6 & 28.9 & 15.4 & 32.0 & 27.3 \\
\hline \multicolumn{7}{|l|}{ Colorado } \\
\hline 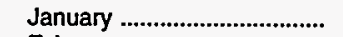 & - & w & - & - & - & $w$ \\
\hline 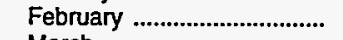 & - & w & - & - & - & $w$ \\
\hline 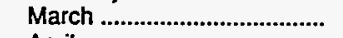 & - & w & - & - & - & $\ddot{w}$ \\
\hline 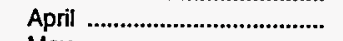 & - & - & - & - & - & - \\
\hline 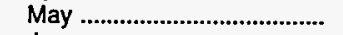 & - & w & - & - & - & $\bar{w}$ \\
\hline 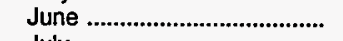 & - & $w$ & - & - & 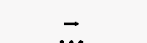 & $w$ \\
\hline July & - & w & w & - & $w$ & $\ddot{w}$ \\
\hline 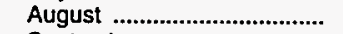 & - & w & - & - & - & $w$ \\
\hline 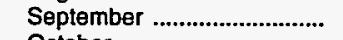 & - & w & - & - & - & $w$ \\
\hline 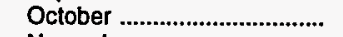 & - & - & - & - & - & - \\
\hline 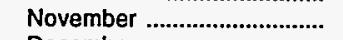 & - & - & - & - & - & - \\
\hline 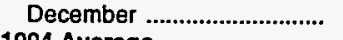 & - & w & - & - & - & $w$ \\
\hline 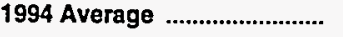 & - & $\mathbf{w}$ & $w$ & - & $w$ & $\ddot{w}$ \\
\hline
\end{tabular}

See footnotes at end of table. 
Table 42. Residual Fuel Oll Prices by PAD District and State (Cents per Gallon Excluding Taxes) - Continued

\begin{tabular}{|c|c|c|c|c|c|c|}
\hline \multirow{2}{*}{$\begin{array}{l}\text { Geographlc Area } \\
\text { Month }\end{array}$} & \multicolumn{2}{|c|}{$\begin{array}{l}\text { Sulfur Less Than } \\
\text { or Equal to } 1 \text { Percent }\end{array}$} & \multicolumn{2}{|c|}{$\begin{array}{c}\text { Sulfur Greator Than } \\
1 \text { Parcent }\end{array}$} & \multicolumn{2}{|c|}{ Average } \\
\hline & $\begin{array}{l}\text { Sales to } \\
\text { End Users }\end{array}$ & $\begin{array}{l}\text { Sales for } \\
\text { Resale }\end{array}$ & $\begin{array}{l}\text { Sales to } \\
\text { End Users }\end{array}$ & $\begin{array}{c}\text { Sales for } \\
\text { Resale }\end{array}$ & $\begin{array}{l}\text { Sales to } \\
\text { End Users }\end{array}$ & $\begin{array}{c}\text { Sales for } \\
\text { Resale }\end{array}$ \\
\hline \multicolumn{7}{|l|}{ Idaho } \\
\hline 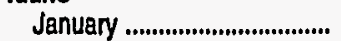 & - & - & $w$ & - & $w$ & _ \\
\hline February .................................. & $w$ & - & w & - & $\dddot{w}$ & - \\
\hline 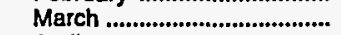 & $w$ & - & $w$ & - & $\ddot{w}$ & - \\
\hline 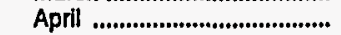 & $w$ & - & $w$ & - & $\ddot{w}$ & - \\
\hline 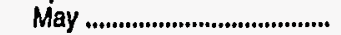 & $\mathbf{w}$ & - & w & - & $w$ & - \\
\hline 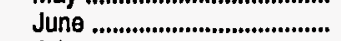 & NA & - & $\ddot{w}$ & - & w & - \\
\hline 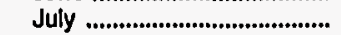 & - & - & - & - & - & - \\
\hline 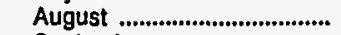 & NA & - & - & - & NA & - \\
\hline September ............................. & - & - & - & - & - & _- \\
\hline 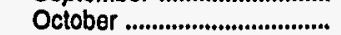 & $w$ & - & - & - & w & _- \\
\hline November ............................. & $w$ & - & w & - & $\ddot{w}$ & _- \\
\hline December ............................... & $\dddot{w}$ & - & $w$ & - & $\dddot{w}$ & - \\
\hline 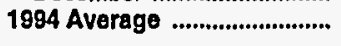 & $\mathbf{w}$ & - & $w$ & - & w & - \\
\hline \multicolumn{7}{|l|}{ Montana } \\
\hline 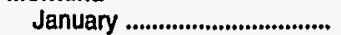 & - & - & w & w & $w$ & w \\
\hline 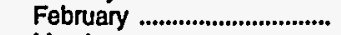 & - & - & w & w & $\mathbf{w}$ & W \\
\hline March ...................................... & - & - & $w$ & $w$ & $\ddot{w}$ & $\dddot{w}$ \\
\hline 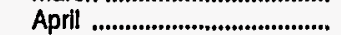 & - & - & $\ddot{w}$ & $\ddot{w}$ & $\dddot{w}$ & $\ddot{w}$ \\
\hline 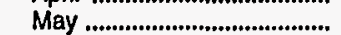 & - & - & - & $w$ & - & $\dddot{w}$ \\
\hline June ....................................... & - & - & w & $w$ & $w$ & $\ddot{w}$ \\
\hline July ............................................... & - & - & - & $w$ & - & $\ddot{w}$ \\
\hline 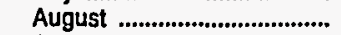 & - & w & NA & $w$ & NA & 30.5 \\
\hline September ................................... & - & - & $w$ & $w$ & $w$ & $w$ \\
\hline October & - & - & NA & $w$ & NA & $w$ \\
\hline 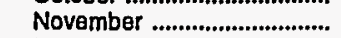 & $\mathbf{w}$ & - & NA & $w$ & $w$ & $w$ \\
\hline December ............................... & $w$ & - & w & $w$ & $w$ & $w$ \\
\hline 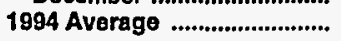 & $\dddot{w}$ & $\mathbf{w}$ & NA & $\mathbf{w}$ & NA & 23.6 \\
\hline \multicolumn{7}{|l|}{ Utah } \\
\hline 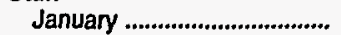 & - & $w$ & w & - & $w$ & $w$ \\
\hline 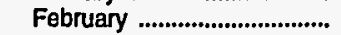 & - & w & W & - & $w$ & $w$ \\
\hline 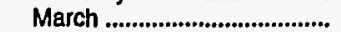 & - & $\ddot{w}$ & 24.1 & - & 24.1 & $\ddot{w}$ \\
\hline 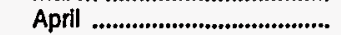 & - & $w$ & $w$ & - & $w$ & $w$ \\
\hline 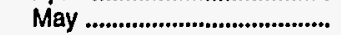 & $w$ & w & $w$ & - & 31.0 & $\ddot{w}$ \\
\hline June ................................... & - & $\ddot{w}$ & $\underline{w}$ & - & $w$ & $\dddot{w}$ \\
\hline July ........................................ & - & - & $w$ & - & $\ddot{w}$ & - \\
\hline August ........................................ & $w$ & NA & $w$ & - & 31.0 & NA \\
\hline September .............................. & w & $w$ & W & - & 27.5 & $w$ \\
\hline 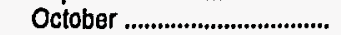 & $w$ & - & W & - & 28.6 & - \\
\hline November ................................... & $W$ & - & W & - & 27.5 & - \\
\hline December ............................. & $w$ & w & w & - & 27.1 & $w$ \\
\hline 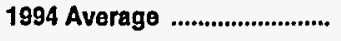 & 45.5 & $\mathbf{w}$ & 27.1 & - & 27.7 & $w$ \\
\hline \multicolumn{7}{|l|}{ Wyoming } \\
\hline January .......................................... & w & $w$ & w & $w$ & $w$ & 29.8 \\
\hline February ................................ & w & $w$ & w & $\ddot{w}$ & $w$ & $w$ \\
\hline 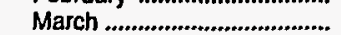 & $w$ & $\ddot{w}$ & $w$ & $w$ & 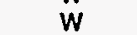 & $\dddot{w}$ \\
\hline 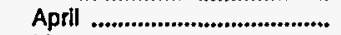 & $w$ & $w$ & $w$ & $w$ & $\ddot{w}$ & 29.8 \\
\hline May .................................... & $w$ & $w$ & $w$ & $w$ & 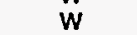 & $w$ \\
\hline 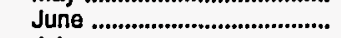 & - & $\ddot{w}$ & - & $\ddot{w}$ & - & 31.9 \\
\hline July ............................................. & w & w & w & w & $w$ & $w$ \\
\hline August ................................. & - & W & $w$ & $w$ & $w$ & 30.5 \\
\hline September ...................................... & - & w & w & w & w & 23.6 \\
\hline October ................................... & - & $w$ & $w$ & w & $\ddot{w}$ & 33.1 \\
\hline 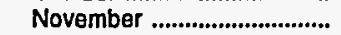 & - & w & NA & w & NA & $w$ \\
\hline 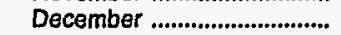 & - & $w$ & $w$ & $w$ & $w$ & $\ddot{w}$ \\
\hline 1994 Average ........................... & $\mathbf{w}$ & $\mathbf{w}$ & $\ddot{w}$ & $\ddot{w}$ & $w$ & 27.2 \\
\hline
\end{tabular}

See lootnotes at end of table. 
Table 42. Residual Fuel Oil Prices by PAD District and State (Cents per Gallon Excluding Taxes) - Continued

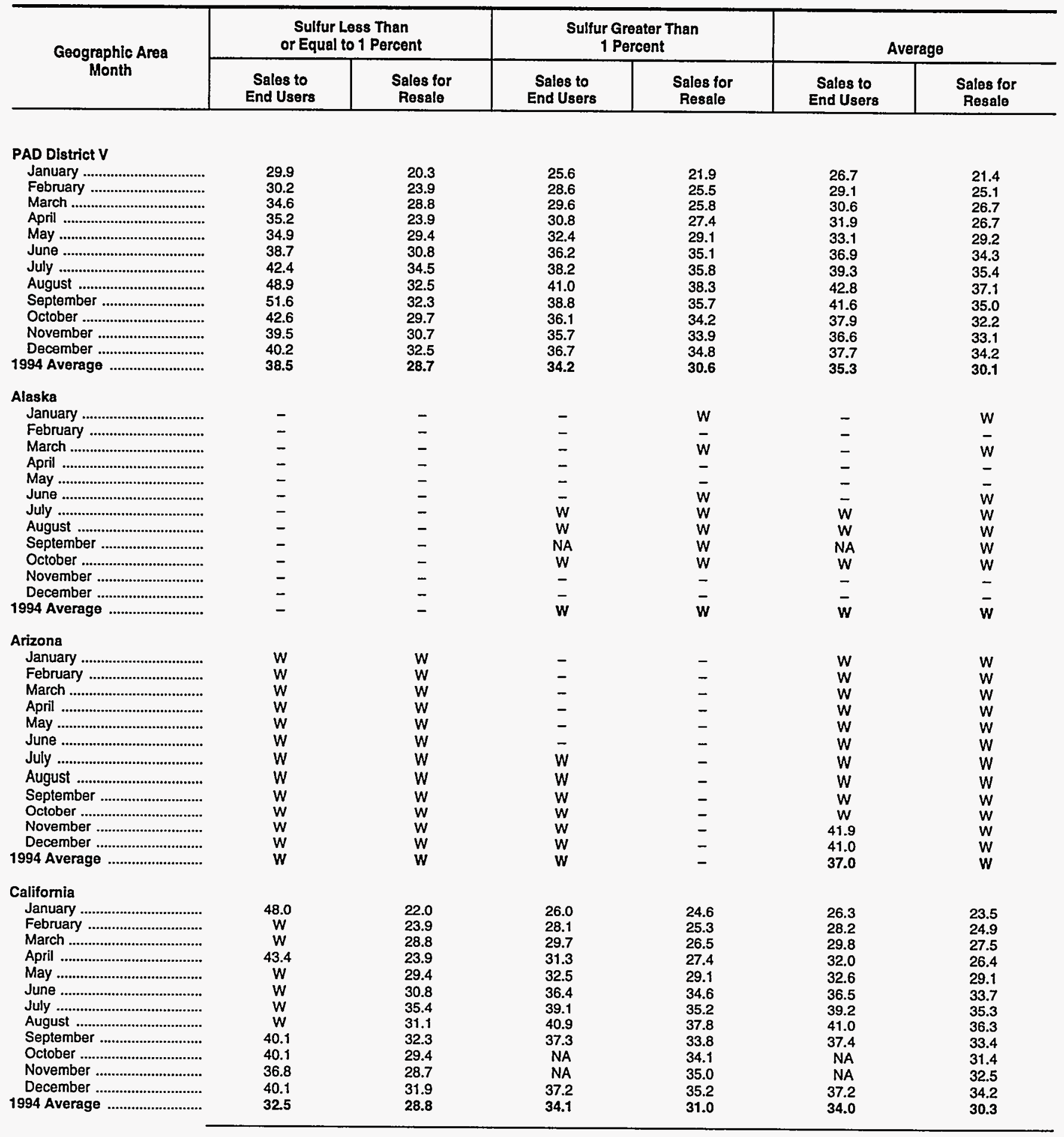

See footnotes at end of table. 
Table 42. Residual Fuel Oil Prices by PAD District and State (Cents per Gallon Excluding Taxes) - Continued

\begin{tabular}{|c|c|c|c|c|c|c|}
\hline \multirow{2}{*}{$\begin{array}{l}\text { Geographic Area } \\
\text { Month }\end{array}$} & \multicolumn{2}{|c|}{$\begin{array}{l}\text { Sulfur Less Than } \\
\text { or Equal to } 1 \text { Percent }\end{array}$} & \multicolumn{2}{|c|}{$\begin{array}{c}\text { Sulfur Greater Than } \\
1 \text { Percent }\end{array}$} & \multicolumn{2}{|c|}{ Average } \\
\hline & $\begin{array}{l}\text { Sales to } \\
\text { End Users }\end{array}$ & $\begin{array}{c}\text { Sales for } \\
\text { Resale }\end{array}$ & $\begin{array}{l}\text { Sales to } \\
\text { End Users }\end{array}$ & $\begin{array}{c}\text { Sales for } \\
\text { Resale }\end{array}$ & $\begin{array}{l}\text { Sales to } \\
\text { End Users }\end{array}$ & $\begin{array}{c}\text { Sales for } \\
\text { Resale }\end{array}$ \\
\hline \multicolumn{7}{|l|}{ Hawall } \\
\hline January ..................................... & $W$ & $w$ & 26.7 & W & 28.8 & $W$ \\
\hline 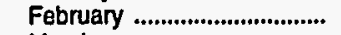 & $W$ & - & 28.4 & W & 30.9 & w \\
\hline March ,..................................... & $w$ & - & 30.4 & 36.2 & 33.6 & 36.2 \\
\hline 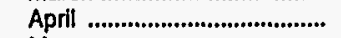 & W & - & 31.7 & $W$ & 33.9 & $W$ \\
\hline May & $W$ & - & 33.9 & 39.8 & 34.6 & 39.8 \\
\hline 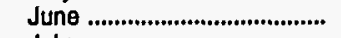 & $W$ & $\overline{-}$ & 36.9 & $W$ & 38.3 & $W$ \\
\hline 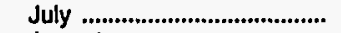 & W & W & 40.0 & W & 42.0 & W \\
\hline August $\ldots . . . . . . . . . . . . . . . . . . . . . . . . . . .$. & $W$ & W & 41.3 & NA & 47.6 & $w$ \\
\hline September ............................. & $W$ & - & 40.3 & W & 49.5 & $w$ \\
\hline 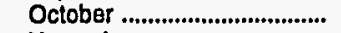 & W & - & 38.3 & $W$ & 41.7 & w \\
\hline November .............................. & $W$ & - & 36.9 & $W$ & 39.0 & $W$ \\
\hline 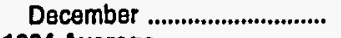 & $w$ & - & 38.0 & $W$ & 39.7 & $W$ \\
\hline 1894 Average .......................... & $\mathbf{W}$ & $\mathbf{W}$ & 35.1 & $\mathbf{W}$ & 38.3 & 29.4 \\
\hline \multicolumn{7}{|l|}{ Nevada } \\
\hline January ................................. & W & - & - & - & W & - \\
\hline 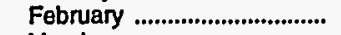 & $W$ & - & - & - & $W$ & - \\
\hline 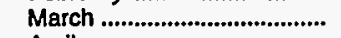 & $w$ & - & - & $W$ & $W$ & $W$ \\
\hline April & $w$ & - & - & $w$ & $W$ & w \\
\hline 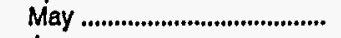 & $W$ & - & - & - & W & - \\
\hline 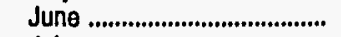 & $W$ & - & - & - & $W$ & - \\
\hline 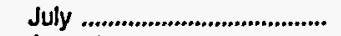 & $W$ & W & W & - & 49.2 & $w$ \\
\hline 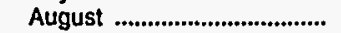 & $w$ & - & $\mathbf{W}$ & - & $W$ & - \\
\hline 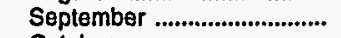 & $w$ & - & - & - & $\mathbf{W}$ & - \\
\hline 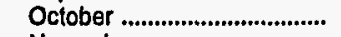 & $W$ & $W$ & - & - & $W$ & $w$ \\
\hline November .................................. & W & W & - & - & W & $w$ \\
\hline 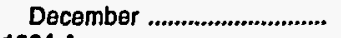 & $W$ & $W$ & - & - & W & $w$ \\
\hline 1994 Average ............................... & $\mathbf{W}$ & $\mathbf{w}$ & $\mathbf{W}$ & $\mathbf{W}$ & $\mathbf{W}$ & $w$ \\
\hline \multicolumn{7}{|l|}{ Oregon } \\
\hline 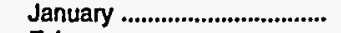 & - & - & 30.4 & $w$ & 30.4 & w \\
\hline February ................................ & - & - & 34.0 & W & 34.0 & $W$ \\
\hline 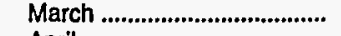 & - & - & 33.1 & $W$ & 33.1 & $W$ \\
\hline April & - & - & $W$ & 31.6 & $W$ & 31.6 \\
\hline 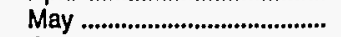 & $\rightarrow$ & - & 35.0 & 33.9 & 35.0 & 33.9 \\
\hline 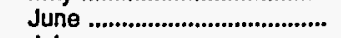 & - & - & 35.2 & W & 35.2 & $W$ \\
\hline 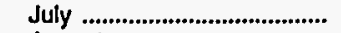 & - & - & 36.6 & NA & 36.6 & NA \\
\hline 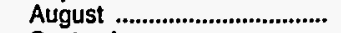 & W & - & 40.8 & NA & 40.9 & NA \\
\hline 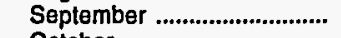 & NA & - & 42.0 & $W$ & 42.1 & $W$ \\
\hline October & NA & - & 38.6 & $W$ & 38.7 & $w$ \\
\hline November ............................. & NA & - & 38.1 & 37.3 & 38.1 & 37.3 \\
\hline 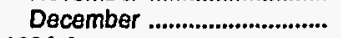 & $w$ & - & 36.6 & 35.9 & 36.8 & 35.9 \\
\hline 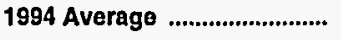 & $\mathbf{w}$ & - & 36.2 & 36.8 & 36.3 & 36.8 \\
\hline \multicolumn{7}{|l|}{ Washington } \\
\hline 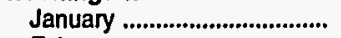 & NA & - & 24.4 & 21.1 & 24.4 & 21.1 \\
\hline 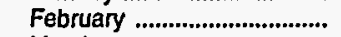 & $W$ & - & 27.7 & 25.3 & 27.7 & 25.3 \\
\hline March ....................................., & - & - & 27.6 & 25.7 & 27.6 & 25.7 \\
\hline April & NA & - & 29.5 & 26.7 & 29.5 & 26.7 \\
\hline 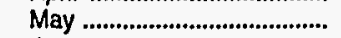 & - & - & 31.3 & 29.0 & 31.3 & 29.0 \\
\hline 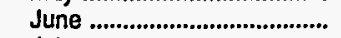 & - & - & 36.1 & 36.9 & 36.1 & 36.9 \\
\hline 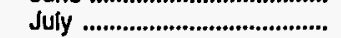 & - & - & 37.4 & 36.9 & 37.4 & 36.9 \\
\hline August................................ & - & - & 40.9 & 39.0 & 40.9 & 39.0 \\
\hline 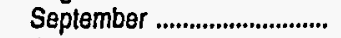 & - & - & 38.5 & 38.3 & 38.5 & 38.3 \\
\hline 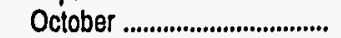 & - & - & 35.5 & 33.5 & 35.5 & 33.5 \\
\hline November ............................. & - & - & 34.7 & 31.9 & 34.7 & 31.9 \\
\hline 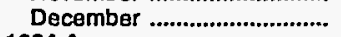 & $W$ & - & 36.0 & 33.1 & 36.0 & 33.1 \\
\hline 1994 Average & $\mathbf{w}$ & - & 33.3 & 30.3 & 33.3 & 30.3 \\
\hline
\end{tabular}

Dash $(-)=$ No data reported.

$N A=$ Not available.

$W=$ Withheld to avold disclosure of individual company data.

Notes: Some State data are not sufficient for publication individually, but are used in calculating the PAD District average.

Sources: Energy Information Administration Forms EIA-782A, "Refiners'/Gas Plant Operators' Monthly Petroleum Product Sales Report, and ElA-782B, 'Aesellers'/Retallers' Monthly Petroleum Product Sales Report." 



\section{Volumes of Petroleum Products}


Table 43. Refiner Motor Gasoline Volumes by Grade, Sales Type, PAD District, and State (Thousand Gallons per Day)



See footnotes at end of taple. 
Table 43. Refiner Motor Gasoline Volumes by Grade, Sales Type, PAD District, and State (Thousand Gallons per Day) - Continued

\begin{tabular}{|c|c|c|c|c|c|c|c|c|c|c|c|c|}
\hline \multirow{3}{*}{$\begin{array}{l}\text { Geographle Area } \\
\text { Month }\end{array}$} & \multicolumn{6}{|c|}{ Premium } & \multicolumn{6}{|c|}{ All Grades } \\
\hline & \multicolumn{2}{|c|}{ Sales to End Users } & \multicolumn{4}{|c|}{ Sales for Resale } & \multicolumn{2}{|c|}{ Sales to End Users } & \multicolumn{4}{|c|}{ Sales for Resale } \\
\hline & $\begin{array}{c}\text { Through } \\
\text { Retall } \\
\text { Outlets }\end{array}$ & Totala & DTW & Rack & Bulk & Total & $\begin{array}{c}\text { Through } \\
\text { Retail } \\
\text { Outlets }\end{array}$ & Totala & DTW & Rack & Bulk & Total \\
\hline \multicolumn{13}{|l|}{ Unitod States } \\
\hline 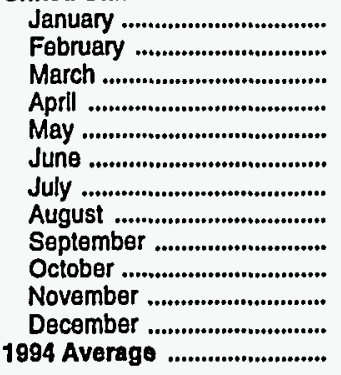 & $\begin{array}{r}9,886.7 \\
11,117.6 \\
10,121.8 \\
10,090.9 \\
10,074.2 \\
10,367.4 \\
10,078.1 \\
9,514.2 \\
9,438.3 \\
9,741.4 \\
9,385.5 \\
9,899.9 \\
9,968.7\end{array}$ & $\begin{array}{r}10,241.8 \\
11,508.1 \\
10,523.2 \\
10,475.8 \\
10,465.8 \\
10,764.0 \\
10,423.9 \\
9,913.3 \\
9,815.7 \\
10,110.7 \\
9,777.0 \\
10,260.1 \\
10,348.8\end{array}$ & $\begin{array}{l}22,061.2 \\
22,159.9 \\
23,237.8 \\
23,324.5 \\
23,382.7 \\
23,551.7 \\
22,795.3 \\
22,284.6 \\
22,020.7 \\
22,155.9 \\
21,849.0 \\
22,352.2 \\
22,600.6\end{array}$ & $\begin{array}{l}27,485.2 \\
28,435.6 \\
29,398.3 \\
29,779.3 \\
30,998.3 \\
31,832.7 \\
30,882.5 \\
30,624.4 \\
29,757.3 \\
29,358.5 \\
29,695.6 \\
30,806.5 \\
29,929.6\end{array}$ & $\begin{array}{l}3,738.0 \\
3,604.6 \\
2,645.0 \\
2,556.8 \\
3,361.2 \\
3,827.5 \\
3,042.7 \\
3,490.7 \\
3,022.3 \\
2,671.2 \\
2,572.3 \\
4,012.2 \\
3,211.2\end{array}$ & $\begin{array}{l}53,284.4 \\
54,200.2 \\
55,281.2 \\
55,660.7 \\
57,742.3 \\
59,211.9 \\
56,720.5 \\
56,399.8 \\
54,800.3 \\
54,185.6 \\
54,116.9 \\
57,170.9 \\
55,741.4\end{array}$ & $\begin{array}{l}49,413.0 \\
51,916.5 \\
52,928.5 \\
52,654.3 \\
53,231.0 \\
54,750.4 \\
53,736.8 \\
54,122.6 \\
52,783.1 \\
51,971.5 \\
52,226.2 \\
53,406.5 \\
52,764.9\end{array}$ & 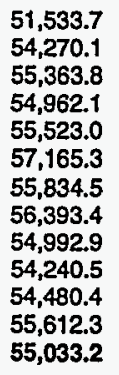 & $\begin{array}{l}78,440.4 \\
81,012.3 \\
84,100.2 \\
84,217.9 \\
84,502.0 \\
86,025.8 \\
84,243.5 \\
84,283.1 \\
82,176.5 \\
82,460.7 \\
82,151.1 \\
83,673.7 \\
83,118.6\end{array}$ & $\begin{array}{l}149,533.7 \\
155,452.6 \\
160,935.2 \\
165,100.1 \\
167,117.5 \\
172,978.3 \\
170,424.2 \\
175,389.1 \\
170,586.2 \\
165,899.5 \\
167,519.8 \\
168,910.4 \\
165,870.4\end{array}$ & $\begin{array}{l}26,494.7 \\
24,722.0 \\
23,961.1 \\
26,847.5 \\
27,795.8 \\
28,704.4 \\
24,542.0 \\
28,707.0 \\
29,238.6 \\
27,711.5 \\
26,237.3 \\
37,378.8 \\
27,718.8\end{array}$ & $\begin{array}{l}254,468.8 \\
261,186.8 \\
268,996.5 \\
276,165.6 \\
279,415.3 \\
287,708.5 \\
279,209.6 \\
288,379.1 \\
282,001.3 \\
276,071.7 \\
275,908.2 \\
289,962.9 \\
276,707.8\end{array}$ \\
\hline \multicolumn{13}{|l|}{ PAD Dlstrict I } \\
\hline 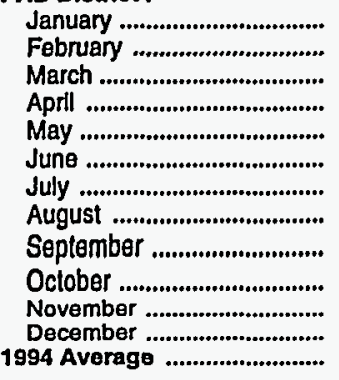 & $\begin{array}{l}3,131.7 \\
3,169.1 \\
3,237.9 \\
3,296.3 \\
3,279.3 \\
3,437.3 \\
3,384.5 \\
3,058.4 \\
2,959.5 \\
3,014.8 \\
2,921.4 \\
3,039.3 \\
3,160.8\end{array}$ & $\begin{array}{l}3,280.2 \\
3,335.6 \\
3,406.1 \\
3,450.2 \\
3,447.3 \\
3,596.3 \\
3,534.5 \\
3,235.1 \\
3,121.9 \\
3,174.4 \\
3,091.7 \\
3,202.4 \\
3,323.0\end{array}$ & $\begin{array}{l}10,543.4 \\
10,944.0 \\
11,324.6 \\
11,547.6 \\
11,542.9 \\
11,574.4 \\
11,151.8 \\
10,799.1 \\
10,640.2 \\
10,878.7 \\
10,559.2 \\
10,809.5 \\
11,026.4\end{array}$ & $\begin{array}{r}10,979.8 \\
11,519.0 \\
W \\
W \\
12,507.9 \\
12,667.5 \\
12,398.5 \\
12,391.8 \\
12,100.0 \\
W \\
W \\
12,262.6 \\
12,079.3\end{array}$ & $\begin{array}{r}1,639.9 \\
1,608.8 \\
W \\
W \\
1,272.8 \\
1,631.4 \\
801.7 \\
1,277.3 \\
976.4 \\
W \\
W \\
1,880.2 \\
1,245.9\end{array}$ & $\begin{array}{l}23,163.1 \\
24,071.8 \\
24,505.8 \\
24,846.3 \\
25,323.6 \\
25,873.4 \\
24,352.0 \\
24,468.2 \\
23,716.7 \\
23,614.3 \\
23,315.5 \\
24,952.3 \\
24,351.6\end{array}$ & $\begin{array}{l}12,752.7 \\
13,348.5 \\
13,635.0 \\
13,894.3 \\
13,802.8 \\
14,053.3 \\
14,024.2 \\
13,888.8 \\
13,263.8 \\
13,363.5 \\
13,157.6 \\
13,491.5 \\
13,557.6\end{array}$ & $\begin{array}{l}13,593.4 \\
14,291.6 \\
14,587.8 \\
14,776.9 \\
14,680.7 \\
14,974.3 \\
14,854.5 \\
14,851.6 \\
14,180.0 \\
14,314.7 \\
14,134.3 \\
14,444.9 \\
14,474.8\end{array}$ & $\begin{array}{l}30,382.5 \\
31,989.1 \\
33,259.7 \\
33,687.6 \\
33,587.9 \\
34,048.7 \\
33,336.5 \\
33,244.2 \\
32,259.3 \\
33,011.4 \\
32,705.6 \\
33,347.4 \\
32,909.5\end{array}$ & $\begin{array}{l}48,137.8 \\
49,831.8 \\
51,386.9 \\
52,554.3 \\
52,965.6 \\
54,350.2 \\
53,734.2 \\
55,852.7 \\
54,646.3 \\
54,081.8 \\
54,280.3 \\
55,315.6 \\
53,112.2\end{array}$ & $\begin{array}{l}5,226.4 \\
6,208.8 \\
6,214.7 \\
5,997.2 \\
6,806.5 \\
7,785.0 \\
6,261.1 \\
6,779.8 \\
8,194.7 \\
6,502.9 \\
5,851.3 \\
8,997.4 \\
6,737.4\end{array}$ & $\begin{array}{l}83,746.7 \\
88,029.7 \\
90,861.4 \\
92,239.1 \\
93,359.9 \\
96,183.9 \\
93,331.8 \\
95,876.6 \\
95,100.2 \\
93,596.1 \\
92,837.3 \\
97,660.4 \\
92,759.1\end{array}$ \\
\hline 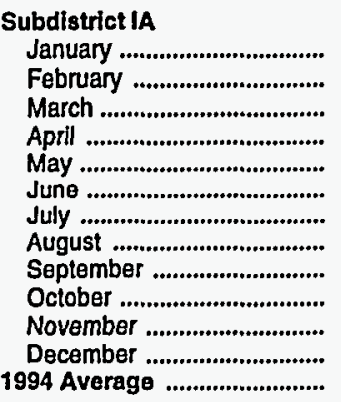 & $\begin{array}{l}163.0 \\
144.0 \\
147.4 \\
156.8 \\
167.1 \\
176.6 \\
179.1 \\
164.3 \\
150.6 \\
151.7 \\
141.2 \\
141.7 \\
157.1\end{array}$ & $\begin{array}{l}179.4 \\
163.1 \\
162.7 \\
171.8 \\
180.9 \\
192.0 \\
193.3 \\
176.7 \\
163.4 \\
168.3 \\
162.7 \\
154.6 \\
172.5\end{array}$ & $\begin{array}{r}1,243.2 \\
W \\
W \\
1,254.2 \\
W \\
W \\
W \\
W \\
W \\
W \\
W \\
W \\
1,252.3\end{array}$ & $\begin{array}{r}1,363.0 \\
1,361.1 \\
W \\
W \\
1,372.0 \\
1,443.4 \\
1,393.7 \\
1,427.4 \\
1,303.1 \\
W \\
W \\
1,268.9 \\
1,346.8\end{array}$ & $\begin{array}{l}148.6 \\
W \\
W \\
W \\
W \\
W \\
W \\
W \\
W \\
W \\
W \\
W \\
101.3\end{array}$ & $\begin{array}{l}2,754.7 \\
2,939.1 \\
2,554.9 \\
2,554.4 \\
2,690.6 \\
2,833.1 \\
2,752.3 \\
2,765.9 \\
2,698.5 \\
2,723.4 \\
2,549.1 \\
2,606.5 \\
2,700.4\end{array}$ & $\begin{array}{l}591.3 \\
544.2 \\
559.1 \\
596.7 \\
640.2 \\
658.9 \\
677.2 \\
668.6 \\
613.1 \\
616.7 \\
574.4 \\
599.2 \\
612.2\end{array}$ & $\begin{array}{l}684.0 \\
646.0 \\
647.3 \\
677.9 \\
719.7 \\
747.9 \\
752.3 \\
746.6 \\
695.0 \\
703.8 \\
670.5 \\
682.9 \\
698.2\end{array}$ & $\begin{array}{l}4,302.8 \\
4,346.4 \\
4,410.3 \\
4,542.0 \\
4,704.7 \\
4,868.6 \\
4,778.7 \\
4,813.2 \\
4,607.5 \\
4,758.0 \\
4,728.3 \\
4,793.9 \\
4,639.7\end{array}$ & $\begin{array}{l}5,638.7 \\
5,567.1 \\
5,396.5 \\
5,477.7 \\
5,682.1 \\
6,051.3 \\
5,898.5 \\
6,151.2 \\
5,760.9 \\
6,103.5 \\
5,718.2 \\
5,850.6 \\
5,776.7\end{array}$ & $\begin{array}{r}345.5 \\
1,087.8 \\
333.8 \\
291.2 \\
1,150.9 \\
561.1 \\
1,325.1 \\
923.7 \\
1,484.2 \\
1,037.8 \\
1,020.9 \\
1,609.3 \\
930.7\end{array}$ & $\begin{array}{l}10,287.0 \\
11,001.3 \\
10,140.6 \\
10,311.0 \\
11,537.7 \\
11,481.0 \\
12,002.3 \\
11,888.2 \\
11,852.6 \\
11,899.3 \\
11,467.4 \\
12,253.8 \\
11,347.0\end{array}$ \\
\hline 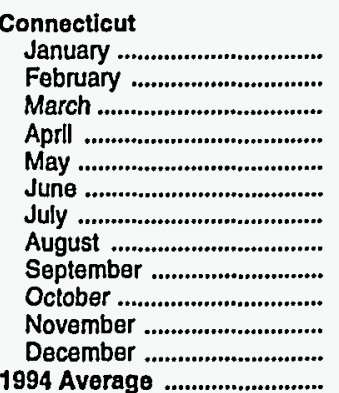 & $\begin{array}{l}w \\
W \\
W \\
W \\
W \\
w \\
W \\
W \\
w \\
w \\
w \\
W \\
w\end{array}$ & $\begin{array}{c}W \\
31.3 \\
W \\
36.6 \\
W \\
W \\
43.8 \\
W \\
W \\
W \\
W \\
W \\
W\end{array}$ & $\begin{array}{c}349.4 \\
341.3 \\
344.6 \\
354.5 \\
W \\
W \\
358.4 \\
W \\
W \\
348.8 \\
361.0 \\
355.9 \\
353.8\end{array}$ & $\begin{array}{c}401.5 \\
403.9 \\
402.1 \\
394.0 \\
W \\
449.3 \\
424.9 \\
W \\
398.9 \\
W \\
397.6 \\
401.8 \\
414.2\end{array}$ & $\begin{array}{c}W \\
- \\
- \\
- \\
\bar{w} \\
- \\
\bar{w} \\
w \\
\bar{W} \\
\overline{14.0}\end{array}$ & $\begin{array}{l}818.8 \\
745.2 \\
746.7 \\
748.5 \\
808.9 \\
865.3 \\
783.4 \\
758.5 \\
757.4 \\
832.3 \\
758.6 \\
757.7 \\
782.1\end{array}$ & $\begin{array}{l}W \\
W \\
W \\
W \\
W \\
W \\
W \\
W \\
W \\
W \\
W \\
W \\
W\end{array}$ & $\begin{array}{c}W \\
116.4 \\
122.9 \\
133.2 \\
141.8 \\
148.4 \\
157.3 \\
157.8 \\
145.2 \\
146.5 \\
132.1 \\
140.4 \\
139.4\end{array}$ & $\begin{array}{r}1,210.3 \\
W \\
1,247.5 \\
1,273.8 \\
W \\
W \\
1,313.7 \\
W \\
W \\
W \\
W \\
W \\
1,304.5\end{array}$ & $\begin{array}{l}1,551.3 \\
1,597.7 \\
1,590.9 \\
1,561.2 \\
1,727.7 \\
1,757.6 \\
1,720.1 \\
1,692.1 \\
1,631.9 \\
1,833.0 \\
1,629.8 \\
1,705.4 \\
1,667.4\end{array}$ & $\begin{array}{c}W \\
W \\
- \\
- \\
W \\
W \\
611.4 \\
W \\
W \\
W \\
W \\
W \\
157.4\end{array}$ & $\begin{array}{l}2,849.9 \\
2,904.9 \\
2,838.5 \\
2,835.0 \\
3,392.9 \\
3,212.4 \\
3,645.2 \\
3,041.4 \\
2,910.7 \\
3,364.2 \\
3,109.2 \\
3,410.4 \\
3,129.2\end{array}$ \\
\hline
\end{tabular}

See footnotes at end of table. 
Table 43. Refiner Motor Gasoline Volumes by Grade, Sales Type, PAD District, and State (Thousand Gallons per Day) - Continued

\begin{tabular}{|c|c|c|c|c|c|c|c|c|c|c|c|c|}
\hline \multirow{3}{*}{$\begin{array}{l}\text { Goographic Area } \\
\text { Month }\end{array}$} & \multicolumn{6}{|c|}{ Regular } & \multicolumn{6}{|c|}{ Midgrade } \\
\hline & \multicolumn{2}{|c|}{ Sales to End Users } & \multicolumn{4}{|c|}{ Sales for Resale } & \multicolumn{2}{|c|}{ Sales to End Usera } & \multicolumn{4}{|c|}{ Sales for Resale } \\
\hline & $\begin{array}{c}\text { Through } \\
\text { Rotall } \\
\text { Outlots }\end{array}$ & Totala & DTW & Rack & Bulk & Total & $\begin{array}{c}\text { Through } \\
\text { Retail } \\
\text { Outlets }\end{array}$ & Totala & DTW & Rack & Bulk & Total \\
\hline \multicolumn{13}{|l|}{ Maine } \\
\hline January ....... & - & $W$ & 57.6 & 696.5 & W & 797.9 & 0.0 & W & 12.9 & 134.5 & - & 147.4 \\
\hline 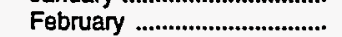 & - & w & $W$ & 648.9 & $W$ & 825.8 & - & w & 12.8 & 141.7 & - & 154.5 \\
\hline 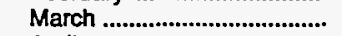 & - & $W$ & 61.4 & 641.6 & 227.6 & 930.6 & - & $w$ & $W$ & $w$ & - & 147.5 \\
\hline April & - & $W$ & W & 651.0 & $W$ & 821.9 & - & $w$ & $W$ & $w$ & - & 136.9 \\
\hline May ........................................... & - & $W$ & $W$ & 669.7 & W & 867.7 & - & $W$ & 14.2 & 137.0 & - & 151.2 \\
\hline June ......................................... & - & W & W & 702.9 & $W$ & $1,004.2$ & - & w & 15.0 & 140.8 & - & 155.8 \\
\hline 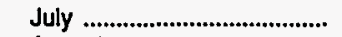 & - & W & $w$ & 780.8 & $W$ & 990.3 & - & W & 16.2 & 156.3 & - & 172.5 \\
\hline 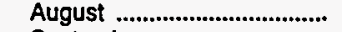 & - & $W$ & 76.5 & 829.7 & 241.3 & $1,147.5$ & - & w & $W$ & W & - & 191.8 \\
\hline 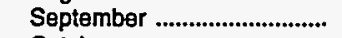 & - & W & $w$ & 768.1 & $W$ & 965.0 & - & $w$ & $w$ & w & - & 165.7 \\
\hline 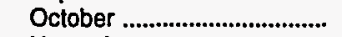 & - & W & $w$ & 786.5 & W & 966.3 & - & $w$ & 13.3 & 128.8 & - & 142.2 \\
\hline November .............................. & - & $W$ & 63.0 & $W$ & $\mathbf{W}$ & 896.7 & - & $W$ & $W$ & W & - & 151.7 \\
\hline 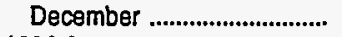 & - & W & 66.5 & W & $W$ & $1,150.1$ & - & W & 14.8 & 140.7 & - & 155.5 \\
\hline 1994 Average ............................ & - & $\mathbf{W}$ & 66.1 & 723.5 & 158.6 & 948.3 & - & $\mathbf{W}$ & 14.2 & 141.9 & - & 156.1 \\
\hline \multicolumn{13}{|l|}{ Massachusetts } \\
\hline 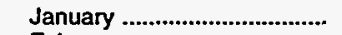 & 166.6 & 197.2 & $1,233.6$ & $1,435.4$ & $w$ & $2,794.2$ & 68.4 & 84.1 & 367.2 & 195.8 & $w$ & 569.8 \\
\hline 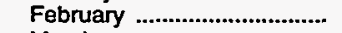 & 160.5 & 197.1 & $1,259.4$ & $w$ & $W$ & $3,094.8$ & 61.4 & 73.5 & 371.5 & 216.5 & - & 588.0 \\
\hline 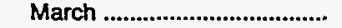 & 166.6 & 198.3 & $1,289.5$ & W & $\mathbf{w}$ & $2,669.8$ & 61.9 & 71.1 & 374.2 & 206.8 & - & 581.0 \\
\hline 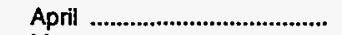 & 177.2 & 204.3 & $w$ & $1,448.2$ & W & $2,859.2$ & 65.6 & 75.2 & 387.5 & 236.3 & - & 623.8 \\
\hline 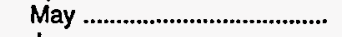 & 191.2 & 218.1 & $1,388.6$ & $W$ & $W$ & $3,463.6$ & 69.8 & 78.7 & 400.0 & 253.5 & - & 653.5 \\
\hline June & 192.8 & 222.5 & W & $1,564.4$ & $W$ & $3,226.7$ & 71.4 & 83.3 & 427.9 & 276.4 & - & 704.2 \\
\hline July & 198.1 & 223.8 & $1,415.0$ & $1,366.6$ & 176.3 & $2,957.9$ & 74.5 & 82.5 & 427.0 & $W$ & W & 688.6 \\
\hline 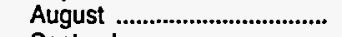 & 203.5 & 230.9 & $1,460.3$ & $W$ & $W$ & $3,497.7$ & 75.3 & 82.5 & 432.2 & 276.8 & - & 709.0 \\
\hline 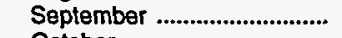 & 186.7 & 215.8 & $1,384.1$ & W & $W$ & $4,013.7$ & 70.2 & 78.7 & 413.8 & 259.7 & - & 673.6 \\
\hline 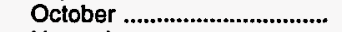 & 186.5 & 216.7 & $W$ & $1,472.0$ & W & $3,229.2$ & 70.9 & 78.5 & W & $W$ & - & 691.9 \\
\hline November ............................... & 160.1 & 193.1 & $1,353.1$ & $1,508.0$ & 700.8 & $3,561.9$ & 81.1 & 95.5 & 419.7 & 216.5 & - & 636.3 \\
\hline 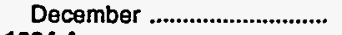 & 160.7 & 189.8 & $1,385.3$ & $1,430.8$ & 742.0 & $3,558.1$ & 91.2 & 101.8 & $w$ & 228.5 & W & 666.5 \\
\hline 1994 Average & 179.4 & 209.1 & $1,364.3$ & $1,445.5$ & 433.4 & $3,243.3$ & 71.9 & 82.2 & 407.3 & 241.0 & $\mathbf{W}$ & 649.2 \\
\hline \multicolumn{13}{|l|}{ New Hampshire } \\
\hline January .............. & 44.7 & 52.5 & 152.9 & 56.8 & $w$ & 210.7 & 17.8 & 18.2 & 51.3 & 14.5 & - & 65.7 \\
\hline (n.......................... & 40.7 & 48.2 & 158.6 & 70.1 & - & 228.7 & 15.4 & 15.7 & 53.3 & 13.6 & - & 67.0 \\
\hline March & 39.3 & 47.3 & 158.8 & 70.9 & - & 229.6 & 14.7 & 14.9 & 50.4 & 16.0 & - & 66.4 \\
\hline April & 42.4 & 48.6 & 164.9 & 74.5 & - & 239.4 & 15.1 & 15.7 & 50.0 & 13.9 & - & 63.9 \\
\hline May & 46.9 & 53.0 & 175.1 & 81.8 & - & 257.0 & 15.5 & 16.1 & 52.8 & 16.2 & - & 69.0 \\
\hline June & 47.5 & 55.0 & 178.4 & 80.6 & - & 259.0 & 16.5 & 16.8 & 54.6 & 18.3 & - & 72.9 \\
\hline July & 47.2 & 52.2 & 181.6 & 75.3 & - & 257.0 & 16.3 & 16.3 & 56.7 & 21.7 & - & 78.4 \\
\hline August & 46.3 & 53.0 & 184.3 & 84.0 & - & 268.2 & 17.2 & 17.5 & 57.0 & 23.9 & - & 80.8 \\
\hline 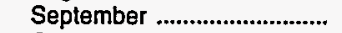 & $W$ & 48.4 & 172.9 & 73.9 & - & 246.8 & $W$ & 15.8 & 53.1 & 17.3 & - & 70.4 \\
\hline 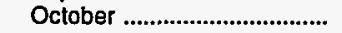 & $W$ & 49.0 & 176.1 & 75.5 & - & 251.5 & W & 16.6 & 55.3 & 16.5 & - & 71.9 \\
\hline November ................................. & $W$ & 46.3 & 169.7 & 67.3 & - & 237.0 & $W$ & $\mathbf{W}$ & 53.8 & 12.9 & - & 66.7 \\
\hline 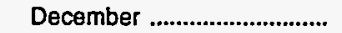 & $W$ & 49.5 & 171.8 & 61.3 & - & 233.2 & $W$ & 17.5 & 56.3 & 29.5 & - & 85.9 \\
\hline 1994 Average & 43.5 & 50.3 & 170.5 & 72.7 & $\mathbf{W}$ & 243.3 & $\mathbf{W}$ & 16.3 & 53.7 & 17.9 & - & 71.6 \\
\hline \multicolumn{13}{|l|}{ Rhode lsland } \\
\hline 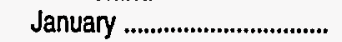 & 30.6 & 38.8 & 211.5 & 407.2 & - & 618.6 & 14.0 & 14.5 & 64.7 & 83.2 & - & 147.9 \\
\hline 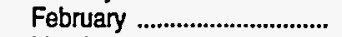 & $w$ & 41.5 & $W$ & 325.2 & W & 661.8 & $W$ & $W$ & $W$ & $w$ & - & 131.9 \\
\hline 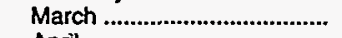 & W & 41.1 & 234.7 & 356.4 & - & 591.1 & $w$ & 15.4 & 67.6 & 67.5 & - & 135.1 \\
\hline April & w & 44.1 & $w$ & 348.2 & W & 677.9 & $w$ & $w$ & 69.6 & 61.7 & - & 131.3 \\
\hline 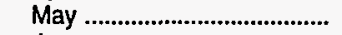 & $w$ & 46.0 & 244.6 & 299.7 & - & 544.3 & $w$ & 17.2 & 71.0 & 55.2 & - & 126.2 \\
\hline June & $\mathbf{W}$ & 46.7 & 239.0 & 349.2 & $\overrightarrow{-}$ & 588.2 & $W$ & 17.8 & 71.2 & 67.9 & - & 139.1 \\
\hline 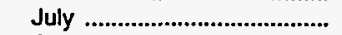 & $w$ & 45.6 & W & 351.6 & w & 918.7 & $w$ & $w$ & $w$ & 68.8 & $\mathbf{w}$ & 140.0 \\
\hline 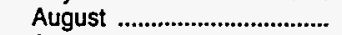 & $W$ & 44.0 & 246.3 & 370.3 & - & 616.6 & $w$ & 18.1 & 74.7 & 72.9 & - & 147.7 \\
\hline September & 37.0 & 40.8 & 241.9 & 333.1 & - & 575.0 & 16.5 & 17.4 & 70.7 & 58.3 & - & 129.0 \\
\hline 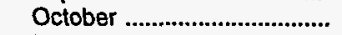 & 36.0 & 40.4 & $W$ & 430.6 & $w$ & 982.5 & 16.6 & 17.3 & 74.2 & 67.1 & - & 141.4 \\
\hline November ............................... & 34.5 & $w$ & 252.9 & $w$ & $w$ & 736.1 & 16.1 & 16.9 & $W$ & $w$ & - & 128.3 \\
\hline 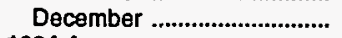 & 36.3 & $w$ & 251.8 & w & W & 837.7 & 16.9 & 18.0 & 74.1 & 63.4 & - & 137.5 \\
\hline 1994 Average & 35.9 & 42.1 & 239.8 & 363.9 & 92.8 & 696.6 & 16.2 & 16.8 & 70.7 & 65.7 & $\mathbf{w}$ & 136.4 \\
\hline
\end{tabular}

See footnotes at end of table. 
Table 43. Refiner Motor Gasoline Volumes by Grade, Sales Type, PAD District, and State (Thousand Gallons per Day) - Continued



See footnotes at end of table. 
Table 43. Refiner Motor Gasoline Volumes by Grade, Sales Type, PAD District, and State (Thousand Gallons per Day) - Continued

\begin{tabular}{|c|c|c|c|c|c|c|c|c|c|c|c|c|}
\hline \multirow{3}{*}{$\begin{array}{c}\text { Geographic Area } \\
\text { Month }\end{array}$} & \multicolumn{6}{|c|}{ Regular } & \multicolumn{6}{|c|}{ Midgrade } \\
\hline & \multicolumn{2}{|c|}{ Sales to End Users } & \multicolumn{4}{|c|}{ Sales for Resale } & \multicolumn{2}{|c|}{ Sales to End Users } & \multicolumn{4}{|c|}{ Sales for Resale } \\
\hline & $\begin{array}{c}\text { Through } \\
\text { Retail } \\
\text { Outlets }\end{array}$ & Totala & DTW & Rack & Bulk & Total & $\begin{array}{c}\text { Through } \\
\text { Rotail } \\
\text { Outlets }\end{array}$ & Totala & DTW & Rack & Bulk & Total \\
\hline \multicolumn{13}{|l|}{ Vermont } \\
\hline 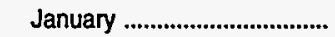 & 0.0 & $W$ & 35.6 & 84.4 & - & 120.0 & 0.0 & - & 11.4 & 17.7 & - & . 29.1 \\
\hline February ............................... & - & $W$ & 37.0 & 82.4 & - & 119.4 & - & - & $W$ & $W$ & - & 30.5 \\
\hline March ...................................... & - & $W$ & $W$ & $W$ & - & 117.2 & - & - & $w$ & $w$ & - & 25.5 \\
\hline April & - & $W$ & 35.9 & 59.3 & - & 95.2 & - & - & $\ddot{w}$ & $w$ & - & 20.5 \\
\hline 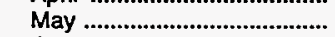 & - & w & 36.6 & 72.4 & - & 109.0 & - & - & $w$ & $w$ & - & 21.7 \\
\hline June & - & $w$ & 39.9 & 84.0 & - & 123.9 & - & - & 11.7 & 15.2 & - & 26.9 \\
\hline July & - & $w$ & $W$ & $w$ & - & 147.9 & - & - & $w$ & $w$ & - & 36.7 \\
\hline August & - & W & $W$ & $W$ & - & 146.5 & - & - & w & $\ddot{w}$ & - & 33.5 \\
\hline 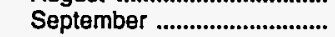 & - & w & 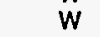 & $\dddot{w}$ & - & 132.1 & - & - & $w$ & $w$ & - & 29.4 \\
\hline October & - & $w$ & 39.3 & 97.1 & - & 136.4 & - & - & w & $w$ & - & 30.7 \\
\hline 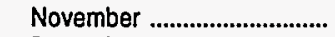 & - & - & 37.2 & 89.8 & - & 127.1 & - & - & $w$ & W & - & 26.1 \\
\hline 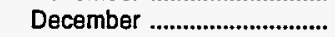 & - & - & $w$ & $W$ & - & 138.9 & - & - & $w$ & $w$ & - & 31.2 \\
\hline 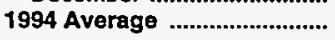 & - & $\mathbf{w}$ & 38.5 & 87.7 & - & 126.3 & - & - & 11.6 & 16.9 & - & 28.5 \\
\hline \multicolumn{13}{|l|}{ Subdistrict IB } \\
\hline 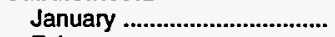 & $2,648.0$ & $2,871.6$ & $7,665.4$ & $8,754.8$ & $2,317.3$ & $18,737.5$ & 764.7 & 796.7 & $2,630.8$ & $1,443.4$ & 3.3 & $4,077.4$ \\
\hline February .................................. & $2,805.5$ & $3,050.1$ & $w$ & $8,958.3$ & $w$ & $20,098.8$ & 792.4 & 825.8 & $W$ & $1,491.3$ & $w$ & $4,253.6$ \\
\hline March & $2,917.4$ & $3,162.0$ & W & $9,072.8$ & $w$ & $20,928.6$ & 800.8 & 838.6 & $\dddot{W}$ & $1,611.4$ & $w$ & $4,484.8$ \\
\hline April & $3,058.7$ & $3,279.6$ & $8,880.4$ & $9,537.1$ & $3,634.5$ & $22,051.9$ & 836.5 & 871.3 & $2,902.3$ & $1,626.1$ & 26.4 & $4,554.7$ \\
\hline 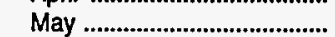 & $3,111.7$ & $3,338.9$ & $8,977.5$ & $9,689.4$ & $3,732.5$ & $22,399.3$ & 888.4 & 919.7 & $W$ & $1,746.2$ & $W$ & $4,728.0$ \\
\hline 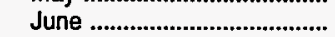 & $3,165.6$ & $3,397.0$ & $9,143.2$ & $10,265.6$ & $4,349.9$ & $23,758.7$ & 844.6 & 875.6 & $w$ & $1,840.0$ & W & $4,967.0$ \\
\hline July & $3,219.7$ & $3,423.9$ & $9,004.7$ & $W$ & W & $22,558.4$ & 869.1 & 901.5 & $3,028.5$ & $W$ & $\ddot{w}$ & $4,983.5$ \\
\hline August & $3,256.8$ & $3,490.9$ & $9,134.3$ & $10,740.2$ & $3,337.4$ & $23,211.9$ & 889.7 & 934.4 & $W$ & $1,921.7$ & $w$ & $4,985.1$ \\
\hline 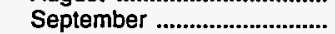 & $3,036.6$ & $3,245.3$ & $8,747.1$ & $10,534.2$ & $4,838.5$ & $24,119.8$ & 847.7 & 880.5 & W & $1,814.8$ & $w$ & $4,812.8$ \\
\hline 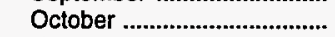 & $3,005.4$ & $3,219.6$ & $w$ & $10,639.9$ & $W$ & $23,495.3$ & 853.7 & 882.1 & W & $W$ & - & $4,759.8$ \\
\hline 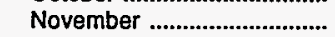 & $3,030.1$ & $3,264.1$ & W & $10,858.9$ & W & $22,819.0$ & 846.6 & 883.9 & $w$ & w & - & $4,682.8$ \\
\hline 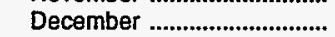 & $3,042.7$ & $3,260.8$ & w & $10,633.7$ & W & $23,912.9$ & 904.6 & 934.2 & $\dddot{W}$ & $1,784.2$ & $w$ & $4,786.4$ \\
\hline 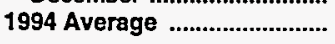 & $3,026.1$ & $3,251.5$ & $8,815.0$ & $9,999.5$ & $3,535.7$ & $22,350.2$ & 845.3 & 879.1 & $2,919.8$ & $1,727.0$ & $\mathbf{W}$ & $4,675.5$ \\
\hline \multicolumn{13}{|l|}{ Delaware } \\
\hline January .................................... & $w$ & 11.9 & 158.2 & 255.9 & - & 414.1 & $w$ & 6.1 & 62.1 & 78.9 & - & 141.0 \\
\hline 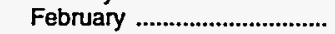 & $w$ & $w$ & 172.6 & $w$ & $W$ & 518.4 & $w$ & $w$ & $w$ & $w$ & - & 158.3 \\
\hline 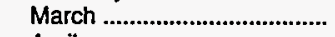 & $W$ & $W$ & 184.2 & W & $W$ & 490.0 & W & $w$ & W & $w$ & - & 161.2 \\
\hline April & $W$ & 20.9 & W & 288.5 & W & 613.8 & $W$ & 7.2 & 67.0 & 104.1 & - & 171.1 \\
\hline May & $W$ & $W$ & 197.6 & $W$ & $W$ & 518.8 & 7.0 & 7.8 & $w$ & $W$ & - & 163.5 \\
\hline June & $w$ & 23.8 & 203.8 & $W$ & $w$ & 506.8 & 7.1 & 7.1 & 67.9 & 97.3 & - & 165.2 \\
\hline 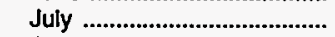 & $W$ & $W$ & 201.0 & W & W & 523.3 & 8.5 & $\dddot{w}$ & $w$ & $w$ & - & 161.0 \\
\hline 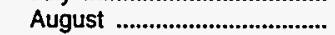 & 19.0 & W & 206.9 & $w$ & $\ddot{W}$ & 532.8 & 8.0 & $\ddot{w}$ & w & $w$ & - & 171.4 \\
\hline 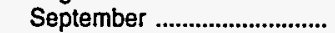 & 14.5 & $W$ & 202.6 & $W$ & $W$ & 592.3 & 6.1 & w & $w$ & $w$ & - & 186.7 \\
\hline October & 16.7 & 22.6 & $W$ & 313.9 & $W$ & 568.5 & 7.0 & w & $w$ & $w$ & - & 179.0 \\
\hline November ............................. & 13.5 & 21.1 & $w$ & 285.7 & $W$ & 515.0 & 5.8 & 5.9 & $\ddot{w}$ & $w$ & - & 153.4 \\
\hline 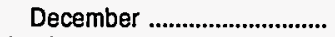 & 15.6 & 21.9 & 207.8 & $W$ & $W$ & 531.1 & 6.8 & $W$ & W & w & - & 181.7 \\
\hline 1994 Average & 14.3 & 20.8 & 195.1 & 285.1 & $w$ & 526.8 & 6.6 & 7.0 & 66.6 & 99.6 & - & 166.1 \\
\hline \multicolumn{13}{|l|}{ District of Columbia } \\
\hline 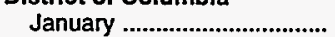 & - & $w$ & 100.2 & $w$ & - & 101.5 & 0.0 & $w$ & 69.7 & $w$ & - & 69.8 \\
\hline 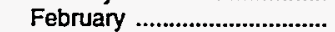 & - & $w$ & $W$ & W & - & 112.1 & - & 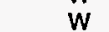 & $\ddot{w}$ & - & - & 76.4 \\
\hline 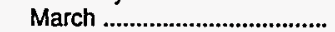 & - & $w$ & $w$ & $w$ & - & 116.3 & - & $w$ & $w$ & $w$ & - & 80.0 \\
\hline April & - & $w$ & $w$ & w & - & 119.3 & - & $w$ & $w$ & - & - & 82.4 \\
\hline 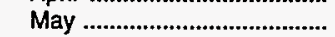 & - & $w$ & w & $w$ & - & 116.9 & - & $w$ & $w$ & - & - & $\begin{array}{l}02.4 \\
82.5\end{array}$ \\
\hline 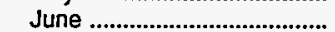 & - & W & $\ddot{w}$ & $\dddot{w}$ & - & 114.0 & - & $w$ & $w$ & - & - & 79.9 \\
\hline 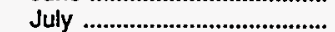 & - & $w$ & 114.9 & - & - & 114.9 & - & w & $w$ & - & - & 80.7 \\
\hline August & - & $w$ & $114 . t$ & - & - & 114.1 & - & $w$ & 80.2 & - & - & 80.2 \\
\hline September ............................. & - & $w$ & 112.6 & - & - & 112.6 & - & $w$ & 80.7 & - & - & 80.7 \\
\hline 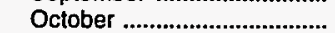 & - & 5.2 & 114.0 & - & - & 114.0 & - & $w$ & 77.5 & - & - & 77.5 \\
\hline November ............................. & - & 7.8 & 124.1 & - & - & 124.1 & - & 3.0 & 84.1 & - & - & 84.1 \\
\hline 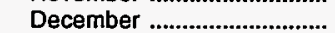 & - & 8.1 & 121.9 & - & - & 121.9 & - & $w$ & 86.5 & - & - & 84.1 \\
\hline 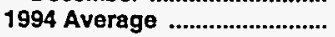 & - & 4.9 & 114.6 & $\mathbf{w}$ & - & 115.1 & - & 2.0 & 80.1 & $\vec{w}$ & - & 80.1 \\
\hline
\end{tabular}

See footnotes at end of table. 
Table 43. Refiner Motor Gasoline Volumes by Grade, Sales Type, PAD District, and State (Thousand Gallons per Day) - Continued

\begin{tabular}{|c|c|c|c|c|c|c|c|c|c|c|c|c|}
\hline \multirow{3}{*}{$\begin{array}{c}\text { Goographic Area } \\
\text { Month }\end{array}$} & \multicolumn{6}{|c|}{ Premium } & \multicolumn{6}{|c|}{ All Grades } \\
\hline & \multicolumn{2}{|c|}{ Sales to End Users } & \multicolumn{4}{|c|}{ Sales for Resale } & \multicolumn{2}{|c|}{ Sales to End Users } & \multicolumn{4}{|c|}{ Sales for Resale } \\
\hline & $\begin{array}{c}\text { Through } \\
\text { Retail } \\
\text { Outlets }\end{array}$ & Totala & DTW & Rack & Bulk & Total & $\begin{array}{c}\text { Through } \\
\text { Retail } \\
\text { Outlets }\end{array}$ & Totala & DTW & Rack & Bulk & Total \\
\hline \multicolumn{13}{|l|}{ Vermont } \\
\hline January ................................... & 0.0 & - & 17.5 & 33.2 & - & 50.7 & - & W & 64.5 & 135.2 & - & 199.8 \\
\hline February ................................. & - & - & $W$ & W & - & 50.0 & - & $W$ & 65.1 & 134.7 & - & 199.9 \\
\hline 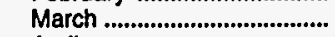 & - & - & $W$ & $W$ & - & 42.4 & - & $W$ & 62.3 & 122.9 & - & 185.1 \\
\hline April & - & - & 14.4 & 19.9 & - & 34.2 & - & $W$ & $W$ & $W$ & - & 149.9 \\
\hline May ......................................... & - & - & W & $W$ & - & 38.4 & - & $\ddot{w}$ & W & $w$ & - & 169.1 \\
\hline June .......................................... & - & - & 15.7 & 28.8 & - & 44.6 & - & $W$ & 67.3 & 128.0 & - & 195.3 \\
\hline 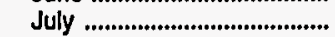 & - & - & $w$ & $W$ & - & 54.5 & - & w & 72.6 & 166.5 & - & 239.2 \\
\hline 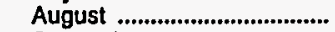 & - & - & 17.0 & 35.0 & - & 52.1 & - & $w$ & 73.9 & 158.1 & - & 232.1 \\
\hline 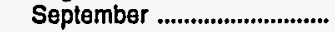 & - & - & 15.3 & 27.7 & - & 43.1 & - & $W$ & 68.6 & 136.0 & - & 204.6 \\
\hline 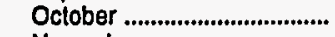 & - & - & 14.6 & 28.3 & - & 42.8 & - & W & $W$ & $W$ & - & 210.0 \\
\hline November .................................. & - & - & $w$ & W & - & 39.5 & - & - & 60.7 & 132.0 & - & 192.7 \\
\hline December .................................. & - & - & 14.1 & 29.3 & - & 43.4 & - & - & 63.1 & 150.3 & - & 213.5 \\
\hline 1994 Averago ............................ & - & - & 15.4 & 29.3 & - & 44.6 & - & $\mathbf{W}$ & 65.5 & 133.9 & - & 199.4 \\
\hline \multicolumn{13}{|l|}{ Subdistrict IB } \\
\hline 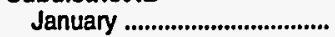 & $1,145.5$ & $1,192.0$ & $5,973.8$ & $3,203.6$ & $1,304.8$ & $10,482.2$ & $4,558.2$ & $4,860.4$ & $16,270.0$ & $13,401.8$ & $3,625.3$ & $33,297.1$ \\
\hline 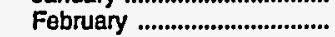 & $1,137.8$ & $1,190.1$ & $6,161.6$ & $3,237.8$ & $1,114.0$ & $10,513.4$ & $4,735.6$ & $5,066.1$ & $17,108.9$ & $13,687.4$ & $4,069.5$ & $34,865.8$ \\
\hline March ..................................... & $1,167.6$ & $1,221.4$ & $6,435.3$ & $3,189.5$ & $1,094.2$ & $10,719.0$ & $4,885.8$ & $5,222.0$ & 17.933 .2 & $13,873.7$ & $4,325.5$ & $36,132.4$ \\
\hline April & $1,218.3$ & $1,264.6$ & $6,694.9$ & $3,463.8$ & 992.5 & $11,151.2$ & $5,113.6$ & $5,415.4$ & $18,477.6$ & $14,626.9$ & $4,653.3$ & $37,757.9$ \\
\hline 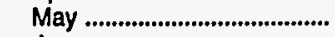 & $1,231.1$ & $1,281.8$ & $w$ & $3,630.9$ & $W$ & $11,591.6$ & $5,231,2$ & $5,540.4$ & $18,681.3$ & $15,066.5$ & $4,971.1$ & $38,718.9$ \\
\hline 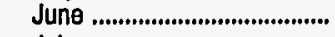 & $1,410.8$ & $1,459.3$ & W & $3,680.6$ & W & $11,861.8$ & $5,421.0$ & $5,731.9$ & $19,018.4$ & $15,786.3$ & $5,782.8$ & $40,587.5$ \\
\hline 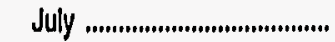 & $1,438.5$ & $1,484.3$ & $6,596.9$ & $3,729.5$ & 630.5 & $10,956.8$ & $5,527.3$ & $5,809.7$ & $18,630.1$ & $15,861.4$ & $4,007.2$ & $38,498.7$ \\
\hline August & $1,224.9$ & $1,284.6$ & $W$ & $3,647.0$ & $W$ & $11,091.4$ & $5,371.4$ & $5,709.9$ & $18,558.4$ & $16,308.9$ & $4,421.0$ & $39,288.4$ \\
\hline 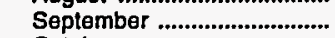 & $1,156.4$ & $1,204.3$ & $w$ & $3,585.3$ & $w$ & $10,572.8$ & $5,040.7$ & $5,330.1$ & $17,988.3$ & $15,934.3$ & $5,582.8$ & $39,505.4$ \\
\hline 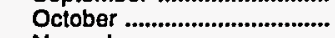 & $1,149.7$ & $1,191.1$ & $6,424.5$ & $W$ & $w$ & $10,512.1$ & $5,008.8$ & $5,292.7$ & $18,467.2$ & 16.116 .3 & $4,183.7$ & $38,767.1$ \\
\hline November ................................ & $1,099.9$ & $1,146.1$ & $6,141.6$ & $W$ & $W$ & $10,276.3$ & $4,976.6$ & $5,294.1$ & $18,135.7$ & $15,981.6$ & $3,660.8$ & $37,778.1$ \\
\hline Decomber ............................... & $1,123.6$ & $1,167.6$ & $6,297.5$ & $3,531.1$ & $1,593.2$ & $11,421.8$ & $5,070.9$ & $5,362.6$ & $18,495.1$ & $15,949.0$ & $5,677.0$ & $40,121.1$ \\
\hline I994 Average ........................... & $1,209.1$ & $1,257.7$ & $6,417.9$ & $3,498.2$ & $1,016.0$ & $10,932.2$ & $5,080.6$ & $5,388.3$ & $18,152.7$ & $15,224.7$ & $4,580.5$ & $37,957.9$ \\
\hline \multicolumn{13}{|l|}{ Delaware } \\
\hline 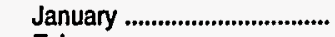 & W & 5.9 & 64.9 & 83.8 & - & 148.7 & $W$ & 23.9 & 285.3 & 418.5 & - & 703.8 \\
\hline February & W & $W$ & W & $W$ & - & 169.8 & $W$ & $w$ & 308.9 & $W$ & $W$ & 846.4 \\
\hline 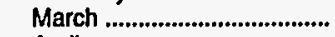 & $W$ & $W$ & $w$ & $W$ & - & 174.7 & $W$ & $w$ & 326.8 & $W$ & $W$ & 825.8 \\
\hline April & $W$ & $W$ & $w$ & $W$ & $\rightarrow$ & 197.5 & $W$ & $w$ & 343.2 & $W$ & $W$ & 982.4 \\
\hline 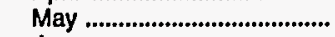 & $w$ & 7.6 & W & $W$ & - & 187.5 & $w$ & $w$ & 343.4 & $w$ & $W$ & 869.7 \\
\hline June ............................................. & $W$ & 7.9 & 81.9 & $W$ & W & 278.0 & $W$ & 38.8 & 353.6 & $W$ & W & 950.0 \\
\hline 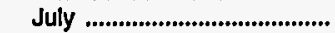 & W & 9.2 & 79.3 & 93.4 & - & 172.7 & W & 41.3 & $w$ & 445.8 & $w$ & 857.0 \\
\hline 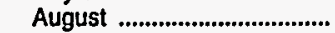 & 7.6 & $W$ & 76.8 & 105.6 & - & 182.4 & 34.6 & $W$ & $w$ & 505.5 & $w$ & 886.5 \\
\hline 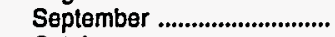 & 6.3 & 7.6 & $W$ & 108.6 & $w$ & 202.7 & 26.9 & 36.4 & $w$ & 552.9 & $w$ & 981.8 \\
\hline 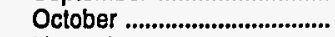 & 7.5 & $W$ & W & W & - & 193.1 & 31.1 & 38.4 & $w$ & 541.1 & $W$ & 940.6 \\
\hline November ................................ & 4.8 & 5.8 & $W$ & $W$ & - & 164.9 & 24.1 & 32.8 & $w$ & 461.4 & $w$ & 833.3 \\
\hline December ............................... & 6.3 & W & $W$ & w & $W$ & 322.9 & 28.7 & 36.3 & W & 500.2 & $w$ & $1,035.7$ \\
\hline 1994 Average & 6.1 & 7.1 & 76.2 & 102.9 & $\mathbf{W}$ & 199.7 & 27.0 & 35.0 & 337.9 & 487.5 & $\mathbf{W}$ & 892.7 \\
\hline \multicolumn{13}{|l|}{ District of Columbla } \\
\hline 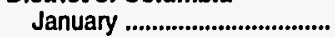 & 0.0 & $W$ & 169.5 & $w$ & - & 169.6 & - & $w$ & 339.5 & $w$ & - & 340.9 \\
\hline 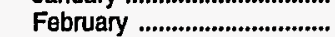 & - & $w$ & $W$ & W & - & 189.0 & - & W & $w$ & w & - & 377.4 \\
\hline March ................... & - & W & $\ddot{w}$ & W & - & 204.0 & - & $\ddot{w}$ & $\ddot{W}$ & $w$ & - & 400.3 \\
\hline April & - & $w$ & W & $w$ & - & 213.4 & - & $\dddot{w}$ & $\ddot{w}$ & $w$ & - & 415.1 \\
\hline 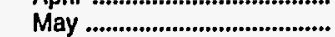 & - & $w$ & w & $\ddot{w}$ & - & 210.7 & - & w & $\ddot{w}$ & w & - & 410.2 \\
\hline June ........................ & - & 1.9 & $\ddot{w}$ & $\ddot{w}$ & - & 201.2 & - & 5.8 & $\ddot{w}$ & $w$ & - & 395.2 \\
\hline 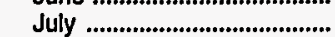 & - & 2.5 & $w$ & - & - & 192.1 & - & 7.3 & 387.7 & - & - & 387.7 \\
\hline August & - & $w$ & 180.3 & - & - & 180.3 & - & $\ddot{w}$ & 374.5 & - & - & 374.5 \\
\hline September ............................ & - & 3.1 & 188.0 & - & - & 188.0 & - & 9.4 & 381.2 & - & - & 381.2 \\
\hline October & - & $w$ & 190.6 & - & - & 190.6 & - & 8.8 & 382.1 & - & - & 382.1 \\
\hline November ........................... & - & 4.3 & 127.7 & - & - & 127.7 & - & 15.1 & 335.9 & - & - & 335.9 \\
\hline December ................................. & - & W & 176.2 & - & - & 176.2 & - & 13.6 & 384.6 & - & - & 384.6 \\
\hline 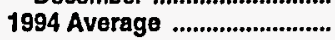 & - & 3.0 & 186.8 & $\mathbf{w}$ & - & 186.9 & - & 9.9 & 381.5 & $w$ & - & 382.1 \\
\hline
\end{tabular}

See lootnotes at end of table. 
Table 43. Refiner Motor Gasoline Volumes by Grade, Sales Type, PAD District, and State (Thousand Gallons per Day) - Continued

\begin{tabular}{|c|c|c|c|c|c|c|c|c|c|c|c|c|}
\hline \multirow{3}{*}{$\begin{array}{l}\text { Geographlc Area } \\
\text { Month }\end{array}$} & \multicolumn{6}{|c|}{ Regular } & \multicolumn{6}{|c|}{ Midgrade } \\
\hline & \multicolumn{2}{|c|}{ Sales to End Users } & \multicolumn{4}{|c|}{ Sales for Resalo } & \multicolumn{2}{|c|}{ Sales to End Usere } & \multicolumn{4}{|c|}{ Sales for Resale } \\
\hline & $\begin{array}{c}\text { Through } \\
\text { Rotail } \\
\text { Outlets }\end{array}$ & Totala & DTW & Rack & Bulk & Total & $\begin{array}{c}\text { Through } \\
\text { Rotail } \\
\text { Outlets }\end{array}$ & Totala & DTW & Rack & Bulk & Total \\
\hline \multicolumn{13}{|l|}{ Maryland } \\
\hline 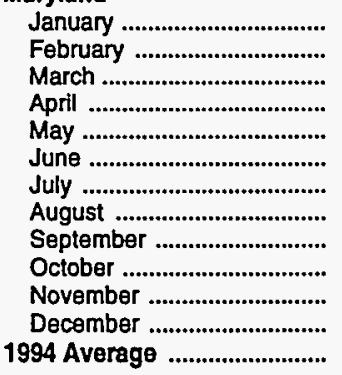 & $\begin{array}{l}W \\
W \\
W \\
W \\
W \\
W \\
W \\
- \\
- \\
- \\
- \\
- \\
W\end{array}$ & $\begin{array}{c}45.0 \\
53.6 \\
50.2 \\
W \\
47.8 \\
W \\
40.6 \\
55.5 \\
45.9 \\
45.8 \\
48.1 \\
44.4 \\
47.5\end{array}$ & $\begin{array}{r}1,469.5 \\
W \\
W \\
1,645.7 \\
W \\
W \\
1,663.0 \\
1,660.8 \\
1,657.1 \\
W \\
1,737.7 \\
W \\
1,658.4\end{array}$ & $\begin{array}{c}877.6 \\
830.5 \\
886.4 \\
W \\
1,024.3 \\
1,071.8 \\
W \\
W \\
W \\
1,090.6 \\
1,036.6 \\
W \\
987.1\end{array}$ & $\begin{array}{l}-\bar{W} \\
W \\
W \\
W \\
W \\
W \\
W \\
W \\
W \\
249.7 \\
104.2 \\
109.6\end{array}$ & $\begin{array}{l}2,347.0 \\
2,448.3 \\
2,590.5 \\
2,671.1 \\
2,775.5 \\
2,845.1 \\
2,799.9 \\
2,923.1 \\
2,818.2 \\
3,005.1 \\
3,024.0 \\
2,794.5 \\
2,755.1\end{array}$ & $\begin{array}{l}w \\
w \\
w \\
w \\
- \\
- \\
- \\
- \\
- \\
- \\
- \\
\bar{w}\end{array}$ & $\begin{array}{c}8.1 \\
9.2 \\
10.4 \\
W \\
W \\
W \\
5.9 \\
14.0 \\
8.6 \\
6.4 \\
8.6 \\
5.8 \\
8.5\end{array}$ & $\begin{array}{c}647.9 \\
W \\
694.1 \\
W \\
711.4 \\
735.3 \\
W \\
718.7 \\
714.5 \\
744.5 \\
714.1 \\
718.6 \\
709.5\end{array}$ & $\begin{array}{c}218.0 \\
W \\
W \\
260.7 \\
337.2 \\
W \\
357.8 \\
W \\
W \\
327.9 \\
317.6 \\
W \\
301.7\end{array}$ & $\begin{array}{l}- \\
\bar{w} \\
w \\
\bar{w} \\
w \\
w \\
w \\
- \\
\bar{w} \\
W\end{array}$ & $\begin{array}{r}865.9 \\
884.6 \\
966.4 \\
986.0 \\
1,048.6 \\
1,096.2 \\
1,101.9 \\
1,099.7 \\
1,069.2 \\
1,072.4 \\
1,031.7 \\
1,015.5 \\
1,020.7\end{array}$ \\
\hline \multicolumn{13}{|l|}{ New Jersey } \\
\hline 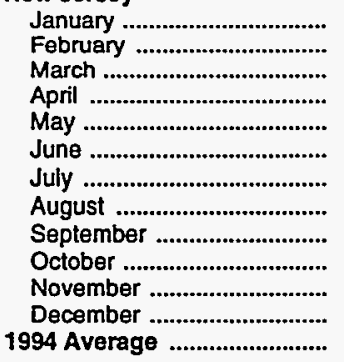 & $\begin{array}{l}544.5 \\
564.5 \\
599.6 \\
625.4 \\
628.3 \\
649.8 \\
682.3 \\
683.3 \\
627.3 \\
622.0 \\
625.4 \\
644.6 \\
625.2\end{array}$ & $\begin{array}{l}589.5 \\
611.0 \\
651.4 \\
673.4 \\
673.7 \\
697.7 \\
718.1 \\
718.7 \\
664.3 \\
664.6 \\
669.2 \\
683.6 \\
668.3\end{array}$ & $\begin{array}{l}1,953.2 \\
2,062.1 \\
2,204.2 \\
2,294.1 \\
2,311.1 \\
2,338.7 \\
2,308.5 \\
2,358.8 \\
2,209.3 \\
2,285.8 \\
2,309.8 \\
2,350.3 \\
2,249.9\end{array}$ & $\begin{array}{l}1,321.2 \\
1,259.1 \\
1,141.7 \\
1,255.3 \\
1,198.7 \\
1,327.9 \\
1,455.2 \\
1,367.1 \\
1,483.4 \\
1,451.1 \\
2,115.9 \\
1,632.3 \\
1,417.3\end{array}$ & $\begin{array}{l}1,253.4 \\
1,534.4 \\
1,639.2 \\
1,646.1 \\
1,684.8 \\
2,066.2 \\
1,428.9 \\
1,866.7 \\
3,347.3 \\
1,873.0 \\
1,619.8 \\
2,829.0 \\
1,899.1\end{array}$ & $\begin{array}{l}4,527.7 \\
4,855.7 \\
4,985.1 \\
5,195.4 \\
5,194.6 \\
5,732.7 \\
5,192.5 \\
5,592.6 \\
7,040.0 \\
5,609.9 \\
6,045.5 \\
6,811.5 \\
5,566.3\end{array}$ & $\begin{array}{l}160.0 \\
170.5 \\
172.9 \\
177.8 \\
164.0 \\
188.5 \\
200.8 \\
200.1 \\
188.8 \\
188.2 \\
184.6 \\
211.9 \\
184.1\end{array}$ & $\begin{array}{l}166.3 \\
178.6 \\
181.5 \\
185.3 \\
171.4 \\
197.8 \\
209.7 \\
209.6 \\
196.5 \\
194.6 \\
192.8 \\
218.2 \\
192.0\end{array}$ & $\begin{array}{l}651.9 \\
678.2 \\
700.7 \\
705.4 \\
711.3 \\
746.2 \\
742.8 \\
746.9 \\
735.7 \\
718.0 \\
722.6 \\
747.5 \\
717.5\end{array}$ & $\begin{array}{c}237.8 \\
W \\
W \\
W \\
W \\
W \\
W \\
W \\
256.1 \\
281.7 \\
282.1 \\
308.2 \\
264.0\end{array}$ & $\begin{array}{l}W \\
W \\
W \\
W \\
W \\
W \\
W \\
W \\
- \\
- \\
- \\
\bar{w}\end{array}$ & $\begin{array}{r}891.7 \\
934.0 \\
950.8 \\
958.3 \\
948.3 \\
1,015.7 \\
1,044.1 \\
1,026.8 \\
991.8 \\
999.7 \\
1,004.7 \\
1,055.7 \\
985.5\end{array}$ \\
\hline \multicolumn{13}{|l|}{ New York } \\
\hline 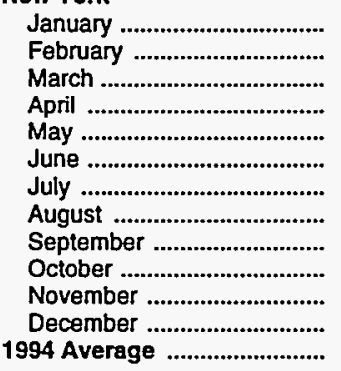 & $\begin{array}{l}1,113.6 \\
1,144.0 \\
1,152.9 \\
1,186.3 \\
1,211.1 \\
1,234.7 \\
1,267.9 \\
1,288.5 \\
1,206.1 \\
1,171.4 \\
1,185.8 \\
1,202.8 \\
1,197.5\end{array}$ & $\begin{array}{l}1,175.9 \\
1,209.7 \\
1,220.5 \\
1,246.6 \\
1,275.6 \\
1,305.1 \\
1,331.6 \\
1,357.0 \\
1,265.5 \\
1,234.6 \\
1,248.9 \\
1,266.4 \\
1,261.8\end{array}$ & $\begin{array}{r}2,360.1 \\
2,451.8 \\
W \\
2,616.0 \\
2,672.5 \\
2,742.1 \\
2,698.3 \\
2,723.1 \\
2,564.8 \\
W \\
W \\
2,675.9 \\
2,616.8\end{array}$ & $\begin{array}{r}3,056.5 \\
3,048.4 \\
3,068.4 \\
W \\
W \\
3,436.9 \\
3,427.3 \\
W \\
W \\
3,411.3 \\
3,235.7 \\
W \\
3,288.2\end{array}$ & $\begin{array}{c}W \\
369.6 \\
W \\
W \\
W \\
195.8 \\
343.3 \\
W \\
W \\
W \\
W \\
W \\
294.4\end{array}$ & $\begin{array}{l}5,675.7 \\
5,869.7 \\
5,968.9 \\
6,043.4 \\
6,277.5 \\
6,374.9 \\
6,468.9 \\
6,599.1 \\
6,260.9 \\
6,447.4 \\
5,965.8 \\
6,403.1 \\
6,199.3\end{array}$ & $\begin{array}{l}246.5 \\
238.5 \\
235.2 \\
243.6 \\
242.5 \\
230.3 \\
244.6 \\
273.6 \\
264.1 \\
269.7 \\
260.8 \\
280.8 \\
252.7\end{array}$ & $\begin{array}{l}254.0 \\
246.5 \\
243.4 \\
251.4 \\
249.4 \\
236.8 \\
254.3 \\
284.1 \\
273.0 \\
278.7 \\
269.9 \\
290.5 \\
261.1\end{array}$ & $\begin{array}{c}706.4 \\
720.7 \\
W \\
764.8 \\
796.8 \\
827.6 \\
829.9 \\
828.8 \\
792.6 \\
805.1 \\
799.9 \\
799.3 \\
785.2\end{array}$ & $\begin{array}{c}289.4 \\
W \\
W \\
W \\
346.3 \\
W \\
W \\
389.8 \\
334.4 \\
327.3 \\
316.5 \\
347.8 \\
331.8\end{array}$ & $\begin{array}{l}W \\
W \\
W \\
W \\
\bar{W} \\
W \\
- \\
- \\
- \\
- \\
\bar{w}\end{array}$ & $\begin{array}{r}996.9 \\
1,015.8 \\
1,039.2 \\
1,059.2 \\
1,143.1 \\
1,185.2 \\
1,219.1 \\
1,218.6 \\
1,127.0 \\
1,132.4 \\
1,116.4 \\
1,147.1 \\
1,117.4\end{array}$ \\
\hline \multicolumn{13}{|l|}{ Pennsylvania } \\
\hline 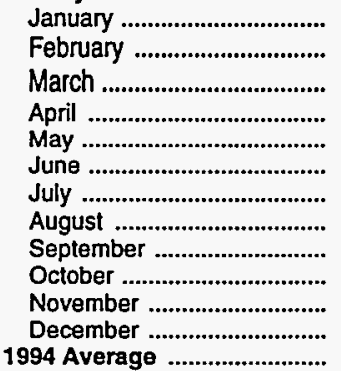 & $\begin{array}{r}981.3 \\
1,088.6 \\
1,148.2 \\
1,231.1 \\
1,255.7 \\
1,263.1 \\
1,250.8 \\
1,266.0 \\
1,188.7 \\
1,195.3 \\
1,205.4 \\
1,179.7 \\
1,188.3\end{array}$ & $\begin{array}{l}1,045.9 \\
1,158.9 \\
1,214.6 \\
1,288.3 \\
1,316.4 \\
1,320.7 \\
1,306.7 \\
1,327.3 \\
1,242.4 \\
1,246.7 \\
1,269.0 \\
1,236.4 \\
1,248.2\end{array}$ & $\begin{array}{r}1,624.3 \\
W \\
W \\
W \\
2,021.4 \\
2,080.9 \\
2,018.9 \\
2,070.5 \\
2,000.7 \\
W \\
2,033.1 \\
2,093.6 \\
1,980.2\end{array}$ & $\begin{array}{l}3,242.4 \\
3,531.2 \\
3,700.6 \\
3,919.4 \\
3,917.5 \\
4,154.4 \\
4,093.1 \\
4,472.3 \\
4,342.9 \\
4,373.1 \\
4,184.9 \\
4,291.6 \\
4,021.2\end{array}$ & $\begin{array}{c}W \\
W \\
W \\
W \\
1,577.3 \\
1,949.8 \\
1,346.7 \\
907.5 \\
952.3 \\
W \\
926.5 \\
865.5 \\
1,186.1\end{array}$ & $\begin{array}{l}5,671.4 \\
6,294.8 \\
6,777.8 \\
7,409.0 \\
7,516.1 \\
\mathbf{8 , 1 8 5 . 1} \\
7,458.8 \\
7,450.2 \\
7,295.9 \\
7,750.4 \\
7,144.6 \\
7,250.7 \\
7,187.5\end{array}$ & $\begin{array}{l}352.1 \\
377.7 \\
385.7 \\
408.6 \\
474.8 \\
418.8 \\
415.2 \\
408.0 \\
388.8 \\
388.8 \\
395.5 \\
405.1 \\
401.8\end{array}$ & $\begin{array}{l}360.6 \\
384.2 \\
393.9 \\
415.2 \\
480.5 \\
426.4 \\
421.5 \\
415.4 \\
394.5 \\
393.4 \\
403.6 \\
410.5 \\
408.5\end{array}$ & $\begin{array}{c}492.9 \\
535.7 \\
564.1 \\
577.5 \\
W \\
W \\
W \\
W \\
558.3 \\
553.8 \\
549.0 \\
562.4 \\
561.0\end{array}$ & $\begin{array}{c}619.2 \\
648.9 \\
723.1 \\
720.3 \\
730.7 \\
778.6 \\
768.3 \\
788.5 \\
W \\
745.1 \\
743.5 \\
737.3 \\
729.9\end{array}$ & $\begin{array}{l}W \\
- \\
- \\
- \\
w \\
W \\
W \\
W \\
w \\
- \\
- \\
- \\
w\end{array}$ & $\begin{array}{l}1,112.1 \\
1,184.6 \\
1,287.3 \\
1,297.8 \\
1,341.9 \\
1,424.7 \\
1,376.7 \\
1,388.4 \\
1,357.4 \\
1,298.9 \\
1,292.5 \\
1,299.7 \\
1,305.8\end{array}$ \\
\hline
\end{tabular}

See footnotes at end of table. 
Table 43. Refiner Motor Gasoline Volumes by Grade, Sales Type, PAD District, and State (Thousand Gallons per Day) - Continued

\begin{tabular}{|c|c|c|c|c|c|c|c|c|c|c|c|c|}
\hline \multirow{3}{*}{$\begin{array}{l}\text { Geographle Area } \\
\text { Month }\end{array}$} & \multicolumn{6}{|c|}{ Premlum } & \multicolumn{6}{|c|}{ All Grades } \\
\hline & \multicolumn{2}{|c|}{ Sales to End Users } & \multicolumn{4}{|c|}{ Sales for Rosale } & \multicolumn{2}{|c|}{ Sales to End Usere } & \multicolumn{4}{|c|}{ Sales for Resale } \\
\hline & $\begin{array}{c}\text { Through } \\
\text { Retail } \\
\text { Outlets }\end{array}$ & Totala & DTW & Rack & Bulk & Total & $\begin{array}{c}\text { Through } \\
\text { Retail } \\
\text { Outlets }\end{array}$ & Totala & DTW & Rack & Bulk & Total \\
\hline 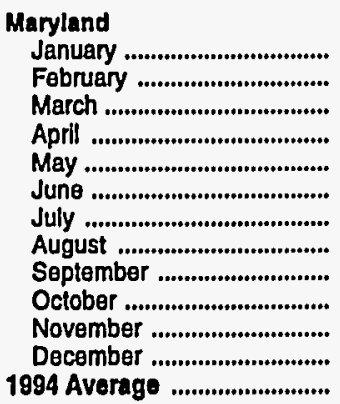 & $\begin{array}{l}w \\
w \\
w \\
w \\
w \\
w \\
w \\
= \\
- \\
- \\
- \\
\bar{w}\end{array}$ & $\begin{array}{r}8.8 \\
9.1 \\
10.5 \\
9.4 \\
W \\
7.4 \\
6.1 \\
19.5 \\
12.0 \\
6.0 \\
8.7 \\
6.2 \\
9.3\end{array}$ & $\begin{array}{c}948.2 \\
992.4 \\
W \\
1,071.6 \\
W \\
W \\
1,052.3 \\
W \\
W \\
1,071.8 \\
962.6 \\
W \\
1,026.3\end{array}$ & $\begin{array}{c}330.9 \\
W \\
W \\
W \\
469.6 \\
W \\
W \\
456.7 \\
453.6 \\
454.5 \\
396.4 \\
345.5 \\
408.0\end{array}$ & $\begin{array}{c}\bar{w} \\
W \\
W \\
W \\
N A \\
W \\
W \\
W \\
- \\
\bar{W} \\
18.7\end{array}$ & $\begin{array}{l}1,279.1 \\
1,301.0 \\
1,432.2 \\
1,485.5 \\
1,564.0 \\
1,603.5 \\
1,515.4 \\
1,502.0 \\
1,496.1 \\
1,526.3 \\
1,359.0 \\
1,361.4 \\
1,453.0\end{array}$ & $\begin{array}{l}w \\
w \\
w \\
w \\
w \\
w \\
w \\
- \\
- \\
\overline{-} \\
\bar{w} \\
\bar{w}\end{array}$ & $\begin{array}{l}61.9 \\
71.9 \\
71.1 \\
65.5 \\
64.8 \\
60.8 \\
52.6 \\
89.0 \\
66.6 \\
58.1 \\
65.4 \\
56.4 \\
65.3\end{array}$ & $\begin{array}{r}3,065.5 \\
W \\
W \\
W \\
W \\
W \\
W \\
W \\
W \\
W \\
W \\
3,414.4 \\
W \\
3,394.1\end{array}$ & $\begin{array}{l}1,426.5 \\
1,323.4 \\
1,513.7 \\
1,607.3 \\
1,831.2 \\
1,895.7 \\
1,814.2 \\
1,898.9 \\
1,851.8 \\
1,872.9 \\
1,750.6 \\
1,549.0 \\
1,696.8\end{array}$ & $\begin{array}{c}\bar{W} \\
W \\
W \\
W \\
W \\
W \\
W \\
W \\
W \\
249.7 \\
W \\
137.9\end{array}$ & $\begin{array}{l}4,492.0 \\
4,633.9 \\
4,989.2 \\
5,142.6 \\
5,388.0 \\
5,544.9 \\
5,417.3 \\
5,524.8 \\
5,383.4 \\
5,603.7 \\
5,414.6 \\
5,171.4 \\
5,228.7\end{array}$ \\
\hline 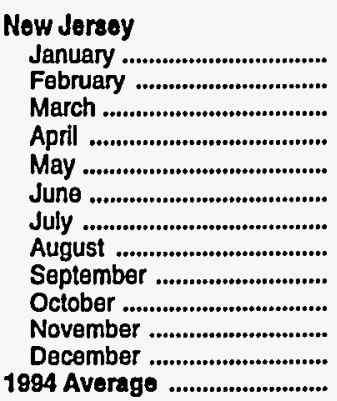 & $\begin{array}{l}307.2 \\
308.3 \\
334.3 \\
356.0 \\
338.6 \\
371.5 \\
396.7 \\
381.1 \\
352.9 \\
337.8 \\
326.7 \\
335.4 \\
345.8\end{array}$ & $\begin{array}{l}322.5 \\
329.4 \\
353.5 \\
373.3 \\
358.9 \\
392.4 \\
414.7 \\
399.3 \\
370.1 \\
355.9 \\
344.6 \\
352.8 \\
364.2\end{array}$ & $\begin{array}{l}1,757.5 \\
1,810.7 \\
1,884.1 \\
2,011.7 \\
2,028.5 \\
2,025.2 \\
1,971.0 \\
1,944.3 \\
1,871.8 \\
1,893.7 \\
1,858.8 \\
1,897.6 \\
1,913.4\end{array}$ & $\begin{array}{c}628.5 \\
W \\
W \\
W \\
W \\
W \\
W \\
W \\
724.9 \\
716.7 \\
728.7 \\
798.8 \\
696.2\end{array}$ & $\begin{array}{c}857.2 \\
W \\
W \\
W \\
W \\
W \\
W \\
W \\
391.7 \\
225.3 \\
423.3 \\
1,214.9 \\
588.3\end{array}$ & $\begin{array}{l}3,243.2 \\
3,086.3 \\
3,219.6 \\
3,103.5 \\
3,333.6 \\
3,313.1 \\
3,050.5 \\
3,256.4 \\
2,988.4 \\
2,835.8 \\
3,010.7 \\
3,911.3 \\
3,197.9\end{array}$ & $\begin{array}{l}1,011.6 \\
1,043.3 \\
1,106.8 \\
1,159.1 \\
1,130.9 \\
1,209.9 \\
1,279.8 \\
1,264.5 \\
1,169.0 \\
1,148.1 \\
1,136.7 \\
1,191.9 \\
1,155.1\end{array}$ & $\begin{array}{l}1,078.4 \\
1,119.0 \\
1,186.5 \\
1,232.0 \\
1,203.9 \\
1,287.9 \\
1,342.6 \\
1,327.7 \\
1,230.9 \\
1,215.2 \\
1,206.6 \\
1,254.6 \\
1,224.4\end{array}$ & $\begin{array}{l}4,362.5 \\
4,551.0 \\
4,789.0 \\
5,011.2 \\
5,050.8 \\
5,110.1 \\
5,022.2 \\
5,050.0 \\
4,816.8 \\
4,897.5 \\
4,891.2 \\
4,995.5 \\
4,880.8\end{array}$ & $\begin{array}{l}2,187.5 \\
2,186.6 \\
1,999.6 \\
2,183.1 \\
2,114.6 \\
2,267.9 \\
2,522.0 \\
2,287.5 \\
2,464.4 \\
2,449.5 \\
3,126.7 \\
2,739.2 \\
2,377.5\end{array}$ & $\begin{array}{l}2,112.7 \\
2,138.4 \\
2,366.8 \\
2,062.8 \\
2,311.1 \\
2,683.5 \\
1,742.9 \\
2,538.3 \\
3,739.0 \\
2,098.3 \\
2,043.1 \\
4,043.9 \\
2,491.4\end{array}$ & $\begin{array}{r}8,662.6 \\
8,876.0 \\
9,155.5 \\
9,257.2 \\
9,476.5 \\
10,061.5 \\
9,287.1 \\
9,875.8 \\
11,020.1 \\
9,445.4 \\
10,061.0 \\
11,778.6 \\
9,749.7\end{array}$ \\
\hline 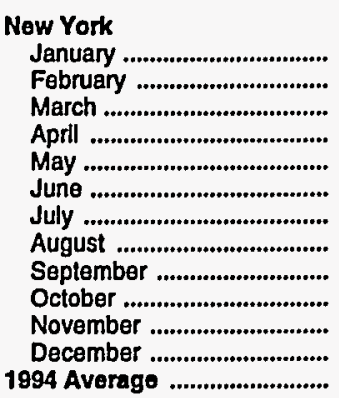 & $\begin{array}{l}403.9 \\
395.5 \\
399.9 \\
410.9 \\
439.1 \\
553.4 \\
566.2 \\
432.4 \\
413.7 \\
397.4 \\
382.0 \\
401.2 \\
433.2\end{array}$ & $\begin{array}{l}415.1 \\
408.1 \\
413.6 \\
420.7 \\
450.1 \\
566.0 \\
578.1 \\
441.9 \\
421.7 \\
406.0 \\
389.9 \\
411.4 \\
443.8\end{array}$ & $\begin{array}{r}2,138.6 \\
2,162.4 \\
2,262.4 \\
2,322.6 \\
2,352.6 \\
2,404.8 \\
2,330.7 \\
2,262.5 \\
2,199.9 \\
W \\
W \\
2,222.4 \\
2,258.7\end{array}$ & $\begin{array}{c}894.9 \\
W \\
W \\
W \\
W \\
W \\
W \\
W \\
W \\
900.8 \\
838.5 \\
W \\
916.2\end{array}$ & $\begin{array}{l}w \\
w \\
w \\
w \\
w \\
w \\
w \\
w \\
W \\
W \\
w \\
W \\
86.2\end{array}$ & $\begin{array}{l}3,191.8 \\
3,204.6 \\
3,210.8 \\
3,265.7 \\
3,369.2 \\
3,454.2 \\
3,412.3 \\
3,300.8 \\
3,191.8 \\
3,230.8 \\
3,069.6 \\
3,223.4 \\
3,261.0\end{array}$ & $\begin{array}{l}1,764.0 \\
1,778.0 \\
1,788.0 \\
1,840.9 \\
1,892.7 \\
2,018.3 \\
2,078.7 \\
1,994.5 \\
1,883.9 \\
1,838.5 \\
1,828.5 \\
1,884.9 \\
1,883.3\end{array}$ & $\begin{array}{l}1,845.0 \\
1,864.3 \\
1,877.5 \\
1,918.6 \\
1,975.2 \\
2,108.0 \\
2,164.0 \\
2,083.0 \\
1,960.2 \\
1,919.3 \\
1,908.8 \\
1,968.3 \\
1,966.8\end{array}$ & $\begin{array}{r}5,205.1 \\
5,334.9 \\
5,576.8 \\
5,703.4 \\
5,821.9 \\
5,974.5 \\
5,859.0 \\
5,814.4 \\
5,557.2 \\
5,710.4 \\
W \\
5,697.6 \\
5,660.6\end{array}$ & $\begin{array}{r}4,240.8 \\
4,224.0 \\
w \\
W \\
4,572.9 \\
4,768.8 \\
4,825.4 \\
4,898.9 \\
4,560.4 \\
4,639.3 \\
4,390.7 \\
4,774.8 \\
4,536.2\end{array}$ & $\begin{array}{c}W \\
531.1 \\
W \\
W \\
395.0 \\
271.0 \\
415.9 \\
405.3 \\
462.1 \\
460.8 \\
W \\
301.2 \\
381.0\end{array}$ & $\begin{array}{r}9,864.5 \\
10,090.0 \\
10,218.9 \\
10,368.3 \\
10,789.8 \\
11,014.3 \\
11,100.3 \\
11,118.5 \\
10,579.7 \\
10,810.5 \\
10,151.8 \\
10,773.5 \\
10,577.8\end{array}$ \\
\hline 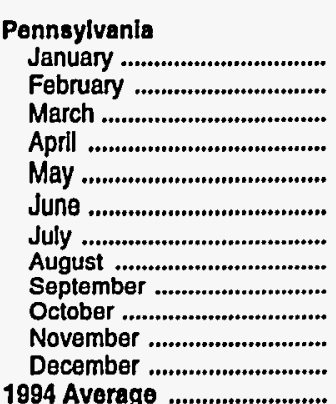 & $\begin{array}{l}428.1 \\
431.3 \\
426.8 \\
445.2 \\
446.4 \\
478.5 \\
467.3 \\
403.8 \\
383.4 \\
407.0 \\
386.4 \\
380.7 \\
423.7\end{array}$ & $\begin{array}{l}437.2 \\
438.1 \\
433.7 \\
451.1 \\
454.3 \\
483.6 \\
473.6 \\
410.6 \\
389.7 \\
412.8 \\
392.7 \\
386.6 \\
430.3\end{array}$ & $\begin{array}{c}895.0 \\
W \\
W \\
W \\
W \\
W \\
W \\
W \\
927.1 \\
W \\
916.1 \\
928.9 \\
956.5\end{array}$ & $\begin{array}{r}1,265.5 \\
1,291.8 \\
1,260.0 \\
1,387.8 \\
1,406.0 \\
1,444.7 \\
1,392.5 \\
1,457.4 \\
w \\
1,495.2 \\
1,323.8 \\
1,356.9 \\
1,374.9\end{array}$ & $\begin{array}{l}W \\
W \\
W \\
W \\
W \\
W \\
W \\
W \\
W \\
W \\
W \\
304.6 \\
140.9 \\
302.2\end{array}$ & $\begin{array}{l}2,449.8 \\
2,562.7 \\
2,477.6 \\
2,885.7 \\
2,926.6 \\
3,011.8 \\
2,613.9 \\
2,669.5 \\
2,505.8 \\
2,535.5 \\
2,544.5 \\
2,426.7 \\
2,633.6\end{array}$ & $\begin{array}{l}1,761.5 \\
1,897.6 \\
1,960.7 \\
2,084.9 \\
2,176.9 \\
2,160.4 \\
2,133.3 \\
2,077.8 \\
1,960.8 \\
1,991.1 \\
1,987.3 \\
1,965.5 \\
2,013.7\end{array}$ & $\begin{array}{l}1,843.7 \\
1,981.2 \\
2,042.2 \\
2,154.6 \\
2,251.1 \\
2,230.7 \\
2,201.8 \\
2,153.4 \\
2,026.6 \\
2,053.0 \\
2,065.4 \\
2,033.5 \\
2,086.9\end{array}$ & $\begin{array}{l}3,012.2 \\
3,310.8 \\
3,475.5 \\
3,582.9 \\
3,611.9 \\
3,709.9 \\
3,571.6 \\
3,590.1 \\
3,486.1 \\
3,530.3 \\
3,498.2 \\
3,584.9 \\
3,497.8\end{array}$ & $\begin{array}{l}\mathbf{5 , 1 2 7 . 1} \\
5,471.8 \\
5,683.7 \\
6,027.5 \\
6,054.2 \\
6,377.7 \\
6,254.0 \\
6,718.2 \\
6,504.9 \\
6,613.4 \\
6,252.3 \\
6,385.8 \\
6,126.0\end{array}$ & $\begin{array}{l}1,094.1 \\
1,259.4 \\
1,383.5 \\
1,982.1 \\
2,118.6 \\
2,534.1 \\
1,623.8 \\
1,199.8 \\
1,168.2 \\
1,441.1 \\
1,231.1 \\
1,006.5 \\
1,503.1\end{array}$ & $\begin{array}{r}9,233.3 \\
10,042.0 \\
10,542.7 \\
11,592.5 \\
11,784.7 \\
12,621.6 \\
11,449.4 \\
11,508.1 \\
11,159.2 \\
11,584.8 \\
10,981.6 \\
10,977.2 \\
11,126.9\end{array}$ \\
\hline
\end{tabular}

See footnotes at end of table. 
Table 43. Refiner Motor Gasoline Volumes by Grade, Sales Type, PAD District, and State (Thousand Gallons per Day) - Continued

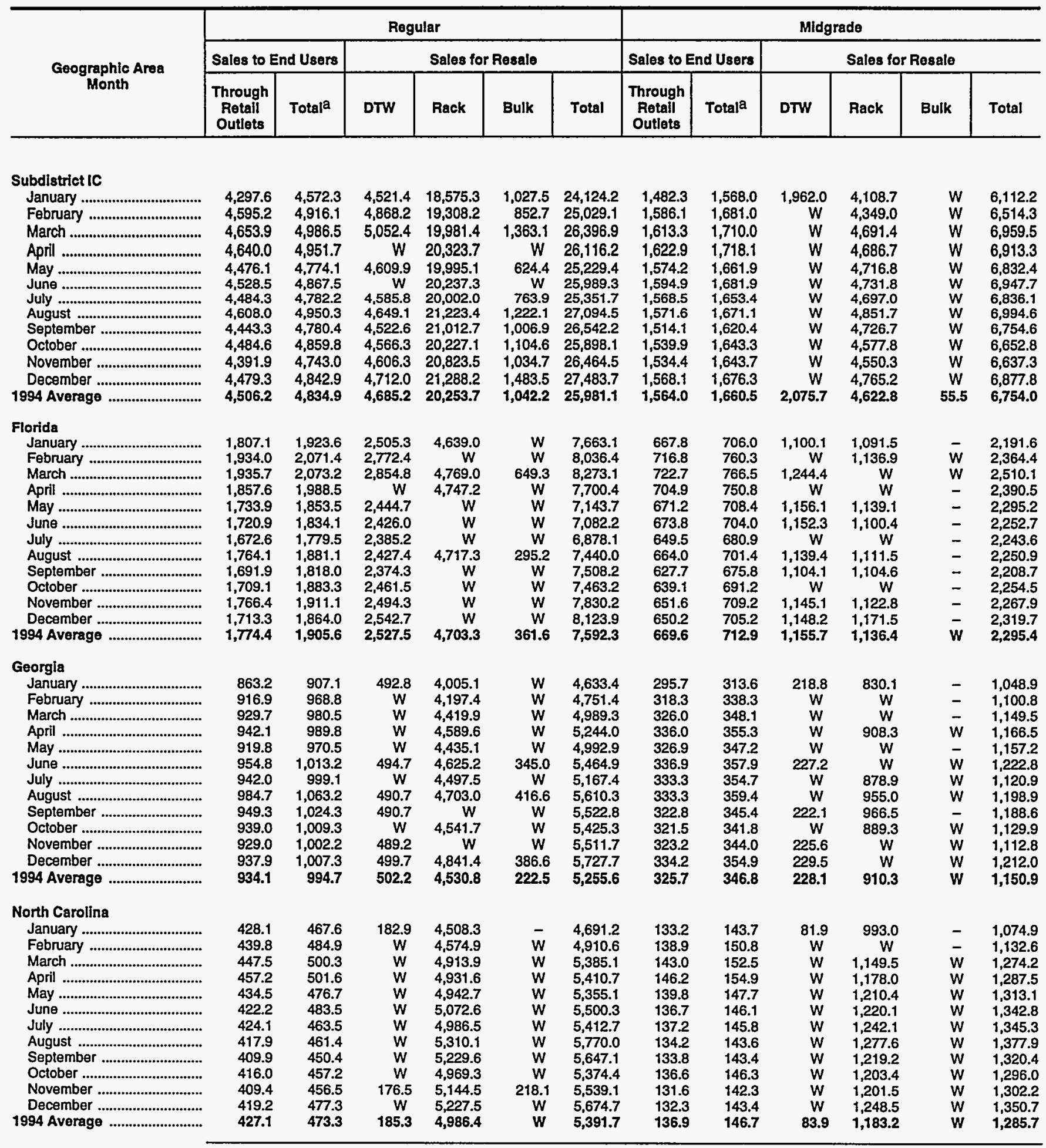

See footnotes at end of table. 
Table 43. Refir:yr Motor Gasoline Volumes by Grade, Sales Type, PAD District, and State

(Thousand Gallons per Day) - Continued

\begin{tabular}{|c|c|c|c|c|c|c|c|c|c|c|c|c|}
\hline \multirow{3}{*}{$\begin{array}{l}\text { Goographic Area } \\
\text { Month }\end{array}$} & \multicolumn{6}{|c|}{ Premlum } & \multicolumn{6}{|c|}{ All Grades } \\
\hline & \multicolumn{2}{|c|}{ Sales to End Users } & \multicolumn{4}{|c|}{ Sales for Resale } & \multicolumn{2}{|c|}{ Sales to End Users } & \multicolumn{4}{|c|}{ Sales for Resale } \\
\hline & $\begin{array}{c}\text { Through } \\
\text { Rotail } \\
\text { Outlots }\end{array}$ & Totala & DTW & Rack & Bulk & Total & $\begin{array}{c}\text { Through } \\
\text { Rotail } \\
\text { Outlets }\end{array}$ & Totaja & DTW & Rack & Bulk & Total \\
\hline
\end{tabular}

Subdlstrict IC

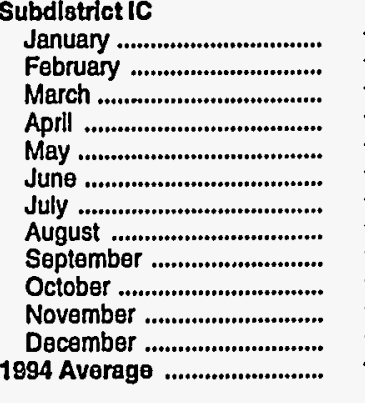

Florida

January ...

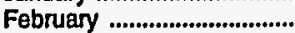

March...

Aprill

May

June

July ......

August .

September

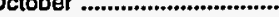

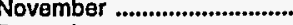

December

1994 Average

Georgia

January

February

March

May

June

July ...

September

October ...

November

December

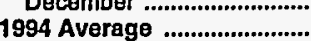

North Carolina

January ..

February

March

Aprll

May

June

August

September

October ...

November .

December ..
1994 Average

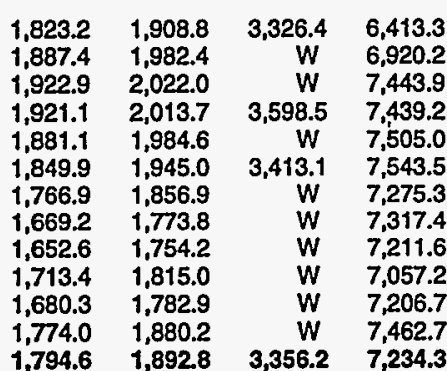

$965.5 \quad 1,003.9$

$1,0109 \quad 1,0539$

$1,013.3 \quad 1,058.6$

$984.9 \quad 1,026.1$

$953.8 \quad 1,007.5$

915.

855.5

834.3

800.8

836.0

867.6

906.5

$1,007.5$
952.9

888.9

870.6

839.6
878.9

892.7

913.0
948.2

$2,104.5 \quad 1,529.3$

$2,281.9$

$2,334.1$

$2,245.8$

$2,162.2$

$2,071.3$

$1,952.0$

$1,863.4$

$1,869.1$

$1,973.4$

$2,058.8$

(3)

$\begin{array}{ll}320.2 & 336.6 \\ 334.8 & 352.2\end{array}$

$\begin{array}{ll}334.8 & 352.2 \\ 346.8 & 364.6\end{array}$

$346.0 \quad 364.2$

$340.9 \quad 357.1$

$334.3 \quad 352.0$

$323.0 \quad 341.9$

$310.6 \quad 336.0$

$311.9 \quad 335.5$

$315.4 \quad 335.5$

$310.7 \quad 335.0$

$\begin{array}{ll}332.7 & 355.8 \\ 327.2 & 347.2\end{array}$

$\begin{array}{cc}320.5 & 1,432.9 \\ W & W \\ 348.7 & W \\ W & 1,686.3 \\ W & W \\ 323.7 & W \\ W & 1,553.0 \\ W & 1,604.6 \\ 306.4 & W \\ W & 1,536.5 \\ 305.5 & 1,611.6 \\ 319.6 & W \\ 322.2 & 1,607.4\end{array}$

$\begin{array}{rr}186.5 & 9,926.2 \\ W & 10,619.3 \\ W & 11,232.0 \\ 103.0 & 11,140.7 \\ W & 11,041.5 \\ 221.9 & 11,178.5 \\ W & 10,642.9 \\ W & 10,611.0 \\ W & 10,445.4 \\ W & 10,378.8 \\ W & 10,490.0 \\ W & 10,923.9 \\ 128.5 & 10,719.0\end{array}$

$7,603.2$

$8,668.7$

$8,190.1$

$8,718.5 \quad 10,916.3 \quad 30,577.4$

$8,184.0 \cdot 8,683.5 \quad 10,668.0 \quad 32,449.6$

$\begin{array}{lllll}7,931.4 & 8,420.6 & 10,201.8 & 32,217.0\end{array}$

$\begin{array}{llll}7,973.4 & 8,494.5 & 10,161.7 & 32,512.6\end{array}$

$7,819.7$

$7,848.8$

$7,610.0$

$8,292.5$

$8,395.1$

$8,155.0$

$927.631,974.3$

$\begin{array}{ll}9,927.6 & 31,974.3 \\ 9,872.5 & 33,392.5\end{array}$

$\begin{array}{ll}9,872.5 & 33,392.5 \\ 9,663.5 & 32,951.1\end{array}$

$7,738.0$

$7,606.6$

$8,318.1$

$8,169.6$

$9,786.2 \quad 31,862$.

$\mathbf{9 , 8 4 1 . 6} \quad 32,580.5$

$7,864.9$

$\begin{array}{lll}8,399.4 & 10,058.3 & 33,516.0 \\ 8,388.2 & 10,117.1 & 32,110.8\end{array}$

$\begin{array}{rr}\mathbf{5 , 7 0 9 . 8} & 7,259.8 \\ \mathbf{W} & \mathbf{7 , 9 1 6 . 5} \\ \mathbf{6 , 4 3 3 . 4} & \mathbf{7 , 7 6 3 . 0} \\ \mathbf{W} & \mathbf{7 , 6 8 0 . 4} \\ \mathbf{5 , 7 6 3 . 0} & 7,380.3 \\ \mathbf{5 , 6 4 9 . 6} & 7,119.8 \\ \mathbf{W} & 7,092.4 \\ \mathbf{5 , 4 3 0 . 2} & 7,417.4 \\ \mathbf{5 , 3 4 7 . 6} & \mathbf{7 , 3 6 5 . 7} \\ \mathbf{W} & \mathbf{7 , 3 7 9 . 4} \\ \mathbf{5 , 6 1 2 . 8} & \mathbf{7 , 7 5 . 4} \\ \mathbf{5 , 7 4 9 . 8} & \mathbf{7 , 7 7 9 . 6} \\ \mathbf{5 , 7 5 4 . 9} & \mathbf{7 , 4 8 9 . 1}\end{array}$

$3,440.5 \quad 3,633.5$

$3,661.6$

$3,885.5$

$3,898.3$

$3,547.3$

$3,765.4$

W $4,018.1$

W $3,914.8$

W $\quad 3,778.7$

$3,358.9$

$3,569.3$

$1,607.2$

$1,588.5$

$W$
$1,567.5$

W

$1,649.4$

- 3,559.1

$3,177.7$

3,491 .

$3,349.3$

W $3,454.9$

$\bar{w} \quad 3,528.3$

W $3,877.0$

$3,120.4$

$3,333.4$

$3,184.2 \quad 3,453.3$

$3,265.3 \quad 3,512.9$

$3,231.0 \quad 3,482$

$46.3 \quad 3,767.5$

W $1,787.1$

$\begin{array}{llll}W & 1,892.8 & 1,570.0 & 1,659.3\end{array}$

$\begin{array}{llll}W & 2,026.1 & 1,602.5 & 1,693.2\end{array}$

W $\quad 2053.8 \quad 1,624.1 \quad 1.709 .3$

- 20018

W $2,127.1$

W $\quad 1,938.4$

$1,587.6 \quad 1,674.8$

$1,626.1 \quad 1,723.1$

$1,598.3 \quad 1,695.8$

$1,628.6 \quad 1,758.5$

$\begin{array}{llll}W & 2,003.0 & 1,584.0 & 1,705.2\end{array}$

$\begin{array}{llll}W & \mathbf{1}, 940.4 & 1,575.8 & 1,686.7\end{array}$

$\begin{array}{llll}- & 1,917.1 & 1,562.9 & 1,681.3\end{array}$

$1,604.8 \quad 1,718.0$

$47.7 \quad 1,977.3$

$\mathbf{1 , 5 8 7 . 0}$

$1,688.6$

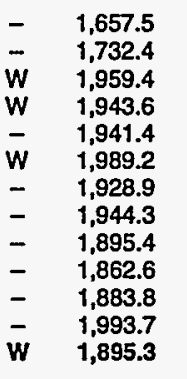

692.5

707.4
724.1

751.7

774.3

796.2

804.8

768.5

763.4

739.7

729.0

717.9

730.8

719.0

762.7

$\mathbf{7 5 4 . 7}$
$1,032.1 \quad 6,268.0$

W $6,626.4$

W $\quad 6,990.7$

W 7,184.1

W 7.024 .8

$1,045.6 \quad 7,259.6$

$\begin{array}{cr}W & 6,929.5 \\ 1,021.6 & 7,262.6\end{array}$

$1,019.2 \quad 7,415.6$

W $\quad 6,967.4$

$1,020.3 \quad 7,167.4$

$1,048.8 \quad 7,472.9$

$1,052.4 \quad 7,048.6$

\begin{tabular}{cccc}
358.1 & $7,065.5$ & - & $7,423.5$ \\
$\mathbf{W}$ & $7,253.5$ & $\mathbf{W}$ & $\mathbf{7 , 7 7 5 . 6}$ \\
$\mathbf{W}$ & $7,904.5$ & $\mathbf{W}$ & $\mathbf{8 , 6 1 8 . 6}$ \\
$\mathbf{W}$ & $7,943.1$ & $\mathbf{W}$ & $\mathbf{8 , 6 4 1 . 8}$ \\
$\mathbf{W}$ & $7,997.0$ & $\mathbf{W}$ & $\mathbf{8 , 6 0 9 . 5}$ \\
$\mathbf{W}$ & $\mathbf{8 , 1 7 8 . 1}$ & $\mathbf{W}$ & $\mathbf{8 , 8 3 2 . 3}$ \\
$\mathbf{W}$ & $\mathbf{8 , 0 6 0 . 1}$ & $\mathbf{W}$ & $\mathbf{8 , 6 8 7 . 0}$ \\
$\mathbf{W}$ & $\mathbf{8 , 4 4 0 . 0}$ & $\mathbf{W}$ & $\mathbf{9 , 0 9 2 . 3}$ \\
$\mathbf{W}$ & $\mathbf{8 , 2 4 8 . 7}$ & $\mathbf{W}$ & $\mathbf{8 , 8 6 2 . 9}$ \\
$\mathbf{W}$ & $\mathbf{7 , 9 4 1 . 8}$ & $\mathbf{W}$ & $\mathbf{8 , 5 3 3 . 1}$ \\
$\mathbf{W}$ & $\mathbf{8 , 1 3 7 . 9}$ & $\mathbf{W}$ & $\mathbf{8 , 7 2 5 . 1}$ \\
$\mathbf{W}$ & $\mathbf{8 , 3 7 3 . 1}$ & $\mathbf{W}$ & $9,019.2$ \\
$\mathbf{3 6 5 . 6}$ & $\mathbf{7 , 9 6 5 . 9}$ & $\mathbf{W}$ & $\mathbf{8 , 5 7 2 . 8}$ \\
\hline
\end{tabular}

W $\quad 7,469.4$

W $\quad 7,745.1$

$W$
$W$

W $8,152.0$

$509.6 \quad 8,814.8$

$\begin{array}{cr}W & 8,226.7 \\ 559.5 & 8,843.7\end{array}$

77.7

W $8,495.6$

$353.9 \quad 8,541.6$

$421.4 \quad 8,943.1$

$282.8 \quad 8,383.8$

$1,255.5 \quad 40,162.5$ $1,051.5 \quad 42,162.7$

$1,555.4 \quad 44,588.4$

$1,052.6 \quad 44,170.2$

1,441.1 44,115.4

$928.9 \quad 42,830.8$

$1,435.1 \quad 44,700.1$

$1,127.7 \quad 43,742.2$

\begin{tabular}{ll}
$42,929.7$ \\
\hline
\end{tabular}

$1,711.145,285.5$

$1,226.2 \quad 43,454.1$

$591.4 \quad 13,561.0$

W $14,478.7$

$722.4 \quad 14,918.7$

W $14,109.0$

$210.5 \quad 13,353.7$

$344.3 \quad 13,113.6$

W $12,680.9$

$295.2 \quad 13,142.8$

$458.6 \quad 13,171.9$

W $13,246.0$

$464.5 \quad 13,832.7$

$411.2 \quad 13,655.2$

See footnotes at end of table. 
Table 43. Refiner Motor Gasoline Volumes by Grade, Sales Type, PAD District, and State (Thousand Gallons per Day) - Continued

\begin{tabular}{|c|c|c|c|c|c|c|c|c|c|c|c|c|}
\hline \multirow{3}{*}{$\begin{array}{l}\text { Goographic Area } \\
\text { Month }\end{array}$} & \multicolumn{6}{|c|}{ Regular } & \multicolumn{6}{|c|}{ Midgrade } \\
\hline & \multicolumn{2}{|c|}{ Sales to End Users } & \multicolumn{4}{|c|}{ Sales for Ressle } & \multicolumn{2}{|c|}{ Sales to End Users } & \multicolumn{4}{|c|}{ Sales for Resale } \\
\hline & $\begin{array}{c}\text { Through } \\
\text { Retail } \\
\text { Outlets }\end{array}$ & Totala & DTW & Rack & Bulk & Total & $\begin{array}{c}\text { Through } \\
\text { Retail } \\
\text { Outlets }\end{array}$ & Totala & DTW & Rack & Bulk & Total \\
\hline \multicolumn{13}{|l|}{ South Carolina } \\
\hline 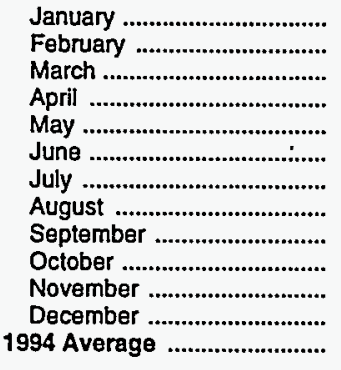 & $\begin{array}{l}502.8 \\
541.5 \\
548.3 \\
559.2 \\
549.6 \\
557.0 \\
561.7 \\
566.7 \\
546.9 \\
542.9 \\
541.1 \\
537.7 \\
546.3\end{array}$ & $\begin{array}{l}522.7 \\
564.9 \\
572.5 \\
583.1 \\
573.3 \\
582.2 \\
587.5 \\
596.7 \\
575.1 \\
570.5 \\
566.0 \\
565.5 \\
571.7\end{array}$ & $\begin{array}{l}83.8 \\
W \\
W \\
W \\
W \\
W \\
W \\
W \\
W \\
W \\
W \\
W \\
79.6\end{array}$ & $\begin{array}{r}2,440.0 \\
2,420.7 \\
2,540.1 \\
2,595.5 \\
2,534.6 \\
2,579.2 \\
2,597.2 \\
2,660.7 \\
2,585.4 \\
2,507.6 \\
W \\
2,660.9 \\
2,553.1\end{array}$ & $\begin{array}{l}W \\
W \\
W \\
W \\
W \\
W \\
W \\
W \\
W \\
W \\
W \\
W \\
110.9\end{array}$ & $\begin{array}{l}2,886.6 \\
2,648.1 \\
2,855.6 \\
2,731.7 \\
2,683.7 \\
2,753.9 \\
2,765.2 \\
2,833.9 \\
2,732.6 \\
2,640.4 \\
2,614.2 \\
2,763.8 \\
2,743.6\end{array}$ & $\begin{array}{l}146.8 \\
158.7 \\
162.2 \\
166.0 \\
160.7 \\
157.3 \\
155.3 \\
158.3 \\
155.1 \\
150.5 \\
154.9 \\
159.6 \\
157.1\end{array}$ & $\begin{array}{l}151.9 \\
163.8 \\
167.0 \\
171.2 \\
166.6 \\
162.6 \\
161.1 \\
163.5 \\
160.2 \\
155.6 \\
158.6 \\
164.2 \\
162.2\end{array}$ & $\begin{array}{c}27.5 \\
30.1 \\
W \\
33.6 \\
W \\
32.8 \\
W \\
W \\
W \\
W \\
W \\
W \\
29.0\end{array}$ & $\begin{array}{c}520.1 \\
W \\
W \\
565.9 \\
W \\
580.3 \\
W \\
W \\
W \\
W \\
W \\
W \\
556.1\end{array}$ & $\begin{array}{l}W \\
W \\
- \\
- \\
- \\
- \\
- \\
- \\
- \\
- \\
- \\
\bar{W}\end{array}$ & $\begin{array}{l}589.0 \\
594.6 \\
606.5 \\
599.5 \\
585.4 \\
613.1 \\
616.3 \\
623.3 \\
581.9 \\
560.6 \\
554.9 \\
572.3 \\
591.5\end{array}$ \\
\hline \multicolumn{13}{|l|}{ Virginia } \\
\hline 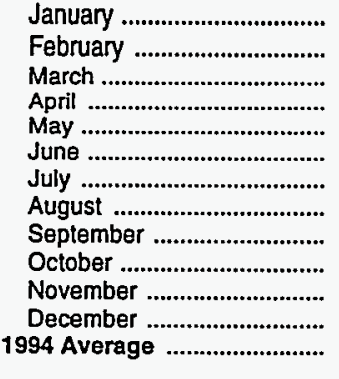 & $\begin{array}{l}453.1 \\
475.5 \\
486.8 \\
499.4 \\
512.3 \\
538.1 \\
530.1 \\
527.1 \\
512.4 \\
549.7 \\
426.8 \\
546.5 \\
505.2\end{array}$ & $\begin{array}{l}489.9 \\
516.9 \\
530.5 \\
540.6 \\
551.7 \\
593.8 \\
576.9 \\
576.5 \\
558.3 \\
591.3 \\
468.0 \\
583.3 \\
548.5\end{array}$ & $\begin{array}{r}1,186.7 \\
W \\
W \\
W \\
W \\
W \\
W \\
W \\
1,306.5 \\
1,279.3 \\
W \\
W \\
1,304.7\end{array}$ & $\begin{array}{r}2,629.0 \\
2,689.9 \\
2,819.8 \\
2,970.1 \\
3,052.0 \\
3,085.0 \\
3,061.1 \\
3,357.7 \\
W \\
W \\
3,036.6 \\
3,161.7 \\
3,012.3\end{array}$ & $\begin{array}{l}\bar{W} \\
W \\
w \\
w \\
W \\
W \\
W \\
W \\
W \\
W \\
W \\
W\end{array}$ & $\begin{array}{l}3,815.8 \\
4,182.5 \\
4,252.2 \\
4,438.0 \\
4,423.9 \\
4,571.6 \\
4,545.5 \\
4,871.0 \\
4,579.7 \\
4,422.3 \\
4,404.4 \\
4,593.0 \\
4,426.2\end{array}$ & $\begin{array}{l}165.1 \\
169.2 \\
170.8 \\
175.9 \\
181.1 \\
191.7 \\
188.9 \\
183.5 \\
179.0 \\
194.3 \\
176.9 \\
194.0 \\
181.0\end{array}$ & $\begin{array}{l}175.8 \\
179.5 \\
182.8 \\
188.1 \\
191.6 \\
207.8 \\
202.8 \\
199.6 \\
194.2 \\
206.1 \\
189.3 \\
206.5 \\
193.8\end{array}$ & $\begin{array}{c}508.9 \\
W \\
W \\
W \\
W \\
W \\
569.4 \\
570.0 \\
W \\
W \\
W \\
W \\
549.5\end{array}$ & $\begin{array}{c}591.1 \\
W \\
704.3 \\
729.5 \\
W \\
762.1 \\
W \\
W \\
W \\
706.6 \\
W \\
707.1 \\
722.4\end{array}$ & $\begin{array}{l}- \\
\bar{w} \\
w \\
\vec{w} \\
w \\
w \\
\bar{w} \\
\bar{w} \\
w \\
w\end{array}$ & $\begin{array}{r}1,100.0 \\
1,195.4 \\
1,278.5 \\
1,312.4 \\
1,333.0 \\
1,364.9 \\
1,357.5 \\
1,391.4 \\
1,310.8 \\
1,263.9 \\
1,249.2 \\
1,275.2 \\
1,286.5\end{array}$ \\
\hline \multicolumn{13}{|l|}{ West Virginia } \\
\hline 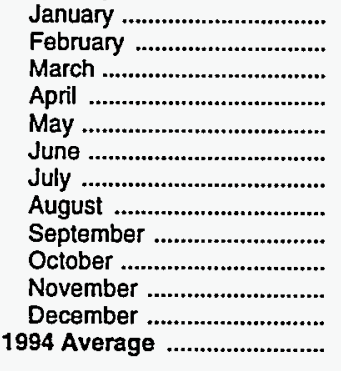 & $\begin{array}{l}243.4 \\
287.5 \\
306.0 \\
324.5 \\
326.0 \\
335.5 \\
353.8 \\
347.5 \\
332.9 \\
327.9 \\
319.2 \\
324.8 \\
319.2\end{array}$ & $\begin{array}{l}261.3 \\
309.1 \\
329.5 \\
348.1 \\
348.4 \\
360.7 \\
375.7 \\
371.3 \\
354.4 \\
348.3 \\
339.2 \\
345.6 \\
341.1\end{array}$ & $\begin{array}{l}69.9 \\
W \\
W \\
W \\
W \\
W \\
W \\
94.9 \\
W \\
W \\
82.8 \\
W \\
86.0\end{array}$ & $\begin{array}{c}353.9 \\
W \\
518.7 \\
489.7 \\
W \\
W \\
W \\
474.5 \\
W \\
W \\
481.9 \\
W \\
467.7\end{array}$ & $\begin{array}{l}W \\
W \\
W \\
W \\
W \\
W \\
- \\
- \\
W \\
W \\
- \\
W \\
W\end{array}$ & $\begin{array}{l}434.3 \\
500.1 \\
641.5 \\
591.3 \\
630.1 \\
616.4 \\
582.7 \\
569.4 \\
551.8 \\
572.5 \\
564.8 \\
600.6 \\
571.8\end{array}$ & $\begin{array}{r}73.7 \\
84.4 \\
88.6 \\
94.0 \\
94.5 \\
98.5 \\
104.1 \\
98.4 \\
95.6 \\
97.9 \\
96.1 \\
97.9 \\
93.7\end{array}$ & $\begin{array}{r}77.0 \\
88.3 \\
93.0 \\
97.8 \\
100.5 \\
103.5 \\
108.2 \\
103.5 \\
101.2 \\
102.3 \\
100.3 \\
102.1 \\
98.2\end{array}$ & $\begin{array}{c}24.8 \\
W \\
W \\
W \\
W \\
W \\
W \\
31.6 \\
W \\
W \\
26.9 \\
W \\
29.6\end{array}$ & $\begin{array}{r}82.9 \\
W \\
W \\
W \\
W \\
W \\
W \\
120.6 \\
W \\
W \\
123.4 \\
W \\
114.3\end{array}$ & $\begin{array}{l}- \\
- \\
- \\
- \\
- \\
- \\
- \\
- \\
- \\
- \\
- \\
-\end{array}$ & $\begin{array}{l}107.7 \\
126.4 \\
140.9 \\
157.0 \\
148.5 \\
151.3 \\
152.5 \\
152.2 \\
144.2 \\
147.8 \\
150.3 \\
147.9 \\
144.0\end{array}$ \\
\hline \multicolumn{13}{|l|}{ PAD District II } \\
\hline 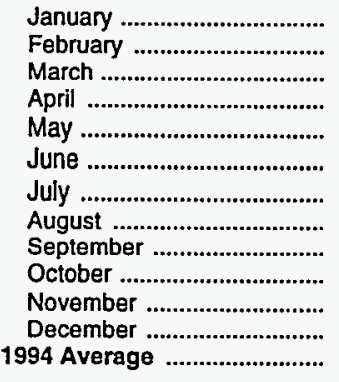 & $\begin{array}{l}12,042.5 \\
12,038.6 \\
12,857.2 \\
13,329.6 \\
13,701.4 \\
14,159.1 \\
14,165.1 \\
14,386.8 \\
13,800.0 \\
13,342.2 \\
13,418.5 \\
13,475.5 \\
13,401.1\end{array}$ & $\begin{array}{l}12,561.4 \\
12,612.8 \\
13,432.6 \\
13,883.6 \\
14,278.5 \\
14,769.8 \\
14,602.5 \\
14,903.7 \\
14,303.9 \\
13,849.9 \\
13,906.1 \\
13,971.0 \\
13,930.5\end{array}$ & $\begin{array}{r}8,872.1 \\
9,543.2 \\
9,731.7 \\
9,844.4 \\
10,050.9 \\
10,421.0 \\
10,211.4 \\
10,375.9 \\
10,095.4 \\
10,026.4 \\
10,050.8 \\
10,065.2 \\
9,942.2\end{array}$ & $\begin{array}{l}37,606.9 \\
40,678.1 \\
41,979.4 \\
43,714.0 \\
44,615.6 \\
46,820.2 \\
46,037.0 \\
47,203.2 \\
46,029.4 \\
44,615.3 \\
44,488.2 \\
45,099.3 \\
44,088.7\end{array}$ & $\begin{array}{l}3,598.9 \\
5,025.1 \\
4,026.3 \\
4,882.2 \\
4,111.4 \\
4,311.3 \\
4,264.1 \\
5,887.5 \\
6,054.2 \\
5,495.0 \\
4,831.5 \\
5,305.3 \\
4,812.1\end{array}$ & $\begin{array}{l}50,077.8 \\
55,246.4 \\
55,737.4 \\
58,440.5 \\
58,777.8 \\
61,552.4 \\
60,512.5 \\
63,466.5 \\
62,179.0 \\
60,136.7 \\
59,370.5 \\
60,469.8 \\
58,843.0\end{array}$ & $\begin{array}{l}3,123.9 \\
3,000.9 \\
3,004.0 \\
3,014.9 \\
3,053.2 \\
3,146.8 \\
3,111.3 \\
3,008.1 \\
2,964.1 \\
3,009.5 \\
3,022.8 \\
3,186.3 \\
3,054.4\end{array}$ & $\begin{array}{l}3,180.2 \\
3,071.3 \\
3,080.3 \\
3,084.2 \\
3,124.7 \\
3,215.1 \\
3,165.9 \\
3,078.5 \\
3,038.4 \\
3,083.0 \\
3,087.8 \\
3,247.0 \\
3,121.9\end{array}$ & $\begin{array}{l}2,808.6 \\
2,883.4 \\
2,831.3 \\
2,829.8 \\
2,856.8 \\
2,933.9 \\
2,813.9 \\
2,757.9 \\
2,716.9 \\
2,749.4 \\
2,763.3 \\
2,816.7 \\
2,812.9\end{array}$ & $\begin{array}{l}2,734.8 \\
2,929.1 \\
3,230.4 \\
3,299.8 \\
3,391.1 \\
3,562.6 \\
3,419.2 \\
3,602.1 \\
3,242.7 \\
3,087.5 \\
2,988.2 \\
3,498.4 \\
3,251.2\end{array}$ & $\begin{array}{l}- \\
- \\
- \\
- \\
- \\
- \\
- \\
- \\
- \\
- \\
-\end{array}$ & $\begin{array}{l}5,543.4 \\
5,812.4 \\
6,061.6 \\
6,129.7 \\
6,247.8 \\
6,496.5 \\
6,233.1 \\
6,360.0 \\
5,959.6 \\
5,836.9 \\
5,751.5 \\
6,315.1 \\
6,064.1\end{array}$ \\
\hline
\end{tabular}

See footnotes at end of table. 
Table 43. Refiner Motor Gasoline Volumes by Grade, Sales Type, PAD District, and State (Thousand Gallons per Day) - Continued

\begin{tabular}{|c|c|c|c|c|c|c|c|c|c|c|c|c|}
\hline \multirow{3}{*}{$\begin{array}{c}\text { Geographic Area } \\
\text { Month }\end{array}$} & \multicolumn{6}{|c|}{ Premium } & \multicolumn{6}{|c|}{ All Grades } \\
\hline & \multicolumn{2}{|c|}{ Sales to End Users } & \multicolumn{4}{|c|}{ Sales for Resale } & \multicolumn{2}{|c|}{ Sales to End Users } & \multicolumn{4}{|c|}{ Sales for Resale } \\
\hline & $\begin{array}{c}\text { Through } \\
\text { Retail } \\
\text { Outlets }\end{array}$ & Totala & DTW & Rack & Bukk & Total & $\begin{array}{c}\text { Through } \\
\text { Retail } \\
\text { Outlets }\end{array}$ & Totala & DTW & Rack & Bulk & Total \\
\hline \multicolumn{13}{|l|}{ South Carolina } \\
\hline 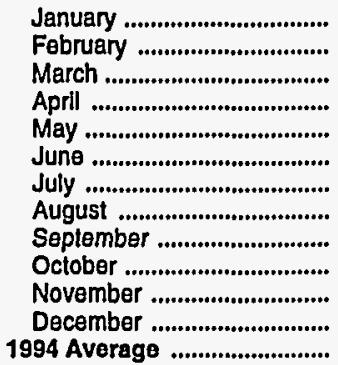 & $\begin{array}{l}138.3 \\
145.3 \\
151.4 \\
154.6 \\
153.2 \\
168.5 \\
168.3 \\
137.7 \\
135.5 \\
148.7 \\
139.2 \\
148.7 \\
149.1\end{array}$ & $\begin{array}{l}144.4 \\
152.9 \\
158.2 \\
160.8 \\
160.0 \\
176.0 \\
177.4 \\
145.9 \\
142.9 \\
157.0 \\
146.6 \\
157.2 \\
156.6\end{array}$ & $\begin{array}{l}38.3 \\
W \\
W \\
W \\
W \\
41.2 \\
W \\
W \\
W \\
W \\
25.1 \\
W \\
36.1\end{array}$ & $\begin{array}{c}766.9 \\
W \\
W \\
875.6 \\
W \\
870.3 \\
W \\
W \\
W \\
W \\
785.2 \\
W \\
827.8\end{array}$ & $\begin{array}{l}\text { w } \\
\bar{w} \\
- \\
- \\
- \\
- \\
- \\
- \\
\bar{w}\end{array}$ & $\begin{array}{l}885.4 \\
888.0 \\
902.5 \\
945.8 \\
892.5 \\
911.6 \\
896.9 \\
882.3 \\
843.7 \\
816.3 \\
810.3 \\
869.6 \\
878.7\end{array}$ & $\begin{array}{l}787.9 \\
845.4 \\
861.9 \\
879.8 \\
863.5 \\
882.7 \\
885.4 \\
862.8 \\
837.6 \\
842.1 \\
835.2 \\
846.0 \\
852.5\end{array}$ & $\begin{array}{l}819.0 \\
881.6 \\
897.8 \\
915.1 \\
899.9 \\
920.8 \\
925.9 \\
906.2 \\
878.2 \\
883.1 \\
871.2 \\
886.9 \\
890.5\end{array}$ & $\begin{array}{c}149.6 \\
W \\
W \\
W \\
W \\
W \\
W \\
W \\
W \\
W \\
W \\
W \\
144.7\end{array}$ & $\begin{array}{l}3,727.0 \\
3,723.2 \\
3,975.7 \\
4,037.0 \\
3,940.6 \\
4,029.9 \\
4,036.4 \\
4,098.7 \\
3,945.9 \\
3,831.4 \\
3,821.5 \\
4,058.4 \\
3,937.0\end{array}$ & $\begin{array}{c}W \\
W \\
W \\
W \\
W \\
W \\
W \\
W \\
W \\
W \\
W \\
W \\
132.1\end{array}$ & $\begin{array}{l}4,361.0 \\
4,130.7 \\
4,364.6 \\
4,277.0 \\
4,161.6 \\
4,278.6 \\
4,278.3 \\
4,339.5 \\
4,158.1 \\
4,017.3 \\
3,979.4 \\
4,205.6 \\
4,213.8\end{array}$ \\
\hline \multicolumn{13}{|l|}{ Virglnla } \\
\hline 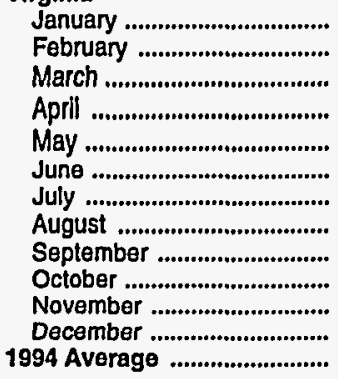 & $\begin{array}{l}211.4 \\
200.1 \\
210.0 \\
221.3 \\
224.0 \\
227.1 \\
219.6 \\
205.4 \\
220.2 \\
223.5 \\
202.9 \\
224.5 \\
215.9\end{array}$ & $\begin{array}{l}220.3 \\
209.6 \\
221.4 \\
232.0 \\
234.2 \\
243.5 \\
233.2 \\
222.2 \\
236.1 \\
236.8 \\
213.2 \\
233.8 \\
228.2\end{array}$ & $\begin{array}{r}741.5 \\
770.1 \\
W \\
W \\
823.6 \\
W \\
W \\
W \\
794.7 \\
785.5 \\
W \\
W \\
797.0\end{array}$ & $\begin{array}{c}1,013.1 \\
W \\
1,155.3 \\
1,164.9 \\
W \\
1,303.8 \\
W \\
W \\
1,294.0 \\
W \\
W \\
1,220.8 \\
1,215.7\end{array}$ & $\begin{array}{l}\bar{w} \\
W \\
W \\
W \\
W \\
w \\
w \\
\bar{w} \\
\bar{w} \\
w\end{array}$ & $\begin{array}{l}1,754.5 \\
1,879.5 \\
1,999.4 \\
2,019.4 \\
2,108.0 \\
2,179.6 \\
2,150.2 \\
2,131.1 \\
2,088.7 \\
2,059.1 \\
1,973.6 \\
2,002.9 \\
2,029.7\end{array}$ & $\begin{array}{l}829.6 \\
844.8 \\
867.5 \\
896.6 \\
917.5 \\
956.9 \\
938.6 \\
916.1 \\
911.7 \\
967.5 \\
806.6 \\
964.9 \\
902.1\end{array}$ & $\begin{array}{r}886.0 \\
906.0 \\
934.8 \\
960.7 \\
977.6 \\
1,045.1 \\
1,012.9 \\
998.4 \\
988.7 \\
1,034.2 \\
870.5 \\
1,023.5 \\
970.4\end{array}$ & $\begin{array}{r}2,437.1 \\
W \\
W \\
W \\
W \\
W \\
W \\
W \\
W \\
W \\
W \\
W \\
2,651.2\end{array}$ & $\begin{array}{l}4,233.3 \\
4,450.3 \\
4,679.4 \\
4,864.4 \\
5,101.6 \\
5,150.9 \\
5,116.4 \\
5,447.0 \\
5,288.5 \\
4,995.7 \\
4,953.6 \\
5,089.6 \\
4,950.4\end{array}$ & $\begin{array}{l}-\bar{w} \\
W \\
w \\
W \\
w \\
w \\
w \\
W \\
w \\
w \\
w \\
w\end{array}$ & $\begin{array}{l}6,670.3 \\
7,257.3 \\
7,530.1 \\
7,769.7 \\
7,864.9 \\
8,116.1 \\
8,053.2 \\
8,393.5 \\
7,979.2 \\
7,745.3 \\
7,627.3 \\
7,871.0 \\
7,742.3\end{array}$ \\
\hline \multicolumn{13}{|l|}{ West Virginia } \\
\hline 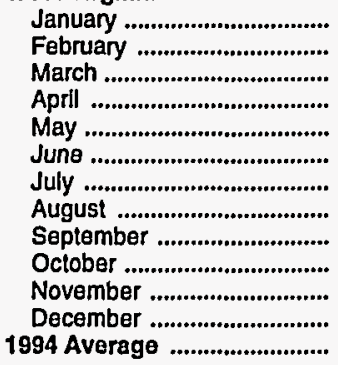 & $\begin{array}{l}56.5 \\
67.7 \\
67.8 \\
76.1 \\
75.1 \\
80.6 \\
78.9 \\
68.4 \\
69.8 \\
72.9 \\
68.6 \\
71.5 \\
71.2\end{array}$ & $\begin{array}{l}63.2 \\
75.3 \\
75.9 \\
82.4 \\
81.7 \\
86.9 \\
85.0 \\
75.0 \\
76.0 \\
79.5 \\
75.2 \\
78.4 \\
77.9\end{array}$ & $\begin{array}{c}28.4 \\
W \\
W \\
W \\
W \\
W \\
36.4 \\
35.0 \\
31.1 \\
29.6 \\
31.2 \\
W \\
32.8\end{array}$ & $\begin{array}{c}106.9 \\
W \\
W \\
W \\
W \\
W \\
133.1 \\
131.9 \\
128.6 \\
142.4 \\
139.4 \\
W \\
137.8\end{array}$ & $\begin{array}{l}- \\
- \\
- \\
- \\
- \\
- \\
- \\
- \\
-\end{array}$ & $\begin{array}{l}135.3 \\
148.6 \\
208.9 \\
160.1 \\
182.9 \\
192.3 \\
169.4 \\
166.9 \\
159.7 \\
172.0 \\
170.7 \\
177.4 \\
170.5\end{array}$ & $\begin{array}{l}373.5 \\
439.5 \\
462.3 \\
494.6 \\
495.6 \\
514.6 \\
536.8 \\
514.2 \\
498.4 \\
498.8 \\
483.9 \\
494.2 \\
484.1\end{array}$ & $\begin{array}{l}401.5 \\
472.8 \\
498.4 \\
528.2 \\
530.6 \\
551.1 \\
568.9 \\
549.8 \\
531.6 \\
530.1 \\
514.7 \\
526.1 \\
517.2\end{array}$ & $\begin{array}{r}123.1 \\
W \\
W \\
W \\
W \\
W \\
165.1 \\
161.5 \\
W \\
W \\
141.0 \\
W \\
148.4\end{array}$ & $\begin{array}{l}543.8 \\
607.5 \\
803.4 \\
740.6 \\
772.7 \\
774.4 \\
739.6 \\
726.9 \\
686.7 \\
746.4 \\
744.8 \\
742.5 \\
719.8\end{array}$ & $\begin{array}{l}w \\
W \\
w \\
w \\
w \\
w \\
- \\
- \\
w \\
w \\
- \\
w \\
w\end{array}$ & $\begin{array}{l}677.3 \\
775.2 \\
991.4 \\
908.5 \\
961.5 \\
960.1 \\
904.7 \\
888.4 \\
855.7 \\
892.4 \\
885.8 \\
925.9 \\
886.3\end{array}$ \\
\hline \multicolumn{13}{|l|}{ PAD District II } \\
\hline 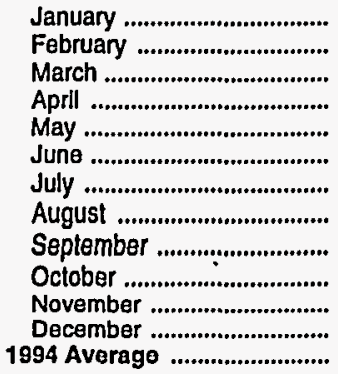 & $\begin{array}{l}3,242.1 \\
4,303.3 \\
3,028.9 \\
3,058.5 \\
3,046.7 \\
3,065.5 \\
2,968.1 \\
2,745.3 \\
2,829.2 \\
2,973.0 \\
2,885.8 \\
3,244.7 \\
3,107.9\end{array}$ & $\begin{array}{l}3,340.2 \\
4,409.1 \\
3,142.4 \\
3,172.8 \\
3,158.7 \\
3,185.5 \\
3,062.5 \\
2,858.9 \\
2,941.0 \\
3,079.4 \\
2,983.6 \\
3,343.0 \\
3,215.0\end{array}$ & $\begin{array}{l}3,682.2 \\
3,545.4 \\
3,481.3 \\
3,463.3 \\
3,501.6 \\
3,571.8 \\
3,457.2 \\
3,300.0 \\
3,299.9 \\
3,388.8 \\
3,387.4 \\
3,540.7 \\
3,468.1\end{array}$ & $\begin{array}{l}7,838.8 \\
8,019.5 \\
8,029.5 \\
8,089.1 \\
8,346.7 \\
8,845.7 \\
8,461.8 \\
8,074.6 \\
7,876.9 \\
8,024.6 \\
8,111.2 \\
8,909.6 \\
8,220.5\end{array}$ & $\begin{array}{r}200.4 \\
240.6 \\
199.0 \\
283.5 \\
97.8 \\
127.7 \\
77.9 \\
243.1 \\
314.8 \\
289.3 \\
220.6 \\
163.9 \\
204.2\end{array}$ & $\begin{array}{l}11,721.4 \\
11,805.6 \\
11,709.9 \\
11,835.9 \\
11,946.2 \\
12,545.3 \\
11,996.9 \\
11,617.7 \\
11,491.6 \\
11,702.7 \\
11,719.3 \\
12,614.2 \\
11,892.9\end{array}$ & $\begin{array}{l}18,408.5 \\
19,342.8 \\
18,890.1 \\
19,403.0 \\
19,801.3 \\
20,371.3 \\
20,244.4 \\
20,140.2 \\
19,593.2 \\
19,324.6 \\
19,327.1 \\
19,906.5 \\
19,563.3\end{array}$ & $\begin{array}{l}19,081.7 \\
20,093.2 \\
19,655.3 \\
20,140.6 \\
20,562.0 \\
21,170.4 \\
20,830.8 \\
20,841.0 \\
20,283.3 \\
20,012.3 \\
19,977.6 \\
20,561.0 \\
20,267.5\end{array}$ & $\begin{array}{l}15,362.8 \\
15,972.0 \\
16,044.3 \\
16,137.5 \\
16,409.3 \\
16,926.7 \\
16,482.6 \\
16,433.7 \\
16,112.2 \\
16,164.6 \\
16,201.6 \\
16,422.7 \\
16,223.2\end{array}$ & $\begin{array}{l}\mathbf{4 8 , 1 8 0 . 5} \\
\mathbf{5 1 , 6 2 6 . 7} \\
\mathbf{5 3}, 239.3 \\
\mathbf{5 5}, \mathbf{1 0 2 . 9} \\
\mathbf{5 6 , 3 5 3 . 4} \\
\mathbf{5 9 , 2 2 8 . 5} \\
\mathbf{5 7 , 9 1 7 . 9} \\
\mathbf{5 8 , 8 7 9 . 9} \\
\mathbf{5 7 , 1 4 9 . 0} \\
\mathbf{5 5 , 7 2 7 . 4} \\
\mathbf{5 5 , 5 8 7 . 7} \\
\mathbf{5 7 , 5 0 7 . 2} \\
\mathbf{5 5 , 5 6 0 . 5}\end{array}$ & $\begin{array}{l}3,799.3 \\
5,265.7 \\
4,225.3 \\
5,165.7 \\
4,209.2 \\
4,439.0 \\
4,342.0 \\
6,130.6 \\
6,368.9 \\
5,784.3 \\
5,052.1 \\
5,469.2 \\
5,016.3\end{array}$ & $\begin{array}{l}67,342.6 \\
72,864.4 \\
73,508.9 \\
76,406.1 \\
76,971.9 \\
80,594.2 \\
78,742.5 \\
81,444.2 \\
79,630.1 \\
77,676.3 \\
76,841.3 \\
79,399.1 \\
76,800.0\end{array}$ \\
\hline
\end{tabular}

See footnotes at end of table. 
Table 43. Refiner Motor Gasoline Volumes by Grade, Sales Type, PAD District, and State (Thousand Gallons per Day) - Continued

\begin{tabular}{|c|c|c|c|c|c|c|c|c|c|c|c|c|}
\hline \multirow{3}{*}{$\begin{array}{l}\text { Geographic Area } \\
\text { Month }\end{array}$} & \multicolumn{6}{|c|}{ Regular } & \multicolumn{6}{|c|}{ Midgrade } \\
\hline & \multicolumn{2}{|c|}{ Sales to End Users } & \multicolumn{4}{|c|}{ Sales for Resale } & \multicolumn{2}{|c|}{ Sales to End Users } & \multicolumn{4}{|c|}{ Sales for Resale } \\
\hline & $\begin{array}{c}\text { Through } \\
\text { Retail } \\
\text { Outlets }\end{array}$ & Total $^{\mathrm{a}}$ & DTW & Rack & Bulk & Total & $\begin{array}{c}\text { Through } \\
\text { Retail } \\
\text { Outlets }\end{array}$ & Totala & DTW & Rack & Bulk & Total \\
\hline \multicolumn{13}{|l|}{ Illinois } \\
\hline 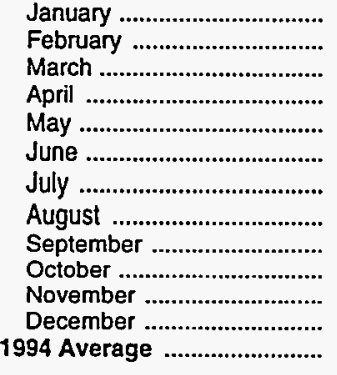 & $\begin{array}{l}1,573.5 \\
1,399.8 \\
1,666.2 \\
1,716.7 \\
1,818.9 \\
1,892.0 \\
1,866.0 \\
1,857.8 \\
1,789.0 \\
1,771.8 \\
1,777.8 \\
1,800.6 \\
1,746.5\end{array}$ & $\begin{array}{l}1,622.8 \\
1,430.2 \\
1,699.0 \\
1,745.4 \\
1,846.7 \\
1,922.3 \\
1,878.2 \\
1,872.0 \\
1,804.0 \\
1,787.3 \\
1,793.6 \\
1,820.2 \\
1,770.7\end{array}$ & $\begin{array}{l}1,790.4 \\
1,860.6 \\
1,887.5 \\
1,891.9 \\
1,914.4 \\
1,957.8 \\
1,924.5 \\
1,961.4 \\
1,941.8 \\
1,972.7 \\
1,969.7 \\
1,970.6 \\
1,920.5\end{array}$ & $\begin{array}{r}4,109.3 \\
W \\
W \\
W \\
4,361.3 \\
W \\
4,388.6 \\
W \\
W \\
W \\
4,333.0 \\
4,826.1 \\
4,464.9\end{array}$ & $\begin{array}{c}W \\
W \\
W \\
W \\
386.6 \\
W \\
799.2 \\
W \\
W \\
W \\
609.1 \\
549.0 \\
601.4\end{array}$ & $\begin{array}{l}6,021.6 \\
7,318.9 \\
6,807.5 \\
7,095.2 \\
6,662.3 \\
6,596.9 \\
7,112.3 \\
7,507.6 \\
7,126.3 \\
7,361.0 \\
6,911.9 \\
7,345.7 \\
6,986.8\end{array}$ & $\begin{array}{l}447.1 \\
415.0 \\
420.9 \\
419.4 \\
442.0 \\
466.9 \\
458.5 \\
451.1 \\
432.0 \\
444.0 \\
452.8 \\
483.3 \\
444.7\end{array}$ & $\begin{array}{l}447.5 \\
415.4 \\
421.7 \\
420.2 \\
442.4 \\
467.5 \\
459.0 \\
451.5 \\
432.7 \\
444.1 \\
454.2 \\
484.6 \\
445.3\end{array}$ & $\begin{array}{l}795.0 \\
787.0 \\
760.3 \\
756.1 \\
765.3 \\
776.8 \\
753.7 \\
742.4 \\
728.6 \\
754.0 \\
770.3 \\
801.2 \\
765.8\end{array}$ & $\begin{array}{l}254.8 \\
233.3 \\
297.9 \\
283.6 \\
300.5 \\
289.7 \\
273.8 \\
259.1 \\
271.8 \\
256.3 \\
249.7 \\
289.3 \\
271.9\end{array}$ & $\begin{array}{l}- \\
- \\
- \\
- \\
- \\
- \\
- \\
- \\
- \\
- \\
-\end{array}$ & $\begin{array}{l}1,049.9 \\
1,020.3 \\
1,058.2 \\
1,039.7 \\
1,065.8 \\
1,066.5 \\
1,027.5 \\
1,001.5 \\
1,000.4 \\
1,010.3 \\
1,020.0 \\
1,090.5 \\
1,037.7\end{array}$ \\
\hline \multicolumn{13}{|l|}{ Indiana } \\
\hline 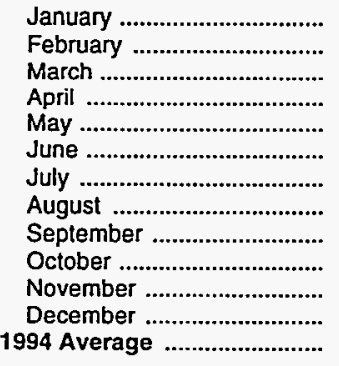 & $\begin{array}{r}982.0 \\
955.8 \\
1,081.1 \\
1,167.5 \\
1,223.8 \\
1,243.7 \\
1,254.1 \\
1,278.6 \\
1,214.6 \\
1,189.1 \\
1,166.0 \\
1,154.8 \\
1,160.5\end{array}$ & $\begin{array}{r}992.1 \\
965.4 \\
1,091.7 \\
1,179.8 \\
1,234.8 \\
1,257.9 \\
1,264.7 \\
1,291.6 \\
1,225.1 \\
1,201.3 \\
1,176.6 \\
1,167.4 \\
1,172.0\end{array}$ & $\begin{array}{c}819.0 \\
W \\
W \\
962.9 \\
972.7 \\
1,008.8 \\
W \\
1,009.8 \\
W \\
975.2 \\
983.3 \\
960.0 \\
955.5\end{array}$ & $\begin{array}{r}2,253.2 \\
2,387.1 \\
2,715.1 \\
2,795.0 \\
W \\
2,959.8 \\
2,988.2 \\
3,073.2 \\
2,884.4 \\
2,894.1 \\
W \\
2,847.0 \\
2,806.8\end{array}$ & $\begin{array}{c}W \\
W \\
W \\
525.1 \\
W \\
188.9 \\
W \\
793.3 \\
W \\
346.4 \\
W \\
667.5 \\
415.4\end{array}$ & $\begin{array}{l}3,180.6 \\
3,533.0 \\
4,238.8 \\
4,283.1 \\
4,227.1 \\
4,157.5 \\
4,297.9 \\
4,876.4 \\
4,371.0 \\
4,215.8 \\
4,225.1 \\
4,474.4 \\
4,177.7\end{array}$ & $\begin{array}{l}266.2 \\
255.8 \\
262.2 \\
268.6 \\
278.9 \\
282.2 \\
286.5 \\
282.4 \\
275.2 \\
273.4 \\
271.9 \\
281.2 \\
273.8\end{array}$ & $\begin{array}{l}267.1 \\
257.1 \\
263.3 \\
269.6 \\
279.5 \\
283.4 \\
286.8 \\
283.0 \\
276.0 \\
274.3 \\
272.3 \\
282.0 \\
274.7\end{array}$ & $\begin{array}{l}275.7 \\
276.2 \\
277.7 \\
279.1 \\
281.2 \\
283.0 \\
276.9 \\
266.7 \\
259.7 \\
267.9 \\
267.3 \\
257.8 \\
272.4\end{array}$ & $\begin{array}{l}267.5 \\
270.8 \\
290.1 \\
308.9 \\
317.8 \\
332.4 \\
319.5 \\
344.5 \\
302.5 \\
319.0 \\
327.9 \\
354.2 \\
313.2\end{array}$ & $\begin{array}{l}- \\
- \\
- \\
- \\
- \\
- \\
- \\
- \\
- \\
- \\
- \\
-\end{array}$ & $\begin{array}{l}543.3 \\
547.0 \\
567.8 \\
587.9 \\
599.1 \\
615.4 \\
596.4 \\
611.2 \\
562.3 \\
586.9 \\
595.2 \\
612.0 \\
585.6\end{array}$ \\
\hline \multicolumn{13}{|l|}{ lowa } \\
\hline 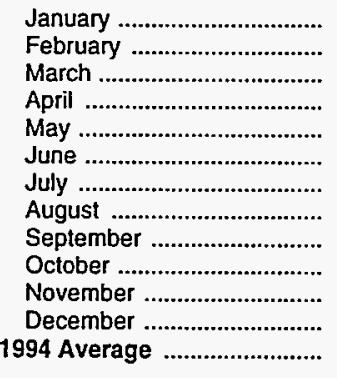 & $\begin{array}{c}225.5 \\
219.0 \\
227.5 \\
228.1 \\
W \\
W \\
230.6 \\
224.5 \\
214.8 \\
212.0 \\
211.1 \\
217.2 \\
222.9\end{array}$ & $\begin{array}{l}230.7 \\
225.3 \\
232.6 \\
234.3 \\
237.8 \\
236.8 \\
234.6 \\
228.4 \\
219.2 \\
217.3 \\
216.5 \\
222.6 \\
228.1\end{array}$ & $\begin{array}{l}W \\
W \\
W \\
W \\
W \\
W \\
W \\
W \\
W \\
W \\
W \\
W \\
W\end{array}$ & $\begin{array}{r}2,601.5 \\
W \\
W \\
W \\
W \\
W \\
W \\
W \\
W \\
W \\
3,139.8 \\
W \\
3,075.4\end{array}$ & $\begin{array}{l}- \\
- \\
- \\
- \\
- \\
- \\
- \\
- \\
- \\
\bar{w} \\
\bar{w}\end{array}$ & $\begin{array}{l}2,764.6 \\
2,961.8 \\
3,089.8 \\
3,332.3 \\
3,363.8 \\
3,458.4 \\
3,344.6 \\
3,511.6 \\
3,372.4 \\
3,439.8 \\
3,370.1 \\
3,264.5 \\
3,274.2\end{array}$ & $\begin{array}{l}W \\
W \\
W \\
W \\
W \\
W \\
W \\
W \\
W \\
W \\
W \\
W \\
W\end{array}$ & $\begin{array}{l}W \\
W \\
W \\
W \\
W \\
W \\
W \\
W \\
W \\
W \\
W \\
W \\
W\end{array}$ & $\begin{array}{l}W \\
W \\
W \\
W \\
W \\
W \\
W \\
W \\
W \\
W \\
W \\
W \\
W\end{array}$ & $\begin{array}{c}19.0 \\
W \\
W \\
W \\
W \\
W \\
W \\
W \\
N A \\
W \\
W \\
W \\
17.4\end{array}$ & $\begin{array}{l}- \\
- \\
- \\
- \\
- \\
- \\
- \\
- \\
- \\
- \\
- \\
- \\
-\end{array}$ & $\begin{array}{l}29.2 \\
29.3 \\
25.1 \\
25.0 \\
25.9 \\
28.4 \\
26.4 \\
26.8 \\
22.7 \\
26.8 \\
27.1 \\
30.6 \\
26.9\end{array}$ \\
\hline \multicolumn{13}{|l|}{ Kansas } \\
\hline 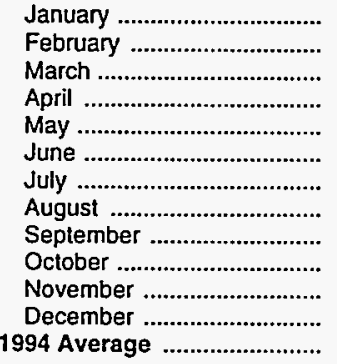 & $\begin{array}{l}494.4 \\
515.3 \\
531.5 \\
541.6 \\
565.4 \\
573.9 \\
573.9 \\
558.4 \\
554.9 \\
546.2 \\
562.0 \\
568.6 \\
549.0\end{array}$ & $\begin{array}{l}510.4 \\
533.0 \\
554.0 \\
563.4 \\
592.2 \\
600.0 \\
598.3 \\
587.6 \\
588.2 \\
566.6 \\
587.7 \\
596.4 \\
573.3\end{array}$ & $\begin{array}{c}116.0 \\
116.6 \\
118.5 \\
119.4 \\
120.9 \\
W \\
W \\
W \\
124.2 \\
W \\
W \\
127.8 \\
124.1\end{array}$ & $\begin{array}{r}2,182.4 \\
W \\
W \\
W \\
W \\
2,682.1 \\
2,552.7 \\
2,554.7 \\
W \\
2,499.4 \\
2,295.8 \\
W \\
2,450.9\end{array}$ & $\begin{array}{l}W \\
W \\
W \\
W \\
W \\
W \\
W \\
W \\
W \\
W \\
W \\
W \\
594.9\end{array}$ & $\begin{array}{l}3,003.1 \\
3,012.1 \\
3,032.9 \\
3,266.9 \\
3,255.2 \\
3,364.1 \\
3,214.0 \\
3,332.8 \\
3,485.8 \\
2,921.9 \\
2,826.5 \\
3,316.4 \\
3,169.9\end{array}$ & $\begin{array}{l}51.9 \\
54.0 \\
54.1 \\
53.4 \\
55.4 \\
54.7 \\
52.7 \\
49.7 \\
50.5 \\
50.4 \\
51.4 \\
54.3 \\
\mathbf{5 2 . 7}\end{array}$ & $\begin{array}{l}\mathbf{5 2 . 1} \\
54.7 \\
55.1 \\
54.3 \\
56.8 \\
55.7 \\
53.9 \\
51.3 \\
51.1 \\
51.5 \\
52.3 \\
55.1 \\
\mathbf{5 3 . 7}\end{array}$ & $\begin{array}{c}W \\
W \\
W \\
W \\
W \\
33.2 \\
31.8 \\
30.1 \\
W \\
30.7 \\
31.3 \\
W \\
32.0\end{array}$ & $\begin{array}{c}18.7 \\
W \\
W \\
W \\
W \\
27.4 \\
28.5 \\
28.2 \\
W \\
18.1 \\
18.6 \\
W \\
22.6\end{array}$ & $\begin{array}{l}- \\
- \\
- \\
- \\
- \\
- \\
- \\
- \\
- \\
- \\
- \\
-\end{array}$ & $\begin{array}{l}52.3 \\
54.3 \\
54.2 \\
53.8 \\
55.9 \\
60.6 \\
60.3 \\
58.3 \\
54.2 \\
48.8 \\
49.9 \\
52.3 \\
54.6\end{array}$ \\
\hline
\end{tabular}

See footnotes at end of table. 
Table 43. Refiner Motor Gasoline Volumes by Grade, Sales Type, PAD District, and State (Thousand Gallons per Day) - Continued

\begin{tabular}{|c|c|c|c|c|c|c|c|c|c|c|c|c|}
\hline \multirow{3}{*}{$\begin{array}{c}\text { Geographic Area } \\
\text { Month }\end{array}$} & \multicolumn{6}{|c|}{ Premium } & \multicolumn{6}{|c|}{ All Grades } \\
\hline & \multicolumn{2}{|c|}{ Sales to End Users } & \multicolumn{4}{|c|}{ Sales for Resale } & \multicolumn{2}{|c|}{ Sales to End Users } & \multicolumn{4}{|c|}{ Sales for Resale } \\
\hline & $\begin{array}{c}\text { Through } \\
\text { Retail } \\
\text { Outlets }\end{array}$ & Totala & DTW & Rack & Bulk & Total & $\begin{array}{c}\text { Through } \\
\text { Retail } \\
\text { Outlets }\end{array}$ & Totala & DTW & Rack & Bulk & Total \\
\hline \multicolumn{13}{|l|}{ Illinols } \\
\hline January ................................. & 513.9 & 515.7 & $1,030.9$ & 850.2 & $W$ & $1,915.1$ & $2,534.5$ & $2,586.0$ & $3,616.3$ & $5,214.3$ & $w$ & $8,986.5$ \\
\hline February .................................. & 852.0 & 853.4 & 963.6 & $W$ & $W$ & $2,007,5$ & $2,666.8$ & $2,699.0$ & $3,611,1$ & $5,793.2$ & 942.4 & $10,346.8$ \\
\hline March ..................................... & 486.8 & 488.3 & 937.6 & $W$ & $W$ & $1,916.6$ & $2,573.8$ & $2,608.9$ & $3,585.3$ & $5,715.5$ & 481.5 & $9,782.2$ \\
\hline 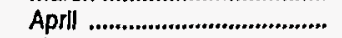 & 480.0 & 481.9 & 930.0 & $W$ & $W$ & $2,033.9$ & $2,616.1$ & $2,647.5$ & $3,577.9$ & $5,779.0$ & 811.9 & $10,168.8$ \\
\hline 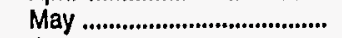 & 496.4 & 497.0 & 929.6 & 910.6 & - & $1,840.2$ & $2,757.4$ & $2,786.1$ & $3,609.2$ & $5,572.4$ & 386.6 & $9,568.3$ \\
\hline June ...................................... & 503.5 & 504.3 & 926.8 & W & W & $1,830.6$ & $2,862.3$ & $2,894.0$ & $3,661.4$ & $5,622.1$ & 210.5 & $9,494.0$ \\
\hline July ........................................... & 469.5 & 470.6 & 888.1 & 820.8 & - & $1,708.9$ & $2,793.9$ & $2,807.8$ & $3,566.4$ & $5,483.2$ & 799.2 & $9,848.7$ \\
\hline 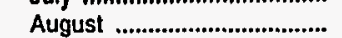 & 436.5 & 437.0 & 853.9 & $W$ & $W$ & $1,585.0$ & $2,745.3$ & $2,760.5$ & $3,557.6$ & $5,500.1$ & $1,036.4$ & $10,094.1$ \\
\hline 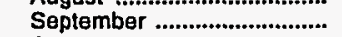 & 430.0 & 431.1 & 864.4 & w & w & $1,707.2$ & $2,651.0$ & $2,667.8$ & 3.534 .8 & $5,645.2$ & 653.8 & $9,833.9$ \\
\hline 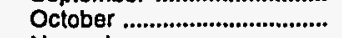 & 473.7 & 474.2 & 895.2 & $w$ & $\dddot{W}$ & $1,683.9$ & $2,689.5$ & $2,705.6$ & $3,621.9$ & $5,321.1$ & $1,112.2$ & $10,055.2$ \\
\hline November ............................... & 444.5 & 445.0 & 906.7 & 744.8 & - & $1,651.5$ & $2,675.1$ & $2,692.8$ & $3,646.7$ & $5,327.5$ & 609.1 & $9,583.3$ \\
\hline December ................................. & 544.0 & 545.0 & 935.7 & 942.2 & - & $1,877.9$ & $2,827.9$ & $2,849.8$ & $3,707.6$ & $6,057.5$ & 549.0 & $10,314.1$ \\
\hline 1994 Average & 508.6 & 509.7 & 921.7 & 847.3 & 42.7 & $1,811.7$ & $2,699.7$ & $2,725.7$ & $3,608.0$ & $5,584,1$ & 644.1 & $9,836.3$ \\
\hline \multicolumn{13}{|l|}{ Indiana } \\
\hline 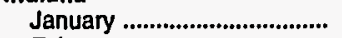 & 309.3 & 309.9 & 333.0 & 584.9 & - & 917.9 & $1,557.4$ & $1,569.1$ & $1,427.8$ & $3,105.6$ & $w$ & $4,641.8$ \\
\hline 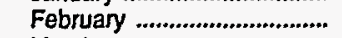 & 449.6 & 450.2 & $W$ & 551.8 & $w$ & 918.3 & $1,661.2$ & $1,672.6$ & $1,473.4$ & $3,209.6$ & 315.3 & $4,998.3$ \\
\hline 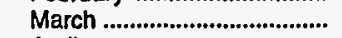 & 301.8 & 302.9 & $w$ & 593.4 & $W$ & 935.6 & $1,645.1$ & $1,657.9$ & 1.492 .5 & $3,598.6$ & 651.2 & $5,742.3$ \\
\hline 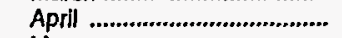 & 290.5 & 291.3 & 327.2 & 658.2 & - & 985.4 & $1,726.6$ & $1,740.7$ & $1,569.2$ & $3,762.1$ & 525.1 & $5,856.4$ \\
\hline 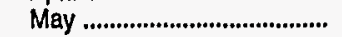 & 297.7 & 298.6 & 325.2 & W & $W$ & 953.5 & $1,800.5$ & $1,813.0$ & $1,579.1$ & $3,848.4$ & 352.3 & $5,779.7$ \\
\hline 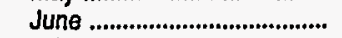 & 284.8 & 285.5 & 338.6 & 655.4 & - & 994.1 & $1,810.7$ & $1,826.8$ & $1,630.4$ & $3,947.6$ & 188.9 & $5,767.0$ \\
\hline 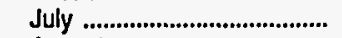 & 279.4 & 280.1 & W & 610.7 & $W$ & 965.6 & $1,820.0$ & $1,831.6$ & $1,636.5$ & $3,918.4$ & 305.0 & $5,859.9$ \\
\hline 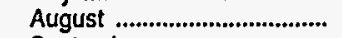 & 283.5 & 283.6 & 321.9 & 583.3 & 86.9 & 992.1 & $1,844.4$ & $1,858.2$ & $1,598.5$ & $4,001.0$ & 880.2 & $6,479.7$ \\
\hline 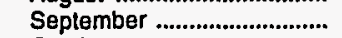 & 311.2 & 311.6 & $W$ & 593.8 & $W$ & 968.6 & $1,800.9$ & $1,812.7$ & $1,547.8$ & $3,780.7$ & 573.4 & $5,901.9$ \\
\hline 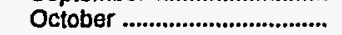 & 301.9 & 302.1 & 333.4 & 641.0 & - & 974.4 & $1,764.4$ & $1,777.7$ & $1,576.5$ & $3,854.2$ & 346.4 & $5,777.1$ \\
\hline 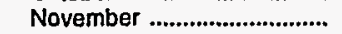 & 283.4 & 283.7 & 329.5 & $w$ & $W$ & $1,005.3$ & $1,721.3$ & $1,732.6$ & $1,580.1$ & $3,929.5$ & 316.0 & $5,825.6$ \\
\hline 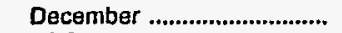 & 319.5 & 319.8 & 321.1 & 670.2 & - & 991.3 & $1,755.4$ & $1,769.3$ & $1,538.8$ & $3,871.4$ & 667.5 & $6,077.7$ \\
\hline 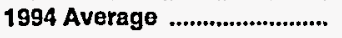 & 308.4 & 309.0 & 326.7 & 618.5 & 21.8 & 967.0 & $1,742.8$ & $1,755.6$ & $1,554.6$ & $3,738.6$ & 437.2 & $5,730.4$ \\
\hline \multicolumn{13}{|l|}{ lowa } \\
\hline 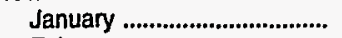 & 26.6 & 26.6 & $W$ & 209.8 & - & 247.8 & 265.4 & 270.7 & $w$ & $2,830.3$ & - & $3,041.6$ \\
\hline 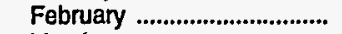 & $W$ & W & W & W & - & 236.0 & 260.7 & 267.0 & $w$ & W & - & $3,227.1$ \\
\hline 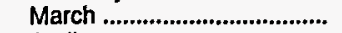 & $w$ & $w$ & $W$ & $W$ & - & 225.7 & 266.2 & 271.3 & w & W & - & $3,340.6$ \\
\hline 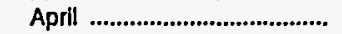 & $W$ & W & W & W & - & 235.5 & 267.1 & 273.3 & $w$ & W & - & $3,592.8$ \\
\hline 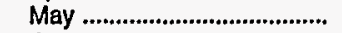 & 27.0 & $W$ & $W$ & $W$ & - & 268.3 & 273.4 & 280.1 & $w$ & W & - & $3,658.0$ \\
\hline 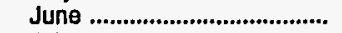 & 28.1 & W & $W$ & $W$ & - & 272.1 & 275.8 & 280.3 & w & $w$ & - & $3,758.8$ \\
\hline 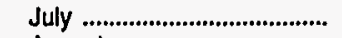 & $W$ & $w$ & $W$ & $W$ & - & 259.6 & 274.8 & 279.0 & $w$ & $w$ & - & $3,630.6$ \\
\hline August & $W$ & $w$ & W & $W$ & - & 249.5 & 265.4 & 269.4 & W & W & - & $3,787.9$ \\
\hline September .............................. & $W$ & $\mathbf{W}$ & W & $W$ & - & 227.6 & 253.7 & 258.1 & $w$ & $w$ & - & $3,622.7$ \\
\hline 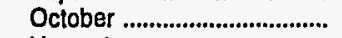 & $W$ & W & $W$ & $W$ & - & 234.1 & 251.3 & 256.5 & w & W & - & $3,700.7$ \\
\hline November ................................ & $W$ & W & W & $W$ & - & 244.2 & 247.9 & 253.3 & W & $3,364.6$ & $w$ & $3,641.4$ \\
\hline December ............................. & $W$ & W & $W$ & $W$ & - & 269.9 & 256.8 & 262.3 & W & W & - & $3,565.1$ \\
\hline 1994 Average ............................. & 26.2 & 26.2 & W & 207.8 & - & 247.6 & 263.3 & 268.5 & W & $3,300.7$ & $W$ & $3,548.7$ \\
\hline \multicolumn{13}{|l|}{ Kansas } \\
\hline 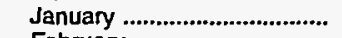 & 74.6 & 78.5 & 30.1 & 243.1 & W & 283.6 & 620.8 & 641.0 & 179.7 & $2,444.3$ & $w$ & $3,339.0$ \\
\hline 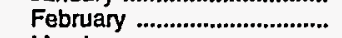 & 73.0 & 77.1 & $w$ & 252.1 & $w$ & 285.1 & 642.3 & 664.8 & 179.9 & $2,478.2$ & 693.4 & $3,351.5$ \\
\hline 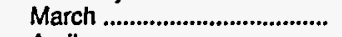 & 77.0 & 81.3 & $W$ & 258.6 & $w$ & 304.1 & 662.6 & 690.4 & 179.6 & $2,667.6$ & 543.9 & $3,391.2$ \\
\hline April & 74.7 & 79.3 & $W$ & 257.0 & $W$ & 288.9 & 669.7 & 697.0 & 178.7 & $2,702.8$ & 728.1 & $3,609.6$ \\
\hline 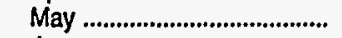 & 79.8 & 83.9 & $w$ & 268.5 & $w$ & 301.3 & 700.6 & 732.9 & 183.4 & $2,784.7$ & 644.3 & $3,612.4$ \\
\hline 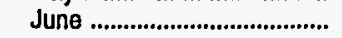 & 79.3 & 83.4 & W & 294.8 & W & 328.9 & 707.8 & 739.1 & 196.8 & $3,004.3$ & 552.6 & $3,753.6$ \\
\hline 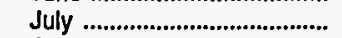 & 77.7 & 81.2 & W & 263.6 & W & 297.3 & 704.4 & 733.3 & $W$ & $2,844.7$ & $W$ & $3,571.5$ \\
\hline 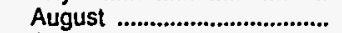 & 69.0 & 73.1 & $w$ & 263.5 & W & 300.9 & 677.1 & 712.0 & 192.0 & $2,846.4$ & 653.5 & $3,692.0$ \\
\hline 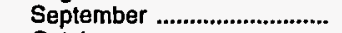 & 71.5 & 77.2 & $w$ & 254.7 & $w$ & 300.3 & 676.9 & 716.5 & 182.0 & $W$ & W & 3.840 .4 \\
\hline October & 73.1 & 76.0 & W & 254.9 & W & 332.2 & 669.7 & 694.1 & 181.8 & $2,772.3$ & 348.7 & $3,302.8$ \\
\hline 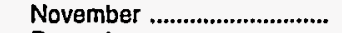 & 74.4 & 78.1 & $W$ & 236.9 & $w$ & 270.2 & 687.8 & 718.1 & $w$ & $2,551.2$ & $w$ & $3,146.6$ \\
\hline December ................................ & 81.6 & 85.6 & W & 274.5 & $w$ & 374.8 & 704.5 & 737.1 & 192.2 & $w$ & $w$ & $3,743.5$ \\
\hline 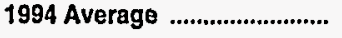 & 75.5 & 79.6 & 29.2 & 260.2 & 16.4 & 305.9 & 677.2 & 706.6 & 185.3 & $2,733.7$ & 611.3 & $3,530.3$ \\
\hline
\end{tabular}

See footnotes at end of table. 
Table 43. Refiner Motor Gasoline Volumes by Grade, Sales Type, PAD District, and State (Thousand Gallons per Day) - Continued

\begin{tabular}{|c|c|c|c|c|c|c|c|c|c|c|c|c|}
\hline \multirow{3}{*}{$\begin{array}{l}\text { Geographic Area } \\
\text { Month }\end{array}$} & \multicolumn{6}{|c|}{ Regular } & \multicolumn{6}{|c|}{ Midgrade } \\
\hline & \multicolumn{2}{|c|}{ Sales to End Users } & \multicolumn{4}{|c|}{ Sales for Resale } & \multicolumn{2}{|c|}{ Sales to End Users } & \multicolumn{4}{|c|}{ Sales for Resale } \\
\hline & $\begin{array}{c}\text { Through } \\
\text { Rotail } \\
\text { Outlets }\end{array}$ & Totala & DTW & Rack & Bulk & Total & $\begin{array}{c}\text { Through } \\
\text { Retail } \\
\text { Outlets }\end{array}$ & Totala & DTW & Rack & Bulk & Total \\
\hline Kentucky & & & & & & & & & & & & \\
\hline 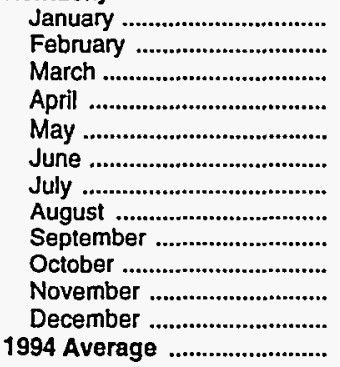 & $\begin{array}{l}387.7 \\
449.6 \\
464.3 \\
489.3 \\
485.2 \\
497.3 \\
514.2 \\
529.4 \\
504.5 \\
505.2 \\
499.6 \\
502.2 \\
485.9\end{array}$ & $\begin{array}{l}436.4 \\
511.5 \\
527.6 \\
548.6 \\
541.7 \\
554.9 \\
567.3 \\
586.5 \\
561.2 \\
564.4 \\
551.4 \\
554.2 \\
542.3\end{array}$ & $\begin{array}{l}271.2 \\
W \\
347.2 \\
372.0 \\
371.1 \\
395.8 \\
358.5 \\
372.3 \\
W \\
379.6 \\
366.5 \\
362.0 \\
358.9\end{array}$ & $\begin{array}{l}1,714.2 \\
2,080.0 \\
2,197.0 \\
2,286.9 \\
2,291.3 \\
2,376.3 \\
2,238.4 \\
2,308.0 \\
2,142.5 \\
2,154.9 \\
2,032.4 \\
2,263.6 \\
2,174.2\end{array}$ & $\begin{array}{l}\bar{w} \\
\overline{-} \\
\overline{-} \\
\overline{-} \\
\bar{w} \\
\overline{-} \\
\overline{-} \\
\bar{w}\end{array}$ & $\begin{array}{l}1,985.4 \\
2,428.2 \\
2,544.1 \\
2,658.9 \\
2,662.4 \\
2,772.1 \\
2,596.9 \\
2,680.3 \\
2,575.5 \\
2,534.5 \\
2,398.8 \\
2,625.7 \\
2,538.8\end{array}$ & $\begin{array}{l}116.8 \\
128.6 \\
131.3 \\
132.5 \\
133.5 \\
140.5 \\
146.9 \\
145.2 \\
144.4 \\
145.6 \\
143.9 \\
143.2 \\
137.7\end{array}$ & $\begin{array}{l}122.2 \\
136.8 \\
139.8 \\
139.9 \\
141.8 \\
149.1 \\
152.9 \\
153.8 \\
152.6 \\
155.2 \\
151.0 \\
149.0 \\
145.4\end{array}$ & $\begin{array}{c}77.9 \\
W \\
W \\
101.4 \\
101.9 \\
108.8 \\
101.4 \\
101.4 \\
W \\
104.7 \\
100.5 \\
95.8 \\
98.4\end{array}$ & $\begin{array}{c}335.5 \\
W \\
W \\
454.6 \\
451.4 \\
447.1 \\
419.5 \\
474.9 \\
W \\
346.8 \\
277.7 \\
376.1 \\
406.9\end{array}$ & $\begin{array}{l}- \\
- \\
- \\
- \\
- \\
- \\
- \\
- \\
- \\
- \\
-\end{array}$ & $\begin{array}{l}413.4 \\
524.4 \\
545.3 \\
556.0 \\
553.2 \\
555.9 \\
520.8 \\
576.3 \\
517.5 \\
451.6 \\
378.2 \\
471.9 \\
505.3\end{array}$ \\
\hline 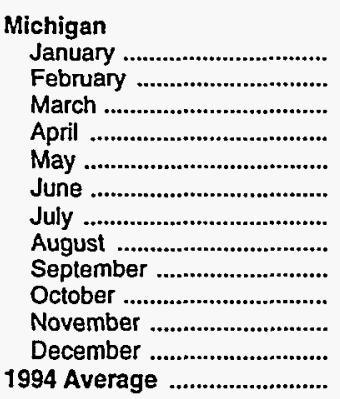 & $\begin{array}{l}1,820.1 \\
1,709.3 \\
1,919.8 \\
1,967.1 \\
2,095.0 \\
2,169.8 \\
2,147.5 \\
2,237.0 \\
2,161.5 \\
2,124.3 \\
2,082.2 \\
2,090.8 \\
2,045.9\end{array}$ & $\begin{array}{l}1,936.4 \\
1,846.4 \\
2,050.5 \\
2,080.0 \\
2,225.8 \\
2,317.1 \\
2,221.0 \\
2,341.7 \\
2,250.4 \\
2,227.2 \\
2,177.4 \\
2,186.0 \\
2,157.0\end{array}$ & $\begin{array}{l}2,151.5 \\
2,331.8 \\
2,348.1 \\
2,329.5 \\
2,421.5 \\
2,503.5 \\
2,449.7 \\
2,483.5 \\
2,426.5 \\
2,401.0 \\
2,394.3 \\
2,413.6 \\
2,388.1\end{array}$ & $\begin{array}{r}3,899.3 \\
4,215.1 \\
4,230.8 \\
4,344.9 \\
4,667.2 \\
4,944.9 \\
4,936.3 \\
5,153.1 \\
W \\
4,669.1 \\
4,672.3 \\
4,561.2 \\
4,600.7\end{array}$ & $\begin{array}{l}\overline{-} \\
- \\
\overline{-} \\
\overline{-} \\
\bar{z} \\
\bar{w} \\
\overline{-} \\
\bar{w} \\
\bar{w}\end{array}$ & $\begin{array}{l}6,050.7 \\
6,546.9 \\
6,578.9 \\
6,674.5 \\
7,088.7 \\
7,448.4 \\
7,386.0 \\
7,636.5 \\
7,338.2 \\
7,070.1 \\
7,066.6 \\
6,974.8 \\
6,990.4\end{array}$ & $\begin{array}{l}386.4 \\
360.3 \\
385.0 \\
366.9 \\
377.3 \\
388.1 \\
381.2 \\
366.7 \\
367.8 \\
379.3 \\
382.1 \\
399.4 \\
378.6\end{array}$ & $\begin{array}{l}389.2 \\
362.9 \\
387.0 \\
369.7 \\
379.0 \\
391.4 \\
382.9 \\
369.6 \\
370.2 \\
382.4 \\
384.3 \\
400.9 \\
381.0\end{array}$ & $\begin{array}{c}572.1 \\
584.8 \\
592.6 \\
595.8 \\
603.8 \\
616.9 \\
576.5 \\
W \\
W \\
568.3 \\
559.9 \\
554.6 \\
580.0\end{array}$ & $\begin{array}{c}297.9 \\
308.1 \\
321.3 \\
339.7 \\
336.7 \\
349.5 \\
306.0 \\
W \\
W \\
262.8 \\
271.9 \\
244.7 \\
303.1\end{array}$ & $\begin{array}{l}- \\
- \\
- \\
- \\
- \\
- \\
- \\
- \\
- \\
- \\
-\end{array}$ & $\begin{array}{l}870.0 \\
892.9 \\
913.9 \\
935.5 \\
940.5 \\
966.5 \\
882.5 \\
875.0 \\
861.7 \\
831.1 \\
831.8 \\
799.4 \\
883.2\end{array}$ \\
\hline 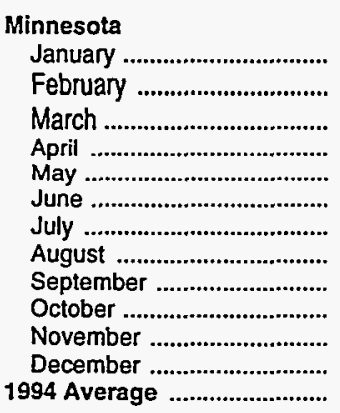 & $\begin{array}{r}1,059.9 \\
1,063.1 \\
989.9 \\
1,010.5 \\
1,029.5 \\
1,087.2 \\
1,076.4 \\
1,118.0 \\
1,057.3 \\
998.2 \\
983.2 \\
996.0 \\
1,039.0\end{array}$ & $\begin{array}{l}1,079.7 \\
1,085.6 \\
1,009.2 \\
1,026.3 \\
1,049.7 \\
1,110.5 \\
1,094.0 \\
1,134.1 \\
1,076.2 \\
1,019.4 \\
1,003.5 \\
1,020.6 \\
1,058.9\end{array}$ & $\begin{array}{l}W \\
W \\
W \\
W \\
W \\
W \\
W \\
W \\
W \\
W \\
W \\
W \\
W\end{array}$ & $\begin{array}{l}2,720.5 \\
2,737.9 \\
2,747.1 \\
2,902.9 \\
3,132.2 \\
3,449.3 \\
3,507.6 \\
3,640.6 \\
3,488.8 \\
3,330.8 \\
3,348.2 \\
3,173.6 \\
3,184.0\end{array}$ & $\begin{array}{l}W \\
W \\
W \\
W \\
W \\
W \\
W \\
W \\
W \\
W \\
W \\
W \\
W\end{array}$ & $\begin{array}{l}3,182.4 \\
3,369.0 \\
3,289.1 \\
3,575.2 \\
3,739.4 \\
4,079.2 \\
4,006.2 \\
4,164.2 \\
4,062.0 \\
3,921.6 \\
3,920.2 \\
3,832.7 \\
3,763.4\end{array}$ & $\begin{array}{l}296.8 \\
182.7 \\
160.8 \\
160.9 \\
162.9 \\
167.6 \\
162.3 \\
153.5 \\
148.3 \\
144.3 \\
147.6 \\
158.5 \\
170.6\end{array}$ & $\begin{array}{l}297.5 \\
183.6 \\
161.5 \\
161.4 \\
163.9 \\
168.0 \\
162.5 \\
153.6 \\
149.3 \\
145.0 \\
148.3 \\
159.4 \\
171.2\end{array}$ & $\begin{array}{l}W \\
W \\
W \\
W \\
W \\
W \\
W \\
W \\
W \\
W \\
W \\
W \\
W\end{array}$ & $\begin{array}{c}91.5 \\
W \\
W \\
W \\
W \\
W \\
W \\
W \\
W \\
W \\
W \\
W \\
133.1\end{array}$ & $\begin{array}{l}- \\
- \\
- \\
- \\
- \\
- \\
- \\
- \\
- \\
- \\
-\end{array}$ & $\begin{array}{l}185.5 \\
173.9 \\
181.0 \\
208.3 \\
237.1 \\
243.6 \\
242.8 \\
245.3 \\
218.8 \\
179.0 \\
183.6 \\
253.6 \\
213.0\end{array}$ \\
\hline 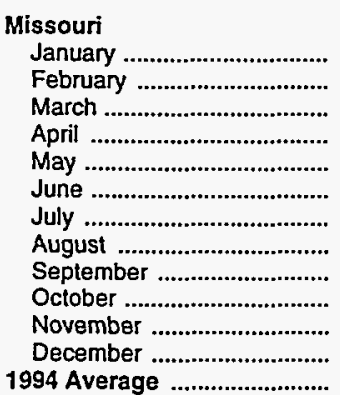 & $\begin{array}{l}708.9 \\
707.3 \\
686.7 \\
700.7 \\
711.8 \\
729.1 \\
720.8 \\
706.0 \\
696.2 \\
689.5 \\
671.9 \\
668.5 \\
699.7\end{array}$ & $\begin{array}{l}748.5 \\
753.4 \\
731.8 \\
739.8 \\
749.5 \\
759.3 \\
734.0 \\
721.1 \\
710.4 \\
703.3 \\
685.3 \\
682.1 \\
726.3\end{array}$ & $\begin{array}{c}525.9 \\
531.4 \\
538.4 \\
W \\
536.5 \\
554.9 \\
532.4 \\
547.5 \\
523.1 \\
531.6 \\
547.2 \\
567.6 \\
538.8\end{array}$ & $\begin{array}{r}2,959.2 \\
W \\
W \\
3,687.3 \\
3,578.3 \\
3,884.1 \\
W \\
W \\
3,650.0 \\
W \\
W \\
W \\
3,588.8\end{array}$ & $\begin{array}{c}W \\
W \\
W \\
W \\
350.5 \\
181.1 \\
W \\
W \\
95.4 \\
W \\
W \\
W \\
189.2\end{array}$ & $\begin{array}{l}3,760.2 \\
4,116.2 \\
4,161.8 \\
4,437.7 \\
4,465.3 \\
4,620.1 \\
4,439.1 \\
4,462.9 \\
4,268.5 \\
4,473.3 \\
4,300.5 \\
4,287.6 \\
4,316.8\end{array}$ & $\begin{array}{l}151.7 \\
145.7 \\
130.8 \\
129.2 \\
131.5 \\
133.9 \\
129.4 \\
121.2 \\
120.3 \\
121.6 \\
121.0 \\
130.8 \\
130.5\end{array}$ & $\begin{array}{l}152.0 \\
146.4 \\
132.0 \\
130.1 \\
132.3 \\
134.3 \\
130.5 \\
122.2 \\
121.0 \\
122.3 \\
121.5 \\
131.5 \\
131.3\end{array}$ & $\begin{array}{c}173.9 \\
W \\
W \\
W \\
169.9 \\
181.8 \\
W \\
W \\
165.2 \\
W \\
W \\
W \\
169.3\end{array}$ & $\begin{array}{c}108.9 \\
W \\
W \\
W \\
111.6 \\
115.5 \\
W \\
W \\
102.7 \\
W \\
W \\
W \\
113.6\end{array}$ & $\begin{array}{l}- \\
- \\
- \\
- \\
- \\
- \\
- \\
- \\
- \\
- \\
- \\
-\end{array}$ & $\begin{array}{l}282.8 \\
277.5 \\
285.6 \\
269.6 \\
281.5 \\
297.3 \\
287.6 \\
284.7 \\
267.8 \\
278.4 \\
281.8 \\
298.7 \\
282.8\end{array}$ \\
\hline
\end{tabular}

See footnotes at end of table. 
Table 43. Refiner Motor Gasoline Volumes by Grade, Sales Type, PAD District, and State (Thousand Gallons per Day) - Continued

\begin{tabular}{|c|c|c|c|c|c|c|c|c|c|c|c|c|}
\hline \multirow{3}{*}{$\begin{array}{l}\text { Geographlc Area } \\
\text { Month }\end{array}$} & \multicolumn{6}{|c|}{ Premlum } & \multicolumn{6}{|c|}{ All Grades } \\
\hline & \multicolumn{2}{|c|}{ Sales to End Users } & \multicolumn{4}{|c|}{ Sales for Resale } & \multicolumn{2}{|c|}{ Sales to End Users } & \multicolumn{4}{|c|}{ Sales for Resale } \\
\hline & $\begin{array}{c}\text { Through } \\
\text { Retall } \\
\text { Outlets }\end{array}$ & Totala & DTW & Rack & Bulk & Total & $\begin{array}{c}\text { Through } \\
\text { Retail } \\
\text { Outlets }\end{array}$ & Totala & DTW & Rack & Bulk & Total \\
\hline \multicolumn{13}{|l|}{ Kentucky } \\
\hline 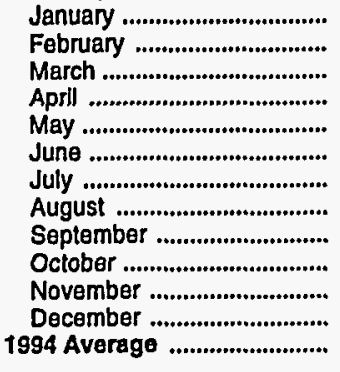 & $\begin{array}{l}139.0 \\
139.4 \\
136.6 \\
139.2 \\
142.4 \\
142.5 \\
142.2 \\
130.0 \\
140.4 \\
146.1 \\
138.9 \\
140.8 \\
139.8\end{array}$ & $\begin{array}{l}152.2 \\
154.4 \\
152.3 \\
153.4 \\
155.7 \\
155.2 \\
156.4 \\
142.5 \\
153.1 \\
158.2 \\
150.1 \\
153.7 \\
153.1\end{array}$ & $\begin{array}{r}125.3 \\
142.3 \\
140.5 \\
139.0 \\
140.8 \\
151.3 \\
142.4 \\
138.2 \\
W \\
147.6 \\
138.5 \\
143.3 \\
140.5\end{array}$ & $\begin{array}{c}571.4 \\
656.2 \\
W \\
694.3 \\
680.5 \\
721.0 \\
654.0 \\
650.1 \\
W \\
688.6 \\
638.3 \\
789.2 \\
672.0\end{array}$ & $\begin{array}{l}\bar{w} \\
\bar{w} \\
\overline{-} \\
\overline{-} \\
\overline{-} \\
\overline{-} \\
\bar{w}\end{array}$ & $\begin{array}{l}696.7 \\
798.5 \\
897.4 \\
833.3 \\
821.3 \\
872.3 \\
796.4 \\
788.3 \\
766.8 \\
836.2 \\
776.8 \\
932.5 \\
\mathbf{8 1 8 . 3}\end{array}$ & $\begin{array}{l}643.6 \\
717.6 \\
732.1 \\
761.0 \\
761.1 \\
780.4 \\
803.3 \\
804.6 \\
789.4 \\
796.9 \\
782.4 \\
786.2 \\
763.4\end{array}$ & $\begin{array}{l}710.7 \\
802.7 \\
819.7 \\
841.9 \\
839.2 \\
859.1 \\
876.6 \\
882.8 \\
866.9 \\
877.8 \\
852.5 \\
856.9 \\
840.7\end{array}$ & $\begin{array}{c}474.4 \\
582.4 \\
W \\
612.4 \\
613.8 \\
655.9 \\
602.3 \\
611.8 \\
W \\
632.0 \\
605.4 \\
601.1 \\
597.8\end{array}$ & $\begin{array}{r}2,621.1 \\
W \\
3,336.0 \\
3,435.8 \\
3,423.1 \\
3,544.4 \\
3,311.9 \\
3,433.0 \\
3,190.5 \\
3,190.3 \\
2,948.3 \\
3,429.0 \\
3,253.0\end{array}$ & $\begin{array}{l}\bar{w} \\
w \\
- \\
- \\
- \\
- \\
\bar{w} \\
- \\
- \\
\bar{w}\end{array}$ & $\begin{array}{l}3,095.5 \\
3,751.1 \\
3,986.9 \\
4,048.2 \\
4,036.9 \\
4,200.3 \\
3,914.2 \\
4,044.8 \\
3,859.8 \\
3,822.3 \\
3,553.8 \\
4,030.1 \\
3,862.3\end{array}$ \\
\hline \multicolumn{13}{|l|}{ Michigan } \\
\hline 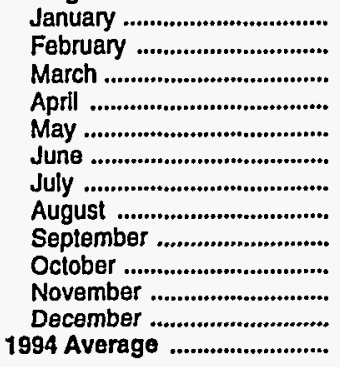 & $\begin{array}{l}414.2 \\
732.7 \\
398.7 \\
432.2 \\
399.1 \\
417.6 \\
418.0 \\
382.2 \\
400.4 \\
412.3 \\
408.0 \\
423.4 \\
434.4\end{array}$ & $\begin{array}{l}443.3 \\
763.0 \\
433.3 \\
468.3 \\
436.3 \\
457.8 \\
443.4 \\
421.9 \\
438.0 \\
446.8 \\
432.1 \\
442.2 \\
466.7\end{array}$ & $\begin{array}{l}776.4 \\
761.3 \\
745.4 \\
727.3 \\
736.9 \\
750.1 \\
725.2 \\
681.1 \\
680.1 \\
717.1 \\
709.0 \\
744.8 \\
729.4\end{array}$ & $\begin{array}{c}872.5 \\
861.0 \\
815.4 \\
804.4 \\
865.1 \\
964.2 \\
935.4 \\
W \\
869.3 \\
865.0 \\
870.9 \\
909.2 \\
878.5\end{array}$ & $\begin{array}{l}- \\
- \\
- \\
- \\
\bar{w} \\
\bar{w} \\
\overline{-} \\
\bar{w}\end{array}$ & $\begin{array}{l}1,648.8 \\
1,622.3 \\
1,560.7 \\
1,531.7 \\
1,602.0 \\
1,714.3 \\
1,660.5 \\
1,609.2 \\
1,549.4 \\
1,582.1 \\
1,579.9 \\
1,653.9 \\
1,609.6\end{array}$ & $\begin{array}{l}2,620.6 \\
2,802.3 \\
2,703.5 \\
2,766.1 \\
2,871.4 \\
2,975.5 \\
2,946.7 \\
2,985.9 \\
2,929.7 \\
2,915.8 \\
2,872.4 \\
2,913.6 \\
2,858.8\end{array}$ & $\begin{array}{l}2,768.8 \\
2,972.3 \\
2,870.8 \\
2,918.0 \\
3,041.1 \\
3,166.3 \\
3,047.3 \\
3,133.3 \\
3,058.6 \\
3,056.4 \\
2,993.8 \\
3,029.1 \\
3,004.6\end{array}$ & $\begin{array}{r}3,499.9 \\
3,677.9 \\
3,686.1 \\
3,652.7 \\
3,762.2 \\
3,870.6 \\
3,751.4 \\
W \\
W \\
3,686.4 \\
3,663.1 \\
3,713.0 \\
3,697.5\end{array}$ & $\begin{array}{l}5,069.6 \\
5,384.3 \\
5,367.4 \\
5,489.0 \\
5,869.0 \\
6,258.6 \\
6,177.6 \\
6,369.4 \\
6,052.9 \\
5,796.9 \\
5,815.2 \\
5,715.1 \\
5,782.3\end{array}$ & $\begin{array}{l}- \\
- \\
- \\
- \\
- \\
- \\
\bar{w} \\
w \\
- \\
- \\
\bar{w}\end{array}$ & $\begin{array}{r}8,569.6 \\
9,062.1 \\
9,053.5 \\
9,141.7 \\
9,631.2 \\
10,129.2 \\
9,929.1 \\
10,120.7 \\
9,749.3 \\
9,483.3 \\
9,478.3 \\
9,428.1 \\
9,483.2\end{array}$ \\
\hline \multicolumn{13}{|l|}{ Minnesota } \\
\hline 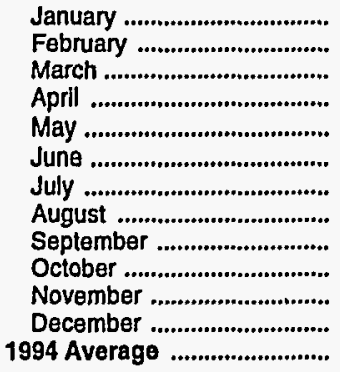 & $\begin{array}{l}173.4 \\
150.1 \\
129.8 \\
137.2 \\
145.0 \\
153.5 \\
150.0 \\
132.5 \\
125.5 \\
120.8 \\
123.0 \\
129.0 \\
139.1\end{array}$ & $\begin{array}{l}173.5 \\
150.3 \\
129.9 \\
137.3 \\
145.5 \\
154.0 \\
150.4 \\
132.6 \\
125.6 \\
121.3 \\
123.1 \\
129.1 \\
139.3\end{array}$ & $\begin{array}{l}W \\
W \\
W \\
W \\
W \\
W \\
W \\
W \\
W \\
W \\
W \\
W \\
W\end{array}$ & $\begin{array}{c}402.4 \\
W \\
W \\
W \\
W \\
W \\
W \\
W \\
W \\
W \\
W \\
W \\
349.0\end{array}$ & $\begin{array}{l}W \\
W \\
W \\
W \\
W \\
W \\
W \\
W \\
W \\
W \\
W \\
W \\
W\end{array}$ & $\begin{array}{l}481.8 \\
441.6 \\
369.1 \\
363.2 \\
399.4 \\
442.7 \\
451.1 \\
430.2 \\
365.3 \\
433.3 \\
476.3 \\
475.5 \\
427.5\end{array}$ & $\begin{array}{l}1,530.2 \\
1,395.9 \\
1,280.5 \\
1,308.6 \\
1,337.5 \\
1,408.3 \\
1,388.7 \\
1,404.0 \\
1,331.0 \\
1,263.3 \\
1,253.8 \\
1,283.5 \\
1,348.6\end{array}$ & $\begin{array}{l}1,550.7 \\
1,419.4 \\
1,300.6 \\
1,325.0 \\
1,359.1 \\
1,432.5 \\
1,406.9 \\
1,420.3 \\
1,351.1 \\
1,285.7 \\
1,275.0 \\
1,309.0 \\
1,369.5\end{array}$ & $\begin{array}{l}W \\
W \\
W \\
W \\
W \\
W \\
W \\
W \\
W \\
W \\
W \\
W \\
W\end{array}$ & $\begin{array}{l}3,214.5 \\
3,174.5 \\
3,135.6 \\
3,317.8 \\
3,608.8 \\
3,970.9 \\
4,036.2 \\
4,170.7 \\
3,925.6 \\
3,799.2 \\
3,858.1 \\
3,747.4 \\
3,666.1\end{array}$ & $\begin{array}{l}W \\
W \\
W \\
W \\
W \\
W \\
W \\
W \\
W \\
W \\
W \\
W \\
W\end{array}$ & $\begin{array}{l}3,849.6 \\
3,984.5 \\
3,839.3 \\
4,146.7 \\
4,375.9 \\
4,765.5 \\
4,700.2 \\
4,839.6 \\
4,646.0 \\
4,534.0 \\
4,580.1 \\
4,561.9 \\
4,403.9\end{array}$ \\
\hline \multicolumn{13}{|l|}{ Missouri } \\
\hline 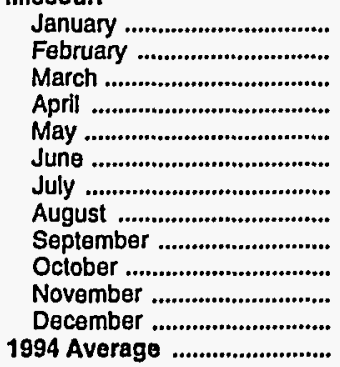 & $\begin{array}{l}160.3 \\
211.1 \\
138.6 \\
136.4 \\
135.8 \\
131.8 \\
124.6 \\
111.9 \\
113.8 \\
120.6 \\
120.6 \\
159.9 \\
138.3\end{array}$ & $\begin{array}{l}165.2 \\
216.6 \\
143.5 \\
141.3 \\
140.0 \\
136.4 \\
128.5 \\
115.5 \\
117.3 \\
124.4 \\
124.7 \\
164.1 \\
142.7\end{array}$ & $\begin{array}{l}180.3 \\
173.0 \\
174.2 \\
168.2 \\
178.3 \\
185.2 \\
175.8 \\
W \\
170.1 \\
166.0 \\
167.5 \\
183.9 \\
173.8\end{array}$ & $\begin{array}{r}647.3 \\
620.7 \\
668.4 \\
685.6 \\
703.2 \\
748.4 \\
722.0 \\
W \\
624.4 \\
683.6 \\
677.7 \\
721.8 \\
683.1\end{array}$ & $\begin{array}{l}w \\
- \\
\overline{-} \\
- \\
- \\
- \\
- \\
- \\
- \\
\bar{w}\end{array}$ & $\begin{array}{l}827.6 \\
793.6 \\
842.6 \\
853.8 \\
881.5 \\
933.6 \\
897.8 \\
850.9 \\
794.5 \\
849.5 \\
845.3 \\
905.7 \\
856.9\end{array}$ & $\begin{array}{r}1,020.9 \\
1,064.1 \\
956.1 \\
966.2 \\
979.1 \\
994.8 \\
974.8 \\
939.1 \\
930.3 \\
931.7 \\
913.6 \\
959.2 \\
968.6\end{array}$ & $\begin{array}{r}1,065.7 \\
1,116.4 \\
1,007.3 \\
1,011.2 \\
1,021.8 \\
1,030.0 \\
992.9 \\
958.7 \\
948.6 \\
950.0 \\
931.5 \\
977.6 \\
1,000.3\end{array}$ & $\begin{array}{c}880.1 \\
W \\
W \\
857.4 \\
884.7 \\
921.9 \\
W \\
875.4 \\
858.4 \\
W \\
W \\
W \\
881.8\end{array}$ & $\begin{array}{r}3,715.4 \\
4,007.9 \\
4,249.0 \\
W \\
4,393.1 \\
4,748.0 \\
4,577.4 \\
W \\
4,377.1 \\
4,485.9 \\
4,522.0 \\
4,462.0 \\
4,385.5\end{array}$ & $\begin{array}{c}W \\
W \\
W \\
W \\
350.5 \\
181.1 \\
W \\
W \\
95.4 \\
W \\
W \\
W \\
189.2\end{array}$ & $\begin{array}{l}4,870.6 \\
5,187.3 \\
5,290.0 \\
5,561.1 \\
5,628.3 \\
5,851.1 \\
5,624.5 \\
5,598.5 \\
5,330.9 \\
5,601.3 \\
5,427.5 \\
5,492.0 \\
5,456.5\end{array}$ \\
\hline
\end{tabular}

See footnotes at end of table. 
Table 43. Refiner Motor Gasoline Volumes by Grade, Sales Type, PAD District, and State (Thousand Gallons per Day) - Continued

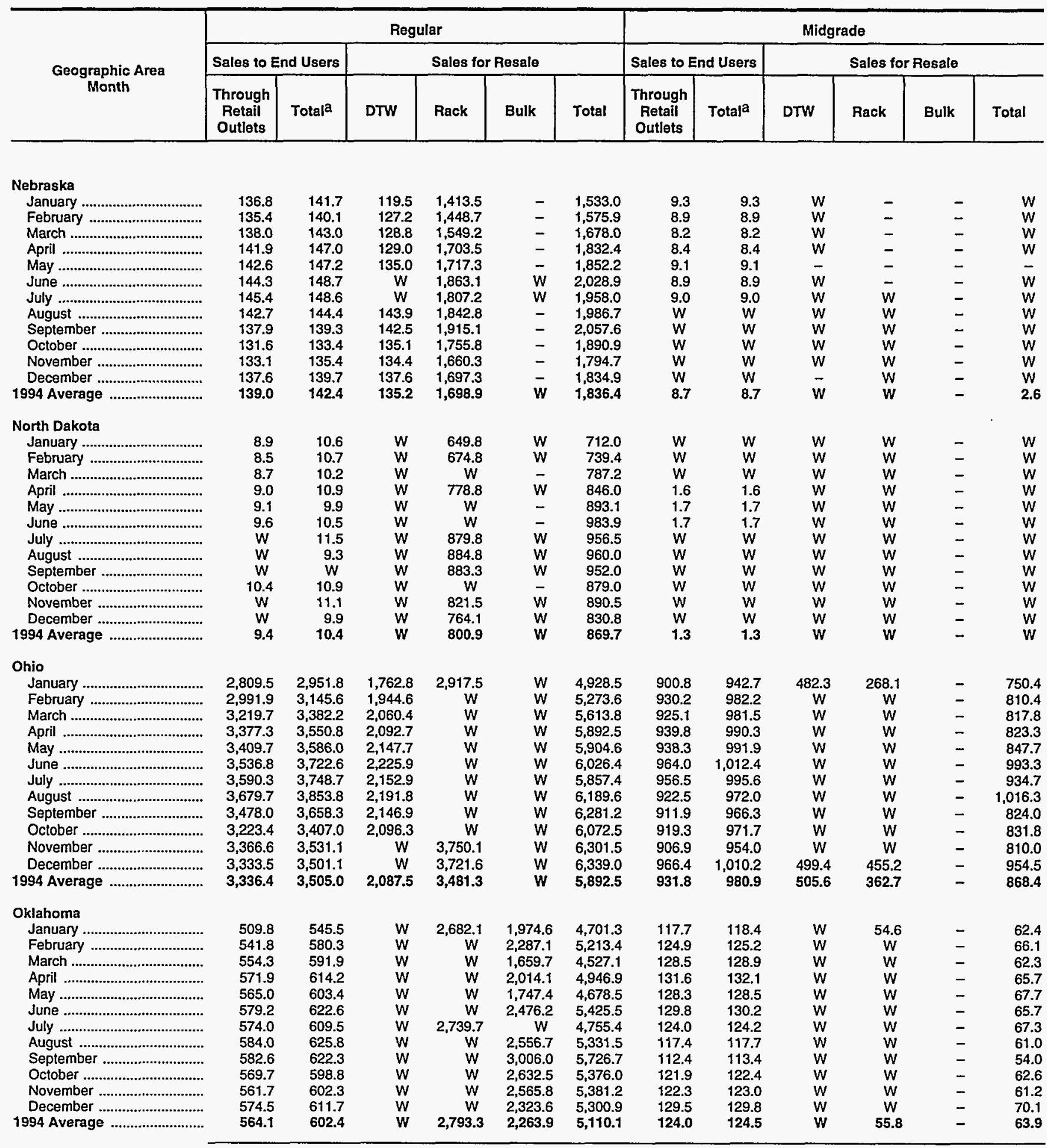

See footnotes at end of table. 
Table 43. Refiner Motor Gasoline Volumes by Grade, Sales Type, PAD District, and Stałe (Thousand Gallons per Day) - Continued

\begin{tabular}{|c|c|c|c|c|c|c|c|c|c|c|c|c|}
\hline \multirow{3}{*}{$\begin{array}{c}\text { Geographlc Area } \\
\text { Month }\end{array}$} & \multicolumn{6}{|c|}{ Promium } & \multicolumn{6}{|c|}{ All Grades } \\
\hline & \multicolumn{2}{|c|}{ Sales to End Users } & \multicolumn{4}{|c|}{ Sales for Resale } & \multicolumn{2}{|c|}{ Sales to End Users } & \multicolumn{4}{|c|}{ Sales for Resale } \\
\hline & $\begin{array}{c}\text { Through } \\
\text { Retall } \\
\text { Outlets }\end{array}$ & Totala & DTW & Rack & Bulk & Total & $\begin{array}{c}\text { Through } \\
\text { Retail } \\
\text { Ottlets }\end{array}$ & Totala & DTW & Rack & Bulk & 1 \\
\hline \multicolumn{13}{|l|}{ Nebraska } \\
\hline January ................................... & 15.7 & 16.0 & $w$ & 71.7 & - & 97.1 & 161.8 & 167.1 & $\$ 44.9$ & $1,485.3$ & - & $1,0,302$ \\
\hline 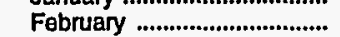 & 15.1 & 15.4 & $w$ & 75.4 & - & $\ddot{w}$ & 159.3 & 164.4 & 175.4 & $1,524.1$ & - & $1+0,45$ \\
\hline 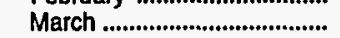 & 15.7 & 16.0 & $\dddot{w}$ & 77.7 & - & $w$ & 161.9 & 167.3 & 154.3 & $1,626.9$ & - & $1-43$ \\
\hline 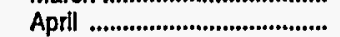 & 16.9 & 17.2 & $\dddot{w}$ & 88.6 & - & W & 167.2 & 172.6 & 156.0 & $1,792.0$ & - & .430 \\
\hline 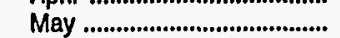 & 17.5 & 17.9 & 28.7 & 95.1 & - & 123.8 & 169.2 & 174.2 & 163.7 & $1,812.4$ & - & 1,4761 \\
\hline 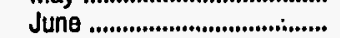 & 17.2 & 17.5 & $w$ & 110.8 & - & W & 170.4 & 175.2 & $w$ & $1,973.9$ & $w$ & 2,1697 \\
\hline 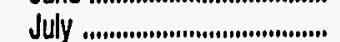 & 16.4 & 16.5 & 28.3 & $W$ & - & W & 170.7 & 174.1 & $\ddot{W}$ & $1,914.9$ & $W$ & $2,094.1$ \\
\hline 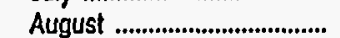 & $W$ & $W$ & $W$ & W & - & $W$ & 166.0 & 167.6 & 171.3 & $1,941.9$ & - & $2,113.2$ \\
\hline 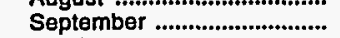 & $w$ & $w$ & $w$ & $w$ & - & $w$ & 161.1 & 162.6 & 169.6 & $2,024.7$ & - & 2,1943 \\
\hline 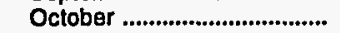 & W & $w$ & w & W & - & w & 154.8 & 156.6 & 161.2 & $1,851.7$ & - & 2,0129 \\
\hline 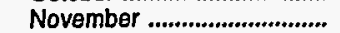 & W & W & $\ddot{w}$ & w & - & $\ddot{w}$ & 157.0 & 159.3 & 161.1 & $1,754.0$ & - & 1,9151 \\
\hline December ............................. & W & $\ddot{W}$ & 27.7 & $w$ & - & W & 162.8 & 164.9 & 165.4 & $1,798.9$ & - & 1,9042 \\
\hline 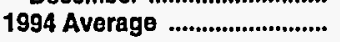 & 15.9 & 16.1 & 27.1 & 93.2 & - & 120.3 & 163.6 & 167.2 & 164.1 & $1,792.9$ & $w$ & $1,959.3$ \\
\hline \multicolumn{13}{|l|}{ North Dakota } \\
\hline 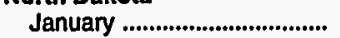 & 1.1 & 1.1 & $w$ & 40.4 & - & 52.9 & 11.4 & 13.1 & $w$ & 701.4 & $w$ & 7958 \\
\hline 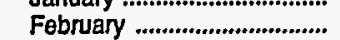 & $\ddot{w}$ & $w$ & $w$ & $W$ & - & $w$ & 11.0 & 13.2 & $\ddot{w}$ & 730.3 & $w$ & 8260 \\
\hline 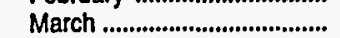 & W & $w$ & $w$ & 40.2 & - & W & 10.8 & 12.3 & w & W & - & 8665 \\
\hline 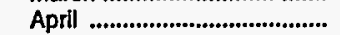 & 1.0 & 1.0 & w & $w$ & - & $\ddot{W}$ & 11.6 & 13.4 & $\dddot{w}$ & 829.9 & $w$ & 9248 \\
\hline 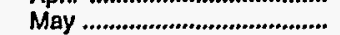 & 0.9 & 0.9 & $\ddot{w}$ & 43.8 & - & $w$ & 11.6 & 12.5 & w & $w$ & - & 9793 \\
\hline 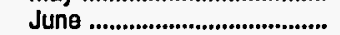 & 0.9 & 0.9 & $w$ & 48.7 & - & W & 12.2 & 13.1 & W & $w$ & - & 1,0785 \\
\hline July & $w$ & $w$ & $w$ & $w$ & - & $w$ & 13.5 & 14.0 & $\ddot{w}$ & 946.2 & $w$ & 1.055 .7 \\
\hline 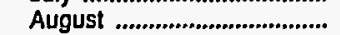 & 1.0 & $W$ & w & $W$ & - & $w$ & 11.0 & 11.7 & $\dddot{w}$ & 946.3 & $\ddot{w}$ & 1,0507 \\
\hline 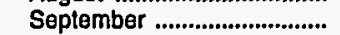 & 0.8 & 0.8 & $w$ & $\ddot{W}$ & - & w & 11.3 & 11.8 & $\dddot{w}$ & 941.2 & $w$ & 1,0377 \\
\hline 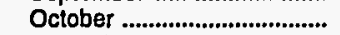 & $W$ & $w$ & $\ddot{w}$ & 40.1 & - & w & 12.4 & 12.9 & w & W & - & 2577 \\
\hline 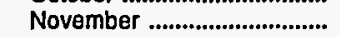 & 1.0 & w & w & $W$ & - & $\dddot{w}$ & 12.2 & 13.1 & w & 878.9 & $w$ & $\therefore 3$ \\
\hline 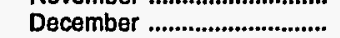 & 1.1 & $\ddot{w}$ & $\ddot{w}$ & $\ddot{w}$ & - & $\ddot{w}$ & 11.9 & 12.2 & w & 825.6 & $w$ & $\therefore .56$ \\
\hline 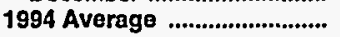 & 1.0 & 1.0 & $\mathbf{w}$ & 43.8 & - & 55.1 & 11.8 & 12.8 & w & 858.1 & $w$ & 56.8 \\
\hline \multicolumn{13}{|l|}{ Ohio } \\
\hline 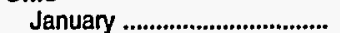 & 876.4 & 905.5 & 722.0 & 595.6 & - & $1,317.5$ & $4,586.7$ & $4,799.9$ & $2,967.1$ & $3,781.1$ & $w$ & $c, y 3 t \&$ \\
\hline February ................................. & $1,115.4$ & $1,147.8$ & 690.1 & 631.0 & - & $1,321.1$ & $5,037.5$ & $5,275.6$ & 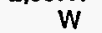 & $4,018.4$ & $w$ & $7,4,-11$ \\
\hline March ....................................... & 776.8 & 809.7 & 681.4 & 625.5 & - & $1,306.9$ & $4,921.5$ & $5,173.4$ & $w$ & $4,230.4$ & $w$ & $7,735:$ \\
\hline Aprll & 777.7 & 811.3 & 673.5 & 645.0 & - & $1,318.5$ & $5,094.8$ & $5,352.4$ & $\ddot{w}$ & $4,453.6$ & W & 8.0343 \\
\hline May .......................................... & 755.8 & 787.8 & 682.6 & 679.5 & - & $1,362.1$ & $5,103.8$ & $5,365.7$ & $\ddot{w}$ & $4,569.4$ & $\ddot{w}$ & $8,114.4$ \\
\hline 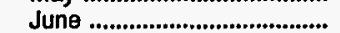 & 756.8 & 793.8 & 694.3 & 694.1 & - & $1,388.4$ & $5,257.6$ & $5,528.8$ & $w$ & $4,726.8$ & W & 8,4081 \\
\hline July & 738.8 & 768.0 & 666.9 & 669.2 & - & $1,336.1$ & $5,285.5$ & $5,512.3$ & $\ddot{w}$ & $4,645.4$ & $w$ & 8.1283 \\
\hline 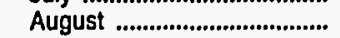 & 682.4 & 715.8 & 645.8 & 624.3 & - & $1,270.1$ & $5,284.6$ & $5,541.5$ & $\ddot{w}$ & $4,772.3$ & $w$ & 8,4760 \\
\hline September ............................. & 711.6 & 744.4 & 648.8 & 641.8 & - & $1,290.6$ & $5,101.4$ & $5,369.0$ & W & $4,576.4$ & $w$ & $8,395.8$ \\
\hline 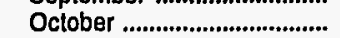 & 775.9 & 808.1 & 662.4 & 652.1 & - & $1,314.5$ & $4,918.5$ & $5,186.9$ & w & $4,542.2$ & $W$ & 8.2188 \\
\hline 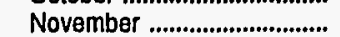 & 752.2 & 788.1 & 661.1 & W & W & $1,369.3$ & $5,025.7$ & $5,273.2$ & w & $4,752.5$ & $w$ & $8+269$ \\
\hline 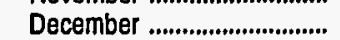 & 846.3 & 879.8 & $w$ & 766.8 & $\ddot{w}$ & $1,511.2$ & $5,146.1$ & $5,391.1$ & $3,307.8$ & $4,943.6$ & 5532 & 8.8016 \\
\hline 1994 Average .......................... & 795.1 & 827.9 & 678.3 & 659.5 & $W$ & $1,342.4$ & $5,063.3$ & $5,313.7$ & $3,271.4$ & $4,503.6$ & $w$ & $: 11\}, 3$ \\
\hline \multicolumn{13}{|l|}{ Oklahoma } \\
\hline 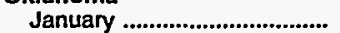 & 125.1 & 134.9 & $\mathbf{w}$ & 560.4 & 142.4 & 716.0 & 752.6 & 798.8 & $w$ & $3,297.1$ & $2,116.9$ & +7 \\
\hline 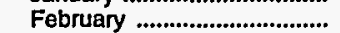 & 126.0 & 136.1 & $\ddot{w}$ & 560.7 & $w$ & 637.5 & 792.7 & 841.5 & $w$ & $3,499.2$ & $W$ & $5,+170$ \\
\hline 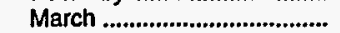 & 128.5 & 139.0 & w & 577.6 & 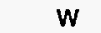 & 597.2 & 811.3 & 859.8 & $w$ & $3,445.3$ & $w$ & 5.1866 \\
\hline 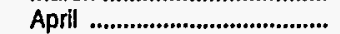 & 131.4 & 142.8 & $w$ & 586.1 & $w$ & 621.6 & 834.9 & 889.1 & $w$ & $3,524.7$ & w & 5,6342 \\
\hline 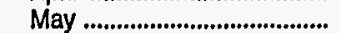 & 129.1 & 139.2 & $w$ & 587.9 & $w$ & 663.0 & 822.4 & 871.1 & $w$ & $3,524.5$ & $W$ & 5.409 .2 \\
\hline 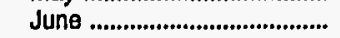 & 130.0 & 140.8 & W & 593.7 & $w$ & 678.7 & 839.0 & 893.6 & $w$ & $3,539.8$ & $w$ & 6.170 .0 \\
\hline 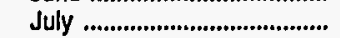 & 121.8 & 130.7 & $w$ & 555.9 & w & $604.5^{\circ}$ & 819.8 & 864.4 & W & W & 1,9916 & 5,4272 \\
\hline 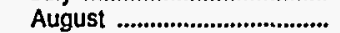 & 110.9 & 120.6 & $w$ & 491.3 & $w$ & 604.0 & 812.3 & 864.2 & $w$ & $3,261.6$ & $w$ & 5,9965 \\
\hline 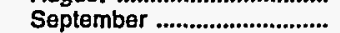 & 113.6 & 122.7 & $\ddot{w}$ & 485.5 & $\ddot{w}$ & 687.9 & 808.6 & 858.4 & $w$ & $3,197.6$ & $w$ & 6,4686 \\
\hline October & 121.0 & 128.9 & $w$ & 515.7 & w & 727.4 & 812.6 & 850.1 & $\ddot{w}$ & $3,261.7$ & W & (i.1€60 \\
\hline November ................................ & 120.4 & 129.6 & $w$ & 517.2 & w & 689.4 & 804.5 & 854.9 & $w$ & $3,333.2$ & $W$ & $1,+9$ \\
\hline December ................................ & 132.4 & 141.4 & $w$ & 600.8 & $w$ & 660.2 & 836.3 & 883.0 & $w$ & $3,592.9$ & $w$ & , \\
\hline 1994 Average & 124.2 & 133.9 & $\ddot{W}$ & 552.7 & 90.9 & 657.3 & 812.3 & 860.8 & w & $3,401.9$ & $2,354 \mathrm{~B}$ & 12 \\
\hline
\end{tabular}

See lootnotes at end of table. 
Table 43. Refiner Motor Gasoline Volumes by Grade, Sales Type, PAD District, and State (Thousand Gallons per Day) - Continued

\begin{tabular}{|c|c|c|c|c|c|c|c|c|c|c|c|c|}
\hline \multirow{3}{*}{$\begin{array}{c}\text { Geographic Area } \\
\text { Month }\end{array}$} & \multicolumn{6}{|c|}{ Regular } & \multicolumn{6}{|c|}{ Midgrade } \\
\hline & \multicolumn{2}{|c|}{ Sales to End Users } & \multicolumn{4}{|c|}{ Sales for Resale } & \multicolumn{2}{|c|}{ Sales to End Users } & \multicolumn{4}{|c|}{ Sales for Resale } \\
\hline & $\begin{array}{c}\text { Through } \\
\text { Retail } \\
\text { Outlets }\end{array}$ & Totala & DTW & Rack & Bulk & Total & $\begin{array}{l}\text { Through } \\
\text { Retall } \\
\text { Outlets }\end{array}$ & Totala & DTW & Rack & Bulk & Total \\
\hline \multicolumn{13}{|l|}{ South Dakota } \\
\hline 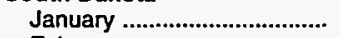 & 20.5 & 24.5 & 31.4 & 820.2 & - & 851.6 & $w$ & W & $w$ & $w$ & - & $w$ \\
\hline 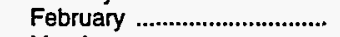 & 19.9 & 23.8 & $w$ & 828.7 & $W$ & 862.7 & W & W & W & $w$ & - & $W$ \\
\hline 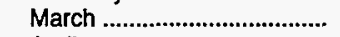 & 19.4 & 23.6 & 32.4 & $W$ & $W$ & 926.4 & W & W & W & W & - & W \\
\hline April & 20.0 & 23.1 & W & 904.7 & W & 942.6 & $w$ & W & $W$ & W & - & $W$ \\
\hline May & W & 24.4 & 37.3 & W & W & $1,023.6$ & $W$ & $W$ & $w$ & W & - & $W$ \\
\hline June & $W$ & 25.5 & 42.8 & W & $w$ & $1,110.1$ & $W$ & $W$ & $w$ & W & - & $W$ \\
\hline 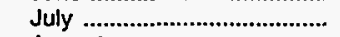 & $w$ & 24.8 & $W$ & $1,129.4$ & $W$ & $1,179.2$ & $w$ & $w$ & $w$ & $w$ & - & $w$ \\
\hline August & W & 22.1 & $W$ & $1,129.0$ & $w$ & $1,179.2$ & $w$ & W & $w$ & $w$ & - & $w$ \\
\hline 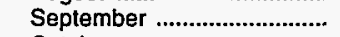 & W & W & W & $1,027.8$ & W & $1,072.0$ & W & W & W & W & - & $W$ \\
\hline 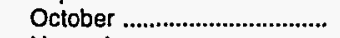 & 22.0 & 22.0 & 41.9 & W & W & $1,056.8$ & $w$ & W & $w$ & W & - & $W$ \\
\hline 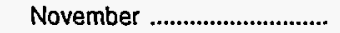 & $W$ & 21.7 & $W$ & 957.7 & $W$ & 996.1 & $W$ & $W$ & w & $W$ & - & $W$ \\
\hline December ................ & $W$ & 22.0 & W & 961.6 & W & 999.6 & $W$ & $W$ & W & W & - & $W$ \\
\hline 1994 Average & 21.3 & 23.2 & 38.4 & 977.2 & $\mathbf{W}$ & $1,017.8$ & $\mathbf{W}$ & $\mathbf{W}$ & W & $\mathbf{W}$ & - & $W$ \\
\hline \multicolumn{13}{|l|}{ Tennessee } \\
\hline 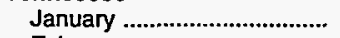 & 736.3 & 752.5 & 294.7 & $3,537.0$ & - & $3,831.7$ & 262.0 & 265.2 & 146.2 & 833.6 & - & 979.8 \\
\hline 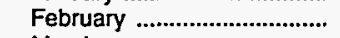 & 724.6 & 752.1 & $W$ & $4,169.8$ & $W$ & $4,565.8$ & 281.6 & 285.0 & W & $w$ & - & $1,037.9$ \\
\hline 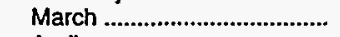 & 750.9 & 774.5 & $W$ & $4,171.3$ & $w$ & $4,630.4$ & 291.8 & 295.6 & $w$ & $w$ & - & $1,188.5$ \\
\hline April & 773.0 & 794.4 & $W$ & $4,279.7$ & $w$ & $4,762.1$ & 297.5 & 301.5 & W & $W$ & - & $1,212.3$ \\
\hline 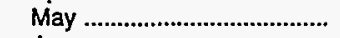 & 758.4 & 783.3 & $W$ & $4,335.3$ & $w$ & $4,775.5$ & 287.1 & 290.6 & $w$ & $w$ & - & $1,205.7$ \\
\hline 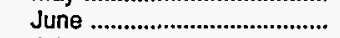 & 786.9 & 814.2 & $W$ & $4,548.6$ & $w$ & $5,034.6$ & 296.7 & 300.7 & $W$ & $w$ & - & $1,230.5$ \\
\hline July & 780.0 & 799.8 & $W$ & $4,400.1$ & $w$ & $4,891.4$ & 290.8 & 294.9 & $w$ & W & - & $1,198.0$ \\
\hline 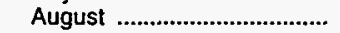 & 769.4 & 805.0 & $W$ & $4,665.1$ & $w$ & $5,176.0$ & 282.5 & 287.5 & w & $w$ & - & $1,230.5$ \\
\hline 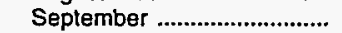 & 755.9 & 787.4 & $\mathbf{W}$ & $4,540.4$ & W & $4,994.0$ & 283.6 & 287.7 & $w$ & W & - & $1,205.6$ \\
\hline October & 744.5 & 778.2 & $W$ & $4,269.7$ & W & $4,728.9$ & 284.5 & 288.1 & $W$ & $W$ & - & $1,164.3$ \\
\hline 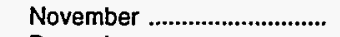 & 768.4 & 801.1 & $W$ & $4,331.5$ & $W$ & $4,823.7$ & 298.4 & 302.0 & $W$ & W & - & $1,169.1$ \\
\hline 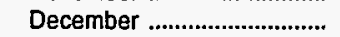 & 793.0 & 826.0 & $W$ & $4,330.7$ & $w$ & $4,798.5$ & 311.4 & 315.4 & $W$ & W & - & $1,269.0$ \\
\hline 1994 Average & 762.0 & 789.2 & 335.5 & $4,297.9$ & $\mathbf{W}$ & $4,750.9$ & 289.0 & 292.9 & 155.7 & $1,019.3$ & - & $1,175.1$ \\
\hline \multicolumn{13}{|l|}{ Wisconsin } \\
\hline 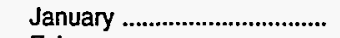 & 569.0 & 577.7 & 424.0 & $3,147.2$ & - & $3,571.2$ & 102.0 & 102.2 & 114.3 & 169.3 & - & 283.5 \\
\hline 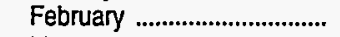 & 597.5 & 609.5 & 444.2 & $3,285.4$ & - & $3,729.5$ & 98.3 & 98.3 & 110.3 & 206.1 & - & 316.4 \\
\hline 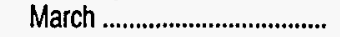 & 599.2 & 610.8 & 439.4 & $3,392.3$ & - & $3,831.6$ & 90.8 & 91.1 & 107.5 & 216.1 & - & 323.5 \\
\hline April & 615.0 & 625.5 & 440.3 & $3,454.1$ & - & $3,894.4$ & 91.3 & 91.3 & 104.6 & 204.9 & - & 309.5 \\
\hline 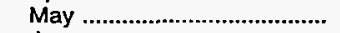 & 634.5 & 646.1 & 452.9 & $w$ & W & $4,186.1$ & 91.5 & 91.5 & $w$ & $w$ & - & 325.8 \\
\hline June & 654.2 & 666.9 & 465.4 & $W$ & $W$ & $4,446.2$ & 96.1 & 96.1 & W & $W$ & - & 323.6 \\
\hline 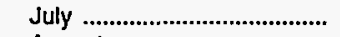 & 657.5 & 667.6 & 469.6 & $4,047.9$ & - & $4,517.5$ & 95.8 & 95.8 & 115.5 & 217.7 & - & 333.3 \\
\hline August & 670.7 & 680.3 & 468.8 & $4,002.4$ & - & $4,471.2$ & 90.9 & 91.2 & 108.6 & 215.6 & - & 324.2 \\
\hline 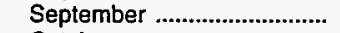 & 622.9 & 631.6 & 448.6 & $4,047.2$ & - & $4,495.8$ & 93.9 & 94.5 & 103.9 & 219.7 & - & 323.6 \\
\hline 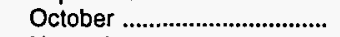 & 604.2 & 612.7 & 447.6 & $3,747.0$ & - & $4,194.6$ & 101.8 & 102.6 & 105.8 & 220.5 & - & 326.3 \\
\hline 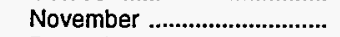 & 603.0 & 611.3 & 446.9 & $3,716.2$ & - & $4,163.1$ & 100.6 & 100.9 & 106.2 & 195.6 & - & 301.8 \\
\hline 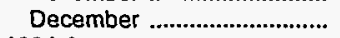 & 607.0 & 611.2 & 462.5 & $3,781.7$ & - & $4,244.2$ & 103.8 & 104.6 & 114.3 & 253.4 & - & 367.7 \\
\hline 1994 Average & 619.7 & 629.4 & 450.9 & $3,693.4$ & $w$ & $4,147.7$ & 96.4 & 96.7 & 109.6 & 212.2 & - & 321.7 \\
\hline \multicolumn{13}{|l|}{ PAD District III } \\
\hline 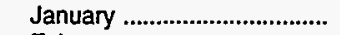 & $4,241.9$ & $4,454.6$ & $2,106.6$ & $25,380.3$ & $12,203.5$ & $39,690.5$ & $1,401.1$ & $1,440.6$ & 786.7 & $3,588.2$ & W & $4,376.7$ \\
\hline 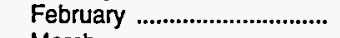 & $4,550.1$ & $4,795.7$ & $2,327.7$ & W & $W$ & $35,643.3$ & $1,502.6$ & $1,542.7$ & 855.9 & W & $W$ & $4,690.3$ \\
\hline (n) & $4,854.4$ & $5,118.5$ & $2,363.4$ & $25,302.3$ & $8,937.7$ & $36,603.5$ & $1,607.0$ & $1,652.7$ & 865.8 & $4,145.7$ & 21.0 & $5,032.5$ \\
\hline 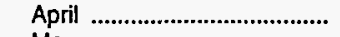 & $4,536.7$ & $4,772.4$ & $2,399.1$ & W & W & $39,517.6$ & $1,547.6$ & $1,590.4$ & 875.3 & $W$ & $W$ & $5,007.1$ \\
\hline May & $4,773.2$ & $4,991.4$ & $2,311.3$ & $25,410.3$ & $10,917.8$ & $38,639.3$ & $1,619.0$ & $1,660.8$ & 863.4 & $4,226.0$ & 20.7 & $5,110.2$ \\
\hline June & $4,610.9$ & $4,857.1$ & $2,321.8$ & $26,077.3$ & $10,924.6$ & $39,323.7$ & $1,583.8$ & $1,629.0$ & 867.7 & W & $W$ & $5,267.0$ \\
\hline July & $4,595.4$ & $4,802.5$ & $2,343.8$ & $26,066.5$ & $7,871.1$ & $36,281.4$ & $1,572.1$ & $1,609.9$ & 871.1 & $4,189.4$ & 34.2 & $5,094.7$ \\
\hline 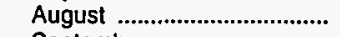 & $4,963.8$ & $5,168.0$ & $2,294.4$ & $26,557.9$ & $9,433.2$ & $38,285.5$ & $1,635.9$ & $1,676.5$ & $W$ & $4,223.3$ & $W$ & $5,104.9$ \\
\hline 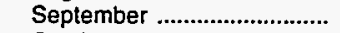 & $4,545.7$ & $4,756.1$ & $2,272.2$ & $25,870.5$ & $9,521.5$ & $37,664.2$ & $1,521.0$ & $1,565.1$ & 818.4 & $4,263.8$ & 34.8 & $5,117.0$ \\
\hline 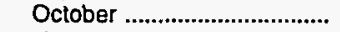 & $4,427.7$ & $4,678.0$ & $2,184.6$ & $w$ & $W$ & $36,271.3$ & $1,495.9$ & $1,540.6$ & 801.8 & $W$ & $W$ & $4,894.4$ \\
\hline 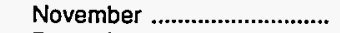 & $4,732.5$ & $4,958.0$ & $2,227.0$ & $w$ & W & $37,221.1$ & $1,668.6$ & $1,709.3$ & 825.4 & $w$ & $w$ & $5,175.7$ \\
\hline 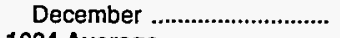 & $4,369.8$ & $4,596.8$ & $2,243.9$ & $25,029.9$ & $16,926.3$ & $44,200.0$ & $1,502.2$ & $1,545.5$ & 832.9 & $4,144.7$ & 48.5 & $5,026.0$ \\
\hline 1994 Average .............................. & $4,600.5$ & $4,829.3$ & $2,282.4$ & $25,459.6$ & $10,556.4$ & $38,298.4$ & $1,554.9$ & $1,597.1$ & 841.9 & $4,121.6$ & 28.7 & $4,992.2$ \\
\hline
\end{tabular}

See footnotes at end of table. 
Table 43. Refiner Motor Gasoline Volumes by Grade, Sales Type, PAD District, and State (Thousand Gallons per Day) - Continued

\begin{tabular}{|c|c|c|c|c|c|c|c|c|c|c|c|c|}
\hline \multirow{3}{*}{$\begin{array}{c}\text { Geographic Area } \\
\text { Month }\end{array}$} & \multicolumn{6}{|c|}{ Premium } & \multicolumn{6}{|c|}{ All Grades } \\
\hline & \multicolumn{2}{|c|}{ Sales to End Users } & \multicolumn{4}{|c|}{ Sales for Resale } & \multicolumn{2}{|c|}{ Sales to End Users } & \multicolumn{4}{|c|}{ Sales for Resale } \\
\hline & $\begin{array}{c}\text { Through } \\
\text { Retall } \\
\text { Outlats }\end{array}$ & Totala & DTW & Rack & Bulk & Total & $\begin{array}{c}\text { Through } \\
\text { Retail } \\
\text { Outlets }\end{array}$ & Totala & DTW & Rack & Bulk & Total \\
\hline
\end{tabular}

\begin{tabular}{|c|c|c|c|c|c|c|c|c|c|c|c|c|}
\hline \multicolumn{13}{|l|}{ South Dakota } \\
\hline 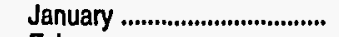 & 1.1 & 2.0 & 5.5 & 54.5 & - & 60.0 & 21.9 & 26.8 & 42.7 & 879.0 & - & 921.7 \\
\hline 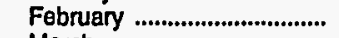 & $w$ & $W$ & 5.5 & $W$ & - & $W$ & 21.3 & 26.0 & $w$ & 891.3 & $w$ & 936.5 \\
\hline 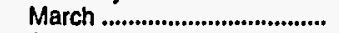 & $w$ & W & $w$ & 79.9 & - & $W$ & 20.7 & 25.6 & 43.2 & $w$ & $\ddot{w}$ & $1,021.2$ \\
\hline April & $W$ & $W$ & 5.9 & $W$ & - & $W$ & 21.2 & 25.2 & $W$ & 968.9 & $w$ & $1,018.7$ \\
\hline May & 0.9 & $W$ & $W$ & 69.6 & - & W & 22.7 & 26.5 & 50.3 & $W$ & w & $1,111.1$ \\
\hline 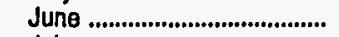 & 0.9 & $W$ & $w$ & 87.7 & - & $W$ & 24.0 & 27.5 & 57.5 & $W$ & W & $1,220.5$ \\
\hline 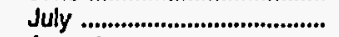 & 1.0 & $W$ & 8.6 & $w$ & - & $w$ & 24.7 & 26.3 & $w$ & $1,243.4$ & W & $1,309.1$ \\
\hline August & 0.9 & $w$ & 8.1 & $w$ & - & W & 23.1 & 23.2 & W & $1,238.9$ & $w$ & $1,303.8$ \\
\hline 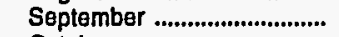 & 0.8 & 0.8 & 6.0 & $W$ & - & W & 21.7 & 21.7 & $w$ & $1,101.3$ & w & $1,157.4$ \\
\hline 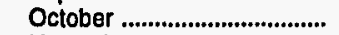 & $w$ & $W$ & $w$ & 67.0 & - & $w$ & 23.1 & 23.2 & 55.0 & $W$ & $w$ & $1,138.0$ \\
\hline 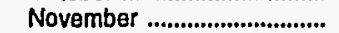 & 1.1 & $w$ & 6.2 & $W$ & - & $W$ & 22.9 & 22.9 & $W$ & $1,025.4$ & w & $1,076.1$ \\
\hline 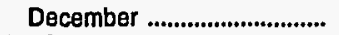 & 1.1 & W & 6.2 & W & - & $w$ & 23.1 & 23.3 & W & $1,030.5$ & $w$ & $1,081.3$ \\
\hline 1994 Average .......................... & 1.0 & 1.4 & 6.5 & 73.6 & - & 80.1 & 22.5 & 24.8 & 51.2 & $1,055.9$ & w & $1,109.2$ \\
\hline \multicolumn{13}{|l|}{ Tennessee } \\
\hline 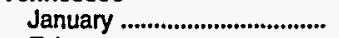 & 290.0 & 293.6 & 181.6 & $1,441.0$ & - & $1,622.6$ & $1,288.3$ & $1,311.3$ & 622.5 & $5,811.6$ & - & $6,434.2$ \\
\hline February .................................. & 302.8 & 307.4 & $W$ & $W$ & - & $1,765.7$ & $1,308.9$ & $1,344.5$ & $W$ & $6,626.9$ & $w$ & $7,369.3$ \\
\hline 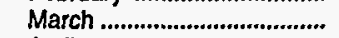 & 310.1 & 315.6 & w & W & - & $1,846.8$ & $1,352.8$ & $1,385.7$ & $w$ & $6,857.2$ & w & $7,665.7$ \\
\hline 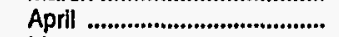 & 312.1 & 316.8 & $\ddot{w}$ & W & - & $1,864.9$ & $1,382.6$ & $1,412.7$ & $\ddot{w}$ & $6,999.8$ & $w$ & $7,839.3$ \\
\hline 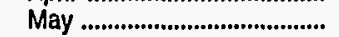 & 315.0 & 322.0 & W & W & - & $1,861.6$ & $1,360.5$ & $1,395.9$ & $\ddot{W}$ & $7,058.4$ & W & $7,842.8$ \\
\hline June & 311.3 & 317.5 & W & $W$ & - & $1,969.1$ & $1,394.9$ & $1,432.4$ & $w$ & $7,399.6$ & $w$ & $8,234.3$ \\
\hline 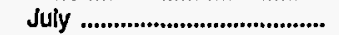 & 295.5 & 301.1 & $W$ & W & - & $1,893.4$ & $1,366.3$ & $1,395.8$ & $w$ & $7,148.3$ & w & $7,982.7$ \\
\hline 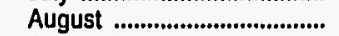 & 274.5 & 283.5 & $w$ & W & - & $1,913.2$ & $1,326.3$ & $1,375.9$ & $\ddot{w}$ & $7,455.9$ & $\ddot{w}$ & $8,319.7$ \\
\hline September .............................. & 280.4 & 288.4 & w & W & - & $1,851.2$ & $1,319.9$ & $1,363.5$ & $W$ & $7,245.2$ & $w$ & $8,050.7$ \\
\hline 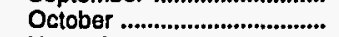 & 281.5 & 291.9 & W & $\ddot{W}$ & - & $1,801.3$ & $1,310.5$ & $1,358.2$ & w & $6,911.3$ & $w$ & $7,694.5$ \\
\hline November .................................. & 285.3 & 293.7 & W & W & - & $1,842.6$ & $1,352.1$ & $1,396.8$ & $w$ & $7,007.7$ & $w$ & $7,835.3$ \\
\hline December .............................. & 313.3 & 324.4 & $w$ & W & - & $1,911.5$ & $1,417.7$ & $1,465.7$ & $w$ & $7,163.8$ & $\ddot{w}$ & $7,979.1$ \\
\hline 1994 Average ............................ & 297.6 & 304.6 & 188.3 & $1,657.3$ & . & $1,845.6$ & $1,348.6$ & $1,386.7$ & 679.5 & $6,974.6$ & w & $7,771.5$ \\
\hline \multicolumn{13}{|l|}{ Wisconsin } \\
\hline 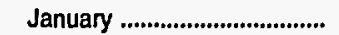 & 121.3 & 122.1 & 142.2 & 693.5 & $\rightarrow$ & 835.6 & 792.3 & 802.0 & 680.4 & $4,009.9$ & - & $4,690.3$ \\
\hline 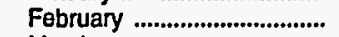 & 105.4 & 106.1 & 132.7 & 623.6 & - & 756.3 & 801.1 & 813.9 & 687.2 & $4,115.1$ & - & $4,802.3$ \\
\hline 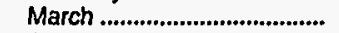 & 101.1 & 102.4 & 120.3 & 547.9 & - & 668.2 & 791.2 & 804.3 & 667.1 & $4,156.2$ & - & $4,823.3$ \\
\hline April & 102.8 & 103.8 & 120.6 & 557.1 & - & 677.7 & 809.1 & 820.6 & 665.5 & $4,216.0$ & - & $4,881.5$ \\
\hline 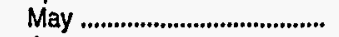 & 104.1 & 105.2 & 125.8 & 610.7 & - & 736.5 & 830.2 & 842.8 & $W$ & $4,539.5$ & $w$ & $5,248.4$ \\
\hline 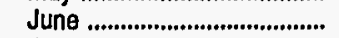 & 107.3 & 108.6 & 129.1 & 694.8 & - & 823.8 & 857.6 & 871.6 & W & $4,864.2$ & $\dddot{W}$ & $5,593.7$ \\
\hline July & 103.7 & 105.0 & 127.8 & 688.0 & - & 815.8 & 857.1 & 868.5 & 713.0 & $4,953.6$ & - & $5,666.6$ \\
\hline 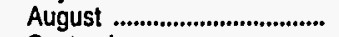 & 89.4 & 90.2 & 117.0 & 614.5 & - & 731.5 & 851.1 & 861.7 & 694.4 & $4,832.6$ & - & $5,527.0$ \\
\hline 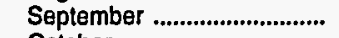 & 89.5 & 89.9 & 113.9 & 607.3 & - & 721.3 & 806.3 & 816.0 & 666.5 & $4,874.2$ & - & $5,540.7$ \\
\hline 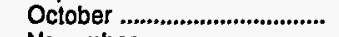 & 104.1 & 105.4 & 115.5 & 574.5 & - & 690.0 & 810.1 & 820.7 & 668.9 & $4,542.0$ & - & $5,210.9$ \\
\hline November ............................... & 95.0 & 95.4 & 116.5 & 607.7 & - & 724.2 & 798.6 & 807.6 & 669.6 & $4,519.5$ & - & $5,189.1$ \\
\hline December & 110.5 & 113.8 & 122.8 & 666.0 & - & 788.8 & 821.4 & 829.7 & 699.5 & $4,701.2$ & - & $5,400.7$ \\
\hline 1994 Average & 102.9 & 104.0 & 123.7 & 623.9 & - & 747.5 & 819.0 & 830.1 & 684.1 & $4,529.4$ & $w$ & $5,217.0$ \\
\hline \multicolumn{13}{|l|}{ PAD District III } \\
\hline January ................................. & $1,548.5$ & $1,602.5$ & $1,192.6$ & $6,064.2$ & $1,734.5$ & $8,991.3$ & $7,191.6$ & $7,497.7$ & $4,085.9$ & $35,032.7$ & $13,939.9$ & $53,058.5$ \\
\hline 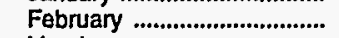 & $1,637.3$ & $1,696.2$ & $1,251.6$ & $6,356.2$ & $1,484.0$ & $9,091.8$ & $7,690.0$ & $8,034.6$ & $4,435.2$ & $35,165.9$ & $9,824.3$ & $49,425.4$ \\
\hline 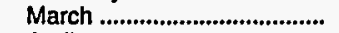 & $1,730.0$ & 1.792 .3 & $1,269.0$ & $6,669.8$ & $1,010.7$ & $8,949.6$ & $8,191.3$ & $8,563.5$ & $4,498.2$ & $36,117.8$ & $9,969.4$ & $50,585.5$ \\
\hline April & $1,659.5$ & $1,719.5$ & $1,258.6$ & $6,497.1$ & 724.6 & $8,480.2$ & $7,743.8$ & $8,082.3$ & $4,533.0$ & $36,786.4$ & $11,685.6$ & $53,004.9$ \\
\hline 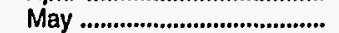 & $1,706.5$ & $1,763.0$ & $1,221.0$ & $6,882.1$ & $1,649.1$ & $9,752.3$ & $8,098.7$ & $8,415.1$ & $4,395.7$ & $36,518.4$ & $12,587.6$ & $53,501.7$ \\
\hline 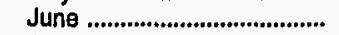 & $1,651.2$ & $1,707.4$ & $1,204.9$ & $W$ & W & $9,910.4$ & $7,846.0$ & $8,193.5$ & $4,394.4$ & $37,467.1$ & $12,639.5$ & $54,501.1$ \\
\hline 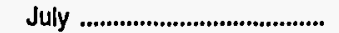 & $1,628.6$ & $1,680.6$ & $1,182.6$ & $6,679.1$ & $1,517.8$ & $9,379.5$ & $7,796.1$ & $8,093.1$ & $4,397.5$ & $36,935.0$ & $9,423.1$ & $50,755.6$ \\
\hline August & $1,633.1$ & $1,686.5$ & $W$ & $6,663.4$ & W & $9,223.3$ & $8,232.8$ & $8,531.0$ & $4,253.2$ & $37,444.6$ & $10,915.9$ & $52,613.7$ \\
\hline 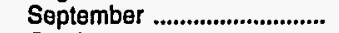 & 1.532 .2 & $1,587.8$ & $1,129.2$ & $6,680.4$ & $1,362.4$ & $9,172.0$ & $7,598.8$ & $7,909.0$ & $4,219.8$ & $36,814.6$ & $10,918.7$ & $51,953.1$ \\
\hline October & $1,545.3$ & $1,605.3$ & $1,106.5$ & $6,224.9$ & $1,390.2$ & $8,721.6$ & $7,468.9$ & $7,823.8$ & $4,092.9$ & $34,248.3$ & $11,546.1$ & $49,887.3$ \\
\hline 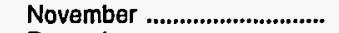 & $1,581.9$ & $1,664.2$ & $1,133.7$ & $6,706.3$ & $1,097.4$ & $8,937.4$ & $7,983.1$ & $8,331.5$ & $4,186.2$ & $35,714.5$ & $11,433.5$ & $51,334.2$ \\
\hline 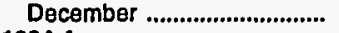 & 1.495 .2 & $1,553.6$ & $1,139.2$ & $6,570.0$ & $1,569.5$ & $9,278.7$ & $7,367.1$ & $7,695.9$ & $4,215.9$ & $35,744.5$ & $18,544.3$ & $58,504.7$ \\
\hline 1994 Average & $1,612.3$ & $1,671.4$ & $1,183.4$ & $6,587.0$ & $1,387.8$ & $9,158.2$ & $7,767.7$ & $8,097.8$ & $4,307.7$ & $36,168.3$ & $11,972.9$ & $52,448.8$ \\
\hline
\end{tabular}

See footnotes at end of table. 
Table 43. Refiner Motor Gasoline Volumes by Grade, Sales Type, PAD District, and State (Thousand Gallons per Day) - Continued

\begin{tabular}{|c|c|c|c|c|c|c|c|c|c|c|c|c|}
\hline \multirow{3}{*}{$\begin{array}{c}\text { Geographic Area } \\
\text { Month }\end{array}$} & \multicolumn{6}{|c|}{ Regular } & \multicolumn{6}{|c|}{ Midgrade } \\
\hline & \multicolumn{2}{|c|}{ Sales to End Users } & \multicolumn{4}{|c|}{ Sales for Resale } & \multicolumn{2}{|c|}{ Sales to End Users } & \multicolumn{4}{|c|}{ Sales for Resale } \\
\hline & $\begin{array}{c}\text { Through } \\
\text { Retail } \\
\text { Outlets }\end{array}$ & Totala & DTW & Rack & Bulk & Total & $\begin{array}{c}\text { Through } \\
\text { Retail } \\
\text { Outlets }\end{array}$ & Totala & DTW & Rack & Bulk & Total \\
\hline \multicolumn{13}{|l|}{ Alabama } \\
\hline 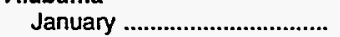 & 215.3 & 233.8 & 152.4 & $2,761.8$ & - & $2,914.2$ & 78.2 & 87.5 & 62.8 & 551.9 & - & 614.7 \\
\hline 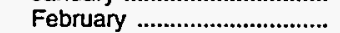 & 233.3 & 254.0 & W & $2,872.6$ & $w$ & $3,079.8$ & 84.3 & 92.5 & $W$ & $w$ & - & 675.4 \\
\hline 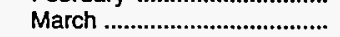 & 231.4 & 256.1 & $w$ & $2,985.8$ & $w$ & $3,221.5$ & 85.8 & 94.0 & $w$ & 634.8 & $\bar{w}$ & 700.1 \\
\hline April & 236.9 & 256.8 & W & $2,996.6$ & w & $3,230.0$ & 88.7 & 96.5 & W & W & - & 700.8 \\
\hline 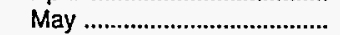 & 235.3 & 257.7 & 128.7 & $W$ & $w$ & $3,211.5$ & 87.3 & 96.1 & 54.4 & $w$ & $w$ & 718.4 \\
\hline June & 235.1 & 258.3 & W & $3,059.8$ & W & $3,337.6$ & 87.6 & 97.3 & 53.1 & 681.3 & - & 734.4 \\
\hline 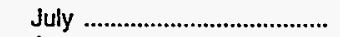 & 233.1 & 254.1 & 113.9 & W & w & $3,155.9$ & 86.9 & 94.6 & 49.1 & 653.3 & - & 702.4 \\
\hline 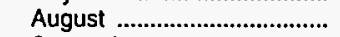 & 226.2 & 252.1 & $W$ & $3,212.8$ & W & $3,398.0$ & 82.0 & 92.1 & $W$ & $W$ & - & 734.4 \\
\hline September .............................. & 229.8 & 255.1 & $w$ & $3,175.3$ & w & $3,326.2$ & 83.9 & 95.2 & $w$ & $w$ & - & 725.3 \\
\hline October & 224.4 & 244.0 & $w$ & $2,966.3$ & W & $3,136.6$ & 83.0 & 92.5 & $w$ & $w$ & - & 700.4 \\
\hline November ................................. & 224.6 & 246.7 & 85.0 & W & $\ddot{w}$ & $3,224.2$ & 84.0 & 92.5 & 40.0 & 654.4 & - & 694.5 \\
\hline 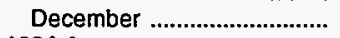 & 219.3 & 238.8 & $W$ & $3,062.9$ & $w$ & $3,239.9$ & 85.0 & 94.8 & $W$ & W & - & 709.4 \\
\hline 1994 Average ............................. & 228.7 & 250.6 & 117.8 & $3,010.5$ & $w$ & $3,206.5$ & 84.7 & 93.8 & 51.5 & 649.1 & $w$ & 700.9 \\
\hline \multicolumn{13}{|l|}{ Arkansas } \\
\hline 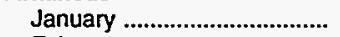 & 198.9 & 202.7 & 20.7 & $2,875.5$ & W & $2,896.5$ & 52.5 & 52.5 & 7.9 & 282.5 & - & 290.4 \\
\hline 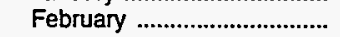 & 203.7 & 208.8 & 20.9 & $2,721.0$ & - & $2,741.9$ & 55.6 & 55.6 & 7.3 & 310.7 & - & 318.0 \\
\hline March & 212.0 & 216.2 & $W$ & $2,733.8$ & W & $2,772.6$ & 59.5 & 59.8 & $\ddot{w}$ & $W$ & - & 344.4 \\
\hline April & 215.5 & 221.3 & $\mathrm{~W}$ & $2,789.9$ & $w$ & $2,832.9$ & 58.3 & 58.6 & $w$ & $w$ & - & 345.1 \\
\hline 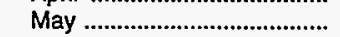 & 219.6 & 223.7 & $w$ & $2,752.8$ & $\mathrm{~W}$ & $2,809.5$ & 61.5 & 61.9 & $w$ & $w$ & - & 360.7 \\
\hline June & 226.8 & 232.2 & $W$ & $2,863.2$ & $w$ & $2,905.8$ & 64.0 & 64.0 & $W$ & $W$ & - & 360.9 \\
\hline July & 235.6 & 242.1 & W & $W$ & - & $3,026.7$ & 64.8 & 64.8 & $w$ & $w$ & - & 362.8 \\
\hline August & 228.2 & 235.7 & $w$ & $w$ & - & $3,085.1$ & 61.8 & 61.8 & $W$ & $W$ & - & 352.7 \\
\hline 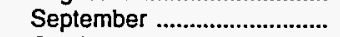 & 214.7 & 223.2 & w & $2,897.6$ & W & $2,969.4$ & 59.1 & 59.1 & $w$ & $w$ & - & 353.9 \\
\hline 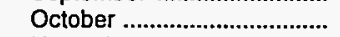 & 202.8 & 211.6 & W & $2,708.5$ & w & $2,813.0$ & 56.5 & 56.7 & $w$ & $W$ & - & 340.7 \\
\hline 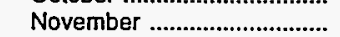 & 204.2 & 210.4 & $\ddot{w}$ & $2,701.0$ & W & $2,810.5$ & 57.1 & 57.1 & $w$ & $w$ & - & 355.5 \\
\hline 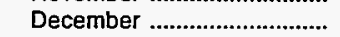 & 210.8 & 219.8 & $W$ & $2,990.7$ & w & $3,048.1$ & 59.5 & 59.5 & $w$ & $w$ & - & 360.8 \\
\hline 1994 Average & 214.5 & 220.7 & 23.0 & $2,842.7$ & 28.4 & $2,894.0$ & 59.2 & 59.3 & 8.4 & 337.3 & - & 345.6 \\
\hline \multicolumn{13}{|l|}{ Louisiana } \\
\hline 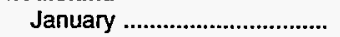 & 363.1 & 381.7 & 259.8 & $2,985.5$ & $2,275.2$ & $5,520.5$ & 145.1 & 150.7 & 122.8 & 502.7 & $w$ & 625.7 \\
\hline 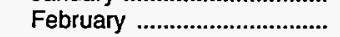 & 386.6 & 406.9 & 286.6 & $2,800.6$ & $1,103.9$ & $4,191.1$ & 155.0 & 162.3 & 131.1 & 525.7 & - & 656.8 \\
\hline March & 407.3 & 429.3 & $W$ & $2,735.7$ & W & $4,238.2$ & 160.4 & 167.3 & 133.6 & 556.3 & - & 690.0 \\
\hline 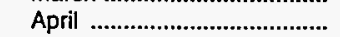 & 387.8 & 408.6 & $w$ & $2,621.0$ & $w$ & $3,891.2$ & 153.3 & 160.6 & 133.5 & 537.8 & - & 671.3 \\
\hline 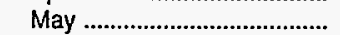 & 396.5 & 417.5 & 284.5 & $2,681.3$ & $1,309.4$ & $4,275.2$ & 160.5 & 167.2 & 129.7 & 556.6 & - & 686.3 \\
\hline June & 389.8 & 411.0 & 276.9 & $2,982.7$ & $1,717.6$ & $4,977.2$ & 159.3 & 166.6 & 125.7 & 561.2 & - & 686.9 \\
\hline 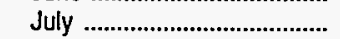 & 389.7 & 405.8 & $W$ & $2,733.8$ & W & $4,457.1$ & 160.4 & 166.1 & 122.0 & 543.7 & - & 665.7 \\
\hline August ................................... & 411.9 & 426.8 & 268.4 & $2,723.8$ & $1,522.8$ & $4,515.1$ & 165.2 & 169.5 & 120.5 & 557.5 & - & 677.9 \\
\hline 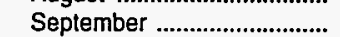 & 389.9 & 404.1 & $W$ & $2,626.5$ & W & $4,454.7$ & 159.0 & 163.0 & 126.0 & 579.5 & - & 705.4 \\
\hline 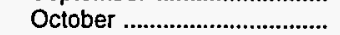 & 377.7 & 394.0 & 265.3 & $2,449.5$ & $1,560.5$ & $4,275.3$ & 154.1 & 158.4 & 118.5 & 566.4 & - & 684.9 \\
\hline November .............................. & 394.8 & 407.8 & $W$ & $2,519.3$ & W & $3,731.5$ & 161.2 & 164.6 & 122.7 & 564.7 & - & 687.4 \\
\hline December .............................. & 379.4 & 394.8 & $\mathbf{W}$ & $2,829.5$ & W & $4,823.3$ & 158.1 & 162.4 & 121.3 & 599.5 & - & 720.8 \\
\hline 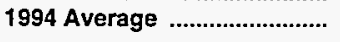 & 389.5 & 407.4 & 276.8 & $2,723.9$ & $1,449.3$ & $4,450.0$ & 157.6 & 163.2 & 125.6 & 554.5 & $w$ & 680.0 \\
\hline \multicolumn{13}{|l|}{ Mississippi } \\
\hline 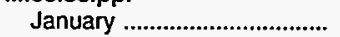 & 64.6 & 79.3 & 43.2 & $1,982.0$ & 677.5 & $2,702.6$ & 20.1 & 24.1 & 14.9 & 342.5 & - & 357.4 \\
\hline 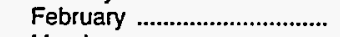 & 64.6 & 78.0 & W & $2,206.5$ & W & $2,353.7$ & $w$ & $w$ & 14.9 & 377.2 & - & 392.0 \\
\hline 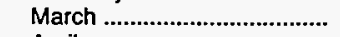 & 65.4 & 82.4 & W & $2,070.9$ & $w$ & $2,184.0$ & $w$ & w & $w$ & $W$ & - & 430.4 \\
\hline April & 67.4 & 86.5 & 26.9 & W & $w$ & $2,823.0$ & $w$ & w & 9.1 & 442.7 & - & 451.8 \\
\hline May & 68.2 & 84.5 & $W$ & $2,156.9$ & w & $3,854.2$ & W & $w$ & 7.7 & 448.7 & - & 456.5 \\
\hline June & 68.5 & 90.1 & 31.8 & $w$ & $W$ & $3,044.1$ & $w$ & $\ddot{w}$ & 9.9 & 465.8 & - & 475.7 \\
\hline 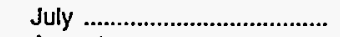 & 68.1 & 84.4 & 30.2 & $w$ & w & $2,670.5$ & $\ddot{W}$ & $\ddot{w}$ & $W$ & $W$ & - & 477.5 \\
\hline August & 73.1 & 89.9 & 17.0 & $w$ & w & $2,436.4$ & $\ddot{W}$ & $w$ & $w$ & $w$ & - & 477.9 \\
\hline September .................................... & 68.7 & 85.2 & 14.8 & $w$ & w & $2,786.5$ & $w$ & $w$ & 10.8 & 463.2 & - & 474.1 \\
\hline 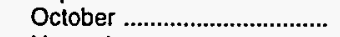 & 65.9 & 83.7 & 14.4 & w & W & $2,507.6$ & 20.4 & 24.5 & 5.5 & 445.0 & - & 450.6 \\
\hline 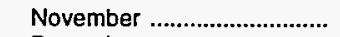 & 68.1 & 85.9 & 14.9 & $2,051.2$ & 583.0 & $2,649.2$ & 20.7 & 24.4 & 10.3 & 434.7 & - & 444.9 \\
\hline 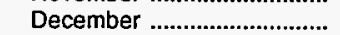 & 68.9 & 87.5 & 13.8 & $W$ & $W$ & $2,686.1$ & 21.6 & 25.7 & 9.5 & 460.5 & - & 470.0 \\
\hline 1994 Average & 67.7 & 84.8 & 25.6 & $2,131.8$ & 569.4 & $2,726.8$ & 21.4 & 25.2 & 10.0 & 436.8 & - & 446.8 \\
\hline
\end{tabular}

See footnotes at end of table. 
Table 43. Refiner Motor Gasoline Volumes by Grade, Sales Type, PAD District, and Siate (Thousand Gallons per Day) - Continued

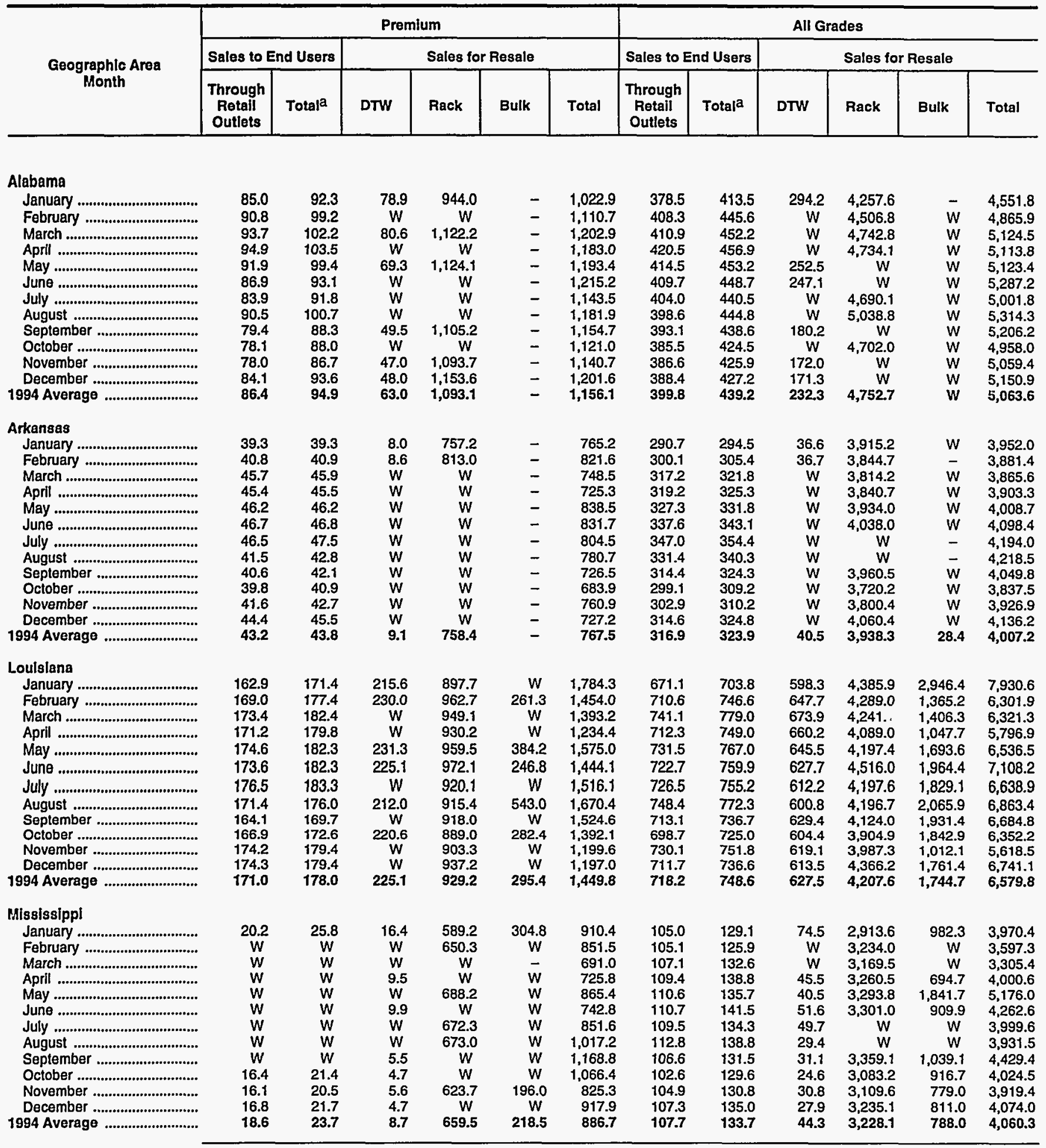

See footnotes at end of table. 
Table 43. Refiner Motor Gasoline Volumes by Grade, Sales Type, PAD District, and State (Thousand Gallons per Day) - Continued

\begin{tabular}{|c|c|c|c|c|c|c|c|c|c|c|c|c|}
\hline \multirow{3}{*}{$\begin{array}{l}\text { Geographic Area } \\
\text { Month }\end{array}$} & \multicolumn{6}{|c|}{ Regular } & \multicolumn{6}{|c|}{ Midgrade } \\
\hline & \multicolumn{2}{|c|}{ Sales to End Users } & \multicolumn{4}{|c|}{ Sales for Resale } & \multicolumn{2}{|c|}{ Sales to End Users } & \multicolumn{4}{|c|}{ Sales for Resale } \\
\hline & $\begin{array}{c}\text { Through } \\
\text { Rotail } \\
\text { Outlets } \\
\end{array}$ & Totaja & DTW & Rack & Bulk & Total & $\begin{array}{c}\text { Through } \\
\text { Retall } \\
\text { Outlots }\end{array}$ & Totaja & DTW & Rack & Bulk & Total \\
\hline \multicolumn{13}{|l|}{ New Mexico } \\
\hline January .... & 274.8 & 280.5 & 180.7 & $1,223.0$ & - & $1,403.7$ & $w$ & $w$ & 17.0 & 34.5 & - & 51.5 \\
\hline February ........... & 286.8 & 294.5 & $w$ & & - & $1,471.6$ & $w$ & $w$ & $w$ & $w$ & - & 49.8 \\
\hline March & 313.6 & 321.2 & 208.8 & $1,311.5$ & - & $1,520.3$ & $w$ & $\ddot{w}$ & $w$ & $w$ & - & 66.9 \\
\hline April & 269.9 & 276.7 & $w$ & $w$ & - & $1,483.4$ & w & $\ddot{w}$ & $w$ & $w$ & - & 64.8 \\
\hline May & 296.0 & 302.9 & w & w & - & $1,440.5$ & w & $w$ & $w$ & $w$ & - & 73.8 \\
\hline 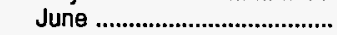 & 287.5 & 294.4 & $w$ & $w$ & - & $1,566.7$ & $w$ & $w$ & 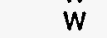 & $\ddot{w}$ & - & 74.8 \\
\hline July & 286.9 & 296.9 & W & w & - & $1,562.4$ & w & $w$ & W & w & - & 77.8 \\
\hline August ................. & 305.4 & 317.1 & w & $w$ & - & $1,562.0$ & $w$ & $w$ & $w$ & $\ddot{w}$ & - & 80.8 \\
\hline 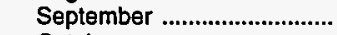 & 281.3 & 292.0 & $w$ & w & - & $1,470.1$ & $w$ & $w$ & $w$ & $\ddot{w}$ & - & 75.8 \\
\hline 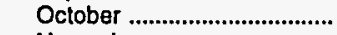 & 277.7 & 290.0 & $w$ & w & w & $1,685.0$ & 15.9 & 15.9 & W & $w$ & - & 72.3 \\
\hline November ............................... & 295.6 & 307.1 & w & w & - & $1,581.0$ & 15.0 & 15.0 & w & $w$ & - & 62.1 \\
\hline 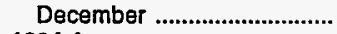 & 271.1 & 281.6 & w & $w$ & - & $1,665.2$ & 16.1 & 16.1 & w & w & - & 60.7 \\
\hline 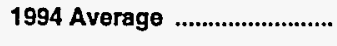 & 287.3 & 296.3 & 217.9 & $1,311.9$ & $w$ & $1,535.0$ & $w$ & $w$ & 18.7 & 49.0 & - & 67.7 \\
\hline \multicolumn{13}{|l|}{ Texas } \\
\hline 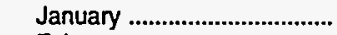 & $3,125.2$ & $3,276.7$ & $1,449.7$ & $13,552.6$ & $9,250.6$ & $24,252.9$ & $1,092.3$ & $1,112.9$ & 561.3 & $1,874.1$ & $w$ & $2,437.1$ \\
\hline 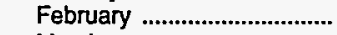 & $3,375.1$ & $3,553.5$ & $1,616.1$ & $13,104.4$ & $7,084.6$ & $21,805.1$ & $1,173.7$ & $1,195.8$ & $w$ & $1,978.6$ & $w$ & $2,598.3$ \\
\hline March & $3,624.6$ & $3,813.3$ & $1,644.4$ & $13,464.7$ & $7,557.9$ & $22,666.9$ & $1,266.6$ & $1,293.5$ & w & $2,151.4$ & $w$ & $2,800.7$ \\
\hline April & $3,359.1$ & $3,522.5$ & $1,697.5$ & $14,357.1$ & $9,202.5$ & $25,257.1$ & $1,211.7$ & $1,234.9$ & $w$ & $2,114.1$ & $\ddot{w}$ & $2,773.3$ \\
\hline 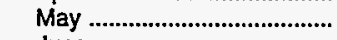 & $3,557.6$ & $3,705.0$ & $1,633.1$ & $13,572.5$ & $7,842.7$ & $23,048.4$ & $1,274.1$ & $1,296.0$ & $\dddot{w}$ & $2,150.5$ & $\dddot{w}$ & $2,814.5$ \\
\hline 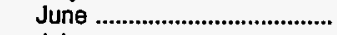 & $3,403.2$ & $3,571.1$ & $1,639.1$ & $13,690.7$ & $8,162.5$ & $23,492.2$ & $1,235.5$ & $1,260.3$ & W & $2,226.2$ & $w$ & $2,934,4$ \\
\hline 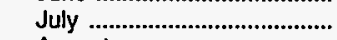 & $3,382.0$ & $3,519.1$ & $1,689.3$ & $13,715.6$ & $6,003.9$ & $21,408.8$ & $1,221.4$ & $1,242.3$ & 661.4 & $2,113.0$ & 34.2 & $2,808.6$ \\
\hline August & 3.719 .2 & $3,846.4$ & $1,656.5$ & $14,050.8$ & $7,581.6$ & $23,288.9$ & $1,289.1$ & $1,311.0$ & 642.1 & $W$ & $w$ & $2,781.1$ \\
\hline 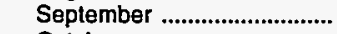 & $3,361.2$ & $3,496.6$ & $1,628.8$ & $13,715.3$ & $7,313.1$ & $22,657.2$ & $1,182.4$ & $1,207.1$ & 613.3 & $2,134.4$ & 34.8 & $2,782.5$ \\
\hline 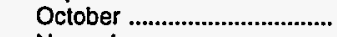 & $3,279.2$ & $3,454.7$ & $1,566.3$ & $12,444.3$ & $7,843.3$ & $21,853.8$ & $1,166.0$ & $1,192.5$ & $w$ & $1,994.2$ & $w$ & $2,645.5$ \\
\hline 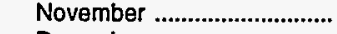 & $3,545.2$ & $3,700.0$ & $1,604.0$ & $13,007.7$ & $8,612.9$ & $23,224.6$ & $1,330.8$ & $1,355.8$ & w & $2,284.7$ & w & $2,931.3$ \\
\hline 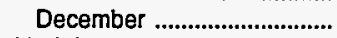 & $3,220.3$ & $3,374.1$ & $1,633.6$ & $12,591.0$ & $14,512.8$ & $28,737.5$ & $1,162.0$ & $1,187.0$ & 634.1 & $2,021.6$ & 48.5 & $2,704.2$ \\
\hline 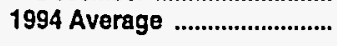 & $3,412.9$ & $3,569.5$ & $1,621.4$ & $13,438.9$ & $8,426.0$ & $23,486.2$ & $1,217.2$ & $1,240.9$ & 627.7 & $2,095.0$ & 28.4 & $2,751.1$ \\
\hline \multicolumn{13}{|l|}{ PAD District IV } \\
\hline 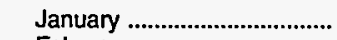 & $1,318.3$ & $1,348.9$ & 710.8 & $4,094.2$ & $w$ & $4,847.1$ & 376.5 & 377.1 & 164.7 & 195.5 & - & 360.1 \\
\hline February ................ & $1,393.0$ & 1.427 .2 & 739.4 & & $w$ & $4,967.9$ & 405.0 & 405.4 & $w$ & $w$ & - & 370.6 \\
\hline March & $1,430.3$ & $1,466.2$ & $w$ & $4,680.7$ & $\ddot{w}$ & $5,449.5$ & 413.3 & 413.3 & W & W & - & 360.6 \\
\hline April & $1,379.2$ & $1,423.0$ & 740.8 & W & $\ddot{w}$ & $5,552.6$ & 408.6 & 408.6 & $w$ & $w$ & - & 375.7 \\
\hline 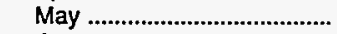 & $1,452.9$ & $1,483.5$ & 761.9 & w & $w$ & $5,756.0$ & 424.6 & 424.7 & $w$ & $w$ & - & 391.7 \\
\hline 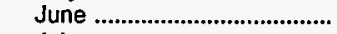 & $1,458.2$ & $1,490.8$ & 912.3 & w & $w$ & $6,393.5$ & 433.3 & 433.3 & $w$ & $w$ & - & 432.0 \\
\hline 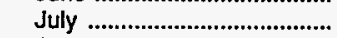 & $1,437.1$ & $1,467.6$ & 914.6 & w & $w$ & $6,397.5$ & 438.0 & 438.3 & $\ddot{w}$ & $\ddot{w}$ & - & 454.0 \\
\hline$\ldots$ & $1,501.9$ & $1,537.5$ & 884.9 & w & $w$ & $6,604.7$ & 445.0 & 445.0 & w & $w$ & - & 447.6 \\
\hline 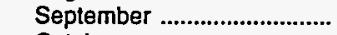 & $1,434.4$ & $1,467.6$ & 857.8 & w & $w$ & $5,840.2$ & 415.1 & 415.4 & $w$ & $w$ & - & 405.2 \\
\hline 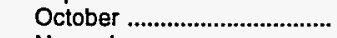 & $1,352.7$ & $1,389.0$ & 840.8 & $\ddot{w}$ & $\ddot{w}$ & $5,803.9$ & 413.5 & 413.8 & w & w & - & 417.8 \\
\hline November ........ & $1,397.3$ & $1,440.3$ & 804.6 & w & $w$ & $5,508.9$ & 446.7 & 447.4 & $w$ & $w$ & - & 419.7 \\
\hline 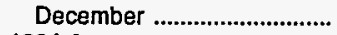 & $1,348.3$ & $1,382.7$ & 804.3 & w & w & $5,428.5$ & 438.9 & 441.2 & w & $\ddot{w}$ & - & 503.1 \\
\hline 1994 Average & $1,408.7$ & $1,443.7$ & 811.8 & ,893.1 & 12.5 & $5,717.4$ & 421.6 & 422.0 & 180.9 & 231.0 & - & 411.9 \\
\hline \multicolumn{13}{|l|}{ Colorado } \\
\hline 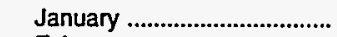 & $1,054.9$ & $1,063.2$ & 365.2 & $1,283.2$ & $w$ & $1,685.4$ & 301.5 & 301.5 & 111.7 & 123.1 & - & 234.8 \\
\hline February ........................................ & $1,129.0$ & $1,136.6$ & 379.8 & $1,359.4$ & - & $1,739.1$ & 326.6 & 326.6 & 118.2 & 121.4 & $\rightarrow$ & 239.6 \\
\hline 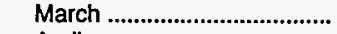 & $1,161.8$ & $1,168.7$ & 390.6 & $1,529.1$ & - & $1,919.7$ & 333.5 & 333.5 & 108.2 & 133.4 & - & 241.6 \\
\hline 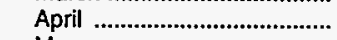 & $1,108.8$ & $1,114.6$ & 378.7 & $1,519.1$ & - & $1,897.8$ & 326.3 & 326.3 & 103.4 & 134.6 & - & 238.0 \\
\hline 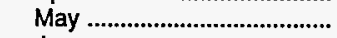 & 1.181 .5 & $1,187.4$ & 391.7 & $1,650.2$ & - & $2,041.9$ & 343.7 & 343.7 & 110.4 & 153.3 & - & 263.6 \\
\hline 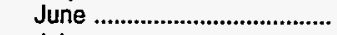 & $1,166.7$ & $1,172.0$ & 417.5 & $1,822.7$ & - & $2,240.2$ & 347.1 & 347.1 & 115.0 & 172.3 & - & 287.3 \\
\hline 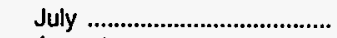 & $1,143.5$ & $1,149.4$ & 434.0 & $1,770.7$ & - & $2,204.7$ & 350.2 & 350.5 & 118.0 & 179.1 & - & 297.1 \\
\hline 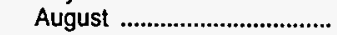 & $1,218.1$ & $1,224.5$ & 448.2 & w & $w$ & $2,304.5$ & 357.4 & 357.4 & 116.8 & 158.0 & - & 274.8 \\
\hline 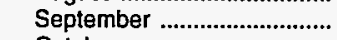 & $1,152.0$ & $1,157.4$ & 472.1 & $1,707.8$ & - & $2,179.8$ & 325.7 & 325.7 & 109.4 & 135.9 & - & 245.2 \\
\hline October & $1,086.5$ & $1,091.6$ & 446.8 & $1,756.0$ & - & $2,202.8$ & 328.7 & 328.7 & 108.5 & 137.9 & - & 246.4 \\
\hline 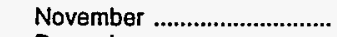 & $1,130.0$ & $1,136.9$ & 439.0 & $1,643.1$ & - & $2,082.1$ & 358.0 & 358.3 & 108.8 & 137.7 & - & 246.5 \\
\hline 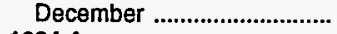 & $1,106.4$ & $1,115.2$ & 437.7 & $1,715.5$ & - & $2,153.2$ & 351.7 & 352.9 & 116.0 & 153.5 & - & 269.5 \\
\hline 1994 Average .............................. & $1,136.6$ & $1,143.2$ & 417.0 & $1,631.7$ & $\mathbf{w}$ & $2,056.4$ & 337.6 & 337.8 & 112.0 & 145.2 & - & 257.2 \\
\hline
\end{tabular}

See footnotes at end of table. 
Table 43. Refiner Motor Gasoline Volumes by Grade, Sales Type, PAD District, and State (Thousand Gallons per Day) - Continued

\begin{tabular}{|c|c|c|c|c|c|c|c|c|c|c|c|c|}
\hline \multirow{3}{*}{$\begin{array}{c}\text { Geographic Area } \\
\text { Month }\end{array}$} & \multicolumn{6}{|c|}{ Premlum } & \multicolumn{6}{|c|}{ All Grades } \\
\hline & \multicolumn{2}{|c|}{ Sales to End Users } & \multicolumn{4}{|c|}{ Sales for Resale } & \multicolumn{2}{|c|}{ Sales to End Users } & \multicolumn{4}{|c|}{ Sales for Resale } \\
\hline & $\begin{array}{c}\text { Through } \\
\text { Retall } \\
\text { Outlets }\end{array}$ & Totala & DTW & Rack & Bulk & Total & $\begin{array}{c}\text { Through } \\
\text { Retail } \\
\text { Outlets }\end{array}$ & Totala & DTW & Rack & Bulk & Total \\
\hline 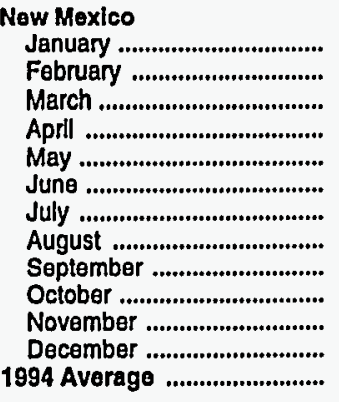 & $\begin{array}{l}34.0 \\
W \\
W \\
W \\
W \\
W \\
W \\
W \\
W \\
42.6 \\
44.8 \\
47.3 \\
42.6\end{array}$ & $\begin{array}{l}34.0 \\
W \\
W \\
W \\
W \\
W \\
W \\
W \\
W \\
45.2 \\
46.6 \\
48.8 \\
43.6\end{array}$ & $\begin{array}{c}20.0 \\
W \\
W \\
26.0 \\
W \\
W \\
29.6 \\
30.6 \\
W \\
28.4 \\
W \\
W \\
26.5\end{array}$ & $\begin{array}{c}153.7 \\
W \\
W \\
162.1 \\
W \\
W \\
210.8 \\
189.8 \\
W \\
195.2 \\
W \\
W \\
181.3\end{array}$ & $\begin{array}{l}- \\
- \\
- \\
- \\
- \\
- \\
- \\
- \\
- \\
-\end{array}$ & $\begin{array}{l}173.7 \\
199.8 \\
191.3 \\
188.1 \\
186.1 \\
222.4 \\
240.4 \\
220.4 \\
192.2 \\
223.6 \\
216.7 \\
237.7 \\
207.8\end{array}$ & $\begin{array}{l}321.7 \\
337.0 \\
367.3 \\
324.1 \\
353.4 \\
346.6 \\
349.1 \\
369.8 \\
338.3 \\
336.2 \\
355.4 \\
334.6 \\
344.6\end{array}$ & $\begin{array}{l}327.3 \\
344.7 \\
375.1 \\
330.9 \\
360.6 \\
353.7 \\
360.5 \\
383.9 \\
350.6 \\
351.1 \\
368.7 \\
346.5 \\
354.6\end{array}$ & $\begin{array}{c}217.7 \\
239.9 \\
251.3 \\
251.5 \\
W \\
W \\
W \\
W \\
W \\
W \\
W \\
W \\
263.1\end{array}$ & $\begin{array}{r}1,411.2 \\
1,481.4 \\
1,527.2 \\
1,484.9 \\
W \\
W \\
W \\
W \\
W \\
1,636.5 \\
W \\
W \\
1,542.2\end{array}$ & $\begin{array}{l}\overline{-} \\
- \\
- \\
\overline{-} \\
- \\
- \\
\bar{w} \\
- \\
\bar{w}\end{array}$ & $\begin{array}{l}1,628.9 \\
1,721.3 \\
1,778.4 \\
1,736.3 \\
1,700.4 \\
1,863.9 \\
1,880.6 \\
1,863.2 \\
1,738.2 \\
1,980.9 \\
1,859.8 \\
1,963.7 \\
1,810.5\end{array}$ \\
\hline 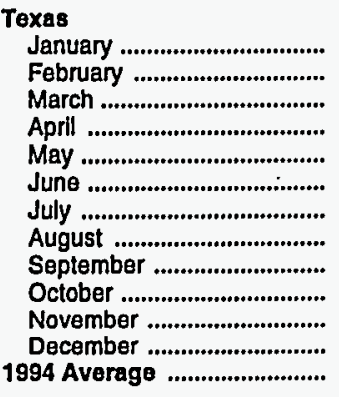 & $\begin{array}{l}1,207.1 \\
1,280.0 \\
1,356.6 \\
1,287.4 \\
1,329.6 \\
1,279.9 \\
1,256.5 \\
1,263.4 \\
1,189.7 \\
1,201.5 \\
1,227.2 \\
1,128.3 \\
1,250.4\end{array}$ & $\begin{array}{l}1,239.8 \\
1,317.1 \\
1,395.8 \\
1,324.0 \\
1,365.7 \\
1,315.4 \\
1,286.7 \\
1,293.4 \\
1,223.6 \\
1,237.3 \\
1,288.4 \\
1,164.7 \\
1,287.4\end{array}$ & $\begin{array}{r}853.7 \\
W \\
W \\
W \\
W \\
W \\
850.7 \\
812.5 \\
811.6 \\
W \\
W \\
823.7 \\
850.9\end{array}$ & $\begin{array}{r}2,722.4 \\
2,726.9 \\
3,007.1 \\
2,906.2 \\
3,121.8 \\
3,209.3 \\
3,003.7 \\
W \\
3,103.6 \\
2,763.1 \\
3,143.7 \\
2,891.4 \\
2,965.6\end{array}$ & $\begin{array}{r}758.6 \\
W \\
W \\
W \\
W \\
W \\
969.0 \\
W \\
489.9 \\
W \\
W \\
1,282.1 \\
873.9\end{array}$ & $\begin{array}{l}4,334.7 \\
4,654.3 \\
4,722.7 \\
4,423.7 \\
5,093.9 \\
5,454.2 \\
4,823.3 \\
4,352.8 \\
4,405.1 \\
4,234.7 \\
4,794.2 \\
4,997.3 \\
4,690.3\end{array}$ & $\begin{array}{l}5,424.6 \\
5,828.8 \\
6,247.8 \\
5,858.3 \\
6,161.4 \\
5,918.7 \\
5,859.9 \\
6,271.7 \\
5,733.3 \\
5,646.8 \\
6,103.2 \\
5,510.5 \\
5,880.6\end{array}$ & $\begin{array}{l}5,629.4 \\
6,066.4 \\
6,502.6 \\
6,081.4 \\
6,366.7 \\
6,146.7 \\
6,048.2 \\
6,450.9 \\
5,927.3 \\
5,884.5 \\
6,344.2 \\
5,725.8 \\
6,097.8\end{array}$ & $\begin{array}{l}2,864.7 \\
3,126.5 \\
3,183.5 \\
3,234.9 \\
3,154.3 \\
3,159.0 \\
3,201.4 \\
3,111.1 \\
3,053.7 \\
2,977.1 \\
3,048.1 \\
3,091.5 \\
3,100.0\end{array}$ & $\begin{array}{l}18,149.1 \\
17,810.0 \\
18,623.1 \\
19,377.3 \\
18,844.9 \\
19,126.2 \\
18,832.2 \\
19,129.2 \\
18,953.3 \\
17,201.6 \\
18,436.1 \\
17,504.1 \\
18,499.4\end{array}$ & $\begin{array}{r}10,010.9 \\
8,121.2 \\
8,383.7 \\
9,841.8 \\
8,957.5 \\
9,595.6 \\
7,007.1 \\
8,182.5 \\
7,837.8 \\
8,555.5 \\
9,465.9 \\
15,843.4 \\
9,328.2\end{array}$ & $\begin{array}{l}31,024.7 \\
29,057.6 \\
30,190.3 \\
32,454.0 \\
30,956.7 \\
31,880.8 \\
29,040.7 \\
30,422.8 \\
29,844.8 \\
28,734.1 \\
30,950.2 \\
36,438.9 \\
30,927.6\end{array}$ \\
\hline 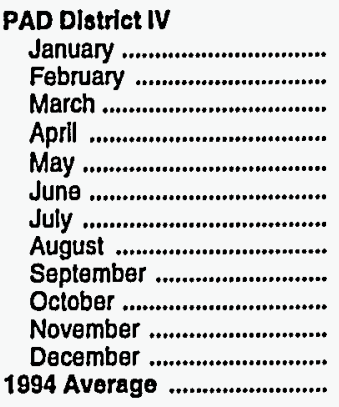 & $\begin{array}{l}347.1 \\
356.5 \\
368.8 \\
364.4 \\
369.8 \\
374.7 \\
371.9 \\
351.1 \\
328.4 \\
332.1 \\
347.9 \\
349.0 \\
355.1\end{array}$ & $\begin{array}{l}355.9 \\
367.1 \\
377.4 \\
373.7 \\
378.3 \\
384.3 \\
380.2 \\
360.5 \\
339.0 \\
341.7 \\
357.6 \\
357.7 \\
364.4\end{array}$ & $\begin{array}{c}211.5 \\
221.0 \\
232.8 \\
227.7 \\
237.9 \\
247.3 \\
253.7 \\
W \\
232.4 \\
231.5 \\
234.8 \\
245.5 \\
235.0\end{array}$ & $\begin{array}{r}847.2 \\
872.5 \\
W \\
1,021.8 \\
1,066.5 \\
1,189.9 \\
1,208.6 \\
1,250.2 \\
1,013.9 \\
1,027.4 \\
1,014.1 \\
1,041.5 \\
1,047.5\end{array}$ & $\begin{array}{l}- \\
\bar{w} \\
- \\
- \\
- \\
\bar{w} \\
- \\
- \\
- \\
\bar{w}\end{array}$ & $\begin{array}{l}1,058.7 \\
1,093.4 \\
1,234.4 \\
1,249.4 \\
1,304.5 \\
1,437.2 \\
1,462.4 \\
1,493.2 \\
1,246.3 \\
1,258.8 \\
1,248.9 \\
1,287.0 \\
1,282.6\end{array}$ & $\begin{array}{l}2,041.8 \\
2,154.5 \\
2,212.4 \\
2,152.2 \\
2,247.3 \\
2,266.2 \\
2,247.0 \\
2,298.1 \\
2,177.9 \\
2,098.2 \\
2,191.9 \\
2,136.2 \\
2,185.4\end{array}$ & $\begin{array}{l}2,081.8 \\
2,199.7 \\
2,257.0 \\
2,205.3 \\
2,286.6 \\
2,308.3 \\
2,286.1 \\
2,343.0 \\
2,221.9 \\
2,144.4 \\
2,245.3 \\
2,181.7 \\
2,230.2\end{array}$ & $\begin{array}{r}1,086.9 \\
W \\
W \\
W \\
W \\
W \\
W \\
W \\
W \\
W \\
W \\
W \\
1,227.7\end{array}$ & $\begin{array}{l}5,136.9 \\
5,291.6 \\
5,878.5 \\
6,043.8 \\
6,276.0 \\
6,912.4 \\
6,943.6 \\
7,159.7 \\
6,209.1 \\
6,224.7 \\
5,949.6 \\
5,962.0 \\
6,171.6\end{array}$ & $\begin{array}{c}W \\
W \\
W \\
W \\
W \\
W \\
W \\
W \\
W \\
W \\
W \\
W \\
12.6\end{array}$ & $\begin{array}{l}6,265.9 \\
6,431.9 \\
7,044.5 \\
7,177.7 \\
7,452.2 \\
8,262.7 \\
8,313.9 \\
8,545.5 \\
7,491.8 \\
7,480.5 \\
7,177.5 \\
7,218.6 \\
7,411.9\end{array}$ \\
\hline 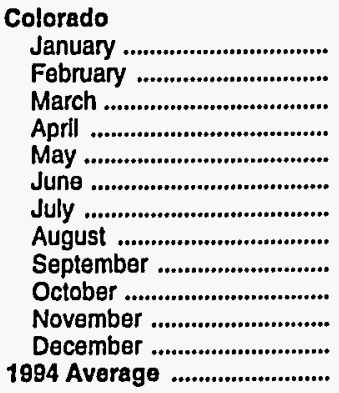 & $\begin{array}{l}229.0 \\
240.2 \\
252.5 \\
247.4 \\
260.0 \\
263.8 \\
258.5 \\
243.4 \\
223.0 \\
230.1 \\
239.9 \\
243.8 \\
244.3\end{array}$ & $\begin{array}{l}229.2 \\
240.9 \\
252.7 \\
248.0 \\
260.3 \\
264.6 \\
259.1 \\
244.0 \\
223.6 \\
230.3 \\
240.4 \\
244.2 \\
244.8\end{array}$ & $\begin{array}{r}95.2 \\
97.0 \\
104.4 \\
91.0 \\
101.5 \\
104.7 \\
108.0 \\
W \\
100.7 \\
96.6 \\
99.0 \\
104.2 \\
99.9\end{array}$ & $\begin{array}{l}228.0 \\
240.6 \\
284.7 \\
283.5 \\
304.2 \\
354.9 \\
354.8 \\
W \\
287.1 \\
317.2 \\
288.7 \\
317.6 \\
300.1\end{array}$ & $\begin{array}{l}- \\
- \\
- \\
- \\
- \\
- \\
- \\
- \\
- \\
- \\
-\end{array}$ & $\begin{array}{l}323.1 \\
337.6 \\
389.2 \\
374.5 \\
405.7 \\
459.6 \\
462.8 \\
430.4 \\
387.8 \\
413.8 \\
387.7 \\
421.7 \\
400.0\end{array}$ & $\begin{array}{l}1,585.4 \\
1,695.8 \\
1,747.7 \\
1,682.5 \\
1,785.2 \\
1,777.7 \\
1,752.3 \\
1,818.9 \\
1,700.7 \\
1,645.3 \\
1,727.9 \\
1,701.9 \\
1,718.6\end{array}$ & $\begin{array}{l}1,593.9 \\
1,704.2 \\
1,754.9 \\
1,688.9 \\
1,791.5 \\
1,783.7 \\
1,759.0 \\
1,825.8 \\
1,706.8 \\
1,650.6 \\
1,735.7 \\
1,712.3 \\
1,725.7\end{array}$ & $\begin{array}{c}572.1 \\
594.9 \\
603.2 \\
573.1 \\
603.6 \\
637.2 \\
659.9 \\
W \\
682.2 \\
652.0 \\
646.8 \\
657.9 \\
628.8\end{array}$ & $\begin{array}{l}1,634.3 \\
1,721.4 \\
1,947.2 \\
1,937.2 \\
2,107.6 \\
2,349.9 \\
2,304.6 \\
2,294.8 \\
2,130.7 \\
2,211.1 \\
2,069.4 \\
2,186.6 \\
2,077.0\end{array}$ & $\begin{array}{l}W \\
- \\
- \\
- \\
- \\
- \\
\bar{w} \\
- \\
- \\
- \\
\bar{w}\end{array}$ & $\begin{array}{l}2,243.4 \\
2,316.4 \\
2,550.4 \\
2,510.3 \\
2,711.2 \\
2,987.1 \\
2,964.6 \\
3,009.7 \\
2,812.9 \\
2,863.1 \\
2,716.2 \\
2,844.5 \\
2,713.5\end{array}$ \\
\hline
\end{tabular}

See footnotes at end of table. 
Table 43. Refiner Motor Gasoline Volumes by Grade, Sales Type, PAD District, and State (Thousand Gallons per Day) - Continued

\begin{tabular}{|c|c|c|c|c|c|c|c|c|c|c|c|c|}
\hline \multirow{3}{*}{$\begin{array}{l}\text { Geographic Area } \\
\text { Month }\end{array}$} & \multicolumn{6}{|c|}{ Regular } & \multicolumn{6}{|c|}{ Midgrade } \\
\hline & \multicolumn{2}{|c|}{ Sales to End Users } & \multicolumn{4}{|c|}{ Sales for Resale } & \multicolumn{2}{|c|}{ Sales to End Users } & \multicolumn{4}{|c|}{ Sales for Resale } \\
\hline & $\begin{array}{c}\text { Through } \\
\text { Retail } \\
\text { Outlets } \\
\end{array}$ & Totala & DTW & Rack & Bulk & Total & $\begin{array}{c}\text { Through } \\
\text { Rotail } \\
\text { Outlets } \\
\end{array}$ & Totala & DTW & Rack & Bulk & Total \\
\hline \multicolumn{13}{|l|}{ Guen } \\
\hline$\ldots$ & $w$ & 7.8 & 115.8 & 687.2 & - & 803.1 & 0.0 & W & - & w & - & w \\
\hline Fig dary . ……………........ & $w$ & 9.3 & 110.1 & 694.9 & - & 805.0 & - & $\ddot{w}$ & $w$ & $w$ & _- & w \\
\hline $\mathrm{P}^{4} \mathrm{r}^{4} \mathrm{Y}$ & $w$ & $w$ & 134.8 & 767.9 & - & 902.7 & - & - & $\ddot{w}$ & $\ddot{w}$ & - & $\ddot{w}$ \\
\hline ................................ & w & w & $w$ & w & - & 944.2 & - & - & $w$ & $\ddot{w}$ & - & $w$ \\
\hline 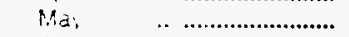 & $w$ & 10.0 & 137.1 & 853.1 & - & 990.2 & - & - & $w$ & 8.3 & - & $w$ \\
\hline$\ldots$ & w & 11.1 & w & w & - & $1,017.8$ & - & - & $w$ & $w$ & - & w \\
\hline$\ldots$ & w & w & w & w & - & $1,042.4$ & - & - & w & $w$ & - & $w$ \\
\hline Aitnust ... & w & 11.4 & w & w & - & $1,073.9$ & - & - & $w$ & $w$ & - & w \\
\hline 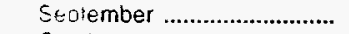 & w & 9.7 & w & w & - & 936.2 & w & w & $w$ & $w$ & - & $\ddot{w}$ \\
\hline 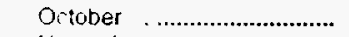 & $w$ & 9.2 & 137.4 & 789.6 & - & 927.0 & $w$ & w & w & 19.8 & - & w \\
\hline 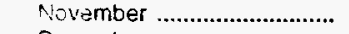 & $w$ & w & 122.2 & 743.4 & - & 865.7 & $w$ & w & w & 19.3 & - & $w$ \\
\hline 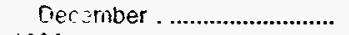 & w & w & 114.2 & 673.7 & - & 787.9 & $w$ & $w$ & $w$ & $w$ & - & 65.8 \\
\hline 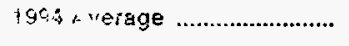 & $w$ & 9.6 & 127.7 & 797.8 & - & 925.5 & $\mathbf{w}$ & w & 1.3 & 20.9 & - & 22.2 \\
\hline \multicolumn{13}{|l|}{1.00 utia } \\
\hline 1, rary & $w$ & 10.3 & w & 724.8 & w & 725.7 & 0.0 & - & - & - & - & - \\
\hline$\because \therefore$ vary & w & $w$ & $w$ & 780.9 & w & 781.9 & - & - & - & - & - & - \\
\hline 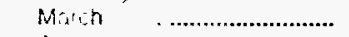 & w & w & $w$ & 850.4 & $w$ & 852.1 & - & - & - & - & - & - \\
\hline ………………........ & $w$ & w & w & w & $w$ & $w$ & - & - & - & - & - & - \\
\hline$\ldots \ldots \ldots$ & w & W & w & w & - & $w$ & $w$ & w & - & - & - & - \\
\hline ............................. & w & w & $w$ & w & - & $1,125.4$ & $w$ & W & - & - & - & - \\
\hline 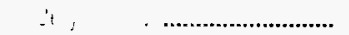 & w & w & $w$ & $1,078.0$ & $w$ & $1,082.3$ & $w$ & w & - & - & - & - \\
\hline A, st & $w$ & w & w & w & w & $1,165.4$ & w & W & - & - & - & - \\
\hline 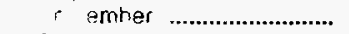 & w & w & $w$ & 981.9 & W & 984.4 & $w$ & $\ddot{w}$ & - & - & - & - \\
\hline 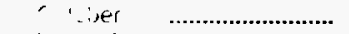 & w & w & w & 995.7 & $w$ & 997.0 & $w$ & w & - & - & - & - \\
\hline$\therefore$ :ember & $w$ & w & w & W & w & 922.4 & $w$ & w & - & - & - & - \\
\hline 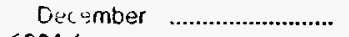 & w & w & $w$ & 850.2 & w & 855.2 & $\mathbf{w}$ & w & - & w & - & w \\
\hline 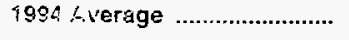 & w & 12.2 & w & 937.7 & $\mathbf{W}$ & 939.9 & $\mathbf{w}$ & w & - & w & - & $\dddot{w}$ \\
\hline \multicolumn{13}{|l|}{ U } \\
\hline$\ldots \ldots \ldots \ldots \ldots \ldots$ & 206.8 & 221.1 & 223.2 & 969.5 & $w$ & $1,197.0$ & 71.9 & 71.9 & 52.7 & 53.7 & - & 106.4 \\
\hline Féuary . . ................... & 205.8 & 223.1 & w & 975.1 & w & $1,221.8$ & $w$ & 75.4 & 57.0 & 52.9 & - & 109.9 \\
\hline . $\quad$ ……….............. & 206.2 & 226.5 & 231.2 & $w$ & w & $1,290.8$ & $w$ & $w$ & $w$ & $w$ & - & 103.1 \\
\hline . . . . . . & 205.9 & 234.8 & 226.8 & w & W & $1,391.9$ & $\dddot{w}$ & $w$ & $w$ & $\ddot{w}$ & - & 118.2 \\
\hline ……………............. & 203.4 & 218.2 & w & $1,081.9$ & W & $1,301.6$ & 77.2 & 77.3 & $w$ & $w$ & - & 118.8 \\
\hline . & 216.2 & 233.2 & $w$ & $1,107.5$ & w & $1,436.5$ & 82.2 & 82.2 & $w$ & $\ddot{w}$ & - & 131.6 \\
\hline 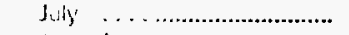 & 212.3 & 227.7 & 298.4 & w & w & 1.426 .7 & 83.5 & 83.5 & $w$ & $w$ & - & 139.1 \\
\hline 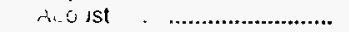 & 207.3 & 227.5 & $w$ & $1,187.7$ & w & $1,459.0$ & 83.3 & 83.3 & $\ddot{w}$ & $\ddot{w}$ & - & 146.6 \\
\hline 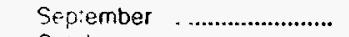 & 211.6 & 231.0 & 243.3 & $w$ & w & $1,248.3$ & 85.3 & 85.3 & w & $w$ & - & 136.6 \\
\hline Criver & 200.3 & 217.9 & 242.0 & w & w & $1,153.6$ & 81.0 & 81.1 & $w$ & $w$ & - & 148.1 \\
\hline Asinber ......................... & 207.8 & 232.8 & 233.4 & w & w & $1,172.2$ & 84.8 & 85.1 & $\ddot{w}$ & $w$ & - & 150.4 \\
\hline O. vamber ............................ & 183.4 & 200.3 & 243.0 & 915.7 & - & $1,158.7$ & 82.2 & 83.3 & 74.3 & 91.8 & _- & 166.1 \\
\hline 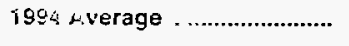 & 205.5 & 224.4 & 250.0 & $1,036.5$ & $w$ & $1,288.5$ & 80.2 & 80.3 & 67.4 & 64.0 & - & 131.4 \\
\hline \multicolumn{13}{|l|}{ Hye. ung } \\
\hline Januany .............................. & 43.0 & 46.5 & w & 429.5 & - & 435.9 & $w$ & $w$ & $w$ & - & - & $w$ \\
\hline Fed, vany . ... ...................... & 44.2 & $W$ & $w$ & $W$ & - & 420.2 & $\dddot{w}$ & $w$ & $w$ & - & - & $w$ \\
\hline 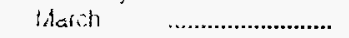 & 47.8 & 50.9 & $w$ & $w$ & - & 484.3 & W & $w$ & $w$ & - & _ & $w$ \\
\hline … ……….............. & 49.4 & 51.9 & 11.2 & $w$ & - & $w$ & W & $w$ & $w$ & - & - & $w$ \\
\hline 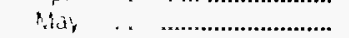 & 52.1 & $w$ & $w$ & $\ddot{w}$ & - & $\ddot{w}$ & w & $w$ & $w$ & - & - & $w$ \\
\hline . ……...................... & 57.4 & $w$ & w & w & - & 573.5 & $w$ & $w$ & $w$ & $w$ & - & $w$ \\
\hline ………………........... & 62.2 & 64.3 & 37.1 & w & w & 641.5 & w & $w$ & $w$ & $w$ & _- & $w$ \\
\hline Augusi $\quad$................................... & 58.3 & w & 33.5 & $w$ & w & 601.9 & w & w & $w$ & $w$ & - & $w$ \\
\hline 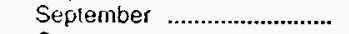 & 54.7 & w & 24.7 & w & w & 491.6 & w & $w$ & $w$ & - & - & $w$ \\
\hline 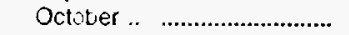 & 51.4 & $w$ & $w$ & w & $\ddot{w}$ & 523.4 & w & $\ddot{W}$ & $\ddot{w}$ & w & - & $\dddot{w}$ \\
\hline November . ................................. & 45.5 & 51.0 & $w$ & $w$ & w & 466.6 & W & 3.6 & $w$ & $w$ & - & $w$ \\
\hline December .................................... & 45.0 & 47.5 & W & $w$ & w & 473.4 & 4.5 & 4.5 & $w$ & $w$ & - & $w$ \\
\hline 1994 Average ........................... & 50.9 & 54.3 & 16.9 & 489.4 & $\mathbf{w}$ & 507.2 & $w$ & $w$ & $w$ & $w$ & - & 1.0 \\
\hline
\end{tabular}

See fanotes at end of table. 
Table 43. Refiner Motor Gasoline Volumes by Grade, Sales Type, PAD District, and State (Thousand Gallons per Day) - Continued

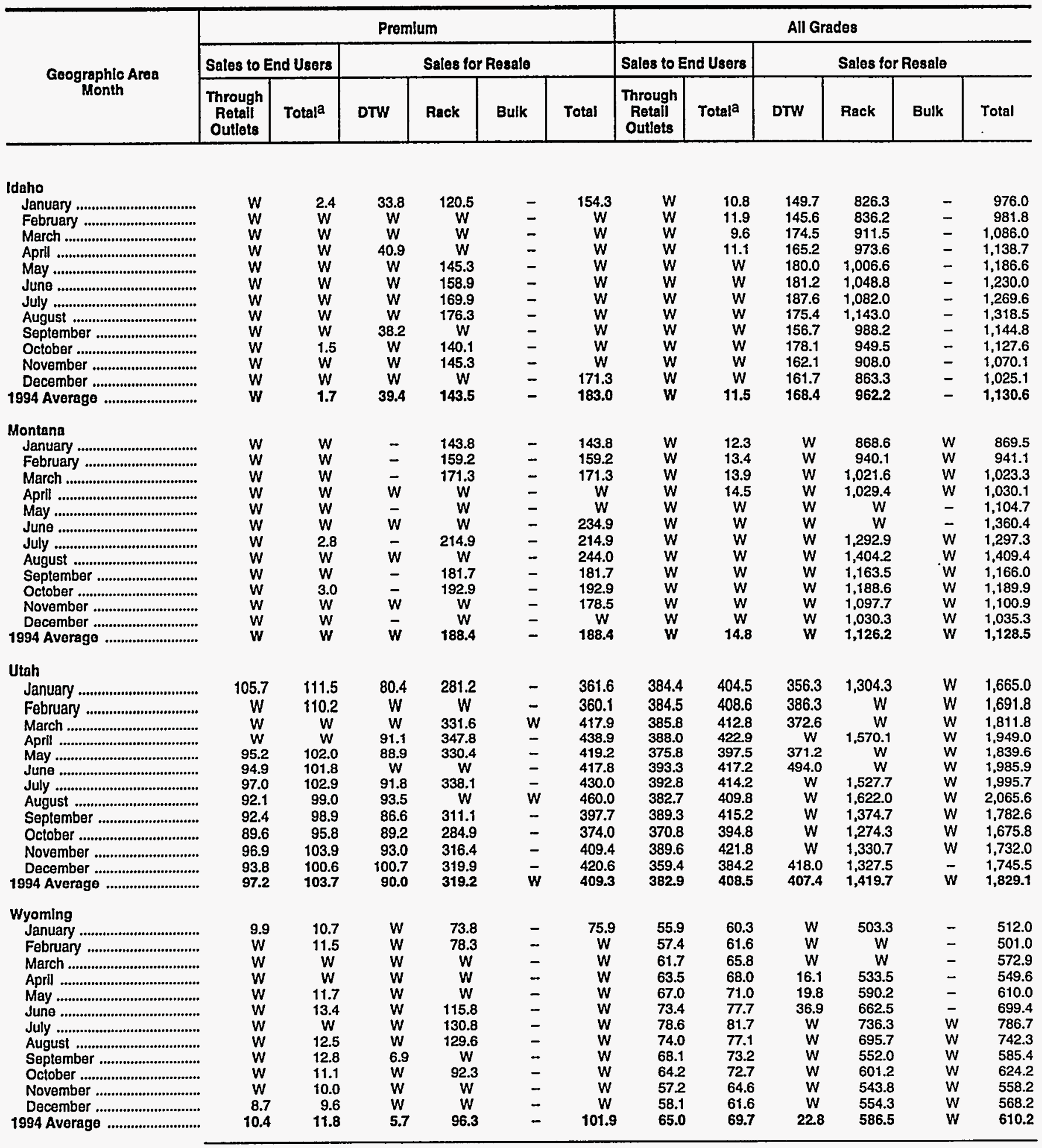

See footnotes at end of table. 
Table 43. Refiner Motor Gasoline Volumes by Grade, Sales Type, PAD District, and State (Thousand Gallons per Day) - Continued



See footnotes at end of table. 
Table 43. Refiner Motor Gasoline Volumes by Grade, Sales Type, PAD District, and State (Thousand Gallons per Day) - Continued

\begin{tabular}{|c|c|c|c|c|c|c|c|c|c|c|c|c|}
\hline \multirow{3}{*}{$\begin{array}{c}\text { Geographlo Area } \\
\text { Month }\end{array}$} & \multicolumn{6}{|c|}{ Premium } & \multicolumn{6}{|c|}{ All Grades } \\
\hline & \multicolumn{2}{|c|}{ Salos to End Users } & \multicolumn{4}{|c|}{ Sales for Resale } & \multicolumn{2}{|c|}{ Sales to End Users } & \multicolumn{4}{|c|}{ Sales for Resale } \\
\hline & $\begin{array}{c}\text { Through } \\
\text { Retail } \\
\text { Outlets }\end{array}$ & Totala & DTW & Rack & Bulk & Total & $\begin{array}{c}\text { Through } \\
\text { Retall } \\
\text { Outlats }\end{array}$ & Totala & DTW & Rack & Bulk & Total \\
\hline 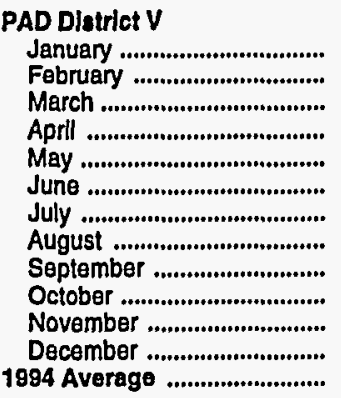 & $\begin{array}{l}1,617.3 \\
1,651.4 \\
1,756.4 \\
1,712.2 \\
1,672.0 \\
1,838.7 \\
1,725.0 \\
1,726.3 \\
1,789.1 \\
1,876.2 \\
1,648.5 \\
1,771.8 \\
1,732.6\end{array}$ & $\begin{array}{l}1,663.1 \\
1,700.1 \\
1,805.0 \\
1,759.6 \\
1,718.4 \\
1,890.5 \\
1,766.1 \\
1,772.4 \\
1,826.0 \\
1,909.9 \\
1,679.9 \\
1,803.4 \\
1,775.0\end{array}$ & $\begin{array}{l}6,431.6 \\
6,198.0 \\
6,930.0 \\
6,827.4 \\
6,879.2 \\
6,953.2 \\
6,749.9 \\
6,824.8 \\
6,718.9 \\
6,550.4 \\
6,533.8 \\
6,617.4 \\
6,687.7\end{array}$ & $\begin{array}{r}1,755.1 \\
1,668.4 \\
1,767.1 \\
W \\
2,195.0 \\
W \\
2,134.5 \\
2,244.5 \\
2,086.1 \\
W \\
W \\
2,022.8 \\
1,995.2\end{array}$ & $\begin{array}{c}163.3 \\
271.3 \\
184.3 \\
W \\
341.5 \\
W \\
645.3 \\
528.1 \\
368.8 \\
W \\
W \\
398.6 \\
373.2\end{array}$ & $\begin{array}{l}8,350.0 \\
8,137.6 \\
8,881.4 \\
9,248.7 \\
9,415.7 \\
9,445.7 \\
9,529.7 \\
9,597.3 \\
9,173.7 \\
8,888.2 \\
8,895.8 \\
9,038.8 \\
9,056.2\end{array}$ & $\begin{array}{r}9,018.4 \\
9,380.7 \\
9,999.7 \\
9,461.0 \\
9,281.0 \\
10,213.6 \\
9,425.0 \\
9,562.7 \\
10,149.4 \\
9,716.3 \\
9,566.5 \\
10,505.2 \\
9,690.8\end{array}$ & $\begin{array}{r}9,279.1 \\
9,651.0 \\
10,300.3 \\
9,757.0 \\
9,578.7 \\
10,518.7 \\
9,770.1 \\
9,826.7 \\
10,398.6 \\
9,945.2 \\
9,791.8 \\
10,728.7 \\
9,963.0\end{array}$ & $\begin{array}{r}27,522.2 \\
W \\
W \\
W \\
W \\
W \\
W \\
W \\
W \\
W \\
W \\
W \\
28,450.5\end{array}$ & $\begin{array}{l}13,045.8 \\
13,536.5 \\
14,312.7 \\
14,612.7 \\
15,004.2 \\
15,020.2 \\
14,893.4 \\
16,052.2 \\
15,767.2 \\
15,617.3 \\
15,987.7 \\
14,381.1 \\
14,858.0\end{array}$ & $\begin{array}{r}3.487 .1 \\
W \\
W \\
W \\
W \\
W \\
W \\
W \\
W \\
W \\
W \\
W \\
3,979.6\end{array}$ & $\begin{array}{l}44,055.1 \\
44,435.4 \\
46,996.2 \\
47,337.7 \\
48,129.6 \\
48,166.7 \\
48,065.8 \\
49,899.1 \\
47,826.1 \\
47,431.5 \\
47,718.0 \\
47,180.1 \\
47,288.0\end{array}$ \\
\hline 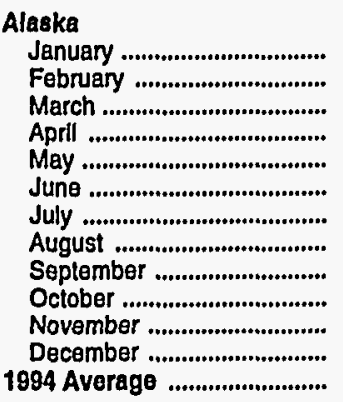 & $\begin{array}{l}27.6 \\
30.4 \\
30.3 \\
31.9 \\
34.6 \\
38.3 \\
39.5 \\
37.8 \\
W \\
W \\
W \\
W \\
34.4\end{array}$ & $\begin{array}{l}30.6 \\
33.6 \\
33.2 \\
34.8 \\
37.6 \\
46.5 \\
49.2 \\
49.6 \\
W \\
W \\
W \\
W \\
39.4\end{array}$ & $\begin{array}{l}20.6 \\
W \\
W \\
W \\
22.8 \\
W \\
W \\
W \\
W \\
22.0 \\
23.1 \\
W \\
22.3\end{array}$ & $\begin{array}{l}12.5 \\
W \\
16.9 \\
20.0 \\
W \\
28.5 \\
W \\
29.7 \\
W \\
W \\
W \\
23.1 \\
22.1\end{array}$ & $\begin{array}{l}- \\
- \\
- \\
- \\
- \\
- \\
- \\
- \\
-\end{array}$ & $\begin{array}{c}33.2 \\
42.1 \\
W \\
W \\
W \\
W \\
W \\
W \\
W \\
W \\
W \\
W \\
44.4\end{array}$ & $\begin{array}{l}195.8 \\
206.3 \\
202.8 \\
207.9 \\
224.3 \\
252.8 \\
257.2 \\
245.0 \\
227.2 \\
218.1 \\
223.1 \\
223.2 \\
223.7\end{array}$ & $\begin{array}{l}213.0 \\
223.6 \\
219.9 \\
226.0 \\
245.5 \\
280.4 \\
313.6 \\
275.4 \\
251.1 \\
233.4 \\
239.7 \\
236.8 \\
246.7\end{array}$ & $\begin{array}{c}105.6 \\
W \\
W \\
W \\
W \\
W \\
W \\
W \\
W \\
W \\
W \\
W \\
121.7\end{array}$ & $\begin{array}{r}170.6 \\
186.7 \\
200.4 \\
204.4 \\
250.7 \\
365.1 \\
391.3 \\
358.2 \\
308.8 \\
224.8 \\
W \\
W \\
258.5\end{array}$ & $\begin{array}{l}- \\
W \\
W \\
W \\
W \\
W \\
W \\
W \\
W \\
W \\
- \\
- \\
W\end{array}$ & $\begin{array}{l}276.3 \\
313.0 \\
318.7 \\
329.2 \\
419.1 \\
538.9 \\
530.9 \\
519.0 \\
451.8 \\
350.5 \\
355.9 \\
324.1 \\
394.3\end{array}$ \\
\hline 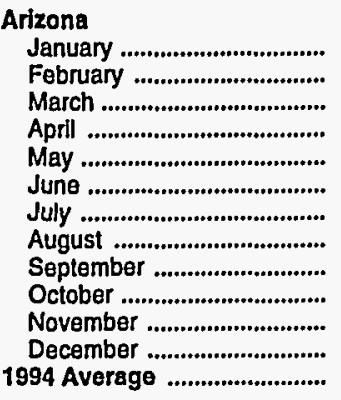 & $\begin{array}{c}188.4 \\
W \\
W \\
W \\
W \\
W \\
W \\
225.8 \\
234.0 \\
225.5 \\
215.5 \\
219.6 \\
215.2\end{array}$ & $\begin{array}{l}189.3 \\
W \\
W \\
W \\
W \\
W \\
W \\
227.3 \\
235.3 \\
227.2 \\
216.7 \\
221.0 \\
216.5\end{array}$ & $\begin{array}{l}307.8 \\
332.4 \\
W \\
W \\
W \\
W \\
W \\
W \\
W \\
W \\
W \\
W \\
345.2\end{array}$ & $\begin{array}{r}132.6 \\
142.7 \\
130.5 \\
172.8 \\
W \\
153.1 \\
151.6 \\
179.0 \\
165.4 \\
135.6 \\
190.1 \\
201.8 \\
162.7\end{array}$ & $\begin{array}{l}W \\
\bar{W} \\
W \\
W \\
W \\
W \\
W \\
W \\
W \\
W \\
W \\
W\end{array}$ & $\begin{array}{r}447.1 \\
475.1 \\
482.0 \\
526.5 \\
580.0 \\
536.1 \\
528.4 \\
558.2 \\
544.9 \\
W \\
531.3 \\
558.6 \\
521.6\end{array}$ & $\begin{array}{l}1,052.4 \\
1,099.8 \\
1,204.4 \\
1,061.6 \\
1,000.1 \\
1,123.9 \\
1,019.9 \\
1,061.5 \\
1,144.8 \\
1,072.8 \\
1,101.5 \\
1,230.2 \\
1,097.6\end{array}$ & $\begin{array}{l}1,073.6 \\
1,130.0 \\
1,230.6 \\
1,081.2 \\
1,021.5 \\
1,144.2 \\
1,034.8 \\
1,081.6 \\
1,162.2 \\
1,092.4 \\
1,119.9 \\
1,245.0 \\
1,117.9\end{array}$ & $\begin{array}{l}1,689.9 \\
1,816.7 \\
1,834.9 \\
1,803.3 \\
1,746.4 \\
1,703.3 \\
1,618.2 \\
1,666.1 \\
1,640.4 \\
1,570.5 \\
1,657.7 \\
1,716.7 \\
1,704.5\end{array}$ & $\begin{array}{r}1,039.8 \\
W \\
W \\
W \\
1,109.5 \\
W \\
W \\
W \\
W \\
W \\
W \\
W \\
1,160.9\end{array}$ & $\begin{array}{c}224.6 \\
W \\
W \\
W \\
233.2 \\
W \\
W \\
W \\
W \\
W \\
W \\
W \\
171.1\end{array}$ & $\begin{array}{l}2,954.4 \\
3,141.1 \\
3,100.4 \\
3,149.8 \\
3,089.0 \\
2,947.2 \\
2,811.6 \\
3,139.2 \\
3,012.1 \\
2,947.1 \\
2,910.4 \\
3,240.9 \\
3,036.4\end{array}$ \\
\hline 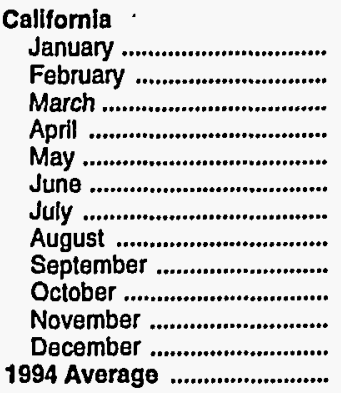 & $\begin{array}{l}1,109.4 \\
1,105.5 \\
1,178.0 \\
1,150.2 \\
1,124.3 \\
1,231.8 \\
1,138.3 \\
1,144.4 \\
1,208.8 \\
1,300.1 \\
1,066.4 \\
1,185.8 \\
1,162.3\end{array}$ & $\begin{array}{l}1,128.6 \\
1,125.8 \\
1,197.9 \\
1,170.1 \\
1,142.6 \\
1,249.0 \\
1,150.2 \\
1,157.6 \\
1,219.9 \\
1,310.1 \\
1,076.5 \\
1,195.7 \\
1,177.4\end{array}$ & $\begin{array}{l}4,924.2 \\
4,641.6 \\
5,454.2 \\
\mathbf{5 , 3 6 3 . 0} \\
\mathbf{5 , 3 7 4 . 4} \\
\mathbf{5 , 4 3 6 . 6} \\
\mathbf{5 , 2 3 6 . 0} \\
\mathbf{5 , 3 0 0 . 0} \\
\mathbf{5 , 2 3 7 . 2} \\
\mathbf{5 , 0 6 2 . 3} \\
\mathbf{5 , 0 5 0 . 6} \\
\mathbf{5 , 1 3 3 . 3} \\
\mathbf{5 , 1 8 7 . 9}\end{array}$ & $\begin{array}{r}909.0 \\
W \\
W \\
W \\
W \\
W \\
W \\
W \\
W \\
W \\
W \\
W \\
1,081.2\end{array}$ & $\begin{array}{l}126.5 \\
W \\
W \\
W \\
W \\
W \\
W \\
W \\
W \\
W \\
W \\
W \\
318.4\end{array}$ & $\begin{array}{l}5,959.7 \\
5,820.6 \\
6,579.5 \\
6,902.9 \\
6,970.5 \\
6,919.0 \\
6,954.2 \\
6,909.9 \\
6,664.8 \\
6,407.5 \\
6,351.1 \\
6,553.1 \\
6,587.6\end{array}$ & $\begin{array}{l}6,048.8 \\
6,254.5 \\
6,664.1 \\
6,362.2 \\
6,282.4 \\
6,889.2 \\
6,335.7 \\
6,445.1 \\
6,869.4 \\
6,616.7 \\
6,412.8 \\
7,088.9 \\
6,523.5\end{array}$ & $\begin{array}{l}6,158.2 \\
6,359.8 \\
6,795.0 \\
6,500.6 \\
6,413.4 \\
7,029.3 \\
6,498.7 \\
6,554.0 \\
6,965.2 \\
6,708.1 \\
6,503.2 \\
7,177.7 \\
6,639.7\end{array}$ & $\begin{array}{l}20,646.0 \\
20,346.4 \\
21,886.2 \\
21,617.5 \\
21,713.4 \\
21,992.9 \\
21,462.1 \\
21,718.6 \\
21,221.8 \\
20,859.0 \\
20,711.8 \\
21,251.2 \\
21,292.2\end{array}$ & $\begin{array}{l}7,019.7 \\
7,859.4 \\
8,123.8 \\
8,362.1 \\
8,511.4 \\
7,977.6 \\
7,784.9 \\
8,725.3 \\
8,852.0 \\
8,972.5 \\
9,450.8 \\
8,011.5 \\
8,304.0\end{array}$ & $\begin{array}{l}1,892.8 \\
2,407.1 \\
2,920.3 \\
3,447.5 \\
3,605.3 \\
3,342.8 \\
3,762.3 \\
3,828.1 \\
3,005.1 \\
3,044.0 \\
3,282.6 \\
3,591.3 \\
3,182.8\end{array}$ & $\begin{array}{l}29,558.6 \\
30,612.9 \\
32,930.3 \\
33,427.0 \\
33,830.1 \\
33,313.2 \\
33,009.2 \\
34,272.0 \\
33,078.9 \\
32,875.5 \\
33,445.2 \\
32,854.0 \\
32,779.0\end{array}$ \\
\hline
\end{tabular}

See footnotes at end of table. 
Table 43. Refiner Motor Gasoline Volumes by Grade, Sales Type, PAD District, and State (Thousand Gallons per Day) - Continued

\begin{tabular}{|c|c|c|c|c|c|c|c|c|c|c|c|c|}
\hline \multirow{3}{*}{$\begin{array}{l}\text { Goographic Area } \\
\text { Month }\end{array}$} & \multicolumn{6}{|c|}{ Regular } & \multicolumn{6}{|c|}{ Midgrade } \\
\hline & \multicolumn{2}{|c|}{ Sales to End Users } & \multicolumn{4}{|c|}{ Sales for Resale } & \multicolumn{2}{|c|}{ Sales to End Users } & \multicolumn{4}{|c|}{ Sales for Resale } \\
\hline & $\begin{array}{c}\text { Through } \\
\text { Retail } \\
\text { Outlets }\end{array}$ & Totala & DTW & Rack & Bulk & Total & $\begin{array}{c}\text { Through } \\
\text { Retail } \\
\text { Outlets }\end{array}$ & Totala & DTW & Rack & Bulk & Total \\
\hline Jawaii & & & & & & & & & & & & \\
\hline 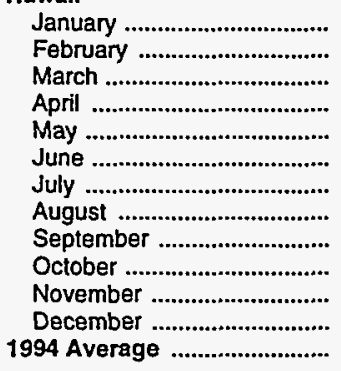 & $\begin{array}{l}103.8 \\
104.3 \\
104.4 \\
106.4 \\
105.9 \\
109.9 \\
110.3 \\
111.3 \\
109.6 \\
107.7 \\
108.9 \\
110.6 \\
107.8\end{array}$ & $\begin{array}{l}149.8 \\
154.0 \\
156.0 \\
155.1 \\
155.0 \\
158.1 \\
162.5 \\
159.4 \\
163.3 \\
154.1 \\
154.7 \\
157.2 \\
156.6\end{array}$ & $\begin{array}{c}307.6 \\
W \\
331.8 \\
323.5 \\
326.6 \\
330.8 \\
332.3 \\
343.8 \\
321.9 \\
319.0 \\
324.2 \\
330.8 \\
326.1\end{array}$ & $\begin{array}{l}74.2 \\
W \\
W \\
77.6 \\
74.8 \\
68.3 \\
76.5 \\
72.9 \\
60.1 \\
68.6 \\
73.9 \\
62.7 \\
71.1\end{array}$ & $\begin{array}{l}\overline{-} \\
\bar{w} \\
\overline{-} \\
\overline{-} \\
\overline{-} \\
- \\
- \\
\overline{-} \\
\bar{w}\end{array}$ & $\begin{array}{l}381.8 \\
385.7 \\
683.6 \\
401.1 \\
401.4 \\
399.2 \\
408.7 \\
416.7 \\
382.0 \\
387.7 \\
398.1 \\
393.5 \\
420.5\end{array}$ & $\begin{array}{l}20.6 \\
20.9 \\
21.2 \\
20.3 \\
22.1 \\
21.3 \\
21.1 \\
20.9 \\
20.6 \\
20.5 \\
20.4 \\
22.2 \\
21.0\end{array}$ & $\begin{array}{l}33.1 \\
33.4 \\
34.0 \\
33.5 \\
35.4 \\
34.9 \\
33.8 \\
32.4 \\
32.3 \\
30.9 \\
30.1 \\
32.6 \\
33.0\end{array}$ & $\begin{array}{c}78.6 \\
W \\
W \\
85.9 \\
88.1 \\
90.0 \\
89.0 \\
W \\
W \\
W \\
W \\
W \\
86.9\end{array}$ & $\begin{array}{l}4.2 \\
W \\
W \\
3.8 \\
3.6 \\
4.4 \\
3.8 \\
W \\
W \\
W \\
W \\
W \\
3.8\end{array}$ & $\begin{array}{l}- \\
- \\
- \\
- \\
- \\
- \\
- \\
- \\
- \\
-\end{array}$ & $\begin{array}{l}82.8 \\
87.4 \\
91.5 \\
89.7 \\
91.8 \\
94.5 \\
92.8 \\
92.5 \\
90.1 \\
89.8 \\
91.5 \\
92.8 \\
90.6\end{array}$ \\
\hline 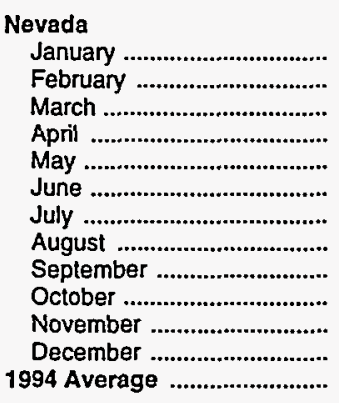 & $\begin{array}{r}121.3 \\
114.9 \\
124.4 \\
108.3 \\
102.2 \\
126.3 \\
103.0 \\
99.7 \\
116.6 \\
97.4 \\
101.1 \\
106.7 \\
110.1\end{array}$ & $\begin{array}{l}133.7 \\
126.1 \\
139.3 \\
120.4 \\
115.8 \\
136.5 \\
116.0 \\
111.4 \\
125.9 \\
106.5 \\
111.1 \\
116.5 \\
121.5\end{array}$ & $\begin{array}{c}719.0 \\
W \\
777.9 \\
W \\
799.4 \\
W \\
W \\
W \\
W \\
W \\
798.4 \\
773.2 \\
794.8\end{array}$ & $\begin{array}{c}371.0 \\
435.1 \\
W \\
470.3 \\
W \\
658.0 \\
621.7 \\
637.2 \\
652.6 \\
603.9 \\
W \\
W \\
545.8\end{array}$ & $\begin{array}{l}W \\
W \\
W \\
W \\
W \\
W \\
W \\
W \\
W \\
W \\
W \\
W \\
W\end{array}$ & $\begin{array}{l}1,289.6 \\
1,376.7 \\
1,464.7 \\
1,395.6 \\
1,435.8 \\
1,622.9 \\
1,534.3 \\
1,589.9 \\
1,545.4 \\
1,547.6 \\
1,440.5 \\
1,426.2 \\
1,472.9\end{array}$ & $\begin{array}{r}W \\
4.8 \\
4.8 \\
5.1 \\
5.7 \\
6.5 \\
6.6 \\
6.6 \\
6.6 \\
6.2 \\
5.8 \\
19.3 \\
6.9\end{array}$ & $\begin{array}{r}4.7 \\
5.4 \\
5.0 \\
5.3 \\
5.9 \\
6.6 \\
6.7 \\
6.7 \\
6.9 \\
6.4 \\
6.0 \\
19.4 \\
7.1\end{array}$ & $\begin{array}{c}90.4 \\
W \\
W \\
W \\
W \\
W \\
W \\
W \\
W \\
W \\
W \\
116.7 \\
87.8\end{array}$ & $\begin{array}{c}48.2 \\
W \\
W \\
W \\
W \\
W \\
W \\
W \\
W \\
W \\
W \\
43.9 \\
56.9\end{array}$ & $\begin{array}{l}- \\
- \\
- \\
- \\
- \\
- \\
- \\
- \\
- \\
- \\
- \\
-\end{array}$ & $\begin{array}{l}138.6 \\
144.9 \\
136.2 \\
132.5 \\
136.3 \\
154.2 \\
159.6 \\
162.5 \\
147.1 \\
130.5 \\
134.0 \\
160.6 \\
144.8\end{array}$ \\
\hline 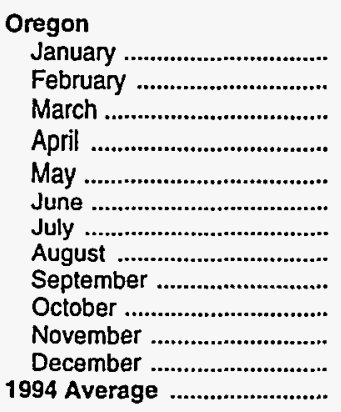 & $\begin{array}{l}310.2 \\
323.3 \\
343.4 \\
337.7 \\
325.7 \\
343.2 \\
338.4 \\
333.7 \\
333.1 \\
317.7 \\
335.3 \\
335.1 \\
331.4\end{array}$ & $\begin{array}{l}318.5 \\
335.0 \\
354.7 \\
349.6 \\
339.5 \\
353.7 \\
346.1 \\
345.2 \\
343.9 \\
328.9 \\
344.4 \\
347.4 \\
342.2\end{array}$ & $\begin{array}{c}887.3 \\
W \\
W \\
W \\
W \\
942.5 \\
951.6 \\
955.7 \\
929.6 \\
917.4 \\
W \\
879.9 \\
918.4\end{array}$ & $\begin{array}{r}1,642.4 \\
1,336.6 \\
W \\
1,477.2 \\
1,355.3 \\
W \\
1,601.5 \\
W \\
W \\
W \\
1,499.9 \\
W \\
1,494.2\end{array}$ & $\begin{array}{c}116.4 \\
W \\
- \\
W \\
W \\
W \\
108.5 \\
W \\
W \\
W \\
W \\
W \\
199.5\end{array}$ & $\begin{array}{l}2,646.1 \\
2,418.7 \\
2,473.5 \\
2,538.0 \\
2,336.5 \\
2,604.8 \\
2,661.7 \\
3,000.5 \\
2,663.1 \\
2,710.1 \\
2,623.2 \\
2,650.3 \\
2,612.1\end{array}$ & $\begin{array}{l}W \\
W \\
W \\
W \\
W \\
W \\
W \\
W \\
W \\
W \\
W \\
W \\
W\end{array}$ & $\begin{array}{l}W \\
W \\
W \\
W \\
W \\
W \\
W \\
W \\
W \\
W \\
W \\
W \\
W \\
W\end{array}$ & $\begin{array}{l}- \\
- \\
- \\
- \\
- \\
- \\
\overline{-} \\
\bar{W} \\
W \\
W \\
W \\
W\end{array}$ & $\begin{array}{l}- \\
- \\
- \\
W \\
W \\
W \\
W \\
W \\
W \\
W \\
W \\
W \\
7.1\end{array}$ & $\begin{array}{l}- \\
- \\
- \\
- \\
- \\
- \\
- \\
- \\
- \\
- \\
- \\
- \\
-\end{array}$ & $\begin{array}{c}- \\
- \\
- \\
W \\
W \\
W \\
W \\
W \\
W \\
W \\
W \\
W \\
10.3\end{array}$ \\
\hline 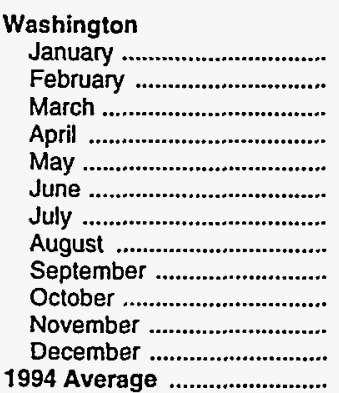 & $\begin{array}{r}867.6 \\
927.0 \\
992.4 \\
922.2 \\
901.5 \\
1,004.0 \\
906.5 \\
918.3 \\
1,007.2 \\
932.2 \\
897.1 \\
1,010.5 \\
940.5\end{array}$ & $\begin{array}{r}878.2 \\
935.1 \\
1,003.6 \\
931.7 \\
912.3 \\
1,013.5 \\
912.6 \\
920.4 \\
1,015.4 \\
938.1 \\
905.1 \\
1,019.9 \\
948.7\end{array}$ & $\begin{array}{r}1,815.8 \\
W \\
1,964.9 \\
1,927.0 \\
W \\
2,058.0 \\
2,033.7 \\
2,039.8 \\
W \\
1,976.2 \\
W \\
W \\
1,966.7\end{array}$ & $\begin{array}{c}1,970.7 \\
1,864.4 \\
2,045.5 \\
W \\
2,431.3 \\
W \\
2,438.4 \\
W \\
2,393.1 \\
2,221.9 \\
2,198.8 \\
2,040.6 \\
2,217.6\end{array}$ & $\begin{array}{c}W \\
W \\
- \\
W \\
W \\
W \\
383.1 \\
W \\
W \\
137.3 \\
W \\
W \\
215.2\end{array}$ & $\begin{array}{l}4,810.1 \\
4,147.6 \\
4,010.5 \\
4,089.6 \\
4,562.7 \\
4,547.7 \\
4,855.2 \\
4,625.5 \\
4,526.6 \\
4,335.4 \\
4,221.1 \\
4,032.3 \\
4,399.6\end{array}$ & $\begin{array}{l}W \\
W \\
W \\
W \\
W \\
W \\
W \\
W \\
W \\
7.3 \\
20.9 \\
W \\
4.7\end{array}$ & $\begin{array}{c}W \\
W \\
W \\
W \\
W \\
W \\
W \\
W \\
W \\
7.3 \\
20.9 \\
W \\
4.7\end{array}$ & $\begin{array}{c}W \\
W \\
W \\
W \\
W \\
W \\
W \\
W \\
W \\
W \\
W \\
W \\
15.9\end{array}$ & $\begin{array}{l}W \\
W \\
W \\
w \\
- \\
\bar{w} \\
\bar{w} \\
w \\
w \\
W \\
w\end{array}$ & $\begin{array}{l}- \\
- \\
- \\
- \\
- \\
- \\
- \\
- \\
- \\
- \\
-\end{array}$ & $\begin{array}{l}6.8 \\
7.7 \\
W \\
W \\
W \\
W \\
W \\
W \\
6.0 \\
W \\
93.7 \\
W \\
24.9\end{array}$ \\
\hline
\end{tabular}

See footnotes at end of table. 
Table 43. Refiner Motor Gasoline Volumes by Grade, Sales Type, PAD District, and State (Thousand Gallons per Day) - Continued

\begin{tabular}{|c|c|c|c|c|c|c|c|c|c|c|c|c|}
\hline \multirow{3}{*}{$\begin{array}{l}\text { Geographic Area } \\
\text { Month }\end{array}$} & \multicolumn{6}{|c|}{ Premium } & \multicolumn{6}{|c|}{ All Grades } \\
\hline & \multicolumn{2}{|c|}{ Sales to End Users } & \multicolumn{4}{|c|}{ Sales for Resale } & \multicolumn{2}{|c|}{ Sales to End Users } & \multicolumn{4}{|c|}{ Sales for Resale } \\
\hline & $\begin{array}{c}\text { Through } \\
\text { Retail } \\
\text { Outlets }\end{array}$ & Totala & DTW & Rack & Bulk & Total & $\begin{array}{c}\text { Through } \\
\text { Retail } \\
\text { Outlets }\end{array}$ & Totala & DTW & Rack & Bulk & Total \\
\hline \multicolumn{13}{|l|}{ Hawali } \\
\hline 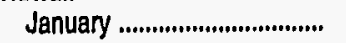 & 46.8 & 68.9 & 202.7 & 31.0 & - & 233.7 & 171.2 & 251.7 & 588.9 & 109.4 & - & 698.3 \\
\hline 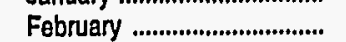 & 47.8 & 70.3 & 210.6 & 29.5 & - & 240.0 & 172.9 & 257.6 & 614.0 & 99.1 & - & 713.1 \\
\hline 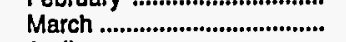 & 47.5 & 70.6 & $W$ & $W$ & - & 252.1 & 173.1 & 260.6 & 635.9 & W & W & $1,027.2$ \\
\hline 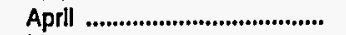 & 48.8 & 71.7 & 211.9 & 35.9 & - & 247.8 & 175.5 & 260.4 & 621.3 & 117.3 & - & 738.6 \\
\hline 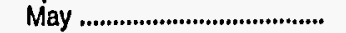 & 48.3 & 71.1 & 216.1 & 34.6 & - & 250.6 & 176.3 & 261.4 & 630.8 & 113.0 & - & 743.8 \\
\hline June ......................................... & 50.6 & 74.4 & 216.9 & 31.9 & - & 248.8 & 181.8 & 267.3 & 637.8 & 104.7 & - & 742.4 \\
\hline 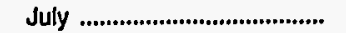 & 50.1 & 68.6 & 216.1 & 32.9 & - & 249.0 & 181.5 & 264.9 & 637.4 & 113.2 & - & 750.5 \\
\hline 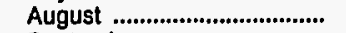 & 49.7 & 68.1 & $W$ & $W$ & - & 251.6 & 181.9 & 259.9 & 650.0 & 110.8 & - & 760.8 \\
\hline September ............................. & 49.5 & 67.0 & W & $W$ & - & 242.1 & 179.7 & 262.5 & 622.4 & 91.8 & - & 714.2 \\
\hline October ................................. & 48.8 & 66.3 & $w$ & $W$ & - & 245.7 & 177.0 & 251.3 & 620.6 & 102.6 & - & 723.2 \\
\hline November ............................... & 49.2 & 64.9 & W & $W$ & - & 243.6 & 178.4 & 249.8 & 625.0 & 108.2 & - & 733.2 \\
\hline December ............................... & 50.7 & 67.4 & $W$ & W & - & 252.5 & 183.5 & 257.3 & 642.9 & $\begin{array}{r}95.9 \\
1069\end{array}$ & $\vec{w}$ & $\begin{array}{l}738.8 \\
7577\end{array}$ \\
\hline f994 Average ......................... & 49.0 & 69.1 & & & & & & & & & & \\
\hline \multicolumn{13}{|l|}{ Nevada } \\
\hline 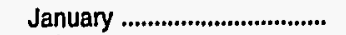 & 18.7 & 18.8 & 177.8 & 60.7 & $W$ & 255.0 & 144.4 & 157.3 & 987.3 & 479.9 & $w$ & $1,683.3$ \\
\hline February ............................... & 18.9 & 18.9 & 185.2 & $W$ & $W$ & 274.6 & 138.6 & 150.4 & $1,030.1$ & $w$ & W & $1,796.1$ \\
\hline March ..................................... & 20.6 & 20.8 & $w$ & $W$ & $w$ & 294.2 & 149.8 & 165.2 & $1,045.5$ & $W$ & $w$ & $1,895.1$ \\
\hline 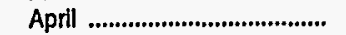 & 19.7 & 19.7 & 195.0 & $W$ & $w$ & 288.1 & 133.0 & 145.4 & $1,045.2$ & $W$ & $w$ & $1,816.2$ \\
\hline May .......................................... & 19.5 & 19.5 & $W$ & 99.7 & $w$ & 321.5 & 127.3 & 141.3 & $1,086.9$ & $W$ & $w$ & $1,893.6$ \\
\hline June ....................................... & 25.2 & 25.2 & 224.9 & $w$ & $w$ & 381.9 & 157.9 & 168.4 & $1,157.1$ & $W$ & $w$ & $2,159.0$ \\
\hline 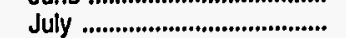 & 21.4 & 21.4 & 220.6 & W & $W$ & 373.9 & 131.0 & 144.1 & $1,123.7$ & W & $w$ & $2,067.8$ \\
\hline August ................................ & 20.8 & 20.8 & 226.4 & $w$ & $w$ & 378.7 & 127.1 & 139.0 & $1,166.5$ & $W$ & W & $2,131.1$ \\
\hline September ............................. & 24.4 & 24.5 & 219.9 & $\ddot{W}$ & $w$ & 373.3 & 147.6 & 157.3 & $1,110.4$ & W & $w$ & $2,065.8$ \\
\hline 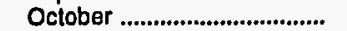 & 19.6 & 19.8 & 210.9 & $w$ & $w$ & 328.5 & 123.2 & 132.7 & $1,115.5$ & $w$ & w & $2,006.5$ \\
\hline November .............................. & 19.4 & 19.4 & $w$ & 89.9 & $w$ & 314.9 & 126.2 & 136.5 & $1,086.9$ & w & $w$ & $1,889.4$ \\
\hline December ............................... & 22.8 & 22.9 & 198.7 & $w$ & $w$ & 316.0 & 148.8 & 158.8 & $1,088.6$ & $w$ & $w$ & $1,902.8$ \\
\hline 1994 Average ........................... & 20.9 & 21.0 & 204.7 & 103.9 & W & 325.3 & 137.9 & 149.6 & $1,087.3$ & 706.5 & $w$ & $1,943.0$ \\
\hline \multicolumn{13}{|l|}{ Oregon } \\
\hline 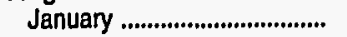 & 53.2 & 53.4 & 205.2 & 245.1 & - & 450.3 & 364.5 & 373.0 & $1,092.5$ & $1,887.5$ & 116.4 & $3,096.3$ \\
\hline February .................................. & $W$ & $W$ & W & $w$ & $W$ & 377.8 & 385.4 & 397.6 & $1,104.1$ & $W$ & $W$ & $2,796.5$ \\
\hline March ..................................... & W & $W$ & W & W & $W$ & 347.7 & 406.1 & 417.7 & $W$ & $1,716.2$ & $W$ & $2,821.2$ \\
\hline April & $\ddot{w}$ & $w$ & W & 199.3 & - & $W$ & 403.1 & 415.4 & $1,067.7$ & W & $W$ & $2,903.7$ \\
\hline 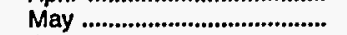 & $w$ & $\ddot{w}$ & w & $w$ & w & w & 391.0 & 405.1 & $1,106.8$ & $1,536.9$ & 59.8 & $2,703.5$ \\
\hline June & $\mathbf{W}$ & W & $w$ & 216.3 & - & w & 411.8 & 422.6 & $w$ & $1,824.9$ & $w$ & $3,007.7$ \\
\hline July & $\ddot{w}$ & $w$ & 195.9 & $w$ & - & $w$ & 409.6 & 417.4 & $1,147.5$ & $1,840.3$ & 108.5 & $3,096.3$ \\
\hline 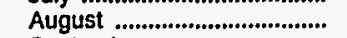 & $w$ & $w$ & 195.0 & $w$ & $w$ & $w$ & 402.2 & 414.2 & $1,150.8$ & $1,835.8$ & 518.0 & $3,504.6$ \\
\hline September ............................ & W & W & 186.8 & W & - & W & 399.9 & 411.1 & W & $1,623.5$ & $w$ & $3,061.2$ \\
\hline 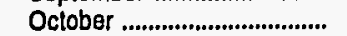 & W & W & 192.1 & W & $W$ & W & 386.1 & 398.3 & $W$ & $1,729.6$ & $W$ & $3,229.3$ \\
\hline November ........................... & w & W & 186.7 & $W$ & $W$ & W & 411.8 & 421.6 & $\ddot{w}$ & $1,745.0$ & W & $3,168.7$ \\
\hline 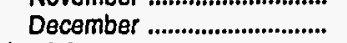 & $\dddot{W}$ & $\ddot{w}$ & $W$ & W & w & $w$ & 408.8 & 421.3 & $1,071.5$ & $1,636.4$ & 430.0 & $3,137.8$ \\
\hline 1994 Average & 63.9 & 64.3 & 186.9 & 213.6 & 23.1 & 423.6 & 398.4 & 409.6 & $1,108.5$ & $1,714.9$ & 222.6 & $3,046.0$ \\
\hline \multicolumn{13}{|l|}{ Washington } \\
\hline 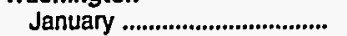 & 173.1 & 173.4 & 593.3 & 364.2 & $w$ & 971.1 & $1,041.3$ & $1,052.2$ & $2,411.9$ & $2,338.8$ & $W$ & $5,788.0$ \\
\hline 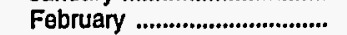 & W & $w$ & W & $w$ & - & 907.3 & $1,123.3$ & $1,132.1$ & $2,456.9$ & $w$ & W & $5,062.7$ \\
\hline 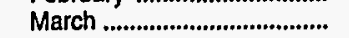 & $w$ & $w$ & W & 344.2 & W & $W$ & $1,199.5$ & $1,211.2$ & $2,513.1$ & $W$ & $w$ & $4,903.2$ \\
\hline 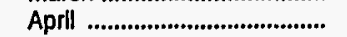 & W & $w$ & $W$ & 353.4 & - & $W$ & 1.117 .7 & $1,128.0$ & $2,457.0$ & $W$ & $w$ & $4,973.2$ \\
\hline May .......................................... & $W$ & W & W & W & - & $W$ & $1,079.6$ & $1,090.5$ & $2,516.8$ & W & $W$ & $5,450.4$ \\
\hline June ...................................... & w & $w$ & 500.9 & $W$ & - & W & $1,196.2$ & $1,206.5$ & W & $2,810.8$ & W & $5,458.2$ \\
\hline 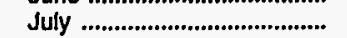 & w & $\ddot{W}$ & $w$ & $W$ & - & $w$ & $1,090.2$ & $1,096.5$ & $2,544.7$ & $2,871.7$ & 383.1 & $5,799.5$ \\
\hline 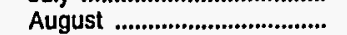 & $W$ & $w$ & 500.9 & $W$ & - & $\ddot{W}$ & $1,100.0$ & $1,102.7$ & W & $2,927.3$ & $w$ & $5,572.4$ \\
\hline September ............................ & $W$ & W & $w$ & $W$ & - & 909.4 & $1,180.8$ & $1,189.2$ & W & $2,824.6$ & $W$ & $5,442.0$ \\
\hline 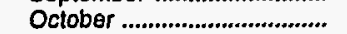 & 183.1 & 183.7 & W & w & - & $w$ & $1,122.5$ & $1,129.1$ & $2,534.6$ & $2,627.6$ & 137.3 & $5,299.5$ \\
\hline November .............................. & 194.7 & 195.2 & W & $W$ & - & 900.5 & $1,112.7$ & $1,121.2$ & $w$ & $2,617.6$ & $w$ & $5,215.2$ \\
\hline December ............................. & W & W & $W$ & 340.8 & $\rightarrow$ & $W$ & $1,221.8$ & $1,231.8$ & $2,543.8$ & $W$ & $W$ & $4,981.6$ \\
\hline 1994 Average ......................... & 186.8 & 187.3 & 526.3 & 379.6 & W & 907.1 & $1,132.0$ & $1,140.8$ & $2,509.0$ & $2,606.2$ & 216.4 & $5,331.6$ \\
\hline
\end{tabular}

Dash $(-)=$ No data reported.

NA $=$ Not avallable.

$W=$ Withheld to avoid disclosure of individual company data.

a Includes sales through retail outlets as well as all direct sales to end users that were not made through company-operated retail outlets, e.g., sales to agricultural customers, commercial sales, and industrlal sales.

Note: Totals may not equal the sum of the components due to rounding.

Source: Energy Information Administration Form EIA-782A, "Refiners'/Gas Plant Operators' Monthly Petroleum Product Sales Report." 
Table 44. Refiner Motor Gasoline Volumes by Formulation, Sales Type, PAD District, and State

(Thousand Gallons per Day)

\begin{tabular}{|c|c|c|c|c|c|c|c|c|c|c|c|c|}
\hline \multirow{3}{*}{$\begin{array}{c}\text { Geographic Area } \\
\text { Month }\end{array}$} & \multicolumn{6}{|c|}{ Conventional } & \multicolumn{6}{|c|}{ Oxygenated } \\
\hline & \multicolumn{2}{|c|}{ Sales to End Users } & \multicolumn{4}{|c|}{ Sales for Resale } & \multicolumn{2}{|c|}{ Sales to End Users } & \multicolumn{4}{|c|}{ Sales for Resale } \\
\hline & $\begin{array}{c}\text { Through } \\
\text { Retail } \\
\text { Outlets }\end{array}$ & Totala & DTW & Rack & Bulk & Total & $\begin{array}{c}\text { Through } \\
\text { Rotall } \\
\text { Outlots }\end{array}$ & Totala & DTW & Rack & Bulk & Total \\
\hline \multicolumn{13}{|l|}{ United States } \\
\hline 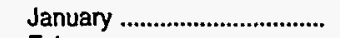 & $35,827.1$ & $37,510.3$ & $37,267.0$ & $131,980.0$ & $23,929.2$ & $193,176.3$ & $13,585.9$ & $14,023.4$ & $41,173.3$ & $17,553.7$ & $2,565.5$ & $61,292.5$ \\
\hline 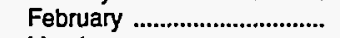 & $40,281.6$ & $42,247.7$ & $45,582.9$ & $142,921.6$ & $23,109.1$ & $211,613.6$ & $11,634.9$ & $12,022.4$ & $35,429.4$ & $12,530.9$ & $1,612.9$ & $49,573.2$ \\
\hline 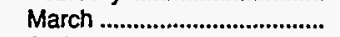 & $48,436.1$ & $50,702.7$ & $72,123.0$ & $156,878.7$ & $23,153.9$ & $252,155.6$ & $4,492.5$ & $4,661.1$ & $11,977.2$ & $4,056.5$ & 807.2 & $16,840.9$ \\
\hline Apri] & $50,391.9$ & $52,641.3$ & $73,945.7$ & $161,644.8$ & $26,306.9$ & $261,897.4$ & $2,262.4$ & $2,320.8$ & $10,272.2$ & $3,455.3$ & 540.6 & $14,268.2$ \\
\hline May & $52,550.1$ & $54,838.3$ & $83,246.0$ & $166,375.7$ & $27,795.8$ & $277,417.5$ & 680.9 & 684.7 & $1,256.0$ & 741.8 & - & $1,997.8$ \\
\hline 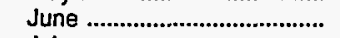 & $54,023.0$ & $56,437.2$ & $W$ & W & $28,704.4$ & $285,829.8$ & 727.4 & 728.1 & W & $W$ & - & $1,878.6$ \\
\hline 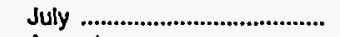 & $53,127.1$ & $55,224.5$ & $w$ & $169,494.5$ & W & $277,298.1$ & 609.7 & 610.0 & $w$ & 929.7 & $w$ & $1,911.5$ \\
\hline August & $53,453.1$ & $55,721.6$ & $W$ & $174,357.3$ & $w$ & $286,092.3$ & 669.5 & 671.8 & $w$ & $1,031.8$ & w & $2,286.8$ \\
\hline 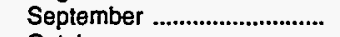 & $51,281.7$ & $53,464.3$ & $76,619.9$ & $168,224.9$ & $27,898.8$ & $272,743.6$ & $1,501.3$ & $1,528.6$ & $5,556.6$ & $2,361.3$ & $1,339.9$ & $9,257.7$ \\
\hline 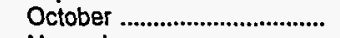 & $41,577.5$ & $43,614.5$ & $47,611.3$ & $151,620.3$ & $25,284.5$ & $224,516.1$ & $10,394.0$ & $10,626.0$ & $34,849.4$ & $14,279.3$ & $2,427,0$ & $51,555.6$ \\
\hline 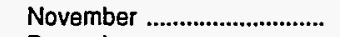 & $37,073.8$ & $38,933.5$ & $37,735.7$ & $146,498.1$ & $21,918.0$ & $206,151.8$ & $14,415.9$ & $14,803.0$ & $40,873.8$ & $19,696.5$ & $2,423.3$ & $62,993.5$ \\
\hline 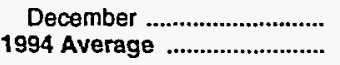 & $\begin{array}{l}31,695.6 \\
45,829.2\end{array}$ & $\begin{array}{l}33,319.9 \\
47,907.1\end{array}$ & $\begin{array}{l}25,588.5 \\
62,688.3\end{array}$ & $\begin{array}{l}129,704.7 \\
156,022.9\end{array}$ & $\begin{array}{l}27,917.3 \\
25,764.8\end{array}$ & $\begin{array}{l}183,210.5 \\
244,475.9\end{array}$ & $\begin{array}{r}10,601.9 \\
5,931.6\end{array}$ & $\begin{array}{r}10,770.1 \\
6,086.3\end{array}$ & $\begin{array}{l}14,937.5 \\
16,474.6\end{array}$ & $\begin{array}{c}W \\
7,403.7\end{array}$ & $\begin{array}{c}W \\
1,127.5\end{array}$ & $\begin{array}{l}28,215.5 \\
25,005.8\end{array}$ \\
\hline \multicolumn{13}{|l|}{ PAD District I } \\
\hline 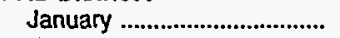 & $10,336.9$ & $10,921.0$ & $15,457.9$ & $41,283.2$ & $3,851.6$ & $60,592.7$ & $2,415.8$ & $2,672.5$ & $14,924.6$ & $6,854.6$ & $1,374.7$ & $23,153.9$ \\
\hline 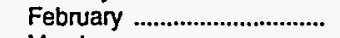 & $10,961.8$ & $11,642.8$ & $16,370.9$ & $43,402.9$ & $4,857.6$ & $64,631.4$ & $2,386.7$ & $2,648.9$ & $15,618.2$ & $6,428.9$ & $1,351.2$ & $23,398.3$ \\
\hline March & $11,893.2$ & $12,709.5$ & $24,820.5$ & $W$ & $W$ & $79,168.4$ & $1,741.8$ & $1,878.3$ & $8,439.2$ & $W$ & W & $11,693.0$ \\
\hline April & $12,381.1$ & $13,207.4$ & $25,029.2$ & $49,879.6$ & $5,456.5$ & $80,365.4$ & $1,513.2$ & $1,569.5$ & $8,658.4$ & $2,674.7$ & 540.6 & $11,873.7$ \\
\hline May & $W$ & $14,657.0$ & $W$ & $W$ & $6,806.5$ & $93,284.2$ & $w$ & 23.7 & $w$ & W & - & 75.7 \\
\hline June & $14,053.3$ & $w$ & $W$ & W & $7,785.0$ & $96,176.7$ & - & $w$ & $w$ & $w$ & - & 7.1 \\
\hline 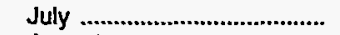 & $14,024.2$ & $14,854.5$ & $W$ & $W$ & W & W & - & - & $w$ & $w$ & $w$ & $w$ \\
\hline August & $13,888,8$ & W & $W$ & $w$ & $6,779.8$ & $w$ & - & $w$ & $w$ & W & - & $w$ \\
\hline September .............................. & $12,972.0$ & $13,877.2$ & $29,834.9$ & W & W & $91,618.8$ & 291.8 & 302.8 & $2,424.4$ & W & $w$ & $3,481,4$ \\
\hline 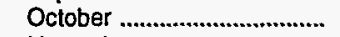 & $11,784.4$ & $12,645.5$ & $22,197.5$ & $49,989.5$ & $5,842.8$ & $78,029.8$ & $1,579.1$ & $1,669.2$ & $10,813.9$ & $4,092.3$ & 660.1 & $15,566.3$ \\
\hline 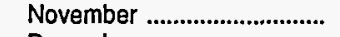 & $10,571.6$ & $11,315.5$ & $15,972.9$ & $46,091.4$ & $3,686.7$ & $65,750.9$ & $W$ & $2,791.3$ & $15,341.8$ & $7,120.5$ & 729.8 & $23,192.1$ \\
\hline 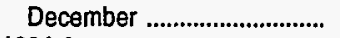 & $8,896.3$ & $9,484.4$ & $9,307.1$ & $37,468.0$ & $2,789.1$ & $49,564.1$ & 409.4 & 456.4 & 622.9 & $1,086.2$ & 71.9 & $1,781.1$ \\
\hline 1994 Average ............................... & $12,134.4$ & $12,934.2$ & $24,475.5$ & $49,009.0$ & $5,615.9$ & $79,100.5$ & $1,065.9$ & $1,155.7$ & $6,330.8$ & $2,591.7$ & 482.4 & $9,404.9$ \\
\hline \multicolumn{13}{|l|}{ Subdistrict IA } \\
\hline 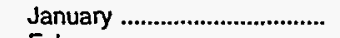 & 513.3 & 581.6 & $3,789.8$ & $5,346.7$ & 345.5 & $9,482.0$ & $w$ & $w$ & 513.0 & 291.9 & - & 805.0 \\
\hline 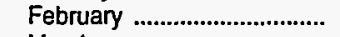 & $W$ & $W$ & $3,842.7$ & $5,277.3$ & $1,087.8$ & $10,207.8$ & $w$ & $W$ & 503.7 & 289.8 & - & 793.5 \\
\hline March & $W$ & $w$ & $W$ & $w$ & W & $9,319.1$ & $W$ & $w$ & W & $W$ & - & 821.5 \\
\hline April & $W$ & $W$ & $W$ & $w$ & 291.2 & $W$ & $W$ & $w$ & $w$ & $w$ & - & W \\
\hline 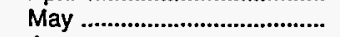 & 640.2 & 719.7 & $w$ & $w$ & $1,150.9$ & $\dddot{w}$ & - & - & $\ddot{w}$ & W & - & $\ddot{w}$ \\
\hline June & 658.9 & 747.9 & $4,868.6$ & $w$ & 561.1 & W & - & - & - & $w$ & - & $w$ \\
\hline July & 677.2 & 752.3 & $4,778.7$ & $5,898.5$ & $1,325.1$ & $12,002.3$ & - & - & - & - & - & - \\
\hline August & 668.6 & 746.6 & $4,813.2$ & $6,151.2$ & 923.7 & $11,888.2$ & - & - & - & - & - & - \\
\hline 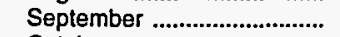 & $w$ & $W$ & W & $5,717.3$ & $W$ & W & $w$ & $w$ & $w$ & 43.6 & - & $w$ \\
\hline 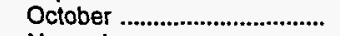 & $W$ & W & $4,227.9$ & $w$ & $W$ & $11,005.9$ & $W$ & $w$ & 530.1 & $w$ & $w$ & 893.4 \\
\hline 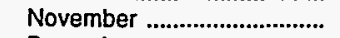 & 498.2 & 592.2 & W & $5,365.6$ & $W$ & $10,457.0$ & W & $\ddot{w}$ & W & $\ddot{w}$ & - & 775.3 \\
\hline December ..... & W & W & $w$ & 702.1 & $W$ & $1,312.7$ & - & - & - & - & - & - \\
\hline 1994 Average & 528.4 & 605.2 & $3,959.7$ & $5,184.2$ & 835.3 & $9,979.2$ & $\mathbf{w}$ & w & 267.3 & 149.1 & $w$ & 419.3 \\
\hline \multicolumn{13}{|l|}{ Connecticut } \\
\hline January ......... & 43.5 & 48.3 & 697.2 & $1,259.7$ & $W$ & $2,045.3$ & $w$ & $w$ & 513.0 & 291.6 & - & 804.6 \\
\hline February .... & 39.6 & $w$ & 700.9 & $w$ & $W$ & $2,111.4$ & $W$ & $W$ & $W$ & $w$ & - & 793.5 \\
\hline March & 36.9 & $w$ & $W$ & $w$ & - & $2,017.0$ & $W$ & $W$ & $w$ & $w$ & - & 821.5 \\
\hline 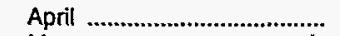 & 41.8 & $w$ & W & $w$ & - & $W$ & $W$ & $W$ & $W$ & $w$ & - & $W$ \\
\hline May ................ & $W$ & 141.8 & $1,316.2$ & W & $W$ & $w$ & - & - & W & $w$ & - & $W$ \\
\hline June ............. & $W$ & 148.4 & $W$ & $w$ & $W$ & $w$ & - & - & - & $w$ & - & $W$ \\
\hline 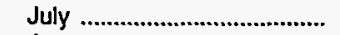 & $W$ & 157.3 & $1,313.7$ & $1,720.1$ & 611.4 & $3,645.2$ & - & - & - & - & - & - \\
\hline August & $W$ & 157.8 & $w$ & $1,692.1$ & $W$ & $3,041.4$ & - & - & - & - & - & - \\
\hline 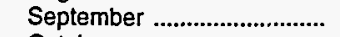 & $W$ & W & $1,133.0$ & $1,588.3$ & $W$ & W & $w$ & $W$ & $w$ & 43.6 & - & W \\
\hline October ............. & 47.8 & $w$ & 784.6 & $w$ & $W$ & $2,470.8$ & $\mathbf{W}$ & $W$ & $W$ & $w$ & $w$ & 893.4 \\
\hline 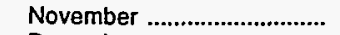 & 42.7 & $w$ & $w$ & $1,324.8$ & $W$ & $2,246.1$ & $w$ & $W$ & $W$ & $w$ & - & 775.3 \\
\hline December .................................... & $W$ & $w$ & $w$ & NA & - & NA & - & - & - & - & - & - \\
\hline 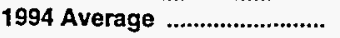 & $w$ & 86.5 & 911.1 & $1,376.0$ & 130.9 & $2,418.0$ & $\mathbf{W}$ & $\mathbf{W}$ & 267.3 & 149.1 & $\mathbf{W}$ & 419.2 \\
\hline
\end{tabular}

See footnotes at end of table. 
Table 44. Refiner Motor Gasoline Volumes by Formulation, Sales Type, PAD District, and State

(Thousand Gallons per Day) - Continued

\begin{tabular}{|c|c|c|c|c|c|c|c|c|c|c|c|c|}
\hline \multirow{3}{*}{$\begin{array}{c}\text { Geographlc Area } \\
\text { Month }\end{array}$} & \multicolumn{6}{|c|}{ Reformulated } & \multicolumn{6}{|c|}{ All Formulations } \\
\hline & \multicolumn{2}{|c|}{ Sales to End Users } & \multicolumn{4}{|c|}{ Sales for Resale } & \multicolumn{2}{|c|}{ Sales to End Users } & \multicolumn{4}{|c|}{ Sales for Resale } \\
\hline & $\begin{array}{c}\text { Through } \\
\text { Retall } \\
\text { Outlets }\end{array}$ & Totala & DTW & Rack & Bulk & Total & $\begin{array}{c}\text { Through } \\
\text { Retall } \\
\text { Outlets }\end{array}$ & Totala & DTW & Rack & Bulk & Total \\
\hline Inited States & & & & & & & & & & & & \\
\hline 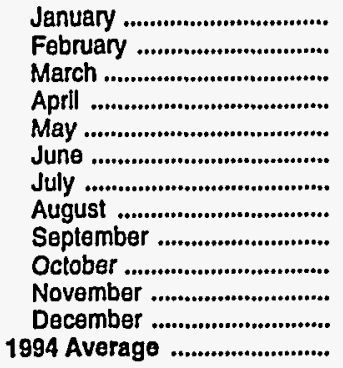 & $\begin{array}{r}\overline{-} \\
\overline{-} \\
\overline{-} \\
\overline{-} \\
\overline{-} \\
\overline{-} \\
\overline{7} \\
736.5 \\
11,109.0 \\
1,004.0\end{array}$ & $\begin{array}{r}\overline{-} \\
\overline{-} \\
\overline{-} \\
\overline{-} \\
\overline{-} \\
\overline{-} \\
\overline{-} \\
743.9 \\
11,522.3 \\
1,039.8\end{array}$ & $\begin{array}{r}- \\
- \\
- \\
- \\
- \\
- \\
- \\
- \\
- \\
- \\
3,541.7 \\
43,147.7 \\
3,955.7\end{array}$ & $\begin{array}{r}- \\
\bar{z} \\
\bar{z} \\
\bar{z} \\
\bar{z} \\
\overline{-} \\
\overline{-} \\
\overline{1,325.3} \\
w \\
2,443.9\end{array}$ & $\begin{array}{r}- \\
- \\
- \\
- \\
- \\
- \\
- \\
- \\
- \\
1,896.0 \\
W \\
826.6\end{array}$ & $\begin{array}{r}- \\
- \\
- \\
- \\
\overline{-} \\
- \\
- \\
- \\
6,763.0 \\
78,537.0 \\
7,226.1\end{array}$ & $\begin{array}{l}49,413.0 \\
51,916.5 \\
52,928.5 \\
52,654.3 \\
53,231.0 \\
54,750.4 \\
53,736.8 \\
54,122.6 \\
52,783.1 \\
51,971.5 \\
52,226.2 \\
53,406.5 \\
52,764.9\end{array}$ & $\begin{array}{l}51,533.7 \\
54,270.1 \\
55,363.8 \\
54,962.1 \\
55,523.0 \\
57,165.3 \\
55,834.5 \\
56,393.4 \\
54,992.9 \\
54,240.5 \\
54,480.4 \\
55,612.3 \\
55,033.2\end{array}$ & $\begin{array}{l}78,440.4 \\
81,012.3 \\
84,100.2 \\
84,217.9 \\
84,502.0 \\
86,025.8 \\
84,243.5 \\
84,283.1 \\
82,176.5 \\
82,460.7 \\
82,151.1 \\
83,673.7 \\
83,118.6\end{array}$ & $\begin{array}{l}149,533.7 \\
155,452.6 \\
160,935.2 \\
165,100.1 \\
167,117.5 \\
172,978.3 \\
170,424.2 \\
175,389.1 \\
170,586.2 \\
165,899.5 \\
167,519.8 \\
168,910.4 \\
165,870.4\end{array}$ & $\begin{array}{l}26,494.7 \\
24,722.0 \\
23,961.1 \\
26,847.5 \\
27,795.8 \\
28,704.4 \\
24,542.0 \\
28,707.0 \\
29,238.6 \\
27,711.5 \\
26,237.3 \\
37,378.8 \\
27,718.8\end{array}$ & $\begin{array}{l}254,468.8 \\
261,186.8 \\
268,996.5 \\
276,165.6 \\
279,415.3 \\
287,708.5 \\
279,209.6 \\
288,379.1 \\
282,001.3 \\
276,071.7 \\
275,908.2 \\
289,962.9 \\
276,707.8\end{array}$ \\
\hline 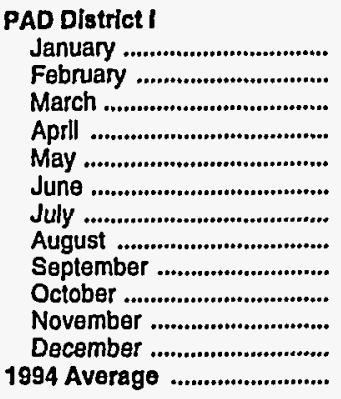 & $\begin{array}{r}\bar{z} \\
\bar{z} \\
\bar{z} \\
\bar{z} \\
\bar{z} \\
\bar{z} \\
\bar{w} \\
4,185.9 \\
357.3\end{array}$ & $\begin{array}{r}- \\
- \\
- \\
- \\
- \\
- \\
- \\
- \\
- \\
27.4 \\
4,504.2 \\
384.8\end{array}$ & $\begin{array}{r}\overline{-} \\
\overline{-} \\
\overline{-} \\
\overline{-} \\
\overline{-} \\
\overline{-} \\
\overline{1}, 390.9 \\
23,417.4 \\
2,103.2\end{array}$ & $\begin{array}{r}- \\
\overline{-} \\
\overline{-} \\
\overline{-} \\
\overline{-} \\
\overline{-} \\
\overline{-} \\
1,068.5 \\
16,761.4 \\
1,511.4\end{array}$ & $\begin{array}{r}\overline{-} \\
= \\
= \\
= \\
= \\
= \\
= \\
1,434.8 \\
6,136.4 \\
639.1\end{array}$ & $\begin{array}{r}- \\
- \\
- \\
- \\
- \\
- \\
- \\
- \\
- \\
3,894.2 \\
46,315.2 \\
4,253.7\end{array}$ & $\begin{array}{l}12,752.7 \\
13,348.5 \\
13,635.0 \\
13,894.3 \\
13,802.8 \\
14,053.3 \\
14,024.2 \\
13,888.8 \\
13,263.8 \\
13,363.5 \\
13,157.6 \\
13,491.5 \\
13,557.6\end{array}$ & $\begin{array}{l}13,593.4 \\
14,291.6 \\
14,587.8 \\
14,776.9 \\
14,680.7 \\
14,974.3 \\
14,854.5 \\
14,851.6 \\
14,180.0 \\
14,314.7 \\
14,134.3 \\
14,444.9 \\
14,474.8\end{array}$ & $\begin{array}{l}30,382.5 \\
31,989.1 \\
33,259.7 \\
33,687.6 \\
33,587.9 \\
34,048.7 \\
33,336.5 \\
33,244.2 \\
32,259.3 \\
33,011.4 \\
32,705.6 \\
33,347.4 \\
32,909.5\end{array}$ & $\begin{array}{l}48,137.8 \\
49,831.8 \\
51,386.9 \\
52,554.3 \\
52,965.6 \\
54,350.2 \\
53,734.2 \\
55,852.7 \\
54,646.3 \\
54,081.8 \\
54,280.3 \\
55,315.6 \\
53,112.2\end{array}$ & $\begin{array}{l}5,226.4 \\
6,208.8 \\
6,214.7 \\
5,997.2 \\
6,806.5 \\
7,785.0 \\
6,261.1 \\
6,779.8 \\
8,194.7 \\
6,502.9 \\
5,851.3 \\
8,997.4 \\
6,737.4\end{array}$ & $\begin{array}{l}83,746.7 \\
88,029.7 \\
90,861.4 \\
92,239.1 \\
93,359.9 \\
96,183.9 \\
93,331.8 \\
95,876.6 \\
95,100.2 \\
93,596.1 \\
92,837.3 \\
97,660.4 \\
92,759.1\end{array}$ \\
\hline 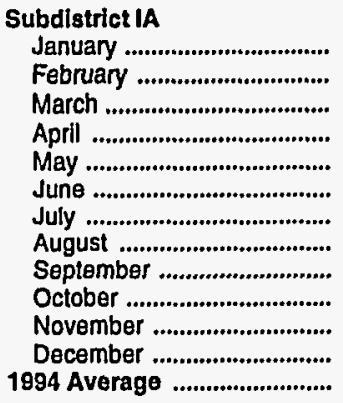 & $\begin{array}{l}- \\
- \\
- \\
- \\
- \\
- \\
- \\
\bar{W} \\
W \\
43.6\end{array}$ & $\begin{array}{l}- \\
- \\
- \\
- \\
- \\
- \\
- \\
- \\
- \\
\bar{W} \\
W \\
50.1\end{array}$ & $\begin{array}{c}- \\
- \\
- \\
- \\
\bar{z} \\
- \\
- \\
\overline{-} \\
\bar{W} \\
W \\
412.8\end{array}$ & $\begin{array}{r}- \\
- \\
- \\
- \\
- \\
- \\
- \\
- \\
- \\
\bar{W} \\
W \\
5,148.5 \\
443.3\end{array}$ & $\begin{array}{c}- \\
- \\
- \\
- \\
- \\
- \\
- \\
- \\
- \\
\bar{W} \\
92.5\end{array}$ & $\begin{array}{r}- \\
- \\
- \\
- \\
- \\
- \\
- \\
- \\
- \\
235.1 \\
10,941.2 \\
948.6\end{array}$ & $\begin{array}{l}591.3 \\
544.2 \\
559.1 \\
596.7 \\
640.2 \\
658.9 \\
677.2 \\
668.6 \\
613.1 \\
616.7 \\
574.4 \\
599.2 \\
612.2\end{array}$ & $\begin{array}{l}684.0 \\
646.0 \\
647.3 \\
677.9 \\
719.7 \\
747.9 \\
752.3 \\
746.6 \\
695.0 \\
703.8 \\
670.5 \\
682.9 \\
698.2\end{array}$ & $\begin{array}{l}4,302.8 \\
4,346.4 \\
4,410.3 \\
4,542.0 \\
4,704.7 \\
4,868.6 \\
4,778.7 \\
4,813.2 \\
4,607.5 \\
4,758.0 \\
4,728.3 \\
4,793.9 \\
4,639.7\end{array}$ & $\begin{array}{l}5,638.7 \\
5,567.1 \\
5,396.5 \\
5,477.7 \\
5,682.1 \\
6,051.3 \\
5,898.5 \\
6,151.2 \\
5,760.9 \\
6,103.5 \\
5,718.2 \\
5,850.6 \\
5,776.7\end{array}$ & $\begin{array}{r}345.5 \\
1,087.8 \\
333.8 \\
291.2 \\
1,150.9 \\
561.1 \\
1,325.1 \\
923.7 \\
1,484.2 \\
1,037.8 \\
1,020.9 \\
1,609.3 \\
930.7\end{array}$ & $\begin{array}{r}10,287.0 \\
11,001.3 \\
10,140.6 \\
10,311.0 \\
11,537.7 \\
11,481.0 \\
12,002.3 \\
11,888.2 \\
11,852.6 \\
11,899.3 \\
11,467.4 \\
12,253.8 \\
11,347.0\end{array}$ \\
\hline 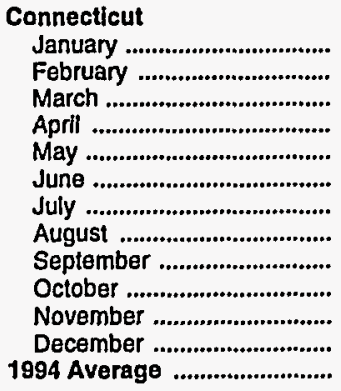 & $\begin{array}{l}\bar{z} \\
\overline{-} \\
\bar{z} \\
\bar{z} \\
\bar{z} \\
\bar{w} \\
\bar{w}\end{array}$ & $\begin{array}{l}- \\
- \\
- \\
- \\
- \\
- \\
- \\
- \\
- \\
\vec{w} \\
11.9\end{array}$ & $\begin{array}{r}\overline{-} \\
\bar{z} \\
\overline{-} \\
\bar{z} \\
\bar{z} \\
\overline{-} \\
\bar{w} \\
1,424.7 \\
126.1\end{array}$ & $\begin{array}{c}\overline{-} \\
\overline{-} \\
\overline{-} \\
\overline{-} \\
\overline{-} \\
\overline{-} \\
\bar{W} \\
W \\
142.2\end{array}$ & $\begin{array}{l}- \\
- \\
- \\
- \\
- \\
- \\
- \\
\overline{-} \\
\bar{w} \\
w\end{array}$ & $\begin{array}{r}\bar{z} \\
\bar{z} \\
\bar{z} \\
\bar{z} \\
\bar{z} \\
\bar{z} \\
\overline{-} \\
87.8 \\
3,353.5 \\
292.0\end{array}$ & $\begin{array}{l}w \\
w \\
w \\
w \\
w \\
w \\
w \\
w \\
w \\
w \\
w \\
w \\
w\end{array}$ & $\begin{array}{c}W \\
116.4 \\
122.9 \\
133.2 \\
141.8 \\
148.4 \\
157.3 \\
157.8 \\
145.2 \\
146.5 \\
132.1 \\
140.4 \\
139.4\end{array}$ & $\begin{array}{r}1,210.3 \\
W \\
1,247.5 \\
1,273.8 \\
W \\
W \\
1,313.7 \\
W \\
W \\
W \\
W \\
W \\
1,304.5\end{array}$ & $\begin{array}{l}1,551.3 \\
1,597.7 \\
1,590.9 \\
1,561.2 \\
1,727.7 \\
1,757.6 \\
1,720.1 \\
1,692.1 \\
1,631.9 \\
1,833.0 \\
1,629.8 \\
1,705.4 \\
1,667.4\end{array}$ & $\begin{array}{c}W \\
W \\
- \\
- \\
W \\
W \\
611.4 \\
W \\
W \\
W \\
W \\
W \\
157.4\end{array}$ & $\begin{array}{l}2,849.9 \\
2,904.9 \\
2,838.5 \\
2,835.0 \\
3,392.9 \\
3,212.4 \\
3,645.2 \\
3,041.4 \\
2,910.7 \\
3,364.2 \\
3,109.2 \\
3,410.4 \\
3,129.2\end{array}$ \\
\hline
\end{tabular}

See lootnotes at end of table. 
Table 44. Refiner Motor Gasoline Volumes by Formulation, Sales Type, PAD District, and State

(Thousand Gallons per Day) - Continued

\begin{tabular}{|c|c|c|c|c|c|c|c|c|c|c|c|c|}
\hline \multirow{3}{*}{$\begin{array}{l}\text { Geographic Area } \\
\text { Month }\end{array}$} & \multicolumn{6}{|c|}{ Conventional } & \multicolumn{6}{|c|}{ Oxygenated } \\
\hline & \multicolumn{2}{|c|}{ Sales to End Users } & \multicolumn{4}{|c|}{ Sales for Resale } & \multicolumn{2}{|c|}{ Sales to End Users } & \multicolumn{4}{|c|}{ Sales for Resale } \\
\hline & $\begin{array}{l}\text { Through } \\
\text { Retail } \\
\text { Outlots }\end{array}$ & Totala & DTw & Rack & Bulk & Total & $\begin{array}{c}\text { Through } \\
\text { Retail } \\
\text { Outlots }\end{array}$ & Totala & DTW & Rack & Bulk & Total \\
\hline
\end{tabular}

Maine

January

February

March

April

May .

July

July ......

Septembe

October ...

November

December .

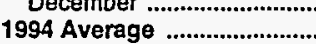

Massachusetts

January ..

February

Alarch

April

July

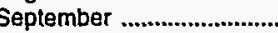

October

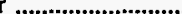

November

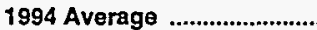

New Hampshire

January ...

April

May

July

August

September

October ....

November

December ..

1994 Averago

Rhode island

January

February

March

April

June

July ..

August

October

November

December

1994 Average

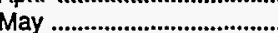

$\begin{array}{ll}- & W \\ - & W \\ - & W \\ - & W \\ - & W \\ - & W \\ - & W \\ - & W \\ - & W\end{array}$

325.0

302.6

310.9

329.8

353.9

363.2

373.0

369.5

339.5

341.8

320.3

317.5

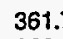

366.0

363.2

377.5
399.3

399.3
416.1

416.7

, 547.5

$2,581.2$

$393.0 \quad 2,538.7$

$W$
363.2

$2,237.5$

83.9
74.0

71.3

75.0

81.1

83.4

82.3
81.9

$\begin{array}{llll}W & 89.4 & 305.8 & 133.8 \\ W & 81.8 & 288.7 & 110.7\end{array}$

77.7

W

$71.1 \quad 78.8$

W

263.7

391.8

529.0

$419.2 \quad 573.4$

W 556.0

$439.4 \quad 488.5$

$432.5 \quad 571.0$

W $\quad 578.1$

$438.2 \quad 604.1$

$429.0 \quad 527.2$

W $\quad 654.7$

$439.9 \quad 536.5$

$\begin{array}{rr}- & 0.6 \\ 391.4 & 523.8\end{array}$
$386.2 \quad 2,342.1$

$391.8 \quad 670.5$

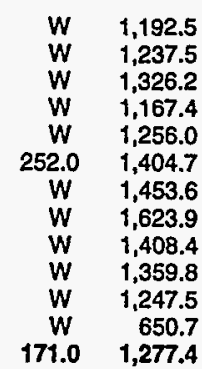

$\begin{array}{lllllll}- & - & - & - & - & - \\ - & - & - & - & - & - \\ - & - & - & - & - & - \\ - & - & - & - & - & - \\ - & - & - & - & - & - \\ - & - & - & - & - & - \\ - & - & - & - & - & - \\ - & - & - & - & - & - \\ - & - & - & - & - & - \\ - & - & - & - & - & - \\ - & - & - & - & - & -\end{array}$

W $4,622.3$

732.8 $\quad 5,231.2$

W 4,420.2

W 4,699.5

$\begin{array}{ll}W & \mathbf{5 , 3 7 9 . 3} \\ W & \mathbf{5 , 2 3 8 . 2}\end{array}$

$214.3 \quad 4,901.0$

$619.9 \quad 5,508.8$

$1,283.0 \quad 5,973.4$

W $5,153.6$

$700.8 \quad 5,282.2$

$452.9 \quad 4,720.1$

$4,720.1$

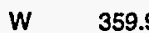

$$
379.7
$$

378.0

383.6

412.5

426.8

426.1

399.4

409

W

$W$
368.7

$\begin{array}{llllll}- & w & - & w & - & w \\ - & - & - & - & - & - \\ - & - & - & - & - & - \\ - & - & - & - & - & - \\ - & - & - & - & - & - \\ - & - & - & - & - & - \\ - & - & - & - & - & - \\ - & - & - & - & - & - \\ - & - & - & - & - & - \\ - & - & - & - & - & - \\ - & - & - & - & - & - \\ - & - & - & - & - & - \\ - & w & - & w & - & w\end{array}$

See footnotes at end of table. 
Table 44. Refiner Motor Gasoline Volumes by Formulation, Sales Type, PAD District, and State

(Thousand Gallons per Day) - Continued

\begin{tabular}{|c|c|c|c|c|c|c|c|c|c|c|c|c|}
\hline \multirow{3}{*}{$\begin{array}{l}\text { Geographic Area } \\
\text { Month }\end{array}$} & \multicolumn{6}{|c|}{ Reformulated } & \multicolumn{6}{|c|}{ All Formulations } \\
\hline & \multicolumn{2}{|c|}{ Sales to End Users } & \multicolumn{4}{|c|}{ Sales for Resale } & \multicolumn{2}{|c|}{ Sales to End Users } & \multicolumn{4}{|c|}{ Sales for Resale } \\
\hline & $\begin{array}{c}\text { Through } \\
\text { Retall } \\
\text { Outlots }\end{array}$ & Totala & DTW & Rack & Bulk & Total & $\begin{array}{c}\text { Through } \\
\text { Retail } \\
\text { Outlets }\end{array}$ & Totala & DTW & Back & Bulk & Total \\
\hline
\end{tabular}

Maine

January

Fobruary

March

Aprll

May

June

July .

October

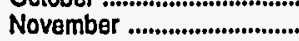

December

1994 Average

Massachusotte

January

Fobruary

March

April

May ......................................... June

July .........................................

August

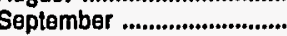

Oclober

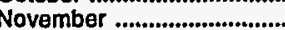

December

1994 Avarago .......

Now Hampshire

January .

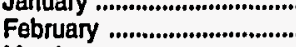

March

April

June

July ....

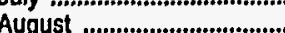

September .............................

October

November

December

1994 Averago

Rhode laland

January

February ................................

March

April

May

June

July .

August .

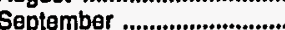

October

November

December

1994 Average

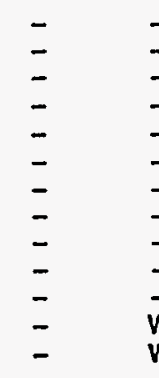

$\begin{array}{ll}- & - \\ - & - \\ \overline{-} & - \\ \overline{-} & - \\ \overline{-} & - \\ \overline{-} & - \\ - & - \\ \bar{w} & \bar{w} \\ w & \mathbf{w}\end{array}$

-
-
-
-
-
-
-
-
-
$W$
639.7
56.4

$\begin{array}{lll}- & - & - \\ - & - & - \\ - & - & - \\ - & - & - \\ - & - & - \\ - & - & - \\ - & - & - \\ - & - & - \\ - & - & - \\ - & - & - \\ \bar{W} & 27.9 & - \\ W & 886.4 & -\end{array}$

$\begin{array}{lllllll}- & - & - & - & - & - & 325.0 \\ - & - & - & - & - & - & 302.6 \\ - & - & - & - & - & - & 310.9\end{array}$

- - -

- $\quad-\quad$

$\begin{array}{lll}- & - \\ - & - & -\end{array}$

$\overline{-}$

$\vec{w}$

$\bar{w}$

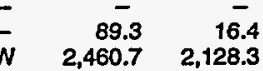

$\begin{array}{ll}W & 216.3\end{array}$

$w$
$w$
$w$
$w$
$w$
$w$
$w$
$w$
$w$
$w$
$w$

$\begin{array}{cr}89.5 & 1,040.0 \\ W & 1.002 .7 \\ W & 962.0 \\ W & 948.6 \\ W & 998.0 \\ 102.4 & 1,050.3 \\ W & 1,173.2 \\ W & 1,255.5 \\ W & 1,127.7 \\ W & 1,132.9 \\ W & 1,066.6 \\ 98.9 & 1,099.6 \\ 98.8 & 1,072.2\end{array}$

$\begin{array}{cc}W & 1,192.5 \\ W & 1,237.5 \\ W & 1,326.2 \\ W & 1,167.4 \\ W & 1,256.0 \\ 252.0 & 1,404.7 \\ W & 1,453.6 \\ W & 1,623.9 \\ W & 1,408.4 \\ W & 1,359.8 \\ W & 1,275.5 \\ 338.6 & 1,537.1 \\ 183.9 & 1,354.9\end{array}$

384.0

366.0
363.2

377.5

399.3

416.1

416.7

413.0

387.1
393.0

393.0
386.2
380.5

380.5

390.4

$2,278.7$
$2,300.8$
$W$
$2,406.6$
$2,494.1$
$W$
$2,547.5$
$2,581.2$
$2,463.0$
$2,538.7$
$2,431.3$
$2,473.7$
$2,453.8$

$2,278.7$
$2,300.8$
$W$
$2,406.6$
$2,494.1$
$W$
$2,547.5$
$2,581.2$
$2,463.0$
$2,538.7$
$2,431.3$
$2,473.7$
$2,453.8$

$2,150.6$
$2,197.6$
$2,038.7$
$W$
$W$
$2,417.3$
$2,139.2$
$2,307.7$
$2,227.5$
$W$
$2,255.7$
$2,136.7$
$2,211.9$

W $\quad 4,622.6$

$732.8 \quad 5,231.2$

W $4,420.2$

W $4,699.5$

W $\quad 5,379.3$

W $5,238.2$

$214.3 \quad 4,901.0$

$619.95,508.8$

$1,283.0 \quad 5,973.4$

W $\quad 5,153.6$

$700.8 \quad 5,387.8$

$496.4 \quad 5,456.8$

\begin{tabular}{|c|c|c|c|c|c|c|c|c|c|c|c|}
\hline - & - & - & - & - & - & 83.9 & 93.0 & 268.0 & 90.9 & $w$ & 359.9 \\
\hline - & - & - & - & - & - & 74.0 & 82.8 & 274.4 & 105.3 & - & 379.7 \\
\hline- & - & - & - & - & - & 71.3 & 80.3 & 269.4 & 108.6 & - & 378.0 \\
\hline- & - & - & - & - & - & 75.0 & 82.5 & 275.7 & 107.9 & - & 383.6 \\
\hline - & - & - & - & - & - & 81.1 & 88.7 & 290.8 & 121.6 & - & 412.5 \\
\hline- & - & - & - & - & - & 83.4 & 92.2 & 299.7 & 127.1 & - & 426.8 \\
\hline- & - & - & - & - & - & 82.3 & 87.9 & 304.7 & 121.4 & - & 426.1 \\
\hline - & - & - & - & - & - & 81.9 & 89.4 & 305.8 & 133.8 & - & 439.6 \\
\hline- & - & - & - & - & - & $w$ & 81.8 & 288.7 & 110.7 & - & 399.4 \\
\hline- & - & - & - & - & - & $w$ & 83.8 & 296.7 & 113.0 & - & 409.7 \\
\hline- & - & $w$ & $W$ & - & W & W & 77.7 & 287.1 & 97.7 & - & 384.8 \\
\hline$w$ & $w$ & $w$ & $w$ & - & $w$ & $w$ & 83.9 & 290.4 & 109.3 & $\overline{-}$ & 399.7 \\
\hline $\mathbf{W}$ & 6.6 & 24.0 & 7.4 & - & 31.5 & 77.4 & 85.4 & 287.7 & 112.4 & $\mathbf{W}$ & 400.2 \\
\hline
\end{tabular}

$\begin{array}{rrrrrrrrrrrr}- & - & - & - & - & - & 60.9 & 70.7 & 391.8 & 670.5 & -5 & 1,062.3 \\ - & - & - & - & - & - & W & 72.3 & W & 529.0 & W & 1,048.1 \\ - & - & - & - & - & - & W & 73.7 & 419.2 & 573.4 & - & 992.5 \\ - & - & - & - & - & - & W & 79.1 & W & 556.0 & W & 1,075.6 \\ - & - & - & - & - & - & W & 82.4 & 439.4 & 488.5 & - & 927.9 \\ - & - & - & - & - & - & W & 84.2 & 432.5 & 571.0 & - & 1,003.4 \\ - & - & - & - & - & - & W & 83.0 & W & 578.1 & W & 1,337.2 \\ - & - & - & - & - & - & W & 79.1 & 438.2 & 604.1 & - & 1,042.3 \\ - & - & - & - & - & - & 68.9 & 73.9 & 429.0 & 527.2 & - & 956.2 \\ - & - & - & - & - & - & 68.3 & 73.7 & W & 654.7 & W & 1,402.0 \\ W & W & W & - & - & W & 65.8 & W & W & 536.5 & W & 1.117 .3 \\ W & 67.5 & W & 648.6 & W & 1,235.8 & 68.1 & W & W & 649.2 & W & 1,236.4 \\ 5.5 & 5.8 & 38.1 & 55.1 & W & 105.5 & 68.7 & 76.1 & 429.5 & 578.9 & 92.8 & 1,101.2\end{array}$

See lootnotes at end of table. 
Table 44. Refiner Motor Gasoline Volumes by Formulation, Sales Type, PAD District, and State

(Thousand Gallons per Day) - Continued

\begin{tabular}{|c|c|c|c|c|c|c|c|c|c|c|c|c|}
\hline \multirow{3}{*}{$\begin{array}{l}\text { Goographic Area } \\
\text { Month }\end{array}$} & \multicolumn{6}{|c|}{ Conventional } & \multicolumn{6}{|c|}{ Oxygenated } \\
\hline & \multicolumn{2}{|c|}{ Sales to End Users } & \multicolumn{4}{|c|}{ Sales for Resale } & \multicolumn{2}{|c|}{ Sales to End Users } & \multicolumn{4}{|c|}{ Sales for Resalo } \\
\hline & $\begin{array}{l}\text { Through } \\
\text { Retail } \\
\text { Outtets }\end{array}$ & Totala & DTW & Rack & Bulk & Total & $\begin{array}{c}\text { Through } \\
\text { Retail } \\
\text { Outlots }\end{array}$ & Totala & DTW & Rack & Bulk & Total \\
\hline \multicolumn{13}{|l|}{ Vermont } \\
\hline 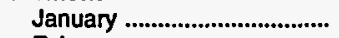 & - & $w$ & 64.5 & 135.2 & - & 199.8 & - & - & - & - & - & - \\
\hline 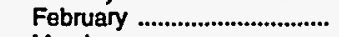 & - & $w$ & $w$ & W & - & 199.9 & - & - & - & - & - & - \\
\hline 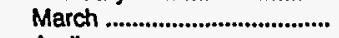 & - & $W$ & W & W & - & 185.1 & - & - & - & - & - & - \\
\hline April & - & $W$ & $W$ & $W$ & - & 149.9 & - & - & - & - & - & - \\
\hline 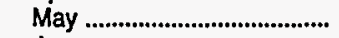 & - & $W$ & $W$ & $W$ & - & 169.1 & - & - & - & - & - & - \\
\hline 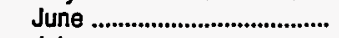 & - & $W$ & 67.3 & 128.0 & - & 195.3 & - & - & - & - & - & - \\
\hline 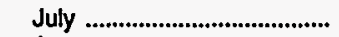 & - & $W$ & 72.6 & 166.5 & - & 239.2 & - & - & - & - & - & - \\
\hline 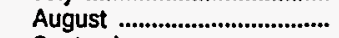 & - & $\ddot{W}$ & 73.9 & 158.1 & - & 232.1 & - & - & - & - & - & - \\
\hline 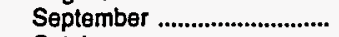 & - & $w$ & 68.6 & 136.0 & - & 204.6 & - & - & - & - & - & - \\
\hline 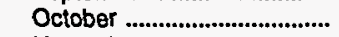 & - & w & $W$ & $W$ & - & 210.0 & - & - & - & - & - & - \\
\hline November ................................ & - & - & $W$ & $W$ & - & 192.7 & - & - & - & - & - & - \\
\hline 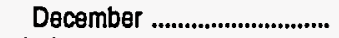 & - & - & $W$ & $W$ & - & $W$ & - & - & - & - & - & - \\
\hline 1994 Average ......................... & - & W & 65.5 & 133.9 & - & 199.4 & - & - & - & - & - & - \\
\hline \multicolumn{13}{|l|}{ Subdistrict IB } \\
\hline 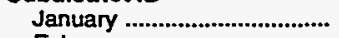 & $2,616.6$ & $2,718.0$ & $3,062.8$ & $8,929.2$ & $2,250.6$ & $14,242.6$ & $1,941.6$ & $2,142.3$ & $13,207.2$ & $4,472.6$ & $1,374.7$ & $19,054.5$ \\
\hline 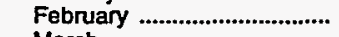 & W & $W$ & W & $9,429.9$ & W & $15,490.7$ & W & $w$ & W & $4,257.5$ & $W$ & $19,375.1$ \\
\hline March & $w$ & $W$ & $w$ & $11,726.6$ & $w$ & $25,291.3$ & $w$ & $w$ & $w$ & $2,147.1$ & $w$ & $10,841.1$ \\
\hline 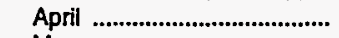 & w & $W$ & $10,355.0$ & $12,228.3$ & $4,112.7$ & $26,696.0$ & $W$ & $w$ & $8,122.6$ & $2,398.6$ & 540.6 & $11,061.9$ \\
\hline 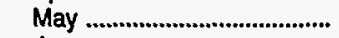 & $w$ & $5,516.7$ & $W$ & W & $4,971.1$ & $38,650.5$ & $W$ & 23.7 & $W$ & $W$ & - & 68.5 \\
\hline 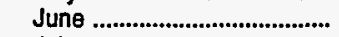 & $5,421.0$ & $W$ & $w$ & $W$ & $5,782.8$ & $40,585.8$ & - & $w$ & $\ddot{w}$ & $w$ & - & 1.7 \\
\hline 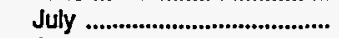 & $5,527.3$ & $5,809.7$ & $w$ & $w$ & $W$ & W & - & - & $w$ & $\ddot{W}$ & $w$ & $\dddot{w}$ \\
\hline 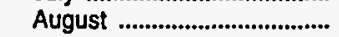 & $5,371.4$ & $W$ & W & $\ddot{w}$ & $4,421.0$ & w & - & $w$ & $w$ & $w$ & - & $\ddot{w}$ \\
\hline September .............................. & $W$ & $W$ & $15,728.4$ & W & W & $36,293.4$ & $w$ & $w$ & $2,259.9$ & $W$ & $w$ & $3,212.0$ \\
\hline 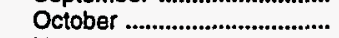 & $\dddot{w}$ & $\dddot{w}$ & $8,563.4$ & w & $w$ & $24,798.5$ & $w$ & $w$ & $9,903.7$ & $w$ & $\dddot{W}$ & $13,968.6$ \\
\hline November ............................... & $2,899.5$ & $3,023.0$ & $W$ & $9,536.4$ & $w$ & $14,441.2$ & $W$ & $2,248.2$ & $13,719.5$ & $W$ & $w$ & $19,952.7$ \\
\hline 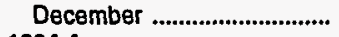 & W & W & $W$ & $5,730.1$ & $W$ & $7,950.1$ & 313.4 & 334.1 & $w$ & 307.8 & $W$ & 790.4 \\
\hline 1994 Average & $3,943.0$ & $4,156.9$ & $10,942.0$ & $12,396.1$ & $3,576.8$ & $26,914.9$ & 892.4 & 967.9 & $5,720.0$ & $1,914.5$ & 465.1 & $8,099.7$ \\
\hline \multicolumn{13}{|l|}{ Delaware } \\
\hline 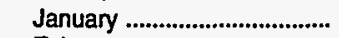 & $w$ & 17.4 & 202.8 & 345.9 & - & 548.7 & W & $w$ & $w$ & 72.7 & - & 155.1 \\
\hline February .................................. & w & $w$ & W & $W$ & $w$ & W & W & w & $w$ & 75.2 & - & W \\
\hline 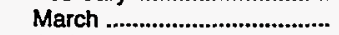 & $w$ & $w$ & 326.8 & $w$ & $w$ & $w$ & - & - & - & W & - & w \\
\hline 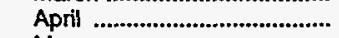 & $w$ & $w$ & 343.2 & 511.5 & $w$ & $w$ & - & - & - & $\ddot{w}$ & - & $\ddot{w}$ \\
\hline 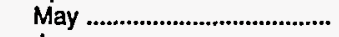 & W & $W$ & 343.4 & 492.5 & $w$ & $w$ & - & - & - & $w$ & - & W \\
\hline 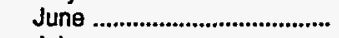 & W & 38.8 & 353.6 & $w$ & w & 950.0 & - & - & - & - & - & - \\
\hline 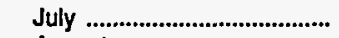 & W & 41.3 & $W$ & 445.8 & $w$ & 857.0 & - & - & - & - & - & - \\
\hline 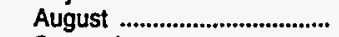 & 34.6 & $W$ & $w$ & 505.5 & $w$ & 886.5 & - & - & - & - & - & - \\
\hline September .............................. & 26.9 & 36.4 & $w$ & 552.9 & $w$ & 981.8 & - & - & - & - & - & - \\
\hline 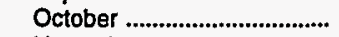 & W & $W$ & 301.1 & $W$ & W & 863.2 & $w$ & $w$ & $w$ & $w$ & - & 77.5 \\
\hline 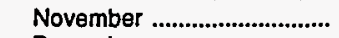 & 24.1 & w & 299.3 & $w$ & W & 696.1 & - & $w$ & w & $\ddot{w}$ & - & $w$ \\
\hline 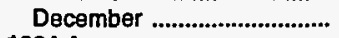 & - & - & W & $w$ & - & W & - & - & - & $\ddot{W}$ & - & $\ddot{w}$ \\
\hline 1994 Average ........................... & 23.5 & 30.8 & 288.1 & 423.7 & $\mathbf{w}$ & 763.5 & $\mathbf{w}$ & $\mathbf{w}$ & $W$ & 24.4 & - & 46.4 \\
\hline \multicolumn{13}{|l|}{ District of Columbia } \\
\hline 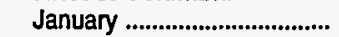 & - & - & - & $W$ & - & $w$ & - & W & 339.5 & - & - & 339.5 \\
\hline February ................................... & - & - & - & $W$ & - & $W$ & - & $W$ & $W$ & - & - & W \\
\hline 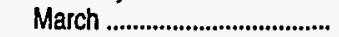 & - & $W$ & 398.6 & $W$ & - & $w$ & - & - & $w$ & - & - & $w$ \\
\hline April & - & $w$ & $w$ & $w$ & - & 415.1 & - & - & - & - & - & - \\
\hline 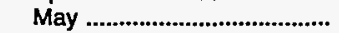 & - & w & $w$ & $w$ & - & 410.2 & - & - & - & - & - & - \\
\hline 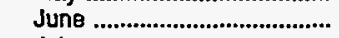 & - & 5.8 & $w$ & $w$ & - & 395.2 & - & - & - & - & - & - \\
\hline 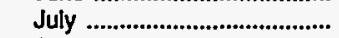 & - & 7.3 & 387.7 & - & - & 387.7 & - & - & - & - & - & - \\
\hline August & - & $w$ & 374.5 & - & - & 374.5 & - & - & - & - & - & - \\
\hline September ............................ & - & 9.4 & 381.2 & - & - & 381.2 & - & - & - & - & - & - \\
\hline 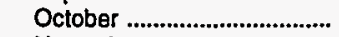 & - & $w$ & 305.6 & - & - & 305.6 & - & $w$ & 76.4 & - & - & 76.4 \\
\hline November .............................. & - & - & - & - & - & - & - & 15.1 & $w$ & - & - & $w$ \\
\hline 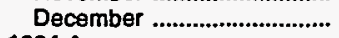 & - & - & - & - & - & - & - & $w$ & - & - & - & - \\
\hline 1994 Average ............................... & - & 5.9 & 257.1 & $\mathbf{W}$ & - & 257.8 & - & 3.5 & 91.5 & - & - & 91.5 \\
\hline
\end{tabular}

See footnotes at end of table. 
Table 44. Refiner Motor Gasoline Volumes by Formulation, Sales Type,

PAD District, and State

(Thousand Gallons per Day) - Continued

\begin{tabular}{|c|c|c|c|c|c|c|c|c|c|c|c|c|}
\hline \multirow{3}{*}{$\begin{array}{l}\text { Geographlc Area } \\
\text { Month }\end{array}$} & \multicolumn{6}{|c|}{ Reformulated } & \multicolumn{6}{|c|}{ All Formulations } \\
\hline & \multicolumn{2}{|c|}{ Sales to End Users } & \multicolumn{4}{|c|}{ Sales for Resale } & \multicolumn{2}{|c|}{ Sales to End Users } & \multicolumn{4}{|c|}{ Sales for Resale } \\
\hline & $\begin{array}{c}\text { Through } \\
\text { Retail } \\
\text { Outlets }\end{array}$ & Totala & DTW & Rack & Bulk & Total & $\begin{array}{l}\text { Through } \\
\text { Retali } \\
\text { Outlets }\end{array}$ & Totala & DTW & Rack & Bulk & Total \\
\hline
\end{tabular}

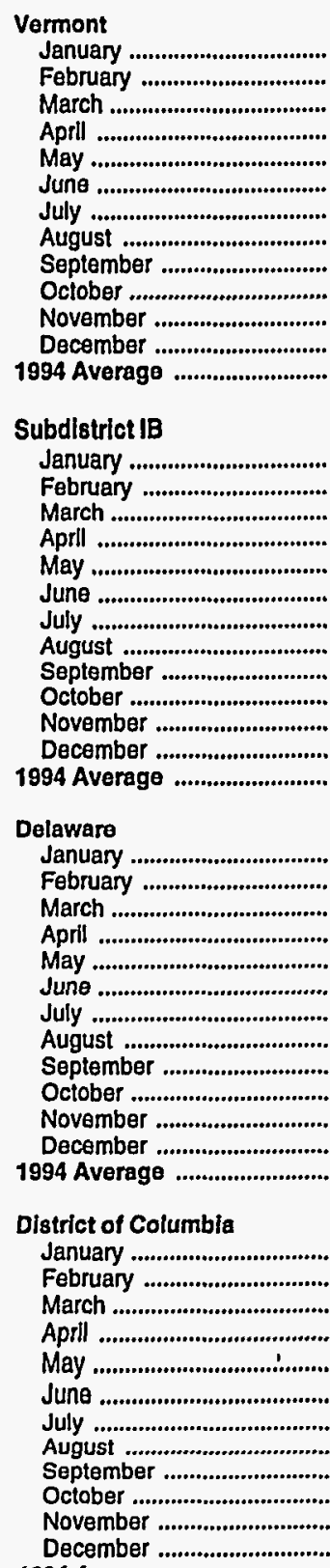

\begin{tabular}{|c|c|c|}
\hline- & - & - \\
\hline - & - & - \\
\hline - & - & - \\
\hline - & - & - \\
\hline - & - & - \\
\hline - & - & - \\
\hline - & - & - \\
\hline - & - & - \\
\hline $\bar{z}$ & $\bar{z}$ & $\bar{z}$ \\
\hline$\overline{-}$ & - & - \\
\hline & - & $w$ \\
\hline - & - & W \\
\hline
\end{tabular}

\begin{tabular}{|c|c|c|}
\hline- & - & - \\
\hline- & - & - \\
\hline- & - & - \\
\hline - & - & - \\
\hline - & - & - \\
\hline - & - & - \\
\hline- & - & - \\
\hline - & - & - \\
\hline- & - & - \\
\hline- & - & - \\
\hline $\bar{w}$ & - & $\bar{w}$ \\
\hline $\begin{array}{l}W \\
w\end{array}$ & - & W \\
\hline 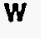 & - & $w$ \\
\hline
\end{tabular}

$\begin{array}{ll}- & w \\ \overline{-} & w \\ \overline{-} & w \\ \overline{-} & w \\ \overline{-} & w \\ \overline{-} & \end{array}$

$\begin{array}{lr}W & 64.5 \\ W & 65.1 \\ W & 62.3 \\ W & W \\ W & W \\ W & 67.3 \\ W & 72.5 \\ W & 73.9 \\ w & 68.5 \\ W & W \\ - & 60.7 \\ \bar{w} & 63.1 \\ & 65.5\end{array}$

$\begin{array}{rrrr}64.5 & 135.2 & - & 199.8 \\ 65.1 & 134.7 & - & 199.9 \\ 62.3 & 122.9 & - & 185.1 \\ W & W & - & 149.9 \\ W & W & - & 169.1 \\ 67.3 & 128.0 & - & 195.3 \\ 72.6 & 166.5 & - & 239.2 \\ 73.9 & 158.1 & - & 232.1 \\ 68.6 & 136.0 & - & 204.6 \\ W & W & - & 210.0 \\ 60.7 & 132.0 & - & 192.7 \\ 63.1 & 150.3 & - & 213.5 \\ 65.5 & 133.9 & - & 199.4\end{array}$

Subdlstrict IB

January

February

Aprll

May

July ...

September ...............................

December

\begin{tabular}{|c|c|c|c|}
\hline - & - & - & - \\
\hline - & - & - & - \\
\hline & - & - & - \\
\hline - & - & - & - \\
\hline- & - & - & - \\
\hline- & - & - & - \\
\hline$\overline{-}$ & I & $\bar{z}$ & $=$ \\
\hline & - & - & - \\
\hline & - & $\bar{w}$ & $\bar{w}$ \\
\hline$w$ & $w$ & $w$ & $9,911.1$ \\
\hline 15.2 & 263.4 & $1,490.7$ & 914.1 \\
\hline
\end{tabular}

\begin{tabular}{|c|c|c|}
\hline- & - & $4,558.2$ \\
\hline & - & $4,735.6$ \\
\hline & & $4,885.8$ \\
\hline & & $5,113.6$ \\
\hline & & $5,231.2$ \\
\hline & & $5,421.0$ \\
\hline & & $5,527.3$ \\
\hline & & $5,371.4$ \\
\hline & & $5,040.7$ \\
\hline & & $5,008.8$ \\
\hline & $3,384.2$ & $4,976.6$ \\
\hline $\begin{array}{c}W \\
538.6\end{array}$ & $\begin{array}{r}31,380.6 \\
2,943.4\end{array}$ & $\begin{array}{l}5,070.9 \\
5,080.6\end{array}$ \\
\hline
\end{tabular}

\begin{tabular}{|l|l|l|}
\hline $4,860.4$ & $16,270.0$ & $13,401.8$ \\
\hline $5,066.1$ & $17,108.9$ & $13,687.4$ \\
\hline $5,222.0$ & $17,933.2$ & $13,873.7$ \\
\hline $5,415.4$ & $18,477.6$ & $14,626.9$ \\
\hline $5,540.4$ & $18,681.3$ & $15,066.5$ \\
\hline $5,731.9$ & $19,018.4$ & $15,786.3$ \\
\hline $5,809.7$ & $18,630.1$ & $15,861.4$ \\
\hline $5,709.9$ & $18,558.4$ & $16,308.9$ \\
\hline $5,330.1$ & $17,988.3$ & $15,934.3$ \\
\hline $5,292.7$ & $18,467.2$ & $16,116.3$ \\
\hline $5,294.1$ & $18,135.7$ & $15,981.6$ \\
\hline $5,362.6$ & $18,495.1$ & $15,949.0$ \\
\hline $5,388.3$ & $18,152.7$ & $15,224.7$
\end{tabular}

$3,625.3 \quad 33,297.1$

$4,069.5 \quad 34,865.8$

$4,325.5 \quad 36,132.4$

$4,653.3 \quad 37,757.9$

$4,971.1 \quad 38,718.9$

$5,782.8 \quad 40,587.5$

$4,007.2 \quad 38,498.7$

$4,421.0 \quad 39,288.4$

$5,582.8 \quad 39,505.4$

$4,183.7 \quad 38,767.1$

$3,660.8 \quad 37,778.1$

$5,677.0 \quad 40,121.1$

Delaware

January .....................................

March

April

July

August ...................................

September .............................

$\begin{array}{rrrrrrr}- & - & - & - & - & - & W \\ - & - & - & - & - & - & W \\ - & - & - & - & - & - & W \\ - & - & - & - & - & - & W \\ - & - & - & - & - & - & W \\ - & - & - & - & - & - & W \\ - & - & - & - & - & - & W \\ - & - & - & - & - & - & 34 . \\ - & - & - & - & - & - & 26.9 \\ - & - & W & - & - & - & 31.1 \\ 28.7 & 36.3 & 325.1 & W & W & 972.6 & 28.7 \\ 2.4 & 3.1 & 27.7 & 39.5 & W & 827 & 27.0\end{array}$

$\begin{array}{lrrrrr}W & 23.9 & 285.3 & 418.5 & - & 703.8 \\ W & W & 308.9 & W & W & 846.4 \\ W & W & 326.8 & W & W & 825.8 \\ W & W & 343.2 & W & W & 982.4 \\ W & W & 343.4 & W & W & 869.7 \\ W & 38.8 & 353.6 & W & W & 950.0 \\ W & 41.3 & W & 445.8 & W & 857.0 \\ 34.6 & W & W & 505.5 & W & 886.5 \\ 26.9 & 36.4 & W & 552.9 & W & 981.8 \\ 31.1 & 38.4 & W & 541.1 & W & 940.6 \\ 24.1 & 32.8 & W & 461.4 & W & 833.3 \\ 28.7 & 36.3 & W & 500.2 & W & 1,035.7 \\ 27.0 & 35.0 & 337.9 & 487.5 & W & 892.7\end{array}$

1994 Average

$\begin{array}{lllllll}- & - & - & - & - & - & - \\ - & - & - & - & - & - & - \\ - & - & - & - & - & - & - \\ - & - & - & - & - & - & - \\ - & - & - & - & - & - & - \\ - & - & - & - & - & - & - \\ - & - & - & - & - & - & - \\ - & - & - & - & - & - & - \\ - & - & - & - & - & - & - \\ - & - & - & - & - & - & 384.6\end{array}$

\begin{tabular}{lrrrrr}
- & $W$ & 339.5 & $W$ & - & 340.9 \\
- & $W$ & $W$ & $W$ & - & 377.4 \\
- & $W$ & $W$ & $W$ & - & 400.3 \\
- & $W$ & $W$ & $W$ & - & 415.1 \\
- & $W$ & $W$ & $W$ & - & 410.2 \\
- & 5.8 & $W$ & $W$ & - & 395.2 \\
- & 7.3 & 387.7 & - & - & 387.7 \\
- & $W$ & 374.5 & - & - & 374.5 \\
- & 9.4 & 381.2 & - & - & 381.2 \\
- & 8.8 & 382.1 & - & - & 382.1 \\
- & 15.1 & 335.9 & - & - & 335.9 \\
- & 13.6 & 384.6 & - & - & 384.6 \\
- & 9.9 & 381.5 & $W$ & - & 382.1 \\
\hline
\end{tabular}

See footnotes at end of table. 
Table 44. Refiner Motor Gasoline Volumes by Formulation, Sales Type, PAD District, and State

(Thousand Gallons per Day) - Continued

\begin{tabular}{|c|c|c|c|c|c|c|c|c|c|c|c|c|}
\hline \multirow{3}{*}{$\begin{array}{l}\text { Geographic Area } \\
\text { Month }\end{array}$} & \multicolumn{6}{|c|}{ Conventional } & \multicolumn{6}{|c|}{ Oxygenated } \\
\hline & \multicolumn{2}{|c|}{ Sales to End Users } & \multicolumn{4}{|c|}{ Sales for Resale } & \multicolumn{2}{|c|}{ Sales to End Users } & \multicolumn{4}{|c|}{ Sales for Resale } \\
\hline & $\begin{array}{c}\text { Through } \\
\text { Retall } \\
\text { Outlets }\end{array}$ & Totala & DTW & Rack & Bulk & Total & $\begin{array}{c}\text { Through } \\
\text { Retail } \\
\text { Outlets }\end{array}$ & Totala & DTW & Rack & Bulk & Total \\
\hline \multicolumn{13}{|l|}{ Maryland } \\
\hline January ................................... & - & 3.0 & 35.3 & 384.7 & - & 420.1 & $w$ & 58.9 & $3,030.2$ & $1,041.7$ & - & $4,071.9$ \\
\hline February ................................ & - & 3.8 & W & $W$ & $W$ & 465.4 & $w$ & 68.1 & $3,193.9$ & W & W & $4,168.5$ \\
\hline 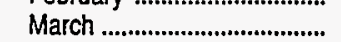 & $w$ & $W$ & $\ddot{W}$ & $1,509.7$ & $\ddot{W}$ & $4,931.5$ & W & $W$ & 53.6 & 4.0 & - & 57.6 \\
\hline April ......................................... & $W$ & 65.5 & $W$ & $1,607.3$ & $W$ & $5,142.6$ & - & - & - & - & - & - \\
\hline 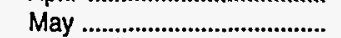 & w & 64.8 & $3,443.8$ & $W$ & $\ddot{w}$ & $W$ & - & - & $w$ & $w$ & - & $w$ \\
\hline June & $w$ & $W$ & W & $1,895.7$ & $w$ & $5,544.9$ & - & $w$ & - & - & - & - \\
\hline July & $\ddot{w}$ & 52.6 & $w$ & $1,814.2$ & $\ddot{w}$ & $5,417.3$ & - & - & - & - & - & - \\
\hline August & $\because$ & 89.0 & $w$ & $1,898.9$ & $w$ & $5,524.8$ & - & - & - & - & - & - \\
\hline 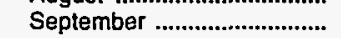 & - & 66.6 & w & W & w & $W$ & - & - & $w$ & W & - & $w$ \\
\hline 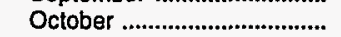 & - & 51.7 & $2,677.7$ & $w$ & w & $4,343.8$ & - & 6.4 & $\ddot{w}$ & W & - & $1,259.9$ \\
\hline November ............................... & - & $W$ & $W$ & 567.0 & $\ddot{w}$ & 676.6 & - & $W$ & $3,132.0$ & $w$ & $w$ & $4,252.1$ \\
\hline 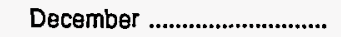 & - & $W$ & NA & $W$ & $w$ & $w$ & - & $W$ & $W$ & W & W & W \\
\hline 1994 Average & $w$ & 45.1 & $2,240.4$ & $1,308.8$ & 113.1 & $3,662.3$ & $w$ & 16.6 & 872.2 & 282.0 & $\ddot{w}$ & $1,162.6$ \\
\hline \multicolumn{13}{|l|}{ New Jersey } \\
\hline 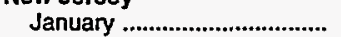 & - & - & - & 59.5 & $1,319.5$ & $1,379.0$ & $1,011.6$ & $1,078.4$ & $4,362.5$ & $2,127.9$ & 793.2 & $7,283.6$ \\
\hline 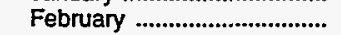 & - & - & - & 118.5 & $1,368.9$ & $1,487.3$ & $1,043.3$ & $1,119.0$ & $4,551.0$ & $2,068.2$ & 769.5 & $7,388.7$ \\
\hline 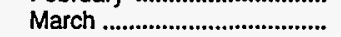 & 323.3 & 329.0 & $1,079.0$ & 663.4 & $1,757.4$ & $3,499.8$ & 783.5 & 857.4 & $3,710.0$ & $1,336.3$ & 609.5 & $5,655.7$ \\
\hline 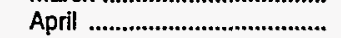 & 418.9 & 464.7 & $1,147.7$ & $W$ & W & $3,443.1$ & 740.2 & 767.3 & $3,863.5$ & W & $W$ & $5,814.1$ \\
\hline 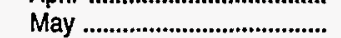 & W & $W$ & W & $\ddot{w}$ & $2,311.1$ & $9,425.7$ & $W$ & $W$ & W & $w$ & - & 50.8 \\
\hline 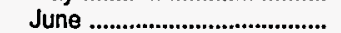 & $1,209.9$ & $W$ & W & $w$ & $2,683.5$ & W & - & $W$ & $w$ & W & - & $w$ \\
\hline 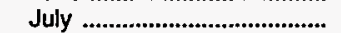 & $1,279.8$ & $1,342.6$ & $w$ & $w$ & W & $\ddot{w}$ & - & - & $w$ & W & W & $w$ \\
\hline August & $1,264.5$ & $1,327.7$ & $5,050.0$ & $2,287.5$ & $2,538.3$ & $9,875.8$ & - & - & - & - & - & - \\
\hline September ............................ & $W$ & W & $3,714.3$ & $W$ & $W$ & $9,272.5$ & $w$ & $w$ & $1,102.5$ & $w$ & $w$ & $1,747.7$ \\
\hline 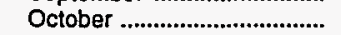 & 538.5 & 571.3 & 735.9 & 608.1 & $1,724.6$ & $3,068.7$ & 609.6 & 643.9 & $4,161,6$ & $1,841.4$ & 373.7 & $6,376.7$ \\
\hline November ............................... & - & - & - & $w$ & $W$ & 674.1 & $1,136.7$ & $1,206.6$ & $w$ & $2,955.2$ & $W$ & $7,987.4$ \\
\hline 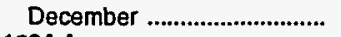 & - & - & - & - & W & 129.9 & W & 203.4 & 2.8 & W & $W$ & 122.4 \\
\hline 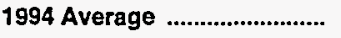 & 602.8 & 637.7 & $2,254.9$ & $1,121.9$ & $1,777.2$ & $5,153.9$ & 468.3 & 497.5 & $2,172.4$ & $1,019.8$ & 309.5 & $3,501.8$ \\
\hline \multicolumn{13}{|l|}{ New York } \\
\hline 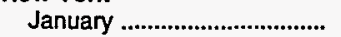 & $1,237.9$ & $1,269.5$ & $1,379.9$ & $3,483.4$ & W & $5,055.5$ & 526.1 & 575.5 & $3,825.2$ & 757.5 & $w$ & $4,808.9$ \\
\hline 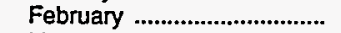 & $1,260.4$ & $1,293.5$ & $1,417.0$ & $w$ & $w$ & $5,260.6$ & 517.6 & 570.8 & $3,917.8$ & $w$ & $w$ & $4,829.4$ \\
\hline March & $1,268.9$ & $1,305.3$ & W & 3.405 .6 & $w$ & $5,101.2$ & 519.1 & 572.1 & W & $W$ & $w$ & $5,117.7$ \\
\hline 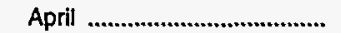 & $1,272.7$ & $1,322.2$ & $1,444.3$ & $W$ & $w$ & $5,120.9$ & 568.1 & 596.5 & $4,259.1$ & $w$ & $w$ & $5,247.3$ \\
\hline 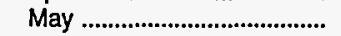 & $W$ & $1,960.4$ & $W$ & $w$ & 395.0 & $10,772.8$ & $W$ & 14.8 & W & w & - & 17.0 \\
\hline June ......................................... & $2,018.3$ & $2,108.0$ & $5,974.5$ & W & 271.0 & W & - & - & - & $w$ & - & $w$ \\
\hline July ........................................... & $2,078.7$ & $2,164.0$ & $5,859.0$ & $4,825.4$ & 415.9 & $11,100.3$ & - & - & - & - & - & - \\
\hline 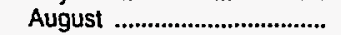 & $1,994.5$ & $w$ & $W$ & $W$ & 405.3 & W & - & $w$ & W & W & - & W \\
\hline 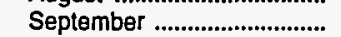 & $1,763.4$ & $1,832.7$ & $\dddot{w}$ & $4,383.4$ & $W$ & $9,151.6$ & 120.5 & 127.5 & $\ddot{w}$ & 176.9 & $w$ & $1,428.1$ \\
\hline 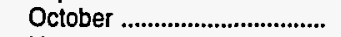 & $1,261.4$ & $1,311.7$ & $1,476.1$ & W & $W$ & $5,347.8$ & 577.1 & 607.6 & $4,234.3$ & $W$ & $w$ & $5,462.7$ \\
\hline 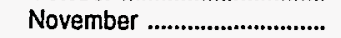 & $1,273.4$ & $1,321.4$ & $w$ & $3,596.0$ & W & $5,093.4$ & 555.1 & W & $3,962.0$ & W & W & $4,682.4$ \\
\hline December ................................. & W & $1,032.0$ & 702.6 & $2,914.1$ & 53.8 & $3,670.4$ & $W$ & 54.1 & 12.6 & 8.2 & - & 20.8 \\
\hline 1994 Average & $1,527.7$ & $1,585.3$ & $3,108.4$ & $3,956.7$ & 266.0 & $7,331.1$ & 285.3 & 306.4 & $2,109.2$ & 411.1 & $w$ & $2,614.3$ \\
\hline \multicolumn{13}{|l|}{ Pennsylvania } \\
\hline January ................................. & $1,368.6$ & $1,428.1$ & $1,444.7$ & $4,654.2$ & 738.9 & $6,837.9$ & 392.9 & 415.5 & $1,567.4$ & 472.8 & $w$ & $2,395.5$ \\
\hline 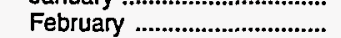 & $1,507.9$ & $1,562.4$ & $1,590.1$ & $W$ & $W$ & $7,598.5$ & 389.8 & 418.8 & $1,720.6$ & $W$ & $w$ & $2,443.5$ \\
\hline 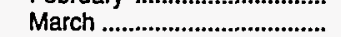 & $W$ & W & W & $w$ & $1,383.5$ & $10,538.0$ & $W$ & $W$ & $W$ & $w$ & - & $\begin{array}{r}2,470.5 \\
4.7\end{array}$ \\
\hline April & $w$ & $w$ & $3,582.9$ & $w$ & $1,982.1$ & $W$ & $w$ & $W$ & - & $w$ & - & W \\
\hline 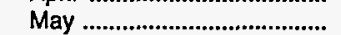 & $2,176.9$ & $w$ & $3,611.9$ & $6,054.2$ & $2,118.6$ & $11,784.7$ & - & $w$ & - & - & - & - \\
\hline 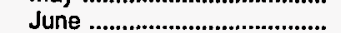 & $2,160.4$ & $2,230.7$ & $3,709.9$ & $6,377.7$ & $2,534.1$ & $12,621.6$ & - & - & - & - & - & - \\
\hline 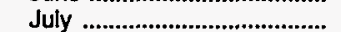 & $2,133.3$ & $2,201.8$ & $3,571.6$ & $6,254.0$ & $1,623.8$ & $11,449.4$ & - & - & - & - & - & - \\
\hline August & $2,077.8$ & $W$ & $3,590.1$ & $6,718.2$ & $1,199.8$ & $11,508.1$ & - & $w$ & - & - & - & - \\
\hline 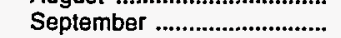 & $1,960.8$ & $2,026.6$ & $3,486.1$ & $W$ & $1,168.2$ & $W$ & - & - & - & $\bar{w}$ & - & $\bar{w}$ \\
\hline 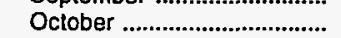 & $1,876.5$ & $1,936.9$ & $3,067.0$ & $6,361,4$ & $1,441.1$ & $10,869.5$ & 114.6 & 116.1 & 463.4 & 252.0 & - & 715.4 \\
\hline 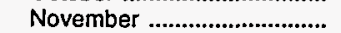 & $1,602.0$ & $1,661.9$ & $1,592.4$ & $4,956.2$ & 752.4 & $7,301.0$ & $w$ & $W$ & $w$ & 778.4 & $w$ & $2,561.3$ \\
\hline 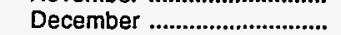 & 886.7 & 913.8 & 723.1 & $W$ & W & $3,607.2$ & 56.7 & 57.8 & $w$ & $w$ & $\underline{-}$ & 239.3 \\
\hline 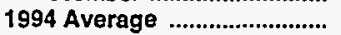 & $1,788.4$ & $1,852.1$ & $2,793.2$ & $5,584.3$ & $1,368.8$ & $9,746.3$ & 136.8 & 142.8 & 452.5 & 177.2 & $w$ & 682.9 \\
\hline
\end{tabular}

See footnotes at end of table. 
Table 44. Refiner Motor Gasoline Volumes by Formulation, Sales Type, PAD District, and State

(Thousand Gallons per Day) - Continued

\begin{tabular}{|c|c|c|c|c|c|c|c|c|c|c|c|c|}
\hline \multirow{3}{*}{$\begin{array}{l}\text { Geographic Area } \\
\text { Month }\end{array}$} & \multicolumn{6}{|c|}{ Reformulated } & \multicolumn{6}{|c|}{ All Formulations } \\
\hline & \multicolumn{2}{|c|}{ Sales to End Users } & \multicolumn{4}{|c|}{ Sales for Resale } & \multicolumn{2}{|c|}{ Sales to End Users } & \multicolumn{4}{|c|}{ Sales for Resale } \\
\hline & $\begin{array}{c}\text { Through } \\
\text { Retall } \\
\text { Outlets }\end{array}$ & Totala & DTW & Rack & Bulk & Total & $\begin{array}{c}\text { Through } \\
\text { Retail } \\
\text { Outlets } \\
\end{array}$ & Totala & DTW & Rack & Bulk & Total \\
\hline \multicolumn{13}{|l|}{ Maryland } \\
\hline January .......................................... & - & - & - & - & - & - & w & 61.9 & $3,065.5$ & $1,426.5$ & - & $4,492.0$ \\
\hline 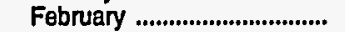 & - & - & - & - & - & - & w & 71.9 & $w$ & $1,323.4$ & w & $4,633.9$ \\
\hline March ..... & - & - & - & - & - & - & w & 71.1 & w & $1,513.7$ & w & $4,989.2$ \\
\hline ................. & - & - & - & - & - & - & w & 65.5 & w & $1,607.3$ & w & $5,142.6$ \\
\hline .................. & - & - & - & - & - & - & $w$ & 64.8 & $w$ & $1,831.2$ & $w$ & $5,388.0$ \\
\hline .................. & - & - & - & - & - & - & w & 60.8 & $w$ & $1,895.7$ & $w$ & $5,544.9$ \\
\hline ………....... & - & - & - & - & - & - & W & 52.6 & w & $1,814.2$ & W & $5,417.3$ \\
\hline August .. & - & - & - & - & - & - & - & 89.0 & $w$ & $1,898.9$ & $w$ & $5,524.8$ \\
\hline 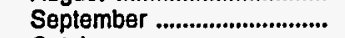 & - & - & - & - & - & - & - & 66.6 & $w$ & $1,851.8$ & $w$ & $5,383.4$ \\
\hline October ......................................... & - & - & - & - & - & - & - & 58.1 & $w$ & $1,872.9$ & $w$ & $5,603.7$ \\
\hline November .................................. & - & - & w & w & w & 485.9 & - & 65.4 & $3,414.4$ & $1,750.6$ & 249.7 & $5,414.6$ \\
\hline December .................................. & - & 42.9 & $3,050.6$ & $w$ & $w$ & $4,284.0$ & - & 56.4 & $w$ & 1.549 .0 & $w$ & $5,171.4$ \\
\hline 1994 Average ................................. & - & 3.6 & 281.5 & 105.9 & $w$ & 403.8 & w & 65.3 & $3,394.1$ & $1,696.8$ & 137.9 & $5,228.7$ \\
\hline \multicolumn{13}{|l|}{ Now Jersey } \\
\hline 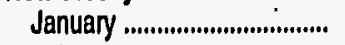 & - & - & - & - & - & - & $1,011.6$ & $1,078.4$ & $4,362.5$ & $2,187.5$ & $2,112.7$ & $8,662.6$ \\
\hline 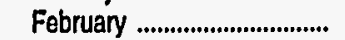 & - & - & - & - & - & - & $1,043.3$ & $1,119.0$ & $4,551.0$ & $2,186.6$ & $2,138.4$ & $8,876.0$ \\
\hline 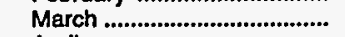 & - & - & - & - & - & - & $1,106.8$ & 1.186 .5 & $4,789.0$ & $1,999.6$ & $2,366.8$ & $9,155.5$ \\
\hline$\ldots$ & - & - & - & - & - & - & 9.1 & $1,232.0$ & 1.2 & 1 & & $9,257.2$ \\
\hline ...................................... & - & - & - & - & - & - & $1,130.9$ & $1,203.9$ & $5,050.8$ & $2,114.6$ & $2,311.1$ & $9,476.5$ \\
\hline 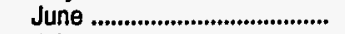 & - & - & - & - & - & - & $1,209.9$ & $1,287.9$ & 110.1 & $2,267.9$ & $2,683.5$ & $10,061.5$ \\
\hline 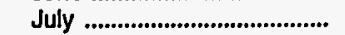 & - & - & - & - & - & - & $1,279.8$ & $1,342.6$ & 022.2 & $2,522.0$ & $1,742.9$ & $9,287.1$ \\
\hline August & - & - & - & - & - & - & $1,264.5$ & $1,327.7$ & 050.0 & $2,287.5$ & $2,538.3$ & $9,875.8$ \\
\hline 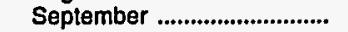 & - & - & - & - & - & - & $1,169.0$ & $1,230.9$ & 16.8 & $2,464.4$ & $3,739.0$ & $11,020.1$ \\
\hline ............................ & - & - & - & - & - & - & $1,148.1$ & $1,215.2$ & $4,897.5$ & & $2,098.3$ & $9,445.4$ \\
\hline 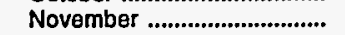 & - & - & w & w & 914.1 & $1,399.5$ & $1,136.7$ & $1,206.6$ & $4,891.2$ & $3,126.7$ & $2,043.1$ & $10,061.0$ \\
\hline December ............................... & $w$ & $1,051.2$ & 4.992 .7 & $W$ & $W$ & $11,526.4$ & 1.191 .9 & $1,254.6$ & $4,995.5$ & $2,739.2$ & $4,043.9$ & $\begin{array}{r}11,778.6 \\
0749.7\end{array}$ \\
\hline 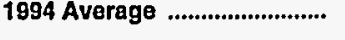 & & 89.3 & 453.5 & & & $1,094.0$ & $1,155.1$ & $1,224.4$ & $4,880.8$ & $2,377.5$ & $2,491.4$ & $9,749.7$ \\
\hline \multicolumn{13}{|l|}{ New York } \\
\hline January. & - & - & - & - & - & - & $1,764.0$ & $1,845.0$ & $5,205.1$ & $4,240.8$ & $w$ & $9,864.5$ \\
\hline 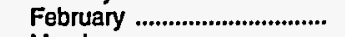 & - & - & - & - & - & - & $1,778.0$ & & & $4,224.0$ & 531.1 & $10,090.0$ \\
\hline March & - & - & - & - & - & - & $1,788.0$ & $1,877.5$ & 3 & $w$ & w & $10,218.9$ \\
\hline (...................... & - & - & - & - & - & - & $1,840.9$ & $1,918.6$ & 3.4 & w & $w$ & $10,368.3$ \\
\hline 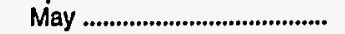 & - & - & - & - & - & - & $1,892.7$ & $1,975.2$ & 821.9 & $4,572.9$ & 395.0 & $10,789.8$ \\
\hline .................................... & - & - & - & - & - & - & $2,018.3$ & $2,108.0$ & 74.5 & 4,7 & 271.0 & $11,014.3$ \\
\hline 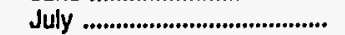 & - & - & - & - & - & - & $2,078.7$ & $2,164.0$ & & & 415.9 & $11,100.3$ \\
\hline 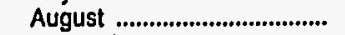 & - & - & - & - & - & - & $1,994.5$ & $2,083.0$ & 814.4 & $4,898.9$ & 405.3 & $11,118.5$ \\
\hline 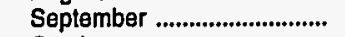 & - & - & - & - & - & - & 83.9 & $1,960.2$ & 7.2 & $4,560.4$ & 462.1 & $10,579.7$ \\
\hline 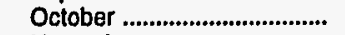 & - & - & - & - & - & - & $1,838.5$ & $1,919.3$ & $5,710.4$ & $4,639.3$ & 460.8 & $10,810.5$ \\
\hline 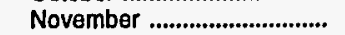 & - & w & w & w & - & 376.0 & $1,828.5$ & $1,908.8$ & w & $4,390.7$ & w & $10,151.8$ \\
\hline 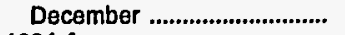 & 827.7 & 882.2 & $4,982.4$ & $1,852.5$ & 247.4 & $7,082.3$ & $1,884.9$ & $1,968.3$ & 697.6 & $4,774.8$ & 301.2 & $10,773.5$ \\
\hline 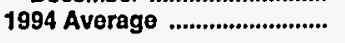 & 70.3 & 75.0 & 443.0 & 168.4 & 21.0 & 6324 & $1,883.3$ & $1,966.8$ & 660.6 & $4,536.2$ & 381.0 & $10,577.8$ \\
\hline \multicolumn{13}{|l|}{ Pennsylvania } \\
\hline 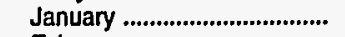 & - & - & - & - & - & - & $1,761.5$ & $1,843.7$ & $3,012.2$ & $5,127.1$ & $1,094.1$ & $9,233.3$ \\
\hline .............................. & - & - & - & - & - & - & & & & & 99.4 & 10.042 .0 \\
\hline 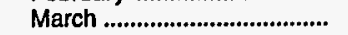 & - & - & - & - & - & - & & & & & & $10,542.7$ \\
\hline ............... & - & - & - & - & - & - & $2,084.9$ & $2,154.6$ & $3,582.9$ & $6,027.5$ & $1,982.1$ & $11,592.5$ \\
\hline May. & - & - & - & - & - & - & $2,176.9$ & $2,251.1$ & 1.9 & $6,054.2$ & $2,118.6$ & $11,784.7$ \\
\hline ....................................... & - & - & - & - & - & - & $2,160.4$ & $2,230.7$ & $3,709.9$ & $6,377.7$ & $2,534.1$ & $12,621.6$ \\
\hline July . & - & - & - & - & - & - & $2,133.3$ & $2,201.8$ & $3,571.6$ & $6,254.0$ & $1,623.8$ & $11,449.4$ \\
\hline August .. & - & - & - & - & - & - & $2,077.8$ & $2,153.4$ & $3,590.1$ & $6,718.2$ & 1.199 .8 & $11,508.1$ \\
\hline September ................. & - & - & - & - & - & - & $1,960.8$ & $2,026.6$ & $3,486.1$ & $6,504.9$ & $1,168.2$ & $11,159.2$ \\
\hline 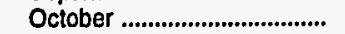 & - & - & - & - & - & - & $1,991.1$ & $2,053.0$ & $3,530.3$ & $6,613.4$ & $1,441.1$ & $11,584.8$ \\
\hline November ................... & w & w & W & 517.7 & w & $1,119.3$ & $1,987.3$ & $2,065.4$ & $3,498.2$ & $6,252.3$ & $1,231.1$ & $10,981.6$ \\
\hline December ..................................... & $1,022.0$ & $1,061.9$ & W & $3,791.0$ & W & $7,130.7$ & $1,965.5$ & $2,033.5$ & $3,584.9$ & $6,385.8$ & $1,006.5$ & $10,977.2$ \\
\hline 1994 Average .............................. & 88.5 & 92.0 & 252.1 & 364.5 & 81.0 & 697.6 & $2,013.7$ & $2,086.9$ & $3,497.8$ & $6,126.0$ & $1,503.1$ & $11,126.9$ \\
\hline
\end{tabular}

See footnotes at end of table. 
Table 44. Refiner Motor Gasoline Volumes by Formulation, Sales Type, PAD Dlstrict, and State

(Thousand Gallons per Day) - Continued

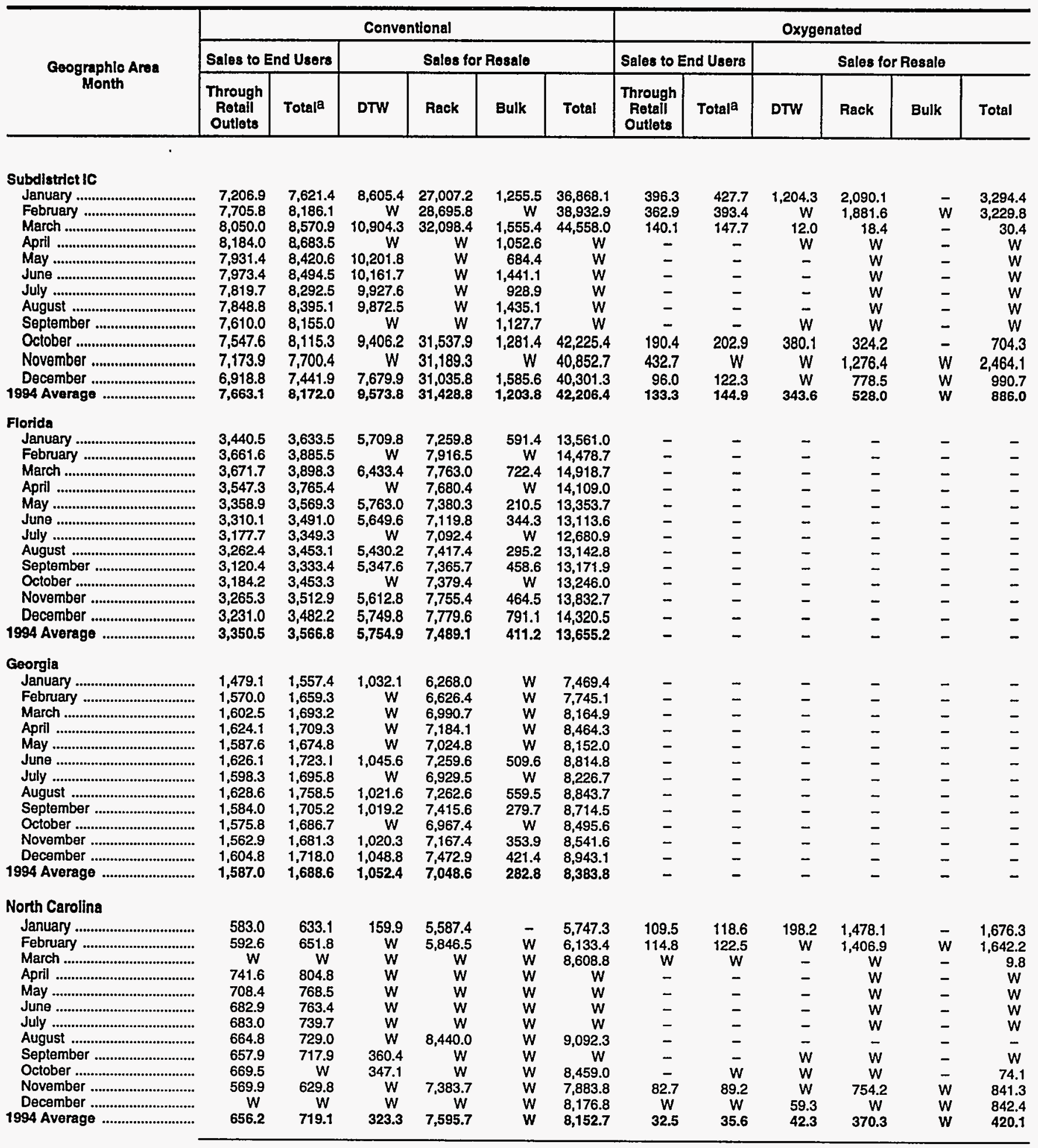

See footnotes at end of table. 
Table 44. Refiner Motor Gasoline Volumes by Formulation, Sales Type, PAD DIstrict, and State

(Thousand Gallons per Day) - Continued

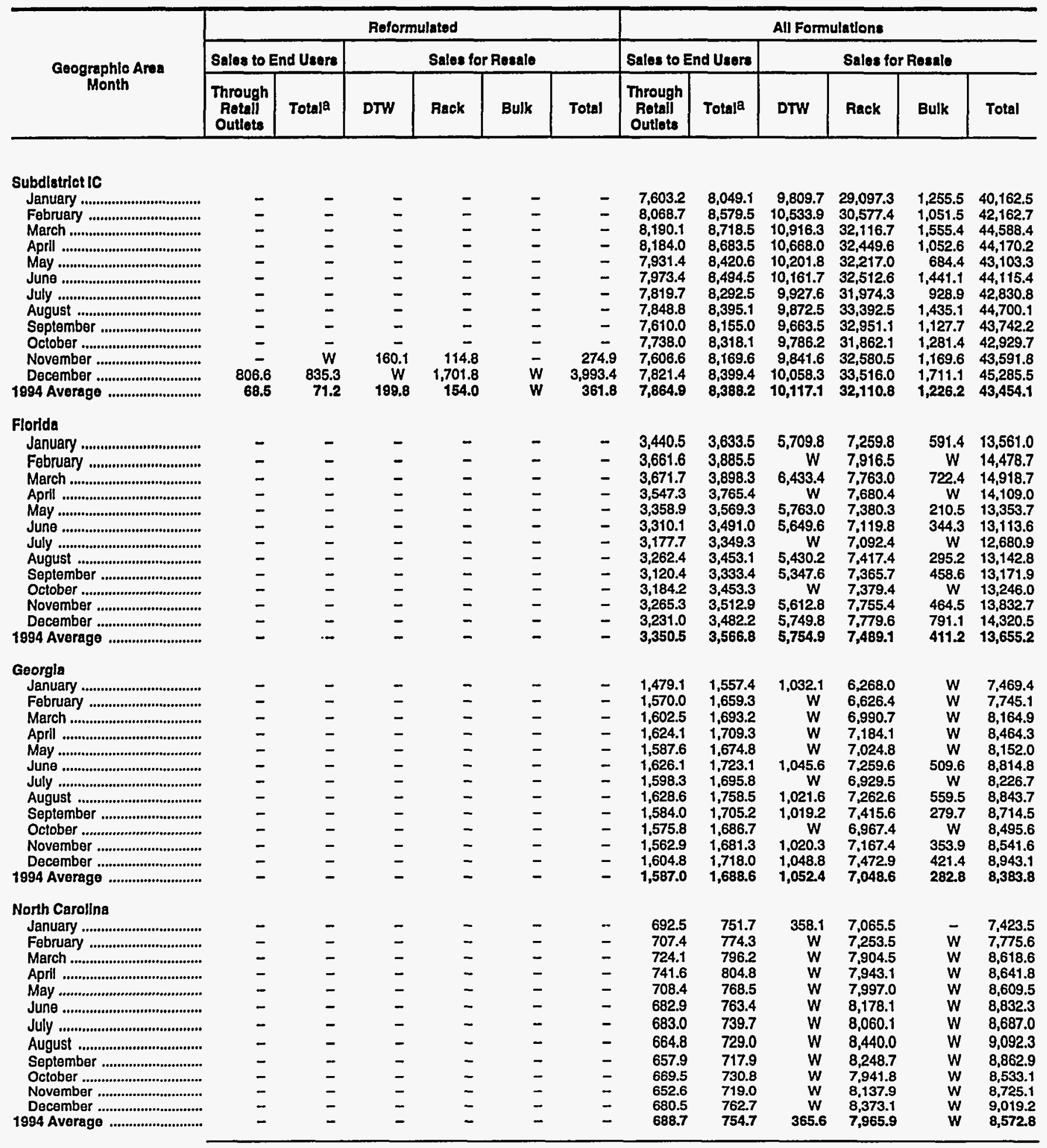

See footnotes at end of table. 
Table 44. Refiner Motor Gasoline Volumes by Formulation, Sales Type, PAD District, and State

(Thousand Gallons per Day) - Continued

\begin{tabular}{|c|c|c|c|c|c|c|c|c|c|c|c|c|}
\hline \multirow{3}{*}{$\begin{array}{l}\text { Geographle Area } \\
\text { Month }\end{array}$} & \multicolumn{6}{|c|}{ Conventional } & \multicolumn{6}{|c|}{ Oxygenated } \\
\hline & \multicolumn{2}{|c|}{ Sales to End Users } & \multicolumn{4}{|c|}{ Sales for Resale } & \multicolumn{2}{|c|}{ Sales to End Users } & \multicolumn{4}{|c|}{ Sales for Resale } \\
\hline & $\begin{array}{c}\text { Through } \\
\text { Retail } \\
\text { Outlets }\end{array}$ & Totala & DTW & Rack & Bulk & Total & $\begin{array}{c}\text { Through } \\
\text { Retall } \\
\text { Outlets }\end{array}$ & Totala & DTW & Rack & Bulk & Total \\
\hline \multicolumn{13}{|l|}{ South Carolina } \\
\hline 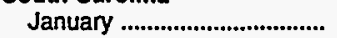 & 787.9 & 819.0 & 149.6 & $3,727.0$ & $\mathbf{W}$ & $4,361.0$ & - & - & - & - & - & - \\
\hline 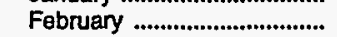 & 845.4 & 881.6 & $W$ & $3,723.2$ & 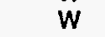 & $4,130.7$ & - & - & - & - & - & - \\
\hline 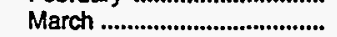 & 861.9 & 897.8 & $\dddot{w}$ & $3,975.7$ & w & $4,364.6$ & - & - & - & - & - & - \\
\hline 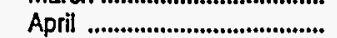 & 879.8 & 915.1 & 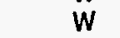 & $4,037.0$ & $\dddot{W}$ & $4,277.0$ & - & - & - & - & - & - \\
\hline Мау & 863.5 & 899.9 & $W$ & $3,940.6$ & $W$ & $4,161,6$ & - & - & - & - & - & - \\
\hline 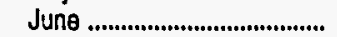 & 882.7 & 920.8 & $W$ & $4,029.9$ & $W$ & $4,278.6$ & - & - & - & - & - & - \\
\hline 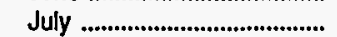 & 885.4 & 925.9 & $W$ & $4,036.4$ & $W$ & $4,278.3$ & - & - & - & - & - & - \\
\hline August & 862.8 & 906.2 & $w$ & $4,098.7$ & $w$ & $4,339.5$ & - & - & - & - & - & - \\
\hline 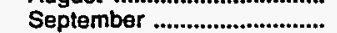 & 837.6 & 878.2 & $w$ & $3,945.9$ & $w$ & $4,158.1$ & - & - & - & - & - & - \\
\hline October & 842.1 & 883.1 & $w$ & $3,831.4$ & $w$ & $4,017.3$ & - & - & - & - & - & - \\
\hline 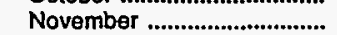 & 835.2 & 871.2 & $W$ & $3,821.5$ & $w$ & $3,979.4$ & - & - & - & - & - & - \\
\hline 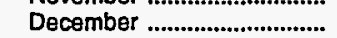 & 846.0 & 886.9 & $W$ & $W$ & $\dddot{W}$ & $4,205.6$ & - & - & - & - & - & - \\
\hline 1994 Average & 852.5 & 890.5 & 144.7 & $3,937.0$ & 132.1 & $4,213.8$ & - & - & - & - & - & - \\
\hline \multicolumn{13}{|l|}{ Virginia } \\
\hline January ................................... & 542.9 & 576.9 & $1,430.9$ & $3,621.3$ & - & $5,052.2$ & 286.7 & 309.1 & $1,006.2$ & 612.0 & - & $1,618.2$ \\
\hline 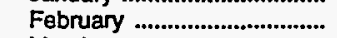 & 596.7 & 635.2 & $W$ & $3,975.6$ & $w$ & $5,669.8$ & 248.1 & 270.9 & $W$ & 474.7 & $w$ & $1,587.6$ \\
\hline 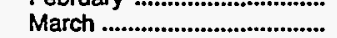 & $w$ & $W$ & $2,653.9$ & $W$ & $w$ & $7,509.5$ & $w$ & $W$ & $w$ & w & - & 20.5 \\
\hline April & 896.6 & 960.7 & $2,708.7$ & $4,864.4$ & $\ddot{w}$ & W & - & - & $\dddot{w}$ & - & - & $w$ \\
\hline 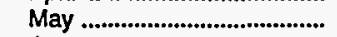 & 917.5 & 977.6 & $W$ & W & $w$ & $w$ & - & - & - & $w$ & - & $\dddot{w}$ \\
\hline 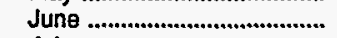 & 956.9 & $1,045.1$ & W & $5,150.9$ & $w$ & $8,116.1$ & - & - & - & 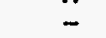 & - & - \\
\hline 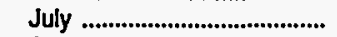 & 938.6 & $1,012.9$ & $W$ & $5,116.4$ & $W$ & $8,053.2$ & - & - & - & - & - & - \\
\hline 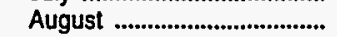 & 916.1 & 998.4 & $w$ & W & W & W & - & - & - & $w$ & - & $w$ \\
\hline 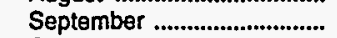 & 911.7 & 988.7 & $2,606.0$ & W & $W$ & $\ddot{w}$ & - & - & $w$ & $w$ & - & $w$ \\
\hline 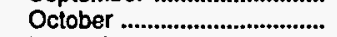 & 777.1 & W & $2,221.6$ & $\ddot{w}$ & $w$ & $7,115.1$ & 190.4 & $w$ & $w$ & $w$ & - & 630.2 \\
\hline 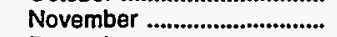 & 456.6 & 490.5 & $W$ & $4,316.5$ & $w$ & $5,729.6$ & 350.0 & w & $w$ & 522.2 & $w$ & $1,622.8$ \\
\hline 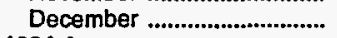 & W & $W$ & 351.9 & $3,362.4$ & $w$ & W & W & $w$ & w & $w$ & - & 148.3 \\
\hline 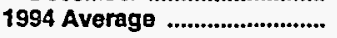 & 732.8 & 789.9 & $2,150.3$ & $4,638.7$ & 126.0 & $6,915.0$ & 100.8 & 109.3 & 301.3 & 157.8 & $\mathbf{w}$ & 465.9 \\
\hline \multicolumn{13}{|l|}{ West Virginia } \\
\hline 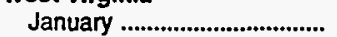 & 373.5 & 401.5 & 123.1 & 543.8 & $w$ & 677.3 & - & - & - & - & - & - \\
\hline 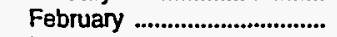 & 439.5 & 472.8 & $W$ & 607.5 & w & 775.2 & - & - & - & - & - & - \\
\hline 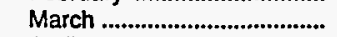 & 462.3 & 498.4 & W & $w$ & $w$ & 991.4 & - & - & - & - & - & - \\
\hline 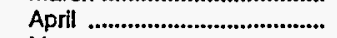 & 494.6 & 528.2 & $\ddot{w}$ & 740.6 & $\ddot{w}$ & 908.5 & - & - & - & - & - & - \\
\hline 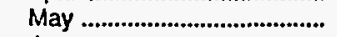 & 495.6 & 530.6 & $\ddot{W}$ & 772.7 & $w$ & 961.5 & - & - & - & - & - & - \\
\hline 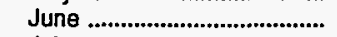 & 514.6 & 551.1 & $w$ & 774.4 & W & 960.1 & - & - & - & - & - & - \\
\hline July & 536.8 & 568.9 & 165.1 & 739.6 & - & 904.7 & - & - & - & - & - & - \\
\hline 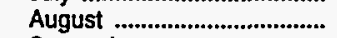 & 514.2 & 549.8 & 161.5 & 726.9 & - & 888.4 & - & - & - & - & - & - \\
\hline 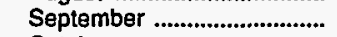 & 498.4 & 531.6 & $W$ & 686.7 & $w$ & 855.7 & - & - & - & - & - & - \\
\hline 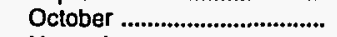 & 498.8 & 530.1 & $W$ & 746.4 & W & 892.4 & - & - & - & - & - & - \\
\hline November ............................... & 483.9 & 514.7 & 141.0 & 744.8 & - & 885.8 & - & - & - & - & - & - \\
\hline 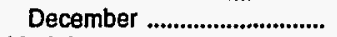 & 494.2 & 526.1 & 131.1 & $W$ & $W$ & W & - & - & - & - & - & - \\
\hline 1994 Average & 484.1 & 517.2 & 148.2 & 719.8 & $\mathbf{W}$ & 886.0 & - & - & - & - & - & - \\
\hline \multicolumn{13}{|l|}{ PAD District II } \\
\hline 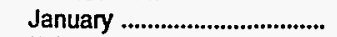 & $17,182.1$ & $17,836.0$ & $14,994.2$ & $47,076.1$ & $3,760.9$ & $65,831.2$ & $1,226.5$ & $1,245.7$ & $W$ & $1,104.5$ & $w$ & $1,511.4$ \\
\hline 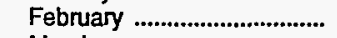 & $19,079.7$ & $19,827.7$ & W & $51,164.5$ & $w$ & $72,357.9$ & 263.1 & 265.5 & W & 462.2 & $w$ & 506.5 \\
\hline March & $W$ & $w$ & $16,044.3$ & W & W & $73,036.1$ & $w$ & $w$ & - & $W$ & $w$ & 472.8 \\
\hline April & $w$ & $W$ & $16,137.5$ & $54,706.1$ & $5,165.7$ & $76,009.2$ & $w$ & $w$ & - & 396.9 & - & 396.9 \\
\hline 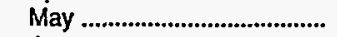 & $W$ & $W$ & $16,409.3$ & $55,935.3$ & $4,209.2$ & $76,553.8$ & W & $w$ & - & 418.1 & - & 418.1 \\
\hline June & $\dddot{w}$ & $w$ & $16,926.7$ & $58,666.2$ & $4,439.0$ & $80,031.9$ & W & w & - & 562.2 & - & 562.2 \\
\hline July & $\ddot{W}$ & $\ddot{w}$ & $16,482.6$ & $57,324.8$ & $4,342.0$ & $78,149.4$ & W & $\ddot{w}$ & - & 593.1 & - & 593.1 \\
\hline 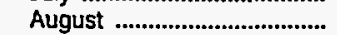 & $\ddot{W}$ & W & W & $W$ & $6,130.6$ & $80,774.7$ & w & w & $w$ & $w$ & - & 669.5 \\
\hline 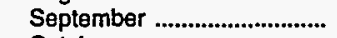 & $W$ & $w$ & w & $w$ & $6,368.9$ & $79,069.5$ & $\mathbf{W}$ & $\ddot{w}$ & 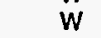 & $w$ & - & 560.6 \\
\hline 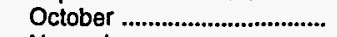 & $18,331.6$ & $19,001.1$ & $w$ & W & $5,784.3$ & $76,055.8$ & 993.0 & $1,011.2$ & $\ddot{W}$ & w & - & $1,620.5$ \\
\hline 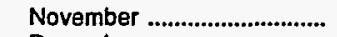 & $18,295.5$ & $18,928.4$ & $15,838.9$ & W & $W$ & W & $1,031.6$ & $1,049.1$ & $\dddot{w}$ & $w$ & - & $1,806.5$ \\
\hline 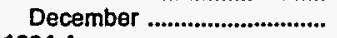 & $17,268.3$ & $17,864.7$ & W & $52,128.8$ & W & $70,070.0$ & $1,058.2$ & $1,080.5$ & $\dddot{w}$ & $\ddot{W}$ & - & $1,961.5$ \\
\hline 1994 Average .......................... & $18,967.4$ & $19,661.7$ & $15,800.4$ & $54,437.4$ & $5,004.4$ & $75,242.2$ & 461.8 & 468.6 & $w$ & 802.0 & $w$ & 927.7 \\
\hline
\end{tabular}

See footnotes at end of table. 
Table 44. Refiner Motor Gasoline Volumes by Formulation, Sales Type, PAD District, and State

(Thousand Gallons per Day) - Continued

\begin{tabular}{|c|c|c|c|c|c|c|c|c|c|c|c|c|}
\hline \multirow{3}{*}{$\begin{array}{l}\text { Geographlo Ares } \\
\text { Month }\end{array}$} & \multicolumn{6}{|c|}{ Reformulated } & \multicolumn{6}{|c|}{ All Formulations } \\
\hline & \multicolumn{2}{|c|}{ Sales to End Users } & \multicolumn{4}{|c|}{ Sales for Resale } & \multicolumn{2}{|c|}{ Sales to End Users } & \multicolumn{4}{|c|}{ Sales for Resale } \\
\hline & $\begin{array}{c}\text { Through } \\
\text { Rotail } \\
\text { Outlets }\end{array}$ & Totala & DTW & Rack & Bulk & Total & $\begin{array}{c}\text { Through } \\
\text { Retail } \\
\text { Ottlets }\end{array}$ & Totala & DTW & Rack & Bulk & Total \\
\hline \multicolumn{13}{|l|}{ South Carolina } \\
\hline 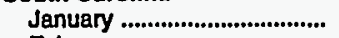 & - & - & - & - & - & - & 787.9 & 819.0 & 149.6 & $3,727.0$ & $\mathbf{w}$ & $4,361.0$ \\
\hline February ................................. & - & - & - & - & - & - & 845.4 & 881.6 & w & $3,723.2$ & W & $4,130.7$ \\
\hline March ...................................... & - & - & - & - & - & - & 861.9 & 897.8 & $W$ & $3,975.7$ & $w$ & $4,364.6$ \\
\hline Aprll & - & - & - & - & - & - & 879.8 & 915.1 & $W$ & $4,037.0$ & $w$ & $4,277.0$ \\
\hline 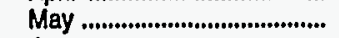 & - & - & - & - & - & - & 863.5 & 899.9 & $W$ & $3,940.6$ & $w$ & $4,161.6$ \\
\hline 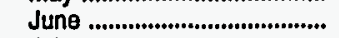 & - & - & - & - & - & - & 882.7 & 920.8 & W & $4,029.9$ & $w$ & $4,278.6$ \\
\hline 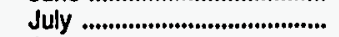 & - & - & - & - & - & - & 885.4 & 925.9 & $w$ & $4,036.4$ & $w$ & $4,278.3$ \\
\hline 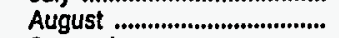 & - & - & - & - & - & - & 862.8 & 906.2 & $w$ & $4,098.7$ & $w$ & $4,339.5$ \\
\hline September ............................. & - & - & - & - & - & - & 837.6 & 878.2 & W & $3,945.9$ & W & $4,158.1$ \\
\hline 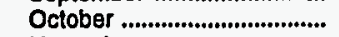 & - & - & - & - & - & - & 842.1 & 883.1 & w & $3,831.4$ & $w$ & $4,017.3$ \\
\hline November .............................. & - & - & - & - & - & - & 835.2 & 871.2 & W & $3,821.5$ & $w$ & $3,979.4$ \\
\hline December ............................... & - & - & - & - & - & - & 846.0 & 886.9 & $W$ & $4,058.4$ & $w$ & $4,205.6$ \\
\hline 1994 Average ............................. & - & - & - & - & - & - & 852.5 & 890.5 & 144.7 & $3,937.0$ & 132.1 & $4,213.8$ \\
\hline \multicolumn{13}{|l|}{ Virginia } \\
\hline 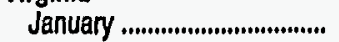 & - & - & - & - & - & - & 829.6 & 886.0 & $2,437.1$ & $4,233.3$ & - & $6,670.3$ \\
\hline 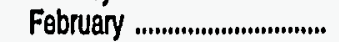 & - & - & - & - & - & - & 844.8 & 906.0 & W & $4,450.3$ & $W$ & $7,257.3$ \\
\hline March .................................... & - & - & - & - & - & - & 867.5 & 934.8 & $w$ & $4,679.4$ & W & $7,530.1$ \\
\hline Aprll & - & - & - & - & - & - & 896.6 & 960.7 & $\ddot{w}$ & $4,864.4$ & $\ddot{w}$ & $7,769.7$ \\
\hline 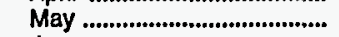 & - & - & - & - & - & - & 917.5 & 977.6 & $w$ & $5,101.6$ & $w$ & $7,864.9$ \\
\hline Juns ........................................ & - & - & - & - & - & - & 956.9 & $1,045.1$ & $w$ & $5,150.9$ & $W$ & $8,116.1$ \\
\hline July .......................................... & - & - & - & - & - & - & 938.6 & $1,012.9$ & $w$ & $5,116.4$ & W & $8,053.2$ \\
\hline 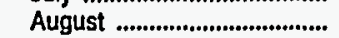 & - & - & - & - & - & - & 916.1 & 998.4 & $\ddot{W}$ & $5,447.0$ & $\ddot{w}$ & $8,393.5$ \\
\hline 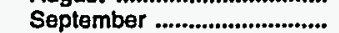 & - & - & - & - & - & - & 911.7 & 988.7 & $W$ & $5,288.5$ & w & $7,979.2$ \\
\hline October & - & - & - & - & - & - & 967.5 & $1,034.2$ & $w$ & $4,995.7$ & $\ddot{w}$ & $7,745.3$ \\
\hline 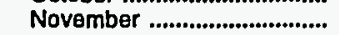 & - & $\mathbf{w}$ & 160.1 & 114.8 & - & 274.9 & 806.6 & 870.5 & $\mathbf{w}$ & $4,953.6$ & $w$ & $7,627.3$ \\
\hline 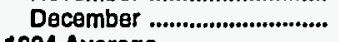 & 806.6 & 835.3 & $2,194.4$ & W & $w$ & W & 964.9 & $1,023.5$ & W & $5,089.6$ & $w$ & $7,871.0$ \\
\hline t994 Average ............................ & 68.5 & 71.2 & 199.5 & 153.9 & $\mathbf{w}$ & 361.5 & 902.1 & 970.4 & $2,651.2$ & $4,950.4$ & $w$ & $7,742.3$ \\
\hline \multicolumn{13}{|l|}{ West Virginla } \\
\hline January .................................. & - & - & - & - & - & - & 373.5 & 401.5 & 123.1 & 543.8 & $w$ & 677.3 \\
\hline 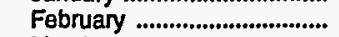 & - & - & - & - & - & - & 439.5 & 472.8 & $W$ & 607.5 & $w$ & 775.2 \\
\hline March ....................................... & - & - & - & - & - & - & 462.3 & 498.4 & $w$ & 803.4 & $w$ & 991.4 \\
\hline 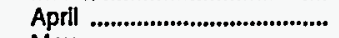 & - & - & - & - & - & - & 494.6 & 528.2 & $w$ & 740.6 & $w$ & 908.5 \\
\hline 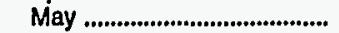 & - & - & - & - & - & - & 495.6 & 530.6 & $w$ & 772.7 & $w$ & 961.5 \\
\hline 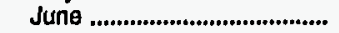 & - & - & - & - & - & - & 514.6 & 551.1 & $w$ & 774.4 & w & 960.1 \\
\hline 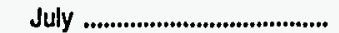 & - & - & - & - & - & - & 536.8 & 568.9 & 165.1 & 739.6 & - & 904.7 \\
\hline August $\ldots . . . . . . . . . . . . . . . . . . . . . . . . . . . . .$. & - & - & - & - & - & - & 514.2 & 549.8 & 161.5 & 726.9 & - & 888.4 \\
\hline September .............................. & - & - & - & - & - & - & 498.4 & 531.6 & $W$ & 686.7 & $w$ & 855.7 \\
\hline 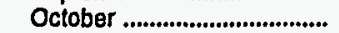 & - & - & - & - & - & - & 498.8 & 530.1 & $w$ & 746.4 & $w$ & 892.4 \\
\hline November ................................ & - & - & - & - & - & - & 483.9 & 514.7 & 141.0 & 744.8 & - & 885.8 \\
\hline December ................................. & - & - & $w$ & $w$ & - & $W$ & 494.2 & 526.1 & $W$ & 742.5 & $w$ & 925.9 \\
\hline 1994 Average ............................ & - & - & $\mathbf{w}$ & $\mathbf{w}$ & - & $\mathbf{W}$ & 484.1 & 517.2 & 148.4 & 719.8 & $\mathbf{w}$ & 886.3 \\
\hline \multicolumn{13}{|l|}{ PAD District II } \\
\hline 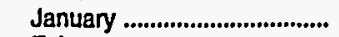 & - & - & - & - & - & - & $18,408.5$ & $19,081.7$ & $15,362.8$ & $48,180.5$ & $3,799.3$ & $67,342.6$ \\
\hline February ................................. & - & - & - & - & - & - & $19,342.8$ & $20,093.2$ & $15,972.0$ & $51,626.7$ & $5,265.7$ & $72,864.4$ \\
\hline March ........................................ & - & - & - & - & - & - & $18,890.1$ & $19,655.3$ & $16,044.3$ & $53,239.3$ & $4,225.3$ & $73,508.9$ \\
\hline 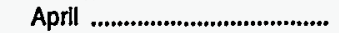 & - & - & - & - & - & - & $19,403.0$ & $20,140.6$ & $16,137.5$ & $55,102.9$ & $5,165.7$ & $76,406.1$ \\
\hline May .......................................... & - & - & - & - & - & - & $19,801.3$ & $20,562.0$ & $16,409.3$ & $56,353.4$ & $4,209.2$ & $76,971.9$ \\
\hline 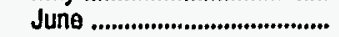 & - & - & - & - & - & - & $20,371.3$ & $21,170.4$ & $16,926.7$ & $59,228.5$ & $4,439.0$ & $80,594.2$ \\
\hline 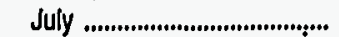 & - & - & - & - & - & - & $20,244.4$ & $20,830.8$ & $16,482.6$ & $57,917.9$ & $4,342.0$ & $78,742.5$ \\
\hline 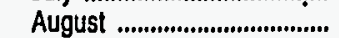 & - & - & - & - & - & - & $20,140.2$ & $20,841.0$ & $16,433.7$ & $58,879.9$ & $6,130.6$ & $81,444.2$ \\
\hline September .............................. & - & - & - & - & - & - & $19,593.2$ & $20,283.3$ & $16,112.2$ & $57,149.0$ & $6,368.9$ & $79,630.1$ \\
\hline 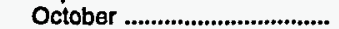 & - & - & - & - & - & - & $19,324.6$ & $20,012.3$ & $16,164.6$ & $55,727.4$ & $5,784.3$ & $77,676.3$ \\
\hline November .............................. & - & - & $\mathbf{w}$ & $w$ & $w$ & $\mathbf{w}$ & $19,327.1$ & $19,977.6$ & $16,201.6$ & $55,587.7$ & $5,052.1$ & $76,841.3$ \\
\hline December ............................... & $1,580.0$ & $1,615.8$ & $3,553.3$ & $\mathbf{w}$ & $w$ & $7,367.6$ & $19,906.5$ & $20,561.0$ & $16,422.7$ & $57,507.2$ & $5,469.2$ & $79,399.1$ \\
\hline 1994 Average ......................... & 134.2 & 137.2 & 304.7 & 321.0 & 4.3 & 630.1 & $19,563.3$ & $20,267.5$ & $16,223.2$ & $55,560.5$ & $5,016.3$ & $76,800.0$ \\
\hline
\end{tabular}

See footnotes at end of table. 
Table 44. Refiner Motor Gasoline Volumes by Formulation, Sales Type, PAD District, and State

(Thousand Gallons per Day) - Continued

\begin{tabular}{|c|c|c|c|c|c|c|c|c|c|c|c|c|}
\hline \multirow{3}{*}{$\begin{array}{l}\text { Goographic Area } \\
\text { Month }\end{array}$} & \multicolumn{6}{|c|}{ Conventional } & \multicolumn{6}{|c|}{ Oxygenated } \\
\hline & \multicolumn{2}{|c|}{ Sales to End Users } & \multicolumn{4}{|c|}{ Sales for Resale } & \multicolumn{2}{|c|}{ Sales to End Users } & \multicolumn{4}{|c|}{ Sales for Resalo } \\
\hline & $\begin{array}{c}\text { Through } \\
\text { Rotall } \\
\text { Outlots }\end{array}$ & Totala & DTW & Rack & Bulk & Total & $\begin{array}{c}\text { Through } \\
\text { Rotail } \\
\text { Outlets }\end{array}$ & Totala & DTW & Rack & Bulk & Total \\
\hline \multicolumn{13}{|l|}{ Illinols } \\
\hline 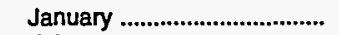 & $2,534.5$ & $2,586.0$ & $3,616.3$ & $5,214.3$ & w & $8,986.5$ & - & - & - & - & - & - \\
\hline 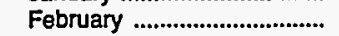 & $2,666.8$ & $2,699.0$ & $3,611.1$ & $5,793.2$ & 942.4 & $10,346.8$ & - & - & - & - & - & - \\
\hline 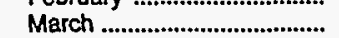 & $2,573.8$ & $2,608.9$ & $3,585.3$ & $5,715.5$ & 481.5 & $9,782.2$ & - & - & - & - & - & - \\
\hline April & $2,616.1$ & $2,647.5$ & $3,577.9$ & $5,779.0$ & 811.9 & $10,168.8$ & - & - & - & - & - & - \\
\hline 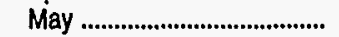 & $2,757.4$ & $2,786.1$ & $3,609.2$ & $5,572.4$ & 386.6 & $9,568.3$ & - & - & - & - & - & - \\
\hline June & $2,862.3$ & $2,894.0$ & $3,661.4$ & $5,622.1$ & 210.5 & $9,494.0$ & - & - & - & - & - & - \\
\hline 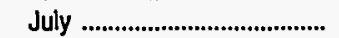 & $2,793.9$ & $2,807.8$ & $3,566.4$ & $5,483.2$ & 799.2 & $9,848.7$ & - & - & - & - & - & - \\
\hline 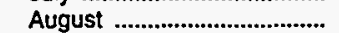 & $2,745.3$ & $2,760.5$ & $3,557.6$ & $5,500.1$ & $1,036.4$ & $10,094.1$ & - & - & - & - & - & - \\
\hline 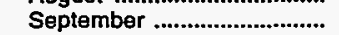 & $2,651.0$ & $2,667.8$ & $3,534.8$ & $5,645.2$ & 653.8 & $9,833.9$ & - & - & - & $\rightarrow$ & - & - \\
\hline 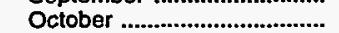 & $2,689.5$ & $2,705.6$ & $3,621.9$ & $5,321.1$ & $1,112.2$ & $10,055.2$ & - & - & - & - & - & - \\
\hline 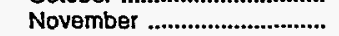 & $2,675.1$ & $2,692.8$ & $w$ & W & 609.1 & W & - & - & - & - & - & - \\
\hline 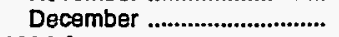 & $1,562.6$ & $1,573.3$ & $W$ & W & $w$ & $5,919.1$ & - & - & - & - & - & - \\
\hline 1994 Average .............................. & $2,592.2$ & $2,617.3$ & $3,373.7$ & $5,442.0$ & 644.1 & $9,459.8$ & - & - & - & - & - & - \\
\hline \multicolumn{13}{|l|}{ Indiana } \\
\hline 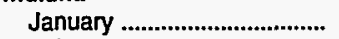 & $1,557.4$ & $1,569.1$ & $1,427.8$ & $3,105.6$ & $w$ & $4,641.8$ & - & - & - & - & - & - \\
\hline 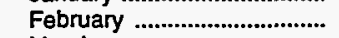 & $1,661.2$ & $1,672.6$ & $1,473.4$ & $3,209.6$ & 315.3 & $4,998.3$ & - & - & - & - & - & - \\
\hline March & $1,645.1$ & $1,657.9$ & $1,492.5$ & $3,598.6$ & 651.2 & $5,742.3$ & - & - & - & - & - & - \\
\hline April & 1.726 .6 & $1,740.7$ & $1,569.2$ & $3,762.1$ & 525.1 & $5,856.4$ & - & - & - & - & - & - \\
\hline 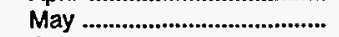 & $1,800.5$ & $1,813.0$ & $1,579.1$ & $3,848.4$ & 352.3 & $5,779.7$ & - & - & - & - & - & - \\
\hline 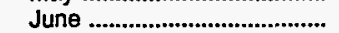 & $1,810.7$ & $1,826.8$ & $1,630.4$ & $3,947.6$ & 188.9 & $5,767.0$ & - & - & - & - & - & - \\
\hline July & $1,820.0$ & $1,831.6$ & $1,636.5$ & $3,918.4$ & 305.0 & $5,859.9$ & - & - & - & - & - & - \\
\hline 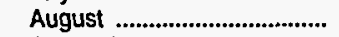 & $1,844.4$ & $1,858.2$ & $1,598.5$ & $4,001.0$ & 880.2 & $6,479.7$ & - & - & - & - & - & - \\
\hline September .............................. & $1,800.9$ & $1,812.7$ & $1,547.8$ & $3,780.7$ & 573.4 & $5,901.9$ & - & - & - & - & - & - \\
\hline 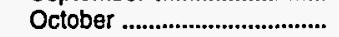 & $1,764.4$ & $1,777.7$ & $1,576.5$ & $3,854.2$ & 346.4 & $5,777.1$ & - & - & - & - & - & - \\
\hline November ............................. & $1,721.3$ & $1,732.6$ & $1,580.1$ & $3,929.5$ & $w$ & W & - & - & - & - & - & - \\
\hline 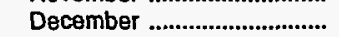 & $w$ & W & W & $3,499.9$ & $W$ & $5,481.9$ & - & - & - & - & - & - \\
\hline 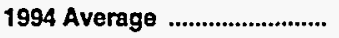 & $1,738.2$ & $1,751.0$ & $1,538.7$ & $3,707.1$ & 432.8 & $5,678.6$ & - & - & - & - & - & - \\
\hline \multicolumn{13}{|l|}{ lowa } \\
\hline 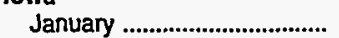 & 265.4 & 270.7 & $w$ & $2,825.7$ & - & $3,037.0$ & - & - & - & $w$ & - & $w$ \\
\hline 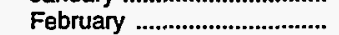 & 260.7 & 267.0 & $w$ & $W$ & - & $3,227.1$ & - & - & - & - & - & - \\
\hline 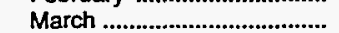 & 266.2 & 271.3 & $w$ & $w$ & - & $3,340.6$ & - & - & - & - & - & - \\
\hline April & 267.1 & 273.3 & $\ddot{w}$ & W & - & $3,592.8$ & - & - & - & - & - & - \\
\hline 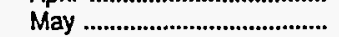 & 273.4 & 280.1 & $\ddot{w}$ & $\ddot{w}$ & - & $3,658.0$ & - & - & - & - & - & - \\
\hline June & 275.8 & 280.3 & W & W & - & $3,758.8$ & - & - & - & - & - & - \\
\hline 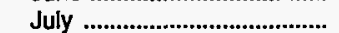 & 274.8 & 279.0 & W & W & - & $3,630.6$ & - & - & - & - & - & - \\
\hline 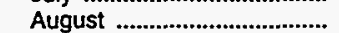 & 265.4 & 269.4 & w & W & - & $3,787.9$ & - & - & - & - & - & - \\
\hline 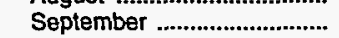 & 253.7 & 258.1 & w & w & - & $3,622.7$ & - & - & - & - & - & - \\
\hline 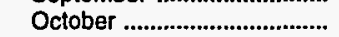 & 251.3 & 256.5 & W & W & - & $3,700.7$ & - & - & - & - & - & - \\
\hline 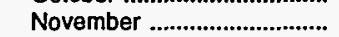 & 247.9 & 253.3 & $\ddot{w}$ & $3,364.6$ & w & $3,641.4$ & - & - & - & - & - & - \\
\hline 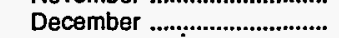 & 256.8 & 262.3 & W & $W$ & - & $3,565.1$ & - & - & - & - & - & - \\
\hline 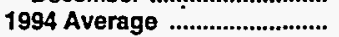 & 263.3 & 268.5 & w & $3,300.3$ & W & $3,548.3$ & - & - & - & $\mathbf{W}$ & - & $\mathbf{W}$ \\
\hline \multicolumn{13}{|l|}{ Kansas } \\
\hline 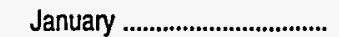 & 620.8 & 641.0 & 179.7 & $2,444.3$ & $W$ & $3,339.0$ & - & - & - & - & - & - \\
\hline 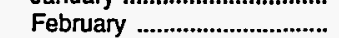 & 642.3 & 664.8 & 179.9 & $2,478.2$ & 693.4 & $3,351.5$ & - & - & - & - & - & - \\
\hline 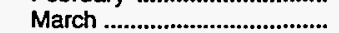 & 662.6 & 690.4 & 179.6 & $2,667.6$ & 543.9 & $3,391.2$ & - & - & - & - & - & - \\
\hline 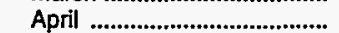 & 669.7 & 697.0 & 178.7 & $2,702.8$ & 728.1 & $3,609.6$ & - & - & - & - & - & - \\
\hline 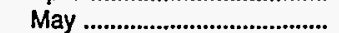 & 700.6 & 732.9 & 183.4 & $2,784.7$ & 644.3 & $3,612.4$ & - & - & - & - & - & - \\
\hline June & 707.8 & 739.1 & 196.8 & $3,004.3$ & 552.6 & $3,753.6$ & - & - & - & - & - & - \\
\hline 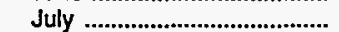 & 704.4 & 733.3 & $w$ & $2,844.7$ & $w$ & $3,571.5$ & - & - & - & - & - & - \\
\hline 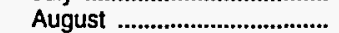 & 677.1 & 712.0 & 192.0 & $2,846.4$ & 653.5 & $3,692.0$ & - & - & - & - & - & - \\
\hline 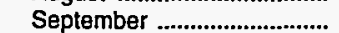 & 676.9 & 716.5 & 182.0 & $W$ & $w$ & $3,840.4$ & - & - & - & - & - & - \\
\hline 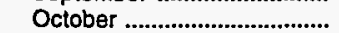 & 669.7 & 694.1 & 181.8 & $2,772.3$ & 348.7 & $3,302.8$ & - & - & - & - & - & - \\
\hline 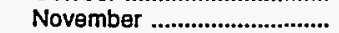 & 687.8 & 718.1 & $w$ & $2,551.2$ & $W$ & $3,146.6$ & - & - & - & - & - & - \\
\hline 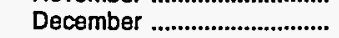 & 704.5 & 737.1 & 192.2 & $W$ & $\ddot{w}$ & $3,743.5$ & - & - & - & - & - & - \\
\hline 1994 Average ............................ & 677.2 & 706.6 & 185.3 & $2,733.7$ & 611.3 & $3,530.3$ & - & - & - & - & - & - \\
\hline
\end{tabular}

See footnotes at end of table. 
Table 44. Refiner Motor Gasoline Volumes by Formulation, Sales Type, PAD District, and State

(Thousand Gallons per Day) - Continued

\begin{tabular}{|c|c|c|c|c|c|c|c|c|c|c|c|c|}
\hline \multirow{3}{*}{$\begin{array}{l}\text { Geographic Area } \\
\text { Month }\end{array}$} & \multicolumn{6}{|c|}{ Reformulated } & \multicolumn{6}{|c|}{ All Formulations } \\
\hline & \multicolumn{2}{|c|}{ Sales to End Users } & \multicolumn{4}{|c|}{ Sales for Resalo } & \multicolumn{2}{|c|}{ Sales to End Users } & \multicolumn{4}{|c|}{ Sales for Resale } \\
\hline & $\begin{array}{c}\text { Through } \\
\text { Retall } \\
\text { Outlats }\end{array}$ & Totala & DTW & Rack & Bulk & Total & $\begin{array}{c}\text { Through } \\
\text { Retall } \\
\text { Outlets }\end{array}$ & Totala & DTW & Rack & Bulk & Total \\
\hline \multicolumn{13}{|l|}{ Illinols } \\
\hline January ................................. & - & - & - & - & - & - & $2,534.5$ & $2,586.0$ & $3,616.3$ & $5,214.3$ & $w$ & $8,986.5$ \\
\hline February ............................... & - & - & - & - & - & - & $2,666.8$ & $2,699.0$ & $3,611.1$ & $5,793.2$ & 942.4 & $10,346.8$ \\
\hline March ........................................ & - & - & - & - & - & - & $2,573.8$ & $2,608.9$ & $3,585.3$ & 5.715 .5 & 481.5 & $9,782.2$ \\
\hline 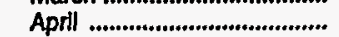 & - & - & - & - & - & - & $2,616.1$ & $2,647.5$ & $3,577.9$ & $5,779.0$ & 811.9 & $10,168.8$ \\
\hline 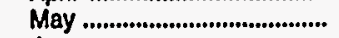 & - & - & - & - & - & - & $2,757.4$ & $2,786.1$ & $3,609.2$ & $5,572.4$ & 386.6 & $9,568.3$ \\
\hline 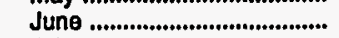 & - & - & - & - & - & - & $2,862.3$ & $2,894.0$ & $3,661.4$ & $5,622.1$ & 210.5 & $9,494.0$ \\
\hline 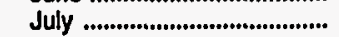 & - & - & - & - & - & - & $2,793.9$ & $2,807.8$ & $3,566.4$ & $5,483.2$ & 799.2 & $9,848.7$ \\
\hline 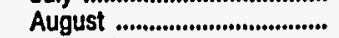 & - & - & - & - & - & - & $2,745.3$ & $2,760.5$ & $3,557.6$ & $5,500.1$ & $1,036.4$ & $10,094.1$ \\
\hline September ............................ & - & - & - & - & - & - & $2,651.0$ & $2,667.8$ & $3,534.8$ & $5,645.2$ & 653.8 & $9,833.9$ \\
\hline 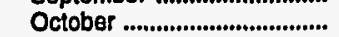 & - & - & - & - & - & - & $2,689.5$ & $2,705.6$ & $3,621.9$ & $5,321.1$ & $1,112.2$ & $10,055.2$ \\
\hline November .............................. & - & - & $w$ & $w$ & - & W & $2,675.1$ & $2,692.8$ & $3,646.7$ & $5,327.5$ & 609.1 & $9,583.3$ \\
\hline December ............................... & $1,265.3$ & $1,276.5$ & $w$ & $w$ & - & $\begin{array}{r}4,395.0 \\
376.5\end{array}$ & $2,827.9$ & $2,849.8$ & $3,707.6$ & $6,057.5$ & 549.0 & $10,314.1$ \\
\hline 1894 Average ........................... & 107.5 & 108.4 & & 142.1 & & 376.5 & $2,699.7$ & $2,725.7$ & & & & \\
\hline \multicolumn{13}{|l|}{ Indlane } \\
\hline January .................................... & - & - & - & - & - & - & $1,557.4$ & $1,569.1$ & $1,427.8$ & $3,105.6$ & $W$ & $4,641.8$ \\
\hline February ................................. & - & - & - & - & - & - & $1,661.2$ & $1,672.6$ & $1,473.4$ & $3,209,6$ & 315.3 & $4,998.3$ \\
\hline 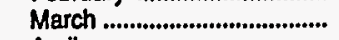 & - & - & - & - & - & - & $1,645.1$ & $1,657.9$ & $1,492.5$ & $3,598.6$ & 651.2 & $5,742.3$ \\
\hline Aprill & - & - & - & - & - & - & $1,726.6$ & $1,740.7$ & $1,569.2$ & $3,762.1$ & 525.1 & $5,856.4$ \\
\hline 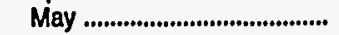 & - & - & - & - & - & - & $1,800.5$ & $1,813.0$ & $1,579.1$ & $3,848.4$ & 352.3 & $5,779.7$ \\
\hline June ............................................ & - & - & - & - & - & - & $1,810.7$ & $1,826.8$ & $1,630.4$ & $3,947.6$ & 188.9 & $5,767.0$ \\
\hline 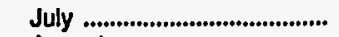 & - & - & - & - & - & - & $1,820.0$ & $1,831.6$ & $1,636.5$ & $3,918.4$ & 305.0 & $5,859.9$ \\
\hline 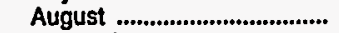 & - & - & - & - & - & - & $1,844.4$ & $1,858.2$ & $1,598.5$ & $4,001.0$ & 880.2 & $6,479.7$ \\
\hline 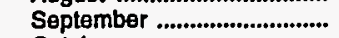 & - & - & - & - & - & - & $1,800.9$ & $1,812.7$ & $1,547.8$ & $3,780.7$ & 573.4 & $5,901.9$ \\
\hline 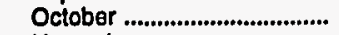 & - & - & - & - & - & - & $1,764.4$ & $1,777.7$ & $1,576.5$ & $3,854.2$ & 346.4 & $5,777.1$ \\
\hline November ................................ & - & - & - & - & W & w & $1,721.3$ & $1,732.6$ & $1,580.1$ & $3,929.5$ & 316.0 & $5,825.6$ \\
\hline 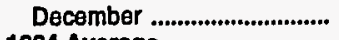 & $W$ & $w$ & $W$ & 371.5 & $W$ & 595.8 & $1,755.4$ & $1,769.3$ & $1,538.8$ & $3,871.4$ & 667.5 & $6,077.7$ \\
\hline 1984 Averago & $\mathbf{W}$ & $\mathbf{w}$ & 15.9 & 31.5 & & 51.8 & $1,742.8$ & $1,755.6$ & $1,554.6$ & $\mathbf{3 , 7 3 8 . 6}$ & 437.2 & $5,730.4$ \\
\hline \multicolumn{13}{|l|}{ lowa } \\
\hline January ................................... & - & - & - & - & - & - & 265.4 & 270.7 & $w$ & $2,830.3$ & - & $3,041.6$ \\
\hline February .................................. & - & - & - & - & - & - & 260.7 & 267.0 & $w$ & $W$ & - & $3,227.1$ \\
\hline March .......................................... & - & - & - & - & - & - & 266.2 & 271.3 & w & $w$ & - & $3,340.6$ \\
\hline 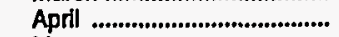 & - & - & - & - & - & - & 267.1 & 273.3 & $\dddot{w}$ & $\ddot{W}$ & - & $3,592.8$ \\
\hline 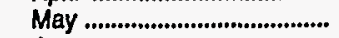 & - & - & - & - & - & - & 273.4 & 280.1 & w & $w$ & - & $3,658.0$ \\
\hline 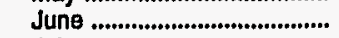 & - & - & - & - & - & - & 275.8 & 280.3 & $\ddot{w}$ & w & - & $3,758.8$ \\
\hline 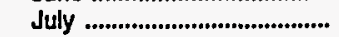 & - & - & - & - & - & - & 274.8 & 279.0 & $\ddot{w}$ & $w$ & - & $3,630.6$ \\
\hline August & - & - & - & - & - & - & 265.4 & 269.4 & W & $w$ & - & $3,787.9$ \\
\hline September ............................... & - & - & - & - & - & - & 253.7 & 258.1 & $w$ & $w$ & - & $3,622.7$ \\
\hline 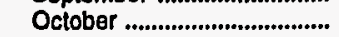 & - & - & - & - & - & - & 251.3 & 256.5 & $w$ & W & - & $3,700.7$ \\
\hline 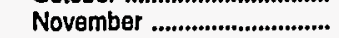 & - & - & - & - & - & - & 247.9 & 253.3 & $w$ & $3,364.6$ & $w$ & $3,641.4$ \\
\hline December ................................ & - & - & - & - & - & - & 256.8 & 262.3 & w & $W$ & - & $3,565.1$ \\
\hline 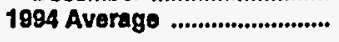 & - & - & - & - & - & - & 263.3 & 268.5 & $\mathbf{w}$ & $3,300.7$ & $w$ & $3,548.7$ \\
\hline \multicolumn{13}{|l|}{ Kansas } \\
\hline 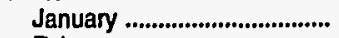 & - & - & - & - & - & - & 620.8 & 641.0 & 179.7 & $2,444.3$ & $w$ & $3,339.0$ \\
\hline February .................................. & - & - & - & - & - & - & 642.3 & 664.8 & 179.9 & $2,478.2$ & 693.4 & $3,351,5$ \\
\hline 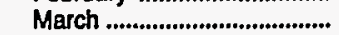 & - & - & - & - & - & - & 662.6 & 690.4 & 179.6 & $2,667.6$ & 543.9 & $3,391.2$ \\
\hline 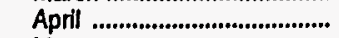 & - & - & - & - & - & - & 669.7 & 697.0 & 178.7 & $2,702.8$ & 728.1 & $3,609.6$ \\
\hline May ............................................ & - & - & - & - & - & - & 700.6 & 732.9 & 183.4 & $2,784.7$ & 644.3 & $3,612.4$ \\
\hline Jung ............................................ & - & - & - & - & - & - & 707.8 & 739.1 & 196.8 & $3,004.3$ & 552.6 & $3,753.6$ \\
\hline 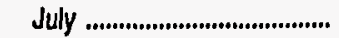 & - & - & - & - & - & - & 704.4 & 733.3 & $W$ & $2,844.7$ & $W$ & $3,571.5$ \\
\hline 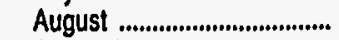 & - & - & - & - & - & - & 677.1 & 712.0 & 192.0 & $2,846.4$ & 653.5 & $3,692.0$ \\
\hline 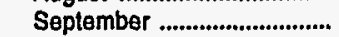 & - & - & - & - & - & - & 676.9 & 716.5 & 182.0 & W & $W$ & $3,840.4$ \\
\hline 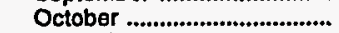 & - & - & - & - & - & - & 669.7 & 694.1 & 181.8 & $2,772.3$ & 348.7 & $3,302.8$ \\
\hline November ................................ & - & - & - & - & - & - & 687.8 & 718.1 & $w$ & $2,551.2$ & $w$ & $3,146.6$ \\
\hline December .................................. & - & - & - & - & - & - & 704.5 & 737.1 & 192.2 & $w$ & w & $3,743.5$ \\
\hline 1994 Average .......................... & - & - & - & - & - & - & 677.2 & 706.6 & 185.3 & $2,733.7$ & 611.3 & $3,530.3$ \\
\hline
\end{tabular}

See lootnotes at end of table. 
Table 44. Refiner Motor Gasoline Volumes by Formulation, Sales Type, PAD District, and State

(Thousand Gallons per Day) - Continued

\begin{tabular}{|c|c|c|c|c|c|c|c|c|c|c|c|c|}
\hline \multirow{3}{*}{$\begin{array}{c}\text { Geographic Area } \\
\text { Month }\end{array}$} & \multicolumn{6}{|c|}{ Conventional } & \multicolumn{6}{|c|}{ Oxygenated } \\
\hline & \multicolumn{2}{|c|}{ Sales to End Users } & \multicolumn{4}{|c|}{ Sales for Resale } & \multicolumn{2}{|c|}{ Sales to End Users } & \multicolumn{4}{|c|}{ Sales for Resale } \\
\hline & $\begin{array}{c}\text { Through } \\
\text { Rotail } \\
\text { Outlets }\end{array}$ & Totala & DTW & Rack & Bulk & Total & $\begin{array}{c}\text { Through } \\
\text { Retail } \\
\text { Outlets }\end{array}$ & Totala & DTW & Rack & Bulk & Total \\
\hline
\end{tabular}

Kentucky

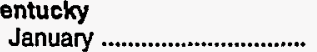

February

March

April

May

June

July .

August

September ............................

October

November

December .

1994 Average

Michigan

January

February ................................

March

April

June

July ...

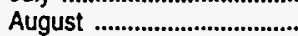

September

October ...

November

December

Minnesot:

January

February

March

Mapril

May

July ...

August

September

October

November

1994 Average

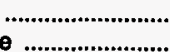

Missouri

January .................................

February

March

April

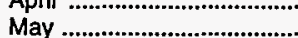

June

July ...

August

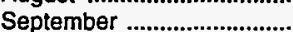

October

November

December

1994 Average

See footnotes at end of table.

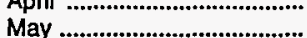

\begin{tabular}{|c|c|c|c|c|c|c|c|c|c|c|c|}
\hline 643.6 & 710.7 & 474.4 & $2,621.1$ & - & $3,095.5$ & - & - & - & - & - & - \\
\hline 717.6 & 802.7 & 582.4 & $W$ & $w$ & $3,751.1$ & - & - & - & - & - & - \\
\hline 732.1 & 819.7 & $W$ & $3,336.0$ & $w$ & $3,986.9$ & - & - & - & - & - & - \\
\hline 761.0 & 841.9 & 612.4 & $3,435.8$ & - & $4,048.2$ & - & - & - & - & - & - \\
\hline 761.1 & 839.2 & 613.8 & $3,423.1$ & - & $4,036.9$ & - & - & - & - & - & - \\
\hline 780.4 & 859.1 & 655.9 & $3,544,4$ & - & $4,200.3$ & - & - & - & - & - & - \\
\hline 803.3 & 876.6 & 602.3 & $3,311.9$ & - & $3,914.2$ & - & - & - & - & - & - \\
\hline 804.6 & 882.8 & 611.8 & $3,433.0$ & - & $4,044.8$ & - & - & - & - & - & - \\
\hline 789.4 & 866.9 & $w$ & $3,190.5$ & $w$ & $3,859.8$ & - & - & - & - & - & - \\
\hline 796.9 & 877.8 & 632.0 & $3,190.3$ & - & $3,822.3$ & - & - & - & - & - & - \\
\hline 782.4 & 852.5 & 605.4 & $2,948.3$ & - & $3,553.8$ & - & - & - & - & - & - \\
\hline$w$ & 772.7 & W & $2,633.7$ & - & W & - & - & - & - & - & - \\
\hline 757.8 & 833.6 & 580.6 & $3,185.5$ & $w$ & $3,777.6$ & - & - & - & - & - & - \\
\hline $2,620.6$ & $2,768.8$ & $3,499.9$ & $5,069.6$ & - & $8,569.6$ & - & - & - & - & - & - \\
\hline $2,802.3$ & $2,972.3$ & $3,677.9$ & $5,384.3$ & - & $9,062.1$ & - & - & - & - & - & - \\
\hline $2,703.5$ & $2,870.8$ & $3,686.1$ & $5,367.4$ & - & $9,053.5$ & - & - & - & - & - & - \\
\hline $2,766.1$ & $2,918.0$ & $3,652.7$ & $5,489.0$ & - & $9,141.7$ & - & - & - & - & - & - \\
\hline $2,871.4$ & $3,041.1$ & $3,762.2$ & $5,869.0$ & - & $9,631.2$ & - & - & - & - & - & - \\
\hline $2,975.5$ & $3,166.3$ & $3,870.6$ & $6,258.6$ & - & $10,129.2$ & - & - & - & - & - & - \\
\hline $2,946.7$ & $3,047,3$ & $3,751.4$ & $6,177.6$ & - & $9,929.1$ & - & - & - & - & - & - \\
\hline $2,985.9$ & $3,133.3$ & $w$ & $6,369.4$ & $W$ & $10,120.7$ & - & - & - & - & - & - \\
\hline $2,929.7$ & $3,058.6$ & $w$ & $6,052.9$ & w & $9,749.3$ & - & - & - & - & - & - \\
\hline $2,915.8$ & $3,056.4$ & $3,686.4$ & $5,796.9$ & - & $9,483.3$ & - & - & - & - & - & - \\
\hline $2,872.4$ & $2,993.8$ & $3,663.1$ & $5,815.2$ & - & $9,478.3$ & - & - & - & - & - & - \\
\hline $2,913.6$ & $3,029.1$ & $3,713.0$ & $5,715.1$ & - & $9,428.1$ & - & - & - & - & - & - \\
\hline $2,858.8$ & $3,004.6$ & $3,697.5$ & $5,782.3$ & $w$ & $9,483.2$ & - & - & - & - & - & - \\
\hline 303.7 & 305.0 & 87.4 & $2,114.6$ & $w$ & $2,342.8$ & $1,226.5$ & $1,245.7$ & $w$ & $1,099.9$ & $w$ & $1,506.8$ \\
\hline $1,132.9$ & $1,153.9$ & $w$ & $2,712.3$ & $w$ & $3,478.0$ & 263.1 & 265.5 & $w$ & 462.2 & $w$ & 506.5 \\
\hline$w$ & $w$ & $w$ & $w$ & $w$ & $3,366.4$ & $w$ & $w$ & - & $w$ & $w$ & 472.8 \\
\hline$w$ & $W$ & $w$ & $2,920.9$ & $w$ & $3,749.8$ & $W$ & $W$ & - & 396.9 & - & 396.9 \\
\hline$w$ & $W$ & $w$ & $3,190.7$ & $w$ & $3,957.8$ & $W$ & $W$ & - & 418.1 & - & 418.1 \\
\hline$w$ & $W$ & $w$ & $3,408.6$ & $w$ & $4,203.3$ & $w$ & $w$ & - & 562.2 & - & 562.2 \\
\hline$w$ & $w$ & $w$ & $3,443.1$ & $w$ & $4,107.1$ & $W$ & $w$ & - & 593.1 & - & 593.1 \\
\hline$w$ & $W$ & $W$ & $W$ & $w$ & $W$ & $w$ & $w$ & - & $w$ & - & $w$ \\
\hline$W$ & $w$ & $w$ & $w$ & $w$ & $4,085.4$ & $W$ & $w$ & $w$ & $w$ & - & 560.6 \\
\hline 270.3 & 274.5 & $w$ & $W$ & $w$ & $2,913.5$ & 993.0 & $1,011.2$ & $w$ & $w$ & - & $1,620.5$ \\
\hline 222.2 & 225.8 & 76.6 & $W$ & $W$ & $2,773.5$ & $1,031.6$ & $1,049.1$ & $W$ & $w$ & - & $1,806.5$ \\
\hline 225.3 & 228.5 & 77.3 & $w$ & $w$ & $2,600.4$ & $1,058.2$ & $1,080.5$ & $W$ & $W$ & - & $1,961.5$ \\
\hline 886.9 & 900.8 & $w$ & $2,864.5$ & $\mathbf{W}$ & $3,476.6$ & 461.8 & 468.6 & $w$ & 801.6 & $w$ & 927.3 \\
\hline $1,020.9$ & $1,065.7$ & 880.1 & $3,715.4$ & $w$ & $4,870.6$ & - & - & - & - & - & - \\
\hline $1,064.1$ & $1,116.4$ & $w$ & $4,007.9$ & $w$ & $5,187.3$ & - & - & - & - & - & - \\
\hline 956.1 & $1,007.3$ & $w$ & $4,249.0$ & $w$ & $5,290.0$ & - & - & - & - & - & - \\
\hline 966.2 & $1,011.2$ & 857.4 & $w$ & $w$ & $5,561.1$ & - & - & - & - & - & - \\
\hline 979.1 & $1,021.8$ & 884.7 & $4,393.1$ & 350.5 & $5,628.3$ & - & - & - & - & - & - \\
\hline 994.8 & $1,030.0$ & 921.9 & $4,748.0$ & 181.1 & $5,851.1$ & - & - & - & - & - & - \\
\hline 974.8 & 992.9 & $w$ & $4,577.4$ & $w$ & $5,624.5$ & - & - & - & - & - & - \\
\hline 939.1 & 958.7 & $W$ & $w$ & $w$ & $w$ & - & - & $w$ & - & - & $w$ \\
\hline 930.3 & 948.6 & 858.4 & $4,377.1$ & 95.4 & $5,330.9$ & - & - & - & - & - & - \\
\hline 931.7 & 950.0 & $w$ & $4,485.9$ & $w$ & $5,601.3$ & - & - & - & - & - & - \\
\hline 913.6 & 931.5 & W & $4,522.0$ & W & $5,427.5$ & - & - & - & - & - & - \\
\hline 959.2 & 977.6 & $w$ & $4,462.0$ & $w$ & $5,492.0$ & - & - & - & - & - & - \\
\hline 968.6 & $1,000.3$ & 881.8 & $4,385.5$ & 189.2 & $5,456.5$ & - & - & $\mathbf{w}$ & - & - & $w$ \\
\hline
\end{tabular}


Table 44. Refiner Motor Gasoline Volumes by Formulation, Sales Type, PAD District, and State

(Thousand Gallons per Day) - Continued

\begin{tabular}{|c|c|c|c|c|c|c|c|c|c|c|c|c|}
\hline \multirow{3}{*}{$\begin{array}{l}\text { Geographlc Area } \\
\text { Month }\end{array}$} & \multicolumn{6}{|c|}{ Reformulated } & \multicolumn{6}{|c|}{ All Formulations } \\
\hline & \multicolumn{2}{|c|}{ Sales to End Users } & \multicolumn{4}{|c|}{ Sales for Resale } & \multicolumn{2}{|c|}{ Sales to End Users } & \multicolumn{4}{|c|}{ Sales for Resale } \\
\hline & $\begin{array}{c}\text { Through } \\
\text { Retail } \\
\text { Outlets }\end{array}$ & Totala & DTW & Rack & Bulk & Total & $\begin{array}{c}\text { Through } \\
\text { Retail } \\
\text { Outlots }\end{array}$ & Totala & DTW & Rack & Bulk & Total \\
\hline Kentucky & & & & & & & & & & & & \\
\hline 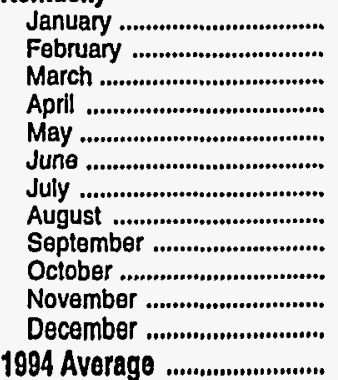 & $\begin{array}{l}\overline{-} \\
\overline{-} \\
\overline{-} \\
\overline{-} \\
\overline{-} \\
\overline{-} \\
\bar{W}\end{array}$ & $\begin{array}{l}- \\
- \\
- \\
- \\
- \\
- \\
- \\
- \\
\overline{84.3} \\
7.2\end{array}$ & $\begin{array}{l}- \\
- \\
- \\
\overline{-} \\
- \\
- \\
- \\
\overline{-} \\
\bar{w} \\
17.1\end{array}$ & $\begin{array}{r}- \\
- \\
= \\
= \\
- \\
= \\
= \\
- \\
795.3 \\
67.5\end{array}$ & $\begin{array}{l}- \\
- \\
- \\
- \\
- \\
- \\
- \\
- \\
-\end{array}$ & $\begin{array}{c}- \\
- \\
- \\
- \\
- \\
- \\
- \\
- \\
- \\
- \\
\bar{w} \\
84.7\end{array}$ & $\begin{array}{l}643.6 \\
717.6 \\
732.1 \\
761.0 \\
761.1 \\
780.4 \\
803.3 \\
804.6 \\
789.4 \\
796.9 \\
782.4 \\
786.2 \\
763.4\end{array}$ & $\begin{array}{l}710.7 \\
802.7 \\
819.7 \\
841.9 \\
839.2 \\
859.1 \\
876.6 \\
882.8 \\
866.9 \\
877.8 \\
852.5 \\
856.9 \\
840.7\end{array}$ & $\begin{array}{c}474.4 \\
582.4 \\
W \\
612.4 \\
613.8 \\
655.9 \\
602.3 \\
611.8 \\
W \\
632.0 \\
605.4 \\
601.1 \\
597.8\end{array}$ & $\begin{array}{r}2,621.1 \\
W \\
3,336.0 \\
3,435.8 \\
3,423.1 \\
3,544.4 \\
3,311.9 \\
3,433.0 \\
3,190.5 \\
3,190.3 \\
2,948.3 \\
3,429.0 \\
3,253.0\end{array}$ & $\begin{array}{l}\bar{w} \\
w \\
\overline{-} \\
\overline{-} \\
\overline{-} \\
\bar{w} \\
\overline{-} \\
\overline{-} \\
\bar{w}\end{array}$ & $\begin{array}{l}3,095.5 \\
3,751.1 \\
3,986.9 \\
4,048.2 \\
4,036.9 \\
4,200.3 \\
3,914.2 \\
4,044.8 \\
3,859.8 \\
3,822.3 \\
3,553.8 \\
4,030.1 \\
3,862.3\end{array}$ \\
\hline 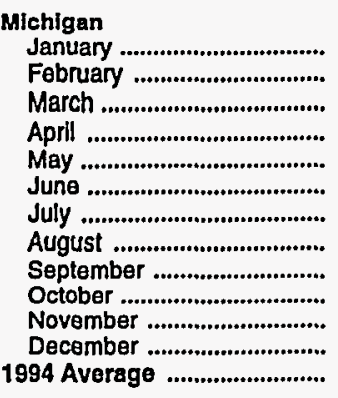 & $\begin{array}{l}- \\
- \\
\overline{-} \\
\overline{-} \\
\overline{-} \\
\bar{z} \\
-\end{array}$ & $\begin{array}{l}- \\
- \\
- \\
- \\
- \\
- \\
- \\
- \\
-\end{array}$ & $\begin{array}{l}- \\
- \\
- \\
- \\
- \\
- \\
- \\
- \\
-\end{array}$ & $\begin{array}{l}- \\
- \\
- \\
- \\
- \\
- \\
- \\
\overline{-} \\
- \\
-\end{array}$ & $\begin{array}{l}- \\
- \\
- \\
- \\
- \\
- \\
- \\
- \\
-\end{array}$ & $\begin{array}{l}\overline{-} \\
\overline{-} \\
\overline{-} \\
\overline{-} \\
\overline{-} \\
\overline{-} \\
\overline{-} \\
-\end{array}$ & $\begin{array}{l}2,620.6 \\
2,802.3 \\
2,703.5 \\
2,766.1 \\
2,871.4 \\
2,975.5 \\
2,946.7 \\
2,985.9 \\
2,929.7 \\
2,915.8 \\
2,872.4 \\
2,913.6 \\
2,858.8\end{array}$ & $\begin{array}{l}2,768.8 \\
2,972.3 \\
2,870.8 \\
2,918.0 \\
3,041.1 \\
3,166.3 \\
3,047.3 \\
3,133.3 \\
3,058.6 \\
3,056.4 \\
2,993.8 \\
3,029.1 \\
3,004.6\end{array}$ & $\begin{array}{r}3,499.9 \\
3,677.9 \\
3,686.1 \\
3,652.7 \\
3,762.2 \\
3,870.6 \\
3,751.4 \\
W \\
W \\
3,686.4 \\
3,663.1 \\
3,713.0 \\
3,697.5\end{array}$ & $\begin{array}{l}\mathbf{5}, 069.6 \\
\mathbf{5 , 3 8 4 . 3} \\
\mathbf{5 , 3 6 7 . 4} \\
\mathbf{5 , 4 8 9 . 0} \\
\mathbf{5 , 8 6 9 . 0} \\
\mathbf{6 , 2 5 8 . 6} \\
\mathbf{6 , 1 7 7 . 6} \\
\mathbf{6 , 3 6 9 . 4} \\
\mathbf{6 , 0 5 2 . 9} \\
\mathbf{5 , 7 9 6 . 9} \\
\mathbf{5 , 8 1 5 . 2} \\
\mathbf{5 , 7 1 5 . 1} \\
\mathbf{5 , 7 8 2 . 3}\end{array}$ & $\begin{array}{l}\overline{-} \\
\overline{-} \\
\bar{z} \\
\overline{-} \\
\bar{w} \\
w \\
\bar{w} \\
\bar{w}\end{array}$ & $\begin{array}{r}8,569.6 \\
9,062.1 \\
9,053.5 \\
9,141.7 \\
9,631.2 \\
10,129.2 \\
9,929.1 \\
10,120.7 \\
9,749.3 \\
9,483.3 \\
9,478.3 \\
9,428.1 \\
9,483.2\end{array}$ \\
\hline 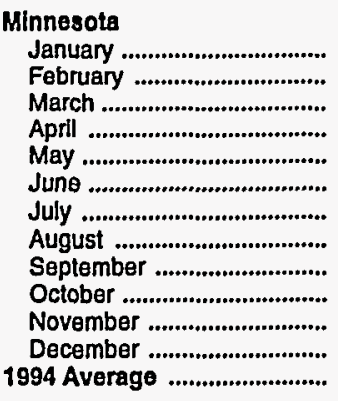 & $\begin{array}{l}- \\
z \\
z \\
z \\
- \\
- \\
- \\
-\end{array}$ & $\begin{array}{l}- \\
\overline{-} \\
\overline{-} \\
- \\
- \\
- \\
- \\
- \\
-\end{array}$ & $\begin{array}{l}- \\
\overline{-} \\
\overline{-} \\
\overline{-} \\
\overline{-} \\
- \\
\overline{-} \\
-\end{array}$ & $\begin{array}{l}- \\
- \\
- \\
- \\
- \\
- \\
- \\
- \\
- \\
-\end{array}$ & $\begin{array}{l}z \\
z \\
z \\
z \\
- \\
z \\
- \\
-\end{array}$ & $\begin{array}{l}- \\
- \\
\overline{-} \\
\overline{-} \\
\overline{-} \\
- \\
- \\
-\end{array}$ & $\begin{array}{l}1,530.2 \\
1,395.9 \\
1,280.5 \\
1,308.6 \\
1,337.5 \\
1,408.3 \\
1,388.7 \\
1,404.0 \\
1,331.0 \\
1,263.3 \\
1,253.8 \\
1,283.5 \\
1,348.6\end{array}$ & $\begin{array}{l}1,550.7 \\
1,419.4 \\
1,300.6 \\
1,325.0 \\
1,359.1 \\
1,432.5 \\
1,406.9 \\
1,420.3 \\
1,351.1 \\
1,285.7 \\
1,275.0 \\
1,309.0 \\
1,369.5\end{array}$ & $\begin{array}{l}W \\
W \\
W \\
w \\
W \\
W \\
W \\
W \\
W \\
W \\
W \\
W \\
W\end{array}$ & $\begin{array}{l}3,214.5 \\
3,174.5 \\
3,135.6 \\
3,317.8 \\
3,608.8 \\
3,970.9 \\
4,036.2 \\
4,170.7 \\
3,925.6 \\
3,799.2 \\
3,858.1 \\
3,747.4 \\
3,666.1\end{array}$ & $\begin{array}{l}W \\
W \\
W \\
W \\
W \\
W \\
W \\
W \\
W \\
W \\
W \\
W \\
W\end{array}$ & $\begin{array}{l}3,849.6 \\
3,984.5 \\
3,839.3 \\
4,146.7 \\
4,375.9 \\
4,765.5 \\
4,700.2 \\
4,839.6 \\
4,646.0 \\
4,534.0 \\
4,580.1 \\
4,561.9 \\
4,403.9\end{array}$ \\
\hline 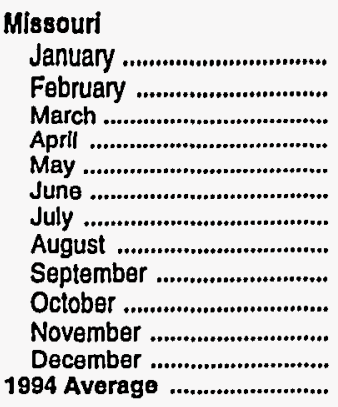 & $\begin{array}{l}- \\
- \\
\bar{z} \\
\overline{-} \\
- \\
- \\
- \\
-\end{array}$ & $\begin{array}{l}- \\
\overline{-} \\
\overline{-} \\
- \\
- \\
- \\
- \\
-\end{array}$ & $\begin{array}{l}- \\
- \\
z \\
z \\
- \\
- \\
- \\
-\end{array}$ & $\begin{array}{l}- \\
- \\
= \\
= \\
- \\
- \\
- \\
-\end{array}$ & $\begin{array}{l}- \\
- \\
\overline{-} \\
- \\
- \\
- \\
- \\
- \\
-\end{array}$ & $\begin{array}{l}- \\
z \\
z \\
z \\
- \\
- \\
- \\
- \\
-\end{array}$ & $\begin{array}{r}1,020.9 \\
1,064.1 \\
956.1 \\
966.2 \\
979.1 \\
994.8 \\
974.8 \\
939.1 \\
930.3 \\
931.7 \\
913.6 \\
959.2 \\
968.6\end{array}$ & $\begin{array}{r}1,065.7 \\
1,116.4 \\
1,007.3 \\
1,011.2 \\
1,021.8 \\
1,030.0 \\
992.9 \\
958.7 \\
948.6 \\
950.0 \\
931.5 \\
977.6 \\
1,000.3\end{array}$ & $\begin{array}{c}880.1 \\
W \\
W \\
857.4 \\
884.7 \\
921.9 \\
W \\
875.4 \\
858.4 \\
W \\
W \\
W \\
881.8\end{array}$ & $\begin{array}{r}3,715.4 \\
4,007.9 \\
4,249.0 \\
W \\
4,393.1 \\
4,748.0 \\
4,577.4 \\
W \\
4,377.1 \\
4,485.9 \\
4,522.0 \\
4,462.0 \\
4,385.5\end{array}$ & $\begin{array}{c}W \\
W \\
W \\
W \\
350.5 \\
181.1 \\
W \\
W \\
95.4 \\
W \\
W \\
W \\
189.2\end{array}$ & $\begin{array}{l}4,870.6 \\
5,187.3 \\
5,290.0 \\
5,561.1 \\
5,628.3 \\
5,851.1 \\
5,624.5 \\
5,598.5 \\
5,330.9 \\
5,601.3 \\
5,427.5 \\
5,492.0 \\
5,456.5\end{array}$ \\
\hline
\end{tabular}

See footnotes at end of table. 
Table 44. Refiner Motor Gasoline Volumes by Formulation, Sales Type, PAD District, and State

(Thousand Gallons per Day) - Continued

\begin{tabular}{|c|c|c|c|c|c|c|c|c|c|c|c|c|}
\hline \multirow{3}{*}{$\begin{array}{l}\text { Geographic Area } \\
\text { Month }\end{array}$} & \multicolumn{6}{|c|}{ Conventional } & \multicolumn{6}{|c|}{ Oxygenated } \\
\hline & \multicolumn{2}{|c|}{ Sales to End Users } & \multicolumn{4}{|c|}{ Sales for Resale } & \multicolumn{2}{|c|}{ Sales to End Users } & \multicolumn{4}{|c|}{ Sales for Resale } \\
\hline & $\begin{array}{c}\text { Through } \\
\text { Retail } \\
\text { Outlets }\end{array}$ & Totala & DTW & Rack & Bulk & Total & $\begin{array}{c}\text { Through } \\
\text { Retail } \\
\text { Outlots }\end{array}$ & Totala & DTW & Rack & Bulk & Total \\
\hline \multicolumn{13}{|l|}{ Nebraska } \\
\hline 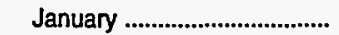 & 161.8 & 167.1 & 144.9 & $1,485.3$ & - & $1,630.2$ & - & - & - & - & - & - \\
\hline 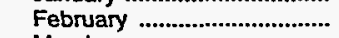 & 159.3 & 164.4 & 175.4 & $1,524.1$ & - & $1,699.5$ & - & - & - & - & - & - \\
\hline March & 161.9 & 167.3 & 154.3 & $1,626.9$ & - & $1,781.3$ & - & - & - & - & - & - \\
\hline April & 167.2 & 172.6 & 156.0 & $1,792.0$ & - & $1,948.0$ & - & - & - & $\rightarrow$ & - & - \\
\hline 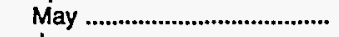 & 169.2 & 174.2 & 163.7 & $1,812.4$ & - & $1,976.1$ & - & - & - & - & - & - \\
\hline 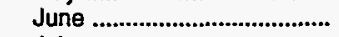 & 170.4 & 175.2 & $W$ & $1,973.9$ & $w$ & $2,169.7$ & - & - & - & - & - & - \\
\hline 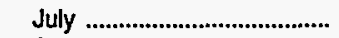 & 170.7 & 174.1 & W & $1,914.9$ & $w$ & $2,094.1$ & - & - & - & - & - & - \\
\hline August & 166.0 & 167.6 & 171.3 & $1,941.9$ & - & $2,113.2$ & - & - & - & - & - & - \\
\hline 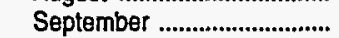 & 161.1 & 162.6 & 169.6 & $2,024.7$ & - & $2,194.3$ & - & - & - & - & - & - \\
\hline October & 154.8 & 156.6 & 161.2 & $1,851.7$ & - & $2,012.9$ & - & - & - & - & - & - \\
\hline 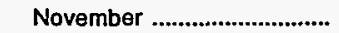 & 157.0 & 159.3 & 161.1 & $1,754.0$ & - & $1,915.1$ & - & - & - & - & - & - \\
\hline 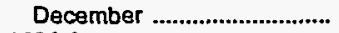 & 162.8 & 164.9 & 165.4 & $1,798.9$ & - & $1,964.2$ & - & - & - & - & - & - \\
\hline 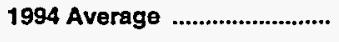 & 163.6 & 167.2 & 164.1 & $1,792.9$ & $\mathbf{w}$ & $1,959.3$ & - & - & - & - & - & - \\
\hline \multicolumn{13}{|l|}{ North Dakota } \\
\hline 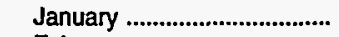 & 11.4 & 13.1 & $w$ & 701.4 & $\mathbf{W}$ & 795.8 & - & - & - & - & - & - \\
\hline 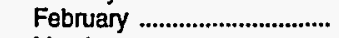 & 11.0 & 13.2 & W & 730.3 & $w$ & 826.0 & - & - & - & - & - & - \\
\hline March & 10.8 & 12.3 & $w$ & $W$ & - & 866.5 & - & - & - & - & - & - \\
\hline 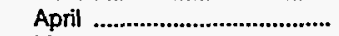 & 11.6 & 13.4 & $w$ & 829.9 & $\mathbf{w}$ & 924.8 & - & - & - & - & - & - \\
\hline 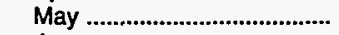 & 11.6 & 12.5 & $w$ & $W$ & - & 979.3 & - & - & - & - & - & - \\
\hline June & 12.2 & 13.1 & $w$ & $W$ & - & $1,078.5$ & - & - & - & - & - & - \\
\hline 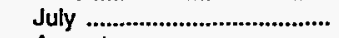 & 13.5 & 14.0 & $w$ & 946.2 & $w$ & $1,055.7$ & - & - & - & - & - & - \\
\hline August & 11.0 & 11.7 & $W$ & 946.3 & $w$ & $1,050.7$ & - & - & - & - & - & - \\
\hline 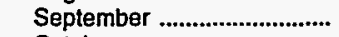 & 11.3 & 11.8 & $w$ & 941.2 & $\mathbf{w}$ & $1,037.7$ & - & - & - & - & - & - \\
\hline 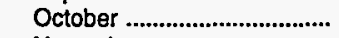 & 12.4 & 12.9 & W & W & - & 958.7 & - & - & - & - & - & - \\
\hline 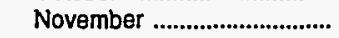 & 12.2 & 13.1 & $W$ & 878.9 & $w$ & 976.3 & - & - & - & - & - & - \\
\hline December ................................ & 11.9 & 12.2 & $W$ & 825.6 & $w$ & 925.6 & - & - & - & - & - & - \\
\hline 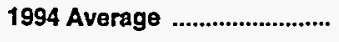 & 11.8 & 12.8 & $\mathbf{w}$ & 858.1 & $\mathbf{W}$ & 956.8 & - & - & - & - & - & - \\
\hline \multicolumn{13}{|l|}{ Ohio } \\
\hline 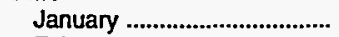 & $4,586.7$ & $4,799.9$ & $2,967.1$ & $3,781.1$ & $w$ & $6,996.4$ & - & - & - & - & - & - \\
\hline 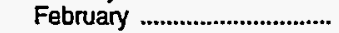 & $5,037.5$ & $5,275.6$ & $w$ & $4,018.4$ & $W$ & $7,405.1$ & - & - & - & - & - & - \\
\hline 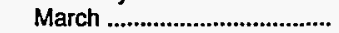 & $4,921.5$ & $5,173.4$ & $\mathbf{W}$ & $4,230.4$ & $w$ & $7,738.5$ & - & - & - & - & - & - \\
\hline 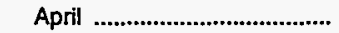 & $5,094.8$ & $5,352.4$ & $w$ & $4,453.6$ & $w$ & $8,034.3$ & - & - & - & - & - & - \\
\hline May & $5,103.8$ & $5,365.7$ & $w$ & $4,569.4$ & $W$ & $8,114.4$ & - & - & - & - & - & - \\
\hline 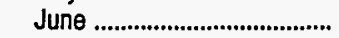 & $5,257.6$ & $5,528.8$ & $W$ & $4,726.8$ & $W$ & $8,408.1$ & - & - & - & - & - & - \\
\hline July ........................................... & $5,285.5$ & $5,512.3$ & $W$ & $4,645.4$ & $W$ & $8,128.3$ & - & - & - & - & - & - \\
\hline August & $5,284.6$ & $5,541.5$ & W & $4,772.3$ & $w$ & $8,476.0$ & - & - & - & - & - & - \\
\hline 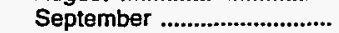 & $5,101.4$ & $5,369.0$ & W & $4,576.4$ & W & $8,395.8$ & - & - & - & - & - & - \\
\hline 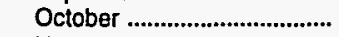 & $4,918.5$ & $5,186.9$ & $W$ & $4,542.2$ & W & $8,218.8$ & - & - & - & - & - & - \\
\hline 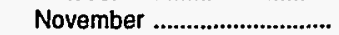 & $5,025.7$ & $5,273.2$ & $w$ & $4,752.5$ & $W$ & $8,480.8$ & - & - & - & - & - & - \\
\hline 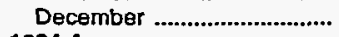 & $5,146.1$ & W & $W$ & W & 553.2 & W & - & - & $\rightarrow$ & - & - & - \\
\hline 1994 Average & $5,063.3$ & $5,313.7$ & $3,271.3$ & $4,502.1$ & $\mathbf{W}$ & $8,101.8$ & - & - & - & - & - & - \\
\hline \multicolumn{13}{|l|}{ Oklahoma } \\
\hline 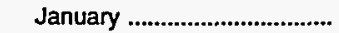 & 752.6 & 798.8 & $w$ & $3,297.1$ & $2,116.9$ & $5,479.7$ & - & - & - & - & - & - \\
\hline 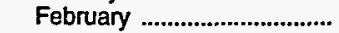 & 792.7 & 841.5 & $w$ & $3,499.2$ & $W$ & $5,917.0$ & - & - & - & - & - & - \\
\hline March & 811.3 & 859.8 & $w$ & $3,445.3$ & $W$ & $5,186.6$ & - & - & - & - & - & - \\
\hline April & 834.9 & 889.1 & $w$ & $3,524.7$ & $W$ & $5,634.2$ & - & - & - & - & - & - \\
\hline 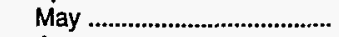 & 822.4 & 871.1 & W & $3,524.5$ & $W$ & $5,409.2$ & - & - & - & - & - & - \\
\hline 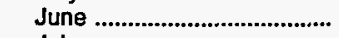 & 839.0 & 893.6 & $W$ & $3,539.8$ & W & $6,170.0$ & - & - & - & - & - & - \\
\hline 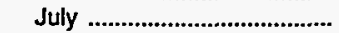 & 819.8 & 864.4 & $w$ & $W$ & $1,991.6$ & $5,427.2$ & - & - & - & - & - & - \\
\hline 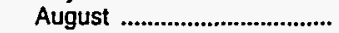 & 812.3 & 864.2 & $w$ & $3,261.6$ & 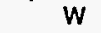 & $5,996.5$ & - & - & - & - & - & - \\
\hline 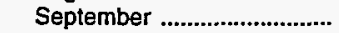 & 808.6 & 858.4 & $w$ & $3,197.6$ & $w$ & $6,468.6$ & - & - & - & - & - & - \\
\hline 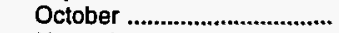 & 812.6 & 850.1 & $w$ & $3,261.7$ & W & $6,166.0$ & - & - & - & - & - & - \\
\hline 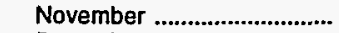 & 804.5 & 854.9 & $w$ & $3,333.2$ & W & $6,131.9$ & - & - & - & - & - & - \\
\hline 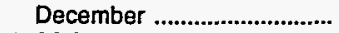 & 836.3 & 883.0 & $w$ & $3,592.9$ & $W$ & $6,031.2$ & - & - & - & - & - & - \\
\hline 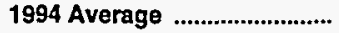 & 812.3 & 860.8 & $\mathbf{W}$ & $3,401.9$ & $2,354.8$ & $5,831.2$ & - & - & - & - & - & - \\
\hline
\end{tabular}

See footnotes at end of table. 
Table 44. Refiner Motor Gasoline Volumes by Formulation, Sales Type,

PAD District, and State

(Thousand Gallons per Day) - Continued

\begin{tabular}{|c|c|c|c|c|c|c|c|c|c|c|c|c|}
\hline \multirow{3}{*}{$\begin{array}{l}\text { Geographle Area } \\
\text { Month }\end{array}$} & \multicolumn{6}{|c|}{ Reformulated } & \multicolumn{6}{|c|}{ All Formulations } \\
\hline & \multicolumn{2}{|c|}{ Sales to End Usera } & \multicolumn{4}{|c|}{ Sales for Resale } & \multicolumn{2}{|c|}{ Sales to End Users } & \multicolumn{4}{|c|}{ Sales for Resale } \\
\hline & $\begin{array}{c}\text { Through } \\
\text { Retall } \\
\text { Outlets }\end{array}$ & Totaja & DTW & Rack & Bulk & Total & $\begin{array}{c}\text { Through } \\
\text { Retail } \\
\text { Outlets }\end{array}$ & Totala & DTW & Rack & Bulk & Total \\
\hline
\end{tabular}

\section{Nobraska}

January

March ...

Aprll

(1)

May

June

August

September

October.

November

December .

North Dakots

January

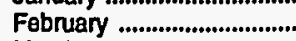

April .

June

July ....

September

October

Novem

December

1994 Average

Ohio

January ...

February

March

April....................................

May

June

July ...

August

October

November

December

1994 Avarago

Oklahoma

January

February ......................................

March

Aprit

May

June

July ...

August

September

October ....

November

December .

1994 Average

Seg lootnotes atend of tablo.

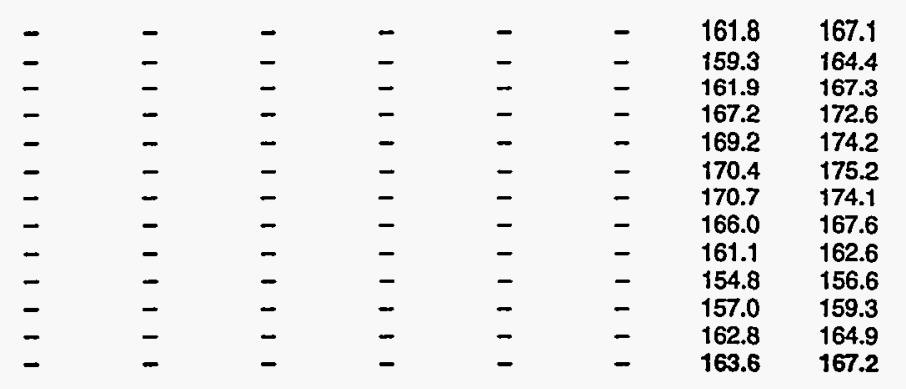

$\begin{array}{rr}144.9 & 1,485.3 \\ 175.4 & 1,524.1 \\ 154.3 & 1,626.9 \\ 156.0 & 1,792.0 \\ 163.7 & 1,812.4 \\ W & 1,973.9 \\ W & 1,914.9 \\ 171.3 & 1,941.9 \\ 169.6 & 2,024.7 \\ 161.2 & 1,851.7 \\ 161.1 & 1,754.0 \\ 165.4 & 1,798.9 \\ 164.1 & 1,792.9\end{array}$

$\begin{array}{ll}- & 1,630.2 \\ - & 1,699.5 \\ - & 1,781.3 \\ - & 1,948.0 \\ - & 1,976.1 \\ w & 2,169.7 \\ w & 2,094.1 \\ - & 2,113.2 \\ - & 2,194.3 \\ - & 2,012.9 \\ - & 1,915.1 \\ - & 1,964.2 \\ \mathbf{w} & 1,959.3\end{array}$

$\begin{array}{llll}- & - & - & - \\ - & - & - & - \\ - & - & - & - \\ - & - & - & - \\ = & - & - & - \\ - & - & - & - \\ = & - & - & - \\ - & - & - & -\end{array}$

$\begin{array}{ll}- & 11.4 \\ - & 11.0 \\ - & 10.8 \\ - & 11.6 \\ - & 11.6 \\ - & 12.2 \\ - & 13.5 \\ - & 11.0 \\ - & 11.3 \\ - & 12.4 \\ - & 12.2 \\ - & 11.9 \\ - & 11.8\end{array}$

13.1
13.2
12.3
13.4
12.5
13.1
14.0
11.7
11.8
12.9
13.1
12.2
12.8

$\begin{array}{lr}W & 701 . \\ W & 730.3 \\ W & W \\ W & 829.9 \\ W & W \\ W & W \\ W & 946 . \\ W & 946.3 \\ W & 941 . \\ W & W \\ W & 878.9 \\ W & 825 . \\ W & 858.1\end{array}$

$\begin{array}{cr}W & 795.8 \\ W & 826.0 \\ - & 866.5 \\ W & 924.8 \\ - & 979.3 \\ - & 1,078.5 \\ W & 1,055.7 \\ W & 1,050.7 \\ W & 1,037.7 \\ \bar{W} & 958.7 \\ W & 976.3 \\ W & 925.6 \\ W & 956.8\end{array}$

-
$=$
$=$
$=$
$=$
$=$
-

$\begin{array}{ll}- & 4,586.7 \\ - & 5,037.5 \\ - & 4,921.5 \\ - & 5,094.8 \\ - & 5,103.8 \\ - & 5,257.6 \\ - & 5,285.5 \\ - & 5,284.6 \\ - & 5,101.4 \\ - & 4,918.5 \\ - & 5,025.7 \\ W & 5,146.1 \\ \mathbf{W} & \mathbf{5 , 0 6 3 . 3}\end{array}$

$4,799.9$
$5,275.6$
$5,173.4$
$5,352.4$
$5,365.7$
$5,528.8$
$5,512.3$
$5,541.5$
$5,369.0$
$5,186.9$
$5,273.2$
$5,391.1$
$5,313.7$

$2,967.1$
$W$
$W$
$W$
$W$
$W$
$W$
$W$
$W$
$W$
$W$
3,307
3,271

$3,781.1$

$\begin{array}{lr}W & 4,018.4 \\ W & 4,230.4\end{array}$

$\begin{aligned} & \text { W } \\ & W\end{aligned} \quad 4,453.6$

$\begin{array}{ll}W & 4,453.6 \\ W & 4,569.4\end{array}$

W $\quad 4,726.8$

W $\quad 4,645.4$

W $4,772.3$

W $\quad 4,576.4$

W $4,542.2$

W $4,752,5$

4,943.6

$\begin{array}{cc}W & 6,996.4 \\ W & 7,405.1 \\ W & 7,738.5 \\ W & 8,034.3 \\ W & 8,114.4 \\ W & 8,408.1 \\ W & 8,128.3 \\ W & 8,476.0 \\ W & 8,395.8 \\ W & 8,218.8 \\ W & 8,480.8 \\ 553.2 & 8,804.6 \\ W & 8,103.3\end{array}$

$\begin{array}{lll}- & - & - \\ - & - & - \\ - & - & - \\ - & - & - \\ - & - & - \\ - & - & - \\ - & - & -\end{array}$

$\begin{array}{ll}752.6 & 798.8 \\ 792.7 & 841.5 \\ 811.3 & 859.8 \\ 834.9 & 889.1 \\ 822.4 & 871.1 \\ 839.0 & 893.6 \\ 819.8 & 864.4 \\ 812.3 & 864.2 \\ 808.6 & 858.4 \\ 812.6 & 850.1 \\ 804.5 & 854.9 \\ \mathbf{8 3 6 . 3} & 883.0 \\ \mathbf{8 1 2 . 3} & 860.8\end{array}$

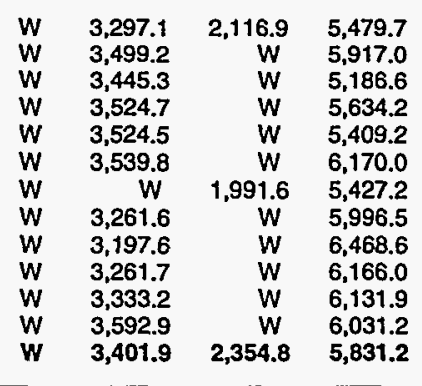

See lootnotes at end of table. 
Table 44. Refiner Motor Gasoline Volumes by Formulation, Sales Type, PAD District, and State

(Thousand Gallons per Day) - Continued

\begin{tabular}{|c|c|c|c|c|c|c|c|c|c|c|c|c|}
\hline \multirow{3}{*}{$\begin{array}{l}\text { Geographic Area } \\
\text { Month }\end{array}$} & \multicolumn{6}{|c|}{ Conventional } & \multicolumn{6}{|c|}{ Oxygenated } \\
\hline & \multicolumn{2}{|c|}{ Sales to End Users } & \multicolumn{4}{|c|}{ Sales for Resale } & \multicolumn{2}{|c|}{ Sales to End Users } & \multicolumn{4}{|c|}{ Sales for Resale } \\
\hline & $\begin{array}{l}\text { Through } \\
\text { Retail } \\
\text { Outlets }\end{array}$ & Totala & DTW & Rack & Bulk & Total & $\begin{array}{l}\text { Through } \\
\text { Retail } \\
\text { Outlots }\end{array}$ & Totaja & DTW & Rack & Bulk & Total \\
\hline
\end{tabular}

South Dakota

January .

............................

February

March

May

une

July .

August

September

October .

November

December .

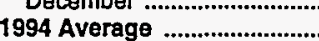

Tennessee

January

Fobruary

March

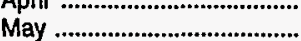

June

July ...

August ....

September ...............................

October.

November

December .

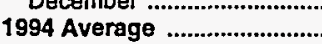

Wisconsin

January

February

March ....

April

May

July .

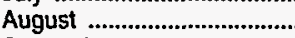

September

October ...

Novembe

December

PAD District III

January ....

March

April

May

June

July

August

September

October ...

November

December ...
1994 Average

$\begin{array}{ll}21.9 & 26.8 \\ 21.3 & 26.0 \\ 20.7 & 25.6 \\ 21.2 & 25.2 \\ 22.7 & 26.5 \\ 24.0 & 27.5 \\ 24.7 & 26.3 \\ 23.1 & 23.2 \\ 21.7 & 21.7 \\ 23.1 & 23.2 \\ 22.9 & 22.9 \\ 23.1 & 23.3 \\ 22.5 & 24.8\end{array}$

$1,288.3 \quad 1,311.3$

$1,308.9 \quad 1,344.5$

$1,352.8 \quad 1,385.7$

$1,382.6 \quad 1,412.7$

$1,360.5 \quad 1,395.9$

$1,394.9 \quad 1,432.4$

$1,366.3 \quad 1,395.8$

$1,326.3 \quad 1,375.9$

$1,319.9 \quad 1,363.5$

$1,310.5 \quad 1,358.2$

$1,352.1 \quad 1,396.8$

$1,417.7 \quad 1,465.7$

$1,348.6 \quad 1,386.7$

$792.3 \quad 802.0$

$801.1 \quad 813.9$

791.2

809.1

830.2

857.6

$810.1 \quad 820.7$

$798.6 \quad 807.6$

$626.3 \quad 629.3$

$802.4 \quad 813.1$

$6,689.6 \quad 6,978$

$7,156.7 \quad 7,480.8$

$7,854.7 \quad 8,211.5$

W

W

W

$W$
$W$
$W$

$7,782.7$

$W$

$4,585.0$

$7,528.0$

$6,894.7$

$\begin{array}{cc}42.7 & 879.0 \\ W & 891.3 \\ 43.2 & W \\ W & 968.9 \\ \mathbf{5 0 . 3} & W \\ 57.5 & W \\ W & 1,243.4 \\ W & 1,238.9 \\ W & 1,101.3 \\ 55.0 & W \\ W & 1,025.4 \\ W & 1,030.5 \\ 51.2 & 1,055.9\end{array}$

$\begin{array}{lr}- & 921.7 \\ W & 936.5 \\ W & 1,021.2 \\ W & 1,018.7 \\ W & 1,111.1 \\ W & 1,220.5 \\ W & 1,309.1 \\ W & 1,303.8 \\ W & 1,157.4 \\ W & 1,138.0 \\ W & 1,076.1 \\ W & 1,081.3 \\ W & 1,109.2\end{array}$

$622.5 \quad 5,811.6$

$\begin{array}{ll}W & 6,626.9 \\ W & 6,857\end{array}$

W $6,999.8$

W 7,058.4

W $7,399.6$

W $\quad 7,148.3$

W $7,455.9$

W 7,245.2

$\begin{array}{ll}W & 6,911.3 \\ W & 7,007.7\end{array}$

W $7,163.8$

$679.5 \quad 6,974.6$

$\begin{array}{ll}- & 6,434.2 \\ W & 7,369.3 \\ W & 7,665.7 \\ W & 7,839.3 \\ W & 7,842.8 \\ W & 8,234.3 \\ W & 7,982.7 \\ W & 8,319.7 \\ W & 8,050.7 \\ W & 7,694.5 \\ W & 7,835.3 \\ W & 7,979.1 \\ W & 7,771.5\end{array}$

$680.4 \quad 4,009.9$

$687.2 \quad 4,115.1$

$667.1 \quad 4,156.2$

$665.5 \quad 4,216.0$

W $4,539.5$

W $4,864.2$

$713.0 \quad 4,953.6$

$694.4 \quad 4,832.6$

$666.5 \quad 4,874.2$

$668.9 \quad 4,542.0$

$669.6 \quad 4,519.5$

$261.1 \quad 3,778.1$

$646.9 \quad 4,451.0$

$\begin{array}{cr}- & 4,690.3 \\ - & 4,802.3 \\ - & 4,823.3 \\ - & 4,881.5 \\ \text { W } & 5,248.4 \\ \text { W } & 5,593.7 \\ - & 5,666.6 \\ - & 5,527.0 \\ - & 5,540.7 \\ - & 5,210.9 \\ - & 5,189.1 \\ - & 4,039.1 \\ \mathbf{W} & \mathbf{5 , 1 0 1 . 3}\end{array}$

$\begin{array}{llll}3,923.6 & 34,098.2 & 13,736.4 & 51,758.2\end{array}$

$\begin{array}{rrrr}4,261.3 & 34,133.0 & 9,824.3 & 48,218.6\end{array}$

$\begin{array}{llrr}W & W & 9,969.4 & 49,853.4\end{array}$

$\begin{array}{llr}W & W & 11,685.6\end{array}$

$W \quad W \quad 12,587.6$

$W \quad W \quad 12,639.5$

$\begin{array}{llll}W & W & 9,423.1 & W\end{array}$

W $\quad W \quad 52,220.2$

$\begin{array}{llll}W & 36,525.2 & 10,918.7 & 51,548.9\end{array}$

$\begin{array}{llll}W & 33,770.5 & W & 49,266.7\end{array}$

W $34,882.3 \quad$ W $49,799.9$

7,209.0

$\begin{array}{rrrr}W & 30,831.6 & W & 50,112.5 \\ 3,971.6 & 35,356.6 & 11,847.9 & 51,176.1\end{array}$

$\begin{array}{llllll}- & - & - & - & - & - \\ - & - & - & - & - & - \\ - & - & - & - & - & - \\ - & - & - & - & - & - \\ - & - & - & - & - & - \\ - & - & - & - & - & - \\ - & - & - & - & - & - \\ - & - & - & - & - & - \\ - & - & - & - & - & - \\ - & - & - & - & - & - \\ - & - & - & - & - & - \\ - & - & - & - & - & - \\ - & - & - & - & - & -\end{array}$

See footnotes at end of table. 
Table 44. Refiner Motor Gasoline Volumes by Formulation, Sales Type, PAD District, and State

(Thousand Gallons per Day) — Continued

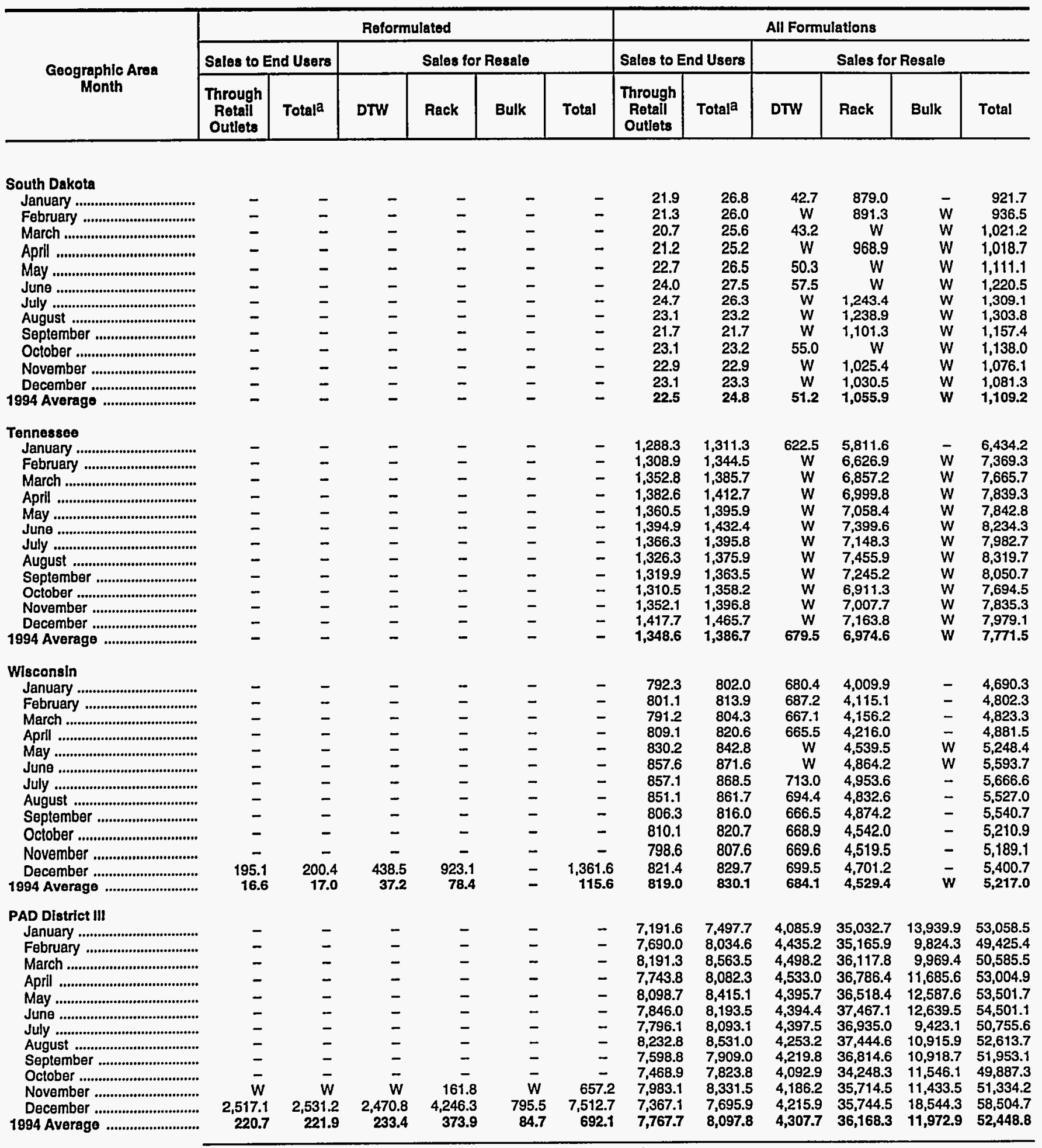

See footnotes at end of table. 
Table 44. Refiner Motor Gasoline Volumes by Formulation, Sales Type, PAD District, and State

(Thousand Gallons per Day) - Continued

\begin{tabular}{|c|c|c|c|c|c|c|c|c|c|c|c|c|}
\hline \multirow{3}{*}{$\begin{array}{l}\text { Geographic Area } \\
\text { Month }\end{array}$} & \multicolumn{6}{|c|}{ Conventional } & \multicolumn{6}{|c|}{ Oxygenated } \\
\hline & \multicolumn{2}{|c|}{ Sales to End Users } & \multicolumn{4}{|c|}{ Sales for Resale } & \multicolumn{2}{|c|}{ Sales to End Users } & \multicolumn{4}{|c|}{ Sales for Resale } \\
\hline & $\begin{array}{c}\text { Through } \\
\text { Retail } \\
\text { Outlets }\end{array}$ & Totala & bTW & Rack & Bulk & Total & $\begin{array}{l}\text { Through } \\
\text { Rotail } \\
\text { Outlote }\end{array}$ & Totaja & DTW & Rack & Bulk & Total \\
\hline \multicolumn{13}{|l|}{ Alabama } \\
\hline 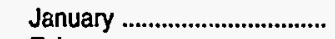 & 378.5 & 413.5 & 294.2 & $4,257.6$ & - & $4,551.8$ & - & - & - & - & - & - \\
\hline 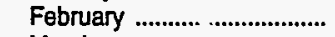 & 408.3 & 445.6 & $W$ & $4,506.8$ & $W$ & $4,865.9$ & - & - & - & - & - & - \\
\hline 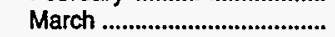 & 410.9 & 452.2 & $W$ & $4,742.8$ & $\ddot{w}$ & $5,124.5$ & - & - & - & - & - & - \\
\hline 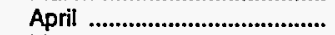 & 420.5 & 456.9 & $\ddot{w}$ & $4,734.1$ & $w$ & $5,113.8$ & - & - & - & - & - & - \\
\hline 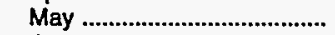 & 414.5 & 453.2 & 252.5 & $W$ & $\ddot{w}$ & $5,123.4$ & - & - & - & - & - & - \\
\hline June & 409.7 & 448.7 & 247.1 & $w$ & $w$ & $5,287.2$ & - & - & - & - & - & - \\
\hline 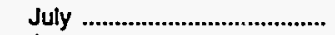 & 404.0 & 440.5 & $W$ & $4,690.1$ & $w$ & $5,001.8$ & - & - & - & - & - & - \\
\hline August & 398.6 & 444.8 & $w$ & $5,038.8$ & $W$ & $5,314,3$ & - & - & - & - & - & - \\
\hline 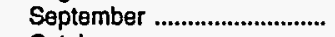 & 393.1 & 438.6 & 180.2 & $W$ & $W$ & $5,206.2$ & - & - & - & - & - & - \\
\hline 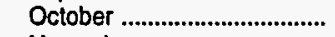 & 385.5 & 424.5 & W & $4,702.0$ & $W$ & $4,958.0$ & - & - & - & - & - & - \\
\hline November .............................. & 386.6 & 425.9 & 172.0 & $W$ & $W$ & $5,059.4$ & - & - & - & - & - & - \\
\hline 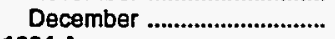 & 388.4 & 427.2 & 171.3 & $w$ & $W$ & $5,150.9$ & - & - & - & - & - & - \\
\hline 1994 Average ........................... & 399.8 & 439.2 & 2323 & $4,752.7$ & $\mathbf{W}$ & $5,063.6$ & - & - & - & - & - & - \\
\hline \multicolumn{13}{|l|}{ Arkansas } \\
\hline 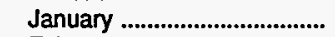 & 290.7 & 294.5 & 36.6 & $3,915.2$ & $w$ & $3,952.0$ & - & - & - & - & - & - \\
\hline 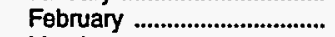 & 300.1 & 305.4 & 36.7 & $W$ & - & $W$ & - & - & - & $w$ & - & $w$ \\
\hline March & 317.2 & 321.8 & $w$ & $3,814.2$ & $w$ & $3,865.6$ & - & - & - & - & - & - \\
\hline April & 319.2 & 325.3 & $\mathbf{W}$ & $3,840.7$ & $w$ & $3,903.3$ & - & - & - & - & - & - \\
\hline 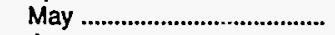 & 327.3 & 331.8 & $w$ & $3,934.0$ & $w$ & $4,008.7$ & - & - & - & - & - & - \\
\hline June & 337.6 & 343.1 & $\mathbf{w}$ & $4,038.0$ & $\mathbf{w}$ & $4,098.4$ & - & - & - & - & - & - \\
\hline July & 347.0 & 354.4 & $w$ & W & - & $4,194.0$ & - & - & - & - & - & - \\
\hline August & 331.4 & 340.3 & $w$ & $W$ & - & $4,218.5$ & - & - & - & - & - & - \\
\hline 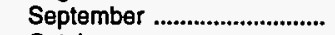 & 314.4 & 324.3 & w & $3,960.5$ & $w$ & $4,049.8$ & - & - & - & - & - & - \\
\hline 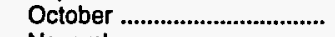 & 299.1 & 309.2 & $w$ & W & $W$ & $3,837.5$ & - & - & - & - & - & - \\
\hline November ............................... & 302.9 & 310.2 & $w$ & $3,800.4$ & $w$ & $3,926.9$ & - & - & - & - & - & - \\
\hline December ................................. & 314.6 & 324.8 & W & $4,060.4$ & $W$ & $4,136.2$ & - & - & - & - & - & - \\
\hline 1994 Average .............................. & 316.9 & 323.9 & 40.5 & $3,937.7$ & 28.4 & $4,006.5$ & - & - & - & $w$ & - & $\mathbf{w}$ \\
\hline \multicolumn{13}{|l|}{ Louisiana } \\
\hline January ...................................... & 671.1 & 703.8 & 598.3 & $4,385.9$ & $2,946.4$ & $7,930.6$ & - & - & - & - & - & - \\
\hline February ............................... & 710.6 & 746.6 & 647.7 & $4,289.0$ & $1,365.2$ & $6,301.9$ & - & - & - & - & - & - \\
\hline March ................................. & 741.1 & 779.0 & 673.9 & $4,241.1$ & $1,406.3$ & $6,321.3$ & - & - & - & - & - & - \\
\hline 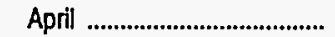 & 712.3 & 749.0 & 660.2 & $4,089.0$ & $1,047.7$ & $5,796.9$ & - & - & - & - & - & - \\
\hline 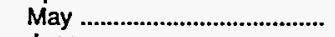 & 731.5 & 767.0 & 645.5 & $4,197.4$ & $1,683.6$ & $6,536.5$ & - & - & - & - & - & - \\
\hline 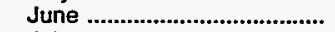 & 722.7 & 759.9 & 627.7 & $4,516.0$ & $1,964.4$ & $7,108.2$ & - & - & - & - & - & - \\
\hline 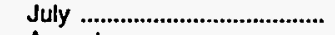 & 726.5 & 755.2 & 612.2 & $4,197.6$ & $1,829.1$ & $6,638.9$ & - & - & - & - & - & - \\
\hline 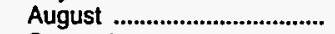 & 748.4 & 772.3 & 600.8 & $4,196.7$ & $2,065.9$ & $6,863.4$ & - & - & - & - & - & - \\
\hline 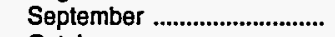 & 713.1 & 736.7 & 629.4 & $4,124.0$ & $1,931.4$ & $6,684.8$ & - & - & - & - & - & - \\
\hline 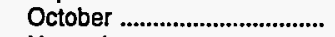 & 698.7 & 725.0 & 604.4 & $3,904.9$ & $1,842.9$ & $6,352.2$ & - & - & - & - & - & - \\
\hline 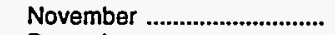 & 730.1 & 751.8 & 619.1 & $3,987.3$ & $1,012.1$ & $5,618.5$ & - & - & - & - & $\rightarrow$ & - \\
\hline 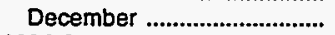 & 711.7 & 736.6 & 613.5 & $4,366.2$ & $w$ & W & - & - & - & - & - & - \\
\hline 1994 Average .............................. & 718.2 & 748.6 & 627.5 & $4,207.6$ & $1,738.9$ & $6,574.0$ & - & - & - & - & - & - \\
\hline \multicolumn{13}{|l|}{ Mississippi } \\
\hline 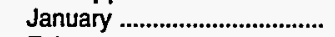 & 105.0 & 129.1 & 74.5 & $2,913.6$ & 982.3 & $3,970.4$ & - & - & - & - & - & - \\
\hline February ................................. & 105.1 & 125.9 & $W$ & $3,234.0$ & $W$ & $3,597.3$ & - & - & - & - & - & - \\
\hline 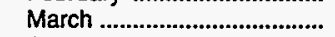 & 107.1 & 132.6 & $w$ & $3,169.5$ & $\ddot{w}$ & $3,305.4$ & - & - & - & - & - & - \\
\hline 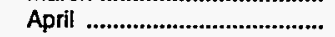 & 109.4 & 138.8 & 45.5 & $3,260.5$ & 694.7 & $4,000.6$ & - & - & - & - & - & - \\
\hline 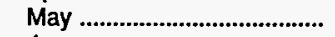 & 110.6 & 135.7 & 40.5 & $3,293.8$ & $1,841.7$ & $5,176.0$ & - & - & - & - & - & - \\
\hline 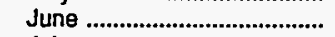 & 110.7 & 141.5 & 51.6 & $3,301.0$ & 909.9 & $4,262.6$ & - & - & - & - & - & - \\
\hline 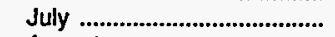 & 109.5 & 134.3 & 49.7 & $W$ & $w$ & $3,999.6$ & - & - & - & - & - & - \\
\hline 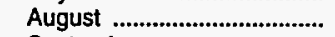 & 112.8 & 138.8 & 29.4 & W & w & $3,931.5$ & - & - & - & - & - & - \\
\hline 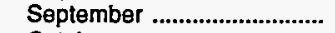 & 106.6 & 131.5 & 31.1 & $3,359.1$ & $1,039.1$ & $4,429.4$ & - & - & - & - & - & - \\
\hline October & 102.6 & 129.6 & 24.6 & $3,083.2$ & 916.7 & $4,024.5$ & - & - & - & - & - & - \\
\hline 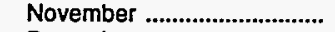 & 104.9 & 130.8 & 30.8 & $3,109.6$ & $W$ & $W$ & - & - & - & - & - & - \\
\hline December ............................... & 107.3 & 135.0 & 27.9 & $3,235.1$ & 811.0 & $4,074.0$ & - & - & - & - & - & - \\
\hline 1994 Average & 107.7 & 133.7 & 44.3 & $3,228.1$ & 776.6 & $4,048.9$ & - & - & - & - & - & - \\
\hline
\end{tabular}

See footnotes at end of table. 
Table 44. Refiner Motor Gasoline Volumes by Formulation, Sales Type, PAD District, and State

(Thousand Gallons per Day) - Continued

\begin{tabular}{|c|c|c|c|c|c|c|c|c|c|c|c|c|}
\hline \multirow{3}{*}{$\begin{array}{l}\text { Geographlc Ares } \\
\text { Month }\end{array}$} & \multicolumn{6}{|c|}{ Reformulated } & \multicolumn{6}{|c|}{ All Formulations } \\
\hline & \multicolumn{2}{|c|}{ Sales to End Users } & \multicolumn{4}{|c|}{ Sales for Resale } & \multicolumn{2}{|c|}{ Sales to End Users } & \multicolumn{4}{|c|}{ Sales for Resale } \\
\hline & $\begin{array}{c}\text { Through } \\
\text { Retall } \\
\text { Outlets }\end{array}$ & Totala & DTW & Rack & Bulk & Total & $\begin{array}{c}\text { Through } \\
\text { Retail } \\
\text { Outlets }\end{array}$ & Totala & DTW & Rack & Bulk & Total \\
\hline \multicolumn{13}{|l|}{ Alabama } \\
\hline 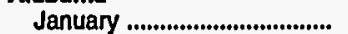 & - & - & - & - & - & - & 378.5 & 413.5 & 294.2 & $4,257.6$ & - & $4,551.8$ \\
\hline Fobruary .................................. & - & - & - & - & - & - & 408.3 & 445.6 & $w$ & $4,506.8$ & w & $4,865.9$ \\
\hline March ........................................ & - & - & - & - & - & - & 410.9 & 452.2 & $\ddot{w}$ & $4,742.8$ & $w$ & $5,124.5$ \\
\hline 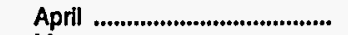 & - & - & - & - & - & - & 420.5 & 456.9 & w & $4,734.1$ & $w$ & $5,113.8$ \\
\hline 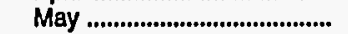 & - & - & - & - & - & - & 414.5 & 453.2 & 252.5 & $w$ & $w$ & $5,123.4$ \\
\hline 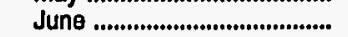 & - & - & - & - & - & - & 409.7 & 448.7 & 247.1 & w & W & $5,287.2$ \\
\hline 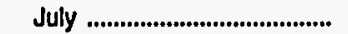 & - & - & - & - & - & - & 404.0 & 440.5 & w & $4,690.1$ & W & $5,001.8$ \\
\hline 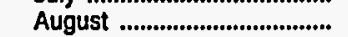 & - & - & - & - & - & - & 398.6 & 444.8 & $w$ & $5,038.8$ & $\ddot{w}$ & $5,314.3$ \\
\hline September .............................. & - & - & - & - & - & - & 393.1 & 438.6 & 180.2 & $w$ & $w$ & $5,206.2$ \\
\hline 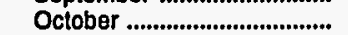 & - & - & - & - & - & - & 385.5 & 424.5 & $w$ & $4,702.0$ & w & $4,958.0$ \\
\hline November ................................... & - & - & - & - & - & - & 386.6 & 425.9 & 172.0 & w & w & $5,059.4$ \\
\hline 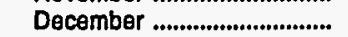 & - & - & - & - & - & - & 388.4 & 427.2 & 171.3 & w & $\ddot{w}$ & $5,150.9$ \\
\hline 1994 Average ............................ & - & - & - & - & - & - & 399.8 & 439.2 & 232.3 & $4,752.7$ & w & $5,063.6$ \\
\hline \multicolumn{13}{|l|}{ Arkansas } \\
\hline 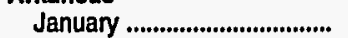 & - & - & - & - & - & - & 290.7 & 294.5 & 36.6 & $3,915.2$ & w & $3,952.0$ \\
\hline 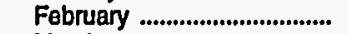 & - & - & - & - & - & - & 300.1 & 305.4 & 36.7 & $3,844.7$ & - & $3,881.4$ \\
\hline 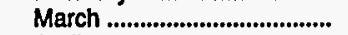 & - & - & - & - & - & - & 317.2 & 321.8 & $w$ & $3,814.2$ & w & $3,865.6$ \\
\hline 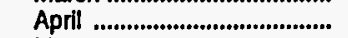 & - & - & - & - & - & - & 319.2 & 325.3 & $w$ & $3,840.7$ & $\ddot{w}$ & $3,903.3$ \\
\hline 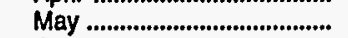 & - & - & - & - & - & - & 327.3 & 331.8 & w & $3,934.0$ & $w$ & $4,008.7$ \\
\hline 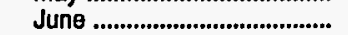 & - & - & - & - & - & - & 337.6 & 343.1 & $w$ & $4,038.0$ & $\ddot{w}$ & $4,098.4$ \\
\hline July .............................................. & - & - & - & - & - & - & 347.0 & 354.4 & w & W & - & $4,194.0$ \\
\hline August ......................................... & - & - & - & - & - & - & 331.4 & 340.3 & w & W & - & $4,218.5$ \\
\hline 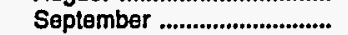 & - & - & - & - & - & - & 314.4 & 324.3 & w & $3,960.5$ & $w$ & $4,049.8$ \\
\hline 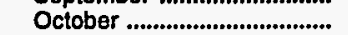 & - & - & - & - & - & - & 299.1 & 309.2 & $w$ & $3,720.2$ & $w$ & $3,837.5$ \\
\hline 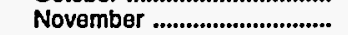 & - & - & - & - & - & - & 302.9 & 310.2 & w & $3,800.4$ & w & $3,926.9$ \\
\hline December ............................... & - & - & - & - & - & - & 314.6 & 324.8 & w & $4,060.4$ & $w$ & $4,136.2$ \\
\hline 1994 Average & - & - & - & - & - & - & 316.9 & 323.9 & 40.5 & $3,938.3$ & 28.4 & $4,007.2$ \\
\hline \multicolumn{13}{|l|}{ Loulsiana } \\
\hline 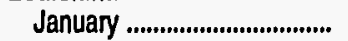 & - & - & - & - & - & - & 671.1 & 703.8 & 598.3 & $4,385.9$ & $2,946.4$ & $7,930.6$ \\
\hline 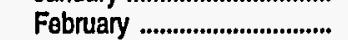 & - & - & - & - & - & - & 710.6 & 746.6 & 647.7 & $4,289.0$ & $1,365.2$ & $6,301.9$ \\
\hline 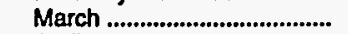 & - & - & - & - & - & - & 741.1 & 779.0 & 673.9 & $4,241.1$ & $1,406.3$ & $6,321.3$ \\
\hline 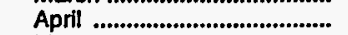 & - & - & - & - & - & - & 712.3 & 749.0 & 660.2 & $4,089.0$ & $1,047.7$ & $5,796.9$ \\
\hline 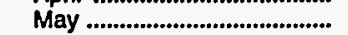 & - & - & - & - & - & - & 731.5 & 767.0 & 645.5 & $4,197.4$ & $1,693.6$ & $6,536.5$ \\
\hline 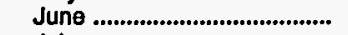 & - & - & - & - & - & - & 722.7 & 759.9 & 627.7 & $4,516.0$ & $1,964.4$ & $7,108.2$ \\
\hline 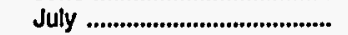 & - & - & - & - & - & - & 726.5 & 755.2 & 612.2 & $4,197.6$ & $1,829.1$ & $6,638.9$ \\
\hline 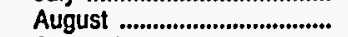 & - & - & - & - & - & - & 748.4 & 772.3 & 600.8 & $4,196.7$ & $2,065.9$ & $6,863.4$ \\
\hline September ................................. & - & - & - & - & - & - & 713.1 & 736.7 & 629.4 & $4,124.0$ & $1,931.4$ & $6,684.8$ \\
\hline 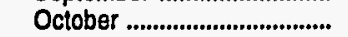 & - & - & - & - & - & - & 698.7 & 725.0 & 604.4 & $3,904.9$ & $1,842.9$ & $6,352.2$ \\
\hline 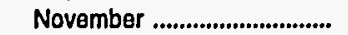 & - & - & - & - & - & - & 730.1 & 751.8 & 619.1 & $3,987.3$ & $1,012.1$ & $5,618.5$ \\
\hline 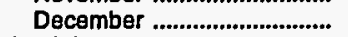 & - & - & - & - & $w$ & w & 711.7 & 736.6 & 613.5 & $4,366.2$ & $1,761.4$ & $6,741.1$ \\
\hline 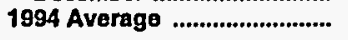 & - & - & - & - & $\mathbf{w}$ & $\mathbf{w}$ & 718.2 & 748.6 & 627.5 & $4,207.6$ & $1,744.7$ & $6,579.8$ \\
\hline \multicolumn{13}{|l|}{ Mississipp] } \\
\hline 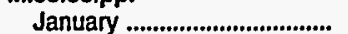 & - & - & - & - & - & - & 105.0 & 129.1 & 74.5 & $2,913.6$ & 982.3 & $3,970.4$ \\
\hline 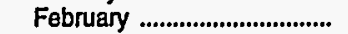 & - & - & - & - & - & - & 105.1 & 125.9 & $w$ & $3,234.0$ & $w$ & $3,597.3$ \\
\hline March & - & - & - & - & - & - & 107.1 & 132.6 & W & $3,169.5$ & w & $3,305.4$ \\
\hline 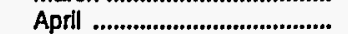 & - & - & - & - & - & - & 109.4 & 138.8 & 45.5 & $3,260.5$ & 694.7 & $4,000.6$ \\
\hline 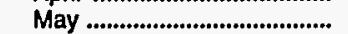 & - & - & - & - & - & - & 110.6 & 135.7 & 40.5 & $3,293.8$ & $1,841.7$ & $5,176.0$ \\
\hline 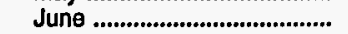 & - & - & - & - & - & - & 110.7 & 141.5 & 51.6 & $3,301.0$ & 909.9 & $4,262.6$ \\
\hline 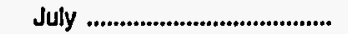 & - & - & - & - & - & - & 109.5 & 134.3 & 49.7 & w & w & $3,999.6$ \\
\hline 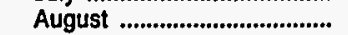 & - & - & - & - & - & - & 112.8 & 138.8 & 29.4 & w & W & $3,931.5$ \\
\hline September .................................. & - & - & - & - & - & - & 106.6 & 131.5 & 31.1 & $3,359.1$ & $1,039.1$ & $4,429.4$ \\
\hline 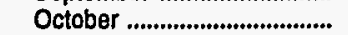 & - & - & - & - & - & - & 102.6 & 129.6 & 24.6 & $3,083.2$ & 916.7 & $4,024.5$ \\
\hline November ............................... & - & - & - & - & w & w & 104.9 & 130.8 & 30.8 & $3,109.6$ & 779.0 & $3,919.4$ \\
\hline 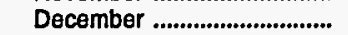 & - & - & - & - & - & - & 107.3 & 135.0 & 27.9 & $3,235.1$ & 811.0 & $4,074.0$ \\
\hline 1994 Average .............................. & - & - & - & - & $\mathbf{w}$ & $\mathbf{w}$ & 107.7 & 133.7 & 44.3 & $3,228.1$ & 788.0 & $4,060.3$ \\
\hline
\end{tabular}

See footnotes at end of table. 
Table 44. Refiner Motor Gasoline Volumes by Formulation, Sales Type,

PAD District, and State

(Thousand Gallons per Day) - Continued

\begin{tabular}{|c|c|c|c|c|c|c|c|c|c|c|c|c|}
\hline \multirow{3}{*}{$\begin{array}{l}\text { Geographic Area } \\
\text { Month }\end{array}$} & \multicolumn{6}{|c|}{ Conventional } & \multicolumn{6}{|c|}{ Oxygenated } \\
\hline & \multicolumn{2}{|c|}{ Sales to End Users } & \multicolumn{4}{|c|}{ Sales for Resale } & \multicolumn{2}{|c|}{ Sales to End Users } & \multicolumn{4}{|c|}{ Sales for Resale } \\
\hline & $\begin{array}{l}\text { Through } \\
\text { Retail } \\
\text { Outlets }\end{array}$ & Totala & DTW & Rack & Bulk & Total & $\begin{array}{l}\text { Through } \\
\text { Retall } \\
\text { Outlots }\end{array}$ & Totala & DTW & Rack & Bulk & Total \\
\hline \multicolumn{13}{|l|}{ New Mexico } \\
\hline January ..... & w & w & 116.1 & $1,123.7$ & - & $1,239.8$ & 262.2 & 265.9 & 101.6 & 287.5 & - & 389.2 \\
\hline 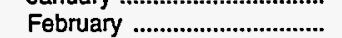 & w & $\ddot{w}$ & $w$ & & - & W & $w$ & w & $w$ & $w$ & - & w \\
\hline March & $w$ & w & w & w & - & w & $w$ & W & $w$ & $w$ & - & w \\
\hline April ......................................... & $w$ & $w$ & $w$ & w & - & $w$ & $w$ & $w$ & $\ddot{w}$ & $w$ & - & 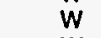 \\
\hline 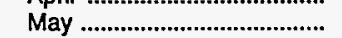 & w & w & 235.5 & w & - & w & $w$ & $w$ & w & - & - & $w$ \\
\hline 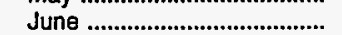 & $w$ & $w$ & 240.2 & $w$ & - & w & W & W & w & - & - & $w$ \\
\hline July .. & w & $w$ & 234.0 & w & - & w & W & $w$ & w & - & - & $w$ \\
\hline August & $w$ & $w$ & 261.1 & w & - & w & W & w & W & - & - & $w$ \\
\hline September ............ & W & w & 259.4 & w & - & w & W & $w$ & W & - & - & w \\
\hline October ................... & $w$ & $w$ & 200.5 & $w$ & w & $1,810.8$ & $w$ & $w$ & $w$ & w & - & 170.1 \\
\hline November ......... & $w$ & $w$ & 140.2 & $w$ & - & W & $w$ & $w$ & w & w & - & $w$ \\
\hline 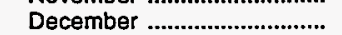 & $\ddot{w}$ & 58.8 & 136.9 & $w$ & - & $w$ & $w$ & 287.8 & w & w & - & w \\
\hline 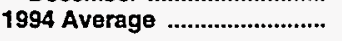 & 170.7 & 179.1 & 200.2 & $1,432.8$ & $\mathbf{w}$ & $1,638.2$ & 173.8 & 175.5 & 62.9 & 109.4 & - & 172.3 \\
\hline \multicolumn{13}{|l|}{ Texas } \\
\hline 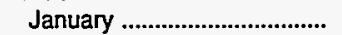 & $5,184.9$ & $5,375.6$ & $2,804.1$ & $17,502.1$ & $9,807.4$ & $30,113.6$ & 239.7 & 253.8 & w & 647.0 & w & 911.1 \\
\hline February ....................................... & & w & & & $8,121.2$ & $28,297.4$ & w & $w$ & w & w & - & 760.3 \\
\hline 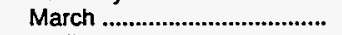 & w & w & w & $17,978.4$ & $8,383.7$ & $w$ & w & $w$ & $w$ & 644.7 & - & $w$ \\
\hline 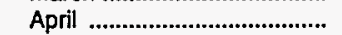 & $5,858.3$ & w & $3,234.9$ & $w$ & $9,841.8$ & $w$ & - & w & - & w & - & w \\
\hline 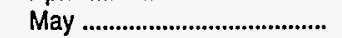 & $6,161.4$ & $6,366.7$ & $3,154.3$ & $w$ & $8,957.5$ & $w$ & - & - & - & W & - & w \\
\hline 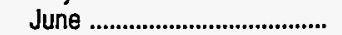 & $5,918.7$ & $6,146.7$ & $3,159.0$ & W & $9,595.6$ & W & - & - & - & W & - & W \\
\hline 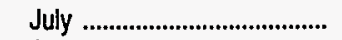 & $5,859.9$ & $6,048.2$ & $3,201.4$ & W & $7,007.1$ & W & - & - & - & W & - & $w$ \\
\hline 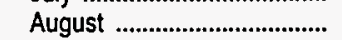 & $6,271.7$ & $6,450.9$ & $3,111.1$ & W & $w$ & $w$ & - & - & - & $W$ & w & $\ddot{w}$ \\
\hline 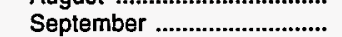 & $w$ & $w$ & $w$ & $18,663.9$ & $7,837.8$ & w & w & w & W & 289.4 & - & W \\
\hline October ....................................... & $5,371.3$ & $5,593.7$ & w & $w$ & w & $28,283.6$ & 275.5 & 290.8 & $w$ & $w$ & w & 450.5 \\
\hline $\mathrm{er}$ & & $5,546.2$ & w & $17,906.3$ & w & $29,993.4$ & 698.2 & $w$ & $\mathbf{w}$ & $w$ & - & w \\
\hline December ..................................... & & $2,902.7$ & $w$ & & $15,115.5$ & $28,573.2$ & w & 291.9 & $w$ & $W$ & w & w \\
\hline 1994 Average & $5,495.7$ & $5,703.5$ & $2,826.9$ & $17,797.7$ & $9,220.3$ & $29,844.9$ & 164.2 & 172.4 & $w$ & 327.7 & $\ddot{w}$ & 407.7 \\
\hline \multicolumn{13}{|l|}{ PAD District IV } \\
\hline 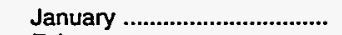 & 591.8 & 623.8 & 871.7 & $4,271.7$ & w & $5,185.5$ & $1,450.0$ & $1,458.0$ & $w$ & 865.2 & - & $1,080.5$ \\
\hline 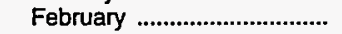 & 596.9 & 634.8 & 910.6 & $\mathbf{w}$ & w & $5,332.0$ & $1,557.6$ & $1,564.9$ & w & w & - & $1,100.0$ \\
\hline March ………………………....... & $w$ & $w$ & $w$ & w & $w$ & $w$ & w & $w$ & W & $w$ & - & w \\
\hline 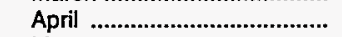 & w & w & w & w & $\ddot{w}$ & $w$ & $w$ & w & - & $w$ & - & $w$ \\
\hline 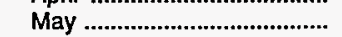 & $w$ & $w$ & w & w & $w$ & w & w & w & - & w & - & $w$ \\
\hline June ............................................ & w & W & W & w & w & w & w & W & - & W & - & w \\
\hline ...................... & w & $w$ & w & $6,749.7$ & w & $8,120.0$ & w & w & - & 193.9 & - & 193.9 \\
\hline$\ldots \ldots \ldots \ldots \ldots \ldots \ldots \ldots$ & $w$ & $w$ & w & $7,004.2$ & w & $8,390.0$ & $w$ & $w$ & - & 155.5 & - & 155.5 \\
\hline September ................................. & w & w & W & w & w & $7,007.3$ & $w$ & w & w & $w$ & - & 484.5 \\
\hline October ..................................... & w & $w$ & 928.9 & w & $w$ & $6,615.3$ & $w$ & $w$ & $w$ & w & - & 865.2 \\
\hline ................................... & 576.6 & w & $w$ & w & $w$ & $5,386.7$ & $1,615.3$ & $w$ & w & w & - & $1,790.8$ \\
\hline December ................................. & 500.7 & 537.3 & 671.7 & $w$ & $w$ & $5,285.7$ & $1,635.5$ & $1,644.4$ & w & w & - & $1,932.8$ \\
\hline 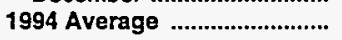 & $1,641.4$ & $1,683.5$ & $1,043.4$ & $5,670.3$ & 12.6 & $6,726.4$ & 544.1 & 546.7 & 184.3 & 501.3 & - & 685.5 \\
\hline \multicolumn{13}{|l|}{ Colorado } \\
\hline 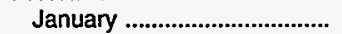 & 140.2 & 141.4 & 368.7 & 971.0 & $w$ & $1,376.7$ & $1,445.2$ & $1,452.5$ & w & 663.3 & - & 866.6 \\
\hline ................................ & w & 144.0 & W & $w$ & - & $1,427.1$ & w & $1,560.2$ & w & w & - & 889.3 \\
\hline 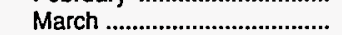 & w & $w$ & W & W & - & $w$ & $w$ & $w$ & w & w & - & $w$ \\
\hline ……………….......... & W & W & 573.1 & w & - & $w$ & $w$ & $w$ & - & $w$ & - & w \\
\hline ....................................... & w & w & 603.6 & w & - & w & $w$ & $w$ & - & w & - & $w$ \\
\hline 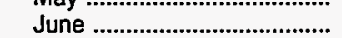 & w & w & 637.2 & $w$ & - & W & w & w & - & w & - & w \\
\hline ……………............. & w & w & 659.9 & $2,110.7$ & - & $2,770.7$ & w & $w$ & - & 193.9 & - & 193.9 \\
\hline .................................... & W & w & $w$ & $2,139.3$ & w & $2,854.2$ & w & $w$ & - & 155.5 & - & 155.5 \\
\hline September ............................. & W & W & $w$ & $1,957.5$ & - & $W$ & $w$ & $w$ & $W$ & 173.2 & - & W \\
\hline 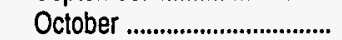 & W & $W$ & 338.8 & $1,696.8$ & - & $2,035.6$ & W & $w$ & 313.2 & 514.3 & - & 827.5 \\
\hline 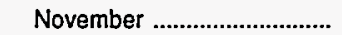 & & 119.8 & 103.2 & 1.108 .1 & - & $1,211.3$ & w & $1,615.8$ & 543.6 & 961.3 & - & $1,504.9$ \\
\hline 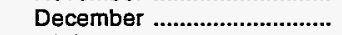 & $w$ & w & 104.9 & $1,103.5$ & - & $1,208.4$ & w & $w$ & 553.0 & $1,083.1$ & - & $1,636.1$ \\
\hline 1994 Average & $1,176.2$ & $1,180.9$ & 452.7 & $1,655.1$ & w & $2,115.6$ & 542.4 & 544.8 & 176.1 & 421.8 & - & 598.0 \\
\hline
\end{tabular}

See footnotes at end of table. 
Table 44. Refiner Motor Gasoline Volumes by Formulation, Sales Type, PAD District, and State

(Thousand Gallons per Day) - Continued

\begin{tabular}{|c|c|c|c|c|c|c|c|c|c|c|c|c|}
\hline \multirow{3}{*}{$\begin{array}{l}\text { Geographlc Area } \\
\text { Month }\end{array}$} & \multicolumn{6}{|c|}{ Reformulated } & \multicolumn{6}{|c|}{ All Formulations } \\
\hline & \multicolumn{2}{|c|}{ Sales to End Users } & \multicolumn{4}{|c|}{ Sales for Resale } & \multicolumn{2}{|c|}{ Sales to End Users } & \multicolumn{4}{|c|}{ Sales for Resale } \\
\hline & $\begin{array}{c}\text { Through } \\
\text { Retaif } \\
\text { Outlots } \\
\end{array}$ & Totala & DTW & Rack & Bulk & Total & $\begin{array}{c}\text { Through } \\
\text { Retail } \\
\text { Outlets }\end{array}$ & Totala & DTW & Rack & Bulk & Total \\
\hline \multicolumn{13}{|l|}{ Now Mexico } \\
\hline 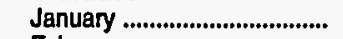 & - & - & - & - & - & - & 321.7 & 327.3 & 217.7 & $1,411.2$ & - & $1,628.9$ \\
\hline 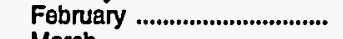 & - & - & - & - & - & - & 337.0 & 344.7 & 239.9 & $1,481.4$ & - & $1,721.3$ \\
\hline March ........................................ & - & - & - & - & - & - & 367.3 & 375.1 & 251.3 & $1,527.2$ & - & $1,778.4$ \\
\hline Aprill & - & - & - & - & - & - & 324.1 & 330.9 & 251.5 & $1,484.9$ & - & $1,736.3$ \\
\hline 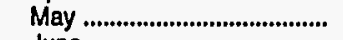 & - & - & - & - & - & - & 353.4 & 360.6 & $W$ & W & - & $1,700.4$ \\
\hline 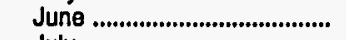 & - & - & - & - & - & - & 346.6 & 353.7 & $W$ & $W$ & - & $1,863.9$ \\
\hline July & - & - & - & - & - & - & 349.1 & 360.5 & $W$ & $W$ & - & $1,880.6$ \\
\hline 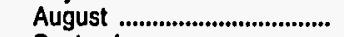 & - & - & - & - & - & - & 369.8 & 383.9 & w & W & - & $1,863.2$ \\
\hline September ............................. & - & - & - & - & - & - & 338.3 & 350.6 & $\ddot{w}$ & $w$ & - & $1,738.2$ \\
\hline 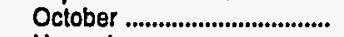 & - & - & - & - & - & - & 336.2 & 351.1 & w & $1,636.5$ & $w$ & $1,980.9$ \\
\hline November .............................. & - & - & - & - & - & - & 355.4 & 368.7 & w & W & - & $1,859.8$ \\
\hline 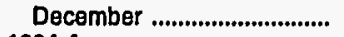 & - & - & - & - & - & - & 334.6 & 346.5 & W & $w$ & - & $1,963.7$ \\
\hline 1994 Average ............................ & - & - & - & - & - & - & 344.6 & 354.6 & 263.1 & $1,542.2$ & $w$ & $1,810.5$ \\
\hline \multicolumn{13}{|l|}{ Texas } \\
\hline 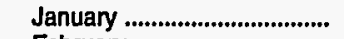 & - & - & - & - & - & - & $5,424.6$ & $5,629.4$ & $2,864.7$ & 18.149 .1 & $10,010.9$ & $31,024.7$ \\
\hline February ............................... & - & - & - & - & - & $\rightarrow$ & $5,828.8$ & $6,066.4$ & $3,126.5$ & $17,810.0$ & $8,121.2$ & $29,057.6$ \\
\hline March ....................................... & - & - & - & - & - & - & $6,247.8$ & $6,502.6$ & $3,183.5$ & $18,623.1$ & $8,383.7$ & $30,190.3$ \\
\hline 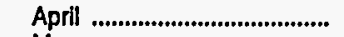 & - & - & - & - & - & - & $5,858.3$ & $6,081.4$ & $3,234.9$ & $19,377.3$ & $9,841.8$ & $32,454.0$ \\
\hline May .......................................... & - & - & - & - & - & - & $6,161.4$ & $6,366.7$ & $3,154.3$ & $18,844.9$ & $8,957.5$ & $30,956.7$ \\
\hline 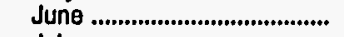 & - & - & - & - & - & - & $5,918.7$ & $6,146.7$ & $3,159.0$ & $19,126.2$ & $9,595.6$ & $31,880.8$ \\
\hline July ........................................ & - & - & - & - & - & - & $5,859.9$ & $6,048.2$ & $3,201.4$ & $18,832.2$ & $7,007.1$ & $29,040.7$ \\
\hline August .................................. & - & - & - & - & - & - & $6,271.7$ & $6,450.9$ & $3,111.1$ & $19,129.2$ & $8,182.5$ & $30,422.8$ \\
\hline Seplember ........................... & - & - & - & - & - & - & $5,733.3$ & $5,927.3$ & $3,053.7$ & $18,953.3$ & $7,837.8$ & $29,844.8$ \\
\hline 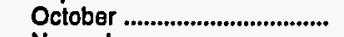 & - & - & - & - & - & $\rightarrow$ & $5,646.8$ & $5,884.5$ & $2,977.1$ & $17,201.6$ & $8,555.5$ & $28,734.1$ \\
\hline November ............................... & $W$ & W & W & $w$ & $W$ & $w$ & $6,103.2$ & $6,344.2$ & $3,048.1$ & $18,436.1$ & $9,465.9$ & $30,950.2$ \\
\hline December ............................... & $2,517.1$ & $2,531.2$ & $2,470.8$ & W & W & $w$ & $5,510.5$ & $5,725.8$ & $3,091.5$ & $17,504.1$ & $15,843.4$ & $36,438.9$ \\
\hline 1994 Average ............................. & 220.7 & 221.9 & & 373.9 & & 675.0 & $5,880.6$ & $6,097.8$ & $3,100.0$ & $18,499.4$ & $9,328.2$ & $30,927.6$ \\
\hline \multicolumn{13}{|l|}{ PAD Dlstrict IV } \\
\hline January .................................... & - & - & - & - & - & - & $2,041.8$ & $2,081.8$ & $1,086.9$ & $5,136.9$ & $w$ & $6,265.9$ \\
\hline 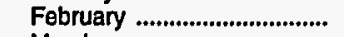 & - & - & - & - & - & - & $2,154.5$ & $2,199.7$ & W & $5,291.6$ & $W$ & $6,431.9$ \\
\hline March ..................................... & - & - & - & - & - & - & $2,212.4$ & $2,257.0$ & $W$ & $5,878.5$ & w & $7,044.5$ \\
\hline 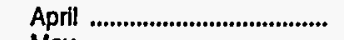 & - & - & - & - & - & - & $2,152.2$ & $2,205.3$ & $w$ & $6,043.8$ & $W$ & $7,177.7$ \\
\hline May .......................................... & - & - & - & - & - & - & $2,247.3$ & $2,286.6$ & $w$ & $6,276.0$ & $W$ & $7,452.2$ \\
\hline June ........................................... & - & - & - & - & - & - & $2,266.2$ & $2,308.3$ & $w$ & $6,912.4$ & $W$ & $8,262.7$ \\
\hline 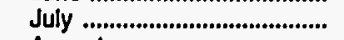 & - & - & - & - & - & - & $2,247.0$ & $2,286.1$ & $w$ & $6,943.6$ & $W$ & $8,313.9$ \\
\hline 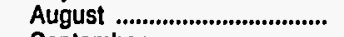 & - & - & - & - & - & $\rightarrow$ & $2,298.1$ & $2,343.0$ & $w$ & $7,159.7$ & $W$ & $8,545.5$ \\
\hline September ............................... & - & - & - & - & - & - & $2,177.9$ & $2,221.9$ & $w$ & $6,209.1$ & $W$ & $7,491.8$ \\
\hline October ................................... & - & - & - & - & - & - & $2,098.2$ & $2,144.4$ & $w$ & $6,224.7$ & $W$ & $7,480.5$ \\
\hline November .............................. & - & - & - & - & - & - & $2,191.9$ & $2,245.3$ & $\ddot{w}$ & $5,949.6$ & $W$ & $7,177.5$ \\
\hline December .............................. & - & - & - & - & - & - & $2,136.2$ & $2,181.7$ & W & $5,962.0$ & $W$ & $7,218.6$ \\
\hline 1994 Average ............................ & - & - & - & - & - & - & $2,185.4$ & $2,230.2$ & $1,227.7$ & $6,171.6$ & 12.6 & $7,411.9$ \\
\hline \multicolumn{13}{|l|}{ Colorado } \\
\hline 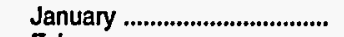 & - & - & - & - & - & - & $1,585.4$ & $1,593.9$ & 572.1 & $1,634.3$ & $w$ & $2,243.4$ \\
\hline February ................................ & - & - & - & - & - & - & $1,695.8$ & $1,704.2$ & 594.9 & $1,721.4$ & - & $2,316.4$ \\
\hline 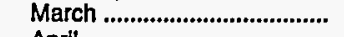 & - & - & - & - & - & - & $1,747.7$ & $1,754.9$ & 603.2 & $1,947.2$ & - & $2,550.4$ \\
\hline April & - & - & - & - & - & - & $1,682.5$ & $1,688.9$ & 573.1 & $1,937.2$ & - & $2,510.3$ \\
\hline 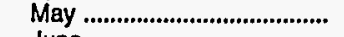 & - & - & - & - & - & - & $1,785.2$ & $1,791.5$ & 603.6 & $2,107.6$ & - & $2,711.2$ \\
\hline June & - & - & - & - & - & - & $1,777.7$ & $1,783.7$ & 637.2 & $2,349.9$ & - & $2,987.1$ \\
\hline July ........................................ & - & - & - & - & - & - & $1,752.3$ & $1,759.0$ & 659.9 & $2,304.6$ & - & $2,964.6$ \\
\hline 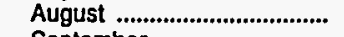 & - & - & - & - & - & - & $1,818.9$ & $1,825.8$ & W & $2,294.8$ & $w$ & $3,009.7$ \\
\hline 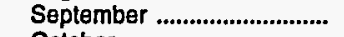 & - & - & - & - & - & - & $1,700.7$ & $1,706.8$ & 682.2 & $2,130.7$ & - & $2,812.9$ \\
\hline 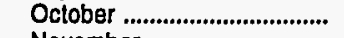 & - & - & - & - & - & - & $1,645.3$ & $1,650.6$ & 652.0 & $2,211.1$ & - & $2,863.1$ \\
\hline November .............................. & - & - & - & - & - & - & $1,727.9$ & $1,735.7$ & 646.8 & $2,069.4$ & - & $2,716.2$ \\
\hline 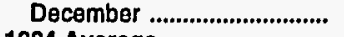 & - & - & - & - & - & - & $1,701.9$ & $1,712.3$ & 657.9 & $2,186.6$ & - & $2,844.5$ \\
\hline 1994 Average & - & - & - & - & - & - & $1,718.6$ & $1,725.7$ & 628.8 & $2,077.0$ & $\mathbf{w}$ & $2,713.5$ \\
\hline
\end{tabular}

See footnotes at end of table. 
Table 44. Refiner Motor Gasoline Volumes by Formulation, Sales Type, PAD District, and State

(Thousand Gallons per Day) - Continued

\begin{tabular}{|c|c|c|c|c|c|c|c|c|c|c|c|c|}
\hline \multirow{3}{*}{$\begin{array}{c}\text { Geographic Area } \\
\text { Month }\end{array}$} & \multicolumn{6}{|c|}{ Conventional } & \multicolumn{6}{|c|}{ Oxygenated } \\
\hline & \multicolumn{2}{|c|}{ Sales to End Users } & \multicolumn{4}{|c|}{ Sales for Resale } & \multicolumn{2}{|c|}{ Sales to End Users } & \multicolumn{4}{|c|}{ Sales for Resale } \\
\hline & $\begin{array}{l}\text { Through } \\
\text { Retail } \\
\text { Outlets }\end{array}$ & Totala & DTW & Rack & Bulk & Total & $\begin{array}{c}\text { Through } \\
\text { Retall } \\
\text { Outlets }\end{array}$ & Totala & DTW & Rack & Bulk & Total \\
\hline
\end{tabular}

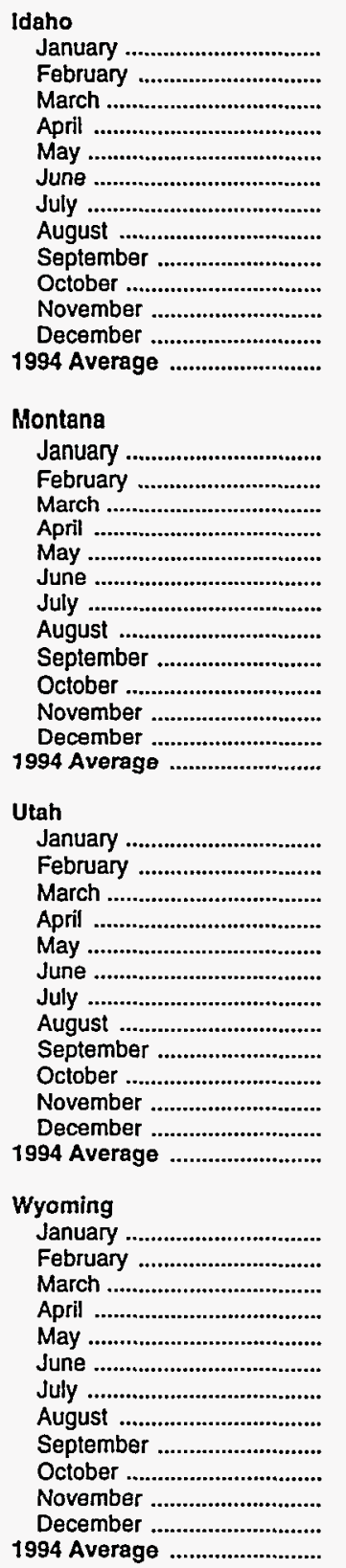

$\begin{array}{lrrrrr}W & 10.8 & 149.7 & 826.3 & - & 976.0 \\ W & 11.9 & 145.6 & 836.2 & - & 981.8 \\ W & 9.6 & 174.5 & 911.5 & - & 1,086.0 \\ W & 11.1 & 165.2 & 973.6 & - & 1,138.7 \\ W & W & 180.0 & 1,006.6 & - & 1,186.6 \\ W & W & 181.2 & 1,048.8 & - & 1,230.0 \\ W & W & 187.6 & 1,082.0 & - & 1,269.6 \\ W & W & 175.4 & 1,143.0 & - & 1,318.5 \\ W & W & 156.7 & 988.2 & - & 1,144.8 \\ W & W & 178.1 & 949.5 & - & 1,127.6 \\ W & W & 162.1 & 908.0 & - & 1,070.1 \\ W & W & 161.7 & 863.3 & - & 1,025.1 \\ W & 11.5 & 168.4 & 962.2 & - & 1,130.6\end{array}$

\begin{tabular}{|c|c|c|c|c|}
\hline - & - & - & - & - \\
\hline - & - & - & - & - \\
\hline- & - & - & - & - \\
\hline $\bar{z}$ & $\overline{-}$ & $=$ & - & $=$ \\
\hline- & - & - & - & - \\
\hline & $\overline{-}$ & $\overline{-}$ & $\overline{-}$ & $=$ \\
\hline- & - & - & - & - \\
\hline & $\bar{z}$ & $=$ & $\bar{z}$ & $\bar{z}$ \\
\hline & 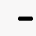 & - & - & - \\
\hline
\end{tabular}

Montana

January .

May

July .

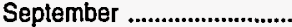

December

1994 Average

$\begin{array}{lc}W & 11.8 \\ W & W \\ W & 13.9 \\ W & 14.5 \\ W & W \\ W & W \\ W & W \\ W & W \\ W & W \\ W & W \\ W & W \\ W & W \\ W & W\end{array}$

$\begin{array}{lr}W & 832.6 \\ W & W \\ W & 1,021.6 \\ W & 1,029.4 \\ W & w \\ W & W \\ W & 1,292.9 \\ W & 1,404.2 \\ W & 1,163.5 \\ W & W \\ W & W \\ W & W \\ W & 1,107.6\end{array}$

$\begin{array}{lr}W & 833.5 \\ W & W \\ w & 1,023.3 \\ w & 1,030.1 \\ - & 1,104.7 \\ \bar{W} & 1,360.4 \\ W & 1,297.3 \\ W & 1,409.4 \\ W & 1,166.0 \\ W & W \\ W & 1.028 .6 \\ W & 967.6 \\ \mathbf{w} & 1,109.9\end{array}$

-
$=$
$=$
$=$
$=$
$=$
$=$

\begin{tabular}{|c|c|c|c|c|}
\hline$W$ & - & $w$ & - & $w$ \\
\hline$W$ & - & $w$ & - & $W$ \\
\hline$\overline{-}$ & - & - & $=$ & - \\
\hline - & - & - & - & - \\
\hline- & $\rightarrow$ & - & - & - \\
\hline- & - & - & - & - \\
\hline$\overline{-}$ & - & - & - & - \\
\hline W & $=$ & $\bar{w}$ & - & $w$ \\
\hline- & - & $w$ & - & 72.3 \\
\hline 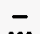 & - & $w$ & - & 67.7 \\
\hline $\mathbf{W}$ & - & 18.6 & - & 18.6 \\
\hline
\end{tabular}

\begin{tabular}{|c|c|c|c|}
\hline 379.6 & 399.6 & 344.5 & $1,138.5$ \\
\hline & & & $1,140.8$ \\
\hline W & $w$ & 372.6 & $1,436.1$ \\
\hline 388.0 & 422.9 & $w$ & $w$ \\
\hline 375.8 & 397.5 & 371.2 & $w$ \\
\hline 393.3 & 417.2 & 494.0 & $w$ \\
\hline 392.8 & 414.2 & $w$ & $1,527.7$ \\
\hline 382.7 & 409.8 & W & $1,622.0$ \\
\hline 389.3 & 415.2 & 394.7 & $w$ \\
\hline$w$ & $w$ & 391.5 & $1,256.3$ \\
\hline w & $w$ & 369.8 & w \\
\hline w & W & w & $w$ \\
\hline & 406.7 & 399.2 & 58. \\
\hline
\end{tabular}

$\begin{array}{lr}W & 1,487.3 \\ W & W \\ W & W \\ W & W \\ W & 1,839.6 \\ W & 1,985.9 \\ W & 1,995.7 \\ W & 2,065.6 \\ W & W \\ W & W \\ W & 1,518.4 \\ \bar{w} & 1,516.5 \\ & 1,760.1\end{array}$

$w$
$w$
$w$
-
-
-
-
$\bar{w}$
$w$
$w$
$w$

$\begin{array}{ll}w & w \\ w & w \\ w & - \\ - & - \\ - & - \\ - & - \\ - & \overline{-} \\ \bar{w} & \bar{w} \\ w & w \\ w & w \\ w & w\end{array}$

$\begin{array}{cccc}W & 165.9 & - & 177.7 \\ W & W & - & W \\ - & W & - & W \\ - & W & - & W \\ - & - & - & - \\ - & - & - & - \\ - & - & - & - \\ \bar{W} & \bar{W} & - & \bar{W} \\ W & 18.0 & - & W \\ W & W & - & 213.5 \\ W & W & - & 229.0 \\ W & W & - & 69.0\end{array}$

See footnotes at end of table. 
Table 44. Refiner Motor Gasoline Volumes by Formulation, Sales Type, PAD District, and State

(Thousand Gallons per Day) - Continued

\begin{tabular}{|c|c|c|c|c|c|c|c|c|c|c|c|c|}
\hline \multirow{3}{*}{$\begin{array}{l}\text { Geographlo Area } \\
\text { Month }\end{array}$} & \multicolumn{6}{|c|}{ Roformulated } & \multicolumn{6}{|c|}{ All Formulations } \\
\hline & \multicolumn{2}{|c|}{ Sales to End Ueors } & \multicolumn{4}{|c|}{ Sales for Resale } & \multicolumn{2}{|c|}{ Sales to End Users } & \multicolumn{4}{|c|}{ Sales for Resale } \\
\hline & $\begin{array}{c}\text { Through } \\
\text { Rotall } \\
\text { Outlots }\end{array}$ & Totala & DTW & Rack & Bulk & Total & $\begin{array}{c}\text { Through } \\
\text { Ratail } \\
\text { Outlets }\end{array}$ & Totala & DTW & Rack & Bulk & Total \\
\hline \multicolumn{13}{|l|}{ Idaho } \\
\hline January ....................................... & - & - & - & - & - & - & $w$ & 10.8 & 149.7 & 826.3 & - & 976.0 \\
\hline 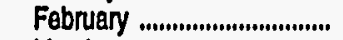 & - & - & - & - & - & - & W & 11.9 & 145.6 & 836.2 & - & 981.8 \\
\hline March ........................................ & - & - & - & - & - & - & W & 9.6 & 174.5 & 911.5 & - & $1,086.0$ \\
\hline 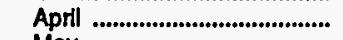 & - & - & - & - & - & - & $\ddot{w}$ & 11.1 & 165.2 & 973.6 & - & $1,138.7$ \\
\hline 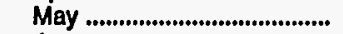 & - & - & - & - & - & - & $w$ & $w$ & 180.0 & $1,006.6$ & - & $1,186.6$ \\
\hline 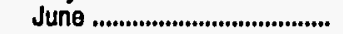 & - & - & - & - & - & - & $\mathbf{w}$ & $w$ & 181.2 & $1,048.8$ & - & $1,230.0$ \\
\hline 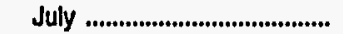 & - & - & - & - & - & - & $w$ & w & 187.6 & $1,082.0$ & - & $1,269.6$ \\
\hline 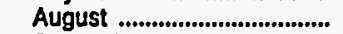 & - & - & - & - & - & - & $w$ & $\ddot{w}$ & 175.4 & $1,143.0$ & - & $1,318.5$ \\
\hline 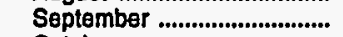 & - & - & - & - & - & - & $\mathbf{w}$ & $\mathbf{w}$ & 156.7 & 988.2 & - & $1,144.8$ \\
\hline 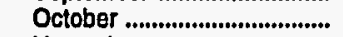 & - & - & - & - & - & - & $w$ & $w$ & 178.1 & 949.5 & - & $1,127.6$ \\
\hline 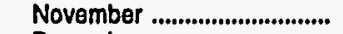 & - & - & - & - & - & - & $\mathbf{w}$ & w & 162.1 & 908.0 & - & $1,070.1$ \\
\hline 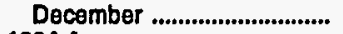 & - & - & - & - & - & - & $w$ & $w$ & 161.7 & 863.3 & - & $1,025.1$ \\
\hline 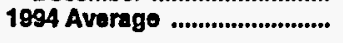 & - & - & - & - & - & - & $w$ & 11.5 & 168.4 & 962.2 & - & $1,130.6$ \\
\hline \multicolumn{13}{|l|}{ Montana } \\
\hline 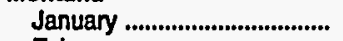 & - & - & - & - & - & - & w & 12.3 & w & 868.6 & $w$ & 869.5 \\
\hline 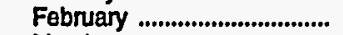 & - & - & - & - & - & - & $w$ & 13.4 & w & 940.1 & $\dddot{W}$ & 941.1 \\
\hline 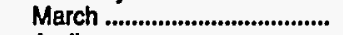 & - & - & - & - & - & - & w & 13.9 & $w$ & $1,021.6$ & $w$ & $1,023.3$ \\
\hline 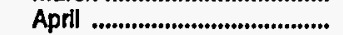 & - & - & - & - & - & - & $w$ & 14.5 & $w$ & $1,029.4$ & $w$ & $1,030.1$ \\
\hline 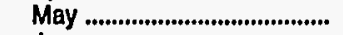 & - & - & - & - & - & - & $w$ & $w$ & $W$ & $w$ & - & $1,104.7$ \\
\hline 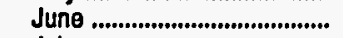 & - & - & - & - & - & - & $\ddot{w}$ & $\ddot{w}$ & $\ddot{W}$ & $\dddot{W}$ & - & $1,360.4$ \\
\hline July ................................................ & - & - & - & - & - & - & $w$ & $w$ & $w$ & $1,292.9$ & $w$ & $1,297.3$ \\
\hline 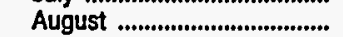 & - & - & - & - & - & - & $w$ & $w$ & $\overleftrightarrow{w}$ & $1,404.2$ & $w$ & $1,409.4$ \\
\hline 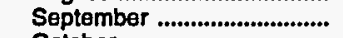 & - & - & - & - & - & - & $w$ & w & $w$ & $1,163.5$ & $w$ & $1,166.0$ \\
\hline 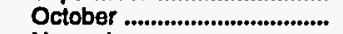 & - & - & - & - & - & - & $w$ & $\ddot{w}$ & $w$ & $1,188.6$ & $w$ & $1,189.9$ \\
\hline 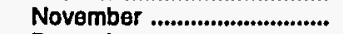 & - & - & - & - & - & - & $w$ & $\ddot{w}$ & $\ddot{w}$ & $1,097.7$ & $\dddot{w}$ & $1,100.9$ \\
\hline December .................................. & - & - & - & - & - & - & $w$ & $w$ & $w$ & $1,030.3$ & $w$ & $1,035.3$ \\
\hline 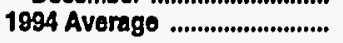 & - & - & - & - & - & - & $\mathbf{w}$ & 14.8 & $\ddot{w}$ & $1,126.2$ & $\ddot{w}$ & $1,128.5$ \\
\hline \multicolumn{13}{|l|}{ Utah } \\
\hline 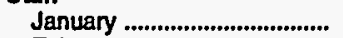 & - & - & - & - & - & - & 384.4 & 404.5 & 356.3 & $1,304.3$ & $w$ & $1,665.0$ \\
\hline 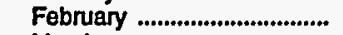 & - & - & - & - & - & - & 384.5 & 408.6 & 386.3 & $w$ & $w$ & $1,691.8$ \\
\hline 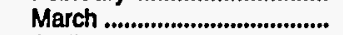 & - & - & - & - & - & - & 385.8 & 412.8 & 372.6 & $w$ & w & $1,811.8$ \\
\hline 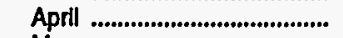 & - & - & - & - & - & - & 388.0 & 422.9 & w & $1,570.1$ & $w$ & $1,949.0$ \\
\hline 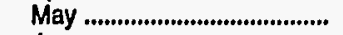 & - & - & - & - & - & - & 375.8 & 397.5 & 371.2 & $w$ & $w$ & $1,839.6$ \\
\hline 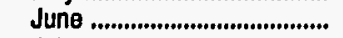 & - & - & - & - & - & - & 393.3 & 417.2 & 494.0 & W & w & $1,985.9$ \\
\hline July ................................................. & - & - & - & - & - & - & 392.8 & 414.2 & W & $1,527.7$ & W & $1,995.7$ \\
\hline 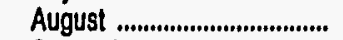 & - & - & - & - & - & - & 382.7 & 409.8 & w & $1,622.0$ & W & $2,065.6$ \\
\hline 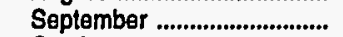 & - & - & - & - & - & - & 389.3 & 415.2 & $w$ & $1,374.7$ & $w$ & $1,782.6$ \\
\hline 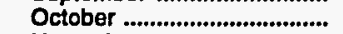 & - & - & - & - & - & - & 370.8 & 394.8 & $w$ & $1,274.3$ & $w$ & $1,675.8$ \\
\hline 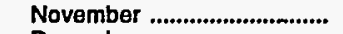 & - & - & - & - & - & - & 389.6 & 421.8 & $\mathbf{w}$ & $1,330.7$ & $w$ & $1,732.0$ \\
\hline 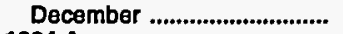 & - & - & - & - & - & - & 359.4 & 384.2 & 418.0 & $1,327.5$ & - & $1,745.5$ \\
\hline 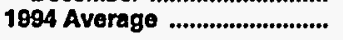 & - & - & - & - & - & - & 382.9 & 408.5 & 407.4 & $1,419.7$ & w & $1,829.1$ \\
\hline \multicolumn{13}{|l|}{ Wyoming } \\
\hline 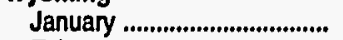 & - & - & - & - & - & - & 55.9 & 60.3 & $w$ & 503.3 & - & 512.0 \\
\hline 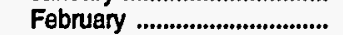 & - & - & - & - & - & - & 57.4 & 61.6 & w & $w$ & - & 501.0 \\
\hline 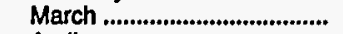 & - & - & - & - & - & - & 61.7 & 65.8 & $w$ & $\ddot{w}$ & - & 572.9 \\
\hline 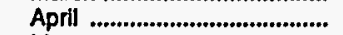 & - & - & - & - & - & - & 63.5 & 68.0 & 16.1 & 533.5 & - & 549.6 \\
\hline 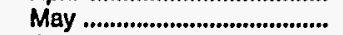 & - & - & - & - & - & - & 67.0 & 71.0 & 19.8 & 590.2 & - & 610.0 \\
\hline 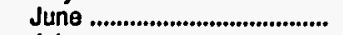 & - & - & - & - & - & - & 73.4 & 77.7 & 36.9 & 662.5 & - & 699.4 \\
\hline July .............................................. & - & - & - & - & - & - & 78.6 & 81.7 & $w$ & 736.3 & $w$ & 786.7 \\
\hline 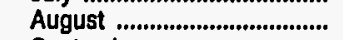 & - & - & - & - & - & - & 74.0 & 77.1 & $w$ & 695.7 & $w$ & 742.3 \\
\hline 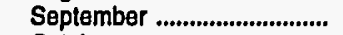 & - & - & - & - & - & - & 68.1 & 73.2 & w & 552.0 & $w$ & 585.4 \\
\hline 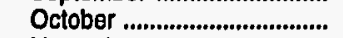 & - & - & - & - & - & - & 64.2 & 72.7 & $\ddot{w}$ & 601.2 & $w$ & 624.2 \\
\hline 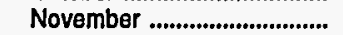 & - & - & - & - & - & - & 57.2 & 64.6 & $w$ & 543.8 & $w$ & 558.2 \\
\hline December ............................. & - & - & - & - & - & - & 58.1 & 61.6 & $\dddot{w}$ & 554.3 & $\dddot{w}$ & 568.2 \\
\hline 1994 Average ................................. & - & - & - & - & - & - & 65.0 & 69.7 & 22.8 & 586.5 & $w$ & 610.2 \\
\hline
\end{tabular}

See footnotes at end of table. 
Table 44. Refiner Motor Gasoline Volumes by Formulation, Sales Type, PAD District, and State

(Thousand Gallons per Day) - Continued

\begin{tabular}{|c|c|c|c|c|c|c|c|c|c|c|c|c|}
\hline \multirow{3}{*}{$\begin{array}{l}\text { Goographic Area } \\
\text { Month }\end{array}$} & \multicolumn{6}{|c|}{ Conventional } & \multicolumn{6}{|c|}{ Oxygenaled } \\
\hline & \multicolumn{2}{|c|}{ Sales to End Users } & \multicolumn{4}{|c|}{ Sales for Resale } & \multicolumn{2}{|c|}{ Sales to End Users } & \multicolumn{4}{|c|}{ Sales for Resale } \\
\hline & $\begin{array}{c}\text { Through } \\
\text { Retall } \\
\text { Outlets }\end{array}$ & Totala & DTW & Rack & Bulk & Total & $\begin{array}{c}\text { Through } \\
\text { Rotall } \\
\text { Outlets }\end{array}$ & Totala & DTW & Rack & Bulk & Total \\
\hline \multicolumn{13}{|l|}{ PAD District V } \\
\hline 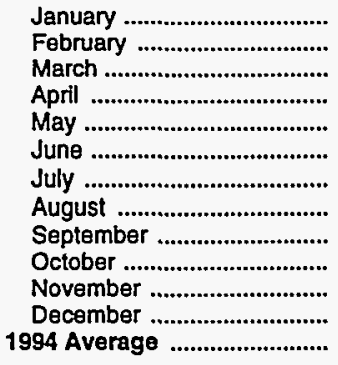 & $\begin{array}{r}1,026.7 \\
2,486.5 \\
7,726.0 \\
W \\
W \\
W \\
W \\
W \\
9,153.8 \\
2,678.1 \\
735.4 \\
742.2 \\
5,877.1\end{array}$ & $\begin{array}{r}1,151.5 \\
2,661.7 \\
8,010.0 \\
W \\
W \\
W \\
W \\
W \\
9,394.4 \\
2,804.5 \\
W \\
848.4 \\
6,099.8\end{array}$ & $\begin{array}{r}2,019.6 \\
W \\
25,684.9 \\
27,141.3 \\
27,764.5 \\
28,342.4 \\
27,728.0 \\
28,073.2 \\
25,599.2 \\
W \\
1,583.0 \\
W \\
17,397.3\end{array}$ & $\begin{array}{r}5,250.8 \\
W \\
W \\
W \\
W \\
W \\
W \\
15,940.8 \\
W \\
W \\
W \\
W \\
11,549.5\end{array}$ & $\begin{array}{r}2,538.2 \\
3,197.6 \\
W \\
W \\
W \\
W \\
W \\
W \\
W \\
2,105.5 \\
W \\
1,941.5 \\
3,284.0\end{array}$ & $\begin{array}{r}9,808.6 \\
21,073.8 \\
W \\
45,696.2 \\
W \\
W \\
W \\
W \\
43,499.1 \\
14,548.5 \\
W \\
8,178.0 \\
32,230.8\end{array}$ & $\begin{array}{r}7,991.7 \\
6,894.2 \\
2,273.7 \\
W \\
W \\
W \\
W \\
W \\
995.6 \\
7,038.2 \\
8,199.8 \\
6,936.9 \\
3,521.8\end{array}$ & $\begin{array}{r}8,127.6 \\
6,989.3 \\
2,290.3 \\
W \\
W \\
W \\
W \\
W \\
1,004.2 \\
7,140.8 \\
8,316.2 \\
7,009.2 \\
3,567.4\end{array}$ & $\begin{array}{r}25,502.6 \\
19,408.4 \\
W \\
W \\
W \\
W \\
W \\
W \\
W \\
23,230.8 \\
24,426.8 \\
13,162.8 \\
9,738.8\end{array}$ & $\begin{array}{r}7,794.9 \\
W \\
W \\
W \\
W \\
W \\
W \\
111.4 \\
W \\
W \\
9,206.8 \\
W \\
3,071.0\end{array}$ & $\begin{array}{r}948.9 \\
W \\
- \\
- \\
- \\
- \\
- \\
- \\
W \\
W \\
1,693.4 \\
W \\
597.1\end{array}$ & $\begin{array}{r}34,246.5 \\
23,361.6 \\
W \\
1,641.5 \\
W \\
W \\
W \\
W \\
4,326.9 \\
32,883.1 \\
35,327.0 \\
21,660.5 \\
13,407.0\end{array}$ \\
\hline \multicolumn{13}{|l|}{ Alaska } \\
\hline 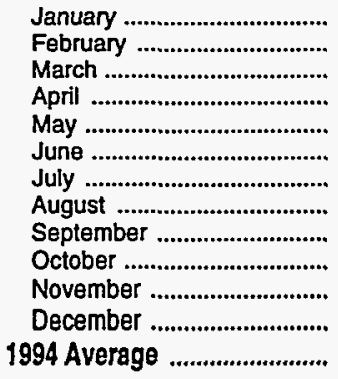 & $\begin{array}{r}195.8 \\
206.3 \\
202.8 \\
207.9 \\
224.3 \\
252.8 \\
257.2 \\
245.0 \\
227.2 \\
218.1 \\
223.1 \\
W \\
223.3\end{array}$ & $\begin{array}{l}213.0 \\
223.6 \\
219.9 \\
226.0 \\
245.5 \\
280.4 \\
313.6 \\
275.4 \\
251.1 \\
233.4 \\
239.7 \\
W \\
246.3\end{array}$ & $\begin{array}{l}105.6 \\
W \\
W \\
W \\
W \\
W \\
W \\
W \\
W \\
W \\
W \\
120.7\end{array}$ & $\begin{array}{r}170.6 \\
186.7 \\
200.4 \\
204.4 \\
250.7 \\
365.1 \\
391.3 \\
W \\
308.8 \\
224.8 \\
W \\
W \\
258.5\end{array}$ & $\begin{array}{l}\bar{w} \\
w \\
w \\
w \\
W \\
w \\
w \\
W \\
w \\
- \\
- \\
W\end{array}$ & $\begin{array}{r}276.3 \\
313.0 \\
318.7 \\
329.2 \\
419.1 \\
538.9 \\
530.9 \\
519.0 \\
451.8 \\
350.5 \\
355.9 \\
W \\
393.3\end{array}$ & $\begin{array}{l}\bar{z} \\
\bar{z} \\
\bar{z} \\
\bar{z} \\
\overline{-} \\
\bar{z} \\
\bar{z} \\
\bar{W} \\
W\end{array}$ & $\begin{array}{l}- \\
\overline{-} \\
- \\
\overline{-} \\
\overline{-} \\
- \\
- \\
- \\
- \\
\bar{W} \\
W\end{array}$ & $\begin{array}{l}- \\
- \\
- \\
- \\
- \\
- \\
- \\
- \\
- \\
\bar{W} \\
W\end{array}$ & $\begin{array}{l}- \\
- \\
- \\
- \\
- \\
- \\
- \\
- \\
- \\
- \\
-\end{array}$ & $\begin{array}{l}- \\
- \\
- \\
- \\
- \\
- \\
- \\
- \\
- \\
- \\
-\end{array}$ & $\begin{array}{l}- \\
- \\
- \\
- \\
- \\
- \\
- \\
- \\
- \\
\bar{W} \\
W\end{array}$ \\
\hline \multicolumn{13}{|l|}{ Arizona } \\
\hline 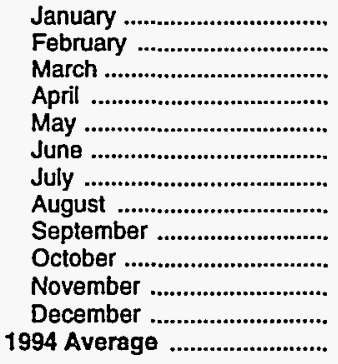 & $\begin{array}{r}W \\
W \\
175.0 \\
W \\
W \\
W \\
W \\
W \\
763.6 \\
42.5 \\
80.1 \\
92.0 \\
539.4\end{array}$ & $\begin{array}{r}41.8 \\
47.5 \\
189.1 \\
W \\
W \\
W \\
W \\
W \\
777.3 \\
54.1 \\
90.4 \\
100.4 \\
554.5\end{array}$ & $\begin{array}{r}365.1 \\
W \\
W \\
W \\
W \\
W \\
W \\
W \\
960.5 \\
279.8 \\
217.3 \\
W \\
951.9\end{array}$ & $\begin{array}{r}889.5 \\
978.2 \\
973.9 \\
1,199.3 \\
W \\
1,072.0 \\
W \\
W \\
W \\
W \\
818.4 \\
925.9 \\
1,041.7\end{array}$ & $\begin{array}{r}224.6 \\
W \\
W \\
W \\
233.2 \\
W \\
W \\
W \\
W \\
W \\
W \\
W \\
171.1\end{array}$ & $\begin{array}{r}1,479.3 \\
1,546.0 \\
1,533.1 \\
3,141.3 \\
W \\
W \\
W \\
W \\
2,281.6 \\
1,511.5 \\
W \\
1,352.6 \\
2,164.7\end{array}$ & $\begin{array}{r}1,021.6 \\
W \\
1,029.5 \\
W \\
W \\
W \\
W \\
W \\
381.2 \\
1,030.3 \\
1,021.3 \\
1,138.2 \\
558.2\end{array}$ & $\begin{array}{r}1,031.8 \\
1,082.4 \\
1,041.6 \\
W \\
W \\
W \\
W \\
W \\
384.9 \\
1,038.3 \\
1,029.4 \\
1,144.6 \\
563.4\end{array}$ & $\begin{array}{r}1,324.8 \\
W \\
W \\
W \\
W \\
W \\
W \\
W \\
679.9 \\
1,290.7 \\
1,440.4 \\
W \\
752.6\end{array}$ & $\begin{array}{c}150.3 \\
W \\
W \\
W \\
W \\
W \\
- \\
\overrightarrow{50.7} \\
144.9 \\
W \\
W \\
119.2\end{array}$ & $\begin{array}{l}- \\
- \\
- \\
- \\
- \\
- \\
- \\
- \\
- \\
- \\
- \\
-\end{array}$ & $\begin{array}{r}1,475.0 \\
1,595.1 \\
1,567.3 \\
8.6 \\
W \\
W \\
W \\
W \\
730.6 \\
1,435.6 \\
W \\
1,888.4 \\
871.7\end{array}$ \\
\hline \multicolumn{13}{|l|}{ California } \\
\hline 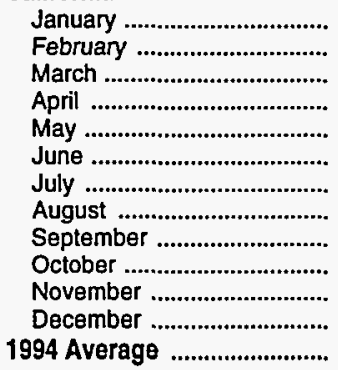 & $\begin{array}{r}- \\
1,614.6 \\
5,696.2 \\
W \\
W \\
W \\
W \\
W \\
6,401.9 \\
1,251.9 \\
- \\
- \\
3,795.9\end{array}$ & $\begin{array}{r}- \\
1,654.7 \\
5,826.4 \\
W \\
W \\
W \\
W \\
W \\
6,493.8 \\
1,258.7 \\
W \\
W \\
3,875.2\end{array}$ & $\begin{array}{r}- \\
5,831.7 \\
W \\
W \\
W \\
W \\
W \\
W \\
19,728.0 \\
W \\
W \\
- \\
12,677.8\end{array}$ & $\begin{array}{r}368.8 \\
W \\
W \\
W \\
W \\
W \\
W \\
8,645.0 \\
W \\
1,981.4 \\
W \\
W \\
5,587.1\end{array}$ & $\begin{array}{r}943.9 \\
W \\
2,920.3 \\
3,447.5 \\
3,605.3 \\
3,342.8 \\
3,762.3 \\
3,828.1 \\
W \\
W \\
1,350.5 \\
W \\
2,487.2\end{array}$ & $\begin{array}{r}1,312.7 \\
13,066.3 \\
31,808.1 \\
W \\
W \\
W \\
W \\
W \\
30,267.2 \\
4,785.3 \\
W \\
1,268.3 \\
20,752.0\end{array}$ & $\begin{array}{r}6,048.8 \\
4,639.9 \\
967.9 \\
W \\
W \\
W \\
W \\
W \\
467.5 \\
5,364.8 \\
5,781.5 \\
4,262.9 \\
2,435.7\end{array}$ & $\begin{array}{r}6,158.2 \\
4,705.1 \\
968.6 \\
W \\
W \\
W \\
W \\
W \\
471.3 \\
5,449.5 \\
5,869.5 \\
W \\
2,468.6\end{array}$ & $\begin{array}{r}20,646.0 \\
14,514.7 \\
W \\
W \\
W \\
W \\
W \\
W \\
1,493.8 \\
W \\
18,880.8 \\
7,544.9 \\
7,300.1\end{array}$ & $\begin{array}{r}6,650.9 \\
W \\
W \\
W \\
W \\
W \\
W \\
80.2 \\
W \\
6,991.1 \\
W \\
W \\
2,479.4\end{array}$ & $\begin{array}{c}948.9 \\
W \\
- \\
- \\
- \\
- \\
- \\
- \\
W \\
W \\
W \\
W \\
597.1\end{array}$ & $\begin{array}{r}28,245.9 \\
17,546.6 \\
1,122.2 \\
W \\
W \\
W \\
W \\
W \\
2,811.8 \\
28,090.3 \\
28,002.7 \\
14,244.2 \\
10,376.7\end{array}$ \\
\hline
\end{tabular}

See footnotes at end of table. 
Table 44. Refiner Motor Gasoline Volumes by Formulation, Sales Type, PAD District, and State

(Thousand Gallons per Day) - Continued

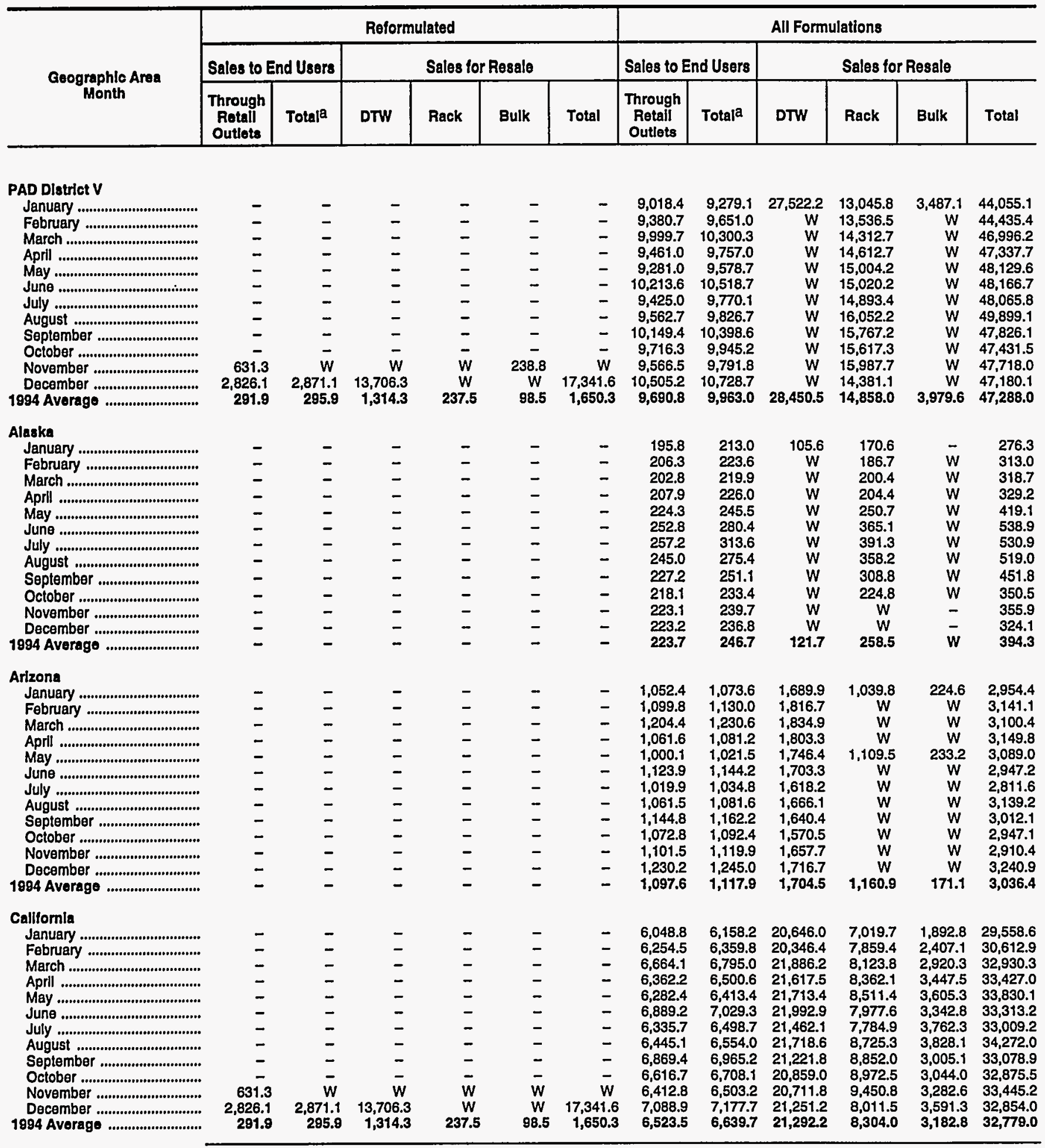

See footnotes at end of table. 
Table 44. Refiner Motor Gasoline Volumes by Formulation, Sales Type, PAD District, and State

(Thousand Gallons per Day) - Continued

\begin{tabular}{|c|c|c|c|c|c|c|c|c|c|c|c|c|}
\hline \multirow{3}{*}{$\begin{array}{c}\text { Goographic Area } \\
\text { Month }\end{array}$} & \multicolumn{6}{|c|}{ Conventional } & \multicolumn{6}{|c|}{ Oxygenated } \\
\hline & \multicolumn{2}{|c|}{ Sales to End Users } & \multicolumn{4}{|c|}{ Sales for Resale } & \multicolumn{2}{|c|}{ Sales to End Usors } & \multicolumn{4}{|c|}{ Sales for Resale } \\
\hline & $\begin{array}{c}\text { Through } \\
\text { Rotall } \\
\text { Outlots }\end{array}$ & Totala & DTW & Rack & Bulk & Total & $\begin{array}{c}\text { Through } \\
\text { Retail } \\
\text { Outlets }\end{array}$ & Totala & DTW & Rack & Bulk & Total \\
\hline \multicolumn{13}{|l|}{ Hawail } \\
\hline 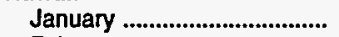 & 171.2 & 251.7 & 588.9 & 109.4 & - & 698.3 & - & - & - & - & - & - \\
\hline February .................................. & 172.9 & 257.6 & 614.0 & 99.1 & - & 713.1 & - & - & - & - & - & - \\
\hline March ........................................ & 173.1 & 260.6 & 635.9 & $W$ & $\mathbf{w}$ & $1,027.2$ & - & - & - & - & - & - \\
\hline 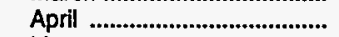 & 175.5 & 260.4 & 621.3 & 117.3 & - & 738.6 & - & - & - & - & - & - \\
\hline May ........................................... & 176.3 & 261.4 & 630.8 & 113.0 & - & 743.8 & - & - & - & - & - & - \\
\hline June ............................................ & 181.8 & 267.3 & 637.8 & 104.7 & - & 742.4 & - & - & - & - & - & - \\
\hline July ............................................ & 181.5 & 264.9 & 637.4 & 113.2 & - & 750.5 & - & - & - & - & - & - \\
\hline 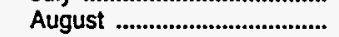 & 181.9 & 259.9 & 650.0 & 110.8 & - & 760.8 & - & - & - & - & - & - \\
\hline 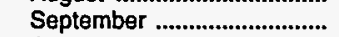 & 179.7 & 262.5 & 622.4 & 91.8 & - & 714.2 & - & - & - & - & - & - \\
\hline October & 177.0 & 251.3 & 620.6 & 102.6 & - & 723.2 & - & - & - & - & - & - \\
\hline 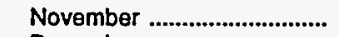 & 178.4 & 249.8 & 625.0 & 108.2 & - & 733.2 & - & - & - & - & - & - \\
\hline Decamber ................................ & 183.5 & 257.3 & 642.9 & 95.9 & - & 738.8 & - & - & - & - & - & - \\
\hline 1994 Average & 177.8 & 258.7 & 627.4 & 106.9 & $\mathbf{w}$ & 757.7 & - & - & - & - & - & - \\
\hline \multicolumn{13}{|l|}{ Nevada } \\
\hline 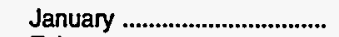 & $w$ & 12.1 & 160.5 & 275.4 & $w$ & 651.9 & 134.6 & 145.2 & 826.8 & 204.6 & - & $1,031.4$ \\
\hline 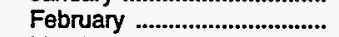 & W & 25.6 & W & 488.6 & $w$ & 941.8 & $W$ & 124.8 & $W$ & $W$ & - & 854.4 \\
\hline 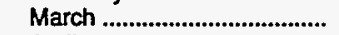 & W & $w$ & $w$ & 614.9 & $w$ & W & W & $W$ & $w$ & $w$ & - & $w$ \\
\hline 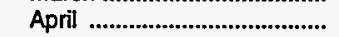 & W & W & $w$ & W & W & w & w & w & W & - & - & $w$ \\
\hline 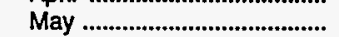 & W & W & $W$ & W & W & $W$ & w & $\ddot{w}$ & w & - & - & $w$ \\
\hline June ....................................... & W & $w$ & $W$ & 864.6 & W & $\ddot{W}$ & W & w & W & 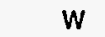 & - & $W$ \\
\hline July .......................................... & W & W & $W$ & 837.8 & W & $W$ & $W$ & $W$ & $w$ & W & - & $w$ \\
\hline August .................................... & $W$ & W & $W$ & 840.9 & $W$ & $W$ & $W$ & W & $W$ & W & - & $w$ \\
\hline 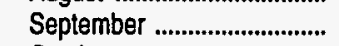 & W & $W$ & $W$ & 828.2 & $W$ & $1,588.5$ & $W$ & $W$ & $W$ & W & - & 477.3 \\
\hline 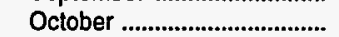 & W & 5.3 & $w$ & 461.6 & $w$ & 650.3 & $w$ & 127.4 & $w$ & W & - & $1,356.2$ \\
\hline November ................................ & $\ddot{w}$ & 12.5 & 59.7 & 429.2 & w & $W$ & $w$ & 124.0 & $1,027.2$ & $w$ & $\mathbf{w}$ & $w$ \\
\hline 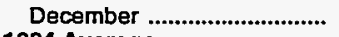 & W & 11.6 & $w$ & 456.0 & $\ddot{w}$ & W & W & 147.2 & W & $w$ & $\rightarrow$ & $w$ \\
\hline 1994 Average & 73.8 & 82.1 & 641.7 & 615.7 & w & $1,406.5$ & 64.1 & 67.5 & 445.6 & 90.9 & $w$ & 536.5 \\
\hline \multicolumn{13}{|l|}{ Oregon } \\
\hline 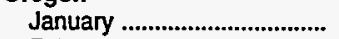 & 211.3 & 217.8 & 329.2 & $1,564.3$ & 116.4 & $2,009.8$ & 153.2 & 155.2 & 763.4 & 323.2 & - & $1,086.5$ \\
\hline 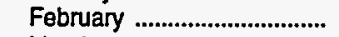 & 181.9 & 188.9 & 365.6 & W & $W$ & $1,793.3$ & 203.6 & 208.7 & 738.5 & 264.7 & - & $1,003.2$ \\
\hline March ..................................... & $W$ & $W$ & $1,102.9$ & W & W & $2,820.0$ & W & $W$ & $W$ & W & - & 1.2 \\
\hline 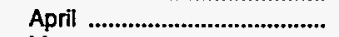 & 403.1 & 415.4 & $1,067.7$ & $1,676.6$ & $\ddot{w}$ & $W$ & - & - & - & $w$ & - & $w$ \\
\hline 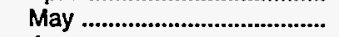 & 391.0 & 405.1 & $1,106.8$ & $1,536.9$ & 59.8 & $2,703.5$ & - & - & - & - & - & - \\
\hline 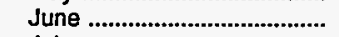 & 411.8 & 422.6 & W & $1,824.9$ & $W$ & $3,007.7$ & - & - & - & - & - & - \\
\hline July ......................................... & 409.6 & 417.4 & $1,147.5$ & $1,840.3$ & 108.5 & $3,096.3$ & - & - & - & - & - & - \\
\hline 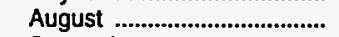 & 402.2 & 414.2 & $1,150.8$ & $1,835.8$ & 518.0 & $3,504.6$ & - & - & - & - & - & - \\
\hline September ................................. & $W$ & W & $W$ & $1,623.5$ & $w$ & $3,061.2$ & $w$ & $W$ & - & - & - & - \\
\hline October & $w$ & 308.8 & 710.8 & $W$ & $w$ & $2,674.0$ & w & 89.5 & $w$ & $w$ & - & 555.3 \\
\hline 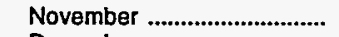 & W & 121.4 & W & $1,212.6$ & $w$ & $1,793.8$ & $\ddot{w}$ & 300.2 & 842.4 & 532.4 & - & $1,374.8$ \\
\hline 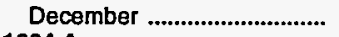 & 115.0 & 120.0 & 234.9 & $1,128.0$ & 430.0 & $1,792.8$ & 293.8 & 301.3 & 836.6 & 508.4 & - & $1,345.0$ \\
\hline 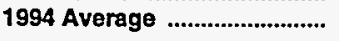 & 312.0 & 321.4 & 811.6 & $1,568.0$ & 222.6 & $2,602.3$ & 86.3 & 88.2 & 296.8 & 146.9 & - & 443.8 \\
\hline \multicolumn{13}{|l|}{ Washington } \\
\hline 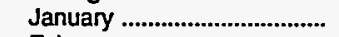 & 407.9 & 415.0 & 470.2 & $1,872.8$ & $w$ & $3,380.3$ & 633.4 & 637.2 & $1,941.6$ & 466.0 & - & $2,407.6$ \\
\hline 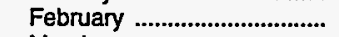 & 258.8 & 263.8 & W & $1,761.4$ & W & $2,700.3$ & 864.5 & 868.3 & W & $W$ & - & $2,362.4$ \\
\hline 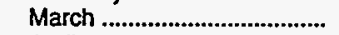 & W & $W$ & $w$ & $2,332.2$ & $\ddot{w}$ & $3,855.3$ & $w$ & W & $\ddot{w}$ & $\mathbf{W}$ & - & $1,048.0$ \\
\hline 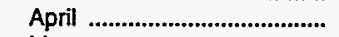 & $w$ & $w$ & $\ddot{W}$ & $2,432.8$ & $\ddot{w}$ & $W$ & $\ddot{w}$ & $\mathbf{W}$ & $w$ & W & - & $W$ \\
\hline 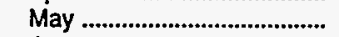 & W & W & 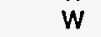 & W & $W$ & $W$ & w & W & w & - & - & $w$ \\
\hline June ......................................... & $1,196.2$ & $1,206.5$ & $\dddot{w}$ & w & W & w & - & - & - & $w$ & - & $w$ \\
\hline July & $1,090.2$ & $1,096.5$ & $2,544.7$ & $w$ & 383.1 & w & - & - & - & w & - & $w$ \\
\hline 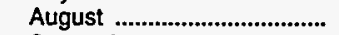 & $W$ & W & $2,516.7$ & W & W & $5,515.1$ & $w$ & $w$ & $w$ & $w$ & - & 57.3 \\
\hline September ............................ & $w$ & W & $2,396.7$ & W & W & 5.134 .7 & $w$ & $w$ & $w$ & W & - & 307.3 \\
\hline 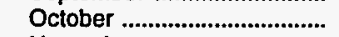 & 688.4 & 692.8 & $1,397.9$ & $2,318.6$ & 137.3 & $3,853.7$ & 434.2 & 436.3 & $1,136.7$ & 309.0 & - & $1,445.7$ \\
\hline November .............................. & 125.0 & 128.1 & $w$ & $1,955.2$ & $w$ & $2,316.9$ & 987.8 & 993.1 & $2,235.9$ & 662.4 & - & $2,898.3$ \\
\hline 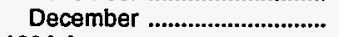 & 123.7 & 126.8 & $w$ & $1,763.8$ & $w$ & $2,088.9$ & $1,098.1$ & $1,105.0$ & W & $w$ & - & $2,892.7$ \\
\hline 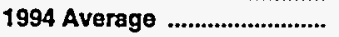 & 754.9 & 761.5 & $1,566.3$ & $2,371.6$ & 216.4 & $4,154.3$ & 377.0 & 379.3 & 942.7 & 234.6 & - & $1,177.3$ \\
\hline
\end{tabular}

See footnotes at end of table. 
Table 44. Refiner Motor Gasoline Volumes by Formulation, Sales Type, PAD District, and State

(Thousand Gallons per Day) - Continued

\begin{tabular}{|c|c|c|c|c|c|c|c|c|c|c|c|c|}
\hline \multirow{3}{*}{$\begin{array}{l}\text { Goographlo Area } \\
\text { Month }\end{array}$} & \multicolumn{6}{|c|}{ Reformulated } & \multicolumn{6}{|c|}{ All Formulations } \\
\hline & \multicolumn{2}{|c|}{ Sales to End Users } & \multicolumn{4}{|c|}{ Sales for Resale } & \multicolumn{2}{|c|}{ Sales to End Users } & \multicolumn{4}{|c|}{ Sales for Resale } \\
\hline & $\begin{array}{l}\text { Through } \\
\text { Retall } \\
\text { Outlots }\end{array}$ & Totala & DTW & Rack & Bulk & Total & $\begin{array}{l}\text { Through } \\
\text { Retail } \\
\text { Outlets }\end{array}$ & Totala & DTW & Rack & Bulk & Total \\
\hline
\end{tabular}

Hawall

January.

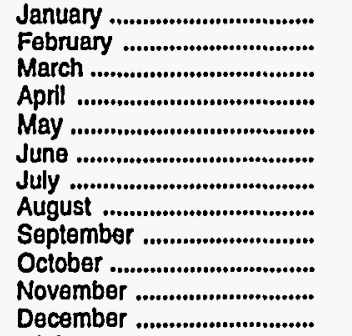

$\begin{array}{ll}- & = \\ = & = \\ = & = \\ = & = \\ = & = \\ = & = \\ = & = \\ - & =\end{array}$

$\begin{array}{ll}= & = \\ = & = \\ = & = \\ = & = \\ = & = \\ = & =\end{array}$

$\begin{array}{ll}= & - \\ = & = \\ = & = \\ = & = \\ = & = \\ = & = \\ = & = \\ & =\end{array}$

$\begin{array}{ll}= & 171.2 \\ = & 172.9 \\ = & 173.1 \\ = & 175.5 \\ = & 176.3 \\ = & 181.8 \\ = & 181.5 \\ = & 181.9 \\ = & 179.7 \\ = & 177.0 \\ = & 178.4 \\ = & 183.5 \\ - & 177.8\end{array}$

251.7
257.6
260.6
260.4
261.4
267.3
264.9
259.9
262.5
251.3
249.8
257.3
258.7

\section{9} 614.0
635.9

621.3

630.8

637.8

637.4

650.0

622.4

620.6

625.0

642.9

627.4

109.4
99.1
$W$
117.3
113.0
104.7
113.2
110.8
91.8
102.6
108.2
95.9
106.9

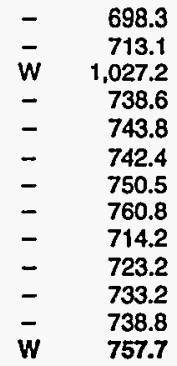

Nevada

January

February

April

May

July ...

August ...

October

November

Decomber

1994 Average

Oregon

January.

February

March

May

(n)

July

August

September

October

November

December .

1994 Averag

Washington

January .

February

March

April

May

June

July ...

August .

September ...........................

October .

November

December

1994 Average

$\begin{array}{lllll}- & - & - & - & - \\ - & - & - & - & - \\ - & - & - & - & - \\ - & - & - & - & - \\ - & - & - & - & - \\ - & - & - & - & - \\ - & - & - & - & - \\ - & - & - & - & - \\ - & - & - & - & - \\ - & - & - & - & - \\ - & - & - & - & - \\ - & - & - & - & -\end{array}$

\begin{tabular}{ll}
- & 144.4 \\
- & 138.6 \\
- & 149.8 \\
- & 133.0 \\
- & 127.3 \\
- & 157.9 \\
- & 131.0 \\
- & 127.1 \\
- & 147.6 \\
- & 123.2 \\
- & 126.2 \\
- & 148.8 \\
\hline & 137.9
\end{tabular}

$\begin{array}{rr}157.3 & 987.3 \\ 150.4 & 1,030.1 \\ 165.2 & 1,045.5 \\ 145.4 & 1,045.2 \\ 141.3 & 1,086.9 \\ 168.4 & 1,157.1 \\ 144.1 & 1,123.7 \\ 139.0 & 1,166.5 \\ 157.3 & 1,110.4 \\ 132.7 & 1,115.5 \\ 136.5 & 1,086.9 \\ 158.8 & 1,088.6 \\ 149.6 & 1,087.3\end{array}$

$\begin{array}{lll}479.9 & W & 1,683.3 \\ W & W & 1,796.1 \\ W & W & 1,895.1 \\ W & W & 1,816.2 \\ W & W & 1,893.6 \\ W & W & 2,159.0 \\ W & W & 2,067.8 \\ W & W & 2,131.1 \\ W & W & 2,065.8 \\ W & W & 2,006.5 \\ W & W & 1,889.4 \\ W & W & 1,902.8 \\ 706.5 & W & 1,943.0\end{array}$

$\begin{array}{llll}- & - & - & - \\ - & - & - & - \\ - & - & - & - \\ - & - & - & - \\ - & - & - & - \\ - & - & -\end{array}$

$\begin{array}{lll}- & - & \\ - & - & \\ - & - & \\ - & - & - \\ - & - & - \\ - & - & - \\ - & - & -\end{array}$

$\begin{array}{ll}- & 364.5 \\ - & 385.4 \\ - & 406.1 \\ - & 403.1 \\ - & 391.0 \\ - & 411.8 \\ - & 409.6 \\ - & 402.2 \\ - & 399.9 \\ - & 386.1 \\ - & 411.8 \\ - & 408.8 \\ - & 398.4\end{array}$

373.0
397.6
417.7
415.4
405.1
422.6
417.4
414.2
411.1
398.3
421.6
421.3
409.6

$1,092.5$

$1,887$.

$116.4 \quad 3,096.3$

104.1

$W$
$1,067.7$

$1,716.2$

$\begin{array}{lr}W & 2,796.5 \\ W & 2,821.2\end{array}$

$\begin{array}{llll}1,067.7 & W & W & 2,903.7\end{array}$

422.6 $\quad w \quad 1,824.9$

$\begin{array}{cr}59.8 & 2,703.5 \\ W & 3,007.7\end{array}$

$\begin{array}{llll}1,147.5 & 1,840.3 & 108.5 & 3,096.3\end{array}$

$\begin{array}{llll}1,150.8 & 1,835.8 & 518.0 & 3,504.6\end{array}$

W $1,623.5$

$\begin{array}{ll}W & 1,623.5 \\ W & 1,729.6 \\ W & 1,745.0\end{array}$

$\begin{array}{cr}W & 1,745.0 \\ 1,071.5 & 1,636.4\end{array}$

$\begin{array}{ll}W & 3,061.2 \\ W & 3,229.3\end{array}$

$\begin{array}{ll}W & 3,229.3 \\ W & 3,168.7\end{array}$

$\begin{array}{ll}430.0 & 3,137.8\end{array}$

$\begin{array}{llll}1,108.5 & 1,714.9 & 222.6 & 3,046.0\end{array}$

Dash $(-)=$ No data reported.

NA $=$ Not avallable.

$W=$ Withheld to avoid disclosure of individual company data.

a Includes sales through retall outlets as well as all direct sales to end users that were not made through company-operated retail outlets, e.g., sales to agricultural customers, commercial sales, and industrial sales.

Note: Totals may not equal the sum of the components due to rounding.

Source: Energy Information Administration Form EIA-782A, "Refiners'/Gas Plant Operators' Monthly Petroleum Product Sales Report." 
Table 45. Refiner Volumes of Aviation Fuels, Kerosene, No. 1 Distillate, and Propane (Consumer Grade) by PAD District and State

(Thousand Gallons per Day)

\begin{tabular}{|c|c|c|c|c|c|c|c|c|c|c|}
\hline \multirow{2}{*}{$\underset{\text { Month }}{\text { Geographic Area }}$} & \multicolumn{2}{|c|}{ Aviation Gasoline } & \multicolumn{2}{|c|}{$\begin{array}{c}\text { Kerosene-Type } \\
\text { Jet Fuel }\end{array}$} & \multicolumn{2}{|c|}{ Kerosene } & \multicolumn{2}{|c|}{ No. 1 Distillate } & \multicolumn{2}{|c|}{$\begin{array}{c}\text { Propane } \\
\text { (Consumer Grade) }\end{array}$} \\
\hline & $\begin{array}{c}\text { Sales to } \\
\text { End Users }\end{array}$ & $\begin{array}{c}\text { Sales for } \\
\text { Resale }\end{array}$ & $\begin{array}{c}\text { Sales to } \\
\text { End Users }\end{array}$ & $\begin{array}{c}\text { Sales for } \\
\text { Resale }\end{array}$ & $\begin{array}{c}\text { Sales to } \\
\text { End Users }\end{array}$ & $\begin{array}{c}\text { Sales for } \\
\text { Resale }\end{array}$ & $\begin{array}{c}\text { Sales to } \\
\text { End Users }\end{array}$ & $\begin{array}{l}\text { Sales for } \\
\text { Resale }\end{array}$ & $\begin{array}{c}\text { Sales to } \\
\text { End Users }\end{array}$ & $\begin{array}{l}\text { Sales for } \\
\text { Resale }\end{array}$ \\
\hline \multicolumn{11}{|l|}{ United States } \\
\hline 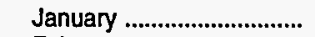 & 158.6 & 414.8 & $40,536.0$ & $8,172.4$ & 646.5 & $6,954.1$ & 810.2 & $5,058.6$ & $3,303.0$ & $40,021.8$ \\
\hline 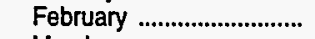 & 179.5 & 472.6 & $41,166.3$ & $7,961.8$ & 560.6 & $4,891.0$ & 798.9 & $3,734.1$ & $2,918.6$ & $33,742.2$ \\
\hline 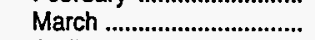 & 228.3 & 620.1 & $43,250.5$ & $7,054.5$ & 266.3 & $2,659.3$ & 471.2 & $1,201.9$ & $2,238.2$ & $26,063.9$ \\
\hline April & 223.6 & 641.1 & $45,584.7$ & $7,507.7$ & 167.7 & $1,058.0$ & 216.5 & 670.2 & $1,743.2$ & $20,966.2$ \\
\hline 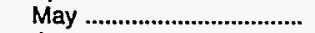 & 245.4 & 763.8 & $45,175.4$ & $9,122.4$ & 447.3 & 884.4 & 196.5 & 589.7 & $1,938.5$ & $19,411.2$ \\
\hline 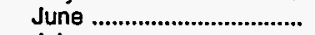 & 259.3 & 852.1 & $46,520.8$ & $9,199.8$ & 365.3 & 695.0 & 262.0 & 601.1 & $1,803.6$ & $22,627.9$ \\
\hline 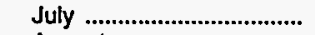 & 240.6 & 912.9 & $46,758.3$ & $10,032.8$ & 155.0 & 710.8 & 196.8 & 450.6 & $1,701.2$ & $24,024.6$ \\
\hline 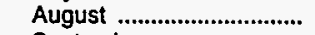 & 266.3 & 892.4 & $48,109.4$ & $11,036.0$ & 554.8 & $1,659.3$ & 245.7 & 661.3 & $2,032.4$ & $26,261.9$ \\
\hline 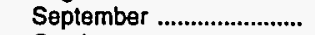 & 249.7 & 780.9 & $47,272.9$ & $9,671.1$ & 392.6 & $1,977.2$ & 269.7 & $1,335.3$ & $1,903.3$ & $27,201.6$ \\
\hline 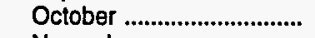 & 225.2 & 616.1 & $46,084.7$ & $9,577.2$ & 479.2 & $2,169.1$ & 265.3 & $1,719.3$ & $2,274.0$ & $32,574.9$ \\
\hline 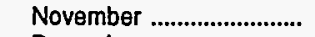 & 201.7 & 507.0 & $45,563.1$ & $9,845.8$ & 641.8 & $2,509.0$ & 407.2 & $3,408.1$ & $2,216.1$ & $31,122.3$ \\
\hline 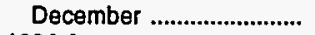 & 193.8 & 435.2 & $46,572.8$ & $10,371.6$ & 660.1 & $3,942.7$ & 495.3 & $3,934.7$ & $2,681.2$ & $36,756.7$ \\
\hline 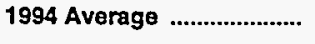 & 222.9 & 660.2 & $45,238.4$ & $9,139.8$ & 444.4 & $2,500.0$ & 383.9 & $1,937.2$ & $2,227.2$ & $28,386.0$ \\
\hline \multicolumn{11}{|l|}{ PAD District I } \\
\hline 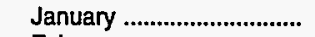 & 62.9 & 90.1 & $12,087.8$ & $1,590.1$ & 445.0 & $4,396.8$ & 53.9 & 325.3 & 94.4 & $6,950.2$ \\
\hline 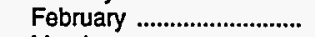 & 70.4 & 95.4 & $12,861.1$ & $1,328.0$ & 403.2 & $3,309.2$ & 57.9 & 173.7 & 93.8 & $5,908.5$ \\
\hline 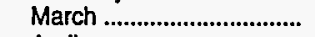 & 97.5 & 121.4 & $12,775.5$ & $1,247.5$ & 169.2 & $1,695.4$ & $W$ & 54.9 & 66.4 & $3,943.2$ \\
\hline April & 96.3 & 137.8 & $13,236.7$ & $1,131.8$ & 128.5 & 553.5 & 5.9 & 9.8 & 39.7 & $2,492.6$ \\
\hline 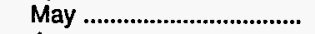 & 95.4 & 137.8 & $13,030.5$ & $1,130.8$ & 207.6 & 438.3 & 6.1 & 7.0 & 38.1 & $2,475.3$ \\
\hline 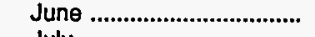 & 90.6 & 142.3 & $13,280.0$ & $1,338.2$ & 119.5 & 346.8 & 6.0 & 4.5 & 41.0 & $3,199.7$ \\
\hline July ..................................... & 85.2 & 159.2 & $13,456.6$ & $1,262.8$ & 130.9 & 312.3 & 5.4 & 4.7 & 36.9 & $3,106.0$ \\
\hline August ............................... & 94.3 & 161.0 & $13,701.1$ & $1,225.9$ & 126.0 & 973.4 & 18.8 & 4.7 & 54.5 & $3,898.0$ \\
\hline 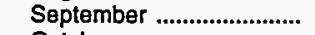 & 97.4 & 140.5 & $13,150.8$ & $1,262.0$ & 92.4 & $1,105.2$ & W & 7.0 & 90.3 & $4,420.8$ \\
\hline 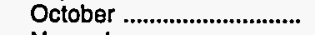 & 89.4 & 130.1 & $13,394.5$ & $1,614.1$ & 131.2 & $1,424.1$ & $W$ & 40.2 & 72.7 & $4,465.2$ \\
\hline November .......................... & 76.2 & 121.1 & $12,484.2$ & $1,547.8$ & 224.6 & $1,434.8$ & $w$ & 29.5 & 57.3 & $4,362.5$ \\
\hline 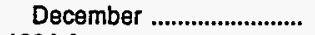 & 77.6 & 109.3 & $13,318.9$ & $1,770.3$ & 259.4 & $2,382,4$ & $W$ & 59.8 & 56.6 & $5,334.9$ \\
\hline 1994 Average ........................... & 86.2 & 129.0 & $13,066.8$ & $1,371.7$ & 202.2 & $1,523.7$ & 20.7 & 59.7 & 61.6 & $4,205.7$ \\
\hline \multicolumn{11}{|l|}{ Subdistrict lA } \\
\hline 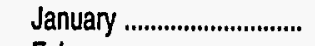 & $W$ & 7.2 & 921.9 & 159.1 & 23.4 & 341.8 & 18.9 & 71.3 & 7.3 & 120.4 \\
\hline 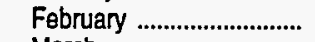 & $W$ & 11.4 & $1,085.9$ & 102.4 & 29.0 & 392.1 & 14.5 & 24.7 & $w$ & 105.8 \\
\hline 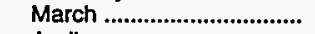 & $w$ & $W$ & $1,084.9$ & 76.5 & 13.4 & 185.7 & 8.6 & 14.7 & $\ddot{W}$ & 94.2 \\
\hline April & $W$ & 14.5 & $1,020.8$ & 88.3 & 1.7 & 66.8 & $W$ & 2.8 & $W$ & 62.3 \\
\hline May & $W$ & $W$ & $1,017.8$ & 60.9 & 1.5 & 69.3 & 4.8 & $W$ & W & 49.5 \\
\hline June & $W$ & W & $1,098.1$ & 77.8 & $W$ & 53.2 & 4.3 & W & $\ddot{W}$ & 61.0 \\
\hline 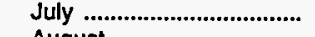 & W & 18.4 & $1,088.2$ & 62.1 & 9.0 & 47.6 & $W$ & w & $\ddot{W}$ & 45.8 \\
\hline 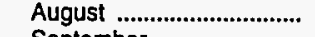 & $W$ & $W$ & $1,194.3$ & 79.5 & $W$ & 46.6 & W & $W$ & $W$ & 48.9 \\
\hline September .......................... & $W$ & $w$ & $1,075.4$ & 76.7 & 3.4 & 70.9 & 2.5 & 2.1 & $\ddot{w}$ & 61.2 \\
\hline October ................................ & W & $W$ & $1,217.0$ & 84.5 & 2.6 & 156.1 & 2.1 & 2.2 & W & 106.8 \\
\hline 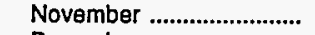 & $W$ & $W$ & $1,149.6$ & 99.1 & 5.5 & 199.2 & 7.1 & 9.4 & W & 159.3 \\
\hline December ............................ & W & $w$ & $1,096.1$ & 120.9 & 14.0 & 322.5 & 14.6 & 16.4 & $\ddot{W}$ & 144.7 \\
\hline 1994 Average & W & $w$ & $1,087.5$ & 90.6 & 8.9 & 161.5 & 7.3 & 12.4 & 3.9 & 88.2 \\
\hline \multicolumn{11}{|l|}{ Connecticut } \\
\hline January ............................... & W & 1.2 & 169.6 & 12.1 & 5.2 & $W$ & 8.6 & 7.7 & $W$ & 34.5 \\
\hline 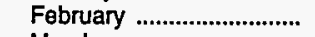 & $W$ & 1.8 & 260.3 & $W$ & $W$ & W & 5.7 & 6.6 & $w$ & 27.0 \\
\hline 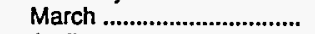 & W & 1.4 & 259.7 & W & W & W & 1.6 & 3.1 & $w$ & 21.7 \\
\hline April & $w$ & 2.1 & 179.6 & $W$ & $w$ & W & $W$ & $w$ & W & 22.2 \\
\hline May & $W$ & $W$ & 231.9 & W & $w$ & W & - & $w$ & $\ddot{w}$ & 15.8 \\
\hline June & $w$ & $w$ & 209.5 & W & W & W & - & $\ddot{w}$ & $\ddot{w}$ & $w$ \\
\hline 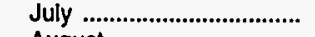 & $W$ & $w$ & 245.0 & $W$ & $w$ & 3.5 & $w$ & W & W & 14.8 \\
\hline 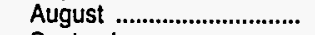 & W & W & 261.7 & $W$ & $W$ & $W$ & W & w & $\dddot{w}$ & 14.7 \\
\hline September ............................ & W & W & 228.0 & $W$ & $w$ & $w$ & W & $\ddot{w}$ & $w$ & 18.4 \\
\hline 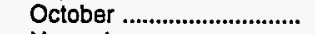 & W & $W$ & $W$ & 12.3 & $w$ & 21.6 & $\ddot{w}$ & w & $w$ & 17.0 \\
\hline 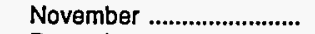 & $W$ & $W$ & 324.7 & $W$ & w & 33.2 & $\ddot{w}$ & w & $w$ & 18.3 \\
\hline December ............................ & $w$ & W & 262.3 & 10.5 & $w$ & 55.6 & 7.9 & $w$ & $w$ & 21.5 \\
\hline 1994 Average & $\mathbf{w}$ & 1.5 & 249.1 & 11.1 & w & 33.2 & 3.1 & 2.3 & $\ddot{W}$ & 20.2 \\
\hline
\end{tabular}

See footnotes at end of table. 
Table 45. Refiner Volumes of Aviation Fuels, Kerosene, No. 1 Distillate, and Propane (Consumer Grade) by PAD District and State

(Thousand Gallons per Day) - Continued

\begin{tabular}{|c|c|c|c|c|c|c|c|c|c|c|}
\hline \multirow{2}{*}{$\begin{array}{l}\text { Goographic Aroa } \\
\text { Month }\end{array}$} & \multicolumn{2}{|c|}{ Aviation Gasoline } & \multicolumn{2}{|c|}{$\begin{array}{l}\text { Kerosene-Type } \\
\text { Jet Fuel }\end{array}$} & \multicolumn{2}{|c|}{ Kerosene } & \multicolumn{2}{|c|}{ No. 1 Distillate } & \multicolumn{2}{|c|}{$\begin{array}{c}\text { Propane } \\
\text { (Consumer Grade) }\end{array}$} \\
\hline & $\begin{array}{l}\text { Sales to } \\
\text { End Users }\end{array}$ & $\begin{array}{l}\text { Sales for } \\
\text { Resale }\end{array}$ & $\begin{array}{l}\text { Sales to } \\
\text { End Users }\end{array}$ & $\begin{array}{l}\text { Sales for } \\
\text { Resale }\end{array}$ & $\begin{array}{l}\text { Sales to } \\
\text { End Users }\end{array}$ & $\begin{array}{l}\text { Sales for } \\
\text { Resale }\end{array}$ & $\begin{array}{l}\text { Sales to } \\
\text { End Users }\end{array}$ & $\begin{array}{l}\text { Sales for } \\
\text { Resalo }\end{array}$ & $\begin{array}{l}\text { Sales to } \\
\text { End Users }\end{array}$ & $\begin{array}{l}\text { Sales for } \\
\text { Resale }\end{array}$ \\
\hline \multicolumn{11}{|l|}{ Maine } \\
\hline 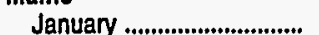 & $w$ & - & 53.5 & w & $w$ & 140.8 & $w$ & 29.0 & w & 12.5 \\
\hline February .............................. & w & $w$ & $w$ & w & $\ddot{W}$ & 127.3 & $\ddot{w}$ & 14.6 & - & 10.0 \\
\hline March ................................... & $w$ & - & $w$ & $\ddot{w}$ & w & 63.6 & w & 8.7 & - & 5.5 \\
\hline Aprill ............................. & $\dddot{w}$ & w & $w$ & $\ddot{w}$ & - & 24.5 & - & 1.6 & - & $w$ \\
\hline 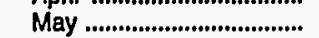 & $\ddot{w}$ & - & $w$ & $w$ & $w$ & 29.5 & $w$ & $w$ & - & 4.4 \\
\hline 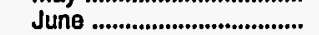 & $w$ & $w$ & $\ddot{w}$ & 4.7 & $w$ & 25.5 & - & $\ddot{w}$ & - & 9.3 \\
\hline 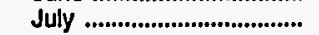 & $w$ & - & $\ddot{w}$ & $w$ & $w$ & 36.5 & - & - & - & 7.5 \\
\hline August .................................. & $w$ & $w$ & $\ddot{w}$ & 5.3 & $w$ & 23.6 & - & w & - & 8.9 \\
\hline September ............................. & $w$ & - & $w$ & 12.3 & W & 35.7 & $w$ & 0.6 & - & 8.2 \\
\hline 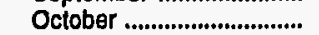 & $w$ & - & $w$ & 18.4 & w & 65.0 & - & 1.2 & - & 11.5 \\
\hline November ........................... & $\underline{w}$ & - & $\mathbb{w}$ & 27.5 & $w$ & 115.6 & - & $w$ & - & $w$ \\
\hline December ....................... & w & w & $w$ & $w$ & $\ddot{w}$ & 205.7 & w & 7.2 & - & 12.5 \\
\hline 1994 Average ......................... & w & $\ddot{w}$ & $w$ & 19.2 & w & 74.3 & w & 5.8 & $w$ & 8.7 \\
\hline \multicolumn{11}{|l|}{ Massachusetts } \\
\hline 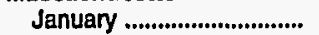 & $w$ & 0.7 & 622.0 & 71.4 & 12.4 & 69.9 & w & w & - & 19.9 \\
\hline 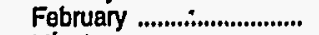 & $w$ & $w$ & 673.5 & 42.5 & 9.8 & 63.3 & w & $w$ & - & 13.1 \\
\hline 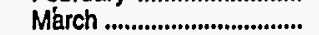 & $w$ & $w$ & 685.2 & 51.1 & $w$ & 40.0 & w & w & - & 12.8 \\
\hline Aprll ........................................ & $w$ & 2.5 & 697.1 & 64.5 & $w$ & 15.3 & - & - & - & 9.8 \\
\hline May .................................. & $w$ & 1.4 & 646.7 & 44.4 & $\ddot{w}$ & 26.6 & $w$ & w & - & 12.3 \\
\hline 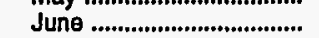 & $\ddot{w}$ & 3.2 & 716.3 & 54.6 & $\ddot{w}$ & 7.2 & $\ddot{w}$ & w & - & 15.8 \\
\hline July ................................... & $w$ & 7.9 & 652.0 & 45.9 & 3.8 & $w$ & - & - & - & 2.7 \\
\hline 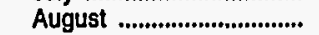 & $w$ & 3.0 & 742.7 & 59.7 & $w$ & 3.5 & - & - & - & 7.5 \\
\hline Soptember ........................ & $\ddot{w}$ & 1.4 & 675.3 & 51.1 & W & $w$ & - & - & - & 13.1 \\
\hline 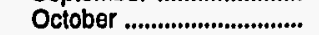 & $w$ & $w$ & 684.2 & 48.3 & 1.6 & 51.5 & NA & $w$ & - & $w$ \\
\hline November .............................. & W & w & 675.5 & 55.7 & 2.9 & 26.7 & - & $w$ & - & 25.9 \\
\hline December ........................... & $w$ & $\ddot{w}$ & 676.4 & 64.8 & 8.6 & 36.4 & $w$ & $\ddot{w}$ & - & 27.7 \\
\hline 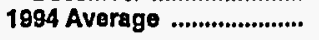 & $\mathbf{w}$ & 2.8 & 678.8 & 54.6 & 4.4 & 29.2 & $w$ & $w$ & - & 15.2 \\
\hline \multicolumn{11}{|l|}{ Now Hampshlie } \\
\hline 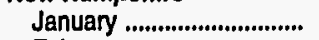 & $w$ & - & 22.2 & w & $w$ & $w$ & $w$ & 10.2 & W & w \\
\hline February ................................. & $w$ & $w$ & 23.0 & $\ddot{w}$ & w & $\ddot{w}$ & W & 0.5 & W & 13.7 \\
\hline 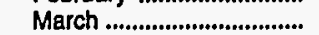 & $w$ & $w$ & 19.4 & $\ddot{w}$ & $w$ & $\ddot{w}$ & w & $w$ & $w$ & 22.4 \\
\hline Aprll & $w$ & $w$ & 22.5 & $w$ & $w$ & $w$ & $w$ & - & $w$ & $w$ \\
\hline 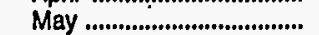 & $w$ & $w$ & 24.7 & $w$ & $w$ & $\ddot{w}$ & w & - & $w$ & $\ddot{w}$ \\
\hline June ........................................... & 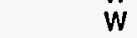 & $\ddot{w}$ & 26.3 & $\ddot{w}$ & $\ddot{w}$ & $\ddot{w}$ & w & - & W & w \\
\hline July ....................................... & $w$ & w & 25.1 & $w$ & W & w & w & w & $w$ & $w$ \\
\hline August & $\ddot{w}$ & $\ddot{w}$ & 28.5 & $\ddot{w}$ & $w$ & 2.6 & $w$ & NA & $\dddot{w}$ & $\ddot{w}$ \\
\hline September ........................ & $\ddot{w}$ & $w$ & 27.6 & $\ddot{w}$ & 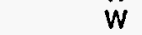 & $w$ & $w$ & - & $w$ & $w$ \\
\hline 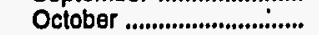 & $w$ & $w$ & $w$ & $w$ & $w$ & w & $w$ & - & $w$ & 40.3 \\
\hline November .......................... & w & $w$ & $w$ & $w$ & W & $w$ & $w$ & $w$ & $w$ & 74.5 \\
\hline December ............................... & $\ddot{w}$ & $w$ & $w$ & $w$ & $w$ & $\ddot{w}$ & w & $\ddot{w}$ & $\ddot{w}$ & NA \\
\hline 1894 Average ............................ & $\mathbb{w}$ & $\underline{w}$ & 25.7 & 2.8 & $w$ & 16.8 & $w$ & 1.0 & $w$ & 23.0 \\
\hline \multicolumn{11}{|l|}{ Rhodo lsland } \\
\hline January ................................ & $w$ & $w$ & 44.4 & w & $w$ & w & $w$ & w & - & 12.3 \\
\hline February ............................... & $w$ & $w$ & 46.9 & 2.8 & $w$ & - & $w$ & - & - & 15.9 \\
\hline 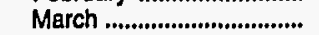 & W & w & 46.9 & $w$ & w & w & $w$ & $w$ & - & 13.1 \\
\hline 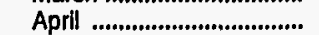 & $w$ & $w$ & 47.1 & $w$ & - & $w$ & - & $\ddot{w}$ & - & $w$ \\
\hline 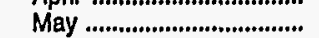 & $w$ & $w$ & 43.9 & $w$ & - & 3.6 & - & $w$ & - & w \\
\hline 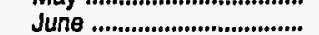 & $\ddot{w}$ & $\ddot{w}$ & 51.2 & $\ddot{w}$ & - & $w$ & w & $\ddot{w}$ & - & $\ddot{w}$ \\
\hline 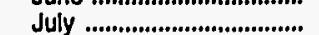 & $w$ & $\dddot{w}$ & 55.4 & $\ddot{w}$ & - & $\ddot{w}$ & $\ddot{w}$ & $\dddot{w}$ & - & $\ddot{w}$ \\
\hline 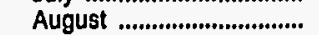 & w & $w$ & 50.1 & $w$ & - & w & w & w & - & w \\
\hline September ........................... & w & w & 54.1 & $w$ & - & $w$ & - & - & - & w \\
\hline October ................................... & $w$ & $w$ & 53.8 & 2.4 & - & $w$ & - & $w$ & - & W \\
\hline November ............................ & $\dddot{w}$ & $w$ & 45.9 & 3.4 & $w$ & 4.1 & $w$ & $\ddot{w}$ & - & $\ddot{w}$ \\
\hline 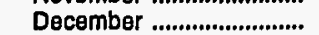 & 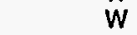 & $w$ & 49.9 & 5.4 & w & $w$ & w & $w$ & - & $\ddot{w}$ \\
\hline 1894 Average .................... & $w$ & $\mathbf{w}$ & 49.1 & 2.0 & w & 2.1 & $\mathbf{w}$ & w & - & 4.9 \\
\hline
\end{tabular}

See footnotes at end of table. 
Table 45. Refiner Volumes of Aviation Fuels, Kerosene, No. 1 Distillate, and Propane (Consumer Grade) by PAD District and State

(Thousand Gallons per Day) - Continued

\begin{tabular}{|c|c|c|c|c|c|c|c|c|c|c|}
\hline \multirow{2}{*}{$\begin{array}{c}\text { Geographic Area } \\
\text { Month }\end{array}$} & \multicolumn{2}{|c|}{ Aviation Gasolino } & \multicolumn{2}{|c|}{$\begin{array}{c}\text { Kerosene-Type } \\
\text { Jet Fuel }\end{array}$} & \multicolumn{2}{|c|}{ Kerosene } & \multicolumn{2}{|c|}{ No. 1 Distillate } & \multicolumn{2}{|c|}{$\begin{array}{c}\text { Propane } \\
\text { (Consumer Grade) }\end{array}$} \\
\hline & $\begin{array}{l}\text { Sales to } \\
\text { End Users }\end{array}$ & $\begin{array}{l}\text { Sales for } \\
\text { Resale }\end{array}$ & $\begin{array}{l}\text { Sales to } \\
\text { End Users }\end{array}$ & $\begin{array}{l}\text { Sales for } \\
\text { Resale }\end{array}$ & $\begin{array}{l}\text { Sales to } \\
\text { End Users }\end{array}$ & $\begin{array}{l}\text { Sales for } \\
\text { Resalo }\end{array}$ & $\begin{array}{l}\text { Sales to } \\
\text { End Users }\end{array}$ & $\begin{array}{l}\text { Sales for } \\
\text { Resale }\end{array}$ & $\begin{array}{l}\text { Sales to } \\
\text { End Users }\end{array}$ & $\begin{array}{l}\text { Sales for } \\
\text { Resalo }\end{array}$ \\
\hline
\end{tabular}

Vermont

January

February

March

April

May.

July .

August

Novemt

December

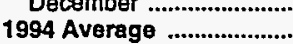

Subdistrict IB

January ...

February

April

April

May

June

September

October ...

November

December

1994 Average

$\begin{array}{llr}W & W & 10.3 \\ W & W & W \\ W & W & W \\ W & W & W \\ W & W & W \\ W & W & W \\ W & W & W \\ W & W & W \\ W & W & W \\ W & W & 9.0 \\ W & W & 9.5 \\ W & W & 11.6 \\ W & W & 9.3\end{array}$

$W$
$W$
1.0
1.6
0.6
0.7
1.0
0.8
0.8
$W$
$W$
$W$
1.0

$\begin{array}{lc}w & W \\ W & 11.1 \\ - & 12.2 \\ - & W \\ - & W \\ - & 0.9 \\ - & W \\ - & W \\ - & W \\ - & 9.3 \\ - & W \\ w & W .8\end{array}$

$w$
$w$
$w$
-
-
-
-
-
$w$
$w$
$w$

$\begin{array}{llr}W & - & 21.6 \\ W & - & 26.1 \\ 1.2 & - & 18.8 \\ W & - & 14.9 \\ W & - & 8.5 \\ W & - & 4.6 \\ W & - & 8.4 \\ W & - & 9.3 \\ W & - & 14.2 \\ W & - & 15.3 \\ W & - & 28.1 \\ W & - & 24.1 \\ W & - & 16.1\end{array}$

Delaware

January ..

February

March

(n)

April

May ...................................

June

July

August

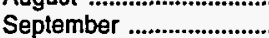

October ...

November

December .............................

1994 Average

$\begin{array}{cc}W & 16 \\ W & 19 \\ W & \\ W & \\ W & \\ W & \\ W & \\ W & \\ W & \\ W & W \\ W & W \\ W & \\ 21.5 & \end{array}$

$5,252.8$

$5,420.6$

$5,494.3$

$\begin{array}{lll}046.9 & 329.7 & 1,879.3\end{array}$

$\begin{array}{lll}841.9 & 316.0 & 1,577.0\end{array}$

$126.2 \quad 865.1$

$\begin{array}{llll}5.841 .3 & 688.6 & 113.9 & 307.6\end{array}$

$5,997.0$

$6,230.1$

739.1

922.6

$511.1 \quad 898.9$

$6,342.5$

$6,193.3$

$6,370.3$

$5,786.2$

808.2

855.4

939.7

889.2

$6,203.2 \quad 976.1$

$196.8 \quad 245.3$

$\begin{array}{ll}196.8 & 245.3 \\ W & 162.3\end{array}$

$\begin{array}{ll}W & 139.4\end{array}$

W 666.2

$76.6 \quad 582.4$

$111.2 \quad 592.5$

$189.3 \quad 552.5$

$186.9 \quad 917.4$

867.7

164.2

703.5

$\begin{array}{cc}25.0 & 180.8 \\ 32.4 & 128.6 \\ 20.3 & 26.7 \\ W & 5.9 \\ W & W \\ W & 2.5 \\ 1.3 & W \\ W & 3.5 \\ W & 4.2 \\ 1.4 & W \\ 2.9 & 17.8 \\ 13.2 & 42.3 \\ 10.8 & 37.2\end{array}$

$2,033.5$

$1,751.2$

$1,060.0$

$1,128.1$

$1,307.9$

$1,095.1$

$1,375.0$

$1,471.4$

$1,797.6$

$1,493.1$

$1,594.2$

$1,446.0$

District of Columbia

January ...............................

March .

April

March

May

July .

August

(n)

September

October .

November

December .

1994 Average

$\begin{array}{lll}w & \bar{w} & 1.5 \\ \bar{w} & w & 1.9 \\ w & w & 2.8 \\ w & w & 2.2 \\ w & w & 2.1 \\ \bar{w} & W & 2.6 \\ w & W & W \\ w & w & 2.7 \\ w & w & 0.9 \\ w & w & 2.9 \\ w & w & 1.7 \\ w & w & 2.0\end{array}$

$\begin{array}{ll}\bar{z} & \\ \bar{w} & \\ \overline{-} & \\ \mathbf{w} & \\ \mathbf{w} & \\ \mathbf{w} & \\ \mathbf{w} & \\ \mathbf{w} & \\ \mathbf{w} & \end{array}$

\begin{tabular}{|c|c|c|c|c|c|}
\hline$w$ & 3.8 & - & - & - & $w$ \\
\hline$w$ & $w$ & - & - & - & $w$ \\
\hline$w$ & $w$ & - & - & - & $w$ \\
\hline- & - & - & - & - & $w$ \\
\hline- & - & - & - & - & $w$ \\
\hline- & - & - & - & - & $w$ \\
\hline- & $w$ & - & - & - & $w$ \\
\hline - & - & - & - & - & $w$ \\
\hline - & - & - & - & - & $w$ \\
\hline w & $w$ & - & - & - & $w$ \\
\hline$w$ & - & - & - & - & $w$ \\
\hline$w$ & $w$ & W & - & - & $w$ \\
\hline $\mathbf{w}$ & 0.6 & $w$ & - & - & $w$ \\
\hline
\end{tabular}

See footnotes at end of table. 
Table 45. Refiner Volumes of Aviation Fuels, Kerosene, No. 1 Distillate, and Propane (Consumer Grade) by PAD.District and State

(Thousand Gallons per Day) - Continued

\begin{tabular}{|c|c|c|c|c|c|c|c|c|c|c|}
\hline \multirow{2}{*}{$\begin{array}{l}\text { Geographic Area } \\
\text { Month }\end{array}$} & \multicolumn{2}{|c|}{ Aviation Gasoline } & \multicolumn{2}{|c|}{$\begin{array}{l}\text { Kerosene-Type } \\
\text { Jet Fuel }\end{array}$} & \multicolumn{2}{|c|}{ Kerosene } & \multicolumn{2}{|c|}{ No. 1 Distillate } & \multicolumn{2}{|c|}{$\begin{array}{c}\text { Propane } \\
\text { (Consumer Grade) }\end{array}$} \\
\hline & $\begin{array}{c}\text { Salos to } \\
\text { End Users }\end{array}$ & $\begin{array}{l}\text { Sales for } \\
\text { Resale }\end{array}$ & $\begin{array}{c}\text { Sales to } \\
\text { End Users }\end{array}$ & $\begin{array}{l}\text { Sales for } \\
\text { Resale }\end{array}$ & $\begin{array}{c}\text { Sales to } \\
\text { End Users }\end{array}$ & $\begin{array}{l}\text { Sales for } \\
\text { Resale }\end{array}$ & $\begin{array}{l}\text { Sales to } \\
\text { End Users }\end{array}$ & $\begin{array}{l}\text { Sales for } \\
\text { Resale }\end{array}$ & $\begin{array}{l}\text { Sales to } \\
\text { End Users }\end{array}$ & $\begin{array}{l}\text { Sales for } \\
\text { Resale }\end{array}$ \\
\hline \multicolumn{11}{|l|}{ Maryland } \\
\hline 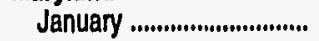 & W & $w$ & 232.2 & 14.3 & 20.7 & 260.2 & 5.4 & $w$ & - & 49.5 \\
\hline February ................................. & W & W & 266.8 & 48.5 & $W$ & 198.0 & 5.4 & 2.4 & - & $w$ \\
\hline 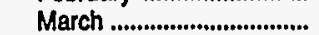 & W & $w$ & 264.0 & 15.1 & $w$ & 106.7 & 4.3 & $w$ & - & w \\
\hline 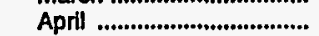 & $w$ & $w$ & 345.7 & $w$ & $\ddot{w}$ & 28.5 & - & $\ddot{w}$ & - & $\ddot{w}$ \\
\hline 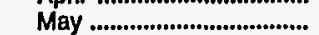 & $w$ & $w$ & 252.3 & 9.4 & $\ddot{w}$ & 36.1 & - & - & - & $w$ \\
\hline 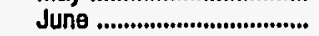 & $w$ & w & 289.1 & 14.8 & w & 18.7 & - & w & - & $\dddot{w}$ \\
\hline July .......................................... & w & W & 262.8 & w & 0.6 & 27.6 & w & NA & - & $w$ \\
\hline 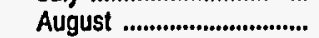 & W & $w$ & W & w & $w$ & $w$ & $w$ & - & - & $w$ \\
\hline 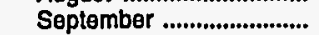 & $w$ & w & 336.3 & $\mathbf{w}$ & $w$ & 49.0 & $\ddot{w}$ & - & - & $\dddot{w}$ \\
\hline 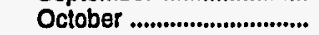 & w & w & 276.5 & w & 4.7 & $w$ & w & w & - & $\ddot{w}$ \\
\hline 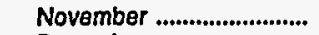 & $w$ & $w$ & 316.6 & w & 4.0 & 75.2 & w & w & - & $w$ \\
\hline 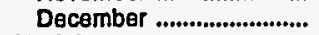 & w & w & 341.7 & w & 4.3 & $w$ & $w$ & $w$ & - & $w$ \\
\hline 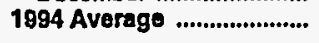 & $\mathbf{w}$ & $\mathbf{w}$ & 291.1 & 17.1 & 5.9 & 81.9 & 1.4 & 1.2 & - & 34.4 \\
\hline \multicolumn{11}{|l|}{ Now Jersey } \\
\hline 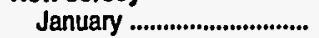 & w & 5.8 & $3,809.0$ & 712.9 & 167.2 & 360.4 & $w$ & $w$ & - & 387.7 \\
\hline 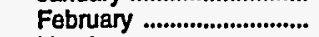 & 4.5 & 5.7 & $3,913.7$ & 519.3 & 139.3 & 380.1 & $w$ & $w$ & w & 325.3 \\
\hline 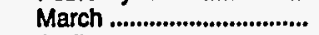 & w & $w$ & $3,939.4$ & 519.3 & 28.6 & 122.4 & $w$ & $w$ & - & 269.2 \\
\hline April & 5.8 & w & $4,237.8$ & 418.0 & $w$ & 63.7 & $w$ & - & w & 115.3 \\
\hline 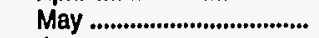 & w & 16.5 & $4,331.1$ & 420.6 & $w$ & 62.5 & - & - & $w$ & 211.3 \\
\hline 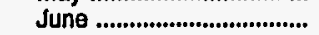 & $w$ & 18.6 & $4,538.1$ & 555.9 & $w$ & 43.7 & - & - & - & 202.1 \\
\hline July ............................................ & $w$ & 14.4 & $4,879.3$ & 630.0 & $w$ & 41.6 & - & - & - & 210.3 \\
\hline August ....................................... & w & 16.7 & $4,610.6$ & 526.2 & w & $w$ & - & - & - & 282.1 \\
\hline September ............................... & W & 12.0 & $4,334.5$ & 484.3 & w & 106.6 & - & - & - & 315.0 \\
\hline 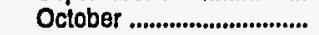 & $w$ & 12.8 & $4,579.9$ & 606.8 & $w$ & 81.8 & - & $w$ & $w$ & 516.2 \\
\hline 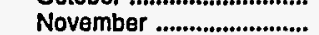 & $w$ & 15.9 & $4,044.7$ & 517.4 & $\ddot{w}$ & 71.6 & w & - & $w$ & 247.8 \\
\hline 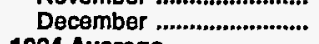 & $w$ & 15.5 & $4,343.8$ & 588.5 & $w$ & 115.7 & $\mathbf{w}$ & $w$ & - & 183.1 \\
\hline 1994 Average ............................. & $\mathbf{5 . 7}$ & 12.9 & $4,300.1$ & 542.3 & $\mathbf{w}$ & 153.9 & $\mathbf{w}$ & $w$ & $\mathbf{w}$ & 272.2 \\
\hline \multicolumn{11}{|l|}{ Now York } \\
\hline 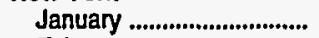 & w & 5.5 & 341.9 & 156.9 & 84.1 & 524.1 & $w$ & 110.4 & - & 400.4 \\
\hline 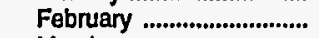 & w & $w$ & 340.6 & 95.6 & 89.8 & 467.6 & $w$ & $w$ & - & 354.0 \\
\hline 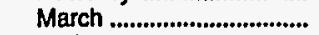 & $w$ & 8.8 & 372.4 & 86.4 & 56.7 & 295.7 & $w$ & $w$ & - & 234.8 \\
\hline April ............................................. & $w$ & 8.4 & 357.1 & $\mathbf{7 4 . 7}$ & 38.9 & 89.3 & $w$ & $w$ & - & 240.7 \\
\hline 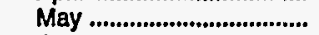 & w & 8.6 & 367.6 & 135.8 & 60.8 & 58.7 & $w$ & $w$ & - & 202.1 \\
\hline 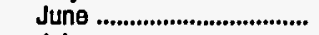 & w & 8.5 & 413.3 & 149.5 & w & 30.7 & w & $w$ & - & 166.3 \\
\hline July ......................................... & $w$ & 26.5 & 434.5 & 80.6 & $w$ & $w$ & $w$ & $\ddot{w}$ & - & 157.5 \\
\hline 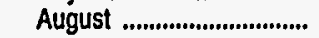 & w & 9.2 & 455.2 & 94.4 & $w$ & 65.3 & w & $w$ & - & 185.8 \\
\hline September ............................. & $w$ & 11.3 & 511.5 & 142.9 & 39.1 & 100.6 & $\ddot{W}$ & $\ddot{w}$ & - & 208.2 \\
\hline 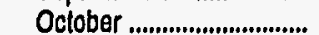 & $w$ & 8.9 & 496.0 & 96.1 & 40.8 & 137.7 & W & W & - & 293.9 \\
\hline November ......................... & $w$ & 6.9 & 483.6 & 114.1 & 45.8 & 177.9 & w & 11.9 & - & 309.8 \\
\hline 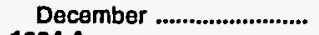 & w & 4.2 & 507.0 & 126.2 & 57.9 & 285.5 & w & 24.5 & - & 371.8 \\
\hline 1994 Averago ........................ & $\mathbf{w}$ & 9.4 & 423.9 & 112.8 & 51.7 & 186.8 & $\mathbf{w}$ & 19.7 & - & 260.0 \\
\hline \multicolumn{11}{|l|}{ Pennsylvania } \\
\hline 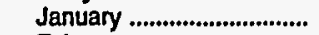 & $w$ & 3.1 & 868.2 & 162.8 & 56.3 & 730.6 & 12.2 & 61.8 & w & \\
\hline 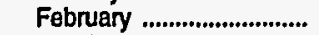 & w & 6.3 & 897.6 & 178.5 & 41.9 & 528.1 & 16.7 & 79.0 & $w$ & 817.1 \\
\hline March ........................................ & w & 8.4 & 916.6 & 178.8 & 29.3 & 340.2 & 7.4 & 7.5 & $w$ & 601.7 \\
\hline April & $w$ & 15.2 & 898.3 & 179.8 & 7.5 & 126.2 & w & 3.9 & - & 586.6 \\
\hline 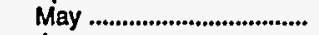 & $w$ & 11.6 & $1,043.8$ & 173.3 & 4.1 & 88.0 & $w$ & 0.9 & $w$ & 619.5 \\
\hline June ......................................... & w & 11.3 & 987.4 & 202.4 & 2.8 & 69.2 & $w$ & $w$ & w & 792.5 \\
\hline July ........................................... & $w$ & 8.5 & 931.9 & 176.5 & 3.5 & 45.4 & $\ddot{w}$ & NA & $\ddot{w}$ & 588.4 \\
\hline August. & w & 13.2 & 964.9 & 171.3 & 5.6 & 161.6 & $w$ & $w$ & w & 737.1 \\
\hline September ....... & w & 12.8 & $1,008.3$ & 216.9 & 7.0 & 326.2 & w & $w$ & w & 730.7 \\
\hline 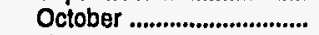 & w & 10.4 & $1,017.0$ & 217.7 & 12.4 & 309.6 & $w$ & 1.3 & $w$ & 781.9 \\
\hline November ............................... & w & $w$ & 938.4 & 236.3 & 17.9 & 227.8 & $w$ & w & w & 717.5 \\
\hline December ................................. & W & 3.8 & $1,008.9$ & 247.6 & 31.5 & 420.8 & 3.4 & 14.6 & $w$ & 726.4 \\
\hline 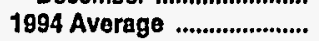 & $\ddot{w}$ & 9.0 & 957.3 & 195.2 & 18.2 & 280.1 & 3.4 & 14.7 & $\mathbf{W}$ & 706.5 \\
\hline
\end{tabular}

See footnotes at end of table. 
Table 45. Refiner Volumes of Aviation Fuels, Kerosene, No. 1 Distillate, and Propane (Consumer Grade) by PAD District and State (Thousand Gallons per Day) - Continued

\begin{tabular}{|c|c|c|c|c|c|c|c|c|c|c|}
\hline \multirow{2}{*}{$\begin{array}{l}\text { Geographic Area } \\
\text { Month }\end{array}$} & \multicolumn{2}{|c|}{ Aviation Gasoline } & \multicolumn{2}{|c|}{$\begin{array}{c}\text { Kerosene-Type } \\
\text { Jet Fuel }\end{array}$} & \multicolumn{2}{|c|}{ Kerosene } & \multicolumn{2}{|c|}{ No. I Distillate } & \multicolumn{2}{|c|}{$\begin{array}{c}\text { Propane } \\
\text { (Consumer Grade) }\end{array}$} \\
\hline & $\begin{array}{l}\text { Sales to } \\
\text { End Users }\end{array}$ & $\begin{array}{l}\text { Sales for } \\
\text { Resale }\end{array}$ & $\begin{array}{l}\text { Sales to } \\
\text { End Users }\end{array}$ & $\begin{array}{c}\text { Salos for } \\
\text { Resale }\end{array}$ & $\begin{array}{l}\text { Sales to } \\
\text { End Users }\end{array}$ & $\begin{array}{l}\text { Sales for } \\
\text { Resale }\end{array}$ & $\begin{array}{l}\text { Sales to } \\
\text { End Users }\end{array}$ & $\begin{array}{l}\text { Sales for } \\
\text { Resale }\end{array}$ & $\begin{array}{l}\text { Sales to } \\
\text { End Users }\end{array}$ & $\begin{array}{c}\text { Sales for } \\
\text { Resale }\end{array}$ \\
\hline \multicolumn{11}{|l|}{ Subdistrict IC } \\
\hline 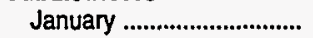 & 48.7 & 67.0 & $5,913.1$ & 384.0 & 91.9 & $2,175.7$ & 9.9 & 73.2 & 86.5 & $4,796.3$ \\
\hline 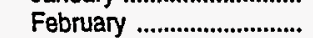 & 48.6 & 65.0 & $6,354.6$ & 383.8 & 58.3 & $1,340.1$ & 11.0 & 20.3 & 86.3 & $4,051.6$ \\
\hline 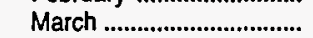 & 67.5 & 82.1 & $6,196.3$ & 371.5 & 29.6 & 644.5 & $W$ & 13.4 & 60.3 & $2,588.9$ \\
\hline 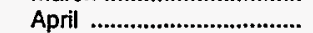 & 66.6 & 85.4 & $6,374.6$ & 354.9 & 12.9 & 179.1 & $w$ & 1.1 & 37.0 & $1,370.3$ \\
\hline 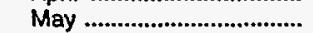 & 61.9 & 81.8 & 6.015 .7 & 330.8 & 9.3 & 123.6 & $w$ & 3.3 & 35.2 & $1,297.7$ \\
\hline 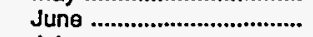 & 53.1 & 82.1 & $5,951.7$ & 337.9 & 8.5 & 131.3 & $w$ & $w$ & 38.6 & $1,830.9$ \\
\hline July & 50.0 & 88.0 & $5,857.4$ & 301.8 & $\ddot{W}$ & 125.3 & $w$ & 3.5 & 34.5 & $1,965.1$ \\
\hline August & 52.8 & 98.1 & $6,164.4$ & 338.2 & 12.1 & 260.6 & $\dddot{w}$ & $w$ & 52.5 & $2,474.1$ \\
\hline 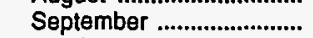 & 55.8 & 85.8 & $5,882.2$ & 330.0 & 12.4 & 451.9 & $\ddot{w}$ & 0.7 & 87.5 & $2,888.3$ \\
\hline 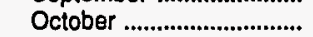 & 52.9 & 77.6 & $5,807.1$ & 590.0 & 17.4 & 675.5 & $\ddot{W}$ & $W$ & 69.7 & $2,560.8$ \\
\hline November ........................... & 48.0 & 78.0 & $5,548.4$ & 559.4 & 29.8 & 683.0 & $\ddot{W}$ & 2.3 & 47.4 & $2,710.1$ \\
\hline December ............................. & 49.6 & 71.5 & $6,019.6$ & 673.4 & 58.5 & $1,142.5$ & $\dddot{w}$ & 1.1 & 51.0 & $3,596.0$ \\
\hline 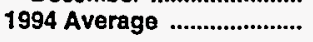 & 54.7 & 80.3 & $6,005.0$ & 413.4 & 29.0 & 658.8 & 2.6 & 10.0 & 57.0 & $2,671.4$ \\
\hline \multicolumn{11}{|l|}{ Florida } \\
\hline 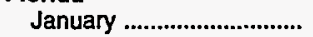 & 32.2 & 36.7 & $3,113.4$ & 201.9 & 15.7 & 101.2 & - & $w$ & w & $1,103.3$ \\
\hline 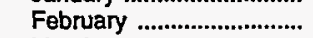 & 33.3 & 32.3 & $3,370.8$ & 209.7 & 9.6 & 53.2 & - & - & $\ddot{w}$ & 773.0 \\
\hline 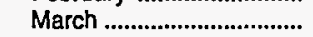 & 43.6 & 37.6 & $3,129.7$ & 214.5 & 6.4 & 28.4 & - & $w$ & $\ddot{w}$ & 630.1 \\
\hline 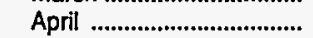 & 45.3 & 41.0 & $3,150.1$ & 188.5 & $w$ & 13.3 & - & - & $\ddot{w}$ & 448.6 \\
\hline 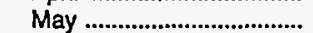 & 35.4 & 37.4 & $2,840.5$ & 172.1 & $w$ & 14.1 & - & - & $w$ & 407.1 \\
\hline 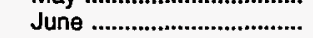 & 32.5 & 33.1 & $2,807.1$ & 159.8 & w & 14.6 & - & - & $\ddot{w}$ & 425.0 \\
\hline 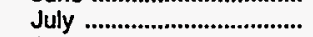 & 30.4 & 34.9 & $2,713.5$ & 150.6 & $w$ & 13.3 & - & - & $\ddot{w}$ & 414.4 \\
\hline 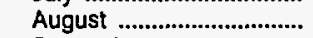 & 29.8 & 38.3 & $2,954.1$ & 171.3 & w & 15.5 & - & - & $w$ & 404.5 \\
\hline September ........................ & 33.2 & 34.0 & $2,386.2$ & 156.8 & $W$ & 20.3 & - & - & $w$ & 475.5 \\
\hline 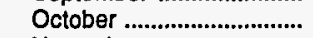 & 28.2 & 33.2 & $2,696.8$ & 176.9 & $w$ & 29.4 & - & - & w & 493.9 \\
\hline November ............................... & 28.6 & 32.0 & $2,644.1$ & 131.2 & 8.6 & 37.0 & - & - & $w$ & 631.4 \\
\hline December .......................... & 30.7 & 37.1 & $3,090.5$ & 225.5 & 13.0 & 72.5 & - & - & W & 720.4 \\
\hline 1994 Average ...................... & 33.6 & 35.7 & $2,906.0$ & 179.9 & 8.3 & 34.4 & - & $\mathbf{W}$ & $w$ & 576.6 \\
\hline \multicolumn{11}{|l|}{ Georgia } \\
\hline January ............................... & 5.0 & $w$ & $1,446.8$ & 93.4 & 14.3 & 159.5 & - & $W$ & $w$ & 962.7 \\
\hline February ............................. & 4.5 & $W$ & $1,640.5$ & 83.4 & 6.4 & 68.1 & $W$ & $W$ & $W$ & 666.1 \\
\hline 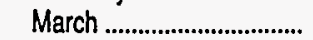 & 5.9 & $W$ & $1,409.2$ & 72.8 & 2.5 & 32.8 & - & - & $w$ & 370.5 \\
\hline April & 6.7 & 14.7 & $1,582.8$ & 75.3 & 1.3 & 12.8 & - & - & - & 252.4 \\
\hline 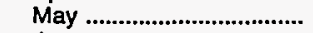 & 7.0 & 12.5 & $1,565.9$ & 68.0 & 0.4 & 9.0 & - & - & $W$ & 238.0 \\
\hline 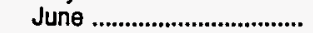 & 4.9 & $W$ & $1,467.2$ & 78.1 & $W$ & 9.6 & - & - & $W$ & 288.1 \\
\hline July ................................... & 4.9 & 22.8 & $1,613.5$ & 69.6 & $W$ & 9.7 & - & - & $w$ & 361.1 \\
\hline 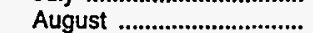 & 5.6 & 24.5 & $1,583.1$ & 76.1 & $\mathbb{W}$ & 19.6 & - & - & $\ddot{W}$ & 417.2 \\
\hline 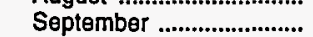 & 6.8 & 19.0 & $1,768.1$ & 78.1 & 0.4 & 42.6 & - & $w$ & $w$ & 485.7 \\
\hline 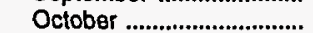 & 6.4 & 17.8 & $1,491.6$ & 277.1 & 1.3 & 37.2 & - & - & - & 520.3 \\
\hline November ......................... & 5.5 & $w$ & $1,436.9$ & 302.2 & 2.5 & 37.2 & - & - & W & 553.1 \\
\hline 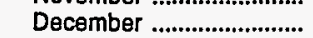 & 5.8 & 12.8 & $1,443.9$ & 312.3 & 12.9 & 66.9 & - & - & $w$ & 724.4 \\
\hline 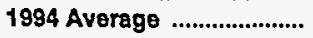 & 5.8 & 16.6 & $1,536.3$ & 132.6 & 3.5 & 42.0 & $\mathbf{w}$ & $\mathbf{w}$ & 1.4 & 486.2 \\
\hline \multicolumn{11}{|l|}{ North Carolina } \\
\hline January .............................. & $w$ & $W$ & 243.2 & 55.1 & 15.6 & 905.3 & 3.8 & 6.0 & 44.9 & $1,208.8$ \\
\hline 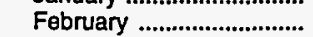 & 2.3 & $w$ & 284.8 & 49.0 & 11.4 & 575.3 & 4.9 & NA & 47.8 & $1,077.8$ \\
\hline March ................................ & $W$ & $w$ & 376.4 & 35.3 & 2.6 & 254.3 & $w$ & 1.3 & 25.5 & 588.2 \\
\hline April & $w$ & W & 341.8 & 37.3 & $w$ & 61.9 & - & - & 15.6 & 295.0 \\
\hline May .................................... & 4.1 & $w$ & 304.8 & 39.8 & $W$ & 46.3 & - & $w$ & 19.1 & 305.1 \\
\hline 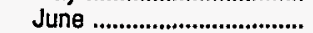 & $w$ & $w$ & 262.1 & 47.6 & $W$ & 44.5 & - & - & 16.3 & 401.3 \\
\hline July ..................................... & 3.5 & $W$ & 317.5 & 41.8 & $W$ & 50.1 & - & - & 18.9 & 535.8 \\
\hline 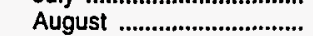 & 5.8 & W & 343.2 & 47.5 & W & 97.8 & - & - & 32.3 & 932.8 \\
\hline September ........................ & 4.6 & W & 417.8 & 48.0 & 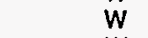 & 194.3 & - & - & $w$ & 989.6 \\
\hline 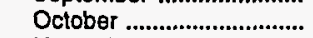 & 5.7 & $w$ & 338.6 & 54.5 & W & 309.8 & - & - & W & 824.2 \\
\hline November .......................... & $w$ & W & 344.5 & 47.8 & 2.9 & 311.6 & - & $w$ & 28.8 & 665.9 \\
\hline 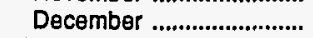 & $w$ & $w$ & 409.9 & 55.0 & 8.0 & 488.7 & $W$ & $w$ & 34.4 & 971.5 \\
\hline 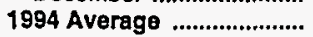 & w & $w$ & 332.3 & 46.5 & 3.5 & 277.3 & 0.8 & 0.9 & 31.3 & 731.7 \\
\hline
\end{tabular}

See footnotes at end of table. 
Table 45. Refiner Volumes of Aviation Fuels, Kerosene, No. 1 Distillate, and Propane (Consumer Grade) by PAD District and State

(Thousand Gallons per Day) - Continued

\begin{tabular}{|c|c|c|c|c|c|c|c|c|c|c|}
\hline \multirow{2}{*}{$\begin{array}{l}\text { Geographic Area } \\
\text { Month }\end{array}$} & \multicolumn{2}{|c|}{ Aviation Gasoline } & \multicolumn{2}{|c|}{$\begin{array}{c}\text { Kerosene-Type } \\
\text { Jet Fuel }\end{array}$} & \multicolumn{2}{|c|}{ Kerosene } & \multicolumn{2}{|c|}{ No. 1 Distillate } & \multicolumn{2}{|c|}{$\begin{array}{c}\text { Propano } \\
\text { (Consumer Grade) }\end{array}$} \\
\hline & $\begin{array}{c}\text { Sales to } \\
\text { End Users }\end{array}$ & $\begin{array}{c}\text { Sales for } \\
\text { Resale }\end{array}$ & $\begin{array}{c}\text { Sales to } \\
\text { End Users } \\
\end{array}$ & $\begin{array}{c}\text { Sales for } \\
\text { Resale }\end{array}$ & $\begin{array}{c}\text { Sales to } \\
\text { End Users }\end{array}$ & $\begin{array}{l}\text { Sales for } \\
\text { Resale }\end{array}$ & $\begin{array}{l}\text { Sales to } \\
\text { End Users }\end{array}$ & $\begin{array}{l}\text { Sales for } \\
\text { Resale }\end{array}$ & $\begin{array}{l}\text { Sales to } \\
\text { End Users }\end{array}$ & $\begin{array}{l}\text { Sales for } \\
\text { Resalo }\end{array}$ \\
\hline 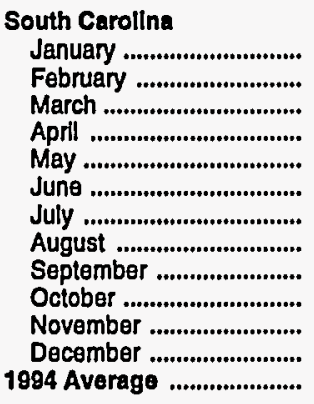 & $\begin{array}{l}W \\
4.1 \\
w \\
4.1 \\
w \\
4.4 \\
w \\
w \\
w \\
3.3 \\
w \\
w \\
3.2 \\
w\end{array}$ & $\begin{array}{l}w \\
w \\
w \\
w \\
w \\
w \\
w \\
w \\
w \\
w \\
w \\
w \\
w \\
w \\
w\end{array}$ & 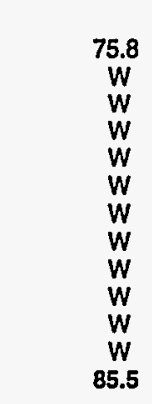 & $\begin{array}{l}W \\
W \\
W \\
W \\
W \\
W \\
W \\
W \\
W \\
W \\
W \\
W \\
W \\
14.3\end{array}$ & $\begin{array}{r}11.5 \\
6.8 \\
3.1 \\
1.1 \\
0.5 \\
0.3 \\
0.3 \\
1.5 \\
0.5 \\
1.9 \\
4.0 \\
6.9 \\
3.2\end{array}$ & $\begin{array}{r}415.0 \\
232.0 \\
105.0 \\
23.1 \\
13.9 \\
12.5 \\
15.4 \\
45.5 \\
85.4 \\
137.9 \\
136.0 \\
217.4 \\
119.6\end{array}$ & $\begin{array}{l}W \\
\bar{w} \\
\overline{-} \\
\overline{-} \\
\overline{-} \\
\overline{-} \\
\overline{-} \\
\overline{-} \\
\bar{w}\end{array}$ & $\begin{array}{c}W \\
W \\
N A \\
- \\
- \\
- \\
- \\
\overline{-} \\
\overline{-} \\
\overline{-} \\
\bar{W}\end{array}$ & $\begin{array}{l}w \\
w \\
w \\
w \\
w \\
w \\
w \\
w \\
w \\
w \\
w \\
w \\
w \\
w\end{array}$ & $\begin{array}{c}907.5 \\
W \\
W \\
174.1 \\
170.5 \\
556.5 \\
346.8 \\
505.1 \\
523.7 \\
439.8 \\
435.4 \\
606.9 \\
472.2\end{array}$ \\
\hline 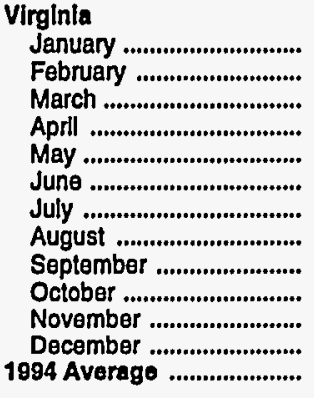 & $\begin{array}{l}W \\
W \\
w \\
w \\
6.9 \\
5.2 \\
w \\
w \\
w \\
w \\
w \\
w \\
w \\
w\end{array}$ & $\begin{array}{c}5.2 \\
W \\
6.4 \\
7.5 \\
7.8 \\
7.0 \\
W \\
9.8 \\
10.1 \\
8.4 \\
8.2 \\
4.5 \\
7.2\end{array}$ & $\begin{array}{r}1,020.9 \\
973.9 \\
1,179.4 \\
1,190.8 \\
1,196.4 \\
1,309.5 \\
1,108.8 \\
1,177.6 \\
1,205.9 \\
1,172.4 \\
1,040.3 \\
974.9 \\
1,128.9\end{array}$ & $\begin{array}{l}21.6 \\
27.5 \\
34.3 \\
36.2 \\
33.3 \\
34.6 \\
25.7 \\
24.8 \\
28.5 \\
65.8 \\
58.9 \\
65.0 \\
38.1\end{array}$ & $\begin{array}{l}7.3 \\
5.2 \\
5.8 \\
W \\
W \\
0.5 \\
0.4 \\
1.1 \\
1.2 \\
1.4 \\
2.6 \\
4.3 \\
2.7\end{array}$ & $\begin{array}{r}519.0 \\
358.8 \\
187.5 \\
59.0 \\
33.9 \\
46.0 \\
33.5 \\
71.8 \\
94.8 \\
144.7 \\
141.4 \\
265.0 \\
162.2\end{array}$ & $\begin{array}{l}3.5 \\
1.6 \\
0.8 \\
W \\
W \\
W \\
W \\
W \\
W \\
W \\
W \\
W \\
W \\
0.9\end{array}$ & $\begin{array}{r}49.6 \\
9.5 \\
11.1 \\
w \\
w \\
w \\
w \\
w \\
w \\
w \\
w \\
w \\
w \\
w \\
6.7\end{array}$ & $\begin{array}{l}w \\
w \\
w \\
w \\
w \\
w \\
w \\
w \\
w \\
w \\
w \\
w \\
w \\
w \\
w\end{array}$ & $\begin{array}{r}563.5 \\
811.6 \\
585.5 \\
W \\
W \\
W \\
W \\
W \\
W \\
W \\
W \\
369.8 \\
W \\
370.2\end{array}$ \\
\hline 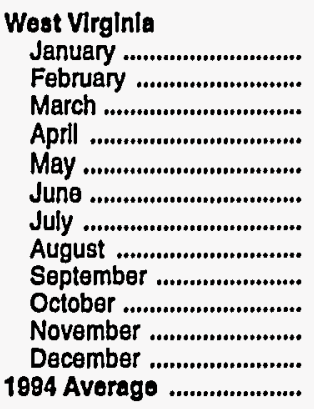 & $\begin{array}{l}w \\
w \\
w \\
w \\
w \\
w \\
w \\
w \\
w \\
w \\
w \\
w \\
w \\
w \\
w \\
w\end{array}$ & $\begin{array}{l}w \\
1.2 \\
w \\
w \\
1.4 \\
w \\
0.8 \\
2.0 \\
w \\
w \\
1.1 \\
0.7 \\
0.8\end{array}$ & $\begin{array}{l}W \\
W \\
w \\
W \\
W \\
W \\
W \\
W \\
w \\
w \\
w \\
w \\
w \\
w \\
w\end{array}$ & $\begin{array}{l}W \\
W \\
w \\
W \\
W \\
W \\
w \\
w \\
w \\
w \\
w \\
w \\
w \\
w\end{array}$ & $\begin{array}{r}27.5 \\
19.0 \\
9.3 \\
2.9 \\
W \\
W \\
1.4 \\
1.6 \\
2.8 \\
4.2 \\
9.4 \\
13.4 \\
7.8\end{array}$ & $\begin{array}{r}75.7 \\
52.7 \\
36.6 \\
9.0 \\
6.5 \\
4.2 \\
3.2 \\
10.4 \\
14.6 \\
16.5 \\
19.9 \\
32.0 \\
23.3\end{array}$ & $\begin{array}{l}W \\
W \\
W \\
W \\
W \\
- \\
\bar{w} \\
\bar{W} \\
W \\
W \\
W \\
W\end{array}$ & $\begin{array}{l}11.2 \\
7.9 \\
0.8 \\
W \\
\bar{w} \\
W \\
W \\
W \\
W \\
W \\
W \\
W \\
1.8\end{array}$ & $\begin{array}{l}z \\
z \\
z \\
z \\
z \\
z \\
z \\
z \\
z\end{array}$ & $\begin{array}{c}W \\
W \\
W \\
W \\
W \\
W \\
W \\
W \\
W \\
W \\
W \\
W \\
54.4 \\
W \\
W\end{array}$ \\
\hline 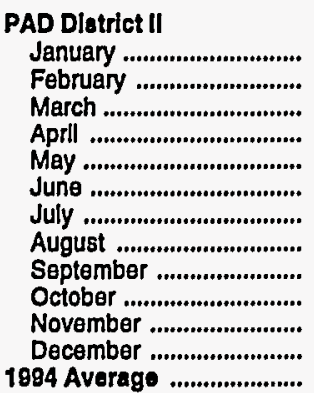 & $\begin{array}{l}37.4 \\
49.8 \\
55.6 \\
55.4 \\
65.6 \\
74.9 \\
67.6 \\
77.5 \\
70.9 \\
69.4 \\
61.0 \\
57.1 \\
61.9\end{array}$ & $\begin{array}{r}86.6 \\
109.7 \\
149.0 \\
153.2 \\
183.7 \\
209.4 \\
220.5 \\
214.5 \\
186.3 \\
163.8 \\
123.5 \\
109.4 \\
159.4\end{array}$ & $\begin{array}{l}7,912.8 \\
7,881.6 \\
8,489.5 \\
8,831.1 \\
8,275.5 \\
8,868.2 \\
8,566.8 \\
9,094.5 \\
8,845.4 \\
9,001.6 \\
8,700.6 \\
9,254.2 \\
8,647.9\end{array}$ & $\begin{array}{r}910.9 \\
1,220.3 \\
856.0 \\
983.4 \\
945.5 \\
896.3 \\
1,078.8 \\
1,287.4 \\
997.1 \\
956.7 \\
1,055.7 \\
1,090.1 \\
1,022.0\end{array}$ & $\begin{array}{r}175.8 \\
132.2 \\
78.1 \\
34.6 \\
32.9 \\
W \\
19.9 \\
17.5 \\
25.7 \\
154.5 \\
124.9 \\
136.8 \\
80.2\end{array}$ & $\begin{array}{r}1,839.7 \\
1,143.8 \\
496.9 \\
178.9 \\
114.2 \\
77.0 \\
84.4 \\
195.9 \\
349.6 \\
484.0 \\
734.8 \\
979.6 \\
554.2\end{array}$ & $\begin{array}{l}552.5 \\
547.1 \\
260.4 \\
163.5 \\
154.2 \\
168.4 \\
132.9 \\
152.9 \\
171.2 \\
161.0 \\
242.9 \\
370.2 \\
254.8\end{array}$ & $\begin{array}{r}3,792.5 \\
2,662.6 \\
7511.8 \\
465.8 \\
351.4 \\
321.5 \\
264.6 \\
427.8 \\
722.7 \\
1,116.1 \\
2,342.4 \\
2,839.1 \\
1,331.4\end{array}$ & $\begin{array}{r}2,005.0 \\
1,718.8 \\
1,084.0 \\
702.8 \\
549.7 \\
486.4 \\
444.2 \\
632.1 \\
511.3 \\
W \\
W \\
849.9 \\
894.5\end{array}$ & $\begin{array}{r}16,464.8 \\
11,848.8 \\
8,090.1 \\
6,657.1 \\
5,589.8 \\
6,772.1 \\
6,430.3 \\
8,185.3 \\
8,146.4 \\
13,381.6 \\
11,488.2 \\
12,816.5 \\
9,653.1\end{array}$ \\
\hline
\end{tabular}

Seo footnotes at end of table. 
Table 45. Refiner Volumes of Aviation Fuels, Kerosene, No. 1 Distillate, and Propane (Consumer Grade) by PAD District and State

(Thousand Gallons per Day) - Continued

\begin{tabular}{|c|c|c|c|c|c|c|c|c|c|c|}
\hline \multirow{2}{*}{$\begin{array}{c}\text { Geographic Area } \\
\text { Month }\end{array}$} & \multicolumn{2}{|c|}{ Aviation Gasoline } & \multicolumn{2}{|c|}{$\begin{array}{l}\text { Kerosene-Type } \\
\text { Jet Fuel }\end{array}$} & \multicolumn{2}{|c|}{ Kerosene } & \multicolumn{2}{|c|}{ No. 1 Distillate } & \multicolumn{2}{|c|}{$\begin{array}{c}\text { Propane } \\
\text { (Consumer Grade) }\end{array}$} \\
\hline & $\begin{array}{c}\text { Sales to } \\
\text { End Users }\end{array}$ & $\begin{array}{l}\text { Sales for } \\
\text { Resale }\end{array}$ & $\begin{array}{l}\text { Sales to } \\
\text { End Users }\end{array}$ & $\begin{array}{l}\text { Sales for } \\
\text { Resale }\end{array}$ & $\begin{array}{c}\text { Sales to } \\
\text { End Users }\end{array}$ & $\begin{array}{l}\text { Sales for } \\
\text { Resale }\end{array}$ & $\begin{array}{l}\text { Sales to } \\
\text { End Users }\end{array}$ & $\begin{array}{l}\text { Sales for } \\
\text { Resale }\end{array}$ & $\begin{array}{l}\text { Sales to } \\
\text { End Users }\end{array}$ & $\begin{array}{l}\text { Sales for } \\
\text { Resale }\end{array}$ \\
\hline \multicolumn{11}{|l|}{ Illinois } \\
\hline 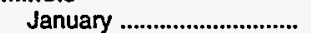 & $w$ & $w$ & $1,258.5$ & 91.6 & 8.3 & 106.3 & 160.4 & 391.9 & $w$ & $1,487.0$ \\
\hline 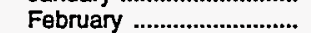 & w & $W$ & $1,277.9$ & 91.8 & 7.2 & 60.2 & 151.6 & 224.8 & 222.1 & $1,424.9$ \\
\hline 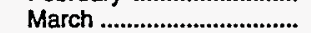 & $w$ & $w$ & $1,423.5$ & 81.6 & 5.4 & 16.9 & $w$ & 52.0 & 144.2 & $1,161.2$ \\
\hline 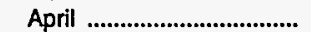 & NA & $W$ & $1,316.8$ & 76.3 & 3.1 & 7.1 & $w$ & 17.2 & 71.2 & 736.7 \\
\hline 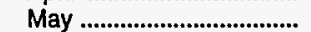 & $w$ & 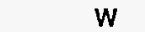 & $1,360.2$ & 92.7 & 4.4 & 4.9 & $W$ & 19.8 & 39.3 & 834.6 \\
\hline June ..................................... & $W$ & $W$ & $1,442.8$ & 89.9 & 3.4 & 6.1 & $W$ & 21.0 & 41.9 & 771.3 \\
\hline 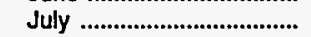 & $w$ & W & $1,550.5$ & 91.7 & 4.9 & 4.8 & w & 16.1 & 49.6 & 761,2 \\
\hline August & W & w & $1,541.7$ & 121.9 & 2.6 & 10.4 & $\ddot{w}$ & 27.8 & 92.3 & $1,077.1$ \\
\hline September ....................... & $w$ & $W$ & $1,570.0$ & 89.5 & 3.6 & 16.9 & $\ddot{w}$ & 37.8 & $W$ & $1,048.1$ \\
\hline 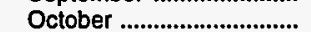 & $w$ & $W$ & $1,533.4$ & 92.5 & 4.8 & 17.4 & $w$ & 57.5 & $w$ & $2,240.2$ \\
\hline November ......................... & $W$ & $W$ & $1,475.9$ & 80.4 & 8.6 & 32.3 & $w$ & 156.2 & $\ddot{w}$ & $1,679.2$ \\
\hline December ......................... & $w$ & $w$ & $1,498.9$ & 86.5 & 9.7 & 44.3 & $w$ & 266.4 & W & $1,936.2$ \\
\hline 1994 Average & $\mathbf{w}$ & $\ddot{w}$ & $1,438.7$ & 90.6 & 5.5 & 27.2 & $w$ & 107.0 & 122.2 & $1,264.0$ \\
\hline \multicolumn{11}{|l|}{ Indiana } \\
\hline 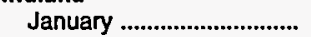 & $w$ & w & $1,464.1$ & 139.8 & 17.2 & 181.5 & 48.1 & 279.9 & w & 806.9 \\
\hline 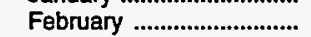 & 2.4 & 16.0 & $1,345.7$ & 304.0 & 12.1 & 114.6 & 38.3 & 214.7 & $\ddot{w}$ & 504.1 \\
\hline 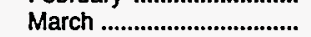 & 2.8 & 13.9 & $1,585.6$ & 114.5 & 5.9 & 53.1 & 8.3 & 74.7 & $w$ & 359.5 \\
\hline April & 2.6 & 17.4 & $1,620.1$ & 95.7 & $W$ & 17.1 & $w$ & 16.7 & w & 248.9 \\
\hline 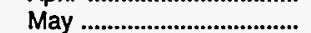 & 2.5 & 19.2 & $1,558.4$ & 104.1 & $w$ & 7.0 & $w$ & 12.3 & $w$ & 139.1 \\
\hline 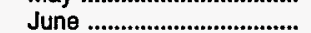 & $w$ & 22.5 & $1,714.1$ & 55.5 & $w$ & 8.7 & $\ddot{w}$ & 10.1 & $\ddot{w}$ & 211.7 \\
\hline 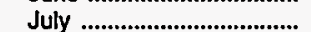 & 2.3 & 19.0 & $1,710.1$ & 216.8 & 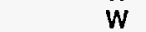 & 9.2 & w & 13.0 & $w$ & 292.6 \\
\hline August & 2.6 & 17.8 & $1,697.6$ & 332.8 & $w$ & 15.9 & 1.1 & 20.1 & $\ddot{w}$ & 400.0 \\
\hline September ..................... & 2.9 & 18.9 & $1,826.4$ & 330.2 & W & 31.7 & $\dddot{w}$ & 19.0 & $W$ & 396.7 \\
\hline 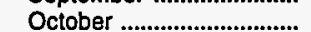 & 2.9 & 20.5 & $1,714.1$ & 123.3 & 2.7 & 37.8 & $w$ & 47.5 & $w$ & 893.6 \\
\hline November ......................... & $w$ & 15.1 & $1,659.3$ & 210.9 & 5.5 & 73.9 & 8.6 & 90.5 & $w$ & 679.6 \\
\hline December ......................... & 2.4 & 14.3 & $1,900.3$ & 252.7 & 8.3 & 146.4 & 22.4 & 152.2 & $w$ & 733.8 \\
\hline 1994 Average ....................... & 2.5 & 17.0 & $1,651.5$ & 189.3 & 4.7 & 57.9 & 11.6 & 78.6 & $\mathbf{W}$ & 472.9 \\
\hline \multicolumn{11}{|l|}{ lowa } \\
\hline January ............................. & $W$ & 4.3 & 45.5 & 19.2 & - & 11.0 & 22.9 & 409.9 & $W$ & 642.9 \\
\hline 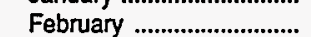 & w & 7.8 & 51.9 & 16.7 & - & 7.1 & 19.2 & 291.6 & $w$ & 517.6 \\
\hline 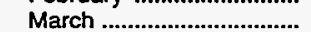 & $w$ & 8.0 & 53.5 & 17.8 & - & 1.7 & 3.6 & 41.2 & $w$ & 273.7 \\
\hline 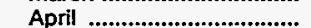 & $\mathbf{w}$ & 8.7 & 49.3 & 18.1 & - & $w$ & $w$ & 11.4 & $w$ & 299.0 \\
\hline May & w & 12.0 & 48.6 & 16.9 & - & 0.9 & $w$ & 9.9 & $w$ & 139.3 \\
\hline June .................................... & $w$ & 13.6 & 54.4 & 21.1 & - & $W$ & 1.8 & 13.7 & w & 320.0 \\
\hline July & $w$ & 14.7 & 50.6 & 16.6 & - & 1.0 & W & 7.8 & $w$ & 271.7 \\
\hline August & $w$ & 15.6 & 56.4 & 19.9 & - & 2.2 & W & 15.0 & $w$ & 472.4 \\
\hline September & $W$ & 13.0 & 53.7 & 18.6 & - & 2.1 & $w$ & 43.4 & $w$ & 467.3 \\
\hline 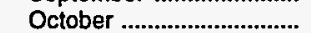 & $w$ & 7.2 & 52.7 & 20.3 & - & 3.2 & W & 80.6 & $w$ & $1,078.9$ \\
\hline November .......................... & $w$ & 7.8 & 128.4 & 20.5 & - & 3.4 & 4.8 & 250.6 & $w$ & 549.9 \\
\hline December ......................... & $w$ & 7.2 & 89.5 & 17.3 & - & 5.6 & $\ddot{w}$ & 335.2 & $w$ & 632.1 \\
\hline 1994 Average ....................... & $w$ & 10.0 & 61.2 & 18.6 & - & 3.3 & 6.1 & 125.0 & $\ddot{w}$ & 472.4 \\
\hline \multicolumn{11}{|l|}{ Kansas } \\
\hline 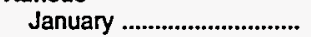 & $w$ & 6.8 & 145.9 & $w$ & - & $w$ & 13.0 & 285.2 & $w$ & $5,888.9$ \\
\hline February .............................. & $w$ & 9.6 & $w$ & 29.3 & - & 12.6 & 11.9 & 186.1 & $w$ & $3,341.6$ \\
\hline March & $w$ & 14.1 & $w$ & $w$ & - & $w$ & 1.4 & 48.4 & $w$ & $2,195.5$ \\
\hline April & $w$ & 16.9 & 89.2 & 54.7 & - & w & - & 63.9 & $w$ & $2,415.6$ \\
\hline May & $w$ & 17.9 & 98.5 & $w$ & - & $w$ & $w$ & 10.7 & $w$ & $1,976.7$ \\
\hline June .................................... & $w$ & 17.8 & 95.4 & $\ddot{w}$ & - & 0.9 & $W$ & 16.7 & 161.3 & $2,559.5$ \\
\hline 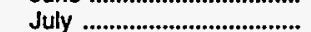 & $\ddot{w}$ & 21.2 & 90.4 & $\ddot{w}$ & - & 0.9 & $w$ & 23.1 & $w$ & $2,225.8$ \\
\hline 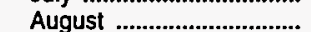 & $w$ & 14.5 & 89.8 & $w$ & - & 1.4 & $W$ & 29.9 & $w$ & $2,207.7$ \\
\hline September ....................... & $w$ & 8.0 & 48.6 & $w$ & - & $\dddot{W}$ & $w$ & 70.8 & W & $1,994.4$ \\
\hline 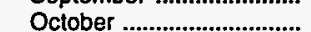 & $\ddot{w}$ & 11.0 & $W$ & $\dddot{w}$ & - & 4.3 & 0.3 & 124.0 & w & $3,014.8$ \\
\hline November ........................ & $\ddot{w}$ & 8.7 & W & $w$ & - & 8.9 & $w$ & 272.4 & $w$ & $2,906.9$ \\
\hline 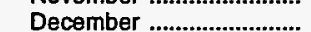 & $w$ & 7.1 & 98.5 & $\ddot{w}$ & - & 6.4 & 10.0 & 243.8 & $w$ & $2,674.5$ \\
\hline 1994 Average ....................... & $w$ & 12.8 & 85.3 & 24.3 & - & 5.4 & 3.5 & 114.1 & 49.4 & $2,782.4$ \\
\hline
\end{tabular}

See footnotes at end of table. 
Table 45. Refiner Volumes of Aviation Fuels, Kerosene, No. 1 Distillate, and Propane (Consumer Grade) by PAD District and State

(Thousand Gallons per Day) - Continued

\begin{tabular}{|c|c|c|c|c|c|c|c|c|c|c|}
\hline \multirow{2}{*}{$\begin{array}{c}\text { Geographic Area } \\
\text { Month }\end{array}$} & \multicolumn{2}{|c|}{ Aviation Gasoline } & \multicolumn{2}{|c|}{$\begin{array}{c}\text { Kerosene-Type } \\
\text { Jet Fuel }\end{array}$} & \multicolumn{2}{|c|}{ Kerosene } & \multicolumn{2}{|c|}{ No. 1 Dlatillate } & \multicolumn{2}{|c|}{$\begin{array}{c}\text { Propane } \\
\text { (Consumer Grade) }\end{array}$} \\
\hline & $\begin{array}{l}\text { Sales to } \\
\text { End Users }\end{array}$ & $\begin{array}{l}\text { Sales for } \\
\text { Resale }\end{array}$ & $\begin{array}{l}\text { Sales to } \\
\text { End Users }\end{array}$ & $\begin{array}{l}\text { Sales for } \\
\text { Resale }\end{array}$ & $\begin{array}{l}\text { Sales to } \\
\text { End Users }\end{array}$ & $\begin{array}{c}\text { Sales for } \\
\text { Resale }\end{array}$ & $\begin{array}{l}\text { Sales to } \\
\text { End Users }\end{array}$ & $\begin{array}{l}\text { Sales for } \\
\text { Resale }\end{array}$ & $\begin{array}{l}\text { Sales to } \\
\text { End Users }\end{array}$ & $\begin{array}{c}\text { Sales for } \\
\text { Resale }\end{array}$ \\
\hline
\end{tabular}

\begin{tabular}{|c|c|c|c|c|c|c|c|c|c|c|}
\hline \multicolumn{11}{|l|}{ Kentucky } \\
\hline January ............................... & $w$ & 2.7 & 483.5 & 45.1 & 42.1 & 250.6 & 16.5 & 38.9 & - & 730.5 \\
\hline February ............................ & $\mathbf{w}$ & $\ddot{w}$ & 593.3 & 55.4 & 25.2 & 143.3 & 12.9 & $W$ & - & 452.6 \\
\hline March .................................. & 3.2 & $W$ & 594.7 & 20.6 & 19.8 & 61.0 & 2.4 & W & $w$ & 330.5 \\
\hline 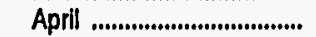 & 2.2 & $W$ & 551.6 & 96.7 & 3.1 & 21.9 & $W$ & $W$ & W & 242.5 \\
\hline May ................................. & 2.1 & 4.7 & 547.8 & 45.8 & 1.3 & 10.4 & $w$ & $t .1$ & - & 289.6 \\
\hline June .................................. & 2.5 & 5.7 & 625.0 & 63.6 & $W$ & 6.7 & $W$ & $w$ & - & 286.2 \\
\hline July ...................................... & 1.6 & 3.0 & 410.7 & 99.4 & $w$ & 7.0 & $w$ & W & - & 315.7 \\
\hline 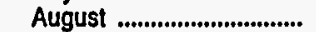 & 2.8 & $w$ & 481.4 & 60.0 & 0.5 & 18.5 & W & $w$ & - & 466.7 \\
\hline September ....................... & 2.2 & 6.3 & 439.4 & 101.7 & $W$ & 40.1 & W & $w$ & - & 313.7 \\
\hline 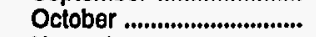 & 2.4 & $w$ & 474.8 & 90.8 & $w$ & 52.3 & w & $w$ & - & 523.3 \\
\hline November ......................... & $W$ & w & 440.7 & 227.5 & 9.2 & 64.2 & 2.9 & $w$ & - & 458.3 \\
\hline December ......................... & 1.6 & w & 534.4 & 265.9 & 15.6 & 117.7 & 7.5 & 15.6 & $w$ & 524.5 \\
\hline 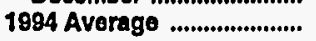 & 2.1 & 3.9 & 514.1 & 97.8 & 10.4 & 65.9 & 3.8 & 8.6 & $w$ & 411.8 \\
\hline \multicolumn{11}{|l|}{ Mlchigan } \\
\hline January .............................. & $w$ & $w$ & 866.2 & 50.4 & 12.3 & 249.6 & 64.3 & 274.1 & $w$ & 444.8 \\
\hline February ........................... & $w$ & w & 891.7 & 69.9 & 8.7 & 159.8 & 87.2 & 232.4 & $W$ & 429.1 \\
\hline 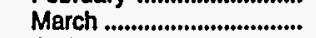 & $\ddot{w}$ & $\ddot{w}$ & 923.9 & 76.1 & 4.0 & 84.6 & 47.5 & 162.7 & $w$ & 307.9 \\
\hline Aprill & $w$ & w & $1,070.1$ & 68.0 & 2.1 & 38.9 & $w$ & 158.9 & $W$ & 326.6 \\
\hline 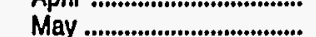 & $w$ & $w$ & 980.2 & 73.6 & 0.9 & 22.6 & $w$ & $W$ & $W$ & 360.8 \\
\hline 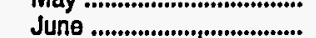 & $w$ & $w$ & 987.7 & 86.7 & 0.4 & 13.6 & $w$ & $w$ & $W$ & 425.2 \\
\hline 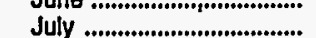 & $w$ & $w$ & 935.7 & 50.0 & 0.2 & 10.7 & $w$ & $w$ & $w$ & $\begin{array}{l}4<0.2 \\
309.6\end{array}$ \\
\hline August & $w$ & $w$ & 924.1 & 69.7 & 0.4 & 34.4 & $w$ & 137.7 & $w$ & 334.6 \\
\hline September ......................... & $w$ & $w$ & 834.4 & 51.4 & 0.9 & 44.0 & $w$ & 148.4 & $w$ & 470.5 \\
\hline 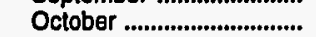 & $\ddot{w}$ & $\ddot{w}$ & 974.1 & 49.5 & 2.1 & 71.2 & w & 198.9 & W & 650.1 \\
\hline November ........................ & $w$ & $\ddot{w}$ & 764.8 & 61.6 & 4.4 & 169.1 & 25.0 & 193.4 & - & 790.0 \\
\hline December .......................... & $\mathbf{w}$ & $W$ & 867.9 & 57.9 & 5.9 & 128.2 & 34.5 & 92.2 & - & 930.5 \\
\hline 1994 Average ..................... & $\mathbf{W}$ & $\mathbf{W}$ & 918.7 & 63.6 & 3.5 & 85.2 & 33.7 & 169.0 & $w$ & 481.8 \\
\hline \multicolumn{11}{|l|}{ MInnesota } \\
\hline January .............................. & $\mathbf{W}$ & 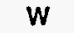 & 918.3 & 54.5 & $w$ & 59.9 & 71.2 & 478.3 & $w$ & $1,121.8$ \\
\hline Fobruary ............................ & W & 10.1 & 948.6 & 92.4 & $W$ & 37.0 & 73.6 & 381.5 & W & 711.6 \\
\hline March .................................. & $w$ & 14.3 & 856.3 & 118.4 & W & 6.3 & 42.0 & 75.6 & $W$ & 410.3 \\
\hline 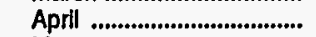 & $W$ & 14.1 & 873.4 & 102.6 & $w$ & 2.5 & $W$ & 25.3 & W & 301.4 \\
\hline May ...................................... & $w$ & 21.8 & 892.4 & 68.3 & W & 1.8 & $w$ & 12.5 & $\ddot{w}$ & 378.3 \\
\hline June .................................. & $\ddot{w}$ & 24.5 & 835.6 & 72.5 & W & 1.0 & 33.5 & 7.9 & W & 363.9 \\
\hline July ...................................... & $W$ & 27.7 & 871.2 & 72.6 & $W$ & 1.9 & $W$ & 10.2 & $W$ & 425.8 \\
\hline August ............................ & $w$ & 28.7 & 951.7 & 84.7 & W & 6.9 & $W$ & 27.3 & $W$ & 617.4 \\
\hline September ........................ & $W$ & 17.3 & 867.3 & 72.5 & $w$ & 16.1 & $w$ & 64.8 & $w$ & 554.0 \\
\hline 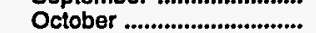 & w & 13.2 & 887.9 & 69.2 & w & 19.2 & $\mathbf{W}$ & 103.2 & $w$ & $1,512.5$ \\
\hline November ........................... & $w$ & 12.8 & 923.5 & 70.6 & $w$ & 25.7 & 42.5 & 338.0 & $w$ & 894.3 \\
\hline December ........................... & $\mathbf{W}$ & 9.5 & 888.4 & 86.0 & $\mathbf{w}$ & 29.9 & 67.6 & 407.2 & $w$ & 971.3 \\
\hline 1994 Average ..................... & $\mathbf{W}$ & 16.8 & 892.6 & 80.3 & $\mathbf{w}$ & 17.3 & 39.9 & 159.7 & $\mathbf{W}$ & 690.1 \\
\hline \multicolumn{11}{|l|}{ Missouri } \\
\hline January .............................. & $W$ & 7.4 & 303.7 & 63.2 & 1.4 & 51.4 & $W$ & 95.8 & - & $1,435.5$ \\
\hline 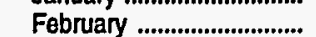 & $\ddot{W}$ & 9.0 & 392.3 & 53.6 & w & 26.4 & $\ddot{w}$ & 70.8 & - & $1,149.5$ \\
\hline March ................................. & $w$ & 11.9 & 408.6 & 61.4 & $w$ & 6.7 & $w$ & 15.0 & - & 713.0 \\
\hline Apri] ....................................... & $W$ & 13.6 & 384.2 & 58.1 & - & 2.7 & $\ddot{w}$ & 2.7 & - & 432.1 \\
\hline 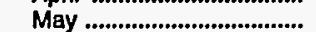 & $\ddot{w}$ & 15.3 & 402.5 & 51.3 & - & 2.2 & $\ddot{w}$ & 0.4 & - & 221.8 \\
\hline June ................................... & w & 16.6 & 426.9 & 47.6 & - & 1.4 & $w$ & $w$ & - & 225.3 \\
\hline 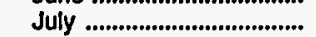 & $w$ & 15.0 & 368.8 & 40.4 & - & 1.7 & w & 4.4 & - & 258.5 \\
\hline 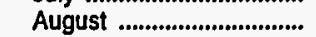 & W & 17.2 & 513.6 & 39.5 & $w$ & 3.9 & $\ddot{w}$ & 6.2 & - & 582.5 \\
\hline September ....................... & $W$ & 16.0 & 402.9 & 42.2 & - & 9.1 & $w$ & 10.2 & - & 701.4 \\
\hline Oclober ............................. & $w$ & 14.0 & 402.6 & 39.5 & $w$ & 7.9 & W & 22.4 & - & 587.5 \\
\hline November ........................ & $w$ & 12.7 & 466.1 & 53.8 & $\ddot{w}$ & 11.2 & $w$ & 48.5 & - & 758.9 \\
\hline December ........................... & $w$ & 9.5 & 454.0 & 42.1 & $\dddot{w}$ & 21.5 & $\ddot{w}$ & 74.2 & - & $1,100.5$ \\
\hline 1994 Average ..................... & $\mathbf{W}$ & 13.2 & 410.6 & 49.3 & $\mathbf{w}$ & 12.1 & w & 29.6 & - & 678.3 \\
\hline
\end{tabular}

See footnotes at end of table. 
Table 45. Refiner Volumes of Aviation Fuels, Kerosene, No. 1 Distillate, and Propane (Consumer Grade) by PAD District and State

(Thousand Gallons per Day) - Continued

\begin{tabular}{|c|c|c|c|c|c|c|c|c|c|c|}
\hline \multirow{2}{*}{$\underset{\text { Month }}{\text { Geographic Area }}$} & \multicolumn{2}{|c|}{ Aviation Gasoline } & \multicolumn{2}{|c|}{$\begin{array}{c}\text { Kerosene-Typo } \\
\text { Jet Fuel }\end{array}$} & \multicolumn{2}{|c|}{ Kerosene } & \multicolumn{2}{|c|}{ No. 1 Distillate } & \multicolumn{2}{|c|}{$\begin{array}{c}\text { Propane } \\
\text { (Consumer Grade) } \\
\end{array}$} \\
\hline & $\begin{array}{c}\text { Sales to } \\
\text { End Users }\end{array}$ & $\begin{array}{c}\text { Sales for } \\
\text { Resale }\end{array}$ & $\begin{array}{c}\text { Sales to } \\
\text { End Users }\end{array}$ & $\begin{array}{c}\text { Sales for } \\
\text { Resalo }\end{array}$ & $\begin{array}{c}\text { Sales to } \\
\text { End Users }\end{array}$ & $\begin{array}{c}\text { Sales for } \\
\text { Resale }\end{array}$ & $\begin{array}{c}\text { Sales to } \\
\text { End Users }\end{array}$ & $\begin{array}{c}\text { Sales for } \\
\text { Resale }\end{array}$ & $\begin{array}{c}\text { Sales to } \\
\text { End Users }\end{array}$ & $\begin{array}{c}\text { Sales for } \\
\text { Resale }\end{array}$ \\
\hline \multicolumn{11}{|l|}{ Nebraska } \\
\hline 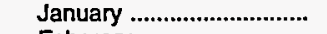 & w & 3.5 & 57.1 & 20.2 & - & 5.5 & $w$ & 183.6 & w & 337.3 \\
\hline 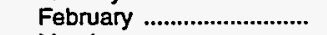 & $w$ & $w$ & 73.1 & 18.3 & - & 1.4 & w & 159.1 & w & 341.5 \\
\hline 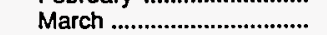 & $w$ & 5.2 & 64.5 & 19.3 & - & w & w & 21.8 & w & 178.6 \\
\hline April & $w$ & w & 57.9 & 20.4 & - & $w$ & w & 4.3 & w & 117.9 \\
\hline 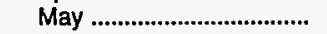 & w & 5.0 & 61.1 & 22.2 & - & w & - & 3.9 & w & 86.2 \\
\hline 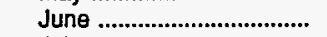 & $w$ & W & 74.3 & 17.7 & - & - & - & 3.8 & $w$ & 209.1 \\
\hline July ................................................... & $w$ & 11.2 & 76.3 & 15.1 & - & w & - & 1.0 & w & 153.8 \\
\hline 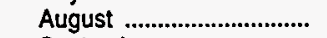 & w & 7.2 & 87.8 & 18.2 & - & 1.5 & $\overrightarrow{-}$ & w & w & 233.5 \\
\hline 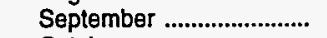 & $w$ & $w$ & 81.4 & 19.5 & - & w & w & 34.6 & w & 262.9 \\
\hline 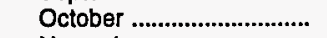 & w & $w$ & 81.9 & 15.2 & - & 1.0 & w & 81.2 & $w$ & 345.5 \\
\hline November ............................... & $w$ & w & 80.6 & 21.3 & - & w & 4.1 & 180.9 & w & 202.0 \\
\hline 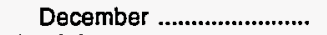 & $w$ & 3.1 & 75.1 & 18.2 & - & 2.3 & 7.9 & 188.3 & w & 269.4 \\
\hline 1994 Average ............................ & $\mathbf{w}$ & 5.2 & 72.6 & 18.8 & - & 1.3 & 3.1 & 71.8 & $w$ & 227.5 \\
\hline \multicolumn{11}{|l|}{ North Dakota } \\
\hline 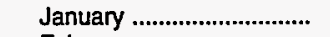 & w & W & 17.7 & 3.6 & w & w & 27.0 & 189.4 & $w$ & 436.4 \\
\hline 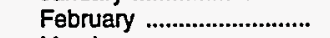 & $w$ & $w$ & 16.4 & w & NA & 0.8 & 18.9 & 114.6 & W & 374.0 \\
\hline 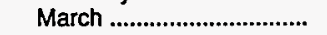 & 0.9 & w & 13.7 & 4.4 & - & w & $w$ & 14.3 & w & 164.7 \\
\hline 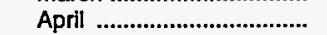 & 2.7 & w & 14.6 & w & - & w & w & 5.3 & w & 101.7 \\
\hline 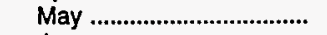 & 2.0 & w & 11.9 & 4.5 & w & - & - & 3.3 & w & 84.9 \\
\hline 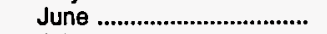 & 2.2 & w & 15.9 & 7.9 & - & w & - & 3.6 & $w$ & 120.3 \\
\hline July …………………................... & 1.9 & w & 24.8 & 6.9 & - & w & - & 2.7 & $w$ & 212.6 \\
\hline 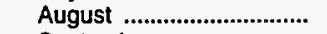 & 2.4 & w & 23.7 & 6.6 & w & w & $w$ & 9.8 & w & 262.5 \\
\hline September ................................ & 3.4 & w & 22.1 & 6.0 & - & w & $w$ & 30.4 & w & 230.9 \\
\hline 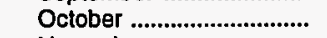 & $w$ & w & 20.6 & 6.0 & w & w & $w$ & 76.4 & w & 252.8 \\
\hline 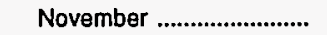 & w & w & $w$ & 4.9 & w & w & $w$ & 157.6 & $w$ & 301.0 \\
\hline 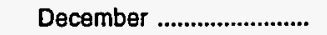 & w & w & 26.6 & 7.7 & - & W & w & 159.3 & $w$ & 336.2 \\
\hline 1994 Average .......................... & 1.6 & W & 19.3 & 5.7 & W & 0.4 & $\mathbf{w}$ & 63.6 & w & 239.3 \\
\hline \multicolumn{11}{|l|}{ Ohio } \\
\hline 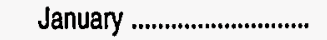 & W & 5.4 & 768.7 & 138.5 & 67.3 & 520.4 & 26.2 & 140.5 & $W$ & 801.5 \\
\hline 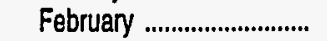 & W & 6.2 & 886.3 & 303.1 & 59.8 & 347.3 & 31.6 & 70.7 & $W$ & 593.3 \\
\hline 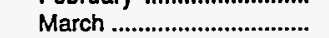 & $w$ & 13.1 & $1,006.0$ & NA & 33.3 & 170.7 & 11.1 & 30.8 & $w$ & 668.4 \\
\hline 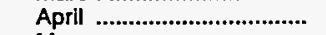 & w & 12.9 & 956.8 & 98.2 & 19.3 & 58.1 & w & 13.6 & $w$ & 443.6 \\
\hline May & w & 15.1 & 917.5 & 128.5 & 21.5 & 36.8 & 0.6 & w & w & 292.7 \\
\hline June ................................................ & W & 15.6 & $1,000.9$ & 92.3 & 21.4 & 28.6 & w & 8.5 & W & 443.2 \\
\hline July ………................................ & $w$ & 22.8 & 932.4 & 141.2 & 10.3 & 28.4 & 0.6 & w & w & 348.0 \\
\hline 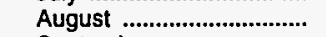 & w & 23.7 & $1,047.2$ & 120.6 & 9.5 & 57.4 & w & 16.9 & $w$ & 454.6 \\
\hline 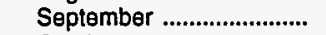 & w & 28.0 & 997.0 & 95.5 & 11.9 & 118.2 & w & $w$ & w & 571.3 \\
\hline October …………....................... & w & 22.0 & $1,042.6$ & 85.2 & 14.4 & 133.6 & w & 27.7 & w & 815.8 \\
\hline 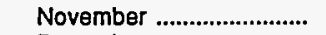 & 5.3 & 9.5 & 818.6 & 74.9 & 21.1 & 199.6 & 4.4 & 36.8 & w & 691.8 \\
\hline December ............................... & w & 10.3 & $1,037.9$ & 83.9 & 25.4 & 265.2 & 16.8 & 58.2 & W & 810.5 \\
\hline 1994 Average ........................... & $w$ & 15.4 & 951.6 & 128.1 & 26.1 & 162.8 & 7.8 & 37.1 & $w$ & 578.2 \\
\hline \multicolumn{11}{|l|}{ Oklahoma } \\
\hline January ...................................... & & 8.5 & 754.6 & 199.1 & $w$ & w & 8.3 & 169.8 & 12.0 & 874.6 \\
\hline February .................................. & $w$ & 9.8 & 536.0 & 116.6 & $w$ & 2.1 & 26.4 & 76.3 & 10.1 & 714.5 \\
\hline 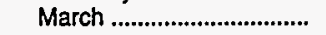 & $w$ & 13.7 & 668.0 & 72.2 & - & w & $w$ & 42.9 & 6.0 & 534.9 \\
\hline 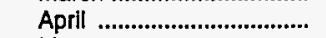 & w & 9.8 & $1,017.2$ & 165.9 & w & $w$ & $w$ & 86.5 & 6.0 & 450.6 \\
\hline 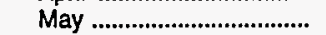 & w & 12.1 & 638.0 & 193.7 & w & - & w & 54.3 & 3.4 & 399.5 \\
\hline 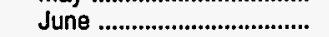 & w & 15.7 & 883.9 & 212.3 & w & w & W & 56.0 & 3.6 & 476.9 \\
\hline 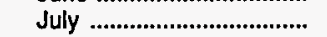 & w & 12.3 & 775.7 & 201.8 & W & w & w & $w$ & 5.1 & 395.0 \\
\hline 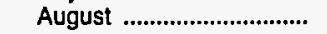 & w & 12.5 & 823.6 & 281.4 & w & w & $w$ & 80.2 & w & 466.5 \\
\hline September ............................... & w & 12.5 & 857.4 & 34.0 & W & w & $w$ & 120.8 & w & 501.3 \\
\hline 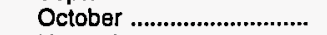 & w & 8.9 & 889.5 & 207.7 & W & 2.6 & $w$ & 91.7 & $w$ & 521.0 \\
\hline 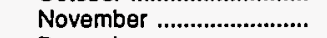 & w & 7.8 & 926.6 & 120.1 & - & 3.3 & $w$ & 126.5 & w & 584.1 \\
\hline December ................................. & w & 7.5 & 931.6 & 31.6 & w & w & 3.7 & 224.6 & w & 755.5 \\
\hline 1994 Average ........................... & w & 10.9 & 809.5 & 153.6 & w & 1.2 & 23.7 & $\mathbf{9 8 . 3}$ & 6.3 & 555.5 \\
\hline
\end{tabular}

See footnotes at end of table. 
Table 45. Refiner Volumes of Aviation Fuels, Kerosene, No. 1 Distillate, and Propane (Consumer Grade) by PAD District and State

(Thousand Gallons per Day) - Continued

\begin{tabular}{|c|c|c|c|c|c|c|c|c|c|c|}
\hline \multirow{2}{*}{$\begin{array}{l}\text { Geographic Area } \\
\text { Month }\end{array}$} & \multicolumn{2}{|c|}{ Aviation Gasoline } & \multicolumn{2}{|c|}{$\begin{array}{l}\text { Keroseno-Type } \\
\text { Jet Fuel }\end{array}$} & \multicolumn{2}{|c|}{ Kerosene } & \multicolumn{2}{|c|}{ No. 1 Distillate } & \multicolumn{2}{|c|}{$\begin{array}{c}\text { Propane } \\
\text { (Consumer Grade) }\end{array}$} \\
\hline & $\begin{array}{l}\text { Sales to } \\
\text { End Users }\end{array}$ & $\begin{array}{l}\text { Sales for } \\
\text { Resale }\end{array}$ & $\begin{array}{l}\text { Sales to } \\
\text { End Users }\end{array}$ & $\begin{array}{l}\text { Sales for } \\
\text { Resale }\end{array}$ & $\begin{array}{c}\text { Sales to } \\
\text { End Users }\end{array}$ & $\begin{array}{l}\text { Sales for } \\
\text { Resale }\end{array}$ & $\begin{array}{l}\text { Sales to } \\
\text { End Users }\end{array}$ & $\begin{array}{l}\text { Sales for } \\
\text { Resale }\end{array}$ & $\begin{array}{c}\text { Sales to } \\
\text { End Users }\end{array}$ & $\begin{array}{l}\text { Sales for } \\
\text { Resale }\end{array}$ \\
\hline 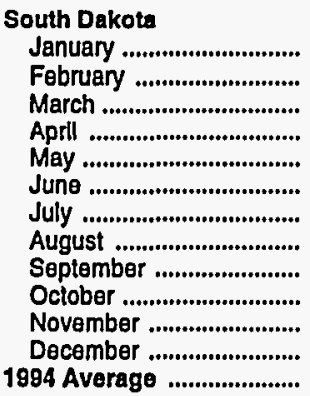 & $\begin{array}{l}W \\
W \\
W \\
w \\
w \\
W \\
W \\
W \\
W \\
W \\
W \\
W \\
W\end{array}$ & $\begin{array}{l}W \\
W \\
W \\
W \\
W \\
W \\
W \\
W \\
W \\
W \\
W \\
W \\
W\end{array}$ & $\begin{array}{c}15.0 \\
W \\
W \\
14.8 \\
13.7 \\
20.2 \\
19.3 \\
18.7 \\
20.2 \\
W \\
24.8 \\
20.7 \\
17.9\end{array}$ & $\begin{array}{l}W \\
W \\
W \\
W \\
W \\
W \\
W \\
W \\
W \\
W \\
W \\
W \\
W\end{array}$ & $\begin{array}{l}- \\
- \\
- \\
- \\
- \\
- \\
- \\
- \\
- \\
-\end{array}$ & $\begin{array}{l}2.7 \\
1.3 \\
w \\
w \\
w \\
- \\
W \\
W \\
2.5 \\
W \\
1.4 \\
2.4 \\
1.0\end{array}$ & $\begin{array}{l}2.5 \\
2.8 \\
W \\
- \\
- \\
- \\
- \\
\overline{-} \\
W \\
W \\
W \\
0.7\end{array}$ & $\begin{array}{r}218.9 \\
154.6 \\
27.6 \\
7.4 \\
4.7 \\
1.1 \\
2.5 \\
7.6 \\
35.6 \\
81.2 \\
185.8 \\
196.9 \\
76.6\end{array}$ & $\begin{array}{l}W \\
W \\
W \\
W \\
W \\
W \\
W \\
W \\
W \\
W \\
W \\
W \\
W\end{array}$ & $\begin{array}{r}246.5 \\
204.9 \\
104.5 \\
59.3 \\
30.5 \\
33.3 \\
59.2 \\
96.3 \\
115.3 \\
221.7 \\
186.9 \\
169.4 \\
127.0\end{array}$ \\
\hline 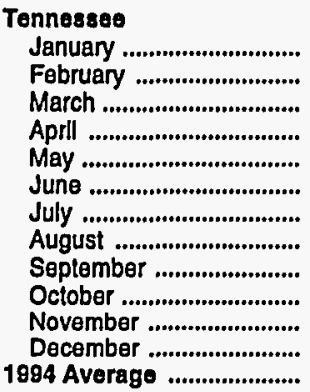 & $\begin{array}{l}4.5 \\
6.4 \\
5.7 \\
6.9 \\
7.1 \\
6.5 \\
5.6 \\
7.5 \\
6.8 \\
6.3 \\
W \\
4.9 \\
6.1\end{array}$ & $\begin{array}{r}6.5 \\
7.5 \\
10.3 \\
13.6 \\
10.6 \\
13.0 \\
13.7 \\
16.8 \\
12.8 \\
12.4 \\
6.9 \\
7.5 \\
11.0\end{array}$ & $\begin{array}{l}653.0 \\
580.9 \\
656.8 \\
712.1 \\
656.2 \\
584.8 \\
658.9 \\
719.4 \\
723.7 \\
767.1 \\
811.0 \\
732.4 \\
688.7\end{array}$ & $\begin{array}{l}25.3 \\
27.2 \\
25.1 \\
60.7 \\
25.8 \\
31.5 \\
26.6 \\
28.3 \\
34.1 \\
37.1 \\
35.6 \\
40.2 \\
33.1\end{array}$ & $\begin{array}{l}24.9 \\
17.2 \\
7.8 \\
4.0 \\
W \\
W \\
W \\
W \\
W \\
4.0 \\
5.9 \\
9.0 \\
7.6\end{array}$ & $\begin{array}{r}359.1 \\
219.9 \\
88.9 \\
28.2 \\
10.5 \\
8.6 \\
16.5 \\
40.6 \\
56.9 \\
128.2 \\
131.0 \\
195.1 \\
106.6\end{array}$ & $\begin{array}{l}W \\
W \\
- \\
- \\
- \\
- \\
- \\
- \\
- \\
- \\
\bar{W} \\
0.0\end{array}$ & $\begin{array}{l}5.7 \\
W \\
W \\
W \\
W \\
W \\
- \\
- \\
- \\
W \\
W \\
3.2 \\
1.5\end{array}$ & $\begin{array}{l}- \\
- \\
- \\
- \\
- \\
- \\
- \\
- \\
\bar{w} \\
w\end{array}$ & $\begin{array}{r}246.1 \\
266.1 \\
111.4 \\
104.2 \\
86.8 \\
104.1 \\
128.2 \\
175.5 \\
173.6 \\
193.8 \\
155.7 \\
201.8 \\
161.7\end{array}$ \\
\hline 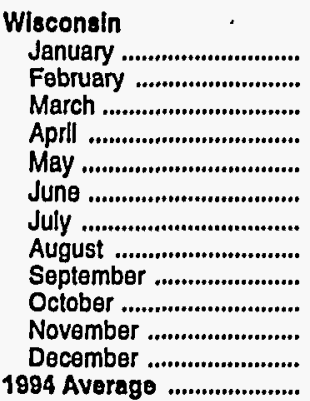 & $\begin{array}{l}W \\
W \\
W \\
W \\
- \\
- \\
w \\
w \\
\bar{w} \\
- \\
- \\
w\end{array}$ & $\begin{array}{r}W \\
9.1 \\
12.9 \\
11.8 \\
13.8 \\
18.3 \\
23.6 \\
20.5 \\
16.8 \\
15.8 \\
13.1 \\
9.6 \\
14.5\end{array}$ & $\begin{array}{r}161.0 \\
165.9 \\
165.0 \\
102.8 \\
88.5 \\
106.5 \\
91.5 \\
117.8 \\
100.9 \\
90.9 \\
102.9 \\
98.1 \\
115.7\end{array}$ & $\begin{array}{c}39.6 \\
26.2 \\
22.3 \\
58.8 \\
87.6 \\
65.7 \\
70.6 \\
\text { NA } \\
73.8 \\
93.2 \\
48.1 \\
76.3 \\
61.6\end{array}$ & $\begin{array}{l}W \\
W \\
W \\
W \\
W \\
W \\
W \\
W \\
W \\
W \\
W \\
W \\
W\end{array}$ & $\begin{array}{r}15.0 \\
10.0 \\
1.7 \\
0.9 \\
W \\
0.7 \\
0.8 \\
1.7 \\
4.8 \\
3.4 \\
9.6 \\
13.8 \\
6.6\end{array}$ & $\begin{array}{c}56.7 \\
37.7 \\
7.6 \\
W \\
W \\
W \\
W \\
W \\
W \\
2.4 \\
8.4 \\
33.1 \\
12.4\end{array}$ & $\begin{array}{r}630.6 \\
459.1 \\
136.5 \\
49.5 \\
29.2 \\
21.6 \\
19.8 \\
41.9 \\
83.6 \\
117.4 \\
296.4 \\
421.9 \\
191.0\end{array}$ & $\begin{array}{l}W \\
W \\
W \\
W \\
W \\
W \\
W \\
W \\
W \\
W \\
W \\
W \\
W\end{array}$ & $\begin{array}{l}964.2 \\
823.6 \\
575.8 \\
377.0 \\
269.0 \\
222.2 \\
272.6 \\
338.0 \\
345.1 \\
530.1 \\
649.7 \\
770.4 \\
510.1\end{array}$ \\
\hline 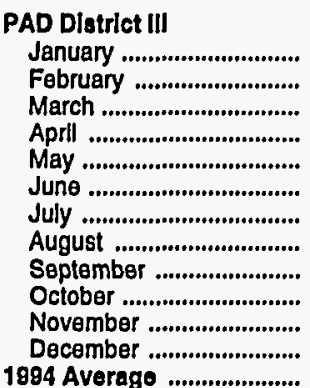 & $\begin{array}{l}18.4 \\
18.4 \\
26.3 \\
21.8 \\
29.8 \\
30.8 \\
28.7 \\
28.5 \\
25.8 \\
22.9 \\
22.9 \\
17.6 \\
24.4\end{array}$ & $\begin{array}{r}97.9 \\
113.9 \\
156.2 \\
144.6 \\
150.7 \\
175.6 \\
180.9 \\
165.6 \\
152.4 \\
118.7 \\
115.3 \\
90.6 \\
138.7\end{array}$ & $\begin{array}{l}7,521.3 \\
7,781.1 \\
8,024.0 \\
9,261.9 \\
9,571.7 \\
9,224.5 \\
9,541.4 \\
9,294.6 \\
9,677.6 \\
8,264.8 \\
9,379.4 \\
9,278.9 \\
8,905.7\end{array}$ & $\begin{array}{l}3,278.5 \\
3,260.6 \\
2,693.5 \\
3,182.5 \\
4,630.3 \\
4,399.8 \\
4,722.7 \\
4,961.5 \\
4,241.0 \\
4,542.5 \\
4,751.8 \\
5,073.5 \\
4,152.1\end{array}$ & $\begin{array}{l}11.7 \\
W \\
4.5 \\
W \\
W \\
W \\
W \\
W \\
W \\
W \\
W \\
W \\
W\end{array}$ & $\begin{array}{l}644.2 \\
339.7 \\
408.1 \\
296.1 \\
311.3 \\
251.2 \\
299.1 \\
458.4 \\
468.1 \\
189.9 \\
191.2 \\
430.7 \\
358.1\end{array}$ & $\begin{array}{c}W \\
28.1 \\
W \\
W \\
W \\
W \\
W \\
W \\
W \\
W \\
W \\
W \\
20.4\end{array}$ & $\begin{array}{r}99.1 \\
139.4 \\
56.9 \\
68.1 \\
132.2 \\
53.0 \\
63.1 \\
71.0 \\
73.5 \\
114.1 \\
165.6 \\
130.1 \\
96.9\end{array}$ & $\begin{array}{r}994.0 \\
873.3 \\
885.0 \\
788.3 \\
1,150.3 \\
1,066.7 \\
1,030.6 \\
1,141.1 \\
1,089.4 \\
1,055.8 \\
1,099.2 \\
1,492.2 \\
1,057.5\end{array}$ & $\begin{array}{r}13,627.6 \\
13,148.3 \\
11,438.7 \\
9,479.5 \\
9,029.2 \\
10,268.6 \\
12,088.7 \\
11,556.7 \\
11,984.1 \\
12,051.0 \\
12,004.7 \\
15,251.2 \\
11,826.3\end{array}$ \\
\hline
\end{tabular}

See tootnotes at end of table. 
Table 45. Refiner Volumes of Aviation Fuels, Kerosene, No. 1 Distillate, and Propane (Consumer Grade) by PAD District and State

(Thousand Gallons per Day) - Continued

\begin{tabular}{|c|c|c|c|c|c|c|c|c|c|c|}
\hline \multirow{2}{*}{$\begin{array}{l}\text { Geographic Area } \\
\text { Month }\end{array}$} & \multicolumn{2}{|c|}{ Aviation Gasoline } & \multicolumn{2}{|c|}{$\begin{array}{l}\text { Keroseno-Type } \\
\text { Jet Fuel }\end{array}$} & \multicolumn{2}{|c|}{ Kerosene } & \multicolumn{2}{|c|}{ No. 1 Distillate } & \multicolumn{2}{|c|}{$\begin{array}{c}\text { Propane } \\
\text { (Consumer Grade) }\end{array}$} \\
\hline & $\begin{array}{l}\text { Sales to } \\
\text { End Usors }\end{array}$ & $\begin{array}{l}\text { Sales for } \\
\text { Resale }\end{array}$ & $\begin{array}{c}\text { Sales to } \\
\text { End Users }\end{array}$ & $\begin{array}{l}\text { Sales for } \\
\text { Resalo }\end{array}$ & $\begin{array}{l}\text { Sales to } \\
\text { End Users }\end{array}$ & $\begin{array}{l}\text { Sales for } \\
\text { Resale }\end{array}$ & $\begin{array}{l}\text { Sales to } \\
\text { End Usors }\end{array}$ & $\begin{array}{l}\text { Sales for } \\
\text { Resale }\end{array}$ & $\begin{array}{l}\text { Sales to } \\
\text { End Users }\end{array}$ & $\begin{array}{l}\text { Sales for } \\
\text { Resalo }\end{array}$ \\
\hline \multicolumn{11}{|l|}{ Alabama } \\
\hline 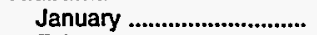 & 3.7 & 5.8 & 93.3 & 22.5 & 7.3 & 73.6 & - & $w$ & $w$ & 719.0 \\
\hline 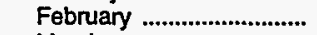 & 3.2 & 11.5 & 96.6 & 45.0 & 4.1 & 38.4 & - & $w$ & $w$ & 541.1 \\
\hline 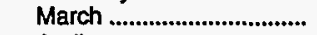 & 4.9 & 9.9 & 97.9 & 24.5 & 0.8 & 15.9 & - & W & $w$ & 350.1 \\
\hline 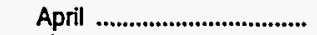 & w & 11.1 & 95.4 & 28.0 & w & 8.4 & - & - & $w$ & 207.7 \\
\hline 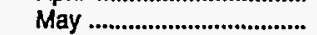 & 4.9 & 10.6 & 97.3 & 29.0 & $w$ & 5.0 & - & $w$ & $w$ & 142.6 \\
\hline June & 5.1 & 9.9 & 100.6 & 176.3 & w & 7.0 & - & - & W & 172.3 \\
\hline July ……………...................... & 3.9 & 10.0 & 108.0 & 23.2 & $w$ & 3.3 & - & w & $\ddot{w}$ & 171.0 \\
\hline 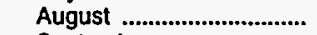 & 6.1 & 10.7 & 116.9 & 26.1 & w & 9.9 & - & - & $w$ & 271.4 \\
\hline September .............................. & 3.6 & 10.1 & 125.6 & 22.8 & w & 15.9 & - & w & $\ddot{w}$ & 326.4 \\
\hline 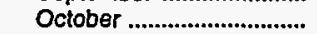 & 4.0 & 8.8 & 126.8 & $w$ & $w$ & 19.1 & - & $w$ & $w$ & 383.3 \\
\hline November ............................... & 4.8 & 6.8 & 123.5 & 24.1 & w & 21.4 & - & $\ddot{w}$ & $w$ & 347.1 \\
\hline December ............................... & 2.9 & 5.3 & 115.5 & 22.7 & 1.3 & 37.7 & - & $w$ & $w$ & 440.3 \\
\hline 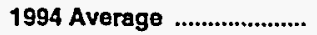 & 4.2 & 9.2 & 108.2 & 39.0 & 1.2 & 21.3 & - & $\mathbf{w}$ & $w$ & 338.5 \\
\hline \multicolumn{11}{|l|}{ Arkansas } \\
\hline 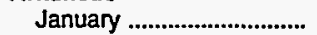 & w & 5.9 & 11.3 & 18.9 & w & 10.6 & - & $w$ & $w$ & 552.5 \\
\hline February ............................. & w & $w$ & 16.2 & 20.5 & W & $w$ & - & 0.8 & $\ddot{w}$ & 333.8 \\
\hline 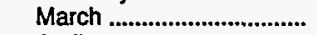 & w & $w$ & 13.7 & 29.2 & w & 2.7 & - & $w$ & $w$ & 177.5 \\
\hline 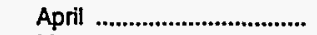 & w & $\mathbf{w}$ & 18.5 & 30.1 & - & $w$ & - & $w$ & w & 72.6 \\
\hline 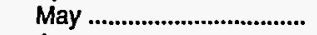 & $w$ & $w$ & 22.3 & 39.9 & - & 22.0 & - & - & w & 36.0 \\
\hline 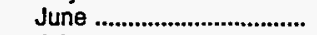 & $w$ & $w$ & 27.9 & 35.7 & - & 22.6 & - & - & $w$ & 46.1 \\
\hline 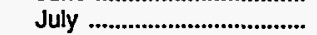 & $w$ & $w$ & 31.1 & 28.6 & - & 20.7 & - & w & $w$ & 66.4 \\
\hline 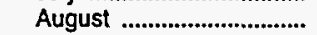 & w & w & 84.6 & 34.3 & - & 21.1 & - & w & $w$ & 104.5 \\
\hline September ............................. & w & 14.5 & 91.6 & 62.9 & - & 18.7 & - & w & $\ddot{w}$ & 154.4 \\
\hline 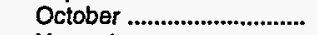 & $w$ & $w$ & 64.9 & 33.8 & - & 23.5 & - & $w$ & $w$ & 204.8 \\
\hline November ............................... & w & 6.8 & 92.5 & 24.7 & w & 23.0 & - & W & $w$ & 176.6 \\
\hline December ............................... & w & w & 100.5 & 66.4 & - & 57.3 & - & $\ddot{w}$ & $w$ & 289.7 \\
\hline 1994 Average ........................ & $\mathbf{w}$ & $\mathbf{w}$ & 48.1 & 35.5 & $\mathbf{w}$ & 25.1 & - & 1.9 & $\mathbf{w}$ & 184.1 \\
\hline \multicolumn{11}{|l|}{ Louisiana } \\
\hline 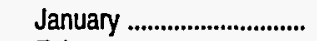 & $w$ & 3.0 & $1,761.2$ & 450.7 & $W$ & 233.4 & - & 3.3 & 241.7 & 841.5 \\
\hline 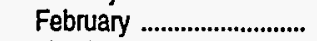 & $w$ & 3.3 & $2,056.0$ & 666.6 & W & 59.0 & - & $W$ & $w$ & 548.7 \\
\hline 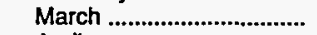 & $w$ & 5.8 & $2,265.0$ & 578.8 & w & 237.0 & - & - & 239.9 & 686.3 \\
\hline April & $\mathbf{w}$ & 4.4 & $2,951.2$ & 975.0 & $w$ & 236.7 & w & w & 191.2 & 539.3 \\
\hline 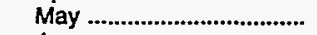 & $w$ & 8.1 & $2,748.3$ & $1,331.7$ & $w$ & $w$ & - & $w$ & $w$ & 545.5 \\
\hline June & $w$ & 8.9 & $3,312.1$ & 836.4 & $w$ & $w$ & - & - & $\ddot{w}$ & 634.3 \\
\hline July & $w$ & 7.6 & $2,853.4$ & 725.3 & w & $\dddot{w}$ & - & - & $w$ & 794.6 \\
\hline 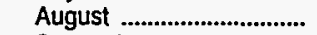 & $w$ & 7.2 & $2,576.2$ & 793.9 & W & 243.7 & - & - & $w$ & $1,005.3$ \\
\hline 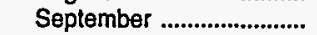 & $w$ & 8.1 & $2,875.8$ & $1,180.0$ & $w$ & $w$ & - & - & $w$ & $1,067.4$ \\
\hline 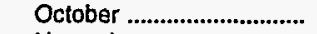 & $w$ & 5.0 & $1,695.7$ & 912.1 & $w$ & 87.5 & - & $w$ & $w$ & 788.5 \\
\hline 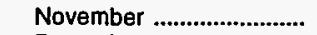 & 3.4 & 4.3 & $2,215.7$ & 831.0 & w & 7.9 & - & $w$ & $w$ & 931.5 \\
\hline 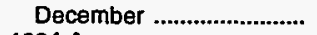 & 3.2 & 4.3 & $2,239.1$ & $1,334.8$ & w & 64.3 & - & $w$ & $w$ & $1,057.8$ \\
\hline 1994 Average ............................ & $\mathbf{w}$ & 5.8 & $2,461.7$ & 885.7 & w & 167.7 & $\mathbf{w}$ & 0.4 & $\mathbf{w}$ & 788.6 \\
\hline \multicolumn{11}{|l|}{ Mississippi } \\
\hline 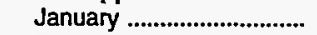 & $w$ & 2.4 & 390.8 & w & w & w & - & - & $w$ & $1,439.9$ \\
\hline February .................................. & $w$ & 5.0 & 411.8 & 421.5 & w & w & - & - & $\ddot{w}$ & $1,044.4$ \\
\hline 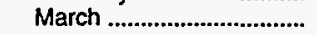 & $w$ & 6.6 & 334.0 & 11.6 & $w$ & $\ddot{w}$ & - & - & $\ddot{w}$ & 600.2 \\
\hline 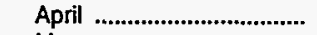 & w & 5.9 & 516.9 & w & w & w & - & - & $w$ & 460.2 \\
\hline 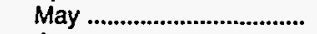 & $w$ & 6.3 & 708.1 & $w$ & w & $w$ & - & - & $\ddot{w}$ & 611.4 \\
\hline 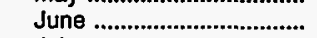 & $\ddot{w}$ & 10.3 & 774.2 & 470.6 & $w$ & $w$ & - & - & $w$ & 541.6 \\
\hline 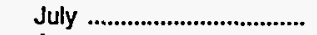 & w & 10.1 & 802.0 & 522.7 & $w$ & $w$ & - & - & $\ddot{w}$ & 505.9 \\
\hline August ............................. & $w$ & 10.8 & 643.5 & 249.3 & $w$ & $w$ & - & - & $\ddot{w}$ & 678.8 \\
\hline 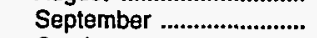 & $w$ & $w$ & 584.7 & 329.2 & w & 73.1 & - & - & $\ddot{w}$ & 677.3 \\
\hline 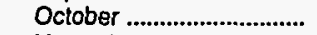 & $w$ & 3.5 & 755.0 & $w$ & W & $w$ & - & - & $\ddot{w}$ & 772.5 \\
\hline November ................................ & $w$ & $w$ & 485.2 & 219.8 & $w$ & $w$ & - & w & $\ddot{w}$ & $1,078.4$ \\
\hline 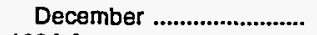 & $w$ & 2.6 & 698.4 & 518.5 & w & $w$ & - & - & $\ddot{w}$ & 967.1 \\
\hline 1994 Average ........................... & $\mathbf{w}$ & 6.1 & 593.5 & 324.5 & W & $w$ & - & $w$ & 4.7 & 780.3 \\
\hline
\end{tabular}

See footnotes at end of table. 
Table 45. Refiner Volumes of Aviation Fuels, Kerosene, No. 1 Distillate, and Propane (Consumer Grade) by PAD District and State

(Thousand Gallons per Day) - Continued

\begin{tabular}{|c|c|c|c|c|c|c|c|c|c|c|}
\hline \multirow{2}{*}{$\begin{array}{l}\text { Goographlc Area } \\
\text { Month }\end{array}$} & \multicolumn{2}{|c|}{ Aviation Gasollne } & \multicolumn{2}{|c|}{$\begin{array}{l}\text { Kerosene-Type } \\
\text { Jet Fuel }\end{array}$} & \multicolumn{2}{|c|}{ Kerosene } & \multicolumn{2}{|c|}{ No. 1 Distillate } & \multicolumn{2}{|c|}{$\begin{array}{c}\text { Propane } \\
\text { (Consumer Grade) }\end{array}$} \\
\hline & $\begin{array}{l}\text { Sales to } \\
\text { End Users }\end{array}$ & $\begin{array}{l}\text { Sales for } \\
\text { Resale }\end{array}$ & $\begin{array}{l}\text { Sales to } \\
\text { End Users }\end{array}$ & $\begin{array}{l}\text { Sales for } \\
\text { Resale }\end{array}$ & $\begin{array}{l}\text { Sales to } \\
\text { End Users }\end{array}$ & $\begin{array}{l}\text { Sales for } \\
\text { Resale }\end{array}$ & $\begin{array}{l}\text { Sales to } \\
\text { End Users }\end{array}$ & $\begin{array}{l}\text { Sales for } \\
\text { Resale }\end{array}$ & $\begin{array}{c}\text { Sales to } \\
\text { End Users }\end{array}$ & $\begin{array}{c}\text { Sales for } \\
\text { Resale }\end{array}$ \\
\hline
\end{tabular}

\begin{tabular}{|c|c|c|c|c|c|c|c|c|c|c|}
\hline \multicolumn{11}{|l|}{ New Mexlco } \\
\hline January ............................. & $W$ & $W$ & 287.2 & 20.9 & $w$ & $W$ & $W$ & 37.1 & $w$ & 665.1 \\
\hline 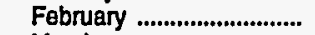 & $W$ & $W$ & 265.5 & 25.8 & - & 4.3 & $w$ & 37.1 & $w$ & 663.1 \\
\hline March ................................... & $w$ & $w$ & 258.5 & 27.7 & - & $w$ & $w$ & 12.0 & $w$ & 543.2 \\
\hline Aprll & $W$ & $W$ & 304.1 & $w$ & - & 1.1 & $w$ & 3.6 & $w$ & 328.6 \\
\hline 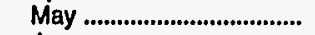 & $W$ & $W$ & 224.5 & $W$ & $w$ & $W$ & $w$ & $w$ & $w$ & 382.2 \\
\hline June & $W$ & $W$ & 186.0 & 33.7 & - & $W$ & $W$ & W & $w$ & 338.0 \\
\hline 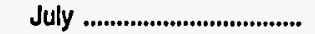 & $W$ & $W$ & 178.6 & 28.1 & - & W & $w$ & $w$ & W & 324.8 \\
\hline 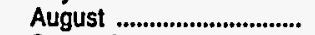 & $W$ & $w$ & 164.1 & 32.5 & - & $w$ & $w$ & $w$ & $w$ & 408.5 \\
\hline September ......................... & $W$ & $W$ & 217.9 & 28.7 & - & $w$ & $\dddot{w}$ & 3.2 & $w$ & 398.0 \\
\hline Oclober ............................... & $W$ & $W$ & 149.5 & 37.7 & - & $w$ & $\dddot{w}$ & 13.5 & $w$ & 450.5 \\
\hline November ........................... & $W$ & $W$ & 210.0 & 30.0 & - & w & $\dddot{w}$ & 24.9 & $w$ & 554.3 \\
\hline December .......................... & $w$ & $w$ & 206.6 & 37.6 & - & w & $\ddot{w}$ & 32.2 & $w$ & 471.0 \\
\hline 1994 Average ......................... & $\mathbf{W}$ & $\mathbf{w}$ & 220.6 & 29.2 & w & $\mathbf{w}$ & $w$ & 14.4 & $\mathbf{w}$ & 459.5 \\
\hline \multicolumn{11}{|l|}{ Texas } \\
\hline 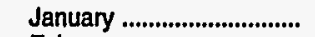 & 6.6 & 73.9 & $4,977.5$ & $2,284.7$ & $w$ & 39.7 & w & 58.0 & 546.1 & $9,409.6$ \\
\hline February ........................... & 6.1 & 82.6 & $4,935.0$ & $2,081.3$ & $w$ & 28.8 & $W$ & 100.5 & 432.8 & $10,017.3$ \\
\hline March .................................... & 9.3 & 119.4 & $5,055.0$ & $2,021.7$ & w & 17.7 & $W$ & 44.1 & 527.9 & $9,081.4$ \\
\hline April & 7.2 & 102.9 & $5,375.7$ & $2,050.2$ & $w$ & 15.6 & w & 64.1 & 527.9 & $7,871.1$ \\
\hline May ...................................... & $w$ & 94.1 & $5,771.3$ & $2,990.8$ & $w$ & 17.4 & - & 128.7 & 582.9 & $7,311.5$ \\
\hline June ..................................... & 10.3 & 103.6 & $4,823.8$ & $2,847.1$ & $w$ & 15.9 & $W$ & W & 592.4 & $8,536.2$ \\
\hline July ........................................ & 9.9 & 115.2 & $5,568.3$ & $3,394.9$ & W & 16.3 & $W$ & 59.3 & 562.0 & $10,225.9$ \\
\hline 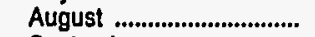 & 8.6 & 108.9 & $5,709.4$ & $3,825.5$ & $w$ & 13.3 & $W$ & 67.5 & 598.2 & $9,088.4$ \\
\hline Seplember ........................ & 10.2 & 101.1 & $5,782.0$ & $2,617.5$ & $w$ & 13.9 & W & 68.2 & 600.3 & $9,360.5$ \\
\hline 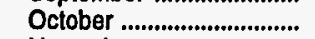 & 10.1 & 84.7 & $5,472.9$ & $3,148.7$ & $w$ & 20.6 & $W$ & 100.1 & 566.1 & $9,451.5$ \\
\hline November .......................... & W & 86.9 & $6,252.5$ & $3,622.1$ & $w$ & 131.2 & $W$ & 103.1 & 688.6 & $8,916.8$ \\
\hline 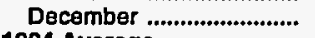 & 7.2 & 65.5 & $5,918.8$ & $3,093.3$ & $w$ & 90.9 & $w$ & 81.8 & 905.8 & $12,025.4$ \\
\hline 1994 Average ....................... & 8.6 & 95.0 & $5,473.6$ & $2,838.2$ & $\mathbf{w}$ & 35.1 & 18.2 & 77.0 & 595.5 & $9,275.1$ \\
\hline \multicolumn{11}{|l|}{ PAD District IV } \\
\hline 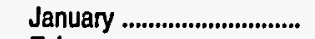 & 6.0 & 24.3 & $1,316.9$ & 106.2 & $w$ & 28.7 & 74.9 & 461.5 & 31.3 & $1,172.3$ \\
\hline 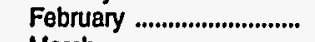 & 5.9 & 21.6 & $1,276.0$ & 109.0 & $W$ & 54.8 & 77.0 & 411.3 & $W$ & $1,194.3$ \\
\hline 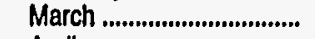 & 10.2 & 31.5 & $1,280.0$ & 133.2 & $W$ & 11.0 & 39.4 & 136.8 & $W$ & 947.1 \\
\hline April & 8.5 & 30.5 & $1,303.1$ & 107.7 & $W$ & 5.6 & $W$ & 51.5 & $W$ & 868.9 \\
\hline May ..................................... & 12.9 & 42.4 & $1,178.5$ & 97.9 & - & 5.0 & $W$ & 31.4 & W & 842.2 \\
\hline 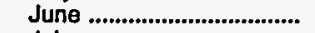 & 13.9 & 45.9 & $1,260.7$ & 122.9 & - & 3.8 & w & 32.5 & w & 779.1 \\
\hline 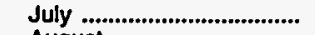 & 18.3 & 60.1 & 1.415 .8 & 142.2 & - & 2.8 & w & 28.8 & $w$ & 805.9 \\
\hline August $\ldots . . . . . . . \ldots \ldots \ldots \ldots \ldots$ & 22.6 & 58.1 & $1,329.7$ & 144.1 & - & 5.8 & $W$ & 44.4 & w & 916.1 \\
\hline September .............................. & 15.9 & 38.2 & $1,306.8$ & 148.4 & - & 10.4 & 33.2 & 85.2 & $w$ & 952.0 \\
\hline 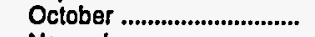 & 7.2 & 24.5 & $1,131.7$ & 82.8 & $W$ & 13.5 & 37.3 & 213.1 & 31.7 & 949.8 \\
\hline November .......................... & 8.4 & 17.3 & $1,028.6$ & 87.9 & $W$ & 24.2 & 63.7 & 496.3 & $W$ & $1,192.2$ \\
\hline December ............................... & 10.0 & 19.1 & $1,276.8$ & 128.1 & $W$ & 23.9 & 47.2 & 479.0 & $w$ & $1,313.9$ \\
\hline 1994 Average ...................... & 11.7 & 34.6 & $1,259.0$ & 117.6 & $\mathbf{W}$ & 15.5 & 41.8 & 204.7 & 32.7 & 993.4 \\
\hline \multicolumn{11}{|l|}{ Colorado } \\
\hline 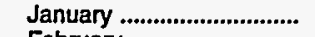 & $w$ & 10.2 & 870.4 & 62.5 & - & $w$ & $w$ & 118.2 & $w$ & 467.7 \\
\hline 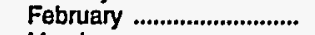 & $w$ & 10.8 & 750.2 & 61.6 & - & 35.1 & 29.5 & 103.3 & w & 458.1 \\
\hline 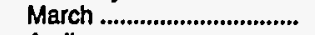 & $w$ & 13.5 & 702.1 & 70.5 & - & 5.6 & $w$ & 52.4 & $\ddot{W}$ & 329.7 \\
\hline Aprll & $W$ & 13.0 & 765.0 & 60.0 & - & $W$ & W & 21.4 & w & 270.0 \\
\hline 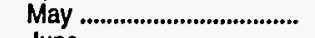 & $W$ & 18.9 & 672.4 & 51.9 & - & $W$ & $W$ & 10.4 & $\ddot{w}$ & 244.5 \\
\hline 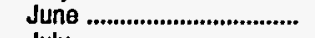 & $W$ & 18.3 & 685.1 & 65.2 & - & 3.0 & w & 10.5 & $\ddot{w}$ & 200.3 \\
\hline 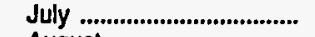 & 3.5 & 22.5 & 726.9 & 81.5 & - & $W$ & $\ddot{w}$ & 8.9 & $\ddot{w}$ & 199.0 \\
\hline 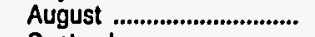 & 2.1 & 21.3 & 642.5 & 70.6 & - & 3.8 & $w$ & 14.4 & $\ddot{w}$ & 276.1 \\
\hline 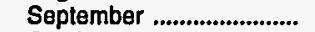 & $w$ & 14.8 & 704.8 & 63.4 & - & 4.7 & $w$ & 33.0 & w & 311.1 \\
\hline 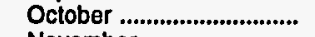 & 1.5 & 11.6 & 655.2 & 52.7 & - & 8.2 & $\ddot{w}$ & 75.2 & NA & 310.3 \\
\hline November ........................... & 1.7 & 10.5 & 599.2 & 54.6 & - & 13.1 & 24.4 & 138.2 & $w$ & 383.9 \\
\hline 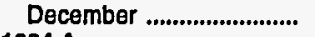 & 2.5 & 10.6 & 769.7 & 88.8 & - & 12.8 & $w$ & 123.9 & W & 454.2 \\
\hline 1994 Average ....................... & 2.0 & 14.7 & 711.9 & 65.4 & - & 8.8 & $\ddot{w}$ & 58.9 & $\mathbf{w}$ & 324.7 \\
\hline
\end{tabular}

See footnotes at end of table. 
Table 45. Refiner Volumes of Aviation Fuels, Kerosene, No. 1 Distillate, and Propane (Consumer Grade) by PAD District and State

(Thousand Gallons per Day) - Continued

\begin{tabular}{|c|c|c|c|c|c|c|c|c|c|c|}
\hline \multirow{2}{*}{$\begin{array}{l}\text { Geographic Area } \\
\text { Month }\end{array}$} & \multicolumn{2}{|c|}{ Aviatlon Gasoline } & \multicolumn{2}{|c|}{$\begin{array}{c}\text { Kerosene-Type } \\
\text { Jet Fuel }\end{array}$} & \multicolumn{2}{|c|}{ Kerosene } & \multicolumn{2}{|c|}{ No. 1 Dlstillate } & \multicolumn{2}{|c|}{$\begin{array}{c}\text { Propane } \\
\text { (Consumer Grade) } \\
\end{array}$} \\
\hline & $\begin{array}{c}\text { Sales to } \\
\text { End Users }\end{array}$ & $\begin{array}{l}\text { Sales for } \\
\text { Resalo }\end{array}$ & $\begin{array}{c}\text { Sales to } \\
\text { End Users }\end{array}$ & $\begin{array}{l}\text { Sales for } \\
\text { Resale }\end{array}$ & $\begin{array}{l}\text { Sales to } \\
\text { End Users }\end{array}$ & $\begin{array}{l}\text { Sales for } \\
\text { Resale }\end{array}$ & $\begin{array}{l}\text { Sales to } \\
\text { End Users }\end{array}$ & $\begin{array}{l}\text { Sales for } \\
\text { Resale }\end{array}$ & $\begin{array}{l}\text { Sales to } \\
\text { End Users }\end{array}$ & $\begin{array}{l}\text { Sales for } \\
\text { Resale }\end{array}$ \\
\hline \multicolumn{11}{|l|}{ Idaho } \\
\hline 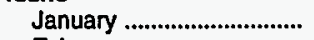 & $w$ & w & 33.9 & 4.4 & - & w & w & 70.4 & $w$ & w \\
\hline 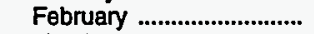 & w & w & 44.8 & 6.7 & - & - & 5.1 & 44.3 & w & - \\
\hline 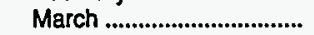 & $w$ & $w$ & 41.6 & 8.5 & - & - & w & 10.5 & $w$ & w \\
\hline 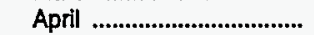 & - & w & 41.4 & 6.6 & - & w & - & 3.1 & $w$ & $w$ \\
\hline May & w & w & 41.7 & 7.3 & - & w & - & $w$ & w & $w$ \\
\hline 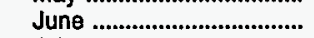 & $w$ & w & 48.0 & 10.3 & - & $w$ & - & 8.4 & $w$ & w \\
\hline 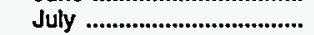 & w & $w$ & 57.3 & 11.8 & - & $w$ & - & 6.0 & $w$ & $w$ \\
\hline 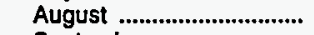 & $w$ & 5.0 & 72.8 & 13.6 & - & $\mathbf{w}$ & - & 8.2 & w & - \\
\hline September .............................. & $w$ & w & 60.1 & 31.7 & - & $w$ & - & $w$ & w & w \\
\hline 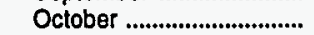 & $w$ & w & 48.7 & 6.6 & - & w & w & 18.5 & w & $w$ \\
\hline November ................................ & $w$ & $w$ & 42.7 & 6.3 & - & $w$ & 7.2 & 87.1 & W & W \\
\hline 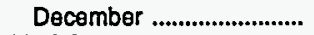 & - & $w$ & 51.7 & 8.2 & - & w & $w$ & 72.5 & w & W \\
\hline 1994 Average ........................... & $w$ & $\mathbf{w}$ & 48.8 & 10.2 & - & $\mathbf{w}$ & 2.1 & 28.0 & $w$ & $w$ \\
\hline \multicolumn{11}{|l|}{ Montana } \\
\hline 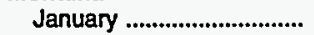 & $w$ & w & 53.6 & w & - & $w$ & 3.4 & 78.8 & w & 167.8 \\
\hline 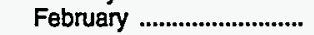 & w & $w$ & 55.7 & w & - & 17.1 & 2.1 & 100.4 & $w$ & 213.3 \\
\hline 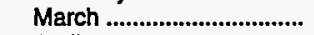 & $w$ & $\mathbf{w}$ & 50.0 & w & - & w & 1.9 & 25.6 & w & 170.1 \\
\hline 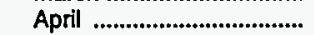 & $w$ & w & 40.7 & w & - & w & - & 12.2 & w & 181.4 \\
\hline 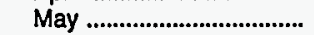 & $w$ & $w$ & $w$ & w & - & $w$ & w & 7.0 & w & 166.9 \\
\hline June & w & $\mathbf{w}$ & 45.0 & $w$ & - & w & - & 7.1 & $w$ & 188.6 \\
\hline 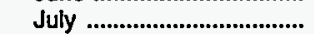 & w & W & 66.1 & w & - & $w$ & w & 4.2 & W & 192.0 \\
\hline August .............................. & w & $\mathbf{w}$ & 79.9 & $w$ & - & w & - & 10.1 & $w$ & 199.4 \\
\hline 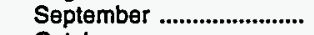 & $w$ & $\mathbf{w}$ & 63.4 & $w$ & - & 3.1 & $w$ & 28.1 & w & 197.8 \\
\hline 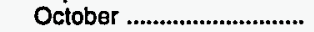 & $\mathbf{w}$ & W & 50.7 & $w$ & - & 2.4 & w & 54.5 & $w$ & 155.1 \\
\hline 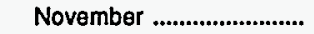 & w & w & 52.3 & $w$ & - & 3.7 & 5.2 & 109.6 & w & 216.4 \\
\hline December ............................. & $w$ & W & 60.5 & $w$ & - & 3.3 & 4.8 & 105.6 & w & 224.5 \\
\hline 1994 Average ............................ & $\mathbf{W}$ & W & 54.5 & w & - & 4.2 & 1.8 & 44.8 & W & 189.0 \\
\hline \multicolumn{11}{|l|}{ Utah } \\
\hline 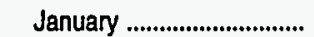 & W & 9.1 & 353.5 & 31.9 & - & $W$ & 18.5 & 99.5 & - & 176.7 \\
\hline February .............................. & 0.9 & 7.5 & 418.3 & 32.0 & - & $w$ & 18.4 & 75.7 & - & 193.8 \\
\hline 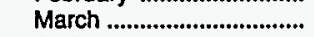 & 0.5 & 9.7 & 481.6 & 43.1 & - & w & 3.9 & 19.7 & w & $w$ \\
\hline April & $w$ & 11.5 & 452.1 & 33.3 & - & w & $w$ & 4.6 & $w$ & w \\
\hline 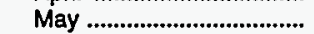 & w & 14.1 & 422.0 & 32.0 & - & $w$ & - & $w$ & $w$ & $w$ \\
\hline 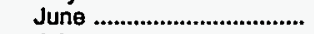 & w & 15.2 & 473.5 & 40.7 & - & w & w & 3.6 & $w$ & $w$ \\
\hline 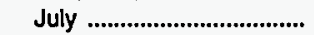 & 0.8 & 24.4 & 553.8 & 35.8 & - & w & - & 6.8 & $w$ & w \\
\hline 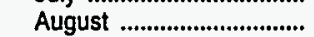 & 0.6 & 23.2 & 521.7 & 36.5 & - & W & w & $w$ & $w$ & 121.7 \\
\hline 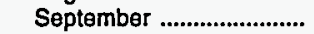 & w & 14.0 & 468.7 & 38.6 & - & w & $w$ & $w$ & $w$ & $w$ \\
\hline October & $w$ & 7.6 & 370.2 & 14.5 & - & w & 2.1 & 25.9 & w & $w$ \\
\hline November ............................. & W & 3.2 & 328.3 & 18.8 & - & w & 10.5 & 97.0 & w & w \\
\hline 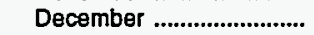 & w & 4.1 & 387.5 & 22.2 & - & w & 15.7 & 104.1 & w & $w$ \\
\hline 1994 Average ........................... & 0.8 & 12.0 & 436.1 & 31.6 & - & $w$ & 5.8 & 37.8 & $w$ & 141.7 \\
\hline \multicolumn{11}{|l|}{ Wyoming } \\
\hline 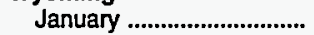 & $w$ & w & 5.6 & w & w & w & 22.0 & 94.6 & 13.7 & 359.6 \\
\hline 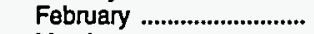 & 0.3 & w & 7.1 & w & w & w & 21.9 & 87.6 & 14.8 & 329.1 \\
\hline 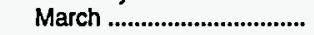 & w & $w$ & 4.6 & $w$ & w & - & 8.2 & 28.6 & 7.2 & 301.3 \\
\hline April ....................................... & w & W & 3.9 & $w$ & w & - & 1.9 & 10.1 & w & 284.9 \\
\hline 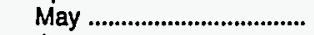 & w & W & w & w & - & - & 1.2 & 4.5 & 6.1 & 324.2 \\
\hline 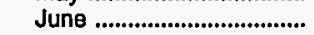 & w & w & 9.1 & w & - & w & 0.4 & 3.0 & $w$ & 297.7 \\
\hline 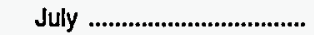 & w & w & 11.7 & w & - & w & w & 2.8 & $w$ & 292.8 \\
\hline August ........................................ & W & W & 12.8 & $w$ & - & - & 1.1 & w & $w$ & 318.9 \\
\hline 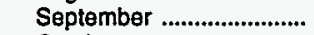 & w & w & 9.8 & w & - & w & 2.3 & 12.9 & NA & 353.4 \\
\hline October ................................... & W & W & 7.0 & W & w & 0.5 & 7.5 & 38.9 & $w$ & 353.5 \\
\hline November .............................. & $w$ & $w$ & 6.2 & $\ddot{w}$ & $\ddot{w}$ & $w$ & 16.3 & 64.3 & $w$ & 409.0 \\
\hline 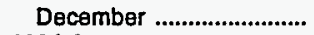 & $w$ & w & 7.5 & w & $w$ & $w$ & 15.1 & 72.9 & 15.5 & 421.2 \\
\hline 1994 Average ............................. & $\mathbf{w}$ & $w$ & 7.6 & $w$ & w & w & 8.1 & 35.2 & 7.3 & 337.2 \\
\hline
\end{tabular}

See footnotes at end of table. 
Table 45. Refiner Volumes of Aviation Fuels, Kerosene, No. 1 Distillate, and Propane (Consumer Grade) by PAD District and State

(Thousand Gallons per Day) - Continued

\begin{tabular}{|c|c|c|c|c|c|c|c|c|c|c|}
\hline \multirow{2}{*}{$\begin{array}{l}\text { Goographlc Area } \\
\text { Month }\end{array}$} & \multicolumn{2}{|c|}{ Aviatto I Gasollne } & \multicolumn{2}{|c|}{$\begin{array}{c}\text { Kerosene-Type } \\
\text { Jet Fuel }\end{array}$} & \multicolumn{2}{|c|}{ Kerosene } & \multicolumn{2}{|c|}{ No. 1 Distillate } & \multicolumn{2}{|c|}{$\begin{array}{c}\text { Propane } \\
\text { (Consumer Grade) }\end{array}$} \\
\hline & $\begin{array}{l}\text { Sales to } \\
\text { End Users }\end{array}$ & $\begin{array}{c}\text { Sales for } \\
\text { Resale }\end{array}$ & $\begin{array}{c}\text { Sales to } \\
\text { End Users }\end{array}$ & $\begin{array}{c}\text { Sales for } \\
\text { Resale }\end{array}$ & $\begin{array}{l}\text { Sales to } \\
\text { End Users }\end{array}$ & $\begin{array}{c}\text { Sales for } \\
\text { Resale }\end{array}$ & $\begin{array}{c}\text { Sales to } \\
\text { End Users }\end{array}$ & $\begin{array}{c}\text { Sales for } \\
\text { Resale }\end{array}$ & $\begin{array}{c}\text { Sales to } \\
\text { End Users }\end{array}$ & $\begin{array}{c}\text { Sales for } \\
\text { Resale }\end{array}$ \\
\hline 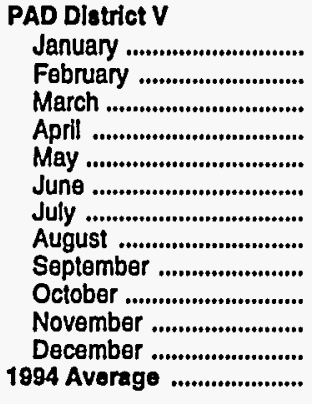 & $\begin{array}{l}33.9 \\
35.0 \\
38.8 \\
41.6 \\
41.7 \\
49.0 \\
40.9 \\
43.4 \\
39.8 \\
36.3 \\
33.2 \\
31.4 \\
38.8\end{array}$ & $\begin{array}{l}115.9 \\
131.9 \\
162.1 \\
174.9 \\
249.2 \\
278.9 \\
292.3 \\
293.1 \\
263.4 \\
179.1 \\
129.9 \\
106.8 \\
198.5\end{array}$ & $\begin{array}{l}11,697.2 \\
11,366.5 \\
12,681.5 \\
12,951.9 \\
13,119.2 \\
13,887.3 \\
13,777.7 \\
14,689.4 \\
14,292.3 \\
14,292.2 \\
13,970.2 \\
13,443.9 \\
13,359.0\end{array}$ & $\begin{array}{l}2,286.7 \\
2,043.9 \\
2,124.4 \\
2,102.3 \\
2,317.7 \\
2,442.7 \\
2,826.3 \\
3,417.0 \\
3,022.6 \\
2,381.0 \\
2,402.7 \\
2,309.6 \\
2,476.4\end{array}$ & $\begin{array}{c}W \\
11.8 \\
W \\
\bar{W} \\
\bar{W} \\
W \\
W \\
\bar{W} \\
W \\
4.4\end{array}$ & $\begin{array}{r}44.6 \\
43.5 \\
48.0 \\
23.9 \\
15.6 \\
16.2 \\
12.3 \\
25.7 \\
43.9 \\
57.5 \\
124.1 \\
126.1 \\
48.5\end{array}$ & $\begin{array}{r}102.9 \\
88.8 \\
110.2 \\
20.9 \\
10.0 \\
15.4 \\
10.6 \\
23.3 \\
22.3 \\
39.8 \\
66.8 \\
46.1 \\
46.2\end{array}$ & $\begin{array}{r}380.2 \\
347.1 \\
201.4 \\
75.0 \\
67.6 \\
189.7 \\
89.4 \\
113.3 \\
446.9 \\
235.9 \\
374.2 \\
426.7 \\
244.5\end{array}$ & $\begin{array}{c}w \\
w \\
w \\
w \\
w \\
w \\
w \\
w \\
w \\
w \\
w \\
183.5 \\
w \\
w\end{array}$ & $\begin{array}{l}1,806.9 \\
1,642.3 \\
1,644.9 \\
1,468.1 \\
1,474.7 \\
1,608.3 \\
1,593.7 \\
1,705.8 \\
1,698.2 \\
1,727.4 \\
2,074.7 \\
2,040.3 \\
1,707.6\end{array}$ \\
\hline 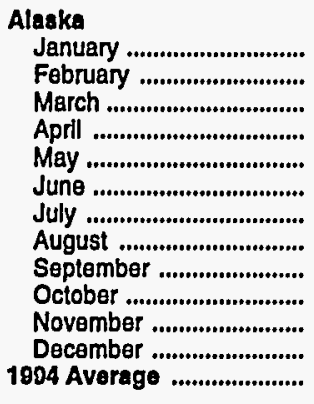 & $\begin{array}{l}w \\
w \\
w \\
w \\
w \\
w \\
w \\
w \\
w \\
w \\
w \\
w \\
w \\
w \\
w\end{array}$ & $\begin{array}{r}W \\
13.6 \\
13.9 \\
23.5 \\
37.2 \\
59.8 \\
84.5 \\
60.4 \\
W \\
21.4 \\
11.6 \\
8.1 \\
34.3\end{array}$ & $\begin{array}{l}1,055.3 \\
1,261.6 \\
1,410.5 \\
1,392.2 \\
1,388.9 \\
1,473.8 \\
1,503.9 \\
1,476.0 \\
1,797.4 \\
1,720.4 \\
1,752.2 \\
1,351.8 \\
1,465.5\end{array}$ & $\begin{array}{r}169.9 \\
143.3 \\
178.6 \\
29.2 \\
170.7 \\
118.1 \\
283.0 \\
281.6 \\
349.7 \\
137.5 \\
57.1 \\
37.0 \\
163.4\end{array}$ & $\begin{array}{l}\overline{-} \\
\overline{-} \\
\overline{-} \\
\overline{-} \\
\overline{-} \\
\overline{-} \\
\overline{-}\end{array}$ & $\begin{array}{l}\overline{-} \\
\overline{-} \\
\overline{-} \\
\bar{z} \\
\bar{z} \\
z \\
z\end{array}$ & $\begin{array}{r}70.5 \\
71.4 \\
102.2 \\
20.1 \\
9.5 \\
15.1 \\
10.5 \\
22.8 \\
21.4 \\
37.4 \\
60.0 \\
35.0 \\
39.5\end{array}$ & $\begin{array}{r}159.0 \\
183.6 \\
170.6 \\
54.7 \\
57.4 \\
174.8 \\
76.3 \\
96.6 \\
419.7 \\
178.4 \\
228.8 \\
256.8 \\
170.7\end{array}$ & $\begin{array}{l}w \\
w \\
w \\
w \\
w \\
w \\
w \\
w \\
w \\
w \\
w \\
w \\
w \\
w\end{array}$ & $\begin{array}{l}W \\
W \\
w \\
w \\
w \\
w \\
w \\
w \\
w \\
w \\
w \\
w \\
w \\
w \\
w\end{array}$ \\
\hline 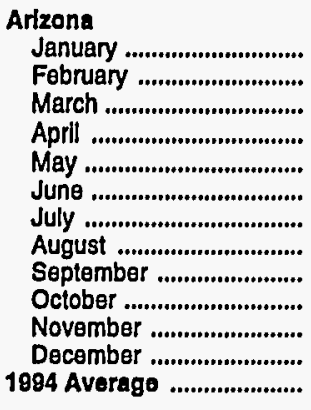 & $\begin{array}{l}W \\
W \\
W \\
W \\
W \\
4.9 \\
6.1 \\
W \\
W \\
W \\
4.8 \\
W \\
5.8\end{array}$ & $\begin{array}{r}11.6 \\
9.5 \\
11.8 \\
13.9 \\
14.3 \\
18.6 \\
13.6 \\
12.5 \\
12.4 \\
13.5 \\
13.3 \\
10.0 \\
12.9\end{array}$ & $\begin{array}{l}761.4 \\
663.5 \\
703.7 \\
596.5 \\
644.0 \\
652.1 \\
592.9 \\
722.4 \\
592.5 \\
641.7 \\
594.8 \\
724.4 \\
658.0\end{array}$ & $\begin{array}{l}77.2 \\
78.1 \\
88.9 \\
84.6 \\
79.5 \\
89.2 \\
78.5 \\
64.3 \\
69.4 \\
68.4 \\
86.6 \\
77.1 \\
78.4\end{array}$ & $\begin{array}{l}W \\
W \\
W \\
\bar{w} \\
\overline{-} \\
\overline{-} \\
\overline{-} \\
\bar{w} \\
w \\
W\end{array}$ & $\begin{array}{l}W \\
W \\
w \\
w \\
w \\
w \\
\bar{w} \\
w \\
w \\
w \\
w \\
w \\
\bar{w}\end{array}$ & $\begin{array}{l}\bar{w} \\
w \\
\overline{-} \\
\overline{-} \\
\overline{-} \\
\overline{-} \\
\overline{-} \\
\bar{w}\end{array}$ & $\begin{array}{l}4.1 \\
2.2 \\
1.7 \\
W \\
- \\
w \\
w \\
W \\
w \\
W \\
w \\
3.4 \\
1.6\end{array}$ & $\begin{array}{l}\bar{z} \\
\bar{z} \\
\bar{z} \\
\bar{z} \\
\bar{z} \\
\bar{z}\end{array}$ & $\begin{array}{r}125.5 \\
33.0 \\
29.7 \\
28.6 \\
8.1 \\
W \\
5.5 \\
8.6 \\
6.6 \\
20.9 \\
27.3 \\
20.9 \\
28.6\end{array}$ \\
\hline 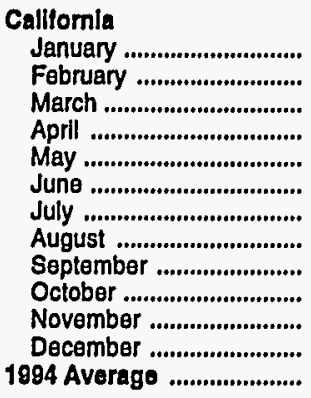 & $\begin{array}{l}16.2 \\
16.1 \\
18.1 \\
20.6 \\
16.9 \\
21.4 \\
18.6 \\
20.0 \\
18.0 \\
15.5 \\
13.1 \\
11.7 \\
17.2\end{array}$ & $\begin{array}{r}67.9 \\
78.5 \\
86.6 \\
87.8 \\
94.3 \\
117.6 \\
112.7 \\
122.2 \\
10.4 \\
96.3 \\
77.0 \\
64.2 \\
82.7\end{array}$ & $\begin{array}{l}7,097.4 \\
6,602.7 \\
7,475.4 \\
7,938.2 \\
8,015.5 \\
8,273.4 \\
8,238.8 \\
8,918.0 \\
8,350.8 \\
8,560.6 \\
8,275.3 \\
8,001.0 \\
7,987.7\end{array}$ & $\begin{array}{l}1,486.1 \\
1,429.8 \\
1,463.1 \\
1,286.0 \\
1,435.9 \\
1,687.8 \\
1,934.5 \\
2,358.6 \\
1,949.4 \\
1,581.2 \\
1,739.2 \\
1,618.8 \\
1,666.1\end{array}$ & $\begin{array}{l}\overline{-} \\
\bar{z} \\
\overline{-} \\
\bar{W} \\
W \\
W \\
\bar{W} \\
W \\
W\end{array}$ & $\begin{array}{r}11.7 \\
14.3 \\
33.3 \\
13.0 \\
6.2 \\
W \\
3.7 \\
8.0 \\
16.3 \\
25.6 \\
53.9 \\
52.2 \\
20.4\end{array}$ & $\begin{array}{l}W \\
W \\
W \\
W \\
\bar{W} \\
\overline{-} \\
\overline{-} \\
\overline{-} \\
\overline{-} \\
\bar{w}\end{array}$ & $\begin{array}{c}W \\
22.0 \\
w \\
w \\
w \\
w \\
w \\
w \\
w \\
w \\
w \\
w \\
5.7\end{array}$ & $\begin{array}{l}w \\
w \\
w \\
w \\
w \\
w \\
w \\
w \\
w \\
w \\
w \\
w \\
w \\
w\end{array}$ & $\begin{array}{r}1,182.0 \\
1,004.3 \\
1,055.7 \\
990.8 \\
1,065.6 \\
1,061.5 \\
1,118.1 \\
1,173.3 \\
1,216.9 \\
1,302.4 \\
1,405.3 \\
1,377.8 \\
1,164.0\end{array}$ \\
\hline
\end{tabular}

See footnotes at end of table. 
Table 45. Refiner Volumes of Aviation Fuels, Kerosene, No. 1 Distillate, and Propane (Consumer Grade) by PAD District and State

(Thousand Gallons per Day) - Continued

\begin{tabular}{|c|c|c|c|c|c|c|c|c|c|c|}
\hline \multirow{2}{*}{$\begin{array}{l}\text { Geographic Area } \\
\text { Month }\end{array}$} & \multicolumn{2}{|c|}{ Aviation Gasoline } & \multicolumn{2}{|c|}{$\begin{array}{l}\text { Kerosene-Typo } \\
\text { Jet Fuel }\end{array}$} & \multicolumn{2}{|c|}{ Kerosene } & \multicolumn{2}{|c|}{ No. 1 Distillato } & \multicolumn{2}{|c|}{$\begin{array}{c}\text { Propane } \\
\text { (Consumer Grade) }\end{array}$} \\
\hline & $\begin{array}{l}\text { Sales to } \\
\text { End Users }\end{array}$ & $\begin{array}{l}\text { Sales for } \\
\text { Resalo }\end{array}$ & $\begin{array}{l}\text { Sales to } \\
\text { End Users }\end{array}$ & $\begin{array}{l}\text { Sales for } \\
\text { Resalo }\end{array}$ & $\begin{array}{l}\text { Sales to } \\
\text { End Users }\end{array}$ & $\begin{array}{l}\text { Sales for } \\
\text { Resale }\end{array}$ & $\begin{array}{l}\text { Sales to } \\
\text { End Users }\end{array}$ & $\begin{array}{l}\text { Sales for } \\
\text { Resalo }\end{array}$ & $\begin{array}{l}\text { Sales to } \\
\text { End Users }\end{array}$ & $\begin{array}{l}\text { Sales for } \\
\text { Resale }\end{array}$ \\
\hline \multicolumn{11}{|l|}{ Hawail } \\
\hline 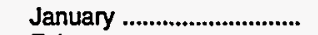 & w & w & 767.3 & $w$ & - & - & w & - & w & w \\
\hline 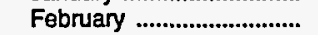 & $w$ & $w$ & 818.0 & $w$ & - & - & - & - & $\ddot{w}$ & $w$ \\
\hline March & w & w & 878.6 & w & - & - & - & - & $w$ & $w$ \\
\hline 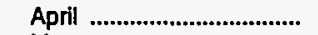 & w & w & 850.9 & w & - & - & - & - & w & $w$ \\
\hline 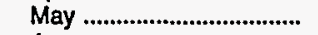 & w & w & 788.6 & w & - & - & - & - & w & $w$ \\
\hline June ................................................ & $w$ & $w$ & 819.9 & $w$ & - & - & - & - & $w$ & $w$ \\
\hline 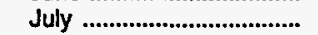 & w & $w$ & 779.4 & $w$ & - & - & - & - & $w$ & $w$ \\
\hline 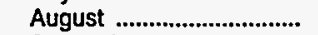 & w & w & 741.8 & $w$ & - & - & - & w & $\ddot{w}$ & $w$ \\
\hline September ............................... & w & w & 758.4 & w & - & - & - & - & w & $w$ \\
\hline 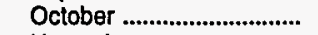 & w & w & 777.7 & w & - & - & - & - & w & w \\
\hline November ............................. & w & w & 709.8 & $w$ & - & - & - & - & $\ddot{w}$ & $\ddot{w}$ \\
\hline 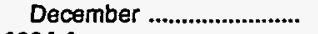 & w & $w$ & 801.6 & $w$ & - & - & - & $w$ & $w$ & $w$ \\
\hline 1994 Average ............................ & w & $\mathbf{w}$ & 790.9 & $\mathbf{w}$ & - & - & $w$ & $w$ & $w$ & $\ddot{w}$ \\
\hline \multicolumn{11}{|l|}{ Nevada } \\
\hline January ................................... & w & 5.4 & 510.5 & 56.7 & - & - & $w$ & 6.2 & - & 42.1 \\
\hline February …............................... & $w$ & 5.3 & 519.0 & 101.1 & - & - & $w$ & 5.8 & - & 68.6 \\
\hline 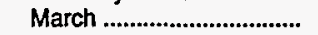 & $w$ & w & 547.6 & w & - & - & $w$ & w & - & 49.1 \\
\hline April & $w$ & w & 543.6 & 85.2 & - & - & - & $w$ & - & 41.0 \\
\hline 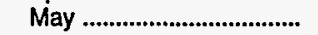 & w & w & 639.9 & 84.7 & - & - & - & $w$ & - & 43.0 \\
\hline 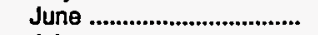 & w & w & 677.8 & 63.7 & - & - & - & $w$ & w & 22.3 \\
\hline July & w & w & 613.4 & 78.5 & - & - & - & $\mathbf{w}$ & w & 34.4 \\
\hline 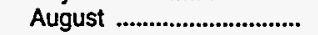 & w & 9.0 & 658.6 & 84.3 & - & - & w & $\ddot{w}$ & $w$ & 51.0 \\
\hline 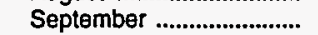 & $w$ & 7.8 & 630.8 & 81.6 & - & w & - & $w$ & 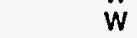 & 40.4 \\
\hline 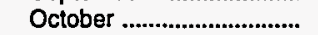 & $w$ & 7.4 & 627.6 & 77.2 & - & - & $w$ & 4.5 & $\ddot{w}$ & 73.5 \\
\hline November ............................... & $w$ & 5.5 & 656.4 & 88.3 & - & w & $w$ & 6.5 & $w$ & 109.8 \\
\hline 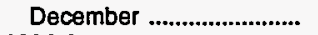 & w & w & 676.6 & 85.6 & - & $w$ & $w$ & 5.9 & w & 98.7 \\
\hline 1994 Average ........................... & $w$ & 6.2 & 609.0 & 80.2 & - & $\mathbf{w}$ & $w$ & 3.8 & $\ddot{w}$ & 56.1 \\
\hline \multicolumn{11}{|l|}{ Oregon } \\
\hline 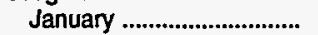 & - & 9.3 & 332.7 & 122.9 & NA & $w$ & 1.6 & 71.7 & $w$ & 7.8 \\
\hline February .................................. & w & 13.0 & 329.7 & $w$ & w & $\ddot{w}$ & 2.3 & 49.9 & W & 8.1 \\
\hline 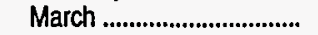 & W & 16.5 & 370.4 & 80.9 & W & W & W & 4.9 & W & 7.5 \\
\hline April .................................. & W & 16.2 & 347.0 & W & - & w & $W$ & 2.3 & $W$ & $w$ \\
\hline May …...................................... & w & 18.1 & 377.0 & $w$ & - & $w$ & $w$ & 1.8 & $\ddot{w}$ & - \\
\hline June & w & 28.2 & 416.4 & $\mathbf{w}$ & - & $\mathbf{w}$ & w & 1.2 & $\mathbf{w}$ & $w$ \\
\hline 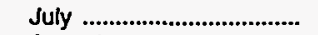 & $w$ & 29.1 & 500.1 & $w$ & - & $\ddot{w}$ & $w$ & $w$ & $w$ & $\ddot{w}$ \\
\hline 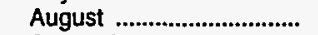 & w & 33.7 & 455.7 & $w$ & - & $w$ & w & 1.3 & $\ddot{w}$ & $\ddot{w}$ \\
\hline September ............................... & w & 28.9 & 497.2 & w & - & 12.7 & $w$ & 5.5 & w & w \\
\hline 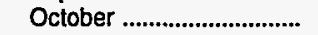 & w & 17.7 & 450.4 & $w$ & - & $w$ & W & 17.3 & $w$ & $w$ \\
\hline 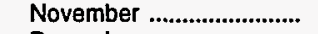 & w & 14.5 & 438.2 & w & - & 36.7 & w & 49.6 & w & 7.7 \\
\hline December .............................. & w & 11.8 & 480.1 & $w$ & - & 44.8 & $w$ & 53.9 & w & $w$ \\
\hline 1994 Average ........................... & $w$ & 19.8 & 416.9 & 39.5 & $\mathbf{w}$ & 14.4 & 0.9 & 21.5 & $\ddot{w}$ & 4.2 \\
\hline \multicolumn{11}{|l|}{ Washington } \\
\hline 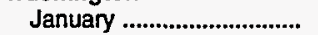 & w & w & $1,172.5$ & 231.2 & - & w & 4.6 & 115.2 & - & 360.8 \\
\hline 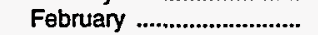 & w & w & 1.171 .9 & 98.0 & $w$ & $w$ & 4.0 & 83.6 & - & 436.9 \\
\hline 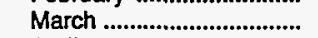 & $w$ & $\ddot{w}$ & $1,295.3$ & 139.6 & $w$ & 8.1 & 2.8 & 17.0 & - & 414.4 \\
\hline 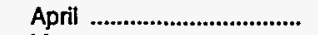 & $w$ & w & $1,283.5$ & 439.1 & - & NA & W & 14.4 & - & 325.1 \\
\hline 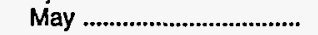 & w & w & $1,265.4$ & 416.4 & - & 5.8 & $w$ & 4.8 & - & 267.1 \\
\hline 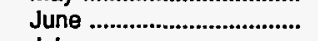 & $\ddot{w}$ & $\ddot{w}$ & $1,574.0$ & 285.7 & - & 7.7 & $w$ & 9.8 & - & 397.5 \\
\hline 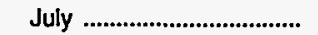 & w & w & $1,549.2$ & 144.3 & - & 6.6 & $w$ & 8.6 & - & 356.3 \\
\hline August ........................................ & $w$ & w & $1,716.9$ & 326.9 & - & 12.1 & $w$ & 11.9 & - & 402.4 \\
\hline 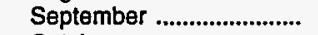 & w & w & $1,665.2$ & 278.4 & - & 13.9 & w & 16.8 & - & 351.0 \\
\hline 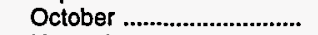 & w & w & $1,513.8$ & 270.2 & - & 16.0 & 1.5 & 27.4 & - & 253.2 \\
\hline November ........................... & $w$ & $w$ & $1,543.5$ & 179.7 & - & 31.9 & 3.0 & 82.6 & - & 451.4 \\
\hline 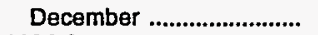 & $w$ & $w$ & 1.408 .4 & 197.1 & - & $w$ & 2.3 & 102.8 & - & 439.9 \\
\hline 1994 Average .............................. & $\mathbf{w}$ & $\mathbf{w}$ & $1,431.1$ & 251.3 & $\mathbf{w}$ & 13.1 & 1.7 & 41.0 & - & 370.7 \\
\hline
\end{tabular}

Dash $(-)=$ No data reported.

NA = Not available.

$W=$ Withheld to avoid disclosure of individual company data.

Notes: PAD District and U.S. totals equal the sum of the volumes for all States. In certain PAD Districts, however, volumes are not shown for every State.

Note: Totals may not equal the sum of the components due to rounding.

Source: Energy Information Administration Form EIA-782A, "Refiners'/Gas Plant Operators' Monthly Petroleum Product Sales Report." 
Table 46. Refiner No. 2 Distillate, Diesel Fuel, and Fuel Oil Volumes by PAD District and State

(Thousand Gallons per Day)

\begin{tabular}{|c|c|c|c|c|c|c|c|c|c|c|}
\hline \multirow{3}{*}{$\begin{array}{c}\text { Geographle Area } \\
\text { Month }\end{array}$} & \multicolumn{6}{|c|}{ No. 2 Diesel Fuel } & \multicolumn{2}{|c|}{ No. 2 Fuel Oil } & \multicolumn{2}{|c|}{ No. 2 Distillate } \\
\hline & \multicolumn{2}{|c|}{ Low-Sulfur } & \multicolumn{2}{|c|}{ Hlgh-Sulfur } & \multicolumn{2}{|c|}{ Total } & \multirow{2}{*}{$\begin{array}{l}\text { Sales to } \\
\text { End Users }\end{array}$} & \multirow{2}{*}{$\begin{array}{c}\text { Sales for } \\
\text { Resale }\end{array}$} & \multirow{2}{*}{$\begin{array}{l}\text { Sales to } \\
\text { End Users }\end{array}$} & \multirow{2}{*}{$\begin{array}{l}\text { Sales for } \\
\text { Resalo }\end{array}$} \\
\hline & $\begin{array}{c}\text { Sales to } \\
\text { End Users }\end{array}$ & $\begin{array}{l}\text { Sales for } \\
\text { Resale }\end{array}$ & $\begin{array}{c}\text { Sales to } \\
\text { End Users }\end{array}$ & $\begin{array}{l}\text { Sales for } \\
\text { Resalo }\end{array}$ & $\begin{array}{c}\text { Sales to } \\
\text { End Users }\end{array}$ & $\begin{array}{l}\text { Sales for } \\
\text { Resale }\end{array}$ & & & & \\
\hline United States & & & & & & & & & & \\
\hline 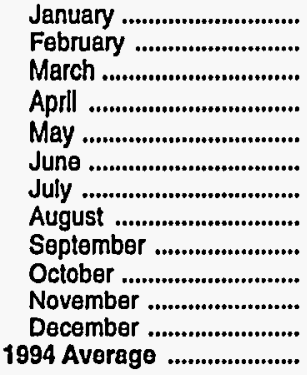 & $\begin{array}{l}11,803.6 \\
12,515.8 \\
12,835.2 \\
12,326.5 \\
13,365.8 \\
13,482.6 \\
12,252.9 \\
13,592.8 \\
13,434.9 \\
13,160.9 \\
13,132.8 \\
12,410.7 \\
12,859.8\end{array}$ & $\begin{array}{l}47,268.5 \\
50,111.1 \\
55,927.1 \\
57,738.4 \\
59,828.0 \\
64,212.3 \\
56,489.3 \\
63,480.3 \\
63,110.1 \\
61,301.6 \\
56,294.8 \\
55,418.7 \\
57,629.9\end{array}$ & $\begin{array}{l}8,045.7 \\
9,094.1 \\
9,701.0 \\
9,809.1 \\
9,185.2 \\
9,381.6 \\
8,712.8 \\
7,863.0 \\
7,748.1 \\
7,201.3 \\
7,067.9 \\
7,365.3 \\
8,425.0\end{array}$ & $\begin{array}{l}16,111.7 \\
15,206.1 \\
15,865.3 \\
16,557.7 \\
15,022.1 \\
15,402.2 \\
13,395.6 \\
13,688.5 \\
15,450.8 \\
14,362.0 \\
12,730.1 \\
13,441.0 \\
14,762.9\end{array}$ & $\begin{array}{l}19,849.3 \\
21,609.9 \\
22,536.2 \\
22,135.6 \\
22,551.0 \\
22,864.2 \\
20,965.7 \\
21,455.8 \\
21,183.0 \\
20,362.1 \\
20,200.7 \\
19,776.0 \\
21,284.8\end{array}$ & $\begin{array}{l}63,380.3 \\
65,317.2 \\
71,792.4 \\
74,296.1 \\
74,850.1 \\
79,614.5 \\
69,884.9 \\
77,168.8 \\
78,560.9 \\
75,663.7 \\
69,024.9 \\
68,859.7 \\
72,392.8\end{array}$ & $\begin{array}{l}4,712.8 \\
4,101.3 \\
3,065.7 \\
2,271.6 \\
2,331.0 \\
2,324.5 \\
2,074.5 \\
3,651.7 \\
3,683.3 \\
3,862.5 \\
3,970.8 \\
4,348.9 \\
3,363.9\end{array}$ & $\begin{array}{l}46,538.3 \\
47,196.4 \\
38,589.0 \\
29,812.7 \\
26,629.5 \\
29,257.9 \\
25,045.2 \\
26,351.3 \\
28,597.7 \\
28,219.3 \\
30,993.5 \\
38,683.1 \\
32,912.6\end{array}$ & $\begin{array}{l}24,562.1 \\
25,711.1 \\
25,601.9 \\
24,407.2 \\
24,882.0 \\
25,188.8 \\
23,040.3 \\
25,107.5 \\
24,866.4 \\
24,224.7 \\
24,171.5 \\
24,124.9 \\
24,648.7\end{array}$ & $\begin{array}{r}109,918.5 \\
112,513.6 \\
110,381.4 \\
104,108.9 \\
101,479.6 \\
108,872.4 \\
94,930.1 \\
103,520.0 \\
107,158.6 \\
103,883.0 \\
100,018.4 \\
107,542.9 \\
105,305.3\end{array}$ \\
\hline 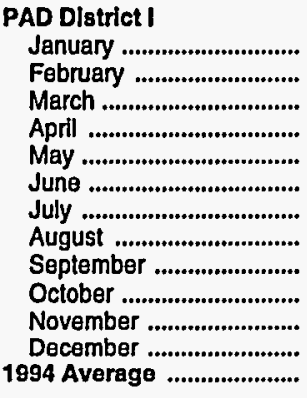 & $\begin{array}{l}4,012.7 \\
4,374.3 \\
4,521.6 \\
4,108.6 \\
4,510.6 \\
4,367.9 \\
3,821.0 \\
4,333.2 \\
4,308.1 \\
4,343.6 \\
4,375.6 \\
4,170.7 \\
4,269.6\end{array}$ & $\begin{array}{l}10,960.0 \\
12,537.8 \\
13,948.2 \\
14,241.4 \\
14,569.9 \\
15,139.3 \\
13,143.3 \\
14,257.1 \\
14,828.9 \\
14,234.8 \\
13,323.9 \\
13,837.3 \\
13,754.9\end{array}$ & $\begin{array}{l}1,347.2 \\
1,610.9 \\
1,505.0 \\
1,448.8 \\
1,650.0 \\
1,593.5 \\
1,482.0 \\
1,352.2 \\
1,319.2 \\
1,321.5 \\
1,324.4 \\
1,420.7 \\
1,446.9\end{array}$ & $\begin{array}{l}2,908.2 \\
2,528.6 \\
2,480.2 \\
1,636.8 \\
1,471.4 \\
1,438.4 \\
1,244.4 \\
1,234.5 \\
2,244.2 \\
1,645.5 \\
1,800.8 \\
1,959.0 \\
1,878.5\end{array}$ & $\begin{array}{l}5,359.9 \\
5,985.2 \\
6,026.6 \\
5,557.4 \\
6,160.6 \\
5,961.3 \\
5,303.0 \\
5,685.4 \\
5,627.3 \\
5,665.1 \\
5,700.0 \\
5,591.4 \\
5,716.5\end{array}$ & $\begin{array}{l}13,868.3 \\
15,066.4 \\
16,428.4 \\
15,878.2 \\
16,041.2 \\
16,577.7 \\
14,387.6 \\
15,491.6 \\
17,073.1 \\
15,880.3 \\
15,124.7 \\
15,796.3 \\
15,633.4\end{array}$ & $\begin{array}{l}3,267.4 \\
2,934.7 \\
2,057.0 \\
1,388.9 \\
1,238.8 \\
1,277.8 \\
1,128.2 \\
1,264.4 \\
1,325.9 \\
1,355.2 \\
1,453.5 \\
1,909.5 \\
1,710.7\end{array}$ & $\begin{array}{l}31,729.1 \\
29,287.5 \\
22,017.5 \\
12,774.1 \\
11,683.3 \\
11,854.0 \\
11,021.2 \\
12,342.8 \\
14,430.0 \\
14,618.9 \\
16,902.8 \\
22,229.3 \\
17,517.2\end{array}$ & $\begin{array}{l}8,627.3 \\
8,919.9 \\
8,083.6 \\
6,946.3 \\
7,399.5 \\
7,239.1 \\
6,431.3 \\
6,949.7 \\
6,953.2 \\
7,020.3 \\
7,153.5 \\
7,501.0 \\
7,427.2\end{array}$ & $\begin{array}{l}45,597.3 \\
44,353.9 \\
38,445.9 \\
28,652.2 \\
27,724.5 \\
28,431.7 \\
25,408.9 \\
27,834.4 \\
31,503.1 \\
30,499.2 \\
32,027.6 \\
38,025.5 \\
33,150.6\end{array}$ \\
\hline 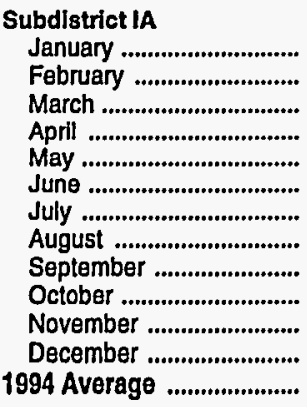 & $\begin{array}{r}252.7 \\
W \\
247.8 \\
233.6 \\
243.4 \\
235.3 \\
204.4 \\
235.0 \\
249.2 \\
W \\
275.1 \\
W \\
238.2\end{array}$ & $\begin{array}{r}1,035.5 \\
W \\
W \\
W \\
W \\
W \\
W \\
1,369.9 \\
W \\
1,737.3 \\
1,177.0 \\
1,217.0 \\
1,302.8\end{array}$ & $\begin{array}{c}27.2 \\
W \\
27.6 \\
22.9 \\
62.5 \\
34.5 \\
32.7 \\
38.5 \\
29.5 \\
W \\
8.9 \\
W \\
27.4\end{array}$ & $\begin{array}{l}W \\
W \\
W \\
W \\
W \\
W \\
W \\
3.4 \\
W \\
5.5 \\
40.5 \\
5.2 \\
W\end{array}$ & $\begin{array}{l}279.9 \\
228.0 \\
275.4 \\
256.5 \\
305.9 \\
269.8 \\
237.0 \\
273.5 \\
278.7 \\
243.0 \\
283.9 \\
253.2 \\
265.6\end{array}$ & $\begin{array}{r}1,455.9 \\
1,170.4 \\
1,439.3 \\
989.5 \\
1,410.6 \\
1,670.7 \\
1,413.9 \\
1,373.3 \\
2,062.3 \\
1,742.7 \\
1,217.6 \\
1,222.2 \\
1,432.2\end{array}$ & $\begin{array}{r}480.5 \\
478.4 \\
307.0 \\
190.1 \\
143.3 \\
108.6 \\
99.0 \\
94.3 \\
63.2 \\
104.1 \\
146.6 \\
236.2 \\
202.9\end{array}$ & $\begin{array}{r}6,701.5 \\
5,919.8 \\
4,459.5 \\
2,368.0 \\
1,636.8 \\
1,139.5 \\
824.3 \\
948.3 \\
1,684.5 \\
2,590.0 \\
3,306.1 \\
5,553.1 \\
3,081.7\end{array}$ & $\begin{array}{l}760.4 \\
706.4 \\
582.4 \\
446.6 \\
449.2 \\
378.4 \\
336.0 \\
367.8 \\
341.9 \\
347.1 \\
430.5 \\
489.4 \\
468.5\end{array}$ & $\begin{array}{l}8,157.4 \\
7,090.1 \\
5,898.8 \\
3,357.4 \\
3,047.4 \\
2,810.3 \\
2,238.2 \\
2,321.6 \\
3,746.8 \\
4,332.8 \\
4,523.7 \\
6,775.2 \\
4,513.9\end{array}$ \\
\hline 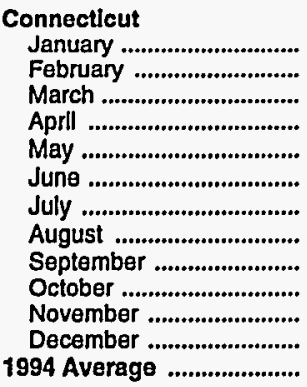 & $\begin{array}{l}84.0 \\
W \\
W \\
W \\
W \\
W \\
W \\
W \\
W \\
W \\
W \\
W \\
81.7\end{array}$ & $\begin{array}{c}246.1 \\
W \\
427.4 \\
345.7 \\
W \\
514.5 \\
286.8 \\
W \\
W \\
W \\
W \\
W \\
360.3\end{array}$ & $\begin{array}{l}W \\
W \\
W \\
W \\
W \\
W \\
W \\
W \\
W \\
W \\
W \\
W \\
W\end{array}$ & $\begin{array}{l}W \\
w \\
- \\
- \\
w \\
- \\
\bar{w} \\
w \\
w \\
w \\
w \\
W\end{array}$ & $\begin{array}{r}93.2 \\
55.6 \\
83.3 \\
82.3 \\
91.4 \\
73.7 \\
71.3 \\
81.7 \\
84.8 \\
92.2 \\
103.6 \\
88.6 \\
83.7\end{array}$ & $\begin{array}{l}246.5 \\
280.7 \\
427.4 \\
345.7 \\
336.9 \\
514.5 \\
286.8 \\
388.0 \\
667.3 \\
433.6 \\
457.8 \\
312.5 \\
391.2\end{array}$ & $\begin{array}{r}31.0 \\
33.2 \\
11.5 \\
10.7 \\
8.2 \\
8.9 \\
W \\
W \\
W \\
W \\
16.3 \\
W \\
16.0\end{array}$ & $\begin{array}{r}1,798.0 \\
1,849.3 \\
1,593.4 \\
654.6 \\
417.3 \\
291.8 \\
265.6 \\
290.1 \\
482.9 \\
949.7 \\
963.5 \\
1,233.5 \\
894.6\end{array}$ & $\begin{array}{r}124.2 \\
88.8 \\
94.8 \\
92.9 \\
99.6 \\
82.6 \\
80.1 \\
100.8 \\
96.6 \\
103.0 \\
119.9 \\
111.3 \\
99.7\end{array}$ & $\begin{array}{r}2,044.5 \\
2,130.0 \\
2,020.7 \\
1,000.3 \\
754.2 \\
806.3 \\
552.4 \\
678.1 \\
1,150.2 \\
1,383.3 \\
1,421.2 \\
1,545.9 \\
1,285.9\end{array}$ \\
\hline
\end{tabular}

See footnotes at end of table. 
Table 46. Refiner No. 2 Distillate, Diesel Fuel, and Fuel Oil Volumes by PAD District and State

(Thousand Gallons per Day) - Continued

\begin{tabular}{|c|c|c|c|c|c|c|c|c|c|c|}
\hline \multirow{3}{*}{$\begin{array}{l}\text { Geographic Area } \\
\text { Month }\end{array}$} & \multicolumn{6}{|c|}{ No. 2 Dlesel Fugl } & \multicolumn{2}{|c|}{ No. 2 Fuel Oil } & \multicolumn{2}{|c|}{ No. 2 Dlstillate } \\
\hline & \multicolumn{2}{|c|}{ Low-Sulfur } & \multicolumn{2}{|c|}{ High-Sulfur } & \multicolumn{2}{|c|}{ Total } & \multirow{2}{*}{$\begin{array}{l}\text { Sales to } \\
\text { End Users }\end{array}$} & \multirow{2}{*}{$\begin{array}{l}\text { Sales for } \\
\text { Resale }\end{array}$} & \multirow{2}{*}{$\begin{array}{l}\text { Sales to } \\
\text { End Users }\end{array}$} & \multirow{2}{*}{$\begin{array}{l}\text { Sales fo } \\
\text { Resale }\end{array}$} \\
\hline & $\begin{array}{l}\text { Sales to } \\
\text { End Users }\end{array}$ & $\begin{array}{c}\text { Sales for } \\
\text { Resale }\end{array}$ & $\begin{array}{l}\text { Sales to } \\
\text { End Users }\end{array}$ & $\begin{array}{l}\text { Sales tor } \\
\text { Resale }\end{array}$ & $\begin{array}{l}\text { Sales to } \\
\text { End Users }\end{array}$ & $\begin{array}{l}\text { Sales for } \\
\text { Resale }\end{array}$ & & & & \\
\hline
\end{tabular}

Maine

January.

February

March ..................................

April

May

June

July

August

October

November ..........................

December

1994 Average .........................

$\begin{array}{cc}12.7 & 83.7 \\ W & W \\ W & W \\ W & W \\ W & W \\ W & W \\ W & W \\ W & W \\ 15.2 & W \\ W & 230.6 \\ W & W \\ W & W \\ 12.6 & 156.2\end{array}$

$-\bar{w}$
-
$W$
$W$
$\bar{w}$
$W$
$W$
$W$
$W$
$W$
$W$

$\begin{array}{lcr}W & 12.7 & 84.0 \\ W & W & 113.6 \\ W & W & 102.0 \\ W & 14.1 & 122.5 \\ W & W & 172.8 \\ W & W & 200.3 \\ W & W & 148.6 \\ W & W & 203.6 \\ W & W & 176.2 \\ - & 16.7 & 230.6 \\ W & W & 170.9 \\ W & 7.1 & 151.5 \\ W & 13.1 & 156.6\end{array}$

$\begin{array}{ll}15.4 & 917.2 \\ W & 906.7 \\ W & 505.4 \\ 3.7 & 336.5 \\ 2.2 & 323.2 \\ W & 162.4 \\ W & 216.1 \\ W & 160.7 \\ W & 336.6 \\ W & 264.9 \\ W & 297.4 \\ W & 751.8 \\ 4.1 & 429.3\end{array}$

$28.1 \quad 1,001.3$

Massachusetts

January

March

April

Mne

July

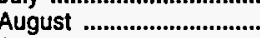

September ..........................

October

November ...........................

December
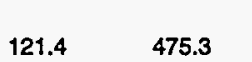

16.2
$W$
24.9
18.3
57.2
30.2
25.6
31.8
25.2
$W$
4.7
$W$
22.2

$\begin{array}{ll}W & 137.5 \\ W & 130.5 \\ W & 143 . \\ W & 116.9 \\ W & 155 . \\ W & 140.5 \\ W & 117.2 \\ W & 141.3 \\ 3.3 & 143.8 \\ 4.8 & 106.6 \\ 3.4 & 128.5 \\ 4.0 & 121.6 \\ W & 132.0\end{array}$

New Hampshire

January

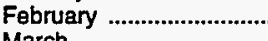

March

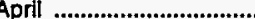

May

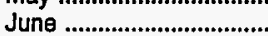

July .

August

September ..........................

October

November

December

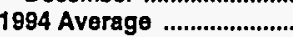

$W$
118.3
98.6

98.6

110.4

91.5

109.5

118.7

$W \quad 704.9$

$\begin{array}{ll}W & 503.7\end{array}$

$109.7 \quad 567.1$

$137.5 \quad 893.5$

661.5

731.1

330.5

674.0

723.4

743.4

589.2

$1,024.7$

709.7

375.2

507.7

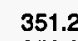

$\begin{array}{ll}356.9 & 1,858.0\end{array}$

$1,310.9$

$\begin{array}{ll}140.9 & 702.4 \\ 115.5 & 539.3\end{array}$

79.3

428.2

206.0

306.2

456.3

653.3

$1,151.5$

$\begin{array}{ll}164.1 & 2,650.1 \\ 147.3 & 1,051.9\end{array}$

$25.0 \quad 1,020.3$

$19.9 \quad 607.4$

$17.8 \quad 459.1$

$17.8 \quad 496.0$

$16.3 \quad 362.7$

$\begin{array}{ll}W & 364.7\end{array}$

$\begin{array}{cc}W & 364.4 \\ 15.5 & 512.8\end{array}$

17.2495 .5

$12.2 \quad 468.2$

$8.0 \quad 903.3$

$17.2 \quad 585.9$

Rhode lsland

January ...............................

March

Aprll ...................................

May

June

July ...

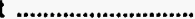

September ...................

October ...

November

December

$\begin{array}{cc}11.7 & 43.0 \\ W & 39.9 \\ W & 57.5 \\ W & 31.8 \\ W & 46.9 \\ W & 32.7 \\ 9.0 & 24.5 \\ 10.9 & W \\ 10.7 & W \\ W & W \\ W & 45.3 \\ W & 46.1 \\ 11.3 & 55.1\end{array}$

$\begin{array}{llr}W & - & 12.5 \\ W & - & 12.8 \\ W & - & 14.0 \\ W & - & 12.2 \\ W & - & 11.5 \\ W & - & 12.2 \\ - & - & 9.0 \\ - & W & 10.9 \\ - & W & 10.7 \\ W & W & 12.2 \\ W & - & 11.5 \\ - & - & W \\ W & w & 11.6\end{array}$

43.0

39.9
57.5

31.8

46.9

32.7

24.5

42.4

30.3
216.9

45.3

46.1

55.1

488.7

$257.8 \quad 1,032.9$

$271.2 \quad 1,213.3$

$219.8 \quad 1,151.6$

$188.9 \quad 949.4$

$198.3 \quad 895.4$

$176.9 \quad 1,481.0$

$177.4 \quad 1,363.0$

$234.3 \quad 1,526.6$

$285.8 \quad 3,157.8$

$1,716.1$

1994 Average

$\begin{array}{ccc}17.4 & 166.7 \\ W & 51.1 & \\ W & W & \\ W & 120.1 & \\ W & W & \\ W & W & \\ W & W & \\ W & W & \\ W & W & \\ W & W & \\ 22.2 & W & \\ 20.9 & 180.8 & \\ 17.5 & 132.8 & \end{array}$

$\begin{array}{ll}N A & W \\ W & - \\ W & W \\ W & W \\ W & W \\ W & W \\ W & W \\ W & W \\ W & W \\ - & -\end{array}$

$\begin{array}{ccr}W & 18.0 & 167.2 \\ \bar{W} & 11.3 & 51.1 \\ - & 14.1 & 80.8 \\ W & 24.6 & 120.1 \\ W & 24.1 & 137.7 \\ W & 22.4 & 158.9 \\ W & 20.4 & 180.4 \\ W & 16.2 & 121.1 \\ W & 16.0 & 127.0 \\ W & W & 127.9 \\ - & 22.2 & 138.2 \\ W & 20.9 & 180.8 \\ W & 18.3 & 133.2\end{array}$

\begin{tabular}{rrrr}
$W$ & $W$ & 61.5 & 209.9 \\
$W$ & $W$ & 57.4 & 147.5 \\
$W$ & $W$ & 45.0 & 157.6 \\
$W$ & $W$ & 26.8 & 169.2 \\
$W$ & $W$ & 22.7 & 85.7 \\
$W$ & $W$ & 21.0 & 52.9 \\
$W$ & $W$ & 15.4 & 47.1 \\
$W$ & $W$ & 17.8 & 82.9 \\
$W$ & $W$ & 21.6 & 69.8 \\
$W$ & $W$ & 24.9 & 265.2 \\
$W$ & $W$ & 26.3 & 140.3 \\
$W$ & $W$ & $W$ & 177.2 \\
$W$ & $W$ & 32.0 & 133.9 \\
& & & \\
& & & \\
27.5 & $1,339.5$ & 45.4 & $1,506.7$ \\
25.4 & $1,113.1$ & 36.7 & $1,164.2$ \\
18.6 & 922.6 & 32.7 & $1,003.5$ \\
18.2 & 493.9 & 42.8 & 614.0 \\
4.8 & 292.1 & 28.9 & 429.8 \\
7.7 & 222.8 & 30.0 & 381.7 \\
10.1 & 109.9 & 30.5 & 290.2 \\
$W$ & 131.5 & 26.0 & 252.6 \\
5.8 & 315.2 & 21.8 & 442.2 \\
5.8 & 645.8 & 14.5 & 773.7 \\
8.3 & 754.7 & 30.5 & 892.9 \\
13.0 & 716.6 & 33.9 & 897.4 \\
12.9 & 585.4 & 31.1 & 718.6 \\
\hline & & & \\
\hline & & &
\end{tabular}

See footnotes at end of table. 
Table 46. Refiner No. 2 Distillate, Diesel Fuel, and Fuel Oil Volumes by PAD District and State

(Thousand Gallons per Day) - Continued

\begin{tabular}{|c|c|c|c|c|c|c|c|c|c|c|}
\hline \multirow{3}{*}{$\begin{array}{c}\text { Geographic Area } \\
\text { Month }\end{array}$} & \multicolumn{6}{|c|}{ No. 2 Diesel Fuel } & \multicolumn{2}{|c|}{ No. 2 Fuol O॥l } & \multicolumn{2}{|c|}{ No. 2 Distillate } \\
\hline & \multicolumn{2}{|c|}{ Low-Sulfur } & \multicolumn{2}{|c|}{ High-Sulfur } & \multicolumn{2}{|c|}{ Total } & \multirow{2}{*}{$\begin{array}{l}\text { Sales to } \\
\text { End Users }\end{array}$} & \multirow{2}{*}{$\begin{array}{l}\text { Sales for } \\
\text { Resale }\end{array}$} & \multirow{2}{*}{$\begin{array}{l}\text { Sales to } \\
\text { End Users }\end{array}$} & \multirow{2}{*}{$\begin{array}{l}\text { Sales for } \\
\text { Resale }\end{array}$} \\
\hline & $\begin{array}{l}\text { Seles to } \\
\text { End Users }\end{array}$ & $\begin{array}{l}\text { Sales for } \\
\text { Resale }\end{array}$ & $\begin{array}{l}\text { Sales to } \\
\text { End Users }\end{array}$ & $\begin{array}{l}\text { Sales for } \\
\text { Resale }\end{array}$ & $\begin{array}{l}\text { Saies to } \\
\text { End Users }\end{array}$ & $\begin{array}{l}\text { Sales for } \\
\text { Resale }\end{array}$ & & & & \\
\hline
\end{tabular}

\begin{tabular}{|c|c|c|c|c|c|c|c|c|c|c|}
\hline \multicolumn{11}{|l|}{ Vermont } \\
\hline 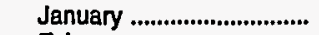 & $W$ & 20.8 & $W$ & $w$ & $w$ & 21.7 & $W$ & $W$ & 12.5 & $w$ \\
\hline February ............................. & 6.6 & $W$ & $W$ & W & $W$ & 23.5 & $W$ & $w$ & 11.1 & 108.5 \\
\hline March ................................. & 6.0 & $W$ & $W$ & $w$ & $W$ & 40.5 & $W$ & $W$ & 13.1 & 67.7 \\
\hline 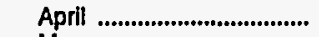 & $W$ & 38.8 & $W$ & - & 6.4 & 38.8 & $W$ & w & 8.4 & 81.9 \\
\hline 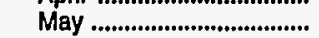 & 5.8 & $W$ & W & $w$ & $\mathrm{~W}$ & 42.3 & W & $\ddot{w}$ & 8.9 & 68.5 \\
\hline June .................................... & 5.6 & 40.9 & $w$ & - & $W$ & 40.9 & $W$ & $w$ & 8.6 & 55.0 \\
\hline July .................................. & $w$ & $w$ & W & $w$ & $\ddot{w}$ & 30.2 & w & $\ddot{w}$ & $w$ & 34.4 \\
\hline 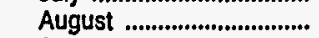 & $w$ & $w$ & $\ddot{W}$ & W & $w$ & 29.0 & $w$ & $\dddot{w}$ & $w$ & 48.3 \\
\hline September ........................ & 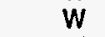 & 36.8 & $W$ & - & $\ddot{W}$ & 36.8 & W & W & 9.5 & 90.8 \\
\hline Oclober .............................. & $W$ & 24.0 & $W$ & - & $w$ & 24.0 & $W$ & $w$ & 10.0 & 52.0 \\
\hline November ......................... & 4.3 & 30.2 & $w$ & - & $w$ & 30.2 & W & $\ddot{w}$ & 7.4 & 74.3 \\
\hline December ......................... & $w$ & 23.6 & W & - & $w$ & 23.6 & $w$ & $w$ & $\ddot{w}$ & 93.7 \\
\hline 1984 Average ...................... & 5.4 & 31.3 & $\mathbf{W}$ & $w$ & $w$ & 31.8 & $w$ & 41.6 & 9.3 & 73.5 \\
\hline \multicolumn{11}{|l|}{ Subdlstrict IB } \\
\hline 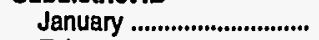 & $1,436.3$ & $3,808.3$ & 451.8 & 615.3 & $1,888.1$ & $4,423.5$ & $1,956.9$ & $20,246.9$ & $3,844.9$ & $24,670.5$ \\
\hline February ............................ & $W$ & W & W & $W$ & $2,013.6$ & $4,706.2$ & $1,829.1$ & $19,217.7$ & $3,842.7$ & $23,923.9$ \\
\hline March .................................. & $1,605.2$ & $W$ & 291.5 & $W$ & $1,896.7$ & $5,713.9$ & $1,267.0$ & $14,918.6$ & $3,163.7$ & $19,832.5$ \\
\hline April & $1,420.0$ & $w$ & 343.9 & w & $1,763.9$ & $6,276.3$ & 796.8 & $7,527.6$ & $2,560.7$ & $13,803.9$ \\
\hline May ................................... & $1,616.4$ & $w$ & 396.6 & W & $2,013.0$ & $6,466.1$ & 611.7 & $7,059.6$ & $2,624.7$ & $13,525.7$ \\
\hline Jung .................................. & $1,657.9$ & $w$ & 413.7 & $w$ & $2,071.6$ & $6,635.5$ & 624.1 & $7,720.9$ & $2,695.7$ & $14,356.5$ \\
\hline July .................................... & $1,456.3$ & $w$ & 374.1 & $w$ & $1,830.4$ & $6,121.0$ & 607.2 & $7,450.4$ & $2,437.6$ & $13,571.4$ \\
\hline 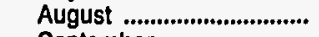 & $1,567.5$ & $6,463.1$ & 352.6 & 284.0 & $1,920.1$ & $6,747.1$ & 576.3 & $8,104.4$ & $2,496.4$ & $14,851.5$ \\
\hline September ......................... & $1,628.8$ & W & 329.9 & $W$ & $1,958.7$ & $6,950.9$ & 642.6 & $9,408.5$ & $2,601.3$ & $16,359.3$ \\
\hline 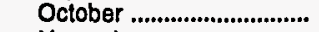 & $W$ & $5,551.5$ & W & 619.6 & $1,980.3$ & $6,171.1$ & 614.2 & $8,663.0$ & $2,594.5$ & $14,834.1$ \\
\hline November .......................... & $1,527.0$ & $5,498.1$ & 357.3 & 553.2 & $1,884.4$ & $6,051.3$ & 698.6 & $10,294.4$ & $2,583.0$ & $16,345.7$ \\
\hline December ........................... & W & $5,654.7$ & W & 660.1 & $1,879.7$ & $6,314.8$ & 976.6 & $12,978.9$ & $2,856.4$ & $19,293.8$ \\
\hline 1994 Average & $1,545.9$ & $5,573.9$ & 378.5 & 480.5 & $1,924.4$ & $6,054.5$ & 928.7 & $11,024.4$ & $2,853.1$ & $17,078.9$ \\
\hline \multicolumn{11}{|l|}{ Delaware } \\
\hline January ................................. & 27.5 & 227.1 & $W$ & $w$ & 28.4 & 234.2 & 25.7 & 546.5 & 54.1 & 780.8 \\
\hline February ............................. & 28.7 & $W$ & W & $W$ & $W$ & 195.4 & $W$ & 473.2 & 95.5 & 668.6 \\
\hline 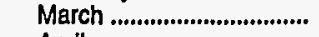 & 27.8 & $W$ & $W$ & $W$ & $W$ & W & $W$ & 373.5 & $W$ & W \\
\hline April & 24.1 & $W$ & $W$ & $W$ & $W$ & 179.0 & $W$ & $W$ & $w$ & 301.7 \\
\hline May .................................... & 23.9 & $W$ & $W$ & W & $w$ & 181.2 & $W$ & W & $w$ & 267.7 \\
\hline 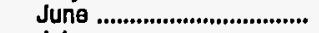 & 22.0 & 287.2 & $w$ & - & $w$ & 287.2 & $W$ & $w$ & $w$ & 461.1 \\
\hline July ..................................... & 20.8 & $W$ & $w$ & $w$ & W & 198.7 & $W$ & W & $W$ & 281.3 \\
\hline August .............................. & 19.2 & $w$ & $W$ & $w$ & $W$ & 299.1 & $W$ & $W$ & W & 407.3 \\
\hline September ........................ & $W$ & $W$ & $W$ & $W$ & 19.8 & $W$ & $W$ & $W$ & 32.9 & $w$ \\
\hline October .............................. & 24.6 & $W$ & $W$ & $W$ & $W$ & W & $W$ & $W$ & $W$ & $W$ \\
\hline November ......................... & W & $W$ & $W$ & $W$ & 22.4 & 180.6 & $W$ & $W$ & 30.8 & 338.2 \\
\hline December .......................... & 19.2 & W & W & $w$ & $w$ & 208.2 & $\ddot{W}$ & $\ddot{W}$ & 27.4 & 450.5 \\
\hline 1994 Average .................... & 23.0 & 223.8 & $\mathbf{W}$ & 2.2 & 25.1 & 226.0 & 18.1 & 220.6 & 43.2 & 446.6 \\
\hline \multicolumn{11}{|l|}{ District of Columbia } \\
\hline January .............................. & 2.4 & 5.4 & - & - & 2.4 & 5.4 & $W$ & 55.4 & 6.6 & 60.8 \\
\hline February ............................ & $W$ & 6.3 & - & - & $W$ & 6.3 & $w$ & 60.8 & 14.5 & 67.1 \\
\hline March ................................. & 1.6 & $w$ & $w$ & - & $w$ & $W$ & $W$ & 66.3 & $w$ & $w$ \\
\hline April & $w$ & 8.1 & - & - & $w$ & 8.1 & $W$ & $W$ & w & 15.7 \\
\hline 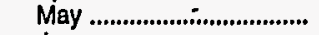 & W & 7.3 & - & - & w & 7.3 & $W$ & $w$ & W & 9.6 \\
\hline 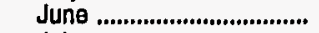 & W & 7.9 & - & - & W & 7.9 & $W$ & $w$ & $w$ & 12.7 \\
\hline July ......................................... & $W$ & 5.9 & - & - & $W$ & 5.9 & $W$ & $W$ & $W$ & 17.5 \\
\hline August ............................... & $W$ & 7.1 & - & - & $W$ & 7.1 & W & W & W & 15.2 \\
\hline September ......................... & $W$ & $W$ & $W$ & - & 3.5 & $W$ & $W$ & $w$ & 7.9 & $w$ \\
\hline 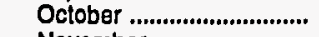 & $W$ & $W$ & - & - & $W$ & $W$ & $W$ & $w$ & $w$ & $w$ \\
\hline November ........................... & W & 20.7 & W & - & 3.9 & 20.7 & $W$ & $w$ & 7.6 & 25.2 \\
\hline 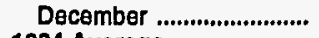 & W & 5.2 & $\bar{z}$ & - & $w$ & 5.2 & $W$ & W & 12.1 & 31.4 \\
\hline 1994 Average ..................... & 3.4 & 7.9 & $\mathbf{W}$ & - & 3.4 & 7.9 & $\mathbf{W}$ & 25.9 & $W$ & 33.8 \\
\hline
\end{tabular}

See footnotes at end of table. 
Table 46. Refiner No. 2 Distillate, Diesel Fuel, and Fuel Oil Volumes by PAD District and State

(Thousand Gallons per Day) - Continued

\begin{tabular}{|c|c|c|c|c|c|c|c|c|c|c|}
\hline \multirow{3}{*}{$\begin{array}{c}\text { Geographic Area } \\
\text { Month }\end{array}$} & \multicolumn{6}{|c|}{ No. 2 Diesel Fuel } & \multicolumn{2}{|c|}{ No. 2 Fuel Oll } & \multicolumn{2}{|c|}{ No. 2 Distlllate } \\
\hline & \multicolumn{2}{|c|}{ Low-Sulfur } & \multicolumn{2}{|c|}{ High-Sulfur } & \multicolumn{2}{|c|}{ Total } & \multirow{2}{*}{$\begin{array}{c}\text { Sales to } \\
\text { End Users }\end{array}$} & \multirow{2}{*}{$\begin{array}{l}\text { Sales for } \\
\text { Resale }\end{array}$} & \multirow{2}{*}{$\begin{array}{l}\text { Sales to } \\
\text { End Users }\end{array}$} & \multirow{2}{*}{$\begin{array}{l}\text { Sales for } \\
\text { Resale }\end{array}$} \\
\hline & $\begin{array}{c}\text { Sales to } \\
\text { End Users }\end{array}$ & $\begin{array}{c}\text { Sales for } \\
\text { Resale }\end{array}$ & $\begin{array}{c}\text { Sales to } \\
\text { End Users }\end{array}$ & $\begin{array}{c}\text { Sales for } \\
\text { Resale }\end{array}$ & $\begin{array}{c}\text { Sales to } \\
\text { End Users }\end{array}$ & $\begin{array}{c}\text { Sales for } \\
\text { Resale }\end{array}$ & & & & \\
\hline Maryland & & & & & & & & & & \\
\hline 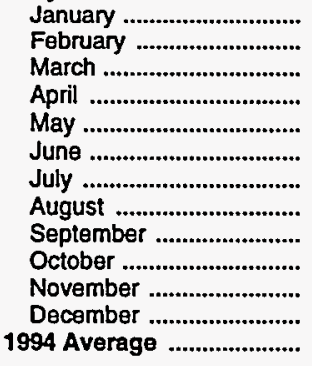 & $\begin{array}{r}164.5 \\
169.9 \\
200.0 \\
W \\
W \\
W \\
W \\
W \\
186.6 \\
199.7 \\
216.1 \\
223.5 \\
188.5\end{array}$ & $\begin{array}{l}419.4 \\
427.8 \\
530.0 \\
467.6 \\
513.1 \\
529.7 \\
500.2 \\
558.2 \\
487.1 \\
507.5 \\
532.4 \\
486.8 \\
497.1\end{array}$ & $\begin{array}{r}81.1 \\
203.0 \\
92.8 \\
W \\
W \\
W \\
W \\
W \\
85.9 \\
85.8 \\
96.9 \\
115.4 \\
104.0\end{array}$ & $\begin{array}{l}70.1 \\
60.8 \\
83.6 \\
48.9 \\
36.5 \\
25.7 \\
20.2 \\
26.6 \\
66.1 \\
55.3 \\
48.1 \\
66.2 \\
50.6\end{array}$ & $\begin{array}{l}245.6 \\
372.9 \\
292.8 \\
307.3 \\
263.6 \\
321.6 \\
229.7 \\
276.5 \\
272.5 \\
285.5 \\
313.0 \\
338.9 \\
292.6\end{array}$ & $\begin{array}{l}489.5 \\
488.6 \\
613.7 \\
516.5 \\
549.6 \\
555.4 \\
520.4 \\
584.8 \\
553.2 \\
562.8 \\
580.5 \\
553.0 \\
547.8\end{array}$ & $\begin{array}{r}256.5 \\
259.4 \\
217.5 \\
81.2 \\
34.9 \\
71.1 \\
55.0 \\
74.9 \\
79.9 \\
77.9 \\
98.0 \\
137.5 \\
119.6\end{array}$ & \begin{tabular}{r|}
$1,353.0$ \\
$1,059.7$ \\
826.0 \\
399.7 \\
205.9 \\
186.1 \\
177.2 \\
312.3 \\
489.2 \\
516.6 \\
439.8 \\
858.7 \\
566.7
\end{tabular} & $\begin{array}{l}502.9 \\
632.3 \\
510.3 \\
388.5 \\
298.5 \\
392.7 \\
284.7 \\
351.4 \\
352.4 \\
363.5 \\
411.0 \\
476.5 \\
412.1\end{array}$ & $\begin{array}{r}1,842.5 \\
1,548.3 \\
1,439.7 \\
916.2 \\
755.5 \\
741.5 \\
697.6 \\
897.1 \\
1,042.4 \\
1,079.4 \\
1,020.4 \\
1,411.7 \\
1,114.5\end{array}$ \\
\hline 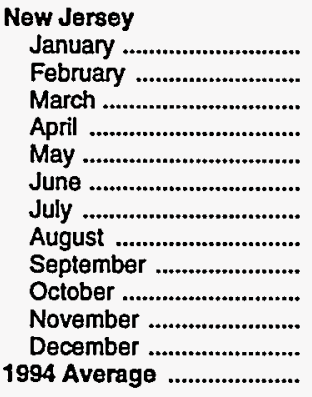 & $\begin{array}{l}337.1 \\
337.8 \\
364.7 \\
356.1 \\
402.1 \\
412.3 \\
294.1 \\
349.3 \\
406.2 \\
410.0 \\
366.3 \\
333.5 \\
364.1\end{array}$ & $\begin{array}{r}911.0 \\
1,009.9 \\
1,427.8 \\
1,783.8 \\
1,919.2 \\
2,011.0 \\
1,790.7 \\
2,040.4 \\
2,141.0 \\
1,547.0 \\
1,405.1 \\
1,746.0 \\
1,647.5\end{array}$ & $\begin{array}{r}60.6 \\
54.4 \\
52.1 \\
35.0 \\
46.1 \\
52.3 \\
142.6 \\
146.8 \\
128.8 \\
100.4 \\
127.5 \\
120.5 \\
89.2\end{array}$ & $\begin{array}{r}196.6 \\
188.8 \\
192.5 \\
127.2 \\
70.2 \\
65.0 \\
62.4 \\
99.7 \\
156.0 \\
390.0 \\
324.3 \\
309.4 \\
181.9\end{array}$ & $\begin{array}{l}397.7 \\
392.2 \\
416.8 \\
391.1 \\
448.2 \\
464.6 \\
436.6 \\
496.1 \\
535.0 \\
510.4 \\
493.8 \\
453.9 \\
453.3\end{array}$ & $\begin{array}{l}1,107.6 \\
1,198.7 \\
1,620.4 \\
1,911.0 \\
1,989.4 \\
2,076.0 \\
1,853.1 \\
2,140.1 \\
2,296.9 \\
1,937.0 \\
1,729.4 \\
2,055.4 \\
1,829.5\end{array}$ & $\begin{array}{l}353.6 \\
342.9 \\
171.2 \\
170.4 \\
104.8 \\
115.8 \\
100.6 \\
133.9 \\
122.9 \\
122.4 \\
139.7 \\
148.7 \\
167.8\end{array}$ & $\begin{array}{l}7,829.8 \\
8,034.7 \\
5,307.4 \\
3,358.7 \\
3,444.0 \\
3,232.0 \\
3,579.9 \\
3,487.4 \\
5,096.8 \\
3,843.8 \\
4,940.7 \\
5,383.4 \\
4,775.2\end{array}$ & $\begin{array}{l}751.4 \\
735.1 \\
588.0 \\
561.5 \\
553.0 \\
580.3 \\
537.3 \\
630.0 \\
657.9 \\
632.8 \\
633.5 \\
602.6 \\
621.2\end{array}$ & $\begin{array}{l}8,937.5 \\
9,233.4 \\
6,927.7 \\
5,269.8 \\
5,433.4 \\
5,307.9 \\
5,433.0 \\
5,627.5 \\
7,393.7 \\
5,780.8 \\
6,670.1 \\
7,438.7 \\
6,604.7\end{array}$ \\
\hline 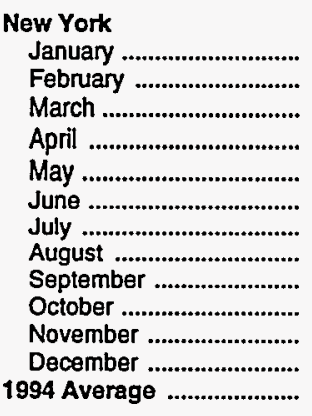 & $\begin{array}{l}320.8 \\
382.9 \\
355.3 \\
317.8 \\
352.5 \\
372.5 \\
339.6 \\
285.0 \\
288.9 \\
292.2 \\
300.3 \\
280.5 \\
323.6\end{array}$ & $\begin{array}{c}778.0 \\
W \\
W \\
W \\
W \\
W \\
W \\
W \\
W \\
W \\
W \\
W \\
975.2\end{array}$ & $\begin{array}{r}16.1 \\
16.8 \\
17.8 \\
13.7 \\
19.4 \\
24.4 \\
20.2 \\
15.8 \\
19.3 \\
23.2 \\
12.5 \\
8.4 \\
17.3\end{array}$ & $\begin{array}{l}W \\
W \\
W \\
W \\
W \\
W \\
W \\
W \\
W \\
W \\
W \\
W \\
42.9\end{array}$ & $\begin{array}{l}336.8 \\
399.7 \\
373.1 \\
331.5 \\
371.9 \\
396.9 \\
359.8 \\
300.8 \\
308.2 \\
315.5 \\
312.8 \\
288.8 \\
340.9\end{array}$ & $\begin{array}{r}849.4 \\
766.8 \\
857.6 \\
1,119.6 \\
1,019.7 \\
1,139.8 \\
1,206.5 \\
1,117.2 \\
1,332.2 \\
994.7 \\
893.7 \\
909.0 \\
1,018.1\end{array}$ & $\begin{array}{l}773.2 \\
683.2 \\
478.2 \\
290.2 \\
156.7 \\
166.1 \\
146.9 \\
154.7 \\
135.8 \\
189.3 \\
251.9 \\
381.7 \\
315.5\end{array}$ & $\begin{array}{l}5,094.1 \\
4,565.9 \\
3,505.5 \\
1,654.2 \\
1,994.3 \\
2,309.4 \\
1,983.8 \\
1,770.8 \\
1,437.3 \\
1,834.8 \\
2,604.0 \\
3,377.7 \\
2,669.5\end{array}$ & $\begin{array}{r}1,110.0 \\
1,082.9 \\
851.3 \\
621.7 \\
528.6 \\
563.0 \\
506.7 \\
455.5 \\
444.0 \\
504.7 \\
564.6 \\
670.5 \\
656.4\end{array}$ & $\begin{array}{l}5,943.5 \\
5,332.7 \\
4,363.1 \\
2,773.8 \\
3,014.0 \\
3,449.2 \\
3,190.2 \\
2,887.9 \\
2,769.5 \\
2,829.5 \\
3,497.6 \\
4,286.7 \\
3,687.6\end{array}$ \\
\hline 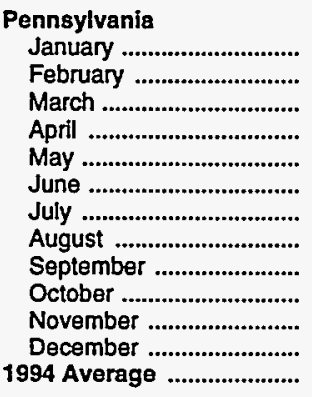 & $\begin{array}{l}584.0 \\
606.9 \\
655.9 \\
553.9 \\
660.1 \\
657.0 \\
622.0 \\
718.5 \\
725.5 \\
685.5 \\
620.3 \\
625.7 \\
643.3\end{array}$ & $\begin{array}{r}1,467.4 \\
1,843.4 \\
2,125.7 \\
W \\
W \\
2,393.5 \\
2,095.4 \\
2,455.6 \\
2,342.9 \\
2,207.5 \\
2,476.8 \\
2,312.5 \\
2,222.3\end{array}$ & $\begin{array}{r}293.1 \\
210.6 \\
123.9 \\
153.3 \\
241.5 \\
203.6 \\
154.7 \\
100.9 \\
94.2 \\
154.7 \\
118.2 \\
141.5 \\
165.7\end{array}$ & $\begin{array}{r}269.9 \\
207.0 \\
299.1 \\
W \\
W \\
175.8 \\
241.1 \\
143.2 \\
167.5 \\
158.3 \\
169.5 \\
271.5 \\
202.9\end{array}$ & $\begin{array}{l}877.1 \\
817.5 \\
779.7 \\
707.3 \\
901.5 \\
860.6 \\
776.7 \\
819.4 \\
819.7 \\
840.2 \\
738.5 \\
767.2 \\
809.0\end{array}$ & $\begin{array}{l}1,737.3 \\
2,050.4 \\
2,424.7 \\
2,542.2 \\
2,718.9 \\
2,569.3 \\
2,336.5 \\
2,598.8 \\
2,510.4 \\
2,365.7 \\
2,646.3 \\
2,584.1 \\
2,425.2\end{array}$ & $\begin{array}{l}543.7 \\
464.9 \\
327.7 \\
194.6 \\
263.5 \\
176.6 \\
249.4 \\
136.2 \\
286.5 \\
173.5 \\
196.9 \\
300.2 \\
275.3\end{array}$ & $\begin{array}{l}5,368.0 \\
5,023.4 \\
4,040.0 \\
1,984.5 \\
1,326.5 \\
1,814.7 \\
1,615.4 \\
2,417.7 \\
2,208.0 \\
2,285.5 \\
2,147.8 \\
3,090.7 \\
2,766.5\end{array}$ & $\begin{array}{r}1,420.8 \\
1,282.4 \\
1,107.5 \\
901.9 \\
1,165.0 \\
1,037.3 \\
1,026.1 \\
955.6 \\
1,106.2 \\
1,013.7 \\
935.5 \\
1,067.3 \\
1,084.3\end{array}$ & $\begin{array}{l}7,105.3 \\
7,073.8 \\
6,464.8 \\
4,526.7 \\
4,045.4 \\
4,384.0 \\
3,951.8 \\
5,016.5 \\
4,718.4 \\
4,651.2 \\
4,794.1 \\
5,674.8 \\
5,191.7\end{array}$ \\
\hline
\end{tabular}

See footnotes at end of table. 
Table 46. Refiner No. 2 Distillate, Diesel Fuel, and Fuel Oil Volumes by PAD District and State

(Thousand Gallons per Day) - Continued

\begin{tabular}{|c|c|c|c|c|c|c|c|c|c|c|}
\hline \multirow{3}{*}{$\begin{array}{l}\text { Geographio Area } \\
\text { Month }\end{array}$} & \multicolumn{6}{|c|}{ No. 2 Dlesel Fuel } & \multicolumn{2}{|c|}{ No. 2 Fuel Oil } & \multicolumn{2}{|c|}{ No. 2 Distillate } \\
\hline & \multicolumn{2}{|c|}{ Low-Sulfur } & \multicolumn{2}{|c|}{ HIgh-Sulfur } & \multicolumn{2}{|c|}{ Total } & \multirow{2}{*}{$\begin{array}{l}\text { Sales to } \\
\text { End Users }\end{array}$} & \multirow{2}{*}{$\begin{array}{l}\text { Sales for } \\
\text { Resale }\end{array}$} & \multirow{2}{*}{$\begin{array}{l}\text { Sales to } \\
\text { End Users }\end{array}$} & \multirow{2}{*}{$\begin{array}{l}\text { Sales for } \\
\text { Resalo }\end{array}$} \\
\hline & $\begin{array}{l}\text { Salos to } \\
\text { End Users }\end{array}$ & $\begin{array}{l}\text { Sales for } \\
\text { Resale }\end{array}$ & $\begin{array}{l}\text { Sales to } \\
\text { End Users }\end{array}$ & $\begin{array}{l}\text { Sales for } \\
\text { Resale }\end{array}$ & $\begin{array}{l}\text { Sales to } \\
\text { End Users }\end{array}$ & $\begin{array}{l}\text { Sales for } \\
\text { Resale }\end{array}$ & & & & \\
\hline 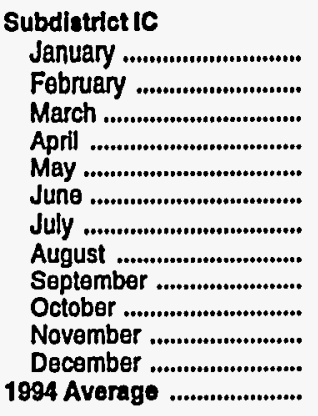 & $\begin{array}{l}2,323.8 \\
2,636.5 \\
2,668.6 \\
2,455.0 \\
2,650.8 \\
2,474.7 \\
2,160.4 \\
2,530.7 \\
2,430.2 \\
2,502.9 \\
2,573.5 \\
2,433.2 \\
2,485.5\end{array}$ & $\begin{array}{l}6,116.2 \\
7,514.8 \\
7,738.8 \\
7,329.7 \\
6,973.1 \\
7,115.2 \\
5,952.5 \\
6,424.1 \\
6,890.1 \\
6,946.0 \\
6,648.8 \\
6,965.5 \\
6,878.2\end{array}$ & $\begin{array}{r}868.1 \\
1,107.0 \\
1,185.9 \\
1,082.1 \\
1,191.0 \\
1,145.2 \\
1,075.3 \\
961.0 \\
959.7 \\
938.9 \\
958.2 \\
1,025.2 \\
1,041.0\end{array}$ & $\begin{array}{r}1,872.6 \\
1,675.1 \\
1,536.5 \\
1,282.7 \\
1,191.4 \\
1,156.2 \\
900.2 \\
947.1 \\
1,169.8 \\
1,020.5 \\
1,207.1 \\
1,293.7 \\
1,268.5\end{array}$ & $\begin{array}{l}3,191.9 \\
3,743.5 \\
3,854.5 \\
3,537.0 \\
3,841.7 \\
3,619.9 \\
3,235.6 \\
3,491.7 \\
3,389.9 \\
3,441.8 \\
3,531.7 \\
3,458.5 \\
3,526.5\end{array}$ & $\begin{array}{l}7,988.8 \\
9,189.9 \\
9,275.2 \\
8,612.4 \\
8,164.5 \\
8,271.4 \\
6,852.7 \\
7,371.2 \\
8,059.9 \\
7,966.5 \\
7,855.9 \\
8,259.3 \\
8,146.6\end{array}$ & $\begin{array}{l}830.1 \\
627.3 \\
483.0 \\
402.0 \\
483.8 \\
545.1 \\
422.0 \\
593.8 \\
620.1 \\
636.9 \\
608.3 \\
696.7 \\
579.1\end{array}$ & $\begin{array}{l}4,780.7 \\
4,150.0 \\
3,439.4 \\
2,878.5 \\
2,986.9 \\
2,993.5 \\
2,746.5 \\
3,290.2 \\
3,337.1 \\
3,365.8 \\
3,302.4 \\
3,697.3 \\
3,411.1\end{array}$ & $\begin{array}{l}4,022.0 \\
4,370.8 \\
4,337.5 \\
3,939.1 \\
4,325.6 \\
4,165.0 \\
3,657.6 \\
4,085.5 \\
4,010.0 \\
4,078.7 \\
4,140.0 \\
4,155.2 \\
4,105.6\end{array}$ & $\begin{array}{r}12,769.5 \\
13,339.8 \\
12,714.6 \\
11,490.9 \\
11,151.4 \\
11,264.9 \\
9,599.3 \\
10,661.4 \\
11,396.9 \\
11,332.3 \\
11,158.2 \\
11,956.5 \\
11,557.8\end{array}$ \\
\hline 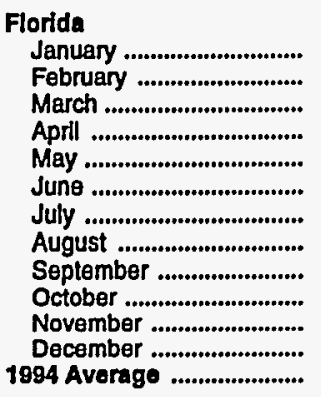 & $\begin{array}{l}795.3 \\
855.5 \\
868.6 \\
821.9 \\
877.0 \\
800.9 \\
693.5 \\
833.1 \\
800.9 \\
798.6 \\
820.8 \\
818.5 \\
815.1\end{array}$ & $\begin{array}{l}1,767.9 \\
1,976.5 \\
2,054.0 \\
1,849.2 \\
1,725.2 \\
1,671.6 \\
1,476.3 \\
1,481.2 \\
1,641.3 \\
1,757.5 \\
1,752.3 \\
1,789.5 \\
1,743.5\end{array}$ & $\begin{array}{l}261.0 \\
303.8 \\
378.8 \\
366.9 \\
479.4 \\
489.0 \\
403.7 \\
323.5 \\
343.8 \\
366.1 \\
352.5 \\
460.1 \\
377.9\end{array}$ & $\begin{array}{l}399.9 \\
415.0 \\
453.7 \\
419.8 \\
407.2 \\
326.0 \\
279.7 \\
295.4 \\
353.1 \\
299.6 \\
502.5 \\
417.5 \\
380.3\end{array}$ & $\begin{array}{l}1,056.3 \\
1,159.3 \\
1,247.4 \\
1,188.8 \\
1,356.3 \\
1,289.9 \\
1,097.3 \\
1,156.6 \\
1,144.7 \\
1,164.7 \\
1,173.3 \\
1,278.5 \\
1,193.0\end{array}$ & $\begin{array}{l}2,167.8 \\
2,391.6 \\
2,507.7 \\
2,269.0 \\
2,132.4 \\
1,997.6 \\
1,756.0 \\
1,776.6 \\
1,994.4 \\
2,057.1 \\
2,254.8 \\
2,207.0 \\
2,123.8\end{array}$ & $\begin{array}{r}113.7 \\
118.7 \\
75.6 \\
84.4 \\
W \\
141.6 \\
132.2 \\
139.5 \\
150.8 \\
71.5 \\
77.3 \\
80.1 \\
117.1\end{array}$ & $\begin{array}{l}543.7 \\
574.9 \\
538.8 \\
671.6 \\
596.0 \\
630.4 \\
579.2 \\
585.6 \\
590.6 \\
597.3 \\
592.0 \\
620.7 \\
593.3\end{array}$ & $\begin{array}{l}1,170.0 \\
1,278.0 \\
1,323.0 \\
1,273.2 \\
1,575.9 \\
1,431.6 \\
1,229.5 \\
1,296.1 \\
1,295.5 \\
1,236.2 \\
1,250.6 \\
1,358.7 \\
1,310.1\end{array}$ & $\begin{array}{l}2,711.5 \\
2,966.5 \\
3,046.5 \\
2,940.5 \\
2,728.4 \\
2,628.1 \\
2,335.2 \\
2,362.3 \\
2,585.0 \\
2,654.4 \\
2,846.8 \\
2,827.7 \\
2,717.0\end{array}$ \\
\hline 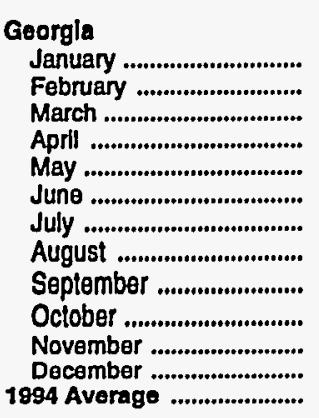 & $\begin{array}{l}635.2 \\
703.7 \\
747.9 \\
669.6 \\
678.0 \\
682.6 \\
605.2 \\
711.5 \\
672.9 \\
699.1 \\
736.9 \\
680.2 \\
685.0\end{array}$ & $\begin{array}{l}1,380.8 \\
1,943.5 \\
1,621.6 \\
1,668.9 \\
1,482.9 \\
1,479.2 \\
1,230.5 \\
1,463.2 \\
1,538.4 \\
1,529.4 \\
1,476.4 \\
1,566.8 \\
1,528.3\end{array}$ & $\begin{array}{r}96.4 \\
173.6 \\
194.5 \\
137.1 \\
179.9 \\
143.7 \\
148.4 \\
161.2 \\
145.5 \\
159.4 \\
143.1 \\
130.6 \\
151.0\end{array}$ & $\begin{array}{l}247.0 \\
394.7 \\
234.7 \\
368.5 \\
253.5 \\
231.7 \\
138.4 \\
175.4 \\
182.4 \\
132.4 \\
159.9 \\
138.3 \\
219.8\end{array}$ & $\begin{array}{l}731.6 \\
877.3 \\
942.4 \\
806.7 \\
857.9 \\
826.3 \\
753.6 \\
872.7 \\
818.4 \\
858.5 \\
880.0 \\
810.8 \\
836.1\end{array}$ & $\begin{array}{l}1,627.9 \\
2,338.2 \\
1,856.3 \\
2,037.4 \\
1,736.4 \\
1,710.9 \\
1,368.8 \\
1,638.6 \\
1,720.8 \\
1,661.7 \\
1,636.4 \\
1,705.1 \\
1,748.1\end{array}$ & $\begin{array}{r}144.3 \\
59.3 \\
78.5 \\
35.4 \\
35.0 \\
48.4 \\
41.6 \\
59.8 \\
76.1 \\
71.9 \\
58.1 \\
90.1 \\
66.7\end{array}$ & $\begin{array}{l}483.7 \\
398.3 \\
391.8 \\
439.6 \\
433.6 \\
704.8 \\
613.9 \\
671.3 \\
631.6 \\
630.6 \\
577.9 \\
644.3 \\
\mathbf{5 5 2 . 6}\end{array}$ & $\begin{array}{r}875.9 \\
936.6 \\
1,020.8 \\
842.1 \\
892.9 \\
874.7 \\
795.2 \\
932.5 \\
894.6 \\
930.4 \\
938.2 \\
900.9 \\
902.8\end{array}$ & $\begin{array}{l}2,111.6 \\
2,736.4 \\
2,248.1 \\
2,477.0 \\
2,170.0 \\
2,415.7 \\
1,982.7 \\
2,309.9 \\
2,352.3 \\
2,292.4 \\
2,214.2 \\
2,349.4 \\
2,300.8\end{array}$ \\
\hline 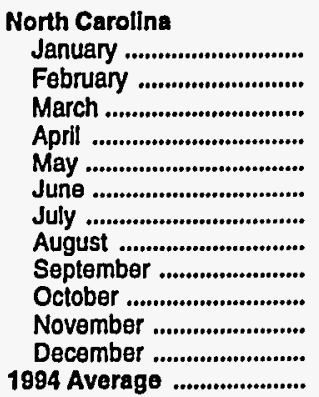 & $\begin{array}{l}349.7 \\
424.5 \\
384.8 \\
352.6 \\
422.7 \\
376.0 \\
322.0 \\
377.3 \\
362.5 \\
368.0 \\
398.5 \\
373.3 \\
375.6\end{array}$ & $\begin{array}{l}1,202.1 \\
1,318.7 \\
1,513.2 \\
1,440.9 \\
1,387.0 \\
1,417.8 \\
1,194.3 \\
1,184.0 \\
1,439.4 \\
1,346.8 \\
1,329.2 \\
1,442.2 \\
1,350.9\end{array}$ & $\begin{array}{r}190.4 \\
193.3 \\
188.5 \\
164.4 \\
157.3 \\
161.5 \\
150.8 \\
56.9 \\
47.9 \\
54.5 \\
84.1 \\
42.7 \\
123.9\end{array}$ & $\begin{array}{l}601.1 \\
392.3 \\
352.7 \\
183.4 \\
230.6 \\
230.6 \\
182.9 \\
227.5 \\
272.6 \\
303.8 \\
282.5 \\
401.5 \\
305.1\end{array}$ & $\begin{array}{l}540.0 \\
617.9 \\
573.4 \\
517.0 \\
580.1 \\
537.5 \\
472.9 \\
434.2 \\
410.4 \\
422.5 \\
482.6 \\
416.1 \\
499.5\end{array}$ & $\begin{array}{l}1,803.1 \\
1,711.0 \\
1,865.9 \\
1,624.3 \\
1,617.5 \\
1,648.4 \\
1,377.1 \\
1,411.5 \\
1,712.0 \\
1,650.6 \\
1,611.6 \\
1,843.6 \\
1,656.0\end{array}$ & $\begin{array}{r}257.8 \\
105.2 \\
120.9 \\
124.7 \\
70.2 \\
123.9 \\
68.0 \\
197.4 \\
205.1 \\
225.6 \\
219.6 \\
294.5 \\
168.3\end{array}$ & $\begin{array}{r}1,241.4 \\
922.4 \\
739.3 \\
642.5 \\
565.1 \\
555.1 \\
601.6 \\
661.0 \\
765.8 \\
757.0 \\
688.9 \\
812.9 \\
745.5\end{array}$ & $\begin{array}{l}797.8 \\
723.1 \\
694.3 \\
641.7 \\
650.3 \\
661.4 \\
540.9 \\
631.5 \\
615.4 \\
648.1 \\
702.1 \\
710.6 \\
667.8\end{array}$ & $\begin{array}{l}3,044.5 \\
2,633.4 \\
2,605.2 \\
2,266.7 \\
2,182.6 \\
2,203.5 \\
1,978.7 \\
2,072.5 \\
2,477.8 \\
2,407.6 \\
2,300.6 \\
2,656.6 \\
2,401.6\end{array}$ \\
\hline
\end{tabular}

See footnotes at end of table. 
Table 46. Refiner No. 2 Distillate, Diesel Fuel, and Fuel Oil Volumes by PAD District and State

(Thousand Gallons per Day) - Continued

\begin{tabular}{|c|c|c|c|c|c|c|c|c|c|c|}
\hline \multirow{3}{*}{$\begin{array}{c}\text { Geographic Area } \\
\text { Month }\end{array}$} & \multicolumn{6}{|c|}{ No. 2 Dlesel Fuel } & \multicolumn{2}{|c|}{ No. 2 Fuel Oil } & \multicolumn{2}{|c|}{ No. 2 Distillate } \\
\hline & \multicolumn{2}{|c|}{ Low-Sulfur } & \multicolumn{2}{|c|}{ High-Sulfur } & \multicolumn{2}{|c|}{ Total } & \multirow{2}{*}{$\begin{array}{l}\text { Sales to } \\
\text { End Users }\end{array}$} & \multirow{2}{*}{$\begin{array}{l}\text { Sales for } \\
\text { Resale }\end{array}$} & \multirow{2}{*}{$\begin{array}{l}\text { Sales to } \\
\text { End Users }\end{array}$} & \multirow{2}{*}{$\begin{array}{c}\text { Sales for } \\
\text { Resale }\end{array}$} \\
\hline & $\begin{array}{l}\text { Sales to } \\
\text { End Users }\end{array}$ & $\begin{array}{l}\text { Sales for } \\
\text { Resale }\end{array}$ & $\begin{array}{l}\text { Sales to } \\
\text { End Users }\end{array}$ & $\begin{array}{l}\text { Sales for } \\
\text { Resale }\end{array}$ & $\begin{array}{l}\text { Sales to } \\
\text { End Users }\end{array}$ & $\begin{array}{l}\text { Sales for } \\
\text { Resale }\end{array}$ & & & & \\
\hline
\end{tabular}

\begin{tabular}{|c|c|c|c|c|c|c|c|c|c|c|}
\hline South Carolina & & & & & & & & & & \\
\hline January ................................ & 260.7 & 554.8 & 20.0 & 164.5 & 280.7 & 719.2 & $W$ & 493.4 & 407.9 & $1,212.6$ \\
\hline 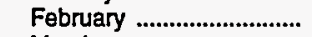 & 297.4 & $w$ & 34.3 & $W$ & 331.6 & 750.2 & w & 429.1 & 427.7 & $1,179.3$ \\
\hline March ................................... & 290.2 & $W$ & 32.8 & $w$ & 323.0 & 898.3 & w & 296.2 & 371.1 & $1,194.5$ \\
\hline 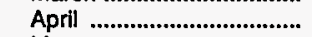 & 274.8 & $\ddot{W}$ & 21.5 & $\ddot{w}$ & 296.2 & 734.9 & $w$ & 234.1 & 336.6 & 969.0 \\
\hline 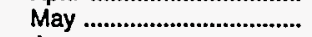 & 285.0 & $w$ & 31.4 & W & 316.3 & 742.0 & 37.5 & 244.3 & 353.8 & 986.3 \\
\hline 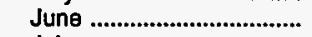 & 262.4 & $W$ & 26.9 & W & 289.3 & 820.8 & $w$ & 226.8 & 356.9 & $1,047.6$ \\
\hline 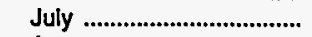 & 254.2 & $W$ & 29.3 & $\ddot{W}$ & 283.5 & 655.2 & $\ddot{w}$ & 233.8 & 321.4 & 889.1 \\
\hline 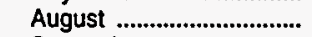 & 279.5 & $W$ & 37.6 & $W$ & 317.0 & 761.2 & w & 264.4 & 350.1 & $1,025.5$ \\
\hline September .......................... & $W$ & $w$ & $w$ & $w$ & 312.3 & 728.7 & $\dddot{w}$ & 320.0 & 361.4 & $1,048.6$ \\
\hline 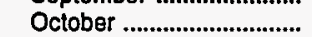 & $w$ & W & $\ddot{W}$ & w & 354.9 & 677.0 & $\dddot{w}$ & 283.5 & 405.8 & 960.5 \\
\hline November ........................... & 301.8 & $W$ & 37.9 & W & 339.7 & 654.0 & 54.3 & 286.4 & 394.0 & 940.3 \\
\hline 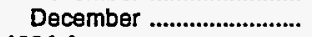 & 275.9 & $w$ & 37.2 & W & 313.2 & 725.3 & 61.2 & 318.0 & 374.4 & $1,043.3$ \\
\hline 1994 Average .......................... & 280.9 & 635.2 & 32.1 & 103.7 & 313.0 & 738.8 & 58.4 & 301.8 & 371.4 & $1,040.7$ \\
\hline Virginia & & & & & & & & & & \\
\hline 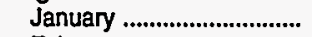 & 178.1 & 994.4 & 177.6 & 398.0 & 355.8 & $1,392.3$ & 118.3 & $1,848.9$ & 474.1 & $3,241.2$ \\
\hline February ............................. & 238.0 & $1,388.5$ & 214.3 & 322.0 & 452.3 & $1,710.5$ & 202.0 & $1,635.0$ & 654.3 & $3,345.5$ \\
\hline March .................................. & 250.6 & $1,509.3$ & 223.4 & 309.7 & 474.0 & $1,819.0$ & 107.9 & $1,299.6$ & 581.9 & $3,118.7$ \\
\hline April & 215.0 & $1,442.0$ & 238.3 & 191.8 & 453.4 & $1,633.8$ & 72.5 & 780.0 & 525.8 & $2,413.8$ \\
\hline 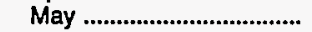 & 266.4 & $1,432.8$ & 174.3 & 169.8 & 440.6 & $1,602.6$ & 47.3 & $1,003.3$ & 487.9 & $2,605.9$ \\
\hline 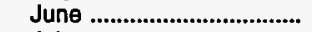 & 221.9 & $1,484.2$ & 177.1 & 229.4 & 399.0 & $1,713.6$ & 81.6 & 700.4 & 480.6 & $2,414.1$ \\
\hline 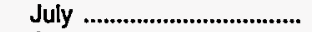 & 174.2 & $1,214.1$ & 191.1 & 182.1 & 365.4 & $1,396.2$ & 84.4 & 552.5 & 449.7 & $1,948.8$ \\
\hline 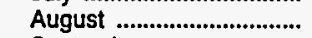 & 200.5 & $1,381.6$ & 201.2 & 136.2 & 401.6 & $1,517.8$ & 105.5 & 840.9 & 507.2 & $2,358.7$ \\
\hline September ......................... & 195.4 & $1,396.0$ & 212.7 & 226.7 & 408.1 & $1,622.7$ & 66.2 & 800.7 & 474.3 & $2,423.4$ \\
\hline 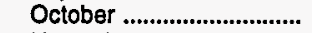 & 196.7 & $1,384.5$ & 171.8 & 162.1 & 368.5 & $1,546.7$ & 102.4 & 880.2 & 470.8 & $2,426.9$ \\
\hline November ............................. & 194.7 & $1,295.0$ & 198.2 & 139.9 & 392.9 & $1,434.9$ & 140.2 & 924.7 & 533.1 & $2,359.6$ \\
\hline December ............................ & 175.7 & $1,235.5$ & 180.7 & 204.8 & 356.4 & $1,440.3$ & 125.1 & $1,085.0$ & 481.5 & $2,525.3$ \\
\hline 1994 Average ...................... & 208.7 & $1,345.5$ & 196.5 & 222.2 & 405.2 & $1,567.7$ & 103.8 & $1,026.8$ & 509.0 & $2,584.5$ \\
\hline West Virginia & & & & & & & & & & \\
\hline 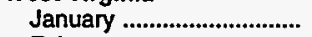 & 104.8 & 216.3 & 122.7 & $w$ & 227.5 & 278.5 & $w$ & 169.6 & 296.2 & 448.1 \\
\hline February ............................. & 117.4 & $W$ & 187.7 & $W$ & 305.1 & 288.5 & $w$ & 190.3 & 351.0 & 478.8 \\
\hline 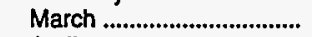 & 126.5 & $W$ & 168.0 & $w$ & 294.5 & 328.0 & w & 173.7 & 346.4 & 501.7 \\
\hline April & 121.1 & $w$ & 153.9 & $w$ & 274.9 & 313.0 & $w$ & 110.8 & 319.7 & 423.8 \\
\hline 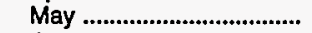 & 121.7 & $W$ & 168.8 & $w$ & 290.5 & 333.6 & $w$ & 144.6 & 364.9 & 478.2 \\
\hline June & 130.9 & W & 147.0 & W & 278.0 & 380.1 & W & 175.9 & 359.8 & 556.0 \\
\hline 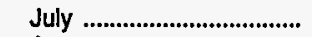 & 111.2 & $W$ & 151.9 & $W$ & 263.1 & 299.3 & W & 165.5 & 321.0 & 464.8 \\
\hline 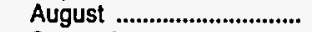 & 128.9 & $W$ & 180.6 & $w$ & 309.5 & 265.5 & W & 267.0 & 368.1 & 532.5 \\
\hline September .......................... & $W$ & $W$ & $W$ & w & 296.1 & 281.3 & W & 228.5 & 368.8 & 509.8 \\
\hline October ............................... & $\ddot{W}$ & $\ddot{W}$ & W & $\ddot{w}$ & 272.9 & 373.3 & $\dddot{w}$ & 217.2 & 387.4 & 590.5 \\
\hline November ........................... & 120.8 & $\ddot{W}$ & 142.4 & $\ddot{w}$ & 263.2 & 264.2 & 58.9 & 232.5 & 322.0 & 496.7 \\
\hline December .......................... & 109.6 & $\ddot{W}$ & 173.8 & w & 283.5 & 337.9 & 45.7 & 216.4 & 329.2 & 554.3 \\
\hline 1994 Average ........................... & 120.1 & 274.7 & 159.6 & $\mathbf{W}$ & 279.7 & 312.2 & $w$ & 191.1 & 344.5 & 503.2 \\
\hline PAD DIstrict II & & & & & & & & & & \\
\hline 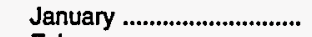 & $4,090.9$ & $13,824.2$ & $2,599.8$ & $3,608.6$ & $6,690.7$ & $17,432.8$ & $1,227.6$ & $8,558.6$ & $7,918.3$ & $25,991.4$ \\
\hline 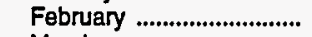 & $4,434.8$ & $14,908.5$ & $3,100.0$ & $2,763.7$ & $7,534.8$ & $17,672.1$ & 995.6 & $8,274.3$ & $8,530.4$ & $25,946.4$ \\
\hline 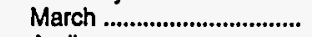 & $4,575.8$ & $17,554.2$ & $3,345.8$ & $3,222.5$ & $7,921.6$ & $20,776.7$ & 810.8 & $8,206.5$ & $8,732.4$ & $28,983.2$ \\
\hline April & $4,517.9$ & $18,305.9$ & $3,345.0$ & $2,930.9$ & $7,862.9$ & $21,236.7$ & 723.5 & $8,539.2$ & $8,586.4$ & $29,775.9$ \\
\hline May ...................................... & $4,789.4$ & $19,037.7$ & $3,190.4$ & $3,207.9$ & $7,979.8$ & $22,245.6$ & 874.8 & $7,282.0$ & $8,854.6$ & $29,527.6$ \\
\hline 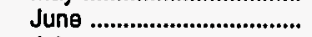 & $4,995.4$ & $19,885.6$ & $3,348.4$ & $3,143.0$ & $8,343.8$ & $23,028.6$ & 885.5 & $7,316.5$ & $9,229.3$ & $30,345.1$ \\
\hline July ....................................... & $4,529.6$ & $17,269.9$ & $2,748.6$ & $2,599.5$ & $7,278.3$ & $19,869.4$ & 826.8 & $6,490.9$ & $8,105.0$ & $26,360.3$ \\
\hline 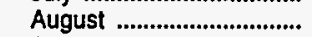 & $4,975.7$ & $19,886.5$ & $2,270.8$ & $3,212.8$ & $7,246.5$ & $23,099.3$ & $2,052.6$ & $7,485.3$ & $9,299.2$ & $30,584.6$ \\
\hline 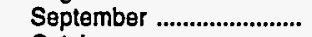 & $4,829.2$ & $20,488.9$ & $2,034.1$ & $3,284.2$ & $6,863.3$ & $23,773.1$ & $1,956.4$ & $8,174.5$ & $8,819.7$ & $31,947.5$ \\
\hline 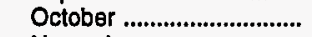 & $4,992.9$ & $20,126.9$ & $1,772.3$ & $3,871.0$ & $6,765.3$ & $23,998.0$ & $2,122.4$ & $8,449.2$ & $8,887.6$ & $32,447.2$ \\
\hline 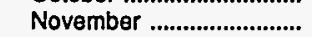 & $4,862.2$ & $18,151.0$ & $1,892.4$ & $3,018.0$ & $6,754.6$ & $21,169.0$ & $2,121.6$ & $7,324.8$ & $8,876.1$ & $28,493.8$ \\
\hline December .............................. & $4,443.7$ & $16,397.9$ & $1,943.4$ & $2,901.7$ & $6,387.1$ & $19,299.6$ & $2,037.8$ & $7,211.1$ & $8,424.9$ & $26,510.6$ \\
\hline 1994 Average .......................... & $4,670.3$ & $17,998.3$ & $2,628.5$ & $3,150.7$ & $7,298.8$ & $21,149.1$ & $1,389.1$ & $7,771.3$ & $8,687.9$ & $28,920.3$ \\
\hline
\end{tabular}

See footnotes at end of table. 
Table 46. Refiner No. 2 Distillate, Diesel Fuel, and Fuel Oil Volumes by PAD District and State

(Thousand Gallons per Day) - Continued

\begin{tabular}{|c|c|c|c|c|c|c|c|c|c|c|}
\hline \multirow{3}{*}{$\begin{array}{c}\text { Geographlc Area } \\
\text { Month }\end{array}$} & \multicolumn{6}{|c|}{ No. 2 Dlesel Fuel } & \multicolumn{2}{|c|}{ No. 2 Fuel Oll } & \multicolumn{2}{|c|}{ No. 2 Distillate } \\
\hline & \multicolumn{2}{|c|}{ Low-Sulfur } & \multicolumn{2}{|c|}{ HIgh-Sulfur } & \multicolumn{2}{|c|}{ Total } & \multirow{2}{*}{$\begin{array}{l}\text { Sales to } \\
\text { End Users }\end{array}$} & \multirow{2}{*}{$\begin{array}{l}\text { Sales for } \\
\text { Resale }\end{array}$} & \multirow{2}{*}{$\begin{array}{l}\text { Sales to } \\
\text { End Users }\end{array}$} & \multirow{2}{*}{$\begin{array}{c}\text { Sales for } \\
\text { Resale }\end{array}$} \\
\hline & $\begin{array}{l}\text { Sales to } \\
\text { End Users }\end{array}$ & $\begin{array}{l}\text { Sales for } \\
\text { Resale }\end{array}$ & $\begin{array}{l}\text { Sales to } \\
\text { End Users }\end{array}$ & $\begin{array}{l}\text { Sales for } \\
\text { Resale }\end{array}$ & $\begin{array}{l}\text { Sales to } \\
\text { End Users }\end{array}$ & $\begin{array}{l}\text { Sales tor } \\
\text { Resale }\end{array}$ & & & & \\
\hline
\end{tabular}

Illinols

\begin{tabular}{|c|c|c|c|c|c|c|c|c|c|c|}
\hline 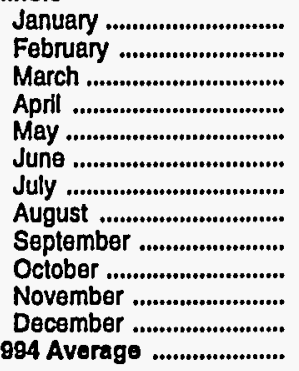 & $\begin{array}{l}398.3 \\
394.0 \\
429.5 \\
389.1 \\
456.5 \\
490.5 \\
470.0 \\
495.5 \\
447.3 \\
527.3 \\
497.3 \\
438.3 \\
453.2\end{array}$ & $\begin{array}{l}1,308.5 \\
1,390.8 \\
1,484.5 \\
1,623.4 \\
1,543.8 \\
1,706.3 \\
1,660.0 \\
2,083.3 \\
1,612.1 \\
1,869.8 \\
1,518.0 \\
1,276.8 \\
1,591.1\end{array}$ & $\begin{array}{r}123.3 \\
228.3 \\
248.5 \\
272.6 \\
213.3 \\
214.1 \\
157.6 \\
103.9 \\
74.5 \\
84.0 \\
43.7 \\
67.3 \\
152.0\end{array}$ & $\begin{array}{l}163.8 \\
227.8 \\
185.7 \\
135.1 \\
162.3 \\
244.3 \\
153.0 \\
157.7 \\
200.1 \\
267.0 \\
181.9 \\
185.4 \\
188.3\end{array}$ & $\begin{array}{l}521.5 \\
622.3 \\
678.0 \\
661.8 \\
669.9 \\
704.6 \\
627.6 \\
599.4 \\
521.8 \\
611.3 \\
541.0 \\
505.6 \\
605.2\end{array}$ & $\begin{array}{l}1,472.4 \\
1,618.6 \\
1,670.2 \\
1,758.5 \\
1,706.1 \\
1,950.6 \\
1,812.9 \\
2,241.0 \\
1,812.2 \\
2,136.8 \\
1,699.9 \\
1,462.2 \\
1,779.5\end{array}$ & $\begin{array}{l}W \\
W \\
W \\
W \\
W \\
W \\
W \\
W \\
W \\
W \\
W \\
W \\
W\end{array}$ & $\begin{array}{l}1,368.2 \\
1,529.7 \\
1,460.4 \\
1,698.5 \\
1,506.4 \\
1,48.5 .2 \\
1,406.1 \\
1,568.1 \\
1,738.3 \\
1,701.7 \\
1,388.2 \\
1,268.9 \\
1,509.1\end{array}$ & $\begin{array}{l}633.4 \\
694.3 \\
726.6 \\
729.4 \\
742.8 \\
767.2 \\
696.5 \\
808.6 \\
736.7 \\
887.9 \\
757.7 \\
707.6 \\
741.0\end{array}$ & $\begin{array}{l}2,840.5 \\
3,148.3 \\
3,130.6 \\
3,457.0 \\
3,212.5 \\
3,435.8 \\
3,219.0 \\
3,809.1 \\
3,550.5 \\
3,838.5 \\
3,088.1 \\
2,731.1 \\
3,288.5\end{array}$ \\
\hline 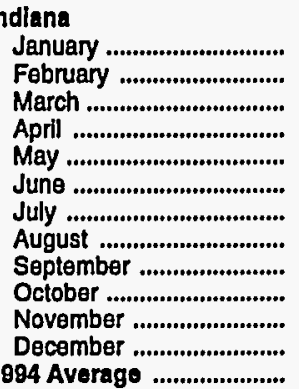 & $\begin{array}{c}454.1 \\
W \\
511.4 \\
622.6 \\
640.7 \\
642.1 \\
W \\
646.5 \\
635.0 \\
678.5 \\
675.4 \\
639.1 \\
601.5\end{array}$ & $\begin{array}{l}1,179.5 \\
1,530.3 \\
1,648.4 \\
1,565.6 \\
1,667.2 \\
1,699.8 \\
1,284.0 \\
1,572.8 \\
1,504.2 \\
1,939.5 \\
1,715.5 \\
1,591.1 \\
1,574.7\end{array}$ & $\begin{array}{r}407.3 \\
W \\
484.0 \\
484.2 \\
435.7 \\
400.1 \\
W \\
67.8 \\
144.1 \\
20.8 \\
24.9 \\
31.8 \\
272.9\end{array}$ & $\begin{array}{l}221.9 \\
174.3 \\
310.2 \\
316.7 \\
324.2 \\
249.7 \\
184.5 \\
188.0 \\
326.6 \\
409.8 \\
217.4 \\
151.6 \\
256.7\end{array}$ & $\begin{array}{r}861.4 \\
920.5 \\
995.3 \\
1,106.8 \\
1,076.4 \\
1,042.1 \\
934.7 \\
714.3 \\
779.1 \\
699.4 \\
700.3 \\
670.9 \\
874.4\end{array}$ & $\begin{array}{l}1,401.5 \\
1,704.6 \\
1,958.6 \\
1,882.3 \\
1,991.4 \\
1,949.5 \\
1,468.5 \\
1,760.8 \\
1,830.8 \\
2,349.2 \\
1,932.9 \\
1,742.7 \\
1,831.4\end{array}$ & $\begin{array}{r}W \\
W \\
W \\
73.9 \\
176.4 \\
119.1 \\
124.5 \\
478.0 \\
437.8 \\
438.5 \\
433.6 \\
426.6 \\
256.2\end{array}$ & $\begin{array}{l}906.5 \\
913.8 \\
881.1 \\
791.6 \\
742.4 \\
720.4 \\
603.7 \\
764.5 \\
887.3 \\
936.7 \\
767.1 \\
733.4 \\
803.3\end{array}$ & $\begin{array}{r}996.1 \\
1,035.5 \\
1,099.7 \\
1,180.6 \\
1,252.8 \\
1,161.2 \\
1,059.2 \\
1,192.2 \\
1,216.9 \\
1,137.8 \\
1,133.9 \\
1,097.6 \\
1,130.6\end{array}$ & $\begin{array}{l}2,307.9 \\
2,618.4 \\
2,839.7 \\
2,673.8 \\
2,733.8 \\
2,669.9 \\
2,072.2 \\
2,525.4 \\
2,718.1 \\
3,285.9 \\
2,700.0 \\
2,476.1 \\
2,634.6\end{array}$ \\
\hline 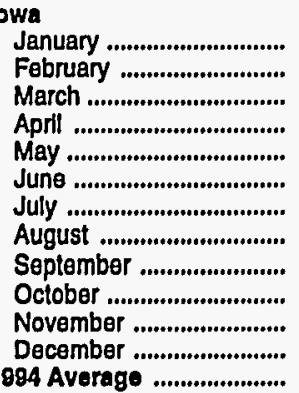 & $\begin{array}{c}146.5 \\
W \\
W \\
W \\
W \\
W \\
W \\
W \\
W \\
188.7 \\
180.8 \\
W \\
171.8\end{array}$ & $\begin{array}{r}771.5 \\
923.7 \\
1,301.6 \\
1,552.1 \\
1,318.8 \\
1,227.2 \\
1,098.4 \\
1,316.7 \\
1,549.6 \\
1,691.4 \\
1,252.9 \\
968.2 \\
1,248.7\end{array}$ & $\begin{array}{l}W \\
W \\
W \\
W \\
W \\
W \\
W \\
W \\
W \\
- \\
- \\
w \\
w\end{array}$ & $\begin{array}{r}109.5 \\
63.4 \\
127.2 \\
131.3 \\
103.4 \\
81.7 \\
47.2 \\
54.8 \\
104.7 \\
142.6 \\
82.7 \\
57.0 \\
92.3\end{array}$ & $\begin{array}{l}251.2 \\
260.7 \\
279.8 \\
285.0 \\
264.9 \\
280.5 \\
276.8 \\
185.8 \\
187.8 \\
188.7 \\
180.8 \\
166.1 \\
233.8\end{array}$ & $\begin{array}{r}881.0 \\
987.1 \\
1,428.8 \\
1,683.4 \\
1,422.2 \\
1,308.8 \\
1,145.6 \\
1,371.5 \\
1,654.3 \\
1,834.0 \\
1,335.6 \\
1,025.2 \\
1,341.0\end{array}$ & $\begin{array}{l}W \\
W \\
W \\
W \\
W \\
W \\
W \\
W \\
W \\
W \\
W \\
W \\
W\end{array}$ & $\begin{array}{l}200.5 \\
151.8 \\
256.2 \\
329.5 \\
247.2 \\
227.3 \\
183.1 \\
170.5 \\
254.5 \\
316.5 \\
214.6 \\
179.6 \\
227.9\end{array}$ & $\begin{array}{l}270.9 \\
264.5 \\
282.5 \\
290.2 \\
267.4 \\
286.0 \\
279.2 \\
301.7 \\
289.4 \\
326.4 \\
308.1 \\
261.3 \\
285.7\end{array}$ & $\begin{array}{l}1,081.5 \\
1,138.9 \\
1,685.0 \\
2,012.9 \\
1,669.4 \\
1,536.1 \\
1,328.7 \\
1,542.0 \\
1,908.8 \\
2,150.6 \\
1,550.2 \\
1,204.8 \\
1,568.9\end{array}$ \\
\hline 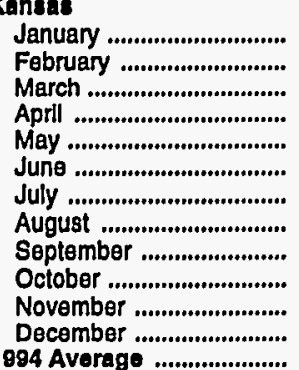 & \begin{tabular}{r|}
183.5 \\
180.1 \\
149.7 \\
183.1 \\
173.6 \\
173.1 \\
175.6 \\
$W$ \\
176.1 \\
225.3 \\
167.3 \\
152.4 \\
176.7
\end{tabular} & $\begin{array}{r}684.8 \\
774.9 \\
1,319.1 \\
1,384.5 \\
1,433.5 \\
1,801.1 \\
1,649.2 \\
1,821.9 \\
1,862.5 \\
1,133.0 \\
1,102.3 \\
931.3 \\
1,327.0\end{array}$ & $\begin{array}{r}262.7 \\
142.6 \\
240.2 \\
258.0 \\
220.7 \\
271.5 \\
194.4 \\
W \\
135.0 \\
64.9 \\
207.5 \\
285.3 \\
193.8\end{array}$ & $\begin{array}{l}358.5 \\
148.6 \\
442.4 \\
382.3 \\
392.0 \\
388.8 \\
376.9 \\
384.0 \\
334.6 \\
300.0 \\
428.1 \\
495.5 \\
371.0\end{array}$ & $\begin{array}{l}446.2 \\
322.7 \\
389.9 \\
441.1 \\
394.3 \\
444.6 \\
369.9 \\
221.5 \\
311.1 \\
290.2 \\
374.7 \\
437.6 \\
370.5\end{array}$ & $\begin{array}{r}1,043.3 \\
923.4 \\
1,761.5 \\
1,766.8 \\
1,825.5 \\
2,189.9 \\
2,026.1 \\
2,205.9 \\
2,197.0 \\
1,433.0 \\
1,530.4 \\
1,426.8 \\
1,698.0\end{array}$ & $\begin{array}{c}1.9 \\
W \\
W \\
3.5 \\
8.0 \\
17.4 \\
W \\
W \\
W \\
W \\
W \\
W \\
W\end{array}$ & $\begin{array}{l}327.0 \\
339.5 \\
352.8 \\
347.0 \\
327.8 \\
319.6 \\
255.2 \\
270.7 \\
323.2 \\
190.5 \\
160.8 \\
123.8 \\
277.5\end{array}$ & $\begin{array}{l}448.1 \\
339.5 \\
426.7 \\
444.6 \\
402.3 \\
462.0 \\
376.5 \\
346.1 \\
361.2 \\
359.2 \\
500.0 \\
508.7 \\
414.9\end{array}$ & $\begin{array}{l}1,370.3 \\
1,262.9 \\
2,114.3 \\
2,113.8 \\
2,153.4 \\
2,509.5 \\
2,281.2 \\
2,476.5 \\
2,520.2 \\
1,623.5 \\
1,691.2 \\
1,550.5 \\
1,975.5\end{array}$ \\
\hline
\end{tabular}

See footnotes at end of table. 
Table 46. Refiner No. 2 Distillate, Diesel Fuel, and Fuel Oil Volumes by PAD District and State

(Thousand Gallons per Day) - Continued

\begin{tabular}{|c|c|c|c|c|c|c|c|c|c|c|}
\hline \multirow{3}{*}{$\begin{array}{c}\text { Geographic Area } \\
\text { Month }\end{array}$} & \multicolumn{6}{|c|}{ No. 2 Diesel Fuel } & \multicolumn{2}{|c|}{ No. 2 Fuel Oil } & \multicolumn{2}{|c|}{ No. 2 Distillate } \\
\hline & \multicolumn{2}{|c|}{ Low-Sulfur } & \multicolumn{2}{|c|}{ High-Sulfur } & \multicolumn{2}{|c|}{ Total } & \multirow{2}{*}{$\begin{array}{l}\text { Sales to } \\
\text { End Users }\end{array}$} & \multirow{2}{*}{$\begin{array}{l}\text { Sales for } \\
\text { Resale }\end{array}$} & \multirow{2}{*}{$\begin{array}{l}\text { Sales to } \\
\text { End Users }\end{array}$} & \multirow[b]{2}{*}{$\begin{array}{c}\text { Sales for } \\
\text { Resale }\end{array}$} \\
\hline & $\begin{array}{l}\text { Sales to } \\
\text { End Users }\end{array}$ & $\begin{array}{l}\text { Sales for } \\
\text { Resale }\end{array}$ & $\begin{array}{l}\text { Sales to } \\
\text { End Users }\end{array}$ & $\begin{array}{l}\text { Sales for } \\
\text { Resale }\end{array}$ & $\begin{array}{l}\text { Sales to } \\
\text { End Users }\end{array}$ & $\begin{array}{l}\text { Sales for } \\
\text { Resale }\end{array}$ & & & & \\
\hline
\end{tabular}

Kentucky

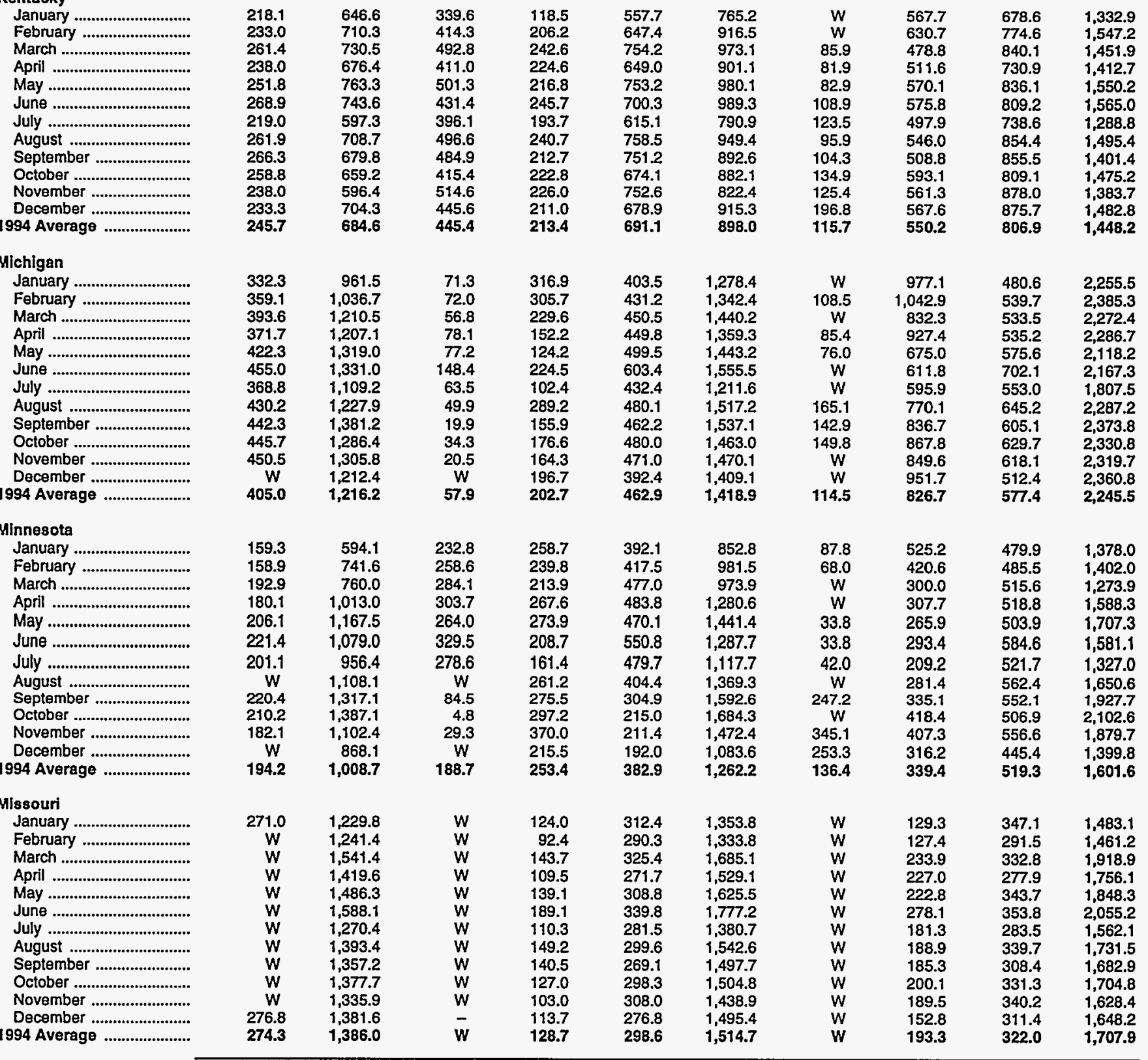

See footnotes at end of table. 
Table 46. Refiner No. 2 Distillate, Diesel Fuel, and Fuel Oil Volumes by PAD District and State

(Thousand Gallons per Day) - Continued

\begin{tabular}{|c|c|c|c|c|c|c|c|c|c|c|}
\hline \multirow{3}{*}{$\begin{array}{c}\text { Geographic Area } \\
\text { Month }\end{array}$} & \multicolumn{6}{|c|}{ No. 2 Diesel Fuel } & \multicolumn{2}{|c|}{ No. 2 Fuel Olt } & \multicolumn{2}{|c|}{ No. 2 Distillate } \\
\hline & \multicolumn{2}{|c|}{ Low-Sulfur } & \multicolumn{2}{|c|}{ High-Sulfur } & \multicolumn{2}{|c|}{ Total } & \multirow{2}{*}{$\begin{array}{l}\text { Sales to } \\
\text { End Users }\end{array}$} & \multirow{2}{*}{$\begin{array}{l}\text { Sales for } \\
\text { Resale }\end{array}$} & \multirow{2}{*}{$\begin{array}{l}\text { Sales to } \\
\text { End Users }\end{array}$} & \multirow{2}{*}{$\begin{array}{l}\text { Sales for } \\
\text { Resale }\end{array}$} \\
\hline & $\begin{array}{l}\text { Sales to } \\
\text { End Users }\end{array}$ & $\begin{array}{l}\text { Sales for } \\
\text { Resale }\end{array}$ & $\begin{array}{l}\text { Sales to } \\
\text { End Users }\end{array}$ & $\begin{array}{l}\text { Sales for } \\
\text { Resale }\end{array}$ & $\begin{array}{l}\text { Sales to } \\
\text { End Users }\end{array}$ & $\begin{array}{l}\text { Sales for } \\
\text { Resale }\end{array}$ & & & & \\
\hline
\end{tabular}

Nebraska

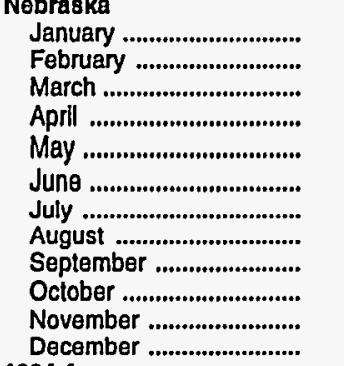

$\begin{array}{cc}51.9 & 400.4 \\ W & 395.9 \\ 28.6 & 658.9 \\ W & 816.7 \\ W & 894.1 \\ W & 966.0 \\ W & 775.6 \\ W & 815.2 \\ W & 911.5 \\ 43.2 & 878.3 \\ W & 653.6 \\ 38.0 & 549.1 \\ 50.5 & 727.8\end{array}$

\begin{tabular}{lrrr}
$\bar{W}$ & 71.6 & 51.9 & 472.0 \\
$\bar{W}$ & 49.1 & 110.0 & 445.0 \\
$W$ & 160.8 & 28.6 & 819.7 \\
$W$ & 148.7 & 29.2 & 965.4 \\
$W$ & 225.4 & 48.1 & $1,119.4$ \\
$W$ & 183.2 & 41.8 & $1,149.2$ \\
$W$ & 155.6 & 47.0 & 931.2 \\
$W$ & 181.3 & 66.9 & 996.5 \\
$\bar{W}$ & 166.8 & 58.0 & $1,078.3$ \\
$\bar{W}$ & 190.1 & 43.2 & $1,068.4$ \\
$W$ & 89.5 & 60.7 & 743.0 \\
1.3 & 70.4 & $W$ & 619.5 \\
\hline & 141.7 & 51.7 & 869.5
\end{tabular}

North Dakota

January...

January .............................

March ...

ay ..............................

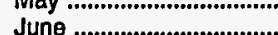

July ...

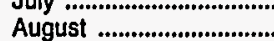

Seplember

October

November

1994 Average

Ohio

January ..............................

February .............................

March .....................................

May

unn

July .................................

August

September ....................

October

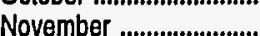

December ........................

1994 Average .......................

Oklahoma

January ..............................

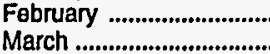

April .................................

May

June ......

July ...

(1)

September

October ...

November

1994 Average

$\begin{array}{rr}9.2 & 178.9 \\ 19.2 & 176.1 \\ W & 281.2 \\ 16.5 & 391.1 \\ 19.1 & 572.4 \\ 17.0 & 421.4 \\ 20.3 & 414.4 \\ 19.5 & 596.7 \\ W & 590.3 \\ 16.9 & 476.2 \\ W & 370.7 \\ W & 317.5 \\ 18.5 & 400.2\end{array}$

$\begin{array}{lr}W & 45.6 \\ W & 34.0 \\ W & 78.7 \\ W & 88.4 \\ W & 149.6 \\ W & 68.6 \\ W & 65.9 \\ W & 117.3 \\ - & 99.7 \\ W & 59.3 \\ - & 47.3 \\ W & 45.0 \\ W & 75.3\end{array}$

$\begin{array}{cc}W & 224.5 \\ W & 210.1 \\ 130.4 & 359.9 \\ W & 479.5 \\ W & 722.0 \\ W & 490.0 \\ W & 480.3 \\ W & 714.0 \\ W & 690.0 \\ W & 535.5 \\ W & 418.0 \\ 20.5 & 362.4 \\ 91.6 & 475.5\end{array}$

$\begin{array}{ll}\text { W } & 88.7 \\ \text { W } & 54.5 \\ \text { W } & 70.2 \\ \text { W } & 62.8 \\ \text { W } & 70.8 \\ \text { W } & 57.9 \\ \text { W } & 50.6 \\ \text { W } & 76.1 \\ \text { W } & 94.4 \\ \text { W } & 75.1 \\ \text { W } & 87.3 \\ \text { W } & 84.2 \\ \text { W } & 72.8\end{array}$

$1,095.5 \quad 1,219.0$

$321.2 \quad 450.4$

$1,416.6 \quad 1,669.4$

$1,711.8$

$\begin{array}{ll}1,197.2 & 1,359.9 \\ 1,216.5 & 1,339.2\end{array}$

$\begin{array}{ll}1,216.5 & 1,339.2 \\ 1,234.0 & 1,262.2\end{array}$

$1,190.5 \quad 1,329.5$

$1,237.4 \quad 1,377.4$

351.8

$1,651.2$

$1,647.8$

$413.7 \quad 304.6$

$\begin{array}{lll}368.2 & 243.0 & 1,558.7\end{array}$

$1,739.0 \quad 1.5822$

$1,455.8 \quad 1,585.3$

$1,542.8 \quad 1,685.0$

$\begin{array}{ll}1,144.2 & 1,488.5\end{array}$

$1,175.6 \quad 1,582.9$

$386.9 \quad 158.9$

$398.6 \quad 196.5$

$435.7 \quad 229.3$

$1,165.1 \quad 1,620.1$

$1,178.0 \quad 1,564.8$

$456.5 \quad 350.1$

$1,611.3 \quad 1,812.2$

$1,970.2$

$1,611.9 \quad 1,843.2$

$\begin{array}{llll}385.1 & 279.8 & 1,485.6 & 1,602.7 \\ 415.4 & 279.8 & 1,581.7 & 1,687.5\end{array}$

$439.2 \quad 1,482.8$

$344.1 \quad 1,396.3$

$304.5 \quad 1,430.6$

$271.9 \quad 1,137.7$

$258.8 \quad 941.7$

$298.8 \quad 920.5$

$\begin{array}{ll}226.0 & 832.0 \\ 324.9 & 990.0\end{array}$

$315.2 \quad 1,153.0$

$286.4 \quad 1,230.5$

$\begin{array}{ll}1,100.5 & 1,322.9 \\ 1,166.3 & 1,407.7\end{array}$

290.8

$1,076.6$

$369.0 \quad 1,258.5$

$1,153.1$

$\begin{array}{rr}71.1 & 519.6 \\ 110.5 & 489.9 \\ 28.6 & 923.1 \\ 29.5 & 1,121.1 \\ 52.1 & 1,256.3 \\ 42.3 & 1,322.1 \\ 50.4 & 1,068.7 \\ 70.5 & 1,137.5 \\ 62.2 & 1,223.6 \\ 43.5 & 1,178.1 \\ 61.0 & 832.6 \\ W & 694.9 \\ 56.3 & 983.1\end{array}$

$\begin{array}{cc}107.6 & 2,207.8 \\ W & 2,022.4 \\ W & 1,999.4 \\ W & 1,717.9 \\ W & 1,857.9 \\ W & 2,361.7 \\ W & 1,904.5 \\ W & 2,053.8 \\ W & 2,118.1 \\ W & 2,077.4 \\ W & 2,313.5 \\ W & 2,134.8\end{array}$

$\begin{array}{ll}W & 685.0 \\ W & 237.4 \\ W & 189.3 \\ W & 178.7 \\ W & 263.5 \\ W & 325.4 \\ W & 314.7 \\ W & 289.2 \\ W & 339.0 \\ W & 601.6 \\ W & 139.6 \\ W & 249.8 \\ W & 319.2\end{array}$

$\begin{array}{ll}536.4 & 2,892.9 \\ 573.3 & 2,259.8 \\ 614.8 & 2,188.6 \\ 566.6 & 1,896.6 \\ 569.9 & 2,121.4 \\ 523.6 & 2,687.1 \\ 635.0 & 2,219.3 \\ 653.0 & 2,343.0 \\ 585.5 & 2,457.0 \\ 646.7 & 2,679.0 \\ 544.1 & 2,453.1 \\ 609.0 & 2,384.7 \\ 588.6 & 2,383.0\end{array}$

\begin{tabular}{cccc}
$W$ & 327.6 & 573.7 & $3,220.5$ \\
$W$ & 302.9 & 614.9 & $2,562.7$ \\
$W$ & 463.4 & 619.6 & $2,652.1$ \\
$W$ & 746.3 & 606.4 & $2,643.0$ \\
19.4 & 349.4 & 589.2 & $2,470.8$ \\
$W$ & 429.4 & 563.5 & $3,116.5$ \\
$W$ & 362.5 & 639.4 & $2,581.7$ \\
$W$ & 362.7 & 659.0 & $2,705.7$ \\
$W$ & 393.4 & 590.1 & $2,850.4$ \\
$W$ & 301.7 & 652.0 & $2,980.7$ \\
$W$ & 201.7 & 548.9 & $2,654.8$ \\
$W$ & 138.1 & 613.1 & $2,522.7$ \\
17.4 & 364.6 & 606.1 & $2,747.5$ \\
\hline
\end{tabular}

See footnotes at end of table. 
Table 46. Refiner No. 2 Distillate, Diesel Fuel, and Fuel Oil Volumes by PAD District and State

(Thousand Gallons per Day) - Continued

\begin{tabular}{|c|c|c|c|c|c|c|c|c|c|c|}
\hline \multirow{3}{*}{$\begin{array}{c}\text { Geographic Area } \\
\text { Month }\end{array}$} & \multicolumn{6}{|c|}{ No. 2 Diesel Fuel } & \multicolumn{2}{|c|}{ No. 2 Fuel Oil } & \multicolumn{2}{|c|}{ No. 2 Distillate } \\
\hline & \multicolumn{2}{|c|}{ Low-Sulfur } & \multicolumn{2}{|c|}{ High-Sulfur } & \multicolumn{2}{|c|}{ Total } & \multirow{2}{*}{$\begin{array}{l}\text { Sales to } \\
\text { End Users }\end{array}$} & \multirow{2}{*}{$\begin{array}{l}\text { Sales for } \\
\text { Resale }\end{array}$} & \multirow{2}{*}{$\begin{array}{l}\text { Sales to } \\
\text { End Users }\end{array}$} & \multirow{2}{*}{$\begin{array}{l}\text { Sales for } \\
\text { Resale }\end{array}$} \\
\hline & $\begin{array}{l}\text { Sales to } \\
\text { End Users }\end{array}$ & $\begin{array}{l}\text { Sales for } \\
\text { Resale }\end{array}$ & $\begin{array}{c}\text { Sales to } \\
\text { End Users }\end{array}$ & $\begin{array}{c}\text { Sales for } \\
\text { Resale }\end{array}$ & $\begin{array}{l}\text { Sales to } \\
\text { End Users }\end{array}$ & $\begin{array}{l}\text { Sales for } \\
\text { Resale }\end{array}$ & & & & \\
\hline \multicolumn{11}{|l|}{ South Dakota } \\
\hline 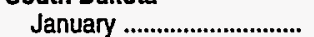 & $W$ & 312.6 & $W$ & 38.1 & W & 350.7 & - & 80.2 & $w$ & 430.9 \\
\hline 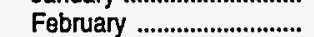 & W & 311.4 & W & 16.8 & W & 328.1 & - & 51.3 & W & 379.4 \\
\hline 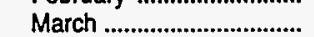 & $W$ & 438.1 & $\ddot{W}$ & 52.9 & 10.2 & 490.9 & - & 59.6 & 10.2 & 550.5 \\
\hline 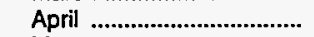 & 7.0 & 558.5 & $W$ & 33.6 & W & 592.1 & - & 75.3 & $w$ & 667.5 \\
\hline 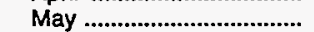 & $w$ & 673.9 & $W$ & 46.8 & $W$ & 720.7 & - & 78.9 & $W$ & 799.6 \\
\hline 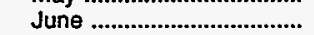 & $\ddot{w}$ & 564.3 & w & 32.5 & $\ddot{W}$ & 596.8 & - & 67.0 & $w$ & 663.8 \\
\hline 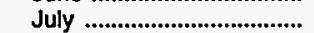 & W & 572.5 & W & 29.4 & W & 601.8 & $w$ & 63.6 & W & 665.5 \\
\hline 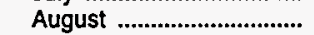 & $W$ & 614.7 & W & 27.3 & $\ddot{w}$ & 642.0 & $w$ & 73.8 & w & 715.8 \\
\hline September ......................... & W & 653.8 & - & 36.6 & $\ddot{W}$ & 690.4 & $w$ & 89.6 & W & 780.1 \\
\hline 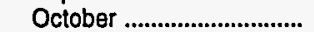 & $W$ & 679.1 & $W$ & 42.2 & $W$ & 721.3 & W & 88.5 & $\ddot{w}$ & 809.8 \\
\hline November ........................... & $W$ & 490.7 & $W$ & 28.2 & $W$ & 518.9 & W & 81.9 & $W$ & 600.8 \\
\hline 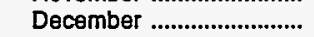 & $\ddot{w}$ & 376.4 & - & 22.6 & W & 399.0 & W & 60.7 & W & 459.7 \\
\hline 1994 Average ........................... & 9.0 & 521.7 & $w$ & 34.1 & 9.8 & $\mathbf{5 5 5 . 8}$ & $\mathbf{w}$ & 72.6 & $\mathbf{w}$ & 628.4 \\
\hline \multicolumn{11}{|l|}{ Tennessee } \\
\hline 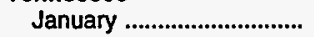 & 469.2 & $1,337.2$ & 146.5 & 167.6 & 615.7 & $1,504.8$ & 102.7 & 601.7 & 718.5 & $2,106.5$ \\
\hline 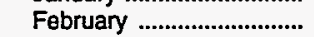 & 608.5 & $1,455.7$ & 324.6 & 281.6 & 933.1 & $1,737.4$ & 68.6 & 504.6 & $1,001.8$ & $2,242.0$ \\
\hline 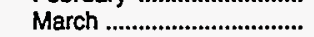 & 582.7 & $1,720.4$ & 314.4 & 199.2 & 897.1 & $1,919.5$ & 62.4 & 669.8 & 959.5 & $2,589.3$ \\
\hline April & 524.1 & $1,804.4$ & 365.6 & 209.6 & 889.7 & $2,014.0$ & 30.9 & 648.9 & 920.6 & $2,662.9$ \\
\hline May ....................................... & 585.6 & $1,593.3$ & 326.0 & 255.8 & 911.6 & $1,849.2$ & 72.5 & 631.9 & 984.1 & $2,481.0$ \\
\hline June & 591.3 & $1,618.3$ & 335.6 & 288.7 & 926.9 & $1,907.0$ & 47.1 & 694.1 & 974.0 & $2,601.1$ \\
\hline July & 528.5 & $1,246.6$ & 209.9 & 363.9 & 738.3 & $1,610.5$ & 50.2 & 699.3 & 788.5 & $2,309.8$ \\
\hline 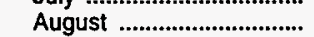 & 591.4 & $1,614.4$ & 466.8 & 433.6 & $1,058.2$ & $2,048.0$ & 84.7 & 780.2 & $1,142.9$ & $2,828.3$ \\
\hline 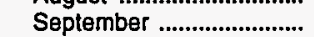 & 564.6 & $1,826.5$ & 205.7 & 422.4 & 770.3 & $2,248.9$ & 93.0 & 670.2 & 863.3 & $2,919.0$ \\
\hline 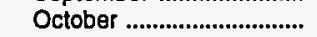 & 558.0 & $1,579.9$ & 186.4 & 384.4 & 744.4 & $1,964.3$ & 100.8 & 777.4 & 845.2 & $2,741.7$ \\
\hline November ......................... & 564.9 & $1,495.2$ & 180.5 & 382.3 & 745.4 & $1,877.5$ & 72.9 & 627.7 & 818.3 & $2,505.2$ \\
\hline 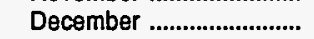 & 495.9 & $1,613.3$ & 188.1 & 315.5 & 684.0 & $1,928.7$ & 87.9 & 607.5 & 771.9 & $2,536.3$ \\
\hline 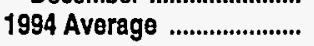 & 554.9 & $1,575.2$ & 270.4 & 308.8 & 825.3 & $1,884.0$ & 73.0 & 660.7 & 898.3 & $2,544.7$ \\
\hline \multicolumn{11}{|l|}{ Wisconsin } \\
\hline 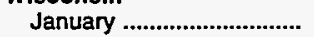 & 189.4 & 791.9 & $w$ & 478.3 & 212.2 & $1,270.2$ & 24.5 & 928.5 & 236.7 & $2,198.6$ \\
\hline 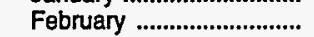 & W & 837.4 & $\ddot{W}$ & 334.8 & 186.1 & $1,172.2$ & 21.3 & 763.5 & 207.4 & $1,935.7$ \\
\hline 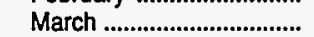 & W & $1,121.0$ & $\ddot{w}$ & 332.4 & 239.3 & $1,453.4$ & 18.6 & 614.2 & 257.9 & $2,067.5$ \\
\hline April & $w$ & $1,313.3$ & w & 248.1 & 241.4 & $1,561.4$ & 15.8 & 572.0 & 257.2 & $2,133.3$ \\
\hline May & $w$ & $1,417.2$ & W & 287.9 & 252.9 & $1,705.1$ & 25.0 & 514.7 & 277.9 & $2,219.9$ \\
\hline 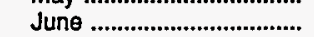 & $\ddot{w}$ & $1,400.6$ & w & 207.3 & 269.9 & $1,607.9$ & 28.4 & 463.3 & 298.3 & $2,071.2$ \\
\hline July & W & $1,305.1$ & w & 181.8 & 247.6 & $1,486.9$ & 42.0 & 413.0 & 289.6 & $1,899.9$ \\
\hline 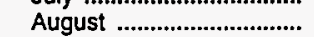 & $\ddot{w}$ & $1,470.5$ & w & 242.8 & 227.8 & $1,713.3$ & 56.2 & 501.3 & 284.0 & $2,214.6$ \\
\hline 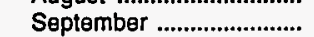 & w & $1,542.1$ & $\dddot{w}$ & 239.9 & 225.7 & $1,782.0$ & 56.3 & 559.4 & 282.0 & $2,341,4$ \\
\hline 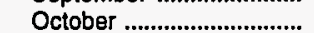 & $w$ & $1,471.9$ & $w$ & 300.2 & 225.1 & $1,772.1$ & 54.9 & 641.5 & 280.0 & $2,413.6$ \\
\hline 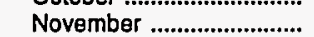 & $w$ & $1,333.2$ & $\dddot{w}$ & 279.5 & 218.3 & $1,612.7$ & 57.5 & 621.6 & 275.8 & $2,234.3$ \\
\hline 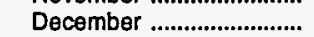 & $\ddot{w}$ & $1,150.3$ & $\ddot{w}$ & 292.2 & 220.1 & $1,442.4$ & 49.3 & 692.6 & 269.4 & $2,135.0$ \\
\hline 1994 Average ........................... & 215.7 & $1,264.9$ & 15.1 & 285.5 & 230.8 & $1,550.4$ & 37.6 & 606.4 & 268.4 & $2,156.8$ \\
\hline PAD District III & & & & & & & & & & \\
\hline 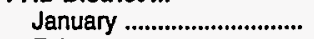 & $1,682.4$ & $11,365.8$ & $2,236.7$ & $5,025.3$ & $3,919.1$ & $16,391.1$ & 66.6 & $5,877.8$ & $3,985.7$ & $22,268.9$ \\
\hline 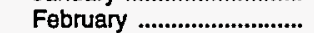 & $1,745.0$ & $12,137.6$ & $2,570.1$ & $5,272.4$ & $4,315.2$ & $17,410.0$ & 26.5 & $8,923.5$ & $4,341.6$ & $26,333.5$ \\
\hline 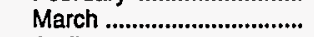 & $1,757.8$ & $12,227.4$ & $2,727.2$ & $5,860.5$ & $4,485.0$ & $18,087.9$ & 49.4 & $8,128.0$ & $4,534.5$ & $26,216.0$ \\
\hline 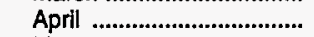 & $1,617.4$ & $12,834.8$ & $2,971.8$ & $7,123.3$ & $4,589.2$ & $19,958.1$ & 52.1 & $8,062.6$ & $4,641.3$ & $28,020.7$ \\
\hline May .................................... & $1,812.9$ & $13,407.2$ & $2,349.6$ & $5,889.2$ & $4,162.5$ & $19,296.4$ & 139.8 & $7,241.6$ & $4,302.4$ & $26,537.9$ \\
\hline June & $1,757.2$ & $15,250.1$ & $2,276.2$ & $6,088.1$ & $4,033.4$ & $21,338.2$ & 80.3 & $9,748.4$ & $4,113.7$ & $31,086.6$ \\
\hline 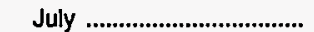 & $1,740.9$ & $13,169.0$ & $2,290.6$ & $5,681.4$ & $4,031.5$ & $18,850.4$ & 48.2 & $7,136.9$ & $4,079.7$ & $25,987.3$ \\
\hline 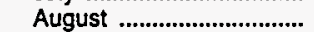 & $1,805.6$ & $14,934.3$ & $2,268.4$ & $4,734.6$ & $4,074.0$ & $19,668.9$ & 159.9 & $6,012.3$ & $4,233.9$ & $25,681.1$ \\
\hline September ......................... & $1,891.9$ & $14,029.5$ & $2,262.3$ & $6,014.7$ & $4,154.2$ & $20,044.2$ & 199.3 & $5,631.6$ & $4,353.5$ & $25,675.8$ \\
\hline 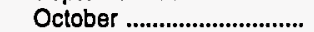 & $1,679.0$ & $13,739.2$ & $2,319.4$ & $4,997.3$ & $3,998.4$ & $18,736.5$ & 146.8 & $4,863.5$ & $4,145.1$ & $23,600.1$ \\
\hline November .......................... & $1,747.1$ & $13,066.6$ & $2,413.9$ & $4,107.4$ & $4,161.0$ & $17,174.0$ & 134.5 & $6,146.7$ & $4,295.5$ & $23,320.7$ \\
\hline 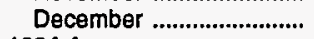 & $1,645.9$ & $13,031.1$ & $2,350.6$ & $4,633.5$ & $3,996.5$ & $17,664.6$ & 139.9 & $8,829.1$ & $4,136.5$ & $26,493.7$ \\
\hline 1994 Average ...................... & $1,740.1$ & $13,269.5$ & $2,417.8$ & $5,449.6$ & $4,157.9$ & $18,719.1$ & 104.1 & $7,200.8$ & $4,262.0$ & $25,920.0$ \\
\hline
\end{tabular}

See footnotes at end of table. 
Table 46. Refiner No. 2 Distillate, Diesel Fuel, and Fuel Oil Volumes by PAD District and State

(Thousand Gallons per Day) - Continued

\begin{tabular}{|c|c|c|c|c|c|c|c|c|c|c|}
\hline \multirow{3}{*}{$\begin{array}{c}\text { Geographlc Area } \\
\text { Month }\end{array}$} & \multicolumn{6}{|c|}{ No. 2 Diesel Fuel } & \multicolumn{2}{|c|}{ No. 2 Fuel Oil } & \multicolumn{2}{|c|}{ No. 2 Distillate } \\
\hline & \multicolumn{2}{|c|}{ Low-Sulfur } & \multicolumn{2}{|c|}{ High-Sulfur } & \multicolumn{2}{|c|}{ Total } & \multirow{2}{*}{$\begin{array}{l}\text { Sales to } \\
\text { End Users }\end{array}$} & \multirow{2}{*}{$\begin{array}{l}\text { Sales for } \\
\text { Resale }\end{array}$} & \multirow{2}{*}{$\begin{array}{l}\text { Sales to } \\
\text { End Users }\end{array}$} & \multirow{2}{*}{$\begin{array}{c}\text { Sales for } \\
\text { Resalo }\end{array}$} \\
\hline & $\begin{array}{l}\text { Sales to } \\
\text { End Users }\end{array}$ & $\begin{array}{l}\text { Sales for } \\
\text { Resale }\end{array}$ & $\begin{array}{l}\text { Sales to } \\
\text { End Users }\end{array}$ & $\begin{array}{l}\text { Sales for } \\
\text { Resale }\end{array}$ & $\begin{array}{c}\text { Sales to } \\
\text { End Users }\end{array}$ & $\begin{array}{l}\text { Sales for } \\
\text { Resale }\end{array}$ & & & & \\
\hline
\end{tabular}

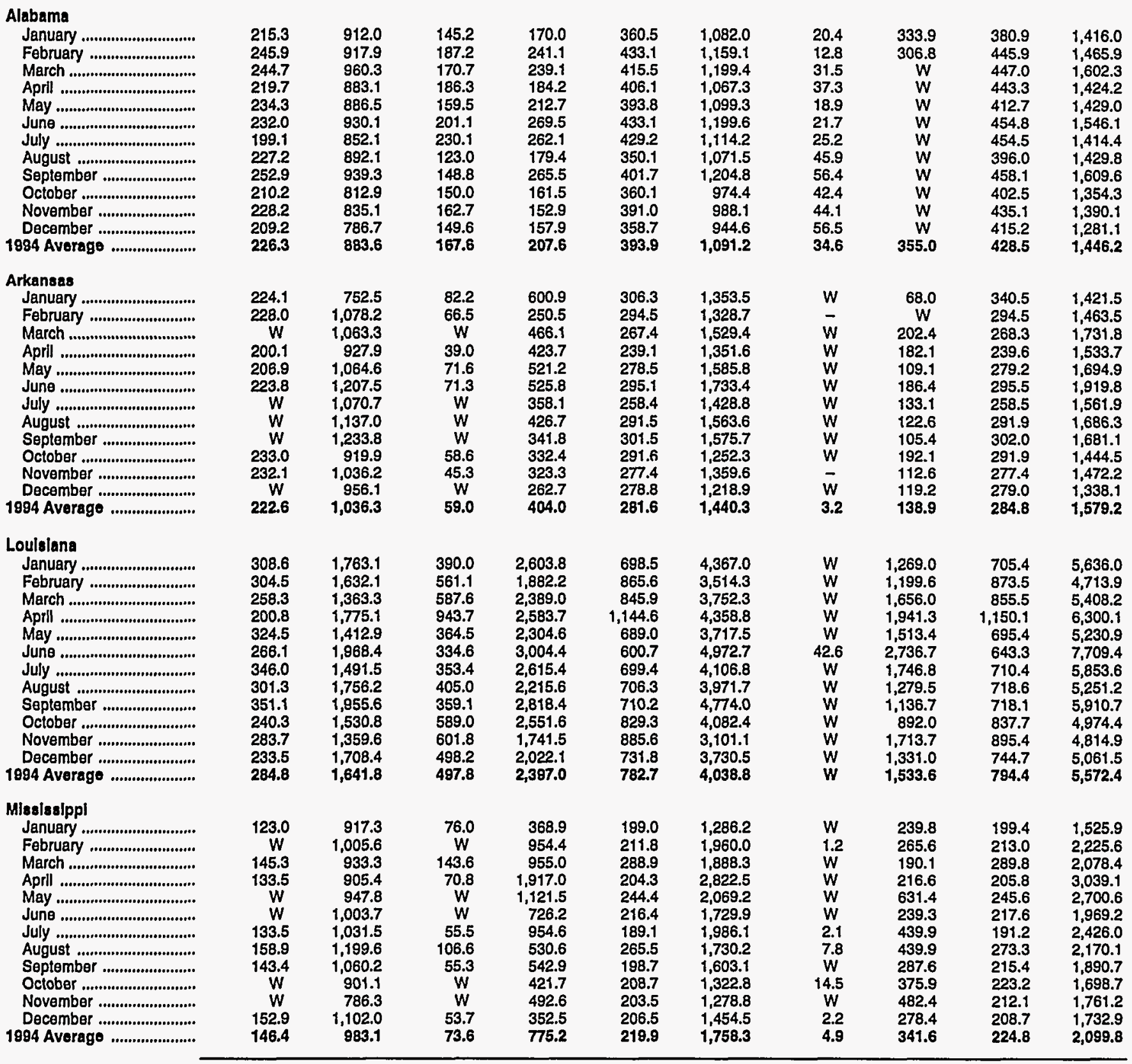

See footnotes at end of table. 
Table 46. Refiner No. 2 Distillate, Diesel Fuel, and Fuel Oil Volumes by PAD District and State

(Thousand Gallons per Day) - Continued

\begin{tabular}{|c|c|c|c|c|c|c|c|c|c|c|}
\hline \multirow{3}{*}{$\begin{array}{l}\text { Geographic Area } \\
\text { Month }\end{array}$} & \multicolumn{6}{|c|}{ No. 2 Dlesel Fuel } & \multicolumn{2}{|c|}{ No. 2 Fuel Oil } & \multicolumn{2}{|c|}{ No. 2 Distillate } \\
\hline & \multicolumn{2}{|c|}{ Low-Sulfur } & \multicolumn{2}{|c|}{ High-Sulfur } & \multicolumn{2}{|c|}{ Total } & \multirow{2}{*}{$\begin{array}{l}\text { Sales to } \\
\text { End Users }\end{array}$} & \multirow{2}{*}{$\begin{array}{l}\text { Sales for } \\
\text { Resale }\end{array}$} & \multirow[b]{2}{*}{$\begin{array}{l}\text { Sales to } \\
\text { End Users }\end{array}$} & \multirow[b]{2}{*}{$\begin{array}{l}\text { Sales for } \\
\text { Resale }\end{array}$} \\
\hline & $\begin{array}{l}\text { Sales to } \\
\text { End Users }\end{array}$ & $\begin{array}{l}\text { Sales for } \\
\text { Resalo }\end{array}$ & $\begin{array}{c}\text { Sales to } \\
\text { End Users }\end{array}$ & $\begin{array}{l}\text { Sales for } \\
\text { Resale }\end{array}$ & $\begin{array}{l}\text { Sales to } \\
\text { End Users }\end{array}$ & $\begin{array}{c}\text { Sales for } \\
\text { Resale }\end{array}$ & & & & \\
\hline \multicolumn{11}{|l|}{ New Mexico } \\
\hline 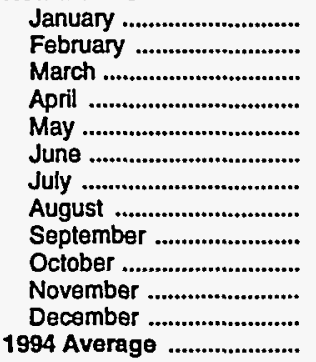 & $\begin{array}{c}137.7 \\
W \\
W \\
151.3 \\
W \\
W \\
W \\
W \\
W \\
W \\
W \\
W \\
137.0\end{array}$ & $\begin{array}{l}552.6 \\
567.6 \\
604.2 \\
604.4 \\
617.5 \\
665.3 \\
622.1 \\
660.4 \\
688.7 \\
724.5 \\
666.5 \\
607.9 \\
632.1\end{array}$ & $\begin{array}{l}W \\
W \\
W \\
\bar{W} \\
W \\
W \\
W \\
W \\
W \\
W \\
W \\
W\end{array}$ & $\begin{array}{l}12.0 \\
16.3 \\
21.3 \\
15.7 \\
16.0 \\
21.0 \\
19.6 \\
20.5 \\
20.8 \\
14.1 \\
17.9 \\
33.0 \\
19.0\end{array}$ & $\begin{array}{l}137.9 \\
138.4 \\
146.7 \\
151.3 \\
154.6 \\
159.1 \\
169.3 \\
150.8 \\
145.6 \\
128.0 \\
142.5 \\
156.9 \\
148.5\end{array}$ & $\begin{array}{l}564.6 \\
583.9 \\
625.4 \\
620.1 \\
633.5 \\
686.3 \\
641.7 \\
680.9 \\
709.6 \\
738.6 \\
684.4 \\
640.9 \\
651.1\end{array}$ & $\begin{array}{l}- \\
\overline{-} \\
- \\
- \\
- \\
- \\
- \\
-\end{array}$ & $\begin{array}{l}W \\
W \\
W \\
W \\
W \\
W \\
W \\
W \\
W \\
W \\
W \\
W \\
w\end{array}$ & $\begin{array}{l}137.9 \\
138.4 \\
146.7 \\
151.3 \\
154.6 \\
159.1 \\
169.3 \\
150.8 \\
145.6 \\
128.0 \\
142.5 \\
156.9 \\
148.5\end{array}$ & $\begin{array}{l}564.9 \\
584.2 \\
626.6 \\
621.1 \\
634.2 \\
688.5 \\
643.2 \\
682.8 \\
710.3 \\
739.2 \\
684.9 \\
641.5 \\
652.1\end{array}$ \\
\hline \multicolumn{11}{|l|}{ Texas } \\
\hline 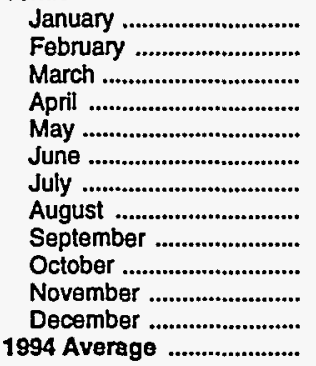 & $\begin{array}{l}673.8 \\
683.1 \\
757.1 \\
712.0 \\
735.7 \\
740.7 \\
689.4 \\
750.5 \\
788.3 \\
720.0 \\
718.5 \\
703.4 \\
722.8\end{array}$ & $\begin{array}{l}6,468.3 \\
6,936.2 \\
7,303.1 \\
7,738.8 \\
8,477.8 \\
9,475.1 \\
8,101.2 \\
9,289.1 \\
8,151.8 \\
8,850.1 \\
8,382.8 \\
7,870.0 \\
8,092.6\end{array}$ & $\begin{array}{l}1,543.0 \\
1,688.8 \\
1,763.5 \\
1,732.0 \\
1,666.5 \\
1,588.4 \\
1,596.7 \\
1,559.2 \\
1,608.3 \\
1,460.5 \\
1,542.6 \\
1,560.4 \\
1,608.4\end{array}$ & $\begin{array}{l}1,269.5 \\
1,927.9 \\
1,790.1 \\
1,999.0 \\
1,713.2 \\
1,541.2 \\
1,471.5 \\
1,361.8 \\
2,025.2 \\
1,515.9 \\
1,379.2 \\
1,805.2 \\
1,646.7\end{array}$ & $\begin{array}{l}2,216.9 \\
2,371.9 \\
2,520.6 \\
2,444.0 \\
2,402.2 \\
2,329.0 \\
2,286.1 \\
2,309.7 \\
2,396.5 \\
2,180.6 \\
2,261.1 \\
2,263.8 \\
2,331.3\end{array}$ & $\begin{array}{r}7,737.8 \\
8,864.0 \\
9,093.2 \\
9,737.8 \\
10,191.0 \\
11,016.3 \\
9,572.7 \\
10,650.8 \\
10,177.0 \\
10,366.0 \\
9,762.0 \\
9,675.2 \\
9,739.4\end{array}$ & $\begin{array}{l}W \\
W \\
W \\
W \\
W \\
W \\
W \\
W \\
W \\
W \\
W \\
W \\
W\end{array}$ & $\begin{array}{l}3,966.8 \\
7,016.4 \\
5,675.5 \\
5,364.7 \\
4,657.4 \\
6,237.3 \\
4,515.5 \\
3,810.1 \\
3,696.4 \\
3,022.9 \\
3,435.5 \\
6,763.5 \\
4,830.8\end{array}$ & $\begin{array}{l}2,221.7 \\
2,376.4 \\
2,527.2 \\
2,451.2 \\
2,514.9 \\
2,343.4 \\
2,295.9 \\
2,403.2 \\
2,514.3 \\
2,261.8 \\
2,333.0 \\
2,331.8 \\
2,381.0\end{array}$ & $\begin{array}{l}11,704.6 \\
15,880.4 \\
14,768.7 \\
15,102.5 \\
14,848.4 \\
17,253.7 \\
14,088.2 \\
14,460.9 \\
13,873.4 \\
13,388.9 \\
13,197.5 \\
16,438.6 \\
14,570.2\end{array}$ \\
\hline \multicolumn{11}{|l|}{ PAD District IV } \\
\hline 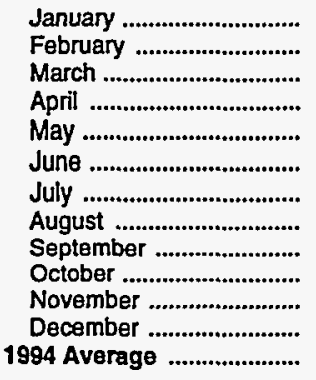 & $\begin{array}{l}517.3 \\
485.9 \\
481.3 \\
485.4 \\
544.4 \\
540.5 \\
483.4 \\
602.1 \\
548.6 \\
446.3 \\
476.2 \\
498.0 \\
509.3\end{array}$ & $\begin{array}{l}1,929.4 \\
2,140.7 \\
2,717.8 \\
2,850.7 \\
2,835.5 \\
3,124.6 \\
3,068.5 \\
3,187.1 \\
2,959.2 \\
2,911.4 \\
2,590.0 \\
2,326.2 \\
2,723.1\end{array}$ & $\begin{array}{l}573.1 \\
482.0 \\
542.9 \\
545.1 \\
582.5 \\
567.4 \\
587.7 \\
520.2 \\
571.8 \\
563.9 \\
502.7 \\
467.6 \\
542.7\end{array}$ & $\begin{array}{l}571.4 \\
406.6 \\
477.0 \\
529.2 \\
410.7 \\
467.3 \\
434.6 \\
516.2 \\
427.1 \\
429.2 \\
338.8 \\
249.7 \\
438.4\end{array}$ & $\begin{array}{r}1,090.4 \\
967.9 \\
1,024.2 \\
1,030.5 \\
1,127.0 \\
1,107.8 \\
1,071.1 \\
1,122.3 \\
1,120.4 \\
1,010.2 \\
978.8 \\
965.6 \\
1,051.9\end{array}$ & $\begin{array}{l}2,500.7 \\
2,547.3 \\
3,194.8 \\
3,379.9 \\
3,246.2 \\
3,591.9 \\
3,503.1 \\
3,703.3 \\
3,386.3 \\
3,340.6 \\
2,928.8 \\
2,575.9 \\
3,161.5\end{array}$ & $\begin{array}{l}W \\
W \\
W \\
W \\
W \\
W \\
W \\
W \\
W \\
W \\
W \\
W \\
W\end{array}$ & $\begin{array}{c}94.2 \\
78.8 \\
93.5 \\
W \\
94.9 \\
117.0 \\
97.9 \\
117.7 \\
91.4 \\
W \\
W \\
W \\
92.1\end{array}$ & $\begin{array}{r}1,090.5 \\
971.4 \\
1,029.4 \\
1,035.9 \\
1,131.4 \\
1,112.8 \\
1,074.7 \\
1,198.5 \\
1,210.6 \\
1,096.3 \\
1,053.5 \\
1,023.8 \\
1,086.5\end{array}$ & $\begin{array}{l}2,594.9 \\
2,626.1 \\
3,288.3 \\
3,496.7 \\
3,341.1 \\
3,709.0 \\
3,601.0 \\
3,821.0 \\
3,477.7 \\
3,416.1 \\
2,994.5 \\
2,637.3 \\
3,253.6\end{array}$ \\
\hline \multicolumn{11}{|l|}{ Colorado } \\
\hline 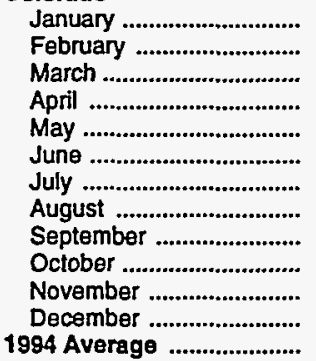 & $\begin{array}{r}94.3 \\
104.5 \\
119.9 \\
89.8 \\
107.0 \\
114.5 \\
117.0 \\
120.7 \\
89.0 \\
86.4 \\
92.6 \\
121.2 \\
104.8\end{array}$ & $\begin{array}{l}526.3 \\
630.4 \\
824.4 \\
795.1 \\
874.5 \\
943.9 \\
844.5 \\
932.5 \\
891.9 \\
882.7 \\
746.1 \\
711.5 \\
801.2\end{array}$ & $\begin{array}{l}199.8 \\
183.2 \\
219.2 \\
219.7 \\
216.3 \\
242.2 \\
217.2 \\
271.2 \\
236.1 \\
240.5 \\
221.7 \\
211.1 \\
223.4\end{array}$ & $\begin{array}{l}70.4 \\
48.9 \\
99.4 \\
93.9 \\
86.7 \\
76.8 \\
47.5 \\
59.0 \\
42.6 \\
41.3 \\
26.7 \\
30.4 \\
60.4\end{array}$ & $\begin{array}{l}294.1 \\
287.7 \\
339.1 \\
309.5 \\
323.4 \\
356.6 \\
334.2 \\
391.9 \\
325.1 \\
326.9 \\
314.2 \\
332.3 \\
328.3\end{array}$ & $\begin{array}{r}596.7 \\
679.4 \\
923.8 \\
889.0 \\
961.2 \\
1,020.7 \\
892.1 \\
991.5 \\
934.5 \\
924.0 \\
772.8 \\
741.9 \\
861.6\end{array}$ & $\begin{array}{l}- \\
\overline{-} \\
\overline{-} \\
\overline{-} \\
\overline{-} \\
w \\
w \\
w \\
\bar{w} \\
w\end{array}$ & $\begin{array}{c}58.4 \\
42.4 \\
W \\
80.5 \\
60.8 \\
80.4 \\
W \\
71.5 \\
W \\
W \\
W \\
W \\
56.6\end{array}$ & $\begin{array}{l}294.1 \\
287.7 \\
339.1 \\
309.5 \\
323.4 \\
356.6 \\
334.2 \\
392.2 \\
326.3 \\
327.2 \\
314.2 \\
332.5 \\
328.4\end{array}$ & $\begin{array}{r}655.1 \\
721.8 \\
978.0 \\
969.5 \\
1,022.0 \\
1,101.1 \\
961.9 \\
1,063.0 \\
987.1 \\
967.1 \\
801.1 \\
778.8 \\
918.3\end{array}$ \\
\hline
\end{tabular}

See footnotes at end of table. 
Table 46. Refiner No. 2 Distillate, Diesel Fuel, and Fuel Oil Volumes by PAD District and State

(Thousand Gallons per Day) - Continued

\begin{tabular}{|c|c|c|c|c|c|c|c|c|c|c|}
\hline \multirow{3}{*}{$\begin{array}{c}\text { Geographlc Area } \\
\text { Month }\end{array}$} & \multicolumn{6}{|c|}{ No. 2 Diesel Fuel } & \multicolumn{2}{|c|}{ No. 2 Fuel Oll } & \multicolumn{2}{|c|}{ No. 2 Distillate } \\
\hline & \multicolumn{2}{|c|}{ Low-Sulfur } & \multicolumn{2}{|c|}{ High-Sulfur } & \multicolumn{2}{|c|}{ Total } & \multirow{2}{*}{$\begin{array}{l}\text { Sales to } \\
\text { End Users }\end{array}$} & \multirow{2}{*}{$\begin{array}{l}\text { Sales for } \\
\text { Resale }\end{array}$} & \multirow{2}{*}{$\begin{array}{l}\text { Sales to } \\
\text { End Users }\end{array}$} & \multirow{2}{*}{$\begin{array}{c}\text { Sales for } \\
\text { Resalo }\end{array}$} \\
\hline & $\begin{array}{l}\text { Sales to } \\
\text { End Users }\end{array}$ & $\begin{array}{l}\text { Sales for } \\
\text { Resale }\end{array}$ & $\begin{array}{l}\text { Sales to } \\
\text { End Users }\end{array}$ & $\begin{array}{l}\text { Sales for } \\
\text { Resale }\end{array}$ & $\begin{array}{l}\text { Sales to } \\
\text { End Users }\end{array}$ & $\begin{array}{l}\text { Sales for } \\
\text { Resale }\end{array}$ & & & & \\
\hline
\end{tabular}

Idaho

January .............................

Fobruary

March

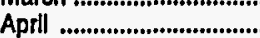

May

July .

August

September....................

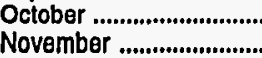

December

1994 Averago

$\begin{array}{cr}W & 291.1 \\ W & W \\ W & 292.8 \\ W & 314.3 \\ W & 290.7 \\ W & 356.3 \\ W & 381.0 \\ 20.5 & 393.1 \\ 17.3 & 315.0 \\ 19.8 & 353.3 \\ 25.3 & 317.6 \\ 14.4 & 239.7 \\ 14.1 & 317.0\end{array}$

$\begin{array}{lc}W & 289.6 \\ W & W \\ W & 193.4 \\ W & 200.7 \\ W & 163.3 \\ W & 186.7 \\ W & 188.9 \\ W & 250.1 \\ W & 222.4 \\ W & 213.6 \\ W & 181.7 \\ W & 116.4 \\ W & 198.3\end{array}$

$\begin{array}{ll}W & 580.7 \\ W & 424.6 \\ W & 486.1 \\ W & 515.0 \\ W & 454.0 \\ W & 543.0 \\ W & 569.9 \\ W & 643.3 \\ W & 537.3 \\ W & 566.8 \\ W & 499.2 \\ W & 356.1 \\ W & 515.3\end{array}$

-
-
-
-
$\bar{w}$
$\overline{-}$
-
$\bar{w}$

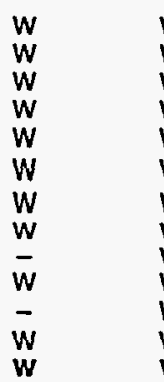

$\begin{array}{ll}\text { W } & 585.7 \\ \text { W } & 432.9 \\ \text { W } & 493.5 \\ \text { W } & 519.2 \\ \text { W } & 457.1 \\ \text { W } & 547.0 \\ \text { W } & 571.2 \\ \text { W } & 647.4 \\ \text { W } & 537.3 \\ \text { W } & 569.0 \\ \text { W } & 499.2 \\ \text { W } & 359.2 \\ \text { W } & 518.8\end{array}$

Montana

January ................................

February .............................

March ..

138.8

188.6
115.4

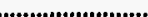

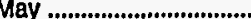

June

July .

(1)...............................

September .............................

October.

November

December

Utah

January

February

March ...................................

May ...............................

June ..............................

July ......

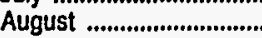

September

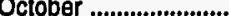

November .........................

December

115.4
163.9

W

131.6

125.8

W

$W$

$W$
$W$
$W$

36.9

274.9

$W$

W

$\begin{array}{lll}9.7 & 159.9 & 284.6\end{array}$

$\begin{array}{cl}188.6 & 393.0 \\ W & 554.7\end{array}$

554.7
622.5

6227

635.6

577.3

678.0

652.4

639.1

531.1

479.8
556.6

$\begin{array}{llrl}- & - & 159.9 & 284.6 \\ - & W & 188.6 & 393.1 \\ - & W & W & 554.8 \\ - & W & W & 623.0 \\ - & W & W & 624.6 \\ - & W & W & 636.0 \\ - & W & W & 577.9 \\ - & W & W & 679.2 \\ W & W & W & 652.8 \\ - & W & W & 639.2 \\ W & W & W & 531.2 \\ \bar{W} & W & W & 479.9 \\ \text { W } & W & 138.9 & 557.1\end{array}$

$\begin{array}{llll}128.0 & 415.4 & 106.7 & 192.5\end{array}$

$\begin{array}{cc}W & 398.9 \\ 116.7 & 509\end{array}$

$58.9 \quad 1622$

$74.5 \quad 161.7$

$80.4 \quad 215.2$

$\begin{array}{rrrr}123.4 & 492.2 & 88.2 & 147.4 \\ 121.0 & 585.6 & 100.8 & 180.7\end{array}$

$121.0 \quad 585$.

$117.2 \quad 616.9$

$80.3 \quad 180.1$

$\begin{array}{cccc}W & 597.7 & W & 181.6 \\ 152.6 & 490.8 & 21.8 & 142.4\end{array}$

137.0

121.9

437.1

$38.6 \quad 152.5$

$12.9 \quad 125.1$

$111.5 \quad 392.1$

$8.7 \quad 98.7$

$234.6 \quad 607.9$

$\begin{array}{cc}W & 561.0 \\ 191.2 & 670.9\end{array}$

$\begin{array}{ll}191.2 & 670.9 \\ 172.8 & 747.8\end{array}$

$211.6 \quad 639.6$

$221.8 \quad 766.3$

$197.5-797.0$

$181.5 \quad 779.3$

$174.3 \quad 633.2$

$175.6 \quad 589.6$

$134.8 \quad 580.4$

$120.3 \quad 490.7$

$181.0 \quad 655.8$

W

1984 Average ...................

$123.3 \quad 494.2$

$57.7 \quad 161.6$

$288.6 \quad 430.7$

$\begin{array}{ll}250.4 & 489.4 \\ 295.1 & 559.3\end{array}$

$\begin{array}{ll}295.1 & 559.3 \\ 295.5 & 605.6\end{array}$

$373.1 \quad 568.7$

299.7

$332.4 \quad 666.8$

$291.4 \quad 611.2$

$368.5 \quad 628.9$

$313.0 \quad 621.1$

$314.4 \quad 545.3$

$314.1 \quad 507.4$

November

December .

1994 Avorage

$\begin{array}{rr}143.8 & 421 \\ W & 479 \\ W & W \\ W & W \\ W & W \\ W & W \\ W & W \\ W & W \\ W & W \\ W & W \\ W & W \\ W & W \\ 130.1 & 562\end{array}$

See footnotes at end of table. 
Table 46. Refiner No. 2 Distillate, Diesel Fuel, and Fuel Oil Volumes by PAD District and State

(Thousand Gallons per Day) - Continued

\begin{tabular}{|c|c|c|c|c|c|c|c|c|c|c|}
\hline \multirow{3}{*}{$\begin{array}{c}\text { Geographic Area } \\
\text { Month }\end{array}$} & \multicolumn{6}{|c|}{ No. 2 Diesel Fuel } & \multicolumn{2}{|c|}{ No. 2 Fuel Oll } & \multicolumn{2}{|c|}{ No. 2 Distillate } \\
\hline & \multicolumn{2}{|c|}{ Low-Sulfur } & \multicolumn{2}{|c|}{ High-Sulfur } & \multicolumn{2}{|c|}{ Total } & \multirow{2}{*}{$\begin{array}{l}\text { Sales to } \\
\text { End Users }\end{array}$} & \multirow{2}{*}{$\begin{array}{l}\text { Sales for } \\
\text { Resale }\end{array}$} & \multirow{2}{*}{$\begin{array}{l}\text { Sales to } \\
\text { End Users }\end{array}$} & \multirow{2}{*}{$\begin{array}{l}\text { Sales for } \\
\text { Resale }\end{array}$} \\
\hline & $\begin{array}{l}\text { Sales to } \\
\text { End Users }\end{array}$ & $\begin{array}{c}\text { Sales for } \\
\text { Resalo }\end{array}$ & $\begin{array}{c}\text { Sales to } \\
\text { End Users }\end{array}$ & $\begin{array}{c}\text { Sales for } \\
\text { Resale }\end{array}$ & $\begin{array}{l}\text { Sales to } \\
\text { End Users }\end{array}$ & $\begin{array}{c}\text { Sales for } \\
\text { Resale }\end{array}$ & & & & \\
\hline \multicolumn{11}{|l|}{ PAD District $V$} \\
\hline 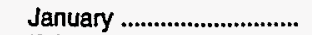 & $1,500.3$ & $9,189.1$ & $1,288.9$ & $3,998.3$ & $2,789.2$ & $13,187.4$ & 150.9 & 278.6 & $2,940.2$ & $13,466.0$ \\
\hline 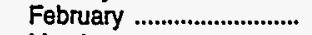 & $1,475.8$ & $8,386.5$ & $1,331.1$ & $4,234.8$ & $2,806.8$ & $12,621.3$ & w & 632.3 & $2,947.9$ & $13,253.6$ \\
\hline 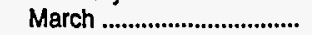 & $1,498.6$ & $9,479.5$ & $1,580.1$ & $3,825.0$ & $3,078.7$ & $13,304.6$ & $w$ & 143.4 & $3,222.0$ & $\$ 3,448.0$ \\
\hline Aprll ...................................... & $1,597.2$ & $9,505.7$ & $1,498.4$ & $4,337.6$ & $3,095.6$ & $13,843.3$ & $w$ & NA & $3,197.2$ & $14,163.3$ \\
\hline May ...................................... & $1,708.5$ & $9,977.7$ & $1,412.5$ & $4,042.9$ & $3,121.1$ & $14,020.7$ & w & 327.7 & $3,194.2$ & $14,348,4$ \\
\hline 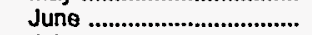 & $1,821.6$ & $10,812.7$ & $1,596.2$ & $4,265.3$ & $3,417.8$ & $15,078.0$ & $\ddot{w}$ & 222.0 & $3,493.8$ & $15,300.0$ \\
\hline July …....................................... & $1,677.9$ & $9,838.6$ & $1,603.9$ & $3,435.7$ & $3,281.8$ & $13,274,4$ & w & 298.4 & $3,349.5$ & $13,572.7$ \\
\hline 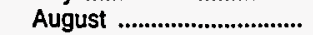 & $1,876.3$ & $11,215.2$ & $1,451.4$ & $3,990.5$ & $3,327.7$ & $15,205.7$ & $w$ & 393.2 & $3,426.3$ & $15,598.9$ \\
\hline September ............................... & $1,857.1$ & $10,803.6$ & $1,560.7$ & $3,480.6$ & $3,417.8$ & $\$ 4,284.2$ & $\ddot{w}$ & 270.2 & $3,529.3$ & $14,554.5$ \\
\hline 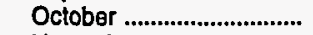 & $1,699.1$ & $10,289.3$ & $1,224.1$ & $3,419.0$ & $2,923.2$ & $13,708.3$ & $w$ & $w$ & $3,075.3$ & $13,920.5$ \\
\hline November ............................... & $1,671.7$ & $9,163.4$ & 934.6 & $3,465.1$ & $2,606.4$ & $12,628.4$ & $w$ & $w$ & $2,793.0$ & $13,181.8$ \\
\hline 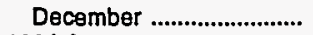 & $1,652.4$ & $9,826.3$ & $1,183.0$ & $3,697.1$ & $2,835.4$ & $13,523.4$ & $w$ & w & $3,038.8$ & $13,875.7$ \\
\hline 1994 Average ........................... & $1,670.6$ & $9,884.0$ & $1,389.1$ & $3,845.7$ & $3,058.7$ & $13,729.8$ & 125.4 & 331.1 & $3,185.1$ & $14,060.9$ \\
\hline \multicolumn{11}{|l|}{ Alaska } \\
\hline 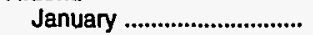 & w & $w$ & w & 223.9 & 21.5 & 225.1 & 80.3 & 182.3 & 101.7 & 407.3 \\
\hline 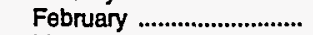 & w & w & 11.9 & $w$ & $w$ & 225.9 & 73.1 & $w$ & $w$ & 800.8 \\
\hline 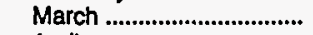 & w & $w$ & 14.7 & w & w & 348.2 & 72.4 & w & $w$ & 463.5 \\
\hline 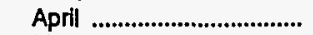 & $w$ & $w$ & w & w & 102.9 & 436.4 & 56.9 & NA & 159.8 & 731.5 \\
\hline 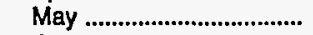 & w & w & 8.6 & $w$ & W & 374.2 & 45.3 & w & W & 692.1 \\
\hline 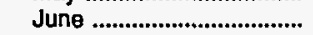 & $w$ & w & 52.6 & w & $w$ & 638.0 & 43.8 & $w$ & $w$ & 850.9 \\
\hline 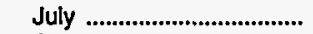 & w & $w$ & 31.2 & w & $w$ & 453.8 & 42.4 & 173.7 & $w$ & 627.5 \\
\hline August & $w$ & $w$ & 38.7 & w & $w$ & 581.1 & 48.3 & 315.7 & $\ddot{w}$ & 896.9 \\
\hline 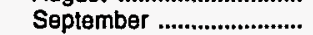 & $w$ & $\ddot{w}$ & 18.7 & $w$ & $w$ & 295.7 & 51.8 & w & $\ddot{w}$ & 540.3 \\
\hline 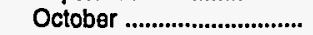 & w & w & 6.4 & W & W & 374.5 & 62.7 & 188.0 & $\ddot{w}$ & 562.5 \\
\hline November ............................... & $w$ & $w$ & 8.8 & w & W & 182.9 & 71.9 & $w$ & $w$ & 684.7 \\
\hline December ........................... & w & $w$ & $w$ & W & W & 234.2 & 82.8 & 285.0 & $\ddot{w}$ & 519.2 \\
\hline 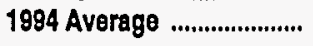 & W & $w$ & 24.0 & 348.7 & 43.7 & 365.0 & 60.9 & 281.2 & 104.7 & 646.3 \\
\hline \multicolumn{11}{|l|}{ Arizona } \\
\hline January ..... & 176.1 & 741.2 & 91.8 & 169.5 & 267.9 & 910.7 & - & - & 267.9 & 910.7 \\
\hline 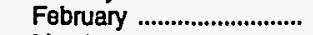 & $w$ & 853.0 & $w$ & NA & 270.4 & 981.8 & - & - & 270.4 & 981.8 \\
\hline 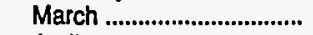 & w & 754.8 & $w$ & 136.0 & 262.7 & 890.8 & - & - & 262.7 & 890.8 \\
\hline 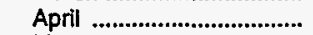 & $w$ & $1,004.3$ & $w$ & 164.9 & 281.2 & $1,169.2$ & - & - & 281.2 & $1,169.2$ \\
\hline 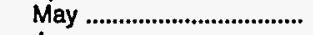 & 189.4 & 843.5 & 80.7 & 199.5 & 270.1 & $1,043.0$ & - & - & 270.1 & $1,043.0$ \\
\hline .................................... & 198.1 & 870.4 & 64.2 & 211.9 & 262.3 & $1,082.2$ & - & - & 262.3 & $1,082.2$ \\
\hline 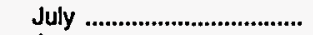 & $w$ & 774.7 & $w$ & 141.1 & 275.3 & 915.8 & - & - & 275.3 & 915.8 \\
\hline August ................................. & 203.1 & 822.9 & 109.8 & 166.2 & 312.9 & 989.1 & - & - & 312.9 & 989.1 \\
\hline September .............................. & 194.5 & 733.7 & 118.8 & 182.7 & 313.4 & $\mathbf{9 1 6 . 4}$ & - & - & 313.4 & 916.4 \\
\hline 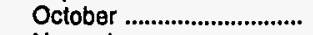 & 199.6 & 808.6 & 93.9 & 183.5 & 293.5 & 992.1 & - & - & 293.5 & 992.1 \\
\hline November ....... & 169.8 & 716.2 & 95.8 & 126.1 & 265.6 & 842.3 & - & - & 265.6 & 842.3 \\
\hline 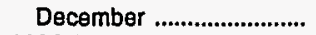 & 165.0 & 801.5 & 90.4 & 167.4 & 255.4 & 968.8 & - & - & 255.4 & 968.8 \\
\hline 1994 Average & 185.5 & 809.8 & 92.1 & 165.0 & 277.6 & 974.8 & - & - & 277.6 & 974.8 \\
\hline Calffornia & & & & & & & & & & \\
\hline 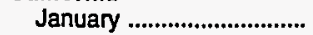 & $1,016.7$ & $5,369.8$ & 133.5 & $1,588.3$ & 1.150 .1 & $6,958.1$ & - & - & $1,150.1$ & $6,958.1$ \\
\hline 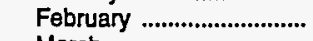 & 992.7 & $4,792.5$ & 144.0 & $1,575.9$ & $1,136.7$ & $6,368.5$ & - & - & $1,136.7$ & $6,368.5$ \\
\hline ……..................... & $1,017.3$ & $5,518.4$ & 138.9 & $1,582.6$ & $1,156.2$ & $7,100.9$ & - & - & $1,156.2$ & $7,100.9$ \\
\hline April & $1,066.0$ & $5,347.2$ & 79.5 & $1,701.8$ & $1,145.5$ & $7,049.1$ & - & - & $1,145.5$ & $7,049.1$ \\
\hline 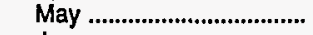 & $1,178.5$ & $5,725.8$ & 115.7 & $1,525.4$ & $1,294.3$ & $7,251.2$ & - & - & $1,294.3$ & $7,251.2$ \\
\hline 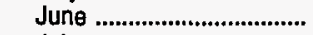 & $1,231.7$ & $6,440.2$ & 156.2 & $1,529.0$ & $1,388.0$ & $7,969.2$ & - & - & $1,388.0$ & $7,969.2$ \\
\hline 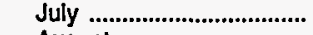 & $1,162.2$ & $5,728.1$ & 101.6 & $1,501.7$ & $1,263.8$ & $7,229.8$ & - & w & $1,263.8$ & $7,331,4$ \\
\hline 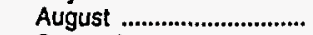 & $1,276.7$ & $6,386.2$ & 119.6 & $1,725.8$ & $1,396.3$ & $8,112.0$ & - & $w$ & $9,396.3$ & $8,179,7$ \\
\hline 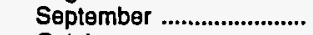 & $1,267.4$ & $6,309.5$ & 133.8 & $1,501.4$ & $1,401.2$ & $7,810.9$ & - & - & $1,401.2$ & $7,810.9$ \\
\hline 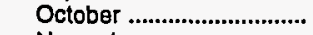 & $1,159.5$ & $6,215.9$ & 114.6 & NA & $1,274.1$ & $7,708.8$ & - & - & $1,274.1$ & $7,708.8$ \\
\hline 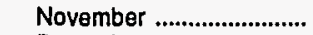 & $1,120.1$ & $5,454.2$ & 106.8 & NA & $1,226.9$ & $6,792.2$ & - & - & $1,226.9$ & $6,792.2$ \\
\hline 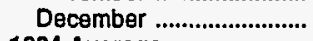 & $1,116.9$ & $5,817.7$ & 338.4 & NA & $1,455.2$ & $7,376.5$ & - & $\overline{-}$ & $1,455.2$ & $7,376.5$ \\
\hline 1994 Average ....................... & $1,134.5$ & $5,765.3$ & 140.4 & $1,552.0$ & $1,275.0$ & $7,317.3$ & - & $\mathbf{w}$ & $1,275.0$ & $7,331.7$ \\
\hline
\end{tabular}

See footnotes at end of table. 
Table 46. Refiner No. 2 Distillate, Diesel Fuel, and Fuel Oil Volumes by PAD District and State

(Thousand Gallons per Day) - Continued

\begin{tabular}{|c|c|c|c|c|c|c|c|c|c|c|}
\hline \multirow{3}{*}{$\begin{array}{l}\text { Geographlc Area } \\
\text { Month }\end{array}$} & \multicolumn{6}{|c|}{ No. 2 Diesel Fuel } & \multicolumn{2}{|c|}{ No. 2 Fuel Oll } & \multicolumn{2}{|c|}{ No. 2 Distillate } \\
\hline & \multicolumn{2}{|c|}{ Low-Sulfur } & \multicolumn{2}{|c|}{ High-Sulfur } & \multicolumn{2}{|c|}{ Total } & \multirow{2}{*}{$\begin{array}{l}\text { Sales to } \\
\text { End Users }\end{array}$} & \multirow{2}{*}{$\begin{array}{l}\text { Sales for } \\
\text { Resale }\end{array}$} & \multirow{2}{*}{$\begin{array}{l}\text { Sales to } \\
\text { End Users }\end{array}$} & \multirow{2}{*}{$\begin{array}{c}\text { Sales for } \\
\text { Resale }\end{array}$} \\
\hline & $\begin{array}{l}\text { Sales to } \\
\text { End Users }\end{array}$ & $\begin{array}{l}\text { Sales for } \\
\text { Resale }\end{array}$ & $\begin{array}{l}\text { Sales to } \\
\text { End Users }\end{array}$ & $\begin{array}{l}\text { Sales for } \\
\text { Resale }\end{array}$ & $\begin{array}{l}\text { Sales to } \\
\text { End Users }\end{array}$ & $\begin{array}{l}\text { Sales for } \\
\text { Resale }\end{array}$ & & & & \\
\hline
\end{tabular}

\begin{tabular}{|c|c|c|c|c|c|c|c|c|c|c|}
\hline Hawail & & & & & & & & & & \\
\hline January ................................... & 30.0 & 76.4 & $W$ & 75.8 & $W$ & 152.1 & $W$ & - & $W$ & 152.1 \\
\hline February ........................... & 45.2 & $W$ & W & $W$ & $W$ & 146.3 & W & - & W & 146.3 \\
\hline 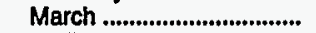 & 48.0 & W & $w$ & $w$ & $\mathbf{W}$ & 157.6 & $\mathbf{W}$ & - & $w$ & 157.6 \\
\hline April & $W$ & W & W & $w$ & W & 168.5 & W & - & $W$ & 168.5 \\
\hline May ..................................... & W & W & $w$ & W & $\mathbf{W}$ & 173.0 & $\mathbf{W}$ & - & $W$ & 173.0 \\
\hline June .................................. & 49.6 & W & $w$ & $w$ & $W$ & 183.2 & $W$ & - & $W$ & 183.2 \\
\hline July ..................................... & 44.8 & $W$ & $w$ & $w$ & W & 171.8 & $W$ & - & $W$ & 171.8 \\
\hline August ............................... & $w$ & $W$ & W & $w$ & $W$ & 169.9 & $W$ & - & W & 169.9 \\
\hline September ........................ & 41.8 & $w$ & $w$ & $w$ & $w$ & 171.6 & W & - & $W$ & 171.6 \\
\hline October .............................. & 43.3 & $W$ & $w$ & $W$ & $W$ & 162.0 & $W$ & - & $W$ & 162.0 \\
\hline November ........................... & 44.3 & $w$ & W & $w$ & $W$ & 157.0 & $w$ & - & $W$ & 157.0 \\
\hline December .......................... & $W$ & $w$ & $w$ & $w$ & W & 233.5 & $w$ & - & W & 233.5 \\
\hline 1994 Average ..................... & 43.8 & 79.0 & $W$ & 91.7 & $\mathbf{W}$ & 170.7 & $w$ & - & $\mathbf{W}$ & 170.7 \\
\hline Nevada & & & & & & & & & & \\
\hline January ............................. & 66.4 & 440.6 & 30.4 & 39.5 & 96.8 & 480.1 & - & $w$ & 96.8 & 480.2 \\
\hline February ............................ & 70.6 & 482.7 & 39.1 & 29.4 & 109.7 & 512.1 & - & - & 109.7 & 512.1 \\
\hline March ................................... & $W$ & 529.8 & $W$ & 27.7 & 111.6 & 557.5 & - & - & 111.6 & 557.5 \\
\hline 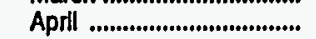 & 59.1 & 500.1 & $\ddot{w}$ & 33.5 & $W$ & 533.5 & - & - & W & $\mathbf{5 3 3 . 5}$ \\
\hline May ..................................... & $W$ & 562.7 & $W$ & 42.5 & 134.3 & 605.2 & - & - & 134.3 & 605.2 \\
\hline June .................................... & W & 586.2 & $W$ & 48.8 & 152.7 & 635.0 & - & - & 152.7 & 635.0 \\
\hline July .................................. & 70.8 & 485.4 & 62.6 & 49.4 & 133.5 & 534.7 & - & - & 133.5 & 534.7 \\
\hline August .............................. & $W$ & 573.2 & $W$ & 26.9 & 112.9 & 600.2 & $W$ & - & 141.8 & 600.2 \\
\hline September ........................ & $\mathbf{W}$ & 523.6 & $W$ & 48.8 & 118.2 & 572.4 & $W$ & - & 147.4 & 572.4 \\
\hline Octobet ............................... & W & 511.7 & $w$ & 56.0 & 91.4 & 567.8 & $w$ & - & 115.4 & 567.8 \\
\hline November ......................... & W & 408.8 & W & 27.8 & 115.8 & 436.6 & W & - & 158.5 & 436.6 \\
\hline December .......................... & W & 469.3 & $W$ & 27.8 & 75.0 & 497.1 & $W$ & - & 109.6 & 497.1 \\
\hline 1994 Average ..................... & 72.6 & 506.4 & 40.9 & 38.2 & 113.5 & 544.6 & $W$ & $w$ & 126.8 & 544.6 \\
\hline Orogon & & & & & & & & & & \\
\hline January ............................ & 77.1 & $1,262.7$ & 354.3 & 340.6 & 431.5 & $1,603.4$ & $W$ & $w$ & 444.8 & $1,619.0$ \\
\hline Fobruary ............................ & 76.2 & $1,061.6$ & 340.6 & 510.2 & 416.8 & $1,571.9$ & W & $w$ & 434.9 & $1,582.8$ \\
\hline March ................................. & 84.1 & $1,188.6$ & 254.8 & 432.6 & 338.9 & $1,621.3$ & $W$ & $w$ & 348.9 & $1,623.7$ \\
\hline 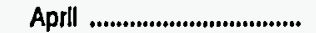 & 97.0 & $1,166.2$ & 308.4 & 547.4 & 405.4 & $1,713.6$ & $W$ & w & 413.6 & $1,715.3$ \\
\hline May ...................................... & 89.4 & $1,258.6$ & 281.5 & 338.2 & 370.9 & $1,596.8$ & $W$ & $w$ & 375.0 & $1,597.3$ \\
\hline June .................................... & 127.5 & $1,319.4$ & 218.4 & 503.7 & 345.9 & $1,823.1$ & $w$ & $W$ & 348.7 & $1,824.0$ \\
\hline July ...................................... & 127.2 & $1,306.8$ & 214.5 & 475.3 & 341.7 & $1,782.1$ & $w$ & $w$ & 342.7 & $1,782.7$ \\
\hline August ............................... & 153.8 & $1,457.9$ & 209.0 & 566.1 & 362.7 & $2,024.0$ & $W$ & $w$ & 364.0 & $2,024.6$ \\
\hline September ........................ & 150.1 & $1,333.6$ & 231.0 & 545.4 & 381.2 & $1,879.0$ & $W$ & $w$ & 382.9 & $1,880.5$ \\
\hline October ................................ & 129.7 & $1,309.7$ & 275.4 & 521.2 & 405.1 & $1,830.9$ & $w$ & $w$ & 409.2 & $1,834.8$ \\
\hline November ......................... & 141.6 & $1,193.7$ & 245.8 & 518.8 & 387.4 & $1,712.5$ & W & $w$ & 400.1 & $1,721.0$ \\
\hline December ......................... & 97.5 & $1,169.9$ & 280.7 & 580.0 & 378.2 & $1,749.9$ & $W$ & $W$ & 393.5 & 1.757 .6 \\
\hline 1994 Average ..................... & 112.7 & $1,254.0$ & 267.4 & 489.4 & 380.2 & $1,743.3$ & $\mathbf{w}$ & 4.5 & 387.8 & $1,747.9$ \\
\hline Washlngton & & & & & & & & & & \\
\hline January ............................. & 122.8 & $1,297.2$ & 363.6 & $1,560.7$ & 486.4 & $2,857.9$ & W & 80.5 & 534.2 & $2,938.5$ \\
\hline February ........................... & 94.3 & $1,114.8$ & 433.5 & $1,700.1$ & 527.8 & $2,814.9$ & 49.5 & 46.6 & 577.4 & $2,861.4$ \\
\hline March .................................. & $W$ & $1,391.9$ & $w$ & $1,236.5$ & 853.3 & $2,628.3$ & $W$ & 25.6 & 904.3 & $2,653.9$ \\
\hline Aprll ................................... & $W$ & $1,393.1$ & $w$ & $1,379.9$ & 764.5 & $2,772.9$ & 32.1 & 23.3 & 796.6 & $2,796.2$ \\
\hline May ...................................... & 94.2 & $1,483.8$ & 559.0 & $1,493.4$ & 653.1 & $2,977.2$ & $W$ & 9.4 & 672.1 & $2,986.6$ \\
\hline 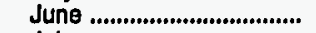 & 102.0 & 1.489 .9 & 712.8 & $1,257.4$ & 814.8 & $2,747.3$ & 23.4 & 8.2 & 838.2 & $2,755.5$ \\
\hline July .................................... & $W$ & $1,438.8$ & $W$ & 747.4 & 855.6 & $2,186.3$ & 18.9 & 22.5 & 874.5 & $2,208.7$ \\
\hline August ............................... & 94.5 & $1,862.6$ & 634.0 & 866.7 & 728.5 & $2,729.4$ & 13.6 & 9.1 & 742.1 & $2,738.5$ \\
\hline September ........................ & $\begin{array}{l}93.3 \\
90.9\end{array}$ & $1,809.4$ & $\begin{array}{l}669.1 \\
373.9\end{array}$ & $\begin{array}{l}828.8 \\
7180\end{array}$ & $\begin{array}{l}762.5 \\
464.8\end{array}$ & $2,638.3$ & 18.7 & 24.1 & 781.2 & $2,662.4$ \\
\hline October ............................... & $\begin{array}{l}90.9 \\
85.3\end{array}$ & $\begin{array}{l}1,354.2 \\
1,298.3\end{array}$ & $\begin{array}{l}373.9 \\
159.8\end{array}$ & $\begin{array}{r}718.0 \\
1206.6\end{array}$ & $\begin{array}{l}464.8 \\
245.1\end{array}$ & $\begin{array}{l}2,072.2 \\
2,504.9\end{array}$ & 52.9 & 20.3 & 517.7 & $2,092.5$ \\
\hline November .......................... & $\begin{array}{r}85.3 \\
162.9\end{array}$ & $\begin{array}{l}1,298.3 \\
1,488.6\end{array}$ & $\begin{array}{l}159.8 \\
186.7\end{array}$ & $\begin{array}{r}1,206.6 \\
974.7\end{array}$ & $\begin{array}{l}245.1 \\
349.6\end{array}$ & $\begin{array}{l}2,504.9 \\
2,463,4\end{array}$ & $\begin{array}{l}45.1 \\
60.5\end{array}$ & 43.1 & 290.2 & $2,548.0$ \\
\hline 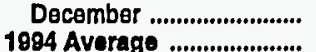 & $\begin{array}{l}162.9 \\
101.7\end{array}$ & $\begin{array}{l}1,488.6 \\
1,454.2\end{array}$ & $\begin{array}{l}186.7 \\
524.4\end{array}$ & $\begin{array}{r}974.7 \\
1,159.7\end{array}$ & $\begin{array}{l}349.6 \\
626.1\end{array}$ & $\begin{array}{l}2,463.4 \\
2,613.9\end{array}$ & $\begin{array}{l}60.5 \\
36.0\end{array}$ & $\begin{array}{l}59.6 \\
31.0\end{array}$ & $\begin{array}{l}410.1 \\
662.1\end{array}$ & $\begin{array}{l}2,523.0 \\
2,644.9\end{array}$ \\
\hline
\end{tabular}

Dash $(-)=$ No data reported.

$\mathrm{NA}=$ Not avallable.

$W=$ Withheld to avold disclosure of individual company data.

Notes: PAD Dlstrict and U.S. totals equal the sum of the volumes for all States. In certain PAD Districts, however, volumes are not shown for every State.

Note: Totals may not equal the sum of the components due to rounding.

Source: Energy Information AdmInistration Form ElA-782A, 'Refiners'/Gas Plant Operators' Monthly Petroleum Product Sales Report." 
Table 47. Refiner Residual Fuel Oil and No. 4 Fuel Volumes by PAD District

(Thousand Gallons per Day)

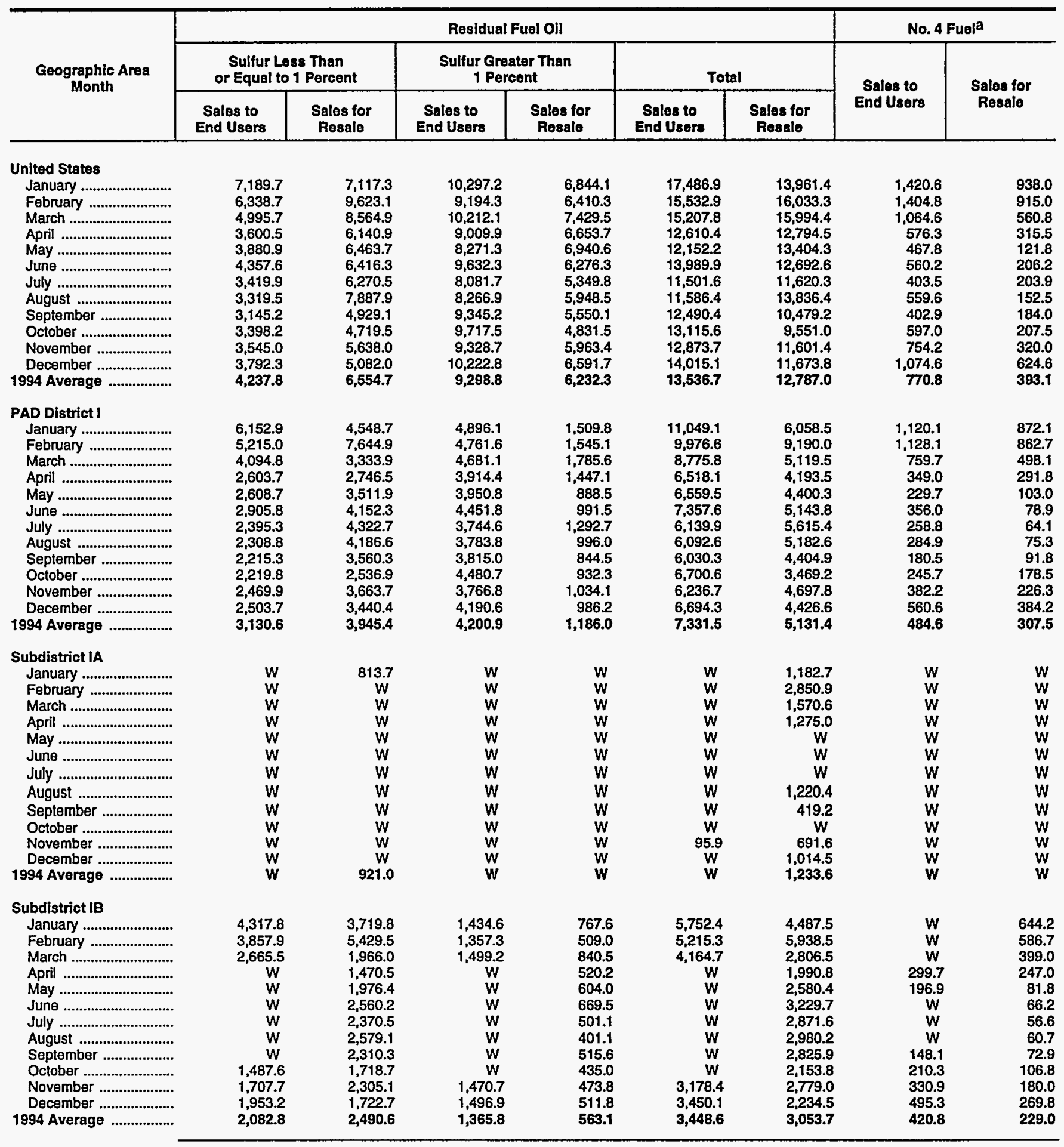

See footnotes at end of table. 
Table 47. Refiner Residual Fuel Oil and No. 4 Fuel Volumes by PAD District (Thousand Gallons per Day) - Continued

\begin{tabular}{|c|c|c|c|c|c|c|c|c|}
\hline \multirow{3}{*}{$\begin{array}{c}\text { Geographic Area } \\
\text { Month }\end{array}$} & \multicolumn{6}{|c|}{ Residual Fuel Oll } & \multicolumn{2}{|c|}{ No. 4 Fuela } \\
\hline & \multicolumn{2}{|c|}{$\begin{array}{l}\text { Sulfur Less Than } \\
\text { or Equal to } 1 \text { Percent }\end{array}$} & \multicolumn{2}{|c|}{$\begin{array}{c}\text { Sulfur Greater Than } \\
1 \text { Percent }\end{array}$} & \multicolumn{2}{|c|}{ Total } & \multirow{2}{*}{$\begin{array}{l}\text { Sales to } \\
\text { End Users }\end{array}$} & \multirow{2}{*}{$\begin{array}{l}\text { Sales for } \\
\text { Resale }\end{array}$} \\
\hline & $\begin{array}{l}\text { Sales to } \\
\text { End Users }\end{array}$ & $\begin{array}{l}\text { Sales for } \\
\text { Resale }\end{array}$ & $\begin{array}{l}\text { Sales to } \\
\text { End Users }\end{array}$ & $\begin{array}{l}\text { Sales for } \\
\text { Resale }\end{array}$ & $\begin{array}{l}\text { Sales to } \\
\text { End Users }\end{array}$ & $\begin{array}{l}\text { Sales for } \\
\text { Resale }\end{array}$ & & \\
\hline
\end{tabular}

Subdistrict IC

January...

March

(n)

Aprll

May ................................

June ...............................

July ....

August ...erser.

September .....................

Oclober ..........................

November

December

1994 Average ..................

PAD Dlstrict II

January ...

March ...

April .................................

May

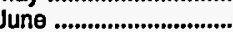

July

August ........................

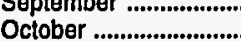

November

December ..............

1994 Average ...................

PAD Dlatrict III

January

February ......................

March

April .................................

May

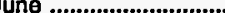

July ...............................

August ...........................

September .....................

October .

November

December ......................

1994 Average

PAD District IV

January ..

February

May

June

August

Soptember ....................

October

November

December

1994 Average

$\begin{array}{lr}W & 3,370.4 \\ W & W \\ W & W \\ W & 2,672.6 \\ W & 2,560.7 \\ W & 3,025.2 \\ W & 2,578.4 \\ W & 2,647.3 \\ W & 2,247.2 \\ W & W \\ W & W \\ W & W \\ 533.8 & 2,781.0\end{array}$

30.2
$W$
$W$
$W$
13.7
$W$
$W$
$W$
$W$
$W$
14.1
$W$
17.7

81.8

$W$
$W$
$W$

38.5

$W$
188.1

W

108.4

$W$
$W$
$W$

108.4

$1,592.2$

$1,447.4$

$3,037.6$

$2,620.9$

$2,634.2$

$1,341.3$

$1,273.2$

$2,844.6$

918.0

$1,442.5$

$1,405.3$

$1,061.5$

$1,807.0$

14.0

$W$
$W$
$W$
$w$
$w$
$W$
$W$
$w$
$w$

300.1

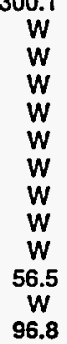

\section{$2,735.0$}

$W$
$W$
$W$
$W$
$W$
$W$
$W$
$W$
$W$
$W$
$W$

$2,620.3$

373.1
$W$
$W$
$W$
$W$
$W$
$W$
$W$
$W$
$W$
$W$
$W$
$W$

$4,534.5$
$W$
$W$
$3,453.8$
$3,802.6$
$3,763.6$
$3,346.6$
$3,365.5$
$2,999.5$
$3,539.1$
$2,962.4$
$W$
$3,564.9$

549.0

$W$
$W$
$W$

336.7

$W$
234.6

W

496.8

$W$
$W$
$W$

352.0

$2,684.5$

$2,228.8$

$3,156.6$

$2,917.4$

$2,800.1$

3,421.4

$2,505.3$

2,8952

$3,028.5$

$2,802.5$

3,415 .0

$3,657.3$

2,962.8

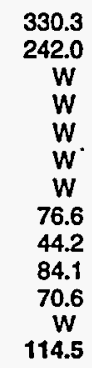

$1,861.0$

$2,914.2$

$2,756.4$

1.763 .1

$2,778.2$

2,239.9

$3,310.5$

$3,038.2$

$2,822.5$

3230.0

2,634.4

$W$
$W$
$W$
$W$
$W$
$W$
$W$
$W$
$W$
$W$
$W$
$W$
46.6

$$
\begin{array}{r}
388.2 \\
400.6 \\
742.4 \\
927.7 \\
W \\
W \\
W \\
982.0 \\
1,159.7 \\
W \\
1,227.3 \\
1,177.6
\end{array}
$$

844.1

$\begin{array}{cc}46.4 & W \\ 37.4 & W \\ 18.7 & W \\ W & W \\ W & W \\ 10.2 & W \\ W & W \\ W & W \\ W & W \\ W & W \\ W & W \\ W & W \\ 16.9 & W\end{array}$

630.8

407.1

$W$
331.7

375.2

369.5

422.7

525.4

6052

619.2

434.6

404.1

$206.6 \quad W$

$\begin{array}{ll}206.6 & W\end{array}$

$\begin{array}{ll}W & - \\ W & -\end{array}$

$-$

W

-

$-$

w

$\bar{w}$

$4,276.7$

$3,676.1$

$6,194.3$

$5,538.3$

$5,434.3$

4.762.6

3.778 .5

$5,739.8$

$3,946.5$

$4,245.0$

$4,820.3$

4718.8

$4,769.8$

622.9
125.4

W

392.3

96.9

526.2

110.4

138.4

95.9

179.5

37.9

280.1

See footnotes at end of table. 


\section{Table 47. Refiner Residual Fuel Oil and No. 4 Fuel Volumes by PAD District}

(Thousand Gallons per Day) - Continued

\begin{tabular}{|c|c|c|c|c|c|c|c|c|}
\hline \multirow{3}{*}{$\begin{array}{c}\text { Geographic Area } \\
\text { Month }\end{array}$} & \multicolumn{6}{|c|}{ Residual Fuel Oll } & \multicolumn{2}{|c|}{ No. 4 Fuela } \\
\hline & \multicolumn{2}{|c|}{$\begin{array}{l}\text { Sulfur Less Then } \\
\text { or Equal to } 1 \text { Percent }\end{array}$} & \multicolumn{2}{|c|}{$\begin{array}{c}\text { Sulfur Greater Than } \\
1 \text { Percent }\end{array}$} & \multicolumn{2}{|c|}{ Total } & \multirow{2}{*}{$\begin{array}{l}\text { Sales to } \\
\text { End Users }\end{array}$} & \multirow{2}{*}{$\begin{array}{l}\text { Sales for } \\
\text { Resale }\end{array}$} \\
\hline & $\begin{array}{l}\text { Sales to } \\
\text { End Users }\end{array}$ & $\begin{array}{c}\text { Sales for } \\
\text { Resale }\end{array}$ & $\begin{array}{l}\text { Sales to } \\
\text { End Users }\end{array}$ & $\begin{array}{c}\text { Sales for } \\
\text { Resale }\end{array}$ & $\begin{array}{l}\text { Sales to } \\
\text { End Users }\end{array}$ & $\begin{array}{c}\text { Sales for } \\
\text { Resale }\end{array}$ & & \\
\hline \multicolumn{9}{|l|}{ PAD District V } \\
\hline 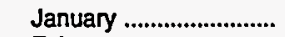 & 995.2 & 313.9 & $2,356.4$ & $2,058.5$ & $3,351.6$ & $2,372.5$ & $w$ & 36.8 \\
\hline February ......................... & $1,097.7$ & 400.8 & $2,338.1$ & $2,233.9$ & $3,435.8$ & $2,634.6$ & w & 45.8 \\
\hline 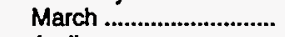 & 882.3 & $1,242.1$ & $2,498.0$ & $2,119.5$ & $3,380.3$ & $3,361.5$ & $w$ & $w$ \\
\hline April & 977.5 & 379.1 & $2,251.5$ & $1,959.7$ & $3,229.1$ & $2,338.7$ & W & $W$ \\
\hline 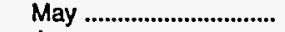 & $1,256.2$ & $W$ & $2,468.7$ & W & $3,724.8$ & $3,097.6$ & $w$ & $w$ \\
\hline 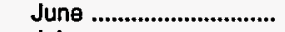 & $1,343.5$ & 372.9 & $2,429.1$ & $1,517.6$ & $3,772.5$ & $1,890.5$ & $W$ & $W$ \\
\hline 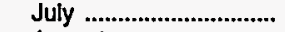 & $1,010.1$ & $W$ & $2,017.7$ & $W$ & $3,027.8$ & $1,693.3$ & - & $W$ \\
\hline 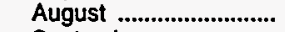 & 972.8 & 549.1 & $2,312.3$ & $1,701.2$ & $3,285.1$ & $2,250.2$ & - & $W$ \\
\hline September ....................... & 914.1 & W & $2,163.9$ & $W$ & $3,078.0$ & $1,426.7$ & $w$ & $w$ \\
\hline 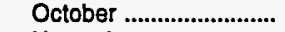 & $1,113.8$ & 275.2 & $2,152.7$ & 762.9 & $3,266.5$ & $1,038.1$ & - & $W$ \\
\hline November ...................... & $1,059.9$ & 458.8 & $2,665.0$ & $1,152.0$ & $3,724.9$ & $1,610.8$ & $w$ & $W$ \\
\hline December .......................... & $1,274.5$ & 517.5 & $2,716.5$ & $1,517.2$ & $3,991.0$ & $2,034.6$ & $w$ & $W$ \\
\hline 1994 Average & $1,074.6$ & 460.4 & $2,364.2$ & $1,685.0$ & $3,438.8$ & $2,145.4$ & $w$ & 37.4 \\
\hline
\end{tabular}

Dash $(-)=$ No data reported.

$W=$ Withheld to avold disclosure of individual company data.

a Includes No. 4 fuel oil and No. 4 diesel fuel.

Note: Totals may not equai the sum of the components due to rounding.

Source: Energy Information Administration Form ElA-782A, "Refiners'/Gas Plant Operators' Monthly Petroleum Product Sales Report." 
Prime Supplier Sales Volumes of Petroleum Products for Local Consumption 
Table 48. Prime Supplier Sales Volumes of Motor Gasoline by Grade, Formulation, PAD District, and State

(Thousand Gallons per Day)

\begin{tabular}{|c|c|c|c|c|c|c|c|c|}
\hline \multirow{2}{*}{$\begin{array}{l}\text { Geographic Area } \\
\text { Month }\end{array}$} & \multicolumn{4}{|c|}{ Regular } & \multicolumn{4}{|c|}{ Midgrade } \\
\hline & Conventionala & Oxygenated & Reformulated & Total & Conventional & Oxygenated & Reformulated & Total \\
\hline \multicolumn{9}{|l|}{ Unitad States } \\
\hline 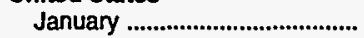 & $148,970.0$ & 50.740 .3 & - & $199,710.3$ & $26,470.5$ & $9,542.2$ & - & $36,012.7$ \\
\hline 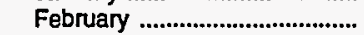 & $167,355.0$ & $43,230.4$ & - & $210,585.4$ & $29,884.4$ & $7,896.4$ & - & $37,780.8$ \\
\hline 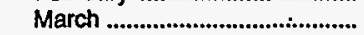 & $203,092.4$ & $14,865.9$ & - & $217,958.3$ & $36,808.5$ & $2,380.0$ & - & $39,188.5$ \\
\hline April & $213,167.1$ & $10,225.6$ & - & $223,392.7$ & $37,184.2$ & $2,126.7$ & - & $39,311.0$ \\
\hline May & $220,736.5$ & $1,604.5$ & - & $222,341.0$ & $39,820.8$ & 136.9 & - & $39,957.7$ \\
\hline 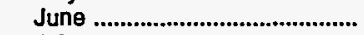 & $229,589.3$ & $1,409.9$ & - & $230,999.2$ & $41,028.8$ & 123.7 & - & $41,152.5$ \\
\hline July & $225,943.5$ & $1,438.8$ & - & $227,382.3$ & $40,517.5$ & 119.4 & - & $40,636.9$ \\
\hline August & $233,715.6$ & $1,626.1$ & - & $235,341.6$ & $40,783.3$ & 144.5 & - & $40,927.8$ \\
\hline September ..................................... & $221,112.4$ & $6,769.5$ & - & $227,881.9$ & $38,376.9$ & $1,141.1$ & - & $39,518.1$ \\
\hline October & $184,845.5$ & $41,224.7$ & - & $226,070.3$ & $31,476.5$ & $7,766.6$ & - & $39,243.1$ \\
\hline 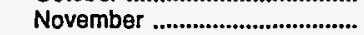 & $168,249.4$ & $52,164.3$ & $4,472.8$ & $224,886.5$ & $28,280.7$ & $10,074.2$ & $1,024.4$ & $39,379.3$ \\
\hline 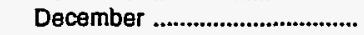 & $142,405.4$ & $28,445.0$ & $54,853.0$ & $225,703.4$ & $22,988.8$ & $4,354.4$ & $14,047.9$ & $41,391.1$ \\
\hline 1994 Average & $196,713.6$ & $21,002.3$ & $5,026.4$ & $222,742.3$ & $34,486.9$ & $3,788.6$ & $1,277.3$ & $39,552.8$ \\
\hline \multicolumn{9}{|l|}{ PAD District I } \\
\hline 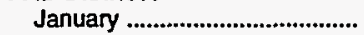 & $47,507.7$ & $14,754.1$ & - & $62,261.8$ & $11,456.6$ & $4,345.1$ & - & $15,801.7$ \\
\hline 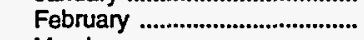 & $51,066.8$ & $15,089.3$ & - & 66.156 .1 & $12,112.9$ & $4,428.6$ & - & $16,541.5$ \\
\hline March & $60,255.1$ & $8,701.4$ & - & $68,956.4$ & $15,181.0$ & $2,088.3$ & - & $17,269.3$ \\
\hline 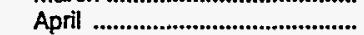 & $61,341.7$ & $8,199.9$ & - & $69,541.6$ & $15,337.6$ & $2,011.8$ & - & $17,349.3$ \\
\hline May & $68,836.7$ & 65.8 & - & $68,902.5$ & $17,514.3$ & 22.2 & - & $17,536.5$ \\
\hline 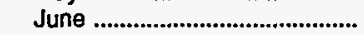 & $71,376.6$ & 6.2 & - & $71,382.9$ & $18,009.3$ & 0.2 & - & $18,009.5$ \\
\hline 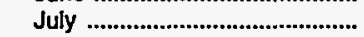 & W & w & - & $70,658.0$ & W & w & - & $18,027.9$ \\
\hline August & $w$ & w & - & $73,963.9$ & $w$ & W & - & $18,327.9$ \\
\hline 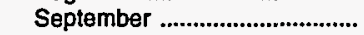 & $69,092.3$ & $1,744.1$ & - & $70,836.3$ & $16,772.9$ & 697.1 & - & $17,470.0$ \\
\hline October & $61,634.3$ & $9,770.1$ & - & $71,404.4$ & $14,675.0$ & $2,714.3$ & - & $17,389.3$ \\
\hline 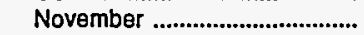 & $53,880.6$ & $14,960.9$ & $2,221.0$ & $71,062.5$ & $12,512.9$ & $4,248.6$ & 576.5 & $17,338.0$ \\
\hline 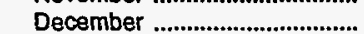 & $39,528.3$ & $1,451.6$ & $31,464.3$ & $72,444.2$ & $9,238.1$ & 501.1 & $8,114.9$ & $17,854.1$ \\
\hline 1994 Average & $60,804.8$ & $6,157.9$ & $2,854.9$ & $69,817.5$ & $14,945.7$ & $1,733.0$ & 736.6 & $17,415.3$ \\
\hline \multicolumn{9}{|l|}{ Subdistrict IA } \\
\hline 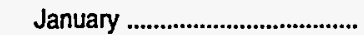 & $8,598.6$ & 586.6 & - & $9,185.2$ & $2,048.4$ & 182.5 & - & $2,231.0$ \\
\hline 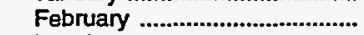 & $8,821.5$ & 603.2 & - & $9,424.8$ & $2,082.6$ & 196.1 & - & $2,278.8$ \\
\hline March & $8,950.3$ & 651.7 & - & $9,602.0$ & $2,025.2$ & 174.6 & - & $2,199.8$ \\
\hline April .................................... & $9,056.7$ & 660.8 & - & $9,717.5$ & $w$ & $w$ & - & $2,217.3$ \\
\hline 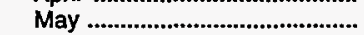 & $w$ & w & - & $10,186.5$ & $w$ & $w$ & - & $2,306.4$ \\
\hline 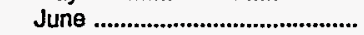 & w & W & - & $10,553.2$ & $w$ & $w$ & - & $2,481.2$ \\
\hline 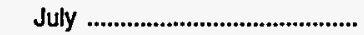 & $10,673.1$ & - & - & $10,673.1$ & w & W & - & $2,545.4$ \\
\hline 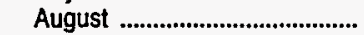 & $11,106.7$ & - & - & $11,106.7$ & $w$ & $W$ & - & $2,598.9$ \\
\hline September ................................. & $10,330.7$ & 99.7 & - & $10,430.4$ & $w$ & $w$ & - & $2,408.4$ \\
\hline 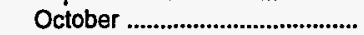 & $9,789.4$ & 636.9 & - & $10,426.3$ & $2,212.7$ & 177.2 & - & $2,389.9$ \\
\hline 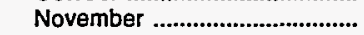 & $9,374.2$ & 601.3 & 228.2 & $10,203.8$ & $2,094.4$ & 167.9 & 81.3 & $2,343.5$ \\
\hline 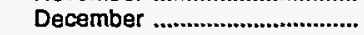 & $1,475.0$ & 6.0 & $8,855.4$ & $10,336.5$ & 344.1 & 1.1 & $2,104.1$ & $2,449.3$ \\
\hline 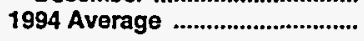 & $9,070.0$ & 318.2 & 770.9 & $10,159.0$ & $2,094.4$ & 91.9 & 185.4 & $2,371.7$ \\
\hline \multicolumn{9}{|l|}{ Connecticut } \\
\hline 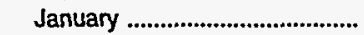 & $1,439.7$ & 570.0 & - & $2,009.6$ & 442.8 & 173.8 & - & 616.7 \\
\hline 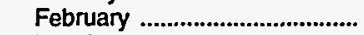 & & & - & $2,086.6$ & $w$ & w & - & 635.4 \\
\hline March & $1,498.9$ & 651.7 & - & $2,150.6$ & 433.5 & 174.6 & - & 608.0 \\
\hline April & $w$ & $\ddot{w}$ & - & $2,195.5$ & 431.7 & 171.5 & - & 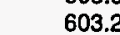 \\
\hline 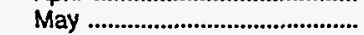 & $w$ & $w$ & - & $2,244.2$ & $w$ & $w$ & - & 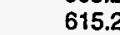 \\
\hline June & w & w & - & $2,363.1$ & $w$ & $w$ & - & 653.1 \\
\hline 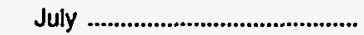 & $2,286.0$ & - & - & $2,286.0$ & $w$ & $w$ & - & 654.3 \\
\hline August & $2,365.0$ & - & - & $2,365.0$ & w & $\ddot{w}$ & - & 652.2 \\
\hline 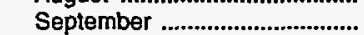 & $2,183.3$ & 99.7 & - & $2,283.0$ & $w$ & $w$ & - & 626.9 \\
\hline 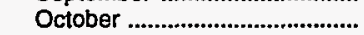 & $w$ & w & - & $2,433.3$ & 474.8 & 177.2 & - & 652.0 \\
\hline 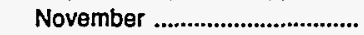 & $1,775.9$ & 601.3 & 74.8 & $2,452.1$ & 464.9 & 167.9 & 23.3 & 656.1 \\
\hline 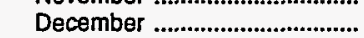 & 42.0 & 6.0 & $2,497.4$ & $2,545.5$ & $w$ & 1.1 & w & 658.5 \\
\hline 1994 Average ................................ & $1,751.6$ & 315.9 & 218.3 & $2,285.7$ & 488.6 & 90.8 & 56.7 & 636.0 \\
\hline
\end{tabular}

See footnotes at end of table. 
Table 48. Prime Supplier Sales Volumes of Motor Gasoline by Grade, Formulation, PAD District, and State

(Thousand Gallons per Day) - Continued

\begin{tabular}{|c|c|c|c|c|c|c|c|c|}
\hline \multirow{2}{*}{$\begin{array}{l}\text { Geographic Area } \\
\text { Month }\end{array}$} & \multicolumn{4}{|c|}{ Premium } & \multicolumn{4}{|c|}{ All Grades } \\
\hline & Conventional & Oxygenatod & Reformulated & Total & Conventional & Oxygenated & Reformulated & Total \\
\hline \multicolumn{9}{|l|}{ United States } \\
\hline January ............................................. & $44,524.8$ & $19,144.2$ & - & $63,669.0$ & $219,965.3$ & $79,426.7$ & - & $299,392.0$ \\
\hline 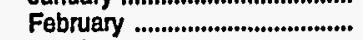 & $49,259.6$ & $17,327.8$ & - & $66,587.4$ & $246,498.9$ & $68,454.6$ & - & $314,953.6$ \\
\hline 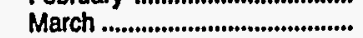 & $58,852.6$ & $8,234.6$ & - & $67,087.2$ & $298,753.5$ & $25,480.5$ & - & $324,234.0$ \\
\hline Aprll & $60,039.7$ & $7,317.3$ & - & $67,357.0$ & $310,391.0$ & $19,669.6$ & - & $330,060.6$ \\
\hline 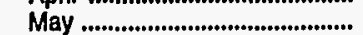 & $67,100.2$ & $1,111.8$ & - & $68,211.9$ & $327,657.5$ & $2,853.2$ & - & $330,510.6$ \\
\hline 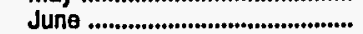 & $69,111.6$ & $1,013.4$ & - & $70,125.0$ & $339,729.7$ & $2,546.9$ & - & $342,276.6$ \\
\hline 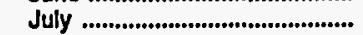 & $67,263.3$ & $1,006.5$ & - & $68,269.8$ & $333,724.2$ & $2,564.7$ & - & $336,288.9$ \\
\hline August & $66,486.6$ & $1,023.9$ & - & $67,510.5$ & $340,985.4$ & $2,794.5$ & - & $343,779.9$ \\
\hline 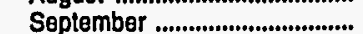 & $62,325.7$ & $3,287.7$ & - & $65,613.4$ & $321,815.0$ & $11,198.4$ & - & $333,013.4$ \\
\hline 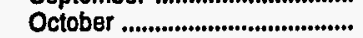 & $49,705.5$ & $15,444.7$ & - & $65,150.2$ & $266,027.6$ & $64,436.0$ & - & $330,463.6$ \\
\hline November ...................................... & $44,617.2$ & $17,833.9$ & $2,712.5$ & $65,163.7$ & $241,147.3$ & $80,072.4$ & $8,209.8$ & $329,429.5$ \\
\hline December ...................................... & $37,497.8$ & $6,829.6$ & $23,550.6$ & $67,878.0$ & $202,891.9$ & $39,628.9$ & $92,451.6$ & $334,972.5$ \\
\hline 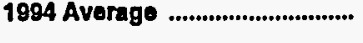 & $56,428.6$ & $8,234.0$ & 2,223.1 & $66,885.7$ & $287,629.1$ & $33,024.8$ & $8,526.8$ & $329,180.8$ \\
\hline \multicolumn{9}{|l|}{ PAD Dlatrict I } \\
\hline 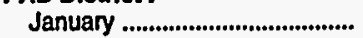 & $18,499.5$ & $9,559.9$ & - & $28,059.4$ & $77,463.8$ & $28,659.2$ & - & $106,122.9$ \\
\hline 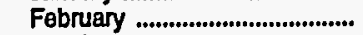 & $19,377.9$ & $9,690.6$ & - & $29,068.5$ & $82,557.6$ & $29,208.5$ & - & $111,766.1$ \\
\hline March ............................................. & $23,986.2$ & $6,122.7$ & - & $30,108.9$ & $99,422.3$ & $16,912.4$ & - & $116,334.6$ \\
\hline April & $24,246.1$ & $6,126.7$ & - & $30,372.7$ & $100,925.3$ & $16,338.4$ & - & $117,263.7$ \\
\hline 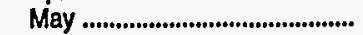 & $30,599.3$ & 48.7 & - & $30,648.0$ & $116,950.3$ & 136.8 & - & $117,087.1$ \\
\hline 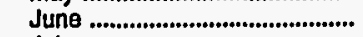 & $31,279.7$ & 0.6 & - & $31,280.3$ & $120,665.6$ & 7.1 & - & $120,672.7$ \\
\hline July & $30,371.7$ & 1.0 & - & $30,372.7$ & W & w & - & $119,058.5$ \\
\hline August & 30.115 .5 & 1.0 & - & $30,116.5$ & $122,402.8$ & 5.4 & - & $122,408.3$ \\
\hline 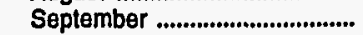 & $27,617.4$ & $1,543.0$ & - & $29,160.3$ & $113,482.6$ & $3,984.1$ & - & $117,466.7$ \\
\hline 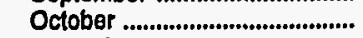 & $22,301.9$ & $6,759.1$ & - & $29,061.0$ & $98,611.2$ & $19,243.5$ & - & $117,854.7$ \\
\hline 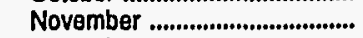 & $18,787.8$ & $8,756.5$ & $1,098.1$ & $28,642.3$ & $85,181.3$ & $27,966.0$ & $3,895.5$ & $117,042.8$ \\
\hline December ..................................... & $13,932.3$ & 706.7 & $14,883.7$ & $29,522.7$ & $62,698.7$ & $2,659.4$ & $54,463.0$ & $119,821.0$ \\
\hline 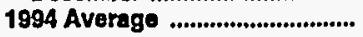 & $24,286.3$ & $4,063.9$ & $1,354.4$ & $29,704.5$ & $100,036.8$ & $11,954.7$ & $4,945.8$ & $116,937.3$ \\
\hline \multicolumn{9}{|l|}{ Subdistrict IA } \\
\hline 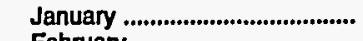 & $3,432.6$ & 332.4 & - & $3,765.0$ & $14,079.6$ & 1.101 .5 & - & $15,181.2$ \\
\hline 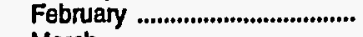 & $3,436.1$ & 310.6 & $\overline{-}$ & $\begin{array}{l}3,746.8 \\
3634.7\end{array}$ & $\begin{array}{l}14,340.3 \\
14287 ?\end{array}$ & $1,110.0$ & - & $15,450.3$ \\
\hline 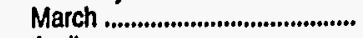 & $3,311.7$ & 322.9 & - & $3,634.7$ & $14,287.2$ & $1,149.3$ & - & $15,436.5$ \\
\hline April & w & $w$ & - & $3,675.0$ & $14,445.4$ & $1,164.4$ & - & $15,609.8$ \\
\hline 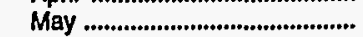 & $w$ & $w$ & - & $3,777.4$ & $16,266.5$ & 3.8 & - & $16,270,2$ \\
\hline 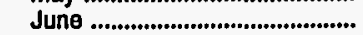 & w & w & - & $4,001.1$ & $w$ & w & - & $17,035.5$ \\
\hline July ..................................................... & w & $\mathbf{w}$ & - & $3,927.5$ & w & w & - & $17,145.9$ \\
\hline 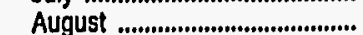 & W & w & - & $3,917.4$ & w & w & - & $17,623.1$ \\
\hline September .................................. & $3,710.7$ & 57.8 & - & $3,768.5$ & W & w & - & $16,607.3$ \\
\hline October ............................................ & $3,374.9$ & 313.4 & - & $3,688.3$ & $15,377.0$ & $1,127.5$ & - & $16,504.5$ \\
\hline 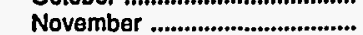 & $3,219.5$ & 291.8 & 104.2 & $3,615.5$ & $14,688.2$ & $1,061.0$ & 413.6 & $16,162.8$ \\
\hline 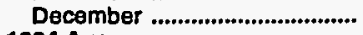 & 392.4 & 4.6 & $3,297.8$ & $3,694.8$ & $2,211.5$ & 11.7 & $14,257.3$ & $16,480.5$ \\
\hline 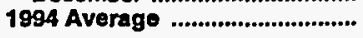 & $3,317.0$ & 162.3 & 288.6 & $3,767.9$ & $14,481.3$ & 572.3 & $1,244.9$ & $16,298.5$ \\
\hline \multicolumn{9}{|l|}{ Connecticut } \\
\hline 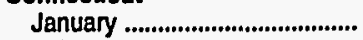 & 618.5 & 319.6 & - & 938.1 & $2,501.0$ & $1,063.5$ & - & $3,564.4$ \\
\hline February .............................................. & w & $\mathbf{w}$ & - & 930.4 & w & W & - & $3,652.4$ \\
\hline March ............................................... & 605.2 & 322.9 & - & 928.1 & $2,537.5$ & $1,149.3$ & - & $3,686.7$ \\
\hline 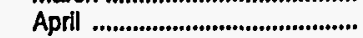 & $w$ & w & - & 949.8 & $w$ & w & - & $3,748.5$ \\
\hline 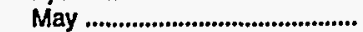 & $\mathbf{w}$ & $w$ & - & 980.6 & $3,836.3$ & 3.8 & - & $3,840.0$ \\
\hline June ........................................... & $w$ & $w$ & - & $1,030.2$ & $w$ & w & - & $4,046.4$ \\
\hline July ............................................... & $\mathbf{w}$ & $\mathbf{w}$ & - & 974.5 & $\mathbf{w}$ & w & - & $3,914.7$ \\
\hline August ........................................ & $\mathbf{w}$ & $\mathbf{w}$ & - & 954.6 & $w$ & $w$ & - & $3,971.8$ \\
\hline 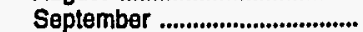 & 877.0 & 57.8 & - & 934.8 & $\mathbf{w}$ & w & - & $3,844.7$ \\
\hline October & 658.8 & 313.4 & - & 972.2 & $w$ & $w$ & _- & $4,057.6$ \\
\hline November ................................... & 638.8 & 291.8 & 35.0 & 965.6 & $2,879.6$ & $1,061.0$ & 133.1 & $4,073.7$ \\
\hline 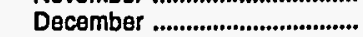 & $w$ & 4.6 & W & 945.4 & 64.9 & 11.7 & $4,072,7$ & $4,149.4$ \\
\hline 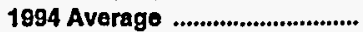 & 716.2 & 160.7 & 81.9 & 958.8 & $2,956.4$ & 567.3 & 356.8 & $3,880.5$ \\
\hline
\end{tabular}

See footnotes at end of table. 
Table 48. Prime Supplier Sales Volumes of Motor Gasoline by Grade, Formulation, PAD District, and State

(Thousand Gallons per Day) - Continued

\begin{tabular}{|c|c|c|c|c|c|c|c|c|}
\hline \multirow{2}{*}{$\begin{array}{l}\text { Geographic Area } \\
\text { Month }\end{array}$} & \multicolumn{4}{|c|}{ Regular } & \multicolumn{4}{|c|}{ Midgrado } \\
\hline & Conventionala & Oxygenated & Reformulated & Total & Conventional & Oxygenated & Reformulated & Total \\
\hline \multicolumn{9}{|l|}{ Malne } \\
\hline 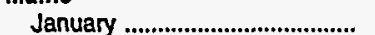 & $1,356.3$ & - & - & $1,356.3$ & 263.8 & - & - & 263.8 \\
\hline 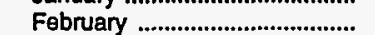 & $1,416.6$ & - & - & $1,416.6$ & 278.2 & - & - & 278.2 \\
\hline March & $1,433.7$ & - & - & $1,433.7$ & 265.7 & - & - & 265.7 \\
\hline 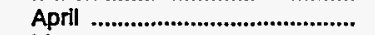 & $1,391.8$ & - & - & $1,391.8$ & 245.2 & - & - & 245.2 \\
\hline 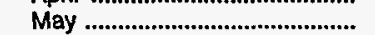 & $1,545.3$ & - & - & $1,545.3$ & 274.6 & - & - & 274.6 \\
\hline 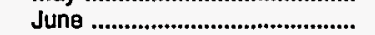 & $1,653.6$ & - & - & $1,653.6$ & 296.3 & - & - & 296.3 \\
\hline July .................................................. & $1,777.4$ & - & - & $1,777.4$ & 327.8 & - & - & 327.8 \\
\hline August & $1,843.1$ & - & - & $1,843.1$ & 346.5 & - & - & 346.5 \\
\hline 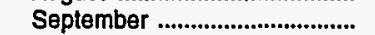 & $1,656.6$ & - & - & $1,656.6$ & 302.7 & - & - & 302.7 \\
\hline October & $1,649.7$ & - & - & $1,649.7$ & 269.8 & - & - & 269.8 \\
\hline 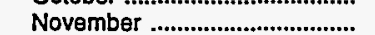 & $1,487.2$ & - & 24.1 & $1,511.4$ & 267.8 & - & 4.2 & 272.0 \\
\hline 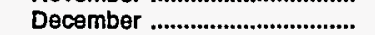 & 683.7 & - & 785.4 & $1,469.0$ & 128.7 & - & 150.6 & 279.3 \\
\hline 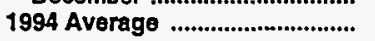 & $1,491.2$ & - & 68.7 & $1,559.9$ & 272.1 & - & 13.1 & 285.3 \\
\hline \multicolumn{9}{|l|}{ Massachusetts } \\
\hline 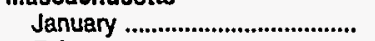 & $3,925.6$ & $w$ & - & $3,942.2$ & 905.7 & $w$ & - & 914.5 \\
\hline 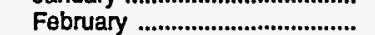 & w & $\ddot{w}$ & - & $3,982.3$ & $w$ & $\ddot{w}$ & - & 929.7 \\
\hline 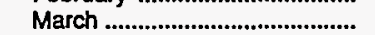 & $4,083.8$ & - & - & $4,083.8$ & 912.1 & - & - & 912.1 \\
\hline 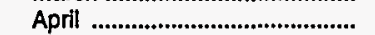 & w & w & - & $4,248.5$ & w & $w$ & - & 962.9 \\
\hline 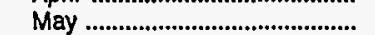 & $4,425.3$ & - & - & $4,425.3$ & 998.8 & - & - & 998.8 \\
\hline 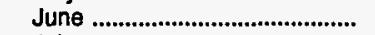 & $4,451.4$ & - & - & $4,451.4$ & $1,074.8$ & - & - & $1,074.8$ \\
\hline 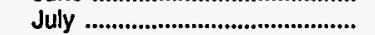 & $4,484.8$ & - & - & $4,484.8$ & $1,073.8$ & - & - & $1,073.8$ \\
\hline 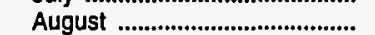 & $4,627.3$ & - & - & $4,627.3$ & $1,083.0$ & - & - & $1,083.0$ \\
\hline 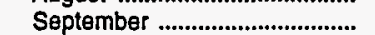 & $4,454.8$ & - & - & $4,454.8$ & $1,032.4$ & - & - & $1,032.4$ \\
\hline 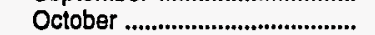 & $4,260.0$ & - & - & $4,260.0$ & $1,019.5$ & - & - & $1,019.5$ \\
\hline 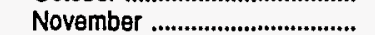 & $4,173.4$ & - & 94.1 & $4,267.5$ & 954.6 & - & 39.4 & 994.0 \\
\hline 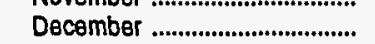 & 67.5 & - & $4,192.1$ & $4,259.5$ & 63.3 & - & $1,002.1$ & $1,065.4$ \\
\hline 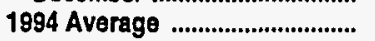 & $3,926.4$ & $\mathbf{W}$ & 363.8 & $4,292,4$ & 916.1 & $w$ & 88.4 & $1,005.6$ \\
\hline \multicolumn{9}{|l|}{ New Hampshire } \\
\hline 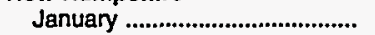 & 652.3 & - & - & 652.3 & 151.4 & - & - & 151.4 \\
\hline 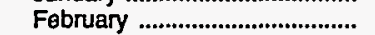 & 679.6 & - & - & 679.6 & 149.2 & - & - & 149.2 \\
\hline 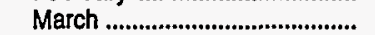 & 675.1 & - & - & 675.1 & 141.5 & - & - & 141.5 \\
\hline 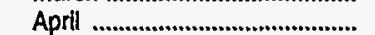 & 685.2 & - & - & 685.2 & 140.4 & - & - & 140.4 \\
\hline 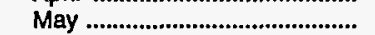 & 722.2 & - & - & 722.2 & 150.1 & - & - & 150.1 \\
\hline 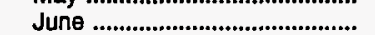 & 788.1 & - & - & 788.1 & 161.4 & - & - & 161.4 \\
\hline 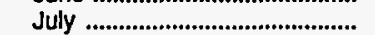 & 779.5 & - & - & 779.5 & 178.3 & - & - & 178.3 \\
\hline August & 826.5 & - & - & 826.5 & 189.3 & - & - & 189.3 \\
\hline 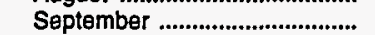 & 730.2 & - & - & 730.2 & 159.2 & - & - & 159.2 \\
\hline October & 732.7 & - & - & 732.7 & 158.8 & - & - & 158.8 \\
\hline 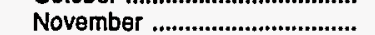 & 665.1 & - & 23.8 & 688.9 & 139.2 & - & 9.3 & 148.5 \\
\hline 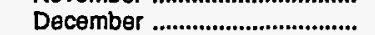 & 256.3 & - & 442.3 & 698.6 & 52.9 & - & 102.6 & 155.5 \\
\hline 1994 Average ...................................... & 682.4 & - & 39.5 & 721.9 & 147.6 & - & 9.5 & 157.1 \\
\hline \multicolumn{9}{|l|}{ Rhode Island } \\
\hline 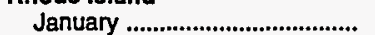 & 832.3 & - & - & 832.3 & 204.1 & - & - & 204.1 \\
\hline 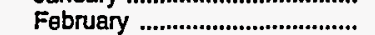 & 846.8 & - & - & 846.8 & 202.9 & - & - & 202.9 \\
\hline 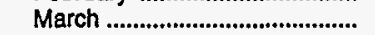 & 843.8 & - & - & 843.8 & 193.1 & - & - & 193.1 \\
\hline April & 811.5 & - & - & 811.5 & 193.8 & - & - & 193.8 \\
\hline 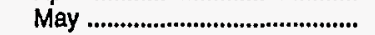 & 834.3 & - & - & 834.3 & 188.7 & - & - & 188.7 \\
\hline 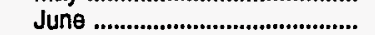 & 865.8 & - & - & 865.8 & 209.0 & - & - & 209.0 \\
\hline 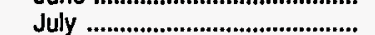 & 882.6 & - & - & 882.6 & 215.5 & - & - & 215.5 \\
\hline August & 907.7 & - & - & 907.7 & 219.7 & - & - & 219.7 \\
\hline 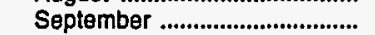 & 844.6 & - & - & 844.6 & 197.5 & - & - & 197.5 \\
\hline October & $w$ & w & - & 885.4 & 198.1 & - & - & 198.1 \\
\hline 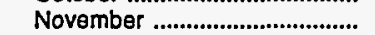 & 849.9 & - & 11.4 & 861.3 & 186.4 & - & 5.0 & 191.5 \\
\hline 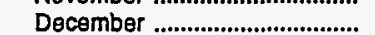 & 5.8 & - & 933.1 & 938.9 & 1.5 & - & 204.1 & 205.6 \\
\hline 1894 Average ............................... & 783.0 & w & 80.2 & 863.2 & 183.9 & - & 17.7 & 201.7 \\
\hline
\end{tabular}

See footnotes at end of table. 
Table 48. Prime Supplier Sales Volumes of Motor Gasoline by Grade, Formulation, PAD District, and State

(Thousand Gallons per Day) - Continued

\begin{tabular}{|c|c|c|c|c|c|c|c|c|}
\hline \multirow{2}{*}{$\begin{array}{c}\text { Goographic Area } \\
\text { Month }\end{array}$} & \multicolumn{4}{|c|}{ Premium } & \multicolumn{4}{|c|}{ All Grades } \\
\hline & Conventional & Oxygenated & Reformulated & Total & Conventional & Oxygenated & Reformulated & Total \\
\hline \multicolumn{9}{|l|}{ Malne } \\
\hline 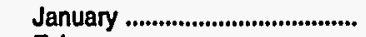 & 382.5 & - & - & 382.5 & $2,002.5$ & - & - & $2,002.5$ \\
\hline February ..................................... & 389.3 & - & - & 389.3 & $2,084.2$ & - & - & $2,084.2$ \\
\hline March ........................................... & 359.9 & - & - & 359.9 & $2,059.3$ & - & - & $2,059.3$ \\
\hline 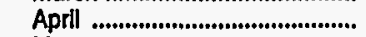 & 333.0 & - & - & 333.0 & $1,970.0$ & - & - & $1,970.0$ \\
\hline 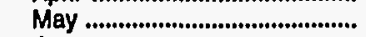 & 366.7 & - & - & 366.7 & $2,186.6$ & - & - & $2,186.6$ \\
\hline 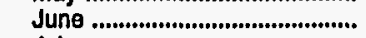 & 396.4 & - & - & 396.4 & $2,346.3$ & - & - & $2,346.3$ \\
\hline July ................................................ & 468.9 & - & - & 468.9 & $2,574.1$ & - & - & $2,574.1$ \\
\hline 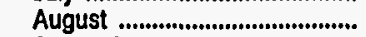 & 447.1 & - & - & 447.1 & $2,636.7$ & - & - & $2,636.7$ \\
\hline September ................................... & 381.9 & - & - & 381.9 & $2,341.2$ & - & - & $2,341.2$ \\
\hline October ......................................... & 396.4 & - & - & 396.4 & $2,315.9$ & - & - & $2,315.9$ \\
\hline November .................................. & 336.8 & - & 6.4 & 343.1 & $2,091.8$ & - & 34.7 & $2,126.5$ \\
\hline December .................................. & 156.3 & - & 192.7 & 349.0 & 968.7 & - & $1,128.6$ & $2,097.3$ \\
\hline 1994 Average ................................ & 367.8 & - & 16.9 & 384.7 & $2,131.2$ & - & 98.7 & $2,229.9$ \\
\hline \multicolumn{9}{|l|}{ Masaachusetts } \\
\hline January ......................................... & $1,689.4$ & $W$ & - & $1,702.2$ & $6,520.7$ & w & - & $6,558.8$ \\
\hline 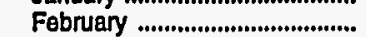 & W & $\dddot{w}$ & - & $1,688.4$ & $W$ & $w$ & - & $6,600.4$ \\
\hline March ............................................... & $1,660.6$ & - & - & $1,660.6$ & $6,656.5$ & - & - & $6,656.5$ \\
\hline 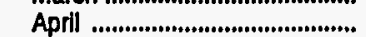 & W & $w$ & - & $1,720.4$ & $W$ & $\bar{w}$ & - & $6,931.8$ \\
\hline May ............................................... & $1,736.8$ & - & - & $1,736.8$ & $7,160.9$ & - & - & $7,160.9$ \\
\hline 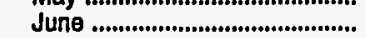 & $1,837.0$ & - & - & $1,837.0$ & $7,363.2$ & - & - & $7,363.2$ \\
\hline 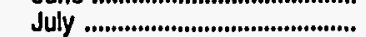 & $1,742.4$ & - & - & $1,742.4$ & $7,301.0$ & - & - & $7,301.0$ \\
\hline 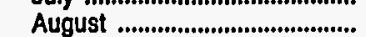 & $1,742.3$ & - & - & $1,742.3$ & $7,452.6$ & - & - & $7,452.6$ \\
\hline September ................................. & $1,776.1$ & - & - & $1,776.1$ & $7,263,4$ & - & - & $7,263.4$ \\
\hline 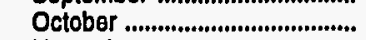 & $1,625.6$ & - & - & $1,625.6$ & $6,905.1$ & - & - & $6,905.1$ \\
\hline November ................................... & $1,604.9$ & - & 47.5 & $1,652.4$ & $6,732.8$ & - & 181.1 & $6,913.9$ \\
\hline 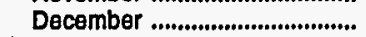 & 36.3 & - & $1,691.4$ & $1,727.7$ & 167.0 & - & $6,885.6$ & $7,052.6$ \\
\hline 1894 Average .................................. & $1,568.4$ & $\mathbf{W}$ & 147.6 & $1,717.6$ & $6,410.9$ & $\mathbf{W}$ & 599.7 & $7,015.6$ \\
\hline \multicolumn{9}{|l|}{ Now Hampshlre } \\
\hline January ....................................... & 216.7 & - & - & 216.7 & $1,020.4$ & - & - & $1,020.4$ \\
\hline February .................................... & 218.1 & - & - & 218.1 & $1,046.9$ & - & - & $1,046.9$ \\
\hline March ......................................... & 201.9 & - & - & 201.9 & $1,018.6$ & - & - & $1,018.6$ \\
\hline 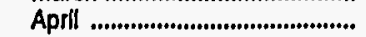 & 199.9 & - & - & 199.9 & $1,025.5$ & - & - & $1,025.5$ \\
\hline May ............................................... & 214.9 & - & - & 214.9 & $1,087.2$ & - & - & $1,087.2$ \\
\hline June ........................................ & 231.2 & - & - & 231.2 & $1,180.7$ & - & - & $1,180.7$ \\
\hline July ........................................... & 237.1 & - & - & 237.1 & $1,194.9$ & - & - & $1,194.9$ \\
\hline 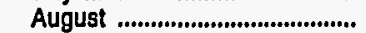 & 244.9 & - & - & 244.9 & $1,260.7$ & - & - & $1,260.7$ \\
\hline September ................................. & 210.5 & - & - & 210.5 & $1,099.9$ & - & - & $1,099.9$ \\
\hline 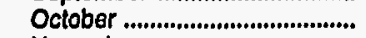 & 216.9 & - & - & 216.9 & $1,108.5$ & - & - & $1,108.5$ \\
\hline November .................................. & 190.0 & - & 8.7 & 198.7 & 994.3 & - & 41.8 & $1,036.1$ \\
\hline December ................................ & 65.2 & - & 138.3 & 203.5 & 374.4 & - & 683.2 & $1,057.6$ \\
\hline 1894 Average ............................. & 203.8 & - & 12.5 & 216.2 & $1,033.8$ & - & 61.5 & $1,095.2$ \\
\hline \multicolumn{9}{|l|}{ Phode foland } \\
\hline January ......................................... & 370.5 & - & - & 370.5 & $1,407.0$ & - & - & $1,407.0$ \\
\hline February .................................... & 361.7 & - & - & 361.7 & $1,411.4$ & - & - & $1,411.4$ \\
\hline March .......................................... & 346.1 & - & - & 346.1 & $1,383.1$ & - & - & $1,383.1$ \\
\hline Aprll ........................................... & 353.4 & - & - & 353.4 & $1,358.7$ & - & - & $1,358.7$ \\
\hline 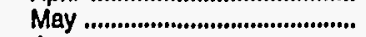 & 349.9 & - & - & 349.9 & $1,372.9$ & - & - & $1,372.9$ \\
\hline June .............................................. & 371.1 & - & - & 371.1 & $1,445.9$ & - & - & $1,445.9$ \\
\hline July .................................................. & 359.2 & - & - & 359.2 & $1,457.3$ & - & - & $1,457.3$ \\
\hline 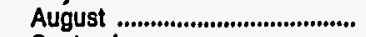 & 362.6 & - & - & 362.6 & $1,490.1$ & - & - & $1,490.1$ \\
\hline Septomber ................................. & 329.8 & - & - & 329.8 & $1,371.9$ & - & - & $1,371.9$ \\
\hline October & 342.2 & - & - & 342.2 & $W$ & W & - & $1,425.7$ \\
\hline November ................................... & 330.1 & - & 6.5 & 336.6 & $1,366.4$ & - & 22.9 & $1,389.4$ \\
\hline December .................................. & 3.0 & - & 342.8 & 345.8 & 10.3 & - & $1,480.0$ & $1,490.3$ \\
\hline 1994 Average ............................. & 322.7 & - & 29.7 & 352.4 & $1,289.6$ & $\mathbf{W}$ & 127.6 & $1,417.3$ \\
\hline
\end{tabular}

See footnotes at end of table. 
Table 48. Prime Supplier Sales Volumes of Motor Gasoline by Grade, Formulation, PAD District, and State

(Thousand Gallons per Day) - Continued

\begin{tabular}{|c|c|c|c|c|c|c|c|c|}
\hline \multirow{2}{*}{$\begin{array}{l}\text { Goographic Area } \\
\text { Month }\end{array}$} & \multicolumn{4}{|c|}{ Regular } & \multicolumn{4}{|c|}{ Midgrade } \\
\hline & Conventionala & Oxygenated & Reformulatod & Total & Conventional & Oxygenated & Reformulated & Total \\
\hline \multicolumn{9}{|l|}{ Vermont } \\
\hline 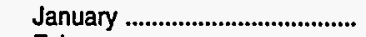 & 392.5 & - & - & 392.5 & 80.5 & - & - & 80.5 \\
\hline 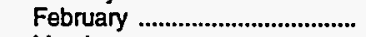 & 412.8 & - & - & 412.8 & 83.5 & - & - & 83.5 \\
\hline 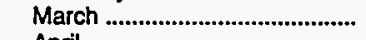 & 414.9 & - & - & 414.9 & 79.3 & - & - & 79.3 \\
\hline April & 385.0 & - & - & $\mathbf{3 8 5 . 0}$ & 71.8 & - & - & 71.8 \\
\hline May & 415.2 & - & - & 415.2 & 79.0 & - & - & 79.0 \\
\hline June & 431.2 & - & - & 431.2 & 86.5 & - & - & 86.5 \\
\hline July & 462.9 & - & - & 462.9 & 95.7 & - & - & 95.7 \\
\hline 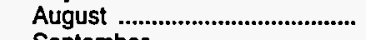 & 537.2 & - & - & 537.2 & 108.2 & - & - & 108.2 \\
\hline 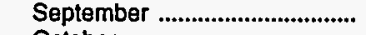 & 461.2 & - & - & 461.2 & 89.6 & - & - & 89.6 \\
\hline October & 465.0 & - & - & 465.0 & 91.6 & - & - & 91.6 \\
\hline 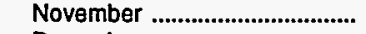 & 422.6 & - & - & 422.6 & 81.5 & - & - & 81.5 \\
\hline 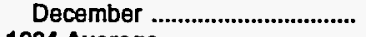 & 419.8 & - & 5.2 & 425.0 & $w$ & - & $w$ & 84.9 \\
\hline 1994 Average & 435.3 & - & 0.4 & 435.8 & 86.1 & - & $w$ & 86.1 \\
\hline \multicolumn{9}{|l|}{ Subdistrict IB } \\
\hline 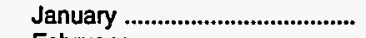 & $11,277.1$ & $11,990.0$ & - & $23,267.0$ & $2,108.3$ & $3,436.9$ & - & $5,545.3$ \\
\hline 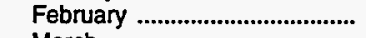 & $12,637.6$ & $12,340.8$ & - & $24,978.4$ & $2,218.1$ & $3,525.5$ & - & $5,743.6$ \\
\hline March & $18,166.8$ & $7,959.2$ & - & $26,126.0$ & $4,116.3$ & $1,878.2$ & - & $5,994.5$ \\
\hline April & $19,148.1$ & $7,538.6$ & - & $26,686.7$ & $4,260.1$ & $1,835.5$ & - & $6,095.6$ \\
\hline 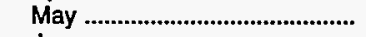 & $26,963.4$ & 60.9 & - & $27,024.3$ & $6,369.3$ & 21.3 & - & 6.390 .6 \\
\hline 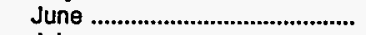 & $28,391.9$ & 0.8 & - & $28,392.8$ & $w$ & w & - & $6,560.1$ \\
\hline July & w & w & - & $27,906.5$ & w & $\mathbf{w}$ & - & $6,619.2$ \\
\hline August & $w$ & $w$ & - & $29,033.4$ & w & $w$ & - & $6,683.1$ \\
\hline 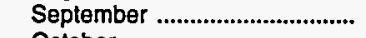 & $26,083.8$ & $1,644.3$ & - & $27,728.1$ & $5,794.1$ & 560.6 & - & $6,354.7$ \\
\hline October & $20,075.2$ & $8,641.1$ & - & $28,716.3$ & $3,977.0$ & $2,349.0$ & - & $6,325.9$ \\
\hline 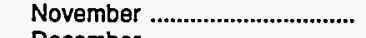 & $13,417.2$ & $12,851.2$ & $1,843.1$ & $28,111.5$ & $2,335.1$ & $3,542.5$ & 437.2 & $6,314.8$ \\
\hline 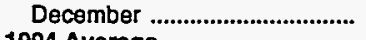 & $7,607.5$ & 780.9 & $19,886.0$ & $28,274.5$ & $1,062.5$ & 282.7 & $5,096.3$ & 6.441 .4 \\
\hline 1994 Average ..................................... & $20,099.4$ & $5,259.5$ & $1,840.4$ & $27,199.3$ & $4,355.0$ & $1,435.3$ & 468.8 & $6,259.1$ \\
\hline \multicolumn{9}{|l|}{ Delaware } \\
\hline 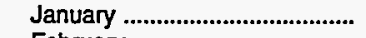 & 447.5 & 74.6 & - & 522.1 & 145.6 & 36.3 & - & 181.9 \\
\hline 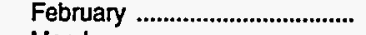 & w & w & - & 603.0 & w & $w$ & - & 205.8 \\
\hline 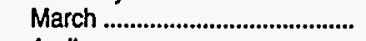 & $w$ & $w$ & - & 673.3 & $w$ & w & - & 229.5 \\
\hline April & 708.6 & 2.3 & - & 710.9 & $W$ & $W$ & - & 234.7 \\
\hline May & $W$ & $W$ & - & 681.8 & $w$ & W & - & 230.8 \\
\hline June & 679.0 & - & - & 679.0 & 233.9 & - & - & 233.9 \\
\hline July & 689.4 & - & - & 689.4 & 234.5 & - & - & 234.5 \\
\hline August & 700.6 & - & - & 700.6 & 238.9 & - & - & 238.9 \\
\hline 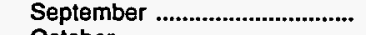 & 752.5 & - & - & 752.5 & 249.8 & - & - & 249.8 \\
\hline October .............................................. & 688.3 & 37.6 & - & 725.9 & 223.9 & 18.5 & - & 242.4 \\
\hline 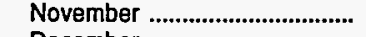 & $w$ & 69.7 & $W$ & 687.7 & $w$ & 26.6 & w & 217.8 \\
\hline 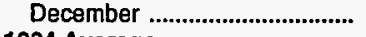 & 33.2 & 20.7 & 669.8 & 723.7 & w & w & 224.3 & 241.0 \\
\hline 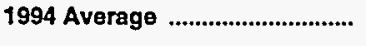 & 596.3 & 23.8 & 59.4 & 679.5 & 198.4 & 9.9 & 20.2 & 228.5 \\
\hline \multicolumn{9}{|l|}{ District of Columbia } \\
\hline 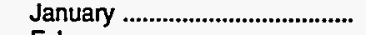 & w & 113.9 & - & 116.8 & w & 75.6 & - & 75.7 \\
\hline February & $\mathbf{W}$ & $w$ & - & 124.3 & $w$ & $w$ & - & 81.5 \\
\hline March & $w$ & w & - & 128.5 & $w$ & w & - & 85.0 \\
\hline April & 129.6 & - & - & 129.6 & 86.5 & - & - & 86.5 \\
\hline 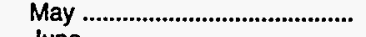 & $w$ & w & - & 127.9 & $w$ & w & - & 87.5 \\
\hline 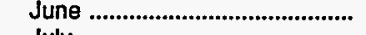 & 125.5 & - & - & 125.5 & 85.6 & - & - & 85.6 \\
\hline July & 127.6 & - & - & 127.6 & 86.6 & - & - & 86.6 \\
\hline August & 128.5 & - & - & 128.5 & 87.9 & - & - & 87.9 \\
\hline 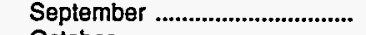 & 124.5 & - & - & 124.5 & 87.3 & - & - & 87.3 \\
\hline October & 96.6 & 30.0 & - & 126.6 & 64.3 & 20.5 & - & 84.8 \\
\hline 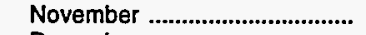 & w & 121.7 & w & 135.9 & $w$ & 80.4 & w & 90.1 \\
\hline December ............................................ & w & $w$ & 109.5 & 136.7 & - & $w$ & w & 92.8 \\
\hline 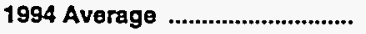 & 83.4 & 33.8 & 10.5 & 127.7 & 56.2 & 22.9 & 6.8 & 85.9 \\
\hline
\end{tabular}

See footnotes at end of table. 
Table 48. Prime Supplier Sales Volumes of Motor Gasoline by Grade, Formulation, PAD District, and State

(Thousand Gallons per Day) — Continued

\begin{tabular}{|c|c|c|c|c|c|c|c|c|}
\hline \multirow{2}{*}{$\begin{array}{l}\text { Goographic Area } \\
\text { Month }\end{array}$} & \multicolumn{4}{|c|}{ Premium } & \multicolumn{4}{|c|}{ All Grades } \\
\hline & Conventional & Oxygenated & Reformulated & Total & Conventional & Oxygenated & Reformulated & Total \\
\hline \multicolumn{9}{|l|}{ Vermont } \\
\hline 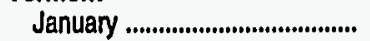 & 155.1 & - & - & 155.1 & 628.1 & - & - & 628.1 \\
\hline 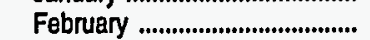 & 158.8 & - & - & 158.8 & 655.0 & - & - & 655.0 \\
\hline 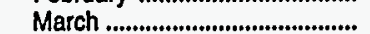 & 138.1 & - & - & 138.1 & 632.3 & - & - & 632.3 \\
\hline April ..................................... & 118.5 & - & - & 118.5 & 575.3 & - & - & 575.3 \\
\hline 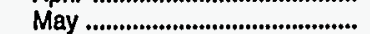 & 128.5 & - & - & 128.5 & 622.6 & - & - & 622.6 \\
\hline June ............................................... & 135.2 & - & - & 135.2 & 652.9 & - & - & 652.9 \\
\hline 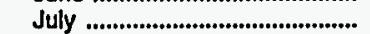 & 145.4 & - & - & 145.4 & 703.9 & - & - & 703.9 \\
\hline 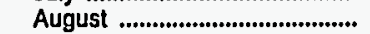 & 165.8 & - & - & 165.8 & 811.2 & - & - & 811.2 \\
\hline 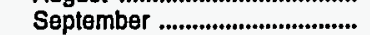 & 135.4 & - & - & 135.4 & 686.2 & - & - & 686.2 \\
\hline 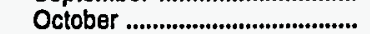 & 135.0 & - & - & 135.0 & 691.6 & - & - & 691.6 \\
\hline November ........................................ & 119.0 & - & - & 119.0 & 623.1 & - & - & 623.1 \\
\hline 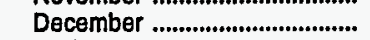 & w & - & w & 123.5 & 626.2 & - & 7.2 & 633.4 \\
\hline 1994 Average & 138.0 & - & 0.2 & 138.1 & 659.3 & - & 0.6 & 660.0 \\
\hline \multicolumn{9}{|l|}{ Subdistrict IB } \\
\hline 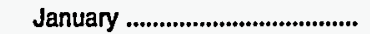 & $3,791.0$ & $8,260.7$ & - & $12,051.7$ & $17,176.4$ & $23,687.6$ & - & $40,864.0$ \\
\hline 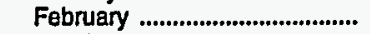 & $3,801.8$ & $8,422.0$ & - & $12,223.8$ & $18,657.5$ & $24,288.3$ & - & $42,945.8$ \\
\hline March & $6,827.7$ & $5,751.5$ & - & $12,579.2$ & $29,110.7$ & $15,589.0$ & - & $44,699.7$ \\
\hline 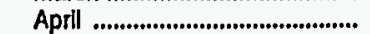 & $7,208.2$ & $5,799.1$ & - & $13,007.3$ & $30,616.4$ & $15,173.1$ & - & $45,789.6$ \\
\hline 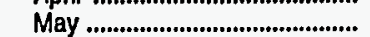 & $13,356.3$ & 45.3 & - & $13,401.5$ & $46,688.9$ & 127.5 & - & $46,816.4$ \\
\hline June ..................................................... & W & $w$ & - & $13,804.4$ & $48,755.7$ & 1.5 & - & $48,757.2$ \\
\hline 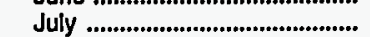 & $w$ & $w$ & - & $13,468.8$ & w & w & - & $47,994.5$ \\
\hline 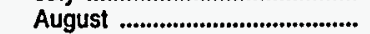 & $13,390.0$ & 0.8 & - & $13,390.7$ & $49,102.4$ & 4.9 & - & $49,107.2$ \\
\hline September ................................. & $11,353.4$ & $1,485.2$ & - & $12,838.6$ & $43,231.3$ & $3,690.1$ & - & $46,921.4$ \\
\hline October & $6,609.5$ & $6,207.4$ & - & $12,816.9$ & $30,661.7$ & $17,197.5$ & - & $47,859.1$ \\
\hline November ................................... & $3,594.9$ & $7,813.3$ & 925.7 & $12,333.9$ & $19,347.2$ & $24,207.0$ & $3,206.0$ & $46,760.2$ \\
\hline December ....................................... & $1,872.6$ & 441.5 & $10,321.0$ & $12,635.0$ & $10,542.6$ & 1,505.1 & $35,303.3$ & $47,350.9$ \\
\hline 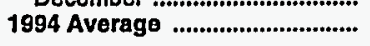 & $8,285.0$ & $3,645.8$ & 952.7 & $12,883.4$ & $32,739.4$ & $10,340.6$ & $3,261.9$ & $46,341.9$ \\
\hline \multicolumn{9}{|l|}{ Delaware } \\
\hline 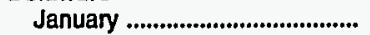 & 135.2 & 43.7 & - & 178.8 & 728.3 & 154.6 & - & 882.9 \\
\hline February ............................................ & $w$ & w & - & 205.8 & $w$ & $w$ & - & $1,014.6$ \\
\hline 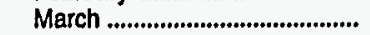 & 226.3 & 1.2 & - & 227.5 & $1,124.6$ & 5.6 & - & 1.130 .2 \\
\hline 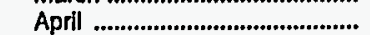 & $w$ & $\mathbf{w}$ & - & 241.0 & W & $w$ & - & $1,186.7$ \\
\hline 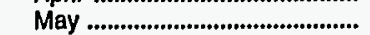 & 234.6 & - & - & 234.6 & w & w & - & $1,147.3$ \\
\hline 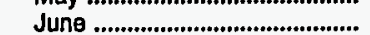 & 233.6 & - & - & 233.6 & $1,146.5$ & - & - & $1,146.5$ \\
\hline July & 224.0 & - & - & 224.0 & $1,147.9$ & - & - & $1,147.9$ \\
\hline August & 230.5 & - & - & 230.5 & $1,170.0$ & - & - & $1,170.0$ \\
\hline September & 249.7 & - & - & 249.7 & $1,252.0$ & - & - & $1,252.0$ \\
\hline 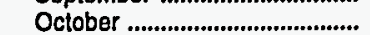 & 221.8 & 18.6 & - & 240.4 & $1,134.0$ & 74.7 & - & $1,208.7$ \\
\hline November .......................... & $w$ & 22.6 & w & 213.8 & $w$ & 119.0 & w & $1,119.3$ \\
\hline 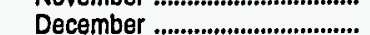 & 14.9 & 2.6 & 217.1 & 234.7 & $w$ & W & $1,111,2$ & $1,199.4$ \\
\hline 1994 Average & 195.8 & 10.9 & 19.5 & 226.3 & 990.5 & 44.6 & 99.2 & $1,134.3$ \\
\hline \multicolumn{9}{|l|}{ District of Columbla } \\
\hline 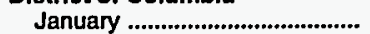 & w & 180.8 & - & 180.8 & $w$ & 370.3 & - & 373.3 \\
\hline 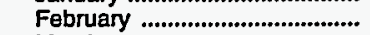 & $w$ & w & - & 197.9 & $w$ & w & - & 403.6 \\
\hline 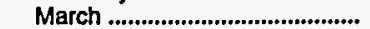 & 212.4 & 0.7 & - & 213.1 & 425.1 & 1.5 & - & 426.6 \\
\hline Aprll ................................................ & w & w & - & 220.8 & $w$ & $w$ & - & 436.9 \\
\hline 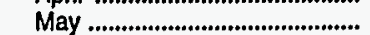 & $w$ & $w$ & - & 220.5 & w & w & - & 435.9 \\
\hline June ................................................ & 210.1 & - & - & 210.1 & 421.2 & - & - & 421.2 \\
\hline 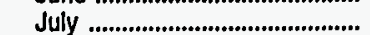 & $w$ & w & - & 204.1 & $w$ & W & - & 418.3 \\
\hline August & $w$ & W & - & 192.3 & w & w & - & 408.7 \\
\hline 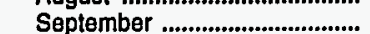 & $w$ & $w$ & - & 199.8 & w & w & - & 411.6 \\
\hline October & 164.1 & 37.0 & - & 201.1 & 325.0 & 87.5 & - & 412.5 \\
\hline 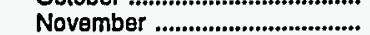 & $\ddot{w}$ & 173.0 & w & 188.1 & $w$ & $\mathbf{3 7 5 . 1}$ & w & 414.1 \\
\hline December & - & $w$ & $w$ & 186.4 & w & w & 317.8 & 415.9 \\
\hline 1994 Average & 136.2 & 52.1 & 13.0 & 201.2 & 275.9 & 108.9 & 30.2 & 414.9 \\
\hline
\end{tabular}

See footnotes at end of table. 
Table 48. Prime Supplier Sales Volumes of Motor Gasoline by Grade, Formulation, PAD District, and State

(Thousand Gallons per Day) - Continued

\begin{tabular}{|c|c|c|c|c|c|c|c|c|}
\hline \multirow{2}{*}{$\begin{array}{l}\text { Geographic Area } \\
\text { Month }\end{array}$} & \multicolumn{4}{|c|}{ Regular } & \multicolumn{4}{|c|}{ Midgrade } \\
\hline & Conventionala & Oxygenated & Reformulated & Total & Conventional & Oxygenated & Reformulated & Total \\
\hline \multicolumn{9}{|l|}{ Maryland } \\
\hline 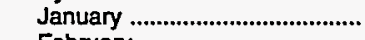 & 347.1 & $2,239.0$ & - & $2,586.1$ & 71.2 & 844.6 & - & 915.9 \\
\hline 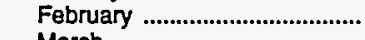 & 312.5 & $2,320.3$ & - & $2,632.8$ & 82.4 & 867.4 & - & 949.8 \\
\hline March & $2,785.2$ & 37.7 & - & $2,822.8$ & 977.8 & 12.7 & - & 990.6 \\
\hline 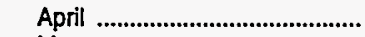 & w & W & - & $2,913.9$ & $1,019.5$ & - & - & $1,019.5$ \\
\hline May & W & w & - & $2,976.5$ & $w$ & w & - & $1,074.1$ \\
\hline 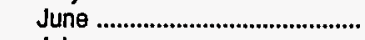 & $w$ & w & - & $3,069.8$ & $1,118.3$ & - & - & $1,118.3$ \\
\hline July & $2,994.5$ & - & - & $2,994.5$ & $1,130.3$ & - & - & $1,130.3$ \\
\hline 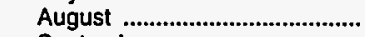 & W & $w$ & - & $3,130.7$ & $1,139.1$ & - & - & $1,139.1$ \\
\hline 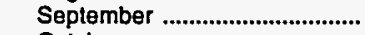 & w & w & - & $3,026.8$ & $w$ & w & - & $1,100.9$ \\
\hline Ociober & $2,471.0$ & 639.4 & - & $3,110.5$ & 814.4 & 261.0 & - & $1,075.4$ \\
\hline 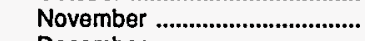 & 503.0 & $2,376.2$ & 194.2 & $3,073.4$ & 114.8 & 857.1 & 91.2 & $1,063.2$ \\
\hline December & W & W & $2,529.9$ & $3,083.4$ & 96.1 & 90.1 & 877.2 & $1,063.4$ \\
\hline 1994 Average & $2,086.7$ & 636.1 & 230.8 & $2,953.6$ & 729.5 & 242.5 & 82.0 & $1,054.0$ \\
\hline \multicolumn{9}{|l|}{ Now Jersey } \\
\hline 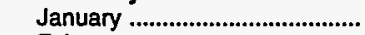 & 473.9 & $4,652.9$ & - & $5,126.8$ & w & $1,146.5$ & - & $1,193.6$ \\
\hline 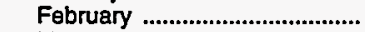 & 814.9 & $4,826.3$ & - & $5,641.2$ & 53.2 & $1,198.0$ & - & $1,251.3$ \\
\hline March & $1,722.7$ & $3,982.8$ & - & $5,705.5$ & 374.2 & 900.9 & - & $1,275.2$ \\
\hline April & $1,983.9$ & $3,749.9$ & - & $5,733.8$ & 395.8 & 889.0 & - & $1,284.7$ \\
\hline May & $\mathbf{5 , 7 5 5 . 1}$ & 41.3 & - & $5,796.4$ & $1,302.0$ & 14.5 & - & $1,316.5$ \\
\hline 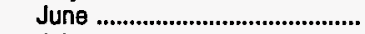 & 6.123 .1 & 0.4 & - & $6,123.4$ & $w$ & W & - & $1,398.0$ \\
\hline 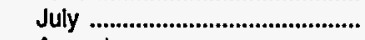 & w & $w$ & - & $6,000.4$ & w & $\dddot{w}$ & - & $1,427.8$ \\
\hline 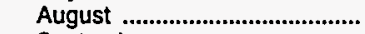 & w & w & - & $6,235.7$ & $1,413.6$ & - & - & $1,413.6$ \\
\hline 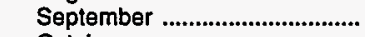 & w & w & - & $5,816.2$ & $w$ & $w$ & - & $1,346.3$ \\
\hline October & $2,348.9$ & $4,244.2$ & - & $6,593.1$ & 325.2 & $1,005.8$ & - & $1,331.0$ \\
\hline 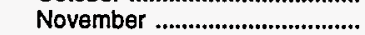 & 297.4 & $5,497.1$ & 858.6 & $6,653.1$ & 16.3 & $1,242.1$ & 103.8 & $1,362.2$ \\
\hline 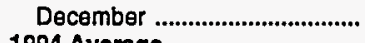 & 256.6 & 298.1 & $5,837.6$ & $6,392.3$ & $w$ & 60.9 & $w$ & $1,430.1$ \\
\hline 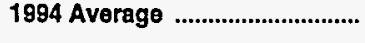 & $3,086.5$ & $2,333.7$ & 566.4 & $5,986.6$ & 655.7 & 555.9 & 124.8 & $1,336.4$ \\
\hline \multicolumn{9}{|l|}{ New York } \\
\hline 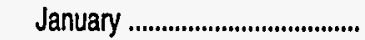 & $4,649.0$ & $3,297.8$ & - & $7,946.9$ & 690.4 & 820.8 & - & $1,511.2$ \\
\hline 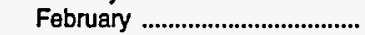 & $4,882.8$ & $3,200.5$ & - & $8,083.3$ & 679.6 & 820.9 & - & $1,500.4$ \\
\hline March & $4,872.8$ & $3,500.8$ & - & $8,373.6$ & 671.4 & 864.1 & - & $1,535.5$ \\
\hline 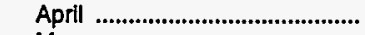 & $4,961.6$ & $3,398.3$ & - & $8,360.0$ & 689.5 & 861.0 & - & $1,550.5$ \\
\hline May & $8,617.2$ & 18.8 & - & $8,636.0$ & $1,662.1$ & 6.6 & - & $1,668.7$ \\
\hline 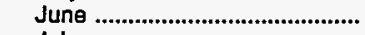 & w & w & - & $8,995.3$ & $w$ & $w$ & - & $1,698.1$ \\
\hline July & $9,084.5$ & - & - & $9,084.5$ & $1,755.0$ & - & - & $1,755.0$ \\
\hline 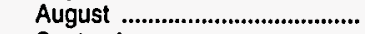 & $9,360.5$ & 0.5 & - & $9,360.9$ & $w$ & $w$ & - & $1,803.2$ \\
\hline 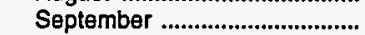 & $8,145.0$ & 683.0 & - & $8,828.0$ & $1,418.5$ & 244.1 & - & $1,662.6$ \\
\hline 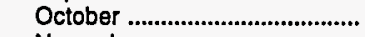 & $5,701.5$ & $3,231.5$ & - & $8,933.0$ & 799.8 & 892.2 & - & $1,692.0$ \\
\hline 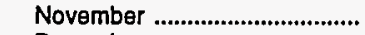 & $5,454.3$ & $2,981.0$ & 251.5 & $8,686.8$ & 760.6 & 833.4 & 76.7 & $1,670.7$ \\
\hline 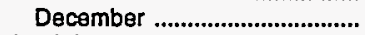 & $3,659.0$ & 172.4 & $5,145.4$ & $8,976.7$ & 476.4 & 70.4 & $1,185.8$ & $1,732.6$ \\
\hline 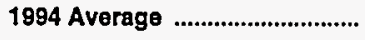 & $6,541.6$ & $1,694.2$ & 457.7 & $8,693.4$ & $1,094.8$ & 447.7 & 107.0 & $1,649.6$ \\
\hline \multicolumn{9}{|l|}{ Pennsylvania } \\
\hline 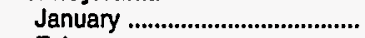 & $5,356.5$ & $1,611.8$ & - & $6,968.3$ & $1,154.0$ & 513.0 & - & $1,667.0$ \\
\hline 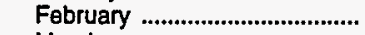 & $6,102.8$ & $1,791.0$ & - & $7,893.8$ & $1,231.4$ & 523.5 & - & $1,754.9$ \\
\hline 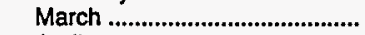 & $7,987.8$ & 434.4 & - & 8.422 .2 & $1,780.1$ & 98.8 & - & $1,878.9$ \\
\hline 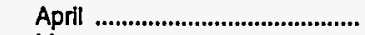 & $w$ & w & - & $8,838.4$ & w & w & - & $1,919.7$ \\
\hline 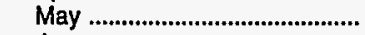 & w & w & - & $8,805.5$ & $2,012.9$ & - & - & $2,012.9$ \\
\hline June & $9,399.7$ & - & - & $9,399.7$ & $2,026.2$ & - & - & $2,026.2$ \\
\hline 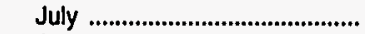 & $9,010.1$ & - & - & $9,010.1$ & $1,985.0$ & - & - & $1,985.0$ \\
\hline 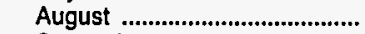 & w & w & - & $9,476.9$ & $2,000.3$ & - & - & $2,000.3$ \\
\hline 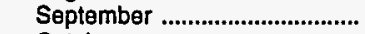 & $9,180.2$ & - & - & $9,180.2$ & W & W & - & $1,907.9$ \\
\hline 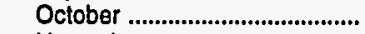 & $8,768.8$ & 458.4 & - & $9,227.2$ & $1,749.5$ & 150.9 & - & $1,900.4$ \\
\hline 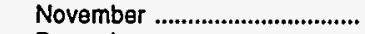 & $6,575.3$ & $1,805.6$ & 493.7 & $8,874.5$ & $1,266.5$ & 502.8 & 141.5 & $1,910.9$ \\
\hline 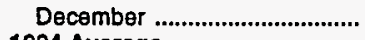 & $3,280.6$ & 87.2 & $5,593.9$ & $8,961.7$ & 475.8 & 36.1 & $1,369.7$ & $1,881.6$ \\
\hline 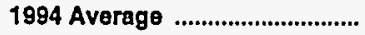 & $7,704.8$ & $\mathbf{5 3 8 . 0}$ & 515.7 & $\mathbf{8 , 7 5 8 . 5}$ & $1,620.4$ & 156.3 & 128.0 & $1,904.6$ \\
\hline
\end{tabular}

See footnotes at end of table. 
Table 48. Prime Supplier Sales Volumes of Motor Gasoline by Grade, Formulation, PAD District, and State

(Thousand Gallons per Day) - Continued

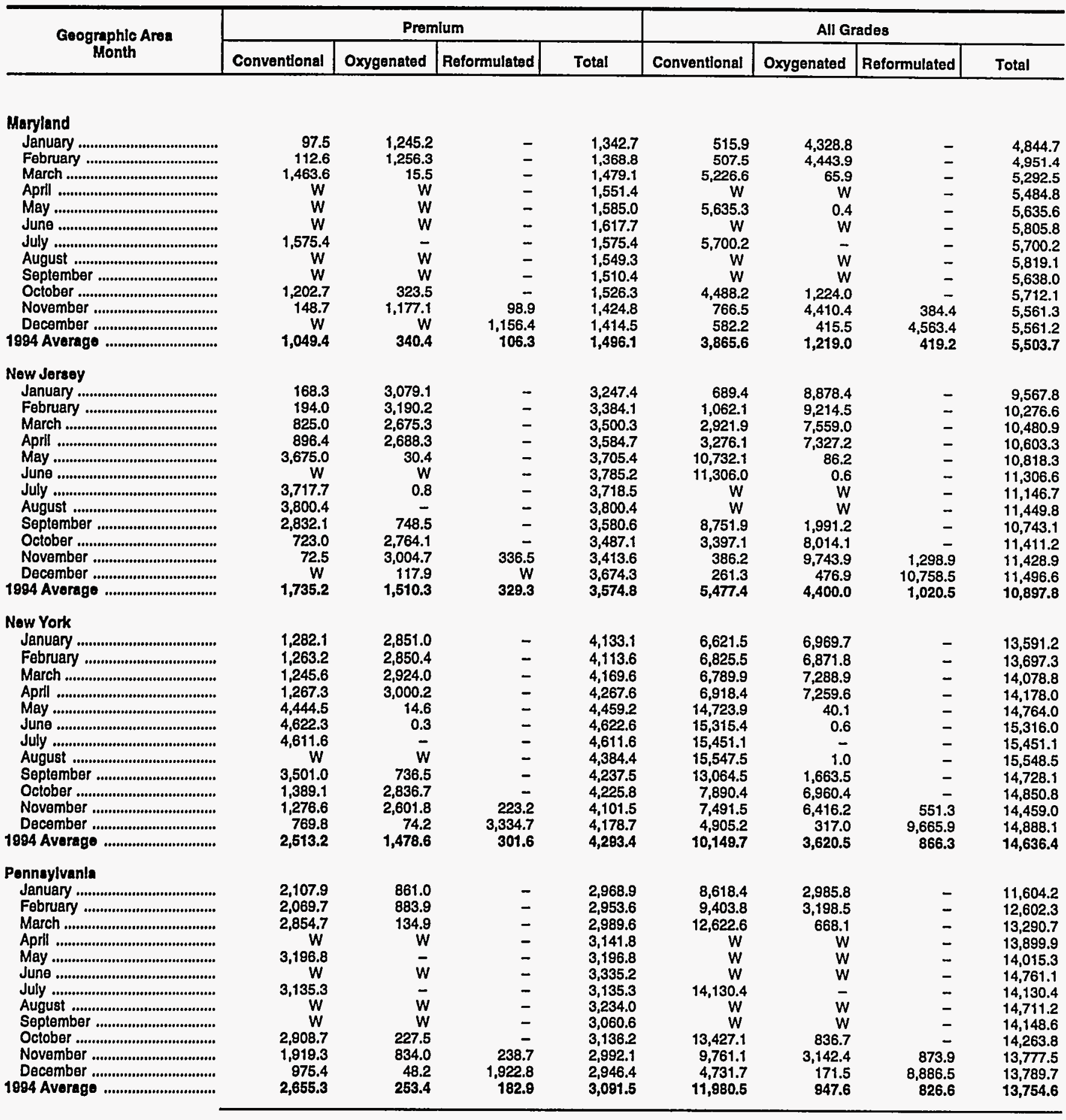

See footnotes at end of table. 
Table 48. Prime Supplier Sales Volumes of Motor Gasoline by Grade, Formulation, PAD District, and State

(Thousand Gallons per Day) - Continued

\begin{tabular}{|c|c|c|c|c|c|c|c|c|}
\hline \multirow{2}{*}{$\begin{array}{l}\text { Geographlc Area } \\
\text { Month }\end{array}$} & \multicolumn{4}{|c|}{ Regular } & \multicolumn{4}{|c|}{ Midgrade } \\
\hline & Conventionala & Oxygenatod & Reformulated & Total & Conventional & Oxygenated & Reformulated & Total \\
\hline \multicolumn{9}{|l|}{ Subdistrict IC } \\
\hline 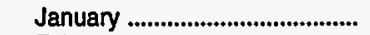 & $27,632.0$ & $2,177.5$ & - & $29,809.5$ & $7,299.9$ & 725.6 & - & $8,025.5$ \\
\hline 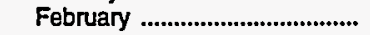 & $29,607.6$ & $2,145.4$ & - & $31,753.0$ & $7,812.1$ & 707.0 & - & $8,519.1$ \\
\hline 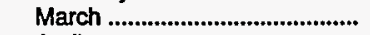 & $33,138.0$ & 90.4 & - & $33,228.4$ & $9,039.5$ & 35.5 & - & $9,075.0$ \\
\hline 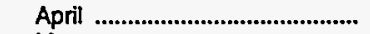 & $33,136.9$ & 0.5 & - & $33,137.4$ & $w$ & w & - & $9,036.4$ \\
\hline 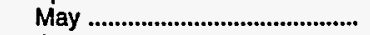 & w & w & - & $31,691.8$ & $w$ & w & - & $8,839.5$ \\
\hline 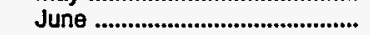 & w & w & - & $32,436.9$ & $8,968.2$ & - & - & $8,968.2$ \\
\hline 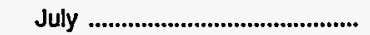 & $w$ & w & - & $32,078.3$ & $8,863.3$ & - & - & $8,863.3$ \\
\hline 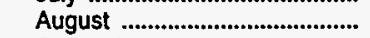 & $w$ & $w$ & - & $33,823.7$ & w & w & - & $9,045.9$ \\
\hline September ..................................... & $32,677.8$ & - & - & $32,677.8$ & w & w & - & $8,706.9$ \\
\hline October & $31,769.7$ & 492.2 & - & $32,261.8$ & $8,485.3$ & 188.1 & - & $8,673.4$ \\
\hline 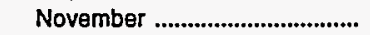 & $31,089.1$ & $1,508.4$ & 149.7 & $32,747.2$ & $8,083.4$ & 538.2 & 58.0 & $8,679.6$ \\
\hline 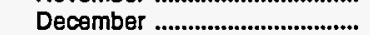 & $30,445.7$ & 664.6 & $2,722.9$ & $33,833.3$ & $7,831.5$ & 217.4 & 914.5 & $8,963.5$ \\
\hline 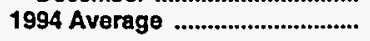 & $31,635.4$ & 580.2 & 243.6 & $32,459.2$ & $8,496.3$ & 205.8 & 82.4 & $8,784.5$ \\
\hline \multicolumn{9}{|l|}{ Florida } \\
\hline 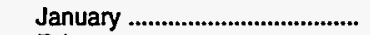 & $9,537.3$ & - & - & $9,537.3$ & $2,986.4$ & - & - & $2,986.4$ \\
\hline 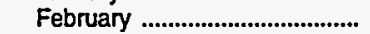 & $10,449.4$ & - & - & $10,449.4$ & $3,202.7$ & - & - & $3,202.7$ \\
\hline 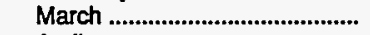 & $10,582.5$ & - & - & $10,582.5$ & $3,399.6$ & - & - & $3,399.6$ \\
\hline April & $10,221.2$ & - & - & $10,221.2$ & $3,267.4$ & - & - & $3,267.4$ \\
\hline 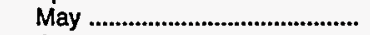 & $9,233.1$ & - & - & $9,233.1$ & $3,079.5$ & - & - & $3,079.5$ \\
\hline June ................................................... & $9,330.5$ & - & - & $9,330.5$ & $3,052.0$ & - & - & $3,052.0$ \\
\hline 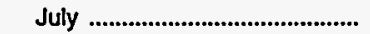 & 9.192 .0 & - & - & $9,192.0$ & $3,034.7$ & - & - & 3.034 .7 \\
\hline August & $9,620.6$ & - & - & $9,620.6$ & $3,049.4$ & - & - & $3,049.4$ \\
\hline 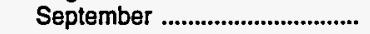 & $9,378.1$ & - & - & $9,378.1$ & $2,966.4$ & - & - & $2,966.4$ \\
\hline 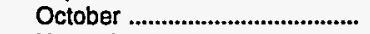 & $9,730.5$ & - & - & $9,730.5$ & $3,072.8$ & - & - & $3,072.8$ \\
\hline 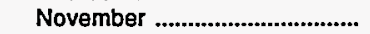 & $9,979.7$ & - & - & $9,979.7$ & $3, \mathbf{1 4 6 . 0}$ & - & - & $3,146.0$ \\
\hline 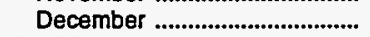 & $10,519.4$ & - & - & $10,519.4$ & $3,192.9$ & - & - & $3,192.9$ \\
\hline 1994 Average & $9,810.3$ & - & - & $9,810.3$ & $3,120.3$ & - & - & $3,120.3$ \\
\hline \multicolumn{9}{|l|}{ Georgia } \\
\hline 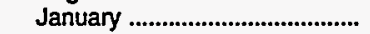 & $5,902.9$ & - & - & $5,902.9$ & $1,491.3$ & - & - & $1,491.3$ \\
\hline 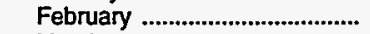 & $6,238.3$ & - & - & $6,238.3$ & $1,574.8$ & - & - & $1,574.8$ \\
\hline March & $6,575.1$ & - & - & $6,575.1$ & $1,638.6$ & - & - & $1,638.6$ \\
\hline April & $6,715.7$ & - & - & $6,715.7$ & $1,663.1$ & - & - & $1,663.1$ \\
\hline May & $6,414.4$ & - & - & $6,414.4$ & $1,636.4$ & - & - & $1,636.4$ \\
\hline June & $6,711.6$ & - & - & $6,711.6$ & $1,678.7$ & - & - & $1,678.7$ \\
\hline 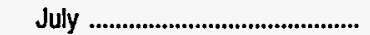 & $6,586.4$ & - & - & $6,586.4$ & $1,611.1$ & - & - & $1,611.1$ \\
\hline August & $7,071.0$ & - & - & $7,071.0$ & $1,690.0$ & - & - & $1,690.0$ \\
\hline 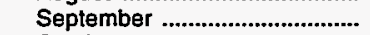 & $6,849.0$ & - & - & $6,849.0$ & $1,651.0$ & - & - & $1,651.0$ \\
\hline 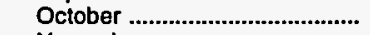 & $6,588.0$ & - & - & $6,588.0$ & $1,604.2$ & - & - & 1.604 .2 \\
\hline 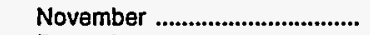 & $6,832.4$ & - & - & $6,832.4$ & $1,618.9$ & - & - & $1,618.9$ \\
\hline 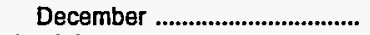 & $6,875.7$ & - & - & $6,875.7$ & $1,702.7$ & - & - & $1,702.7$ \\
\hline 1994 Average …................................... & $6,614.7$ & - & - & $6,614.7$ & $1,630.3$ & - & - & $1,630.3$ \\
\hline \multicolumn{9}{|l|}{ North Carolina } \\
\hline 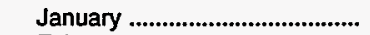 & 4,433.2 & $1,155.4$ & - & $5,588.6$ & 935.9 & 316.5 & - & $1,252.3$ \\
\hline 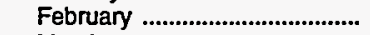 & $4,669.4$ & $1,142.0$ & - & $5,811.4$ & 994.6 & 312.7 & - & $1,307.3$ \\
\hline 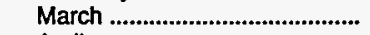 & $6,265.5$ & 13.6 & - & $6,279.2$ & $1,452.2$ & 0.9 & - & $1,453.1$ \\
\hline April & w & w & - & $6,192.0$ & $1,465.9$ & - & - & $1,465.9$ \\
\hline 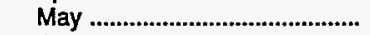 & $w$ & $w$ & - & $6,127.5$ & $1,486.6$ & - & - & $1,486.6$ \\
\hline June & w & w & - & $6,214.8$ & $1,513.2$ & - & - & $1,513.2$ \\
\hline 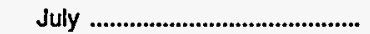 & w & $w$ & - & $6,137.7$ & $1,508.3$ & - & - & $1,508.3$ \\
\hline August & $6,480.6$ & - & - & $6,480.6$ & $1,552.3$ & - & - & $1,552.3$ \\
\hline 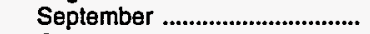 & $6,297.0$ & - & - & $6,297.0$ & w & w & - & $1,489.9$ \\
\hline 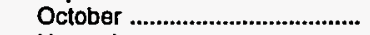 & w & w & - & $6,007.4$ & $1,435.8$ & 23.4 & - & $1,459.2$ \\
\hline 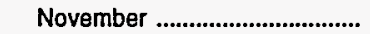 & $5,657.5$ & 492.6 & - & $6,150.2$ & $1,287.7$ & 157.6 & - & $1,445.3$ \\
\hline 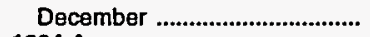 & $w$ & 516.4 & w & $6,270.1$ & w & 182.9 & w & $1,517.3$ \\
\hline 1994 Average ....................................... & $5,853.2$ & $2 \pi 7.8$ & $\mathbf{w}$ & $6,131.4$ & $1,370.7$ & 84.4 & w & $1,455.2$ \\
\hline
\end{tabular}

See footnotes at end of table. 
Table 48. Prime Supplier Sales Volumes of Motor Gasoline by Grade, Formulation, PAD District, and State

(Thousand Gallons per Day) - Continued

\begin{tabular}{|c|c|c|c|c|c|c|c|c|}
\hline \multirow{2}{*}{$\begin{array}{l}\text { Geographlc Area } \\
\text { Month }\end{array}$} & \multicolumn{4}{|c|}{ Premlum } & \multicolumn{4}{|c|}{ All Grades } \\
\hline & Conventional & Oxygenated & Reformulated & Total & Conventional & Oxygenated & Reformulated & Total \\
\hline \multicolumn{9}{|l|}{ Subdlatrict IC } \\
\hline 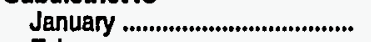 & $11,275.8$ & 966.8 & - & $12,242.7$ & $46,207.7$ & $3,870.0$ & - & $50,077.7$ \\
\hline 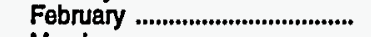 & $12,140.1$ & 957.9 & - & $13,098.0$ & $49,559.8$ & $3,810.2$ & - & $53,370.0$ \\
\hline 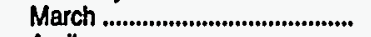 & $13,846.8$ & 48.3 & - & $13,895.1$ & $56,024.4$ & 174.1 & - & $56,198.5$ \\
\hline April & $W$ & $W$ & - & $13,690.5$ & $55,863.5$ & 0.8 & - & $55,864.3$ \\
\hline 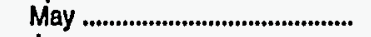 & $W$ & W & - & $13,469.1$ & $53,994.9$ & 5.5 & - & $54,000.5$ \\
\hline June ................................................... & $13,474.9$ & - & - & $13,474.9$ & W & $W$ & - & $54,880.0$ \\
\hline July ................................................. & $12,976.4$ & - & - & $12,976.4$ & $W$ & $W$ & - & $53,918.0$ \\
\hline August ......................................... & W & $W$ & $\rightarrow$ & $12,808,4$ & $W$ & $w$ & - & $55,677.9$ \\
\hline September .................................... & $12,553.2$ & - & - & $12,553.2$ & $W$ & $W$ & - & $53,938.0$ \\
\hline October ........................................ & $12,317.5$ & 238.3 & $\overline{0}$ & $12,555.8$ & $52,572.5$ & 918.5 & $-\overrightarrow{0}$ & $53,491.1$ \\
\hline 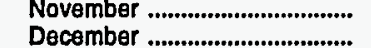 & $\begin{array}{l}11,973.4 \\
11.667 .3\end{array}$ & $\begin{array}{l}651.4 \\
260.6\end{array}$ & $\begin{array}{r}68.2 \\
1.264 .9\end{array}$ & $\begin{array}{l}12,693.0 \\
13,192.8\end{array}$ & $51,145.9$ & $\begin{array}{l}2,698.0 \\
1.142 .6\end{array}$ & $\begin{array}{r}275.9 \\
4.902 .4\end{array}$ & $54,119.8$ \\
\hline 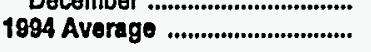 & $12,684.4$ & 255.8 & $1,204.9$ & $13,053.2$ & $\begin{array}{l}49,544.0 \\
52,816.0\end{array}$ & $\begin{array}{l}1,142.6 \\
1,041.8\end{array}$ & $\begin{array}{r}4,902.4 \\
439.0\end{array}$ & 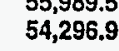 \\
\hline \multicolumn{9}{|l|}{ Florida } \\
\hline 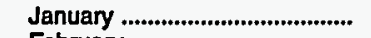 & $4,776.1$ & - & - & $4,776.1$ & $17,299.8$ & - & - & $17,299.8$ \\
\hline February ..................................... & $5,229.0$ & - & - & $5,229.0$ & $18,881.0$ & - & - & $18,881.0$ \\
\hline March & $5,361.5$ & - & - & $5,361.5$ & $19,343.5$ & - & - & $19,343.5$ \\
\hline April & $5,138.3$ & - & - & $5,138.3$ & $18,626.9$ & - & - & $18,626.9$ \\
\hline 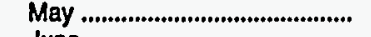 & $4,976.9$ & - & - & $4,976.9$ & $17,289.5$ & - & - & $17,289.5$ \\
\hline June & $4,837.2$ & - & - & $4,837.2$ & $17,219.7$ & - & - & $17,219.7$ \\
\hline 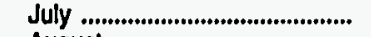 & $4,622.4$ & - & - & $4,622.4$ & $16,849.1$ & - & - & $16,849.1$ \\
\hline August & $4,462.0$ & - & - & $4,462.0$ & $17,132.0$ & - & - & $17,132.0$ \\
\hline September ................................. & $4,379.7$ & - & - & $4,379.7$ & $16,724.2$ & - & - & $16,724.2$ \\
\hline 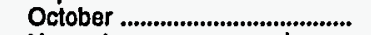 & $4,537.6$ & - & - & $4,537.6$ & $17,341.0$ & - & - & $17,341.0$ \\
\hline 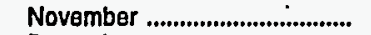 & $4,686.8$ & - & - & $4,686.8$ & $17,812.5$ & - & - & $17,812.5$ \\
\hline December .................................... & $4,838.4$ & - & - & $4,838.4$ & $18,550.7$ & - & - & $18,550.7$ \\
\hline 1994 Average .................................. & $4,817.8$ & - & - & $4,817.8$ & $17,748.3$ & - & - & $17,748.3$ \\
\hline \multicolumn{9}{|l|}{ Georgla } \\
\hline 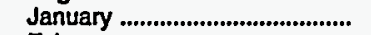 & $2,221.1$ & - & - & $2,221.1$ & $9,615.2$ & - & - & $9,615.2$ \\
\hline February ................................... & $2,400.1$ & - & - & $2,400.1$ & $10,213.1$ & - & - & $10,213.1$ \\
\hline March & $2,576.3$ & - & - & $2,576.3$ & $10,789.9$ & - & - & $10,789.9$ \\
\hline Aprill & $2,581.8$ & - & - & $2,581.8$ & $10,960.6$ & - & - & $10,960.6$ \\
\hline 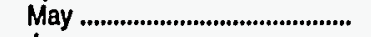 & $2,496.4$ & - & - & $2,496.4$ & $10,547.2$ & - & - & $10,547.2$ \\
\hline 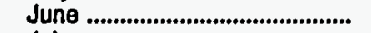 & $2,517.3$ & - & - & $2,517.3$ & $10,907.5$ & - & - & $10,907.5$ \\
\hline 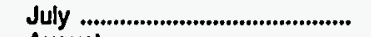 & $2,368.7$ & - & - & $2,368.7$ & $10,566.3$ & - & - & $10,566.3$ \\
\hline 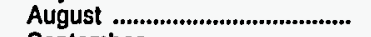 & $2,414.9$ & - & - & $2,414.9$ & $11,175.9$ & - & - & $11,175.9$ \\
\hline 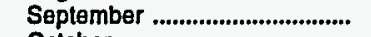 & $2,387.5$ & - & - & $2,387.5$ & $10,887.5$ & - & - & $10,887.5$ \\
\hline 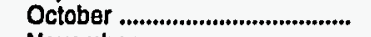 & $2,321.5$ & - & - & $2,321.5$ & $10,513.7$ & - & - & $10,513.7$ \\
\hline 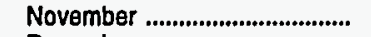 & $2,416.5$ & - & - & $2,416.5$ & $10,867.8$ & - & - & $10,867.8$ \\
\hline 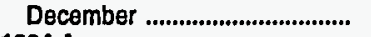 & $2,493.5$ & - & - & $2,493.5$ & $11,072.0$ & - & - & $11,072.0$ \\
\hline 1994 Average .............................. & $2,432.8$ & - & - & $2,432,8$ & $10,677.7$ & - & - & $10,677.7$ \\
\hline \multicolumn{9}{|l|}{ North Carolina } \\
\hline 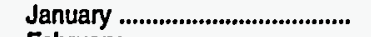 & $1,470.2$ & 444.7 & - & $1,914.9$ & $6,839.3$ & $1,916.6$ & - & $8,755.9$ \\
\hline 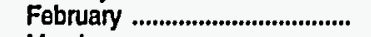 & $1,582.8$ & 435.6 & - & $2,018.4$ & $7,246.7$ & $1,890.3$ & - & $9,137.0$ \\
\hline 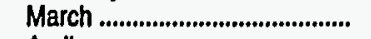 & $2,191.1$ & 2.4 & - & $2,193.5$ & $9,908.8$ & 17.0 & - & $9,925.8$ \\
\hline April & W & W & - & $2,213.9$ & $W$ & $W$ & - & $9,871.8$ \\
\hline 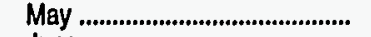 & $2,185.3$ & - & - & $2,185.3$ & $W$ & $W$ & - & $9,799.4$ \\
\hline June & $2,156.4$ & - & - & $2,156.4$ & $w$ & $w$ & - & $9,884.5$ \\
\hline 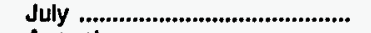 & $2,120.1$ & - & - & $2,120.1$ & $W$ & $\mathbf{W}$ & - & $9,766.0$ \\
\hline 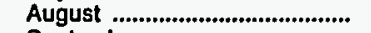 & $2,118.6$ & - & - & $2,118.6$ & $10,151.5$ & - & - & $10,151.5$ \\
\hline 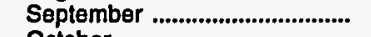 & $2,072.4$ & $\overline{-}$ & - & $2,072.4$ & W & $w$ & - & $9,859.4$ \\
\hline 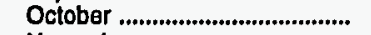 & $W$ & $W$ & - & $2,009.5$ & $9,361.8$ & 114.3 & - & $9,476.1$ \\
\hline November ................................... & $1,875.5$ & 193.4 & - & $2,069.0$ & $8,820.7$ & 843.7 & - & $9,664.4$ \\
\hline December ................................. & $W$ & 215.2 & $w$ & $2,165.3$ & W & 914.5 & W & $9,952.6$ \\
\hline 1994 Average ............................... & $1,995.9$ & 107.5 & $\mathbf{W}$ & $2,103.5$ & $9,219.8$ & 469.6 & $\mathbf{w}$ & $9,690.1$ \\
\hline
\end{tabular}

See footnotes at end of table. 
Table 48. Prime Supplier Sales Volumes of Motor Gasoline by Grade, Formulation, PAD District, and State

(Thousand Gallons per Day) - Continued

\begin{tabular}{|c|c|c|c|c|c|c|c|c|}
\hline \multirow{2}{*}{$\begin{array}{l}\text { Geographic Area } \\
\text { Month }\end{array}$} & \multicolumn{4}{|c|}{ Regular } & \multicolumn{4}{|c|}{ Midgrade } \\
\hline & Conventional ${ }^{\mathrm{a}}$ & Oxygenated & Reformulated & Total & Conventional & Oxygenated & Reformulated & Total \\
\hline \multicolumn{9}{|l|}{ South Carolina } \\
\hline 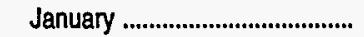 & $3,282.8$ & - & - & $3,282.8$ & 711.6 & - & - & 711.6 \\
\hline February ....................................... & $3,418.0$ & - & - & $3,418.0$ & 760.9 & - & - & 760.9 \\
\hline March & $3,586.5$ & - & - & $3,586.5$ & 816.5 & - & - & 816.5 \\
\hline April & $3,633.4$ & - & - & $3,633.4$ & 804.5 & - & - & 804.5 \\
\hline 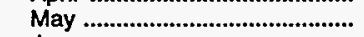 & $3,500.4$ & - & - & $3,500.4$ & 784.1 & - & - & 784.1 \\
\hline June & $3,581.7$ & - & - & $3,581.7$ & 812.1 & - & - & 812.1 \\
\hline 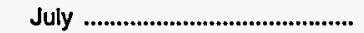 & $3,590.2$ & - & - & $3,590.2$ & 805.7 & - & - & 805.7 \\
\hline 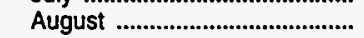 & $3,739.5$ & - & - & $3,739.5$ & 826.4 & - & - & 826.4 \\
\hline 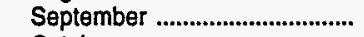 & $3,626.3$ & - & - & $3,626.3$ & 762.3 & - & - & 762.3 \\
\hline 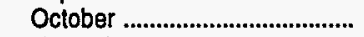 & $3,448.5$ & - & - & $3,448.5$ & 736.2 & - & - & 736.2 \\
\hline November .................................. & $3,471.9$ & - & - & $3,471.9$ & 738.6 & - & - & 738.6 \\
\hline 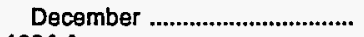 & $3,542,4$ & - & - & $3,542.4$ & 756.8 & - & - & 756.8 \\
\hline 1994 Average & $3,535.6$ & - & - & $3,535.6$ & 776.4 & - & - & 776.4 \\
\hline \multicolumn{9}{|l|}{ Virginia } \\
\hline January ....................................... & $3,664.8$ & $1,015.3$ & - & $4,680.0$ & 983.2 & 406.8 & - & $1,390.0$ \\
\hline 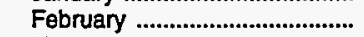 & $3,873.3$ & $1,003.4$ & - & $4,876.6$ & $1,052.6$ & 394.3 & - & $1,446.9$ \\
\hline 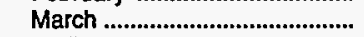 & $5,027.2$ & 76.7 & - & $5,103.9$ & $1,487.8$ & 34.5 & - & $1,522.4$ \\
\hline April & $W$ & $W$ & - & $5,304.0$ & $W$ & W & - & $1,568.6$ \\
\hline 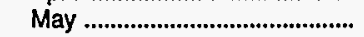 & $W$ & $w$ & - & $5,313.5$ & $W$ & W & - & $1,591.2$ \\
\hline 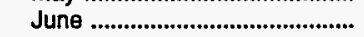 & $5,484.0$ & - & - & $5,484.0$ & $1,644.9$ & - & - & $1,644.9$ \\
\hline July & $5,483.3$ & - & - & $5,483.3$ & $1,630.5$ & - & - & $1,630.5$ \\
\hline August ......................................... & $W$ & $W$ & - & $5,835.6$ & $W$ & $w$ & - & $1,659.9$ \\
\hline 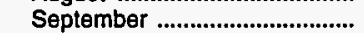 & $5,488.2$ & - & - & $5,488.2$ & w & 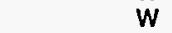 & - & $1,579.2$ \\
\hline 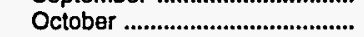 & $5,004.6$ & 424.0 & - & $5,428.6$ & $\mathbf{W}$ & $w$ & - & $1,537.5$ \\
\hline 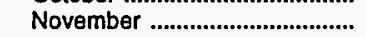 & $4,101.7$ & $1,015.7$ & 149.7 & $5,267.1$ & $1,030.8$ & 380.6 & 58.0 & $1,469.4$ \\
\hline 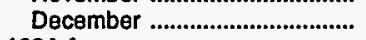 & $2,666.4$ & 148.2 & $2,716.4$ & $5,531.0$ & 587.2 & 34.5 & 912.3 & $1,534.0$ \\
\hline 1994 Average & $4,774.3$ & 301.9 & 243.0 & $5,318.2$ & $1,345.1$ & 121.2 & 82.2 & $1,548.5$ \\
\hline \multicolumn{9}{|l|}{ West Virginia } \\
\hline 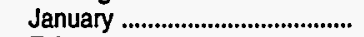 & 811.1 & $W$ & - & 818.0 & 191.5 & $W$ & - & 193.9 \\
\hline 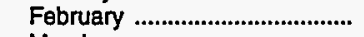 & 959.4 & - & - & 959.4 & 226.5 & - & - & 226.5 \\
\hline March & $1,101.2$ & - & - & $1,101.2$ & 244.8 & - & - & 244.8 \\
\hline April ........................................... & $1,071,2$ & - & - & $1,071.2$ & 266.9 & - & - & 266.8 \\
\hline 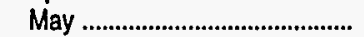 & $1,102.9$ & - & - & $1,102.9$ & 261.8 & - & - & 261.8 \\
\hline 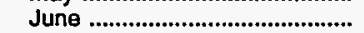 & $1,114.3$ & - & - & $1,114.3$ & 267.3 & - & - & 267.3 \\
\hline 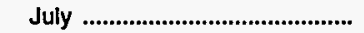 & $1,088.7$ & - & - & $1,088.7$ & 272.9 & - & - & 272.9 \\
\hline 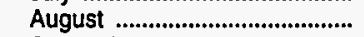 & $1,076.3$ & - & - & $1,076.3$ & 267.9 & - & - & 267.9 \\
\hline 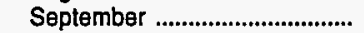 & $1,039.3$ & - & - & $1,039.3$ & 258.1 & - & - & 258.1 \\
\hline October ......................................... & $W$ & $W$ & - & $1,058.7$ & $W$ & W & - & 263.5 \\
\hline November .................................. & $1,046.0$ & - & - & $1,046.0$ & 261.4 & - & - & 281.4 \\
\hline 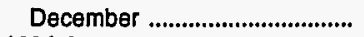 & W & - & $W$ & $1,094.6$ & W & - & W & 259.8 \\
\hline 1994 Average & $1,047.3$ & $\mathbf{w}$ & $\mathbf{W}$ & $1,048.1$ & 253.6 & $\mathbf{w}$ & W & 253.9 \\
\hline \multicolumn{9}{|l|}{ PAD District II } \\
\hline 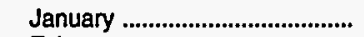 & $59,922.3$ & $2,068.5$ & - & $61,990.8$ & $8,702.2$ & 324.1 & - & $9,026.4$ \\
\hline February ....................................... & $64,711.2$ & 668.8 & - & $65,380.0$ & $9,122.8$ & 46.4 & - & $0,169.2$ \\
\hline 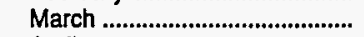 & $67,442.7$ & 539.4 & - & $67,982.2$ & $9,388.7$ & 56.9 & - & $8,445.6$ \\
\hline April & $70,572.9$ & 468.7 & - & $71,041.6$ & $9,428.2$ & 58.8 & - & $9,487.0$ \\
\hline 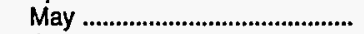 & $71,138.7$ & 491.1 & - & $71,629.7$ & $9,626.3$ & 61.8 & - & $9,688.1$ \\
\hline June & $74,609.6$ & 537.9 & - & $75,147.5$ & $W$ & $\mathbf{W}$ & - & $10,015.7$ \\
\hline July & $73,307.3$ & 562.2 & - & $73,869.5$ & $9,675.5$ & 65.2 & - & $9,740.7$ \\
\hline 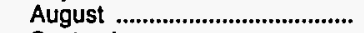 & $74,700.4$ & 635.8 & - & $75,336.2$ & $9,439.6$ & 68.2 & - & $9,507.7$ \\
\hline 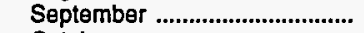 & $72,873.5$ & 803.4 & - & $73,677.0$ & $9,235.1$ & 54.1 & - & $9,289.2$ \\
\hline 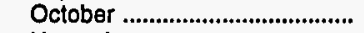 & $70,776.5$ & $2,031.9$ & - & $72,808.4$ & $8,953.6$ & 297.0 & - & $8,250.5$ \\
\hline 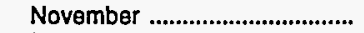 & $69,570.1$ & $W$ & W & $71,834.6$ & $8,760.8$ & W & W & $9,153.5$ \\
\hline December .................................. & $63,716.6$ & $2,272.3$ & $5,742.5$ & $71,731.3$ & $8,203.7$ & 363.0 & $1,214.9$ & $9,781.6$ \\
\hline 1994 Average & $69,457.1$ & $1,107.2$ & 497.2 & $71,081.5$ & $9,206.3$ & 151.7 & 107.1 & $9,465.1$ \\
\hline
\end{tabular}

See footnotes at end of table. 
Table 48. Prime Suppller Sales Volumes of Motor Gasoline by Grade, Formulation, PAD District, and State

(Thousand Gallons per Day) - Continued

\begin{tabular}{|c|c|c|c|c|c|c|c|c|}
\hline \multirow{2}{*}{$\begin{array}{c}\text { Geographle Area } \\
\text { Month }\end{array}$} & \multicolumn{4}{|c|}{ Promlum } & \multicolumn{4}{|c|}{ All Grades } \\
\hline & Conventional & Oxygenated & Reformulated & Total & Conventional & Oxygenated & Reformulated & Total \\
\hline \multicolumn{9}{|l|}{ South Carolina } \\
\hline January ...................................... & 988.0 & - & - & 988.0 & $4,982.4$ & - & - & $4,982.4$ \\
\hline February ..................................... & $1,037.7$ & - & - & $1,037.7$ & $5,216.6$ & - & - & $5,216.6$ \\
\hline March ............................................ & $1,142.0$ & - & - & $1,142.0$ & $5,545.1$ & - & - & $5,545.1$ \\
\hline 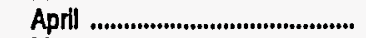 & $1,163.8$ & - & - & $1,163.8$ & $5,601.7$ & - & - & $5,601.7$ \\
\hline 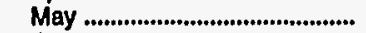 & $1,114.1$ & - & - & $1,114.1$ & $5,398.6$ & - & - & $5,398.6$ \\
\hline 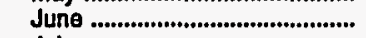 & 1.147 .5 & - & - & $1,147.5$ & $5,541.2$ & - & - & $5,541.2$ \\
\hline 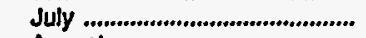 & $1,126.8$ & - & - & $1,126.8$ & $5,522.8$ & - & - & $5,522.8$ \\
\hline 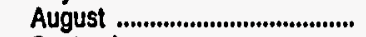 & $1,089.2$ & - & - & $1,089.2$ & $5,655.1$ & - & - & $5,655.1$ \\
\hline September .................................. & $1,038.6$ & - & - & $1,038.6$ & $5,427.3$ & - & - & $5,427.3$ \\
\hline 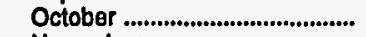 & $1,028.5$ & - & - & $1,028.5$ & $5,213.2$ & - & - & $5,213.2$ \\
\hline November .................................... & $1,028.8$ & - & - & $1,028.8$ & $5,239.3$ & - & - & $5,239.3$ \\
\hline 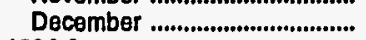 & $1,085.5$ & - & - & $1,085.5$ & $5,384.7$ & - & - & $5,384.7$ \\
\hline 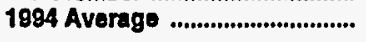 & $1,082.8$ & - & - & $1,082.8$ & $5,394.8$ & - & - & $5,394.8$ \\
\hline \multicolumn{9}{|l|}{ Virginia } \\
\hline January ....................................... & $1,593.5$ & 519.7 & - & $2,113.2$ & $6,241.5$ & $1,941.8$ & - & $8,183.2$ \\
\hline 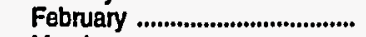 & $1,628.6$ & 522.3 & - & $2,150.9$ & $6,554.5$ & $1,919.9$ & - & $8,474.4$ \\
\hline March .......................................... & $2,253.6$ & 45.9 & - & $2,299.5$ & $8,768.7$ & 157.2 & - & $8,925.8$ \\
\hline Aprll & $W$ & $w$ & - & $2,317.1$ & $W$ & $w$ & - & $9,189.7$ \\
\hline 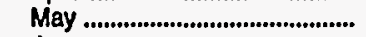 & $W$ & $w$ & - & $2,395.0$ & $w$ & $\ddot{w}$ & - & $9,299.8$ \\
\hline 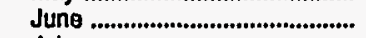 & $2,500.6$ & - & - & $2,500.6$ & $9,629.5$ & - & - & $9,629.5$ \\
\hline 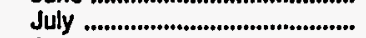 & $2,447.5$ & - & - & $2,447.5$ & $9,561.3$ & - & - & $9,561.3$ \\
\hline 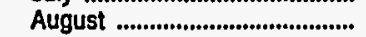 & W & $w$ & - & $2,446.6$ & $W$ & $w$ & - & $9,942.2$ \\
\hline September ................................ & $2,403.9$ & - & - & $2,403.9$ & $w$ & $\dddot{w}$ & - & $9,471.2$ \\
\hline 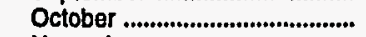 & $2,156.4$ & 215.3 & - & $2,371.7$ & w & W & - & $9,337.8$ \\
\hline November .................................. & $1,682.0$ & 458.0 & 68.2 & $2,208.2$ & $6,814.5$ & $1,854.3$ & 275.9 & $8,944.7$ \\
\hline 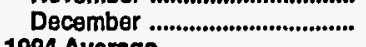 & $1,004.2$ & 45.4 & $1,260.6$ & $2,310.3$ & $4,257.8$ & 228.1 & $4,889.3$ & $9,375.2$ \\
\hline 1994 Average & $2,070.8$ & 148.1 & 112.7 & $2,331.6$ & $8,190.1$ & 571.2 & 437.9 & $9,199.2$ \\
\hline \multicolumn{9}{|l|}{ West Virginla } \\
\hline 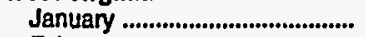 & 226.9 & $\mathbf{w}$ & - & 229.4 & $1,229.6$ & $w$ & - & $1,241.3$ \\
\hline February ..................................... & 261.9 & - & - & 261.9 & $1,447.8$ & - & - & $1,447.8$ \\
\hline March ........................................... & 322.3 & - & - & 322.3 & $1,668.3$ & - & - & $1,668.3$ \\
\hline 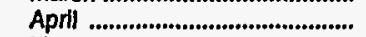 & 275.5 & - & - & 275.5 & $1,613.6$ & - & - & $1,613.6$ \\
\hline May .............................................. & 301.4 & - & - & 301.4 & $1,666.1$ & - & - & $1,666.1$ \\
\hline 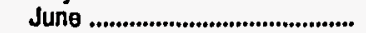 & 315.8 & - & - & 315.8 & $1,697.5$ & - & - & $1,697.5$ \\
\hline 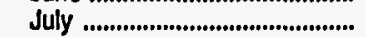 & 290.9 & - & - & 290.9 & $1,652.6$ & - & - & $1,652.6$ \\
\hline 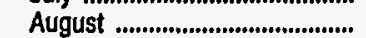 & 277.0 & - & - & 277.0 & $1,621.2$ & - & - & $1,621.2$ \\
\hline September ................................... & 271.0 & - & - & 271.0 & $1,568.4$ & - & - & $1,568.4$ \\
\hline 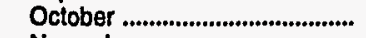 & $W$ & w & - & 287.1 & $W$ & W & - & $1,609.3$ \\
\hline November .................................... & 283.8 & - & - & 283.8 & $1,591.1$ & - & - & $1,591.1$ \\
\hline December ................................... & $W$ & $\overline{-}$ & $W$ & 299.9 & & - & $w$ & $1,654.3$ \\
\hline 1994 Average ............................... & 284.4 & $\mathbf{w}$ & 0.2 & 284.8 & $1,585.3$ & $w$ & 0.4 & $1,586.8$ \\
\hline \multicolumn{9}{|l|}{ PAD District II } \\
\hline 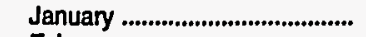 & $15,053.6$ & 433.1 & - & $15,486.7$ & $83,678.1$ & $2,825.8$ & - & $86,503.9$ \\
\hline February .................................... & $16,102.6$ & 150.4 & - & $16,253.0$ & $89,936.6$ & 865.6 & - & $90,802.2$ \\
\hline March ......................................... & $14,949.4$ & 83.6 & - & $15,033.0$ & $91,780.8$ & 680.0 & - & $92,460.8$ \\
\hline Apr|l .......................................... & $14,913.7$ & 73.2 & - & $14,986.9$ & $94,914.8$ & 600.7 & - & $95,515.5$ \\
\hline May .............................................. & $15,173.9$ & 93.8 & - & $15,267.6$ & $95,938.8$ & 646.7 & - & $96,585.5$ \\
\hline 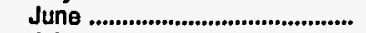 & $w$ & $w$ & - & $15,840.5$ & $100,292.4$ & 711.3 & - & $101,003.7$ \\
\hline 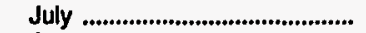 & $15,098.1$ & 114.6 & - & $15,212.7$ & $98,080.9$ & 742.0 & - & $98,822.9$ \\
\hline 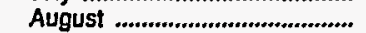 & $14,373.5$ & 113.8 & - & $14,487.3$ & $98,513.4$ & 817.8 & - & $99,331.2$ \\
\hline September ................................. & $14,428.9$ & 90.6 & - & $14,519.5$ & $96,537.5$ & 948.1 & - & $97,485.6$ \\
\hline 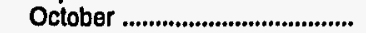 & $14,561.5$ & 268.9 & - & $14,830.5$ & $94,291.6$ & $2,597.8$ & - & $96,889.4$ \\
\hline November ................................... & $14,434.9$ & $w$ & w & $14,828.7$ & $92,765.8$ & $w$ & W & $95,816.8$ \\
\hline December ................................... & $13,562.2$ & 412.9 & $1,860.2$ & $15,835.3$ & $85,482.5$ & $3,048.2$ & $8,817.5$ & $97,348.2$ \\
\hline 1994 Average .............................. & $14,855.3$ & 190.6 & 162.6 & $15,208.5$ & $93,518.6$ & $1,449.6$ & 766.9 & $95,735.1$ \\
\hline
\end{tabular}

See footnotes at end of table. 
Table 48. Prime Supplier Sales Volumes of Motor Gasoline by Grade, Formulation, PAD District, and State

(Thousand Gallons per Day) - Continued

\begin{tabular}{|c|c|c|c|c|c|c|c|c|}
\hline \multirow{2}{*}{$\begin{array}{c}\text { Geographic Area } \\
\text { Month }\end{array}$} & \multicolumn{4}{|c|}{ Rogular } & \multicolumn{4}{|c|}{ Midgrado } \\
\hline & Conventionala & Oxygenated & Roformulated & Total & Conventional & Oxygenated & Reformulated & Total \\
\hline \multicolumn{9}{|l|}{ Illinois } \\
\hline 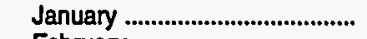 & $7,623.3$ & - & - & $7,623.3$ & $1,612.0$ & - & - & $1,612.0$ \\
\hline 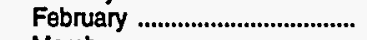 & $7,554.9$ & - & - & $7,554.9$ & $1,540.8$ & - & - & $1,540.8$ \\
\hline 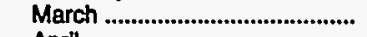 & $8,140.1$ & - & - & $8,140.1$ & $1,579.4$ & - & - & $1,579.4$ \\
\hline 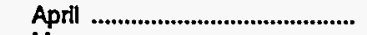 & $8,451.1$ & - & - & $8,451.1$ & $1,559.8$ & - & - & $1,559.8$ \\
\hline 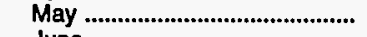 & $8,175.2$ & - & - & $8,175.2$ & $1,615.5$ & - & - & $1,615.5$ \\
\hline 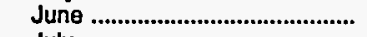 & $8,435.6$ & - & - & $8,435.6$ & $1,636.1$ & - & - & $1,636.1$ \\
\hline July & $8,349.8$ & - & - & $8,349.8$ & $1,588.0$ & - & - & $1,588.0$ \\
\hline 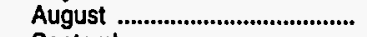 & $8,480.4$ & - & - & $8,480.4$ & $1,543.3$ & - & - & $1,543.3$ \\
\hline 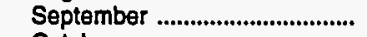 & $8,592.9$ & - & - & $8,592.9$ & $1,533.2$ & - & - & $1,533.2$ \\
\hline 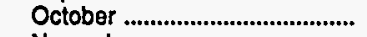 & $8,611.6$ & - & - & $8,611.6$ & $1,557.5$ & - & - & $1,557.5$ \\
\hline 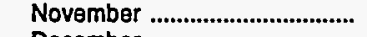 & W & - & $W$ & $8,409.5$ & W & - & $w$ & $1,578.8$ \\
\hline December .................................. & $4,851.2$ & - & $3,560.3$ & $8,411.5$ & 791.5 & - & 880.7 & $1,672.2$ \\
\hline 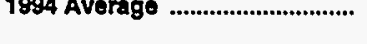 & $7,967.2$ & - & & $8,273.3$ & $1,509.0$ & - & & $\mathbf{1 , 5 8 5 . 2}$ \\
\hline \multicolumn{9}{|l|}{ Indiana } \\
\hline 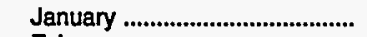 & $4,562.3$ & - & - & $4,562.3$ & 844.5 & - & - & 844.5 \\
\hline 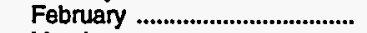 & $4,790.1$ & - & - & $4,790.1$ & 846.1 & - & - & 846.1 \\
\hline March & $5,156.4$ & - & - & $5,156.4$ & 869.5 & - & - & 869.5 \\
\hline April & $5,607.5$ & - & - & $5,607.5$ & 899.9 & - & - & 899.9 \\
\hline May & $5,478.8$ & - & - & $5,478.8$ & 920.4 & - & - & 920.4 \\
\hline 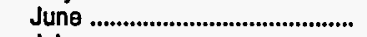 & $5,648.0$ & - & - & $5,648.0$ & 937.5 & - & - & 937.5 \\
\hline 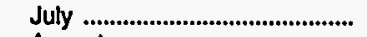 & $5,704.3$ & - & - & $5,704.3$ & 914.2 & - & - & 914.2 \\
\hline 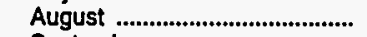 & $5,759.7$ & - & - & $5,759.7$ & 914.7 & - & - & 914.7 \\
\hline 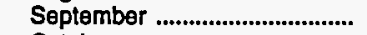 & $5,544.8$ & - & - & $5,544.8$ & 870.0 & - & - & 870.0 \\
\hline 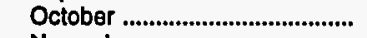 & $5,600.0$ & - & - & $5,600.0$ & 874.9 & - & - & 874.9 \\
\hline 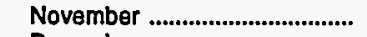 & W & - & W & $5,493.9$ & W & - & $W$ & 881.6 \\
\hline 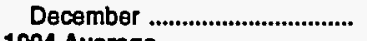 & 4.986 .6 & - & 449.1 & $5,435.7$ & 867.9 & - & 67.5 & 935.5 \\
\hline 1994 Average ................................. & $5,363.2$ & - & 38.4 & $5,401.5$ & 886.9 & - & 6.8 & 892.7 \\
\hline \multicolumn{9}{|l|}{ lowa } \\
\hline 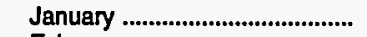 & $3,160.7$ & - & - & $3,160.7$ & 46.4 & - & - & 46.4 \\
\hline 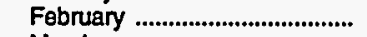 & $3,298.7$ & - & - & $3,298.7$ & 45.7 & - & - & 45.7 \\
\hline March & $3,464.3$ & - & - & $3,464.3$ & 46.2 & - & - & 46.2 \\
\hline 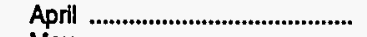 & $3,610.2$ & - & - & $3,610.2$ & 46.4 & - & - & 46.4 \\
\hline May & $3,546.0$ & - & - & $3,546.0$ & 46.8 & - & - & 46.8 \\
\hline 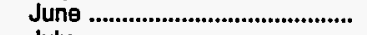 & $3,798.3$ & - & - & $3,798.3$ & 50.9 & - & - & 50.9 \\
\hline 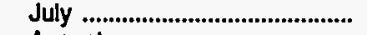 & $3,663.6$ & - & - & $3,663.6$ & 48.1 & - & - & 48.1 \\
\hline August & $3,822.2$ & - & - & $3,822.2$ & 53.9 & - & - & 53.9 \\
\hline 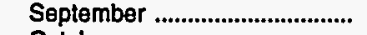 & $3,765.2$ & - & - & $3,765.2$ & 43.6 & - & - & 43.6 \\
\hline 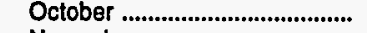 & $3,741.4$ & - & - & $3,741.4$ & 44.7 & - & - & 44.7 \\
\hline 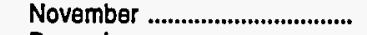 & $3,679.7$ & - & - & $3,679.7$ & 46.0 & - & - & 46.0 \\
\hline 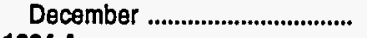 & $3,598.7$ & - & - & $3,598.7$ & 48.6 & - & - & 48.6 \\
\hline 1994 Average .............................. & $3,596.9$ & - & - & $3,596.9$ & 47.3 & - & - & 47.3 \\
\hline \multicolumn{9}{|l|}{ Kansas } \\
\hline 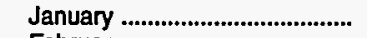 & $3,021.5$ & - & - & $3,021.5$ & 130.8 & - & - & 130.8 \\
\hline 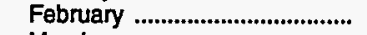 & $3,138.5$ & - & - & $3,138.5$ & 136.0 & - & - & 138.0 \\
\hline 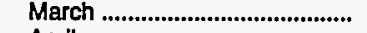 & $3,358.1$ & - & - & $3,358.1$ & 136.8 & - & - & 138.8 \\
\hline April & $3,410.2$ & - & - & $3,410.2$ & 133.4 & - & - & 133.4 \\
\hline May & $3,456.5$ & - & - & $3,456.5$ & 139.4 & - & - & 139.4 \\
\hline 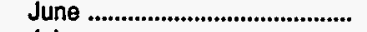 & $3,703.6$ & - & - & $3,703.6$ & 141.1 & - & - & 141.1 \\
\hline 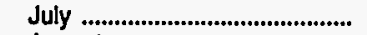 & $3,439.5$ & - & - & $3,439.5$ & 140.2 & - & - & 140.2 \\
\hline 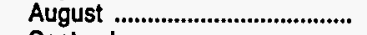 & $3,521.5$ & - & - & $3,521.5$ & 134.1 & - & - & 134.1 \\
\hline 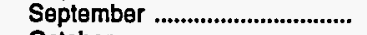 & $3,481.8$ & - & - & $3,481.8$ & 130.2 & - & - & 130.2 \\
\hline 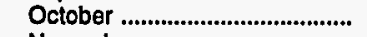 & $3,365.5$ & - & - & $3,365.5$ & 127.5 & - & - & 127.5 \\
\hline November .................................... & $3,304.4$ & - & - & $3,304.4$ & 131.7 & - & - & 131.7 \\
\hline 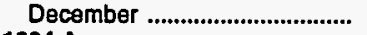 & $3,614.3$ & - & - & $3,614.3$ & 139.5 & - & - & 139.5 \\
\hline 1994 Average .................................... & $3,402.6$ & - & - & $3,402.6$ & 135.1 & - & - & 135.1 \\
\hline
\end{tabular}

See footnotes at end of table. 
Table 48. Prime Supplier Sales Volumes of Motor Gasoline by Grade, Formulation, PAD Dlstrict, and State

(Thousand Gallons per Day) - Continued

\begin{tabular}{|c|c|c|c|c|c|c|c|c|}
\hline \multirow{2}{*}{$\begin{array}{l}\text { Geographle Ana } \\
\text { Month }\end{array}$} & \multicolumn{4}{|c|}{ Pramlum } & \multicolumn{4}{|c|}{ All Grades } \\
\hline & Conventional & Oxygented & Roformulated & Total & Conventional & Oxygenated & Roformulated & Total \\
\hline \multicolumn{9}{|l|}{ Illinole } \\
\hline January ........................................ & $2,451.4$ & - & - & $2,451.4$ & $11,686.7$ & - & - & $11,686.7$ \\
\hline 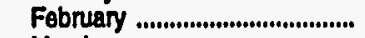 & $2,652.3$ & - & - & $2,652.3$ & $11,748.0$ & - & - & $11,748.0$ \\
\hline March ............................................ & $2,284.2$ & - & - & $2,284.2$ & $12,003.7$ & - & - & $12,003.7$ \\
\hline 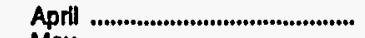 & $2,256.8$ & - & - & $2,256.8$ & $12,267.7$ & - & - & $12,267.7$ \\
\hline May ................................................. & $2,303.7$ & - & - & $2,303.7$ & $12,094.4$ & - & - & $12,094.4$ \\
\hline June & $2,250.8$ & - & - & $2,250.8$ & $12,322.6$ & - & - & $12,322.6$ \\
\hline 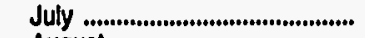 & $2,156.0$ & - & - & $2,156.0$ & $12,093.9$ & - & - & $12,093.9$ \\
\hline August .......................................... & $2,034.6$ & - & - & $2,034.6$ & $12,058.3$ & - & - & $12,058.3$ \\
\hline September .................................. & $2,139.6$ & - & - & $2,139.6$ & $12,265.7$ & - & - & $12,265.7$ \\
\hline 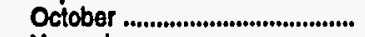 & $2,162.0$ & - & - & $2,162.0$ & $12,331.1$ & - & - & $12,331.1$ \\
\hline 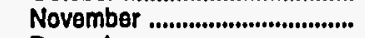 & $W$ & $\rightarrow$ & $w$ & $2,153.7$ & W & - & w & $12,142.1$ \\
\hline $\begin{array}{l}\text { December .................................... } \\
\text { t984 Average ............................... }\end{array}$ & $\begin{array}{l}1,087.4 \\
2,154.8\end{array}$ & $\overline{-}$ & $\begin{array}{r}1,241.9 \\
107.2\end{array}$ & $\begin{array}{l}2,329.3 \\
2,262.0\end{array}$ & $\begin{array}{r}6,730.1 \\
11,631.0\end{array}$ & $\overline{-}$ & $\begin{array}{r}5,682.9 \\
489.6\end{array}$ & $\begin{array}{l}12,413.0 \\
12,120.5\end{array}$ \\
\hline \multicolumn{9}{|l|}{ Indinne } \\
\hline January ........................................ & $1,334.9$ & - & - & $1,334.9$ & $6,741.7$ & - & - & $6,741.7$ \\
\hline 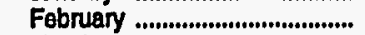 & $1,418.6$ & - & - & $1,419.6$ & $7,055.9$ & - & - & $7,055.9$ \\
\hline March ............................................ & $1,312.3$ & - & - & $1,312.3$ & $7,338.2$ & - & - & $7,338.2$ \\
\hline 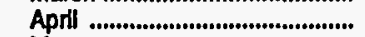 & $1,331.9$ & - & - & $1,331.9$ & $7,839.3$ & - & - & $7,839.3$ \\
\hline May .............................................. & $1,320.0$ & - & - & $1,320.0$ & $7,719.2$ & - & - & $7,719.2$ \\
\hline 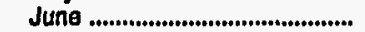 & $1,357.1$ & - & - & $1,357.1$ & $7,942.6$ & - & - & $7,942.6$ \\
\hline July ............................................... & $1,329.2$ & - & - & $1,329.2$ & $7,947.7$ & - & - & $7,947.7$ \\
\hline 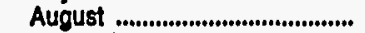 & $1,269.8$ & - & - & $1,269.8$ & $7,944.3$ & - & - & $7,944.3$ \\
\hline September ................................... & $1,318.7$ & - & - & $1,318.7$ & $7,733.5$ & - & - & $7,733.5$ \\
\hline October ........................................ & $1,381.8$ & - & - & $1,381.8$ & $7,856.8$ & - & - & $7,856.8$ \\
\hline November ..................................... & $w$ & - & $w$ & $1,335.8$ & $W$ & - & $W$ & $7,711.3$ \\
\hline December .................................... & $1,287.7$ & - & 145.0 & $1,432.7$ & $7,142.3$ & - & 661.7 & $7,804.0$ \\
\hline 1094 Average .............................. & $1,332,4$ & - & 12.4 & $1,344.8$ & $7,582.5$ & - & 56.6 & $7,639.1$ \\
\hline \multicolumn{9}{|l|}{ lown } \\
\hline 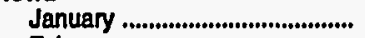 & 276.8 & - & - & 276.8 & $3,484.0$ & - & - & $3,484.0$ \\
\hline 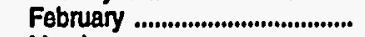 & 264.5 & - & - & 264.5 & $3,608.9$ & - & - & $3,608.9$ \\
\hline March ............................................ & 251.8 & - & - & 251.8 & $3,762.2$ & - & - & $3,762.2$ \\
\hline 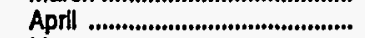 & 265.4 & - & - & 265.4 & $3,922.0$ & - & - & $3,922.0$ \\
\hline 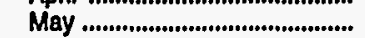 & 294.3 & - & - & 294.3 & $3,887.1$ & - & - & $3,887.1$ \\
\hline June ............................................... & 309.8 & - & - & 309.8 & $4,158.9$ & - & - & $4,158.9$ \\
\hline 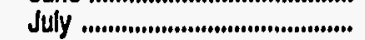 & 294.1 & - & - & 294.1 & $4,005.8$ & - & - & $4,005.8$ \\
\hline August ..................................... & 291.1 & - & - & 291.1 & $4,167.2$ & - & - & $4,167.2$ \\
\hline Seplember ................................. & 256.7 & - & - & 256.7 & $4,065.5$ & - & - & $4,065.5$ \\
\hline 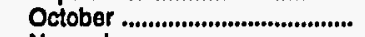 & 253.3 & - & - & 253.3 & $4,039.4$ & - & - & $4,039.4$ \\
\hline November ....................................... & 265.0 & - & - & 265.0 & $3,990.7$ & - & - & $3,990.7$ \\
\hline December ...................................... & 296.1 & - & - & 296.1 & $3,943.4$ & - & - & $3,943.4$ \\
\hline 1094 Average ............................... & 276.7 & - & - & 276.7 & $3,920.9$ & - & - & $3,920.8$ \\
\hline \multicolumn{9}{|l|}{ Kanese } \\
\hline January ..................................... & 396.4 & - & - & 396.4 & $3,548.7$ & - & - & $3,548.7$ \\
\hline February ..................................... & 390.6 & - & - & 390.6 & $3,665.1$ & - & - & $3,665.1$ \\
\hline March .......................................... & 405.1 & - & - & 405.1 & $3,900.0$ & - & - & $3,900.0$ \\
\hline 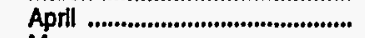 & 390.1 & - & - & 390.1 & $3,933.7$ & - & - & $3,933.7$ \\
\hline 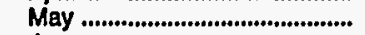 & 407.2 & - & - & 407.2 & $4,003.1$ & - & - & $4,003.1$ \\
\hline 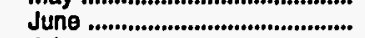 & 437.5 & - & - & 437.5 & $4,282.1$ & - & - & $4,282.1$ \\
\hline July ............................................. & 407.5 & - & - & 407.5 & $3,987.2$ & - & - & $3,987.2$ \\
\hline 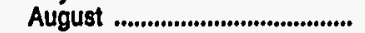 & 385.7 & - & - & 385.7 & $4,041.2$ & - & - & $4,041.2$ \\
\hline September .............................. & 432.4 & - & - & 432.4 & $4,044.4$ & - & - & $4,044.4$ \\
\hline October ........................................ & 411.4 & - & - & 411.4 & $3,904.5$ & - & - & $3,904.5$ \\
\hline November .................................. & 382.2 & - & - & 382.2 & $3,818.4$ & - & - & $3,818.4$ \\
\hline December ................................... & 445.8 & - & - & 445.8 & $4,199.5$ & - & - & $4,199.5$ \\
\hline 1994 Average .............................. & 407.8 & - & - & 407.8 & $3,845.5$ & - & - & $3,945.5$ \\
\hline
\end{tabular}

See lootnotes at end of table. 
Table 48. Prime Supplier Sales Volumes of Motor Gasoline by Grade, Formulation, PAD District, and State

(Thousand Gallons per Day) - Continued

\begin{tabular}{|c|c|c|c|c|c|c|c|c|}
\hline \multirow{2}{*}{$\begin{array}{l}\text { Goographic Aree } \\
\text { Month }\end{array}$} & \multicolumn{4}{|c|}{ Regular } & \multicolumn{4}{|c|}{ Midgrado } \\
\hline & Conventionala & Oxygenated & Reformulated & Total & Conventional & Oxygenated & Reformulated & Total \\
\hline \multicolumn{9}{|l|}{ Kentucky } \\
\hline January ............................................. & $2,761.1$ & - & - & $2,761.1$ & 594.8 & - & - & 594.8 \\
\hline 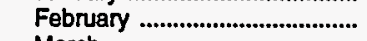 & $3,294.7$ & - & - & $3,294.7$ & 697.9 & - & - & 697.9 \\
\hline March & $3,451.2$ & - & - & $3,451.2$ & 748.3 & - & - & 748.3 \\
\hline April & $3,622.0$ & - & - & $3,622.0$ & 777.9 & - & - & 777.9 \\
\hline 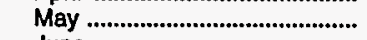 & $3,565.0$ & - & - & $3,565.0$ & 768.6 & - & - & 768.6 \\
\hline June & $3,739.0$ & - & - & $3,739.0$ & 787.3 & - & - & 787.3 \\
\hline July & $3,628.5$ & - & - & $3,628.5$ & 764.1 & - & - & 764.1 \\
\hline August & $3,634.5$ & - & - & $3,634.5$ & 731.0 & - & - & 731.0 \\
\hline 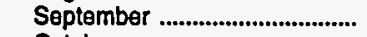 & $3,483.9$ & - & - & $3,483.9$ & 734.2 & - & - & 734.2 \\
\hline 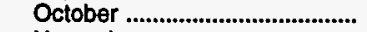 & $3,617.1$ & - & - & $3,617.1$ & 691.5 & - & - & 691.5 \\
\hline 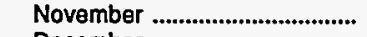 & w & - & $w$ & $3,382.2$ & $w$ & - & w & 573.8 \\
\hline 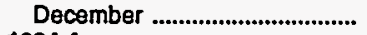 & $2,806.8$ & - & 596.3 & $3,403.1$ & $w$ & - & $w$ & 624.3 \\
\hline 1994 Average ...................................... & $3,409.5$ & - & 56.1 & $3,465.6$ & 692.8 & - & 15.0 & 707.8 \\
\hline \multicolumn{9}{|l|}{ Michigan } \\
\hline 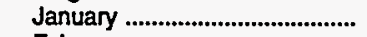 & $8,143.5$ & - & - & $8,143.5$ & $1,257.4$ & - & - & $1,257.4$ \\
\hline 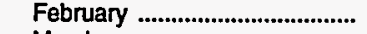 & $8,420.2$ & - & - & $8,420.2$ & $1,265.5$ & - & - & $1,265.5$ \\
\hline March & $8,682.0$ & - & - & $8,682.0$ & $1,296.5$ & - & - & $1,296.5$ \\
\hline April & $8,812.5$ & - & - & $8,812.5$ & $1,285.0$ & - & - & $1,285.0$ \\
\hline 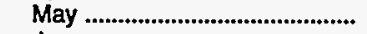 & $9,347.6$ & - & - & $9,347.6$ & $1,332.0$ & - & - & $1,332.0$ \\
\hline June & $9,808.5$ & - & - & $9,808.5$ & $1,360.3$ & - & - & $1,360.3$ \\
\hline 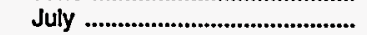 & $9,657.2$ & - & - & $9,657.2$ & $1,298.1$ & - & - & $1,298.1$ \\
\hline 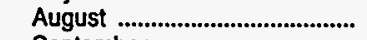 & $9,990.3$ & - & - & $9,990.3$ & $1,250.4$ & - & - & $1,250.4$ \\
\hline 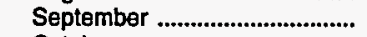 & $9,575.4$ & - & - & $\mathbf{9 , 5 7 5 . 4}$ & $1,240.3$ & - & - & $1,240.3$ \\
\hline 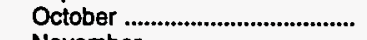 & $9,326.7$ & - & - & $9,326.7$ & $1,198.7$ & - & - & $1,198.7$ \\
\hline 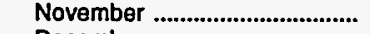 & $9,301.4$ & - & - & $9,301.4$ & $1,220.5$ & - & - & $1,220.5$ \\
\hline 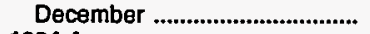 & $9,186.4$ & - & - & $\mathbf{9 , 1 8 6 . 4}$ & $1,200.1$ & - & - & $1,200.1$ \\
\hline 1994 Average & $9,191.9$ & - & - & $9,191.9$ & $1,267.0$ & - & - & $1,267.0$ \\
\hline \multicolumn{9}{|l|}{ Minnesota } \\
\hline 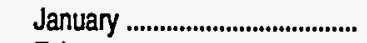 & $2,337.1$ & $2,068.5$ & - & $4,405.6$ & 53.4 & 324.1 & - & 377.5 \\
\hline 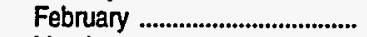 & $3,947.8$ & 668.8 & - & $4,616.6$ & 309.3 & 46.4 & - & 355.7 \\
\hline 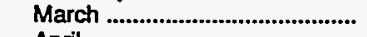 & $3,924.3$ & 539.4 & - & $4,463.7$ & 302.3 & 56.9 & - & 359.2 \\
\hline April & $4,289.9$ & 468.7 & - & $4,758.6$ & 308.9 & 58.8 & - & 367.7 \\
\hline May ................................................... & $4,492.0$ & 491.1 & - & $4,983.1$ & 337.6 & 61.8 & - & 399.4 \\
\hline 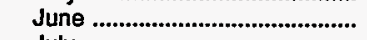 & $4,765.3$ & 537.9 & - & $5,303.2$ & w & $w$ & - & 408.9 \\
\hline July & $4,655.8$ & 562.2 & - & $5,218.0$ & 338.1 & 65.2 & - & 403.3 \\
\hline August & $4,822.1$ & 635.8 & - & $5,457.9$ & 325.1 & 68.2 & - & 393.3 \\
\hline 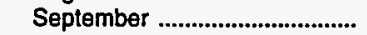 & $4,440.1$ & 803.4 & - & $5,243.5$ & 312.3 & 54.1 & - & 366.4 \\
\hline 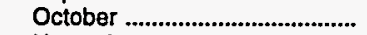 & $3,023.4$ & $2,031.9$ & - & $5,055.3$ & 51.3 & 297.0 & - & 348.3 \\
\hline 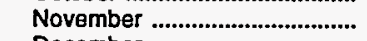 & $w$ & $w$ & - & $5,014.3$ & $w$ & $w$ & - & 385.3 \\
\hline 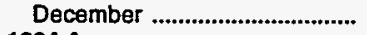 & $2,667.5$ & $2,272.3$ & - & $4,939.7$ & 61.3 & 363.0 & - & 424.2 \\
\hline 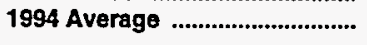 & $3,849.1$ & $1,107.2$ & - & $4,956.4$ & 230.9 & 151.7 & - & 382.6 \\
\hline \multicolumn{9}{|l|}{ Missouri } \\
\hline 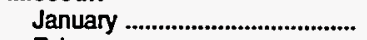 & $4,892.3$ & - & - & $4,892.3$ & 568.1 & - & - & 568.1 \\
\hline 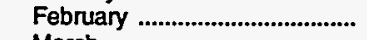 & $5,345.9$ & - & - & $5,345.9$ & 562.5 & - & - & 562.5 \\
\hline 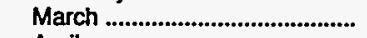 & $5,482.5$ & - & - & $5,482.5$ & 556.7 & - & - & 556.7 \\
\hline April & $5,575.4$ & - & - & $5,575.4$ & 539.1 & - & - & 539.1 \\
\hline 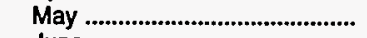 & $5,688.8$ & - & - & $5,688.8$ & 552.4 & - & - & 552.4 \\
\hline June & $6,039.1$ & - & - & $6,039.1$ & 571.8 & - & - & 571.8 \\
\hline July & $5,847.4$ & - & - & $5,847.4$ & 551.6 & - & - & 551.6 \\
\hline August & $\mathbf{5 , 8 9 3 . 0}$ & - & - & $5,893.0$ & 541.8 & - & - & 541.8 \\
\hline 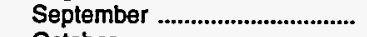 & $5,775.8$ & - & - & $5,775.8$ & 525.2 & - & - & 525.2 \\
\hline 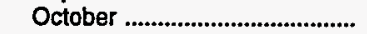 & $5,857.1$ & - & - & $5,857.1$ & 538.0 & - & - & 538.0 \\
\hline 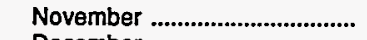 & $5,828.1$ & - & - & $5,828.1$ & 539.2 & - & - & 539.2 \\
\hline 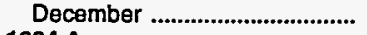 & $5,728.8$ & - & - & $5,728.8$ & 571.0 & - & - & 571.0 \\
\hline 1994 Average & $5,663.9$ & - & - & $5,663.9$ & 551.4 & - & - & 551.4 \\
\hline
\end{tabular}

See footnotes at end of table. 
Table 48. Prime Supplier Sales Volumes of Motor Gasoline by Grade, Formulation, PAD District, and State

(Thousand Gallons per Day) - Continued

\begin{tabular}{|c|c|c|c|c|c|c|c|c|}
\hline \multirow{2}{*}{$\begin{array}{l}\text { Geographic Area } \\
\text { Month }\end{array}$} & \multicolumn{4}{|c|}{ Promium } & \multicolumn{4}{|c|}{ All Grades } \\
\hline & Conventional & Oxygenated & Reformulated & Total & Conventional & Oxygenated & Reformulated & Total \\
\hline \multicolumn{9}{|l|}{ Kentucky } \\
\hline 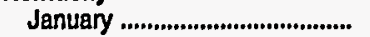 & 986.6 & - & - & 986.6 & $4,342.5$ & - & - & $4,342.5$ \\
\hline February ................................... & $1,105.8$ & - & - & $1,105.8$ & $5,098.3$ & - & - & $5,098.3$ \\
\hline 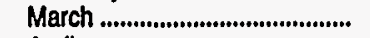 & $1,197.2$ & - & - & $1,197.2$ & $5,396.7$ & - & - & $5,396.7$ \\
\hline 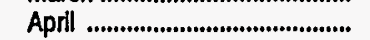 & $1,157.9$ & - & - & $1,157.9$ & $5,557.8$ & - & - & $5,557.8$ \\
\hline 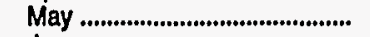 & $1,131.5$ & - & - & $1,131.5$ & $5,465.0$ & - & - & $5,465.0$ \\
\hline 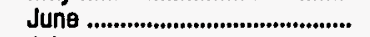 & $1,196.7$ & - & - & $1,196.7$ & $5,723.0$ & - & - & $5,723.0$ \\
\hline July .............................................. & $1,131.8$ & - & - & $1,131.8$ & $5,524.4$ & - & - & $5,524.4$ \\
\hline 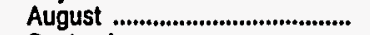 & $1,047.0$ & - & - & $1,047.0$ & $5,412.5$ & - & - & $5,412.5$ \\
\hline September .................................. & $1,084.5$ & - & - & $1,084.5$ & $5,302.6$ & - & - & $5,302.6$ \\
\hline 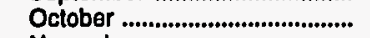 & $1,135.3$ & - & - & $1,135.3$ & $5,443.8$ & - & - & $5,443.8$ \\
\hline November .................................... & W & - & $w$ & $1,048.0$ & $W$ & - & $w$ & $5,004.0$ \\
\hline 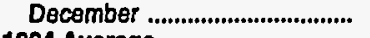 & 883.5 & - & 245.1 & $1,128.5$ & W & - & $w$ & $5,156.0$ \\
\hline 1994 Average & $1,089.0$ & - & 23.6 & $1,112.5$ & $5,191.2$ & - & 94.7 & $5,285.9$ \\
\hline \multicolumn{9}{|l|}{ Michigan } \\
\hline January ...................................... & $2,114.4$ & - & - & $2,114.4$ & $11,515.2$ & - & - & $11,515.2$ \\
\hline 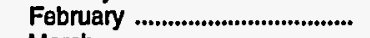 & $2,381.0$ & - & - & $2,381.0$ & $12,066.7$ & - & - & $12,066.7$ \\
\hline 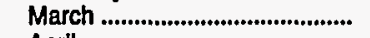 & $1,994.5$ & - & - & $1,994.5$ & $11,973.1$ & - & - & $11,973.1$ \\
\hline Aprll & $1,984.3$ & - & - & $1,984.3$ & $12,081.8$ & - & - & $12,081.8$ \\
\hline 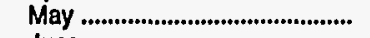 & $2,032.1$ & - & - & $2,032.1$ & $12,711.7$ & - & - & $12,711.7$ \\
\hline 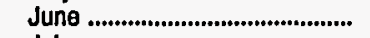 & $2,163.4$ & - & - & $2,163.4$ & $13,332.2$ & - & - & $13,332.2$ \\
\hline July .................................................. & $2,098.5$ & - & - & $2,098.5$ & $13,053.8$ & - & - & $13,053.8$ \\
\hline 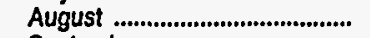 & $2,032.2$ & - & - & $2,032.2$ & $13,272.8$ & - & - & $13,272.8$ \\
\hline September ................................... & $1,979.4$ & - & - & $1,979.4$ & $12,795.1$ & - & - & $12,795.1$ \\
\hline 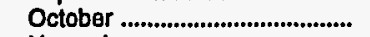 & $2,018.3$ & - & - & $2,018.3$ & $12,543.8$ & - & - & $12,543.8$ \\
\hline 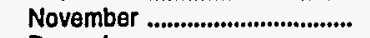 & $2,001.8$ & - & - & $2,001.8$ & $12,523.7$ & - & - & $12,523.7$ \\
\hline December ................................... & $2,070.2$ & - & - & $2,070.2$ & $12,456.6$ & - & - & $12,456.6$ \\
\hline 1994 Average ............................... & $2,070.4$ & - & - & $2,070.4$ & $12,529.3$ & - & - & $12,529.3$ \\
\hline \multicolumn{9}{|l|}{ Minnesota } \\
\hline January ......................................... & 245.4 & 433.1 & - & 678.5 & $2,635.8$ & $2,825.8$ & - & $5,461.5$ \\
\hline 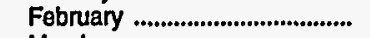 & 462.3 & 150.4 & - & 612.7 & $4,719.4$ & 865.6 & - & $5,585.0$ \\
\hline 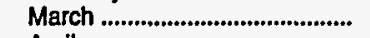 & 421.1 & 83.6 & - & 504.8 & $4,647.7$ & 680.0 & - & $5,327.7$ \\
\hline April & 433.5 & 73.2 & - & 506.7 & $5,032.3$ & 600.7 & - & $5,633.0$ \\
\hline 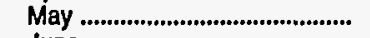 & 473.6 & 93.8 & - & 567.4 & $5,303.3$ & 646.7 & - & $5,949.9$ \\
\hline 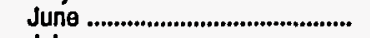 & $W$ & W & - & 598.3 & $5,599.0$ & 711.3 & - & $6,310.4$ \\
\hline 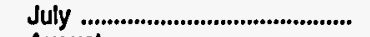 & 496.0 & 114.6 & - & 610.6 & $5,489.9$ & 742.0 & - & $6,231.9$ \\
\hline 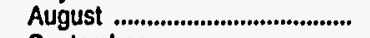 & 461.8 & 113.8 & - & 575.6 & $5,609.0$ & 817.8 & - & $6,426.8$ \\
\hline September ................................... & 411.0 & 90.6 & - & 501.5 & $5,163.3$ & 948.1 & - & $6,111.4$ \\
\hline October & 189.0 & 268.9 & - & 457.9 & $3,263.6$ & $2,597.8$ & - & $5,861.5$ \\
\hline November .................................. & W & $W$ & - & 540.4 & $W$ & $W$ & - & $5,940.1$ \\
\hline 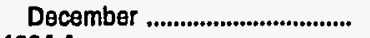 & 200.8 & 412.9 & - & 613.7 & $2,929.5$ & $3,048.2$ & - & $5,977.7$ \\
\hline 1994 Average .............................. & 373.3 & 190.6 & - & 563.9 & $4,453.4$ & $1,449.6$ & - & $5,902.9$ \\
\hline \multicolumn{9}{|l|}{ Missouri } \\
\hline January ......................................... & $1,114.2$ & - & $\cdot-$ & $1,114.2$ & $6,574.6$ & - & - & $6,574.6$ \\
\hline February ..................................... & $1,127.0$ & - & - & $1,127.0$ & $7,035.4$ & - & - & $7,035.4$ \\
\hline March .......................................... & $1,114.1$ & - & - & $1,114.1$ & $7,153.4$ & - & - & $7,153.4$ \\
\hline April & $1,108.5$ & - & - & $1,108.5$ & $7,223.0$ & - & - & $7,223.0$ \\
\hline 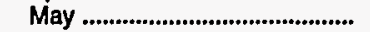 & $1,120.6$ & - & - & $1,120.6$ & $7,361.8$ & - & - & $7,361.8$ \\
\hline 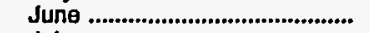 & $1,170.1$ & - & - & $1,170.1$ & $7,780.9$ & - & - & $7,780.9$ \\
\hline 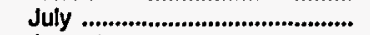 & 1.114 .5 & - & - & 1.114 .5 & $7,513.5$ & - & - & $7,513.5$ \\
\hline 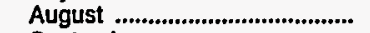 & $1,061.1$ & - & - & $1,061.1$ & $7,495.9$ & - & - & $7,495.9$ \\
\hline September ................................... & $1,014.8$ & - & - & $1,014.8$ & $7,315.8$ & - & - & $7,315.8$ \\
\hline October & $1,076.9$ & - & - & $1,076.9$ & $7,472.0$ & - & - & $7,472.0$ \\
\hline 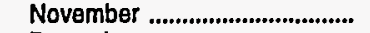 & $1,068.9$ & - & - & $1,068.9$ & $7,436.2$ & - & - & $7,436.2$ \\
\hline 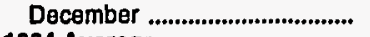 & $1,143.8$ & - & - & $1,143.8$ & $7,443.6$ & - & - & $7,443.6$ \\
\hline 1894 Average ................................ & $1,102.8$ & - & - & $1,102.8$ & $7,318.2$ & - & - & $7,318.2$ \\
\hline
\end{tabular}

See footnotes at end of table. 
Table 48. Prime Supplier Sales Volumes of Motor Gasoline by Grade, Formulation, PAD District, and State

(Thousand Gallons per Day) - Continued

\begin{tabular}{|c|c|c|c|c|c|c|c|c|}
\hline \multirow{2}{*}{$\begin{array}{l}\text { Goographic Area } \\
\text { Month }\end{array}$} & \multicolumn{4}{|c|}{ Regular } & \multicolumn{4}{|c|}{ Mldgrade } \\
\hline & Conventionala & Oxygenated & Roformulated & Total & Conventional & Oxygonated & Reformulated & Total \\
\hline \multicolumn{9}{|l|}{ Nebraska } \\
\hline 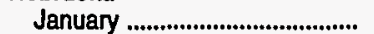 & $1,734.0$ & - & - & $1,734.0$ & 9.4 & - & - & 8.4 \\
\hline 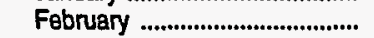 & $1,785.9$ & - & - & $1,785.9$ & 9.1 & - & - & 9.1 \\
\hline 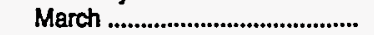 & $1,894.0$ & - & - & $1,894.0$ & 8.3 & - & - & 8.3 \\
\hline 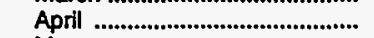 & $2,061.6$ & - & - & $2,061.6$ & 8.4 & - & - & 8.4 \\
\hline May & $2,072.3$ & - & - & $2,072.3$ & 9.1 & - & - & 9.1 \\
\hline 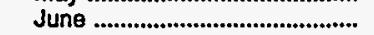 & $2,266.8$ & - & - & $2,266.8$ & 9.1 & - & - & 0.1 \\
\hline 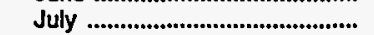 & $2,161.4$ & - & - & $2,161.4$ & 9.4 & - & - & 9.4 \\
\hline August & $2,168.8$ & - & - & $2,168.8$ & 10.3 & - & - & 10.3 \\
\hline 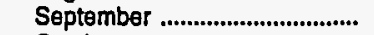 & $2,228.9$ & - & - & $2,228.9$ & 9.7 & - & - & 9.7 \\
\hline 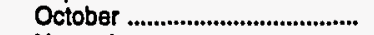 & $2,065.8$ & - & - & $2,065.8$ & 10.5 & - & - & 10.5 \\
\hline 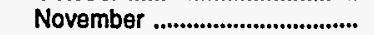 & $2,003.4$ & - & - & $2,003.4$ & 10.8 & - & - & 10.8 \\
\hline 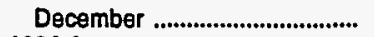 & $2,055.5$ & - & - & $2,055.5$ & 10.6 & - & - & 10.6 \\
\hline 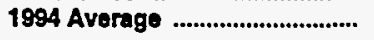 & $2,042.6$ & - & - & $2,042.6$ & 9.6 & - & - & 9.6 \\
\hline \multicolumn{9}{|l|}{ North Dakota } \\
\hline 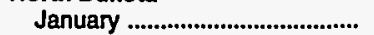 & 772.2 & - & - & 772.2 & w & - & - & $w$ \\
\hline 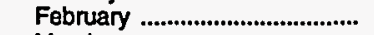 & 770.5 & - & - & 770.5 & $w$ & - & - & $\mathbf{w}$ \\
\hline 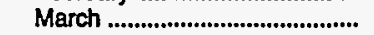 & 795.9 & - & - & 795.9 & $w$ & - & - & $w$ \\
\hline April & 869.9 & - & - & 869.9 & $\ddot{w}$ & - & - & $\ddot{w}$ \\
\hline 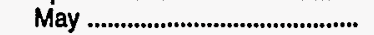 & 932.5 & - & - & 932.5 & $w$ & - & - & $w$ \\
\hline 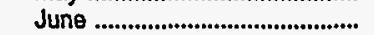 & $1,020.3$ & - & - & $1,020.3$ & $w$ & - & - & $w$ \\
\hline 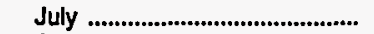 & 984.2 & - & - & 984.2 & $w$ & - & - & $\dot{w}$ \\
\hline 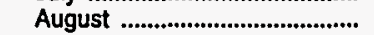 & 989.0 & - & - & 989.0 & $\ddot{w}$ & - & - & $w$ \\
\hline 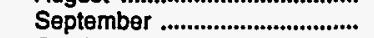 & 986.6 & - & - & 986.6 & $\ddot{w}$ & - & - & $w$ \\
\hline October & 900.4 & - & - & 900.4 & $w$ & - & - & $\ddot{w}$ \\
\hline 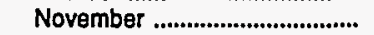 & 929.0 & - & - & 929.0 & $w$ & - & - & $w$ \\
\hline 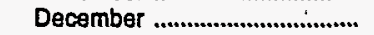 & 895.4 & - & - & 895.4 & $w$ & - & - & $w$ \\
\hline 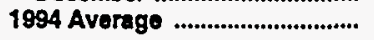 & 904.4 & - & - & 904.4 & $\ddot{w}$ & - & - & w \\
\hline \multicolumn{9}{|l|}{ Ohio } \\
\hline 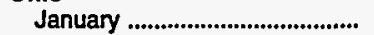 & $8,171.2$ & - & - & $8,171.2$ & $1,813.5$ & - & - & $1,813.5$ \\
\hline 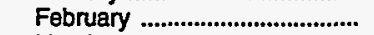 & $8,408.8$ & - & - & $8,408.8$ & $1,808.0$ & - & - & $1,808.0$ \\
\hline 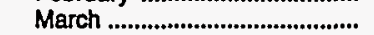 & $8,885.5$ & - & - & $8,885.5$ & $1,814.8$ & - & - & $1,814.8$ \\
\hline 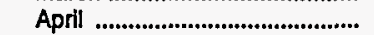 & $9,313.7$ & - & - & $9,313.7$ & $1,836.8$ & - & - & $1,836.8$ \\
\hline 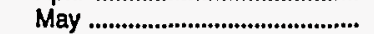 & $9,405.1$ & - & - & $9,405.1$ & $1,855.1$ & - & - & $1,855.1$ \\
\hline 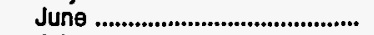 & $9,593.1$ & - & - & $9,593.1$ & $2,020.8$ & - & - & $2,020.8$ \\
\hline 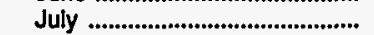 & $9,666.2$ & - & - & $9,666.2$ & $1,955.4$ & - & - & $1,955.4$ \\
\hline 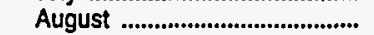 & $9,840.7$ & - & - & $9,840.7$ & $1,889.7$ & - & - & $1,889.7$ \\
\hline 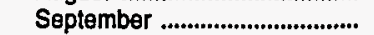 & $9,480.3$ & - & - & $9,480.3$ & $1,805.7$ & - & - & $1,805.7$ \\
\hline 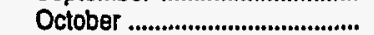 & $9,149.4$ & - & - & $9,149.4$ & $1,827.8$ & - & - & $1,827.8$ \\
\hline 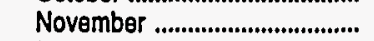 & $9,551.6$ & - & - & $9,551.6$ & $1,782.6$ & - & - & $1,782.6$ \\
\hline 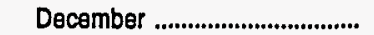 & w & - & w & $9,467.5$ & $w$ & - & $w$ & $1,983.1$ \\
\hline 1994 Averago ................................. & $9,247.7$ & - & $\mathbf{w}$ & $9,248.7$ & $1,866.4$ & - & $\mathbf{w}$ & $1,866.6$ \\
\hline \multicolumn{9}{|l|}{ Oklahoma } \\
\hline 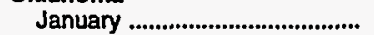 & $3,437.9$ & - & - & $3,437.9$ & 197.3 & - & - & 197.3 \\
\hline 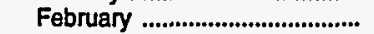 & $3,812.7$ & - & - & $3,812.7$ & 204.9 & - & - & 204.9 \\
\hline 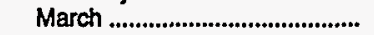 & $3,727.5$ & - & - & $3,727.5$ & 211.7 & - & - & 211.7 \\
\hline April & $4,146.0$ & - & - & $4,146.0$ & 216.5 & - & - & 216.5 \\
\hline 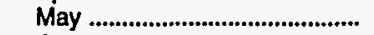 & $4,008.9$ & - & - & $4,008.9$ & 216.3 & - & - & 216.3 \\
\hline 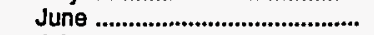 & $4,188.9$ & - & - & $4,188.9$ & 215.4 & - & - & 215.4 \\
\hline 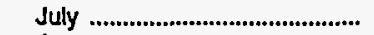 & $3,920.7$ & - & - & $3,920.7$ & 207.2 & - & - & 207.2 \\
\hline 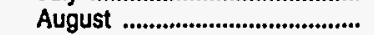 & $3,899.5$ & - & - & $3,899.5$ & 197.5 & - & - & 197.5 \\
\hline 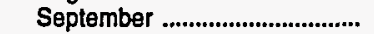 & $4,016.8$ & - & - & $4,016.8$ & 194.1 & - & - & 194.1 \\
\hline 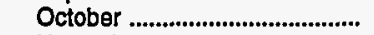 & $4,411.9$ & - & - & $4,411.9$ & 206.4 & - & - & 206.4 \\
\hline 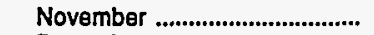 & $3,880.8$ & - & - & $3,880.8$ & 202.6 & - & - & 202.6 \\
\hline 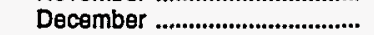 & $3,897.7$ & - & - & $3,897.7$ & 214.3 & - & - & 214.3 \\
\hline 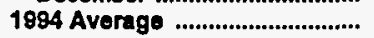 & $3,845.6$ & - & - & $3,945.6$ & 207.0 & - & - & 207.0 \\
\hline
\end{tabular}

See footnotes at end of table. 
Table 48. Prime Supplier Sales Volumes of Motor Gasoline by Grade, Formulation, PAD District, and State

(Thousand Gallons per Day) — Continued

\begin{tabular}{|c|c|c|c|c|c|c|c|c|}
\hline \multirow{2}{*}{$\begin{array}{l}\text { Geographic Aros } \\
\text { Month }\end{array}$} & \multicolumn{4}{|c|}{ Premlum } & \multicolumn{4}{|c|}{ All Grades } \\
\hline & Conventional & Oxygenated & Reformulated & Total & Conventional & Oxygenated & Reformulated & Total \\
\hline \multicolumn{9}{|l|}{ Nobraska } \\
\hline January .............,.,.......................... & 115.6 & - & - & 115.6 & $1,859.1$ & - & - & $1,859.1$ \\
\hline February ............................................... & 118.3 & - & - & 118.3 & $1,913.4$ & - & - & $1,913.4$ \\
\hline 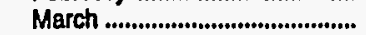 & 122.3 & - & - & 122.3 & $2,024.5$ & - & - & $2,024.5$ \\
\hline Aprl! & 134.5 & - & - & 134.5 & $2,204.6$ & - & - & $2,204,6$ \\
\hline May ……….............................................. & 140.2 & - & - & 140.2 & $2,221.7$ & - & - & $2,221.7$ \\
\hline Jung & 158.2 & - & - & 158.2 & $2,434.1$ & - & - & $2,434.1$ \\
\hline 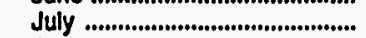 & 149.0 & - & - & 149.0 & $2,319.8$ & - & - & $2,319.8$ \\
\hline 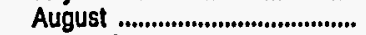 & 133.8 & - & - & 133.8 & $2,312.9$ & - & - & $2,312.9$ \\
\hline September ......................................... & 143.9 & - & - & 143.9 & $2,382.6$ & - & - & $2,382.6$ \\
\hline October .................................................... & 131.7 & - & - & 131.7 & $2,208.0$ & - & - & $2,208.0$ \\
\hline November .......................................... & 132.6 & - & - & 132.6 & $2,146.8$ & - & - & $2,146.8$ \\
\hline 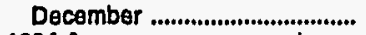 & 143.4 & - & - & 143.4 & $2,209.6$ & - & - & $2,209.6$ \\
\hline 1994 Avorage .................................... & 135.4 & - & - & 135.4 & $2,187.5$ & - & - & $2,187.5$ \\
\hline \multicolumn{9}{|l|}{ North Dakota } \\
\hline 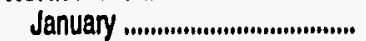 & 58.8 & - & - & 58.9 & 863.4 & - & - & 863.4 \\
\hline February ...................................... & $W$ & - & - & $W$ & 861.0 & - & - & 861.0 \\
\hline March .................................. & $\dddot{w}$ & _ & - & $w$ & 880.5 & _ & _- & 880.5 \\
\hline April & w & - & - & $w$ & 955.2 & - & - & 955.2 \\
\hline 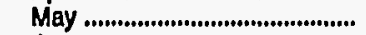 & $w$ & - & - & w & $1,027.5$ & - & - & $1,027.5$ \\
\hline June & w & - & - & w & $1,125.8$ & - & - & $1,125.8$ \\
\hline 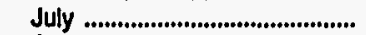 & w & - & - & w & $1,090.4$ & - & - & $1,090.4$ \\
\hline August & $w$ & - & - & $w$ & $1,083.7$ & - & - & $1,083.7$ \\
\hline 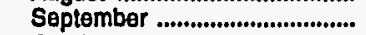 & $w$ & - & - & $\ddot{w}$ & $1,079.6$ & - & - & $1,079.6$ \\
\hline 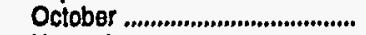 & w & - & - & w & 984.3 & - & - & 984.3 \\
\hline November .............................................. & w & - & - & $w$ & $1,019.9$ & - & - & $1,019.9$ \\
\hline Decomber .......................................... & $w$ & - & - & w & 999.4 & - & - & 999.4 \\
\hline 1984 Average ................................... & 60.0 & - & - & 60.0 & 998.1 & - & - & 998.1 \\
\hline \multicolumn{9}{|l|}{ Ohlo } \\
\hline 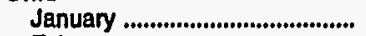 & $2,321.4$ & - & - & $2,321.4$ & $12,306.1$ & - & - & $12,306.1$ \\
\hline 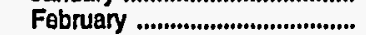 & $2,475.6$ & - & - & $2,475.6$ & $12,692.3$ & - & - & $12,692.3$ \\
\hline 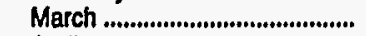 & $2,111.8$ & - & - & $2,111.8$ & $12,812.1$ & - & - & $12,812.1$ \\
\hline April & $2,134,8$ & - & - & $2,134,8$ & $13,285.3$ & - & - & $13,285.3$ \\
\hline 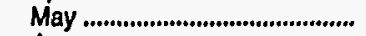 & $2,142.8$ & - & - & $2,142.8$ & $13,402.9$ & - & - & $13,402.9$ \\
\hline 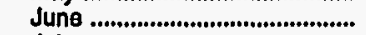 & $2,168.9$ & - & - & $2,168.9$ & $13,782.8$ & - & - & $13,782.8$ \\
\hline 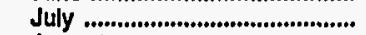 & $2,063.2$ & - & - & $2,063.2$ & $13,684.8$ & - & - & $13,684.8$ \\
\hline August & $1,988.5$ & - & - & $1,988.5$ & 13.718 .9 & - & - & $13,718.9$ \\
\hline 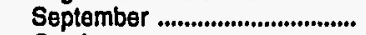 & $2,017.3$ & - & - & $2,017.3$ & $13,303.3$ & - & - & $13,303.3$ \\
\hline October ........................................... & $2,124,8$ & - & - & $2,124.8$ & $13,102.1$ & - & - & $13,102.1$ \\
\hline November ........................................... & $2,163.1$ & - & - & $2,163.1$ & $13,497.3$ & - & - & $13,497.3$ \\
\hline 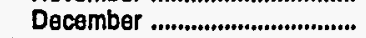 & $w$ & - & w & $2,317.0$ & & - & w & $13,767.6$ \\
\hline 1984 Average ........................................ & $2,166.9$ & - & $w$ & $2,167.1$ & $13,281.1$ & - & w & $13,282.4$ \\
\hline \multicolumn{9}{|l|}{ Oklahoma } \\
\hline January .............................................. & 813.2 & - & - & 813.2 & $4,448.4$ & - & - & $4,448.4$ \\
\hline 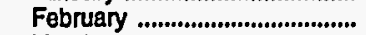 & 770.3 & - & - & 770.3 & $4,787.9$ & - & - & $4,787.9$ \\
\hline 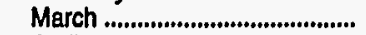 & 792.3 & - & - & 792.3 & $4,731.4$ & - & - & $4,731.4$ \\
\hline 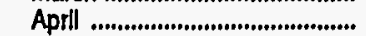 & 808.5 & - & - & 808.5 & $5,171.0$ & - & - & $5,171.0$ \\
\hline May & 808.8 & - & - & 808.8 & $5,034.0$ & - & - & $5,034.0$ \\
\hline 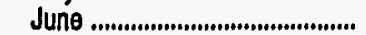 & 841.3 & - & - & 841.3 & $5,245.6$ & - & - & $5,245.6$ \\
\hline 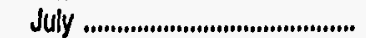 & 751.2 & - & - & 751.2 & $4,879.1$ & - & - & $4,879.1$ \\
\hline August ............................................. & 699.3 & - & - & 699.3 & $4,796.3$ & - & - & $4,796.3$ \\
\hline 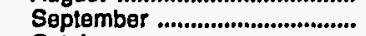 & 718.8 & - & - & 718.8 & $4,929.7$ & - & - & $4,929.7$ \\
\hline 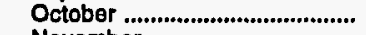 & 789.7 & - & - & 789.7 & $\mathbf{5 , 4 0 8 . 0}$ & - & - & $5,408.0$ \\
\hline November ....................................... & 817.1 & - & - & 817.1 & $4,900.5$ & - & - & $4,900.5$ \\
\hline 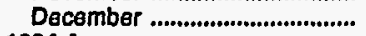 & 804.6 & - & - & 804.6 & $4,916.6$ & - & - & $4,916.6$ \\
\hline 1994 Average .................................. & 784.6 & - & - & 784.6 & $4,937.2$ & - & - & $4,937.2$ \\
\hline
\end{tabular}

See footnotes at end of table. 
Table 48. Prime Supplier Sales Volumes of Motor Gasoline by Grade, Formulation, PAD District, and State

(Thousand Gallons per Day) — Continued

\begin{tabular}{|c|c|c|c|c|c|c|c|c|}
\hline \multirow{2}{*}{$\begin{array}{c}\text { Geographic Area } \\
\text { Month }\end{array}$} & \multicolumn{4}{|c|}{ Regular } & \multicolumn{4}{|c|}{ Mldgrado } \\
\hline & Conventionala & Oxygenated & Reformulated & Total & Conventional & Oxygenated & Reformulated & Total \\
\hline \multicolumn{9}{|l|}{ South Dakota } \\
\hline 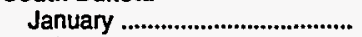 & 888.8 & - & - & 888.8 & $w$ & - & - & $w$ \\
\hline 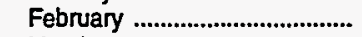 & 902.2 & - & - & 902.2 & $w$ & - & - & w \\
\hline 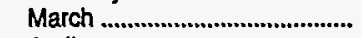 & 911.5 & - & - & 911.5 & W & - & - & $w$ \\
\hline April & 987.4 & - & - & 987.4 & $W$ & - & - & W \\
\hline 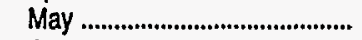 & $1,081.3$ & - & - & $1,081.3$ & $w$ & - & - & $w$ \\
\hline 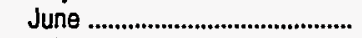 & $1,182.8$ & - & - & $1,182.8$ & W & - & - & w \\
\hline 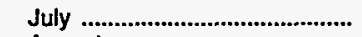 & $1,230.2$ & - & - & $1,230.2$ & $w$. & - & - & $w$ \\
\hline 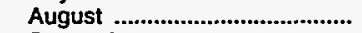 & $1,173.7$ & - & - & $1,173.7$ & $w$ & - & - & $w$ \\
\hline 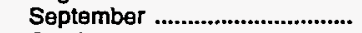 & $1,105.7$ & - & - & $1,105.7$ & $w$ & - & - & $w$ \\
\hline 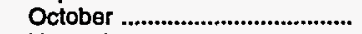 & $1,107.0$ & - & - & $1,107.0$ & $w$ & - & - & $w$ \\
\hline 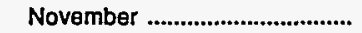 & $1,024.8$ & - & - & $1,024.8$ & $w$ & - & - & $w$ \\
\hline 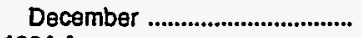 & $1,045.7$ & - & - & $1,045.7$ & $w$ & - & - & $W$ \\
\hline 1994 Average & $1,054.4$ & - & - & $1,054.4$ & $\mathbf{W}$ & - & - & $\mathbf{W}$ \\
\hline \multicolumn{9}{|l|}{ Tennessee } \\
\hline 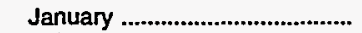 & $4,194.9$ & - & - & $4,194.9$ & $1,140.3$ & - & - & $1,140.3$ \\
\hline 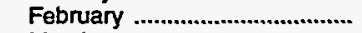 & $4,778.0$ & - & - & $4,778.0$ & $1,235.9$ & - & - & $1,235.9$ \\
\hline 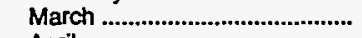 & $5,067.1$ & - & - & $5,067.1$ & $1,356.3$ & - & - & $1,356.3$ \\
\hline April & $5,177.6$ & - & - & $5,177.6$ & $1,389.9$ & - & - & $1,389.9$ \\
\hline May ............................................... & $4,989.5$ & - & - & $4,989.5$ & $1,367.0$ & - & - & $1,367.0$ \\
\hline 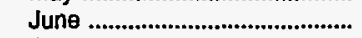 & $5,266.2$ & - & - & $5,266.2$ & $1,402.1$ & - & - & $1,402.1$ \\
\hline 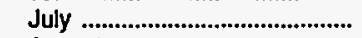 & $5,171.7$ & - & - & $5,171.7$ & $1,365.6$ & - & - & $1,365.6$ \\
\hline August & $5,439.0$ & - & - & $5,439.0$ & $1,373.7$ & - & - & $1,373.7$ \\
\hline 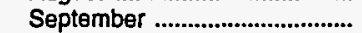 & $5,234.3$ & - & - & $5,234.3$ & $1,362.0$ & - & - & $1,362.0$ \\
\hline 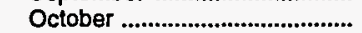 & $5,068.2$ & - & - & $5,068.2$ & $1,333.6$ & - & - & $1,333.6$ \\
\hline 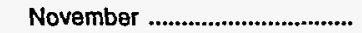 & $5,176.4$ & - & - & $5,176.4$ & $1,348.2$ & - & - & $1,348.2$ \\
\hline 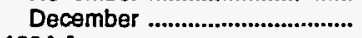 & $5,166.2$ & - & - & $5,166.2$ & $1,454.6$ & - & - & $1,454.6$ \\
\hline 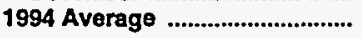 & $5,061.4$ & - & - & $5,061.4$ & $1,344.7$ & - & - & $1,344.7$ \\
\hline \multicolumn{9}{|l|}{ Wisconsin } \\
\hline 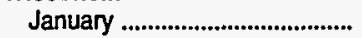 & $4,221.6$ & - & - & $4,221.6$ & 391.5 & - & - & 391.5 \\
\hline 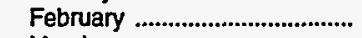 & $4,462.3$ & - & - & $4,462.3$ & 420.6 & - & - & 420.6 \\
\hline March & $4,502.5$ & - & - & $4,502.5$ & 421.9 & - & - & 421.9 \\
\hline April & $4,637.9$ & - & - & $4,637.9$ & 381.4 & - & - & 381.4 \\
\hline May & $4,899.2$ & - & - & $4,899.2$ & 421.8 & - & - & 421.8 \\
\hline 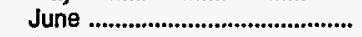 & $5,154.2$ & 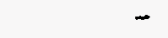 & - & $5,154.2$ & 423.4 & - & - & 423.4 \\
\hline 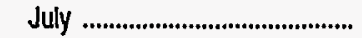 & $5,226.7$ & - & - & $5,226.7$ & 438.8 & - & - & 438.8 \\
\hline 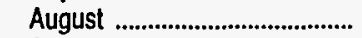 & $5,266.1$ & - & - & $5,266.1$ & 424.8 & - & - & 424.8 \\
\hline 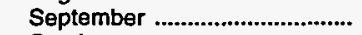 & $5,161,1$ & - & - & $5,161.1$ & 427.8 & - & - & 427.8 \\
\hline 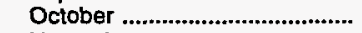 & $4,931.0$ & - & - & $4,931.0$ & 453.0 & - & - & 453.0 \\
\hline 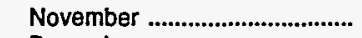 & $W$ & - & $w$ & $4,855.1$ & W & - & $w$ & 411.5 \\
\hline 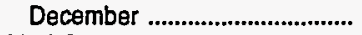 & $w$ & - & $\mathbf{w}$ & $4,885.1$ & 338.1 & - & 116.4 & 454.5 \\
\hline 1994 Average & $4,756.7$ & - & 95.7 & $4,852.3$ & 412.8 & - & 9.9 & 422.7 \\
\hline \multicolumn{9}{|l|}{ PAD District III } \\
\hline 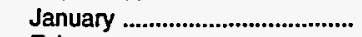 & $29,048.4$ & $1,322.6$ & - & $30,371.0$ & $5,726.6$ & 123.6 & - & $5,850.2$ \\
\hline 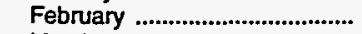 & $30,461.6$ & $1,453.0$ & - & $31,914.5$ & $6,160.3$ & 134.0 & - & $6,294.4$ \\
\hline March & $31,581.6$ & 885.7 & - & $32,467.4$ & $6,612.9$ & 98.5 & - & $6,711.4$ \\
\hline April & $w$ & $w$ & - & $33,105.9$ & $w$ & W & - & $6,683.4$ \\
\hline May & $w$ & $w$ & - & $32,265.0$ & $w$ & W & - & $6,846.5$ \\
\hline 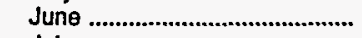 & W & $w$ & - & $33,462.1$ & $w$ & W & - & $6,938.0$ \\
\hline 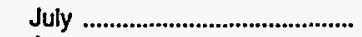 & $w$ & $w$ & - & $33,217.5$ & $w$ & $w$ & - & $6,737.9$ \\
\hline 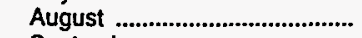 & W & $w$ & - & $34,572.0$ & $W$ & w & - & $6,823.7$ \\
\hline 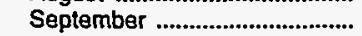 & $33,825.9$ & 298.0 & - & $34,123.8$ & $6,661.1$ & 58.8 & - & $6,719.9$ \\
\hline October & $31,867.6$ & 868.7 & - & $32,736.3$ & $6,344.4$ & 117.8 & - & $6,462.1$ \\
\hline 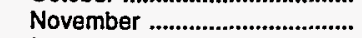 & $32,102.5$ & W & $w$ & $33,796.0$ & $6,349.9$ & W & $w$ & $6,638.4$ \\
\hline 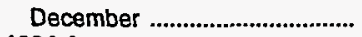 & $27,279.5$ & $1,172.4$ & $5,613.3$ & $34,065.3$ & $4,847.1$ & 97.9 & $1,532.2$ & $6,477.2$ \\
\hline 1994 Average & $31,832.3$ & 662.8 & 515.2 & $33,010.3$ & $6,371.0$ & 84.5 & 144.0 & $6,599.5$ \\
\hline
\end{tabular}

See footnotes at end of table. 
Table 48. Prime Suppller Sales Volumes of Motor Gasoline by Grade, Formulation, PAD District, and State

(Thousand Gallons per Day) - Continued

\begin{tabular}{|c|c|c|c|c|c|c|c|c|}
\hline \multirow{2}{*}{$\begin{array}{c}\text { Geographle Ares } \\
\text { Month }\end{array}$} & \multicolumn{4}{|c|}{ Premium } & \multicolumn{4}{|c|}{ All Grades } \\
\hline & Conventional & Oxyesneted & Reformulated & Total & Conventional & Oxygenated & Reformulated & Total \\
\hline \multicolumn{9}{|l|}{ South Dakota } \\
\hline January ...................................... & 62.4 & - & - & 62.4 & 961.6 & $\rightarrow$ & - & 961.6 \\
\hline Fobruary ...................................... & $W$ & - & - & $w$ & 978.6 & - & - & 978.6 \\
\hline March ........................................... & $W$ & - & - & $w$ & 997.5 & - & - & 997.5 \\
\hline 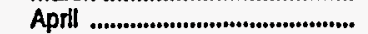 & $w$ & - & - & $\ddot{w}$ & $1,067.9$ & - & - & $1,067.9$ \\
\hline May .............................................. & $W$ & - & - & W & $1,170.9$ & - & - & $1,170.9$ \\
\hline June .............................................. & $w$ & - & - & $w$ & $1,296.1$ & - & - & $1,296.1$ \\
\hline July ................................................ & $W$ & - & - & $\mathbf{W}$ & $1,360.7$ & - & - & $1,360.7$ \\
\hline August ...................................... & $W$ & - & - & $\mathbf{W}$ & $1,297.8$ & - & - & $1,297.8$ \\
\hline September ............................... & $w$ & - & - & $W$ & $1,191.7$ & - & - & $1,191.7$ \\
\hline 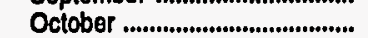 & $\ddot{w}$ & - & - & $\dddot{w}$ & $1,189.6$ & - & - & $1,189.6$ \\
\hline November ...................................... & $\mathbf{w}$ & - & - & W & $1,104.1$ & - & - & $1,104.1$ \\
\hline December ..................................... & w & - & - & $w$ & 1.128 .0 & - & - & $1,128.0$ \\
\hline 1994 Avernge ............................... & 80.5 & - & - & 80.5 & $1,146.5$ & - & - & $1,146.5$ \\
\hline \multicolumn{9}{|l|}{ Tenneacee } \\
\hline January ....................................... & $1,789.5$ & - & - & $1,789.5$ & $7,124.7$ & - & - & $7,124.7$ \\
\hline February ....................................... & $1,924.0$ & - & - & 1.924 .0 & $7,937.8$ & - & - & $7,937.8$ \\
\hline March .............................................. & $2,032.5$ & - & - & $2,032.5$ & $8,455.9$ & - & - & $8,455.9$ \\
\hline 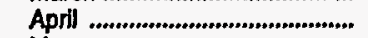 & $2,030.2$ & - & - & $2,030.2$ & $8,597.7$ & - & - & $8,597.7$ \\
\hline 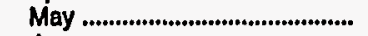 & 2,0052 & - & - & $2,005.2$ & $8,361.8$ & - & - & $8,361.8$ \\
\hline 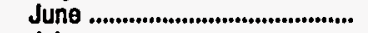 & $2,085.9$ & - & - & $2,085.9$ & $8,754.2$ & - & - & $8,754.2$ \\
\hline July & $1,998.1$ & - & - & $1,996.1$ & $8,533.4$ & - & - & $8,533.4$ \\
\hline 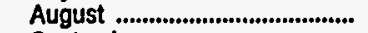 & $1,988.0$ & - & - & $1,988.0$ & $8,800.7$ & - & - & $8,800.7$ \\
\hline September ................................... & $1,953.2$ & - & - & $1,953.2$ & $8,549.4$ & - & - & $8,549.4$ \\
\hline October ......................................... & 1.930 .0 & - & - & $1,930.0$ & $8,331.8$ & - & - & $8,331.8$ \\
\hline November ..................................... & $1,957.1$ & - & - & $1,957.1$ & $8,481.6$ & - & - & $8,481.6$ \\
\hline December ...................................... & $2,064.2$ & - & - & $2,064.2$ & $8,685.0$ & - & - & $8,685.0$ \\
\hline 1994 Average ................................. & $1,979.8$ & - & - & $1,979.8$ & $8,385.9$ & - & - & $8,385.9$ \\
\hline \multicolumn{9}{|l|}{ Wheconsin } \\
\hline January ...................................... & 972.5 & - & - & 972.5 & $5,585.6$ & - & - & $5,585.6$ \\
\hline February ........................................ & 885.3 & - & - & 885.3 & $5,768.2$ & - & - & $5,768.2$ \\
\hline March ........................................... & 779.7 & - & - & 779.7 & $5,704.1$ & - & - & $5,704.1$ \\
\hline 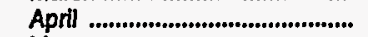 & 756.4 & - & - & 756.4 & $5,775.6$ & - & - & $5,775.6$ \\
\hline 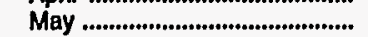 & 853.6 & - & - & 853.6 & $6,174.6$ & - & - & $6,174.6$ \\
\hline 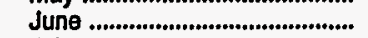 & 934.8 & - & - & 934.8 & $6,512.5$ & - & - & $6,512.5$ \\
\hline 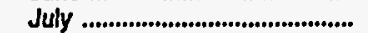 & 931.0 & - & - & 931.0 & $6,596.5$ & - & - & $6,596.5$ \\
\hline 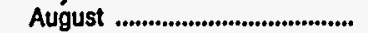 & 811.1 & - & - & 811.1 & $6,501.9$ & - & - & $6,501.9$ \\
\hline Seplember ................................ & 826.4 & - & - & 826.4 & $6,415.3$ & - & - & $6,415.3$ \\
\hline October ........................................ & 829.0 & - & - & 829.0 & $6,212.9$ & - & - & $6,212.9$ \\
\hline 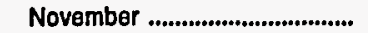 & $W$ & - & $w$ & 833.6 & $W$ & - & $w$ & $6,100.2$ \\
\hline December .................................. & $W$ & - & $w$ & 908.7 & $4,780.1$ & - & $1,468.2$ & $6,248.3$ \\
\hline 1994 Average ................................. & 841.0 & - & 19.2 & 860.2 & $6,010.5$ & - & 124.8 & $6,135.2$ \\
\hline \multicolumn{9}{|l|}{ PAD District III } \\
\hline January ....................................... & $8,615.3$ & 211.3 & - & $8,826.6$ & $43,390.3$ & $1,657.5$ & - & $45,047.8$ \\
\hline Fobruary ................................... & $9,095.8$ & 232.8 & - & $9,328.5$ & $45,717.6$ & $1,819.8$ & - & $47,537.4$ \\
\hline March ............................................... & $9,534.9$ & 158.9 & - & $9,693.8$ & $47,729.5$ & $1,143.2$ & - & $48,872.6$ \\
\hline 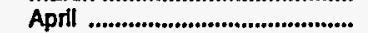 & $w$ & $w$ & - & $9,576.6$ & $w$ & $\bar{w}$ & - & $49,365.9$ \\
\hline 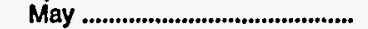 & $\mathbf{w}$ & $\mathbf{w}$ & - & $9,758.0$ & $\mathbf{w}$ & $\mathbf{w}$ & - & $48,869.5$ \\
\hline 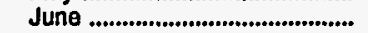 & $w$ & $\mathbf{W}$ & - & $9,981.4$ & $w$ & $w$ & - & $50,381.6$ \\
\hline 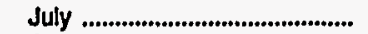 & $w$ & $w$ & - & $9,602.5$ & $w$ & $w$ & - & $49,557.8$ \\
\hline August & $w$ & $W$ & - & $9,693.0$ & $50,802,8$ & 285.9 & - & $51,088.7$ \\
\hline Seplember ................................. & $9,266.1$ & 101.8 & - & $9,368.0$ & $49,753.1$ & 458.6 & - & $50,211.7$ \\
\hline 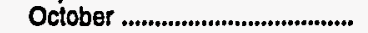 & $8,710.3$ & 182.6 & - & $8,892.9$ & $46,922.2$ & $1,169.1$ & - & $48,091.3$ \\
\hline November ................................. & $8,873.1$ & $W$ & $\mathbf{W}$ & $9,327.6$ & $47,325.5$ & $W$ & W & $49,762.1$ \\
\hline December .................................... & $7,507.5$ & 202.6 & $2,139.9$ & $9,850.0$ & $39,634.2$ & 1.472 .8 & $9,285.4$ & $50,392.5$ \\
\hline 1994 Average ............................. & $9,163,2$ & 137.3 & 201.6 & 9,492.1 & $47,356.6$ & 884.7 & 860.7 & $49,102.0$ \\
\hline
\end{tabular}

See footnotes at end of table. 
Table 48. Prime Supplier Sales Volumes of Motor Gasoline by Grade, Formulation, PAD District, and State

(Thousand Gallons per Day) - Continued

\begin{tabular}{|c|c|c|c|c|c|c|c|c|}
\hline \multirow{2}{*}{$\begin{array}{c}\text { Geographic Area } \\
\text { Month }\end{array}$} & \multicolumn{4}{|c|}{ Rogular } & \multicolumn{4}{|c|}{ MIdgrade } \\
\hline & Conventionala & Oxygenatod & Reformulated & Total & Conventional & Oxygenated & Roformulated & Total \\
\hline \multicolumn{9}{|l|}{ Alabama } \\
\hline 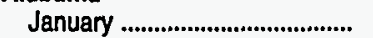 & $3,219.5$ & - & - & $3,219.5$ & 714.4 & - & - & 714.4 \\
\hline 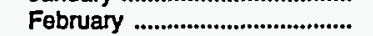 & $3,407.1$ & - & - & $3,407.1$ & 796.9 & - & - & 796.9 \\
\hline 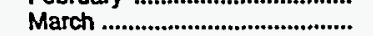 & $3,592.5$ & - & - & $3,592.5$ & 812.0 & - & - & 812.0 \\
\hline 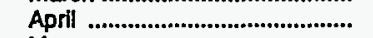 & $3,581.7$ & - & - & $3,581.7$ & 828.3 & - & - & 828.3 \\
\hline 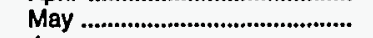 & $3,539.2$ & - & - & $3,539.2$ & 828.2 & - & - & 828.2 \\
\hline 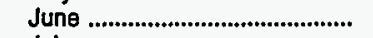 & $3,673.2$ & - & - & $3,673.2$ & 850.7 & - & - & 850.7 \\
\hline 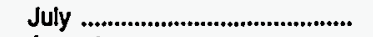 & $3,492.6$ & - & - & $3,492.6$ & 812.7 & - & - & 812.7 \\
\hline 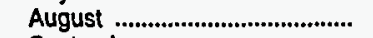 & $3,728.2$ & - & - & $3,728.2$ & 846.7 & - & - & 846.7 \\
\hline 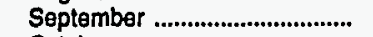 & $3,663.8$ & - & - & $3,663.8$ & 834.2 & - & - & 834.2 \\
\hline 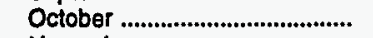 & $3,469.6$ & - & - & $3,469.6$ & 810.1 & - & - & 810.1 \\
\hline 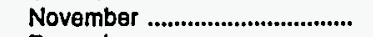 & $3,549.9$ & - & - & $3,549.9$ & 796.3 & - & - & 796.3 \\
\hline December ...................................... & $3,585.6$ & - & - & $3,585.6$ & 822.6 & - & - & 822.6 \\
\hline 1994 Average ............................... & $3,542.2$ & - & - & $3,542.2$ & 812.7 & - & - & 812.7 \\
\hline \multicolumn{9}{|l|}{ Arkansas } \\
\hline 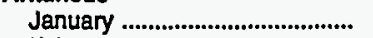 & $2,564.0$ & - & - & $2,564.0$ & 351.4 & - & - & 351.4 \\
\hline 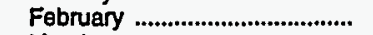 & $2,831.2$ & - & - & $2,831.2$ & 382.8 & - & - & 382.8 \\
\hline March ........................................... & $2,903.4$ & - & - & $2,903.4$ & 416.9 & - & - & 416.9 \\
\hline April & $3,010.9$ & - & - & $3,010.9$ & 423.3 & - & - & 423.3 \\
\hline 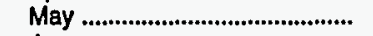 & $2,957.9$ & - & - & $2,957.9$ & 433.9 & - & - & 433.9 \\
\hline June & $3,172,4$ & - & - & $3,172.4$ & 435.7 & - & - & 435.7 \\
\hline July .................................................. & $3,144.2$ & - & - & $3,144.2$ & 434.4 & - & - & 434.4 \\
\hline 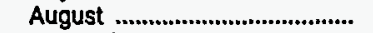 & $3,200.0$ & - & - & $3,200.0$ & 431.5 & - & - & 431.5 \\
\hline 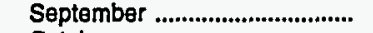 & $3,178.3$ & - & - & $3,178.3$ & 422.5 & - & - & 422.5 \\
\hline 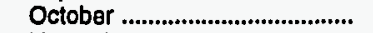 & $2,946.5$ & - & - & $2,946.5$ & 405.7 & - & - & 405.7 \\
\hline 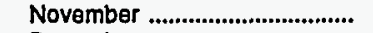 & $2,991.3$ & - & - & $2,991.3$ & 425.7 & - & - & 425.7 \\
\hline December ................................... & $2,942.4$ & - & - & $2,942.4$ & 432.4 & - & - & 432.4 \\
\hline 1994 Avorage & $2,987.1$ & - & - & $2,987.1$ & 416.5 & - & - & 416.5 \\
\hline \multicolumn{9}{|l|}{ Louisiana } \\
\hline 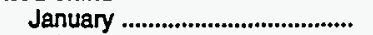 & $3,235.5$ & - & - & $3,235.5$ & 766.5 & - & - & 766.5 \\
\hline 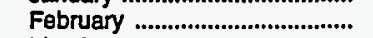 & $3,770.1$ & - & - & $3,770.1$ & 814.4 & - & - & 814.4 \\
\hline March ........................................... & $3,519.3$ & - & - & $3,519.3$ & 855.4 & - & - & 855.4 \\
\hline April & $3,310.5$ & - & - & $3,310.5$ & 828.8 & - & - & 828.8 \\
\hline May ............................................... & $3,358.6$ & - & - & $3,358.6$ & 850.8 & - & - & 850.8 \\
\hline June .............................................. & $3,468.2$ & - & - & $3,468.2$ & 848.2 & - & - & 848.2 \\
\hline 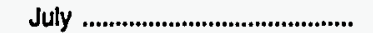 & $3,452.1$ & - & - & $3,452.1$ & 826.6 & - & - & 826.6 \\
\hline 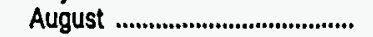 & $3,691.5$ & - & - & $3,691.5$ & 848.0 & - & - & 848.0 \\
\hline September ................................ & $3,461.7$ & - & - & $3,461.7$ & 863.3 & - & - & 863.3 \\
\hline 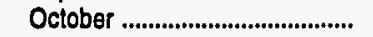 & $3,308.0$ & - & - & $3,308.0$ & 839.3 & - & - & 839.3 \\
\hline November ................................. & $3,426.2$ & - & - & $3,426.2$ & 855.3 & - & - & 855.3 \\
\hline 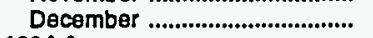 & W & - & $w$ & $3,540.5$ & 877.5 & - & - & 877.5 \\
\hline 1894 Average ............................... & $3,456.9$ & - & $\mathbf{W}$ & $3,459.8$ & 839.6 & - & - & 839.6 \\
\hline \multicolumn{9}{|l|}{ Missinsippi } \\
\hline January ........................................ & $2,318.5$ & - & - & $2,318.5$ & 405.7 & - & - & 405.7 \\
\hline February ........................................ & $2,349.2$ & - & - & $2,349.2$ & 402.9 & - & - & 402.9 \\
\hline 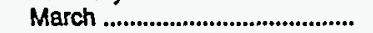 & $2,360.2$ & - & - & $2,360.2$ & 482.0 & - & - & 482.0 \\
\hline April & $2,445.4$ & - & - & $2,445.4$ & 502.9 & - & - & 502.9 \\
\hline 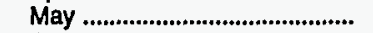 & $2,399.6$ & - & - & $2,399.6$ & 501.3 & - & - & 501.3 \\
\hline June & $2,452.2$ & - & - & $2,452.2$ & 521.8 & - & - & 521.8 \\
\hline 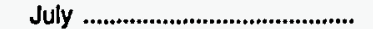 & $2,372.2$ & - & - & 2,372.2 & 523.1 & - & - & 523.1 \\
\hline 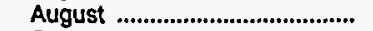 & $2,407.7$ & - & - & $2,407.7$ & 511.9 & - & - & 511.9 \\
\hline September ...................................... & $2,458.0$ & - & - & $2,458.0$ & 521.5 & - & - & 521.5 \\
\hline 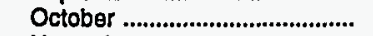 & $2,306.9$ & - & - & $2,306.9$ & 491.2 & - & - & 491.2 \\
\hline November ................................... & $2,399.4$ & - & - & $2,399.4$ & 497.5 & - & - & 497.5 \\
\hline December ................................... & $2,422.2$ & - & - & $2,422.2$ & 520.3 & - & - & 520.3 \\
\hline 1894 Average .............................. & $2,390.8$ & - & - & $2,390.8$ & 490.7 & - & - & 490.7 \\
\hline
\end{tabular}

See footnotes at end of table. 
Table 48. Prime Supplier Sales Volumes of Motor Gasoline by Grade, Formulation, PAD District, and State

(Thousand Gallons per Day) - Continued

\begin{tabular}{|c|c|c|c|c|c|c|c|c|}
\hline \multirow{2}{*}{$\begin{array}{l}\text { Geographlo Ans } \\
\text { Month }\end{array}$} & \multicolumn{4}{|c|}{ Promium } & \multicolumn{4}{|c|}{ All Grades } \\
\hline & Conventional & Oxygenatud & Rotormulated & Total & Conventional & Oxygenated & Reformulated & Total \\
\hline
\end{tabular}

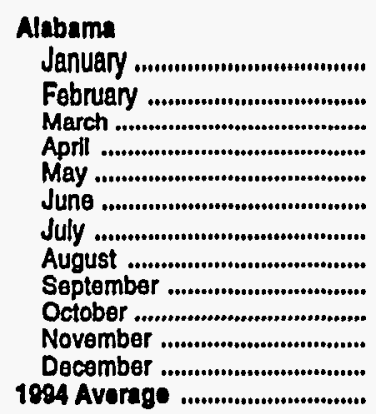

Arkansas

February ........................................

March

Aprll ..................................................

May

June

August

September ....................................

October

November .....................................

December

1994 Average

Loulaiana

January .....................................

February

March

Aprill

May ...........................................

June

July

August

August ...........................................

September

October ...

November

December

1894 Average ................................

Mleslestppi

January.

March

Aprll

May ..................................................

June

July ..................................................

August

(2)

September

November

December

1094 Average

$1,142.8$
$1,234.4$
$1,344.6$
$1,344.8$
$1,319.2$
$1,338.0$
$1,263.8$
$1,286.4$
$1,270.7$
$1,235.7$
$1,254.9$
$1,327.8$
$1,280.4$

712.2

736.9

793.9

787.3

804.6

843.3

828.0

803.7

757.7

750.9

782.7

780.1

782.0

$1,319.6$

$1,346.9$

$1,414.1$

$1,337.2$

$1,369.0$

$1,408.4$

$1,343.4$

$1,385.8$

,366.4

$1,327.5$

$1,307.5$

$1,367.0$

$1,357.9$

708.7

778.6
771.1

771.1

764.2

778.4

745.1

758.8

849.5

724.7

744.0

758.3

762.2

$\begin{array}{lll}- & - & 1,142.8 \\ - & - & 1,234.4 \\ - & - & 1,344.6 \\ - & - & 1,344.8 \\ - & - & 1,319.2 \\ - & - & 1,338.0 \\ - & - & 1,263.8 \\ - & - & 1,286.4 \\ - & - & 1,270.7 \\ - & - & 1,235.7 \\ - & - & 1,254.9 \\ - & - & 1,327.8 \\ - & - & 1,280.4\end{array}$

$\mathbf{5 , 0 7 6 . 7}$
$\mathbf{5 , 4 3 8 . 4}$
$\mathbf{5 , 7 4 9 . 1}$
$\mathbf{5 , 7 5 4 . 7}$
$\mathbf{5 , 6 8 6 . 5}$
$\mathbf{5 , 8 6 1 . 9}$
$\mathbf{5 , 5 6 9 . 1}$
$\mathbf{5 , 8 6 1 . 4}$
$\mathbf{5 , 7 6 8 . 6}$
$\mathbf{5 , 5 1 5 . 4}$
$\mathbf{5 , 6 0 1 . 1}$
$\mathbf{5 , 7 3 6 . 0}$
$\mathbf{5 , 6 3 5 . 3}$

$\begin{array}{lll}- & - & 5,076.7 \\ - & - & 5,438.4 \\ - & - & 5,749.1 \\ - & - & 5,754.7 \\ - & - & 5,686.5 \\ - & - & 5,861.9 \\ - & - & 5,569.1 \\ - & - & 5,861.4 \\ - & - & 5,768.6 \\ - & - & 5,515.4 \\ - & - & 5,601.1 \\ - & - & 5,736.0 \\ - & - & 5,635.3\end{array}$

$\begin{array}{lll}- & - & 712.2 \\ - & - & 738.9 \\ - & - & 793.9 \\ - & - & 787.3 \\ - & - & 804.6 \\ - & - & 843.3 \\ - & - & 828.0 \\ - & - & 803.7 \\ - & - & 757.7 \\ - & - & 750.9 \\ - & - & 782.7 \\ - & - & 780.1 \\ & - & 782.0\end{array}$

$3,627.6$

$3,950.9$

$4,114.2$

$4,221.5$

$4,196.4$

$4,451.3$

$4,406.7$

$4,435.3$

$4,358.4$

$4,103.1$

$4,199.7$

$4,154.9$

$4,185.6$

$5,321.7$

$5,931.4$

$5,788.7$

$5,476.6$

$5,578.5$

$5,724.8$

$5,622.0$

$5,925.5$

$5,691.4$

$5,474.8$

$5,589.0$

$5,654.4$

$1,367.0$
$1,357.9$

$\begin{array}{ll}- & 706.7 \\ - & 778.6 \\ - & 771.1 \\ - & 773.7 \\ - & 764.2 \\ - & 778.4 \\ - & 745.1 \\ - & 758.8 \\ - & 849.5 \\ - & 724.7 \\ - & 744.0 \\ - & 756.3 \\ - & 762 .\end{array}$

$\begin{array}{ll}- & 3,627.6 \\ - & 3,950.9 \\ - & 4,114.2 \\ - & 4,221.5 \\ - & 4,196.4 \\ - & 4,451.3 \\ - & 4,406.7 \\ - & 4,435.3 \\ - & 4,358.4 \\ - & 4,103.1 \\ - & 4,199.7 \\ - & 4,154.9 \\ - & 4,185.6\end{array}$

$5,321.7$

$5,931.4$

$5,788.7$

$5,476.6$

$5,578.5$

$5,724.8$

$5,622.0$

$5,925.5$

$5,691.4$

$5,474.8$

$5,589.0$

$5,785.1$

$5,657.3$
July

February ........................................

Ap r...........................................
$3,430.9$

$3,530.8$

$3,613.3$

$3,722.0$

$3,665.1$

$3,752.4$

$3,640.5$

$3,678.5$

$3,829.1$

$3,522.8$

$3,641.0$

$3,698.8$

$3,643.7$
See footnotes at end of table. 
Table 48. Prime Supplier Sales Volumes of Motor Gasoline by Grade, Formulation, PAD District, and State

(Thousand Gallons per Day) - Continued

\begin{tabular}{|c|c|c|c|c|c|c|c|c|}
\hline \multirow{2}{*}{$\begin{array}{l}\text { Geographíc Area } \\
\text { Month }\end{array}$} & \multicolumn{4}{|c|}{ Regular } & \multicolumn{4}{|c|}{ Midgrado } \\
\hline & Conventionaja & Oxygenated & Reformulated & Total & Conventional & Oxygonated & Reformulatod & Total \\
\hline \multicolumn{9}{|l|}{ Now Mexico } \\
\hline 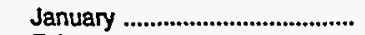 & $1,223.2$ & 570.3 & - & $1,793.5$ & 24.6 & 32.1 & - & 56.7 \\
\hline 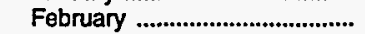 & $1,302.3$ & 633.3 & - & $1,935.6$ & 22.6 & 33.4 & - & 56.0 \\
\hline 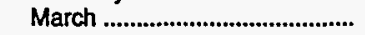 & $w$ & w & - & $1,941.6$ & 82.1 & - & - & 82.1 \\
\hline 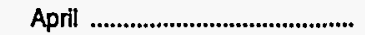 & w & w & - & $1,956.7$ & $w$ & w & - & 80.6 \\
\hline 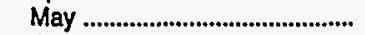 & $w$ & w & - & $1,937.5$ & 88.9 & - & - & 88.9 \\
\hline 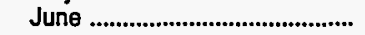 & $w$ & w & - & $2,046.8$ & 91.1 & - & - & 91.1 \\
\hline 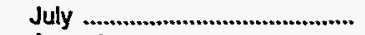 & w & w & - & $2,050.9$ & 94.3 & - & - & 94.3 \\
\hline August & $\ddot{w}$ & $\ddot{w}$ & - & $2,025.0$ & 97.3 & - & - & 97.3 \\
\hline 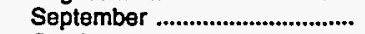 & $\mathbf{w}$ & w & - & $1,963.1$ & 92.2 & - & - & 92.2 \\
\hline October & $1,760.0$ & 315.0 & - & $2,075.0$ & 67.8 & 16.9 & - & 84.8 \\
\hline November .......................................... & w & w & - & $2,066.7$ & $w$ & W & - & 64.1 \\
\hline 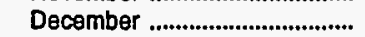 & $w$ & $w$ & - & $2,090.9$ & 27.7 & 36.9 & - & 64.6 \\
\hline 1994 Average & $1,680.6$ & 309.9 & - & $1,990.5$ & 66.7 & 12.8 & - & 79.5 \\
\hline \multicolumn{9}{|l|}{ Texas } \\
\hline 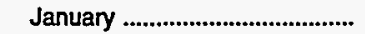 & $16,487.7$ & 752.3 & - & $17,240.0$ & $3,464.0$ & 91.5 & - & $3,555.5$ \\
\hline 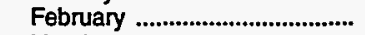 & $16,801.7$ & 819.7 & - & $17,621.4$ & $3,740.8$ & 100.6 & - & $3,841.4$ \\
\hline 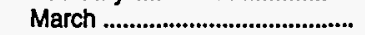 & $w$ & w & - & $18,150.4$ & $3,964.6$ & 98.5 & - & $4,063.1$ \\
\hline 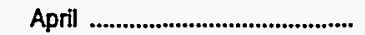 & $\mathbf{w}$ & w & - & $18,800.7$ & $w$ & $w$ & - & $4,019.5$ \\
\hline 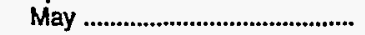 & w & w & - & $18,072.1$ & $w$ & w & - & $4,143.4$ \\
\hline 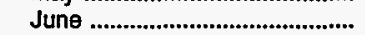 & $18,649.4$ & - & - & $18,649.4$ & $w$ & $w$ & - & $4,190.6$ \\
\hline 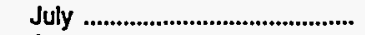 & $18,705.5$ & - & - & $18,705.5$ & $w$ & w & - & $4,046.7$ \\
\hline 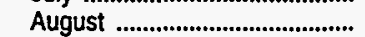 & $W$ & w & - & $19,519.6$ & $w$ & W & - & $4,088.2$ \\
\hline 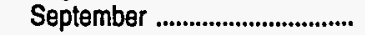 & w & w & - & $19,398.9$ & $3,927.5$ & 58.8 & - & $3,986.2$ \\
\hline October & $18,076.5$ & 553.7 & - & $18,630.2$ & $3,730.3$ & 100.8 & - & $3,831.1$ \\
\hline 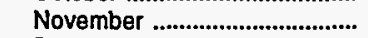 & W & 575.0 & $w$ & $19,362.4$ & $w$ & 84.1 & w & $3,999.5$ \\
\hline 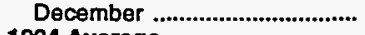 & $13,378.5$ & $w$ & $w$ & $19,483.6$ & $2,166.5$ & 60.9 & $1,532.2$ & 3.759 .6 \\
\hline 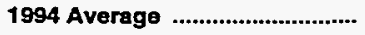 & $17,774.7$ & 352.9 & 512.3 & $18,640.0$ & $3,744.8$ & 71.6 & 144.0 & $3,960.4$ \\
\hline \multicolumn{9}{|l|}{ PAD District IV } \\
\hline 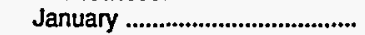 & $4,943.3$ & $2,011.1$ & - & $6,954.4$ & 339.7 & 417.0 & - & 756.7 \\
\hline 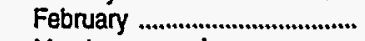 & $5,118.3$ & $2,115.4$ & - & $7,233.7$ & 352.4 & 460.8 & - & 813.3 \\
\hline March & $7,570.4$ & 151.1 & - & $7,721.5$ & 800.5 & 1.1 & - & 801.6 \\
\hline April & $w$ & w & - & $7,838.1$ & w & $w$ & - & 805.6 \\
\hline 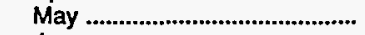 & w & w & - & $8,108.0$ & $w$ & w & - & 852.4 \\
\hline 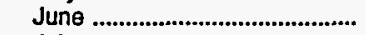 & w & w & - & $8,823.9$ & 900.1 & - & - & 900.1 \\
\hline July .................................................. & $8,574.8$ & 171.0 & - & $8,745.8$ & $w$ & w & - & 925.6 \\
\hline 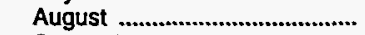 & $8,927.1$ & 131.8 & - & $9,058.9$ & w & W & - & 924.1 \\
\hline 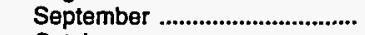 & $7,784.2$ & 381.3 & - & $8,165.5$ & $\mathbf{w}$ & w & - & 843.1 \\
\hline October & $6,980.8$ & 941.2 & - & $7,922.0$ & 703.2 & 148.1 & - & 851.3 \\
\hline 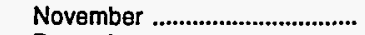 & $5,325.0$ & $2,388.4$ & - & $7,713.3$ & 348.5 & 543.7 & - & 892.2 \\
\hline 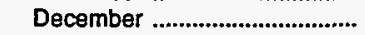 & $4,943.7$ & $2,491.3$ & - & $7,435.0$ & 406.8 & 561.3 & - & 968.2 \\
\hline 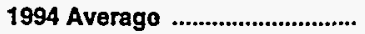 & $7,054.2$ & 926.9 & - & $7,981.1$ & 682.9 & 178.7 & - & 861.6 \\
\hline \multicolumn{9}{|l|}{ Colorado } \\
\hline 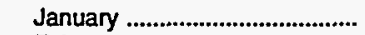 & $1,077.4$ & $1,847.7$ & - & $2,925.1$ & 135.2 & 405.5 & - & 540.6 \\
\hline 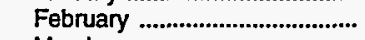 & $1,178.2$ & $1,953.6$ & - & $3,131.9$ & 124.9 & 451.0 & - & 575.9 \\
\hline 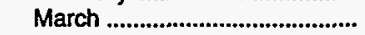 & $w$ & w & - & $3,285.1$ & $w$ & W & - & 582.4 \\
\hline April & $3,045.3$ & 144.2 & - & $3,189.5$ & $w$ & w & - & 565.1 \\
\hline 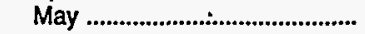 & w & w & - & $3,383.5$ & $w$ & w & - & 621.1 \\
\hline 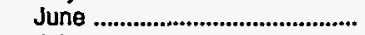 & w & w & - & $3,573.0$ & 645.2 & - & - & 645.2 \\
\hline 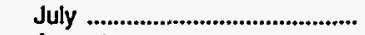 & $3,384.3$ & 171.0 & - & $3,555.3$ & w & w & - & 659.5 \\
\hline August & $3,573.5$ & 131.8 & - & $3,705.4$ & w & W & - & 644.3 \\
\hline September .................................... & $w$ & w & - & $3,463.4$ & $w$ & $\ddot{w}$ & - & 576.1 \\
\hline October & w & w & - & $3,342.7$ & $w$ & W & - & 576.5 \\
\hline 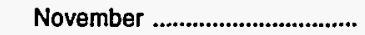 & $1,164.0$ & $2,169.0$ & - & $3,333.0$ & 84.5 & 533.0 & - & 617.5 \\
\hline 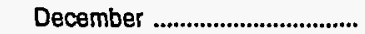 & $1,053.4$ & $2,272.2$ & - & $3,325.6$ & 86.7 & 545.6 & - & 632.3 \\
\hline 1994 Average ................................... & $2,490.7$ & 861.8 & - & $3,352.5$ & 428.7 & 174.5 & - & 603.3 \\
\hline
\end{tabular}

See footnotes at end of table. 
Table 48. Prime Suppller Sales Volumes of Motor Gasoline by Grade, Formulation, PAD District, and State

(Thousand Gallons per Day) - Continued

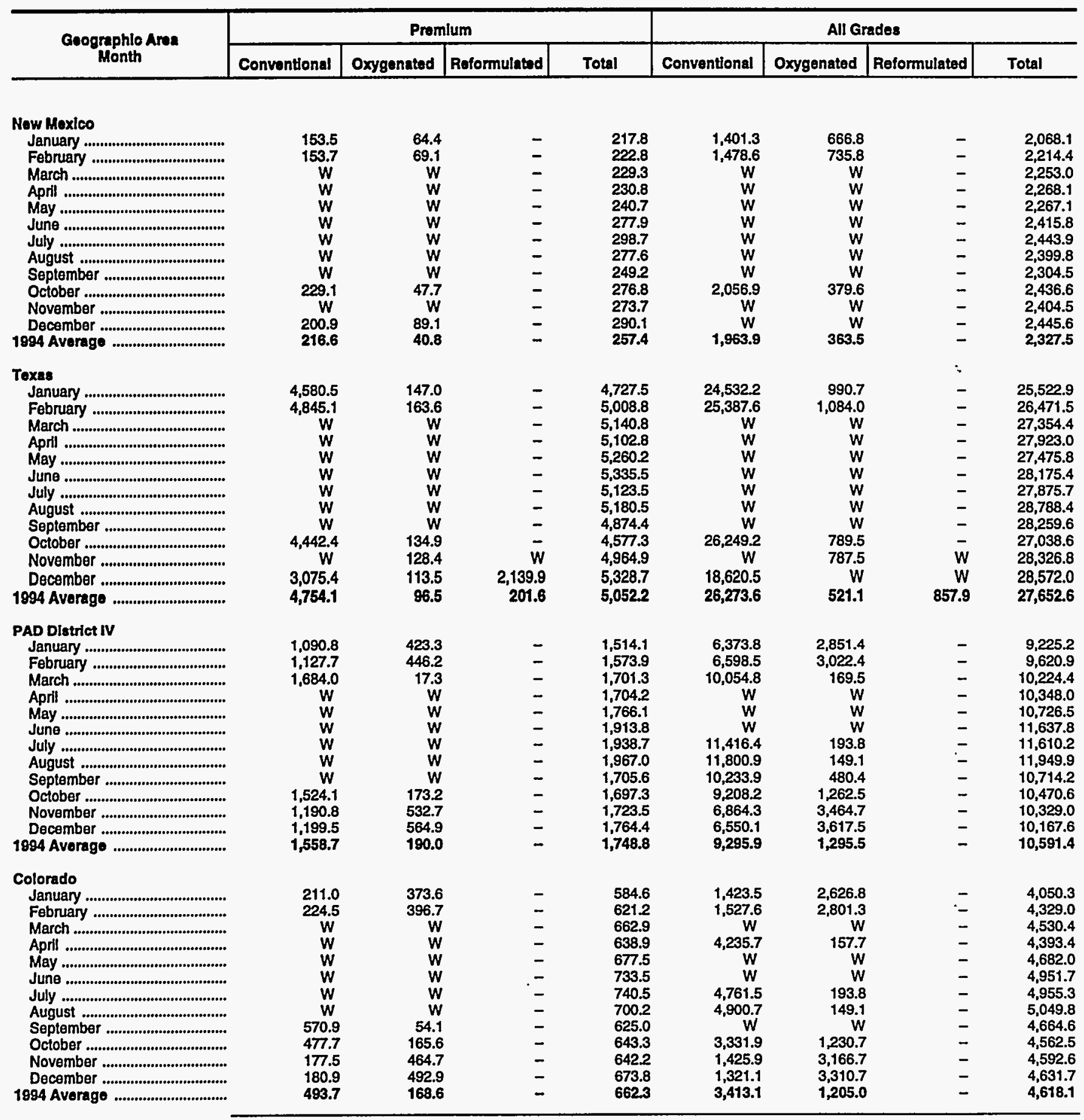

See footnotes at end of table. 
Table 48. Prime Supplier Sales Volumes of Motor Gasoline by Grade, Formulation, PAD District, and State

(Thousand Gallons per Day) - Continued

\begin{tabular}{|c|c|c|c|c|c|c|c|c|}
\hline \multirow{2}{*}{$\begin{array}{l}\text { Geographic Area } \\
\text { Month }\end{array}$} & \multicolumn{4}{|c|}{ Regular } & \multicolumn{4}{|c|}{ Midgrade } \\
\hline & Conventionala & Oxygonated & Roformulatad & Total & Conventional & Oxygenated & Roformulated & Total \\
\hline \multicolumn{9}{|l|}{ Idaho } \\
\hline 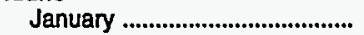 & $1,034.4$ & - & - & $1,034.4$ & 22.4 & - & - & 22.4 \\
\hline 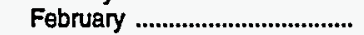 & $1,050.9$ & - & - & $1,050.9$ & 25.1 & - & - & 25.1 \\
\hline 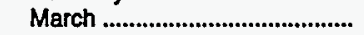 & $1,175.0$ & - & - & $1,175.0$ & 19.2 & - & - & 19.2 \\
\hline April & $1,218.7$ & - & - & $1,218.7$ & 22.5 & - & - & 22.5 \\
\hline May & $1,288.2$ & - & - & $1,288.2$ & 12.6 & - & - & 12.6 \\
\hline 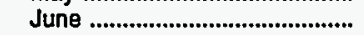 & $1,322.6$ & - & - & $1,322.6$ & 14.2 & - & - & 14.2 \\
\hline 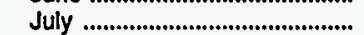 & $1,349.2$ & - & - & $1,349.2$ & 17.7 & - & - & 17.7 \\
\hline August & $1,354.1$ & - & - & $1,354.1$ & 30.7 & - & - & 30.7 \\
\hline September ...................................... & $1,204.1$ & - & - & $1,204.1$ & 28.5 & - & - & 28.5 \\
\hline 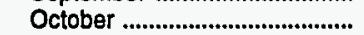 & $1,183.9$ & - & - & $1,183.9$ & 25.5 & - & - & 25.5 \\
\hline 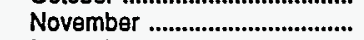 & $1,088.5$ & - & - & $1,088.5$ & 24.5 & - & - & 24.5 \\
\hline 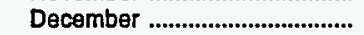 & 956.0 & - & - & 958.0 & 69.9 & - & - & 69.8 \\
\hline 1894 Average & $1,186.3$ & - & - & $1,186.3$ & 26.1 & - & - & 26.1 \\
\hline \multicolumn{9}{|l|}{ Montana } \\
\hline 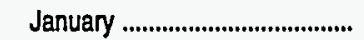 & 811.5 & W & - & 841.5 & - & - & - & - \\
\hline 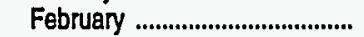 & W & W & - & 893.4 & - & - & - & - \\
\hline 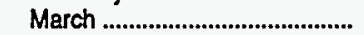 & 978.0 & - & - & 978.0 & - & - & - & - \\
\hline April & 996.1 & - & - & 996.1 & - & - & - & - \\
\hline 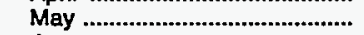 & $1,063.2$ & - & - & $1,063.2$ & $\mathbf{w}$ & - & - & w \\
\hline 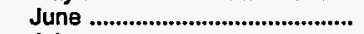 & $1,300.1$ & - & - & $1,300.1$ & $w$ & - & - & $\ddot{w}$ \\
\hline 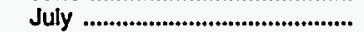 & $1,224.3$ & - & - & $1,224.3$ & $w$ & - & - & $\ddot{w}$ \\
\hline 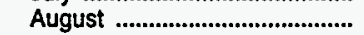 & $1,335.0$ & - & - & $1,335.0$ & $w$ & - & - & $\ddot{w}$ \\
\hline 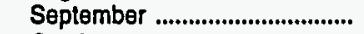 & $1,126.0$ & - & - & $1,126.0$ & w & - & - & w \\
\hline October & W & w & - & $1,124.2$ & w & - & - & w \\
\hline 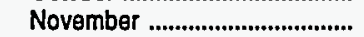 & 986.4 & 60.6 & - & $1,047.0$ & w & - & - & $\ddot{w}$ \\
\hline 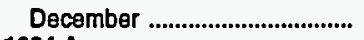 & 897.0 & 56.3 & - & 953.2 & $w$ & $w$ & - & w \\
\hline 1994 Average ................................. & $1,059.8$ & 14.7 & - & $1,074.5$ & $\ddot{w}$ & $\ddot{w}$ & - & $\ddot{w}$ \\
\hline \multicolumn{9}{|l|}{ Utah } \\
\hline 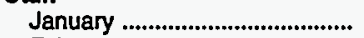 & 1,456.1 & 133.5 & - & $1,589.6$ & 178.5 & 11.6 & - & 190.1 \\
\hline 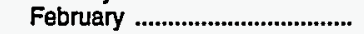 & & $w$ & - & $1,602.1$ & 198.9 & 9.9 & - & 208.8 \\
\hline March & w & w & - & $1,687.9$ & w & w & - & 196.1 \\
\hline April & w & W & - & $1,839.3$ & 213.8 & - & - & 213.8 \\
\hline May & $1,709.3$ & - & - & $1,709.3$ & 213.8 & - & - & 213.8 \\
\hline June & $1,864.8$ & - &.- & $1,864.8$ & 234.2 & - & - & 234.2 \\
\hline 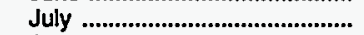 & $1,774.6$ & - & - & $1,774.6$ & 239.9 & - & - & 239.8 \\
\hline 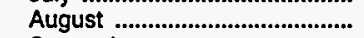 & $1,874.0$ & - & - & $1,874.0$ & 243.6 & - & - & 243.6 \\
\hline 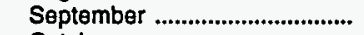 & $w$ & w & - & $1,701.4$ & 233.6 & - & - & 233.6 \\
\hline October & $1,573.4$ & 21.5 & - & $1,594.9$ & $w$ & w & - & 242.3 \\
\hline 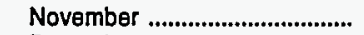 & $1,480.4$ & 158.7 & - & $1,639.1$ & 232.3 & 10.7 & - & 243.0 \\
\hline 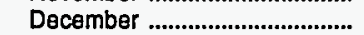 & $1,448.2$ & 162.9 & - & $1,611.1$ & $w$ & $w$ & - & 258.9 \\
\hline 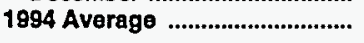 & $1,657.3$ & 50.4 & - & $1,707.6$ & 222.5 & 4.1 & - & 226.6 \\
\hline \multicolumn{9}{|l|}{ Wyoming } \\
\hline 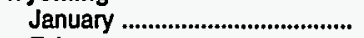 & 563.8 & - & - & 563.8 & 3.6 & - & - & 3.6 \\
\hline 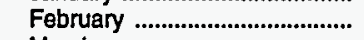 & 555.4 & - & - & 555.4 & 3.5 & - & - & 3.5 \\
\hline 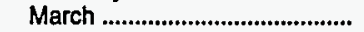 & 595.5 & - & - & 585.5 & 3.9 & - & - & 3.9 \\
\hline April & 594.6 & - & - & 594.6 & 4.3 & - & - & 4.3 \\
\hline 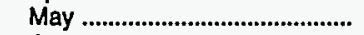 & 663.8 & - & - & 663.8 & $w$ & - & - & w \\
\hline June & 763.4 & - & - & 763.4 & $w$ & - & - & $w$ \\
\hline July & 842.5 & - & - & 842.5 & $w$ & - & - & w \\
\hline August & 790.4 & - & - & 790.4 & $w$ & - & - & $w$ \\
\hline 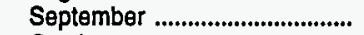 & 670.6 & - & - & 670.6 & w & - & - & $w$ \\
\hline 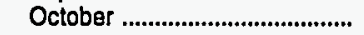 & 676.4 & - & - & 676.4 & $w$ & - & - & $\ddot{w}$ \\
\hline 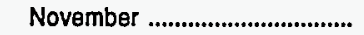 & 605.7 & - & - & 605.7 & $w$ & - & - & $\ddot{w}$ \\
\hline 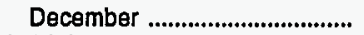 & 589.1 & - & - & 589.1 & $w$ & - & - & $\ddot{w}$ \\
\hline 1894 Average .................................. & 660.1 & - & - & 660.1 & 5.4 & - & - & 6.4 \\
\hline
\end{tabular}

See footnotes at end of table. 
Table 48. Prime Supplier Sales Volumes of Motor Gasoline by Grade, Formulation, PAD Dlstrict, and State

(Thousand Gallons per Day) - Continued

\begin{tabular}{|c|c|c|c|c|c|c|c|c|}
\hline \multirow{2}{*}{$\begin{array}{l}\text { Goographlo Area } \\
\text { Month }\end{array}$} & \multicolumn{4}{|c|}{ Premium } & \multicolumn{4}{|c|}{ All Grades } \\
\hline & Conventional & Oxygenated & Roformulatad & Total & Conventional & Oxygenated & Reformulated & Total \\
\hline \multicolumn{9}{|l|}{ Idaho } \\
\hline 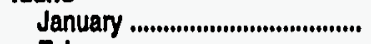 & 168.8 & - & - & 168.8 & $1,225.6$ & - & - & $1,225.6$ \\
\hline Fobruary ....................................... & 169.8 & - & - & 169.8 & $1,245.8$ & - & - & $1,245.8$ \\
\hline 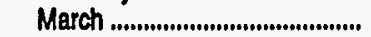 & 182.8 & - & - & 182.8 & $1,377.0$ & - & - & $1,377.0$ \\
\hline 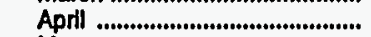 & 191.2 & - & - & 191.2 & $1,432.3$ & - & - & $1,432.3$ \\
\hline 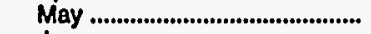 & 205.4 & - & - & 205.4 & $1,508.3$ & - & - & $1,506.3$ \\
\hline Juns & 219.1 & - & - & 219.1 & $1,555.9$ & - & - & $1,555.9$ \\
\hline 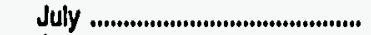 & 230.7 & - & - & 230.7 & $1,597.5$ & - & - & $1,597.5$ \\
\hline August & 238.5 & - & - & 238.5 & $1,623.4$ & - & - & $1,623.4$ \\
\hline September ...................................... & 204.2 & - & - & 204.2 & $1,436.9$ & - & - & $1,436.9$ \\
\hline 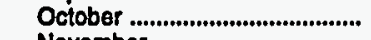 & 198.0 & - & - & 198.0 & $1,407.4$ & - & - & 1.407 .4 \\
\hline November ............................................. & 203.6 & - & - & 203.6 & $1,316.5$ & - & - & $1,316.5$ \\
\hline 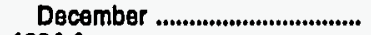 & 188.4 & - & - & 188.4 & $1,214.3$ & - & - & $1,214.3$ \\
\hline 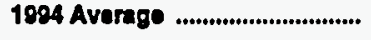 & 200.2 & - & - & 200.2 & $1,412.7$ & - & - & $1,412.7$ \\
\hline \multicolumn{9}{|l|}{ Montana } \\
\hline 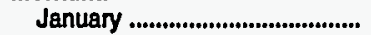 & 138.7 & $w$ & - & 146.0 & 950.3 & $w$ & - & 987.5 \\
\hline 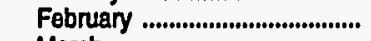 & $w$ & $w$ & - & 160.0 & $w$ & $\ddot{w}$ & - & $1,053.4$ \\
\hline 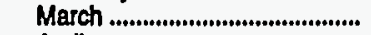 & 173.0 & - & - & 173.0 & $1,151.0$ & - & - & $1,151.0$ \\
\hline 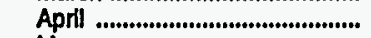 & 172.2 & - & - & 172.2 & $1,168.3$ & - & - & $1,168.3$ \\
\hline 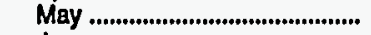 & w & - & - & $\mathbf{w}$ & $1,252.9$ & - & - & $1,252.9$ \\
\hline 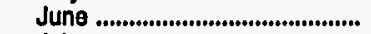 & w & - & - & $\mathbf{w}$ & $1,537.2$ & - & - & $1,537.2$ \\
\hline 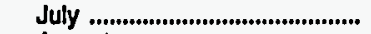 & w & - & - & $\mathbf{w}$ & $1,439.8$ & - & - & $1,439.8$ \\
\hline August & $\mathbf{w}$ & - & - & $w$ & $1,580.8$ & - & - & $1,580.8$ \\
\hline September ........................................ & W & - & - & $\mathbf{w}$ & $1,309.2$ & - & - & $1,309.2$ \\
\hline October ...................................................... & 192.8 & $\mathbf{w}$ & - & $\mathbf{w}$ & $w$ & W & - & $1,317.5$ \\
\hline 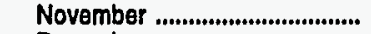 & 164.6 & $\mathbf{w}$ & - & $\mathbf{w}$ & $\mathbf{w}$ & w & - & $1,226.4$ \\
\hline 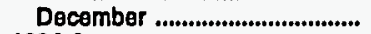 & $\mathbf{w}$ & $w$ & - & $w$ & $1,063.8$ & 71.0 & - & $1,134.9$ \\
\hline 1994 Average ............................... & 188.1 & 3.6 & - & 189.7 & $1,246.1$ & 18.3 & - & $1,264.4$ \\
\hline \multicolumn{9}{|l|}{ Utah } \\
\hline 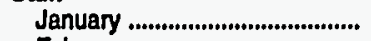 & 479.2 & 42.3 & - & 521.5 & $2,113.8$ & 187.4 & - & $2,301.2$ \\
\hline February ............................................ & $w$ & W & - & 524.0 & $w$ & W & - & $2,334.9$ \\
\hline 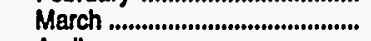 & $w$ & $\ddot{w}$ & - & 574.6 & $w$ & w & - & $2,458.5$ \\
\hline 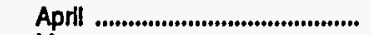 & $\mathbf{w}$ & $\mathbf{w}$ & - & 594.6 & $\mathbf{w}$ & w & - & $2,647.8$ \\
\hline 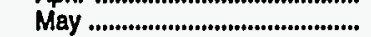 & 568.8 & - & - & 568.9 & $2,492.0$ & - & - & $2,492.0$ \\
\hline June …............................................ & 574.1 & - & - & 574.1 & $2,673.2$ & - & - & $2,673.2$ \\
\hline 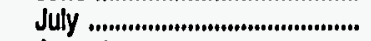 & 583.9 & - & - & 583.9 & $2,598.4$ & - & - & $2,598.4$ \\
\hline 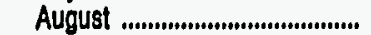 & 614.5 & - & - & 614.5 & $2,732.2$ & - & - & $2,732.2$ \\
\hline September .......................................... & W & W & - & 570.6 & w & W & - & $2,505.6$ \\
\hline 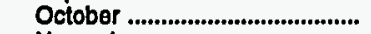 & $w$ & w & - & 544.6 & w & $\mathbf{w}$ & - & $2,381.8$ \\
\hline November .......................................... & 534.0 & 53.4 & - & 587.4 & $2,246.7$ & 222.8 & - & $2,469.5$ \\
\hline 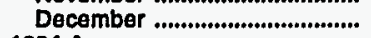 & $w$ & $\dot{w}$ & - & 608.9 & $2,243.0$ & 235.8 & - & $2,478.8$ \\
\hline 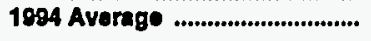 & 554.8 & 17.8 & - & 572.6 & $2,434.5$ & 72.3 & - & $2,506.8$ \\
\hline \multicolumn{9}{|l|}{ Wyoming } \\
\hline 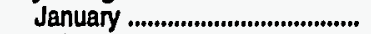 & 93.1 & - & - & 93.1 & 660.5 & - & - & 660.5 \\
\hline February ....................................... & 88.9 & - & - & $\mathbf{9 8 . 9}$ & 657.8 & - & - & 657.8 \\
\hline March .............................................. & 108.0 & - & - & 108.0 & 707.5 & - & - & 707.5 \\
\hline April & 107.3 & - & - & 107.3 & 706.2 & - & - & 706.2 \\
\hline 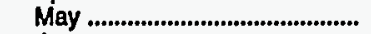 & $w$ & - & - & $w$ & 793.4 & - & - & 793.4 \\
\hline June & $w$ & - & - & $w$ & 919.8 & - & - & 919.8 \\
\hline 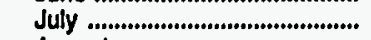 & $w$ & - & - & $w$ & $1,019.1$ & - & - & $1,019.1$ \\
\hline August & $w$ & - & - & $w$ & 963.8 & - & - & 963.8 \\
\hline 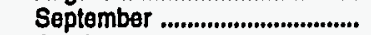 & $\mathbf{w}$ & - & - & W & 798.0 & - & - & 798.0 \\
\hline 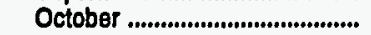 & $w$ & - & - & W & 801.5 & - & - & 801.5 \\
\hline 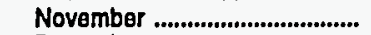 & 111.1 & w & - & w & $w$ & $w$ & - & 723.9 \\
\hline December ......................................... & $w$ & - & - & $\mathbf{w}$ & 707.9 & - & - & 707.9 \\
\hline 1984 Average ................................... & 123.9 & $\mathbf{W}$ & - & 123.9 & 789.4 & $\mathbf{w}$ & - & 789.4 \\
\hline
\end{tabular}

See footnotes at end of table. 
Table 48. Prime Supplier Sales Volumes of Motor Gasoline by Grade, Formulation, PAD Distrlct, and State

(Thousand Gallons per Day) - Continued

\begin{tabular}{|c|c|c|c|c|c|c|c|c|}
\hline \multirow{2}{*}{$\begin{array}{l}\text { Goographic Area } \\
\text { Month }\end{array}$} & \multicolumn{4}{|c|}{ Regular } & \multicolumn{4}{|c|}{ MIdgrade } \\
\hline & Conventlonala & Oxygennted & Roformulated & Total & Conventional & Oxygenated & Reformulated & Total \\
\hline \multicolumn{9}{|l|}{ PAD District V } \\
\hline 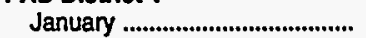 & $7,548.3$ & $30,584.0$ & - & $38,132.3$ & 245.3 & $4,332.3$ & - & $4,577.6$ \\
\hline February ........................................ & $15,997.1$ & $23,903.9$ & - & $39,801.1$ & $2,135.9$ & $2,826.5$ & - & $4,962.5$ \\
\hline 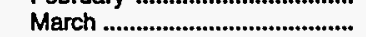 & $36,242.5$ & $4,588.3$ & - & $40,830.8$ & $4,825.5$ & 135.2 & - & $4,960.6$ \\
\hline 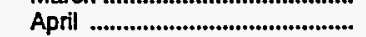 & $40,648.1$ & $1,217.4$ & - & $41,865,4$ & $4,985.1$ & 0.5 & - & $4,985.6$ \\
\hline May ............................................... & W & $W$ & - & $41,435.7$ & $5,034.2$ & - & - & $5,034.2$ \\
\hline 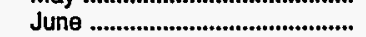 & $\dddot{w}$ & W & - & $42,182.8$ & $5,289.1$ & - & - & $5,289.1$ \\
\hline 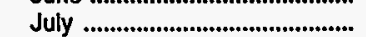 & w & $w$ & - & $40,891.5$ & $W$ & $w$ & - & $5,204.8$ \\
\hline August & $41,725.5$ & 685.3 & - & $42,410.7$ & $w$ & $w$ & - & $5,344.4$ \\
\hline 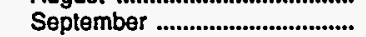 & $37,536.5$ & $3,542.7$ & - & $41,079.3$ & w & $w$ & - & $5,195.9$ \\
\hline 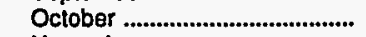 & $13,586.4$ & $27,612.8$ & - & $41,199.2$ & 800.4 & $4,489.5$ & - & $5,289.9$ \\
\hline 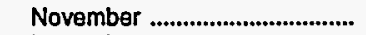 & $7,371.2$ & $31,439.8$ & $1,669.2$ & $40,480.2$ & 308.6 & $4,817.2$ & 231.3 & $5,357.1$ \\
\hline December ................................... & $6,937.2$ & $21,057.4$ & $12,032.9$ & $40,027.6$ & 293.0 & $2,831.1$ & $3,185.9$ & $6,310.0$ \\
\hline 1994 Aversge & $27,565.2$ & $12,147.5$ & $1,169.2$ & $40,871.8$ & $3,281.0$ & $1,640.7$ & 289.6 & $5,211.4$ \\
\hline \multicolumn{9}{|l|}{ Alaska } \\
\hline 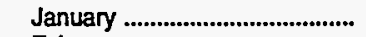 & 447.0 & - & - & 447.0 & - & - & - & - \\
\hline 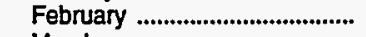 & 490.1 & - & - & 490.1 & $\overline{-}$ & - & - & - \\
\hline March & 492.9 & - & - & 492.9 & $W$ & - & - & $W$ \\
\hline April & 502.8 & - & - & 502.8 & W & - & - & $W$ \\
\hline 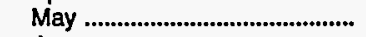 & 606.5 & - & - & 606.5 & $\mathbf{W}$ & - & - & $W$ \\
\hline 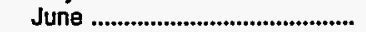 & 750.9 & - & - & 750.9 & $\mathbf{W}$ & - & - & $w$ \\
\hline 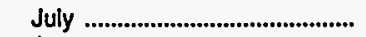 & 772.6 & - & - & 772.6 & $W$ & - & - & 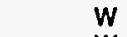 \\
\hline 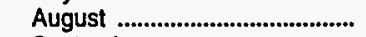 & 716.8 & - & - & 716.8 & $W$ & - & - & W \\
\hline September .................................. & 634.2 & - & - & 634.2 & $\mathbf{W}$ & - & - & W \\
\hline 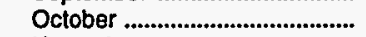 & 511.5 & - & - & 511.5 & $w$ & - & - & $w$ \\
\hline November .................................... & 528.2 & - & - & 528.2 & $\mathbf{W}$ & - & - & $w$ \\
\hline December ..................................... & $W$ & $W$ & - & 479.2 & $W$ & $w$ & - & $w$ \\
\hline 1994 Average .............................. & 577.2 & $\mathbf{W}$ & - & 678.2 & $\mathbf{W}$ & $\mathbf{W}$ & - & $\mathbf{W}$ \\
\hline \multicolumn{9}{|l|}{ Arizona } \\
\hline 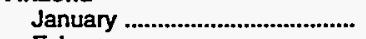 & $1,314.4$ & $2,504.1$ & - & $3,818.5$ & 45.1 & $w$ & - & 46.2 \\
\hline 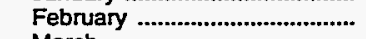 & $1,410.1$ & $2,672.9$ & - & $4,083.0$ & $w$ & $w$ & - & 48.9 \\
\hline March & $1,496.5$ & $2,518.5$ & - & $4,015.0$ & w & $\mathbf{W}$ & - & 54.8 \\
\hline 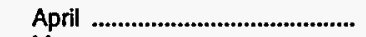 & $3,951.5$ & 54.2 & - & $4,005.7$ & 14.8 & - & - & 14.8 \\
\hline May ............................................. & $W$ & $W$ & - & $3,779.9$ & 15.1 & - & - & 15.1 \\
\hline June & $w$ & $w$ & - & $3,714.4$ & 15.8 & - & - & 15.8 \\
\hline 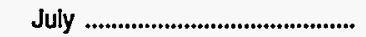 & $w$ & $W$ & - & $3,589.5$ & 14.6 & - & - & 14.6 \\
\hline 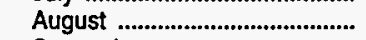 & w & $w$ & - & $3,905.4$ & 13.3 & - & - & 13.3 \\
\hline 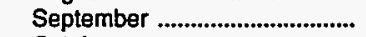 & $2,902.9$ & 920.4 & - & $3,823.3$ & 11.0 & - & - & 11.0 \\
\hline 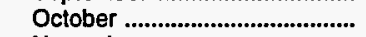 & $1,637.8$ & $2,096.5$ & - & $3,734.3$ & 19.9 & 73.6 & - & 93.5 \\
\hline November ....................................... & W & $2,309.9$ & $w$ & $3,650.8$ & 40.5 & 98.5 & - & 139.0 \\
\hline December & $1,480.4$ & $2,490.3$ & - & $3,970.7$ & 36.0 & 104.7 & - & 140.7 \\
\hline 1994 Average & $2,545.6$ & $1,283.4$ & $\mathbf{W}$ & $3,839.3$ & 27.2 & 23.5 & - & $\mathbf{5 0 . 7}$ \\
\hline \multicolumn{9}{|l|}{ California } \\
\hline 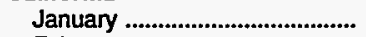 & 786.3 & $22,488.9$ & - & $23,275.2$ & 45.1 & $4,222.0$ & - & $4,267.2$ \\
\hline 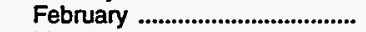 & $9,518.4$ & $15,379.0$ & - & $24,897.4$ & $1,889.5$ & $2,741.7$ & - & $4,631.1$ \\
\hline 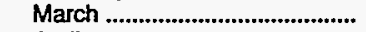 & $24,716.3$ & 901.1 & - & $25,617.4$ & $4,493.8$ & 133.9 & - & $4,627.6$ \\
\hline April & $w$ & $\mathbf{W}$ & - & $26,560.3$ & $\mathbf{W}$ & $w$ & - & $4,697.9$ \\
\hline May & W & $W$ & - & $26,217.4$ & $4,735.9$ & - & - & $4,735.9$ \\
\hline June & $w$ & $W$ & - & $26,244.5$ & $4,971.2$ & - & - & $4,971.2$ \\
\hline 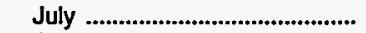 & $w$ & $W$ & - & $24,989.8$ & $w$ & $\mathbf{W}$ & - & $4,884.0$ \\
\hline 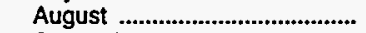 & $\mathbf{w}$ & $W$ & - & $26,222.5$ & $w$ & $w$ & - & $5,021.8$ \\
\hline September & $23,545.9$ & $1,841.1$ & - & $25,387.0$ & $4,618.1$ & 272.8 & - & $4,890.9$ \\
\hline 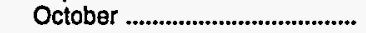 & $3,552.4$ & $22,117.9$ & - & $25,670.4$ & 534.3 & $4,253.4$ & - & $4,787.6$ \\
\hline 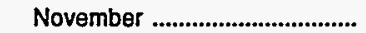 & $W$ & $23,129.6$ & $W$ & $25,414.2$ & 42.2 & $4,514.8$ & 231.3 & $4,788.3$ \\
\hline December ................................... & 348.9 & $12,639.5$ & $12,032.9$ & $25,021.4$ & 39.3 & $2,477.2$ & $3,185.9$ & $5,702.3$ \\
\hline 1994 Average & $15,906.9$ & $8,393.8$ & $1,158.8$ & $25,458.6$ & $2,998.2$ & $1,547.7$ & 289.6 & $4,835.5$ \\
\hline
\end{tabular}

See footnotes at end of table. 
Table 48. Prime Supplier Sales Volumes of Motor Gasoline by Grade, Formulation, PAD District, and State

(Thousand Gallons per Day) — Continued

\begin{tabular}{|c|c|c|c|c|c|c|c|c|}
\hline \multirow{2}{*}{$\begin{array}{l}\text { Geographlo Aroa } \\
\text { Month }\end{array}$} & \multicolumn{4}{|c|}{ Premlum } & \multicolumn{4}{|c|}{ Alt Grades } \\
\hline & Conventional & Oxygenated & Reformulated & Total & Conventional & Oxygenated & Reformulated & Total \\
\hline
\end{tabular}

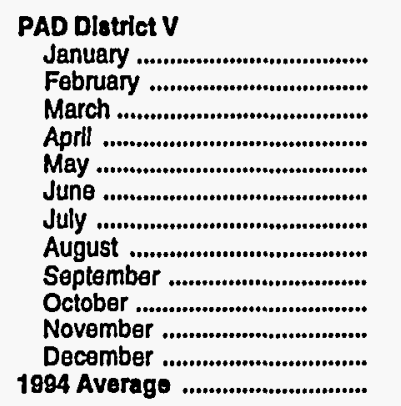

$\begin{array}{rr}1,265.6 & 8,516.5 \\ 3,555.6 & 6,807.9 \\ 8,698.1 & 1,852.0 \\ 9,682.6 & 1,033.9 \\ W & W \\ W & W \\ W & W \\ W & W \\ W & W \\ 2,607.7 & 8,060.9 \\ 1,330.7 & 7,994.0 \\ 1,296.3 & 4,942.5 \\ 6,575.1 & 3,652.1\end{array}$

$\begin{array}{rr}- & 9,782.2 \\ - & 10,363.5 \\ - & 10,550.1 \\ - & 10,716.5 \\ - & 10,772.2 \\ - & 11,108.9 \\ - & 11,143.3 \\ - & 11,246.7 \\ - & 10,860.0 \\ - & 10,668.5 \\ 1,316.9 & 10,641.5 \\ 4,666.9 & 10,905.6 \\ \mathbf{5 0 4 . 6} & 10,731.8\end{array}$
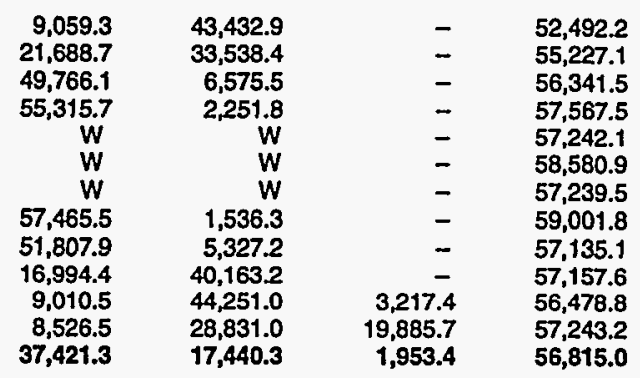

Alaske

January.

February ........................................

March....

April ..........................................

May.

June

July ....

August .......................................

September

October ...

November .....................................

December ......................................

1994 Averago

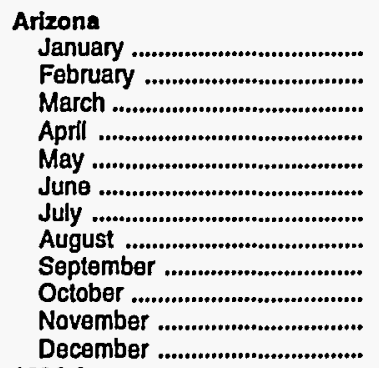

66.8

75.8

W

W

$\underset{W}{W}$

$W$
$W$

$W$

$W$
81.6

81.6
83.9

140.9

W

727

W

$W$
$W$
$w$

552.8

211.5

186.0

197.6

458.2

Callformia

January

Februany

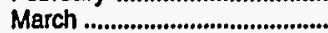

April

May

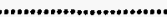

July

August ....

October

November

December

1994 Avorage
89.4

$2,426.3$

$6,650.9$

$w$
$W$
$w$
$w$

$W$
$6,684.9$

795.4

54.0

32.3
351.3

-
$\overline{-}$
$\bar{z}$
$\overline{-}$
$\overline{-}$
$\bar{z}$
$\bar{w}$
$w$

\begin{tabular}{|c|c|}
\hline- & 66.8 \\
\hline- & 75.8 \\
\hline- & $W$ \\
\hline- & $w$ \\
\hline- & $w$ \\
\hline- & $w$ \\
\hline & $w$ \\
\hline 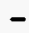 & W \\
\hline - & $W$ \\
\hline- & $w$ \\
\hline - & $w$ \\
\hline - & $w$ \\
\hline - & 84.1 \\
\hline
\end{tabular}

$$
\begin{array}{r}
504.2 \\
W \\
W \\
14.4 \\
W \\
W \\
W \\
W \\
202.8 \\
531.3 \\
578.1 \\
594.1 \\
289.4
\end{array}
$$

$\begin{array}{ll}- & 645.1 \\ - & 682.8 \\ - & 728.9 \\ - & 741.7 \\ - & 786.9 \\ - & 774.0 \\ - & 762.8 \\ - & 789.7 \\ - & 755.6 \\ - & 742.8 \\ - & 764.1 \\ - & 791.7 \\ - & 747.6\end{array}$

$6,960.4$
$5,121.1$

980.3

W

$W$
$W$
$W$
$1,105.6$
$6,748.1$
$6,153.4$
$3,115.1$
$2,841.0$
513.8

565.9

566.5

580.5

691.9

851.6

876.3

824.4

725.9

601.3

623.5

$W$
665.4

$1,500.4$

$1,605.1$

$1,772.5$

$4,693.6$

$4,567.3$

$4,494.3$

$4,355.5$

4,699.5

$3,466.7$

W

$3,031.0$

$\begin{array}{rr}- & 7,049.7 \\ - & 7,547.4 \\ - & 7,631.2 \\ - & 7,781.3 \\ - & 7,757.0 \\ - & 7,964.9 \\ - & 7,950.0 \\ - & 8,003.7 \\ - & 7,790.6 \\ - & 7,543.5 \\ 1,316.9 & 7,524.3 \\ 4,666.9 & 7,814.3 \\ 504.6 & 7,697.0\end{array}$

$\begin{array}{rrrr}920.7 & 33,671.3 & - & 34,592.0 \\ 13,834.2 & 23,241.8 & - & 37,076.0 \\ 35,861.0 & 2,015.3 & - & 37,876.3 \\ W & W & - & 39,039.5 \\ W & W & - & 38,710.3 \\ W & W & - & 39,180.6 \\ W & W & - & 37,823.8 \\ W & W & - & 39,248.0 \\ 34,848.9 & 3,219.5 & - & 38,068.4 \\ 4,882.1 & 33,119.4 & - & 38,001.5 \\ W & 33,797.7 & W & 37,726.8 \\ 420.5 & 18,231.8 & 19,885.7 & 38,538.0 \\ 23,256.4 & 12,782.5 & 1,953.0 & 37,992.0\end{array}$

Seo footnotes at end of table. 
Table 48. Prime Suppller Sales Volumes of Motor Gasoline by Grade, Formulation, PAD District, and State

(Thousand Gallons per Day) - Continued

\begin{tabular}{|c|c|c|c|c|c|c|c|c|}
\hline \multirow{2}{*}{$\begin{array}{l}\text { Geographic Area } \\
\text { Month }\end{array}$} & \multicolumn{4}{|c|}{ Regular } & \multicolumn{4}{|c|}{ Midgrade } \\
\hline & Conventionala & Oxygenated & Roformulated & Total & Conventional & Oxygenated & Roformulated & Total \\
\hline \multicolumn{9}{|l|}{ Hawall } \\
\hline 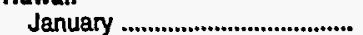 & 535.7 & - & - & 535.7 & 115.7 & _ & - & 115.7 \\
\hline 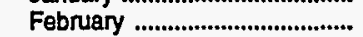 & 493.4 & - & - & 493.4 & $w$ & - & - & w \\
\hline March .................................. & 565.8 & - & - & 565.8 & 126.3 & - & - & 126.3 \\
\hline April & 554.7 & - & - & 554.7 & 122.1 & - & - & 122.1 \\
\hline 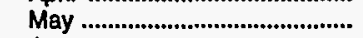 & 556.6 & - & - & 556.6 & 127.3 & - & - & 127.3 \\
\hline 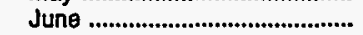 & 557.6 & - & - & 557.6 & 129.6 & - & - & 129.6 \\
\hline 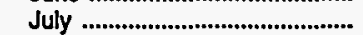 & 570.5 & - & - & 570.5 & 126.6 & - & - & 126.6 \\
\hline August & 583.8 & - & - & 583.8 & 125.5 & - & - & 125.5 \\
\hline 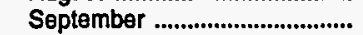 & 544.0 & - & - & 544.0 & $w$ & - & - & w \\
\hline 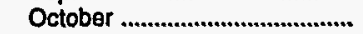 & 553.1 & - & - & 553.1 & 122.1 & - & - & 122.1 \\
\hline 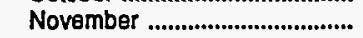 & 559.3 & - & - & 559.3 & 122.3 & - & - & 122.3 \\
\hline 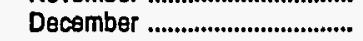 & 556.4 & - & - & 556.4 & 125.9 & - & - & 125.9 \\
\hline 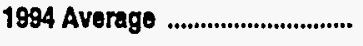 & 553.0 & - & - & 553.0 & 123.9 & - & - & 123.8 \\
\hline \multirow{2}{*}{\multicolumn{9}{|c|}{ Novada }} \\
\hline & & & & & & & & 139.3 \\
\hline 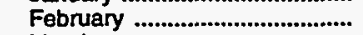 & 632.9 & 836.8 & - & 1.469 .7 & 73.8 & 77.3 & - & 151.1 \\
\hline March & $w$ & w & - & $1,556.4$ & 142.0 & - & - & 142.0 \\
\hline 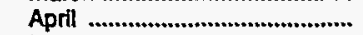 & w & $\mathbf{w}$ & - & $1,504.5$ & $w$ & $\mathbf{w}$ & - & 138.8 \\
\hline 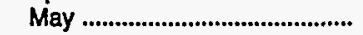 & w & w & - & $1,546.5$ & 143.6 & - & - & 143.6 \\
\hline June & w & w & - & $1,721.3$ & 161.6 & - & - & 161.6 \\
\hline 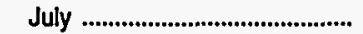 & w & $\mathbf{w}$ & - & $1,645.0$ & 167.4 & - & - & 167.4 \\
\hline August & w & w & - & $1,732.2$ & 171.3 & - & - & 171.3 \\
\hline 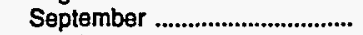 & $w$ & $\mathbf{w}$ & - & $1,652.4$ & 131.9 & 22.3 & - & 154.2 \\
\hline October & 560.5 & $1,110.6$ & - & $1,671.2$ & 39.4 & 103.1 & - & 142.5 \\
\hline 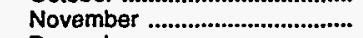 & $w$ & & - & $1,558.4$ & 38.4 & 102.9 & - & 141.3 \\
\hline 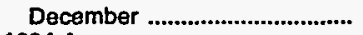 & $w$ & w & - & $1,498.6$ & 34.3 & 140.9 & - & 175.2 \\
\hline 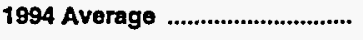 & $1,111.7$ & 469.9 & - & $1,581.6$ & 106.7 & 45.7 & - & 162.4 \\
\hline \multicolumn{9}{|l|}{ Oregon } \\
\hline 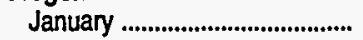 & $1,903.8$ & $1,355.8$ & - & $3,259.7$ & w & $w$ & - & $w$ \\
\hline 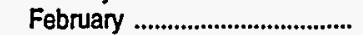 & $1,567.3$ & $1,398.5$ & - & $2,965.8$ & w & $w$ & - & $\ddot{w}$ \\
\hline 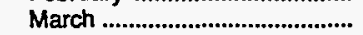 & W & w & - & $2,940.2$ & $w$ & $w$ & - & $\ddot{w}$ \\
\hline April & w & w & - & $2,943.6$ & 2.6 & - & - & 2.6 \\
\hline May ................................................... & $2,843.5$ & - & - & $2,843.5$ & $w$ & - & - & w \\
\hline 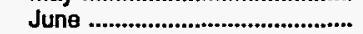 & $3,082.9$ & - & - & $3,082.9$ & 4.1 & - & - & 4.1 \\
\hline July & $3,164.3$ & - & - & $3,164.3$ & 4.7 & - & - & 4.7 \\
\hline August & w & w & - & $3,161.5$ & 4.8 & - & - & 4.8 \\
\hline 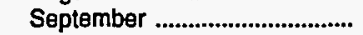 & $w$ & w & - & $3,008.1$ & 5.6 & - & - & 5.6 \\
\hline October & $2,488.9$ & 626.8 & - & $3,115.7$ & $w$ & $w$ & - & $w$ \\
\hline 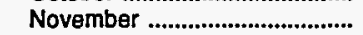 & $1,564.8$ & $1,490.7$ & - & $3,055.4$ & $w$ & $w$ & - & $\ddot{w}$ \\
\hline 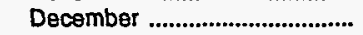 & $1,599.2$ & $1,442.6$ & - & $3,041.8$ & $w$ & 24.1 & - & $\ddot{w}$ \\
\hline 1994 Average ...................................... & $2,527.4$ & 522.1 & - & $3,049.5$ & 8.5 & 5.4 & - & 13.9 \\
\hline \multicolumn{9}{|l|}{ Washington } \\
\hline 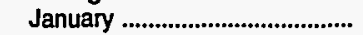 & $2,108.1$ & $3,272.5$ & - & $5,380.6$ & w & 5.5 & - & 8.3 \\
\hline 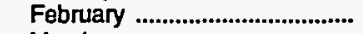 & $1,885.0$ & $3,616.7$ & - & $5,501.8$ & w & $\mathbf{w}$ & - & 8.9 \\
\hline 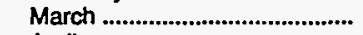 & $4,539.7$ & $1,103.4$ & - & $5,643.1$ & w & - & - & $w$ \\
\hline April & $w$ & w & - & $5,793.9$ & $w$ & - & - & 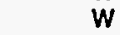 \\
\hline 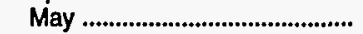 & w & w & - & $5,885.3$ & w & - & - & w \\
\hline 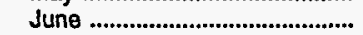 & $6,111.3$ & - & - & $6,111.3$ & $w$ & - & - & $w$ \\
\hline 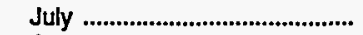 & $w$ & w & - & $6,159.7$ & $\mathbf{w}$ & - & - & w \\
\hline 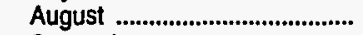 & $5,945.5$ & 143.0 & - & $6,088.5$ & W & - & - & w \\
\hline 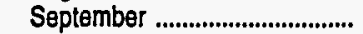 & $5,670.4$ & 359.9 & - & $6,030.2$ & W & W & - & 7.3 \\
\hline 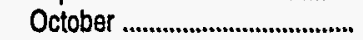 & $4,282.0$ & $1,661.0$ & - & $5,943.0$ & w & $\ddot{w}$ & - & $W$ \\
\hline 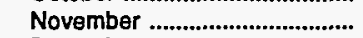 & $w$ & w & - & $5,713.8$ & $w$ & $w$ & - & 112.4 \\
\hline 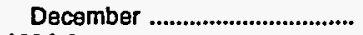 & $1,996.2$ & $3,463.2$ & - & $5,459.4$ & 31.1 & $\mathbf{w}$ & - & w \\
\hline 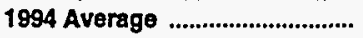 & $4,343.3$ & $1,467.3$ & - & $5,810.6$ & 12.2 & 18.3 & - & 30.5 \\
\hline
\end{tabular}

See footnotes at end of table. 
Table 48. Prime Suppller Sales Volumes of Motor Gasoline by Grade, Formulation, PAD District, and State

(Thousand Gallons per Day) - Continued

\begin{tabular}{|c|c|c|c|c|c|c|c|c|}
\hline \multirow{2}{*}{$\begin{array}{c}\text { Coographlo Aren } \\
\text { Month }\end{array}$} & \multicolumn{4}{|c|}{ Promlum } & \multicolumn{4}{|c|}{ All Grades } \\
\hline & Conventonal & Oxygenated & Roformulated & Total & Conventional & Oxygenated & Reformulated & Total \\
\hline \multicolumn{9}{|l|}{ Hawall } \\
\hline January ........................................ & 305.1 & - & - & 305.1 & 956.5 & - & - & 956.5 \\
\hline February ...................................... & $W$ & - & - & W & 924.7 & - & - & 924.7 \\
\hline 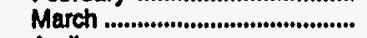 & 323.6 & - & - & 323.6 & $1,015.7$ & - & - & $1,015.7$ \\
\hline 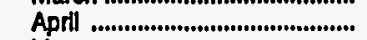 & 318.3 & - & - & 318.3 & 995.1 & - & - & 995.1 \\
\hline May ............................................ & 322.2 & - & - & 322.2 & $1,006.1$ & - & - & $1,006.1$ \\
\hline 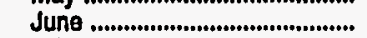 & 323.5 & - & - & 323.5 & $1,010.7$ & - & - & $1,010.7$ \\
\hline July ................................................. & 317.2 & - & - & 317.2 & $1,014.4$ & - & - & $1,014.4$ \\
\hline 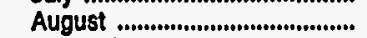 & 322.1 & - & - & 322.1 & $1,031.4$ & - & - & $1,031.4$ \\
\hline September ............................... & $w$ & - & - & $w$ & 975.2 & - & - & 975.2 \\
\hline October ......................................... & 312.5 & - & - & 312.5 & 987.7 & - & - & 987.7 \\
\hline November ................................... & 309.9 & - & - & 309.9 & 991.5 & - & - & 991.5 \\
\hline December ................................... & 322.0 & - & - & 322.0 & $1,004.3$ & - & - & $1,004.3$ \\
\hline 1094 Average ............................... & 316.4 & - & - & 316.4 & 993.3 & - & - & 993.3 \\
\hline \multicolumn{9}{|l|}{ Novada } \\
\hline January ....................................... & 61.7 & 211.5 & - & 273.2 & 551.2 & $1,277.0$ & - & $1,828.2$ \\
\hline 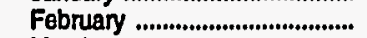 & 99.6 & 188.8 & - & 288.5 & 806.3 & $1,103.0$ & - & $1,909.3$ \\
\hline 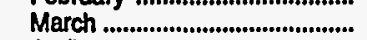 & 305.3 & 0.7 & - & 306.1 & $w$ & W & - & $2,004.5$ \\
\hline 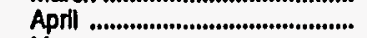 & $w$ & $w$ & - & 298.9 & w & w & - & $1,942.3$ \\
\hline 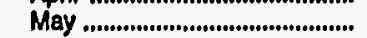 & 338.9 & - & - & 338.9 & $\ddot{w}$ & $\ddot{w}$ & - & $2,029.0$ \\
\hline Jung ............................................. & W & $W$ & - & 395.2 & $\mathbf{W}$ & 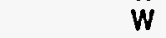 & - & $2,278.1$ \\
\hline July ................................................. & $W$ & $W$ & - & 390.4 & $w$ & $W$ & - & $2,202.8$ \\
\hline 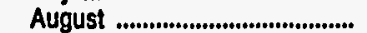 & 403.6 & - & - & 403.6 & $W$ & $\mathbf{W}$ & - & $2,307.2$ \\
\hline September .................................. & 278.0 & 113.1 & - & 391.1 & $w$ & $\mathbf{w}$ & - & $2,197.8$ \\
\hline 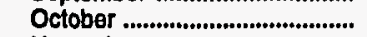 & 91.7 & 270.2 & - & 361.8 & 691.6 & $1,483.9$ & - & $2,175.5$ \\
\hline November .................................... & 87.1 & 246.4 & - & 333.5 & W & W & - & $2,033.1$ \\
\hline December .................................. & W & $W$ & - & 334.4 & $\mathbf{W}$ & W & - & $2,008.2$ \\
\hline 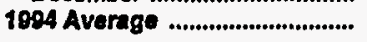 & 237.5 & 105.8 & - & 343.3 & $1,456.0$ & 621.3 & - & $2,077.3$ \\
\hline \multicolumn{9}{|l|}{ Oregon } \\
\hline 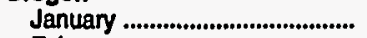 & 246.2 & 209.2 & - & 455.4 & $2,150.2$ & $1,565.9$ & - & $3,716.2$ \\
\hline 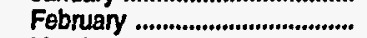 & $w$ & $W$ & - & W & $1,759.0$ & $1,633.0$ & - & $3,392.0$ \\
\hline 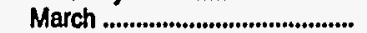 & 403.0 & $w$ & - & $W$ & $W$ & $W$ & - & $3,347.6$ \\
\hline 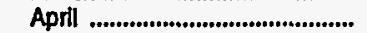 & $W$ & $w$ & - & 429.2 & $\ddot{w}$ & W & - & $3,375.3$ \\
\hline May ............................................ & $w$ & - & - & $\bar{w}$ & $3,268.5$ & - & - & $3,268.5$ \\
\hline 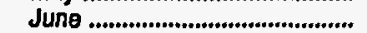 & 464.8 & - & - & 464.8 & $3,551.9$ & - & - & $3,551.9$ \\
\hline July ......................................... & 506.5 & - & - & 506.5 & $3,675.5$ & - & - & $3,675.5$ \\
\hline 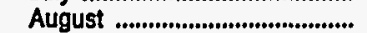 & W & $w$ & - & 511.1 & $W$ & $W$ & - & $3,677.5$ \\
\hline September ................................. & W & $w$ & - & 455.7 & $\ddot{w}$ & W & - & $3,469.3$ \\
\hline 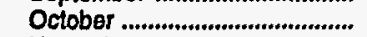 & w & w & - & $w$ & $2,936.6$ & 773.1 & - & $3,709.7$ \\
\hline November .................................... & $\ddot{W}$ & 285.6 & - & w & $W$ & $w$ & - & $3,641.8$ \\
\hline 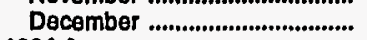 & w & 270.7 & - & $w$ & $1,863.3$ & $1,737.5$ & - & $3,600.7$ \\
\hline 1894 Avernge .............................. & 379.9 & 93.7 & 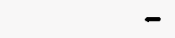 & 473.6 & $2,915.8$ & 621.2 & - & $\mathbf{3 , 5 3 7 . 0}$ \\
\hline \multicolumn{9}{|l|}{ Washington } \\
\hline 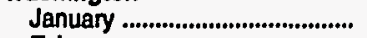 & 355.6 & 631.3 & - & 986.9 & $2,466.5$ & $3,909.3$ & - & $6,375.7$ \\
\hline 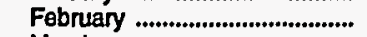 & $W$ & W & - & $1,033.9$ & $2,193.6$ & $4,351.0$ & - & $6,544.6$ \\
\hline 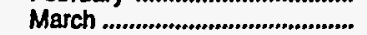 & W & 361.8 & - & $w$ & $5,267.1$ & $1,465.2$ & - & $6,732.3$ \\
\hline April & 865.2 & W & - & $w$ & $w$ & $W$ & - & $6,872.7$ \\
\hline 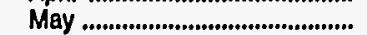 & $1,002.5$ & $\ddot{w}$ & - & W & w & $w$ & - & $6,954.5$ \\
\hline June ............................................. & $1,089.2$ & $w$ & - & $w$ & $\ddot{W}$ & W & - & $7,203.8$ \\
\hline July .............................................. & $1,116.2$ & $w$ & - & $w$ & w & w & - & $7,279.9$ \\
\hline 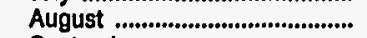 & $W$ & 14.6 & - & $\mathbf{W}$ & $7,047.3$ & 157.6 & - & $7,204.9$ \\
\hline September ................................. & W & $W$ & - & $1,071.0$ & $6,681.0$ & 427.6 & - & $7,108.6$ \\
\hline October ......................................... & W & W & - & & $5,026.0$ & $2,085.4$ & - & 7.111 .4 \\
\hline 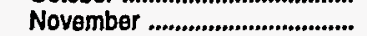 & 351.5 & 730.5 & - & $1,082.0$ & $2,649.1$ & $4,259.1$ & - & $6,908.2$ \\
\hline December ................................... & 326.7 & $W$ & - & W & $2,354.0$ & $4,260.1$ & - & $6,614.1$ \\
\hline 1984 Average ............................. & 747.9 & 322.0 & - & $1,069.9$ & $5,103.3$ & $1,807.6$ & - & $6,911.0$ \\
\hline
\end{tabular}

Dash (-) = No data reported.

$W=$ Withheld to avold disciosure of individual company data.

a Includes leaded gasoline data.

Note: Totals may not equal the sum of the components due to rounding.

Source: Energy Information Administration, Form ElA-782C, "Monthly Report of Prime Supplier Sales of Petroleum Products Sold for Local Consumption." 
Table 49. Prime Supplier Sales Volumes of Aviation Fuels, Propane, and Residual Fuel Oll by PAD District and State

(Thousand Gallons per Day)

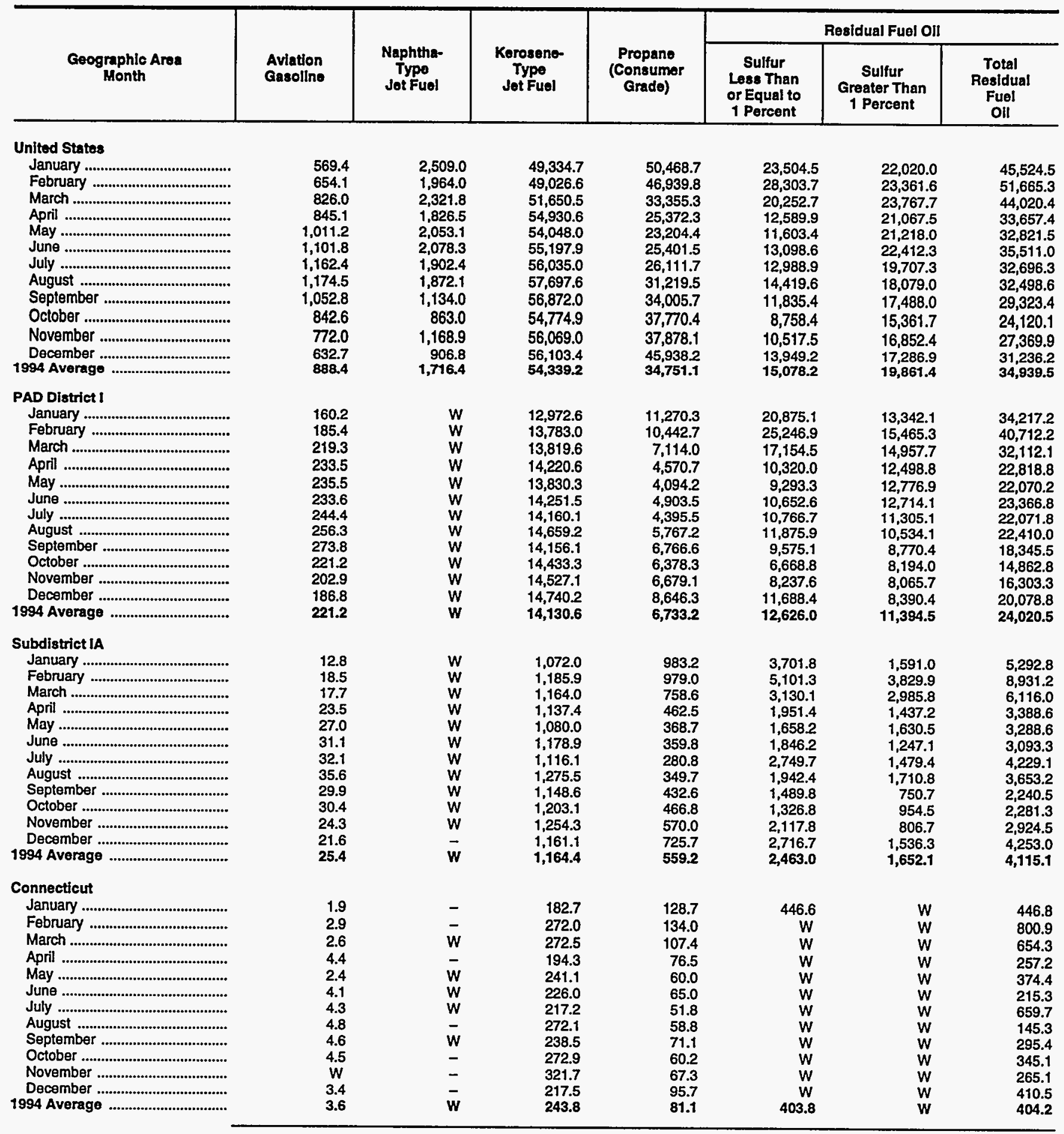

See tootnotes at end of table. 
Table 49. Prime Supplier Sales Volumes of Aviation Fuels, Propane, and Residual Fuel Oil by PAD District and State

(Thousand Gallons per Day) - Continued

\begin{tabular}{|c|c|c|c|c|c|c|c|}
\hline \multirow[b]{2}{*}{$\begin{array}{c}\text { Geographic Area } \\
\text { Month }\end{array}$} & \multirow[b]{2}{*}{$\begin{array}{l}\text { Aviation } \\
\text { Gasoline }\end{array}$} & \multirow[b]{2}{*}{$\begin{array}{l}\text { Naphtha- } \\
\text { Type } \\
\text { Jet Fuel }\end{array}$} & \multirow[b]{2}{*}{$\begin{array}{l}\text { Kerosene- } \\
\text { Type } \\
\text { Jet Fuel }\end{array}$} & \multirow[b]{2}{*}{$\begin{array}{l}\text { Propane } \\
\text { (Consumer } \\
\text { Grado) }\end{array}$} & \multicolumn{3}{|c|}{ Residual Fuel Oil } \\
\hline & & & & & $\begin{array}{c}\text { Sulfur } \\
\text { Less Than } \\
\text { or Equal to } \\
1 \text { Percent }\end{array}$ & $\begin{array}{c}\text { Sulfur } \\
\text { Greater Than } \\
1 \text { Percent }\end{array}$ & $\begin{array}{l}\text { Total } \\
\text { Residual } \\
\text { Fuel } \\
\text { Oll }\end{array}$ \\
\hline \multicolumn{8}{|l|}{ Malne } \\
\hline January ......................................... & $\mathbf{W}$ & - & 107.6 & 121.7 & 426.0 & 612.3 & $1,038.3$ \\
\hline 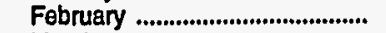 & $W$ & - & 111.0 & 104.2 & 456.1 & 918.1 & $1,374.2$ \\
\hline 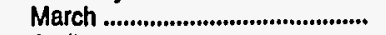 & $W$ & - & 71.7 & 76.2 & 352.7 & 776.6 & $1,129.4$ \\
\hline 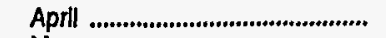 & $W$ & - & 73.8 & 52.3 & 350.0 & 556.2 & 906.2 \\
\hline 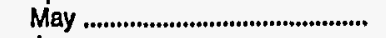 & $W$ & - & 69.1 & 51.9 & 209.4 & 669.1 & 878.4 \\
\hline 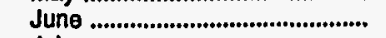 & $W$ & - & $W$ & 55.9 & 207.4 & 409.9 & 617.2 \\
\hline July .................................................. & $W$ & - & W & 45.0 & 598.6 & 492.3 & $1,090.9$ \\
\hline 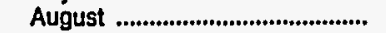 & $W$ & - & 105.5 & 51.1 & 598.5 & 708.9 & $1,307.4$ \\
\hline 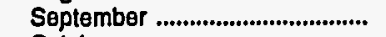 & $W$ & - & 89.5 & 58.8 & 318.3 & 491.8 & 810.1 \\
\hline 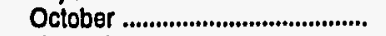 & $W$ & - & 96.6 & 62.8 & 198.9 & 473.1 & 672.0 \\
\hline November ........................................ & $W$ & - & 85.9 & 65.8 & 292.6 & 541.5 & 834.1 \\
\hline December ...................................... & $W$ & - & 101.9 & 95.1 & 563.6 & 801.9 & $1,365.5$ \\
\hline 1994 Average .................................. & $\mathbf{W}$ & - & 92.2 & 69.9 & 381.4 & 618.9 & $1,001.2$ \\
\hline \multicolumn{8}{|l|}{ Massachusetts } \\
\hline January ............................................ & 2.9 & $W$ & 693.3 & 231.6 & $2,552.8$ & 717.1 & $3,269.9$ \\
\hline 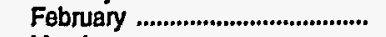 & 3.6 & W & 716.0 & 214.0 & $3,553.2$ & $1,869.0$ & $5,422.3$ \\
\hline 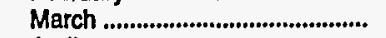 & $w$ & - & 737.5 & 161.4 & $1,775.6$ & $1,374.4$ & $3,150.0$ \\
\hline April & 5.9 & W & 762.2 & 104.9 & $1,147.3$ & 720.0 & $1,867.2$ \\
\hline 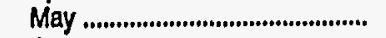 & 5.9 & $W$ & 692.0 & 97.1 & 883.9 & 418.9 & $1,302.8$ \\
\hline June ............................................... & 7.4 & $W$ & 772.1 & 94.7 & $1,323.4$ & 410.0 & $1,733.5$ \\
\hline 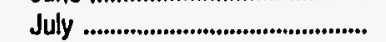 & 13.1 & - & 697.6 & 66.8 & W & $W$ & $1,962.4$ \\
\hline 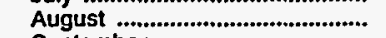 & 8.5 & $w$ & 802.9 & 98.8 & $1,105.0$ & 483.0 & $1,588.0$ \\
\hline 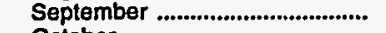 & 6.0 & $\bar{m}$ & 726.6 & 100.5 & 810.0 & 105.1 & 915.1 \\
\hline October & 7.3 & $w$ & 735.8 & 106.2 & 646.4 & 349.8 & 996.1 \\
\hline November ....................................... & 7.5 & W & 750.7 & 113.6 & $1,411.4$ & 97.4 & $1,508.8$ \\
\hline 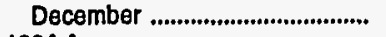 & 6.4 & - & 740.7 & 159.4 & $1,474.2$ & 548.4 & $2,022.6$ \\
\hline 1994 Average .................................... & 6.7 & $\boldsymbol{W}$ & 735.6 & 128.7 & $1,492.9$ & 632.0 & $2,125.0$ \\
\hline \multicolumn{8}{|l|}{ New Hampshiro } \\
\hline 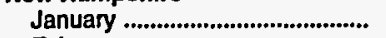 & W & - & 30.9 & 273.3 & 37.0 & 221.8 & 258.8 \\
\hline February ......................................... & 1.5 & - & 28.4 & 272.5 & 39.7 & $1,005.9$ & $1,045.6$ \\
\hline March ............................................... & 1.1 & - & 20.8 & 211.1 & 87.4 & 798.5 & 886.0 \\
\hline April & $w$ & - & 23.6 & 109.5 & 38.2 & 134.9 & 173.1 \\
\hline 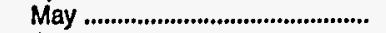 & 2.4 & - & 25.9 & 82.7 & 23.0 & 522.3 & 545.4 \\
\hline 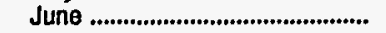 & 1.8 & - & 27.7 & 77.2 & 18.8 & 408.2 & 427.0 \\
\hline 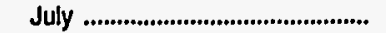 & 2.6 & - & 29.0 & 60.4 & 18.2 & 397.6 & 415.8 \\
\hline 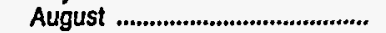 & 2.2 & - & 30.6 & 76.7 & 13.7 & 505.5 & 519.2 \\
\hline 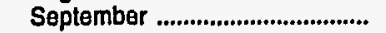 & 2.2 & - & 29.6 & 107.4 & 19.3 & 137.8 & 157.0 \\
\hline October & 2.5 & - & 31.2 & 134.4 & 70.6 & 111.1 & 181.7 \\
\hline November .................................... & 2.3 & - & 28.9 & 197.9 & 71.0 & 142.4 & 213.4 \\
\hline December ......................................... & $w$ & - & 33.6 & 203.9 & 126.0 & 158.1 & 284.0 \\
\hline 1994 Average & 1.9 & - & 28.4 & 149.9 & 47.1 & 375.4 & 422.5 \\
\hline \multicolumn{8}{|l|}{ Rhode lsland } \\
\hline 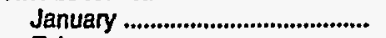 & $W$ & - & 45.1 & 61.3 & 236.3 & - & 236.3 \\
\hline 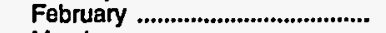 & $W$ & - & 49.7 & 65.9 & 246.1 & - & 246.1 \\
\hline March ............................................... & W & - & 48.7 & 49.2 & $W$ & $w$ & 258.5 \\
\hline April & $W$ & - & 48.7 & 25.8 & 155.9 & - & 155.9 \\
\hline 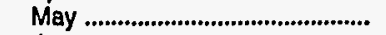 & W & - & 45.3 & 21.1 & 165.9 & - & 165.9 \\
\hline June & $W$ & - & 52.9 & 22.3 & 80.4 & - & 80.4 \\
\hline 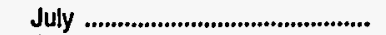 & W & - & 57.0 & 17.8 & 82.6 & - & 82.6 \\
\hline August & $W$ & - & 53.1 & 19.4 & 79.2 & - & 79.2 \\
\hline September .................................... & $\mathbf{W}$ & - & 54.8 & 21.8 & 42.2 & - & 42.2 \\
\hline 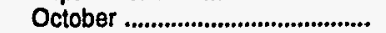 & $W$ & - & 56.5 & 20.4 & 63.2 & - & 63.2 \\
\hline 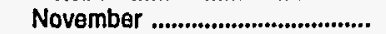 & W & - & 55.1 & 25.1 & 74.2 & - & 74.2 \\
\hline December ..................................... & $W$ & - & 55.3 & 33.9 & 137.1 & - & 137.1 \\
\hline 1994 Average ................................ & $\mathbf{W}$ & - & 51.8 & 31.8 & 134.5 & $\mathbf{W}$ & 134.7 \\
\hline
\end{tabular}

See footnotes at end of table. 
Table 49. Prime Supplier Sales Volumes of Aviation Fuels, Propane, and Residual Fuel Oil by PAD District and State

(Thousand Gallons per Day) - Continued

\begin{tabular}{|c|c|c|c|c|c|c|c|}
\hline \multirow[b]{2}{*}{$\begin{array}{l}\text { Geographic Aren } \\
\text { Month }\end{array}$} & \multirow[b]{2}{*}{$\begin{array}{l}\text { Aviation } \\
\text { Gusoline }\end{array}$} & \multirow[b]{2}{*}{$\begin{array}{l}\text { Naphthe- } \\
\text { Type } \\
\text { Jot Fuel }\end{array}$} & \multirow[b]{2}{*}{$\begin{array}{c}\text { Korosene } \\
\text { Type } \\
\text { Jet Fuel }\end{array}$} & \multirow[b]{2}{*}{$\begin{array}{c}\text { Propane } \\
\text { (Consumer } \\
\text { Crade) }\end{array}$} & \multicolumn{3}{|c|}{ Residual Fuel Oll } \\
\hline & & & & & $\begin{array}{l}\text { Sulfur } \\
\text { Lese Than } \\
\text { or Equal to } \\
1 \text { Percent }\end{array}$ & $\begin{array}{c}\text { Sulfur } \\
\text { Greater Than } \\
1 \text { Percent }\end{array}$ & $\begin{array}{l}\text { Total } \\
\text { Resldual } \\
\text { Fuel } \\
\text { Oll }\end{array}$ \\
\hline \multicolumn{8}{|l|}{ Vermont } \\
\hline January ........................................... & 1.2 & - & 12.4 & 166.6 & $w$ & 39.6 & 42.7 \\
\hline February .......................................... & 1.6 & - & 8.8 & 188.4 & W & W & 42.1 \\
\hline 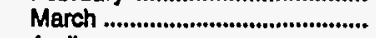 & $w$ & - & 12.9 & $\$ 53.2$ & $w$ & $w$ & 37.8 \\
\hline 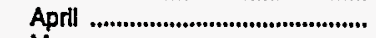 & 0.9 & - & 34.7 & 93.3 & $w$ & $w$ & 29.0 \\
\hline 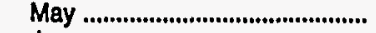 & 1.5 & - & 6.7 & 56.0 & $W$ & $W$ & 21.8 \\
\hline 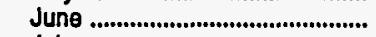 & 2.4 & - & $\vec{W}$ & 44.8 & $w$ & $\dddot{w}$ & 19.9 \\
\hline July .................................................. & 1.2 & - & $\ddot{w}$ & 39.0 & $w$ & $\dddot{W}$ & 17.6 \\
\hline 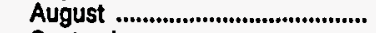 & 1.7 & - & 11.4 & 44.9 & $W$ & $W$ & 14.0 \\
\hline 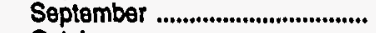 & 1.6 & - & 9.5 & 73.0 & $w$ & $W$ & 20.7 \\
\hline 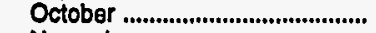 & 1.4 & - & 10.1 & 82.9 & $\mathbf{W}$ & $W$ & 23.1 \\
\hline 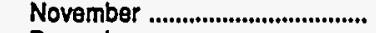 & 1.2 & - & 12.1 & 100.4 & $W$ & $W$ & 29.0 \\
\hline December ........................................ & $W$ & - & 12.2 & 137.8 & $W$ & $W$ & 33.3 \\
\hline 1984 Avernge ................................. & 1.3 & - & 12.7 & 97.8 & 3.3 & 24.2 & 27.6 \\
\hline \multicolumn{8}{|l|}{ Subdietrict IB } \\
\hline 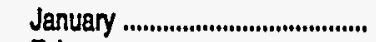 & 24.6 & $W$ & $6,072,4$ & $3,328.2$ & $14,857.0$ & $4,430.7$ & $19,287.8$ \\
\hline 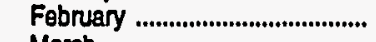 & 34.3 & $W$ & $6,249.0$ & $3,461.2$ & $18,355.6$ & $3,433.0$ & 21.788 .6 \\
\hline 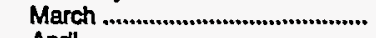 & 51.2 & W & $6,306.4$ & $2,667.6$ & $11,455.7$ & $4,531,1$ & $15,888,8$ \\
\hline Aprll & 58.0 & $W$ & $6,692.9$ & $1,865,1$ & $5,215.9$ & $2,630.1$ & $7,846.0$ \\
\hline 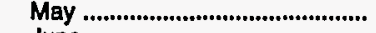 & 64.7 & $W$ & $6,691.0$ & $1,732.1$ & $3,850.0$ & $2,276.5$ & $6,126,5$ \\
\hline 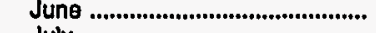 & 68.3 & $W$ & $7,104.9$ & $1,926.2$ & $6,472.0$ & $2,930.2$ & $9,402.1$ \\
\hline July & 74.3 & $W$ & $7,162.4$ & $1,510.4$ & $6,082.5$ & $2,261.3$ & $8,343.9$ \\
\hline 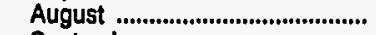 & 70.0 & $W$ & $7,148.5$ & $1,856.4$ & $7,589.4$ & $1,834.7$ & $0,424.1$ \\
\hline September ........................................ & 102.3 & W & $7,045.9$ & $2,191.0$ & $6,052.5$ & $2,111.7$ & $8,164.3$ \\
\hline 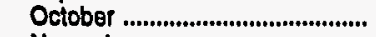 & 59.6 & $W$ & $7,069.6$ & $2,103.8$ & $4,435.5$ & $2,078.2$ & $6,613.6$ \\
\hline November ......................................... & 49.5 & $W$ & $7,271.3$ & $2,237,4$ & $4,819.8$ & $2,132.7$ & $6,852.6$ \\
\hline 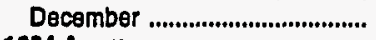 & 44.5 & $W$ & $7,083.8$ & $2,777.7$ & $7,024.5$ & $2,226.4$ & $0,250.8$ \\
\hline 1994 Average .................................. & 58.6 & w & 6,827.3 & $\mathbf{2 , 2 9 8 . 0}$ & $7,858.6$ & $2,737.2$ & $10,696.8$ \\
\hline \multicolumn{8}{|l|}{ Delaware } \\
\hline January ........................................... & $W$ & - & 4.6 & $w$ & 804.3 & 69.7 & 874.0 \\
\hline 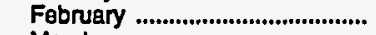 & $w$ & $W$ & 6.5 & 238.3 & 670.9 & $w$ & $\mathbf{W}$ \\
\hline 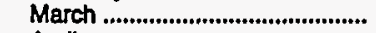 & 1.2 & - & 6.0 & $w$ & W & 137.5 & $w$ \\
\hline April & 1.4 & $w$ & 6.8 & 126.2 & $w$ & $w$ & $w$ \\
\hline 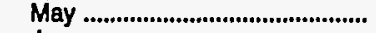 & $w$ & - & 6.9 & 95.2 & 153.6 & $w$ & $w$ \\
\hline 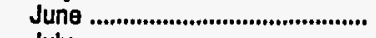 & $W$ & - & 5.3 & 142.4 & 700.8 & $w$ & W \\
\hline 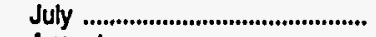 & $W$ & - & 7.1 & 118.2 & 328.0 & $W$ & $w$ \\
\hline 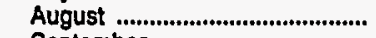 & $W$ & - & 5.5 & 150.5 & $w$ & $w$ & 605.7 \\
\hline 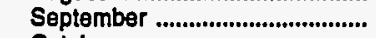 & $w$ & - & 7.1 & 201.6 & W & $w$ & 481.6 \\
\hline October .............................................. & 2.3 & - & 5.5 & 153.1 & $w$ & $w$ & W \\
\hline 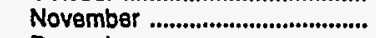 & $w$ & - & 6.7 & 114.0 & W & W & 575.2 \\
\hline December .................................... & 1.5 & $W$ & 6.1 & 229.9 & $w$ & $w$ & $\bar{W}$ \\
\hline 1984 Average ................................. & 1.4 & $\mathbf{W}$ & 6.2 & 183.4 & 465.4 & 94.7 & 560.0 \\
\hline \multicolumn{8}{|l|}{ District of Columbla } \\
\hline January ........................................ & - & - & - & - & $w$ & - & $w$ \\
\hline February ....................................... & $W$ & - & - & - & $W$ & - & $w$ \\
\hline 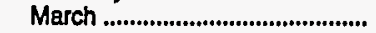 & - & - & - & $w$ & $\ddot{W}$ & - & $\ddot{W}$ \\
\hline 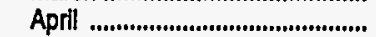 & - & - & - & - & $\ddot{W}$ & - & $w$ \\
\hline May ................................................. & $W$ & - & - & - & $w$ & - & $W$ \\
\hline June ............................................. & W & - & - & - & $w$ & - & $\dddot{w}$ \\
\hline July & - & - & - & - & $w$ & - & $\ddot{w}$ \\
\hline 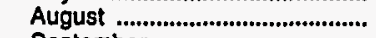 & $w$ & - & - & - & $w$ & - & $w$ \\
\hline September ....................................... & $W$ & - & - & $w$ & $W$ & - & $\ddot{W}$ \\
\hline 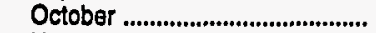 & - & - & - & - & $w$ & - & W \\
\hline November & W & - & - & - & W & - & W \\
\hline 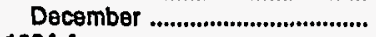 & - & - & - & - & W & - & W \\
\hline 1994 Avorage .................................. & $\mathbf{W}$ & - & - & $\mathbf{W}$ & $\mathbf{W}$ & - & $\ddot{W}$ \\
\hline
\end{tabular}

See footnotes at end of table. 
Table 49. Prime Supplier Sales Volumes of Aviation Fuels, Propane, and Residual Fuel OII by PAD District and State

(Thousand Gallons per Day) - Continued

\begin{tabular}{|c|c|c|c|c|c|c|c|}
\hline \multirow[b]{2}{*}{$\begin{array}{c}\text { Coographlo Area } \\
\text { Month }\end{array}$} & \multirow[b]{2}{*}{$\begin{array}{l}\text { Aviation } \\
\text { Gasoline }\end{array}$} & \multirow[b]{2}{*}{$\begin{array}{l}\text { Nephthe- } \\
\text { Type } \\
\text { Let Funl }\end{array}$} & \multirow[b]{2}{*}{$\begin{array}{c}\text { Korosene- } \\
\text { Type } \\
\text { Jot Fuel }\end{array}$} & \multirow[b]{2}{*}{$\begin{array}{l}\text { Propane } \\
\text { (Consumer } \\
\text { Crade) }\end{array}$} & \multicolumn{3}{|c|}{ Residual Fuel OIf } \\
\hline & & & & & $\begin{array}{l}\text { Sulfur } \\
\text { Loss Than } \\
\text { or Equal to } \\
1 \text { Percent }\end{array}$ & $\begin{array}{l}\text { Sulfur } \\
\text { Greater Than } \\
1 \text { Porcent }\end{array}$ & $\begin{array}{l}\text { Total } \\
\text { Resldual } \\
\text { Fuel } \\
\text { Oll }\end{array}$ \\
\hline 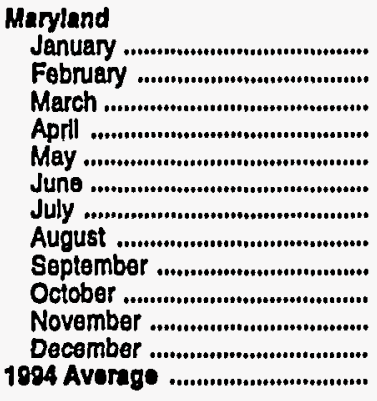 & $\begin{array}{l}2.4 \\
4.0 \\
7.7 \\
6.0 \\
6.7 \\
8.6 \\
W \\
9.9 \\
8.0 \\
7.2 \\
4.8 \\
6.1 \\
6.6\end{array}$ & $\begin{array}{l}\overline{-} \\
\overline{-} \\
\bar{w} \\
w \\
w \\
- \\
- \\
\overline{-} \\
\overline{-} \\
\bar{w}\end{array}$ & $\begin{array}{l}246.5 \\
282.3 \\
279.5 \\
361.7 \\
261.9 \\
302.8 \\
274.1 \\
326.3 \\
347.0 \\
294.9 \\
341.8 \\
356.5 \\
306.1\end{array}$ & $\begin{array}{r}229.6 \\
241.9 \\
213.9 \\
109.8 \\
74.3 \\
81.8 \\
54.8 \\
70.1 \\
W \\
114.5 \\
164.2 \\
222.8 \\
139.2\end{array}$ & $\begin{array}{r}517.4 \\
W \\
450.7 \\
W \\
W \\
W \\
W \\
W \\
W \\
W \\
W \\
W \\
340.8\end{array}$ & $\begin{array}{r}1,828.7 \\
W \\
1,223.7 \\
W \\
W \\
W \\
W \\
W \\
W \\
W \\
W \\
W \\
670.3\end{array}$ & $\begin{array}{r}2,346.1 \\
1,863.0 \\
1,674.4 \\
1,168.2 \\
484.0 \\
1,491.9 \\
1,274.2 \\
W \\
W \\
375.5 \\
W \\
524.5 \\
1,011.1\end{array}$ \\
\hline 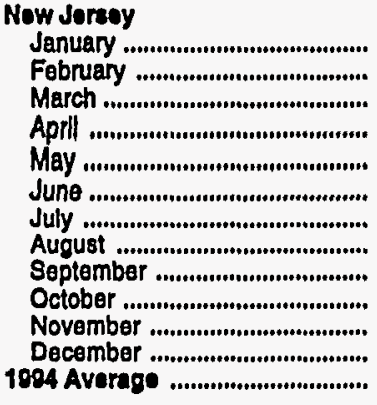 & $\begin{array}{r}7.2 \\
8.8 \\
14.3 \\
15.2 \\
24.3 \\
25.2 \\
19.7 \\
24.1 \\
52.7 \\
18.2 \\
21.3 \\
18.6 \\
20.8\end{array}$ & $\begin{array}{l}W \\
- \\
W \\
W \\
W \\
W \\
W \\
W \\
W \\
W \\
W \\
W \\
W\end{array}$ & $\begin{array}{l}4,355.5 \\
4,448.2 \\
4,464.5 \\
4,814.7 \\
4,768.4 \\
5,065.8 \\
5,235.5 \\
5,111.6 \\
4,880.9 \\
4,961.6 \\
5,080.6 \\
4,830.4 \\
4,837.3\end{array}$ & $\begin{array}{l}511.4 \\
571.8 \\
468.4 \\
264.6 \\
334.5 \\
377.9 \\
270.3 \\
360.8 \\
420.9 \\
285.5 \\
381.0 \\
474.5 \\
392.4\end{array}$ & $\begin{array}{r}3,595.9 \\
4,076.1 \\
2,183.5 \\
938.6 \\
697.0 \\
1,291.2 \\
1,061.8 \\
2,370.6 \\
1,188.7 \\
715.8 \\
821.2 \\
1,453.6 \\
1,686.8\end{array}$ & $\begin{array}{l}828.4 \\
488.3 \\
404.7 \\
570.1 \\
421.5 \\
418.5 \\
438.2 \\
358.0 \\
394.3 \\
456.6 \\
569.2 \\
789.1 \\
511.8\end{array}$ & $\begin{array}{l}4,424.3 \\
4,564.4 \\
2,588.2 \\
1,508.8 \\
1,118.4 \\
1,709.8 \\
1,500.0 \\
2,728.6 \\
1,581.0 \\
1,172.5 \\
1,390.4 \\
2,242.6 \\
2,198.7\end{array}$ \\
\hline 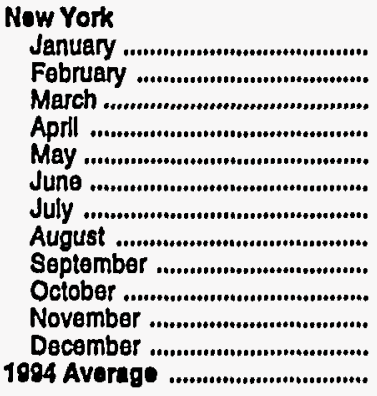 & $\begin{array}{r}8.4 \\
9.1 \\
11.1 \\
12.0 \\
12.3 \\
11.8 \\
30.3 \\
13.2 \\
17.0 \\
12.7 \\
9.7 \\
7.9 \\
13.0\end{array}$ & $\begin{array}{l}\bar{w} \\
\bar{w} \\
\overline{-} \\
\overline{-} \\
\overline{-} \\
\overline{-} \\
\bar{w}\end{array}$ & $\begin{array}{l}449.4 \\
436.8 \\
463.8 \\
430.8 \\
438.4 \\
541.5 \\
538.4 \\
550.2 \\
607.4 \\
590.0 \\
612.4 \\
622.4 \\
523.7\end{array}$ & $\begin{array}{r}1,027.9 \\
1,036.6 \\
802.0 \\
570.7 \\
444.4 \\
434.9 \\
343.9 \\
408.9 \\
508.8 \\
557.1 \\
609.0 \\
811.0 \\
627.3\end{array}$ & $\begin{array}{l}8,194.0 \\
9,661.0 \\
7,279.5 \\
2,754.9 \\
2,187.1 \\
3,191.8 \\
1,908.6 \\
3,109.8 \\
3,606.2 \\
2,427.2 \\
2,541.1 \\
4,012.8 \\
4,208.3\end{array}$ & $\begin{array}{r}1,042.2 \\
804.1 \\
2,071.0 \\
663.9 \\
742.9 \\
625.0 \\
418.1 \\
490.0 \\
768.4 \\
640.8 \\
603.1 \\
496.1 \\
781.6\end{array}$ & $\begin{array}{r}9,236.2 \\
10,465.2 \\
9,350.6 \\
3,418.8 \\
2,930.0 \\
3,816.9 \\
2,326.7 \\
3,599.8 \\
4,374.6 \\
3,068.0 \\
3,144.2 \\
4,508.9 \\
4,989.8\end{array}$ \\
\hline 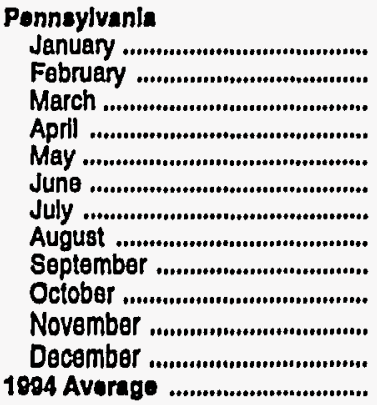 & $\begin{array}{r}6.1 \\
11.2 \\
16.9 \\
23.4 \\
19.4 \\
20.5 \\
15.7 \\
21.4 \\
22.9 \\
19.2 \\
12.1 \\
10.4 \\
16.6\end{array}$ & $\begin{array}{l}- \\
- \\
- \\
- \\
- \\
- \\
- \\
- \\
-\end{array}$ & $\begin{array}{l}1,016.4 \\
1,075.3 \\
1,092.5 \\
1,078.9 \\
1,217.4 \\
1,189.4 \\
1,109.3 \\
1,155.0 \\
1,193.4 \\
1,217.6 \\
1,229.8 \\
1,268.4 \\
1,154.0\end{array}$ & $\begin{array}{r}1,135.2 \\
1,372.7 \\
974.8 \\
793.8 \\
783.7 \\
889.1 \\
723.2 \\
866.1 \\
960.6 \\
993.6 \\
969.2 \\
1,039.5 \\
855.7\end{array}$ & $\begin{array}{r}1,613.8 \\
3,432.4 \\
760.4 \\
817.8 \\
561.4 \\
879.7 \\
2,289.2 \\
1,455.0 \\
655.6 \\
855.8 \\
832.0 \\
925.6 \\
1,243.7\end{array}$ & $\begin{array}{l}661.7 \\
749.3 \\
694.0 \\
673.5 \\
743.5 \\
668.7 \\
500.0 \\
687.6 \\
758.0 \\
722.1 \\
655.3 \\
640.3 \\
678.8\end{array}$ & $\begin{array}{l}2,275.6 \\
4,181.7 \\
1,454.4 \\
1,491.3 \\
1,305.0 \\
1,548.4 \\
2,789.2 \\
2,142.6 \\
1,413.5 \\
1,577.8 \\
1,487.3 \\
1,566.0 \\
1,922.6\end{array}$ \\
\hline
\end{tabular}

See footnotes at end of table. 
Table 49. Prime Supplier Sales Volumes of Aviation Fuels, Propane, and Residual Fuel Oil by PAD District and State

(Thousand Gallons per Day) - Continued

\begin{tabular}{|c|c|c|c|c|c|c|c|}
\hline \multirow[b]{2}{*}{$\begin{array}{l}\text { Geographic Area } \\
\text { Month }\end{array}$} & \multirow[b]{2}{*}{$\begin{array}{l}\text { Aviation } \\
\text { Gasoline }\end{array}$} & \multirow[b]{2}{*}{$\begin{array}{c}\text { Naphtha- } \\
\text { Typo } \\
\text { Jet Fuel }\end{array}$} & \multirow[b]{2}{*}{$\begin{array}{c}\text { Keroseno- } \\
\text { Typo } \\
\text { Jet Fuel }\end{array}$} & \multirow[b]{2}{*}{$\begin{array}{c}\text { Propane } \\
\text { (Consumer } \\
\text { Grade) }\end{array}$} & \multicolumn{3}{|c|}{ Residual Fuel Oll } \\
\hline & & & & & $\begin{array}{l}\text { Sulfur } \\
\text { Less Than } \\
\text { or Equal to } \\
1 \text { Percent }\end{array}$ & $\begin{array}{c}\text { Sulfur } \\
\text { Greater Than } \\
1 \text { Percent }\end{array}$ & $\begin{array}{l}\text { Total } \\
\text { Residual } \\
\text { Fuel } \\
\text { Ol] }\end{array}$ \\
\hline \multicolumn{8}{|l|}{ Subdistrict IC } \\
\hline 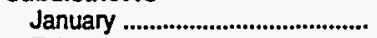 & 122.7 & - & $5,828.3$ & $6,958.9$ & $2,316.3$ & $7,320.4$ & $9,636.6$ \\
\hline 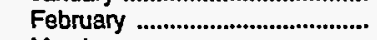 & 132.6 & - & $6,348.0$ & $6,002.5$ & $1,790.0$ & $8,202.4$ & $9,992.4$ \\
\hline 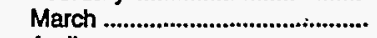 & 150.3 & - & $6,349.2$ & $3,687.8$ & $2,568.6$ & $7,440.8$ & $10,009.4$ \\
\hline April & 152.0 & - & $6,390.3$ & $2,243.2$ & $3,152.7$ & $8,431.5$ & $11,584.2$ \\
\hline May ................................................... & 143.9 & - & $6,059.2$ & $1,993.4$ & $3,785.1$ & $8,870.0$ & $12,655.1$ \\
\hline June & 134.1 & - & $5,967.7$ & $2,617.5$ & $2,334.5$ & $8,536.9$ & $10,871.4$ \\
\hline July & 138.0 & - & $5,881.6$ & $2,604.4$ & $1,934.5$ & $7,564.4$ & $9,498.9$ \\
\hline August & 150.7 & - & $6,235.2$ & $3,561.1$ & $2,344.1$ & $6,988.6$ & $9,332.7$ \\
\hline 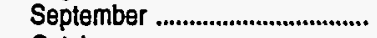 & 141.6 & $W$ & $5,961.7$ & $4,143.1$ & $2,032.8$ & $5,907.9$ & $7,940.7$ \\
\hline 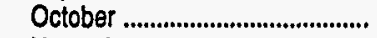 & 131.2 & - & $6,160.5$ & $3,807.6$ & 906.6 & $5,161.3$ & $6,067.9$ \\
\hline 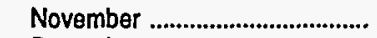 & 129.1 & $W$ & $6,001.5$ & $3,871.7$ & $1,300.0$ & $5,126.3$ & $6,426.3$ \\
\hline $\begin{array}{l}\text { December } \\
1994 \text { Average }\end{array}$ & $\begin{array}{l}120.7 \\
137.3\end{array}$ & $\begin{array}{l}\mathbf{w} \\
\mathbf{w}\end{array}$ & $\begin{array}{l}6,495.3 \\
6,138.8\end{array}$ & $\begin{array}{l}5,142.9 \\
3,876.1\end{array}$ & $\begin{array}{l}1,947.2 \\
2,204.4\end{array}$ & $\begin{array}{l}4,627.8 \\
7,005.2\end{array}$ & $\begin{array}{l}6,575.0 \\
9,209.6\end{array}$ \\
\hline \multicolumn{8}{|l|}{ Florida } \\
\hline 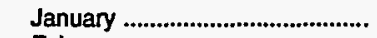 & 68.9 & - & $2,931.0$ & $1,474.5$ & $2,201.0$ & $4,029.7$ & $6,230.7$ \\
\hline 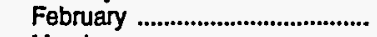 & 65.6 & - & $3,252.2$ & $1,134.8$ & $1,203.8$ & $4,517.4$ & $5,721.1$ \\
\hline 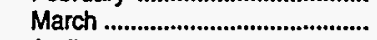 & 82.2 & - & $3,112.3$ & 907.4 & $2,174.2$ & $5,018.6$ & $7,192.8$ \\
\hline April & 86.3 & - & $2,997.1$ & 758.9 & $3,093.6$ & $6,444.2$ & $9,537.8$ \\
\hline 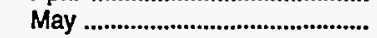 & 72.7 & - & $2,715.9$ & 658.8 & $3,706.4$ & $6,903.7$ & $10,610.1$ \\
\hline 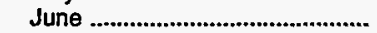 & 65.5 & - & $2,649.7$ & 711.1 & $2,228.0$ & $6,503.4$ & $8,731.4$ \\
\hline 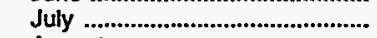 & 65.3 & - & $2,575.0$ & 641.8 & $1,826.5$ & $5,946.5$ & $7,773.0$ \\
\hline 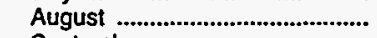 & 68.4 & - & $2,847.7$ & 636.0 & $2,088.8$ & $4,975.9$ & $7,064.6$ \\
\hline 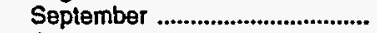 & 67.3 & $\rightarrow$ & $2,282.2$ & 776.9 & $1,951.0$ & $4,270.3$ & $6,221.3$ \\
\hline 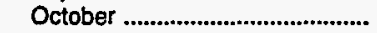 & 61.8 & - & $2,606.9$ & 772.0 & $W$ & W & $3,453.1$ \\
\hline 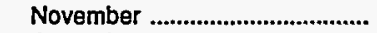 & 62.2 & - & $2,567.8$ & $1,007.4$ & $1,160.9$ & $3,275.5$ & $4,436.3$ \\
\hline December ...................................... & 67.8 & - & $3,140.3$ & $1,140.4$ & $1,825.7$ & $2,773.5$ & $4,599.3$ \\
\hline 1994 Average & 69.5 & - & $2,804.8$ & 883.7 & $1,988.3$ & $4,813.4$ & $6,801.7$ \\
\hline \multicolumn{8}{|l|}{ Georgia } \\
\hline 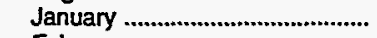 & 15.5 & - & $1,450.0$ & $1,661.0$ & $W$ & 718.5 & 719.5 \\
\hline 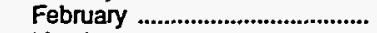 & 16.3 & - & $1,722.9$ & $1,283.6$ & $\mathbf{W}$ & W & 621.7 \\
\hline March & 21.9 & - & $1,479.7$ & 656.5 & - & 470.6 & 470.6 \\
\hline April & 21.5 & - & $1,656.8$ & 402.1 & - & 403.7 & 403.7 \\
\hline 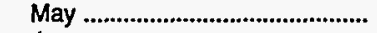 & 19.6 & - & $1,633.3$ & 350.9 & - & 450.8 & 450.8 \\
\hline 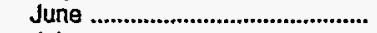 & 25.1 & - & $1,529.5$ & 430.7 & - & 575.9 & 575.9 \\
\hline 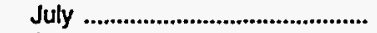 & 27.8 & - & $1,684.2$ & 532.6 & - & 390.1 & 390.1 \\
\hline 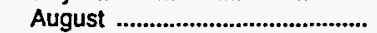 & 30.0 & - & $1,660.0$ & 670.4 & - & 356.3 & 356.3 \\
\hline 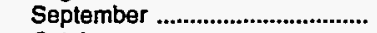 & 25.8 & W & $1,845.5$ & 758.7 & - & 401.7 & 401.7 \\
\hline October & 24.2 & - & $1,775.4$ & 802.0 & - & $\mathbf{3 7 8 . 8}$ & 378.8 \\
\hline November ...................................... & 22.6 & $W$ & $1,783.0$ & 822.1 & - & 394.9 & 394.9 \\
\hline December & 18.6 & $W$ & $1,711.6$ & $1,170.4$ & - & 411.8 & 411.8 \\
\hline 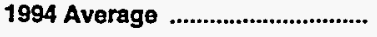 & 22.4 & $\mathbf{W}$ & $1,660.0$ & 793.2 & $\mathbf{W}$ & 463.4 & 463.6 \\
\hline \multicolumn{8}{|l|}{ North Carolina } \\
\hline 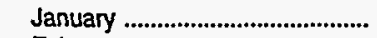 & 13.7 & - & 304.6 & $1,803.2$ & $W$ & 995.9 & $1,052.0$ \\
\hline 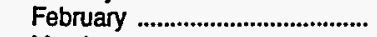 & 13.1 & - & 273.8 & $1,686.6$ & $W$ & $W$ & $1,067.5$ \\
\hline 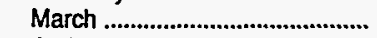 & 19.2 & - & 426.7 & 949.5 & $\ddot{W}$ & $w$ & 818.8 \\
\hline April & 17.3 & - & 379.2 & 474.5 & $W$ & $w$ & 660.6 \\
\hline May & 20.7 & - & 348.0 & 439.6 & $W$ & W & 614.7 \\
\hline 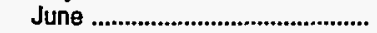 & 19.3 & - & 311.8 & 569.1 & $W$ & $w$ & 565.2 \\
\hline 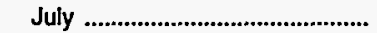 & 18.4 & - & 361.1 & 720.4 & $W$ & $w$ & 520.6 \\
\hline 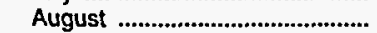 & 22.9 & - & 393.4 & $1,271.7$ & W & $w$ & 561.6 \\
\hline 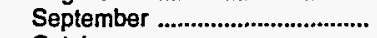 & 20.0 & - & 469.7 & $1,464.5$ & 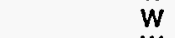 & $w$ & 561.0 \\
\hline 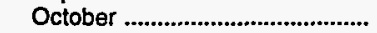 & 16.7 & - & 393.6 & $1,153.2$ & $W$ & W & 585.9 \\
\hline 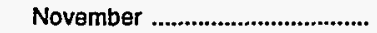 & 18.3 & - & 399.2 & 961.8 & $W$ & $w$ & 753.6 \\
\hline 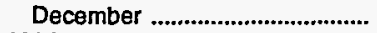 & 15.1 & - & 467.8 & $1,349.6$ & W & $W$ & 686.5 \\
\hline 1994 Average & 17.9 & - & 378.1 & $1,067.5$ & W & 671.8 & 701.8 \\
\hline
\end{tabular}

See footnotes at end of table. 
Table 49. Prime Supplier Sales Volumes of Aviation Fuels, Propane, and Residual Fuel OII by PAD Distrlet and State

(Thousand Gallons per Day) - Continued

\begin{tabular}{|c|c|c|c|c|c|c|c|}
\hline \multirow[b]{2}{*}{ monul } & \multirow[b]{2}{*}{$\begin{array}{l}\text { Aviation } \\
\text { Caseoline }\end{array}$} & \multirow[b]{2}{*}{$\begin{array}{c}\text { Nephthe- } \\
\text { Type } \\
\text { Jet Fus }\end{array}$} & \multirow[b]{2}{*}{$\begin{array}{c}\text { Kerosene- } \\
\text { Typy } \\
\text { Jet Fust }\end{array}$} & \multirow[b]{2}{*}{$\begin{array}{l}\text { Propane } \\
\text { (Consumer } \\
\text { Crade) }\end{array}$} & \multicolumn{3}{|c|}{ Residual Fuel Oil } \\
\hline & & & & & $\begin{array}{l}\text { Sulfur } \\
\text { Lese Than } \\
\text { or Equal to } \\
1 \text { Percent }\end{array}$ & $\begin{array}{l}\text { Sulfur } \\
\text { Greater Than } \\
1 \text { Percent }\end{array}$ & $\begin{array}{c}\text { Total } \\
\text { Residual } \\
\text { Fuel } \\
\text { Oll }\end{array}$ \\
\hline
\end{tabular}

South Garolina

January

February

March .................................................

Aprll

May

(1)

July

August ..........................................

Seplember

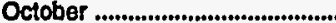

November

December

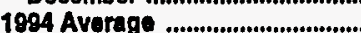

Virginin

January ...........................................

February

March ..............................................

April ..................................................

May

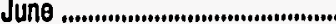

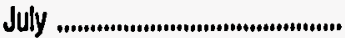

August

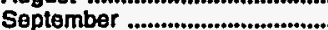

October.

November .........................................

December

1994 Average

West Virginla

January.

Fobruary

March

April

May

June

July

August

October .

November

December

1994 Average

PAD District II

January.

February ..........................................

March .

April

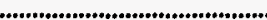

May

June

July

August

September

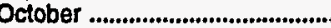

November

December

1994 Avorage

$W$
9.2
$W$
11.8
11.5
$W$
$W$
10.0
9.9
$W$
9.1
8.0
10.1

$\begin{array}{lr}- & 86.9 \\ - & 86.6 \\ - & 102.0 \\ - & 109.5 \\ - & 110.2 \\ - & 101.6 \\ - & 102.4 \\ - & 108.0 \\ - & 104.3 \\ - & 107.5 \\ - & 107.6 \\ - & 101.2 \\ - & 102.4\end{array}$

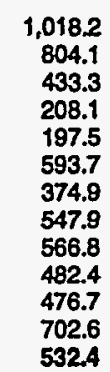

16.0

25.3

12.5

12.7

14.7

11.2

12.3

14.9

15.4

15.0

13.4
8.5

14.2

$\begin{array}{lr}- & 1,041.1 \\ - & 999.2 \\ - & 1,211.8 \\ - & 1,228.7 \\ - & 1,234.8 \\ - & 1,351.2 \\ - & 1,141.5 \\ - & 1,207.0 \\ - & 1,239.4 \\ - & 1,258.9 \\ - & 1,130.1 \\ - & 1,057.9 \\ - & 1,175.9\end{array}$

899.6
974.4

653.1

354.4

303.2

265.1

291.7

375.7

507.6

529.4

530.1

684.4

528.3

$\begin{array}{ll}- & 14.7 \\ - & 13.4 \\ - & 16.7 \\ - & 19.0 \\ - & 17.0 \\ - & 23.9 \\ - & 17.3 \\ - & 19.1 \\ - & 20.6 \\ - & 18.3 \\ - & 13.7 \\ - & 16.5 \\ - & 17.5\end{array}$

102.3

119.0

88.2

45.3

43.4

47.8

42.9

59.5

68.7
68.6

73.5

95.5

71.0

$\begin{array}{lll}644.4 & 8,615.1 & 19,901.1\end{array}$

717.6

779.5

626.2

723.6

585.2

672.7

444.8

341.9

357.0

267.4

572.9

$8,896.5$

$9,311.0$

$9,794.6$

$9,256.4$

9,706.1

$9,450.7$

$10,095.1$

$9,575.3$

$\mathbf{9 , 7 9 8 . 3}$

$10,024.0$

$10,205.4$

$9,563.4$

$18,069.5$

$10,955.5$

$7,728.1$

$6,214.2$

$6,739.8$

$7,041.6$

$9,516.4$

$10,412.5$

$15,310.8$

$13,662.0$

$15,953.4$

$11,764.1$

228.3

$\begin{array}{ll}w & w \\ w & w \\ w & w \\ w & w \\ w & w \\ w & w \\ w & w \\ w & w \\ w & w \\ w & w \\ w & w \\ w & w \\ w & w\end{array}$

$W$
$W$
$W$
$W$
$W$
$W$
$W$
$W$
$W$
$W$
$W$
$W$
$W$

27.2
$W$
331.8
17.9
14.0
40.6
28.1
195.8
29.1
$W$
43.2
29.1
144.0

$\begin{array}{rr}842.7 & 869.9 \\ W & 1,861.9 \\ 745.6 & 1,077.5 \\ 710.8 & 728.7 \\ 690.4 & 704.4 \\ 620.7 & 661.4 \\ 580.1 & 608.2 \\ 910.0 & 1,105.8 \\ 442.1 & 471.2 \\ W & 1,327.9 \\ 450.0 & 493.2 \\ 483.0 & 512.1 \\ 719.5 & 863.4\end{array}$

See footnotes at end of table. 
Table 49. Prime Supplier Sales Volumes of Aviation Fuels, Propane, and Residual Fuel OII by PAD District and State

(Thousand Gallons per Day) - Continued

\begin{tabular}{|c|c|c|c|c|c|c|c|}
\hline \multirow[b]{2}{*}{$\begin{array}{l}\text { Geographic Area } \\
\text { Month }\end{array}$} & \multirow[b]{2}{*}{$\begin{array}{l}\text { Aviation } \\
\text { Gasollne }\end{array}$} & \multirow[b]{2}{*}{$\begin{array}{l}\text { Naphtha- } \\
\text { Typo } \\
\text { Jaf Fual }\end{array}$} & \multirow[b]{2}{*}{$\begin{array}{l}\text { Korosono- } \\
\text { Typo } \\
\text { Jot Fuol }\end{array}$} & \multirow[b]{2}{*}{$\begin{array}{c}\text { Propane } \\
\text { (Conaumer } \\
\text { Grado) }\end{array}$} & \multicolumn{3}{|c|}{ Rosidual Fual Oll } \\
\hline & & & & & $\begin{array}{l}\text { Sulfur } \\
\text { Lose Than } \\
\text { or Equal to } \\
\text { I Porcent }\end{array}$ & $\begin{array}{l}\text { Sulfur } \\
\text { Greator Than } \\
1 \text { Percent }\end{array}$ & $\begin{array}{l}\text { Total } \\
\text { Residual } \\
\text { Fuel } \\
\text { Oll }\end{array}$ \\
\hline \multicolumn{8}{|l|}{ Illinois } \\
\hline 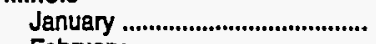 & $w$ & - & 856.3 & $2,256.5$ & $w$ & $w$ & 37.1 \\
\hline 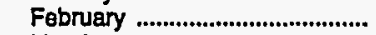 & w & - & 808.0 & $1,978.5$ & $\ddot{w}$ & - & $w$ \\
\hline March & $w$ & w & 860.1 & $1,427.8$ & $\ddot{w}$ & - & $\ddot{w}$ \\
\hline 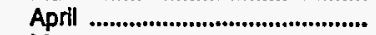 & w & - & 897.4 & 816.4 & $\ddot{w}$ & w & $\ddot{w}$ \\
\hline May & w & - & 900.9 & 851.5 & W & $w$ & 49.7 \\
\hline 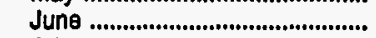 & $\ddot{w}$ & - & $1,007.4$ & 772.1 & $\ddot{w}$ & $w$ & 246.3 \\
\hline 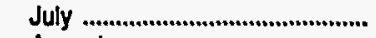 & w & w & 987.7 & 764.2 & $\ddot{w}$ & $w$ & 280.1 \\
\hline 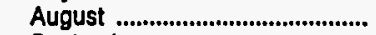 & w & $w$ & $1,050.8$ & $1,283.2$ & $w$ & $\ddot{W}$ & 56.7 \\
\hline 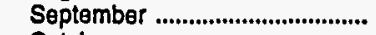 & $w$ & NA & $1,010.7$ & $1,226.3$ & NA & W & $w$ \\
\hline 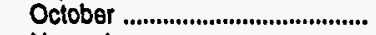 & W & - & 964.4 & $2,138.5$ & W & W & $w$ \\
\hline 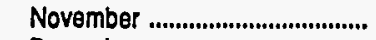 & $W$ & - & 952.4 & $1,568.8$ & - & 203.1 & 203.1 \\
\hline 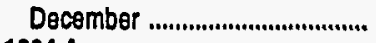 & $W$ & $W$ & 917.2 & $1,801.6$ & $W$ & W & $w$ \\
\hline 1984 Average ................................. & $w$ & w & 935.1 & $1,405.8$ & $\mathbf{w}$ & 63.2 & 90.2 \\
\hline \multicolumn{8}{|l|}{ Indlane } \\
\hline 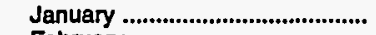 & 11.7 & w & $1,532.4$ & $1,335.9$ & 11.6 & 168.8 & 178.5 \\
\hline 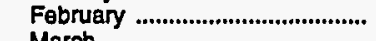 & 18.4 & $W$ & $1,394.9$ & 1.056 .5 & $w$ & w & 52.5 \\
\hline 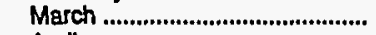 & 17.4 & w & $1,643.5$ & 726.1 & $\mathbf{w}$ & $\dot{w}$ & 38.2 \\
\hline April & 20.0 & w & $1,673.2$ & 465.0 & W & $w$ & w \\
\hline May & 21.7 & w & $1,622.6$ & 379.0 & W & $\mathbf{W}$ & w \\
\hline June & 25.0 & w & $1,759.7$ & 373.2 & w & $\ddot{w}$ & $\dddot{w}$ \\
\hline July & 21.3 & W & $1,749.1$ & 611.6 & w & $\ddot{w}$ & $\ddot{w}$ \\
\hline 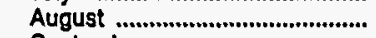 & 20.4 & $\mathbf{w}$ & $1,750.6$ & 630.5 & $\mathbf{w}$ & $\mathbf{w}$ & 55.3 \\
\hline 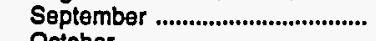 & 21.7 & NA & $1,893.8$ & 738.1 & NA & $\mathbf{w}$ & $w$ \\
\hline 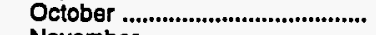 & 23.4 & w & $1,764.9$ & $1,298.6$ & w & $\mathbf{w}$ & 24.8 \\
\hline 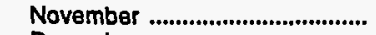 & 18.0 & $\mathbf{w}$ & $9,727.3$ & $1,131.5$ & $w$ & $w$ & 22.9 \\
\hline Decomber ............................................ & 16.7 & $W$ & $1,978.8$ & $1,175.0$ & W & $w$ & $W$ \\
\hline 1894 Avorage ...................................... & 19.6 & $\mathbf{W}$ & $1,709.5$ & 826.3 & 9.1 & 48.8 & 57.8 \\
\hline \multicolumn{8}{|l|}{ lowa } \\
\hline 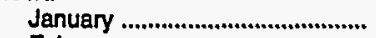 & 4.3 & w & 64.6 & $1,612.6$ & - & $w$ & w \\
\hline 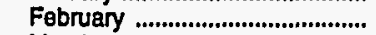 & 8.1 & $w$ & 68.6 & $1,308.9$ & - & 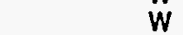 & $w$ \\
\hline March & 8.3 & w & 71.2 & 689.5 & - & $\ddot{w}$ & $w$ \\
\hline 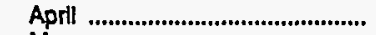 & 8.8 & $\mathbf{w}$ & 67.5 & 455.7 & - & - & - \\
\hline 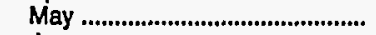 & 12.5 & $w$ & 65.8 & 268.7 & - & - & - \\
\hline 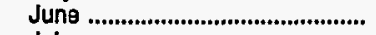 & 13.9 & w & 75.5 & 418.6 & - & $w$ & w \\
\hline 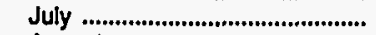 & 14.9 & w & 67.2 & 443.2 & - & $w$ & $w$ \\
\hline August & 15.8 & w & 76.4 & 768.5 & - & - & - \\
\hline September .................................... & 13.3 & w & 72.4 & 900.8 & - & - & - \\
\hline 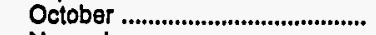 & 7.4 & w & 73.0 & $1,986.4$ & - & - & - \\
\hline 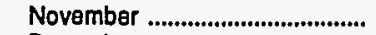 & 8.4 & - & 148.3 & $1,120.8$ & - & - & - \\
\hline 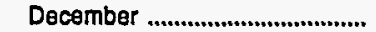 & 7.2 & - & 106.7 & $1,250.0$ & - & - & _ \\
\hline 1994 Average ........................................ & 10.3 & $\mathbf{w}$ & 79.7 & 934.4 & - & $\bar{w}$ & $w$ \\
\hline \multicolumn{8}{|l|}{ Kansas } \\
\hline 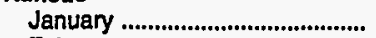 & 7.5 & w & 126.5 & $2,116.8$ & - & - & - \\
\hline 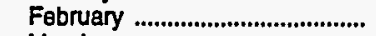 & 10.2 & $w$ & 135.6 & $2,077.3$ & - & - & - \\
\hline 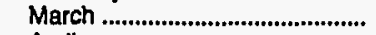 & 15.5 & w & 82.1 & $1,290.7$ & - & - & - \\
\hline Aprll & 17.5 & w & 109.4 & $1,512.9$ & - & - & - \\
\hline May & 18.1 & w & 119.5 & $1,149.5$ & - & - & - \\
\hline June & 18.3 & $W$ & 120.5 & $1,450.3$ & - & - & - \\
\hline 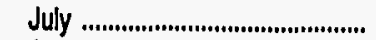 & 22.1 & $W$ & 112.0 & $1,542.4$ & - & - & - \\
\hline 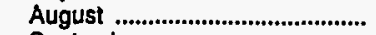 & 15.9 & $\mathbf{w}$ & 110.8 & $1,478.9$ & - & - & - \\
\hline 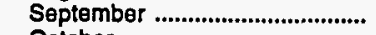 & 9.0 & w & 100.4 & $1,351,5$ & - & - & - \\
\hline 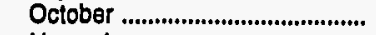 & 12.1 & W & $W$ & $1,424.5$ & - & $\mathbf{w}$ & w \\
\hline 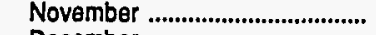 & 9.9 & - & 138.5 & $1,597.2$ & - & - & - \\
\hline 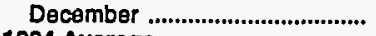 & 7.7 & - & 234.1 & $1,616.8$ & w & - & w \\
\hline 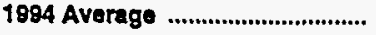 & 13.7 & $\mathbf{w}$ & 130.1 & $1,547.2$ & $\mathbf{w}$ & $\mathbf{w}$ & $\ddot{w}$ \\
\hline
\end{tabular}

Seo footnotes at end of table. 
Table 49. Prime Supplier Sales Volumes of Aviation Fuels, Propane, and Residual Fuel Oll by PAD District and State

(Thousand Gallons per Day) - Continued

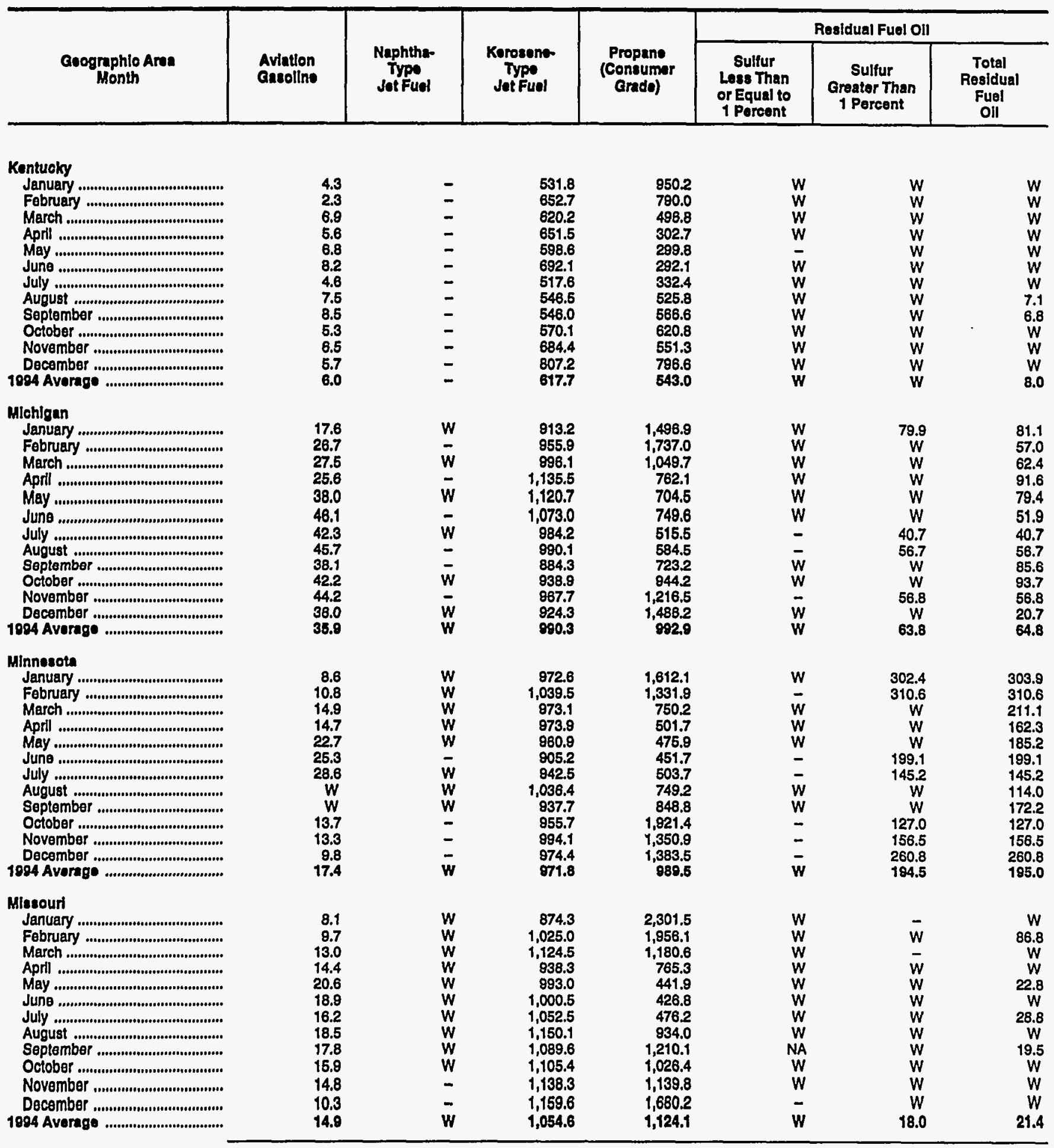

See footnotes at end of table. 
Table 49. Prime Supplier Sales Volumes of Aviation Fuels, Propane, and Residual Fuel Oil by PAD District and State

(Thousand Gallons per Day) - Continued

\begin{tabular}{|c|c|c|c|c|c|c|c|}
\hline \multirow[b]{2}{*}{$\begin{array}{c}\text { Geographic Area } \\
\text { Month }\end{array}$} & \multirow[b]{2}{*}{$\begin{array}{l}\text { Aviation } \\
\text { Gasoline }\end{array}$} & \multirow[b]{2}{*}{$\begin{array}{l}\text { Naphtha- } \\
\text { Type } \\
\text { Jot Fuel }\end{array}$} & \multirow[b]{2}{*}{$\begin{array}{c}\text { Keroseno- } \\
\text { Type } \\
\text { Jot Fuel }\end{array}$} & \multirow[b]{2}{*}{$\begin{array}{c}\text { Propane } \\
\text { (Consumer } \\
\text { Crade) }\end{array}$} & \multicolumn{3}{|c|}{ Residual Fuol Oil } \\
\hline & & & & & $\begin{array}{l}\text { Sulfur } \\
\text { Less Than } \\
\text { or Equal to } \\
1 \text { Percent }\end{array}$ & $\begin{array}{l}\text { Sulfur } \\
\text { Greater Than } \\
1 \text { Porcent }\end{array}$ & $\begin{array}{c}\text { Total } \\
\text { Residual } \\
\text { Fuel } \\
\text { Oll }\end{array}$ \\
\hline
\end{tabular}

Nebraska

\begin{tabular}{|c|c|c|c|c|c|c|c|}
\hline \\
\hline 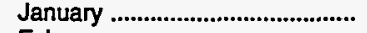 & 4.7 & $W$ & 77.1 & 647.6 & - & $w$ & $\mathbf{W}$ \\
\hline 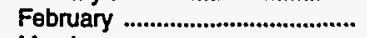 & 4.4 & $W$ & 91.5 & 622.5 & - & $w$ & $w$ \\
\hline March & 6.5 & $\mathbf{W}$ & 83.7 & 315.5 & - & $w$ & $w$ \\
\hline April & 6.0 & $W$ & 78.3 & 182.3 & - & - & - \\
\hline 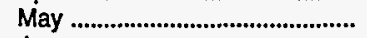 & 6.5 & $W$ & 83.3 & 149.6 & - & - & - \\
\hline 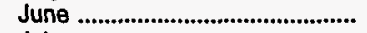 & 9.1 & $W$ & 92.1 & 287.9 & - & $w$ & W \\
\hline July & 13.8 & $W$ & 91.5 & 234.3 & - & $w$ & $W$ \\
\hline 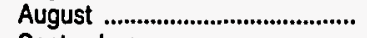 & 9.0 & $W$ & 106.0 & 370.5 & - & - & - \\
\hline 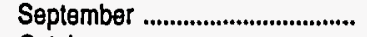 & 7.4 & $W$ & 101.0 & 431.9 & - & - & - \\
\hline 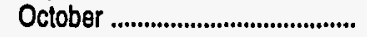 & 6.0 & $W$ & 97.1 & 579.8 & - & - & - \\
\hline 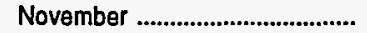 & 5.5 & - & 101.9 & 337.6 & - & - & - \\
\hline 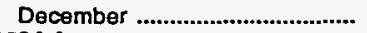 & 4.2 & - & 93.3 & 475.9 & - & $w$ & $\mathbf{w}$ \\
\hline 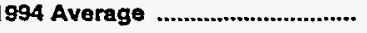 & 6.9 & $\mathbf{w}$ & 91.4 & 385.2 & - & $\mathbf{W}$ & $\mathbf{W}$ \\
\hline \multicolumn{8}{|l|}{ North Dakota } \\
\hline 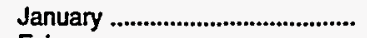 & $W$ & $W$ & 21.3 & 424.5 & - & W & $w$ \\
\hline 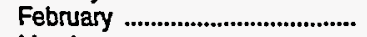 & $W$ & $W$ & 21.6 & 388.3 & - & - & - \\
\hline March & $W$ & $W$ & 18.1 & 182.8 & - & - & - \\
\hline April & W & $W$ & 18.5 & 103.4 & - & - & - \\
\hline 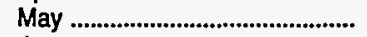 & 4.2 & $W$ & 16.4 & 86.6 & - & - & - \\
\hline June & 4.1 & - & 23.9 & 122.5 & - & - & - \\
\hline July & W & $\mathbf{W}$ & 30.6 & 219.3 & - & - & - \\
\hline 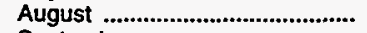 & 3.7 & $W$ & 30.4 & 280.3 & - & - & - \\
\hline 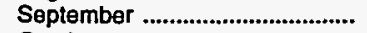 & 5.1 & $w$ & 28.1 & 182.4 & - & - & - \\
\hline October & $w$ & - & 26.1 & 257.7 & - & - & - \\
\hline 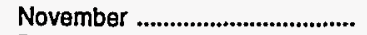 & W & - & 27.9 & 341.3 & - & $\mathbf{W}$ & $\mathbf{W}$ \\
\hline 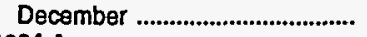 & W & - & 32.6 & 412.6 & - & - & - \\
\hline 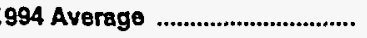 & 3.0 & W & 24.6 & 249.7 & - & $\mathbf{w}$ & $\mathbf{w}$ \\
\hline \multicolumn{8}{|l|}{ Ohio } \\
\hline 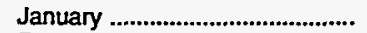 & 15.0 & $\mathbf{W}$ & 915.4 & $1,391.3$ & w & 114.5 & 127.4 \\
\hline February & 18.4 & $\mathbf{W}$ & $1,206.8$ & $1,492.7$ & W & W & 158.0 \\
\hline 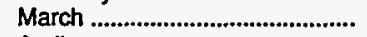 & 27.8 & $W$ & $1,159.7$ & 899.9 & w & $w$ & 158.6 \\
\hline April & 27.4 & $W$ & $1,108.2$ & 592.4 & $w$ & $w$ & 101.2 \\
\hline 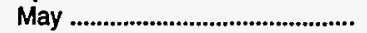 & 30.3 & $w$ & $1,062.8$ & 433.8 & W & $\mathbf{w}$ & 106.4 \\
\hline 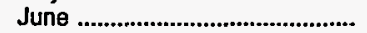 & 32.8 & $W$ & $1,117.4$ & 406.3 & 22.3 & 62.6 & 84.9 \\
\hline 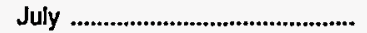 & 39.4 & $W$ & $1,085.5$ & 393.0 & W & $w$ & 62.5 \\
\hline 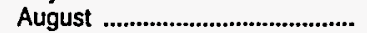 & 41.3 & $W$ & $1,210.4$ & 536.0 & $w$ & W & 78.3 \\
\hline 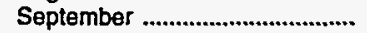 & 45.7 & $\mathbf{W}$ & $1,090.7$ & 696.8 & $W$ & $W$ & 152.2 \\
\hline October & 39.3 & $W$ & $1,184.7$ & $1,107.4$ & $w$ & $\ddot{w}$ & 45.2 \\
\hline 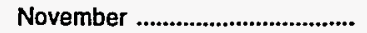 & 27.0 & $W$ & $1,200.6$ & $1,078.4$ & $w$ & $W$ & 59.7 \\
\hline 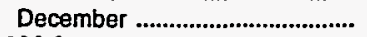 & 22.2 & W & $1,159.8$ & $1,186.3$ & $\mathbf{w}$ & $w$ & 54.8 \\
\hline 1994 Average .................................. & 30.6 & $\mathbf{W}$ & $1,124.5$ & 847.6 & 13.8 & 84.8 & 98.6 \\
\hline \multicolumn{8}{|l|}{ OkJahoma } \\
\hline 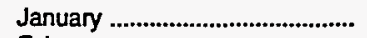 & 9.9 & W & 757.5 & 926.3 & - & - & - \\
\hline 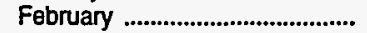 & 9.9 & $W$ & 597.4 & 772.0 & $w$ & - & $\mathbf{W}$ \\
\hline March & 14.2 & $W$ & 728.8 & 547.5 & - & $w$ & $w$ \\
\hline April & 10.6 & $W$ & $1,147.8$ & 442.7 & - & - & - \\
\hline 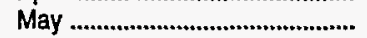 & 12.3 & $W$ & 762.0 & 381.0 & - & - & - \\
\hline June & 14.8 & $W$ & 954.1 & 457.4 & w & - & $w$ \\
\hline July & 11.3 & $W$ & 909.8 & 358.9 & $w$ & - & $w$ \\
\hline 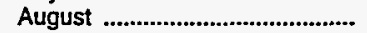 & 11.8 & $W$ & 980.8 & 455.7 & $w$ & $w$ & W \\
\hline 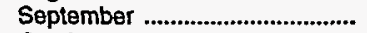 & 12.5 & $\mathbf{W}$ & 861.8 & 503.1 & $w$ & - & $W$ \\
\hline October & 8.3 & $W$ & 929.4 & 521.4 & W & $w$ & W \\
\hline 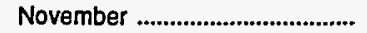 & 9.0 & $W$ & 897.8 & 581.4 & $w$ & - & W \\
\hline 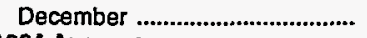 & 8.2 & $W$ & 846.0 & 697.6 & $w$ & $w$ & 38.7 \\
\hline 1994 Average ................................. & 11.1 & $\mathbf{w}$ & 865.5 & 552.6 & $\mathbf{w}$ & $\mathbf{W}$ & 34.3 \\
\hline
\end{tabular}

See footnotes at end of table. 
Table 49. Prime Supplier Sales Volumes of Aviation Fuels, Propane, and Residual Fuel Oll by PAD District and State

(Thousand Gallons per Day) - Continued

\begin{tabular}{|c|c|c|c|c|c|c|c|}
\hline \multirow[b]{2}{*}{$\begin{array}{l}\text { Goographic Ares } \\
\text { Month }\end{array}$} & \multirow[b]{2}{*}{$\begin{array}{l}\text { Aviation } \\
\text { Gusoline }\end{array}$} & \multirow[b]{2}{*}{$\begin{array}{l}\text { Naphtha- } \\
\text { Type } \\
\text { Jet Fuel }\end{array}$} & \multirow[b]{2}{*}{$\begin{array}{l}\text { Korosene. } \\
\text { Type } \\
\text { Jet Fubl }\end{array}$} & \multirow[b]{2}{*}{$\begin{array}{l}\text { Propans } \\
\text { (Consumer } \\
\text { Grado) }\end{array}$} & \multicolumn{3}{|c|}{ Residual Fuel Oll } \\
\hline & & & & & $\begin{array}{l}\text { Sulfur } \\
\text { Less Than } \\
\text { or Equal to } \\
1 \text { Percent }\end{array}$ & $\begin{array}{c}\text { Sulfur } \\
\text { Greater Than } \\
1 \text { Percent }\end{array}$ & $\begin{array}{c}\text { Total } \\
\text { Residual } \\
\text { Fuel } \\
\text { Oll }\end{array}$ \\
\hline \multicolumn{8}{|l|}{ South Dakota } \\
\hline 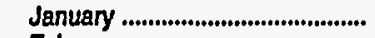 & $\mathbf{w}$ & w & 21.7 & 454.4 & - & w & w \\
\hline February & $\mathbf{w}$ & W & 26.5 & 403.3 & - & - & - \\
\hline 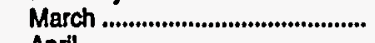 & 6.6 & $\mathbf{w}$ & 23.3 & 201.4 & - & $\mathbf{w}$ & w \\
\hline April & 6.7 & w & 20.1 & 112.8 & - & $w$ & $w$ \\
\hline 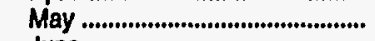 & $w$ & $w$ & 24.3 & 73.7 & - & $\ddot{w}$ & $w$ \\
\hline 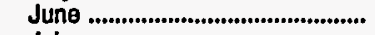 & $w$ & w & 27.4 & 67.8 & - & $w$ & w \\
\hline July & 9.5 & $\mathbf{w}$ & 26.1 & 94.4 & - & $w$ & w \\
\hline August & 9.4 & $w$ & 27.2 & 161.5 & - & $w$ & w \\
\hline 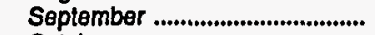 & 6.8 & w & 25.4 & 178.4 & - & $w$ & $w$ \\
\hline October & W & w & w & 346.4 & - & - & - \\
\hline 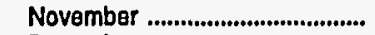 & 4.7 & w & 31.1 & 328.9 & - & $w$ & w \\
\hline December ......................................... & $w$ & $w$ & 24.3 & 327.3 & - & $w$ & $w$ \\
\hline 1994 Average & w & $\mathbf{W}$ & 25.1 & 228.4 & - & $\mathbf{w}$ & w \\
\hline \multicolumn{8}{|l|}{ Tennesseo } \\
\hline 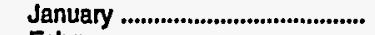 & 11.0 & - & 749.8 & 556.5 & $w$ & $w$ & 72.0 \\
\hline 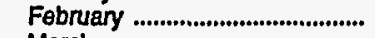 & 13.9 & $w$ & 682.9 & 609.1 & $\mathbf{w}$ & w & 65.0 \\
\hline 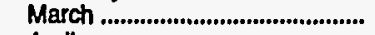 & 16.0 & $\mathbf{w}$ & 739.4 & 209.2 & $w$ & $w$ & 47.7 \\
\hline April & 20.6 & - & 813.4 & 118.7 & w & $w$ & 36.8 \\
\hline May & 18.5 & - & 749.1 & 83.2 & W & W & 20.3 \\
\hline June & 19.5 & - & 685.2 & 118.9 & $W$ & W & 36.3 \\
\hline July & 19.6 & - & 732.2 & 165.0 & $w$ & $w$ & 34.4 \\
\hline 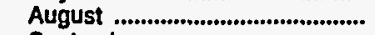 & 24.2 & - & 834.0 & 237.7 & $w$ & $w$ & 35.3 \\
\hline 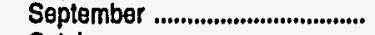 & 19.6 & - & 758.7 & 287.5 & NA & w & 35.8 \\
\hline 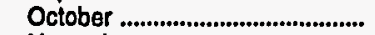 & 18.7 & - & 803.8 & 293.0 & $w$ & $w$ & 63.2 \\
\hline 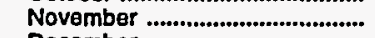 & 17.2 & - & 850.0 & 258.5 & $w$ & $w$ & 19.1 \\
\hline 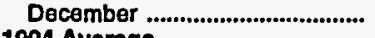 & 30.6 & $\overrightarrow{\mathrm{w}}$ & 772.8 & 372.3 & $w$ & w & 23.0 \\
\hline 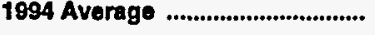 & 19.2 & $\mathbf{w}$ & $\mathbf{7 6 4 . 8}$ & 273.9 & 19.2 & $\mathbf{w}$ & 40.6 \\
\hline \multicolumn{8}{|l|}{ Wisconsin } \\
\hline 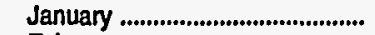 & w & - & 200.7 & $1,818.2$ & $w$ & w & w \\
\hline 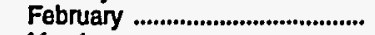 & 9.1 & - & 189.5 & $1,546.4$ & w & $w$ & w \\
\hline March & 12.9 & - & 187.3 & 987.9 & - & 145.0 & 145.0 \\
\hline April & 12.1 & - & 161.6 & 593.9 & $w$ & $w$ & 104.4 \\
\hline 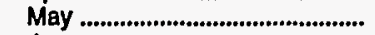 & 13.8 & - & 176.4 & 435.2 & - & 105.8 & 105.8 \\
\hline 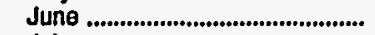 & 18.3 & - & 172.0 & 344.6 & - & 98.3 & 98.3 \\
\hline July & 23.6 & - & 162.1 & 387.6 & - & 146.7 & 146.7 \\
\hline August & 20.5 & - & 194.7 & 520.0 & - & 200.5 & 200.5 \\
\hline 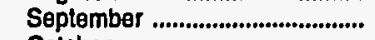 & 16.8 & - & 174.8 & 566.9 & - & 138.8 & 138.8 \\
\hline 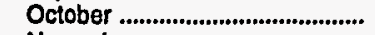 & 29.4 & - & 184.1 & 846.2 & - & 167.2 & 167.2 \\
\hline 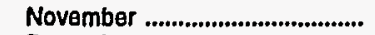 & 13.1 & - & 163.7 & $1,059.0$ & - & 165.6 & 165.6 \\
\hline 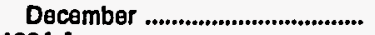 & 9.6 & - & 174.4 & $1,291.4$ & - & 162.9 & 162.9 \\
\hline 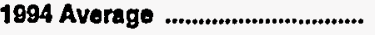 & 15.7 & - & 178.5 & 863.3 & $\mathbf{w}$ & 143.3 & 143.5 \\
\hline \multicolumn{8}{|l|}{ PAD District III } \\
\hline 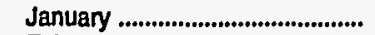 & 105.1 & $1,352.8$ & $11,724.4$ & $15,007.6$ & $1,048.4$ & $4,207.4$ & $5,255.7$ \\
\hline 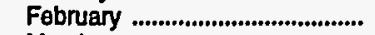 & 121.8 & 831.5 & $10,468.4$ & $13,924.3$ & 607.8 & $3,323.1$ & $3,930.9$ \\
\hline 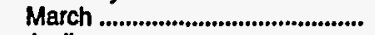 & 160.1 & 974.9 & $11,382.8$ & $11,692.5$ & $1,660.8$ & $4,398.3$ & $6,059.0$ \\
\hline April & 152.6 & 501.3 & $13,432.0$ & $9,896.0$ & 805.9 & $3,954.3$ & $4,760.2$ \\
\hline May & 174.8 & 517.8 & $13,476.7$ & $9,987.1$ & 736.5 & $3,293.8$ & $4,030.4$ \\
\hline 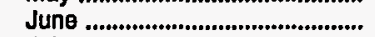 & 204.8 & 613.2 & $12,990.0$ & $10,681.6$ & 648.5 & $5,237.0$ & $5,885.5$ \\
\hline 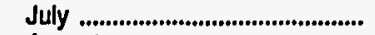 & 220.9 & 572.6 & $13,847.1$ & $11,756.2$ & 715.8 & $4,356.1$ & $5,071.9$ \\
\hline August & 219.1 & 588.2 & $13,255.7$ & $12,789.1$ & 985.1 & $3,275.9$ & $4,261.0$ \\
\hline September ....................................... & 169.1 & 103.5 & $13,989.3$ & $13,309.3$ & 843.1 & $4,546.3$ & $5,389.3$ \\
\hline 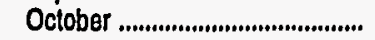 & 134.1 & 130.2 & $12,532.9$ & $12,605.7$ & 578.3 & $3,639.8$ & $4,218.1$ \\
\hline November ....................................... & 180.8 & 223.2 & $13,358.7$ & $12,898.9$ & 715.7 & $4,111.6$ & $4,827.3$ \\
\hline $\begin{array}{l}\text { December } \\
1994 \text { Average }\end{array}$ & $\begin{array}{l}101.0 \\
162.2\end{array}$ & $\begin{array}{l}211.8 \\
551.5\end{array}$ & $\begin{array}{l}12,875.2 \\
12789.5\end{array}$ & $\begin{array}{l}16,165.0 \\
12,557.7\end{array}$ & $\begin{array}{l}462.9 \\
819.8\end{array}$ & 4.465 .4 & $4,928.3$ \\
\hline & & & & & & & \\
\hline
\end{tabular}

See footnotes at end of table. 
Table 49. Prime Supplier Sales Volumes of Avlation Fuels, Propane, and Residual Fuel OIl by PAD District and State

(Thousand Gallons per Day) - Continued

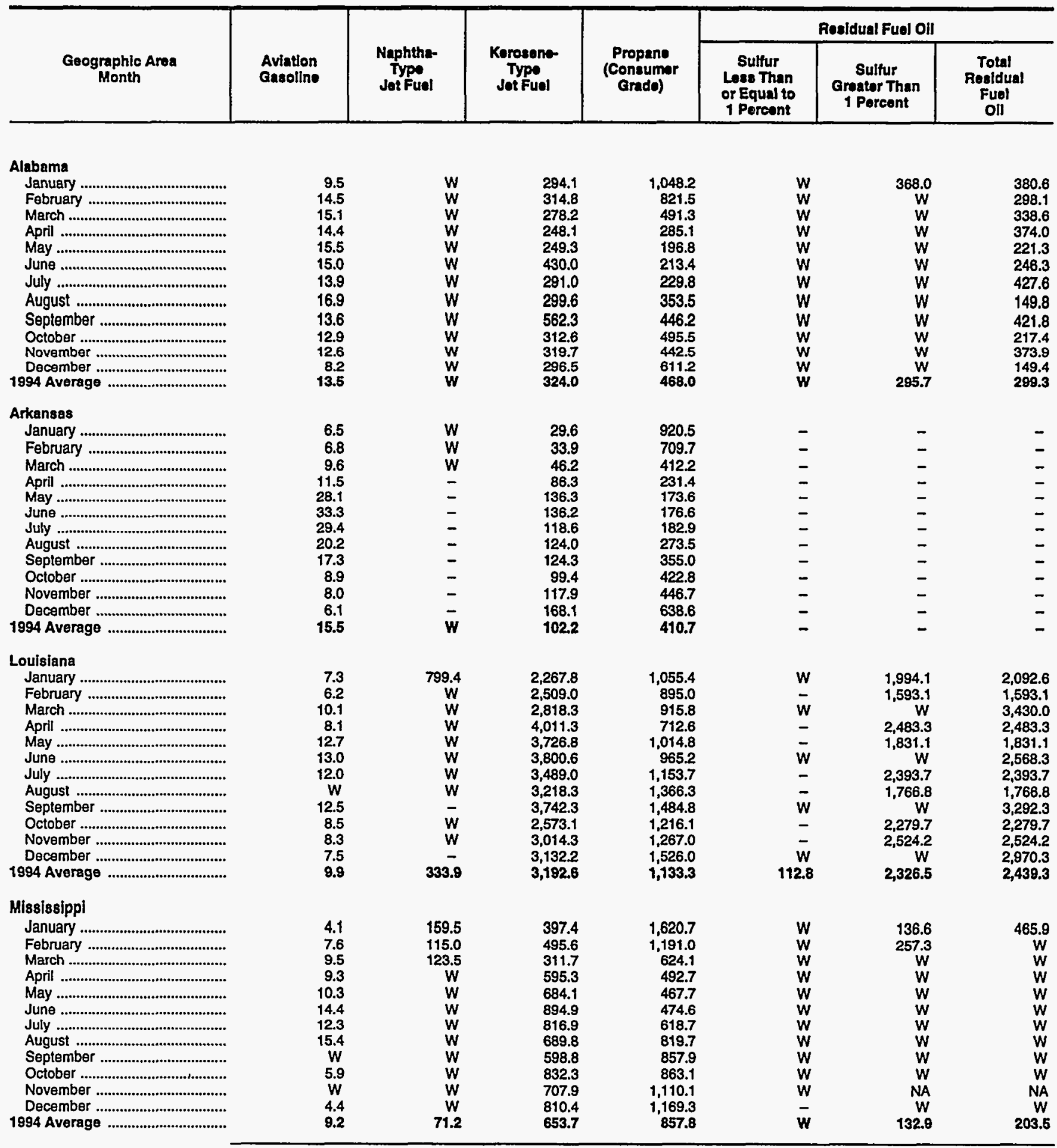

See footnotes at end of table. 
Table 49. Prime Suppller Sales Volumes of Aviation Fuels, Propane, and Residual Fuel Oil by PAD District and State

(Thousand Gallons per Day) - Continued

\begin{tabular}{|c|c|c|c|c|c|c|c|}
\hline \multirow[b]{2}{*}{$\begin{array}{l}\text { Ceographle Area } \\
\text { Month }\end{array}$} & \multirow[b]{2}{*}{$\begin{array}{l}\text { Aviation } \\
\text { Gasoline }\end{array}$} & \multirow[b]{2}{*}{$\begin{array}{l}\text { Naphtha- } \\
\text { Type } \\
\text { Jot Fuel }\end{array}$} & \multirow[b]{2}{*}{$\begin{array}{c}\text { Kerosene- } \\
\text { Type } \\
\text { Jet Fuel }\end{array}$} & \multirow[b]{2}{*}{$\begin{array}{c}\text { Propane } \\
\text { (Consumer } \\
\text { Grade) }\end{array}$} & \multicolumn{3}{|c|}{ Residual Fuel OII } \\
\hline & & & & & $\begin{array}{c}\text { Sulfur } \\
\text { Less Than } \\
\text { or Equal to } \\
1 \text { Percent }\end{array}$ & $\begin{array}{c}\text { Sulfur } \\
\text { Greater Than } \\
1 \text { Percent }\end{array}$ & $\begin{array}{l}\text { Total } \\
\text { Resldual } \\
\text { Fuol } \\
\text { Oll }\end{array}$ \\
\hline
\end{tabular}

\section{New Moxico}

January ...

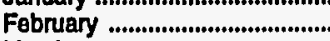

March .

June

July ...

September ...................................

Oclober ...

November

1984 Average

Texne

January ..........................................

February .......................................

March ..............................................

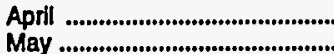

June

July ................................................

August ..........................................

September ...................................

October.

November , ....................................

December ...

1994 Average ..................................

PAD Diatrict IV

January.

April ...................................................

May

July

Aly .......................

August .........................................

September

October

November .....................................

December

Colorado

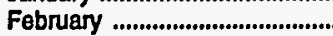

March

April .............................................

May ...............................................

June ...............................................

July .................................................

August .............................................

September ..................................

November .......................................

December

1994 Average
August

Decomber ...................................

1994 Average .................................

January .......................................

....................................

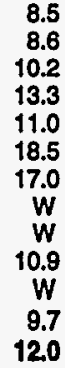

12.0

69.3
78.1
105.5
96.0
97.1
110.6
136.3
141.3
102.1
87.1
134.7
65.1
102.0

$W$
$W$
$W$
$W$
$W$
$W$
$W$
$W$
$W$
$W$
$W$
$W$
$W$

308.1

291.3

286.1

358.0

250.3

219.7

258.9

196.6

246.6

187.7

240.5

244.2

257.0

785.9

765.7

617.4

371.2

456.8

355.1

360.5

455.

435.4

499.1

609.3

544.7

520.2

$8,427.3$

$6,823.8$

$7,642.3$

$8,133.0$

$8,429.8$

$7,508.5$

$8,872.8$

$8,727.4$

$8,714.9$

$8,527.7$

$8,958.4$

$8,223.8$

$8,260.0$

$9,577.0$

$9,541.3$

$8,631.7$

$7,803.0$

$7,677.4$

$8,496.8$

$9,210.5$

$9,520.9$

$9,730.1$

$9,109.0$

$\mathbf{9 , 0 2 3 . 4}$

$11,675.2$

9,167.7

$1,406.6$

$1,385.6$

$1,424.9$

$1,411.5$

$1,281.8$

$1,384.5$

$1,541.3$

$1,466.7$

$1,407.7$

$1,200.6$

$1,096.0$

$1,394.2$

$1,367.1$

$1,349.1$

$1,449.5$

$1,037.5$

903.8

799.3

796.6

803.5

8972

$1,052.8$

$1,047.5$

$1,386.9$

$1,644.4$

$\mathbf{1 , 0 9 5 . 1}$

529.4

539.0

360.7

293.4

230.8

192.5

185.7

228.1

313.0

317.0

425.9

543.8

345.5

734.

693.9

632.

768.1

$W$
$W$
$W$
$W$
$W$
$W$
$W$
$W$
$W$
$W$
$W$
$W$
$W$

See footnotes at end of table.
603.8

601.2

706.1

573.5

533.7

544.8

709.5

977.7

629.2

571.1

W

374.0

627.8

$\begin{array}{rrr}62.2 & 63.7 & 125.9 \\ 68.9 & 40.1 & 109.0 \\ W & W & 73.4 \\ W & W & 94.7 \\ W & W & 78.8 \\ W & W & 62.2 \\ W & W & 77.9 \\ W & W & 58.3 \\ W & W & 92.9 \\ W & W & 44.4 \\ W & W & 50.0 \\ W & W & 80.6 \\ 30.1 & 48.7 & 78.8\end{array}$

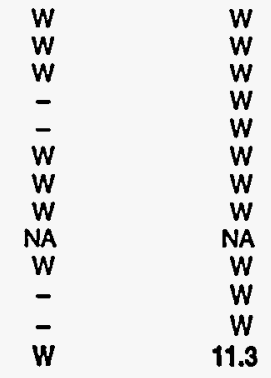

$1,704.5 \quad 2,308.4$

$1,174.3 \quad 1,775.5$

$2,137.8$

$1,222.5 \quad 1,756.1$

$1,305.4 \quad 2,014.9$

$1,316.4 \quad 2,294.1$

$998.0 \quad 1,627.2$

$1,679.6$

$\begin{array}{rr}W & 1,818.3 \\ 1,405.5 & 1,779.5\end{array}$

$\begin{array}{ll}1,405.5 & 1,779.5 \\ 1,307.8 & 1,935.6\end{array}$

$\begin{array}{lll}W & - & w \\ W & - & w \\ w & - & w \\ \bar{w} & - & \bar{w} \\ W & - & w \\ W & - & w \\ W & - & w \\ W & - & w \\ - & - & - \\ - & \bar{w} & \bar{w} \\ \bar{w} & w & w\end{array}$


Table 49. Prime Supplier Sales Volumes of Avlation Fuels, Propane, and Residual Fuel OII by PAD District and State

(Thousand Gallons per Day) - Continued

\begin{tabular}{|c|c|c|c|c|c|c|c|}
\hline \multirow[b]{2}{*}{$\begin{array}{l}\text { Geographle Ares } \\
\text { Month }\end{array}$} & \multirow[b]{2}{*}{$\begin{array}{l}\text { Avintion } \\
\text { Gasollne }\end{array}$} & \multirow[b]{2}{*}{$\begin{array}{l}\text { Naphthe } \\
\text { Typo } \\
\text { Jot Fuel }\end{array}$} & \multirow[b]{2}{*}{$\begin{array}{c}\text { Koreane } \\
\text { Type } \\
\text { Jet Fuel }\end{array}$} & \multirow[b]{2}{*}{$\begin{array}{l}\text { Propano } \\
\text { (Contumar } \\
\text { Crade) }\end{array}$} & \multicolumn{3}{|c|}{ Residual Fuel Oll } \\
\hline & & & & & $\begin{array}{l}\text { Bulfur } \\
\text { Lose Than } \\
\text { or Equal to } \\
1 \text { Percent }\end{array}$ & $\begin{array}{l}\text { Sulfur } \\
\text { Greater Than } \\
\text { I Percent }\end{array}$ & $\begin{array}{l}\text { Total } \\
\text { Resldual } \\
\text { Fuel } \\
\text { Oll }\end{array}$ \\
\hline
\end{tabular}

Idaho

$\begin{array}{lll}W & 38.5 & 97.0\end{array}$

January .

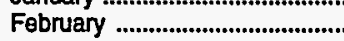

March ...

April

May

July .....

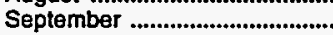

Octaber

November

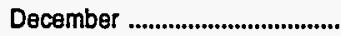

1994 Averago

1.1

$W$

W

3.2

6.4

W.1

Montana

January ............................................

March

April

May

June

July ....

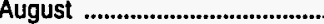

September ....................................

October.

November

994 Average

Utah

January

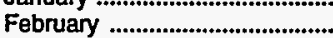

March .

April

June

July

August ....

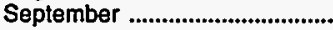

October .

November

December

1994 Average

Wyoming

January

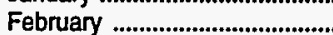

March

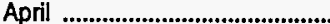

May ...................................................

June

July

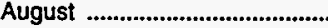

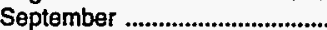

October ...

November

December

1994 Average

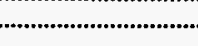

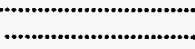

See footnotes at end of table.

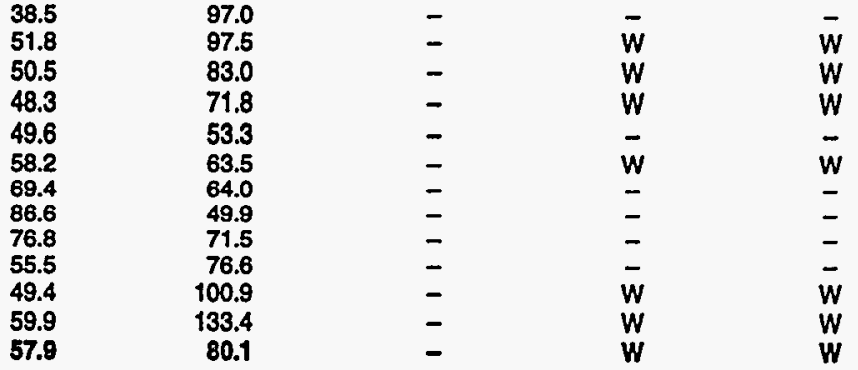

59.0

218.0

132.6

112.3

96.1
123.5

134.9

180.8

176.2

155.3

236.0

160.7

229.8

257.5

143.8

143.6

1652

159.6

158.8

184.9

$261 ?$

3098

199.2

324.3

337.5

269.5

237.6

275.4

273.5

253.7

278.8

333.3

313.7

400.2

421.4

308.7

$\begin{array}{rr}W & W \\ W & W \\ 19.2 & 19.2 \\ W & W \\ W & W \\ W & W \\ W & W \\ W & W \\ W & W \\ W & W \\ W & W \\ 27.7 & 27.7 \\ 18.7 & 18.7\end{array}$

$\begin{array}{lrr}W & W & 78.5 \\ W & W & W \\ W & W & W \\ W & W & W \\ W & W & W \\ W & W & W \\ -W & W & W \\ W & W & W \\ W & W & 16.3 \\ W & W & 11.0 \\ W & W & W \\ W & W & W \\ W & 14.1 & 19.9\end{array}$


Table 49. Prime Supplier Sales Volumes of Aviation Fuels, Propane, and Residual Fuel Oll by PAD District and State

(Thousand Gallons per Day) - Continued

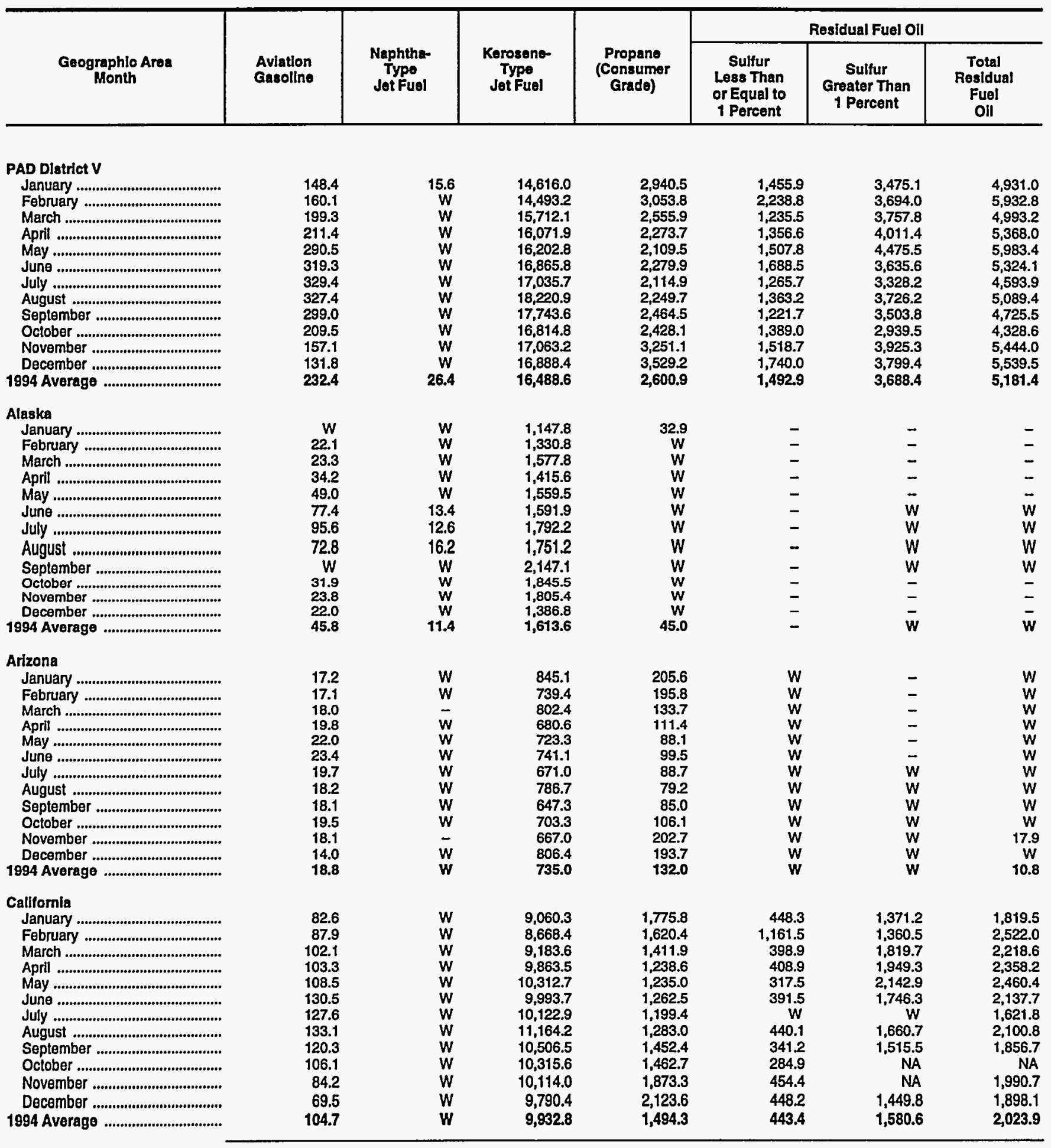

See footnotes at end of table. 
Table 49. Prime Supplier Sales Volumes of Aviation Fuels, Propane, and Residual Fuel OII by PAD District and State

(Thousand Gallons per Day) - Continued

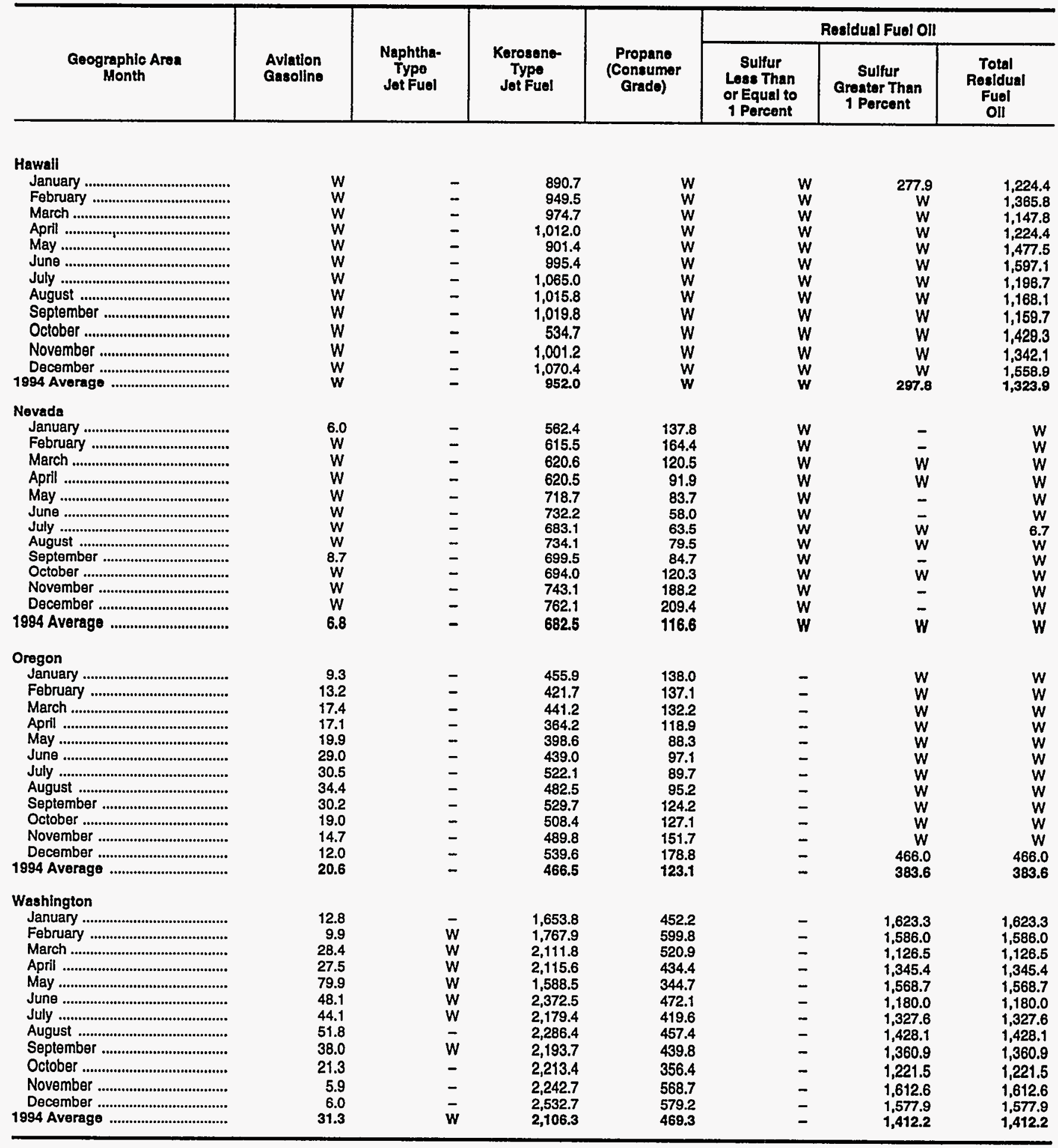

Dash $(-)=$ No data reported.

$N A=$ Not avallable.

$W=$ Withheld to avoid disclosure of individual company data.

Note: Totals may not equal the sum of the components due to rounding.

Source: Energy Information Administration, Form EIA-782C, "Monthly Report of Prime Supplier Sales of Petroleum Products Sold for Local Consumption." 
Table 50. Prime Suppller Sales Volumes of Distillate Fuel Oils and Kerosene by PAD Dlstrict and State

(Thousand Gallons per Day)

\begin{tabular}{|c|c|c|c|c|c|c|c|c|c|}
\hline \multirow{3}{*}{$\begin{array}{c}\text { Coographlo Aren } \\
\text { Month }\end{array}$} & \multirow{3}{*}{ Kerosene } & \multirow{3}{*}{$\begin{array}{c}\text { No. } 1 \\
\text { Dlstllate }\end{array}$} & \multicolumn{5}{|c|}{ No. 2 Distillate } & \multirow{3}{*}{ No. 4 Fuela } & \multirow{3}{*}{$\begin{array}{c}\text { Total } \\
\text { Distlliate } \\
\text { and } \\
\text { Kerosene }\end{array}$} \\
\hline & & & \multirow{2}{*}{$\begin{array}{l}\text { No. } 2 \text { Fuel } \\
\text { Olf }\end{array}$} & \multicolumn{3}{|c|}{ No. 2 Dlesel Fuel } & \multirow{2}{*}{$\begin{array}{c}\text { No. } 2 \\
\text { Distlilate }\end{array}$} & & \\
\hline & & & & Low-Sulfur & High-Sultur & Total & & & \\
\hline \multicolumn{10}{|l|}{ United States } \\
\hline 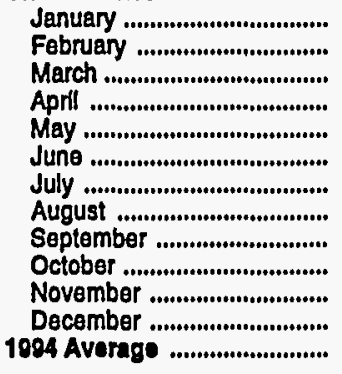 & $\begin{array}{r}8,811.9 \\
6,213.1 \\
3,391.9 \\
1,370.6 \\
1,011.1 \\
1,055.6 \\
948.6 \\
1,475.7 \\
2,124.2 \\
2,949.7 \\
3,544.2 \\
5,280.1 \\
3,169.1\end{array}$ & $\begin{array}{r}6,127.7 \\
4,905.2 \\
1,922.5 \\
1,051.0 \\
890.6 \\
1,027.2 \\
765.3 \\
1,053.1 \\
1,855.8 \\
2,125.8 \\
3,853.1 \\
4,688.9 \\
2,608.8\end{array}$ & $\begin{array}{l}68,199.7 \\
62,191.5 \\
49,804.4 \\
32,960.3 \\
27,444.2 \\
26,009.7 \\
22,623.7 \\
27,619.0 \\
30,391.2 \\
32,976.0 \\
34,185.7 \\
45,932.5 \\
38,247.5\end{array}$ & $\begin{array}{l}61,034.2 \\
66,337.4 \\
72,423.2 \\
72,486.3 \\
74,112.4 \\
77,880.6 \\
69,656.5 \\
77,285.8 \\
77,732.1 \\
75,571.2 \\
73,543.8 \\
69,071.7 \\
72,275.4\end{array}$ & $\begin{array}{l}19,031.5 \\
18,887.7 \\
21,182.5 \\
20,459.6 \\
20,249.3 \\
21,638.2 \\
19,449.1 \\
21,243.2 \\
20,705.8 \\
21,153.5 \\
19,402.8 \\
19,746.1 \\
20,270.6\end{array}$ & $\begin{array}{l}80,065.7 \\
85,225.1 \\
93,605.7 \\
92,945.9 \\
94,361.7 \\
99,518.8 \\
89,105.6 \\
98,529.0 \\
98,437.9 \\
96,724.6 \\
92,946.6 \\
88,817.8 \\
92,546.0\end{array}$ & $\begin{array}{l}148,265.4 \\
147,416.6 \\
143,410.1 \\
125,906.1 \\
121,806.0 \\
125,528.5 \\
111,729.3 \\
126,148.0 \\
128,829.1 \\
129,700.7 \\
127,132.3 \\
134,750.3 \\
130,793.6\end{array}$ & $\begin{array}{r}3,049.1 \\
3,132.1 \\
2,284.3 \\
1,202.5 \\
731.8 \\
827.7 \\
568.6 \\
745.2 \\
641.8 \\
1,001.8 \\
1,339.7 \\
2,072.5 \\
1,457.8\end{array}$ & $\begin{array}{l}166,254.0 \\
161,667.0 \\
151,008.7 \\
129,530.2 \\
124,439.5 \\
128,439.0 \\
114,011.8 \\
129,422.0 \\
133,451.0 \\
135,778.0 \\
135,869.3 \\
146,791.7 \\
137,929.4\end{array}$ \\
\hline \multicolumn{10}{|l|}{ PAD Dlstrict I } \\
\hline 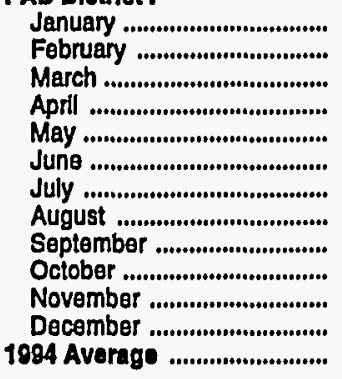 & $\begin{array}{r}6,431.1 \\
4,635.1 \\
2,633.1 \\
1,012.9 \\
782.1 \\
676.1 \\
588.6 \\
1,041.2 \\
1,439.7 \\
2,025.2 \\
2,145.7 \\
3,665.2 \\
2,247.1\end{array}$ & $\begin{array}{l}525.9 \\
468.3 \\
284.6 \\
157.2 \\
154.5 \\
125.1 \\
117.4 \\
124.6 \\
234.6 \\
175.5 \\
212.5 \\
265.2 \\
235.8\end{array}$ & $\begin{array}{l}55,258.9 \\
50,190.4 \\
37,885.3 \\
20,976.3 \\
15,836.9 \\
13,747.9 \\
12,184.6 \\
15,713.8 \\
17,983.2 \\
20,441.1 \\
22,592.5 \\
34,511.0 \\
26,331.8\end{array}$ & $\begin{array}{l}18,165.3 \\
20,457.0 \\
22,221.0 \\
21,214.3 \\
21,868.8 \\
22,404.7 \\
19,850.7 \\
21,911.5 \\
21,946.5 \\
21,653.8 \\
21,608.8 \\
20,998.3 \\
21,181.2\end{array}$ & $\begin{array}{l}4,152.5 \\
3,693.0 \\
3,577.1 \\
3,105.6 \\
3,617.3 \\
3,396.1 \\
3,052.5 \\
2,912.0 \\
3,433.6 \\
3,373.5 \\
3,715.9 \\
3,978.1 \\
3,500.0\end{array}$ & $\begin{array}{l}22,317.7 \\
24,150.0 \\
25,798.1 \\
24,320.0 \\
25,486.1 \\
25,800.8 \\
22,903.2 \\
24,823.5 \\
25,380.1 \\
25,027.3 \\
25,324.7 \\
24,976.4 \\
24,691.1\end{array}$ & $\begin{array}{l}77,576.7 \\
74,340.4 \\
63,683.4 \\
45,296.2 \\
41,322.9 \\
39,548.7 \\
35,087.9 \\
40,537.3 \\
43,363.3 \\
45,468.3 \\
47,917.2 \\
59,487.4 \\
51,022.9\end{array}$ & $\begin{array}{r}2,735.1 \\
2,817.3 \\
1,926.0 \\
965.4 \\
484.2 \\
562.3 \\
414.1 \\
494.3 \\
411.1 \\
633.3 \\
952.2 \\
1,521.2 \\
1,150.9\end{array}$ & $\begin{array}{l}87,268.7 \\
82,261.1 \\
68,527.1 \\
47,431.7 \\
42,743.7 \\
40,912.2 \\
36,207.9 \\
42,197.4 \\
45,448.6 \\
48,302.3 \\
51,227.7 \\
64,939.0 \\
54,656.7\end{array}$ \\
\hline \multicolumn{10}{|l|}{ Subdlatrlet IA } \\
\hline 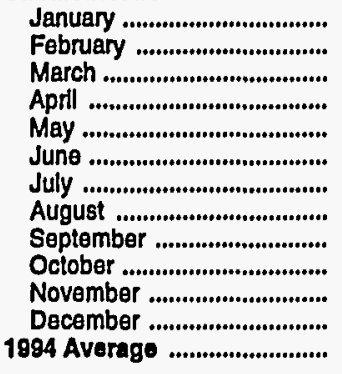 & $\begin{array}{r}974.3 \\
728.8 \\
454.5 \\
169.8 \\
160.6 \\
84.6 \\
72.3 \\
141.2 \\
204.1 \\
287.0 \\
330.1 \\
628.6 \\
351.6\end{array}$ & $\begin{array}{r}79.5 \\
35.5 \\
22.7 \\
W \\
8.2 \\
W \\
W \\
W \\
39.7 \\
3.3 \\
16.5 \\
31.0 \\
21.4\end{array}$ & $\begin{array}{r}16,999.6 \\
15,140.5 \\
11,562.6 \\
6,080.0 \\
4,154.6 \\
3,029.7 \\
2,420.1 \\
3,272.7 \\
4,216.2 \\
5,313.0 \\
6,610.0 \\
11,484.1 \\
7,488.8\end{array}$ & $\begin{array}{l}1,933.3 \\
2,033.7 \\
2,184.1 \\
2,158.7 \\
2,306.2 \\
2,482.2 \\
2,274.7 \\
2,399.9 \\
2,499.3 \\
2,404.8 \\
2,332.1 \\
2,408.7 \\
2,286.0\end{array}$ & $\begin{array}{l}56.8 \\
43.7 \\
47.8 \\
42.3 \\
83.2 \\
64.0 \\
54.7 \\
70.2 \\
53.8 \\
41.9 \\
34.6 \\
33.3 \\
\mathbf{5 2 . 3}\end{array}$ & $\begin{array}{l}1,990.1 \\
2,077.4 \\
2,231.9 \\
2,201.0 \\
2,389.4 \\
2,546.2 \\
2,329.4 \\
2,470.1 \\
2,553.1 \\
2,446.6 \\
2,366.7 \\
2,442.0 \\
2,338.3\end{array}$ & $\begin{array}{r}18,989.7 \\
17,218.0 \\
13,794.5 \\
8,281.0 \\
6,544.0 \\
5,575.9 \\
4,749.5 \\
5,742.8 \\
6,769.3 \\
7,759.6 \\
8,976.7 \\
13,926.1 \\
9,827.1\end{array}$ & $\begin{array}{r}579.4 \\
617.1 \\
510.3 \\
W \\
110.9 \\
W \\
W \\
W \\
103.0 \\
167.9 \\
244.9 \\
410.7 \\
267.2\end{array}$ & $\begin{array}{r}20,622.8 \\
18,597.4 \\
14,782.0 \\
8,699.4 \\
6,823.7 \\
5,758.6 \\
4,882.8 \\
5,981.7 \\
7,116.1 \\
8,217.8 \\
9,568.1 \\
14,996.4 \\
10,467.2\end{array}$ \\
\hline \multicolumn{10}{|l|}{ Connectlcut } \\
\hline 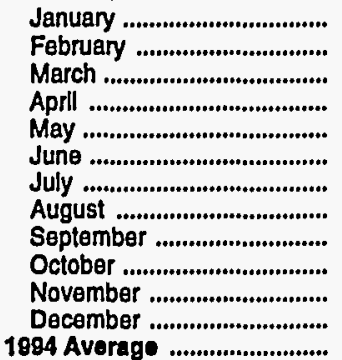 & $\begin{array}{r}138.8 \\
W \\
64.6 \\
W \\
W \\
23.1 \\
19.0 \\
21.1 \\
31.9 \\
36.6 \\
44.6 \\
78.2 \\
52.4\end{array}$ & $\begin{array}{r}15.9 \\
12.1 \\
4.6 \\
W \\
W \\
W \\
W \\
W \\
W \\
W \\
W \\
W \\
5.3\end{array}$ & $\begin{array}{r}4,058.4 \\
3,623.9 \\
2,881.6 \\
1,435.4 \\
960.1 \\
657.6 \\
571.9 \\
720.7 \\
919.8 \\
1,298.5 \\
1,472.4 \\
2,738.0 \\
1,770.2\end{array}$ & $\begin{array}{l}452.2 \\
W \\
W \\
W \\
W \\
W \\
W \\
W \\
W \\
W \\
W \\
W \\
523.3\end{array}$ & $\begin{array}{l}19.4 \\
W \\
W \\
W \\
W \\
W \\
W \\
W \\
W \\
W \\
W \\
W \\
3.0\end{array}$ & $\begin{array}{l}471.6 \\
456.3 \\
523.4 \\
541.4 \\
529.5 \\
584.9 \\
483.1 \\
542.7 \\
536.6 \\
541.8 \\
539.2 \\
560.5 \\
526.2\end{array}$ & $\begin{array}{l}4,530.0 \\
4,080.2 \\
3,405.0 \\
1,976.8 \\
1,489.5 \\
1,242.5 \\
1,055.0 \\
1,263.5 \\
1,456.4 \\
1,840.4 \\
2,011.7 \\
3,298.4 \\
2,296.4\end{array}$ & $\begin{array}{l}W \\
W \\
79.4 \\
39.5 \\
22.3 \\
W \\
W \\
W \\
W \\
W \\
W \\
W \\
W\end{array}$ & $\begin{array}{l}4,800.9 \\
4,337.4 \\
3,553.6 \\
2,043.9 \\
1,531.8 \\
1,283.8 \\
1,088.4 \\
1,306.6 \\
1,511.8 \\
1,914.9 \\
2,104.6 \\
3,454.6 \\
2,402.6\end{array}$ \\
\hline
\end{tabular}

See tootnotes at end of table. 

Table 50. Prime Supplier Sales Volumes of Distillate Fuel Oils and Kerosene
by PAD District and State

(Thousand Gallons per Day) - Continued

\begin{tabular}{|c|c|c|c|c|c|c|c|c|c|}
\hline \multirow{3}{*}{$\begin{array}{l}\text { Geographic Area } \\
\text { Month }\end{array}$} & \multirow{3}{*}{ Kerosene } & \multirow{3}{*}{$\begin{array}{c}\text { No. } 1 \\
\text { Distillate }\end{array}$} & \multicolumn{5}{|c|}{ No. 2 Distillate } & \multirow{3}{*}{ No. 4 Fuela } & \multirow{3}{*}{$\begin{array}{c}\text { Total } \\
\text { Dlstillate } \\
\text { and } \\
\text { Kerosene }\end{array}$} \\
\hline & & & \multirow{2}{*}{$\begin{array}{l}\text { No. } 2 \text { Fuel } \\
\text { Oll }\end{array}$} & \multicolumn{3}{|c|}{ No. 2 Diesel Fuel } & \multirow{2}{*}{$\begin{array}{c}\text { No. } 2 \\
\text { Distillate }\end{array}$} & & \\
\hline & & & & Low-Sulfur & High-Sulfur & Total & & & \\
\hline \multicolumn{10}{|l|}{ Maino } \\
\hline 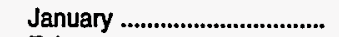 & 402.6 & 29.4 & $2,213.9$ & 308.0 & 3.6 & 311.6 & $2,525.6$ & $w$ & $2,985.8$ \\
\hline 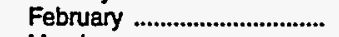 & 283.4 & $w$ & $1,970.5$ & 331.9 & 5.2 & 337.1 & $2,307.5$ & $w$ & $2,636.9$ \\
\hline 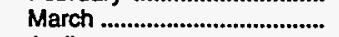 & 190.9 & $w$ & $1,371.5$ & 351.5 & 5.5 & 357.0 & $1,728.5$ & $w$ & $1,956.9$ \\
\hline April & 60.2 & $W$ & 927.1 & 346.4 & 6.5 & 352.9 & $1,280.0$ & $w$ & $1,358.2$ \\
\hline 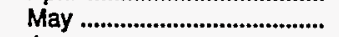 & 51.9 & $W$ & 700.0 & 402.1 & 4.5 & 406.6 & 1.106 .6 & $w$ & $1,166.6$ \\
\hline June .......................................... & 34.4 & NA & 456.8 & 443.0 & 4.8 & 447.8 & 904.5 & 5.0 & 944.6 \\
\hline July & 16.0 & - & 386.7 & 379.5 & 7.4 & 386.9 & 773.5 & 4.0 & 793.5 \\
\hline 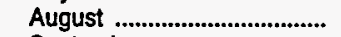 & 60.8 & $W$ & 478.5 & 454.3 & 10.5 & 464.7 & 943.3 & $w$ & $1,017.5$ \\
\hline 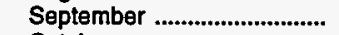 & 80.5 & $W$ & 675.6 & $w$ & W & 435.2 & $1,110.9$ & $\ddot{w}$ & $1,197.6$ \\
\hline October & 113.1 & $W$ & 718.5 & 452.9 & 7.1 & 460.0 & $1,178.4$ & $\dddot{w}$ & $1,302.7$ \\
\hline 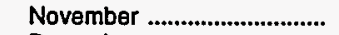 & 149.0 & $W$ & 960.8 & 406.9 & 5.0 & 411.8 & $1,372.6$ & $W$ & $1,539.7$ \\
\hline 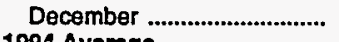 & 289.4 & 7.5 & $1,668.8$ & 386.3 & 4.6 & 390.8 & $2,059.6$ & 16.9 & $2,373.5$ \\
\hline 1994 Average & 143.9 & 5.9 & $1,039.6$ & 391.5 & 5.7 & 397.2 & $1,436.8$ & 14.8 & $1,601.4$ \\
\hline \multicolumn{10}{|l|}{ Massachusetts } \\
\hline 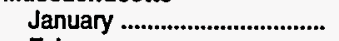 & 180.4 & $w$ & $6,636.7$ & 629.3 & 28.8 & 658.1 & $7,294.7$ & 380.2 & $7,861.9$ \\
\hline 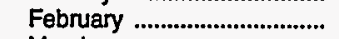 & $W$ & $w$ & $5,891.3$ & 708.2 & 31.9 & 740.1 & $6,631.4$ & 334.9 & $7,130.4$ \\
\hline 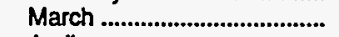 & $W$ & $W$ & $4,774.8$ & 787.5 & 34.4 & 821.9 & $5,596.6$ & 289.2 & $5,983.2$ \\
\hline 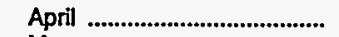 & 43.7 & - & $2,197.9$ & 717.4 & 25.5 & 742.9 & $2,940.8$ & 93.4 & $3,078.0$ \\
\hline May & $W$ & $w$ & $1,658.1$ & 782.2 & 65.1 & 847.3 & $2,505.4$ & 53.0 & $2,603.7$ \\
\hline 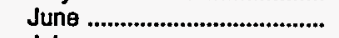 & $W$ & $w$ & $1,289.4$ & 814.0 & 41.8 & 855.7 & $2,145.1$ & 39.2 & $2,196.4$ \\
\hline July .......................................... & 27.6 & - & 789.4 & 883.5 & 33.6 & 917.1 & $1,706.5$ & 24.0 & $1,758.1$ \\
\hline 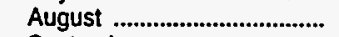 & 31.5 & - & $1,126.3$ & 782.0 & 44.3 & 826.3 & $1,952.5$ & 31.2 & $2,015.3$ \\
\hline September .............................. & 39.9 & - & $1,542.4$ & 924.8 & 35.2 & 960.0 & $2,502.4$ & 43.8 & $2,586.1$ \\
\hline 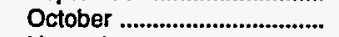 & $W$ & $w$ & $2,018.1$ & 789.9 & 22.6 & 812.6 & $2,830.7$ & 84.1 & $2,990.5$ \\
\hline November ............................... & $w$ & $w$ & $2,481.1$ & 776.0 & 16.6 & 792.6 & $3,273.7$ & 136.7 & $3,472.0$ \\
\hline 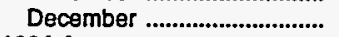 & $\ddot{W}$ & $\ddot{w}$ & $4,462.1$ & 851.8 & 20.6 & 872.5 & $5,334.6$ & 243.2 & $5,693.3$ \\
\hline 1994 Average ............................ & 73.1 & 1.6 & $2,892.4$ & 787.6 & 33.4 & 821.1 & $3,713.4$ & 145.3 & $3,933.5$ \\
\hline \multicolumn{10}{|l|}{ New Hampshire } \\
\hline 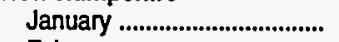 & 192.3 & 12.6 & $1,636.1$ & 296.7 & $W$ & 297.7 & $1,933.9$ & 14.8 & $2,153.6$ \\
\hline February ............................... & 113.7 & 1.3 & $1,370.1$ & 312.4 & 0.8 & 313.1 & $1,683.2$ & 40.4 & $1,838.6$ \\
\hline 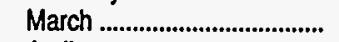 & 60.8 & 1.1 & 931.7 & $W$ & $W$ & 289.9 & $1,221.7$ & 33.2 & $1,316.9$ \\
\hline April & 28.5 & $W$ & 600.9 & 284.4 & 1.1 & 285.5 & 886.4 & W & 934.0 \\
\hline 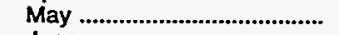 & $w$ & $w$ & 390.5 & 312.2 & 0.9 & 313.2 & 703.6 & 10.5 & 730.4 \\
\hline 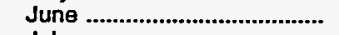 & $W$ & $w$ & 262.8 & 340.0 & 1.8 & 341.8 & 604.5 & 14.0 & 632.4 \\
\hline 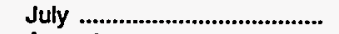 & $w$ & $W$ & 215.0 & $w$ & $w$ & 288.1 & 503.1 & 6.4 & 516.2 \\
\hline 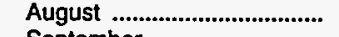 & 17.3 & $w$ & 356.9 & $W$ & $w$ & 349.0 & 705.9 & $w$ & 738.9 \\
\hline September .............................. & 32.3 & $W$ & 435.6 & 324.1 & 1.4 & 325.5 & 761.1 & $W$ & 838.9 \\
\hline 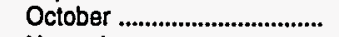 & 36.7 & $W$ & 515.1 & 334.3 & 1.9 & 336.2 & 851.3 & $W$ & 903.4 \\
\hline November ............................. & 51.5 & $W$ & 622.8 & $W$ & $W$ & 327.8 & 950.5 & W & $1,020.3$ \\
\hline 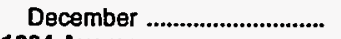 & 112.8 & $W$ & $1,120.1$ & $W$ & $w$ & 333.9 & $1,454.0$ & $W$ & $1,600.1$ \\
\hline 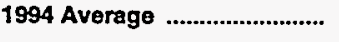 & 56.5 & 4.9 & 701.8 & 315.4 & 1.4 & 316.8 & $1,018.6$ & 18.6 & $1,098.6$ \\
\hline \multicolumn{10}{|l|}{ Rhode Island } \\
\hline 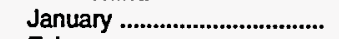 & 30.5 & $w$ & $2,106.6$ & 185.8 & W & 186.2 & $2,292.9$ & 33.8 & $2,364.1$ \\
\hline 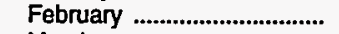 & W & $w$ & $1,938.9$ & $W$ & $W$ & 160.0 & $2,098.9$ & 81.4 & $2,200.9$ \\
\hline March & $W$ & $w$ & $1,370.5$ & W & $W$ & 158.0 & $1,528.6$ & 71.2 & $1,615.0$ \\
\hline April & $w$ & W & 777.3 & $W$ & $w$ & 187.7 & 965.1 & 32.7 & $1,005.7$ \\
\hline 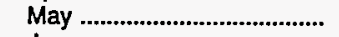 & 31.6 & $W$ & 362.9 & $w$ & $w$ & 196.3 & 559.2 & W & 606.1 \\
\hline June & 3.7 & w & 313.1 & $w$ & W & 215.8 & 528.9 & $w$ & 546.7 \\
\hline July & 2.8 & w & 422.2 & $\ddot{w}$ & W & 173.6 & 595.9 & $\ddot{W}$ & 608.4 \\
\hline 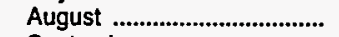 & 5.8 & $W$ & 529.5 & $\ddot{W}$ & W & 201.4 & 730.9 & $\ddot{W}$ & 749.6 \\
\hline 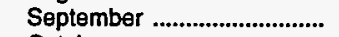 & 8.1 & NA & 554.6 & $\ddot{w}$ & W & 205.3 & 759.8 & 20.0 & 788.4 \\
\hline 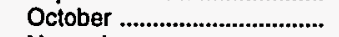 & $w$ & $W$ & 651.3 & $W$ & W & 222.6 & 873.9 & $W$ & 896.6 \\
\hline November ............................... & $w$ & W & 916.3 & $w$ & $\dddot{W}$ & 219.2 & $1,135.5$ & W & $1,176.0$ \\
\hline Decamber ............................... & $w$ & W & $1,263.6$ & 206.5 & - & 206.5 & $1,470.1$ & $\dddot{W}$ & $1,531.0$ \\
\hline 1994 Average & 12.3 & $\mathbf{w}$ & 928.9 & 193.5 & $\mathbf{w}$ & 194.5 & $1,123.4$ & 30.7 & $1,168.8$ \\
\hline
\end{tabular}

See footnotes at end of table. 
Table 50. Prime Supplier Sales Volumes of Distillate Fuel Oils and Kerosene by PAD District and State

(Thousand Gallons per Day) - Continued

\begin{tabular}{c|c|c|c|c|c|c|c|}
\hline \multirow{2}{*}{$\begin{array}{c}\text { Geographic Area } \\
\text { Month }\end{array}$} & Kerosene & $\begin{array}{c}\text { No.1 } \\
\text { Distillate }\end{array}$ & $\begin{array}{c}\text { No.2 Fuel } \\
\text { Oil }\end{array}$ & \multicolumn{2}{|c|}{ No.2 Distillate } \\
\cline { 4 - 6 } & & Lo.2 Diesel Fuel & $\begin{array}{c}\text { Total } \\
\text { Distillate }\end{array}$ & $\begin{array}{c}\text { No.4 Fuela } \\
\text { and }\end{array}$ & Kerosene \\
\hline
\end{tabular}

Vermont

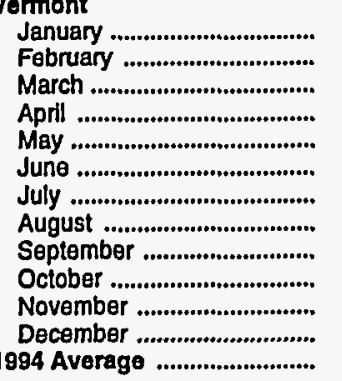

Subdistrict IB

January ...

February ...................................

March

Aprll

May ............................................

June .........................................

July

August ....................................

September .............................

October.

November

December ...............................

1994 Average

Delaware

January ....................................

February .................................

March ...

April

May

Jun日 ........................................

July .........................................

August .................................

September ..............................

October.

November ............................

December

1994 Average ..........................

Dlstrict of Columbia

January .

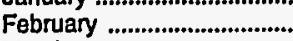

March .

April

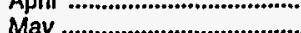

June

July

August ...................................

September ..............

October .

November

December .

1994 Average

29.5
22.3
30.2
$W$
$W$
$W$
$W$
4.7
11.5
17.5
13.2
22.1
13.3

$2,975.3$

$2,379.9$

$1,375.1$

594.0

476.8

445.0

351.9

602.2

683.9

953.2

$1,020.7$

$1,626.7$

$1,118.2$

$\begin{array}{rll}49.7 & - & 749.3 \\ W & - & 888.2 \\ W & - & 575.5 \\ W & - & 224.5 \\ W & - & 148.3 \\ W & - & 219.8 \\ W & - & 137.5 \\ W & - & 143.9 \\ W & - & 212.2 \\ W & - & 241.3 \\ W & - & 242.8 \\ 23.3 & W & 348.6 \\ 23.3 & W & 341.2\end{array}$

$\begin{array}{ccr}W & W & 374.4 \\ W & W & 277.2 \\ W & W & 364.6 \\ W & W & 107.1 \\ - & W & 60.5 \\ - & W & 103.2 \\ W & W & 66.7 \\ - & W & 78.8 \\ - & - & 55.7 \\ W & - & 106.7 \\ - & - & 93.1 \\ - & - & 169.9 \\ \text { W } & \text { W } & 154.5\end{array}$

$346.9 \quad 31,198.9$

$\begin{array}{ll}364.6 & 28,970.5 \\ 222.5 & 21,460.3\end{array}$

$124.8 \quad 10,894.5$

$123.6 \quad 7.667 .5$

$101.5 \quad 6,772.0$

$92.8 \quad 6,173.7$

$8,135.5$

$9,305.6$

$10,631.9$

$11,579.5$

$18,044.8$

61.3
66.6
75.3
84.0
87.5
88.6
71.6
76.3
79.5
65.5
68.4
71.5
74.7

$W$
4.3
6.4
6.6
9.0
11.6
9.0
9.6
11.0
7.9
7.7
6.4
7.8

64.8
70.9
81.7
90.6
96.5
100.2
80.6
85.9
90.5
73.4
76.0
77.8
82.4

$1,238.3$

$6,296.5$

$7,131.5$

$7,997.5$

$8,099.2$

$8,263.2$

$8,654.8$

$7,941.0$

$8,863.8$

$8,768.6$

$8,460.6$

$8,414.7$

$7,796.5$

$1,059.1$

897.5

827.6

$1,147.6$

911.9

911.2

806.4

914.0

$1,048.8$

$1,225.0$

$1,405.5$

$1,033.2$

$7,534.9$

$8,190.5$

$8,895.0$

$8,926.8$

$9,410.8$

$9,566.7$

$8,852.2$

$9,670.2$

$9,682.5$

$9,509.4$

9,639.7

$9,202.0$

$9,093.5$

$\begin{array}{rrr}194.9 & 20.9 & 215.8 \\ W & W & 276.8 \\ W & W & 292.3 \\ W & W & 273.5 \\ W & W & 262.5 \\ W & W & 366.2 \\ W & W & 296.9 \\ W & W & 379.2 \\ W & W & 307.2 \\ W & W & 397.5 \\ W & W & 250.9 \\ W & W & 267.5 \\ 282.0 & 17.0 & 299.0\end{array}$

965.0

$1,165.0$

867.7

498.1

410.7

586.0

434.4

523.1

519.4

638.8

493.7

$616 ?$

640.2

\begin{tabular}{rrrrrr}
14.5 & - & 14.5 & 388.8 & $W$ & 556.8 \\
$W$ & $W$ & 16.1 & 293.3 & $W$ & 480.8 \\
$W$ & $W$ & 17.1 & 381.7 & $W$ & 476.5 \\
$W$ & $W$ & 18.2 & 125.3 & $W$ & 149.9 \\
$W$ & $W$ & 16.4 & 76.9 & $W$ & 97.3 \\
$W$ & $W$ & 17.9 & 121.1 & $W$ & 308.5 \\
$W$ & $W$ & 16.0 & 82.7 & $W$ & 211.9 \\
$W$ & $W$ & 13.6 & 92.5 & $W$ & 224.1 \\
$W$ & $W$ & 17.4 & 73.1 & $W$ & 75.7 \\
$W$ & $W$ & 19.5 & 126.1 & $W$ & 160.5 \\
$W$ & $W$ & 22.5 & 115.5 & $W$ & 125.2 \\
$W$ & $W$ & 23.5 & 193.5 & $W$ & 205.1 \\
16.8 & $W$ & 17.7 & 172.2 & $W$ & 255.3 \\
\hline
\end{tabular}

$\begin{array}{rr}W & 456.5 \\ W & 453.2 \\ W & 356.4 \\ 42.7 & 279.7 \\ 3.7 & 185.0 \\ 3.2 & 154.7 \\ 1.5 & 118.1 \\ W & 153.9 \\ W & 193.3 \\ W & 209.6 \\ 8.6 & 255.5 \\ 11.8 & 343.9 \\ 9.4 & 262.2\end{array}$

$2,008.9$

$1,970.7$

$1,382.8$

708.0

363.4

459.7

350.8

389.1

296.5

428.5

687.9

$1,050.1$

835.4

$44,064.9$

$41,876.2$

$33,335.7$

$21,248.1$

$18,042.2$

$17,344.9$

$15,821.4$

$18,897.7$

$20,156.3$

$21,688.6$

$23,111.8$

$30,146.7$

$25,398.0$

See footnotes at end of table. 
Table 50. Prime Supplier Sales Volumes of Distillate Fuel Oils and Kerosene * by PAD District and State

(Thousand Gallons per Day) - Continued

\begin{tabular}{|c|c|c|c|c|c|c|c|c|c|}
\hline \multirow{3}{*}{$\begin{array}{l}\text { Geographic Area } \\
\text { Month }\end{array}$} & \multirow{3}{*}{ Kerosene } & \multirow{3}{*}{$\begin{array}{c}\text { No. } 1 \\
\text { Distillate }\end{array}$} & \multicolumn{5}{|c|}{ No. 2 Diatillate } & \multirow{3}{*}{ No. 4 Fueja } & \multirow{3}{*}{$\begin{array}{l}\text { Total } \\
\text { Distillate } \\
\text { and } \\
\text { Kerosene }\end{array}$} \\
\hline & & & \multirow{2}{*}{$\begin{array}{c}\text { No. } 2 \text { Fuel } \\
\text { Oll }\end{array}$} & \multicolumn{3}{|c|}{ No. 2 Diesel Fuel } & \multirow{2}{*}{$\begin{array}{c}\text { No. } 2 \\
\text { Distillato }\end{array}$} & & \\
\hline & & & & Low-Sulfur & High-Sulfur & Total & & & \\
\hline
\end{tabular}

Maryland

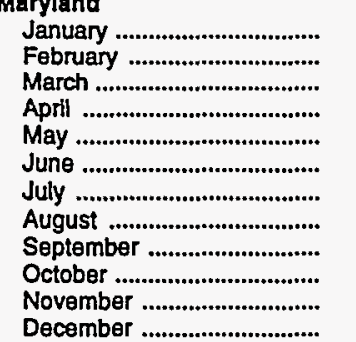

\subsection{7}

217.7
128.1

28.0

17.1

$W$
28.3

W

56.7

86.2

97.7

142.4

1994 Average

New Jersey

January

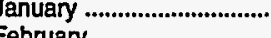

March

June

July

August

September

October....

November

December .

1994 Average

Now York

January ...

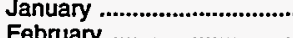

March ...

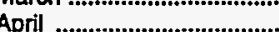

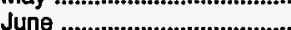

July .

August

September

October

November

December .

1994 Average ..........................

Pennsylvania

January .

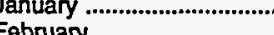

March

April

May

June

July .

August

September

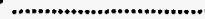

November

December ..

1894 Average

681.6

550.6

256.5

202.5

208.0

184.3

166.7

192.3
$W$

243.6

$W$
325.9

282.6

932.3

932.3
812.2

508.5

211.2

141.4

139.5

88.

175.6

$W$

$W$
590.5

368.8

$1,002.8$

146.4

W
88.0

88.0
67.8

190.2

215.3

296.8

284.7

544.7

343.2

$\begin{array}{rr}33.6 & 3,195.9 \\ 29.7 & 2,202.0 \\ W & 1,718.1 \\ W & 670.2 \\ W & 392.5 \\ 15.4 & 401.5 \\ W & 327.9 \\ W & 429.6 \\ W & 523.3 \\ 0.4 & 749.3 \\ W & 829.5 \\ W & 1,305.5 \\ 14.3 & 1,057.7\end{array}$

783.1
774.0
826.7
824.6
900.3
911.2
823.8
944.9
863.6
892.1
873.1
890.0
859.6

$44.6 \quad 10,217.3$

$58.9 \quad 9,940.1$

$7,224.1$

$3,583.8$

2,576.1

$2,255.3$

$2,192.6$

$2,026.2$

$3,157.0$

$3,221.3$

$3,538.5$

$5,443.0$

4,587.1

149.1

117.6
65.7

9.5

21.9

18.1
11.9

11.9
18.8

W

W

144.3

$10,020.5$

$9,375.0$

$6,771.5$

$4,008.3$

$2,535.0$

$2,074.5$

$1,578.5$

$2,724.1$

$2,694.4$

$3,471.0$

$4,112.2$
$6,781.7$

$6,781.7$
$4,656.3$
79.2

103

W

$6,287.9$

$4,806.5$

$2,300.6$

$1,955.1$

$1,717.7$

$1,870.5$

$2,732.9$

2,663.1

2,842.4

$2,763.5$

$3,996.0$

$3,368.8$
$6,641.6 \quad 2,214.4$
$1,570.4$

$1,822.8$

$2,152.6$

$2,185.6$

$2,173.1$

$2,311.2$

$2,137.1$

$2,139.2$

$2,554.5$

153.5

319.4

$2,161.5$

$2,140.5$

$1,519.3$

$1,573.2$

$1,685.2$

$1,754.3$

,853.9

$1,910.5$

$1,704.8$

$1,945.5$

$1,728.8$

$1,812.6$

$1,670.9$

$1,662.8$

$2,689.1$

$3,056.4$

$3,075.1$

$3,157.7$

$3,457.8$

$3,312.6$

$3,206$.

$2,806.4$
$3,025.2$

139.9
257.3
170.9
177.8
132.0
164.5
74.5
124.5
141.8
151.9
161.2
197.8
157.0

353.6

242.1

198.2

139.0

127.7

122.3

230.3

251.8

286.1

347.2

600.6

606.0

292.5

103.2

125.8

95.9

116.9

144.3

146.1
130.3

104.4

138.3

139.1

89.3

91.0

118.6

620.8

413.3

414.3

380.5

725.7

459.0

458.6

309.4

332.3

389.5

356.4

495.4

447.2

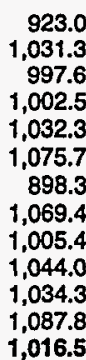

$1,924.0$

$2,065.0$

$2,350.8$

$2,324.6$

$2,300.8$

$2,433.6$

$2,367.4$

$2,391.0$

$2,840.6$

2500.6

$2,919.9$

$2,767.6$

$2,433.0$

$1,622.5$

$1,699.0$

$1,781.1$

$1,871.1$

$1,998.2$

2056.6

$1,835.1$

$2,049.8$

$1,867.1$

$1,951.7$

$1,760.2$

$1,753.7$

$1,854.7$

2,835.2

$3,102.4$

3.456 .1

$3,436.9$

$3,800.8$

$3,616.8$

$3,438.6$

$3,767.2$

$3,644.9$

$3,596.0$

$3,651.8$

$3,301.8$
$3,472.5$

$4,118.9$
$3,233.4$
$2,715.7$
$1,672.7$
$1,424.8$
$1,477.2$
$1,226.2$
$1,499.0$
$1,528.6$
$1,793.4$
$1,863.8$
$2,393.4$

W $4,504.2$

$53.2 \quad 3,534.0$

$\begin{array}{ll}W & 2,894.4 \\ W & 1,723.7\end{array}$

W $\quad 1,461.5$

W $\quad 1,527.4$

W $\quad 1,275.9$

W $\quad 1,558.7$

W $\quad 1,594.9$

$1,594.9$

$1,887.7$
$1,977.3$

$2,561.1$

2,203.0

$12,141.3$

$12,005.1$

$9,574.9$

$5,908.4$

$4,876.9$ 
Table 50. Prime Supplier Sales Volumes of Distillate Fuel Oils and Kerosene by PAD District and State

(Thousand Gallons per Day) - Continued

\begin{tabular}{|c|c|c|c|c|c|c|c|c|c|}
\hline \multirow{3}{*}{$\begin{array}{c}\text { Ceographlo Area } \\
\text { Month }\end{array}$} & \multirow{3}{*}{ Kerosene } & \multirow{3}{*}{$\begin{array}{c}\text { No. } 1 \\
\text { Distlliate }\end{array}$} & \multicolumn{5}{|c|}{ No. 2 Disttllate } & \multirow{3}{*}{ No. 4 Fuela } & \multirow{3}{*}{$\begin{array}{l}\text { Total } \\
\text { Distillate } \\
\text { and } \\
\text { Kerosene }\end{array}$} \\
\hline & & & \multirow{2}{*}{$\begin{array}{c}\text { No. } 2 \text { Fuel } \\
\text { oll }\end{array}$} & \multicolumn{3}{|c|}{ No. 2 Diesel Fuel } & \multirow{2}{*}{$\begin{array}{c}\text { No. } 2 \\
\text { Distillate }\end{array}$} & & \\
\hline & & & & Low-Sulfur & High-Sulfur & Total & & & \\
\hline 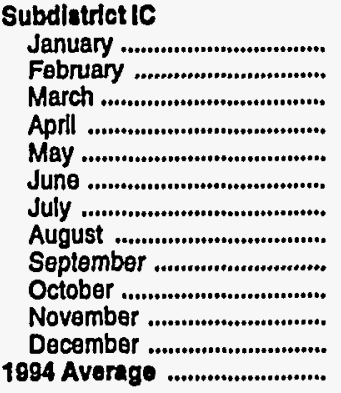 & $\begin{array}{r}2,481.5 \\
1,528.4 \\
803.5 \\
249.1 \\
144.6 \\
146.6 \\
164.4 \\
297.9 \\
551.7 \\
785.0 \\
795.0 \\
1,409.8 \\
777.4\end{array}$ & $\begin{array}{r}99.6 \\
68.2 \\
39.4 \\
W \\
22.7 \\
W \\
W \\
W \\
7.0 \\
6.6 \\
12.0 \\
11.1 \\
29.0\end{array}$ & $\begin{array}{l}7,060.4 \\
6,079.4 \\
4,862.5 \\
4,001.8 \\
4,014.7 \\
3,946.2 \\
3,590.8 \\
4,305.6 \\
4,461.4 \\
4,496.1 \\
4,403.0 \\
4,982.0 \\
4,677.5\end{array}$ & $\begin{array}{r}9,935.5 \\
11,291.9 \\
12,039.3 \\
10,956.5 \\
11,299.4 \\
11,267.7 \\
9,635.0 \\
10,647.8 \\
10,678.6 \\
10,788.4 \\
10,862.0 \\
10,793.1 \\
10,845.0\end{array}$ & $\begin{array}{l}2,857.3 \\
2,590.2 \\
2,631.8 \\
2,235.7 \\
2,386.5 \\
2,420.2 \\
2,086.6 \\
2,035.4 \\
2,465.8 \\
2,282.8 \\
2,456.3 \\
2,539.3 \\
2,414.5\end{array}$ & $\begin{array}{l}12,792.8 \\
13,882.0 \\
14,671.1 \\
13,192.1 \\
13,685.9 \\
13,687.9 \\
11,721.6 \\
12,683.2 \\
13,144.5 \\
13,071.3 \\
13,318.3 \\
13,332.4 \\
13,259.4\end{array}$ & $\begin{array}{l}19,853.2 \\
19,961.5 \\
19,533.6 \\
17,193.9 \\
17,700.6 \\
17,634.1 \\
15,312.4 \\
16,988.8 \\
17,605.9 \\
17,567.4 \\
17,721.3 \\
18,314.5 \\
17,936.9\end{array}$ & $\begin{array}{r}146.8 \\
229.5 \\
32.9 \\
W \\
9.9 \\
W \\
W \\
W \\
11.6 \\
36.9 \\
19.5 \\
60.5 \\
48.2\end{array}$ & $\begin{array}{l}22,581.0 \\
21,787.5 \\
20,409.4 \\
17,484.2 \\
17,877.9 \\
17,808.7 \\
15,503.7 \\
17,317.9 \\
18,176.2 \\
18,395.9 \\
18,547.8 \\
19,795.9 \\
18,791.5\end{array}$ \\
\hline 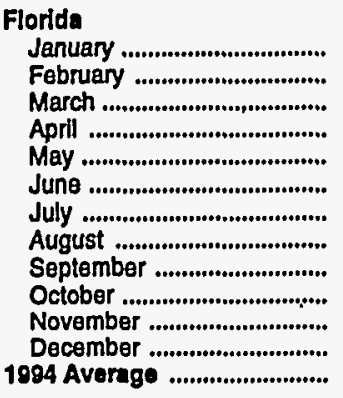 & $\begin{array}{r}134.7 \\
W \\
28.0 \\
12.7 \\
15.2 \\
15.1 \\
15.3 \\
17.3 \\
21.5 \\
38.2 \\
W \\
86.1 \\
41.0\end{array}$ & $\begin{array}{l}W \\
W \\
W \\
W \\
W \\
W \\
W \\
W \\
W \\
W \\
W \\
W \\
W\end{array}$ & $\begin{array}{l}598.1 \\
730.5 \\
667.4 \\
733.3 \\
853.6 \\
782.5 \\
777.2 \\
831.5 \\
854.5 \\
724.2 \\
722.7 \\
750.2 \\
752.1\end{array}$ & $\begin{array}{l}2,675.4 \\
3,020.9 \\
3,186.1 \\
2,815.7 \\
2,794.7 \\
2,722.3 \\
2,408.4 \\
2,626.5 \\
2,528.9 \\
2,762.2 \\
2,868.2 \\
2,887.0 \\
2,773.1\end{array}$ & $\begin{array}{r}931.4 \\
933.9 \\
980.1 \\
994.6 \\
1,067.5 \\
1,082.6 \\
917.1 \\
707.4 \\
993.6 \\
958.2 \\
1,109.4 \\
1,065.1 \\
978.1\end{array}$ & $\begin{array}{l}3,606.8 \\
3,954.8 \\
4,166.3 \\
3,810.4 \\
3,862.3 \\
3,804.9 \\
3,325.5 \\
3,333.9 \\
3,522.5 \\
3,720.4 \\
3,977.6 \\
3,952.2 \\
3,751.2\end{array}$ & $\begin{array}{l}4,204.9 \\
4,685.3 \\
4,833.6 \\
4,543.7 \\
4,715.9 \\
4,587.4 \\
4,102.8 \\
4,165.4 \\
4,377.0 \\
4,444.5 \\
4,700.4 \\
4,702.3 \\
4,503.3\end{array}$ & $\begin{array}{l}10.0 \\
W \\
W \\
W \\
W \\
W \\
W \\
W \\
W \\
W \\
W \\
W \\
6.1\end{array}$ & $\begin{array}{l}4,353.4 \\
4,766.7 \\
4,877.9 \\
4,566.9 \\
4,741.7 \\
4,612.3 \\
4,126.1 \\
4,194.4 \\
4,408.3 \\
4,489.6 \\
4,757.2 \\
4,797.2 \\
4,555.6\end{array}$ \\
\hline 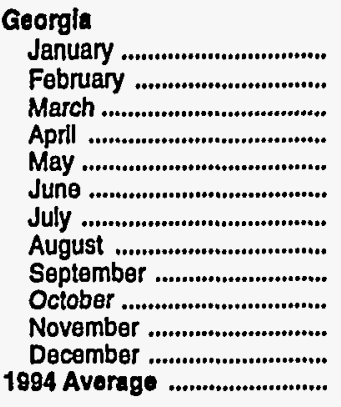 & $\begin{array}{r}182.5 \\
82.7 \\
36.5 \\
W \\
W \\
W \\
W \\
W \\
37.9 \\
W \\
W \\
90.8 \\
48.2\end{array}$ & $\begin{array}{l}4.4 \\
W \\
W \\
W \\
W \\
W \\
W \\
W \\
W \\
W \\
W \\
W \\
1.0\end{array}$ & $\begin{array}{l}785.9 \\
622.1 \\
603.5 \\
628.2 \\
685.7 \\
637.8 \\
566.4 \\
673.2 \\
700.1 \\
667.4 \\
660.1 \\
670.5 \\
658.7\end{array}$ & $\begin{array}{l}2,491.9 \\
2,816.6 \\
2,987.6 \\
2,674.0 \\
2,677.5 \\
2,659.0 \\
2,313.4 \\
2,710.1 \\
2,605.8 \\
2,495.0 \\
2,623.3 \\
2,522.4 \\
2,629.8\end{array}$ & $\begin{array}{l}347.9 \\
348.9 \\
385.8 \\
349.6 \\
414.0 \\
356.7 \\
270.4 \\
345.7 \\
337.9 \\
302.4 \\
312.1 \\
277.6 \\
337.3\end{array}$ & $\begin{array}{l}2,839.8 \\
3,165.6 \\
3,373.5 \\
3,023.6 \\
3,091.5 \\
3,015.7 \\
2,583.8 \\
3,055.8 \\
2,943.7 \\
2,797.4 \\
2,935.4 \\
2,800.0 \\
2,967.1\end{array}$ & $\begin{array}{l}3,625.7 \\
3,787.7 \\
3,976.9 \\
3,651.8 \\
3,777.2 \\
3,653.5 \\
3,150.2 \\
3,729.0 \\
3,643.8 \\
3,464.8 \\
3,595.4 \\
3,470.5 \\
3,625.8\end{array}$ & $\begin{array}{l}W \\
W \\
w \\
- \\
- \\
- \\
- \\
- \\
w \\
- \\
\vec{w} \\
w\end{array}$ & $\begin{array}{l}3,818.4 \\
3,876.5 \\
4,014.5 \\
3,665.8 \\
3,787.1 \\
3,664.3 \\
3,162.1 \\
3,749.6 \\
3,683.3 \\
3,504.8 \\
3,640.1 \\
3,564.4 \\
3,676.1\end{array}$ \\
\hline 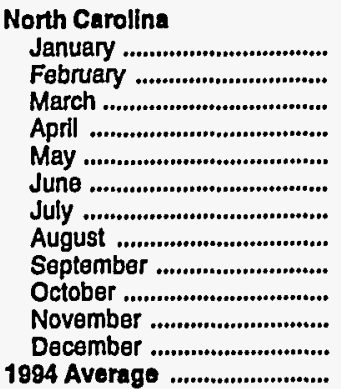 & $\begin{array}{r}923.4 \\
574.6 \\
284.3 \\
75.1 \\
48.8 \\
W \\
W \\
W \\
W \\
W \\
332.9 \\
552.2 \\
296.7\end{array}$ & $\begin{array}{c}11.9 \\
W \\
W \\
W \\
W \\
- \\
- \\
- \\
- \\
\bar{W} \\
W \\
2.5\end{array}$ & $\begin{array}{r}1,828.4 \\
1,366.1 \\
1,084.5 \\
945.3 \\
842.3 \\
855.0 \\
810.1 \\
915.5 \\
1,025.2 \\
1,044.3 \\
997.7 \\
1,214.1 \\
1,076.3\end{array}$ & $\begin{array}{l}1,829.9 \\
2,035.4 \\
2,170.1 \\
2,030.9 \\
2,153.6 \\
2,124.7 \\
1,812.4 \\
1,837.7 \\
2,029.9 \\
2,035.5 \\
2,010.0 \\
2,031.9 \\
2,007.8\end{array}$ & $\begin{array}{l}684.2 \\
468.0 \\
417.9 \\
215.5 \\
277.0 \\
290.2 \\
236.0 \\
289.2 \\
324.6 \\
369.3 \\
369.8 \\
462.8 \\
366.9\end{array}$ & $\begin{array}{l}2,514.1 \\
2,503.5 \\
2,588.0 \\
2,246.4 \\
2,430.6 \\
2,414.9 \\
2,048.4 \\
2,126.9 \\
2,354.5 \\
2,404.7 \\
2,379.8 \\
2,494.7 \\
2,374.8\end{array}$ & $\begin{array}{l}4,342.5 \\
3,869.5 \\
3,672.5 \\
3,191.7 \\
3,272.9 \\
3,269.8 \\
2,858.5 \\
3,042.5 \\
3,379.7 \\
3,449.0 \\
3,377.5 \\
3,708.7 \\
3,451.1\end{array}$ & $\begin{array}{l}W \\
W \\
W \\
W \\
W \\
W \\
W \\
W \\
W \\
W \\
W \\
W \\
W\end{array}$ & $\begin{array}{l}5,290.1 \\
4,468.7 \\
3,963.1 \\
3,274.7 \\
3,324.4 \\
3,318.1 \\
2,911.4 \\
3,150.9 \\
3,638.1 \\
3,773.6 \\
3,716.3 \\
4,271.7 \\
3,755.6\end{array}$ \\
\hline
\end{tabular}

Seo footnotes at end of table. 
Table 50. Prime Supplier Sales Volumes of Distillate Fuel Oils and Kerosene by PAD District and State

(Thousand Gallons per Day) - Continued

\begin{tabular}{|c|c|c|c|c|c|c|c|c|c|}
\hline \multirow{3}{*}{$\begin{array}{l}\text { Geographic Area } \\
\text { Month }\end{array}$} & \multirow{3}{*}{ Kerosene } & \multirow{3}{*}{$\begin{array}{c}\text { No. } 1 \\
\text { Distillate }\end{array}$} & \multicolumn{5}{|c|}{ No. 2 Distillate } & \multirow{3}{*}{ No. 4 Fuela } & \multirow{3}{*}{$\begin{array}{l}\text { Total } \\
\text { Distillate } \\
\text { and } \\
\text { Kerosene }\end{array}$} \\
\hline & & & \multirow{2}{*}{$\begin{array}{l}\text { No. } 2 \text { Fuel } \\
\text { Oll }\end{array}$} & \multicolumn{3}{|c|}{ No. 2 Dlesel Fuel } & \multirow{2}{*}{$\begin{array}{c}\text { No. } 2 \\
\text { Distillate }\end{array}$} & & \\
\hline & & & & Low-Sulfur & HIgh-Sulfur & Total & & & \\
\hline
\end{tabular}

South Carolina

January....

February ..............................

March

April

May

June

July ....

August ......

October

November

December .

Virginia

January

March

April

May

July

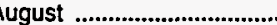

September ..............................

October...

November ................................

December

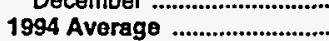

West Virginia

January

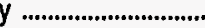

April

July

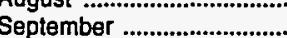

October

November

December

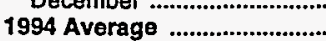

PAD District II

February .

March

April

May
June
July

August

August ...2.

September

October .

November

1994 Average

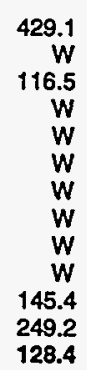

672.1

453.7

277.0

102.6

44.6

56.2

64.2

89.6

115.5

207.0

181.5

356.7

217.6

139.7

104.0

61.2

19.5

10.3
6.9

7.3

18.0

28.8

32.9

46.2

74.7

45.5

$2,021.9$

$1,307$.

221.

221.0

W

$w$

$W$
$W$
$W$

$1,082.9$

667.9

\begin{tabular}{cc}
$W$ & 700.0 \\
\hline$W$ & 555.0 \\
- & 365.0 \\
- & 305.6 \\
- & 313.7 \\
- & 326.6 \\
- & 298.9 \\
- & 334.0 \\
- & 413.3 \\
$W$ & 365.0 \\
$W$ & 370.7 \\
0.2 & 413.8 \\
\hline & 396.0
\end{tabular}

$1,010.5$
$1,056.6$
$1,166.1$
$1,051.1$
$1,115.8$
$1,148.8$
$1,018.3$
$1,121.3$
$1,143.9$
$1,103.0$
$1,078.5$
$1,075.4$
$1,090.9$

$\begin{array}{rr}159.4 & 1,169.9 \\ 108.1 & 1,164.7 \\ 177.2 & 1,343.3 \\ 86.4 & 1,137.5 \\ 100.8 & 1,216.6 \\ 139.8 & 1,288.6 \\ 82.3 & 1,100.6 \\ 121.5 & 1,242.9 \\ 116.3 & 1,260.2 \\ 104.9 & 1,207.9 \\ 118.3 & 1,196.8 \\ 128.8 & 1,204.2 \\ 120.5 & 1,211.4\end{array}$

$1,869.9$
$1,719.8$
$1,708.3$
$1,443.1$
$1,530.3$
$1,615.2$
$1,399.5$
$1,576.9$
$1,673.5$
$1,572.9$
$1,567.5$
$1,618.0$
$1,607.3$

$\begin{array}{ll}W & 2,303.1 \\ W & 1,974.0 \\ W & 1,827.9 \\ W & 1,469.9 \\ W & 1,547.6 \\ W & 1,628.8 \\ W & 1,415.4 \\ W & 1,624.2 \\ W & 1,766.2 \\ W & 1,718.6 \\ W & 1,714.9 \\ W & 1,868.5 \\ W & 1,737.4\end{array}$

$\begin{array}{rr}62.2 & 2,796.9 \\ W & 2,433.9 \\ 25.6 & 1,815.8 \\ 15.3 & 1,139.4 \\ W & 1,018.7 \\ W & 998.7 \\ W & 856.5 \\ W & 1,152.6 \\ 0.6 & 1,098.4 \\ W & 1,269.0 \\ 1.1 & 1,287.7 \\ 1.1 & 1,589.1 \\ 16.3 & 1,450.2\end{array}$

$1,595.8$

$1,979.5$

$2,078.6$

$1,957.2$

$2,116.5$

$2,096.3$

$1,699.0$

$1,947.8$

$1,984.8$

$1,916.9$

$1,912.0$

$1,831.0$

$1,925.2$

$525.6 \quad 2,121.4$

$480.4 \quad 2,459.9$

$469.4 \quad 2,548.0$

$392.7 \quad 2,349.9$

$310.7 \quad 2,427.2$

$371.2 \quad 2,467.4$

$367.3 \quad 2,066.2$

$359.2 \quad 2,306.9$

$468.7 \quad 2,453.6$

$347.2 \quad 2,264.1$

$360.9 \quad 2,272.9$

$393.0 \quad 2,224.0$

403.3

$2,224.0$
$2,328.4$

$16.5 \quad 351.1$

17.1

351.1

326.4

250.0

300.7

345.7

281.8

398.8

370.0

426.3

364.2

344.5

344.2

332.0

382.8

450.7

427.5

441.2

516.7

383.5

404.4

385.3

475.9

370.1

445.4

208.8

250.8

201.4

196.9

216.4

179.7

213.6

212.4

224.7

200.9

185.8

212.0

208.4

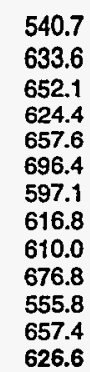

$18,465.9$

$19,829.8$

23,006.7

$24,166.3$

$5,122.4$

$5,066.6$

$5,960.5$

$5,464.9$

$24,802.2$

$5,702.0$

$5,703.8$

$4,654.0$

$5,929.4$

$5,755.1$

$6,172.6$

$5,382.2$

$\begin{array}{r}5,497.9 \\ \hline\end{array}$

$24,038.8$

$2,476.1$

$9,080.8$

$21,714.0$

23,588.2

$24,896.4$

$28,967.2$

$20,631$.

$30,504.2$

$31,521.3$

$26,856.7$

$31,452.8$

$31,877.7$

$32,395.7$

$29,421.0$

$26,744.0$

$29,003.9$

$4,918.4$
$4,893.8$
$4,363.8$
$3,489.3$
$3,446.0$
$3,466.1$
$2,922.7$
$3,459.5$
$3,552.0$
$3,533.0$
$3,560.6$
$3,813.0$
$3,778.7$

$115.3 \quad 5,768.0$

W $\quad 5,575.0$

$4,681.8$

$3,611.1$

$3,506.9$

$3,535.5$

$3,002.3$

$3,565.0$

$3,671.3$

$3,772.5$

$3,751.2$

$4,214.2$

$4,046.6$

$1,597.5$

See footnotes at end of table. 
Table 50. Prime Supplier Sales Volumes of Distillate Fuel Oils and Kerosene by PAD District and State

(Thousand Gallons per Day) - Continued

\begin{tabular}{|c|c|c|c|c|c|c|c|c|c|}
\hline \multirow{3}{*}{$\begin{array}{c}\text { Geographlc Area } \\
\text { Month }\end{array}$} & \multirow{3}{*}{ Kerosene } & \multirow{3}{*}{$\begin{array}{c}\text { No.1 } \\
\text { Distillate }\end{array}$} & \multicolumn{5}{|c|}{ No. 2 Distillate } & \multirow{3}{*}{ No. 4 Fuela } & \multirow{3}{*}{$\begin{array}{c}\text { Total } \\
\text { Distillate } \\
\text { and } \\
\text { Kerosene }\end{array}$} \\
\hline & & & \multirow{2}{*}{$\begin{array}{c}\text { No. } 2 \text { Fuel } \\
\text { Oll }\end{array}$} & \multicolumn{3}{|c|}{ No. 2 Dlesel Fuel } & \multirow{2}{*}{$\begin{array}{c}\text { No. } 2 \\
\text { Distillate }\end{array}$} & & \\
\hline & & & & Low-Sulfur & High-Sulfur & Total & & & \\
\hline \multicolumn{10}{|l|}{ IIIInols } \\
\hline 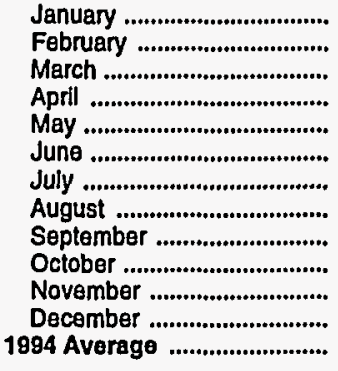 & $\begin{array}{r}134.2 \\
W \\
W \\
W \\
W \\
W \\
W \\
W \\
w \\
W \\
W \\
W \\
39.0\end{array}$ & $\begin{array}{r}574.7 \\
405.5 \\
157.6 \\
99.1 \\
92.6 \\
103.2 \\
73.4 \\
96.2 \\
113.9 \\
127.0 \\
244.9 \\
399.5 \\
206.4\end{array}$ & $\begin{array}{l}1,348.8 \\
1,416.9 \\
1,470.1 \\
1,672.2 \\
1,500.8 \\
1,425.7 \\
1,288.4 \\
1,420.7 \\
1,497.8 \\
1,670.5 \\
1,391.4 \\
1,295.5 \\
1,449.7\end{array}$ & $\begin{array}{l}1,735.9 \\
1,813.3 \\
2,155.8 \\
2,135.7 \\
2,210.5 \\
2,159.3 \\
1,873.2 \\
2,424.9 \\
2,231.0 \\
2,550.5 \\
2,294.2 \\
1,904.2 \\
2,125.7\end{array}$ & $\begin{array}{l}282.3 \\
337.3 \\
435.3 \\
427.9 \\
451.8 \\
497.4 \\
303.5 \\
426.9 \\
463.5 \\
721.8 \\
346.0 \\
327.6 \\
419.0\end{array}$ & $\begin{array}{l}2,018.2 \\
2,150.6 \\
2,591.1 \\
2,563.7 \\
2,662.3 \\
2,656.7 \\
2,176.7 \\
2,851.8 \\
2,694.5 \\
3,272.4 \\
2,640.2 \\
2,231.8 \\
2,544.7\end{array}$ & $\begin{array}{l}3,367.0 \\
3,567.4 \\
4,061.2 \\
4,235.9 \\
4,163.2 \\
4,082.4 \\
3,465.1 \\
4,272.6 \\
4,192.3 \\
4,942.9 \\
4,031.6 \\
3,527.3 \\
3,994.3\end{array}$ & $\begin{array}{l}W \\
W \\
W \\
W \\
W \\
W \\
W \\
W \\
W \\
W \\
W \\
W \\
W\end{array}$ & $\begin{array}{l}4,176.7 \\
4,122.4 \\
4,317.9 \\
4,417.9 \\
4,357.7 \\
4,263.2 \\
3,613.3 \\
4,481.9 \\
4,385.3 \\
5,202.4 \\
4,383.4 \\
4,115.5 \\
4,321.0\end{array}$ \\
\hline \multicolumn{10}{|l|}{ Indlana } \\
\hline 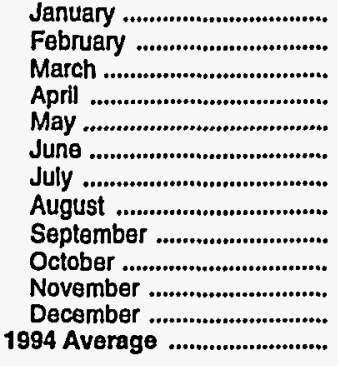 & $\begin{array}{r}222.5 \\
W \\
W \\
19.6 \\
W \\
W \\
W \\
50.4 \\
61.9 \\
74.8 \\
138.6 \\
W \\
88.0\end{array}$ & $\begin{array}{r}367.1 \\
285.7 \\
63.5 \\
W \\
14.5 \\
18.1 \\
16.0 \\
W \\
W \\
W \\
W \\
198.1 \\
99.6\end{array}$ & $\begin{array}{l}1,483.0 \\
1,531.3 \\
1,343.6 \\
1,305.3 \\
1,338.7 \\
1,228.8 \\
1,173.7 \\
1,302.7 \\
1,209.5 \\
1,343.1 \\
1,330.4 \\
1,249.4 \\
1,318.8\end{array}$ & $\begin{array}{l}1,918.0 \\
2,015.6 \\
2,292.5 \\
2,485.1 \\
2,578.7 \\
2,671.9 \\
2,023.1 \\
2,307.7 \\
2,610.3 \\
2,731.6 \\
2,714.3 \\
2,502.0 \\
2,405.1\end{array}$ & $\begin{array}{l}316.5 \\
235.2 \\
537.1 \\
505.6 \\
522.0 \\
436.9 \\
276.3 \\
399.3 \\
505.2 \\
584.7 \\
340.9 \\
265.5 \\
411.5\end{array}$ & $\begin{array}{l}2,234.5 \\
2,250.8 \\
2,829.6 \\
2,990.7 \\
3,100.7 \\
3,108.8 \\
2,299.4 \\
2,707.1 \\
3,115.4 \\
3,316.3 \\
3,055.1 \\
2,767.5 \\
2,816.5\end{array}$ & $\begin{array}{l}3,717.5 \\
3,782.1 \\
4,173.2 \\
4,296.0 \\
4,439.4 \\
4,337.6 \\
3,473.1 \\
4,009.8 \\
4,325.0 \\
4,659.5 \\
4,385.6 \\
4,016.9 \\
4,135.3\end{array}$ & $\begin{array}{l}w \\
w \\
w \\
w \\
w \\
w \\
w \\
w \\
w \\
w \\
w \\
W \\
w\end{array}$ & $\begin{array}{l}4,368.8 \\
4,262.8 \\
4,392.5 \\
4,386.0 \\
4,537.5 \\
4,501.3 \\
3,626.4 \\
4,161.7 \\
4,533.5 \\
4,919.8 \\
4,760.8 \\
4,459.2 \\
4,408.9\end{array}$ \\
\hline \multicolumn{10}{|l|}{ lowa } \\
\hline 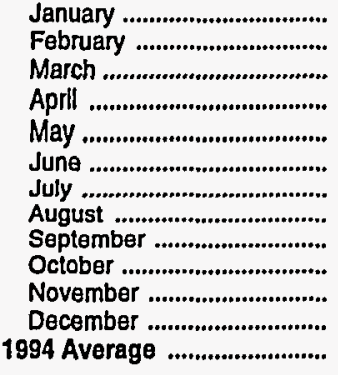 & $\begin{array}{r}15.0 \\
23.4 \\
10.5 \\
0.6 \\
0.9 \\
0.8 \\
1.3 \\
1.9 \\
2.9 \\
3.8 \\
4.2 \\
8.7 \\
6.1\end{array}$ & $\begin{array}{r}469.9 \\
333.0 \\
51.9 \\
12.8 \\
11.9 \\
18.3 \\
9.8 \\
18.9 \\
49.5 \\
92.8 \\
284.7 \\
386.3 \\
144.0\end{array}$ & $\begin{array}{l}333.9 \\
269.8 \\
404.3 \\
467.7 \\
362.5 \\
343.5 \\
295.7 \\
306.8 \\
373.8 \\
459.6 \\
361.6 \\
268.5 \\
354.3\end{array}$ & $\begin{array}{r}991.3 \\
1,131.5 \\
1,625.8 \\
1,900.1 \\
1,617.2 \\
1,580.0 \\
1,369.9 \\
1,614.7 \\
1,869.4 \\
2,022.7 \\
1,556.7 \\
1,237.6 \\
1,544.4\end{array}$ & $\begin{array}{r}125.3 \\
68.2 \\
158.0 \\
183.2 \\
130.4 \\
94.2 \\
60.7 \\
73.7 \\
130.4 \\
190.8 \\
97.2 \\
73.0 \\
115.7\end{array}$ & $\begin{array}{l}1,116.5 \\
1,199.6 \\
1,783.8 \\
2,083.3 \\
1,747.6 \\
1,674.2 \\
1,430.6 \\
1,688.4 \\
1,999.9 \\
2,213.5 \\
1,653.9 \\
1,310.6 \\
1,660.1\end{array}$ & $\begin{array}{l}1,450.5 \\
1,469.4 \\
2,188.1 \\
2,551.0 \\
2,110.1 \\
2,017.7 \\
1,726.4 \\
1,995.2 \\
2,373.7 \\
2,673.1 \\
2,015.5 \\
1,579.2 \\
2,014.4\end{array}$ & $\begin{array}{l}- \\
- \\
- \\
- \\
- \\
- \\
- \\
-\end{array}$ & $\begin{array}{l}1,935.4 \\
1,825.8 \\
2,250.5 \\
2,564.4 \\
2,123.0 \\
2,036.8 \\
1,737.4 \\
2,015.9 \\
2,426.1 \\
2,769.7 \\
2,304.3 \\
1,974.2 \\
2,164.6\end{array}$ \\
\hline 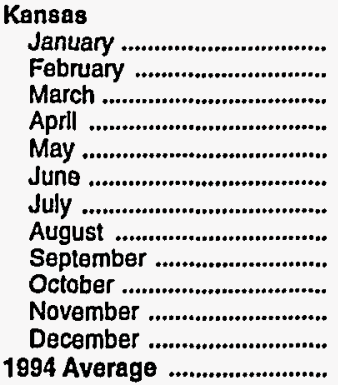 & $\begin{array}{r}W \\
17.9 \\
5.4 \\
W \\
W \\
1.4 \\
0.9 \\
1.4 \\
W \\
5.2 \\
10.3 \\
6.7 \\
6.2\end{array}$ & $\begin{array}{r}195.9 \\
165.2 \\
34.1 \\
W \\
W \\
15.1 \\
23.3 \\
26.0 \\
W \\
142.2 \\
159.8 \\
219.5 \\
91.6\end{array}$ & $\begin{array}{l}299.7 \\
299.8 \\
352.2 \\
426.9 \\
373.1 \\
396.7 \\
331.5 \\
304.1 \\
250.5 \\
238.8 \\
237.4 \\
163.0 \\
306.0\end{array}$ & $\begin{array}{r}884.7 \\
960.7 \\
1,196.9 \\
1,252.3 \\
1,418.5 \\
1,790.3 \\
1,511.6 \\
1,691.3 \\
1,644.1 \\
1,407.9 \\
1,052.3 \\
1,074.9 \\
1,325.6\end{array}$ & $\begin{array}{l}338.8 \\
259.9 \\
630.4 \\
442.8 \\
463.0 \\
490.2 \\
471.2 \\
432.0 \\
480.1 \\
422.6 \\
514.8 \\
679.4 \\
470.3\end{array}$ & $\begin{array}{l}1,223.5 \\
1,220.6 \\
1,827.2 \\
1,695.1 \\
1,881.5 \\
2,280.5 \\
1,982.8 \\
2,123.3 \\
2,124.2 \\
1,830.5 \\
1,567.0 \\
1,754.3 \\
1,795.9\end{array}$ & $\begin{array}{l}1,523.2 \\
1,520.4 \\
2,179.5 \\
2,122.0 \\
2,254.6 \\
2,677.2 \\
2,314.4 \\
2,427.5 \\
2,374.6 \\
2,069.3 \\
1,804.4 \\
1,917.3 \\
2,101.8\end{array}$ & $\begin{array}{l}- \\
\overline{-} \\
\overline{-} \\
\overline{-} \\
- \\
- \\
- \\
- \\
-\end{array}$ & $\begin{array}{l}1,740.7 \\
1,703.5 \\
2,218.9 \\
2,185.9 \\
2,265.8 \\
2,693.7 \\
2,338.5 \\
2,454.8 \\
2,426.1 \\
2,216.6 \\
1,974.5 \\
2,143.5 \\
2,199.6\end{array}$ \\
\hline
\end{tabular}

See footnotes at end of table. 
Table 50. Prime Supplier Sales Volumes of Distillate Fuel Oils and Kerosene by PAD District and State

(Thousand Gallons per Day) - Continued

\begin{tabular}{|c|c|c|c|c|c|c|c|c|c|}
\hline \multirow{3}{*}{$\begin{array}{c}\text { Geographic Area } \\
\text { Month }\end{array}$} & \multirow{3}{*}{ Kerosene } & \multirow{3}{*}{$\begin{array}{c}\text { No. } 1 \\
\text { Distillate }\end{array}$} & \multicolumn{5}{|c|}{ No. 2 Distlllate } & \multirow{3}{*}{ No. 4 Fuela } & \multirow{3}{*}{$\begin{array}{c}\text { Total } \\
\text { Dlstillate } \\
\text { and } \\
\text { Keroseno }\end{array}$} \\
\hline & & & \multirow{2}{*}{$\begin{array}{c}\text { No. } 2 \text { Fuel } \\
\text { Oll }\end{array}$} & \multicolumn{3}{|c|}{ No. 2 Dlesel Fusl } & \multirow{2}{*}{$\begin{array}{c}\text { No. } 2 \\
\text { Distiliato }\end{array}$} & & \\
\hline & & & & Low-Sulfur & High-Sulfur & Total & & & \\
\hline \multicolumn{10}{|l|}{ Kentucky } \\
\hline 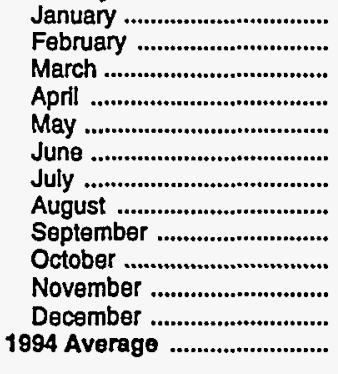 & $\begin{array}{r}331.2 \\
201.0 \\
99.4 \\
31.1 \\
14.5 \\
9.8 \\
9.0 \\
24.7 \\
55.1 \\
77.1 \\
102.1 \\
168.6 \\
93.2\end{array}$ & $\begin{array}{l}38.0 \\
W \\
W \\
W \\
W \\
W \\
W \\
W \\
W \\
W \\
W \\
9.6\end{array}$ & $\begin{array}{l}825.1 \\
878.7 \\
824.7 \\
790.7 \\
824.2 \\
893.6 \\
813.6 \\
830.8 \\
799.7 \\
886.6 \\
823.4 \\
889.9 \\
840.8\end{array}$ & $\begin{array}{l}1,075.7 \\
1,125.8 \\
1,246.2 \\
1,299.6 \\
1,204.8 \\
1,346.7 \\
1,111.3 \\
1,295.1 \\
1,332.8 \\
1,303.1 \\
1,229.1 \\
1,208.0 \\
1,231.6\end{array}$ & $\begin{array}{l}479.8 \\
643.4 \\
779.6 \\
685.7 \\
817.4 \\
720.5 \\
614.7 \\
785.6 \\
795.4 \\
701.6 \\
822.5 \\
696.7 \\
712.0\end{array}$ & $\begin{array}{l}1,555.5 \\
1,769.1 \\
2,025.8 \\
1,985.3 \\
2,022.2 \\
2,067.2 \\
1,725.9 \\
2,080.7 \\
2,128.3 \\
2,004.7 \\
2,051.6 \\
1,904.8 \\
1,943.6\end{array}$ & $\begin{array}{l}2,380.6 \\
2,647.9 \\
2,850.6 \\
2,776.0 \\
2,846.4 \\
2,960.8 \\
2,539.5 \\
2,911.5 \\
2,928.0 \\
2,901.3 \\
2,875.0 \\
2,794.6 \\
2,784.4\end{array}$ & $\begin{array}{l}W \\
W \\
W \\
W \\
W \\
W \\
W \\
W \\
W \\
W \\
W \\
W \\
W\end{array}$ & $\begin{array}{l}2,750.5 \\
2,883.1 \\
2,958.7 \\
2,810.6 \\
2,863.2 \\
2,971.8 \\
2,549.5 \\
2,938.4 \\
2,986.4 \\
2,986.9 \\
2,985.2 \\
2,982.5 \\
2,888.4\end{array}$ \\
\hline \multicolumn{10}{|l|}{ Michigan } \\
\hline 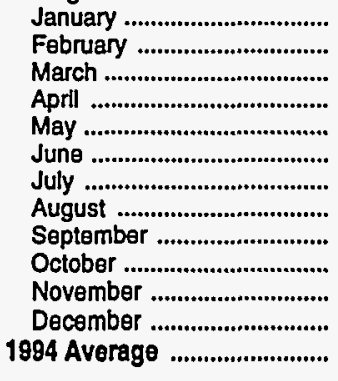 & $\begin{array}{r}277.1 \\
177.3 \\
W \\
W \\
23.6 \\
14.3 \\
11.0 \\
36.1 \\
47.7 \\
W \\
W \\
138.4 \\
92.2\end{array}$ & $\begin{array}{r}358.9 \\
346.0 \\
221.1 \\
191.9 \\
207.0 \\
169.2 \\
121.3 \\
155.2 \\
167.1 \\
219.9 \\
220.6 \\
W \\
208.2\end{array}$ & $\begin{array}{r}1,145.7 \\
1,183.5 \\
909.5 \\
947.5 \\
817.2 \\
840.2 \\
744.7 \\
914.8 \\
946.6 \\
979.9 \\
963.7 \\
1,042.5 \\
951.4\end{array}$ & $\begin{array}{l}1,368.6 \\
1,470.6 \\
1,666.3 \\
1,654.3 \\
1,810.8 \\
1,879.8 \\
1,569.0 \\
1,756.6 \\
1,887.9 \\
1,821.4 \\
1,795.5 \\
1,678.6 \\
1,697.3\end{array}$ & $\begin{array}{l}337.3 \\
330.0 \\
232.0 \\
173.3 \\
144.8 \\
281.7 \\
115.7 \\
360.1 \\
206.8 \\
245.9 \\
269.6 \\
237.0 \\
243.9\end{array}$ & $\begin{array}{l}1,705.9 \\
1,800.6 \\
1,898.3 \\
1,827.6 \\
1,955.6 \\
2,161.5 \\
1,684.7 \\
2,116.6 \\
2,094.7 \\
2,067.3 \\
2,065.2 \\
1,915.6 \\
1,941.2\end{array}$ & $\begin{array}{l}2,851.6 \\
2,984.1 \\
2,807.8 \\
2,775.0 \\
2,772.8 \\
3,001.7 \\
2,429.4 \\
3,031.4 \\
3,041.2 \\
3,047.2 \\
3,028.9 \\
2,958.1 \\
2,892.6\end{array}$ & $\begin{array}{l}w \\
\bar{w} \\
w \\
- \\
- \\
- \\
- \\
\bar{w} \\
W \\
W \\
W\end{array}$ & $\begin{array}{l}3,488.0 \\
3,507.4 \\
3,119.2 \\
3,008.7 \\
3,003.5 \\
3,185.1 \\
2,561.7 \\
3,222.7 \\
3,256.0 \\
3,395.5 \\
3,500.0 \\
3,302.3 \\
3,209.8\end{array}$ \\
\hline \multicolumn{10}{|l|}{ Minnesota } \\
\hline 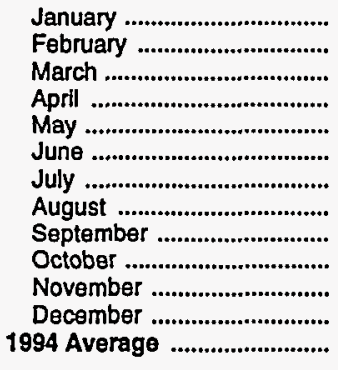 & $\begin{array}{r}60.8 \\
W \\
6.8 \\
W \\
2.1 \\
1.3 \\
W \\
7.1 \\
W \\
W \\
W \\
W \\
38.7\end{array}$ & $\begin{array}{r}667.1 \\
527.2 \\
152.7 \\
54.4 \\
46.7 \\
43.9 \\
37.3 \\
56.2 \\
107.2 \\
146.5 \\
431.0 \\
549.6 \\
233.4\end{array}$ & $\begin{array}{l}618.0 \\
489.5 \\
339.5 \\
346.0 \\
297.9 \\
328.1 \\
253.1 \\
439.9 \\
583.8 \\
712.5 \\
753.2 \\
571.0 \\
477.3\end{array}$ & $\begin{array}{r}749.6 \\
891.5 \\
1,007.1 \\
1,242.8 \\
1,369.1 \\
1,345.9 \\
1,204.7 \\
1,385.0 \\
1,595.5 \\
1,638.4 \\
1,327.1 \\
971.6 \\
1,228.5\end{array}$ & $\begin{array}{l}621.3 \\
585.2 \\
606.8 \\
649.4 \\
623.9 \\
615.3 \\
516.7 \\
541.1 \\
448.0 \\
427.9 \\
512.8 \\
353.0 \\
541.3\end{array}$ & $\begin{array}{l}1,370.9 \\
1,476.7 \\
1,613.9 \\
1,892.2 \\
1,992.9 \\
1,961.2 \\
1,721.4 \\
1,926.1 \\
2,043.5 \\
2,066.3 \\
1,839.9 \\
1,324.6 \\
1,769.7\end{array}$ & $\begin{array}{l}1,988.9 \\
1,966.3 \\
1,953.5 \\
2,238.2 \\
2,290.8 \\
2,289.3 \\
1,974.5 \\
2,366.0 \\
2,627.3 \\
2,778.7 \\
2,593.1 \\
1,895.6 \\
2,247.1\end{array}$ & $\begin{array}{l}W \\
w \\
\bar{W} \\
- \\
\bar{w} \\
\bar{w} \\
W \\
W \\
W \\
W\end{array}$ & $\begin{array}{l}2,732.2 \\
2,552.1 \\
2,113.0 \\
2,295.7 \\
2,339.6 \\
2,334.5 \\
2,015.2 \\
2,429.3 \\
2,751.7 \\
3,065.8 \\
3,119.8 \\
2,536.5 \\
2,522.4\end{array}$ \\
\hline \multicolumn{10}{|l|}{ Missouri } \\
\hline 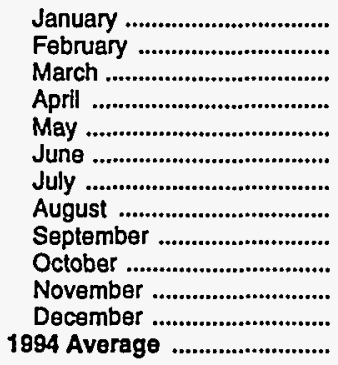 & $\begin{array}{r}62.2 \\
33.6 \\
10.9 \\
4.3 \\
4.4 \\
3.6 \\
2.2 \\
4.6 \\
9.8 \\
8.2 \\
17.9 \\
28.2 \\
15.8\end{array}$ & $\begin{array}{r}135.6 \\
104.6 \\
32.1 \\
7.3 \\
9.3 \\
10.5 \\
6.4 \\
10.4 \\
11.7 \\
28.1 \\
69.7 \\
103.5 \\
43.8\end{array}$ & $\begin{array}{l}238.1 \\
210.9 \\
321.0 \\
301.2 \\
336.8 \\
308.4 \\
250.6 \\
258.0 \\
270.0 \\
276.5 \\
233.9 \\
221.8 \\
269.3\end{array}$ & $\begin{array}{l}1,809.9 \\
1,839.4 \\
2,222.9 \\
2,022.3 \\
2,103.7 \\
2,245.2 \\
1,872.8 \\
2,051.3 \\
2,062.8 \\
2,076.7 \\
2,001.3 \\
1,996.1 \\
2,026.3\end{array}$ & $\begin{array}{l}269.5 \\
202.3 \\
207.6 \\
155.2 \\
195.8 \\
241.5 \\
151.5 \\
181.5 \\
175.8 \\
190.8 \\
137.6 \\
139.7 \\
187.4\end{array}$ & $\begin{array}{l}2,079.5 \\
2,041.7 \\
2,430.5 \\
2,177.5 \\
2,299.5 \\
2,486.7 \\
2,024.3 \\
2,232.8 \\
2,238.6 \\
2,267.6 \\
2,138.9 \\
2,135.9 \\
2,213.7\end{array}$ & $\begin{array}{l}2,317.5 \\
2,252.6 \\
2,751.5 \\
2,478.7 \\
2,636.4 \\
2,795.0 \\
2,275.0 \\
2,490.8 \\
2,508.6 \\
2,544.1 \\
2,372.9 \\
2,357.6 \\
2,483.0\end{array}$ & $\begin{array}{l}- \\
- \\
- \\
- \\
- \\
- \\
- \\
- \\
- \\
-\end{array}$ & $\begin{array}{l}2,515.4 \\
2,390.8 \\
2,794.6 \\
2,490.3 \\
2,650.1 \\
2,809.1 \\
2,283.5 \\
2,505.8 \\
2,530.1 \\
2,580.4 \\
2,460.5 \\
2,489.3 \\
2,542.6\end{array}$ \\
\hline
\end{tabular}

See footnotes at end of table. 
Table 50. Prime Suppller Sales Volumes of Distillate Fuel Oils and Kerosene by PAD District and State

(Thousand Gallons per Day) - Continued

\begin{tabular}{|c|c|c|c|c|c|c|c|c|c|}
\hline \multirow{3}{*}{$\begin{array}{l}\text { Geographlo Area } \\
\text { Month }\end{array}$} & \multirow{3}{*}{ Kerosene } & \multirow{3}{*}{$\begin{array}{c}\text { No. } 1 \\
\text { Distillate }\end{array}$} & \multicolumn{5}{|c|}{ No. 2 Distillate } & \multirow{3}{*}{ No. 4 Fuela } & \multirow{3}{*}{$\begin{array}{l}\text { Total } \\
\text { Distillate } \\
\text { and } \\
\text { Kerosene }\end{array}$} \\
\hline & & & \multirow{2}{*}{$\begin{array}{c}\text { No. } 2 \text { Fuel } \\
\text { Oll }\end{array}$} & \multicolumn{3}{|c|}{ No. 2 Dlesel Fuel } & \multirow{2}{*}{$\begin{array}{c}\text { No. } 2 \\
\text { Dlstillate }\end{array}$} & & \\
\hline & & & & Low-Sulfur & Hlgh-Sulfur & Total & & & \\
\hline 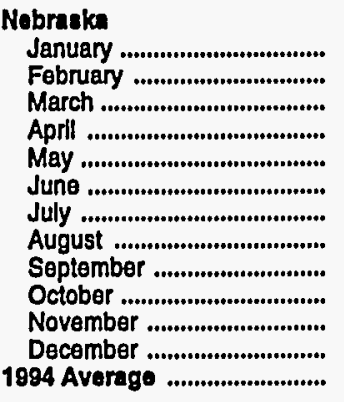 & $\begin{array}{l}5.5 \\
1.4 \\
W \\
W \\
W \\
-\vec{W} \\
1.5 \\
2.0 \\
1.0 \\
W \\
2.6 \\
1.4\end{array}$ & $\begin{array}{r}206.8 \\
178.9 \\
W \\
W \\
W \\
6.1 \\
W \\
6.5 \\
35.4 \\
83.5 \\
W \\
198.6 \\
77.7\end{array}$ & $\begin{array}{r}68.8 \\
46.3 \\
113.0 \\
157.2 \\
145.6 \\
183.8 \\
147.7 \\
162.0 \\
153.6 \\
114.6 \\
91.0 \\
102.6 \\
124.2\end{array}$ & $\begin{array}{r}465.5 \\
528.9 \\
717.9 \\
882.2 \\
965.7 \\
1,047.1 \\
849.1 \\
897.1 \\
976.6 \\
941.2 \\
741.5 \\
598.0 \\
802.0\end{array}$ & $\begin{array}{l}327.0 \\
260.5 \\
475.1 \\
417.2 \\
459.9 \\
419.4 \\
425.5 \\
404.4 \\
391.0 \\
468.3 \\
318.5 \\
341.7 \\
393.5\end{array}$ & $\begin{array}{r}792.6 \\
790.4 \\
1,193.0 \\
1,299.4 \\
1,425.6 \\
1,466.4 \\
1,274.6 \\
1,301.4 \\
1,367.6 \\
1,409.5 \\
1,060.0 \\
939.7 \\
1,195.5\end{array}$ & $\begin{array}{r}861.4 \\
836.7 \\
1,306.0 \\
1,456.6 \\
1,571.3 \\
1,650.3 \\
1,422.3 \\
1,463.4 \\
1,521.2 \\
1,524.1 \\
1,151.0 \\
1,042.3 \\
1,319.8\end{array}$ & $\begin{array}{l}- \\
\overline{-} \\
- \\
- \\
- \\
- \\
- \\
- \\
-\end{array}$ & $\begin{array}{l}1,073.6 \\
1,017.0 \\
1,330.6 \\
1,462.1 \\
1,576.5 \\
1,656.3 \\
1,426.0 \\
1,471.4 \\
1,558.6 \\
1,608.7 \\
1,338.6 \\
1,243.5 \\
1,398.9\end{array}$ \\
\hline 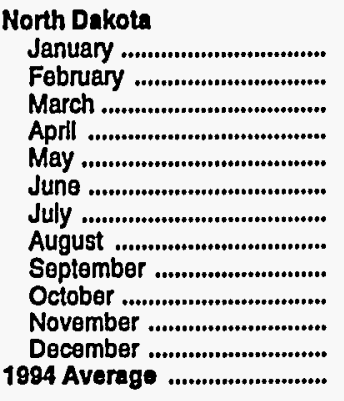 & $\begin{array}{l}W \\
0.8 \\
W \\
W \\
W \\
W \\
W \\
W \\
W \\
1.0 \\
0.7 \\
W \\
0.4\end{array}$ & $\begin{array}{r}214.1 \\
132.0 \\
W \\
W \\
W \\
3.7 \\
2.5 \\
13.6 \\
W \\
77.3 \\
164.5 \\
W \\
70.4\end{array}$ & $\begin{array}{r}194.7 \\
193.3 \\
209.7 \\
209.0 \\
310.8 \\
W \\
W \\
W \\
237.9 \\
219.6 \\
229.6 \\
195.8 \\
223.0\end{array}$ & $\begin{array}{l}197.4 \\
200.8 \\
309.8 \\
422.4 \\
592.3 \\
444.1 \\
432.7 \\
608.0 \\
591.5 \\
501.9 \\
408.9 \\
339.0 \\
422.0\end{array}$ & $\begin{array}{r}56.6 \\
55.9 \\
64.2 \\
71.3 \\
101.1 \\
63.5 \\
49.9 \\
121.8 \\
106.6 \\
67.6 \\
62.9 \\
55.7 \\
73.2\end{array}$ & $\begin{array}{l}254.0 \\
256.6 \\
374.0 \\
493.7 \\
693.4 \\
507.6 \\
482.6 \\
729.8 \\
698.1 \\
569.5 \\
471.8 \\
394.7 \\
495.2\end{array}$ & $\begin{array}{r}448.7 \\
449.9 \\
583.7 \\
702.7 \\
1,004.2 \\
736.1 \\
666.4 \\
990.9 \\
936.0 \\
789.1 \\
701.3 \\
590.5 \\
718.2\end{array}$ & $\begin{array}{l}- \\
- \\
- \\
- \\
- \\
- \\
- \\
- \\
- \\
- \\
-\end{array}$ & $\begin{array}{r}663.4 \\
582.7 \\
601.7 \\
708.2 \\
1,007.5 \\
739.8 \\
669.0 \\
1,004.9 \\
977.2 \\
867.4 \\
866.5 \\
765.0 \\
789.1\end{array}$ \\
\hline 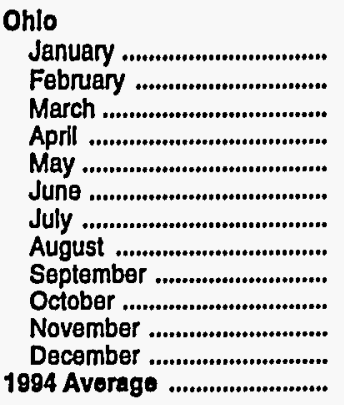 & $\begin{array}{r}564.3 \\
405.1 \\
204.6 \\
77.2 \\
58.3 \\
52.2 \\
38.2 \\
64.6 \\
128.2 \\
137.8 \\
211.4 \\
282.7 \\
184.3\end{array}$ & $\begin{array}{r}167.7 \\
W \\
W \\
W \\
W \\
15.6 \\
W \\
W \\
W \\
W \\
W \\
W \\
50.7\end{array}$ & $\begin{array}{l}1,961.6 \\
1,822.8 \\
1,715.8 \\
1,402.8 \\
1,175.5 \\
1,272.6 \\
1,058.7 \\
1,273.3 \\
1,480.3 \\
1,499.0 \\
1,313.3 \\
1,603.1 \\
1,463.0\end{array}$ & $\begin{array}{l}2,399.2 \\
2,722.3 \\
2,705.9 \\
2,642.6 \\
2,637.7 \\
2,780.8 \\
2,629.6 \\
2,868.3 \\
2,911.8 \\
2,850.6 \\
2,834.6 \\
2,606.6 \\
2,715.0\end{array}$ & $\begin{array}{l}762.4 \\
795.3 \\
770.8 \\
684.8 \\
620.0 \\
647.5 \\
518.8 \\
604.1 \\
700.4 \\
843.2 \\
762.6 \\
663.6 \\
697.0\end{array}$ & $\begin{array}{l}3,161.6 \\
3,517.6 \\
3,476.7 \\
3,327.4 \\
3,257.7 \\
3,428.3 \\
3,148.4 \\
3,472.4 \\
3,612.3 \\
3,693.8 \\
3,597.3 \\
3,270.2 \\
3,411.9\end{array}$ & $\begin{array}{l}5,123.2 \\
5,340.4 \\
5,192.5 \\
4,730.2 \\
4,433.2 \\
4,700.9 \\
4,207.2 \\
4,745.6 \\
5,092.6 \\
5,192.8 \\
4,910.6 \\
4,873.3 \\
4,875.0\end{array}$ & $\begin{array}{l}W \\
W \\
W \\
W \\
W \\
- \\
W \\
W \\
W \\
W \\
W \\
W \\
W\end{array}$ & $\begin{array}{l}5,855.8 \\
5,854.0 \\
5,443.6 \\
4,828.3 \\
4,508.5 \\
4,768.7 \\
4,263.0 \\
4,836.6 \\
5,251.1 \\
5,367.0 \\
5,170.3 \\
5,238.0 \\
5,110.5\end{array}$ \\
\hline 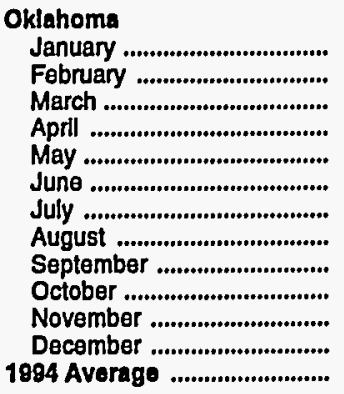 & $\begin{array}{l}4.5 \\
2.5 \\
0.5 \\
W \\
W \\
W \\
W \\
0.7 \\
1.2 \\
2.8 \\
W \\
1.2 \\
4.5\end{array}$ & $\begin{array}{r}118.5 \\
75.3 \\
65.7 \\
W \\
W \\
83.4 \\
W \\
108.5 \\
149.3 \\
85.8 \\
W \\
188.8 \\
103.0\end{array}$ & $\begin{array}{l}133.6 \\
137.3 \\
204.0 \\
248.2 \\
257.8 \\
312.5 \\
182.0 \\
223.4 \\
191.7 \\
112.4 \\
132.7 \\
123.0 \\
188.3\end{array}$ & $\begin{array}{l}1,553.1 \\
1,468.9 \\
1,521.5 \\
1,584.8 \\
1,501.5 \\
1,762.5 \\
1,554.7 \\
1,818.7 \\
1,460.4 \\
1,556.8 \\
1,596.0 \\
1,515.5 \\
1,575.1\end{array}$ & $\begin{array}{l}533.3 \\
455.1 \\
333.0 \\
336.5 \\
379.9 \\
452.7 \\
362.1 \\
487.0 \\
476.7 \\
467.5 \\
360.8 \\
434.1 \\
423.1\end{array}$ & $\begin{array}{l}2,086.5 \\
1,924.0 \\
1,854.5 \\
1,921.3 \\
1,881.4 \\
2,215.2 \\
1,916.8 \\
2,305.7 \\
1,937.1 \\
2,024.3 \\
1,956.8 \\
1,949.7 \\
1,998.3\end{array}$ & $\begin{array}{l}2,220.1 \\
2,061.3 \\
2,058.5 \\
2,169.5 \\
2,139.2 \\
2,527.7 \\
2,098.9 \\
2,529.0 \\
2,128.7 \\
2,136.7 \\
2,089.5 \\
2,072.7 \\
2,186.5\end{array}$ & $\begin{array}{l}\overline{-} \\
\overline{-} \\
\overline{-} \\
\bar{w} \\
\bar{w} \\
\overline{-} \\
\overline{-} \\
\overline{-} \\
\bar{w}\end{array}$ & $\begin{array}{l}2,343.0 \\
2,139.2 \\
2,124.8 \\
2,280.6 \\
2,216.2 \\
2,612.1 \\
2,173.3 \\
2,638.2 \\
2,279.3 \\
2,225.3 \\
2,226.5 \\
2,262.7 \\
2,294.1\end{array}$ \\
\hline
\end{tabular}

See footnotes at end of table. 
Table 50. Prime Supplier Sales Volumes of Distillate Fuel Oils and Kerosene by PAD District and State

(Thousand Gallons per Day) - Continued

\begin{tabular}{|c|c|c|c|c|c|c|c|c|c|}
\hline \multirow{3}{*}{$\begin{array}{l}\text { Geographic Area } \\
\text { Month }\end{array}$} & \multirow{3}{*}{ Kerosene } & \multirow{3}{*}{$\begin{array}{l}\text { No. } 1 \\
\text { Distillate }\end{array}$} & \multicolumn{5}{|c|}{ No. 2 Distillate } & \multirow{3}{*}{ No. 4 Fueja } & \multirow{3}{*}{$\begin{array}{c}\text { Total } \\
\text { Distillate } \\
\text { and } \\
\text { Keroseno }\end{array}$} \\
\hline & & & \multirow{2}{*}{$\begin{array}{l}\text { No. } 2 \text { Fuel } \\
\text { Oil }\end{array}$} & \multicolumn{3}{|c|}{ No. 2 Diesel Fuel } & \multirow{2}{*}{$\begin{array}{c}\text { No. } 2 \\
\text { Distillate }\end{array}$} & & \\
\hline & & & & Low-Sulfur & High-Sulfur & Total & & & \\
\hline \multicolumn{10}{|l|}{ South Dakota } \\
\hline 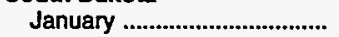 & 2.7 & 232.9 & 79.5 & 329.9 & 38.0 & 367.9 & 447.4 & - & 683.0 \\
\hline 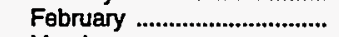 & 1.3 & 167.7 & 53.0 & 352.2 & 17.9 & 370.0 & 423.0 & - & 592.0 \\
\hline 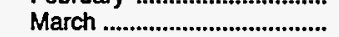 & $\ddot{w}$ & W & 59.9 & 413.4 & 42.9 & 456.3 & 516.2 & - & 542.7 \\
\hline 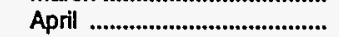 & $w$ & $W$ & 75.0 & 589.1 & 35.5 & 624.6 & 699.6 & - & 707.5 \\
\hline 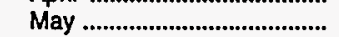 & $\ddot{W}$ & W & 80.0 & 682.1 & 49.0 & 731.1 & 811.1 & - & 815.9 \\
\hline June & - & 2.7 & W & 579.6 & 34.1 & 613.8 & 683.0 & - & 685.7 \\
\hline July ......................................... & $\mathbf{w}$ & $w$ & w & $\mathbf{5 7 8 . 5}$ & 30.7 & 609.2 & 680.1 & - & 682.6 \\
\hline 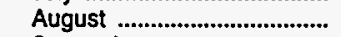 & $w$ & W & $\ddot{w}$ & 555.1 & 26.9 & 582.0 & 660.1 & - & 668.4 \\
\hline September .............................. & 2.5 & 35.5 & 89.6 & 653.5 & 33.3 & 686.8 & 776.4 & - & 814.3 \\
\hline 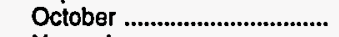 & 1.0 & 80.6 & 88.7 & 686.8 & 44.7 & 731.5 & 820.2 & - & 901.8 \\
\hline November ............................... & 1.4 & 185.3 & 82.6 & 507.3 & 38.4 & 545.7 & 628.3 & - & 814.9 \\
\hline December ................................. & 2.4 & 197.8 & 60.9 & 380.7 & 23.0 & 403.7 & 464.6 & - & 664.9 \\
\hline 1994 Average .............................. & 1.0 & 78.8 & 74.1 & 526.5 & 34.7 & 561.2 & 635.2 & - & 715.0 \\
\hline \multicolumn{10}{|l|}{ Tennesser } \\
\hline 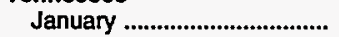 & 295.1 & 5.3 & 509.7 & $1,917.3$ & 284.0 & $2,201.4$ & $2,711.1$ & $w$ & $3,019.2$ \\
\hline 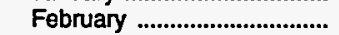 & 161.3 & $W$ & 436.8 & $2,213.3$ & 567.3 & $2,780.5$ & $3,217.3$ & $w$ & $3,391.2$ \\
\hline 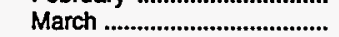 & 77.2 & $\ddot{w}$ & 474.4 & $2,493.0$ & 461.6 & $2,954.6$ & $3,429.0$ & $\ddot{w}$ & $3,514.6$ \\
\hline 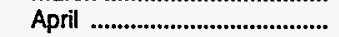 & $\bar{w}$ & - & 464.5 & $2,457.7$ & 508.7 & $2,966.4$ & $3,430.9$ & $w$ & $3,466.5$ \\
\hline May ........................................ & 11.7 & $W$ & 507.6 & $2,373.4$ & 543.6 & $2,917.0$ & $3,424.6$ & w & $3,438.8$ \\
\hline 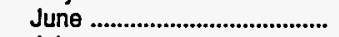 & 10.1 & $w$ & 534.3 & $2,428.1$ & 558.1 & $2,986.2$ & $3,520.5$ & $w$ & $3,533.0$ \\
\hline July ........................................... & 10.0 & $W$ & 451.2 & $1,987.7$ & 615.1 & $2,602.7$ & $3,054.0$ & $w$ & $3,065.9$ \\
\hline 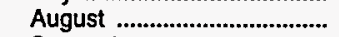 & $W$ & - & 543.1 & $2,469.2$ & 910.0 & $3,379.1$ & $3,922.2$ & $w$ & $3,959.1$ \\
\hline September ................................ & w & - & 499.8 & $2,462.0$ & 629.1 & $3,091.1$ & $3,590.8$ & $w$ & $3,680.6$ \\
\hline 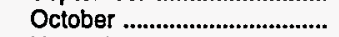 & 93.2 & $w$ & 581.1 & $2,405.6$ & 580.6 & $2,986.3$ & $3,567.4$ & w & $3,666.8$ \\
\hline November .................................. & 95.9 & $W$ & 470.5 & $2,359.1$ & 583.9 & $2,943.0$ & $3,413.4$ & $w$ & $3,516.0$ \\
\hline 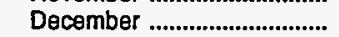 & 167.8 & $\ddot{W}$ & 463.0 & $2,250.6$ & 517.5 & $2,768.1$ & $3,231.2$ & $\ddot{w}$ & $3,407.5$ \\
\hline 1994 Average & 89.3 & 1.0 & 495.2 & $2,317.7$ & 563.2 & $2,880.9$ & $3,376.1$ & $\ddot{w}$ & $3,471.4$ \\
\hline \multicolumn{10}{|l|}{ Wisconsin } \\
\hline 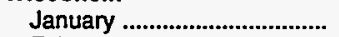 & 24.9 & 636.5 & $1,067.9$ & $1,069.6$ & 350.4 & $1,419.9$ & $2,487.8$ & $w$ & $3,169.3$ \\
\hline 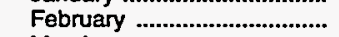 & $W$ & 469.8 & 778.0 & $1,094.2$ & 253.3 & $1,347.5$ & $2,125.5$ & $w$ & $2,653.4$ \\
\hline March & $w$ & 113.6 & 676.7 & $1,431.7$ & 226.1 & $1,657.8$ & $2,334.5$ & $\ddot{w}$ & $2,519.7$ \\
\hline April & $W$ & 40.1 & 588.2 & $1,595.2$ & 187.9 & $1,783.1$ & $2,371.3$ & $\ddot{w}$ & $2,489.2$ \\
\hline 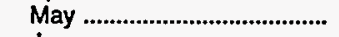 & $W$ & 24.1 & 506.8 & $1,736.2$ & 199.4 & $1,935.5$ & $2,442.3$ & $w$ & $2,545.4$ \\
\hline 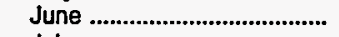 & W & 20.6 & 534.5 & $1,756.2$ & 150.8 & $1,906.9$ & $2,441.5$ & w & $2,542.0$ \\
\hline 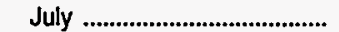 & $W$ & 16.5 & 464.5 & $1,634.6$ & 141.7 & $1,776.3$ & $2,240.8$ & $w$ & $2,296.4$ \\
\hline 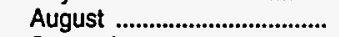 & W & 34.3 & 541.0 & $1,780.4$ & 175.1 & $1,955.5$ & $2,496.5$ & $w$ & $2,590.5$ \\
\hline 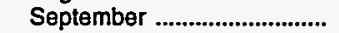 & $W$ & 63.5 & 580.8 & $1,833.1$ & 212.7 & $2,045.7$ & $2,626.6$ & $\ddot{w}$ & $2,742.9$ \\
\hline October & $w$ & 101.7 & 740.4 & $1,728.0$ & 214.3 & $1,942.3$ & $2,682.7$ & $\ddot{w}$ & $2,835.9$ \\
\hline November ............................... & $W$ & 260.9 & 666.1 & $1,621.0$ & 213.8 & $1,834.7$ & $2,500.8$ & $\ddot{w}$ & $2,836.6$ \\
\hline 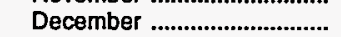 & $\ddot{w}$ & 387.2 & 733.7 & $1,450.3$ & 222.5 & $1,672.8$ & $2,406.5$ & w & $2,876.1$ \\
\hline 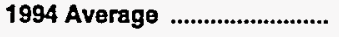 & 7.8 & 179.3 & 656.3 & $1,563.2$ & 212.2 & $1,775.4$ & $2,431.6$ & $w$ & $2,675.2$ \\
\hline \multicolumn{10}{|l|}{ PAD District III } \\
\hline 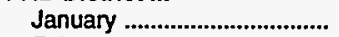 & 266.2 & 172.3 & $2,035.7$ & $11,039.5$ & $5,392.4$ & $16,431.8$ & $18,467.5$ & - & $18,906.0$ \\
\hline 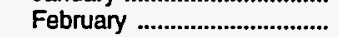 & $W$ & 149.4 & f,804.5 & $12,281.4$ & $5,754.2$ & $18,035.5$ & $19,840.0$ & $\bar{w}$ & $20,144.9$ \\
\hline 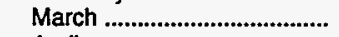 & W & 91.6 & $2,066.7$ & $12,511.1$ & $6,867.6$ & $19,378.7$ & $21,445.4$ & $w$ & $21,627.8$ \\
\hline Apri] & 109.7 & $W$ & $2,012.6$ & $12,078.8$ & $6,914.5$ & $18,993.3$ & $21,005.9$ & $w$ & $21,190.1$ \\
\hline May & $w$ & 69.4 & $2,288.5$ & $12,065.4$ & $6,134.1$ & $18,199.5$ & $20,488.0$ & $w$ & $20,616.8$ \\
\hline 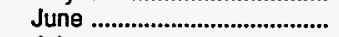 & $W$ & 103.8 & $2,816.8$ & $13,003.5$ & $7,129.3$ & $20,132.8$ & $22,949.5$ & $w$ & $23,217.2$ \\
\hline 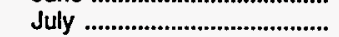 & W & 89.4 & $2,226.9$ & $11,807.9$ & $6,798.6$ & $18,606.5$ & $20,833.4$ & W & $21,080.9$ \\
\hline 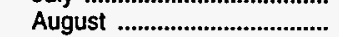 & W & 135.7 & $2,311.0$ & $12,892.1$ & $7,049.6$ & $19,941.7$ & $22,252.7$ & $w$ & $22,542.0$ \\
\hline 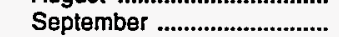 & $w$ & 140.3 & $2,565.1$ & $12,952.0$ & $6,507.3$ & $19,459.3$ & $22,024.4$ & $\dddot{w}$ & $22,348.2$ \\
\hline 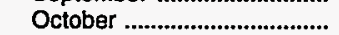 & W & 139.9 & $2,062.6$ & $11,814.2$ & $6,554.1$ & $18,368.3$ & $20,430.9$ & $w$ & $20,768.9$ \\
\hline November ............................... & 300.5 & 171.4 & $2,016.5$ & $12,231.2$ & $6,495.1$ & $18,726.4$ & $20,742.9$ & - & $21,214.8$ \\
\hline December ................................ & 373.8 & $w$ & $1,954.6$ & $11,229.7$ & $6,126.3$ & $17,356.0$ & $19,310.6$ & $\bar{w}$ & $19,864.4$ \\
\hline 1994 Average & 184.2 & 126.2 & $2,181.3$ & $12,153.4$ & $6,479.7$ & $18,633.2$ & $20,814.5$ & $w$ & $21,125.4$ \\
\hline
\end{tabular}

See footnotes at end of table. 
Table 50. Prime Supplier Sales Volumes of Distillate Fuel Oils and Kerosene by PAD District and State

(Thousand Gallons per Day) - Continued

\begin{tabular}{|c|c|c|c|c|c|c|c|c|c|}
\hline \multirow{3}{*}{$\begin{array}{l}\text { Geographlc Area } \\
\text { Month }\end{array}$} & \multirow{3}{*}{ Kerosene } & \multirow{3}{*}{$\begin{array}{c}\text { No. } 1 \\
\text { Distillate }\end{array}$} & \multicolumn{5}{|c|}{ No. 2 Distillate } & \multirow{3}{*}{ No. 4 Fuela } & \multirow{3}{*}{$\begin{array}{l}\text { Total } \\
\text { Distillate } \\
\text { and } \\
\text { Kerosene }\end{array}$} \\
\hline & & & \multirow{2}{*}{$\begin{array}{l}\text { No. } 2 \text { Fuel } \\
\text { Oil }\end{array}$} & \multicolumn{3}{|c|}{ No. 2 Diesel Fuel } & \multirow{2}{*}{$\begin{array}{c}\text { No. } 2 \\
\text { Distillate }\end{array}$} & & \\
\hline & & & & Low-Sulfur & High-Sulfur & Total & & & \\
\hline
\end{tabular}

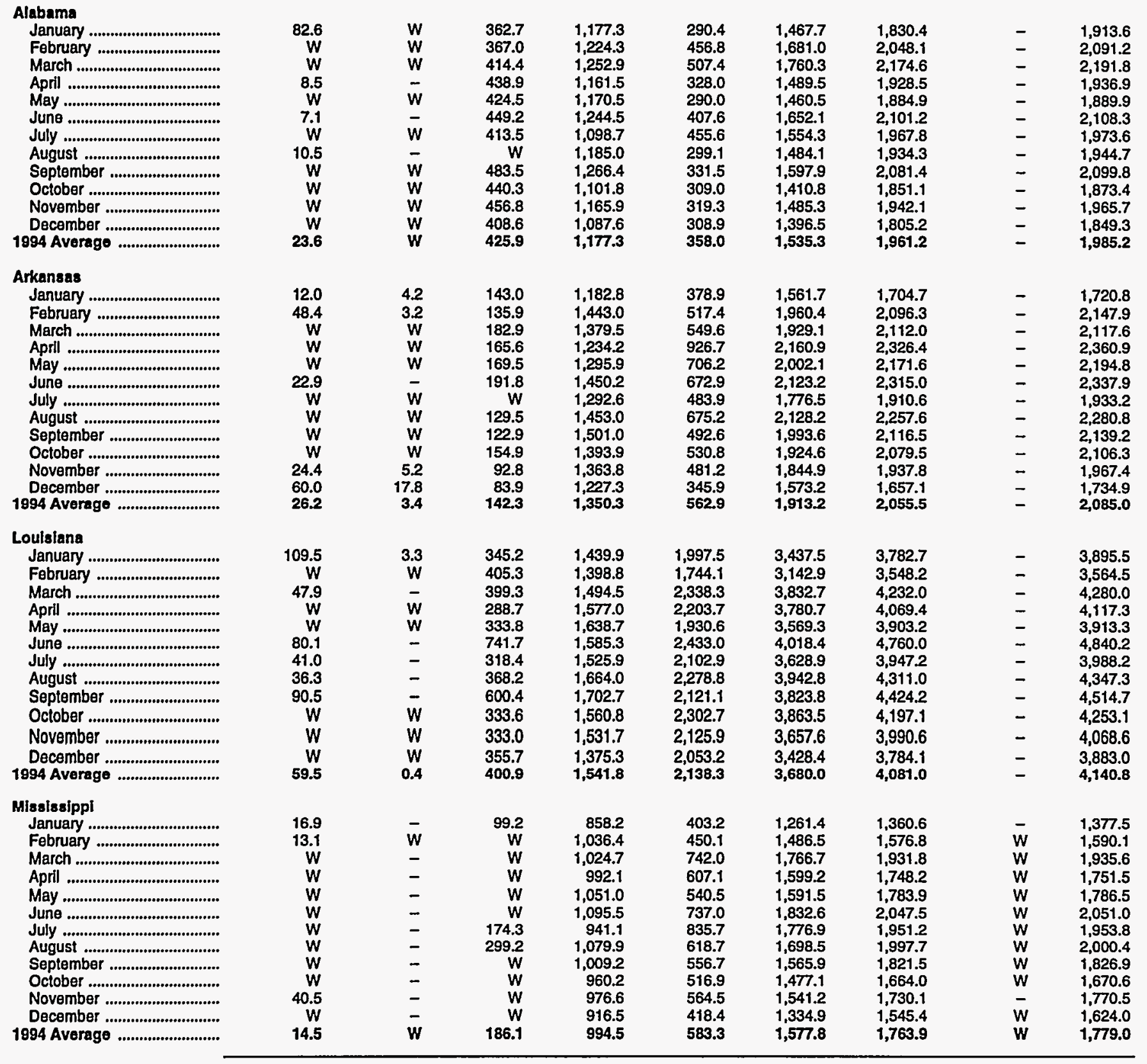

See footnotes at end of table. 
Table 50. Prime Supplier Sales Volumes of Dlstillate Fuel Olls and Kerosene by PAD District and State

(Thousand Gallons per Day) - Continued



See footnotes at end of table. 
Table 50. Prime Supplier Sales Volumes of Distillate Fuel Olls and Kerosene by PAD District and State

(Thousand Gallons per Day) - Continued

\begin{tabular}{|c|c|c|c|c|c|c|c|c|c|}
\hline \multirow{3}{*}{$\begin{array}{l}\text { Ceographlo Area } \\
\text { Month }\end{array}$} & \multirow{3}{*}{ Korosene } & \multirow{3}{*}{$\begin{array}{c}\text { No. } 1 \\
\text { Dlatiliate }\end{array}$} & \multicolumn{5}{|c|}{ No. 2 Dletillate } & \multirow{3}{*}{ No. 4 Fuela } & \multirow{3}{*}{$\begin{array}{c}\text { Total } \\
\text { Dlstillate } \\
\text { and } \\
\text { Koroseno }\end{array}$} \\
\hline & & & \multirow{2}{*}{$\begin{array}{c}\text { No. } 2 \text { Fuel } \\
\text { Oll }\end{array}$} & \multicolumn{3}{|c|}{ No. 2 Dlesel Fuel } & \multirow{2}{*}{$\begin{array}{c}\text { No. } 2 \\
\text { Distillate }\end{array}$} & & \\
\hline & & & & Low-Sulfur & High-Sulfur & Total & & & \\
\hline \multicolumn{10}{|l|}{ Idno } \\
\hline January ................................. & $W$ & 81.2 & $W$ & 327.2 & 390.3 & 717.5 & 722.5 & - & 808.0 \\
\hline Fabruary ............................... & W & 53.8 & $W$ & 307.0 & 250.1 & 557.1 & 565.4 & - & 623.8 \\
\hline March ..................................... & $w$ & 14.2 & $W$ & W & $W$ & 617.4 & 624.8 & - & 639.8 \\
\hline 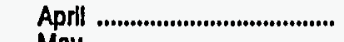 & $W$ & 5.2 & $W$ & 374.7 & 279.7 & 654.4 & 658.6 & - & 664.5 \\
\hline May .............................................. & W & 10.3 & $W$ & 341.7 & 247.3 & 589.1 & 592.2 & - & 602.8 \\
\hline June ......................................... & $W$ & 12.0 & $W$ & $W$ & W & 679.1 & 683.2 & - & 695.8 \\
\hline July ............................................. & $w$ & 6.0 & $w$ & 431.6 & 258.8 & 690.4 & 691.6 & - & 698.6 \\
\hline August .................................... & $w$ & 8.2 & $w$ & 454.2 & 325.9 & 780.1 & 784.8 & - & 794.5 \\
\hline September ............................ & 1.9 & 4.3 & $\bar{\mu}$ & 370.3 & 296.7 & 667.0 & 667.0 & - & 673.2 \\
\hline October ....................................... & $W$ & 21.3 & $w$ & $W$ & $W$ & 712.8 & 715.0 & - & 738.9 \\
\hline & 6.7 & 99.4 & - & $W$ & $W$ & 629.4 & 629.4 & - & 735.5 \\
\hline 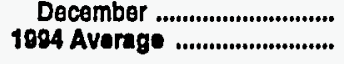 & $\begin{array}{l}W \\
2.6\end{array}$ & $\begin{array}{l}82.8 \\
33.1\end{array}$ & $\underset{W}{W}$ & $\begin{array}{l}291.6 \\
371.0\end{array}$ & $\begin{array}{l}174.3 \\
276.3\end{array}$ & $\begin{array}{l}465.9 \\
647.3\end{array}$ & $\begin{array}{l}469.0 \\
650.9\end{array}$ & $\overline{-}$ & $\begin{array}{l}558.6 \\
686.6\end{array}$ \\
\hline \multicolumn{10}{|l|}{ Montana } \\
\hline January .................................... & $w$ & 81.1 & - & 423.9 & 30.8 & 454.6 & 454.6 & - & 549.6 \\
\hline February ................................ & $w$ & 101.2 & $w$ & $W$ & W & 583.1 & 583.3 & - & 701.9 \\
\hline March ...................................... & $W$ & 41.2 & $W$ & 642.7 & 15.4 & 658.1 & 658.2 & - & 704.5 \\
\hline Aprll & $w$ & 12.0 & $w$ & $W$ & $w$ & 740.6 & 741.1 & - & 754.3 \\
\hline May .......................................... & $w$ & 7.3 & $W$ & W & $w$ & 740.1 & 742.0 & - & 750.0 \\
\hline 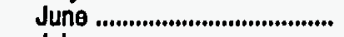 & $w$ & 6.9 & $W$ & W & $W$ & 759.3 & 759.7 & - & 767.0 \\
\hline July ........................................... & $w$ & 3.9 & $W$ & $W$ & $w$ & 696.3 & 696.9 & - & 701.2 \\
\hline 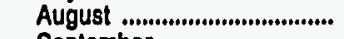 & $\mathbf{W}$ & 10.2 & $W$ & $W$ & $w$ & 841.1 & 842.3 & - & 853.6 \\
\hline Seplember ............................ & $W$ & 27.9 & $W$ & W & $W$ & 814.8 & 815.8 & - & 846.9 \\
\hline & $W$ & 55.5 & $W$ & 710.3 & 11.5 & 721.8 & 721.9 & - & 779.9 \\
\hline November ................................ & $\underset{w}{W}$ & 109.9 & $W$ & 649.4 & NA & 655.9 & 656.3 & - & 768.8 \\
\hline 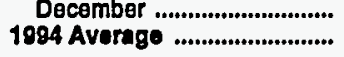 & $\begin{array}{l}W \\
4.2\end{array}$ & $\begin{array}{r}107.2 \\
46.7\end{array}$ & $\begin{array}{l}W \\
W\end{array}$ & $\begin{array}{r}W \\
679.1\end{array}$ & $\begin{array}{r}W \\
10.5\end{array}$ & $\begin{array}{l}605.7 \\
689.6\end{array}$ & $\begin{array}{l}605.8 \\
690.1\end{array}$ & - & $\begin{array}{l}715.5 \\
741.0\end{array}$ \\
\hline \multicolumn{10}{|l|}{ Utah } \\
\hline January ..................................... & $W$ & 116.7 & $W$ & 694.6 & 229.9 & 924.6 & $1,023.6$ & - & $1,144.7$ \\
\hline 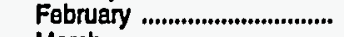 & $W$ & 92.5 & $W$ & 666.3 & 180.6 & 846.9 & 915.9 & - & $1,012.5$ \\
\hline March ........................................ & $W$ & 23.4 & $W$ & 782.7 & 182.7 & 965.4 & $1,053.5$ & - & $1,077.9$ \\
\hline Aprll & $\mathbf{W}$ & $W$ & $W$ & 765.5 & 240.2 & $1,005.7$ & $1,094.1$ & - & $1,099.0$ \\
\hline 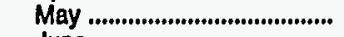 & $W$ & 2.4 & $W$ & 751.6 & 175.7 & 927.3 & $1,016.5$ & - & $1,019.5$ \\
\hline June ........................................... & $W$ & 3.6 & $W$ & 817.6 & 213.5 & $1,031.1$ & $1,132.7$ & - & $1,136.8$ \\
\hline July ........................................... & $W$ & 6.8 & $W$ & 831.6 & 212.0 & $1,043.7$ & $1,118.2$ & - & $1,125.3$ \\
\hline August .................................. & $w$ & $W$ & $W$ & 845.3 & 205.4 & $1,050.7$ & $1,165.5$ & - & $1,172.5$ \\
\hline September ............................. & $W$ & 10.2 & $W$ & 762.5 & 164.2 & 926.7 & $1,051.3$ & - & $1,062.7$ \\
\hline 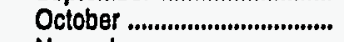 & $W$ & 28.0 & $W$ & 705.6 & 181.5 & 887.2 & $1,002.2$ & - & $1,031.5$ \\
\hline November ............................... & $W$ & 107.3 & $W$ & 725.0 & 138.0 & 863.0 & 972.3 & - & $1,086.0$ \\
\hline 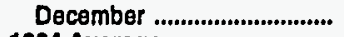 & $W$ & 119.9 & $W$ & 644.5 & 107.4 & 751.9 & 830.5 & - & 958.8 \\
\hline 1894 Average .......................... & $\mathbf{W}$ & 43.3 & $\mathbf{W}$ & 749.9 & 185.8 & 935.8 & $1,032.0$ & - & $1,077.6$ \\
\hline \multicolumn{10}{|l|}{ Wyoming } \\
\hline January ................................... & $w$ & 113.9 & $w$ & 607.4 & $W$ & 762.6 & 764.9 & - & 882.7 \\
\hline February ................................ & $W$ & 108.8 & $W$ & W & $W$ & 823.8 & 825.4 & - & 937.3 \\
\hline March ................................... & $W$ & 37.2 & $w$ & $w$ & $W$ & 972.3 & 974.6 & - & $1,017.1$ \\
\hline April ........................................ & $w$ & 11.0 & W & $W$ & $w$ & $1,002.0$ & $1,006.0$ & - & $1,017.9$ \\
\hline May ......................................... & - & $W$ & $w$ & $W$ & $w$ & $1,057.2$ & $1,061.4$ & - & $1,068.8$ \\
\hline June ....................................... & $w$ & 5.2 & $w$ & 914.5 & 153.2 & $1,067.7$ & $1,071.2$ & - & $1,076.7$ \\
\hline July ........................................... & $w$ & $W$ & $w$ & W & $W$ & $1,109.5$ & $1,113.2$ & - & $1,116.9$ \\
\hline August .................................. & - & $W$ & $W$ & w & $W$ & $1,046.4$ & $1,047.9$ & - & $1,054.0$ \\
\hline September ............................ & $w$ & 16.1 & $w$ & $w$ & $W$ & $1,164.3$ & $1,166.5$ & - & $1,182.8$ \\
\hline October ................................... & $W$ & 49.6 & $W$ & W & $W$ & $1,055.7$ & $1,056.5$ & - & $1,112.1$ \\
\hline November .............................. & $W$ & 86.8 & $w$ & $w$ & $\ddot{W}$ & 982.6 & 985.0 & - & $1,078.0$ \\
\hline December ............................. & $w$ & 91.9 & $W$ & W & $W$ & 923.4 & 923.8 & - & $1,021.5$ \\
\hline 1984 Average ........................... & 2.8 & 44.3 & $\mathbf{W}$ & 806.3 & $\mathbf{W}$ & 998.1 & $1,000.5$ & - & $1,047.6$ \\
\hline
\end{tabular}

See footnotes at end of table. 
Table 50. Prime Supplier Sales Volumes of Distillate Fuel Oils and Kerosene by PAD District and State

(Thousand Gallons per Day) - Continued

\begin{tabular}{|c|c|c|c|c|c|c|c|c|c|}
\hline \multirow{3}{*}{$\begin{array}{c}\text { Goographic Area } \\
\text { Month }\end{array}$} & \multirow{3}{*}{ Kerosene } & \multirow{3}{*}{$\begin{array}{c}\text { No. } 1 \\
\text { Distillate }\end{array}$} & \multicolumn{5}{|c|}{ No. 2 Distillate } & \multirow{3}{*}{ No. 4 Fuela } & \multirow{3}{*}{$\begin{array}{l}\text { Total } \\
\text { Distillate } \\
\text { and } \\
\text { Kerosene }\end{array}$} \\
\hline & & & \multirow{2}{*}{$\begin{array}{l}\text { No. } 2 \text { Fuel } \\
\text { Oll }\end{array}$} & \multicolumn{3}{|c|}{ No. 2 Diesel Fuel } & \multirow{2}{*}{$\begin{array}{c}\text { No. } 2 \\
\text { Distiliate }\end{array}$} & & \\
\hline & & & & Low-Sulfur & High-Sulfur & Total & & & \\
\hline \multicolumn{10}{|l|}{ PAD District V } \\
\hline 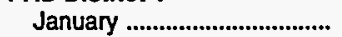 & 53.6 & 499.5 & 422.9 & $10,645.0$ & $3,291.2$ & $13,936.2$ & $14,359.1$ & $W$ & $15,018.6$ \\
\hline 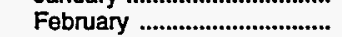 & $w$ & 459.0 & 323.6 & $10,821.4$ & $3,504.2$ & $14,325.6$ & $14,649.2$ & W & $15,278.2$ \\
\hline 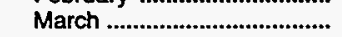 & 56.4 & 331.2 & 275.9 & $11,150.2$ & $3,809.9$ & $14,960.0$ & $15,236.0$ & 109.6 & $15,733.2$ \\
\hline 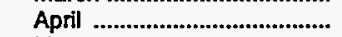 & 19.7 & 99.7 & 387.0 & $11,333.0$ & $3,954.7$ & $15,287.8$ & $15,674.7$ & 27.8 & $15,822.0$ \\
\hline 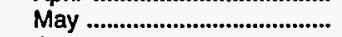 & 15.5 & 79.3 & 320.4 & $11,711.5$ & $3,845.4$ & $15,556.9$ & $15,877.3$ & 10.5 & $15,982.5$ \\
\hline 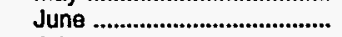 & $w$ & 221.4 & 351.0 & $12,647.3$ & $4,438.7$ & $17,085.9$ & $17,437.0$ & W & $17,734.2$ \\
\hline 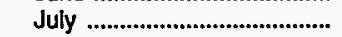 & W & 100.7 & 346.6 & $11,945.2$ & $3,968.1$ & $15,913.3$ & $16,259.9$ & $W$ & $16,382.0$ \\
\hline 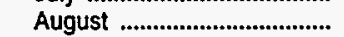 & $\ddot{W}$ & 136.7 & 535.3 & $12,844.7$ & $4,308.2$ & $17,152.9$ & $17,688.2$ & $W$ & $97,867.1$ \\
\hline September ........................... & W & 468.8 & 489.0 & $12,796.9$ & $4,008.3$ & $16,805.2$ & $17,294.2$ & W & $17,815.1$ \\
\hline October & $w$ & 275.4 & 371.6 & $12,191.0$ & $4,073.9$ & $16,264.8$ & $16,636.4$ & W & $16,987.0$ \\
\hline November ............................ & $w$ & 439.4 & $w$ & $12,252.9$ & $2,962.0$ & $15,214.9$ & $15,569.7$ & $W$ & $16,179.2$ \\
\hline 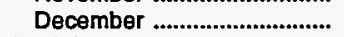 & $w$ & 470.5 & w & $12,008.0$ & $3,900.2$ & $15,908.2$ & $16,271.4$ & w & $16,998.8$ \\
\hline 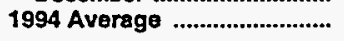 & 49.1 & 297.0 & 378.7 & $11,866.5$ & $3,841.4$ & $15,707.9$ & $16,086.6$ & 55.8 & $16,488.6$ \\
\hline \multicolumn{10}{|l|}{ Alaska } \\
\hline 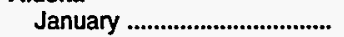 & - & 234.2 & 262.5 & 14.1 & 236.8 & 250.9 & 513.4 & $W$ & 844.6 \\
\hline 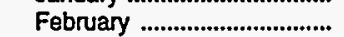 & - & $W$ & 201.5 & 23.2 & 233.1 & 256.3 & 457.8 & W & 809.4 \\
\hline March ...................................... & - & $W$ & 185.2 & 25.5 & 362.5 & 387.9 & 573.2 & $W$ & 915.0 \\
\hline 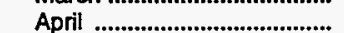 & - & $\dddot{W}$ & 323.6 & 33.8 & 517.5 & 551.3 & 874.8 & $W$ & 970.0 \\
\hline 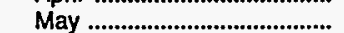 & - & W & 282.6 & 46.2 & 375.2 & 421.4 & 703.9 & $\mathbf{w}$ & 773.4 \\
\hline June ......................................... & - & W & 257.0 & 53.7 & 547.6 & 601.3 & 858.3 & W & $1,052.4$ \\
\hline 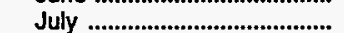 & - & $\ddot{W}$ & 216.2 & $W$ & $W$ & 528.7 & 744.9 & $\ddot{W}$ & 833.8 \\
\hline 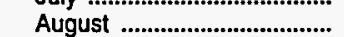 & - & $w$ & 369.0 & 55.9 & 587.5 & 643.4 & $1,012.4$ & W & $1,133.6$ \\
\hline September ......................... & - & $W$ & 296.5 & 48.0 & 305.7 & 353.7 & 650.1 & $w$ & $1,093.5$ \\
\hline 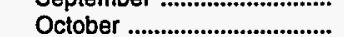 & - & $W$ & 250.7 & $W$ & $W$ & 407.2 & 657.8 & $w$ & 875.4 \\
\hline 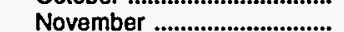 & - & $w$ & 191.9 & 43.3 & 179.0 & 222.3 & 414.2 & $w$ & 741.3 \\
\hline December & - & $w$ & 178.3 & 29.6 & 238.7 & 268.3 & 446.6 & $w$ & 840.2 \\
\hline 1994 Average .......................... & - & 212.0 & 251.5 & 38.3 & 370.4 & 408.7 & 660.2 & $w$ & 907.1 \\
\hline \multicolumn{10}{|l|}{ Arizona } \\
\hline 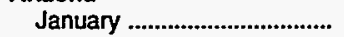 & $w$ & 4.1 & - & $1,081.3$ & 258.9 & $1,340.2$ & $1,340.2$ & - & $1,354.1$ \\
\hline 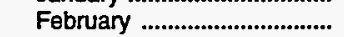 & $w$ & $W$ & - & $1,230.0$ & 232.6 & $1,462.7$ & $1,462.7$ & - & $1,475.6$ \\
\hline 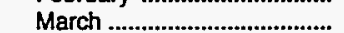 & $w$ & 2.1 & $w$ & $1,091.9$ & 241.6 & $1,333.5$ & $1,333.7$ & - & $1,345.2$ \\
\hline April & $w$ & $w$ & $\ddot{w}$ & $1,109.8$ & 255.5 & $1,365.3$ & $1,365.6$ & - & $1,366.3$ \\
\hline 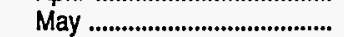 & w & - & W & $1,077.1$ & 280.3 & $1,357.4$ & $1,357.6$ & - & $1,357.8$ \\
\hline June ........................................... & - & $W$ & $W$ & $1,221.6$ & 276.1 & $1,497.7$ & $1,497.9$ & - & $1,506.1$ \\
\hline 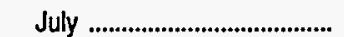 & $W$ & $W$ & $W$ & $1,088.1$ & 234.3 & $1,322.4$ & $1,322.6$ & - & $1,323.1$ \\
\hline 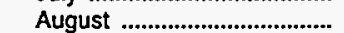 & $w$ & $W$ & $w$ & $1,102.3$ & 276.0 & $1,378.3$ & $1,378.5$ & - & $1,379.0$ \\
\hline 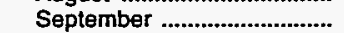 & w & $w$ & $w$ & $1,045.5$ & 301.5 & $1,347.0$ & $1,347.2$ & - & $1,347.9$ \\
\hline 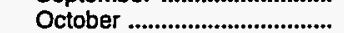 & $\mathbf{w}$ & 3.6 & $w$ & $1,139.5$ & 277.4 & $1,416.9$ & $1,417.4$ & - & $1,421.5$ \\
\hline November .............................. & $w$ & $w$ & - & $1,059.1$ & 221.9 & $1,281.1$ & $1,281.1$ & - & $1,285.5$ \\
\hline 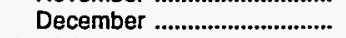 & w & w & - & $1,140.3$ & 257.9 & $1,398.1$ & $1,398.1$ & - & 1.402 .5 \\
\hline 1994 Average ........................... & $\ddot{w}$ & 2.4 & $\mathbf{W}$ & $1,114.7$ & 259.7 & $1,374.3$ & $1,374.5$ & - & $1,379.6$ \\
\hline \multicolumn{10}{|l|}{ Califomia } \\
\hline January ................................... & 16.5 & 27.6 & $W$ & $6,064.7$ & 461.0 & $6,525.7$ & $6,529.2$ & w & $6,582.6$ \\
\hline 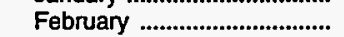 & $W$ & 26.4 & - & $6,395.6$ & 445.6 & $6,841.2$ & $6,841.2$ & W & $6,897.0$ \\
\hline March .................................. & 33.3 & 7.7 & - & $6,650.9$ & 412.7 & $7,063.6$ & $7,063.6$ & 15.0 & $7,119.7$ \\
\hline 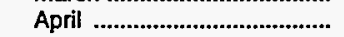 & 12.4 & $w$ & - & $6,686.7$ & 480.2 & $7,166.9$ & $7,166.9$ & $W$ & $7,190.2$ \\
\hline 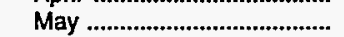 & 6.2 & $\ddot{W}$ & - & $6,948.4$ & 651.6 & $7,600.0$ & $7,600.0$ & $\ddot{w}$ & $7,614.3$ \\
\hline June ........................................... & 5.8 & $w$ & - & $7,581.1$ & 644.0 & $8,225.1$ & $8,225.1$ & $\ddot{w}$ & $8,289.1$ \\
\hline 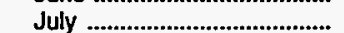 & 4.2 & $\dddot{w}$ & $W$ & $7,083.3$ & 497.1 & $7,580.4$ & $7,581.9$ & $w$ & $7,593.2$ \\
\hline 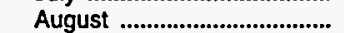 & 8.7 & W & $W$ & $7,370.0$ & 726.4 & $8,096.5$ & $8,098.5$ & $w$ & $8,122.6$ \\
\hline 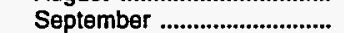 & 16.6 & $w$ & W & $7,503.3$ & 550.9 & $8,054.2$ & $8,065.8$ & $w$ & $8,089.8$ \\
\hline 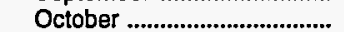 & 25.6 & W & - & $7,254.5$ & 624.8 & $7,879.3$ & $7,879.3$ & $w$ & $7,926.3$ \\
\hline November ............................ & 54.2 & $\ddot{w}$ & $w$ & $7,553.1$ & 444.2 & $7,997.3$ & $8,001,6$ & $\ddot{w}$ & $8,071.5$ \\
\hline December ............................. & 53.6 & $w$ & - & $7,247.0$ & 940.0 & $8,187.0$ & $8,187.0$ & w & $8,277.6$ \\
\hline 1994 Average & 21.0 & 6.9 & $W$ & $7,030.1$ & 574.7 & $7,604.8$ & $7,606.7$ & $w$ & $7,651.1$ \\
\hline
\end{tabular}

See footnotes at end of table. 
Table 50. Prime Supplier Sales Volumes of Distillate Fuel Oils and Kerosene by PAD District and State

(Thousand Gallons per Day) — Continued

\begin{tabular}{|c|c|c|c|c|c|c|c|c|c|}
\hline \multirow{3}{*}{$\begin{array}{l}\text { Geographle Area } \\
\text { Month }\end{array}$} & \multirow{3}{*}{ Kerosene } & \multirow{3}{*}{$\begin{array}{c}\text { No. } 1 \\
\text { Distillate }\end{array}$} & \multicolumn{5}{|c|}{ No. 2 Dlstillate } & \multirow{3}{*}{ No. 4 Fuela } & \multirow{3}{*}{$\begin{array}{c}\text { Total } \\
\text { Distillate } \\
\text { and } \\
\text { Kerosene }\end{array}$} \\
\hline & & & \multirow{2}{*}{$\begin{array}{c}\text { No. } 2 \text { Fuel } \\
\text { Oll }\end{array}$} & \multicolumn{3}{|c|}{ No. 2 Dlesel Fuel } & \multirow{2}{*}{$\begin{array}{c}\text { No. } 2 \\
\text { Distillate }\end{array}$} & & \\
\hline & & & & Low-Sulfur & High-Sulfur & Total & & & \\
\hline \multicolumn{10}{|l|}{ Hawall } \\
\hline January ..................................... & - & $w$ & W & 135.1 & 380.8 & 515.9 & 525.5 & - & 539.8 \\
\hline February ............................... & - & - & w & 120.6 & 344.5 & 465.1 & 465.4 & - & 465.4 \\
\hline 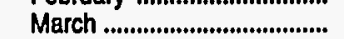 & - & - & $w$ & 135.7 & 348.1 & 483.9 & 493.8 & - & 493.8 \\
\hline 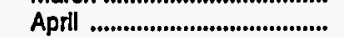 & - & - & w & 132.8 & 320.6 & 453.4 & 457.7 & - & 457.7 \\
\hline 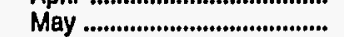 & - & - & W & 128.5 & 411.2 & 539.8 & 544.5 & - & 544.5 \\
\hline June ...................................... & - & - & $w$ & 134.1 & 422.1 & 556.2 & 562.2 & - & 562.2 \\
\hline 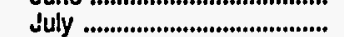 & - & - & $w$ & W & W & 529.0 & 534.5 & - & 534.5 \\
\hline August & - & $w$ & $w$ & 131.3 & 397.5 & 528.8 & 535.5 & - & 535.6 \\
\hline September ............................. & - & - & W & 122.2 & 447.7 & 569.9 & 579.8 & - & 579.8 \\
\hline 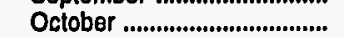 & - & - & W & W & $w$ & $1,003.2$ & $1,011.6$ & - & $1,011.6$ \\
\hline November ............................. & - & - & W & 120.8 & 377.4 & 498.2 & 512.3 & - & 512.3 \\
\hline December ............................... & - & $W$ & $W$ & 114.5 & 422.4 & 536.9 & 547.0 & - & 547.1 \\
\hline 1894 Average ............................ & - & w & $w$ & 133.6 & 424.2 & 557.9 & 565.4 & - & 566.6 \\
\hline \multicolumn{10}{|l|}{ Novada } \\
\hline 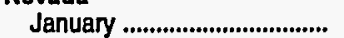 & - & 18.6 & $W$ & 505.4 & 68.8 & 574.2 & 574.4 & - & 592.9 \\
\hline 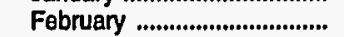 & - & $W$ & - & 568.2 & 69.6 & 637.8 & 637.8 & $w$ & 655.6 \\
\hline March ...................................... & - & W & - & 581.7 & 76.6 & 658.3 & 658.3 & $\ddot{w}$ & 664.5 \\
\hline 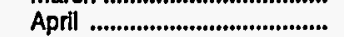 & - & $\ddot{W}$ & - & 558.1 & 85.6 & 643.7 & 643.7 & W & 646.5 \\
\hline 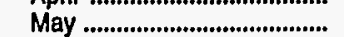 & - & W & - & 561.7 & 87.6 & 649.3 & 649.3 & $w$ & 653.6 \\
\hline June ...................................... & - & W & - & 581.2 & 117.2 & 698.4 & 698.4 & - & 700.9 \\
\hline 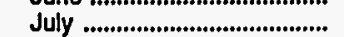 & - & $W$ & - & 596.1 & 105.4 & 701.5 & 701.5 & - & 704.5 \\
\hline 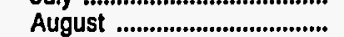 & - & W & $\mathbf{W}$ & 676.6 & 59.5 & 736.0 & 764.9 & - & 767.7 \\
\hline September ........................... & $w$ & $W$ & $w$ & 681.6 & 84.3 & 765.9 & 795.1 & - & 799.1 \\
\hline 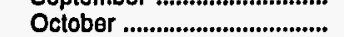 & - & $w$ & $w$ & 631.2 & 76.2 & 707.4 & 731.4 & - & 736.2 \\
\hline November ............................ & $w$ & 8.6 & $w$ & 640.4 & 52.3 & 692.7 & 735.5 & - & 744.7 \\
\hline 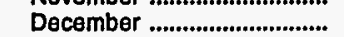 & $\dddot{w}$ & 12.4 & $\dddot{w}$ & 601.3 & 49.2 & 650.5 & 685.2 & - & 697.9 \\
\hline 1894 Average & w & 6.8 & $\mathbf{w}$ & 598.7 & 77.7 & 676.4 & 689.7 & $\mathbf{w}$ & 697.1 \\
\hline \multicolumn{10}{|l|}{ Oregon } \\
\hline January ................................... & W & 76.8 & $W$ & $1,285.3$ & 684.1 & $1,969.4$ & $1,998.4$ & - & $2,094.6$ \\
\hline 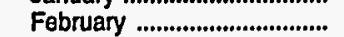 & $\dddot{w}$ & 63.6 & $\ddot{W}$ & $1,248.6$ & 762.2 & $2,010.8$ & $2,037.8$ & - & $2,116.7$ \\
\hline 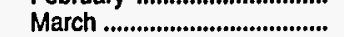 & $w$ & NA & W & $1,103.9$ & 709.7 & $1,813.6$ & $1,823.8$ & - & $1,845.0$ \\
\hline 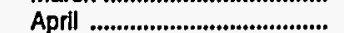 & $\ddot{w}$ & 2.6 & $W$ & $9,266.6$ & 811.1 & $2,077.7$ & $2,086.0$ & - & $2,091.9$ \\
\hline May ...................................... & $\ddot{w}$ & 1.8 & $w$ & $1,329.3$ & 666.5 & $1,995.9$ & $2,000.0$ & - & $2,004.7$ \\
\hline June .................................... & W & 1.4 & W & $1,419.9$ & 742.5 & $2,162.5$ & $2,221.1$ & - & $2,224.7$ \\
\hline July .................................... & w & $\ddot{w}$ & $\ddot{W}$ & $1,434.4$ & 700.0 & $2,134.4$ & $2,192.8$ & - & $2,195.4$ \\
\hline August ............................... & 5.5 & $\ddot{W}$ & $W$ & $1,535.8$ & 795.0 & $2,330.7$ & $2,384.5$ & - & $2,391.5$ \\
\hline September .......................... & 12.2 & $W$ & $W$ & $1,459.8$ & 811.3 & $2,271.1$ & $2,349.0$ & - & $2,366.8$ \\
\hline October ................................ & $W$ & 18.0 & $W$ & $1,451.6$ & 815.5 & $2,267.1$ & $2,281.8$ & - & $2,314.7$ \\
\hline November ............................. & $w$ & 51.6 & $w$ & $1,397.2$ & 734.5 & $2,131.7$ & $2,164.7$ & - & $2,249.4$ \\
\hline 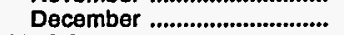 & $\ddot{w}$ & 56.5 & $\ddot{w}$ & $1,347.8$ & 826.1 & $2,173.9$ & $2,203.4$ & - & $2,298.6$ \\
\hline 1994 Average ......................... & 12.9 & 24.4 & 33.6 & $1,357.3$ & 754.6 & $2,111.9$ & $2,145.5$ & - & $2,182.8$ \\
\hline \multicolumn{10}{|l|}{ Washington } \\
\hline January .................................. & W & 124.0 & 118.4 & $1,559.1$ & $1,200.7$ & $2,759.8$ & $2,878.2$ & - & $3,009.9$ \\
\hline February .............................. & W & 87.8 & 94.8 & $1,235.1$ & $1,416.6$ & $2,651.7$ & $2,746.4$ & W & $2,858.4$ \\
\hline March .................................... & 7.9 & $w$ & 70.4 & $1,560.6$ & $1,658.6$ & $3,219.3$ & $3,289.6$ & $\dddot{w}$ & $3,350.0$ \\
\hline April ....................................... & 3.6 & 15.9 & 50.4 & $1,545.3$ & $1,484.2$ & $3,029.5$ & $3,080.0$ & - & $3,099.4$ \\
\hline 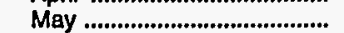 & 6.2 & $w$ & 28.7 & $1,620.4$ & $1,372.9$ & $2,993.3$ & $3,022.0$ & $w$ & $3,034.3$ \\
\hline June ..................................... & $\mathbf{W}$ & 17.4 & 29.2 & $1,655.7$ & $1,689.2$ & $3,344.8$ & $3,374.0$ & $w$ & $3,398.7$ \\
\hline July ....................................... & 6.5 & 9.3 & 64.7 & $1,567.3$ & $1,549.7$ & $3,116.9$ & $3,181.7$ & - & $3,197.5$ \\
\hline 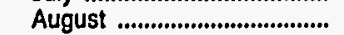 & 11.3 & 12.0 & 74.7 & $1,972.9$ & $1,466.3$ & $3,439.2$ & $3,513.9$ & - & $3,537.2$ \\
\hline September .......................... & 14.0 & 17.1 & 63.7 & $1,936.5$ & $1,506.9$ & $3,443.4$ & $3,507.1$ & - & $3,538.2$ \\
\hline 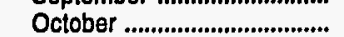 & 15.6 & 28.6 & 73.3 & $1,478.5$ & $1,105.2$ & $2,583.8$ & $2,657.1$ & - & $2,701.4$ \\
\hline November ................................ & 30.6 & 83.4 & 68.8 & $1,438.9$ & 952.6 & $2,391.6$ & $2,460.4$ & - & $2,574.4$ \\
\hline 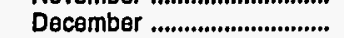 & 28.3 & 102.5 & 110.7 & $1,527.5$ & $1,165.8$ & $2,693.4$ & $2,804.1$ & - & $2,934.9$ \\
\hline 1994 Average ........................... & 12.4 & 43.3 & 70.6 & $1,593.8$ & $1,380.1$ & $2,974.0$ & $3,044.6$ & $\mathbf{w}$ & $3,104.3$ \\
\hline
\end{tabular}

Dash $(-)=$ No data reported.

NA $=$ Not avallable.

$W=$ Withheld to avoid disclosure of individual company data.

a Inciudes No. 4 fuel oil and No. 4 dlesel fuel.

Notes: Total Distillate $=$ No. 1 Distillate + No. 2 Distillate + No. 4 Fuel Oil.

Note: Totals may not equal the sum of the components due to rounding.

Source: Energy Information AdmInistration, Form EIA-782C, "Monthly Report of Prime Supplier Sales of Petroleum Products Sold for Local Consumption." 



\section{Explanatory}

Notes 


\section{Explanatory Notes}

\section{The EIA-782 Survey}

\section{Background}

The EIA-782 surveys were implemented in 1983 to fulfill the data requirements necessary to meet Energy Information Administration (EIA) legislative mandates and user community data needs. The requirements include petroleum product price, market distribution, demand (or sales), and product supply data, which are needed for a complete evaluation of petroleum market performance. The EIA-782 series includes the Form EIA-782A, "Refiners'/Gas Plant Operators' Monthly Petroleum Product Sales Report"; Form EIA-782B, "Resellers'/Retailers' Monthly Petroleum Product Sales Report"; and Form EIA-782C, "Monthly Report of Prime Supplier Sales of Petroleum Products Sold for Local Consumption."

The Form EIA-782A collects refiner and gas plant operator monthly price and volume data at a State level on 14 petroleum products for various retail and wholesale marketing categories. The Form EIA-782B collects reseller/retailer monthly price and volume data at a State level for gasoline, No. 2 distillate, propane, and residual fuel. The Form EIA-782C collects prime supplier monthly volume data on 15 petroleum products. The EIA-782 forms were modified in October 1993 to reflect the changes in refined petroleum products arising out of the requirements of the Clean Air Act Amendments of 1990 (CAAA). The CAAA require that oxygenated gasoline be sold during the winter months in carbon monoxide nonattainment areas beginning October 1, 1992. They require that reformulated gasoline be sold in ozone nonattainment areas beginning January 1, 1995. Beginning October 1 , 1993, diesel fuel sold for on-highway use must be low-sulfur diesel fuel (i.e., diesel fuel containing less than or equal to 0.05 percent sulfur). As a result of these environmental regulations, gasoline data collected on the EIA-782 forms were divided into conven. tional, oxygenated, and reformulated categories. Diesel fuel sales were separated into low- and high-sulfur categories. The wholesale gasoline categories on the EIA-782A and EIA-782B forms were also modified to include dealer tank wagon, rack, and bulk sales. The retail categories for propane on the EIA-782A and EIA-782B were expanded to include residential, commercial/institutional, industrial, sales through company. operated retail outlets, petrochemical, and other end user sales.

\section{Discussion of Sample Design}

The Form EIA-782A is sent to a census of refiners and gas plant operators. Respondents are selected with certainty due to their small number and because of the relative size of their sales volume.

The Form EIA-782B is sent to a scientifically selected sample of motor gasoline resellers, and distillate, propane, and residual fuel oil resellers and retailers. The Form EIA-863, "Petroleum Product Sales Identification Survey," served as the basis of the sampling frame of dealers. Information obtained from the Form EIA863 is supplemented with information from the Form EIA-821, "Annual Fuel Oil and Kerosene Sales Report." The sales volumes obtained from these surveys are used to create separate stratification schemes that vary by product and State. Dealers selling in more than four States and company/State units comprising 5 percent or more of sales in a State were selected with certainty. The remaining company/State units on the frame were stratified within geographic area and sales type by urban/rural designation and volume of product sales. The geographic areas were defined as (a) the 24 States in which No. 2 distillate was a significant heating source and 50 States and the District of Columbia for residual and motor gasoline, or as (b) the PAD Districts for districts where not all State estimates are provided. The type-of-sale classifications were retail and resale for motor gasoline and residual fuel oil, and residential and nonresidential retail and wholesale for 
distillate. Three volume-of-sales classifications (zero, low, and high) were defined with volume boundaries and numbers of strata, differing by State, sales type, and product.

The design of the EIA-782B sample was based on seven target variables: total retail motor gasoline, total wholesale motor gasoline, residential No. 2 fuel oil, other retail No. 2 fuel oil, total wholesale No. 2 fuel oil, total retail residual fuel oil, and total wholesale residual fuel oil. The required level of accuracy for each target variable was defined by a volume coefficient of variation (CV) of 15 percent for No. 2 distillate and 10 percent for motor gasoline and residual fuel oil, determined at the publishable State level (24 States for distillate, 50 States and the District of Columbia for motor gasoline and residual). Studies on the relationship of volume CV to price CV have shown that this will produce price CVs of less than 1 percent. The reliability of current month estimates will vary from these goals due to the deterioration of the frame over time and the changing distributions of price and volume.

Beginning in October 1993, the sample design was modified to include a supplemental sample of propane dealers. The name and address list of propane dealers was constructed by extracting those companies on the EIA-863 who had indicated that they sold propane. This list was supplemented by: (1) respondents on other surveys who reported propane sales, (2) names and addresses of propane dealers furnished by industry associations and State Energy Offices, and (3) commercial lists. Since no information existed to predetermine the sales volumes of propane dealers, two strata for propane dealers were used. A certainty stratum of the known, large, multi-State dealers was created. These companies were identified using establishment lists and industry surveys. All other companies were assigned to the second stratum and sample weights were calculated as the inverse sample was selected. Sample weights were calculated as the inverse of the probability of selection $(\mathrm{N} / \mathrm{n})$.

The samples resulting from the separate stratification schemes for the products other than propane were combined by means of a linked-selection procedure designed to maximize the overlap among samples. This procedure produced a sample size of approximately 3,500 companies. Each company selected was required to file completed survey forms for all States in which it had petroleum sales.
The Form EIA-782C was sent to all prime suppliers of any of the selected products on the EIA-782C. A prime supplier is a firm that produces, imports, or transports any of the selected petroleum products across State boundaries and local marketing areas and sells the product to local distributors, local retailers, or end users. They were selected with certainty due to their small number and the relative size of their sales volumes.

\section{Discussion of the Sampling Frame}

The EIA-782A survey consists of a census of respondents who either directly or indirectly control a refinery or gas plant facility. The EIA-782A form collects sales data on 14 refined petroleum products. In 1994, 154 companies responded to the EIA-782A survey.

The EIA-863 data base provided the sampling frame for the EIA-782B survey. The Form EIA-863, "Petroleum Product Sales Identification Survey," was mailed to approximately 22,000 companies in January 1992, in order to collect 1991 State-level sales volume data for No. 2 distillate, residual, and motor gasoline. The No. 2 distillate data were further identified by residential/nonresidential end-use and non-end-use sales, while the residual and motor gasoline data were identified by end-use and non-end-use sales. The mailing list for the EIA-863 survey was constructed by merging and unduplicating the previous master frame file and approximately 71 State and commercial lists.

Data from the 1991 EIA-821, "Annual Fuel Oil and Kerosene Sales Report" survey were merged with data from the EIA-863 survey to yield a combined file. A transformed and edited version of this file was created to form the sample file used to design and select the EIA-782B sample.

NOTE: Truck stops selling No. 2 diesel fuel were not specifically included in the frame. Therefore, the EIA782B end-use category, "sales through company outlets," does not incorporate all sales of No. 2 distillate.

The EIA-782C survey consists of a census of suppliers who produce, import, or transport any of the 15 refined petroleum products listed on the form across State boundaries and local marketing areas, and who sell the product to local distributors, local retailers, or end users. In 1994, 254 firms respond to the EIA-782C survey. 


\section{Reliability of Data}

Two types of errors are possible in an estimate based on a sample survey: sampling and nonsampling. Sampling errors occur because observations are made only on a sample, not on the entire population. Non-sampling errors can be attributed to many sources in the collection and processing of data. The accuracy of survey results is determined by the joint effects of sampling and nonsampling errors.

\section{Measures of Sampling Variability}

Tables 14 through 18, 31 through 34, and 38 through 41 utilize a sample of nonrefiners and, therefore, have sampling error. The remainder of the tables published are based on census data; therefore, there is no error due to sampling. The particular sample used for the EIA-782B is one of a large number of all possible samples that could have been selected using the same design. Estimates derived from the different samples would differ from each other. The average of these estimates would be close to the estimate derived from a complete enumeration of the population (a census), assuming that a complete enumeration has the same nonsampling errors as the sample survey.

The sampling error, or standard error of the estimate, is a measure of the variability among the estimates from all possible samples of the same size and design and, thus, is a measure of the precision with which an estimate from a particular sample approximates the results of a complete enumeration.

\section{Nonsampling Errors}

Nonsampling errors can be attributed to many sources: (1) inability to obtain complete information about all cases in the sample (i.e., nonresponse), (2) response errors, (3) definitional difficulties, (4) differences in the interpretation of questions, (5) mistakes in recording or coding the data obtained, and (6) other errors of collection, response, coverage, and estimation for missing data. These nonsampling errors also occur in complete censuses.

Although no direct measurement of the biases due to nonsampling errors can be obtained, precautionary steps were taken in all phases of the frame development and data collection, processing, and tabulation proc- esses, in an effort to minimize their influence. In addition, the close cooperative consultation between EIA and the EIA-782 survey respondents and data users results in a more accurate information gathering and reporting process.

\section{Imputation and Estimation}

Survey data gathered from the respondents invariably contain incomplete reporting, nonresponse, and values that fail editing. These missing data are estimated, or imputed for, as follows. First, for all survey units, the previous month's reported value and the previous month's predicted value are weighted together to yield a predicted value for the current month. The sum of the weighted, predicted values for nonrespondents in the current month is then multiplied by a chain link multiplier (the ratio of the sum of the weighted, reported values for respondents in the current month to the sum of the weighted, predicted values for respondents in the current month). The resulting estimate for nonreported values is then added to the reported values. That is,

$$
\hat{V}_{t .}=\sum_{R} W_{i}^{*} V_{i, t}+\sum_{N R} W_{j}^{*} V_{j, t}
$$

and similarly

$$
\hat{Q}_{t .}=\sum_{R} W_{i}^{*} V_{i, t} P_{i, t}+\sum_{N R} W_{j}^{*} V_{j, t}^{\prime} P_{j, t}^{\prime}
$$

where

$$
\begin{gathered}
V_{j, t}=\frac{\sum_{R, P A D D} W_{i}^{*} V_{i}}{\sum_{R, P A D D} W_{i}^{*} \widetilde{V}_{i, t}} \tilde{V}_{j, t} \\
P_{j, t}^{\prime}=\frac{\sum_{R, P A D D} P_{i, t}}{\sum \widetilde{P}_{i, t}} \widetilde{P}_{j, t} \\
R, P A D D
\end{gathered}
$$


and,

$$
W_{i}^{*}=\frac{N}{\sum_{i=1}^{n} W_{i}}\left(W_{i}\right)
$$

$W_{i}=$ the weight for company $\mathrm{i}$. For resellers/retailers responding to EIA-782B, $W i$ is inversely proportional to the probability of inclusion. For all certainty units $W i=1$. The certainty units are all respondents to the EIA-782A, the EIA-782C, and the units selected with certainty for the EIA782B.

$N=$ total number of population units,

$n=$ number of sampled units,

$\sum_{R}=\begin{aligned} & \text { summation across current month respon- } \\ & \text { dents } \mathrm{i}\end{aligned}$

$\sum_{N R}=\begin{aligned} & \text { summation across current month nonre- } \\ & \text { spondents } \mathrm{j},\end{aligned}$

$V_{i, t}=$ current month $(t)$ reported volume for company $i$,

$P_{i, t}=$ current month $(t)$ reported price for company $i$,

$\hat{V}_{t}=$ current month $(\mathrm{t})$ estimated total volume,

$\hat{Q}_{t}=$ current month $(t)$ estimated total revenue,

$\widetilde{V}_{i, t}=$ current month $(\mathrm{t})$ predicted volume for company $i$, respondent,

$\widetilde{P}_{i, t}=$ current month $(\mathrm{t})$ predicted price for company $i$, respondent,

$\widetilde{V}_{i, t}=\alpha V_{i, t-1}+(1-\alpha) V_{i, t-1}$

$\widetilde{P}_{i, t}=\alpha P_{i, t-1}^{\prime}+(1-\alpha) P_{i, t-1}$

where

$$
\begin{aligned}
& V_{i, t-1}= \text { previous month }(\mathrm{t}-1) \text { reported volume } \\
& \text { for company } \mathrm{i}
\end{aligned}
$$

$$
\begin{aligned}
P_{i, t-1}= & \begin{array}{l}
\text { previous month }(t-1) \text { reported price } \\
\text { for company } i,
\end{array} \\
\alpha= & \begin{array}{l}
\text { constant between } 0 \text { and } 1, \text { set by form, } \\
\text { product, type of sale and price or vol- } \\
\text { ume, }
\end{array}
\end{aligned}
$$

and

$$
\hat{P}_{t .}=\frac{\hat{Q} t .}{\hat{V}_{t}},
$$

the resulting estimate of price at the published level for month $\mathrm{t}$.

To obtain annual estimates presented in this publication, the monthly revenue and volume estimates, $Q_{t}$ and $V_{t}$, are summed to the annual level. Total annual revenue is then divided by total annual volume to yield annual averages.

Multiple product data collection and linked sample selection yield two types of respondents: basic and supplemental. Both types are used for imputation, estimation, and standard errors.

The variance estimate is :

$\operatorname{VAR} \hat{\left(P_{t .}\right)}=\frac{1}{\hat{V}_{t .}^{2}} \sum_{k} N_{k}^{2} n k\left(1-f_{k}\right) \frac{M_{k}}{\left(\sum_{i} W_{i k}\right)^{2}}$

where

$N_{k}=$ the number of population units in group $\mathrm{k}$,

$n_{k}=$ the number of basic and volunteer respondents in group $k$,

$W_{i k}=$ the sampling weight for respondent $\mathrm{i}$ in group $\mathrm{k}$,

$f_{k}=\frac{n_{k}}{N_{k}}$

and $\hat{P}_{t .}$ and $\hat{V}_{t .}$ are previously defined.

The term $M_{k}$ is computed as follows: 


$$
M_{k}=\frac{\sum_{i}\left(M_{i k}\right)^{2}}{n_{k}-1}
$$

where

$$
M_{i k}=W_{i k} V_{i k} D_{i k}-\frac{W_{i k}}{\left(\sum_{i} W_{i k}\right)} \times\left(\sum_{i} W_{i k} V_{i k} D_{i k}\right)
$$

and

$$
\begin{aligned}
D_{i k}= & P_{i k}-\hat{P}_{t .} \\
V_{i k}= & \begin{array}{l}
\text { reported volume for respondent } \mathrm{i} \text { in } \\
\text { group } \mathrm{k}
\end{array} \\
P_{i k}= & \text { reported price for respondent i in group } \mathrm{k} .
\end{aligned}
$$

\section{Data Continuity}

When the EIA-782 series was implemented in 1983, it replaced prior surveys that had been used to meet the Energy Information Administration's data requirements. The Form EIA-782A replaced the refiner and gas plant operator portions of the Form EIA-460, "Petroleum Industry Monthly Report for Product Prices"; and Form EIA-9A, "No. 2 Distillate Price Monitoring Report"; the Form EIA-782B replaced the nonrefiner portions of the Form EIA-460 and Form EIA-9A; and the Form EIA-782C replaced Form EIA25, "Prime Supplier's Monthly Report."

Since the transition from the EIA-460, the EIA-9A, and the EIA-25 to the EIA-782 took place over a period of 4 months, rather than occurring at one time, it was possible to compare data from the predecessor surveys with data from the new survey during the transition period for some data elements. This comparative analysis yielded adjustment factors which reflected the estimated overall effect of the changes.

These adjustment factors were applied to the appropriate predecessor survey prices to yield a backcast estimate. A complete description of the estimation of historical data prior to January 1983 is contained in the feature article of the December 1983(3) issue of the PMM.
The backcast price estimation employed the predecessor survey published price as the initial approximation. The initial approximation, however, frequently represented less aggregated product categories and more aggregated seller/sales categories. Therefore, more comparable product categories were formed by volume weighting the disaggregated predecessor survey product prices. For the EIA-9A, comparable categories were formed by subtracting from the price the average taxes reported. Comparable seller/sales categories were formed by multiplying the predecessor price by the ratio of the EIA-782 price for the category to be estimated divided by the volume weighted prices for the aggregate of the EIA-782 categories most comparable to the predecessor category. That is,

$\hat{\hat{P}}_{460, i}=\hat{P}_{460, j} \frac{\hat{\hat{P}}_{782, i}}{\hat{\hat{P}}_{782 j}}$

where i represents the EIA-782 category to be backcast and $j$ represents the most similar category on the predecessor survey.

The backcast price series were estimated by multiplying the estimate for the previous time period from the predecessor survey by an adjustment factor:

$\hat{\hat{P}}_{782, i, t}=\hat{P}_{\text {Predecessoji,t }} \times($ Adjustment Factor $)$

where $t=$ reference month.

Adjustment factors were computed by dividing the EIA-782 December price by the derived December predecessor price for comparable categories:

Adjustment Factor $=\frac{\hat{P}_{782, i, D e c e m b e r}}{\hat{\hat{P}}_{\text {Predecessoji,December }}}$

The EIA-782 December 1982 price for all respondents had to be estimated since not all of the EIA-782 respondents were reporting in December. This estimate was based on the average of the ratios of the prices for the December respondents to the prices for all respondents in January, February, and March of 1982. That is, 

$\hat{\hat{P}}_{782, i, \text { December }}=\hat{P}_{782, i, r, \text { December }} \div \frac{\sum_{m} \frac{\hat{P}_{782, i, r, m}}{\hat{P}_{782, i, m}}}{3}$

where $r=$ respondents who reported in the December reference month and $\mathrm{m}=$ the months of January, February, and March.

Starting with the September 1990 final estimates, prices published were derived using the sample described under "Discussion of Sample Design." Prices published for January 1984 through August 1990 were derived using different samples and slightly different designs (refer to the 1987 PMA for a further description). Also, the monthly price estimates from January through December 1983 were derived using another sample design (see the December 1983(3) issue of the PMM). Therefore, there may be some minor discontinuity in price estimates between August 1988 and September 1988 and between December 1983 and January 1984.

\section{Collection Methods}

Survey data are collected by mail every month. It is mandatory for each respondent to submit completed forms to EIA within the specified time allotted. For the EIA-782A and B, completed forms must be submitted no later than 30 calendar days after the close of each reference month. For the EIA-782C, completed forms must be submitted no later than 20 calendar days after the close of the reference month. Telephone follow-up calls to nonrespondents begin the day after the established due date in order to collect all outstanding data. Late submissions and resubmissions are processed when received.

\section{Data Processing}

As EIA-782 forms are received, they are logged into an automated Survey Control File which maintains monthly status codes for each company. The data are reviewed manually and then entered onto the computer files. They are then processed through an automated edit program which detects missing data, inconsistent prices, volumes and prices that significantly differ from those previously reported by the company, and outlying values that will affect published estimates. Data that fail the edits are resolved through telephone calls to the data reporters, and corrections and verification codes are entered onto the computer files. Statistical reports, including publication tables, are then generated using only acceptable and verified data.

\section{Nondisclosure}

The data contained in this publication are subject to statistical nondisclosure procedures. The objective of the disclosure-avoidance procedures, as stated in the Energy Information Administration Standard 88-05. 06, Subject: "Nondisclosure of Company Identifiable Data in Aggregate Cells," is to ensure that confidential, company-identifiable data are not disclosed in tables where "company specific responses may be proprietary and prohibited from public disclosure by 18 U.S.C. 1905." Statistics representing data aggregated from fewer than three companies or that are dominated by input from one or two companies are withheld. EIA identifies cells that are sensitive according to these criteria by applying a statistical formula to the data contained in each cell to determine if a few companies "dominate" the cell.

If a cell is sensitive, the data in that cell are suppressed and a "W" is placed in the publication cell. Also, since many tables include row or column totals, some nonsensitive data cells have been suppressed to prevent the reader from calculating the suppressed numbers by simply subtracting the published numbers from the total.

\section{Processing of Late Submissions and Resubmissions}

The PMA utilized data from EIA-782 forms which were late submissions or which were resubmitted by respondents after the PMM published 1994 monthly estimates. Late submissions and resubmissions of data for reference months January through December 1994 were processed with data in the monthly computer files. The data are manually reviewed and processed through an automated edit program in the month the data are received. Data which fail the edits are resolved in the same manner as discussed in the data processing section. 
Table EN1. Federal and State Motor Fuel Taxes'

(Cents per Gallon)

\begin{tabular}{|c|c|c|c|c|c|c|c|}
\hline & $\begin{array}{l}\text { Motor } \\
\text { Gasoline }\end{array}$ & $\begin{array}{l}\text { Dlesel } \\
\text { Fuel }\end{array}$ & Gasohol & & $\begin{array}{l}\text { Motor } \\
\text { Gasoline }\end{array}$ & $\begin{array}{l}\text { Diesel } \\
\text { Fuel }\end{array}$ & Gasohol \\
\hline Federal $^{2}$ & 18.40 & 24.40 & 13.00 & Missouri ${ }^{4}$ & 15.04 & 15.04 & 15.04 \\
\hline Average State Tax . . . & 19.80 & 19.53 & 19.47 & Montana ${ }^{4}$ & 27.00 & 27.75 & 27.00 \\
\hline Alabama ${ }^{4}$. & 18.00 & 19.00 & 18.00 & Nebraska . & 24.70 & 24.70 & 24.70 \\
\hline$\ldots \ldots$ & 8.00 & 8.00 & 8.00 & Nevada $^{4}$ & 23.60 & 27.60 & 23.60 \\
\hline Arizona & 18.00 & 18.00 & 18.00 & New Hampshire. . . . . & 18.80 & 18.80 & 18.80 \\
\hline Arkansas & 18.70 & 18.70 & 18.70 & New Jersey . . . . . . . & 14.50 & 17.50 & 14.50 \\
\hline Californla $^{34}$ & 18.60 & 18.60 & 18.60 & New Mexico ${ }^{4} \ldots \ldots$ & 21.00 & 19.00 & 21.00 \\
\hline$\ldots \ldots$ & 27.00 & 20.50 & 22.00 & New York ${ }^{34} \ldots \ldots$ & 22.56 & 24.56 & 22.56 \\
\hline Connecticut ${ }^{3} \ldots \ldots$ & 31.00 & 18.00 & 30.00 & North Carolina . . . . & 22.05 & 22.05 & 22.05 \\
\hline Delaware . . . . . . . & 22.00 & 19.00 & 22.00 & North Dakota . . . . . . & 18.03 & 18.03 & 18.03 \\
\hline District of Columbia ${ }^{3} \ldots$ & 22.50 & 22.50 & 22.50 & Ohio $\ldots \ldots \ldots$ & 22.00 & 22.00 & 22.00 \\
\hline Florida $^{4}$ & 12.10 & 12.10 & 12.10 & Oklahoma........ & 17.00 & 14.00 & 17.00 \\
\hline Georgia $^{34}$ & 7.70 & 7.70 & 7.70 & Oregon $^{4} \ldots$ & 24.00 & 24.00 & 24.00 \\
\hline$\ldots \ldots$ & 16.00 & 16.00 & 16.00 & Pennsylvania . . . . . . & 22.35 & 22.35 & 22.35 \\
\hline Idaho & 22.00 & 22.00 & 22.00 & Rhode Island . . . . . & 28.00 & 28.00 & 28.00 \\
\hline |illinois ${ }^{34}$ & 19.30 & 21.80 & 19.30 & South Carolina ${ }^{4} \ldots$ & 16.75 & 16.75 & 16.75 \\
\hline Indiana $^{3}$ & 15.80 & 16.80 & 15.80 & South Dakota . . . . . & 20.00 & 20.00 & 18.00 \\
\hline$\ldots \ldots$ & 20.00 & 22.50 & 19.00 & Tennessee & 21.40 & 18.40 & 21.40 \\
\hline Kansas . . . . . . . & 18.02 & 20.02 & 18.02 & Texas $\ldots \ldots \ldots \ldots$ & 20.00 & 20.00 & 20.00 \\
\hline Kentucky & 15.10 & 12.10 & 15.10 & Utah $\ldots \ldots \ldots$ & 19.50 & 19.50 & 19.50 \\
\hline Loulsiana $^{3}$ & 20.03 & 20.03 & 20.03 & Vermont & 16.00 & 17.00 & 16.00 \\
\hline Maine . . . . . . . . & 19.00 & 20.00 & 19.00 & Virginia $^{3} \ldots$ & 17.70 & 16.20 & 17.70 \\
\hline Maryland . . . . . . & 23.50 & 24.25 & 23.50 & Washington ${ }^{4}$ & 23.12 & 23.12 & 23.12 \\
\hline Massachusetts . . . . . & 21.00 & 21.00 & 21.00 & West Virginia $^{3}$ & 20.50 & 20.50 & 20.50 \\
\hline Michigan $^{3}$. & 15.88 & 15.88 & 15.88 & Wisconsin . . . . . . & 26.10 & 26.10 & 26.10 \\
\hline Minnesota $^{3}$ & 20.00 & 20.00 & 20.00 & Wyoming & 9.00 & 9.00 & 5.00 \\
\hline Mlssissippi ${ }^{4}$. & 18.40 & 18.40 & 18.40 & & & & \\
\hline
\end{tabular}

${ }^{1}$ This figure lists rates of general application (including, but not limited to, excise taxes, environmental taxes, special taxes, and inspection fees), exclusive of county and local taxes. Rates are also exclusive of any State taxes based on gross or net receipts. The State rates are effective July $1,1994$.

${ }^{2}$ The Federal tax on motor gasoline and diesel fuel increased 4.3 cents, to 18.4 and 24.4 cents, respectively, on October $1,1993$.

${ }^{3}$ Additional State taxes are levied as follows: California: 7.25 percent sales tax; Connecticut: 5 percent gross earnings tax; Georgia: 3 percent sales tax; Hawail: 4 percent sales tax; Illinois: 6.25 percent sales tax; Indiana: 5 percent sales tax; lowa: 1 percent environmental protection tax; Michigan: 4 percent sales tax; Minnesota: clean-up fund rate of $1.5-2.0$ cents per gallon based on storage size; New York: 4 percent sales tax; Virginia: 2 percent sales tax in areas where mass transit systems exist; West Virginia: Consumer and sales tax of 4.85 cents per gallon.

${ }^{4}$ Local option taxes (LOTS) are allowed. In Florida, the State assesses a State Comprehensive Enhanced Transportation System (SCETS) tax which is two-thirds of each county's rate. In addition, the State collects a "ninth cent tax" and a second local tax. These taxes add an average of 11.5 cents to the motor fuel State tax. In Hawail, LOTS are as follows: Honolulu: 16.5 cents per gallon; Maui: 11.0 cents per gallon; Hawaii: 8.8 cents per gallon; Kauai: 10.0 cents per gallon. 
Table EN 2. U.S. Postal Two-Letter State Abbreviations

\begin{tabular}{lll|l|l|l|l}
\hline $\begin{array}{l}\text { State } \\
\text { Code }\end{array}$ & \multicolumn{1}{|c|}{ State } & $\begin{array}{l}\text { State } \\
\text { Code }\end{array}$ & State & $\begin{array}{l}\text { State } \\
\text { Code }\end{array}$ & State \\
\hline AL & Alabama & KY & Kentucky & ND & North Dakota \\
AK & Alaska & LA & Louisiana & OH & Ohio \\
AZ & Arizona & ME & Maine & OK & Oklahoma \\
AR & Arkansas & MD & Maryland & OR & Oregon \\
CA & California & MA & Massachusetts & PA & Pennsylvania \\
CO & Colorado & MI & Michigan & RI & Rhode Island \\
CT & Connecticut & MN & Minnesota & SC & South Carolina \\
DE & Delaware & MS & Mississippi & SD & South Dakota \\
DC & District of Columbia & MO & Missouri & TN & Tennessee \\
FL & Florida & MT & Montana & TX & Texas \\
GA & Georgia & NE & Nebraska & UT & Utah \\
HI & Hawaii & NV & Nevada & VT & Vermont \\
ID & Idaho & NH & New Hampshire & VA & Virginia \\
IL & Illinois & NJ & New Jersey & WA & Washington \\
IN & Indiana & NM & New Mexico & WI & Wisconsin \\
IA & lowa & NY New York & WV & West Virginia \\
KS & Kansas & NC & North Carolina & WY & Wyoming \\
& & & & & \\
\hline & & & & &
\end{tabular}

\section{Relationship of Refiner and Prime Supplier Sales Volumes}

The refiner sales volumes collected on the EIA-782A are related to the prime supplier sales volumes collected on the EIA-782C, but conceptual differences exist that cause variations between these data. In general, EIA-782A volumes are intended to reflect refiner sales of petroleum products into all secondary and tertiary markets, while EIA-782C volumes are designed to measure prime supplier sales into only the local markets of final consumption. Specifically:

- The reporting universe for the EIA-782C survey is significantly larger than that of the EIA-782A. While nearly all refiners and gas plant operators report on both surveys (a small number do not qualify as prime suppliers), some large, inter-State distributors and retailers, as well as some importers, report only on the EIA-782C.

- EIA-782A respondents are asked only to exclude sales to other refiners (that is, other respondents that comprise the primary market), while EIA-
$782 \mathrm{C}$ respondents are asked to exclude sales to any company that is not a local distributor, local retailer, or end user (DRE). Therefore, EIA-782C respondents are asked not only to exclude sales to refiners, but also to most large inter-State resellers, importers, traders, and retailers who transport products across State boundaries.

- The EIA-782A is designed to gather data on the sales of selected petroleum products made in each State, regardless of where the products are physically located or will be consumed. In contrast, the EIA-782C is designed to collect data reflecting only delivered sales of selected petroleum products into those States where the products are expected to be locally consumed.

Consequently, EIA-782A and EIA-782C volumetric data generally vary at national, regional, and State levels. In particular, differences are expected in States and regions in which major supply origination, pipeline distribution, or transfer points are located. In these States, large volumes of products may change hands many times, often for eventual shipment outside 
the State. Since the EIA $-782 \mathrm{C}$ is intended to measure only those sales into the final local markets of consumption (sales to DREs), all preceding sales are excluded. Furthermore, sales by EIA-782C respondents are reported wherever the product was delivered, which may differ from the State where title transferred. In contrast, the EIA-782A reflects all sales made to secondary resellers, wherever title transfers.

Additionally, the EIA-782C reflects imports by firms that are neither refiners nor gas plant operators, that would not be measured on the EIA-782A unless they were transferred to a distribution chain. This mostly affects regions with a high level of product imports, such as the New England or Mid-Atlantic States.

Therefore, States with major refining areas, such as Texas or California, generally show higher volumes on the EIA-782A survey than the EIA-782C survey, since some of the volumes reported on the EIA-782A are excluded on the EIA-782C or are reported in different States. Conversely, net consuming States (e.g., most PAD District I and PAD District II States) may show larger prime supplier sales on the EIA-782C due to inter-State movements or imports by resellers and/or differences in State of delivery versus title transfer. However, this may be partially or entirely offset by some refiners reporting larger sales volumes on the EIA-782A than on the EIA-782C (due to fewer exclusions taken on the EIA-782A).
In summary, caution should be exercised when comparing sales volumes between refiners and prime suppliers. Whereas EIA-782A data reflect the marketing of products by refiners to non-refiners where the sale occurs, EIA-782C data reflect prime supplier sales to local distributors, local retailers, and end users where the product is delivered. Therefore, the EIA-782A and EIA-782C surveys differ by the respondents reporting (refiners versus prime suppliers), the types of sales reported (sales to non-refiners versus sales to DREs), and the location of the reported sales (point of title transfer versus destination of the sale).

\section{Revision Error}

The petroleum product price and volume data shown for the current month are preliminary. These numbers may be revised in the next month's publication based on data received late or revisions received. For example, if the latest data shown are for the month of February, the February data are preliminary and the January data may have been revised due to the receipt of late or revised data. The data are final upon publication in the Petroleum Marketing Annual (PMA). The difference between the data when they appear as preliminary data in the Petroleum Marketing Monthly (PMM) and when they appear in the PMA is called the revision error. The amount of revision error for some selected EIA-782 data series is shown in the following tables.

\section{Table EN3. Revision Error in Selected I 994 U.S. Average Price Data}

(Cents per Gallon Excluding Taxes)

\begin{tabular}{|c|c|c|c|c|c|c|c|c|c|}
\hline \multirow{2}{*}{ Date } & \multicolumn{3}{|c|}{$\begin{array}{l}\text { Refiner/Reseller Regular Gasoline } \\
\text { Sales Through Retall Outlets }\end{array}$} & \multicolumn{3}{|c|}{$\begin{array}{l}\text { No. } 2 \text { Distillate Sales } \\
\text { to Residential Customers }\end{array}$} & \multicolumn{3}{|c|}{$\begin{array}{l}\text { Residual Fuel Oll Sales } \\
\text { to End Users }\end{array}$} \\
\hline & PMM & Final & Difference & PMM & Final & Difference & PMM & Final & Difference \\
\hline January. & 62.3 & 62.3 & 0.0 & 89.7 & 89.6 & 0.1 & 32.5 & 33.4 & -0.9 \\
\hline February . & 63.1 & 63.3 & -0.2 & 92.8 & 92.9 & -0.1 & 37.5 & 37.3 & 0.2 \\
\hline March..$\ldots \ldots \ldots \ldots \ldots \ldots$ & 62.9 & 63.0 & -0.1 & 91.4 & 91.4 & 0.0 & 34.0 & 33.9 & 0.1 \\
\hline Aprll................. & 64.9 & 65.0 & -0.1 & 88.0 & 88.2 & -0.2 & 31.6 & 31.3 & 0.3 \\
\hline May........... & 66.6 & 66.7 & -0.1 & 85.8 & 86.1 & -0.3 & 32.6 & 32.4 & 0.2 \\
\hline June ..... & 69.6 & 69.6 & 0.0 & 84.9 & 85.2 & -0.3 & 34.8 & 34.8 & 0.0 \\
\hline July ...... & 72.6 & 72.7 & -0.1 & 82.2 & 82.7 & -0.5 & 37.6 & 37.8 & -0.2 \\
\hline August... & 76.7 & 76.7 & 0.0 & 82.0 & 82.1 & -0.1 & 38.3 & 38.3 & 0.0 \\
\hline September. . & 75.2 & 75.1 & 0.1 & 81.5 & 83.2 & -1.7 & 34.8 & 34.8 & 0.0 \\
\hline October.... & 72.8 & 72.8 & 0.0 & 84.5 & 84.7 & -0.2 & 34.8 & 34.8 & 0.0 \\
\hline November .... & 72.9 & 73.0 & -0.1 & 85.7 & 85.7 & 0.0 & 36.9 & 37.2 & -0.3 \\
\hline December .... & 70.5 & 70.4 & 0.1 & 86.3 & 86.8 & -0.5 & 38.7 & 38.9 & -0.2 \\
\hline
\end{tabular}

Sources: PMM data are from Tables 15, 31, and 42 of the Petroleum Marketing Monthly. Final data are from Tables 15, 31, and 42 of the Petroleum Marketing Annual, 1994. 
Table EN4. Revision Error in Selected 1994 Refiner Sales Volume Data (Million Gallons per Day)

\begin{tabular}{|c|c|c|c|c|c|c|c|c|c|}
\hline \multirow{2}{*}{ Date } & \multicolumn{3}{|c|}{$\begin{array}{l}\text { Motor Gasoline } \\
\text { Sales for Resale }\end{array}$} & \multicolumn{3}{|c|}{$\begin{array}{l}\text { No. } 2 \text { Distillate } \\
\text { Sales for Resale }\end{array}$} & \multicolumn{3}{|c|}{$\begin{array}{l}\text { Residual Fuel Oll } \\
\text { Sales to End Users }\end{array}$} \\
\hline & PMM & Final & $\begin{array}{l}\text { Percent } \\
\text { Change }\end{array}$ & PMM & Final & $\begin{array}{l}\text { Percent } \\
\text { Change }\end{array}$ & PMM & Final & $\begin{array}{l}\text { Percent } \\
\text { Change }\end{array}$ \\
\hline$\ldots . .$. & 253.3 & 254.5 & -0.5 & 109.4 & 109.9 & -0.5 & 16.7 & 17.5 & -4.8 \\
\hline February . . . . . . . . . & 257.5 & 261.2 & -1.4 & 111.9 & 112.5 & -0.5 & 15.2 & 15.5 & -2.0 \\
\hline March . & 267.0 & 269.0 & -0.7 & 109.4 & 110.4 & -0.9 & 14.2 & 15.2 & -7.0 \\
\hline April . & 274.7 & 276.2 & -0.5 & 103.2 & 104.1 & -0.9 & 12.5 & 12.6 & -0.8 \\
\hline - & 277.6 & 279.4 & -0.6 & 101.5 & 101.5 & 0.0 & 10.6 & 12.2 & -15.1 \\
\hline June & 285.8 & 287.7 & -0.7 & 107.5 & 108.9 & -1.3 & 13.4 & 14.0 & -4.5 \\
\hline July & 277.4 & 279.2 & -0.6 & 94.1 & 94.9 & -0.9 & 12.0 & 11.5 & 4.2 \\
\hline August & 287.9 & 288.4 & -0.2 & 103.5 & 103.5 & 0.0 & 11.6 & 11.6 & 0.0 \\
\hline September . . & 281.4 & 282.0 & -0.2 & 106.1 & 107.2 & -1.0 & 12.6 & 12.5 & 0.8 \\
\hline October . & 274.8 & 276.1 & -0.5 & 103.4 & 103.9 & -0.5 & 13.1 & 13.1 & 0.0 \\
\hline November & 273.4 & 275.9 & -0.9 & 100.0 & 100.0 & 0.0 & 13.9 & 12.9 & 7.2 \\
\hline December . . & 290.3 & 290.0 & 0.1 & 107.6 & 107.5 & 0.1 & 14.5 & 14.0 & 3.4 \\
\hline
\end{tabular}

Sources: PMM data are from Tables 7, 46, and 47 of the Petroleum Marketing Monthly. Final data are from Tables 7, 46, and 47 of the Petroleum Marketing Annual, 1994.

\section{Table EN5. Revision Error in Selected Volumes of 1994 First Sales Data} (Million Gallons per Day)

\begin{tabular}{|c|c|c|c|c|c|c|c|c|c|}
\hline \multirow{2}{*}{ Date } & \multicolumn{3}{|c|}{ Total Motor Gasoline } & \multicolumn{3}{|c|}{ Total No. 2 Distillate } & \multicolumn{3}{|c|}{ Total Residual Fuel Oil } \\
\hline & PMM & Final & $\begin{array}{l}\text { Percent } \\
\text { Change }\end{array}$ & PMM & Final & $\begin{array}{l}\text { Percent } \\
\text { Change }\end{array}$ & PMM & Final & $\begin{array}{l}\text { Percent } \\
\text { Change }\end{array}$ \\
\hline January & 297.8 & 299.4 & -0.5 & 146.5 & 148.3 & -1.2 & 41.5 & 45.5 & -9.6 \\
\hline February & 314.8 & 315.0 & -0.1 & 149.7 & 147.4 & 1.5 & 51.2 & 51.7 & -1.0 \\
\hline March & 323.0 & 324.2 & -0.4 & 146.4 & 143.4 & 2.0 & 42.9 & 44.0 & -2.6 \\
\hline April & 329.2 & 330.1 & -0.3 & 127.3 & 125.9 & 1.1 & 34.1 & 33.7 & 1.2 \\
\hline May & 331.5 & 330.5 & 0.3 & 123.2 & 121.8 & 1.1 & 33.5 & 32.8 & 2.1 \\
\hline$\ldots \ldots$ & 343.1 & 342.3 & 0.2 & 126.9 & 125.5 & 1.1 & 36.6 & 35.5 & 3.0 \\
\hline$\cdots \cdot$ & 337.9 & 336.3 & 0.5 & 112.9 & 111.7 & 1.1 & 35.6 & 32.7 & 8.1 \\
\hline August & 346.5 & 343.8 & 0.8 & 128.6 & 126.1 & 1.9 & 33.3 & 32.5 & 2.4 \\
\hline$\ldots \ldots \ldots$ & 335.4 & 333.0 & 0.7 & 131.8 & 128.8 & 2.3 & 31.8 & 29.3 & 7.9 \\
\hline October . & 331.7 & 330.5 & 0.4 & 131.0 & 129.7 & 1.0 & 25.5 & 24.1 & 5.5 \\
\hline November & 329.3 & 329.4 & 0.0 & 128.9 & 127.1 & 1.4 & 29.4 & 27.4 & 6.8 \\
\hline December . & 334.1 & 335.0 & -0.3 & 135.3 & 134.8 & 0.4 & 32.0 & 31.2 & 2.5 \\
\hline
\end{tabular}

Sources: PMM data are from Tables 48, 49, and 50 of the Petroleum Marketing Monthly. Final data are from Tables 48, 49, and 50 of the Petroleum Marketing Annual, 1994. 


\section{The Crude Oil Price Surveys}

\section{Background}

\section{Form EIA-182: "Domestic Crude Oil First Purchase Report"}

Each month, the Form EIA-182 collects data from the buyers on first purchases of domestic crude oil. A "first purchase" constitutes a transfer of ownership of crude oil during or immediately after the physical removal of the crude oil from a production property for the first time. Transactions between affiliated companies are reported as if they were "arms-length" transactions. (This definition is consistent with the Windfall Profits Tax (WP'T) concepts of "first sale" and "removal price.") The primary objective is to calculate an average first purchase price at various levels of aggregation. A company's monthly average first purchase prices are volume weighted across given geographical areas for selected crude streams and gravity bands. Prices are computed from the following reported data elements:

- Area of production. The producing State or nonState production "area" (i.e., Alaska North Slope, Alaska Other Mainland, Federal Offshore California and Federal Offshore Gulf-about one-fifth off Texas and the remainder off Louisiana).

- Average cost. Reported f.o.b. the lease boundary and based on the actual purchase expenditures, including discounts or premiums paid.

- Total volume purchased. The amount of crude bought and paid for as it is measured at the lease boundary (usually at a lease automatic custody transfer unit-a LACT unit), adjusted for basic sediment and water (BS\&W) and temperature.

Prices published from data collected on Form EIA-182 are calculated by dividing the sum of the total average costs paid by the sum of the total volumes purchased.

\section{Form EIA-856: "Monthly Foreign Crude Oil Acquisition Report"}

The Form EIA-856 collects monthly price and volume data for about 90 percent of all crude oil imported into the United States. It also collects classification data that enable EIA to determine the terms of an acquisi- tion. The data are reported for the parent company and all the affiliates controlled by the parent. Under this definition, the acquisition price reported for each cargo is the one paid to an unaffiliated seller, in principle an "arms-length" price, which is consistent with use of the data to represent market trends, rather than monitoring internal company transfer pricing policies.

Each month, respondents report the following for cargos acquired for U.S. importation:

- Offshore inventories. Crude oil owned by the respondent that is intended for importation into the United States. These inventories include oil in tankers enroute to the United States and floating or on-land storage outside the United States.

- Crude type. Includes the country of origin of the cargo of crude, the stream or type of crude oil (e.g., Saudi Light), and the API gravity.

- Volume acquired. The number of 42 U.S. gallon barrels in the cargo.

- Dates. The date of loading/acquisition and the expected date of landing.

- Transportation. Ports of loading and landing and the name of the vessel.

- Prices. Acquisition cost, landed cost, and other costs such as demurrage, agent's fees, import tariffs and fees, etc. (all costs are reported in dollars per barrel).

- Days credit. The number of days credit is extended to the purchaser by the seller.

- Purchase classifying information. Type of transaction (e.g., purchase from host government), terms of transaction (spot or contract), and point of transaction (f.o.b. (free on board), country of origin or CIF (cost, insurance, and freight), U.S. port of entry).

Published prices are calculated by first multiplying the purchase volume by a price to obtain a total cost, then the sums of the total costs are divided by the sums of the purchase volumes.

The prices associated with data collected on Form EIA-856 are aggregated within the month of acquisition, which can be the month of loading, the month 
of landing, or sometime between those events. By design, the prices are not aggregated for the month in which they are determined, unless the acquisition and price determination month are the same. EIA-856 data reflect types of trades occurring over the entire spectrum of international crude oil markets, ranging from continuing supply agreements to spot market purchases. Prices can be determined at time of loading or at time of landing. Prices can be negotiated between the parties involved or tied to spot or futures market price levels. The methodology chosen for the EIA-856 provides a consistent historical series even though its prices may not always agree with measures of prices from other sources.

International crude oil markets are complex and dynamic. For example, a cargo of Saudi Arabian crude oil could be acquired in June at a loading port in Saudi Arabia. The cargo may land in the United States in August. The price for the crude oil could be determined by spot crude oil prices in effect during the 5 days before and after landing. For the PMM, the price for this cargo will be aggregated in the month of June, when it was acquired. Conversely, a cargo of Brent crude may be acquired in June, but its price may have been determined in the forward Brent market in April. This cargo's price will also be aggregated in June, when the purchaser took title to the crude.

In the early 1980's, most crude oil prices were set by the country selling the crude. Gradually, as the supply of crude oil became more abundant, markets became more competitive. A robust spot market for crude evolved, in which prices for crude oil were determined by demand and supply. Frequently, the official sales price set by the selling government was considerably different than spot market assessments. As buyers began to purchase more crude oil on the spot market, the control that sellers had theretofore exercised eroded.

In order to protect their market share, crude oil producing governments began to tie prices for their crude to market-related prices. When these market-related pricing formulas came into prominence in late 1985, many crude oil prices were tied to a "netback realization," wherein a crude oil's value was determined by volume weighted spot market prices of products derivable from that crude. The weights essentially reflected the relative yield of selected products from a given crude stream. These netback-based formulas gradually gave way to formulas based on spot crude oil assessments.
The formulas and terms used by sellers of crude oil continue to change. Since the EIA-856 prices are aggregated by month of acquisition-not necessarily the same as month of price determination-they may not always show the same pattern as a series from another source (e.g., trade-press publications). During periods of dramatic change in crude oil prices, aggregate prices derived from EIA-856 data will tend to "lead" the market. That is, these prices will show the emerging trend earlier, reach the inflection point sooner, and then return to the underlying trend. When averaged over longer periods of time, however, EIA-856 prices show the same relative price movements as exogenous sources.

\section{Form EIA-14: "Refiners' Monthly Cost Report"}

The EIA-14 is a monthly census of all U.S. refiners. It collects the net acquisition costs and volumes of crude oil, both domestic and imported, on a corporate national basis (i.e., not for individual refineries). Included in the costs are all charges associated with the acquisition, transportation, and storage of crude incurred by respondents up to the time the oil is booked into their refineries.

Each month, refiners report the volume (in thousands of barrels) and costs (in thousands of dollars) for:

- Domestic crude oil. Oil produced in the United States or from its outer continental shelf.

- Imported crude oil. Oil produced outside the United States and brought into the United States for domestic processing.

- Unfinished oil. All other oils, both domestic and imported, requiring further refining, except those requiring only mechanical blending.

Average prices are calculated by dividing the sum of the costs by the sum of the volumes.

\section{Respondent Frame}

\section{Form EIA-182:}

All firms that buy domestic crude oil at the lease boundary, acquiring ownership of the crude in a first purchase transaction. The list initially was compiled from the 1974 Federal Energy Administration (FEA) 
Oil and Gas Survey of Producers and Operators. Collection of data from first purchasers began in February 1976. By 1978, the frame consisted of 340 respondents. Of these, 198 purchased more than 150,000 barrels per year and together represented 99.9 percent of the total reported volume.

Adjustments to the frame have mostly been "deaths," with relatively few "births." Following decontrol in January 1981, there was a major contraction of the list of active first purchasers. Many small firms went out of business or were absorbed by larger companies. More recent changes include several mergers among majors and one breakup of a major company. In 1994, the EIA-182 survey collected data from 102 active respondents.

\section{Form EIA-856:}

All companies that were reporting data on the ERA51, "Transfer Pricing Report," as of June 1982, regardless of the total volumes of crude oil that are imported. In addition, all other companies that acquire more than 500,000 barrels of foreign crude oil in the report month for importation into the United States are required to prepare and submit an EIA-856 for that month.

\section{Form EIA-14:}

All refiners of crude oil in the United States, including its territories and possessions. In 1994, there were 107 active respondents to the EIA-14.

The list of respondents to the EIA-14 is updated annually by supplementation from the EIA-782A, "Refiners'/Gas Plant Operators' Monthly Petroleum Product Sales Report," and the EIA-810, "Monthly Refinery Report."

\section{Data Collection Processing}

All three crude oil data collection systems are operated independently. Each performs similar data collection and processing functions that are outlined below.

Survey data are collected by mail every month. It is mandatory for each respondent to submit completed forms to EIA no later than 30 calendar days after the close of each reference month. Telephone follow-up calls to nonrespondents begin 2 days after the established due date in order to collect all outstanding data.
Late submissions and resubmissions are processed when received.

The forms are logged and reviewed manually. The data are then entered onto computer files. The files are then processed through an automated edit program which detects missing data, inconsistent prices, and outlying values that affect published estimates. Data that fail the edits are resolved through telephone calls to data reporters, and corrections and verification codes are entered onto computer files. Statistical reports, including publication tables, are then generated using only acceptable and verified data. Response rates are normally 100 percent by the time final statistics are calculated.

\section{Nondisclosure}

The data contained in this publication are subject to statistical nondisclosure procedures. The objective of the disclosure-avoidance procedures, as stated in the Energy Information Administration Standard 88-0506, Subject: "Nondisclosure of Company Identifiable Data in Aggregate Cells," is to ensure that confidential, company-identifiable data are not disclosed in tables where "company specific responses may be proprietary and prohibited from public disclosure by 18 U.S.C. 1905." Statistics representing data aggregated from fewer than three companies or that are dominated by input from one or two companies are withheld. EIA identifies cells that are sensitive according to these criteria by applying a statistical formula to the data contained in each cell to determine if a few companies "dominate" the cell.

If a cell is sensitive, the data in that cell are suppressed and a "W" is placed in the publication cell. Also, since many tables include row or column totals, some nonsensitive data cells have been suppressed to prevent the reader from calculating the suppressed numbers by simply subtracting the published numbers from the total.

\section{Data Continuity}

The crude oil statistics published in the Petroleum Marketing Montbly constitute both a republishing of numbers that already appear in the Montbly Energy Review (MER) and the Annual Energy Review (AER), and a simple extension of the detail of such statistics. These statistics have been published for a number of 
years in the MER and AER. The data currently collected through the crude oil surveys are compatible with data used to derive statistics for the historical series. The definitions, respondents, and processing have not changed substantially over the years the data have been collected. The target populations and the computational algorithms have remained virtually unchanged.

\section{Reliability of Data}

There are two types of errors possible in an estimate based on a sample survey: sampling and nonsampling. Sampling errors occur because observations are made only on a sample, not on the entire population. Since the crude oil surveys are based on a census of the population, these surveys contain no sampling error.

Nonsampling errors can be attributed to many sources: (1) inability to obtain complete information from all respondents in the survey (i.e., nonresponse), (2) response errors, (3) definitional difficulties, (4) differences in the interpretation of questions, (5) mistakes in recording or coding the data obtained, and (6) other errors of collection, response, coverage, and estimation for missing data.

Although no direct measurement of the biases due to nonsampling errors can be obtained, precautionary steps were taken in all phases of the frame development and data collection, processing, and tabulation processes, in an effort to minimize their influence. In addition, the close cooperative consultation between EIA and the survey respondents and data users results in a more accurate information gathering and reporting process.

\section{Imputation}

Since the response rates for the crude oil survey are virtually 100 percent, there are no imputation procedures in the PMM data for nonresponse to these surveys. Imputation is performed, however, on EIA182 volume data used in estimating crude oil production published in the Petroleum Supply Montbly (PSM). Since production estimates for the PSM are required on an expedited schedule, some responses are imputed for the PSM. However, all responses are received prior to the publication of the PMM, thus no imputation is required for the price data published in the PMM. See Note 4 in the Explanatory Notes in the PSM for additional information on the use of EIA-182 data in estimating domestic crude oil production.

\section{Revision Error}

The crude oil values shown for Domestic First Purchase Prices and Refiner Acquisition Cost (RAC) for the current month and for Average Landed Costs for the current 2 months are preliminary. These numbers are revised in the month after the preliminary month(s) based on data received late or revisions received. For example, in the February publication, the February RAC data are preliminary and the January RAC data may have been revised due to receipt of late or revised data. The data are final upon publication in the Petroleum Marketing Annual (PMA). In the above example, the difference between the January RAC data in the Petroleum Marketing Montbly (PMM) and when they appear in the PMA is called the revision error. The amount of revision error for some selected crude oil data series is shown in the tables that follow. 
Table EN6. Revision Error in 1994 Refiner Acquisition Cost Data (Dollars per Barrel)

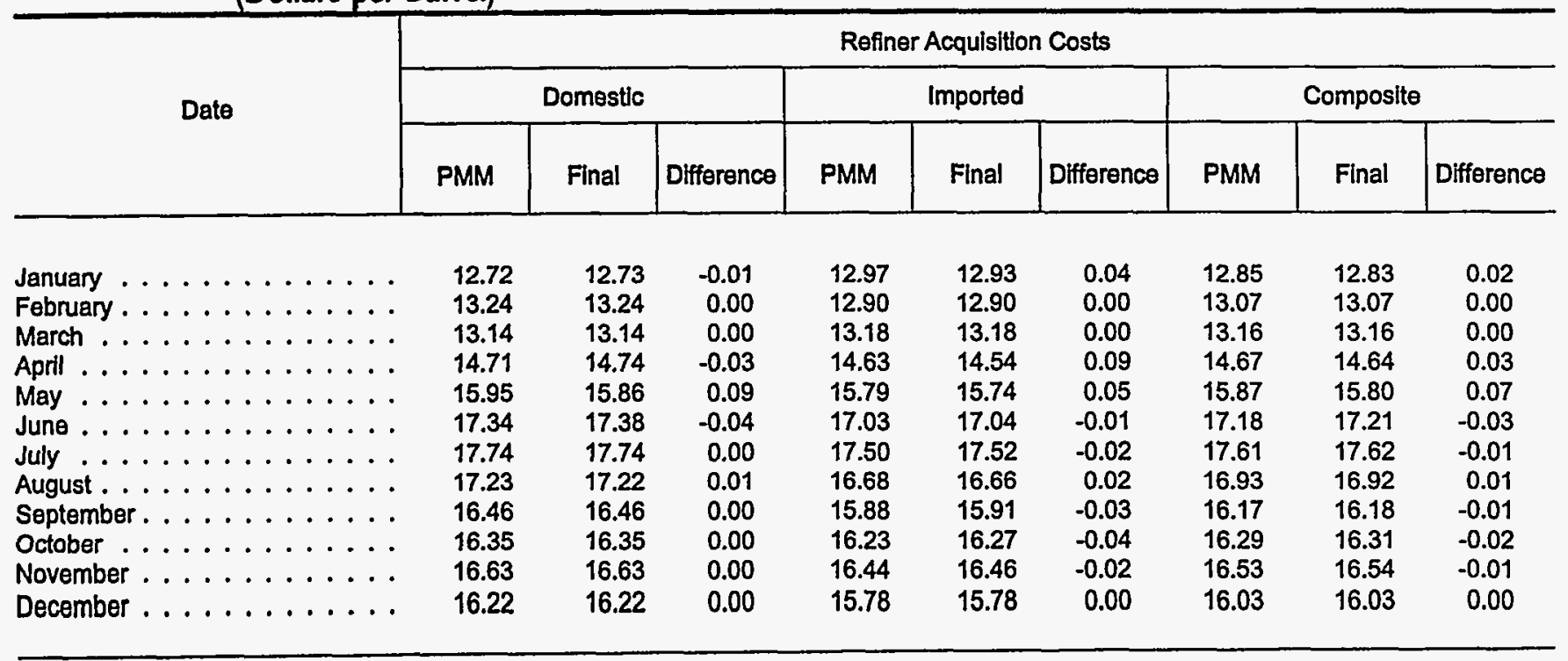

Sources: PMM data are from Table 1 of the Petroleum Marketing Monthly. Final data are from Table 1 of the Petroleum Marketing Annual, 1994.

Table EN7. Revision Error in 1994 Domestic First Purchase Price Data (Dollars per Barrel)

\begin{tabular}{|c|c|c|c|}
\hline Month & PMM & Final & Difference \\
\hline January $\ldots \ldots \ldots \ldots \ldots \ldots \ldots \ldots \ldots \ldots$ & 10.51 & 10.49 & 0.02 \\
\hline 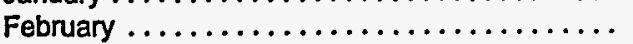 & 10.73 & 10.71 & 0.02 \\
\hline March. ............................ & 10.81 & 10.94 & -0.13 \\
\hline 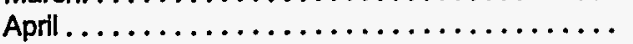 & 12.33 & 12.31 & 0.02 \\
\hline May $\ldots \ldots \ldots \ldots \ldots \ldots \ldots \ldots \ldots$ & 14.03 & 14.02 & 0.01 \\
\hline 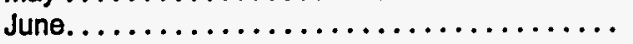 & 14.94 & 14.93 & 0.01 \\
\hline July $\ldots \ldots \ldots \ldots \ldots \ldots \ldots \ldots \ldots \ldots$ & 15.32 & 15.34 & -0.02 \\
\hline August $\ldots \ldots \ldots \ldots \ldots \ldots \ldots \ldots \ldots$ & 14.50 & 14.50 & 0.00 \\
\hline September. . . . . . . . . . . . . . . . . . & 13.62 & 13.62 & 0.00 \\
\hline 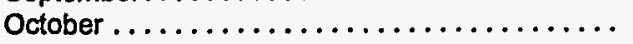 & 13.85 & 13.84 & 0.01 \\
\hline November $\ldots \ldots \ldots \ldots \ldots \ldots \ldots \ldots \ldots$ & 14.14 & 14.14 & 0.00 \\
\hline December $\ldots \ldots \ldots \ldots \ldots \ldots \ldots \ldots \ldots \ldots \ldots$ & 13.43 & 13.43 & 0.00 \\
\hline
\end{tabular}

Sources: Preliminary data are from Table 1 of the Petroleum Marketing Monthly for each respective month. Final data are from Table 1 of the Petroleum Marketing Annual, 1994. 
Table EN8. 1994 Revision Error: Form EIA-856 ${ }^{\prime}$ (Dollars per Barrel)

\begin{tabular}{|c|c|c|c|c|c|c|}
\hline \multirow{2}{*}{ Month } & \multicolumn{3}{|c|}{ FOB Cost of Imports } & \multicolumn{3}{|c|}{ Landed Cost of Imports } \\
\hline & PMM & Final & Difference & PMM & Final & Difference \\
\hline January . . . . . . . . . . . . . . . . . & 12.01 & 12.07 & -0.06 & 12.61 & 12.74 & -0.13 \\
\hline February . . . . . . . . . . . . . . & 11.95 & 12.05 & -0.10 & 12.57 & 12.71 & -0.14 \\
\hline 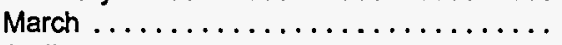 & 12.04 & 12.38 & -0.34 & 12.66 & 13.00 & -0.34 \\
\hline April . . . . . . . . . . . . . . & 13.38 & 13.55 & -0.17 & 14.08 & 14.30 & -0.22 \\
\hline May $\ldots \ldots \ldots \ldots \ldots \ldots \ldots \ldots \ldots$ & 14.54 & 14.67 & -0.13 & 15.46 & 15.62 & -0.16 \\
\hline June . . . . . . . . . . . . . . . . & 15.49 & 15.44 & 0.05 & 16.51 & 16.51 & 0.00 \\
\hline July $\ldots \ldots \ldots \ldots \ldots \ldots \ldots \ldots \ldots \ldots$ & 16.21 & 16.10 & 0.11 & 17.22 & 17.15 & 0.07 \\
\hline August $\ldots \ldots \ldots \ldots \ldots \ldots \ldots \ldots \ldots$ & 15.03 & 14.94 & 0.09 & 16.18 & 16.07 & 0.11 \\
\hline September. . . . . . . . . . . . . . . . . . . & 14.26 & 14.32 & -0.06 & 15.39 & 15.47 & -0.08 \\
\hline October ......... & 14.61 & 14.74 & -0.13 & 15.59 & 15.66 & -0.07 \\
\hline November . . . . . . . . . . . . . . . & 14.84 & 14.88 & -0.04 & 15.98 & 15.98 & 0.00 \\
\hline December .................... & 14.30 & 14.46 & -0.16 & 15.48 & 15.61 & -0.13 \\
\hline
\end{tabular}

Sources: PMM data are from Table 1 of the Petroleum Marketing Monthly for each respective month. Final data are from Table 1 of the Petroleum Marketing Annual, 1994. 
Product Guide 


\begin{tabular}{|c|c|c|}
\hline \multirow{2}{*}{ Category } & \multicolumn{2}{|c|}{ Table } \\
\hline & Prices & Volumes \\
\hline \multicolumn{3}{|l|}{ Crude Oil } \\
\hline Refiner Acquisition Cost. . . . . . . . . . . . . . . . . & 1 & - \\
\hline $\begin{array}{l}\text { Domestic First Purchases } \ldots \ldots \ldots \ldots \ldots \ldots \ldots \ldots \ldots \ldots \ldots \\
\text { from selected States } \ldots \ldots \ldots \ldots \ldots \ldots \ldots \ldots \ldots \ldots \ldots \\
\text { by API gravity } \ldots \ldots \ldots \ldots \ldots \ldots \ldots \ldots \\
\text { for selected crude streams. } \ldots \ldots \ldots \ldots \ldots \ldots \ldots\end{array}$ & $\begin{array}{l}1 \\
21 \\
23 \\
22\end{array}$ & $\begin{array}{l}- \\
- \\
-\end{array}$ \\
\hline 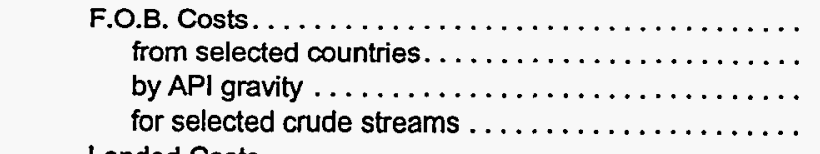 & $\begin{array}{l}1 \\
24 \\
26 \\
29\end{array}$ & $\begin{array}{l}- \\
- \\
-\end{array}$ \\
\hline Landed Costs $\ldots \ldots \ldots \ldots \ldots \ldots \ldots \ldots \ldots \ldots$ & 1 & - \\
\hline from selected countries. . . . . . . . . . . . . . & 25 & - \\
\hline by API gravity $\ldots \ldots \ldots \ldots \ldots \ldots \ldots \ldots \ldots \ldots$ & 27 & - \\
\hline for selected crude streams $\ldots \ldots \ldots \ldots \ldots \ldots \ldots$ & 30 & - \\
\hline Percentage by Gravity Band. . . . . . . . . . . . . . . . . & 28 & - \\
\hline 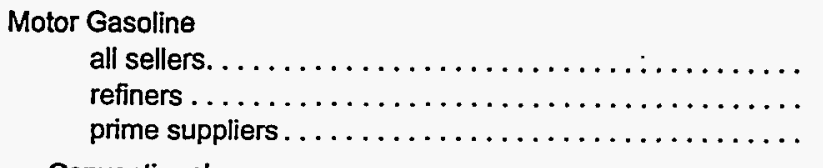 & $\begin{array}{c}31 \\
2,4,6,35 \\
-\end{array}$ & $\begin{array}{l}-\overline{3,5,7,43,44} \\
48\end{array}$ \\
\hline 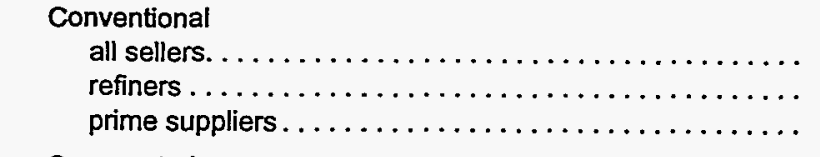 & $\begin{array}{c}32 \\
8 \\
-\end{array}$ & $\begin{array}{c}-\overline{44} \\
48\end{array}$ \\
\hline 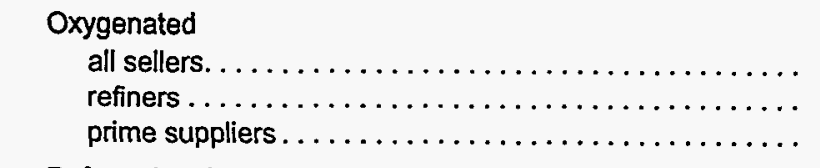 & $\begin{array}{l}33 \\
10 \\
-\end{array}$ & $\begin{array}{c}- \\
11,44\end{array}$ \\
\hline 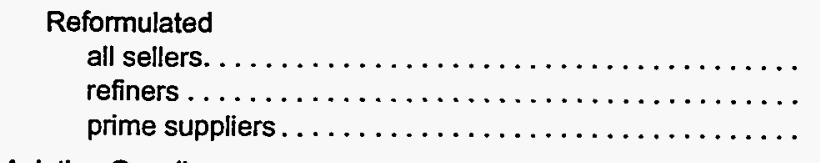 & $\begin{array}{l}34 \\
12 \\
-\end{array}$ & $\begin{array}{c}- \\
48,44\end{array}$ \\
\hline 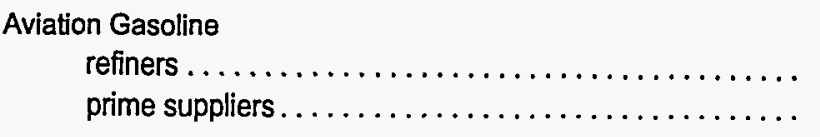 & $\begin{array}{c}2,4,36 \\
-\end{array}$ & $\begin{array}{c}3,5,45 \\
49\end{array}$ \\
\hline 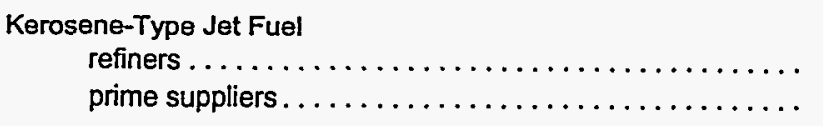 & $2,4,36$ & $\begin{array}{c}3,5,45 \\
49\end{array}$ \\
\hline $\begin{array}{l}\text { Naphtha-Type Jet Fuel } \\
\text { prime suppliers } \ldots \ldots \ldots \ldots \ldots \ldots \ldots \ldots \ldots \ldots\end{array}$ & - & 49 \\
\hline 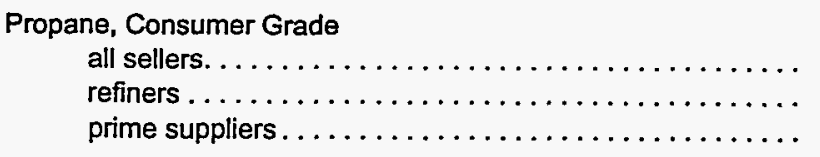 & $\begin{array}{c}14,38 \\
2,4 \\
-\end{array}$ & $\begin{array}{l}3, \overline{5}, 45 \\
49\end{array}$ \\
\hline
\end{tabular}




\begin{tabular}{|c|c|c|}
\hline \multirow{2}{*}{ Category } & \multicolumn{2}{|c|}{ Table } \\
\hline & Prices & Volumes \\
\hline 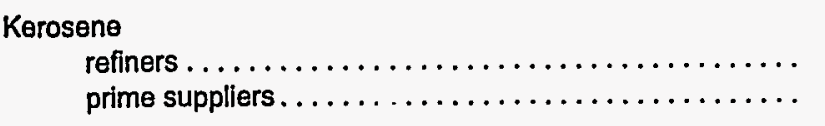 & $\begin{array}{c}2,4,36 \\
-\end{array}$ & $\begin{array}{c}3,5,45 \\
50\end{array}$ \\
\hline 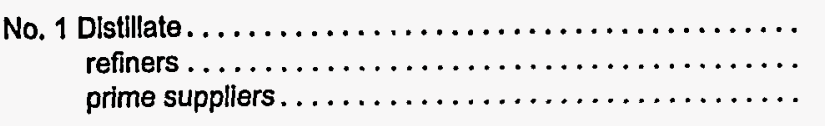 & $\begin{array}{c}2,4,37 \\
-\end{array}$ & $\begin{array}{c}3,5,45 \\
50\end{array}$ \\
\hline 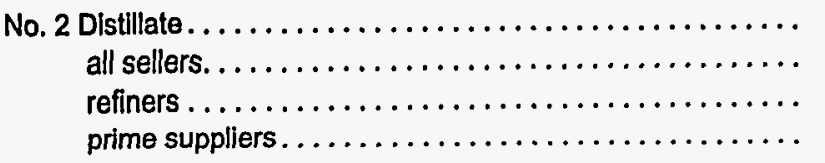 & $\begin{array}{c}15,18,39 \\
2,4,37 \\
-\end{array}$ & $\begin{array}{l}3, \overline{5,46} \\
50\end{array}$ \\
\hline 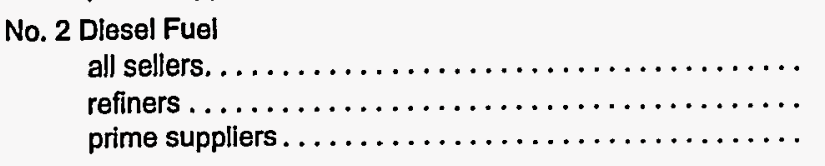 & $\begin{array}{c}16,17,40 \\
2,4 \\
-\end{array}$ & $\begin{array}{c}- \\
3,5,46 \\
50\end{array}$ \\
\hline 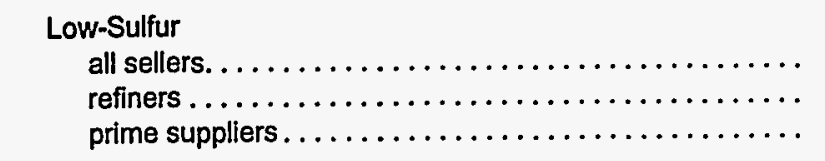 & $\begin{array}{l}17,41 \\
- \\
-\end{array}$ & $\begin{array}{l}3,5,46 \\
50\end{array}$ \\
\hline 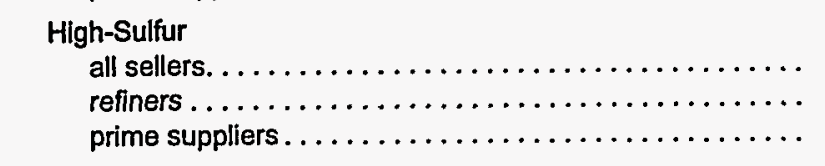 & $\begin{array}{l}17.41 \\
- \\
-\end{array}$ & $\begin{array}{l}3, \overline{5,46} \\
50\end{array}$ \\
\hline 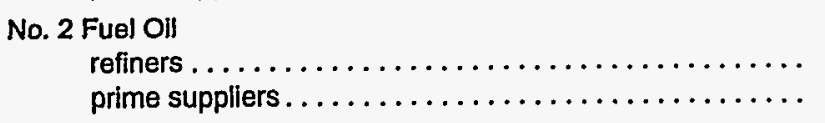 & $\begin{array}{c}2,4 \\
-\end{array}$ & $\begin{array}{c}3,5,46 \\
50\end{array}$ \\
\hline 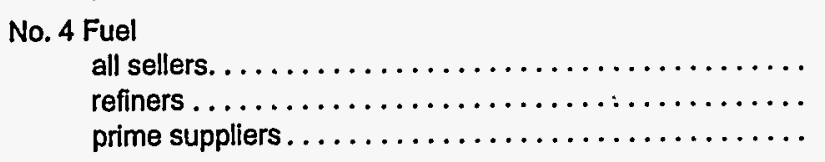 & $\begin{array}{l}37 \\
2,4 \\
-\end{array}$ & $\begin{array}{l}3, \overline{5,47} \\
50\end{array}$ \\
\hline 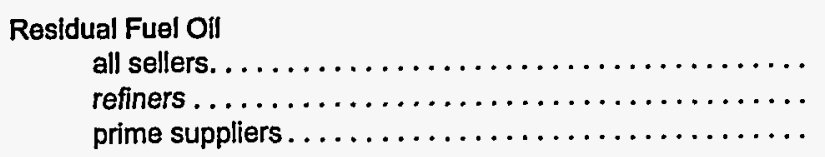 & $\begin{array}{c}42 \\
2,4,19 \\
-\end{array}$ & $\begin{array}{l}-\overline{20}, 47 \\
49\end{array}$ \\
\hline 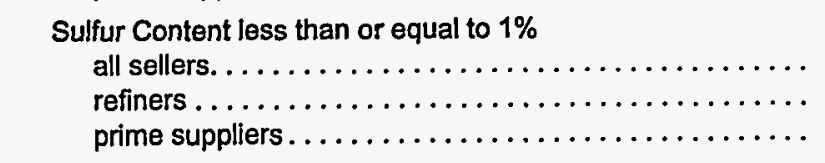 & $\begin{array}{l}42 \\
19 \\
-\end{array}$ & $\begin{array}{c}- \\
20,47 \\
49\end{array}$ \\
\hline 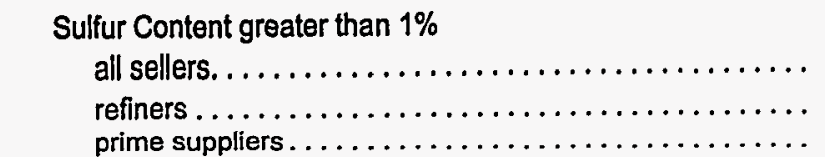 & $\begin{array}{l}42 \\
19 \\
-\end{array}$ & 20,47 \\
\hline
\end{tabular}


Glossary 



\section{Glossary}

API Gravity: An arbitrary scale expressing the gravity or density of liquid petroleum products. The measuring scale is calibrated in terms of degrees API; it may be calculated in terms of the following formula:

Deg $A P I=\frac{141.5}{s p \operatorname{gr} 60 \operatorname{deg} F / 60 \operatorname{deg} F}-131.5$

The higher the API gravity, the lighter the compound. Light crudes generally exceed 38 degrees API and heavy crudes are commonly labeled as all crudes with an API gravity of 22 degrees or below. Intermediate crudes fall in the range of 22 degrees to 38 degrees API gravity.

ASTM: The American Society for Testing and Materials.

Aviation Gasoline (Finished): All special grades of gasoline for use in aviation reciprocating engines, as given in ASTM Specification D 910 and Military Specification MIL-G-5572. Excludes blending components which will be used in blending or compounding into finished aviation gasoline.

Barrel: A volumetric unit of measure for crude oil and petroleum products equivalent to 42 U.S. gallons.

Bulk Sales: Wholesale sales of gasoline in individual transactions which exceed the size of a truckload.

CIF: Cost, insurance, and freight. A type of sale in which the buyer of the product agrees to pay a unit price that includes the f.o.b. value of the product at the point of origin plus all costs of insurance and transportation. This type of transaction differs from a "delivered" purchase, in that the buyer accepts the quantity as determined at the loading port (as certified by the bill of loading and quality report) rather than pay based on the quantity and quality ascertained at the unloading port. It is similar to the terms of an f.o.b. sale, except that the seller, as a service for which he is compensated, arranges for transportation and insurance.

Commercial/Institutional: Firms engaged in transportation, wholesale or retail trade, finance, insurance, and real estate. Also included are apartment buildings/complexes and other multifamily dwellings, hotels and office buildings or complexes, local, State, or Federal facilities or organizations including the military, schools, hospitals, religious institutions, universities, and all other government-supported organizations.

\section{Conventional Gasoline: See Motor Gasoline.}

Crude Oil (including lease condensate): A mixture of hydrocarbons that existed in liquid phase in underground reservoirs and remains liquid at atmospheric pressure after passing through surface separating facilities. Includes lease condensate and drip gas, as well as liquid hydrocarbons produced from tar sands, gilsonite, and oil shale. Excludes topped crude oil, residual oil, other unfinished oils, and liquids produced at natural gas processing plants and mixed with crude oil, where identifiable. Crude oil is considered as either domestic or imported according to the following:

1. Domestic Crude Oil: Crude oil produced in the United States or from its "outer continental shelf" as defined in 43 U.S.C. 1331.

2. Imported Crude Oil: Crude oil produced outside the United States and brought into the United States.

3. First purchase volume and cost data for crude oil are classified in accordance with what the product was sold as, regardless of the actual specifications. Hence, its volumes may include some of the excluded liquids discussed above. 
Crude Oil Acquisitions (unfinished oil acquisitions): The volume of crude oil either (1) acquired by the respondent for processing for its own account in accordance with accounting procedures generally accepted and consistently and historically applied by the refiner concerned, or (2) in the case of a processing agreement, delivered to another refinery for processing for the respondent's own account.

Crude oil which has been added by a refiner to inventory, and which is thereafter sold or otherwise disposed of without processing for the account of that refiner, shall be deducted from its crude oil purchases at the time when the related cost is deducted from refinery inventory in accordance with accounting procedures generally applied by the refiner concerned.

Dealer Tank Wagon (DTW) Sales: Wholesale sales of gasoline priced on a delivered basis to a retail outlet.

Distillate Fuel Oil: A general classification for one of the petroleum fractions produced in conventional distillation operations. It is used primarily for space heating, on- and off-highway diesel engine fuel (including railroad engine fuel and fuel for agricultural machinery), and electric power generation. Included are products known as No. 1, No. 2, and No. 4 fuel oils and No. 1, No. 2, and No. 4 diesel fuels.

1. No. 1 Distillate: A petroleum distillate which meets the specifications for No. 1 heating or fuel oil as defined in ASTM D 396 and/or the specifications for No. 1 diesel fuel as defined in ASTM Specification D 975, with distillation temperatures of 420 degrees Fahrenheit at the 10 -percent recovery point and 550 degrees Fahrenheit at the 90-percent recovery point, and kinematic viscosities between 1.4 and 2.2 centistokes at 100 degrees Fahrenheit.

a. No. 1 Diesel Fuel: A volatile distillate fuel oil with a boiling range between 300-575 degrees Fahrenheit and used in high-speed diesel engines generally operated under wide variations in speed and load. Includes type C-B diesel fuel used for city buses and similar operations. Properties are defined in ASTM Specification D 975.

b. No. 1 Fuel Oil: A light distillate fuel oil intended for use in vaporizing pot-type burners. ASTM Specification D 396 specifies for this grade maximum distillation temperatures of 400 degrees Fahrenheit at the 10-percent recovery point and 550 degrees Fahrenheit at the 90-percent point, and kinematic viscosities between 1.4 and 2.2 centistokes at 100 degrees Fahrenheit.

2. No. 2 Distillate: A petroleum distillate which meets the specifications for No. 2 heating or fuel oil as defined in ASTM D 396 and/or the specifications for No. 2 diesel fuel as defined in ASTM Specification D 975.

a. No. 2 Diesel Fuel: A gas oil type distillate of lower volatility with distillation temperatures at the 90-percent point between 540640 degrees Fahrenheit for use in high speed diesel engines generally operated under uniform speed and load conditions. Includes Type R-R diesel fuel used for railroad locomotive engines, and Type T-T for diesel-engine trucks. Properties are defined in ASTM Specification D 975.

- Low Sulfur: The sulfur level does not exceed 0.05 percent by weight.

- High Sulfur: The sulfur level is above 0.05 percent by weight.

b. No. 2 Fuel Oil: A distillate fuel oil for use in atomizing type burners for domestic heating or for moderate capacity commercial-industrial burner units. ASTM Specification D 396 specifies for this grade distillation temperatures at the 90-percent point between 540 and 640 degrees Fahrenheit, and kinematic viscosities between 2.0 and 3.6 centistokes at 100 degrees Fahrenheit.

NOTE: Published volume and price data for No. 2 diesel fuel and No. 2 fuel oil are classified in accordance to what the product was sold as, regardless of the actual specifications of that product; i.e., if a No. 2 distillate was sold as a heating or fuel oil, the volume and price would be published in the category "No. 2 Fuel Oil" even if the product conformed to the higher specifications of a diesel fuel.

3. No. 4 Fuel: A fuel oil for commercial burner installations not equipped with preheating $\mathrm{fa}^{-}$ cilities. It is used extensively in industrial plants. This grade is a blend of distillate fuel 
oil and residual fuel oil stocks that conforms to ASTM Specification D 396 or Federal Specification VV-F-815C; its kinematic viscosity is between 5.8 and 26.4 centistokes at 100 degrees Fahrenheit. Also included is No. 4-D, a fuel oil for low- and medium-speed diesel engines that conforms to ASTM Specification D 975.

First Purchase (of crude oil): An equity (not custody) transaction involving an arms-length transfer of ownership of crude oil associated with the physical removal of the crude oil from a property (lease) for the first time. A first purchase normally occurs at the time and place of ownership transfer where the crude oil volume sold is measured and recorded on a run ticket or other similar physical evidence of purchase. The reported cost is the actual amount paid by the purchaser, allowing for any adjustments (deductions or premiums) passed on to the producer or royalty owner.

F.o.b. Price (free on board): The f.o.b. price is the price actually charged at the producing country's port of loading. The reported price includes deductions for any rebates and discounts or additions of premiums where applicable and should be the actual price paid with no adjustment for credit terms.

Gas Plant Operator: Any firm, including a gas plant owner, which operates a gas plant and keeps the gas plant records. A gas plant is a facility in which natural gas liquids are separated from natural gas, or in which natural gas liquids are fractionated or otherwise separated into natural gas liquid products or both. For the purposes of this publication, gas plant operator data are contained in the refiner categories.

Gasohol: A blend of finished motor gasoline and alcohol (generally ethanol but sometimes methanol) in which 10 percent or less of the product is alcohol. For the purposes of this publication, gasohol may be included in any of the types of gasoline, depending on how it was marketed.

Industrial: Firms engaged in mining, construction, or manufacturing.

Kerosene: A petroleum distillate that has a maximum distillation temperature of 401 degrees Fahrenheit at the 10-percent recovery point, a final boiling point of 572 degrees Fahrenheit, and a minimum flash point of 100 degrees Fahrenheit. Included are the two grades designated in ASTM D3699: No. 1-K and No. 2-K, and all grades of kerosene called range or stove oil which have properties similar to No. 1 fuel oil, but with a gravity of about 43 degrees API and a maximum endpoint of 625 degrees Fahrenheit. Kerosene is used in space heaters, cook stoves, and water heaters; it is suitable for use as an illuminant when burned in wick lamps.

Kerosene-Type Jet Fuel: A quality kerosene product with maximum distillation temperature of $400 \mathrm{de}-$ grees Fahrenheit at the 10-percent recovery point and a final maximum boiling point of 572 degrees Fahrenheit. The fuel is designated in ASTM Specification D 1655 and Military Specifications MIL-T-5624P and MIL-T-83133D (Grades JP-5 and JP-8). A relatively low freezing point distillate of the kerosene type used primarily for commercial turbojet and turboprop aircraft engines.

Landed Cost: Landed cost represents the dollar per barrel price of crude oil at the port of discharge. Includes charges associated with the purchase, transporting, and insuring of a cargo from the purchase point to the port of discharge. Does not include charges incurred at the discharge port (e.g., import tariffs or fees, wharfage charges, and demurrage).

Motor Gasoline (Finished): A complex mixture of relatively volatile hydrocarbons, with or without small quantities of additives, blended to form a fuel suitable for use in spark-ignition engines. Specifications for motor gasoline, as given in ASTM Specification D 439-88 or Federal Specification VV-G-1690B, include a boiling range of 122 to 158 degrees Fahrenheit at the 10-percent recovery point to 365 to 374 degrees Fahrenheit at the 90 -percent recovery point. "Motor Gasoline" includes conventional gasoline, oxygenated gasoline (EPA approved), and reformulated gasoline. Blendstock (including ethanol and MTBE) are excluded until blending has been completed.

1. Conventional Gasoline: Motor gasoline not included in the oxygenated or reformulated gasoline categories. Excludes reformulated gasoline blendstock for oxygenate blending (RBOB).

2. Oxygenated Gasoline: Gasoline formulated for use in motor vehicles that is intended for use in EPA approved carbon monoxide) nonattainment State programs. Excludes reformulated gasoline, oxygenated fuels program reformulated gasoline (OPRG) and reformu- 
lated gasoline blendstock for oxygenate blending ( $R B O B)$.

3. Reformulated Gasoline: Gasoline formulated for use in motor vehicles, the composition and properties of which meet the requirements of the reformulated gasoline regulations promulgated by the U.S. Environmental Protection Agency under Section 211(k) of the Clean Air Act. Includes oxygenated fuels program reformulated gasoline (OPRG). Excludes reformulated gasoline blendstock for oxygenate blending (RBOB).

a. Regular Gasoline: Gasoline having an antiknock index $((R+M) / 2)$ greater than or equal to 85 and less than 88 .

b. Midgrade Gasoline: Gasoline having an antiknock index $((R+M) / 2)$ greater than or equal to 88 and less than or equal to 90 .

c. Premium Gasoline: Gasoline having an antiknock index $((R+M) / 2)$ greater than 90 .

NOTE: For this publication, gasoline sales are reported by grade in accordance with their classification at the time of sale. In general, automotive octane requirements are lower at high altitudes. Therefore, in some areas of the United States, such as the Rocky Mountain States, the octane ratings for the gasoline grades above may be 2 or more octane points lower.

MTBE (methyl tertiary butyl ether): An ether eligible for gasoline blending, blends up to 15.0 percent by volume MTBE which must meet the ASTM D 4814 Specifications. Blenders must take precautions that the blends are not used as base gasolines for other oxygenated blends.

Naphtha: A generic term applied to a petroleum fraction with an approximate boiling range between 122 and 400 degrees Fahrenheit.

Naphtha-Type Jet Fuel: A fuel in the heavy naphtha boiling range with an average gravity of 52.8 degrees API and 20 to 90 percent distillation temperatures of 290 degrees to 470 degrees F., meeting Military Specification MIL-T-5624L (Grade JP-4). JP-4 is used for turbojet and turboprop aircraft engines, primarily by the military. Excludes ram-jet and petroleum rocket fuels.
OPEC: Organization of Petroleum Exporting Countries, oil-producing and exporting countries that have organized for the purpose of negotiating with oil companies on matters of oil production, prices, and future concession rights. Current members are Algeria, Gabon, Indonesia, Iran, Iraq, Kuwait, Libya, Nigeria, Qatar, Saudi Arabia, United Arab Emirates, and Venezuela. Prior to January 1, 1993, Ecuador was a member of OPEC.

OPRG: "Oxygenated Fuels Program Reformulated Gasoline" is reformulated gasoline which is intended for use in an oxygenated fuels program control area during an oxygenated fuels program control period.

Other End Users: For motor gasoline, all direct sales to end users other than those made through company outlets. For No. 2 distillate, all direct sales to end users other than residential, commercial/institutional, industrial sales, and sales through company outlets. Included in the "other end users" category are sales to utilities and agriculture.

Oxygenated Gasoline: See Motor Gasoline.

Oxygenates: Any substance which, when added to gasoline, increases the amount of oxygen in that gasoline blend.

PAD District: Petroleum Administration for Defense Districts

\section{PAD District I:}

Subdistrict IA: Connecticut, Maine, Massachusetts, New Hampshire, Rhode Island, Vermont.

Subdistrict IB: Delaware, District of Columbia, Maryland, New Jersey, New York, Pennsylvania.

Subdistrict IC: Florida, Georgia, North Carolina, South Carolina, Virginia, West Virginia.

\section{PAD District II:}

Illinois, Indiana, Iowa, Kansas, Kentucky, Michigan, Minnesota, Missouri, Nebraska, North Dakota, Ohio, Oklahoma, South Dakota, Tennessee, Wisconsin. 


\section{PAD District III:}

Alabama, Arkansas, Louisiana, Mississippi, New Mexico, Texas, Federal Offshore Gulf.

\section{PAD District IV:}

Colorado, Idaho, Montana, Utah, Wyoming.

\section{PAD District V:}

Alaska (North Slope and Other Mainland), Arizona, California, Hawaii, Nevada, Oregon, Washington, Federal Offshore California.

Petrochemical Sales: Sales of propane to a manufacturer of chemicals derived from petroleum or natural gas, or from raw materials derived from petroleum or natural gas.

Petroleum Products: Petroleum products are obtained from the processing of crude oil (including lease condensate), natural gas, and other hydrocarbon compounds. Petroleum products include unfinished oils, liquefied petroleum gases, pentanes, plus aviation gasoline, motor gasoline, naphtha-type jet fuel, kerosene, distillate fuel oil, residual fuel oil, petrochemical feedstocks, special naphthas, lubricants, waxes, petroleum coke, asphalt, road oil, still gas, and miscellaneous products.

Prime Supplier: A firm that produces, imports, or transports selected petroleum products across State boundaries and local marketing areas, and sells the product to local distributors, local retailers, or end users.

Propane, Consumer Grade: A normally gaseous paraffinic compound $\left(\mathrm{C}_{3} \mathrm{H}_{8}\right)$, which includes all products covered by Natural Gas Policy Act (NGPA) Specifications for commercial use and HD-5 propane and ASTM Specification D 1835. It is a colorless paraffinic gas that boils at a temperature of -43.67 degrees Fahrenheit. It does not include the propane portion of any natural gas liquids (NGL) mixes; i.e., butane-propane mix.

Rack Sales: Wholesale truckload sales or smaller of gasoline where title transfers at a terminal.

RBOB: "Reformulated Gasoline Blendstock for Oxygenate Blending" is a motor gasoline blending component which, when blended with a specified type and percentage of oxygenate, meets the definition of reformulated gasoline.

Reference Month: The calendar month and year to which the reported cost, price, and volume information relates.

Refiner: A firm or the part of a firm that refines products or blends and substantially changes products, or refines liquid hydrocarbons from oil and gas field gases, or recovers liquefied petroleum gases incident to petroleum refining and sells those products to resellers, retailers, resellers/retailers, or ultimate consumers. "Refiner" includes any owner of products which contracts to have those products refined and then sells the refined products to resellers, retailers, or ultimate consumers. For the purposes of this publication, gas plant operator data are included in this category.

\section{Reformulated Gasoline: See Motor Gasoline.}

Reseller: A firm (other than a refiner) that carries on the trade or business of purchasing refined petroleum products and reselling them to purchasers other than ultimate consumers.

Reseller/Retailer: A firm (other than a refiner) that carries on the trade or business activities of both a reseller and a retailer; i.e., purchasing refined petroleum products and reselling them to purchasers who may be either ultimate or other than ultimate consumers.

Residential: Sales of No. 2 distillate and propane to individual customers or households (as opposed to businesses or institutions) who ostensibly use the fuel in a residence for space heating, cooking, etc Sales to apartment buildings/complexes or to other multi-family dwellings are excluded from the "Residential Sales" category and are included in the "Commercial/Institutional Sales" category.

Residual Fuel Oils: The topped crude of refinery operations, which includes No. 5 and No. 6 fuel oils as defined in ASTM Specification D 396 and Federal Specification VV-F-815C, Navy Special fuel oil as defined in Military Specification MIL-F-859E including Amendment 2 (NATO Symbol F-77), and Bunker C fuel oil. Residual fuel oil is used for the production of electric power, space heating, vessel bunkering, and various industrial purposes.

Retailer: A firm (other than a refiner, reseller, or reseller/retailer) that carries on the trade or business 
of purchasing refined petroleum products and reselling them to ultimate consumers.

Retail Outlet: Any company-owned outlet (e.g., service station) selling gasoline, on-highway low-sulfur diesel fuel, or propane for on-highway vehicle use which is under the direct control of the firm filing the EIA -782 by virtue of the ability to set the retail product price and directly collect all or part of the retail margin. This category includes retail outlets: (1) being operated by salaried employees of the company and/or its subsidiaries and affiliates, and/or (2) involving personnel services contracted by the firm.

Sale: The transfer of title from the seller to a buyer for a price. Excludes intrafirm transfers, products consumed directly by the reporting firm, or sales of bonded fuel. Also excludes products delivered/loaned to exchange partners, except where the amount supplied exceeds the amount received and the differential is invoiced as a sale during the reference month.

Sales for Resale: Sales of refined petroleum products to purchasers who are other-than-ultimate consumers; wholesale sales.

Sales to End Users: Sales made directly to the consumer of the product. Includes bulk consumers such as agriculture, industry, and utilities, as well as residential and commercial consumers.

Sales Type: Sales categories of sales to end users and sales for resale.

Unit Price: Total revenue derived from the sale of product during the reference month divided by the total volume sold; also known as the weighted average price. Total revenue excludes all taxes but includes transportation costs that were paid as part of the purchase price.

United States: For the crude oil statistics, the United States includes the 50 States, the District of Columbia, Puerto Rico, the Virgin Islands, and all American Territories and Possessions. For the petroleum products data, United States includes the 50 States and the District of Columbia.

Wellhead: The point at which the crude (and/or natural gas) exits the ground. Following historical precedent, the volume and price for crude oil production are labeled as "wellhead," even though the cost and volume are now generally measured at the lease boundary. In the context of domestic crude price data, the term "wellhead" is the generic term used to reference the production site or lease property. 


\section{List of Articles}




\section{Articles}

Feature articles on energy-related subjects are frequently included in the Petroleum Marketing Montbly.

The following articles and special focus items appeared in the PMM prior to January 1, 1995.

Distillate Fuel Oil Assessment for Winter 1994-1995 . . . . . . . . . . . . . . . November 1994

Propane Assessment for Winter $1994-1995$. . . . . . . . . . . . . . . . . . . . . November 1994

Sales of Fuel Oil and Kerosene in $1993 \ldots \ldots$. . . . . . . . . . . . . November 1994

Impact of New Low-Sulfur Diesel Requirements,

October through December 1993 . . . . . . . . . . . . . . . . . . . . . November 1994

Reformulated Gasoline Supply Issues . . . . . . . . . . . . . . . . . . . . . November 1994

A Comparison of Selected EIA-782 Data With Other Data Sources . . . . . . . . . October 1994

Demand, Supply, and Price Outlook for Reformulated Motor Gasoline 1995 . . . . . . August 1994

The Second Oxygenated Gasoline Season . . . . . . . . . . . . . . . . . . June 1994

Changes to the 1994 Petroleum Marketing Montbly . . . . . . . . . . . . . . May 1994

Summer 1994 Motor Gasoline Outlook . . . . . . . . . . . . . . . . . . . . . May 1994

Sales of Fuel Oil and Kerosene in 1992 . . . . . . . . . . . . . . . . . . . . December 1993

Low-Sulfur Diesel: Requirements and Impacts . . . . . . . . . . . . . . . . . December 1993

Distillate Fuel Oil Outlook for Winter 1993-94 . . . . . . . . . . . . . . . . November 1993

Propane Outlook for Winter 1993-1994 . . . . . . . . . . . . . . . . . November 1993

A Comparison of Selected EIA-782 Data with Other Data Sources . . . . . . . . August 1993

The Economics of the Clean Air Act Amendments of 1990: Review of the

1992-1993 Oxygenated Motor Gasoline Season . . . . . . . . . . . . . . . . August 1993

Changes to Form ELA-782C "Monthly Report of Petroleum Products

Sold into States for Consumption" . . . . . . . . . . . . . . . . May 1993

Summer 1993 Motor Gasoline Outlook . . . . . . . . . . . . . . . . May 1993

Economics of Energy Futures Markets . . . . . . . . . . . . . . . . . September 1991 
Economics of Gasoline Pool Octane Growth . . . . . . . . . . . . . . . . . March 1990

A Comparison of Selected EIA-782 Data with Other Data Sources . . . . . . . . . August 1989

The Introduction of Unleaded Midgrade Gasoline . . . . . . . . . . . . . . . . April 1989

A Review of Valdez Oil Spill Market Impacts . . . . . . . . . . . . . . . . . March 1989

California Crude Oil Price Levels . . . . . . . . . . . . . . . . . . . . April 1987

Determining Minimum Acceptable Bid Prices for the Test Sale of

Strategic Petroleum Reserve Crude Oil . . . . . . . . . . . . . . . . . August 1986

Commercial/Industrial Sales of Residual Fuel Oil . . . . . . . . . . . . . . . . . December 1985

Crude Oil High-Seas Stocks . . . . . . . . . . . . . . . . . . . . . . August 1985

Foreign Crude Oil Prices: The Differential Dilemma . . . . . . . . . . . . . . . May 1985

A Short-Term Analysis of the Effects of Concentration on Price

in the Gasoline Market . . . . . . . . . . . . . . . . . . . . A . April 1985

Petroleum Marketing Monthly Initiates Crude Oil Data Series . . . . . . . . . . . . February 1985

Estimated Historic Time Series for the ELA-782 . . . . . . . . . . . . . . December 1983[3] 
Appendix 
Table A1. Refiner/Reseller Motor Gasoline Prices by Grade, PAD District and State, 1984-Present

(Cents per Gallon Excluding Taxes)

\begin{tabular}{|c|c|c|c|c|c|c|c|c|}
\hline \multirow[b]{2}{*}{$\begin{array}{c}\text { Geographic Area } \\
\text { Year }\end{array}$} & \multicolumn{2}{|c|}{ Regular } & \multicolumn{2}{|c|}{ Midgrade } & \multicolumn{2}{|c|}{ Premium } & \multicolumn{2}{|c|}{ All Grades } \\
\hline & $\begin{array}{c}\text { Through } \\
\text { Retail } \\
\text { Outlets }\end{array}$ & $\begin{array}{c}\text { Sales } \\
\text { for } \\
\text { Resale }\end{array}$ & $\begin{array}{c}\text { Through } \\
\text { Retail } \\
\text { Outlets }\end{array}$ & $\begin{array}{c}\text { Sales } \\
\text { for } \\
\text { Resale }\end{array}$ & $\begin{array}{l}\text { Through } \\
\text { Retail } \\
\text { Outlets }\end{array}$ & $\begin{array}{c}\text { Sales } \\
\text { for } \\
\text { Resale }\end{array}$ & $\begin{array}{c}\text { Through } \\
\text { Retail } \\
\text { Outlets }\end{array}$ & $\begin{array}{c}\text { Sales } \\
\text { for } \\
\text { Resale }\end{array}$ \\
\hline \multicolumn{9}{|l|}{ United States } \\
\hline 1984 & 93.2 & 84.9 & NA & NA & 101.8 & 92.4 & 92.0 & 83.8 \\
\hline 1985 & 93.3 & 84.9 & NA & NA & 102.3 & 92.8 & 92.4 & 84.1 \\
\hline 1986 & 63.6 & 52.9 & NA & NA & 74.6 & 61.7 & 64.2 & 53.8 \\
\hline 1987 & 67.0 & 57.2 & NA & NA & 78.8 & 67.4 & 68.4 & 59.2 \\
\hline 1988 & 66.1 & 55.1 & NA & NA & 79.4 & 67.5 & 68.6 & 58.0 \\
\hline 1989 & 73.7 & 62.3 & 80.2 & 69.1 & 88.3 & 75.2 & 77.3 & 65.8 \\
\hline 1990 & 87.2 & 76.2 & 93.6 & 82.3 & 100.1 & 87.7 & 90.1 & 78.9 \\
\hline 1991 & 78.1 & 68.2 & 85.6 & 74.4 & 92.5 & 80.0 & 81.3 & 70.8 \\
\hline 1992 & 75.2 & 64.9 & 83.0 & 71.3 & 91.5 & 77.6 & 79.1 & 68.0 \\
\hline 1993 & 71.7 & 59.7 & 79.9 & 66.4 & 88.5 & 72.2 & 75.8 & 62.8 \\
\hline 1994 & 69.4 & 57.1 & 77.7 & 64.1 & 86.3 & 69.6 & 73.6 & 60.2 \\
\hline \multicolumn{9}{|l|}{ PAD District I } \\
\hline 1984 & 92.3 & 84.8 & NA & NA & 102.5 & 92.4 & 91.6 & 84.2 \\
\hline 1985 & 93.6 & 85.2 & NA & NA & 104.2 & 93.3 & 93.4 & 85.2 \\
\hline 1986 & 63.9 & 53.2 & NA & NA & 76.1 & 62.1 & 65.3 & 55.2 \\
\hline 1987 & 67.5 & 57.7 & NA & NA & 80.5 & 68.2 & 69.9 & 60.6 \\
\hline 1988 & 67.1 & 56.1 & NA & NA & 81.3 & 68.7 & 70.8 & 60.2 \\
\hline 1989 & 74.1 & 62.7 & 82.0 & 70.0 & 90.5 & 76.7 & 79.4 & 67.9 \\
\hline 1990 & 87.6 & 77.7 & 94.8 & 83.2 & 101.9 & 89.0 & 91.8 & 81.5 \\
\hline 1991 & 79.2 & 70.6 & 87.5 & 75.7 & 95.9 & 83.2 & 83.8 & 74.2 \\
\hline 1992 & 74.0 & 65.1 & 84.1 & 71.4 & 93.0 & 78.4 & 79.6 & 69.3 \\
\hline 1993 & 69.7 & 59.0 & 80.2 & 66.1 & 89.5 & 72.8 & 75.6 & 63.4 \\
\hline 1994 & 67.3 & 56.6 & 77.6 & 63.6 & 86.7 & 70.3 & 73.2 & 60.9 \\
\hline \multicolumn{9}{|l|}{ Subdistrict IA } \\
\hline 1984 & 93.1 & 85.4 & NA & NA & 105.7 & 92.7 & 93.4 & 85.3 \\
\hline 1985 & 95.5 & 87.0 & NA & NA & 106.8 & 95.2 & 95.9 & 87.6 \\
\hline 1986 & 68.2 & 55.8 & NA & NA & 79.1 & 65.2 & 70.0 & 58.2 \\
\hline 1987 & 71.4 & 60.2 & NA & NA & 83.5 & 71.8 & 74.1 & 63.7 \\
\hline 1988 & 73.2 & 58.9 & NA & NA & 87.1 & 72.9 & 77.1 & 63.8 \\
\hline 1989 & 79.7 & 64.9 & 87.2 & 73.2 & 96.2 & 79.8 & 85.1 & 70.5 \\
\hline 1990 & 91.7 & 80.7 & 99.2 & 86.9 & 106.4 & 92.6 & 96.0 & 84.5 \\
\hline 1991 & 87.5 & 74.1 & 94.8 & 79.5 & 102.0 & 87.0 & 91.5 & 77.7 \\
\hline 1992 & 80.3 & 66.7 & 89.7 & 73.6 & 97.8 & 80.1 & 85.5 & 70.5 \\
\hline 1993 & 73.8 & 59.9 & 83.4 & 66.8 & 92.1 & 72.8 & 79.2 & 63.7 \\
\hline 1994 & 71.9 & 57.6 & 82.5 & 65.5 & 90.8 & 71.6 & 77.5 & 61.6 \\
\hline \multicolumn{9}{|l|}{ Connecticut } \\
\hline 1984 & 93.3 & 85.3 & NA & NA & 108.9 & 93.2 & 94.4 & 85.6 \\
\hline 1985 & 94.5 & 87.4 & NA & NA & 107.3 & 95.4 & 95.4 & 88.3 \\
\hline 1986 & 68.9 & 57.4 & NA & NA & 80.2 & 66.6 & 70.7 & 60.1 \\
\hline 1987 & 71.8 & 61.6 & NA & NA & 82.4 & 73.0 & 74.1 & 65.5 \\
\hline 1988 & 74.6 & 60.8 & NA & NA & 87.8 & 73.1 & 78.2 & 65.8 \\
\hline 1989 & 79.5 & 65.9 & 90.8 & 74.5 & 98.1 & 79.9 & 85.9 & 71.9 \\
\hline 1990 & 92.7 & 80.2 & 100.8 & 86.8 & 107.2 & 92.6 & 97.5 & 84.7 \\
\hline 1991 & 85.2 & 73.6 & 92.7 & 79.5 & 101.0 & 87.1 & 90.0 & 77.8 \\
\hline 1992 & 79.5 & 67.9 & 89.0 & 74.5 & 99.0 & 81.1 & 85.6 & 72.2 \\
\hline 1993 & 74.4 & 61.3 & 85.2 & 67.7 & 95.6 & 74.9 & 81.0 & 65.6 \\
\hline 1994 & 71.1 & 58.9 & 82.6 & 65.8 & 92.3 & 72.9 & 77.7 & 63.2 \\
\hline \multicolumn{9}{|l|}{ Maine } \\
\hline 1984 & 95.8 & 85.7 & NA & NA & 104.8 & 91.4 & 95.2 & 84.6 \\
\hline 1985 & 98.5 & 87.7 & NA & NA & 107.5 & 94.3 & 98.1 & 86.9 \\
\hline 1986 & 71.2 & 55.1 & NA & NA & 81.3 & 62.2 & 72.1 & 56.1 \\
\hline 1987 & 72.1 & 58.8 & NA & NA & 84.1 & 68.5 & 74.1 & 60.8 \\
\hline 1988 & 72.8 & 56.6 & NA & NA & 86.0 & 68.2 & 75.6 & 59.6 \\
\hline 1989 & 82.2 & 63.6 & 88.2 & 68.7 & 97.7 & 75.9 & 86.1 & 66.9 \\
\hline 1990 & 95.0 & 79.9 & 101.0 & 82.4 & 108.6 & 88.9 & 98.0 & 81.8 \\
\hline 1991 & 91.1 & 71.9 & 101.1 & 76.6 & 106.8 & 83.5 & 94.7 & 74.2 \\
\hline 1992 & 83.0 & 65.3 & 94.2 & 71.1 & 98.8 & 76.8 & 87.0 & 67.9 \\
\hline 1993 & 77.8 & 58.0 & 86.7 & 62.3 & 94.3 & 68.9 & 81.7 & 60.5 \\
\hline 1994 & 75.1 & 57.1 & 84.6 & 62.9 & 91.7 & 68.8 & 79.2 & 59.8 \\
\hline
\end{tabular}

See footnotes at end of table. 
Table A1. Refiner/Reseller Motor Gasoline Prices by Grade, PAD District and State, 1984-Present

(Cents per Gallon Excluding Taxes) - Continued

\begin{tabular}{|c|c|c|c|c|c|c|c|c|}
\hline \multirow[b]{2}{*}{$\begin{array}{c}\text { Goographic Area } \\
\text { Year }\end{array}$} & \multicolumn{2}{|c|}{ Regular } & \multicolumn{2}{|c|}{ Midgrade } & \multicolumn{2}{|c|}{ Premium } & \multicolumn{2}{|c|}{ All Grades } \\
\hline & $\begin{array}{c}\text { Through } \\
\text { Retail } \\
\text { Outlets }\end{array}$ & $\begin{array}{c}\text { Sales } \\
\text { for } \\
\text { Resale }\end{array}$ & $\begin{array}{c}\text { Through } \\
\text { Retail } \\
\text { Outlets }\end{array}$ & $\begin{array}{c}\text { Sales } \\
\text { for } \\
\text { Resale }\end{array}$ & $\begin{array}{c}\text { Through } \\
\text { Retail } \\
\text { Otutlets }\end{array}$ & $\begin{array}{c}\text { Sales } \\
\text { for } \\
\text { Resale }\end{array}$ & $\begin{array}{c}\text { Through } \\
\text { Retail } \\
\text { Outlets }\end{array}$ & $\begin{array}{c}\text { Sales } \\
\text { for } \\
\text { Resale }\end{array}$ \\
\hline $\begin{array}{r}\text { Massachusetts } \\
1984 \\
1985 \\
1986 \\
1987\end{array}$ & $\begin{array}{l}91.5 \\
94.4 \\
65.9 \\
70.9 \\
73.1 \\
78.0 \\
89.0 \\
86.2 \\
79.2 \\
71.6 \\
69.8\end{array}$ & $\begin{array}{l}85.0 \\
86.1 \\
54.6 \\
59.6 \\
58.4 \\
64.3 \\
80.4 \\
74.9 \\
66.0 \\
59.3 \\
56.7\end{array}$ & $\begin{array}{l}\text { NA } \\
\text { NA } \\
\text { NA } \\
\text { NA } \\
\text { NA } \\
86.2 \\
97.6 \\
94.0 \\
89.0 \\
81.9 \\
81.2\end{array}$ & $\begin{array}{l}\text { NA } \\
\text { NA } \\
\text { NA } \\
\text { NA } \\
\text { NA } \\
74.1 \\
88.3 \\
80.5 \\
73.8 \\
67.2 \\
65.9\end{array}$ & $\begin{array}{r}104.4 \\
106.8 \\
77.8 \\
83.2 \\
86.7 \\
95.1 \\
105.1 \\
101.3 \\
97.3 \\
90.8 \\
89.6\end{array}$ & $\begin{array}{l}92.3 \\
95.0 \\
64.7 \\
71.7 \\
74.0 \\
80.5 \\
93.4 \\
87.7 \\
80.1 \\
72.0 \\
71.2\end{array}$ & $\begin{array}{r}92.0 \\
95.0 \\
68.2 \\
73.9 \\
77.3 \\
84.2 \\
94.1 \\
90.6 \\
84.7 \\
77.5 \\
76.0\end{array}$ & $\begin{array}{l}84.9 \\
86.9 \\
57.3 \\
63.3 \\
63.8 \\
70.4 \\
84.7 \\
78.6 \\
69.8 \\
63.1 \\
60.9\end{array}$ \\
\hline $\begin{array}{l}\text { New Hampshire } \\
1984 \\
1985 \\
1986\end{array}$ & $\begin{array}{l}94.0 \\
96.7 \\
69.4 \\
71.9 \\
72.5 \\
79.2 \\
92.5 \\
88.9 \\
81.5 \\
74.8 \\
73.3\end{array}$ & $\begin{array}{l}86.8 \\
89.2 \\
58.3 \\
62.3 \\
61.9 \\
68.9 \\
83.6 \\
76.3 \\
68.7 \\
62.6 \\
61.2\end{array}$ & $\begin{array}{r}\text { NA } \\
\text { NA } \\
\text { NA } \\
\text { NA } \\
\text { NA } \\
86.2 \\
99.4 \\
95.3 \\
91.6 \\
85.2 \\
83.9\end{array}$ & $\begin{array}{r}\text { NA } \\
\text { NA } \\
\text { NA } \\
\text { NA } \\
\text { NA } \\
73.5 \\
87.3 \\
80.3 \\
74.1 \\
68.7 \\
67.4\end{array}$ & $\begin{array}{r}104.7 \\
107.0 \\
81.0 \\
86.6 \\
88.7 \\
95.9 \\
106.5 \\
103.8 \\
100.0 \\
93.5 \\
91.3\end{array}$ & $\begin{array}{l}93.3 \\
96.4 \\
66.0 \\
72.6 \\
74.8 \\
82.3 \\
94.0 \\
88.5 \\
82.1 \\
76.0 \\
74.5\end{array}$ & $\begin{array}{l}94.0 \\
96.8 \\
70.8 \\
75.1 \\
76.6 \\
84.5 \\
96.5 \\
92.5 \\
86.4 \\
79.8 \\
78.1\end{array}$ & $\begin{array}{l}86.7 \\
89.5 \\
60.0 \\
65.3 \\
66.2 \\
73.8 \\
86.7 \\
79.3 \\
71.9 \\
66.2 \\
64.9\end{array}$ \\
\hline $\begin{array}{l}\text { Rhode Island } \\
1984 \\
1985 \\
1986 \\
1987 \\
1988\end{array}$ & $\begin{array}{l}88.3 \\
92.7 \\
66.0 \\
67.9 \\
69.6 \\
76.6 \\
91.7 \\
85.8 \\
78.1 \\
70.9 \\
72.3\end{array}$ & $\begin{array}{l}84.7 \\
86.3 \\
54.3 \\
59.2 \\
57.6 \\
63.1 \\
79.9 \\
72.2 \\
65.1 \\
57.6 \\
55.1\end{array}$ & $\begin{array}{r}\text { NA } \\
\text { NA } \\
\text { NA } \\
\text { NA } \\
\text { NA } \\
83.7 \\
99.7 \\
91.9 \\
85.5 \\
78.3 \\
81.5\end{array}$ & $\begin{array}{r}\text { NA } \\
\text { NA } \\
\text { NA } \\
\text { NA } \\
\text { NA } \\
71.0 \\
85.3 \\
77.6 \\
71.2 \\
64.1 \\
62.7\end{array}$ & $\begin{array}{r}99.9 \\
102.4 \\
73.5 \\
79.2 \\
84.2 \\
92.0 \\
105.5 \\
98.1 \\
92.4 \\
85.0 \\
88.5\end{array}$ & $\begin{array}{l}91.8 \\
94.2 \\
63.1 \\
69.5 \\
70.0 \\
77.0 \\
90.2 \\
84.7 \\
77.8 \\
70.1 \\
69.2\end{array}$ & $\begin{array}{l}89.1 \\
93.4 \\
68.1 \\
70.8 \\
74.3 \\
82.4 \\
96.1 \\
89.8 \\
83.1 \\
75.9 \\
77.8\end{array}$ & $\begin{array}{l}84.7 \\
86.8 \\
56.5 \\
62.6 \\
62.0 \\
68.5 \\
83.7 \\
75.7 \\
68.9 \\
61.4 \\
58.9\end{array}$ \\
\hline $\begin{array}{c}\text { Vermont } \\
1984 \\
1985 \\
1986 \\
1987 \\
1988 \\
1989\end{array}$ & $\begin{array}{l}99.1 \\
99.3 \\
75.1 \\
75.6 \\
76.5 \\
85.4 \\
95.8 \\
92.6 \\
84.5 \\
78.9 \\
77.2\end{array}$ & $\begin{array}{l}89.5 \\
91.9 \\
62.0 \\
64.3 \\
63.1 \\
71.4 \\
87.3 \\
78.8 \\
72.7 \\
66.2 \\
64.7\end{array}$ & $\begin{array}{r}\text { NA } \\
\text { NA } \\
\text { NA } \\
\text { NA } \\
\text { NA } \\
89.0 \\
100.1 \\
98.8 \\
92.2 \\
87.5 \\
86.8\end{array}$ & $\begin{array}{l}\text { NA } \\
\text { NA } \\
\text { NA } \\
\text { NA } \\
\text { NA } \\
75.9 \\
90.8 \\
82.3 \\
77.4 \\
71.8 \\
70.5\end{array}$ & $\begin{array}{r}107.5 \\
108.5 \\
85.1 \\
88.0 \\
90.3 \\
99.6 \\
108.8 \\
106.2 \\
99.2 \\
95.0 \\
94.7\end{array}$ & $\begin{array}{l}97.4 \\
99.0 \\
70.6 \\
75.0 \\
75.8 \\
84.3 \\
97.7 \\
90.5 \\
85.1 \\
78.8 \\
77.2\end{array}$ & $\begin{array}{l}98.0 \\
98.4 \\
75.8 \\
77.5 \\
79.7 \\
89.1 \\
99.1 \\
95.9 \\
88.4 \\
83.1 \\
81.9\end{array}$ & $\begin{array}{l}89.1 \\
91.5 \\
62.9 \\
66.8 \\
66.9 \\
75.7 \\
90.4 \\
81.7 \\
76.0 \\
69.6 \\
68.2\end{array}$ \\
\hline $\begin{array}{c}\text { Subdistrict IB } \\
1984 \\
1985 \\
1986 \\
1987\end{array}$ & $\begin{array}{l}92.0 \\
93.4 \\
63.6 \\
66.9 \\
66.5 \\
74.6 \\
88.8 \\
82.0 \\
75.8 \\
70.5 \\
69.0\end{array}$ & $\begin{array}{l}84.4 \\
85.0 \\
53.1 \\
57.3 \\
55.8 \\
62.9 \\
78.1 \\
71.6 \\
65.9 \\
59.7 \\
57.8\end{array}$ & $\begin{array}{c}\text { NA } \\
\text { NA } \\
\text { NA } \\
\text { NA } \\
\text { NA } \\
83.3 \\
96.6 \\
90.2 \\
86.0 \\
80.3 \\
79.0\end{array}$ & $\begin{array}{l}\text { NA } \\
\text { NA } \\
\text { NA } \\
\text { NA } \\
\text { NA } \\
70.7 \\
84.6 \\
77.6 \\
73.5 \\
67.9 \\
66.1\end{array}$ & $\begin{array}{r}102.7 \\
104.7 \\
76.4 \\
81.7 \\
82.6 \\
93.1 \\
102.9 \\
98.7 \\
95.0 \\
89.6 \\
87.8\end{array}$ & $\begin{array}{l}92.6 \\
93.8 \\
62.8 \\
68.8 \\
69.4 \\
77.9 \\
89.9 \\
85.1 \\
80.0 \\
74.2 \\
72.2\end{array}$ & $\begin{array}{l}91.6 \\
93.4 \\
65.8 \\
70.1 \\
71.0 \\
80.6 \\
93.1 \\
86.5 \\
81.4 \\
76.1 \\
74.7\end{array}$ & $\begin{array}{l}83.6 \\
85.0 \\
55.6 \\
60.8 \\
60.4 \\
68.5 \\
82.4 \\
75.8 \\
70.7 \\
64.6 \\
62.6\end{array}$ \\
\hline
\end{tabular}

See tootnotes at end of table. 
Table A1. Refiner/Reseller Motor Gasoline Prices by Grade, PAD District and State, 1984-Present

(Cents per Gallon Excluding Taxes) - Continued

\begin{tabular}{c|c|c|c|c|c|c|c|c|}
\hline \multirow{2}{*}{$\begin{array}{c}\text { Geographic Area } \\
\text { Year }\end{array}$} & \multicolumn{3}{|c|}{ Regular } & \multicolumn{2}{c|}{ Midgrade } & \multicolumn{2}{c|}{ Premilum Grades } \\
\cline { 2 - 6 } & $\begin{array}{c}\text { Through } \\
\text { Retall } \\
\text { Outlets }\end{array}$ & $\begin{array}{c}\text { Sales } \\
\text { for } \\
\text { Resale }\end{array}$ & $\begin{array}{c}\text { Through } \\
\text { Retail } \\
\text { Outlets }\end{array}$ & $\begin{array}{c}\text { Sales } \\
\text { for } \\
\text { Resale }\end{array}$ & $\begin{array}{c}\text { Through } \\
\text { Retail } \\
\text { Outlets }\end{array}$ & $\begin{array}{c}\text { Sales } \\
\text { for } \\
\text { Resale }\end{array}$ & $\begin{array}{c}\text { Through } \\
\text { Retall } \\
\text { Outlets }\end{array}$ & $\begin{array}{c}\text { Sales } \\
\text { for } \\
\text { Resale }\end{array}$ \\
\hline
\end{tabular}

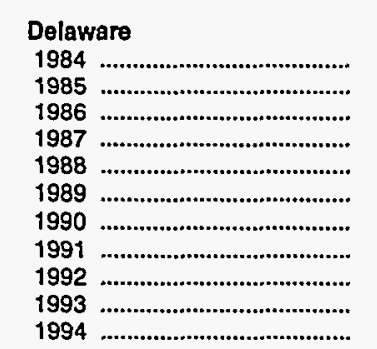

$\begin{array}{ll}90.8 & 80.5 \\ 92.7 & 85.6 \\ 62.8 & 54.5 \\ 65.4 & 56.8 \\ 65.4 & 57.0 \\ 72.4 & 63.7 \\ 88.7 & 79.1 \\ 80.4 & 71.4 \\ 74.7 & 64.8 \\ 67.6 & 58.7 \\ 66.5 & 56.9\end{array}$

NA
NA
NA
NA
80.4
95.6
89.2
83.7
76.1
77.2

NA
NA
NA
NA
NA
69.5
82.6
74.9
69.5
63.8
62.2

102.4
104.0
73.5
78.3
80.9
91.2
104.9
99.1
93.8
86.1
86.0

85.1
91.5
59.8
62.8
64.1
73.4
85.7
82.2
76.0
70.7
68.7

$\begin{array}{ll}90.6 & 81.3 \\ 92.9 & 86.7 \\ 64.9 & 56.7 \\ 68.2 & 58.9 \\ 69.5 & 59.9 \\ 78.7 & 67.9 \\ 93.5 & 81.6 \\ 85.6 & 74.3 \\ 80.3 & 68.2 \\ 72.9 & 62.1 \\ 72.3 & 60.4\end{array}$

\section{District of Columbia}

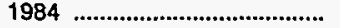

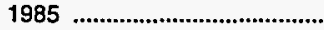

1986

1987 .

1988 .

1989

1990

1992

1993

1994

$\begin{array}{cc}W & 86.5 \\ -W & 86.9 \\ W & 59.5 \\ W & 60.5 \\ W & 61.5 \\ W & 69.0 \\ W & 81.6 \\ W & 73.0 \\ W & 72.3 \\ W & 66.9 \\ W & 65.8\end{array}$

$\begin{array}{ll}\text { NA } & \text { NA } \\ \text { NA } & \text { NA } \\ \text { NA } & \text { NA } \\ \text { NA } & \text { NA } \\ \text { NA } & \text { NA } \\ \text { W } & 74.8 \\ \text { W } & 86.7 \\ \text { W } & 77.6 \\ \text { W } & 78.1 \\ \text { W } & 72.4 \\ \text { W } & 70.6\end{array}$

Maryland

1984

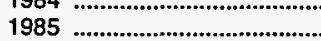

1986

1987

1988 ...................................

1990

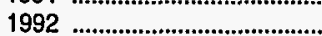

1993

1994

$94.3 \quad 86.1$

$\begin{array}{ll}92.9 & 86.3 \\ 65.1 & 56.2\end{array}$

$66.6 \quad 60.1$

$69.2 \quad 60.4$

$77.5 \quad 66.8$

$90.6 \quad 81.3$

$79.8 \quad 72.2$

$76.1 \quad 69.2$

$69.4 \quad 62.1$

$68.2 \quad 60.3$

New Jersey

1984

1985 ........................................

1987

1988

1991

1992

1994 ............................

$92.0 \quad 82.4$

$94.9 \quad 83.9$

$66.3 \quad 51.1$

$68.4 \quad 55.3$

$68.8 \quad 53.9$

$76.4 \quad 60.1$

$88.5 \quad 75.0$

$81.2 \quad 70.5$

$79.4 \quad 64.9$

$\begin{array}{ll}74.5 & 59.3 \\ 71.4 & 57.2\end{array}$

NA

NA

NA

NA

83.3

95.9

90.1

87.4

79.5

78.1

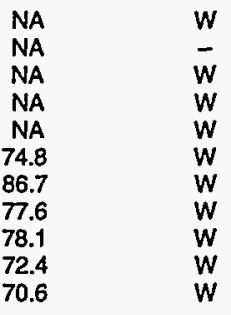

94.4

95.4

68.1

70.5

73.9

83.2

93.4

85.8

86.4

80.6

78.8

\begin{tabular}{cc}
$W$ & 89.3 \\
\hline$W$ & 90.2 \\
$W$ & 64.2 \\
$W$ & 65.5 \\
$W$ & 67.6 \\
$W$ & 77.3 \\
$W$ & 88.2 \\
$W$ & 79.8 \\
$W$ & 80.0 \\
$W$ & 74.4 \\
& 73.1
\end{tabular}

Now York

1984

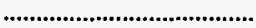

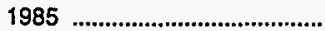

1987

1988

1989

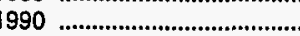

991

1994

$\begin{array}{ll} & \\ 93.1 & 86.7 \\ 94.1 & 85.7 \\ 64.4 & 56.5 \\ 68.6 & 60.7 \\ 68.4 & 59.4 \\ 76.8 & 66.8 \\ 89.7 & 80.9 \\ 83.3 & 73.7 \\ 75.6 & 66.7 \\ 71.7 & 60.8 \\ 69.8 & 58.7\end{array}$

NA
NA
NA
NA
NA
89.6
98.7
90.3
91.7
88.7
85.3

93.0

94.0
64.7

64.7

71.8

80.5

92.4

85.1

81.9

74.6

73.6

93.9

66.7

69.3

72.5

82.5
94.8

85.2

82.0

74.9

66.9

84.7

73.6

87.1

58.4

62.8

64.3

72.6

85.6

76.6

73.8

66.6

65.1

See footnotes at end of table. 
Table A1. Refiner/Reseller Motor Gasoline Prices by Grade, PAD District and State, 1984-Present

(Cents per Gallon Excluding Taxes) - Continued

\begin{tabular}{|c|c|c|c|c|c|c|c|c|}
\hline \multirow[b]{2}{*}{$\begin{array}{c}\text { Geographic Area } \\
\text { Year }\end{array}$} & \multicolumn{2}{|c|}{ Regular } & \multicolumn{2}{|c|}{ Midgrade } & \multicolumn{2}{|c|}{ Premium } & \multicolumn{2}{|c|}{ All Grades } \\
\hline & $\begin{array}{c}\text { Through } \\
\text { Retall } \\
\text { Outlets }\end{array}$ & $\begin{array}{c}\text { Sales } \\
\text { for } \\
\text { Resale }\end{array}$ & $\begin{array}{c}\text { Through } \\
\text { Retail } \\
\text { Outlets }\end{array}$ & $\begin{array}{c}\text { Sales } \\
\text { for } \\
\text { Resale }\end{array}$ & $\begin{array}{c}\text { Through } \\
\text { Retail } \\
\text { Outlets }\end{array}$ & $\begin{array}{c}\text { Sales } \\
\text { for } \\
\text { Resale }\end{array}$ & $\begin{array}{c}\text { Through } \\
\text { Retail } \\
\text { Outlets }\end{array}$ & $\begin{array}{c}\text { Sales } \\
\text { for } \\
\text { Resale }\end{array}$ \\
\hline $\begin{array}{l}\text { Pennsylvania } \\
1984 \\
1985 \\
1986 \\
1987 \\
1988 \\
1989\end{array}$ & $\begin{array}{l}90.8 \\
92.2 \\
61.6 \\
64.9 \\
63.5 \\
71.1 \\
87.7 \\
81.4 \\
74.9 \\
68.3 \\
67.7\end{array}$ & $\begin{array}{l}83.9 \\
85.0 \\
50.9 \\
56.0 \\
53.4 \\
61.6 \\
77.9 \\
70.8 \\
64.8 \\
58.1 \\
56.4\end{array}$ & $\begin{array}{c}\text { NA } \\
\text { NA } \\
\text { NA } \\
\text { NA } \\
\text { NA } \\
80.7 \\
95.3 \\
89.3 \\
84.2 \\
77.5 \\
77.1\end{array}$ & $\begin{array}{c}\text { NA } \\
\text { NA } \\
\text { NA } \\
\text { NA } \\
\text { NA } \\
66.3 \\
81.3 \\
75.5 \\
70.4 \\
64.8 \\
63.3\end{array}$ & $\begin{array}{r}100.3 \\
102.2 \\
74.2 \\
80.5 \\
80.1 \\
89.6 \\
101.3 \\
98.0 \\
92.6 \\
85.5 \\
85.1\end{array}$ & $\begin{array}{l}90.8 \\
92.6 \\
58.7 \\
65.2 \\
64.7 \\
73.5 \\
87.2 \\
82.4 \\
76.8 \\
70.4 \\
68.8\end{array}$ & $\begin{array}{l}90.1 \\
91.7 \\
63.7 \\
68.0 \\
67.9 \\
77.2 \\
91.8 \\
85.7 \\
79.9 \\
73.3 \\
73.0\end{array}$ & $\begin{array}{l}83.1 \\
84.7 \\
52.5 \\
58.5 \\
56.8 \\
65.7 \\
80.8 \\
74.1 \\
68.3 \\
61.7 \\
60.0\end{array}$ \\
\hline $\begin{array}{c}\text { Subdistrict IC } \\
1984 \ldots \ldots \\
1985 \\
1986 \\
1987\end{array}$ & $\begin{array}{l}92.4 \\
93.4 \\
63.3 \\
66.8 \\
66.0 \\
72.7 \\
86.0 \\
76.5 \\
72.1 \\
68.5 \\
65.5\end{array}$ & $\begin{array}{l}85.1 \\
84.8 \\
52.3 \\
57.1 \\
55.5 \\
61.8 \\
76.5 \\
68.5 \\
63.8 \\
58.1 \\
55.2\end{array}$ & $\begin{array}{l}\text { NA } \\
\text { NA } \\
\text { NA } \\
\text { NA } \\
\text { NA } \\
80.2 \\
93.1 \\
85.2 \\
82.4 \\
79.6 \\
76.2\end{array}$ & $\begin{array}{l}\text { NA } \\
\text { NA } \\
\text { NA } \\
\text { NA } \\
\text { NA } \\
68.4 \\
81.3 \\
73.3 \\
69.4 \\
64.8 \\
61.7\end{array}$ & $\begin{array}{r}101.7 \\
103.4 \\
75.3 \\
78.9 \\
79.3 \\
88.4 \\
100.4 \\
93.6 \\
91.3 \\
88.9 \\
85.4\end{array}$ & $\begin{array}{l}92.1 \\
92.1 \\
60.3 \\
66.1 \\
66.2 \\
74.3 \\
86.8 \\
79.8 \\
76.1 \\
71.3 \\
68.1\end{array}$ & $\begin{array}{l}91.3 \\
92.8 \\
64.2 \\
68.7 \\
69.3 \\
77.8 \\
90.3 \\
81.2 \\
77.8 \\
74.7 \\
71.6\end{array}$ & $\begin{array}{l}84.6 \\
84.7 \\
53.9 \\
59.4 \\
58.7 \\
66.4 \\
79.7 \\
71.6 \\
67.5 \\
62.3 \\
59.3\end{array}$ \\
\hline $\begin{aligned} & \text { Florida } \\
& 1984 \\
& 1985\end{aligned}$ & $\begin{array}{l}93.1 \\
93.6 \\
62.7 \\
67.9 \\
67.2 \\
73.5 \\
87.5 \\
77.3 \\
72.9 \\
70.4 \\
66.9\end{array}$ & $\begin{array}{l}85.3 \\
85.3 \\
53.3 \\
57.6 \\
56.7 \\
62.4 \\
76.3 \\
67.9 \\
63.7 \\
59.6 \\
55.9\end{array}$ & $\begin{array}{r}\text { NA } \\
\text { NA } \\
\text { NA } \\
\text { NA } \\
\text { NA } \\
81.2 \\
94.7 \\
85.8 \\
84.2 \\
82.6 \\
78.5\end{array}$ & $\begin{array}{c}\text { NA } \\
\text { NA } \\
\text { NA } \\
\text { NA } \\
\text { NA } \\
70.3 \\
82.2 \\
72.7 \\
69.7 \\
67.3 \\
63.4\end{array}$ & $\begin{array}{r}102.9 \\
102.8 \\
75.4 \\
79.3 \\
79.9 \\
88.8 \\
101.1 \\
93.4 \\
92.0 \\
91.3 \\
87.0\end{array}$ & $\begin{array}{l}92.5 \\
93.3 \\
62.2 \\
67.8 \\
68.4 \\
76.5 \\
88.5 \\
80.4 \\
77.8 \\
75.8 \\
71.4\end{array}$ & $\begin{array}{l}92.1 \\
93.0 \\
63.5 \\
70.3 \\
71.0 \\
79.4 \\
92.1 \\
82.3 \\
79.2 \\
77.1 \\
73.4\end{array}$ & $\begin{array}{l}85.0 \\
85.5 \\
55.2 \\
60.4 \\
60.5 \\
68.1 \\
80.8 \\
72.0 \\
68.5 \\
65.3 \\
61.3\end{array}$ \\
\hline $\begin{array}{c}\text { Georgila } \\
1984 \\
1985\end{array}$ & $\begin{array}{l}90.8 \\
93.5 \\
62.8 \\
65.4 \\
63.6 \\
70.7 \\
83.9 \\
75.8 \\
70.6 \\
66.8 \\
63.1\end{array}$ & $\begin{array}{l}84.3 \\
83.9 \\
51.1 \\
56.4 \\
54.0 \\
60.6 \\
76.5 \\
69.1 \\
63.5 \\
57.2 \\
54.0\end{array}$ & $\begin{array}{c}\text { NA } \\
\text { NA } \\
\text { NA } \\
\text { NA } \\
\text { NA } \\
77.8 \\
91.3 \\
85.3 \\
81.0 \\
77.3 \\
73.3\end{array}$ & $\begin{array}{c}\text { NA } \\
\text { NA } \\
\text { NA } \\
\text { NA } \\
\text { NA } \\
66.1 \\
81.1 \\
73.8 \\
69.0 \\
63.1 \\
59.8\end{array}$ & $\begin{array}{r}98.8 \\
103.8 \\
75.7 \\
79.3 \\
78.3 \\
85.6 \\
97.7 \\
94.1 \\
90.6 \\
86.9 \\
82.8\end{array}$ & $\begin{array}{l}92.0 \\
91.2 \\
59.1 \\
64.5 \\
63.8 \\
71.6 \\
85.6 \\
80.0 \\
75.2 \\
69.4 \\
65.4\end{array}$ & $\begin{array}{l}89.1 \\
92.5 \\
64.2 \\
67.5 \\
67.3 \\
75.4 \\
87.9 \\
80.8 \\
76.6 \\
73.0 \\
69.1\end{array}$ & $\begin{array}{l}84.6 \\
84.2 \\
53.1 \\
58.6 \\
57.1 \\
64.4 \\
79.3 \\
72.0 \\
66.9 \\
60.8 \\
57.5\end{array}$ \\
\hline $\begin{array}{r}\text { North Carolina } \\
1984 \\
1985 \\
1986 \\
1987\end{array}$ & $\begin{array}{l}91.7 \\
92.7 \\
63.4 \\
65.8 \\
65.1 \\
71.2 \\
85.3 \\
75.4 \\
70.9 \\
66.3 \\
64.5\end{array}$ & $\begin{array}{l}84.8 \\
84.6 \\
51.5 \\
56.6 \\
54.8 \\
61.5 \\
75.9 \\
68.4 \\
63.5 \\
57.4 \\
54.7\end{array}$ & $\begin{array}{l}\text { NA } \\
\text { NA } \\
\text { NA } \\
\text { NA } \\
\text { NA } \\
77.1 \\
91.4 \\
83.7 \\
79.9 \\
76.2 \\
74.1\end{array}$ & $\begin{array}{r}\text { NA } \\
\text { NA } \\
\text { NA } \\
\text { NA } \\
\text { NA } \\
66.6 \\
80.1 \\
73.1 \\
68.9 \\
63.0 \\
60.4\end{array}$ & $\begin{array}{r}100.2 \\
103.2 \\
74.5 \\
77.6 \\
78.2 \\
87.1 \\
99.4 \\
92.4 \\
89.0 \\
85.8 \\
83.9\end{array}$ & $\begin{array}{l}91.3 \\
91.4 \\
58.7 \\
64.6 \\
64.2 \\
72.3 \\
84.8 \\
78.5 \\
74.2 \\
68.0 \\
65.8\end{array}$ & $\begin{array}{l}90.4 \\
92.0 \\
64.2 \\
67.4 \\
67.9 \\
75.8 \\
89.0 \\
79.6 \\
76.0 \\
71.8 \\
70.3\end{array}$ & $\begin{array}{l}83.9 \\
84.1 \\
52.8 \\
58.6 \\
57.5 \\
65.1 \\
78.5 \\
70.9 \\
66.5 \\
60.4 \\
58.0\end{array}$ \\
\hline
\end{tabular}

See footnotes at end of table. 
Table A1. Refiner/Reseller Motor Gasoline Prices by Grade, PAD District and State, 1984-Present

(Cents per Gallon Excluding Taxes) - Continued

\begin{tabular}{|c|c|c|c|c|c|c|c|c|}
\hline \multirow[b]{2}{*}{$\underset{\text { Year }}{\text { Geographic Area }}$} & \multicolumn{2}{|c|}{ Regular } & \multicolumn{2}{|c|}{ Midgrade } & \multicolumn{2}{|c|}{ Premium } & \multicolumn{2}{|c|}{ All Grades } \\
\hline & $\begin{array}{l}\text { Through } \\
\text { Retail } \\
\text { Outlets }\end{array}$ & $\begin{array}{l}\text { Sales } \\
\text { for } \\
\text { Resale }\end{array}$ & $\begin{array}{l}\text { Through } \\
\text { Retail } \\
\text { Outlets }\end{array}$ & $\begin{array}{l}\text { Sales } \\
\text { for } \\
\text { Resale }\end{array}$ & $\begin{array}{l}\text { Through } \\
\text { Retail } \\
\text { Outlets }\end{array}$ & $\begin{array}{c}\text { Sales } \\
\text { for } \\
\text { Resale }\end{array}$ & $\begin{array}{l}\text { Through } \\
\text { Retail } \\
\text { Outlots }\end{array}$ & $\begin{array}{c}\text { Sales } \\
\text { for } \\
\text { Resale }\end{array}$ \\
\hline \multicolumn{9}{|l|}{ South Carolina } \\
\hline 1984 & 91.2 & 84.6 & NA & NA & 101.2 & 91.3 & 89.3 & 83.9 \\
\hline 1985 & 91.6 & 83.9 & NA & NA & 101.5 & 91.2 & 90.1 & 83.5 \\
\hline 1986 & 61.2 & 50.9 & NA & NA & 71.8 & 58.4 & 61.4 & 52.3 \\
\hline 1987 & 66.4 & 56.7 & NA & NA & 77.6 & 65.9 & 67.3 & 58.9 \\
\hline 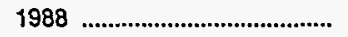 & 64.2 & 54.4 & NA & NA & 77.9 & 65.1 & 66.5 & 57.3 \\
\hline 1989 & 72.0 & 61.1 & 78.2 & 66.6 & 88.8 & 72.9 & 75.7 & 64.7 \\
\hline 1990 & 85.2 & 75.7 & 93.0 & 79.7 & 102.9 & 85.4 & 89.6 & 78.2 \\
\hline 1991 & $\begin{array}{l}76.2 \\
70.5 \\
65.2 \\
62.8\end{array}$ & $\begin{array}{l}68.3 \\
63.8 \\
56.5 \\
53.9\end{array}$ & $\begin{array}{l}84.8 \\
81.0 \\
76.5 \\
73.9\end{array}$ & $\begin{array}{l}72.9 \\
68.0 \\
61.6 \\
59.3\end{array}$ & $\begin{array}{l}95.0 \\
90.7 \\
86.4 \\
84.0\end{array}$ & $\begin{array}{l}78.4 \\
73.7 \\
66.7 \\
64.9\end{array}$ & $\begin{array}{l}80.4 \\
75.4 \\
70.9 \\
68.7\end{array}$ & $\begin{array}{l}70.7 \\
66.2 \\
59.2 \\
56.9\end{array}$ \\
\hline \multicolumn{9}{|l|}{ Virginia } \\
\hline 1984 & 93.1 & 85.5 & NA & NA & 103.0 & 92.4 & 93.1 & 84.9 \\
\hline 1985 & 93.7 & 85.3 & NA & NA & 104.5 & 92.5 & 94.6 & 85.2 \\
\hline 1986 & 64.9 & 52.9 & NA & NA & 76.9 & 60.9 & 66.1 & 54.5 \\
\hline 1987 & 66.8 & 57.3 & $\mathrm{NA}$ & NA & 78.8 & 66.2 & 68.7 & 59.7 \\
\hline 1988 & 68.2 & 56.3 & NA & NA & 80.2 & 67.1 & 71.0 & 59.5 \\
\hline 1989 & 74.4 & 62.8 & 82.0 & 69.6 & 90.2 & 75.5 & 79.8 & 67.6 \\
\hline 1990 & 86.5 & 77.2 & 93.2 & 82.4 & 100.5 & 87.6 & 90.9 & 80.8 \\
\hline $1991 \ldots$ & 76.0 & 68.3 & 84.6 & 73.4 & 93.1 & 80.0 & 80.9 & 71.8 \\
\hline 1992 & 73.4 & 64.4 & 83.4 & 70.4 & 93.0 & 76.5 & 79.2 & 68.4 \\
\hline 1993 & 69.8 & 58.8 & 80.6 & 65.8 & 89.7 & 71.2 & 76.1 & 63.1 \\
\hline 1994 & 67.2 & 56.7 & 77.6 & 63.5 & 86.6 & 69.3 & 73.5 & 61.0 \\
\hline \multicolumn{9}{|l|}{ West Virginia } \\
\hline 1984 & 96.5 & 88.3 & NA & NA & 105.0 & 94.6 & 95.0 & 87.6 \\
\hline 1985 & 96.5 & 87.3 & NA & NA & 106.0 & 93.0 & 95.2 & 86.7 \\
\hline 1986 & 68.5 & 55.7 & NA & NA & 78.3 & 61.8 & 68.9 & 56.5 \\
\hline 1987 & 69.7 & 59.7 & NA & NA & 81.7 & 68.0 & 71.6 & 61.7 \\
\hline 1988 & 70.1 & 58.3 & NA & NA & 84.0 & 68.5 & 73.3 & 61.6 \\
\hline 1989 & 77.4 & 65.9 & 86.0 & 70.8 & 95.6 & 77.5 & 82.4 & 69.8 \\
\hline 1990 & 89.3 & 79.3 & 98.2 & 83.3 & 105.8 & 88.3 & 93.5 & 81.9 \\
\hline 1991 & 82.0 & 71.1 & 91.5 & 77.4 & 99.0 & 82.2 & 86.1 & 73.9 \\
\hline 1992 & 78.4 & 66.9 & 88.3 & 73.1 & 95.5 & 78.8 & 82.9 & 70.2 \\
\hline 1993 & 74.7 & 61.5 & 84.7 & 68.2 & 91.4 & 74.0 & 79.2 & 65.0 \\
\hline 1994 & 72.1 & 59.3 & 82.2 & 65.4 & 88.8 & 71.7 & 76.9 & 52.8 \\
\hline \multicolumn{9}{|l|}{ PAD District II } \\
\hline $1984 \ldots \ldots$ & 93.2 & 85.1 & NA & NA & 99.8 & 92.6 & 92.1 & 84.0 \\
\hline 1985 & 93.5 & 85.3 & NA & NA & 100.3 & 93.2 & 92.5 & 84.4 \\
\hline 1986 & 62.9 & 51.4 & NA & NA & 72.9 & 61.2 & 63.2 & 52.1 \\
\hline 1987 & 66.6 & 57.4 & NA & NA & 78.0 & 67.0 & 67.8 & 58.6 \\
\hline 1988 & 64.9 & 54.9 & NA & NA & 77.5 & 66.0 & 67.0 & 56.6 \\
\hline 1989 & 72.9 & 62.5 & 79.4 & 69.2 & 86.5 & 73.8 & 75.9 & 64.7 \\
\hline 1990 & 86.4 & 75.7 & 93.0 & 82.1 & 98.4 & 85.5 & 88.7 & 77.4 \\
\hline 1991 & 77.9 & 68.7 & 84.3 & 74.0 & 90.7 & 78.6 & 80.4 & 70.4 \\
\hline 1992 & 73.6 & 63.7 & 80.8 & 69.8 & 87.1 & 73.7 & 76.3 & 65.6 \\
\hline 1993 & 70.2 & 58.4 & 77.6 & 65.0 & 83.7 & 68.4 & 73.1 & 60.4 \\
\hline 1994 & 68.5 & 56.6 & 76.2 & 63.7 & 82.5 & 66.8 & 71.6 & 58.8 \\
\hline \multicolumn{9}{|l|}{ Illinois } \\
\hline 1984 & 90.8 & 84.8 & NA & NA & 98.5 & 92.8 & 91.0 & 84.1 \\
\hline 1985 & 92.1 & 85.4 & NA & NA & 100.0 & 93.8 & 92.6 & 85.1 \\
\hline 1986 & 61.3 & 52.6 & NA & NA & 74.3 & 62.3 & 62.8 & 53.4 \\
\hline 1987 & 66.6 & 58.0 & NA & NA & 79.3 & 68.5 & 68.1 & 59.5 \\
\hline 1988 & 65.7 & 56.1 & NA & NA & 79.0 & 68.7 & 68.5 & 58.4 \\
\hline 1989 & 72.7 & 62.2 & 81.2 & 72.5 & 86.6 & 75.8 & 76.3 & 65.3 \\
\hline 1990 & 85.5 & 75.2 & 92.8 & 83.5 & 97.9 & 86.7 & 88.5 & 77.6 \\
\hline 1991 & 77.9 & 68.7 & 85.0 & 75.4 & 91.6 & 80.0 & 80.9 & 71.1 \\
\hline 1992 & 73.8 & 63.1 & 81.6 & 71.3 & 89.1 & 74.8 & 77.1 & 65.9 \\
\hline 1993 & 70.2 & 58.1 & 77.2 & 67.3 & 83.6 & 70.1 & 73.2 & 61.1 \\
\hline 1994 & 69.4 & 56.9 & 76.4 & 67.8 & 83.8 & 69.9 & 72.7 & 60.3 \\
\hline
\end{tabular}

See footnotes at end of table. 
Table A1. Refiner/Reseller Motor Gasoline Prices by Grade, PAD District and State, 1984-Present

(Cents per Gallon Excluding Taxes) - Continued

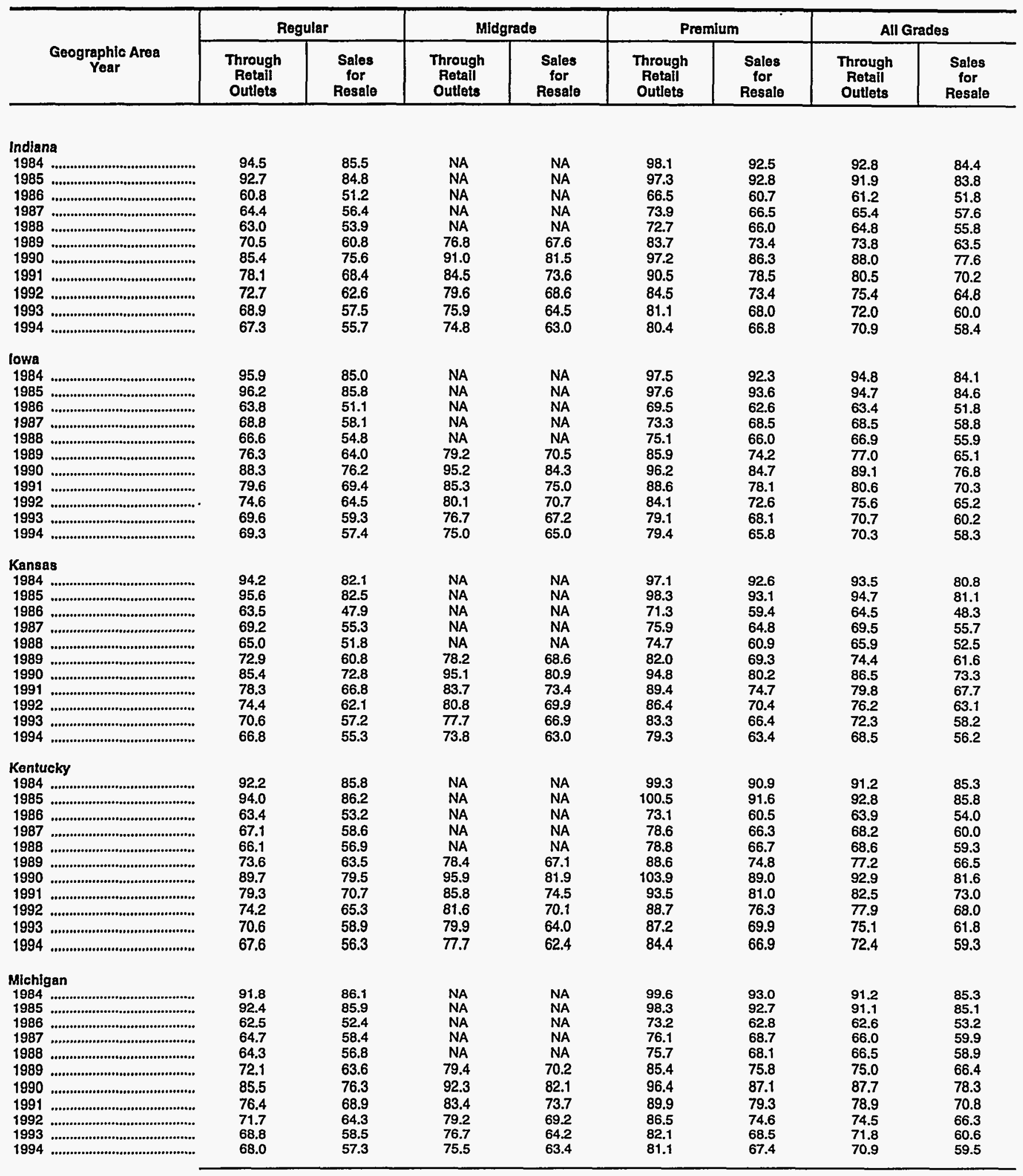

See footnotes at end of table. 
Table A1. Refiner/Reseller Motor Gasoline Prices by Grade, PAD District and State, 1984-Present

(Cents per Gallon Excluding Taxes) - Continued

\begin{tabular}{|c|c|c|c|c|c|c|c|c|}
\hline \multirow[b]{2}{*}{$\begin{array}{c}\text { Geographic Area } \\
\text { Year }\end{array}$} & \multicolumn{2}{|c|}{ Regular } & \multicolumn{2}{|c|}{ Midgrade } & \multicolumn{2}{|c|}{ Premium } & \multicolumn{2}{|c|}{ All Grades } \\
\hline & $\begin{array}{c}\text { Through } \\
\text { Retail } \\
\text { Outlets }\end{array}$ & $\begin{array}{c}\text { Sales } \\
\text { for } \\
\text { Resale }\end{array}$ & $\begin{array}{c}\text { Through } \\
\text { Retail } \\
\text { Outlets }\end{array}$ & $\begin{array}{c}\text { Sales } \\
\text { for } \\
\text { Resale }\end{array}$ & $\begin{array}{c}\text { Through } \\
\text { Retail } \\
\text { Outlets }\end{array}$ & $\begin{array}{c}\text { Sales } \\
\text { for } \\
\text { Resale }\end{array}$ & $\begin{array}{c}\text { Through } \\
\text { Retail } \\
\text { Outlets }\end{array}$ & $\begin{array}{c}\text { Sales } \\
\text { for } \\
\text { Resale }\end{array}$ \\
\hline
\end{tabular}

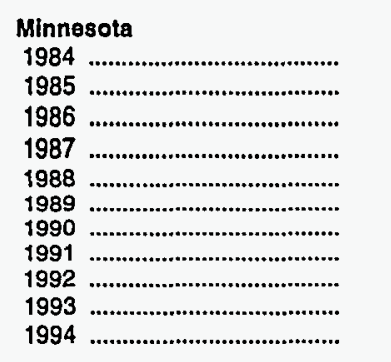

$\begin{array}{ll}94.2 & 86.2 \\ 96.7 & 87.4 \\ 67.2 & 52.4 \\ 69.9 & 59.4 \\ 69.0 & 56.4 \\ 79.1 & 65.8 \\ 89.8 & 76.4 \\ 81.9 & 70.8 \\ 78.5 & 66.2 \\ 78.2 & 62.2 \\ 75.9 & 60.4\end{array}$

$\begin{array}{rr}\text { NA } & \text { NA } \\ \text { NA } & \text { NA } \\ \text { NA } & \text { NA } \\ \text { NA } & \text { NA } \\ \text { NA } & \text { NA } \\ 84.8 & 74.7 \\ 98.0 & 81.7 \\ 88.8 & 75.7 \\ 85.7 & 73.3 \\ 83.8 & 68.1 \\ 80.9 & 65.6\end{array}$

$\begin{array}{rr}\text { NA } & 100.5 \\ \text { NA } & 106.3 \\ \text { NA } & 72.4 \\ \text { NA } & 76.9 \\ \text { NA } & 78.1 \\ 74.7 & 89.9 \\ 81.7 & 99.7 \\ 75.7 & 90.7 \\ 73.3 & 88.0 \\ 68.1 & 90.4 \\ 65.6 & 89.1\end{array}$

92.7
95.7
60.9
67.2
65.1
74.8
83.6
79.1
74.3
70.6
68.5

$\begin{array}{ll}92.4 & 84.7 \\ 95.3 & 86.2 \\ 66.7 & 52.9 \\ 69.8 & 60.1 \\ 70.0 & 57.4 \\ 80.8 & 67.0 \\ 91.3 & 77.1 \\ 83.5 & 71.8 \\ 80.2 & 67.3 \\ 80.3 & 63.4 \\ 77.7 & 61.6\end{array}$

\section{Missouri}

1984

1985 ..............................

1986

1987

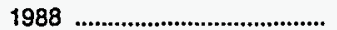

1989

1990

1991 .....................................

1992

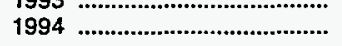

$92.8 \quad 85.0$

$\begin{array}{ll}92.6 & 85.3 \\ 61.8 & 50.7\end{array}$

67.3

63.2

70.5

85.2

75.8

70.6

66.9

65.4

NA
NA
NA
NA
NA
79.0
94.7
82.5
78.6
75.6
74.2

$\begin{array}{rr}\text { NA } & 104.0 \\ \text { NA } & 102.3 \\ \text { NA } & 71.3 \\ \text { NA } & 77.1 \\ \text { NA } & 75.8 \\ 68.8 & 84.8 \\ 82.0 & 97.5 \\ 73.2 & 89.3 \\ 69.6 & 84.8 \\ 65.4 & 81.5 \\ 63.7 & 81.3\end{array}$

91.8

92.2
59.4

59.4
66.0

64.0

71.9

83.6

77.0

72.3

67.2

Nebraska

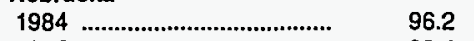

$1985 \ldots$

1986

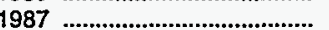

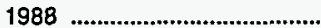

1990

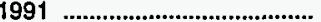

1992 ..........................................

1993.

67.3

69.0

65.5

77.0
89.1

79.6

76.0

71.6

86.0

52.2

56.9

53.8

63.5

75.8

69.3

65.3

59.7

57.8

NA

NA

NA

NA

97.7

85.3

81.8

80.4

NA $\quad 101.1$

$\begin{array}{lr}\text { NA } & 100.5 \\ \text { NA } & 70.3\end{array}$

NA $\quad 70.3$

NA $\quad 72.5$

$\begin{array}{ll}\text { NA } & 70.5 \\ W & 83.7\end{array}$

80.7

75.5

72.9

67.4

65.3

$$
95.1
$$

88.6

85.8

83.2

82.0

92.9

93.4

61.0

67.8

64.5

73.3

$$
83.3
$$

73.5

68.3

66.4

91.2

61.7

67.9

65.1

73.5

87.9

78.6

73.7

70.0
68.4

North Dakota

1984

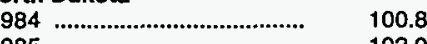

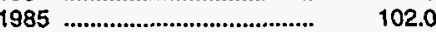

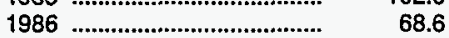

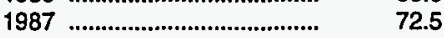

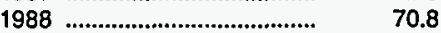

989 .......................................

1991 ............................................

992

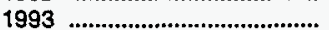

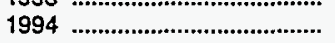

84.0
97.8

97.8
87.4

83.8

83.1

86.2

86.1

52.7

60.4

56.4

66.5

76.6
71.5

71.5
67.4

62.4

\section{NA}

NA

NA

$$
\begin{array}{r}
\text { NA } \\
93.0
\end{array}
$$

93.0
107.1

93.2

90.6

90.8

NA
NA
NA
NA
NA
W
W
78.6
76.4
74.2
67.3

\section{W}

96.2
79.5

78.3

79.1

93.2

103.7

91.5

91.8

92.3

88.7

\section{6}

98.2

67.4

70.7

66.2

72.7

77.4

80.9

77.4

71.9

70.4

95.7

$\begin{array}{ll}96.8 & 85.2 \\ 66.8 & 52.4\end{array}$

68.9

65.6

65.6

77.8
89.5

81.1

64.2

75.9

70.0

$77.6 \quad 66.1$

$75.5 \quad 60.5$

$\begin{array}{ll}72.9 & 58.6\end{array}$

Ohio

1984

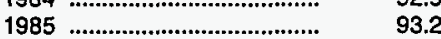

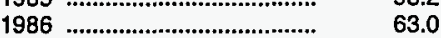

1987

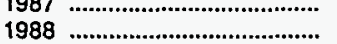

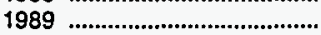

1991 .

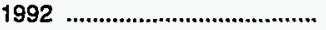

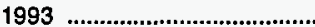

1994

\section{4}

$\begin{array}{rr}\text { NA } & \text { NA } \\ \text { NA } & \text { NA } \\ \text { NA } & \text { NA } \\ \text { NA } & \text { NA } \\ \text { NA } & \text { NA } \\ 80.0 & 69.4 \\ 92.5 & 81.1 \\ 84.7 & 73.8 \\ 81.2 & 70.4 \\ 77.5 & 65.5 \\ 77.0 & 64.5\end{array}$

101.5

103.5

77.5

83.0

82.8

90.7

101.3
92.0

88.2

84.1

83.3

92.9
92.5
61.2
67.8
67.0
74.7
85.8
78.3
74.8
69.6
68.7

$\begin{array}{ll}98.2 & 84.2 \\ 99.3 & 84.4 \\ 69.3 & 52.7 \\ 72.9 & 61.5 \\ 71.0 & 57.6 \\ 84.5 & 67.3 \\ 97.8 & 76.7 \\ 88.0 & 72.1 \\ 84.6 & 68.1 \\ 84.1 & 63.3 \\ 81.5 & 61.1\end{array}$

See footnotes at end of table. 
Table A1. Refiner/Reseller Motor Gasoline Prices by Grade, PAD District and State, 1984-Present

(Cents per Gallon Excluding Taxes) - Continued

\begin{tabular}{c|c|c|c|c|c|c|c|c|}
\hline \multirow{2}{*}{$\begin{array}{c}\text { Geographio Area } \\
\text { Year }\end{array}$} & \multicolumn{2}{|c|}{ Regular } & \multicolumn{2}{c}{ Midgrade } & \multicolumn{2}{c}{ Premium } \\
\cline { 2 - 6 } & $\begin{array}{c}\text { Through } \\
\text { Retall } \\
\text { Outlets }\end{array}$ & $\begin{array}{c}\text { Sales } \\
\text { for } \\
\text { Resale }\end{array}$ & $\begin{array}{c}\text { Through } \\
\text { Retail } \\
\text { Outlets }\end{array}$ & $\begin{array}{c}\text { Sales } \\
\text { for } \\
\text { Resale }\end{array}$ & $\begin{array}{c}\text { Through } \\
\text { Retall } \\
\text { Outlets }\end{array}$ & $\begin{array}{c}\text { Sales } \\
\text { for } \\
\text { Resale }\end{array}$ & $\begin{array}{c}\text { Through } \\
\text { Retall } \\
\text { Outlets }\end{array}$ & $\begin{array}{c}\text { Sales } \\
\text { for } \\
\text { Resale }\end{array}$ \\
\hline
\end{tabular}

Oklahoma
$1984 \ldots \ldots \ldots \ldots$
1985
1986
1987

\section{South Dakota}

1984 .............................................

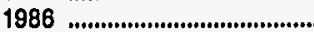

1987 ........................................

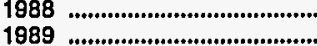

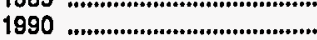

1991

1992

1993

1994 .......................................

Tennessee

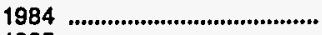

1985

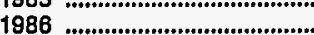

1987

1889

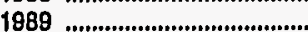

1990

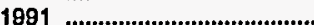

1992 ...........................................

1993

1994

93.8
94.5
60.4
66.2
64.8
71.7
84.5
76.2
70.6
66.7
63.5

83.7
84.5
49.6
54.7
51.4
60.4
72.6
66.8
60.9
55.9
53.6

NA
NA
NA
NA
NA
77.1
90.9
80.7
77.0
73.9
70.8

$\begin{array}{rr}\text { NA } & 100.7 \\ \text { NA } & 100.9 \\ \text { NA } & 67.0 \\ \text { NA } & 74.2 \\ \text { NA } & 72.6 \\ 62.9 & 80.3 \\ 86.4 & 93.0 \\ 71.0 & 85.8 \\ 67.1 & 81.9 \\ 62.7 & 79.3 \\ 61.2 & 76.3\end{array}$

101.2

99.4

66.6

67.8

83.5

93.2

84.2

82.0

79.2
75.4

85.6
86.4
52.1
58.5
55.8
65.2
77.2
70.3
67.3
62.8
60.2

NA
NA
NA
NA
NA
-
112.3
89.6
81.9
82.4
81.3

NA
NA
NA
NA
NA
W
88.5
75.6
72.0
71.8
65.6

93.0

92.3
63.7

65.2

64.6

70.9

85.3

74.1

70.9
67.2

64.6

85.4
85.4
51.1
56.7
54.1
60.1
77.3
68.7
63.1
56.6
53.9

NA

NA

$$
\text { NA }
$$$$
\begin{array}{r}
\text { NA } \\
78.5
\end{array}
$$$$
\begin{aligned}
& 78.5 \\
& 93.6
\end{aligned}
$$$$
83.3
$$$$
\begin{aligned}
& 81.3 \\
& 77.5
\end{aligned}
$$

Wleconsin

1884 .

1985

1986 ...........................................

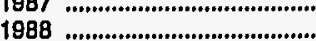

1989

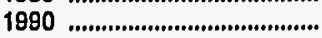

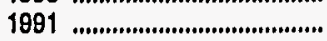

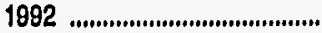

1993

1994

$\begin{array}{lll}94.3 & 85.1 & \\ 94.1 & 85.1 & \\ 62.8 & 50.3 & \\ 67.2 & 57.5 & \\ 64.4 & 55.5 & 78.0 \\ 72.5 & 63.0 & 95.7 \\ 86.4 & 75.7 & 95.9 \\ 79.6 & 69.0 & 8 \\ 75.4 & 63.4 & 82 . \\ 70.4 & 58.2 & 77 \\ 70.0 & 57.3 & 77.8\end{array}$

\section{PAD Dlstrlct III}

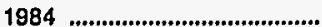

1985

1986

1987

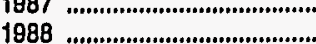

1989

1990 .

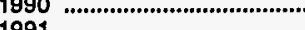

1992

1993

1994

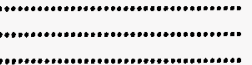

..............................................

70.0

75.1

NA
NA
NA
NA
NA
65.6
82.2
73.4
68.4
62.5
59.8

101.4
102.2
76.6
76.9
79.2
94.7
99.4
94.6
94.3
90.5
88.3

$\begin{array}{rr}\text { NA } & \text { NA } \\ \text { NA } & \text { NA } \\ \text { NA } & \text { NA } \\ \text { NA } & \text { NA } \\ 78.0 & 70.2 \\ 95.9 & 80.9 \\ 84.3 & 72.6 \\ 82.4 & 68.9 \\ 77.9 & 64.1 \\ 77.8 & 63.1\end{array}$

88.9
90.1
55.1
61.2
58.5
68.3
80.7
74.7
69.3
63.4
61.6

$\begin{array}{ll}92.2 & 81.6 \\ 92.8 & 82.3 \\ 60.4 & 49.7 \\ 66.7 & 55.2 \\ 65.6 & 52.4 \\ 73.2 & 61.4 \\ 85.9 & 73.4 \\ 78.1 & 67.8 \\ 72.9 & 62.0 \\ 69.3 & 56.9 \\ 66.1 & 54.7\end{array}$

$\begin{array}{rrrrr}\text { NA } & 101.9 & 92.3 & 92.6 & 83.9 \\ \text { NA } & 101.4 & 91.8 & 92.6 & 83.9 \\ \text { NA } & 70.7 & 58.3 & 62.8 & 50.9 \\ \text { NA } & 75.9 & 66.1 & 67.9 & 58.4 \\ \text { NA } & 74.3 & 65.3 & 66.1 & 57.0 \\ 70.2 & 84.7 & 74.0 & 75.1 & 65.0 \\ 80.9 & 97.2 & 84.9 & 88.4 & 77.1 \\ 72.6 & 91.1 & 78.0 & 81.5 & 70.3 \\ 68.9 & 87.2 & 72.4 & 77.4 & 64.9 \\ 64.1 & 83.3 & 67.4 & 72.7 & 59.8 \\ 63.1 & 83.6 & 66.7 & 72.5 & 59.0\end{array}$

See footnotes at end of table. 
Table A1. Refiner/Reseller Motor Gasoline Prices by Grade, PAD District and State, 1984-Present

(Cents per Gallon Excluding Taxes) - Continued

\begin{tabular}{c|c|c|c|c|c|c|c|c|}
\hline \multirow{2}{*}{$\begin{array}{c}\text { Geographic Area } \\
\text { Year }\end{array}$} & \multicolumn{2}{|c|}{ Regular } & \multicolumn{2}{c}{ Midgrade } & \multicolumn{2}{c|}{ Promium Grades } \\
\cline { 2 - 6 } & $\begin{array}{c}\text { Through } \\
\text { Retail } \\
\text { Outlets }\end{array}$ & $\begin{array}{c}\text { Sales } \\
\text { for } \\
\text { Resale }\end{array}$ & $\begin{array}{c}\text { Through } \\
\text { Retall } \\
\text { Outlets }\end{array}$ & $\begin{array}{c}\text { Sales } \\
\text { for } \\
\text { Resale }\end{array}$ & $\begin{array}{c}\text { Through } \\
\text { Retail } \\
\text { Outlots }\end{array}$ & $\begin{array}{c}\text { Sales } \\
\text { for } \\
\text { Resale }\end{array}$ & $\begin{array}{c}\text { Through } \\
\text { Retail } \\
\text { Outlets }\end{array}$ & $\begin{array}{c}\text { Sales } \\
\text { for } \\
\text { Resale }\end{array}$ \\
\hline
\end{tabular}

\begin{tabular}{|c|c|c|c|c|c|c|c|c|}
\hline \multicolumn{9}{|l|}{ Alabama } \\
\hline 1984 & 93.8 & 85.1 & NA & NA & 104.2 & 93.0 & 91.4 & 84.5 \\
\hline 1985 & 95.4 & 84.7 & NA & NA & 103.8 & 91.8 & 93.4 & 83.9 \\
\hline 1986 & 66.5 & 51.6 & NA & NA & 76.7 & 58.9 & 66.4 & 53.1 \\
\hline 1987 & 68.1 & 55.7 & NA & NA & 76.8 & 64.3 & 68.1 & 58.0 \\
\hline 1988 & 66.1 & 53.1 & NA & NA & 76.3 & 64.1 & 67.5 & 56.2 \\
\hline 1989 & 77.6 & 61.8 & 81.2 & 68.6 & 91.2 & 72.8 & 80.9 & 64.9 \\
\hline 1990 & 89.0 & 76.0 & 94.0 & 81.8 & 103.8 & 86.5 & 92.8 & 78.8 \\
\hline 1991 & 79.0 & 68.7 & 86.1 & 73.8 & 94.6 & 79.6 & 82.6 & 71.3 \\
\hline 1992 & 74.7 & 63.8 & 83.2 & 69.5 & 91.9 & 75.5 & 79.1 & 67.0 \\
\hline 1993 & 70.4 & 57.3 & 79.1 & 63.2 & 88.3 & 68.7 & 75.6 & 60.6 \\
\hline 1994 & 67.4 & 54.6 & 76.3 & 60.6 & 85.3 & 66.1 & 72.7 & 58.1 \\
\hline \multicolumn{9}{|l|}{ Arkansas } \\
\hline 1984 & 92.7 & 84.3 & NA & NA & 99.5 & 89.9 & 89.3 & 82.8 \\
\hline 1985 & 92.6 & 84.8 & NA & NA & 100.0 & 90.2 & 89.1 & 83.1 \\
\hline 1986 & 61.6 & 51.1 & NA & NA & 69.8 & 59.0 & 60.9 & 52.1 \\
\hline 1987 & 66.4 & 56.0 & NA & NA & 75.5 & 63.6 & 66.1 & 57.3 \\
\hline 1988 & 64.0 & 53.2 & NA & NA & 74.4 & 62.5 & 65.1 & 55.4 \\
\hline 1989 & 71.3 & 61.1 & 76.4 & 62.7 & 83.4 & 71.4 & 73.8 & 63.6 \\
\hline 1990 & 85.3 & 75.3 & 89.6 & 78.8 & 96.4 & 83.2 & 87.4 & 76.9 \\
\hline 1991 & 76.4 & 67.7 & 83.4 & 71.8 & 90.7 & 76.4 & 79.0 & 69.5 \\
\hline 1992 & 71.6 & 62.2 & 79.4 & 66.6 & 86.8 & 71.4 & 74.9 & 64.2 \\
\hline 1993 & 69.4 & 56.4 & 78.6 & 61.0 & 86.8 & 65.3 & 73.1 & 58.5 \\
\hline 1994 & 66.3 & 53.6 & 76.0 & 58.4 & 83.1 & 62.6 & 70.2 & 55.8 \\
\hline \multicolumn{9}{|l|}{ Louisiana } \\
\hline 1984 & 92.9 & 83.4 & NA & NA & 107.8 & 93.0 & 93.8 & 84.1 \\
\hline 1985 & 91.2 & 82.4 & NA & NA & 104.2 & 91.9 & 92.2 & 83.2 \\
\hline 1986 & 62.4 & 49.7 & NA & NA & 73.6 & 58.3 & 63.7 & 51.1 \\
\hline 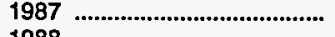 & 62.9 & 54.4 & NA & NA & 74.2 & 63.5 & 65.0 & 56.6 \\
\hline 1988 & 63.7 & 51.7 & NA & NA & 76.4 & 63.7 & 66.6 & 55.2 \\
\hline 1989 & 70.5 & 58.9 & 75.3 & 65.4 & 82.8 & 70.1 & 74.3 & 62.5 \\
\hline 1990 & 85.9 & 75.7 & 91.3 & 81.1 & 97.0 & 83.2 & 89.2 & 77.8 \\
\hline 1991 & 78.1 & 66.8 & 86.5 & 73.5 & 93.3 & 77.7 & 82.4 & 69.4 \\
\hline 1992 & 73.5 & 61.9 & 83.0 & 69.5 & 90.0 & 74.4 & 78.6 & 65.3 \\
\hline 1993 & 70.3 & 55.6 & 81.0 & 64.1 & 89.2 & 67.8 & 76.3 & 59.0 \\
\hline 1994 & 66.3 & 52.1 & 77.3 & 60.6 & 85.5 & 63.7 & 72.3 & 55.6 \\
\hline \multicolumn{9}{|l|}{ Mississippi } \\
\hline 1984 & 95.2 & 83.5 & NA & NA & 103.0 & 90.8 & 93.2 & 82.5 \\
\hline 1985 & 95.0 & 82.7 & NA & NA & 103.4 & 90.0 & 93.4 & 82.2 \\
\hline 1986 & 67.2 & 49.6 & NA & NA & 76.8 & 56.6 & 66.8 & 50.7 \\
\hline 1987 & 69.5 & 54.3 & NA & NA & 77.8 & 62.8 & 69.8 & 56.1 \\
\hline 1988 & 67.9 & 50.8 & NA & NA & 78.8 & 63.0 & 69.9 & 53.7 \\
\hline 1989 & 74.9 & 59.4 & 82.5 & 66.1 & 91.4 & 70.0 & 79.7 & 62.4 \\
\hline 1990 & 88.5 & 74.9 & 95.7 & 80.7 & 104.1 & 84.8 & 92.2 & 77.3 \\
\hline 1991 & 77.9 & 67.3 & 85.6 & 72.1 & 92.8 & 76.5 & 81.5 & 69.3 \\
\hline 1992 & 72.8 & 61.0 & 80.9 & 67.2 & 88.4 & 72.0 & 77.0 & 63.3 \\
\hline 1993 & 68.9 & 55.4 & 78.1 & 60.5 & 86.5 & 62.9 & 73.8 & 57.4 \\
\hline 1994 & 66.9 & 52.2 & 75.8 & 58.9 & 83.9 & 61.6 & 71.7 & 54.9 \\
\hline \multicolumn{9}{|l|}{ New Mexico } \\
\hline 1984 & 96.7 & 87.5 & NA & NA & 103.5 & 95.6 & 95.1 & 85.6 \\
\hline 1985 & 97.6 & 88.8 & NA & NA & 105.4 & 95.9 & 95.6 & 87.1 \\
\hline 1986 & 68.8 & 57.2 & NA & NA & 75.7 & 62.7 & 67.7 & 57.0 \\
\hline 1987 & 75.3 & 63.8 & NA & NA & 82.1 & 70.9 & 74.6 & 64.0 \\
\hline 1988 & 71.9 & 59.1 & NA & NA & 81.3 & 67.2 & 71.8 & 59.6 \\
\hline 1989 & 80.5 & 68.7 & $W$ & $W$ & 90.1 & 77.1 & 80.8 & 69.5 \\
\hline 1990 & 92.5 & 79.3 & 99.4 & 94.5 & 102.5 & 85.5 & 93.1 & 79.9 \\
\hline 1991 & 81.2 & 69.0 & 85.7 & 74.0 & 92.9 & 77.7 & 82.3 & 70.0 \\
\hline 1992 & 82.2 & 68.2 & 88.6 & 71.8 & 94.5 & 77.5 & 83.5 & 69.3 \\
\hline 1993 & 83.1 & 67.4 & 88.9 & 73.5 & 96.1 & 76.7 & 84.8 & 68.7 \\
\hline 1994 & 75.4 & 61.7 & 81.5 & 67.9 & 89.4 & 71.0 & 77.4 & 63.0 \\
\hline
\end{tabular}

See footnotes at end of table. 
Table A1. Refiner/Reseller Motor Gasoline Prices by Grade, PAD District and State, 1984-Present

(Cents per Gallon Excluding Taxes) - Continued

\begin{tabular}{|c|c|c|c|c|c|c|c|c|}
\hline \multirow[b]{2}{*}{$\begin{array}{c}\text { Geographic Area } \\
\text { Year }\end{array}$} & \multicolumn{2}{|c|}{ Aegular } & \multicolumn{2}{|c|}{ Midgrade } & \multicolumn{2}{|c|}{ Premium } & \multicolumn{2}{|c|}{ All Grades } \\
\hline & $\begin{array}{c}\text { Through } \\
\text { Retall } \\
\text { Outlets }\end{array}$ & $\begin{array}{c}\text { Sales } \\
\text { for } \\
\text { Resale }\end{array}$ & $\begin{array}{c}\text { Through } \\
\text { Retail } \\
\text { Outlets }\end{array}$ & $\begin{array}{c}\text { Sales } \\
\text { for } \\
\text { Resale }\end{array}$ & $\begin{array}{c}\text { Through } \\
\text { Retail } \\
\text { Outlots }\end{array}$ & $\begin{array}{c}\text { Sales } \\
\text { for } \\
\text { Resale }\end{array}$ & $\begin{array}{c}\text { Through } \\
\text { Retail } \\
\text { Outlets }\end{array}$ & $\begin{array}{c}\text { Sales } \\
\text { for } \\
\text { Resale }\end{array}$ \\
\hline $\begin{array}{c}\text { Texa8 } \\
1984 \\
1985 \\
1986 \\
1987\end{array}$ & $\begin{array}{l}92.6 \\
91.0 \\
60.8 \\
65.1 \\
65.1 \\
70.9 \\
86.6 \\
79.2 \\
73.6 \\
69.7 \\
67.3\end{array}$ & $\begin{array}{l}82.1 \\
81.4 \\
47.8 \\
53.4 \\
50.3 \\
58.0 \\
71.8 \\
66.1 \\
60.9 \\
55.4 \\
52.5\end{array}$ & $\begin{array}{l}\text { NA } \\
\text { NA } \\
\text { NA } \\
\text { NA } \\
\text { NA } \\
76.7 \\
92.4 \\
86.2 \\
83.1 \\
79.7 \\
77.2\end{array}$ & $\begin{array}{r}\text { NA } \\
\text { NA } \\
\text { NA } \\
\text { NA } \\
\text { NA } \\
64.3 \\
79.3 \\
72.7 \\
68.4 \\
62.7 \\
60.3\end{array}$ & $\begin{array}{r}103.0 \\
102.1 \\
72.0 \\
75.9 \\
77.2 \\
84.0 \\
98.0 \\
92.9 \\
90.4 \\
87.3 \\
85.0\end{array}$ & $\begin{array}{l}88.9 \\
88.4 \\
55.2 \\
61.8 \\
61.1 \\
68.6 \\
83.4 \\
75.8 \\
70.9 \\
65.5 \\
63.3\end{array}$ & $\begin{array}{l}91.9 \\
90.9 \\
62.0 \\
66.6 \\
67.3 \\
74.7 \\
89.7 \\
82.8 \\
78.3 \\
74.5 \\
72.2\end{array}$ & $\begin{array}{l}80.3 \\
79.7 \\
48.5 \\
54.9 \\
52.6 \\
60.3 \\
73.8 \\
67.8 \\
63.0 \\
57.5 \\
54.8\end{array}$ \\
\hline $\begin{array}{c}\text { PAD Dlstrict IV } \\
1984 \\
1985 \\
1986 \\
1987 \\
1988\end{array}$ & $\begin{array}{l}92.9 \\
95.0 \\
64.6 \\
69.5 \\
67.0 \\
76.0 \\
87.6 \\
78.4 \\
81.0 \\
77.6 \\
76.1\end{array}$ & $\begin{array}{l}84.4 \\
84.7 \\
52.3 \\
58.7 \\
56.5 \\
65.0 \\
76.3 \\
68.6 \\
70.2 \\
64.9 \\
63.2\end{array}$ & $\begin{array}{l}\text { NA } \\
\text { NA } \\
\text { NA } \\
\text { NA } \\
\text { NA } \\
73.9 \\
91.2 \\
80.8 \\
85.6 \\
85.3 \\
85.8\end{array}$ & $\begin{array}{l}\text { NA } \\
\text { NA } \\
\text { NA } \\
\text { NA } \\
\text { NA } \\
68.9 \\
86.6 \\
72.4 \\
74.9 \\
69.1 \\
68.0\end{array}$ & $\begin{array}{l}96.9 \\
99.1 \\
71.1 \\
77.5 \\
75.9 \\
84.6 \\
95.3 \\
88.0 \\
91.9 \\
90.6 \\
91.3\end{array}$ & $\begin{array}{l}91.1 \\
92.2 \\
58.5 \\
66.2 \\
64.1 \\
72.6 \\
82.1 \\
76.0 \\
77.7 \\
73.1 \\
72.3\end{array}$ & $\begin{array}{l}91.5 \\
93.2 \\
63.6 \\
68.9 \\
67.5 \\
77.1 \\
88.7 \\
80.2 \\
83.2 \\
80.4 \\
79.6\end{array}$ & $\begin{array}{l}82.6 \\
83.0 \\
52.6 \\
59.3 \\
57.6 \\
66.2 \\
77.0 \\
69.7 \\
71.6 \\
66.5 \\
65.1\end{array}$ \\
\hline $\begin{array}{c}\text { Colorado } \\
1984 \\
1985 \\
1986 \\
1987 \\
1988\end{array}$ & $\begin{array}{l}91.7 \\
96.5 \\
64.1 \\
70.0 \\
65.3 \\
74.2 \\
86.1 \\
78.0 \\
80.8 \\
78.9 \\
77.8\end{array}$ & $\begin{array}{l}83.3 \\
85.1 \\
50.8 \\
58.1 \\
55.5 \\
62.9 \\
76.4 \\
69.1 \\
69.6 \\
63.1 \\
61.3\end{array}$ & $\begin{array}{c}\text { NA } \\
\text { NA } \\
\text { NA } \\
\text { NA } \\
\text { NA } \\
73.2 \\
89.7 \\
81.3 \\
87.1 \\
87.8 \\
89.0\end{array}$ & $\begin{array}{c}\text { NA } \\
\text { NA } \\
\text { NA } \\
\text { NA } \\
\text { NA } \\
68.6 \\
84.8 \\
72.2 \\
74.8 \\
68.6 \\
68.2\end{array}$ & $\begin{array}{l}96.9 \\
99.0 \\
70.1 \\
78.2 \\
74.9 \\
84.0 \\
95.1 \\
88.2 \\
93.7 \\
96.3 \\
97.4\end{array}$ & $\begin{array}{l}91.6 \\
93.2 \\
57.3 \\
65.6 \\
63.4 \\
71.7 \\
82.9 \\
76.2 \\
77.3 \\
71.6 \\
70.7\end{array}$ & $\begin{array}{l}90.7 \\
94.3 \\
62.2 \\
68.8 \\
65.7 \\
75.5 \\
87.4 \\
80.1 \\
83.7 \\
82.6 \\
82.2\end{array}$ & $\begin{array}{l}81.6 \\
83.5 \\
51.2 \\
58.8 \\
56.7 \\
64.5 \\
77.3 \\
70.4 \\
71.4 \\
64.9 \\
63.4\end{array}$ \\
\hline $\begin{array}{l}\text { Idaho } \\
1984 \\
1985 \\
1986 \\
1987 \\
1988\end{array}$ & $\begin{array}{l}96.7 \\
95.8 \\
67.6 \\
69.5 \\
69.3 \\
78.2 \\
90.9 \\
77.8 \\
80.9 \\
74.9 \\
74.1\end{array}$ & $\begin{array}{l}87.8 \\
85.8 \\
55.8 \\
60.2 \\
58.1 \\
66.1 \\
75.8 \\
67.6 \\
72.0 \\
67.0 \\
65.2\end{array}$ & $\begin{array}{c}\text { NA } \\
\text { NA } \\
\text { NA } \\
\text { NA } \\
\text { NA } \\
\text { W } \\
114.0 \\
80.5 \\
79.4 \\
86.3 \\
80.5\end{array}$ & $\begin{array}{c}\text { NA } \\
\text { NA } \\
\text { NA } \\
\text { NA } \\
\text { NA } \\
- \\
W \\
W \\
78.2 \\
72.0 \\
67.2\end{array}$ & $\begin{array}{r}104.8 \\
107.6 \\
84.6 \\
81.5 \\
81.2 \\
88.2 \\
98.8 \\
88.1 \\
90.5 \\
83.6 \\
86.1\end{array}$ & $\begin{array}{l}93.3 \\
91.9 \\
63.9 \\
69.6 \\
67.1 \\
74.2 \\
82.3 \\
75.7 \\
80.6 \\
75.6 \\
74.7\end{array}$ & $\begin{array}{l}94.5 \\
93.5 \\
67.3 \\
69.5 \\
70.0 \\
78.9 \\
91.2 \\
78.5 \\
81.8 \\
76.0 \\
75.8\end{array}$ & $\begin{array}{l}85.5 \\
83.7 \\
55.5 \\
60.5 \\
58.7 \\
66.7 \\
76.1 \\
68.3 \\
72.9 \\
68.2 \\
66.8\end{array}$ \\
\hline $\begin{array}{r}\text { Montana } \\
1984 \\
1985 \\
1986\end{array}$ & $\begin{array}{l}94.5 \\
94.5 \\
64.9 \\
69.6 \\
69.6 \\
80.5 \\
92.2 \\
83.9 \\
85.8 \\
82.8 \\
81.0\end{array}$ & $\begin{array}{l}83.4 \\
83.7 \\
52.4 \\
59.4 \\
57.2 \\
67.2 \\
78.3 \\
69.5 \\
70.8 \\
67.3 \\
67.1\end{array}$ & $\begin{array}{c}\text { NA } \\
\text { NA } \\
\text { NA } \\
\text { NA } \\
\text { NA } \\
W \\
- \\
- \\
W \\
85.2 \\
80.1\end{array}$ & $\begin{array}{c}N A \\
N A \\
N A \\
N A \\
N A \\
- \\
W \\
W \\
- \\
N A \\
W\end{array}$ & $\begin{array}{r}101.9 \\
99.8 \\
65.6 \\
74.7 \\
74.1 \\
86.3 \\
96.5 \\
90.7 \\
92.3 \\
92.1 \\
90.9\end{array}$ & $\begin{array}{l}89.0 \\
90.8 \\
56.3 \\
64.8 \\
63.3 \\
72.9 \\
82.7 \\
76.2 \\
77.8 \\
75.4 \\
76.0\end{array}$ & $\begin{array}{l}92.1 \\
92.3 \\
64.9 \\
70.0 \\
70.1 \\
81.3 \\
92.5 \\
85.0 \\
86.9 \\
84.1 \\
82.6\end{array}$ & $\begin{array}{l}81.3 \\
81.4 \\
52.4 \\
59.5 \\
57.9 \\
68.0 \\
78.8 \\
70.5 \\
71.9 \\
68.5 \\
68.5\end{array}$ \\
\hline
\end{tabular}

See footnotes at end of table. 
Table A1. Refiner/Reseller Motor Gasoline Prices by Grade, PAD District and State, 1984-Present

(Cents per Gallon Excluding Taxes) - Continued

\begin{tabular}{|c|c|c|c|c|c|c|c|c|}
\hline \multirow[b]{2}{*}{$\underset{\text { Gear }}{\text { Geographic Area }}$} & \multicolumn{2}{|c|}{ Regular } & \multicolumn{2}{|c|}{ Midgrade } & \multicolumn{2}{|c|}{ Premium } & \multicolumn{2}{|c|}{ All Grades } \\
\hline & $\begin{array}{c}\text { Through } \\
\text { Retail } \\
\text { Outlots }\end{array}$ & $\begin{array}{c}\text { Sales } \\
\text { for } \\
\text { Resale }\end{array}$ & $\begin{array}{c}\text { Through } \\
\text { Retail } \\
\text { Outlets }\end{array}$ & $\begin{array}{c}\text { Sales } \\
\text { for } \\
\text { Resale }\end{array}$ & $\begin{array}{c}\text { Through } \\
\text { Retail } \\
\text { Outlets }\end{array}$ & $\begin{array}{c}\text { Sales } \\
\text { for } \\
\text { Resale }\end{array}$ & $\begin{array}{c}\text { Through } \\
\text { Retail } \\
\text { Outlets }\end{array}$ & $\begin{array}{c}\text { Sales } \\
\text { for } \\
\text { Resale }\end{array}$ \\
\hline \multicolumn{9}{|l|}{ Utah } \\
\hline $\begin{array}{l}1984 \\
1985 \\
1986 \\
1987 \\
1988 \\
1989 \\
1990 \\
1991 \\
1992\end{array}$ & $\begin{array}{l}91.7 \\
91.3 \\
63.4 \\
67.0 \\
68.8 \\
75.2 \\
86.8 \\
75.8 \\
77.3 \\
73.1 \\
70.0\end{array}$ & $\begin{array}{l}83.7 \\
83.3 \\
52.4 \\
58.2 \\
56.4 \\
65.2 \\
74.3 \\
67.2 \\
68.8 \\
64.3 \\
61.9\end{array}$ & $\begin{array}{l}\text { NA } \\
\text { NA } \\
\text { NA } \\
\text { NA } \\
\text { NA } \\
\text { W } \\
99.3 \\
78.9 \\
80.5 \\
77.6 \\
76.8\end{array}$ & $\begin{array}{l}\text { NA } \\
\text { NA } \\
\text { NA } \\
\text { NA } \\
\text { NA } \\
\text { W } \\
92.7 \\
72.4 \\
74.9 \\
69.5 \\
68.0\end{array}$ & $\begin{array}{l}95.5 \\
98.5 \\
69.5 \\
74.7 \\
77.2 \\
82.6 \\
92.8 \\
85.3 \\
86.8 \\
84.1 \\
83.5\end{array}$ & $\begin{array}{l}88.8 \\
89.9 \\
59.7 \\
66.4 \\
64.2 \\
72.4 \\
79.9 \\
75.1 \\
76.5 \\
72.5 \\
70.9\end{array}$ & $\begin{array}{l}90.2 \\
89.8 \\
62.8 \\
66.9 \\
68.9 \\
76.1 \\
87.6 \\
77.6 \\
79.5 \\
75.9 \\
73.6\end{array}$ & $\begin{array}{l}82.3 \\
81.9 \\
52.7 \\
58.9 \\
57.4 \\
66.3 \\
75.0 \\
68.5 \\
70.3 \\
66.2 \\
64.4\end{array}$ \\
\hline \multicolumn{9}{|l|}{ Wyoming } \\
\hline 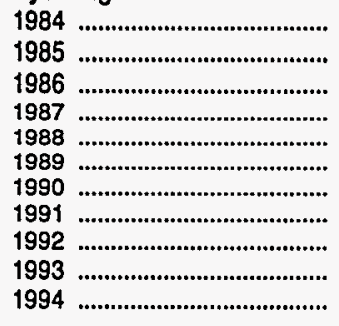 & $\begin{array}{l}99.8 \\
97.1 \\
69.1 \\
71.7 \\
70.9 \\
83.5 \\
93.5 \\
85.8 \\
88.3 \\
82.1 \\
80.7\end{array}$ & $\begin{array}{l}86.2 \\
86.6 \\
53.5 \\
59.1 \\
57.3 \\
66.4 \\
79.1 \\
70.7 \\
71.2 \\
65.4 \\
63.7\end{array}$ & $\begin{array}{l}\text { NA } \\
\text { NA } \\
\text { NA } \\
\text { NA } \\
\text { NA } \\
\bar{W} \\
\text { W } \\
89.9 \\
84.4 \\
88.3\end{array}$ & $\begin{array}{l}\text { NA } \\
\text { NA } \\
\text { NA } \\
\text { NA } \\
\text { NA } \\
\text { W } \\
91.9 \\
74.7 \\
75.3 \\
68.5 \\
71.7\end{array}$ & $\begin{array}{r}111.9 \\
105.7 \\
82.7 \\
80.3 \\
78.8 \\
90.7 \\
101.3 \\
94.6 \\
97.8 \\
91.9 \\
92.6\end{array}$ & $\begin{array}{l}93.4 \\
94.7 \\
61.1 \\
67.7 \\
65.7 \\
74.2 \\
85.0 \\
78.0 \\
79.2 \\
73.5 \\
73.1\end{array}$ & $\begin{array}{l}97.7 \\
95.6 \\
70.0 \\
72.0 \\
71.1 \\
84.2 \\
94.4 \\
86.9 \\
89.5 \\
83.5 \\
82.8\end{array}$ & $\begin{array}{l}84.0 \\
84.6 \\
53.8 \\
59.6 \\
58.4 \\
67.4 \\
79.8 \\
71.8 \\
72.3 \\
66.8 \\
65.3\end{array}$ \\
\hline \multicolumn{9}{|l|}{ PAD District V } \\
\hline $\begin{array}{l}1984 \\
1985 \\
1986 \\
1987 \\
1988 \\
1989 \\
1990 \\
1991\end{array}$ & $\begin{array}{l}95.3 \\
93.4 \\
67.7 \\
67.6 \\
68.1 \\
76.5 \\
88.9 \\
75.1 \\
82.9 \\
80.0 \\
76.1\end{array}$ & $\begin{array}{l}86.5 \\
86.3 \\
59.9 \\
60.0 \\
58.8 \\
65.0 \\
78.3 \\
64.5 \\
70.4 \\
67.1 \\
62.9\end{array}$ & $\begin{array}{l}\text { NA } \\
\text { NA } \\
\text { NA } \\
\text { NA } \\
\text { NA } \\
\text { W } \\
88.8 \\
72.7 \\
86.8 \\
86.5 \\
84.4\end{array}$ & $\begin{array}{l}\text { NA } \\
\text { NA } \\
\text { NA } \\
\text { NA } \\
\text { NA } \\
\text { W } \\
79.4 \\
64.9 \\
77.4 \\
74.5 \\
70.9\end{array}$ & $\begin{array}{r}106.4 \\
105.4 \\
78.6 \\
80.0 \\
81.6 \\
90.1 \\
101.0 \\
87.6 \\
98.4 \\
97.5 \\
94.6\end{array}$ & $\begin{array}{l}93.5 \\
93.2 \\
65.9 \\
70.0 \\
70.8 \\
77.3 \\
90.4 \\
76.3 \\
85.2 \\
82.1 \\
78.4\end{array}$ & $\begin{array}{l}92.5 \\
91.3 \\
67.0 \\
68.3 \\
69.5 \\
78.2 \\
90.4 \\
76.9 \\
85.4 \\
83.0 \\
79.8\end{array}$ & $\begin{array}{l}85.2 \\
85.2 \\
59.2 \\
61.3 \\
61.0 \\
67.7 \\
80.7 \\
66.8 \\
73.8 \\
70.4 \\
66.4\end{array}$ \\
\hline \multicolumn{9}{|l|}{ Alaska } \\
\hline $\begin{array}{l}1984 \\
1985 \\
1986 \\
1987 \\
1988 \\
1989 \\
1990 \\
1991 \\
1992 \\
1993\end{array}$ & $\begin{array}{r}96.7 \\
103.5 \\
97.7 \\
92.5 \\
92.0 \\
96.4 \\
114.1 \\
104.1 \\
111.9 \\
105.8 \\
109.1\end{array}$ & $\begin{array}{l}88.0 \\
90.7 \\
68.6 \\
65.0 \\
69.7 \\
80.0 \\
94.1 \\
75.1 \\
80.8 \\
78.7 \\
76.4\end{array}$ & $\begin{array}{c}\text { NA } \\
\text { NA } \\
N A \\
N A \\
N A \\
- \\
- \\
W \\
- \\
\overline{N A}\end{array}$ & $\begin{array}{c}N A \\
N A \\
N A \\
N A \\
N A \\
W \\
W \\
128.6 \\
-\bar{W} \\
86.2\end{array}$ & $\begin{array}{r}W \\
W \\
92.1 \\
98.3 \\
101.3 \\
101.7 \\
117.5 \\
103.8 \\
111.8 \\
109.9 \\
111.2\end{array}$ & $\begin{array}{r}93.5 \\
96.7 \\
71.3 \\
76.5 \\
79.7 \\
91.3 \\
103.7 \\
85.8 \\
89.4 \\
88.0 \\
86.3\end{array}$ & $\begin{array}{r}92.9 \\
100.9 \\
98.2 \\
96.1 \\
94.9 \\
97.8 \\
114.8 \\
103.9 \\
111.2 \\
106.0 \\
109.8\end{array}$ & $\begin{array}{l}85.8 \\
88.8 \\
67.5 \\
66.3 \\
70.8 \\
81.3 \\
94.9 \\
76.6 \\
81.8 \\
79.7 \\
77.5\end{array}$ \\
\hline \multicolumn{9}{|l|}{ Arizona } \\
\hline 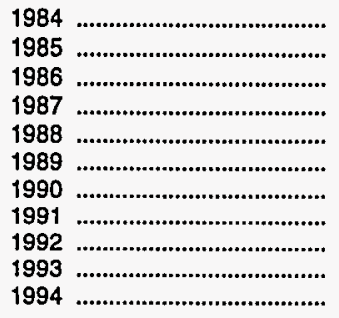 & $\begin{array}{l}95.9 \\
95.4 \\
69.3 \\
71.4 \\
66.0 \\
75.8 \\
89.1 \\
76.1 \\
82.0 \\
84.3 \\
79.6\end{array}$ & $\begin{array}{l}85.3 \\
87.0 \\
58.6 \\
62.0 \\
55.7 \\
64.8 \\
80.6 \\
67.1 \\
72.3 \\
72.7 \\
66.4\end{array}$ & $\begin{array}{l}\text { NA } \\
\text { NA } \\
\text { NA } \\
\text { NA } \\
\text { NA } \\
84.6 \\
W \\
77.3 \\
85.4 \\
90.7 \\
89.7\end{array}$ & $\begin{array}{l}\text { NA } \\
\text { NA } \\
\text { NA } \\
\text { NA } \\
\text { NA } \\
- \\
75.5 \\
68.4 \\
77.3 \\
73.7 \\
70.7\end{array}$ & $\begin{array}{r}108.2 \\
107.0 \\
79.9 \\
83.5 \\
82.1 \\
90.5 \\
99.7 \\
88.3 \\
97.7 \\
100.2 \\
96.8\end{array}$ & $\begin{array}{l}91.0 \\
92.9 \\
63.3 \\
70.4 \\
65.2 \\
75.4 \\
91.3 \\
76.7 \\
84.5 \\
85.5 \\
79.5\end{array}$ & $\begin{array}{l}92.6 \\
92.7 \\
68.1 \\
71.9 \\
67.5 \\
77.1 \\
90.1 \\
77.4 \\
83.4 \\
86.0 \\
82.6\end{array}$ & $\begin{array}{l}83.5 \\
85.5 \\
57.6 \\
62.7 \\
57.1 \\
66.4 \\
81.8 \\
68.3 \\
73.8 \\
74.6 \\
68.6\end{array}$ \\
\hline
\end{tabular}

See footnotes at end of table. 
Table A1. Refiner/Reseller Motor Gasoline Prices by Grade, PAD District and State, 1984-Present

(Cents per Gallon Excluding Taxes) - Continued

\begin{tabular}{|c|c|c|c|c|c|c|c|c|}
\hline \multirow[b]{2}{*}{$\begin{array}{c}\text { Geographlc Area } \\
\text { Yoar }\end{array}$} & \multicolumn{2}{|c|}{ Regular } & \multicolumn{2}{|c|}{ Midgrade } & \multicolumn{2}{|c|}{ Premium } & \multicolumn{2}{|c|}{ All Grades } \\
\hline & $\begin{array}{c}\text { Through } \\
\text { Retall } \\
\text { Outlets }\end{array}$ & $\begin{array}{c}\text { Sales } \\
\text { for } \\
\text { Resale }\end{array}$ & $\begin{array}{c}\text { Through } \\
\text { Retall } \\
\text { Outlets }\end{array}$ & $\begin{array}{c}\text { Sales } \\
\text { for } \\
\text { Resale }\end{array}$ & $\begin{array}{c}\text { Through } \\
\text { Retail } \\
\text { Outlets }\end{array}$ & $\begin{array}{c}\text { Sales } \\
\text { for } \\
\text { Resale }\end{array}$ & $\begin{array}{c}\text { Through } \\
\text { Retail } \\
\text { Outlets }\end{array}$ & $\begin{array}{c}\text { Sales } \\
\text { for } \\
\text { Resale }\end{array}$ \\
\hline $\begin{array}{l}\text { Callfomla } \\
1984 \\
1985 \\
1986 \\
1987 \\
1988 \\
1989\end{array}$ & $\begin{array}{l}95.3 \\
92.4 \\
66.8 \\
67.7 \\
69.1 \\
76.3 \\
87.9 \\
71.8 \\
81.3 \\
77.0 \\
71.8\end{array}$ & $\begin{array}{l}86.5 \\
86.1 \\
59.5 \\
60.3 \\
59.2 \\
64.5 \\
77.6 \\
63.1 \\
69.6 \\
66.3 \\
61.8\end{array}$ & $\begin{array}{c}\text { NA } \\
\text { NA } \\
\text { NA } \\
\text { NA } \\
\text { NA } \\
\text { W } \\
\text { NA } \\
69.9 \\
86.5 \\
85.6 \\
83.0\end{array}$ & $\begin{array}{c}\text { NA } \\
\text { NA } \\
\text { NA } \\
\text { NA } \\
\text { NA } \\
\text { W } \\
78.0 \\
62.6 \\
77.3 \\
74.2 \\
70.5\end{array}$ & $\begin{array}{r}106.6 \\
105.3 \\
78.8 \\
80.4 \\
82.3 \\
89.9 \\
100.6 \\
84.9 \\
97.4 \\
95.6 \\
91.7\end{array}$ & $\begin{array}{l}93.6 \\
93.0 \\
65.7 \\
70.1 \\
71.4 \\
77.2 \\
90.0 \\
74.8 \\
84.9 \\
81.5 \\
77.5\end{array}$ & $\begin{array}{l}92.6 \\
90.6 \\
66.8 \\
68.9 \\
70.8 \\
78.3 \\
89.8 \\
74.0 \\
85.0 \\
81.3 \\
76.5\end{array}$ & $\begin{array}{l}85.5 \\
85.2 \\
59.1 \\
61.9 \\
61.8 \\
67.6 \\
80.3 \\
65.6 \\
73.6 \\
70.1 \\
65.7\end{array}$ \\
\hline $\begin{array}{c}\text { Hawall } \\
1984 \\
1985 \\
1986 \\
1987\end{array}$ & $\begin{array}{r}107.2 \\
108.9 \\
87.9 \\
86.6 \\
86.6 \\
94.3 \\
101.4 \\
96.3 \\
100.9 \\
107.0 \\
102.9\end{array}$ & $\begin{array}{l}93.6 \\
94.3 \\
72.8 \\
75.8 \\
78.3 \\
81.6 \\
91.3 \\
81.7 \\
87.3 \\
91.3 \\
84.9\end{array}$ & $\begin{array}{r}\text { NA } \\
N A \\
N A \\
N A \\
N A \\
96.2 \\
111.5 \\
110.9 \\
113.6 \\
111.7 \\
107.2\end{array}$ & $\begin{array}{l}\text { NA } \\
\text { NA } \\
\text { NA } \\
\text { NA } \\
\text { NA } \\
80.8 \\
96.8 \\
89.4 \\
94.9 \\
97.5 \\
94.4\end{array}$ & $\begin{array}{l}115.5 \\
122.1 \\
101.4 \\
102.2 \\
101.1 \\
110.2 \\
118.6 \\
113.6 \\
118.3 \\
124.1 \\
121.1\end{array}$ & $\begin{array}{r}97.9 \\
97.8 \\
78.8 \\
84.0 \\
87.4 \\
93.5 \\
103.4 \\
97.2 \\
102.2 \\
104.6 \\
100.5\end{array}$ & $\begin{array}{r}106.3 \\
106.9 \\
85.0 \\
87.7 \\
89.5 \\
98.6 \\
107.2 \\
102.6 \\
107.2 \\
112.0 \\
108.0\end{array}$ & $\begin{array}{l}94.1 \\
94.5 \\
73.7 \\
78.2 \\
81.7 \\
86.6 \\
96.4 \\
87.4 \\
93.0 \\
96.6 \\
91.1\end{array}$ \\
\hline $\begin{array}{l}\text { Nevada } \\
1984 \\
1985 \\
1986 \\
1987\end{array}$ & $\begin{array}{l}93.1 \\
92.5 \\
67.6 \\
61.0 \\
65.0 \\
75.6 \\
88.7 \\
80.0 \\
84.3 \\
81.5 \\
80.8\end{array}$ & $\begin{array}{l}85.9 \\
86.7 \\
58.5 \\
56.3 \\
56.3 \\
64.4 \\
78.8 \\
66.7 \\
69.6 \\
65.1 \\
63.2\end{array}$ & $\begin{array}{l}\text { NA } \\
\text { NA } \\
\text { NA } \\
\text { NA } \\
\text { NA } \\
\text { W } \\
\text { W } \\
85.1 \\
83.5 \\
86.1 \\
87.5\end{array}$ & $\begin{array}{l}\text { NA } \\
\text { NA } \\
\text { NA } \\
\text { NA } \\
\text { NA } \\
\text { W } \\
98.9 \\
65.4 \\
73.1 \\
71.5 \\
70.5\end{array}$ & $\begin{array}{r}100.5 \\
101.8 \\
77.0 \\
71.0 \\
76.8 \\
88.4 \\
101.2 \\
92.6 \\
99.3 \\
99.0 \\
98.9\end{array}$ & $\begin{array}{l}92.8 \\
93.7 \\
64.8 \\
64.4 \\
67.6 \\
75.2 \\
88.2 \\
78.3 \\
82.0 \\
78.5 \\
77.6\end{array}$ & $\begin{array}{l}89.9 \\
89.1 \\
66.1 \\
61.3 \\
65.7 \\
76.8 \\
90.2 \\
81.6 \\
86.5 \\
84.7 \\
84.4\end{array}$ & $\begin{array}{l}84.3 \\
85.0 \\
57.4 \\
57.2 \\
57.9 \\
66.1 \\
79.9 \\
68.4 \\
71.9 \\
67.6 \\
66.1\end{array}$ \\
\hline $\begin{array}{l}\text { Oregon } \\
1984 \\
1985 \\
1986 \\
1987\end{array}$ & $\begin{array}{l}96.3 . \\
96.6 \\
69.0 \\
64.8 \\
67.3 \\
80.4 \\
91.7 \\
81.7 \\
87.6 \\
83.2 \\
78.8\end{array}$ & $\begin{array}{l}86.2 \\
86.3 \\
61.6 \\
56.8 \\
58.5 \\
67.9 \\
78.8 \\
66.6 \\
71.9 \\
67.2 \\
62.7\end{array}$ & $\begin{array}{c}N A \\
N A \\
N A \\
N A \\
N A \\
\vec{W} \\
W \\
W \\
94.7 \\
80.0\end{array}$ & $\begin{array}{c}N A \\
N A \\
N A \\
N A \\
N A \\
\vec{W} \\
84.0 \\
W \\
W \\
69.9\end{array}$ & $\begin{array}{r}107.5 \\
106.2 \\
79.6 \\
76.8 \\
79.3 \\
93.7 \\
103.3 \\
96.3 \\
102.7 \\
99.4 \\
95.4\end{array}$ & $\begin{array}{l}92.7 \\
93.1 \\
64.7 \\
67.4 \\
69.7 \\
80.0 \\
90.4 \\
79.7 \\
85.7 \\
81.9 \\
77.7\end{array}$ & $\begin{array}{l}93.7 \\
94.1 \\
67.3 \\
64.8 \\
67.7 \\
81.2 \\
91.9 \\
82.3 \\
88.1 \\
84.4 \\
81.0\end{array}$ & $\begin{array}{l}83.8 \\
84.1 \\
59.7 \\
57.9 \\
59.9 \\
69.5 \\
79.7 \\
67.9 \\
73.3 \\
69.0 \\
64.8\end{array}$ \\
\hline 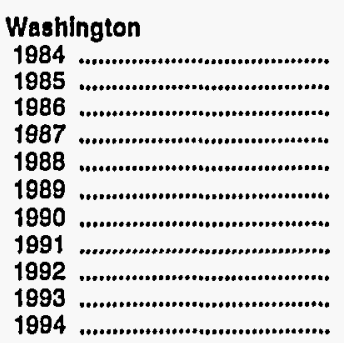 & $\begin{array}{l}93.5 \\
93.1 \\
66.5 \\
65.1 \\
65.3 \\
73.1 \\
88.8 \\
77.4 \\
80.9 \\
76.0 \\
76.8\end{array}$ & $\begin{array}{l}86.6 \\
85.7 \\
57.9 \\
55.6 \\
54.6 \\
62.1 \\
78.2 \\
66.5 \\
70.8 \\
65.9 \\
64.1\end{array}$ & $\begin{array}{c}\text { NA } \\
\text { NA } \\
\text { NA } \\
\text { NA } \\
\text { NA } \\
74.9 \\
94.2 \\
\bar{W} \\
84.8 \\
81.3\end{array}$ & $\begin{array}{c}\text { NA } \\
\text { NA } \\
\text { NA } \\
\text { NA } \\
\text { NA } \\
W \\
W \\
73.1 \\
77.8 \\
71.8 \\
72.7\end{array}$ & $\begin{array}{r}104.1 \\
104.6 \\
76.7 \\
77.2 \\
78.1 \\
86.4 \\
100.1 \\
91.3 \\
96.1 \\
93.2 \\
94.2\end{array}$ & $\begin{array}{l}93.0 \\
92.7 \\
64.7 \\
65.7 \\
65.2 \\
72.4 \\
89.0 \\
79.3 \\
84.0 \\
79.9 \\
79.2\end{array}$ & $\begin{array}{l}90.9 \\
90.6 \\
65.0 \\
65.7 \\
66.8 \\
74.8 \\
89.5 \\
78.7 \\
82.0 \\
77.7 \\
79.6\end{array}$ & $\begin{array}{l}84.5 \\
83.9 \\
57.0 \\
56.9 \\
56.6 \\
64.2 \\
79.7 \\
68.4 \\
72.7 \\
68.0 \\
66.8\end{array}$ \\
\hline
\end{tabular}

$\operatorname{Dash}(-)=$ No data reported.

NA $=$ Not avallable.

$W=$ Withheld to avoid disclosure of individual company data.

Sources: Energy Information Administratlon Forms ElA-762A, "Relliners'/Gas Plant Operators' Monthly Petroleum Product Sales Report," and EIA-782B, "Resellers'/Retallers' Monthly Petroleum Product Sales Report." 
Table A2. Refiner/Reseller Prices of Aviation Fuels, Propane, and Kerosene, by PAD District, 1983-Present

(Cents per Gallon Excluding Taxes)

\begin{tabular}{|c|c|c|c|c|c|c|c|c|}
\hline \multirow{2}{*}{$\begin{array}{c}\text { Geographic Area } \\
\text { Year }\end{array}$} & \multicolumn{2}{|c|}{ Avlation Gasoline } & \multicolumn{2}{|c|}{ Kerosene-Type Jet Fuel } & \multicolumn{2}{|c|}{ Propane } & \multicolumn{2}{|c|}{ Kerosene } \\
\hline & $\begin{array}{l}\text { Sales to } \\
\text { End Users }\end{array}$ & $\begin{array}{l}\text { Sales for } \\
\text { Resale }\end{array}$ & $\begin{array}{l}\text { Sales to } \\
\text { End Users }\end{array}$ & $\begin{array}{l}\text { Sales for } \\
\text { Resale }\end{array}$ & $\begin{array}{l}\text { Sales to } \\
\text { End Users }\end{array}$ & $\begin{array}{l}\text { Sales for } \\
\text { Resale }\end{array}$ & $\begin{array}{l}\text { Sales to } \\
\text { End Users }\end{array}$ & $\begin{array}{l}\text { Sales for } \\
\text { Resale }\end{array}$ \\
\hline \multicolumn{9}{|l|}{ United States } \\
\hline 1983 & 125.5 & 117.8 & 87.8 & 85.4 & 70.9 & 48.4 & 96.1 & 89.2 \\
\hline 1984 & 123.4 & 116.5 & 84.2 & 83.0 & 73.7 & 45.0 & 103.6 & 91.6 \\
\hline 1985 & 120.1 & 113.0 & 79.6 & 79.4 & 71.7 & 39.8 & 103.0 & 87.4 \\
\hline 1986 & 101.1 & 91.2 & 52.9 & 49.5 & 74.5 & 29.0 & 79.0 & 60.6 \\
\hline 1987 & 90.7 & 85.9 & 54.3 & 53.8 & 70.1 & 25.2 & 77.0 & 59.2 \\
\hline 1988 & 89.1 & 85.0 & 51.3 & 49.5 & 71.4 & 24.0 & 73.8 & 54.9 \\
\hline 1989 & 99.5 & 95.0 & 59.2 & 58.3 & 61.5 & 24.7 & 70.9 & 66.9 \\
\hline 1990 & 112.0 & 106.3 & 76.6 & 77.3 & 74.5 & 38.6 & 92.3 & 83.9 \\
\hline 1991 & 104.7 & 100.1 & 65.2 & 65.0 & 73.0 & 34.9 & 83.8 & 72.2 \\
\hline 1992 & 102.7 & 99.1 & 61.0 & 60.5 & 64.3 & 32.8 & 78.8 & 63.2 \\
\hline 1993 & 99.0 & 96.5 & 58.0 & 57.7 & 67.3 & 35.1 & 75.4 & 60.4 \\
\hline 1994 & 95.7 & 93.3 & 53.4 & 53.4 & 77.6 & 33.6 & 66.0 & 61.8 \\
\hline \multicolumn{9}{|l|}{ PAD District I } \\
\hline 1983 & 127.8 & 123.0 & 87.0 & 87.8 & 91.3 & 52.8 & 94.5 & 90.1 \\
\hline 1984 & 124.7 & 119.5 & 83.5 & 85.0 & 93.3 & 50.9 & 106.0 & 92.2 \\
\hline 1985 & 121.4 & 115.3 & 78.5 & 82.2 & 91.5 & 44.9 & 104.9 & 88.1 \\
\hline 1986 & 100.6 & 91.8 & 52.8 & 52.2 & 86.0 & 32.7 & 81.0 & 61.6 \\
\hline 1987 & 90.9 & 85.0 & 54.1 & 55.6 & 82.3 & 31.0 & 78.1 & 58.9 \\
\hline 1988 & 89.5 & 82.9 & 51.2 & 51.3 & 84.8 & 29.8 & 73.3 & 55.3 \\
\hline 1989 & 99.2 & 92.2 & 59.1 & 60.1 & 75.8 & 29.2 & 69.3 & 67.2 \\
\hline 1990 & 112.3 & 105.3 & 75.9 & 78.3 & 91.8 & 45.0 & 86.4 & 84.4 \\
\hline 1991 & 105.6 & 100.3 & 65.3 & 67.2 & $W$ & 40.5 & 81.0 & 74.0 \\
\hline 1992 & 101.9 & 97.9 & 60.9 & 62.5 & $w$ & 38.4 & 75.1 & 64.0 \\
\hline 1993 & 97.2 & 94.3 & 56.7 & 58.4 & 85.8 & 38.3 & 73.1 & 61.1 \\
\hline 1994 & 94.9 & 92.5 & 52.8 & 54.9 & 94.9 & 40.1 & 69.7 & 62.8 \\
\hline \multicolumn{9}{|l|}{ Subdistrict IA } \\
\hline 1983 & 129.6 & 129.5 & 93.3 & 100.5 & 99.9 & 57.5 & 96.3 & 90.3 \\
\hline 1984 & 128.2 & 126.6 & 87.2 & 95.8 & 99.7 & 53.5 & 113.3 & 96.3 \\
\hline 1985 & 124.3 & 122.3 & 82.3 & 83.6 & 99.7 & 48.6 & 106.9 & 91.2 \\
\hline 1986 ............................................ & 103.1 . & 102.7 & 57.4 & 53.6 & $W$ & 37.1 & 82.0 & 68.1 \\
\hline 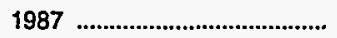 & 96.7 & 92.7 & 56.4 & 54.5 & W & 34.3 & 75.3 & 58.4 \\
\hline 1988 & w & 87.7 & 54.5 & 54.9 & $w$ & 32.9 & 71.1 & 57.0 \\
\hline 1989 & $W$ & 98.2 & 62.7 & 63.0 & 89.6 & 29.3 & 66.6 & 67.8 \\
\hline 1990 & W & 114.9 & 79.9 & 81.2 & $w$ & 45.7 & 84.4 & 84.5 \\
\hline 1991 & $w$ & 104.2 & 68.4 & 69.1 & $w$ & 41.9 & 75.0 & 72.7 \\
\hline 1992 & W & W & 63.7 & 65.8 & $W$ & 38.9 & 63.2 & 63.3 \\
\hline 1993 & W & $w$ & 59.8 & 60.9 & $w$ & 40.3 & 63.3 & 60.6 \\
\hline 1994 & $w$ & $w$ & 56.1 & 59.8 & 102.4 & 46.7 & 68.9 & 62.6 \\
\hline \multicolumn{9}{|l|}{ Connecticut } \\
\hline 1983 & - & - & 96.3 & W & 94.5 & 54.1 & W & 91.2 \\
\hline 1984 & - & - & 89.2 & $W$ & 92.7 & 51.6 & 103.3 & 98.6 \\
\hline 1985 & - & - & 84.9 & $W$ & 98.5 & 46.4 & 96.2 & 91.5 \\
\hline 1986 & - & - & 60.7 & 62.4 & 93.6 & 34.8 & 65.5 & 62.8 \\
\hline 1987 & - & - & 58.6 & 52.0 & 95.4 & 33.3 & $W$ & 58.5 \\
\hline 1988 & NA & NA & 54.0 & 53.2 & 92.4 & 31.8 & $w$ & 58.5 \\
\hline 1989 & NA & NA & 63.1 & 62.1 & 81.4 & 29.2 & $W$ & 68.2 \\
\hline 1990 & $W$ & $W$ & 79.8 & 85.7 & $w$ & 46.2 & $w$ & 81.4 \\
\hline 1991 & $\mathbf{W}$ & W & 68.9 & $w$ & $W$ & 41.4 & $w$ & 74.1 \\
\hline 1992 & $W$ & $\mathbf{W}$ & 63.2 & $\mathbf{W}$ & $W$ & 39.2 & $W$ & 64.6 \\
\hline 1993 & $W$ & $W$ & 59.6 & 61.0 & $w$ & 41.7 & 63.7 & 63.1 \\
\hline 1994 & $W$ & 95.7 & 56.0 & 56.7 & - & - & $w$ & 64.9 \\
\hline
\end{tabular}

See footnotes at end of table. 
Table A2. Refiner/Reseller Prices of Aviation Fuels, Propane, and Kerosene, by PAD District, 1983-Present

(Cents per Gallon Excluding Taxes) - Continued

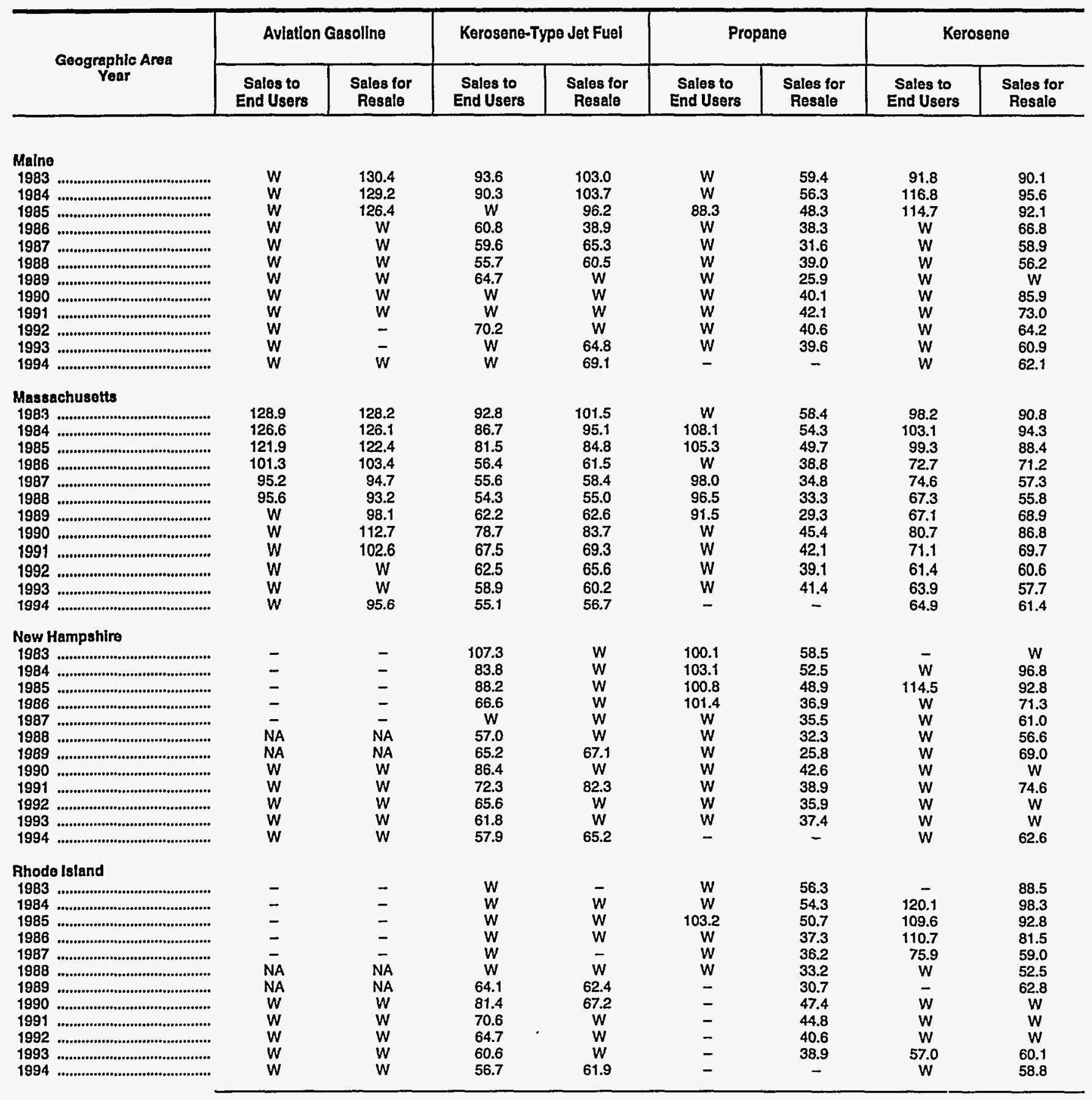

See footnotes at end of table. 
Table A2. Refiner/Reseller Prices of Aviation Fuels, Propane, and Kerosene, by PAD District, 1983-Present

(Cents per Gallon Excluding Taxes) - Continued

\begin{tabular}{|c|c|c|c|c|c|c|c|c|}
\hline \multirow{2}{*}{$\begin{array}{c}\text { Geographic Area } \\
\text { Year }\end{array}$} & \multicolumn{2}{|c|}{ Aviation Gasoline } & \multicolumn{2}{|c|}{ Kerosene-Type Jet Fuel } & \multicolumn{2}{|c|}{ Propane } & \multicolumn{2}{|c|}{ Kerosene } \\
\hline & $\begin{array}{l}\text { Sales to } \\
\text { End Users }\end{array}$ & $\begin{array}{l}\text { Sales for } \\
\text { Resale }\end{array}$ & $\begin{array}{l}\text { Sales to } \\
\text { End Users }\end{array}$ & $\begin{array}{l}\text { Sales for } \\
\text { Resale }\end{array}$ & $\begin{array}{l}\text { Sales to } \\
\text { End Users }\end{array}$ & $\begin{array}{c}\text { Sales for } \\
\text { Resale }\end{array}$ & $\begin{array}{l}\text { Sales to } \\
\text { End Users }\end{array}$ & $\begin{array}{c}\text { Sales for } \\
\text { Resale }\end{array}$ \\
\hline \multicolumn{9}{|l|}{ Vermont } \\
\hline 1983 & - & - & 93.3 & $W$ & $W$ & 58.6 & 95.6 & 94.1 \\
\hline 1984 & - & - & $w$ & $w$ & 99.7 & 55.1 & $W$ & 95.7 \\
\hline 1985 & - & - & W & W & 98.3 & 49.8 & W & 92.6 \\
\hline 1986 & - & - & $W$ & $W$ & $w$ & 36.8 & 103.9 & 68.0 \\
\hline 1987 & - & - & W & W & W & 36.5 & 74.7 & 61.5 \\
\hline 1988 & NA & NA & W & 60.5 & $w$ & 33.4 & 73.3 & 56.8 \\
\hline 1989 & NA & NA & 72.0 & 65.7 & $W$ & 31.5 & $W$ & 69.7 \\
\hline 1990 & $w$ & $W$ & 89.1 & 88.5 & $W$ & 48.7 & $W$ & 85.1 \\
\hline 1991 & $W$ & $W$ & $w$ & 89.2 & W & 44.7 & W & 73.0 \\
\hline 1992 & $w$ & $W$ & W & $W$ & $W$ & 40.9 & $W$ & $W$ \\
\hline 1993 & W & $W$ & 69.6 & 65.5 & W & 40.9 & $W$ & $w$ \\
\hline 1994 & $w$ & $W$ & 64.2 & 63.8 & - & - & W & 62.9 \\
\hline \multicolumn{9}{|l|}{ Subdistrict IB } \\
\hline 1983 & 131.5 & 129.9 & 86.6 & 85.9 & 88.9 & 52.9 & 93.7 & 90.3 \\
\hline 1984 & 129.9 & 124.1 & 83.2 & 83.7 & 92.9 & 51.6 & 106.2 & 92.5 \\
\hline 1985 & W & 117.7 & 78.1 & 81.1 & 93.3 & 45.5 & 108.2 & 88.3 \\
\hline 1986 & $W$ & 88.6 & 52.5 & 50.1 & 89.9 & 32.1 & 82.0 & 61.0 \\
\hline 1987 & $w$ & 86.7 & 54.4 & 54.9 & 86.1 & 31.5 & 75.5 & 59.1 \\
\hline 1988 & 92.8 & 81.5 & 51.7 & 50.0 & 89.2 & 29.9 & 70.7 & 55.3 \\
\hline 1989 & $W$ & 92.0 & 59.2 & 58.9 & 80.6 & 28.7 & 65.7 & 67.0 \\
\hline 1990 & $W$ & 106.8 & 75.7 & 76.8 & $W$ & 43.7 & 82.6 & 82.6 \\
\hline 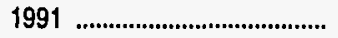 & W & 102.5 & 65.0 & 66.5 & 95.4 & 38.9 & 77.4 & 73.4 \\
\hline 1992 & $W$ & 99.8 & 60.4 & 61.2 & $W$ & 37.1 & 72.0 & 62.8 \\
\hline 1993 & 99.2 & 93.3 & 56.3 & 57.1 & $\ddot{w}$ & 37.5 & 69.8 & 61.1 \\
\hline 1994 & 99.1 & 93.0 & 52.6 & 54.0 & 104.4 & 39.7 & 67.4 & 64.4 \\
\hline \multicolumn{9}{|l|}{ Delaware } \\
\hline 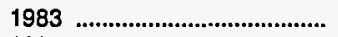 & - & - & 108.0 & $w$ & 83.2 & 51.8 & 93.1 & 85.9 \\
\hline 1984 & - & - & 96.1 & 88.2 & 91.7 & 51.0 & 108.4 & 90.2 \\
\hline 1985 & - & - & 89.5 & $w$ & $94.9^{\circ}$ & 44.5 & 111.7 & 77.6 \\
\hline 1986 & - & - & 65.8 & W & $W$ & $w$ & 93.3 & 55.8 \\
\hline 1987 & - & - & $w$ & W & $W$ & 30.1 & 79.3 & 57.2 \\
\hline 1988 & NA & NA & 56.1 & $w$ & $W$ & $w$ & 81.2 & 55.9 \\
\hline 1989 & NA & NA & 64.8 & W & $W$ & W & 87.9 & 72.2 \\
\hline 1990 & $w$ & $w$ & 85.4 & $W$ & $W$ & W & 103.2 & 86.3 \\
\hline 1991 & $W$ & W & 74.4 & 75.1 & W & $w$ & $W$ & 74.9 \\
\hline 1992 & W & W & 69.4 & 66.5 & - & $w$ & $W$ & 65.1 \\
\hline 1993 & $w$ & $W$ & 65.9 & $w$ & - & $w$ & $w$ & 61.4 \\
\hline 1994 & W & $W$ & 63.7 & $W$ & - & - & $W$ & 83.2 \\
\hline \multicolumn{9}{|l|}{ District of Columbla } \\
\hline 1983 & - & - & $w$ & - & W & - & W & $W$ \\
\hline 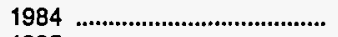 & - & - & W & $w$ & W & - & W & 96.2 \\
\hline 1985 & - & - & $W$ & - & W & - & W & 89.6 \\
\hline 1986 & - & - & $w$ & - & W & - & w & $W$ \\
\hline 1987 & - & - & - & W & W & - & W & W \\
\hline 1988 & NA & NA & - & - & W & - & w & $w$ \\
\hline 1989 & NA & NA & - & - & - & - & - & $W$ \\
\hline 1990 & NA & NA & - & - & - & - & - & W \\
\hline 1991 & NA & NA & - & - & - & - & - & $W$ \\
\hline 1992 & $w$ & - & - & - & - & - & - & $W$ \\
\hline 1993 & $W$ & - & $w$ & - & - & - & - & $W$ \\
\hline 1994 & $W$ & - & - & - & - & - & - & $W$ \\
\hline
\end{tabular}

See footnotes at end of table. 
Table.A2. Refiner/Reseller Prices of Aviation Fuels, Propane, and Kerosene, by PAD District, 1983-Present

(Cents per Gallon Excluding Taxes) - Continued

\begin{tabular}{|c|c|c|c|c|c|c|c|c|}
\hline \multirow{2}{*}{$\underset{\text { Year }}{\text { Geographic Area }}$} & \multicolumn{2}{|c|}{ Aviation Gasoline } & \multicolumn{2}{|c|}{ Kerosene-Type Jet Fuel } & \multicolumn{2}{|c|}{ Propane } & \multicolumn{2}{|c|}{ Kerosene } \\
\hline & $\begin{array}{l}\text { Sales to } \\
\text { End Users }\end{array}$ & $\begin{array}{c}\text { Sales for } \\
\text { Resale }\end{array}$ & $\begin{array}{c}\text { Sales to } \\
\text { End Users }\end{array}$ & $\begin{array}{c}\text { Sales for } \\
\text { Resale }\end{array}$ & $\begin{array}{c}\text { Sales to } \\
\text { End Users }\end{array}$ & $\begin{array}{c}\text { Sales for } \\
\text { Resale }\end{array}$ & $\begin{array}{l}\text { Sales to } \\
\text { End Users }\end{array}$ & $\begin{array}{c}\text { Sales for } \\
\text { Resale }\end{array}$ \\
\hline \multicolumn{9}{|l|}{ Maryland } \\
\hline 1983 & - & - & 86.9 & $W$ & 88.4 & 53.4 & 103.4 & 91.2 \\
\hline 1984 & - & $\rightarrow$ & 83.1 & 88.6 & 92.1 & 53.1 & 109.9 & 91.8 \\
\hline 1985 & - & - & 78.3 & 87.0 & 95.0 & 47.5 & 106.2 & 89.9 \\
\hline 1986 & - & - & 54.1 & 63.9 & 92.8 & 36.6 & 73.1 & 62.2 \\
\hline 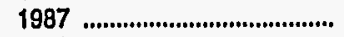 & - & - & 54.1 & 58.0 & 89.7 & 33.7 & 64.1 & 59.4 \\
\hline 1988 & NA & NA & 50.6 & 57.6 & W & 33.4 & 60.7 & 56.5 \\
\hline 1989 & NA & NA & 59.1 & 65.1 & 82.6 & 28.2 & 56.4 & 67.4 \\
\hline 1990 & W & $W$ & 73.8 & 78.7 & $W$ & 61.6 & 64.1 & 87.7 \\
\hline 1991 & $\ddot{w}$ & $W$ & 64.5 & 65.9 & W & 38.2 & 72.2 & 75.9 \\
\hline $1992 \ldots$ & $W$ & $W$ & 60.6 & 62.9 & $W$ & 35.4 & 64.5 & 63.8 \\
\hline 1993 & W & $W$ & 56.2 & 58.2 & $W$ & 37.6 & 58.6 & 61.5 \\
\hline 1994 & W & W & 52.0 & 53.9 & - & - & 62.6 & 65.5 \\
\hline \multicolumn{9}{|l|}{ New Jersey } \\
\hline 1983 & 128.8 & 126.5 & 85.9 & 84.6 & 97.0 & 52.1 & $w$ & 89.8 \\
\hline 1984 & W & 119.0 & 82.7 & 84.0 & 101.7 & 51.4 & $w$ & 91.9 \\
\hline 1985 & $w$ & 113.0 & 77.7 & 81.3 & 102.9 & 44.6 & 90.8 & 86.8 \\
\hline 1986 & $w$ & 85.7 & 51.9 & 49.1 & 98.1 & 31.4 & 49.8 & 58.3 \\
\hline 1987 & $\ddot{w}$ & 84.3 & 54.2 & 54.7 & 95.0 & 31.0 & $w$ & 57.0 \\
\hline 1988 & w & W & 51.2 & 49.6 & 93.4 & 29.9 & 54.1 & 53.3 \\
\hline 1989 & $\ddot{w}$ & W & 58.6 & 57.9 & 83.6 & 27.8 & $w$ & 64.1 \\
\hline 1990 & W & $W$ & 75.6 & 75.2 & 87.1 & 45.5 & 64.5 & 77.8 \\
\hline 1991 & w & $W$ & 64.7 & 65.7 & 78.7 & 40.1 & 73.5 & 69.9 \\
\hline 1992 & $w$ & W & 60.0 & 60.7 & 87.6 & 36.3 & 64.3 & 61.8 \\
\hline 1993 & 97.6 & 90.4 & 56.0 & 56.6 & 94.0 & 36.7 & 62.5 & 58.4 \\
\hline 1994 & 98.5 & 92.1 & 52.2 & 53.6 & - & - & $w$ & 62.1 \\
\hline \multicolumn{9}{|l|}{ Now York } \\
\hline 1983 & 131.6 & 132.6 & 93.7 & 104.0 & 101.7 & 54.4 & 98.3 & 92.8 \\
\hline 1984 & W & 128.6 & 92.7 & 94.2 & 101.7 & 52.0 & 117.9 & 93.2 \\
\hline 1985 & $W$ & 124.1 & 87.9 & 83.7 & 102.5 & 46.0 & 115.8 & 89.7 \\
\hline 1986 & W & 105.0 & 59.7 & 55.6 & 100.7 & 33.8 & 102.5 & 63.3 \\
\hline 1987 ............................................ & $W$ & 97.3 & 61.4 & 64.7 & 98.4 & 33.1 & 88.3 & 60.3 \\
\hline 1888 & $W$ & 94.9 & 56.0 & 58.4 & 97.5 & 31.7 & 81.9 & 57.6 \\
\hline 1989 & W & $W$ & 63.4 & 64.9 & 85.3 & 29.7 & 70.2 & 68.5 \\
\hline 1990 & W & 118.0 & 81.4 & 85.5 & $w$ & 46.3 & 88.7 & 83.9 \\
\hline 1991 & W & 108.7 & 69.9 & 73.3 & $W$ & 41.7 & 80.9 & 75.3 \\
\hline 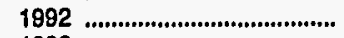 & W & 98.2 & 65.3 & 64.5 & $W$ & 39.1 & 75.3 & 63.4 \\
\hline 1993 & $W$ & 93.7 & 60.3 & 59.4 & $W$ & 40.4 & 72.2 & 62.8 \\
\hline 1994 & W & 94.5 & 55.9 & 58.2 & - & - & 73.0 & 66.8 \\
\hline \multicolumn{9}{|l|}{ Pennaylvania } \\
\hline 1983 & 132.7 & 129.6 & 88.1 & 84.4 & 74.0 & 52.2 & 105.3 & 90.5 \\
\hline 1984 & 130.4 & 126.9 & 84.3 & 80.8 & 79.2 & 51.2 & 117.1 & 92.6 \\
\hline 1985 & W & 121.1 & 78.9 & 79.6 & 76.5 & 45.6 & 109.8 & 88.8 \\
\hline 1986 & 103.6 & 97.6 & 52.8 & 49.2 & 74.0 & 31.1 & 88.2 & 62.1 \\
\hline 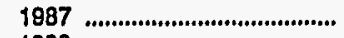 & 92.5 & 86.2 & 54.3 & 54.8 & 68.1 & 30.8 & 82.3 & 59.8 \\
\hline 1988 ..................................... & 90.3 & 84.2 & 52.0 & 49.5 & 74.7 & 29.3 & 82.1 & 55.0 \\
\hline 1989 & 100.2 & 91.0 & 59.9 & 60.1 & 71.9 & 28.3 & 79.6 & 67.9 \\
\hline 1890 & 114.1 & 108.0 & 75.4 & 78.4 & $W$ & 42.9 & 101.5 & 84.9 \\
\hline 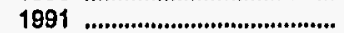 & $W$ & 104.3 & 65.0 & 64.7 & $W$ & 38.3 & 91.8 & 73.1 \\
\hline 1992 & W & 101.8 & 60.6 & 60.9 & $W$ & 36.6 & 79.8 & 62.6 \\
\hline $1893 \ldots \ldots \ldots \ldots$ & $w$ & 97.3 & 56.3 & 56.7 & w & 36.8 & 75.7 & 61.3 \\
\hline 1994 & W & 93.1 & 52.7 & 52.7 & - & - & 78.1 & 63.6 \\
\hline
\end{tabular}

See footnotes at end of table. 
Table A2. Refiner/Reseller Prices of Aviation Fuels, Propane, and Kerosene, by PAD District, 1983-Present

(Cents per Gallon Excluding Taxes) - Continued

\begin{tabular}{|c|c|c|c|c|c|c|c|c|}
\hline \multirow{2}{*}{$\begin{array}{c}\text { Geographic Area } \\
\text { Year }\end{array}$} & \multicolumn{2}{|c|}{ Aviation Gasoline } & \multicolumn{2}{|c|}{ Kerosene-Type Jet Fuel } & \multicolumn{2}{|c|}{ Propane } & \multicolumn{2}{|c|}{ Kerosene } \\
\hline & $\begin{array}{l}\text { Sales to } \\
\text { End Users }\end{array}$ & $\begin{array}{c}\text { Sales for } \\
\text { Resale }\end{array}$ & $\begin{array}{l}\text { Sales to } \\
\text { End Users }\end{array}$ & $\begin{array}{c}\text { Sales for } \\
\text { Resale }\end{array}$ & $\begin{array}{l}\text { Sales to } \\
\text { End Users }\end{array}$ & $\begin{array}{c}\text { Sales for } \\
\text { Resale }\end{array}$ & $\begin{array}{l}\text { Sales to } \\
\text { End Users }\end{array}$ & $\begin{array}{c}\text { Sales for } \\
\text { Resale }\end{array}$ \\
\hline \multicolumn{9}{|l|}{ Subdistrict IC } \\
\hline 1983 & 125.2 & 119.5 & 86.3 & 91.7 & 89.9 & 52.1 & 99.4 & 89.8 \\
\hline 1984 & 121.2 & 116.7 & 83.0 & 88.2 & 89.7 & 50.1 & 101.5 & 90.9 \\
\hline 1985 & 118.7 & 113.0 & 78.3 & 85.0 & 84.4 & 43.9 & 93.2 & 87.2 \\
\hline 1986 & 99.2 & 91.9 & 52.3 & 60.1 & 77.9 & 32.5 & 76.6 & 61.4 \\
\hline 1987 & 88.1 & 83.3 & 53.5 & 57.7 & 75.1 & 30.2 & 90.7 & 58.8 \\
\hline 1988 & 86.2 & 82.4 & 50.2 & 55.0 & 79.2 & 29.3 & 89.6 & 55.0 \\
\hline 1989 & 97.1 & 91.3 & 58.3 & 62.5 & 71.5 & 29.5 & 90.4 & 67.4 \\
\hline 1990 & 109.5 & 103.7 & 75.3 & 81.6 & 87.6 & 45.8 & 105.1 & 86.5 \\
\hline 1991 & 103.4 & 99.3 & 64.9 & 69.2 & 91.1 & 41.4 & 105.4 & 74.8 \\
\hline 1992 & 99.8 & 97.0 & 60.8 & 65.9 & 86.6 & 39.2 & 96.0 & 65.1 \\
\hline 1993 & 95.4 & 94.6 & 56.6 & 60.6 & 82.4 & 38.6 & 89.9 & 61.2 \\
\hline 1994 & 91.9 & 91.9 & 52.4 & 55.9 & 87.5 & 39.4 & 82.8 & 61.2 \\
\hline \multicolumn{9}{|l|}{ Florida } \\
\hline 1983 & 122.7 & 119.1 & 86.9 & 90.1 & 103.5 & 53.2 & 96.8 & 93.7 \\
\hline 1984 & 118.2 & 115.5 & 84.2 & 86.1 & 102.4 & 51.4 & 97.9 & 93.1 \\
\hline 1985 & 116.4 & 112.0 & 79.7 & 83.6 & 96.4 & 45.1 & $W$ & 88.9 \\
\hline 1986 & 97.1 & 91.5 & 56.6 & 57.7 & 88.0 & 34.5 & 63.6 & 67.3 \\
\hline 1987 & 85.4 & 82.5 & 55.0 & 56.3 & 80.8 & 31.2 & 83.5 & 58.8 \\
\hline 1988 & 84.4 & 80.8 & 51.6 & 54.5 & 86.4 & 31.3 & 122.4 & 55.6 \\
\hline 1989 & 95.4 & 89.9 & 59.8 & 62.5 & 80.2 & 31.0 & 121.5 & 70.1 \\
\hline 1990 & 107.6 & 102.2 & 76.2 & 84.9 & $W$ & 47.1 & 108.2 & 91.0 \\
\hline 1991 & 101.5 & 97.2 & 66.5 & 72.3 & W & 44.3 & 116.0 & 75.6 \\
\hline 1992 & 97.9 & 94.7 & 61.5 & 66.5 & W & 42.0 & 107.2 & 65.3 \\
\hline 1993 & 93.3 & 92.0 & 57.1 & 60.9 & $W$ & 41.6 & 86.7 & 62.2 \\
\hline 1994 & 88.6 & 88.9 & 53.0 & 56.6 & - & - & NA & 60.1 \\
\hline \multicolumn{9}{|l|}{ Georgia } \\
\hline 1983 & 124.3 & 119.9 & 84.6 & 96.5 & 79.9 & 50.6 & 96.7 & 89.2 \\
\hline 1984 & 119.8 & 118.3 & 81.1 & 92.8 & 79.9 & 49.0 & 93.5 & 89.5 \\
\hline 1985 & 117.8 & 114.3 & 76.4 & 90.0 & $W$ & 42.9 & 89.6 & 85.9 \\
\hline 1986 & 101.0 & 92.6 & 47.4 & 66.7 & 71.6 & 31.2 & 88.2 & 62.1 \\
\hline 1987 & 88.3 & 83.7 & 50.9 & 58.4 & 70.7 & 28.8 & 106.2 & 58.6 \\
\hline 1988 & 86.8 & 84.3 & 47.8 & 53.5 & 73.0 & 27.8 & 115.0 & 54.8 \\
\hline 1989 & 98.0 & 93.1 & 55.6 & 60.9 & 67.0 & 28.1 & 106.4 & 67.0 \\
\hline 1990 & 107.8 & 105.1 & 73.6 & 75.7 & $w$ & 44.5 & 112.4 & 86.2 \\
\hline 1991 & 103.7 & 101.6 & 62.2 & 65.8 & $w$ & 40.3 & 120.1 & 74.4 \\
\hline 1992 & 101.2 & 98.9 & 59.3 & 64.1 & W & 37.4 & 118.7 & 63.9 \\
\hline 1993 & 96.7 & 97.4 & 55.7 & 58.6 & $w$ & 36.5 & NA & 60.4 \\
\hline 1994 & 95.2 & 94.0 & 51.3 & 53.5 & - & - & NA & 60.9 \\
\hline \multicolumn{9}{|l|}{ North Carolina } \\
\hline 1983 & $w$ & 119.8 & 86.4 & 92.9 & 83.7 & 52.0 & 94.1 & 89.4 \\
\hline 1984 & $w$ & 115.6 & 83.3 & 91.7 & 84.3 & 49.6 & 96.3 & 90.9 \\
\hline 1985 & W & 112.2 & 77.9 & 86.3 & 80.0 & 43.3 & 91.5 & 87.5 \\
\hline 1986 & w & 91.1 & 52.0 & 63.0 & 75.4 & 31.4 & 77.8 & 61.5 \\
\hline 1987 & w & 83.6 & 53.5 & 59.6 & 72.5 & 30.2 & 89.9 & 58.9 \\
\hline 1988 & w & 83.5 & 50.1 & 53.6 & 75.7 & 28.5 & 87.7 & 55.5 \\
\hline 1989 & w & 92.0 & 58.0 & 65.2 & 69.3 & 28.9 & 85.3 & 67.5 \\
\hline 1990 & w & 105.0 & 76.3 & 80.3 & 81.2 & 45.4 & 106.1 & 88.3 \\
\hline 1991 & 107.2 & 101.5 & 64.6 & 69.5 & $w$ & 40.7 & 106.8 & 75.7 \\
\hline 1992 & 105.2 & $w$ & 60.5 & 68.0 & W & 38.9 & 93.1 & 65.6 \\
\hline 1993 & 99.7 & $W$ & 56.6 & 61.4 & 71.0 & 38.1 & 95.3 & 61.1 \\
\hline 1994 & W & W & 52.3 & 57.6 & - & - & NA & 60.4 \\
\hline
\end{tabular}

See footnotes at end of table. 
Table A2. Refiner/Reseller Prices of Aviation Fuels, Propane, and Kerosene, by PAD District, 1983-Present

(Cents per Gallon Excluding Taxes) - Continued

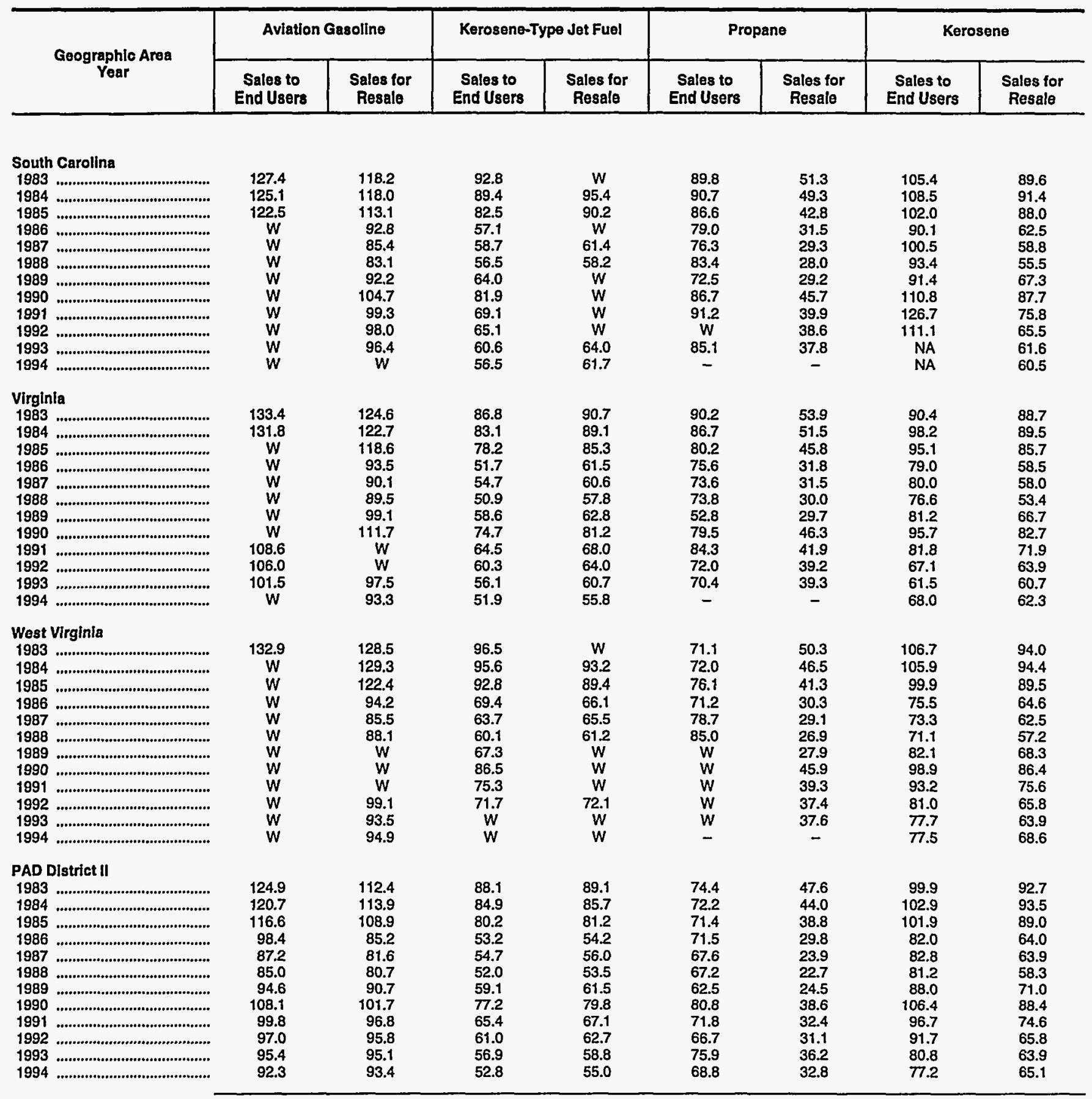

See footnotes at end of table. 
Table A2. Refiner/Reseller Prices of Aviation Fuels, Propane, and Kerosene, by PAD District, 1983-Present (Cents per Gallon Excluding Taxes) - Continued

\begin{tabular}{|c|c|c|c|c|c|c|c|c|}
\hline \multirow{2}{*}{$\underset{\text { Gear }}{\text { Geographic Area }}$} & \multicolumn{2}{|c|}{ Aviation Gasoline } & \multicolumn{2}{|c|}{ Kerosene-Type Jet Fuel } & \multicolumn{2}{|c|}{ Propane } & \multicolumn{2}{|c|}{ Kerosene } \\
\hline & $\begin{array}{l}\text { Sales to } \\
\text { End Users }\end{array}$ & $\begin{array}{c}\text { Sales for } \\
\text { Resale }\end{array}$ & $\begin{array}{l}\text { Sales to } \\
\text { End Users }\end{array}$ & $\begin{array}{c}\text { Sales for } \\
\text { Resale }\end{array}$ & $\begin{array}{l}\text { Sales to } \\
\text { End Users }\end{array}$ & $\begin{array}{c}\text { Sales for } \\
\text { Resale }\end{array}$ & $\begin{array}{l}\text { Seles to } \\
\text { End Users }\end{array}$ & $\begin{array}{c}\text { Sales for } \\
\text { Resale }\end{array}$ \\
\hline \multicolumn{9}{|l|}{ Illinois } \\
\hline 1983 & $W$ & 118.0 & 89.5 & 92.2 & 64.0 & 47.7 & 101.2 & 96.4 \\
\hline 1984 & $\ddot{W}$ & 112.3 & 86.7 & 91.0 & 67.4 & 46.0 & 91.2 & 91.8 \\
\hline 1985 & $\ddot{w}$ & 109.2 & 81.0 & 83.2 & 76.3 & 42.8 & 90.3 & 85.0 \\
\hline 1986 & W & 88.4 & 57.0 & 60.3 & 63.7 & 31.9 & 67.6 & 64.6 \\
\hline 1987 & $W$ & 82.9 & 56.8 & 61.1 & 59.7 & 25.1 & $w$ & 61.7 \\
\hline 1988 & 84.1 & 81.9 & 51.8 & 58.1 & 60.5 & 23.3 & 63.0 & 52.6 \\
\hline 1989 & W & 92.6 & 58.3 & 63.5 & 62.1 & 25.2 & 74.0 & 67.2 \\
\hline 1990 & $W$ & 103.5 & 78.9 & 87.0 & 82.4 & 39.8 & 92.0 & 87.0 \\
\hline 1991 & $W$ & 96.0 & 64.1 & 65.8 & 73.7 & 32.8 & 92.7 & 70.9 \\
\hline 1992 & $W$ & W & 60.0 & 60.2 & 67.6 & 32.1 & 87.0 & 61.0 \\
\hline 1993 & $W$ & $W$ & 55.6 & 56.8 & 74.3 & 36.3 & 78.5 & 60.8 \\
\hline 1994 & W & W & 51.6 & 54.8 & - & - & 79.4 & 61.7 \\
\hline \multicolumn{9}{|l|}{ Indlane } \\
\hline 1983 & 122.2 & 118.4 & 86.7 & 89.0 & 79.7 & 49.2 & 96.1 & 88.7 \\
\hline 1984 & 114.9 & 112.8 & 82.9 & 86.1 & 75.6 & 47.2 & 105.9 & 92.1 \\
\hline 1985 & 109.4 & 105.9 & 78.4 & 81.2 & 74.3 & 42.3 & 122.1 & 88.7 \\
\hline 1986 & 108.3 & 84.5 & 51.3 & 51.6 & 68.7 & 30.9 & 88.5 & 64.9 \\
\hline 1987 & 86.5 & 74.0 & 53.4 & 53.2 & 65.8 & 26.5 & 95.0 & 63.8 \\
\hline 1988 & 83.8 & 74.7 & 50.5 & 51.0 & 64.7 & 25.0 & 85.6 & 56.4 \\
\hline 1989 & 91.9 & 86.1 & 58.4 & 59.4 & 68.5 & 28.2 & 78.9 & 71.0 \\
\hline 1990 & 105.3 & 99.1 & 75.9 & 79.7 & $W$ & 43.7 & 100.5 & 89.7 \\
\hline 1991 & 98.1 & 93.4 & 64.2 & 64.2 & 82.7 & 36.4 & 97.1 & 74.4 \\
\hline 1992 & 95.3 & 94.0 & 59.6 & 59.4 & 72.7 & 34.8 & 100.0 & 64.3 \\
\hline 1993 & 96.4 & 94.6 & 55.4 & 56.5 & 79.4 & 37.8 & 103.7 & 62.7 \\
\hline 1994 & 95.3 & 94.1 & 51.6 & 53.4 & - & - & 104.9 & 63.4 \\
\hline \multicolumn{9}{|l|}{ lowa } \\
\hline 1983 & - & - & 90.9 & 95.7 & $w$ & 48.8 & $w$ & 93.1 \\
\hline 1984 & - & - & 88.4 & 93.5 & W & 44.7 & $\ddot{W}$ & 94.5 \\
\hline 1985 & - & - & 84.8 & 90.2 & 70.8 & 40.6 & $W$ & 90.7 \\
\hline 1986 & - & - & 58.8 & 60.8 & $w$ & 30.9 & $w$ & 63.0 \\
\hline 1987 & - & - & 57.7 & 63.4 & 56.2 & 25.5 & W & 63.5 \\
\hline 1988 & NA & NA & 55.6 & 58.7 & 54.2 & 23.7 & $W$ & 57.0 \\
\hline 1989 & NA & NA & 61.7 & 65.8 & 45.7 & 28.0 & $W$ & 69.9 \\
\hline $1990 \ldots$ & $W$ & NA & 82.5 & 79.5 & 41.9 & 37.0 & - & 92.3 \\
\hline 1991 & W & NA & 70.3 & 70.7 & $w$ & 33.2 & - & 81.2 \\
\hline 1992 & W & 96.8 & 64.5 & 66.0 & $\ddot{w}$ & 32.2 & - & 70.4 \\
\hline 1993 & $\ddot{w}$ & 95.8 & 61.0 & 65.1 & $w$ & 38.1 & $w$ & 62.7 \\
\hline 1994 & W & 94.3 & 57.5 & 61.6 & - & - & - & 66.7 \\
\hline \multicolumn{9}{|l|}{ Kanses } \\
\hline 1983 & - & - & 89.1 & 86.1 & 61.6 & 46.1 & $w$ & 94.3 \\
\hline 1984 & - & - & 87.1 & 82.1 & 50.7 & 42.3 & $\ddot{w}$ & 94.0 \\
\hline 1985 & - & - & 80.2 & 77.4 & 35.5 & 36.4 & W & 91.9 \\
\hline $1986 \ldots \ldots \ldots \ldots \ldots \ldots \ldots$ & - & - & 50.4 & 50.3 & $w$ & 28.3 & $w$ & 60.0 \\
\hline 1987 & - & - & 54.2 & 53.7 & $W$ & 21.7 & $W$ & 61.1 \\
\hline $1988 \ldots \ldots \ldots \ldots \ldots \ldots$ & NA & NA & 51.4 & 50.2 & $W$ & 20.3 & $w$ & 54.2 \\
\hline 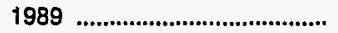 & NA & NA & 57.6 & 57.9 & $w$ & 21.6 & W & 64.8 \\
\hline 1990 & $W$ & NA & 75.2 & 77.0 & 35.4 & 36.4 & $W$ & 82.3 \\
\hline $1991 \ldots$ & $W$ & NA & 65.0 & 70.3 & 29.5 & 29.6 & W & 74.3 \\
\hline 1992 & $W$ & 95.5 & 58.8 & 69.8 & $w$ & 28.1 & $\mathbf{W}$ & 67.7 \\
\hline 1993 & $W$ & 93.1 & 56.5 & 64.8 & 35.9 & 34.3 & . W & 71.3 \\
\hline 1994 & $W$ & 90.5 & 55.7 & 59.9 & - & - & - & 64.6 \\
\hline
\end{tabular}

See footnotes at end of table. 
Table A2. Refiner/Reseller Prices of Aviation Fuels, Propane, and Kerosene, by PAD District, 1983-Present

(Cents per Gallon Excluding Taxes) - Continued

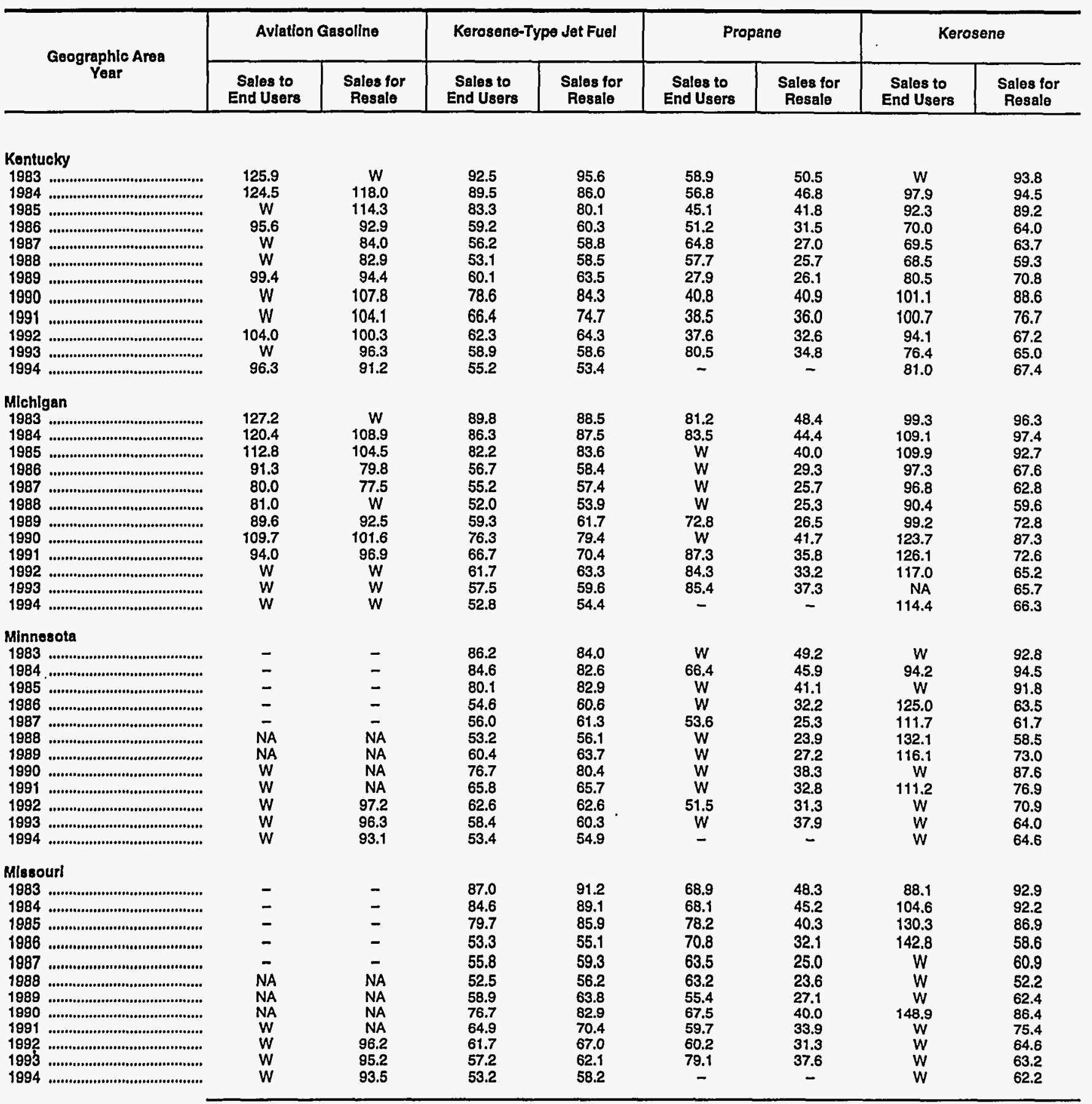

See footnotes at end of table. 
Table A2. Refiner/Reseller Prices of Aviation Fuels, Propane, and Kerosene, by PAD District, 1983-Present

(Cents per Gallon Excluding Taxes) - Continued

\begin{tabular}{c|c|c|c|c|c|c|c|c|}
\hline \multirow{2}{*}{$\begin{array}{c}\text { Geographic Area } \\
\text { Year }\end{array}$} & \multicolumn{3}{|c|}{ Aviation Gasoline } & \multicolumn{3}{c|}{ Kerosene-Type Jet Fuel } & \multicolumn{2}{c|}{ Reropane } \\
\cline { 2 - 6 } & $\begin{array}{c}\text { Sales to } \\
\text { End Users }\end{array}$ & $\begin{array}{c}\text { Sales for } \\
\text { Resale }\end{array}$ & $\begin{array}{c}\text { Sales to } \\
\text { End Users }\end{array}$ & $\begin{array}{c}\text { Sales for } \\
\text { Resale }\end{array}$ & $\begin{array}{c}\text { Sales to } \\
\text { End Users }\end{array}$ & $\begin{array}{c}\text { Seles for } \\
\text { Resale }\end{array}$ & $\begin{array}{c}\text { Sales to } \\
\text { End Users }\end{array}$ & $\begin{array}{c}\text { Sales for } \\
\text { Resale }\end{array}$ \\
\hline
\end{tabular}

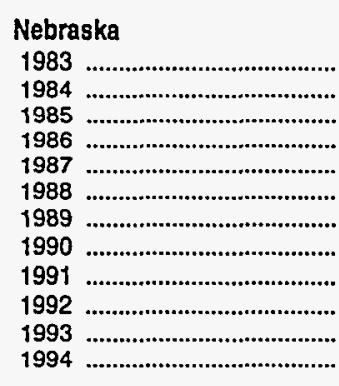

$\begin{array}{lr}W & 116.9 \\ W & 115.5 \\ W & 112.1 \\ W & 86.6 \\ W & 86.1 \\ W & 86.2 \\ W & 91.7 \\ W & 103.0 \\ W & 96.2 \\ W & 95.9 \\ W & 94.9 \\ W & 94.1\end{array}$

$\begin{array}{ll}89.5 & 95.9 \\ 87.7 & 92.4 \\ 83.5 & 87.8 \\ 59.8 & 57.8 \\ 59.1 & 60.4 \\ 55.9 & 58.8 \\ 61.3 & 65.1 \\ 81.4 & 78.3 \\ 67.7 & 73.6 \\ 62.6 & 70.6 \\ 58.5 & 65.3 \\ 53.9 & 61.3\end{array}$

$\begin{array}{cc}66.8 & 49.2 \\ 63.7 & 45.3 \\ 59.4 & 39.8 \\ W & 30.5 \\ W & 24.4 \\ W & 23.0 \\ W & 25.8 \\ W & 37.5 \\ W & 32.3 \\ W & 32.0 \\ 56.5 & 38.3 \\ - & -\end{array}$

$\begin{array}{cc}W & 94.9 \\ W & 93.7 \\ W & 92.3 \\ - & 62.8 \\ \bar{W} & 63.5 \\ - & W \\ - & 69.1 \\ - & 100.4 \\ - & W \\ - & 74.0 \\ - & 69.6 \\ & 66.5\end{array}$

\section{North Dakota}

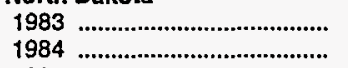

1985

1986

1987

1988

1989

1991

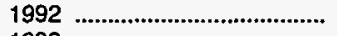

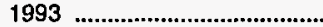

1994

$\begin{array}{llll}- & - & 93.3 & 99.4\end{array}$

- $\quad$ - $\quad$ -

$\begin{array}{lll}- & - & 86.9\end{array}$

$\begin{array}{lll}- & - & 66.1\end{array}$

NA

NA

NA

99.1

96.3

Ohio

1983

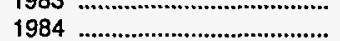

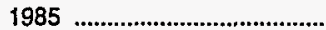

1986

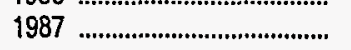

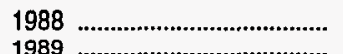

1989

1990

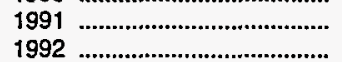

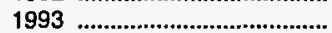

1994

87.9

$$
\text { NA }
$$

NA $\quad 59.0$

NA $\quad 64.4$

$\begin{array}{ll}W & 82.5 \\ W & 69.8\end{array}$

$\begin{array}{ll}W & 69.8 \\ W & 66.0\end{array}$

$\begin{array}{ll}W & 66.0 \\ W & 64.9\end{array}$

64.9
61.7

W $\quad 117.8$

$\begin{array}{ll}W & 114.0 \\ W & 110.1\end{array}$

W $\quad 110.1$

$\begin{array}{cr}W & 83.3 \\ 89.1 & 84.5\end{array}$

$\begin{array}{ll}89.1 & 84.5 \\ 84.6 & 81.3\end{array}$

$\begin{array}{cr}84.6 & 81.3 \\ W & 92.9 \\ W & 105.3\end{array}$

$\begin{array}{lr}W & 95.9 \\ W & 98.3\end{array}$

$\begin{array}{ll}W & 98.3 \\ W & 94.8\end{array}$

$\begin{array}{ll}W & 94.8 \\ W & 96.9 \\ & 94.4\end{array}$

\section{8}

87.2

81.6

52.0

54.5

52.9

60.6
77.4

66.8

62.7

58.1

54.3

$W$
$W$
$W$
$W$
46.8
43.0
31.6
53.2
$W$
$W$
$W$

44.9

96.1
89.2

66.7

62.1

63.3

68.0

85.6
72.0

69.3

69.4

68.0

$86.6 \quad 86$

Oklahoma

1983

1985

.

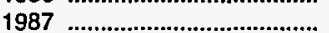

1988

1989

.

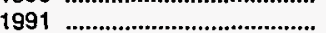

1992

1993

1994

$\begin{array}{rr}119.9 & 97.4 \\ 115.5 & 109.9 \\ 110.3 & 105.6 \\ 89.3 & 82.8 \\ 86.2 & 80.4 \\ 83.3 & 77.2 \\ 88.5 & 86.2 \\ 101.3 & 92.9 \\ 82.7 & 94.1 \\ 90.6 & 91.3 \\ W & 91.9 \\ W & 88.7\end{array}$

86.6
84.2
79.2
53.2
52.7
50.6
57.6
80.1
63.8
59.7
55.6
51.9

90.7

86.8

54.8

57.4

54.7

61.5

87.2

$$
65.9
$$

64.4

60.0

55.6

\section{1}

81.0

80.9
74.5

71.4

73.6

71.6
$W$

$W$
82.5

76.6

81.3

86.5
82.9
80.5
54.7
55.5
52.9
59.6
68.3
67.7
60.8
56.2
53.3

65.5

55.3

60.1

W

$W$
43.0

46.7
46.0

46.0
52.5

52.5
38.6

57.3

$$
41.1
$$

34.8

$$
\begin{aligned}
& 27.6 \\
& 19.8
\end{aligned}
$$

19.7

19.7
22.5

22.5
35.8

29.7

28.5

36.0

$\begin{array}{cc}- & - \\ - & - \\ - & - \\ \bar{N} & \overline{-} \\ \text { NA } & \text { NA } \\ \text { NA } & \text { NA } \\ W & \text { NA } \\ W & W \\ W & W \\ W & W \\ W & 68.7\end{array}$

See footnotes at end of table. 
Table A2. Refiner/Reseller Prices of Aviation Fuels, Propane, and Kerosene, by PAD District, 1983-Present

(Cents per Gallon Excluding Taxes) - Continued

\begin{tabular}{|c|c|c|c|c|c|c|c|c|}
\hline \multirow{2}{*}{$\begin{array}{c}\text { Geographlc Area } \\
\text { Year }\end{array}$} & \multicolumn{2}{|c|}{ Aviation Gasoline } & \multicolumn{2}{|c|}{ Kerosene-Type Jet Fuel } & \multicolumn{2}{|c|}{ Propane } & \multicolumn{2}{|c|}{ Kerosene } \\
\hline & $\begin{array}{l}\text { Sales to } \\
\text { End Users }\end{array}$ & $\begin{array}{l}\text { Sales for } \\
\text { Resale }\end{array}$ & $\begin{array}{l}\text { Sales to } \\
\text { End Users }\end{array}$ & $\begin{array}{l}\text { Sales for } \\
\text { Resale }\end{array}$ & $\begin{array}{l}\text { Sales to } \\
\text { End Users }\end{array}$ & $\begin{array}{l}\text { Sales for } \\
\text { Resale }\end{array}$ & $\begin{array}{l}\text { Sales to } \\
\text { End Users }\end{array}$ & $\begin{array}{c}\text { Sales for } \\
\text { Resale }\end{array}$ \\
\hline
\end{tabular}

\section{South Dakota}

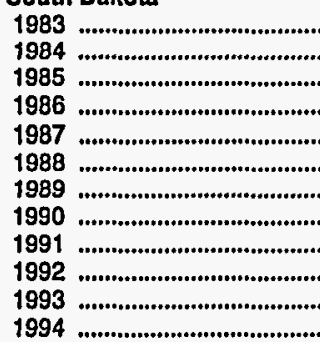

1994

\section{Tennessee}

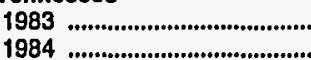

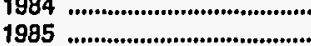

1987

1989

1990

1991

1993

1994

\section{Wisconsin}

1983 .........................................

1984 ......................................

1985

1986 ...........................................

1987

1988 ...........................................

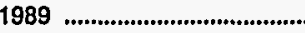

1990

1991 .

1992

1993 ............................................

1994

\section{PAD District ill}

1983 ......................................

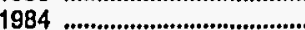

1985 ...........................................

1986 ........................................

1987

1988 ...

1989

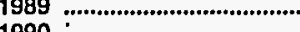

1991

1992

1993

(n)

1994

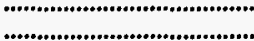

See footnotes at end of table.

$\begin{array}{lrr}W & W & 94.2 \\ W & 116.0 & 89.1 \\ W & 114.2 & 84.9 \\ W & 91.3 & 61.7 \\ W & 86.5 & 59.2 \\ W & 86.4 & 58.8 \\ W & 94.6 & 64.2 \\ W & 104.4 & 83.8 \\ W & W & 72.3 \\ W & W & 69.6 \\ W & W & 66.2 \\ W & W & 61.8\end{array}$

98.2
96.6
91.2
62.7
64.2
$W$
$W$
$W$
$W$
$W$
$W$
$W$

$\begin{array}{lc}W & 49.1 \\ W & 46.3 \\ - & 41.6 \\ - & 31.9 \\ W & 25.1 \\ W & 23.8 \\ W & 26.5 \\ W & 37.6 \\ W & 33.9 \\ W & 32.0 \\ W & 38.5 \\ - & -\end{array}$

$$
\begin{aligned}
& - \\
& - \\
& - \\
& \overline{-} \\
& \text { NA } \\
& \text { NA } \\
& \text { NA } \\
& \text { NA } \\
& - \\
& \text { W } \\
& -
\end{aligned}
$$

-
-
-
-
NA
NA
NA
NA
W
W
67.4

$125.4 \quad 119.8$

$\begin{array}{lll}125.4 & 119.8 & 86.9\end{array}$

122.9

$W \quad 111.1$

111.1
88.3

80.8

80.8

91.9

103.5

101.6

97.4
94.7

92.6

82.9
78.7

78.7
$\mathbf{5 1 . 5}$

54.2

51.6
58.6

75.3

65.1

61.5

56.5

\section{2}

88.0

88.4

60.2

53.5

54.7

63.2

70.3

66.1

61.6

94.5

52.9

57.5

91.1

87.1

83.5

60.1
57.8

55.5

62.5
80.8

71.0

62.6

57.5

53.8

95.2

93.0

89.8
65.6

65.6
63.0

59.4

65.7

83.1

65.6

65.6
60.6

55.2

68.9
69.9
74.3
71.9
71.9
75.7
72.2
$W$
$W$
$W$
$W$
-

51.6

48.6

43.7

34.4

31.4

30.2

30.0

50.6

42.3

38.5

40.0

110.3

48.6

46.2

41.3

32.6

26.1

25.1

27.7

41.0

35.1

32.6

39.3

$119.7 \quad 118.1$

$117.9 \quad 113.1$

114.5

96.7

109.3

$\begin{array}{ll}84.8 & 83.0 \\ 81.8 & 80.5\end{array}$

76.9

48.7

52.4

48.4

56.1

74.1

62.7

58.3

54.4

83.0
80.5
77.4
47.7
52.4
47.1
55.3
75.2
62.8
58.0
54.5
51.1

47.0

43.3

37.7

26.3

24.1

22.7

22.7

36.6
34.7

32.5

32.4

30.9
92.8

88.0

66.4

83.9

96.4
87.8

$\begin{array}{r}101.5 \\ \hline\end{array}$

93.2

104.3

85.1

$\begin{array}{cc}W & 80.5 \\ - & 84.9 \\ - & 78.0 \\ - & 60.4 \\ - & 59.3 \\ - & 55.0 \\ W & 68.5 \\ W & 80.8 \\ W & 75.0 \\ W & 70.9 \\ W & 65.8 \\ W & 61.3\end{array}$

90.1

90.5

86.2

60.1

59.8

54.8

88.6

74.3

65.3

61.8

62.0

80.5

84.9

60.4

59.3

55.0

80.8

65.8

$\begin{array}{ll}91.3 & 83.9 \\ 88.0 & 85.5\end{array}$

$85.8 \quad 81.3$

$61.5 \quad 51.0$

$\begin{array}{ll}66.2 & 55.2 \\ 57.8 & 48.6\end{array}$

$57.8 \quad 59.2$

$87.6 \quad 75.8$

58.9

$w$
$82.4 \quad 62.4$ 
Table A2. Refiner/Reseller Prices of Aviation Fuels, Propane, and Kerosene, by PAD District, 1983-Present

(Cents per Gallon Excluding Taxes) - Continued

\begin{tabular}{|c|c|c|c|c|c|c|c|c|}
\hline \multirow{2}{*}{$\underset{\text { Year }}{\text { Geographic Area }}$} & \multicolumn{2}{|c|}{ Aviation Gasoline } & \multicolumn{2}{|c|}{ Kerosene-Type Jet Fuel } & \multicolumn{2}{|c|}{ Propane } & \multicolumn{2}{|c|}{ Kerosene } \\
\hline & $\begin{array}{c}\text { Sales to } \\
\text { End Users }\end{array}$ & $\begin{array}{c}\text { Sales for } \\
\text { Resale }\end{array}$ & $\begin{array}{c}\text { Sales to } \\
\text { End Users }\end{array}$ & $\begin{array}{c}\text { Sales for } \\
\text { Resale }\end{array}$ & $\begin{array}{l}\text { Sales to } \\
\text { End Users }\end{array}$ & $\begin{array}{c}\text { Sales for } \\
\text { Resale }\end{array}$ & $\begin{array}{l}\text { Sales to } \\
\text { End Users }\end{array}$ & $\begin{array}{c}\text { Sales for } \\
\text { Resalo }\end{array}$ \\
\hline \multicolumn{9}{|l|}{ Alabama } \\
\hline 1983 & 122.4 & 120.0 & 91.0 & 85.3 & $w$ & 49.8 & 101.7 & 92.4 \\
\hline 1984 & 119.1 & 119.0 & 88.0 & 79.2 & $\ddot{w}$ & 48.1 & 98.6 & 93.5 \\
\hline 1985 & 117.6 & 114.9 & 83.3 & 76.5 & $\ddot{w}$ & 41.5 & 90.0 & 90.2 \\
\hline 1986 & 96.7 & 94.4 & 60.1 & 48.8 & $w$ & 29.7 & W & 62.1 \\
\hline 1987 & 87.1 & 86.2 & 59.2 & 51.0 & W & 27.2 & 77.2 & 56.2 \\
\hline 1988 & 86.8 & 86.4 & 55.0 & 53.7 & W & 25.4 & 111.0 & 48.6 \\
\hline 1989 & 97.7 & 95.1 & 62.6 & 58.0 & 65.8 & 26.0 & 94.2 & 66.4 \\
\hline 1990 & 111.0 & 106.4 & 80.8 & 80.8 & 73.1 & 42.5 & 116.5 & 92.8 \\
\hline 1991 & 105.9 & 103.4 & 67.9 & 69.3 & 80.7 & 39.4 & W & 77.9 \\
\hline 1992 & 102.9 & 99.8 & 63.9 & 65.6 & 79.0 & 36.1 & 118.4 & 65.1 \\
\hline 1993 & 97.4 & 95.8 & 59.6 & 61.5 & 79.3 & 35.3 & NA & 60.8 \\
\hline 1994 & 93.4 & 92.2 & 55.5 & 55.9 & - & - & NA & 62.9 \\
\hline \multicolumn{9}{|l|}{ Arkansas } \\
\hline 1983 & $w$ & 115.3 & 88.0 & 90.3 & 62.5 & 49.8 & 99.8 & 86.3 \\
\hline 1984 & W & 113.2 & 84.4 & 87.3 & 64.5 & 48.5 & $W$ & 87.3 \\
\hline 1985 & 111.5 & 111.1 & 80.4 & 82.4 & 74.2 & 43.1 & 93.2 & 82.6 \\
\hline 1986 & 101.9 & 89.7 & 53.1 & 60.4 & 67.9 & 30.0 & $W$ & 56.2 \\
\hline 1987 & $W$ & 84.3 & 54.9 & 58.3 & 62.1 & 30.0 & $w$ & 59.0 \\
\hline 1988 & $W$ & 83.3 & 49.4 & 57.8 & 64.8 & 27.3 & $w$ & 52.6 \\
\hline 1989 & $W$ & 91.2 & 57.7 & 63.9 & 64.9 & 29.8 & $w$ & 65.4 \\
\hline $1990 \ldots$ & W & 100.4 & 79.6 & 80.3 & 81.3 & 46.4 & W & 74.1 \\
\hline 1991 & $W$ & 96.9 & 67.7 & 70.3 & 87.9 & 41.1 & $w$ & 69.6 \\
\hline 1992 & 99.7 & $W$ & 61.0 & 67.8 & W & 37.8 & $w$ & 65.1 \\
\hline 1993 & W & $W$ & 60.1 & 60.8 & W & 39.3 & W & 59.5 \\
\hline 1994 & W & W & 58.1 & 57.0 & - & - & W & 52.1 \\
\hline \multicolumn{9}{|l|}{ Loulsiana } \\
\hline $1983 \ldots$ & 118.8 & 119.2 & 84.4 & 82.7 & 52.7 & 47.8 & 92.4 & 81.7 \\
\hline 1984 & 118.8 & 113.6 & 81.9 & 79.9 & 49.9 & 44.3 & 93.0 & 81.6 \\
\hline 1985 & 116.8 & 110.9 & 77.0 & 77.5 & 43.6 & 38.2 & 88.3 & 84.1 \\
\hline 1986 & $W$ & 93.4 & 49.6 & 47.6 & 48.7 & 27.7 & 63.7 & 51.5 \\
\hline 1987 & $W$ & 84.3 & 52.7 & 52.0 & 50.4 & 24.2 & 63.4 & 53.4 \\
\hline 1988 & $W$ & 84.0 & 48.7 & 46.4 & 49.6 & 22.9 & 51.1 & 47.3 \\
\hline 1989 & $W$ & 93.8 & 55.6 & 54.4 & 47.0 & 22.4 & 66.1 & 58.0 \\
\hline 1990 & 111.0 & 103.1 & 78.1 & 73.8 & 67.0 & 36.7 & 82.7 & 81.8 \\
\hline 1991 & $W$ & 98.2 & 63.0 & 60.2 & 66.7 & 34.2 & $W$ & 61.5 \\
\hline 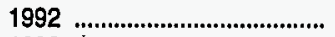 & $w$ & 98.1 & 57.9 & 57.4 & 35.7 & 31.8 & W & 59.7 \\
\hline 1993 & W & 89.7 & 54.3 & 54.1 & 36.3 & 32.0 & $w$ & 53.5 \\
\hline 1994 & W & 88.2 & 50.9 & 51.4 & - & - & $\mathbf{W}$ & 49.7 \\
\hline \multicolumn{9}{|l|}{ Mlssissippi } \\
\hline 1983 & 120.4 & 113.2 & 83.0 & 82.6 & $W$ & 48.6 & 92.7 & 79.6 \\
\hline 1984 & $W$ & 112.1 & 81.5 & 79.7 & W & 46.6 & 84.8 & 79.1 \\
\hline 1985 & 115.8 & 109.4 & 78.9 & 75.0 & 61.7 & 40.3 & 86.4 & 75.0 \\
\hline 1986 & 101.5 & 86.1 & 46.0 & 49.6 & 65.9 & 29.1 & 65.0 & 44.5 \\
\hline 1987 & 85.5 & 82.6 & 53.6 & 52.2 & 69.2 & 26.1 & 59.0 & $w$ \\
\hline 1988 & 84.4 & 82.1 & 46.3 & 47.3 & 72.5 & 24.8 & $w$ & $W$ \\
\hline 1989 & 96.0 & 92.8 & 52.9 & 55.1 & 73.8 & 24.5 & W & $W$ \\
\hline 1990 & 109.3 & 100.4 & 69.7 & 83.4 & $W$ & 42.0 & 63.4 & w \\
\hline 1991 & 103.8 & 97.5 & 61.9 & 63.3 & $W$ & 36.7 & $w$ & W \\
\hline 1992 & 101.0 & 98.6 & 58.5 & 57.3 & W & 35.3 & $\mathbf{W}$ & $\ddot{w}$ \\
\hline 1993 & 95.2 & 94.6 & 53.4 & 54.7 & $W$ & 34.5 & $w$ & $w$ \\
\hline 1994 & W & 90.6 & 50.0 & 50.9 & - & - & W & $w$ \\
\hline
\end{tabular}

See footnotes at end of table. 
Table A2. Refiner/Reseller Prices of Aviation Fuels, Propane, and Kerosene; by PAD District, 1983-Present

(Cents per Gallon Excluding Taxes) - Continued

\begin{tabular}{|c|c|c|c|c|c|c|c|c|c|}
\hline \multirow{2}{*}{\multicolumn{2}{|c|}{$\begin{array}{c}\text { Geographlc Area } \\
\text { Year }\end{array}$}} & \multicolumn{2}{|c|}{ Aviation Gasoline } & \multicolumn{2}{|c|}{ Kerosene-Type Jet Fuel } & \multicolumn{2}{|c|}{ Propane } & \multicolumn{2}{|c|}{ Kerosene } \\
\hline & & $\begin{array}{l}\text { Sales to } \\
\text { End Users }\end{array}$ & $\begin{array}{l}\text { Sales for } \\
\text { Resale }\end{array}$ & $\begin{array}{l}\text { Sales to } \\
\text { End Users }\end{array}$ & $\begin{array}{l}\text { Sales for } \\
\text { Resale }\end{array}$ & $\begin{array}{l}\text { Sales to } \\
\text { End Users }\end{array}$ & $\begin{array}{l}\text { Sales for } \\
\text { Resale }\end{array}$ & $\begin{array}{l}\text { Sales to } \\
\text { End Users }\end{array}$ & $\begin{array}{c}\text { Sales for } \\
\text { Resale }\end{array}$ \\
\hline $\begin{array}{l}\text { New N } \\
1983 \\
1984 \\
1985 \\
1986 \\
1987 \\
1988 \\
1989 \\
1990 \\
1991 \\
1992 \\
1993 \\
1994\end{array}$ & Mexico & $\begin{array}{r}123.3 \\
W \\
117.3 \\
92.7 \\
W \\
W \\
W \\
W \\
W \\
W \\
W \\
W\end{array}$ & $\begin{array}{r}122.2 \\
118.1 \\
114.8 \\
95.1 \\
89.9 \\
88.8 \\
W \\
W \\
W \\
W \\
W \\
W\end{array}$ & $\begin{array}{l}91.0 \\
85.8 \\
84.2 \\
59.3 \\
57.8 \\
56.3 \\
64.6 \\
81.2 \\
65.3 \\
61.7 \\
60.8 \\
54.5\end{array}$ & $\begin{array}{l}90.4 \\
83.4 \\
85.9 \\
59.0 \\
59.3 \\
58.9 \\
64.6 \\
79.3 \\
68.1 \\
64.0 \\
60.5 \\
55.0\end{array}$ & $\begin{array}{c}W \\
W \\
62.4 \\
56.4 \\
52.8 \\
53.1 \\
52.6 \\
66.2 \\
47.4 \\
32.4 \\
W \\
-\end{array}$ & $\begin{array}{c}39.4 \\
35.0 \\
33.1 \\
22.6 \\
18.2 \\
23.0 \\
22.3 \\
38.7 \\
34.6 \\
30.7 \\
33.8 \\
-\end{array}$ & $\begin{array}{c}W \\
89.0 \\
W \\
64.9 \\
W \\
W \\
W \\
W \\
W \\
W \\
W \\
W\end{array}$ & $\begin{array}{c}92.9 \\
93.7 \\
92.2 \\
66.9 \\
67.2 \\
62.4 \\
73.9 \\
90.9 \\
83.4 \\
79.7 \\
77.4 \\
W\end{array}$ \\
\hline $\begin{array}{l}\text { Texas } \\
1983 \\
1984 \\
1985 \\
1986 \\
1987 \\
1988 \\
1989 \\
1990 \\
1991 \\
1992 \\
1993 \\
1994\end{array}$ & (n) & $\begin{array}{r}119.1 \\
116.6 \\
113.1 \\
95.1 \\
89.8 \\
87.1 \\
96.3 \\
110.8 \\
103.4 \\
99.2 \\
92.6 \\
90.6\end{array}$ & $\begin{array}{r}118.2 \\
112.1 \\
108.2 \\
84.7 \\
80.2 \\
79.7 \\
85.8 \\
98.4 \\
90.8 \\
87.6 \\
82.4 \\
80.0\end{array}$ & $\begin{array}{l}84.7 \\
81.6 \\
76.5 \\
48.1 \\
52.0 \\
48.2 \\
56.1 \\
73.0 \\
62.6 \\
58.3 \\
54.2 \\
50.3\end{array}$ & $\begin{array}{l}82.8 \\
80.6 \\
77.5 \\
47.3 \\
52.5 \\
47.1 \\
55.3 \\
74.6 \\
63.4 \\
58.0 \\
54.5 \\
50.9\end{array}$ & $\begin{array}{c}48.2 \\
43.5 \\
36.9 \\
36.0 \\
31.3 \\
30.2 \\
22.2 \\
34.5 \\
35.4 \\
33.7 \\
32.1 \\
-\end{array}$ & $\begin{array}{c}47.0 \\
43.1 \\
37.5 \\
25.9 \\
24.0 \\
22.3 \\
22.1 \\
35.6 \\
34.3 \\
32.1 \\
31.8 \\
-\end{array}$ & $\begin{array}{c}87.7 \\
86.4 \\
83.5 \\
55.9 \\
60.4 \\
54.1 \\
56.4 \\
81.8 \\
75.9 \\
67.1 \\
\text { NA } \\
\text { W }\end{array}$ & $\begin{array}{l}85.3 \\
86.7 \\
84.2 \\
56.3 \\
57.7 \\
51.3 \\
62.3 \\
77.1 \\
67.4 \\
62.0 \\
55.6 \\
55.1\end{array}$ \\
\hline $\begin{array}{l}\text { PAD D } \\
1983 \\
1984 \\
1985 \\
1986 \\
1987 \\
1988 \\
1989 \\
1990 \\
1991 \\
1992 \\
1993 \\
1994\end{array}$ & Dlstrlat IV & $\begin{array}{r}126.9 \\
124.2 \\
121.6 \\
100.7 \\
93.4 \\
91.8 \\
101.2 \\
109.0 \\
105.5 \\
107.3 \\
102.2 \\
101.1\end{array}$ & $\begin{array}{r}124.1 \\
120.7 \\
117.6 \\
98.3 \\
92.8 \\
91.1 \\
97.5 \\
104.8 \\
100.6 \\
102.6 \\
100.9 \\
97.2\end{array}$ & $\begin{array}{l}89.9 \\
86.7 \\
82.0 \\
54.2 \\
55.7 \\
52.6 \\
60.6 \\
77.1 \\
67.9 \\
63.9 \\
61.6 \\
57.7\end{array}$ & $\begin{array}{l}91.7 \\
87.9 \\
84.1 \\
64.4 \\
60.9 \\
58.2 \\
64.7 \\
79.5 \\
70.4 \\
68.4 \\
64.6 \\
62.0\end{array}$ & $\begin{array}{l}63.3 \\
65.6 \\
65.7 \\
58.6 \\
54.2 \\
54.0 \\
56.7 \\
71.6 \\
74.7 \\
76.1 \\
75.5 \\
72.1\end{array}$ & $\begin{array}{l}45.6 \\
41.4 \\
37.7 \\
27.7 \\
21.4 \\
21.7 \\
23.9 \\
36.4 \\
31.9 \\
28.4 \\
35.1 \\
31.6\end{array}$ & $\begin{array}{c}100.6 \\
104.0 \\
W \\
60.5 \\
W \\
W \\
59.1 \\
W \\
W \\
W \\
W \\
W\end{array}$ & $\begin{array}{l}92.0 \\
91.7 \\
87.0 \\
68.4 \\
68.0 \\
57.2 \\
65.4 \\
86.8 \\
80.1 \\
72.7 \\
74.1 \\
66.1\end{array}$ \\
\hline $\begin{array}{l}\text { Color } \\
1983 \\
1984 \\
1985 \\
1986 \\
1987 \\
1988 \\
1889 \\
1990 \\
1891 \\
1992 \\
1993 \\
1994\end{array}$ & ado & $\begin{array}{l}W \\
W \\
W \\
W \\
W \\
W \\
W \\
W \\
W \\
W \\
W \\
W \\
95.8\end{array}$ & $\begin{array}{r}123.7 \\
118.8 \\
115.3 \\
94.5 \\
89.5 \\
88.7 \\
93.2 \\
102.5 \\
97.3 \\
100.1 \\
99.3 \\
96.4\end{array}$ & $\begin{array}{l}87.3 \\
85.0 \\
80.2 \\
52.9 \\
54.7 \\
51.0 \\
58.1 \\
75.4 \\
65.8 \\
60.3 \\
57.4 \\
53.8\end{array}$ & $\begin{array}{l}89.8 \\
86.3 \\
82.1 \\
63.9 \\
59.5 \\
55.8 \\
62.4 \\
77.3 \\
67.3 \\
65.0 \\
60.5 \\
58.1\end{array}$ & $\begin{array}{c}55.0 \\
55.7 \\
52.5 \\
44.2 \\
35.6 \\
36.6 \\
51.4 \\
51.2 \\
W \\
73.3 \\
67.1 \\
-\end{array}$ & $\begin{array}{c}49.7 \\
43.8 \\
37.5 \\
29.4 \\
21.7 \\
22.0 \\
23.0 \\
38.7 \\
33.5 \\
30.1 \\
36.2 \\
-\end{array}$ & $\begin{array}{c}103.5 \\
103.6 \\
W \\
W \\
W \\
W \\
W \\
W \\
- \\
W \\
- \\
-\end{array}$ & $\begin{array}{c}93.1 \\
92.7 \\
91.9 \\
68.5 \\
68.7 \\
54.3 \\
64.4 \\
84.4 \\
77.4 \\
W \\
W \\
62.9\end{array}$ \\
\hline
\end{tabular}

See foothotes at end of table. 
Table A2. Refiner/Reseller Prices of Aviation Fuels, Propane, and Kerosene, by PAD District, 1983-Present

(Cents per Gallon Excluding Taxes) - Continued

\begin{tabular}{|c|c|c|c|c|c|c|c|c|}
\hline \multirow{2}{*}{$\begin{array}{c}\text { Geographic Area } \\
\text { Year }\end{array}$} & \multicolumn{2}{|c|}{ Aviation Gasoline } & \multicolumn{2}{|c|}{ Kerosene-Type Jet Fuel } & \multicolumn{2}{|c|}{ Propane } & \multicolumn{2}{|c|}{ Kerosene } \\
\hline & $\begin{array}{l}\text { Sales to } \\
\text { End Users }\end{array}$ & $\begin{array}{l}\text { Sales for } \\
\text { Resalo }\end{array}$ & $\begin{array}{l}\text { Sales to } \\
\text { End Users }\end{array}$ & $\begin{array}{c}\text { Sales for } \\
\text { Resale }\end{array}$ & $\begin{array}{l}\text { Sales to } \\
\text { End Users }\end{array}$ & $\begin{array}{l}\text { Sales for } \\
\text { Resalo }\end{array}$ & $\begin{array}{l}\text { Sales to } \\
\text { End Users }\end{array}$ & $\begin{array}{c}\text { Sales for } \\
\text { Resale }\end{array}$ \\
\hline \multicolumn{9}{|l|}{ Idaho } \\
\hline 1983 & 125.7 & 119.3 & 100.2 & 102.2 & $w$ & 49.5 & - & - \\
\hline 1984 & W & 125.0 & 93.8 & 97.0 & W & 51.3 & - & - \\
\hline 1985 & $W$ & 122.3 & 90.2 & 95.9 & 80.5 & 45.8 & - & - \\
\hline 1986 & W & $W$ & 59.4 & 67.3 & $W$ & 38.2 & - & - \\
\hline 1987 & 96.0 & W & 59.3 & 65.9 & 69.5 & 23.0 & - & - \\
\hline 1988 & $w$ & 98.6 & 57.3 & 62.4 & 69.5 & 27.8 & NA & NA \\
\hline 1989 & W & 110.8 & 66.5 & 69.9 & 66.5 & 28.0 & NA & NA \\
\hline 1990 & W & W & 82.0 & 83.5 & $W$ & 36.4 & NA & $w$ \\
\hline 1991 & W & 113.4 & 74.3 & 79.1 & w & 34.3 & NA & $w$ \\
\hline 1992 & $W$ & 112.6 & 73.5 & 77.3 & w & 28.7 & - & $w$ \\
\hline 1993 & $W$ & 111.6 & 73.2 & 76.6 & $W$ & 40.3 & - & W \\
\hline 1994 & $W$ & $W$ & 67.6 & 69.9 & - & - & - & $W$ \\
\hline \multicolumn{9}{|l|}{ Montana } \\
\hline $1983 \ldots$ & $w$ & 128.7 & 98.1 & $w$ & 51.4 & 43.0 & - & - \\
\hline 1984 & $w$ & 123.9 & 94.9 & 89.3 & 61.9 & 41.1 & - & - \\
\hline 1985 & $w$ & 119.2 & 89.7 & 83.8 & 61.7 & 36.9 & - & - \\
\hline 1986 & $W$ & 100.5 & 65.0 & 54.1 & 53.5 & 25.8 & - & - \\
\hline 1987 & W & 95.7 & 59.1 & $w$ & 50.3 & 19.5 & - & - \\
\hline 1988 & W & $W$ & 58.5 & 63.7 & 50.0 & 19.6 & NA & NA \\
\hline 1989 & $w$ & $W$ & 64.7 & $W$ & 52.4 & 23.4 & NA & NA \\
\hline 1990 & $w$ & $w$ & 84.5 & w & $w$ & 35.2 & $w$ & NA \\
\hline 1991 & $\mathbf{w}$ & $W$ & 73.8 & $W$ & $w$ & 28.9 & $W$ & NA \\
\hline 1992 & $\mathbf{W}$ & $w$ & 73.7 & $w$ & $w$ & 27.0 & - & - \\
\hline 1993 & $\mathbf{W}$ & W & 72.8 & $w$ & $w$ & 33.8 & - & W \\
\hline 1994 & $W$ & $w$ & 67.8 & $w$ & - & - & - & 65.0 \\
\hline \multicolumn{9}{|l|}{ Utah } \\
\hline 1983 & 126.8 & 124.5 & 94.8 & 98.0 & $w$ & 45.6 & - & - \\
\hline 1984 & 118.9 & 120.1 & 89.5 & 94.8 & $w$ & 44.2 & - & - \\
\hline 1985 & $W$ & 116.9 & 84.4 & 90.0 & 70.5 & 44.5 & - & - \\
\hline 1986 & 99.1 & 98.1 & 54.7 & 67.4 & $w$ & 29.5 & - & - \\
\hline 1987 & $w$ & 92.6 & 56.5 & 62.0 & $w$ & 24.0 & - & - \\
\hline 1988 & 87.8 & 89.1 & 53.3 & 61.5 & $w$ & 25.2 & NA & NA \\
\hline 1989 & 95.8 & 99.5 & 62.1 & 67.9 & 58.6 & 27.3 & NA & NA \\
\hline 1990 & W & 104.9 & 77.6 & 82.6 & $W$ & 37.1 & NA & NA \\
\hline 1991 & 99.9 & 102.0 & 69.2 & 76.7 & $W$ & 35.1 & NA & $W$ \\
\hline 1992 & 103.5 & 103.8 & 67.0 & 73.0 & w & 29.4 & - & $w$ \\
\hline 1993 & 101.0 & 101.0 & 66.3 & 69.2 & $w$ & 37.2 & - & W \\
\hline 1994 & 99.7 & 96.3 & 61.5 & 64.4 & - & - & - & $w$ \\
\hline \multicolumn{9}{|l|}{ Wyoming } \\
\hline 1983 & W & 128.3 & 99.3 & 98.2 & $w$ & 43.1 & - & - \\
\hline 1984 & W & 120.5 & 95.3 & 96.6 & 74.3 & 39.2 & - & - \\
\hline 1985 & 118.4 & 117.7 & 88.1 & 92.5 & 71.9 & 35.2 & - & - \\
\hline 1986 & W & $W$ & 61.5 & 68.7 & 65.2 & 26.4 & - & - \\
\hline 1987 & 92.0 & 93.5 & 62.2 & 64.1 & $w$ & 21.1 & - & - \\
\hline 1988 & 91.9 & 93.1 & 62.4 & 58.9 & $\ddot{W}$ & 21.0 & NA & NA \\
\hline 1989 & 100.0 & $w$ & 68.3 & 65.4 & 56.7 & 23.5 & NA & NA \\
\hline 1990 & 110.5 & W & 87.1 & 85.2 & 54.7 & 34.8 & NA & $w$ \\
\hline 1991 & $W$ & W & 81.7 & 79.1 & 69.7 & 31.0 & NA & w \\
\hline 1992 & $w$ & $W$ & 79.4 & $w$ & 55.5 & 27.2 & - & - \\
\hline 1993 & 103.5 & W & 77.1 & 72.1 & 53.5 & 33.9 & $w$ & $w$ \\
\hline 1994 & $W$ & W & 71.4 & $w$ & - & - & $w$ & $w$ \\
\hline
\end{tabular}

See footnotes at end of table. 
Table A2. Refiner/Reseller Prices of Aviation Fuels, Propane, and Kerosene, by PAD District, 1983-Present

(Cents per Gallon Excluding Taxes) - Continued

\begin{tabular}{c|c|c|c|c|c|c|c|c|}
\hline \multirow{2}{*}{$\begin{array}{c}\text { Geographic Area } \\
\text { Year }\end{array}$} & \multicolumn{2}{|c|}{ Aviation Gasoline } & \multicolumn{2}{c|}{ Kerosene-Type Jet Fuel } & \multicolumn{2}{c}{ Kropane } \\
\cline { 2 - 6 } & $\begin{array}{c}\text { Sales to } \\
\text { End Users }\end{array}$ & $\begin{array}{c}\text { Sales for } \\
\text { Resale }\end{array}$ & $\begin{array}{c}\text { Sales to } \\
\text { End Users }\end{array}$ & $\begin{array}{c}\text { Sales for } \\
\text { Resale }\end{array}$ & $\begin{array}{c}\text { Sales to } \\
\text { End Users }\end{array}$ & $\begin{array}{c}\text { Sales for } \\
\text { Resale }\end{array}$ & $\begin{array}{c}\text { Sales to } \\
\text { End Users }\end{array}$ & $\begin{array}{c}\text { Sales for } \\
\text { Resale }\end{array}$ \\
\hline
\end{tabular}

\section{PAD District $V$}

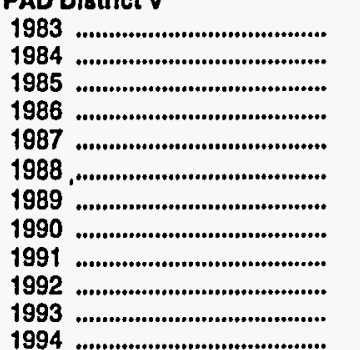

126.7
126.4
123.7
106.7
94.6
93.3
104.8
116.5
108.6
110.3
108.9
104.6

121.0

121.0
119.2
117.9

117.9
99.4

92.7

91.8

103.9

113.8

107.1

107.6

105.8

100.1

Alaska

1983 .........................................

1984

1985

1986

1988

1989

1990

1991

1992

1993

1994

\section{Arizona}

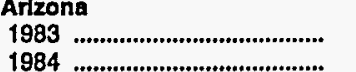

1985 .............................................

1986

1987 .......................................

1988

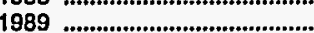

1990

1991

1993

199

\section{Calffomla}

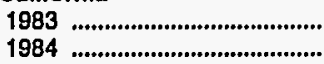

1985

1986

1987

1989

1990

1991

1992

1993

1994

135.4

135.6

105.6

99.9

97.8

112.8

121.6

W

119.5

113.9

122.9

121.2

105.2

98.7

97.6
110.1

110.1
116.4

106.2

101.7

100.2

94.9

90.1
85.8
81.8
55.0
55.4
52.9
61.6
79.1
66.7
62.8
62.1
55.8

87.3
84.2
80.7
49.9
54.5
51.3
61.1
78.8
66.0
61.8
61.8
55.4

W

83.3

$W$
78.5

74.2

74.6

70.9

W

79.9

79.1

96.0

90.7

87.4

81.9

56.2

55.8

55.9

63.3

83.3

74.2

69.5

61.2

91.4

$W$
82.2

53.8

57.1
56.5

65.4

84.1

71.8

66.7

65.0

58.4

W

106.2

112.1

59.8

$\begin{array}{ll}W & 54.7 \\ W & 57.3\end{array}$

106.4

$W$
$W$
$W$

$\begin{array}{lll}122.7 & 90.6 & 96.3\end{array}$

90.6
86.6
83.7
57.4
58.9
56.0
64.8
81.6
67.9
63.7
63.3
57.2

89.3

90.8

65.3

62.3

55.8

66.1
83.3

69.7

65.9

65.6

59.1

89.2
84.8
81.1
53.9
54.5
51.9
60.8
77.8
64.8
61.2
60.8
54.4

85.4
82.3
79.6
48.5
54.0
50.3
60.0
78.4
65.2
61.0
60.8
54.6

85.4
82.3
79.6
48.5
54.0
50.3
60.0
78.4
65.2
61.0
60.8
54.6

53.1
52.8
50.5
36.2
30.3
29.8
29.9
40.4
38.2
33.0
39.1

39.5

$\begin{array}{rr}108.1 & 91.7 \\ 106.9 & 88.8 \\ 143.7 & 88.9 \\ 64.1 & 61.9 \\ 60.4 & 61.9 \\ 65.4 & 64.0 \\ 69.2 & 70.9 \\ 95.7 & 92.4 \\ W & 78.1 \\ W & 66.4 \\ 73.6 & 66.0 \\ 64.3 & 64.2\end{array}$

See footnotes at end of table. 
Table A2. Refiner/Reseller Prices of Aviation Fuels, Propane, and Kerosene, by PAD District, 1983-Present

(Cents per Gallon Excluding Taxes) - Continued

\begin{tabular}{|c|c|c|c|c|c|c|c|c|}
\hline \multirow{2}{*}{$\underset{\text { Gear }}{\text { Geographic Area }}$} & \multicolumn{2}{|c|}{ Aviation Gasoline } & \multicolumn{2}{|c|}{ Kerosene-Type Jet Fuel } & \multicolumn{2}{|c|}{ Propane } & \multicolumn{2}{|c|}{ Kerosene } \\
\hline & $\begin{array}{l}\text { Sales to } \\
\text { End Users }\end{array}$ & $\begin{array}{c}\text { Sales for } \\
\text { Resale }\end{array}$ & $\begin{array}{l}\text { Sales to } \\
\text { End Users }\end{array}$ & $\begin{array}{l}\text { Sales for } \\
\text { Resale }\end{array}$ & $\begin{array}{l}\text { Sales to } \\
\text { End Users }\end{array}$ & $\begin{array}{l}\text { Sales for } \\
\text { Resale }\end{array}$ & $\begin{array}{l}\text { Sales to } \\
\text { End Users }\end{array}$ & $\begin{array}{c}\text { Salos for } \\
\text { Resale }\end{array}$ \\
\hline \multicolumn{9}{|l|}{ Hawaii } \\
\hline 1983 & $W$ & $w$ & 93.1 & $W$ & $\overrightarrow{-}$ & $W$ & - & - \\
\hline 1984 & $w$ & W & 88.4 & 95.7 & $w$ & $w$ & - & - \\
\hline 1985 & W & W & 83.8 & $W$ & - & $W$ & - & - \\
\hline 1986 & $W$ & $w$ & 58.9 & W & - & $W$ & - & - \\
\hline 1987 & W & w & 58.1 & $\ddot{w}$ & - & iv & - & - \\
\hline 1988 & W & W & 54.6 & 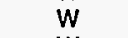 & - & $W$ & NA & NA \\
\hline 1989 & $\ddot{W}$ & w & 62.0 & $W$ & - & $W$ & NA & NA \\
\hline 1990 & $W$ & W & 80.8 & W & - & $W$ & NA & NA \\
\hline 1991 & W & W & 69.8 & 69.4 & - & $W$ & NA & NA \\
\hline 1992 & $W$ & $W$ & 66.1 & W & $W$ & $W$ & - & - \\
\hline 1993 & $W$ & W & 64.6 & 67.8 & $W$ & 51.1 & - & - \\
\hline 1994 & $W$ & W & 58.2 & W & - & - & - & - \\
\hline \multicolumn{9}{|l|}{ Nevada } \\
\hline 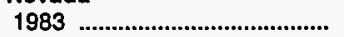 & 121.3 & 121.2 & 91.3 & 90.8 & $w$ & 54.9 & - & - \\
\hline 1984 & 118.8 & 120.8 & 87.1 & 90.1 & $W$ & 55.4 & - & - \\
\hline 1985 & $W$ & 119.7 & 84.0 & 95.1 & $W$ & 50.1 & - & - \\
\hline 1986 & W & $w$ & 57.4 & 70.5 & $\mathbf{W}$ & 36.4 & - & - \\
\hline 1987 & W & 98.2 & 57.7 & 58.8 & $W$ & 29.1 & - & - \\
\hline 1988 & w & 92.7 & 55.1 & 54.1 & $w$ & 30.4 & NA & NA \\
\hline 1989 & $\mathbf{W}$ & 104.9 & 64.7 & 63.4 & 88.4 & 31.8 & NA & NA \\
\hline 1990 & 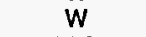 & 116.4 & 84.5 & 81.9 & W & 43.1 & NA & $W$ \\
\hline 1991 & 114.2 & 107.2 & 67.5 & 68.5 & $w$ & 42.9 & NA & $W$ \\
\hline 1992 & $W$ & W & 63.5 & 66.5 & $W$ & 36.0 & - & - \\
\hline 1993 & W & 101.4 & 63.3 & 64.3 & W & 40.8 & - & - \\
\hline 1994 & W & 98.9 & 57.1 & 58.6 & - & - & - & $w$ \\
\hline \multicolumn{9}{|l|}{ Oregon } \\
\hline $1983 \ldots \ldots \ldots \ldots \ldots \ldots \ldots \ldots \ldots$ & 122.8 & 121.7 & 91.3 & 100.7 & $W$ & $W$ & - & - \\
\hline 1984 & $W$ & 119.5 & 86.7 & 96.5 & W & 52.2 & - & - \\
\hline 1985 & W & 117.5 & 83.1 & 89.9 & 81.1 & 50.4 & - & - \\
\hline 1986 & $W$ & 99.2 & 57.2 & 59.6 & $w$ & 35.9 & - & - \\
\hline 1987 & W & 95.4 & 58.4 & 62.9 & 72.1 & 29.7 & - & - \\
\hline 1988 & $w$ & 94.3 & 54.5 & 59.9 & 72.9 & 32.4 & NA & NA \\
\hline 1989 & $\ddot{W}$ & 108.2 & 64.3 & 68.1 & 75.0 & 34.1 & NA & NA \\
\hline 1990 & W & 113.2 & 80.1 & 84.7 & $W$ & 44.0 & NA & NA \\
\hline 1991 & W & 105.9 & 67.6 & 70.9 & $W$ & 44.8 & $W$ & $W$ \\
\hline 1992 & W & 106.1 & 63.1 & 69.2 & $W$ & 36.6 & $W$ & $W$ \\
\hline 1993 & W & 102.8 & 62.4 & 67.5 & $W$ & 44.9 & W & $w$ \\
\hline 1994 & W & 96.5 & 56.2 & 59.3 & - & - & $W$ & 62.8 \\
\hline \multicolumn{9}{|l|}{ Washington } \\
\hline 1983 & 124.0 & 121.9 & 89.3 & 85.4 & $W$ & 49.0 & - & - \\
\hline 1984 & 123.4 & 119.6 & 85.3 & 83.9 & $W$ & 45.7 & - & - \\
\hline 1985 & 121.0 & 117.2 & 81.4 & 80.2 & 80.1 & 42.3 & - & - \\
\hline 1986 & 103.8 & 100.1 & 54.1 & 49.9 & $W$ & 32.2 & - & - \\
\hline 1987 & 97.3 & 92.5 & 54.3 & 53.2 & $W$ & 25.7 & - & - \\
\hline 1988 & 96.1 & 92.7 & 51.1 & 49.5 & $W$ & 20.8 & NA & NA \\
\hline 1989 & 107.7 & 104.8 & 60.8 & 61.4 & $W$ & 21.9 & NA & NA \\
\hline 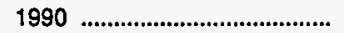 & 116.9 & 113.1 & 76.7 & 73.1 & $W$ & 32.3 & NA & NA \\
\hline 1991 & W & 106.8 & 64.3 & 65.6 & $W$ & 29.8 & NA & $W$ \\
\hline 1992 & $W$ & 107.3 & 61.5 & 62.0 & $W$ & 25.4 & - & 68.2 \\
\hline 1993 & 109.0 & W & 61.3 & 61.5 & $W$ & 32.3 & W & W \\
\hline 1994 & $W$ & $W$ & 55.2 & 54.1 & - & - & W & 67.2 \\
\hline
\end{tabular}

Dash $(-)=$ No data reported.

NA $=$ Not available.

$W=$ Withneld to avold disclosure of individual company data.

Sources: Energy Information Administration Forms ElA-782A, "Refiners'/Gas Plant Operators' Monthly Petroleum Product Sales Report," and ElA-782B 'Resellers'/Retailers' Monthly Petroleum Product Sales Report." 
Table A3. Refiner/Reseller Prices of Distillate and Residual Fuel Oils, by PAD District, 1983-Present

(Cents per Gallon Excluding Taxes)

\begin{tabular}{|c|c|c|c|c|c|c|c|c|}
\hline \multirow{2}{*}{$\begin{array}{c}\text { Geographlo Area } \\
\text { Year }\end{array}$} & \multicolumn{2}{|c|}{ No. 1 Distlllate } & \multicolumn{2}{|c|}{ No. 2 Distillatea } & \multicolumn{2}{|c|}{ No. 4 Fuelb } & \multicolumn{2}{|c|}{ Residual Fuel Oil } \\
\hline & $\begin{array}{l}\text { Sales to } \\
\text { End Users }\end{array}$ & $\begin{array}{l}\text { Sales for } \\
\text { Resale }\end{array}$ & $\begin{array}{l}\text { Sales to } \\
\text { End Users }\end{array}$ & $\begin{array}{c}\text { Sales for } \\
\text { Resale }\end{array}$ & $\begin{array}{l}\text { Sales to } \\
\text { End Users }\end{array}$ & $\begin{array}{l}\text { Sales for } \\
\text { Resale }\end{array}$ & $\begin{array}{l}\text { Sales to } \\
\text { End Users }\end{array}$ & $\begin{array}{c}\text { Sales for } \\
\text { Resale }\end{array}$ \\
\hline $\begin{array}{c}\text { United States } \\
1983 \ldots \ldots \\
1984 \ldots \ldots \ldots \ldots \\
1985 \\
1986 \\
1987\end{array}$ & $\begin{array}{l}96.2 \\
92.7 \\
88.0 \\
62.0 \\
60.4 \\
56.4 \\
66.1 \\
81.9 \\
74.0 \\
66.6 \\
66.6 \\
64.0\end{array}$ & $\begin{array}{l}89.6 \\
89.2 \\
86.3 \\
57.9 \\
59.9 \\
54.9 \\
66.8 \\
83.8 \\
73.0 \\
65.2 \\
64.6 \\
61.5\end{array}$ & $\begin{array}{l}83.9 \\
83.7 \\
79.9 \\
49.1 \\
55.6 \\
50.7 \\
58.5 \\
72.6 \\
65.0 \\
62.0 \\
60.2 \\
55.6\end{array}$ & $\begin{array}{l}81.2 \\
81.3 \\
77.4 \\
47.0 \\
53.1 \\
47.3 \\
56.6 \\
69.5 \\
61.8 \\
58.5 \\
55.9 \\
52.2\end{array}$ & $\begin{array}{l}76.6 \\
79.6 \\
77.3 \\
48.9 \\
51.3 \\
46.1 \\
51.2 \\
62.2 \\
58.0 \\
52.6 \\
50.1 \\
50.1\end{array}$ & $\begin{array}{l}72.6 \\
70.7 \\
67.2 \\
40.9 \\
46.2 \\
42.5 \\
48.0 \\
59.0 \\
55.6 \\
49.5 \\
48.8 \\
46.2\end{array}$ & $\begin{array}{l}65.1 \\
69.6 \\
62.3 \\
35.8 \\
42.6 \\
33.9 \\
39.3 \\
45.5 \\
34.7 \\
34.6 \\
34.1 \\
35.8\end{array}$ & $\begin{array}{l}60.9 \\
65.8 \\
58.2 \\
31.5 \\
39.9 \\
31.5 \\
37.8 \\
43.4 \\
33.0 \\
32.6 \\
30.1 \\
32.2\end{array}$ \\
\hline 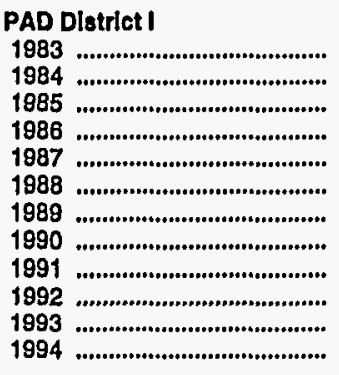 & $\begin{array}{l}92.9 \\
90.2 \\
87.4 \\
63.7 \\
57.8 \\
57.4 \\
66.4 \\
82.3 \\
77.3 \\
65.5 \\
64.5 \\
67.7\end{array}$ & $\begin{array}{l}91.3 \\
90.8 \\
86.7 \\
60.3 \\
58.9 \\
54.5 \\
66.4 \\
83.9 \\
73.7 \\
62.5 \\
60.8 \\
66.5\end{array}$ & $\begin{array}{l}87.1 \\
87.9 \\
82.7 \\
52.8 \\
57.2 \\
53.1 \\
59.0 \\
73.7 \\
66.6 \\
62.7 \\
59.8 \\
55.9\end{array}$ & $\begin{array}{l}82.3 \\
83.3 \\
78.6 \\
50.4 \\
53.2 \\
48.3 \\
57.4 \\
70.3 \\
63.7 \\
58.3 \\
54.8 \\
51.7\end{array}$ & $\begin{array}{l}79.4 \\
81.8 \\
78.1 \\
51.5 \\
52.0 \\
47.2 \\
52.0 \\
64.9 \\
59.3 \\
53.6 \\
51.2 \\
51.4\end{array}$ & $\begin{array}{l}77.5 \\
80.9 \\
76.0 \\
47.3 \\
47.2 \\
46.1 \\
51.1 \\
64.6 \\
58.1 \\
50.1 \\
49.4 \\
47.9\end{array}$ & $\begin{array}{l}66.2 \\
71.3 \\
64.3 \\
37.6 \\
43.8 \\
35.2 \\
41.6 \\
47.6 \\
36.0 \\
36.2 \\
35.7 \\
37.3\end{array}$ & $\begin{array}{l}63.6 \\
69.7 \\
62.9 \\
36.1 \\
43.3 \\
34.8 \\
41.6 \\
48.3 \\
37.5 \\
37.1 \\
34.5 \\
35.1\end{array}$ \\
\hline $\begin{array}{c}\text { Subdiatrict IA } \\
1983 \\
1984 \\
1985\end{array}$ & $\begin{array}{l}92.0 \\
90.8 \\
87.9 \\
63.7 \\
63.2 \\
57.2 \\
65.8 \\
80.3 \\
74.2 \\
63.2 \\
61.5 \\
65.9\end{array}$ & $\begin{array}{l}92.2 \\
88.9 \\
86.9 \\
63.4 \\
61.5 \\
57.1 \\
70.8 \\
86.9 \\
78.7 \\
63.9 \\
61.4 \\
66.7\end{array}$ & $\begin{array}{l}96.9 \\
94.2 \\
87.8 \\
59.0 \\
59.6 \\
57.5 \\
63.5 \\
76.7 \\
69.1 \\
64.0 \\
61.4 \\
59.9\end{array}$ & $\begin{array}{l}82.3 \\
84.6 \\
80.6 \\
53.8 \\
53.9 \\
50.3 \\
59.0 \\
72.8 \\
66.4 \\
58.1 \\
55.1 \\
52.4\end{array}$ & $\begin{array}{l}79.4 \\
81.9 \\
76.2 \\
50.6 \\
53.7 \\
48.7 \\
52.0 \\
66.6 \\
W \\
W \\
W \\
W\end{array}$ & $\begin{array}{c}W \\
79.2 \\
W \\
45.7 \\
45.0 \\
43.5 \\
48.0 \\
61.3 \\
55.6 \\
W \\
W \\
W\end{array}$ & $\begin{array}{l}65.4 \\
71.2 \\
63.4 \\
36.2 \\
42.3 \\
34.2 \\
40.2 \\
43.7 \\
33.8 \\
33.3 \\
34.9 \\
36.0\end{array}$ & $\begin{array}{l}61.0 \\
68.7 \\
63.7 \\
37.2 \\
42.3 \\
34.3 \\
39.2 \\
42.5 \\
34.5 \\
35.7 \\
33.6 \\
35.3\end{array}$ \\
\hline $\begin{array}{l}\text { Connectlcut } \\
1983 \\
1984 \\
1985 \\
1986 \\
1987\end{array}$ & $\begin{array}{c}W \\
W \\
86.2 \\
65.4 \\
63.7 \\
W \\
67.7 \\
82.8 \\
76.3 \\
64.8 \\
63.3 \\
63.2\end{array}$ & $\begin{array}{l}93.3 \\
97.0 \\
91.6 \\
64.1 \\
61.3 \\
55.2 \\
65.9 \\
83.0 \\
78.9 \\
64.2 \\
63.0 \\
66.8\end{array}$ & $\begin{array}{r}102.6 \\
101.6 \\
96.1 \\
66.3 \\
57.8 \\
50.6 \\
60.6 \\
75.3 \\
66.9 \\
62.8 \\
58.1 \\
54.9\end{array}$ & $\begin{array}{l}82.3 \\
84.6 \\
80.1 \\
54.9 \\
54.4 \\
49.8 \\
59.1 \\
73.7 \\
66.5 \\
58.5 \\
55.3 \\
52.7\end{array}$ & $\begin{array}{l}- \\
- \\
- \\
- \\
- \\
- \\
- \\
- \\
\bar{w}\end{array}$ & $\begin{array}{l}- \\
- \\
- \\
- \\
- \\
- \\
- \\
- \\
\overline{-} \\
\bar{w}\end{array}$ & $\begin{array}{l}67.8 \\
73.1 \\
65.2 \\
38.9 \\
43.5 \\
35.8 \\
42.1 \\
45.0 \\
37.3 \\
35.7 \\
37.5 \\
44.6\end{array}$ & $\begin{array}{c}W \\
69.3 \\
61.2 \\
36.0 \\
43.1 \\
36.4 \\
42.5 \\
48.4 \\
37.4 \\
35.4 \\
W \\
37.7\end{array}$ \\
\hline
\end{tabular}

See footnotes at end of table. 
Table A3. Refiner/Reseller Prices of Distillate and Residual Fuel Oils, by PAD District, 1983-Present

(Cents per Gallon Excluding Taxes) - Continued

\begin{tabular}{|c|c|c|c|c|c|c|c|c|}
\hline \multirow{2}{*}{$\begin{array}{c}\text { Geographic Area } \\
\text { Year }\end{array}$} & \multicolumn{2}{|c|}{ No. 1 Distillate } & \multicolumn{2}{|c|}{ No. 2 Distillatea } & \multicolumn{2}{|c|}{ No. 4 Fuelb } & \multicolumn{2}{|c|}{ Residual Fuel Oll } \\
\hline & $\begin{array}{l}\text { Sales to } \\
\text { End Users }\end{array}$ & $\begin{array}{l}\text { Sales for } \\
\text { Resale }\end{array}$ & $\begin{array}{l}\text { Sales to } \\
\text { End Users }\end{array}$ & $\begin{array}{l}\text { Sales for } \\
\text { Resale }\end{array}$ & $\begin{array}{l}\text { Sales to } \\
\text { End Users }\end{array}$ & $\begin{array}{l}\text { Sales for } \\
\text { Resale }\end{array}$ & $\begin{array}{l}\text { Sales to } \\
\text { End Users }\end{array}$ & $\begin{array}{c}\text { Sales for } \\
\text { Resale }\end{array}$ \\
\hline
\end{tabular}

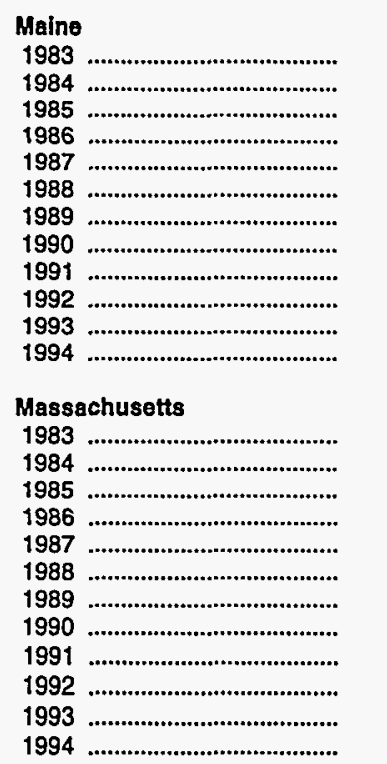

93.8
97.0
95.0
69.3
67.8
59.2
66.7
78.9
77.2
62.8
62.4
$W$

$\begin{array}{ll}91.5 & 86.3 \\ 93.6 & 88.9 \\ 88.1 & 83.3 \\ 64.2 & 52.7 \\ 61.9 & 58.9 \\ 57.5 & 56.0 \\ 72.9 & 59.6 \\ 84.6 & 74.5 \\ 77.1 & 66.7 \\ 64.0 & 60.8 \\ 62.4 & 56.6 \\ 67.1 & 55.3\end{array}$

83.4
84.8
80.7
53.1
53.6
49.7
59.8
70.8
66.0
58.2
54.7
52.4

-
-
-
-
-
-
-
$\overline{-}$

$\begin{array}{lll}- & W & 62.3 \\ - & 70.7 & 67.9 \\ - & 64.1 & 63.0 \\ - & 35.2 & 34.5 \\ - & 41.7 & 40.9 \\ - & 33.2 & 32.2 \\ - & 40.4 & 39.7 \\ - & 41.5 & 44.9 \\ - & 34.0 & 32.7 \\ - & 34.9 & 31.7 \\ \bar{W} & 34.4 & 34.2 \\ \text { W } & 34.7 & 35.3\end{array}$

New Hampshira

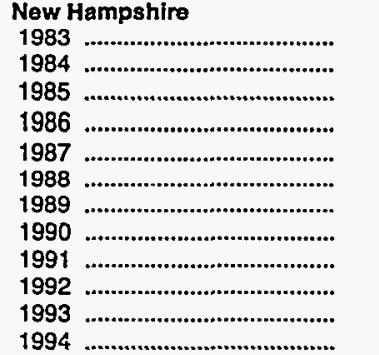

93.3

92.1

88.6

60.2

61.6

56.3

66.8

77.2

76.9

62.8

07.1

55.3

81.9

92.7
$W$
84.9
62.5
61.2
56.8
70.7
96.4
$W$
$W$
57.9
$W$

\section{1}

91.9

85.0
57.0

58.6

$$
\begin{aligned}
& 58.2 \\
& 65.4 \\
& 77.2
\end{aligned}
$$$$
\begin{aligned}
& 77.2 \\
& 70.4
\end{aligned}
$$$$
64.7
$$$$
63.2
$$

61.5

$$
\begin{aligned}
& 84.2 \\
& 80.6
\end{aligned}
$$

53.1

\subsection{7}

$$
87.2
$$

58.4

$$
62.4
$$$$
62.0
$$$$
75.6
$$$$
66.8
$$$$
60.1
$$

59.6

81.5

85.6

$$
82.3
$$

$\begin{array}{lll}- & 63.4 & 60.4 \\ - & 69.6 & 68.5 \\ - & 61.5 & 65.1 \\ - & 35.1 & 38.1 \\ - & 41.7 & 42.2 \\ - & 33.6 & 34.1 \\ - & 38.4 & 38.6 \\ - & 43.5 & 43.1 \\ - & 32.5 & 35.5 \\ - & 32.3 & 37.2 \\ \overline{\text { W }} & 35.1 & 33.0 \\ & 35.8 & 35.3\end{array}$

\section{Rhode Island}

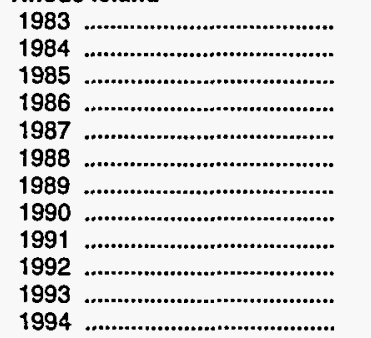

$\begin{array}{ll}- & - \\ - & - \\ - & - \\ - & \text { NA } \\ \text { NA } & \text { NA } \\ \text { W } & \text { NA } \\ \text { W } & \text { W } \\ \text { W } & \text { W } \\ \text { W } & \text { W }\end{array}$

$\begin{array}{cc}- & 91.1 \\ - & 91.1 \\ - & 86.7 \\ - & 54.7 \\ \text { - } & 60.2 \\ \text { NA } & 56.3 \\ \text { NA } & 63.9 \\ \text { NA } & 81.4 \\ \text { NA } & 68.3 \\ \text { W } & 67.1 \\ \text { W } & 62.2 \\ \text { W } & 61.1\end{array}$

82.1
84.8
80.1
54.9
53.6
48.5
59.8
72.9
65.5
57.5
54.1
51.5

-
-
-
-
-
-
-
-
-
-
$w$
-
-
-
-
-
-
-
-
-

$\begin{array}{cr}W & N A \\ 68.8 & 67.8 \\ 62.9 & 59.6 \\ 33.4 & 37.9 \\ 42.8 & 39.1 \\ 33.2 & 36.3 \\ 39.3 & 39.8 \\ 45.8 & W \\ 33.8 & 27.8 \\ 31.6 & 32.0 \\ 30.7 & W \\ 35.2 & 32.9\end{array}$

See footnotes at end of table. 
Table A3. Refiner/Reseller Prices of Distillate and Residual Fuel Oils, by PAD District, 1983-Present

(Cents per Gallon Excluding Taxes) - Continued

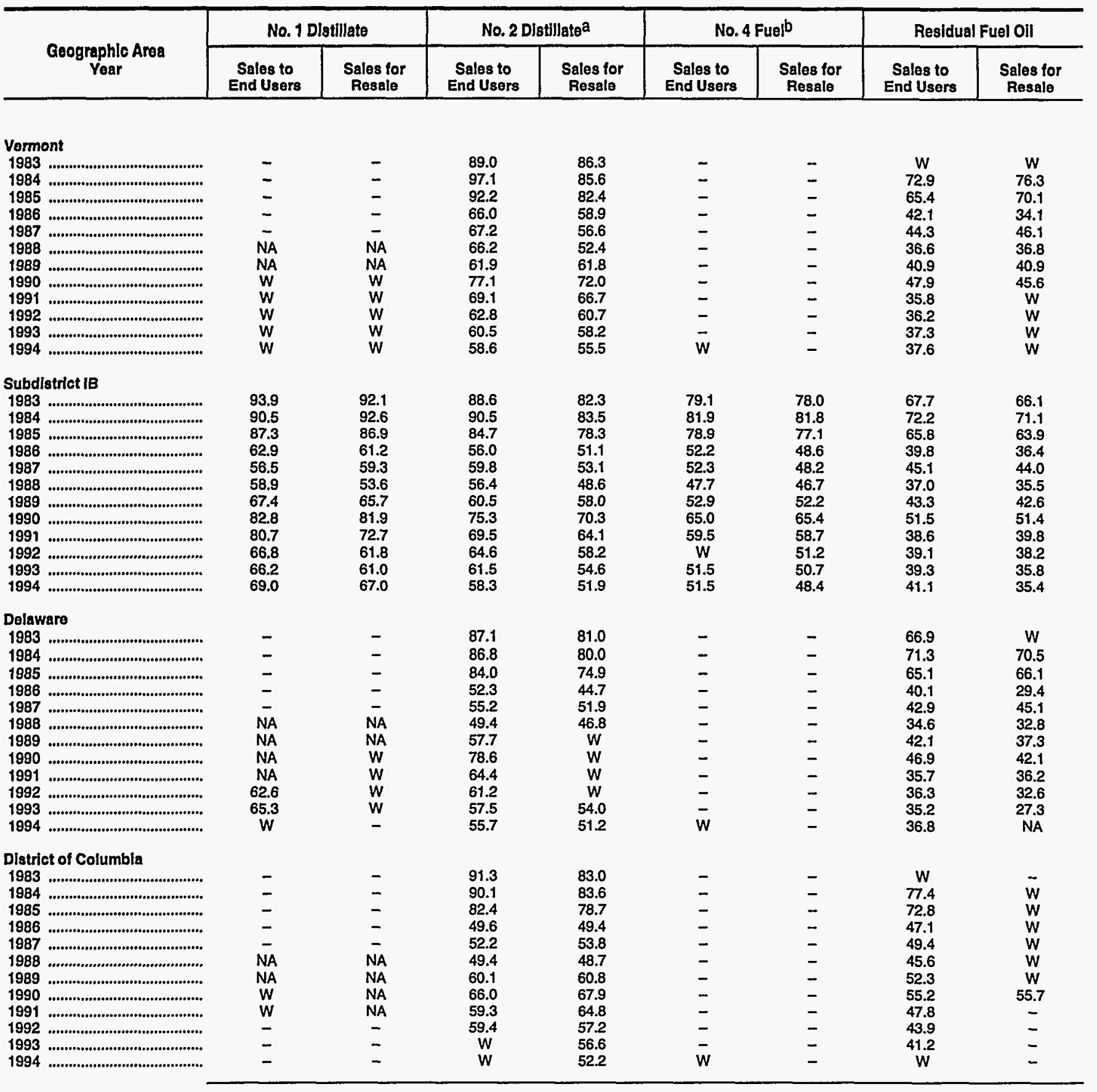

See footnotes at end of table. 
Table A3. Refiner/Reseller Prices of Distillate and Residual Fuel Oils, by PAD District, 1983-Present

(Cents per Gallon Excluding Taxes) - Continued

\begin{tabular}{|c|c|c|c|c|c|c|c|c|}
\hline \multirow{2}{*}{$\begin{array}{c}\text { Geographic Area } \\
\text { Year }\end{array}$} & \multicolumn{2}{|c|}{ No. 1 Distillate } & \multicolumn{2}{|c|}{ No. 2 Dlstillate ${ }^{a}$} & \multicolumn{2}{|c|}{ No. 4 Fuel b } & \multicolumn{2}{|c|}{ Residual Fuel Oll } \\
\hline & $\begin{array}{l}\text { Sales to } \\
\text { End Users }\end{array}$ & $\begin{array}{c}\text { Sales for } \\
\text { Resale }\end{array}$ & $\begin{array}{l}\text { Sales to } \\
\text { End Users }\end{array}$ & $\begin{array}{c}\text { Sales for } \\
\text { Resale }\end{array}$ & $\begin{array}{l}\text { Sales to } \\
\text { End Users }\end{array}$ & $\begin{array}{c}\text { Sales for } \\
\text { Resale }\end{array}$ & $\begin{array}{l}\text { Sales to } \\
\text { End Users }\end{array}$ & $\begin{array}{c}\text { Sales for } \\
\text { Resale }\end{array}$ \\
\hline \multicolumn{9}{|l|}{ Maryland } \\
\hline $1983 \ldots \ldots \ldots \ldots \ldots \ldots$ & - & - & 87.4 & 82.6 & - & - & 65.5 & 64.9 \\
\hline 1984 & - & - & 87.7 & 84.5 & - & - & 70.5 & 71.6 \\
\hline 1985 & - & - & 81.4 & 79.7 & - & - & 62.9 & 62.3 \\
\hline 1986 & - & - & 47.2 & 50.0 & - & - & 36.5 & 31.3 \\
\hline 1987 & - & - & 52.9 & 53.7 & - & - & 44.8 & 45.8 \\
\hline 1988 & NA & NA & 47.3 & 49.1 & - & - & 34.1 & 33.4 \\
\hline 1989 & NA & NA & 55.9 & 59.1 & - & - & 40.2 & 38.5 \\
\hline 1990 & NA & NA & 69.9 & 70.3 & - & - & 44.6 & 42.0 \\
\hline 1991 & NA & NA & 63.4 & 64.4 & - & - & 33.7 & 30.7 \\
\hline 1992 & 63.2 & 65.8 & 59.3 & 58.9 & - & - & 32.2 & 34.5 \\
\hline 1993 & 65.2 & 64.3 & 56.5 & 55.4 & - & - & 33.8 & 33.3 \\
\hline 1994 & 68.5 & 65.1 & 52.2 & 52.4 & W & $w$ & 34.3 & 34.1 \\
\hline \multicolumn{9}{|l|}{ New Jersey } \\
\hline $1983 \ldots$ & 91.2 & 90.3 & 85.2 & 81.9 & - & - & 69.0 & 65.3 \\
\hline 1984 & 89.0 & 95.0 & 87.4 & 82.6 & - & - & 72.0 & 71.0 \\
\hline 1985 & 85.2 & 85.3 & 82.7 & 77.3 & - & - & 64.4 & 62.8 \\
\hline 1986 & 65.1 & 62.8 & 54.6 & 52.7 & - & - & 37.7 & 37.0 \\
\hline 1987 & 53.7 & $W$ & 58.0 & 52.4 & - & - & 44.1 & 43.4 \\
\hline 1988 & 57.1 & 53.5 & 53.4 & 48.1 & - & - & 35.9 & 34.6 \\
\hline 1989 & 65.2 & 68.7 & 57.5 & 57.4 & - & - & 42.0 & 42.1 \\
\hline $1990 \ldots$ & 80.0 & 69.9 & 72.8 & 69.9 & - & - & 48.6 & 50.9 \\
\hline 1991 & 79.0 & 68.5 & 67.0 & 63.9 & - & - & 36.9 & 39.1 \\
\hline 1992 & 62.5 & 58.7 & 61.9 & 57.8 & - & - & 36.0 & 36.9 \\
\hline 1993 & 60.9 & 57.9 & 58.7 & 53.9 & - & - & 38.3 & 34.7 \\
\hline 1994 & $W$ & W & 55.3 & 50.8 & 53.8 & 49.9 & 40.3 & 35.4 \\
\hline \multicolumn{9}{|l|}{ Now York } \\
\hline 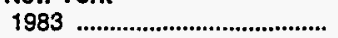 & 93.7 & 92.6 & 94.3 & 82.5 & - & - & 66.2 & 68.3 \\
\hline 1984 & 93.5 & 90.5 & 94.3 & 85.2 & - & - & 72.4 & 71.7 \\
\hline 1985 & 87.4 & $W$ & 88.0 & 80.3 & - & - & 66.8 & 66.0 \\
\hline 1986 & 61.7 & 60.7 & 62.3 & 51.9 & - & - & 42.1 & 38.4 \\
\hline 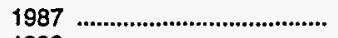 & 58.7 & $W$ & 63.7 & 54.4 & - & - & 46.3 & 44.2 \\
\hline 1988 & W & 56.7 & 60.9 & 50.2 & - & - & 38.5 & 37.5 \\
\hline 1989 & 63.3 & 67.7 & 63.2 & 59.9 & - & - & 44.9 & 44.6 \\
\hline 1990 & 84.1 & 87.8 & 78.4 & 71.6 & - & - & 54.0 & 53.6 \\
\hline $1991 \ldots$ & 73.7 & 72.7 & 74.0 & 65.5 & - & - & 40.7 & 42.8 \\
\hline 1992 & 64.3 & 62.7 & 68.2 & 58.6 & - & - & 41.6 & 41.7 \\
\hline 1993 & $W$ & 62.4 & 64.3 & 55.5 & - & - & 41.5 & 39.1 \\
\hline 1994 & W & 62.2 & 61.9 & 53.1 & w & w & 44.4 & 38.9 \\
\hline \multicolumn{9}{|l|}{ Pennsylvania } \\
\hline 1983 & 99.2 & 92.5 & 88.1 & 83.1 & - & - & 67.2 & 65.9 \\
\hline 1984 & 91.3 & 94.3 & 90.9 & 84.3 & - & - & 72.8 & 69.8 \\
\hline 1985 & 92.4 & 88.5 & 84.4 & 79.6 & - & - & 66.4 & 62.3 \\
\hline 1986 & 62.0 & 61.3 & 56.2 & 48.5 & - & - & 38.3 & 34.6 \\
\hline 1987 & 73.6 & 58.4 & 60.5 & 53.5 & - & - & 43.1 & 44.0 \\
\hline 1988 & 65.2 & 51.9 & 57.4 & 48.1 & - & - & 35.9 & 34.1 \\
\hline 1989 & 77.0 & 63.2 & 63.7 & $\mathbf{5 7 . 5}$ & - & - & 42.6 & 40.7 \\
\hline 1990 & 91.7 & 81.5 & 77.7 & 70.0 & - & - & 48.8 & 48.9 \\
\hline 1991 & 87.0 & 74.2 & 70.8 & 63.4 & - & - & 35.4 & 35.8 \\
\hline 1992 & 72.8 & 62.3 & 65.5 & 58.5 & - & - & 35.5 & 34.5 \\
\hline 1993 & 70.1 & 61.2 & 63.0 & 54.8 & - & - & 35.8 & 34.4 \\
\hline 1994 & 80.3 & 72.4 & 60.5 & 52.2 & $w$ & $w$ & 37.2 & 36.1 \\
\hline
\end{tabular}

See footnotes at end of table. 
Table A3. Refiner/Reseller Prices of Distillate and Residual Fuel Oils, by PAD District, 1983-Present

(Cents per Gallon Excluding Taxes) - Continued

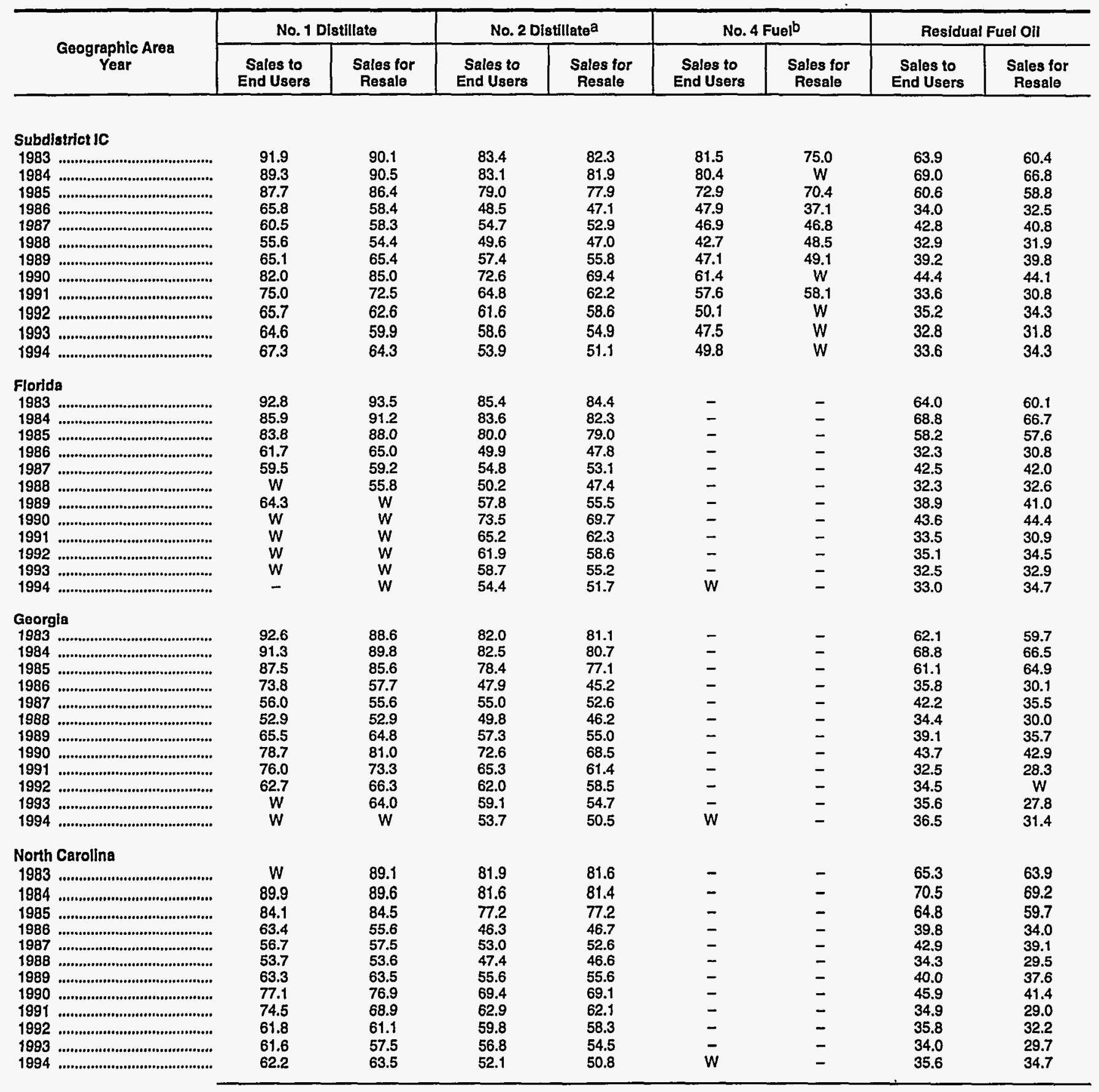

See footnotes at end of table. 
Table A3. Refiner/Reseller Prices of Distillate and Residual Fuel Oils, by PAD District, 1983-Present

(Cents per Gallon Excluding Taxes) - Continued

\begin{tabular}{|c|c|c|c|c|c|c|c|c|}
\hline \multirow{2}{*}{$\begin{array}{c}\text { Geographic Area } \\
\text { Year }\end{array}$} & \multicolumn{2}{|c|}{ No. 1 Distillate } & \multicolumn{2}{|c|}{ No. 2 Distillatea } & \multicolumn{2}{|c|}{ No. 4 Fuelb } & \multicolumn{2}{|c|}{ Residual Fuel OII } \\
\hline & $\begin{array}{l}\text { Sales to } \\
\text { End Users }\end{array}$ & $\begin{array}{l}\text { Sales for } \\
\text { Resale }\end{array}$ & $\begin{array}{l}\text { Sales to } \\
\text { End Users }\end{array}$ & $\begin{array}{l}\text { Sales for } \\
\text { Resale }\end{array}$ & $\begin{array}{l}\text { Sales to } \\
\text { End Users }\end{array}$ & $\begin{array}{l}\text { Sales for } \\
\text { Resale }\end{array}$ & $\begin{array}{l}\text { Sales to } \\
\text { End Users }\end{array}$ & $\begin{array}{c}\text { Sales for } \\
\text { Resale }\end{array}$ \\
\hline \multicolumn{9}{|l|}{ South Carolina } \\
\hline 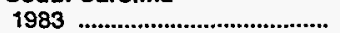 & $w$ & 89.4 & 84.0 & 81.9 & - & - & 62.6 & $w$ \\
\hline 1984 & 91.4 & 90.0 & 83.3 & 81.6 & - & - & 69.4 & 68.9 \\
\hline 1985 & 92.7 & 86.1 & 79.0 & 77.5 & - & - & 64.1 & 64.0 \\
\hline 1986 & 79.2 & 58.2 & 47.7 & 46.4 & - & - & 38.1 & 44.6 \\
\hline 1987 & 57.9 & 57.2 & 55.0 & 53.0 & - & - & 42.4 & $W$ \\
\hline 1988 & 53.3 & 54.4 & 49.7 & 47.0 & - & - & 34.2 & 30.5 \\
\hline 1989 & 66.2 & 63.8 & 57.3 & 55.7 & - & - & 40.0 & 38.2 \\
\hline 1990 & 76.1 & 88.3 & 73.8 & 69.0 & - & - & 46.3 & 37.3 \\
\hline 1991 & 78.3 & 76.9 & 64.9 & 62.4 & - & - & 36.9 & $w$ \\
\hline 1992 & 60.9 & 59.7 & 61.0 & 58.7 & - & - & 37.2 & - \\
\hline 1993 & 72.1 & 55.5 & 58.7 & 55.0 & - & - & $w$ & w \\
\hline 1994 & $w$ & $w$ & 54.6 & 51.0 & $w$ & - & $\ddot{w}$ & w \\
\hline \multicolumn{9}{|l|}{ Virginia } \\
\hline $1983 \ldots \ldots$ & 87.2 & 89.4 & 82.2 & 81.8 & - & - & 64.0 & 60.8 \\
\hline 1984 & 89.7 & 90.7 & 82.8 & 82.6 & - & - & 69.0 & 66.8 \\
\hline 1985 & 85.4 & 86.1 & 78.3 & 78.1 & - & - & 62.3 & 60.0 \\
\hline 1986 & 60.2 & 56.9 & 47.6 & 48.2 & - & - & 34.9 & 34.2 \\
\hline 1987 & 59.6 & 58.3 & 53.9 & 52.8 & - & - & 44.1 & 39.1 \\
\hline 1988 & 55.7 & 54.6 & 48.5 & 47.3 & - & - & 33.5 & 31.2 \\
\hline 1989 & 62.0 & 65.3 & 57.3 & 56.5 & - & - & 39.4 & 37.9 \\
\hline 1990 & 81.9 & 87.9 & 71.8 & 69.7 & - & - & 47.8 & 45.8 \\
\hline 1991 & 75.1 & 72.8 & 64.4 & 62.4 & - & - & 33.5 & 33.6 \\
\hline 1992 & 62.7 & 61.6 & 60.8 & 58.4 & - & - & 34.9 & 34.1 \\
\hline 1993 & 60.6 & 59.9 & 57.5 & 54.7 & - & - & 32.1 & 30.7 \\
\hline 1994 & 62.3 & 64.2 & 51.6 & 51.0 & $w$ & $W$ & 34.2 & 33.2 \\
\hline \multicolumn{9}{|l|}{ West Virginia } \\
\hline 1983 & 99.0 & 94.1 & 85.3 & 84.2 & - & - & 61.3 & $w$ \\
\hline 1984 & 99.1 & 97.6 & 86.5 & 84.1 & - & - & $W$ & 67.1 \\
\hline 1985 & 94.1 & 92.4 & 82.2 & 79.3 & - & - & 57.1 & $W$ \\
\hline 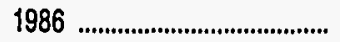 & 72.7 & 62.8 & 52.6 & 48.9 & - & - & 36.6 & $w$ \\
\hline 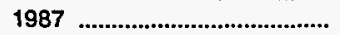 & 70.3 & 67.1 & 58.9 & 55.0 & - & - & 40.0 & $w$ \\
\hline 1988 & 68.2 & 62.6 & 54.8 & 49.5 & - & - & 33.6 & $w$ \\
\hline 1989 & 79.4 & 66.5 & 60.9 & 58.2 & - & - & 37.4 & $w$ \\
\hline 1990 & 98.4 & 92.8 & 75.1 & 72.2 & - & - & 37.9 & $w$ \\
\hline 1991 & 84.0 & 82.2 & 66.7 & 63.2 & - & - & 27.1 & $\ddot{w}$ \\
\hline 1992 & 75.9 & 69.6 & 64.7 & 60.0 & - & - & 30.8 & 41.2 \\
\hline 1993 & 78.4 & 67.5 & 61.4 & 56.9 & - & - & 34.0 & $W$ \\
\hline 1994 & $w$ & 67.0 & 58.1 & 53.9 & $w$ & W & 34.5 & 33.9 \\
\hline \multicolumn{9}{|l|}{ PAD District II } \\
\hline 1983 & 93.2 & 88.6 & 83.7 & 81.9 & 77.6 & 68.0 & 68.6 & 59.2 \\
\hline 1984 & 92.2 & 88.4 & 84.1 & 82.5 & 76.2 & 63.8 & 66.0 & 63.4 \\
\hline 1985 & 86.6 & 85.9 & 79.6 & 78.3 & 72.3 & 62.9 & 60.4 & 57.2 \\
\hline 1986 & 60.1 & 57.2 & 48.7 & 47.1 & 40.3 & 34.6 & 37.6 & 31.2 \\
\hline 1987 & 59.4 & 59.8 & 55.6 & 54.4 & $W$ & 36.9 & 39.2 & 36.1 \\
\hline 1988 & 54.7 & 54.2 & 50.2 & 48.0 & $w$ & 41.5 & 35.4 & 28.9 \\
\hline 1989 & 65.1 & 66.5 & 58.6 & 56.7 & $w$ & 44.9 & 36.5 & 31.0 \\
\hline 1990 & 77.2 & 83.6 & 71.7 & 69.4 & $w$ & $W$ & 37.6 & 32.9 \\
\hline 1991 & 70.1 & 71.3 & 63.7 & 61.1 & $\ddot{w}$ & 46.2 & 33.5 & 26.0 \\
\hline 1992 & 62.6 & 63.2 & 61.1 & 59.2 & $\mathbf{W}$ & $w$ & 32.8 & 27.2 \\
\hline 1993 & 61.9 & 62.0 & 58.8 & 56.3 & W & $w$ & 34.7 & 28.6 \\
\hline 1994 & 60.6 & 59.7 & 54.6 & 53.0 & $w$ & w & 33.7 & 30.0 \\
\hline
\end{tabular}

See footnotes at end of table. 
Table A3. Refiner/Reseller Prices of Distillate and Residual Fuel Oils, by PAD District, 1983-Present

(Cents per Gallon Excluding Taxes) - Continued

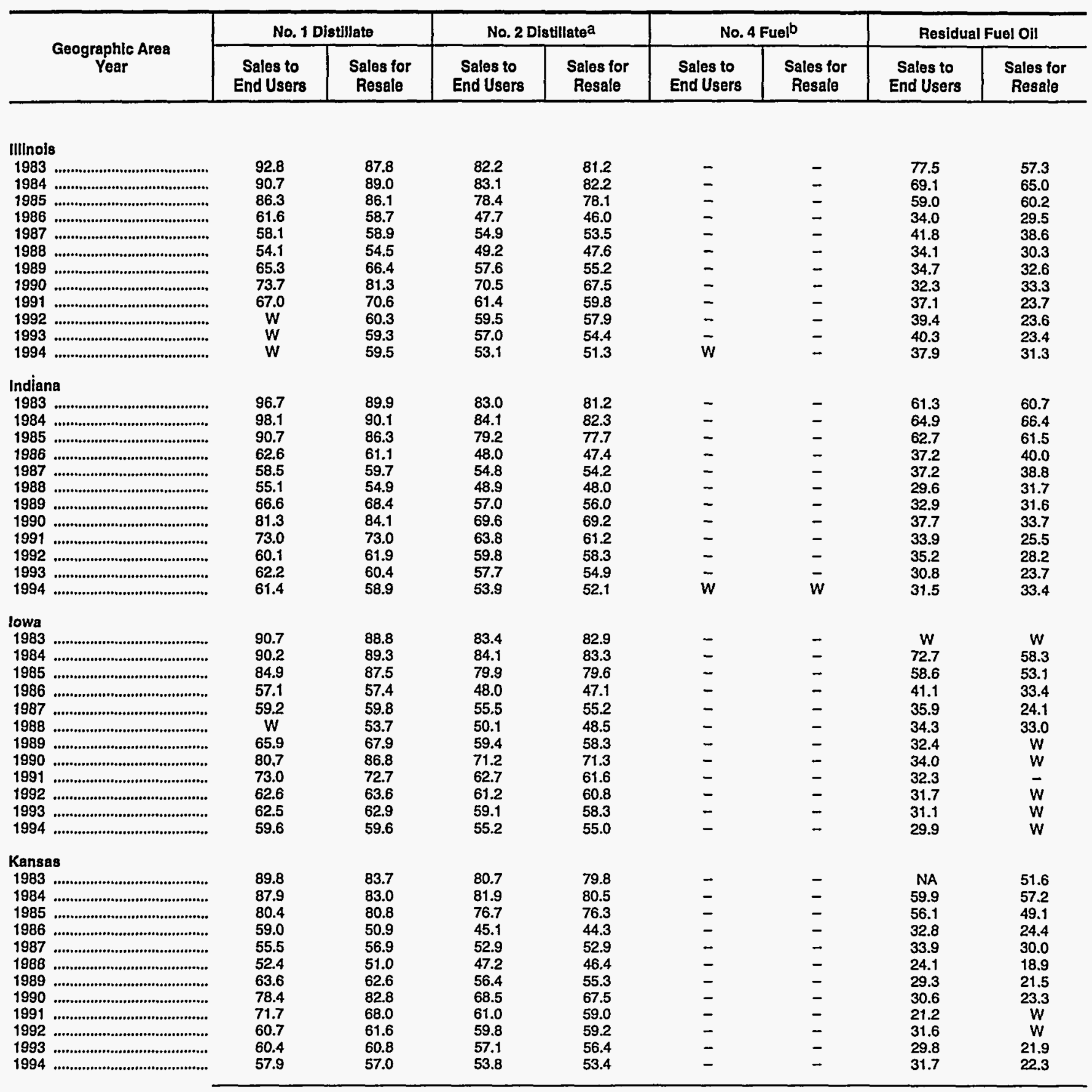

See footnotes at end of table. 
Table A3. Refiner/Reseller Prices of Distillate and Residual Fuel Oils, by PAD District, 1983-Present

(Cents per Gallon Excluding Taxes) - Continued

\begin{tabular}{|c|c|c|c|c|c|c|c|c|}
\hline \multirow{2}{*}{$\begin{array}{c}\text { Geographic Area } \\
\text { Year }\end{array}$} & \multicolumn{2}{|c|}{ No. 1 Distillate } & \multicolumn{2}{|c|}{ No. 2 Distillatea } & \multicolumn{2}{|c|}{ No. 4 Fuel $^{b}$} & \multicolumn{2}{|c|}{ Residual Fuel Oll } \\
\hline & $\begin{array}{l}\text { Sales to } \\
\text { End Users }\end{array}$ & $\begin{array}{c}\text { Sales for } \\
\text { Resale }\end{array}$ & $\begin{array}{l}\text { Sales to } \\
\text { End Users }\end{array}$ & $\begin{array}{l}\text { Sales for } \\
\text { Resale }\end{array}$ & $\begin{array}{l}\text { Sales to } \\
\text { End Users }\end{array}$ & $\begin{array}{c}\text { Sales for } \\
\text { Resale }\end{array}$ & $\begin{array}{l}\text { Sales to } \\
\text { End Users }\end{array}$ & $\begin{array}{c}\text { Sales for } \\
\text { Resale }\end{array}$ \\
\hline \multicolumn{9}{|l|}{ Kentucky } \\
\hline 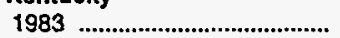 & 95.1 & 92.5 & 84.4 & 82.7 & - & - & 66.6 & 60.6 \\
\hline 1984 & 95.3 & 93.1 & 84.8 & 83.6 & - & - & 72.6 & 76.6 \\
\hline 1985 & 92.1 & 87.7 & 80.1 & 78.6 & - & - & 69.7 & 80.5 \\
\hline 1986 & 69.8 & 62.0 & 49.5 & 48.2 & - & - & 43.9 & 24.9 \\
\hline 1987 & 64.9 & 61.5 & 56.1 & 54.7 & - & - & 42.5 & $W$ \\
\hline 1988 & 59.0 & 57.2 & 50.7 & 48.4 & - & - & 41.5 & 31.2 \\
\hline 1989 & 68.8 & 71.2 & 59.2 & 57.0 & - & - & 43.5 & $w$ \\
\hline 1990 & 85.9 & 87.1 & 72.6 & 71.5 & - & - & 51.0 & $w$ \\
\hline 1991 & 75.7 & 75.7 & 65.5 & 62.7 & - & - & 44.0 & $w$ \\
\hline 1992 & 68.6 & 66.0 & 62.3 & 59.5 & - & - & 38.2 & $w$ \\
\hline 1993 & 69.8 & 64.2 & 59.8 & 56.3 & - & - & 39.0 & w \\
\hline 1994 & 78.3 & 63.3 & 55.6 & 52.9 & W & $W$ & 36.1 & 38.7 \\
\hline \multicolumn{9}{|l|}{ Michigan } \\
\hline 1983 & 98.4 & 89.5 & 86.1 & 83.2 & - & - & 64.0 & 62.2 \\
\hline 1984 & 100.5 & 89.4 & 85.7 & 83.7 & - & - & 68.5 & 62.7 \\
\hline 1985 & 94.1 & 85.9 & 80.6 & 79.5 & - & - & 63.2 & 56.8 \\
\hline 1986 & 67.1 & 58.4 & 49.8 & 49.7 & - & - & 43.5 & 36.5 \\
\hline 1987 & 62.8 & 61.2 & 56.1 & 55.8 & - & - & 41.7 & 35.3 \\
\hline 1988 & 55.1 & 55.5 & 50.9 & 49.5 & - & - & 46.0 & 32.1 \\
\hline 1989 & 64.1 & 65.6 & 58.1 & 57.8 & - & - & 45.1 & 32.8 \\
\hline 1990 & 77.2 & 79.4 & 71.2 & 70.4 & - & - & 45.4 & 37.1 \\
\hline 1991 & 70.9 & 69.9 & 63.3 & 62.0 & - & - & 40.1 & 33.9 \\
\hline 1992 & 62.8 & 64.3 & 60.6 & 59.1 & - & - & 38.3 & 33.5 \\
\hline 1993 & 62.1 & 61.6 & 58.2 & 55.9 & - & - & 40.7 & 38.6 \\
\hline 1994 & 61.1 & 58.6 & 54.2 & 52.7 & $w$ & - & 39.9 & 37.6 \\
\hline \multicolumn{9}{|l|}{ Minnesota } \\
\hline 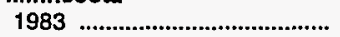 & 89.2 & 88.7 & 83.4 & 83.0 & - & - & 60.7 & $w$ \\
\hline 1984 & 89.2 & 89.4 & 83.2 & 83.0 & - & - & 62.7 & 61.2 \\
\hline 1985 & 84.2 & 87.9 & 78.5 & 79.3 & - & - & 57.9 & 56.8 \\
\hline 1986 & 54.6 & 59.2 & 47.9 & 48.5 & - & - & 40.4 & W \\
\hline 1987 & 58.8 & 61.1 & 55.6 & 56.2 & - & - & 34.3 & 35.4 \\
\hline 1988 & 52.8 & 54.5 & 49.1 & 48.8 & - & - & 33.4 & $w$ \\
\hline 1989 & 64.3 & 68.1 & 59.2 & 59.2 & - & - & 33.6 & 35.0 \\
\hline 1990 & 76.8 & 86.9 & 73.1 & 72.2 & - & - & 35.3 & 36.1 \\
\hline 1991 & 68.5 & 73.3 & 63.1 & 62.6 & - & - & 29.8 & 28.6 \\
\hline 1992 & 63.5 & 64.5 & 62.0 & 61.2 & - & - & 25.3 & W \\
\hline 1993 & 62.9 & 64.0 & 57.6 & 59.1 & - & - & 30.8 & $w$ \\
\hline 1994 & 60.3 & 61.8 & 54.3 & 56.1 & $w$ & - & 30.7 & $w$ \\
\hline \multicolumn{9}{|l|}{ Missouri } \\
\hline $1983 \ldots$ & 89.1 & 87.2 & 81.3 & 81.3 & - & - & $w$ & NA \\
\hline 1984 & 87.9 & 87.8 & 82.4 & 81.8 & - & - & 67.0 & 67.0 \\
\hline 1985 & 83.9 & 84.5 & 77.9 & 78.0 & - & - & 59.0 & 62.5 \\
\hline 1986 & 63.0 & 57.2 & 45.5 & 46.0 & - & - & 32.3 & 32.6 \\
\hline 1987 & 58.7 & 57.8 & 53.7 & 53.7 & - & - & 37.5 & 38.4 \\
\hline 1988 & 53.7 & 52.7 & 49.5 & 47.3 & - & - & 31.6 & 27.2 \\
\hline 1989 & 64.7 & 66.6 & 58.4 & 56.3 & - & - & 34.6 & 39.8 \\
\hline 1990 & 80.8 & 84.4 & 72.4 & 69.4 & - & - & 37.3 & 35.3 \\
\hline 1991 & 72.7 & 71.4 & 62.9 & 60.4 & - & - & 31.8 & 35.6 \\
\hline 1992 & $w$ & 63.4 & 61.2 & 59.3 & - & - & 32.7 & 36.5 \\
\hline 1993 & 62.4 & 61.8 & 59.4 & 56.7 & - & - & 32.5 & 27.4 \\
\hline 1994 & $W$ & 59.1 & 54.2 & 53.1 & - & - & 23.3 & 30.3 \\
\hline
\end{tabular}

See footnotes at end of table. 
Table A3. Refiner/Reseller Prices of Distillate and Residual Fuel Oils, by PAD District, 1983-Present

(Cents per Gallon Excluding Taxes) - Continued

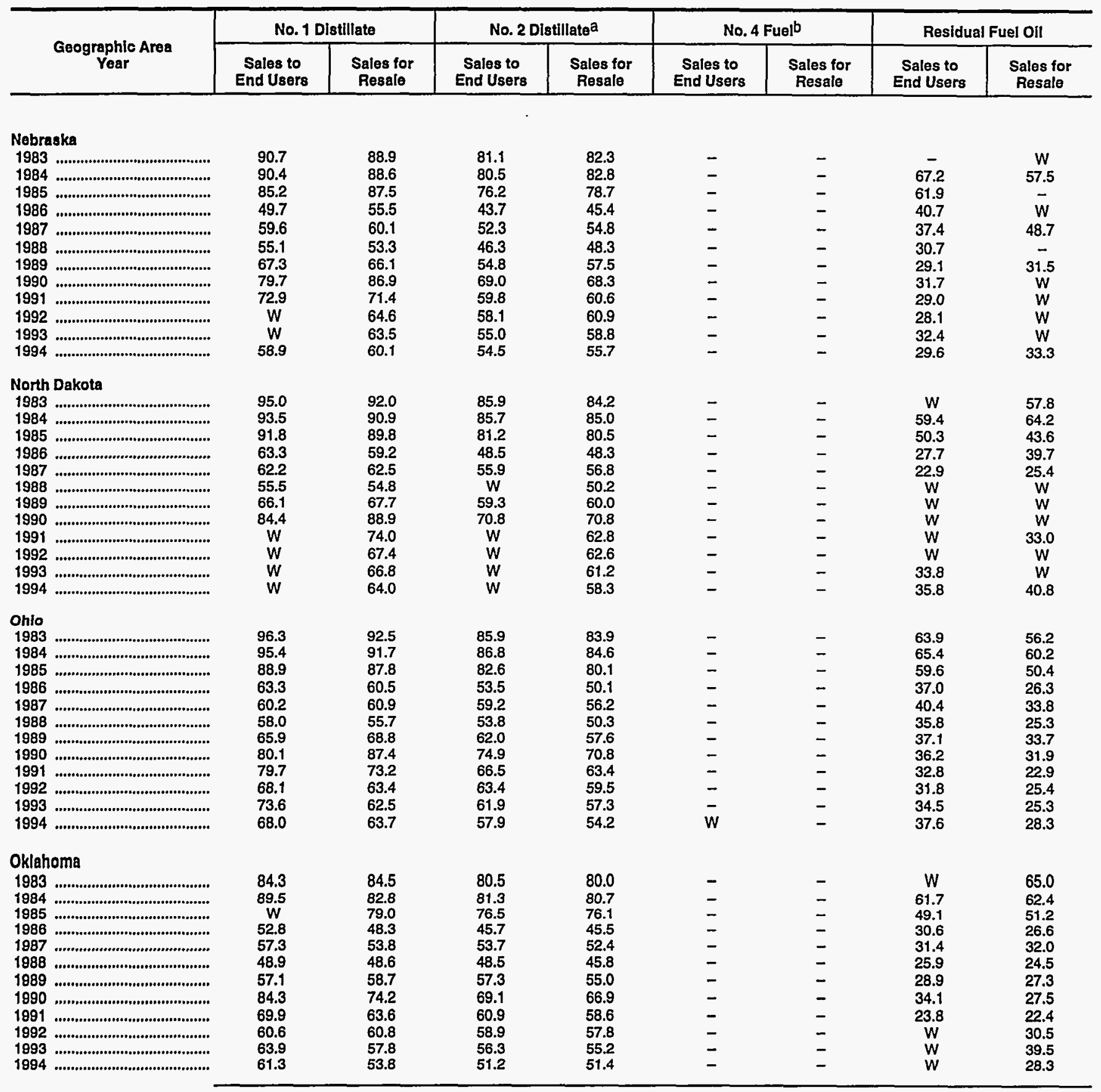

See footnotes at end of table. 
Table A3. Refiner/Reseller Prices of Distillate and Residual Fuel Oils, by PAD District, 1983-Present

(Cents per Gallon Excluding Taxes) - Continued

\begin{tabular}{|c|c|c|c|c|c|c|c|c|}
\hline \multirow{2}{*}{$\begin{array}{c}\text { Geographic Area } \\
\text { Year }\end{array}$} & \multicolumn{2}{|c|}{ No. 1 Distlliate } & \multicolumn{2}{|c|}{ No. 2 Distillatea } & \multicolumn{2}{|c|}{ No. 4 Fuelb } & \multicolumn{2}{|c|}{ Residual Fuel Oll } \\
\hline & $\begin{array}{l}\text { Sales to } \\
\text { End Users }\end{array}$ & $\begin{array}{l}\text { Sales for } \\
\text { Ressle }\end{array}$ & $\begin{array}{l}\text { Sales to } \\
\text { End Users }\end{array}$ & $\begin{array}{l}\text { Sales for } \\
\text { Resale }\end{array}$ & $\begin{array}{l}\text { Sales to } \\
\text { End Users }\end{array}$ & $\begin{array}{c}\text { Sales for } \\
\text { Resale }\end{array}$ & $\begin{array}{l}\text { Sales to } \\
\text { End Users }\end{array}$ & $\begin{array}{c}\text { Sales for } \\
\text { Resale }\end{array}$ \\
\hline \multicolumn{9}{|l|}{ South Dakota } \\
\hline 1983 & 97.9 & 90.4 & 85.7 & 83.3 & - & - & 53.8 & W \\
\hline 1984 & 95.0 & 89.9 & 85.0 & 84.1 & - & - & 66.2 & 63.6 \\
\hline 1985 & 88.8 & 89.0 & 79.9 & 80.0 & - & - & 63.9 & NA \\
\hline 1986 & $w$ & 57.5 & 47.4 & 47.7 & - & - & 33.6 & $w$ \\
\hline 1987 & 61.4 & 62.3 & 56.3 & 56.3 & - & - & 40.5 & $w$ \\
\hline 1988 & 55.9 & 54.1 & 48.8 & 49.5 & - & - & 33.8 & 31.6 \\
\hline 1989 & 67.9 & 66.9 & 58.7 & 59.2 & - & - & 30.9 & 25.5 \\
\hline 1990 & 85.2 & 87.4 & 69.2 & 70.6 & - & - & $w$ & $w$ \\
\hline 1991 & $w$ & 73.3 & 61.4 & 62.6 & - & - & $w$ & $W$ \\
\hline 1992 & W & 66.4 & $W$ & 62.3 & - & - & $W$ & - \\
\hline 1993 & 63.2 & 65.2 & 59.6 & 60.4 & - & - & W & $w$ \\
\hline 1994 & 61.4 & 62.4 & W & 57.2 & - & $w$ & W & $\ddot{W}$ \\
\hline \multicolumn{9}{|l|}{ Tennessee } \\
\hline 1983 & 87.2 & 88.8 & 83.7 & 81.1 & - & - & 64.8 & 64.2 \\
\hline 1984 & 87.1 & 89.6 & 81.6 & 80.8 & - & - & 69.5 & 67.3 \\
\hline 1985 & 84.9 & 86.2 & 77.9 & 77.4 & - & - & 68.1 & 56.2 \\
\hline 1986 & 64.6 & 58.9 & 45.7 & 45.5 & - & - & 40.1 & 37.1 \\
\hline 1987 & 59.0 & 58.8 & 53.6 & 52.6 & - & - & 40.9 & 41.8 \\
\hline 1988 & 52.5 & 55.3 & 49.1 & 46.3 & - & - & 37.2 & 32.9 \\
\hline 1989 & 62.2 & 67.0 & 57.4 & 55.2 & - & - & 38.2 & 36.6 \\
\hline 1990 & 74.8 & 82.6 & 71.8 & 69.2 & - & - & 44.9 & 42.4 \\
\hline 1991 & 71.5 & 72.6 & 63.8 & 61.2 & - & - & 35.2 & 29.4 \\
\hline 1992 & 62.8 & 62.9 & 61.1 & 58.3 & - & - & 37.7 & 32.3 \\
\hline 1993 & 61.5 & 60.1 & 58.1 & 54.5 & - & - & 38.4 & 26.4 \\
\hline 1994 & 59.5 & 61.3 & 52.5 & 50.6 & $w$ & W & 40.5 & 30.7 \\
\hline \multicolumn{9}{|l|}{ Wisconsin } \\
\hline 1983 & 94.3 & 88.6 & 84.0 & 82.4 & - & - & 57.3 & 59.5 \\
\hline $1984 \ldots$ & 93.6 & 89.0 & 84.2 & 82.8 & - & - & 67.6 & 65.9 \\
\hline 1985 & 82.1 & 86.5 & 79.3 & 78.6 & - & - & 64.2 & 55.7 \\
\hline 1986 & 53.4 & 58.4 & 48.9 & 48.1 & - & - & 41.4 & 32.4 \\
\hline 1987 & 57.3 & 59.6 & 55.3 & 54.7 & - & - & 36.3 & 36.3 \\
\hline 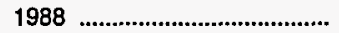 & 54.7 & 54.4 & 48.8 & 48.0 & - & - & 35.0 & 29.6 \\
\hline 1989 & 65.5 & 67.1 & 57.2 & 57.2 & - & - & 34.2 & 30.5 \\
\hline 1990 & 76.8 & 82.6 & 70.8 & 68.9 & - & - & 34.4 & 35.2 \\
\hline 1991 & 71.5 & 72.7 & 62.2 & 61.3 & - & - & 33.5 & 24.3 \\
\hline 1992 & 61.4 & 62.7 & 60.9 & 59.1 & - & - & 31.8 & 25.3 \\
\hline 1993 & 60.1 & 61.0 & 58.1 & 55.7 & - & - & 35.6 & 30.8 \\
\hline 1994 & 59.0 & 60.4 & 54.5 & 52.7 & $w$ & - & NA & 24.6 \\
\hline \multicolumn{9}{|l|}{ PAD District III } \\
\hline 1983 & 87.0 & 90.2 & 80.6 & 79.6 & 74.9 & 72.9 & 59.5 & 59.7 \\
\hline 1984 & 88.6 & 89.9 & 80.5 & 78.9 & 72.2 & 70.5 & 65.0 & 64.2 \\
\hline 1985 & 84.4 & 84.1 & 77.2 & 75.5 & 75.3 & 61.3 & 57.7 & 55.1 \\
\hline 1986 & 52.9 & 52.1 & 45.5 & 44.4 & 44.7 & 35.3 & 29.9 & 29.2 \\
\hline 1987 & 59.4 & 59.8 & 53.3 & 51.1 & 51.0 & 41.5 & 38.2 & 38.1 \\
\hline 1988 & 53.1 & 53.8 & 47.7 & 44.9 & W & 37.3 & 27.4 & 28.0 \\
\hline 1989 & 63.8 & 64.7 & 55.3 & 53.4 & 51.9 & 43.0 & 33.0 & 36.3 \\
\hline 1990 & 73.5 & 85.4 & 71.7 & 67.8 & 58.0 & 43.9 & 37.3 & 40.1 \\
\hline 1991 & 67.1 & 67.9 & 63.3 & 59.8 & W & 45.2 & 28.6 & 28.5 \\
\hline 1992 & 61.7 & 64.3 & 60.2 & 56.6 & 50.2 & $W$ & 29.2 & 29.6 \\
\hline 1993 & 59.9 & 59.2 & 58.5 & 53.0 & $w$ & NA & 27.7 & 27.2 \\
\hline 1994 & 60.7 & 59.2 & 52.8 & 48.9 & $w$ & $w$ & 30.1 & 29.4 \\
\hline
\end{tabular}

See footnotes at end of table. 
Table A3. Refiner/Reseller Prices of Distillate and Residual Fuel Oils, by PAD District, 1983-Present

(Cents per Gallon Excluding Taxes) - Continued

\begin{tabular}{|c|c|c|c|c|c|c|c|c|}
\hline \multirow{2}{*}{$\begin{array}{c}\text { Geographlc Area } \\
\text { Year }\end{array}$} & \multicolumn{2}{|c|}{ No. 1 Distlllate } & \multicolumn{2}{|c|}{ No. 2 Distillatea } & \multicolumn{2}{|c|}{ No. 4 Fuelb } & \multicolumn{2}{|c|}{ Residual Fuel Oll } \\
\hline & $\begin{array}{l}\text { Sales to } \\
\text { End Users }\end{array}$ & $\begin{array}{l}\text { Sales tor } \\
\text { Resale }\end{array}$ & $\begin{array}{l}\text { Sales to } \\
\text { End Users }\end{array}$ & $\begin{array}{l}\text { Sales for } \\
\text { Resale }\end{array}$ & $\begin{array}{l}\text { Sales to } \\
\text { End Users }\end{array}$ & $\begin{array}{l}\text { Sales for } \\
\text { Resale }\end{array}$ & $\begin{array}{l}\text { Sales to } \\
\text { End Users }\end{array}$ & $\begin{array}{l}\text { Sales for } \\
\text { Resale }\end{array}$ \\
\hline \multicolumn{9}{|l|}{ Alabama } \\
\hline $1983 \ldots$ & - & - & 81.4 & 80.9 & - & - & 61.3 & 66.2 \\
\hline 1984 & - & - & 81.2 & 80.4 & - & - & 65.4 & 64.1 \\
\hline 1985 & - & - & 77.4 & 76.0 & - & - & 57.9 & 56.4 \\
\hline 1986 & - & - & 45.9 & 44.5 & - & - & 31.1 & 30.3 \\
\hline 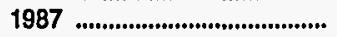 & - & - & 52.7 & 51.4 & - & - & 38.5 & 40.4 \\
\hline 1988 & NA & NA & 46.3 & 45.2 & - & - & 28.6 & 27.6 \\
\hline 1989 & NA & NA & 55.0 & 54.5 & - & - & 34.3 & 38.0 \\
\hline 1990 & NA & NA & 69.5 & 68.2 & - & - & 38.2 & 39.3 \\
\hline 1991 & NA & NA & 62.8 & 61.1 & - & - & 30.6 & 26.5 \\
\hline 1992 & 63.1 & $w$ & 59.7 & 58.0 & - & - & 30.7 & 30.2 \\
\hline 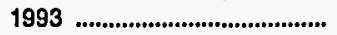 & 61.7 & 60.6 & 56.5 & 54.0 & - & - & 30.0 & 26.4 \\
\hline 1994 & - & $W$ & 51.7 & 50.1 & - & $\mathbf{w}$ & 32.3 & 34.8 \\
\hline \multicolumn{9}{|l|}{ Arkansas } \\
\hline 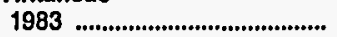 & - & - & 80.2 & 79.6 & - & - & $w$ & $w$ \\
\hline 1984 & - & - & 81.3 & 80.3 & - & - & 66.3 & 63.4 \\
\hline 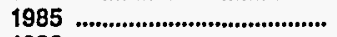 & - & - & 77.9 & 76.6 & - & - & $W$ & 61.7 \\
\hline 1986 & - & - & 45.7 & 45.3 & - & - & 34.8 & 30.7 \\
\hline $1987 \ldots$ & - & - & 53.2 & 52.9 & - & - & 39.4 & 38.8 \\
\hline $1988 \ldots$ & NA & NA & 49.5 & 46.6 & - & - & 35.8 & 35.0 \\
\hline 1989 & NA & NA & 58.3 & 54.8 & - & - & 38.6 & $w$ \\
\hline 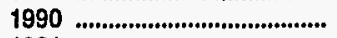 & NA & NA & 73.4 & 68.2 & - & - & 36.5 & W \\
\hline $1991 \ldots$ & NA & NA & 64.5 & 60.1 & - & - & 32.9 & - \\
\hline 1992 & 65.8 & 69.0 & 60.7 & 58.1 & - & - & 28.7 & - \\
\hline 1993 & 68.4 & 62.6 & 58.5 & 54.5 & - & - & 29.8 & - \\
\hline 1994 & - & 54.1 & 54.3 & 50.7 & - & - & 33.1 & - \\
\hline \multicolumn{9}{|l|}{ Louisiana } \\
\hline $1983 \ldots \ldots$ & - & - & 80.5 & 78.9 & - & - & 59.8 & 58.9 \\
\hline 1984 & - & - & 80.7 & 78.0 & - & - & 65.6 & 63.8 \\
\hline 1985 & - & - & 76.5 & 74.5 & - & - & 59.3 & 54.6 \\
\hline 1986 & - & - & 45.3 & 43.8 & - & - & 30.8 & 28.6 \\
\hline 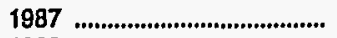 & - & - & 53.7 & 50.9 & - & - & 38.5 & 38.3 \\
\hline 1988 & NA & NA & 46.9 & 44.4 & - & - & 27.5 & 28.6 \\
\hline 1989 & NA & NA & 54.3 & 52.5 & - & - & 32.9 & 36.0 \\
\hline 1990 & $w$ & NA & 69.7 & 66.4 & - & - & 37.7 & 41.5 \\
\hline 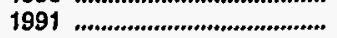 & $\ddot{w}$ & NA & 62.3 & 59.7 & - & - & 29.2 & 28.9 \\
\hline 1992 & W & $W$ & 58.0 & 55.8 & - & - & 29.1 & 29.2 \\
\hline 1993 & $w$ & $w$ & 56.2 & 51.6 & - & - & 27.7 & 26.9 \\
\hline 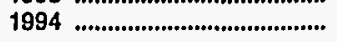 & W & 55.5 & 50.3 & 47.6 & - & - & 29.8 & 30.2 \\
\hline \multicolumn{9}{|l|}{ MIssissippi } \\
\hline $1983 \ldots$ & - & - & 81.2 & 79.8 & - & - & 60.1 & 59.1 \\
\hline 1984 & - & - & 81.1 & 78.7 & - & - & 68.2 & 64.3 \\
\hline 1985 & - & - & 76.6 & 75.4 & - & - & 61.2 & 58.6 \\
\hline 1986 & - & - & 48.6 & 44.8 & - & - & 29.9 & 28.4 \\
\hline 1987 & - & - & 52.4 & 51.2 & - & - & 30.8 & 39.6 \\
\hline 1988 & NA & NA & 46.0 & 44.7 & - & - & $W$ & 25.7 \\
\hline 1989 & NA & NA & 53.9 & 53.0 & - & - & 38.3 & 41.5 \\
\hline 1990 & NA & $w$ & 70.2 & 70.4 & - & - & 42.7 & $W$ \\
\hline 1991 & NA & $W$ & 62.5 & 59.9 & - & - & $w$ & $W$ \\
\hline 1992 & 62.5 & $\mathbf{W}$ & 59.0 & 56.6 & - & - & $w$ & $w$ \\
\hline 1993 & 60.4 & $W$ & 55.4 & 52.2 & - & - & 28.2 & 26.1 \\
\hline 1994 & - & W & 51.8 & 48.5 & $w$ & $w$ & 32.5 & NA \\
\hline
\end{tabular}

See footnotes at end of table. 
Table A3. Refiner/Reseller Prices of Distillate and Residual Fuel Oils, by PAD District, 1983-Present

(Cents per Gallon Excluding Taxes) - Continued

\begin{tabular}{|c|c|c|c|c|c|c|c|c|}
\hline \multirow{2}{*}{$\begin{array}{c}\text { Geographic Area } \\
\text { Year }\end{array}$} & \multicolumn{2}{|c|}{ No. 1 Distillate } & \multicolumn{2}{|c|}{ No. 2 Distillatea } & \multicolumn{2}{|c|}{ No. 4 Fuelb } & \multicolumn{2}{|c|}{ Residual Fuel Oil } \\
\hline & $\begin{array}{l}\text { Sales to } \\
\text { End Users }\end{array}$ & $\begin{array}{l}\text { Sales for } \\
\text { Resale }\end{array}$ & $\begin{array}{l}\text { Sales to } \\
\text { End Users }\end{array}$ & $\begin{array}{c}\text { Sales for } \\
\text { Resale }\end{array}$ & $\begin{array}{l}\text { Sales to } \\
\text { End Users }\end{array}$ & $\begin{array}{c}\text { Sales for } \\
\text { Resale }\end{array}$ & $\begin{array}{c}\text { Sales to } \\
\text { End Users } \\
\end{array}$ & $\begin{array}{c}\text { Sales for } \\
\text { Resale }\end{array}$ \\
\hline \multicolumn{9}{|l|}{ Now Mexico } \\
\hline 1983 & $w$ & 89.9 & 81.1 & 81.6 & - & - & $w$ & 50.8 \\
\hline 1984 & W & 88.7 & 83.7 & 82.3 & - & - & $w$ & $W$ \\
\hline 1985 & 88.2 & 86.6 & 87.1 & 81.3 & - & - & $w$ & 49.1 \\
\hline 1986 & W & 57.1 & 48.9 & 47.9 & - & - & $w$ & 26.0 \\
\hline 1987 & 62.8 & 62.5 & 58.9 & 57.5 & - & - & 40.8 & 30.1 \\
\hline 1988 & 59.0 & 58.5 & 56.7 & 52.2 & - & - & 25.8 & $w$ \\
\hline 1989 & 67.9 & 69.7 & 65.9 & 59.7 & - & - & 28.0 & w \\
\hline 1990 & 87.1 & 89.1 & 80.9 & 73.1 & - & - & $W$ & 43.6 \\
\hline 1991 & 73.7 & 80.3 & 68.6 & 63.1 & - & - & - & 24.4 \\
\hline 1992 & 68.0 & 71.2 & 69.9 & 63.2 & - & - & - & 22.2 \\
\hline 1993 & $W$ & 72.3 & 71.7 & 62.7 & - & - & - & 21.6 \\
\hline 1994 & $w$ & 69.6 & 63.9 & 58.0 & - & - & - & 19.1 \\
\hline \multicolumn{9}{|l|}{ Texas } \\
\hline 1983 & $w$ & 87.5 & 80.4 & 79.5 & - & - & 59.2 & 60.2 \\
\hline 1984 & 88.3 & 87.4 & 80.0 & 78.8 & - & - & 64.3 & 64.4 \\
\hline 1985 & 84.7 & 81.3 & 76.7 & 75.4 & - & - & 55.6 & 55.3 \\
\hline 1986 & 50.4 & 49.7 & 44.8 & 44.4 & - & - & 28.7 & 29.7 \\
\hline 1987 & 59.4 & 58.9 & 52.7 & 50.6 & - & - & 38.0 & 37.9 \\
\hline 1988 & 52.9 & 52.2 & 47.0 & 44.6 & - & - & 26.8 & 27.5 \\
\hline 1989 & 61.6 & 62.7 & 54.6 & 53.2 & - & - & 32.9 & 36.6 \\
\hline 1990 & 72.3 & 89.3 & 71.3 & 67.4 & - & - & 36.7 & 39.1 \\
\hline 1991 & 65.6 & 69.5 & 62.7 & 59.6 & - & - & 27.5 & 28.3 \\
\hline 1992 & $W$ & 64.1 & 59.8 & 56.3 & - & - & 29.1 & 29.9 \\
\hline 1993 & W & 58.2 & 58.3 & 52.9 & - & - & 27.3 & 27.5 \\
\hline 1994 & 59.3 & 57.6 & 53.1 & 48.7 & - & W & 29.9 & 28.8 \\
\hline \multicolumn{9}{|l|}{ PAD District IV } \\
\hline 1983 & 92.4 & 91.7 & 82.6 & 82.7 & W & $w$ & 54.5 & 61.2 \\
\hline 1984 & 92.1 & 90.7 & 83.6 & 84.0 & $w$ & 80.1 & 59.7 & 59.9 \\
\hline 1985 & 86.8 & 86.5 & 78.0 & 79.3 & W & 67.3 & 52.8 & 55.6 \\
\hline 1986 & 62.5 & 59.4 & 47.5 & 47.5 & W & - & 34.0 & 31.8 \\
\hline 1987 & 61.7 & 60.8 & 54.7 & 56.2 & W & - & 32.2 & 36.6 \\
\hline 1988 & 57.9 & 56.0 & 50.2 & 50.8 & $W$ & - & 26.4 & 31.9 \\
\hline 1989 & 65.9 & 65.6 & 59.6 & 60.7 & $W$ & $\mathbf{w}$ & 23.6 & 33.8 \\
\hline 1990 & 87.5 & 85.6 & 73.5 & 73.0 & - & $W$ & 35.8 & 33.7 \\
\hline 1991 & 80.5 & 77.3 & 64.5 & 64.0 & - & $W$ & 32.9 & 31.5 \\
\hline 1992 & 72.5 & 69.3 & 64.7 & 64.8 & $W$ & - & 25.4 & 22.5 \\
\hline 1993 & 77.9 & 73.0 & 64.4 & 64.0 & - & $W$ & 29.6 & 25.0 \\
\hline 1994 & 74.0 & 67.9 & 59.0 & 59.7 & - & - & 32.0 & 27.3 \\
\hline \multicolumn{9}{|l|}{ Colorado } \\
\hline 1983 & 88.9 & 90.2 & 81.3 & 81.3 & - & - & $w$ & $w$ \\
\hline 1984 & 89.1 & 88.9 & 81.8 & 81.8 & - & - & 66.9 & 52.7 \\
\hline 1985 & 85.6 & 84.8 & 77.4 & $\pi 7.9$ & - & - & 59.1 & 43.9 \\
\hline 1986 & 59.8 & 56.2 & 46.3 & 46.1 & - & - & $w$ & $w$ \\
\hline 1987 & 58.9 & 59.1 & 54.0 & 54.3 & - & - & 39.0 & w \\
\hline 1988 & 55.4 & 53.2 & 48.1 & 47.7 & - & - & $w$ & $\ddot{w}$ \\
\hline 1989 & 67.1 & 62.6 & 57.7 & 56.9 & - & - & 26.2 & $\ddot{w}$ \\
\hline $1990 \ldots$ & 88.7 & 82.3 & 74.6 & 71.2 & - & - & $w$ & 23.1 \\
\hline 1991 & 79.3 & 74.2 & 64.8 & 62.1 & - & - & $\ddot{W}$ & 43.1 \\
\hline 1992 & 76.8 & 67.1 & 65.0 & 64.4 & - & - & $\ddot{W}$ & $w$ \\
\hline 1993 & 82.4 & 68.4 & 63.0 & 61.1 & - & - & W & W \\
\hline 1994 & $w$ & 62.5 & 57.1 & 57.1 & - & - & $\ddot{w}$ & $w$ \\
\hline
\end{tabular}

See footnotes at end of table. 
Table A3. Refiner/Reseller Prices of Distillate and Residual Fuel Oils, by PAD District, 1983-Present

(Cents per Gallon Excluding Taxes) - Continued

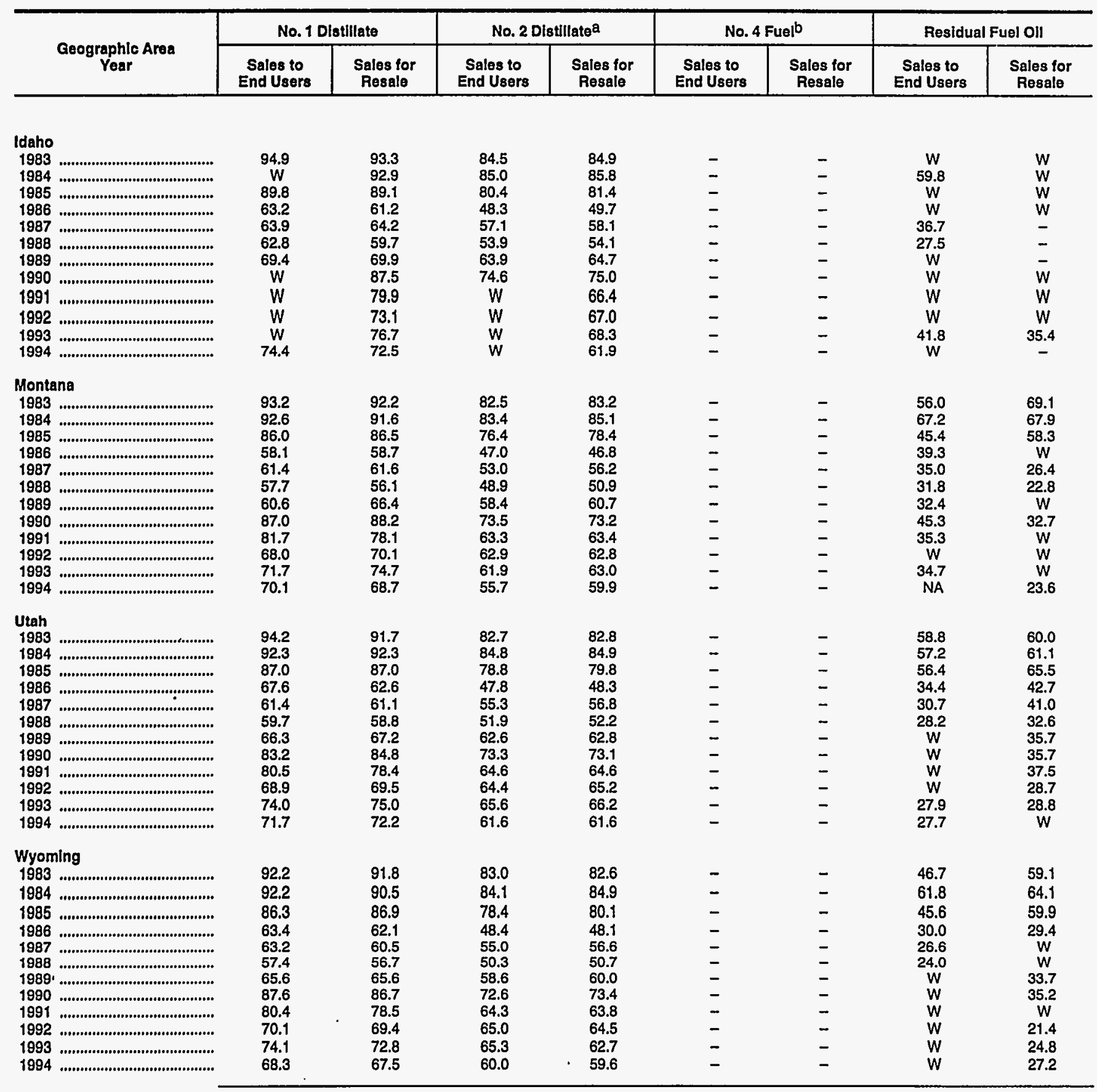

See footnotes at end of table. 
Table A3. Refiner/Reseller Prices of Distillate and Residual Fuel Oils, by PAD District, 1983-Present

(Cents per Gallon Excluding Taxes) - Continued

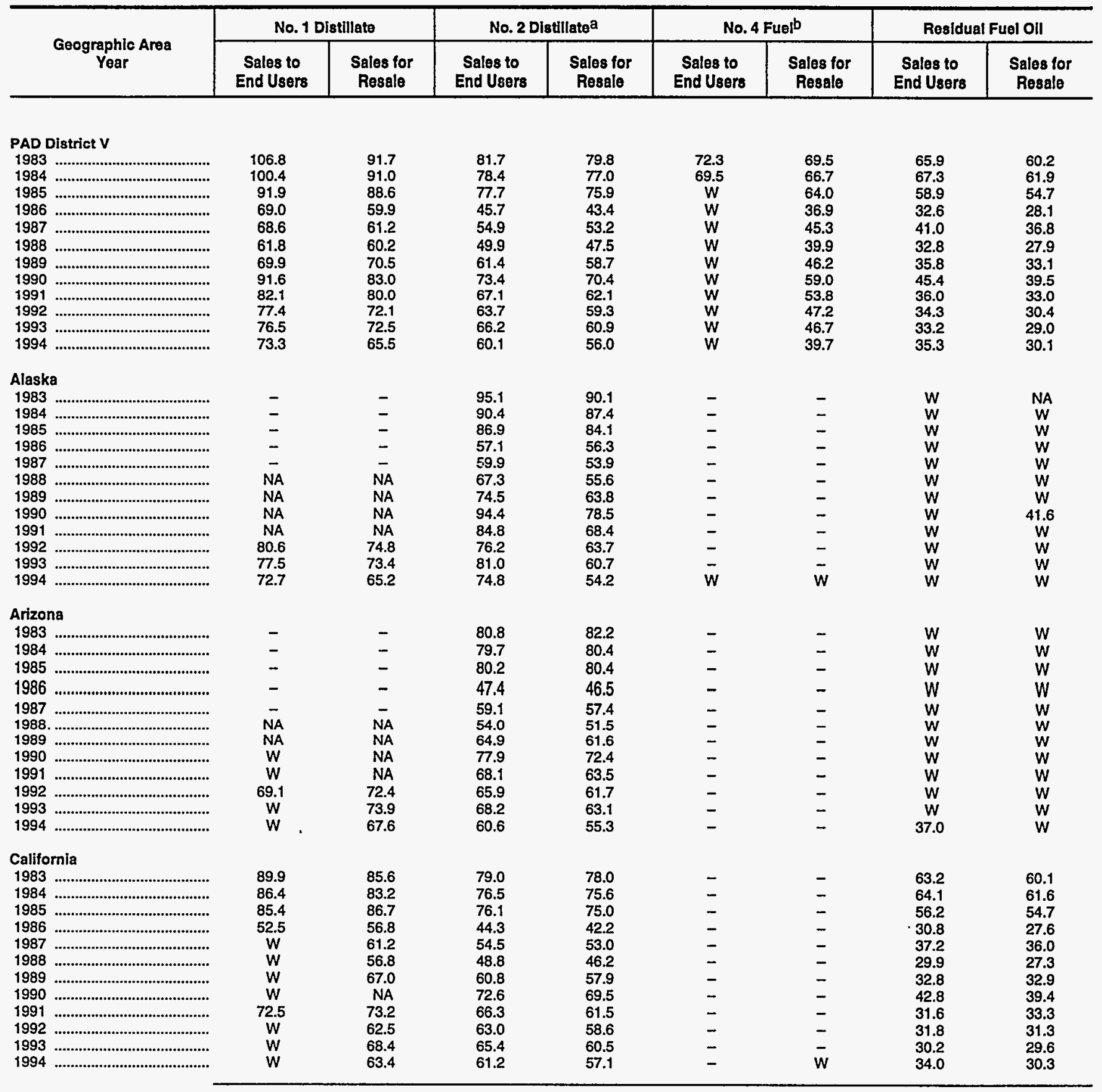

See footnotes at end of table. 
Table A3. Refiner/Reseller Prices of Distillate and Residual Fuel Oils, by PAD District, 1983-Present

(Cents per Gallon Excluding Taxes) - Continued

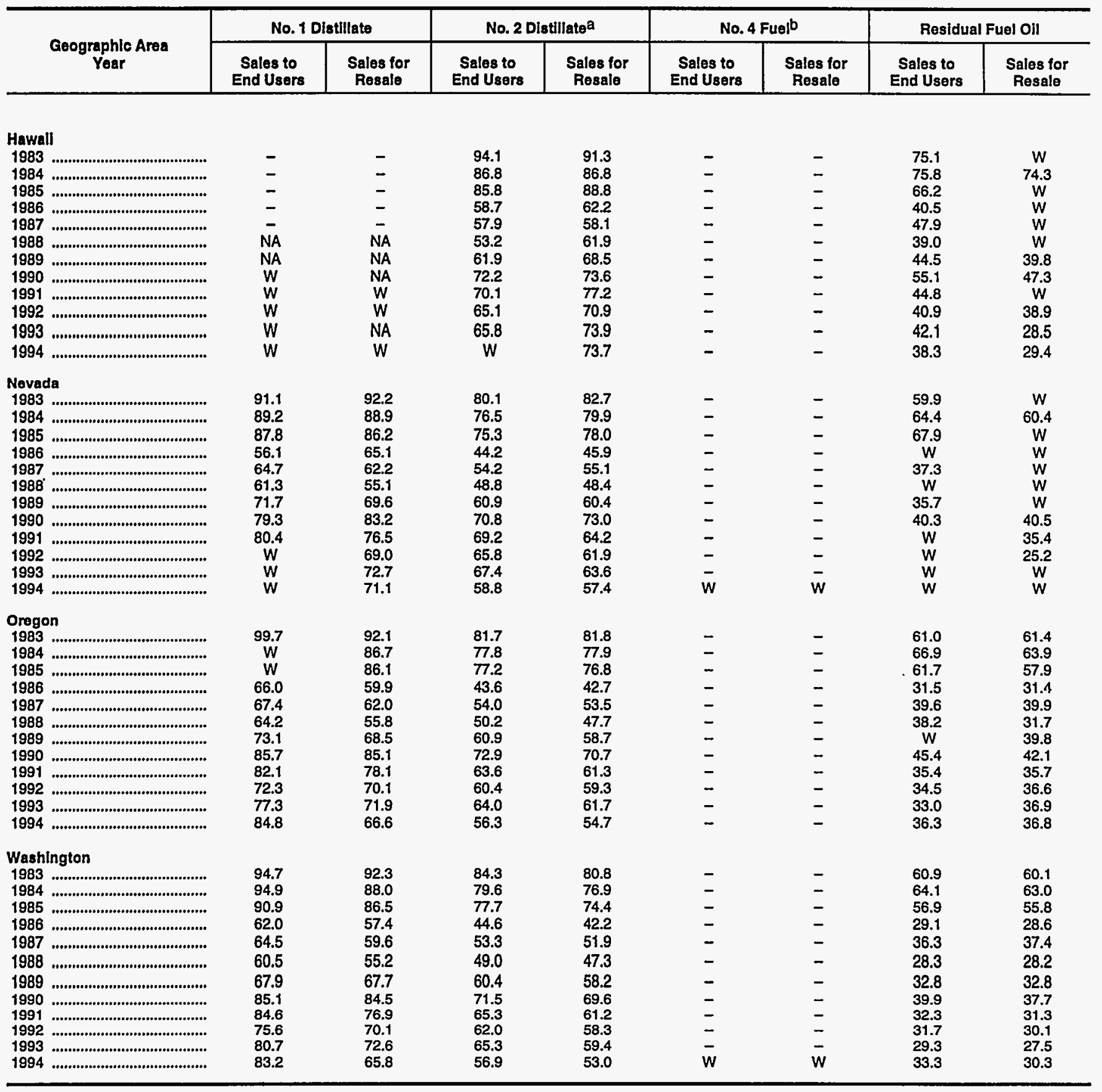

Dash $(-)=$ No data reported.

$N A=$ Not avallable.

$W=$ Withheld to avoid disclosure of Individual company data.

a includes sales of No. 2 fuel oll and high- and low-sulfur diesel fuels.

b Includes No. 4 fuel oll and No. 4 diesel fuel.

Sources: Energy Informatlon Adminlstration Forms EIA-782A, "Refiners'/Gas Plant Operators' Monthly Petroleum Product Sales Report," and EIA-782B,

"Resellers'/Retallers' Monthly Petroleum Product Sales Report." 